\title{
IUCN
}

\section{Protected Area Governance and Management}

Editors: Graeme L. Worboys, Michael Lockwood, Ashish Kothari,

Sue Feary and lan Pulsford

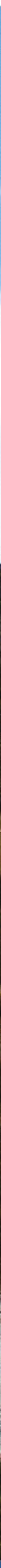

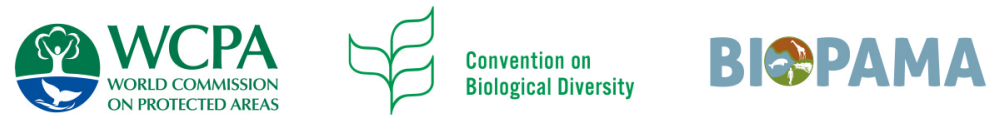





\section{Protected Area Governance and Management}

Editors: Graeme L. Worboys, Michael Lockwood, Ashish Kothari,

Sue Feary and lan Pulsford 


\section{IUCN}

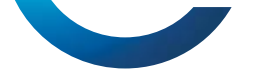

\section{IUCN (International Union for Conservation of Nature)}

IUCN helps the world find pragmatic solutions to our most pressing environment and development challenges. IUCN works on biodiversity, climate change, energy, human livelihoods and greening the world economy by supporting scientific research, managing field projects all over the world, and bringing governments, NGOs, the UN and companies together to develop policy, laws and best practice. IUCN is the world's oldest and largest global environmental organisation, with more than 1,200 government and NGO members and almost 11,000 volunteer experts in some 160 countries. IUCN's work is supported by over 1,000 staff in 45 offices and hundreds of partners in public, NGO and private sectors around the world.

\section{www.iucn.org}

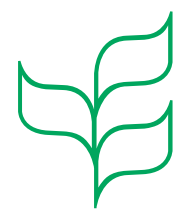

\section{Convention on Biological Diversity}

\section{Convention on Biological Diversity}

The Convention on Biological Diversity (CBD), which entered into force in December 1993, is an international treaty for the conservation of biodiversity, the sustainable use of the components of biodiversity and the equitable sharing of the benefits derived from the use of genetic resources. With 193 Parties, the Convention has near universal participation among countries. The Convention seeks to address all threats to biodiversity and ecosystem services through scientific assessments, the development of tools, incentives and processes, the transfer of technologies and good practices, and the full and active involvement of relevant stakeholders including indigenous and local communities, youth, NGOs, women and the business community. The tenth meeting of the Conference of the Parties to the CBD, held in 2010, adopted a revised and updated Strategic Plan for Biodiversity for 2011-2020, comprising five strategic goals and 20 Aichi Biodiversity Targets. The Plan is the overarching framework on biodiversity, not only for the biodiversity-related conventions, but for the entire United Nations system.

\section{BIOPAMA}

\section{BIOPAMA}

The Biodiversity and Protected Area Management (BIOPAMA) programme aims to address threats to biodiversity in African, Caribbean and Pacific (ACP) countries, while reducing poverty in communities in and around protected areas. It is financially supported by resources from the intra-ACP envelope of the European Commission's (EC) 10th European Development Fund (EDF). BIOPAMA combines improving data availability with capacity development to strengthen protected area management. It has two main components: one concerning protected areas, jointly implemented by the International Union for Conservation of Nature (IUCN) and the EC's Joint Research Centre (JRC), and another dealing with access and benefit sharing (ABS), implemented by the Multi-Donor ABS Capacity Development Initiative managed by Deutsche Gesellschaft für Internationale.

\section{www.biopama.org}

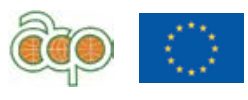

An initiative of the ACP Secretariat funded by the European Union under the 10th EDF

Implemented by
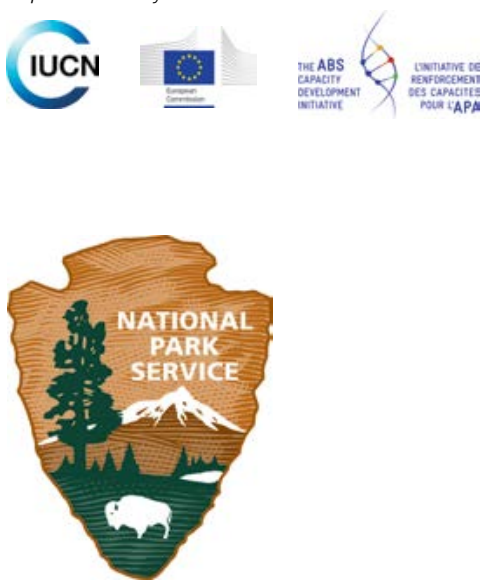

\section{US National Park Service}

The National Park Service, United States Department of the Interior, preserves unimpaired the natural and cultural resources and values of the national park system for the enjoyment, education, and inspiration of this and future generations. The Park Service cooperates with partners to extend the benefits of natural and cultural resource conservation and outdoor recreation throughout the USA and the world.

\section{www.nps.gov}




\section{s. \\ UNEP WCMC \\ UNEP-WCMC}

The United Nations Environment Programme World Conservation Monitoring Centre (UNEP-WCMC) is the specialist biodiversity assessment centre of the United Nations Environment Programme (UNEP), the world's foremost intergovernmental environmental organisation. The Centre has been in operation for over 30 years, combining scientific research with practical policy advice.

www.unep-wcmc.org

\section{S UNIVERSITY of TAS MAN IA}

\section{University of Tasmania}

The University of Tasmania is among the top two per cent of the world's universities, and has a growing reputation as one of Australia's premier learning and research institutions. The University offers an internationalised curricula and broad access to a diverse range of degrees, student exchanges and learning experiences. The University of Tasmania is committed to the creation and dissemination of knowledge, with research activity and expertise that is recognised globally. The University is playing a lead role in the Protected Areas Learning \& Research Collaboration that is fostering excellence in protected area governance and management in the Asia-Pacific and Oceania regions.

www.utas.edu.au

\section{THE GREAT RATER RANGES

\author{
connecting people...connecting nature
}

\section{Great Eastern Ranges Initiative, Australia}

\section{ANU Press}

ANU Press, originally known as ANU E Press, was established in 2003 to explore and enable new modes of scholarly publishing. Taking advantage of new information and communication technologies to make available the intellectual output of the ANU academic community, ANU Press was Australia's first primarily electronic academic publisher. The press has been operational for over 10 years and plays a leading role in the scholarly output of Australian Universities. The primary focus of ANU Press is the electronic production of scholarly works.

press.anu.edu.au

\section{ANU Fenner School}

The Fenner School of Environment and Society, The Australian National University, is a leading Australian centre for research, research training and education in environment and sustainability. With staff, PhD scholars and teaching programs covering a wide range of natural and social science disciplines, it has major programs in areas such as biodiversity conservation ecology, water resources management, environmental policy, land management and climate adaptation.

fennerschool.anu.edu.au
The Great Eastern Ranges Initiative is a connectivity conservation project that brings people and organisations together to protect, link and restore healthy habitats over 3,600 kilometres of eastern Australia from western Victoria through NSW and the ACT to far north Queensland. It is a visionary response to help conserve Australia's biodiversity and to help mitigate the potential impacts of invasive species, land clearing, climate change and other environmental changes. The Initiative is focused on the Great Eastern Ranges which includes a rich diversity of plants and animals and helps protect catchments that provide reliable, clean water for over 11 million people. It is a globally important connectivity conservation project that involves hundreds of organisations, local communities and private landholders.

www.greateasternranges.org.au

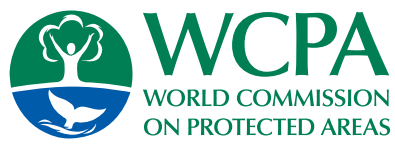

\section{IUCN World Commission on Protected Areas (WCPA)}

IUCN WCPA is the world's premier network of protected area expertise. It is administered by IUCN's Programme on Protected Areas and has over 1,400 members, spanning 140 countries. IUCN WCPA works by helping governments and others plan protected areas and integrate them into all sectors; by providing strategic advice to policy makers; by strengthening capacity and investment in protected areas; and by convening the diverse constituency of protected area stakeholders to address challenging issues. For more than 50 years, IUCN and WCPA have been at the forefront of global action on protected areas. 
Published by ANU Press

The Australian National University

Canberra ACT 0200, Australia

Email: anupress@anu.edu.au

This title is also available online at http://press.anu.edu.au

National Library of Australia Cataloguing-in-Publication entry

Author: Worboys, Graeme, author, editor.

Title: $\quad$ Protected area governance and management / Graeme L. Worboys, Michael Lockwood, Ashish Kothari, Sue Feary and lan Pulsford, authors and editors.

ISBN: $\quad 9781925021684$ (paperback) 9781925021691 (ebook)

Subjects: $\quad$ Protected areas--Management--Handbooks, manuals, etc.

Conservation of natural resources--Handbooks, manuals, etc.

Natural resource management areas--Handbooks, manuals, etc.

Nature conservation--Handbooks, manuals, etc.

Other Authors/Contributors:

Lockwood, Michael, author, editor.

Kothari, Ashish, author, editor.

Feary, Sue, author, editor.

Pulsford, lan, author, editor.

Dewey Number: $\quad 333.78216$

Reproduction of this publication for educational or other non-commercial purposes is authorised without prior written permission from the copyright holder provided the source is fully acknowledged. Reproduction of this publication for resale or other commercial purposes is prohibited without prior written permission of the copyright holder.

This publication has been produced with support of the 10th EDF. The contents of this publication are the sole responsibility of the authors and can in no way be taken to reflect the views of the European Union nor of the ACP Secretariat.

The views expressed in this publication do not necessarily reflect those of IUCN, SCBD, BIOPAMA, US NPS, UNEP-WCMC, ANU, UTAS or the GER.

The designation of geographical entities in this book, and the presentation of the material, do not imply the expression of any opinion whatsoever on the part of IUCN [or other participating organisations] concerning the legal status of any country, territory, or area, or of its authorities, or concerning the delimitation of its frontiers or boundaries.

This publication has been made possible in part by funding from BIOPAMA, ANU, Michael Lockwood and Graeme Worboys, and the GER and significant in-kind contribution from the US NPS, UNEP-WCMC, ANU Press and UTAS.

Copyright permissions:

Every effort has been made to trace the original source of copyright material contained in this book. The publisher would be pleased to hear from copyright holders to rectify any errors or omissions.

Cover design and layout by Teresa Prowse.

Illustrations by lan Charles.

Cartography by UNEP-WCMC and US NPS.

Indexing by Jan Borrie.

Citation: G. L. Worboys, M. Lockwood, A. Kothari, S. Feary and I. Pulsford (eds) (2015) Protected Area Governance and Management, ANU Press, Canberra.

Cover photograph: The peaks of Thamserku and Kangtega tower above Khumjung village, Sagarmatha National Park, Nepal. The park is inscribed as both a natural and cultural World Heritage property, the area is part of the Sacred Himalayan Landscape and it is the traditionally governed and conserved territory of the Sherpa people.

Source: lan Pulsford.

Special note: The Buddhist chorten shown was built and dedicated to distinguished international conservationist Mingma Norbu Sherpa following his untimely death in 2006. Mingma was born and raised in the national park and was the first Sherpa to serve as its warden. The inscription reads: 'Dedicated to the memory of MINGMA NORBU SHERPA He was a conservation leader in Himalayas and Globally'.

The paper used for the text of this book is FSC certified. FSC (the Forest Stewardship Council) is an international network to promote responsible management of the world's forests.

Printed on elemental chlorine-free paper.

Printed by Griffin Press

This edition (c) 2015 ANU Press

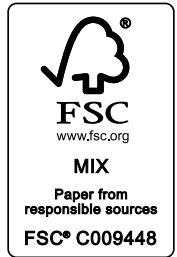




\section{Contents}

Figures $\quad$ xi

Tables $\quad$ xv

Acknowledgments $\quad$ xvii

The Editors $\quad$ xix

Foreword $\quad$ xxi

Foreword $\quad$ xxiii

References $\quad$ xxvi

Chapter 1 Introduction $\quad 1$

Introduction $\quad 3$

References $\quad 8$

Chapter 2 Concept, Purpose and Challenges 99

Introduction 11

Concept and purpose 11

Types of protected areas: IUCN categories 16

Systems of protected areas $\quad 20$

Status of protected area coverage $\quad 21$

Other international protected area and conservation types 22

Challenges for protected areas $\quad 28$

Conclusion $\quad 32$

Supplementary reading $\quad 32$

References $\quad 34$

Appendix 2.1: Key IUCN WCPA and related publications 40

Chapter 3 Earth's Natural Heritage $\quad 43$

Introduction $\quad 45$

Earth's natural processes $\quad 45$

Geodiversity $\quad 50$

Biodiversity $\quad 51$

Protected areas as safeguards for Earth's natural heritage $\quad 66$

Global biodiversity conservation priorities 69

Introducing ecosystem management $\quad 73$

$\begin{array}{ll}\text { Conclusion } & 73\end{array}$

References $\quad 75$

$\begin{array}{lr}\text { Chapter } 4 \text { Earth's Cultural Heritage } & \mathbf{8 1}\end{array}$

Introduction 83

A brief history of humans on Earth: The long view of cultural change and diversity 83

Humans, culture and nature $\quad 85$

Defining and understanding cultural heritage: A short history of ideas on cultural heritage 86

A diversity of cultural heritage $\quad 88$

Introducing cultural heritage management 105

Connections between culture, heritage and protected areas 109

Conclusion $\quad 110$

References 112 
Chapter 5 Social and Economic Influences Shaping Protected Areas

Introduction

Trends and forecasting

Anthropocence: Humans take charge $\quad 120$

Values, norms and duties $\quad 121$

Human rights, indigenous rights and custodianship in the 21st century 128

Economic trends impacting on the state, communities and protected areas 132

Conclusion 139

References 141

Chapter 6 Values and Benefits of Protected Areas $\quad 145$

Introduction 147

Protected area benefits: Maintaining our life-support systems 149

Understanding and managing benefits 155

References 166

Chapter 7 Governance for the Conservation of Nature $\quad 169$

Introduction $\quad 171$

History, power, culture and nature $\quad 171$

Governing protected and conserved areas 179

The governance frontiers 198

Conclusion 201

References $\quad 203$

Chapter 8 Managing Protected Areas $\quad 207$

Introduction 209

The need for management $\quad 209$

Management: Definition and functions

Strategic management $\quad 213$

Frameworks and tools $\quad 217$

Managing protected area systems $\quad 222$

Management guidance for IUCN protected area categories $\quad 227$

Management for protected area governance types $\quad 235$

Managing protected areas in special contexts $\quad 242$

Conclusion $\quad 246$

References $\quad 247$

Chapter 9 Capacity Development 251

Introduction 253

Capacity development in protected area systems 254

Basic concepts and capacity development approaches 255

Capacity development $\quad 260$

Education in a changing world $\quad 265$

Capacity development planning and assessment 267

Why do we need protected area professionals?

Knowledge management $\quad 272$

Competence-based approaches to capacity development 272

Performance review and certification programs 277

Learning resources 280

Conclusion $\quad 282$

References 283

Appendix 9.1: Example capacity development organisations 288 
Chapter 10 Benefiting from Complexity Thinking 291

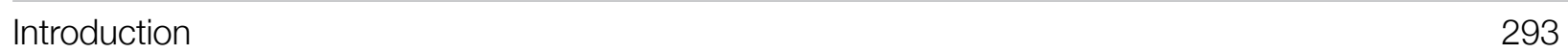

Characterising complexity $\quad 296$

Simplifying complexity $\quad 304$

Engaging complexity $\quad 310$

Conclusion: Governing and managing adaptively 321

References $\quad 323$

Chapter 11 Knowledge Generation, Acquisition and Management $\quad 327$

$\begin{array}{ll}\text { Introduction } & 329\end{array}$

What is knowledge? $\quad 329$

Drivers of knowledge generation 330

Inputs for knowledge generation 334

Importance of standards $\quad 339$

Knowledge sharing $\quad 342$

Knowledge management $\quad 342$

$\begin{array}{ll}\text { Knowledge use } & 342\end{array}$

Resourcing considerations $\quad 345$

$\begin{array}{lr}\text { Conclusion } & 349\end{array}$

References $\quad 350$

Chapter 12 Leadership and Executive Management 353

$\begin{array}{ll}\text { Introduction } & 355\end{array}$

Leadership 356

Executive management $\quad 362$

Executive management: Working with people 367

$\begin{array}{ll}\text { Conclusion } & 377\end{array}$

References $\quad 380$

Chapter 13 Planning $\quad 381$

Introduction 383

Types of plans relevant to protected areas 383

Approaches to planning $\quad 385$

Planning for protected area networks 394

$\begin{array}{ll}\text { Protected area management planning } & 400\end{array}$

$\begin{array}{ll}\text { Conclusion } & 407\end{array}$

$\begin{array}{ll}\text { References } & 409\end{array}$

Chapter 14 Engagement and Participation in Protected Area

Management: Who, why, how and when? $\quad \mathbf{4 1 3}$

\begin{tabular}{ll}
\hline Introduction & 415
\end{tabular}

The emergence of collaborative arrangements 415

General principles of engagement $\quad 419$

Engage with whom? $\quad 422$

Why: The purposes of engagement 425

How: Forms of engagement and participation $\quad 426$

When should engagement occur? $\quad 428$

$\begin{array}{lr}\text { Conclusion } & 429\end{array}$

$\begin{array}{ll}\text { References } & 438\end{array}$ 
$\begin{array}{lr}\text { Introduction } & 443 \\ \text { Types of media } & 444 \\ \text { Strategic use of the media } & 446 \\ \text { Media planning } & 449 \\ \text { News releases and media interviews } & 452 \\ \text { Media management skills } & 458 \\ \text { Communication planning } & 463 \\ \text { Media management at major incidents } & 467 \\ \text { Conclusion } & 469 \\ \text { References } & 472 \\ \text { Chapter 16 Managing Threats } & \mathbf{4 7 3}\end{array}$

$\begin{array}{ll}\text { Introduction } & 475\end{array}$

Classification of threats $\quad 475$

Threat assessment and management $\quad 481$

Governance dimensions of addressing threats 491

Conclusion $\quad 492$

References $\quad 492$

Chapter 17 Climate Change and Protected Areas $\quad 495$

$\begin{array}{ll}\text { Introduction } & 497\end{array}$

Climate change research findings $\quad 497$

Nature-based solutions $\quad 502$

Implications for biodiversity 503

Implications for values people and communities obtain from protected areas 508

Mitigating climate change $\quad 510$

Adaptation management $\quad 512$

Climate-ready planning $\quad 519$

Climate-ready organisation $\quad 522$

Climate-ready implementation 523

Climate-ready evaluation $\quad 526$

Conclusion $\quad 526$

References

Chapter 18 Geoconservation in Protected Areas $\quad 531$

Introduction 533

The need for geoconservation in protected areas 535

Managing geoconservation in protected areas $\quad 552$

Conclusion $\quad 561$

References $\quad 561$

Chapter 19 Managing Freshwater, River, Wetland and Estuarine

$\begin{array}{ll}\text { Protected Areas } & 569\end{array}$

Introduction $\quad 571$

Freshwater ecosystems $\quad 571$

Managing specific freshwater ecosystems 579

Managing freshwater protected areas in the landscape 588

Conclusion $\quad 596$

References $\quad 600$ 
Progress in establishing marine protected areas 611

Types of marine protected areas $\quad 613$

Benefits of marine protected areas 616

Governance of marine protected areas 622

Management of marine protected areas 629

Management effectiveness $\quad 642$

$\begin{array}{ll}\text { Conclusion } & 644\end{array}$

References $\quad 645$

Chapter 21 Managing Protected Areas for Biological Diversity and Ecosystem Functions $\quad 651$

Introduction 653

The relationship between biodiversity and ecological function 653

Assessing protected area condition: Ecological integrity 657

$\begin{array}{ll}\text { Managing protected areas for biodiversity } & 659\end{array}$

Managing threats to protected areas 666

Monitoring and assessment of ecological condition in protected areas 670

$\begin{array}{ll}\text { Conclusion } & 677\end{array}$

References $\quad 678$

Chapter 22 Managing Cultural Uses and Features $\quad 685$

$\begin{array}{ll}\text { Introduction } & 687\end{array}$

$\begin{array}{ll}\text { Managing for contemporary cultural practices } & 687\end{array}$

Managing cultural use with integrative approaches $\quad 689$

$\begin{array}{ll}\text { Managing for cultural spiritual values } & 696\end{array}$

$\begin{array}{ll}\text { Managing cultural use of sacred sites } & 697\end{array}$

Managing cultural features (tangible cultural heritage) $\quad 705$

$\begin{array}{ll}\text { Conclusion } & 711\end{array}$

References $\quad 711$

Chapter 23 Visitor Management $\quad \mathbf{7 1 5}$

\begin{tabular}{ll}
\hline Introduction & 717
\end{tabular}

$\begin{array}{ll}\text { The conservation imperative } & 717\end{array}$

$\begin{array}{ll}\text { Visitor management } & 718\end{array}$

$\begin{array}{ll}\text { Tourism management } & 722\end{array}$

Recreation opportunities management $\quad 736$

$\begin{array}{ll}\text { Visitor services and facilities } & 737\end{array}$

Visitor impact management $\quad 739$

$\begin{array}{ll}\text { Conclusion } & 746\end{array}$

$\begin{array}{ll}\text { References } & 747\end{array}$

Chapter 24 Managing Operations and Assets $\quad 751$

Introduction $\quad 753$

Operations in protected areas $\quad 753$

Programming operations $\quad 759$

$\begin{array}{ll}\text { Planning operations } & 763\end{array}$

Delivering operations $\quad 772$

Asset management and operations $\quad 780$

Reviewing the effectiveness of operations $\quad 785$

$\begin{array}{ll}\text { Conclusion } & 785\end{array}$

$\begin{array}{ll}\text { References } & 787\end{array}$ 
Introduction

Resource use in and around protected areas 791

Development and protected areas 808

Conclusion $\quad 811$

References $\quad 812$

Chapter 26 Managing Incidents $\quad 823$

$\begin{array}{ll}\text { Introduction } & 825\end{array}$

$\begin{array}{ll}\text { Types of incidents } & 825\end{array}$

Pre-incident planning and preparation 828

Responding to incidents $\quad 834$

$\begin{array}{ll}\text { Managing incidents } & 841\end{array}$

Recovery
Conclusion

$\begin{array}{lr}\text { Conclusion } & 846\end{array}$

References

Chapter 27 Connectivity Conservation Management $\quad 851$

Introduction 853

The science of connectivity conservation management 853

The global network of connectivity corridors 857

Managing connectivity conservation corridors 858

Monitoring and evaluating corridor performance 866

Connectivity conservation governance 867

Transboundary corridor governance $\quad 874$

Legal considerations $\quad 874$

$\begin{array}{ll}\text { Conclusion } & 881\end{array}$

References $\quad 881$

Chapter 28 Protected Area Management Effectiveness $\quad 889$

$\begin{array}{ll}\text { Introduction } & 891\end{array}$

What is protected area management effectiveness evaluation? 892

Purposes of protected area management effectiveness evaluation 894

Protected area management effectiveness evaluation globally 895

The IUCN protected area management effectiveness framework 900

Designing and implementing assessments 902

Making a difference: Towards more effective management 919

$\begin{array}{lr}\text { Conclusion } & 922\end{array}$

$\begin{array}{lr}\text { References } & 923\end{array}$

Chapter 29 Conclusion $\quad 929$

$\begin{array}{ll}\text { Index } & 933\end{array}$




\section{Figures}

1.1 Structure and content of Protected Area Governance and Management book 5

1.2 A learning journey for middle-level protected area managers focused on information underpinning practical and operational aspects

1.3 A learning journey for senior protected area managers focused on information that underpins protected area systems-level concepts and practice $\quad 7$

$2.1 \quad$ Naturalness and IUCN protected area categories 20

2.2 Growth in the percentage of terrestrial and marine area covered

by protected areas, 1990-2014

2.3 Total areal extent $\left(\mathrm{km}^{2}\right)$ of protected areas in the WDPA in each of the IUCN management categories, 1950-2014

3.1 Distribution of the 222 natural and mixed World Heritage sites and case study locations (red markers)

$\begin{array}{lll}4.1 & \text { Origin and dispersal of modern humans } & 84\end{array}$

4.2 Returning stolen movable heritage 94

$\begin{array}{lll}4.3 & \text { Elements of a cultural landscape } & 104\end{array}$

6.1 Ecosystem services and related goods from protected areas 147

7.1 Incomplete overlap between conserved and protected areas 178

7.2 Incomplete overlaps among conserved areas, protected areas and privately conserved areas

7.3 Incomplete overlaps among conserved areas, protected areas and ICCAs

7.4 The modified IUCN Protected Area Matrix: A classification system comprising both management category and governance type

7.5 A schematic summary of governance characteristics

8.1 Strengths, weaknesses, opportunities and threats analysis 214

8.2 The park management framework used by the NSW NPWS 217

8.3 Percentage of terrestrial area of nations reserved as protected area in 2014

8.4 The IUCN Protected Area Matrix: A classification system for protected areas comprising both IUCN management category and governance type 236

9.1 Framework for clinical assessment 257

9.2 Kolb's Cycle of Experiential Learning 259

9.3 A systems approach to capacity development 261

9.4 Dynamic model of capacity development 262

9.5 The shift in paradigm to a capacity development approach 263

9.6 Five core capabilities required to achieve organisational capacity 264

10.1 Key points in the chapter 294

10.2 A system can be conceived of as a basin 299

10.3 A simplified representation of a complex social-ecological system 306

$10.4 \quad$ Using root-cause analysis 317

11.1 The continuum of understanding from the gathering of data, the presentation
of information, generation of knowledge and ultimate wisdom 
11.2 The Conservation Measures Partnership adaptive management project planning cycle

11.3 Deforestation (red areas) in Virunga National Park (outlined in blue),

Democratic Republic of Congo, measured from 2000 to 2012

11.4 The six knowledge products delivered through the IUCN

11.5 PARCC project process for production and sharing of global, regional and national data

13.1 The planning hierarchy

13.3 The Open Standards for the Practice of Conservation

13.4 Revised Open Standards Approach as Healthy Country Planning using more appropriate language and simplified concepts

14.1 Hierarchy of governance and participation

408

16.1 Example of a three-level threat classification 476

16.2 The main threats to the protected area system of Ghana 478

16.3 Poaching intensity in the protected areas of Ghana 478

16.4 Key steps in assessing threats to biodiversity in protected areas 482

16.5 Adaptive management approach for invasive species 487

16.6 Distribution of four representative invasive species, India 488

17.1 IPCC climate change projections for two carbon dioxide concentration levels for temperature, precipitation, sea-ice extent and ocean surface $\mathrm{pH} \quad 500$

17.2 Climate extremes: probability schematics 501

17.3 Modelling of impacts of climate change on vascular plants in Australia where red identifies greatest change and green, least change 507

17.4 Forecast changes in the distributions of five major biomes to the end of the 21st century 508

17.5 The conservation policy cycle

17.6 Assigning species to an 'adaptation management response space'

18.1 Schematic illustration of the goods and services derived from geodiversity:

The grey layer above the bedrock represents soil

18.2 Steps in the use of the Geoheritage Toolkit to identify and assess sites of geoheritage significance

18.3 Logo of the UNESCO-assisted Global Geoparks Network 544

18.4 Core and additional values of geoheritage 545

19.1 Global distribution of wetlands $\quad 572$

19.2 Pantanal wetlands, South America $\quad 577$

19.3 Cosumnes River Preserve, United States of America 578

19.4 Kruger National Park, South Africa 581

$19.5 \quad$ Links between water basins at different scales and of different types 584

19.6 Integrated lake basin management 585

19.7 Global peatland distribution 586

19.8 Chilika Lagoon, India 589

19.9 Distribution of inland freshwater Ramsar sites 591

19.10 Kakadu National Park 592

19.11 Millingerwaard, the Netherlands, showing nature reserves developed along

19.12 Ecological movement pathways 596

19.13 Catchments and jurisdictional boundaries $\quad 597$

19.14 Murray-Darling Basin, showing the location of 16 designated Ramsar wetlands 598

20.1 Global extent of Marine Protected Areas (MPAs) 612

20.2 Ecosystem Connectivity 618

20.3 The Kimbe Bay Marine Management Area, including Locally Managed Marine Areas (LMMAs) established within areas of interest 624

20.4 OSPAR network of MPAs, as of December $2012 \quad 627$

20.5 Traditional-use marine resource agreement area 628 
21.1 The relationship between ecological function and biodiversity

21.2 Some of the world's most important protected areas for conservation of amphibian, bird and mammal species

21.3 The protected area management loop

21.4 Current and historical distribution of the greater prairie chicken

(Tympanuchus cupido pinnatus), USA

661

21.5 Combined threat and severity ratings to determine threat magnitude

21.6 Combined assessments of threat irreversibility and magnitude to prioritise management actions

671

21.7 Threat summary rating for an example ecosystem

22.1 Indicative location on the African continent, Rwenzori Mountains National Park, Uganda

22.2 Indicative location on the Indian subcontinent, Nanda Devi Biosphere Reserve, India

22.3 Indicative location in Europe, Mount Athos, Greece

22.4 Indicative location on the Iberian Peninsula, Montserrat, Catalonia, Spain

22.5 Steps in the conservation planning process

23.1 Illustration of incremental, tourism operator-driven developments within protected areas, for a hypothetical waterfall attraction

23.2 Butler's tourism destination lifecycle 725

23.3 Scales of tourism businesses $\quad 729$

23.4 Brand positioning pyramid, Ningaloo-Shark Bay, Australia 735

23.5a Uluru-Kata Tjuta National Park and World Heritage Area Australia: standard image 736

23.5b Uluru-Kata Tjuta National Park and World Heritage Area Australia: 'Uluru experience' 736

24.1 The operations cycle 753

24.2 Corporate 'line of sight' to operations 754

24.3 'Levels of Protection' step process for determining environmental and cultural program operational priorities

760

24.4 'Levels of Service' step process for determining visitor experience program operational priorities 



\section{Tables}

$2.1 \quad$ Some post-1945 protected area events 14

2.2 Details of the protected area definition 16

3.1 Twelve distinct climates of Earth 49

3.2 Described eukaryote species and possible total number of species 53

3.3 Selected biogeographic classification systems for terrestrial, freshwater and marine areas 55

3.4 Examples of major ecosystem types in marine and freshwater environments 64

$\begin{array}{lll}3.5 & \text { Protected area coverage of terrestrial realms } & 67\end{array}$

3.6 Protected area coverage of terrestrial biomes 68

3.7 Selected methods for biodiversity conservation prioritisation 70

4.1 Cultural and protected area values 107

$\begin{array}{lll}4.2 & \text { Comparing cultural and protected area values } & 108\end{array}$

7.1 What is the difference between management and governance? 171

7.2 Understanding governance in the IUCN definition of protected areas 176

7.3 Possible combinations of national and international recognition of conserved areas (de facto conservation)

7.4 Considerations helpful to assess 'quality of governance' in different circumstance and under all governance types

8.1 Management frameworks and tools for assisting protected area management (organised by management function)

8.2 Examples of international conventions relevant to protected area management 225

9.1 Capacity development at different scales 261

9.2 Comparison of approaches to training and learning 274

9.3 The difference between certification and certificate qualifications 279

9.4 References and training materials for protected areas 281

10.1 Points at which to intervene in a system, ordered by increasing leverage 317

13.1 Shifts in approach to conservation planning 389

14.1 Communities and stakeholders in environmental and natural resource management, with examples relevant to protected area management 423

14.2 The purposes of participation, with examples relevant to protected area management 426

14.3 The timing of engagement, with generic examples from protected area management 429

16.1 Threats to protected areas: Examples of direct threats 477

16.2 Threats to protected areas: Examples of indirect threats 479

16.3 Threats to protected areas: Examples of underlying causes 480

17.1 Examples of impacts on biodiversity from changes in climate and
atmospheric parameters

Factors that will increase the vulnerability of Australian taxonomic groups
to climate change

17.3 Examples of impacts from changes in climate on values held by humans for natural
and cultural phenomena

17.4 Examples of climate change impacts and working with communities 510

18.1 Principal human-induced threats to geoheritage in protected areas 536

18.2 Key elements of a geoheritage protected area system 542

18.3 Examples of geoheritage protected areas in the IUCN management categories 547

18.4 Geoheritage and the appropriate IUCN management category 547

18.5 Category III protected areas compared with other categories 548

18.6 Classification of geosite types for conservation management in the United Kingdom 553

19.1 Estimates of inland wetland area (million hectares) 572

19.2 Environmental flow methods: Comparison of the four main types of methods used worldwide to estimate environmental flows = environmental water allocations (EWA) 582 
19.3 Criteria for listing Wetlands of International Importance and long-term targets for the Ramsar List $\quad 590$

19.4 Number of inland freshwater wetlands included in the Ramsar List as of February 2014591

20.1 Pioneer large-scale marine protected areas 616

20.2 Five marine protected area governance approaches with examples 625

20.3 Five categories of incentives 626

20.4 Limits for planning settings 632

21.1 Threat categories and some examples of the current unified IUCN-CMP classification of conservation threats $\quad 669$

21.2 Example of a selection template for ecological integrity monitoring measures 673

21.3 General guideline on the number of observations required to detect trends 677

$\begin{array}{lll}22.1 & \text { Cultural heritage values } & 707\end{array}$

23.1 Types of official visitors to protected areas (including Indigenous Peoples' and

23.2 Indicative visitor use of protected areas 719

23.3 Visitor management considerations for protected areas 721

23.4 Alternative methods for entry charges 731

23.5 Methods for collecting revenue from the tourism industry 731

23.6 Visitor research tools $\quad 733$

23.7 Positioning a protected area $\quad 735$

23.8 Carrying capacity definitions 743

24.1 Indicative operations business milestone checklist 763

24.2 Components of a project plan for operations 764

26.1 Incidents relevant to protected areas 826

26.2 Climate change predictions and implications for incident management 827

26.3 NSW National Parks and Wildlife Service risk management for fire management 829

$26.4 \quad$ Potential protected area incident management plans 831

26.5 Prevention actions to minimise incidents 833

27.1 Types of monitoring indicating their purpose, targets and associated risks 867

28.1 Approaches to assessing the effectiveness of protected areas 892

28.2 Criteria for each element in the IUCN WCPA Framework 907

28.3 Headings for the indicator matrix 908

28.4 Example of a four-point scale measuring aspects of ecological integrity 909

28.5 A summary of actions taken to improve management effectiveness in
South Africa, 2010-14

$28.6 \quad$ CapeNature METT-SA Results 921 
Acknowledgments

Protected Area Governance and Management is a free, e-available resource for students and practitioners. The book has been achieved thanks to the enormous collective volunteer and professional efforts by many people from around the world: International Union for Conservation of Nature (IUCN) World Commission on Protected Areas (WCPA) members; other IUCN Commission members; IUCN Global Programme on Protected Areas personnel; scientists and researchers; protected area practitioners and experts; the professional expertise of cartographers and graphic artists; and the editors and designer from the ANU Press production team. Here we, the five editors of the book, extend our particular appreciation for these inputs.

\section{Institutional support}

\section{World Commission on Protected Areas}

The concept of the book project was supported in June 2010 by WCPA Chairperson Nik Lopoukhine at the Jasper, Canada, meeting of the WCPA. It was then endorsed as an official WCPA Project at the full WCPA Steering Committee meeting in April 2011 in Gland, Switzerland. Refinements to the structure, content and competency levels to be targeted were developed by the WCPA in Costa Rica in May 2012. Particular contributions at this time by Eduard Müller and David Reynolds assisted with the book's development. A plan for the development of the book was finalised in July 2012 following considerable feedback and the full (volunteer) production process of the book commenced. Many WCPA Steering Committee members undertook principal author roles. A review of progress was completed at the Montenegro WCPA meeting in April 2013 and further adjustments were made to the book's structure. These were endorsed by WCPA Chair, Ernesto Enkerlin, and Deputy Chair, Kathy MacKinnon. Appreciation is expressed to the WCPA Steering Committee and other WCPA members for the input to and support for the book concept over this four-year development period.

\section{Global Programme on Protected Areas}

The IUCN's Global Programme on Protected Areas (GPAP) and the Biodiversity and Protected Areas Management Programme (BIOPAMA) team have been particularly supportive of this book concept from its inception. The editors would like to express our appreciation to Trevor Sandwith and the GPAP and BIOPAMA teams for their assistance and support. In particular, we would like to thank Roxana Bucioaca, Nick Cox, Delwyn Dupuis, Deborah Murith, David Reynolds, Pedro Rosabal and Zsuzsa Toros.

\section{Sponsors}

Appreciation is expressed to our sponsors for their commitment to, and financial and in-kind support for, this project. We have recognised each sponsor organisation on pages ii-iii.

\section{Indigenous and Community Conserved Areas Consortium}

Members of the Indigenous and Community Conserved Areas Consortium were most helpful in locating sources of information and people who could provide inputs to the book, and a collective thanks is extended to the Consortium.

\section{Production support}

\section{Book steering committee}

The formative development of the book was guided by a WCPA Steering Committee comprising Kathy MacKinnon (Chair), David Reynolds, Eduard Müller, Dan Laffoley and Nigel Dudley. Their assistance was particularly important for shaping the book's structure and contents. Kathy's feedback on the book as it has evolved has been particularly appreciated.

\section{Chapter, case study and special box authors}

This book is founded on the special expertise of our authors, and we extend our appreciation for their essential contributions. Authors of boxes have provided technical background and insight into special subjects, and case study authors have helped to bring the book to life with their illustrative examples from all over the world. Acknowledgment for authors is provided in each chapter, and special recognition for others who may have assisted with the chapter development. 


\section{Photographers}

Every photograph published in this book complements the text and aims to provide a protected area-related educational message. We extend our sincere appreciation to photographers who provided images for the book.

\section{Illustrator}

We sincerely thank Ian Charles of Nature Tourism Services for his commitment, support and extensive work in producing most of the figures presented in this book.

\section{Maps - US National Park Service}

The Director of the US National Park Service (NPS), $\mathrm{Mr}$ Jon Jarvis, pledged support for the development of this book and specifically for sponsoring the development of the many maps. This assistance has been greatly appreciated. The editors have particularly appreciated the facilitation provided by David Reynolds throughout the development of the book. Many other NPS staff assisted with the book production process. In particular the editors would like to thank Don Kodak, Stephen Morris, Thomas Patterson (Senior Cartographer) and Lori Simmons (Cartographer).

\section{Maps and data - United Nations Environment Programme, World Conservation Monitoring Centre}

The United Nations Environment Programme, World Conservation Monitoring Centre (UNEPWCMC) based in Cambridge, United Kingdom, has collaboratively developed protected area management related maps; undertaken data analysis of the World Database on Protected Areas; and developed figures for the book. This work, led by Naomi Kingston, has been greatly appreciated. To Naomi and her team, for their hard work and timely assistance, we would like to extend our special thanks and in particular we thank Diego Juffe-Bignoli, Brian MacSharry and Yichuan Shi.

\section{Other mapping work}

Our thanks are extended to Clinton Jenkins for the animal richness map (Chapter 3) and for the work completed by Bastian Bertzky in checking and refining the maps prepared for Chapter 3 .

\section{Website}

Our website <protectedareabook.org> was developed and maintained as a volunteer contribution by WCPA Deputy Vice Chair (Connectivity Conservation and Mountains) Linda McMillan. This communication tool has been enormously supportive for book stakeholders and the editors throughout the book production process. We have greatly appreciated Linda's creativity in developing the site and her constant updating work.

\section{ANU Press publishing and production}

Our special thanks are extended to Lorena Kanellopoulos and the ANU Press staff and contractors for their professionalism, dedication and perseverance. We would like to sincerely thank David Gardiner, Information Editor; Beth Battrick, Editorial Assistant; Jan Borrie, Copyeditor; and Teresa Prowse, Designer.

\section{ANU Fenner School}

The Australian National University Fenner School of Society and Environment hosted the Project Manager during the book's production. Special thanks are extended to Professor Stephen Dovers and Kevin Mahoney.

\section{Peer reviewers}

Every chapter of this book was reviewed by at least one person with expertise relevant to the chapter topic. In addition, the entire manuscript was subject to a doubleblind review implemented by Professor Brian Kennett and Professor Mike Smithson of The Australian National University. Authors have received and responded to the constructive comments and criticisms provided by these reviews in a process overseen by the editors. We sincerely thank these reviewers for their valuable time and expertise: Harry Biggs; Tom Brooks, IUCN; Guy Castley, Griffith University; Jose Corrau, IUCN; Don Driscoll, The Australian National University; Michael Dunlop, Commonwealth Scientific and Industrial Research Organisation; Stephen Dovers, The Australian National University; Penny Figgis AM, IUCN WCPA Vice-Chair, Oceania; James Fitzsimons, The Nature Conservancy; Ghana Gurung, WWF Nepal; Dave Harmon, George Wright Forum; Graham Kelleher; Robyn Kruk; Nik Lopoukhine; Gregor Manson, Australian Government; Karen Markwort, Great Barrier Reef Marine Park Authority; Geoffroy Mauvais, IUCN; Sue Moore, Murdoch University; Catherine Pickering, Griffith University; David Salt, The Australian National University; Peter Shadie, IUCN; Dermot Smyth; André Sovinj, Klagenfurt University; Andy Spate; Sharon Sullivan, James Cook University; Martin Taylor, WWF; and Peter Valentine, James Cook University. 


\section{The Editors}

GRAEME L. WORBOYS has 42 years of protected area management experience, is $\mathrm{Co}-\mathrm{Vice}-\mathrm{Chair}$, Connectivity Conservation and Mountains, International Union for Conservation of Nature, World Commission on Protected Areas (IUCN WCPA), Managing Director of Jagumba Consulting Pty Ltd and an Adjunct Fellow at the Fenner School, The Australian National University.

MICHAEL LOCKWOOD has 36 years' experience as an environmental practitioner and academic and is an Associate Professor, Geography and Spatial Science, School of Land and Food, University of Tasmania, Australia.

ASHISH KOTHARI has worked and published on conservation issues for $\mathbf{3 6}$ years, is a founding member of Indian environmental group Kalpavriksh, has taught at the Indian Institute of Public Administration, co-chaired the International Union for Conservation of Nature (IUCN), Theme Group and Strategic Direction on Governance, Livelihoods, Equity in Relation to Protected Areas, and helped found the global ICCA Consortium.
SUE FEARY is an archaeologist and national park manager, with 25 years' experience in management of natural and cultural heritage and consulting with Aboriginal Australians.

IAN PULSFORD has 36 years of protected area management experience, is an independent consultant and is a member of the IUCN WCPA, Connectivity Conservation and Mountains theme, Australia.

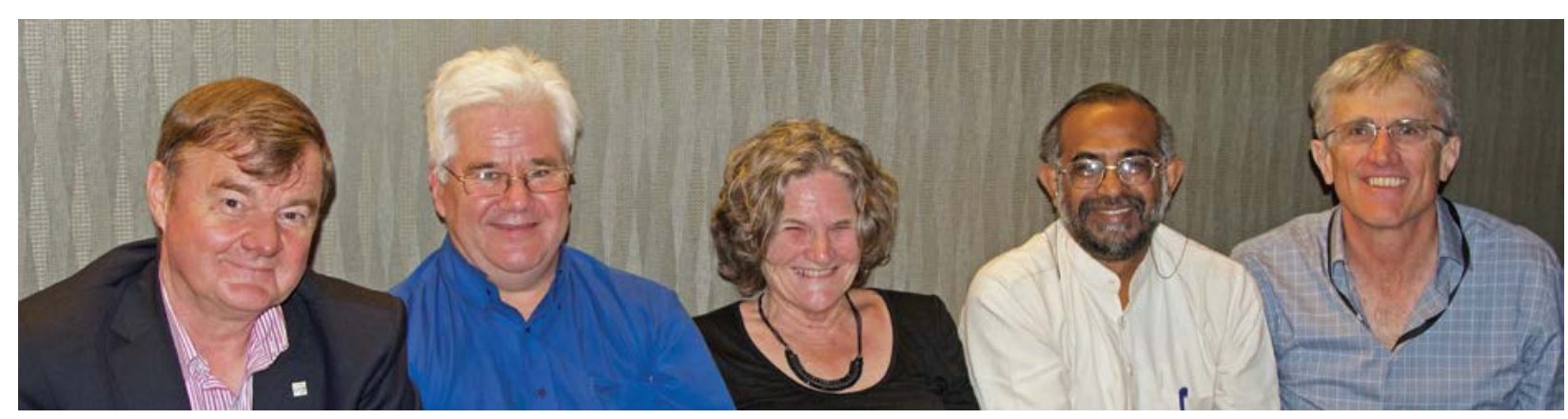

Book authors and editors (left to right): Graeme L. Worboys; Michael Lockwood; Sue Feary; Ashish Kothari and lan Pulsford Source: Lorena Kanellopoulos 
Protected Area Governance and Management

Reproduction of this ANU Press publication for educational or other non-commercial purposes is authorised without prior written permission from the copyright holder, provided the source is fully acknowledged. Reproduction of this publication for resale or other commercial purposes is prohibited without prior written permission of the copyright holder. 


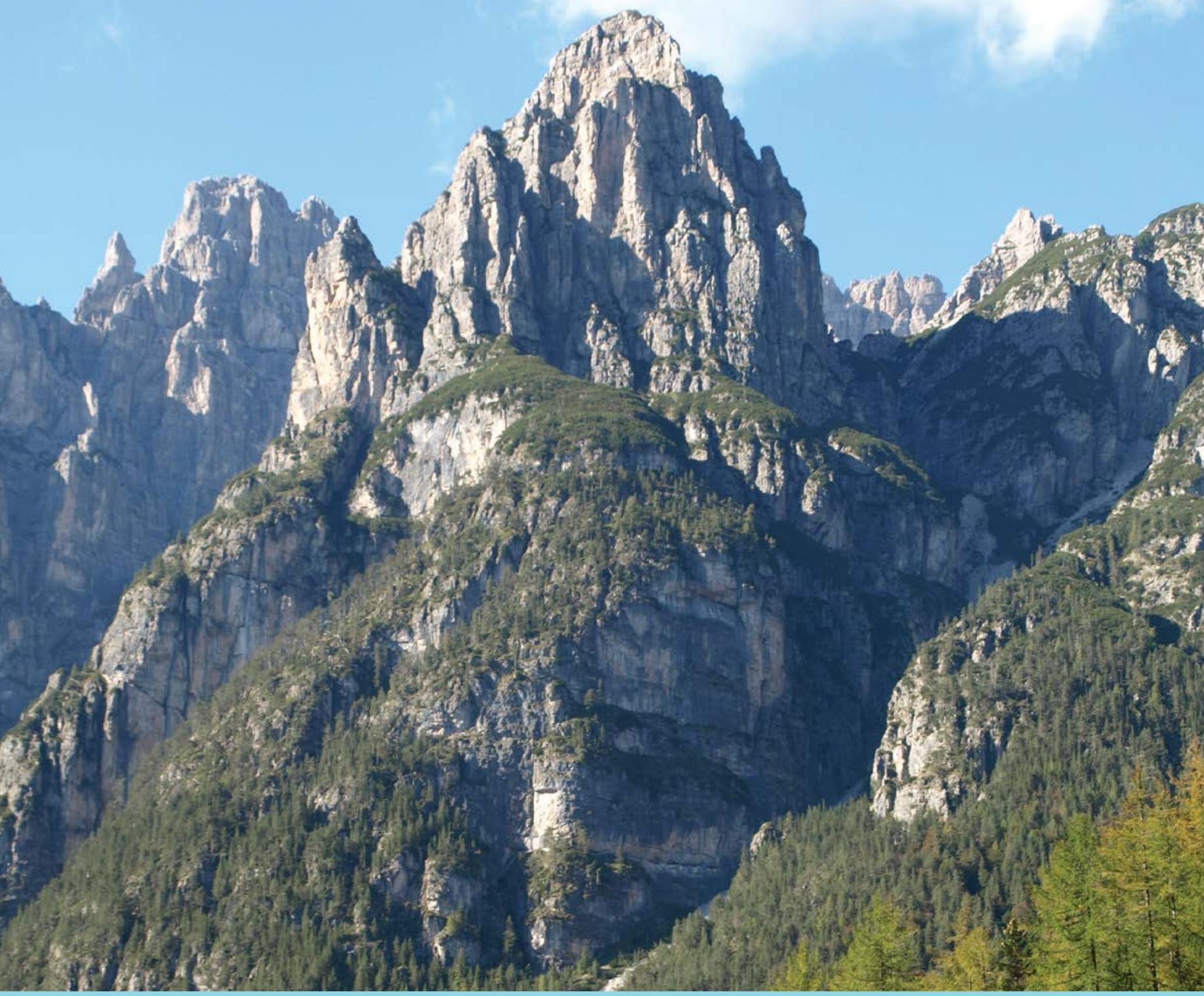

FOREWORD

Principal author:

Trevor Sandwith

\section{Supporting authors:}

Kathy MacKinnon and Ernesto Enkerlin Hoeflich

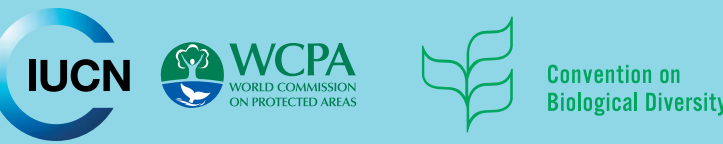




\section{PRINCIPAL AUTHOR}

TREVOR SANDWITH is Director of the International Union for Conservation of Nature (IUCN) Global Protected Areas Programme, and overall Director of the IUCN World Parks Congress 2014.

\section{SUPPORTING AUTHORS}

KATHY MACKINNON is Deputy Chair of the IUCN World Commission on Protected Areas.

ERNESTO ENKERLIN HOEFLICH is Chair of the IUCN World Commission on Protected Areas.

\section{ACKNOWLEDGMENT}

Pedro Rosabal is thanked for reviewing an early draft of the manuscript.

\section{CITATION}

Sandwith, T. S., MacKinnon, K. and Enkerlin Hoeflich, E. (2015) 'Foreword', in G. L. Worboys, M. Lockwood, A. Kothari, S. Feary and I. Pulsford (eds) Protected Area Governance and Management, pp. xxi-xxvi, ANU Press, Canberra.

\section{TITLE PAGE PHOTO}

Dolomites, World Heritage Property and protected area, Italy

Source: Graeme L. Worboys 


\section{Foreword}

The world's more than 200000 protected areas come in many forms, on land and at sea, and occur in every country (Bertzky et al. 2012). They are places that people establish to conserve natural and cultural heritage and to sustain their benefits for society. Among other values, protected areas allow people to connect with nature for their inspiration, education, wellbeing and recreation. While protecting ecosystems that are essential for life, they can support human livelihoods and aspirations and offer nature-based solutions for the complex challenges faced by the world today. Contemporary systems of protected areas include a great variety of areas established over generations by diverse actors and for many purposes, yet they have some very important features in common, regardless of their origins or their direction. The International Union for Conservation of Nature (IUCN) definition of a protected area creates a common framework for understanding the essence of the governance and management regimes that are at the heart of every protected area as a 'clearly defined geographical space, recognised, dedicated and managed, through legal or other effective means, to achieve the long-term conservation of nature with associated ecosystem services and cultural values' (Dudley 2008:8).

Protected areas are the cornerstones of biodiversity conservation. In recognition of this role, the Convention on Biological Diversity (CBD) adopted a Programme of Work on Protected Areas (PoWPA), including recommendations from the 2003 IUCN World Parks Congress (CBD 2004; IUCN 2005). Subsequently, the CBD adopted the Strategic Plan for Biodiversity 2011-20, with 20 Aichi Targets (CBD 2011), many of which depend on the successful implementation of protected area systems and sites. In particular, Target 11 on Protected Areas requires that:

By 2020, at least 17 per cent of terrestrial and inland water, and 10 per cent of coastal and marine areas, especially areas of particular importance for biodiversity and ecosystem services, are conserved through effectively and equitably managed, ecologically representative and well-connected systems of protected areas and other effective area-based conservation measures, and integrated into the wider landscapes and seascapes (CBD 2012).

Achieving Target 11 will also contribute to achieving many of the other Aichi Targets but requires much greater investment in capacity development for implementation, as these targets emphasise quality over quantity and greater integration within conservation and

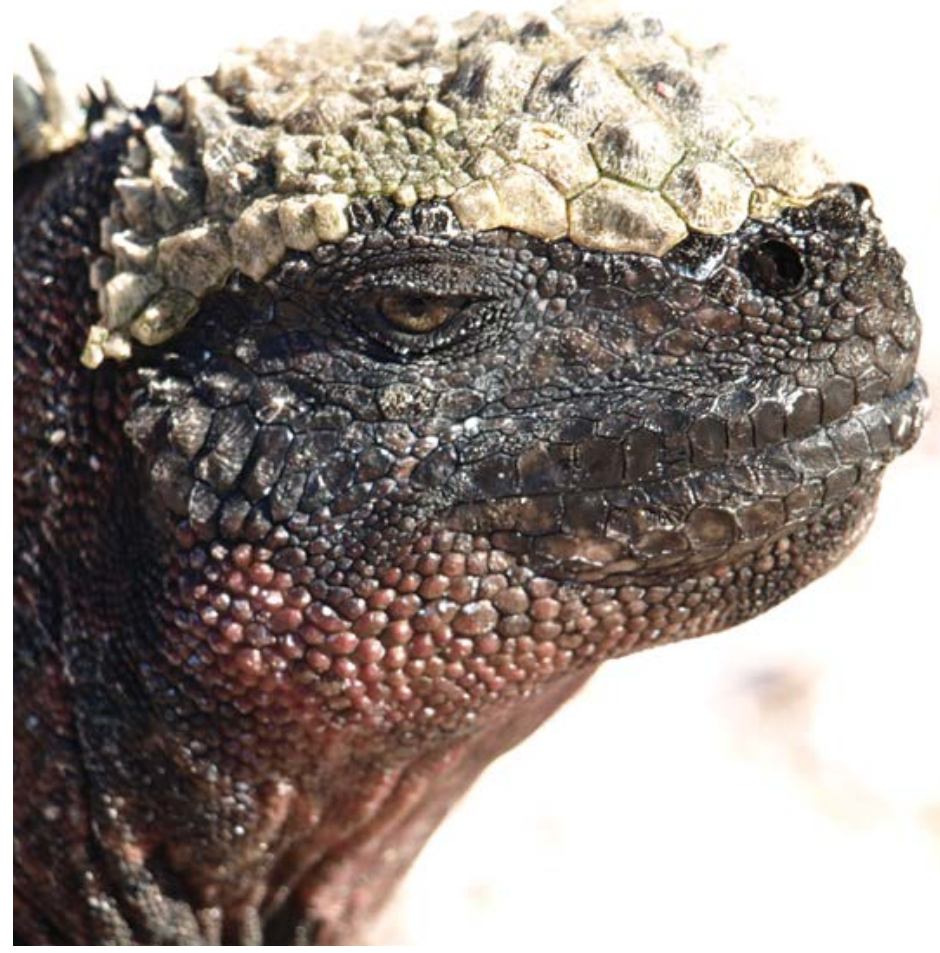

Marine iguana (Amblyrhynchus cristatus), Galápagos National Park World Heritage Property Source: Graeme L. Worboys

development planning arenas. The decisions of the CBD request the IUCN, its World Commission on Protected Areas (WCPA) and other organisations to provide specific guidance to the parties on how to implement these goals, many aspects of which are not well understood. This book is one such contribution to developing capacity among conservation professionals for improved planning, management and governance of protected area sites and systems. It builds on the IUCN's long history of producing guidance designed to strengthen protected area management (MacKinnon et al. 1986; IUCN 2005; Lockwood et al. 2006), including the IUCN WCPA Best Practice Guideline Series. A key feature of this book is to promote better governance of protected areas and thereby to promote more effective management that will achieve the desired outcomes. In some countries, all areas that meet the IUCN definition are regarded as part of the national system of protected areas; in others, some forms of protected or conserved areas, and particularly those that are established by non-state actors, are not yet fully recognised (Borrini-Feyerabend et al. 2013). The IUCN, however, maintains a wide and inclusive definition and promotes the appropriate recognition of all forms of protected areas, however they are established, governed and managed, allowing also for the recognition of a variety of 'other effective area-based conservation measures'. Achieving more effective and equitable management requires the appropriate capacity among all institutions and individuals involved. This volume provides an accessible and valuable resource to underpin future capacity development efforts. 


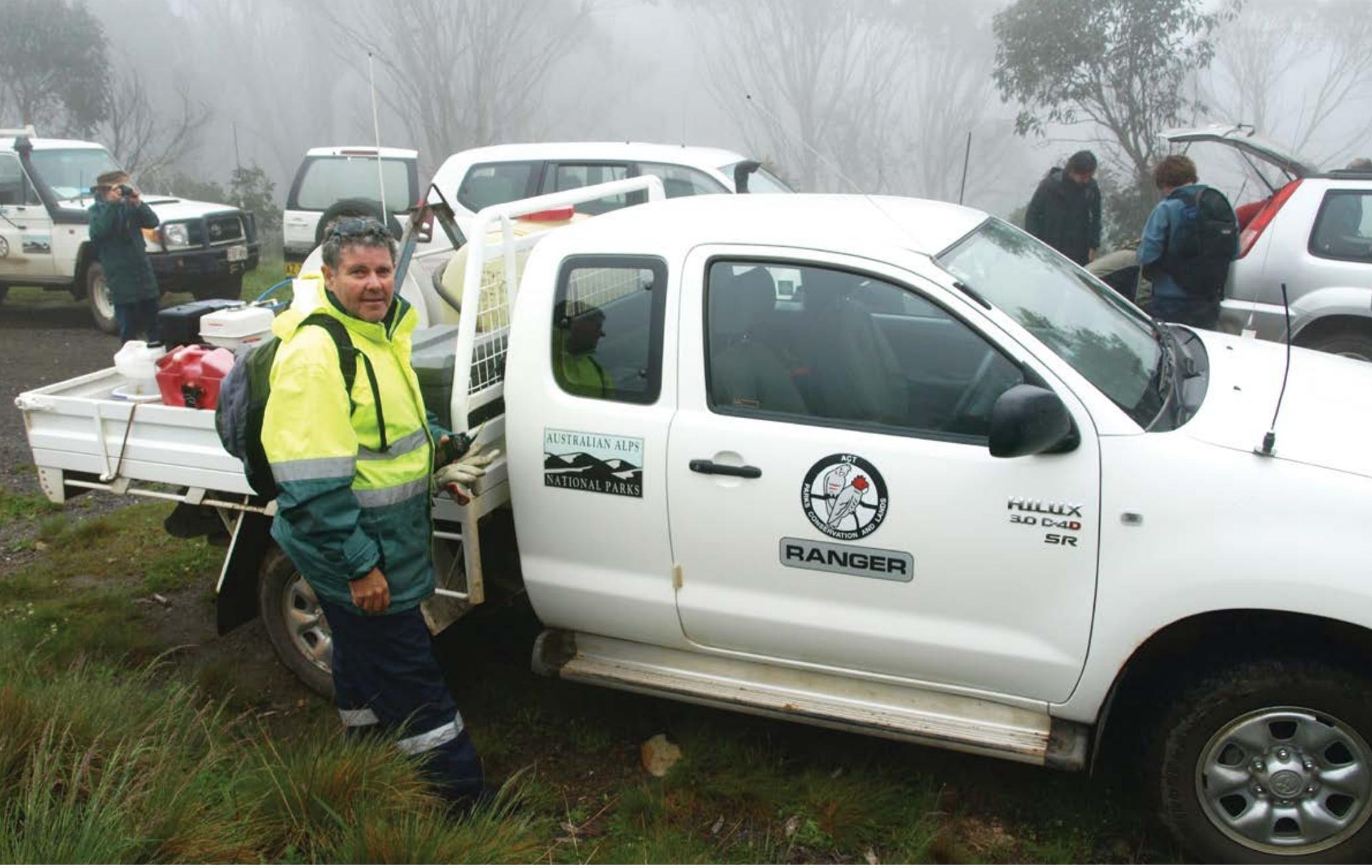

Namadgi National Park Ranger Dave Whitfield, Australian Capital Territory, Australian Alps

Source: Graeme L. Worboys

Capacity development is a complex enterprise involving individual and institutional strengthening in support of enhanced implementation and performance. At its heart, learning, education and training encompass a complex of approaches that can contribute to individual and institutional competencies to achieve the desired outcomes. In both formal and informal education, this can involve determining levels of competence and the understanding and skills required by institutions and individuals to govern and manage protected areas. In more formal settings, this includes the senior administrators who have overall responsibility for protected area networks, protected area managers responsible for sites and those who carry out the many day-to-day management roles - that is, the field rangers and staff and the communities involved in the protected area sites. For management to be effective, all of these players must be enabled by competent community or public institutions that include the full range of actors who together can manage complex operational conservation and sustainable development programs.

If one's purpose is to deliberately enhance capacity in an accountable way, first, standards for competence and accredited qualifications must be established and applied for protected area professionals. Second, once the competencies for effective performance have been established, a broad spectrum of learning methods, both formal and informal, is required to prepare individuals for their roles as professionals in this field. These can include residential and distance learning, universitybased, college and school programs that lead to degrees, diplomas and certificates, and may themselves incorporate experiential learning through internships, assignments and other field-based applications. Informal education and training approaches include an even more diverse range of in-service training, mentored learning, apprenticeships, peer-to-peer exchanges, self-study or simply learning by doing in practice. The learning methods vary according to the competencies. For example, the capture and care of wild animals require a very different learning environment compared with the design of an effective business plan, and yet both are needed for the implementation of a translocation policy to maintain genetic diversity in wildlife management. The complexity of interdisciplinary skills needed for these functions demands much more than the average training program, and the learning process needs to be conducted by individuals who are not only technically competent themselves, but also able to facilitate adult education and training - a demanding and skilled profession. 
Finally, apart from the availability, willingness and motivation of the individuals who become involved in the capacity development process itself, there is the whole question of the resources that are available to support the processes described above. These include not just the physical resources of space and facilities, the time required for learning to take place, the availability of skilled educators, trainers and mentors, the existence of institutions which are prepared to invest in the development of professional skills, and the financial resources to support the process, but also the intellectual learning resources that will support study and learning. Fortunately, the world of protected areas and the people involved in them have been willing to lend their experience towards the development of such resources.

The IUCN and WCPA have a long-term commitment to strengthening protected area management and governance and to providing the resource materials, best-practice guidelines and training to strengthen protected area management. Many of these efforts have been derived from hard-won experience in the field and involved the broader WCPA network of conservation professionals applying their expertise to the resolution of problems faced in practice. The WCPA's voluntary specialist groups and task forces have played a key role in developing best-practice materials and expanding professional skills and networks for protected areas globally. Many have contributed actively to this volume. The value of these initiatives has been recognised by the parties to the CBD, who have exhorted the IUCN, and specifically the WCPA and other international organisations, to develop further guidance on new and emerging topics relevant to protected area management.

While there remain significant challenges for ensuring competent management and governance of protected areas to meet their goals, protected area professionals are also required increasingly to meet new demands and challenges and their job is becoming ever more complex. The rationale for the establishment of protected areas includes the maintenance of the functions and value of natural ecosystems to address, amongst other objectives, the concerns and needs of human society. Rather than being 'set aside', these areas are a legitimate and wise use of land and aquatic resources that will provide value to society both now and in the future. These life-support and ecosystem service functions will become ever more valuable as ecosystems in the production landscape are compromised by over-extraction, habitat loss and degradation. It is increasingly apparent that many protected areas not only provide essential ecosystem services, but also can contribute natural solutions to critical environmental challenges (Lopoukhine et al. 2012).

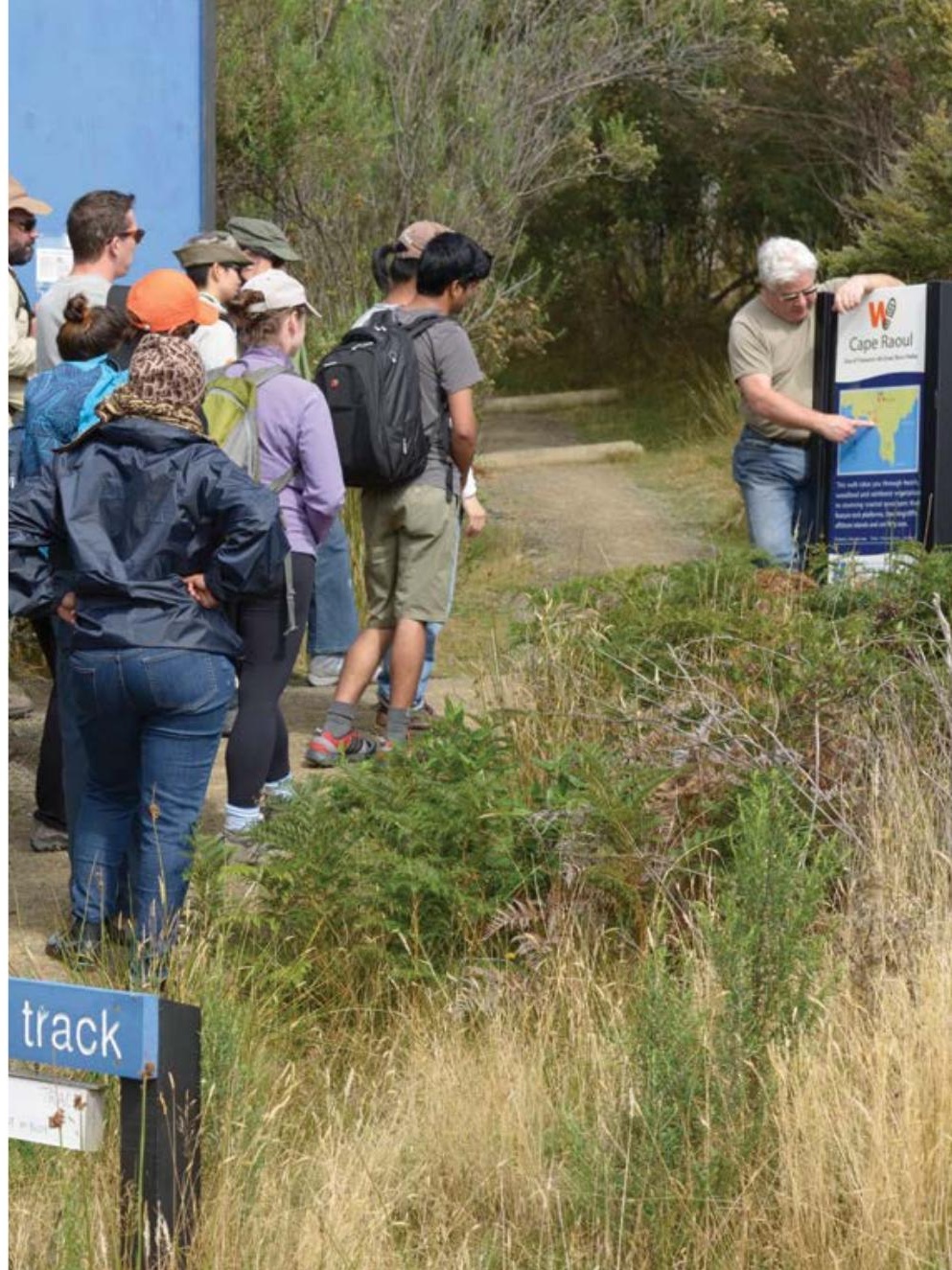

Protected area management students,

Tasman National Park, Tasmania, Australia

Source: Graeme L. Worboys

There are two main gaps in knowledge, understanding and practice that this situation presents. On the one hand, protected area managers have to face up to the increasing pressures on the protected area systems themselves. For example, at the system and site scales, they have to deal with the impact of a changing climate, and how this affects the distribution and viability of wild populations in changing environments, or how the changed behaviour of alien invasive species affects the integrity of conserved natural ecosystems. On the other hand, protected area systems can also be part of the solution to new challenges faced by society, such as sealevel rise and storm surges that affect coasts and islands, or the increased incidence and severity of fire due to seasonal weather changes. The governors and managers of these areas need knowledge and skills both to manage and mitigate the impacts on protected areas and to collaborate with other sectors of society concerned with finding solutions to such issues as global climate change, human health and wellbeing, addressing food and water security and managing for disaster risk reduction.

To do this, protected area practitioners' capacity to govern, plan and manage in multi-agency and multistakeholder settings has to be enhanced. It takes diverse skills and resources to address the implementation of 


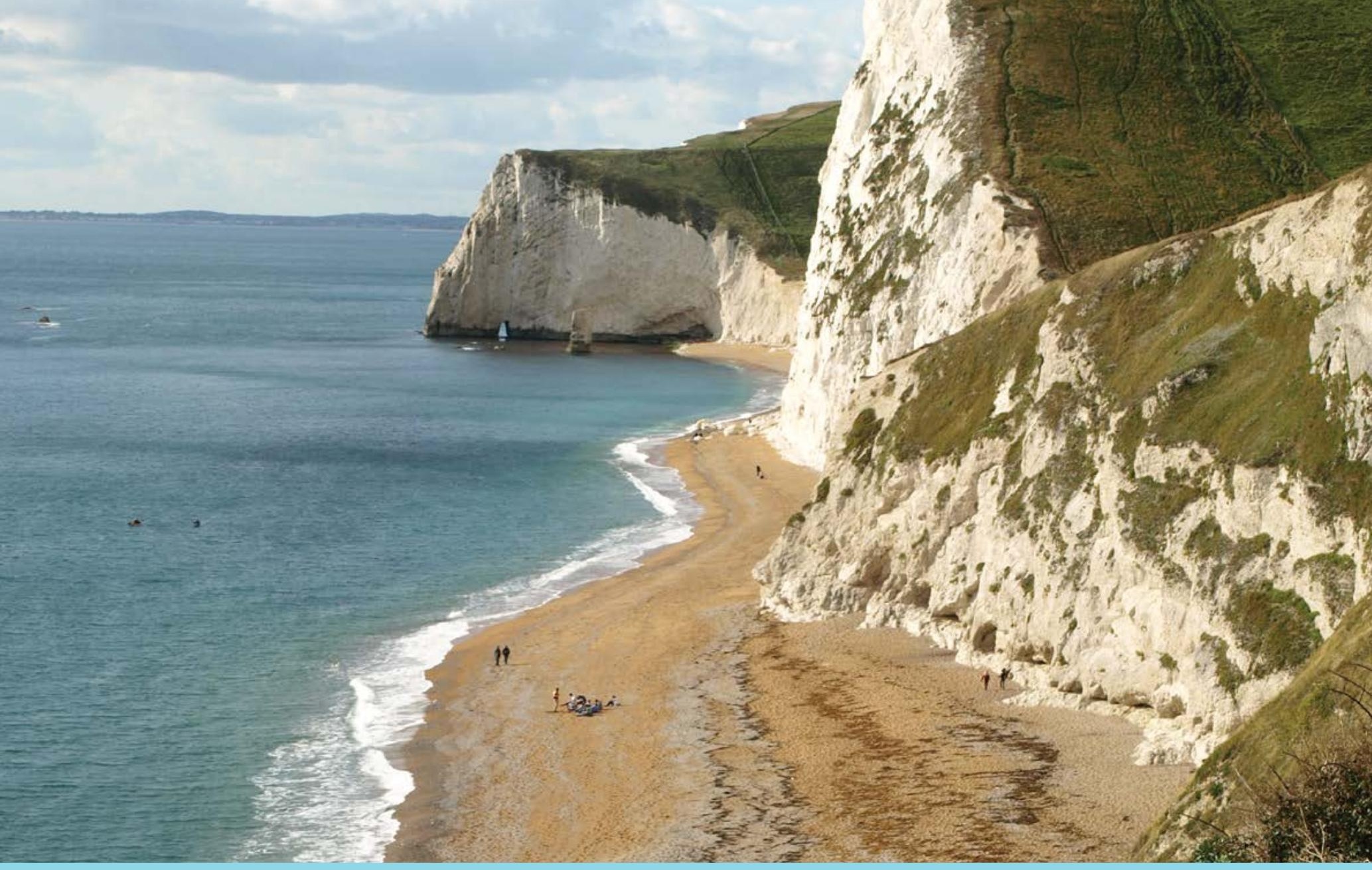

CHAPTER 1

INTRODUCTION

Principal author:

Graeme L. Worboys

IUCN 5 WCPA 


\section{PRINCIPAL AUTHOR}

GRAEME L. WORBOYS is Co-Vice-Chair, Connectivity Conservation and Mountains, International Union for Conservation of Nature World Commission on Protected Areas and an Adjunct Fellow at the Fenner School, The Australian National University.

\section{ACKNOWLEDGMENTS}

Sue Feary, lan Pulsford, Ashish Kothari and Michael Lockwood, are thanked for reviewing an early draft of this chapter.

\section{CITATION}

Worboys, G. L. (2015) 'Introduction', in G. L. Worboys, M. Lockwood, A. Kothari, S. Feary and I. Pulsford (eds) Protected Area Governance and Management, pp. 1-8, ANU Press, Canberra.

\section{TITLE PAGE PHOTO}

Dorset and East Devon Coast World Heritage Property, United Kingdom. The cliffs and coastline of this World Heritage property conserve globally significant geological and geomorphological features including fossil rich exposures of $\mathbf{1 8 5}$ million years of Earth's history for the Triassic, Jurassic and Cretaceous.

Source: Graeme L. Worboys 


\section{Box 1.1 A note from the editors}

This book is about the governance and management of protected areas. It presents a compendium of original text, case studies and examples from across the world, by drawing on the literature, and on the knowledge and experience of those involved in protected areas. The book can be used as a reference text by protected area practitioners (including local communities) and professionals; in student teaching; for informing policy makers; and for wider public education. It is intended as an investment in the skills and competencies of people and consequently, the effective governance and management of protected areas for which they are responsible, now and into the future.

The book synthesises current knowledge and cuttingedge thinking from the diverse branches of practice and learning relevant to protected area governance and management. Each of the book's 27 subject chapters explores a specific component of protected area governance and management, from the pragmatism of managing operations to the subtleties and nuances around the role of protected areas in poverty alleviation and social justice. Although each chapter is presented as a stand-alone resource, every component of managing and governing a protected area affects others - as with ecosystems that protected areas aim to conserve, everything is connected.

The global success of the protected area concept lies in its shared vision to protect natural and cultural heritage for the long term, and organisations such as International Union for Conservation of Nature are a unifying force in this regard. Nonetheless, protected areas are a socio-political phenomenon and the ways that nations understand, govern and manage them is always open to contest and debate. There are different views about protected areas and their role in the protection and conservation of natural features and cultural values. This is healthy, and ensures that protected areas are continually evolving as a concept and improving in how they are governed and managed.
This book does not engage in debate about whether or not protected areas are a good thing; we begin from the position that they are. However, we have not attempted to harmonise chapter information or to present a single intellectual position. Indeed, some of the content does not always reflect the views of some or all of the editors, or the IUCN, but has been included as it constitutes legitimate points of view that will benefit readers' understanding of key topics.

A non-harmonisation approach also means there are variations in how some terms, such as 'landscape', have been used. Differences also occur between chapters about generic matters such as governance, because this reflects the experience and expertise of the chapter authors. Several chapters, for instance, have been written predominantly with large organisations in mind, including governments, NGOs and private bodies. Others are written from a Western science perspective while others make reference to more community-based approaches that employ traditional or local knowledge and/or governance structures. This adds to the richness of this book and ensures its broad application and use for all forms of protected area governance and management.

The book aims to enlighten, educate and above all to challenge readers to think deeply about protected areas-their future and their past, as well as their present. We hope readers will enjoy and benefit from the range of professional and experiential information that has been presented. We also hope readers will feel inspired to contribute to the future of one of the great intergenerational investments of humankind, that of protected areas.
This book has been prepared by the very best and most experienced protected area practitioners and experts from around the world. It is an integrated compilation and has been designed as a learning journey. The journey commences with introductory text on 'the concept and purpose of protected areas' and concludes with a 'management effectiveness evaluation' chapter (Figure 1.1). All steps are important, though compartmentalisation into 29 discrete chapters recognises each chapter as a stand-alone document as well as a critical and integrated part of a larger book. The 'chapter compartmentalisation' recognises a need by universities and other protected area training organisations to use specific management topics for their curricula. It allows for 'cherrypicking' of chapters to suit situational training needs and training audiences at different levels of need. This 'compartmentalised and integrated' approach introduces important design elements to the book. Strong cross-referencing from within each chapter to the larger book is provided. There is also a deliberate reinforcement of some important information in more than one chapter, though there is always only one chapter location where the core subject text resides. 
Concept, Purpose and Challenges

Earth's Natural Heritage

\section{$\rightarrow$ Social and Economic Influences} Shaping Protected Area

$\rightarrow$ Governance for the Conservation of Nature; Capacity Development; Benefiting from Complexity Thinking; Knowledge Generation, Acquisition and Management; Leadership and Executive Management

$\rightarrow$ Engagement and Participation in Protected Area Management, Who, Why, How and When; The Media and Protected Areas

Managing Threats; Climate Change and Protected Areas; Geoconservation in Protected Areas

$>$ Managing Resource Use and Development; Managing Incidents

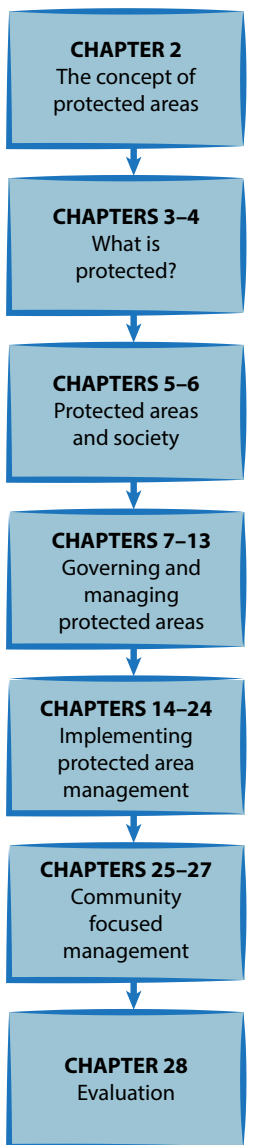

\section{Target Competency Levels}

Skilled Worker - (Patrol Ranger)

> Middle Manager - (Head Ranger)

$\rightarrow$ Senior Manager - (Senior Protected Area Manager), and

Executive - (Protected Area Systems Level Managers and Chief Executives)

Earth's Cultural Heritage

Values and Benefits of Protected Areas

Managing Protected Areas; Planning

Managing Fresh Water, River, Wetlands and Estuarin Protected Areas; Marine Protected Area Management; Managing Protected Areas for Biological Diversity and Ecosystem Functions: Managing Cultural Uses and Features; Visitor Management; Managing Operations and Assets

Area Management Effectiveness

Figure 1.1 Structure and content of Protected Area Governance and Management book

There are different levels of competency training targeted and the book also establishes the opportunity for more than one learning journey. Most chapters target training information for middle and senior levels of protected area managers (Figure 1.1). Typically these chapters are presented as highly referenced and guideline-rich text with case studies and boxes that contain supplementary information. A selection of chapters at different competency target levels may be an approach preferred by readers or there may be a focus. The preferred learning journey for middle managers, for example, may focus on operational topics (Figure 1.2). Systems-level managers may, on the other hand, wish to focus more on subjects that provide a greater depth of theoretical guidance, the presentation of conceptual issues and exposure to the rich experience of global protected area leaders (Figure 1.3). This compendium text provides the opportunity for a range of different learning journeys that can be customised to suit situational capacity development needs.
For the entire book, the Protected Area Governance and Management learning journey commences with Chapter 2 , with its introductory and context-setting information (Figure 1.1). This chapter describes the concept and purpose of protected areas and provides a definition for these areas. It also identifies that the IUCN recognises six protected area management categories and describes each of these. A resource list of the majority of the IUCN World Commission on Protected Area's management guidelines generated between 1976 and 2014 has been itemised in Chapter 2 to provide a valuable aid for readers seeking further protected area management guidance information.

'What is protected by a protected area' is addressed in Chapters 3 and 4. The special natural and cultural heritage values of Earth are described, albeit at an overview level. This information will help protected area practitioners to establish a context and to better appreciate the contribution that their individual protected area is making towards the conservation of the 


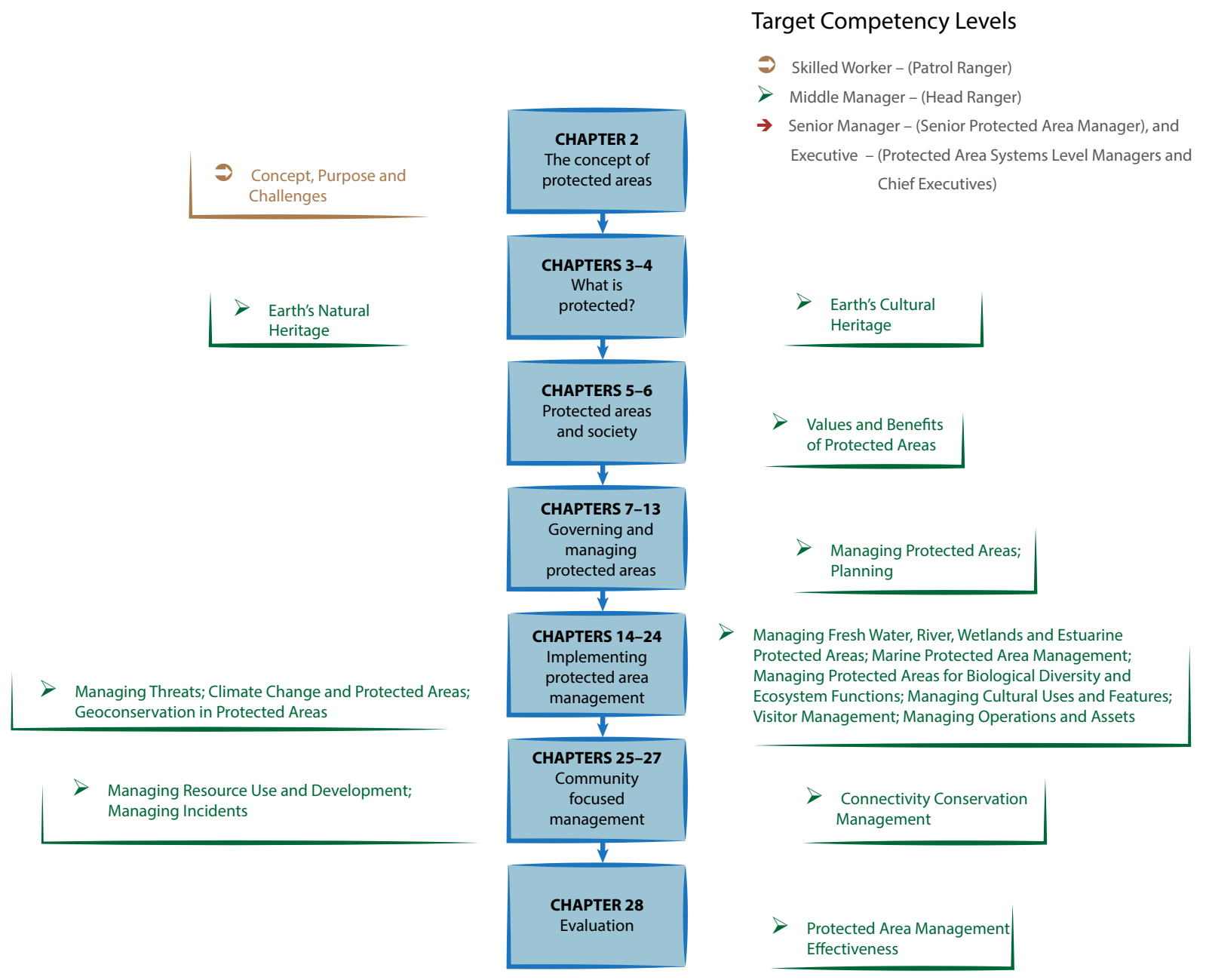

Figure 1.2 A learning journey for middle-level protected area managers focused on information underpinning practical and operational aspects

heritage of Earth. The natural heritage chapter presents ecoregions, hotspots, and Alliance for Zero Extinction and other special areas for biodiversity. For practitioners with responsibilities at the national and international levels, such as protected area systems managers and connectivity conservation managers, this contextual information is particularly important.

Protected areas are a concept of human society; they are supported by society and their status and management are guided and defined by societal influences. Understanding these influences further forms an important part of the protected area learning journey (Chapter 5). This guidance helps with the development of the situational context information needed by practitioners if they are to be effective. The benefits of protected areas are important and can be an integral part of how society views protected areas (Chapter 6). Understanding and communicating these benefits are important parts of securing pride in communities about reserves and their intergenerational role and status.
The next chapters (Chapters 7-13) are about getting organised, undertaking leadership and planning and preparing for well-informed management of protected areas. Implementation by trained staff is also fundamental. Once protected areas are established, they need to be actively and effectively governed and managed given the alternative could be a 'paper park' that is exploited for its plants, animals and other heritage values. This part of the book focuses on how protected areas are governed (Chapter 7) and managed (Chapter 8) and how they ensure that their staff have the right skills and competencies to undertake their work (Chapter 9). Often, the issues faced by protected area leaders and managers are complex, and approaches to dealing with complexity are described (Chapter 10) and timely, relevant and evidenced-based and other information is critical (Chapter 11). Additional inspirational guidance for future protected area leaders has been presented in the chapter dealing with leadership and executive 


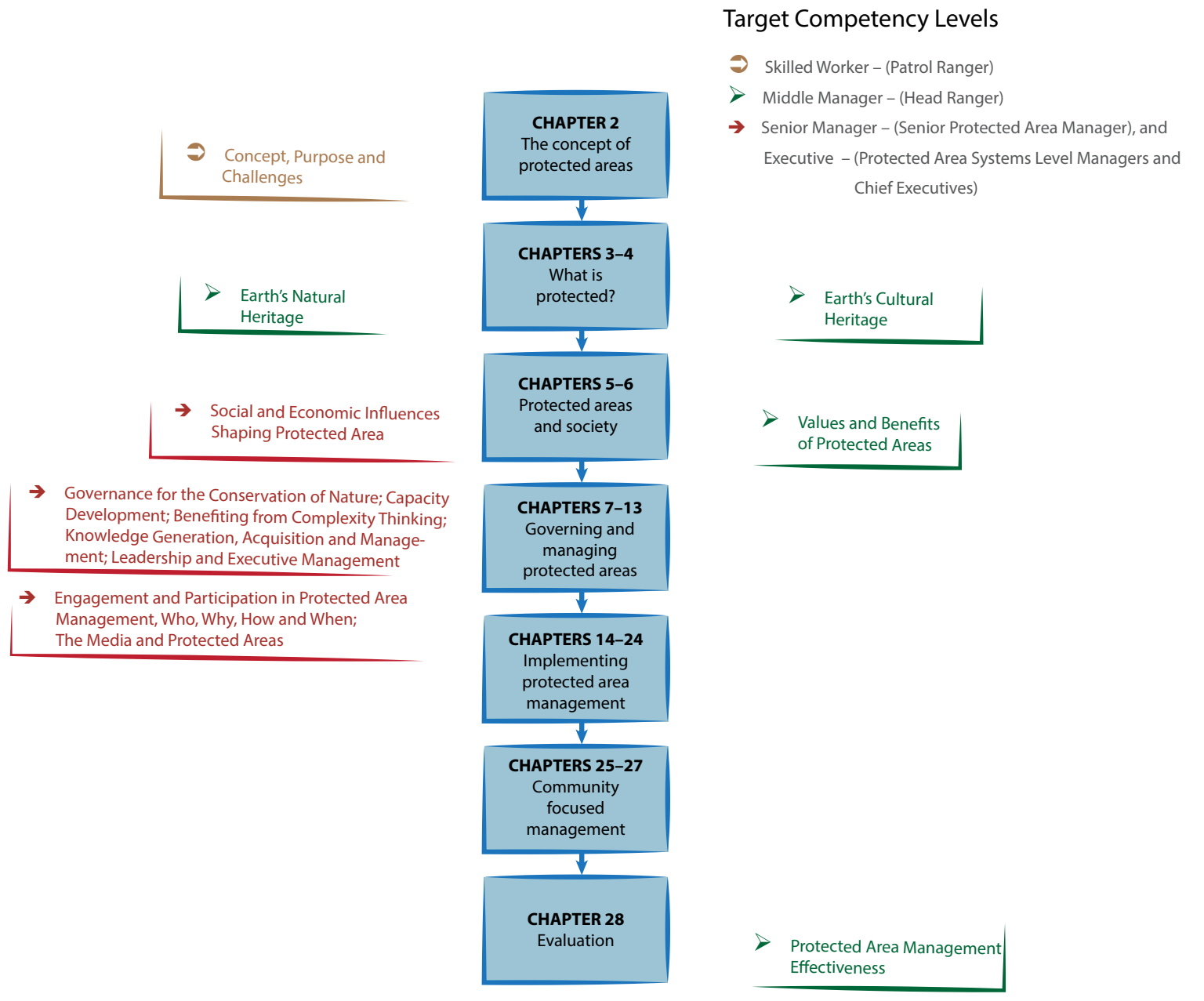

Figure 1.3 A learning journey for senior protected area managers focused on information that underpins protected area systems-level concepts and practice

management (Chapter 12). How managers undertake their planning to achieve improved futures is also presented (Chapter 13).

The 'implementation' chapters (Chapters 14-24) focus on active 'on-ground' and 'on-water' management. At this detailed implementation level, guidance is provided for protected area managers working with neighbours and key stakeholders, given protected areas are an integral part of society and of local communities (Chapter 14). Communicating messages and dealing with the media to provide important information (Chapter 15) form an important part of this role. Understanding and dealing with threats are high-priority tasks for protected areas (Chapter 16), especially the threat of climate change (Chapter 17). Managing for natural heritage requires specialist insights such as for geoheritage (Chapter 18); fresh water and wetlands (Chapter 19); marine protected areas including the high seas (Chapter 20); and biodiversity and ecosystem services (Chapter 21). For cultural heritage, we have focused on managing cultural uses and features (Chapter 22). Visitor use and its management, including tourism, are dealt with (Chapter 23), and how to manage major works in protected areas and to keep track of protected area assets are described (Chapter 24).

Working with the community is a critical part of protected area governance and management and this may include communities living within some protected areas. The topics presented include resource use and development within some protected areas (Chapter 25); dealing with incidents that affect people and livelihoods, both inside and outside reserves (Chapter 26); and managing for connectivity conservation areas, which may interconnect and embed protected areas (Chapter 27).

Our learning journey finishes with the presentation of the chapter dealing with management effectiveness evaluation (Chapter 28). Management effectiveness helps to ensure that protected areas are in fact intergenerational. A conclusion with important insights from more than the two years of development of this compendium text is then presented (Chapter 29). 




\section{PRINCIPAL AUTHOR}

GRAEME L. WORBOYS is Co-Vice-Chair, Connectivity Conservation and Mountains, International Union for Conservation of Nature World Commission on Protected Areas and an Adjunct Fellow at the Fenner School, The Australian National University.

\section{ACKNOWLEDGMENTS}

Appreciation is expressed to Sue Feary, Penny Figgis, Emeritus Professor Larry Hamilton, Ashish Kothari, Michael Lockwood and Emeritus Professor Adrian Phillips who contributed importantly to the content and development of early versions of this chapter. Appreciation is expressed to Ashish Kothari for his contributions to the ICCA sections of the Chapter.

\section{CITATION}

Worboys, G. L. (2015) 'Concept, purpose and challenges', in G. L. Worboys, M. Lockwood, A. Kothari, S. Feary and I. Pulsford (eds) Protected Area Governance and Management, pp. 9-42, ANU Press, Canberra.

\section{TITLE PAGE PHOTO}

Gray Lake Glacier, Torres del Paine National Park, Chile Source: Eduard Müller 


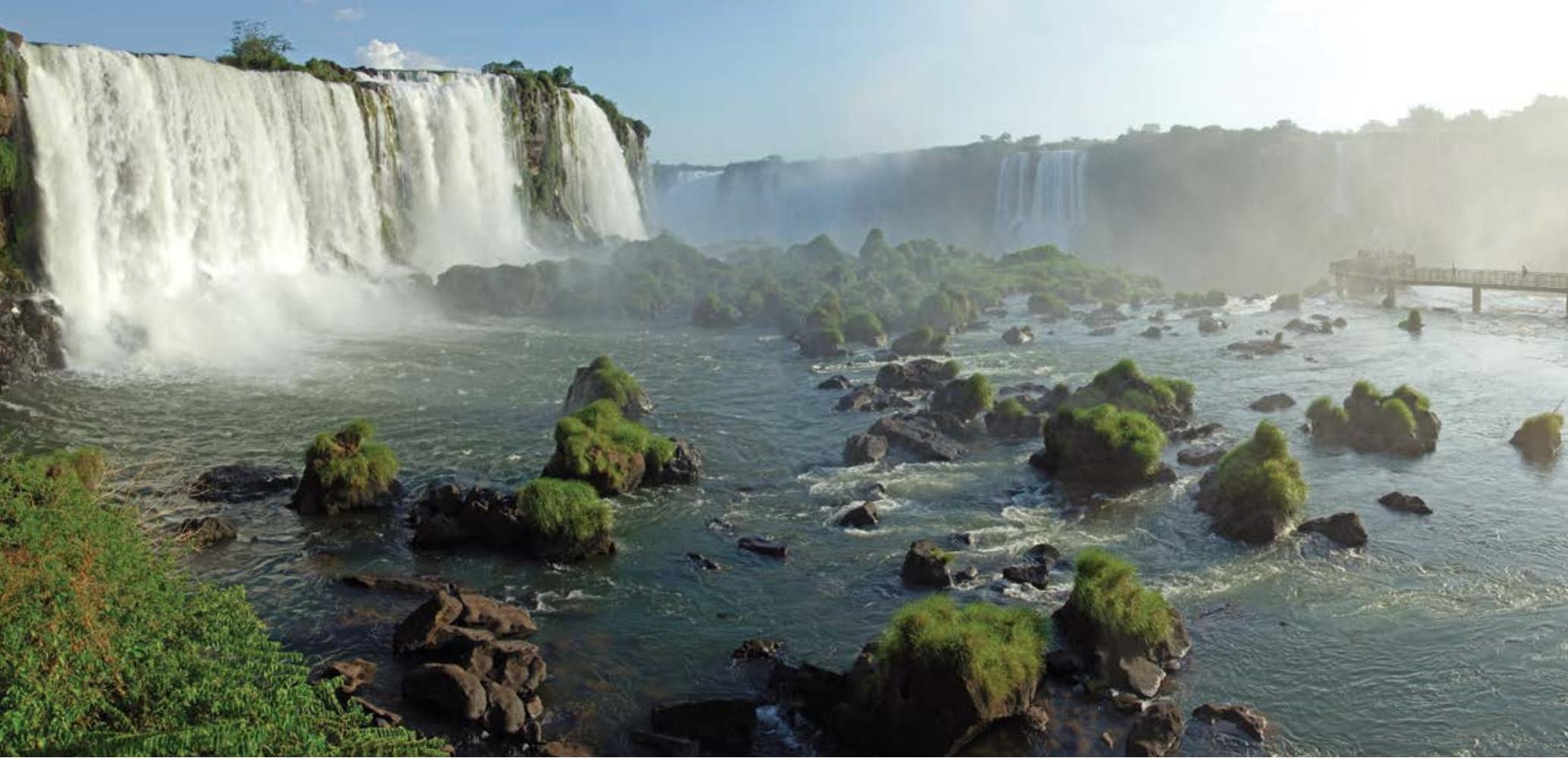

Iguazu Falls, Iguazu National Park, Brazil

Source: Eduard Müller

\section{Introduction}

Protected areas are the places where we aim to retain the extraordinary beauty and richness of the Earth and all its benefits to humanity - the evolutionary heritage of more than four billion years and for all we know unique in the vastness of the universe. They may include grand scenery; remarkable animals and plants; precipitous mountains; spectacular formation-rich caves; grand towering forests; dramatic plunging waterfalls; immense wetlands and lakes; vast deserts; and untouched coastlines, deep ocean mounts and expansive coral reefs. They can also hold landscapes of great beauty and cultural values, created by human communities over time and through traditional management practices.

Nations are proud of their protected areas and they are valued, loved and visited by people from all over the world. Protected areas are critical for maintaining healthy ecosystems and a healthy environment for people and all other species. They are essential for biodiversity conservation; they deliver clean water and air; they are vital to the cultures and livelihoods of traditional and indigenous communities for sustainable sustenance; they bring sustainable development benefits to millions of people through nature-based tourism; and they are a critical natural solution for climate change. They are also important for their rich history and the cultural associations they conserve including grand historical sites, and their special cultural landscapes, features and sites of spiritual, social and historical significance to a nation's peoples. They are typically protected, in perpetuity, by a nation's strongest laws.
In this chapter, we introduce important protected area concepts, including the definition of protected areas, protected area categories, governance and their management. Geographic areas that contribute to conservation other than protected areas are also introduced. The majority of IUCN protected area capacity development information developed since 1947 has been identified and listed in an annexure of this chapter to provide a single source list to assist readers and researchers.

\section{Concept and purpose}

Protected areas and their establishment and professional management are particularly a 20th and 21 st-century phenomenon, but it could surprise many that the concept of protected areas has existed for tens of thousands of years. Very old protected areas may still be found, including some where religious devotion has helped to conserve natural environments. The island of Itsukushima near Hiroshima, Japan, for example, has been a shrine to Shintoism since the 6th century and the island's sacred natural forests have been protected for their intrinsic values and for providing replacement timbers for the shrine's wooden structures (Stolton 2010). An even earlier example is Mount Kailas in Tibet, which was mentioned as a holy mountain in the 4th century BC, and is revered and protected by Buddhist, Hindu, Jain and Bon adherents, making it the world's most sacred mountain (Bernbaum 1990). In many other areas, communities have managed their activities to conserve the ecosystems that sustain them. 


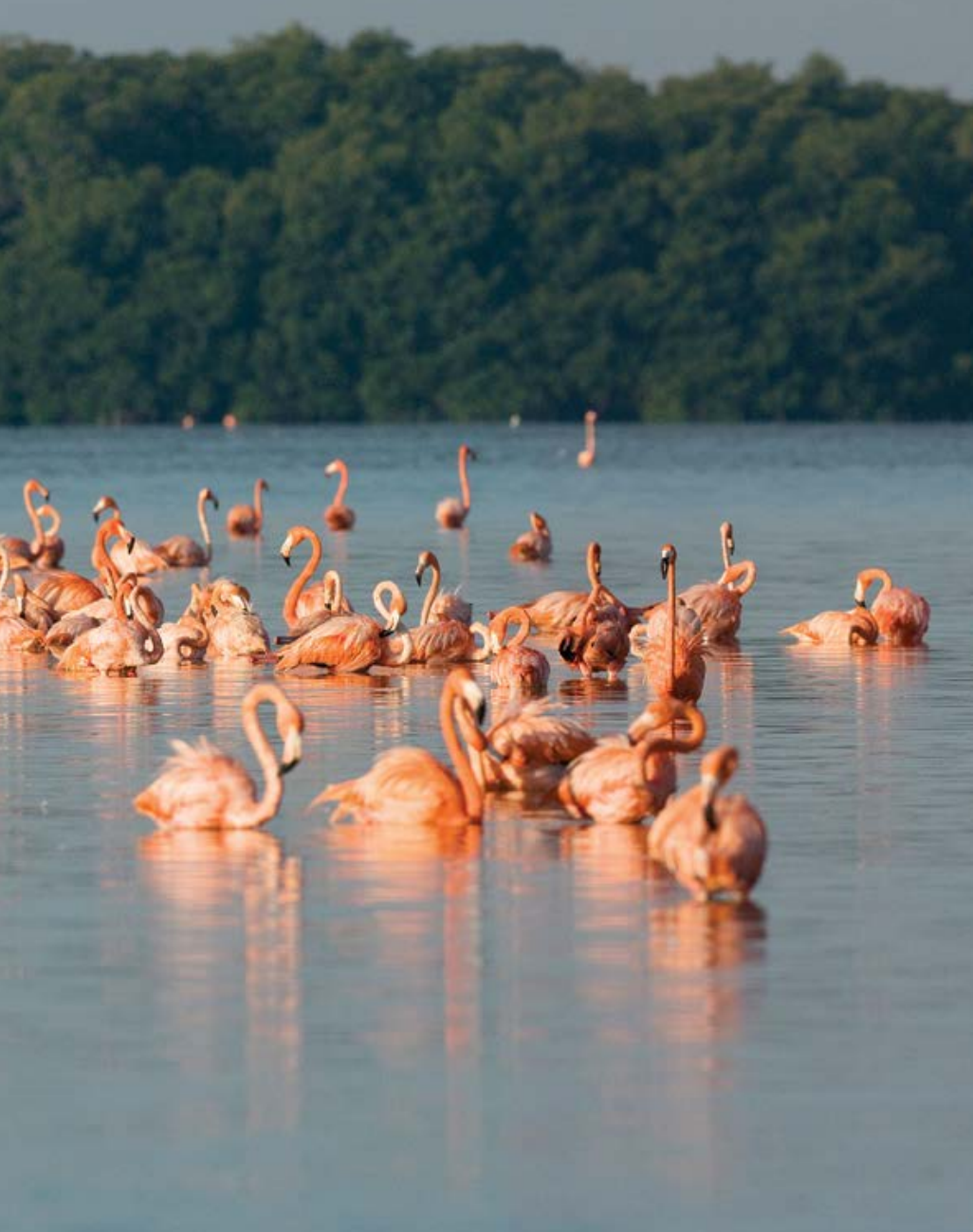

Flamingos, Panorama, Celestún National Park, Mexico

Source: Eduard Müller

In a British colony on the other side of the world, Australia, there was also emergent conservation thinking. The importance of Bunya pine (Araucaria bidwillii) to Indigenous Australians was recognised by Governor Gipps of the Colony of New South Wales when, in 1842, he issued a special decree that no timber licences be issued for any rainforest north of Brisbane that contained this species (Worboys et al. 2005). It was a conservation edict that respected the values and needs of Aboriginal Australians. In 1866, the Jenolan Caves Reserve in New South Wales was established by law to protect outstanding limestone caves from vandalism (Finlayson and Hamilton-Smith 2003). In 2014, this same Jenolan Caves Reserve formed part of the Greater Blue Mountains World Heritage Property.

Two broad concepts of conservation emerged in California during the debate over the controversial 1908-13 damming of the Hetch Hetchy Valley: the preservationist concept of John Muir, which was driven by a religious reverence for nature and the idea of the essential wild as an antidote to development, and a utilitarian concept of conservation proposed by Gifford Pinchot of wise use and 'banking' of nature for possible future use. The debate influenced the development of an international conservation movement: 'Dam Hetch

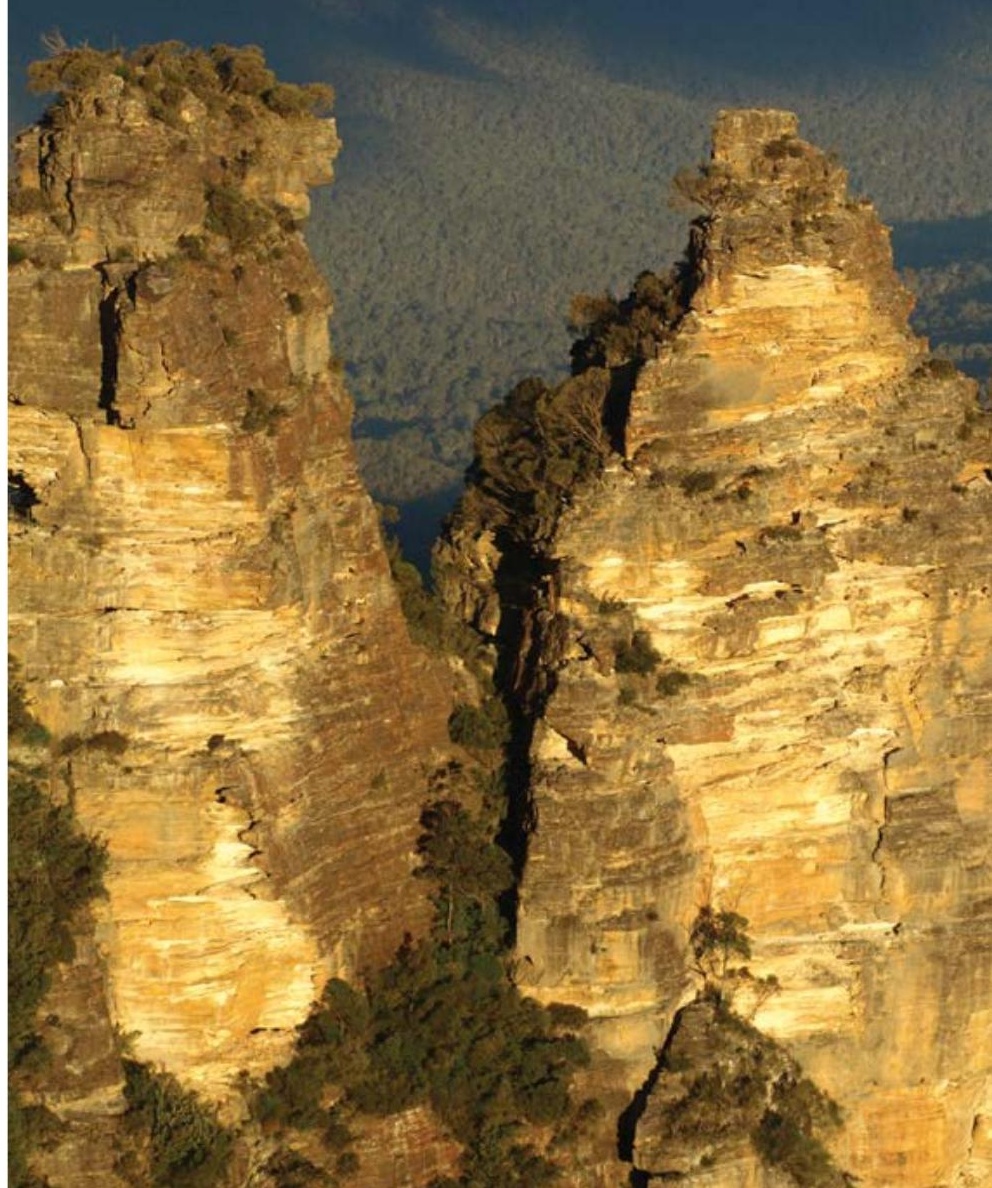

Greater Blue Mountains World Heritage Property, Australia

Source: Graeme L. Worboys

Hetchy! As well dam for water-tanks the people's cathedrals and churches, for no holier temple has ever been consecrated by the heart of man' (Muir 1912).

The protected area concept soon spread throughout the world in the 20th century, and new areas continue to be reserved in the 21 st century. Some important protected area-focused historical events since the end of World War II are provided in Table 2.1. 
Table 2.1 Some post-1945 protected area events

\begin{tabular}{|c|c|}
\hline Date & Event \\
\hline 1948 & $\begin{array}{l}\text { The International Union for Protection of Nature (IUPN) was formed as the first global organisation } \\
\text { for nature protection and was based in Brussels }\end{array}$ \\
\hline 1956 & The IUPN changed its name to the International Union for Conservation of Nature (IUCN) \\
\hline 1958 & IUCN's International Commission on National Parks was established \\
\hline 1962 & The first UN list of protected areas was prepared by the IUCN \\
\hline 1962 & The First World Conference on National Parks was held in Seattle, USA \\
\hline 1969 & An agreed definition of a national park was established by the IUCN General Assembly in New Delhi \\
\hline 1970 & UNESCO's Man and the Biosphere programme was launched \\
\hline 1971 & The Ramsar Convention on wetlands was adopted in Ramsar, Iran \\
\hline 1972 & The World Heritage Convention was adopted \\
\hline 1972 & The Second World Conference on National Parks was held at Yellowstone National Park, USA \\
\hline 1973 & $\begin{array}{l}\text { The Convention on International Trade in Endangered Species of Wild Fauna and Flora (CITES) } \\
\text { was adopted }\end{array}$ \\
\hline 1975 & $\begin{array}{l}\text { The IUCN International Commission on National Parks was changed to the IUCN Commission on } \\
\text { National Parks and Protected Areas (CNPPA) }\end{array}$ \\
\hline 1980 & $\begin{array}{l}\text { IUCN, the World Wide Fund for Nature (WWF) and the United Nation's Environment Programme (UNEP) } \\
\text { prepared the 'World Conservation Strategy' }\end{array}$ \\
\hline 1981 & $\begin{array}{l}\text { UNEP's World Conservation Monitoring Centre (UNEP-WCMC), based in Cambridge, undertook } \\
\text { responsibility for collecting and collating data on protected areas in partnership with the IUCN }\end{array}$ \\
\hline 1982 & The Third Word Congress on National Parks was held in Bali, Indonesia \\
\hline 1987 & $\begin{array}{l}\text { The report of the World Commission on Environment and Development (Our Common Future), dealing } \\
\text { with the sustainable development agenda, was published }\end{array}$ \\
\hline 1988 & IUCN adopted a definition for marine protected areas \\
\hline 1990 & The first report of the Intergovernmental Panel on Climate Change (IPCC) was produced \\
\hline 1991 & IUCN, WWF and UNEP prepared the document Caring for Earth: A strategy for sustainable living \\
\hline 1992 & $\begin{array}{l}\text { UNEP-WCMC in collaboration with IUCN CNPPA prepared a four-volume review of protected area } \\
\text { systems of the world }\end{array}$ \\
\hline 1992 & The Fourth World Congress on National Parks and Protected Areas was held in Caracas, Venezuela \\
\hline 1992 & $\begin{array}{l}\text { The Convention on Biological Diversity (CBD) was agreed to, recognising the need to conserve } \\
\text { biodiversity and the essential role of protected areas in doing this }\end{array}$ \\
\hline 1992 & The UN Framework Convention on Climate Change was achieved \\
\hline 1994 & IUCN published Guidelines for Protected Area Management Categories \\
\hline 1996 & The title of IUCN's CNPPA changed to the World Commission on Protected Areas (WCPA) \\
\hline 2000 & $\begin{array}{l}\text { The UN Millennium Development Goals were published and identified the need for } \\
\text { environmental sustainability }\end{array}$ \\
\hline 2000 & Conservation International identified its global environmental hotspots \\
\hline 2001 & WWF published its global ecoregions \\
\hline 2003 & IUCN's Fifth World Parks Congress was held in Durban, South Africa \\
\hline 2004 & $\begin{array}{l}\text { The Programme of Work on Protected Areas (PoWPA) was agreed to by the Convention on Biological } \\
\text { Diversity's Conference of Parties }\end{array}$ \\
\hline 2008 & $\begin{array}{l}\text { An improved definition of protected area and IUCN management categories and governance types } \\
\text { was approved at the Barcelona IUCN World Conservation Congress }\end{array}$ \\
\hline 2008 & The World Database on Protected Areas (WDPA) was upgraded and launched as an online database \\
\hline 2010 & $\begin{array}{l}\text { The CBD Strategic Plan for Biodiversity 2011-20 was launched and called for further protected areas to } \\
\text { be established, with improved connectivity, effective management and with due regard to people }\end{array}$ \\
\hline
\end{tabular}




\begin{tabular}{|l|l|}
\hline Date & Event \\
\hline 2010 & $\begin{array}{l}\text { IUCN WCPA prepared 'natural solutions' to emphasise the importance of protected areas as a } \\
\text { natural response to climate change }\end{array}$ \\
\hline 2011 & Guidelines for protected area legislation were prepared by IUCN's Environmental Law Centre and WCPA \\
\hline 2014 & $\begin{array}{l}\text { The Biodiversity and Protected Area Management (BIOPAMA) program was undertaken by the IUCN } \\
\text { to address threats to biodiversity in African, Caribbean and Pacific countries while reducing poverty } \\
\text { in communities in and around protected areas }\end{array}$ \\
\hline
\end{tabular}

Source: Adapted from Worboys (2014).

For readers interested further in the history of conservation, protected areas and the IUCN, an excellent text on these subjects is The Green Web by Martin Holdgate (1999).

The global concept of protected areas has benefited greatly from this evolving post-1945 thinking, discussion and refinement, and the importance of protected areas has increased, not diminished, during this time. Contemporary protected areas are lands and seas where people and communities of Earth have recognised the special natural, biodiversity, ecological, ecosystem service and/or social and cultural values and where they have taken steps to protect these values for the long term. The concept is intergenerational and recognises that the protection is supported by community and customary rules and/or the law of the land and that the area is actively managed. The concept may relate to very small or very large areas of Earth. They may be extremely fragile areas and managed sensitively; they may sustain communities; and they may host regular visits given their outstanding natural beauty.

\section{Purpose}

Protected areas are the principal mechanism for the conservation of biodiversity on Earth (as well as other natural and cultural heritage). This role for conserving biodiversity was formally recognised by 168 nation-states in 1992 in Article 8 of the newly created Convention on Biological Diversity (CBD). In the 21 st century, nearly all nations support the concept of protected areas. These areas underpin virtually all national and international conservation strategies where land, water or sea has been identified as vital and given special protection to maintain functioning natural ecosystems, to act as refuges for species and to maintain ecological processes that cannot otherwise survive in intensely managed areas such as agricultural or urban areas (Dudley 2008). Protected areas help to protect nature and this includes biodiversity at genetic, species and ecosystems levels as well as geodiversity including geoheritage, landforms, scenery, soils and water. Protected areas also protect cultural heritage given that the status and the management of

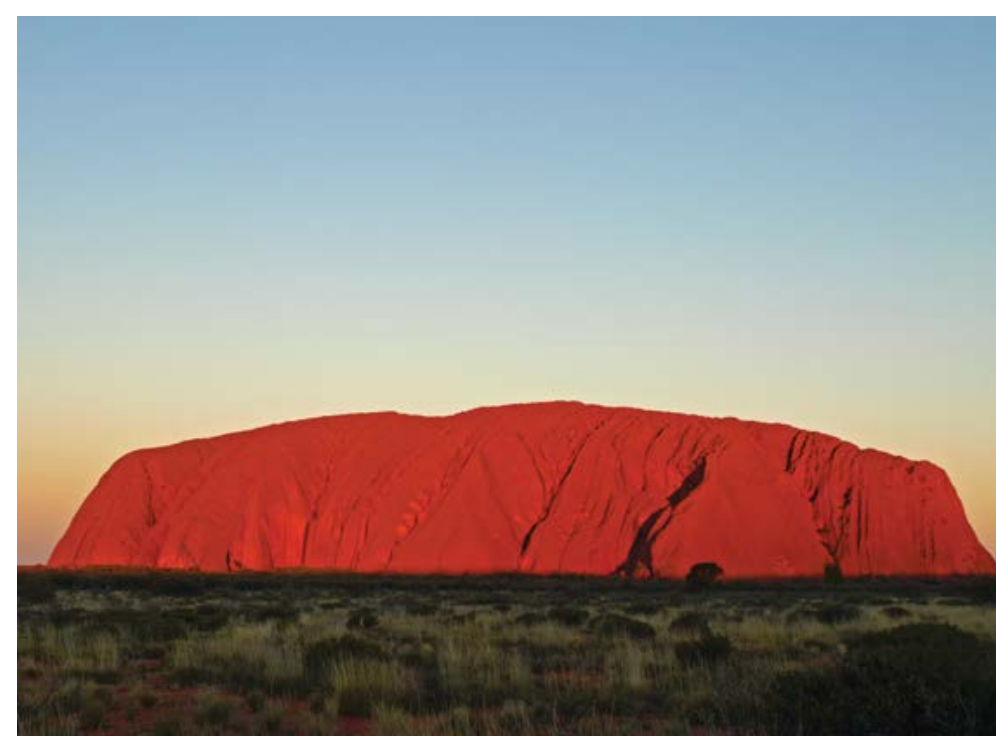

Uluru-Kata Tjuța National Park World Heritage Property, Australia

Source: Graeme L. Worboys

such cultural phenomena are not inconsistent with biodiversity conservation outcomes (Dudley 2008). For the sake of conciseness, henceforward in this book whenever we speak of 'biodiversity conservation' the additional values of ecosystem services, geodiversity and cultural heritage should be understood to be included. By articulating this greater purpose of protected areas it has helped to establish a protected area definition.

\section{Definition}

A protected area has been defined by the IUCN as '[a] clearly defined geographical space, recognised, dedicated and managed, through legal or other effective means, to achieve the long-term conservation of nature with associated ecosystem services and cultural values' (Dudley 2008:8).

Every word and phrase of this definition is important and has a clearly prescribed meaning. An explanation of this meaning has been prepared by Nigel Dudley of the IUCN and a summary of his description is provided here (Dudley 2008:8-9) (Table 2.2). 
Table 2.2 Details of the protected area definition

\begin{tabular}{|c|c|}
\hline Word or phrase & Explanation \\
\hline $\begin{array}{l}\text { Clearly defined } \\
\text { geographical space }\end{array}$ & $\begin{array}{l}\text { Geographical area: This includes land, inland water, marine and coastal areas or } \\
\text { a combination of two or more of these } \\
\text { Space: This has three dimensions and may include airspace and water column } \\
\text { space above land or above the bottom of the water body and subsurface areas } \\
\text { (such as caves) } \\
\text { Clearly defined: Implies a spatially defined area with agreed and demarcated } \\
\text { boundaries }\end{array}$ \\
\hline Recognised & $\begin{array}{l}\text { Protection can include a range of governance types declared by people as well } \\
\text { as those identified by a nation, but such sites should be recognised in some way } \\
\text { (such as listing on the World Database on Protected Areas) }\end{array}$ \\
\hline Dedicated & $\begin{array}{l}\text { Implies a specific binding commitment to conservation in the long term such as } \\
\text { international conventions and agreements; national, provincial and local laws; } \\
\text { customary law; covenants of NGOs; private trust and company policies; and } \\
\text { certification schemes }\end{array}$ \\
\hline Managed & $\begin{array}{l}\text { This assumes some active steps are being taken to conserve the natural } \\
\text { (and other) values for which the protected area was established. It may also } \\
\text { include a decision of non-intervention as the best conservation strategy }\end{array}$ \\
\hline $\begin{array}{l}\text { Legal or other effective } \\
\text { means }\end{array}$ & $\begin{array}{l}\text { Protected areas must be gazetted, recognised through an international } \\
\text { convention or agreement or else managed through other effective but non- } \\
\text { gazetted means such as through recognised traditional rules under which } \\
\text { community conserved areas operate or the policies of established NGOs }\end{array}$ \\
\hline ... to achieve & This implies some level of effectiveness of management \\
\hline Long term & $\begin{array}{l}\text { Protected areas should be managed in perpetuity and not as a short-term or } \\
\text { temporary management strategy }\end{array}$ \\
\hline Conservation & $\begin{array}{l}\text { This is the in situ maintenance of ecosystems and natural and semi-natural } \\
\text { habitats and of viable populations of species in their natural surroundings, and in } \\
\text { the case of domesticated or cultivated species, in the surroundings where they } \\
\text { have developed their distinctive properties }\end{array}$ \\
\hline Nature & $\begin{array}{l}\text { (In this context) always refers to biodiversity at genetic, species and ecosystem } \\
\text { levels and often also refers to geodiversity, landform and broader natural values }\end{array}$ \\
\hline $\begin{array}{l}\text { Associated ecosystem } \\
\text { services }\end{array}$ & $\begin{array}{l}\text { These are ecosystem services that are related to, but do not interfere with, the } \\
\text { aim of nature conservation - these can include provisioning (food and water) } \\
\text { services; regulating services (floods, drought, land degradation and disease); } \\
\text { support services (such as soil formation and nutrient cycling); and cultural } \\
\text { services such as recreational, spiritual, religious and other non-material benefits }\end{array}$ \\
\hline Cultural values & These include cultural values that do not interfere with the conservation outcome \\
\hline
\end{tabular}

\section{Types of protected areas: IUCN categories}

The IUCN has developed an internationally accepted category system for protected areas that identifies six categories of protected areas (Dudley 2008). A specific IUCN protected area category is assigned to a protected area consistent with its principal management objective. This IUCN framework serves as a common language for distinguishing, describing and working with broad protected area management types. This is critical given nations have otherwise assigned a wide range of descriptive terms that represent protected areas such as 'conservation park', 'conservation reserve', 'feature protection area', 'flora reserve', 'forest reserve', 'indigenous protection area', 'karst conservation reserve', 'national park', 'nature park', 'nature reserve', 'reference area', 'scientific area', and many others.

The six IUCN categories are differentiated by clear primary management objectives, and this common language helps to provide uniformity for data collection internationally and a capability for comparative analysis for the global protected area system. A definition and more specific differentiating guidelines help to define the 
- protected areas should usually aim to maintain or, ideally, increase the degree of naturalness of the ecosystem being protected

- the definition and categories of protected areas should not be used as excuses for dispossessing people of their land (Dudley 2008:10).

\section{Objectives}

Objectives of management that are common to all IUCN protected area categories include:

- conserve the composition, structure, function and evolutionary potential of biodiversity

- contribute to regional conservation strategies

- maintain diversity of landscape or habitat and of associated species and ecosystems

- be of sufficient size to ensure the integrity and longterm maintenance of the specified conservation targets

- maintain the values for which they were assigned in perpetuity

- be operating under the guidance of a management plan and a monitoring and evaluation program that support adaptive management

area near Ust Koksa, Altai Republic, Russia

Source: Graeme L. Worboys

six IUCN protected area categories and each has been described here along with this guiding information. First, however, there is a set of fundamental management principles and objectives that are common to all IUCN categories.

\section{Principles}

Principles for IUCN protected area categories help to clarify exactly what the IUCN means by protected areas and help to maintain the integrity of its categories. Consistent with the IUCN definition of a protected area, key principles for the IUCN categories are:

- only those areas where the main objective is conserving nature can be considered protected areas

- protected areas must prevent, or eliminate where necessary, any exploitation or management practice that will be harmful to the objectives of designation

- the choice of category should be based on the primary objective(s) stated for each protected area

- the category system is not intended to be hierarchical

- any category can exist under any governance type and vice versa

- possess a clear and equitable governance system (Dudley 2008:12).

\section{IUCN protected area categories}

The six IUCN categories are individually introduced, defined and their primary objective presented. These descriptions are a critical guide for the effective management of protected areas and should always be aspirational whatever the situational circumstances of individual protected areas.

\section{Category la: Strict Nature Reserve}

Category Ia Strict Nature Reserves conserve ecosystems, species and geodiversity and may be important sites for scientific research, environmental monitoring and education. They may also be important sites for conserving cultural and spiritual values associated with nature. Strict nature reserves are extremely important in the 21 st century, for there are fewer and fewer areas where the activities of humans are limited. They help to protect scarce natural heritage that would otherwise be lost without this designation, and they may provide a baseline for long-term environmental monitoring as well as protecting other scarce natural resources and ecosystem services. 


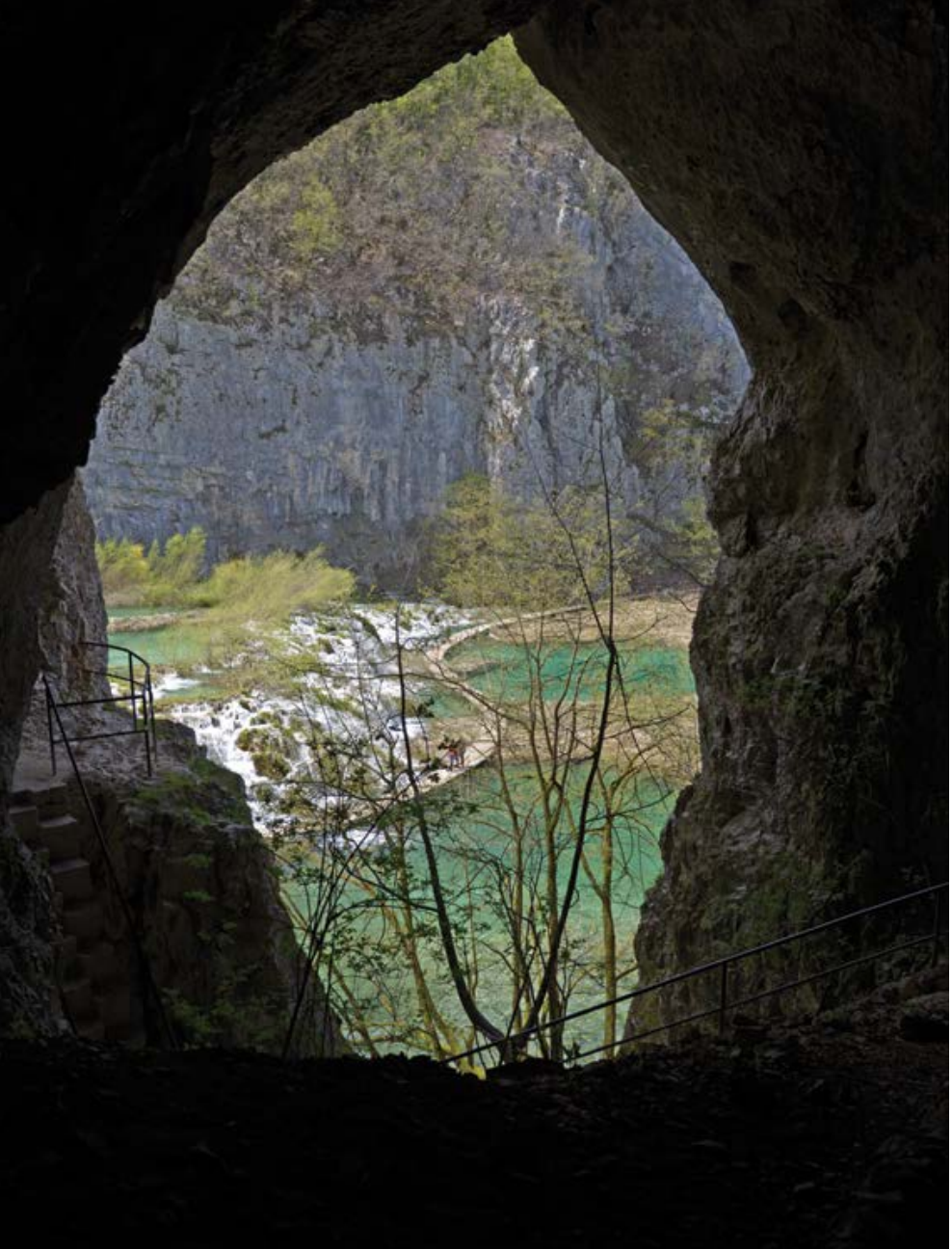

Plitvice Lakes National Park, World Heritage Property, Croatia

Source: Graeme L. Worboys

\section{Definition}

Category Ia are strictly protected areas set aside to protect biodiversity and also possibly geological/ geomorphological features, where human visitation, use and impacts are strictly controlled and limited to ensure protection of the conservation values. Such protected areas can serve as indispensable reference areas for scientific research and monitoring (Dudley 2008:13).

\section{Primary objective}

The primary objective of a Category Ia protected area is to conserve regionally, nationally or globally outstanding ecosystems, species (occurrences or aggregations) and/ or geodiversity features. These attributes will have been formed mostly or entirely by non-human forces and will be degraded or destroyed when subjected to all but very light human impact (Dudley 2008:13).

\section{Category lb: Wilderness Area}

Category Ib Wilderness Areas help protect relatively untouched and functioning ecosystems, and consequently, provide opportunities for evolution to continue in as natural a state as possible and where species can survive. They provide opportunities for limited numbers of visitors to experience wilderness and may also include livestock grazing by nomadic peoples.

\section{Definition}

Category Ib protected areas are usually large unmodified or slightly modified areas, retaining their natural character and influences, without permanent or significant human habitation, which are protected and managed so as to preserve their natural condition (Dudley 2008:14).

\section{Primary objective}

The primary objective of a Category Ib protected area is to protect the long-term ecological integrity of natural areas that are undisturbed by significant human activity, free of modern infrastructure and where natural forces and processes predominate, so that current and future generations have the opportunity to experience such areas (Dudley 2008:14).

\section{Category II: National Park}

Category II National Parks are large areas where natural ecological processes, including evolutionary processes with less human interference, may continue. They help conserve superlative natural scenery, diverse landscapes, rich geoheritage, biodiversity including key species, ecosystem services and rich cultural heritage, and they may form a core area for larger connectivity conservation initiatives. They may be internationally famous for their scenic grandeur, their remarkable natural phenomena and exceptional wildlife species and often include a range of visitor services and support facilities.

\section{Definition}

Category II protected areas are large natural or near natural areas set aside to protect large-scale ecological processes, along with the complement of species and ecosystems characteristic of the area, which also provide a foundation for environmentally and culturally compatible spiritual, scientific, educational, recreational and visitor opportunities (Dudley 2008:16).

\section{Primary objective}

The primary objective of a Category II protected area is to protect natural biodiversity along with its underlying ecological structure and supporting environmental processes, and to promote education and recreation (Dudley 2008:16). 


\section{Category III: Natural Monument or Feature}

Category III protected areas are typically small and are focused on a natural feature or features and their associated ecosystems. They could include features such as cliffs, waterfalls, caves or forest groves, and may also be of importance as cultural sites including sacred natural sites. Visitor use of the site may be encouraged.

\section{Definition}

Category III protected areas are set aside to protect a specific natural monument, which can be a landform, seamount, submarine cavern, geological feature such as a cave or even a living feature such as an ancient grove. They are generally quite small protected areas and often have high visitor value (Dudley 2008:17).

\section{Primary objective}

The primary objective of a Category III protected area is to protect specific outstanding natural features and their associated biodiversity and habitats (Dudley 2008:17).

\section{Category IV: Habitat/Species Management Area}

Category IV protected areas help to protect fauna and flora species that are usually of international, national or local importance and they help to protect key habitats. They may be small, but the size of these areas varies. They may include only fragments of an ecosystem, which may require regular and active management to sustain and perhaps more than implemented for Category I and II protected areas.

\section{Definition}

Category IV protected areas aim to protect particular species or habitats and management reflects this priority. (Many Category IV protected areas will need regular, active interventions to address the requirements of particular species or to maintain habitats, but this is not a requirement of the category [Dudley 2008:19].)

\section{Primary objective}

The primary objectives of a Category IV protected area are to maintain, conserve and restore species and habitats (Dudley 2008:19).

\section{Category V: Protected Landscape/ Seascape}

Category V protected areas are landscapes/seascapes of distinctive scenic quality and include important flora and fauna habitats and cultural features. They ideally feature a balanced interaction between humans and nature and provide opportunities for the restoration of nature and the maintenance of place-dependent cultural activities. They play an important role at a landscape or seascape scale and may contribute to conservation as part of a mosaic of conservation land or sea use that could include other protected area categories and connectivity conservation areas.

\section{Definition}

The Category V protected landscape/seascape is a protected area where the interaction of people and nature over time has produced an area of distinct character with significant ecological, biological, cultural and scenic values, and where safeguarding the integrity of this interaction is vital to protecting and sustaining the area and its associated nature conservation and other values (Dudley 2008:20).

\section{Primary objective}

The primary objectives of a Category V protected area are to protect and sustain important landscapes/seascapes and the associated nature conservation and other values created by interactions with humans through traditional management practices (Dudley 2008:20).

\section{Category VI: Protected Area with Sustainable Use of Natural Resources}

Category VI protected areas may be large areas and may be part of conservation initiatives such as large connectivity conservation areas. They are areas where the sustainable use of natural resources is a means to help achieve nature conservation together with protection objectives. This category does not accommodate largescale industrial harvesting and it is recommended by the IUCN that a proportion (such as 66 per cent) of the area is retained in a natural condition.

\section{Definition}

Category VI protected areas conserve ecosystems and habitats, together with associated cultural values and traditional natural resource management systems. They are generally large, with most of the area in a natural condition, where a proportion is under sustainable natural resource management and where low-level non-industrial use of natural resources compatible with nature conservation is seen as one of the main aims of the area (Dudley 2008:22). 


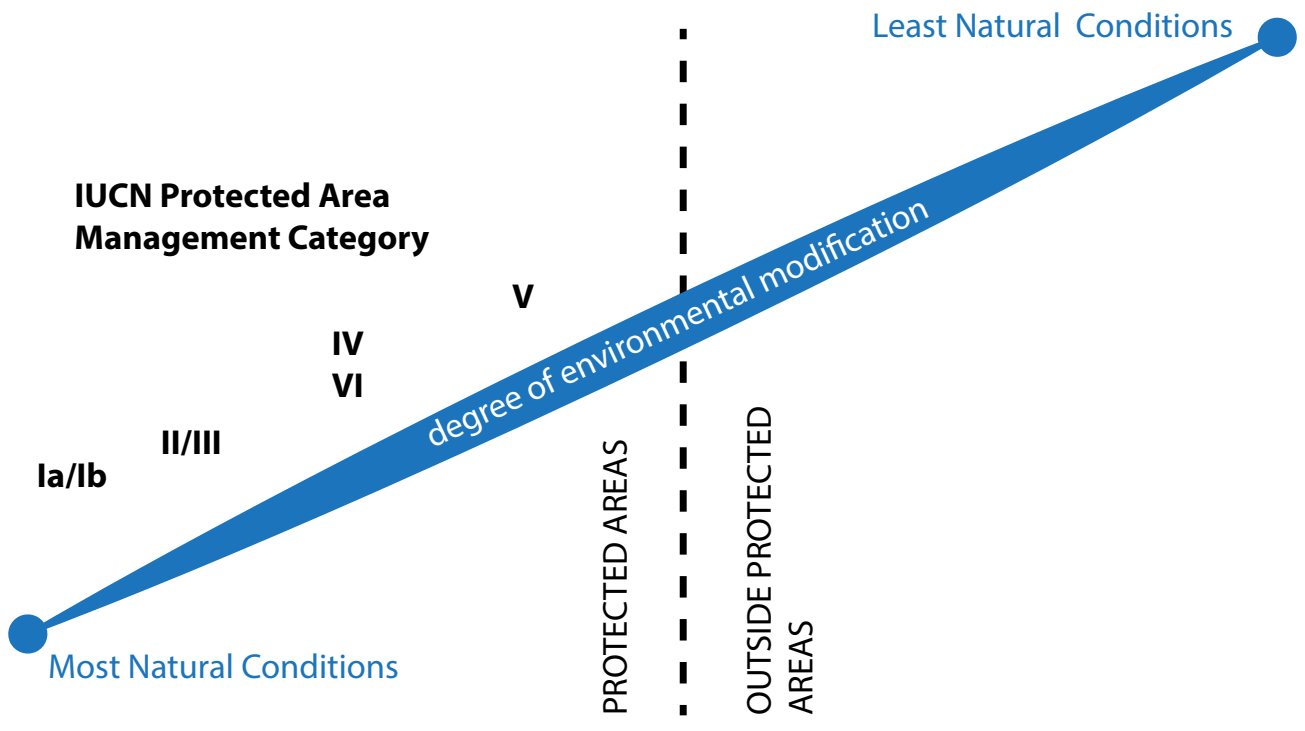

Figure 2.1 Naturalness and IUCN protected area categories

Source: Adapted from Dudley (2008:24)

\section{Primary objective}

The primary objectives of a Category VI protected area are to protect natural ecosystems and use natural resources sustainably when conservation and sustainable use can be mutually beneficial (Dudley 2008:22).

\section{The six categories}

The six categories are not designed as a hierarchical suite of categories in terms of quality, importance or naturalness; rather, their application is situational and is based on maximising nature conservation for a particular landscape/seascape context (Dudley 2008:24). The application of the IUCN categories in the context of 'naturalness' is illustrated in Figure 2.1.

\section{Systems of protected areas}

Systems of protected areas are where a number of protected areas have been established by a nation, sub-national governments, NGOs or other private organisations. In national protected area systems, the diversity of landforms, ecosystems, fauna and flora as found in each nation is ideally conserved through a conservation sampling within a number of carefully selected protected areas. Such a national system of protected areas aims to maximise the in situ conservation of a nation's natural heritage and ideally has five key elements that underpin the system (Davey 1998; Dudley 2008). Protected areas as a system need to also demonstrate the principles of good governance (Chapter 7), and a protected area system may include a diversity of governance types such as government managed, co-managed, indigenous peoples' and community conserved territories and areas, and private protected areas. The five key elements that characterise a protected area system are as follows (Davey 1998).

1. Representative, comprehensive and balanced: There are high-quality examples of the full range of environment types within a country and the protected areas in the system provide a balanced sample.

2. Adequate: Each protected area has integrity (it is in good condition) and there is sufficiency of spatial extent and arrangement of contributing units to ensure the viability of species and ecological processes.

3. Coherent and complementary: There is a positive contribution of each protected area in the system towards the conservation and sustainable development objectives of a nation.

4. Consistent: There is consistency in approach to achieving management objectives for the entire system.

5. Cost effective, efficient and equitable: There is balance between costs and benefits and equity in the distribution of financial resources within the system and there is efficiency with the system (the minimum number and size of protected areas have been established to achieve system objectives). 


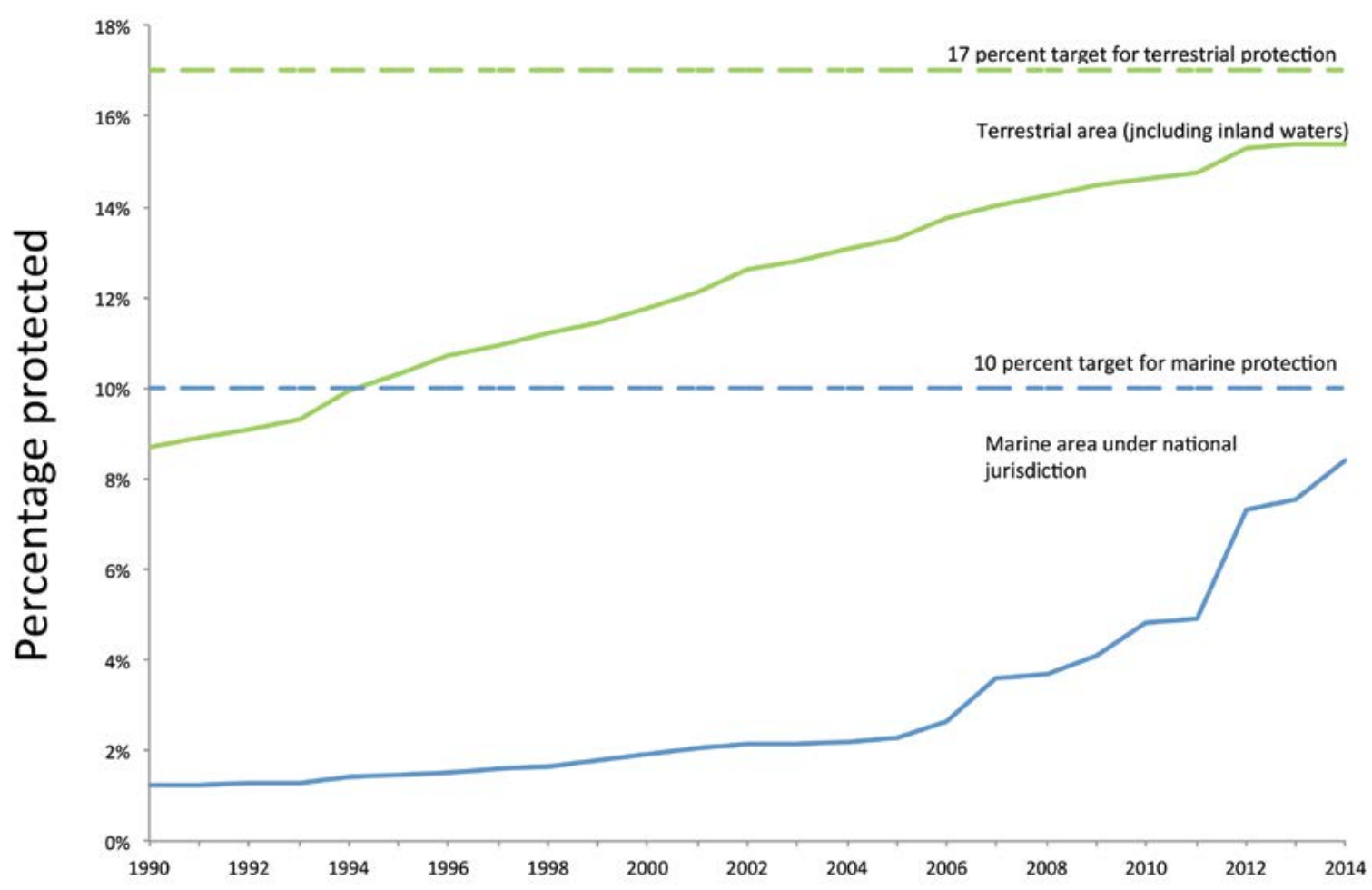

Figure 2.2 Growth in the percentage of terrestrial and marine area covered by protected areas, 1990-2014. The years are extracted from the protected area status year reported to the World Database on Protected Areas (WDPA). Protected areas with no reported status year were included in the 1990 baseline. Global statistics from the WDPA, August 2014

Source: UNEP-WCMC Cambridge

\section{Status of protected area coverage}

In 1962, at the first World Conference on National Parks in Seattle, Washington, there were just 9214 protected areas identified for the world (Chape et al. 2003), and just 52 years later, in 2014, there were over 209,000 designated protected areas (IUCN and UNEP-WCMC 2014). This 20th and 21st-century transformation has meant that by 2014 , some 15.4 per cent of the world's terrestrial and inland waters were protected, as were 3.4 per cent of the total marine area, including 8.4 per cent of marine areas under national jurisdiction and 8.0 per cent of national exclusive economic zones (IUCN and UNEPWCMC 2014). It has been a remarkable achievement. It is one of the greatest peaceful land-use and sea-use transformations in human history (Figure 2.2), though this work is unfinished.

The data and protected area statistics described have been compiled in the World Data Base on Protected Areas (WDPA) that is managed by UNEP's World Conservation Monitoring Centre in Cambridge and includes protected areas of all IUCN governance types. In addition to government protected areas it includes hundreds of community-managed, co-managed and private protected areas (including vast areas in Brazil and Australia). However, it is not complete, as the majority of such non-government protected areas are not formally recognised or reported by governments for various reasons. An indicative appraisal of the larger (nonrecorded) extent of Indigenous Peoples' and Community Conserved Territories and Areas (ICCAs) has been completed (Kothari et al. 2012). The number of ICCAs may have equalled or exceeded the number and extent of WDPA recognised protected areas.

Protected areas are recognised as an effective tool for conserving biodiversity and specifically many endangered species at a time of global change (Butchart et al. 2012). This is at a time when the sixth great extinction event on Earth is forecast, caused primarily by human activity (UNEP 2007). The aspirational target for 2020 reservation for nations established by the Convention on Biological Diversity's strategic plan 2011-20 (CBD 2011) is 17 per cent for their terrestrial area and 10 per cent for marine areas. The target calls on the areas to be important for biodiversity conservation such as key biodiversity areas (see Chapter 3). All IUCN protected area categories are important for biodiversity conservation, although some key biodiversity areas may need special protection to ensure species remain extant. Such management may 


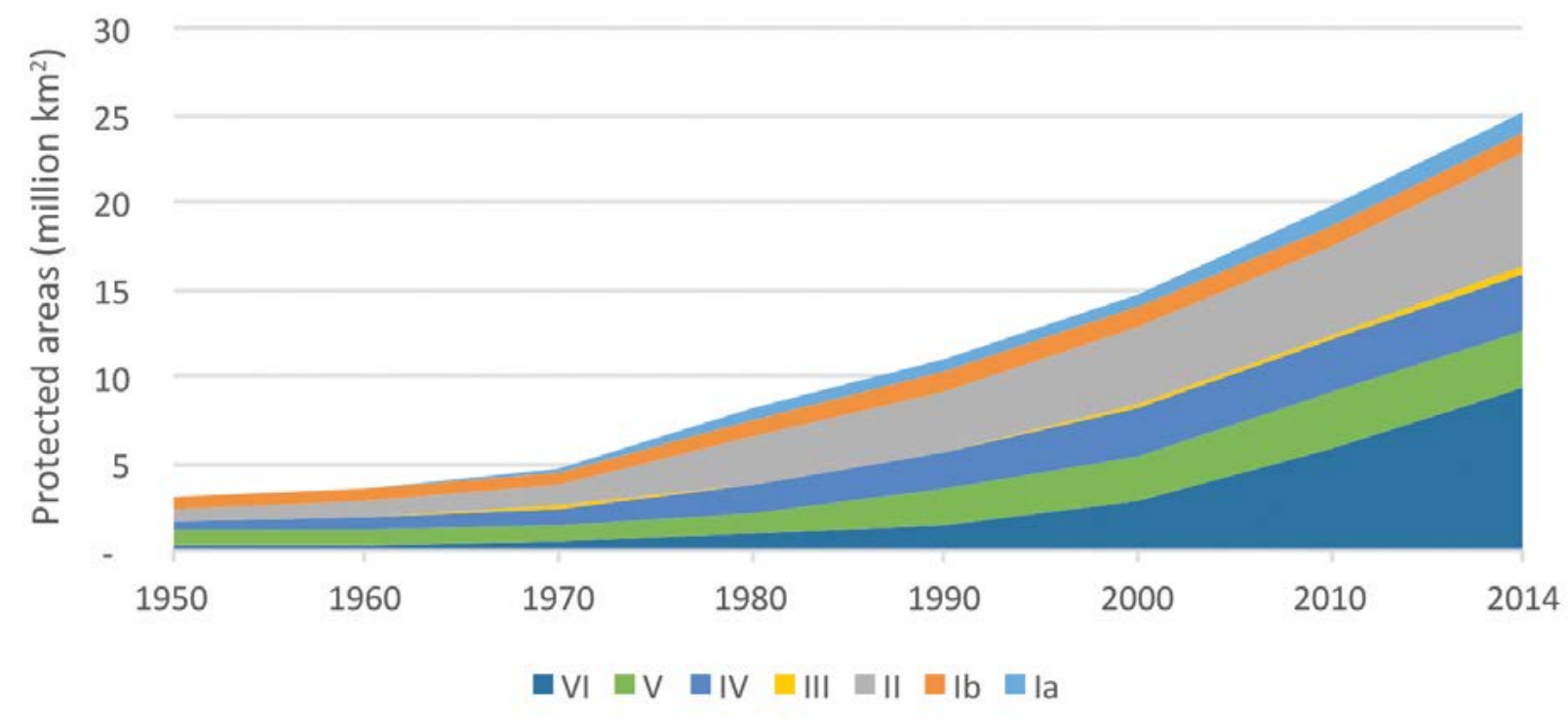

Figure 2.3 Total areal extent $\left(\mathrm{km}^{2}\right)$ of protected areas in the WDPA in each of the IUCN management categories, 1950-2014. The overall protected area in all categories is inflated due to overlaps of protected areas within and across categories. The graph includes undated protected areas with category information in all years and excludes protected areas with no category information.

Source: WDPA August 2014

be best established under the objectives and management guidance for Category I-IV protected areas (Figure 2.3), although Categories V and VI also play a valuable role in contributing to such biodiversity conservation.

\section{Other international protected area and conservation types}

\section{World Heritage properties}

In 1972, adoption of the World Heritage Convention (UNESCO 2013a) by the United Nations established the World Heritage List and provided an opportunity to recognise the most exceptional natural and cultural heritage places of Earth. This is a prestigious list, and in 2012 there were 190 parties who had ratified the convention (UNESCO 2013b), meaning it was almost universally adopted.

The convention recognises that World Heritagelisted natural and cultural heritage are irreplaceable assets of outstanding universal value not only for each nation but also for humanity as a whole (UNESCO 2011). The convention aims for the identification, protection, conservation, presentation and transmission to future generations of cultural and natural heritage of 'outstanding universal value' (OUV) (UNESCO 2011). For 'cultural heritage', the convention recognises monuments, groups of buildings and sites that feature the works of people or the combined works of nature and people (UNESCO 2011). The World Heritage 'natural heritage' criteria include natural aesthetic landscape features, geological and physiographic formations, significant ecosystems and ecosystem processes, species and precisely defined natural areas of OUV (UNESCO 2011). The convention also recognises 'mixed cultural and natural heritage properties' and 'cultural landscapes'.

There is a rigorous process for achieving inscription on the World Heritage List that includes assessments against the OUV criteria, an evaluation of integrity/ and or authenticity and a review of the protection and management of the property. If World Heritage status is achieved, as part of the convention, there is a requirement for each state party to maintain the World Heritage OUV and to provide periodic reports on the condition and trend in condition of the OUV. World Heritage properties may be designated over any land tenure, however, there is a requirement that the OUV is conserved. Usually World Heritage properties are inscribed over lands coincident with established protected areas, especially given the need for an effective management regime. World Heritage sites around the world are therefore special and ideally represent the 'best of the best' of Earth's natural and cultural heritage. Chapter 3 provides further information about natural World Heritage properties recognised by the World Heritage Convention. 


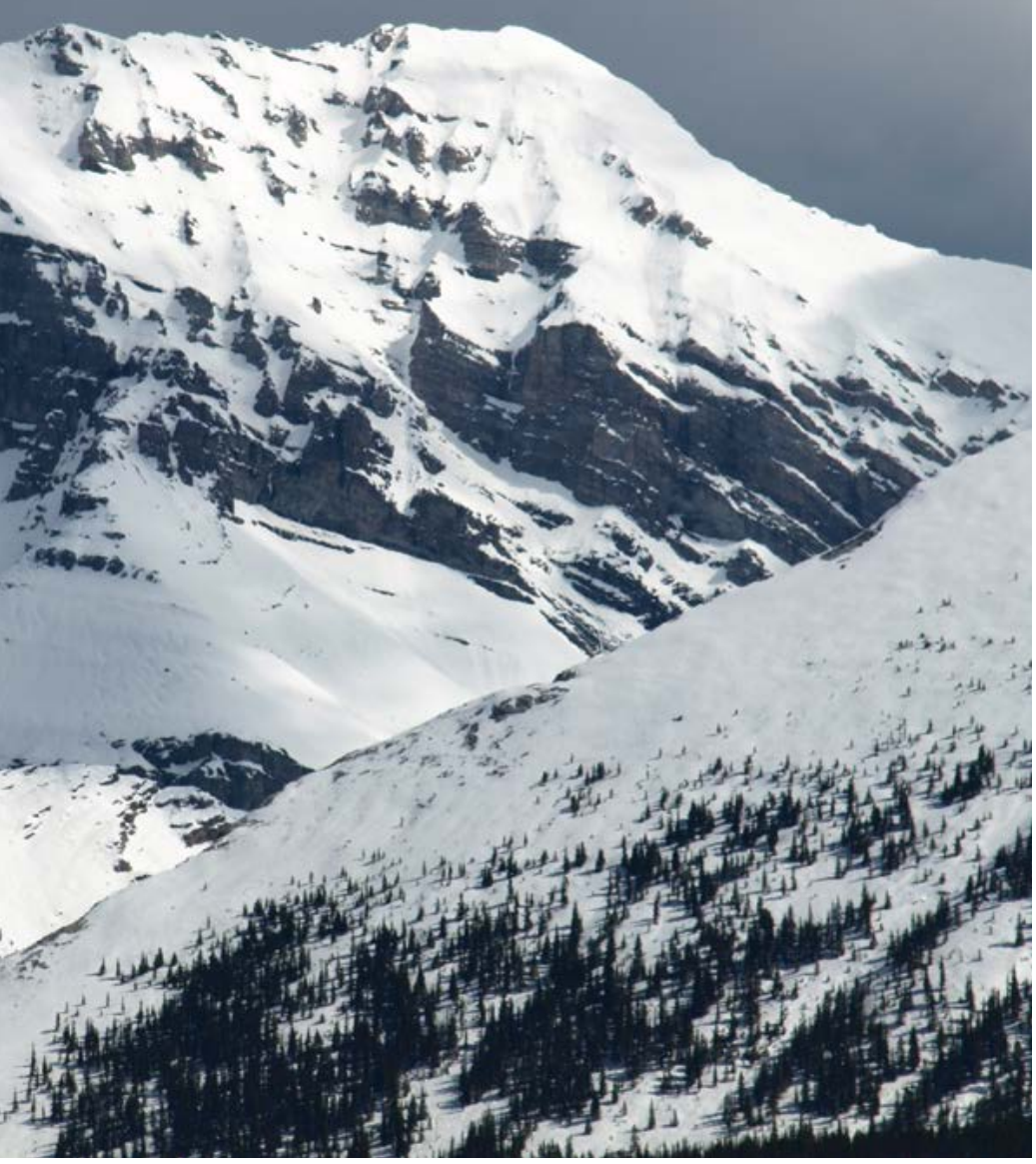

Banff National Park World Heritage Property, Canada

Source: Graeme L. Worboys

\section{Ramsar Wetlands}

Wetlands of importance may be officially recognised under the provisions of the Ramsar Convention. This treaty was adopted in 1971 in the city of Ramsar, Iran, and in 2013 there were 168 contracting parties to the convention and 2168 recognised sites around the world (Ramsar 2013). The convention uses a broad definition of the types of wetlands covered by its mission including lakes and rivers; swamps and marshes; wet grasslands and peatlands; oases; estuaries; deltas and tidal flats; near-shore marine areas; mangroves and coral reefs; and human-made sites such as fish ponds, rice paddies, reservoirs and salt pans. The convention's mission is 'the conservation and wise use of all wetlands through local and national actions and international cooperation, as a contribution towards achieving sustainable development throughout the world' (Ramsar 2013:1). The parties commit to undertaking an inventory of their wetlands and preparing a strategic framework for the Ramsar list. This includes establishing systematic and representative national designation and management of wetland habitat types. There is no obligation for Ramsar sites to be legally protected, though listing status does enhance protection (Dudley 2008). Chapter 19 of this book deals further with areas recognised by the Ramsar Convention.

\section{UNESCO Man and the Biosphere Programme (biosphere reserves)}

Biosphere reserves are part of the Man and the Biosphere (MAB) Programme. It was launched by the UN Educational, Scientific and Cultural Organisation (UNESCO) in 1971 as an intergovernmental scientific program that aims to set a scientific basis for the improvement of the relationships between people and their environment globally (UNESCO 2013c). In 2013, the World Network of Biosphere Reserves included 621 reserves in 117 countries (UNESCO 2013c). The MAB Programme combines natural and social sciences, economics and education to improve human livelihoods and safeguard natural ecosystems, and thus aims to promote innovative approaches to economic development that are socially and culturally appropriate and environmentally sustainable.

Biosphere reserves aim to achieve the integrated management of land, fresh water, marine waters and living resources by establishing bioregional planning schemes (and zones) to achieve sustainable development. Implementation of the zones is left to the discretion of nations, and they include core zones (ideally protected areas) that are surrounded by buffer zones (where conservation is emphasised) and a transition zone (or area of cooperation that promotes sustainable development) (UNESCO 2002). Biosphere reserves are described on their nomination form by UNESCO (2013b:1):

Biosphere reserves are areas of terrestrial and coastal/marine ecosystems, or a combination thereof, which are internationally recognized within the framework of UNESCO's Programme on Man and the Biosphere (MAB). They are established to promote and demonstrate a balanced relationship between humans and the biosphere. Biosphere reserves are designated by the International Coordinating Council of the MAB Programme at the request of the State concerned. Individual biosphere reserves remain under the sovereign jurisdiction of the State where they are situated. Collectively, all biosphere reserves form a World Network in which participation by States is voluntary. 
The World Network of Biosphere Reserves is governed by a framework adopted by the UNESCO General Conference in 1995, which presents the definition, objectives, criteria and designation procedure for biosphere reserves. The actions recommended for the implementation of biosphere reserves are set out in a document referred to as the 'Seville Strategy', and this was further developed as the 'Madrid Action Plan' (2008-13) (UNESCO 2013d). Requirements for areas to be recognised as a biosphere reserve are given in Box 2.1.

\section{UNESCO Geoparks}

The concept of geoparks evolved as a basis for protecting areas of special geological features. UNESCO adopted the concept in 2001, and provided the following guidance:
A Global Geopark is a unified area with geological heritage of international significance. Geoparks use that heritage to promote awareness of key issues facing society in the context of the dynamic planet we all live on. Many Geoparks promote awareness of geological hazards, including volcanoes, earthquakes and tsunamis and many help prepare disaster mitigation strategies among local communities. Geoparks hold records of past climate change and are educators on current climate change as well as adopting a best practice approach to utilising renewable energy and employing the best standards of green tourism. (UNESCO 2014:1)

Geoparks provide information about the sustainable use of and need for natural resources, whether they are mined, quarried or harnessed from the surrounding environment, while at the same time promoting respect for the environment and the integrity of the landscape. Geoparks are not a legislative designation, though the key geoheritage sites within a geopark should be protected under the appropriate legislation (UNESCO 2013e). The Global Network of National Geoparks is a voluntary network supported by UNESCO whose members are committed to work together and exchange ideas of best practice and join in common projects (UNESCO 2013e). Chapter 18 of this book deals further with UNESCO geoparks.

\section{Introducing non-government protected areas}

'Conventional' protected areas are commonly thought of as protected areas established and managed by national governments, especially given the commitment of these governments to the Convention on Biological Diversity and to the implementation of the CBD strategic plan 2011-20. Sub-national governments also establish protected areas. In addition to these government protected areas, around the world in the 21 st century, there has been greater recognition of the traditional and continuing role of indigenous peoples and local communities, and of individuals, civil society organisations and the private sector in the conservation of land, including the governance and management of protected areas.

Innovation in conservation, protection and management has been called for (Figgis 2012) at a time when a cocktail of threats such as increased human pressures including habitat destruction and poaching, pollution and climate change, severe weather events and fires, and introduced species are impacting the Earth's biodiversity. Two types of non-government protected areas are recognised widely, including by the IUCN and by governments as part of the CBD Programme of Work on Protected Areas: Indigenous Peoples' and Community Conserved Territories and Areas (ICCAs) and Private Protected Areas (PPAs). A third type, Shared Governance or Collaboratively Managed Protected Areas, contains sites managed by two or more of these agencies and groups. Together with government-protected areas, these constitute the four governance types now globally recognised (see Chapter 7).

\section{Indigenous Peoples and Community Conserved Territories and Areas}

Outside formal tribal governments such as those in the United States, indigenous peoples and local and mobile communities may establish, govern and manage ICCAs (Borrini-Feyerabend et al. 2004). ICCAs provide an important contribution to biodiversity conservation in many parts of the world. They have been defined as 'natural and modified ecosystems with significant biodiversity, ecological and related cultural values, voluntarily conserved by indigenous peoples and local communities through customary laws or other effective means' (Kothari et al. 2012:16). 


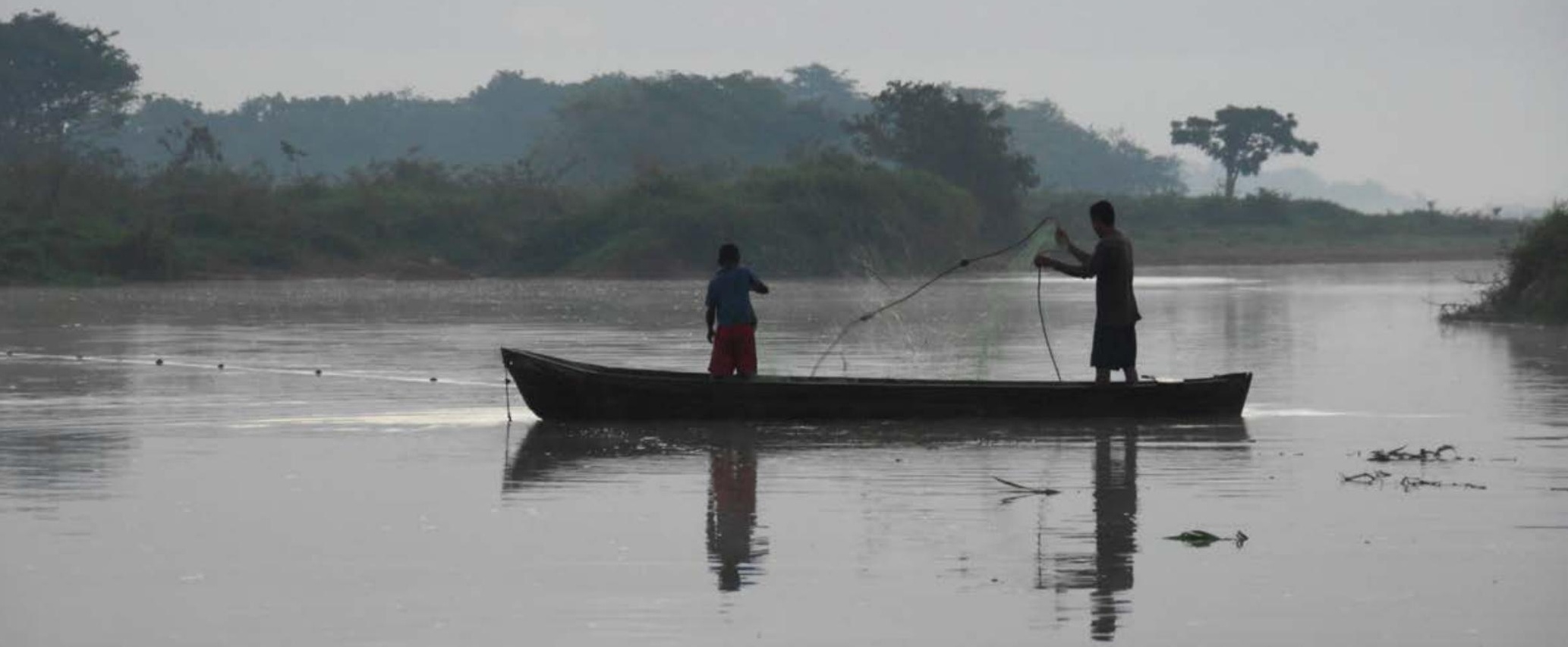

Rio Platano Biosphere Reserve, Honduras

Source: Eduard Müller

\section{Box 2.1 UNESCO criteria for designation as biosphere reserve}

Article 4 of the biosphere reserve framework presents seven general criteria for an area to be qualified for designation as a biosphere reserve. It would:

1. Encompass a mosaic of ecological systems representative of major biogeographic region(s), including a gradation of human interventions.

2. Be of significance for biological diversity conservation.

3. Provide an opportunity to explore and demonstrate approaches to sustainable development on a regional scale.

4. Have an appropriate size to serve the three functions of biosphere reserves.

5. Through appropriate zonation, achieve

a. a legally constituted core area or areas devoted to long-term protection, according to the conservation objectives of the biosphere reserve, and of sufficient size to meet these objectives

b. a buffer zone or zones clearly identified and surrounding or contiguous with the core area or areas, where only activities compatible with the conservation objectives can take place c. an outer transition area where sustainable resource management practices are promoted and developed.

6. Have organisational arrangements that provide for the involvement and participation of a suitable range of inter alia public authorities, local communities and private interests in the design and carrying out of the functions of a biosphere reserve.

7. Have mechanisms for implementation that include

a. mechanisms to manage human use and activities in the buffer zone or zones

b. a management policy or plan for the area as a biosphere reserve

c. a designated authority or mechanism to implement this policy or plan

d. programs for research, monitoring, education and training?

Source: UNESCO (2013b) 
This encompasses three essential features (Kothari et al. 2012:17).

1. A well-defined people or community with a close and profound relation with an equally well-defined site (a territory, area or species habitat, though the boundaries may be flexible) and/or species; this is a relation rooted in culture, sense of identity and/or dependence for livelihood or wellbeing.

2. The people or community as the major player in decision-making and implementation regarding the governance and management of the site and/or species, implying local institutions have the de facto and/or the de jure (formal equality) capacity to develop and enforce decisions. Other rights-holders and stakeholders may collaborate as partnersespecially when the land is owned by the statebut local decisions and management efforts are predominant.

3. The people's or community's management decisions and efforts lead to the conservation of habitats, species, genetic diversity, ecological functions/ benefits and associated cultural values, even when the conscious objectives of management are not conservation alone.

There are many different types of ICCAs (Box 2.2). Not all of these ICCAs are protected areas, but all of them help to conserve biodiversity and include many values and benefits (Box 2.3). ICCAs may be very small or extend over several million hectares, and are found in many countries of the world. Neema Pathak (Case Study 2.1) has researched details of their characteristics in India. Chapter 7 provides further information on ICCAs.

\section{Australian Indigenous Protected Areas}

The Australian Government has supported the development of Indigenous Protected Areas (IPAs) since 1997 and has defined these as 'an area of Indigenousowned land or sea where traditional owners have entered into an agreement with the Australian Government to promote biodiversity and cultural resource conservation' (Government of Australia 2013:1).

IPAs do not have an overarching legal framework; rather they rely on Indigenous communities identifying their wish to dedicate their land for conservation purposes. IPAs are formally recognised as a protected area under Australia's National Reserve System through the 'legal and other effective means' clause of the IUCN protected area definition (Rose 2013). In 2013, there were 60 declared IPAs covering just more than 48 million hectares across Australia, contributing more than one-third of the National Reserve System (Government of Australia
2013). IPAs deliver more than environmental benefits; importantly, they provide communities with significant health, education, economic and social benefits as well as protecting their significant cultural values.

\section{Private protected areas}

Privately owned and managed protected areas have been in existence for centuries (such as the private hunting reserves of Mongolia and Europe) (Langholz 2005). Privately protected areas are now being encouraged by some nations as a mechanism for biodiversity conservation that complements community-based and government reserves. The IUCN defined a private protected area at the 2003 IUCN World Parks Congress as 'a land parcel of any size that is 1) predominantly managed for biodiversity conservation; 2) protected with or without formal government recognition; and 3) is owned or otherwise secured by individuals, communities, corporations or non-governmental organisations' (Chape et al. 2008:102).

Private protected areas have been established, for example, in Chile (Pumalin Park), southern and eastern Africa (such as the game reserves that adjoin Kruger National Park), Namibia (Namib Rand Nature Reserve), the United States (the Gray Ranch) and the United Kingdom (the Royal Society for the Protection of Birds with its 150 reserves totalling more than 240 000 hectares) (Langholz 2005). In Australia several NGOs have purchased substantial properties and manage them for biodiversity outcomes, including Bush Heritage Australia, the Australian Wildlife Conservancy and Tasmanian Land Conservancy. Also notable are The Nature Conservancy preserves and easement lands in the United States, which currently protect approximately 6.1 million hectares (TNC 2013).

\section{Other conservation initiatives that complement protected areas}

There are many initiatives and effective area-based conservation measures that do not meet the definition of a protected area or where protected area status is not sought, but still contribute to biodiversity conservation outcomes. These include voluntary wildlife sanctuaries, roadside greenways, conserved riparian areas in production forests, conservation areas in government-owned forests, wetlands and forested areas retained on farmland, along streams, tourist areas, private ecotourism destinations, ICCAs outside the protected area system, military areas and even university campuses. Regenerating former agricultural areas, urban parks, public gardens and private estates and gardens (especially with native species) can all contribute to conservation of native biodiversity in the landscape. 


\section{Case Study 2.1 Community Conserved Areas in India}

Neema Pathak, in her contribution to our knowledge of community conserved areas (CCAs) in India, acknowledged the enormous challenge of defining CCAs for her country. She established a working definition, which identified CCAs as '[n]atural ecosystems (forest/ marine/wetlands/grasslands/others), including those with minimum to substantial human influence, containing significant wildlife and biodiversity value, being conserved by communities for cultural, religious, livelihood, or political purposes, using customary law or other effective means' (Pathak 2009:49).

She also identified six criteria for recognising CCAs for India.

1. There is an identified group of people who can be considered a community who are involved in the effort.

2. The concerned communities have substantial ethical livelihood, cultural, economic or spiritual associations with and dependence on the conserved area.
3. The concerned communities are the major players or among the major players in decision-making and implementation of decisions.

4. The concerned communities have established systems (institutions, regulations, processes) for achieving their objectives.

5. Irrespective of the objective of the initiative, the efforts lead to maintenance or enhancement of one or more natural ecosystems and species therein.

6. The effort is taking place within a locally identified boundary (Pathak 2009:50-1).

Source: Pathak (2009)

\section{Box 2.2 Types of ICCAs}

There are several kinds of ICCAs and they are listed here. Not all of these ICCAs are protected areas, but they do help to conserve biodiversity (see Chapter 7 ).

- Indigenous peoples' territories governed and managed as part of their history and life, encompassing sustainable use, cultural values and/or, in more recent times, explicit conservation objectives. For example, indigenous territories with multiple villages in Suriname, Indigenous Protected Areas in Australia, indigenous reserves in Costa Rica and indigenous 'Comarcas' in Panama.

- Territories (terrestrial or marine) over which mobile or nomadic communities have traditionally roamed, managing the resources through customary regulations and practices-for example, customary rangelands of tribal confederacies in Iran, and pastoral landscapes in Kenya and Ethiopia.

- Sacred natural sites or spaces, ranging from tiny groves and wetlands to entire landscapes and seascapes, often (but not necessarily) left completely or largely inviolate. For example, sacred groves and landscapes of South Asia, sacred lakes and marine burial sites in the Philippines and sacred forests of Kenya.

- Resource catchment areas, from which communities make their essential livelihoods or from which key ecosystem benefits are derived, managed in such a way that these benefits are sustained over time. For example, locally managed marine areas in the South Pacific and Madagascar, autonomous marine protected areas and Satoumi seascapes in Japan, marine areas for responsible fishing in Costa Rica, and community forests in Tanzania.
- Areas conserved for optimising productivity of related ecosystems-for example, 'fisher forests' or 'fish-breeding forests' in Japan.

- Areas and species populations sustainably managed for commercial benefits-for example, sites managed for ecotourism in Suriname and Kenya and areas managed for sustainable hunting and ecotourism like Namibia's Communal Conservancies.

- Nesting or roosting sites, other critical habitats of wild plants and animals, or wildlife populations spread over large territories, conserved for ethical or other reasons explicitly oriented towards protecting these plants and animals. For example, bird nesting and roosting sites in India, sacred crocodile ponds of Gambia and Mali, certain tree species like arawone (Tabebuia serratifolia) in Suriname and marine turtle nesting sites in Chile, Costa Rica and Suriname.

Source: Kothari et al. (2012) 


\section{Box 2.3 Values and benefits of ICCAs}

ICCAs, many of which a formally recognised as protected areas, include important values and provide many benefits including:

- providing the context and means for the sociocultural, economic, political, spiritual, and physical wellbeing of thousands of indigenous peoples and local communities, involving hundreds of millions of people

- helping to conserve critical ecosystems and threatened species across a broad range of biogeographic regions of the world

- maintaining essential ecosystem functions, such as water security, soil conservation and maintenance of gene pools

- providing connectivity conservation corridors and linkages for species movements including often between two or more protected areas

- providing secure and sustainable (though not necessarily adequate in all cases) livelihoods in a variety of occupations-both subsistence and revenue-generating-including forestry, fisheries, pastoralism, crafts, health, tourism and others

- helping to conserve a diversity of agricultural ecosystems, species/genes, and practices, as well as synergising links between agricultural biodiversity and wildlife and providing larger land and waterscapelevel integration for conservation

- offering crucial lessons for participatory governance that are useful for providing guidance for every form of governance including government-managed protected areas

- offering lessons in integrating customary and statutory laws, and formal and non-formal institutions that aim to achieve effective conservation

- building on and validating sophisticated local ecological knowledge systems, elements of which have wider positive use
- aiding communities with resistance to destructive development and saving territories and habitats from mining, dams, logging, tourism, over-fishing, agricultural expansion by settler populations, and others

- helping communities in empowering themselves, especially to reclaim or securing territories, tenure and rights to or control over resources they depend on or relate to

- aiding communities to better define their territories, such as through mapping

- helping to create a greater sense of community identity and cohesiveness, and also a renewed vitality and sense of pride in local cultures including amongst youth who may otherwise be alienated through modern influences

- creating conditions for other developmental inputs to flow into the community such as funds for schools, health clinics, water connections and livelihood enterprises

- leading to greater equity within a community (e.g. between classes, men and women, and ethnic groups) and between the community and outside agencies (e.g. in decision-making)

- conserving biodiversity at relatively low financial cost (though often high labour inputs), with costs of management often covered as part of normal livelihood or cultural activities, through existing systems and structures

- providing examples of relatively simple and effective administration and decision-making structures, and avoiding complex bureaucracies.

Values and benefits of protected areas are discussed further in Chapter 6.

Source: Kothari et al. (2012)
The Aichi Target 11 of the CBD recognises that if the global goal of 17 per cent terrestrial and 10 per cent marine coverage of conservation is to be achieved, it will have to be through a combination of protected areas and 'other effective area-based conservation measures', such as the examples above.

\section{Challenges for protected areas}

Protected area governance authorities and managers (Box 2.4) have enormous challenges in the 21st century. The footprint of human disturbance and change can be seen on every continent of Earth including Antarctica, and transformation of natural environments has gained momentum, not diminished during this century. Assessments of the challenges facing protected areas made by Charles Barber and his colleagues in 2004 are essentially unchanged (Barber et al. 2004), though they are perhaps clearer in 2014, such as the increasingly entrenched effects of climate change (IPCC 2013) and population growth, which could see 9.2 billion people on Earth in 2050 (UNEP 2013). In this book we appraise such underlying causes of threats to protected areas (Chapter 16) and provide responses to the consequent challenges facing protected area governors and managers. Our aim is to equip protected area practitioners with the information they need to achieve effective management of their areas as a basis for creating improved futures 


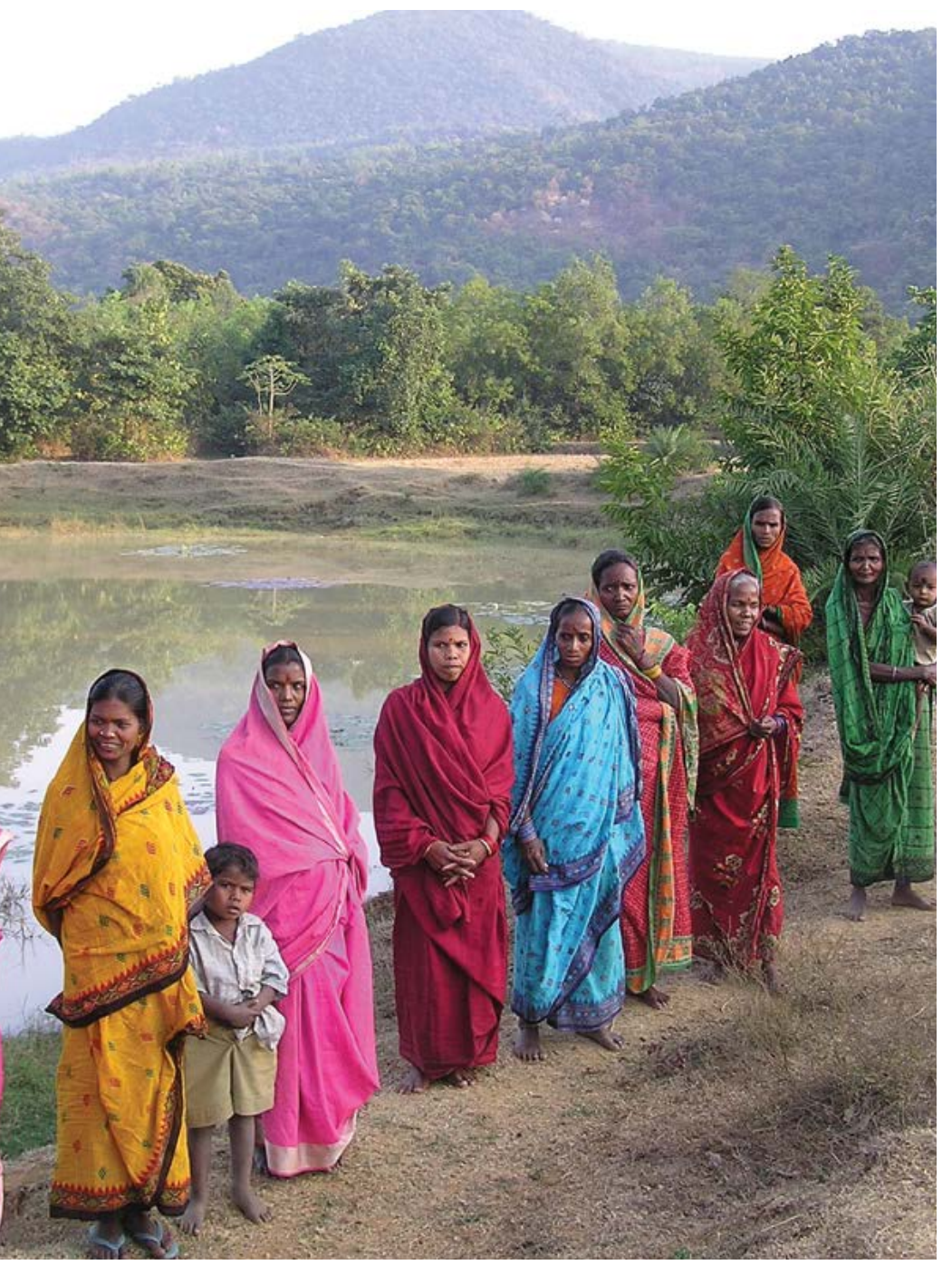

Women's forest protection committee at Dangejheri village, Odisha, India

Source: Ashish Kothari

for species, ecosystems and other heritage and for maintaining healthy environments and consequently healthy people on our planet. Here we briefly consider some significant challenges and introduce the book chapters that respond to these issues. These challenges below comprise facts, observations by many people and some personal reflections based on the author's 40 years of protected area professional management.

\section{Challenge: Global change}

Global change is a major challenge for protected area governors and managers. In the 21 st century they will need to deal with a shifting climate with its associated more frequent and more severe storm and weather systems; with sea-level rise and the inundation of islands, and estuarine and low-lying areas; and with the melting of many mountain glaciers and the transformation of

\section{Box 2.4 Governance and management}

Governance is a critical part of protected areas that identifies how organisations administer a protected area and the associated power and decision-making arrangements. It addresses who makes decisions for protected areas and their management, and how the decisions are made. It is different from management that focuses on what responses are needed for a given situation or a location in need of attention. Governance is about how power is exercised, how decisions are taken on issues of public concern and how citizens or other stakeholders have their say (Graham et al. 2003). Global conservation policy has also recognised the importance of the quality of governance, including whether individual protected areas or the protected area system as a whole incorporate principles such as accountability, fairness, equity, participation, subsidiarity, effectiveness for achieving biodiversity conservation, and others. Chapter 7 discusses governance and protected areas in more detail.

Management is about the coordination of people, resources and activities to achieve the objectives of a protected area organisation (Hitt et al. 2011), and there are four basic functions that are undertaken in any process of management: planning, organising, leading and evaluating. Protected areas need active management for the conservation of biodiversity, other natural heritage and cultural heritage. If this management is not effective then a protected area may be reduced to being a 'paper park' with its heritage values lost. Chapter 8 of this book describes in more detail how protected areas are established and managed and Chapter 28 describes the concept of management effectiveness evaluation. perennial streams to ephemeral streams (Chapter 17). These changes will see enhanced threats from droughts, flooding rains and incidents such as wildfire, and the effects of storm surges will be more frequent and require new skills and responses for protected area professionals (Chapter 26). These climate change trends will also witness shifts in areas suitable for vegetation types, changes in habitats and invasions of alien species that will require more strategic, more frequent and often larger and more sophisticated management responses (Chapter 16).

It will be a world of increasing human population and associated increasing demand for Earth's finite resources, enhanced industrialisation, globalised commerce, instant communication, and the resulting transformation and reduction in area of natural habitats and impacts on Earth's species (Barber et al. 2004). Increased tension and conflict are potentially major issues as human demands 
and industries endeavour to access existing protected areas and threats from outside park boundaries impact on the health of the ecosystems and species. Pollution of the atmosphere, creeks, rivers, estuaries and oceans can be expected to increase and other threats such as habitat destruction and poaching can be expected to prevail given more people on Earth (Barber et al. 2004). Some issues may be amenable to global responses such as acceptance of a broadscale international ban on mining in protected areas (Categories $\mathrm{I}-\mathrm{V}$ ) in accordance with the 21 st-century IUCN position. Other issues may be suitable for protected area system-level responses where governments, organisations and communities vigorously and faithfully uphold the IUCN protected area category objectives of management. Many issues, however, will need to be dealt with as they impact individual protected areas.

The pressures of some commerce, business sectors and agriculture on society to move substantially away from conservation and protection in favour of utilisation and development will increase. Forces advocating and facilitating the 'regression' and 'back-sliding' of protected areas for 'use' and for vested interests may grow as populations grow and as resources become scarce. In different parts of the world, the equivalent of the 1913 Hetch Hetchy Dam 'utilisation versus conservation' debate in Yosemite National Park in the United States could occur. In 1912, John Muir wrote:

Hetch Hetchy is a grand landscape garden, one of nature's rarest and most precious mountain temples. As in Yosemite, the sublime rocks of its walls seem to glow with life ... while birds, bees, and butterflies help the river and waterfalls to stir all the air into music ... These temple destroyers, devotees of ravaging commercialism, seem to have a perfect contempt for Nature, and, instead of lifting their eyes to the God of the mountains, lift them to the Almighty Dollar. (Muir 1912)

Thankfully in the 21st century, people like Muir continue to inspire and seek to conserve protected areas for future generations. Part of this inspiration is the knowledge that if these areas are utilised and despoiled, there will be few (if any) remaining equivalent lands on finite Earth. Their intergenerational inheritance status, their long-term immense and sustainable contribution to ecosystem services, their purpose in protecting a nation's species, their role in retaining healthy environments and their natural beauty are what is enjoyed so much by people (Chapter 6).
Leadership and effective governance and management of protected areas will need to anticipate and deal with 'use' advocacy pressures (Chapters 7, 8 and 12). The concept of protected areas as intergenerational or 'forever protected' lands will need to be deeply valued by all societies. It will need to be constantly championed. Protected area leaders (Chapter 12) will need to effectively communicate protection messages (Chapter 15), work positively with people and decision-makers (Chapter 14) and ensure that information about the importance and benefits of protected areas is readily available (Chapter 11). Dealing with the larger issue of the sustainable use of Earth's finite resources will be a critical part of helping to protect the natural values of protected areas in the long term (Chapter 8).

\section{Challenge: Establishing new protected areas}

Protected area governors and managers have the comfort and knowledge that well-managed protected areas are effective in their role of protecting individual species, biodiversity and ecosystem services and other natural and cultural heritage. In 2014, however, there is inadequate coverage of protected areas on Earth. Only 15.4 per cent of the Earth's terrestrial area (outside Antarctica) and 3.4 per cent of its marine environment are under officially recognised protected areas (IUCN and UNEP-WCMC 2014), and this is not enough to adequately conserve Earth's species. This challenge was identified by the Convention on Biological Diversity strategic plan 2011-20 and especially Target 11:
By 2020, at least 17 per cent of terrestrial and inland water areas, and 10 per cent of coastal and marine areas, especially areas of particular importance for biodiversity and ecosystem services, are conserved through effectively and equitably managed, ecologically representative and well-connected systems of protected areas and other effective area-based conservation measures, and integrated into the wider landscapes and seascapes. (CBD 2011:3)

Consequently, nations of Earth have agreed that additional protected areas need to be established, and recognition provided to currently unrecognised conservation initiatives by communities and the private sector to fill gaps. Establishing exactly where new protected areas are needed is critical, and a gap analysis supported by systematic conservation planning approaches is often used to achieve this (Chapter 13). In 


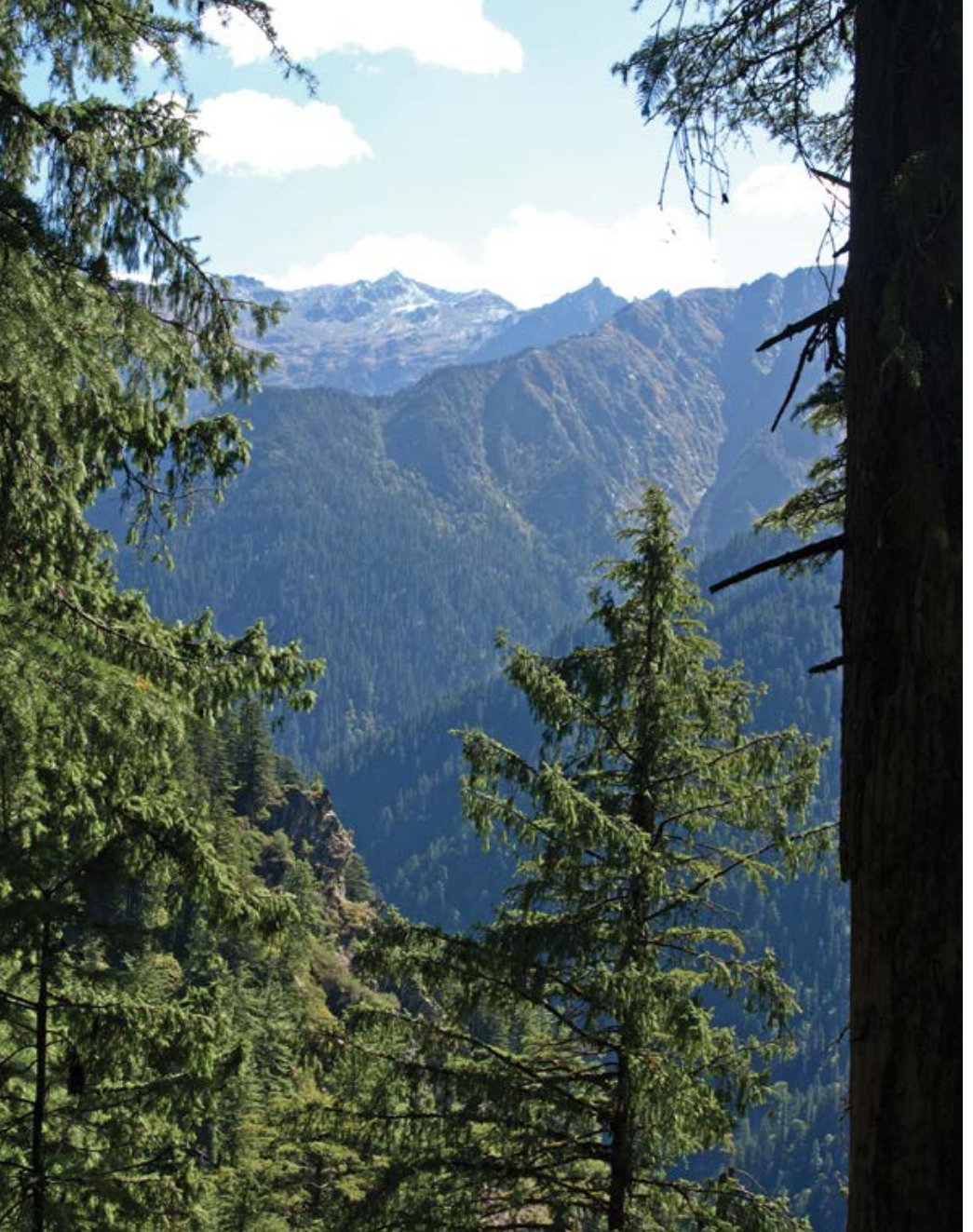

Great Himalayan National Park, India

Source: Graeme L. Worboys

2014, more sophisticated data aggregation approaches are also being used to identify key biodiversity areas (Chapter 21).

The introductory descriptions of the Earth's major environment types (Chapter 3) underpin more detailed identification of terrestrial areas that represent important biodiversity areas and potential gaps of biodiversity conservation significance (Chapters 3 and 21; Butchart et al. 2012). Consideration of cultural heritage (Chapter 4), geoheritage (Chapter 18), freshwater and estuarine environments (Chapter 19) and marine environments (Chapter 20) helps identify the importance of conserving natural and cultural heritage. Establishing the locations, purposes and management objectives is an important part of the reservation process, and the six universally accepted IUCN categories described above provide essential guidance in this regard. Visionary leadership is also a key part of establishing new protected areas (Chapter 12), as is a clear understanding of the social and political contexts and societal influences and global change (Chapter 5).

\section{Challenge: Effective governance and management}

The practice of protected area governance and management is an essential profession for facilitating a healthy environment and for helping to conserve life on Earth. Ideally it is underpinned by both formal tertiarylevel protected area governance and management qualifications and vocation-based training (Chapter 9), and achieving this standard is a global challenge. Local traditional knowledge held by indigenous communities also provides a critical contribution to conservation management (Chapters 7 and 25).

Achieving effective governance for protected areas is vital (Chapter 7). Organisations and communities will need to be adaptive and responsive to changes, and local professional protected area managers will need to have the freedom to manage (Chapter 8), albeit within established statutory, corporate and planned guidelines, as well as with community input and guidance. The imposition of directives from centralised power bases, for example, which disempowers the ability of 'managers to manage' and otherwise protect nature, is poor governance practice and a threat to nature conservation.

In addition to staff with the right competencies and training, effective management is based on good planning (Chapter 13), good business management, a sound knowledge of managing biodiversity conservation needs (Chapter 21), the ability to manage for cultural heritage management requirements (Chapter 22), resource use (Chapter 25) and operations management (Chapter 24), as well as looking after the needs of visitors (Chapter 23). This important work may extend to managing World Heritage properties (Chapter 3) or working off-reserve or conservation area to help facilitate connectivity conservation areas (Chapter 27). Evaluating the effectiveness of all of this professional management activity and reporting on the good work are fundamental for the future (Chapter 28). Achieving a minimum professional standard of protected area governance and management for all protected areas on Earth provides a fundamental contribution to the conservation of life on Earth. It is a formidable challenge in the early part of the 21 st century, with this book providing one response to this challenge.

\section{Challenge: The future}

Protected areas provide a key response to many of the environmental issues facing all nations of Earth in the coming decades and in particular climate change, water stress, food security, energy production and biodiversity 
loss (MacKinnon et al. 2011). They have a formidable responsibility, for protected areas are the principal tools for conserving Earth's diversity of life and for protecting a wealth of natural and cultural heritage on behalf of nations. The concept of protected areas has been implemented with confidence by governments and others since the 20th century, and science has confirmed that effectively managed protected areas have been successful in conserving biodiversity. As we progress further and further into the 21 st century, with its associated human population increases, development and consumption, deepening impacts of climate change, post-peak oil energy changes, resource shortages and potential social disorder, there will be increasing challenges for protected areas and their managers. The actions in the 20th and early 21 st centuries to reserve and establish protected areas, though formidably tough to achieve, will in retrospect be seen as the easy (though essential) part of the history of governing and managing for protected areas.

In the future, protected areas may well be among the last natural lands. If so, they would be a focus of attention. They would be the only places where certain resources were available and where the last of some species continued to exist in the wild. Knowing human behaviour, one inevitable threat would be in the form of the seemingly irresistible forces that seek to access and utilise (either legally or illegally) the last of these resources, despite the consequences. The illegal shooting of rhinoceros for their horns in Kruger National Park, South Africa, in 2013 to meet the demand from Asian medicine markets (irrespective of the decline in rhinoceros population numbers) is one example of such a potential future. Mining is another formidable threat. It is currently one of the severest threats to protected areas and even to World Heritage sites, for income from mining royalties is hard for economically struggling economies to resist.

We need to be optimistic that planet Earth and its peoples will never allow a situation where short-term resource gains have precedence over lands and seas protected for their outstanding values for all generations. We need to invest in a healthy planet where the diversity of life can continue, and where the natural inheritance of future generations is held in trust and effectively managed. There is no doubt, however, that protected area managers will be challenged more and more in the future. These challenges will come from many environmental threats as well as the social and political contexts in which protected areas operate. This book has been designed to help equip 21 st-century protected area managers to deal with such issues and to provide the type of leadership necessary to help secure protected areas as long-term treasured assets of the community that are 'too precious to lose'.

\section{Conclusion}

The 20th century and the first part of the 21st century have witnessed one of the great peaceful land-use and sea-use transformations in human history with the establishment of protected areas by nearly all nations of Earth, although this action is unfinished and ongoing. In 2014, protected areas covered 15.4 per cent of the terrestrial area of Earth, 3.4 per cent of the sea and 8.4 per cent of seas under national jurisdiction (IUCN and UNEP-WCMC 2014). The urgency of protected area establishment is one critical response to today's challenges and those of the future, including threats from habitat loss and climate change.

The Convention on Biological Diversity's 'Strategic Plan for Biodiversity 2011-20' (CBD 2011) challenges nations to achieve protected area (and other effective area-based conservation area) targets of at least $17 \%$ for terrestrial areas and $10 \%$ for marine areas by 2020 . This reflects great confidence in the concept of protected areas as a critical conservation tool. Such confidence is based on lived experience and demonstrated conservation successes. It is also confidence achieved through the clarity of purpose for protected areas that is underpinned by robust supporting information. Protected areas are clearly defined; the different management types are formally recognised including six IUCN management categories; their different governance types are formally described; and the principles of their management are clearly articulated. Protected areas are also effective thanks to planned, active and competent management implemented by trained practitioners. Protected areas help conserve biodiversity and other natural heritage and cultural heritage and they are an intergenerational investment in a better world.

\section{Supplementary reading}

The IUCN has produced a suite of important guidelines and other protected area governance and management literature, many of which are listed in Appendix 2.1. 


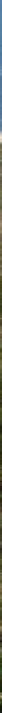

Cape Point, Cape of Good Hope section, Table Mountain National Park, South Africa: the park includes Cape Flora vegetation communities, one of the world's richest temperate flora that includes fynbos (shrubland that is dominated by fine-leaved shrubs). The park is part of the Cape Floral Region Serial World Heritage Property.

Source: Graeme L. Worboys

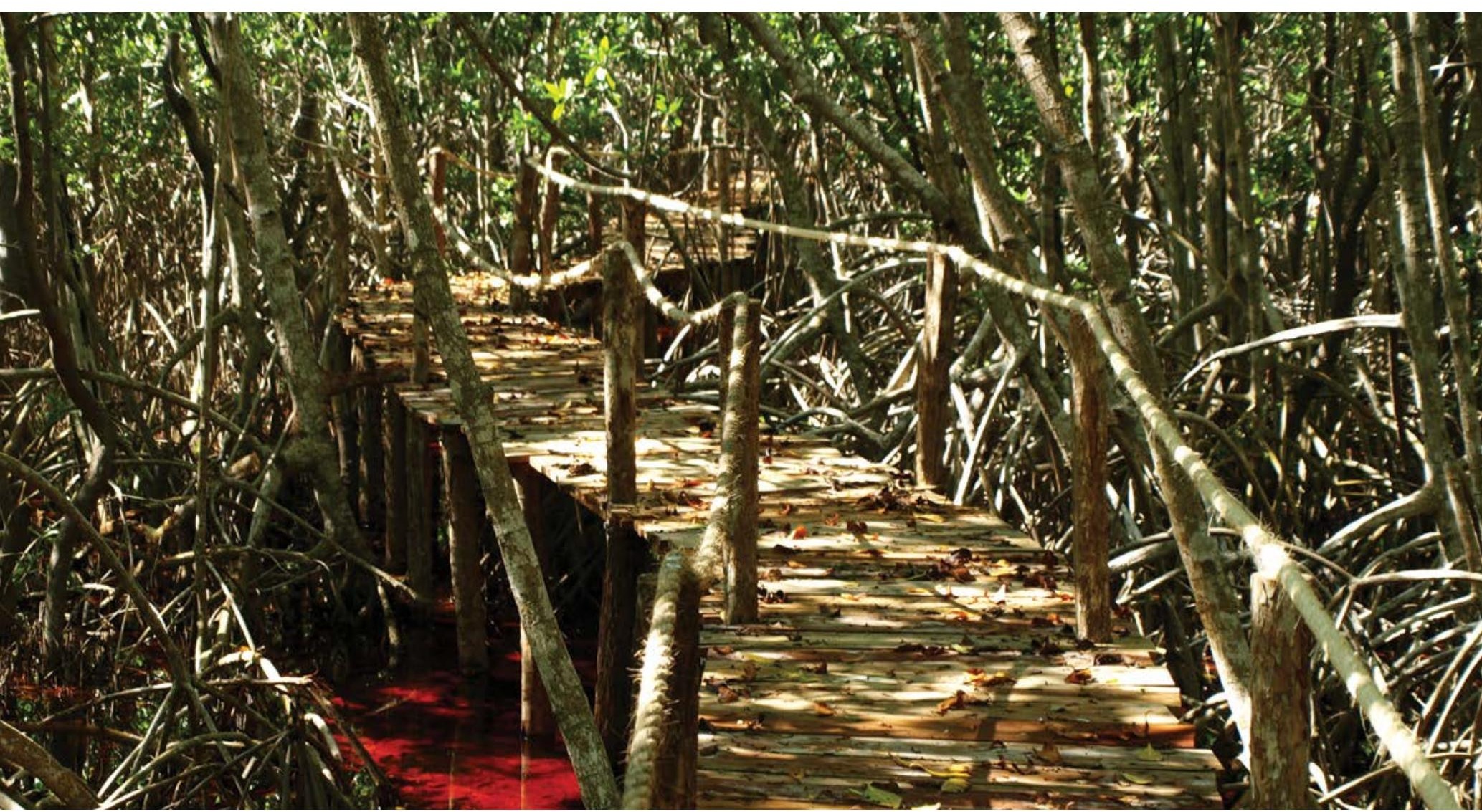

The boardwalk shown provides visitor access through rich mangrove communities within the Celestun Biosphere Reserve, Yucatan State, Mexico: the fresh water cenotes, mangrove and estuarine habitats of the reserve help to protect flocks of flamingos (Phoenicopterus sp.) and herons; it is an important resting and breeding site for migratory birds and it is a hatching ground for turtle species.

Source: Graeme L. Worboys 


\section{References}

Recommended reading

Ali, S. (ed.) (2007) Peace Parks, Conservation and Conflict Resolution, MIT Press, Cambridge, Mass.

Amend, T., Brown, J., Kothari, A., Phillips, A. and Stolton, S. (eds) (2008) Protected Landscapes and Agrobiodiversity Values. Volume 1, Values of Protected Landscapes and Seascapes Series, IUCN WCPA Specialist Group on Protected Landscapes and GTZ on behalf of the Federal Ministry of Economic Cooperation and Development of Germany, Heidelberg.

Barber, C. V., Miller, K. R. and Boness, M. (eds) (2004) Securing Protected Areas in the Face of Global Change: Issues and strategies, IUCN WCPA, Gland.

Beltrán, J. (ed.) (2000) Indigenous and Traditional Peoples and Protected Areas: Principles, guidelines and case studies, IUCN, Gland.

Bennett, A. F. (2003) Linkages in the Landscape: The role of corridors and connectivity in wildlife conservation, 2nd edn, IUCN Forests Program, Gland.

Bennett, G. (2004) Integrating Biodiversity Conservation and Sustainable Use: Lessons learned from ecological networks, IUCN, Gland.

Bernbaum, E. (1990) Sacred Mountains of the World, Sierra Club and University of California Press, Berkeley.

D Bertzky, B., Corrigan, C., Kemsey, J., Kenney, S., Ravilious, C., Besançon, C. and Burgess, N. (2012) Protected Planet Report 2012: Tracking progress towards global targets for protected areas, UNEPWCMC, Cambridge.

Bertzky, B., Shi, Y., Hughes, A., Engels, B., Ali, M. K. and Badman, T. (2013) Terrestrial Biodiversity and the World Heritage List: Identifying broad gaps, and potential candidate sites for inclusion in the Natural World Heritage network, IUCN, Gland, and UNEP-WCMC, Cambridge.

Bishop, K., Dudley, N., Phillips, A. and Stolton, S. (2004) Speaking a Common Language: The uses and performance of management categories for protected areas, IUCN, Gland.
Borrini-Feyerabend, G., Dudley, N., Jaeger, T., Lassen, B., Pathak Broome, N., Phillips, A. and Sandwith, T. (2013) Governance of Protected Areas: From understanding to action, Best Practice Series No. 20, IUCN, Gland.

Borrini-Feyerabend, G., Kothari, A. and Oviedo, G. (2004) Indigenous and Local Communities and Protected Areas: Towards equity and enhanced conservation, IUCN, Gland.

Braack, L., Sandwith, T., Peddle, D. and Petermann, T. (2006) Security Considerations in the Planning and Management of Transboundary Conservation Areas, WCPA Task Force on Transboundary Conservation, IUCN, Gland.

Brockman, C. F. (1959) Recreational Use of Wild Lands, McGraw Hill, New York.

Brown, J., Mitchell, N. and Beresford, M. (eds) (2005) The Protected Landscape Approach: Linking nature, culture and community, IUCN WCPA, Gland.

Butchart, S. H. M., Scharlemann, J. P. W., Evans, M. I., Quader, S., Aricò, S., Arinaitwe, J., Balman, M., Bennun, L. A., Bertzky, B., Besançon, C., Boucher, T., Brooks, T. M., Burfield, I. J., Burgess, N. D., Chan, S., Clay, R. P., Crosby, M. J., Davidson, N. C., de Silva, N., Devenish, C., Dutson, G. C. L., Fernández, D. F. D. z., Fishpool, L. D. C., Fitzgerald, C., Foster, M., Heath, M. F., Hockings, M., Hoffmann, M., Knox, D., Larson, F. W., Lamoreux, J. F., Loucks, C., May, I., Millett, J., Molloy, D., Morling, P., Parr, M., Ricketts, T. H., Seddon, N., Skolnik, B., Stuart, S. M., Upgren, A. and Woodley, S. (2012) 'Protecting important sites for biodiversity contributes to meeting global conservation targets', PLoS ONE 7(3): e32529.

Campbell, C. (ed.) (2011) A Century of Parks Canada, 1911-2011, University of Calgary Press, Calgary.

Catlin, G. (1844) 'Letter No. 31', Letters and Notes on the Manners, Customs and Condition of the North American Indians, Wiley \& Putnam, New York. $<$ user.xmission.com/ - drudy/mtman/html/catlin/>

Ceballos-Lascuráin, H. (1996) Tourism, Ecotourism and Protected Areas, Protected Areas Programme, IUCN, Gland.

Chape, S., Blyth, L., Fish, P. and Spalding, M. (2003) 2003 United Nations List of Protected Areas, IUCN, Gland, and UNEP-WCMC, Cambridge. 
DD Chape, S., Spalding, M. and Jenkins, M. (2008) The World's Protected Areas: Status, values and prospects in the 21st century, University of California, Berkeley.

Commission on National Parks and Protected Areas (CNPPA) (1994) Guidelines for Protected Area Management Categories, IUCN, Gland.

Convention on Biological Diversity (CBD) (2011) Strategic Plan for Biodiversity 2011-2020 and the Aichi Targets, Secretariat of the Convention on Biological Diversity, Montreal. <www.cbd.int/sp/ targets/default.shtml>

Davey, A. G. (1998) National System Planning for Protected Areas, IUCN, Gland.

DD Dudley, N. (2008) Guidelines for Applying Protected Area Management Categories, IUCN, Gland.

Dudley, N. and Phillips, A. (2006) Forests and Protected Areas: Guidance on the use of the IUCN protected area management categories, IUCN WCPA, Gland.

Dudley, N. and Stolton, S. (eds) (2012) Protected Landscapes and Wild Biodiversity. Volume 3, Values of Protected Landscapes and Seascapes Series, IUCN WCPA Specialist Group on Protected Landscapes, Gland.

DD Dudley, N., Stolton, S., Belokurov, A., Krueger, L., Lopoukhine, N., MacKinnon, K., Sandwith, T. and Sekran, N. (eds) (2010) Natural Solutions: Protected areas helping people cope with climate change, IUCN WCPA, The Nature Conservancy and Wildlife Conservation Society, Gland; The World Bank, Washington, DC; UNDP and WWF, New York.

Eagles, P. F. J., McCool, S. F. and Haynes, C. D. (2002) Sustainable Tourism in Protected Areas: Guidelines for planning and management, IUCN, Gland.

Emerton, L., Bishop, J. and Thomas. L. (2006) Sustainable Financing of Protected Areas: A global review of challenges and options, IUCN WCPA, Gland.

Figgis, P. (2012) 'Innovation in conservation', in P. Figgis, J. Fitzsimons and J. Irving (eds) Innovation for 21st Century Conservation, pp. 10-15, Australian Committee for IUCN, Sydney.
Figgis, P. and Koss R. (eds) (2012) Conserving Australia's Marine Environment: Key directions statement, Australian Committee for IUCN, Sydney.

Figgis, P., Leverington, A., Mackay, R., Maclean, A. and Valentine, P. (2013) Keeping the Outstanding Exceptional: The future of world heritage in Australia, Australian Committee for IUCN, Sydney.

Finlayson, B. and Hamilton-Smith, E. (2003) Beneath the Surface: A natural history of Australian caves, UNSW Press, Sydney.

Government of Australia (2013) Indigenous Protected Areas, Australian Government, Canberra. <www. environment.gov.au/indigenous/ipa/>

Graham, J., Amos, B. and Plumptre, T. (2003) Governance principles for protected areas in the 21st century, Paper prepared for the Fifth World Parks Congress, Durban, South Africa, Institute of Governance, Ottawa.

Grove, R. (1995) Green Imperialism: Colonial expansion, tropical island Edens and the origins of environmentalism, 1600-1860, Cambridge University Press, Cambridge.

Dd Hamilton, L. and McMillan, L. (2004) Guidelines for Planning and Managing Mountain Protected Areas, IUCN WCPA, Gland.

Hamilton, L. S., Bauer, D. and Takeuchi, H. F. (1993) Parks, Peaks and People: A collection of papers arising from an international consultation on protected areas in mountain environments held in Hawaii Volcanoes National Park 26 October - 2 November 1991, East West Centre Program on Environment, IUCN Commission on National Parks and Protected Areas, Woodlands Mountain Institute and US National Parks Service, Honolulu.

Hamilton, L. S., Mackay, J. C., Worboys, G. L., Jones, R. A. and Manson, G. B. (1996) Transborder Protected Area Cooperation, Australian Alps Liaison Committee, Canberra.

Harmon, D. and Putney, A. D. (2003) The Full Value of Parks: From economics to the intangible, Rowman \& Littlefield, New York.

Harmon, D. and Worboys, G. L. (eds) (2004) Managing Mountain Protected Areas: Challenges and responses for the 21st century, IUCN WCPA, Andromeda Editrice, Colledara, Italy. 
Hitt, M. A., Black, S. and Porter, L. W. (2011) 'The nature of management', in A. Jayawardana (ed.) Management and Organisations, pp. 4-28, Pearson Australia, Sydney.

Hockings, M., Stolton, S. and Dudley, N. (2000) Evaluating Effectiveness: A framework for assessing the management of protected areas, No. 6, IUCN, Gland.

Dd Hockings, M., Stolton, S., Leverington, F., Dudley, N. and Courrau, J. (2006) Evaluating Effectiveness: A framework for assessing management effectiveness of protected areas, 2 nd edn, No. 14, IUCN WCPA, Gland.

Holdgate, M. (1999) The Green Web: A union for world conservation, Taylor \& Francis, London.

Hornback, K. E. and Eagles, P. F. J. (1999) Guidelines for Public Use Measurement and Reporting at Parks and Protected Areas, IUCN, Gland.

Intergovernmental Panel on Climate Change (IPCC) (2013) Climate Change 2013: The physical science basis_Headline statements for policy makers, Intergovernmental Panel on Climate Change, Geneva. <www.ipcc.ch/>

International Union for Conservation of Nature (IUCN) (1992) Protected Areas of the World: A review of national systems. Volume 1: Indomalaya, Oceania, Australia and Antarctic, IUCN, Gland and Cambridge.

International Union for Conservation of Nature (IUCN) (1994a) Guidelines for Protected Area Management Categories, IUCN, Gland and Cambridge.

International Union for Conservation of Nature (IUCN) (1994b) Parks for Life: Action for protected areas in Europe, IUCN, Gland.

International Union for Conservation of Nature (IUCN) (1995) African Heritage 2000: The future of protected areas in Africa, IUCN, Gland.

International Union for Conservation of Nature (IUCN) (2005) Benefits beyond Boundaries: Proceedings of the Vth IUCN World Park's Congress, IUCN, Gland.

International Union for Conservation of Nature (IUCN) (2010) 50 Years of Working for Protected Areas: A brief history of the IUCN World Commission on Protected Areas, IUCN, Gland.
International Union for Conservation of Nature, United Nations Environment Programme and World Wildlife Fund (IUCN/UNEP/WWF) (1980) World Conservation Strategy: Living resource conservation for sustainable development, IUCN, UNEP and WWF, Gland.

International Union for Conservation of Nature, United Nations Environment Programme and World Wide Fund for Nature (IUCN/UNEP/ WWF) (1991) Caring for the Earth: A strategy for sustainable living, IUCN, UNEP and WWF, Gland.

International Union for Conservation of Nature (IUCN) and United Nations Environment Programme World Conservation Monitoring Centre (UNEP-WCMC) (2014) The World Database on Protected Areas: August 2014, UNEP-WCMC, Cambridge.

1 Keenleyside, K., Dudley, N., Cairns, S., Hall, C. and Stolton, S. (2012) Ecological Restoration for Protected Areas: Principles, guidelines and best practices, No. 18, IUCN WCPA Ecological Task Force, Gland.

Kelleher, G. (1999) Guidelines for Marine Protected Areas, No. 3, IUCN, Gland.

Kelleher, G. and Kenchington, R. (1992) Guidelines for Establishing Marine Protected Areas, IUCN, Gland.

Kopylova, S. L. and Danilina, N. R. (eds) (2011) Protected Area Staff Training: Guidelines for planning and management, No. 17, IUCN WCPA, Gland.

Kothari, A. (2006) 'Community conserved areas: towards ecological and livelihood security', Parks 16(1): 3-13.

Dd Kothari, A., Corrigan, C., Jonas, H., Neumann, A. and Shrumm, H. (eds) (2012) Recognising and Supporting Territories and Areas Conserved by Indigenous Peoples and Local Communities: Global overview and national case studies, Secretariat of the Convention on Biological Diversity, CBD Technical Series No. 64, ICCA Consortium, Kalpavriksh and Natural Justice, Montreal. 
Langhammer, P. F., Bakarr, M. I., Bennun, L. A., Brooks, T. M., Clay, R. P., Darwall, W., de Silva, N., Edgar, G. J., Eken, G., Fishpool, L. D. C., da Fonseca, G. A. B., Foster, M. N., Knox, H. D., Matiku, P., Radford, E. A., Rodriques, A. S. L., Salaman, P., Sechrest, W. and Tordoff, A. W. (2007) Identification and Gap Analysis of Key Biodiversity Areas: Targets for comprehensive protected area systems, No. 15, IUCN WCPA, Gland.

Langholz, J. (2005) 'Seven myths about private protected areas', Parks 15(2): 14-16.

Lausche, B. (2011) Guidelines for Protected Area Legislation, IUCN, Gland.

Lausche, B., Farrier, D., Verschuuren, J., La Vina, A. G. M., Trouwborst, A., Born, C.-H. and Aug, L. (2013) The Legal Aspects of Connectivity Conservation: A concept paper, IUCN, Gland.

Lockwood, M. (2006) 'Values and benefits', in M. Lockwood, G. L. Worboys and A. Kothari (eds) Managing Protected Areas: A global guide, pp. 10115, Earthscan, London.

Lockwood, M., Worboys, G. L. and Kothari, A. (2006) Managing Protected Areas: A global guide, Earthscan, London.

MacKinnon, K., Dudley, N. and Sandwith, T. (2011) 'Natural solutions: protected areas helping people to cope with climate change', Oryx 45(4): 461-2.

Mackinnon, K., Mackinnon, J., Child, G. and Thorsell, J. (1986) Managing Protected Areas in the Tropics, IUCN, Gland and Cambridge.

Mallarach, J.-M. (ed.) (2008) Protected Landscapes and Cultural and Spiritual Values. Volume 2, Values of Protected Landscapes and Seascapes Series, IUCN WCPA Specialist Group on Protected Landscapes, GTZ and Obra Social de Caixa Catalunya, Kasparek Verlag, Heidelberg.

Mallarach, J.-M. and Papayannis, T. (eds) (2007) Protected Areas and Spirituality: Proceedings of the first workshop of the Delos Initiative, IUCN WCPA Task Force on Cultural and Spiritual Values of Protected Areas, Gland, and Publicacions de l'Abadia de Montserrat, Montserrat.

Muir, J. (1912) 'Hetch Hetchy Valley', in The Yosemite, Century, New York. <www.sierraclub.org/john_ muir_exhibit/writings/the_yosemite/>
Pathak, N. (2009) Community Conserved Areas in India-A directory, Kalpavriksh, Pune, India.

Phillips, A. (2002) Management Guidelines for Category V Protected Areas: Protected landscapes/seascapes, No. 9, IUCN WCPA, Gland.

Poore, D. (ed.) (1992) Guidelines for Mountain Protected Areas, IUCN Protected Area Programme Series No. 2, Gland.

Ramsar (2013) Introduction to Ramsar. <www.ramsar. org/cda/en/ramsar-home/main/ramsar/1_4000_0>

Rose, B. (2013) 'Indigenous protected areasinnovation beyond the boundaries', in P. Figgis, J. Fitzsimons and J. Irving (eds) Innovation for 21st Century Conservation, pp. 50-55, Australian Committee for IUCN, Sydney.

Sandwith, T., Shine, C., Hamilton, L. and Sheppard, D. (2001) Transboundary Protected Areas for Peace and Co-Operation, No. 7, IUCN, Gland.

Stolton, S. (2010) 'Protected areas: linking environment and well-being', in S. Stolton and N. Dudley (eds) Arguments for Protected Areas: Multiple benefits for conservation and use, pp. 1-12, Earthscan, London.

Stolton, S. and Dudley, N. (2010) Arguments for Protected Areas: Multiple benefits for conservation and use, Earthscan, London.

Taylor, M. and Figgis, P. (2007) Protected Areas: Buffering nature against climate change. Proceedings of a WWF and IUCN World Commission on Protected Areas Symposium, 18-19 June 2007, Canberra, WWF Australia, Sydney.

Thomas, L. and Middleton, L. (2003) Guidelines for Management Planning of Protected Areas, No. 10, IUCN, Gland.

Thorsell, J. (ed.) (1990) Parks on the Borderline: Experience in transfrontier conservation, IUCN, Gland.

Theme on Indigenous and Local Communities Equity and Protected Areas and Theme on Governance, Equity and Rights (TILCEPA and TGER) (2008) Recognising and supporting indigenous and community conservation: ideas and experiences from the grassroots, CEESP Briefing Note 9, Commission on Environmental, Economic and Social Policy, IUCN, Gland. 
The Nature Conservancy (TNC) (2013) Vision and Mission, The Nature Conservancy, Arlington, VA. $<$ www.nature.org/about-us/vision-mission/index. htm>

Trzyna, T. (ed.) (2005) The Urban Imperative: Urban outreach strategies for protected area agencies, IUCN WCPA, Santa Monica Mountains Conservancy and InterEnvironment California Institute of Public Affairs, Sacramento.

Trzyna, T. (2014) Urban Protected Areas: Profiles and best practice guidelines, IUCN WCPA Best Practice Guideline No. 22, IUCN, Gland.

United Nations Environment Programme (UNEP) (2013) GEO-5: Environment for the future we want, Progress Press, Malta.

United Nations Environment Programme World Conservation Monitoring Centre (UNEP-WCMC) (1992) Protected Areas of the World: A review of national systems, (4 vols), IUCN, Gland.

United Nations Environment Programme (UNEP) (2007) Global Environmental Outlook Geo-5: Environment for development, UNEP, Nairobi.

United Nations Educational, Scientific and Cultural Organisation (UNESCO) (2002) Biosphere Reserves: On-ground testing for sustainable development, UNESCO Man and the Biosphere Program, GTOZ Print Investments, t/a Capture Press, South Africa.

United Nations Educational, Scientific and Cultural Organisation (UNESCO) (2010) Global Geoparks Network: Guidelines and criteria for national geoparks seeking UNESCO's assistance to join the Global Geoparks Network, UNESCO, Paris.

10 United Nations Educational, Scientific and Cultural Organisation (UNESCO) (2011) Operational Guidelines for the Implementation of the World Heritage Convention, UNESCO World Heritage Centre, Paris.

United Nations Educational, Scientific and Cultural Organisation (UNESCO) (2013a) World Heritage History, UNESCO, Paris. <whc.unesco.org/en/ convention/>

United Nations Educational, Scientific and Cultural Organisation (UNESCO) (2013b) Parties to the World Heritage Convention, UNESCO, Paris. <whc. unesco.org/en/statesparties/>
United Nations Educational, Scientific and Cultural Organisation (UNESCO) (2013c) Man and the Biosphere Program, UNESCO, Paris. <www. unesco.org/new/en/natural-sciences/environment/ ecological-sciences/man-and-biosphereprogramme/>

United Nations Educational, Scientific and Cultural Organisation (UNESCO) (2013d) Biosphere Reserve Designation Criteria, UNESCO, Paris. <www. unesco.org/new/en/natural-sciences/environment/ ecological-sciences/biosphere-reserves/designationprocess/>

United Nations Educational, Scientific and Cultural Organisation (UNESCO) (2013e) About Geoparks, UNESCO, Paris. <www.unesco.org/new/en/ natural-sciences/environment/earth-sciences/globalgeoparks/some-questions-about-geoparks/what-is-aglobal-geopark/>

United Nations Educational, Scientific and Cultural Organisation (UNESCO) (2014) What is the Global Geoparks Network?, UNESCO, Paris. <www.unesco. org/new/en/natural-sciences/environment/earthsciences/global-geoparks/some-questions-aboutgeoparks/what-is-a-global-geopark/>

Dd Vershuuren, B., Wild, R., McNeely, J. A. and Oviedo, G. (2010) Sacred Natural Sites: Conserving nature and culture, Earthscan, London.

Dd Watson, J., Hamilton-Smith, E., Gillieson, D. and Kiernan, K. (1997) Guidelines for Cave and Karst Protection, WCPA Working Group on Cave and Karst Protection, IUCN, Gland.

Wild, R. and McLeod, C. (2008) Sacred Natural Sites: Guidelines for protected area managers, No. 16, IUCN WCPA, Gland.

Worboys, G. L. (2014) Research completed for the preparation of the protected area governance and management book, Unpublished Protected Area Historical Research Paper, The Australian National University, Canberra.

Dd Worboys, G. L., Francis, W. and Lockwood, M. (2010) Connectivity Conservation Management: A global guide, Earthscan, London.

Worboys, G. L., Lockwood, M. and de Lacy, T. (2001) Protected Area Management: Principles and practice, Oxford University Press, Melbourne. 
Worboys, G. L., Lockwood, M. and de Lacy, T. (2005) Protected Area Management: Principles and practice, 2nd edn, Oxford University Press, Melbourne.

World Commission on Protected Areas (WCPA) (1998) Economic Values of Protected Areas: Guidelines for protected area managers, No. 2, Task Force on Economic Benefits of Protected Areas for the IUCN WCPA in collaboration with the Economic Service Unit of IUCN, Gland.

World Commission on Protected Areas (WCPA) (2000) Financing Protected Areas: Guidelines for protected area managers, No. 5, Financing Protected Areas Task Force, IUCN WCPA in collaboration with the Economics Unit of IUCN, Gland.

World Resources Institute, International Union for Conservation of Nature and United Nations Environment Programme (WRI/IUCN/UNEP) (1992) Global Biodiversity Strategy: Guidelines for action to save, study and use Earth's biotic wealth sustainably and equitably, IUCN, Gland. 


\section{Appendix 2.1}

\section{Key IUCN WCPA and related publications}

Please note: While every effort has been made in the research time available to identify key sources, this list is not complete.

\begin{tabular}{|c|c|c|}
\hline Year & Title & Reference \\
\hline \multicolumn{3}{|c|}{$1973-82$} \\
\hline 1976 & Parks Magazine launched (produced volumes for a while) & Various \\
\hline 1980 & $\begin{array}{l}\text { World Conservation Strategy: Living resource conservation for sustainable } \\
\text { development }\end{array}$ & IUCN et al. (1980) \\
\hline \multicolumn{3}{|c|}{$1983-92$} \\
\hline 1986 & Managing Protected Areas in the Tropics & Mackinnon et al. (1986) \\
\hline 1990 & Parks on the Borderline: Experience in transfrontier conservation & Thorsell (1990) \\
\hline 1991 & $\begin{array}{l}\text { The journal Parks recommenced (volumes produced until 2008, and then } \\
\text { recommenced in 2012) }\end{array}$ & Various \\
\hline 1991 & Caring for the Earth & IUCN et al. (1991) \\
\hline 1992 & Global Biodiversity Strategy & WRI et al. (1992) \\
\hline 1992 & Protected Areas of the World: A review of national systems (four volumes) & UNEP-WCMC and IUCN (1991) \\
\hline 1992 & Guidelines for Establishing Marine Protected Areas & Kelleher and Kenchington (1992) \\
\hline 1992 & Guidelines for Mountain Protected Areas & Poore (1992) \\
\hline \multicolumn{3}{|c|}{ 1992-2003 } \\
\hline 1993 & $\begin{array}{l}\text { Parks, Peaks and People: A collection of papers arising from an } \\
\text { international consultation on protected areas in mountain environments } \\
\text { held in Hawaii Volcanoes National Park } 26 \text { October - } 2 \text { November } 1991\end{array}$ & Hamilton et al. (1993) \\
\hline 1994 & Guidelines for Protected Area Management Categories & IUCN (1994a) \\
\hline 1994 & Parks for Life: Action for protected areas in Europe & IUCN (1994b) \\
\hline 1995 & African Heritage 2000 & IUCN (1995) \\
\hline 1996 & Transborder Protected Area Co-Operation & Hamilton, et al. (1996) \\
\hline 1996 & Tourism, Ecotourism and Protected Areas & Ceballos-Lascuráin (1996) \\
\hline 1997 & Guidelines for Cave and Karst Protection & Watson et al. (1997) \\
\hline 1998 & $\begin{array}{l}\text { National System Planning for Protected Areas: Best practice guideline } \\
\text { (No. 1) }\end{array}$ & Davey (1998) \\
\hline 1998 & $\begin{array}{l}\text { Economic Values of Protected Areas: Guidelines for protected area } \\
\text { managers (No. 2) }\end{array}$ & WCPA (1998) \\
\hline 1999 & The Green Web: A union for world conservation & Holdgate (1999) \\
\hline 1999 & Guidelines for Marine Protected Areas (No. 3) & Kelleher (1999) \\
\hline 1999 & $\begin{array}{l}\text { Guidelines for Public Use Measurement and Reporting at Parks and } \\
\text { Protected Areas }\end{array}$ & Hornback and Eagles (1999) \\
\hline 1999 & $\begin{array}{l}\text { Linkages in the Landscape: The role of corridors and connectivity in } \\
\text { wildlife conservation }\end{array}$ & Bennett (2003) \\
\hline 2000 & $\begin{array}{l}\text { Indigenous and Traditional Peoples and Protected Areas: Principles, } \\
\text { guidelines and case studies (No. 4) }\end{array}$ & Beltrán (2000) \\
\hline 2000 & $\begin{array}{l}\text { Financing Protected Areas: Guidelines for protected area managers (No. } \\
\text { 5) }\end{array}$ & WCPA (2000) \\
\hline 2000 & $\begin{array}{l}\text { Evaluating Effectiveness: A framework for assessing the management of } \\
\text { protected areas (No. 6) }\end{array}$ & Hockings et al. (2000) \\
\hline 2001 & Protected Area Management: Principles and practice & Worboys et al. (2001) \\
\hline
\end{tabular}




\begin{tabular}{|c|c|c|}
\hline Year & Title & Reference \\
\hline 2001 & Transboundary Protected Areas for Peace and Co-Operation (No. 7) & Sandwith et al. (2001) \\
\hline 2002 & $\begin{array}{l}\text { Sustainable Tourism in Protected Areas: Guidelines for planning and } \\
\text { management (No. 8) }\end{array}$ & Eagles et al. (2002) \\
\hline 2002 & $\begin{array}{l}\text { Management Guidelines for Category V Protected Areas: Protected } \\
\text { landscapes/seascapes (No. 9) }\end{array}$ & Phillips (2002) \\
\hline 2003 & Guidelines for Management Planning of Protected Areas (No. 10) & Thomas and Middleton (2003) \\
\hline 2003 & The Full Value of Parks: From economics to the intangible & Harmon and Putney (2003) \\
\hline \multicolumn{3}{|c|}{ 2003-14 } \\
\hline 2004 & $\begin{array}{l}\text { Integrating Biodiversity Conservation and Sustainable Use: Lessons } \\
\text { learned from ecological networks }\end{array}$ & Bennett (2004) \\
\hline 2004 & $\begin{array}{l}\text { Indigenous and Local Communities and Protected Areas: Towards equity } \\
\text { and enhanced conservation (No. 11) }\end{array}$ & Borrini-Feyerabend et al. (2004) \\
\hline 2004 & $\begin{array}{l}\text { Speaking a Common Language: The uses and performance of } \\
\text { management categories for protected areas }\end{array}$ & Bishop et al. (2004) \\
\hline 2004 & Guidelines for Planning and Managing Mountain Protected Areas & Hamilton and McMillan (2004) \\
\hline 2004 & $\begin{array}{l}\text { Managing Mountain Protected Areas: Challenges and responses for the } \\
21 \text { st century }\end{array}$ & Harmon and Worboys (2004) \\
\hline 2004 & $\begin{array}{l}\text { Securing Protected Areas in the Face of Global Change: Issues and } \\
\text { strategies }\end{array}$ & Barber et al. (2004) \\
\hline 2005 & Protected Area Management: Principles and practice (2nd edn) & Worboys et al. (2005) \\
\hline 2005 & $\begin{array}{l}\text { The Urban Imperative: Urban outreach strategies for protected area } \\
\text { agencies }\end{array}$ & Trzyna (2005) \\
\hline 2005 & $\begin{array}{l}\text { The Protected Landscape Approach: Linking nature, culture and } \\
\text { community }\end{array}$ & Brown et al. (2005) \\
\hline 2005 & $\begin{array}{l}\text { Benefits beyond Boundaries: Proceedings of the Vth IUCN World Parks } \\
\text { Congress, Durban South Africa, 8-17 September } 2003\end{array}$ & IUCN (2005) \\
\hline 2006 & $\begin{array}{l}\text { Security Considerations in the Planning and Management of } \\
\text { Transboundary Conservation Areas }\end{array}$ & Braack et al. (2006) \\
\hline 2006 & Managing Protected Areas: A global guide & Lockwood et al. (2006) \\
\hline 2006 & $\begin{array}{l}\text { Forests and Protected Areas: Guidance on the use of the IUCN protected } \\
\text { area management categories (No. 12) }\end{array}$ & Dudley and Phillips (2006) \\
\hline 2006 & $\begin{array}{l}\text { Sustainable Financing of Protected Areas: A global review of challenges } \\
\text { and options (No. 13) }\end{array}$ & Emerton et al. (2006) \\
\hline 2006 & $\begin{array}{l}\text { Evaluating Effectiveness: A framework for assessing management } \\
\text { effectiveness of protected areas ( } 2 \text { nd edn) (No. 14) }\end{array}$ & Hockings et al. (2006) \\
\hline 2007 & Peace Parks & Ali (2007) \\
\hline 2007 & $\begin{array}{l}\text { Protected Areas and Spirituality: Proceedings of the First Workshop of the } \\
\text { Delos Initiative }\end{array}$ & Mallarach and Papayannis (2007) \\
\hline 2007 & $\begin{array}{l}\text { Identification and Gap Analysis of Key Biodiversity Areas: Targets for } \\
\text { comprehensive protected area systems (No. 15) }\end{array}$ & Langhammer et al. (2007) \\
\hline 2007 & Protected Areas: Buffering nature against climate change & Taylor and Figgis (2007) \\
\hline 2008 & Sacred Natural Sites: Guidelines for protected area managers (No. 16) & Wild and McLeod (2008) \\
\hline 2008 & $\begin{array}{l}\text { Protected Landscapes and Agrobiodiversity Values. Volume } 1 \text { in the series } \\
\text { Values of Protected Landscapes and Seascapes }\end{array}$ & Amend et al. (2008) \\
\hline 2008 & $\begin{array}{l}\text { Protected Landscapes and Cultural and Spiritual Values. Volume } 2 \text { in the } \\
\text { series Values of Protected Landscapes and Seascapes }\end{array}$ & Mallarach (2008) \\
\hline 2008 & Guidelines for Applying Protected Area Management Categories & Dudley (2008) \\
\hline 2010 & Connectivity Conservation Management: A global guide & Worboys et al. (2010) \\
\hline
\end{tabular}




\begin{tabular}{|c|c|c|}
\hline Year & Title & Reference \\
\hline 2010 & $\begin{array}{l}\text { Natural Solutions: Protected areas helping people cope with climate } \\
\text { change }\end{array}$ & Dudley et al. (2010) \\
\hline 2010 & Sacred Natural Sites: Conserving nature and culture & Verschuuren et al. (2010) \\
\hline 2010 & Arguments for Protected Areas: Multiple benefits for conservation and use & Stolton and Dudley (2010) \\
\hline 2010 & $\begin{array}{l}50 \text { Years of Working for Protected Areas: A brief history of the IUCN World } \\
\text { Commission on Protected Areas }\end{array}$ & IUCN (2010) \\
\hline 2011 & IUCN Guidelines for Protected Area Legislation & Lausche (2011) \\
\hline 2011 & $\begin{array}{l}\text { Protected Area Staff Training: Guidelines for planning and management } \\
\text { (No. 17) }\end{array}$ & Kopylova and Danilina (2011) \\
\hline 2012 & $\begin{array}{l}\text { Ecological Restoration for Protected Areas: Principles, guidelines and best } \\
\text { practices (No. 18) }\end{array}$ & Keenleyside et al. (2012) \\
\hline 2012 & $\begin{array}{l}\text { Protected Landscapes and Wild Biodiversity. Volume } 3 \text { in the series } \\
\text { Values of Protected Landscapes and Seascapes }\end{array}$ & Dudley and Stolton (2012) \\
\hline 2012 & Innovation for 21st Century Conservation & Figgis et al. (2012) \\
\hline 2012 & Conserving Australia's Marine Environment: Key directions statement & Figgis and Koss (2012) \\
\hline 2012 & Parks relaunched as an e-journal (after a gap in publication from 2008) & Various \\
\hline 2013 & Terrestrial Biodiversity and the World Heritage List & Bertzky et al. (2013) \\
\hline 2013 & $\begin{array}{l}\text { Keeping the Outstanding Exceptional: The future of world heritage in } \\
\text { Australia }\end{array}$ & Figgis et al. (2013) \\
\hline 2013 & The Legal Aspects of Connectivity Conservation & Lausche et al. (2013) \\
\hline 2013 & Governance of Protected Areas: From understanding to action & Borrini-Feyerabend et al. (2013) \\
\hline 2014 & Urban Protected Areas - Profiles and Best Practice Guidelines & Trzyna (2014) \\
\hline 2015 & Protected Area Governance and Management & Worboys et al. (2015) \\
\hline
\end{tabular}




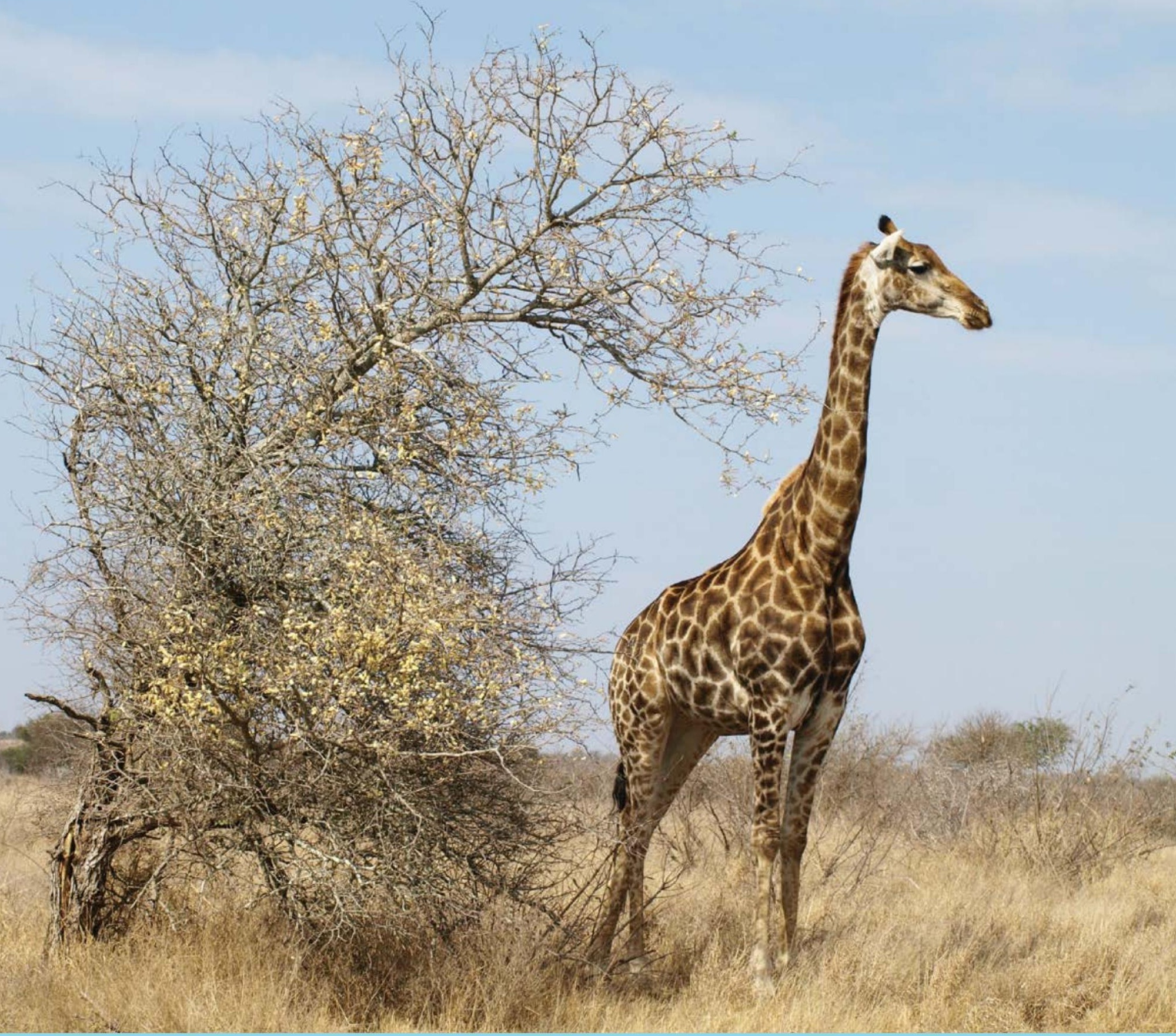

CHAPTER 3

EARTH'S NATURAL HERITAGE

Principal authors:

Bastian Bertzky, Monika Bertzky and

Graeme L. Worboys

\section{Supporting author:}

Lawrence S. Hamilton

\section{CONTENTS}

- Introduction

- Earth's natural processes

- Geodiversity

- Biodiversity

- Protected areas as safeguards for Earth's natural heritage

- Global biodiversity conservation priorities

- Introducing ecosystem management

- Conclusion

- References

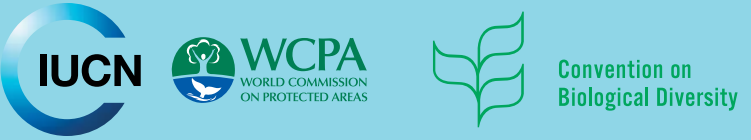




\section{PRINCIPAL AUTHORS}

BASTIAN BERTZKY is a Postdoctoral Researcher, European Commission, Joint Research Centre, Italy, and member of the IUCN World Commission on Protected Areas (WCPA).

MONIKA BERTZKY is an independent consultant based in Italy, and member of the IUCN WCPA.

GRAEME L. WORBOYS is Co-Vice-Chair, Connectivity Conservation and Mountains, IUCN WCPA, and an Adjunct Fellow at the Fenner School, The Australian National University.

\section{SUPPORTING AUTHOR}

LAWRENCE S. HAMILTON is an honorary member of the IUCN, Senior Advisor to the IUCN WCPA and a member of the WCPA Connectivity Conservation and Mountains Specialist Group Executive.

\section{ACKNOWLEDGMENTS}

The authors would like to thank Guy Castley and two anonymous reviewers for their valuable review comments and the following individuals and organisations for their contributions to this chapter: Clinton Jenkins, Escola Superior de Conservação Ambiental e Sustentabilidade, Instituto de Pesquisas Ecológicas, Brazil; Naomi Kingston and Diego Juffe-Bignoli, United Nations Environment Programme World Conservation Monitoring Centre (UNEPWCMC); Christelle Perruchoud, IUCN; Yichuan Shi, IUCN and UNEP-WCMC; and Javier Martinez-López, European Commission, Joint Research Centre.

\section{CITATION}

Bertzky, B., Bertzky, M., Worboys, G. L. and Hamilton, L. S. (2015) 'Earth's natural heritage', in G. L. Worboys, M. Lockwood, A. Kothari, S. Feary and I. Pulsford (eds) Protected Area Governance and Management, pp. 43-80, ANU Press, Canberra.

\section{TITLE PAGE PHOTO}

Giraffe (Giraffa camelopardalis), Kruger National Park, South Africa. The giraffe is the world's tallest living terrestrial animal, standing up to 5 to 6 metres in height with its unmistakeable long neck and legs. It is a native of African dry savannahs and open woodland and browses higher than any other mammal. It is a remarkable species and part of the rich natural heritage of Earth. Source: Graeme L. Worboys 


\section{Introduction}

Earth is a very special place. It may seem large, maybe even infinite in size, but when viewing images captured by remote robots from Mars early in the 21st century, we quickly appreciate how Earth is just one bright dot in a vast expanse of space. From Mars, Earth is dwarfed by an immensity of the Milky Way Galaxy and the Universe beyond, and images like these are what help us appreciate that Earth really is a finite ark of life. Earth hosts extraordinary natural wonders, formed over 4.5 billion years of geological and evolutionary change. It is a dynamic world exhibiting breathtaking geological events; oceanic and atmospheric turbulence and turmoil; a relentlessness of forces of weathering, erosion and landform development; and of course, it hosts a remarkably rich assemblage of life forms with their own dynamics of adaptation, evolution and critical contributions to a healthy, liveable planet.

For all of these reasons Earth is a unique planet. It is in the interests of humans and all other species on Earth that its intrinsic values are understood, respected, and its life-support systems are protected and sustained. Securing Earth's natural heritage reinforces the role and importance of protected areas and conservation practice on Earth at a global scale. These areas and such action help to conserve Earth's natural heritage and the essential ecosystem processes, habitats and species that help support life. The moderating influence provided by protection and conservation is essential, given the voracious capacity of Earth's expanding human population to consume and alter natural resources at a rate that threatens the very planetary life-support systems (MEA 2005).

For professionals tasked with managing protected areas, it is imperative that they have a broad understanding of the intrinsic natural values of our planet. In this chapter, we provide this overview. We describe some of Earth's natural processes and its exceptional geodiversity and biodiversity. Then we briefly introduce, at a global scale, the impacts that humans are having on Earth's natural heritage early in the 21 st century. This helps to emphasise why protected areas of all types, including governmental, non-governmental, private, and Indigenous Peoples' and Community Conserved Territories and Areas (ICCAs) are needed and why the efforts of each individual manager or ranger working in support of their local protected area or protected area system are so critical. Fundamentally, it is the sum total of these individual and local conservation efforts that is contributing to the retention of life on Earth.
This chapter will also provide an ecoregional context for these individual conservation contributions. It will reinforce how the conservation and protection efforts of each individual protected area professional, each protected area organisation and each nation are in effect part of a much larger global effort of conserving the diversity of life. Park managers and rangers the world over strive to conserve iconic and threatened species while enhancing the viability of protected populations. This could include, for example, protected area managers in Australia helping to conserve the koala (Phascolarctos cinereus) and kangaroo (Macropusspp.); their counterparts in India and Nepal conserving the tiger (Panthera tigris) and rhinoceros (Rhinoceros unicornis); in Africa, the elephant (Loxodonta africana) and lion (Panthera leo); and in North America, the grizzly bear (Ursus arctos) and bison (Bison bison); and so on. The key point here is that it is a finite world and the conservation of biodiversity is benefiting from a great deal of professional protected area work. For many staff and organisations, there is also collaboration across borders to help conserve habitats for international migratory species.

This chapter includes short descriptions of 12 World Heritage properties to exemplify aspects of the Earth's outstanding natural heritage in conjunction with the primary text. The case studies represent major natural phenomena and ecosystem types in terrestrial, freshwater and marine environments (Figure 3.1). The World Heritage Convention, adopted in 1972, seeks to encourage the identification and protection of cultural and natural heritage of 'outstanding universal value'. Early in the 21st century, the Convention has almost universal adoption among the nations of the world and in 2014 it included 222 of the world's greatest protected areas on its prestigious World Heritage List. Together, the 222 natural and mixed (natural and cultural) properties cover 7 per cent of the total recorded terrestrial protected area and 19 per cent of the total recorded marine protected area (IUCN 2013a), representing a wide range of protected area governance types and management categories.

\section{Earth's natural processes}

Protected areas help to conserve nature, but the forces of nature directly affect protected areas and how they are managed. There is a basic expectation that protected area managers will be extremely knowledgeable about how nature, in all its dynamic manifestations, may interact with and affect their area of responsibility. Understanding and interpreting when nature is at work and what is not nature enhance decision-making and implementation of corrective human interventions. 


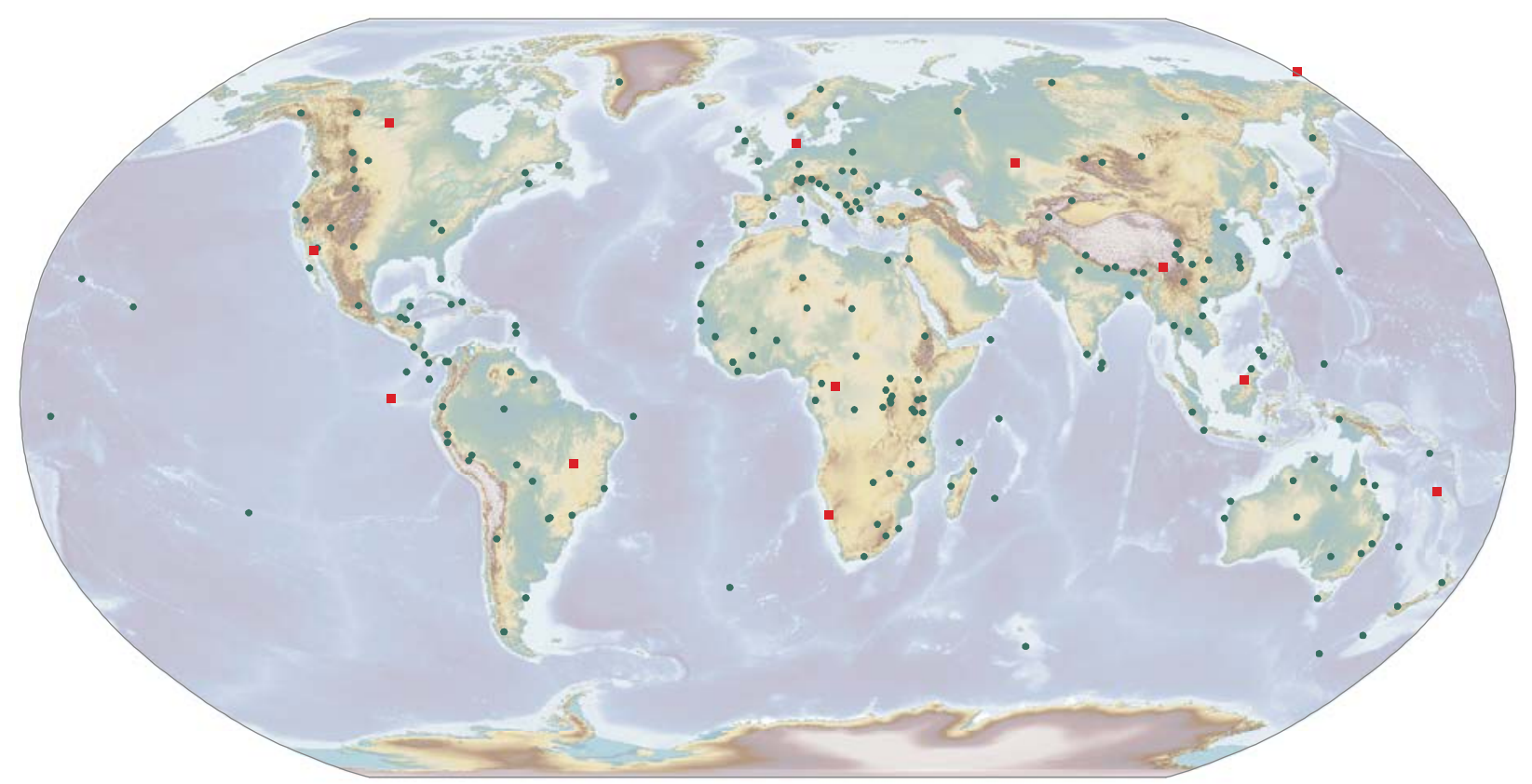

Figure 3.1 Distribution of the 222 natural and mixed World Heritage properties and case study locations (red markers)

Source: IUCN and UNEP-WCMC (2014)

\section{Geological processes}

The Earth's crust is the cool, brittle outer layer that includes oceanic crust and continental crust and is collectively referred to as the lithosphere. There are seven major tectonic plates covering the majority of this lithosphere and they are in constant motion. This movement is less observable on a yearly basis, but is clearly manifest over geological time, giving rise to the present-day continental distribution. The localised effects of a dynamic lithosphere may be witnessed in various global locations. Geological phenomena such as sea floor spreading, oceanic plate movement including downward movements below continents (subduction), mountain building, volcanism, earthquakes, weathering, erosion, solution and deposition are all processes affecting the Earth's crust. While these processes occur over geological time frames, protected areas may still be directly affected by them from time to time and especially by earthquakes, volcanism, weathering and erosion. Being prepared for potential geological effects and incidents by understanding the underlying causes for such events is paramount for managers responsible for such areas.

Many famous protected areas help to conserve geological evidence of Earth's dynamic crust (see Chapter 18). Outstanding examples of the effects of these geological processes are, for mountains, Mount Everest and the Dolomites; for karst, the immense caverns in Phong NhaKe Bang National Park in Vietnam; for grand, aesthetic waterfalls, Yosemite Falls, USA; and for volcanism, the active volcanoes on the Kamchatka Peninsula, Russia.

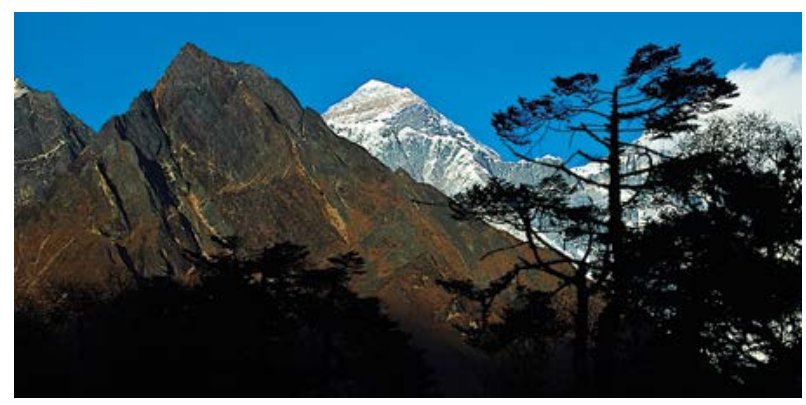

Sagarmatha (Mount Everest) National Park World Heritage Property landscape and site of ancient conservation practices

Source: Ashish Kothari

For managers in many of these areas the likelihood of such geological events may be small but in others it is an ever-present risk. For example, the Galápagos Islands World Heritage Property in Ecuador (Case Study 3.1) lies on the fastest moving plate on Earth, the Nazca Tectonic Plate. This plate is moving eastwards and southwards towards South America and has moved over a stationary volcanic thermal plume, triggering frequent volcanic eruptions (Constant 2004). These volcanic eruptions (over a considerable period) formed an archipelago of islands, with the youngest at the hotspot and the oldest, relocated by plate tectonic movements, closer to the South American mainland. The primary succession of increasingly younger islands, isolation and adaptation of species assisted one of the world's greatest naturalists, Charles Darwin, in formulating his theory of natural selection as an argument for evolution. 


\section{Case Study 3.1 Galápagos Islands, Ecuador: World Heritage property since 1978}

\section{Biogeographic realm: Neotropical; biome: deserts} and xeric shrublands

An archipelago of 127 volcanic islands, islets and rocks located about 1000 kilometres off the Ecuadorian coast in the Pacific Ocean, the Galápagos Islands cover more than 140600 square kilometres of land and ocean. The difference in age between the younger islands in the west and the older ones in the east reveals insights into ongoing geological and volcanic processes. The Galápagos Islands lie at the junction of three major tectonic plates, leading to continuous seismic activity. In fact, the two youngest islands, Isabela and Fernandina, are still being formed.

Charles Darwin was the first to spread the word about how extraordinary the biodiversity is on the Galápagos Islands. The evolutionary process of adaptive radiation can be observed not only on the isolated archipelago compared with the mainland, but also from one island to the next. Darwin's finches may be the world's best-known example of this, but they are not the only one. Mockingbirds, marine iguanas, land snails, flightless cormorants, giant tortoises and several plant and insect groups have equally been found to demonstrate such evolutionary specialisation, and endemism levels are accordingly high.

The sea surrounding the islands is well protected in the Galápagos Marine Reserve and biodiversity in these waters is just as awe-inspiring as on land. Three oceanic currents meet here, supporting what is considered one of the richest marine ecosystems in the world. To date, more than 2900 marine species have been recorded, with endemism levels exceeding 18 per cent. As a consequence of all of the above, the Galápagos Islands are also known as a living museum and showcase of evolution.

Source: Adapted from UNESCO (2014)

\section{Climate}

We often take the Earth's atmosphere for granted and we may assume it has been and will always be the same. But we make this assumption at our peril, for the atmosphere is finite, it is dynamic and it has changed substantially over the 4.5 billion years of Earth's history. Most important is a realisation by humans that it is actually life on Earth that has created the conditions suitable for all other life forms dependent on oxygen. The oxygen in our atmosphere, the oxygen we breathe, has been produced by living organisms and it is this oxygen that continues to be sustained by life on Earth.

\section{Atmospheric composition}

In the 21 st century, the atmosphere is dominated by nitrogen (about 78 per cent), oxygen (about 21 per cent) and argon (about 1 per cent), with a number of other gases including carbon dioxide and water vapour as well as dust and smoke particles. Oxygen was not present, however, on early Earth. About 3.8 billion years ago, the planet's early atmosphere was established by intense volcanic activity and outgassing that released nitrogen, carbon dioxide, water vapour, ammonia, methane and smaller amounts of other gases. There was no atmospheric oxygen, but water sourced from volcanic steam venting helped form the early oceans on Earth (Palmer 2009).

Living organisms such as blue-green algae used the sunshine, carbon dioxide and water of early Earth to produce carbohydrates and, importantly, oxygen as waste products (Biello 2009). The levels of oxygen gradually built up in the atmosphere, fluctuating over time but supporting the evolution of life. At some critical times,

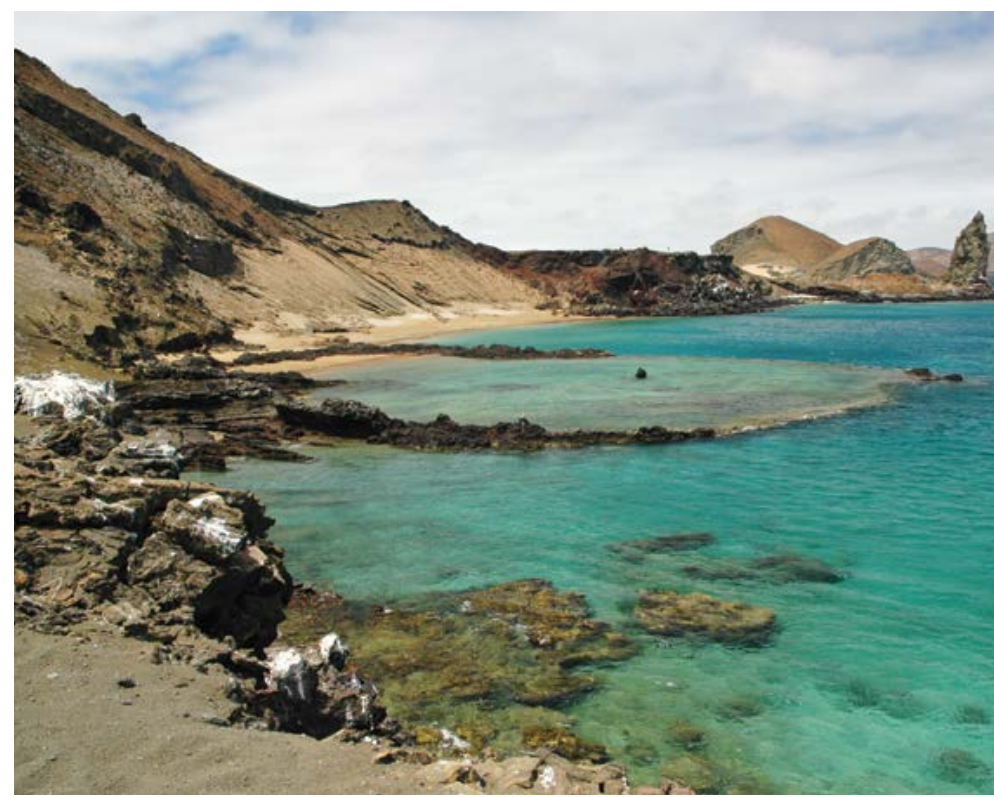

Bartolome Island, Galápagos Islands World Heritage Property, Ecuador

Source: IUCN Photo Library @ Imène Meliane

there has been insufficient oxygen. During the PermianTriassic about 252 million years ago, for example, sudden and dramatic changes in the composition of the Earth's atmosphere occurred and resulted in a mass extinction event. Massive volcanism and the associated venting of sulphur dioxide and water vapour occurred in the Siberian Traps during this time and the oceans became starved of oxygen, with most marine species as well as many terrestrial plant and animal species becoming extinct (McNamara 2009). 
David Beerling, in his book The Emerald Planet (2007:44), describes the role of atmospheric oxygen in more recent geological times (during the Phanerozoic) this way: 'Earth's atmospheric oxygen content is intimately linked to the evolution of plant life ... it begins with photosynthesising plants adding to the oxygen of the atmosphere as they manufacture biomass.'

He states that when plants (marine or terrestrial) die there are 'rich pickings for animals, bacteria and fungi that break down their remains, consuming oxygen in the process' (Beerling 2007:44). Beerling (2007:44) also identifies, however, that not all of the organic material is decomposed and

the gradual and continual burial of the fragmentary remains of plants on land and in the sea means that a fraction of the oxygen produced during its synthesis cannot be reclaimed by chemical or biological processes. Instead, it is free to accumulate, adding tiny amounts of oxygen to our atmosphere year by year.

Later, geological processes of uplift, weathering and erosion expose and breakdown these rocks, consuming oxygen in the process (Beerling 2007). During this oxidation, the balance of oxygen in the atmosphere is restored, and this process controls the oxygen content in the atmosphere over geological time, though 'the oxygen content of the air we breathe is not fixed at 21 [per cent]' (Beerling 2007:59)—it does vary.

The composition of the atmosphere is dynamic, oxygen levels are sustained by life on Earth and human activities such as habitat destruction do affect this balance and process. Protected areas help to maintain healthy ecosystems that directly benefit oxygen levels in the atmosphere, ecological processes and the life-supporting health of our atmosphere.

Carbon dioxide, a powerful greenhouse gas, is another gas whose concentration in the atmosphere varies, especially in recent times as a consequence of human activity. This change in concentration through human-caused pollution has serious consequences for the climate (see Chapter 17), and retaining and managing natural carbon stocks and sinks is an important part of the human response to this threat. Protected areas, for example, help conserve natural forests - the world's largest terrestrial carbon sink-so that they may continue to sequester carbon. Maintaining natural forests is one critical 'natural solution' to the Earth's deepening climate change challenge (Dudley et al. 2010) (see Chapter 17). Some key marine environments such as seagrass meadows are also important carbon sinks (see Chapter 20). Protected areas have the potential to be a key element in our efforts to reduce carbon dioxide pollution to minimise the negative effects of global warming. Protected areas also help to reduce dust and aerial contaminants and achieve a healthier chemical composition of the atmosphere.

\section{Atmospheric circulation}

Air is constantly moving and atmospheric circulation simplistically may be described as warm air moving to higher latitudes and cold air moving towards the tropics, though of course this is complicated by the Coriolis effect and the effects of the jet stream. Ancient sailors took advantage of Earth's prevailing winds, just as seasonal shifts in wind direction herald the arrival of monsoons and the life-giving rains required for agriculture. Such changes in seasonal wind conditions may also reflect the onset of the dry season.

The overall atmospheric circulation influences the climate experienced by any protected area. It influences the nature of seasons, the daily weather and the condition and change in condition of species and their habitats. Climate change-caused higher average air temperatures may result in higher evaporation, greater water moisture in the atmosphere, higher energy levels and more frequent high-energy storm events in some areas. In other areas, dryness and droughts have been enhanced. In a 21 st-century climate change world, the nature of the atmospheric circulation is changing and protected area managers need to understand the implications of this dynamic in terms of the weather events that the changes may trigger as well as any consequent changes to the natural environments of the protected areas for which they are responsible.

\section{Climates of the world}

Climate is the average pattern of weather determined over a very long time by measures such as temperature, precipitation, wind and atmospheric pressure. For any given protected area, the climate will also be influenced by the latitude, altitude, terrain, proximity to mountains and proximity to large water bodies. The broad climates of the world have been mapped using the KöppenGeiger system of climate classification, which recognises 12 distinct climates for Earth (Table 3.1). 
Table 3.1 Twelve distinct climates of Earth

\begin{tabular}{|c|c|}
\hline \multicolumn{2}{|r|}{$\begin{array}{l}\text { For tropical rainy climates, the average annual temperatures are above } 18^{\circ} \mathrm{C} \text {, there is no winter season and annual } \\
\text { rainfall is large and exceeds annual evaporation. They include: }\end{array}$} \\
\hline & Hot climates with year-round rain (the rainfall of the driest month is $>6 \mathrm{~cm}$ ) \\
\hline & Hot climates with monsoon rain (the rainfall of the driest month is $<6 \mathrm{~cm}$ ) \\
\hline & $\begin{array}{l}\text { Hot climates with seasonal rains - tropical savannah climates (the rainfall of the driest month is }<6 \mathrm{~cm} \text { and the } \\
\text { dry season is strongly developed) }\end{array}$ \\
\hline \multicolumn{2}{|c|}{ Dry climates } \\
\hline \multicolumn{2}{|r|}{ For dry climates, evaporation exceeds the precipitation on average throughout the year. These climates include: } \\
\hline & $\begin{array}{l}\text { Steppe climates - characterised by grasslands (this is an intermediate climate between desert climates and } \\
\text { more humid climates) }\end{array}$ \\
\hline & Desert climates (these are arid areas where the annual precipitation is $<40 \mathrm{~cm}$ ) \\
\hline \multicolumn{2}{|r|}{ Mild humid climates } \\
\hline \multicolumn{2}{|r|}{$\begin{array}{l}\text { Mild humid climates have both a summer and a winter, with the coldest month being less than } 18^{\circ} \mathrm{C} \text { but above }-3^{\circ} \mathrm{C} \\
\text { and at least one month is above } 10^{\circ} \mathrm{C} \text {. These climates include: }\end{array}$} \\
\hline & Mild humid climates with no dry season (precipitation in the driest month is $>3 \mathrm{~cm}$ ) \\
\hline & Mild humid climates with a dry winter (where 70 per cent of the precipitation falls in the warmer six months) \\
\hline & Mild humid climates with a dry summer (where 70 per cent of the precipitation falls in the six months of winter) \\
\hline \multicolumn{2}{|c|}{ Snowy-forest climates } \\
\hline \multicolumn{2}{|r|}{$\begin{array}{l}\text { The average temperature of the coldest month is less than }-3^{\circ} \mathrm{C} \text { and the warmest month average temperature is above } \\
10^{\circ} \mathrm{C} \text {. These climates include: }\end{array}$} \\
\hline & Snowy-forest climate with a moist winter (no dry season) \\
\hline & Snowy-forest climate with a dry winter \\
\hline \multicolumn{2}{|r|}{ Polar climates } \\
\hline \multicolumn{2}{|r|}{ The average temperature of the warmest month is below $10^{\circ} \mathrm{C}$ and there is no true summer. These climates include: } \\
\hline & Tundra climate (where the mean temperature of the warmest month is above $0^{\circ} \mathrm{C}$ but below $10^{\circ} \mathrm{C}$ ) \\
\hline & Perpetual frost climate (where the mean monthly temperatures of all months are below $0^{\circ} \mathrm{C}$ ) \\
\hline
\end{tabular}

Source: Strahler (2011:260-2)

The climates of Earth do change. Meteorologists have used models enabling them to forecast changes in climates based on increased concentrations of carbon dioxide and they have identified broad patterns that include enhanced temperatures, more or less rainfall, enhanced droughts, and more frequent severe storm events. These climate change effects will challenge protected area managers and their conservation management of biodiversity as these climatic shifts may bring shifts in species distributions that cannot be captured by static protected area boundaries (see Chapter 17).

\section{Oceans}

The five great oceans covering more than 70 per cent of Earth's surface are a remarkable part of dynamic Earth. They are perpetually in motion, whether this is caused by tides, surface water circulation, wind effects and waves, local currents, deep-water currents, upwellings or by other means. Adding to this are the influences of severe storms and their associated storm surges as well as earthquakes and their potential tsunami phenomena. The relative sea-level has also changed over geological time and these fluctuations have helped shape our coastal environments. The Pleistocene and Holocene sea-level lows, for example, influenced the movement of humans out of Africa and the colonisation of other continents (see Chapter 4). As a result of human-caused climate change, the world today is witnessing rising sealevels due to the thermal expansion of sea water and the melting of glaciers around the world-notably, the Greenland ice cap and Antarctic ice cap (IPCC 2013).

The higher carbon dioxide levels in the atmosphere and their consequential higher temperatures are affecting both the average temperatures of the world's oceans and their acidity (given greater amounts of dissolved carbon dioxide and the formation of a mild acid). This in turn has affected life in the oceans including bleaching of 
coral reef systems and acidification impacts such as the rate of calcification or dissolution of marine organisms like corals, crustaceans and molluscs (see Chapters 17 and 20).

The recent rate of human-caused atmospheric changes has been a catalyst for enhancing natural phenomena. Increased sea-levels and greater energy in storm systems will bring the transformation of coastal landforms that have been stable for at least 8000 years as well as the creation of new landforms. This could include the erosion of coastal sand deposits such as beaches, sand spits, foredunes and dune barrier systems; the drowning of low-lying salt marshes, wetlands, low-lying river valleys and deltas; and the enhanced and more energetic erosion of headlands and barrier reef systems due to more frequent high-energy storm events (Short and Woodroffe 2009).

Protected area managers need to understand these dynamic marine processes in addition to the conservation needs of the world's marine and coastal biodiversity. Many coastal and marine protected areas will feel the full force of climate-affected and turbocharged nature in the future. Anticipating and responding to these inevitable situations will require managers to integrate their knowledge of these forces and associated impacts using the prevailing science as well as their experience of local circumstances. Undoubtedly, these strategies will also be influenced by variable sociopolitical regimes and global attitudes to climate change.

Managers also need to anticipate the high probability that there may be reactive political responses to protected area issues when the full effects of climate change are finally acknowledged. One enemy that managers face is the seemingly 'quick-fix' political response, with such responses potentially being harmful to their protected areas. The manager needs to anticipate inevitable issues and bring forward, well in advance, carefully considered solutions based on rigorous science. Managers should constantly and clearly present such cases for adaptive responses (see Chapter 17).

\section{Geodiversity}

Geodiversity is the term used to describe the geological component of abiotic nature and is defined by Gray (2004:8) as ' $[t]$ he natural range (diversity) of geological (rocks, minerals, fossils), geomorphological (landform processes) and soil features. It includes their assemblages, relationships, properties, interpretations and systems.'
For managers, a fundamental understanding of geodiversity and more specific concepts such as geoheritage and geoconservation is an integral part of conserving protected areas. All of these terms have been defined in this book (see Chapter 18), and the importance of geodiversity as a foundation for life and as a key determinant of biodiversity for a protected area is also presented.

The geodiversity of Earth is in a dynamic state. New rocks are formed through plutonic (below the Earth's surface) and volcanic (above the Earth's surface) processes, through sedimentary deposition and compaction, and through metamorphism and metasomatic effects. These rocks, when exposed on the surface, are affected by physical, chemical and biological weathering as well as erosion. The erosion may be by water, wind and ice (glaciation) and the subsequent deposition of eroded material may produce water-borne, wind-borne and glacial deposits. Volcanic eruptions produce ash, nuée ardente (ultra-hot, rapidly downward-moving volcanic ash flow) and aerosol deposits. Rare meteorite impacts create unique craters and potentially ring structures.

The mass movement of material on steep slopes may generate avalanches of rock debris, the movement of unconsolidated soil and debris and rapidly moving lahars (water-saturated rock and mud flows). Landslides, cliff collapses, solifluction (movement caused by freeze and thaw) and slumping on steep slopes are all part of these dynamic erosion processes. New landforms are also generated. Tectonic activity can give rise to new mountain or basin structures; it can precipitate landslides and the damming of rivers and can cause tsunamis in marine environments. New volcanoes may be formed, geothermal areas with their geysers produce sinter deposits; carbonate-charged rivers generate travertine and tufa deposits; and waterfalls and sedimentcharged river systems create levees, islands and deltas. The geodiversity of Earth is indeed rich in dynamic natural processes for protected area managers to consider when planning and managing the geoheritage of their area (Gray 2004). There is a level of technical detail that managers may need to appreciate, as illustrated by the following examples.

- Rock type: The presence of serpentinite and other ultramafic rocks often includes elevated concentrations of chromium and nickel that are toxic to some plants and influence the composition of vegetation.

- Suitability of rock types as track and road materials: The chemical make-up of different volcanic and plutonic rocks, especially the type of feldspar(s) 


\section{Case Study 3.2 Gunung Mulu National Park, Malaysia: World Heritage property since 2000}

\section{Biogeographic realm: Indo-Malayan; biome: tropical and subtropical moist broadleaf forests}

Located on the island of Borneo, Gunung Mulu National Park covers almost 530 square kilometres of land and includes the world's most researched tropical karst area. With its deep canyons, wild rivers, waterfalls and rainforest-covered mountains, the highest of which reaches almost 2380 metres, Gunung Mulu's landscape features spectacular natural beauty. In addition, underneath its surface, the site features some of the world's largest caves. Sarawak Chamber, 600 metres long and 415 metres wide with a height of 80 metres, is considered one of the largest cave chambers discovered globally. The world record for the largest cave passage and the longest cave in Asia can be found here. The site is also significant as an extraordinary example of major changes in Earth's history. Three major rock formations made of shale, sandstone and limestone occur, and their terrestrial alluvial deposits, jointly with the subterranean geomorphology and hydrology, reveal important information about the tectonic and climatic evolution of Borneo.

Gunung Mulu's biodiversity is also exceptional. Within 17 different vegetation types, the site supports as many as 3500 species of vascular plants, and with 109 species is among the richest sites in the world for palms. More than 200 species of cave fauna have been identified and Deer Cave supports the largest bat species richness recorded in a single cave. It is also home to one of the world's largest colonies of free-tailed bats (Chaerephon plicata), exceeding three million individuals. Another cave hosts the world's largest colony of cave swiftlets (Aerodramus sp.). Many species occurring here are endemic and 41 are considered endangered.

Source: Adapted from UNESCO (2014) (a rock-forming mineral) present, influences the suitability of the rock type as track construction material and whether a track or road should be constructed within such geological parent material. It will also influence the cost of track construction.

- Limestone and dolomite karst: The need to manage for subterranean water flows, troglobitic fauna and the conservation and protection of caves, speleothems, subfossil deposits and cave-based human cultural values such as at the World Heritage property of Gunung Mulu National Park in Malaysia (Case Study 3.2).

- Geothermal areas: The need to deal with visitor safety in environments of superheated water and mud and rare extremophile fauna and flora.

- Mountains and cliff areas: Considerations for the safety of people for potential cliff edge collapse and landslides.

Protected area management teams may include geologists or geophysicists or they may seek such expertise to assist with decision-making for a range of these dynamic Earth processes.

\section{Biodiversity}

Life on Earth is precious, reflecting ancient beginnings with the simplest of life forms billions of years ago to the past 600 million years of extraordinary evolutionary development. Life has endured five major extinction events and may be on the verge of a sixth-the first to be caused by humans (Box 3.1). From the poles to the equator, from continent to continent, there is an immense diversity of life. The distribution of plants, animals and

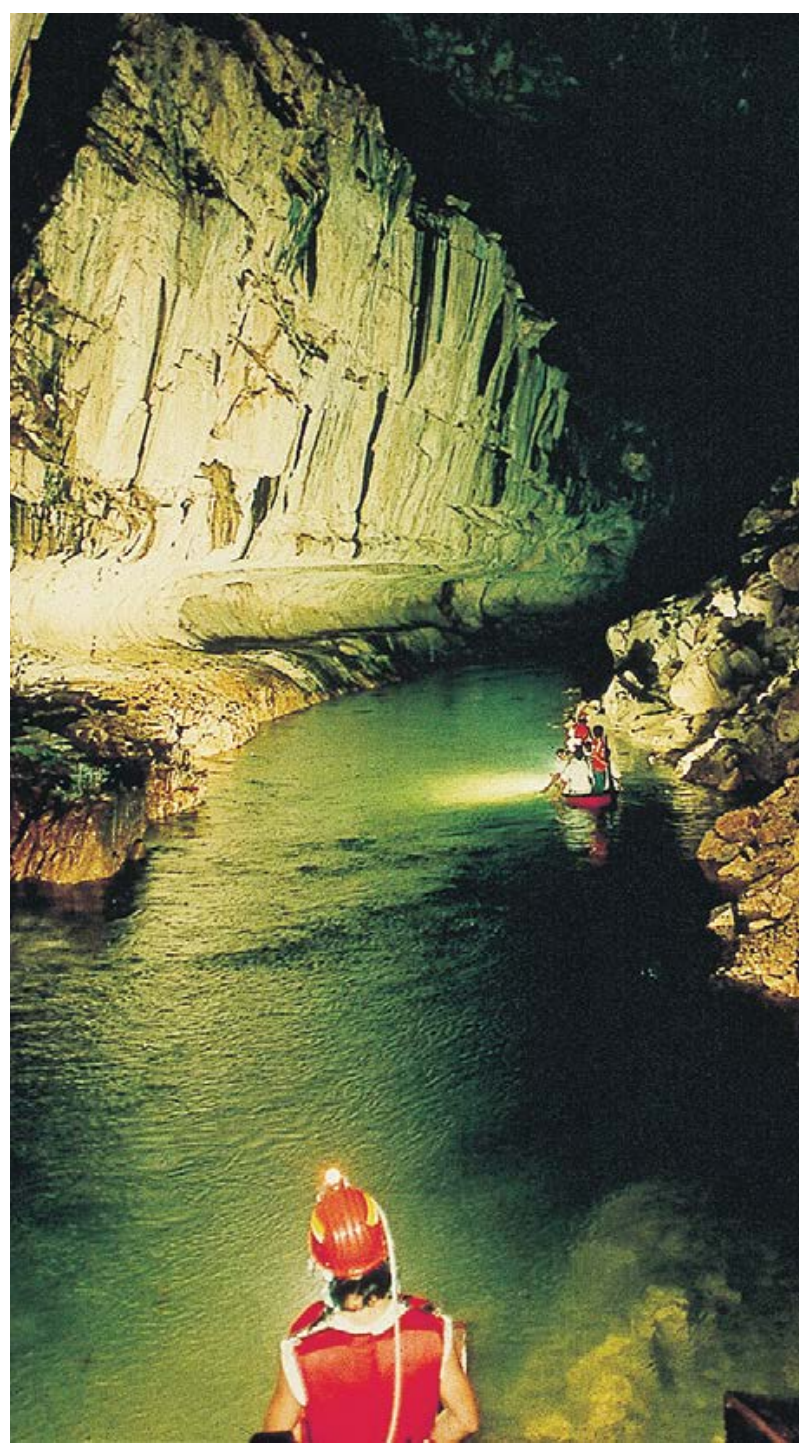

Gunung Mulu National Park, Borneo, Malaysia

Source: IUCN Photo Library @ Jim Thorsell 
other organisms is not even and is influenced by dynamic geological processes, the world's climates, its geodiversity and its geographical-based evolutionary development. In this section, we introduce this rich biodiversity including Earth's species and their major habitats.

For the establishment and management of effective protected areas it is essential to have at least a basic understanding of an area's biodiversity features, including key species and ecosystems, their conservation status and the conservation actions required to maintain or improve their status. Information on the area's global or national irreplaceability for the conservation of specific biodiversity features, if available, can also help guide protected area establishment and management (Ricketts et al. 2005; Langhammer et al. 2007; Le Saout et al. 2013).

\section{Defining biodiversity}

So, what is biodiversity? The term biological diversity, or biodiversity, refers to the variety of life on Earth. This includes plants, animals, fungi and micro-organisms, the genetic information they contain, the ecosystems they form and the ecological processes that bind them across multiple scales. Biodiversity has been defined in Article 2 of the UN Convention on Biological Diversity (CBD) as the 'variability among living organisms from all sources including, inter alia, terrestrial, marine and other aquatic ecosystems and the ecological complexes of which they are part; this includes diversity within species, between species and of ecosystems' (CBD 1992:3).

A species is widely defined as a group of organisms with a shared, closed gene pool (for example, the giant panda, Ailuropoda melanoleuca, is a species), although speciation can also occur without genetic isolation. Genes hold the information to develop and maintain an organism's cells and pass this information to offspring. A habitat is the natural environment in which a particular organism lives (for example, temperate montane forests with dense stands of bamboo in China are the habitat of the giant panda), and an ecosystem is a community of living organisms together with their non-living environment (for example, a forest with its soils, a lake or river with its bed, or a coral reef ecosystem with its surrounding waters).

\section{Major divisions of species}

Almost all species are directly or indirectly dependent on primary production through photosynthesis or chemosynthesis. Plants are multicellular organisms in the taxonomic kingdom Plantae and include, for example, all flowering plants (angiosperms), conifers and other gymnosperms, ferns and mosses. Using energy from light (photosynthesis), most plants produce oxygen and organic compounds such as carbohydrates from inorganic molecules such as carbon dioxide and water. Plants are the primary producers in most terrestrial ecosystems and form the basis of the food web in those ecosystems. Algae and phytoplankton fulfil the same function in marine and other aquatic ecosystems. Some micro-organisms such as bacteria can also use the energy released by chemical reactions (chemosynthesis) to produce organic matter.

Animals are multicellular organisms in the taxonomic kingdom Animalia and include, for example, mammals, birds, reptiles, amphibians, fish, insects, corals and sponges. Animals function as consumers in terrestrial, marine and other aquatic food webs and obtain organic carbon by eating primary producers or other animals. Unlike plants, most animals are able to move spontaneously and actively in a purposeful manner, at least at some stage of their life.

Fungi form their own taxonomic kingdom, for they are neither plants nor animals, and can be both unicellular (for example, yeasts) and multicellular (for example, moulds and mushrooms). They perform an essential role in the decomposition of organic matter and, together with all other organisms, play an important role in nutrient cycling and recycling, and the functioning of ecosystems.

\section{Measuring biodiversity}

Biodiversity can be measured in many different ways (Gaston 2000; Purvis and Hector 2000; Groombridge and Jenkins 2002; Hoekstra et al. 2010). From a 'compositional' perspective, one of the most commonly asked questions is: how many species are there on Earth? Global species estimates vary greatly and, in the past, have ranged from three million to more than 100 million species. One recent estimate arrives at 9.9 million eukaryotic species - that is, 'higher life forms' that have a membrane-bound cell kernel, of which 19 per cent have been described (Chapman 2009; Table 3.2). Another recent study estimates there are 8.7 million $( \pm 1.3$ million) eukaryotic species globally, of which some 14 per cent have been described (Mora et al. 2011). Estimating the number of prokaryotic species, which do not have a membrane-bound cell kernel (for example, bacteria), is difficult and recent estimates still vary from as little as 10000 to more than one million (Chapman 2009; Mora et al. 2011). 
Table 3.2 Described eukaryote species and possible total number of species

\begin{tabular}{|l|c|c|}
\hline Kingdom & $\begin{array}{c}\text { Estimated number of } \\
\text { described species }\end{array}$ & $\begin{array}{c}\text { Estimated total number } \\
\text { of species }\end{array}$ \\
\hline Animalia (animals) & 1424153 & 6836330 \\
\hline Plantae (plants) & 310129 & 390800 \\
\hline Fungi & 98998 & 1500000 \\
\hline Other eukaryotes (for example, algae) & 53915 & $>1200500$ \\
\hline Total & 1887195 & 9927630 \\
\hline
\end{tabular}

Source: Adapted from Chapman (2009)

Many of the species described so far are considered threatened-that is, they are facing a higher risk of extinction as a result of human-derived or natural impacts. The IUCN Red List of Threatened Species provides a global standard for assessing and recording the conservation status of species, the threats affecting them and the conservation actions in place or required (Rodrigues et al. 2006; Mace et al. 2008; Salafsky et al. 2008). At the beginning of the 21 st century, 41 per cent of the world's amphibians, 25 per cent of the mammals and 13 per cent of the birds are recognised as being 'critically endangered', 'endangered' or 'vulnerable' (IUCN 2013b). Plant groups with a high proportion of such threatened species include cycads (63 per cent), conifers (34 per cent) and cacti ( 31 per cent) (IUCN 2013b). Recent extinction rates have been estimated to be 100 to 1000 times higher than in prehuman times (Pimm et al. 1995), and this has led to suggestions that the sixth major extinction event in Earth's history may be underway (Leakey and Lewin 1992; Box 3.1).

\section{Major divisions of ecosystems}

An ecosystem is defined as a biotic community (an association of interacting species populations) and its abiotic environment (for example, climate, water, soil and sunlight), and these ecosystems can be at various scales, with larger-scale ecosystems synonymous with a landscape or seascape (Sinclair et al. 2006). The most basic classification of ecosystems distinguishes terrestrial, freshwater and marine ecosystems. Within each of these broad classes, a number of major ecosystem types can be distinguished, each characterised by fairly similar climatic conditions and ecological communities (for example, tropical and temperate forests, mountains, lakes, rivers and coral reef ecosystems). These major ecosystem types (or biomes) are described in the next section. Similar to species, ecosystems can also be threatened, and a corresponding IUCN Red List of Threatened Ecosystems is currently under development (Rodríguez et al. 2011).

\section{Box 3.1 The sixth major extinction event: triggered by humans?}

The number of species alive has probably never been greater than today, although up to 99 per cent of all species that ever lived on our planet have become extinct. Extinction is a widespread natural process that usually occurs slowly, affecting only small numbers of species over long periods (Barnosky et al. 2011). As a result of human activities, however, populations of many species are likely to go extinct in the near future, or have already gone extinct in prehistoric and historical times (Barnosky et al. 2011; Dullinger et al. 2013; Duncan et al. 2013).

Due to various natural causes, Earth has experienced five mass extinctions in the past, each time losing more than 75 per cent of all species in a geologically short period (several hundred thousand to several million years) (Barnosky et al. 2011). The most famous of these is the Cretaceous event around 65 million years ago, which was most likely triggered by a meteorite impact and subsequent rapid global cooling, which ended the 'age of the dinosaurs'.

Based on recent extinction rates, which are already substantially higher than in prehuman times (Pimm et al. 1995), and the extinction risk of extant species recorded in the IUCN Red List of Threatened Species (IUCN 2013b), it has been estimated that Earth could again lose 75 per cent of all species within as little as three centuries (Barnosky et al. 2011). This suggests that the sixth mass extinction is under way-for the first time caused by an individual species: humans.

As human societies begin to respond to the ongoing biodiversity extinction crisis, conservation actionsincluding area-based conservation measures such as protected areas-can help to prevent extinctions, or reduce the extinction risk of species and populations (for example, Butchart et al. 2006, 2012). The Alliance for Zero Extinction (AZE), for example, is coordinating work to identify and protect centres of imminent extinction where highly threatened species are confined to single sites (Ricketts et al. 2005; Figure 3.10). 


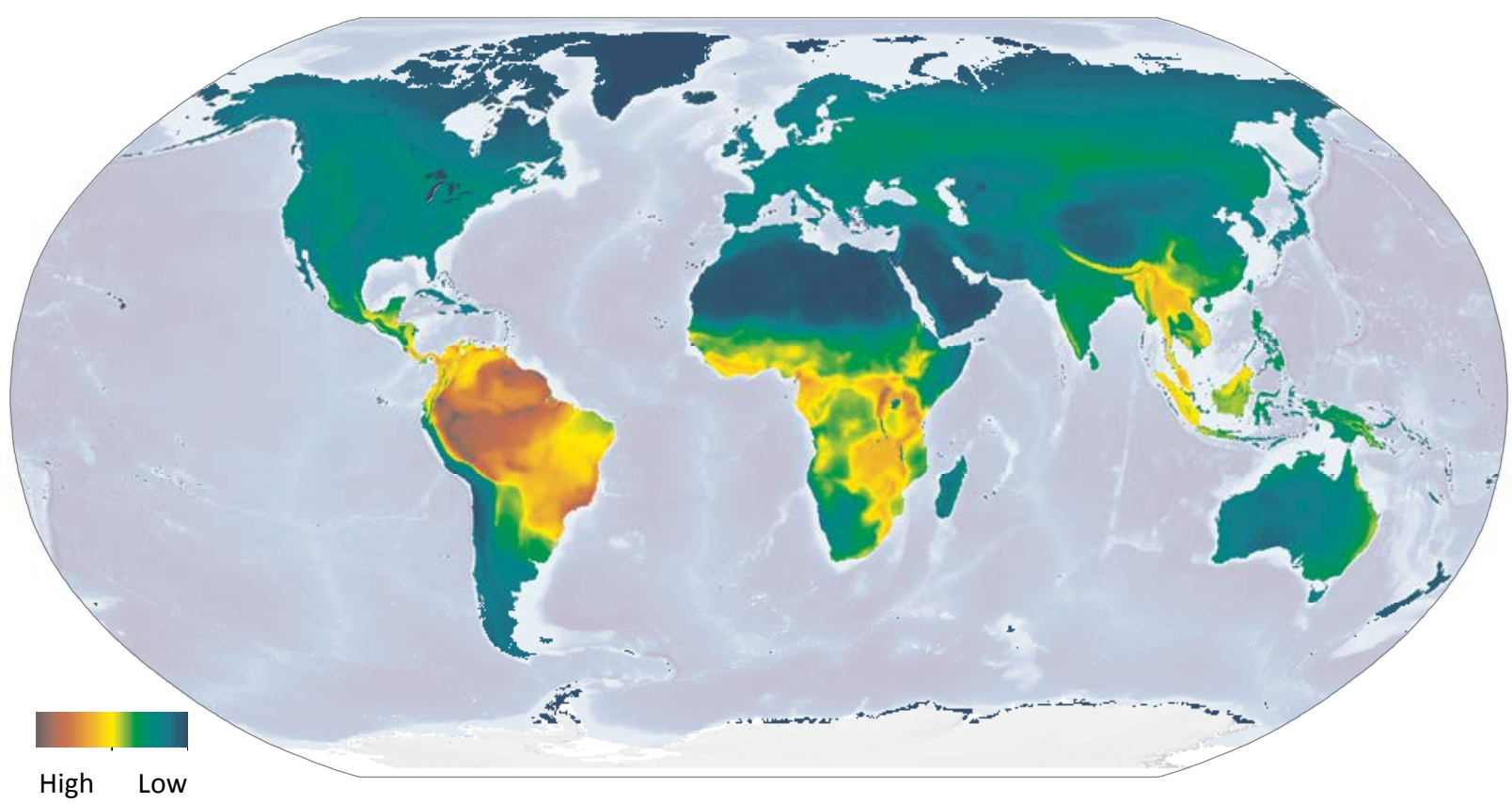

Figure 3.2 Global diversity of mammal, bird and amphibian species

Source: Modified from SavingSpecies and Globaïa (2012), based on data provided by IUCN, BirdLife International and NatureServe

All ecosystems together make up the world's biospherethat is, all the places from the top of the atmosphere to the bottom of the ocean and into the Earth's rocks and soils that are occupied by living organisms. The biosphere is an intricately interconnected system, and ultimately sets the rules for the survival of species of all sorts, including humans (White 2003). The biosphere has evolved over billions of years in interaction with the non-living environment (atmosphere, hydrosphere and lithosphere) and this has determined the natural distribution of biodiversity on Earth.

\section{Distribution of biodiversity}

Biodiversity is not evenly distributed across the Earth. The number and type of species and ecosystems present change with factors such as climate, altitude, latitude, available space, time and energy (Gaston 2000). Overall species richness, for example, increases from polar regions to temperate regions to the tropics (Figure 3.2). This also applies within most of the taxonomic groups (for example, there are more bird species in the tropics than in temperate regions) and within most similar ecosystems (for example, there are more species in tropical forests than in temperate forests) (Gaston 2000).

Biogeography is the study of the distribution of species and ecosystems in space and time. Biogeographic classification systems seek to delineate distinct ecological areas based on their biotic and abiotic characteristics, including the Earth's broad climate zones. They help to understand Earth's natural heritage and are widely viewed as essential tools for biodiversity conservation science, policy, planning and management. Global classification systems are used by biodiversity related conventions such as the CBD, Ramsar Convention and World Heritage Convention to guide the identification, classification and conservation of important biodiversity sites, and to establish and manage ecologically representative networks of protected areas. The CBD also has several thematic programs that deal with specific 'biomes', including marine and coastal ecosystems, inland waters, mountains, islands, forests and drylands. In addition to the global classification systems, many national and regional classification systems exist, informing conservation policy and practice.

Different approaches to biogeographic classification of the world's terrestrial, freshwater and marine environments have been developed and refined over time, serving different purposes, and all of them have limitations (Ladle and Whittaker 2011; Whittaker et al. 2013). Some recent approaches make use of our ever-increasing but still imperfect knowledge of species distributions and the phylogenetic relationships of species to delineate biogeographic regions (Kreft and Jetz 2010; Holt et al. 2013). Other approaches subdivide the world into major biomes and ecoregions based on the distribution of ecological communities.

Several of the last approaches have been developed specifically for, and found wide application in, the field of biodiversity conservation. These include the biogeographical provinces defined by Udvardy (1975) 
Table 3.3 Selected biogeographic classification systems for terrestrial, freshwater and marine areas

\begin{tabular}{|c|c|c|c|}
\hline System & Description & Units & References \\
\hline $\begin{array}{l}\text { Terrestrial ecoregions } \\
\text { of the world (TEOW) }\end{array}$ & $\begin{array}{l}\text { Provides a classification of the world's } \\
\text { terrestrial ecosystems. Based on review } \\
\text { of existing information and expert } \\
\text { knowledge. Overlaps with freshwater } \\
\text { ecoregions }\end{array}$ & $\begin{array}{l}\text { Nested system of } 8 \text { realms, } \\
14 \text { biomes and } 827 \\
\text { terrestrial ecoregions }\end{array}$ & Olson et al. (2001) \\
\hline $\begin{array}{l}\text { Freshwater ecoregions } \\
\text { of the world (FEOW) }\end{array}$ & $\begin{array}{l}\text { Provides a classification of the world's } \\
\text { freshwater ecosystems. Based on } \\
\text { the distributions and compositions } \\
\text { of freshwater fish species and major } \\
\text { ecological and evolutionary patterns. } \\
\text { Overlaps with terrestrial ecoregions }\end{array}$ & 426 freshwater ecoregions & Abell et al. (2008) \\
\hline $\begin{array}{l}\text { Marine ecoregions of } \\
\text { the world (MEOW) }\end{array}$ & $\begin{array}{l}\text { Provides a classification of the world's } \\
\text { coastal and shelf waters }(<200 \mathrm{~m} \\
\text { depths). Based on review of existing } \\
\text { information and expert knowledge of } \\
\text { pelagic and benthic biotas. Closely aligns } \\
\text { with the pelagic provinces of the world }\end{array}$ & $\begin{array}{l}\text { Nested system of } 12 \\
\text { realms, } 62 \text { provinces and } \\
232 \text { marine ecoregions }\end{array}$ & $\begin{array}{l}\text { Spalding et al. } \\
(2007)\end{array}$ \\
\hline $\begin{array}{l}\text { Pelagic provinces of } \\
\text { the world }\end{array}$ & $\begin{array}{l}\text { Provides a classification of the world's } \\
\text { off-shelf surface waters ( }<200 \text { m depths). } \\
\text { Based on review of existing information } \\
\text { and expert knowledge of pelagic biota. } \\
\text { Closely aligns with the marine ecoregions } \\
\text { of the world }\end{array}$ & $\begin{array}{l}\text { Nested system of } 4 \text { realms, } \\
7 \text { biomes and } 37 \text { pelagic } \\
\text { provinces }\end{array}$ & $\begin{array}{l}\text { Spalding et al. } \\
(2012)\end{array}$ \\
\hline $\begin{array}{l}\text { Deep-sea benthic } \\
\text { provinces of the world }\end{array}$ & $\begin{array}{l}\text { Proposes global biogeographic provinces } \\
\text { for the lower bathyal and abyssal } \\
\text { benthos (> } 800 \text { m depths). Based on } \\
\text { oceanographic proxies and location data } \\
\text { for select benthic marine species }\end{array}$ & $\begin{array}{l}\text { Proposed system includes } \\
14 \text { lower bathyal }(800-3500 \\
\mathrm{m}) \text { and } 14 \text { abyssal }(3500- \\
6500 \mathrm{~m}) \text { provinces }\end{array}$ & Watling et al. (2013) \\
\hline
\end{tabular}

under IUCN auspices, and the more recent terrestrial, marine and freshwater ecoregions of the world (Table 3.3; Olson et al. 2001; Spalding et al. 2007; Abell et al. 2008). These systems have been used, for example, in ecological gap analyses of the global protected area network and to measure progress towards the protected area targets of the CBD (Brooks et al. 2004; Chape et al. 2005; Spalding et al. 2008; Jenkins and Joppa 2009; CBD 2010a; Bertzky et al. 2012). Additional systems have recently been developed to cover the high seas (Table 3.3; Spalding et al. 2012; Watling et al. 2013). These systems can be used for conservation science, policy, planning and management (Hoekstra et al. 2010).

\section{Terrestrial biomes}

The 'terrestrial ecoregions of the world' system of Olson et al. (2001) is used here to describe in more detail the natural distribution of terrestrial ecosystems on Earth. It recognises eight biogeographic realms-large areas within which organisms have been evolving in relative isolation over long periods - and 14 vegetated biomes (Figure 3.3). While the realms are characterised by the related evolutionary history of the organisms they contain, the biomes represent major ecosystem types that are characterised by fairly similar climatic conditions and ecological communities. Major biomes such as forests, grasslands and deserts are easily recognised, including from space, and influence the distribution of species on Earth.

Key characteristics of each of the 14 biomes are summarised below based on Olson et al. (2000). Mountains are briefly described as a separate biome as recognised by Udvardy (1975). Throughout this section, we use World Heritage case studies to showcase a selected sample of the world's most widespread biomes.

\section{Tropical and subtropical moist broadleaf forests}

This biome occurs around the world mostly along the equatorial belt and between the Tropics of Cancer and Capricorn as large, discontinuous patches of semievergreen and evergreen forests. Their largest stretches can be found in the Amazon Basin, the Congo Basin (Case Study 3.3) and the Indo-Malayan archipelagos. Low variability in annual temperature combined with high levels of rainfall (> 2000 millimetres annually) is characteristic for this biome. Tropical and subtropical moist broadleaf forests harbour the highest number of species of any terrestrial biome-estimated to account 


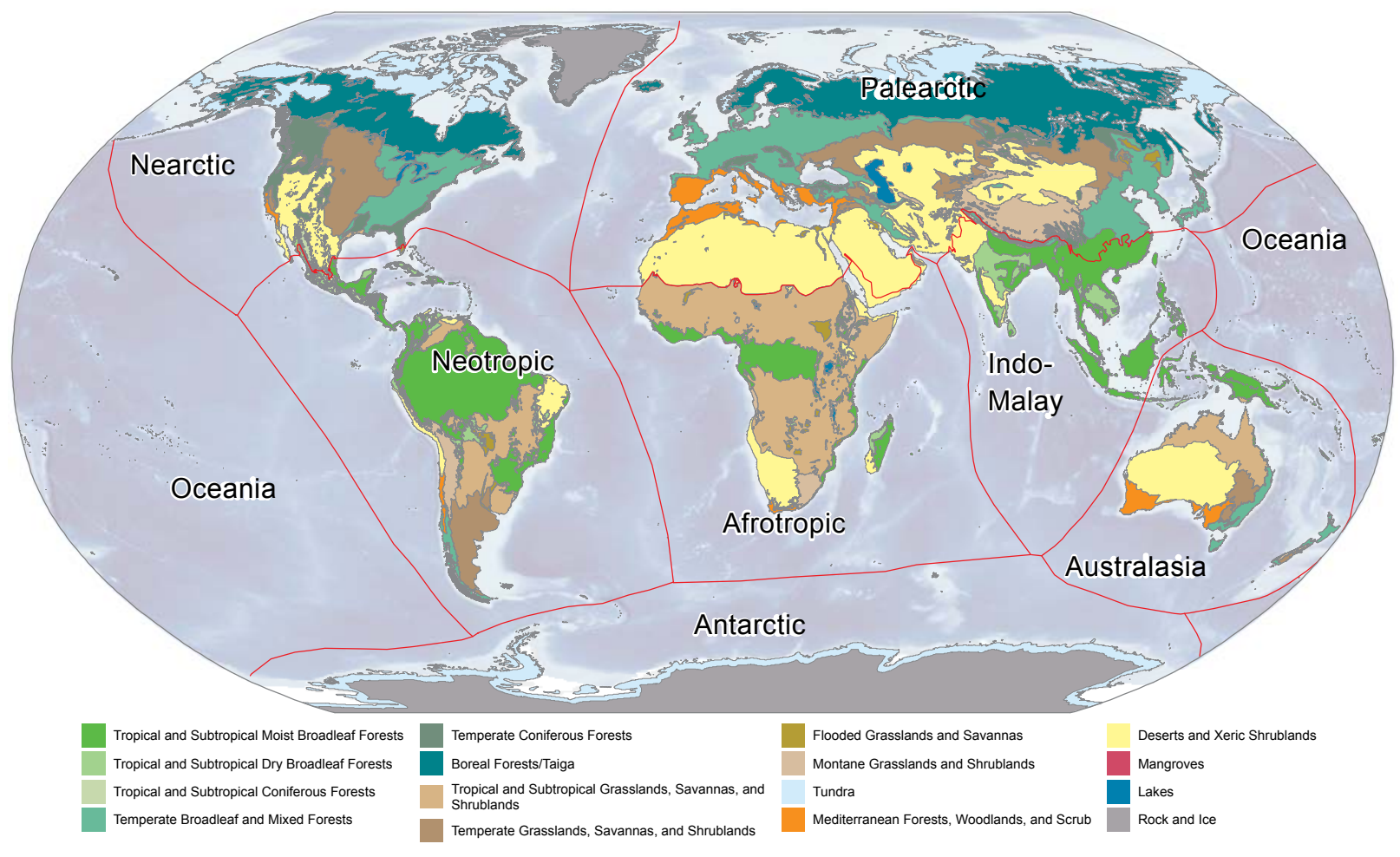

Figure 3.3 The eight biogeographic realms and 14 biomes of the world

Source: Modified from Olson et al. (2001)

for up to half of the world's known species (Figure 3.2). Species richness is highest in the forest canopies, while a lack of sunlight makes life on the forest floor less varied. Still, one square kilometre of these forests can host as many as 1000 different species of trees. With a total of 50 ecoregions, tropical and subtropical moist broadleaf forests include more ecoregions than any other biome, further emphasising their diversity and complexity.

\section{Tropical and subtropical dry forests}

Just as in rainforests, in this biome temperature varies little, and there is enough rainfall for forests to grow. There is, however, a dry season lasting several months, causing deciduous instead of evergreen tree species to dominate the forest. When the trees shed their leaves to conserve water during the dry season, sunlight can reach the forest floor, supporting the growth of dense understorey vegetation. Tropical and subtropical dry forests provide important habitat for wildlife, including monkeys, large cats, parrots and ground-dwelling birds. Overall biodiversity, however, is lower than in tropical and subtropical moist broadleaf forests. The biome can be found in southern Mexico, valleys of the northern Andes, coastal Ecuador and Peru, eastern Bolivia and central Brazil, the Caribbean, south-eastern Africa, Madagascar, central India, Indochina, the Lesser Sundas and New Caledonia.

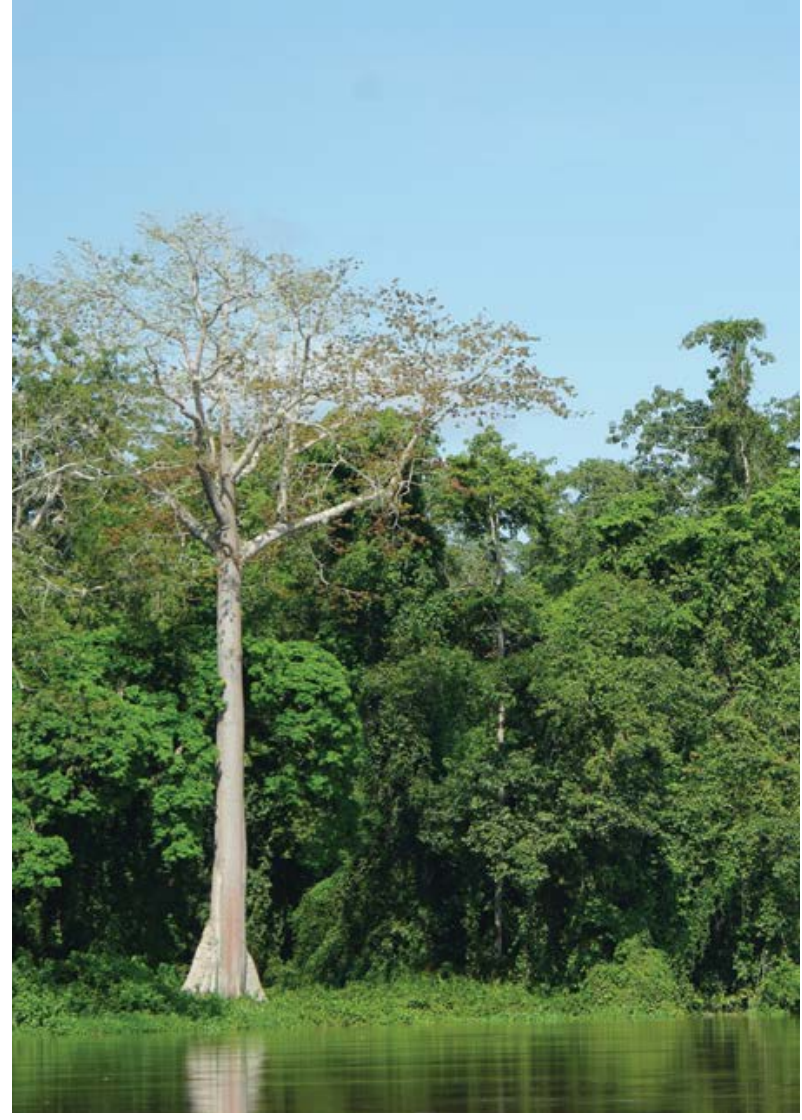

Sangha Trinational, Cameroon, Central African Republic and Republic of the Congo

Source: IUCN Photo Library @ C Charles Doumenge 


\section{Case Study 3.3 Sangha Trinational, Cameroon, Central African Republic and Republic of the Congo: World Heritage property since 2012}

Biogeographic realm: Afrotropic; biome: tropical and subtropical moist broadleaf forests

Combining three national parks in the Congo Basin-Parc National de Lobeké in Cameroon, Parc National de DzangaNdoki in the Central African Republic and Parc National de Nouabalé-Ndoki in the Republic of the Congo-this trans-boundary World Heritage property covers about 7500 square kilometres of land. The property's diverse ecosystems include tropical evergreen forests, swamp forests and periodically flooded forests, as well as various types of forest clearings, all of which are connected at a landscape level.

The property is outstanding due to the maintenance of ecological and evolutionary processes in a mostly intact forest landscape at huge scale, and a large buffer zone surrounding the property in all three countries helps conserve this status. The property supports viable populations of many forest species such as the critically endangered tree species mukulungu (Autranella congolensis), critically endangered western lowland gorilla (Gorilla gorilla), endangered chimpanzee (Pan troglodytes), the endangered antelope species sitatunga (Tragelaphus spekii) and bongo (Tragelaphus eurycerus), and forest elephants (Loxodonta cyclotis). The numerous types of forest clearings are also home to unique plant assemblages.

Source: Adapted from UNESCO (2014)

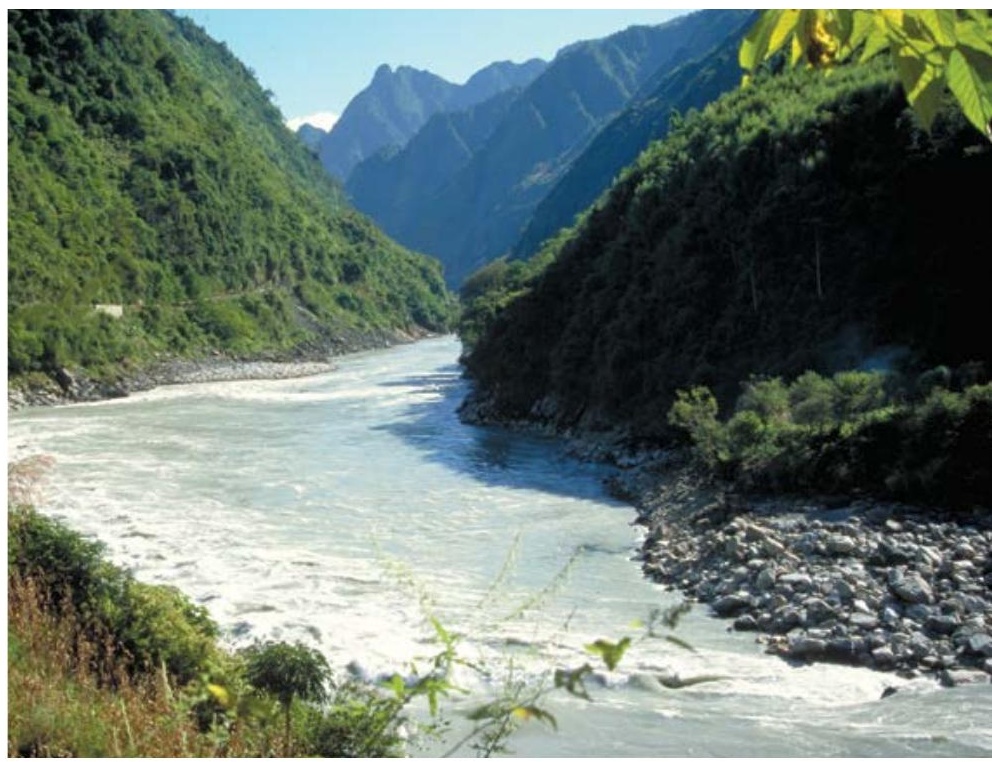

Three Parallel Rivers of Yunnan Protected Areas, China

Source: IUCN Photo Library @ J Jim Thorsell

inland where climates are drier or in mountainous areas. Pine (Pinus spp.), cedar (Cedrus spp.), fir (Abies spp.), juniper (Juniperus spp.), spruce (Picea spp.), podocarpus (Podocarpus spp.) and redwood (Sequoia, Sequoiadendron and Metasequoia spp.) are among the common tree species. Needle-leaf species do not always dominate this biome; in some places the forest is composed of broadleaf evergreen species or a mixture of both broadleaf and needle-leaf species. Temperate coniferous forests store the highest levels of biomass of all terrestrial ecosystems and trees can reach an average height of 50-85 metres (Sequoiadendron giganteum). These forests can be found, for example, in western and south-eastern North America and many mountain ranges of the Palaearctic realm (Case Study 3.4).

\section{Temperate coniferous forests}

Warm summers and cool winters support this type of evergreen forest, which is typically found in coastal areas with mild winters and heavy rainfall, further 


\section{Case Study 3.4 Three Parallel Rivers of Yunnan Protected Areas, China: World Heritage property since 2003}

\section{Biogeographic realm: Palaearctic; biome: temperate coniferous forests}

Spanning a total of 17000 square kilometres, the Three Parallel Rivers of Yunnan Protected Areas in Yunnan Province, southern China, combines 15 protected areas grouped into eight geographical clusters. As its name indicates, this serial (multi-part) property includes upper sections of three of the great rivers of Asia-the Yangtze, Mekong and Salween-which run roughly parallel from north to south through the incorporating Three Parallel Rivers National Park. The landscape is stunning, with the rivers running through gorges up to 3000 metres deep flanked by snow-covered peaks of up to 6000 metres in altitude. The mountains display a range of different rock types and landforms, including alpine karst, granite monolith and Danxia sandstone, reflecting the property's varied geological history. Dense forests, lakes and meadows dominate the landscape between the rivers.
The combination of a wide range of altitudes, climates and habitats close to the intersection of three major biogeographic realms (East Asian, South-East Asian and Tibetan Plateau) favours very high biodiversity. Nowhere in China is biodiversity richer than in the north-west of Yunnan Province, and compared with other temperate regions this property may be the most biologically diverse. About 6000 plant species have been identified to date, and up to 25 per cent of the world's animals are believed to occur here, many of which are endemic, relict or endangered. Wellknown examples include the red panda (Ailurus fulgens), Chinese grouse (Bonasa sewerzowi) and Asiatic wild dog (Cuon alpinus).

Source: Adapted from UNESCO (2014)

\section{Boreal forests and taiga}

This biome occurs where annual temperatures are low and precipitation, falling mostly as snow, ranges between 400 and 1000 millimetres per year. Soils can be under permafrost and drainage consequently is poor, leading to low nutrient levels. Many tree species are not able to grow on such soils, but there are exceptions, including coniferous and broadleaf tree species such as fir (Abies spp.), spruce (Picea spp.), larch (Larix spp.), pine (Pinus spp.), birch (Betula spp.) and poplar (Populus spp.). Mosses and lichens typically dominate the ground layer. While less rich in species numbers and endemism, this biome is an important stage of large-scale migrations of caribou (Rangifer tarandus). In addition, some places still harbour intact assemblages of predators with large home ranges. These species depend upon vast expanses of boreal forests and taiga, or at least large-scale linkages of natural habitat, to allow movements in response to natural disturbance regimes. This vast biome is restricted to the northern Palaearctic and Nearctic, with the largest expanses occurring in central and eastern Russia, followed by Canada (Case Study 3.5).

\section{Tropical and subtropical grasslands, savannahs and shrublands}

This biome is characterised by little annual temperature variation, rainfall between 900 and 1500 millimetres, and distinct wet and dry seasons. Drought conditions and frequent natural fires during the dry season lead to a landscape dominated by grasses and scattered trees. Grasslands, savannahs (wooded grasslands) and shrublands typically form a transitional biome between forests and deserts. While grasses are dominant, the trees and shrubs that exist are often drought, fire or

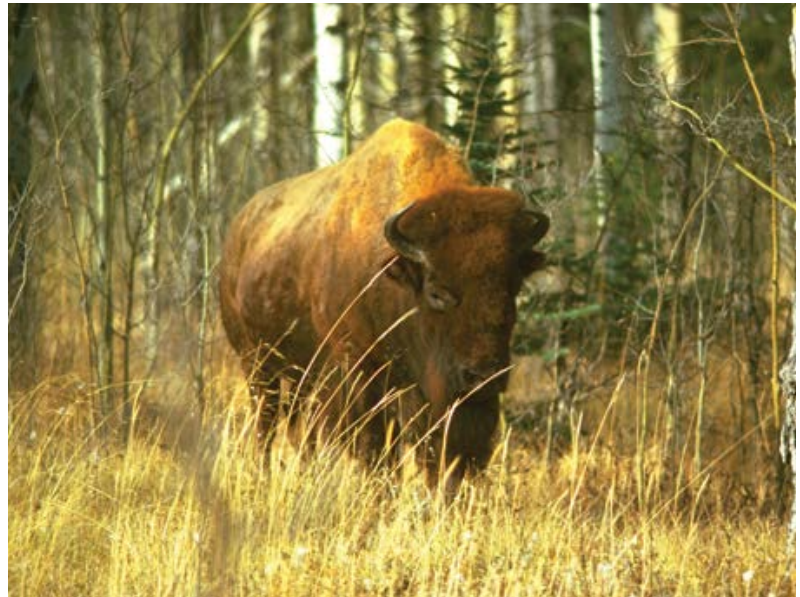

Wood buffalo or wood bison (Bison bison athabascae), Wood Buffalo National Park, Canada Source: @ Jim Thorsell

browse-resistant. Large herbivores traversing these lands are characteristic and in some regions they are in large numbers. No other biome harbours so many hoofed animals and in such density, which in turn support large predator populations. The largest and richest of these ecosystems can be found in Africa, where the most intact species compositions occur in the East African acacia (Acacia spp.) savannahs and Zambezian savannahs. The Llanos in Colombia and Venezuela is one of the best examples of this biome in South America due to its floristic and habitat diversity, but larger expanses can be found in Brazil (Case Study 3.6). The biome is also important in northern Australia and southern Papua New Guinea. Australian savannahs reflect the dominance of termites as herbivores and support distinctive marsupial communities. 


\section{Case Study 3.5 Wood Buffalo National Park, Canada: World Heritage property since 1983}

\section{Biogeographic realm: Nearctic; biome: boreal forests and taiga}

Located in the north-central region of Canada, the 44807 square kilometre Wood Buffalo National Park contains huge tracts of boreal forest as well as the largest extent of North America's Great Plains boreal grassland ecosystem. It also includes the world's largest inland delta, formed by the three rivers Peace, Athabasca and Slave, and associated ecosystems such as floodplains and mudflats.

North America's largest population of threatened wood bison (Bison bison athabascae) roams the plains of Wood Buffalo National Park and it is one of the few places in the world where the relationship between predator and prey-here, grey wolf (Canis lupus) and wood bisonhas remained undisturbed. It is also globally unique in providing precious breeding habitat for the endangered whooping crane (Grus americana). The inland river delta is a popular stopover point for migratory waterbirds. Overall, 46 mammal species and 227 bird species have been recorded, including Arctic fox (Vulpes lagopus), moose (Alces alces), black bear (Ursus americanus), snowy owl (Bubo scandiacus) and boreal chickadee (Parus hudsonicus).

Source: Adapted from UNESCO (2014)

\section{Case Study 3.6 Cerrado Protected Areas-Chapada dos Veadeiros and Emas National Parks, Brazil: World Heritage properties since 2001}

Biogeographic realm: Neotropical; biome: tropical and subtropical grasslands, savannahs and shrublands

The Cerrado Protected Areas cover about 3670 square kilometres and contain exceptional examples of one of the world's oldest and most diverse tropical savannah ecosystems. The property spans two national parks, Chapada dos Veadeiros and Emas. The first forms part of central Brazil's highest plain and includes wide plateaus, waterfalls and springs as well as deep rocky canyons and valleys. Emas National Park forms part of the Serra dos Caiapós plateau, a gently rolling plain that serves as the divide between the La Plata and Amazon rivers.
The Cerrado has provided key species refuges during past climatic changes and the altitudinal ranges and vast undisturbed habitats will continue to do so for species adjusting to recent change. More than 60 per cent of all Cerrado plant species and almost 80 per cent of its vertebrate species are represented within the property, including most of its threatened mammals, such as the giant armadillo (Priodontes maximus) and marsh deer (Blastocerus dichotomus). Emas National Park also hosts a number of bird species specialised to living in these grasslands, some of which are endemic, including the endangered white-winged nightjar (Eleothreptus candicans) and the marsh seedeater (Sporophila palustris).

Source: Adapted from UNESCO (2014)

\section{Temperate grasslands, savannahs and shrublands}

Precipitation levels in this temperate biome are generally too low for trees to grow in abundance, and annual temperature variation, usually with hot summers and cold winters, is much greater than in the tropics and subtropics. Additionally, strong winds often blow over these areas, exacerbating evapotranspiration and hence drought conditions. The species composition of temperate grasslands, savannahs and shrublands is consequently very different from that of their tropical and subtropical counterparts. Trees are almost entirely absent, with only a few exceptions such as riparian or gallery forests occurring along streams and rivers. A number of large grazing mammals are characteristic, together with associated predators, and numerous species of birds and insects. Natural fire regimes are important to sustain this biome, and vast expanses of land are required for

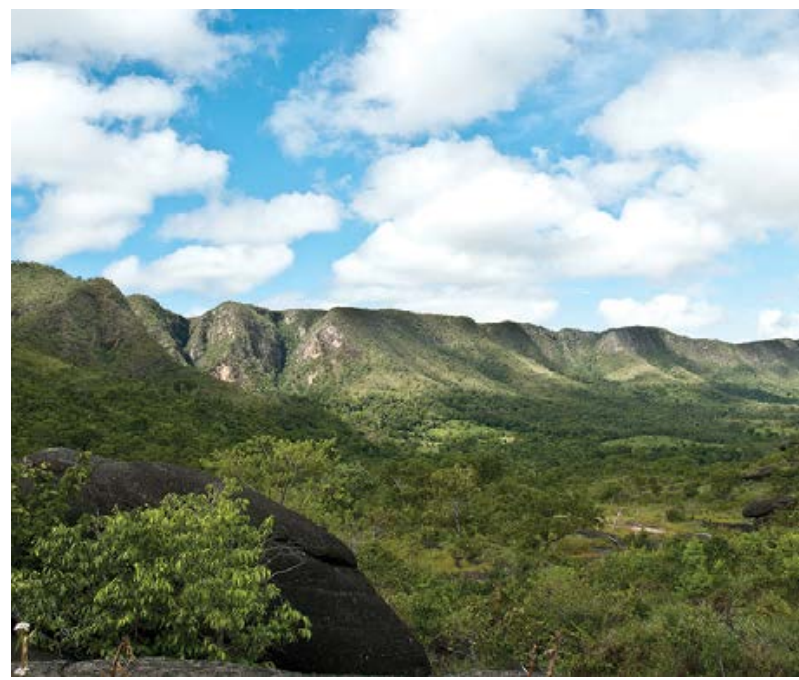

Cerrado Protected Areas: Chapada dos Veadeiros and Emas National Parks, Brazil

Source: () Bruno Poppe 


\section{Case Study 3.7 Saryarka-Steppe and Lakes of Northern Kazakhstan, Kazakhstan: World Heritage property since 2008}

\section{Biogeographic realm: Palaearctic; biome: temperate grasslands, savannahs and shrublands}

Saryarka comprises two protected areas-Naurzum State Nature Reserve and Korgalzhyn State Nature Reservelocated some 350 kilometres apart in the Kazakh Uplands. They jointly cover an area of about 4500 square kilometres, of which 44 per cent is Central Asian steppe with the remainder consisting mainly of fresh and saltwater lakes and associated wetland ecosystems.

The steppe in Saryarka is home to more than half of the typical floristic species found in this region's steppe ecosystem. Every year when the grass begins to sprout, large herds of the critically endangered saiga antelope (Saiga tatarica) migrate across the steppe from south to north. The species occurs nowhere else but in the Central Asian steppe and Saryarka is important for their survival. The property's wetlands and lakes are of global significance for migratory waterbirds along the Central Asian flyways. Species from Africa, Asia and Europe visit the Saryarka lakes on journeys to their breeding grounds in western and eastern Siberia. Jointly, the lakes in Saryarka support up to 850000 nesting waterfowl. Many globally threatened species are among the migrants, including the critically endangered Siberian white crane (Grus leucogeranus) and the vulnerable Dalmatian pelican (Pelecanus crispus) and Palla's fish eagle (Haliaeetus leucoryphus).

Source: Adapted from UNESCO (2014) species to escape such disturbance, or to move between seasonal or patchy resources. This biome is widespread and known under different names from one continent to the next, such as prairie in North America, pampas in South America and steppe in Asia (Case Study 3.7).

\section{Flooded grasslands and savannahs}

Usually located in temperate-warm to tropical-hot climates, these grasslands and savannahs are flooded seasonally or year-round, creating wetland mosaics across the landscape. They are often referred to as swamps. The soil is very moist to water-saturated and typically nutrient rich. A large variety of uniquely adapted plants and animals can be found in these habitats, which harbour numerous bird species, including many migrants. The biome is found on four continentsNorth America, South America, Africa and Asiawith the Everglades in North America one of the bestknown examples. Other well-known examples include the Pantanal in South America and the Sahelian and Zambezian flooded savannahs, including the Okavango Delta, in Africa.

\section{Montane grasslands and shrublands}

Occurring in high-elevation areas of the tropics, subtropics and temperate regions on five continents, this biome is characterised by cool, often wet conditions and intense sunlight. Ecosystems within this biome have often evolved as virtual islands, separated from similar montane ecosystems by areas of lower elevation and warmer climate. Consequently, their flora and fauna are not only well adapted to the specific climatic conditions (such as through waxy surfaces and hairy leaves), but also support local or regional endemics. Giant rosette plants from different families, including lobelia in Africa and puya in South America, are typical for tropical montane grasslands and shrublands and can grow in altitudes of up to 4600 metres. Tropical and subtropical montane

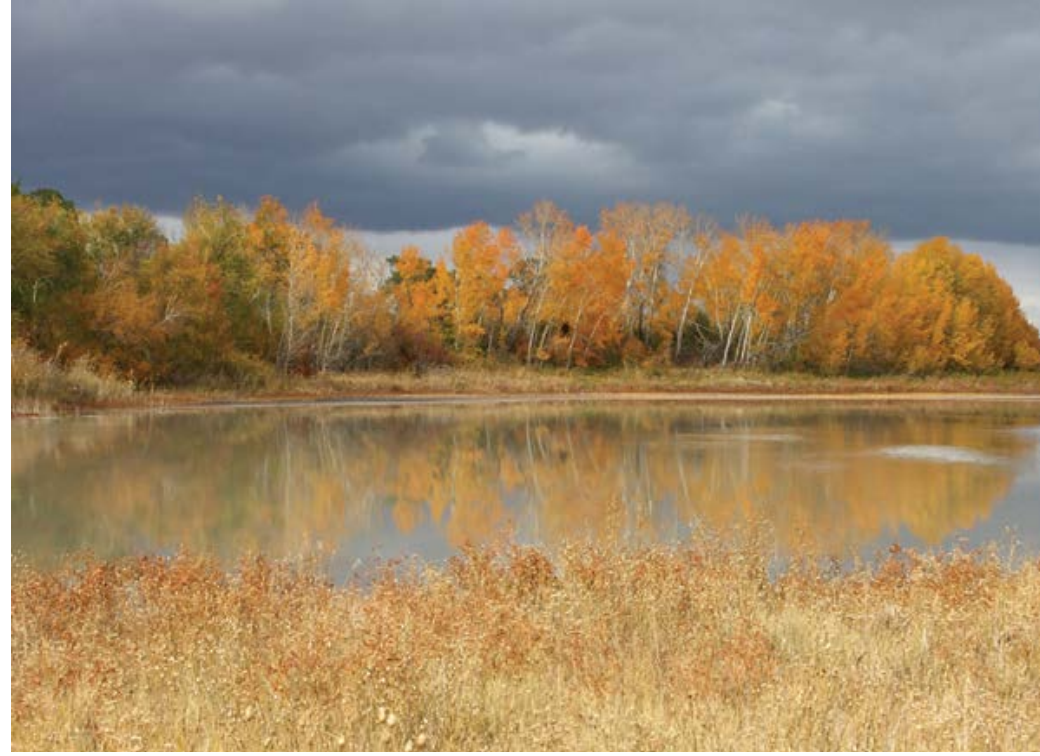

Sayarka-Steppe and Lakes of Northern

Kazakhstan, Kazakhstan

Source: IUCN Photo Library @ Jim Thorsell

grasslands and shrublands can be found in the northern Andes, where the ecosystem is called páramo, mountains and highlands in eastern and southern Africa, Mount Kinabalu in Borneo, and mountain areas in Papua New Guinea. Drier, temperate montane grasslands and shrublands can be found, for example, on the Tibetan Plateau and in the Altai Mountain Range.

\section{Tundra}

Long, dry winters with months of darkness and very low temperatures characterise this biome, which is typical of polar regions north of the taiga belt. Precipitation levels are very low and most rain falls during the summer months, while it tends to be windy all year round. Soils, if not permanently frozen, are saturated with water and are acidic. During the summer months, where the permafrost melts, the tundra is covered by marshes, lakes, bogs and streams. 


\section{Case Study 3.8 Natural System of Wrangel Island Reserve, Russian Federation: World Heritage property since 2004}

\section{Biogeographic realm: Palaearctic; biome: tundra}

Located in the high Arctic between the Chukchi and the East Siberian seas, Wrangel Island Reserve consists of Wrangel Island and Herald Island and their surrounding waters, overall covering about 9160 square kilometres of land and water.

Wrangel Island Reserve has evolved self-sustained and uninterrupted by the glaciation in the Quaternary. This fascinating natural history is visible in many ways. Mammoth tusks and skulls discovered here have been found to be so recent (some only 3700 years old) that Wrangel Island is considered the last place in the world where mammoths lived. The range of terrain types and geological formations and the rapid succession and mosaic of tundra types create a variety of different habitats for flora and fauna. The result of all this is remarkably high biodiversity and endemism. For example, the numbers of identified vascular plant species are double those of other Arctic tundra ecosystems of similar size and include 23 endemics. About 100 migratory bird species use the islands as their northernmost nesting ground, and many of them are endangered. The world's largest population of Pacific walrus (Odobenus rosmarus divergens) resides on Wrangel Island, Asia's only snow goose (Chen caerulescens) population breeds there, and it is also where the highest density of ancestral polar bear dens can be found. The waters around the islands, which are low in salinity but high in oxygen, are an important feeding ground for migrating grey whales (Eschrichtius robustus).

\section{Source: Adapted from UNESCO (2014)}

In general the landscape is barren, often covered with rocks and patches of low-growing vegetation, including heath, sedges and dwarf shrubs, mosses and lichens. Only in some places do trees occur, but they are scattered. Biodiversity in these areas is generally low, however, millions of migrating birds visit the tundra every year to breed in the marshes. Additionally, the tundra is an important habitat for caribou (Rangifer tarandus) migration. Tundra occurs primarily in Alaska, Canada, Russia (Case Study 3.8), Greenland, Iceland and Scandinavia, as well as on Antarctica and several sub-Antarctic islands.

\section{Mediterranean forests, woodlands and scrubs}

Long, hot and dry summers and mild and rainy winters characterise this biome, resulting in diverse vegetation types, ranging from forests and woodlands to savannahs, shrublands and grasslands. Quite often several of these vegetation types occur in a heterogeneous mosaic, depending on soil characteristics, topography, exposure to sun, wind and rain, and fire history. Fauna and flora are well adapted to water scarcity and many species are also adapted to fire. For some, their persistence depends on natural fire regimes. Biodiversity is typically very rich, and regional and local endemism common. The fynbos in South Africa's Cape Floristic Region is an important example of this biome. Here, 68 per cent of the 8600 known vascular plant species that occur in an area of only 90000 square kilometres are endemic. Globally, this biome is relatively rare, restricted to only five regions where the specific Mediterranean climatic conditions occur: the Mediterranean, south-central and south-western Australia, the fynbos of southern Africa, the Chilean matorral and the Mediterranean ecosystems of California.

\section{Deserts and xeric shrublands}

Deserts and xeric shrublands are located in tropical, subtropical and temperate regions that receive a maximum of 250 millimetres of rainfall per year.

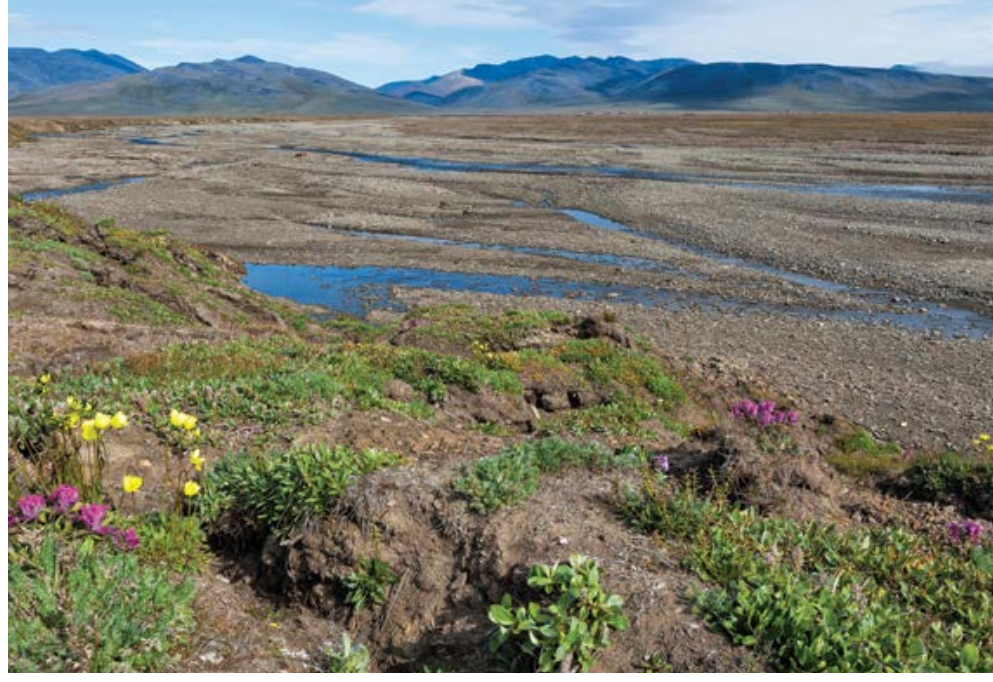

Natural System of Wrangel Island Reserve,

\section{Russian Federation}

Source: (c) Gabrielle and Michelle Therin-Weise

Evaporation usually exceeds rainfall, sometimes by far. Extreme temperature variation between day and night is typical, with searing daytime temperatures dropping steeply in the night due to the lack of insulation that is provided elsewhere by humidity and cloud cover. Soils are often sandy or rocky and organic material content tends to be low. Where vegetation occurs, it consists of woodystemmed shrubs and plants specialised to minimise water loss. Animals are well adapted to these harsh climatic conditions and many of them are nocturnal to avoid moisture loss. The diversity of plants and animals can be quite high, especially the reptile fauna, and local endemism can be high in some places. Deserts and xeric shrublands are the largest of all the biomes, covering an estimated 19 per cent of the world's land area. Floristically, the most diverse ecosystem falling into this biome is the Namib-Karoo in south-western Africa (Case Study 3.9), closely followed by the Chihuahuan Desert and central Mexican deserts in the Neotropics. 


\section{Case Study 3.9 Namib Sand Sea, Namibia: World Heritage property since 2013}

\section{Biogeographic realm: Afrotropic; biome: deserts and} xeric shrublands

The Namib Sand Sea is a hyper-arid desert covering 30000 square kilometres of land along the Namibian coastline entirely within the Namib-Naukluft Park. The property contains gravel plains, rocky hills, a coastal lagoon and ephemeral rivers, but is mainly composed of different types of shifting sand dunes whose only source of water is fog. It is the only coastal desert in the world where this is the case. While most other dunes are composed of in situ eroded bedrock, the Namib Sand Sea is composed of sand originating from inland Africa. It is transported to the coast over thousands of kilometres by rivers, ocean currents and wind. Wind-driven sand transport processes have subsequently shaped the site's geomorphology and ecology, creating a 'sea of sand dunes' landscape.

Fauna and flora are remarkably well adapted to the climatic conditions, as reflected in species' behaviour, morphology and physiology, leading to large numbers of endemics. More than 50 per cent of the plant and insect species in the sand sea are endemic, and for arachnids (spiders, scorpions and ticks) this figure exceeds 80 per cent. Some fascinating adaptations include ways to filter moisture out of the air to minimise species' dependency on other water sources.

Source: Adapted from UNESCO (2014)

\section{Mangroves}

Mangroves are a vegetation type dominated by salttolerant tree species that grow between the intertidal zone and the high-tide mark of tropical and subtropical coastlines. About 60 tree species from 12 different genera make up 'mangrove' communities. Soils are waterlogged, salty and oxygen poor, and mangroves are often exposed to tidal movements and seasonal weather fluctuations. A variety of different adaptations to cope with these special conditions can be observed: a massive root system helps mangroves gain a foothold in the soft ground, aerial roots absorb oxygen from the air and the leaves of mangroves can excrete excess salt. Together with a variety of other associated aquatic and saline plants, mangroves provide important habitat, especially nursing grounds, for numerous marine animal species, such as oysters, shrimp and mud lobster. Mangrove biodiversity is highest in South Asia, and the Sundarbans mangroves shared by Bangladesh and India represent the world's largest expanse of this vegetation type.

\section{Mountains}

Mountains are sometimes considered a separate biome (Udvardy 1975) due to their special characteristics although they support a wide range of major ecosystem types including deserts, grasslands, forests and alpine tundra. Mountains are major Earth features found on every continent (Hamilton and McMillan 2004) and in 197 of the world's 237 countries (Rodríguez-Rodríguez et al. 2011). Mountains defy precise definition but many mountain scholars use the definition developed by UNEP-WCMC (2002), which considers elevation, slope and local elevation range, bringing into the fold some of the 'low' mountains of the world (Figure 3.4). Using this definition, mountains cover 27 per cent of the Earth's surface (UNEP-WCMC 2002). We explore the special values of mountains further in Box 3.2.

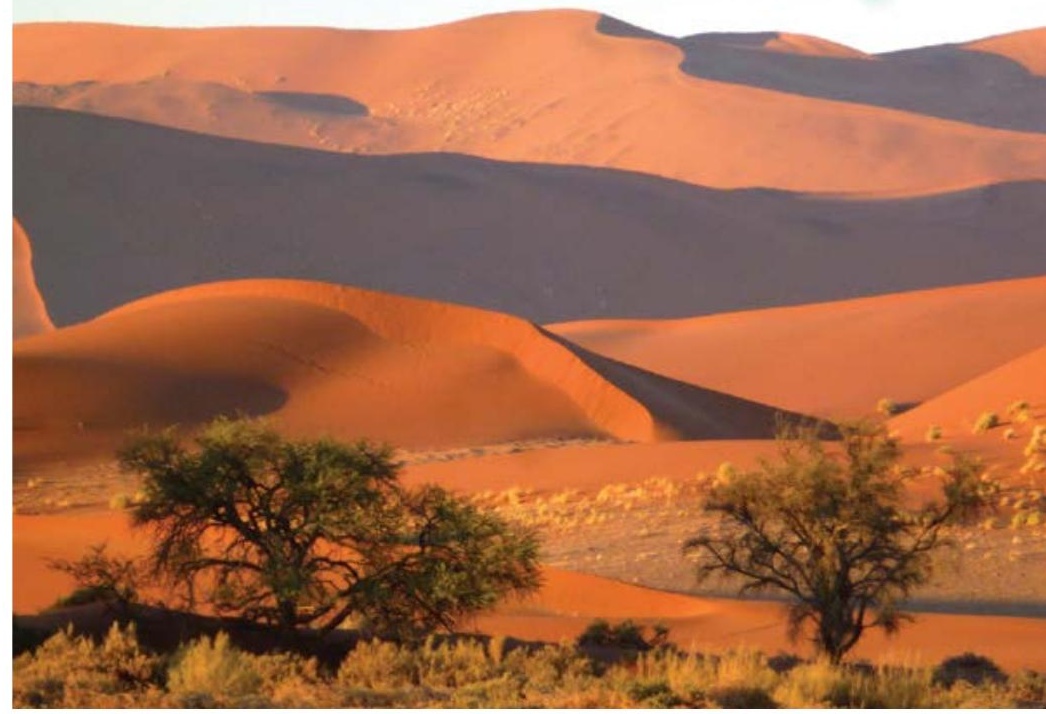

Namib Sand Sea, Namibia

Source: IUCN Photo Library @ Peter Howard

\section{Marine and freshwater biomes}

In contrast with the 'terrestrial ecoregions of the world' system, the corresponding systems for marine and freshwater ecoregions (Spalding et al. 2007; Abell et al. 2008) do not differentiate major ecosystem types such as those examples shown in Table 3.4. The 'pelagic provinces of the world' system (Spalding et al. 2012) recognises the following seven major biomes in the world's off-shelf surface waters:

- polar

- gyre

- eastern boundary currents

- western boundary currents

- equatorial

- transitional

- semi-enclosed seas.

Case Studies 3.10, 3.11 and 3.12 highlight the diversity of coastal and marine ecosystems. 


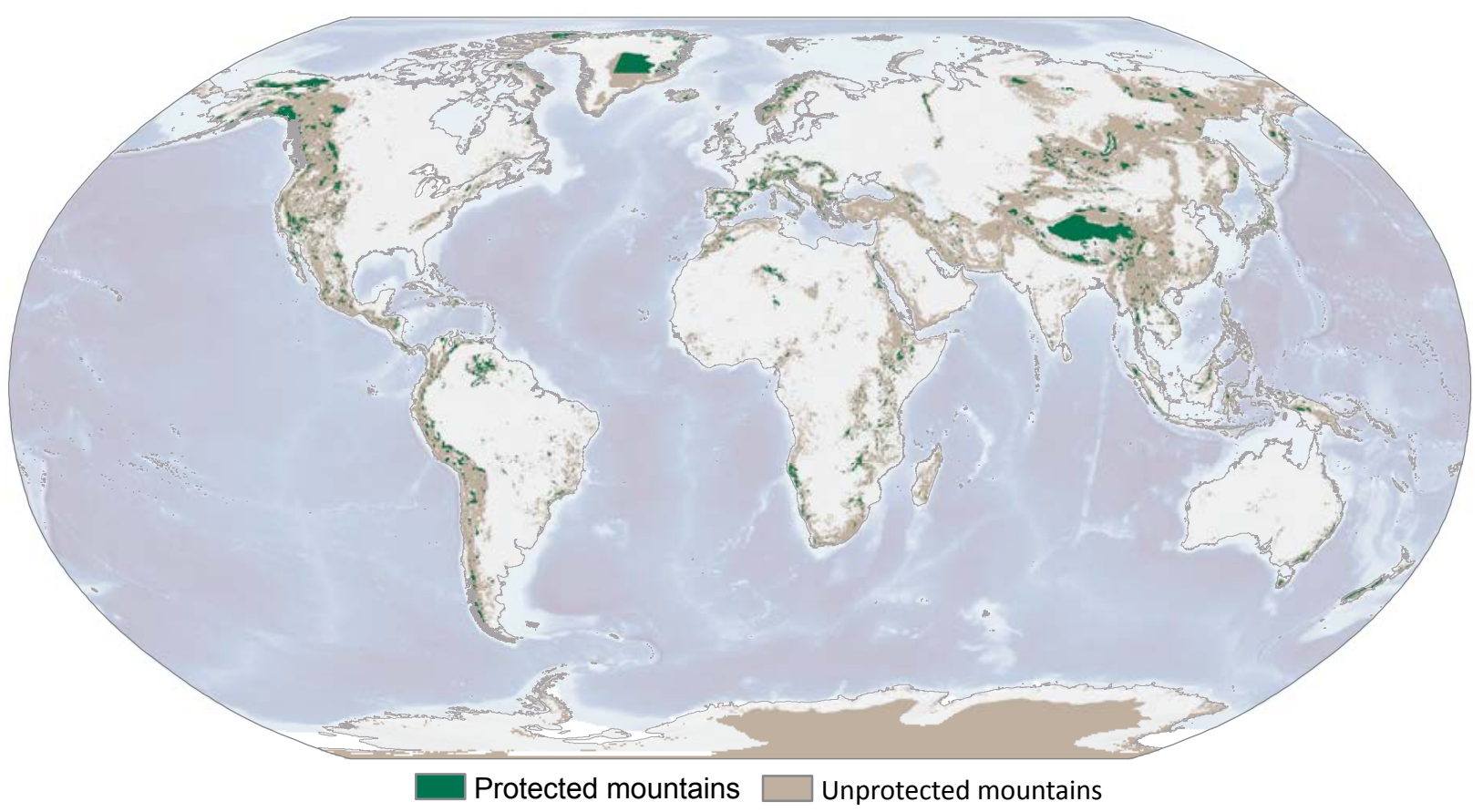

Figure 3.4 Mountain areas and mountain protected areas of the world

Sources: UNEP-WCMC (2002); IUCN and UNEP-WCMC (2014)

\section{Box 3.2 The special values of mountains and mountain protected areas}

Mountains are critical for biodiversity, ecosystem services and human wellbeing. Much of the world's native biodiversity is found in mountains. Their species and ecosystem richness is due largely to the extreme heterogeneity of environments (climates and soils), resulting from the rapid altitudinal changes, variable orientation (aspects) and abundant microhabitats of rough topography. Moreover, a great share of the world's endemic species is found in mountains due to the isolated island nature of mountain massifs, which are often the last bastions of wild nature.

At the same time mountains are home to 12 per cent of the world's human population and 26 per cent of all humans live in or adjacent to mountains (Price 2004). More than half of humanity relies on the freshwater that emanates from mountains (Linniger et al. 1998), and mountain protected areas play a critical role in freshwater provision for many cities and communities. Many mountains are also special because they take on deep spiritual and cultural significance (for example, Mount Fuji in Japan). To some traditional peoples, mountains are held in awe or fear, or are sacred sites where religious ceremonies are held. On the other hand, mountain ranges frequently form national borders, and frontier conflict, even open warfare, has not been uncommon.

Mountain ecosystems are often fragile and face multiple threats to their natural and cultural values (Hamilton 2002). Half of the world's biodiversity hotspots are located in mountains (Kohler and Maselli 2009) and, of the 587 sites threatened with imminent species extinctions identified by the Alliance for Zero Extinction (AZE), 81 per cent are mountainous (Rodríguez-Rodríguez et al. 2011).

Mountain protected areas can provide refuges for biodiversity. Nearly 17 per cent of the world's mountain area outside Antarctica falls in protected areas (not always well managed), but many priority mountain areas for conserving biodiversity remain unprotected, including 45 per cent of the mountains identified by AZE (Rodríguez-Rodríguez et al. 2011). To effectively conserve biodiversity, mountain protected areas need to be enlarged downslope and buffered by sustainably managed surrounding lands. Isolated mountain protected areas need to be connected to the lowlands to facilitate altitudinal species migration from these lower areas in response to climate change or continued land conversion. They also need to be connected where possible to other mountain protected areas. Fortunately, many mountain ranges provide natural connectivity for corridors of conservation (see Chapter 27).

Because of their outstanding natural and/or cultural values, many mountain areas have been included on the World Heritage List: 159 of the 222 natural and mixed (natural and cultural) World Heritage sites contain mountain areas (UNEP-WCMC 2002; IUCN and UNEPWCMC 2014) (Figure 3.1). This includes many well-known sites such as the Canadian Rocky Mountains, Hawai'i Volcanoes, Mounts Huascaran, Kilimanjaro, Kinabalu and Sagarmatha (Everest), Swiss Alps Jungfrau-Aletsch, Mount Tongariro and the Volcanoes of Kamchatka. 


\section{Case Study 3.10 Islands and Protected Areas of the Gulf of California, Mexico: World Heritage property since 2005}

Located in the Sea of Cortez in north-eastern Mexico, the Islands and Protected Areas of the Gulf of California consist of 244 islands, islets and coastal areas covering almost 6900 square kilometres. The natural beauty of this property contrasts the high cliffs and sandy beaches of the mostly barren mountainous or volcanic islands with the surrounding turquoise waters.

Almost all major oceanographic processes, such as upwelling and wind-driven currents and high tidal mixing, can be observed in these waters and contribute to the extraordinary marine productivity and biodiversity that characterise the Gulf of California. Almost 900 species of fish, 90 of them endemic, as well as 39 per cent of the world's marine mammals occur here. Terrestrial biodiversity is equally high, supported by the combination of oceanic islands that were populated by air and sea and 'bridge islands' populated by land when ocean levels were lower during past glaciations. Floral composition reflects that of the Sonoran Desert, with almost 700 vascular plant species. Typical species include elephant tree (Bursera microphylla), desert ironwood (Olneya tesota), white bursage (Ambrosia spp.) and cacti such as the columnar cardon (Pachycerus pringlei), viejito (Mammillaria capensis) and prickly pears (Opuntia spp.).

Source: Adapted from UNESCO (2014)

Table 3.4 Examples of major ecosystem types in marine and freshwater environments

\begin{tabular}{|l|l|}
\hline Marine & Freshwater \\
\hline Open ocean & Lakes \\
\hline Deep sea & Ponds \\
\hline Sea floor & Rivers \\
\hline Coral reefs & Streams \\
\hline Seagrass beds & Springs \\
\hline Salt marshes & Wetlands \\
\hline Mangrove forests & \\
\hline
\end{tabular}

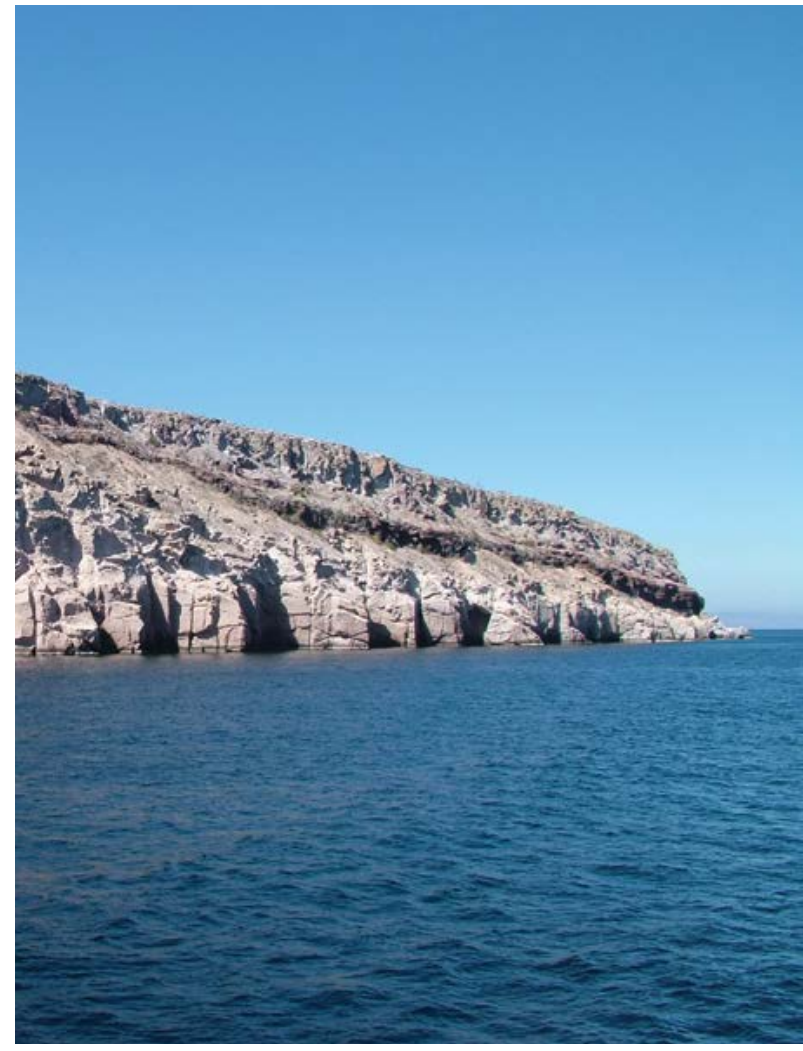

Islands and Protected Areas of the Gulf of California, Mexico

Source: IUCN Photo Library @ David Sheppard

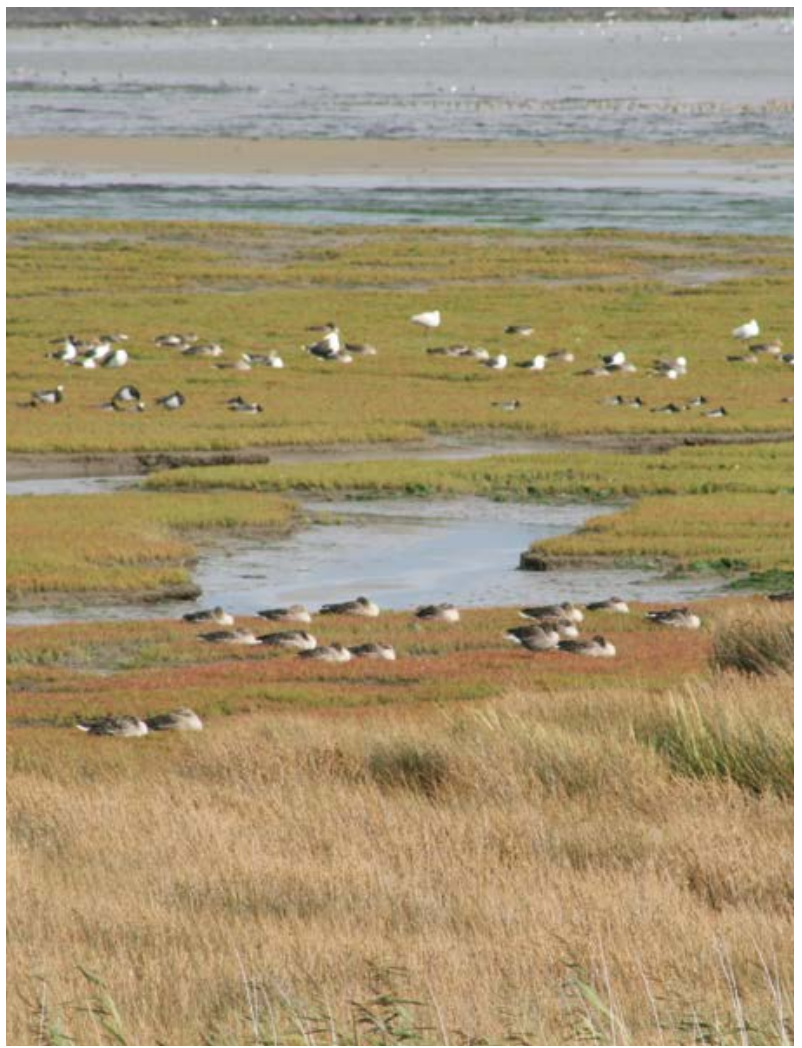

The Wadden Sea, Germany and the Netherlands Source: IUCN Photo Library @ Pedro Rosabal 


\section{Case Study 3.11 The Wadden Sea, Germany and Netherlands: World Heritage property since 2009}

The Wadden Sea World Heritage Property combines the Dutch Wadden Sea Conservation Area with the German Wadden Sea national parks of Lower Saxony and Schleswig-Holstein and covers 9820 square kilometres of coastland. The site represents one of the few remaining temperate intertidal ecosystems where natural processes - such as the creation of barrier islands, channels, flats and gullies-continue almost undisturbed at such a large scale. It is also the world's largest unbroken system of intertidal sand and mud flats.

Habitat diversity is remarkable in the Wadden Sea, featuring tidal channels, sandy shoals, seagrass meadows, mussel beds, sandbars, mudflats, salt marshes, estuaries, beaches and dunes. While coastal wetlands do not generally rank very high in terms of their faunal diversity, the Wadden Sea is different. The salt marshes are home to about 2300 plant and animal species, and another 2700 species inhabit the marine and brackish areas. The abundance of food attracts abundant birdlife. The Wadden Sea is among the world's most important places for migratory birds, playing a crucial role for species travelling the East Atlantic Flyway as well as for African-Eurasian migratory waterbirds. More than six million birds may be present at a single time and an estimated 10-12 million pass through every year.

Source: Adapted from UNESCO (2014)

\section{Case Study 3.12 Lagoons of New Caledonia: Reef Diversity and Associated Ecosystems, France-World Heritage property since 2008}

The Lagoons of New Caledonia are vast, covering more than 15700 square kilometres of mainly seascape in the French Pacific Ocean archipelago of New Caledonia. They represent all the main types of coral reefs and associated ecosystems, featuring tropical lagoons, coral islands, fringing reefs, double barrier reefs and atolls, as well as seagrass meadows and mangroves. As an additional specialty, the reef complex is 'freestanding' in the ocean, encircling New Caledonia, and as a consequence exposed to both cold and warm currents.

The barrier reefs and atolls are among the world's three most extensive reef systems and have at least the same or higher coral and fish diversity as Australia's much larger Great Barrier Reef. The property's stunning underwater world contains reef fissures, arches and caves as well as impressive displays of coral structures and diversity. Its intact ecosystems support healthy populations of a variety of threatened fish, including top predators, but also marine turtles and the world's third-largest population of the vulnerable dugong (Dugong dugon).

Source: Adapted from UNESCO (2014)

\section{Human impact on the distribution of biodiversity}

Human alteration of the global environment has caused considerable changes to the natural distribution of biodiversity (Chapin et al. 2000; Ellis and Ramankutty 2008; Ellis et al. 2010; Barnosky et al. 2012). The human impact on the biosphere can be assessed in many ways. Recent estimates of the human appropriation of net primary production suggest, for example, that 24 per cent of the potential net primary productivity of the world's terrestrial ecosystems is consumed by humans (Haberl et al. 2007).

The level of human influence on the terrestrial biosphere can also be measured and mapped through the human footprint index (Figure 3.5; Sanderson et al. 2002). This index combines information on human population density, land transformation (for example, through agriculture or in built-up areas), human accessibility (for example, along roads, major rivers and coastlines)
Lagoons of New Caledonia: Reef Diversity and Associated Ecosystems, France

Source: IUCN Photo Library (C Dan Laffoley 


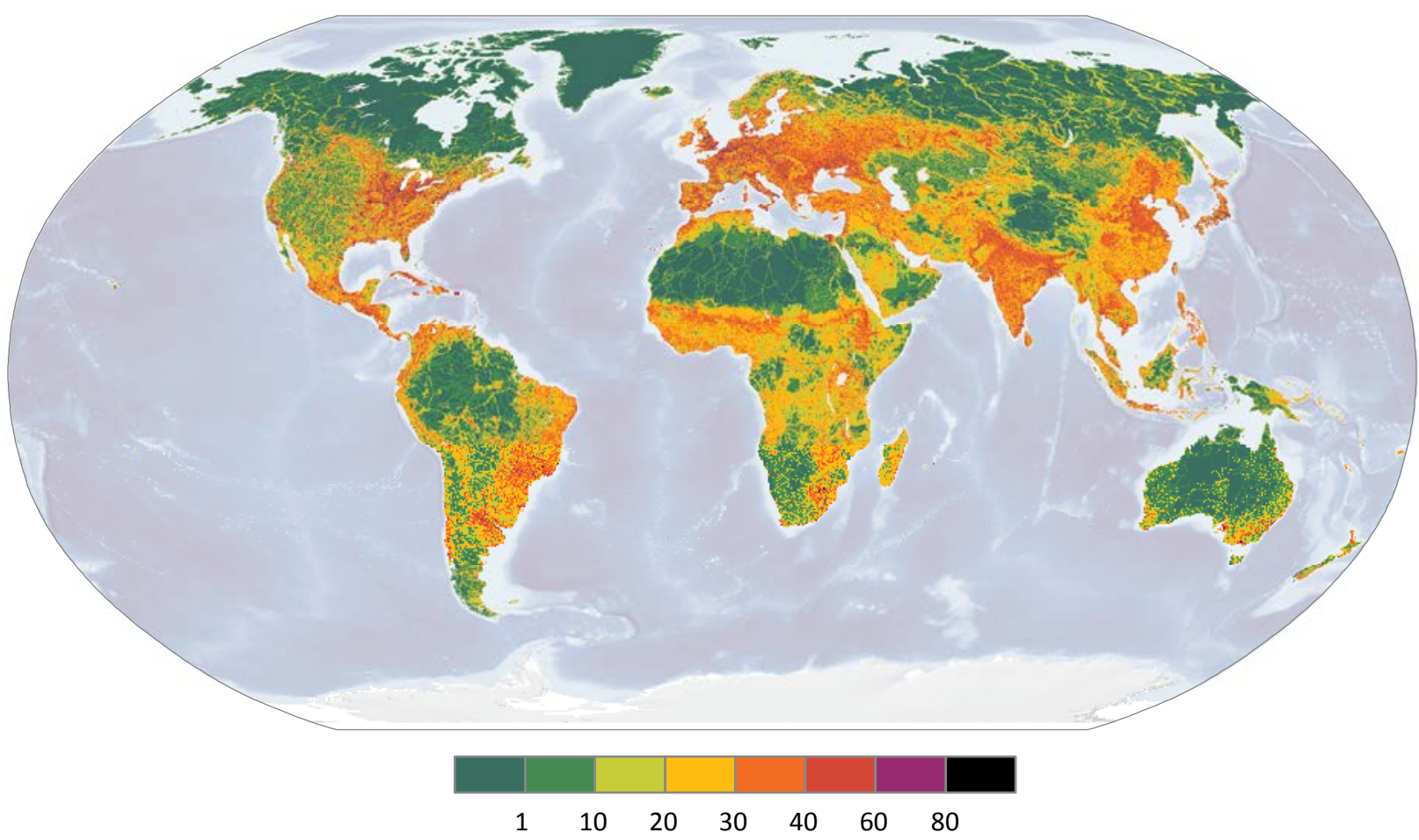

Figure 3.5 The human footprint on the global land area

Source: Modified from Sanderson et al. (2002)

and electrical power infrastructure (inferred from nighttime lights). It measures the relative human influence in each terrestrial biome. A value of zero indicates the least-influenced part of the biome, and a value of 100 indicates the most-influenced part of the biome. So an index score of 10 in moist tropical forests in the Afrotropic realm indicates the area is among the 10 per cent leastinfluenced areas in its biome, the same as a score of 10 in the tundra of the Palaearctic realm, although the absolute amount of influence in those two places may be very different (Sanderson et al. 2002).

\section{Protected areas as safeguards for Earth's natural heritage}

Effectively managed protected areas play a key role in the conservation of the Earth's natural heritage. Through associated ecosystem services, protected areas also support the livelihoods of more than one billion people worldwide (UN Millennium Project 2005), and contribute billions of dollars to local, national and global economies (Kettunen et al. 2011).

To be effective, however, protected areas need to be located in the right places, well governed and managed, and adequately planned and resourced (Lockwood et al. 2006). This has long been recognised in a number of international multilateral environmental agreements such as the CBD, Ramsar Convention and World Heritage Convention. In 2010, the 193 parties to the CBD adopted the Strategic Plan for Biodiversity 20112020, including 20 headline targets collectively known as the Aichi Biodiversity Targets (CBD 2010b). Target 11 deals specifically with protected areas and sets an ambitious agenda for the years ahead:

By 2020, at least 17 per cent of terrestrial and inland water areas, and 10 per cent of coastal and marine areas, especially areas of particular importance for biodiversity and ecosystem services, are conserved through effectively and equitably managed, ecologically representative and well connected systems of protected areas and other effective area-based conservation measures, and integrated into the wider landscapes and seascapes. (CBD 2010b:9)

\section{Global protected area coverage}

By mid 2014, protected areas, comprising all nationally and internationally designated protected areas of all IUCN management categories and governance types (including 'unknown') except for UNESCO biosphere reserves recorded in the World Database on Protected Areas (WDPA), covered 15.4 per cent of the global land area (outside Antarctica) and 3.4 per cent of the global ocean area (Figure 3.6; IUCN and UNEP-WCMC 2014). 


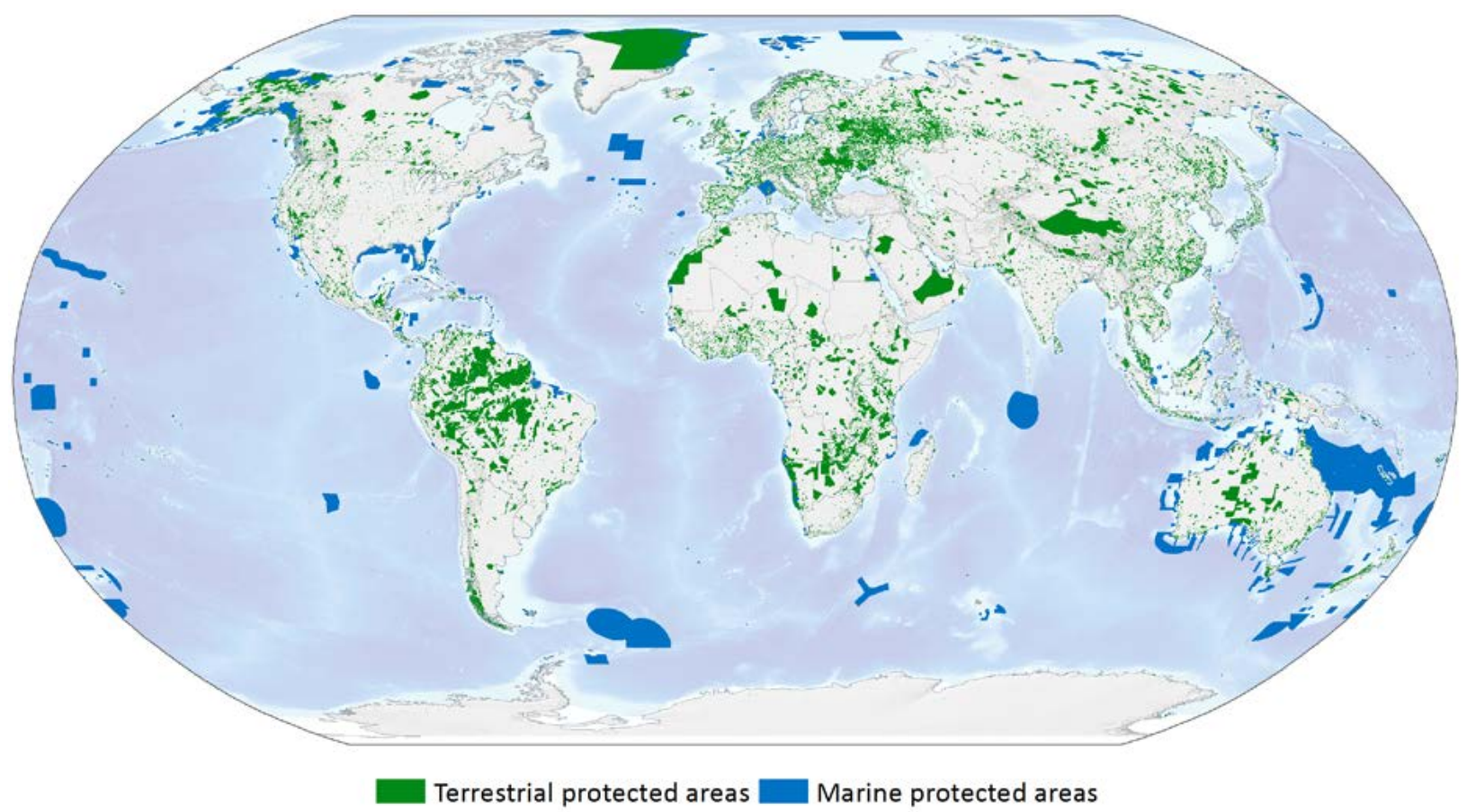

Figure 3.6 Protected areas of the world

Source: IUCN and UNEP-WCMC (2014)

Table 3.5 Protected area coverage of terrestrial realms

\begin{tabular}{|l|c|c|c|}
\hline Terrestrial realm & Total land area $\left.\mathbf{( k m}^{2}\right)$ & Protected area $\left.\mathbf{( k m}^{2}\right)$ & Protected area (\%) \\
\hline Afrotropic & 21630400 & 3558059 & 16.4 \\
\hline Australasia & 9268092 & 1375024 & 14.8 \\
\hline Indo-Malayan & 8543097 & 829286 & 9.7 \\
\hline Nearctic & 20472280 & 2534229 & 12.4 \\
\hline Neotropic & 19386026 & 4633935 & 23.9 \\
\hline Oceania & 49199 & 4552 & 9.3 \\
\hline Palearctic & 52859883 & 6918957 & 13.1 \\
\hline
\end{tabular}

Coverage was calculated based on all protected areas shown in Figure 3.6, eliminating spatial overlaps of different protected areas.

Sources: Olsen et al. (2001); IUCN and UNEP-WCMC (2014)

This included 8.4 per cent of the marine areas under national jurisdiction, here defined as extending from the shoreline to the outer limit of the exclusive economic zone (EEZ) at 200 nautical miles (370 kilometres), and 10.9 per cent if only near-coastal areas (0-12 nautical miles, or 0-22 kilometres, from land) are considered.

The global protected area network does not yet meet the requirement of ecological representativeness stipulated in Target 11, and several biogeographic realms, in particular the Oceanian and Indo-Malayan realms, are underrepresented (Table 3.5; IUCN and UNEPWCMC 2014). Greater coverage is also needed in a number of biomes, especially temperate grasslands, savannahs and shrublands, and tropical and subtropical dry broadleaf forests (Table 3.6). At present, 350 (43 per cent) of the world's 823 terrestrial ecoregions outside the Antarctic mainland meet the 17 per cent target (Figure 3.7; IUCN and UNEP-WCMC 2014), and 78 (34 per cent) of the 232 marine ecoregions meet the 10 per cent target (Figure 3.8; see also Spalding et al. 2013). 
Table 3.6 Protected area coverage of terrestrial biomes

\begin{tabular}{|c|c|c|c|}
\hline Terrestrial biome & Total land area $\left(\mathbf{k m}^{2}\right)$ & Protected area $\left(\mathbf{k m}^{2}\right)$ & Protected area (\%) \\
\hline $\begin{array}{l}\text { Tropical and subtropical moist } \\
\text { broadleaf forests }\end{array}$ & 19896257 & 4712331 & 23.7 \\
\hline $\begin{array}{l}\text { Tropical and subtropical dry } \\
\text { broadleaf forests }\end{array}$ & 3025997 & 290896 & 9.6 \\
\hline $\begin{array}{l}\text { Tropical and subtropical coniferous } \\
\text { forests }\end{array}$ & 712617 & 83513 & 11.7 \\
\hline $\begin{array}{l}\text { Temperate broadleaf and mixed } \\
\text { forests }\end{array}$ & 12835688 & 1540766 & 12.0 \\
\hline Temperate coniferous forests & 4087094 & 687694 & 16.8 \\
\hline Boreal forests/taiga & 15077946 & 1570569 & 10.4 \\
\hline $\begin{array}{l}\text { Tropical and subtropical } \\
\text { grasslands, savannahs and } \\
\text { shrublands }\end{array}$ & 20295446 & 2973704 & 14.7 \\
\hline $\begin{array}{l}\text { Temperate grasslands, savannahs } \\
\text { and shrublands }\end{array}$ & 10104108 & 456517 & 4.5 \\
\hline Flooded grasslands and savannahs & 1096130 & 339170 & 30.9 \\
\hline $\begin{array}{l}\text { Montane grasslands and } \\
\text { shrublands }\end{array}$ & 5203411 & 1393007 & 26.8 \\
\hline $\begin{array}{l}\text { Tundra (excluding four Antarctic } \\
\text { ecoregions) }\end{array}$ & 8313849 & 1812734 & 21.8 \\
\hline $\begin{array}{l}\text { Mediterranean forests, woodlands } \\
\text { and scrub }\end{array}$ & 3227268 & 512190 & 15.9 \\
\hline Deserts and xeric shrublands & 27984645 & 3382967 & 12.1 \\
\hline Mangroves & 348519 & 97983 & 28.1 \\
\hline
\end{tabular}

Coverage was calculated based on all protected areas shown in Figure 3.6, eliminating spatial overlaps of different protected areas. Sources: Olsen et al. (2001); IUCN and UNEP-WCMC (2014)

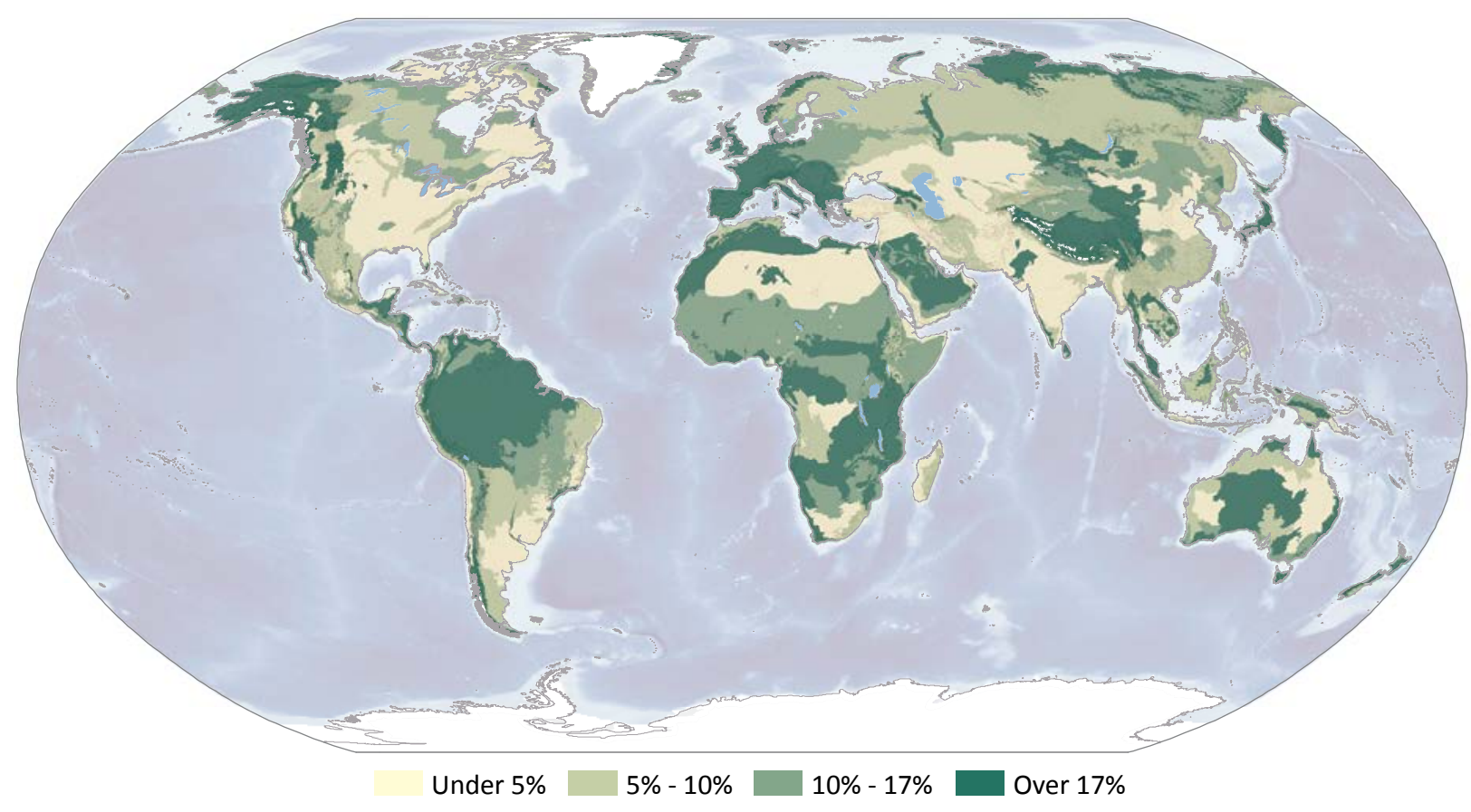

Figure 3.7 Percentage area of each terrestrial ecoregion covered by protected areas Sources: Olsen et al. (2001); IUCN and UNEP-WCMC (2014) 


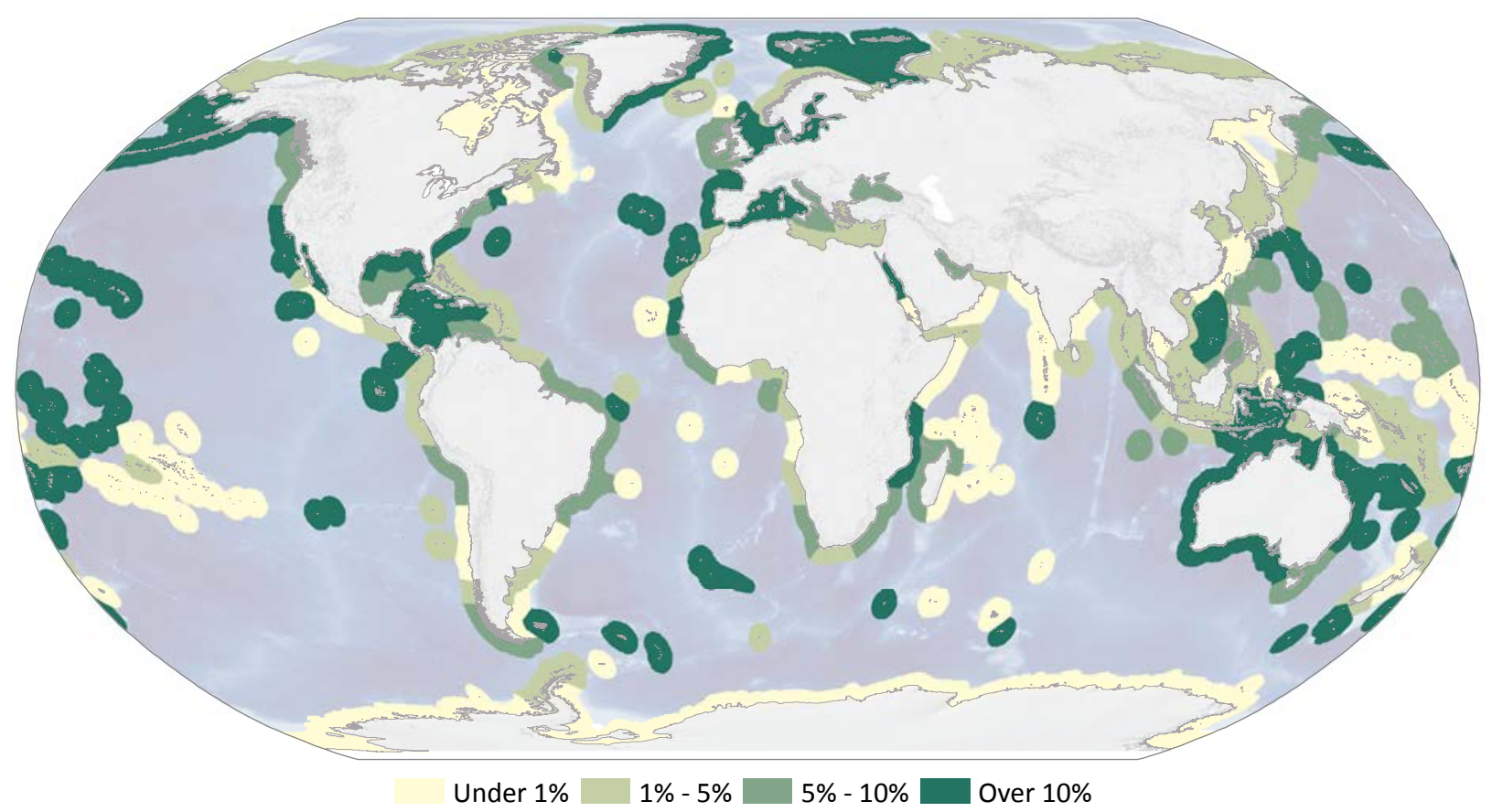

Figure 3.8 Percentage area of each marine ecoregion (out to $200 \mathrm{~m}$ depth) covered by protected areas Sources: Spalding et al. (2007); IUCN and UNEP-WCMC (2014)

Many studies have also shown that existing protected area networks, from national to global scales, do not yet provide adequate coverage of threatened species (for example, Rodrigues et al. 2004; Watson et al. 2011) and the key sites that support them (Butchart et al. 2012). It should also be noted, however, that a vast number of species is already entirely confined to protected areas and sometimes just a single protected area.

Coverage is just one of many indicators that can be used to evaluate the strengths and weaknesses of the existing protected area networks. Subsequent chapters in this book address protected area management effectiveness measures in detail, including good governance, competent management and the adequate planning and resourcing of different types of protected areas. Since resources for conservation will always be limited, conservation efforts need to be prioritised. This is the matter we discuss next.

\section{Global biodiversity conservation priorities}

Prioritising conservation action is necessary because the resources available for conservation are limited, and biodiversity and the threats to it are not evenly distributed (Brooks et al. 2006, 2010). In short, prioritisation helps to decide where, when and how to act, with effective protected areas one of the key tools in our toolbox of conservation actions.
Several major templates for the identification of global priority areas for biodiversity conservation have been developed to guide the allocation of resources and actions (Brooks et al. 2006, 2010). All these approaches, however, have their strengths and weaknesses-for example, with regard to their taxonomic or geographic coverage, criteria and thresholds used and practical value for designing effective and efficient protected area networks.

All the templates apply one or more of the following concepts to prioritise specific sites, (eco)regions or clusters of ecoregions for conservation (Margules and Pressey 2000; Brooks et al. 2006, 2010; Schmitt 2011):

$$
\begin{array}{ll}
\text { - } & \text { irreplaceability } \\
\text { - } & \text { vulnerability } \\
\text { representativeness. }
\end{array}
$$

Irreplaceability is about the spatial conservation options available - that is, the importance of an area for the conservation of specific biodiversity features such as species or ecosystems. Irreplaceability has often been measured based on the number of endemic species present in an area but other measures exist (Brooks et al. 2006). In contrast, vulnerability is an indicator of the temporal conservation options available, or the urgency for conservation action. This can be assessed, for example, based on the occurrence of threatened species, past or present habitat loss, land tenure and human population pressure (Brooks et al. 2006). Representativeness refers to the need to represent, or sample, the full variety 
of biodiversity features, including both patterns and processes, within a network of priority areas or protected areas (Margules and Pressey 2000).

Most of the major templates prioritise high irreplaceability, but some prioritise high vulnerability and others prioritise low vulnerability (Brooks et al. 2006). Representativeness was an important consideration, for example, in the identification of Global 200 priority ecoregions (Olson et al. 2000; Olson and Dinerstein 2002; Schmitt 2011).

An overview of six selected biodiversity conservation priority templates is provided in Table 3.7. With the exception of the Global 200 priority ecoregions, which explicitly include 43 marine priority ecoregions, most of the well-known templates cover only terrestrial and freshwater environments. In recent years, however, an increasing number of studies has also identified global priority areas in the marine environment (Tittensor et al. 2010; Selig et al. 2014), and some existing templates are also being expanded to include more and more marine sites (BirdLife International 2010).

A summary of broadscale approaches can be found in Brooks et al. $(2006,2010)$, while site-based approaches collectively known as key biodiversity areas (KBAs) are summarised in Langhammer et al. (2007). In the next subsections, we describe biodiversity hotspots and highbiodiversity wilderness areas as examples of broadscale approaches, and AZE sites as an example of site-based approaches. We close this section with information on the wider KBA standard that includes AZE sites.

Table 3.7 Selected methods for biodiversity conservation prioritisation

\begin{tabular}{|c|c|c|c|c|c|c|}
\hline Template & Definition & Scale & $\begin{array}{l}\text { Number } \\
\text { of areas } \\
\text { or sites }\end{array}$ & $\begin{array}{l}\text { Total land } \\
\text { area (million } \\
\mathbf{k m}^{2} \text { ) }\end{array}$ & $\begin{array}{l}\text { Percentage } \\
\text { of global land } \\
\text { area (\%) }\end{array}$ & References \\
\hline $\begin{array}{l}\text { Biodiversity } \\
\text { hotspots }\end{array}$ & $\begin{array}{l}\text { Biogeographically similar } \\
\text { aggregations of ecoregions holding } \\
\geq 0.5 \% \text { of the world's plants as } \\
\text { endemics, and with } \geq 70 \% \text { of primary } \\
\text { habitat already lost }\end{array}$ & $\begin{array}{l}\text { Ecoregion } \\
\text { clusters }\end{array}$ & 35 & 23.6 & $15.9 \%$ & $\begin{array}{l}\text { Myers et } \\
\text { al. (2000); } \\
\text { Mittermeier } \\
\text { et al. (2004); } \\
\text { Williams et al. } \\
\text { (2011) }\end{array}$ \\
\hline $\begin{array}{l}\text { High- } \\
\text { biodiversity } \\
\text { wilderness } \\
\text { areas }\end{array}$ & $\begin{array}{l}\text { Biogeographically similar aggregations } \\
\text { of ecoregions holding } \geq 0.5 \% \text { of the } \\
\text { world's plants as endemics, and with } \\
\geq 70 \% \text { of primary habitat remaining } \\
\text { and } \leq 5 \text { people per } \mathrm{km}^{2}\end{array}$ & $\begin{array}{l}\text { Ecoregion } \\
\text { clusters }\end{array}$ & 5 & 11.8 & $7.9 \%$ & $\begin{array}{l}\text { Mittermeier } \\
\text { et al. (2002, } \\
\text { 2003) }\end{array}$ \\
\hline $\begin{array}{l}\text { Global } 200 \\
\text { priority } \\
\text { ecoregions }\end{array}$ & $\begin{array}{l}\text { Aggregations of ecoregions within } \\
\text { biomes characterised by high species } \\
\text { richness, endemism, taxonomic } \\
\text { uniqueness, unusual phenomena or } \\
\text { global rarity of major ecosystem type }\end{array}$ & $\begin{array}{l}\text { Ecoregion } \\
\text { clusters }\end{array}$ & $\begin{array}{l}142 \\
\text { terrestrial } \\
\text { (plus } 53 \\
\text { freshwater } \\
\text { and } 43 \\
\text { marine) } \\
\end{array}$ & 55.1 & $37.0 \%$ & $\begin{array}{l}\text { Olson et } \\
\text { al. (2000); } \\
\text { Olson and } \\
\text { Dinerstein } \\
\text { (2002) }\end{array}$ \\
\hline $\begin{array}{l}\text { Endemic } \\
\text { bird areas }\end{array}$ & $\begin{array}{l}\text { Sole area where } \geq 2 \text { bird species with } \\
\text { global breeding ranges of }<50000 \\
\mathrm{~km}^{2} \text { occur }\end{array}$ & $\begin{array}{l}\text { Region or } \\
\text { site }\end{array}$ & 218 & 14.2 & $9.5 \%$ & $\begin{array}{l}\text { Stattersfield } \\
\text { et al. (1998) }\end{array}$ \\
\hline $\begin{array}{l}\text { Alliance } \\
\text { for Zero } \\
\text { Extinction } \\
\text { sites }\end{array}$ & $\begin{array}{l}\text { Site is sole area where an } \\
\text { endangered (EN) or critically } \\
\text { endangered (CR) species occurs } \\
\text { (or contains }>95 \% \text { of the EN or CR } \\
\text { species' global population for at least } \\
\text { one life history segment) }\end{array}$ & Site & 588 & 0.6 & $0.4 \%$ & $\begin{array}{l}\text { Ricketts et al. } \\
\text { (2005); AZE } \\
\text { (2012) }\end{array}$ \\
\hline $\begin{array}{l}\text { Important } \\
\text { bird areas }\end{array}$ & $\begin{array}{l}\text { Sites hold significant numbers of } \\
\text { one or more globally threatened } \\
\text { bird species; site is one of a set } \\
\text { of sites that together hold a suite } \\
\text { of restricted-range bird species or } \\
\text { biome-restricted bird species; and/ } \\
\text { or has exceptionally large numbers } \\
\text { of migratory or congregative bird } \\
\text { species }\end{array}$ & Site & 10,993 & 8.8 & $5.9 \%$ & $\begin{array}{l}\text { Evans (1994); } \\
\text { BirdLife } \\
\text { International } \\
\text { et al. (2012) }\end{array}$ \\
\hline
\end{tabular}

Sources: Brooks et al. (2006, 2010); Schmitt (2011); Bertzky et al. (2013) 


\section{Biodiversity hotspots and high- biodiversity wilderness areas}

Both biodiversity hotspots and high-biodiversity wilderness areas (HBWAs) support exceptional concentrations of endemic species (Table 3.7). Each of these broadscale priority areas is home to at least 1500 endemic species of vascular plants - that is, more than 0.5 per cent of the world's estimated 300000 vascular plant species (Myers et al. 2000; Mittermeier et al. 2002, 2004). While hotspots and HBWAs are comparable in terms of their overall irreplaceability, they differ in their vulnerability: hotspots have already lost more than 70 per cent of their primary vegetation while HBWAs retain more than 70 per cent of their primary vegetation and are sparsely populated (less than five people per square kilometre).

To date, 35 hotspots and five HBWAs have been identified around the world (Figure 3.9). Together, the hotspots and HBWAs have been estimated to support more than 50 per cent of the world's vascular plant species and terrestrial vertebrate species (mammals, birds, reptiles and amphibians), plus countless other species including invertebrates and fungi (Stork and Habel 2013), on 23.8 per cent of the global land area. Although these areas are clearly critical for the survival of the diversity of life on Earth, it should be noted that they do not encompass all known global priority areas even for vertebrates (Jenkins et al. 2013), let alone other taxonomic groups.

\section{Alliance for Zero Extinction sites}

AZE sites, on the other hand, are an example of sitescale priority areas. In short, these sites are of exceptional irreplaceability and vulnerability as they represent 'centres of imminent extinction, where highly threatened species are confined to single sites' (Ricketts et al. 2005:18497). The 588 AZE sites identified to date (Figure 3.10; Table 3.7) cover only 0.4 per cent of the global land area but are critical to the survival of 919 critically endangered or endangered vertebrate and conifer species (Butchart et al. 2012). More such sites are likely to exist for other taxa but have not yet been formally identified as AZE sites.

Protection of AZE sites remains inadequate although it has been shown that species occurring in AZE sites with greater protected area coverage tend to be better off. Butchart et al. (2012) showed that the increase in extinction risk over the past two decades was one-third lower for mammals, birds and amphibians restricted to AZE sites completely covered by protected areas compared with those restricted to unprotected sites or sites that are only partially protected. They also found, however, that only 22 per cent of the 588 known AZE sites were completely covered by protected areas, while 51 per cent remained entirely unprotected by 2008 (Figure 3.10). Green points in Figure 3.10 indicate sites that are completely covered by protected areas, yellow points partially covered sites, and red points unprotected sites.

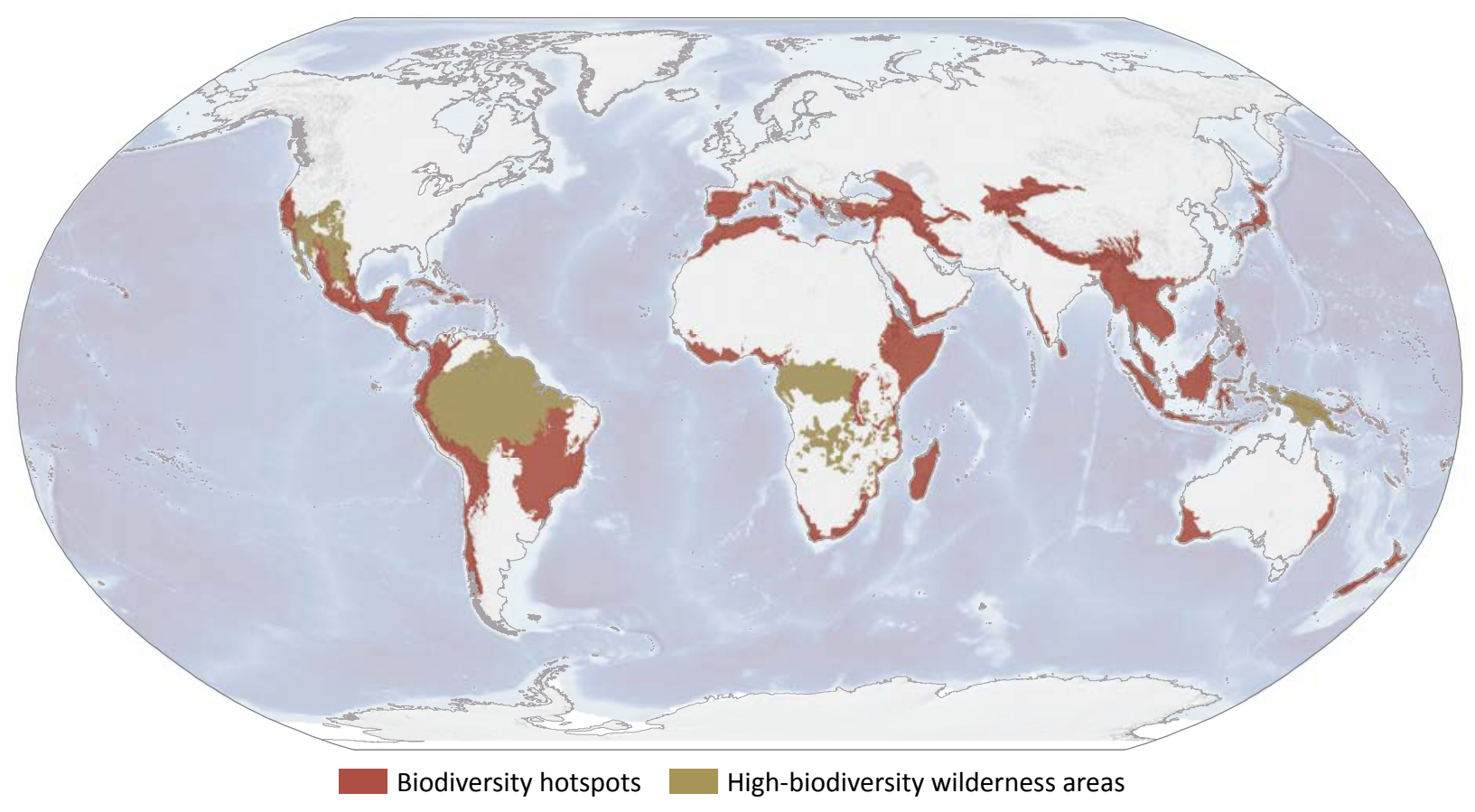

Figure 3.9 Biodiversity hotspots and high-biodiversity wilderness areas of the world

Sources: Modified from Mittermeier et al. (2002, 2004); Williams et al. (2011) 


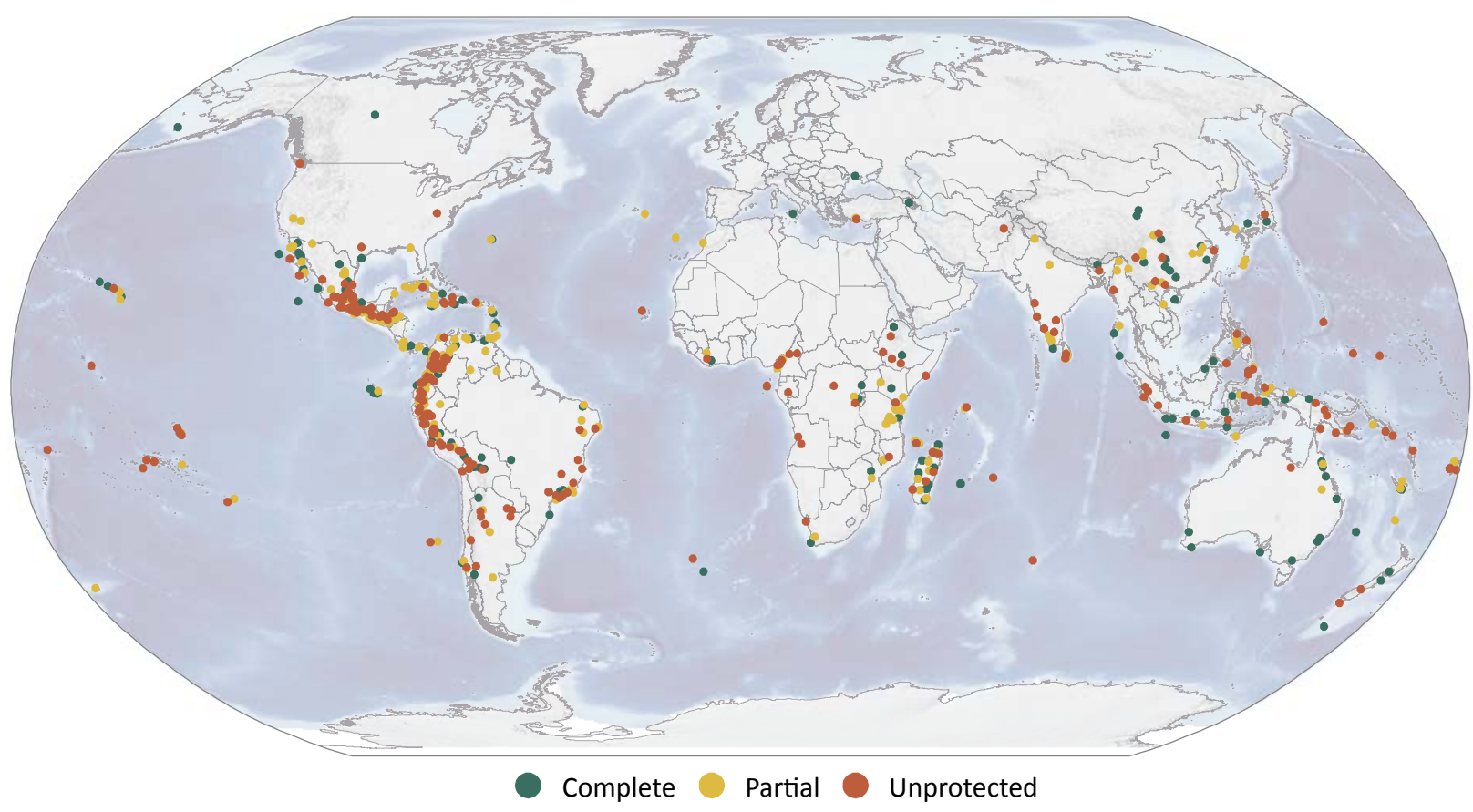

Figure 3.10 Protection status of Alliance for Zero Extinction sites

Source: Modified from Butchart et al. (in prep.)

\section{Key biodiversity areas}

AZE sites are the highest priority subset of KBAs - that is, sites that contribute significantly to the global persistence of biodiversity according to globally standardised criteria (Langhammer et al. 2007). Other well-known subsets of KBAs include important bird areas (IBAs) (Table 3.7) and important plant areas (IPAs), both representing priority areas identified within specific taxonomic groups. The KBA approach can also be applied in marine and freshwater environments (BirdLife International 2010; Holland et al. 2012) and, through the CBD, the complementary concept of ecologically or biologically significant marine areas (EBSAs) has been advanced in recent years.

The KBA inventories have informed the selection of sites for protection under national and international legislation, are considered in international sustainability performance standards, and are included under multilateral environmental agreements' (IUCN 2012:2). One example of the latter is the use of AZE sites and IBAs to achieve and measure progress towards the Aichi Biodiversity Targets of the CBD_for example, as priority sites for reducing species and habitat loss through the targeted establishment and management of protected areas.

The IUCN is currently leading a global consultation process to consolidate the different existing KBA criteria and thresholds into a new KBA standard. The new standard is proposed to be launched in 2015, and is expected to find wide application in conservation planning and decision-making:

The final goal of this process is to provide an objective, scientifically rigorous methodology that is easy to apply, to identify KBAs across terrestrial, freshwater, and marine biomes. This new IUCN standard will guide decisionmakers on areas that require safeguarding and will help a range of end users to define their conservation priorities, achieve their international commitments, and comply with their environmental policies. (IUCN 2012:2)

\section{Systematic conservation planning}

Knowledge about KBAs and other priority areas can also inform the important process of systematic conservation planning. This process can help to design effective and efficient protected areas and protected area networks that meet the overall goals of representativeness and persistence of biodiversity in the most cost-effective way (Margules and Pressey 2000). To achieve this, systematic conservation planning uses the best available data on biodiversity patterns and processes, including their irreplaceability and vulnerability, existing protected areas, the cost of establishing and managing new protected areas, and the opportunity costs of competing land 
uses. In the words of Margules and Pressey (2000:243), the power of systematic conservation planning comes from its 'efficiency in using limited resources to achieve conservation goals, its defensibility and flexibility in the face of competing land uses, and its accountability in allowing decisions to be critically reviewed'. More information on systematic conservation planning can be found in Chapter 13.

\section{Introducing ecosystem management}

We have briefly introduced Earth's abiotic and biotic natural heritage in this chapter. Protected area managers are at the frontline of managing for the protection and conservation of major ecosystems that help support life on Earth. Once the important biodiversity areas identified have been formally protected, they need to be effectively managed.

This management may include responses to threats such as habitat destruction and fragmentation, overexploitation, invasive alien species, disease, disturbance, pollution and climate change (Sinclair et al. 2006) (see Chapter 16).

Protected area problems are, however, generally more complex than single issues. This complexity needs to be understood by managers and it is part of managing in a dynamic world (see Chapter 10). The root causes of threats to biodiversity need to be assessed and responded to strategically rather than in a reactive manner that may just deal with the symptoms of threats (see Chapter 16). One complex challenge is climate change. It is a major threat for all species (see Chapter 17), and strategic guidance has been provided for protected area management in the form of the following six guiding principles:

1. Maintain well-functioning ecosystems: 'Maintaining or enhancing the resilience of ecosystems is crucial to ensure the adequate functioning; but when, under climate change, does it become counter-productive and facilitation of new ecosystems become more important?' (Steffen et al. 2009:150). As climate change transformation becomes more common later this century, monitoring the functioning of these new ecosystems and their ability to deliver the services on which society depends will be critical (see Chapters 11 and 21).

2. Protect a representative array of ecological systems: 'All environments should be represented in regional reserve systems, and a diversity of landscape architectures in terms of the arrangements of patches and connecting habitats should be represented in regional on and off-reserve landscapes' (Steffen et al. 2009:150) (see Chapters 13 and 27).

3. Remove or minimise existing stressors: '[W]ith particular attention to those that may benefit from climate change' (Steffen et al. 2009:150) (see Chapter 16).

4. Manage appropriate connectivity of species, landscapes, seascapes and ecosystem processes: 'This principle implies the need to reverse the trend towards simplicity and efficiency (loss of diversity) in landscapes and in the coastal zone and to build landscapes and ecosystems with more complexity, redundancy and resilience' (Steffen et al. 2009:151) (see Chapter 27).

5. Eco-engineering may be needed to assist the transformation of some communities under climate change: " $[T]$ here will be cases where a passive "let nature adapt" approach can and should be augmented by more proactive measures to conserve biodiversity' (Steffen et al. 2009:151).

6. Genetic preservation must be considered in some cases: 'As a last resort approach, some species may need to be preserved outside of an ecosystem context, whether it is an existing or transformed natural ecosystem or a human engineered ecosystem' (Steffen et al. 2009:151) (see Chapter 17).

\section{Conclusion}

In this chapter, we have provided a global overview of critical matters for protected area managers from a natural heritage management perspective. We have emphasised that the Earth is a marvel of nature, but finite in size. The lithosphere that we occupy, the atmosphere we breathe and the biosphere and life forms we share Earth with are all finite. We have identified that the Earth is also a dynamic place, with geological processes constantly changing the nature of our planet's geodiversity, and how early life on Earth has helped to create the atmospheric conditions suitable for the organisms present today. We described how this, in turn, through evolutionary responses has culminated in a rich and biodiverse natural world. We introduced this diversity and described the major ecosystem types on Earth.

We also introduced how Earth's life-support systems have been affected by human activity and subsequent climate change. We have reflected on what this means for protected area managers in the 21 st century and 
what the challenges are for working in a dynamic natural world that has been impacted by humans. We have, in effect, introduced the nature, scope, complexity and enormity of the challenge for protected area managers, worldwide, in helping to conserve life on Earth and its other natural treasures. We have also provided the basis for other chapters of this book that examine in more detail particular aspects of the profession of protected area management.

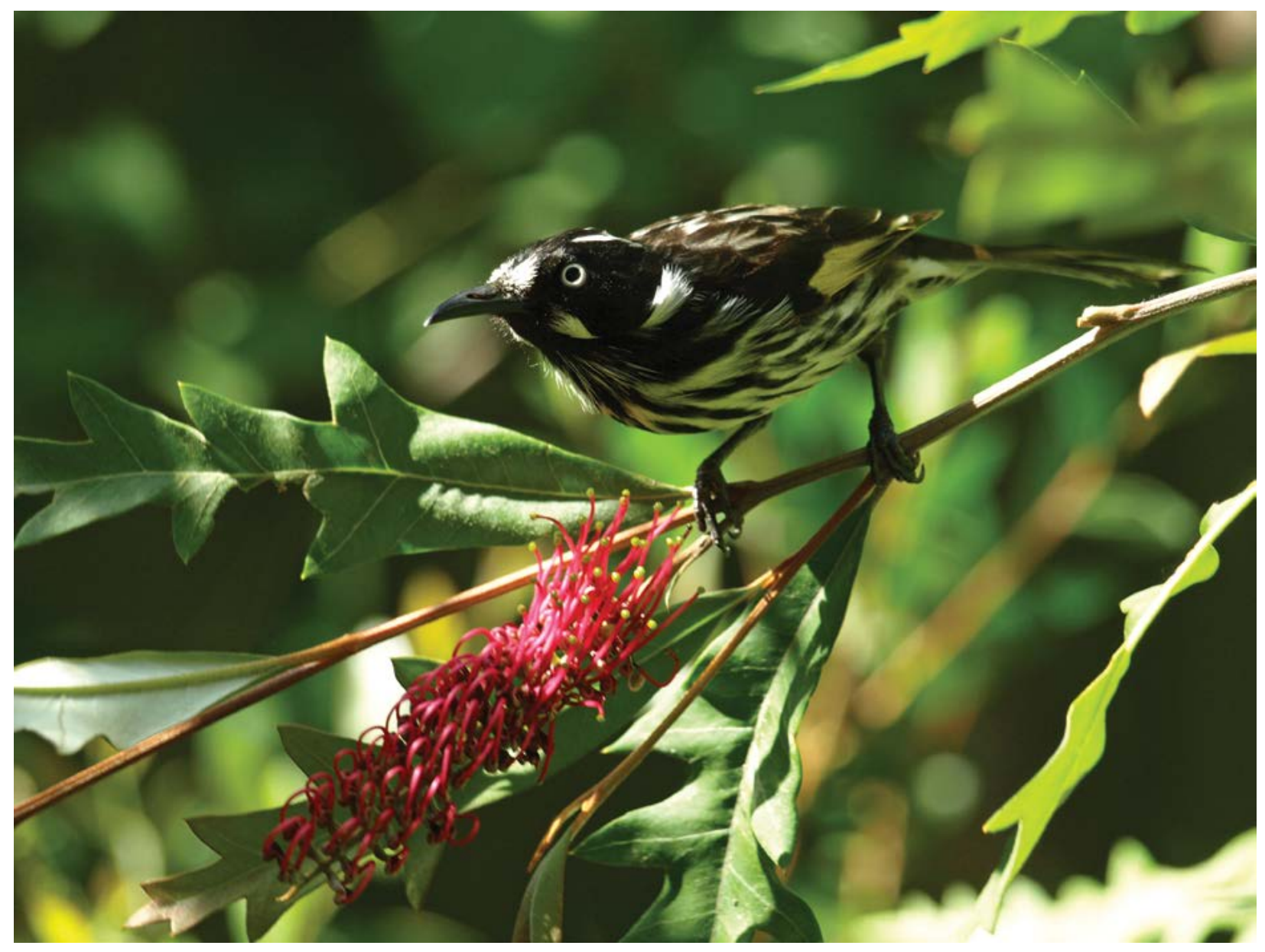

The New Holland honeyeater (Phylidonyris novaehollandiae) is a frequent, welcome and busy visitor to many southern Australian homes and gardens. It is one of Australia's 898 recorded bird species and is a native to habitats that include forests and woodlands, creek sides, and coastal scrubs and heathlands. It is shown here with one of its favoured nectar sources, the flower of a native Grevillea sp., a relic Gondwanan Proteaceae species (Gondwana is the ancient super continent that included Antarctica, Australia, Africa, India and South America). Some Australian birds illustrate convergent evolution to species elsewhere, with honeyeaters resembling northern hemisphere sunbirds.

Source: Graeme L. Worboys 


\section{References}

Recommended reading

Abell, R., Thieme, M. L., Revenga, C., Bryer, M., Kottelat, M., Bogutskaya, N., Coad, B., Mandrak, N., Balderas, S. C., Bussing, W., Stiassny, M. L. J., Skelton, P., Allen, G. R., Unmack, P., Naseka, A., Ng, R., Sindorf, N., Robertson, J., Armijo, E., Higgins, J. V., Heibel, T. J., Wikramanayake, E., Olson, D., López, H. L., Reis, R. E., Lundberg, J. G., Pérez, M. H. S. and Petry, P. (2008) 'Freshwater ecoregions of the world: a new map of biogeographic units for freshwater biodiversity conservation', BioScience 58: 403-14.

Alliance for Zero Extinction (AZE) (2012) $2010 \mathrm{AZE}$ Update: March 2012, Alliance for Zero Extinction, Washington, DC. <www.zeroextinction.org>

Barnosky, A. D., Hadly, E. A., Bascompte, J., Berlow, E. L., Brown, J. H., Fortelius, M., Getz, W. M., Harte, J., Hastings, A., Marquet, P. A., Martinez, N. D., Mooers, A., Roopnarine, P., Vermeij, G., Williams, J. W., Gillespie, R., Kitzes, J., Marshall, C., Matzke, N., Mindell, D. P., Revilla, E. and Smith, A. B. (2012) 'Approaching a state shift in Earth's biosphere', Nature 486: 52-8.

Barnosky, A. D., Matzke, N., Tomiya, S., Wogan, G. O. U., Swartz, B., Quental, T. B., Marshall, C., McGuire, J. L., Lindsey, E. L., Maguire, K. C., Mersey, B. and Ferrer, E. A. (2011) 'Has the Earth's sixth mass extinction already arrived?', Nature 471: 51-7.

Beerling, D. (2007) The Emerald Planet, Oxford University Press, Oxford.

Bertzky, B., Corrigan, C., Kemsey, J., Kenney, S., Ravilious, C., Besançon, C. and Burgess, N. D. (2012) Protected Planet Report 2012: Tracking progress towards global targets for protected areas, IUCN, Gland, and UNEP-WCMC, Cambridge.

Bertzky, B., Shi, Y., Hughes, A., Engels, B., Ali, M. K. and Badman, T. (2013) Terrestrial Biodiversity and the World Heritage List: Identifying broad gaps and potential candidate sites for inclusion in the natural World Heritage network, IUCN, Gland, and UNEPWCMC, Cambridge.
Biello, D. (2009) 'The origin of oxygen in Earth's atmosphere', Scientific American, 19 August. $<$ www.scientificamerican.com/article/origin-ofoxygen-in-atmosphere/>

BirdLife International (2010) Marine Important Bird Areas: Priority sites for the conservation of biodiversity, BirdLife International, Cambridge.

BirdLife International, Conservation International and Partners (2012) Global Key Biodiversity Areas Dataset: March 2012, BirdLife International, Cambridge. <www.birdlife.org/datazone/site>

Brooks, T. M., Bakarr, M. I., Boucher, T., da Fonseca, G. A. B., Hilton-Taylor, C., Hoekstra, J. M., Moritz, T., Olivier, S., Parrish, J., Pressey, R. L., Rodrigues, A. S. L., Sechrest, W., Stattersfield, A., Strahm, W. and Stuart, S. N. (2004) 'Coverage provided by the global protected-area system: is it enough?', BioScience 54: 1081-91.

Brooks, T. M., Mittermeier, R. A., da Fonseca, G. A. B., Gerlach, J., Hoffmann, M., Lamoreux, J. F., Mittermeier, C. G., Pilgrim, J. D. and Rodrigues, A. S. L. (2006) 'Global biodiversity conservation priorities', Science 313: 58-61.

Brooks, T. M., Mittermeier, R. A., da Fonseca, G. A. B., Gerlach, J., Hoffmann, M., Lamoreux, J. F., Mittermeier, C. G., Pilgrim, J. D. and Rodrigues, A. S. L. (2010) 'Global biodiversity conservation priorities: an expanded review', in J. C. Lovett and D. G. Ockwell (eds) A Handbook of Environmental Management, pp. 8-29, Edward Elgar, Cheltenham, UK.

Butchart, S. H. M., Scharlemann, J. P. W., Evans, M. I., Quader, S., Arico, S., Arinaitwe, J., Balman, M., Bennun, L. A., Bertzky, B., Besançon, C., Boucher, T. M., Brooks, T. M., Burfield, I. J., Burgess, N. D., Chan, S., Clay, R. P., Crosby, M. J., Davidson, N. C., de Silva, N., Devenish, C., Dutson, G. C. L., Fernandez, D., Fishpool, L. D. C., Fitzgerald, C., Foster, M., Heath, M. F., Hockings, M., Hoffmann, M., Knox, D., Larsen, F. W., Lamoreux, J. F., Loucks, C., May, I., Millett, J., Molloy, D., Morling, P., Parr, M., Ricketts, T. H., Seddon, N., Skolnik, B. and Stuart, S. (2012) 'Protecting important sites for biodiversity contributes to meeting global conservation targets', PLoS ONE 7(3): e32529. 
Butchart, S. H. M., Stattersfield, A. J. and Collar, N. J. (2006) 'How many bird extinctions have we prevented?', Oryx 40(3): 266-78.

Chape, S., Harrison, J., Spalding, M. and Lysenko, I. (2005) 'Measuring the extent and effectiveness of protected areas as an indicator for meeting global biodiversity targets', Philosophical Transactions of the Royal Society B 360: 443-55.

Chapin, F. S. III, Zavaleta, E. S., Eviner, V. T., Naylor, R. L., Vitousek, P. M., Reynolds, H. L., Hooper, D. U., Lavorel, S., Sala, O. E., Hobbie, S. E., Mack, M. C. and Diaz, S. (2000) 'Consequences of changing biodiversity', Nature 405: 234-42.

Chapman, A. D. (2009) Number of Living Species in Australia and the World, 2nd edn, Australian Biological Resources Study, Canberra.

Constant, P. (2004) Galapagos: A natural history guide, 6th edn, Odyssey, Hong Kong.

Convention on Biological Diversity (CBD) (1992) Convention on Biological Diversity, Secretariat of the Convention on Biological Diversity, Montreal.

Dd Convention on Biological Diversity (CBD) (2010a) Global Biodiversity Outlook 3, Secretariat of the Convention on Biological Diversity, Montreal.

Convention on Biological Diversity (CBD) (2010b) Decision X/2 of the Conference of the Parties to the Convention on Biological Diversity, Secretariat of the Convention on Biological Diversity, Montreal.

Dudley, N., Stolton, S., Belokurov, A., Krueger, L., Lopoukhine, N., MacKinnon, K., Sandwith, T. and Sekran, N. (eds) (2010) Natural Solutions: Protected areas helping people cope with climate change, IUCN WCPA and WWF, Gland, The Nature Conservancy, Arlington, UNDP and Wildlife Conservation Society, New York, and The World Bank, Washington, DC.

Dullinger, S., Essl, F., Rabitsch, W., Erb, K. H., Gingrich, S., Haberl, H., Hülber, K., Jarošik, V., Krausmann, F., Kühn, I., Pergl, J., Pyšek, P. and Hulme, P. E. (2013) 'Europe's other debt crisis caused by the long legacy of future extinctions', Proceedings of the National Academy of Sciences 110: 7342-7.
Duncan, R. P., Boyer, A. G. and Blackburn, T. M. (2013) 'Magnitude and variation of prehistoric bird extinctions in the Pacific', Proceedings of the National Academy of Sciences 110: 6436-41.

Ellis, E. C. and Ramankutty, N. (2008) 'Putting people in the map: anthropogenic biomes of the world', Frontiers in Ecology and the Environment 6: 439-47.

Ellis, E. C., Goldewijk, K. K., Siebert, S., Lightman, D. and Ramankutty, N. (2010) 'Anthropogenic transformation of the biomes, 1700 to 2000', Global Ecology and Biogeography 19: 589-606.

Evans, M. I. (1994) Important Bird Areas in the Middle East, BirdLife International, Cambridge.

Gaston, K. J. (2000) 'Global patterns in biodiversity', Nature 405: 220-7.

DD Gray, M. (2004) Geodiversity: Valuing and conserving abiotic nature, Wiley \& Sons, Chichester, UK.

Droombridge, B. and Jenkins, M. D. (2002) World Atlas of Biodiversity: Earth's living resources in the 21st century, University of California Press, Berkeley, and UNEP-WCMC, Cambridge.

Haberl, H., Erb, K. H., Krausmann, F., Gaube, V., Bondeau, A., Plutzar, C., Gingrich, S., Lucht, W. and Fischer-Kowalski, M. (2007) 'Quantifying and mapping the human appropriation of net primary production in earth's terrestrial ecosystems', Proceedings of the National Academy of Sciences 104: 12 942-7.

Hamilton, L. S. (2002) 'Why mountains matter', IUCN World Conservation Bulletin 1: 4-5.

Dd Hamilton, L. S. and McMillan, L. (2004) Guidelines for Planning and Managing Mountain Protected Areas, IUCN, Gland.

Dd Hoekstra, J., Molnar, J. L., Jennings, M., Revenga, C., Spalding, M. D., Boucher, T. M., Robertson, J. C., Heibel, T. J. and Ellison, K. (2010) The Atlas of Global Conservation: Changes, challenges, and opportunities to make a difference, University of California Press, Berkeley.

Holland, R. A., Darwall, W. R. T. and Smith, K. G. (2012) 'Conservation priorities for freshwater biodiversity: the key biodiversity area approach refined and tested for continental Africa', Biological Conservation 148: 167-79. 
Holt, B. G., Lessard, J. P., Borregaard, M. K., Fritz, S. A., Araújo, M. B., Dimitrov, D., Fabre, P. H., Graham, C. H., Graves, G. R., Jønsson, K. A., Nogués-Bravo, D., Wang, Z., Whittaker, R. J., Fjeldså, J. and Rahbek, C. (2013) 'An update of Wallace's zoogeographic regions of the world', Science 339: 74-8.

Intergovernmental Panel on Climate Change (IPCC) (2013) Climate Change 2013: The physical science basis_-Headline statements for policy makers, Intergovernmental Panel on Climate Change, Geneva. <www.ipcc.ch/>

International Union for Conservation of Nature (IUCN) (2012) Consolidating the Criteria for Identifying Sites of Significance for Biodiversity: A global consultation process_-Progress update, IUCN, Gland.

International Union for Conservation of Nature (IUCN) (2013a) Natural World Heritage Facts and Figures 2013, IUCN, Gland. <www.iucn.org/about/ work/programmes/wcpa_worldheritage/about/ wcpa_whfacts/>

International Union for Conservation of Nature (IUCN) (2013b) The IUCN Red List of Threatened Species: Version 2013.2, IUCN, Gland. <www. iucnredlist.org>

International Union for Conservation of Nature (IUCN) and United Nations Environment Programme World Conservation Monitoring Centre (UNEP-WCMC) (2014) Global Statistics from The World Database on Protected Areas (WDPA): August 2014, UNEP-WCMC, Cambridge.

Jenkins, C. N. and Joppa, L. (2009) 'Expansion of the global terrestrial protected area system', Biological Conservation 142: 2166-74.

Jenkins, C. N., Pimm, S. L. and Joppa, L. (2013) 'Global patterns of terrestrial vertebrate diversity and conservation', Proceedings of the National Academy of Sciences 110: 2602-10.

Kettunen, M., Dudley, N., Bruner, A., Pabon, L., Conner, N., Berghöfer, A., Vakrou, A., Mulongoy, K. J., Ervin, J. and Gidda, S. B. (2011) 'Recognising the value of protected areas', in P. ten Brink (ed.) The Economics of Ecosystems and Biodiversity in National and International Policy Making, pp. 345400, Earthscan, London.
Kohler, T. and Maselli, D. (eds) (2009) Mountains and Climate Change: From understanding to action, Geographica Bernensia, Bern.

Kreft, H. and Jetz, W. (2010) 'A framework for delineating biogeographical regions based on species distributions', Journal of Biogeography 37: 2029-53.

Dd Ladle, R. J. and Whittaker, R. J. (eds) (2011) Conservation Biogeography, Wiley-Blackwell, Oxford.

Langhammer, P. F., Bakarr, M. I., Bennun, L. A., Brooks, T. M., Clay, R. P., Darwall, W., de Silva, N., Edgar, G. J., Eken, G., Fishpool, L. D. C., da Fonseca, G. A. B., Foster, M. N., Knox, D. H., Matiku, P., Radford, E. A., Rodrigues, A. S. L., Salaman, P., Sechrest, W. and Tordoff, A. W. (2007) Identification and Gap Analysis of Key Biodiversity Areas: Targets for comprehensive protected area systems, IUCN, Gland.

Leakey, R. and Lewin, R. (1992) The Sixth Extinction: Patterns of life and the future of humankind, Doubleday, New York.

Le Saout, S., Hoffmann, M., Shi, Y., Hughes, A., Bernard, C., Brooks, T. M., Bertzky, B., Butchart, S. H. M., Stuart, S. N., Badman, T. and Rodrigues, A. S. L. (2013) 'Protected areas and effective biodiversity conservation', Science 342: 803-5.

Linniger, H., Weingartner, R. and Grossjean, M. (1998) Mountains of the World: Water towers for the 21st century, Mountain Agenda, University of Bern, Bern.

Lockwood, M., Worboys, G. L. and Kothari, A. (2006) Managing Protected Areas: A global guide, Earthscan, London.

Mace, G. M., Collar, N. J., Gaston, K. J., HiltonTaylor, C., Akçakaya, H. R., Leader-Williams, N., Milner-Gulland, E. J. and Stuart, S. M. (2008) 'Quantification of extinction risk: IUCN's system for classifying threatened species', Conservation Biology 22: 1424-42.

Margules, C. R. and Pressey, R. L. (2000) 'Systematic conservation planning’, Nature 405: 243-53.

McNamara, K. (2009) Prehistoric Life: The definitive visual history of life on Earth, Permian, Dorling Kindersley, London. 
Millennium Ecosystem Assessment (MEA) (2005) Ecosystems and Human Well-Being. Volume 1: Current State and Trends, Findings of the Condition and Trends Working Group, Island Press, Washington, DC.

Mittermeier, R. A., Gil, P. R., Hoffman, M., Pilgrim, J., Brooks, T., Mittermeier, C. G., Lamoreux, J. and da Fonseca, G. A. B. (2004) Hotspots Revisited: Earth's biologically richest and most endangered terrestrial ecoregions, CEMEX, Mexico City.

Mittermeier, R. A., Mittermeier, C. G., Brooks, T. M., Pilgrim, J. D., Konstant, W. R., da Fonseca, G. A. B. and Kormos, C. (2003) 'Wilderness and biodiversity conservation', Proceedings of the National Academy of Sciences 100: 10 309-13.

Mittermeier, R. A., Mittermeier, C. G., Gil, P. R., Pilgrim, J., da Fonseca, G. A. B., Konstant, W. R. and Brooks, T. (2002) Wilderness: Earth's last wild places, CEMEX, Mexico City.

Mora, C., Tittensor, D. P., Adl, S., Simpson, A. G. B. and Worm, B. (2011) 'How many species are there on Earth and in the ocean?', PLoS Biology 9(8): e1001127.

Myers, N., Mittermeier, R. A., Mittermeier, C. G., da Fonseca, G. A. B. and Kent, J. (2000) 'Biodiversity hotspots for conservation priorities', Nature 403: 853-8.

Olson, D. M. and Dinerstein, E. (2002) 'The Global 200: priority ecoregions for global conservation', Annals of the Missouri Botanical Garden 89: 199-224.

Olson, D. M., Dinerstein, E., Abell, R., Allnutt, T., Carpenter, C., McClenachan, L., d'Amico, J., Hurley, P., Kassem, K., Strand, H., Taye, M. and Thieme, M. (2000) The Global 200: A representation approach to conserving the Earth's distinctive ecoregions, WWF-US, Washington, DC.

Olson, D. M., Dinerstein, E., Wikramanayake, E. D., Burgess, N. D., Powell, G. V. N., Underwood, E. C., d'Amico, J. A., Itoua, I., Strand, H. E., Morrison, J. C., Loucks, C. J., Allnutt, T. F., Ricketts, T. H., Kura, Y., Lamoreux, J. F., Wettengel, W. W., Hedao, P. and Kassem, K. R. (2001) 'Terrestrial ecoregions of the world: a new map of life on Earth', BioScience 51: 933-8.
Palmer, D. (2009) Prehistoric Life: The definitive visual history of life on Earth, Young Earth, Dorling Kindersley, London.

Pimm, S. L., Russell, G. J., Gittleman, J. L. and Brooks, T. M. (1995) 'The future of biodiversity', Science 269: 347-50.

Price, M. F. (ed.) (2004) Conservation and Sustainable Development in Mountain Areas, IUCN, Gland.

Purvis, A. and Hector, A. (2000) 'Getting the measure of biodiversity', Nature 405: 212-19.

Ricketts, T. H., Dinerstein, E., Boucher, T., Brooks, T. M., Butchart, S. H. M., Hoffmann, M., Lamoreux, J. F., Morrison, J., Parr, M., Pilgrim, J. D., Rodrigues, A. S. L., Sechrest, W., Wallace, G. E., Berlin, K., Bielby, J., Burgess, N. D., Church, D. R., Cox, N., Knox, D., Loucks, C., Luck, G. W., Master, L. L., Moore, R., Naidoo, R., Ridgely, R., Schatz, G. E., Shire, G., Strand, H., Wettengel, W. and Wikramanayake, E. (2005) 'Pinpointing and preventing imminent extinctions', Proceedings of the National Academy of Sciences 102: 18 497-501.

Rodrigues, A. S. L., Andelman, S. J., Bakarr, M. I., Boitani, L., Brooks, T. M., Cowling, R. M., Fishpool, L. D. C., da Fonseca, G. A. B., Gaston, K. J., Hoffmann, M., Long, J. S., Marquet, P. A., Pilgrim, J. D., Pressey, R. L., Schipper, J., Sechrest, W., Stuart, S. N., Underhill, L. G., Waller, R. W., Watts, M. E. J. and Yan, X. (2004) 'Effectiveness of the global protected area network in representing species diversity', Nature 428: 640-3.

Rodrigues, A. S. L., Pilgrim, J. D., Lamoreux, J. F., Hoffmann, M. and Brooks, T. M. (2006) 'The value of the IUCN Red List for conservation', Trends in Ecology and Evolution 21: 71-6.

Rodríguez, J. P., Rodríguez-Clark, K. M., Baillie, J. E. M., Ash, N., Benson, J., Boucher, T., Brown, C., Burgess, N. D., Collen, B., Jennings, M., Keith, D. A., Nicholson, E., Revenga, C., Reyers, B., Rouget, M., Smith, T., Spalding, M., Taber, A., Walpole, M., Zager, I. and Zamin, T. (2011) 'Establishing IUCN Red List criteria for threatened ecosystems', Conservation Biology 25: 21-9.

Rodríguez-Rodríguez, D., Bomhard, B., Butchart, S. H. M. and Foster, M. (2011) 'Progress towards targets for protected area coverage in mountains: a multi-scale assessment', Biological Conservation 144: 2978-83. 
Salafsky, N., Salzer, D., Stattersfield, A. J., HiltonTaylor, C., Neugarten, R., Butchart, S. H. M., Collen, B., Cox, N., Master, L. L., O’Connor, S. and Wilkie, D. (2008) 'A standard lexicon for biodiversity conservation: unified classifications of threats and actions', Conservation Biology 22: 897-911.

Sanderson, E. W., Jaiteh, M., Levy, M. A., Redford, K. H., Wannebo, A. V. and Woolmer, G. (2002) 'The human footprint and the last of the wild', BioScience 52: 891-904.

SavingSpecies and Globaïa (2012) Global Diversity of Mammal, Bird and Amphibian Species. <savingspecies.org/2012/stunning-new-biodiversitymaps-show-where-to-prioritize-conservation/>

Dd Schmitt, C. B. (2011) 'A tough choice: approaches towards the setting of global conservation priorities', in F. E. Zachos and J. C. Habel (eds) Biodiversity Hotspots: Distribution and protection of conservation priority areas, pp. 23-42, Springer, Berlin.

Selig, E. R., Turner, W. R., Troëng, S., Wallace, B. P., Halpern, B. S., Kaschner, K., Lascelles, B. G., Carpenter, K. E. and Mittermeier, R. A. (2014) 'Global priorities for marine biodiversity conservation', PLoS ONE 9(1): e82898.

Short, A. D. and Woodroffe, C. D. (2009) The Coast of Australia, Cambridge University Press, New York.

Sinclair, A. R. E., Fryxell, J. M. and Caughley, G. (2006) Wildlife Ecology, Conservation and Management, 2nd edn, Blackwell, Oxford.

Spalding, M. D., Agostini, V. N., Rice, J. and Grant, S. M. (2012) 'Pelagic provinces of the world: a biogeographic classification of the world's surface pelagic waters', Ocean and Coastal Management 60: 19-30.

Spalding, M. D., Fish, L. and Wood, L. J. (2008)

'Toward representative protection of the world's coasts and oceans-progress, gaps, and opportunities', Conservation Letters 1: 217-26.

Spalding, M. D., Fox, H. E., Allen, G. R., Davidson, N., Ferdaña, Z. A., Finlayson, M., Halpern, B. S., Jorge, M. A., Lombana, A., Lourie, S. A., Martin, K. D., McManus, E., Molnar, J., Recchia, C. A. and Robertson, J. (2007) 'Marine ecoregions of the world: a bioregionalization of coast and shelf areas', BioScience 57: 573-83.
Spalding, M. D., Meliane, I., Milam, A., Fitzgerald, C. and Hale, L. Z. (2013) 'Protecting marine spaces: global targets and changing approaches', in A. Chircop, S. Coffen-Smout and M. McConnell (eds) Ocean Yearbook 27, pp. 213-48, Brill/Nijhoff, Leiden.

Stattersfield, A. J., Crosby, M. J., Long, A. J. and Wege, D. C. (1998) Endemic Bird Areas of the World: Priorities for biodiversity conservation, BirdLife International, Cambridge.

Steffen, W., Burbidge, A. A., Hughes, L., Kitching, R., Lindenmayer, D., Musgrave, W., Stafford Smith, M. and Werner, P. (2009) Australia's Biodiversity and Climate Change, CSIRO Publishing, Melbourne.

Stork, N. E. and Habel, C. (2013) 'Can biodiversity hotspots protect more than tropical forest plants and vertebrates?', Journal of Biogeography 41: 421-8.

Dd Strahler, A. N. (2011) Introducing Physical Geography, 5th edn, John Wiley \& Sons, Hoboken, NJ.

Tittensor, D. P., Mora, C., Jetz, W., Lotze, H. K., Ricard, D., Berghe, E. V. and Worm, B. (2010) 'Global patterns and predictors of marine biodiversity across taxa', Nature 466: 1098-101.

Udvardy, M. D. F. (1975) A Classification of the Biogeographical Provinces of the World, IUCN, Morges.

United Nations (UN) Millennium Project (2005) Environment and Human Well-Being: A practical strategy, Report of the Task Force on Environmental Sustainability, Earthscan, London.

United Nations Environment Programme World Conservation Monitoring Centre (UNEP-WCMC) (2002) Mountain Watch: Environmental change and sustainable development in mountains, UNEPWCMC, Cambridge.

United Nations Educational, Scientific and Cultural Organisation (UNESCO) (2014) World Heritage List, UNESCO, Paris. <whc.unesco.org/en/list/>

Watling, L., Guinotte, J., Clark, M. R. and Smith, C. R. (2013) 'A proposed biogeography of the deep ocean floor', Progress in Oceanography 111: 91-112. 
Watson, J. E. M., Evans, M. C., Carwardine, J., Fuller, R. A., Joseph, L. N., Segan, D. B., Taylor, M. F. J., Fensham, R. J. and Possingham, H. P. (2011) 'The capacity of Australia's protected area system to represent threatened species', Conservation Biology 25: 324-32.

White, M. E. (2003) Earth Alive: From microbes to a living planet, Rosenburg Publishing, Sydney.

Whittaker, R. J., Riddle, B. R., Hawkins, B. A. and Ladle, R. J. (2013) 'The geographical distribution of life and the problem of regionalization: 100 years after Alfred Russel Wallace', Journal of Biogeography 40: 2209-14.

Williams, K. J., Ford, A., Rosauer, D. F., de Silva, N., Mittermeier, R., Bruce, C., Larsen, F. W. and Margules, C. (2011) 'Forests of east Australia: the 35th biodiversity hotspot', in F. E. Zachos and J. C. Habel (eds) Biodiversity Hotspots: Distribution and protection of conservation priority areas, pp. 295-310, Springer, Berlin. 


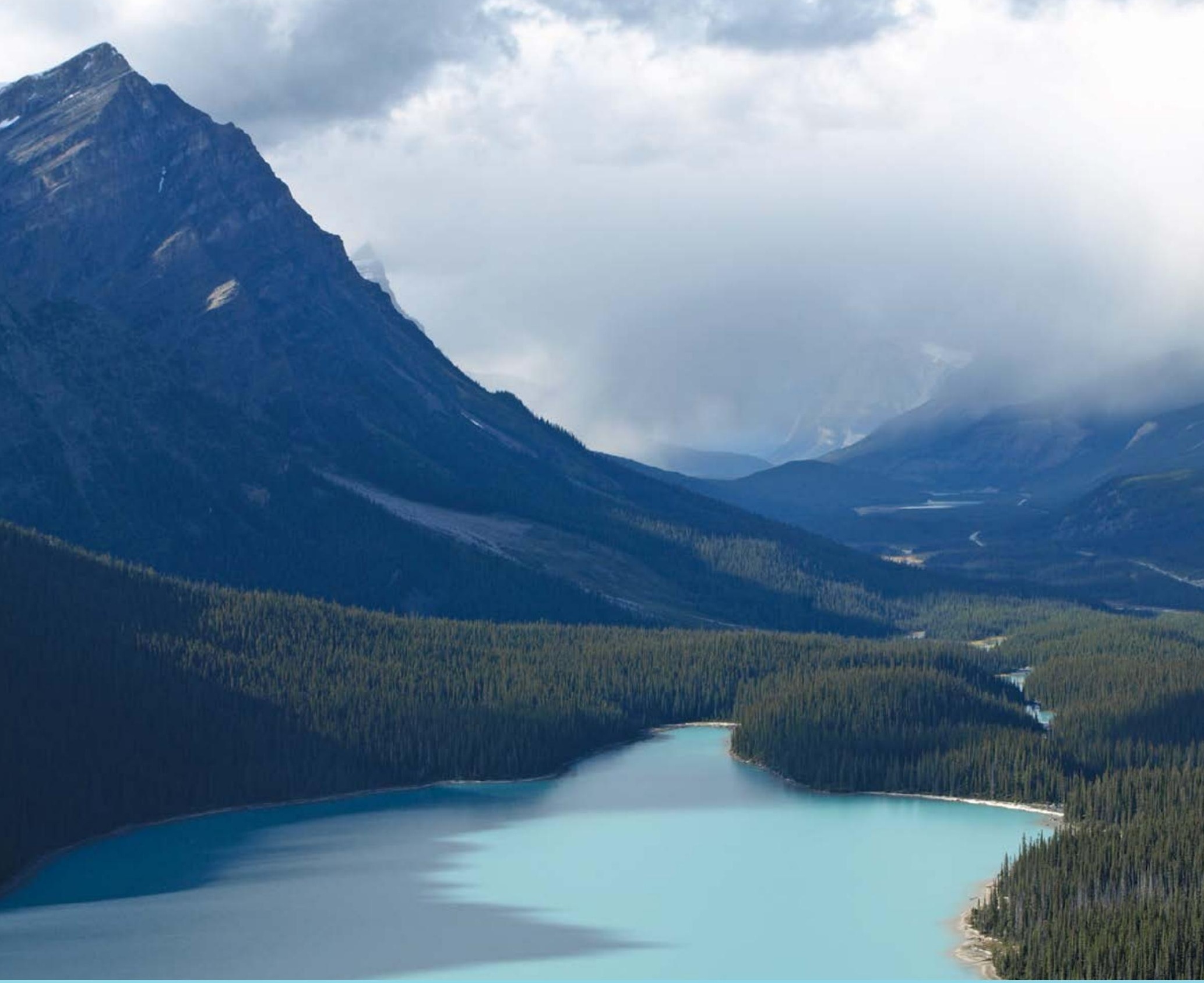

\section{CHAPTER 4}

\section{EARTH'S CULTURAL HERITAGE}

\section{Principal author:}

Sue Feary

\section{Supporting authors:}

Steve Brown, Duncan Marshall, Ian Lilley,

Robert McKinnon, Bas Verschuuren and Robert Wild

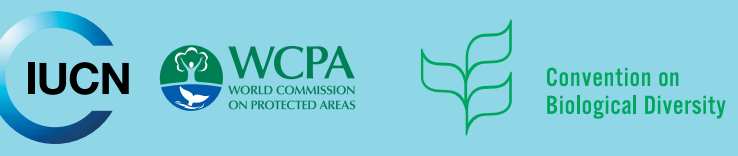

\section{CONTENTS}

- Introduction

- A brief history of humans on Earth: The long view of cultural change and diversity

- Humans, culture and nature

- Defining and understanding cultural heritage: A short history of ideas on cultural heritage

- A diversity of cultural heritage

- Introducing cultural heritage management

- Connections between culture, heritage and protected areas

- References 


\section{PRINCIPAL AUTHOR}

SUE FEARY is an archaeologist and national park manager, with 25 years' experience in management of natural and cultural heritage and consulting with Aboriginal Australians.

\section{SUPPORTING AUTHORS}

STEVE BROWN is a PhD scholar at the University of Sydney, Australia.

DUNCAN MARSHALL is a heritage consultant, Australia.

IAN LILLEY is a professor in the Aboriginal and Torres Strait Islander Studies Unit, University of Queensland, Australia.

ROBERT MCKINNON is Strategic Programs Officer, NSW National Parks and Wildlife Service, Australia.

BAS VERSCHUUREN is a Researcher, Department of Sociology and Development Change, Wageningen, Netherlands.

ROBERT WILD is an independent consultant, specialising in natural resources and community development, based in the United Kingdom.

\section{ACKNOWLEDGMENTS}

The authors would like to acknowledge helpful comments from Sharon Sullivan on an early draft, and an anonymous reviewer.

\section{CITATION}

Feary, S., Brown, S., Marshall, D., Lilley, I., McKinnon, R., Verschuuren, B. and Wild, R. (2015) 'Earth's cultural heritage', in G. L. Worboys, M. Lockwood, A. Kothari, S. Feary and I. Pulsford (eds) Protected Area Governance and Management, pp. 81-116, ANU Press, Canberra.

\section{TITLE PAGE PHOTO}

Protecting nature is part of humanity's cultural heritage. Peyto Lake, Banff National Park World Heritage Property, Canada

Source: Graeme L. Worboys 


\section{Introduction}

Earth's seven billion people and their forebears have left, and are continuing to leave, a rich legacy of their cultural activities, values and beliefs. This collective cultural heritage goes back hundreds of thousands of years and takes many forms, from an ancient stone flake to the remains of a city, to a song. It has resonance at all scales, from intensely personal, to the crux of a national identity, to an international icon.

The existence of protected areas is a cultural legacy in itself. Gazettal of America's Yellowstone National Park in 1872 formalised recognition of protected areas, but for thousands of years before this, humans protected natural places of high cultural value. Although not consciously identified for what Western science calls their biodiversity, these ancient places demonstrate that protected areas are not just the hallmark of modern society and complex government schemes.

Protected areas frequently encapsulate cultural heritage, be it tangible evidence of past human endeavour, intangible heritage encapsulated within the natural landscape or the cultural practices of people inhabiting protected areas. This is hardly surprising given the history of modern humans is one of a diverse and complex relationship with the natural environment, ranging from deep spiritual connection to wholesale destruction. It would be virtually impossible for a protected area not to include culturally derived phenomena.

The relationship between protected areas, the cultural heritage within them and the peoples to whom they belong has had a long and sometimes troubled history, with early management regimes giving sparse recognition to cultural heritage and at times disadvantaging or dispossessing local communities in their quest to save nature. Global movements to achieve rights and social justice for indigenous people and local communities broadened the meaning of cultural heritage by acknowledging the not always obvious cultural links between humans and nature.

This chapter aims to guide and inspire a land manager in his/her quest to professionally manage all manifestations of cultural heritage within a protected area context. The chapter begins with human evolution and a brief history of humans' interactions with the landscape. The next section discusses the history of ideas concerning cultural heritage, followed by exploration of the diversity of cultural heritage found in protected areas. The material on 'nature as cultural heritage' teases out the complexities of intangible heritage as it relates to place. The concept of 'entangled landscapes' is introduced as a way of understanding natural and cultural heritage as an integrated system and a basis for holistic management. The concept and practice of cultural heritage management are introduced, and the final section considers whether or not protected area systems are effective in protecting cultural heritage.

\section{A brief history of humans on Earth: The long view of cultural change and diversity}

Without humans there is no culture and therefore no cultural heritage, so we begin with a brief overview of the history of modern humans on Earth. This section draws on scientific inquiry to explain the origin and evolution of modern humans. We recognise and respect, however, the diversity of ways in which different cultures and religions explain the formation of the biophysical world and the humans who inhabit it, including mainstream faiths and indigenous cosmologies.

\section{Out of Africa}

From a scientific perspective, the natural environment of Earth has evolved over almost five billion years, creating ecosystems devoid of humans for most of their existence. The first hominans appeared a mere six million years ago, with palaeoanthropological, archaeological and genetic evidence pointing strongly to Africa as the major centre for the origins of both ancient and modern humans, although new technologies and discoveries are constantly challenging theories of human origins. Various hominid species successively rose and interbred or were replaced until anatomically modern humans appeared and began to move out of eastern Africa from 45000 to 60000 years ago (Henn et al. 2012).

From Africa, human populations expanded rapidly, fanning out to colonise Eurasia, followed by Australasia and eventually crossing the Bering Strait to the Americas (Figure 4.1). The islands of the oceanic Pacific were the last places on Earth to be colonised, during the great sea voyages of Austronesian-speaking peoples commencing around 4000 years ago, ending with Polynesian settlement of New Zealand and the remote, enigmatic Rapa Nui (Easter Island) (Bellwood 1978; Fischer 2005).

\section{Ancient beginnings}

Human history has been largely concerned with foodits production, acquisition, storage, processing and distribution (Heiser 1973). Humans have been hunters 


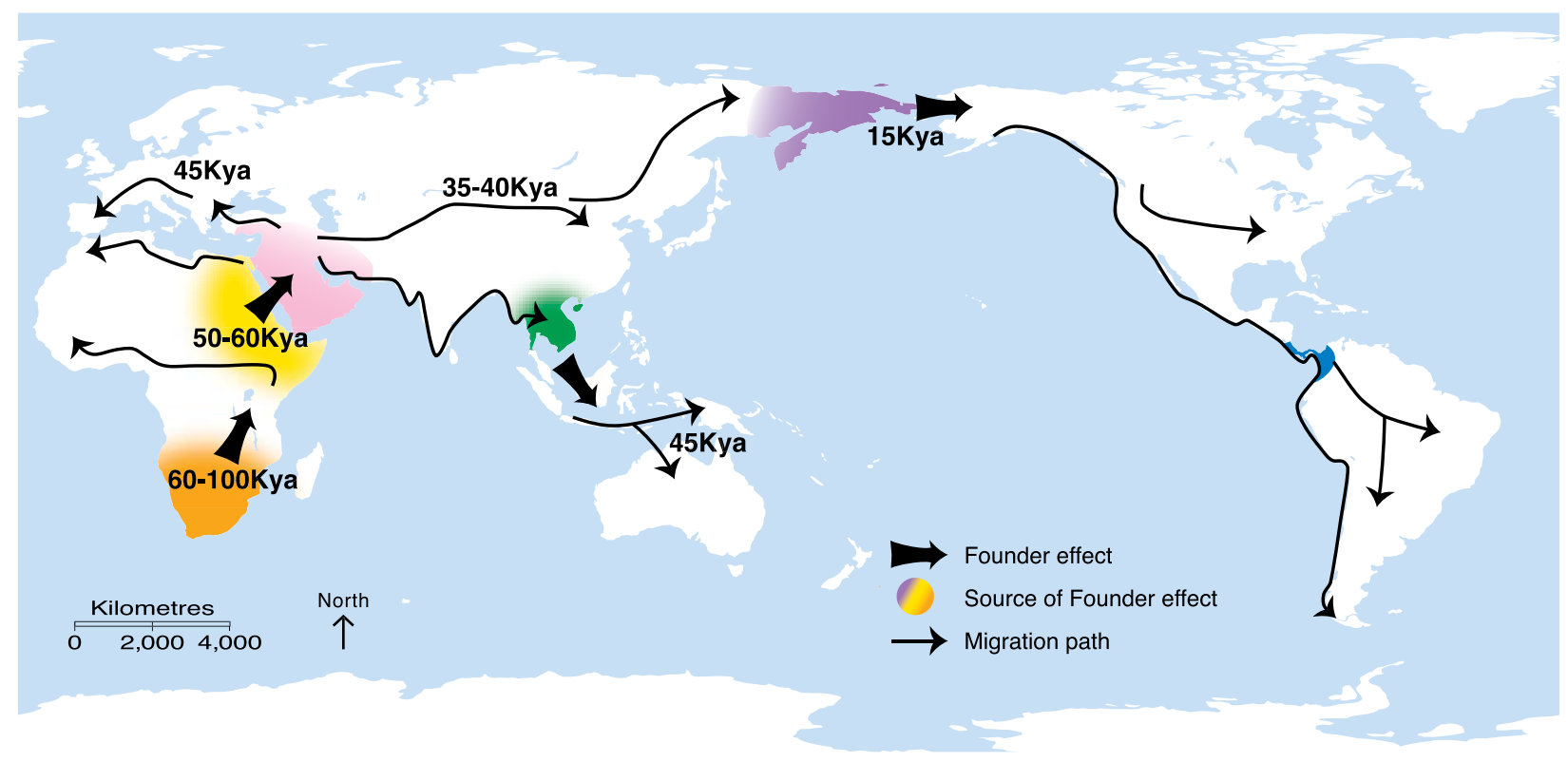

Figure 4.1 Origin and dispersal of modern humans

Source: Adapted from Henn et al. (2012)

and gatherers for most of their history, relying directly on nature as a source of all foods. Hunter-gatherer economies were based on the seasonal availability of plant and animal resources needed for food, medicine, shelter, ceremonial activity and tool-making. They lived in mobile extended family groups, often with complex systems of land ownership and kinship relations, but with few material possessions. Their relationship with nature was close and grounded in spiritual and animistic beliefs. Survival depended on an intimate knowledge and manipulation of the natural world, understood through a cosmological lens. Localised adaptations led to distinctive morphological types, technologies, cultural traditions and languages, and by around 11000 years ago, hunter-gatherer populations had spread across the Earth. This, the longest era of human history, known as the Stone Age or Palaeolithic, has left a rich archaeological record.

\section{Agriculture and after}

The rise and spread of agriculture were the next major events in human history, often termed the 'Neolithic revolution', although in reality it was a gradual process, with humans actively modifying local ecosystems and manipulating biotic communities long before the manifestation of morphological indicators of both plant and animal domestication (Zeder 2011). Beginning with evidence of crop domestication in the Near East around 11500 years ago (Zeder 2011), agricultural systems emerged independently across most continents then spread to adjacent regions (Ellis et al. 2013). The drivers for humans to move from hunting and gathering to agriculture are still debated but were likely to have been population pressure and climate change. Control of water and irrigation was also significant, with both essential for the growth of crops in the dry mountains of the Tigris and Euphrates valleys of the Middle East (Heiser 1973).

Agriculture allowed larger population densities, a more sedentary existence and permanent dwellings. Food surpluses were produced and stored for leaner times and, importantly, could support people not directly involved in food production, leaving them free to develop specialist skills, leading to social diversification. Over time, communities became larger, incorporating chiefdoms and social stratification. More sophisticated systems evolved for storage of food, animal husbandry and genetic manipulation and these, together with trade and exchange networks, fostered larger and ever more permanent settlements.

Some village settlements expanded to form cities-first, in Mesopotamia, in the river valleys of the Tigris and Euphrates, where the main centres of Assyria, Sumer and Babylon were important cultural, political and religious centres of the ancient world, and later, along other major rivers such the Nile, Yangtze and Indus. The cultural significance of many of these early centres of civilisation has been recognised through World Heritage listings (see Case Study 4.1).

Slowly, the great civilisations of the world arose: the Roman and Chinese empires and the beginnings of the British Empire, leaving extensive physical remains and having a profound effect on the environment, and 


\section{Case Study 4.1 The marshlands of Mesopotamia: Iraq's first national park}

The Mesopotamian Marshlands of southern Iraq were once the third-largest wetlands in the world, originally extending between 12000 and 15000 square kilometres. They were a vital resource for regional fisheries, reeds and other natural resources and the home of the indigenous Ma'dan Marsh Arabs, who are directly linked to ancient Sumeria. They are globally important for large numbers of migrant and wintering birds, and are the native habitat of endemic birds and other valuable wildlife.

The livelihoods of the Ma'dan were compromised by dam building and draining of the wetlands during the regime of Saddam Hussein, but since 2006 there have been concerted efforts to restore water flows to the marshlands. In 2013, the area was declared Iraq's first national park.
The marshlands have been on the World Heritage tentative list since 2003, for both natural and cultural values, and the creation of the national park seeks not only to conserve the natural values but also to demonstrate the critical role of the marshlands and the lifestyles of its Ma'dan people in the development of civilisation (UNESCO 2014a). on humanity over a large area-for example, intensive cultivation in China and South-East Asia, the profound effect of the Roman Empire on Africa in particular, and the European settlement of the New World.

\section{Mechanisation and the Industrial Revolution}

A period of rapid increase in human populations followed the social and economic upheavals instigated by the Industrial Revolution in Britain in the late 18th century. Mechanisation, which led to improvements in farm technology and increases in food production, spread across Europe and into North America (Szirmai 2009). By 1850, the Earth's population had reached 1.2 billion people.

In the early 21 st century, the majority of the world's population are still farmers; a few hunter-gatherers and herders still exist as minority groups in nation-states, and urbanisation is rapid. There are rich countries and desperately poor countries, but regardless, their citizens have created and continue to create a cultural heritage. Whether a nation's cultural heritage is recognised, valued or protected, however, depends on myriad political, social and economic factors. Seven billion humans now occupy most of the planet, the exceptions being the frozen Antarctic and the most northerly parts of the Arctic. The population is continuing to expand at different rates across the world, with a predicted peak of 9.1 billion by 2050 .

\section{Humans, culture and nature}

\section{Human influences on nature}

Humans have transformed ecosystems across most of the terrestrial biosphere, causing major global changes in biodiversity, biogeochemistry, geomorphic processes and climate (Ellis et al. 2013). Environmental change is an inevitable consequence of human history and palaeoecological and archaeological evidence present a story of increasing human impact on the environment over time, accelerating in recent millennia (Head 2000).

From the use of fire by hunter-gatherers thousands of years ago in prehistoric Australia to the building of the Three Gorges Dam on the Yangtze River in China, the human legacy has been and continues to be one of environmental modification and impact. In fact, a visibly changed environment is often thought of as a principle hallmark of culture. The first white explorers and settlers in Australia judged Aboriginal people uncivilised, uncultured savages on the basis of (what they thought was) no evidence for cultivation of the soil or other signs of environmental modification (Mulvaney and Kamminga 1999). We know now that Aboriginal fire management has had profound impacts on some Australian ecosystems.

Theenvironmentalimpactsfrom hunter-gatherersocieties were benign compared with agricultural development from around 11500 years ago. As geographer Carl Sauer (1952) says, people prospered by disturbing the natural order. A review of pre-European deforestation in the Pacific pointed to slash-and-burn agriculture being responsible for the evolution of fire climax forests, grassland savannahs, degraded lands and major erosion on many Pacific Islands (Thaman and Clarke 1993). Boyden (2004) has coined the term 
'biohistory' - a biological perspective on human culture as a force in nature-to describe how culture, through people's behaviour, impacts on other humans and on other living systems. Documenting and understanding the nature of environmental change are a major study on their own (Head 2000).

\section{Human protection of nature}

Environmental disturbance may be the hallmark of human development but so is the setting aside of areas from that disturbance. For thousands of years, preindustrial indigenous and tribal communities excluded certain places and species on a temporary or permanent basis. Deeply embedded in their cosmologies and world views, such mechanisms include totems, taboos and sacred groves, often with the concept of sacredness underpinning their protection.

Among indigenous populations in Australia and North America, totemism is part of the broader 'caring for country' spectrum for helping to conserve certain species and their habitat, for both religious and utilitarian reasons. The term totemism is used to describe the threeway relationship between people, species and the land/ sea (Rose 1996). Totems can represent an aspect of the natural world and provide kinship links between people who identify with a particular totem, and to the natural world.

Some raptor species play a significant cultural role in many indigenous societies, due perhaps to their position as top predator, large size and magnificent countenance. The North American bald eagle (Haliaeetus leucocephalus) is sacred to some Native American tribes and the white-bellied sea eagle (H. leucogaster) is totemic in some Australian Aboriginal communities and for some individuals (Baldwin 2010).

Localised protection systems of pre-industrial societies still exist across the world, but by the late 1800s, more concerted national efforts were needed to save nature. The conservation movement arose in Britain and the United States and spread across the Western world. This process was and is a fundamental and tangible component part of the culture and heritage of modern society, operating at the global level, nationally through formal declarations and also locally.

The long and complex history of humans on Earth has produced a rich legacy of intangible and tangible phenomena commonly described as 'cultural heritage'. But there have been and continue to be inequalities in its recognition due to historical legacies, ignorance, geopolitics and many other sociocultural factors.
For example, the cultural heritage of genocide is sometimes hidden, or that of a marginalised ethnic group is ignored. What is and what is not cultural heritage have their own history, having been the subject of debates over many decades.

The next section reviews the meaning of cultural heritage and the development of ideas around its construction, as a concept and a reality.

\section{Defining and understanding cultural heritage: A short history of ideas on cultural heritage}

While most of us have some sense of what cultural heritage is, it is a slippery concept. One book read while researching for this chapter claimed that 'heritage is ubiquitous' (Harrison 2013:3), while another opined 'there is no such thing as heritage' (Smith 2006:11). Yet another said heritage means 'anything you want' (Davison 2008:33). Many indigenous languages have no word for heritage as such. Such a diversity of understandings is a challenge for any protected area manager. The two components of cultural heritage are 'culture' and 'heritage', although the terms are often used interchangeably.

\section{Culture}

Culture denotes an ideational unity-a set of shared meanings, values and representations associated with any society or a discrete group within a society. It suggests a unity that serves to structure human thought and behaviour and put order into sociality (Helliwell and Hindess 1999). Geographer Carl Sauer (1952) pronounced culture in simple terms: as a way of life. As early as 1871 in his influential publication Primitive Culture, English anthropologist E. D. Tylor defined culture as 'that complex whole which includes knowledge, belief, art, morals, law, custom, and any other capabilities and habits acquired by man as a member of society' (Seymour-Smith 1986:60).

\section{Heritage}

Like 'culture', the term 'heritage' is complex and multilayered (Davis 2007). It arose from concern over loss of buildings and monuments during war and natural disasters (Smith 2006). Original meanings of heritage were drawn from old ideas of inheritance: the passing 
on of property to the next generation (Davison 2008). It is also concerned with memory, reflection and the transmission of culture (Davis 2007). Heritage, therefore, is embedded in a 'past' and 'antiquity', but since heritage is something preserved for posterity, its frame of reference is the future as much as the past (Davison 2008). Lowenthal (2005) argues that each generation of human beings receives communal legacies from two sources: the natural environment and the creations of humans. Many heritage conservation discourses contain statements such as 'the things we want to keep', inclusive of both natural and cultural heritage.

Nevertheless, the term heritage is often used to mean cultural heritage only, with natural heritage existing in a different paradigm, as is reflected in the format of this book. Later in the chapter, we explore how the term 'cultural landscape' acts as a unifying concept for natural and cultural heritage, avoiding the need to create a dichotomy between the two.

\section{Cultural heritage}

What, then, is cultural heritage? Although heritage had its beginnings in 19th-century Europe (Smith 2006), use of the past to construct ideas of individual and group identity has been part of the human condition for much longer. Harvey (2010) notes that heritage has always been with us and every society has a relationship with its past, even those who have chosen to ignore it.

A universal definition of cultural heritage emerged after World War II in the context of recognising the need to protect monuments as part of national identity (Lennon 2006). Since that time, defining a common terminology and scope of heritage has been driven by the UN Educational, Scientific and Cultural Organisation (UNESCO) and the International Council of Monuments and Sites (ICOMOS), which arose from the Venice Charter of 1964 (Ahmad 2006).

Early definitions of cultural heritage were Eurocentric and, due to the influence of architects in the global arena, put emphasis on the built environment (Ahmad 2006). Amid the sweeping social changes of the 1960 s and 1970s, indigenous and tribal people's demands for rights over their land and heritage led to the realisation that the definitions excluded and disempowered entire sections of the global community. In 1992 UNESCO's definition was expanded to include cultural landscapes, in recognition of the long history of landscape modification by humans, and in 2003 , it was again amended to include intangible heritage. The latter is particularly relevant to societies whose heritage does not lie in buildings but in connections with the natural landscape, verified through oral traditions handed down over generations. Because meanings and values linked to cultural heritage are embedded in these dynamic and changing social contexts, it has been argued that cultural heritage is a process in itself (Smith 2006).

Some useful definitions of cultural heritage are given below.

Monuments, buildings, landscape, artefacts and object; as well as cultural traditions, music, theatre and dialect; it can be aesthetically pleasing and it can be ugly, unsafe and unprepossessing; it can be tangible_-as many of these things are-or intangible. It can also be old, and it can be new. It is something valued by society, by specific groups within society, and by individuals. (Schofield 2008:19)

Cultural heritage is the way we understand the world and the means by which we shape it. It is rooted in our cultural identities and provides a source of wisdom and knowledge to strengthen sustainable development policies and practices. (Bokova 2012:ix).

The modern concept of cultural heritage embraces all the signs that document human activities over time. It relates to the tangible built environment in an ecological context; and requires the reading of layers of evidence present in the environment. It also encompasses the intangible heritage of culture such as language, dance, music, folk ways and craft skills. Intangible heritage is often associated with particular localities, giving meanings and significance to these places. (Lennon 2006:448)

Inclusion of cultural landscapes and intangible heritage in definitions of cultural heritage has had a significant impact on the way protected areas are managed. Cultural heritage is no longer about a disconnected past; instead it is linked to a contemporary society which wants to ensure its heritage is adequately managed and which also holds the information that gives value to that heritage, giving rise to inclusive participatory processes and greater community involvement.

Having traced the development of the meaning of cultural heritage from very narrow (monuments) to very broad (tangible and intangible), we can now explore the diverse expressions of cultural heritage, with an emphasis on the cultural heritage of protected areas. 


\section{Box 4.1 Investigating the archaeological record}

Archaeology is the study of the material remains of human history, from the time of our earliest ancestors to now. At its most ancient extremities, archaeology blurs with palaeontology in the study of the fossil remains of early human progenitors and relatives. At its most recent end, archaeology blends with fields such as history, geography and anthropology. The discipline takes a highly forensic approach to its subject matter and works with a great many other disciplines in the natural, physical and social sciences as well as the humanities to draw the most from its data. It can inform us about the whole of human history, and provide detailed information about long-term changes in the Earth's physical and biological environments as well as shifts in human behaviour.

Archaeological investigation often involves systematic and controlled excavation of physical evidence that exists under the ground, as shown in the popular BBC series Time Team.

\section{A diversity of cultural heritage}

In this section, recognised experts present a global picture of cultural heritage. We have categorised cultural heritage, but recognise that categories are somewhat artificial, with considerable overlap-for example, a cultural landscape can also be an archaeological site. The 'types' of cultural heritage are described in the following sections.

\section{Tangible heritage: The physical evidence}

Tangible heritage can be seen and touched. It can be movable or immovable, occur above or under the ground or in water. Tangible heritage includes the built environment, such as temples and monuments, archaeological sites, movable material and underwater heritage. It includes features of the natural environment such as vistas, waterfalls, rock outcrops, mountains or a specific location of cultural expression, associated with intangible heritage. Cultural landscapes are tangible heritage in that they contain visible modifications to the landscape arising from human endeavour.

\section{Archaeological heritage}

Archaeological sites are the physical remains of past human action and occur everywhere around the world on land and under water. In one sense, all terrestrial landscapes and many underwater landscapes are archaeological landscapes-landscapes that contain evidence of, and may be shaped by, past human action. Archaeology is the study of these remains (Box 4.1).

\section{Examples of archaeological heritage}

There is a huge diversity of archaeological heritage, including within, or as the basis of, protected areas, including:

- ancient hunters' campsites, stone tools and food remains, such as those found in Uluru-Kata Tjuta National Park in Australia's outback or the Manú National Park in the jungles of Peru, but also lying unprotected under the M25 motorway around London and among the rice paddies of northern Japan

- entire villages of buildings buried under the ground such as the 8000-year-old early agricultural settlement of World Heritage-listed Çatal Hüyük in Turkey

- World Heritage farming landscapes as different as the Kuk Early Agricultural Landscape in the Papua New Guinea Highlands, dating from the end of the last ice age, and medieval wine estates in Hungary

- the rock-art sites on the World Heritage List, such as the painted Buddhist temples in caves on Central Asia's Silk Route and the cave paintings in Botswana's Tsodilo Hills in the Kalahari Desert or Aboriginal art in Kakadu National Park in Australia

- industrial sites of all ages, from Roman goldmines in the World Heritage Las Médulas site in Spain, to 20th-century mines such as the World Heritage Sewell Mining Town in Chile or the 'city under the city' revealed every time a new rail tunnel or sewer is dug in many towns and cities

- 'terraced' cultural landscapes such as the extensive prehistoric taro and yam gardens in New Caledonia, but also World Heritage places such as the rice terraces of the Philippines and the canals of Venice and Amsterdam

- the surviving remains of any raft, canoe, boat, ship and submarine that has ever sunk anywhere.

Archaeological heritage includes all physical remains of human history, and while this conjures images of the pyramids of Egypt, Machu Picchu in Peru or Chinese imperial graves full of life-sized terracotta warriors, it also includes fossil remains of remote ancestral species 


\section{Case Study 4.2 Archaeological heritage in South Africa's protected areas}

Many of South Africa's protected areas contain archaeological sites of immense significance, some being World Heritage properties such as uKhahlambaDrakensberg World Heritage site in Drakensberg Park in eastern South Africa, which contains around 35000 paintings in rock overhangs, done by the San (Bushmen) (Verlag Wolfgang Kunth GmbH \& Co. 2010).

The Mapungubwe National Park (formerly Vhembe Dongola National Park) encompasses the Mapungubwe Cultural Landscape, the seat of a powerful kingdom from AD 900 and the subject of archaeological investigations since 1933 (Kuman et al. 2005). Among the most significant archaeological finds are the ruins of the city centres and a rich material culture based on gold. These finds provide evidence of the early smithing of gold in southern Africa and of the extensive wealth and social differentiation of the people of Mapungubwe. Most spectacular among these finds is a gold foil rhinoceros moulded over what was likely a soft core of sculpted wood (UNESCO 2014b).

In Augrabies Falls National Park, there are numerous stone cairns and graves dating back 22000 years, and the park is increasingly focusing on the cultural heritage of the Nama people (Department of Environmental Affairs and Tourism 2003). in Africa and Asia; the art, burials, remains of houses and other structures, fireplaces, food remains (for example, bones, scales, seeds, marine shells) and craft and industrial remains (for example, bone, shell, stone, wooden and metal tools, weapons, household items and ornaments, decorative and functional pottery, glass and plastic, and the debris created in manufacturing all these things) left in and around the homes, sacred places and sites of work and leisure of all the people who have ever lived (Case Studies 4.2 and 4.3).

\section{Recognising archaeological heritage}

Official recognition and protection of archaeological heritage - as part of humanity's inheritance from its own past-have sometimes been constrained by a lack of appreciation of deep time: the very long-term perspective on human history. The 'city beneath the city' that survives under nearly every modern urban area is a case in point. A great deal of money and effort go into the protection of above-ground architectural heritage; however, the remains of the villages, towns and cities that lie under such architectural monuments and bear witness to the history behind the above-ground heritage frequently receive less attention. Such remains are important to understand and preserve because they can tell us how, when and why modern cities emerged as they did, and so help us understand why things are as they are today.

Another important case is 'the archaeology in wilderness'. Most of the world's archaeological record is faint and unobtrusive; substantial monuments are in fact rare, even though they attract the most attention. There are vast tracts of the Earth that those with a trained eye know to contain physical evidence of past human action but which most people see as devoid of human activityfor example, changed vegetation patterns through long-term deliberate burning, or changed hydrological regimes through long-term water management practices. Lack of recognition of the subtle archaeological evidence

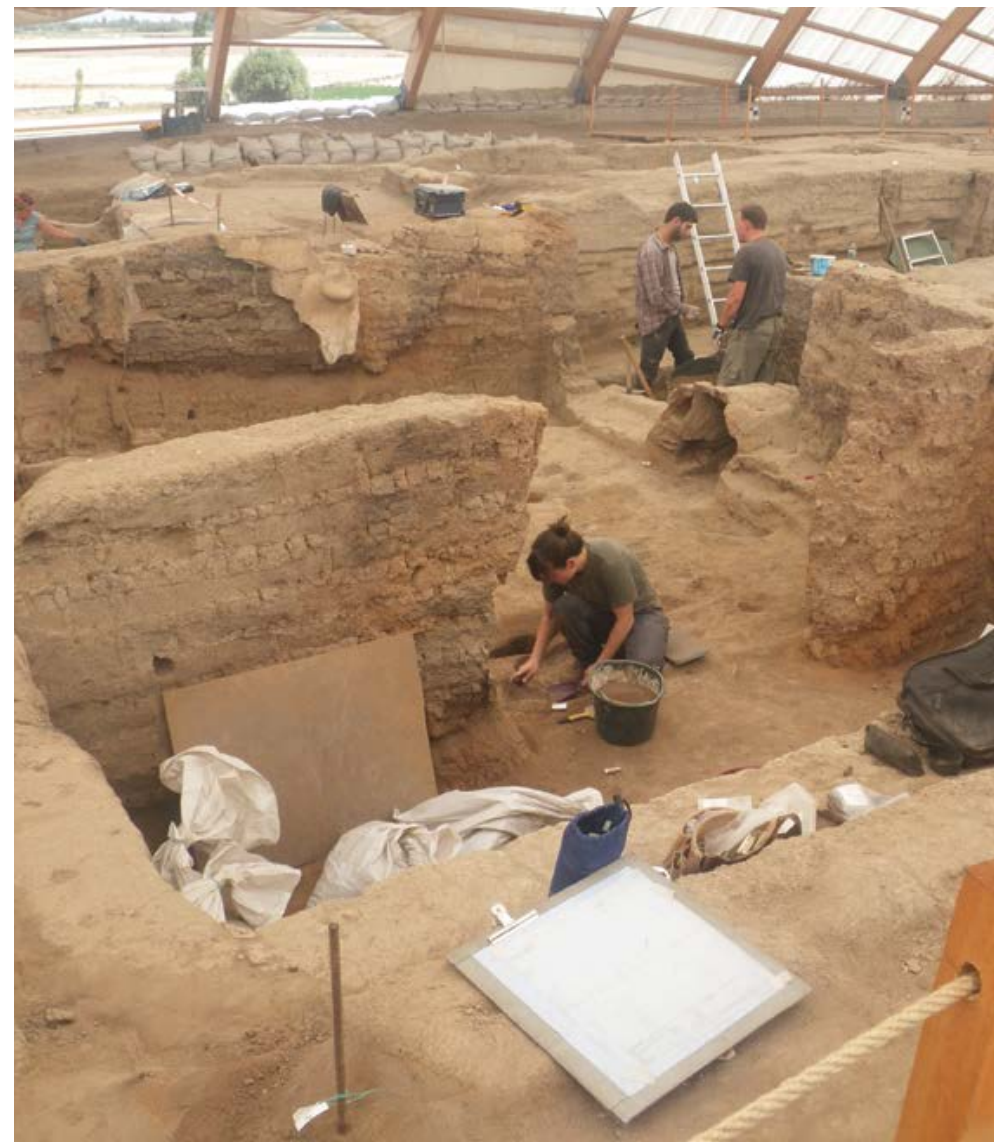

An international team of archaeologists excavating during the 2012 field season at Çatal Hüyük,

Turkey.

Source: S. Feary

for the immensely long periods of occupation and use by humans contributed to early conservation approaches that denied the history of the people who live or lived in areas proposed as protected areas.

International bodies such as ICOMOS have specialised working groups-for example, the International Scientific Committee for Archaeological Heritage Management (ICAHM) - to promote the recognition of archaeological heritage in all its manifestations. 


\section{Case Study 4.3 Archaeological heritage in Australia's protected areas}

Many of Australia's protected areas contain pre-European archaeological sites as well as more recent 'historical' sites. Some of these sites, such as the Aboriginal sites on World Heritage-listed Fraser Island or the Great Barrier Reef, occur in protected areas created on the basis of their 'natural' values, while others, such as in World Heritage properties in south-west Tasmania and Kakadu, the Aboriginal heritage was the major reason for declaration.

Protected as a mixed World Heritage site on the basis of its archaeological sites and natural geological values is the Willandra Lakes National Park in south-west New South Wales. The national park includes the dramatic Lake Mungo, long dry, but featuring a vast, eroding dune known as the Walls of China, which contains ancient human burials dating back 40 000-50 000 years, along with many other signs of past human activity (Bowler et al. 1970). A series of preserved human footprints has been dated to 20000 years ago (Webb et al. 2006). The Willandra Lakes area also includes many archaeological heritage sites dating to the historical period following European colonisation.

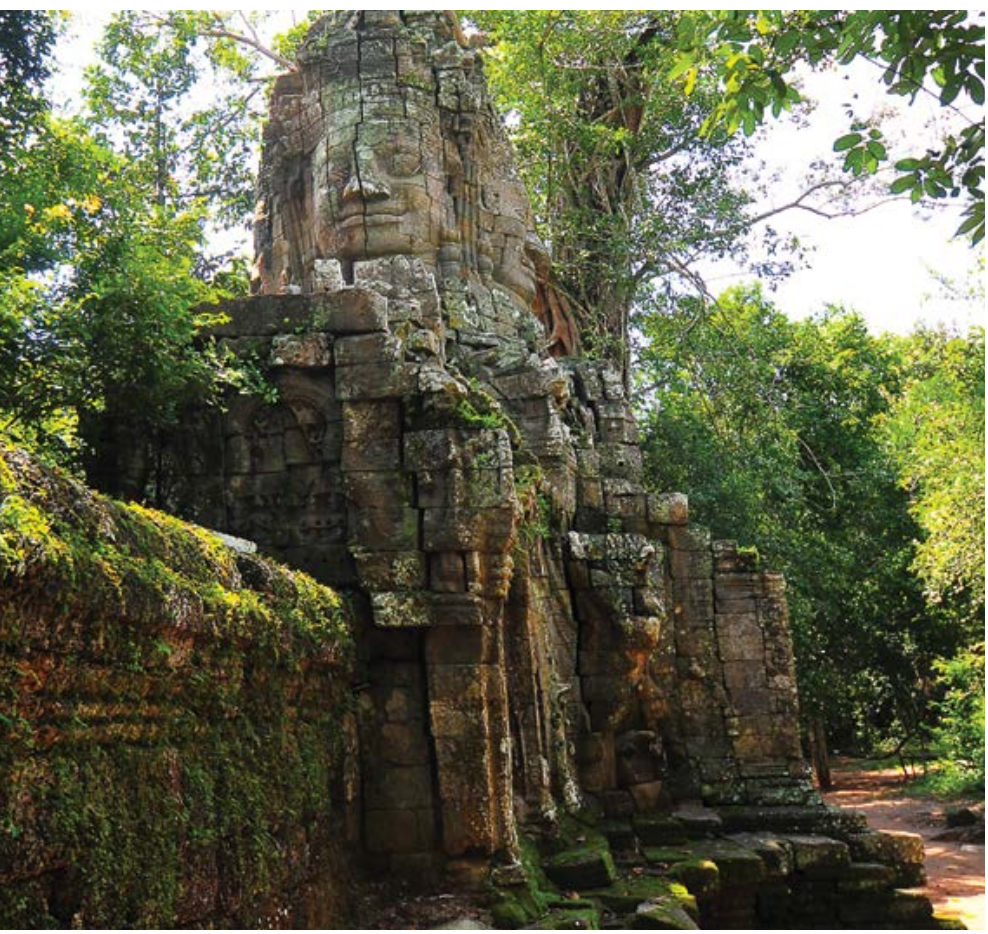

Profile of a gopura (entrance building) on the outer wall enclosing Ta Prohm, Angkor, Cambodia Source: S. Palu

They are beginning to work closely with the IUCN to develop more integrated approaches to cultural and natural heritage. This is particularly relevant where local landowners' history and heritage consist of unobtrusive archaeological remains that may go unrecognised by decision-makers.

Impressive monumental sites can also overwhelm the rest of the archaeology in the area. The Angkor Archaeological Park, a well-known World Heritage property in Cambodia, is a good example. The problems of preserving such places from both natural deterioration and the impact of intense tourist interest are complex and expensive to mitigate, and can be made more difficult with the ongoing discovery of monumental remains in surrounding areas. It is understandable that, in such cases, there may be less focus on the non-monumental (archaeological) remains that lie between and under these places. It is not unknown for local people's connections to major sites to be denied, even when the non-monumental evidence shows that it is likely the people in question have always lived in the area and even contributed to the construction of the monument as builders, labourers or suppliers of food and other goods and services to workers. This asserted disconnection between modern populations and the local monumental archaeological record can create friction and lead to significant local resistance to archaeological heritage management efforts.

\section{Built heritage}

Perhaps the most physically obvious types of cultural heritage found in protected areas are buildings or other structures reflecting former or continuing human activities. The range of buildings and other structures that might be found in protected areas is very broad. It includes those associated with:

- residential activities such as huts, more substantial houses, lodges and hotels

- religious activities including shrines, temples and churches

- memorial activities such as individual commemorative structures and cemeteries

- military activities including fortifications

- mining and other extractive industries including headframes, engine houses, mills, workshops, offices, dams, channels, tanks, railways and roads

- a range of industries, from car manufacturing to filmmaking

- farming activities such as shearing sheds, yards, fencing and storage sheds

- forestry activities such as engine houses, mills, workshops, offices, channels, log-hauling equipment and railways

- scientific activities including observatories, telescopes, antennae, offices and workshops 


\section{Case Study 4.4 Tikal National Park, Guatemala}

This park is one of the most important reserves in Guatemala because of its archaeological and bioecological interest. Rivers, lakes, swamps and flooding savannahs are important for biodiversity and for migratory birds. The reserve contains the largest area of tropical rainforest in Guatemala and Central America, with a wide range of unspoilt natural habitats. A large area of the reserve still comprises dense broadleaved forests with more than 300 species of commercially useful trees.

In the heart of the jungle lies one of the major sites of the Mayan civilisation. The ceremonial centre contains temples and palaces, and public squares accessed by ramps. Remains of dwellings can also be found scattered throughout the surrounding countryside. The ruined city reflects the evolution of Mayan society from huntergathering to farming and agriculture. They developed an elaborate religious, artistic and scientific culture which finally collapsed in the late 9th century, but at its height, $A D$ $700-800$, the city contained a population of 90000 Mayan Indians, with over 3000 separate buildings dating from 600 $B C$ to $A D$ 900, including temples, residences, religious monuments often highly decorated with hieroglyphic inscriptions and tombs. Archaeological excavations have yielded evidence for cotton, tobacco, beans, pumpkins, peppers and many fruits of pre-Columbian origin, demonstrating the importance for Mayan culture of domestication of plants (UNESCO 2014c).

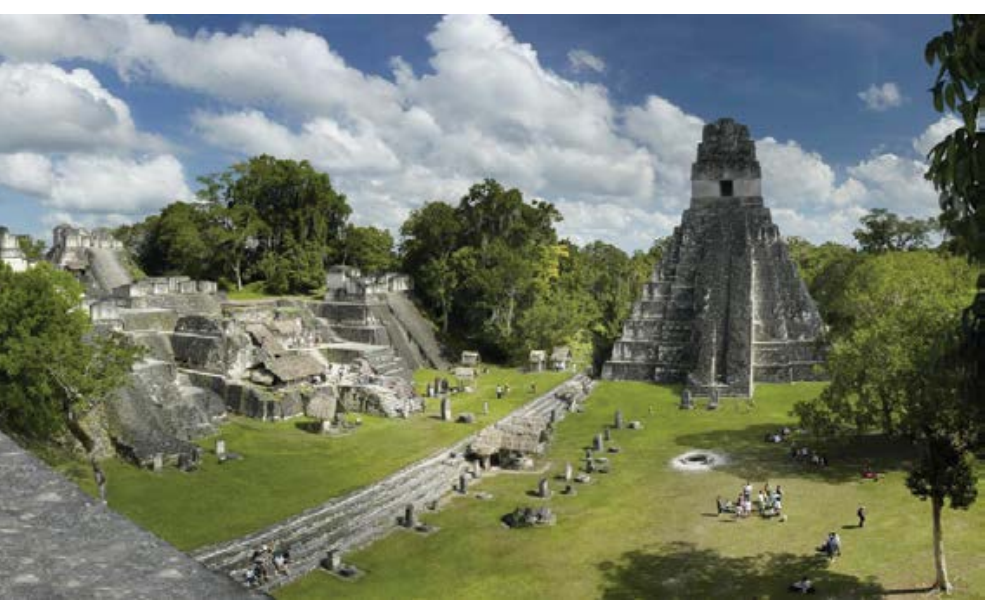

Mayan structures in Tikal National Park

Source: Magnus Manske, Wikimedia Commons

heritage may not be a priority for identification or protection. In such cases, identifying cultural heritage might only arise with the development of holistic heritage management practices, or perhaps as a result of community pressure.

In other situations, cultural heritage is recognised as an integral part of the protected area, to be identified and protected along with the natural heritage values as part of managing all heritage values in the protected area. The Sundarbans National Park in India contains the world's largest mangrove forests and also contains significant built heritage, including ruins of a city built by the Chaand Sandagar merchant community around AD 200-300. During the Mughal Empire from the 16th century, Raja Basand Rai and his nephew took refuge in the city from the advancing armies of Emperor Akbar. They erected buildings which subsequently fell to Portuguese pirates, salt smugglers and dacoits in the 17 th century (UNESCO 2014d).

\section{Why are buildings and structures important?}

Like any form of cultural heritage, buildings or structures can have important values reflecting stories or themes in human history that should be acknowledged, understood, respected, cherished and interpreted. In some cases, buildings or structures are part of continuing cultural traditions, and protecting this cultural heritage is part of protecting the cultural wellbeing of the associated community. The example noted above of the Cliff of Bandiagara with its hundreds of villages is such a case. In other situations, the cultural heritage is an important relic or evidence of past activity, providing a tangible reminder of a significant aspect of human activity. The physical evidence of the Mayan civilisation in Tikal National Park is a good example. Buildings and structures can also be important for a range of other reasons including their role in economic or social activities such as in farming, transport or tourism. But these are not necessarily heritage values.

\section{Connection between buildings/structures and protected areas}

This brief discussion suggests many ways in which buildings and structures can be connected to protected areas. The connections might be very recent or very old, they might be quite limited or extensive geographically, they may have evolved over a long period as part of an organically evolved environment with intimate relationships, or they may be incidental, and the protected area status itself may have generated the connection.

Depending on the historical significance, physical condition of the structure (from a public safety perspective) and (sometimes) the category of protected area, buildings and structures may be recognised and embraced as part of the cultural heritage of the protected area. Conversely, the features may be considered of low or no cultural significance, present a safety hazard or, in 
some instances, their presence may be perceived to be inconsistent with nature conservation objectives-for example, in wilderness areas. For example, in the early decades of the NSW National Parks and Wildlife Service, the presence of early to mid 20th-century stockmen's huts in wilderness areas of Kosciuszko National Park posed a management problem because of the logistical difficulties of undertaking regular maintenance in such remote areas. For a while there was a policy of 'manage as a ruin', which meant not undertaking any activity to conserve the building, allowing gradual decay instead, leading ultimately to removal due to public safety risks.

Although 'doing nothing' is an acceptable option under international guidelines such as ICOMOS, in reality it is likely to be unacceptable to historical preservationists and, more importantly, the descendants of the people whose lives were deeply embedded in use of the hut and surrounding landscape for grazing. Researching the history of such buildings in collaboration with relevant families can affirm the cultural significance of such places for their historical as well as their social value and raise their status above that of a ruin-for example, Teddy's Hut in Kosciuszko National Park (Higgins 1988).

\section{Movable heritage}

Movable heritage is a vital component of cultural heritage at local, national and global scales. Movable heritage refers to cultural objects that can be taken away from their original context and, as such, they often exist as collections in museums or in private hands (Box 4.2). Movable heritage is often archaeological in nature. Grave goods associated with a double human burial discovered in southern New South Wales, Australia, in 1992 and dated to 7000 years BP included a necklace made from more than 300 kangaroo teeth, each containing a drilled hole, presumably originally strung together with string (Feary 1993). Such items are priceless at all levels.

\section{Threats to movable heritage}

Because of its transportability, movable heritage is particularly vulnerable to illicit trafficking between and within countries and to being stolen during war (Figure 4.2). Since adoption of the 1970 Convention on the Means of Prohibiting and Preventing the Illicit Import, Export and Transfer of Ownership of Cultural Property, UNESCO has had many successes in the return of stolen movable heritage to its rightful country. The International Council of Museums (ICOM) maintains Red Lists of countries and regions that classify endangered categories of archaeological objects or works of art in the most vulnerable areas of the world, in order to prevent them being sold or illegally exported.

\section{Box 4.2 Defining movable heritage}

Movable heritage became a separate category of cultural property/heritage, with the following definition adopted by UNESCO in 1978:

[M]ovable cultural property shall be taken to mean all movable objects which are the expression and testimony of human creation or of the evolution of nature and which are of archaeological, historical, artistic, scientific or technical value and interest, including items in the following categories:

- products of archaeological exploration and excavations conducted on land and under water;

- antiquities such as tools, pottery, inscriptions, coins, seals, jewellery, weapons and funerary remains, including mummies;

- items resulting from the dismemberment of historical monuments;

- material of anthropological and ethnological interest;

- items relating to history, including the history of science and technology and military and social history, to the life of peoples and national leaders, thinkers, scientists and artists and to events of national importance;

- items of artistic interest, such as: paintings and drawings, produced entirely by hand on any support and in any material (excluding industrial designs and manufactured articles decorated by hand); original prints, and posters and photographs, as the media for original creativity; original artistic assemblages and montages in any material; works of statuary art and sculpture in any material; works of applied art in such materials as glass, ceramics, metal, wood, etc.;

- manuscripts and incunabula, codices, books, documents or publications of special interest;

- items of numismatic (medals and coins) and philatelic interest;

- archives, including textual records, maps and other cartographic materials, photographs, cinematographic films, sound recordings and machine-readable records;

- items of furniture, tapestries, carpets, dress and musical instruments; and

- zoological, botanical and geological specimens.

Source: Jokilehto (2005:27)

Movable heritage can include human skeletal remains taken from burial sites in the past and sent to museums within and outside their country of origin, as well as culturally significant animals. 
The Laponian World Heritage Area in Sweden is a vast Arctic landscape that encompasses four national parks and two nature reserves. It is the home of the Saami or Lapp people, the only formally recognised indigenous people of Scandinavia. It is the largest area in the world (and one of the last) with an ancestral way of life based on the seasonal movement of livestock. Every summer, the Saami lead their huge herds of reindeer towards the mountains after spending winter in the coniferous forests to the east. The area has outstanding universal value for its natural heritage and has been occupied continuously by the Saami people for 7000 years.

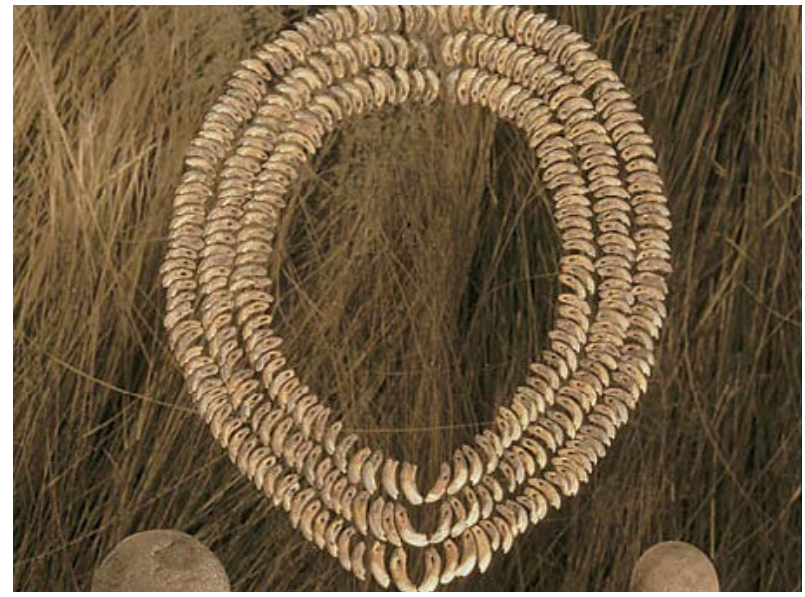

Rare kangaroo-tooth necklace from an Aboriginal site, southern New South Wales, Australia

Source: NSW Office of Environment and Heritage

\section{Repatriation of human skeletal remains}

During the late 19th and early 20th centuries in Australia, anthropologists and colonial officials made extensive collections of the ancestral skeletal remains of Aboriginal Australians to satisfy scientific curiosity about different cultures, and notions of racial superiority fuelled by social Darwinism. Thousands of remains ended up in private collections, museums and scientific institutions across the world as well as in Australia's major natural history museums. Repatriation of these ancestral remains is an important element of the reconciliation process in Australia, and from the 1960s Aboriginal people have agitated for the return of the remains of their ancestors so they can be reburied on their country.

Because of the high degree of Aboriginal involvement in national park management in Australia, it is not uncommon for remains to be repatriated within a national park. For example, in September 2005, the NSW Government declared seven new sites within parks and reserves for the reburial of Aboriginal remains, giving them extra protection under the New South Wales National Parks and Wildlife Act 1974 (Truscott 2006).

\section{Herding and transhumance}

Transhumance is an ancient practice whereby herders move seasonally with their animals to find water and pasture. Accessible land for the seasonal movement of herds and

\section{0 paintings seized by Nazis found}

A private stash of 1500 paintings seized by the Nazis, including works by Pablo Picasso and Henri Matisse, has been found in Germany. Customs investigators found the missing art more than two years ago in the dusty, rubbish-filled Munich apartment of an 80-year-old man, but this was not disclosed at the time, news magazine Focus reported. The Nazis seized vast hoards of fine art during their 12 years in power and some of it remains missing. While some items were destroyed in bombing raids, it has always been suspected many items are in private hands. Focus estimated the stash was worth $€ 1$ billion ( $\$ 1.45$ billion). The art once belonged to Jewish collectors, who were forced to sell it for a pittance before the Holocaust, or it was confiscated by Nazi censors from galleries because it was allegedly "degenerate". Under German law, most art acquisitions made under Nazi duress have to be reversed and the heirs of the original owners can reclaim the art.

Figure 4.2 Returning stolen movable heritage Source: Sydney Morning Herald, 5 November 2013.

the availability of suitable land and water for grazing are vital to the maintenance of the cultural traditions of herders. Examples include the cattle of the Maasai in Kenya and the reindeer herds of the Saami people of the Arctic region (Case Study 4.5). Some protected areas, such as the World Heritage-listed Arctic Laponian Area in northern Sweden, are helping to preserve the cultural traditions of transhumance (Verlag Wolfgang Kunth GmbH \& Co. 2010:15). Culturally significant plants and animals are discussed later in this chapter.

\section{Underwater heritage}

The UNESCO Convention on the Protection of the Underwater Cultural Heritage defines underwater cultural heritage as all traces of human existence having a cultural, historical or archaeological character that have been partially or totally underwater, periodically or continuously, for at least 100 years (UNESCO 2001). The convention has been ratified by 20 countries. 


\section{Case Study 4.6 Excavation and museum display: The Mary Rose}

The Mary Rose, Henry VIII's prestigious battleship, was built in Portsmouth, England, in 1509. On 19 July 1545, she sank during battle with a French invasion force in the confined waters of the Solent. The circumstances of the disaster are unclear although she heeled over unexpectedly and sank quickly. Of the 700 men on board, fewer than 40 survived (McKee 1982). The wreck of the ship quickly settled into the soft mud of the Solent and silt piled up inside her. The Mary Rose's partly intact hull, with its precious contents, remained relatively undisturbed until 1971 when the largest underwater archaeological excavation yet to be mounted in Britain began. The wet silt that wrapped the Mary Rose protected many of the organic materials that are usually the first to disappear. Thousands of finds were recorded and conserved, and loose timbers and internal structures were carefully surveyed, dismantled and stored for later reconstruction. On 11 October 1982, the empty hull was raised and sprayed with soluble wax polyethylene glycol to preserve it and a museum was built to house the objects (Throckmorton 1987).

\section{Case Study 4.7 Port of Caesarea, Caesarea National Park, Israel}

The ancient port of Caesarea was a harbour built by King Herod, and was the largest port in the Roman Empire built to honour Herod's patron, Caesar Augustus, in 10 BC. Caesarea was the first large-scale artificial harbour in history and one of the most impressive harbours of its time. Thousands of men were recruited to build the port over 12 years, among them divers who descended by holding their breath or possibly in a diving bell. To build the port, Roman engineers invented a type of cement known as pozzolana, consisting of the volcanic powder deposited around Mount Vesuvius mixed with lime and rubble hardened in water. This hydraulic concrete was imported to Caesarea and used to fill wooden frames that were then lowered into the water to lay the foundations for the port. The harbour, however, started sinking soon after completion and by the 6 th century $A D$ it was unusable.

Over the past three decades the site has been excavated by a team from the University of Haifa and has become one of the world's first underwater museums. The submerged port was declared a national park in 1952 and is a popular destination for divers. Divers can now tour the signposted remains of the magnificent harbour, including a Roman shipwreck, a ruined lighthouse, an ancient breakwater, the port's original foundations, anchors and pedestals. They are given a waterproof map that describes in detail each of the numbered sites along the way. One of the trails is accessible to snorkellers (Old Caesarea Diving Centre 2014).
Human evolution has involved a close relationship with the marine environment, with a long history of living close to the shoreline. As a consequence, much of humanity's development took place on areas now submerged due to sea-level rises since the end of the last ice age. Hence the richness of the world's underwater cultural heritage is often underestimated because it is not easily visible and requires specialist techniques for its documentation and assessment. The ocean offers excellent conditions for preservation, and many shipwrecks and ruins of cities and buildings underwater are better preserved than similar sites on land. The water has protected underwater heritage for centuries but the capacity to understand and document is relatively recent, due to improvements in diving technologies. This has made it more accessible but also increasingly vulnerable to being damaged and pilfered.

Underwater cultural heritage is enormously varied and rich. It is estimated that more than three million shipwrecks are scattered on the ocean floors of the planet. Notable vessels include ships of the Spanish Armada, the Titanic and ships of Columbus, Kublai Khan's sunken fleet and Dutch wrecks including the Batavia off the west coast of Australia. Shipwrecks can provide precious historical information. They can be seen as a time capsule, providing a snapshot of life on board at the time of sinking. Wrecks are also an indicator of trade and cultural exchange between people (UNESCO 2001). Many other types of underwater sites have been located, including the ruins of the Alexandria lighthouse and Cleopatra's palace (Egypt), part of ancient Carthage (Tunisia) and Jamaica's Port Royal, destroyed by an earthquake in 1692. Underwater cultural heritage also includes entire landscapes and rock-art caves now at the bottom of the sea (Intergovernmental Oceanographic Commission 2014). 
Underwater heritage exists within protected areas, including marine protected areas and terrestrial protected areas with a marine component, such as coastal and island protected areas; however, many countries have yet to undertake full inventories of the cultural heritage of their marine protected areas.

\section{Submerged prehistoric sites}

A very wide range of archaeological material apart from shipwrecks may be found underwater, but it is only within the past decade that there has been clear recognition of how important the missing data are from sites covered by sea-level rises. This drowned landscape preserves valuable sedimentary archives of long-term environmental and climatic changes, and an increasing number of archaeological remains have been found documenting human response and adaptation to rapidly changing environments.

With the intensification of commercial activity on the seabed and improved research technology, the quantity of evidence is increasing rapidly (Case Study 4.6). So too are the threats of destruction. In response, the European Commission has initiated the Submerged Prehistoric Archaeology and Landscapes of the Continental Shelf (Splashcos) Project. Splashcos is a four-year (2009-13) research network funded by the European Commission. Its aim is to bring together archaeologists, marine geoscientists, heritage agencies, and commercial and industrial organisations interested in researching, managing and preserving the archaeological and palaeoclimatic information locked up on the drowned prehistoric landscapes of the European continental shelf, and to disseminate that knowledge to a wider audience (Splashcos 2014).

\section{In situ conservation}

Underwater cultural heritage is fascinating due to the mystery of its location underwater and its historical context. Some recent initiatives have allowed visitors in situ experiences, while at the same time ensuring the protection of the original site (Case Study 4.7).

\section{Intangible heritage}

Recognition that cultural heritage is not only tangible but also intangible has come rather late in the world of heritage protection. Nonetheless, since its adoption in 2003, the Convention for the Safeguarding of the Intangible Cultural Heritage has experienced rapid ratification, by more than 150 state parties in less than 10 years. The convention is now the main international framework for considering intangible heritage.
The definition of intangible heritage under the convention is:

[T] he practices, representations, expressions, knowledge, skills — as well as the instruments, objects, artefacts and cultural spaces associated therewith-that communities, groups and, in some cases, individuals recognize as part of their cultural heritage. This intangible cultural heritage, transmitted from generation to generation, is constantly recreated by communities and groups in response to their environment, their interaction with nature and their history, and provides them with a sense of identity and continuity, thus promoting respect for cultural diversity and human creativity. (UNESCO 2003:2)

Intangible cultural heritage is expressed through:

- oral traditions and expressions, including language

- performing arts

- social practices, rituals and festive events

- knowledge and practices concerning nature and the universe (including ethnobotanical knowledge)

- traditional craftsmanship (UNESCO 2003).

UNESCO has recently added traditional Japanese washoku cooking methods, Korean kimchi-making and China's use of the abacus to its 'intangible cultural heritage' list.

Much of this intangible heritage relates to place-for example, the locations where resources were collected for traditional crafts or food, places of ritual, social or ceremonial activity or where people followed a traditional route to a particular location or conducted a specific activity. Continued connections with these places can be important for the cultural identity of a diverse array of communities, from indigenous peoples to picnickers.

Identifying and protecting intangible heritage in the context of protected areas can be complex and challenging. Intangible heritage exists intellectually within a social group and helps to bind that group, and is almost always held orally, at community, family and individual levels. Effective processes for consulting with knowledge-holders is therefore essential if the information is to be incorporated into protected area management-for example, in the development of a plan of management (see Chapter 13). Safeguarding measures for ensuring the viability of intangible cultural heritage often include transforming oral information into written records. In the process of transforming this information, due consideration must be given to confidentiality of culturally sensitive information and intellectual property rights. 


\section{Case Study 4.8 Mount Kailas: A sacred mountain}

Mount Kailas in Tibet is the most sacred mountain in the world for up to a billion people in Asia. This famed snowshrouded holy peak, situated to the north of the Himalayan barrier in western Tibet, is one of the most revered pilgrimage sites for Hindus, Buddhists, Jains and Bonpos (pre-Buddhists) and draws pilgrims from India, Nepal,
Mongolia, Tibet, Japan, China, South-East Asia and other parts of the world. At the slopes of Kailas, a stream is said to pour into Lake Manasarovar and from this lake flow four of Asia's great rivers: the Indus, the Brahmaputra, the Karnali and the Sutlej. It is the most sacred lake in the world for most Hindus.

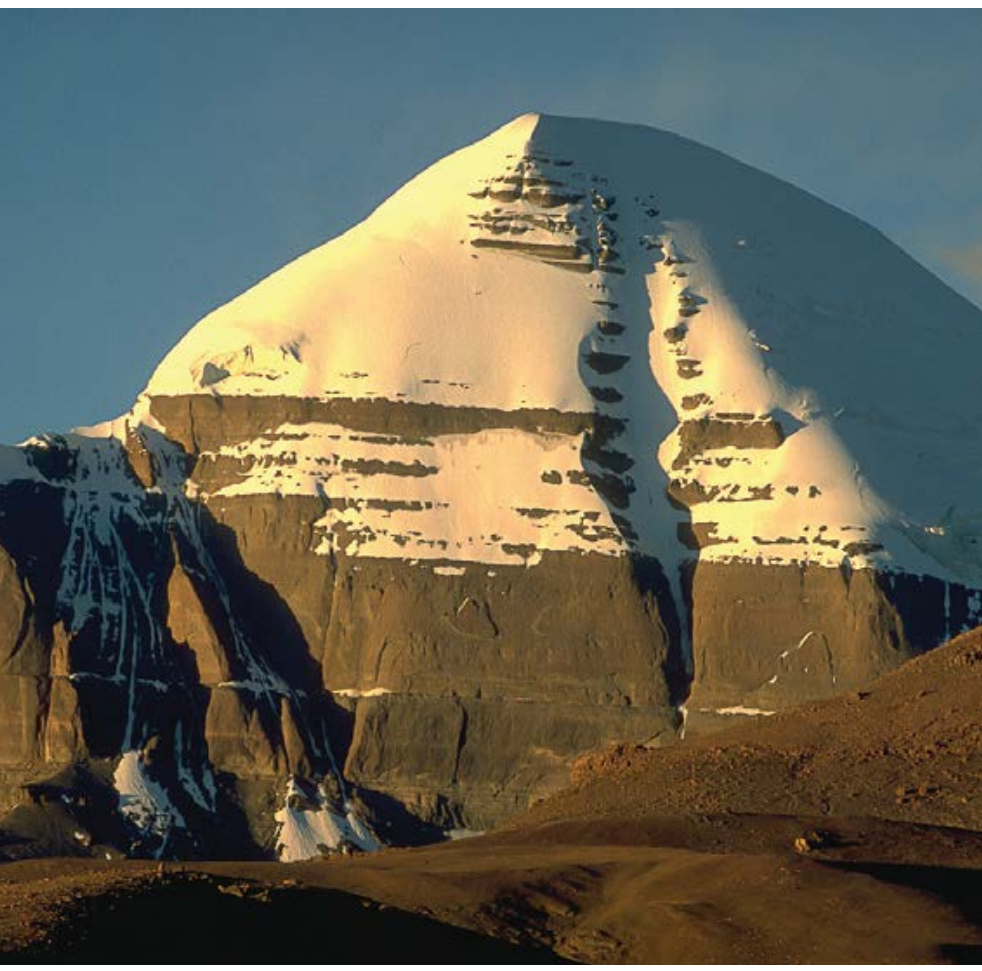

Mt Kalias, Tibet

Source: (c) Edwin Bernbaum

Thus they are indivisible from traditional knowledge and therefore from the peoples who hold that knowledge. In the past two decades, the conservation movement has been engaging much more in valuable dialogue with the guardians of sacred natural sites, some of whom are themselves interested in gaining a better understanding of the natural sciences as a basis for conservation management of the site.

\section{Social places}

For the purposes of this book, social places are distinguished from sacred places, although the boundaries are fuzzy. Whereas knowledge of sacred places is often privileged and passed on to selected individuals through ritualised behaviour, social places hold collective meaning for a community (Case Study 4.9) or a nation: a strong emotional attachment arising from historical or religious use or a particular event associated with that location or natural feature. People across the world intellectually or physically create their own social places, including nonindigenous communities in settler societies, minority ethnic groups and transnational groups such as refugees fleeing to Australia from war-torn countries of the Middle East.

Protected areas are social places in themselves, either in their entirety or in relation to places or features within protected areas. Formal protected areas and the use of science to determine their location, size and management regimes are as much part of the cultural heritage of contemporary society as are the sacred groves and taboo sites of indigenous and tribal societies; they just come about by a different pathway. The protected area system, as well as being a political response to the ongoing and increasing impacts of humans on the environment, also reflects societies' emotional attachment to the natural environment (Box 4.3).

That some places are important to a community for social (as opposed to utilitarian) reasons became apparent during debates in the 1980s on sustainable development leading to the 'triple bottom line' approach to development, with 'social' factors being given equal weighting to 'environmental' and 'economic' factors (WCED 1987). The sustainable development discourse emerged from the bitter clashes over forest logging and its impacts on poor people in developing countries, going on to have far-reaching consequences for community involvement in natural resource management, including protected area management.

Johnston (1992) ascribes the following attributes to social places:

- spiritual and traditional connections to past and present (sacred places)

- tie the past affectionately to the present, but may blot out events for which we have no affection-for example, the Holocaust, genocide in colonial history, slavery

- reference point for a community's identity or sense of self-but not necessarily inclusive of all the community

- visible in daily workings of a community, but can also include places with no visible character 


\section{Case Study 4.9 The role of protected areas in the lives of recent migrants}

While globalisation and air transport give people choices to move all over the world, citizens of countries experiencing war may have little choice but to flee to a country that will accept them as refugees. A recent study of new migrants to Sydney, Australia's largest city, demonstrates the important role protected areas play in stabilising the lives of displaced and traumatised peoples.

Byrne and Goodall (2013) have shown that the practice of place-making - the way inhabitants of an area work to make spaces habitable by imprinting them with the patterns of their own local lives-is particularly significant for migrants. Through their interviews and observations of recent migrants from Vietnam and the Middle East using Georges River National Park, in Sydney, the researchers found that picnicking in the national park close to their suburb enabled migrants to maintain and extend social ties and contacts at the same time as they acquainted themselves with the Australian natural environment. The picnics tended to be held at specific, chosen locations in the park and as these areas became more familiar they constituted a foothold for recent migrants in the park environment. These picnics are less about ethnicity and more about homesickness, shared identity and a shared experience of being outsiders in a new city (Byrne and Goodall 2013).
National parks are attractive to recent migrants partly because they constitute space that is not 'fixed' or 'constrained' in the same way as built urban space. Protected areas such as national parks are relatively unstructured and unsupervised spaces that are far more open and unconstrained than most of the built public spaces of cities. In the course of the picnics, associations are created between a locale and the social experiences people have there. The activity at a locale, especially if it is repeated regularly over time, creates a 'cultural place out of a natural space'. The bonds formed with the natural environment play a role in the settlement of migrants in unfamiliar lands. They also evoke memories of activities in the home country and a kind of cross-border social connectivity termed 'transnationalism'. Thus, certain villages in countries like Lebanon and China are now more intimately connected to suburbs in Sydney than they are to other population centres in Lebanon and China.

Development of a sense of ownership of protected area space, via place-making, is fundamental to the development of a sense of responsibility for that space. Recognition by protected area managers of migrant place-making will enhance the sense of responsibility by these visitors, who represent a growing proportion of the constituency national parks rely on for support.
- provide a community function that develops into a deeper attachment beyond utility, which could be physical or associated with a place

- shape community behaviour and attitudes

- accessible to the public, repeated use and ongoing connection

- where people meet and gather as a community.

People's social attachment to the natural world is the basis of much of the conflict and debate over protected area management, particularly in relation to access and resource use. Promotion of protected areas for their recreation opportunities requires management responses to ensure against potential environmental degradation and, in some cases, this means exclusion of certain human activities (Chapter 23).

Despite sound justification for such exclusion, when visitors are no longer able to camp where they have for generations, when pastoralists can longer graze their cattle or when people can no longer collect firewood or fish, the ensuing sadness and anger are a reflection of their social attachments to the places and things they hold dear.

\section{Culturally significant animals and plants}

Human history is characterised by the nature of its relationships with plants and other animals, and in this sense, all plants and animals are culturally significant (Willow 2011). Many species of plants and animals and their genetic signatures have special cultural significance to different cultures across the world-for example, in medicine, religious and ritual behaviour and in ceremonial life. The relationship between humans and plants/animals is particularly prevalent in animistic or indigenous religions in which plants and animals can be 'spirit beings', imbued with spiritual meaning that connects people with nature, and is the basis of the world view of many indigenous cultures across the world.

A cultural species is one for which there are deeply held cultural values associated with the species. Some animals are deeply sacred and never consumed, such as cows in Hinduism; others have both a ritual and a utilitarian function, such as pigs in Melanesia and the Maasai's cattle in Kenya, while others assume a special status through human sentiments, such as the quasi-spiritual attachment Western society has developed for cetaceans through the 'new age' movement (Case Study 4.10). Such attachments are positive in that they engender public support for protection of the species-unfortunately not extending to other, less charismatic creatures such as the legless lizards of Australia (Aprasia sp.) or southern bluefin tuna (Thunnus sp.) that are equally in need of conservation.

Many plant species are also culturally significant. Yams (Dioscorea sp.), wild and cultivated, are one of the most important food crops in Pacific cultures, with great utilitarian as well as symbolic significance. Yams are used extensively in religious ceremonies and some varieties are credited with magical properties. Events in the yam agricultural cycle are widely celebrated (Alexander and Coursey 1969). 


\section{Box 4.3 Wilderness: Places of high social value}

Wilderness (IUCN Category lb) is land least modified by humans when compared with other IUCN categories (see Chapters 2 and 8). Arguably, wilderness is the most 'socially constructed' of all protected areas, and in recent years, one of the most controversial. Many people have derided wilderness for putting humans outside nature and effectively negating cultures whose religions and world views are deeply embedded in the natural environment. It is also enigmatic insofar as wilderness areas have been declared over tracts of land that contain subtle, or even obvious, evidence of the hand of humans, from Aboriginal rock paintings to historical mining sites, bridle paths, huts and timber harvesting.

The United States was the first country to legally define and designate wilderness areas, reflecting a metamorphosis in American attitudes to 'wild places'from something to be feared to something to be revered. One settler in the early 1600 s stated that '[w]ilderness is a dark and dismal place where all manner of wild beasts dash about uncooked' (Wilderness.net 2014). In settler societies such as Australia and North America, the struggle to clear and cultivate natural lands was a way of civilising wild places. In contrast with this utilitarian ideal, three centuries later, an American author stated that wilderness 'is the ultimate source of health-terrestrial and human' (Wilderness.net 2014). Subsequently, countries around the world have protected areas modelled after the American Wilderness Act of 1964.

Wilderness means different things to different people. Influential 18th-century writer and literary critic Samuel Johnson described wilderness as 'a tract of solitude and savageness' (Ransom 1991:19). It is also described in terms of national identity:

$[T]$ he land that was-wild land beyond the frontier ... land that shaped the growth of our nation and the character of its people. Wilderness is the land that is-rare, wild places where one can retreat from civilization, reconnect with the Earth, and find healing, meaning and significance. (Wilderness.net 2014)

There are also the urban equivalents: 'tame' wildernesses, such as nature strips or large city parks (Ransom 1991:18).

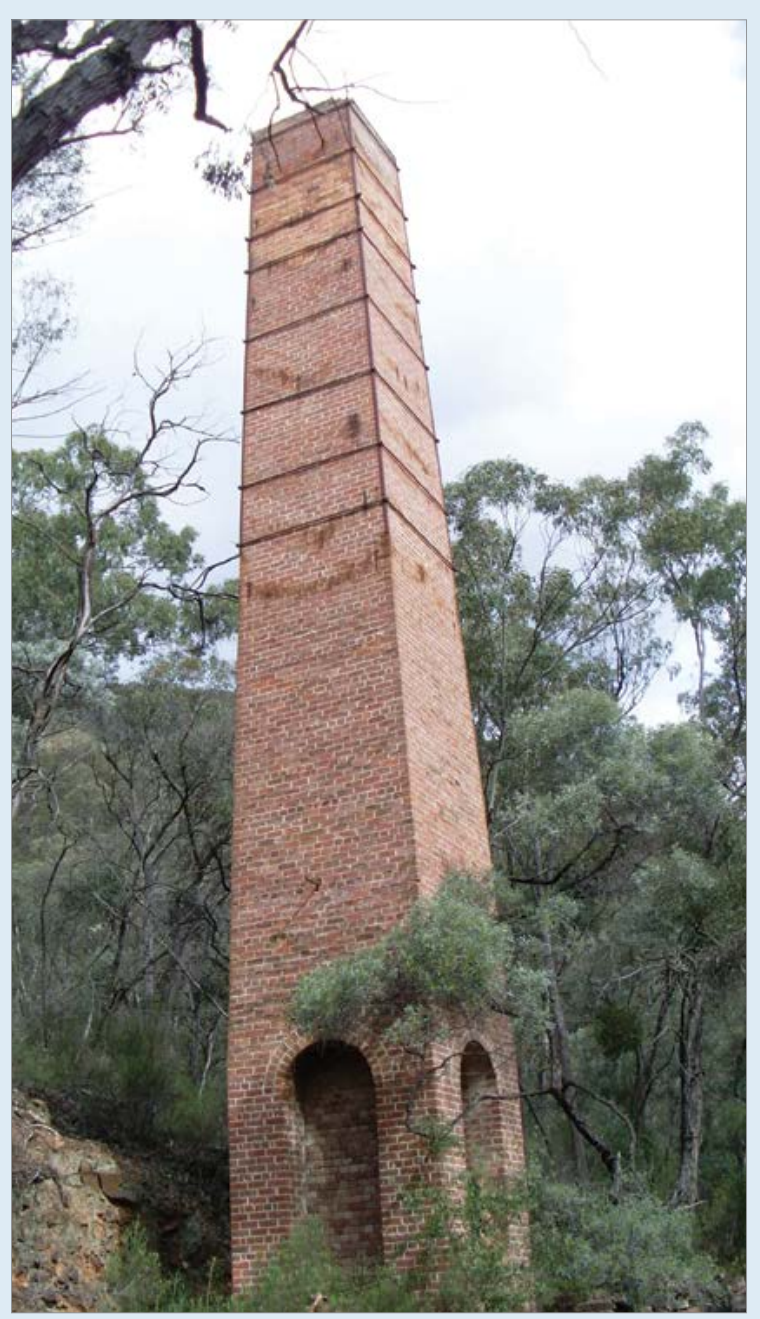

Chimney at the abandoned Tolwong copper mine, Ettrema wilderness, Morton National Park, Australia

Source: S. Feary

Regardless of how 'wild' they really are, wilderness areas contribute to the social health and wellbeing of humans, at least in the Western world. The benefits wilderness areas provide are as diverse as the areas themselves and are highly valued. Wilderness continues to be contested ground in debates around the nature-culture divide, but that it has become a deeply spiritual place for hardy bushwalkers, artists and poets coping with an urbanised Western world cannot be denied. 


\section{Case Study 4.10 Interactions between humans and dolphins}

Dolphins are wild marine mammals with which many humans form strong emotional attachments. There are numerous books and websites advocating the strong, almost spiritual affinity between humans and dolphins, including stories of dolphins saving people from drowning or protecting them from harm at sea-for example, a surfer being saved from a shark attack by dolphins in Monterey Bay, California. Some believe that dolphins often serve as our guides and protectors and are nurturers and healers, producing feelings of peace, harmony or overall acceptance and wellbeing (Psychic Universe 2014). In Western Australia, thousands of humans flock to the World Heritage-listed Shark Bay Marine Park Area to visit Monkey Mia, one of the few places where it is possible to 'commune' with quasi-tame dolphins in their natural environment.

\section{Case Study 4.11 Protecting traditional breeds of cattle}

Traditional forms of land use are still practised in Hortobágy National Park-the Puszta, in eastern Hungary. The present landscape has been shaped by a shepherding culture evolved over many centuries, resulting in unique styles of clothing, architecture and tending of animal species. Animals being grazed on this vast grassland plain, the largest in Europe, include the historical domestic cattle breed 'Hungarian grey' (Bos primigenius taurus Hungaricus), once threatened with extinction. The most imposing of all Hungary's farm animals, the breed played a significant role in Hungarian agriculture from the Middle Ages until the beginning of the 20th century. It was bred as beef cattle that could be driven to the markets of Western countries but was also used for draught. Their presence in Hortobágy National Park maintains the cultural landscape, preserves a gene bank and ensures preservation of the traditional knowledge associated with its husbandry (Puszta.com 2014). In 1993 the Hungarian Puszta was listed as a World Heritage cultural landscape shaped by a pastoral human society, preserving intact and visible the evidence of its traditional use over more than two millennia and representing the harmonious interaction between human beings and nature (UNESCO 2014e).
Protected areas, particularly those with lived-in landscapes, have a very important role to play in conserving agrobiodiversity (Amend et al. 2008). There are a number of ways that protected areas can safeguard culturally significant domesticated fauna and flora including

- protection of archaeological and historical evidence for the significance of the species-for example, paintings, sculptures and figurines depicting the nature of the human-animal relationship

- protection of the species and its genetic formula, including historical domestic breeds threatened with extinction (Case Studies 4.11 and 4.12)

- protection of the traditional knowledge (intangible heritage) that gives cultural meaning to the species. For generations, herdsmen and nomads have used their cultural and technical knowledge to actively manipulate species to increase production but it is only now being recognised. Indigenous breeding knowledge is made up of various concepts and practices used by livestock breeders to influence the genetic composition of their herds (KöhlerRollefson 2014).

\section{Beautiful places}

There is more than a passing connection between beauty or aesthetic appeal and protected areas: 'aesthetic experience of nature has been and continues to be a vitally important factor in the protection and preservation of natural environments [and] this relationship between aesthetic appreciation and environmentalism has a long and interesting history' (Carlson 2010:290).

Beauty is that combination of qualities that pleases the aesthetic senses of human beings, particularly the visual senses. Providing opportunities for people to experience picturesque and scenic places drove the earliest national park proclamations, and protection of Yosemite Valley in the mid 19th century was based primarily on scenic value, with similar examples found across the world (Mitchell 2013). Protection of aesthetic quality is often an objective for a protected area-for example, it is a primary objective for some of China's national parks (Wang et al. 2012).

Loss and degradation of landscape beauty became of increasing concern to many countries in the mid 20th century (Selman and Swanwick 2010). In recognition 


\section{Case Study 4.12 Protecting potato varieties}

In the Peruvian highlands, six communities of the Quechua people have established el Parque de la Papa to conserve 1200 potato varieties occurring in more than 8500 hectares of communal land as well as natural ecosystems of the Andes. This is the pilot project for the Ruta Sagrada del Condor-Wiracocha network of protected landscapes based on traditional agriculture across seven countries, from Venezuela to Chile, covering the pre-Hispanic Andean region (Sarmiento et al. 2005).

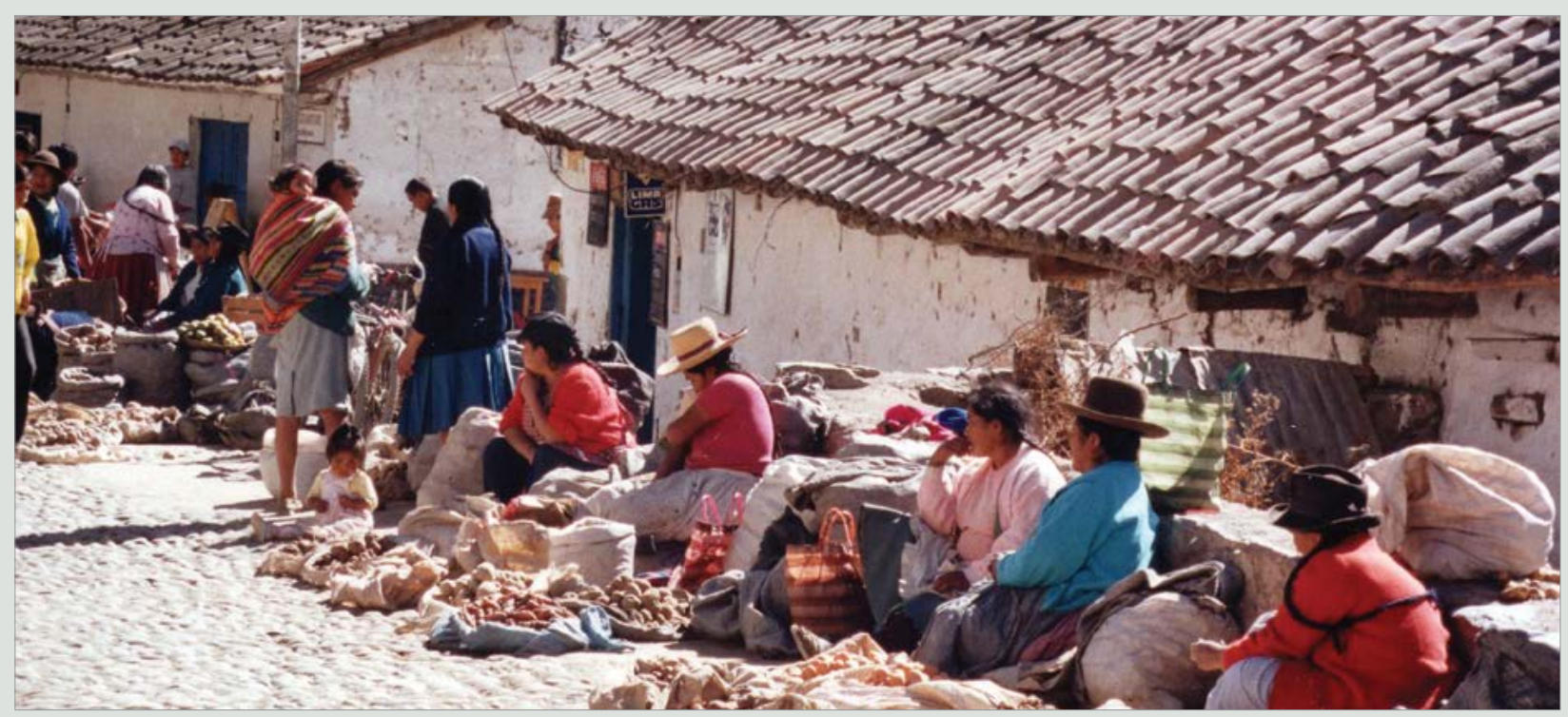

Women selling their potatoes at market, Peru, South America

Source: S. Feary

of the close relationship between aesthetic appeal and landscape attributes, the 1972 World Heritage Convention defined 'natural heritage' as follows:

- natural features consisting of physical and biological formations or groups of such formations, which are of outstanding universal value from the aesthetic or scientific point of view

- natural sites or precisely delineated natural areas of outstanding universal value from the point of view of science, conservation or natural beauty (UNESCO 1972).

Criterion (vii) for natural heritage in the current World Heritage Convention operational guidelines recognises beautiful places as containing superlative natural phenomena or areas of exceptional natural beauty and aesthetic importance' (UNESCO 2013:21). Thus, problematically, the convention and Criterion (vii) both view the beauty and aesthetic value of places as intrinsic or inherent qualities of the natural world. In contrast, social scientists view the aesthetic appeal of landscapes as a subjective human sensory experience (Mitchell 2013). The idea of beauty and aesthetics is best recognised as a combination of natural features and human perception (Case Study 4.13).
Aesthetic qualities or values are not confined to the visual senses. The Australian ICOMOS Committee defines aesthetic value as human sensory responses to such attributes as form, colour, scale, texture and materials, as well as smells and sounds associated with the place and its use (Australia ICOMOS 2000). This meaning is intended to refer to both the built environment and natural areas. People often have visceral responses (that is, give meaning) to being in places of outstanding beauty and aesthetic appeal, demonstrating the strong psychological element to aesthetic appeal.

A recent IUCN review of the application of World Heritage List Criterion (vii) notes that there are currently 133 properties inscribed on the list on the basis of Criterion (vii), the majority of which occur within protected areas (Mitchell 2013). The review identified inconsistences in application of the criterion over time and discussed the challenges of finding methodologies for objective evaluation of 'exceptional natural beauty and aesthetic importance'.

In the evaluation of Mount Sanqingshan National Park, in China, the IUCN determined that the property met Criterion (vii) because the 'remarkable granite rock formations combined with diverse forest, near and 


\section{Case Study 4.13 Monarch Butterfly Reserve, Mexico}

In 2008, the Monarch Butterfly Biosphere Reserve in Mexico was inscribed on the World Heritage List under Criterion (vii)-aesthetic value. It is a conservation area and World Heritage site within the wintering grounds of most of the monarch butterflies that migrate from east of the Rocky Mountains for up to 4000 kilometres south to central Mexico. The IUCN's evaluation considered that the overwintering concentration of the monarch butterfly (Danaus plexippus) is a superlative natural phenomenon in the meaning of Criterion (vii). The monarch butterfly migration is considered the classic example of two-way insect migration, involves millions of individuals and is as long as or longer than the distance covered by any other insect migration. Of many insect migrations, none compares with that of the monarch butterfly in terms of length, regularity, singularity and visibility on site (Mitchell 2013) distant vistas, and striking meteorological effects to create a landscape of exceptional scenic quality [and that] the most notable aspect is the concentration of fantastically shaped pillars and peaks' (Mitchell 2013:20).

Aesthetics is a complex topic and we touch on some of the more relevant aspects including familiarity, accessibility, knowledge and wellbeing. Familiarity refers to the attachments and connections that people develop for landscapes and the sense of loss that can ensue from changes to familiar landscapes (Itami 1993). For example, the new glacier skywalk in Jasper National Park is a stunning piece of architecture, but it is controversial because it confronts the senses of those who yearn for naturalness in a national park.

A deep affection for landscapes can arise from knowledge of the place (Itami 1993). Increasing people's knowledge of the landscape through education can increase the value they place on the landscape. Hence the importance and popularity of nature-based television documentaries and protected area field education programs during school holidays.

There is an extensive body of literature that demonstrates the positive benefits to humans that arise out of contact with natural settings, exemplified in the 'Healthy Parks, Healthy People' philosophies being embraced by many protected area agencies across the world. A sense of wellbeing can be understood within the meaning of aesthetics. For example, taking troubled youth 'out bush' is a therapeutic technique that has been shown to provide benefits. In Australia, the 1991 Royal Commission of Inquiry into Aboriginal Deaths in Custody recommended programs for getting Aboriginal people back on country through involvement in land management to assist in improving health and cultural wellbeing (Government of Australia and Johnston 1991). This was an important driver for development of national park co-management arrangements in many Australian States and Territories.

\section{Entangled landscapes of nature and culture (biocultural/cultural landscapes)}

\section{Nature and culture as coevolved}

Earlier we discussed how the idea of heritage originated in Western knowledge systems - a scheme that has a long history of viewing nature and culture as separate parts of the same landscape. This separation is embedded, for example, in the Operational Guidelines for the Implementation of the World Heritage Convention (UNESCO 2013), which recognise sites as natural, cultural or mixed. The history of protected areas, again originating as a Western concept, also has a long history of conceptualising nature and culture as separate. This separation is hard to maintain when we examine closely the real world of people's lives and their engagement with and 'being in' the environment.

Separation of nature from culture is a distinctive feature of Western thinking and is not how many other cultures conceptualise the world. For example, for contemporary Australian Aboriginal people the concept of 'caring for country' is a complex notion related to personal and group belonging and to maintaining and looking after the ecological and spiritual wellbeing of the land and of oneself. Equally, the traditional Chinese view of nature emphasises harmony and 'oneness with nature', in which nature and people form a cosmological whole (Han 2012:92-3). Aside from the strong influence of indigenous and Eastern world views, an approach to breaking down the division of nature/culture in Western thinking has been to adopt a concept of cultural landscape.

\section{What is a cultural landscape?}

The term cultural landscape has its origins in Western knowledge systems. Landscape, in this context, means land shaped by its people, their institutions and customs (Tuan 2002). Culture means people's 'way of life', thus cultural landscape, in general terms, means 'those areas which clearly represent or reflect the patterns of settlement or use of the landscape over a long time, as well as the evolution of cultural values, norms and attitudes toward the land' (Context et al. 2002:9). 


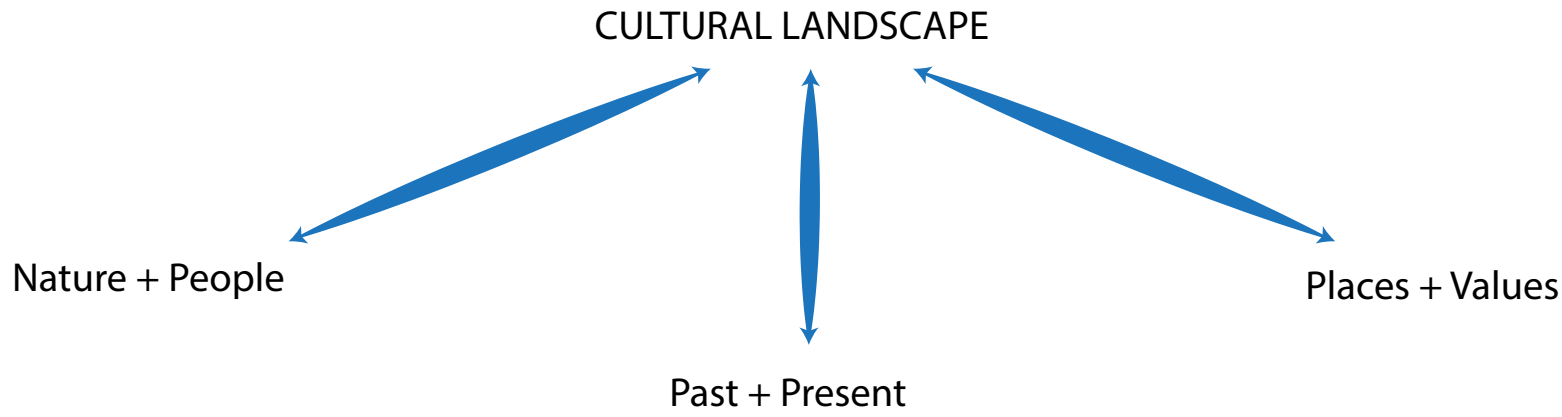

Figure 4.3 Elements of a cultural landscape

Source: Phillips (2002)

The idea of cultural landscapes, which emerged from within the field of geography in the late 19th century, is defined by UNESCO as the combined works of nature and humankind. Thus, the cultural landscape concept emphasises the landscape-scale of history and the process of connectivity between people and places. It recognises the present landscape as the product of long-term and complex entanglements between people and the environment, and challenges the nature-culture dichotomy. A way of representing the idea of cultural landscape is illustrated in Figure 4.3.

\section{Examples of cultural landscapes}

The idea of cultural landscapes emphasises the coevolution and entanglement of geographical areas, biophysical processes and human presence. So in one sense the whole of the Earth is a cultural landscape because either humans have been present or human presence has affected ecosystems. Some pasts may have 'touched the landscape only lightly'-for example, parts of the Amazon Basin, the boreal forests of Canada, Antarctica or the deep ocean floors - while some places of historical activity are marked by imposing built structures (for example, the pyramids of Egypt) or are commemorated for their association with important events or people (for example, Nelson Mandela's association with Robben Island, South Africa).

In practice, the idea of cultural landscapes is applied to specific parts of the planet for the purpose of identifying, evaluating, managing and celebrating important heritage values. The World Heritage List currently recognises 82 properties as cultural landscapes. Three examples from the diverse range of cultural landscape are the following.

- Tongariro National Park (New Zealand): The first World Heritage-listed cultural landscape, the volcanic Mount Tongariro plays a fundamental role through oral tradition in defining and confirming the cultural identity of the Ngati Tuwharetoa iwi; and the natural beauty of Tongariro is the spiritual and historical centre of Maori culture (Lennon 2006).

- Chief Roi Mata’s Domain (Vanuatu): Landscapes and waterscapes associated with the life and death of the last paramount chief of Vanuatu in the early 17th century (Galla 2012).

- Agave Landscape and Ancient Industrial Facilities of Tequila (Mexico): Part of an expansive landscape of blue agave, shaped by the culture of the plant used since the 16th century to produce tequila spirit and for at least 2000 years to make fermented drinks and cloth. The property also contains agricultural terraces, housing, temples, ceremonial mounds and ball courts associated with Teuchitlan culture (UNESCO 2014f).

In applying the idea of cultural landscape in World Heritage listing, UNESCO adopts three categories: 'designed landscapes'-landscapes that are designed and intentionally created such as gardens and parklands; 'organically evolved landscapes'-large areas resulting from social, economic, administrative and/or religious activities over time, including agricultural landscapes; and 'associative landscapes'-locations with powerful religious, artistic or cultural associations (UNESCO World Heritage Centre 2011:Annex 3).

In the United States, large-scale regional landscapes of national importance are designated as National Heritage Areas (Mitchell and Melnick 2012). These are cultural landscapes where history and heritage intersect with everyday places where people live and work. They can be described, for example, as 'lived-in landscapes' and include industrial landscapes_-for example, Blackstone River Valley National Heritage Corridor and Augusta Canal. 


\section{Applying cultural landscapes in protected area management}

The idea of cultural landscapes offers a conceptual tool that can be applied in protected area management to work towards the integration of natural, cultural, tangible and intangible heritage, and biological and cultural diversity. In order to achieve such integration, it is necessary for protected area staff trained in the Western traditions of environmental sciences, as well as those trained in the humanities/social sciences, to be able to break free of disciplinary boundaries in order to recognise the socio-natural construction of landscape. This can be a challenging task, but in recent decades, the idea of cultural landscape has been widely applied in the field of protected area management (Buggey 1999; Lennon 2006; Brown 2010). Previously, cultural heritage sites tended to be seen as isolated points or pathways set in a natural landscapethe 'dots on the landscape' approach. They may be subject to legislation and regulation separate from that for the natural environment.

A cultural landscape approach offers an opportunity to integrate natural and cultural heritage conservation by seeing culture and nature as interconnected dimensions of the same space. As we have seen above, this is because '[a] cultural landscape perspective explicitly recognises the history of a place and its cultural traditions in addition to its ecological value ... A landscape perspective also recognises the continuity between the past and with people living and working on the land today' (Mitchell and Buggey 2001:19).

One approach to recognising cultural landscapes in protected areas is to apply general principles. For example, in New South Wales, Australia, applying a cultural landscape approach to the management of protected areas uses a number of general principles:

- landscape is a living entity, and is the product of change, dynamic patterns and evolving interrelationships between past ecosystems, history and cultures

- the interactions between people and landscape are complex, multi-layered and are distinctive to each different space and time

- multiple engagement and dialogue, where all people's values are noted and respected, are characteristic of a cultural landscape mentality

- all parts of Australia's landscape have community connection and associated values and meanings

- a key element of cultural landscapes is the continuity of past and present (Brown 2010, 2012).
A key emphasis of this cultural landscape approach is the need to integrate people's stories, memories and aspirations continually into management processesthat is, to recognise that the cultural values of landscapes are inextricably bound up with the lived experiences, identities and connections of past and present individuals and communities as well as with ecology, hydrology and geodiversity. Active management programs need to take into account the spiritual and symbolic meanings that people ascribe to protected area landscapes as well as the written history and physical evidence. Furthermore, protected area managers need to understand how these meanings support community identity, wellbeing and human rights. By understanding, respecting and acknowledging people's attachments to and feelings for landscapes, park managers can help ensure there is longterm community support for protected areas.

It can be useful to identify selected parts of protected areas as cultural landscapes for the purpose of management. Specific management objectives will determine where this can be an effective conservation approach (Case Study 4.14).

\section{Introducing cultural heritage management}

Previous sections in this chapter have described cultural heritage - the tangible and intangible evidence for human presence on Earth-and its intersections with protected areas. This section examines how a society comes to value its heritage, and the translation of those values into management and conservation of cultural heritage. Global agencies concerned with management and protection of cultural heritage include UNESCO, the International Council for Monuments and Sites (ICOMOS), the International Centre for the Study of the Preservation and Restoration of Cultural Property (ICCROM) and the International Council of Museums (ICOM).

The Venice Charter of 1974 for the Conservation and Restoration of Monuments and Sites was the first to develop a code of professional standards that continues to provide an international framework for the preservation and restoration of ancient buildings. Numerous UNESCO conventions have since recognised intangible heritage and cultural landscapes as cultural heritage. The processes, practices and policies laid out by these and other agencies for managing and protecting cultural heritage have been shaped by transformations in the meaning of cultural heritage, which has in turn responded to social changes across the globe, particularly recognition of social values. 


\section{Case Study 4.14 Forest as historic artefact: The cultural landscape of Washpool National Park, Australia}

Washpool National Park comprises a landscape of diverse forest types on the Great Dividing Range in eastern Australia. In 2007 a study was undertaken to investigate the extent to which the forests are a product of cumulative transformation through seasonal grazing and forestry operations-that is, a cultural landscape. The 'forest as historic artefact' study endeavoured to integrate information derived from both historical and ecological sources. The historical methods involved a literature review of the history of the landscape and the field study involved field-based discussions with current and former land-users, which provided invaluable understandings of vegetation-based evidence of past and current land-use and land management practices. The ecological methods utilised for the study involved a literature review of the ecology of the landscape as well as a field-recording program. The field study examined 12 sample plots and two examples illustrate the field process and results.

A field sample plot was located in the former Curramore State Forest, an area that has never been logged and was leased for cattle grazing by the Sloman family from the early years of the 20th century to the 1990s. Seasonal (winter) grazing in the local dry open forest involved regular (spring) low-intensity burning to encourage understorey regrowth. Two features of the vegetation structure were recognised that result from high-frequency fire regimes and grazing pressure on vegetation. First, the firing regime and seasonal grazing changed the species composition and structure of the forest understorey and increased the density of naturally occurring grass species. Second, there has been a reduction in the regeneration capacity of canopy trees leading to long-term change in vegetation structure.
A second field sample plot (Coombadja Creek) was located in an area of dry sclerophyll forest that was selectively logged in the late 1960s. Material evidence of logging includes multiple cut tree stumps, reject saw logs on the heavily overgrown track, a log loading ramp, log loading area and evidence of tree damage caused by forestry machinery. A key feature of the local vegetation subject to logging is, not surprisingly, reduced density of old-growth trees, reflecting the resource focus on saw log production.

Disentangling disturbance evidencing past and present activity from ecosystem processes within a forested landscape is a complex task. Nevertheless, a cultural landscape approach is useful in conceptualising forested landscapes as continually transforming as a result of complex interactions between ecological processes and human activities. Each historical activity not only adds a new and distinct layer, but also influences the trajectory of later forest regeneration and transformation processes.

The implication for forest management is not that forested landscapes should or can be 'frozen' in time such that markers of historical activity are conserved, but rather that documenting and understanding ecosystems and past/present human land use are an essential part of conservation. Such an approach does not undermine an aim of optimum biodiversity and ecosystem health and resilience, but does challenge park management to be clear concerning what it is that is being conserved. It assists with the management of a complex system (see Chapter 10).

Sources: Adapted from Dean-Jones and Brown (2012); Brown (2012)
Contemporary cultural heritage management is a multidimensional and pluralistic process and there is a vast literature on the subject. Put briefly, cultural heritage management is a rational process for deciding whether and why a cultural phenomenon is worth protecting and the form of that protection. The process is shown in Box 4.4 .

\section{Using values as a basis for management}

The steps in Box 4.4 are a clear indication that 'value' provides the motivation for protection of cultural heritage and the direction for its management (as it does for natural heritage). In this context, value refers to the quality and character of a phenomenon (Mason 2008). It is self-evident that no society makes an effort to conserve what it does not value (Mason 2008).

Values are socially constructed, determined by a range of social and cultural factors. What is valued by one section of society may not be valued by another, or may be valued for a different reason, or one generation may value it but it may not be valued by the next generation (Lockwood 2006; Chapter 6). Values are dynamic and frequently contested, so the process of assigning values to something must be rigorous, transparent and objective. Many different sets of criteria exist for evaluating and articulating cultural heritage values. The Australian Burra Charter, an Australian adaptation of ICOMOS, identifies five cultural values, as shown in Table 4.1. The table also includes a classification of protected area values. 
Table 4.1 Cultural and protected area values

\begin{tabular}{|c|c|}
\hline Cultural value type & Description \\
\hline Aesthetic value & $\begin{array}{l}\text { Sensory perception such } \\
\text { as form, scale, colour, } \\
\text { texture and material of the } \\
\text { fabric or the smells and } \\
\text { sounds associated with the } \\
\text { place and its use }\end{array}$ \\
\hline Historic value & $\begin{array}{l}\text { A place has influenced, or } \\
\text { has been influenced by, } \\
\text { a historic figure, event, } \\
\text { phase or activity; site of an } \\
\text { important event }\end{array}$ \\
\hline Scientific/research value & $\begin{array}{l}\text { Importance of the data; } \\
\text { rarity, representativeness, } \\
\text { degree to which the place } \\
\text { may contribute further } \\
\text { substantial information }\end{array}$ \\
\hline Social value & $\begin{array}{l}\text { Qualities for which a place } \\
\text { has become a focus of } \\
\text { spiritual, political, national } \\
\text { or other cultural sentiment } \\
\text { to a majority or minority } \\
\text { group }\end{array}$ \\
\hline Spiritual value & $\begin{array}{l}\text { Used to capture the } \\
\text { attachment between } \\
\text { humans and the natural } \\
\text { environment/place, being } \\
\text { more specific than social or } \\
\text { aesthetic value }\end{array}$ \\
\hline $\begin{array}{l}\text { Protected area } \\
\text { value type }\end{array}$ & Description \\
\hline Intrinsic values & $\begin{array}{l}\text { Fauna, flora, ecosystems, } \\
\text { landscapes and seascapes }\end{array}$ \\
\hline $\begin{array}{l}\text { Off-site goods and } \\
\text { services }\end{array}$ & $\begin{array}{l}\text { Life support; water and } \\
\text { air quality; fishery and } \\
\text { agriculture protection; } \\
\text { protection of human } \\
\text { settlements }\end{array}$ \\
\hline $\begin{array}{l}\text { On-site goods and } \\
\text { services }\end{array}$ & $\begin{array}{l}\text { Animal and plant products; } \\
\text { recreation and tourism; } \\
\text { historic sites and artefacts; } \\
\text { scientific knowledge, } \\
\text { research and education; } \\
\text { representations }\end{array}$ \\
\hline $\begin{array}{l}\text { Community value (non- } \\
\text { material) }\end{array}$ & $\begin{array}{l}\text { Culture, identity, spiritual } \\
\text { meaning, social wellbeing; } \\
\text { bequest for future } \\
\text { generations }\end{array}$ \\
\hline $\begin{array}{l}\text { Individual value/experiential } \\
\text { values (non-material) }\end{array}$ & $\begin{array}{l}\text { Satisfaction (existence and } \\
\text { experiential), physical and } \\
\text { mental health, spiritual } \\
\text { wellbeing }\end{array}$ \\
\hline
\end{tabular}

Sources: Australia ICOMOS (2000); Lockwood (2006).

\section{Box 4.4 Assessing cultural significance: Steps in the process}

1. Recognise the existence of the cultural phenomenon.

Note: not all protected area staff are formally trained to be able to recognise tangible or intangible cultural heritage.

2. Record and document the evidence-physical, written and oral.

Note: This often generates an inventory or a database. There can be issues around the 'ownership' of such databases and who controls their use.

3. Decide what is important about the place/feature and assign it to one or more categories. These categories are sometimes termed 'values'. An object, place or a cultural practice is assessed as having one or more defined values. To be recognised in protected area management, these values need to be connected with place, which could be an entire protected area, a specific location or a linear pathway.

Note: Values can be in conflict, interdependent or overlapping. Values are sometimes equated with significance. In this book, significance describes the degree to which a heritage phenomenon possesses the defined values (Lennon 2006:450).

4. Assessment of the significance of the cultural heritage phenomenon against a set of criteria as determined by relevant legislation or official guidance material: this determines the degree to which that value is expressed. Assessment of cultural significance is often conducted at several scales: international, national, regional and local.

Note: The final assessment integrates significance levels against all criteria although it may be predetermined that one criterion will be given greater emphasis-for example, social significance may be more important than historical significance.

5. Deciding on the most appropriate management approach, depending on the cultural significance but also cognisant of other factors such as financial requirements, political imperatives and broader protected area directions and priorities.

Note: This may include preparing a conservation or management plan for the cultural phenomenon.

6. Developing and implementing a program for managing/protecting the value and/or place, including a reporting and monitoring component. 
Table 4.2 indicates connections between cultural values and protected area values (highlighted). Individual values (protected area) can be equated with aesthetic and spiritual values (cultural) in the broadest meaning of the term, in that they both refer to personal sensory experiences, while community value (protected area) and social value (cultural) are also roughly equivalent. The protected area definition of 'on-site goods and services' includes scientific and historical values and alludes to social values (education and recreation). On-site goods and services have cultural value to the people who rely on them for their livelihoods. Off-site goods and services (protected area) include protection of human settlements, which is a social value, and ecosystem services are cultural insofar as they are critical to human life.

The remaining protected area value, intrinsic value, confers a value to the natural environment for what it is, independent of human attitudes or judgments, giving it a right to exist for itself (Nash 1989). Whether or not cultural heritage is likewise intrinsically valuable continues to be a source of academic debate. Some argue that heritage exists mainly in the context of the rise of cultural heritage management in the Western world in the late 20th century. It is defined with reference to social action that selectively commodifies and emphasises particular places as important (Harrison et al. 2008).

Randell Mason (2008) offers another view, arguing that typologies of heritage values should consider the notion of authenticity, which presumes that historic value is inherent in some truly old and therefore authentic material (insofar as it has witness to history and carries the authority of that witness). Similarly, Jane Lennon (2006) ascribes inherent/intrinsic values to accumulated historical character and material properties of historic heritage, illustrating historical testimonies and associated cultural values. Byrne (2008) also points out that much of the heritage discourse on intrinsic values has paid insufficient attention to the fact that a large proportion of the world's population believes that many heritage places are inherently sacred. It could be argued that intangible heritage is intrinsically valuable because there are no other ways of assessing it. If, for example, a person states that a place is sacred, can that be reliably and fairly assessed without questioning the very basis of that person's identity? A protected area manager can find this challenging, particularly when information about intangible heritage cannot be divulged.

\section{Who assigns values?}

Who is best placed to assign value and conduct significance assessment of cultural heritage? This is where the differences between tangible and intangible heritage become most apparent. Identification and assessment of most tangible heritage (archaeological, historic and maritime sites and movable heritage) rely on the testimonies of heritage experts from a range of professions and disciplines, such as archaeology, maritime archaeology, architecture, geography (physical and human), history and museology. Thus, an extensive worldwide heritage industry and its practitioners have 'owned' cultural heritage management for many decades.

In contrast, recognising and understanding intangible heritage require involvement of and dialogue with holders of the cultural information: local communities who live in or around the park, or park visitors and users. Participatory processes for involvement of knowledgeholders - often local indigenous or tribal communitiesmust be used in protected area management to ensure that intangible heritage is respected and that its physical manifestations are protected (see Chapter 22).

Table 4.2 Comparing cultural and protected area values

\begin{tabular}{|c|c|c|c|c|c|c|}
\hline \multicolumn{7}{|c|}{ Protected area values } \\
\hline & & Intrinsic & On-site & Off-site & Community & Individual \\
\hline \multirow{5}{*}{ 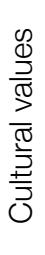 } & Aesthetic & & & & & \\
\hline & Historic & & & & & \\
\hline & Scientific & & & & & \\
\hline & Social & & & & & \\
\hline & Spiritual & & & & & \\
\hline
\end{tabular}




\section{Connections between culture, heritage and protected areas}

The extent to which culture and heritage benefit from the existence of protected areas is influenced by commonality and/or compatibility of the goals of cultural heritage and protected area management. Table 4.2 indicates some level of synergy in the values of the two systems and this provides a strong foundation for the managerial and operational capacity for achieving the goals of cultural heritage management in a protected area context.

At another level, protected areas have a unique capacity to protect cultural heritage. For the most part they have been set aside, as biodiversity and heritage conservation refuges, from the ravages of major developments or industrial-scale resource exploitation. These remnants of past landscapes come with their cultural elementsthe intangible and tangible cultural heritage-relatively intact. The extent to which the cultural heritage is given priority by managers, however, depends on four important considerations.

\section{Protected area category}

The IUCN's protected area categories, from Category I to Category VI (see Chapters 2 and 8), reflect a gradation of human intervention in the protected area, in both character and management (see Figure 2.1) (Dudley 2008). Category I (including wilderness) gives the least emphasis to humans, while Category V (protected landscape/seascape) and Category VI (protected area with sustainable use of natural resources) explicitly recognise human modifications to landscape character and/or human communities living in the protected area.

All categories recognise cultural heritage, particularly when the concept of cultural landscapes is applied. Category VI can allocate high priority to intangible cultural heritage, because human communities are often continuing their cultural traditions in the protected area and have primary responsibility for its management, as they do for Indigenous Peoples' and Community Conserved Territories and Areas (ICCAs).

Other management arrangements, such as joint management of a national park, can also enhance appreciation of cultural heritage (see Chapter 7). In Australia, the 55 Aboriginal-owned and managed Indigenous Protected Areas (2014) are in several IUCN categories (Hill et al. 2011).

\section{Protected area legislation may narrowly define cultural heritage as tangible heritage}

This is particularly relevant in the Western world and reflects a hangover from early definitions of cultural heritage. There is, however, sound evidence to demonstrate that protected areas may not achieve their goal of protecting nature without the support of citizens - often gained only by recognising the intangible cultural heritage encapsulated within the protected areas. For example, research into sustainable management of resources in the ecologically rich Mount Elgon region of Kenya has demonstrated that social unrest, environmental damage and wildlife poaching escalated until the central government recognised the critical importance of the national park for local livelihoods and also appreciated that local communities had managed resources sustainably for thousands of years prior to British colonisation (Gatunda 2002).

As with many other countries, in China, the national park system has both social and ecological goals, measured by its capacity to reduce poverty, promote long-term rehabilitation of wildlife habitats and protect Chinese culture and biodiversity (Wang et al. 2012).

\section{Staff may need training in managing cultural heritage}

Some protected area staff (and natural resource management staff more generally) may have limited training, skills or qualifications in cultural heritage management or social science, or an unrealistic understanding of what the job really entails:

Young natural resources or environmental managers are usually attracted to their professions to be outdoors, away from the maddening crowd and its socio political problems, working with physical and biological resources. Yet these new foresters, wildlife biologists, or ecologists often find themselves immersed in less tangible, more ambiguous social value issues as much as the natural resources they love and want to manage (e.g., owls vs. jobs vs. biological diversity values). This is especially true of those professionals employed by public agencies. Many young natural resource graduates are disappointed and frustrated to discover that being an effective professional and public servant is ultimately a social endeavour (Kennedy and Thomas 1995:311) 
To effectively manage cultural heritage, a protected area manager needs to know how to build a team which can recognise and protect an archaeological site, stabilise a historic building, document a cultural landscape, collect oral history information and understand community connections to place.

\section{Perceptions of cultural heritage management as being too difficult, less important than natural heritage or even an impediment to protecting biodiversity}

Staff untrained in or with no experience of cultural heritage management may find it overwhelming. Those with no interest may think it unimportant and in some cases outside the responsibilities of protected areas. This is more likely to occur among Western-trained staff, as indicated by this comment on the NSW National Parks and Wildlife Service in Australia: 'The Service has been through several phases of embracing or reluctantly accepting its role as historic site manager, a role it appears to feel sits uneasily with its nature conservation role' (Pearson and Sullivan 1995:60).

We conclude this section by noting that community social values are not always harmonious with nature conservation. Cultural heritage can involve practices and traditions inconsistent with protection of biodiversity, such as killing animals for traditional medicine, overzealous hazard reduction burning, hunting endangered species for food or recreational overuse.

\section{Conclusion}

This chapter has looked at cultural heritage through a lens of the relationship of people with the natural environment and with each other, in space and over time. We have shown that the cultural legacies of these relationships are interesting and diverse phenomena with both tangible and intangible dimensions. Cultural heritage is about the past but also connects humans with the present and envisages a future. It is the crux of identity; it can be uncomfortable, contested or divisive, but protected area managers will ignore it at their peril.

The concept and practice of protected area management are themselves cultural heritage, being the tangible expressions of societally generated beliefs and values about the natural world that have existed for thousands of years. Indigenous people's spiritual associations with the natural world were the foundation for the earliest forms of locally based environmental protection and remain pertinent in many parts of the world. Modern protected area management is guided by global systems manifested through the regulations of nation-states. Recognition of cultural heritage, especially intangible cultural heritage and social value, has been a major driver of substantive changes in protected area management philosophy and practice, placing it firmly in the arena of rights and social justice. Early definitions of cultural heritage were confined to monuments and sites, privileging rich countries and certain professions. The broadening to embrace intangible heritage and cultural landscapes increased understanding of the spiritual and social values of protected areas and gave some power back to the owners of that heritage.

We have shown that throughout the world protected areas have deep cultural values, to the extent that many are seen as flagships of nationality and often the cornerstone of national tourist industries. Protected areas and cultural heritage are not only compatible; they are also inexorably interconnected. Failure to comprehend the importance of cultural heritage to people is likely to result in a failure to meet biodiversity objectives due to lack of community support. Just as cultural heritage cannot be separated from the people who value it, neither can protected areas exist in isolation from and without the support of the broader community.

What are the benefits of protected areas for protecting cultural heritage? Protected areas endeavour to protect nature and natural processes in a world where development and change continue to encroach on the natural environment. At a global scale in 2014, protected areas are only 15.4 per cent of the Earth's terrestrial surface-a precious phenomenon. They are highly valued by humans, not only for their biodiversity, but also for the intangible and tangible cultural heritage they envelop, which may otherwise be destroyed by development. Being able to leave tangible cultural heritage within its landscape setting is much better than collecting it and putting it somewhere else, as is the ability to leave large cultural landscapes or places of spiritual value. It is virtually impossible to do this anywhere else. Protected areas are critical for the conservation of cultural heritage. 


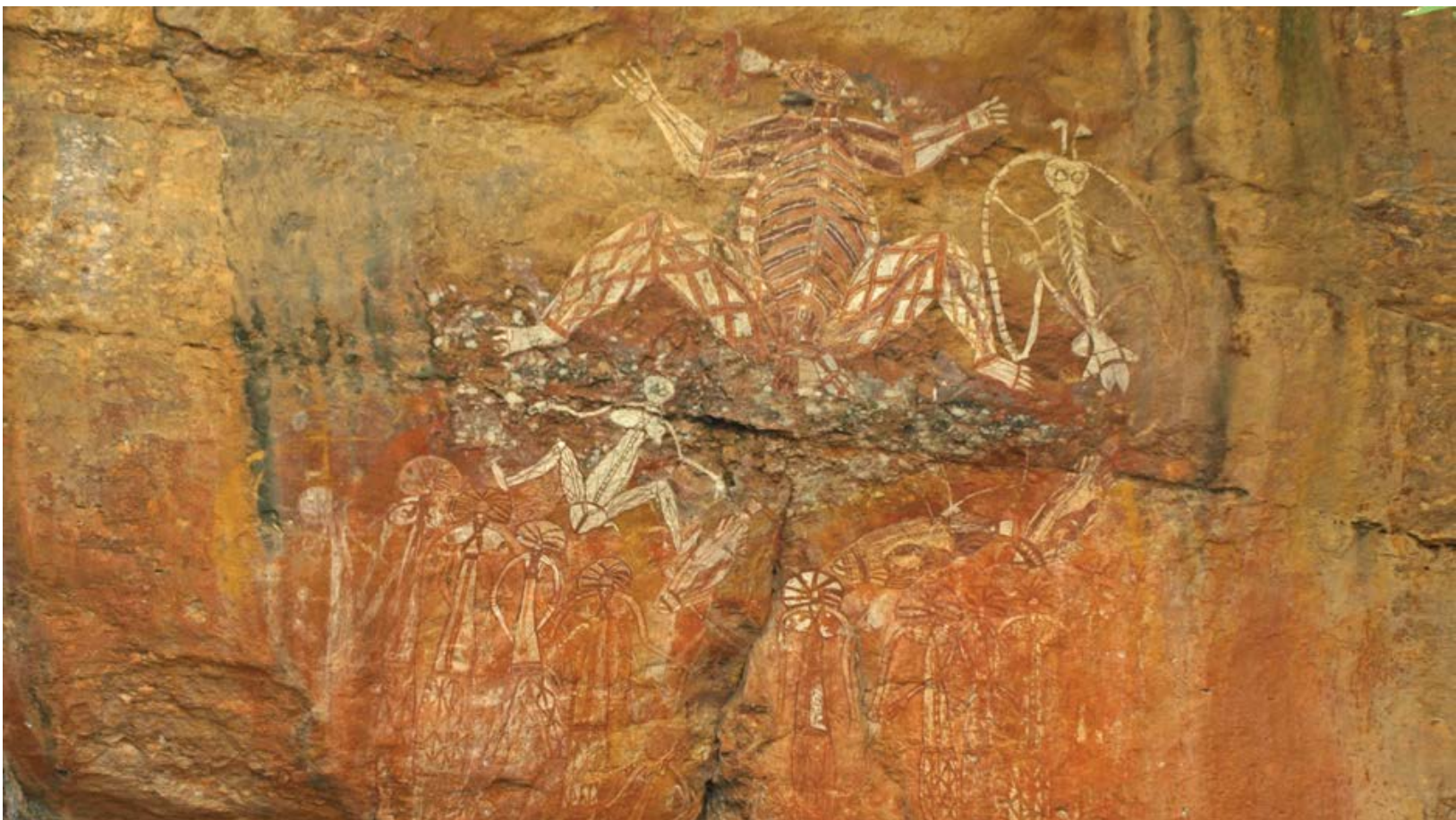

The outstanding Australian Aboriginal art work on public display at the Anbangbang rock shelter gallery, Kakadu National Park, a natural and cultural World Heritage property. The paintings include Namarrgon the lightning man (upper far right) who wears his lightning around him and it connects his arms, leg and head. The stone axes that may be seen on his knees and elbows create the thunder.

Source: Graeme L. Worboys

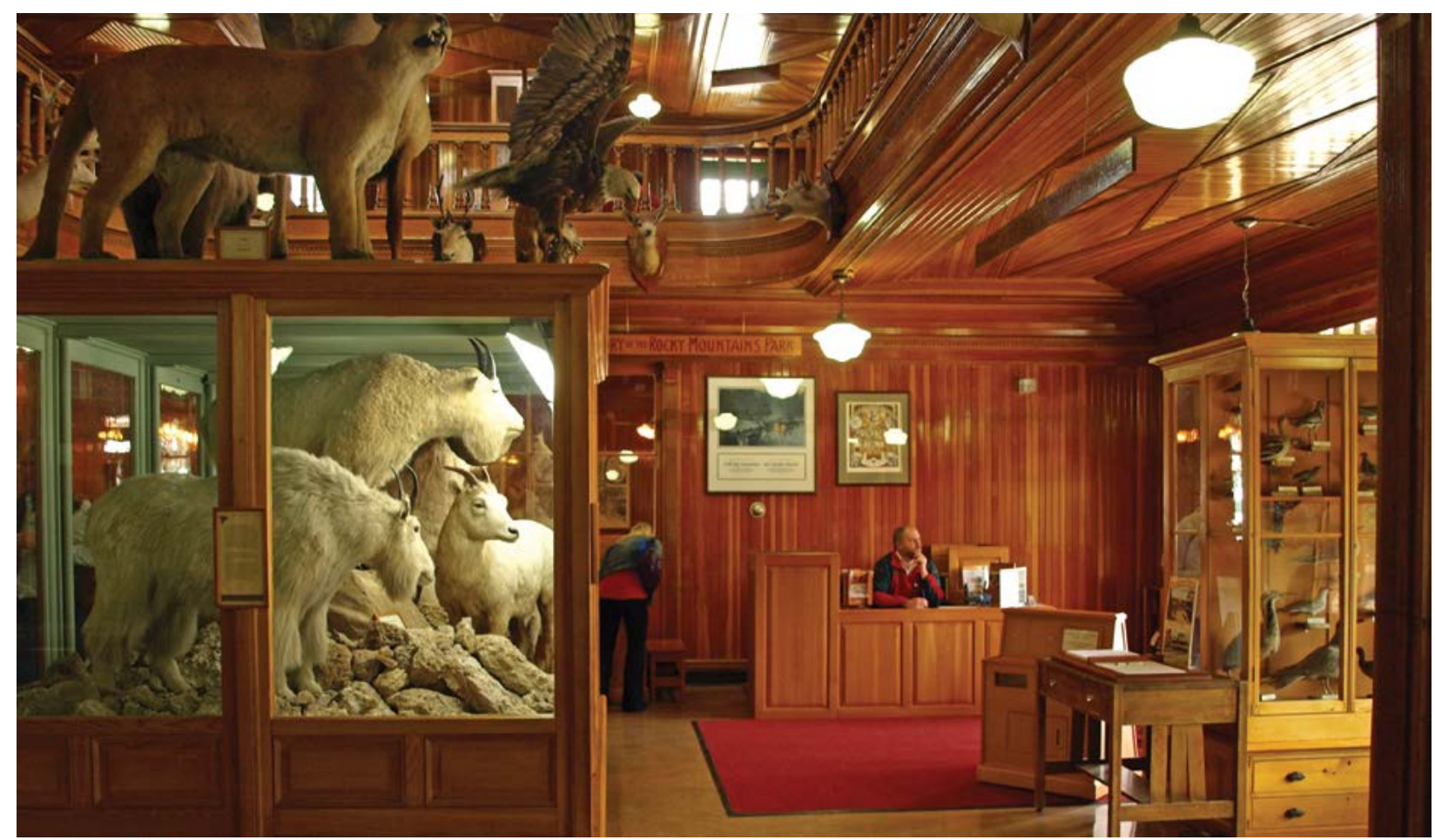

The Banff Park Museum is located centrally in the historic Banff National Park of Canada, a World Heritage property. Refurbished in 1985, the museum faithfully retains the products and style of interpretation displays developed in and around 1914. The building was constructed in 1903, and its presence and displays reflect the energy and commitment of Norman Bethune Sanson, the Museum's curator from 1896 to 1932.

Source: Graeme L. Worboys 


\section{References}

Recommended reading

Ahmad, Y. (2006) 'The scope and definitions of heritage: from tangible to intangible', International Journal of Heritage Studies 12(3): 292-300.

Alexander, J. and Coursey, D. (1969) 'The origins of yam cultivation', in P. Ucko and G. Dimbleby (eds) The Domestication and Exploitation of Plants and Animals, pp. 405-26, Duckworth, London.

Amend, T., Brown, J., Kothari, A., Phillips, A. and Stolton, S. (eds) (2008) Protected Landscapes and Agrobiodiversity Values. Volume 1, Protected Landscapes and Seascapes Series, IUCN and GTZ, Kasparek Verlag, Heidelberg.

Australian National Committee of International Council of Monuments and Sites (Australia ICOMOS) (2000) The Burra Charter 1999, Australia ICOMOS, Melbourne.

Baldwin, A. (2010) The white-bellied sea eagle in the Jervis Bay region: an exploration of the cultural, ecological and conservation significance, MSc thesis, University of Wollongong, Wollongong, NSW.

Bellwood, P. (1978) Man's Conquest of the Pacific, Collins, Auckland.

Bokova, I. (2012) 'Preface', in UNESCO, World Heritage: Benefits beyond borders, UNESCO and Cambridge University Press, Cambridge.

Bowler, J., Jones, R., Allen, H. and Thorne, A. (1970) 'Pleistocene human remains from Australia: a living site and human cremation from Lake Mungo, western New South Wales', World Archaeology 2: $39-60$.

Boyden, S. (2004) The Biology of Civilisation, UNSW Press, Sydney.

Brown, S. (2010) Cultural Landscapes: A practical guide for park management, Department of Environment, Climate Change and Water, Sydney.

Brown, S. (2012) 'Applying a cultural landscape approach in park management: an Australian scheme', Parks 18(1): 99-110.

Buggey, S. (1999) An Approach to Aboriginal Cultural Landscapes, Historic Sites and Monument Board of Canada, Government of Canada, Ottawa.
Byrne, D. (2008). 'Heritage as social action', in G. Fairclough, R. Harrison, J. Jameson Jr. and J. Schofield (eds) The Heritage Reader, pp. 149-74, Routledge, London and New York.

Byrne, D. and Goodall, H. (2013) 'Place-making and transnationalism: recent migrants and a national park in Sydney, Australia', Parks 19(1): 63-72.

Carlson, A. (2010) 'Contemporary environmental aesthetics and the requirements of environmentalism', Environmental Values 19: 289314.

Context, Urban Initiatives and Doyle, H. (2002) Port Arthur Historic Site Landscape Management Plan, Port Arthur Historic Site Management Authority, Hobart.

Davis, M. (2007) Writing Heritage, Australian Scholarly Publishing, Melbourne.

Davison, G. (2008) 'Heritage: from patrimony to pastiche', in G. Fairclough, R., Harrison, J., Jameson, Jr. and J. Schofield (eds) The Heritage Reader, pp. 31-41, Routledge, London and New York.

Dean-Jones, P. and Brown, S. (2012) 'Forest as historic artefact: understanding cumulative landscape transformation in grazed and logged forests in north east NSW', in B. J. Stubbs, J. Lennon, A. Specht and J. Taylor (eds) Australia's Ever-Changing Forests VI: Proceedings of the Eighth National Conference on Australian Forest History, Australian Forest History Society, Lismore, pp. 57-82, Australian Forest History Society Inc., Canberra.

Department of Environmental Affairs and Tourism (2003) People, Parks and Transformation in South Africa: A century of conservation, a decade of democracy, Department of Environmental Affairs and Tourism, Pretoria.

Dudley, N. (2008) Guidelines for Applying Protected Area Management Categories, IUCN, Gland.

Dudley, N., Bhagwat, S., Higgins-Zogib, L., Lassen, B., Verschuuren, B. and Wild, R. (2010) 'Conservation of biodiversity in sacred natural sites in Asia and Africa: a review of the scientific literature', in B. Verschuuren, R. Wild, J. McNeely and G. Oviedo (eds) Sacred Natural Sites, Conserving Culture and Nature, pp. 19-32, Earthscan, London. 
Ellis, E., Kaplan, J., Fuller, D., Vavrus, S. and Goldewijk, P. (2013) 'Used planet: a global history', Proceedings of the National Academy of Science 20: 7978-85.

DD Fairclough, G., Harrison, R., Jameson, J., Jr, and Schofield, J. (eds) (2008) The Heritage Reader, Routledge, London and New York.

Feary, S. (1993) 'An Aboriginal burial with grave goods near Cooma, New South Wales', Australian Archaeology 43: 40-2.

Fischer, S. (2005) Island at the End of the World, Reaktion Press, London.

Galla, A. (2012) 'Legacy of a chief: Chief Roi Mata's domain, Vanuatu', in UNESCO, World Heritage: Benefits beyond borders, pp. 169-77, UNESCO and Cambridge University Press, Cambridge.

Gatunda, C. (2002) Strengthening a community-based approach for resource management: opportunities for achieving sustainability in the Mt. Elgon ecosystem, Kenya, Masters of Environmental Science thesis, The Australian National University, Canberra.

Government of Australia and Johnston, E. (1991) Royal Commission into Aboriginal Deaths in Custody, Australian Government Publishing Service, Canberra.

Han, F. (2012) 'Cultural landscape: a Chinese way of seeing nature', in K. Taylor and J. Lennon (eds) Managing Cultural Landscapes, pp. 90-108, Routledge, London and New York.

Harrison, R. (2013) Heritage: Critical approaches, Routledge, London and New York.

Harrison, R., Fairclough, G., Jameson, J. Jr. and Schofield, J. (2008) 'Heritage, memory and modernity', in G. Fairclough, R. Harrison, J. Jameson, Jr, and J. Schofield (eds) The Heritage Reader, pp. 1-12, Routledge, London and New York.

Harvey, D. (2010) 'Heritage pasts and heritage presents: temporality, meaning and the scope of heritage studies', International Journal of Heritage Studies 7(4): 319-38.

Head, L. (2000) Cultural Landscapes and Environmental Change, Arnold, London.
Heiser, C. (1973) Seed to Civilisation: The story of man's food, W. H. Freeman \& Company, San Francisco.

Helliwell, C. and Hindess, B. (1999) "“Culture", "society" and the figure of man', History of the Human Sciences 12(4): 1-20.

Henn, B., Cavalli-Sforza, L. and Feldman, M. (2012) 'The great human expansion', Proceedings of the National Academy of Sciences 109(44): 17 758-64.

Higgins, M. (1988) Teddy's Hut: A history, Kosciusko Huts Association Inc., Canberra.

Hill, R., Walsh, F., Davies, J. and Sandford, M. (2011) Our Country Our Way: Guidelines for Australian Indigenous Protected Area management plans, CSIRO and Government of Australia, Cairns, Queensland.

Intergovernmental Oceanographic Commission (2014) Underwater Cultural Heritage, UNESCO, Paris. $<$ www.ioc-unesco.org/index.php?option=com_conte nt\&view=article\&id=83: underwater-cultural-heritag e\&catid=14\&Itemid $=100063>$

Itami, R. (1993) 'Characteristics of landscape aesthetic value and implications for assessment methodology', More than Meets the Eye, Technical Workshop Series 7, pp. 13-22, Australian Heritage Commission, Canberra.

Johnston, C. (1992) What is Social Value?, Australian Heritage Commission, Canberra.

Jokilehto, J. (2005) Definition of Cultural Heritage, ICCROM Working Group Heritage and Society, Rome.

Kennedy, J. and Thomas, J. (1995) 'Managing natural resource value', in L. Knight and S. Bates (eds) $A$ New Century for Natural Resource Management, pp. 311-21, Island Press, Washington, DC.

Köhler-Rollefson, I. (2014) Indigenous knowledge of animal breeding and breeds, GTZ Issues Paper, German Technical Cooperation, Eschborn. <www2. gtz.de/dokumente/bib/04-5104a2.pdf>

Kuman, K., Baron, J. and Gibbon, R. (2005) 'Earlier stone age archaeology of the Vhembe-Dongala National Park (South Africa) and vicinity', Quaternary International (2005) 129: 23-32.

Lennon, J. (2006) 'Cultural heritage management', in M. Lockwood, G. L. Worboys and A. Kothari (eds) Managing Protected Areas: A global guide, pp. 448-73, Earthscan, London. 
Lockwood, M. (2006) 'Values and benefits', in M. Lockwood, G. L. Worboys and A. Kothari (eds) Managing Protected Areas: A global guide, pp. 10115, Earthscan, London.

Lowenthal, D. (2005) 'Natural and cultural heritage', International Journal of Heritage Studies 11(1): 81-92.

McKee, A. (1982) How We Found the Mary Rose, Souvenir Press, London.

Mason, R. (2008) 'Assessing values in conservation planning', in G. Fairclough, R. Harrison, J. Jameson, Jr, and J. Schofield (eds) The Heritage Reader, pp. 99-124, Routledge, London and New York.

Mitchell, N. (2013) Study on the Application of Criterion (vii): Considering superlative natural phenomena and exceptional natural beauty, IUCN, Gland.

Mitchell, N. and Buggey, S. (2001) Category V protected landscapes in relation to World Heritagecultural landscapes: taking advantages of diverse approaches, Conservation Study Institute Landscape Conservation: An international working session on the stewardship of protected landscapes, conservation and stewardship Publication No. 1, IUCN and QLF/Atlantic Centre for the Environment, Woodstock, VT.

Mitchell, N. and Melnick, R. (2012) 'Shifting paradigms: new dimensions in cultural landscape conservation for twenty-first-century America', in K. Taylor and J. Lennon (eds) Managing Cultural Landscapes, pp. 232-52, Routledge, London and New York.

Mulvaney, J. and Kamminga, J. (1999) Prehistory of Australia, Allen \& Unwin, Sydney.

Nash, R. (1989) The Rights of Nature, Primavera Press, Sydney.

Old Ceasera Diving Centre (2014) Dive Sites. <www. caesarea-diving.com>

Oviedo, G. and Jeanrenaud, S. (2007) 'Protecting sacred natural sites of indigenous and traditional peoples', in J. Mallarach and T. Papayannis (eds) Protected Areas and Spirituality: Proceedings of the First Workshop of the Delos Initiative, Montserrat, 23-26 November 2006, pp. 77-100, IUCN, Gland, and Publicaciones de l'Abadia de Montserrat, Montserrat.
Pearson, M. and Sullivan, S. (1995) Looking after Heritage Places, Melbourne University Press, Melbourne.

Phillips, A. (2002) Management Guidelines for IUCN Category V Protected Areas: Protected landscapes/ seascapes, IUCN, Gland and Cambridge.

Psychic Universe (2014) Dolphins: Spiritual messengers from the sea. <www.psychicsuniverse.com/articles/ spirituality/living-spiritual-life/dolphins-spiritual>

Puszta.com (2014) Hungarian Grey Cattle. <www. puszta.com/eng/hungary/cikk/szurkemarha.>

Ransom, D. (1991) 'Wasteland to wilderness: changing perceptions of the environment', in J. Mulvaney (ed.) The Humanities and the Australian Environment, pp. 5-20, Highland Press, Canberra.

Rose, D. (1996) Nourishing Terrains: Australian Aboriginal views of landscape and wilderness, Australian Heritage Commission, Canberra.

Sarmiento, F., Rodriguez, G. and Argumedo, A. (2005) 'Cultural landscapes of the Andes: indigenous and colono culture, traditional knowledge and ethnoecological heritage', in J. Brown, N. Mitchell and M. Beresford (eds) The Protected Landscape Approach: Linking nature, culture and community, pp. 147-62, IUCN, Gland.

Sauer, C. (1952) Agricultural Origins and Dispersals, American Geographical Society, New York.

Schofield, J. (2008) 'Heritage management, theory and practice', in G. Fairclough, R. Harrison, J., Jameson, $\mathrm{Jr}$, and J. Schofield (eds) The Heritage Reader, pp. 15-30, Routledge, London and New York.

Selman, P. and Swanwick, C. (2010) 'On the meaning of natural beauty in landscape legislation', Landscape Research 35(1): 3-26.

Seymour-Smith, C. (1986) Macmillan Dictionary of Anthropology, Macmillan, London.

Shengii, P. (2010) 'The road to the future? The biocultural values of the Holy Hill forests of Yunnan Province, China', in B. Verschuuren, R. Wild, J. McNeely and G. Oviedo (eds) Sacred Natural Sites, pp. 98-106, Earthscan, London.

Smith, L. (2006) Uses of Heritage, Routledge, London and New York. 
South African San Institute (2014) CRAM. <www.san. org.za/cram.php>

Studley, J. (2010) 'Uncovering the intangible values of earth care: using cognition to reveal the eco-spiritual domains and sacred values of the peoples of eastern Kham', in B. Verschuuren, R. Wild, J. McNeely and G. Oviedo (eds) Sacred Natural Sites, Conserving Culture and Nature, pp. 107-18, Earthscan, London.

Submerged Prehistoric Archaeology and Landscapes of the Continental Shelf (Splashcos) (2014) About Splaschos. <www.splashcos.org/about>

Szirmai, A. (2009) Industrialisation as an engine of growth in developing countries, 1950-2005, UNU-MERIT Working Paper, United Nations University-Maastricht Economic and Social Research Institute on Innovation and Technology, Maastricht. <www.merit.unu.edu/publications/ working-papers/?year_id=2009>

Thaman, R. and Clarke, W. (1993) 'Introduction', in W. Clarke and R. Thaman (eds) Agroforestry in the Pacific Islands: Systems for sustainability, pp. 1-16, United Nations University Press, Tokyo.

Throckmorton, P. (1987) History from the Sea, Michael Beazley Publishers, London.

Truscott, M. (2006) Repatriation of Indigenous cultural property, Paper prepared for the 2006 Australian State of the Environment Committee, Department of Environment and Heritage, Canberra.

Tuan, Y.-F. (2002) 'Foreword', in K. Olwig (ed.) Landscape, Nature and the Body Politic: From Britain's Renaissance to America's New World, University of Wisconsin Press, Madison.

United Nations Educational, Scientific and Cultural Organisation (UNESCO) (1972) Convention Concerning Protection of the World Natural and Cultural Heritage, UNESCO, Paris.

United Nations Educational, Scientific and Cultural Organisation (UNESCO) (2001) Convention on the Protection of the Underwater Cultural Heritage, UNESCO, Paris. <unesdoc.unesco.org/ images/0012/001260/126065e.pdf >

United Nations Educational, Scientific and Cultural Organisation (UNESCO) (2003) Convention for the Safeguarding of the Intangible Cultural Heritage, UNESCO, Paris.
[Dd United Nations Educational, Scientific and Cultural Organisation (UNESCO) (2012) World Heritage: Benefits beyond borders, UNESCO and Cambridge University Press, Cambridge.

United Nations Educational, Scientific and Cultural Organisation (UNESCO) (2013) Operational Guidelines for the Implementation of the World Heritage Convention, UNESCO, Paris.

United Nations Educational, Scientific and Cultural Organisation (UNESCO) (2014a) The Marshlands of Mesopotamia, UNESCO, Paris. <whc.unesco.org/ en/tentativelists/1838/>

United Nations Educational, Scientific and Cultural Organisation (UNESCO) (2014b) Mapungubwe Cultural Landscape, UNESCO, Paris. <whc.unesco. org/en/list/1099>

United Nations Educational, Scientific and Cultural Organisation (UNESCO) (2014c) Tikal National Park, UNESCO, Paris. http://whc.unesco.org/en/ list/64

United Nations Educational, Scientific and Cultural Organisation (UNESCO) (2014d) Sundarbans National Park, UNESCO, Paris. <whc.unesco.org/ en/list/452>

United Nations Educational, Scientific and Cultural Organisation (UNESCO) (2014e) Hortobágy National Park-the Puszta, UNESCO, Paris. <whc. unesco.org/en/list/474>

United Nations Educational, Scientific and Cultural Organisation (UNESCO) (2014f) Agave Landscape and Ancient Industrial Facilities of Tequila,

UNESCO, Paris. <whc.unesco.org/en/list/1209>

United Nations Educational, Scientific and Cultural Organisation (UNESCO) World Heritage Centre (2011) Operational Guidelines for the Implementation of the World Heritage Convention, UNESCO, Paris.

Verlag Wolfgang Kunth GmbH \& Co. (2010) World Heritage, Monaco Books, Munich.

DDd Vershuuren, B., Wild, R., McNeely, J. A. and Oviedo, G. (eds) (2010) Sacred Natural Sites, Conserving Nature and Culture, Earthscan, London.

Wang, G., Innes, J., Wu, S., Krzyzanowski, J., Yin, Y., Dai, S., Zhang, X. and Liuet, S. (2012) 'National park development in China: conservation or commercialisation', AMBIO 41: 247-61. 
Protected Area Governance and Management

Webb, S., Cupper, M. and Robins, R. (2006)

'Pleistocene human footprints from the Willandra Lakes, southeastern Australia', Journal of Human Evolution 50(4): 405-13.

Wild, R. and McLeod, C. (2008) Sacred Natural Sites: Guidelines for protected area managers, IUCN, Gland.

Wilderness.net (2014) The Idea of Wilderness. <www. wilderness.net/NWPS/WhatIsWilderness>

Willow, A. (2011) 'Culturally significant natural resources-where nature and culture meet', in T. King (ed.) A Companion to Cultural Resource Management, Blackwell, Chichester, UK.

World Commission on Environment and Development (WCED) (1987) Our Common Future, Oxford University Press, London.

Zeder, M. (2011) 'The origins of agriculture in the Near East', Current Anthropology 52(Supplement 4): S221-35. 


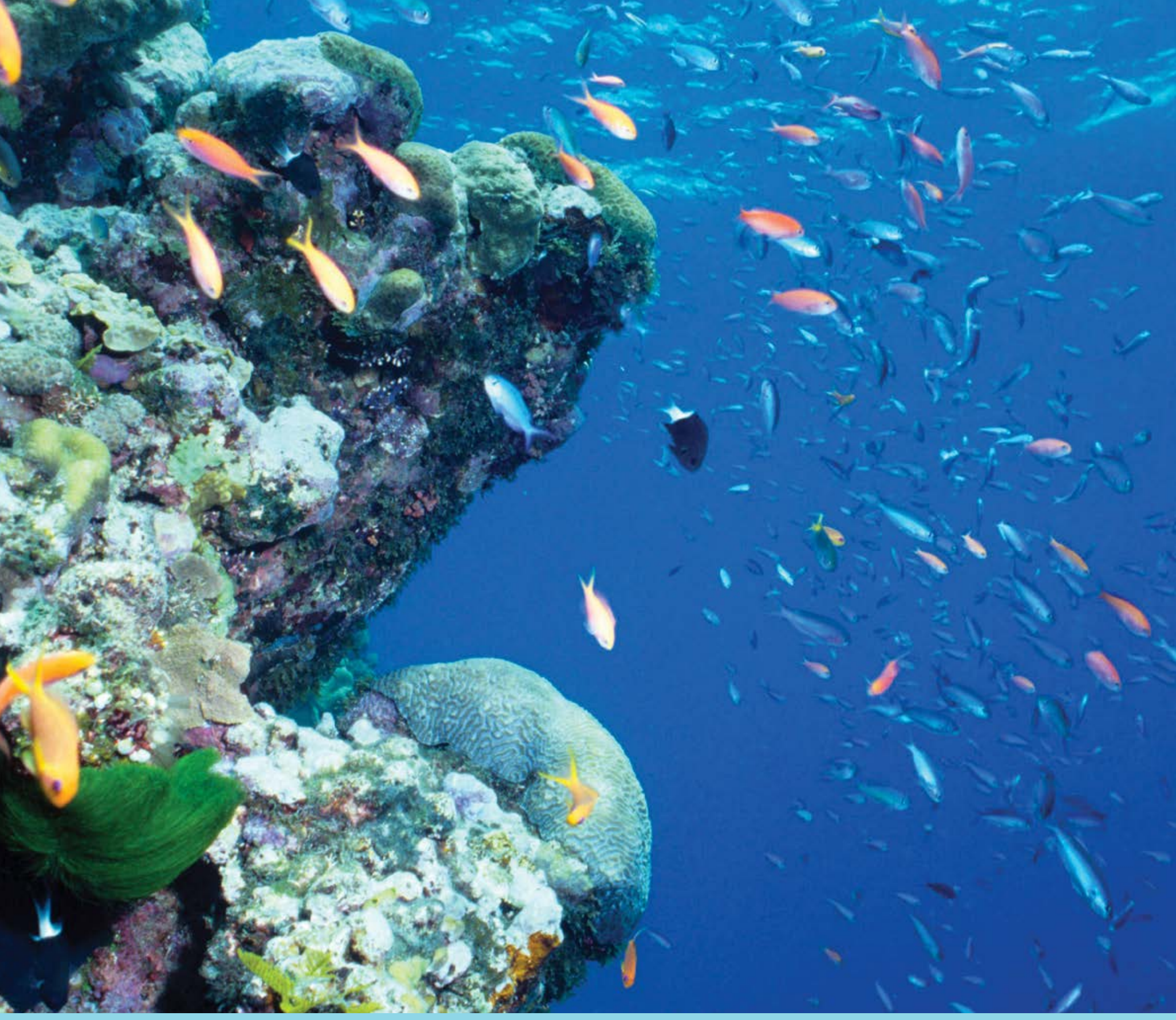

\section{CHAPTER 5}

\section{SOCIAL AND ECONOMIC INFLUENCES SHAPING}

PROTECTED AREAS

Principal author:

Nigel Crawhall

\section{CONTENTS}

- Introduction

- Trends and forecasting

- Anthropocene: Humans take charge

- Values, norms and duties

- Human rights, indigenous rights and custodianship in the 21 st century

- Economic trends impacting on the state, communities and protected areas

- Conclusion

- References 


\section{PRINCIPAL AUTHOR}

NIGEL CRAWHALL is Director of the Secretariat to the Indigenous Peoples of Africa Coordinating Committee (IPACC) and Co-Chair of the International Union for Conservation of Nature (IUCN) Theme on Indigenous Peoples, Local Communities, Equity and Protected Areas.

\section{ACKNOWLEDGMENTS}

Appreciation is expressed for contributions to this chapter from Trisha Kehāulani Sproat-Watson (on Hawai' ian culture and on Elinor Ostrom); Alejandro Nadal (on macro-economics and conservation); and Stephen Dovers (on multilateral environmental instruments and for editorial support).

\section{CITATION}

Crawhall, N. (2015) 'Social and economic influences shaping protected areas', in G. L. Worboys, M. Lockwood, A. Kothari, S. Feary and I. Pulsford (eds) Protected Area Governance and Management, pp. 117-144, ANU Press, Canberra.

\section{TITLE PAGE PHOTO}

The Great Barrier Reef Marine Park, Queensland Australia, a UNESCO World Heritage property and one of the great marine protected areas of the world

Source: () Great Barrier Reef Marine Park Authority

Extract, Chapter 5 (p. 139): “... in Australia in 2014, the Australian Government and the Great Barrier Reef Marine Park Authority had made decisions regarding dredging spoil that posed a threat to the Great Barrier Reef-another iconic natural World Heritage Site. The Great Barrier Reef is threatened by several extractive industries, fossil fuel-related pollution sources, associated busy shipping lanes and plans for further coal exporting from Abbot Point. Such threats are being seen on a global scale. The roots of the problem take us back to the tensions about values, custodianship and possibly also changes in the character and interests of the state itself". 


\section{Introduction}

This chapter explores trends in societal values, human rights and economics that have shaped how protected areas are understood, valued, managed and governed. The chapter highlights some of the contradictory social and economic trends that may define the future of protected area policymaking, governance and integrity.

The function of the chapter is to locate protected areas in a broader societal and policy context and give consideration to the role of public perception, values, norms and commitment to ensuring that conservation aims, including the effective use of protected areas, are supported by social, economic and political processes that may not at first appear to be germane to conservation policymaking. Within the different policy spheres and social trends, there is scope to shape public opinion, social cohesion, solidarity and political commitment and to anticipate problems arising from certain economic frames of reference that can potentially undermine the effectiveness of protected areas if not monitored and addressed.

Examining some historical trends may provide insights into what protected area policymakers, managers, conservationists, local custodians, traditional owners and civil society can anticipate in the years ahead. Understanding the past and how humans engage with nature gives us insights into issues that we may need to consider and prepare for in meeting future targets of conservation, landscape/seascape connectivity, upholding human rights and enabling a shared human commitment to sustain the planet for future generations. We are in a time of rapid global economic and social integration, with high-speed communications capacity and globalising cultural systems - factors that facilitate building public support and understanding. In contrast, we also live in a context of a high degree of human inequality combined with expanding commodification and consumption of natural resources, which create conditions for conflict and competition. These conditions mean that protected areas are sites of contestation and complex policy spaces.

The chapter concludes with some key considerations of threats and opportunities, and a call to consider the fundamental issue of human custodianship and our duty to the rest of the living world, which supports our health and wellbeing. As we move into an ever-accelerating world of changing technologies, global economic integration and land-use changes, we may also need to consider a refreshed human social compact to conserve biodiversity, enhance connectivity beyond political borders as well as prepare for new variables including climate instability, genetic modification in agriculture, new energy technologies and changes in the role of the state.

\section{Trends and forecasting}

Much of this book deals with the technical and managerial considerations for successful conservation in and beyond protected areas; however, other priorities in human organisation, culture, economics and politics ultimately create the conditions within which protected areas have arisen and will develop in the decades to come. Some of these trends are positive but others will cut against the efforts of biodiversity and ecosystem conservation. Understanding these trends goes outside the usual domain of professional skills training and biological sciences. Understanding the contexts of the trends that impact on protected areas requires looking into the social science toolbox.

The main aim of this chapter is to consider how to locate protected area management, policy and successful governance in the bigger context of human behaviour, values, economics and trends that may shape future plans and ways of working. This book describes in a number of chapters the changing dynamics of the relationship between humans and nature. The modern trend in favour of protected areas has accelerated dramatically, in part driven by the evidence of drivers of biodiversity loss, radical changes in land use across the globe and a growing awareness that if we do not react expeditiously and effectively we will experience consequences that are negative for life on Earth, including for our own species.

The scope of the chapter is broad and hence it is meant as an overview of some key issues. Any foray into political, social and economic theory comes with assumptions, epistemologies and theoretical models, which are open to debate and dispute. Here we try to look at some of the issues in broad and recognisable strokes, rather than presenting a specific materialist or positivist framework. For specialists, some of this may be insufficient. The goal is to introduce social, political and economic considerations for non-specialists and add to debates in more specialised constituencies.

The chapter starts with the premise that human society and political economy are never static. Given that we find ourselves in an era known as the Anthropocene, whatever conservation aims we set for ourselves will depend on the degree to which humans and our social, political and economic institutions take into account the need for conserving biodiversity and ecosystems. Some human systems, such as globalisation of commodity markets and capitalist macro-economic frameworks in national policymaking, may seem remote and self-driven, but they arise only in human culture, imagination and value systems. Shifting value systems and changes in the duties and scales of governance and custodianship in relation 
to protected areas and other area-based conservation measures will impact on both the effectiveness and the availability of resources, including social and political support for protected areas.

A key concept in the discussion is 'custodianship': the belief that an individual or network of humans has feelings in relation to a particular territory, seascape or landscape, which lead her/him/them to conserve, protect and/or sustainably use the territory. In this chapter, we suggest that in our modern times, custodianship is an area of rapid change, contestation, changing scales and ambiguity, all of which will ultimately play a central role in the effectiveness of protected areas.

We consider the global historical shift from localised custodianship to increasing state authority and then the changing nature of the state within globalised economics, trade and natural resource extraction. In recent times, the legal custodianship duties of the state may be reoriented, even diverted, to facilitate degradation of the environment, poaching of wildlife and a further breakdown of ecosystem integrity, primarily driven by economic ideologies and the influence of private transnational interests that do not have an evolved nature-based value system or accountability to other scales of custodians.

Two noteworthy trends that are not explored in the chapter include changing human demographics and anthropogenic climate change (see Chapter 17). These can both be taken as frame conditions, in the sense that those working on protected areas have limited capacity to change human rates of reproduction or global greenhouse gas emissions. For protected areas, both of these trends will impact in complex ways on protected area policy and effectiveness.

Before delving into the issue of custodianship, it is worth giving some thought to how and why humans value nature, and how changing material and social conditions act on these value systems, which in turn shape where we put our attention, energy and resources. Human society has reached a point where it has exceeded natural variables as a primary driver of changes in biodiversity, ecosystems and even climatic systems. What we do next will shape the whole history of the planet, our species and many other species.

\section{Anthropocence: Humans take charge}

In 2000, biologist Eugene Stoermer and Nobel Prizewinning chemist Paul Crutzen published the term 'Anthropocene' in a newsletter of the International Geosphere-Biosphere Programme. The term was formally adopted by the Geological Society of London in 2008. This term acknowledged that our geological and climatic context is now less determined by natural trends than by human behaviour and human-driven changes to both the physical Earth (soil loss, pollution, extraction through mining and exploration) and our atmosphere (the most notable impact being the emission of greenhouse gases leading to global warming and climate instability, with impacts on ocean acidification and glacial melting and terrestrial impacts).

Adding up the full picture of what humans have been doing to the Earth and the atmosphere over the past century is distressing and can plunge one into a state of anxiety. As this chapter, and indeed this book, suggests, the drivers of the threats to our biodiversity, ecosystems, food sovereignty and climate stability derive from human behaviour and culture (Boyden 1987), so logically it is within our capacity to mitigate these dangerous trends, and through our intentions and mindful actions we are capable of adjusting the course of the planet towards a more sustainable one.

A useful point of departure is to consider the findings of the Global Biodiversity Outlook 3 (GBO-3) (see CBD Secretariat 2010). This UN document, submitted to the UN Convention on Biological Diversity's Fifteenth Subsidiary Body on Scientific, Technical and Technological Advice, reviewed the available science on biodiversity and ecosystem trends. This is just one of a number of important documents on biodiversity trends. What stood out in GBO-3 was that biodiversity is declining in all regions of the world and at an accelerating pace, and new problems such as alien species distribution are increasing, while the only apparently positive trend was the growth in protected area designation.

While some would argue that increasing protected areas has not slowed biodiversity loss, bringing into question whether protected areas are really a sufficient response to drivers of biodiversity loss, our point of departure is that protected areas are increasingly seen by state parties (signatories to the Convention on Biological Diversity) as important bulwarks against the impacts of such drivers (see Chapter 21). Reflecting on the GBO-3 report and the success of the Programme of Work on Protected Areas (PoWPA) under the Convention on Biological Diversity 


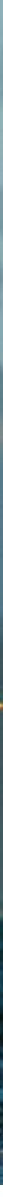

Tierra del Fuego, de Agostini National Park, Cape Horn Biosphere Reserve, Chile Source: Eduard Müller

(CBD), including the refreshed protected area Target 11 of the Strategic Plan for Biodiversity 2011-20 and the Aichi Biodiversity Targets (CBD 2011), this chapter is postulating that protected areas at this time are seen as a solution to other threats and risks. Furthermore, it appears that the global multilateral treaty system is having a more positive effect on this domain of state environmental planning than in many other domainsmost notably, the poor performance in climate change negotiations.

If state parties are seeing protected areas as a solution to certain environmental challenges, it stands to reason that this perception is shared among many citizens and the electorate, at least where there are functional democratic regimes. Though protected area staff may sometimes feel they are struggling with great challenges and low political prestige, at least at the policy level there are progressive trends. Not only are terrestrial parks receiving increasing attention, we also are seeing greater interest in how the terrestrial model of protected areas can be transposed into the coastal and marine environments and adjusted to fit. The Tenth Conference of Parties (COP) of the CBD, which met in Nagoya, Japan, set new targets for both terrestrial and marine protection under Target 11 of the Aichi Biodiversity Targets, part of the CBD 20112020 strategic plan.

\section{Values, norms and duties}

Humans are part of the primate order and much time has been dedicated over the ages to understanding what motivates our primate and/or human behaviour, which is typically social in nature, and includes elements of cooperation, self-interest and altruism (for a robust discussion on the role of language in humans as an instrument for managing these tensions, see Dunbar 1996). Rather than simply acting instinctually, our conduct is shaped by social systems, affective and solidarity systems and also a general ability to understand and engage with ethics, as expressed through our cultures, languages and belief systems.

As our societies have become more complex, we have developed systems of hierarchies in our power relations, and class systems have emerged that mean there are differential systems in terms of ownership of resources, control of lands and the ability to influence decisionmaking. We thus find ourselves living in societies where we have the capacity for ethical reflection, we live in rule-governed systems and we are born into socially constructed systems of power that were not of our own making and produce substantially different results for those who have access to power and those who do not. 
The inherent social character of human society and our ability to develop shared systems of belief create a foundation for individual and collective value systems, which in turn shape what things we protect, conserve, promote, study and defend. Where there is intense disputation of power or inequality of control over resources, we can anticipate that values will also be disputed and there may be less social consensus about what is valuable, including what should be conserved and protected.

During the Summit for Sustainability in Africa (24-25 May 2012), the chairperson of the Theme on Indigenous and Local Communities, Equity, and Protected Areas (TILCEPA) was able to pose to Pavan Sukhdev, the lead author of The Economics of Ecosystems and Biodiversity (TEEB 2010) initiative, a question about whether valuation was accelerating the commodification of nature and hence facilitating its non-renewable extraction to enter into capital markets. Sukhdev's reply was that valuation should not be confused with commodification or even capital valuation. He recounted how in his work in India, he could work with rural villagers with limited to no literacy or experience with capital markets, who were highly reliant on natural resources for subsistence, and who had their own system of valuation that helped guide them in their conservation activities. According to Sukhdev, the problem is not whether nature has a value; it is how that value (and whose valuation) is represented in national policymaking.

In this section, we give some thought to how humans value nature, why we value nature and how this impacts on the decisions we make and the priorities we establish for ourselves and our political and social systems. An initial dichotomy can be made between those things we see as having 'intrinsic' value and those considered to have 'extrinsic' value (for a further discussion on valuation and the intrinsic value of nature, see Phillips 2003; Chapter 6). Something with intrinsic value has a value in and of itself. Whether nature has an intrinsic value, or at least whether human society adheres to such a principle, is central to where we locate our conservation duties within our social, political and economic systems.

Contemporary environmental ethicists have argued that humans tend to see nature as having an intrinsic value. Sandler (2012) quotes Soulé (1985) as holding that 'biotic diversity has intrinsic value'. This view is also held by influential ethicists Rolston (1986) and Callicott (1989). The intrinsic value of nature has been enshrined in recent UN instruments including the 1982 World Charter for Nature and the 2000 Earth Charter.
Typical expressions of humans valuing the intrinsic qualities of nature or a natural resource (species, landscape, ecosystem) include sacred natural sites; legislative or state actions to conserve species, water systems or landscapes primarily due to their aesthetic qualities; and spiritual associations or intrinsic values in sustaining life (for examples, see Chapters 3 and 4). Modern protected areas are in part an expression of an intrinsic value system being applied to a landscape, seascape, ecosystem, geological formation or territory necessary for species conservation.

In his book Tread Lightly on the Earth, Sri Lankabhimanya Christopher Weeramantry, Vice-President of the International Court of Justice, develops an argument that all of the major world religions contain specific scriptural obligations for followers to value, respect and protect nature. He argues that before our modern age, the intrinsic value of nature was a foundation of religious and legal systems (Weeramantry 2009). The scriptural obligations range from conservation of specific species and landscape obligations to more general approaches to understanding our human duties within an abundant but fragile natural world.

Weeramantry suggests that duties to the Earth were normal in all cultures but became marginalised during the phase of modern colonial economic development and industrialisation. Natural law, which once included laws regarding the intrinsic values of nature and concomitant duties, was distorted to facilitate a shift to extrinsic valuation, where nature was subordinated to other priorities, notably to favour overuse of resources by the powerful at the expense of the poor. The sacred aspect of nature also creates a relationship between intrinsic and instrumental approaches to nature, as well as evidently providing a greater external point of reference beyond short-term interests (Weeramantry 2009).

Extrinsic value posits that the value of something is relational. For the purposes of this discussion, the evident line of thinking is that nature, an ecosystem or a species has a value because it serves some purpose that is valued by humans. Typically, for human society, nature is often seen to have an instrumental value. Water is essential to human life, hence conservation of water and water catchments, including forests or other characteristics of the water system, all have instrumental value. Most societies appear to have clear rules on water conservation and rights of access, and sometimes rights of ownership and control.

The 2004 Addis Ababa Principles and Guidelines for the Sustainable Use of Biodiversity (AAPG), which were adopted by the seventh COP of the CBD, speak directly 
to the principle that where a community is reliant on a natural resource or landscape that supports such resources, it is understood that they will be the natural custodians of such a resource. The AAPG create a multilateral principle regarding custodianship within the logic of instrumental value. This principle was greatly elaborated on by Nobel Economics Prize winner, the late Dr Elinor Ostrom (1990; Ostrom et al. 1994, 2010).

The notion that we need protected areas is a value judgment in and of itself. Though this book provides numerous examples of different types of conserved landscapes and seascapes throughout recorded history and across all cultures, our modern problems create the context in which protected areas are established, designed, governed and measured. At the root of this modern heritage is a strange mix of altruism and power play; an interest in conserving nature while in some cases also using conservation legislation to undermine the custodianship powers and duties of one group of people in favour of a dominant group.

Bogd Khan Uul, in Mongolia, was established as a nature reserve in 1778, giving it the apparent crown of the first 'modern' protected area-that is, a state-proclaimed territory dedicated for the primary purpose of nature conservation. Yellowstone National Park was gazetted as the first national park in 1872 and is usually considered the first of its kind as a dedicated estate for wilderness conservation.

Some of the most iconic national parks were established as part of the global experience of colonisation, conquest and displacement following violent conflict with indigenous people (Colchester 2004a, 2004b). Yellowstone National Park was proclaimed over the top of Arapaho lands, known by the indigenous peoples as Héetíhco'oo. The Arapaho were displaced as part of the cycle of conquest and proclamation of this protected area. Kruger National Park was established by colonial authorities in South Africa in 1898, securing its claim as the first African modern protected area. Kruger, like Yellowstone, involved displacement of the local peoples who had occupied the territory for centuries. This colonial form of protection was often associated with ethnic and power struggles between indigenous peoples and settler populations. It was also rationalised based on sudden biodiversity declines associated with colonial occupation, particularly clearing of land for agriculture and pastoralism, massive hunting impacts without regulatory controls, and concerns of 'civilising' landscapes while sustaining what would be considered selected 'pristine' landscapes (see, for example, Crosby 1986; Beinart and Coates 1995; MacKenzie 1997).
Contrary to some colonial settler beliefs that they were the ones who invented conservation, the idea of limiting human resource use in specifically defined territories to protect biodiversity and ecosystem services, either permanently or temporarily, seems to have been an ancient practice and common to most cultures and civilisations. A few such examples include the Polynesian system of tapu (or taboo) to control access to marine resources.

In Hawai $i$, the management system of freshwater rights and other natural resources derives directly from the traditional Hawai' ian land tenure system and is wholly unique among resource management systems used across the United States. First developed in the 1400s by the high island chief Mā'ilikūkahi, the ahupua'a system divided the land area into sustainable ecosystems that extended from the top of the individual watershed out to the fringing reef. The resources were regulated by a strict kapu system, akin to the Polynesian tapu system. After foreign contact in the 18th century, Hawai ian mō'i (kings) established a sovereign nationstate so as to contend with the world's emerging globalisation. Recognising the importance of natural resource management to the wellbeing of their people, the mō'i codified pre-contact practices into law and subsequently into land titles. Those codifications, deeply embedded in law, land tenure and custom, have survived socioeconomic changes and continue today.

India is covered with a network of sacred groves and forests, as well as other sacred natural sites associated with indigenous and local people's belief systems and Hindu religious customs. Africa is similarly criss-crossed with locally managed sacred natural forests, springs, lakes, mountains and other specific conserved sites. Nomadic peoples such as the M'bororo of West Africa have specific indigenous terminology for protected areas, 'haddaade', originally used for territories set apart by local chiefs for conservation, but now used in reference to national parks (IPACC 2012).

These traditional systems of biodiversity and ecosystem conservation are not unique to indigenous peoples. Various forms of community-based conservation are found in most societies that rely on natural resources. Where colonialism and ensuing 'modernisation' have not dislocated the relationship between traditional systems of governance and access regimes, there are interesting examples of a state system growing up organically around a local custodianship system. Finland offers some examples of this flow from local custodianship into new models of synergistic forms of governance and landscape/ riparian/lacustrine conserved spaces (Box 5.1). 


\section{Box 5.1. Natural resource governance systems in present-day Finland}

Finland has at least three major non-state regulatory systems that predate the Finnish state and function in parallel with the modern state system. These custodianbased institutions have the force of administrative law and in some cases there is further supportive national legislation. These include the kalastuskunta (a sitespecific administrative regulatory body for fishing rights and other types of hydrology governance), the paliskunta (the northern reindeer herding administrative regulatory bodies) and the yhteismetsä (a modern private collective forest administrative regulatory body, which allowed small private forest territories to be aggregated into commonage managed by the non-state regulatory body). These exist in parallel with municipalities and are specific to older Finnish usage systems. The Finnish regulatory bodies were so strong that when the private sector started damming rivers in the 1960s, they were obliged by local moral suasion to ensure that salmon spawning could continue in parallel and also do fish stock breeding to keep the fishing systems functional.

A court decision of 1642 makes specific reference to the customary law, the kalastuskunta regulations and municipal territorial delineation. In 1902, several years before Finnish national independence, the Vesioikeuslaki (water rights law) formalised state recognition of these customary water regulatory bodies.

Finland had been under the influence of two neighbouring empires, Sweden and Russia. Due to its self-managing autonomy, it managed to sustain its customary natural resource institutions into the current era. The modern Finnish state was proclaimed in 1917. The non-state regulatory systems stayed in place, run by local communities, and the administrative laws and recognition of these systems emerged organically, without the state assuming greater authority. In parallel, the state did develop a protected area network, run by the Metsähallitus (literally 'forest government').

Source: Personal communication from Jorma Leinonen of Paltamo, Kainuu, as interpreted by his son Tuomo Leinonen. See also Vesitalous (2010).

Europe became a powerful colonising force from the 16 th century onwards, and along with the acceleration of the European mercantilist economic system into the Industrial Revolution, this meant the Western world experienced a dramatic shift away from the intrinsic and spiritual values of nature conservation. This shift saw a new set of values emerge, in which nature's value was not only extrinsic but also focused on the wealth that could be extracted from the resources provided by the natural world. This process of economic and cultural

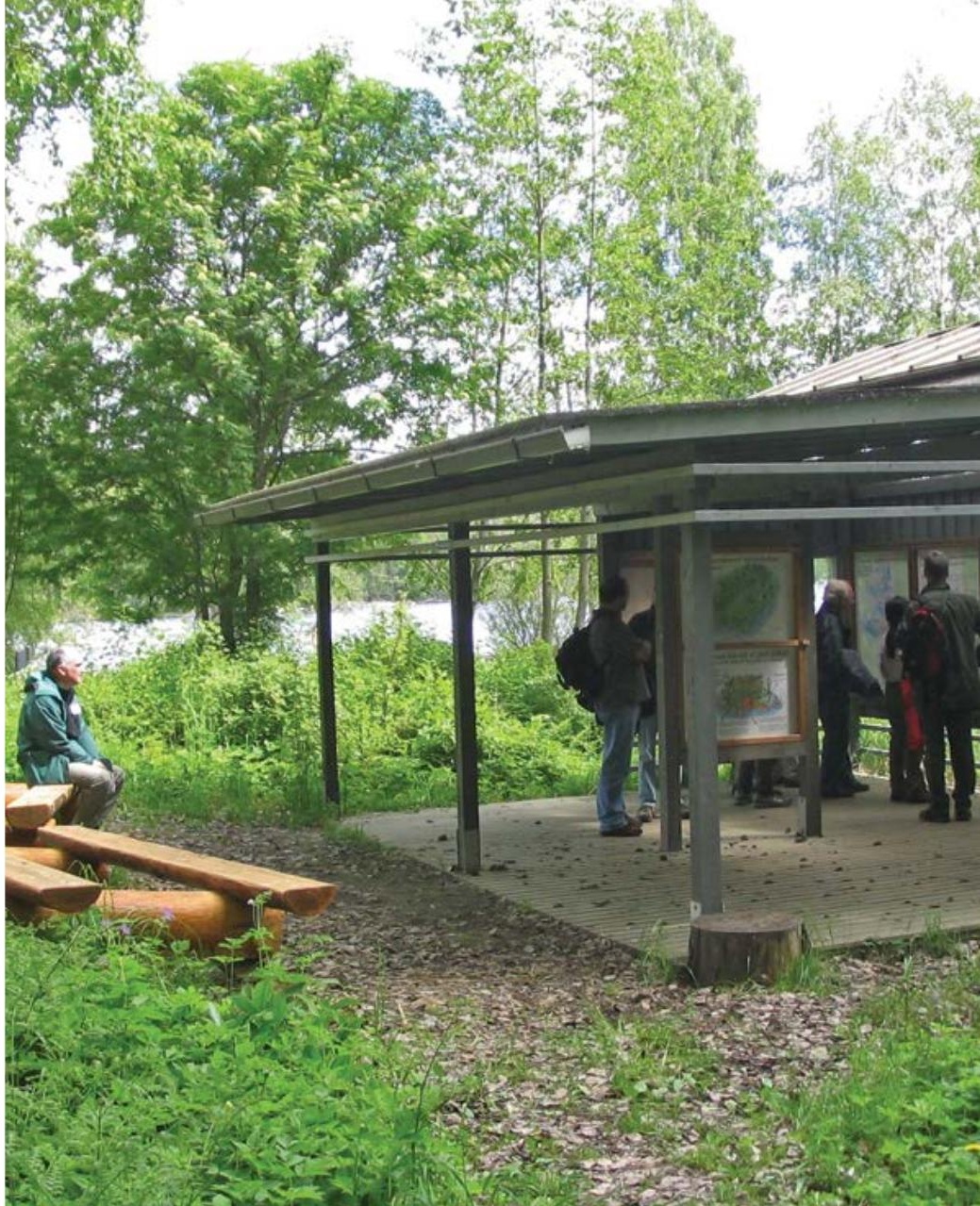

Visitor facilities, Linnansaari National Park, Finland, managed by Metsähallitus.

Source: Graeme L. Worboys

shift was the primary driver of a cycle of biological loss, extreme pollution and social upheaval, extending out of the European context into a global network of colonial resource extraction.

As Europe moved into the peak of its industrialisation phase, rapid technological changes and major shifts in demographics and human density, so some of its most profound value systems also changed. Once the seat of powerful religious doctrines and religious power, Europe began to move away from its religious convictions into a rising interest in science and the secularising of the state and society. This transition did not happen overnight, and writers such as B. Alan Wallace (Wallace and Hodel 2008) have suggested that Western science never gave up some of its Judaeo-Christian epistemology and references.

In 1967, Professor Lynn Townsend White, Jr, published a seminal article in Science, wherein he argued that certain doctrinal issues in medieval Christian thought set the stage for an anthropocentrism in Judaeo-Christian societies, which, when combined with the Industrial Revolution, led to our modern ecological crisis. At the heart of White's argument was the notion that Christians had been encouraged to see themselves not as custodians of God's creation, but as having God-given dominion over nature (White 1967). This dominion mindset 
reduced the societal perception that Christianity obliged its followers to respect the intrinsic value of nature as God's creation, and to replace this with a notion of the right to exploit.

White's critique came in the 1960s, at a time when the global environmental crisis was becoming clear, and led to a deeper debate in religious circles about what the Scriptures were saying about the value of nature and religious obligations to defend this value. Religious philosophers such as Thomas Berry (1999, 2006) have re-examined Christian Scriptures and come to a different conclusion, emphasising the sacred character of God's creation and the human duty to act as stewards of creation, as well as giving attention to issues of equity, compassion and justness in natural resource governance. More than just posing a particular challenge to the Christian churches about their role in conservation and custodianship of nature, we can see that White's critique may also apply more widely to Western values that are also present in the secular and scientific elements of society. That is, the dominion thinking of medieval Christian thought, buffered by colonial supremacy and conquest, emerging as a secular capitalist political economy may have facilitated a chain of evolving ethical justifications for the terrible treatment of nature, biodiversity and ecosystems as well as the rights of traditional custodians by technologically 'modern' societies.

Weeramantry (2009) concludes that to restore a global legal framework for nature conservation requires jurists and environmental advocates to restore a universal framework of respect for nature in both law and religion, putting 'nature' back into natural law and then applying this in an evolving jurisprudence. One of the interesting aspects of his work is that it suggests that the way into a new paradigm of renewed custodianship of the Earth may involve a convergence of spiritual (that is, intrinsic) values and legal norms and interpretations of natural law that also speak to the extrinsic value of sustainability.

In terms of considering the future of protected areas, the societal value placed on nature conservation, as expressed in religion, national identity, political leadership, the media and so forth, will invariably determine where nature conservation fits within national priorities. The clearer the sense of national custodianship and duty, the easier it is for conservationists to shape resource allocation to ensure effective conservation. Where there is a countervailing ideology that we have no accountability for how we abuse nature, other species or ecosystems, it will be a constant struggle to assert protected areas as a national priority.

\section{Contested custodianship and the duties of the state}

Whose job is conservation? The answer to this question has shifted over time and will be critical to changing the current trajectory of biodiversity loss and climate destabilisation. The issue includes our understanding of duty, commitment, capacity and the likelihood of cooperation. In a global study by the University of Queensland on protected area management effectiveness, Hockings has noted that three of the top seven significant variables relate to social policy and the cohesion of intention between professional managers and the society in which the protected area is located (IUCN TILCEPA 2010:9).

In this section we consider how custodianship has changed according to changing economic and political contexts. This reflection then takes us back to a new generation of rights that involves the reassertion of custodianship by sub-national groups as well as the need to rethink the human social compact necessary for protected areas and conservation to be effective in our modern context.

It is beyond the scope of this chapter to discuss the entire planet's history of natural resource management, conservation and protected area custodianship. Instead, a general pattern is proposed here to allow us to jump from early indigenous systems of direct dependency on natural resources and cultural systems of custodianship, to consider the rise of larger entities of power, particularly the emergence of the modern state, which has to some degree usurped the role of custodianship over wildlife, lands and natural resources.

The heuristic pattern is described here as a historical flow from local custodianship embedded in cultural systems of knowledge and governance and accompanying customary land tenure-biocultural systems-which were transformed over the past century due to the emergence of newly organised systems of nationstate authority and the multilateral principle of state sovereignty. Other chapters of this book provide us with more detail on patterns of protected area and natural resource governance at supra-community levels in ancient times-for example, the legislative framework of the Mauryan Empire in 300 BCE India. Evidently, we did not jump from autonomous hunter-gatherer systems of natural resource management directly into the modern nation-state. Nonetheless, it can be argued that the expansion of European power through colonisation created dynamics that ruptured customary tenure systems of indigenous and local peoples, and replaced these in most cases with a centralised state with the 
primary function of extracting wealth for use in Europe (during colonialism) and later for national elites and global partners (in the postcolonial context). There is a major body of literature on understanding postcolonial economies in the global system (see, for example, Ralston Saul 2005; Shivji 2009; Amin-Khan 2012).

From at least the 18th century through to the 20th century, there was an intensification of the pattern of local custodianship being displaced or modified by consolidation of colonial and metropolitan states. In Europe and in territories occupied by Europe, there was a newly imposed centralised state administration, which became the global norm. This pattern was most pronounced where there was full European colonisation, which undermined many subordinated systems of natural resource governance, customary use and previously autonomous political systems. The same pattern, however, is also apparent in societies that were only lightly colonised or sustained their own autonomy. The pattern in both colonised and uncolonised polities reinforces the argument that the important 19th and 20th-century surge in the designation of modern protected areas is closely associated with the consolidation of the authority of the nation-state and its role as the primary custodian of nature conservation. Other factors, including the evident decline in biodiversity and increase in human population, were significant, but for our purposes the interesting element is to understand where the power resided in terms of territorial custodianship and then to consider what the current trends indicate.

Important variables in this assessment of trends are the role and character of the state itself. The state is a product of particular ordering of human society. It arises from historical, economic, geographic and cultural contexts. It is shaped by forces internal to it and by the external context. This chapter argues that the rise of modern state sovereignty, particularly in the colonial and postcolonial contexts, caused a breakdown of local custodianship and a centralisation of decision-making. Though this likely contributed to protected area policymaking and standardisation, it also created new challenges of accountability, particularly when the state became associated with economic globalisation and globalised demands for resource extraction.

Despite arguing that there is a visible trend in terms of custodianship authority, the historical flow of authority and duty is neither linear nor unidirectional. It is often punctuated by assertions by non-state actors and rights-holders as well as other disputes over paradigms of political economy. While the function, duties and character of the modern state change, so the power and responsibility of custodianship remain contested.
When colonisation and industrialisation combined to create a global economic and political hegemony, there was also for the first time a new global ethic of redefining nature as a resource to be exploited and converted into economic profit without consideration for the sustainability of people or ecosystems. We shifted from a localised paradigm that combined intrinsic and instrumental values to a nakedly extrinsic and consumptive paradigm freed from all sacred associations and aimed at subjugating nature and extracting its value.

This paradigm of human dominion over nature is arguably still the dominant paradigm on the planet, particularly in the Western world. There are other significant paradigms about the relationship between humanity and nature, such as the Japanese concept of satoyama and satoumi, whereby harmony is achieved by sustaining a relationship between nature and human use. The 2013 Asia Parks Congress spent time exploring whether there is a distinct ethic in Asia regarding human relationships with nature and landscapes (APC 2013). This congress also triggered a reverse effect, of trying to distinguish between pristine and romantic landscapes, soon shaped into protected areas, and the more general approach to unsustainable degradation of natural resources and ecosystems. The colonial era associated extraction of labour and natural resources with increased national power, national esteem and economic growth, regardless of the natural consequences or human suffering this entailed. This trend impacted on the colonising countries and at the same time on distant lands, ruled by people who never set eyes on those territories. This disjunction between users and consumers of natural resources and the usual system of local use and local custodianship also manifested as a major shift in the ideology of our human relationship with nature.

The colonial land-use patterns are characterised by radical disconnections between older ecosystem-based natural resource management and the power of centralised authorities to create exclusive-use reserves without reference to either the characteristics of the ecosystem or the pre-existing governance models that sustained these areas. We have the colonial model meshing with postcolonial contexts where state elites see protected areas as important for tourism and international funding. These mixed colonial-postcolonial models have generated new patterns of protected areas, particularly in Africa, that have complicated relationships with local custodians and rights-holders (see Anderson and Grove 1995; Nelson and Hossack 2003).

Looking at conservation and protected areas through the lens of colonial political economy can leave the impression that at least early protected areas were a result 
of a mix of altruism and conquest. As other chapters of this book explore, the severity of the biodiversity crisis in the 19th and 20th centuries was the trigger for the Western, and eventually global, conservation movements. The rise of consciousness about our impact on the world manifested most clearly with the idea of setting aside territories for conservation, expressed as the modern tradition of protected areas. The overall relationship between the power to exploit unsustainably and the countertrend to assert the intrinsic value of nature and its psycho-social importance for humanity shifted from a highly contested space into a general direction of finding harmony between different cultural perspectives on landscape and seascape conservation within a rights-based approach to governance.

The issue of who is qualified and who is mandated to conserve is still contested in many countries. Debates around co-management, private management, indigenous management and other forms of cooperation with traditional and new custodians continue. The research on successful sustainable land and natural resource management continues to point in favour of combining professionalised conservation with good governance and an enabling environment for indigenous peoples and other local custodians. The resistance to such evidence of efficacy derives not from a science argument, but may find its origins in the legacy of early power struggles, racism, corruption and/or bureaucratic centralisation of power. The state and the civil society, in combination, provide the framework that will either facilitate or impede conservation that is embedded successfully in the human landscapes, economies and governance systems that can support conservation aims.

One of the most important theorists and empirical researchers on the issue of natural resource custodianship is Elinor Ostrom. Ostrom studied different indigenous and local systems of sustainable natural resource governance regimes. She emphasised that sustainability requires some kind of human governance system that permits exclusion of outsiders from resource use, supported by a local monitoring and decision-making system to protect sustainable biodiversity levels and ecosystem functions. Local governance systems were typically rule-governed but also quite flexible to cope with seasonal or sudden changes in the configuration of biodiversity abundance and human needs (Ostrom and Hess 2007; Ostrom et al. 1994, 2010).

Ostrom showed that a community could efficiently manage collective-pool resources when certain variables were in place. Contrary to other researchers who believed the commons or other collective actions were inevitably doomed to fail, Ostrom found evidence of diverse communities in which common resources were successfully and sustainability managed over the long term. Her contribution to the 2011 Sharing Power conference in Whakatane, New Zealand, presented three different fishing communities along the Baja California coastline who showed different degrees of marine conservation directly related to the capacity of the community to control and govern its common-pool resources. Influenced by a commitment to ethnography and understanding the role cultural values played in developing cooperative management regimes at the local level, Ostrom unsettled the dominant belief that common resources could not be managed by a local citizenship and instead needed to be managed by the state or privatised.

This work has important implications for protected areas and speaks to a shift in thinking on what constitutes effective long-term conservation. Whereas a state agency can be granted the powers to fully exclude human access to natural resources in a particular territory, this may not deliver the intended results. Some landscapes thrive in part due to human management and traditional systems of resource use, including, for example, traditional livestock herding, which may stimulate rather than impede biodiversity. The famous examples of Zimbabwe's Campfire program and Namibia's community conservancies are evidence that a wellplanned, equitable benefit-sharing agreement, which strengthens community custodianship, may provide the best biodiversity results feasible in landscapes that would otherwise be overexploited.

The approach that conservation is only possible if it breaks down traditional or customary rights of indigenous and local custodians may contribute to biodiversity loss rather than restoration. Ignorance of how customary commons management operates and the complex systems of knowledge, reciprocity, moral obligations and customary sanctions that sustain it, including the right to exclude users who have no rights in the landscape, may be one of the factors impeding landscape and seascape conservation. On the other side of the argument, we may find that simply asserting that a community has traditional rights claims to a territory, without working through how changes in human demographics, power distribution, human and animal density and other landuse changes in the area will cause substantive changes in sustainability, would be naive and will not ensure sustainability. There are likely no formulaic answers, but whatever options are pursued need to be informed by a full understanding of how protected areas fit into pre- 
existing governance norms, custodianship and cultural systems, which may not necessarily be understood by the national protected area authority.

Our conclusion at this point is that protected areas are inherent to most human cultures (see Chapter 4), but how they are coded into human cultural, social and political systems varies substantially. This cultural, spiritual and religious heritage of landscape and seascape conservation provides a framework for understanding the modern idea of protected areas and for developing shared systems of values to promote their sustainability and success. At the same time, we can recognise tensions between indigenous peoples and local communities who have had historical custodianship relationships with lands and seas in their territories, and the shifting of power to state authorities, sometimes within the colonial/postcolonial framework, sometimes within the framework of undemocratic or unrepresentative states, and the potential for a clash between human rights and conservation aims.

As we enter the 21st century, the pendulum appears to be swinging back from an exclusionary approach to protected areas to a better integration of local custodianship and support from a state-based duty to conserve. This was the clear message in the design of the CBD in 1992, in the IUCN World Parks Congress of 2003 and in the PoWPA (see Chapter 8). This conservation trend has been influenced and shaped by renewed assertions by local custodians of nature that they have rights and a role to play in conservation. This is clearly expressed in the 2007 UN Declaration on the Rights of Indigenous Peoples (UNDRIP). These trends are explored in the next section of this chapter, looking at changing norms in international human rights policy that impact on protected areas.

\section{Human rights, indigenous rights and custodianship in the 21st century}

The United Nations was formed after World War II, in an attempt to govern conflicts between states and to try to ensure global peace and sustainability. Its birth came after two devastating world wars, after the earlier body the League of Nations, at a time when colonialism was fading and the winds of change were sweeping across the countries of the global 'South'. Many new states were entering into the multilateral system and bringing in fresh ideas about human rights, fundamental freedoms, equality and global governance norms.
The UN system was built on an important dichotomy that has remained pertinent to this day. The United Nations was established on the principle of state sovereignty. In theory at least, all states are equal at the United Nations: they are sovereign, and they can choose to associate with specific treaties, agreements and actions. In December 1948, the United Nations adopted the Universal Declaration on Human Rights. This declaration set out the counterbalancing principle to state sovereignty—namely, that human rights are universal and they trump the sovereignty of the state at the United Nations. The idea was and remains that no state may violate the fundamental rights of its citizens or non-citizens under its watch. Should this happen, there are mechanisms and principles that allow other states to take actions to protect the rights of such people or at least to place substantial moral pressure on the state party to comply with international norms and standards.

These principles were elaborated in subsequent decades with specific attention to the rights of constituencies that struggled to be recognised under the rubric of 'universal' human rights (Box 5.2). In the 1960s, two other important documents came out of the United Nations: one, the International Covenant on Civil and Political Rights, and the second, the International Covenant on Economic, Social and Cultural Rights. These two covenants are referred to respectively as 'first-generation' and 'second-generation' rights.

First-generation rights are considered to restrain the behaviour of the state in relation to human beings. They affirm the rights of people to freedom of assembly, free political choices and the right not to be harmed, tortured or otherwise have their quality of life unfairly or unduly impacted on by the state and its representatives. Firstgeneration rights include rights associated with access to justice, and proper conduct of the courts, police and security services. A state may not impede the enjoyment of such first-generation rights.

Second-generation rights are considered positive rights - these highlight what the state is responsible for ensuring, including the positive recognition of the rights to linguistic and cultural diversity, the right to a livelihood, health, housing and certain standards of living, and the right to engage in the economic life of the country. Second-generation rights emphasise the equality of citizens and access to state services and guarantees of duties.

In the 1970s a 'third generation' of rights began to be asserted, commonly associated with environmental and developmental rights (see Harris 2013). These were articulated in documents such as the Stockholm 
Declaration of 1972 and elaborated into their most developed multilateral form at the 1992 UN Conference on the Environment and Development (UNCED, or Earth Summit) held in Rio de Janeiro, Brazil. At UNCED, civil society, scientists, churches, indigenous peoples and others lobbied states to adopt three major pieces of multilateral legislation on the environment, known as the Rio Declarations: the UN Framework Convention on Climate Change, the UN Convention on Biological Diversity (CBD) and the UN Convention to Combat Desertification.

Although third-generation rights have had less elaboration and commitment than first and secondgeneration rights at the United Nations, there is a clear trend to their expansion and use, from national courts through to multilateral norms and standards. This trend towards all three generations of rights is apparent in the UNDRIP, which was adopted in 2007. Africa was one of the more progressive regions as it included first and second-generation rights into its regional treaty, and also incorporated such rights as collective rights of selfdetermination into the African Charter of Human and Peoples' Rights.

In an interrelated and parallel process, indigenous peoples engaged with the United Nations to assert their human rights, and to elaborate a framework of rights that spoke to their specific experience of being dependent on natural resources, having being colonised by states that did not arise from their own cultures, and to assert their collective right to survival through self-determination.

There is much to say about the long struggle for the recognition of indigenous people's rights. The notable point here is that indigenous peoples have not only asserted their cultural distinctiveness, they also called into question whether the official state party represents their interests. They have asserted that they have their own forms of governance, closely associated with landscape and seascape custodianship, which need to be considered in a legal and a moral sense.

Indigenous people's claims are based on the aggregation of the instruments we have already cited: the Universal Declaration of Human Rights, the two covenants dealing with civil and political rights and with economic, social and cultural rights, and then third-generation rights associated with the environment and development. Their arguments and assertions speak to the heart of the original UN dichotomy between the sovereignty of the state and the rights of people living within that state-governed territory. As the United Nations is only composed of state parties, it was not surprising that the passage of the first major international instrument

\section{Box 5.2 United Nations' human rights instruments}

The UN system has different types of instruments with different degrees of obligations to implement and adjust national legislation.

A declaration is a normative instrument and does not require ratification or adjustment of national laws. A convention is a binding instrument and once ratified requires that the state adjusts national legislation and reports back to the United Nations on implementation.

Though it may appear that a non-binding instrument is weaker, this is not always the case as the Universal Declaration on Human Rights is one of the most influential normative instruments and is regularly used in national court processes and in international law, despite it not requiring ratification.

Major human rights instruments under the UN system include:

- Universal Declaration on Human Rights

- International Convention on the Elimination of All Forms of Racial Discrimination

- International Covenant on Civil and Political Rights

- International Covenant on Economic, Social and Cultural Rights

- Convention on the Elimination of All Forms of Discrimination against Women

- Convention against Torture and Other Cruel, Inhuman or Degrading Treatment or Punishment

- Convention on the Rights of the Child

- International Convention on the Protection of the Rights of All Migrant Workers and Members of their Families

- International Convention for the Protection of All Persons from Enforced Disappearance

- Convention on the Rights of Persons with Disabilities

- Declaration on the Rights of Indigenous Peoples.

to recognise indigenous people's rights was an arduous negotiation requiring 25 years from initiation to adoption (Charters and Stavenhagen 2009). Two key articles in the UNDRIP are relevant to protected areas:

\section{Article 3}

Indigenous peoples have the right to selfdetermination. By virtue of that right they freely determine their political status and freely pursue their economic, social and cultural development. (UN 2007:4) 
Article 29

Indigenous peoples have the right to the conservation and protection of the environment and the productive capacity of their lands or territories and resources. States shall establish and implement assistance programmes for indigenous peoples for such conservation and protection, without discrimination. (UN 2007:11)

Within this formulation is the idea of revitalising and affirming custodianship. Indigenous rights, in distinction to minority rights, assume that the identity and sustainability of a people are associated with their territory. This builds on the contemporary understanding that languages and cultures are very closely aligned to the landscapes and ecosystems where they flourished initially (Nettle and Romaine 2000).

Not only did indigenous peoples succeed in getting the United Nations to adopt the UNDRIP in 2007, but also they had a transformational impact on how the United Nations operates, asserting the right of non-state actors to be at the negotiation table to make moral and legal claims, and to provide information, advice and reports on multilateral norms and standards. This last point is likely a trend we will see continue into the coming decades. The idea that states can make decisions between themselves without consulting the constituencies impacted by those decisions is becoming less acceptable.

The process of getting the United Nations to agree to the declaration was accompanied by a much broader mobilisation of indigenous peoples within different multilateral institutions and treaty mechanisms, including the CBD and within the IUCN. In 2003, the IUCN hosted the fifth World Parks Congress (WPC 5), a decadal event and influential policy and practitioner forum.

WPC 5 was distinguished by its serious engagement on the questions of rights-holders, governance and how to understand protected areas as being within human landscapes-their cultural relevance, the economic landscape and the political landscape. WPC 5 helped contextualise protected areas in a way that had previously been resisted or deflected but which was mirroring the growing global attention to both the fragility of the planet and the need to reconcile human rights and conservation.

WPC 5 was held in Durban, South Africa, and had as its patron Nelson Mandela, the image of emancipation and human rights. The South African National Parks service itself was busy addressing the legacy of the colonial heritage of its estate, and the democratic government was working with many constituencies to reconcile South Africa's commitment to biodiversity and its challenges of redressing human rights violations and addressing systemic poverty. In many ways, South Africa served as a reference point for WPC 5: sitting between East and West, North and South, between the industrialised First World and the postcolonial Third World, with South Africa representing the new generation of 'emerging' economies.

During the first decade of the 21st century, a series of events combined to enhance and affirm the rights of indigenous peoples and local communities as stakeholders, rights-holders and knowledge-holders in relation to protected areas. In summary, we saw a progressive evolution of the new paradigm, including the 2003 WPC 5 and its landmark 'Durban Accord', the conversion of the WPC 5 outcomes into the CBD's PoWPA in 2004, the adoption of the UNDRIP in 2007, and the adoption of the declaration as a standards reference by the IUCN World Conservation Congress in Barcelona in 2008. Though some may have perceived the rights versus conservation dynamic as antagonistic, it is also possible to look at the same processes and see the relationship between the affirmation of human diversity and biological diversity as complementary. Within this nexus was also the coming wave of socio-ecological 'resilience' thinking and greater attention to the interface between human cultural diversity and natural biological diversity (Kassam 2009; Maffi and Woodley 2010).

There were other complementary instruments and decisions adopted in the multilateral systems-most notably, the CBD's Articles $8 \mathrm{j}$ and $10 \mathrm{c}$, which affirmed the importance of indigenous people's knowledge systems and customary use rights. COP 7 of the CBD adopted the Addis Ababa Principles and Guidelines for the Sustainable Use of Biodiversity (CBD Secretariat 2004), which emphasised the importance of sustainable use and the role of local and traditional custodians and knowledge-holders. The UN Educational, Scientific and Cultural Organisation (UNESCO) elaborated new work on intangible heritage and indigenous knowledge systems, including linking this to climate change adaptation and mitigation.

Throughout the multilateral system we were witnessing an effort to reconcile a number of competing interests: the rights of local custodians, the role of the state, the rising urgency for effective conservation, and the challenges of poverty and changing land-use patterns, including surging human populations and rapid urbanisation. 
World Commission on Protected Areas (WCPA) and the Commission on Environmental, Economic and Social Policy (CEESP), has served as an advisory body and catalytic agent in the IUCN's processes.

TILCEPA has emphasised the need to link a series of tools and approaches together, including protected area management effectiveness, with the social assessment of protected areas, and the elaboration of governance practices for both protected areas and larger connectivity landscapes and seascapes (IUCN TILCEPA 2010). TILCEPA has encouraged synergies between local marine and terrestrial custodians and the state-driven protected area system.

TILCEPA, CEESP and WCPA with their partners have published a series of reports and publications dealing with the main themes of rights, governance, social assessment and the renowned guidelines on protected area management and governance types.

In 2011, CEESP hosted an influential and landmark conference on Sharing Power in conservation. The global conference was hosted by the Ngāti Awa iwi (tribe) in Whakatane, New Zealand/Aotearoa. The Maori tribal authority is itself a case study of colonisation, dispossession, treaties, territorial claims, redress and restoration. As the iwi has regained its territorial rights and authority, it has emphasised the need to balance human use with environmental conservation. Members of the iwi have formal and non-formal qualifications in conservation and have entered into contractual relations with the national government to conserve coastal and marine territory-notably, a set of islands, Rurima, Moutoki and Tokata, which are unpopulated nature reserves. The sites were under national conservation authority, but with the land restitution process, from 2011 the Ngāti Awa iwi now manages the islands as a nature reserve and conducts alien species eradication according to both traditional Maori knowledge and scientific principles (Wikipedia 2014).

The 2011 Sharing Power conference emphasised the rights, duties and value systems of indigenous peoples and local communities as custodians of nature and as competent conservationists. It signalled the need for a frank discussion about power within the conservation sector, including examining the relationship between state conservation and the rights and roles of indigenous peoples and local communities.

The trend we are seeing in relation to social policy and the role of local custodians has two distinct elements: a greater assertion and recognition of human rights in relation to conservation; and growing confidence 
that sustainability and conservation success require cooperation between professional conservationists and local custodians. These two trends interact with each other around the issues of land tenure, authority and co-management as well as the challenge of science and other knowledge systems (traditional, local, indigenous, spiritual) being accepted within one decision-making process.

The issue of multiple knowledge streams and how to find relationships between different forms of knowledge, data and evidence for conservation management and monitoring has been gaining attention in the CBD and the Intergovernmental Platform on Biodiversity and Ecosystem Services. We also see this in terms of the growth of 'citizen science'- that is, participation in scientific projects by un-credentialed volunteers-and the application of indigenous knowledge in conservation science. Government authorities seem to be slowly recognising the importance of diverse knowledge systems and associated skills, such as traditional tracking and observation competencies. With connectivity conservation, the need to recognise knowledge diversity is even more acute as part of negotiating new social compacts for connectivity landscapes and seascapes, where tenure systems are diverse and much larger social alliances and cohesion are required.

Not everyone appreciates the diversity of human understanding of nature. There are still challenges in harmonising very different approaches to knowledge and values associated with biodiversity, and landscape and seascape management. A scientific approach compared with a culturally based sense of spiritual and ancestral duties to lands, waters and species can focus on different variables, evidence and models. The challenge is not simply to understand that there are different knowledge and value systems available, but also that there is a power dynamic that influences how the holders of the knowledge are respected and treated in their intercultural engagement.

[I]ndigenous peoples must first and foremost control their own information. It has also become clear over the years that the knowledge base of indigenous peoples is vital, dynamic and evolving. Merely 'collecting' and 'documenting' indigenous environmental knowledge is in fact counterproductive. These knowledge systems have been under serious attack for centuries and the social systems that support them have been seriously undermined ... It is not a question of recovery and recording indigenous knowledge, it is one of respect and revitalisation. (Brooke and Kemp 1995:27)
Custodians of local territories have been asserting their role in conservation and governance in combination with multilateral mechanisms that uphold human rights, due process and fundamental freedoms. As leaders or partners in conservation, custodians from outside the civil service, representing diverse constituencies, bring with them diverse values, knowledge and skills. Each such assertion and partnership require an interactive and intercultural process of mediation (Rambaldi et al. 2007; Crawhall 2008).

The newest conceptual addition to protected area multilateral agreements is that of Indigenous Peoples' and Community Conserved Territories and Areas (ICCAs), which received a surge of interest in the past decade and were formalised in the CBD PoWPA in 2010 at the CBD COP 10 in Nagoya (see Chapter 8). This makes it a recent multilateral policy term, but in practice it recognises this age-old global human pattern of managing landscapes and seascapes according to intergenerational responsibilities and belief systems, according to specific governance systems along with concomitant rights and duties. The recognition of ICCAs and the introduction of the Target 11 language on 'other effective area-based conservation measures' suggest an important trend of greater synergies between state-based protected areas, customary conservation measures (including sacred natural sites, indigenous peoples and local community conserved areas) and private conservation estates.

\section{Economic trends impacting on the state, communities and protected areas}

It is not possible to think about the future of protected areas without giving sufficient attention to economic trends. For decades, the environmental and conservation sector has been grappling with the evident contradictions between the political pressures to grow economies and the need to conserve our natural heritage and ecosystems.

The main argument presented here is that we are not achieving the balance between economics and sustainability. As noted earlier, this is an issue of values and priorities-not an immutable force in the universe. As such, communications around both economics and conservation remain critical in this generation.

There are different interpretations of what is driving biodiversity loss and the role of our current economic models. According to some writers, one key element is that macro-economics is the dominant national tool for economic planning and measurement. The growth- 
oriented and production-based tools for guiding macroeconomic policy may distort the picture of our increasing vulnerability and inequality. The bias in such policy instruments may indeed be driving a predisposition to facilitating the spread of extractive industries at the expense of healthy landscapes, seascapes and ecosystems.

Recently, a number of major projects have considered in some detail the relationship between nature and economics: prominent have been The Economics of Ecosystems and Biodiversity (TEEB), the UN Environment Programme (UNEP) Green Economy Initiative (GEI), and the international framework of the System of Environmental-Economic Accounts.

The UNEP GEI, despite criticisms regarding its logic and design (see IPACC 2011), does successfully argue that governments do not understand, evaluate or work with the true value of nature, ecosystem services and natural resources in relation to sustaining human wellbeing, health and nutrition. The failure to calculate the real value of nature in human life is leading to accelerating erosion of ecosystem capacity and with that a growth in human poverty and social disintegration. According to GBO-3, protected areas are apparently the main global policy tool for conservation, yet in practice, protected areas are subject to the same macro-economic trends as other landscapes, and hence we see a growth in mining and extractive industries being permitted in protected areas, including the iconic World Heritage sites (see IUCN 2011, 2013). Though the protected area estate may be growing, we can anticipate that if the current trend continues, the effectiveness of protected areas will continually decrease.

How we should respond to the problem of macroeconomic policy that excludes conservation, sustainability and effective landscape/seascape planning is a hotly contested issue. One of the trending responses has been to concentrate on how the environment, ecosystems and nature are to be 'valued'. According to the TEEB and the GEI, the argument is that nature has a number of values that can be understood by national economic policymakers. These may be in terms of their commodity value and longevity; it may involve measuring the value of an ecosystem service, such as the availability of drinking water and its replacement value if damaged or destroyed; or it may consider how alternative industrial and energy pathways could generate new forms of wealth that are not so destructive to the natural environmentfor example, the use of solar energy.

The critics of the 'valuation' approach emphasise that putting a commodity value on nature just encourages the private sector and the macro-economists to accelerate the extraction of the good (that is, shift it from its natural state into a commodity of capital value) or it may lead to its privatisation. In the case of the former, this could degrade nature at an ever-accelerating pace, thus increasing poverty and vulnerability; in the latter, it makes some people very wealthy but overall it impoverishes those who are not the owners and they in turn must extract more from a smaller pool of natural resources, creating a downward ecological and human spiral.

The capitalist model of economic organisation has emerged as the dominant system in the 21 st century. The wealth and power gap between former colonising and colonised countries has been transformed; though inequalities are greater on a global scale, there are more countries from the global South that are emerging as politically and economically important. Countries such as China, Brazil, India and South Africa have entered the ranks of middle-income countries with their own industrial production bases, and the ability to exploit natural resources and labour markets for their own national territories and in other distant countries. These trends have transformed power relations and energy consumption, greenhouse gas emissions and the demand for raw materials for trade and production. Poorer African countries have found it is in their political interest to engage with both Asia and the West as economic partners and markets for raw resources. Africa increasingly navigates its options in selling to emerging Asian economies from which they also secure advantageous loan and infrastructure cooperation while still maintaining their economic ties to the West, either to the former European colonisers in Europe or to North America and Australia. The current crisis of ivory and rhino-horn poaching, which is driven by Asian consumers unsustainably extracting from African client states, raises interesting issues about where nature fits in such South-South economic relations. The growing capacity and need for fossil fuel extraction have also opened up new opportunities for globalisation of the extraction and commodification of new fossil fuel sources including in sensitive marine environments.

The 20th century was defined by sharp disputes over economic and political theories. The sharpest distinction was between the capitalist 'free-market' Western countries and the alliance of Second World socialist countries, most notably the Soviet Union and the Peoples' Republic of China. Africa, Asia and Latin America all found themselves on a continuum between these polar opposite views of how human political economy should be organised and the role of the state in relation to provision of comfort, wealth and justice. 
The interesting aspect, in relation to environmental conservation and sustainability, is that despite the bitter and sometimes violent opposition between these two world views of political economy, both tended to see the environment from an instrumentalist and utilitarian perspective. Capitalists and communists generally considered that any extraction from nature that could contribute to production would help grow an affluent society. The socialist economies are sometimes particularly singled out for their assault on local custodianship to force natural resources into the control of the centralised and planned economy (for a discussion on socialism and the coherence of the peasant economy in Tanzania, see Hyden 1980).

In the capitalist language, production and growth are associated with private initiative, reward and a generally more affluent society from top to bottom. From the socialist and communist perspective, the growth of national production represented an opportunity of wellbeing for the proletariat, who were now the owners of production. Production in the socialist economy was not to be driven by individual benefit, but was intended to achieve a more just and balanced society. In neither case did the environment fare particularly well, nor did the socialist superpowers use their revolutionary model to protect biodiversity and ecosystems; perhaps the best-captured experience of socialist environmental devastation was found at Lake Baikal (for an overview of Soviet environmental issues, see Josephson et al. 2013). The only positive legacy to come out of the experience was that those countries that freed themselves from Soviet occupation and control often emphasised greater attention to environmental conservation. The protection of the local environment and the role of the environmental movement to unite people in the Baltic States were both elements of the transformation process and points of national pride in the post-Soviet period of independence (see, for example, Högselius 2008).

By the close of the 20th century, this great tension between political economic paths was over. The Soviet Union had collapsed and swung into an aggressive form of private capital accumulation and the People's Republic of China, though nominally still communist and steered by the Chinese Communist Party, in practice enthusiastically espoused personal enrichment and the private sector.

\section{Capitalism, growth models and sustainability}

To understand more about Western economic theory and the tenacity of an approach to economics that places us on a collision course with the capacity of the planet to sustain us, we turn to one of the classics in considering the assumptions and principles of capitalism in the United States. In his landmark book on capitalism, The Affluent Society, John Kenneth Galbraith (1998) provides a summary of capitalism's promises and premises on achieving universal comfort for the Western world. Galbraith's book not only describes the rise of wealth in the Western world and examines its ideological heritage, but also challenges the dominant belief that capitalism is a universal law that governments must recognise and facilitate and not block with regulatory measures.

Galbraith's main argument is that Western civilisation adopted the premise that a society's success was measured by the production of goods, which permitted both income generation and consumption. The cycle of production, income, consumption and further production created, it was believed, a virtuous cycle that created an affluent society, in which universal and transhistorical poverty began to give way to a general shift upwards in wealth. Galbraith challenges this belief, and questions whether such a reductionist view of happiness and wellbeing is adequate for either the individual or the society. He nonetheless espouses the view that capitalism offered (at least to the Western world) a level of economic security and broadly based distribution of resources; that it provided an attractive model of political economy despite its counter-ideologies. Galbraith noted nonetheless that poverty had not been eradicated, and in contrast with earlier systems, the idea that poverty was a problem became a central feature of Western economic and political thinking (Galbraith 1998:238-41).

According to orthodox capitalists, growth in production could be unlimited and was guided by an invisible hand' of self-interest, driving the individual to combat threats of scarcity through noble economic pursuit. The marriage of personal interest and the dynamics of supply and demand should, in theory, create an everexpanding model of economic growth and distribution of wealth. Galbraith's summary returned to the influence of Adam Smith, an 18th-century Scottish philosopher and pioneer of political economy theory who focused on aggregated wealth deriving from a classically liberal model of a capitalist economy (Galbraith 1998:21).

Every individual ... generally, indeed, neither intends to promote the public interest, nor knows how much he is promoting it. 


\section{Box 5.3 Macro-economics and environmental decision-making}

Macro-economics is the study of the large design and performance of an economy. This can be at national, regional or even global levels. Macro-economics focuses on aggregated information from the whole economy and is influential in national policymaking. Macro-economic policymaking focuses on aggregated indicators such as GDP or the sum of national transactions in goods and services. There has been increasing attention to growth indicators in national economies as well as the scale of trade, consumption and investment.

The set of macro-economic policies is a powerful instrument for change and includes fiscal, monetary and financial policies, income policies, trade policy and the overall balance-of-payments posture. It also includes policies affecting prices of goods that have economywide implications (basic foodstuffs, energy, and so on).

Macro-economic policies affect the rate of economic activity and investment dynamics, usage rates of natural resources, relations between real and financial sectors, asset composition of investment portfolios, income distribution and a country's insertion in the international economy. Macro-economic policies play a critical role in structural or economy-wide transformations. From the environmental and sustainability perspectives, they play a role of paramount importance as they determine the aggregate amount of resources allocated for conservation and environmental stewardship. In summary, they affect production strategies and the resource management capabilities of all economic agents, from the largest corporations to the smallest subsistence farmer.

Macro-economics is important because sustainable development is not a notion restricted to individual economic sectors. It is concerned with the aggregate relations of modern economies expressed in the dynamics of income, savings, investment and employment. The fundamental issues of fairness in access to opportunities, the preservation of livelihoods and equitable income distribution are core components of sustainable development. And if we don't bring macroeconomics to the discussion of sustainability, we will fail in the endeavour to make this a better world.

CEESP macro-economic specialist Alejandro Nadal has provided a critique of how macro-economic policy shapes sectoral decision-making. His argument is that national governments subsume all sectoral decisionsincluding in agriculture, energy and conservation-to the larger indicators. The larger indicators do not account for the sustainability of the resources, only their scales of extraction, production and sale. The dangers for the environment are evident, in that ecosystems and biodiversity, including water security, may be destroyed in a quest to increase mining production and exports.

Conservationists, and particularly those interested in community custodianship and the benefits of sustainable use, need to be better informed on what constitutes macro-economic policy and how to influence this level of policymaking. Today the priorities of macro-economic policies, such as price stability and balanced budgets, continue to dominate sector-level and environmental policies. This is why there is insufficient allocation for protected areas, whether they have a communitybased management approach or not, and this is why there is little support for small-scale agriculture. In fact, these macro-economic priorities have shaped a style of agricultural policy that in many cases compromises the long-term survivability of protected areas. Macroeconomic policies should be subordinated to the overarching priorities of sustainable development, environmental integrity, fairness and economic justice.

Source: Nadal (2011)
By preferring the support of domestic to that of foreign industry he intends only his own security; and by directing that industry in such a manner as its produce may be of the greatest value, he intends only his own gain, and he is in this, as in many other cases, led by an invisible hand to promote an end which was no part of his intention. (Smith 1904:265)

In Smith's writing, the idea that the aggregation of individual interest generated a pattern for the economy was a novel observation. The idea of the invisible hand' soon rose to mythic proportions, particularly in the United States, and continues to inform global macro-economic ideology. Smith, however, did not say that the state did not have a role in mediating social vulnerability, rights or conservation of nature; this was a later extrapolation.

The ideology of the invisible hand-that there is logic to capitalism that is outside the realm of human intervention, and thus needs to be facilitated rather than blocked-has a very direct impact on contemporary decision-making about whether to subject protected areas to the same kinds of economic forces (see also Box 5.3).

The modern interpretation of Smith's invisible hand and the theory that the only economic indicators worth knowing about are ones that demonstrate production or more generally growth of gross domestic product (GDP) can be seen as being in diametric opposition to Ostrom's studies of successful management of natural resources 
through systems of common-pool resources. Ostrom has shown that social cooperation and attention to ecosystem capacity, negotiated rules and shared knowledge systems determine successful sustainability. The capitalist creed in its crude form has no such concept of sustainability or even valuation of natural resources other than as commodities or capital. This has major implications for policymaking and the future of protected areas. It equally has an impact on whether decision-makers see landscape and seascape conservation as cooperative actions or subsumed in models of dominion, extraction and commodification. The history of protected areas suggests that we are caught on the horns of this particular dilemma.

Another trend in past decades has been the rise of support for the privatisation of property.

'In every civilized society property rights must be carefully safeguarded; ordinarily and in the great majority of cases, human rights and property rights are fundamentally and in the long run, identical' (Roosevelt 1910:8).

Traditional systems of land and sea management relied on a mixture of family duties and rights over a specific territory or resource, and larger collective control, duties and governance systems, usually finely tuned to ecological trends and the abundance of resources. The degree of exclusion in the governance system-that is, the degree to which one defined human group had exclusive rights, or the conditions for access through reciprocal access - was related to the abundance of the resources, the capacity of the ecosystem to regenerate and the human population pressures on the territory. This is evident in nomadic pastoralist societies, where vast rangelands were rule-governed to ensure sustainability of plant biodiversity, water resources, livestock, wildlife and human populations.

As capitalism became more firmly established in the Western world, the idea of privatising land and resources, and legalising ownership to the exclusion of other users, became normalised and emerged as a dominant theme in Western constitutional law, and from there the trend spread globally to all corners of the planet (for a particular and controversial perspective on property, see de Soto 2000). The collapse of the Soviet Union and the American influence in the reconstruction of Eastern Europe provided an additional boost for the promotion of the privatisation agenda on a global scale. Privatisation is ideologically directly associated with the economic principles of capitalism that wealth and wellbeing are to be measured by production outputs, growth in consumption and trade, and the reduction of a regulatory environment to protect other human values, and in some cases, the wellbeing of nature and ecosystem services.

Privatisation has implications for the future of protected areas. First and foremost, the privatisation of land for industrial production and resource extraction poses major threats to the environment, and the trend is for greater penetration by extractive industries into protected areas than we have previously witnessed. This pattern has even acquired its own acronym: PADDD—protected area downgrading, downsizing and degazettement (WWF 2014). The logic of PADDD is being driven by a macro-economic perspective that views any activity that involves production and commodification as inherently of higher value than any public benefit and resource that will not generate the same indicators.

The other aspect of privatisation has been a concomitant rise in private protected areas. Different parts of the planet have seen various models of land privatisation for the purposes of conservation or at least tourism benefits associated with conservation (effective or otherwise). Further, there have been joint ventures where people of wealth have supported private protected area acquisitions in third countries, particularly as a 'North-South' partnership. There are non-governmental agencies, private foundations and private philanthropists who all support projects to privatise land and bring it into the privately managed conservation estate.

The other pattern is that privatisation of lands and resources poses a direct threat to existing protected areas and other area-based conservation efforts. Africa has experienced a sudden and dramatic process of land privatisation and alienation, leaving indigenous peoples, local communities and conservationists with increasingly fragmented landscapes, where the traditional systems of transhumance and seasonal migrations have been interrupted, placing greater population pressures on smaller areas of available communal lands.

The privatisation trend has not been without resistance: indigenous peoples in some parts of the globe have been highly critical of privatisation, demonstrating how it is inherently insensitive to nature's needs. They call for a socially just compact within humanity, between peoples, and between humans and other species. In 2010 there was a global gathering of civil society in Cochabamba, Bolivia, for the World People's Conference on Climate Change and the Rights of Mother Earth. The Cochabamba Declaration and other efforts by civil society assert that the current economic model is not sustainable, that it is leading to catastrophic climate instability, and that we need to reconsider a more equitable model of 'living 
well' with nature and with each other. Gaia Foundation and its indigenous peoples' alliances around the planet have promoted 'Earth jurisprudence' and the rights of Mother Earth, arguing that there are traditional legal systems that recognise the Earth as a living entity and that privatisation and exploitation of natural resources need to be balanced with the rights of the Earth itselfrights that should constrain our rights and actions.

The privatisation trend is accompanied by a parallel process of strengthening multilateral laws and agreements applying to private intellectual property rights. The patenting of life forms and natural genetic material, including seeds, has become a major area of legal contestation. One of the most important pieces of multilateral treaty legislation in recent years has been the Nagoya Protocol on the Access and Benefit Sharing of Genetic Resources (ABS Protocol), adopted by the tenth Conference of Parties to the CBD in Nagoya, Japan. The relevance of the ABS Protocol to protected areas remains to be understood and explored.

Indian civil society has reacted strongly to the threats of seed patenting, legalistic promotion of genetically modified organisms and the privatisation of traditional knowledge. Dr Vandana Shiva has become a global spokesperson for the struggle against what has become known as 'bio-piracy', against genetically modified organisms, the privatisation of life forms and efforts to dispossess the poor of their biocultural heritage. The International Association for the Study of the Commons has hosted a series of global conferences to bring together diverse civil society groups interested in defending common-property natural resource regimes and resilience strategies.

In his summary of the threats to ecosystems and protected areas in Africa, Leo Niskanen, the IUCN's regional expert for East and southern Africa, highlighted that changes in biotechnologies, genetically modified organism (GMO) seed modification and the promotion of biofuels all introduce the potential to penetrate previously hostile biomes and ecosystems for conversion to agricultural uses that were not previously viable (IUCN 2014).

One initiative that struck a global chord of interest was the emergence of the Bhutanese Gross National Happiness (GNH) Index. The term was coined in 1972 by Bhutan's former king Jigme Singye Wangchuk and was subsequently elaborated as a measurement for quantifying the happiness of citizens rather than relying on economic indicators to determine the relative success of a national political economy. The GNH from its inception drew attention to the relationship between nature and human wellbeing, arguing for a strong commitment to conservation as a context for human happiness and sustainability.

The GNH was proffered by Bhutan during the United Nations' preparations of the Millennium Development Goals. At the time, Western economists found it difficult to accommodate a subjective notion of happiness and were more interested in measuring dollar-based incomes and other indicators of basic development. Psychologists found the GNH to be a useful and valid concept and it has remained in global public discourse, particularly in those countries that are finding growth in material wealth does not translate into satisfaction or sustainability.

There is a fulsome literature on economic trends and the relationship between capitalism, globalisation and the use or conservation of natural resources. The issue that will most likely need monitoring, and which is anchored in these economic models, priorities and policy frameworks, has to do with the regulatory system in relation to extractive industries - notably, mining and fossil fuel extraction-which pose direct threats to biodiversity and ecosystems, and increasingly are seen to be violating the boundaries of World Heritage sites and protected areas. Beyond the regulatory policy issues, there is a larger political and conceptual discussion about what matters to humans, what we require to live well and how these issues can be part of macro-economic policy and decision-making.

\section{Extractive industries and protected area effectiveness}

The first part of this chapter and various chapters of the book show increasing policy support for protected areas supported by multilateral agreements, norms and targets, increasing professionalism, increasing understanding of the social compacts required for successful conservation, as well as the assertion of both human rights and custodianship duties to achieve conservation objectives. In the section on capitalist economics, we have noted that there is a sharp tension over what value nature has within national economic planning. There are economic trends likely to pose a major challenge to protected areas. A key challenge is the surge of globalised extractive industries and the inability or unwillingness of nation-states to constrain destructive activities in and around protected areas and other fragile landscapes and seascapes.

It is axiomatic that politics and economics have complex and intimate impacts on each other. The global extractive industries have ceased to have strong national roots and have moved into a sphere of autonomy that 
the multilateral system struggles to regulate. The state is the primary agency that has regulatory powers over multinationals within their national territory. Some individual states may be showing patterns of reducing their own sovereignty to facilitate access by extractive, mining and fossil fuel industries to resources, which pose a direct threat to the environment in general and protected areas in particular.

Currently, this is expressed as the increased power of multinational extractive industries to penetrate increasingly remote territories and fragile ecosystems, at times regardless of national environmental policies. The state now finds itself with a high degree of authority with regards to protected areas, but is also caught between custodian and customary-use rights claims by local communities and indigenous peoples on the one hand, and the rising influence of privatisation of lands and resources, changing land-use pressures and the power of global extractive industries on the other.

This chapter does not explore the biophysical or social consequences of extractive industries. That literature is available. The trend of interest here is the surprising willingness of an increasing number of countries to proclaim protected areas, to establish UNESCO World Heritage sites and then also grant access to these sites or the general ecosystem for extractive industries, including mining and fossil fuel extraction.

Addressing root causes of this substantial threat to protected areas involves finding connections between different policy tools. This chapter attempts to show that regulatory measures that will protect landscapes and seascapes are likely to be shaped by a consideration of human rights, the assertion of the rights-holders and stewards of locally conserved areas, engagement on valuation and economic policies, and the use of the multilateral system to create norms and standards that shape national policy and behaviours.

In October 2013, at the WILD 10 Congress in Salamanca, Spain, a diverse coalition of interests gathered to generate a resolution on mining and extractive industries in relation to conserved and protected areas. The resolution entitled "Resolution 12: Building a Global Alliance to assert "No-Go Areas" for Mining and other Extractive Industries and destructive activities threatening World Heritage Sites, and Protected Areas, including Indigenous Peoples' and Local Community Conserved Areas and Territories (ICCAs) and Sacred Natural Sites and Territories' was supported by the Indigenous Peoples of Africa Coordinating Committee (IPACC), the African Biodiversity Network, the Gaia Foundation, the WCPA and the CEESP.
The resolution called for a halt to mining and destructive industrial extraction in protected areas, World Heritage sites, indigenous people's territories and sacred natural sites. The resolution has no legal weight or binding force and was adopted in a forum outside both the UN and the IUCN systems. It does, however, indicate the degree of concern that both conservationists and custodians share about the impacts of mining and extractive industries.

Some indigenous peoples have expressed their concerns that extractive industries and mining are moving into ever more remote rural areas. Where indigenous peoples do not have secure tenure, they are faced with eviction and dire consequences of the impacts. During the Indigenous and Community Lands and Seas Forum at WILD 10, Aboubacar Albachir, the Vice-Sultan of Airr in northern Niger, recounted the traumas of radioactive pollution from uranium mining on desert communities in that country, and how the massive profits from mining do not go into infrastructure or services within the indigenous territory. The Australian delegate from the Kimberley, Wayne Bergman, explained that they felt they had little choice but to negotiate with the mines directly. Either they negotiated or their lands would be taken without consent and without them being able to influence the impacts. These constituencies may be seen as marginal compared with international mining corporations, and yet we know that human rights and specifically indigenous peoples' capacity to represent themselves, use national and international law, and assert their custodianship role are on the rise rather than on the wane.

It is perhaps surprising, considering how multilateral environmental agreements have flourished since 1992, that we have very few relating to extractive industries or their relationship with protected areas or other conserved territories.

The IUCN has a number of site and ecosystem-specific resolutions on mining and extractive industries from its various congresses. The key global resolution on mining and protected areas came from the IUCN's second World Conservation Congress, in Amman, Jordan, in 2000. Resolution 2.82, 'Protection and conservation of biological diversity of protected areas from the negative impacts of mining and exploration', called for the IUCN and its members to uphold the exclusion of mining from protected area Categories I-IV. The resolution asked member states to use legislation and policy to protect and conserve the biological diversity of these protected areas from the negative impacts of mining and exploration. 
Since Amman in 2000, the problem has apparently worsened, with new and more destructive forms of extraction, particularly in the fossil fuel industry, and more penetration into remote and sensitive ecosystems, iconic World Heritage sites and protected areas.

The IUCN is challenged by its expert role in advising the UNESCO World Heritage Committee and the sudden spread of mining contracts and extractive industry permits within World Heritage properties. For example, the United Republic of Tanzania has authorised uranium mining in the Selous Game Reserve, a World Heritage site. As the IUCN prepared for the Sixth World Parks Congress, in Australia in 2014, the Australian Government and the Great Barrier Reef Marine Park Authority had made decisions regarding dredging spoil that posed a threat to the Great Barrier Reef-another iconic natural World Heritage property. The Great Barrier Reef is threatened by several extractive industries, fossil fuel-related pollution sources, associated busy shipping lanes and plans for further coal exporting from Abbot Point. Such threats are being seen on a global scale. The roots of the problem take us back to the tensions about values, custodianship and possibly also changes in the character and interests of the state itself.

During the Sixth World Parks Congress in Australia and the subsequent multilateral meetings, this surge in threats to the environment and protected areas was debated by a broad range of actors and rights-holders. It is less evident that effective coalitions are ready to be formed between groups with different understandings of economics, custodianship and the place of nature in human culture and political economy.

\section{Conclusion}

The message of this chapter is that nothing is certain and at the same time we can see a flow of events from cause to effect that shapes our interest in protected areas, their use as conservation instruments and the threats posed to them. Economics, politics and society are the products of complex dynamics but they all originate in the human mind. If we intend conservation of life to be effective, and protected areas are a cornerstone of that strategy, it will continually require both understanding and influencing human values, priorities and decisionmaking.

Some trends we know are likely to continue; other shifts in values, economics, politics, demographics and climate will shape the future of protected areas. Ignoring the political economy is unlikely to benefit those interested in protected areas; forewarning is key to mitigating the impacts of different trends and shifts in values. Ignoring social constituencies and potential allies is also unwise. The 'fortress' approach to conservation not only poses moral dilemmas; this chapter suggests that it also poses strategic weaknesses as it weakens the sense of custodianship of the people whom one is counting on to support protected areas.

We can see a pattern of shifting scales of custodianship and responsibility for landscape and ecosystem conservation over recent centuries and decades. It is likely that the issue of power and custodianship will remain acutely important. If we consider that ecosystems function at different scales, it is significant that the custodianship and governance of ecosystems, in the context of the Anthropocene, should ideally be aligned to create positive synergies and cohesion. The rights, duties and capacity of each scale of ecosystem governance need to be well attended to and the different scales should not work against each other.

At the May 2013 World Indigenous Network conference in Darwin, Australia, Ashley Iserfoff, the Deputy Grand Chief of the Grand Council of the Cree (Eeyou Istchee), made a presentation on how the Cree tribal authority in northern Quebec could not find a suitable national or provincial legislative policy framework to permit a joint land and sea protected area connection. Existing legislation did not facilitate this Cree initiative to improve terrestrial-marine connectivity. With a sense of duty and custodianship, the Cree were able to craft an innovative legal framework, drawing ultimately on their own sense of duty and responsibility. Thus far we have not seen many such holistic approaches to landscape and seascape governance. The rising interest in social and ecological connectivity suggests that this might be the new agenda.

This chapter has argued that the colonial and centralised states, intentionally or otherwise, reduced the authority and powers of local custodians of nature and their powers to govern and respond to environmental changes. The environment progressively became seen as the domain of a centralised state with new scales of planning, landscape and seascape interests and varying degrees of conflict and convergence with the older systems. More recently, state systems have become increasingly integrated into globalised commodity markets where national custodianship is less certain, and new threats are driven by foreign profit motives and commodity markets, sometimes determined by companies on the other side of the planet. This has left landscape and seascape custodianship in complex patterns that mix de facto local custodianship with de jure national legal authority of the state, and the ambiguous relationship between 
transnational commercial interests and national elites. Within this shifting political economy, we also see some degree of ambiguity about the value of nature (intrinsic versus local sustainable use dependency versus utilitarian and commodifying) and what constitutes a human duty in relation to nature and ecosystem integrity.

Most cultures and most religions seem to ascribe value to nature. If this has slipped from human consciousness, it may be a temporary aberration. Perhaps our sudden shift into industrialisation and capitalism created psychological and economic conditions that led us away from both our spiritual insights and the role that nature plays in our wellbeing, health and survival. The current crisis of biodiversity loss, surging human population, breakdown of ecosystem integrity and the rapid destabilisation of our climate will have consequences that may cause humanity to revisit our obligations to the living world. In a traditional system, there were rights, responsibilities, social mores and norms to guide the equitable and sustainable use of nature. These were rulegoverned but flexible, and still exist in many rural areas of the world. It is evident that many indigenous, local and spiritually governed territories retain their older forms of governance to this day, along with innovations and transformations. These human constituencies are becoming more engaged in protected area discussions, governance, management and policymaking.

As the world continues to change, whatever future sustainability we hope to achieve will demand reconciliation between human stewardship of the environment and other interests, including wealth aggregation, macro-economics, international politics and the changing nature of the state. What is certain is there is no way back to an earlier way of living; whatever is possible will come from coping with the changing context and finding sufficient will to adjust our impact on the Earth, waters and atmosphere.

The growing international attention to connectivity and larger scales of landscape and seascape management and conservation is not only of scientific interest; it also has major social, political and economic implications. Connectivity conservation landscapes and seascapes by definition take us out of the framework of statecontrolled territories, and into complex multi-tenured landscapes, where governance is negotiated with different types of owners and users of lands, waters and natural resources (see Chapter 27). As Worboys et al. (2010) stress, connectivity is not a new technical process of conservation; each case involves substantial engagement with society and interest groups, leading to a new form of social compact that marries diverse interests, cultures and values within an overall paradigm of cooperation.
Another message of this chapter is that just as humans are the drivers of climate change and biodiversity loss, we are also capable of being good custodians. Political economy and the policies that shape both the economy and nature conservation arise in human hearts and minds. They are not separate from our human will, even if they are shaped by systems into which we are born-cultural, economic, social, political and environmental systems that form the foundation for our actions. Conservation and sustainability are a matter of human values, human will and an enabling policy environment.

Simply increasing the number or territorial extent of protected areas is unlikely to achieve the stated aims of conservation. This is particularly true if economic trends that are undermining the effectiveness of protected areas continue to gain momentum at the same time as we are increasing their physical extent. If indeed we are building a bridge of sustainability on one side of the river, while chopping it down at an ever greater rate on the other side, the forecast is for a sudden collapse underneath us and a plunge into a substantially different context.

The synchronisation of scales of governance and scales of ecosystems speaks to a human understanding of both science and value systems. Success hinges on issues of shared duties, allied responsibilities, checks and balances, accountability, authority and responsibility.

For protected area staff, this may all seem daunting or out of reach. With all of the other challenges of professionalising and upgrading conservation capacity, this chapter suggests that sustainable protected areas, in the broad sense of the term, also require an interaction with those who understand and are competent in other disciplines and areas of expertise that may at first seem remote to wildlife management. Not least amongst these is the ability to develop alliances and solidarity with communities, social movements, economists, influence-makers, those in industry and those engaged in legislation and multilateral treaty systems.

The IUCN's Sixth World Parks Congress in 2014 explored the idea of a new social compact-a rethinking of how we work together in different economic, political, cultural and social contexts to ensure custodianship. Sustainability and a custodian-based constituency to support protected areas and other area-based conservation and sustainable use regimes will require solidarity and cooperation, rights and the sharing of benefits, costs and duties. A new social compact to protect the fragility of the Earth and the natural resource base would involve a substantial paradigm shift in which protected areas and connectivity landscapes and seascapes will play a major role. 


\section{SYDNEY 2014}

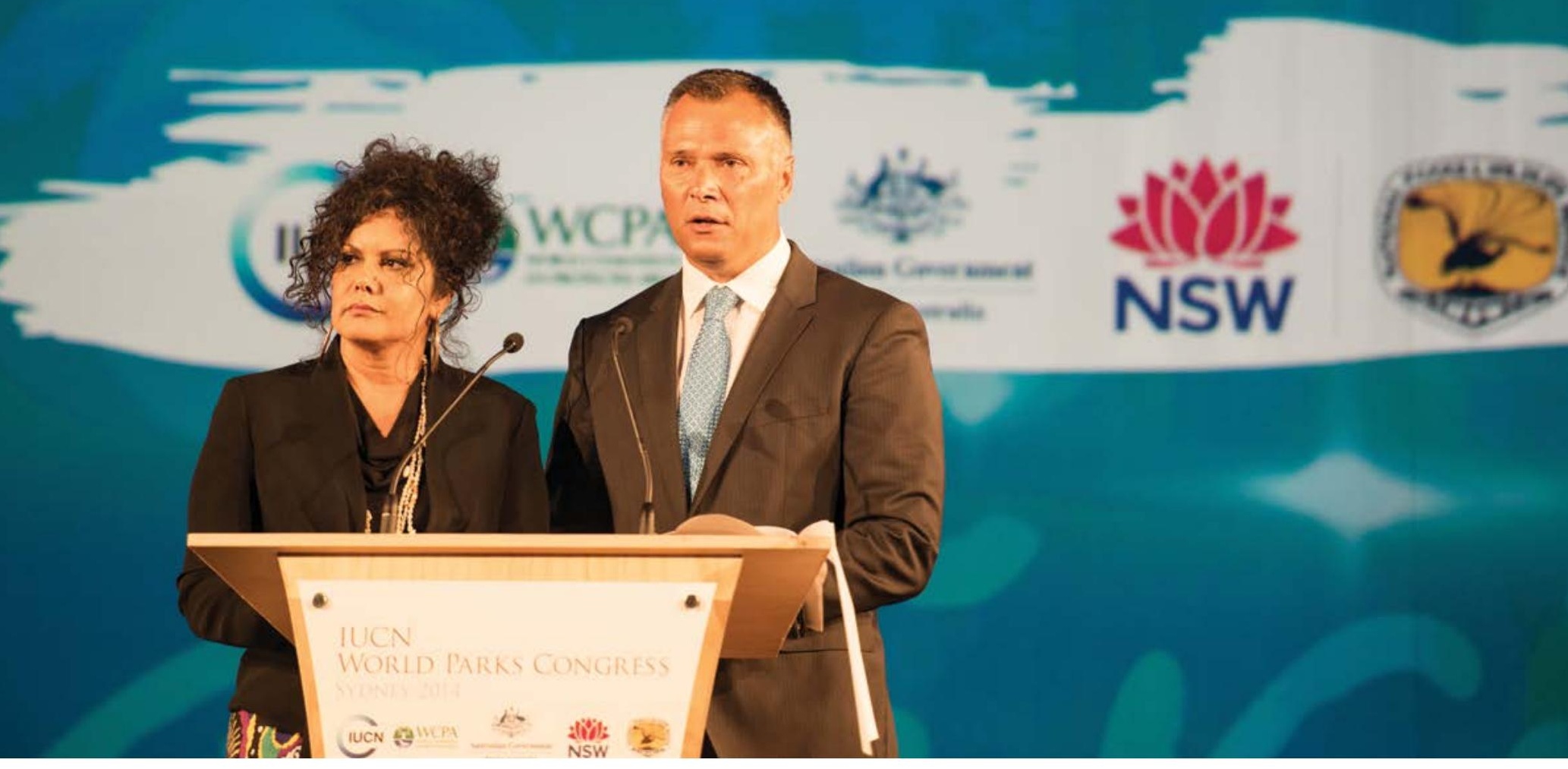

Masters of Ceremonies presenting at the opening ceremony of the Sixth IUCN World Parks Congress, Olympic Park, Sydney Australia, November 2014. The idea of a new social compact was discussed at the Congress.

Source: Graeme L. Worboys

\section{References}

Recommended reading

Amin-Khan, T. (2012) The Post-Colonial State in the Era of Capitalist Globalization: Historical, political and theoretical approaches to state formation, Routledge, New York.

Dd Anderson, D and Grove, R. (eds) (1995 [1987]) Conservation in Africa: Peoples, policies and practice, Cambridge University Press, Cambridge.

Asia Parks Congress (APC) (2013) First Asia Parks Congress, Sendai, Japan. <asia-parks.org/>

Beinart, W. and Coates, P. (1995) Environment and History: The taming of nature in the USA and South Africa, Routledge, London.

Berry, T. (1999) The Great Work: Our way into the future, Bell Tower/Random House, New York.

Berry, T. (2006) Evening Thoughts: Reflecting on Earth as sacred community, ed. M. E. Tucker, Sierra Club with University of California Press, Berkeley.
Borrini-Feyerabend, G., Pimbert, M., Farvar, M. T., Kothari, A. and Renard, Y. (2004) Sharing Power: Learning by doing in co-management of natural resources throughout the world, IIED and IUCN/CEESP/CMWG, Cenesta, Tehran.

Boyden, S. V. (1987) Western Civilization in Biological Perspective: Patterns in biohistory, Clarendon Press, Oxford.

Brooke, L. and Kemp, W. (1995) 'Towards information self-sufficiency: the Nunavik Inuit gather information on ecology and land use', Cultural Survival Quarterly Special Issue: Geomatics: Who needs it? 18(4). <www.culturalsurvival.org/ publications/cultural-survival-quarterly/canada/ towards-information-self-sufficiency-nunavikinuit-g>

Callicott, J. B. (1989) In Defense of the Land Ethic: Essays in environmental philosophy, State University of New York Press, Albany. 
Campese, J., Sunderland, T., Greiber, T. and Oviedo, G. (eds) (2009) Rights-Based Approaches: Exploring issues and opportunities for conservation, Center for International Forestry Research and IUCN, Bogor, Indonesia.

Charters, C. and Stavenhagen, R. (eds) (2009) Making the Declaration Work: The United Nations Declaration on the Rights of Indigenous Peoples, IWGIA, Copenhagen.

Chatty, D. and Colchester, M. (eds) (2002) Conservation and Mobile Indigenous Peoples: Displacement, forced settlement and sustainable development, Studies in Forced Migration Volume 10, Berghahn Books, New York and Oxford.

Colchester, M. (2004a) 'Conservation policy and indigenous peoples', Environmental Science and Policy 7: 145-53.

Colchester, M. (2004b) 'Indigenous lands or national park?', Cultural Survival Quarterly Issue: Conservation Policy and Indigenous Peoples 28(1) (Spring). <www.culturalsurvival.org/publications/ cultural-survival-quarterly/none/indigenous-landsor-national-parks>

Convention on Biological Diversity (CBD) (2011) Strategic Plan for Biodiversity 2011-2020 and the Aichi Biodiversity Targets, Secretariat of the Convention on Biological Diversity, Montreal. $<$ www.cbd.int/sp/default.shtml>

Crawhall, N. (2008) Heritage Education for Sustainable Development: Dialogue with indigenous communities in Africa, IPACC and UNESCO, Paris. <www. ipacc.org.za/uploads/docs/090505b_ESD_ composite_report_Africa08_final.pdf>

Crosby, A. W. (1986) Ecological Imperialism: The biological expansion of Europe, 900-1900, Cambridge University Press, Cambridge.

Crutzen, P. J., and Stoermer, E. F. (2000) 'The "Anthropocene"', Global Change Newsletter 41: 17-18.

de Soto, H. (2000) The Mystery of Capital: Why capitalism triumphs in the West and fails everywhere else, Basic Books, New York.

Dunbar, R. (1996) Grooming, Gossip and the Evolution of Language, Harvard University Press, Cambridge, Mass.
Galbraith, J. K. (1998 [1958]) The Affluent Society, Houghton Mifflin Company, Boston and New York.

De Harris, P. (ed.) (2013) The Routledge Handbook of Global Environmental Politics, Routledge, London.

Högselius, P. (2008) The Country of Mountains of Black Ash. <balticworlds.com/environment-the-countryof-mountains-of-black-ash/>

Hyden, G. (1980) Beyond Ujamaa in Tanzania: Underdevelopment and an uncaptured peasantry, Heinemann, London.

Indigenous Peoples of Africa Coordinating Committee (IPACC) (ed.) (2008) African Indigenous Peoples' Workshop on Effective Use of Information Communication Technology in Environmental Advocacy, IPACC, Cape Town.

Indigenous Peoples of Africa Coordinating Committee (IPACC) (2011) African Indigenous Peoples and the UNEP Green Economy Initiative: ||Hui!gaeb report on green economy, equity \& green governance, IPACC, Cape Town.

Indigenous Peoples of Africa Coordinating Committee (IPACC) (2012) Influencing Regional Policy Processes in Climate Change Adaptation through the Interaction of African Pastoralist Traditional Knowledge and Meteorological Science, IPACC, Cape Town.

International Union for Conservation of Nature (IUCN) (2011) Mining Threats on the Rise in World Heritage Sites, IUCN, Gland. <www.iucn. org/?7742/Mining-threats-on-the-rise-in-WorldHeritage-sites>

International Union for Conservation of Nature (IUCN) (2013) IUCN World Heritage Advice Note: Mining and oil/gas projects, IUCN, Gland. $<$ cmsdata.iucn.org/downloads/iucn_advice_note_ on_mining_in_wh_sites_final_060512_2_.pdf>

International Union for Conservation of Nature (IUCN) (2014) Improving Protected Area Governance for Livelihood Security and Biodiversity in Southern Africa: A High Level Dialogue, Windhoek, 21-22 May 2014.

D. International Union for Conservation of Nature Commission on Environmental, Economic and Social Policy (IUCN CEESP) (2004) Policy Matters: History culture and conservation, IUCN, Gland. 
D International Union for Conservation of Nature Commission on Environmental, Economic and Social Policy (IUCN CEESP) (2006) Policy Matters: Poverty, wealth and conservation, IUCN, Gland.

International Union for Conservation of Nature Theme on Indigenous and Local Communities, Equity, and Protected Areas (IUCN TILCEPA) (2010) Protected Areas: Joint PAEL-TILCEPA workshop on protected areas management evaluation and social assessment of protected areas, IUCN, Gland.

Josephson, P., Dronin, N., Mnatsakanian, R., Cherp, A., Efremenko, D. and Larin, V. (2013) An Environmental History of Russia, Studies in Environment and History, Cambridge University Press, Cambridge.

Kassam, K. A. S. (2009) Biocultural Diversity and Indigenous Ways of Knowing: Human ecology in the Arctic, University of Calgary Press, Calgary.

MacKenzie, J. (1997) 'Empire and the ecological apocalypse: the historiography of the imperial environment', in T. Griffiths and L. Robin (eds) Ecology and Empire: Environmental history of settler societies, pp. 215-28, Keele University Press, Edinburgh.

Dd Maffi, L. and Woodley, E. (2010) Biocultural Diversity Conservation: A global sourcebook, Earthscan, New York.

Nadal, A. (2011) Rethinking Macroeconomics for Sustainability, Zed Books, London.

Nelson, J. and Hossack, L. (2003) From Principles to Practice: Indigenous peoples and protected areas in Africa, Forest Peoples Programme, UK.

Nettle, D. and Romaine, S. (2000) Vanishing Voices: The extinction of the world's languages, Oxford University Press, Oxford.

Dd Ostrom, E. (1990) Governing the Commons: The evolution of institutions for collective action, Cambridge University Press, New York.

Ostrom, E. (2012) The Future of the Commons: Beyond market failure and government regulation, The Institute of Economic Affairs, London.

Ostrom, E. and Hess, C. (eds) (2007) Understanding Knowledge as a Commons: From theory to practice, MIT Press, Cambridge, Mass.
Ostrom, E., Dietz, T., Dolšak, N., Stern, P. C., Stonich, S. and Weber, E. (eds) (2002) The Drama of the Commons, Committee on the Human Dimensions of Global Change, National Research Council, National Academies Press, Washington, DC.

Ostrom, E., Gardner, R. and Walker, J. (1994) Rules, Games, and Common-Pool Resources, University of Michigan Press, Ann Arbor, MI.

Ostrom, E., Poteete, A. R. and Janssen, M. A. (2010) Working Together: Collective action, the commons, and multiple methods in practice, Princeton University Press, Princeton, NJ.

Dd Phillips, A. (2003) 'Turning ideas on their head: the new paradigm for protected areas', George Wright Forum 20(2): 8-32.

Ralston Saul, J. (2005) The Collapse of Globalism, Atlantic Books, London.

Rambaldi, G., Muchemi, J., Crawhall, N. and Monaci, L. (2007) 'Through the eyes of huntergatherers: participatory 3D modelling among Ogiek indigenous peoples in Kenya', Information Development 23(2-3): 113-28.

Rolston, H. III (1986) Philosophy Gone Wild: Essays in environmental ethics, Prometheus Press, Buffalo, NY.

Roosevelt, T. (1910) Citizenship in a republic, Address at the Sorbonne, Paris, 23 April 1910. <www. theodore-roosevelt.com/images/research/speeches/ maninthearena.pdf>

Sandler, R. (2012) 'Intrinsic value, ecology, and conservation', Nature Education Knowledge 3(10): 4. <www.nature.com/scitable/ knowledge/library/intrinsic-value-ecology-andconservation-25815400>

Secretariat of the Convention on Biological Diversity (CBD Secretariat) (2004) Addis Ababa Principles and Guidelines for the Sustainable Use of Biodiversity, Montreal.

Secretariat of the Convention on Biological Diversity (CBD Secretariat) (2010) Global Biodiversity Outlook-3, Montreal.

Shivji, I. (2009) Accumulation in an African Periphery: A theoretical framework, Mkuki Na Nyota Publishers, Dar es Salaam. 
Smith, A. (1904 [1776]) An Inquiry into the Nature and Causes of the Wealth of Nations, 5th edn, Methuen \& Co., London.

Soulé, M. E. (1985) 'What is conservation biology?', BioScience 35(11): 727-34.

DD The Economics of Ecosystems and Biodiversity (TEEB) (2010) The Economics of Ecosystems and Biodiversity: Mainstreaming the economics of nature-A synthesis of the approach, conclusions and recommendations of TEEB, Geneva.

United Nations (UN) (2007) United Nations Declaration on the Rights of Indigenous Peoples, United Nations, New York and Geneva. <www. un.org/esa/socdev/unpfii/documents/DRIPS_ en.pdf>

Vesitalous (2010) Document dealing with Finland's resource governance, [in Finnish]. <www.vesitalous. fi/wp-content/uploads/2010/02/5_2002.pdf>

Wallace, B. A. and Hodel, B. (2008) Embracing Mind: The common ground of science and spirituality, Shambhala Publications, Boston and London.

Weeramantry, C. G. (2009) Tread Lightly on the Earth: Religion, the environment and the human future, Stamford Lake, Sri Lanka.

White, L. T., Jr (1967) 'The historical roots of our ecological crisis', Science (NS) 155(3767) (10 March): 1205.

Wikipedia (2014) Rurima Island. <en.wikipedia.org/ wiki/Rurima_Island>

Worboys, G. L., Francis, W. and Lockwood, M. (eds) (2010) Connectivity Conservation Management: A global guide, Earthscan, London.

World Wide Fund for Nature (WWF) (2014) Protected Area Downgrading, Downsizing and Degazettement (PADDD), WWF, Gland. <www.padddtracker.org/> 


\section{CHAPTER 6}

\section{VALUES AND BENEFITS OF PROTECTED AREAS}

\section{Principal authors:}

Sue Stolton and Nigel Dudley

\section{Supporting authors:}

Başak Avcıoğlu Çokçalışkan, Danny Hunter, Kasandra-Zorica Ivanić, Erustus Kanga,

Marianne Kettunen, Yoshitaka Kumagai, Nigel Maxted, John Senior, Mike Wong, Karen Keenleyside,

Dan Mulrooney and John Waithaka

\section{CONTENTS}

- Introduction

- Protected area benefits: Maintaining our life-support systems

- Understanding and managing benefits

- References

\section{IUCN $W$ WCPA}




\section{PRINCIPAL AUTHORS}

SUE STOLTON is a partner in Equilibrium Research and member of the International Union for Conservation of Nature (IUCN) World Commission on Protected Areas (WCPA) and the IUCN Commission on Environmental, Economic and Social Policy (CEESP).

NIGEL DUDLEY is a partner in Equilibrium Research and member of the IUCN WCPA and the IUCN CEESP.

\section{SUPPORTING AUTHORS}

BAŞAK AVCIOĞLU ÇOKÇALIŞKAN is a landscape architect and member of the IUCN WCPA.

DANNY HUNTER is a Senior Scientist at Bioversity International and member of the IUCN WCPA.

KASANDRA-ZORICA IVANIĆ works for WWF Med PO, Croatia. ERUSTUS KANGA works for Kenya Wildlife Service.

MARIANNE KETTUNEN is a Senior Policy Analyst at the Institute for European Environmental Policy in London, and a member of the IUCN WCPA.

YOSHITAKA KUMAGAI is a Professor at Akita International University, Japan and Regional Vice Chair for East Asia for IUCN WCPA.

NIGEL MAXTED is a Professor at the University of Birmingham, Co-Chair of the IUCN Species Survival Commission Crop Wild Relative Specialist Group; Chair of the UK Plant Genetic Resources Group Committee and Senior Scientific Advisor for the GEF/World Bank on Plant Genetic Resources.

JOHN SENIOR was until recently the manager of the Parks Sector Partnerships at Parks Victoria (Australia) and is project managing the preparation of Healthy Parks Healthy People best-practice guidelines for the IUCN.

MIKE WONG is Executive Director, Natural Resource Conservation, Parks Canada.

KAREN KEENLEYSIDE is National Science Advisor, Office of the Chief Ecosystem Scientist, Parks Canada.

DAN MULROONEY is Senior Socio-economist with Parks Canada.

JOHN WAITHAKA is a Conservation Biologist, Natural Resource Conservation, Parks Canada.

\section{CITATION}

Stolton, S., Dudley, N., Avcıoğlu Çokçalışkan, B., Hunter, D., Ivanić, K.-Z., Kanga, E., Kettunen, M., Kumagai, Y., Maxted, N., Senior, J., Wong, M., Keenleyside, K., Mulrooney, D., Waithaka, J. (2015) 'Values and benefits of protected areas', in G. L. Worboys, M. Lockwood, A. Kothari, S. Feary and I. Pulsford (eds) Protected Area Governance and Management, pp. 145-168, ANU Press, Canberra, Australia.

\section{TITLE PAGE PHOTO}

Fitzroy Falls, Morton National Park, NSW Australia

Source: Graeme L. Worboys 


\section{Introduction}

Protected areas are places where conscious efforts are made to preserve not only wild species, but also the ecosystems in which species live. In parts of the world where most of the landscape has already been transformed by agriculture or industry, protected areas may be the only natural or near natural ecosystems remaining for large areas. The wider socioeconomic and cultural values of these natural ecosystems are increasingly being recognised, as are the important ecosystem services they provide (see Box 6.1). Until recently these services have often been taken so much for granted that their values have been underestimated, forgotten or simply never noticed. The acknowledgment of ecosystem services was boosted by a seminal paper by Robert Costanza (1997), who noted ecosystem goods (such as food) and services (such as waste assimilation) represent the benefits human populations derive, directly or indirectly, from ecosystem functions. In 2003, the Millennium Ecosystem Assessment suggested a simple typology to summarise the various services from natural ecosystems (MEA 2003). This typology has been expanded and adapted for different purposes, including for protected areas (Kettunen and ten Brink 2013). Figure 6.1 outlines the various ecosystem services we might expect from protected areas and lists the benefits associated with these services (these benefits are introduced in more detail in the next section).
We should not forget that nature conservation remains the primary aim of protected areas. Conservation of biodiversity — of species, genetic diversity within species and of habitats and ecosystems-underpins ecosystem function (Cardinale et al. 2012) and has many practical, utilitarian benefits, as described below.

There is in addition wide agreement that we have an ethical obligation to maintain the full range of the planet's living diversity - in other words, not to speed up the rate of extinction beyond what would be expected in natural circumstances. We are manifestly failing in this aim at present, with species declining and disappearing all the time, often before they have even been recognised and described by scientists. Nonetheless, research across multiple data sets provides strong evidence that protected areas are one of the most effective tools for slowing the rate of biodiversity loss and many species continue to survive only because of the protection provided by national parks, nature reserves and other protected areas (see Chapter 21). The ethical basis of biodiversity conservation is recognised by signatories of the Convention on Biological Diversity, nationally through wildlife protection and protected area legislation, by senior members of all the world's major religions (Palmer and Finlay 2003), and by much of the general public.

SUPPORTING SERVICES

(i.e. services necessary for the provision of all other ecosystem services)

Ecosystem process maintenance (soil formation, nutrient cycling, primary production etc.)
Lifecycle maintenance (nursery habitats, seed dispersal, species interactions etc.)
Biodiversity maintenance and protection (genetic, species and habitat diversity)

PROVISIONING SERVICES

(i.e. ecosystems' ability to provide resources)

Food provisioning

כ Water provisioning

$\partial$ Provisioning of raw material (timber, wood, fuel, fibre)

D Provisioning of medicinal resources / biochemicals (natural medicines, cosmetics, pharmaceuticals etc.)

$\partial$ Provisioning of ornamental resources

$\partial$ Provisioning of genetic resources

\section{REGULATING SERVICES}

(i.e. ecosystems' beneficial regulatory processes)

$\Rightarrow$ Climate regulation

$\Rightarrow$ Natural hazards regulation

$\partial$ Purification and detoxification of water, air and soil

$\Rightarrow$ Water/waterflow regulation

$\Rightarrow$ Erosion and soil fertility regulation

$\partial$ Pollination

$\partial$ Pest and disease regulation
CULTURAL SERVICES

(i.e. ecosystems' non-material benefits)

Opportunities for recreation and tourism

$\Rightarrow$ Aesthetic values

$\partial$ Inspiration for the arts

$\Rightarrow$ Information for education and research

$\rightarrow$ Spiritual and religious experience

$\Rightarrow$ Cultural identity and heritage

O Mental wellbeing and health

$\Rightarrow$ Peace and stability

Figure 6.1 Ecosystem services and related goods from protected areas

Sources: Kettunen and ten Brink (2013); adapted from MEA (2003); de Groot et al. (2010); and UK NEA (2011) 


\section{Box 6.1 What happens when we lose ecosystem functioning and ecosystem services?}

\section{Nigel Dudley}

Ecosystem services are a perfect example of the old truism that we only really value things once they are gone. When natural ecosystems become degraded, lose key aspects of their ecological functioning or disappear altogether, we almost always suffer in consequence. But when those ecosystem functions and the services they maintain were lost a long time ago, or are disappearing so gradually no-one notices, the resulting problems sometimes remain disconnected from ecology in the minds of many people. Loss of natural vegetation in dryland ecosystems creates deserts, dust storms and frighteningly high levels of respiratory disease in cities like Kuwait. Overfishing has dramatically reduced fish populations in many oceans, but we need to look at old fishery records to really understand what we have lost. Felling of mangroves has left coastal communities vulnerable to storms and sea surge in South-East Asia and elsewhere. Many African cities are facing a crisis of contaminated water and infant diarrhoea due to loss of upland forests. In parts of China farmers now have to pollinate their crops by hand with paintbrushes because pollinating insects have declined so dramatically. When we say that protected areas provide us with irreplaceable resources, for once the term 'irreplaceable' is, in many parts of the world, not in any way an exaggeration, and our ability to adapt to these losses is becoming ever more difficult.

There are three aspects to transforming these recognised ecosystem services into measurable socioeconomic benefits for human communities: 1) quantifying and assessing (often qualitatively) the value of the various benefits; 2) understanding them in relation to other benefits including benefits forgone by retaining the ecosystem; and 3) understanding who receives the various benefits. None of these is particularly straightforward.

We summarise information on several techniques for quantifying and valuing benefits in economic and other terms below. But the benefits also need to be understood in the context of competing benefits (so-called tradeoffs) - for example, retaining a forest to protect water also means that the timber in the forest is not available for sale or the land for conversion to agriculture or development-and that these benefits and their relative values accrue to different people. One of the persistent challenges in securing ecosystem services is that many services maintained by sustainable management or

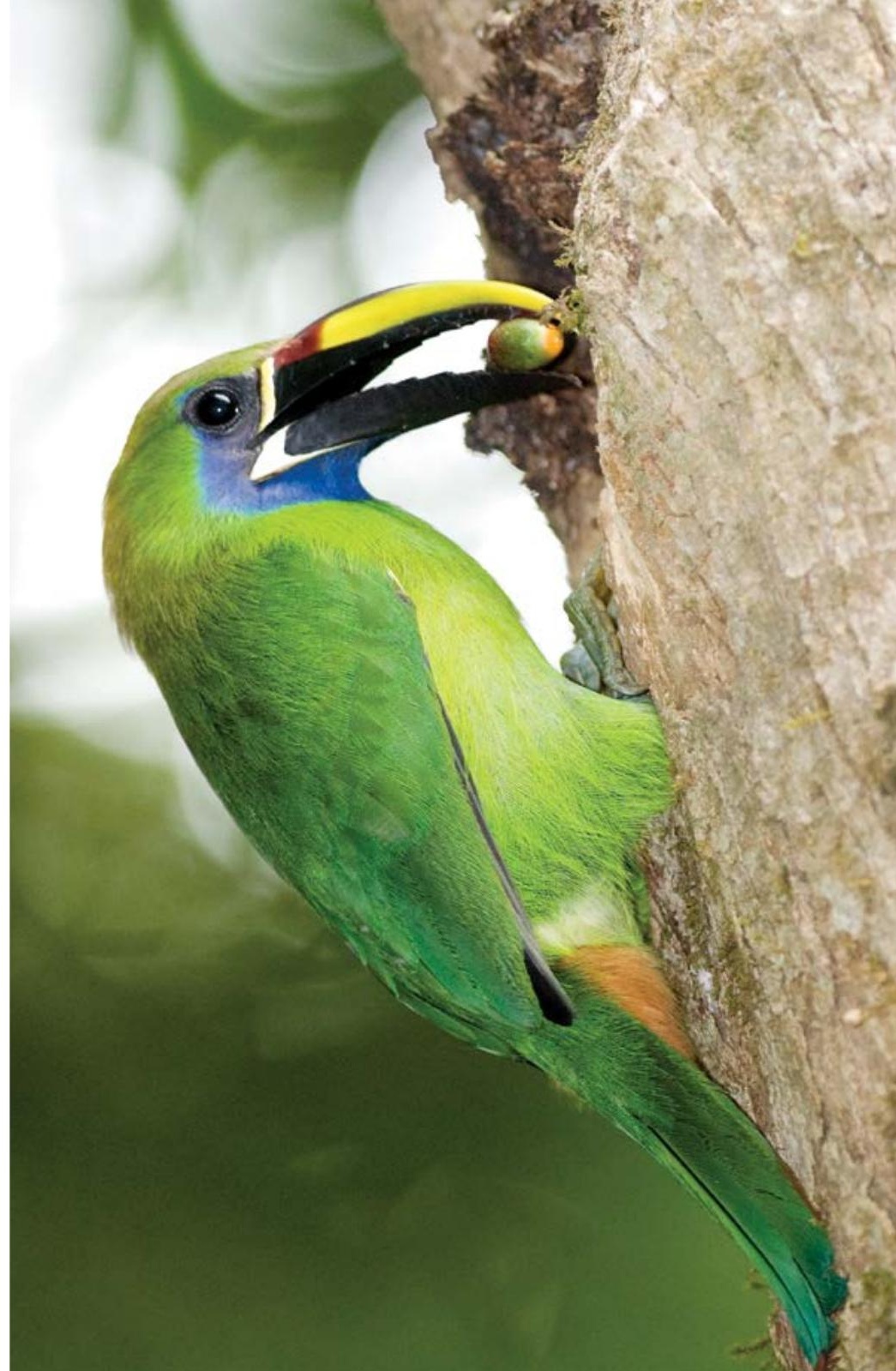

Emerald toucanet (Aulacorhynchus prasinus), Monteverde Cloud Forest Reserve, Costa Rica Source: Charles Besançon

protection of ecosystems are diffuse in nature, providing many people with a small number of a hard-to-measure benefits (for example, non-monetised and with no clear ownership rights), while unsustainable use provides one or a few people with a lot of benefit (for example, wellmonetised with clear ownership rights).

So, the landowner who chops down a forest in a watershed and sells the timber receives a pile of money in their pocket, while the city downstream loses water quality and pays in extra purification costs or extra stomach upsets. The net watershed values to society as a whole may be much greater than the net timber value gained, but not to the landowner who has clear ownership rights to the timber, while the city-dwellers downstream have no clear ownership rights to the clean water produced by the forest. 
This means in turn that the perception of and attitudes to the benefits from protected areas will alter with who is benefiting. At an extreme, people who suffer from poverty and inequality and have been displaced from their traditional lands to create a protected area are likely to remain resentful and largely oblivious to any wider regional or global values. On the other hand, people who benefit culturally, spiritually, through direct or indirect jobs and through recognised ecosystem services will probably have a very different perspective. And the way people view protected areas can also change over time as benefits are more widely appreciated, fair access and equitable sharing of any benefits are assured and management learns to respond more sensitively to the needs of a wide variety of stakeholders.

Finding ways of rewarding people for retaining ecosystem services is one of the critical steps in concretely capturing the socioeconomic value of protected area benefits and, consequently, retaining or regaining support for protected area policies. Protected area managers who are aware of both the full range of protected area benefits and the range of stakeholders affected have a far better chance of managing successfully. In the remainder of this chapter, we provide an overview of the range of benefits that can come from protected areas and look at how these can be measured, utilised and managed.

\section{Protected area benefits: Maintaining our life-support systems}

Exactly what are the benefits from protected areas? A very short summary follows; more detailed sources are available (Stolton and Dudley 2010a; Kettunen and ten Brink 2013). Although most of these benefits can come from any natural ecosystem, protected areas often have the advantage that they are already established as efficient, successful and cost-effective tools for sustainable ecosystem management, with associated laws and policies, management and governance institutions, knowledge, staff and capacity. They thus often maintain a wider range of ecosystem services than other areas and they also come with far more associated security than unmanaged, unregulated areas that are more open to rapid degradation and change. We are not, however, claiming that protected areas are the only such vehicle: other well-managed land and water controlled by communities, governments and companies can play similar functions.

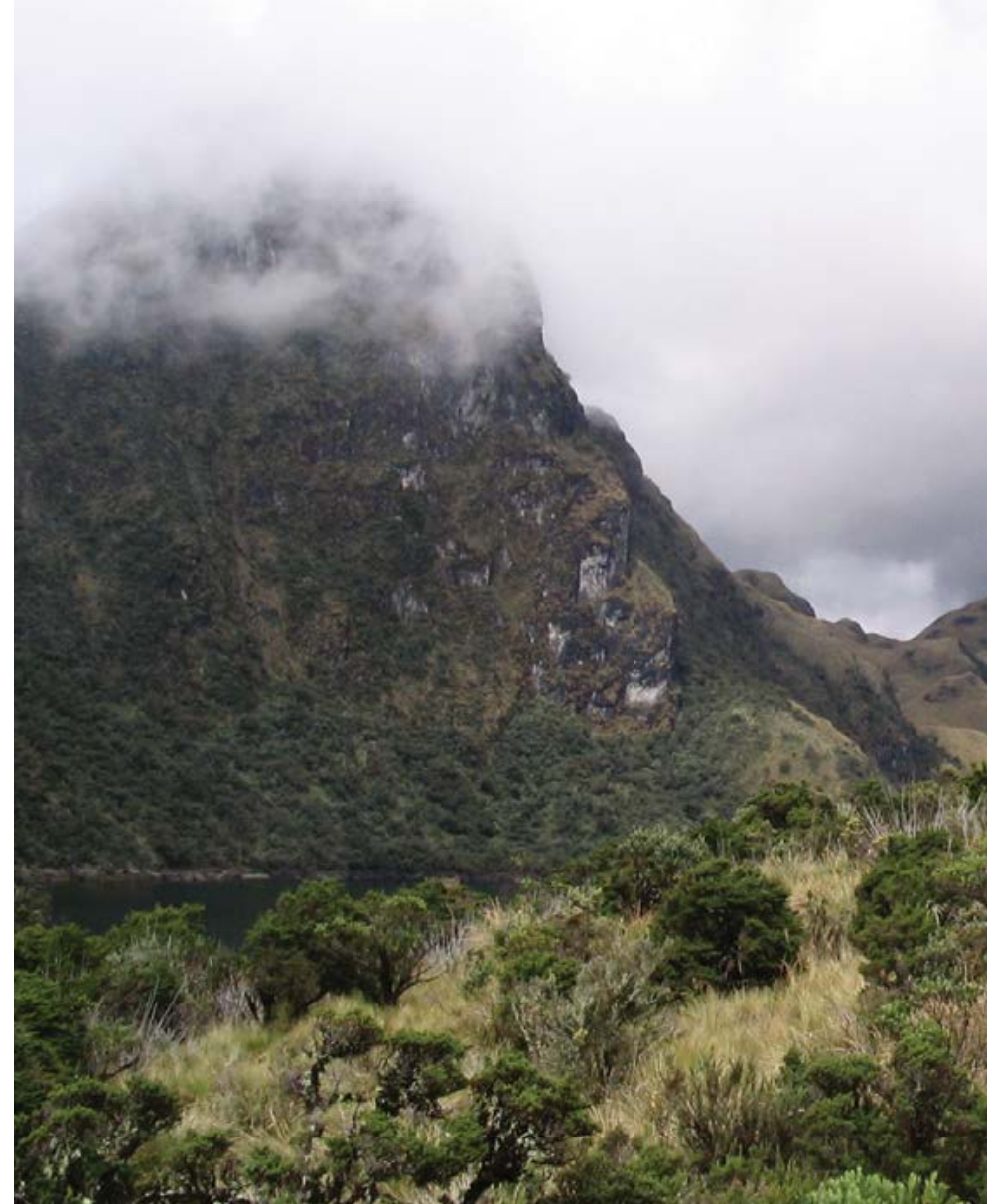

High-altitude paramos water catchment area of Cayamba-Coca Ecological Reserve, Ecuador, which provides ecological services (water) for the capital city of Quito

Source: Graeme L. Worboys

\section{Supporting services}

At a time when many agricultural systems are becoming increasingly reliant on inputs of fertilisers, pesticides and large amounts of fossil fuel energy, natural ecosystems that are self-regulating and powered solely by the sun are more rare. 'Supporting processes and functions' refer to the basic running of an ecosystem: soil formation and nutrient cycling; life-cycle maintenance for species by provision of services like fish nursery habitats, means of seed dispersal and continued species interactions; along with conservation of the full range of biodiversity. By protecting functioning ecosystems, protected areas provide services to surrounding ecosystems, both through the direct spillover of soils, nutrients and intercepted solar energy and from the potential to use protected areas as baselines of information and raw materials for restoration within the rest of the landscape.

For example, demonstration of the opportunities for land restoration through dryland habitat protection amasses important information, and builds confidence, for authorities to tackle desertification issues in the Arabian Peninsula. Reductions of desertification and dust storms 


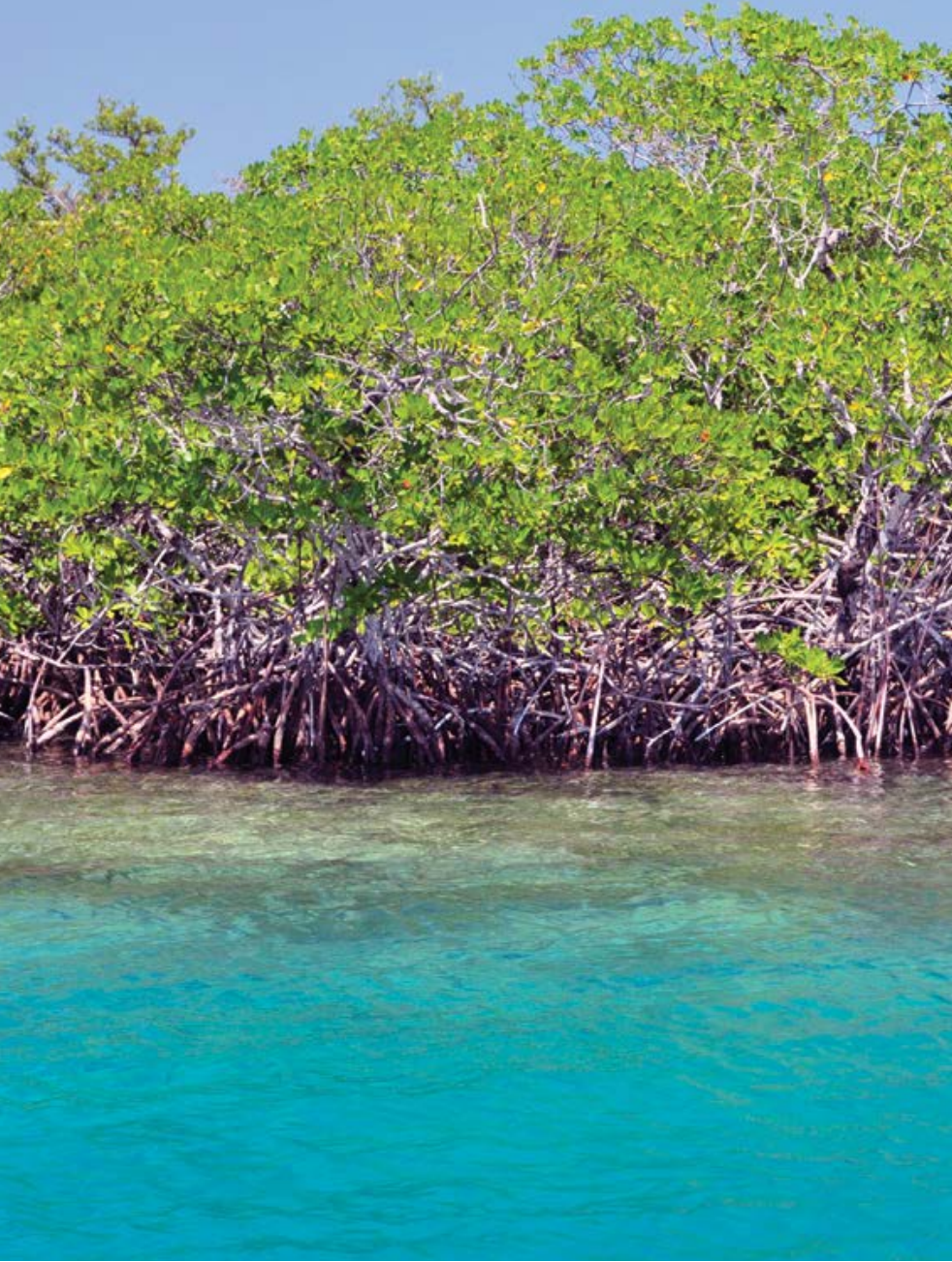

Mangroves, Pelican Cayes, Belize

Source: Eduard Müller

are two concrete results that can become apparent in a small number of years; however, major challenges here are that a generation or more of people have grown up believing that the highly degraded ecosystems covering most settled parts of the peninsula are 'natural'. Policy changes rely not only on proof that protection and restoration can work, but also on a long-term effort to build understanding about ecology in the countries concerned.

\section{Provisioning services}

Of more immediate interest to people are the various tangible resources that protected areas either provide directly or support.

\section{Food}

Well-managed natural ecosystems play a key role in food security, particularly for the poorest members of society, many of whom are still leading a subsistence lifestyle and are dependent on a diversity of edible products from protected areas. For example, freshwater and marine protected areas and coastal mangroves provide valuable breeding grounds for fish, ensuring the populations do not collapse and providing spillover into surrounding waters (Roberts and Hawkins 2000). Many marine protected areas also allow sustainable fishing for local communities, or follow traditional seasonal closures. Terrestrial protected areas also enhance food security, by such measures as providing emergency grazing during times of drought in drylands, sources of fodder as long as this is harvested in a sustainable manner and even allowing controlled extraction of food species from within the protected area boundaries. Illegal overhunting within protected areas is conversely a major problem. The use of protected areas as 'emergency' food supplies is highlighted, for instance, in some parts of northern and eastern Africa (Dudley et al. 2008).

\section{Water}

Some ecosystems also increase the net amount of available water, particularly watersheds containing cloud forests, where leaves 'scavenge' water from mist and cloud, condensing it on specially evolved leaf parts and then funnelling it down branches and trunks. The city of Tegucigalpa in Honduras is one of several large Latin American cities that protect surrounding cloud forest to guarantee water supplies, in this case in the La Tigra National Park (Hamilton 2008). In some ecosystems forests can hold more rainfall in the catchment than cleared land, reducing water export and (depending on geology) increasing aquifer storage (Siriwardena et al. 2006).

\section{Raw materials}

Many protected areas have been established explicitly to conserve natural resources such as timber and valuable plants. But an increasing number also sanction some level of collection, usually by local communities and focusing on items like poles for building and fencing, grasses for thatching, firewood and more valuable timber for carving, boatbuilding and numerous other nontimber forest products (NTFPs). Some extractive reserves (IUCN Category VI) have been set up explicitly to allow sustainable harvesting of key products from natural ecosystems; here protection and production inherently go hand-in-hand. Rubber collecting in Amazonian extractive reserves is the original, classic example. The Mamirauá Sustainable Development Reserve in Brazil is part of a large conservation complex of more than 6 million hectares where biodiversity conservation is balanced with the needs of sustainable development. But today such approaches are being used in land and waterbased protected areas throughout the world; it is now the fastest-growing of all protected area management categories (Bertzky et al. 2012). 


\section{Box 6.2 Crop wild relatives}

Danny Hunter and Nigel Maxted

Crop wild relatives contain a wealth of genetically important traits due to their adaptation to a diverse range of habitats and the fact that they have not passed through the genetic bottlenecks of domestication. The ability of breeders to increase or even sustain crop yield and quality in the face of a growing magnitude of threats is being questioned without much greater use of the natural range of diversity found in CWR taxa and the genetic traits they provide. The global value of the introduction of new genes from CWR to crops is estimated to be US $\$ 115$ billion annually (Pimental et al. 1997). The taxa cannot, however, continue to be used by plant breeders to sustain food security if they are not conserved and available for utilisation. At present, CWR conservation is largely neglected, unfortunately, even in protected areas (Hunter and Heywood 2011; Maxted et al. 2012). CWR in these sites are likely to be passively conserved and they may come under threat or even be lost entirely.

Although sites where in situ CWR populations are actively managed are still rare, the position has improved significantly in recent years due to the growing threat to global food security and the realisation that they may offer at least a partial solution. The threat to CWR is very real; in a recent Red List assessment of 572 European species from 25 economically important crop groups, 11.5 per cent (66) of the species were threatened, with 3.3 per cent (19) of them critically endangered (Kell et al. 2012). The Convention on Biological Diversity Strategic Plan Target 13 calls '[b]y 2020, [for] the status of crop and livestock genetic diversity in agricultural ecosystems and of wild relatives [to have] been improved'. Although CWR are currently poorly conserved and threatened, their more active conservation in protected areas is essential to sustain humankind itself (Hunter et al. 2012).

In 2000, its then 39 national parks were estimated to store 4.432 billion tonnes of carbon (Kulshreshtha et al. 2000). Carbon management is seen as an important factor in persuading governments to conserve natural ecosystems, although current compensation schemes proposed under Reducing Emissions from Deforestation and Forest Degradation (REDD+) are not usually enough on their own to make up for values forgone in development. Carbon financing also expands the scope for the strategic growth of protected areas to encompass degraded or deforested land that is regrown, replanted or restored to protect ecosystems, endangered species or habitats, including corridors, which also contribute to adaptation to climate change.

\section{Mitigation of natural hazards}

Natural ecosystems also make cost-effective ways of mitigating various extreme weather events and the after effects of major earth movements; many of the former are becoming more frequent and more intense due to climate change. Natural ecosystems in protected areas can mitigate a wide range of hazards: 1) natural vegetation including particularly forests can help to control landslip due to snowfall and avalanche, hillside soil erosion or earth movement; 2) mangroves, coral reefs and sand dunes all act as barriers against storms, typhoons, sea-level rise and ocean surge following tsunamis; 3) riverside forest and protected natural floodplains help to absorb floodwaters; 4) natural vegetation in dryland and arid areas can prevent desertification, and reduce dust storms and dune movement; and 5) several intact forest ecosystems, particularly in the tropics, are far more resistant to fire than degraded or fragmented ecosystems (Stolton et al. 2008). The term mitigation needs to be defined clearly. No-one is suggesting that natural vegetation can prevent all damage from every extreme weather event, any more than can engineering solutions such as dykes, levees and firebreaks. But experience suggests that well-managed ecosystems can prevent or reduce damage from many, often most, such events and save money and lives in the process (Stolton et al. 2008).

\section{Purification and detoxification of water, air and soil}

In an increasingly polluted world, ways of reducing the pollution load are urgently required. Natural ecosystems, if not overwhelmed, can help reduce many forms of pollution. Forests and vegetation types such as paramos in Latin America naturally produce pure water, and some freshwater plants play an active role in detoxification of certain pollutants. For example, in Florida's cypress swamps, 98 per cent of all nitrogen and 97 per cent of all phosphorous entering the wetlands from wastewater were removed before this water entered the groundwater reservoirs (Ramsar Convention Bureau 2008). Research found that one-third of the world's 100 largest cities draw a substantial proportion of their drinking water from forest protected areas (Dudley and Stolton 2003). Similarly, forests and other vegetation types can absorb a certain amount of air pollution and provide valuable shading. The ability of an ecosystem to neutralise pollutants is significant and important, but by no means infinite, and high pollution levels are also a major threat to some protected areas, most dramatically in the case of ocean acidification due to rising carbon dioxide levels in the atmosphere. Wetland protected areas also provide valuable water storage services, and protection of buffer zones around lakes and rivers helps to prevent pollution. 


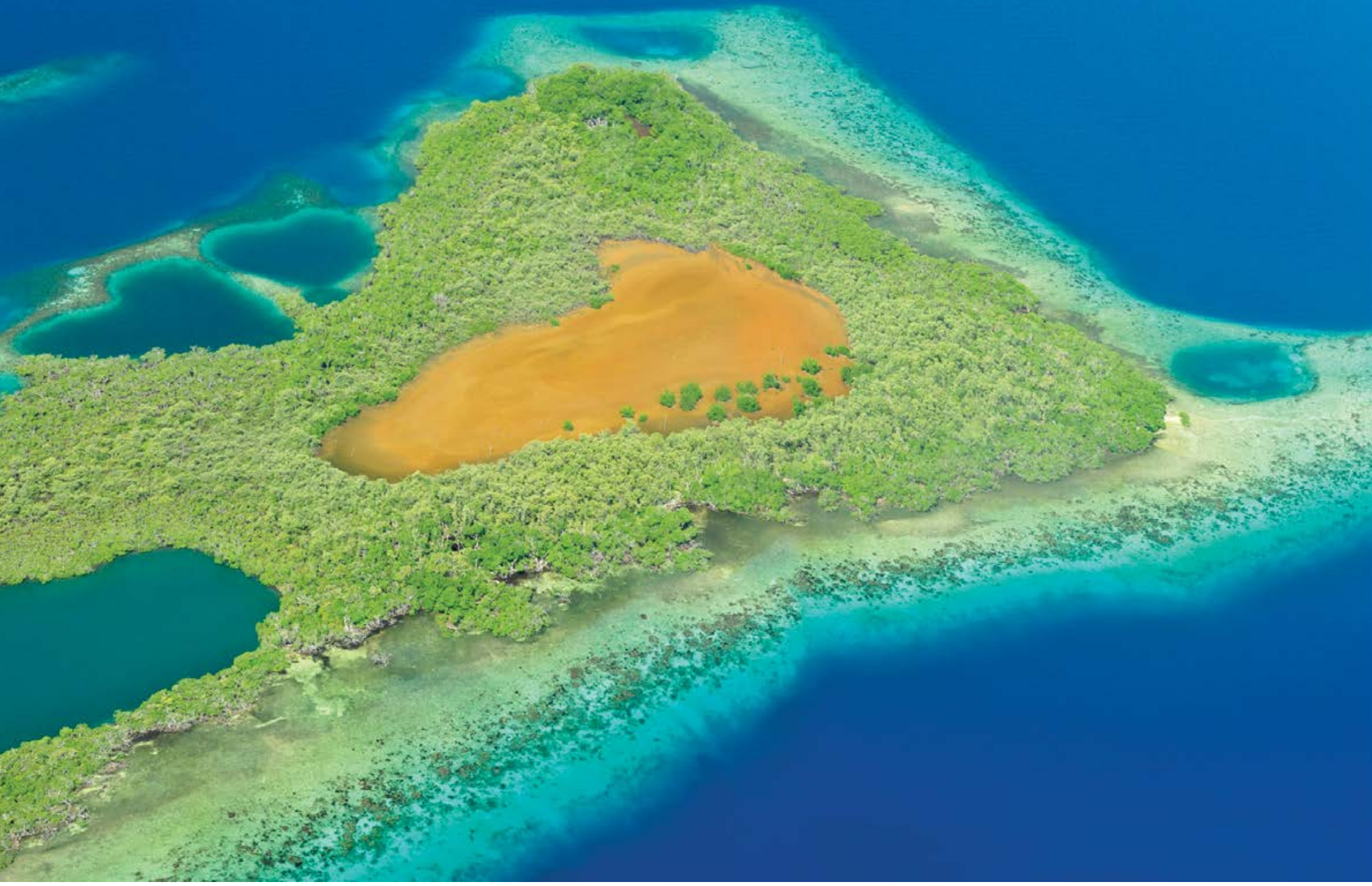

Coral and mangroves, Pelican Caye World Heritage Property, Belize

Source: Eduard Müller

\section{Pollination}

Apart from its critical role in maintaining species diversity and vegetation patterns, pollination has direct utilitarian roles for humans, as an essential part of agriculture and fruit growing, and as a stimulant for the production of honey. In a world where pesticides, industrial pollution and habitat loss have had a catastrophic impact on insect numbers, protected areas are increasingly being seen as a tool for maintaining pollination services. Many protected areas allow local beekeepers to place beehives with native bee species within the protected area. Farmers benefit from pollination services maintained within the protected area itself and spilling out into farmland and orchards, and protected area planners are starting to realise that they need to include the retention and where necessary restoration of pollination pathways within conservation planning exercises.

\section{Pest and disease regulation}

Controlling serious pests and diseases is increasingly important as the degree of threat from invasive alien species is recognised and climate change encourages the spread of pests and diseases into new ecosystems. Protected areas can help minimise these problems in a number of ways, particularly by physically blocking unwanted species: many invasive plants are coloniser species and do not penetrate into mature vegetation. The same is true of some insect pests like the tsetse fly, and malarial mosquitoes have also been recorded as moving far more slowly through dense forests.

\section{Cultural services}

Clearly not all the benefits we derive from natural ecosystems are narrowly utilitarian: humans enjoy a wealth of complicated cultural, psychological and spiritual links with the natural world. Because protected areas tend to be established in particularly beautiful and pristine parts of nature, these cultural services are particularly strongly represented (see Chapter 4).

\section{Recreation and tourism}

The day-to-day uses of nature for relaxation, exercise and psychological renewal stretch back way beyond recorded history and have been a major driver for protected area creation. Most visitors tend to cluster around the edges of large reserves and keep to footpaths - for walks, family outings, picnics and nature watching; a smaller subset of visitors likes to penetrate much deeper, walking, riding or canoeing for days inside the larger national parks. For these people, the sense of isolation and wilderness is a key part of the attraction. With tourism now arguably 


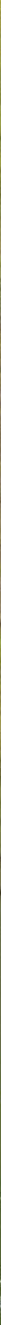

Visitors, boardwalk and the spectacular cascading waterfalls of the Plitvice Lakes National Park World Heritage Property, Croatia

Source: Graeme L. Worboys

the world's largest single industry, the potential for ecotourism in protected areas is growing all the time and is already the largest foreign currency earner in countries such as Tanzania (see Chapter 23).

\section{(Nature-based) physical and mental wellbeing}

As well as the benefits from recreational use of protected areas, research and practice have found that people with physical and mental problems or alcohol and other drug addictions can benefit positively from immersion in an attractive landscape. Health authorities in the United Kingdom are encouraging use of local nature reserves as safe and appealing places for exercise, to combat a national obesity problem. The 'Healthy Parks Healthy People' movement, started in Melbourne, Australia, links protected area and health agencies and uses parks to provide relaxing places for people with mental health issues and/or substance addiction. These approaches have proved very encouraging and a pleasant environment has proven to be good psychological and physical therapy (Stolton and Dudley 2010b).

\section{Aesthetic value and a sense of place and inspiration for arts, science and technology}

Perceptions of beauty are culturally formed. The Romantic movement in the arts was a major stimulus for the development of national parks in Europe (Box 6.3). Iconic national parks like Yellowstone in the United States, the Blue Mountains outside Sydney, Australia, the Lake District in the United Kingdom and the Japanese Alps have inspired artists and writers for generations, and on a more local scale protected areas provide rich sources of ideas and energy for poets, painters, musicians and other artists. A 'sense of place' is also a useful concept for describing and understanding the attachments some people form with protected areas (Lin and Lockwood 2013). Such place attachments can include emotional (including identity) and functional aspects even for communities who have only recent connections with a protected area (Byrne and Goodall 2013). 


\section{Education and research}

Protected areas provide an ideal location for ecological research as they are often in fairly pristine condition, and have sympathetic staff and sometimes facilities for visiting scientists. A proportion of reserves are set up specifically for research purposes, and these are amongst the most strictly protected areas in terms of access and disturbance, so ecological processes and interactions can be studied under the best possible circumstances. Other protected areas have extensive education programs, often developed in association with local schools and colleges, giving children an increasingly rare opportunity to interact directly with nature.

\section{Spiritual and religious experience}

Many protected areas contain sites of spiritual importance (see Chapters 4 and 23). Protected areas can, if sensitively managed, accommodate such interests, and can provide both additional protection and a pleasant surrounding environment for meditation and worship. In Amber Mountain National Park, northern Madagascar, local people can visit a sacred waterfall within the park, and in Donaña National Park in southern Spain every year a major pilgrimage takes place, linked to the Catholic Church. To an increasing extent, resident faith groups within protected areas are becoming actively involved in conservation, as in Rila National Park in Bulgaria, where the monks in Rila Monastery manage their own lands as a nature reserve, in accordance with teachings about the sanctity of nature (Mallarach and Torcal 2009).

\section{Cultural identity and heritage}

The cultural and historical values found within protected areas are also often very important although sometimes rather difficult to define. In the same way that iconic buildings, writers, musicians and football teams can come to embody the heart of a nation or region, so too can special views, landscapes or wild species. Climbing Mount Triglav, in the national park of the same name, is something many Slovenians intend to do at least once in their life. Further east in Europe, Mount Kazbegi has a potent mixture of cultural and spiritual values for many Georgians, who visit the ancient church built high in the mountains under its shadow. These issues are discussed in greater detail in Chapter 23.

\section{Peace and stability}

Many conflicts between nation-states focus on the borders between countries. The first trans-boundary conservation initiative in the modern sense of the term is attributed to the Waterton-Glacier International Peace Park, which was declared in 1932 to commemorate the peace and

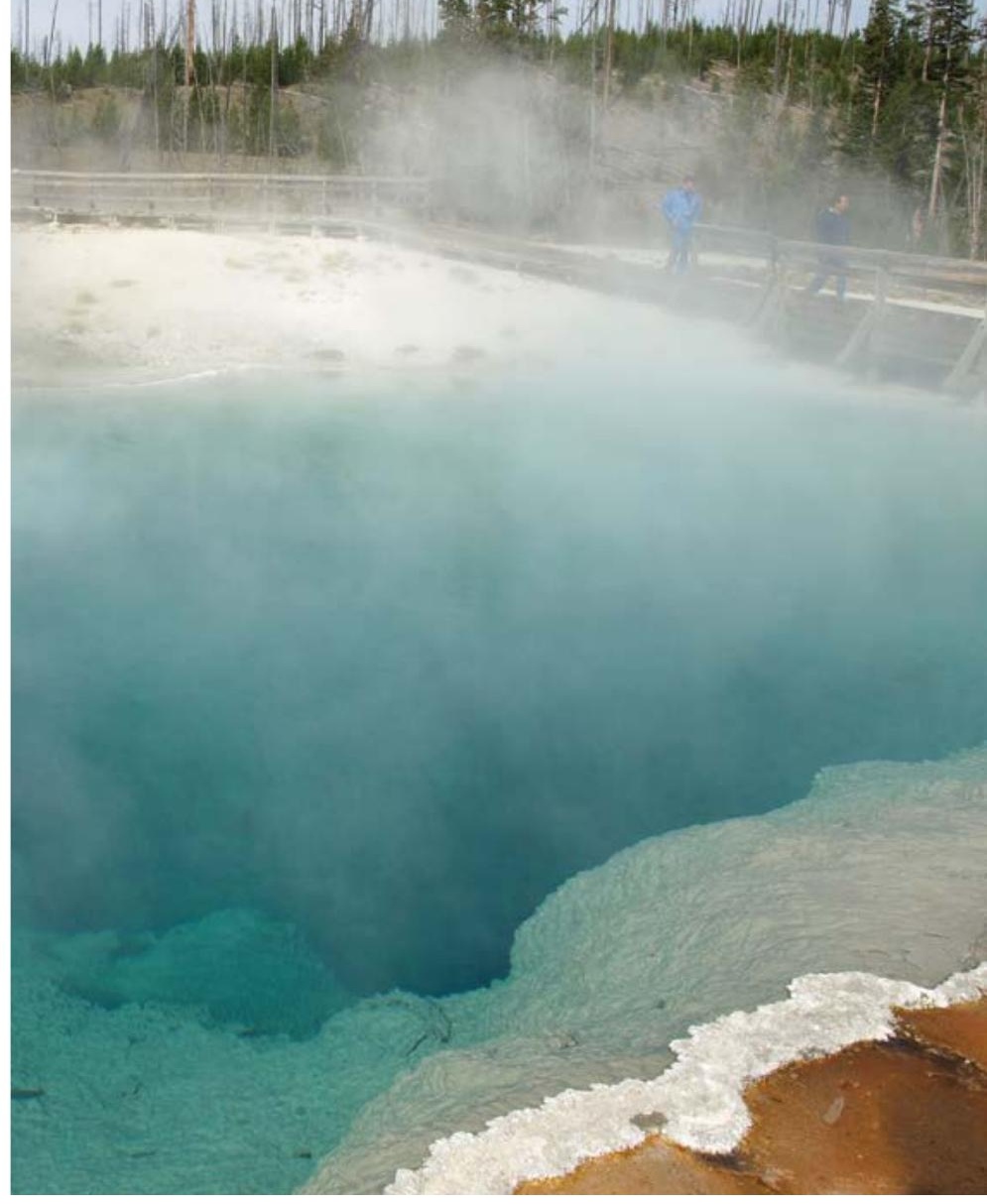

Aesthetic translucent blue of a geothermal boiling water pool, Yellowstone National Park, USA

Source: Graeme L. Worboys

goodwill that exist along the world's longest undefended border, between Canada and the United States. Several other trans-boundary protected areas have been effective in helping resolve boundary disputes between countries. For example, the establishment of protected areas in the Carpathian Mountains in Central and Eastern Europe between 1949 and 1967 helped settle boundary disputes, and the Cordillera del Cóndor Transboundary Protected Area along a portion of the border between Ecuador and Peru was declared as part of the resolution of a boundary dispute between the two countries (Stolton and Dudley 2010b).

\section{Understanding and managing benefits}

Recognising socioeconomic benefits is only the first step; we also need to understand the related value (including relative values compared with alternative uses of the natural resources) and have an agreed plan for their management. Over the years, a variety of tools has been developed for measuring and valuing natural resources, including those within protected areas. These range from detailed and costly economic and social valuation techniques to simple questionnaire-based approaches, 
Box 6.3 Aesthetic links with Snowdonia National Park, Wales

Nigel Dudley

The national park movement in the United Kingdom draws on a sensibility that derived from the Romantic movement, typified by poets such as William Wordsworth, who reversed millennia of disdain for wild, rugged landscapes and converted them into places of particular importance in people's minds. Like all UK national parks, Snowdonia in Wales was first designated primarily for its landscape values of mountains, steep valleys and moors. Artists like Richard Wilson first popularised wild mountain scenes despite the objections of some of the cultural critics of the day. But these areas were not wilderness in any usual sense of the term: most of the uplands are used for sheep pasture and forestry and these uses overlay a dense history of prehistoric settlements and more recent mining and quarrying. The whole landscape has been transformed and scarred. Nor was designation a local concern; decisions were made in parliament in London, driven primarily by middle-class English who had absorbed the Romantic aesthetic. Transforming these external sensibilities into a vehicle for biodiversity conservation and ecosystem services, supported by the communities who live there, remains a challenge today (Hourahane et al. 2008).

which are quicker to use but provide more approximate information. While economic valuation is important, it is not the only way in which to assess the value of the natural world and/or resources, and over-reliance solely on economic values can be dangerous, overlooking the range of broader welfare benefits and associated values outlined above.

\section{Categorising and illustrating values}

'Value' is a vague word, although a number of typologies exist to help provide more detail (Harmon and Putney 2003; Pagiola et al. 2004; van Beukering et al. 2007).

First, assessments often distinguish between 'intrinsic value' and 'value to humans' (or 'instrumental value'). The meaning of the latter is fairly clear and the subject of much of this chapter. Intrinsic value on the other hand attempts to capture values that are distinct from human interests. This is inevitably difficult: humans are the ones who are trying to define non-human values so that we are still viewing these through our own eyes, but the attempt is important. The intrinsic value of species is their place in the evolutionary process, which is responsible for the continuation of life on Earth; they hold that value whether or not they have any direct or indirect use to people, or even if their continued existence is antithetical to people's interests. Development of theories of intrinsic value marks an important step forward: particularly in the West, people used to believe that nature only had value to the extent that it was of use to us and had no 'rights' independent of humans. These ideas (which were never accepted by most Eastern philosophies) are being increasingly challenged.

The overall value of the natural world to humans consists of both economic values and broader cultural and other non-economic values and can be captured in the following typology. While easier to define than intrinsic values, the human values also contain a number of nuances and it should be noted that the distinctions outlined below are not necessarily clear-cut.

\section{Direct use values}

These refer to the immediate uses we make of ecosystem services. Examples might be catching fish whose populations are maintained within marine protected areas, or the jobs that the protected area provides. They often refer to some kind of harvesting and are often provisioning services. Generally, it is relatively easy to understand direct use values and also to assign them socioeconomic values.

\section{Indirect use values}

These refer to values that come in more diffuse form, often affecting a large number of people and sometimes including populations far from the origin of the value. They tend to be non-consumptive values and are often regulating services. Indirect use values tend to include such benefits as clean water from a forested watershed or disaster risk reduction from coastal protection and soil stabilisation. Although indirect use values have important economic and welfare consequences, they are relatively more difficult to assign economic values and more difficult still to link with particular beneficiaries.

\section{Non-use values and/or options for future use}

These refer to the values of leaving a natural species or ecosystem in place even when we are not benefiting immediately from its existence. Several categories exist, including: option values, which relate to maintaining an area in case it may be needed for its natural resources in the future; bequest values of leaving things in place for future generations; and existence values that we consider important even though we do not benefit ourselves. 
6. Values and Benefits of Protected Areas

that economic valuation is dangerous, not least because clever economists can often argue that using a resource now is more valuable than leaving it for the future and partly on the philosophical grounds that we have no right to reduce the rest of nature to figures on a balance sheet. We recognise the pitfalls but nonetheless believe that careful use of economic valuation can be useful.

\section{Assessing multiple benefits to multiple stakeholders}

When approaching protected area valuations, it is important to consider all values and all stakeholders over a lengthy period. We have pointed out that for the individual, non-sustainable extractive uses (like felling timber) are often immediate and highly profitable to the owner of the resource, while the costs (such as soil erosion, poorer water quality and the release of carbon into the atmosphere) are borne to a small extent by many people over a much longer period. Eventually all the 'small' hidden costs of environmental degradation add up to a large cost to society as a whole. Similarly, a valuation that only looks, for instance, at the profits from ecotourism but ignores the benefits forgone by local communities will not produce a complete picture. It is therefore important that an assessment takes account as far as possible of the views and values of all stakeholders (see Box 6.4). In addition, valuation should not look at a single snapshot in time, but should consider long-term implications as well: some values are short term while others exist for years, decades or even centuries. This makes valuation inherently complex; our understanding of benefits and their value changes over time. Ten years ago the role of protected areas in carbon sequestration was hardly discussed; today it is at the top of the list for many valuation studies.

It is also important to acknowledge that benefits provided by protected areas come with costs related to the implementation of management activities. Like benefits, costs can be experienced by different stakeholders at different levels ranging from global to local, from international donors to local communities. Therefore, when assessing the overall value of benefits provided by protected areas it is also necessary to think about the associated costs. This allows conclusions to be drawn on the actual net benefits (for further information, see Kettunen and ten Brink 2013). Importantly, complementing the assessment of benefits with information on related costs guides the appropriate uptake of valuation results in practice (as elaborated in the next section). (TEEB 2011) has highlighted the role of economic assessment, although TEEB is careful to note that this is only one form of valuation. Others remain concerned 


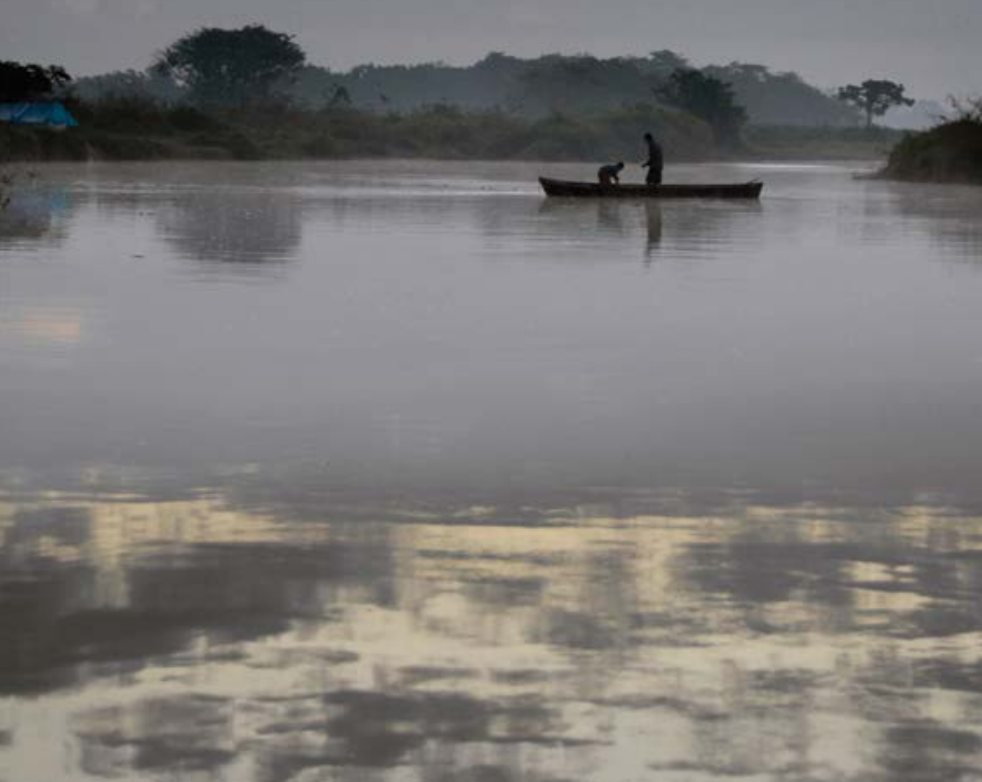

Fishermen, Rio Platano Biosphere Reserve, Honduras

Source: Eduard Müller

\section{Building on different indicators of value}

The value of benefits can be assessed at three levels: qualitative, quantitative and monetary (Kettunen and ten Brink 2013). Qualitative valuation focuses on non-numerical indications of value-for example, by describing the role of a protected area in supporting local culture and identity. Quantitative indicators of value focus on numerical data including, for example, visitors to or the quantity of carbon stored in a protected area. Monetary valuation focuses on capturing or reflecting the different values in monetary terms-for example, by calculating the revenue generated by visitors or defining the value of carbon storage. Only a limited number of benefits can be captured through monetary indicators. Therefore, a comprehensive assessment of protected area benefits is likely to build on a combination of qualitative, quantitative and monetary indications of value.

A range of methods is available and is currently used to estimate the value of protected area benefits. Kettunen and ten Brink (2013) provide a more comprehensive overview of the available methods and their appropriate application. As a rule of thumb, market values and prices are generally useful when assessing the value of benefits related to the access to biodiversity resources, and opportunities for recreation and tourism. There are also several benefits that are not currently captured by the markets but can be valued in monetary terms. For example, the value of protected areas in purifying water can be captured as the avoided costs of pre-treatment by water companies. Similarly, several survey-based methods are available, designed to assess indicative or 'hypothetical' market values for different benefits. The wider welfare (non-economic) values are difficult to capture in monetary terms. For example, it is difficult to find monetary indicators that would sensibly reflect the role protected areas play in supporting mental health and cultural identity. In these cases, qualitative and quantitative methods are often the most feasible approaches for valuation.

\section{The purpose of assessments}

Identifying the purpose of an activity is a key to its success: in order to guide practical decision-making, the benefit assessment and related valuation need to be fit for purpose (Kettunen and ten Brink 2013; TEEB 2013). For example, socioeconomic assessment of benefits, building mainly on qualitative and quantitative information (see above), is often very suitable for raising initial awareness of the benefits among stakeholders. These assessments can be carried out in the context of a scoping study designed to both collect information and engage relevant stakeholders (for example, Stolton and Dudley 2009; Kettunen and ten Brink 2013). Such assessments also form a useful starting point for further valuation: they help to avoid creating an imbalanced overview of benefits by focusing on benefits for which monetary evidence is available while ignoring benefits with less readily available information.

Detailed economic valuation, including monetary assessment, can usefully complement and further specify the overview of total benefits (see Box 6.5). For example, economic valuation can be required when there is a need to demonstrate protected area benefits in relation to alternative land-use practices. Similarly, the development of concrete management mechanisms, such as Payment for Ecosystem Services or new markets for sustainably produced goods, requires detailed economic valuation.

\section{Managing for multiple benefits in protected areas}

Identifying and assessing the value of benefits and understanding the stakeholder dynamics involved in maintaining and using the benefits are key steps towards their management (see Box 6.6). Once we have this information, we have the tools needed to reach some kind of consensus about how the various benefits from a protected area can be divided up, managed and maintained in a sustainable and equitable manner. 


\section{Box 6.4 The PA-BAT in the Balkans and Turkey}

Sue Stolton, Başak Avcıoğlu Çokçalışkan and Kasandra-Zorica Ivanić

The Protected Area Benefit Assessment Tool (PA-BAT) provides a standardised format for documenting and assessing multiple benefits of protected areas amongst different stakeholders (Stolton and Dudley 2009). The PA-BAT is essentially a set of datasheets that collects basic information about the types of benefits (that is, permissible activities in relation to resource use and ecosystem services), to whom they are important, qualitative information about their level of importance, their relationship to the protected area and the times of year in which they are important. Twenty-four sheets cover assessments of biodiversity values, protected area management (jobs), benefits related to food, benefits related to water (provisioning and regulating services), cultural and spiritual benefits and values, health and recreation values, knowledge, materials, and environmental services.

The Küre Mountains National Park (Küre Dağları Milli Parkı, KDMP) in Turkey was declared in July 2000. There are almost no settlements in the core area of KDMP, but there are some 20000 villagers in 123 villages in the buffer zone. The PA-BAT was implemented in KDMP in March 2009. At the time KDMP had no management plan, but management had a strong focus on involving local people in planning initiatives related to the national park and buffer zone.

Three meetings were held around KDMP to assess the values and benefits of the protected area in two provinces (Bartın and Kastamonu). The first public meeting was attended mainly by local Muhtars (leaders of the village). The meeting concentrated on using a simplified version of the PA-BAT based around a PowerPoint presentation and assessed the values (subsistence, economic and potential) for local people living inside and near the protected area. The second meeting was for representatives of park management (national parks and forestry) and local university departments. The group was divided into two working groups, who between them completed all the PA-BAT datasheets relevant to the park. The third meeting was also a public meeting of mainly local officials from the forest, water and parks sectors.

The assessment and discussion around each of the values highlighted significant differences in the perceptions of local people, managers and service providers. For example, the local community noted the major importance of sacred springs in the area, while managers, researchers and service providers assessed these as being of minor importance. The importance of permitted traditional agriculture, wild food plants and medicinal herbs in the buffer zone was also assessed differently between the groups, with managers thinking traditional agriculture was more important than the local people, whilst managers thought collection of medicinal herbs was of no importance whereas local people assessed this as being of major importance.

As the PA-BAT was one of the first examples in Turkey of assessing ecosystem services and their benefits in protected areas, it served as a basis for the development of a business plan for KDMP during the management planning process. The tool also increased the awareness and technical capacity of park managers and experts on how to integrate benefits in protected area planning and management.

In the Dinaric Arc region of Europe the PA-BAT was being implemented in 2013 and 2014 in all the national parks in the eight countries of the region-the first time such a tool has been used on a regional basis. For many protected areas in the region, the PA-BAT workshops have been the first time that stakeholders have been asked to participate actively in, and comment on, park management. For managers and stakeholders engaged in the process, the workshops have provided a fascinating insight into local cultures and traditions and have raised awareness of the range of benefits provided by the park (for example, ecosystem services are generally a new concept introduced during the workshops). Across the region some clear patterns are emerging of how protected areas can better promote conservation, protect local culture and develop sustainable funding strategies. For instance, there is clearly potential in developing branding for local/regional products from protected areas (for example, honey, mushrooms, medicinal plants, cheese) that highlights that these products come from 'healthy and sustainable' sources. The role of protected areas in the mountainous regions of the Dinaric Arc (a karst region) in providing clean water to the population of the whole region is known scientifically. In theory, the development of Payment for Ecosystem Services (PES) schemes could help support the conservation of these areas; however, these resources have been taken for granted for so long that there is a vast task of educating policymakers and citizens of the role protected areas play in providing water before any such scheme could be developed. 
most protected area managers, and ensuring that one person's benefit does not substantially undermine other people is an important priority. At the same time, the primary role of nature conservation should not be overshadowed in the rush to develop other protected area values. Good assessment and, where necessary, valuation of ecosystem services can help to address these conflicts. Here synergies and opportunities can play a role. For example, understanding the links between protected areas and the surrounding landscape can ensure support from local beekeepers to help conserve flowering plants, which make high-quality honey, or local farmers who rely on the pollinators who thrive on flora in a protected area to pollinate crops or orchards.

\section{Access and benefit sharing}

The need for equitable distribution of costs and benefits has gained important backing through the development of 'access and benefit sharing' (ABS) agreements within several international treaties and instruments, including the Convention on Biological Diversity (see Chapter 26). In particular, the 'Nagoya Protocol on Access to Genetic Resources and the Fair and Equitable Sharing of Benefits Arising from their Utilization' was adopted by the Conference of the Parties to the Convention on Biological Diversity at its tenth meeting on 29 October 2010 in Nagoya, Japan. It is an international agreement aimed at sharing the benefits arising from the utilisation of genetic resources in a fair and equitable way. This includes appropriate access to genetic resources and transfer of relevant technologies.

A key aspect of protected area management is to understand the synergies and conflicts between the wants and needs of different users and to manage the trade-offs and build on the opportunities that result. One important aspect of this is managing different, and sometimes conflicting, demands on ecosystem services, in turn keeping in mind their various implications for biodiversity conservation. Human-wildlife conflict is a classic example of conflict and trade-off. An expanding population of elephants, large cats or monkeys may be a success for the protected area, in terms of both achieving conservation goals and increasing potential for tourism, but a problem for local villagers whose crops are damaged or children endangered. Similarly, a new tourist complex may bring visitors and money into the protected area but also generate significant waste streams that may pollute nearby seawater, negatively impact marine ecosystem's natural nursery functions and imperil the livelihoods of local fishing communities. Preventing local people from riding horses inside protected areas may create a more pristine environment for biodiversity and visitors alike and help to maintain the soil's natural regeneration capacity but loses support among key constituencies. Managing these conflicts is a key aspect of the lives of

The ways in which the ABS protocol will be implemented are still subject to much discussion: from the perspective of protected areas it has important considerations relating to the rights of traditional owners, local communities and the managers of the parks themselves, depending on the area's history. While the ABS protocol does not address all protected area benefits, the need to ensure that protected area benefits and costs are balanced out equitably between those who benefit and those who manage or experience the costs remains critical.

\section{Communicating benefits to a range of audiences}

One key aspect of successful management is to make sure that people understand and appreciate the wide range of benefits from protected areas. Many, particularly indirect, values have long been treated as 'free goods' and the problems that have arisen only when they disappear, such as water pollution, soil erosion and coastal damage, are what have focused attention on their good management. 


\section{Box 6.5 Parks Canada: Thousand Islands National Park ecosystem services}

Dan Mulrooney and Karen Keenleyside

The Thousand Islands National Park (TINP) is named after the larger Thousand Islands ecosystem of Eastern Ontario, Canada. The park was established in 1904 and is one of the smallest national parks in Canada. The total area is $22.3 \mathrm{sq} \mathrm{km}$ while the entire ecosystem covers an area of $3000 \mathrm{sq} \mathrm{km}$ that is bisected by the international border between Canada and the United States.

Thousand Islands has historically been a rich area that has provided a host of ecosystem services (food, water, recreation) to First Nations, early settlers and modernday residents and visitors. The park itself was primarily created as a place for recreational activities such as picnicking, camping and boating. More recently, the park has become better known for protecting a unique Canada-United States trans-boundary ecosystem that is part of an extension of the Canadian Shield, connecting the Appalachian forest of the south-eastern United States to the northern boreal forest. The park provides critical habitat for a great diversity of plant and animal life, including more than 30 species at risk.

The population of Eastern Ontario has grown significantly in recent years. In 2011, for example, approximately 2 million people lived within $100 \mathrm{~km}$ of the Thousand Islands ecosystem-an increase in population of 47 per cent since 1981. Today, the TINP ecosystem is influenced by habitat fragmentation, pollution and other activities on the landscape that are associated with rapid population growth in the region. While population growth and other pressures have created challenges for the park, they have also highlighted the importance and value of the ecosystem services it protects. Parks Canada is working broadly with First Nations, adjacent communities, organisations and volunteers to protect and connect visitors with this special place while assessing and ensuring a lasting flow of ecosystem services.

A land-cover analysis using satellite imagery formed the base data from which estimates of the value of ecosystem services were produced. Within the Thousand Islands ecosystem, the three primary land covers were forest (31 per cent), cropland (24 per cent) and water (22 per cent), while wetlands and urban areas covered 7 per cent and 6 per cent of the area respectively. TINP has higher forest cover (82 per cent) and wetlands (10 per cent) and lower cropland/field ( 2 per cent) and built-up areas ( 2 per cent) compared with the entire ecosystem.

Estimating monetary values from ecosystem services protected by and flowing from the TINP supports park management, policy development and public education purposes. Two methods were used to estimate the monetary values for ecosystem services. The first method reproduced the results of the study Estimating Ecosystem Services in Southern Ontario by Troy and Bagstad (2009) for the case study area. The second method involved making estimates of selected ecosystem services by land-cover type, drawing from published valuation studies and transferring monetary values found in similar areas within the park. Using the first approach, estimates of the annual value of ecosystem services for the TINP were produced, ranging from $\mathrm{C} \$ 12.5$ million to $\$ 14.7$ million (2012 dollars). Using the second method, the value of the park's recreation services as well as option, bequest and existence values associated with the park's wetlands were produced. The annual recreational services for all land-cover types in the park were valued at C\$3.9 million (2012 dollars). Finally, the annual option, bequest and existence values of the park's wetlands ranged from C\$434 000 to $\$ 531000$ (2012 dollars).

The monetary values identified for the TINP are conservative estimates and represent an experimental effort by Canadian Government departments and agencies. Depending on the approach taken and the data sets used to support the analysis, a range of value estimates can be generated. Much consideration needs to be given to the valuation methods, the supporting data and the selection of the ecosystem service or suite of services measured and reported. As demonstrated by the TINP case study, even with the selection of a small data-rich area, the analysis does not represent the total value of the national park area.

For further information concerning the case study and the production of the experimental monetary valuations for TINP, see Statistics Canada (2013). 


\section{Box 6.6 Managing for crop wild relatives}

Nigel Maxted and Danny Hunter

Most genetic reserves (areas where the specific goal is to conserve the genetic diversity of CWR species) will be established in existing protected areas to avoid the cost of establishing new sites (Maxted 2003). Their implementation may be divided into five steps.

1. 'Ground truth' potential in in situ conservation sites. Having established the in situ conservation goals, an ordered list of potential in situ conservation sites should be established. The list of potential sites is likely to have been achieved remotely from the actual sites using eco-geographic or geographical information systems (GIS) techniques and the potential sites must be visited to check if the prediction matches the reality at the site and the CWR population is viable.

2. Reformulate protected area management goals. The first step in formulating the revised management plan is to observe the biotic and abiotic dynamics of the site for both CWR and non-CWR species. A survey of the species present in the site should be performed to help understand the ecological interactions within the reserve. A clear conservation goal should be decided, the management interventions recommended for the site and how the CWR are to be monitored to ensure the management is promoting CWR population health.

3. Ensure the in situ conservation sites comply with (at least) the minimum quality standards. The quality standards are related to enable the genetic reserve to function and fulfil its conservation objectives (Iriondo et al. 2012) and include such factors as: sites being identified through a rigorous scientific process; the site is of sufficient size to conserve the populations of the target taxon, its natural habitat and to maintain natural processes; a management plan using participatory and evidence-based criteria has been developed; and the site has a legal foundation that underpins long-term site stability.

4. Integrate in situ conservation priorities with national/ international agro-environmental schemes. The selected protected areas that contain genetic reserves constitute a national network of genetic reserves and should be integrated with agro-environmental schemes.

5. Ensure local communities value and use their local CWR diversity. Promoting the involvement of local communities in in situ conservation and management of CWR is often crucial for conservation to be effective. Awareness of the value of CWR may need to be raised among the different stakeholders.

Finally, it should be stressed that the implementation of specific CWR in situ conservation actions within protected areas will ultimately be pragmatic, dictated by the resources available as well as national and regionallevel governmental will, and NGO and local community involvement (Hunter et al. 2012).
Communication is therefore critical. Protected areas have the opportunity to reach a wide variety of visitors, and along with information on wildlife and walking trails, a growing number are telling people about the other values they contain (see Chapter 15). Perhaps even more important is to work with local communities to understand the full range of values - through community evaluations (see Box 6.5), meetings, discussions on community radio and articles in local newspapers. Just as essential from the protected area's perspective, however, is that large downstream users understand and where necessary pay a contribution towards the benefits, through such initiatives as payments for ecosystem services schemes (see Chapter 8).

\section{Learning from best practice}

There are an increasing number of case studies from protected areas around the world where local people, rights-holders and stakeholders are working closely together to ensure the full range of socioeconomic benefits is conserved. Three examples are given in Boxes 6.7 to 6.9, and many more can be found in peer-reviewed and published literature (see, for example, Stolton and Dudley 2010b; Kettunen and ten Brink 2013). 


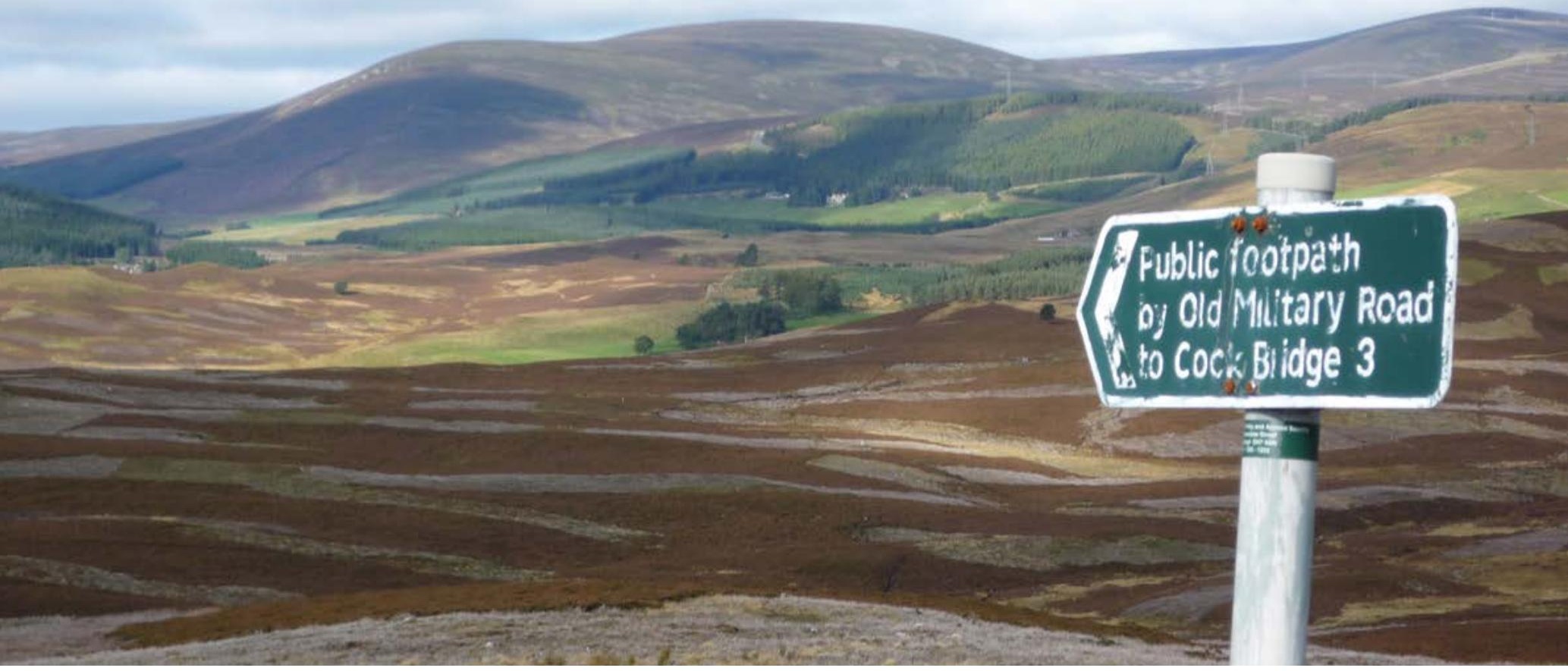

Cairngorms landscape, Scotland

Source: Michael Lockwood

\section{Box 6.7 Healthy Parks, Healthy People}

John Senior

In the United Kingdom, the Cairngorms Walking to Health project started in 2004 as a community health and learning initiative. Inspired by an initial demonstration health walk organised as part of a health fair, the project has since gone from strength to strength, extending geographically each year into new areas, and involving more people. In 2009, the original project, focused on Deeside and Donside in Scotland, was extended to include the whole of the Cairngorms National Park and surrounding area, and to include walk programs targeting specific health issues.

The project is led by Cairngorms Outdoor Access Trust (COAT), which employs a part-time freelance project manager, and two part-time staff who support volunteer walk leaders. The project has established 37 different walking groups, led by 60 trained and active volunteers, attracting an average of 215 walkers each week, with the number of participants increasing weekly.

Weekly walks, varying in duration from 30 to 60 minutes, aim to encourage outdoor exercise in a safe and socially enjoyable way. The walks are targeted at people who would benefit from increasing their physical activity, ranging from people struggling to lose weight to those suffering from cancer or diabetes. Considerable time and effort have been invested in developing close links with doctors and encouraging direct referral, but participation by service users and their carers is entirely voluntary. Approximately 95 per cent of participants are female, mainly aged over 55 , but walks have also been established targeting younger people.

Pedometer challenges have encouraged new mothers and vulnerable adults from Aviemore to increase how far they walk each day, while on Deeside, academic evidence of the benefits of walking in delaying symptoms

of early onset Alzheimer's is used to encourage patients diagnosed with the condition to take part in health walks. Group walks are also part of the range of services on offer to support people after quitting smoking.

To demonstrate the benefits of Cairngorms Walking to Health, COAT has collaborated with Paths for All, the Centre for Rural Health (a department of the University of the Highlands and Islands) and the Scottish Agricultural College in a comprehensive evaluation using six different research methods. New walker and follow-up physical activity questionnaires to monitor health improvements were complemented by focus groups, interviews, participant feedback postcards, case studies and longitudinal studies with participants and leaders. The evaluation clearly demonstrated that the project is making a very significant and highly cost-effective contribution to Scottish and local government priorities in relation to health improvement, volunteer development, long-term health condition and self-care strategies, community development and engagement, and in providing highquality access to the local environment.

Cairngorms Walking to Health costs approximately $£ 30000$ per annum to deliver, funded by Cairngorms National Park Authority, LEADER Programme, Scottish Natural Heritage and Paths for All, with additional inkind support from NHS Grampian and NHS Highland. Per capita, the cost of running the project works out at approximately $£ 140$ per walker per year, which represents excellent value for money in terms of associated health and wider community benefits. 


\section{Box 6.8 Ecological restoration in and around national parks in Kenya}

\section{John Waithaka, Karen Keenleyside and Erustus Kanga}

Kenya is famous for its beautiful national parks, great wildlife diversity and panoramic landscapes and is dependent on biological resources for much of its social and economic development. Agriculture, livestock, forestry, nature-based tourism and fisheries account for nearly all the employment, economic output and export earnings. To safeguard its rich biodiversity resources, Kenya has designated an extensive network of protected areas.

Wildlife tourism, which is based primarily in protected areas, is among the top sources of revenue for Kenya, contributing 21 per cent of the total foreign exchange, 12 per cent of the country's gross domestic product (GDP), and supporting the livelihoods of several million people (WRI 2007).

In addition to tourism, Kenya's protected areas support other sectors of the economy such as energy, water, agriculture, security, forestry and horticulture. In Tsavo West National Park, for example, the Mzima Springs, which are the park's most important natural feature, provide habitat for wildlife, attract thousands of visitors and supply 360 million litres of water daily to about 2.5 million people downstream, including in Kenya's second-largest city, Mombasa (NWCPC 1998). In Tsavo East National Park, the largest national park in the country, the Voi River is a major source of water for wildlife and for communities which border the park. Similarly, swamps that are mainly located in Amboseli National Park sustain wildlife and people in the greater Amboseli ecosystem. In the mountains of central Kenya, Mount Kenya National Park (which is also a UNESCO World Heritage property) and the Aberdare National Park are the sources of rivers that provide water to approximately half of Kenya's population and produce nearly 60 per cent of Kenya's hydroelectric power (UNEP 2009).

Many of the important benefits that Kenya's national parks provide to the Kenyan people and their economy are even more crucial in the context of climate change. Droughts are becoming more frequent, prolonged and severe in the south and unusual weather patterns appear to be contributing to unpredictable river flows and lake water-level fluctuations in the central highlands and Rift Valley. These changes can put increased pressure on natural resources and the benefits derived from them. The conservation of healthy park ecosystems is recognised as an important strategy for helping Kenyan wildlife and human communities adapt to climate change. Additional pressures on park ecosystems, however, such as overgrazing by wildlife and livestock, and the spread of invasive species, which are sometimes also aggravated by climate change, mean that park managers have to actively manage these systems to ensure they remain resilient to climate-related changes and can continue to provide important benefits into the future.

The Kenya Wildlife Service is taking action to reduce pressures on national park ecosystems and restore areas that have already been damaged in order to build the resilience of ecosystems and the communities which depend on them to climate change and other stressors. For example, riparian areas around Mzima Springs in Tsavo West National Park, which were degraded due to overgrazing by wildlife, have been fenced and revegetated to reduce erosion and siltation. At the same time, alternative watering sites for wildlife inside the park have been installed, thus helping to protect clean water for downstream users and reducing the risk of human-wildlife conflicts that could result from wildlife seeking alternative water sources outside the park. Similar work has been conducted to restore terrestrial habitat and swamps in Amboseli National Park. There, community and livestock watering sites outside the park have also been improved to reduce grazing pressure on the park ecosystem while helping to maintain the traditional way of life of the local people.

Reafforestation in Mount Kenya and Aberdare National Parks has been an important part of restoration efforts aimed at helping to retain water in the important watersheds that these parks protect. The work has also resulted in benefits for local people, including training of members of local community forest associations in modern propagation and reafforestation techniques and the modernisation of community tree nurseries. Along with community groups, park visitors have been directly involved in restoration efforts such as tree plantings, which have not only provided memorable experiences for them but have helped to build support for restoration efforts and raise awareness of the important climate change adaptation benefits these protected areas provide.

As is the case in many protected areas, invasive species are a management issue for Kenya's protected areas, as well as for local communities which practise subsistence agriculture. In Amboseli, Tsavo East and Lake Nakuru National Parks, local people have been trained in invasive species identification and have been employed by the Kenya Wildlife Service to help with eradication efforts. Invasive species removal has not only improved wildlife habitat in the parks, but also has improved wildlife viewing opportunities for visitors. Employment opportunities provided by the parks have been important for local communities but, perhaps more importantly, local people have, through participation in this work, gained important knowledge and skills that are transferable to other aspects of their daily lives.

Whether the benefits of protected areas are associated with tourism, provisioning of water, regulation of or adaptation to climate change, knowledge transfer, or support for traditional lifestyles, implementation of active management strategies aimed at maintaining or restoring these benefits is often necessary. The Kenyan work described above is just one example of how multiple benefits can be maintained or restored through actions that simultaneously address ecological issues associated with the structure and function of ecosystems while at the same time considering visitor experience, learning opportunities and the needs and values of local people. 


\section{Box 6.9 Kenozersky National Park, Russia: The benefits of joint management}

John Senior

Kenozersky National Park, located in the north of the European part of Russia, was established in 1991. The park is one of the most attractive places in Russia, recreating an atmosphere of amazing harmony between humans and nature by initiating the significant involvement of local residents in joint management.

Active local residents within the park were interested in the development of the local economy and wanted to 'take their lives into their own hands'. The establishment and implementation of territorial public self-government, named locally the 'Spark of Hope', has realised this goal.

Over the past decade, a tourism development program has helped the local population become more open to cooperation with park management. The program has a number of elements: food production, activity-based tourism, heritage restoration and education. The first of these relates to the production of organically grown foods, restoring the traditions of Pomorian cuisine (Pomor being one of the ethnic groups of the population in the north of Russia).

A micro-credit fund was established to support local people for the development and maintenance of small nature-friendly businesses to serve visitors. Since 2001, the park has actively developed rural tourism, which is attractive for Russian and foreign tourists. More than 30 local families converted their homes in the park to guesthouses providing activity-based services (boating, fishing, sightseeing, biking and hiking) with relatively inexpensive accommodation for the night, weekend or holiday period in cosy farmhouses. Hosts are always ready to show all the attractions in the vicinity and provide opportunities to try local traditional home cooking, fishing, picking mushrooms and berries, and horseback riding. Visitors can also take part in some simple farm work, such as haymaking, feeding animals and harvesting vegetables.

Kenozersky National Park is now well known in Russia not only for its picturesque natural forests and lakes but also for the numerous examples of restored timber architecture (especially chapels and farm buildings) that blend into the northern landscapes. Once these structures have been restored using traditional skills at state cost, community leaders become permanent employees of the park as the guardians of these heritage buildings. The special spiritual experience that has been created through the presence of 'live' objects of cultural heritage together with the revival of the traditions of the local population is one of the main factors of attractiveness of the area for tourists.

Education, through annual children's environmental camps, has become a major feature of the park. The camps are attended by students from the Arkhangelsk region as well as from Moscow, and even from neighbouring Finland. These camps also accept children from the villages located in the park as well as from orphanages and socially disadvantaged families. The main campsite is in a picturesque setting near the Maselga village. It is a small log-cabin 'town' in a setting vastly different from what the visiting city children are accustomed to. Children actively participate in a range of subjects, including meteorology, geobotany, hydrobiology, as well as studying the history of the village and the cultural heritage of the region. In addition to outdoor exploration, each child takes part in masterclasses in traditional crafts including birch bark weaving, modelling clay toys and learning traditional folk songs. Local elders and artisans provide much of the tuition for these classes.

Together these four elements have enabled a revival in the local economy, provided pride and self-esteem to locals and recreated Kenozero National Park as a vibrant visitor attraction. 


\section{References}

Recommended reading

Bertzky, B., Corrigan, C., Kemsey, J., Kenney, S. and Ravilous, C. (2012) Protected Planet Report 2012, UNEP-WCMC, Cambridge.

Byrne, D. and Goodall, H. (2013) 'Placemaking and transnationalism: recent migrants and a national park in Sydney, Australia', PARKS: The International Journal of Protected Areas and Conservation 19(1): 63-72.

Cardinale, B. J., Duffy, J. E., Gonzalez, A., Hooper, D. U., Perrings, C., Venail, P., Narwani, A., Mace, G. M., Tilman, D., Wardle, D. A., Kinzig, A. P., Daily, G. C., Loreau, M., Grace, J. B., Larigauderie, A., Srivastava, D. S. and Naeem, S. (2012) 'Biodiversity loss and its impact on humanity', Nature 486: 59-67.

Costanza, R. (1997) 'The value of the world's ecosystem services and natural capital', Nature 387: 253-60.

de Groot, R., Fisher, B., Christie, M., Aronson, J., Braat, L., Gowdy, J., Haines-Young, R., Maltby, E., Neuville, A., Polasky, S., Portela, R. and Ring, I. (2010) 'Integrating the ecological and economic dimensions in biodiversity and ecosystem services valuation', in P. Kumar (ed.) The Economics of Ecosystems and Biodiversity (TEEB) Ecological and Economic Foundations, pp. 9-40, Earthscan, London.

Dudley, N. and Stolton, S. (eds) (2003) Running Pure: The importance of forest protected areas to drinking water, WWF International, Gland, and The World Bank, Washington, DC.

Dudley, N., Mansourian, S., Stolton, S. and Suksuwan, S. (2008) Safety Net: Protected areas and poverty reduction, WWF International, Gland.

Dudley, N., Stolton, S., Belokurov, A., Krueger, L., Lopoukhine, N., MacKinnon, K., Sandwith T. and Sekhran, N. (eds) (2009) Natural Solutions: Protected areas helping people cope with climate change, IUCN WCPA, The Nature Conservancy and Wildlife Conservation Society, Gland; The World Bank, Washington, DC; United Nations Development Programme and WWF, New York.
Hamilton, L. (2008) Forests and Water, FAO Forestry Paper 155, FAO, Rome.

Harmon, D. and Putney, A. D. (2003) The Full Value of Parks: From economics to the intangible, Rowman \& Littlefield, Lanham, MD.

Dd Hunter, D. and Heywood, V. H. (eds) (2011) Crop Wild Relatives: A manual of in situ conservation, Issues in Agricultural Biodiversity, Earthscan, London.

Hunter, D., Maxted, N., Heywood, V., Kell, S. and Borelli, T. (2012) 'Protected areas and the challenge of conserving crop wild relatives', PARKS: The International Journal of Protected Areas and Conservation 18(1): 87-97.

Iriondo, J. M., Maxted, N., Kell, S. P., Ford-Lloyd, B. V., Lara-Romero, C., Labokas, J. and Magos Brehm, J. (2012) 'Quality standards for genetic reserve conservation of crop wild relatives', in N. Maxted, M. E. Dulloo, B. V. Ford-Lloyd, L. Frese, J. M. Iriondo and M. A. A. Pinheiro de Carvalho (eds) Agrobiodiversity Conservation: Securing the diversity of crop wild relatives and landraces, pp. 72-7, CAB International, Wallingford, UK.

Keenleyside, K., Dudley, N., Cairns, S., Hall, C. and Stolton, S. (eds) (2012) Ecological Restoration for Protected Areas: Principles, guidelines and best practice, Best Practice Protected Area Guidelines No. 18, IUCN, Gland.

Kell, S. P., Maxted, N. and Bilz, M. (2012) 'European crop wild relative threat assessment: knowledge gained and lessons learnt', in N. Maxted, M. E. Dulloo, B. V. Ford-Lloyd, L. Frese, J. M. Iriondo and M. A. A. Pinheiro de Carvalho (eds) Agrobiodiversity Conservation: Securing the diversity of crop wild relatives and landraces, pp. 218-42, CAB International, Wallingford, UK.

Kettunen, $M$ and ten Brink, P. (eds) (2013) Social and Economic Benefits of Protected Areas: An assessment guide, Routledge, Adbingdon, UK.

Kulshreshtha, S. N., Lac, S., Johnston, M. and Kinar, C. (2000) Carbon sequestration in protected areas of Canada: An economic valuation, Economic Framework Project Report 549, Canadian Parks Council, Warsaw, Ontario. 
Lin, C.-C. and Lockwood, M. (2013) 'Assessing sense of place in natural settings: a mixed-method approach', Journal of Environmental Planning and Management: 1-24. <dx.doi.org/10.1080/09640568 .2013.811401>

Mallarach, J. M. and Torcal, L. M. (2009), 'Rila Monastery Natural Park, Bulgaria', in T. Papayannis and J. M. Mallarach (eds) The Sacred Dimension of Protected Areas: Proceedings of the Second Workshop of the Delos Initiative-Ouranoupolis, Greece, 24-27 October 2007, pp. 173-6, IUCN, Gland, and MedINA, Athens.

Maxted, N. (2003) 'Conserving the genetic resources of crop wild relatives in European protected areas', Biological Conservation 113(3): 411-17.

Maxted, N., Kell, S. P., Ford-Lloyd, B. V., Dulloo, M. E. and Toledo, A. (2012) 'Toward the systematic conservation of global crop wild relative diversity', Crop Sciences 52(2): 774-85.

Millennium Ecosystem Assessment (MEA) (2003) Ecosystems and Human Wellbeing: A framework for assessment, Millennium Ecosystem Assessment, Island Press, New York.

National Water and Conservation Pipeline Corporation (NWCPC) (1998) National Water and Conservation Pipeline Corporation, Ministry of Water Resources, Annual Report 1997, National Water and Conservation Pipeline Corporation, Republic of Kenya, Government Printer, Nairobi.

Pagiola, S., von Ritter, K. and Bishop, J. (2004) Assessing the economic value of ecosystem conservation, Paper No. 101, The World Bank Environment Department in collaboration with The Nature Conservancy and IUCN, Washington, DC. <www. biodiversityeconomics.org/library/basics/index. html>

Palmer, M. and Finlay, V. (2003) Faith in Conservation: New approaches to religions and the environment, The World Bank, Washington, DC.

Pimentel, D., Wilson, C., McCullum, C., Huang, R., Dwen, P., Flack, J., Tran, Q., Saltman, T. and Cliff, B. (1997) 'Economic and environmental benefits of biodiversity', BioScience 47: 747-57.

Ramsar Convention Bureau (2008) Water Purification: Wetland values and functions, Leaflet, Ramsar Bureau, Gland.
Roberts, C. M. and Hawkins, J. P. (2000) FullyProtected Marine Reserves: A guide, WWF Endangered Seas Campaign, Washington, DC, and Environment Department, University of York, Heslington, UK.

Siriwardena, L., Finlayson, B. L. and McMahon, T. A. (2006) 'The impact of land use change on catchment hydrology in large catchments: the Comet River, Central Queensland, Australia', Journal of Hydrology 326(1): 199-214.

Statistics Canada (2013) Human Activity and the Environment-Measuring ecosystem goods and services in Canada, December 2013, Environment Accounts and Statistics Division, Catalogue No. 16-201-X, ISSN 1923-6751, Statistics Canada, Ottawa.

Stolton, S. and Dudley, N. (2009) The Protected Areas Benefits Assessment Tool, WWF, Gland.

Stolton, S. and Dudley, N. (2010a) Vital Sites: The contribution of protected areas to human health. WWF, Gland.

Dd Stolton, S. and Dudley, N. (eds) (2010b) Arguments for Protected Areas, Earthscan, London.

Stolton, S., Hourahane, S., Falzon, C. and Dudley, N. with Phillips, A. and Lee, G. (2008) 'Landscape, aesthetics and changing cultural values in the British national parks', in J.-M. Mallarach (ed.) Protected Landscapes and Cultural and Spiritual Values. Volume 2, Values of Protected Landscapes and Seascapes Series, pp. 177-89, IUCN, GTZ and Obra Social de Caixa Catalunya, Kasparek Verlag, Heidelberg.

Stolton, S., Dudley, N. and Randall, J. (2008) Natural Security: Protected areas and hazard mitigation, WWF, Gland.

Stolton, S., Maxted, N., Ford-Lloyd, B., Kell, S. and Dudley, N. (2006) Food Stores: Using protected areas to secure crop genetic diversity, WWF, Gland.

United Nations Environment Programme World Conservation Monitoring Centre (UNEP-WCMC) (2008) State of the World's Protected Areas: An annual review of global conservation progress, UNEPWCMC, Cambridge.

The Economics of Ecosystems and Biodiversity (TEEB) (2011) The Economics of Ecosystems and Biodiversity in National and International Policy Making, Earthscan, London. 
The Economics of Ecosystems and Biodiversity (TEEB) (2013) Guidance Manual for TEEB Country Studies. Version 1.0, Geneva. <www. teebweb.org/media/2013/10/TEEB_ GuidanceManual_2013_1.0.pdf>

Troy, A. and Bagstad, K. (2009) Estimating Ecosystem Services in Southern Ontario, Ontario Ministry of Natural Resources, Peterborough. <www.mnr.gov. on.ca/stdprodconsume/groups/lr/@mnr/@lueps/ documents/document/279512.pdf>

United Kingdom National Ecosystem Assessment (UK NEA) (2011) The UK National Ecosystem Assessment: Synthesis of the key findings, National Ecosystem Assessment, UNEP-WCMC, Cambridge. <uknea. unep-wcmc.org>

United Nations Environment Programme (UNEP) (2009) Kenya: Atlas of our changing environment, Division of Early Warning and Assessment, UNEP, Nairobi.

Dd van Beukering, P., Brander, L., Tompkins, E. and McKenzie, E. (2007) Valuing the Environment in Small Islands: An environmental economics toolkit, Joint Nature Conservation Committee, Peterborough, UK. <www.jncc.gov.uk/page-4065>

Worboys, G. L. and Good, R. B. (2011) Caring for Our Australian Alps Catchments: Summary report for policy makers, Department of Climate Change and Energy Efficiency, Canberra.

World Resources Institute (WRI) (2007) Nature's Benefits in Kenya: An atlas of ecosystems and human well-being, World Resources Institute, Washington, DC. 


\section{$19 x=a$}

6

\section{CHAPTER 7}

\section{GOVERNANCE FOR THE CONSERVATION OF NATURE}

\section{Principal authors:}

Grazia Borrini-Feyerabend and Rosemary Hill

\section{CONTENTS}

\section{Introduction}

- History, power, culture and nature

- Governing protected and conserved areas

- The governance frontiers

- Conclusion

- References

IUCN 3 WCPA 


\section{PRINCIPAL AUTHORS}

GRAZIA BORRINI-FEYERABEND is Global Coordinator of the ICCA Consortium, Member of the Governing Board of French National Parks and President of the Paul K. Feyerabend Foundation.

ROSEMARY (RO) HILL is Principal Research Scientist at the Commonwealth Scientific and Industrial Research Organisation (CSIRO), Australia; and is a member of the Expert Task Force on Indigenous and Local Knowledge Systems of the Intergovernmental Platform on Biodiversity and Ecosystem Services.

\section{ACKNOWLEDGMENTS}

The authors greatly appreciate the insightful comments of Dermot Smyth, Trevor Sandwith, Jackie Sunde, Mike Jones and two anonymous referees. Dr Borrini-Feyerabend would like to acknowledge the moral support and invaluable learning from the Members of the ICCA Consortium, which were essential for the development of this chapter. Dr Hill would like to acknowledge the support of the Australian National Environmental Research Program's Tropical Ecosystem Hub, CSIRO's Land and Water Flagship and James Cook University's Division of Tropical Environments and Societies that made her contributions to this chapter possible.

\section{CITATION}

Borrini-Feyerabend, G. and Hill, R. (2015) 'Governance for the conservation of nature', in G. L. Worboys, M. Lockwood, A. Kothari, S. Feary and I. Pulsford (eds) Protected Area Governance and Management, pp. 169-206, ANU Press, Canberra.

\section{TITLE PAGE PHOTO}

Gatherings to discuss issues of relevance for the conservation of nature are common among communities engaged in governing their territories and natural resources, as here in the iconic ICCA of Coron Island, Palawan, the Philippines Source: Grazia Borrini-Feyerabend 


\section{Introduction}

In many cultures, humans perceive themselves as capable of developing cogent decisions about what to do with nature and implementing those decisions through skilful and technology-enriched means. Other cultures see decisions about nature as arising from the spiritual and ancestral beings who are part of nature, and affect us much more than we are able to affect them. Some people perceive nature as benign and sacred, to be treated with reverence and moderation. Others see it as a condition of life, which needs to be dominated and controlled. Still others sense it as an inscrutable phenomenon controlling us from within: attempting to bend nature to the will of people is, for them, just an act of hubris. Whether we believe we are exercising power over nature or feel that nature is controlling us, whether we seek power from nature or simply feel at peace within it, we all live with nature and make sense of that interaction in order to survive and add meaning to our lives.

Broadly understood as the conscious determination of action via the use of various forms of power, governance is a timeless phenomenon that humans experience in their interaction with nature. Today, the phenomenon is reaching extreme proportions and consequences in the Anthropocene era, with humans altering the conditions of the entire planet (Crutzen 2006). The human impact on the planet is the ultimate result of innumerable acts of decision-making that affect nature or, in a more institutional sense, innumerable acts of exercising power, authority and responsibility with direct relevance to nature. Governance has thus to do with policy (stated intentions backed up by authority) and with practice (the direct acts of humans affecting nature). In between, it has to do with the complex web of conditionsunderstanding, communicating, and allocating power and resources-which create matches and mismatches between the two.

Governance for the conservation of nature seeks a balance between the requirements of human and economic development and those of conserving biological diversity. The major international policy expressions of that are the Convention on Biological Diversity (CBD) and the UN Framework Convention on Climate Change. In this chapter, we will make reference to those comprehensive international agreements, but will focus attention at the national and local levels, and on area-based measures in particular. We will approach governance for the conservation of nature from an understanding of its historical and cultural roots, and we will seek to clarify how it can be affected, and possibly improved.

\section{History, power, culture and nature}

Management and governance are closely related but distinct phenomena (Table 7.1). Until the beginning of the new millennium, however, when describing decisions and action meant to conserve nature, only the term 'management' was used. This implied a tendency to focus on the technical rather than the political-that is, policy and power-related-aspects of conservation.

Table 7.1 What is the difference between management and governance?

\begin{tabular}{|l|l|l|}
\hline Management & is about ... & $\begin{array}{l}\text { What is done in pursuit of } \\
\text { given objectives } \\
\text { The means and actions to } \\
\text { achieve such objectives }\end{array}$ \\
\hline Governance & is about ... & $\begin{array}{l}\text { Who decides what the } \\
\text { objectives are, what to do } \\
\text { to pursue them and with } \\
\text { what means } \\
\text { How those decisions are } \\
\text { taken } \\
\text { Who holds power, } \\
\text { authority and responsibility } \\
\text { Who is (or should be) held } \\
\text { accountable }\end{array}$ \\
\hline
\end{tabular}

In reality, the policy and practice of conservation have always been enmeshed with the struggles for 'power over nature' that have unfolded throughout history. Considerations of governance-that is, who holds de facto power, authority and responsibility to take and implement decisions - are crucial for the conservation of nature. But what decisions are we discussing here?

In the distant past, the interaction between people and the environment were more likely shaped by patterns of necessity and adaptation than by 'decisions'. Fishing and shell collection provide a natural way for people to survive in a tropical estuary, as do nomadic pastoralism in dryland plains, transhumant pastoralism in alpine conditions, rice cultivation in regularly flooded areas or a hunter-gatherer lifestyle in tropical forests. Often, these interactions - the 'perceived vocation' of a given environment-allowed livelihoods to be sustained with limited disturbance of the ecosystem functions.

\section{Landscapes, seascapes and their 'units'}

Through time, landscapes and seascapes were identified as 'units', or territories of different people, often on the basis of different perceived vocations and 
patterns of interactions between people and nature. With the increased complexity of societies, expanded communication and trade, enhanced knowledge of the environment and enhanced technology to exploit its riches, both such interactions and units have changed, sometimes dramatically. Thus, we refer today to an area as the 'breadbasket of the country', a communication hub, a national recreation area or an industrial area. The perceived vocation of a given environment is still the result of intrinsic conditions - such as accessibility, climate or the presence of natural resources-but increasingly also of decisions taken by relevant people and authorities. Similarly, the units (a village territory, a country, an administrative region, the property of a given family) are increasingly more politically determined than determined on the basis of the intrinsic properties of the ecosystems.

Previous generations of people on the planet had much less access than many of us to stored information, but an amazing capacity to learn and accumulate observations and experiences, in particular regarding specific places. Through time, acting and receiving feedback from nature consolidated into bodies of local knowledge and skills, varieties of carefully selected seeds and breeds, and allocation of different uses to different units in the landscapes and seascapes, based on deep knowledge and understanding of their potential. Many indigenous peoples and local communities continue to govern and manage their landscapes drawing from these accumulated observations and experiences.

Throughout history, however, humans not only perceived and adapted to their ecosystems, they also affected them in important ways. This began with the use of fire, the movement of seeds by hunter-gatherers and the changes to soil and waters made by agriculturalists (Goudie 1990). In the past few centuries, fossil fuels and powerful technologies have allowed us to affect nature in ways well beyond its capacity to re-establish itself as it originally was (regenerate). We pour cement and build settlements on top of a country's most productive topsoil. We pump aquifers dry and add chemical fertilisers to the land to grow tomatoes and sugar cane on unsuitable terrain. We build homes in the middle of forests that should naturally burn to regenerate- and then invest resources in preventing fires. We understand the ecosystems with the help of sophisticated research, instruments and analyses, but we often choose to transform them in irreversible ways.

Our landscapes and seascapes are cut into administrative units to be governed by politicians (elected or appointed) with the help of technical experts. The decisions about such units have mostly to do with how the landscape or seascape is to be developed and how much importance is given to considerations of sustainability and the conservation of ecological and cultural values. In other words: are the pressures of urbanisation, trade, infrastructure, industry, agriculture, aquaculture, mining, logging or large-scale tourism going to be reined in? Do decision-makers uphold the local ecological and cultural values by declaring that at least a given area is 'protected', that a watershed should not be altered, or that a given species is endangered and must be cared for? The compromises struck by politicians about these questions are at the heart of today's governance of the conservation of nature. And, in many such situations, the fundamental decision is about breaking the landscape or seascape into governance sub-units-some dedicated to development and others to conservation-generally under different governing bodies.

\section{Socioecological coherence of the governance 'units'}

The degree of ecological and social coherence of governance units is a basic issue in governing landscapes and seascapes for conservation. Is the governing body taking decisions over a unit that has ecological sensethat is, forms an ecosystem? Can it take decisions that make economic sense-for example, bring returns on investments? And, is the governing body legitimate? Is it supported by a coherent social body (Case Study 7.1)?

A watershed provides a clear example. Local decisionmaking bodies can find themselves unable to affect the health of a river when they are responsible for only a small part of its course. Because of that, economic investments are less secure (for example, can we be confident that flooding will not damage the harvest) and the willingness to invest in conservation diminishes (for example, why should we invest in watershed protection if the benefits will flow away to other people). Yet, it may be politically difficult to establish a governing body for the river as a whole, as the river basin may not have enough 'social coherence': the upper and lower parts of the watershed may be inhabited by different peoples, and only in smaller units along the watershed might it be possible to find the cohesion, legitimacy, cooperation and compliance needed to have rules agreed to and respected. In addition, as mobility increases, communities tend to become even more diverse and less cohesive.

As noted by Murphree (2000), while ecological and economic considerations suggest large-scale regimes, social topography often suggests small-scale regimes-a tension that exists in virtually all environments and societies. This apparent mismatch can be harmonised by well-functioning nested governance regimes and by 


\section{Case Study 7.1 Decision-making at the ecosystem level}

The Western Ghats mountain range is a major ecological feature of the Indian peninsula. The creation of an ecosystem-scale governance authority for the Western Ghats was recommended by a recent expert analysis that considered the ecological significance of the Ghats for the Indian peninsula (Western Ghats Ecology Expert Panel 2011). The proposed authority would cut across administrative boundaries and have jurisdiction over the whole mountain chain. It would preside over environmental legislation, approve industrial developments and major infrastructure, coordinate land-use planning, and secure the rights of the least powerful communities. Any proposed activity that could have an adverse impact on ecology and society would have to be submitted to this authority for approval, and the authority would consider issues at the ecosystem scale-larger than any individual protected areas within the Ghats. The proposal envisages that the Western Ghats Ecology Authority would exercise powers under the Environment Protection Act. It would focus on environmental issues (for example, protection of upper catchments of rivers, conservation of germplasm of wild relatives of cultivated plants, prevention of groundwater pollution) and arrange field investigations, marshal facts and institute action. The authority would be part of a governing system that involves many levels and actorsstate and non-state-addressing diverse knowledge domains, social relationships and competing interests. At the time of writing, the proposal is strongly challenged and not yet accepted in theory, let alone enforced.

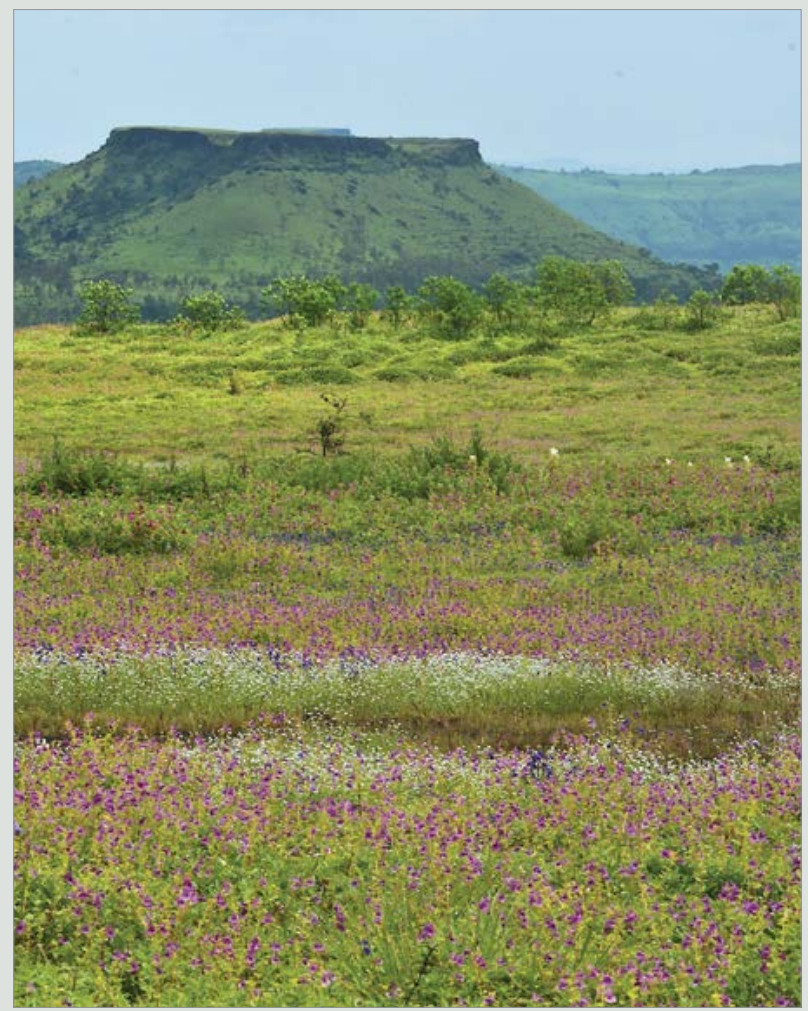

Wildflowers on Kaas Plateau, Western Ghats, India Source: Ashish Kothari strengthening linkages and connections among actors, levels and partners. Governance is only partially an issue of how the landscape and seascape are broken down into units and which authorities preside over them. Governance is also about coherence, the integrity and robustness of social units, and how well they interact, connect and fit with other social units and governing authorities (Case Study 7.2).

Some decisions affecting nature apply non-specifically to the entire landscape or seascape (for example, the prohibition against lighting a fire or killing a species) while others apply specifically to a determined subunit and are referred to as 'area-based measures'. Areabased and non area-based measures interplay under any governance system and their coherence is key for conserving nature.

\section{Area-based measures for conservation and their constituent acts and processes}

An area-based measure applies to a defined area of land, inland and intertidal water and/or sea. It may be ancient or recent, explicit or implicit. It may demand an active management intervention over resources, such as clearing out an invasive species, or just passive interventions, such as barring or limiting access. The area in question may possess, or lack, any visible demarcation on the ground. The area may even be unstable in terms of position or extension, as some ecological units, such as a riverbed, are dynamic and design their own shape through time. Commonly, area-based measures result from a combination of understandings, practices, constraints and pressures at different levels.

For a given natural area (for example, a lake), the constituent act of an area-based measure for conservation originates when a relevant authority establishes a vision for it (for example, maintaining its ecological integrity, so that it can keep providing safe drinking water) and some clear objectives about how the vision can be achieved (for example, maintaining the flow and quality of affluent water, and preventing pollution and the spread of invasive species). A prime example of such a constituent act-which is a key governance act-is a decree to declare the basin of a lake a protected area (see also Case Study 7.3). The decree could be signed by the minister of the environment, establish a management board and assign human and financial resources to the management tasks. Or the decree could be by a council 


\section{Case Study 7.2 Undermining a national symbol?}

The Menabé region is host to Madagascar's national symbol: the spectacular baobabs (Adansonia grandidieri) of the baobab alley of Bamanonga. The surprise is to find their feet in water even in the dry season-a recent condition, bound to break their reproductive cycle and eliminate them from the landscape. Unfortunately, the region went against its 'pastoral vocation'-the livelihood of choice for the people indigenous to this semi-arid environment-when it allowed intensive production of sugar cane under irrigation from deep aquifers. This production became possible because of capital, technologies, crops and people from outside the region. Today, the water overrun from the huge production areas is slowly but surely altering the natural environment. With that, local tourism options may wane and Madagascar may even lose its national symbol. While there is more than a single decision involved here, investing massively in sugarcane production in a dryland environment is clearly going 'against the grain of the land'.

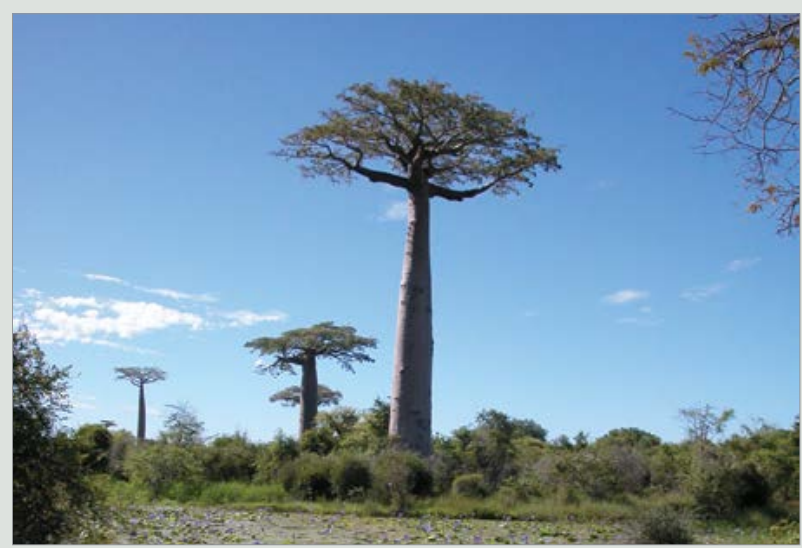

Baobab in Bamanonga, Menabé region, Madagascar

Source: Grazia Borrini-Feyerabend of elders reaffirming and reproducing a traditional pattern of care and respect for the lake and its tributaries, and stringent rules for the sacred island within it; or by a corporation which buys the rights to bottle water from the lake, and demands a basin conservation clause in its concession contract. In some cases, parallel decrees can operate on the same place at the same time-for example, a national park established under the minister for the environment and elders reaffirming a traditional pattern of care and respect. Clarity is always needed about who are the people in charge of implementing the decisions (responsible managers), how the needed resources will be obtained and allocated, which local, national and international rules apply (for example, about sanctions, respect of pre-existing rights, conflictmanagement procedures), and how different groups with different decision-making authorities will interact with one another. It should also be unambiguous which governing body has the authority to review, maintain, strengthen or revoke the constituent act or acts.

Within the area itself, once the vision and objectives are determined, further management decisions are likely to deal with the demarcation of the area and the rules and procedures of access to natural resources, possibly via a management plan with or without a zoning system establishing diverse rules for different zones. Such decisions are important and they should be made with the engagement of local actors who know and care about the issues at stake. Debates may cover where and when to establish a no-take zone, how much should be spent to eradicate an invasive species or whether use regulations should be relaxed in a time of social stress. Decisions at this level, which affect local livelihoods, development and the local sharing of the benefits and costs of the area-based measure, are best taken in a learning-by-doing mode.

The key actors who participate in the constituent act(s) are fundamental for the existence and functioning of a given area-based measure. Through such act(s), these actors take upon themselves the governance authority, responsibility and accountability for that area or territory. An area-based measure draws much of its effectiveness and strength from the coherence between its constituent act(s) and destinations and those prevalent in the surrounding landscape or seascape. The area may thus be explicitly dedicated to industrial development, protection of biodiversity or as migration territory of an indigenous people, but other and possibly competing destinations may interact or coexist with that, with outcomes determined by the interactions among diverse forces and values. In other words, the act of governance that establishes an area-based measure is always nested within other governance decisions and levels, and crucial conditions that include political feasibility, available human and financial resources and dominant perceptions and values. Moreover, any constituent act is rooted in a particular moment in time, and measures are bound to evolve in response to changes in context and needs.

A constituent act, such as signing a decree or buying a piece of land, is often crucial, but decisions that are effectively implemented and have a strong and lasting impact are complex processes that arise and evolve over both space and time. Thus, while it is true that single decisions taken at the appropriate moment can make a fundamental difference for people and nature, governance systems also need to learn, change and evolve-in one word, have a measure of 'vitality'. 


\section{Case Study 7.3 Meares Island: indigenous resistance as a 'constituent act'}

The Tla-o-qui-aht Tribal Parks of British Columbia, Canada, are based on a long history of relationships between the people and the watersheds, coastal areas and islands in their ancient territory, in what is now Vancouver Island in British Columbia. Part of the Tla-o-qui-aht traditional territory, Meares Island was declared a Tribal Park in 1984 by a pronouncement of the Hawiih hereditary chiefs. Basically, the chiefs set up a peaceful blockade to impede a forestry corporation from logging their island's ancient trees. A legal action ensued and the court granted an injunction to stop logging, as the hereditary chiefs still held an unresolved claim about their traditional territory there. In 2007, the Tla-o-qui-aht First Nations took several more steps to formalise Meares Island and several adjacent watersheds as Tribal Parks, which are now recognised by the Pacific Rim National Park Reserve, various municipalities and ministries.

- Eli Enns

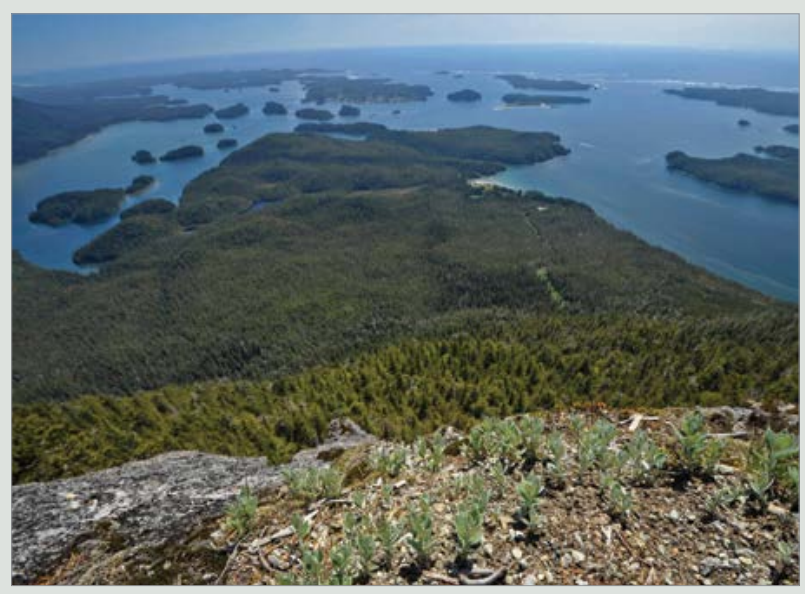

Meares Island, British Columbia, Canada

Source: Eli Enns Tla-o-qui-aht Tribal Parks
Because of this, governance analysis should deal with who makes decisions and how, but also with how actors and decisions connect and relate with other actors and decisions in society, and how they learn and evolve through time, shaping the ecological and social history of the concerned territory or area.

While governance for the conservation of nature is a political phenomenon, it is also, and always, a cultural expression, reflecting the concepts, values and world views of diverse societies. Deciding about a territoryor motherland, home or country, as expressed in different cultures — engages issues of livelihood, identity, autonomy and freedom. The territory is a connecting tie among generations, preserving memories from the past and connecting those to the desired future. It is the ground on which communities learn, identify values and develop material and spiritual wealth. For many, territory is also a connection between visible and invisible realities, and the source of dignity, self-rules and self-determination as peoples.

\section{Protected and conserved areas}

While historical and cultural analyses can ground the understanding of governance, many readers of this volume are likely to face governance-first and foremost - as a large body of national executive policies and regulations, embedded in lobbying pressures, unresolved conflicts, a likely scarcity of resources and a variety of all-too-human relationships.

Within a country's legal system, a hierarchy of legal instruments and operational tools is typically in place to regulate conservation. A principal legislative element (an act or law) usually provides the key requirements, and various codes, decrees, policies, norms, rules and subsidiary orders add the implementation details. When more than one body of law exists (for example, statutory and customary law), their relationship can be clearly articulated, difficult to discern or a mixture of both. In general, important legal instruments relate to area-based measures and a number of organisations are involved, ranging from national ministries and agencies to advisory committees, scientific committees and formal and informal local implementation bodies.

The national legislation and policy that deal with protected areas usually specify — implicitly or explicitlythe governance types that can be formally recognised. Voluntary conservation practices may be recognised, promoted and regulated (Lausche and Burhenne 2011). The provision of incentives and disincentives is an important tool to encourage such practices, which are fundamental for connectivity, biodiversity restoration and the maintenance of ecological processes outside protected areas (Lausche et al. 2013).

\section{Protected areas}

The national legal and policy contexts of governing protected areas are embedded in international legal frameworks: conventions, plans of work, declarations, pronouncements and widely accepted best practices that link them to an evolving body of learning and work that is a hopeful and exciting feature of modern societies. The broad definition of a protected area adopted by the International Union for Conservation of Nature (IUCN) (Dudley 2008:9) is foundational to our knowledge of governance for nature conservation: 'a clearly defined geographical space, recognised, dedicated and managed, 
through legal or other effective means, to achieve the long-term conservation of nature with associated ecosystem services and cultural values.' The definition is accompanied by, among others, this main principle: 'Only those areas where the main objective is conserving nature can be considered protected areas ... in case of conflict, nature conservation will be the priority' (Dudley 2008:10). These are instructive starting points to begin our discussion of what governance means, in practice, with regard to protected areas.
The questions in Table 7.2 can be used to deconstruct the definition of protected area and explore the details of formal designation and authority to reveal how the decisions that affect conservation are influenced by history and culture and by the interplay among formal, customary and context-specific institutions. Governance is not only about who holds authority de jure, but also about who makes decisions de facto, and about how these decisions are made. It is useful to enter into some detail, referring to the key issues introduced by the IUCN definition.

Table 7.2 Understanding governance in the IUCN definition of protected areas

\begin{tabular}{|c|c|}
\hline Terms & Governance issues \\
\hline $\begin{array}{l}\text { Clearly defined } \\
\text { geographical space }\end{array}$ & $\begin{array}{l}\text { Who defines the geographical space that is to be 'protected'? } \\
\text { Who traces and demarcates the borders? } \\
\text { Who can modify that, and how? }\end{array}$ \\
\hline Dedicated & $\begin{array}{l}\text { Who 'dedicates' the land and resources to conservation? How? } \\
\text { Through legal means? Through customary laws and rules? } \\
\text { Is the decision imposed by law? Is it voluntary? } \\
\text { Who will solve controversies among conflicting objectives and priorities? }\end{array}$ \\
\hline Recognised & $\begin{array}{l}\text { How is the protected area recognised? By whom? } \\
\text { Consider informal and formal recognition modalities and different levels of recognition, including } \\
\text { - by local peoples and communities } \\
\text { - by society in general } \\
\text { - by local customary and/or legal authorities } \\
\text { - by national authorities } \\
\text { - by multi-country governmental bodies }\end{array}$ \\
\hline Managed & $\begin{array}{l}\text { Who develops and approves the natural resource rules or the management plan, where it exists? } \\
\text { Who appoints the managers in charge of implementing the rules and/or plan? } \\
\text { What is the managers' scope of decisions in interpreting the rules and/or plan? }\end{array}$ \\
\hline $\begin{array}{l}\text { Legal or other } \\
\text { effective means }\end{array}$ & $\begin{array}{l}\text { Are the authority, responsibility and accountability concerning the area codified in legislation? } \\
\text { Are they regulated by specific agreements or customary processes, institutions and means? } \\
\text { How are rules formed and enforced? }\end{array}$ \\
\hline To achieve & $\begin{array}{l}\text { Who decides how to implement the management plan or rules? } \\
\text { Who decides what is 'effective'? } \\
\text { Who defines the indicators? Who is in charge of monitoring and evaluating the results? } \\
\text { Who decides about eventual needed changes in the management plan or practices? }\end{array}$ \\
\hline Long-term & $\begin{array}{l}\text { Who developed the vision of what the protected area should be like 'in the long term'? } \\
\text { What does 'long term' actually mean? } \\
\text { What guarantees are in place that the protected area will actually exist in the long term? } \\
\text { Who will be accountable for this? }\end{array}$ \\
\hline Conservation & Who decides what should be conserved and how? Who defines the conservation priorities? \\
\hline Nature & $\begin{array}{l}\text { Whose definition of 'nature' is applied? } \\
\text { Who interprets the definition for application to specific policies, mandates or sites? }\end{array}$ \\
\hline $\begin{array}{l}\text { Associated } \\
\text { ecosystem services }\end{array}$ & $\begin{array}{l}\text { Who benefits from ecosystem services? } \\
\text { Who carries the burden of maintaining them, including the related opportunity costs? }\end{array}$ \\
\hline Cultural values & $\begin{array}{l}\text { Whose culture? } \\
\text { Who benefits from the conserved 'cultural values'? } \\
\text { How are decisions taken to conserve or promote certain cultural values instead of others? }\end{array}$ \\
\hline
\end{tabular}




\section{Case Study 7.4 The Mapuche-Pewenche: people of the Araucaria tree}

In an ancient ceremony (ngillatun), the indigenous peoples of southern Chile ask the spirits to support the reproduction of the pewen tree (Araucaria araucana), which plays a central role in their social, economic and spiritual lives. These people are so connected to the pewen that they call themselves Mapuche-Pewenche ('the people of the Araucaria tree'). In this case, when the people feel as one with the land and the trees, dedicating the territory to conservation may be an understatement for a phenomenon rooted in the people's identity and in centuries of experience. And yet, these same people may not state that conservation is the primary objective of their relationship with nature.

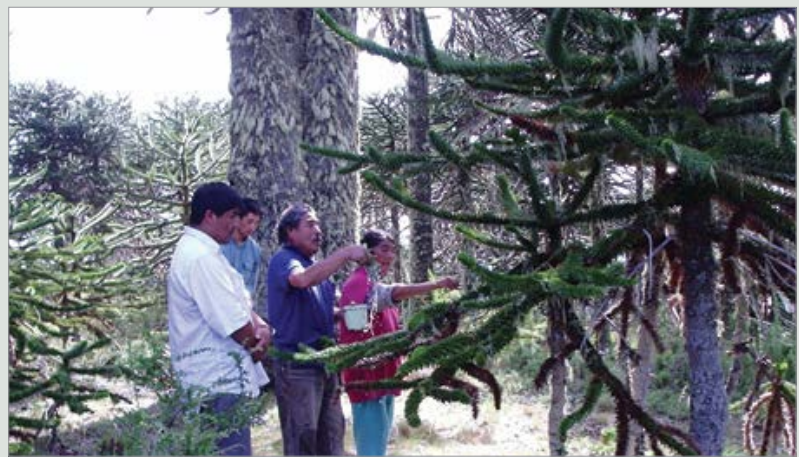

Mapuche-Pewenche people with araucaria trees, southern Chile

Source: @ Associación Mapuche-Pewenche Markan Kura

\section{Conservation}

The World Conservation Strategy (UNEP et al. 1980:1) stipulates that conservation includes the 'preservation, maintenance, sustainable utilization, restoration, and enhancement of the natural environment'. Preservation or protection is a conscious effort to avoid or limit damage to nature's capacity to self-regenerate. Sustainable use strives for the maintenance of renewable resources while making use of them for the benefit of present and future generations. And restoration and enhancement attempt the recovery of degraded ecosystems into healthier and more sustainable conditions-for instance, via reafforestation with locally native species or improvement of habitats for greater resilience or authenticity. For any specific site, conservation generally means a combination of activities to protect, use sustainably and restore nature in different proportions according to the situation, and the perceptions and aims of its governing body. Relative priorities among such activities are a matter of debate, and the way that debate is conducted and solved characterises the quality of a governance regime.

\section{Dedication}

The IUCN definition stresses 'dedication' as a requirement: conservation of nature must be a conscious objective, and in fact the primary objective of any protected area, as it must prevail in case of conflict with other, equally legitimate objectives. This requirement for protected areas leaves out those areas that might be conserved effectively but incidentally or as a secondary consideration: an area restricted for national security, a landscape managed to attract tourists, a forest preserved as a sacred resting ground of the ancestors and a place of rituals. At some point, some such effective area-based measures may become explicitly or primarily dedicated to conservation and thus could be seen as protected areas under the IUCN definition. But others will not, and it is still important that their contributions - if they have a reasonable expectation to last through time-are properly recognised and supported (Case Study 7.4). The term 'voluntary conservation' captures the idea that conservation may be a desired result of governance as a primary objective but also as a secondary, implicit or not fully conscious objective. In other cases, when conservation is a fully unintended consequence of managing nature, the term 'ancillary conservation' is more appropriate.

\section{Recognition}

Protected area recognition happens at several levelsnotably, internationally, nationally and locally. The IUCN definition and the related IUCN management categories and governance types provide an international language and reference points for recognition and comparison. Article 2 of the CBD states that a protected area is 'a geographically defined area which is designated or regulated and managed to achieve specific conservation objectives' (CBD 1992:4). The IUCN definition, which is not identical to the CBD definition but is considered to be fully compatible (Dudley 2008), specifies that recognition can happen by legal or other effective means. Importantly, this implies that an area-based measure that is informally but effectively recognised-for instance, by custom or by the will of a landowner-may be 'internationally recognised' as a protected area even when it does not qualify and is not recognised and listed as a protected area in its relevant country. At the country level, on the other hand, national legislation and policy are usually the only accepted means of recognition. In addition, a large variety of protected area definitions, means and rules exists for any given country, and only some of them are fully compatible with the IUCN and CBD definitions. Thus, an area-based measure that a 
given country recognises and lists as a protected area may not be internationally recognised as such. These layers of complexity are illustrated in Table 7.3 in conjunction with the concept of 'conserved area'.

\section{Conserved areas}

As seen above, area-based measures within a broader landscape or seascape are defined by the IUCN as protected areas only when they are recognised and dedicated to achieving long-term conservation. At the local level, however, we need to come to terms with another consideration, which is de facto conservation.

What can we observe at the level of the specific land, water and natural resource? Is conservation happening? Is it possible to perceive a positive conservation trend? Is that trend likely to be maintained in the long term? We use here the term 'conserved area' to describe areabased measures that, regardless of recognition and dedication, and at times even regardless of explicit and conscious management practices, achieve de facto conservation and/or are in a positive conservation trend and likely to maintain it in the long term. According to this definition, conserved areas have a major overlap with protected areas (as defined by the IUCN but also by national governments throughout the world) - but they do not coincide. For instance, some area-based measures that are nationally defined as protected areas do not manage to conserve nature (they are protected areas but not conserved areas, and some use the derogatory term 'paper parks' to describe them) and others are conserved areas but not protected areas (they do not fit the IUCN definition, or they do not fit the definition of the relevant country, or both) or, even if they fit such definitions, the concerned peoples simply do not wish them to be recognised as protected areas.

Noticeably, conserved areas that are not protected areas according to a specific country (not recognised there by legislation or policy) may be locally recognised by customary law (that is, by indigenous peoples and local communities) or by the will of their landowners. Examples of areas where biodiversity may be thriving regardless of national legal or policy recognition and dedication include commercial hunting operations designed to be sustainable, well-managed farming systems and watersheds, restored community mangroves and military no-go areas. Among such practices, those described above as voluntary conservation may fit the IUCN definition of protected areas. Others-in particular, ancillary conservation or benign neglectclearly do not. With this in mind, we can roughly picture the situation, as in Figure 7.1, where conserved areas cover a broader proportion of land, water and sea than protected areas (according to both international and national definitions). The figure also shows the extensive but not complete overlap between the two.

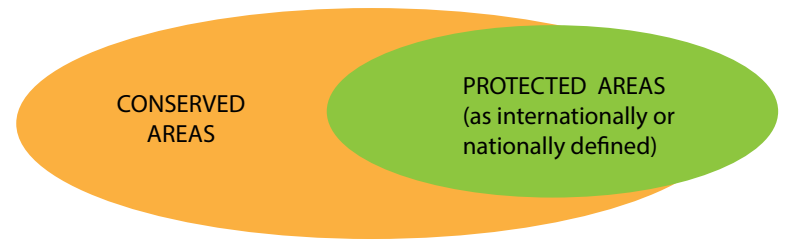

Figure 7.1 Incomplete overlap between conserved and protected areas

\section{'Other effective area-based conservation measures' and CBD Aichi Target 11}

The concept of conserved areas or de facto conservation has become even more important since the parties to the $\mathrm{CBD}$ have used the term 'other area-based effective conservation measures' (OECMs). The CBD Strategic Plan for Biodiversity 2011-2020 (CBD 2011) set 20 targets to be met by all 193 country parties by 2020 . Target 11 addresses area-based conservation and stipulates that 17 per cent of terrestrial and inland water areas and 10 per cent of coastal and marine areas will be conserved by 2020 via systems of 'protected areas and other effective area-based conservation measures' (CBD 2011:3).

While the term 'other' indicates that these measures are not protected areas (for the IUCN and/or for the country at stake), the terms 'effective' and 'area-based' remind us of the conserved areas defined above. In the simplest and most direct interpretation, an OECM would thus be a clearly defined geographical space where de facto conservation of nature and associated ecosystem services and cultural values is achieved and expected to be maintained in the long-term regardless of specific recognition and dedication'. In this sense, OECMs would include first and foremost areas well conserved and reasonably expected to remain so in the long term that are not recognised, nationally or internationally, as protected areas (Table 7.3). With respect to the IUCN definition, in particular, they would comprise areabased measures of secondary voluntary conservation and ancillary conservation with a reasonable expectation to be maintained in the long term. 
Table 7.3 Possible combinations of national and international recognition of conserved areas (de facto conservation)

\begin{tabular}{|l|l|l|}
\hline $\begin{array}{l}\text { Conserved areas (areas conserved de } \\
\text { facto, with a reasonable expectation } \\
\text { that conservation will be maintained in } \\
\text { the long term) }\end{array}$ & $\begin{array}{l}\text { Recognised as a protected area under } \\
\text { international definition (IUCN/CBD) }\end{array}$ & $\begin{array}{l}\text { Not recognised as a protected area } \\
\text { under international definition } \\
\text { (IUCN/CBD) }\end{array}$ \\
\hline $\begin{array}{l}\text { Recognised as a protected area by } \\
\text { national legislation and/or policy }\end{array}$ & $\begin{array}{l}\text { The area is a protected area in the } \\
\text { country at stake and internationally }\end{array}$ & $\begin{array}{l}\text { The area is a protected area in } \\
\text { the country at stake, although not } \\
\text { internationally, where it could be } \\
\text { considered an effective area-based } \\
\text { conservation measure }\end{array}$ \\
\hline $\begin{array}{l}\text { Not recognised as a protected area by } \\
\text { national legislation and/or policy }\end{array}$ & $\begin{array}{l}\text { The area is a protected area } \\
\text { internationally, although not in the } \\
\text { country at stake, where it should be } \\
\text { considered an effective area-based } \\
\text { conservation measure }\end{array}$ & $\begin{array}{l}\text { The area is not a protected area; it } \\
\text { could be considered an effective area- } \\
\text { based conservation measure }\end{array}$ \\
\hline
\end{tabular}

For a country reviewing its system of protected areas to report to the CBD about progress towards Aichi Target 11 , it would be important to proceed through an analysis of specific cases, their contexts, history and progress, and approach with an open mind the governance arrangements that are not recognised as protected areas but actually result in the conservation of nature. These rules of thumbs can be proposed:

- those arrangements that meet the IUCN's definition of a protected area but are not recognised as part of the national system should be counted as OECMs (and discussion could be initiated to see whether the protected area label is possible, appropriate and desirable)

- for those arrangements that do not meet the IUCN's definition of a protected area, discussions should be initiated to ascertain whether they can ensure conservation in the long term, and whether they wish to be included in national reporting as OECMs; if they provide the assurances and are willing, they should be counted as such; if they are unable or unwilling to do so they should not be counted.

The crucial consideration here is that the contributions to conservation made by governance arrangements that some may consider unusual should not be ignored and potentially damaged, but rather recognised and secured. And, in case a country lists a set of OECMs for Aichi Target 11, what moral and legal obligations (under the CBD) does it assume to support, secure, strengthen, respect or defend them? This should be clarified before a country is allowed to 'count' such OECMs towards Aichi Target 11.

\section{Governing protected and conserved areas}

Conserved areas that are not recognised as formal protected areas generally enjoy lower levels of legal protection and support from governmental programs and face greater threats than protected areas, being more vulnerable to appropriation for alternative uses. For some, conserved areas appear as unmanaged and underexploited lands-ideal places to develop extractive industries, large-scale monocultures or major infrastructure. Even less obvious than for terrestrial environments, coastal and marine areas conserved by customary governance may appear unmanaged and invite unsustainable exploitation by outsiders. How can conserved areas be better recognised and respected? Can 'governance' help? Indeed it can, and to understand how we now retrace how governance of protected areas was defined and introduced in the conservation arena at the beginning of the new millennium.

In 2003, the Canadian Institute on Governance offered a definition of governance of protected areas as 'the interactions among structures, processes and traditions that determine how power and responsibilities are exercised, how decisions are taken and how citizens and other stakeholders have their say' (Graham et al. 2003:2). This definition is elegant, but provides few parameters and indicators to assess and evaluate the phenomenon, which are clearly useful to have.

A practical point of departure for considering governance are the key actors, governmental and nongovernmental, engaged in decision-making. The crucial actors are those endowed with a national mandate (for example, an agency in charge on the basis of a ministerial decree), possessing legal rights (for example, property, lease, concession) or possessing customary 


\section{Box 7.1 Rights-holders and stakeholders}

In the context of protected and conserved areas, we refer to 'rights-holders' as actors socially endowed with legal or customary rights with respect to land, water and natural resources.

'Stakeholders' possess direct or indirect interests and concerns about those, but do not necessarily enjoy a legally or socially recognised entitlement to them.

\section{Box 7.2 Instruments and powers}

Key actors use diverse instruments and powers to exercise authority and responsibility for protected and conserved areas. For formal protected areas, the crucial instruments are national laws, plans and agreements, often backed by international agreements and conventions, best-practice standards and financial support from national ministries and possibly also international agencies. Financial incentives and disincentives may be at play, as well as long-term initiatives, including education, research and training programs, technical advice, staff and rangers deployed in the field and compliance processes. Formal protected areas are often demarcated and under surveillance and possess a management plan, dedicated staff, a budget, a functioning geographic information system and a monitoring and evaluation protocol. In conserved areas, on the other hand, customary laws and social norms are more often at play, but also financial mechanisms and powers when non-governmental organisations (NGOs), individuals, communities and corporations buy territories and resources in order to conserve them, or when they actually conserve them in order to gain their livelihoods, economic benefits or visibility in a given sector. Physical barriers and active surveillance are also used, but also interiorised rules, through spiritual and cultural convictions or social pressure to conform. Both protected and conserved areas are usually governed by a combination of diverse instruments and powers, strategically applied at various levels by different actors and agencies.

rights (for example, traditional use, age-old association, continuous residence) with respect to land, water and natural resources. Other actors also possess legitimate interests and concerns (for example, they wish to set up a tourism enterprise or they are engaged in scientific research) and may be willing to invest substantially in caring for nature. In this chapter, we broadly refer to them as 'rights-holders' and 'stakeholders' respectively (Box 7.1).
A finer classification further distinguishes among the various types of instruments and powers-for example, regulatory, financial, related to knowledge or related to coercion (Box 7.2) - that the key actors apply when they take and implement decisions. And a further important consideration is the scale of decision-making and operations (for example local, at ecosystem level, national, trans-boundary, international).

For simplicity, the IUCN first chose to make sense of the governance concept as related to protected areas by focusing on two main parameters: governance diversity and governance quality. Currently, it is exploring a third: governance vitality, which we will describe later. While the first two parameters were initially defined and discussed in relation to protected areas only, we broaden the framing here to consider all three parameters in relation to both protected and conserved areas.

Furthermore, for the governance diversity of protected areas, the IUCN distinguishes only on the basis of key actors engaged in the primary or main constituent act(s). This decision has been criticised in the specialised literature (Eagles 2009; Paterson 2010, 2011) as unable to fully represent a much more complex reality. While the criticism has merit, a more complex and numerous set of governance types would render the classification more cumbersome, and it is not clear whether it would add much to the comprehension of the phenomenon.

\section{Governance diversity}

The IUCN characterises the diversity of governance for protected areas according to the key actors holding authority and responsibility for the main decisions affecting it. As many decisions are involved, however, which ones are the most important? For instance, is 'formally establishing the protected area' on the same level of importance as 'approving a zoning plan'? As a rule of thumb, we refer to the actors responsible for the constituent act(s) for the protected or conserved area, and/ or to the best answer to the question: who could decide, today, to undo the protection or conservation regime (that is, de-gazette or delegitimise the practices leading to conservation) for the area at stake? The answer would orient us towards one of four main governance types:

1. governance by government (at various levels)

2. governance by various rights-holders and stakeholders together (shared governance)

3. governance by private individuals and organisations

4. governance by indigenous peoples and/or local communities. 
Together with management category, governance type is a key characteristic of protected areas, as graphically represented in the IUCN Protected Area Matrix (Box 7.5) as modified by Borrini-Feyerabend et al. (2013) from Dudley (2008). Noticeably, questions of legal and customary tenure (who holds the legal or customary rights over land and resources) are important in determining governance type, but they are not the sole determinant. On the contrary, a mix of tenure regimes can be present under all governance types, also through a variety of instruments such as formal delegation, leasing and agreements. As stated by the IUCN Guidelines for Protected Area Legislation: 'Tenure is a separate consideration from governance (although) important when considering the appropriate governance approaches for a particular site' (Lausche and Burhenne 2011:126).

\section{Type A. Governance by government}

In this type, one or more government bodies (such as a ministry or protected area agency reporting directly to the government, or a sub-national or municipal body) hold the authority, responsibility and accountability for managing a protected area, determining its conservation objectives (such as the ones that distinguish the IUCN categories) and developing and enforcing its management plan. The State or federal government often owns the land, water and natural resources, but not always, as the protected area can include lands, waters and resources legally owned or customarily controlled by private individuals or companies, local communities or indigenous peoples, or under multiple rights regimes. Governments can also be responsible for conserved areas, such as military reserves, where de facto conservation is ancillary.

Reflecting the trend towards administrative decentralisation, sub-national and municipal governments have become prominent in declaring and managing protected areas. In some cases, the relevant government retains overall control and takes all major decisions, but delegates the planning and/or daily management of the protected area to other actors, such as an NGO, private operator or community (Case Study 7.5). Under a national legal framework and governance system, there may or may not be a legal obligation to inform or consult local rights-holders and stakeholders prior to establishing the protected area and/or making or enforcing management decisions. Public accountability measures also vary from country to country.

\section{Type B. Shared governance}

Shared governance is based on institutional mechanisms and processes by which authority and responsibility are shared among two or more actors. This model is widely adopted for protected areas, and many countries have adopted specific laws, policies and administrative arrangements for it. In the case of conserved areas, customary institutions have devised specific models and processes all over the world. Different nuances or subtypes of shared governance may be identified (BorriniFeyerabend et al. 2004). In 'collaborative governance', formal decision-making authority, responsibility and accountability rest with one agency (for example, a national governmental agency), but the agency is required, by law or policy, to collaborate with other stakeholders. In a weak connotation, such collaboration may mean just informing and consulting other parties. In a strong connotation, it may mean that a multi-party body develops and approves the technical proposals to be later decided upon. In 'joint governance', decisionmaking authority, responsibility and accountability are shared in a formal way, with various actors entitled to one or more seats on a governing body. This can also be stipulated in an agreement that sets out how different authorities interact with one another. Because various actors need to be involved, some form of shared governance is particularly suited for trans-boundary conservation (Sandwith et al. 2001; see also Box 7.3).

Shared governance responds to the variety of interlocked entitlements accepted in democratic societies, whereby different actors recognise one another's legitimacy and capacity to represent their constituencies (Case Study 7.6). The representatives are usually trusted experts, opinion leaders, line managers or elected politicians. It may be specified that the decision-making process has to be fully transparent, in which case debates have to be open to public scrutiny, and accountability is likely to improve. As a drawback, open debates tend to polarise positions and favour populism. Crucial to the functioning of this governance type are the decision-making modalities.

\section{Type C. Governance by private actors}

Private governance has a relatively long history, as monarchs and aristocracies throughout the world preserved for themselves areas of land or the privilege to hunt wildlife. Such private reserves had important secondary conservation benefits. Today, private ownership is still an enormously powerful force in conservation. For instance, many conservation NGOs buy, lease or manage land specifically for conservation, or receive it for that purpose from individual philanthropists. Individual landowners pursue conservation objectives because of their sense of respect for the land or their desire to maintain its beauty and ecological value. And corporate bodies become involved through social responsibility policies or biodiversity offset initiatives. Utilitarian purposes, such as gaining revenue from ecotourism or reducing levies 


\section{Case Study 7.5 Delegated management of government-governed protected areas: Retezat National Park}

Romania has adopted the delegated approach for all its protected areas, with the Ministry of Environment establishing management contracts for each of them with the National Forestry Administration, various NGOs, universities, county councils and even private individuals. The delegation does not come with resources, nor are there proper coordination and monitoring, so this approach is less effective than it could otherwise be. For Retezat National Park, management is delegated to the National Forest Administration, but this park also pioneered the establishment of consultative councils-that is, platforms of key stakeholders to coordinate and discuss all important management decisions.

Source: Stanciu and Ioniță (2013)

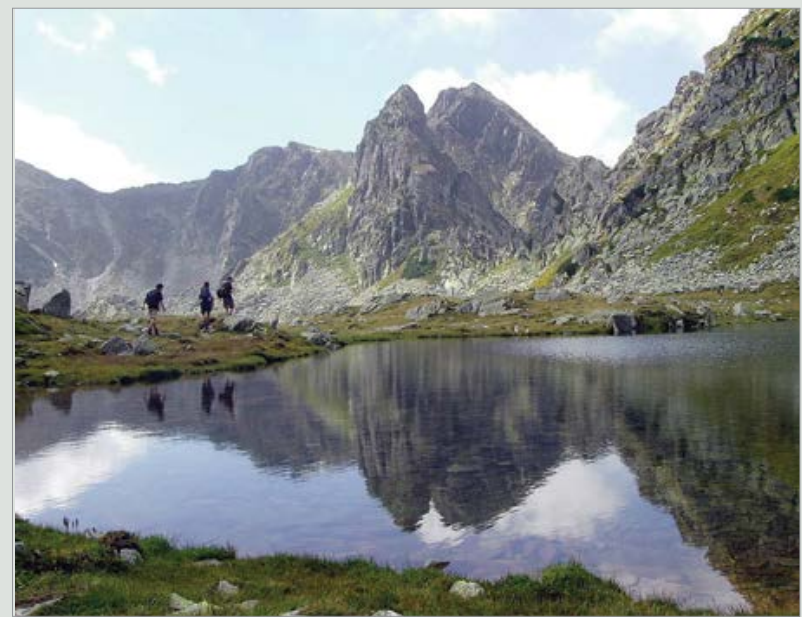

Retezat National Park, Romania

Source: Andreas Beckmann

\section{Box 7.3 Trans-boundary conservation governance}

Trans-boundary conservation offers opportunities to promote the conservation of nature, ecosystem services and cultural values while promoting peace and cooperation among nations. Trans-boundary conservation areas (TBCAs) are highly diverse and their governance is usually complex, ranging from formal arrangements between governments to informal, grassroot initiatives in civil society. The parties may include governmental agencies, private landowners, NGOs, indigenous peoples and local communities. Governance is always 'shared', but it can involve different levels of cooperation, from minimal to formal state decisions. Informal approaches are often effective as they take advantage of local knowledge, and have local legitimacy and easier implementation.

Many challenges can stand in the way of effective trans-boundary governance. Political indifference is the most common, resulting in inadequate or unreliable government commitment. Further challenges include the absence of adequate financial resources; poor compatibility among the legislation and policy systems

and taxes, can be additional incentives or even the main ultimate aim. In all cases, under private governance, the authority for managing the land and natural resources rests with the landowners, who determine the conservation objectives and the rules to be respected.

A privately conserved area refers to a land parcel owned by individuals, corporations or NGOs and conserved $d e$ facto. When the land and resources are also dedicated to conservation and recognised as such-for instance, by in the involved countries; lack of clarity regarding interagency authority and responsibility; inadequate capacities of partners; language barriers; cultural differences that cause misunderstandings; and political tensions between countries.

There is no single model for trans-boundary conservation governance-each arrangement must be designed and administered to meet the unique needs and interests of the particular region. Settings are usually dynamic, evolving on the basis of negotiation and adaptability. The most effective governance arrangements are genuinely collaborative, nested at various levels, and adaptive. Without collaboration in governance and management, there is no active and functional TBCA. And without ongoing processes of monitoring and evaluation, there is no adaptive management. Appropriate governance must fit the context and may include formal or informal arrangements, networks, partnerships or dedicated institutions (IUCN WCPA 2013).

- Adapted from Maja Vasilijevic

(Personal communication, 2014)

a national government or by an international agencyone can speak about privately protected areas under the IUCN definition. In privately conserved areas, conservation visibility may be poor and accountability to the larger society limited. Formal recognition of the value of the estate for conservation may, however, be agreed with national governments under a variety of national legislative or policy procedures. In such cases, visibility and accountability can be negotiated as part of national recognition of 'privately protected areas' 


\section{Case Study 7.6 Crafting complex decisions for the Galápagos Marine Reserve}

A five-member Participatory Management Board (PMB) was agreed for Galápagos Marine Reserve by a special law passed by the Government of Ecuador in 1998. The board was not designed to have decision-making power but the technical proposals that reached a consensus in the PMB carried an important social weight at the higher ministerial authority level, where the proposals were to be approved and were basically always approved without modification. Interestingly, a participatory board enabled difficult agreements to be negotiated and concluded about issues that seemed impossible to resolve in one-toone discussions with individual parties, such as no-take zones extending to 30 per cent of coastal areas in the archipelago, and fishing calendars.

Source: Bravo and Heylings (2002)

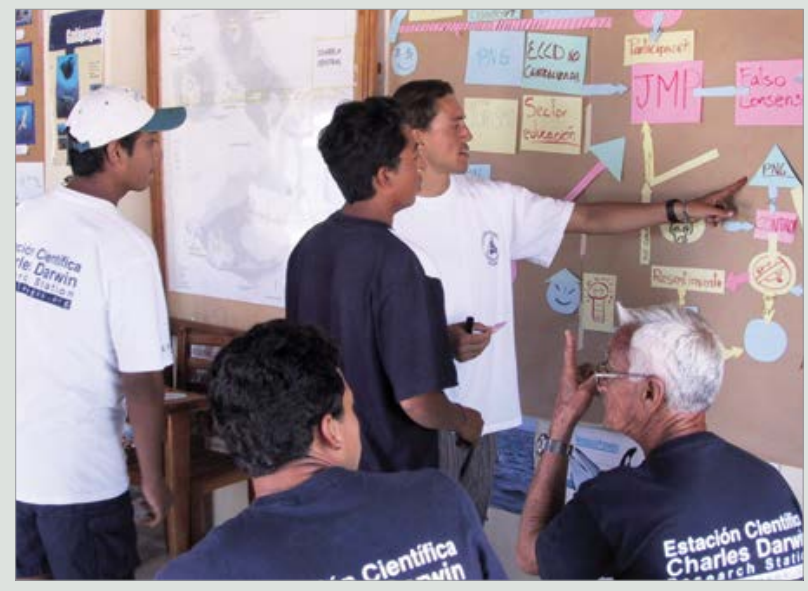

Decision-making at Galápagos Marine Reserve, Ecuador

Source: Grazia Borrini-Feyerabend or other forms of conservation covenant (Mitchell and Brown 1998). These agreements may restrict the freedom of landowners, who voluntarily accept certain obligations in exchange for specific forms of social and/ or economic acknowledgment. In rare cases, a private protected area is established by involuntary surrender of management rights because of imposed legal restrictions (Dudley 2008). Figure 7.2 graphically represents privately conserved areas as a subset of all conserved areas and with an overlap but not overall coincidence with protected areas (as recognised by the IUCN and nationally). Not depicted, but possible, is the case of privately protected areas that do not conserve nature de facto, and thus do not fit within 'conserved areas'.

A growing interest in landscape-scale conservation has encouraged groups of neighbouring private landholders to form collaborative conservancies that manage large conservation units together (Case Study 7.7). While individual ownership is retained, the private landholdings are effectively managed as a single entity, with the landowners mutually accountable to one another and helping to enforce common conservation objectives and management plans. Privately conserved or protected areas can also address accountability by forming alliances and associations whose members need to adhere to some best-practice guidelines. Such associations receive important forms of recognition as they get involved in a variety of programs, from education to monitoring and surveillance.

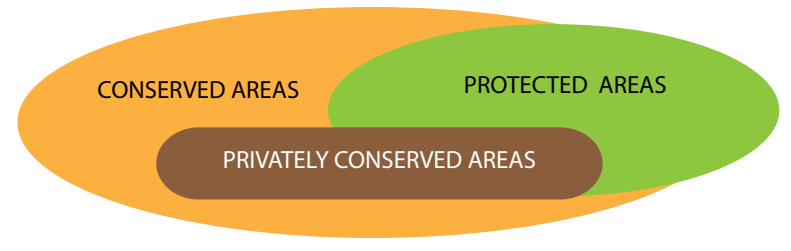

Figure 7.2 Incomplete overlaps among conserved areas, protected areas and privately conserved areas

\section{Type D. Governance by indigenous peoples and local communities}

Governance by indigenous peoples and local communities (Box 7.4) is the oldest form of governance of land and natural resources and is still widespread, applying to all forms of 'commons' - that is, land, water and natural resources governed and managed collectively by a community of people, settled or mobile. Throughout the world and over thousands of years, human communities have been developing their livelihood strategies, responding to the opportunities and challenges of their environments. Often, this meant fitting the local ecological conditions - that is, trying to use, manage, conserve and enrich nature-rather than altering such conditions in substantial ways. Many human cultures were actually created around that 'fitting' process, generating precious biocultural diversity (Posey 1999). Although intentional conservation of biodiversity was unlikely to be at play, by pursuing other objectives (for example, survival, security, spirituality, beauty), they did achieve the conservation of ecosystems, species and ecosystem-related values. 


\section{Case Study 7.7 Zululand Rhino Reserve}

Zululand Rhino Reserve was established in 2004 as a partnership among 17 landowners who removed the fences on their land to create a reserve for endangered species. Located in northern Zululand in the Province of KwaZulu-Natal, South Africa, the area includes open savannah thornveld, bushveld and riverine woodland. The reserve has more than 70 mammal species and an exceptional diversity of birdlife. The World Wide Fund for Nature (WWF) Black Rhino Range Expansion Project was the conduit for the formation of the reserve, which was chosen as a release site for rhinos from other protected areas in South Africa. The reserve has put substantial resources into the monitoring and protection of rhinos, and this new population is reproducing well. In April 2009, the reserve was proclaimed a Nature Reserve under the Protected Areas Act 57 of 2003, meaning it now officially contributes to provincial protected area targets.

- Sue Stolton

\section{Box 7.4 What are 'local communities' and 'indigenous peoples'?}

A local community is a human group sharing a territory and involved in different but related aspects of livelihoods-such as managing natural resources held as 'commons', developing productive technologies and practices, and producing knowledge and culture. We speak of a local community when its members are likely to have face-to-face encounters and/or mutual influences in their daily life-whether they are permanently settled or mobile. A community's sense of identity and cultural characteristics are often shared, although multiple ethnic groups can be found in the same community. A local community can only be self-identified.

While most people have an intuitive understanding of what a local community is, the term 'indigenous peoples' is often misunderstood. Convention 169 of the International Labour Organisation (ILO) defines indigenous peoples as 'tribal peoples in independent countries whose social, cultural, and economic conditions distinguish them from other sections of the national community, and whose status is regulated wholly or partially by their own customs or traditions or by special laws or regulations' and those 'regarded as indigenous on account of their descent from the populations that inhabited the country, or a geographical region to which the country belongs, at the time of conquest or colonisation or the establishment of present state boundaries and who, irrespective of their legal status, retain some or all of their own social, economic, cultural and political institutions'. (ILO 1989)

Self-identification as indigenous or tribal is to be regarded as a fundamental criterion for determining the groups to which the provisions of the convention apply. Building upon ILO Convention 169, a major step for the international status of indigenous peoples was taken in 2007 with the UN Declaration on the Rights of Indigenous Peoples.

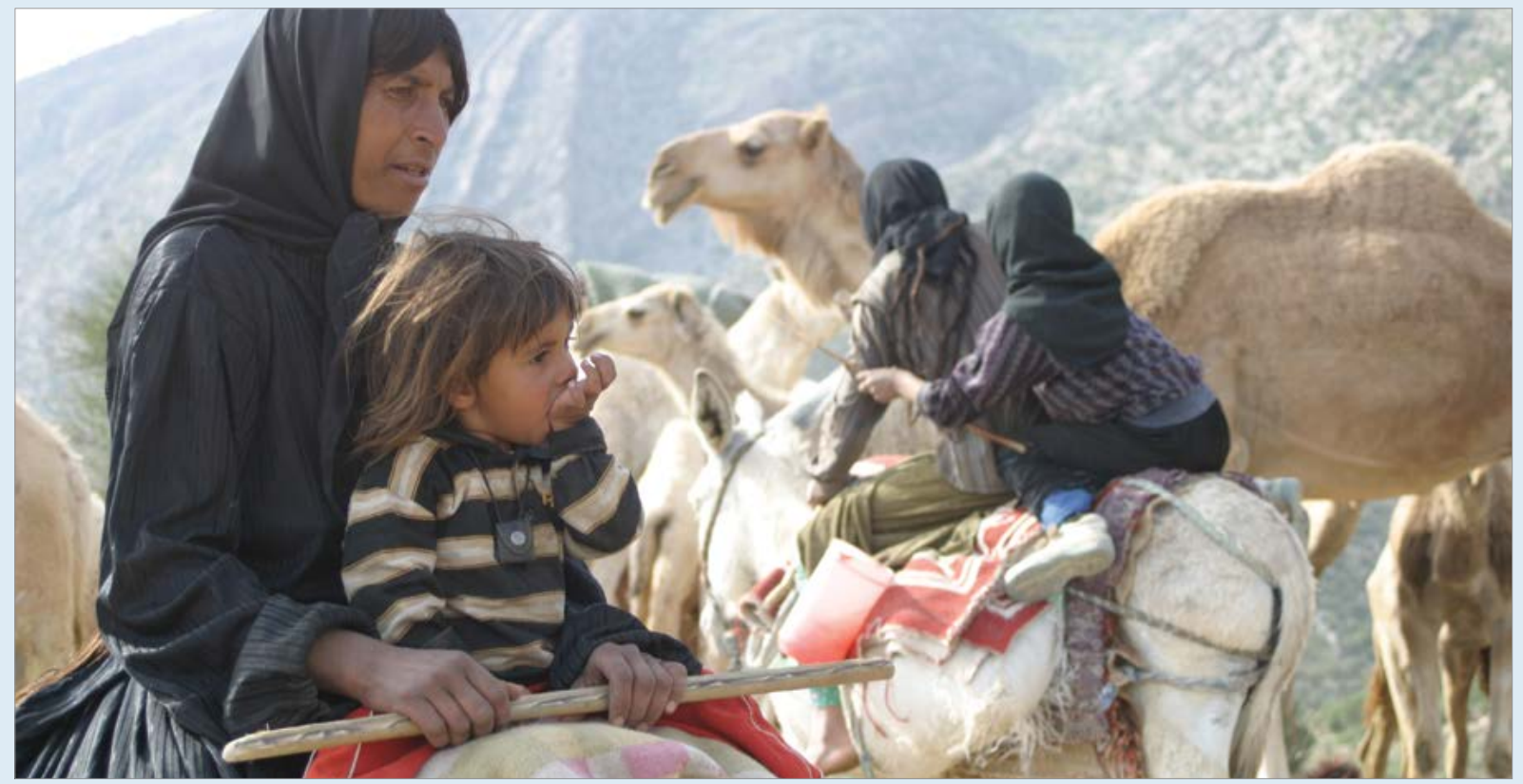

Qasqai mobile indigenous people, Iran Source: CENESTA 


\section{Case Study 7.8 Numerous and well-managed marine and coastal ICCAs}

In Japan, government assigns exclusive access to coastal fishery resources to Fishery Cooperative Associations. The associations acquire the relevant licence and establish collective rules for resource exploitation, including specific fishing limitations and no-take zones. This has fostered the establishment of more than 1000 fisheries regulated areas under locally agreed rules that possess all the attributes of ICCAs and are locally referred to as sato-umi. Many of them include well-respected no-take areas, sometimes seasonally limited, and two-thirds of them receive some form of government recognition.

From the Japanese experience, it appears that fishers' self-imposed rules are effective in terms of surveillance, enforcement and compliance, and this is true even when rules are applied only at prescribed times. Scientists and governments support local marine ICCAs by providing scientific data and helping to reach a consensus among the fishers about the most appropriate collective rules.

- Shinichiro Kakuma and Nobuyuki Yagi

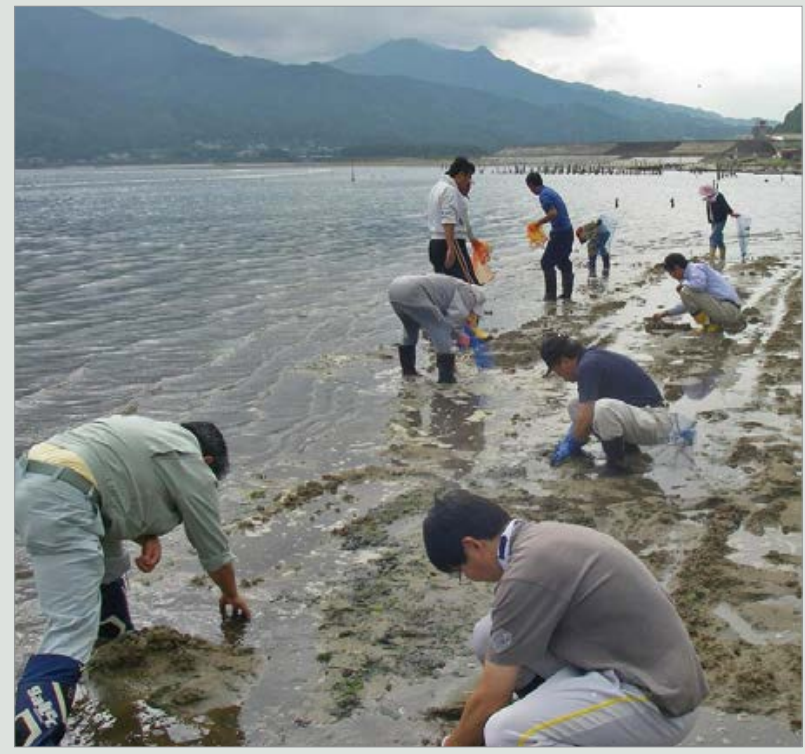

Coastal habitat restoration in Mikayo, Iwate Prefecture, Japan

Source: Satoshi Yoshinaga
Most indigenous peoples and many traditional communities are characterised by a very close relationship with their territories and natural resources, conferring on them unique advantages and limitations as governing bodies of conserved and protected areas. They generally advocate for collective rather than individual rights to their land, water and natural resources, and such a collective approach tends to maintain the integrity of a territory, avoid ecological fragmentation and foster longterm objectives_all key requirements for biodiversity conservation. Collective relationships have more to do with identity than with property and monetary values. And collective rights also provide a strong basis for the functioning of community institutions, which are indispensable for sound governance and longterm management practices. In turn, recognising the conservation role and capacities of indigenous peoples and local communities provides a strong argument to promote the formal recognition of their customary collective rights.

An effective governance regime implies an institutional arrangement for taking decisions and developing rules for the land, water and natural resources. For indigenous peoples and local communities, customary and local organisations and rules are as diverse and complex as cultures. Land, for instance, may be collectively owned and managed, but particular resources, such as a type of tree, may be owned or managed individually or on a clan basis. Different indigenous peoples or communities may be in charge of the same area at different times of the year, or of different resources within the same area. And specific procedures and/or rituals may need to be respected for activities to be allowed.

In a generic sense, and respecting their innate uniqueness and variability, the territories and areas conserved by indigenous peoples and local communities are today generally referred to with the abbreviation 'ICCAs' (Dudley 2008; Kothari et al. 2012). Conservation may involve strict protection or maintenance of an area in its natural state; preservation of specific natural features; restricted use of species or habitats; shaping and maintenance of valuable landscapes and seascapes; and sustainable and biodiversity-friendly use of natural resources (BorriniFeyerabend et al. 2010; Case Study 7.8). There are three essential characteristics common to ICCAs:

- an indigenous people or local community possesses a close and profound relation with a site (territory, area or habitat)

- the people or community are the major players in decision-making related to the site and have de facto and/or de jure capacity to develop and enforce regulations

- the people's or community's decisions and efforts lead to the conservation of biodiversity, ecological functions and associated cultural values, regardless of original or primary motivations. 


\section{Case Study 7.9 Recognising and strengthening traditional forms of respect and care}

The Bijagos archipelago of Guinea-Bissau has been de facto conserved by its inhabitants for as long as anyone can remember. Some islands, in particular, have been maintained in a pristine state, as people could visit them only once a year for ceremonial practices. In the 1990s, some of these islands were recognised as the most important nesting sites for the green sea turtle (Chelonia mydas) and other species of marine turtles on the Atlantic side of Africa. This prompted their recognition as João Vieira-Poilão National Park-offered as a 'gift to the
Earth' in 2001. As local respect is only strengthened by this declaration, all should be fine. Yet, local fishers are upset at not being able to fish in a large area surrounding the park where sportfishing is instead allowed by licence from government officials. In theory, socially legitimate and legal measures coincide but, in practice, there are conflicts because of differing interpretations of what this entails. The relationship among government officials, local residents and wealthy foreigners is not always easy.

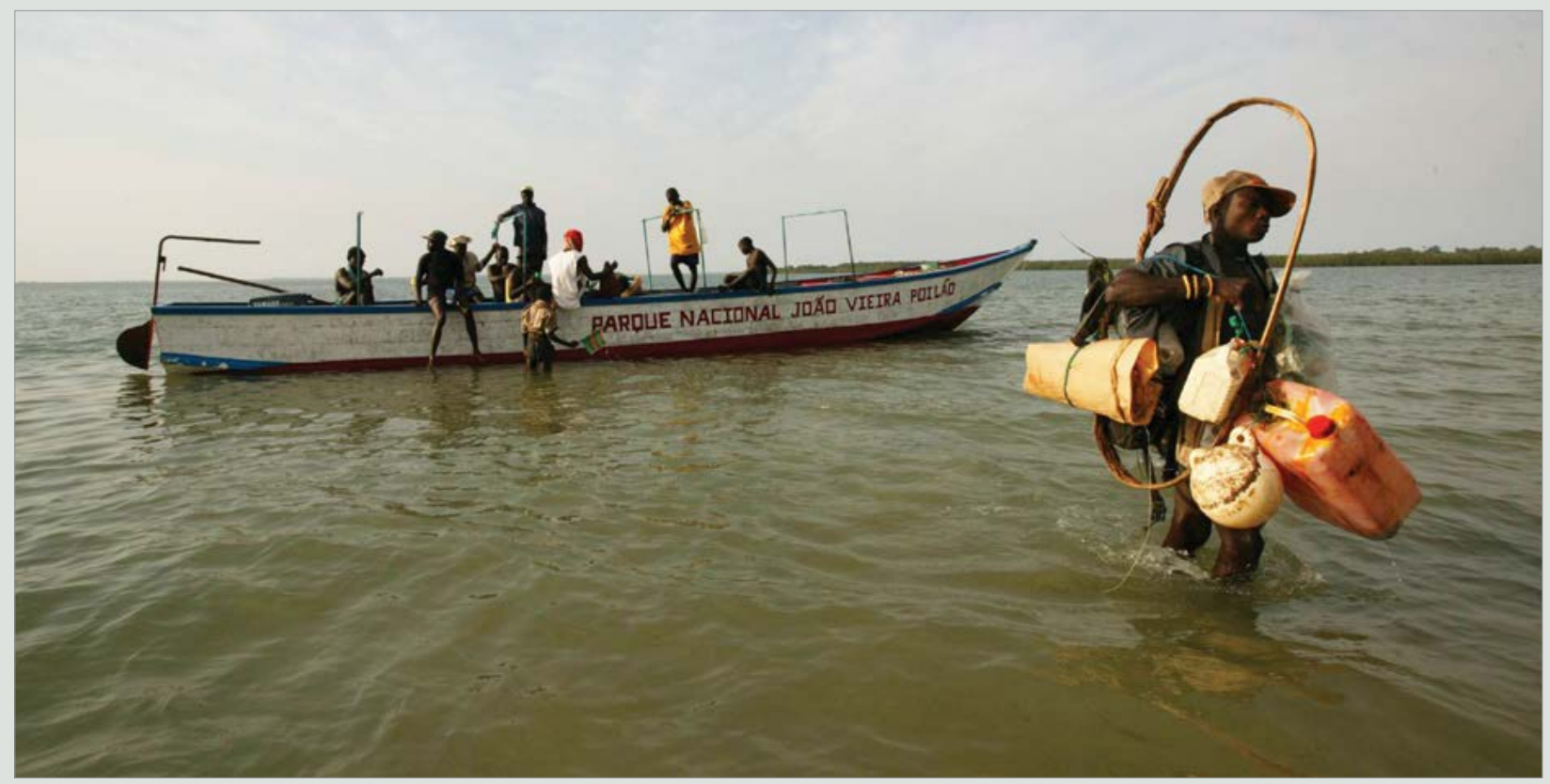

Fishers at João Vieira-Poilão, Guinea-Bissau

Source: Hellio \& Van Ingen

Because they are by definition 'conserved areas', ICCAs make up only a subset of all territories and areas governed by indigenous peoples and local communities. When their governing institutions decide to have an explicit dedication to conservation and ensure some form of management continuity, the IUCN recognises that such ICCAs also possess the characteristics of protected areas. Yet, most ICCAs in the world are not recognised for their conservation value in their own countries-that is, they are neither recognised as part of their national protected area systems (which may or may not be desirable) nor offered recognition and support for the conservation benefits they offer to society at large. Figure 7.3 pictures the incomplete overlap between ICCAs and protected areas, which differs if we consider protected areas recognised by the IUCN or by national governments.

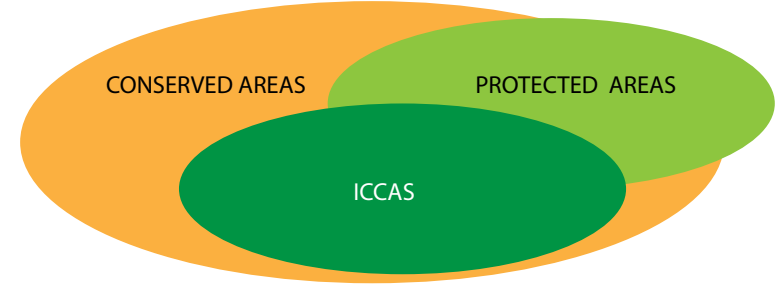

Figure 7.3 Incomplete overlaps among conserved areas, protected areas and ICCAs

\section{Nested and overlapping governance types}

In some cases, a protected or conserved area of given governance type is nested within another type or partially overlaps with it. Examples would be a large governmentgoverned protected area containing a private reserve, such as Repovesi National Park (Finland), or a valley sacred to an indigenous people, such as Sagarmatha (Mount Everest) National Park (Nepal). Another example would be an indigenous conserved territory including a wetland 


\section{Box 7.5 Protected area systems and the IUCN Matrix}

Management categories and governance types capture important characteristics of any protected area and, as they are independent, they can be juxtaposed in a matrix, creating a 'space of options' helpful for visualising their possible combinations. The resulting IUCN Matrix as modified by the author (Figure 7.4) is particularly helpful for visualising the combinations of management category and governance type that exist in a country's protected area system-and those that might exist. For instance, the IUCN Matrix has been valuable to show that a national system could include much more than the areas protected by governmental agencies alone, and was able to sprout useful reforms in national conservation systems (Borrini-Feyerabend and Dudley 2005). Interestingly, the IUCN Matrix can apply not only to protected areas, but also to the conserved territories and areas that fit, in practice, the key objectives of the IUCN management categories.

\begin{tabular}{|c|c|c|c|c|c|c|c|c|c|c|c|}
\hline \multirow[b]{2}{*}{$\begin{array}{l}\text { Management } \\
\text { category }\end{array}$} & \multicolumn{3}{|c|}{$\begin{array}{l}\text { A. Governance } \\
\text { by government }\end{array}$} & \multicolumn{3}{|c|}{$\begin{array}{l}\text { B. Shared } \\
\text { governance }\end{array}$} & \multicolumn{3}{|c|}{$\begin{array}{l}\text { C. Private } \\
\text { governance }\end{array}$} & \multicolumn{2}{|c|}{$\begin{array}{l}\text { D. Governance } \\
\text { by indigenous } \\
\text { peoples and local } \\
\text { communities }\end{array}$} \\
\hline & 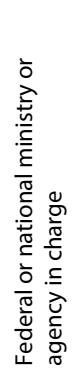 & 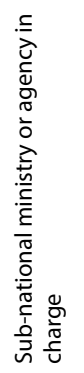 & 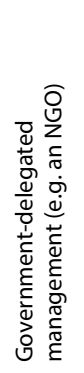 & 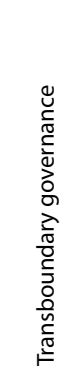 & 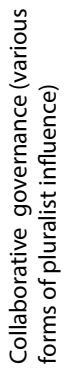 & 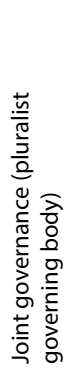 & 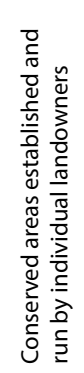 & 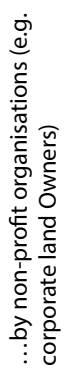 & 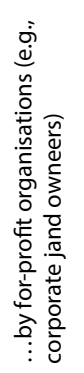 & 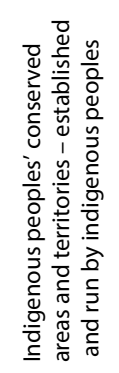 & 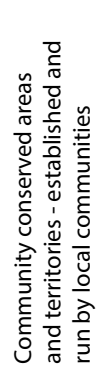 \\
\hline \multicolumn{12}{|l|}{$\begin{array}{l}\text { I a. Strict Nature } \\
\text { Reserve }\end{array}$} \\
\hline \multicolumn{12}{|l|}{ Ib. Wilderness Area } \\
\hline \multicolumn{12}{|l|}{ II. National Park } \\
\hline \multicolumn{12}{|l|}{ III. Natural Monument } \\
\hline \multicolumn{12}{|l|}{$\begin{array}{l}\text { IV. Habitat/ Species } \\
\text { Management }\end{array}$} \\
\hline \multicolumn{12}{|l|}{$\begin{array}{l}\text { V. Protected } \\
\text { Landscape/ } \\
\text { Seascape }\end{array}$} \\
\hline $\begin{array}{l}\text { VI. Protected Area } \\
\text { with Sustainable Use } \\
\text { of Natural Resources }\end{array}$ & & & & & & & & & & & \\
\hline
\end{tabular}

Figure 7.4 The updated IUCN Protected Area Matrix (as modified by the authors): A classification system comprising both management category and governance type

Source: Borrini-Feyerabend et al. (2013) 


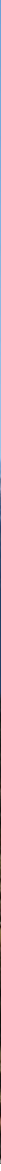

The Sagarmatha biocultural and World Heritage landscape comprises ICCAs and a national park

Source: Ashish Kothari

of international importance, such as the Kushk-e Zar (Namdan) Ramsar site, the heart of the migration territory of the Kuhi tribe (Iran). In the first case, the state may have left no choice to a community or a private landowner other than to accept the imposition of a protected area upon their land. Too often this was even accompanied by the eviction of the area's inhabitants and caretakerscreating tragic situations of loss and resentment. In other cases, indigenous peoples, local communities and landowners continue to live within the protected area and make contributions to conservation by maintaining their own governance and management practices.

The case of ICCAs within government-governed protected areas is quite common. If the ICCA is maintained under community governance without recognition from or coordination with the government, there is a risk the governance and management practices may be inadvertently undermined or deliberately suppressed and replaced, generating conflicts between governments and communities. Government attempts to secure its authority may be perceived as threats to ICCA integrity, and local residents may fear a violation of their rights and capacity to exercise collective responsibilities. At times, however, one finds mutual recognition and positive collaboration between the governing bodies of protected areas and ICCAs, to the benefit of everyone involved. It is even possible that a government adheres to the 'long-term vision' of a national park solely governed by its rights-holding aboriginal community (Farrier and Adams 2011). On the basis of an examination of several cases of overlaps, it is recommended that protected area authorities acknowledge and value ICCAs, refrain from interfering with them and support them in mutually agreed ways (Stevens and Pathak-Broome 2014).

As part of ICCAs or not, a large proportion of the world's protected areas is inhabited by indigenous peoples and local communities, or in many ways remains crucial to them because of livelihoods and/or cultural and spiritual relationships. Such peoples and communities are among the most concerned and best equipped to conserve the relevant territories and resources, if given a chance and the proper means (Ostrom and Nagendra 2006; Case Study 7.9). The challenge for conservation agencies is to overcome the practices of the past and engage people in governance for the benefit of both their own livelihoods and conservation. As part of that, the CBD Programme of Work on Protected Areas (PoWPA) and the IUCN recommend to embrace and support a variety of governance types in protected and conserved areas (Borrini-Feyerabend et al. 2013). In this sense, combinations and overlaps of diverse governance types are a conservation opportunity, where governments and societies at large can more easily share the burdens and benefits of conservation.

\section{Governance quality}

The CBD PoWPA stresses the need to recognise and support different types of protected area governance but also encourages parties to improve the quality of governance of their protected areas, regardless of 
type. Establishing criteria, principles and values can help to guide action. Inspiration can be taken from a variety of principles discussed by the United Nations as part of work on human rights and the promotion of public involvement in environmental governance prompted since the UN Conference on Environment and Development in 1992 (UNDP 1997, 1999, 2002). Building upon that work, the IUCN has recently published a volume of guidelines for countries willing to engage in governance assessment and evaluation processes for protected area systems or individual sites (Borrini-Feyerabend et al. 2013). Table 7.4, an extract from that work, offers a variety of considerations related to the five main good-governance principles recognised by the IUCN for protected areas.

The principles encourage the people and institutions responsible for governing protected and conserved areas to merge concerns for effectiveness (vision, performance, accountability) and concerns for equity (fairness, respect for procedural and substantial rights). Unlike governance type, however, quality of governance does not relate to a specific classification or scale. In fact, governance quality can only be understood in relation to a particular context, as culture and values strongly affect the standards of what is considered appropriate. In addition, in different situations it may be important to stress different principles, or components of principles, such as information sharing (for example, do people know and discuss the vision and aim of the protected area), legitimacy (for example, are decisions reflecting the true priorities of society) or fairness (for example, is any group truly disadvantaged by the decisions being taken).

Typically, national governments are responsible for the overall system of protected areas in their countries and should be accountable for both its management effectiveness (see Chapter 28) and governance quality. For the former, governments have to develop and foster relevant capacities and promote the overall conditions (including budgetary support and authorities that perform well and are perceived as legitimate). For the latter, governments need to ensure fair and well-enforced legislation and rules, which leave space for civil society to organise and take on autonomous or collaborating roles. In this sense, good governance of protected and conserved areas in large part depends on the overall relations and mutual engagement among governments, private and corporate landholders, NGOs, indigenous and local communities and civil society at large.

In the new millennium, the concerns, capacities and institutions of non-governmental actors-indigenous peoples, local communities, NGOs, private and corporate landowners and even civil society at large-have acquired enhanced weight and visibility in conservation in general and in area-based measures in particular.
This notwithstanding, national governmental agencies continue to fulfil a paramount governance role. On the one hand, they are the fallback actor when others have little interest in conservation. On the other, governmental agencies have a moral obligation to give voice to 'silent nature', protect the intrinsic value of plants, animals and natural systems and conserve them for future human generations. In some countries, such as Ecuador, this is actually being codified into constitutional principles.

To make matters more concrete, we will now discuss some 'quality of governance' issues of particular concern for different actors in conservation.

\section{Quality of governance for national and sub- national government agencies}

Most of the world's official protected areas and systems are governed by governments, which are complex systems of ministries, agencies, administrative levels and actors that work in coordination, and sometimes in tension, with one another. Often, such agencies have different agendas and capabilities, and unclear mandates. While interagency struggles for influence are relatively common, under the impulse of PoWPA, a shift towards more collaborative decision-making has occurred (Dearden et al. 2005). This shift is increasingly inscribed in legislation.

A major aspect of protected area governance by governmental agencies is accountability to the publicthat is, the use of mechanisms that inform tasks and objectives being completed on time and public funds being spent for the purpose intended. A trend towards an increased use of such mechanisms and better communication efforts is evident. State of protected area reports, annual reports and external audits are more frequently available and national advisory committees, stakeholder roundtables and parliamentary debates are more often used. There is also an indication that the proportion of protected area funding provided by government agencies and private donors has been decreasing while the proportion provided by NGOs and user fees has increased (Dearden et al. 2005).

In recent decades, protected areas are more commonly established and managed at provincial, regional and local levels, where arrangements may be simpler, more flexible and better connected with local actors, including through innovative governance arrangements that directly involve civil society. Government agencies at the national level continue to have unique roles to play as policymakers, coordinators of protected area systems, monitors and evaluators of performance, guiding agencies for training and distributors of resources. National agencies may be wisely advised to strengthen their capacity to provide these services rather than focus only on direct protected area management. 
Table 7.4 Considerations helpful to assess 'quality of governance' in different circumstance and under all governance types

\begin{tabular}{|c|c|}
\hline Principles & Considerations related to the principles \\
\hline Legitimacy and voice & $\begin{array}{l}\text { Establishing and maintaining governance institutions that enjoy broad acceptance and } \\
\text { appreciation in society } \\
\text { Ensuring that all rights-holders and stakeholders concerned receive appropriate and } \\
\text { sufficient information, can be represented and can have a say in advising and/or making } \\
\text { decisions } \\
\text { Fostering the active engagement of social actors in support of protected areas, upholding } \\
\text { diversity and gender equity } \\
\text { Extending special support to vulnerable groups, such as indigenous peoples, women and } \\
\text { youth, and preventing discrimination on the basis of ethnicity, gender, social class, financial } \\
\text { assets, etc. } \\
\text { Maintaining an active dialogue and seeking consensus on solutions that meet, at least in } \\
\text { part, the concerns and interest of everyone } \\
\text { Promoting mutual respect among all rights-holders and stakeholders } \\
\text { Honouring agreed rules, which are respected because they are 'owned' by the people and } \\
\text { not only because of fear of repression and punishment } \\
\text { As much as possible attributing management authority and responsibility to the capable } \\
\text { institutions closest to natural resources (subsidiarity) }\end{array}$ \\
\hline Direction & $\begin{array}{l}\text { Developing and following an inspiring and consistent strategic vision (broad, long-term } \\
\text { perspective) for the protected areas and their conservation objectives, grounded in agreed } \\
\text { values and an appreciation of the ecological, historical, social and cultural complexities } \\
\text { unique to each context } \\
\text { Ensuring that governance and management practices for protected areas are consistent with } \\
\text { the agreed values } \\
\text { Ensuring that governance and management practices for protected areas are compatible } \\
\text { and well coordinated with the plans and policies of other levels and sectors in the broader } \\
\text { landscape/seascape and respectful of national and international obligations (including the } \\
\text { CBD PoWPA) } \\
\text { Providing clear policy directions for the main issues of concern for the protected area and, } \\
\text { in particular, for contentious issues (for example, conservation priorities, relationships with } \\
\text { commercial interests and extractive industries) and ensuring those are consistent with both } \\
\text { budgetary allocations and management practice } \\
\text { Evaluating and guiding progress on the basis of regular monitoring results and a conscious } \\
\text { adaptive management approach } \\
\text { Favouring the emergence of champions, generating new ideas and carefully allowing/ } \\
\text { promoting the testing of innovations, including governance and management innovations for } \\
\text { protected areas }\end{array}$ \\
\hline Performance & $\begin{array}{l}\text { Achieving conservation and other objectives as planned and monitored, including through } \\
\text { ongoing evaluation of management effectiveness } \\
\text { Promoting a learning culture for protected area policy and governance practice on the basis } \\
\text { of mechanisms, tools and partnerships that promote ongoing collaborative learning and } \\
\text { cross-fertilisation of experience } \\
\text { Engaging in advocacy and outreach for the benefit of protected areas } \\
\text { Being responsive to the needs of rights-holders and stakeholders, including by providing } \\
\text { timely and effective responses to inquiries and reasonable demands for changes in } \\
\text { governance and management practices } \\
\text { Ensuring that protected area staff, and rights-holders and stakeholders, as appropriate, have } \\
\text { the capacities necessary to assume their management roles and responsibilities and that } \\
\text { those capacities are used effectively } \\
\text { Making efficient use of financial resources and promoting financial sustainability } \\
\text { Promoting social sustainability and resilience-that is, the ability to manage risks, overcome } \\
\text { the inevitable crises and emerge strengthened from the experience }\end{array}$ \\
\hline
\end{tabular}




\begin{tabular}{|c|c|}
\hline Principles & Considerations related to the principles \\
\hline Accountability & $\begin{array}{l}\text { Upholding the integrity and commitment of all in charge of specific responsibilities for the } \\
\text { protected areas } \\
\text { Ensuring transparency, with rights-holders and stakeholders having timely access to } \\
\text { information about: what is at stake in decision-making; which processes and institutions } \\
\text { can exert influence; who is responsible for what; and how these people can be made } \\
\text { accountable } \\
\text { Ensuring a clear and appropriate sharing of roles for the protected areas, as well as lines of } \\
\text { responsibility and reporting/answerability } \\
\text { Ensuring that the financial and human resources allocated to manage the protected areas } \\
\text { are properly targeted according to stated objectives and plans } \\
\text { Evaluating the performance of the protected area, of its decision-makers and of its staff, and } \\
\text { linking quality of results with concrete and appropriate rewards and sanctions } \\
\text { Establishing communication avenues (for example, websites) where protected area } \\
\text { performance records and reports are accessible } \\
\text { Encouraging performance feedback from civil society groups and the media } \\
\text { Ensuring that one or more independent public institutions (for example, ombudsperson, } \\
\text { human rights commission, auditing agency) have the authority and capacity to oversee and } \\
\text { question the actions of the protected area governing bodies and staff }\end{array}$ \\
\hline Fairness and rights & $\begin{array}{l}\text { Striving towards an equitable sharing of the costs and benefits of establishing and managing } \\
\text { protected areas and fairness in taking all relevant decisions } \\
\text { Making sure that the livelihoods of vulnerable people are not adversely affected by the } \\
\text { protected areas; that protected areas do not create or aggravate poverty and socially } \\
\text { disruptive migration patterns; and that the costs of protected areas-especially when borne } \\
\text { by vulnerable people-do not go without appropriate compensation } \\
\text { Making sure that conservation is undertaken with decency and dignity, without humiliating or } \\
\text { harming people } \\
\text { Dealing fairly with protected area staff and temporary employees } \\
\text { Enforcing laws and regulations in impartial ways, consistently through time, without } \\
\text { discrimination and with a right to appeal (rule of law) } \\
\text { Taking concrete steps to respect substantive rights (legal or customary, collective or } \\
\text { individual) over land, water and natural resources related to protected areas, and to redress } \\
\text { past violations of such rights } \\
\text { Taking concrete steps to respect procedural rights on protected area issues, including: } \\
\text { appropriate information and consultation of rights-holders and stakeholders; fair conflict- } \\
\text { management practices; and non-discriminatory recourse to justice } \\
\text { Respecting human rights, including individual and collective rights, and gender equity } \\
\text { Respecting the rights of indigenous peoples, as described in the UN Declaration on the } \\
\text { Rights of Indigenous Peoples } \\
\text { Ensuring strictly the free, prior and informed consent of indigenous peoples for any proposed } \\
\text { resettlement related to protected areas } \\
\text { Promoting the active engagement of rights-holders and stakeholders in establishing and } \\
\text { governing protected areas }\end{array}$ \\
\hline
\end{tabular}

\section{Quality of governance for NGOs}

International, national and local NGOs dealing with environmental concerns and protected areas under all governance types have dramatically risen in number and influence in the past 30 years. For government-governed protected areas, they can act as delegated managers (this is the case of the Audubon Society in Belize) or providers of technical advice. Many NGOs play crucial policy advisory roles to governments, with additional influence related to their capacity to offer or withhold supportive funds or services, and/or to affect the opinion of donors. They usually advocate for national provisions to incorporate international agreements, such as the $\mathrm{CBD}$, the World Heritage Convention or the Ramsar Convention, and play a vital role in forging supranational protected area agreements and initiatives.

In protected areas under shared governance, NGOs can be full partners, with a role at times enshrined in national law, or act as facilitators, trainers, convenors, mediators, conflict managers and providers of legal, technical and administrative support. Many conservation NGOs are 
also managers of privately protected areas, as they buy land, or receive it from private donors, explicitly for conservation purposes. This is common in the United States, the United Kingdom and Australia, where NGOs assume public trust responsibility as non-profit entities, which confers on them tax exemptions and other benefits. Other NGOs play invaluable roles as promoters of coalitions of private owners to set up their own protected areas through land-use trusts. An increasing number of NGOs have taken upon themselves to assist indigenous peoples and local communities in asserting, defending, establishing and managing their own conserved and/or protected areas and in setting up national coalitions and federations to the same purposes.

NGOs are particularly well suited to foster improvements in governance quality. They spread information and innovative ideas, help civil society to mobilise, and facilitate dialogues and negotiation processes. They provide technical support and training to communities or smaller and younger NGOs, monitor compliance of environmental law and policies, serve as policy advocates, and suggest innovative practices (for example, create a demand for certified goods or assist people to get to court). NGOs also have limitations, however, and can inadvertently have negative impacts. They at times overstep their roles, absorb all available resources or centralise upon themselves technical issues, disempowering local actors. They may also become unduly enmeshed in local politics, creating new conflicts or overriding local agendas and priorities. Foreign NGOs, in particular, need to implement programs only on the basis of a careful understanding of community history and dynamics (Alcorn et al. 2005).

\section{Quality of governance for private landowners}

Many private landowners manage part or all of their land with important results for conservation and have obtained some form of recognition as part of the protected estate of different countries (Langholz and Krug 2004). In countries such as Costa Rica, Brazil, Chile and South Africa, the amount of protected land under private governance is estimated to be larger than that under national government agencies (Anderson 2003). In South Africa and Namibia, individual landowners often pull their land together as conservancies to allow large habitats for wildlife and set up tourist enterprises, often in partnership with the governmental agencies which manage adjacent parks. Corporate landowners are also increasingly willing to devote part of their lands to conservation, sometimes as a form of offset for the damages they cause to nature elsewhere.

Nayakheda village youth, western India, in a recently recognised community forest Source: Ashish Kothari

A governance advantage of private landowners is that private property confers a broad set of powers and the dedication to conservation can be easily established and even inscribed in the property deeds, obliging also future owners. As this often implies social and economic advantages, however, some have expressed concern that private parks may contribute to the concentration of landownership by the wealthy. Indeed, a major social pitfall of private parks is that they can become 'islands for elites'-places where wealthy landowners host affluent tourists (Langholz and Krug 2004). As ecotourism and private hunting reserves grow in popularity and profitability, the value of land that can support such enterprises goes up. Depending upon the legal and political contexts, communities living on or near such lands may be forced to move away, either by threat of force or by economic necessity, or they may stay but lose the right to access game, medicinal plants or other resources on land designated as a reserve. Questions of equity become even more troubling where foreign ownership is involved. Governments ought to play a proactive role in monitoring and evaluating the effectiveness and equity of private conservation effortsin particular, when conservation incentives are at stake.

\section{Quality of governance for indigenous peoples and local communities}

Many local communities and indigenous peoples possess customary organisations with a role in governing nature and natural resources - some with centuries of experience, others relatively new or recently revived in contemporary forms. What most have in common is that they represent local rights-holders-people first in line to pay the price for wrong management decisions and possessing traditional knowledge, skills and the accumulated local experience necessary to protect or restore specific sites 
and/or use natural resources in sustainable ways. Despite their diversity and complexity, and possibly because of that, customary and local institutions appear to function effectively and make important contributions to conserve natural and modified ecosystems (Kothari 2006). They do so voluntarily, in countries all over the world, through customary laws or other effective means (CBD 2010).

Besides being the repository of age-old knowledge and skills, carved on the specifics of given territories and resources, community-based governance institutions are generally flexible, responsive and capable of bending around a variety of factors and responding to change in ways that can be rapid and effective. In addition, they are often self-motivated and self-financed, as governance of a locally conserved or protected area is crucial for people whose livelihoods and cultural identity are intimately related with the natural resources. They also, however, have limitations. On the one hand, customary institutions are peculiar to their cultures and some do not reflect the achievements of universal human rights and liberating principles, such as rights to information, participation in decision-making or accountability. On the other, they often encounter problems in their relationship with governments-in particular, at the interface between traditional and modern institutions.

Often the state offers no formal recognition to the ethnic and local organisations which govern conserved areas, or not even to the indigenous people or local community themselves, which may 'not exist' as a collective legal subject but only as agglomerations of individuals. This is true in many places in Africa, Asia and Europe. In other countries-for example, South Africa-customary law is recognised by the constitution as an independent body of law. Through that, indigenous peoples and local communities are winning legal collective tenure to at least part of their lands and, with that, the right to govern them collectively. Although implementation is highly variable, this has been happening in countries as diverse as Colombia, the Philippines, Australia, Brazil, Bolivia, Italy, the United States, Canada, India, Iran, Madagascar, Tanzania and Indonesia, opening the way for governments to acknowledge their contributions to conservation. Indigenous conservation territories, tribal parks, conserved forests in mountain communities, indigenous protected areas and conserved ancestral domains are now formally recognised via a variety of negotiated agreements, which at times require guarantees for management effectiveness and governance quality.

\section{Quality of governance for civil society at large}

Civil society refers to a variety of collective actors and initiatives - distinct from family, state and the marketwhich maintain a degree of autonomy, ensure space and nourishment for pluralism, and engage in constructive relationships with politics and public policy. All voluntary associations attempting to influence decision-making in conserved or protected areas belong to civil society and represent a formidable potential for conservation. At times, however, they also represent a source of instability and problems. Associations created specifically to develop and exert influence on a particular protected area can be very influential. They can challenge external threats but also fight decisions that sacrifice part of their local interests for the larger common good.

Lay actors and civil society can influence conservation decisions through their power of position or unique knowledge; through personal, family or group influence and economic might; through political influence and legal expertise; and even through violent coercion or nonviolent civil disobedience. These powers can be brought to bear, more or less openly, upon decision-makers. A protected area model that openly calls for the involvement of civil society at large is that of national parks and natural regional parks in France, where it is foreseen by law that workshops, broad consultations and public deliberations are to be widely used to discuss and develop ideas that will be compiled into a protected area charter including key objectives and management priorities.

There also exist less fair pathways for influence. For instance, some may attempt to bypass the decisionmaking chain with a persuasive phone call to top authorities. This may or may not work, but it offers an example of why the engagement of civil society is seen by some as undemocratic, as it depends on the action and opinions of a few, and not the counted votes of the majority of those with legitimate rights (an elected representative, on the other hand, rarely has discussed with his or her electors the specific decisions with regard to a protected area).

\section{Governance vitality}

The conservation community is gradually becoming accustomed to using two main parameters to understand governance: type (who holds authority, responsibility and accountability for the key decisions, the 'constituent act' of the area-based measure?) and quality (are decisions taken by respecting 'good governance' principles?). While these parameters are useful and informative, they do not describe whether a governance setting is able to learn, evolve and meet its role and responsibilities 
in ways that are timely, intelligent, appropriate and satisfactory for everyone concerned. We refer to this property as governance vitality and we will describe here some initial considerations and ideas about it. This is not a fully developed treatment and, in the months and years to come, we hope the conservation community will come to define this property of governance in a more precise and complete way. Precision is not necessary, however, to understand the usefulness of the concept or to have a broad sense of what to do to enhance it for the betterment of nature and people.

As a starting point, we argue that the vitality of a governance setting (see Figure 7.5) is related to being:

- well integrated and functionally connected-that is, having abundant, meaningful and systemic interactions with a variety of actors at various levels in society and across sectors (including those actors who render decisions effective through political, social and financial support)

- adaptive-that is, flexible, reflective, engaged in knowledge exchange, dialogue and debate, capable of learning from experience, capable of weighing options and taking prompt and meaningful decisions even under challenging circumstances

- wise-that is, having agreed to take decisions of meaningful scope (for example, regarding the size and socioecological coherence of the unit to manage, the number of actors to involve); being motivated by the common good and solidarity rather than greed (for example, avoiding accumulation and waste, encouraging respect, goodwill, conviviality and generosity); and not only allowing, but also fostering the engagement of as many relevant actors in society as possible

- innovative and creative-that is open to new ideas, able to reinvent and renew itself as a living system does, providing innovative solutions, supporting the emergence of new rules and norms, responding positively to change and continuing to develop

- empowered - that is, self-conscious and self-directed, capable of demonstrating leadership responses to emerging environmental conditions, problems and opportunities; self-disciplined and self-critical, and able to take on responsibilities in effective and dependable ways.

\section{Governance that is well integrated and functionally connected}

Protected areas have too often been conceived as 'islands' of conservation in a 'sea' of development. Today, we increasingly recognise that conservation inside protected areas depends in essential ways on their physical and biological connections with nature across landscapes, seascapes, with the atmosphere above, and with the soils and aquifers below. We have also begun to understand the less-visible social connections among actors in societythe farmers who decide which crops to sow and where, the NGOs campaigning for policy changes, and the national agencies setting national conservation targets and plans to reach them. Effective governance for the conservation of nature involves building positive and coherent connections among the people, sectors and decision-making levels that determine the many factors and conditions that contribute to, or impede, conservation. This understanding is not new, and resonates with what traditional cultures have known for centuries.

A backyard, a farm, a local administrative unit, a province, a nation, a continent, planet Earth-all are examples of different spatial scales, from local to global. The key actors and institutions in the governance of nature operate at these different scales both in space and over time. The principle of subsidiarity - that is, the idea that governance should be devolved to local communities closest to the natural resources with capacity to take care of themgained prominence early this century as a way of securing community tenure and empowering local institutions that contribute to sustainability and social justice (Berkes 2004). Experience, however, has shown that it can have mixed results, sometimes buttressing local elites who enforce conformity and marginalise minorities.

Because some types of decisions are best made at particular scales, some people stress the value of networks that enable collaboration among governance actors operating at different spatial and temporal scales (Cash and Moser 2000). For example, the family is best placed to decide what to grow in its backyard and to look after it, but local councils can help make sure that native birds and wildlife can still thrive in cities by providing guidelines for wildlife-friendly plantings, or prohibiting the cutting down of key habitat trees that are essential nesting places for birds and mammals. Drawing on Hill et al. (2010), we refer to this phenomenon as scaledependent comparative advantage. In all networks, the people who bear the most direct consequences of decisions should have a voice in shaping those decisions and using their knowledge, skills and undoubted comparative advantages.

Forging linkages and connections across scales is critical for effective outcomes and happens via all sorts of information flows and social learning-for example, through collaboration among organisations in scenario planning, visioning and open discussion of alternatives. Crucially, information flow and collaboration can 


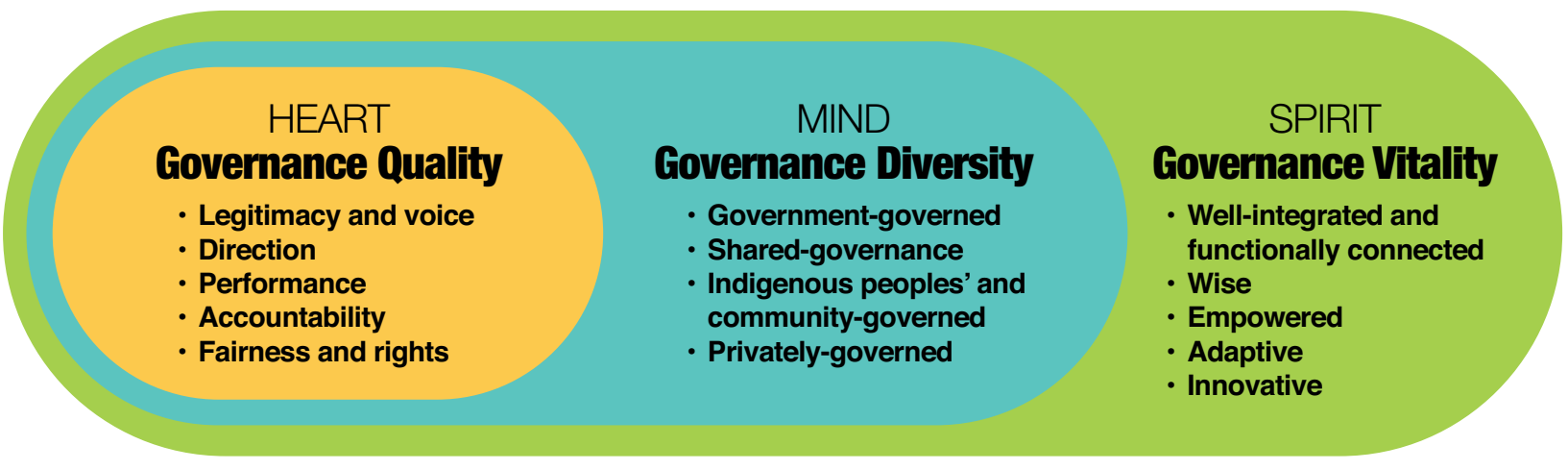

Figure 7.5 A schematic summary of governance characteristics (Reproduced with permission from CSIRO)

bridge groups with different cultures, interests and levels of power towards goals that are positive for nature and people (Lebel et al. 2006). Terms like multi-level, polycentric and collaborative environmental governance are used to describe both the governance system and the processes of actively linking governance across scales.

\section{Adaptive governance}

Our world is changing, and is doing so at unprecedented pace and reach. Across the planet, people are growing in number, moving to cities and expanding them into megacities, changing their demographic patterns and their patterns of strengths and vulnerabilities. Food demands and consumption are changing in type and increasing overall, leading to estimates that the world will need to double food production this century, and make major investments to deliver food to mega-cities (Tilman et al. 2011), where disruptions to food transport systems, through climatic problems or lack of fuel supply, could lead to severe shortages in a matter of days. Growing consumption of mineral and fossil fuel resources is increasing the occurrence and risk of environmental disasters, such as oil spills, and accelerating humaninduced climate change and ongoing biodiversity loss. This combination threatens life as it exists on our planet (Hansen et al. 2013). Economies and technologies, societies and cultures are all changing rapidly, influenced by the revolution in information technologies (Young et al. 2006). How do we respond to the multiple challenges that pervasive and rapid change pose to the governance of nature?

Adaptive governance may be the answer. The concept of adaptive governance draws on that of adaptive management (Holling 1978; Walters 1986), which in its simplest form is 'learning by doing' (see Chapter 8). Adaptive governance is the conscious adoption of a learning attitude in organisations (Borrini-Feyerabend et al. 2004), where evolving functions and agreements are allowed to shape the decision-making organisation rather than organisational forms being imposed as straitjackets.
Through dialogue, negotiation, goodwill and careful experimentation, decision-making institutions can evolve in ways that are satisfactory and lead to betterrespected decisions. In adaptive governance much of the learning takes place in actual decision-making and enforcement of decisions, and in their ongoing review. In this way, the crises and top-down restructuring of organisations that are a traumatic experience for many can be replaced with conscious ongoing adjustments and learning.

Adopting an adaptive governance approach means allowing institutions to mature through time. For instance, after an emphasis on legality and technical expertise, a governance organisation may evolve towards enhanced legitimacy, more widely shared responsibilities or supporting the development of new associations among rights-holders. Both empirical experience and theory suggest that the 'organisational culture'-that is, the combination of the individual opinions, shared knowledge, values and norms of the people who belong to the organisation-is the most fundamental level at which transformation needs to take place. For protected area professionals and staff, perspectives about peopleenvironment interactions are the central element of such organisational cultures. For example, an emphasis on relatively stable ecosystems feeds into the development of policies and scientific practices for conservation controlled by professionals and distant organisations. Conversely, notions of uncertainty, spatial variability and complex non-equilibrium ecological dynamics emphasise flexibility, mobility and adaptive resource management in which local people are central actors.

Simplified and ahistorical perspectives perpetuated by the powerful have been a persistent feature of environmental policies and interventions. Local people (often depicted as destructive, uneducated, backward or non-innovative) are blamed for environmental degradation and interventions are imposed to 'prevent further deterioration'. Such crisis narratives and practices are robust, hard to challenge and slow to change. They structure options, define relevant 
data and exclude other views within bureaucracies and professional circles. And yet, research has often debunked orthodox views on people-environment interactions (Borrini-Feyerabend et al. 2004; Fairhead et al. 2012), and historical analyses, social anthropology, participatory methods and insights from non-equilibrium ecology are slowly promoting different narratives (attention to governance being a crucial component) and more peoplecentred organisational cultures.

A learning attitude in organisations can be consciously and constructively promoted via:

- participatory analysis and planning (for example, visioning, scenarios, trend analysis and participatory mapping)

- co-production and wide sharing of knowledge (for example, dialogue and exchanges among academic scientists and people with experience-based and traditional forms of knowledge; using maps and models that make assumptions and values explicit; adopting new media platforms and variables, such as digital ethno-biology and biocultural diversity measures)

- developing agreements through time (for example, foreseeing processes, mechanisms and tools for sharing information, communicating among diverse forms of knowledge, values and world views; adopting calm and intelligent ways of solving conflicts; monitoring functions, results, social acceptance of decisions and impacts in society-including in terms of collaboration and equity).

Even more fundamentally, a learning attitude can be promoted by organisational policies that foster lateral communication, collegial authority and flexible roles and procedures. Small self-managed teams within a given organisation can be endowed with the freedom to experiment, motivate and learn from mistakes. Professionals can be encouraged to work as 'intra-preneurs' (entrepreneurs within organisations), to directly manage part of the budget and pilot innovations. Specific incentives and rewards can encourage collaboration, integrity, mutual trust, continuity of initiatives, knowledge exchange, dialogue, debate, ongoing improvements in performance and the emergence of 'champions' with enabling attitudes and values.

Through such policies, governance has a chance to become more flexible and intelligent, capable of learning from experience, weighing options and taking rapid and meaningful decisions even under difficult circumstances. But adaptive governance has challenges of its own (Case Study 7.10). Dealing with relative uncertainties may be a problem for those parties who realise that governance patterns are changing and incentives to respect current governance systems are diminishing, rendering them less sure about investing in the long term. Participatory processes and the negotiation of different and evolving values, claims, rights and responsibilities are time-consuming, and can exhaust the motivation, capacities and resources of participating actors. Financing the transaction costs (consultations, meetings) is necessary to guide and adapt the adaptive governance regimes, but can also be expensive and can overwhelm existing resources.

\section{Wise governance}

A wise person is usually honest and good, but an honest and good person is not necessarily wise. Similarly, wise governance is more than just 'good governance'. We propose here that a wise governance setting is one in which decisions of meaningful scope are taken, which enhance the common good and solidarity and which not only allow, but also foster, the engagement of all relevant actors in society.

What would meaningful scope entail? As noted earlier, governance units should have socioecological coherence, and thus not be so large as to be unmanageable or so small as to be irrelevant. The number of actors to involve should not be overwhelming but manageable, so that they can work together in harmonious and effective ways. In addition, wisdom transpires when decisions are motivated by the common good and solidarity. For instance, decisions-makers can strive to avoid accumulation and waste, encourage respect, goodwill and conviviality, and discourage selfishness and greed. In this sense, wise governance needs human qualities: a sense of appreciation and understanding, a positive attitude, curiosity, attention, care, generosity, patience, even humbleness, but also perseverance, determination and, more often than not, courage. Building upon these qualities, some 'decisions' can help people be the best they can be.

The structures of decision-making, however, are also extremely important. If democracy is government by the people, in representative democracy the power vested in people is exercised through electing some representatives who govern on their behalf. Alternatively, in participatory or strong democracy, the power vested in people is exercised directly, through processes that strengthen people's connections with each other and, via diverse associations, provide for oversight of governments and allow the innate wisdom of peoples and nations to emerge, building upon the capacities of all. For many ICCAs in traditional societies, strong democracy is the 


\section{Case Study 7.10 Evaluating governance in a tropical forest environment}

Rainforest Aboriginal Peoples are involved in governing their traditional lands in Australia's tropical forest region with numerous other actors, including national, provincial and local governments, environmental NGOs, local landholders and private businesses. Through a coresearch project with social scientists, spatial analysts and other partners, a diagnostic tool was developed to measure the strengths and weaknesses of such partnerships. The rainforest Aboriginal peoples defined co-governance as 'a continual solution-building process, not a fixed state, involving extensive talking, negotiations and jointly learning, so it gets better over time' (Hill et al. 2013a:1). The diagnostic tool contains a number of parts, one of which is focused on measuring the health of their institutions for 'keeping engagement strong'. They recognised that their effective engagement with their partners requires that they are thriving and able to keep their own knowledge systems alive. The diagnostic tool thus also assesses the factors that 'keep Rainforest Aboriginal Peoples strong'. Their participatory evaluation identified that the Indigenous Protected Areas, which are protected areas dedicated by Indigenous peoples under their own cultural authority (Rose 2013), brought people together in a flexible, ongoing relationship that changes over time-whereas negotiation of legal rights and agreements alone (such as Indigenous land-use agreements that put the Government and Indigenous parties on opposite sides of the table) produced a static document as its outcome. While rights recognition is a foundation of much progress and Indigenous Land Use Agreements can contribute to collaborative management, processes for ongoing solution building are critical.

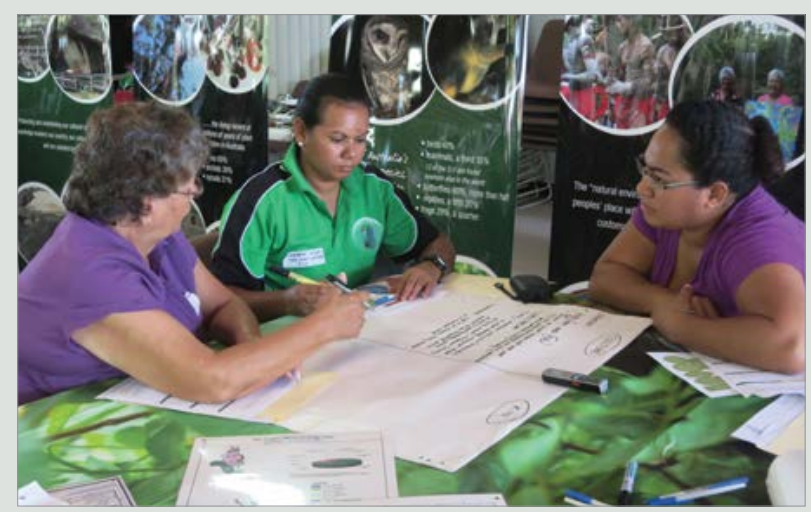

Rainforest Aboriginal Peoples Alliance workshop, north Queensland, Australia

Source: () Michelle Esparon. Reproduced with the permission of the people in the photograph. basic pattern of decision-making. The general assembly at village level is the form it usually takes, at times strengthened by the requirement that decision-making can be taken only by consensus. Knowledge systems that underpin rights to country and culture and are mediated by connections to kin are strengthened by such indigenous and community forms of governance (Hill et al. 2012). As long as people feel free and competent to speak on issues, strong democracy allows them to shape governance pathways and opportunities. Broad public debates and 'deliberations' allow people to attempt to persuade one another of the value of their claims, while their own opinions and understandings evolve in the process. For instance, many indigenous peoples and local communities in Latin America engage in strong democracy grounded in their shared space of life when they develop their life plans (planes de vida) —a practice that has ancient roots but which spread again, recently, also as a form of resistance to externally imposed development plans (Aparicio 2002).

\section{Governance that is innovative and lively}

The many and seemingly intractable challenges facing our world-climate change, biodiversity loss, the growing need for food, freshwater and social services for huge numbers of people- highlight the need to find new solutions and discover new values, rules and norms. One new way of thinking that has emerged has been focusing on 'complex systems', nonlinear dynamics, thresholds, uncertainty, surprise and interactions across temporal and spatial scales (Folke 2006). In that light, innovations emerge through both gradual and sudden changes, in adaptive cycles that include periods of rapid change (exploitation), periods of rigidity (conservation), periods of readjustment and collapse (release), and periods of reorganisation (renewal). Some type of disturbance triggers the sequence from a period of gradual change to one of rapid change, possibly in conjunction with larger cycles. Looking at this world as a complex adaptive system can help us understand how the parts influence each other, and how we might be able to intervene to make the system more able to innovate for desired social, environmental, economic and cultural outcomes (Hill et al. 2013b; Simonsen et al. 2014).

The capacity to reinvent and renew itself is a characteristic of all living and healthy systems and appears to be related to a 'learning attitude'-openness to new ideas, willingness to experiment and curiosity that motivates people to carry out action-research and not be satisfied with easy explanations, platitudes and scapegoats. A powerful trigger can be the wise merging of local and non-local knowledge and skills_-those grounded in the traditions and accumulated experience of indigenous peoples and local communities and those extracted by formal scientists through a careful analysis of different cases and contexts, or simply those based on the experience of peoples from diverse environments. Some refer to this as syncretic solutions - the wise merging of bits 
of seemingly incompatible nature, which can prove surprisingly fresh and effective. In fact, this is possibly the essence of adaptive governance-the existence of lively institutions, capable of responding through time to the changing conditions that embed both conservation and human livelihoods and cultures.

\section{Governance that is empowered}

We understand as empowered governance a decisionmaking system that is self-conscious and self-directed, capable of organising its own responses to changing environmental conditions and capable of enforcing its decisions. This statement may appear trivial. Governance is the exercise of authority and responsibility by definition, yet true empowerment is rare. True empowerment is, more than anything else, a matter of capacities and a deep recognition and assumption of responsibility. Capacity-including knowledge, means and leadership qualities-is necessary to make authority meaningful. Having authority over wildlife in a given territory means little without reliable data on the presence of such wildlife, on the habitat and conditions of reproduction, and the means necessary to survey the territory and fend off poachers. It will also mean little without the willingness to demonstrate leadership. And responsibility means being mature enough to curb some of one's own rights and privileges to recognise those of others-future generations, the dispossessed, other species on this planet-all of whom bear the costs of what is done by the powerful today.

True empowerment is not only with respect to others, but with respect to oneself. Even legally autonomous governance settings — such as a management board legally in charge of a protected area or a customary authority governing an indigenous territory-include legitimate actors marginalised from decision-making for a variety of reasons, from poor access to means of communication to lack of social recognition. These people often include women, the landless, youth, indigenous, ethnic or religious minorities, mobile pastoralists and people displaced during violent conflicts or as a result of natural disasters such as floods and droughts, households affected by HIV/AIDS, and so on (Katz 2010). Levelling the playing field so that those in a position of authority fairly express the concerns of their entire constituencies - including the less powerful-is crucial to achieving empowered governance. Last but not least, empowerment is about being self-disciplined and self-critical-capacities necessary to take on responsibilities in effective and dependable ways.

\section{The governance frontiers}

Despite recent growth in coverage of protected areas, major gaps still need to be brought under conservation governance and management to secure specific ecosystems and species (CBD 2010). In addition, even existing area-based conservation measures need to become much better connected and dramatically improve their management practices (Leverington et al. 2010). Overall, society at large must become more aware of environmental issues, supportive of appropriate activities and capable of providing reasonable limits to the forces of economic development. Working on governance is the expression of the hope that we can still curb excessive and inequitably distributed economic growth, consumerism and environmental destruction, stop destructive financial speculation and find more sustainable, equitable and satisfying challenges for the evolution of human society and cultures.

We already see the benefits of improved governance awareness and action.

Attention to governance has allowed an increase in the coverage of protected areas in national systems. Many CBD parties have reviewed their systems of protected areas and understand that only an innovative treatment of governance allows them to expand their coverage as foreseen by Target 11 of the CBD Strategic Plan for Biodiversity 2011-2020 and the Aichi Targets. France instituted in 2006 a new Protected Area Law that requires shared governance of all its national parks. It is only as a consequence of that law that it has become possible to create three new national parks since 2006, protecting more than 2 million hectares. In Australia, innovative governance under Indigenous Protected Areas has resulted, over the past 15 years, in the dedication of more than 60 new protected areas, totalling more than 48 million hectares and representing about 40 per cent of Australia's total protected area estate. In Namibia, the coverage of community conservancies and other similar arrangements has increased to about one-quarter of the surface of the country, generating major financial benefits for their residents and the country as a whole (NACSO 2013). Ecuador and Madagascar have also embraced the full suite of IUCN governance types for their protected area systems (Ministry of Environment of Ecuador 2006; Madagascar Protected Area System 2009), allowing not only their expansion, but also their consolidation and better shared responsibilities.

Attention to governance has been improving the effectiveness and efficiency of management. Besides global analyses that confirm the relationship between governance and management effectiveness (Leverington 
et al. 2010), countries such as Finland and Canada (Väisänen, cited in Borrini-Feyerabend et al. 2013; Johnston 2006) provide evidence that investing in accountability and public engagement renders the work of national protected area agencies more effective, and better appreciated in society. From Australia to Colombia, from Canada to Namibia, governments, funding agencies, regulatory bodies and stakeholders in general are also becoming well aware that territories under shared governance or directly conserved by indigenous peoples, local communities and private landowners provide conservation benefits at little cost to society - a strong recommendation for supporting their efforts.

Attention to governance has been improving the appropriateness and equity of decisions. Protected areas require many types of decisions, responding to opportunities and threats to their ecological integrity and social and cultural significance. Weak results are often due to the failure of legislation, policies and decisionmaking processes to understand and 'fit' the situation, and to make available meaningful guidance and effective incentives (for example, social recognition, financial support) to managers and others. As well exemplified by current processes in the Philippines (Lim 2012), when governmental agencies support legitimate and responsive governance settings, they can solve socioecological dilemmas, including conflicts with indigenous peoples. Governance diversity can also maximise the ecological, social and cultural benefits derived from area-based conservation measures. For instance, wildlife conservation areas in Tanzania and group ranches in Kenya are generating important benefits for the engaged communities, which used to bear only costs from the presence of wildlife in their territories.

Attention to governance has promoted better linkages between area-based conservation measures and the surrounding landscapes and seascapes. Governance arrangements that fit their context nourish linkages to the wider landscape/seascape and help to connect to broader decision-making. Appropriate and responsive governance processes engage the rights-holders and stakeholders who live and work with the land and the sea and can address environmental issues outside the borders of area-based conservation measures. For example, in Australia, the Wilinggin, Dambimangari, Uunguu and Balanggarra Aboriginal groups work with the North Kimberley Fire Abatement project to set up businesses based on 'burning country the right way' to reduce greenhouse gas emissions under the Australian Government's Carbon Farming Initiative (KLC 2014) within and outside their Indigenous Protected Areas.
Attention to governance has been providing precious help in facing ongoing challenges and global change. Far from being immutable, area-based measures for conservation can be dynamic and adaptive processes, capable of responding to existing challenges and global change. Who could have foreseen, a decade ago, that in one of the poorest and most neglected regions of Senegal, grassroots conservation would restore mangroves and fish biodiversity, quadruple fish catch, inspire communities, convince regional and national authorities and shoot to international attention in just a few years (ICCA Registry 2012)? New area-based conservation measures such as these, which pioneer the merging of traditional and modern features and are based on governance by grassroots institutions, should be accepted with caution and on the basis of thorough analysis; but conservation must be open to them if it wishes to be visionary and nourish new energies and insights.

\section{Improving governance for sustainable living}

The focus on governance of protected areas that began in Durban in 2003 has helped to broaden the spectrum of legitimate actors and area-based measures in conservation, and stresses considerations of principles and values that produce concrete benefits for conservation. We are now ready to implement solutions, beyond established parameters and comfort zones, to improve governance for the conservation of nature- the basis for sustainable living on our planet.

But how does governance improve? In some cases, change comes from within, and in others, it is brought about by recriminations and conflicts from outside. Another possible way is through conscious collective analysis and planning. Numerous CBD decisions and IUCN resolutions and recommendations appear to encourage this last option, and a recent work, co-sponsored by the IUCN and CBD, offers a methodology to assess and evaluate governance and plan to improve it for systems of protected areas or individual sites (Borrini-Feyerabend et al. 2013).

A central novelty of the IUCN and CBD methodology is that it focuses clearly on landscapes, seascapes and conserved territories and areas, including but not limited to protected areas. What works, in practice, to conserve nature? Who can take the key governance decisions? What have we learned about rendering such decisions as informed, legitimate, fair, appropriate, prompt and as wise as possible? The methodology suggests that the concerned actors should approach these questions from an in-depth understanding of local natural and social history. Which 
species appear to grow and live well in the context? What major natural phenomena-animal migrations, water flows, regeneration processes - characterise it? How did people live there for generations? How did they cope with the seasons? Where did they build? What did they eat? What are the fundamental features of their culture, those that did not develop through imitation of distant others but by adaptation to the unique local environment? From an understanding of the ecological and social history and identity of the place, we can draw useful lessons about conservation as well as development. Are we seconding and allowing nature or are we impeding it? Are we trying to grow corn on dry land suitable for mobile pastoralism? Are we raising cattle on thin tropical soil? Are we planting eucalyptus or pines where chestnut or araucaria could thrive? Are we choking waterways, eroding hillsides, exhausting aquifers? What can we do to live well in tune with nature and not waste natural resources, going against the grain of nature?

Many cultural landscapes and seascapes in the world look aesthetically pleasing and filled with culture because they express the capacity of people to understand nature and thrive by following that understanding. Sometimes this involves leaving nature to follow its own course, like protecting a forest and using its resources in a careful and limited way. At other times people work hard to build terraces, channels, steps and pathways, orchards and gardens, pastures and wells. When they do that with respect, intelligence and care, both the landscape and the people benefit, and the results are immediately visible. They express a form of deep connectivity between people and nature, a mode of interaction that keeps distinctive nature alive, within and outside protected areas.

But, is such deeper connectivity related to governance? It seems bound to be. The hypothesis that immediately comes to mind is that only governance settings of appropriate type and rooted in the socioecological history of the place can nourish this type of connectivity; only learning through time can nourish its store of local knowledge, skills, decisions and institutions. This is an area for analysis and research, as measurable parameters to describe deep connectivity would need to be developed and studied in relation to governance diversity, quality and vitality.

In the meantime, a variety of innovative pathways towards the governance of nature for sustainable livingcombining human wellbeing and conservation of natureis being advanced and tested by peoples, communities, government agencies, researchers, enterprises, elders, spiritual leaders and citizens with intelligence, care and willingness to engage. These include:
- rethinking and reorganising the landscape and seascape into more coherent socioecological units

- assigning authority for development matters to ecosystem-wide authorities, responsible (and accountable) for conserving ecosystem functions and promoting social peace, economic equity and wellbeing

- providing recognition and incentives to a proliferation of conservation models, such as protected areas under any appropriate governance types, conserved areas, voluntary and ancillary conservation

- reviving the commons via securing collective rights to land and natural resources for the indigenous peoples and local communities strongly connected to them

- promoting deliberative and inclusive methods for environmental decision-making (for example, open discussion of alternatives via citizen juries, future searches, consensus conferences, polls, referendums, open comparison of scientific and traditional ecological knowledge, of business models and solidarity economies)

- promoting a sound business model to the environmental sector (for example, using financial incentives and disincentives to regulate behaviour, as in the 'polluter pays' principle for climate change)

- focusing attention on social justice and eradicating inequities based on gender, class, caste, ethnicity, race, etc.

- intensifying connections and feedback among decision-makers in different sectors and at different levels via major investments in information and communication

- applying to the conservation arena lessons drawn from innovative political movements throughout history and lessons about resilience in a variety of sectors (for example, education, health)

- promoting economic democracy with mechanisms such as participatory budgeting, citizen income (freedom from abject poverty and degrading conditions), community-based savings and loans (solidarity economy), high taxes on financial speculations, truly green innovative production and producer and consumer control over the market

- promoting information democracy by reform in the education sector (education for critical thinking and well-informed decision-making) and the communication sector (investigative journalism, news pluralism, regulation of media businesses)

- developing community plans towards living well-including about local production of food 


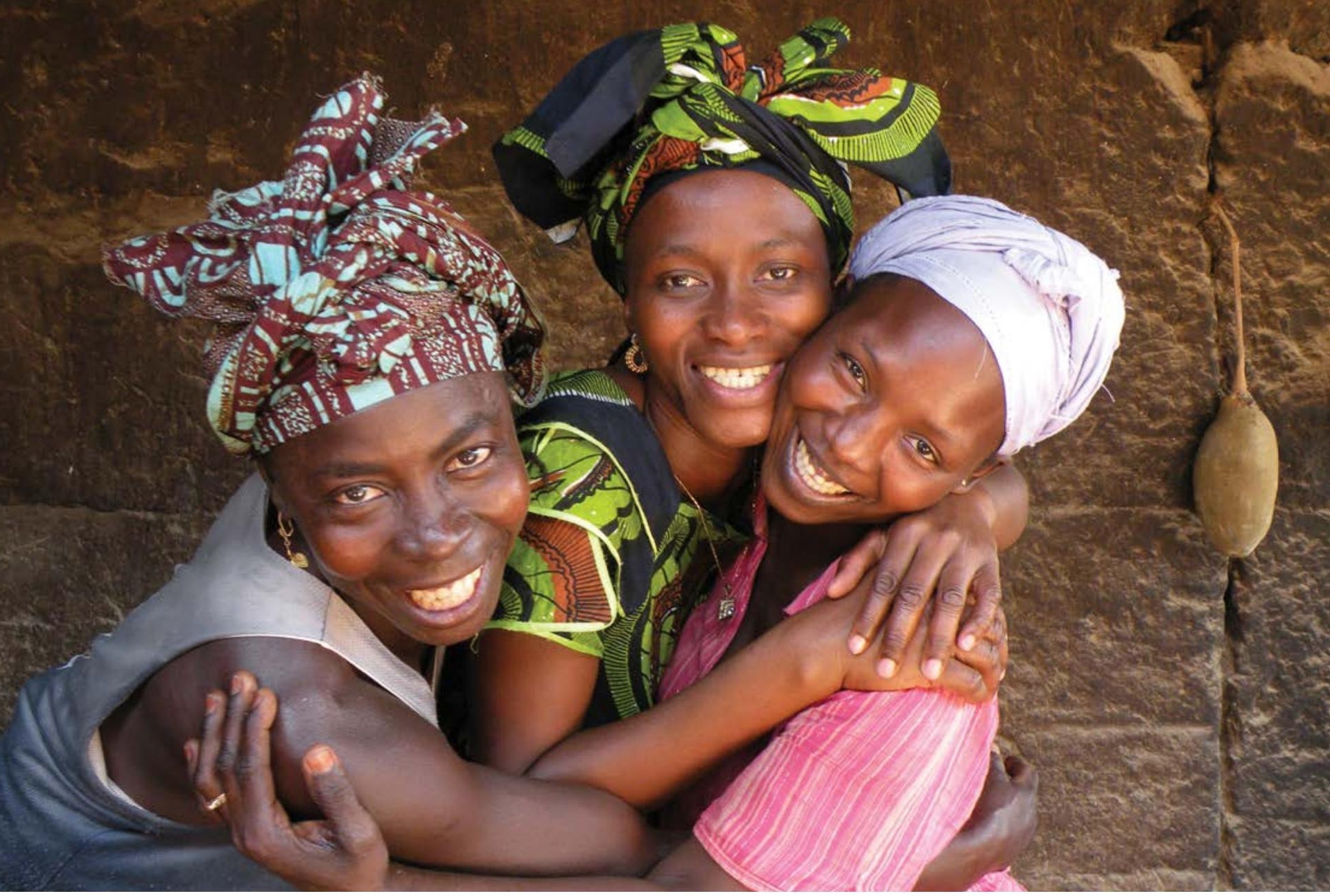

Enhanced solidarity is a by-product of successful community conservation initiatives

in Casamance, Senegal

Source: Grazia Borrini-Feyerabend

and satisfaction of basic needs-and exchanging, comparing and integrating those at various levels

- improving policymaking by mandatory participatory research and planning, affirmative action to redistribute authority and responsibilities (for example, to compensate for gender discrimination), and clear mechanisms for accountability

- supporting environmental agencies to promote an internal learning culture so as to become flat, responsive organisations that offer incentives for engagement and innovation

- ensuring a measure of direct democracy, by which people always have a chance to engage in taking the key decisions the consequences of which are primarily felt by them, but also to assume their responsibilities towards society in general and the constitutional principles upon which society is founded.

\section{Conclusion}

On the eve of the World Parks Congress in Durban in 2003, governance questions began to be broadly examined for protected areas throughout the world. Building upon initial insights, in the following decade it became possible to develop a system of governance types and recommended adherence to good governance principles that are slowly but steadily being embraced by the country parties to the CBD. Today, the visible face of enhanced diversity and quality of governance for conservation of nature is apparent in new and emerging actors and collaborations, new policies being approved, and new practices taking root on the ground. In the space of a few years, this has enlarged the coverage of protected areas, and improved the effectiveness and efficiency of management and equity of decisions. It has also provided better links with surrounding landscapes and seascapes and precious help in facing ongoing challenges and global change. A flurry of ideas and pathways-in combination or as alternatives-is also emerging to foster governance vitality and learning-by-doing for the conservation of nature.

Yet we need to remain careful. All stakeholders cannot have an equal say in matters crucial for livelihoods and conservation. Equity is not equality, and existing rights, the quantity and quality of engagement and fair compensation cannot be pushed aside. Similarly, a sense of governance stability is necessary. Adaptive governance is needed, but constant change, rules that are not dependable and lack of security for investments generate chaos. Subsidiarity and attention to contexts 
and respect for local cultures and values are important, but so is the common good, including viable ecosystems and a stable climate, as are universal human values, such as those that put a brake on greed, selfishness and violent and destructive behaviours. People with diverse values, opposing interpretations of the world and divergent interests need to be heard and engaged in dialogues, but conflicting values and visions for the future cannot be pursued together. Decisions must be taken and maintained through time for governance to have coherent results.

How do we strike a balance between fairness and acquired rights, stability and innovation, local meaning and values and broader liberating principles? We suggest a 'human rights-based approach', by which a multiplicity of procedural and substantive rights is respected. But we also suggest that the effectiveness of decision-making and the rule of law are secured, and that rights are always balanced by responsibilities, including towards the rights of future generations and the rights of nature. There is no recipe to ensure that, but lessons and insights are accumulating in learning-by-doing processes throughout the world. In conscious and participatory efforts towards enhancing its own diversity, quality and vitality, governance can unfold at its best for the conservation of nature.

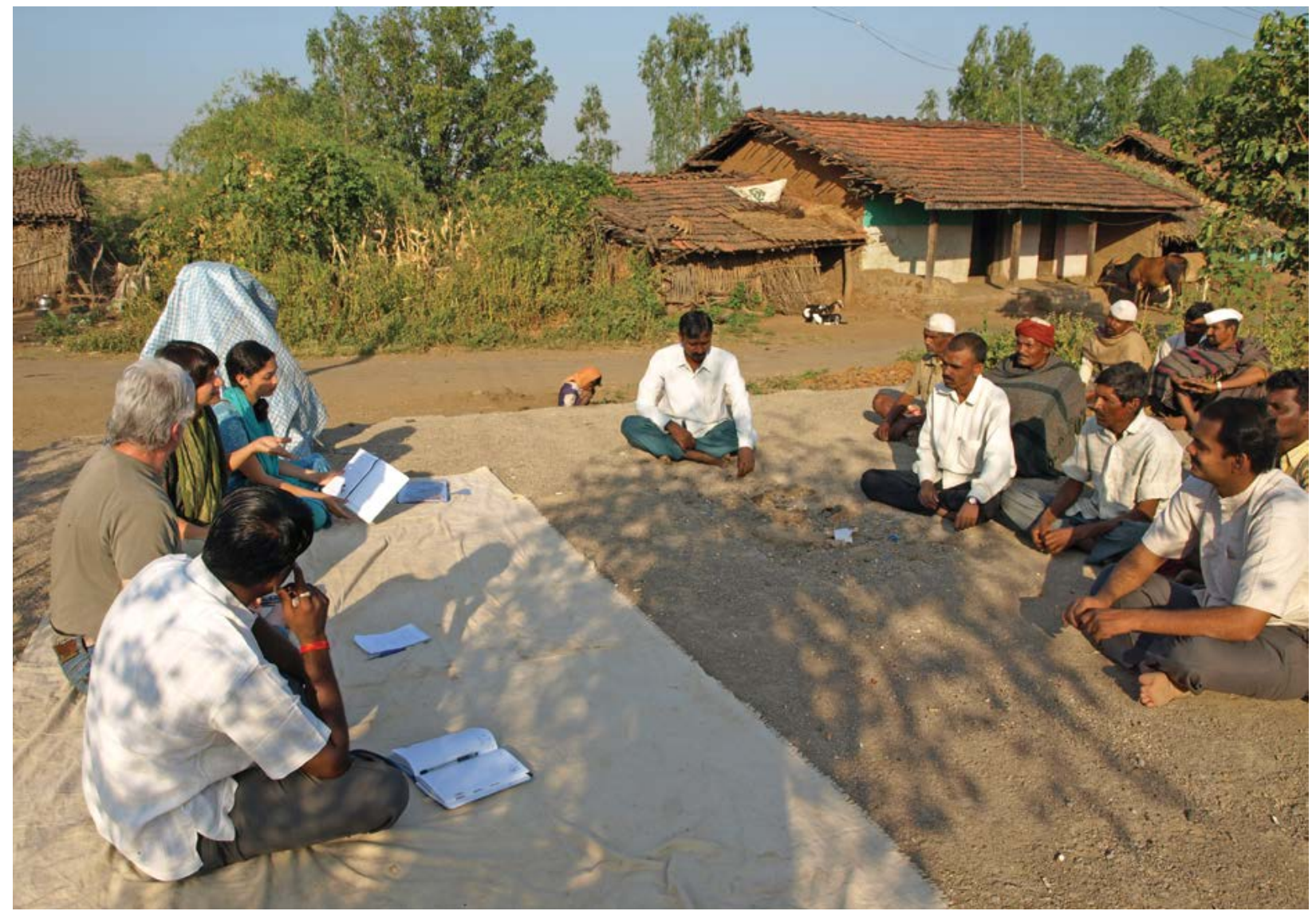

Meeting between visitors Neema Pathak and Michael Lockwood and villagers/custodians at Baripada near Pune, India, to hear about the conservation management of the area including how catchment protection and restoration work had improved the reliability of the local water supply and the subsequent benefits for cropping.

Source: Graeme L. Worboys 


\section{References}

Recommended reading

Alcorn, J., Luque, A. and Weisman, W. (2005) 'Nongovernmental organisations and protected area governance', in D. Pansky (ed.) Governance Stream of the Vth World Parks Congress, Parks Canada and IUCN WCPA, Ottawa.

Anderson, P. (2003) The contributions made by private game reserves and landowners to conservation in South Africa, Presentation in the governance stream to Benefits beyond Boundaries, Fifth World Parks Conference, 8-17 September, Durban.

Aparicio, M. (2002) Los Pueblos Indigenas y el Estado [Indigenous Peoples and the State], Cedes Editorial, Barcelona.

Berkes, F. (2004) 'Rethinking community-based conservation', Conservation Biology 18(3): 621-30.

Borrini-Feyerabend, G. and Dudley, N. (2005) Les Aires Protégées à Madagascar: bâtir le système à partir de la base [Protected areas in Madagascar: building the system from the ground up], Report for IUCN and SAPM Commission, IUCN WCPA/CEESP, Gland.

DDd Borrini-Feyerabend, G., Dudley, N., Jaeger, T., Lassen, B., Broome, N. P., Phillips, A. and Sandwith, T. (2013) Governance of Protected Areas: From understanding to action, IUCN, Gland.

Borrini-Feyerabend, G., Pimbert, M., Farvar, M. T., Kothari, A. and Renard, Y. (2004) Sharing Power: Learning by doing in co-management of natural resources throughout the world, IIED and IUCN CEESP/CMWG, Cenesta, Tehran.

Borrini-Feyerabend, G., Lassen, B., Stevens, S., Martin, G., Riasco de la Pena, J. C., Raez-Luna, E. F. and Farvar, T. (2010) Biocultural Diversity Conserved by Indigenous Peoples and Local Communities, ICCA Consortium and Cenesta for GEF SGP, GTZ, IIED and IUCN CEESP, Tehran.

Bravo, M. and Heylings, P. (2002) 'Sistema de manejo participativo de la Reserve Marina de Galapagosactividades en 2001 y resultados de la primera evaluacion participativa [Shared governance system of Galapagos Marine Reserve-activities in 2001 and results of the first participatory evaluation]', Policy Matters 10: 115-20.
Cash, D. W. and Moser, S. C. (2000) 'Linking global and local scales: designing dynamic assessment and management processes', Global Environmental Change 10(2): 109-20.

Convention on Biological Diversity (CBD) (1992) Convention on Biological Diversity, United Nations New York.

Convention on Biological Diversity (CBD) (2010) Global Biodiversity Outlook 3, Secretariat of the Convention on Biological Diversity, Montreal.

Convention on Biological Diversity (CBD) (2011) Strategic Plan for Biodiversity 2011-2020 and the Aichi Targets, Secretariat of the Convention on Biological Diversity, Montreal.

Crutzen, P. J. (2006) 'The "anthropocene", in E. Ehlers and T. Krafft (eds) Earth System Science in the Anthropocene, pp. 13-18, Springer, Berlin and Heidelberg.

Dearden, P., Bennett, M. and Johnston, J. (2005)

'Trends in global protected area governance, 19922002', Environmental Management 36(1): 89-100.

Diegues, A. C. (n.d.) The Myth of Wilderness in the Brazilian Rainforest. <www.iccaconsortium.org/wpcontent/uploads/images/stories/Database/myth\%20 final.pdfs

Dudley, N. (2008) Guidelines for Applying Protected Area Management Categories, IUCN, Gland.

Eagles, P. F. J. (2009) 'Governance of recreation and tourism partnerships in parks and protected areas', Journal of Sustainable Tourism 17(2): 231-48.

Estifania, E., de Vera, P., Lucero-Diola, F. and Silang, P. (eds) (2012) Nature Conservation in the Footsteps of Our Ancestors. Proceedings of the First National Conference on Indigenous Community Conserved Areas (ICCAs) in the Philippines, University of the Philippines National College of Public Administration and Governance and Protected Areas and Wildlife Bureau in partnership with NewCAPP Project, UNDP-GEF, Manila. <www.google. $\mathrm{com} /$ url? sa $=\mathrm{t} \& \mathrm{rct}=\mathrm{j} \& \mathrm{q}=\&$ esrc $=\mathrm{s} \& \mathrm{frm}=1 \&$ source $=\mathrm{w}$ eb\&cd $=6 \& \mathrm{cad}=\mathrm{rja} \&$ uact $=8 \& \mathrm{ved}=0 \mathrm{CEAQFjAF \& u}$ $\mathrm{rl}=\mathrm{http} \% 3 \mathrm{~A} \% 2 \mathrm{~F} \% 2 \mathrm{Fwww}$.newcapp.org\%2Fimages \%2Fwhatsnew\%2Fdownload\%2F1008201203294 9ICCA\%2520Conference.pdf\&ei=pTInU62fGofn4 QSorYCgBA\&usg=AFQjCNFh85567UHG0UFxu OT-ZCsdlQxNBQ\&bvm=bv.62922401,d.bGE> 
Fairhead, J., Leach, M. and Scoones, I. (2012) 'Green grabbing: a new appropriation of nature?', Journal of Peasant Studies 39(2): 237-61.

Farrier, D. and Adams, M. (2011) 'Indigenousgovernment co-management of protected areas: Booderee National Park and the national framework in Australia', in B. Lausche and F. Burhenne (eds) Guidelines for Protected Area Legislation, IUCN, Gland.

Folke, C. (2006) 'Resilience: the emergence of a perspective for social-ecological systems analyses', Global Environmental Change 16(3): 253-67.

Goudie, A. (1990) The Human Impact on the Natural Environment, Basil Blackwell, Oxford.

Graham, J., Amos, B. and Plumptre, T. (2003) Governance principles for protected areas in the 21st century, Discussion Paper, Institute on Governance in collaboration with Parks Canada and Canadian International Development Agency, Ottawa.

Hansen, J., Kharecha, P., Sato, M., Masson-Delmotte, V., Ackerman, F., Beerling, D. J., Hearty, P. J., Hoegh-Guldberg, O., Hsu, S.-L., Parmesan, C., Rockstrom, J., Rohling, E. J., Sachs, J., Smith, P., Steffen, K., van Susteren, L., von Schuckmann, $\mathrm{K}$. and Zachos, J. C. (2013) 'Assessing "dangerous climate change": required reduction of carbon emissions to protect young people, future generations and nature', Plos One 8(2).

Hill, R., Williams, K. J., Pert, P. L., Robinson, C. J., Dale, A. P., Westcott, D. A., Grace, R. A. and O'Malley, T. (2010) 'Adaptive community-based biodiversity conservation in Australia's tropical rainforests', Environmental Conservation 37(1): 73-82.

Hill, R., Grant, C., George, M., Robinson, C. J., Jackson, S. and Abel, N. (2012) 'A typology of Indigenous engagement in Australian environmental management: implications for knowledge integration and social-ecological system sustainability', Ecology and Society 17(1): 23. <dx. doi.org/10.5751/ES-04587-170123>

Hill, R., Maclean, K., Pert, P. L., Rist, P., Joyce, A., Schmider, J. and Tawake, L. (2013a) Participatory evaluation of co-management in wet tropics country. Interim report, Report to the National Environmental Research Program, Reef and Rainforest Research Centre Limited, Cairns, Queensland.
Hill, R., Halamish, E., Gordon, I. J. and Clark, M. (2013b) 'The maturation of biodiversity as a global social-ecological issue and implications for future biodiversity science and policy', Futures 46(1): 41-9.

Holling, C. S. (ed.) (1978) Adaptive Environmental Assessment and Management, John Wiley \& Sons, New York.

ICCA Registry (2012) 'Association Kawawana', ICCA Registry 2012, UNEP-WCMC, Cambridge. $<w w w . i c c a r e g i s t r y . o r g / e n / s i t e s / 26>$

International Labour Organisation (ILO) (1989) Convention No. 169, International Labour Organisation, Geneva. <www.ilo.org/indigenous/ Conventions/no169/lang--en/index.htm>

International Union for Conservation of Nature World Commission on Protected Areas (IUCN WCPA) (2013) Global Transboundary Conservation Network, [Online], IUCN, Gland. <www.tbpa.net/page. php?ndx=83>

Johnston, J. (2006) Information for G. BorriniFeyerabend, J. Johnston and D. Pansky, 'Governance of protected areas', in M. Lockwood, A. Kothari and G. L. Worboys (eds) Managing Protected Areas: A global guide, p. 139, Earthscan, London.

Katz, E. (2010) Land Tenure, Property Rights, and Natural Resource Management: Land tenure and property rights reform in the developing world - who is vulnerable, United States Agency for International Development, Burlington, VT.

Kimberley Land Council (KLC) (2014) North Kimberley Ranger Groups and Aboriginal Corporations Discuss Carbon Business, Kimberley Land Council, Broome, WA. <klc.org.au/2013/01/23/ north-kimberley-ranger-groups-and-aboriginalcorporations-discuss-carbon-business/>

Kothari, A. (2006) 'Community conserved areas: towards ecological and livelihood security', PARKS 16(1): 3-13.

Dd Kothari, A., Corrigan, C., Jonas, H., Neumann, A. and Shrumm, H. (eds) (2012) Recognising and Supporting Territories and Areas Conserved by Indigenous Peoples and Local Communities: Global overview and national case studies, Technical Series No. 64, Secretariat of the Convention on Biological Diversity, ICCA Consortium, Kalpavriksh and Natural Justice, Montreal. 
Langholz, J. A. and Krug, W. (2004) 'New forms of biodiversity governance: non-state actors and the private protected area action plan', Journal of International Wildlife Law and Policy 7(1-2): 9-29.

Lausche, B. and Burhenne, F. (2011) Guidelines for Protected Area Legislation, IUCN, Gland.

Lausche, B., Farrier, D., Verchuuren, J., La Vina, A. G. M., Trouwborst, A., Born, C. H. and Aug, L. (2013) The legal aspects of connectivity conservation: a concept paper, IUCN, Gland.

Lebel, L., Anderies, J. M., Campbell, B., Folke, C., Hatfield-Dodds, S., Hughes, T. P. and Wilson, J. (2006) 'Governance and the capacity to manage resilience in regional social-ecological systems', Ecology and Society 11(1): 21.

Leverington, F., Costa, K. L., Pavese, H., Lisle, A. and Hockings, M. (2010) 'A global analysis of protected area management effectiveness', Environmental Management 46(5): 685-98.

Lim, T. M. (2012) ICCA recognition in the Philippines and its role in the achievement of Aichi Targets, Presentation delivered at the CBD Colloquium on ICCAs, CBD COP 11, Hyderabad, India, 13 October.

Madagascar Protected Area System (SAPM) (2009) Capitalisation des expériences et des acquis en matière de gouvernance des aires protégées en cogestion et des aires protégées communautaires à Madagascar [Learning from Experience and Advances about Governance of Co-Managed Protected Areas and ICCAs in Madagascar], Ministry of Environment, Forests and Tourism of Madagascar, Antananarivo.

Ministry of Environment of Ecuador (2006) Politicas y Plan Estratégico del Sistema Nacional de Áreas Protegidas 2007-2016 [Policy and Strategic Plan for the National System of Protected Areas 2007-2010], Proyecto Sistema Nacional de Áreas Protegidas (SNAP-GEF), Quito.

Mitchell, B. A. and Brown, J. L. (1998) 'Stewardship: a working definition', Environments 26(1): 8-17.

Murphree, M. (2000) Boundaries and borders: the question of scale in the theory and practice of common property management, Paper presented to the Eighth IASCP Conference, Bloomington, Indiana, 31 May - 4 June.
Namibian Association of CBNRM Support Organisations (NACSO) (2013) The State of Community Conservation in Namibia, NACSO, Windhoek.

Nelson, R., Howden, M. and Smith, M. S. (2008) 'Using adaptive governance to rethink the way science supports Australian drought policy', Environmental Science and Policy 11(7): 588-601.

Ostrom, E. and Nagendra, H. (2006) 'Insights on linking forests, trees, and people from the air, on the ground, and in the laboratory', Proceedings of the National Academy of Sciences of the United States of America 103(5): 19 224-31.

Paterson, A. R. (2010) 'Clearing or clouding the discourse - a South African perspective on the utility of the IUCN protected areas governance typology', South African Law Journal 127(3): 490-514.

Paterson, A. R. (2011) Bridging the gap between conservation and land reform: communallyconserved areas as a tool for managing South Africa's natural commons, Thesis, Department of Public Law, University of Cape Town, South Africa.

Posey, D. A. (ed.) (1999) Cultural and Spiritual Values of Biodiversity, UNEP, Nairobi, and Intermediate Technology Publications, London.

Rose, D. B. (1996) Nourishing Terrains: Australian Aboriginal views of landscapes and wilderness, Australian Heritage Commission, Canberra.

Rose, D. B. (2013) 'Indigenous Protected Areas innovation beyond the boundaries'. <www.nature. org/cs/groups/webcontent/@web/@australia/ documents/document/prd_062372.pdf>

Sandwith, T., Shine, C., Hamilton, L. and Sheppard, D. (2001) Transboundary Protected Areas for Peace and Cooperation, IUCN, Gland.

Simonsen, S. H., Biggs, R., Schlüter, M., Schoon, M., Bohensky, E. L., Cundill, G., Dakos, V., Dayw, T., Kotschy, K., Leitch, A. M., Qunilan, A., Peterson, G. and Moberg, F. (2014) Applying Resilience Thinking. Seven principles for building resilience in social-ecological systems, Stockholm Resilience Centre, Stockholm. 
Stanciu, E. and Ioniță, A. (2013) Governance of Protected Areas in Eastern Europe. Overview on different governance types, case studies and lessons learned, Study commissioned to ProPark, Romania, by the German Federal Agency for Nature Conservation BfN, Skripten Braşov, Romania.

Stevens, S. and Pathak-Broome, N. (2014) Appropriate recognition and respect for indigenous peoples' and community conserved territories and areas which overlap protected areas, Draft manuscript for the ICCA Consortium.

Tilman, D., Balzer, C., Hill, J. and Befort, B. L. (2011) 'Global food demand and the sustainable intensification of agriculture', Proceedings of the National Academy of Sciences of the United States of America 108(50): 20 260-4.

United Nations Development Programme (UNDP) (1997) Governance for Sustainable Human Development: A UNDP policy document, United Nations Development Programme, New York.

United Nations Development Programme (UNDP) (1999) Human Development Report 1999:

Globalisation with a human face, United Nations Development Programme, New York.

United Nations Development Programme (UNDP) (2002) Human Development Report 2002: Deepening democracy in a fragmented world, United Nations Development Programme, New York.

United Nations Environment Program (UNEP), International Union for Conservation of Nature (IUCN) and World Wildlife Fund (WWF) (1980) World Conservation Strategy, IUCN Online, Gland. $<$ data.iucn.org/dbtw-wpd/edocs/WCS-004.pdf>

Walters, C. (1986) Adaptive Management of Renewable Resources, Macmillan, New York.

Western Ghats Ecology Expert Panel (2011) Report of the Western Ghats Ecology Expert Panel. Part I, Submitted to the Ministry of Environment and Forests of India. <moef.nic.in/downloads/publicinformation/wg-23052012.pdf>

Woodley, S., Bertzky, B., Crawhall, N., Dudley, N., Miranda Londoño, J., MacKinnon, K., Redford, K. and Sandwith, T. (2012) 'Meeting Aichi Target 11: what does success look like for protected area systems?', PARKS 18(1): 24-34.
Wyborn, C. and Bixler, R. P. (2013) 'Collaboration and nested environmental governance: scale dependency, scale framing, and cross-scale interactions in collaborative conservation', Journal of Environmental Management 123(1): 58-67.

Young, I. M. (2001) 'Activist challenges to deliberative democracy', Political Theory 29(5): 670-90.

Young, O. R., Berkhout, F., Gallopin, G. C., Janssen, M. A., Ostrom, E. and Leeuw, S. V. D. (2006) 'The globalization of socio-ecological systems: an agenda for scientific research', Global Environmental Change-Human and Policy Dimensions 16(3): 304-16. 

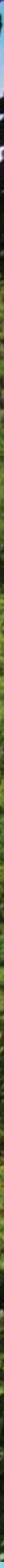

\section{CHAPTER 8}

\section{MANAGING PROTECTED AREAS}

Principal author:

Graeme L. Worboys

\section{Supporting author:}

Ted Trzyna

\section{CONTENTS}

- Introduction

- The need for management

- Management: Definition and functions

- Strategic management

- Frameworks and tools

- Managing protected area systems

- Management guidance for IUCN protected area categories

- Management for protected area governance types

- Managing protected areas in special contexts

- Conclusion

- References

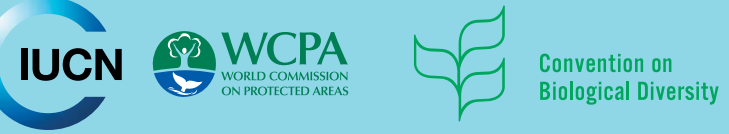




\section{PRINCIPAL AUTHOR}

GRAEME L. WORBOYS is Co-Vice-Chair, Connectivity Conservation and Mountains, International Union for Conservation of Nature World Commission on Protected Areas, and an Adjunct Fellow at the Fenner School, The Australian National University.

\section{SUPPORTING AUTHOR}

TED TRZYNA is Chair of the IUCN WCPA Urban Specialist Group and President of the InterEnvironment Institute, an affiliate of Claremont Graduate University in California, USA.

\section{ACKNOWLEDGMENTS}

Michael Lockwood and Ashish Kothari are thanked for reviewing an earlier draft of this chapter. Appreciation is expressed to Nitin D. Rai, Ankila J. Hiremath, Siddappa Setty and Michael Treanor for their contributions to this chapter.

\section{CITATION}

Worboys, G. L. and Trzyna, T. (2015) 'Managing protected areas', in G. L. Worboys, M. Lockwood, A. Kothari, S. Feary and I. Pulsford (eds) Protected Area Governance and Management, pp. 207-250, ANU Press, Canberra.

\section{TITLE PAGE PHOTO}

Entrance to Kayangan Lake, Coron Island, Philippines, a formal 'ancestral domain' of the Tagbanwa people, one of the oldest ethnic groups in the Philippines: the protected area is also recognised as a national reserve and a marine reserve Source: Ashish Kothari 


\section{Introduction}

'Managing protected areas' is a fundamental chapter for protected area practitioners and policymakers. As with governance (Chapter 7 ), it is a basic building block of supporting information essential for the professional management of protected areas. This chapter primarily focuses on large protected area management organisations including government agencies, nongovernmental organisations (NGOs) and private organisations. In adopting this focus, we recognise that for many Indigenous Peoples' and Community Conserved Territories and Areas (ICCAs), management is less formal, with planning undocumented and part of everyday decisions by communities that are evolving, informal and intuitive (Kothari, pers. comm.). The principles and practices described in this chapter are, however, broadly relevant to all protected areas, and we indicate specific aspects that are relevant to ICCAs, individual land managers and those acting for small organisations. This chapter also emphasises, for all governance types, the need for active protected area management to achieve conservation outcomes.

The chapter presents some management theory in providing a definition for management that includes its four core functions. We introduce strategic management considerations, planning frameworks and many support tools and frameworks to assist practitioners to improve management effectiveness and inspire further innovation. Management for national systems of protected areas is considered. These systems may include government and private protected areas and ICCAs. For individual protected areas, management guidance has been provided for each of the six International Union for Conservation of Nature (IUCN) protected area management categories. Management considerations for working with officials and other people who are living, working and using protected areas are also presented. Different governance arrangements need different approaches to management, and the management associated with four governance types recognised by the IUCN is described, including working and operating within a government protected area system, shared governance arrangements, and introductions to private protected areas and ICCA governance arrangements. Protected areas are also established in special contexts, and reserves within or near urban areas, such as Category II protected areas, are also described.

\section{The need for management}

In mid 2014, some 15.4 per cent of the terrestrial surface of Earth and 3.4 per cent of global ocean area, which included 8.4 per cent of marine areas under national jurisdiction, had been officially recognised as protected areas (UNEP-WCMC 2014). These protected areas need constant and effective management to respond to multiple issues and land and sea management responsibilities. Such management is an investment in healthy environments, biodiversity conservation, other natural heritage conservation, cultural heritage conservation and healthy people.

\section{Active management}

Protected areas constantly face threats such as climate change effects, introduced species, visitor impacts, vandalism, poaching, pollution events, development and extractive activities, civil unrest, incidents such as extreme storms and wildfire events and other issues. Being responsive in a planned and effective way is critical. Protected area practitioners undertake many other tasks such as species management, anti-poaching patrolling, providing for visitor services, dealing with emergencies, research and monitoring, and restoration work. At the government policy level, responses to development threats to protected areas need to be made. Social, economic and environmental outcomes from active and responsive protected area management benefit visitors, neighbours, researchers, local communities, businesses, private organisations, governments and future generations.

\section{Land-use changes}

With the growth in the number of protected areas, and recommendations by the Convention on Biological Diversity (CBD) for further increases, there are usually social and political issues associated with such land-use change that need to be managed. Protected areas are a relatively new concept (Chapter 2), and in the 2010s there are many individuals, neighbours and communities who are directly experiencing this land use for the first time. This is a change for people, and settling in a new protected area land use will take time. Acceptance for some may be immediate or it may take time and active on-ground management, and constantly working with and participating in management with communities and neighbours will be critical. For other areas such as ICCAs, securing protected area status would probably mean conservation land-use practices undertaken for 


\section{The 'planning' function}

Planning is a key function of management. It is based on the very best environmental, social, cultural, historical, managerial and political context information and, by including modelling and analysis of data, planning can identify both preferred futures and the circumstances and conditions within which they may be facilitated. Three levels of planning are recognised for large protected area organisations.

1. Strategic planning: Typically these plans are whole-of-protected area organisation in their application and define the long-term goals sought.

2. Tactical plans: These plans help to implement a strategic plan. They provide order and priorities in implementing organisational goals for a functional area or a geographic part of a protected area system.

3. Operational plans: These are quite specific documents. They may be prepared to implement individual projects or the actions of a protected area organisational unit consistent with the organisation's goals and priorities.

Planning is typically undertaken for most protected area management activities and it is specifically discussed in Chapter 13 and within chapters including planning for visitors (Chapter 23), operations (Chapter 24) and incidents (Chapter 26).

\section{The 'organising' function}

A management action needs to be thoroughly planned, but it is the 'organising function' that efficiently and effectively marshals and coordinates the expertise, material resources, equipment and support services such as transport, accommodation and safety support, which are necessary to undertake an action. The routine operations of protected area managers require them to be constantly responding to visitor services, cooperative actions with neighbours and communities, policing tasks and incidents and emergencies. Governance arrangements, especially organisational structures, should support this ongoing need.

For organisations managing national systems of protected areas, five competency levels have been recognised by the IUCN (Box 8.1). In organising staff as part of a management response, appreciation of these five levels is most important. For the purposes of this chapter, we have described key protected area staff as frontline staff (field-based staff of at least Level 2); middle-level staff (middle-level experienced staff who have supervisory responsibilities or technical specialist competencies,

\section{Box 8.1 Global protected area competencies}

The IUCN has initiated a Global Partnership for Professionalising Protected Area Management Development and part of its work has been the development of international competence standards for five levels of protected area professionals (Chapter 9).

\section{Level 5 Executive}

Competencies relate mainly to activities that involve strategising and directing for an entire protected area system and promoting and supporting the system nationally and internationally. These competencies involve processes more than individual skills. Responsibilities would include national and regional policy development and spatial and strategic planning. They would be responsible for the direction of complex programs and plans.

\section{Level 4 Senior manager}

Competencies relate mainly to activities that involve planning, managing and decision-making. Level 4 staff may direct and manage medium-sized organisations. Their work could include the planning and management of projects and programs within strategic frameworks and they may conduct and implement specific and technical assignments according to technical specialty that requires a combination of technical and theoretical training and the opportunity to apply what has been learnt in the workplace in the course of a management cycle.

\section{Level 3 Middle manager, technical specialist}

Competencies relate to groups of technical skills and tasks that require organisation, supervision and decision-making. They are responsible for the organisation and leadership of technical sections and teams implementing plans and projects. They may complete specific and technical assignments requiring some technical ability and responsibility, which will require technical and theoretical training followed by opportunities to practise and gain experience in the workplace.

\section{Level 2 Skilled worker with some supervisory responsibilities}

Competencies relate to single or relatively small sets of practical skills that could be taught or learnt in the workplace or on short courses. Workers complete mainly practical tasks and assignments requiring some technical ability and responsibility.

\section{Level 1 Unskilled labourer}

Unskilled labourers complete practical tasks under continuous supervision.

Source: Appleton (2013) 
typically at Level 3); and top-level staff who ultimately have responsibility for parts of an organisation or an entire organisation (Levels 4 and 5) (Box 8.1). It should be noted also that this book has focused on providing information in support of protected area practitioner Levels 2 to 5 (see Chapter 1). These staff may operate in any governance setting, but the information supplied is particularly targeted to formal protected area organisations. Additional practical, vocationalbased capacity development and approaches taken by communities in managing ICCAs would complement the information provided by this book.

\section{The 'leading' (directing) function}

The leading function involves people influencing other people to assist achieving tasks and actions that help meet an organisation's objectives. This function has also been described as the 'directing' function (Hitt et al. 2011), though this title is perhaps too militaristic for contemporary protected area management. The leading function may be manifest in many ways at a person-toperson level depending on the nature of the management action, the situational context for the action and the background, experience and competencies of the people concerned (Chapter 12). A leader may use a range of approaches that includes motivation, communication and working with groups or teams. At the wholeof-organisation level, the leading function may be guided by a range of considerations such as judgment in decision-making and the inherent characteristics of institutions to enable the adaptive capacity of society and the potential for institutional design improvement (Gupta et al. 2010).

For any given action, protected area management staff appreciate being briefed on the strategic organisational context of a proposed action, why it is important, what their role is and what outcomes are expected. This communication is typically inspiring, since staff appreciate that they have been briefed, that their work contribution is meaningful and that it will be 'value-adding' to the organisation's mission. Even with some cultural traditions that are highly respectful of organisational hierarchies, this two-way protected area leadership communication is wise, since experienced staff responsible for undertaking tasks nearly always have contributions that improve the implementation. This interactive and teamwork focus for protected area leadership is common and helps to spawn creativity and innovation in the workplace. It also strongly reflects the necessity of protected area staff to work as teams in responding to matters such as threats (Chapter 16), incidents (Chapter 26), park operations (Chapter 24) and dealing with visitors (Chapter 23).

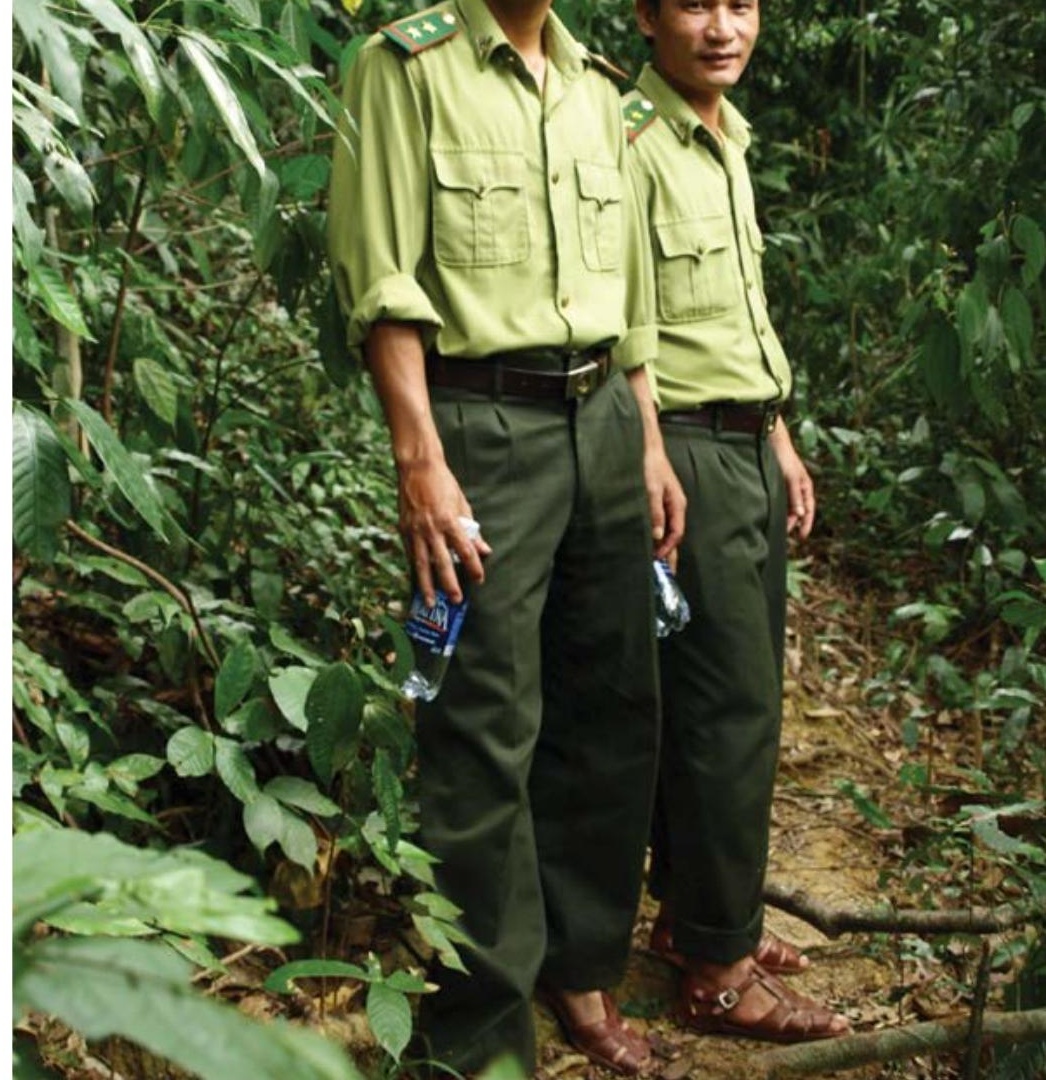

Protected area staff, Phong Nha-Ke Bang National Park World Heritage Property, Vietnam: these protected area practitioners play a key role in protecting the forest from illegal logging as well as other duties

Source: Graeme L. Worboys

This leadership is also manifest by top-level and middlelevel staff taking an interest in the progress of operations, including talking to frontline staff and receiving firsthand feedback and potentially even resolving immediately small but annoying perturbations in an otherwise smooth project implementation.

\section{The 'evaluating' function}

Planning for management actions should identify an evaluation process that reviews the progress of implementation against predetermined objectives and standards. The evaluation function responds to this requirement. Evaluation may identify if milestones have been met during the course of an action or whether an output or outcome has been achieved. These milestones could, for example, be framed according to financial management targets; operational milestones; safety, construction and quality standards; efficiency and effectiveness of management processes; and environmental sustainability indicators. Such assessment measures should be planned before a project commences, with evaluation data collected as a management action 
is implemented. This constant (routine) reviewing of performance against predetermined standards or objectives provides the basis for any necessary corrective actions to be implemented.

The evaluation function is important whether the action is undertaken as part of a large protected area organisation's program or whether it is a private protected area or an ICCA. How it is undertaken will vary between these different governance environments.

\section{Strategic management}

Strategic management for a large protected area organisation is typically guided by an inspirational 'vision' of the desired future of the organisation and of the lands, waters and natural and cultural heritage for which the organisation is responsible. It is also guided by an articulated and clear purpose for its work (or a mission); a discrete set of management goals that succinctly articulate how the organisation's preferred outcomes will be achieved; and a suite of prioritised (strategic) wholeof-organisation actions that are designed to achieve the desired goals. Once established, this direction needs to be subject to ongoing scrutiny and, as appropriate, refinement and adjustment.

The strategic management positioning is based on careful thinking, careful research and considerable planning effort. For a large protected area organisation, in addition to a vision and a mission, it may include preparing strategic plans such as a corporate strategy, a business plan and functional strategies. We discuss these strategic management investments further.

\section{Understanding the operating environment}

Understanding a protected area organisation's operating environment includes:

- comprehending the historical, sociocultural, economic and political contexts

- identifying statutory legislation requirements, the needs of the government, board of management determinations and the needs of local communities

- identifying the natural and cultural heritage values to be protected and their significance

- assessing threats and the condition and trend in condition of the natural and cultural heritage resources to be managed
- reviewing the internal operating environment and the capacity of the protected area organisation to manage including considerations from all four functions of management

- researching and analysing trends in the operating environment

- responding to management effectiveness evaluation of protected areas such as state of the parks reporting, independent audits, government inquiries, parliamentary inquiries and the findings of court hearings

- a need to work nationally and internationally and to share and globalise conservation efforts to help achieve biodiversity conservation outcomes.

\section{Vision statement}

A vision statement answers the question 'what do we want to become?' (Lockwood 2006). It is the vision statement that communicates to staff and to others the very clear aspirational direction of an organisation. For example, New Zealand's Department of Conservation (DOC), which administers New Zealand's protected area system as well as other environmental and conservation responsibilities, expresses its vision statement in a positive and proactive way. Importantly, supplementary information also articulates the intended interpretation of the vision statement:

New Zealand is the greatest living space on Earth

Kāore he wāhi i tua atu i a Aotearoa, hei wahi noho $i$ te ao

By 'living space' we're talking about our physical environment and the people, plants and animals that it supports

By 'greatest' we mean New Zealand being the best it can be-a country that prospers socially, economically and environmentally. (DOC 2013:1)

\section{Mission statement}

A mission statement is a statement of purpose that is enduring (Lockwood 2006). It differs from the vision statement by focusing exclusively on the organisation. Such a statement provides clarity for staff and for others about what a protected area organisation is trying to achieve and the scope of the organisation's products and services. It provides order, direction and organisational priorities. In continuing our example from New Zealand, 
the DOC provides a statement of its purpose (mission), followed by a clarification of how this statement is to be interpreted:

Conservation leadership for a prosperous New Zealand

By 'prosperous New Zealand' we mean a country that is flourishing socially, economically and environmentally.

(DOC 2013:1)

\section{Strategic planning}

Strategic planning underpins an organisation's strategic management and helps define organisational goals within the context of the vision and mission. Development of strategic plans involves protected area top-level managers and a planning process that may use a 'strengths, weaknesses, opportunities and threats' (SWOT) analysis. Given its useful role, SWOT analysis is described in Figure 8.1.

Three types of strategic planning documents may be developed by organisations which use such SWOT processes: a corporate strategy, a business strategy and functional strategies (Robbins et al. 2012).

\section{Corporate strategy}

A corporate strategy identifies the nature of a protected area organisation's priority goals in the context of its mission, vision and goals, and broader government goals. It identifies what the organisation wants to do and the roles different parts of the organisation will play. Continuing our New Zealand example, DOC's primary outcome is: 'New Zealanders gain environmental, social and economic benefits from healthy functioning ecosystems, recreation opportunities and living our history' (DOC 2013:1).

A corporate strategy may be used to guide expansion, renewal and revitalisation strategies, or it may also be an important document for guiding the status quo or a diminishment of services (Robbins et al. 2012). A corporate plan may, for example, guide a protected area organisation that has been requested by government to establish and manage new protected areas as part of an expanded reserve system.

\section{Business plan}

A national protected area organisation is, typically, a big business. Millions of people may visit protected areas, commercial services are provided and local and even national economies are dependent on them being both well managed and accessible. Business management is an integral part of many modern protected areas, and a business plan, developed in the context of a protected

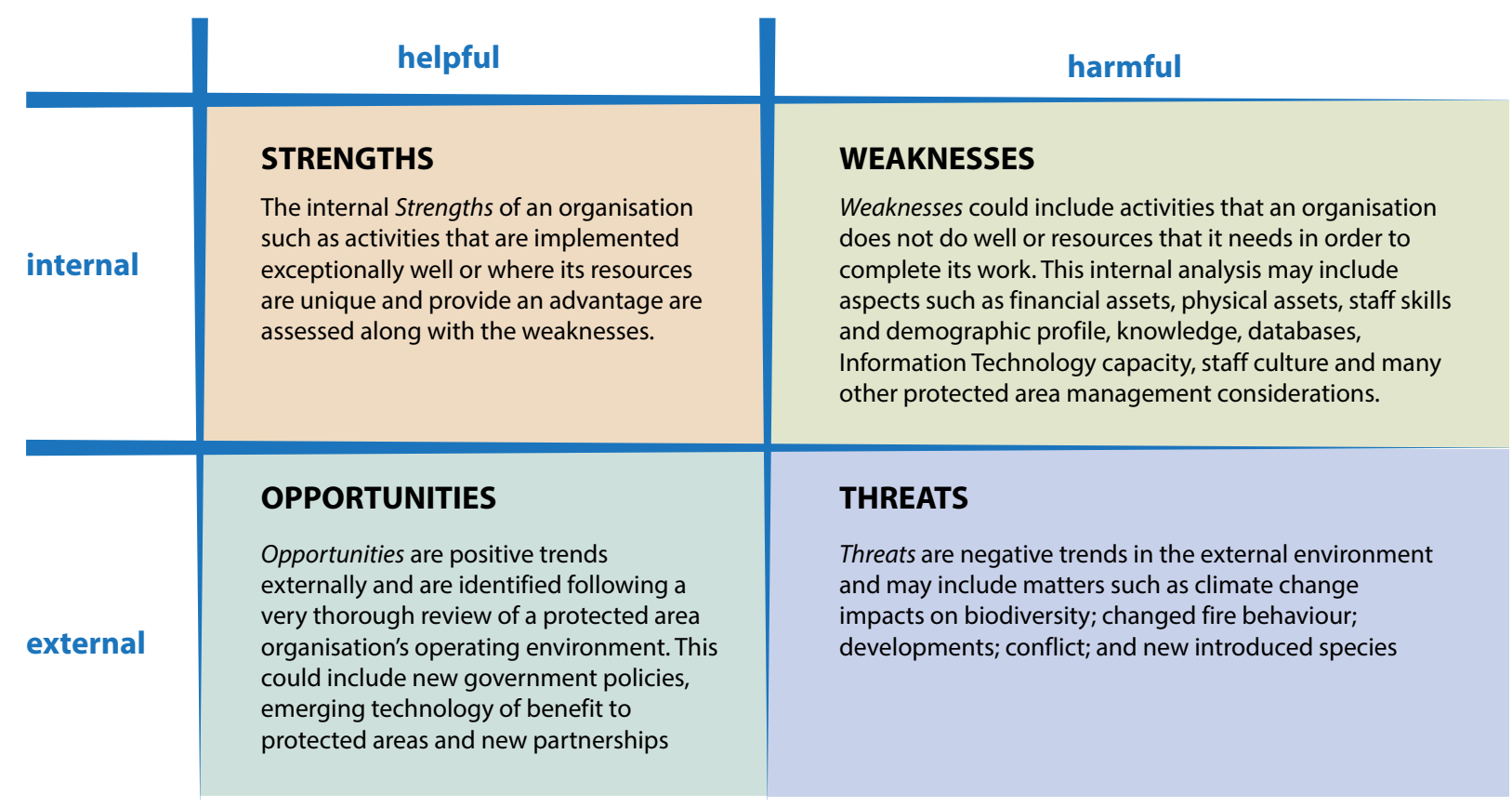

Figure 8.1 Strengths, weaknesses, opportunities and threats analysis

Source: Adapted from Robbins et al. (2012) 
area organisation's corporate plan, is an important tool. The primary reasons for developing a business plan are to:

- provide a clear, practical blueprint for an organisation's future development

- enable everyone in the organisation to agree upon and share common goals

- ensure the participation of key stakeholders

- ensure the organisation's goals can be achieved with the available resources

- identify key risks and put plans in place to mitigate these

- achieve a smooth handover at times of staff change (UNESCO 2008).
A business plan may also:

- support applications for financial support

- inform strategies for particular capital or revenue initiatives

- review organisational structure, approaches to training and personnel management, technological resources or monitoring procedures (UNESCO 2008).

At the individual protected area level, a business plan is different from but complementary to a management plan. The management plan sets out the objectives of management and actions needed to respond to the purpose of a protected area and the business plan focuses on the financial and organisational dimensions. It documents how to resource the delivery of the management plan (UNESCO 2008). Business planning at the level of an individual protected area is further outlined in Box 8.2.

\section{Box 8.2 Business planning}

Robust business planning will help ensure that every component of a protected area-from internal staff and programs to third-party partners and commercial service operators-is working towards the same mission and within the same parameters.

\section{Business plans and the plan of management}

Business plans take on many forms depending on the size and complexity of the protected area, but they should be based on a long-range (10 or more years) plan of management that defines the area's mission and desired state (Chapter 13). The guiding plan of management should contain an assessment of the key features of the protected area, including critical habitats, cultural and historical resources, and sensitive ecosystems; it should have been developed with community involvement and should have been based on objective science. This will have resulted in a plan that delineates either no development at all in the protected area or some appropriate development and use intensity in very carefully selected and zoned areas.

\section{The business plan}

The business plan itself fits within the long-term plan of management, focusing on operations in the short to medium terms. A business plan is specific and detailed enough to drive annual work planning within the protected area. An effective business plan must be:

- focused on a realistic time horizon-ideally two to five years

- data-driven and rigorous

- concise enough to be useful

- realistic and grounded in sound budget assumptions and projections.
Depending on the model through which commercial services are delivered (for-profit companies, not-forprofit organisations, or government-owned and operated services), a business plan's components may vary. In general, a business plan should include the following:

- a definition of the mission and legal basis for the protected area

- the current operating context, including the organisation structure, current budget, funding sources and historical trends and resource allocation (both budget and labour hours)

- planning program responsibilities and near-term goals and priorities

- financial and programmatic metrics that are tied to protected area priorities and that can be tracked over time to support performance management activities

- revenue projections that include both realistic assumptions of the near-term budget picture and an assessment of the relative stability/riskiness of each funding source

- cost scenarios that are based on priorities and potential staffing and investments

- strategies that link priorities to resource allocation and help the protected area close gaps between projected funding and costs.

- Jason Gibson, Program Manager, US National Park Service Business Management Group 


\begin{abstract}
Pod of humpback whales (Megaptera novaeangliae) offshore from Ben Boyd National Park, New South Wales, Australia, migrating southwards to Antarctic waters for summer. In New South Wales, National Parks and Wildlife Service staff are responsible for the safety and welfare of this protected species Source: Graeme L. Worboys
\end{abstract}

\section{Functional strategies}

Achieving the implementation of a corporate strategy and a business plan across an entire organisation may require a series of what have been described as 'functional strategies' (Robbins et al. 2012). These functional strategies achieve a corporate standardisation of protected area operational matters and could include, for example, matters such as a human resources management manual, a signage design standard, an infrastructure standards manual, guidelines for facilities establishment and management, and a vehicle fleet management manual.

\section{Change management}

The implementation of innovative, new and strategic management may require changes in the way in which an organisation is structured to deliver its management goals. Implementing change respectfully, transparently and with clear purpose relative to the vision and mission of an organisation is critical, as is the professional management of the change process. Normally organisational change would be guided by a 'change management plan' and by staff with human resource management technical expertise. Organisations may need to adjust priorities, refocus investments and adapt to new and changing social, political and environmental circumstances. Effective change management is necessary if biodiversity and other heritage conservation actions are to succeed.

\section{Biodiversity conservation priorities}

Protected area organisations help conserve species and biodiversity in protected area systems and this is especially important given there have been marked declines in species around the world (Chapter 3). All-important strategic conservation implementation actions need to be achieved in addition to the routine implementation and seemingly endless protected area organisation governance and administration processes. Conservation responses need to be in the context of ecosystem process requirements, habitat needs and specific animal and plant species requirements (Chapter 21). This could include the conservation and restoration of habitats, the protection of animal migration routes, specialised breeding season conservation needs, guarding against any species vulnerabilities and dealing with threats. For the strategic management of protected areas, these actions are a fundamental priority. From such priorities the potential for implementation of other organisational programs can then be assessed.

\section{Evaluation}

Strategic management investments need to be evaluated. Such a whole-of-organisation assessment would preferably be completed in terms of outcomes for biodiversity and cultural heritage conservation as well as other evaluation 
measures. For example, managers should seek to be in a position to answer basic monitoring questions such as: what native species are present in a protected area, what is their condition, what is the trend in their condition, what threats are present, what is the severity of these threats and what is the trend in severity of these threats?

These are fundamental questions and it is a legitimate aspirational mission for top-level managers to pursue adequate responses given they help to underpin the future strategic management of protected area systems. It is the type of organisational approach that Parks Canada has pursued by implementing its ecological integrity program (Chapter 21) and South African National Parks (SANParks) has pursued with its 'thresholds of potential concern' work pioneered in Kruger National Park (du Toit et al. 2003).

\section{Frameworks and tools}

There are a number of management frameworks and tools that assist protected area management organisations to undertake their operations. These frameworks and tools help provide an orderly and systematic approach to management across what may be a large, diverse and decentralised national or sub-national protected area system. Examples of useful management frameworks and tools available to protected area managers for a range of governance types are given in Table 8.1. The park management framework, for example, provides one valuable method for guiding management. The framework was developed by the National Parks and Wildlife Service (NPWS) of New South Wales, Australia, to guide an orderly approach to its management (DEC 2005) (Figure 8.2). It is based on the IUCN protected area management evaluation framework (Hockings et al. 2006) and includes the core functions of management. The NPWS organising its process of management around the park management framework has brought many benefits given it is logical, orderly and clear to all management personnel. In addition, it organises the NPWS's management effectiveness evaluation process so that it is consistent with the IUCN framework (Chapter 28). The key questions posed as part of the park management framework help to create an orderly approach to management (Figure 8.2).

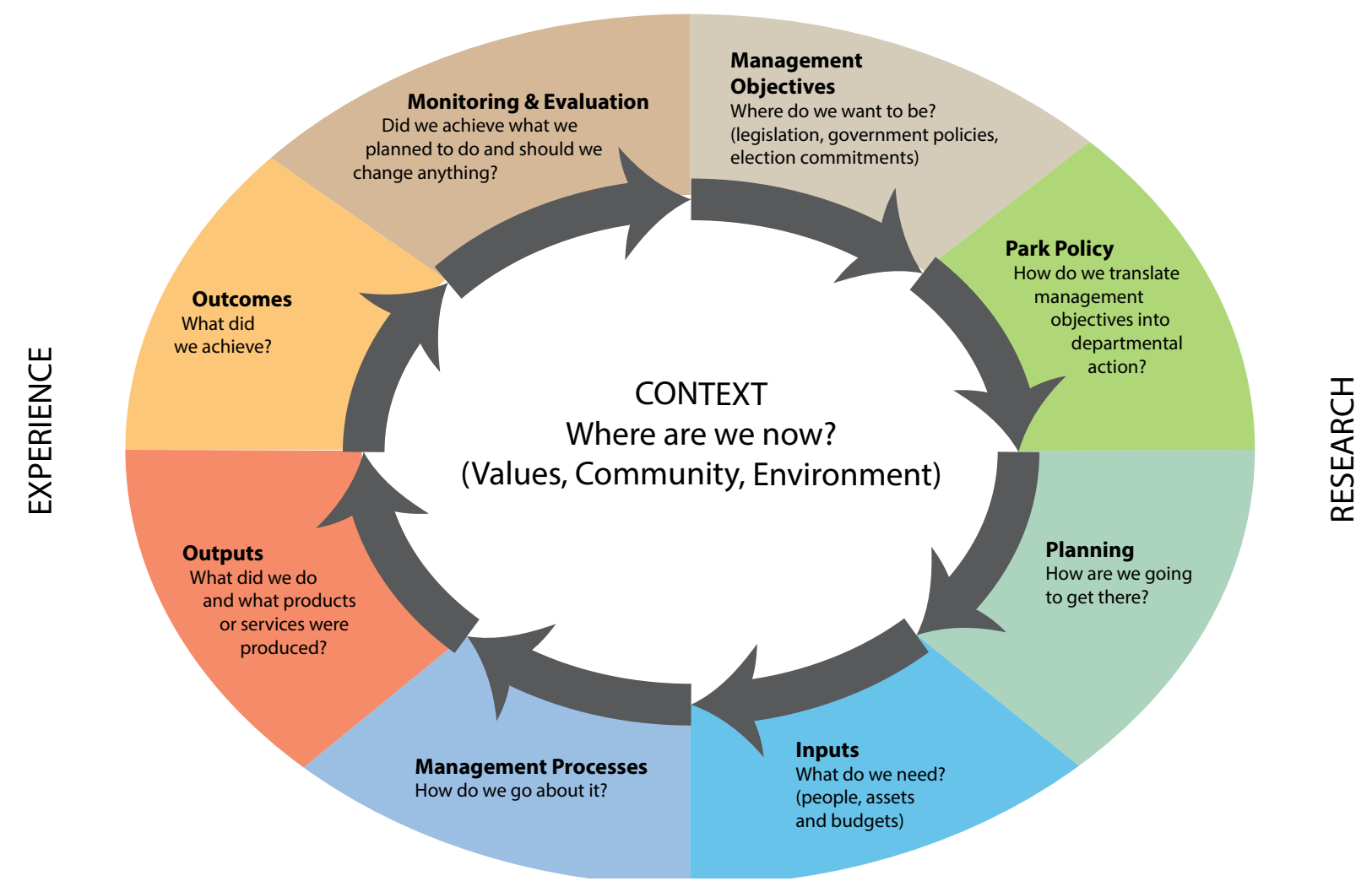

Figure 8.2 The park management framework used by the NSW NPWS

Source: Adapted from DEC (2005) 
Table 8.1 Management frameworks and tools for assisting protected area management (organised by management function)

\begin{tabular}{|c|c|c|}
\hline $\begin{array}{l}\text { Management tool } \\
\text { or framework }\end{array}$ & Background notes and reference & $\begin{array}{l}\text { Chapter cross- } \\
\text { reference (where } \\
\text { applicable) }\end{array}$ \\
\hline \multicolumn{3}{|l|}{ Planning } \\
\hline $\begin{array}{l}\text { Natural Heritage } \\
\text { Charter }\end{array}$ & $\begin{array}{l}\text { Developed in Australia, the Natural Heritage Charter describes a 10- } \\
\text { step process for conserving natural heritage. It provides a planning } \\
\text { process in detail and provides guidance information for each step. It } \\
\text { is a very valuable tool for assisting with the conservation planning of a } \\
\text { natural heritage site or place (COA 2003) }\end{array}$ & \\
\hline $\begin{array}{l}\text { International Council } \\
\text { on Monuments and } \\
\text { Sites (ICOMOS) } \\
\text { cultural heritage } \\
\text { charter }\end{array}$ & $\begin{array}{l}\text { ICOMOS provides planning guidance to heritage conservation } \\
\text { professionals for their work. This guidance includes the Charter for } \\
\text { the Protection and Management of Cultural Heritage. More specific } \\
\text { ICOMOS guidance has been prepared such as Australia's Burra } \\
\text { Charter (Marquis-Kyle and Walker 1992) }\end{array}$ & Chapter 22 \\
\hline $\begin{array}{l}\text { Conservation action } \\
\text { planning }\end{array}$ & $\begin{array}{l}\text { The Nature Conservancy's Conservation Action Planning (CAP) method } \\
\text { is a framework to help practitioners focus their conservation strategies } \\
\text { on biodiversity elements or conservation targets and associated threats } \\
\text { and to measure success to permit adaptation and learning over time } \\
\text { (TNC 2007) }\end{array}$ & Chapter 13 \\
\hline $\begin{array}{l}\text { IUCN framework } \\
\text { for connectivity } \\
\text { conservation } \\
\text { management }\end{array}$ & $\begin{array}{l}\text { The IUCN WCPA developed a framework for providing a systematic } \\
\text { approach to connectivity conservation management that } \\
\text { accommodates the multi-tenured landownership, multi-sectoral land } \\
\text { use, different spatial scales of operating and situational and dynamic } \\
\text { operating environment of a large connectivity conservation area } \\
\text { (corridor) (Worboys et al. 2010) }\end{array}$ & Chapter 27 \\
\hline $\begin{array}{l}\text { Wildlife Institute of } \\
\text { India planning tool }\end{array}$ & $\begin{array}{l}\text { A guide for planning wildlife management in protected areas and } \\
\text { managed landscapes has been prepared by the Wildlife Institute } \\
\text { of India; each protected area is meant to follow these guidelines } \\
\text { (Sawarkar 2002) }\end{array}$ & \\
\hline $\begin{array}{l}\text { A toolkit to support } \\
\text { conservation by } \\
\text { indigenous peoples } \\
\text { and local communities }\end{array}$ & $\begin{array}{l}\text { A guide for building capacity and sharing knowledge for Indigenous } \\
\text { Peoples' and Community Conserved Territories and Areas (ICCAs) } \\
\text { that includes management planning, monitoring and evaluation, } \\
\text { communication, finance and values (Corrigan and Hay-Edie 2013) }\end{array}$ & Chapter 7 \\
\hline $\begin{array}{l}\text { Environmental } \\
\text { management systems }\end{array}$ & $\begin{array}{l}\text { Environmental management systems such as ISO } 14001 \text { establish } \\
\text { a process by which organisations can minimise their environmental } \\
\text { impacts. The International Organisation for Standardisation (ISO) is } \\
\text { located in Geneva. ISO 14001, for example, is based on a system } \\
\text { of continuous improvement that includes 'plan' (set objectives); 'do' } \\
\text { (implement the task); 'check' (monitor performance) and 'act' (improve } \\
\text { the performance) (EPA 2013) }\end{array}$ & Chapter 24 \\
\hline $\begin{array}{l}\text { Environmental impact } \\
\text { assessment }\end{array}$ & $\begin{array}{l}\text { Environmental impact assessment is a means to protect and conserve } \\
\text { the environment. It is a procedure that evaluates the effects of activities } \\
\text { on the environment with the assessment findings influencing decisions } \\
\text { about whether a development should proceed as proposed, proceed } \\
\text { with conditions or not proceed (Thomas 2001). Its application in } \\
\text { protected areas may be guided by legislation }\end{array}$ & Chapter 24 \\
\hline $\begin{array}{l}\text { Recreation opportunity } \\
\text { spectrum planning tool }\end{array}$ & $\begin{array}{l}\text { The recreation opportunity spectrum was developed by the US Forest } \\
\text { Service for managing recreation in natural areas. It is a powerful } \\
\text { planning tool for a protected area manager that distinguishes a } \\
\text { range of recreational settings that offer visitors a range of recreation } \\
\text { opportunities. It provides strong guidance for the nature and limits of } \\
\text { services and facilities for settings that guarantee recreation types are } \\
\text { retained (Clarke and Stankey 1979) }\end{array}$ & Chapter 23 \\
\hline
\end{tabular}




\begin{tabular}{|c|c|c|}
\hline $\begin{array}{l}\text { Management tool } \\
\text { or framework }\end{array}$ & Background notes and reference & $\begin{array}{l}\text { Chapter cross- } \\
\text { reference (where } \\
\text { applicable) }\end{array}$ \\
\hline $\begin{array}{l}\text { Public use } \\
\text { measurement and } \\
\text { reporting system }\end{array}$ & $\begin{array}{l}\text { Prepared by Kenneth Hornback and Paul Eagles for the IUCN WCPA, } \\
\text { this tool assists managers to prepare a comprehensive approach to } \\
\text { collecting information, undertaking analysis and reporting public use of } \\
\text { protected areas (Hornback and Eagles 1999) }\end{array}$ & \\
\hline Design standards tool & $\begin{array}{l}\text { Many protected area organisations establish corporate design } \\
\text { standards for their logos, park furniture design, park building design } \\
\text { and other assets. It is also common for them to utilise approved } \\
\text { industry design standards for disabled access and for the safety of } \\
\text { structures such as viewing platforms and buildings. International design } \\
\text { symbols may be used to assist visitors with a range of languages. } \\
\text { Organisations may develop a design standard toolkit for use }\end{array}$ & \\
\hline
\end{tabular}

\section{Organising}

\section{Administration and staff support tools}

Financial management systems

Staff management systems systems

Staff counselling services

\section{Occupational health} and safety systems

Insurance systems

Asset management systems
Financial management systems in the 21 st century are almost always computerised, with off-the-shelf applications such as SAPTM enterprise applications commonly used. Systems are useful that: 1) track inputs with outputs and outcomes, and 2) track assets maintenance and service delivery needs. The financial system of some protected area organisations may form part of much larger government systems and such systems would usually need to be customised further to deal with the 24-hour-a-day and seven-day-a-week on-ground operations of protected areas

Staff management and payroll systems are computerised (and usually linked to financial management systems) and use off-the-shelf products like SAP'M . Corporate reporting of staff demographics, competencies, training completed and levels of fitness may be important for organisations whose staff face regular physically demanding operations such as remote area work, work in extreme weather and incident response operations

Staff induction is an important investment and systems may include personal introductions and vocational training associated with equipment, vehicles, wildlife, incidents, law enforcement, employee rights and entitlements, computer software applications and other organisational processes and systems

These services may be contracted out, but they are an important part of dealing with the daily pressures of protected area management. Incidents involving people such as wildlife, fire operations and conflict may impact on staff and initiate the need for such counselling

Occupational health and safety systems help ensure a safe work environment for staff. Organisations with such systems in place and good records of safety often pay lower insurance premiums

Protected areas include a range of assets, from visitor centres, offices, workshops, accommodation and training facilities to plant and equipment. Insurance systems that provide cover for loss or damage of these assets, as well as insurance for people, are essential

Protected areas include a range of physical assets that provide services for the enjoyment or management of protected areas. Typically these assets include access tracks and roads, lookouts, toilets, buildings, plant and equipment, vehicles and other assets. Asset management systems are usually computer based and record details of the asset, its life history and maintenance requirements 


\section{Management tool Background notes and reference} or framework

\section{Information support tools}

Computer software systems

Geographic

information systems

Internet and intranet

tools for accessing

and disseminating

information

Integrated

management

information systems

Computer software systems and their application are rapidly evolving.

The best management systems will be those that are adaptive and permit individuals and organisations to be at the cutting edge of their work and supported (where possible) by an information technology team

Spatial information is critical for protected area management.

Geographic information system data of individual protected areas and their associated national system can facilitate heritage inventories, the spatial analysis of information and the immediate presentation of incoming data from a range of sources including live incident and satellite data

Modern search engines permit the immediate retrieval of information necessary for managing protected areas. For individual protected areas this may include their history and all aspects of their management. Implementing such systems will achieve cost efficiencies in the future. Web content management systems are also available

The Tasmanian Parks and Wildlife Service has developed a system for its visitor management that integrates its recreation opportunity spectrum setting planning, its levels of service determination, its assets information, its risk management assessment and its budgeting information to assist with its prioritisation decisions (Poll 2006)

\section{Decision-support tools}

\begin{tabular}{|c|c|c|}
\hline Marxan software & $\begin{array}{l}\text { The Marxan computer spatial prioritisation software includes a suite } \\
\text { of tools that assists conservation planning. It includes economic } \\
\text { considerations and assists managers to prioritise tasks and includes } \\
\text { using financial (costing) inputs }\end{array}$ & Chapter 8 \\
\hline $\begin{array}{l}\text { The Investment } \\
\text { Framework for } \\
\text { Environmental } \\
\text { Resources (INFFER) }\end{array}$ & $\begin{array}{l}\text { INFFER }{ }^{\mathrm{TM}} \text { is one method that assists managers to prioritise a range of } \\
\text { competing conservation management projects }\end{array}$ & \\
\hline $\begin{array}{l}\text { Structured decision- } \\
\text { making }\end{array}$ & $\begin{array}{l}\text { This is a process of decision-making that involves experts and } \\
\text { practitioners, that deals with complex issues, establishes clear } \\
\text { objectives and provides a transparent rationale for a preferred } \\
\text { management decision }\end{array}$ & \\
\hline \multicolumn{3}{|c|}{$\begin{array}{l}\text { Leading (implementation) } \\
\text { Protected area operations tools }\end{array}$} \\
\hline $\begin{array}{l}\text { Project management } \\
\text { tools }\end{array}$ & $\begin{array}{l}\text { The Conservation Action Planning System (TNC 2007) and the Open } \\
\text { Standards Miradi software (CMP 2013) are two tools that provide } \\
\text { effective project management for protected area actions }\end{array}$ & Chapter 13 \\
\hline $\begin{array}{l}\text { Risk-management } \\
\text { systems }\end{array}$ & $\begin{array}{l}\text { Risk-management systems identify risks to management. They are } \\
\text { analysed against an organisational risk-assessment criteria and treated } \\
\text { where a risk is unacceptably high. Such systems constantly monitor } \\
\text { risks (Worboys and Winkler 2006b) }\end{array}$ & \\
\hline $\begin{array}{l}\text { Incident management } \\
\text { systems }\end{array}$ & $\begin{array}{l}\text { The National Interagency Incident Management System developed in } \\
\text { the United States has been modified and adopted by many nations } \\
\text { and organisations. This 'incident control system' identifies the functions } \\
\text { of incident controller, planning, operations and logistics and concepts } \\
\text { such as span of control and 12-hourly shift changes. It has been a } \\
\text { highly successful method for multiple organisations working together }\end{array}$ & Chapter 26 \\
\hline
\end{tabular}




\section{Management tool Background notes and reference} or framework

Chapter crossreference (where applicable)

Sustainable organisation systems of the Fiji Locally Managed Marine Areas Network

Media management
systems

Sustainable organisation management systems such as the commercial Earthcheck tool (Earthcheck 2013) allow organisations to assess their quantified environmental performance for energy consumption, water use, and liquid and solid waste generation against baseline standards. Environmental design considerations can also be assessed

Guidelines or goals including the establishment of community and network research priorities and protocols that govern any collaborating researchers, minimum monitoring approaches, communications and intellectual property issues, and membership criteria (Govan and Meo 2011)

Some protected area organisations employ commercial media monitoring systems to track commentary and internal systems where local protected area issues (and responses) are communicated routinely to central office with or without associated media coverage

\section{Evaluation}

\section{Management effectiveness evaluation and monitoring}

\begin{tabular}{|c|c|c|}
\hline $\begin{array}{l}\text { Ecological integrity } \\
\text { monitoring system }\end{array}$ & $\begin{array}{l}\text { The Parks Canada Ecological Integrity (El) monitoring is a system for } \\
\text { measuring and reporting maintenance or restoration of El in protected } \\
\text { areas. The system enables a quantified assessment of condition and } \\
\text { change in condition for biodiversity and enables outcomes to be } \\
\text { measured relative to objectives established (PC 2007) }\end{array}$ & Chapter 21 \\
\hline $\begin{array}{l}\text { 'State of the parks' } \\
\text { reporting }\end{array}$ & $\begin{array}{l}\text { Protected area organisations within a number of nations (such as } \\
\text { Canada, South Korea and Finland) and States within a nation (such as } \\
\text { Australia's New South Wales and Victoria) have instituted state of the } \\
\text { parks reporting for their protected area systems. These may report on } \\
\text { the ecological integrity (biodiversity condition), threats and management } \\
\text { effectiveness for their protected areas }\end{array}$ & Chapter 28 \\
\hline $\begin{array}{l}\text { IUCN management } \\
\text { effectiveness } \\
\text { evaluation framework }\end{array}$ & $\begin{array}{l}\text { The Protected Area Management Effectiveness Evaluation (PAME) } \\
\text { framework is based on a cycle of management for protected area } \\
\text { organisations with six key elements: context, planning, inputs, process, } \\
\text { outputs and outcome (Hockings et al. 2000, 2006). The IUCN PAME } \\
\text { framework has been adopted by the World Bank and many protected } \\
\text { area organisations as their principal evaluation framework tool }\end{array}$ & Chapter 28 \\
\hline $\begin{array}{l}\text { World Wide Fund for } \\
\text { Nature (WWF)/World } \\
\text { Bank Tracking Tool }\end{array}$ & $\begin{array}{l}\text { This scorecard tool is very brief; it is based on the IUCN PAME } \\
\text { framework's six elements and it is very effective (Worboys 2007). } \\
\text { It focuses on evaluating individual protected areas and monitors } \\
\text { effectiveness relative to targets }\end{array}$ & Chapter 28 \\
\hline $\begin{array}{l}\text { IUCN Green List } \\
\text { of Well Managed } \\
\text { Protected Areas }\end{array}$ & $\begin{array}{l}\text { The Green List is an IUCN initiative to encourage, measure and } \\
\text { celebrate the success of protected areas in reaching good standards of } \\
\text { management (Hockings 2012). It is based on the widespread adoption } \\
\text { of the PAME assessment (Hockings et al. 2000, 2006) and identifies } \\
\text { good management practice }\end{array}$ & \\
\hline $\begin{array}{l}\text { World Heritage: } \\
\text { Enhancing Our } \\
\text { Heritage }\end{array}$ & $\begin{array}{l}\text { UNESCO and the IUCN have developed this evaluation framework } \\
\text { based on the PAME method, and it is used for assessing World } \\
\text { Heritage sites and their current activities to identify any problems, } \\
\text { issues and responses (Hockings et al. 2008) }\end{array}$ & Chapter 28 \\
\hline $\begin{array}{l}\text { Visitor use: limits of } \\
\text { acceptable change }\end{array}$ & $\begin{array}{l}\text { This method assesses the limits of acceptable change for visitor use } \\
\text { of natural areas and is closely aligned with the recreation opportunity } \\
\text { spectrum planning tool. It was prepared by George Stankey and other } \\
\text { researchers from the US Forest Service (Stankey et al. 1985) }\end{array}$ & Chapter 23 \\
\hline $\begin{array}{l}\text { Other management } \\
\text { effectiveness } \\
\text { evaluation systems }\end{array}$ & $\begin{array}{l}\text { There are other evaluation tools that have been developed in the past } \\
\text { that are applicable to protected areas, including the Parks in Peril Site } \\
\text { Consolidation Scorecard and the Enhanced 5S Project Management } \\
\text { Process developed by The Nature Conservancy (Worboys 2007) }\end{array}$ & \\
\hline
\end{tabular}




\section{Adaptive management}

Adaptive management is a protected area management process that may be used by practitioners and policymakers (Chapter 13). It is seemingly an intuitive approach though it is research based and this is not always fully understood. It has been defined as 'a systematic approach for improving resource management by learning from management outcomes' (Williams et al. 2009:1). Adaptive management has been described as involving six key steps.

1. Identification of clear management goals.

2. Specification of multiple management options.

3. Hypothesising how the system will respond to management interventions.

4. Implementing management action(s).

5. Monitoring the system response to see if it supports the hypothesis or otherwise.

6. Based on the analysis results, refining and adjusting management practice (Williams et al. 2009).

US Forest Service researcher George Stankey and his colleagues reviewed the theory and concepts of adaptive management and arrived at the following key conclusions.

- Though widely acclaimed as a model for resource management under conditions of risk and uncertainty, adaptive management remains primarily an ideal.

- There are many definitions, though typically they do not include core characteristics of an adaptive approach by not including explicit hypothesis testing, monitoring and evaluation.

- Experimentation is at the core of adaptive management involving hypotheses, controls and replication.

- It includes explicit research designs (including problem framing and solving processes, documentation and monitoring protocols and assessment and evaluation processes).

- It is irreducibly socio-political in nature.

- It is grounded in a recognition and acceptance of risk and uncertainty.

- Learning is a key output (Stankey et al. 2005).

\section{Open Standards for the Practice of Conservation}

The Open Standards for the Practice of Conservation (CMP 2013) is a method that includes adaptive management and has been established by a group known as the Conservation Measures Partnership (CMP), a consortium of conservation organisations 'whose mission is to advance the practice of conservation by developing, testing and promoting principles and tools to credibly assess and improve the effectiveness of conservation actions' (CMP 2013:i). The CMP has combined principles and best practice in adaptive management and results-based management to create the open standards. Open standards is a process aimed at establishing good project design, management and monitoring, and is organised into a five-step project management cycle.

1. Conceptualise the project vision and context.

2. Plan actions and monitoring.

3. Implement actions and monitoring.

4. Analyse the data, use the results and adapt.

5. Capture and share the learning (CMP 2013).

These steps describe the general process necessary for the successful implementation of conservation projects. Importantly, the entire process and its analysis include human wellbeing inputs and climate change considerations. The process develops result chains; prioritises strategies; develops a monitoring plan with monitoring methods and indicators; develops an operational plan with associated shorter-term work plans; prepares a budget; undertakes implementation; and analyses the performance.

\section{Managing protected area systems}

A well-designed national system of protected areas provides a strategic approach to the conservation of a nation's biodiversity (Davey 1998). Ideally, such systems have been developed using systematic conservation planning techniques or have been influenced by these techniques. The establishment of protected areas and systems of protected areas is considered further in Chapter 13). 


\section{Protected area systems: Strategic targets}

Global guidance for an ideal minimum area that should be reserved in national reserve systems has been established following lengthy negotiations and discussions between nations signatory to the $\mathrm{CBD}$ and the development of a strategic plan. In 2010 in Nagoya, Japan, the Strategic Plan for Biodiversity 2011-2020 and the Aichi Targets was adopted by parties to the CBD with the purpose of inspiring all countries and stakeholders to implement broad-based action in support of biodiversity conservation over the next decade (CBD 2011). The strategy provides a rationale, vision, mission and targets for the conservation of biodiversity and guidance, and through these 'Aichi Targets', the establishment of enhanced protected area systems. This is an important management action for governments and protected area organisations or groups whether they are government, private, indigenous peoples' or community groups. Target 11 of the strategic plan specifically identifies spatial area targets for establishing marine and terrestrial national reserve systems.

The 2011-20 strategy establishes a planning context that identifies the importance of the Earth's biodiversity:

\begin{abstract}
Biological diversity underpins ecosystem functioning and the provision of ecosystem services essential for human well-being. It provides for food security, human health, the provision of clean air and water; it contributes to local livelihoods, and economic development, and is essential for the achievement of the Millennium Development Goals, including poverty reduction. In addition it is a central component of many belief systems, worldviews and identities. Yet despite its fundamental importance, biodiversity continues to be lost. (CBD 2011:4)
\end{abstract}

The strategy's vision clearly identifies that long-term leadership is needed and that a great deal more needs to be done to ensure the conservation of biodiversity: 'By 2050, biodiversity is valued, conserved, restored and wisely used, maintaining ecosystem services, sustaining a healthy planet and delivering benefits essential for all people' (CBD 2011:2).
The strategy's mission statement identifies a compelling need and immediacy of action for achieving biodiversity conservation with words like 'urgent', 'effective action' and 'halt the loss':

Take effective and urgent action to halt the loss of biodiversity in order to ensure that by 2020 ecosystems are resilient and continue to provide essential services, thereby securing the planet's variety of life, and contributing to human well-being, and poverty eradication. To ensure this, pressures on biodiversity are reduced, ecosystems are restored, biological resources are sustainably used and benefits arising out of utilization of genetic resources are shared in a fair and equitable manner; adequate financial resources are provided, capacities are enhanced, biodiversity issues and values mainstreamed, appropriate policies are effectively implemented, and decisionmaking is based on sound science and the precautionary approach. (CBD 2011:3)

The strategy recognises 20 targets, with many relating to protected areas. Target 11 recognises the effectiveness of protected areas in the conservation of biodiversity (Chapter 2) and the strategy identifies enhanced area targets and quality protected area attributes for protected area systems for nations:

By 2020, at least 17 per cent of terrestrial and inland water, and 10 per cent of coastal and marine areas, especially areas of particular importance for biodiversity and ecosystem services, are conserved through effectively and equitably managed, ecologically representative and well-connected systems of protected areas and other effective area-based conservation measures, and integrated into the wider landscape and seascapes. (CBD 2011:2)

These targets relate to governments and other organisations and communities, as a nation's protected area system may comprise a mix of government, private, indigenous and community-based protected areas. The 2020 CBD strategic target to conserve biodiversity is a challenge for nations and for national systems of protected areas given that in 2014 many nations had not met the following global targets. Progress in achieving Target 11 (from a spatial area perspective) is indicated in Figure 8.3. 


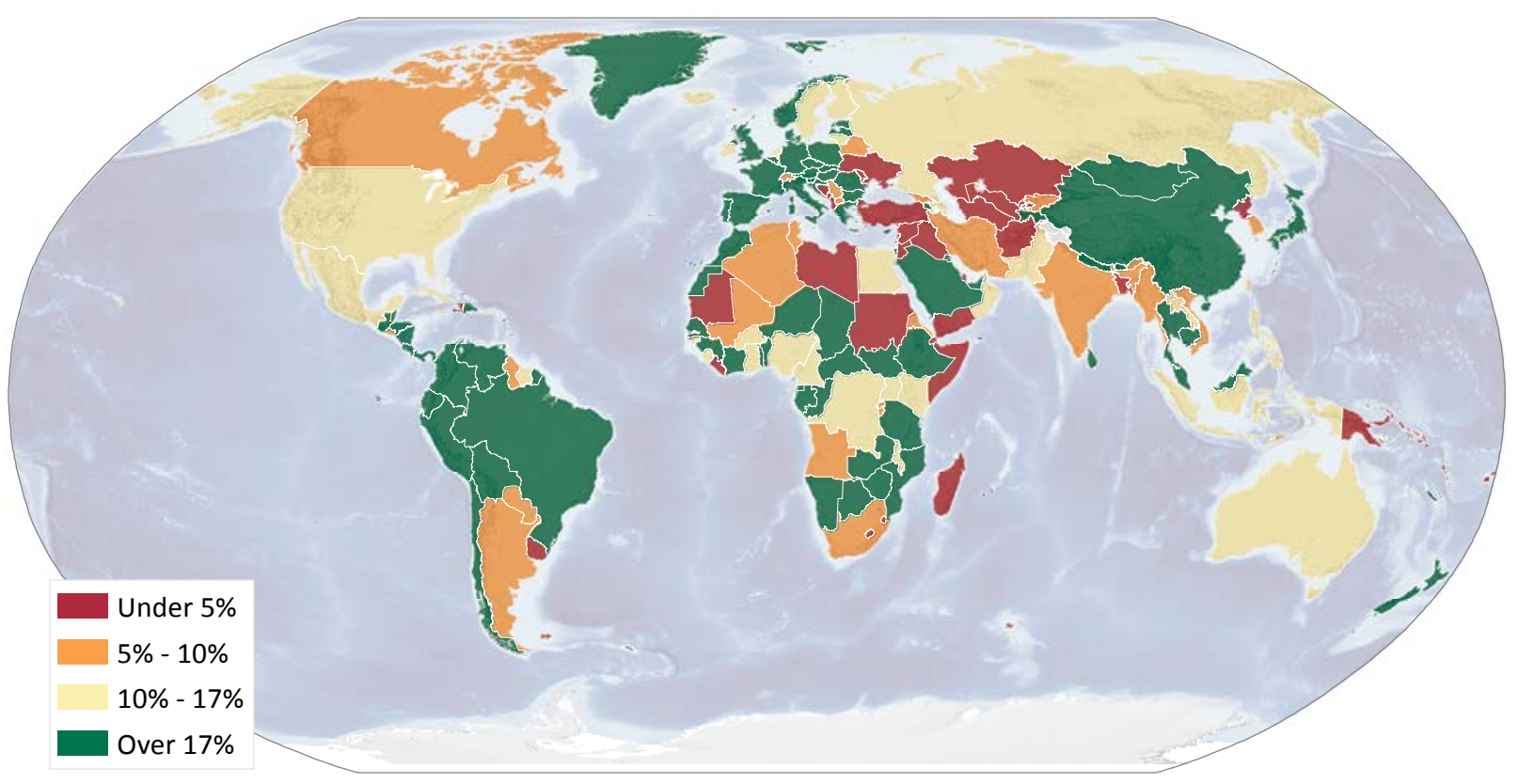

Figure 8.3 Percentage of terrestrial area of nations reserved as protected area in 2014

Note: Nations that have met the CBD's Target 11 spatial target (only) in 2014 for protected areas are shown in green. Areas conserved by other effective means are not presented.

Disclaimer: Disputed territories have been given 'no value' and no colour on the map. The boundaries of nations as identified do not represent the views of the UNEP-WCMC.

Source: IUCN and UNEP-WCMC (2014)

\section{Governments and protected area systems}

There are many critical management actions governments undertake in support of protected area systems. These include facilitating the expansion of the protected area system; facilitating biodiversity conservation at a whole-of-government level; managing for international conventions and treaties; facilitating trans-boundary cooperation; providing national protected area data; and facilitating connectivity conservation corridors. Accountability for collecting and supplying high-quality protected area spatial data and IUCN protected area category data for a nation's protected area system rests with each national government (Chapter 11).

\section{New protected areas}

Governments, in enhancing the protected area system, may establish protected areas in their own right; they may encourage their establishment by facilitating mechanisms for NGOs and the private sector to reserve and manage land; and they may help indigenous peoples and local communities establish protected areas, or recognise existing ICCAs as protected areas with the consent of the relevant people or community.

\section{Biodiversity conservation and protected areas}

Governments may facilitate biodiversity conservation in protected areas and beyond by:

- implementing the full provisions of the CBD strategy (CBD 2011) across all relevant sectors of government and society

- preparing a national biodiversity conservation strategy that recognises and responds to any gaps in protected areas that may exist

- preparing a national plan for large-scale and important connectivity conservation areas that interconnect protected areas and the natural landscape

- providing incentives for the private sector and indigenous peoples and local communities to participate in the establishment of protected areas. 


\section{International considerations}

International considerations that form part of an organisation's responsibility for managing a protected area system include:

- observing and responding to international conventions (Table 8.2)

- participating in cooperative trans-boundary protected area management (Chapter 7)

- observing and facilitating international migratory species agreements (Chapter 21)
- working on large-scale connectivity conservation corridors (Chapter 27)

- providing shared national protected area data for the international UNEP-WCMC World Database on Protected Areas (WDPA) (Chapter 11)

- meeting World Heritage management standards and reporting requirements (Chapter 2)

- meeting biosphere reserve and Ramsar requirements (Chapter 2)

- having regard for international treaties and declarations such as the UN Declaration on the Rights of Indigenous Peoples.

Table 8.2 Examples of international conventions relevant to protected area management

\begin{tabular}{|c|c|c|}
\hline Year & n & Reference \\
\hline 1946 & $\begin{array}{l}\text { Convention for the Regulation of Whaling } \\
\text { The International Convention for the Regulation of Whaling was established to provide for } \\
\text { the proper conservation of whale stocks and to help facilitate the orderly development of the } \\
\text { whaling industry. It established the International Whaling Commission and included the provision } \\
\text { for fixing sanctuary areas }\end{array}$ & UN (2014a) \\
\hline 1971 & $\begin{array}{l}\text { Ramsar Convention } \\
\text { In 1971, the Ramsar Convention on Wetlands of International Importance, especially as } \\
\text { Waterfowl Habitat was adopted in Ramsar, Iran. The convention is an intergovernmental } \\
\text { treaty that provides the framework for national action and international cooperation for the } \\
\text { conservation and wise use of wetlands and their resources }\end{array}$ & $\begin{array}{l}\text { Ramsar } \\
\text { (2013) }\end{array}$ \\
\hline 1972 & $\begin{array}{l}\text { World Heritage Convention } \\
\text { In 1972, the Convention Concerning the Protection of the World Cultural and Natural Heritage } \\
\text { developed from the merging of two separate initiatives: the first focusing on the preservation } \\
\text { of cultural sites, and the second dealing with the conservation of nature. The World Heritage } \\
\text { Convention protects the world's natural and cultural heritage considered to be of outstanding } \\
\text { universal value }\end{array}$ & $\begin{array}{l}\text { UNESCO } \\
(2013)\end{array}$ \\
\hline 1973 & $\begin{array}{l}\text { CITES Convention } \\
\text { The Convention on International Trade in Endangered Species of Wild Fauna and Flora (CITES) } \\
\text { was adopted in } 1973 \text { by many countries. The convention helps to protect species that are highly } \\
\text { sought after illegally such as for traditional medicines and pelts. These animal products could, } \\
\text { for example, be sourced from snow leopards (Panthera uncia) (pelts); tigers (Panthera tigris) } \\
\text { (medicine); musk deer (Moschus spp.) (medicine); African elephants (Loxodonta spp.) (ivory); } \\
\text { and rhinoceros (Ceratothirium simum and Diceros bicornis) (medicine) }\end{array}$ & CITES (2013) \\
\hline 1979 & $\begin{array}{l}\text { Migratory Species Convention } \\
\text { The Convention on the Conservation of Migratory Species of Wild Animals (also known as CMS or } \\
\text { the Bonn Convention) aims to conserve terrestrial, aquatic and avian migratory species throughout } \\
\text { their range. It is an intergovernmental treaty, concluded under the aegis of the UN Environment } \\
\text { Programme, concerned with the conservation of wildlife and habitats on a global scale }\end{array}$ & CMS (2013) \\
\hline 1982 & $\begin{array}{l}\text { Convention on the Law of the Sea } \\
\text { In 1982, the United Nations adopted the Convention on the Law of the Sea (UNCLOS) and } \\
\text { this (among many matters) provided coastal states with sovereign rights for a 200-nautical } \\
\text { mile exclusive economic zone with respect to natural resources, certain economic activities, } \\
\text { jurisdiction over marine science research and the opportunity for environmental protection within } \\
\text { this zone. It did not come into force until } 1994\end{array}$ & UN (2013) \\
\hline 1992 & $\begin{array}{l}\text { Convention on Biological Diversity } \\
\text { The CBD has been fundamental for recognising the need to conserve biodiversity and the role } \\
\text { and importance of protected areas as part of this. Protected areas are recognised by parties } \\
\text { to the convention as a key response in stemming the loss of biodiversity, and Article } 8 \text { of the } \\
\text { convention requires each contracting party, as far as possible and appropriate, to establish } \\
\text { a system of protected areas or areas where special measures need to be taken to conserve } \\
\text { biological diversity }\end{array}$ & CBD (1992) \\
\hline
\end{tabular}




\begin{tabular}{|c|c|c|}
\hline Year & International Convention & Reference \\
\hline 1992 & $\begin{array}{l}\text { United Nations Framework Convention on Climate Change } \\
\text { The } 1992 \text { UN Framework Convention on Climate Change (UNFCCC) provides a framework for } \\
\text { negotiating specific international treaties (called 'protocols') that may set binding limits on the } \\
\text { emission of greenhouse gases. It was a start to an international response to greenhouse gas } \\
\text { pollution of the atmosphere }\end{array}$ & $\begin{array}{l}\text { UNFCCC } \\
(2014)\end{array}$ \\
\hline 1994 & $\begin{array}{l}\text { The United Nations Convention on the Law of the Sea } \\
\text { The UN Convention on the Law of the Sea (UNCLOS) came into force and was critical in global } \\
\text { efforts to establish marine protected areas. It defines the rights and responsibilities of nations in } \\
\text { their use of the world's oceans, establishing guidelines for businesses, the environment and the } \\
\text { management of marine natural resources }\end{array}$ & UN (2014b) \\
\hline
\end{tabular}

\section{Box 8.3 Convention on Biological Diversity Programme of Work on Protected Areas}

The Programme of Work on Protected Areas (PoWPA) is one of the strongest reflections of the policies of the IUCN and its members. It was agreed to by the CBD in February 2004, and the PoWPA draws heavily on the Durban Action Plan that emerged six months earlier at the end of the IUCN's Fifth World Parks Congress. The essence of the PoWPA is a commitment that countries develop participatory, ecologically representative and effectively managed national and regional systems of protected areas, stretching where necessary across national boundaries, integrated into other land uses and contributing to human wellbeing. The PoWPA includes four program elements, 16 goals (each with a more specific target) and 92 activities for parties, many with timetables for suggested implementation. The four main themes and associated elements are as follows.

1. Direct actions for planning, selecting, establishing, strengthening and managing protected area systems and sites

- building protected area networks and the ecosystem approach

- site-based protected area planning and management

- addressing threats to protected areas.

2. Governance, participation, equity and benefit sharing

- improving the social benefits of protected areas.

3. Enabling activities

- creating an enabling policy environment

- capacity building

- ensuring financial sustainability.

4. Standards, assessment and monitoring

- management standards and effective management

- using science.

Source: Stolton et al. (2008)

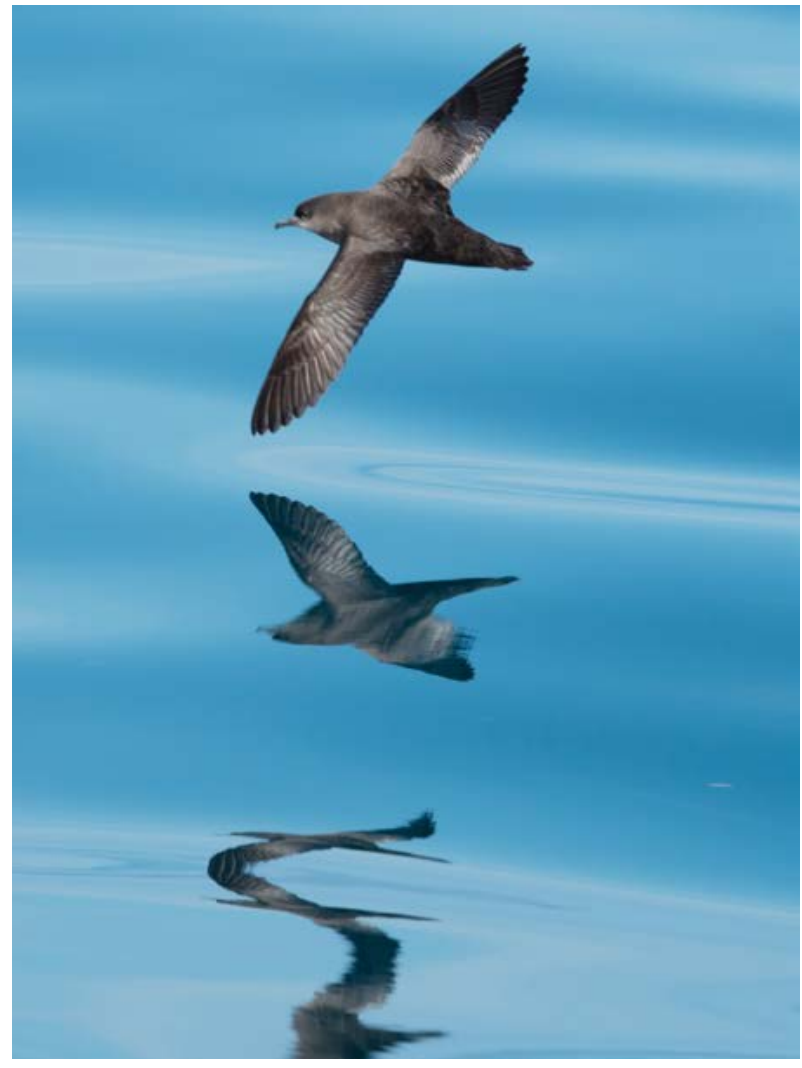

Wedge-tailed shearwater (Puffinus pacificus), South Coast of New South Wales, Australia: this species migrates large distances between hemispheres and breeds during the southern summer on many islands in southern Australia. This species and many others benefit from conventions that help protect migratory species. Source: Graeme L. Worboys

The CBD Programme of Work on Protected Areas (PoWPA) signifies the greatest commitment by the international community to protected areas to date. It provides a framework for cooperation between governments, donors, NGOs and local communities in order to develop a participatory, ecologically representative and effectively managed national and regional system of protected areas (Box 8.3) (CBD 2004). 


\section{Box 8.4 General reserve management principles for IUCN protected area categories}

The following principles of management for Australian protected areas have been developed for all six IUCN protected area categories by the Australian Government. They have international relevance.

\section{Community participation}

Management arrangements should, to the extent practicable, provide for broad and meaningful participation by the community, public organisations and private interests in designing and carrying out the functions of the reserve or zone.

\section{Effective and adaptive management}

Management arrangements should be effective and appropriate to the biodiversity objectives and the socioeconomic context of the reserve or zone. They should be adaptive in character to ensure a capacity to respond to uncertainty and change.

\section{Precautionary principle}

A lack of full scientific certainty should not be used as a reason for postponing measures to prevent degradation of the natural and cultural heritage of a reserve or zone where there is a threat of serious or irreversible damage.

\section{Minimum impact}

The integrity of a reserve or zone is best conserved by protecting it from disturbance and threatening processes. Potential adverse impacts on the natural, cultural and social environments and surrounding communities should be minimised as far as practicable.

\section{Ecologically sustainable use}

If resource use is consistent with the management principles that apply to a reserve or zone, it should (if it is carried out) be based on the principle of ecologically sustainable use, which is that:

- natural resources should only be used within their capacity to sustain natural processes while maintaining the life-support systems of nature

- the benefit of the use to the present generation should not diminish the potential of the reserve or zone to meet the needs and aspirations of future generations.

\section{Transparency of decision-making}

The framework and processes for decision-making for management of the reserve or zone should betransparent. The reasons for making decisions should be publicly available, except to the extent that information, including information that is culturally sensitive or commercial-inconfidence, needs to be treated as confidential.

\section{Joint management}

If the reserve or zone is wholly or partly owned by aboriginal people, continuing traditional use of the reserve or zone by resident indigenous people, including the protection and maintenance of cultural heritage, should be recognised.

Note: In the text provided, 'reserve' or 'zone' refers to an Australian Government management context where the principles may be applied to an entire protected area or a geographic part of that protected area (commonly identified by a plan of management as a zone).

Source: CoA (1999)

\section{Management guidance for IUCN protected area categories}

In this section, we present management principles and guidance information for each of the IUCN management categories and discuss the conservation emphasis of each category. This guidance is particularly relevant for planning purposes, where it can assist in the development of management objectives. We also describe managing for 'official people' who live within different IUCN protected area category reserve types.

Biodiversity conservation and other natural and cultural heritage conservation are undertaken for all six IUCN protected area management categories (I-VI) though there are important differences in approach. Australian guidance material of international relevance for each IUCN category is given in Boxes 8.4-8.11. The principles have been sourced from the Australian Government's Environment Protection and Biodiversity Conservation Act (1999) and supporting papers (Box 8.4).

\section{Managing IUCN Categories I-IV}

All IUCN management categories are important for biodiversity conservation, but Categories I-IV provide a particular focus on the protection of biodiversity and other natural and cultural heritage (Dudley 2008). This protection and management are what contribute directly to the conservation of species and biodiversity at a time when there is rapid species decline and continuing loss of habitats. These reserves are what provide a key contribution to the conservation of many of the world's rarest and most endangered species in the wild. They also contribute critically to keeping common species common. 


\section{Box 8.5 Reserve management principles for IUCN Category la protected areas (strict nature reserve) - Australia}

The reserve or zone should be managed primarily for scientific research or environmental monitoring based on the following principles.

- Habitats, ecosystems and native species should be preserved in as undisturbed a state as possible.

- Genetic resources should be maintained in a dynamic and evolutionary state.

- Established ecological processes should be maintained.

- Structural landscape features or rock exposures should be safeguarded.

- Examples of the natural environment should be secured for scientific studies, environmental monitoring and education, including baseline areas from which all avoidable access is excluded.

- Disturbance should be minimised by careful planning and execution of research and other approved activities.

- Public access should be limited to the extent that is consistent with these principles.

Source: CoA (1999)

\section{Managing 'strict nature reserves' (IUCN Category la)}

Strict nature reserves are among very few areas on Earth where human activities are strictly limited, and they are extraordinarily important for helping to conserve Earth's heritage (Dudley 2008). Many of Earth's species would not exist without the existence of this category. Managing these areas will often be challenging and should take into account guidance principles for Category Ia protected areas (Box 8.5). Management should have regard to:

- strict regulation of official and other visitor use and access through permits and supported by on-ground patrols and regulatory responses to illegal access and poaching; this may have special regard to wildlife management requirements such as breeding and birthing seasons, winter dormancy requirements (bats in caves), species migration patterns and the presence of dangerous animals

- application of invasive species prevention best practice linked to access management including quarantine measures; IUCN guidelines prepared by Wittenberg and Cock (2001) are useful for this work
- implementation of introduced species eradication programs such as those being implemented for Macquarie Island, Tasmania, Australia (TPWS 2014)

- encouragement and facilitation of scientific research including the establishment of reference sites for baseline and long-term measurement of the environment

- respecting and recognising the values and rules of communities governing sites considered sacred or otherwise culturally important in ways that no resource use is allowed

- regular communication with scientists about the special responsibilities they have when entering protected areas and especially a strict nature reserveproviding entry and use guidance (as well as access permission) such as identified in the 2013 IUCN draft Code of Practice for Research-is important (Box 8.6).

\section{Managing 'wilderness areas' (IUCN Category lb)}

Wilderness areas are formally recognised by the IUCN as a protected area category. They are typically large natural areas, and many species need such large areas that are essentially unmodified by humans and that have little permanent or significant human habitation for their survival. They are often the only areas remaining where this opportunity is available. Designated wilderness areas are managed in order to protect their long-term ecological integrity and the natural forces and processes that predominate. They are also managed to be largely undisturbed by human activity and free of modern infrastructure (Dudley 2008). It is also understood that some people do not accept the term 'wilderness', and many cultures around the world have no equivalent term for what in some Western countries is considered a neat dichotomy between 'wild' and 'domesticated'. Such cultural differences and views helped to shape the concept of wilderness prepared by the IUCN in Barcelona in 2008 (Dudley 2008), and further discussions may be anticipated in the future.

Managing IUCN Category Ib wilderness areas should have regard to:

- guidance material prepared for these reserves (Box 8.7)

- providing for public access at low use levels and in a manner that retains the wilderness (natural) condition of the area; this may include policies that emphasise self-reliant recreation and restrict the use of pack animals (such as horses), motorised vehicles (motorcycles, four-wheel drives) and aircraft (fixedwing and rotary wing) 


\section{Box 8.6 Draft code of practice for responsible research and monitoring in protected areas}

1. All research must have the necessary national, State or Territory and local approvals and permits, pay any fees required, and strictly follow laws, regulations and social norms and protocols relating to research within protected areas, including with respect to access and benefit sharing under the CBD.

2. All research should obtain necessary ethics approval from research organisations, funding agencies and protected areas with respect to both animal research and social research.

3. Field researchers must adopt the highest precautionary standards to avoid the accidental introduction and distribution of invasive and pathogenic organisms.

4. Field research should minimise disturbance both to the organisms being studied and to other species and ecosystems.

5. Data collection involving the killing of an organism should only take place when this is absolutely essential to the research and has been agreed by managers and follows national rules.

6. Researchinvolving significantalteration to ecosystems including through the killing of organisms should normally not be undertaken in IUCN Category I-IV protected areas unless there is no feasible alternative research location, or unless research is likely to be of significant importance to the conservation goals of the protected area. In all such cases, a detailed impact assessment and cost-benefit analysis should be undertaken before permission is granted, and research should focus on less strictly protected zones of the protected area. Particular attention should be given to whether the areas or species are considered sacred or culturally important to indigenous peoples or local communities and to the degree of threat faced by the species (drawing on the IUCN Red List categories).

7. Where research involves fieldwork in areas occupied by people, or affects species or ecosystems to which people have de facto or de jure tenure rights or cultural connections, it must have free prior and informed consent from rights-holders in relation to the rights that may be affected, and must be carried out in a way that respects local beliefs, economic and cultural interests, and rights.

8. Managers of protected areas should seek to partner with research organisations to develop collaborative research that will both inform management and meet the needs of the research community for cuttingedge science. In turn, researchers should seek collaborative relationships with managers where the results of their research are likely to inform park or conservation management and build capacity.

9. Researchers should consider the aesthetic values of protected areas and impacts on visitor experience when selecting methods of data collection, radio collaring, constructing research plots, field bases and other actions, and remove all equipment and other materials at the end of the research.

10. Researchers employed by protected area organisations or associated government departments should abide by the same rules and code of conduct, where applicable, as external researchers.

11. Protected area managers should welcome research as an important value of protected areas. They should create clear conditions for permitting research and seek to encourage suitable research in protected areas ideally through a process (such as a research working group) that identifies research priorities.

Source: Hockings et al. (2013)

- guidance provided by $A$ Handbook on International Wilderness Law and Policy prepared by the Wild Foundation, which states that ' $[\mathrm{w}]$ ilderness legislation seeks to protect large natural areas in as wild a state as possible and to maintain the biological integrity of these areas into the future' (Kormos 2008:355), and that wilderness is not about excluding people, 'rather, the key point is that wilderness legislation regulates human use of certain areas to preserve certain wilderness values, while allowing those uses that are consistent with those values' (p. 356)

- enabling indigenous communities to maintain their traditional lifestyle in wild areas in ways compatible with the protected area's conservation objectives

- protecting the cultural and spiritual values of wilderness areas that are special to indigenous and non-indigenous populations

- facilitating low-impact research and educational activities

- restoration of any disturbed areas

- active management of threats such as introduced plants and animals, poaching, and other humancaused threats (Chapter 16). 


\section{Box 8.7 Reserve management principles for IUCN Category Ib protected areas (wilderness) - Australia}

The reserve or zone should be protected and managed to conserve its unmodified condition based on the following principles.

- Future generations should have the opportunity to experience, understand and enjoy reserves or zones that have been largely undisturbed by human action over a long period.

- The essential attributes and qualities of the environment should be maintained over the long term.

- Public access should be provided at levels and of a type that will best serve the physical and spiritual wellbeing of visitors and maintain the wilderness qualities of the reserve or zone for present and future generations.

- Indigenous human communities living at low density and in balance with the available resources should be able to maintain their lifestyle.

Source: CoA (1999)

\section{Managing 'national parks' (IUCN Category II)}

National parks are the best understood and probably the most visited of all the IUCN protected area categories by visitors and communities from around the world. They are primarily managed to protect natural biodiversity along with its underlying ecological structure and supporting environmental processes, but importantly, they promote opportunities for education and recreation in some of the most beautiful natural areas of Earth (Dudley 2008).

National parks are critical for the conservation and protection of species, and may contribute to the conservation of wide-ranging species, regional ecological processes and migration routes, and often form core areas of very large connectivity conservation areas (Chapter 27; Dudley 2008). They are managed for appropriate visitor use for inspirational, educational, cultural and recreational purposes, and national park management of nature-based tourism contributes importantly to local economies (see Chapter 23). Contemporary global policy for national parks takes into account the needs of indigenous peoples and local communities responsibly and equitably, consistent with reserve management objectives, though in practice, in some countries, more needs to be done. National parks provide important opportunities for research, with many research sites monitoring changes in natural environments such as those due to climate change.

Managing IUCN Category II national parks should have regard to:

- guidance material for the management of national parks (Box 8.8)

- management planning and zoning to ensure that large-scale ecological processes are protected; that opportunities for conserving wilderness are secured; that connectivity areas are maintained for wildlife; and that a range of opportunities for visitors for recreation and enjoyment of the park is provided

- working with neighbours and local communities

- restoration of disturbed areas

- active management of threats and incidents

- facilitation of research and opportunities for research

- active management of visitor facilities and visitor services and any emergencies involving people within a park.

\section{Managing 'natural monuments or features' (IUCN Category III)}

The focus of management for IUCN Category III protected areas is the protection of specific outstanding natural features and their associated biodiversity and habitats (Dudley 2008). Many of these features are geological phenomena such as karst sites or volcanic landscape features, and are described further in Chapter 18. Many of these protected areas may be culturally significant and may be managed for their natural and cultural heritage values. Managing IUCN Category III 'natural monuments or features' should have regard to:

- guidance material for IUCN Category III protected areas (Box 8.9)

- use of IUCN specialist guidance material for caves and karst protection prepared by Watson et al. (1997)

- use of active threat management, conservation work and restoration action that target the conservation of specific species found only at the monument or feature; this could include, for example, bat colonies within caves and flora species found only within the spray zone of waterfalls

- facilitation of research of the protected area and its natural phenomena

- active management of appropriate visitor use of the protected area. 


\section{Box 8.8 Reserve management principles for IUCN Category II protected areas (national park) - Australia}

The reserve or zone should be protected and managed to conserve its natural condition according to the following principles.

- Natural and scenic areas of national and international significance should be protected for spiritual, scientific, educational, recreational or tourism purposes.

- Representative examples of physiographic regions, biotic communities, genetic resources and native species should be perpetuated in as natural a state as possible to provide ecological stability and diversity.

- Visitor use should be managed for inspirational, educational, cultural and recreational purposes at a level that will maintain the reserve or zone in a natural or near-natural state.

- Management should seek to ensure that exploitation or occupation inconsistent with these principles does not occur.
- Respect should be maintained for the ecological, geomorphologic, sacred and aesthetic attributes for which the reserve or zone was assigned to this category.

- The needs of indigenous people should be taken into account, including subsistence resource use, to the extent that they do not conflict with these principles.

- The aspirations of traditional owners of land within the reserve or zone, their continuing land management practices, the protection and maintenance of cultural heritage and the benefit the traditional owners derive from enterprises, established in the reserve or zone consistent with these principles, should be recognised and taken into account.

Source: CoA (1999)

\section{Box 8.9 Reserve management principles for IUCN Category III (natural monument) - Australia}

The reserve or zone should be protected and managed to conserve its natural or cultural features based on the following principles.

- Specific outstanding natural features should be protected or conserved in perpetuity because of their natural significance, unique or representational quality or spiritual connotations.

- Opportunities for research, education, interpretation and public appreciation should be provided to an extent consistent with these principles.
- Management should seek to ensure that exploitation or occupation inconsistent with these principles does not occur.

- People with rights or interests in the reserve or zone should be entitled to benefits derived from activities in the reserve or zone that are consistent with these principles.

Source: CoA (1999)

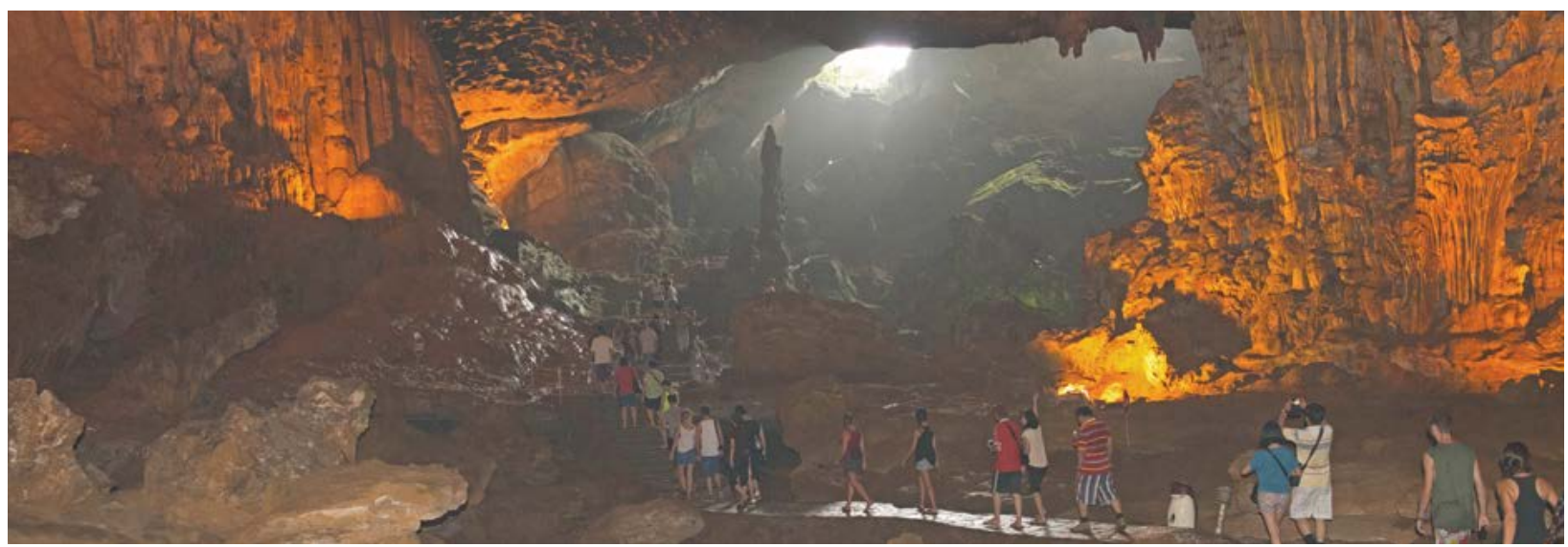

Hang Sung Sot Cave, Ha Long Bay World Heritage Property, Vietnam: this World Heritage limestone karst feature, with its large numbers of visitors, has active management to help conserve its geological and geomorphic values

Source: Graeme L. Worboys 
Box 8.10 Management principles for IUCN Category IV (habitat/species management area) - Australia

The reserve or zone should be managed primarilyincluding, if necessary, through active interventionto ensure the maintenance of habitats or to meet the requirements of collections of or specific species based on the following principles.

- Habitat conditions necessary to protect significant species, groups or collections of species, biotic communities or physical features of the environment should be secured and maintained, if necessary, through specific human manipulation.

- Scientific research and environmental monitoring that contribute to reserve management should be facilitated as primary activities associated with sustainable resource management.

- The reserve or zone may be developed for public education and appreciation of the characteristics of habitats, species or collections and of the work of wildlife management.

- Management should seek to ensure that exploitation or occupation inconsistent with these principles does not occur.

- People with rights or interests in the reserve or zone should be entitled to benefits derived from activities in the reserve or zone that are consistent with these principles.

- If the reserve or zone is declared for the purpose of a botanic garden, it should also be managed for the increase of knowledge, appreciation and enjoyment of a country's plant heritage by establishing, as an integrated resource, a collection of living and herbarium specimens of native and related plants for study, interpretation, conservation and display.

Source: CoA (1999)

\section{Managing 'habitat/species management areas' (IUCN Category IV)}

Many protected areas have been reserved specifically to conserve flora and fauna species and their habitats. Often they are very small but they are critical for wildlife, such as remote islands and their use by birds for resting during migration or for nesting. In contrast with IUCN Category I-III protected areas, these areas may require regular management intervention to deal with threats, to achieve restoration and to achieve the conservation of species and their habitats (Dudley 2008).
Managing IUCN Category IV habitat/species management areas should have regard to:

- guidance material for IUCN Category IV protected areas (Box 8.10)

- seasonal (wildlife-focused) management requirements for these protected areas and the role they may provide as an integral part of protecting an entire migration route for a trans-hemisphere migratory species

- the role they may play as part of a core protected area within a larger connectivity conservation area (corridor)

- the possible need for active restoration and threat management on an ongoing basis

- opportunities that are available for providing public education and the appreciation of wildlife species.

\section{Managing IUCN Category V and VI protected areas}

IUCN CategoryV protected areas involve ongoing human change to a landscape and seascape as the value basis for a particular landscape and, for Category VI, resource use. One key purpose is to conserve biodiversity-as with all IUCN protected area categories-but management also involves balancing nature and human use and the management of human cultural landscape features.

\section{Managing 'protected landscapes/ seascapes' (IUCN Category V)}

Managing Category $\mathrm{V}$ protected areas focuses on protecting and sustaining important landscapes and seascapes (and their associated nature conservation and other values) that have been created by humans through traditional management practices (Dudley 2008). Managing IUCN Category $\mathrm{V}$ protected landscapes/ seascapes should have regard to:

- guidance material for IUCN Category V protected areas (Box 8.11)

- guidance material prepared by Phillips (2002) and subsequent material generated by the IUCN WCPA (Brown et al. 2005; Amend et al. 2008; Mallarach 2008; Dudley and Stolton 2012)

- balancing the interaction between nature and culture through actively protecting nature and working with local communities and indigenous peoples to help retain traditional practices

- recognising and working with local communities and indigenous peoples to help retain traditional practices, including the sustainable governance of their biocultural landscapes and seascapes (Chapter 7) 


\section{Box 8.11 Reserve management principles for IUCN Category V protected areas (protected landscape/seascape) - Australia}

The reserve or zone should be managed to safeguard the integrity of the traditional interactions between people and nature based on the following principles.

- The harmonious interaction of nature and culture should be maintained through the protection of the landscape or seascape and the continuation of traditional uses, building practices and social and cultural manifestations.

- Lifestyles and economic activities that are in harmony with nature and the conservation of the social and cultural fabric of the communities in the reserve or zone concerned should be supported.

- The diversity of landscape, seascape and habitat, and of associated species and ecosystems, should be maintained.

- Land and sea uses and activities that are inappropriate in scale or character should not occur.
- Opportunities for public enjoyment should be provided through recreation and tourism appropriate in type and scale to the essential qualities of the reserve or zone.

- Scientific and educational activities that will contribute to the long-term wellbeing of resident populations and to the development of public support for the environmental protection of similar areas should be encouraged.

- Benefits to the local community and contributions to its wellbeing, through the provision of natural products and services, should be sought and promoted if they are consistent with these principles.

Source: CoA (1999)

\section{Box 8.12 Reserve management principles for IUCN Category VI (protected area with sustainable use of natural resources) - Australia}

The reserve or zone should be managed mainly for the ecologically sustainable use of natural ecosystems based on the following principles.

- Biological diversity and other natural values of the reserve or zone should be protected and maintained in the long term.
- Management practices should be applied to ensure ecologically sustainable use of the reserve or zone.

- Management of the reserve or zone should contribute to regional and national development to the extent that this is consistent with these principles.

Source: CoA (1999)
- dealing with native species that have evolved in association with cultural management systems

- working with the landscape as a buffer area to core protected areas

- working with the landscape/seascape as part of a larger connectivity conservation area/corridor.

\section{Managing 'protected areas with sustainable use of natural resources' (IUCN Category VI)}

Some large and essentially natural areas may be managed for objectives of conservation and sustainable use that are mutually beneficial and have been recognised as Category VI areas (Dudley 2008). Managing these areas should have regard to:

- guidance material for IUCN Category VI protected areas (Box 8.12) achieving sustainable use of natural resources from the perspective of ecological, economic and social dimensions as a means to secure nature conservation (Chapter 25)

- working with local communities to assist in securing social and economic benefits as well as conserving ecosystems and habitats

- recognising and facilitating ICCAs_for instance, sustainable community forestry, locally managed marine areas and other such approaches (Chapter 7)

- working to ensure threats are actively managed, including the potential for large-scale industrial harvesting of natural resources

- ensuring that a large proportion of the Category VI protected area is retained as a no-take zone (twothirds has been used as a guide by some countries) (Dudley 2008). 


\section{Managing for people officially present in protected areas}

A nation's protected areas are typically part of rich and diverse cultural landscapes and multi-sectoral societies (Chapter 5). In addition to visitors (Chapter 23), there are people who may live within protected areas because they are community members of an ICCA, they own or co-own the protected area or they are present for other official reasons. Such people are involved in living and working in and using protected areas as part of their daily lives, and some activities relevant to protected area management are described here. These people and communities are officially present, they are an integral part of protected areas and protected area practitioners need to manage for this.

\section{People living in protected areas for official reasons}

There may be many people living in protected areas for official reasons. These could include:

- rangers and protected area law enforcement staff

- protected area field officers responsible for works and services

- protected area entrance station, visitor centre and security staff

- research staff and scientists participating in longterm park-based research projects

- quarantine management and border security staff

- police, ambulance, doctor and fire station staff

- general maintenance and road management staff (such as for snow clearing and road-ice management)

- military personnel within the protected area who assist with the protection of the reserve and, potentially, deal with conflict

- external contract staff responsible for operating services such as water supply, waste removal and sewage treatment works operations

- visitor service support staff for retail outlets, accommodation, restaurants, tours and expeditions, transport/taxi support and other services

- people who lived in the protected area prior to its establishment

- communities living in protected areas of various governance types with various rights such as ownership, resource use and residency status.
Managers would be expected to assist people for protected area management-related matters, including for:

- operational matters such as permit systems for official residents, dealing with emergencies such as humanwildlife issues, emergency medical evacuations and responding to emergency events such as vehicle incidents or pollution spills

- logistical issues such as the provision of power, water, solid waste removal and sewerage services; telecommunication equipment and accommodation; and support services for a range of official organisations

- sensitive social issues such as dealing with trauma and death-some agencies such as the US National Park Service (NPS) have protocols for handling such matters.

From time to time, it may be necessary to deal with a minority of 'official people' to ensure that the reserve is protected. This intervention by 'official people' could include responding to illegal activities such as poaching, theft of protected resources and illegal access.

\section{People working in protected areas}

Many people commute to and from or through protected areas for their daily work. Often they bring with them their equipment and materials needed for their work. This access relates to all aspects of management including visitor access services, tourism services and services that underpin operations and work within the protected area. Management considerations may include:

- practical permit systems for access that assist locals

- practical permit systems that assist access for temporary work such as for filming or special events

- the danger of vehicle-wildlife interactions and other safety concerns

- quarantine issues - the introduction of materials and organisms that are adverse to the protected area

- illegal activities such as poaching.

\section{People using and contributing to protected areas}

Many people use and positively contribute to protected areas and enjoy these areas in many different ways. Ensuring that their visit is a safe and positive experience is very important. Subject to the specific IUCN categories, management access and service support considerations may include:

- for recreational visitors, a range of recreation opportunities and facilities that matches, where possible, tourism market segments seeking use of the protected area (Chapter 23) 


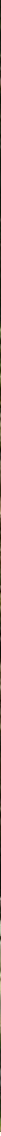

Superintendent's cottage, Mammoth, Yellowstone National Park: this historical structure was built about 1910 as part of the US Army's presence within the park, and forms part of the official staff presence in the park

Source: Graeme L. Worboys

- for visitors accessing for cultural and spiritual reasons, the provision of access services and respectful backup support especially for key events and ceremonies

- for volunteers, the provision of training support, access transport, equipment and materials, where appropriate

- for remote area and other users, the capacity to provide first-aid facilities and, where necessary, emergency evacuation

- for locals, providing assistance to commemorate special historical events and customary occasions.

\section{Management for protected area governance types}

There are different forms of governance for protected areas (Chapter 7), with four principal types being recognised (Figure 8.4). Management of protected areas within these different governance types varies, and some aspects of the management for government, shared, private and ICCA protected area governance types are described here. Many management considerations presented will apply to all governance types.

\section{Government managed protected areas}

A great many IUCN Category I-VI protected areas around the world are managed by governments as part of a national or sub-national reserve or local government reserve system, and some of the many management requirements of working in a government system are described here. We have already described the all-important governance of protected areas and its focus on the allocation and use of power in different organisations and organisational structures (Chapter 7). Here, for management, we focus on the characteristics of management processes, systems and actions that may need to be completed within a government protected area organisation. It can be expected there will also be some parallel processes and systems for NGOs and for private sector institutions.

\section{Whole-of-government processes}

A government protected area organisation is often part of an entire government environment and must manage within this context. Depending on the nation's constitution, its governance structures and the laws of the land, this context may include receiving management response requests from the government, the parliament, executive government and the judiciary. A protected area agency chief executive will need to respond to such requirements. 


\begin{tabular}{|c|c|c|c|c|c|c|c|c|c|c|c|}
\hline \multirow[t]{2}{*}{ Governance types } & \multicolumn{3}{|c|}{$\begin{array}{l}\text { A. Governance by } \\
\text { government }\end{array}$} & \multicolumn{3}{|c|}{ B. Shared governance } & \multicolumn{3}{|c|}{ C. Private governance } & \multicolumn{2}{|c|}{$\begin{array}{l}\text { D. Governance } \\
\text { by indigenous } \\
\text { peoples } \\
\text { and local } \\
\text { communities }\end{array}$} \\
\hline & 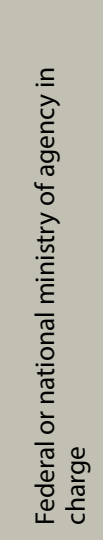 & 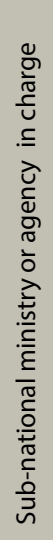 & 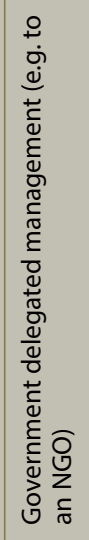 & 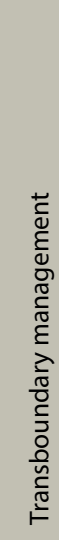 & 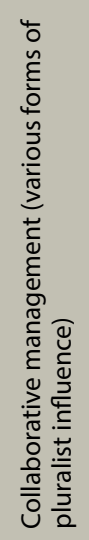 & 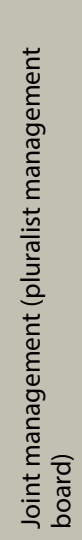 & 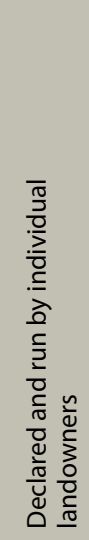 & 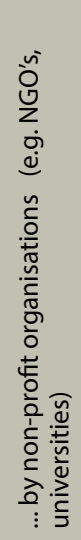 & 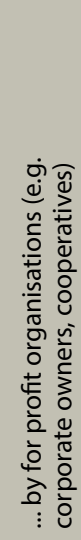 & 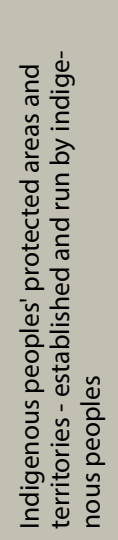 & 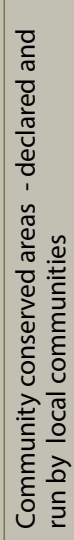 \\
\hline \multicolumn{12}{|l|}{ la. Strict Nature Reserve } \\
\hline \multicolumn{12}{|l|}{$\begin{array}{l}\text { Ib. Wilderness } \\
\text { Area }\end{array}$} \\
\hline $\begin{array}{l}\text { II. National } \\
\text { Park }\end{array}$ & & & & & & & & & & & \\
\hline \multicolumn{12}{|l|}{$\begin{array}{l}\text { III. Natural } \\
\text { Monument }\end{array}$} \\
\hline \multicolumn{12}{|l|}{$\begin{array}{l}\text { IV. Habitat/Species } \\
\text { Management }\end{array}$} \\
\hline \multicolumn{12}{|l|}{$\begin{array}{l}\text { V. Protected Landscape/ } \\
\text { Seascape }\end{array}$} \\
\hline $\begin{array}{l}\text { VI. Protected Area with } \\
\text { Sustainable Use of } \\
\text { Natural Resources }\end{array}$ & & & & & & & & & & & \\
\hline
\end{tabular}

Figure 8.4 The IUCN Protected Area Matrix: A classification system for protected areas comprising both IUCN management category and governance type

Source: Dudley (2008)

\section{Legislative requirements}

In many countries, as a manager of land, freshwater and marine environments, a protected area organisation will be accountable to protected area legislation as well as (potentially) a range of other legislative (or executive) requirements. Specific accountabilities may also be prescribed, including environmental land-use planning, local government administration, building codes and standards, emergency management, criminal incidents, agriculture quarantine measures, pest animal control, introduced plant species control, fire management and emergency response, anti-pollution responses (water, air, solid waste), mining rights, fishery controls, marine mammal protection, use of firearms, road construction, use of explosives, design standards, workplace management laws, and occupational health and safety requirements. Managers will need to ensure they are knowledgeable of the entire suite of government legislative responsibilities they are accountable for when they manage their protected areas.

\section{Requirements of parliament}

Parliament (or equivalent organisations) may instruct that certain actions are undertaken by a protected area organisation. Interestingly, this could include legislation passed by a parliament that is not the legislation of the elected government in power. This circumstance has happened in a democratic parliament where the elected government did not have a majority and was reliant on independents for power. Non-elected government legislation was enacted, it became law and the protected area chief executive was required to implement the legislation, even though it was neither the elected government's policy nor (from their perspective) a priority. Parliament may also request that protected area 
experts and top-level managers provide formal evidence to inquiries they are conducting, and parliamentary inquiries and delegations may require assistance for onsite inspections of protected areas.

\section{Requirements of government}

In a democracy, the election policies, commitments and promises of an incoming government will set the scene for the protected area organisation's priorities. Responding to these commitments will be the highest priority for protected area organisations and may require substantial realignment of priorities including the cessation of some work and the commencement of new tasks. Once this organisational realignment has been achieved, it will be important for a protected area organisation to implement the policies efficiently and effectively. This requires change management and is a normal and essential part of an organisation's operation. Protected area organisations are independent of party politics and are required to provide information to government in response to issues. Such processes need to be managed efficiently. Organisations will also be expected to routinely provide information on the conservation status and management of protected areas including through state of the parks reporting, annual reports and, potentially in the future, through the IUCN's Green List processes.

\section{Ministerial requirements}

A minister in charge of a protected area portfolio will have multiple logistical requirements that need to be managed. Everything from organising briefing meetings, policy preparation, the flow of paperwork for approval and signature and the organisation of very important person meetings to organising special launch events and preparing speeches and field inspections all need to be managed with great precision. Organisations typically have internal systems and checking processes to ensure that briefing notes to the minister, for example, are timely, accurate and concise. For a new minister, organisations usually prepare a briefing portfolio and provide opportunities to meet staff and visit key protected area localities as early as possible in the minister's term. (Most ministers in charge of national parks believe they have the best portfolio in government.) Specific requests for action by the minister need to be accounted for and processes put in place to implement the request. This may also require internal organisational changes for a protected area agency.

\section{Requirements of the courts}

Given a nation's courts are independent from the legislature and the police, protected area organisations may receive directives from courts in relation to the management of their areas that may conflict with other directives. Inquiries run by coroners and the courts will usually finish with a range of recommendations for implementation, many (or all) of which are confirmed by government as directives for managers. In an interesting possibility, protected area managers in charge of an area may be required to respond to the requirements of government, the recommendations of the courts and the directives of parliament—all in relation to the same issue.

\section{Requirements of other authorities}

There may be a range of legislation that applies to the geography of a protected area and, subject to the circumstances, there may be different, overriding governance accountabilities and responsibilities for management. In an emergency such as a search and rescue, the police may take charge of operations in a protected area. For a wildfire, it may be the fire service that is responsible for the emergency, and for a quarantine issue, responsibility for management may be with an agriculture department. Managers need to ensure that each top-level manager in charge (and their support staff) of these different areas of responsibility is thoroughly briefed on the purpose and management of the protected area and its special protection and conservation needs.

\section{Protected area chief executives managing for biodiversity conservation}

In addition to running a protected area organisation efficiently and effectively, a chief executive may be called on to provide advice to a minister and government on key biodiversity conservation issues. Protected areas may be the last location for some species on Earth, and a chief executive will be busy assisting a government to achieve its policies as well as protecting a nation's native species. Regrettably sometimes, proposed government policy requirements will conflict with species' needs and some decisions may mean the demise of a species at a location or even its extinction. In working with a minister and government to resolve such difficult issues, chief executives would, of course, be respectful and courteous; they would use their negotiation skills, their detailed knowledge of the species' needs, their understanding of the specific issue and pre-prepared practical alternatives to help secure an outcome in favour 
of species conservation. Such proactive leadership and courage may be needed from time to time if we are to stem the loss of species on our planet. It is also useful to reflect that such attributes of a chief executive described here are considered essential in the 21 st century and are described further in Chapter 12.

\section{Organisational change}

Organisational change is normal for protected area organisations. It needs to be conducted for legitimate reasons and especially as an investment in achieving goals more effectively, including biodiversity conservation outcomes. Ideally, organisational change takes place in collaboration with staff and may include downsizing due to budget cuts or the enlargement of an organisation due to the addition of new protected areas. Major organisational changes would usually involve a business strategy, a human resource management strategy and an organisational change strategy. A human resource management strategy considers all aspects of working with people in an organisation affected by the change, including, as appropriate, information flow and briefings, capacity development, meeting industry award requirements, employment opportunities, redundancy opportunities, new organisation structures, position descriptions and interview requirements. Factors that are important in developing the human resource strategy would be the degree of change proposed and the type of change leadership to be exercised (Dunphy and Stace 1991). Getting these approaches right is important, and change management specialists would normally play a key role in this process.

\section{Budgets and financial inputs}

Managing finances is a basic, routine and essential part of a protected area manager's responsibilities within government (and other organisations). Protected area organisations prepare a financial budget, as do the managers of individual protected areas and individual projects. The same principles apply at each of these levels, though clearly the complexity changes. At the heart of financial management lies a budget plan. At the protected area systems level, this will have been developed from corporate (strategic) planning priorities, routine financial estimates of annual operating costs and inputs from a bidding process where corporately aligned and realistic budget proposals are submitted. Characteristics of a protected area organisation's 12-month budget plan include:

- details of the overall organisational budget amount available
- sources of income that would include capital funds, recurrent funds, funds sourced from revenue and other sources such as donations

- operating expenses such as employee salaries, payroll tax, superannuation, insurance and other costs

- assets and liabilities

- priority budget expenditure programs (which are linked to government priorities and consequently to corporate planning and strategic planning priorities).

Frontline managers in charge of projects are responsible for tracking and managing their expenditure and financial commitments, with both over-expenditure and underexpenditure being issues for an organisation at the end of a financial year. Basic spreadsheet financial controls (or online software equivalents) would itemise income, expenditure and forecast expenditure, allow for regular budget reconciliations and identify project budget milestones. Depending on the type of organisation and the location, these may be achieved using a simple traditional accountant's ledger, a computer spreadsheet program or a much larger whole-of-organisation computerised financial management system.

Middle-level managers often have the responsibility of managing the efficient and effective management of multiple project budgets. Top-level managers are accountable for the entire organisation's budget. Typically there is an end of financial year annual report, which accounts for all aspects of an organisation's budget performance, and there is a routine (annual) financial audit. From time to time, external government organisations such as an auditor-general's department may complete an independent audit of an organisation's financial management.

In managing finances, corruption is always a risk and all managers need to be alert to this potential. Hopefully, this never happens; however, vigilance, regular audits and an 'anti-corruption plan' to avert corrupt conduct are recommended best practice. Areas of financial management particularly vulnerable to corruption include tendering procedures, licensing, the receipt of revenue and the handling of expenditure. Organisations may need to consider implementing special ethics training for employees, and may need to put in place special protection arrangements for whistleblowers.

\section{Human resource inputs}

Effective human resource management ensures that the right people are appointed to the right positions at the right time. It also ensures that the right systems to support staff are in place. A government human resource management process may include: 
The Biligiri Rangaswamy Temple Tiger Reserve in India is home to the indigenous Soligas community and is an area of high biological diversity. The forest area was declared a wildlife sanctuary in 1974, resulting in the displacement of Soligas from their traditional settlements; they were settled into colonies either along roads or on the periphery of the reserve. Customary practices-including shifting cultivation, hunting and the use of early dry season fireswere banned. The notification of the wildlife sanctuary altered the social, agricultural and ecological practices of the Soliga. The outcomes of this cessation of customary practice are now becoming evident. Today the forest is covered by the invasive species lantana (Lantana camara). Long-term monitoring of the Temple forest across its 540 square kilometre area has demonstrated the rate and extent of lantana spread. Between 1997 and 2008, there was a doubling in extent of lantana presence in sampling plots and a sixfold increase in the density of lantana (Sundaram and Hiremath 2011). There has been a corresponding decline in the occurrence of native plant species, with fewer adult trees of important non-timber forest produce such as Indian gooseberry (Phyllanthus emblica) and terminalia (Terminalia chebula) as well as other tree species such as axlewood (Anogeissus latifolia) and Kydia calycina.

The Soligas have a nuanced understanding of the role of fires and their interaction with lantana. They claim that the cessation of fire has produced the above consequences through increased mortality due to deficiency of sunlight for regeneration, and the availability of grazing areas for wildlife has shrunk significantly. They maintain that lowintensity ground fires early in the dry season (taragu benki or litter fire) help to control weeds, encourage regeneration of native species and produce fresh grass for wildlife. Their understanding has, however, so far gone unheeded by managers, resulting in an accumulation of biomass that causes canopy fires in the dry season, affecting many wildlife species. Evidence is now accumulating from ecological studies to support the Soliga theory of fire, including that it kills lantana seeds in the soil.

The Soligas have also highlighted the interactions between fire, mistletoes and host tree mortality. Mistletoes are tree hemi-parasites that eventually reduce fruit yield and kill the trees they infest. Observations show that mistletoe infestation on gooseberry is increasing, resulting in more than 50 per cent mortality. Soligas have long held that fires kill mistletoes. It is clear from Soliga situated knowledge and from long-term studies that the suspension of customary management practices in the 1970s has resulted in unintended and adverse consequences. This shows that situated local knowledge and scientific studies can facilitate our understanding of the dynamics of human impacts on natural landscapes. Protected area policy has to urgently incorporate adaptive and situated management practices if we are to prevent the erosion of ecological values and knowledge systems.

- Nitin D. Rai, Ankila J. Hiremath and Siddappa Setty
- planning for human resources (including approved staffing levels and management requirements)

- conducting formal recruitment processes

- selection (that may include organisational affirmativeaction targets for particular sectors of the workforce)

- induction

- training and development

- performance management

- compensation payment (for services provided, including industrial award considerations)

- promotions, demotions, terminations or lateral movement

- employee welfare, services, accommodation, transfer support and occupational health and safety support (Worboys and Winkler 2006c).

Each of these matters needs to be carefully managed. Safety and health in the workplace are also particularly important for protected area management. Staff may be operational within protected areas in extreme weather or extreme environments; they may face dangerous circumstances such as wildfire, wild animals and armed poachers; they may use powerful chemicals such as herbicides and pesticides; and they may be operational in aircraft, boats, four-wheel-drive vehicles and using equipment such as chainsaws. Their safety and wellbeing are paramount, and considerations for their training, necessary safety equipment, insurance cover and backup medical support (if needed) are critical (see Chapter 24). Safety may also be more than preventing accidents. In the United States, for example, protected area law enforcement officers may be hurt or killed in the line of duty by law-breakers. In Africa and elsewhere, protected area rangers have been killed in the line duty, with an estimated 1000 rangers killed between 2004 and 2014, mostly by poachers and militia groups (TGL 2014). Organisations may need to actively manage and prepare for such potential dangers to staff.

\section{Local knowledge}

Benefiting from local knowledge and experience is an important part of managing protected areas. When combined with professional management expertise and additional scientific inputs (see Chapter 21), it can be of great assistance to biodiversity conservation. One aspect of local knowledge and its application to protected area management are given in Case Study 8.1. 


\section{Box 8.13 Shared governance}

Complex institutional mechanisms and processes are employed to share management authority and responsibility among a plurality of-formally and informally-entitled governmental and nongovernmental actors. Shared governance-sometimes also referred to as co-management-comes in many forms. In 'collaborative' management, decisionmaking authority and responsibility rest with one agency but the agency is required-by law or policyto inform or consult other stakeholders. Participation in collaborative management can be strengthened by assigning to multi-stakeholder bodies the responsibility of developing technical proposals for protected area regulation and management, to be submitted ultimately to a decision-making authority for approval. In 'joint' management, various actors sit on a management body with decision-making authority and responsibility. Decisions may or may not require consensus. In any of these cases, once decisions about management are taken, their implementation needs to be delegated to agreed bodies or individuals.

Source: Dudley (2008)

\section{Shared governance of protected areas}

Shared governance is an important approach to protected area management that brings with it special management requirements. The concept of shared governance is explained in Box 8.13.

Shared governance may include a range of management responses including:

- cultural awareness capacity building for protected area practitioners

- operational capacity building for all protected area practitioners, especially vocational training for the use of specialised plant and equipment

- enhanced consultation and meeting processes

- agreed dispute-resolution processes

- different time frames for decision-making.

From recent Australian Indigenous Protected Area (IPA) management experiences, for example, special management requirements have included:

- enhanced collaboration and indigenous engagement to enhance cooperative or joint management arrangements over a range of different government protected areas

- recognition of cultural aspirations for indigenous peoples as well as protected area management purposes
- revised protected area management plans and potential lease-back arrangements for management (Rose 2012).

\section{Trans-boundary initiatives}

One form of shared governance relates to transboundary protected areas, which involve at least two or more governments and possibly other local actors (Dudley 2008). Cooperative trans-boundary agreements between nations can help conserve habitats such as those needed by migratory species. In relation to the Altai-Sayan area of Russia, for example, a 2009 transboundary agreement between Kazakhstan and Russia (for two adjoining protected areas) was an important contribution to protecting endangered species (Badenkov et al. 2012). Trans-boundary agreements are discussed further in Chapters 7 and 27.

\section{Private protected areas}

Exclusive hunting reserves established by the monarchs and aristocracies of Europe and elsewhere reflect the antiquity of the concept of private protected areas. Private governance comprises protected areas under individual, cooperative, NGO or corporate control and/ or ownership, which are managed under not-for-profit or for-profit schemes (Dudley 2008). Private reserve systems are growing rapidly in number around the world (Mitchell 2005) and, if they are integrated into a national reserve system framework, they can potentially provide a powerful contribution to biodiversity conservation (Figgis et al. 2005). There are many private protected areas around the world, and a contemporary description of them was crafted by Brent Mitchell of the IUCN WCPA, who stated:

Origins of the private approach to protected areas can be traced to private initiatives to create conventional, public protected areas, and in most cases are inextricably linked to government conservation regimes. (Examples of private individuals creating protected areas and gifting them to the public for governments to manage are many and familiar. Some are centrepieces of national systems of protected areas.) What sets private protected areas apart is that land ownership is not relinquished to the state, or at least not fully. The origin of the word private is the Latin privatus, 'withdrawn from public life,' in turn derived from privus, 'single, individual.' But oddly neither of these necessarily apply to private protected areas. Though private ownership is retained, when 


\section{Protected areas governed by indigenous peoples and local communities}

This governance type includes two main subsets: first, indigenous peoples' areas and territories established and run by indigenous peoples, and second, community conserved areas established and run by local communities. The subsets, which may not be neatly separated, apply to both sedentary and mobile peoples and communities (Dudley 2008). The concept and role of ICCAs as important contributors to heritage conservation and especially biodiversity conservation have been championed by a number of organisations and individuals, and in particular, the IUCN's Theme on Indigenous Peoples, Local Communities, Equity and Protected Areas (TILCEPA) and the ICCA Consortium. Kothari (2006:1) states that ICCAs have burst upon the global conservation scene and 'are the most exciting development since the concept of "protected areas" came into vogue, over a century back'. Though the generic term ICCAs is increasingly in use, other terms such as indigenous protected areas, biocultural heritage sites, and community reserves, are also used (Kothari et al. 2012). 'The conservation of sites and species by indigenous peoples and local communities is age-old. But the fact that these are equivalent in many ways to conventional, government-managed "protected areas", has only recently been recognised' (Kothari 2006:1).

\section{ICCAs in the landscape}

ICCAs can be very small or very large and provide multiple conservation values, harbouring important biodiversity or forming integral links to other protected areas, or being part of landscape conservation initiatives such as connectivity conservation areas. Many ICCAs are part of national reserve systems, but most are not yet formally recognised as sites of conservation importance.

\section{ICCA vision}

For many indigenous peoples and local communities, the vision for a protected area is often unwritten; it is orally transmitted over generations, and is encompassed within a larger understanding such that it may not even be clearly distinguished from other aspects of life.

\section{ICCA management}

ICCAs have been introduced and defined in Chapter 2, their governance described in Chapter 7, with further aspects of their management presented in Chapter 25. Management actions may include:

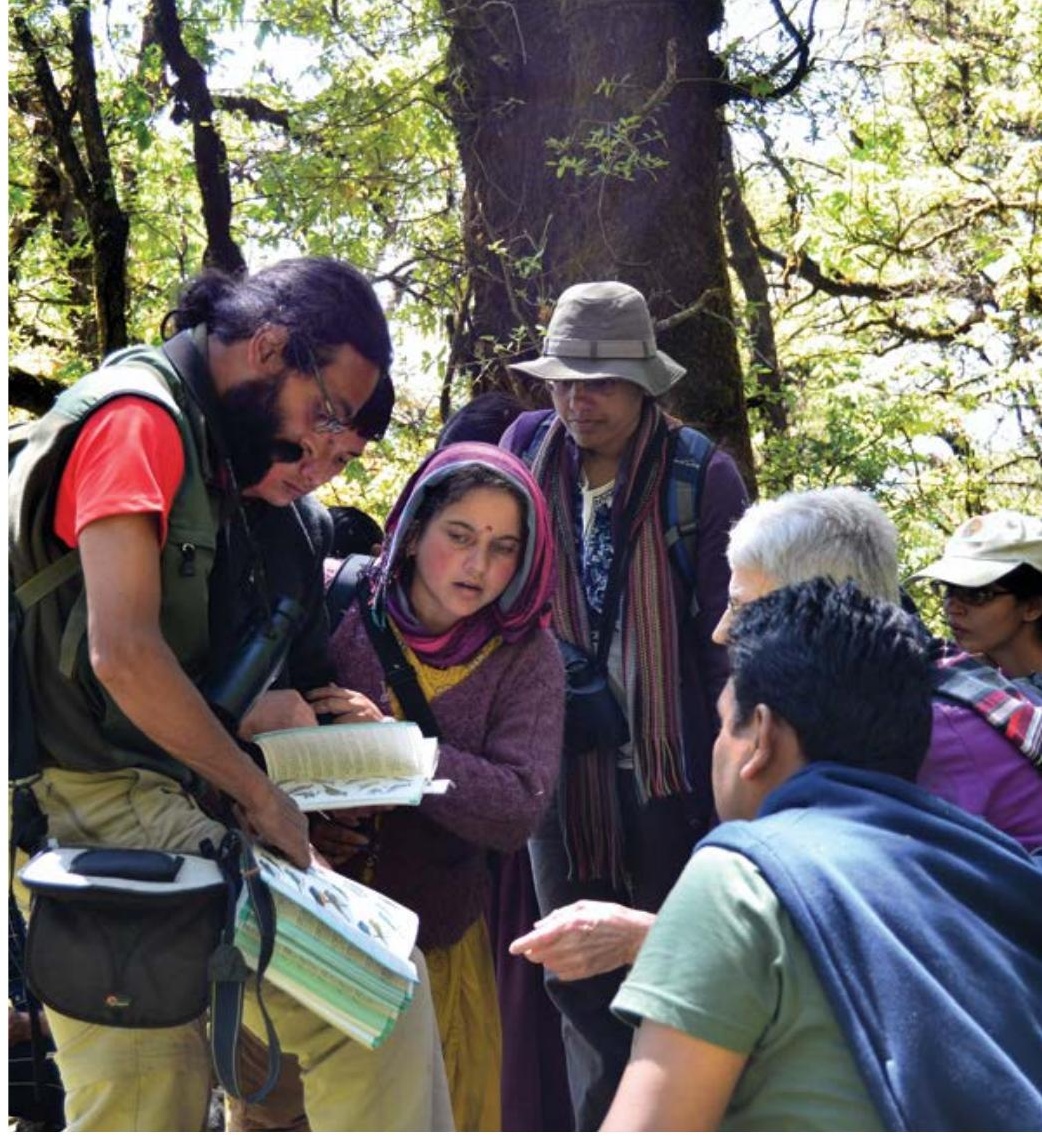

Villagers of Munsiari, Western Himalaya, India, undergoing bird identification training

Source: Ashish Kothari

- clearly mapping the boundaries of their ICCA

- establishing formal recognition by government(s) of the ICCA

- developing a community protocol for conservation of the area

- developing consultation with outside groups which may threaten unwanted developments

- preparing and implementing a monitoring plan for natural resources to track the condition of scarce species

- preparing and implementing a management plan for the area

- undertaking climate change awareness planning and responses

- managing finances to maintain local traditions and livelihoods while protecting the ICCA (UNEPWCMC 2013).

\section{Managing protected areas in special contexts}

Many protected areas have been established or exist in very different social, political and environmental contexts. In this book, for example, we have specifically recognised the management of protected areas for geoheritage sites (Chapter 18), freshwater areas (Chapter 19), marine environments (Chapter 20) and biodiverse 
sites (Chapter 21). In this chapter, we focus on protected areas situated in or at the edge of large population centres, which are referred to as 'urban protected areas'.

\section{Managing urban protected areas}

Urban protected areas technically may be any one of IUCN Categories Ia to VI, but most commonly they are Category II and Category V protected areas. They may technically be from any of the four governance types, though most of them are administered by governments at national, state or provincial, or local levels, with some managed by NGOs, businesses or communities and some as collaborative efforts. These are IUCN category protected areas in every sense and do not include conventional urban parks with lawns, flowerbeds and sports fields. They often require special management. Urban protected areas are distinctive in several ways. They:

- receive large numbers of visitors, including many who visit frequently, even daily; many of these visitors lack experience of wilder forms of nature, and they tend to be much more diverse ethnically and economically than visitors to non-urban protected areas

- relate to numerous actors in the urban arena, including government decision-makers, communications, media and opinion leaders, and key educational and cultural institutions

- are threatened by urban sprawl and intensification of urban development

- are disproportionately affected by crime, vandalism, littering, rubbish dumping and light and noise pollution

- are subject to such urban edge effects as more frequent and more severe fires, air and water pollution, and the introduction of invasive alien species (Trzyna 2014).

\section{Why they matter}

Urban protected areas are important for all the reasons any protected area is important, such as providing ecosystem services, protecting species and supporting the local economy with income from tourism. They have a critical role, however, that sets them apart from other protected areas. They provide opportunities for large numbers of urban people to experience nature, including many people who may not be able to visit more remote protected areas (Box 8.14). This is important for two reasons.

1. Regular contact with nature is good for people. Aside from the benefits of outdoor exercise, there is growing scientific evidence to support the idea that spending time in nature improves physical and mental health, and the concept of 'healthy parks, healthy people' has emerged (Chapter 6).

2. Urban people are critical for nature conservation nationally and globally. More than half of humanity lives in urban areas and this proportion is growing dramatically. Wealth is concentrated in cities, as are communications media. Worldwide, there is a general trend towards more democratic political systems in which voters hold ultimate power. Conservation depends on support from urban voters, urban donors and urban communicators. Yet urban people tend to have less and less contact with nature. People will value nature only if they care about nature where they live.

\section{Twelve challenges and opportunities especially relevant to urban protected areas}

The following management challenges and opportunities are pertinent to some IUCN category protected areas, but they are especially relevant to zoned IUCN Category II protected areas, for example, in or adjoining large population centres.

1. Providing access for all, reaching out to diverse ethnic groups and the underprivileged: This includes accommodating disabled people, choosing words and symbols for compliance signs carefully, and using a range of languages in signs and publications where appropriate. It also includes encouraging direct public transportation, supplying transportation if necessary, providing well-mapped and clearly marked trails and making bicycle routes and rental bicycles available where possible.

2. Engendering a local sense of ownership: To promote appreciation of their protected area among local residents, managers should draw on writers, artists and other creative people and their works and ideas that relate to it. They should promote appreciation of their area's cultural, as well as natural, assets. Making facilities available for the events of governmental agencies, NGOs and businesses helps build good relations with these organisations.

3. Demonstrating, facilitating and promoting good environmental behaviour: Urban protected areas offer opportunities to reach large numbers of people with information about the causes and consequences of climate change and demonstrations of energy efficiency, energy and water conservation, and reduction, reuse and recycling of materials. 


\section{Box 8.14 Urban protected areas around the world}

The following examples of urban protected areas represent different world regions, socioeconomic situations, natural environments, sizes and styles of management.

- The harmonious interaction of nature and culture: Table Mountain National Park: Cape Town, South Africa (metropolitan population: 3.9 million; Category II; 25000 hectares of land; 100000 hectares of the Atlantic Ocean). The park includes iconic Table Mountain, the Cape of Good Hope and unparalleled floral diversity. It is managed by South African National Parks and is part of a natural World Heritage property.

- Hong Kong Country Parks: Hong Kong (metropolitan population: 7 million; Category V; 44000 hectares of land; 1430 hectares of marine park). These mountainous parks cover 40 per cent of Hong Kong's otherwise intensively developed territory. They are administered by the Government of the Hong Kong Special Administrative Region of China.

- Blue and John Crow Mountains National Park: Kingston, Jamaica (metropolitan population: 580 000; Category II; 580000 hectares). This national park protects wet tropical forests that are habitat for diverse wildlife and a key source of water for cities and agriculture. It is managed by an NGO, the Jamaica Conservation and Development Trust, under contract from the National Government.

- London Wetland Centre: London, United Kingdom (metropolitan population: 8.3 million; Category IV; 42 hectares). The centre is a 're-creation' of wetlands along the River Thames. It has been created and managed by an NGO, the Wildfowl and Wetlands Trust.

- Santa Monica Mountains National Recreation Area: Los Angeles, California, USA (metropolitan population: 18 million; Category V; 62300 hectares). This recreation area extends from the city's heart to the Pacific Ocean, and top-predator mountain lions (Felix concolour) are resident. The recreation area is managed as a cooperative effort between the US National Park Service and two California State protected area agencies.

- Calanques National Park: Marseille, France (metropolitan population: 1.5 million; Category II;
8500 hectares of land and 43500 hectares of the Mediterranean Sea, plus buffer zones). This park includes rocky inlets, headlands and islands that have been heavily influenced by human activity over millennia. The park is managed by an administrative council comprising representatives of national and regional agencies and local governments, various interest groups, residents of the park and park staff.

- Nairobi National Park: Nairobi, Kenya (metropolitan population: 3 million; Category II; 11700 hectares). This park is a protected corner of a large savannah ecosystem, and is home to an impressive array of wildlife species, including the black rhinoceros (Diceros bicornis) (IUCN critically endangered), lion (Panthera leo), leopard (Panthera pardus), buffalo (Syncerus cafer) and hippopotamus (Hippopotamus amphibus). The park is managed by the Kenya Wildlife Service.

- Tijuca National Park: Rio de Janeiro, Brazil (metropolitan population: 12.8 million; Category II; 4000 hectares). This is a mountainous national park that is almost entirely covered by restored tropical rainforest. It is part of a cultural World Heritage property and is jointly managed by the municipality and the national protected area agency, the Instituto Chico Mendes de Conservação da Biodiversidade (Chico Mendes Institute for Biodiversity Conservation).

- Bukhansan National Park: Seoul, Republic of Korea (metropolitan population: 25 million; Category V; 8000 hectares). The park is dominated by granite mountain slopes and wooded valleys and receives more than 10 million visitors a year. It is managed by the Korea National Park Service.

- Royal National Park: Sydney, Australia (metropolitan population: 4.7 million; Category II; 16000 hectares). This national park is the second-oldest in the world, established in 1879. Formerly on the outskirts of Sydney, it now lies to the east of extensive urban suburbs. The park includes natural heathland, woodland, forest, rainforest, streams and wetlands, and is bordered by the Pacific Ocean, an estuarine inlet, suburbs and a transportation corridor. It is managed by the NSW National Parks and Wildlife Service.
4. Demonstrating, facilitating and promoting the health benefits of being in contact with nature as well as good eating habits: Urban protected areas have an important role to play in encouraging a healthy lifestyle. Spending time in the healthy environment of nature improves both physical and mental health. For parks that have food outlets, an alternative to selling conventional fast-food items can be the provision of nutritious, local and sustainable fresh food for visitors.
5. Preventing littering: Littering is a perennial problem in many urban protected areas, with their large numbers of visitors, many of whom regard these places as extensions of the built environment. Managers should draw on the results of local research on littering behaviour; however, certain measures apply everywhere: cleaning up litter frequently and consistently, providing plenty of containers for rubbish and cigarette butts, and informing visitors of the importance of and reasons for not littering. 
6. Reducing human-wildlife interaction and conflict: Although conflict between people and wildlife can occur almost anywhere, dense human populations near urban protected areas increase the likelihood of such encounters. Predator animals are of particular concern. Managers should help people protect themselves from predators and seek to maintain a balance between them and their wild prey. Public education has a key role. Keeping habitat as natural as possible helps control emerging zoonotic diseases (diseases transmitted between other animals and humans).

7. Controlling invasive species: The main pathways by which invasive alien species invade new territory are urban. These include seaports, river ports, airports, rail and truck yards, plant nurseries and gardens. Urban protected areas can be both facilitators and victims of such traffic. Managers should survey their lands and waters regularly to detect new invasions and participate in local and national partnerships for quarantine, prevention, early detection, eradication and control (Chapter 16).

8. Promoting connections to other natural areas: Managers should cooperate with other public agencies and NGOs to prevent their areas becoming green islands, including by containing or guiding urban sprawl, maintaining and creating corridors to other natural areas and rural lands, and creating and maintaining buffer zones. Trails linking urban natural areas are physical and psychological connectors to the natural environment.

9. Helping infuse nature into the built environment: Managers of urban protected areas and their supporters should participate in regionwide nature conservation coalitions, projects to develop comprehensive local biodiversity strategies, and efforts to protect, restore and infuse natural elements in the built environment.

10. Controlling encroachment: Illegal building in protected areas may be associated with the poor as well as the wealthy and politically well connected. Managers should prevent and control all encroachment by remaining vigilant, enforcing the law, seeking help from local authorities and enlisting the cooperation of local people.

11. Reducing impacts of noise and artificial nighttime light: Noise-defined as unwanted soundand artificial night-time light can be problems in any protected areas, but those in urban settings are especially vulnerable. Humans and wildlife are stressed by noise from visitors, road and rail traffic, aircraft and other sources. Artificial night-time light interferes with organism and ecosystem function, impedes visitors' enjoyment of the night sky, as well as astronomy, and can intrude on appreciation of cultural heritage sites in their authentic state. Some urban protected areas are making progress towards protecting natural soundscapes and the night sky by developing indicators and standards, educating visitors, enforcing regulations and working with local authorities and businesses in adjoining communities.

12. Cooperating with institutions that have complementary missions: Educating young people about nature through visits by school and youth groups is a core mission of almost all urban protected areas. Another set of connections is less obvious. Typically there are several kinds of museums and similar institutions in metropolitan areas aimed at educating and sensitising people to the natural world, but these institutions rarely work together. Managers of urban protected areas could encourage natural history museums, science centres, zoos, aquariums and botanic gardens to provide information and exhibits about nature and conservation challenges in their regions and cooperate towards that purpose. This can start with cross-promotion such as a museum providing visitors with information about natural places to visit nearby and exhibits in protected areas directing visitors to museums.

Other problems especially relevant to urban protected areas include fire, crime, vandalism, flooding, and air and water pollution. Other opportunities include training urban teachers, taking advantage of highly motivated and well-educated urban volunteers, and cooperating with urban universities. These matters are discussed further in Trzyna (2014).

\section{Understanding the differences between urban and non-urban protected areas}

In a protected area system, urban national parks and nature reserves are almost always a minority. The organisational cultures of such systems tend to be based on protected areas that are more remote. Their staff members often come to urban assignments from posts in non-urban protected areas. It is imperative therefore that those staff with experience in managing urban protected areas should share their experience with their nonurban colleagues (Case Study 8.2). This can be done at protected area organisation training sessions, on field trips and through staff exchanges. 
Nestled within and surrounded by Sydney Harbour is a unique collection of natural reserves that constitute Sydney Harbour National Park. At just less than 400 hectares, the park is made up of islands, massive sandstone headlands and bush remnants isolated by the Sydney City urban area. The natural bushland and cliffs of the park set the scene for one of the most beautiful and famous harbours in the world. These natural gems have been saved by virtue of being important for past military and quarantine purposes, or they have been conserved by local communities which use and enjoy them. The Federal and NSW State governments established the park in April 1975 , completing a vision that had begun in the late 1800 s.

The park has protected many important Aboriginal sites, and we are fortunate that after more than 200 years, the Koori community has survived and thrived and is reclaiming their heritage, lore and connection to land around the harbour. The park is managed by a small professional team supported by specialist sections of the NSW National Parks and Wildlife Service (NPWS). An annual budget of about $\mathrm{A} \$ 3$ million in 2014 is supplemented by departmental programs such as capital works, targeted government and external grants and revenue from the many tourism ventures, events, filming and business operators who use the park.

The staff manage the park by balancing a range of sometimes conflicting values, uses and assets. This necessitates a robust and adaptive management approach, strongly focused on communications and consultation. Key to this is the plan of management (2012), which outlines the guiding principles, key values, threats and desired outcomes.

The park's diverse nature means that different precincts need to be managed in different ways using a suite of strategies to address the conservation values, recreational uses and local community needs. North Head, for example, is managed primarily for the endangered communities of little penguin (Eudyptula minor), long-nosed bandicoot (Perameles nasuta) and eastern Sydney banksia scrub (less than 3 per cent remains in New South Wales). On the other hand, Nielsen Park is a highly managed 'modified natural environment' that includes open parklands and the historical Greycliffe House (1852), juxtaposed alongside the only known population of endangered Nielsen Park she-oak (Allocasuarina portuensis).
While the primary aim of the plan of management is the protection of natural and heritage values, it also emphasises improving visitation, accessibility and transport linkages to the park's islands and headlands. There is also the increasing challenge of event and venue management, including weddings, filming and the spectacular New Year's Eve events on the harbour, which attract millions of visitors hosted across multiple tenures and responsible authorities.

The park's team also has responsibility for wildlife across the majority of inner Sydney. This can range from basic native fauna issues to the resource-intensive management and monitoring of whales, dolphins and other marine life in the harbour and coastal waters. Experts, volunteers and the media all assist with implementing adaptive and integrated management, education and communications strategies essential for a good outcome.

The park is forging closer ties with the private sector in an attempt to improve its management efficiency and financial returns in support of key objectives. The aim is to maintain the heritage values of hundreds of historic sites and buildings, including the adaptive reuse of many significant heritage assets. Community and corporate volunteers contribute tens of thousands of hours of their time to improve the park every year, as well as providing significant funding via donations and grants. They are primarily involved in successful bush regeneration of heavily impacted semi-natural or 'anthropogenic' ecosystems, which has resulted in many native animals, including more than 150 recorded bird species, resettling in this 'new nature'.

The Sydney Harbour National Park, in its iconic harbour and international setting, serves as a focus of the importance of both New South Wales' national parks and protected areas nationally and worldwide. The park provides a unique opportunity for the public to be actively engaged and inspired to take on stewardship of its parks, reserves and the broader environment. It also plays a vital role in introducing the next generation to the bush, a mini-version of the 'big' parks as well as protecting our oldest European heritage in Australia and some of the oldest Indigenous heritage in Sydney.

- Michael Treanor, Area Manager, Sydney Harbour National Park, NPWS, Office of Environment and Heritage, New South Wales, Australia

\section{Conclusion}

Management is an intuitive concept and it is part of what we do in our everyday lives. For official management actions, we usually need to be more organised, and this chapter has reinforced the importance of a process of management and four underpinning functions of management: planning, organising, implementing and evaluating. These functions are common to most management-written or unwritten-and underpin management frameworks and many management support tools. Managing systems of protected areas and individual protected areas strategically and consistent with established principles provides a basis for the effective conservation of biodiversity and other natural and cultural heritage. This includes considerations at a global level as well as site-based requirements. Four different governance types help achieve management implementation but in turn they each need different management support. There are also variations in how protected areas are managed in particular physical, social and political contexts: in this chapter, protected areas in urban areas have been examined in detail. 


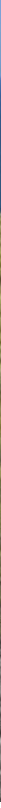

Sydney Harbour National Park, The Spit to Manly walk: natural bushland in the heart of the City of Sydney, New South Wales, Australia

Source: Hamilton Lund, DNSW

\section{References}

Recommended reading

Amend, T., Brown, J., Kothari, A., Phillips, A. and Stolton, S. (eds) (2008) Protected Landscapes and Agrobiodiversity Values, Values of Protected Landscapes and Seascapes Vol. 1, IUCN WCPA Specialist Group on Protected Landscapes and GTZ on behalf of the Federal Ministry of Economic Cooperation and Development of Germany, Heidelberg.

Appleton, M. (2013) Instruction for the Review of the First Working Draft of the Global Competence Standards for Protected Area Personnel, Global Partnership for Professionalising Protected Area Management, IUCN Capacity Development Programme, IUCN, Gland.

Badenkov, Y., Yashina, T. and Worboys, G. L. (2012) 'Altai-Sayan, Eurasia', in J. A. Hilty, C. C. Chester and M. S. Cross (eds) Climate and Conservation: Landscape and seascape science, planning and action, Island Press, Washington, DC.

Brown, J., Mitchell, N. and Beresford, M. (eds) (2005) The Protected Landscape Approach: Linking nature, culture and community, IUCN WCPA, Gland.
Clarke, R. N. and Stankey, G. M. (1979) The Recreation Opportunity Spectrum: A framework for planning, management and research, General Technical Report PNW-98, US Forest Service, Department of Agriculture, Fort Collins, CO.

Commonwealth of Australia (CoA) (1999) Environmental Protection and Biodiversity Conservation Act, 1999: Regulations, Commonwealth of Australia, Canberra. <www.environment.gov.au/ topics/about-us/legislation/environment-protectionand-biodiversity-conservation-act-1999>

Commonwealth of Australia CoA (2003) Protecting Natural Heritage, Using the Australian Natural Heritage Charter, 2nd edn, Commonwealth of Australia, Canberra.

Dd Conservation Measures Partnership (CMP) (2013) Open Standards for the Practice of Conservation. Edition 3. <www. conservationmeasures.org/wp-content/ uploads/2013/05/CMP-OS-V3-0-Final.pdf>

Convention on Biological Diversity (CBD) (1992) Convention on Biological Diversity, Secretariat of the Convention on Biological Diversity, Montreal.

Convention on Biological Diversity (CBD) (2004) Programme of Work on Protected Areas, Secretariat of the Convention on Biological Diversity, Montreal. 
Convention on Biological Diversity (CBD) (2011) Strategic Plan for Biodiversity 2011-2020 and the Aichi Targets, Secretariat of the Convention on Biological Diversity, Montreal. <www.cbd.int/doc/ strategic-plan/2011-2020/Aichi-Targets-EN.pdf>

Convention on the Conservation of Migratory Species of Wild Animals (CMS) (2013) Introduction and Background. <www.cms.int/about/intro.htm>

Convention on International Trade in Endangered Species of Wild Fauna and Flora (CITES) (2013) CITES Background and History. <www.cites.org/ eng/disc/what.php>Corrigan, C. and Hay-Edie, T. (2013) A Toolkit to Support Conservation by Indigenous Peoples and Local Communities, UNEPWCMC, Cambridge.

Davey, A. (1998) National System Planning for Protected Areas, IUCN Best Practice Series No. 1, IUCN, Gland.

Department of Conservation (DOC) (2013) Vision Statement, New Zealand Department of Conservation, Wellington. <www.doc.govt.nz/ about-doc/role/vision-role-overview-and-statutorymandate/vision-purpose-and-outcome/>

Department of Environment and Conservation (DEC) (2005) State of the Parks 2004, NSW Department of Environment and Conservation, Sydney.

DD Dudley, N. (2008) Guidelines for Applying Protected Area Management Categories, IUCN, Gland.

Dudley, N. and Stolton, S. (eds) (2012) Protected Landscapes and Wild Biodiversity, Values of Protected Landscapes and Seascapes Series Vol. 3, IUCN WCPA Specialist Group on Protected Landscapes, Gland.

Dunphy, D. and Stace, D. (1991) Under New Management: Australian organisations in transition, McGraw-Hill, Sydney.

du Toit, J. T., Rogers, K. H. and Biggs, H. C. (eds) (2003) The Kruger Experience: Ecology and management of savanna heterogeneity, Island Press, Washington, DC.

Earthcheck (2013) Earthcheck Certified Organisation, Earthcheck, Brisbane. <www.earthcheck.org/>
Environmental Protection Agency (EPA) (2013) ISO 14001: Frequently asked questions, US EPA, Washington, DC. <water.epa.gov/polwaste/ wastewater/Environmental-Management-SystemISO-14001-Frequently-Asked-Questions.cfm>

Figgis, P., Humann, D. and Looker, M. (2005) 'Conservation on private land in Australia', Parks 15(2): 19-29.

Govan, H. and Meo, S. (2011) Fiji Locally Managed Marine Area Operations Guide: The way we work together, FLMMA, Fiji. < bit.ly/m3WrkC>

Gupta, J., Termeer, K., Klostermann, J., Meijerink, S., van den Brink, M., Nooteboon, S. and Bergsma, E. (2010) 'The adaptive capacity wheel: a method to assess the inherent characteristics of institutions to enable the adaptive capacity of society', Environmental Science and Policy 13(6): 459-71.

Dd Hitt, M. A., Black, S. and Porter, L. W. (2011) Management, 3rd edn, Pearson Education, Upper Saddle River, NJ.

D. Hockings, M. (2012) IUCN Green List of WellManaged Protected Areas, IUCN, Gland. <www. iucn.org/about/work/programmes/gpap_home/ gpap_quality/gpap_greenlist/>

Hockings, M., Adams, W. M., Brooks, T. M., Dudley, N., Jonas, H., Lotter, W., Mathur, V., Väisänen, R. and Woodley, S. (2013) 'A draft code of practice for research and monitoring in protected areas', Parks 19(2): 85-94.

Hockings, M., James, R., Stolton, S., Dudley, N., Mathur, V., Makombo, J., Corrau, J. and Parrish, J. (2008) Enhancing Our Heritage Toolkit: Assessing management effectiveness of natural World Heritage sites, UNESCO World Heritage Centre, Paris.

Hockings, M., Stolton, S. and Dudley, N. (2000) Evaluating Effectiveness: A framework for assessing the management of protected areas, IUCN, Gland.

Hockings, M., Stolton, S., Leverington, F., Dudley, N. and Corrau, J. (2006) Evaluating Effectiveness: A framework for assessing the management of protected areas, 2nd edn, IUCN, Gland.

Hornback, K. E. and Eagles, P. F. J. (1999) Guidelines for Public Use Measurement and Reporting at Parks and Protected Areas, IUCN, Gland. 
International Union for Conservation of Nature (IUCN) and United Nations Environment Programme World Conservation Monitoring Centre (UNEP-WCMC) (2014) Percentage Terrestrial Area of Nations Reserved as Protected Area, August 2014 , IUCN and UNEP-WCMC, Cambridge.

Kormos, C. (ed.) (2008) A Handbook on International Wilderness Law and Policy, Fulcrum Publishing, Golden, CO.

Kothari, A. (2006) 'Community conserved areas', [Editorial], Parks 16(1): 1.

Kothari, A., Corrigan, C., Jonas, H., Nuemann, A. and Shrumm, H. (eds) (2012) Recognising and Supporting Territories and Areas Conserved by Indigenous Peoples and Local Communities, CBD Technical Series No. 64, Secretariat of the Convention on Biological Diversity, ICCA Consortium, Kalpavriksh and Natural Justice, Montreal.

Lockwood, M. (2006) 'Management planning', in M. Lockwood, G. L. Worboys and A. Kothari (eds) Managing Protected Areas: A global guide, pp. 292327, Earthscan, London.

Mallarach, J.-M. (ed.) (2008) Protected Landscapes and Cultural and Spiritual Values, Values of Protected Landscapes and Seascapes Series Vol. 2, IUCN WCPA Specialist Group on Protected Landscapes, GTZ and Obra Social de Caixa Catalunya, Kasparek-Verlag, Heidelberg.

Marquis-Kyle, P. and Walker, M. (1992) The Illustrated Burra Charter: Making good decisions about the care of important places, Australia ICOMOS, Sydney.

Mitchell, B. (2005) 'Private protected areas', [Editorial], Parks 15(2): 1.

Mitchell, B. (2013) Private Protected Areas, IUCN, Gland. <www.iucn.org/about/work/programmes/ gpap_home/gpap_people/gpap_tilcepa/gpap_ privatepas/>

Parks Canada (PC) (2007) Monitoring and Reporting Ecological Integrity in Canada's National Parks. Volume 2: A park level guide to establishing EI monitoring, Parks Canada, Ottawa.

Dd Phillips, A. (2002) Management Guidelines for Category V Protected Areas: Protected landscapes/ seascapes (No. 9), IUCN WCPA, Gland.
Poll, M. (2006) 'Reserves standards framework: a levels-of-service approach, Tasmania, Australia', in M. Lockwood, G. L. Worboys and A. Kothari (eds) Managing Protected Areas: A global guide pp. 51416, Earthscan, London.

Rai, N., Madegowda, C. and Setty, S. (2007) 'Taragu Benki: fire use by Soliga Adivasis in Biligiri Rangaswamy Temple Wildlife Sanctuary, Karnataka', in R. Pai, A. Hiremath and Umakant (eds) Rethinking Forest Fires: Proceedings of the National Workshop on Forest Fires, pp. 87-9, Ministry of Environment and Forests, New Delhi.

Robbins, S., Bergman, R., Coulter, M. and Stagg, I. (2012) 'Strategic management', in S. Robbins, R. Bergman, I. Stagg and M. Coulter Management, pp. 321-54, 6th edn, Pearson Australia, Sydney.

Rose, B. (2012) 'Indigenous protected areasinnovation beyond the boundaries', in P. Figgis, J. Fitzsimons and J. Irving (eds) Innovation for 21st Century Conservation, pp. 50-5, Australia Committee for IUCN, Sydney.

Sawarkar, V. B. (2002) A Guide for Planning Wildlife Management in Protected Areas and Managed Landscapes, Wildlife Institute of India, Dehradun.

Stankey, G. H., Clark, R. N. and Bormann, B. T. (2005) Adaptive management of natural resources: theory, concepts and management institutions, General Technical Report PNW-GTR-654, US Department of Agriculture, Washington, DC.

Stankey, G. H., Cole, D. N., Lucas, R. C., Petersen, M. E. and Frissell, S. S. (1985) The limits of acceptable change (L.A.C.) system for wilderness planning, General Technical Report INT-176, US Forest Service, Department of Agriculture, Fort Collins, CO. Stolton, S., Ervin, J. and Dudley, N. (2008) 'Editorial', Parks 17(1): 1-3.

Sundaram B. and Hiremath, A. J. (2011) 'Lantana camara invasion in a heterogeneous landscape: patterns of spread and correlation with changes in native vegetation', Biological Invasions 14(6): 1127-41.

Tasmania Parks and Wildlife Service (TPWS) (2014) Macquarie Island Pest Eradication Project, Tasmania Parks and Wildlife Service, Hobart. <www.parks.tas. gov.au/index.aspx?base $=12982>$ 
The Nature Conservancy (TNC) (2007) Conservation Action Planning Handbook: Developing strategies, taking action and measuring success at any scale, The Nature Conservancy, Arlington, VA.

The Ramsar Convention on Wetlands (Ramsar) (2013) Introduction to Ramsar, Ramsar Secretariat, Gland. <www.ramsar.org/cda/en/ramsar-home/main/ ramsar/1_4000_0>

Thin Green Line Foundation (TGL) (2014) Information on Rangers Killed on Duty, Thin Green Line Foundation, Melbourne. <thingreenline.org. $\mathrm{au} />$

Thomas, I. (2001) Environmental Impact Assessment in Australia: Theory and practice, The Federation Press, Sydney.

Dd Trzyna, T. (2014) Urban Protected Areas: Profiles and best practice guidelines, IUCN WCPA Best Practice Guideline No. 22, IUCN, Gland.

United Nations (UN) (2013) United Nations Convention on the Law of the Sea of 10 December 1982, United Nations, New York. <www.un.org/ depts/los/convention_agreements/convention_ overview_convention.htm>

United Nations (UN) (2014a) International Convention for the Regulation of Whaling, United Nations, New York. <treaties.un.org/pages/showDetails. aspx?objid $=0800000280150135>$

United Nations (UN) (2014b) International Convention on the Law of the Sea: Overview, United Nations, New York. <www.un.org/depts/los/convention_ agreements/convention_overview_convention.htm>

United Nations Educational, Scientific and Cultural Organisation (UNESCO) (2008) Business Planning for Natural World Heritage Sites: A toolkit, Shell Foundation, UNESCO, Paris. <whc.unesco.org/en/ businessplanningtoolkit/>

United Nations Educational, Scientific and Cultural Organisation (UNESCO) (2013) World Heritage History, UNESCO, Paris. <whc.unesco.org/en/ convention/>

United Nations Environment Programme World Conservation Monitoring Centre (UNEP-WCMC) (2013) A Toolkit to Support Conservation by Indigenous Peoples and Local Communities, UNEPWCMC, Cambridge.
United Nations Environment Programme World Conservation Monitoring Centre (UNEP-WCMC) (2014) Global Statistics from the World Database on Protected Areas, August 2014, UNEP-WCMC, Cambridge.

United Nations Framework Convention on Climate Change (UNFCCC) (2014) Background about the Convention, Climate Change Secretariat, Bonn. $<$ unfccc.int/essential_background/convention/ items/2627.php>

Watson, J., Hamilton-Smith, E., Gillieson, D. and Kiernan, K. (1997) Guidelines for Caves and Karst Protection, IUCN WCPA, Gland.

Williams, B. K., Szaro, R. C. and Shapiro, C. D. (2009) Adaptive Management: The U.S. Department of the Interior technical guide, Adaptive Management Working Group, US Department of the Interior, Washington, DC.

Wittenberg, R. and Cock, M. J. W. (2001) Invasive Alien Species: A toolkit of best prevention and management practices, Global Invasive Species Programme, CAB International, Wallingford, UK. <www.issg.org/pdf/publications/GISP/Guidelines _ Toolkits_BestPractice/Wittenberg\&Cock_2001_ EN.pdf>

Worboys, G. L. (2007) Evaluation subjects and methods required for managing protected areas, $\mathrm{PhD}$ thesis, Griffith University, Gold Coast, Queensland.

Worboys, G. L. and Winkler, C. (2006a) 'Process of management', in M. Lockwood, G. L. Worboys and A. Kothari (eds) Managing Protected Areas: A global guide, pp. 146-63, Earthscan, London.

Worboys, G. L. and Winkler, C. (2006b) 'Operations for management', in M. Lockwood, G. L. Worboys and A. Kothari (eds) Managing Protected Areas: A global guide, pp. 406-20, Earthscan, London.

Worboys, G. L. and Winkler, C. (2006c) 'Managing staff, finances and assets', in M. Lockwood, G. L. Worboys and A. Kothari (eds) Managing Protected Areas: A global guide, pp. 359-76, Earthscan, London.

Worboys, G. L., Francis, W. L. and Lockwood, M. (eds) (2010) Connectivity Conservation Management: A global guide, Earthscan, London. 


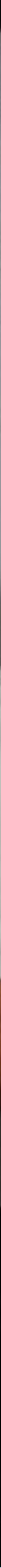

\section{CHAPTER 9}

\section{CAPACITY DEVELLPMENT}

\section{Principal authors:}

Eduard Müller, Michael R. Appleton and Glenn Ricci

\section{Supporting authors:}

Allan Valverde and

David W. Reynolds

\section{CONTENTS}

- Introduction

- Capacity development in protected area systems

- Basic concepts and capacity development approaches

- Capacity development

- Education in a changing world

- Capacity development planning and assessment

- Why do we need protected area professionals?
- Knowledge management

- Competence-based approaches to capacity development

- Performance review and certification programs

- Learning resources

- Conclusion

- References

- Appendix 9.1: Example capacity development organisations 


\section{PRINCIPAL AUTHORS}

EDUARD MÜLLER is Vice Chair, Education and Learning, International Union for Conservation of Nature World Commission on Protected Areas, President, Universidad para la Cooperación Internacional, Costa Rica, UNESCO Chair for Biosphere Reserves and Natural and Mixed World Heritage Properties, and Coordinator of the WCPA Global Partnership for Professionalising Protected Area Management.

MICHAEL R. APPLETON is an independent consultant based in the UK specialising in protected areas and sustainable development, and an adviser to Global Environment Facility financed projects.

GLENN RICCI is Coastal Management Specialist at the Coastal Resources Center, University of Rhode Island, Narragansett, Rhode Island, USA.

\section{SUPPORTING AUTHORS}

ALLAN VALVERDE is Training Specialist, Universidad para la Cooperación Internacional (UCl), Costa Rica.

DAVID W. REYNOLDS is Senior Advisor, Capacity Development, IUCN Global Protected Areas Programme, based in Medford, New Jersey, USA.

\section{ACKNOWLEDGMENTS}

Appreciation is expressed to Theresa Sowry, James Barborak, Ryan Finchum, Wayne Lotter, Natalia Danilina, Vinod Mathur and Michael Lockwood for their work on Appendix 9.1.

\section{CITATION}

Müller, E., Appleton, M. R., Ricci, G., Valverde, A. and Reynolds, D. (2015) 'Capacity development', in G. L. Worboys, M. Lockwood, A. Kothari, S. Feary and I. Pulsford (eds) Protected Area Governance and Management, pp. 251-290, ANU Press, Canberra.

\section{TITLE PAGE PHOTO}

Student receiving a bachelor degree in protected area management, December 2007, Costa Rica

Source: Eduard Müller 


\section{Introduction}

Today's protected areas are becoming increasingly complex institutions that require a competent, motivated and adequately resourced workforce that has access to the most current ideas and best practices developed through decades of lesson learning around the world. Many protected area directors, managers and staff, however, lack the necessary range of competencies to ensure the effective and equitable management of these areas, and they have limited capacity for sustained and adaptive organisational management. Despite being responsible for the complex management of a significant proportion of the world's natural capital, protected area management is still not recognised in many countries as a distinct profession with its own standards, qualifications and career structure. In this chapter, we will discuss the need to move towards the professionalisation of protected area staff and how different approaches for capacity development can lead to competence levels that allow for effective management.
Understanding capacity development as the development of knowledge, skills and attitudes in individuals, organisations, institutions and society to set and achieve their own objectives, we will discuss knowledge management, skills development and the role that attitude plays to ensure competence. Also discussed are recent developments that are geared towards a shift of educational paradigms, where competence-based learning and the use of online educational alternatives are rapidly changing the way we deliver capacity development throughout the world.

This chapter will be useful for anyone interested in capacity development in protected areas though it is mainly intended for professionals responsible for developing capacity in protected areas and protected area systems-from planning to implementation and evaluation. The discussion of the most relevant concepts and methods will make it easier to select the best programs for specific capacity development tasks at the protected area level or within a system. Academic institutions can also benefit and incorporate new approaches to training or education. We have provided a brief summary of some key capacity development concepts and developments that provide a prelude to this chapter (Box 9.1).

\section{Box 9.1 A summary of key capacity development concepts}

\section{Capacity}

Capacity is more than just the knowledge and skills of individuals. There are also capacities of organisations and institutions to perform, though people are central to making anything work. Capacity is also about individuals' motivation and leadership in line with the organisation and societal actors. To achieve management effectiveness of protected areas, there must be combined performance from individuals and organisations working together. This is often best achieved in society through professionalising the field.

\section{Methods}

Methods to develop capacity are expanding, though the most critical advancement is the codifying of competencies that drive individual and organisational capacity development. The methods used to build competencies are increasing due to new technologies and the limitations of financial resources. There is a renewed focus on going beyond short-term training courses and traditional formal degrees, which remain effective in selected contexts. Online learning, internal mentoring and apprenticeships managed through an organisation's knowledge management system can be very effective. Additionally, the focus is moving to an approach to training that tailors the process around the needs of the individual learner and takes a holistic perspective to solving real work issues. All methods, when linked together as a system for capacity development, are appropriate for selected situations.

\section{Individual capacity development}

Individual capacity development according to job function in protected areas can be grouped into three core levels: policy and planning, site management and field operations. A diversity of competencies is required to be a protected area professional at any level, including in traditional areas of conservation science and enforcement as well as policy development, compliance strategies, communications, wider ecosystem services, financing/ budgeting, consensus building, leadership and ethics.

\section{Organisational capacity development}

The capacity of individuals/staff is of minimal value if the organisation is not structured, responsive and working in partnership with communities and other actors. Professionalising the field of protected area management will also influence organisational capacity and performance.

\section{Professionalising protected area governance and} management

A profession serves as a framework to tie together all elements of capacity development-from individuals to organisations and to institutions of interrelated actors. Professions focus on competencies required to perform at minimum standards, to create a common language and formal and informal means to learn competencies, to promote leadership and to identify ethics for the professional community. Currently, there are many competency programs established in protected area systems and some innovative certification programs to complete the system. 


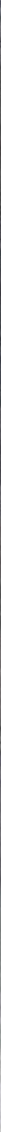

Virginia Falls, Nahanni National Park, Canada

Source: Alison Woodley

\section{Capacity development in protected area systems}

Protected areas are the most effective means for conserving biodiversity, ecosystems and a large array of services provided for the maintenance of the diversity of life on Earth, including human wellbeing. Though there has been great progress in the establishment of a global network of protected areas, there is still a great way to go. The establishment alone of protected areas and protected area systems does not guarantee that their objectives will be achieved. Global analysis of management effectiveness assessments reveals that a large proportion of designated protected areas are still inadequately managed (IUCN 2014a). In order to achieve effective management of protected areas and protected area systems, appropriate institutional and governance arrangements and competent professionals are required.

Nature has a value of its own, reflected through the thousands of years of dependency humans have developed for their livelihoods. Conserving biodiversity is our responsibility since human factors are the most important in causing the losses we are observing. In the Western world, where monetary value is often given more importance than social or spiritual values, we can argue that protected areas are home to greater economic assets than many of the productive alternatives that are often impacting on them. The value of the world's ecosystem services and natural capital is becoming more and more recognised since Costanza et al. (1997) published one of the first papers on the topic, estimating ecosystem services at US\$33 trillion per year. Using updated data, unit values and changes to biome areas, total global ecosystem services in 2011 were US $\$ 125$ trillion per year, with a yearly loss in the order of US $\$ 20$ trillion (Costanza et al. 2014).

The achievement of conservation goals and the future provisioning of these services depend on the capacity of individuals to make the correct decisions but also on the institutional capacity and enabling environment to allow for effective action. The decisions taken by protected area staff must be based on knowledge, experience and skills. The ways in which decisions are implemented are dependent on the attitude of staff at all levels. Institutional capacity is composed of many factors, including funding, legal and policy backing, the number of staff, public awareness, and many others. Nevertheless, achieving institutional capacity also boils down to the capacity of the individuals within the institution to build it up and run it effectively. The role of capacity development in protected areas is increasingly recognised at all levels, including in Goal 3.2 of the Convention on Biological Diversity (CBD) Programme of Work on Protected Areas (PoWPA) (CBD 2014a; Box 9.2). The Aichi Targets, especially Target 11, set the stage for action until the end of 2020. Within each target, we can identify the capacity that has to be developed at individual, institutional, national and global levels. 
There are largevariations in job structures within protected area systems depending on many factors such as resource availability, especially funding; whether the country is developing or developed; years of establishment; social and political recognition; governance type at site level; and many others. In well-staffed and trained systems, we can find specific job descriptions, whereas in some countries, the small number of staff assigned to an area (in some cases only one person) requires them to fulfil a large set of activities. Nevertheless, we can establish at least three basic levels of staff_-system management (including policy and planning), site management, and operational or field level (park rangers, wardens, and so on) _ and in some cases, we still have a further level comprising lower-skilled workers. The domains of these levels can be very similar but the competencies for each vary. For a system manager, site planning will probably entail a national scope wherein conservation gaps and long-term land-use planning might be the area of focus, while the site manager is concerned with zoning, buffer and connectivity areas, and threat analysis or community development. The operational level will be more involved with on-the-ground enforcement, visitor management and protection. These differences require specificities in the capacity development strategies for each of these levels.

\section{Basic concepts and capacity development approaches}

In order to design and implement effective capacity development processes, we need to understand the different components related to proficiency in performing on the job. Through self-assessment processes, a person or organisation can identify where the major gaps are and seek specific strengthening. We can design different capacity development strategies that focus on different aspects. In the following paragraphs, we define some of the most relevant components of capacity development.

\section{Ability}

'Ability is usually regarded as a set of innate attributes that determine our potential for a given activity. Such potential may be developed into skilled behaviour by training and practice' (Egate and Groome 2005:100). In other words, ability is not something that can easily be taught and is related to genetic abilities and the environment in which the person grew up. Examples are the ability to dance samba or to learn different languages.

\section{Box 9.2 Convention on Biological Diversity Programme of Work on Protected Areas: Goal 3.2}

This goal is concerned with building capacity for the planning, establishment and management of protected areas. The goal was established in 2004 following the 2003 World Parks Congress in Durban. By 2014, implementation of the goals had been steady, but further work was required. The original goals are repeated here, as they set a context for ongoing capacity development work.

Target: By 2010, comprehensive capacity-building programs and initiatives are implemented to develop knowledge and skills at individual, community and institutional levels, and raise professional standards.

The suggested activities of the parties include the following.

- By 2006 complete national protected area capacity needs assessments and establish capacity-building programs on the basis of these assessments, including the creation of curricula, resources and programs for the sustained delivery of protected area management training.

- Establish effective mechanisms to document existing knowledge and experiences of protected area management, including traditional knowledge in accordance with Article 8(j) and related provisions, and identify knowledge and skill gaps.

- Exchange lessons learnt, information and capacitybuilding experiences among countries and relevant organisations, through the clearing house mechanisms and other means.

- Strengthen the capacities of institutions to establish cross-sectoral collaboration for protected area management at regional, national and local levels.

- Improve the capacity of protected area institutions to develop sustainable financing through fiscal incentives, environmental services, and other instruments.

Source: CBD (2014a)

\section{Skills}

There are many definitions for skills depending on the area of endeavour, such as sport, business, handcrafts, and so on. For the purpose of this chapter, we define skill as 'the ability to do something that comes from training, experience, or practice' (Merriam-Webster Dictionary 2012), or 'the learned ability to bring about predetermined results with maximum certainty, often with the minimum outlay of time or energy or both' (Knapp 1963:11). There are four main characteristics of skills: 
1. a learned ability

2. predetermined results: a specific goal or target is reached

3. maximum certainty: repeatable results every time

4. maximum efficiency: lowest effort and time.

Cornford (1999:266) defined the following attributes of skill and skilled performance:.

1. Skill is learned or acquired and does not consist of innate, instinctive actions and simple or reflex actions, which everyone possesses.

2. Skill involves motivation, purpose and goals.

3. A mental plan or schema is required before a skill can be performed; this should include components, processes, correct sequences of components and temporal elements.

4. Skills require specific content and context knowledge and also specific stimuli, which signal the appropriate time and circumstances in which to perform or apply the knowledge.

5. Skills involve problem solving relevant to the particular context.

6. There are individual differences in skilled performance and the same level of skill performance cannot always be obtained with different people.

7. Standards of excellence are required to judge performance.

8. Skill involves comparable replication or consistency of application over time.

9. Considerable time is required to achieve high levels of skill, especially where more complex patterns of thought and behaviour are involved.

In relation to job performance, we also have further refinements of capacity development terms.

\section{Hard skills}

These are the capabilities required for specific occupations, usually related to professional knowledge, tools or techniques that allow us to work within our profession. They are easy to observe, quantify and measure. They are also usually easy to teach when new to the learner and where no 'unlearning' is necessary.

\section{Soft skills}

Also called 'people skills', these are the complete collection of our social, communication and selfmanagement behaviours and are vital for professional success. These are the skills that enable us to work effectively and 'fit in' in the workplace. Soft skills are usually hard to observe, quantify or measure and are used both for day-to-day life and for work. It usually takes a greater effort to change or develop them since often they are already embedded into behaviour. Change in soft skills can be achieved through frequent reinforcement over the long term, preferably by a knowledgeable coach or co-workers (Coates 2006). Examples of soft skills are: time management, reliability, team work, interpersonal communication, language and a desire to learn and be trained; demonstrating integrity and ethical behaviour; being motivated and having a positive attitude; and critically analysing information (Phani 2007).

\section{Competence (competency)}

Competence can be defined as '[t]he ability of the individual within an occupation to carry out a defined task' (Appleton et al. 2003:2). A more detailed definition can be found in Sanchez and Ruiz (2008:29), in which competence is 'good performance in diverse, authentic contexts based on integration and activation of knowledge, rules and standards, techniques, procedures, abilities and skills, attitudes and values'. The concept of competence is not new. White (1959:297) used the term, relating it to 'an organism's capacity to interact effectively with its environment'. Miller (1990) developed a framework for clinical assessment that simplifies understanding of the transition from knowledge-based to competence-based education and assessment (Figure 9.1). Competencebased learning builds on the existence of three learning domains: cognitive (knowledge), psychomotor (skills) and affective (attitudes).

Competence-based learning is becoming more and more popular. Its most important characteristic is that the focus of education is not on what academics believe students need to know (teacher centred), but rather on what students need to know and be able to do in varying and complex situations (job focused) (Coates 2006). Competence-based programs do not assume that the achievement of learning outcomes is reached by successful completion of a series of courses within a study plan. Rather they are learner centred, focused more on the use of many different learning opportunities and activities that allow students to learn and demonstrate their capacities at their own pace.

Competence-based programs in recent years include peer-to-peer social networks, open educational sources, learning management systems and online advising and coaching (Klein-Collins 2013). Competencebased learning requires the definition of the necessary 


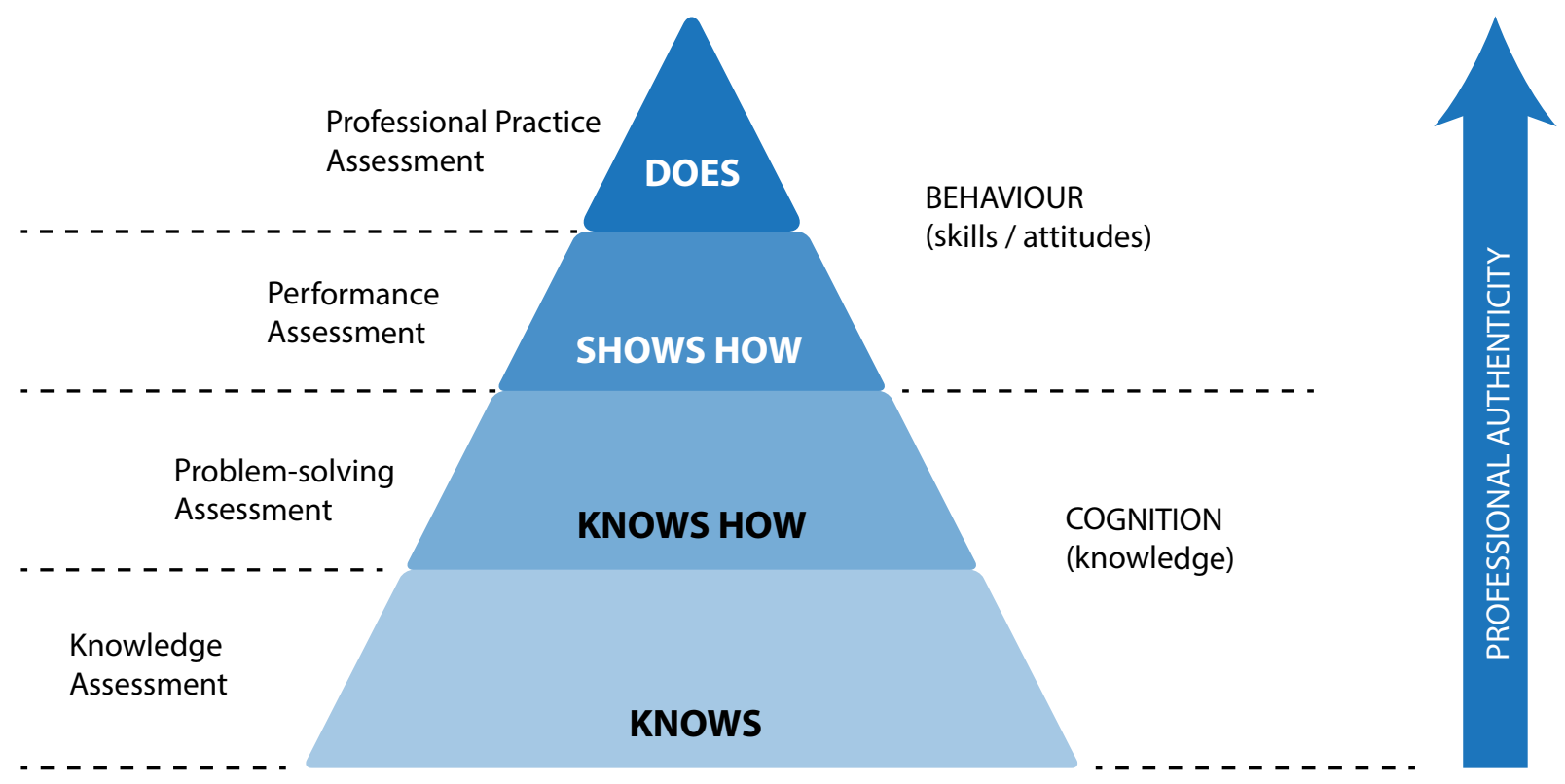

Figure 9.1 Framework for clinical assessment

Source: Adapted from Miller (1990)

competencies pertaining to a profession or job. Knowledge is then integrated with attitudes and values according to each student's professional or personal life. It is important to note that it seeks to promote the ability of students to learn how to learn (Sanchez and Ruiz 2008).

Competencies are also being used for protected area training and learning. Appleton et al. (2003) developed competence standards for protected area jobs in SouthEast Asia. These are recommendations for skills and knowledge required for 24 key jobs in protected areas, divided into 17 categories and five levels. During 2013 and 2014, a new effort, led by Appleton as part of the World Commission on Protected Areas (WCPA) Education and Learning Task Force, was undertaken to define global competencies for protected area jobs. Another initiative in Africa developed competencies tailored to marine protected areas with means for assessing performance leading to certification (Squillante et al. 2010), and this is discussed later in this chapter.

Leadership is a soft competence yet critical to most positions within understaffed protected area systems with significant challenges in meeting their mandates. How protected area staff internalise the concept of leadership is illustrated in Box 9.3 (Squillante et al. 2010). Leadership in protected areas is discussed further in Chapter 12.

\section{Box 9.3 About leadership}

\section{Actions}

- Hands dirty and feet wet.

- Initiative: lead by example.

- Do not ask others to do what you would not do (that is, apprehending).

- Ahead of the game (fingers on the pulse).

- Take a hard decision at the right time.

- Own success; do not disown failure.

- Consistency.

\section{Interactions with staff}

- Motivate others by mentoring and team building.

- Delegate properly; do not micromanage.

- Exhibit trust in staff.

- Take responsibility for honest mistakes by junior staff.

- Prepare to stand your ground.

\section{Interactions with communities}

- Be respectful.

- Listen first.

- Become almost part of the community (embedded, approachable, fair).

- Do not disrespect but do your job.

- Seek respect (from staff and stakeholders) - not to be 'liked'.

Source: Squillante et al. (2010) 


\section{Learning}

Learning is a continuous process of creating knowledge grounded in experience (Kolb 1984). Learning builds on pre-existing knowledge or experiences. Thus, an educator not only must implant new ideas but also has to help modify or dispose of old ones. This is important to take into consideration when designing and applying a training process. The more we can build on existing knowledge or experience, the easier it will be for the student to pick up what is being taught. If existing knowledge or practices are incorrect, a greater effort must be made in the learning process.

Motivation is fundamental to learning; only an individual who wants to learn can do so. Thus, motivation is one of the most important aspects of capacity development and must be worked into the starting phase of any training or educational event. The learner must know what the scope of the training event is and what outcomes are expected from him or her. A person learns more easily if he or she can identify with clarity what is the use of what is learnt in their day-to-day job or personal performance. This is something that often was previously not taken sufficiently into account in protected area training, especially when cooperation projects had built-in training components that were designed by the education provider, with little or no participation from the protected area staff in the design process.

It is also important to relate new knowledge areas or skills to the existing knowledge or skills of the individual. The construction of schemas or mental plans enables better learning by relating acquired knowledge to existing knowledge in the memory. Learning-tolearn strategies make it easier for a student to construct mental models and schemas that will guide performance (Cornford 1997). The construction of mental models requires attention, retention and motivation: 'Most human behaviour is learned observationally through modelling: from observing others, one forms an idea of how new behaviours are performed, and on later occasions this coded information serves as a guide for action' (Bandura 1977:22).

\section{Experience-based learning or learning by doing}

Tell me, and I will forget. Show me, and I may remember. Involve me, and I will understand.

- Confucius, cited by Ostashewski et al. (2011)

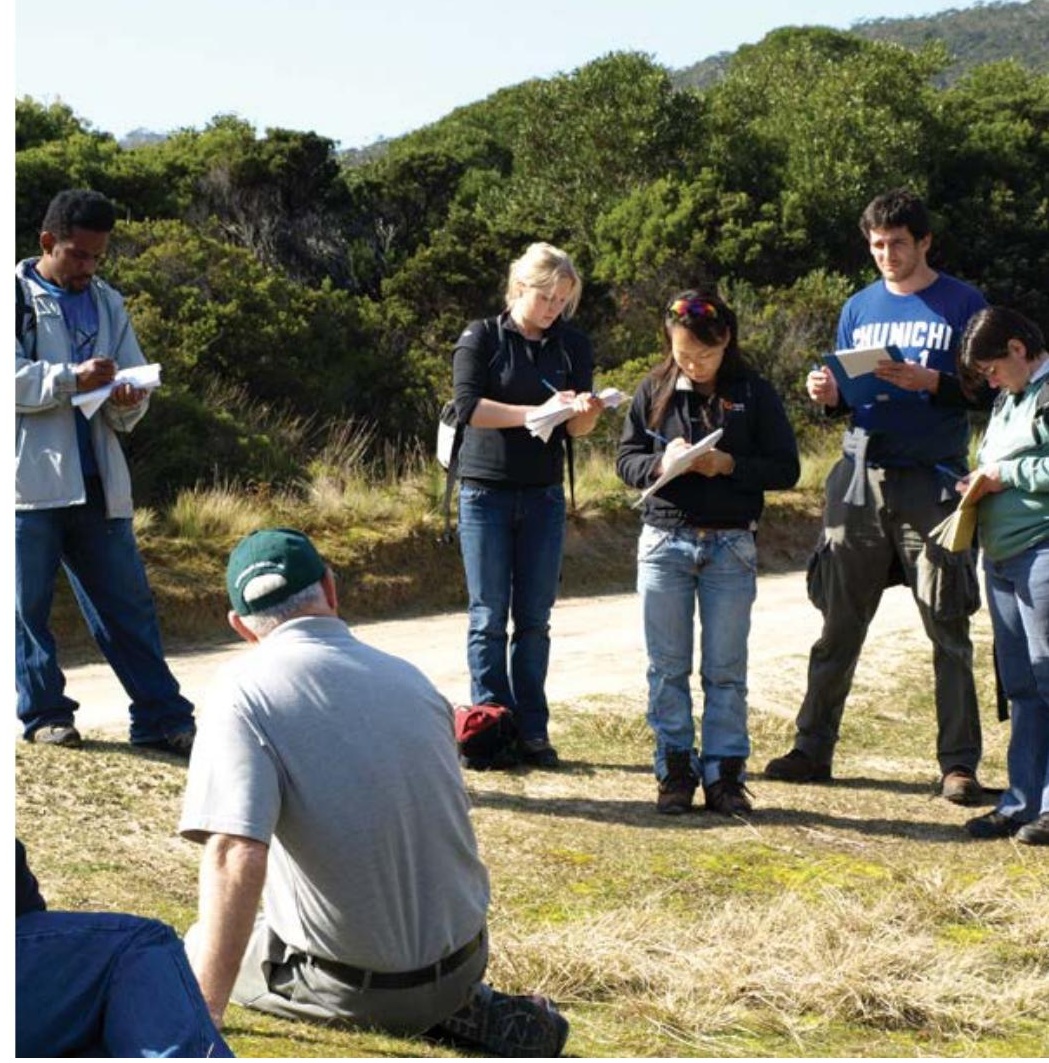

Postgraduate University of Tasmania protected area management students working with experienced and senior Tasmanian protected area management staff on site at Cockle Creek, South West National Park, Tasmania

Source: Graeme L. Worboys

Experiential learning is 'the process whereby knowledge is created through the transformation of experience' (Kolb 1984:38), or in other words, 'the personal acquisition of knowledge through practice' (University of Iowa 2014). Whereas the traditional classroom focuses on knowledge, experiential learning involves three domains of the student: intellect, feelings and senses (Andresen et al. 1999).

Kolb (1984) describes experiential learning as a cycle that starts with a concrete experience, which is then followed by personal reflection on this experience (Figure 9.2). The person then applies general rules or known theories to this experience-called abstract conceptualisation (the process of making sense of what has been observed) (Kolb 2014) - to construct ways of possibly modifying the next occurrence of the experience. In other words, how we can put this into practice (active experimentation) to finally go to the next experience. An effective learner must then perceive information, reflect on how it impacts on their life, compare it with their own experience and then think about how they can find new ways to act (Conner 2007). This may occur very rapidly or over a longer period. For those who want to go into a more detailed analysis and application of this cycle, there are additional reports (see Atherton 2013). 


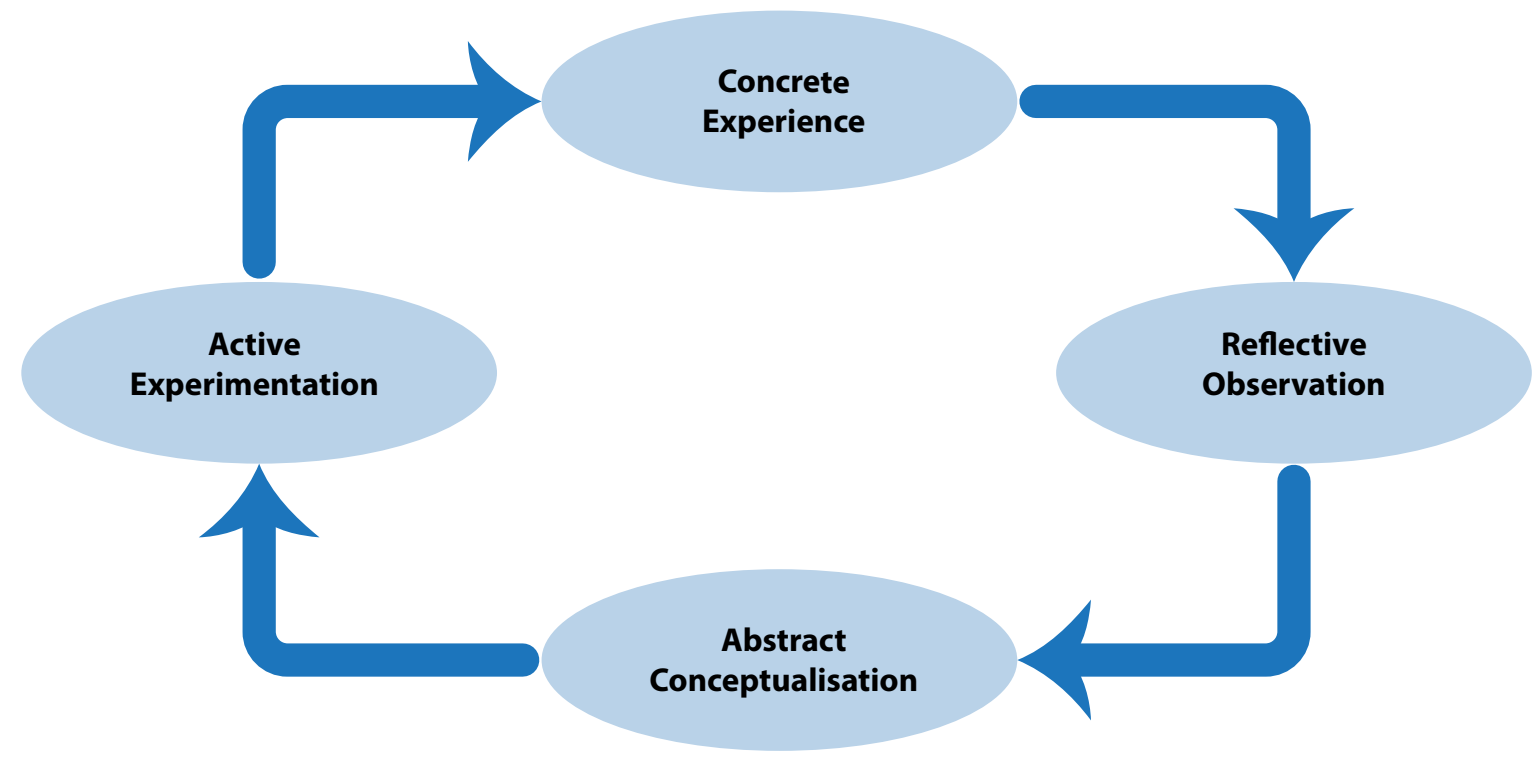

Figure 9.2 Kolb's Cycle of Experiential Learning

Source: Adapted from Oxendine et al. (2004)

For experience-based learning to be successful, we must first clearly define the goal and how this goal is significant to the individual. We then need to assure personal engagement with the experience and bring previous experience and knowledge to the learning process to ensure an adequate process of reflection and conceptualisation (Andresen et al. 1999). Experiencebased learning is highly adequate for internal institutional capacity development, where experienced protected area staff can mentor younger or newer staff.

\section{Vocational training or learning}

Vocational training is oriented towards improving or updating knowledge and skills or to the acquisition of new ones required for a specific job function or trade. It is usually oriented towards the technical level and can be successfully used to enhance job performance by learning how to use new instruments, methodologies or technology. In protected areas, it is often employed at the operational or ranger level, especially for learning to use new tools or techniques such as a global positioning system (GPS), trail construction or wildlife monitoring.

\section{Induction training}

Induction training is given to new employees or employees coming to a new area in order to facilitate the adjustment to the new job tasks, other members of staff and the work environment, reducing the time needed to become productive. It can cover the organisation's mission and vision, objectives, organisational chart, terms and conditions, working culture, equipment, information and communication systems, health and safety, and monitoring and evaluation. It is site or organisation specific and can cover a wide range of geographies, topographies, vegetation cover, water, caves, wild animal presence, climate extremes, incidents, social environments, political environments, conflict zones and other environmental and managerial considerations. Induction training is not about skills; it is about the basic routine tasks that have to be understood. Often protected area systems run in-house training for new staff or to update existing staff.

\section{Informal/self-directed learning}

Thanks to increased communication, self-directed learning is rapidly growing in importance. Increased access to the Internet, efficient and easy to use browsers, discussion forums, social networking, video instruction (TedX, for example), online courses (many of them free, such as Coursera), live streaming of meetings and conferences, and many others, allow easy and timely access to the latest information.

\section{Mentoring/apprenticeship}

Mentoring and/or informal peer learning can be highly effective and very low cost, especially for training young staff. A mentoring culture has to be promoted within the organisation, avoiding knowledge and skills being used as a power play. The possibility of having staff from one protected area interact with mentors from other 
protected areas can also be very effective, using protected areas with good capacity and thus management, as training places. This is also the case with partnerships, including international ones that allow staff from different countries to do internships in well-managed protected areas.

\section{Formal education}

Formal education is provided by accredited institutions and is based on a curriculum that leads to degree-granting programs — often required by professional associations to allow people to work in a given field. Formal education has an important advantage in that it allows for the deeper transformation of a person and changes in their mindset. Formal recognition or accreditation is required, be it through a ministry of education, an accreditation board or other means. In many cases, the validity of a degree obtained in a foreign country must undergo a set of steps to receive final recognition as being equivalent to a similar degree within a country. In many protected area systems, having a formal degree is a prerequisite for higher positions within an institution and is normally accompanied by better salaries.

Formal education specifically designed for protected areas is still scarce throughout the globe. In part, this could be due to the lack of recognition in the past of the need to professionalise protected area management, but other constraints can be easily identified. University degree programs in protected areas are difficult to run as there are few new job openings and most potential students are in fact current protected area staff who cannot leave their areas to sit in classrooms. Long-term sustainability is not easy to achieve, especially in smaller countries, where the total staff who can be potentially trained is limited to a few hundred, taking into account that not all staff want to or can go through a degree program (often protected area staff do not have the requirements for higher education, and many times they have not even finished secondary education).

Finding adequate teachers who have the required academic background in protected areas, teaching/ learning skills and real-world experience in protected areas is difficult. The Latin American School for Protected Areas at the University for International Cooperation has tried to overcome some of these limitations by offering online and blended-learning alternatives that reach out to protected area systems in many countries. Online education (which is discussed later in this chapter) allows for the involvement of students and teachers from many countries, but it does not solve the issue of limited funds for degree education within protected area systems and

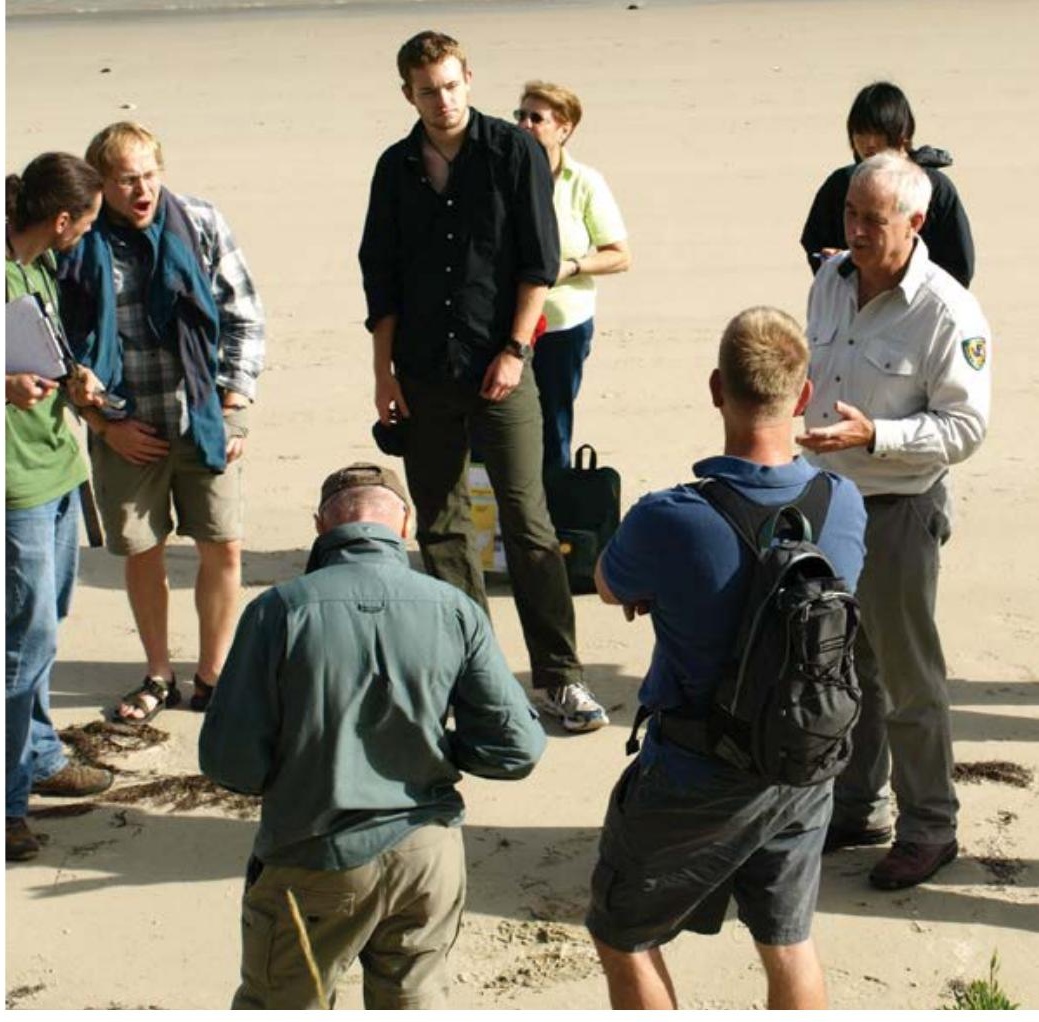

Onsite postgraduate protected area management tuition from an experienced Tasmania Parks and Wildlife Service ranger, South West National Park, Tasmania

Source: Graeme L. Worboys

the inability of protected area staff to pay for their own studies due to low income. This situation compromises the long-term financial sustainability of such delivery. Many efforts to set up protected area management schools have ended when the international grants that started them terminated.

\section{Capacity development}

According to the Organisation for Economic Cooperation and Development (OECD 2006), adequate country capacity is one of the critical factors missing from development. If the development of sustainable capacity is not given the correct attention, development efforts will fail, even if supported by substantially increased funding. In the early part of the 21 st century, much effort is being put into rethinking capacity development. Capacity development must go beyond the enhancement of the skills and knowledge of individuals and is very closely related to the quality of the organisations in which they work. An enabling environment is crucial for an organisation to be effective. Thus, capacity development must take place at three levels-individuals, organisations and society (Nuffic 2014)_as represented in the following classic and often-cited model for capacity in a nested structure (Figure 9.3).

In terms of protected areas using this model, we can identify many initiatives for capacity development at different scales (Table 9.1). 


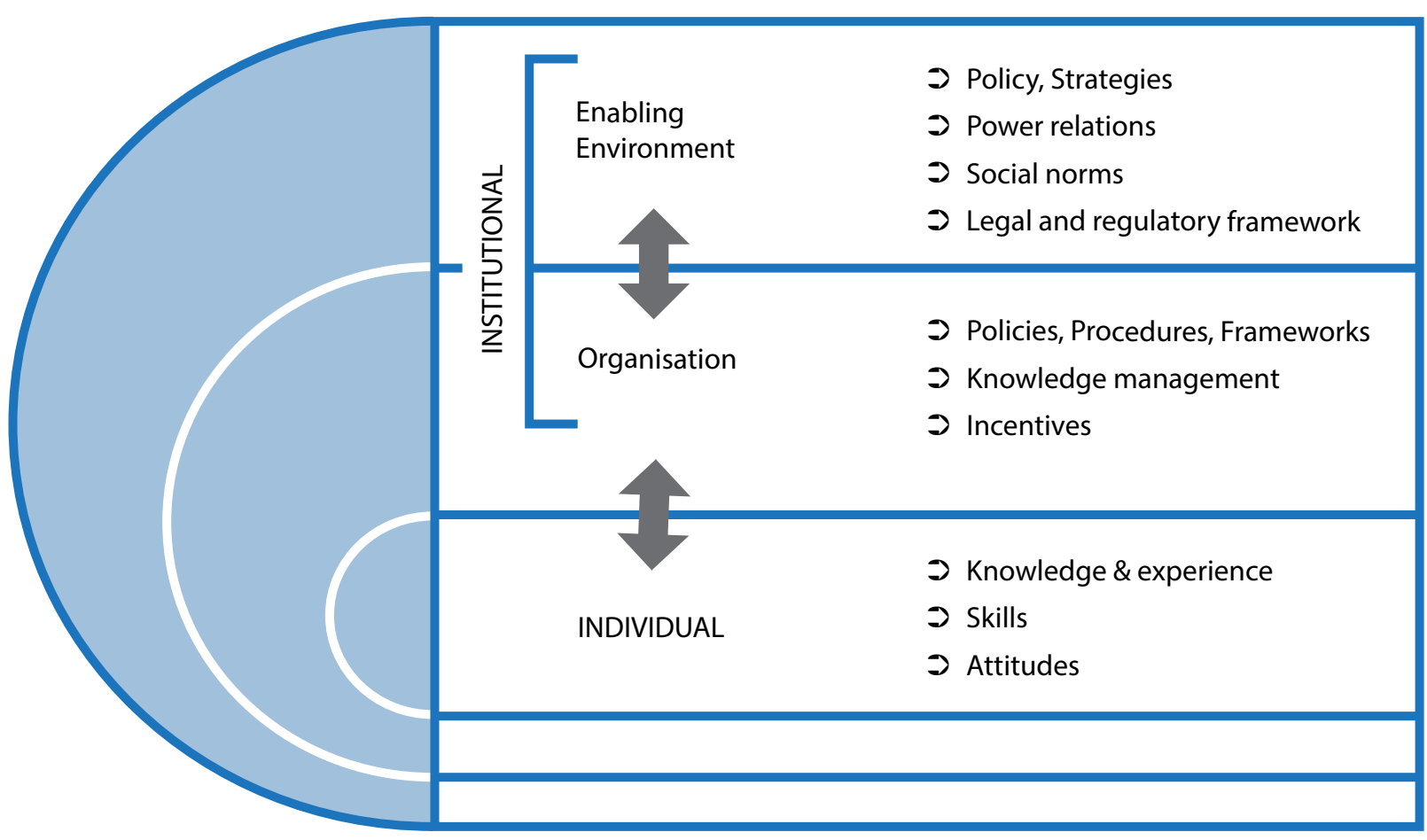

Figure 9.3 A systems approach to capacity development

Source: Adapted from UNDP (2009)

Table 9.1 Capacity development at different scales

\begin{tabular}{|c|c|}
\hline Capacity scale & Examples \\
\hline $\begin{array}{l}\text { Enabling environment (system) } \\
\text { - policy, strategies } \\
\text { - power relations } \\
\text { - } \text { social norms } \\
\text { - legal and regulatory framework }\end{array}$ & $\begin{array}{l}\text { - } \quad \text { IUCN work on legislation } \\
\text { - IUCN work on governance } \\
\text { - } \quad \text { IUCN (and others') work on financing } \\
\text { - } \quad \text { Species Survival Commission (red lists, species action plans) } \\
\text { - } \quad \text { protected area categories } \\
\text { - } \text { Programme of Work on Protected Areas } \\
\text { - Convention on Biological Diversity Aichi Targets }\end{array}$ \\
\hline $\begin{array}{l}\text { Organisation } \\
\text { - policies, procedures, frameworks } \\
\text { - } \quad \text { knowledge management } \\
\text { - incentives }\end{array}$ & $\begin{array}{l}\text { - IUCN/WCPA guidance on system planning, management planning, } \\
\text { - } \text { governance, financing (see Chapter 2) } \\
\text { - } \text { Programement effectiveness evaluation and the Green List } \\
\text { - } \quad \text { processes and procedures such as human resources, monitoring and } \\
\text { reporting, institutional development, and organisational cultures }\end{array}$ \\
\hline $\begin{array}{l}\text { Individual } \\
\text { - knowledge and experience } \\
\text { - } \quad \text { skills } \\
\text { - } \quad \text { attitudes }\end{array}$ & $\begin{array}{l}\text { - } \text { lempetence } \\
\text { - learning resources (body of knowledge) } \\
\text { - } \quad \text { curricula } \\
\text { - learnification of individuals } \\
\text { learning support such as training, courses and mentoring }\end{array}$ \\
\hline
\end{tabular}

The nested model described in Table 9.1 is very simplistic and a more adequate representation is provided in Figure 9.4, which reflects the true dynamics that exist between the three levels.
In the past, capacity building was viewed as a technical process whereby knowledge or organisational models were transferred from high Human Development Index (HDI) countries to low HDI countries, where it was about teaching and training directed to individuals (OECD 2006; Walters 2007). The word 'building' suggested that previous capacity did not exist. 


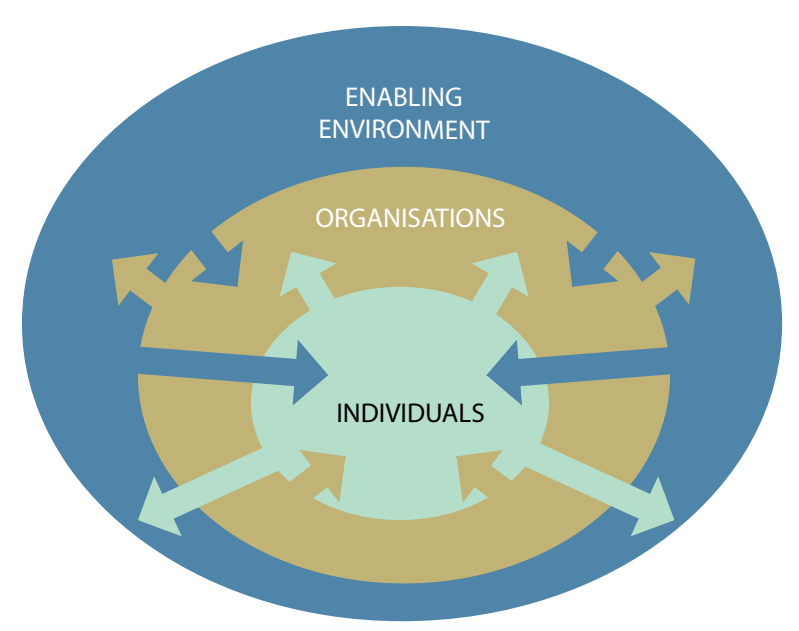

Figure 9.4 Dynamic model of capacity development

The broader political and social context under which capacity development efforts took place was not taken adequately into account (OECD 2006). The focus on providing the right answers without knowing the right questions often led to capacity development initiatives that did not respond to true needs, especially in developing countries. This then led to the lack of recognition of the importance of capacity development and could explain why there is very little recognition of having well-trained and educated staff in protected area management.

Many projects with the goal of resolving diverse conservation and development challenges have focused on the provision of technical solutions and funding with very little effort (and funding) provided for true capacity development. This has proven insufficient and has led to a 'renewed focus on the underlying human and organisational capabilities that need to be strengthened, through working more closely with the individuals, organisations and societies that were the intended beneficiaries of development support' (Capacity. org 2013).

Many current and past capacity development initiatives were provided through technical cooperation projects or training providers, many of which are active at a global scale. This often created supply-driven capacity development based on inputs. Today it has become obvious that the focus must be on demand and on needs based on outcomes (Figure 9.5), and capacity development programs must be tailored to these. The inclusion of local views and knowledge is fundamental and the capacity development process must be appropriated by the 'receptors' in order to be effective, long lasting and actually contribute to the development of individual, institutional and societal capacity.
The new consensus, articulated strongly in the 2005 Paris Declaration on Aid Effectiveness, sees capacity development as a necessarily endogenous process, strongly led from within a country, with donors playing a supporting role (OECD 2006:12).

This requires political recognition of and leadership on the importance of stimulating capacity development as a basis for achieving true country-level development.

There are many definitions of capacity development and its scope. The OECD (2006:12) has defined 'capacity' as 'the ability of people, organisations and society as a whole to manage their affairs successfully, and "capacity development" is understood as the process whereby people, organisations and society as a whole unleash, strengthen, create, adapt and maintain capacity over time'. Ubels et al. (2010:4) emphasise the intrinsic dynamic character when they define capacity as the ability of a human system to perform, sustain itself and self-renew'. They refine this further, affirming that it is not a static state but instead leads to changes in capacity over time. It is about creating added value for members and the outside world through permanent action and adjusting and developing over time. Defining it as a human system reflects the fact that there are different scales or levels of human organisation-from individuals to teams, organisations and networks.

More importantly, especially in times of rapid change, capacity will always evolve in interaction with the surrounding environment. In order to develop or build capacity, we must make deliberate efforts to 'stimulate, guide, strengthen, unleash, nurture and grow capacities beyond the existing condition' (Ubels et al. 2010:4). Thus, capacity is the 'ability of people concerned to (collectively) perform and deliver results in a chosen area, to sustain the activities required and adapt them over time' (Ubels et al. 2010:5).

According to Ubels et al. (2010:ix), this means that capacity development requires engagement with reallife issues and results, in which 'abstract organisational abilities must be seen to be believed', and where 'capacity develops as much through relationships between actors as it does within an individual organisation, therefore involving unleashing collaboration'.

Finally, capacity is fuelled by local actors' ambitions and resources, which cannot be replaced with external inputs and finance.

Capacity development at the protected area level can be challenging since the person or group of persons defining any capacity development program have to be able to clearly answer 'capacity for what' and 'capacity 


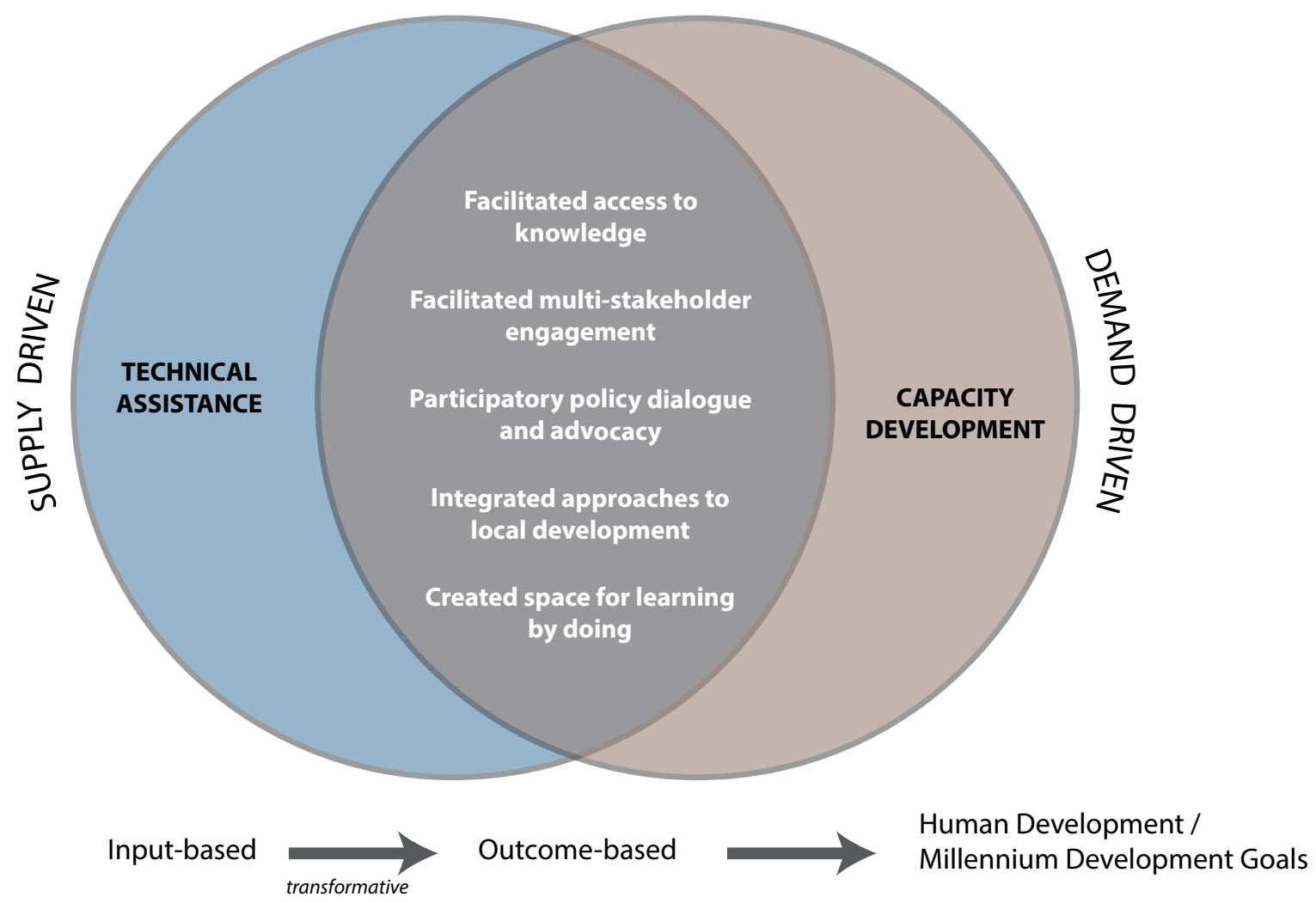

Figure 9.5 The shift in paradigm to a capacity development approach

Source: Adapted from UNDP (2009)

for whom', and focus on specific capacities required to accomplish clearly defined goals under particular circumstances (technical, environmental, political and financial) in which these goals must be reached. Rapid changes due, for example, to climate change require permanent analysis of the main factors of change, which must be identified, quantified and monitored, requiring a permanent process of capacity development. We must identify the capacity that already exists but we must be able to determine if it effectively enables both individuals and their organisations to perform and achieve the goals they want to achieve. Under this premise, capacity development is about closing the gap between actual and desired performance (Walters 2007).

At the protected area systems level, the planners' or policy-level perspective of capacity development will benefit from more holistic approaches to capacity. The European Centre for Development Policy Management, in a study report by Baser and Morgan (2008) and Capacity Development in Practice (Ubels et al. 2010), identify five core capabilities that are required to achieve organisational capacity (although they also apply to individual capacity). Their combined results are provided in Figure 9.6.

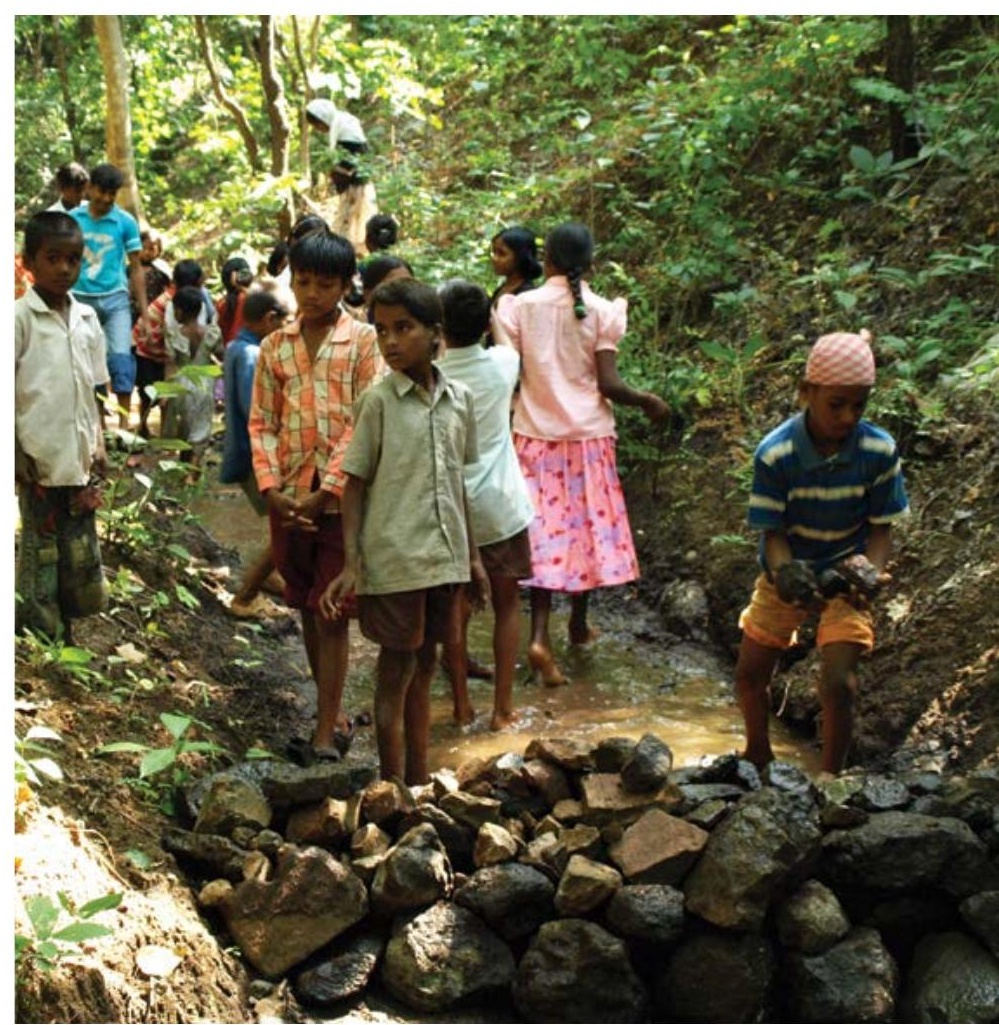

Stream erosion prevention and soil conservation work, Baripada ICCA, near Pune, India: village children learning by doing at an early age

Source: Graeme L. Worboys 


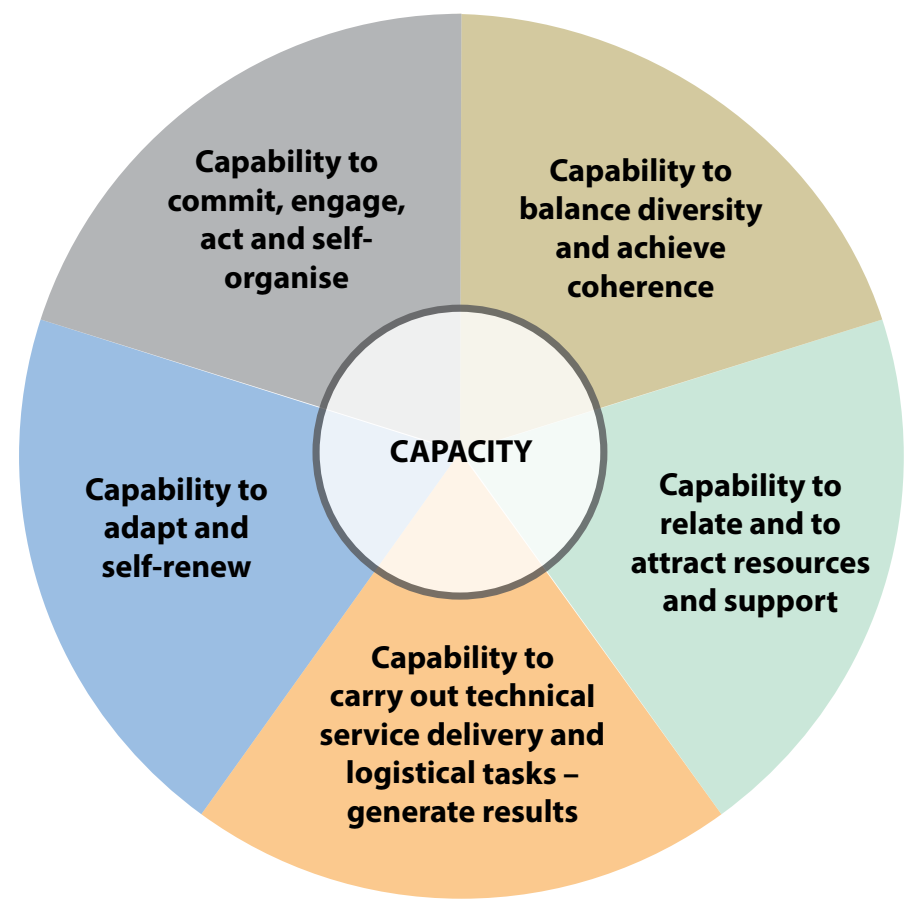

Figure 9.6 Five core capabilities required to achieve organisational capacity

Source: Adapted from Baser and Morgan (2008)

If we try to relate these to existing protected area systems and their functioning, we might be able to identify more effectively where capacity development must be enhanced.

\section{1) Commit and engage}

This core capability is often not recognised. It has to do with the importance of ownership and motivation, and is what allows organisations to empower themselves and have intrinsic capabilities for long-term capacity development. This capability is very closely tied to the essential components of competencies, which are attitude and self-perception, the human side of which often is what makes people motivated, have the energy to act and achieve their goals, leading to higher selfesteem and improved competencies overall (Baser and Morgan 2008).

\section{2) Technical, service delivery and logistical tasks}

This core capability is most commonly associated with traditional capacity-building processes and is focused on performance and results (Baser and Morgan 2008). Within protected area systems, this is often attended by hiring consultants or companies that deliver supplydriven short courses.

\section{3) Capability to relate and to attract resources and support}

This core capability is related to true and demonstrated achievements resulting from the development of key relationships required for organisational survival. It relates to earning the trust of others through credibility and legitimacy, including internal and external relationships (Baser and Morgan 2008). This is highly required, both at the protected area level involving local communities and stakeholders and at the system level, where, for example, a good communication strategy with the minister of finance might be able to solve a lack of government recognition of the role of protected areas in the national accounting and thus solve many of the problems related to lack of funding or political support. Achieving capacity at this level requires the correct attitude and skills and will be strongly enhanced through experience and personal ability.

\section{4) Adapt and self-renew}

This core capability is fundamental for long-term sustainability, especially in times of rapid change. It requires a collective awareness of the state, intrinsic capabilities, leadership, a critical need for foresight, continuous discussions and brainstorming and an understanding of the importance of adapting to change (Baser and Morgan 2008). Spaces for collective interaction that allow this are usually not found within 
protected area systems. Additionally, the biggest challenge is to overcome the resistance to change of individuals and organisational structures —often related to power issues.

\section{5) Balancing diversity and coherence}

This core capability is about finding a balance between the diversity of thoughts, perspectives, beliefs and ways of doing things and developing the coherence needed to avoid fragmentation in order not to lose focus or break apart (Baser and Morgan 2008). This can be especially challenging for system and protected area management, due to the diversity and complexity of fields and very diverse individual backgrounds that have to be integrated.

Defining core capabilities can be challenging for protected area systems since it must contemplate the institutional structure, which is often complex, depending on centralised or decentralised decision-making, very diverse thematic or program areas, territorial distribution, and effective institutional communication channels. In many protected area systems, there is a lack of staff with highlevel managerial, administrative or project management training or education, often due to the fact that staff has been promoted from the field to central offices based on their on-the-ground performance, which might not always suffice for higher-level strategic management.

\section{Education in a changing world}

Today it is less important to possess knowledge than to be able to find it, select it and apply it—and do all this swiftly. Change, even environmental change, is not an exception any more; it is the rule. This makes it imperative to be able to permanently seek new approaches and solutions to the increasing complexity of current development. For adaptive management, we look back at monitoring results, making the necessary changes as we move forward to reach our planned objectives. Today, rapid change does not allow us to base our strategies only on past experiences; we must also look at future scenarios and lay the groundwork to try to reach the best-case scenarios. This is creative management.

The need to be permanently alert and choose different sources of information has changed the perception of what a successful student or professional is. Several decades ago, students went to school with an 'empty suitcase', which was slowly filled up each semester until graduation. After several years at university, students could go home and open this 'suitcase' and start exercising to gain the competencies required by the labour market.
They were able to use the acquired knowledge for many years of professional practice with only occasional updates. Today, if a graduate is not able to permanently update and further develop his or her knowledge, skills and even attitudes, he or she will be obsolete for the labour market very soon after graduation.

This change in the learning process has not come about by chance. The accessibility of information in the era of the Internet and information technology, where mobile phones with their increased power and transportability are replacing computers, and the sheer amount of information that has become available at the click of a button, allow the close to two billion people who have access to the Internet to be part of the information era. Technological developments are permanently changing the way we educate and learn. It took many decades for distance education to gain a reputation; it has taken only a few years for online, e-learning and virtual education to change the educational paradigm. Most of the detractors of online education are people who themselves are not connected. It is true that there are many things that cannot or should not be taught without face-to-face time, but the support of technology is required for most learning processes today.

Another important shift in knowledge management comes from a realisation that conventional scientific approaches are not sufficient in many instances for the development of solutions to current problems. The use of alternative knowledge systems such as communitarian or indigenous knowledge has proven essential for the understanding of ecosystem functioning and the use of ecosystem services by local communities. Restoration of functional landscapes must inherently incorporate local knowledge. In fact, modern science has proven today that 'natural' ecosystems such as the forests in Mexico's Yucatan Peninsula (Levy-Tacher et al. 2002) or in the Amazon Basin (Coomes et al. 2009) have been modified by humans over hundreds of years to match their productivity with people's needs for food, fibre, fuel, medicine, and so on. Today we must learn to recognise local knowledge as equally important for decision-making. It is highly relevant to bring science to local people so they can understand phenomena like climate change, which are not imprinted in traditional knowledge.

\section{Learning versus teaching}

An important shift in capacity development is the transition from teaching to learning. Today's information and communication technology makes knowledge available at a fingertip through most smartphones. 
Thus, a successful capacity development program today is not one that teaches knowledge; instead it is one that enables the learning process, allowing for collective construction of knowledge through learning communities and learning by doing. The possibility of the learner to immediately apply the knowledge and skills will lead to a more confident person, with a positive attitude towards his or her working environment. For the educator, it is often not an easy shift from being a teacher to becoming a mentor or moderator of a learning process. This does not disregard the importance of the experience a teacher might have acquired or their immense knowledge-often constructed through their own experiences. The learning process must be accomplished by the student according to his or her existing capabilities and deficiencies. Students learn by self-assessment through actual doing, more than through teacher evaluations or exams. As in other disciplines, in protected areas, teachers usually have a good subject background but have not been trained and are not very active in pedagogy and its development. Personal experience shows that it is not easy for protected area experts to take on the role of mentorship to assist the learning process as most of them still want to 'teach' (Case Study 9.1).

\section{Reductionist versus holistic approaches}

During the past decades there has been a growing critique of the traditional reductionist framework of education, wherein a complex whole is taken apart into 'boxes' that are studied through different disciplines. The assumption is that if we understand the parts, we can understand the whole. Where this fails is that many of the interactions are lost, making it difficult to deal with complexity. A good example of this is climate change. The huge complexity of climate change makes it difficult to find effective solutions through institutions that are set within a sectorial framework and which see only parts, but there is no institution to oversee the whole.

In the reductionist framework, the educational process seeks the transfer of what a teacher knows to the student. The assumption is that knowledge is discrete, identifiable, objective and impersonal, and learning is static and additive in nature. Under this approach

knowledge is made up of elementary units of experience which are grouped, related, and generalised, and ... the parts of a given learning experience are equal to the whole... In this model, which units are to be taught and in what sequence they will be presented is determined by the teacher or a curriculum specialist. (MacInnis 1995:8)

Holistic educators focus on the construction of knowledge, where the learner transforms new experiences into knowledge by relating them to previously acquired knowledge and transforming both of these into something new and meaningful. Learning goes then from a whole to the parts and then back to the whole. A good example for better understanding is the need to learn the letters of the alphabet prior to attempting to write or otherwise trying to communicate in writing; letters will be learned as needed (MacInnnis 1995). If we truly intend to increase the effectiveness of conservation and development goals, the complexity of management of protected areas will benefit from a shift to more holistic approaches, both in management and in capacity development.

\section{Delivery: Face-to-face, online or blended learning}

We will not go into an in-depth discussion of the different delivery methods and their advantages and disadvantages since this is not the scope of this chapter and more often than not these aspects are bound to the education or training institutions. Nevertheless, it is important for protected area staff to understand the basics of these delivery methods and the potential each of them has for different protected area capacity development efforts. Internet access is growing quickly, especially through smartphones, making connectivity issues less relevant as time passes.

Most people have been brought up with traditional faceto-face learning, be it in classrooms, as a cross-generational (elders to youth) system or within the working arena. The main drawback is that students have to travel to the training site and there is a limit to the number of students who can attend a class with satisfactory results. Costs are elevated and, especially where air travel is involved, some of these courses are becoming prohibitively expensive. Face-to-face education has many advantages, starting with the human interaction that is essential, for example, in increasing communication and teamwork skills. It is valuable for complex field processes where direct observation and then practice with expert supervision can lead to more effective mastering of these skills. Game roles and other interactive methods are excellent training events, especially when conducted within an organisation or team. 
Moving away from the traditional approach where a student first 'learns' all the subject areas and then moves on to implementation and integration, the learner starts by mapping the protected area in which he or she works, including its surroundings. The task lies in using maps or geographical information systems (GIS) to identify and plot all issues that influence or affect the protected area. When working with each of the themes, the learner has to go to different sources and see which aspects have the highest relevance for a desired outcome. Any of the subject areas can serve as a starting point-for example, the ecological and conservation biology aspects, identifying if size and borders allow the conservation goals to be met, determining whether the connectivity and buffer zones are present or where they can be established, and their effectiveness for different species and under the influence of climate change. Communities can be mapped, identifying threats and opportunities and areas for conflict management or support for community education, involvement and development.
Visitor management can be analysed, including joint efforts with local tour providers to increase visitor experience and seek co-investments. Research requirements to provide information for management can be prioritised and links to academic institutions identified. Within the final steps is determining what the required linkages are with the whole protected area system in terms of budget, technical assistance, alignment with national and global policies such as the PoWPA, and innovative funding sources. The learner can use different sources for acquiring information including guidance from a mentor or peers, internet searches, paper reports, management plans, and interviews with fellow workers or even community members.

$\mathrm{He}$ or she can choose the sequence by prioritising problems, gaps or previous experience. At the end, the map allows a holistic view of the protected area and all of the required processes to be undertaken to achieve the conservation goals, and the learner has the opportunity to gain knowledge and skills in the array of fields that affect a protected area.
Distance learning relates to having teachers and students in different places. Delivery originally was through materials sent by mail with instructional designs that allowed the student to learn by studying the materials at his or her own pace; these were often called correspondence courses. Online learning or e-learning, also called virtual learning, has gained enormous ground over the past two decades, facilitated by improved internet connectivity and speed and the development of different platforms, especially Moodle, which was the most widely used interface early in the 21 st century. The main characteristic of online education is rapid change as technology develops further. Less than a decade ago no-one would have thought of the possibility of attending university programs through a mobile phone. Internet delivery was seen as something for the few and left many people, especially those from lessdeveloped countries, out on a limb. In 2013, 39 per cent of the world population was using the Internet, up from 16 per cent in 2005. In the developing world, 31 per cent of the population used the Internet, up from 8 per cent in 2005, whereas 77 per cent of the people in the developed world used the Internet in 2013 (ITU 2014).

Face-to-face educators and even educational authorities have often offered resistance to the online process, and for many years it was considered to have lower quality than the face-to-face process. It is true that, under present conditions, some disciplines are still impossible to learn exclusively through the Internet. Nevertheless, technology is stepping in and we now have, for example, surgical training through high-tech communications systems, where expert surgeons assist students or lessexperienced professionals in remote areas using video communication, coaching the apprentice through every step.

Blended learning is a mix of both worlds and has proven to enhance the learning process when practical experiences are required. Online programs are now fostering face-to-face encounters between students based on geographic proximity. These self-managed working groups help construct knowledge collectively, allowing for the development of skills and attitudes. In recent years, massive open online courses (MOOCs) have gained popularity and will probably completely transform the educational process, even at world-renowned universities such as the Massachusetts Institute of Technology (MIT) and Stanford University, which have invested significantly in their development.

\section{Capacity development planning and assessment}

Establishing a capacity development action plan allows for better alignment and synchrony between the capacity development efforts and personal, institutional and community goals. The CBD has developed a guiding process for the establishment of capacity development action plans for protected areas (Box 9.4).

There are many different methods for assessing capacity needs. The basis is frequently a comparison of the current situation (existing capacity) versus a desired 
one (assessment of future capacity) and the road map for how to get there. There are several guides to capacity assessment methodology (UNDP 2007, 2008). There are also different levels for capacity assessment related to the enabling environment, organisations and individuals (Kay et al. 2008), while other authors add still another layer related to the network level of organisations where capacity development should aim at improving the relationships between different stakeholders in order to fully utilise their diverse capacities (Nielsen 2011).

In protected area systems, we find many different assessments for capacity development needs and many different approaches are taken to establish them. Some assessments are based on expert opinion (don Carlos et al. 2013); others are based on questionnaires to staff working in protected areas, buffer zones and central offices (Acevedo et al. 2006); and others have used broader samples, including on-site questionnaires and detailed self-assessment questionnaires (Gombos et al. 2011). We also find more complex assessments where a combination of participatory and iterative methods was used, including focus group discussions, field visits, interviews, literature review and intensive consultation with key stakeholders carried out at the community level.

This is the case of the Centre for People and Forests (RECOFTC) capacity-building needs assessment for the development of community forestry and community protected areas in Cambodia (The Learning Institute and RECOFTC 2011) and for the development of community forestry in Indonesia (Siscawati and Zakaria 2010). The more complex processes usually render more accurate results but require higher investments, in terms of both time and funding.

The advancement of management effectiveness evaluations (Hockings et al. 2006) based on the establishment of management standards and assessment of performance against these standards, which lead to benchmarks for protected area management using a stepped scoring system from 'complete failure' to 'full compliance', can ease the identification of the areas that require capacity development, which can then be targeted

\section{Box 9.4 What is a protected area capacity plan?}

While most protected area management effectiveness studies identify and prioritise critical threats and key weaknesses, they often do not identify the specific capacities and corresponding opportunities and strategies needed to address them. On the other hand, many capacity plans are based on a generic checklist of potential capacity needs, rather than on a systematic assessment of the actual management weaknesses and threats within the protected area system.

Ideally, planners will integrate management effectiveness results into the capacity action planning process, in order to ensure that the results are relevant and are focused on improving the most urgent weaknesses and abating the most prevalent threats. Furthermore, many capacity assessments focus exclusively on individual capacity needs and skill development, rather than on broader institutional and societal capacities. Ideally, planners will consider the range of capacity levels needed to ensure a comprehensive and well-managed protected area system.

A protected area capacity action plan is defined as a suite of strategies and actions aimed at strengthening the individual, institutional and societal capacities needed to create a representative and comprehensive protected area network, address critical management weaknesses, abate key threats and improve the enabling environment within a protected area system.

While the actual process of developing a capacity action plan will vary from country to country, the following are some basic principles that are likely to apply to all cases.
- Build on the results of existing assessments of protected area management effectiveness.

- Focus on the capacities needed to address key management weaknesses and abate critical threats as the basis for the action plan.

- Consider individual and institutional capacities and, depending on the scope of the assessment and available resources, societal capacities.

- Engage the right actors at the right time-park guards and field-level staff can provide one level of input into the capacity plan, while ministerial staff and policymakers can provide another. Often several meetings will be needed to include different levels of expertise.

- Include multiple actors from different sectors, including, for example, tourism, economic development, land-use planning, forestry, fisheries and agriculture.

- Emphasise a self-assessment approach, empowering protected area staff and administrators to identify their capacity needs and constraints.

- Ensure the support of senior-level management in conducting the capacity assessment and following up with the results.

- Ensure that the capacity action plan is integrated into national budgetary processes in order to increase the likelihood that the plan will be implemented.

Source: CBD $(2014 b: 4,6)$ 
with specific training. In a global study (Leverington et al. 2010), overall management effectiveness was most strongly linked to adequate infrastructure, equipment and information; good administration and communication; adequacy of information and staff training; and good management planning-all of which are linked to capacity.

We must be aware, however, that there is often a fundamental gap when capacity development needs are assessed, and it is based on the premise that one does not know what one does not know. In other words, often organisations and individuals are not up-to-date with knowledge, science and development trends and thus may not be aware of the need to develop capacities in one or another field. This is especially true where lower capacity exists or where language or technological barriers have not allowed for new trends or needs to be incorporated. One good example of this is climate change. The words 'climate change', 'mitigation' and 'adaptation' are often found on capacity development needs assessments but with further inquiry there is often a misunderstanding or vague definition of what is actually required under each of these headings.

In order to overcome these limitations, it is necessary to seek expert support or at least establish processes through which the systems are kept up-to-date in terms of knowledge, science and technology. Adequate political leadership is fundamental for this to happen but recognition of the importance at all levels is also needed and this, in itself, is part of capacity development. Engaging external stakeholders and 'clients' can help an organisation assess its capacity or more importantly its performance and determine whether or not the gap is caused by a capacity issue.

It is often difficult to measure the impact of capacity development activities, especially in the short term. Since capacity development happens at the individual, organisational and community levels, assessment must happen at these levels also. Outcomes, however, depend strongly on the enabling environment, which depends on external factors such as policy or politics, the capacity of high-ranking officials nominated politically, worker unions, funding and other factors. Constant change to organisations also affects capacity as does a lack of organisational response to change, as this will render the highest capacity useless over time. The most difficult level of assessment is the community or society level due to the high complexity of this setting and the almost impossible task of identifying the direct results of capacity development processes. In the long term, the behaviour of a community or society will allow for a wider recognition of capacity that will nevertheless be difficult to clearly attribute to specific capacity development processes. This becomes highly relevant when protected area community outreach programs are evaluated, especially those that are donor funded and require reporting on effectiveness.

One of the most widely used evaluations for training programs was developed by Kirkpatrick in 1959, redefined by the same author in 1998 (Kirkpatrick 1998). The evaluation model has four levels.

- Step 1: Reaction-How well did the learners like the learning process?

- Step 2: Learning - What did they learn (knowledge and skills gained by learners)?

- Step 3: Behaviour-Resulting changes in job performance from the learning process (capability to perform the newly learned skills while on the job).

- Step 4: Results-Tangible results of the learning process in terms of reduced cost, improved quality, increased production, efficiency and other measures.

Organisational capacity development is of the utmost importance if we want effective protected area systems; assessing the impact of capacity development at this level can prove complex and challenging. Hailey et al. (2005:12) have identified some clear methodological and practical challenges associated with measuring impact:

1. unclear program and process design

2. power, control and ownership: whose needs and agenda

3. measuring complex and intangible change

4. demonstrating causality and attribution

5. responding to context and culture

6. committing to the investment costs.

These authors have developed approaches that have been adopted to overcome the challenges and put impact assessment into practice:

1. stakeholder involvement and prioritisation

2. self-assessment

3. triangulation

4. balance of different methods and tools

5. simple and systemic

6. accept plausible association, not direct attribution

7. recognise levels of investment

8. organisational learning: linking assessment with action (Hailey et al. 2005:12-13). 
Assessing the impact at the individual level is somewhat easier, though it varies with the scope of the process. When training activities focus on specific tools such as the use of GIS, trail design and building, fire control, first aid or similar, it becomes simpler. More structured and longer-term processes will require different approaches for evaluation. It is critical, however, to recognise that there can be institutional limitations that do not allow trained staff to put in place what they have learned. This is especially true when the upper hierarchical levels have not received training and feel threatened by more capable subordinates.

Due to the increased need, more and more assessment frameworks are being developed. The Australian Centre for International Agricultural Research (ACIAR) has developed a well-designed step-by-step assessment framework (Gordon and Chadwick 2007; Templeton 2009) that aims to map and substantiate the linkages between the training provided and the intended or realised benefits, thus facilitating the attribution of benefits to specific capacity-building investments. It is based on estimating the value of the impact resulting from the change in practice and behaviour of organisations and then determining what share of these benefits can be attributed to the capacity-building activity (Gordon and Chadwick 2007). A similar effort for protected areas or conservation efforts could possibly facilitate impact evaluation.

\section{Why do we need protected area professionals?}

At the beginning of protected area designations, managers were confronted mainly with landscape preservation for visitation. Later, the importance of protected areas for conserving nature, especially emblematic species, was recognised. With the transition from preservation to conservation and the development of concepts such as biodiversity and ecosystem services, the role of protected areas for local livelihoods became increasingly recognised and thus social and economic aspects were incorporated into management, challenging the natural sciences background of many protected area staff. Today, we see protected areas as one of the most efficient and cost-effective natural solutions to help the fight against climate change. At the same time, the challenges of climate change impacts-with great variability throughout regions and countries, the need to manage uncertainties and risk, and develop management strategies that require a look into the future with scenario analysis, and the search for creative solutions to both adaptation and mitigation-have surpassed the current capacity of many of today's staff involved in protected area management.

In an attempt to fill the gaps, staff have often been trained through short courses, and we frequently find personnel with long lists of capacity-building events in their curriculum vitae. Interestingly enough, unlike other professions, in protected area management, no real professional or degree programs were established until the 1980s. An early associate diploma course in park management, for example, was established by the Riverina College of Advanced Education in Australia by 1983, with a degree course being provided soon after. There are only a few academic institutions around the world that offer formal programs in protected area management, and frequently there is a bias in these programs towards training in biology and ecology. Protected areas in many developing countries are frequently managed by non-professionals or professionals in fields such as biology, geography, geology, anthropology, forestry, agronomy, architecture or some other profession, who have modified their career paths. In economic sectors other than protected areas, typically only well-prepared professionals are hired for managerial positions, requiring usually at least an MBA or equivalent degree related to what they are managing. It would be difficult to imagine designing a house without an architect and building it without an engineer or hiring a person without proper education for bank management.

The complexity of protected area management today requires professionals with adequate competencies in diverse fields who have been adequately trained to be able to take a leading role in integrating the diverse knowledge areas and having the necessary skills and attitude to succeed. Nevertheless, the need to professionalise protected area management, especially in developing countries, has still not been adequately recognised. The provision of effective professional development programs for a large number of professionals is crucial to ensuring they are capable of facing current issues and are prepared for the new challenges of adaptation to climate change.

An effective protected area manager must understand ecological and biological aspects with broad knowledge of conservation biology and monitoring, including population dynamics, genetic diversity and trophic chains. This professional must also understand social dynamics and local community development, law enforcement and policing, governance, socioeconomic issues, mediation and conflict management to integrate protected areas with surrounding communities. Knowledge of general administration, accounting, 


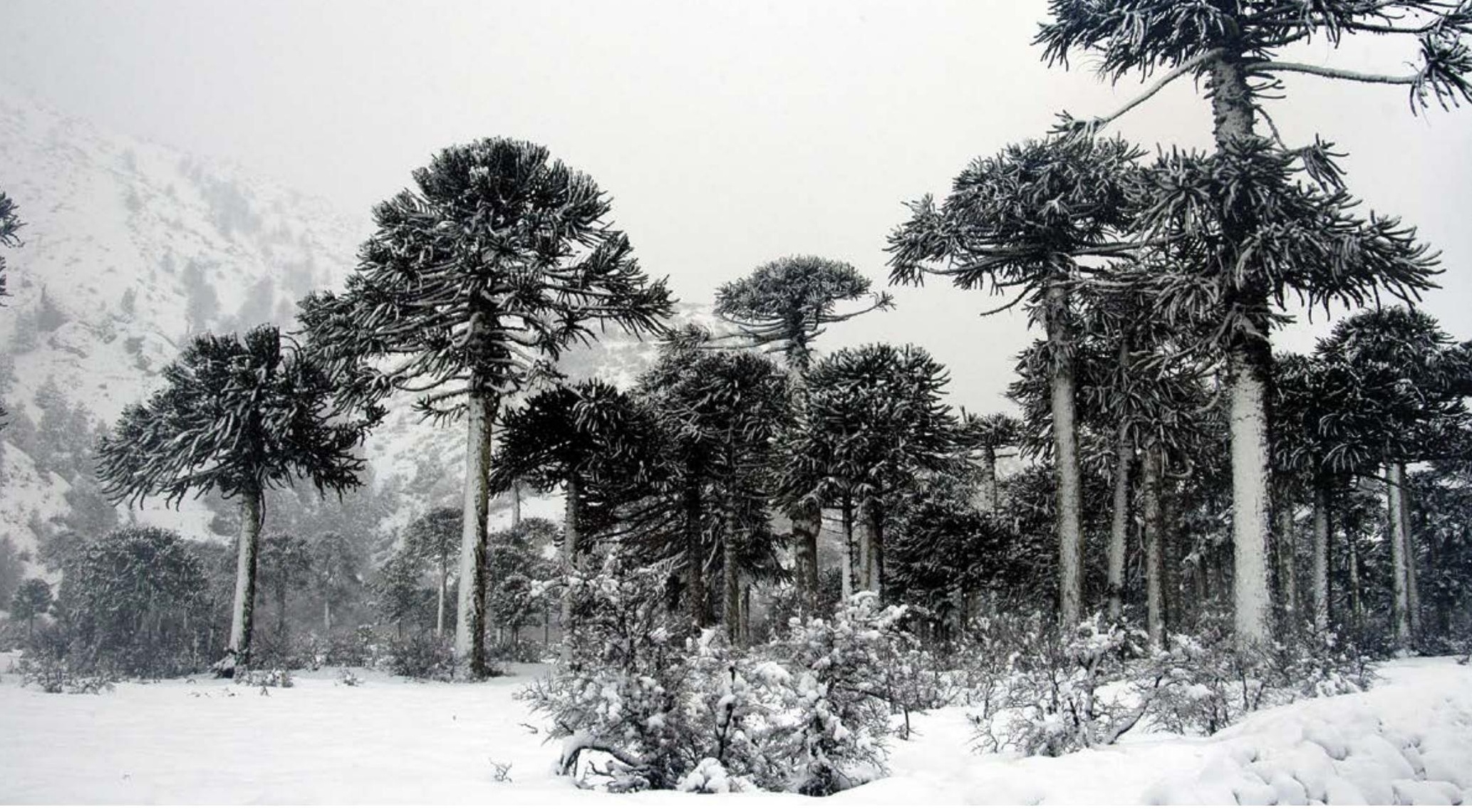

Araucaria forest: outstanding biodiversity in Villarrica National Park, Chile

Source: Eduard Müller

project management, planning, budgets, human resource management, risk and emergency management, public use and tourism, sustainability education, infrastructure maintenance, fundraising and many other areas is also necessary. This person must also be a leader and have the capacity for keen observation, analysis and creativity to be able to accomplish true adaptive management.

She or he must also be familiar with legislation and the institutional nature of protected areas, the economic role and the valuation of services, especially ecosystem services and biodiversity value. Spiritual and intangible values are highly relevant in many parts of the globe. This person must also be able to influence policy and decision-makers. As mentioned, climate change adds new requirements, many of which have not yet been well defined for protected area managers. Marine and coastal areas bring great challenges with very dynamic processes happening with the many different stakeholders and in spatial planning.

The goals of protected area management can be highly diverse, including conservation and sustainable use of biodiversity and ecosystem services, protection of indigenous livelihoods, sustainable tourism, multi-use recreation and climate change resilience. The complexity of modern protected area management requires professionals with knowledge of disparate fields who have been adequately trained to comfortably integrate diverse skills. Advanced professional development programs for a diverse array of staff roles are crucial to ensure protected areas are capable of withstanding current threats and are prepared for new challenges such as climate change.

Many national protected area systems are understaffed, in terms of both quantity of staff and depth of expertise. This limitation has led to a dependency on international and national non-governmental organisations (NGOs) and bilateral technical assistance projects that often do not last. Due to the limited number of academic programs in protected area management, few long-term employees have specialised education that integrates the above fields of protected area management. Challenges are increased for governments since many professionals migrate to the NGO or consulting sectors and the capacity for national systems to train new personnel is often very limited.

If we recognise the value of the national heritage and ecosystem services at stake, we realise the urgency of professionalising protected area management. We need professionals to manage not only the field and officescale issues of individual protected areas but also the administration of larger national and even transboundary and regional systems. These professionals require advanced skills in policy, strategic planning, consensus building, communications and fundraising. Professionals at all levels require specialised training and a diverse array of follow-up opportunities. 
Education for protected area management must be expanded globally under new educational paradigms. Today we face the need for professionals who can deal with crosscutting disciplines using holistic approaches on an everyday basis. The complexity of the problems that conservation in general and protected areas especially are facing requires a permanent search for innovative solutions. For example, there is no recipe for adaptation to climate change. There will be important differences in adaptation strategies for sites that are a short distance apart, such as high, middle and lower parts of a river basin. Thus, the ability of a professional to collect all the necessary information, including forecast models, scenario development, policy and development trends, national and international trends in business, trade agreements and natural resource use, will make him or her more competent and thus successful.

\section{Knowledge management}

Adequate knowledge management is fundamental for success in management, including protected area management. Often, an organisation has a lot of knowledge spread throughout, be it in documents, other media and organisational processes and even in its people. If this knowledge is not systematised in an adequate way, it is frequently not, or not effectively, used. The adequate use of knowledge can lead, for example, to a set of best practices and lessons learnt. Timely use of knowledge can assist in solving problems or generating strategies. The complexity of individual protected area and protected area systems management requires adequate knowledge management in order to construct solid strategies. This uses both positive experiences transformed into best practices and negative experiences used as lessons learned to improve practice. Nevertheless, we rarely find adequate knowledge management or knowledge management systems that allow for quick searches to support decision-making in day-to-day protected area management. Very often, research results are found in one hardcopy that sits on a desk or bookshelf, not only making access difficult but also concealing its existence. The possibility of having modern web-based information systems and ensuring their widespread use would enhance capacity at all levels.

'Knowledge is information or data, organised in a way that is useful to the organisation' (Suryanarayana and Adapa 2013:53). It is about getting the right knowledge to the right person at the right time. Knowledge is abundant and accessible through the Internet. The challenge lies in how to gather, evaluate, classify, systematise and use this knowledge constructively to achieve the organisational objectives. Intellectual capital and institutional or organisational knowledge are highly relevant and all organisations should have mechanisms in place not to lose these. Additionally, the use of local, community or indigenous knowledge has become highly relevant and is practically indispensable for ecosystem management and restoration and the establishment of functional landscapes (Levy-Tacher et al. 2002; Diemont et al. 2011; Aronson et al. 2007).

Knowledge management can be defined as a multidisciplinary approach to achieving organisational objectives by making the best use of knowledge. It includes processes such as acquisition, organisation, development and sharing of knowledge and the cultural and technical foundations that support and promote the use of it (Kundu 2013; see also Chapter 11). Knowledge management may be viewed in terms of:

- identification of knowledge needs and resources

- acquisition, creation, evaluation, classification or elimination of knowledge-related resources, processes or environments

- people-how do you increase the ability of an individual to influence others with their knowledge

- technology as a crucial enabler rather than a solution: it needs to be chosen according to the requirements of a knowledge management initiative and should not be the starting point

- knowledge-focused culture within the organisation; this is the biggest enabler of successful knowledgedriven organisations

- structure, which refers to the business processes and organisational structures that facilitate the storage, retrieval, application and sharing of knowledge (Balakumaran 2013; University of North Carolina 2014).

Knowledge is only useful if it is used. An organisation should have strategies that promote the use and exchange of knowledge, establishing best practices, and ensuring that new knowledge is permanently constructed, especially if this is done collectively (Box 9.5).

\section{Competence-based approaches to capacity development}

As discussed previously, traditional university education has been based mainly on knowledge, with some skill development within each knowledge area. Today we are witnessing a change towards competence-based 
education. In order to give some further insight to protected area personnel involved with education and training, we will describe an ongoing WCPA initiative that seeks the establishment of competencies and competence-based education and certification in protected areas globally.

The competence-based approach addresses the need for developing and measuring capacity by focusing primarily on the ability of individuals to perform in their jobs effectively, rather than on delivery of training and acquisition of qualifications. Competence is the proven ability to do a job and is often defined in terms of the required combination of knowledge (to know), skills (to know how to do) and attitude (to know how to be) —often referred to as KSA-allowing individuals to function in the real world. Knowledge provides an understanding of the technical and theoretical background of the task and an appreciation of its purpose; skills ensure the ability to perform a task reliably and consistently; and having the right attitude helps ensure that an individual works professionally, ethically and conscientiously.

An adequate level of competency to perform a particular task or job is often defined as a 'competence standard' or 'occupational standard', which is 'a definition, usually developed and accepted by industry, of the knowledge and competencies required to successfully perform work-related functions within an occupation' (IUCN WCPA et al. 2003:207).

Competence standards are developed with the relevant sector-for example, a protected area agency, supported by multidisciplinary teams and educators (rather than by academic and training institutions alone). A full competence standard for a particular job usually comprises:

- what a person should be able to do

- the range of conditions under which the person should be able to demonstrate their competence (sometimes referred to as the 'scope' of the competence or as a 'range statement')

- the underpinning knowledge required for the person to be competent

- the ways in which competence can be objectively judged.

The competence approach differs in many ways from conventional approaches to training, learning and assessment. These differences are summarised in Table 9.2.

\section{Box 9.5 Knowledge management strategies}

Knowledge management strategies include:

- rewards (as a means of motivating for knowledge sharing)

- storytelling (as a means of transferring tacit knowledge)

- cross-project learning

- post-action reviews

- knowledge mapping (a map of knowledge repositories within a company accessible by all)

- communities of practice

- expert directories (to enable the knowledge seeker to reach out to the experts)

- best-practice transfer

- knowledge fairs

- competence management (systematic evaluation and planning of the competencies of individual organisation members)

- proximity and architecture (the physical situation of employees can be either conducive or obstructive to knowledge sharing)

- master-apprentice relationships

- collaborative technologies such as groupware

- knowledge repositories (databases, bookmarking engines and so on)

- measuring and reporting intellectual capital (a way of making explicit knowledge for companies)

- knowledge brokers (some organisational members take on responsibility for a specific field and act as first reference for others to talk to about a specific subject)

- social software (wikis, social bookmarking, blogs and so on)

- inter-project knowledge transfer.

Source: Suryanarayana and Adapa (2013:55-6) 
Table 9.2 Comparison of approaches to training and learning

\begin{tabular}{|c|c|c|}
\hline $\begin{array}{l}\text { Element of training, } \\
\text { learning and assessment }\end{array}$ & 'Conventional' approach & $\begin{array}{l}\text { Competence approach (additional } \\
\text { to the conventional approach) }\end{array}$ \\
\hline $\begin{array}{l}\text { Development of 'curriculum' } \\
\text { and learning targets }\end{array}$ & $\begin{array}{l}\text { Training and educational institutions } \\
\text { Experts in the field }\end{array}$ & $\begin{array}{l}\text { Practitioners } \\
\text { Representatives of the sector }\end{array}$ \\
\hline Curriculum implementation & $\begin{array}{l}\text { Disciplinary courses, knowledge } \\
\text { based with practical training for } \\
\text { skills } \\
\text { Teacher-based }\end{array}$ & $\begin{array}{l}\text { Holistic problem-based approach with the } \\
\text { integration of diverse knowledge areas and } \\
\text { skills, strengthening the development of } \\
\text { adequate behaviour } \\
\text { Student-based }\end{array}$ \\
\hline Learning & $\begin{array}{l}\text { Classroom learning } \\
\text { Practical training }\end{array}$ & $\begin{array}{l}\text { Multiple approaches, with a strong focus on } \\
\text { learning in the workplace and self-directed } \\
\text { learning }\end{array}$ \\
\hline $\begin{array}{l}\text { Access to training and } \\
\text { learning }\end{array}$ & $\begin{array}{l}\text { Suitably qualified individuals } \\
\text { Attendees of formal education and } \\
\text { training programs }\end{array}$ & Any motivated individual in the sector \\
\hline Assessment & $\begin{array}{l}\text { Exams, tests and dissertations } \\
\text { Attendance at training courses }\end{array}$ & $\begin{array}{l}\text { Assessment and verification of work-related } \\
\text { skills } \\
\text { Demonstration of all aspects of competence } \\
\text { in the workplace }\end{array}$ \\
\hline Mode of learning & Full-time and part-time courses & $\begin{array}{l}\text { Multiple routes to lifelong learning: vocational } \\
\text { training, mentoring, learning by doing, self- } \\
\text { directed learning }\end{array}$ \\
\hline Delivery of training & $\begin{array}{l}\text { Training and educational institutions } \\
\text { Experts and trainers }\end{array}$ & $\begin{array}{l}\text { Learning organisations } \\
\text { Colleagues, mentors, individuals }\end{array}$ \\
\hline
\end{tabular}

Competence-based learning is not new; it has been used in many sectors for a long time. The most familiar competence standard for most people is probably the driving test. We also expect professionals such as medical doctors to be competent as well as suitably qualified. The International Labour Organisation (ILO) has published guidance on the development of competence standards (ILO 2006).

In the past 20 years, there has been increasing interest in adopting a competence-based approach for protected area staff. This can help address the need for improved capacity in many ways. Occupational standards can help to establish a professional profile for protected area management, encouraging its formal recognition as an occupation, establishing clear career paths, attracting more new recruits, encouraging the development of courses by educational institutions and attracting more funding. Some key areas where a competence-based approach may be applied are described here.

\section{Professionalising protected area management}

Occupational standards can help to establish a professional profile for protected area management, encouraging its formal recognition as an occupation, establishing clear career paths, attracting more recruits, encouraging development of courses by educational institutions and attracting more funding.

\section{Widening access to capacity development and qualifications}

Adoption of competence standards can enable far more protected area staff to improve their skills and to acquire qualifications in service.

\section{Improving organisational structures and recruitment}

Competence standards can help protected area authorities to develop detailed job descriptions and organisational structures, judge the suitability of applicants for jobs from chief executive to field officer, and to assess performance.

\section{Helping to analyse capacity needs}

Competencies provide a comprehensive framework for assessing and identifying capacity and capacity development needs, enabling the accurate and efficient targeting of resources for capacity development. 


\section{Assisting training providers}

Competence standards can provide a basis for designing and delivering education and training programs, ensuring that providers are working to common standards and helping trainees to assess the scope of courses offered to them.

\section{Recognising different modes of learning}

Adoption of competence standards can help people gain recognition of their skills in new and different ways.

\section{Enabling transferability and regional recognition of skills and courses}

Common standards can make qualifications 'portable' and provide a common language for competence across the sector.

Competence-based approaches in protected area management and conservation have been evolving in various ways for many years. Since 1985, the United Kingdom has been developing competence-based national vocational qualifications (NVQs) for almost every occupation, including environmental conservation (Lantra 2014). In 1995, more than 200 US National Park Service employees contributed to the development of more than 225 job competency descriptions and a set of universal essential competencies applying to all employees in the service (NPS 1995). In New Zealand a set of competence-based vocational qualifications is available (NZQA 2014), while in Canada the National Occupational Standards for Environmental Employment have been developed through the Environmental Careers Organisation (ECO Canada 2014). The Caribbean Association of National Training Agencies has developed competencies and certification for Maintenance of Parks and Protected Terrestrial Areas (Level 2) (NTATT 2014). The Third World Congress of the International Ranger Federation in 2000 identified three levels of ranger and agreed on the 'universal essential competence' in terms of knowledge and skills/abilities for rangers for the 'Master Ranger' level (IRF 2000).

In 2002, the Association of South-East Asian Nations (ASEAN) Regional Centre for Biodiversity Conservation developed a set of competence standards for protected area staff in South-East Asia with the aim of providing a common, yet flexible platform across the 10 ASEAN countries for improving protected area management and capacity (Appleton et al. 2009). Through a participatory process, a set of 250 competencies for up to five levels in 17 categories was identified. The standards were published (NZQA 2014), translated into regional languages, and were formally adopted by ASEAN in
2009. The standards were developed as a 'tool not a rule' and their specific application and implementation were left to the individual countries and users to develop; they have since been widely used across the region and in many other countries.

The 2014 Western Indian Ocean Certification of Marine Protected Area Professionals (WIO-COMPAS) program is linking standards to qualifications by providing a framework to promote competence, professionalism, leadership, innovation and ethical conduct in marine protected area management. The program:

- defines the full spectrum of core competencies required to perform a range of functions, at three professional levels, associated with the effective management of marine protected areas

- establishes standards within each of these competence areas

- ensures employers/donors are hiring appropriately qualified individuals

- reassures communities that they have a professional committed to working in an ethical manner, which includes consideration of client/stakeholder needs.

In Madagascar in 2014, the Network of Conservation Educators and Practitioners is working to strengthen long-term capacity for biodiversity conservation in Madagascar through the expansion and enhancement of training opportunities in biodiversity conservation for universities and conservation professionals. This initiative has revised and validated national competency standards for protected area management, defining the skills and knowledge needed by managers of a protected area and/or a conservation site in order to be effective. The network has also developed curricula for training and certification in 11 thematic areas.

The capacity development stream at the IUCN's Fifth World Parks Congress in Durban in 2003 recommended that the WCPA should move towards common standards of competency by:

- agreeing on generic global competency standards for protected area staff, which can be adapted at local, regional and national levels

- encouraging and enabling the use of standards and self-assessments to support the improved effectiveness of protected area staff and training.

The WCPA, recognising the need to professionalise protected area management, has launched the Global Partnership for Professionalising Protected Area Management (GPPPAM) (Box 9.6). GPPPAM has been working towards these objectives by developing a global 


\section{Box 9.6 Global Partnership for Professionalising Protected Area Management}

To address the global need to professionalise protected area management and build the competence of protected area staff, the IUCN WCPA and the Global Protected Areas Program (GPAP) of the IUCN Secretariat are leading an initiative called the Global Partnership for Professionalising Protected Area Management (GPPPAM). This global initiative was launched with the support of the Secretariat of the CBD at the IUCN's World Conservation Congress in Jeju, South Korea, in 2012.

GPPPAM aims to support the full life-cycle development of protected area professionals and organisations. It innovates by moving beyond stand-alone training programs that are based on the assumption that knowledge, not competence, is the main basis of job performance. GPPPAM achieves this by building the foundations for a profession with its associated elements, serving the needs of both young and veteran protected area professionals throughout their career. The ultimate goal of this initiative is to formalise and support protected area professional practice, professionalise protected areas as organisations and lead to higher management effectiveness. While external factors cannot be directly controlled, protected areas must start with what they can influence-internal processes and staff competence. By starting with protected area staff, their full spectrum of core competence will flow over to engage other stakeholders to fully participate. Competent individuals will in turn be better equipped to transform their organisations, and ultimately, protected area systems. There are four main components.

\section{Core competence standards}

GPPPAM is identifying the full range of skills, knowledge and personal qualities potentially required for working in today's protected areas. Based on these, it is developing a comprehensive set of competencies for protected area work at four staff levels: skilled workers, middle managers, senior protected area managers, and higher-level staff of protected area systems. These competencies can be used in many ways: to plan organisational structures, to define job descriptions, to measure and assess current skills and performance, and as the basis for capacity development programs and qualifications.

\section{Body of knowledge}

A profession must codify its best practices for achieving its required competencies. An open-source database will be curated by recognised protected area professionals, to include the best existing materials in the field of protected area management that will aid in developing staff and organisational performance. Materials include this book, various methodologies, IUCN Best Practice Protected Area Guidelines (see Chapter 2), technical reports, resources for training and learning, presentations, videos, exercises and more.

\section{Formal curricula leading to certificates and degrees}

Based on the competencies and body of knowledge, detailed curricula will be developed and made available online to individuals or organisations willing to use them in order to work towards common standards around the world. Global feedback will facilitate further development or adaptation. A network of accredited institutions will provide the courses.

\section{Assessment and certification}

A profession is strengthened when it recognises those who are competent. This can be achieved through performance assessments on the job and/or independent certifications. GPPPAM will create guidelines and criteria to develop or recognise national/regional certification programs, based on the competencies, the body of knowledge and the curricula. Certification addresses the demand of protected area professionals for recognition of their work, career guidance and growth, and networking. It provides incentives for career-long engagement and for innovative leadership.

GPPPAM is being developed through a collaborative effort with partners, including academic institutions, NGOs, national protected area systems and other organisations. set of competencies for protected area staff. GPPPAM is about full life-cycle development of protected area professionals and innovates by moving beyond training programs alone to provide incentives for protected area staff to pursue the new opportunities that will professionalise protected area management. Many protected area systems have already taken the first steps in this direction: Costa Rica, Chile, Bolivia, South Africa, Russia, and others. A global GPPPAM effort will make these initiatives easier for countries and, by having professionals in protected area management, the goals established under the CBD can be better achieved. 


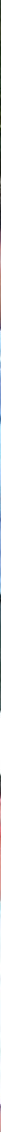

Protected area training course, Paraguay

Source: Eduard Müller

\section{Performance review and certification programs}

Identifying the core competencies and providing learning opportunities are the first steps to building the capacity of individuals and organisations. If, however, those capacities are not applied properly, a performance gap remains. Thus, an important element of a capacity development program (or better, a system with feedback loops) is the use of performance assessment tools. These tools are for assessing performance on the job as opposed to end-of-course or training evaluations. The most common method is the annual performance review of staff, though increasingly as we move towards professionalising protected area management, another tool is becoming valuable: certification. Used in tandem, they can close the loop in a capacity development system to achieve management effectiveness.

Performance reviews (or appraisals/assessments) are defined as a 'structured formal interaction between a subordinate and supervisor, that usually takes the form of a periodic interview (annual or semi-annual), in which the work performance of the subordinate is examined and discussed, with a view to identifying weaknesses and strengths as well as opportunities for improvement and skills development' (North 2010). There are pros and cons to these performance reviews mostly based on the quality of the reviews, the incentives linked to the outcomes and the follow-up actions to improve performance. When seen through the lens of capacity development and driven by transparent competencies, performance reviews can serve as a valuable tool to accelerate the learning process of protected area staff. Organisations can also identify their strengths and deficiencies when surveying overall staff competencies.

Several protected area programs, including the Kenya Wildlife Service and Cape Nature in South Africa, are working to improve their existing performance review programs by linking to individual competencies and a certification program (Case Study 9.2). Using the evidence-based assessment tools involved with competencies and certification, managers have clear guidance to judge staff performance, moving from subjective to more objective. By streamlining the system, protected area managers can link their organisational objectives to staff capacity development action plans and daily staff activities. This can accelerate the learning and performance periods. When actions and incentives are linked to the performance reviews, there is shared interest in the process.

While every organisation can use a performance review process, some are choosing to also include certification systems. Certification has been used in many professions and professional areas for many years, from medical fields to software development and project management. Most certification processes seek to determine if a person is fit to carry out specific tasks, based on knowledge but also on skills-real on-the-job performance. Competence-based certification programs are somewhat newer and also bring in a joint evaluation that includes 
In 2004, the marine protected areas (MPAs) across eight countries in the Western Indian Ocean (WIO) region were not achieving the necessary performance results from short-term training courses and guidebooks. To address the need for improved management effectiveness, the Western Indian Ocean Marine Science Association in partnership with the Coastal Resources Center at the University of Rhode Island led the development of a voluntary professional certification program tailored to the needs of MPA practitioners in the region and supported by MPA management agencies which would need to integrate the program into their management objectives.

The overall goal of the WIO Certification of MPA Professionals (WIO-COMPAS) program is to establish a professional association that provides a framework to promote competence, professionalism, leadership, innovation and ethical conduct in MPA management, which recognises those individuals working in MPAs whose knowledge and skills currently meet a clearly defined professional standard. The program then further enhances individuals' knowledge and skills through dialogue and networking with other professionals as a way to share new ideas and think about MPA management and coastal governance. The certification process is not about training, though the competencies provide guidance on specific gaps that training providers can address to assist individuals in achieving competence.

WIO-COMPAS is a professional certification program that:

- has set internationally recognised standards of competencies for MPA professionals at three levels: policy and planning, site management, and marine field operations

- rigorously assesses professionals' performance in these competencies

- formally recognises and certifies MPA professionals whose performance meets the standards

- encourages MPA management agencies to base their recruitment and training of MPA personnel on these competency standards

- strengthens the career path for MPA professionals
- hosts a regional network of MPA professionals to share learning and experiences between MPAs and between countries

- promotes leadership development and adherence to a professional code of ethics

- promotes professional growth through exchanges, short courses and sharing the latest thinking, research and trends in the field of MPA management.

More than 60 leading MPA professionals in the WIO region have completed the certification program. An evaluation of the program stated that 'a large number of the MPA [professionals] have significantly changed their approach to MPA management as evidenced by their greater confidence in tackling management issues; encouraging stakeholder collaboration and communitybased management; assessing their staff performance; and better handling of park visitors' (Sisitka et al. 2013:27).

WIO-COMPAS is now supporting MPA management agencies in strengthening their capacity development systems and formalising the relationship with WIOCOMPAS as a third-party certifier. Future plans include expanding WIO-COMPAS into site certification to address organisational performance. attitude-often included under the concept of soft skills. Many professions use certification as a methodology for attesting to the skill level of the professional in their area of expertise. Certifications are not intended to teach an individual how to 'become' a certain type of professional, but rather measure that individual's knowledge and skills and ability to apply them in reallife professional situations. The differences between the individual who has earned a certificate and the one who has earned certification are summarised in Table 9.3. Certification recognises the certified individual as having met predetermined qualifications and signifies that the certified individual is competent to perform on the job.
A goal of certification is to standardise the credentials for excellence in a profession and to help ensure that those professionals who receive the certification speak the same (professional) language, have a common understanding of the issues and share the same concepts-even as application of these may differ and need to be adapted to accommodate differences in the geopolitical, social and economic contexts. 
Table 9.3 The difference between certification and certificate qualifications

\begin{tabular}{|l|l|}
\hline Certification & Certificate \\
\hline $\begin{array}{l}\text { Results from an assessment process that recognises } \\
\text { an individual's knowledge, skills and competency in a } \\
\text { particular specialty }\end{array}$ & Results from an educational process \\
\hline Typically requires professional experience & For both newcomers and experienced professionals \\
\hline Awarded by a third-party, standard-setting organisation & Awarded by educational programs or institutions \\
\hline $\begin{array}{l}\text { Indicates mastery/competence as measured against } \\
\text { a defensible set of standards - usually by application, } \\
\text { exam, demonstration, and so on }\end{array}$ & $\begin{array}{l}\text { Indicates successful completion of a course or series of } \\
\text { courses with a specific focus (different than a degree- } \\
\text { granting program) }\end{array}$ \\
\hline $\begin{array}{l}\text { Standards set through a defensible, industry-wide } \\
\text { process (job analysis/role delineation), which results in an } \\
\text { outline of required knowledge and skills }\end{array}$ & $\begin{array}{l}\text { Course content determined by the specific provider or } \\
\text { institution; not necessarily standardised }\end{array}$ \\
\hline $\begin{array}{l}\text { Typically results in credentials to be listed after one's } \\
\text { name }\end{array}$ & Usually listed on a résumé detailing education \\
\hline $\begin{array}{l}\text { Has ongoing requirements in order to maintain validity; } \\
\text { holder must demonstrate they continue to meet } \\
\text { requirements }\end{array}$ & $\begin{array}{l}\text { Demonstrates knowledge of course content at the end of a } \\
\text { set period }\end{array}$ \\
\hline
\end{tabular}

Source: AALNC (2014)

\section{What are the benefits of certification?}

Most governments require a certification program to be formally recognised before it can provide salary rewards for certification. Working on a voluntary basis, management agencies can include certification in their consideration for promotions, work placement and shortterm special assignments based on merit. Management agencies also value the third-party assessment process that avoids conflicts of interest when a supervisor must decide the fate of their staff-especially when incentives are involved.

\section{Who are the certifying bodies?}

Is this a voluntary or mandatory program? If voluntary, any established organisation can provide the certification. The quality and rigour of the assessment as judged by the protected area professionals and organisations are the best measures of value.

\section{What is being certified?}

Certification can be narrow (for instance, handling a firearm) or broad (such as protected area site management). The important criterion is that the certification provides meaning to the individual as well as the organisation. Certifications can also be for an individual or an organisation. We do not recommend certification for narrow skills such as handling firearms, boat captaincy or law enforcement. There are existing national bodies that already certify competence in these specific skills. The complexity of protected area management demands certification for competencies across a broad skill set, which is often not assessed in existing sectors.

\section{What are the levels of certification?}

Once the specific type of certification is outlined, the next decision is to determine how many levels or types of certification to offer. Competencies vary across a protected area organisation and require unique skills and knowledge related to the position. Major job roles include policy and planning, site management and field operations.

\section{What are the specific competencies?}

For each certification level, a set of competencies with varying standards is required to provide the basis for the assessment. Each competence should have a standard, range statement and weighting/scoring allocated to it. Competencies will likely vary in each region or country though a ranger is still a ranger no matter which country they operate in, and thus most competencies will be the same internationally. A key factor to consider is that while more competencies would provide details to the position, this also increases the complexity of the assessment for candidates and assessors alike. There is a fine balance to ensure that a minimum of competencies covers the major aspects of a professional performing at that level. 
Protected Area Governance and Management

\section{Which assessment instruments to use?}

There are various methods-referred to as assessment instruments - that can accurately assess a person's competence. The selection of instruments should be evaluated based on the key qualities of validity, feasibility and relevance to actual practice.

\section{How to score competence?}

The process of scoring competencies can become complex. Some competencies might be more significant than others and thus require some sort of weighting system. What is a passing score? Will all competence areas require a passing score or just the overall average?

\section{What are the certification renewal requirements?}

Like all professionals, one must continually improve to stay current with advancements in the profession. Consider how long a certification lasts and what are the requirements that a certified person must meet in order to be renewed. It is important to clarify that certification is different from the traditional certificate offered by academic institutions, as shown in Table 9.3 (Squillante et al. 2010)

\section{Lessons on certification}

While certification is new to the protected area community, early results indicate that individuals strongly value the certification and overall professionalisation of their field for reasons of career development, staff retention and motivation. Organisations also value the full capacity development system embodied in a professional program as it aligns organisational objectives with staff development while using many of their existing management systems. While the establishment of certification programs does include upfront development costs, there are a few models that can be rapidly adapted and result in certifications that are equal to the costs of traditional short courses but with significant impacts to individuals and organisations. All of the concepts and innovations addressed in this chapter can be organised into a larger capacity development system with meaningful feedback loops. Professionalising the protected area community provides that structure with certification as just one piece of the program.

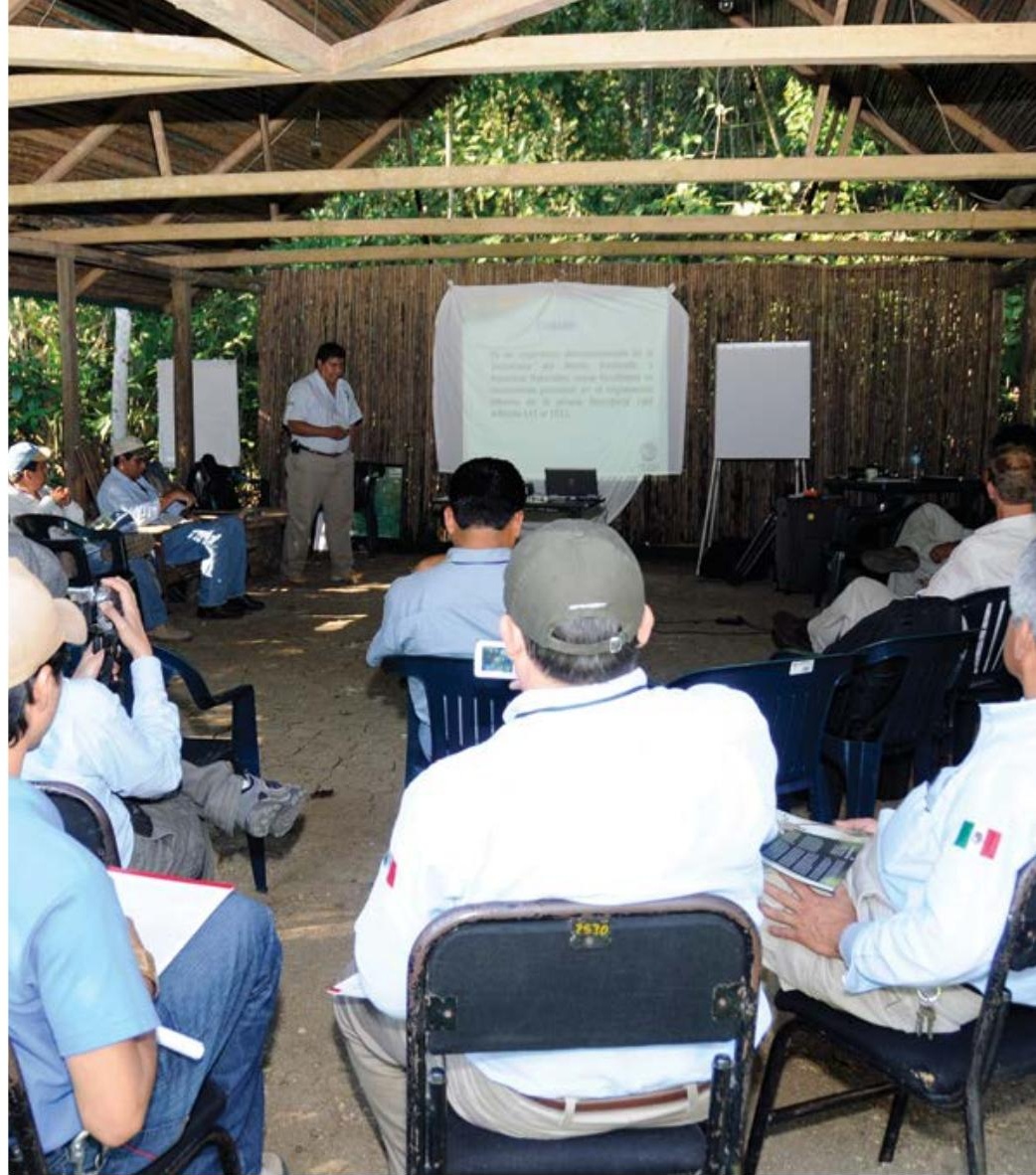

Training, Montes Azules Biosphere Reserve, south-east Mexico

Source: Eduard Müller

\section{Learning resources}

Today through the Internet there is access to a wealth of information related to protected areas, nature conservation, biodiversity, connectivity conservation, and so on. The IUCN is renowned for its best-practice guidelines (see Chapter 2; IUCN 2014b). Multimedia resources are also available (IUCN 2014c). IUCN publications cover many different aspects, from conserving nature and developing capacity (this book) to achieving quality, respecting people and offering solutions. It also publishes the Parks journal electronically. Parks is the ideal instrument for exchanging experiences and encourages not only scientists but also practitioners from around the world to share their experiences.

Many other organisations also offer a wealth of publications and resources (Table 9.4). It is important to know that today there are many resources other than printed or electronic documents. Multimedia resources are abundant and in many cases are available in many languages other than just English. Important efforts have been made to establish learning portals, such as Conservation Training (CT 2014) or the CBD e-learning modules (CBD 2014b). Another very useful tool is Protected Planet, a UN Environment Programme World Conservation Monitoring Centre (UNEPWCMC)/IUCN portal on protected areas (Protected Planet 2014). 
Table 9.4 References and training materials for protected areas

\begin{tabular}{|c|c|}
\hline African Wildlife Foundation & (AWF 2014) \\
\hline $\begin{array}{l}\text { American Museum of Natural History Network of Conservation } \\
\text { Educators and Practitioners }\end{array}$ & (AMNH 2014) \\
\hline Ashoka organisation & (Ashoka 2014) \\
\hline Audubon organisation & (Audubon 2014) \\
\hline Australian Institute of Aboriginal and Torres Strait Islander Studies & (AIATSIS 2014) \\
\hline Birdlife International & (Birdlife International 2014) \\
\hline Conservation Finance Alliance & (CFA 2014) \\
\hline Conservation International & (Cl 2014) \\
\hline Conservation Measures Partnership & (CMP 2014) \\
\hline Conservation Training & (CT 2014) \\
\hline Conserve Online & (CO 2010) \\
\hline Convention on Biological Diversity & (CBD 2014c) \\
\hline Cornell Center for Wildlife Conservation & (CCWC 2014) \\
\hline Equilibrium Research & (Equilibrium Research 2014) \\
\hline Global Environment Facility & (GEF 2014) \\
\hline Global Transboundary Conservation Network & (GTCN 2011) \\
\hline International Centre for Environmental Management & (ICEM 2014) \\
\hline International Ranger Federation & $(\mathrm{IRF} 2014)$ \\
\hline Library of Congress & (LC 2014) \\
\hline National Aeronautics and Space Administration & (NASA 2013) \\
\hline Natural England & (Natural England 2014) \\
\hline Natural Justice & (Natural Justice 2011) \\
\hline Nature Conservation journal & (Pensoft Publishers 2014) \\
\hline Ramsar Convention on Wetlands & (Ramsar 2014) \\
\hline Routledge Environment and Sustainability/Earthscan & (Routledge 2014) \\
\hline Sierra Club, BC & (Sierra Club 2014) \\
\hline The Nature Conservancy & (TNC 2014) \\
\hline United Nations Educational, Scientific and Cultural Organisation & (UNESCO 2014) \\
\hline United Nations Environment Programme & (UNEP 2014) \\
\hline United Nations World Tourism Organisation & (UNWTO 2014) \\
\hline United States Fish and Wildlife Service & (USFWS 2014) \\
\hline United States Forest Service & (USFS 2014) \\
\hline Wetlands International & (WI 2014) \\
\hline Wild Foundation & (Wild Foundation 2014) \\
\hline Wildlife Conservation Society & (WCS 2014) \\
\hline World Bank & (World Bank 2014) \\
\hline World Wide Fund for Nature & (WWF 2014) \\
\hline YouTube & (YouTube 2014) \\
\hline
\end{tabular}




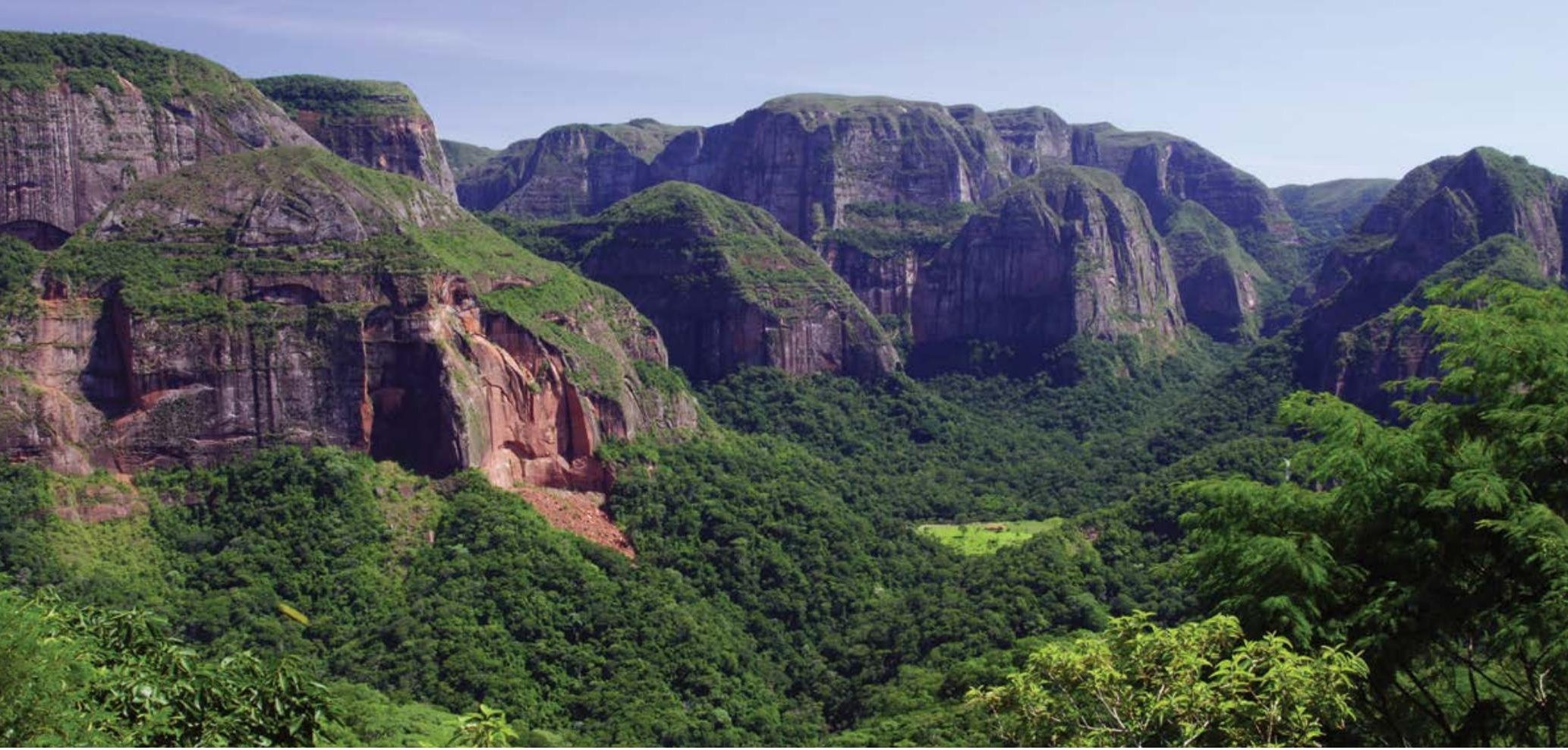

Amboro National Park, Bolivia

Source: Eduard Müller

\section{Conclusion}

Today's protected areas require a competent, motivated and adequately resourced workforce that has access to the most current ideas and best practices developed through decades of lesson learning around the world. Protected areas are complex institutions that are home to much of the world's remaining natural capital comprising landscapes, ecosystems and biodiversity, valued in trillions of dollars and a vital component of natural solutions to climate and global change. Development and climate change threats to protected areas are increasing in most parts of the world. The search for sustainable-use alternatives requires clearly defined strategies that fully integrate all different stakeholders and true interdisciplinary approaches. Biodiversity loss is critical and can severely hamper the ability of ecosystems to continue to provide essential ecosystem services for life. Protected areas are the most important natural storage for biological and genetic diversity, required to restore ecosystems and recover degraded lands. Food security, health, the economy and general wellbeing are all dependent on functional landscapes that can be achieved through connectivity conservation.

Though not yet adequately recognised, this complexity in protected area management and the integration of protected areas with the broader landscapes and seascapes require the establishment of adequate career paths to allow staff to fully develop the competencies for the different professional levels required to adequately deal with the diversity of issues that influence management and the achievement of long-term conservation goals. Today's information and communication technology linked to new learning methods allows us to go beyond traditional capacity-building approaches. The new learning paradigm, where knowledge-based face-to-face teaching is being replaced with competence-based online or blended learning, together with the increase in internet coverage in most of the globe, pose new challenges to those involved in capacity development, but at the same time offer a wide array of new possibilities that can help in developing capacity, knowledge management, collective knowledge construction and the required increase in capacity at individual, organisational, institutional and societal levels. The trend towards professional certification instead of obtaining certificates is also present in protected area capacity development, and if the same trend occurs as in other professional areas, we should expect an increase in these processes.

Currently, opportunities for professional education in protected area management are limited, and professionalising protected area management throughout the globe may seem an impossible achievement. The WCPA has taken the lead to facilitate this task, with the establishment of GPPPAM, which is in the process of identifying global competencies that are being used for competence-based curriculum and course development to be used by academic and training institutions worldwide to strengthen or develop their own programs with permanent feedback loops, which is possible due to the increased communication possibilities we have today. The IUCN's longstanding efforts to provide training and education materials will be enhanced through this increased capacity. This book is part of this effort, and the truly global approach sets a solid base for future development. A description of some institutions providing protected area capacity development is provided in Appendix 9.1. 


\section{References}

Recommended reading

Acevedo, C., Vásquez, N. and Robles, G. (2006) Capacitación para el manejo de áreas protegidas en América Latina; Una aproximación a la demanda de los actors, Report from the Protected Area Alliance for Conservation Learning, CATIE, CCT, UPeace, OTS, ELAP-UCI and ICOMVIS, San Jose, Costa Rica.

African Wildlife Foundation (AWF) (2014) Website, African Wildlife Foundation, Washington, DC. $<$ www.awf.org/>

American Association of Legal Nurse Consultants (AALNC) (2014) Certification vs. Certificate, AALNC, Chicago. <www.aalnc. org/?page=certificate>

American Museum of Natural History (AMNH) (2014) Website, American Museum of Natural History, New York. <ncep.amnh.org>

Andresen, L., Boud, D. and Cohen, R. (1999) 'Experience-based learning', in G. Foley (ed.) Understanding Adult Education and Training, 2nd edn, pp. 225-39, Allen \& Unwin, Sydney. <complexworld.pbworks.com/f/Experiencebased\%20learning.pdf>

Appleton, M. R., Texon, G. I. and Uriarte, M. T. (2009) ASEAN Guidelines on Competence Standards for Protected Area Jobs, ASEAN Regional Centre for Biodiversity Conservation, Los Baños, Philippines.

Appleton, M. R., Texton, G. I. and Uriarte, M. T. (2003) Competence Standards for Protected Area Jobs in South-East Asia, ASEAN Regional Centre for Biodiversity Conservation, Los Baños, Philippines.

Appleton, M. R., Ioniţă, A., Niţu, R. and Stanciu, E. (2014) Assessment of Capacity Development Needs of Protected Area Staff in Eastern Europe, PROPARK Foundation for Protected Areas, Brasov, Romania. <www.propark.ro/en/publicatii/ assessment-of-capacity-development-needs-ofprotected-area-staff-in-eastern-europe-187.html>

Aronson, J., Renison, D., Rangel-Ch., J. O., LevyTacher, S., Ovalle, D. and Del Pozo, A. (2007) 'Restauración del Capital Natural: sin reservas no hay bienes ni servicios', Ecosistemas 16(3): 15-24.
Ashoka (2014) Website, Ashoka, Arlington, VA. $<$ www.ashoka.org/>

Atherton, J. S. (2013) The Experiential Learning Cycle. <www.learningandteaching.info/learning/ experience.htm>

Audubon (2014) Audubon Magazine, New York. $<$ mag.audubon.org/multimedia $>$

Australian Institute of Aboriginal and Torres Strait Islander Studies (AIATSIS) (2014) AIATSIS Research Program: Peer-reviewed publications and other research resources, AIATSIS, Canberra. <www. aiatsis.gov.au/research/publications.html>

Balakumaran, S. (2013) 'Enhancement of humans' potential through knowledge management', Research Journal of Social Science \& Management 2(11): 137-41.

Bandura, A. (1977) Social Learning Theory, PrenticeHall, Englewood Cliffs, NJ.

Baser, H. and Morgan, P. (2008) Capacity, change and performance study report, ECDPM Discussion Paper 59B, European Centre for Development Policy Management, Maastricht.

Birdlife International (2014) Website, Birdlife International, Cambridge, UK. <www.birdlife.org/>

Capacity.org (2013) People Matter: Introduction to capacity development. <capacity.org/capacity/ opencms/en/topics/introduction-to-cd/index.html>

Coates, D. (2006) People Skills Training: Are you getting a return on your investment? < $<w w$. praxisconsulting. org/PeopleSkills.pdf>

Conner, M. L. (2007) 'Learning from experience', in Ageless Learner, 1997-2007. <agelesslearner.com/ intros/experiential.html>

Conservation Finance Alliance (CFA) (2014) Library. <conservationfinance.org/library.php>

Conservation International (CI) (2014) Website, Conservation International, Arlington, VA. <www.conservation.org>

Conservation Measures Partnership (CMP) (2014) Website. <www.conservationmeasures.org/>

Conservation Training (CT) (2014) Website, Conservation Training, Arlington, VA. $<$ www.conservationtraining.org/> 
Conserve Online (CO) (2010) Measures: Key reports, sites and materials from Conserve Online. $<$ www.conservationgateway.org/Pages/COL. aspx?Src $=>$

Convention on Biological Diversity (CBD) (2014a) Programme of Work on Protected Areas: Goal 3.2, Secretariat of the Convention on Biological Diversity, Montreal. <www.cbd.int/protected/pow/ learnmore/intro/>

Convention on Biological Diversity (CBD) (2014b) Capacity Action Planning for Protected Areas: A quick guide for protected area practitioners, Secretariat of the Convention on Biological Diversity, Montreal. <www.cbd.int/doc/pa/tools/ Capacity\%20action\%20planning\%20for\%20 protected $\% 20$ areas.pdf $>$

Convention on Biological Diversity (CBD) (2014c) Website, Secretariat of the Convention on Biological Diversity, Montreal. <www.cbd.int/>

Coomes, O. T., Abizaid, C. and Lapointe, M. (2009) 'Human modification of a large meandering Amazonian river: genesis, ecological and economic consequences of the Masisea cutoff on the central Ucayali, Peru', Ambio 38(3): 130-4.

Cornell Centre for Wildlife Conservation (CCWC) (2014) Website, Cornell University, Ithaca, NY. <www.ccwc.cornell.edu/>

Cornford, I. R. (1997) 'Competency-based training: an assessment of its strengths and weaknesses by New South Wales vocational teachers', Australian and New Zealand Journal of Vocational Education Research 5(1): 53-76.

Cornford, I. (1999) 'Skill learning and the development of expertise', in J. Athanasou (ed.) Adult Educational Psychology, p. 266, Social Science Press, Katoomba, NSW.

Costanza, R., d'Arge, R., de Groot, R., Farber, S., Grasso, M., Hannon, B., Limburg, K., Naeem, S., O’Neill, R. V., Paruelo, J. Raskin, R. G., Sutton, P. and van den Belt, M. (1997) 'The value of the world's ecosystem services and natural capital', Nature 387: 253-60.

Costanza, R., de Groot, R., Sutton, P., van der Ploeg, S., Anderson, S. J., Kubiszewski, I., Farber, S. and Turner, R. K. (2014) 'Changes in the global value of ecosystem services', Global Environmental Change 26(2014): 152-8.
Council on Education for Public Health (2006) Competencies and Learning Objectives, Council on Education for Public Health, Silver Spring, MD. <ceph.org/assets/Competencies_TA.pdf>

Coursera (2014) Coursera website, Stanford University, Stanford, Calif. <www.coursera.org/>

Diemont, S. A. W., Bohn, J., Rayome, D., Kelsen, S. and Cheng, K. (2011) 'Comparisons of Mayan forest management, restoration, and conservation', Forest Ecology and Management 261: 1696-705.

don Carlos, A. W., Teel, T., Manfredo, M. F. and Mathur, V. B. (2013) 'Building capacity to enhance protected area management effectiveness: a current needs assessment for the Asian context', George Wright Forum 30(2). <www.georgewright. org/302doncarlos.pdf>

Egate, A. and Groome, D. (2005) An Introduction to Applied Cognitive Psychology, Psychology Press, New York.

Environmental Careers Organization (ECO Canada) (2014) Occupational Standards, Environmental Careers Organization, Calgary, Alberta. <www.eco. ca/occupational-standards/>

Equilibrium Research (2014) Website, Equilibrium Research, Bristol, UK. <www.equilibriumresearch. $\mathrm{com} />$

Global Environment Facility (GEF) (2014) Protected area publications, Global Environment Facility, Washington, DC. <www.thegef.org/gef/taxonomy/ term/251>

Global Transboundary Conservation Network (GTCN) (2011) Website. <www.tbpa.net/page.php?ndx=77>

Gombos, M., Arrivillage, A., Wusinich-Mendez, D., Glazer, B., Frew, S., Bustamante, G., Doyle, E., Vanzella-Khourie, A., Acosta, A. and Causey, B. (2011) A Management Capacity Assessment of Selected Coral Reef Marine Protected Areas in the Caribbean, Commissioned by NOAA, CRCP, GCFI and CaMPAM, Caribbean Challenge and Gulf and Caribbean Fisheries Institute, Fort Pierce, Fla. <campam.gcfi.org/CapAssess/ CaMPAMCapacityAssessment2011.pdf> 
Gordon, J. and Chadwick, K. (2007) Impact assessment of capacity building and training: assessment framework and two case studies, CGIAR Impact Assessment Series Report No. 44, Consultative Group on International Agricultural Research, Montpellier, France.

Hailey, J., James, R. and Wrigley, R. (2005) Rising to the Challenges: Assessing the impacts of organisational capacity building, The International NGO Training and Research Centre, Oxford.

Hockings, M., Stolton, S., Leverington, F., Dudley, N. and Courrau, J. (2006) Evaluating Effectiveness: A framework for assessing management effectiveness of protected areas, 2nd edn, IUCN, Gland.

International Centre for Environmental Management (ICEM) (2014) Materials, International Centre for Environmental Management, Hanoi. <www.icem. com.au/02_contents/06_materials/06-04-padreports.htm>

International Labour Organisation (ILO) (2006) Guidelines for Development of Regional Model Competency Standards (RMCS), International Labour Organisation, Bangkok. <www.ilo.org/ wcmsp5/groups/public/---asia/---ro-bangkok/ documents/publication/wcms_bk_pb_234_en.pdf>

International Ranger Federation (IRF) (2000) Resolution of the Third World Congress of the International Ranger Federation, Sept. 10-17, 2000, Kruger National Park, South Africa, Association of National Park Rangers, Golden, CO. <www.internationalrangers.org/wpcontent/uploads/2012/06/Kruger-Resolution_2000_ english.pdf>

International Ranger Federation (IRF) (2014) Website, International Ranger Federation, Sydney. $<$ internationalrangers.org/>

International Telecommunication Union (ITU) (2014) Website, International Telecommunication Union, Geneva. <www.itu.int/en/Pages/default.aspx>

International Union for Conservation of Nature (IUCN) (2014a) Global Protected Areas Programme, IUCN, Gland. <www.iucn.org/about/work/ programmes/gpap_home/gpap_capacity2/>

International Union for Conservation of Nature (IUCN) (2014b) Reports and Publications, IUCN, Gland. <www.iucn.org/about/work/programmes/ gpap_home/gpap_capacity2/gpap_bpg/>
International Union for Conservation of Nature (IUCN) (2014c) Multimedia Reports, IUCN, Gland. <www.iucn.org/knowledge/multimedia/>

International Union for Conservation of Nature World Commission on Protected Areas (IUCN WCPA), Southeast Asia Regional Forum, Association of South-East Asian Nations Regional Centre for Biodiversity Conservation, Ambassade and Philippines Department of Environment and Natural Resources (2003) Building on Lessons from the Field: Protected area management experiences in Southeast Asia. Proceedings of the IUCN-World Commission on Protected Areas 3rd Southeast Asia Regional Meeting, April 1-5, 2003, Edsa Shangri-la, Mandaluyong City, Philippines, IUCN, Gland.

Kay, M., Franks, T. and Tato, S. (2008) Capacity Needs Assessment Methodology and Processes, Food and Agriculture Organisation, Rome. <ftp.fao.org/ docrep/fao/008/y5899e/y5899e01.pdf>

Kirkpatrick, D. (1998) Evaluating Training Programs: The four levels, Berrett-Koehler Publishers, San Francisco.

Klein-Collins, R. (2013) Sharpening Our Focus on Learning: The rise of competency-based approaches to degree completion, National Institute for Learning Outcomes Assessment, University of Illinois at Urbana-Champaign. <learningoutcomesassessment. org/documents/Occasional\%20Paper\%2020.pdf>

Knapp, B. (1963) Skill in Sport: The attainment of proficiency, Routledge \& Kegan Paul, London.

Kolb, D. A. (1984) Experiential Learning: Experience as the source of learning and development, Prentice Hall, Englewood Cliffs, NJ.

Kopylova, S. L. and Danilina, N. R. (eds) (2011) Protected Area Staff Training: Guidelines for planning and management, IUCN Best Practice Guidelines, Gland.

Kundu, S. (2013) 'Knowledge management: value, technologies and its implications', International Journal of Computer Engineering \& Technology 4(5): 182-8.

Lantra (2014) Environmental Conservation: National occupational standards, Lantra, Coventry, UK. $<$ www.lantra.co.uk/NOS/atech> 
Leverington, F., Costa, K. L., Pavese, H., Lisle, A. and Hockings, M. (2010) Management Effectiveness Evaluation in Protected Areas: A global study, 2nd edn, University of Queensland, Brisbane.

Levy-Tacher, S., Aguirre, J. R., Martínez, M. M. and Durán, A. (2002) 'Caracterización del uso tradicional de la flora espontánea en la comunidad Lacandona de Lacanhá, Chiapas-México', Interciencia 27(10): 512-20.

Library of Congress (LC) (2014) Classroom Materials, Library of Congress, Washington, DC. <www.loc. gov/teachers/classroommaterials/themes/nature/ exhibitions.html>

MacInnnis, C. (1995) 'Holistic and reductionist approaches in special education: conflicts and common ground', McGill Journal of Education, 30(1): 7-20.

Merriam-Webster Dictionary (2012) Merriam-Webster Dictionary Online. <www.merriam-webster.com/ dictionary/skill>

Miller, G. E. (1990) 'The assessment of clinical skills/ competence/performance', Academic Medicine 65(Supplement): S63-7.

Mobbs, R. (2014) How to be an E-Tutor, Graduate School, University of Leicester, UK. <www2.le.ac. uk/departments/gradschool/training/eresources/ teaching/theories/kolb>

National Aeronautics and Space Administration (NASA) (2013) Multimedia, NASA, Washington, DC. <www.nasa.gov/multimedia/\#.Uxdt4f5Nio>

National Park Service (NPS) (1995) Essential Competencies for National Park Service Employees, National Park Service, US Department of the Interior, Washington, DC. <www.nps.gov/training/ npsonly/npsescom.htm>

National Training Agency-Trinidad and Tobago (NTATT) (2014) Maintenance of Parks and Protected Terrestrial Areas: Level 2, National Training Agency-Trinidad and Tobago, Chaguanas. <ntatt. org/images/stories/PDF/ROS/Maintenance $\% 20$ of $\% 20$ Parks $\% 20$ and $\% 20$ Protected $\% 20$ Terrestrial\%20Areas\%20Level\%202.pdf>

Natural England (2014) Website, Natural England, Sheffield, UK. <www.naturalengland.org.uk/>
Natural Justice (2011) Protected Areas, Natural Justice, Cape Town. <naturaljustice.org/our-work/ international-advocacy/biodiversity/protected-areas>

Network of Conservation Educators and Practitioners (NCEP) (2014) Network of Conservation Educators and Practitioners Program, American Museum of Natural History, New York. <ncep.amnh.org/index. php?lang=fr\&globalnav=about\&sectionnav=>

New Zealand Qualifications Authority (NZQA) (2014) Qualifications and Standards, NZQA, Government of New Zealand, Wellington. <www.nzqa.govt.nz>

Nielsen, G. (2011) Capacity development in protected area management, Diploma thesis, University of Greifswald Institute for Geography and Geology, Greifswald, Germany.

North, A. (2010) Introduction to Performance Appraisal, Archer North \& Associates, Australia. <www. performance-appraisal.com/intro.htm>

Dd Nuffic (2014) The Five Capabilities Approach in Capacity Development of Organisations, Netherlands Organisation for International Cooperation in Higher Education, The Hague. <www.nuffic. nl/en/library/the-five-capabilities-approachin-capacity-building-of-organisations.pdf/ view?searchterm $=5 \% 20$ capabilities>

Organisation for Economic Cooperation and Development (OECD) (2006) The Challenge of Capacity Development: Working towards good practice, OECD, Paris.

Ostashewski, N., Moisey, S. and Reid, D. (2011) 'Applying constructionist principles to online teacher professional development', The International Review of Research in Open and Distance Learning 12(6): 143-56. <www.irrodl.org/index.php/irrodl/ article/view/976/1958>

Oxendine, C., Robinson, J. and Willson, G. (2004) 'Experiential learning', in M. Orey (ed.) Emerging Perspectives on Learning, Teaching, and Technology, Department of Educational Psychology and Instructional Technology, University of Georgia, Athens. <projects.coe.uga.edu/epltt/>

Pensoft Publishers (2014) Nature Conservation, Pensoft Publishers, Sofia. <www.pensoft.net/journals/ natureconservation/> 
Phani, C. R. (2007) 'The top 60 soft skills at work', rediff News, 8 January 2007. <www.rediff.com/ getahead/2007/jan/08soft.htm>

Protected Planet (2014) Website. $<$ www.protectedplanet.net/>

Ramsar Convention on Wetlands (Ramsar) (2014) Website. <www.ramsar.org>

Routledge (2014) Website, Routledge Environment and Sustainability, Abingdon, Oxon. <www. routledge.com/sustainability/>

Sanchez, V. A. and Ruiz, M. (eds) (2008) Competence-Based Learning, University of Deusto, Bilbao.

Sierra Club (2014) Parks and protected area publications, Sierra Club of BC Foundation, Victoria, British Columbia. <www.sierraclub.bc.ca/ publications/parks-protected-areas-publications $>$

Siscawati, M. and Zakaria, R. Y. (2010) Capacity building needs assessment for community forestry development in Indonesia, Summary Report, ed. C. Veer, The Center for People and Forests, Bangkok. $<$ www.recoftc.org/site/uploads/content/pdf/ CBNA\%20Indonesia\%20Report\%20Short\%20 Version_365.pdf>

Sisitka, L., Ricci, G. and Squillante, L. (2013) Certifying Marine Protected Area Professionals: Reflections on the first generation and setting a new course, WIO-COMPAS, Zanzibar, Tanzania.

Smith, L. (2012) ' 5 education providers offering MOOCs now or in the future', Education DIVE, 31 July. <www.educationdive.com/news/5-moocproviders/44506/>

Squillante, L. J., Ricci, G., Francis, J. and Sisitka, L. (2010) 'Innovations in capacity building: certification of marine protected area professionals', Coastal Management 38(3): 272-90.

Suryanarayana, V. and Adapa, R. (2013) 'Role of knowledge management in business environment', International journal of Innovative Research in Management 2(2): 53-8.

Templeton, D. J. (2009) A Framework for Assessing the Impact of Capacity Building, Australian Centre for International Agricultural Research, Canberra.
The Learning Institute and The Center for People and Forests (RECOFTC) (2011) Capacity development needs assessment for community forestry and community protected areas in Cambodia, Summary Report, The Center for People and Forests, Bangkok. <www.recoftc.org/site/uploads/ content/pdf/Cambodia_CBNA\%20Report\%20 Summary_12282011_Final_Text_200.pdf>

The Nature Conservancy (TNC) (2014) Website, The Nature Conservancy, Arlington, VA. $<$ www.nature.org/>

Ubels, J., Acquaye-Baddoo, N.-A. and Fowler, A. (2010) Capacity Development in Practice, Earthscan, London.

United Nations Development Group (UNDG) (2009) Capacity Assessment Methodology, UNDG, New York. <www.undg.org/docs/8948/CapacityDevelopment-UNDG-August-2009.pdf>

United Nations Development Programme (UNDP) (2007) Capacity Assessment Methodology Users' Guide, United Nations Development Programme, New York. <europeandcis.undp.org/uploads/public/ File/Capacity_Development_Regional_Training/ UNDP_Capacity_Assessment_Users_Guide_ MAY_2007.pdf>

United Nations Development Programme (UNDP) (2008) Capacity Assessment Practice Note, UNDP, New York. <www.unpcdc.org/media/12068/undp_ practice_note_on_ca_october-2008.pdf>

United Nations Development Programme (UNDP) (2009) Capacity Assessment Methodology, UNDP, New York. <www.undg.org/docs/8948/CapacityDevelopment-UNDG-August-2009.pdf>

Dd United Nations Development Programme (UNDP) (2014) A Training Guide to Capacity Assessment, UNDP, New York. <regionalcentrebangkok.undp.or.th/ practices/capacitydevelopment/documents/ TRAININGGUIDETOCAPACITY ASSESSMENT.pdf>

United Nations Educational, Scientific and Cultural Organisation (UNESCO) (2014) Online resources, UNESCO, Paris. <www.unesco.org/new/en/unesco/ resources/>

United Nations Environment Programme (UNEP) (2014) UNEP Knowledge Repository, UNEP, Nairobi. <www.unep.org/publications/> 
United Nations World Tourism Organisation (UNWTO) (2014) Ecotourism and Protected Areas, UNWTO, Madrid. <sdt.unwto.org/en/content/ ecotourism-and-protected-areas>

United States Fish and Wildlife Service (USFWS) (2014) Website, Fish and Wildlife Service, Washington, DC. <https://www.fws.gov/>

United States Forest Service (USFS) (2014) Multimedia, Forest Service, US Department of Agriculture, Washington, DC. <www.fs.usda.gov/ main/conservationeducation/programs/multimedia $>$

University of Iowa (2014) Experience-Based Learning, University of Iowa, Iowa City. <honors.uiowa.edu/ academics/experience-based-learning >

University of North Carolina (2014) Introduction to Knowledge Management, University of North Carolina at Chapel Hill. <www.unc.edu/ -sunnyliu/ inls258/Introduction_to_Knowledge_Management. html>

Walters, H. (2007) Capacity development, institutional change and theory of change: what do we mean and where are the linkages, Manuscript.

Western Indian Ocean Certification of Marine Protected Area Professionals (WIO-COMPAS) (2014) Website. <www.wio-compas.org/>

Wetlands International (WI) (2014) Website. <www. wetlands.org/>

White, R. W. (1959) 'Motivation reconsidered: the concept of competence', Psychological Review 66(5): 297-333.

Wild Foundation (2014) Website. <www.wild.org/>

Wildlife Conservation Society (WCS) (2014) Website. <www.wcs.org/>

Wildlife Institute of India (2010) Annual Report of the Wildlife Institute of India 2009-2010, Wildlife Institute of India, Dehradun.

World Bank (2014) Publications, The World Bank, Washington, DC. < publications.worldbank.org/>

World Wide Fund for Nature (WWF) (2014) Publication and Resources, WWF, Washington, DC. <wwf.panda.org/about_our_earth/all_ publications/>

YouTube (2014) Website. <www.youtube.com>

\section{Appendix 9.1: Example capacity development organisations}

\section{Africa: Southern African Wildlife College}

The Southern African Wildlife College was established in 1997 to serve the training needs of conservation organisations, becoming a Southern Africa Development Community recognised centre of specialisation in 2007 for its role in capacity-building for staff of conservation areas in the region. It is also a recognised centre of occupational excellence and is accredited with the relevant training authority in South Africa.

The college's programs are designed as a direct response to the needs of the conservation industry, and the college prides itself on the monitoring and evaluation of programs conducted every few years in order for it to stay current with its offerings. Of major importance was the college's development of two higher education qualifications for registration with the South African Qualifications Authority. It also has recently opened a division specifically focused on developing field rangers at different levels for protected areas. This division now encompasses the African Field Ranger Training Services, which had more than 20 years of specialised training and was a well-known and respected training provider in the industry. Of importance to the increased poaching scourge in the early part of the 21st century, this division is able to respond rapidly to needs and has developed training capacity across different languages specialising in anti-poaching and the professionalisation of field rangers.

The Southern African Wildlife College opened the Innovation and Development division, which tests best practice and new concepts for implementation across the region. Of special interest is the role of communities in ensuring sustainable use of natural resources and allowing them to understand the true value and governance of benefit flows.

\section{Australia-Oceania-Asia: Protected area learning and research collaboration}

The WCPA has identified a need in Asia and Oceania for capacity building to equip protected area practitioners with the necessary knowledge, skills and competencies for effective management of protected area systems on land and sea. A consortium of protected area practitioners 
from universities, government, private protected areas and conservation organisations has been established to meet this need. Founding partners include the University of Tasmania, Tasmanian Land Conservancy, Tasmanian Parks and Wildlife Service, Murdoch University, Charles Darwin University, James Cook University, Parks Australia, Parks Victoria, the Secretariat of the Pacific Region Environment Program and the WCPA. The collaboration continues to grow, with the recent involvement of the University of the South Pacific, the Wildlife Institute of India and others. The purposes of the collaboration are, among other things, to:

- provide accredited training programs that meet the needs of the protected area sector, focusing on the Australasian, Western Pacific and Asian regions

- build international capacity and collaboration in protected area management and training to support continuous learning and improvement

- foster, coordinate and disseminate protected area research.

In its first year in 2015, the collaboration will provide short courses, graduate certificate and masters courses delivered by the University of Tasmania, James Cook University and Murdoch University. These courses, and future offerings developed under the collaboration, will specifically address the competence standards identified by GPPPAM (Box 9.6).

\section{Russia: Environmental Education Centre for Zapovedniks}

The Environmental Education Centre for Zapovedniks is a Russian NGO established in 1996 to raise public awareness and support for protected areas. Its mission is to bring together conservation professionals and others who have a common interest in fostering public support for Russia's state nature reserves and national parks.

For 18 years (to 2014), the Centre for Zapovedniks has been organising capacity-building events for protected area managers, including training courses in different aspects of protected area management, professional study tours and seminars. The first success story of the centre was the development of a new specialisation for protected areas in Russia, 'Specialists in Environmental Education on Protected Areas'. The Government has approved this new specialty for protected areas and, since 2005, the centre has been the only training centre for protected areas in Russia. The curricula of the training courses are adjusted annually based on the needs of staff of protected areas, in agreement with the Ministry of Natural Resources and Environmental Protection, which manages the federal system of protected areas. The centre initiated and promoted the establishment of training centres for protected area staff in Ukraine, Kazakhstan and Belarus (within the project of the UNEP Global Environment Facility in 2005-08). Since 2000, all newly appointed directors of national parks and reserves in Russia are trained in seminars at the Centre for Zapovedniks. The seminars are organised in Moscow, where the Centre for Zapovedniks is based, as well as in protected areas throughout Russia. The centre's other areas of work include development of ecological trails and visitor centres in national parks and other protected areas, publication of best practices in environmental education, tourism in protected areas, sustainable livelihoods, teaching ecology to children and volunteer camps, and other work.

\section{Latin America and the Caribbean: Latin American School for Protected Areas, University for International Cooperation}

The University for International Cooperation (UCI) was established in Costa Rica in 1994 to educate professionals to lead changes required in economic, environmental, sociocultural and political development in Latin America and the Caribbean with students from close to 60 countries. UCI is known for its innovative programs as well as its extensive and pioneering experience with online education. In 1997, through the UCI's Latin American School for Protected Areas (ELAP), one of the first professional degree programs in protected area management was established. Today UCI offers innovative graduate programs in many fields related to protected areas: coastal and ocean management, connectivity conservation, environmental law, ecosystem-based adaptation, ecological economics, climate change adaptation and risk management, project management, and others.

The school provides education, training and technical assistance to strengthen the capacities of protected area and conservation managers in Latin America, the Caribbean and elsewhere. ELAP has developed tailor-made curricula for protected areas in several countries and has been working closely with the WCPA in the development of GPPPAM, with the CBD Secretariat to support capacity building for the effective implementation of the Programme of Work on Protected Areas (PoWPA) in Latin America and also hosts the UNESCO Chair for Biosphere Reserves and Natural and Mixed World Heritage Sites. UCI is dedicated to the full implementation of GPPPAM and the development of 
MOOCs and other online methods to massively increase capacity for conservation, sustainable development and protected area management globally.

\section{United States of America: Warner College of Natural Resources}

Often called the 'ranger factory' because of its role in training generations of protected area professionals, the Warner College of Natural Resources (WCNR) at Colorado State University is among the oldest and largest natural resource faculties in the United States. The college possesses more than a century of experience in teaching, research and outreach on conservation issues, working with public and private sectors in protected area management at the local, regional, national and international levels. A hallmark of the university's approach is linking students and graduates to employment and lifelong learning and networking opportunities. Service learning and career preparation are promoted through programs that place students in volunteer and internship positions with businesses, NGOs and government agencies working in conservation. Programs promote communities of practice through websites, social media and learning portals. The college is rapidly expanding into online and blended approaches to better meet the needs of conservationists who lack the time, resources or access to undertake traditional degree programs. Colorado State University partnered with the US National Park Service and five other universities to create a public lands leadership certificate program delivered through a blended approach for protected area managers. The university's Centre for Protected Area Management develops teaching, research and outreach projects related to protected areas around the world. The centre's core team associates with the global conservation community to determine needs for, design, implement and evaluate the effectiveness of capacitybuilding programs. Conservation training programs for practitioners and on-campus and virtual degree programs are linked, allowing graduates of short courses, such as the centre's protected area management course, to later enrol in degree programs at Colorado State University. The centre also partners with external universities and institutes.

\section{India: Wildlife Institute of India}

The Wildlife Institute of India was set up in 1986 as an autonomous institution of the Ministry of Environment and Forests, with a mission to 'nurture the development of wild life science and promote its applications in the field in a manner that accords with the country's economic and socio-cultural milieu' (Wildlife Institute of India 2010:4).
The institute has the mandate to:

- build scientific knowledge of wildlife resources

- train personnel at various levels for conservation and management of wildlife

- carry out research relevant to management including the development of techniques appropriate to Indian conditions

- provide information and advice on specific wildlife management problems

- collaborate with international organisations on wildlife research, management and training

- develop as a regional centre of international importance on wildlife and natural resource conservation.

The institute has emerged as an eminent regional centre for academics, training and research in the field of wildlife conservation in South and South-East Asia. It is a prominent seat of learning for protected area professionals, for students pursuing postgraduate courses in wildlife science and for natural resource managers, foresters and protected area managers seeking specialised training in wildlife management. In 2014 the institute was recognised as the first UNESCO Centre on World Natural Heritage Training and Management for the Asia-Pacific region.

\section{Global: International Ranger Federation}

The International Ranger Federation is a non-profit organisation established to raise awareness of and support for the critical work that the world's park rangers do in conserving our natural and cultural heritage. Founded in 1992, the federation has a membership of 60 ranger associations from 46 countries, on six continents. The role of the International Ranger Federation is to empower rangers by supporting them through their national or State ranger organisations. The federation exists, inter alia, to further the professional standards of rangers throughout the world, to share knowledge and resources, and to foster professional exchanges between rangers. It provides training, capacity building and exchange programs to its members in order to ensure park rangers are well trained and properly equipped to manage the world's most precious wildernesses. This is done through federation member organisations with the necessary capacity to do so-for example, the PAMS Foundation and the Protected Area Workers Association-and with the support of the International Ranger Federation's primary fundraising partner, The Thin Green Line Foundation. 


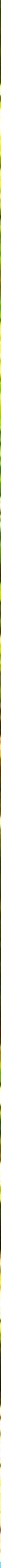

CHAPTER 10

BENEFITING FROM

COMPLEXITY THINKING

\section{Principal authors:}

Stephen F. McCool, Wayne A. Freimund and Charles Breen

\section{Supporting authors:}

Julia Gorricho, Jon Kohl and Harry Biggs

\section{CONTENTS}

\section{Introduction}

- Characterising complexity

- Simplifying complexity

- Engaging complexity

- Conclusion: Governing and managing adaptively

- References

IUCN 3 WCPA 


\section{PRINCIPAL AUTHORS}

STEPHEN F. MCCOOL is Professor Emeritus in the Department of Society and Conservation at the University of Montana.

WAYNE A. FREIMUND is Arkwright Professor of Protected Area Studies and Chair of the Department of Society and Conservation at the University of Montana.

CHARLES BREEN is Fellow and Honorary Research Associate of the University of KwaZulu-Natal, South Africa.

\section{SUPPORTING AUTHORS}

JULIA GORRICHO is a $\mathrm{PhD}$ candidate at the Institute of Environmental Social Science and Geography, Albert-LudwigsUniversität, Freiburg.

JON KOHL is Facilitating Coordinator of PUP Global Heritage Consortium.

HARRY BIGGS was program integrator, Adaptive Biodiversity Outcomes, with South African National Parks (SANParks), until he retired in 2014.

\section{ACKNOWLEDGMENTS}

The authors thank their many friends and colleagues for their inspiration over many years and challenging questions and observations about the complexity of social-ecological systems and their management. They also thank the reviewers for their keen observations and suggestions on making the chapter more readable and persuasive.

\section{CITATION}

McCool, S. F., Freimund, W. A. and Breen, C. (2015) 'Benefiting from complexity thinking', in G. L. Worboys, M. Lockwood, A. Kothari, S. Feary and I. Pulsford (eds) Protected Area Governance and Management, pp. 291-326, ANU Press, Canberra.

\section{TITLE PAGE PHOTO}

The symbolic intermixed complexity of an ancient rainforest tree's trunks, buttress roots and an accompanying liana, part of the Great Eastern Ranges corridor, Monga National Park, New South Wales, Australia

Source: Graeme L. Worboys 
The more we study the major problems of our time, the more we come to realise that they cannot be understood in isolation. They are systemic problems, which means they are interconnected and interdependent (Capra 1996:4).

\section{Introduction}

As our knowledge grows, technology advances, human populations increase and demands on our natural resources deepen and diversify, we realise that there is no longer an opportunity to avoid or ignore the complexity of protected area management, its governance and its role within the intersection of social-ecological systems. While we all engage complexity every day at a personal level, it is not a skill set that most of us are trained to use in a professional capacity. In fact, we spend considerable portions of our life learning how to simplify the overwhelming amount of information and complicated character of problems that come towards us in any given day. Small experiments that we conduct each day (known as trial and error) subtly guide us to the behaviours that will result in predictable outcomes. There are many ways in which we simplify our world and eventually those simplifications are instilled in us as habits. Those habits can actually inhibit the degree to which we learn, assimilate new information, adapt and perform as protected area managers.

In this chapter, we examine how our habits - which are functions of the mental models we discuss later in the chapter-can hinder our ability to sense change that is occurring around us in time for us to proactively and constructively attempt to influence that change. Sometimes these changes occur in large-scale societal shifts of perception that result in new pressures on governance systems. At other times they are more subtle and influence the way we interact with partners, colleagues, staff or community members. Still others are dramatic, visible and immediate. These changes come about because the complexity of the world is great, producing uncertainty and resulting in surprises for which our habits have ill prepared us.

In the following pages, we offer a way of thinking that views this complexity as an opportunity for benefit rather than as a source of overwhelming confusion. Systems thinking is the tool we use to first help us characterise complexity and then understand how we can simplify it when confronted. Systems thinking is a process by which we view a set of interrelated parts as a 'whole' rather than seeing them as unrelated components. By using this approach, we offer ways to recognise that in our simplifications we can still be strategic in understanding the changes occurring around us and how we can influence them both in governance and in management. Once we understand the basic characteristics of how a system operates, we can attempt to use its behaviour to our advantage and find places in that system where the resources we do have will result in the largest amount of influence. We benefit from this kind of thinking by building resilience into the socialecological systems we manage and govern. We conclude by suggesting six practices to engage complexity that if used strategically will enable protected area managers to benefit from the complexity they engage with rather than being controlled by it. The key philosophical points in the chapter are outlined in Figure 10.1. We begin this journey by relating two stories of resource management and governance that we believe illustrate the importance of understanding complex systems.

\section{Protecting the lowveld in South Africa}

Historically, the low-lying land (lowveld) along the eastern border of South Africa was inhospitable. Malaria, trypanosomiasis, foot and mouth disease, horse sickness, swine fever and anthrax, among other diseases, largely protected the area from human influence and later from agricultural expansion that came with the settlers. These conditions made the establishment of the Kruger National Park (KNP) less contentious than it might otherwise have been. Together with concern for the loss of game that wandered out of the park in search of water and grazing during dry spells (Mabunda et al. 2003), these features provided justification for fencing the park to minimise the risk of transmission of animal diseases (Bengis et al. 2003). This was a policy decision that was to have many unforeseen and far-reaching consequences that would expose the inherent socialecological complexity of the park.

Fencing prevented game animals accessing water in the wetter areas outside the park, particularly during droughts. And, as agriculture expanded, water was abstracted, reducing river flows through the park. The solution seemed so obvious and simple: force animals to become less dependent on water supply from outside the park by erecting dams and wind pumps to support wildlife during droughts. The architects of the policy believed it would ensure 'a healthy and productive environment which can accommodate long-term natural changes, is conducive to relative stability and which ensures population fluctuations of manageable proportions' (Pienaar 1983, cited in Gaylard et al. 2003:29). 


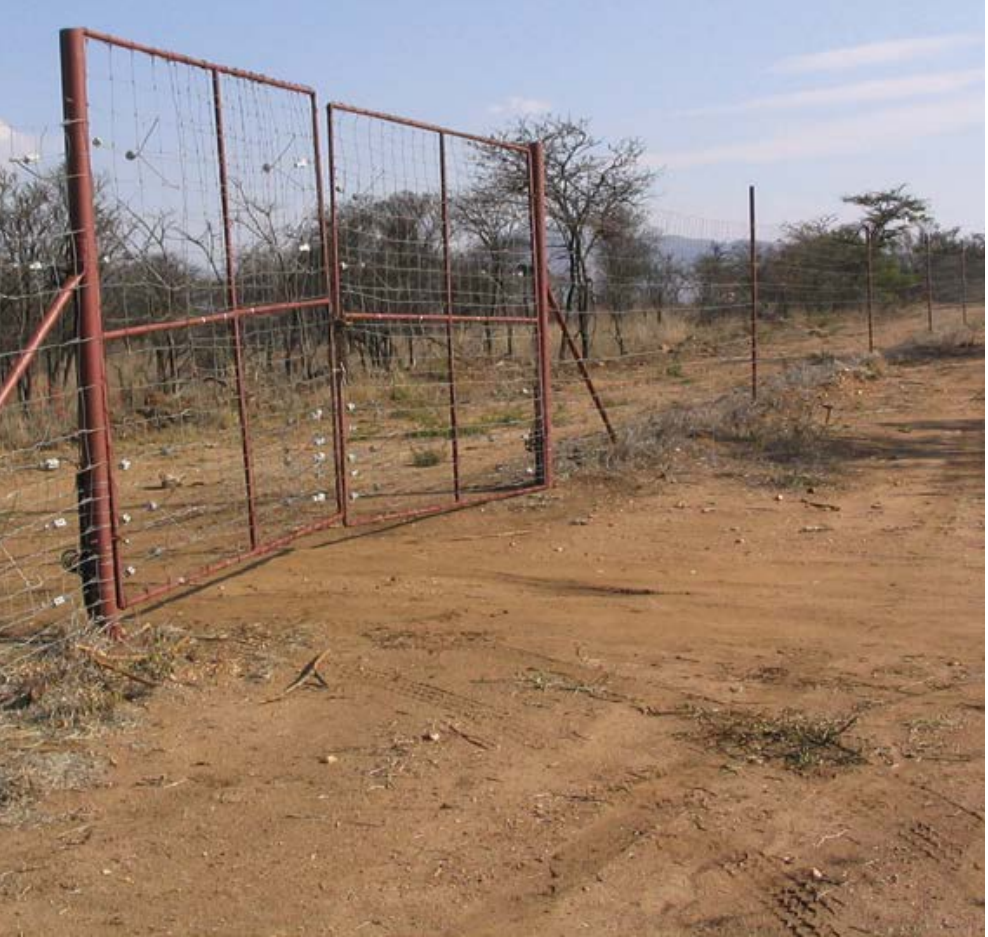

Wildlife-proof boundary fence between Kruger National Park (left) and agricultural land

Source: Graeme L. Worboys

The first structures were built in 1933 after a dry spell and, by 1995, 365 boreholes and 50 earthen dams had been constructed (Gaylard et al. 2003). These changed the spatial pattern of water available to wildlife and set in motion a complex web of interactions that could not be predicted but which would have far-reaching implications for sustaining species diversity and heterogeneity in the park. Species such as water buck, zebra, wildebeest and impala that are usually found close to water could now live permanently in places that in the past could be used only during wet periods.
Herbivore populations increased, and grazing impacts became more homogeneous across the park, leaving little forage available during droughts. In short, the lowveld system was transformed from one in which natural forces dominated to one in which human influences moved the system from one developmental trajectory to another.

Crossing this threshold then led to a number of other concerns and impacts-none expected. Crowding around waterholes increased the opportunity for the spread of contagious disease and parasites between herbivores and carnivores (and among herbivores) (Bengis et al. 2003). The consequences became starkly evident during 1982-83 when drought resulted in herbivore population mortalities of $20-30$ per cent in the park. In the neighbouring Klaserie Private Nature Reserve, which had a higher density of human-made water points, mortalities were estimated to be between 70 and 90 per cent (Bengis et al. 2003).

Fear of mortalities during droughts and increasing evidence of impact on vegetation around water points motivated yet another management response: culling during wet seasons (Freitag-Ronaldson and Foxcroft 2003). Elephants were one species targeted, and between 1966 and 2002, 16666 were 'removed from the population' (Whyte et al. 2003:339), contributing to the emergence of strong political opposition to culling. In 1994, lobbying by animal-rights groups resulted in a moratorium being placed on further killing. A scientific assessment in 2006 concluded, among other things, that 'culling elephants alone may have ramifying

\begin{tabular}{|c|c|c|}
\hline $\begin{array}{l}\text { COMPLEXITY IS } \\
\text { OVERWHELMING AND } \\
\text { IGNORED }\end{array}$ & $\begin{array}{l}\text { SYSTEMS THINKING IS } \\
\text { USED TO FIND ORDER AND } \\
\text { BEHAVIOUR IN SYSTEMS }\end{array}$ & $\begin{array}{l}\text { COMPLEXITY IS } \\
\text { CHARACTERISED AS } \\
\text { BENEFICIAL }\end{array}$ \\
\hline $\begin{array}{l}\text { Complexity is viewed } \\
\text { as unmanageable } \\
\text { Systems do not } \\
\text { become better } \\
\text { understood } \\
\text { Simplification occurs } \\
\text { without scrutiny }\end{array}$ & 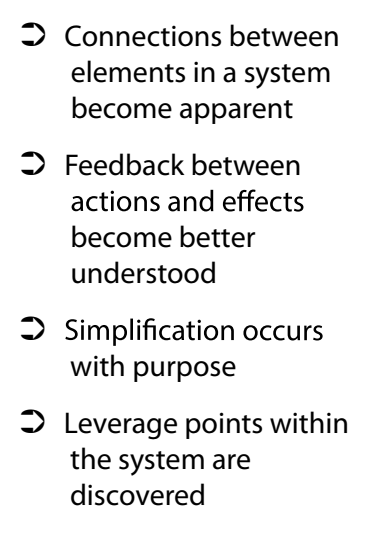 & $\begin{array}{l}\text { Change is better } \\
\text { anticipated }\end{array}$ \\
\hline
\end{tabular}

Figure 10.1 Key points in the chapter 
The Forest Service policy towards management of wildland fire and South Africa's attempts at managing wildlife exemplify the content of this chapter. Institutions, public values and biophysical systems are in a state of constant change; uncertainty challenges managers of protected areas every day; surprises happen; knowledge is tentative; dynamic complexity permeates both the social and the biophysical worlds in which managers function; public values and meanings matter; and conflict confronts us at every juncture. With each choice a manager considers, risks — some known, many not-abound. Implementation leads to consequences that are both intended and unintended and may not be perceived for a long time. Six decades of fire suppression, for example, led to accumulation of fuels in forests where fire was a natural process, which science eventually acknowledged. Accumulated fuels, once ignited, caused fires to burn with greater intensity, increasing damage and accelerating suppression costs (wildland fire suppression costs in the United States now average close to US\$2 billion per year). In short, the fire suppression policy led to more severe fires costing more to control.

And years of water point development led to not only increases in populations, but also their redistributionconsequences that were not anticipated. Attempts to simplify and control the system as another consequence led to other control-based actions, such as culling elephants, which resulted in international outcry, putting pressure on the South African Government to change its policy. Second and third-order effects across many scales were surprises to management, indicating how complex the system had become.

Engaging with this complexity using systems thinking, we argue in this chapter, allows managers to develop new and useful insights about the systems in which they function. Thinking and acting in complexity terms lead to strategies that retain their complexity and resilience, not to attempts to simplify and control.

\section{Summary}

The two examples reveal that social-ecological systems are inherently complex; that when we take governance action or make management decisions without understanding this complexity, surprises and unanticipated consequences frequently follow; that poorly informed responses to surprises inevitably lead to more problems, less resilience and to developmental trajectories that are more challenging to deal with. In this chapter, we suggest that when we understand and engage with this complexity, we become more aware of how effective our interventions and policies are, we develop better insights about the particular social-ecological system in which we function daily and use those new insights to make improved choices (Box 10.1). We also better recognise the risks associated with those choices.

We benefit from complexity thinking (the application of systems thinking to complex systems) by making systems more resilient, understanding the equity consequences of alternatives, and leave more options available for the future. Framing a protected area as a component of a social-ecological system helps deal with the inherent uncertainties facing managers that come from a variety of sources: 'Fundamental uncertainty is introduced both by our limited understanding of human and ecological processes, by the intrinsic indeterminism of complex dynamic systems (involving natural, human-made and human components), and by myriad of human choices and goals' (Gallopin et al. 2001:222).

\section{Characterising complexity}

The search for simple_-if not simplemindedsolutions to complex problems is a consequence of the inability to deal effectively with complexity (Ackoff 1999a:252).

If the world is so complex, uncertain and contentious, why are we still here? If we have survived this long, why would complexity thinking benefit us both personally and professionally? The fact of the matter is, we deal with complexity at the personal level almost subconsciously (and most of the time well enough to get by) using models and simplifications that work in most situations, but we are challenged to function at larger social and spatial scales. But as Capra suggested at the start of this chapter, we have begun to realise that the socially and politically challenging problems of the time are connected; we cannot solve them one at a time.

To work in a complex world, we must first strive to understand it. Once we understand this complexity, we can develop approaches and methods to simplify it so we can apply our understanding to governance and management. Underlying this understanding is description, which is what we focus on in this section. We describe the world in which we work and live using the concepts, terminology and ideas of systems thinking. We begin initially by addressing our own personal experience in dealing with complexity and then enlarge the scale of discussion. 
While we all have patterns in our daily routine, we seldom know all of the specific events that will greet us each day. In fact, for most of us, it is our routine that we depend on each day to help us meet the unexpected events we encounter. The behavioural patterns associated with routine provide us with the simplification we need to be able to make decisions, allocate our time, prioritise our activities and negotiate the unexpected events we inevitably encounter.

In our hard working lives, we may not take the time to consider what was needed for us to develop our routines. We may consider that our good judgment, experience, intuition or intellect are what guide us in our actions. All of these features of our personality are important but, in fact, what we do on a regular basis is to simplify an overwhelmingly complex set of stimuli into a series of relevant and actionable meanings. One of the ways we simplify on a personal level is to stereotype (generalising the specific to the general) people, situations and events in ways that reflect and reinforce our previous experience and beliefs. We filter new information through those beliefs and decide whether we should accept or reject its meanings for us. Another way is to defer our judgment on a situation to someone we perceive to be more of an authority on the subject than ourselves. For example, we hire trained forest or protected area managers to take care of special and complex places.

Further, we develop institutional structures such as a protected area management agency to organise the system of protected areas into a broader and easily comprehendible collection of places, all with rules and processes to make life simpler and more predictable. Those institutions adopt rules for our behaviour within our protected areas so that we can comfortably navigate how to engage nature's places.

We need to be able to describe a protected area system in a way that promotes our understanding so that when we do simplify, we do so acknowledging the consequences of simplification. The language of systems thinking helps us describe complexity, dispel myths and eventually formulate models which simplify that complexity in ways that promote learning. This is all the more important, given the changing assumptions about the world (Box 10.1).

\section{The myth of stability}

A protected area-including linkages with other elements, the people and organisations who manage it and interact with it - can be conceived of as a ball in a basin, which is a metaphor presented by Walker and Salt (2006). The forces and couplings both external to the system and within it define its shape and depth. The basin describes the set of possible states that a socialecological system may have and still retain its structure and function. At any given point in time, the system will be in a particular state (see Figure 10.2 for depictions of the basin), represented by the position of the ball in the basin. The basin's shape and depth indicate the range of variability that normally occurs, and as long as the ball remains within the basin, any potential conditions could be described as 'normal'. Thus, ecosystems are not static, but ever-changing.

Within a basin (where the system has essentially the same structure and function, and the same kinds of feedbacks), the ball tends to roll to the bottom. In systems terms, it tends towards some equilibrium state. In reality, this equilibrium is constantly changing due to changing external conditions; however, the ball will always be moving towards it. The net effect is that one never finds a system in equilibrium - that is, with the ball at the bottom of the basin. The shape of the basin is always changing as external conditions change and so is the position of the ball. So the system is always tracking a moving target and being pushed off course as it does so. From a resilience perspective, the question is how much change can occur in the basin and in the system's trajectory without the system leaving the basin.

Beyond some limit (the edge of the basin), there is a change in the feedbacks that drive the system's dynamics, and the system tends towards a different equilibrium. The system in this new basin has a different structure and function. The system is said to have crossed a threshold into a new basin of attraction-a new regime. These differences can have important consequences for society, so some basins of attraction are deemed 'desirable', while others are not.

And it is not just the state of the system (the position of the ball) in relation to the threshold that is important. If conditions cause the basin to get smaller, resilience declines, and the potential for the system to cross into a different basin of attraction becomes easier. It takes a progressively smaller disturbance to nudge the system over the threshold. 


\section{Box 10.1. Changes in assumptions about the character of social-ecological systems}

Since primary school, most park managers have learned assumptions about the world long before they realised that there were other ways to understand change. The conventional view, consequently, still controls how they manage change in protected areas. But with the increasing complexity and accelerating change of civilisation, the older view no longer gets the job done. We could characterise the old and new perspectives as a clash between the PLUS and DICE world views. PLUS, named after the simple mathematical operation, stands for 'predictability, linearity, understandability and stability', and infuses almost all tools and processes used today in protected areas. Because our 10000 -year-old civilisation emerged during a relatively stable climate and amid slow change on cultural, social and environmental fronts, modern society holds strong faith in its ability to predict or foresee the future. Indeed for most recent anthropological history, the future has looked very much like the past. By assuming a predictable future, managers formulate management plans with five-year or 10-year planning horizons, during which they predict conditions and offer solutions to management challenges well into the future. Isaac Newton himself taught that if we have enough information about a bouncing ball's velocity, angle of approach, composition, and so on, we can calculate exactly where it will bounce. Similarly, planners assume that if they can generate enough information, they too can calculate the future likelihood of events.

We are also taught very early about linearity, which assumes that the effect is proportional to the cause and that things occur closely in time and space. Many people, for example, assume that $x$ amount of greenhouse gas emissions will produce $x$ amount of warming, and when we start to truly see such warming, we can ease back on the gas and cool the planet in proportional fashion. Also, if we see a certain amount of poaching, managers must incrementally increase anti-poaching measures to mitigate the threat. Carrying capacity is the quintessential linear tool by which each additional person implies an incremental amount of additional impact: two people are twice as damaging as one. Further, managers need the world to be understandable. If they can comprehend the nature of a management problem-protecting an endangered species from a new virus-they can devise rational, quantitative solutions. Any limits to our understanding, the thought goes, must be attributable to a lack of money, time, personnel or information.

Predictability rests on stability. In the past, parents often expected conditions for their children to be largely the same as they were for themselves. As climate change, population growth, economic consumption, consciousness evolution and the Arab Spring show, moreover, forces of change continue to accelerate. Though management plans routinely extrapolate conditions at the time of planning into the future, the stability assumption grows risky in a world that increasingly boasts surprises. Since adherence to PLUS assumptions very often precipitates unimplemented plans, unyielding problems or problems that return after having been 'solved', many fields have promoted new theories: adaptive co-management, systems thinking, resilience thinking, organisational learning, high-resilience organising, limits of acceptable change, situational leadership, dialogue, holistic planning, mutual gains approach, integral theory, chaos theory, complexity theory, and evolutionary enlightenment. We can summarise these theories with the DICE world, a reference to the semi-random throwing of dice. This world view, in contrast with PLUS, is dynamic, impossible to completely understand, complex, and ever changing or evolving.

'Dynamic' refers to continuous change, activity or progress. A dynamic world undermines simplistic attempts to predict the future, such as estimating tourist arrivals, population growth curves and economic returns on investment. Of course the further into the future we look, the bigger are the risks of error. Dynamic worlds are nonlinear and dance to tunes of tipping points, thresholds and massive system changes.

In the DICE world, no matter how much information we have, we cannot completely know the future or even completely understand any problem. We can simplify complex social and ecological problems, but that does not make them simple. Things change too quickly and relationships prove too many to properly understand, so DICE means we need to decide with humility not overconfidence. 'Complexity' refers to an interconnected arrangement and interaction of parts, units, and so on, exhibiting behaviours that cannot be predicted by studying individual parts alone. Descartes showed us the power of reductionism for simpler questions, but for systems with lots of parts operating at different times, scales, places and objectives, the result should be awe not certainty. Last, the DICE world is ever changing and in many ways evolving to higher forms of self-organisation, interconnectivity and consciousness. To live in a DICE world means that managers need to be conscious of change, make decisions under stressful uncertainty, and learn apace with a world that will not stay still.

- Jon Kohl 
1.

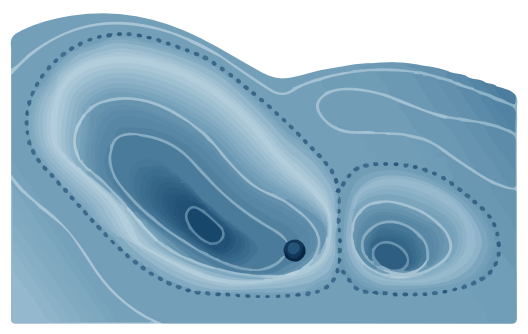

1.

The ball is the state of the social-ecological system. The basin in which it is moving is the set of states which have the same kinds of functions and feedbacks. The dotted line is a threshold separating an alternate basin. In the alternate basin the system behaves differently (it has different function and feedbacks)
2.

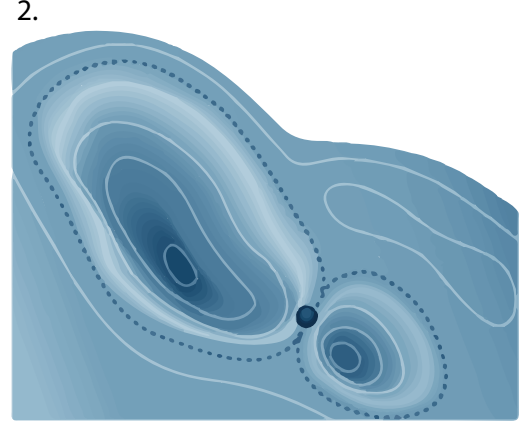

2.

A disturbance has pushed the ball over the threshold

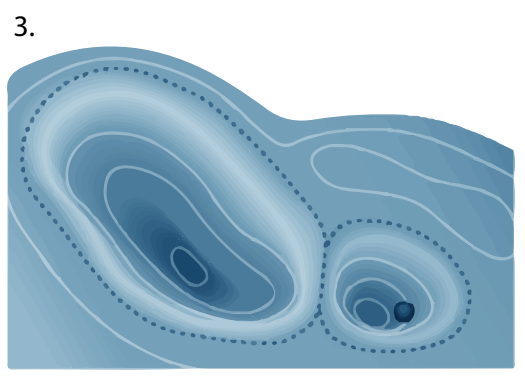

3.

The above represents the system state having moved into an alternate basin, sometimes referred to as a regime shift

Figure 10.2 A system can be conceived of as a basin

Returning to the fire example, we see that the policy of fire suppression led to management interventions that changed the position of the ball (the state of the system) in the basin. As the system adapted to the absence of fire, it moved progressively towards the threshold of the basin and, had the practices persisted for long enough, it may have reached the threshold and overtopped the rim, passing into a basin characterised by the absence of fire. Had it done so, it would exhibit fundamentally different properties than in the previous 'basin'; however, the natural fire that was beyond our ability to control returned the ball to a state that was more consistent with the range of environmental variability to which it had adapted. This was complemented by a series of governance policy decisions relating to evolving unacceptable conditions, raising levels of risk from fire to both humans and their natural environment. While we cannot describe these actions as truly adaptive governance, they did recognise that thresholds were likely to be crossed without changes in policy, that a simplified fire environment threatened social-ecological systems and that uncertainty existed with respect to continued suppression. Under the revised policy and management practices, the ball is not being forced along a trajectory that takes it to the lip of the basin. The ability to retain system integrity-defined by Walker and Salt (2006) as the self-structuring capacity of systems) after disturbance (an imposed fire management regime) — is indicative of resilience.

Stability in the context of dynamic complexity, at both the personal and the larger scales, may be something we desire or seek, but complex systems are always changing because a shift in one element of that system affects others. This is particularly illustrated in the South
African example, where placement of boreholes and dams shifted the distribution of animals, which then affected vegetation, but also increased the vulnerability of animal populations to drought. These social-ecological systems are complex, adaptive systems-that is, they respond to changes and processes and adjust to them by following a cycle of renewal and adaptation. In a very real sense, such systems show, more or less, the property of resilience. Resilience describes the ability of a system to retain its integrity and return to its developmental trajectory after disturbance (see Box 10.2 for further definitions).

Thus, stability is an impossible goal to achieve but resilience is something we most likely desire. Change is everywhere, and responding to it, as shown in Figure 10.2, requires different strategies, depending on the amount of change. Adaptation occurs when the system is subject to perturbations, but remains within the realm of natural variation-the basin in Figure 10.2. But at times and places, changes have been so dramatic that thresholds have been crossed and resulting conditions are untenable; in these situations, transformation to another or previous system is required. In the examples earlier, transformative processes were needed to return conditions to a more manageable situation. In both examples, governance systems were forced to act. In South Africa, governance was needed to direct management on the issue of elephant culling in response to untenable international relations. In the United States, Congress passes legislation and appropriates funding for treating hazardous fuels (by using fire and logging) near communities, thereby reducing risk of loss and fire intensity. 


\section{Box 10.2. What is resilience?}

An oft-stated goal of managing complex socialecological systems is to retain their resilience. But what is resilience? Walker et al. (2006:14) used this definition: 'resilience is the capacity of a system to experience shocks while retaining essentially the same function, structure, feedbacks, and therefore identity.' Folke et al. (2010:20) define resilience as '[t]he capacity of a system to absorb disturbance and reorganize while undergoing change so as to still retain essentially the same function, structure and feedbacks, and therefore identity, that is, the capacity to change in order to maintain the same identity'.

Basically, what this means is the capacity of a social-ecological system to return to a previous developmental trajectory after being impacted by a perturbation or disturbance. For example, a typhoon may hit a small island country in the South Pacific, destroying transportation and other infrastructure, isolating the country for a while, and hindering efforts at poverty alleviation. A country that is resilient would be able to return to its previous developmental course without an irreversible impact to its former structure, function and feedback. Resilience does not necessarily mean returning to a pre-existing state. Systems are always changing, adapting and shifting in response to disturbances and ongoing processes. Retaining the system's ability to adapt is thus a major goal of the management of protected areas.

Sharing power and structuring decision-making processes are matters of governance that are key factors in building resilience, as is management. Adaptive governance requires devolution of some management decisionmaking authority to more local levels, engagement of multiple interests and sharing power among scales of policy (see Folke et al. 2005). Engagement of interests, the distribution of power and the structure of decisionmaking processes are also important elements in any characterisation of a complex system, as how they shift or remain the same influences relationships among elements of the system (see Chapter 7 for more discussion of how governance can facilitate resilience).

The direction and intensity of change are dictated by the nature of the relationships among the various system elements, and are subject to delays of varying lengths. Thus, in our daily lives, we interact at work with other individuals, with our interactions mediated through organisational rules and norms to produce plans and implement them. In a system, we cannot understand the function of parts without understanding their relation to other parts. If one of our co-workers takes ill and misses a meeting or an assignment, the effects on the whole depend on the co-worker's role and responsibility in the organisation and the nature of any specific task.

\section{What makes a system complex?}

A system deals with a 'whole' and as such the system has properties that occur as a whole or, as Jackson (2003:3) observes, '[s]imply defined, a system is a complex whole the functioning of which depends on its parts and the interactions between those parts'. So, an automobile may be defined as a system, with the motor, front door, transmission and electrical pieces as several of its components. Each component has a function that can be defined only in relation to other components. And in a system, the properties of the whole (the automobile) cannot be derived from the properties of the parts. For example, we cannot describe what an automobile does if we only have a rear bumper in hand. And when we change a part, we change the system. Properties of the whole are termed emergent properties. So, if one of us decides not to come to work one day (say she is ill), the resulting work product will be different.

What makes some systems complex is that the relationships, or cause-effect interaction, among at least some of the parts are nonlinearly dynamic - that is, a little change in one component may lead to a larger change in another component (or vice versa) or in the system as a whole. For example, a casual conversation about a waterfall along the Rio Carabinani in Brazil's Jau National Park could lead to a dramatic increase in visitors at the waterfall, particularly kayakers desiring a first descent of a river. This in turn would spawn a number of other impacts, ranging from increased visibility of visitor-induced biophysical impacts to greater expenditures by visitors leading to more jobs for local residents, and increased uncertainty as to the long-term social and political consequences resulting from visitor use. Thus, while we do enjoy the occasional day in which everything goes as planned, we are clearly outnumbered in the ways that uncertainty can be introduced into the systems in which we are embedded.

While our routines of thinking or behaviour may become resistant to change, they are based on a flawed assumption that the past will predict the future. Dispelling that myth is truly our only hope for building personal resilience in the face of continuous change. If we go beyond accepting the importance and inevitability of the unexpected, to embracing it, learning, introspection and professional effectiveness can be improved. We develop better insights about the particular social-ecological system in which we function and understand how those insights help us 


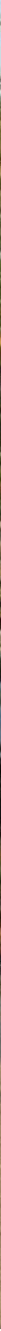

Skukuza research and management centre, Kruger National Park, South Africa

Source: Graeme L. Worboys

make improved choices. Rigid governance structures, policies and bureaucracies thus do not work well in a world of change. National-level policies may lead to disruptive equity issues at the local level or may impact resilience, threatening vulnerable biodiversity or human communities.

We note here that components of systems may be either tightly or loosely coupled. In tightly coupled systems, effects of changes in one component touch those immediately downstream - that is, cause-effect relationships are more or less deterministic and effects occur after only short delays. For example, since access to a protected area is often tightly coupled with government policy and funding, changes may lead to catastrophic financial losses to local businesses dependent on tourism, as was demonstrated in October 2013 in a funding dispute between branches of the US Government, leading to the closure of national park units.

Loosely coupled systems are characterised by longer delays between causes and effects, multiple causes leading to the same effects, slow feedback times, the number of linkages between causes and consequences, spatial discontinuities between causes and effects, and so on (Weick 1976). For example, changing climate causes uncertainty about the distribution of vegetation in some protected areas, such as Mexico's Monarch Butterfly Biosphere Reserve, potentially threatening scarce and vulnerable winter habitat for the butterfly. Social-ecological systems show both tightly and loosely coupled connections, but implicit assumptions that such systems are narrowly and rigidly defined as consisting of tightly coupled relationships tend to dominate the planning discourse because of the compulsion to reduce complexity to something that is (illusorily) manageable. As a result, many 'fixes' (management actions) often fail, or actually make things worse (Senge 1990).

An individual subsystem follows its own trajectory of adaptation and renewal in response to so-called outside influences (Walker et al. 2004; Walker and Salt 2006). These trajectories can be significantly changed in response to human or naturally induced disturbances, such as withdrawal of water from a river for irrigation, development of new tourism facilities, introduction of new animal or plant species, a meteorological event or change in climatic regime. Importantly, these events are not treated as variables exogenous to the protected area system but as endogenous and thus subject to some kind of managerial influence or response. 


\section{Box 10.3 Navigating complexity in and around Kruger National Park}

\section{Beginning to think about complexity}

Science-management collaboration helped form the early basis for South Africa's Kruger National Park (KNP) being considered a leader in benefiting from complexity thinking. A long tradition of science-informed decisions, coupled with democratisation of the country in 1994 and the insights resulting from an adaptive focus on river management in a unique program in and around the park during the 1990s, laid the foundation for later seeing the park as primarily embedded within a complex socialecological system (Berkes et al. 2000). A variety of other factors, such as realising the benefits of reflection (Biggs et al. 2011), long-term interaction with resilience and complexity scholars (Walker and Salt 2012; Cilliers et al. 2013), collaboration and testing of adaptive management ideas in catchments supplying water to the park (Pollard et al. 2014) as well as incorporation of the park into a larger trans-frontier protected area (Cumming 2004) reinforced this trend. As a consequence, decisions became better informed and more systemically founded, as can be seen, for instance, in the elephant management debate (Scholes and Mennell 2008).

\section{Strategic adaptive management as a response}

Park scientists and managers responded to the growing recognition that the park was part of a social-ecological system by developing a strategic adaptive management (SAM) approach to decisions. SAM involves a variety of management innovations, including wide contextual scanning (with a strong emphasis on surfacing the various deeply held underlying beliefs), co-construction of a requisitely simple version (Stirzaker et al. 2010) of the key interacting drivers that influence the system and development of specific, quantifiable objectives, thresholds of change that trigger management action and the feedbacks that allow adaptation and ongoing learning and reflection at multiple nested levels.

With the impetus from KNP, SAM expanded to other national parks in South Africa (Roux and Foxcroft 2011), and in doing so pointed out the role of organisational culture (Stirzaker et al. 2011) in building interest and support. Implementation of SAM also influenced other aspects of resource management, such as South Africa's post-apartheid National Water Act, which, inter alia, helps address catchment management for the rivers feeding KNP. Social-ecological systems thinking and/or the adaptive planning process from SAM is used as the basis for these and other strategies such as the Animal Health for the Environment and Development (AHEAD) initiative (Cumming 2004) developed in response to the World Parks Congress and several other research initiatives operating in the region (Coetzee et al. 2012). Many of these initiatives have incorporated important dimensions from the complexity dialogue that provide the conceptual grounding for interventions in such dimensions as sustainable economic development and poverty alleviation.

\section{What has been accomplished?}

One of the key realisations from applying complexity thinking is that, first, there are no panaceas for problems arising in complex systems, and second, it takes time to infuse, and to obtain the visible impacts of, such an approach to management. It engages scientists, managers, consultants, funders, administrators and citizens to be more comfortable with variation in time, space and operating culture, and to use better thoughtthrough and more trans-disciplinary interventions as learning platforms. There is some evidence of a more strongly shared systemic view by several key players, and many examples of individuals and groups seeing themselves as part of a linked picture. These attitudes, along with the explicit values elicited in SAM, may lead us to a more sustainable future, in which science plays an important but value-contextualised role, rather than trying to lead alone.

\section{Where is this all headed?}

Some of the most exciting advances informed by complexity thinking include using trans-disciplinary social learning dimensions for communities in the Olifants River Basin and adapting institutional arrangements to help partly integrate multiple similar development projects in the Kruger to Canyons Biosphere (Coetzee et al. 2012). Together with several of the other initiatives mentioned above and emergent ones using similar frameworks, we hope pragmatic enthusiasts in the region will continue to learn together. This would help them navigate and manage the complex social-ecological system in which KNP plays a critical role. We begin to feel the benefit of complexity thinking and of a more systemic orientation, not in rejection of alternative (sometimes more conventional) approaches, but in complementing these by providing an overall jointly constructed and more defensible basis for making decisions and managing. Because the systemic view is often new and sometimes perceived as threatening to some participants, it requires sufficient mediation and emphasis, and an overarching position in the broader overall approach. Our experience in doing so makes us modest but optimistic.

- Harry C. Biggs 


\section{Complexity and leadership}

In contrast with the quest for control, stability and predictability, bring to your mind someone who you think is a very good leader or protected area manager. Chances are that person will have a good repertoire of technical skills, but sets themselves apart through their ability to anticipate and understand changing social and ecological conditions. They likely have highly effective social skills that include respecting, listening, learning and validating the value of a variety of opinions and knowledge. They anticipate emerging challenges or threats and inspire others to coalesce around a vision for addressing those challenges. They ask good questions and have built a considerable network of advisors that also benefits from their insights. They provide good advice about when and where to act and their advice often shows considerable, visible effect. In other words, they use certain skills to benefit from the complexity around them and better contribute to management. They are aware of their place in a system and its context. They do not see problems as simple. They pay close attention to operations and suggest actions that result in large returns relative to inputs of staffing or other resources. They accept and learn from failure. They draw on and contribute to networks of knowledge that are broad and often challenging. They invest in relationships, often giving more than they appear to receive, and above all, continuous learning is a part of their routine. Consciously or unconsciously, they benefit from complexity.

Understanding complexity requires an acceptance of the inherent connectedness of the systems in which we are embedded. It further requires skills in experimentation, constructive thinking, sensing our surroundings, learning and adaptation, copying good examples, responding to uncertainty, communication, building support systems and imagining potential futures. Those skills increase capability for managing social and material relationships and for finding increased meaning in our lives. While we use these skills frequently, too often we do so unconsciously and do not challenge ourselves to refine them or draw greater advantage and personal comfort from seemingly chaotic environments.

When we fail to apply these skills, we can fall into what Peter Senge (1990) refers to as organisational learning disabilities such as allowing ourselves to be defined by our job descriptions, blaming negative results of change on an 'enemy out there', fooling ourselves about how much control over situations we have or failing to see the larger patterns of change that are occurring due to a fixation on events. Use of panaceas may also be promoted when governance does not act adaptively.

\section{Some tools for characterising complexity}

Our ability to characterise complex systems and to respond to perturbations is directly impacted by the tools we use. A number of tools are available that help us understand the components and relationships that exist in complex systems, as well as what policies might be robust in the face of uncertain change. First, the Resilience Alliance (2010) has created a useful workbook for identifying and assessing the various components of a social-ecological system that may be under stress. The workbook covers system dynamics, cross-scale interactions and governance as well as guiding the user through a process to identify actions.

Second, one may choose to use scenario planning as a method of identifying potential future conditions or states and then testing what policies might be robust across them (Peterson et al. 2003). Scenario planning for conservation is useful in situations with high degrees of uncertainty and little 'controllability'. Developing and examining scenarios with the engagement of constituencies provide them opportunities to discuss, engage and learn about how various policies may function in different potential future conditions.

Note that we suggest the term constituency rather than the more frequently used 'stakeholder' to represent those who have an interest in a protected area. A constituency represents those who are served by an organisation or benefit from a protected area. Stakeholders are those who have an investment or share in some thing. The term constituency is preferred to stakeholder because it implies a broader diversity of individuals and values affected by a protected area. We believe the term constituency is not only more inclusive, but also more appropriate for systems thinking.

A third tool that may assist involves mind-mapping-a process for uncovering how people see the connections and variables involved in a particular problem or issue and that reveals the underlying mental models (see next section) influencing governance, policy and management. Mosimane et al. (2013) used mind-mapping to expose critical factors affecting human-wildlife conflict in Namibia, finding that some ministries which on the surface seem uninvolved have a great deal of influence on such conflicts. 


\section{Section summary}

Through acknowledging the nature of complexity, we have taken the first step towards being able to benefit from that complexity. At this point in the chapter, we have illustrated the following.

- We manage and govern protected areas in a context that is best described as dynamic, impossible to completely understand, complex and ever changing: the DICE world. Thus, managers needing to be conscious of change make decisions under stressful uncertainty, and learn apace with a world that will not stay still.

- We must strive to understand this complex world and our own behaviour in the way we engage with it. Through this understanding, we will see patterns in how we tend to simplify complexity at our personal, professional and societal levels. Simplification, while important, needs to be strategic if we are to consciously benefit from complexity.

- Systems thinking frees us from the myth of stability and gives us tools for understanding how systems are organised and ever changing. Insights gained from examining change enable us to better understand the causes of change and better anticipate the emerging conditions of the future.

- Concepts such as resilience assist us in engaging with the complexity of the system we have an interest in.

- What makes some systems complex is that the relationships, or cause-effect interaction, among at least some of the parts are not linear: a little change in one component may lead to a larger change in another component (or vice versa) or in the system as a whole. Further, lag times between cause and effect can be long and can disguise the fundamental relationships that are influencing change.

- Leadership within a context of complexity requires an acceptance of the inherent connectedness of the systems in which we are embedded. It further requires skills in experimentation, constructive thinking, sensing our surroundings, learning and adaptation, copying good examples, responding to uncertainty, communication, building support systems and imagining potential futures. Effective leaders are often those who know how to benefit from the complexity they are immersed within.

\section{Simplifying complexity}

Simplicity does not precede complexity, but follows it (Perlis 1982:8).

If systems are so complex-and complicated-how is it possible not only to make our lives easier, but also to benefit from the insights that complexity thinking provides? If we recognise a system as complex, how do we function without overwhelming ourselves? In short, we simplify. But we simplify based on an understanding of the complex systems with which we engage. This is what we mean by getting to the other side of complexity. We engage that complexity by focusing on a few key variables, processes and relationships through the application of systems thinking. Gharajedaghi (2011:335) argues that '[s]ystems thinking is the art of simplifying complexity. It is about seeing through chaos. We see the world as increasingly more complex and chaotic because we use inadequate concepts to explain it. When we understand something, we no longer see it as chaotic or complex.'

We simplify the inherent complexity of a system to be able to better conceptualise, communicate about, understand and act on a forthcoming decision. When you think about it, we actually defer a great deal of our decisionmaking to experts, clergy, celebrities, institutions, family and friends or community leaders, scientists, biologists, planners, and so on. This process of simplifying the complexity of our world is remarkably effective and often reinforces our decisions quite positively-for example, the physician's recommendation worked. As we discussed with the myth of stability, there is a downside to our quest for a simplified, predictable and stable life. While simplification is necessary for us to function effectively, it comes with a risk that we assume predictability for which there may be little justification. When this occurs we are often surprised by events that we have not anticipated. Our stereotypes can be very counterproductive-for example, racism and sexism. Thus, it is highly valuable to build a contemplation of complexity into our routines so that we can better anticipate change and become more strategic in how we handle disruptions to our routine.

\section{Models as methods of simplification}

In applying systems thinking, we construct a model of our environment. A model is a simplified representation of the real world, the system in which we operate, 
be it our household, community, transportation infrastructure, biophysical system or a large protected area. Models come in several forms: as ideas connecting one system component with another through some kind of relationship; as equations that predict an outcome from one or more variables or system components; or as figures depicting system components connected by relationships and feedback loops. What model we choose to represent any particular system is influenced by our own knowledge and needs, the importance of a particular system, the resources and capacities we have at our disposal, and the risks and consequences involved in choosing alternative approaches.

In developing a model, we are often confronted with the question of what to include in the model that represents a system. Donella Meadows (2008:97) argues that ' $[\mathrm{w}]$ here to draw a boundary around a system depends on the questions we want to ask' (emphasis added). So in a very real sense, the protected area may be involved in a variety of systems, and thus there is no 'correct' or 'right' system depiction for governance and management of a protected area system. As a result, multiple mental models of the same system often abound, which result from different questions being sought and from the varying perspectives of protected area constituencies.

One fundamental purpose of modelling is to develop insights to create situational awareness. Endsley (2000:4) defines situational awareness as 'knowing what is going on around you'. A variety of factors affects situational awareness: experience, background, training, personal and organisational mental models and the context within which a planner, manager or constituency may be functioning. Each factor influences what cues are perceived, how they are interpreted and what meanings are assigned. For example, managing elephants in Kruger National Park in South Africa is now driven as much by animal-rights beliefs as by the ecology and reproductive character of elephant populations. Providing good stewardship of the Great Barrier Reef World Heritage Area in Australia requires as much understanding about human uses, values and preferences as it does about the relationship among reefs, rivers and currents.

How a manager or constituency describes a particular situation-what contextual variables are operative, what legal, policy and political factors are salientinfluences the process used in framing problems and making decisions (Endsley 1995). The characterisation of a situation, developed through sense-making and awareness-building, is determined by mental models. Mental models are the internal representations of external reality that people use to interact with the world around them' (Jones et al. 2011:1). These mental models simplify our perceptions of how real-world systems behave (Nkhata and McCool 2012) and have a great influence on what things we attend to. Such simplified models are needed for humans to function effectively in a world of complexity — and many have been developed out of successful past experience.

The test of an appropriate model is its usefulness in making sense, building situational awareness, and enhancing learning and choosing among alternatives. In the systems in which protected areas are found, models will need to reflect the dynamic complexity, turbulence and contentiousness of those systems in order for managers to work effectively. While all models will always be wrong (Sterman 2002) in the sense that they are simplistic representations of reality, they will be more or less useful in the sense of the learning they stimulate (Box and Draper 1987). Thus, the test of an adequate model will be how well it furthers learning.

Constructing and adapting models are processes embedded in daily human life-done well in many cases, leading to unanticipated challenges in others. As the scale of the system grows, however, model-building becomes more difficult and needs to be more explicit, even if only in our own minds. The benefit of modelling a system, when we do it explicitly, lies not so much in the outcomes from using the model, but rather in the fact that it enhances and accelerates learning about the system we are modelling (Sterman 2002).

\section{Protected areas as a component of a complex social-ecological model}

Given the growing recognition of protected areas as a component of a complex social-ecological system, it is quite clear that more explicit models are needed for more effective management and governance. We state this because of rising conflicts, a growing diversity of expectations, increasing dependency on protected areas to preserve natural heritage and mounting hopes that they will become an important tool for raising incomes and alleviating poverty in nearby communities. Various constituencies may each carry their own mental models, which may appear to have little in common with one another.

Protected areas exist as one component of a socialecological system nested within a larger social-ecological system, which can be succinctly stated as civil society and its interactions with the biophysical environment. For example, elephant management in KNP is now situated within a larger debate about animal rights, 
vegetation dynamics and human-wildlife conflicts. Elephant management is influenced by society's perceptions and valuation of elephants perhaps more so than by scientific descriptions of their ecology. Society is the larger 'cloud' within which protected areas (including their governance and management) are embedded. As values, preferences and needs change in this cloud, the meanings, and thus management, of protected areas unfold as well.

The conceptualisation of a protected area as a component of a complex social-ecological system is distinctly different from the common conception that it is a geographical area defined by a visible and politically defined boundary, although permeable, which is assumed to be relatively independent of activities and processes occurring outside it. Because protected areas are established by society, they are systems embedded within larger systems that influence and impact the protected area, with systems within the protected area often impacting those outside it.

There are many ways to model and graphically characterise a social-ecological system. We choose to use a model prepared by Anderies et al. (2004) as it is one that matches our mental model of such systems and probably that of many protected area managers as well. In the following, we work through this model, discussing and exemplifying its applicability to protected areas.
The term social-ecological system denotes a social subsystem in which human interactions are mediated through connections (tightly or loosely coupled) with the ecological subsystem. Whereas the ecological subsystem refers to an interdependent system of organisms or biophysical units (at varying spatial scales), the social subsystem represents interdependent human relationships that develop at varying temporal, spatial and social-organisational scales. The socialecological system consists of multiple subsystems that are embedded in multiple larger systems. Although both ecological and social systems comprise subsystems that appear independent of each other, each affects and is affected by other systems through coupled relationships.

The system depicted in Figure 10.3 consists of: a) the resource (in this case, a protected area-the values contained within it and the stock and flow of materials and biophysical-based processes) and the meanings attached to it by various constituencies; b) resource users (constituencies, such as visitors, tourism providers, companies that extract commodities and materials, residents who access the area for medicinal plants or fish, communities which use water flowing out of the protected area, groups who value various aspects of the environment_-such as wildlife_-and so on) who hold expectations and articulate demands for both what values are to be protected and how decisions about management are to be made; c) infrastructure providers

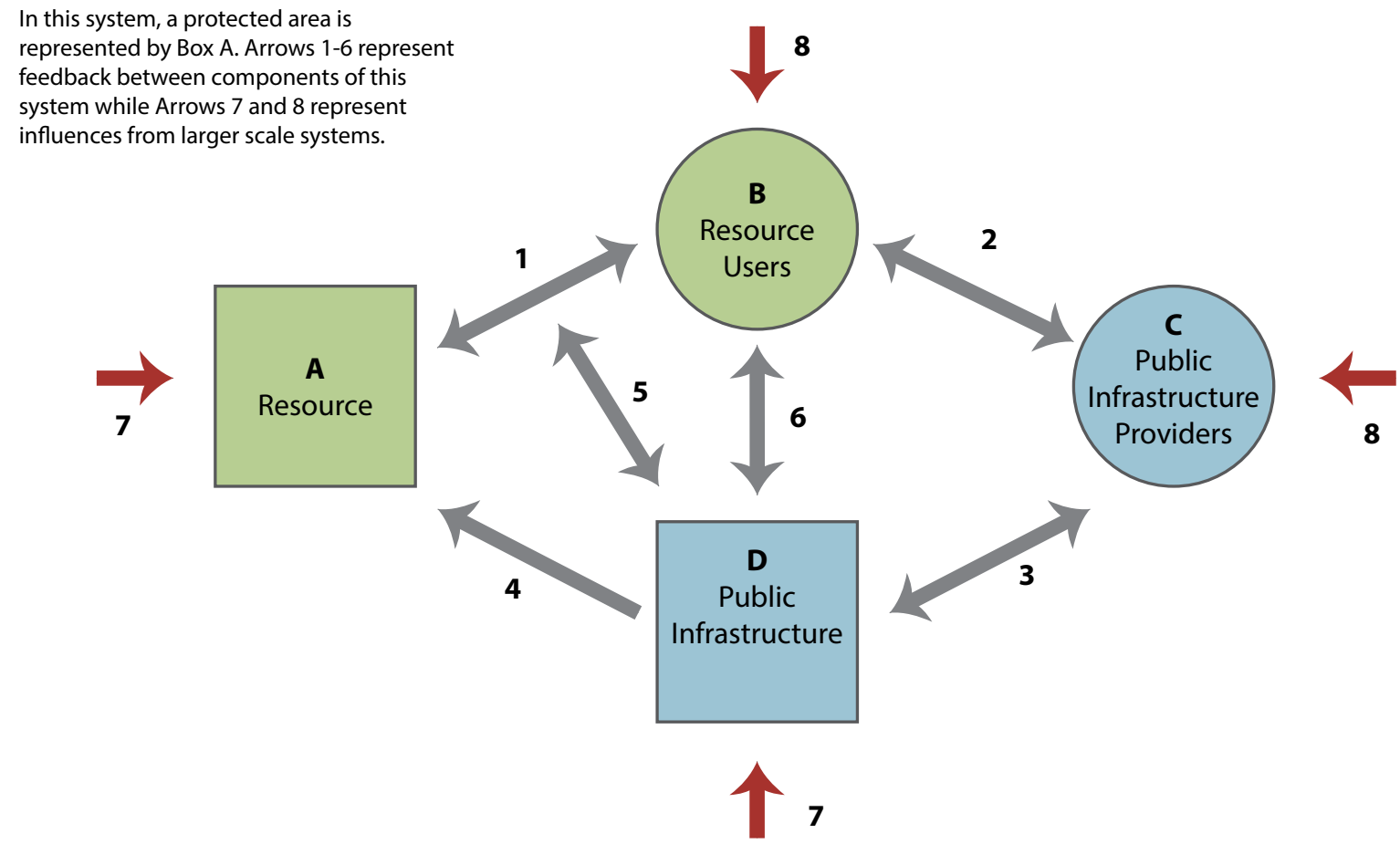

Figure 10.3 A simplified representation of a complex social-ecological system

Source: Adapted from Anderies et al. (2004:18) 
(the protected area organisation and its staff and in many cases other land management or regulatory agencies, non-governmental organisations, laws and governmental policies about the environment, decision-making and governance); and d) public infrastructure (facilities, roads, policies that guide management, access, and decision-making processes).

The components of the system are coupled and exist at varying temporal and organisational scales. US Forest Service (public infrastructure provider) fire management policy changed over very long time scales (half a century and more) in response to enhanced knowledge about the effects of fire suppression on fuel accumulation, particularly in low-elevation dry forests that, previous to aggressive suppression, had burned relatively frequently with low intensity. Because the very definition of a system means coupling of components, changes in one component-for example, infrastructure provider policy established by some governance mechanismimpact other components, but there may be significant temporal delays or impacts could occur in another location. The successful implementation of the White Cap Creek fire management policy, for example, led to hundreds more decisions in many other places about letting naturally ignited fires in wilderness burn without interference. Another example is that a decision in Brazil by the central government prohibiting fishing in national parks impacts one group of resource users: local people living along a river.

On the other hand, drilling boreholes in KNP was built upon assumptions of control and simplificationassumptions that proved invalid at longer time scales. As the consequences of this policy became more apparent, occurring concurrently with a change in governance structure at the national level, management goals shifted to building resilience rather than controlling for stability.

Because the system is a nested hierarchy, changes occurring in the larger social-ecological system impact on processes and conditions at smaller scales and vice versa. For example, increased scientific knowledge about the role of fire in western North American forested ecosystems coupled with passage of the Wilderness Act in 1964 (which stated that a wilderness is to remain 'untrammelled', meaning that the wild character of natural processes was not to be interfered with) led to significant changes in attitudes towards naturalness and natural processes not only among the public (resource users), but also within the agencies (infrastructure providers). Changes in both interacted, leading to new demands, mental models, policies and management actions.
Positive and negative feedbacks (arrows 1-6 in Figure 10.3) among the subsystems shape the structure and function of a social-ecological system. The strength, coupling and character of these feedback loops are what make the four components a system. Changes in one component-for example, fire management policyinevitably lead to changes in the other three components, often through a variety of feedback mechanisms with varying delays. As we noted earlier, the delay between the aggressive suppression policy implemented following the Big Burn and the accumulation of fuels in dry forests was measured in decades. The delay between noticing this accumulation, reflecting upon it, developing policy in response and implementing that policy was also lengthy. Such delays reflect knowledge differentials among resource users and infrastructure providers, delays in transferring knowledge from one to the other, ongoing resistance to framing fire in wildland settings as a beneficial process, and bureaucratic processes involved in assessing the consequences of framing fire in new ways.

The ecological subsystem interacts with the social subsystem through flows of information, energy and matter. The meanings that various resource users (constituencies) place on these form an important component of this process. For example, a large part of the debate about elephant culling in southern Africa has been influenced by shifting values and beliefs about elephants among constituencies living outside that region. And in the north-western United States in the 1990s, people opposed to timber harvesting commonly characterised old-growth forests as 'ancient forests' to build support opposing harvesting.

The social-ecological system in Figure 10.3 is susceptible to various inputs, as we have alluded to previously: biophysical (arrow 7) and in public infrastructure and socioeconomic conditions (arrow 8). These inputs may, however, be treated as disturbances or exogenous forces when our mental model is one of a smaller system. When including the cloud (society in general, for example), they are not disturbances but simply processes that exist at larger scales. This point is illustrated explicitly in Box 10.4, which uses the insights from complexity thinking to describe the apparently chaotic situation in Macarena National Park in Colombia.

Resource users or constituencies hold varying values and perspectives. These values and perspectives themselves are influenced by processes and forces occurring in the contextualising social-ecological system, such as demand for cocaine emanating in North America in the Macarena National Park case study, in shifts in attitudes toward animals occurring in Europe and elsewhere in the case 


\section{Box 10.4. Complexity and conflict in Macarena National Park, Colombia}

The Sierra de la Macarena National Park covers 6200 square kilometres of ecologically unique territory in which the flora and fauna of the Amazon, Orinoco and Andes regions meet. Located in south-central Colombia, it boasts a large diversity of ecosystems and vast environmental resources, which are crucial for carbon sequestration and freshwater supply to massive subcontinental basins such as the Amazon. Due to its strategic geographic location, the Macarena mountain range has been at the heart of Colombia's armed conflict and illicit drug economy.

In the 1980s, Colombia's security situation deteriorated sharply with the emergence of large-scale illicit production and trafficking of cocaine, influenced greatly by drug demand emanating in other parts of the world. Powerful trafficking organisations and extreme right-wing paramilitary groups appeared, which led to violence and war with the conventional government. With time, all of Colombia's non-state armed groups became deeply involved in the illegal drug business (Pécaut 2001; ICG 2002, 2008). Macarena became the site of illicit drug production and military contest between these groups and government armed forces. The monetary income from this illicit economy attracted large numbers of landless settlers to the region.

The Colombian state has historically had only a small or no presence in the region. The Revolutionary Armed Forces of Colombia (FARC: Fuerzas Armadas Revolucionarias de Colombia) exploited this institutional weakness by building a 'virtual state within a state' (de Shazo et al. 2009), controlling the area and providing new physical infrastructure (such as roads, schools and health centres) and social infrastructure (such as rules for natural resources management and conservation), both of which have been incompatible with the national park's mission, thus showing the interests of different governance scales. Unregulated construction of makeshift roads especially has impacted on the unique ecosystems through fragmentation. While the FARCcontrolled roads encouraged more colonisation around and inside Macarena, law enforcement by park rangers was almost impossible. Fishing in the rivers surrounding the park and wildlife hunting were regulated by FARC through 'gunpoint conservation' (Álvarez 2003), which included the use of banned antipersonnel mines and curfews. Consequently, the park is today one of Colombia's protected areas with the largest number of planted landmines.

The National Park Service of Colombia faced the daunting task of developing effective management strategies for this protected area. How could this be achieved? The first step consisted of understanding the different components and relationships of this particular social-ecological system. This exercise, carried out in a 2002 evaluation, revealed that many of the challenges and threats Macarena was facing were linked to the broader conflict and political context.
It became clear that a range of complex issues related to national security and transnational drug trafficking impacted on the dynamics around Macarena's natural resources, their users and the different stakeholders providing infrastructure. This situation required a new intervention model that would be different from the way Colombia's national parks had been managed thus far-that is, as independent and isolated units. Rather, the National Park Service of Colombia needed to use the power of networks and reach out to other sectors of the government and civil society to look for joint solutions. This was facilitated through the establishment of a governance arrangement bringing together different state institutions and civil society organisations.

The role played by Colombian National Parks in this endeavour was crucial. First, having been among the few government institutions with a continuous presence in the region, its work was perceived by people in Macarena, including FARC, as neutral and trustworthy. This leverage point was essential to empower local settler organisations by encouraging their active participation, which was important in and of itself in a setting characterised by violence and armed conflict.

Second, Colombian National Parks emphasised the importance of environmental management of the territory, advocating, for instance, for a comprehensive approach to relocating settlers outside the park. A major thrust was to identify areas where the relocation of these families would not have a negative ecological impact. Interventions were also needed to provide people with much needed infrastructure, such as legal access to land and productive activities. This required coordination between a range of central, regional and local government institutions, including the Ministry of Agriculture, the agency in charge of rural development, the Ministry of Defence and local municipalities.

There have been many challenges. Fundamentally, Colombian National Parks has been overstretched by this broadening of its fundamental conservation mission. Although it was not its responsibility to secure access to land, housing and alternative livelihoods for families living in the park, its leadership was crucial for coordinating with other agencies. It has done this, however, without appropriate funding and has been challenged with trying to exert leadership without risking damage to its good reputation among local communities.

These interventions sent a strong message that colonisation of land in the park would not be tolerated. At the national level, Colombian National Parks took a lead in adopting a planning approach to protected areas management involving a range of central and regional government entities. This has called attention to the need for a broader definition of conservation than simply management of biodiversity in a complex socialecological system characterised by weak institutions.

$$
\text { - Julia Gorricho }
$$


of elephant management in southern Africa, or in rising expectations of indigenous peoples in Brazil's Amazon for greater autonomy in conservation governance.

Understanding these demands, the constituencies expressing them and how they evolve over time requires 'sensing' mechanisms that monitor changes in the social and political contexts. It means that managers interact with constituencies on a regular basis both consciously and unconsciously (Pimbert and Pretty 1995). Sensing changes in constituency preferences and values has been difficult in the past because some constituencies (such as indigenous peoples, minorities and women) were given few opportunities to have a voice or to be heard in some societies. Also, conventional models of planning and decision-making privilege scientific and technical knowledge over experiential sources (see, for example, Yankelovich 1991 and his discussion about the 'culture of technical control'). New models of governance (developing in the larger social-ecological system) require organisations to advance and manage networks to attend to relationships, listen and respond to a wider variety of voices, and at times become more than biodiversity conservation agencies.

Constituencies act to maintain or change policies developed and implemented by infrastructure providers. In Kruger National Park, for example, animal-rights constituencies exerted influence not only on the SANParks organisation to change its elephant culling policy but also on the larger South African Government. Constituencies also lobby parliaments for funding programs that will benefit their interests.

We always simplify. But making our simplification explicit helps us ask if we really understand what the system is and why it works the way it does (Ackoff $1999 \mathrm{~b})$. To provide useful insights, models then must be built upon knowledge of how something worksthe characterisation of a complex system. Once we have knowledge and understanding, we can engage with the complexity we face every day.

Let us also consider that no matter how hard we try to simplify 'our' system, we are always connected to other people, each of whom will be constructing a different simplification as they try to make sense of their world. They engage with it differently and apply their personal forms of simplification to understanding it. They will have their own stereotypes operating to filter new information. As a result there are multiple meanings associated with any given situation, and information that challenges rather than reinforces a particular belief is likely to be contested when they collide in resolving competing demands.
We seek authorities such as scientists, spiritual leaders and those with more experience to simplify situations for us, to construct governance that reflects our understanding of how the system is structured and functions. We may want to copy the approaches other professionals have used or offer as best management practices. Within these contested settings, some voices will be louder than others and some may have more real power than others-for example, political or financial voices. We may fall into our own routines of understanding and learning and fail to hear important voices because we do not appreciate the legitimacy of their authority. We may also fail to anticipate change, recognise how contexts are developing or appreciate the loosely coupled nature of causes and consequences. Inversely, we may become so convinced that we can direct change that we take too long to accommodate it. In sum, while we are trying to solve problems in a contested and complex environment, we are likely to be contributing to new problems that may not emerge in obvious ways. In other words, we may be doing our job well but are not providing needed leadership for something as complex as managing and governing protected areas.

\section{Section summary}

After we acknowledge the complexity and character of the system, we can quickly see how to go about simplifying complexity into a set of meanings and practices that are manageable. Some of the common methods we use to make sense of the world can lead to oversimplification or be driven by the intensity of issues or voices that emanate from a small portion of the system. In this section, we analysed common practices used to constructively simplify systems. Insights that emerge from that process are as follows.

- When we understand something, it no longer seems as complex.

- We simplify the inherent complexity of a system to be able to better conceptualise, communicate about, understand and act on a forthcoming decision.

- While simplification is necessary for us to function effectively, it comes with a risk that we assume predictability for which there may be little justification. When we focus on prediction rather than understanding, we are often surprised by events that we have not anticipated.

- In applying systems thinking, we construct a model of our environment based on our understanding of linkages, components and contextual influences. A model is a simplified representation of the real world and the system in which we operate. 
- Models connect one system component with another through some kind of relationship. What model we choose to represent any particular system is influenced by our own knowledge and needs, the importance of a particular system, the resources and capacities we have at our disposal, and the risks and consequences involved in choosing alternative pathways.

- A model should help you describe and bound your system, as well as help you find leverage points among the relationships within it. Leverage points are those places within the system where a small amount of change can lead to larger changes in other parts of the system.

- Modelling assists us in developing insights to create situational awareness, which is a key practice for benefiting from complexity. When you know where and how to look, it is much easier to know what is going on around you.

- The mental models within us are how we make sense of the external reality with which we interact. These mental models simplify our perceptions of the real world and have a great influence on what things we attend to and of which we are aware.

- Numerous models are available to help us understand the system properties and relationships inherent in the management and governance of protected areas. These models help us see the broader picture of the complex social-ecological system we are operating within. Seeing how the system works, we are able to assess our own mental models and processes for simplification relative to a broader context. This assessment provides a check and balance on our own decision-making, ensuring that we have not oversimplified a situation or are only listening to the voices emanating from one part of the system.

\section{Engaging complexity}

Human beings, viewed as behaving systems, are quite simple. The apparent complexity of our behavior over time is largely a reflection of the complexity of the environment in which we find ourselves (Simon 1996:110).

How can we avoid the dangers of simplification and put ourselves in the position of engaging complexity effectively? Sterman (2002:504) cautions us that we also need to get away from 'the narrow, event-oriented, reductionist world view most people live by' if we are to be successful in governing and managing protected areas.
In other words, we must simplify to understand, but not 'oversimplify', which would repeat the ineffective approaches of the past to complex problems.

Acting in the complex world of protected area governance and management requires that we engage the complexity we have characterised and modelled. Engaging complexity requires wisdom that has been developed out of the knowledge and understanding created through characterising and simplifying complexity. Wisdom, Ackoff (1999b:16) stated, is the 'ability to perceive and evaluate the long run consequences of behavior'. In this section, we discuss six 'complexity practices' that we believe build wisdom while enhancing governance and management when viewed through the lenses of complexity and systems thinking. The practices are not limited to the resource providers; we would recommend all constituencies deploy them.

\section{Building situational awareness}

\section{Being a keen observer of the situation}

Managers operate in an era of change, uncertainty and surprise. Our strategy for functioning in this context is to heighten awareness so that we sense the unexpected early and prepare to manage in ways that help sustain resilience (Weick and Sutcliffe 2001). In other words, managers who have well-developed situational awareness make continuous adjustments that prevent errors from accumulating and enlarging (Weick and Sutcliffe 2001).

One does not have to spend long among animals in the wild to appreciate the evolutionary significance of situational awareness for both animals and humans. Perhaps what separates humans from most other animals is our ability to reflect on and consciously fabricate situational awareness. We are able to create rules that order behaviour, making it easier for us to interpret and respond to what we observe so that we can better cope with the complexity that attends our lives. For example, driving in city traffic has been made more predictable through the development and enforcement of rules that guide behaviour. Road users learn what to expect, the signals to look out for and how to respond, transforming potentially chaotic situations into ones that are ordered, consistent, more predictable and less confusing. The rules 'simplify' complexity and reduce uncertainty, allowing us to build situational awareness appropriate to the context. When we arrive at work, although the context changes, we are guided by other rules and signals. For example, in a meeting, we pay close attention to body language or tone of voice in order to plan how and when to respond to emerging issues; we reflect on previous experiences 
with participants to interpret their responses and guide our behaviour. When we set out to consciously build situational awareness, we better draw on lessons from past experiences, shape our response to the present and plan for the future.

\section{How do we build situational awareness skills?}

A first step is to appreciate how situational awareness plays a determinative role in our daily activities and that because we live in a changing world, awareness is largely a consequence of how we gather information, reflect and learn. Because the 'rules of the game' we adopt as we progress through life can be so effective in simplifying complexity, we easily become insensitive, perhaps even resistant, to signs and information that do not accord with current preferences and understanding. When this happens surprises become more frequent and may reach serious levels before we become willing to acknowledge them. So, we have to change our habits, consciously building and sustaining learning relationships, characterising the system, modelling it and encouraging acceptance of complexity. Rather than feeling threatened by different understandings people hold of system structure, function and change, we should view them as learning opportunities. Because of the uncertainty that is associated with complex, changing systems, we cannot expect ideas or understandings to be clearly expressed; we have to be patient, inquisitive and encouraging if new shared understandings are to emerge and provide a foundation for collaboration and collective action appropriate to the emerging conditions.

The history of protected areas has its origin in strong conviction of the need to protect natural heritage. Not surprisingly, early approaches to governance of many national parks fostered a culture characterised by protection, exclusion and control, often with a passion that polarised citizenry and management. This culture helped define the context in which governance was exercised, establishing orderliness in roles and routines that simplified complexity and provided a filter for information; information that conformed was accepted and that which did not was rejected. This made the system, and more particularly the people in it, resistant and slow to change. Paul Cilliers (2008) drew attention to the need for 'enduring structures' if a complex system is to retain its identity. He went on to argue that while systems must change if they are to continue to exist, they must also resist some change if they are to retain a recognisable identity. Building situational awareness helps us prepare for and manage the tension between the need for stability and identity in conservation and the imperative for change.
Here are some specific things that we can do to build situational awareness: draw others into dialogue; encourage the sceptics and listen attentively so that the exchanges become learning opportunities; because we all experience the world differently, search for and be open to alternative frames of reference; pay attention to interpersonal skills so that others feel safe raising concerns and new ideas; and welcome others into your thought processes by thinking out loud. Because social learning through interactions with family, friends and colleagues enables us to benefit, we need to invest in developing and sustaining personal relationships.

\section{Invest in personal relationships}

In the previous section of this chapter, we illustrated how the system in which protected area governance and management occurs includes many actors. Within that system the various actors serve as resource users, public infrastructure providers and numerous others indirectly related to those two functions. Thus, how the relationships among those actors are developed, nurtured, encouraged and maintained will be a critical ingredient of the success of protected area governance.

Important considerations include both the nature of the relationship among parties within the system and the structures that provide the platform for those relationships to occur (control, governance, coordination mechanisms, norms, contracts, monitoring routines, and so on). These structures between organisations and among individuals can provide consistency and predictability within the relationships. Over time, these structures also enable the environment for learning, creativity and building trust and respect. Interpersonal relationships assist us in building relational capital and social cohesion that can adapt and remain resilient in the face of challenge or change. When we view our job as partly one of managing relationships (McCool et al. 2013), we position ourselves well to construct the collaborative forms of governance that may have a higher probability of long-term success when we are functioning within a nested hierarchy of social-organisational scales. Collaboration from this perspective can be viewed as a behavioural approach to governance that is guided by a belief that a variety of components working together will provide benefits beyond what would occur in unilateral decision-making. Working together, especially if it occurs over a lasting time frame, reduces transactional costs, enhances performance and develops greater socialecological resilience. 


\section{How does systems thinking lead to beneficial relationships?}

Due to the complexity of governance systems, we also know that these relationships occur at several scales. Panarchy is often referred to as a structure in which system elements at various scales are not only interlinked, but are also adapting together within a non-hierarchical system. We can think of these scales as being nested one inside the other, but of varying value and importance to the behaviour of the system. We can also think of the scales occurring across time frames. Thus, a manager needs to think about the relationships they must maintain within a system in a four-dimensional sense. There are the obvious relationships that are necessary within the same scale: colleagues, partners, and so on. The manager also must be thinking about relationships that go higher in government than where he or she works, as well as the relationships to be maintained with those who are affected by the decisions made.

Further, managers must realise that some of the issues they deal with today result from relationships that occurred in the past. Likewise, the results of the decisions they make today may not materialise until some time in the future. While we easily identify the formal relationships we must maintain amongst organisations and institutions, we must also consider interpersonal relationships with the individuals who make those organisations and institutions work (Nkhata et al. 2008).

How does managing relationships help us engage with complexity? First, taking a good look at the system as described in the 'Characterising complexity' section of this chapter enables us to see who is involved in the system and better understand how existing relationships are the legacies of previous interactions or lack of interaction. Second, being aware of the system we are working within may lead to a better understanding of the need for relationships that may actually seem counterintuitive. For example, managers may find it quite advantageous to the natural heritage of protected areas to build a functional relationship with key staff within companies who represent extractive interests associated with the protected areas they manage. While at some moments the goals of these two parties may seem at odds, in other situations it may be quite possible to complement one another's agendas.

Relationships, like other components of complex systems, are always changing. Further, those changes are not likely to be linear in direction or development. Thus, one cannot expect that relationships with colleagues will automatically improve through more interaction. Rather, as we see in our closest family ties, evolution in the strength of our relationships often occurs when the relationship is tested and challenged. Nkhata et al. (2008) recently used Holling's adaptive cycle to illustrate how changes in relationships can be anticipated and how those changes can test the relationship's resilience. In their paper, the authors argue that collaboration can best occur when there is a high degree of relational connectedness and a high potential for relational capital. In other words, if two or more parties are clearly forced to engage and do so with the benefit of solid relationships, their opportunity for creative collaboration is high. If, however, their degree of connectedness is high but they do not have the benefit of constructive relationships, they are much more likely to operate in an adversarial-type relationship. It is not uncommon for a relationship that has been collaborative for some time to quickly lose relational capital and descend into an adversarial structure. While there are often many reasons for these changes that are beyond the control of managers, there are many things a manager can do on an interpersonal level to nurture and maintain a good environment for collaborative relationships.

\section{How do we develop and maintain positive relationships?}

Suggestions as to how to maintain healthy relationships are many. While the success or failure of many strategies will depend on the context of an interaction, there are some basic ideas that do tend to transcend humanity. For example, in Malcolm Gladwell's book Blink (2005), he describes the work of psychologist John Gottman. In Dr Gottman's career of examining the success or failure of interpersonal relationships, he developed several universal predictors of success. Among the most significant are to sincerely provide five positive interactions for every negative interaction in a relationship. This principle suggests that as humans we react more strongly to negative encounters than positive. Some negative encounters are worse than others. For example, showing signs of contempt for or superiority over a party within the relationship is a sure sign of hard times to come. Unfortunately, it is not uncommon to see exactly this form of interaction on issues related to protected area management. Contempt is often displayed towards those embracing differing sources of information and knowledge, having differing levels of authority relative to land management, or who are expressing values that are not shared by the other party. It is incumbent on us as protected area managers to rise above these forms of interaction.

A systems approach instructs us that losses in relational capital can have devastating effects on our ability to be effective in protected area management. Moving out of adversarial interaction styles requires a reorganisation 


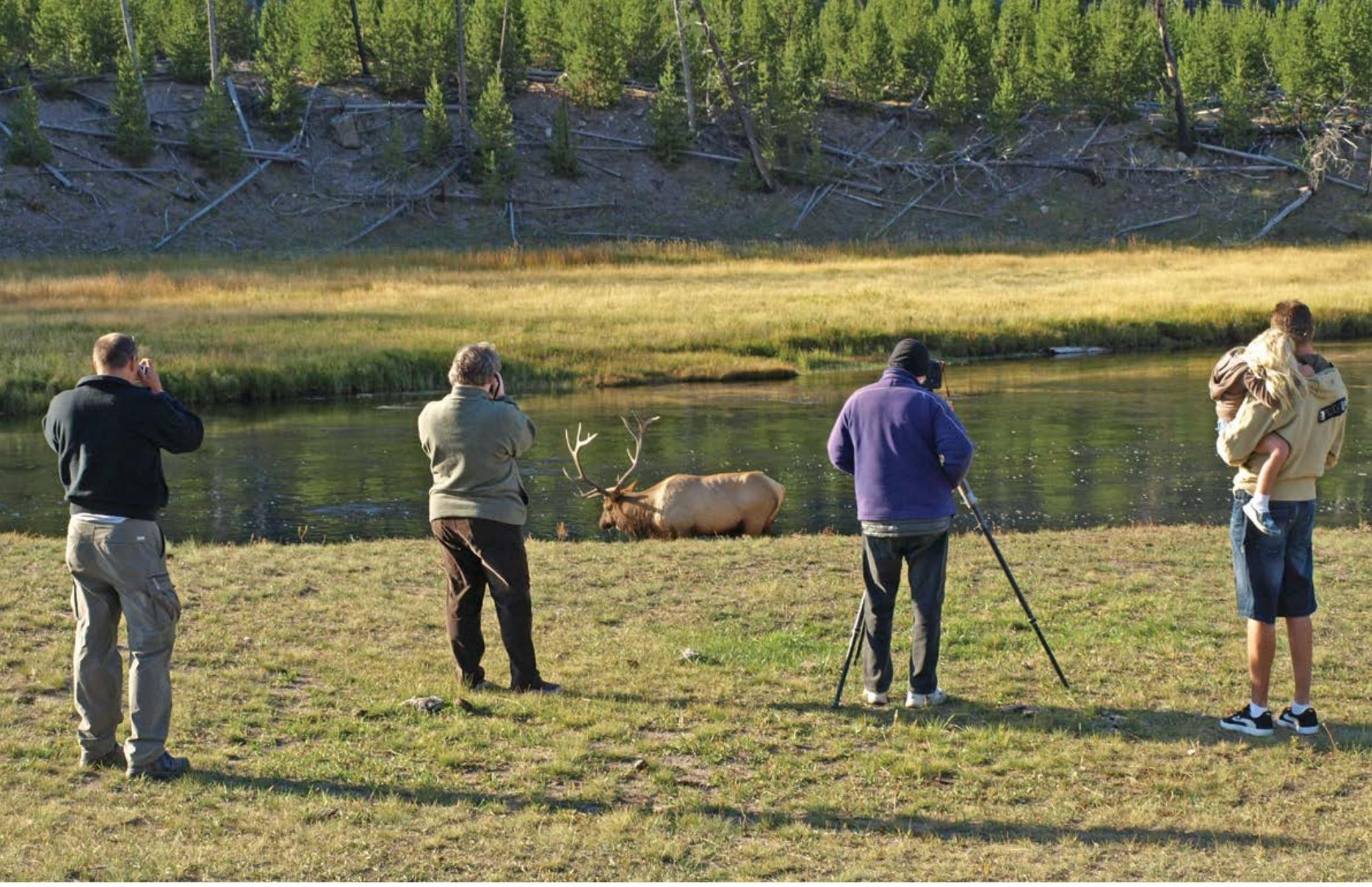

Wildlife and human interaction in Yellowstone National Park, USA

Source: Graeme L. Worboys

of the relationships within the system and often the development of a new vision for moving forward. Thus, the manager should think carefully about how much change this area can absorb before they dismiss the concerns of those who are disagreeing with them.

\section{Appreciate the power of networks}

\section{What is a network?}

The complex systems in which protected areas are embedded are composed of many separate entities that are connected at various scales that create a system with a purpose that is larger than the sum of its parts. Networks are what hold systems together. They provide mechanisms and pathways for communication, exchange among actors and development of shared or disparate visions. Using networks composed of people helps build in the various perspectives needed to characterise and simplify complexity. Ormerod (2012) describes three types of networks. Scale-free networks are those in which most people are not connected but a small portion within the system is tightly connected to many people. These are the type of networks that can be easily understood through ideas such as six degrees of separation, which suggests that most people within a system can find acquaintance with another with no more than six people between them. Thus, the readers of this book may be from all over the world but with careful analysis may be able to find the people who link them in common. In many cases, it will take far fewer than six people to make the connection. For example, if you work in protected areas, no matter the country, you probably know somebody who knows somebody who knows the other readers of this book.

The second type of network is termed a small-world network. Rather than a small number of people being highly connected to many people, these are overlapping sets of acquaintances or friends. Thus, while the leverage points of influence are less obvious in these types of networks, the potential for adoption of ideas is still quite high. In fact, in small-world networks it is less demanding to spend the time finding the connecting people who are critical to scale-free networks. Much social media that guides the way we communicate today could be characterised as small-world networks. This is often the way videos, pictures, incidents or stories can quickly go viral and enjoy global consumption. In small-world networks, attraction to popular items has a disproportionate effect on people's choices. For example, if a video of a game ranger chasing an elephant is posted on YouTube and becomes 'popular' or 'trends', 
many people will see it simply because of its popularity. The more novel, provocative or interesting the item is, the more likely it is that it will continue to progress through networks of friends until it has reached across what in this case can be a global system.

The third type of network referred to is a random network. In these networks, behaviour is transmitted through random conductivity within the system. This type of system can often be compared to the transmission of a virus. For example, you may be unlucky enough to sit next to somebody on a train who has a cold and catch it. Then as you move through your day you transmit the same virus to other people who were equally unlucky to come in contact with you. Once enough people come in contact with others, this cold can infect an entire system. Or we may sit next to a person on a plane who happens to share an interest in protected areas and who also is an important stakeholder. That random network then may be converted to a small-world network.

\section{Why is using networks important for engaging complexity?}

Ormerod (2012:153) tells us:

The crucial challenge for policymakers is to understand and take account of the fact that networks are becoming more and more important in the social and economic world. The Internet revolution in communications technology is obviously a key factor. But the entire second half of the 20th century featured the massive rise in globalisation, a huge increase in travel, and a greater and greater proportion of the world's population living in cities, exposed to many more people, many more networks than they would be in the confines of the village.

Thus, since the scale and scope of the systems we are dealing with are global, behaviours and pressures in this system may occur in ways we would never anticipate and come from places that are far from our day-today mindsets. For example, we pointed out earlier that international animal-rights groups can now have an impact on management policy within any given country. Depending on the types of networks that are operating, those international reactions to an issue can be almost instantaneous and overwhelming. Thus, we must consider the way networks affect not only the behaviour of individuals, but also the forces that are affecting the social-ecological systems in which we are engaged.
When confronted with complexity and the desire to simplify it, one mechanism is to copy the actions of others (Ormerod 2012). When doing so, we assume that others may be more informed than we are on any given topic. Accessing examples or tools to copy can be one of the most powerful benefits of engaging networks. In fact, we organise considerable opportunities for training, higher education, mentoring and various certifications to enhance our awareness and understanding of tools and concepts. When combined with positive personal relationships, as described in the previous section, these networks can help us increase our capacity (intellectual, financial or workforce) and address complexity.

Networks, however, can generate their own behaviour. This can occur, for example, when numerous people begin to copy one another, all thinking the other is more informed, leading to a herd mentality; dissemination may be all but instantaneous and rapid change can occur with unpredictable consequences. We see examples of this behaviour in financial markets and in recent political protests and rebellions assisted by digital social networking platforms.

\section{Exploiting networks}

From a protected area perspective, we can think of many ways that networks are formed. For example, consider a protected area such as Yellowstone National Park, which receives more than three million visits per year, with as many as 30000 of those visitors in the park on any given summer day. Each has the opportunity to interact with the others and may have many kindred interests that would make those interactions likely. Through their interactions, they can inform one another of the locations of wildlife sightings, how to find good campsites or where to find good meals in the park. Ormerod would consider these positive links, in which the network takes on its own behaviour, leading to mutually beneficial results for people connected in a network. With the easy access of digital communication technology, those 30000 people can also be interacting with many more people who are outside Yellowstone through small-scale networks. By updating their Facebook pages, YouTube or Twitter accounts, they can form a much larger network focused on the park. If an incident were to occur, such as a tragic human-wildlife interaction, that incident is likely to reach thousands of people and be resubmitted to thousands more before management has the opportunity to craft a communication to either the visitors or the broader society. This is an example of how small-world networks are changing the relationship management has with society and illustrating how limited managers may be in controlling events. 
So what does all this mean for governance and management? First, we need to recognise the importance of networks within the systems in which we are embedded. In many cases, the people within those networks may have more influence on the system than the policy we may be proposing. In all types of networks, decision-making is often based on relatively superficial understandings, with great faith given to copying other people. Thus, popularity has a disproportionate influence on the dissemination of ideas, behaviour and support for or resistance to policy. Anticipating this, it is critical that we engage networks rather than ignore or avoid them. The authors have often heard discourse among management that rejects the emergence or importance of information technology and social networking systems. Thus, smart phone apps, Facebook pages or interactive websites are often considered trivial, inauthentic or inappropriate for a protected area setting. We reject these at our own peril. Society is moving in this direction and without the capacity to engage these networks constructively we give up what little influence we do have on how they are connected to our protected areas.

Second, by engaging networks, particularly scale-free networks, we can find opportunities to gain considerable leverage through expanding resources, influencing public opinion or designing and implementing policy. By taking the time to understand who within a given network seems to be connected to everybody else, and investing in relationships with those individuals, we can not only learn considerable lessons about what the people they know think, we also have an increased opportunity to influence the system we are embedded within.

Third, by analysing a network, particularly a scalefree network, we can understand who within it is the most connected and therefore would possibly be a good ally or source of information. For example, if you are working in a community, there are probably several people who know everybody and also have considerable influence. Thus, gaining their insight on goals, visions and interventions may have a disproportionate effect in a large portion of the community. The importance of networks has been illustrated by the International Seminar on Protected Area Management (Box 10.5).

\section{Identify and use leverage points}

Children playing on a seesaw in a park quickly learn the relationship between action and reaction, between cause and effect, and between source and outcome, even though they may have little understanding of the physics of levers. They know where and how to act to bring about (to leverage) change to achieve a preferred outcome. When cause and effect are linearly related and tightly coupled, it is relatively easy to identify points of leverage. It is much more difficult in complex systems because of the way effects are propagated through networks, being weakened or strengthened, arising unexpectedly and sometimes after long delays. Yet, because society depends on preferred sets of benefits from ecosystems, management is directed towards identifying leverage points that can be applied to either sustain or bring about this preferred set.

A leverage point is a place in a system where managers can intervene to change conditions or trajectories of system development. We seek leverage points because we detect, most often, a failure in achieving a goal or a problem that has arisen and now has become a major challenge.

Consider a protected area manager confronted with rising visitor use at a popular, but sensitive site within a national park, such as the Victoria Falls World Heritage Property along the Zambezi River astride the Zimbabwe-Zambia border. Myriad choices await the manager because doing nothing would endanger the very values for which the protected area was established. These choices involve many domains: identifying specific goals for visitor and tourism management, constructing alternative management actions or interventions, deploying personnel, securing funding for implementation, choosing indicators to monitor implementation and outcomes, measuring consequences to the local business community, defining at what point impacts become unacceptable, understanding how to incorporate and exploit various forms of knowledge in the decisions to be made, convincing politicians to support actions that may impact negatively on the local economy in the short term, and determining what opportunities for visitor experiences exist and are appropriate. What action has the greatest leverage in addressing impacts?

In addition to selecting among many avenues of intervention, managers commonly operate in settings where available information is inadequate, understanding is superficial, research provides ambiguous, even conflicting, interpretations, and levels of uncertainty are high. If intervention seems necessary, focusing on identifying points of leverage not only helps decide where and how to intervene but, importantly, it allows the logic that was used to make the decision to be recorded in a meaningful way. Revisiting the logic allows us to learn from experience and is an important process in adaptive management. 


\section{Box 10.5 The International Seminar on Protected Area Management as network-building}

The power of networks as a change agent is illustrated by the International Seminar on Protected Area Management, a training program conducted annually since 2000. More than 400 managers have cycled through the three-week intensive program in its 15 years. Over that time, the authors of this chapter, who also are involved in directing the seminar, have seen it serve as a force involved in changing one of the conventional paradigms of protected area planning from one of command and control or fences and fines to one of greater inclusiveness. This conventional paradigm regarded the utmost possible protection of nature from human intervention as the principal means of biodiversity conservation.

Over the past decade of the seminar, however, we have seen a dramatic movement away from conventional approaches to greater enthusiasm for adoption of more community-based management paradigms that seek ways for the benefits of conservation to be shared with local people and to demonstrate the direct positive and beneficial connections between conservation and their lives. Seminar participants often engage in dialogue challenging conventional paradigms while seeking approaches to conservation involving communities, as they see these as simply more effective.

It is clear to us as instructors, however, that the general understanding of what it means to engage communities is highly superficial. Participants in our seminar will quickly comment that engaging communities is essential to conservation. But when asked basic questions about how to engage communities or even to find them, responses are limited and quite varied. This demonstrates how a change in the fundamental perception of what protected area management is occurs not because managers are deeply steeped in theory, analysis or experience, but rather because discourse about protected area management has rapidly included the need for community engagement. People in the management community are adopting that language with a limited understanding of what it really means.

This example illustrates that networks at different scales may operate very differently with vastly different consequences. So while a global network of protected area managers may build awareness of new approaches, challenges or opportunities, smaller scale networks are probably better suited to building competencies and confidence. This adoption of a new management paradigm is one example of what Ormerod (2012:127) refers to as 'a world characterized by the psychology of the society of individuals each of whom is endeavoring to copy the others. A world in which the optimal decision can never be known ... And a world in which the unexpected happens all the time.' Depending on your perspective, of course, whether this change towards community conservation is positive or negative will be based on how you filter this new information through your existing world view. The point here, rather, is that even those who resisted increased access for local community members for much of their careers have quickly changed their mind and moved towards what is emerging as an increasingly popular idea.

\section{Why focus on leverage?}

Interventions are how systems, conditions and processes are changed. We focus on leverage because we want our interventions to be not only effective but also efficient. We want to achieve the maximum change with the minimal effort. We often search for leverage points in determining how to achieve goals or change the system. These searches are often popularised by the notions of the 'silver bullet', 'magic number' or 'getting the biggest bang for the buck'.

It may not be intuitively clear where to intervene in the system, how to intervene and what interventions would lead to the greatest positive or negative consequences. Given that protected area goals are usually vaguely defined and at least partly competing, the situation is muddled if nothing else. Protected area systems have both negative and positive feedback loops, and choosing where to intervene can result in unanticipated consequences and even lead to effects completely the opposite of what was intended.

Donella Meadows (1999) identified a number of places where interventions in a system may occur. These are shown in Table 10.1. What is clear in this table is that managers must understand the nature of the system in which they are functioning in order to choose interventions that will work and have leverage on changing conditions. 
Table 10.1 Points at which to intervene in a system, ordered by increasing leverage

\begin{tabular}{|c|c|}
\hline Places to Intervene in a System & $\begin{array}{l}\text { Example of How These Places Could Be Used to } \\
\text { Manage High Levels of Visitor Use }\end{array}$ \\
\hline Constants, parameters, numbers & Change length of stay \\
\hline Sizes of buffers and other stabilising stocks relative to their flows & Reduce size of parking facility \\
\hline $\begin{array}{r}\text { The structure of material stocks and flows (such as transport } \\
\text { networks, population age structure) }\end{array}$ & Construct additional trails to disperse visitor use \\
\hline Lengths of delays relative to the rate of system change & Monitor use and impacts more frequently \\
\hline $\begin{array}{r}\text { Strength of negative feedback loops, relative to the impacts they } \\
\text { are trying to correct against }\end{array}$ & $\begin{array}{l}\text { Make access more difficult, for example, by charging fees based on } \\
\text { visitor group size }\end{array}$ \\
\hline Gains around driving positive feedback loops & $\begin{array}{l}\text { Provide more visitor education about the importance of natural } \\
\text { heritage values }\end{array}$ \\
\hline $\begin{array}{r}\text { Structure of information flows (who does and does not have } \\
\text { access to what kinds of information) }\end{array}$ & $\begin{array}{l}\text { Provide timely information to visitors about temporal patterns of } \\
\text { visitation }\end{array}$ \\
\hline Rules of the system (e.g. incentives, punishments, constraints) & Charge differential visitor use fees by time \\
\hline $\begin{array}{r}\text { The power to add, change, evolve, or self-organise system } \\
\text { structure }\end{array}$ & $\begin{array}{l}\text { Revise management plan to address visitor-induced social and } \\
\text { biophysical impacts }\end{array}$ \\
\hline Goals of the system & Change objectives with respect to visitor experiences \\
\hline Mindset or paradigm out which the system arises & Reframe the purpose of the protected area \\
\hline Power to transcend paradigms & $\begin{array}{l}\text { Consider alternative ways of administering the protected area } \\
\text { (e.g. contracting the park, allowing private sector administration, } \\
\text { prohibiting visitor use) }\end{array}$ \\
\hline
\end{tabular}

\begin{tabular}{|c|c|c|c|c|c|c|}
\hline $\begin{array}{c}\text { A } \\
\text { Difficult } \\
\text { Social } \\
\text { Problem }\end{array}$ & $\begin{array}{l}\text { can only be } \\
\text { solved by }\end{array}$ & $\begin{array}{c}\text { TOOL } 1 \\
\text { ROOT } \\
\text { CAUSE } \\
\text { ANALYSIS }\end{array}$ & $\begin{array}{l}\text { doing this reliably } \\
\text { and efficiently } \\
\text { requires }\end{array}$ & $\begin{array}{c}\text { TOOL } 2 \\
\text { PROCESS } \\
\text { DRIVEN } \\
\text { PROBLEM } \\
\text { SOLVING }\end{array}$ & $\begin{array}{l}\text { getting this right } \\
\text { for this type of } \\
\text { problem requires }\end{array}$ & $\begin{array}{c}\text { TOOL } 3 \\
\text { MODEL } \\
\text { BASED } \\
\text { ANALYSIS }\end{array}$ \\
\hline
\end{tabular}

Figure 10.4 Using root-cause analysis

Source: Adapted from Thwink (2014)

\section{Enhancing use of leverage}

There are a number of ways that leverage can be used and enhanced. We note that identifying and implementing leverage points may be neither obvious nor easy. The further down in Table 10.1 we move, the more costly the interventions become. The further down we go, however, the more likely is change to occur and the more likely it is our actions will elicit fundamental rather than symptomatic change. A process to help identify leverage points is identified in Figure 10.4. One begins first with root-cause analysis, which attempts to identify the fundamental causes of the problem.

This is sometimes conducted by simply asking why five times. Each time the why is answered, the answer is subjected to why. So, for example, if the impacts of visitor use are high, one would ask why? If the answer is 'too many people', one would ask why again, repeating until a fundamental cause or causes are identified.
By progressing to causes that seem to be fundamental, we are positioned to identify leverage points that are more likely to effect change that will lead to the preferred state.

A word of caution: because of the networked nature of protected area systems, coupling may be loose such that an outcome can arise through alternative pathways and take a long time to manifest, or it may be tight such that effects immediately arise upon implementation of an action. Observed change can be a result of a sequence of management decisions, each of which on its own may seem inconsequential. Under these conditions it becomes difficult, even impossible in some situations, to trace a 'root cause' that provides a locus for leverage. And because we may feel the need to show decisiveness, we willingly accept simplification, thereby raising the risk of selecting a leverage point and making a decision that aggravates the problem and compounds the difficulty of finding a better approach. The situation is not hopeless. 
Unlike mechanical systems, social-ecological systems are loosely coupled, which means there is always 'slack' in the system that allows time for reflection. And, if we conduct ourselves with heightened situational awareness so that we become more conscious of small changes and early warnings, we can experiment with and learn from change.

One can also conduct a problem-solving process. For example, Mosimane et al. (2013) asked why humanwildlife conflicts were growing in Namibia despite significant, and growing, investments in management to prevent them. They reported that the mental models of conflict included the Ministry of Agriculture and Lands because that ministry identified land suitable for farming that regularly included wildlife habitat. This analysis thus suggested that working with this ministry could be a key leverage in reducing conflict.

\section{Employ different forms of knowledge}

\section{What do we mean by knowledge?}

Knowledge is, as Russell Ackoff (1999b) argued, knowhow, or information about how systems work. Knowledge of how to do things is critical to planning, implementing and monitoring interventions to retain or restore system structure, function and pattern, in determining if a system is close to an important threshold, or in identifying leverage points. In contemporary Western society, we typically think of knowledge as being sourced from science. Managers often proclaim there are not enough data to indicate what alternative to choose, how to assess consequences or to determine what and how a species might be impacted by a particular intervention. But knowledge as knowhow is not restricted to that developed by scientists. Knowledge accumulates from experience, either that formally constructed from scientific experimentation and research or that constructed from other kinds of experience. Our experience may be direct or we may learn from othersthe whole point of formal education-either directly or indirectly. We also accumulate knowledge in other ways such as through informal interactions with friends and colleagues and from rituals, norms and behaviours of our or others' culture. In dealing with the complex systems in which protected areas are embedded, most of our knowledge will actually come from others. US Forest Service fire managers had little direct experience with accumulating fuels, for example, but relied on measures of accumulation by others and on theories of plant succession formulated by others.
In addition to scientifically/technically based knowledge, there has been increased interest in indigenous knowledge as important in managing complex socialecological systems. Berkes et al. (2000:1252) define this kind of knowledge as as a cumulative body of knowledge, practice, and belief, evolving by adaptive processes and handed down through generations by cultural transmission, about the relationship of living beings (including humans) with one another and with their environment'. Such indigenous knowledge can play important roles in making decisions about interventions, particularly when other forms of knowledge are deficient.

\section{Why should we use different forms of knowledge?}

To survive in a world of ever-changing challenge, people rely on knowledge and mental models of the systems in which they are embedded. We have noted how these mental models are influenced by our own experience, background and other factors. Mental models are neither right nor wrong, but are more or less useful. For a long time, management of protected areas was dominated by reliance on formal systems of knowledge, which we generally term scientific or technically based. This reliance was influenced by a mental model of planning based on the perceived efficacy of expertise in solving problems. The result was an approach often termed 'rational-comprehensive planning', which relied on and thus required enormous-and expensive-amounts of data for decisions.

Yet, a close examination of the underlying assumptions of rational comprehensive planning reveals important limits. For example, it assumes a single objective about which there is a consensus. Further, it assumes a comprehensive search for alternatives, requiring huge amounts of information for evaluation, despite the reality that rarely do the budget, time or political willingness to permit this exist. Perhaps most importantly, it implicitly treats problems as technical and value-free-and thus subject to technical-rational analysis and resolutionwhen increasingly, the value-based, political nature of such problems is acknowledged as the primary driver: views that are built upon the assumptions of the PLUS world. And what kind of knowledge we need is based on understanding answers to the 'why' questions we noted earlier. For example, in the decade-long controversy over management of snowmobiles in Yellowstone National Park, the kind of knowledge managers seek to resolve this issue now also includes a greater emphasis on underlying beliefs and values about the purpose of the park and the role of snowmobile access in that purpose. 
Other forms of knowledge, such as those based in personal experience and cultural values, are often as useful as scientific knowledge in making decisions. Such knowledge involves descriptions and uses of plants, animals and minerals, the spatial and temporal distribution of the availability of these, and a social frame of reference concerning the way in which people use, allocate and manage these attributes as resources within the context of their experience and cultural norms (Johannes 1993).

By incorporating diverse forms of knowledge, our mental models become more useful in creating insights about how something works, and eventually developing wisdom, our understanding of a complex system, particularly its purpose, and how it relates to other systems. This understanding moves concerns about interventions from the realm of efficiency to those of effectiveness and equity.

\section{Learn continuously}

\section{Why we need to learn}

It is quite clear that governing and managing protected areas must be based on a diverse knowledge base while at the same time recognising that knowledge is tentative, that science and other forms of knowledge evolve and lead to new discoveries, insights and understandings, and that learning is an essential strategy for managers and constituencies embedded within protected area socialecological systems. Given the dynamic complexity of these systems, surprises occur, unintended consequences happen and impacts may be greater or lesser than anticipated. As we apply new knowledge, we begin to reduce the risk of these outcomes. And as diverse sources of knowledge are also applied, we begin to enhance the capacity of protected area managers to better understand the systems and structures underlying this complexity, and thus increase the capacity of organisations and constituencies to anticipate, absorb and respond to both slow and fast processes affecting the protected area.

\section{What is learning?}

Building system resilience requires new ways of thinking about learning, governance, management and planning (Garmestani and Benson 2013). By framing goals as part of building system resilience, we begin to ask new and insightful questions about how and why we learn, what is the objective of learning and what role do protected area managers, scientists and other constituencies play in enhancing learning. By considering the notion of a system, we ask questions about delays and leverage points-both important characteristics of protected area systems (Meadows 1999).

Learning may be defined as the detection and correction of error (Argyris and Schon 1978) or the acquisition of information, knowledge or wisdom (Ackoff 1999b). We learn by making mistakes, reflecting on those mistakes, understanding their causes and correcting them with actions. We learn by being confronted with alternative perspectives and viewpoints, reflecting on them and assessing their relevancy and validity in the system being discussed. We learn through conflict and contention when we attempt to resolve competing demands. We learn when we take action, consider the outcomes and revise the action to make it more effective, efficient and equitable.

Learning requires the ability to sense the contextualising environment (in a number of different domains), to understand the changes occurring, to reflect on and evaluate them and then act appropriately. Doing so leads to single-loop learning - a process of detecting errors and correcting them. This style of learning is what we are most comfortable dealing with and it is what we have generally been taught. The feedback loop is tight in the sense that monitoring a management action and reflecting on the results can provide relatively immediate information as to the consequences of it.

In the complex world of protected areas, however, a number of 'governing' variables - such as the design of a conservation organisation, its cultural norms or the mental model of its mission-operate and make learning more challenging. By attending to larger scale relationships and conditions that provide the context for smaller scale management actions, we learn about the factors that may question whether the standard or norm is the most appropriate one. Argyris and Schon (1978) term this 'double-loop' learning. Double-loop learning is particularly important in eras of change, uncertainty and complexity, when the systemic causes of errors may be difficult to uncover.

For example, shifts in the preferences and values of society in the 'cloud' may call into question a protected area's mission that is defined solely as biodiversity conservation. Such a mission would likely eliminate human uses of resources that historically had occurred. Action to prohibit extraction of a resource- say, thatching grasscould be tested to see how effective the prohibition is. This would represent single-loop learning. The result of this adaptive management implementation might be that local people continue to violate the prohibition. Examining the organisation's mission, however, might 
reveal that a reframing of the mission to integration of biodiversity conservation and enhancement of local residents' lives would gain more influence over biodiversity conservation by developing ownership of the management of thatching-grass harvesting by the local community and thus reduce impacts on biodiversity more than a complete prohibition on that activity.

\section{Encouraging learning}

There are a number of ways we can encourage managers to learn; we briefly present three of them.

\section{Monitoring the implementation of management action}

Monitoring may be defined as the periodic and systematic measurement of key variables reflecting the outcomes of a specific management action. Monitoring provides the means by which management may detect error and affords the foundation by which correction of the error may occur and be monitored. Too often, however, monitoring is viewed as an action external to actual management, with many protected area agencies indicating they have no funding for monitoring.

\section{Reflection and evaluation}

To learn, we must detect errors, mistakes and unanticipated consequences. This means we not only explicitly monitor the results of a management action, but we also reflect on the outcomes and evaluate them in light of the objective of the action-for example, reduce impacts from thatching-grass harvesting. We reflect on the data developed from monitoring implementation. If outcomes are not as expected, we need time for reflection and evaluation to identify the causes of error and ways in which to correct them that are efficient, effective and equitable.

\section{Focus on developing, adapting and revising models}

Sterman (2002:521) noted that the primary benefit of explicating models is that focusing on 'modeling rather than on the results of any particular model speeds learning and leads to better models, better policies, and a greater chance of implementation and system improvement'. This learning is fundamental to adaptation. Without the learning, our adaptation is simply trial and error.

\section{Section summary}

If we are to be successful in governing and managing protected areas, we must simplify to understand, but not 'oversimplify' the system in which we are immersed. We suggest six practices that, if worked into our routines, will aid us in balancing our need for simplification with our need to progress within a complex environment. Following these practices, governors and managers will be better prepared to benefit from complexity.

- Situational awareness enables us to better see and understand the system in which we are embedded. Understanding our role within the system helps us to better see the effects of our decisions and anticipate change.

- Leverage points are the places within the system where we can have the greatest effect. Finding and focusing on leverage points will take the greatest advantage of the resources we have to prioritise our energy to those areas where we can realistically have the greatest impact.

- Systems thinking helps us see that relationships are a fundamental component within a system. Focusing on these relationships will help us leverage our resources, and sense change, issues, emerging demands and concerns within the social system that affects us. By proactively focusing on the relationships among individuals, agencies and organisations that are central to our mission, we build relational capital during the good times that is indispensable amid times of challenge.

- Social systems are largely characterised by networks. Understanding how networks function and how information is used within different types of networks is an emerging skill required for effective management. Only by understanding network effects will protected area managers or those governing protected areas be able to proactively engage networks to assist in relationship building and situational awareness.

- Modelling the complexity of the system quickly illustrates a variety of relationships that occur between protected areas and their social context. While quite different, each of those varying relationships illustrates the opportunity to gain knowledge and wisdom about the system. Thus, we can no longer rely on the power of science, academic education or policy to accurately understand the nature of the system. We must employ and take advantage of a variety of knowledge forms to truly benefit from the complexity of the systems with which we are engaged.

- The rapid pace of change we are experiencing now illustrates that today's knowledge is clearly tentative and that what we learned yesterday may not be what we need tomorrow. Thus, specifically building learning into our routine is more important now than ever. 


\section{Conclusion: Governing and managing adaptively}

In complex systems in which protected area governance and management occur, uncertainty looms large, knowledge is tentative at best and likely incomplete, and consequences are routinely temporally and spatially discontinuous. There is no option but to manage protected areas adaptively. By this, we mean that a culture of reflection, learning and adaptation permeates the conservation organisation. Mistakes and problems are inevitable, and as quantum mathematician David Deutsch (2011) promises, they are also solvable. And thus we manage adaptively, at both the personal and the organisational levels. To do otherwise is to facilitate our demise. Certainly, the US Forest Service found that full suppression of fire did not lead to fewer and lessdamaging wildland fires and it could not 'stay the course' in light of this knowledge.

Governance creates the environment in which management can be adaptive, but to truly create that environment, it must itself reflect the adaptability that it expects of management. Adaptive governance processes are designed to allow for strategic dialogue and negotiations around societal beliefs and values represented by diverse constituencies, which then are formally expressed through mandates, policy and multi-level institutions. When governance creates this environment, we benefit by the variety of perspectives expressed and debated, thus enabling the opportunity to address resilience.

Managing adaptively means that we decide, monitor, reflect, learn and decide again. And again. Managing adaptively means that we move towards expanding understanding and developing wisdom-both forms of learning geared towards the future, not focused on the past. Managing adaptively means that organisational cultures and institutions must in many cases also change, away from perceiving conservation as a routine, and towards being ever changing. Sometimes it takes a while for this conclusion to develop, as with the US Forest Service and its fire management policy.

Organisations will need to be agile if they want to manage adaptively. Organisations will need to be functionally fit - holding the capacities needed to manage adaptively, employing the personnel who can think critically and encouraging leaders who promote the culture of reflection and learning that is fundamental to managing adaptively.
The world is complex; it is filled with uncertainty, and it is nearly always contentious. These are the facts of life, so the principal question for protected areas is how can we more effectively operate in such a world? We can do so by first characterising the complexity that confronts us, then simplifying based on that knowledge and then engaging it. As a result, we move towards resilience, and we benefit. The key to understanding and operating effectively is to accept the necessity for simplification while retaining a healthy reluctance to simplify. We integrate these two considerations when making decisions, knowing that they are a way of testing our simplified interpretation, of experimenting, learning and adapting. In this approach, we make smaller, less disruptive and less uncertain decisions more frequently and large decisions that are potentially very disruptive and more uncertain less frequently.

Characterising complexity requires knowledge, which is about how things work. Simplifying complexity is about understanding, which is about why things work the way they do. Engaging complexity is about wisdom, which is about sensing long-term consequences. By thinking in terms of complexity, we benefit from that complexity.

We have illustrated how complexity enriches our lives and how we learn to cope with it. And so it is with governance and management of protected areas. They are embedded in complex social-ecological systems. When we accept that complexity, simplify after developing knowledge and develop situational awareness, we are better at building relationships that widen our circles of learning, helping us to pick up and make sense of early warning signs pointing to the loss of resilience. We are better prepared for surprises and become less reactive and more reflective and willing to accept human fallibility. We allow the trajectory of change to shape our approach to management so that the system retains identity while changing; we are able to intentionally manage in ways that promote resilience. 


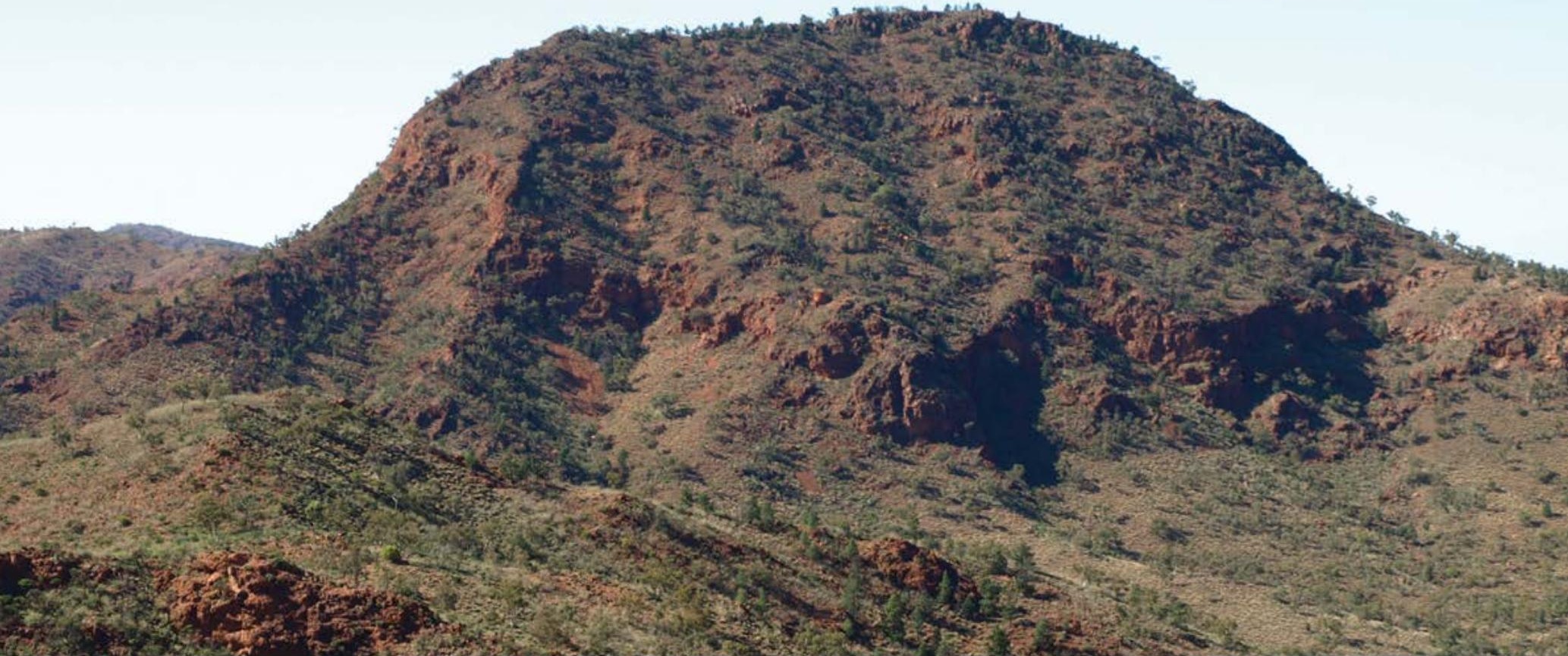

Mount Painter, Arkaroola Protection Area, South Australia: the very top of this mountain features an ancient (Permian) valley with geological evidence of geothermal activity similar to the modern geysers and hot pools of Yellowstone National Park. The surrounding rocks contain many rare and outstanding geological minerals, structures and petrological features including some evidence of uranium mineralisation. It is a geological hotspot of immense value for geologist field survey training and despite the complexity of past mining leases and political processes, the privately owned area has been permanently protected by the South Australian Government.

Source: Graeme L. Worboys

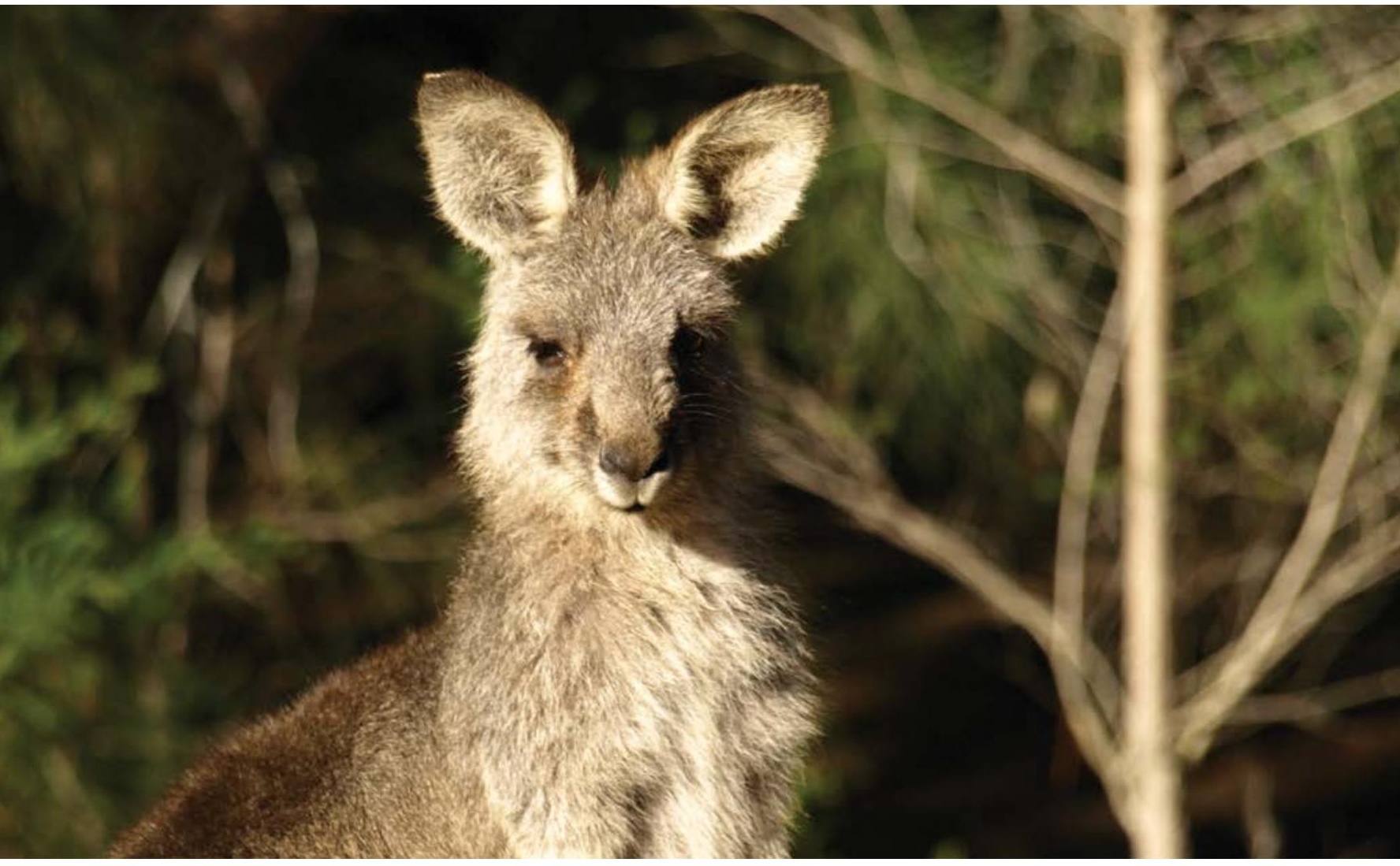

The Eastern Grey Kangaroo (Macropus giganteus) is found free-ranging in Eastern Australia and in many protected areas. It has benefited from a predator-free environment and many populations have outgrown the capacity of their home reserves to support them. For urban and near-urban areas in particular, the issue of managers undertaking any culling of kangaroos (for the sake of other species survival in reserves) is often highly charged and complex and has included high-level political intervention. 


\section{References}

Recommended reading

Ackoff, R. L. (1999a) Re-Creating the Corporation: A design of organizations for the 21st century, Oxford University Press, New York.

Ackoff, R. L. (1999b) 'On learning and the systems that facilitate it', Reflections: The SoL Journal 1(1): 14-24.

Álvarez, M. D. (2003) 'Forests in the time of violence', Journal of Sustainable Forestry 16(3-4): 47-68. <doi: 10.1300/J091v16n03_03>

Dd Anderies, J. M., Janssen, M. A. and Ostrom, E. (2004) 'A framework to analyze the robustness of social-ecological systems from an institutional perspective', Ecology and Society 9(1): 18. <www.ecologyandsociety.org/vol9/iss1/art18/>

Argyris, C. and Schon, D. (1978) Organizational Learning: A theory of action approach, AddisonWesley, Reading.

Bengis, R., Grant, R. and de Vos, V. (2003) 'Wildlife diseases and veterinary controls: a savannah ecosystem perspective', in J. T. du Toit, K. H. Rogers and H. C. Biggs (eds) The Kruger Experience: Ecology and management of savanna heterogeneity, pp. vi-vii, Island Press, Washington, DC.

Berkes, F., Colding, J. and Folke, C. (2000) 'Rediscovery of traditional ecological knowledge as adaptive management', Ecological Applications 10(5): 1251-62.

Dd Biggs, H. C., Breen, C., Slotow, R., Freitag, S. and Hockings, M. (2011) 'How assessment and reflection relate to more effective learning in adaptive management', Koedoe 53(2): 1001. <doi:10.4102/koedoe.v53i2.1001>

Box, G. E. P. and Draper, N. R. (1987) Empirical Model-Building and Response Surfaces, Wiley, Hoboken, NJ.

Bourque, J., Inglis, J. T. and LeBlanc, P. (1993) 'Preface', in J. Inglis (ed.) Traditional Ecological Knowledge: Concepts and cases, pp. 349-69, International Development Research Center, Ottawa.
Capra, F. (1996) The Web of Life: A new scientific understanding of living systems, Random House, New York.

Christensen, N. L., Agee, J. K., Brussard, P. F., Hughes, J., Knight, D. H., Minshall, G. W., Peek, J. M., Pyne, S. J., Swanson, F. J., Thomas, J. W., Wells, S., Williams, S. E. and Wright, H. A. (1989) 'Interpreting the Yellowstone fires of 1988', Bioscience 39(10): 678-85.

Cilliers, P. (1998) Complexity and Postmodernism: Understanding complex systems, Routledge, London.

Cilliers, P. (2008) 'On the importance of a certain slowness', ECO 8(3): 106-13.

Cilliers, P., Biggs, H. C., Blignaut, S., Choles, A. G., Hofmeyr, J. S., Jewitt, G. P. W. and Roux, D. J. (2013) 'Complexity, modeling, and natural resource management', Ecology and Society 18(3): 1. $<$ doi org/10.5751/ES-05382-180301>

Coetzee, M., Biggs, H. C. and Malan, S. (2012) Sharing the benefits of biodiversity: a regional action plan to nurture and sustain the contribution of biodiversity and ecosystem services to livelihoods and resilient economic development within the Kruger to Canyons Biosphere, Report first officially presented 16 November 2012, Nelspruit, South Africa. <www.kruger2canyons.org/ consolidatedtechnicalreportvfin.pdf $>$

Cumming, D. H. M. (2004) Sustaining animal health and ecosystem services in large landscapes - 2nd draft, Concept for a program to address wildlife, livestock and related human and ecosystem health issues in the Greater Limpopo Transfrontier Conservation Area. <www.wcs-ahead.org/documents/gltfca cumming.pdf $>$

Department of Water Affairs and Forestry (DWAF) (2007) Guidelines for the Development of Catchment Management Strategies: Towards equity, efficiency and sustainability in water resources management, Department of Water Affairs and Forestry, Pretoria.

de Shazo, P., McLean, P. and Mendelson, J. (2009) Colombia's Plan de Consolidacion Integral de la Macarena: An assessment, CSIS Americas Program, Washington, DC.

Deutsch, D. (2011) The Beginning of Infinity: Explanations that transform the world, Penguin Press, New York. 
du Toit, J. T., Rogers, K. H. and Biggs, H. C. (eds) (2003), The Kruger Experience: Ecology and management of savanna heterogeneity, Island Press, Washington, DC.

Endsley, M. R. (1995) 'Toward a theory of situation awareness in dynamic systems', Human Factors 37(1): 32-64.

Endsley, M. R. (2000) 'Theoretical underpinnings of situation awareness', in M. R. Endsley and D. J. Garland (eds) A Critical Review in Situation Awareness Analysis and Measurement, pp. 3-28, Lawrence Erlbaum Associates, Mahwah, NJ.

Dd Folke, C., Carpenter, S. R., Walker, B., Scheffer, M., Chapin, T. and Rockström, J. (2010) 'Resilience thinking: integrating resilience, adaptability and transformability', Ecology and Society 15(4): 20. $<$ www.ecologyandsociety.org/vol15/iss4/art20/>

Dd Folke, C., Hahn, T., Olsson, P. and Norberg, J. (2005) 'Adaptive governance of social-ecological systems', Annual Review of Environmental Resources 30: 441-73.

Freitag-Ronaldson, S. and Foxcroft, L. C. (2003) 'Anthropogenic influences at the ecosystem level', in J. T. du Toit, K. H. Rogers and H. C. Biggs (eds) The Kruger Experience: Ecology and management of savanna heterogeneity, pp. 391-421, Island Press, Washington, DC.

Gallopín, G. C., Funtowicz, S., O’Connor, M. and Ravetz, J. (2001) 'Science for the 21st century: from social contract to the scientific core', International Social Science Journal (168): 219-29.

Garmestani, A. S. and Benson, M. H. (2013) 'A framework for resilience-based governance of social-ecological systems', Ecology and Society 18(1): 9. <doi.org/10.5751/ES-05180-1801099>

Gaylard, A., Owen-Smith, N. and Redfern, J. (2003) 'Surface water availability: implications for heterogeneity and ecosystem processes', in J. T. du Toit, K. H. Rogers and H. C. Biggs (eds) The Kruger Experience: Ecology and management of savanna heterogeneity, pp. 171-88, Island Press, Washington, DC.

Gharajedaghi, J. (2011) Systems Thinking: Managing chaos and complexity. A platform for designing business architecture, Butterworth-Heinemann, Boston.
Gladwell, M. (2005) Blink: The power of thinking without thinking, Little, Brown \& Co., New York.

Hanson, T., Brooks, T. M., da Fonseca, G. A., Hoffmann, M., Lamoreux, J. F., Machlis, G. and Pilgrim, J. D. (2009) 'Warfare in biodiversity hotspots', Conservation Biology: The Journal of the Society for Conservation Biology 23(3): 578-87.

International Crisis Group (ICG) (2002) Colombia's Elusive Quest for Peace, International Crisis Group, Bogotá and Brussels.

International Crisis Group (ICG) (2008) Latin American Drugs I: Losing the fight, International Crisis Group, Bogotá and Brussels.

Jackson, M. C. (2003) Systems Thinking: Creative holism for managers, John Wiley \& Sons, Chichester, UK.

Johannes, R. E. (1993) 'Integrating traditional ecological knowledge and management with environmental impact assessment', in J. Inglis (ed.) Traditional Ecological Knowledge: Concepts and cases, pp. 33-40, International Development Research Center, Ottawa.

Jones, N. A., Ross, H., Lynam, T., Perez, P. and Leitch, A. (2011) 'Mental models: an interdisciplinary synthesis of theory and methods', Ecology and Society 16(1): 46. <www.ecologyandsociety.org/ vol16/iss1/art46/>

Mabunda, D., Pienaar, D. J. and Verhoef, J. (2003) 'The Kruger National Park: a century of management research', in J. T. du Toit, K. H. Rogers and H. C. Biggs (eds) The Kruger Experience: Ecology and management of savanna heterogeneity, pp. 3-21, Island Press, Washington, DC.

Dd McCool, S. F., Nkhata, B., Breen, C. and Freimund, W. (2013) 'A heuristic framework for reflecting on protected areas and their stewardship in the 21st century', Journal of Outdoor Recreation and Tourism 1(1-2): 9-17.

Meadows, D. (1999) Leverage Points: Places to intervene in a system, The Sustainability Institute, Hartland, VT.

Meadows, D. (2008) Thinking in Systems, D. Wright (ed.), Chelsea Green, White River Junction, VT. 
Mosimane, A. W., McCool, S., Brown, P. and Ingrebretson, J. (2013) 'Using mental models in the analysis of human-wildlife conflict from the perspective of a social-ecological system in Namibia', Oryx 48(1): 64-70. <doi:10.1017/ S0030605312000555>

Nkhata, A. B. and Breen, C. M. (2010) 'A framework for exploring integrated learning systems for the governance and management of public protected areas', Environmental Management 45(2): 403-13.

Nkhata, A. B. and McCool, S. F. (2012) 'Coupling protected area governance and management through planning', Journal of Environmental Policy and Planning 14(4): 394-410.

Nkhata, A. B., Breen, C. M. and Freimund, W. A. (2008) 'Resilient social relationships and collaboration in the management of socialecological systems', Ecology and Society 13(1): 2. <www.ecologyandsociety.org/vol13/iss1/art2>

Ormerod, P. (2012) Positive Linking: How networks can revolutionize the world, Faber \& Faber, London.

Owen-Smith, N., Kerley, G. I. H., Page, B., Slotow, R. and van Aarde, R. J. (2006) 'A scientific perspective on the management of elephants in the Kruger National Park and elsewhere', South African Journal of Science 102: 389-94.

Pécaut, D. (2001) Guerra contra la sociedad, Espasa, Bogotá.

Perlis, A. J. (1982) 'Epigrams on programming', $A C M$ SIGPLAN 17(9): 7-13.

Peterson, G. D., Cummings, G. S. and Carpenter, S. R. (2003) 'Scenario planning: a tool for conservation in an uncertain world', Conservation Biology 17: 358-66.

Pienaar, D., Biggs, H., Deacon, A., Gertenbach, W., Joubert, S., Nel, F., van Rooyen, L. and Venter, F. (1997) A Revised Water-Distribution Policy for Biodiversity Maintenance in the KNP Kruger Park Management Plan. Volume 8, South African National Parks, Skukuza, South Africa.

Pienaar, U. de V. (1970) 'Water resources of the Kruger Park', African Wildlife 24: 180-91.

Pimbert, M. P. and Pretty, J. N. (1995) Parks, People and Professionals: Putting 'participation' into protected area management, Discussion Paper No. 57, United Nations Research Institute, Geneva.
Pollard, S. P., Biggs, H. C. and du Toit, D. (2014) 'A systemic framework for context-based decision making in natural resource management: reflections on an integrative assessment of water and livelihood security outcomes following policy reform in South Africa', Ecology and Society 19(2): 63. <www.ecologyandsociety.org/vol19/iss2/art63/>

Resilience Alliance (2010) Assessing Resilience in Social-Ecological Systems: Workbook for practitioners, Version 2: 54. <www.resilience.org>

Roux, D. J. and Foxcroft, L. C. (2011) 'The development and application of strategic adaptive management within South African national parks', Koedoe 53(2): 1049. <doi:10.4102/koedoe. v53i2.1049>

Scholes, R. J. and Mennell, K. G. (eds) (2008) Elephant Management: A scientific assessment for South Africa, Wits University Press, Johannesburg.

Senge, P. (1990) The Fifth Discipline: The art and practice of the learning organization, Double Day, New York.

Simon, H. A. (1996) The Sciences of the Artificial, 3rd edn, MIT Press, Cambridge, MA.

Sterman, J. D. (2002) 'All models are wrong: reflections on becoming a systems scientist', System Dynamics Review 18(4): 501-31.

Stirzaker, R. J., Biggs, H. C., Roux, D. J. and Cilliers, P. (2010) 'Requisite simplicities to help negotiate complex problems', Ambio 39: 600-7. <doi:10.1007/s13280-0100075-7>, PMid:21141779.

Stirzaker, R. J., Roux, D. J. and Biggs, H. C. (2011) 'Learning to bridge the gap between adaptive management and organisational culture', Koedoe 53(2): 1007. <doi:10.4102/koedoe.v53i2.1007>

Thwink (2014) Process Driven Problem Solving. <www.thwink.org/sustain/glossary/ ProcessDrivenProblemSolving.htm>

Tidwell, T. (2013) Wildland fire management, Statement of Tom Tidwell, Chief, USDA Forest Service, before the Committee on Energy and Natural Resources, US Senate, Washington, DC.

Turner, M. G., Romme, W. H. and Tinker, D. B. (2003) 'Surprises and lessons from the 1988 Yellowstone fires', Frontiers in Ecology and the Environment 1(7): 351-8. 
United States Agency for International Development (USAID) (2013) Resilience in the Limpopo Basin Program (RESILM): Olifants catchment, USAID, Washington, DC. <www.usaid.gov/sites/default/ files/documents/1860/RESILIM\%20O\%20 Fact\%20Sheet.pdf>

Dd Walker, B. and Salt, D. (2006) Resilience Thinking: Sustaining ecosystems and people in a changing world, Island Press, Washington, DC.

Walker, B. and Salt, D. (2012) Resilience Practice: Building capacity to absorb disturbance and maintain function, Island Press, Covelo, CA.

Dd Walker, B. H., Gunderson, L. H., Kinzig, A. P., Folke, C., Carpenter, S. R. and Schultz, L. (2006) 'A handful of heuristics and some propositions for understanding resilience in social-ecological systems', Ecology and Society 11(1): 13.

<www.ecologyandsociety.org/vol11/iss1/art13/>

Walker, B., Holling, C. S., Carpenter, S. R. and Kinzig, A. (2004) 'Resilience, adaptability and transformability in social-ecological systems', Ecology and Society 9(2): 5. <www.ecologyandsociety. org/vol9/iss $2 /$ art5/>

Weick, K. (1976) 'Educational organizations as loosely coupled systems', Administrative Science Quarterly 21: 1-9.

Weick, K. E. and Sutcliffe, K. M. (2001) Managing the Unexpected, Jossey-Bass, San Francisco.

Whyte, I. J., van Aarde, R. and Pimm, S. L. (2003) 'Kruger's elephant population: its size and consequences for ecosystem heterogeneity', in J. T. du Toit, K. H. Rogers and H. C. Biggs (eds) The Kruger Experience: Ecology and management of savanna heterogeneity, pp. 332-48, Island Press, Washington, DC.

Yankelovich, D. (1991) Coming to Public Judgment: Making democracy work in a complex world, Syracuse University Press, Syracuse, NY. 


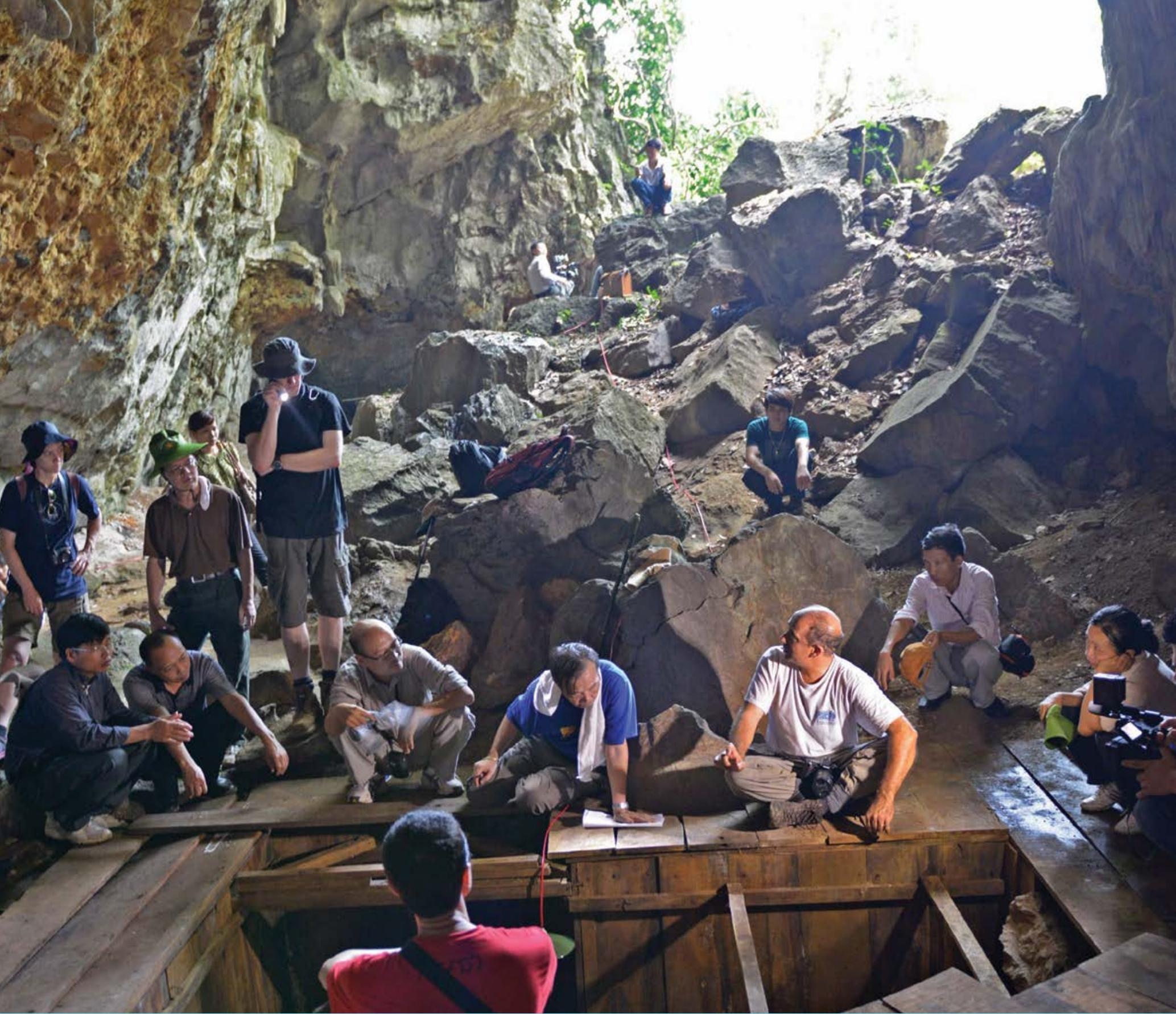

\section{CHAPTER 11}

\section{KNOWLEDGE GENERATION, ACQUISITION AND MANAGEMENT}

\section{Principal authors:}

Naomi Kingston, Brian MacSharry, Marcelo Gonçalves de Lima, Elise M. S. Belle and Neil D. Burgess

\section{CONTENTS}

- Introduction

- What is knowledge?

- Drivers of knowledge generation

- Inputs for knowledge generation

- Importance of standards

- Knowledge sharing

- Knowledge management

- Knowledge use

- Resourcing considerations

- Conclusion

- References
IUCN 


\section{PRINCIPAL AUTHORS}

NAOMI KINGSTON is Head of the Protected Areas Programme at the UN Environment Programme World Conservation Monitoring Centre (UNEP-WCMC), Cambridge, UK.

BRIAN MACSHARRY is a Senior Program Officer in the Protected Areas Programme at UNEP-WCMC, where he manages the World Database on Protected Areas, Cambridge, UK.

MARCELO GONÇALVES DE LIMA is a Senior Program Officer in the Protected Areas Programme at UNEP-WCMC, working with Protected Areas Effectiveness and Connectivity Conservation, Cambridge, UK.

ELISE BELLE is a Senior Program Officer in the Protected Areas Programme at UNEP-WCMC, Cambridge, UK.

NEIL D. BURGESS is Head of Science at UNEP-WCMC and part-time Professor of Conservation Science at the University of Copenhagen, Denmark.

\section{ACKNOWLEDGMENTS}

The authors would like to thank the following individuals who contributed to the development of this chapter: Charles Besançon, CBD Secretariat; Christian Elloran, Association of South-East Asian Nations (ASEAN) Centre for Biodiversity; Diego Juffe-Bignoli, Kelly Malsch and Alison Rosser, UNEP-WCMC; Noelle Krumpe and Olivia Needham, ZSL; Jane Smart and Thomas Brooks, International Union for Conservation of Nature (IUCN); Yichuan Shi, IUCN and UNEP-WCMC.

\section{CITATION}

Kingston, N., MacSharry, B., de Lima, M. G., Belle, E. M. S. and Burgess, N. D. (2015) 'Knowledge generation, acquisition and management', in G. L. Worboys, M. Lockwood, A. Kothari, S. Feary and I. Pulsford (eds) Protected Area Governance and Management, pp. 327-352, ANU Press, Canberra.

\section{TITLE PAGE PHOTO}

The collection of primary data is a critical part of knowledge generation, acquisition and management. Here, at Hang Moi Cave, Trang An World Heritage Property, Vietnam, archaeologists are shown briefing a World Heritage inspection group about an excavation; the layered sediments that the vertical archaeological dig exposed and the subsequent analysis of material from the different layers and their dating. The information obtained included evidence of human occupation of the cave between $10000 \mathrm{BP}$ and $5500 \mathrm{BP}$ which forms part of the important cultural heritage values of this World Heritage property Source: Graeme L. Worboys 


\section{Introduction}

Decisions are made about protected area management every day. Decision-making can occur at different scales, including local, national or global, and by a range of different actors, such as site managers, planners or policymakers, politicians, business managers or funding bodies. In order to make good decisions, all these actors require access to quality data and information to understand and mitigate threats and pressures affecting protected areas and the implications of those threats for biodiversity, ecosystem services and the human communities they support. This chapter focuses on knowledge generation, acquisition and management, with particular reference to protected areas. Very often the terms 'data', 'information' and 'knowledge' are used interchangeably, but there are important distinctions between these terms that are critical to understand in the context of this chapter.

\section{What is knowledge?}

Data are raw numbers associated with measurements or observations, perhaps associated with an ecological process or species, and the nature of data, their collection, analysis, management and communication can be represented as a cycle.
Information is obtained when data have been organised or analysed for a particular context, and knowledge is based on an understanding of the meaning of that information. Cleveland (1982) viewed understanding as a continuum, taking data as a view of the past, knowledge as the present and going one step further to describe 'wisdom' as the future result (Figure 11.1). In the case of protected areas, the knowledge would relate to how information based on data is subsequently used to make decisions that inform policy or affect management activities.

Scarce resources mean that data gathering, information generation and knowledge management need to be as efficient as possible. Modern technologies allow for streamlined data flows, from field-based data collection to web-based data analysis producing information in a form that can be interpreted. Over the past years streamlining, interoperability (the ability for systems to link up and work seamlessly together) and internet-based data sharing have resulted in a paradigm shift in knowledge management. For example, where in the past, biodiversity data were collected at a site level, with the specimens curated in museums and published through the scientific literature, now global data-sharing initiatives, national-level data portals, online publishing and scientifically published data papers facilitate the wide distribution of data and information within a short time, and increasingly in near real-time-for example, the World Database on Protected

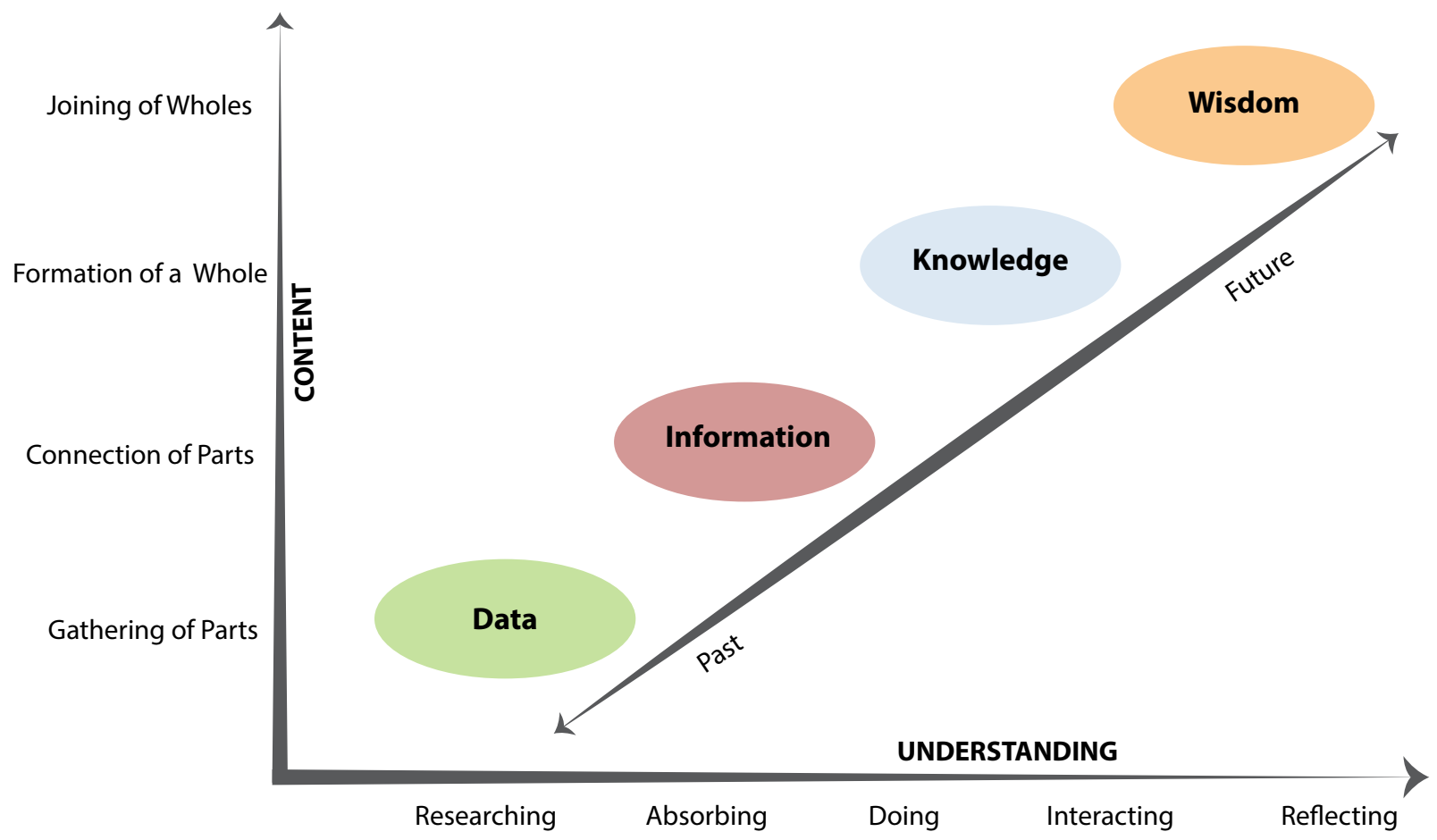

Figure 11.1 The continuum of understanding from the gathering of data, the presentation of information, generation of knowledge and ultimate wisdom

Source: Adapted from Cleveland (1982) 
be adaptive and informed by the information collected through monitoring programs. Where protected areas are open to the public, management authorities may decide to collect information on visitor numbers and their use of a site so they can manage visitor facilities and infrastructure, reduce impacts and threats to both visitors and biodiversity and target education and recreation activities.

Systematic conservation planning is a target-based approach for designing protected area networks and other conservation landscapes and seascapes. It seeks to provide transparent and scientifically defensible information that can be used to guide decision-makers and spatial planners (Margules and Pressey 2000). There are numerous tools available to assist with systematic conservation planning, requiring varying levels of complexity and input information (discussed in detail in Bowles-Newark et al. 2014).

The Conservation Measures Partnership (CMP) has developed Miradi software that applies the Open Standards for the Practice of Conservation-based on the experiences of several conservation organisations in

\section{Box 11.1 Miradi: Software for conservation project planning}

The Conservation Measures Partnership (CMP) has developed a user-friendly software called 'Miradi' (Swahili for 'project' or 'goal') that enables conservation practitioners such as park managers to design, manage, monitor and, above all, receive and perceive feedback from their projects and undertake adaptive management to increase the chances of achieving their goals. For protected areas, this is translated into better management effectiveness towards biodiversity conservation. Miradi can be used for the specific conservation project planning of a species or a set of species, for an entire landscape or ecosystem, or for elaborating management plans, among many other possibilities, by utilising the Open Standards adaptive management cycle shown in Figure 11.2 (see also Chapter 13).

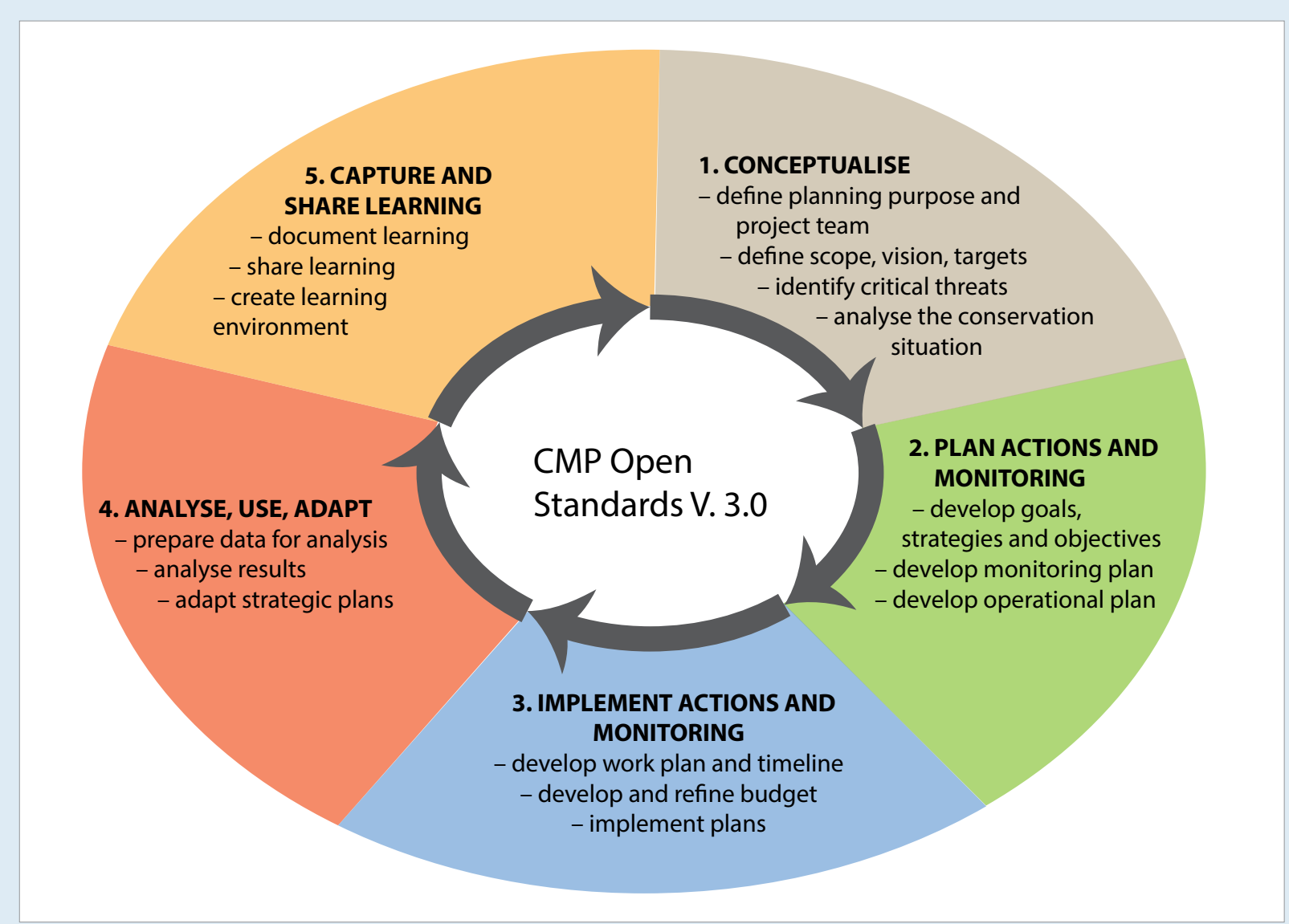

Figure 11.2 The Conservation Measures Partnership adaptive management project planning cycle Source: Adapted from CMP (2013) 


\section{Box 11.2 SMART}

The Spatial Monitoring and Reporting Tool (SMART) is designed to improve anti-poaching efforts and overall law-enforcement effectiveness in established conservation areas and management zones. SMART makes it possible to collect, store, communicate and evaluate data on patrol efforts (such as time spent on patrols, areas visited and distances covered), patrol results (for example, snares removed and arrests made) and threat levels. When effectively used to create and sustain information flows between ranger teams, analysts and conservation managers, the SMART approach can help to substantially improve the protection of wildlife and their habitats.

The SMART approach can be introduced to any conservation area that relies on patrol teams to protect wildlife and the natural ecosystems on which they depend. This approach has already demonstrated its effectiveness in improving law-enforcement effort, improving the morale of enforcement teams and reducing threats to wildlife and other natural resources in multiple sites across the world. At present, SMART is being implemented in more than 120 conservation areas in 27 countries worldwide and is fast becoming a global standard for law-enforcement monitoring and management. The advantage of using a system such as SMART is that it:

- uses the power of information and accountability to help direct resources to the places where they are needed the most

- empowers conservation managers with timely and accurate information on what threats are occurring, where they are occurring and how enforcement teams are responding

- guides conservation managers to use the information strategically to better plan and manage patrolling operations

- ensures accountability and good governance by providing clear and standardised measures of lawenforcement performance for staff, management, administration and reporting

- is affordable; SMART is free to download and use.

SMART was formally launched in early 2011 by the six founding members of the SMART Partnership: the Convention on International Trade in Endangered Species of Wild Fauna and Flora Monitoring the Illegal Killing of Elephants (CITES-MIKE), the Frankfurt Zoological Society, the North Carolina Zoo, the Wildlife Conservation Society, the World Wide Fund for Nature (WWF) and the Zoological Society of London.

- Olivia Needham, Zoological Society of London, on behalf of the SMART Partnership

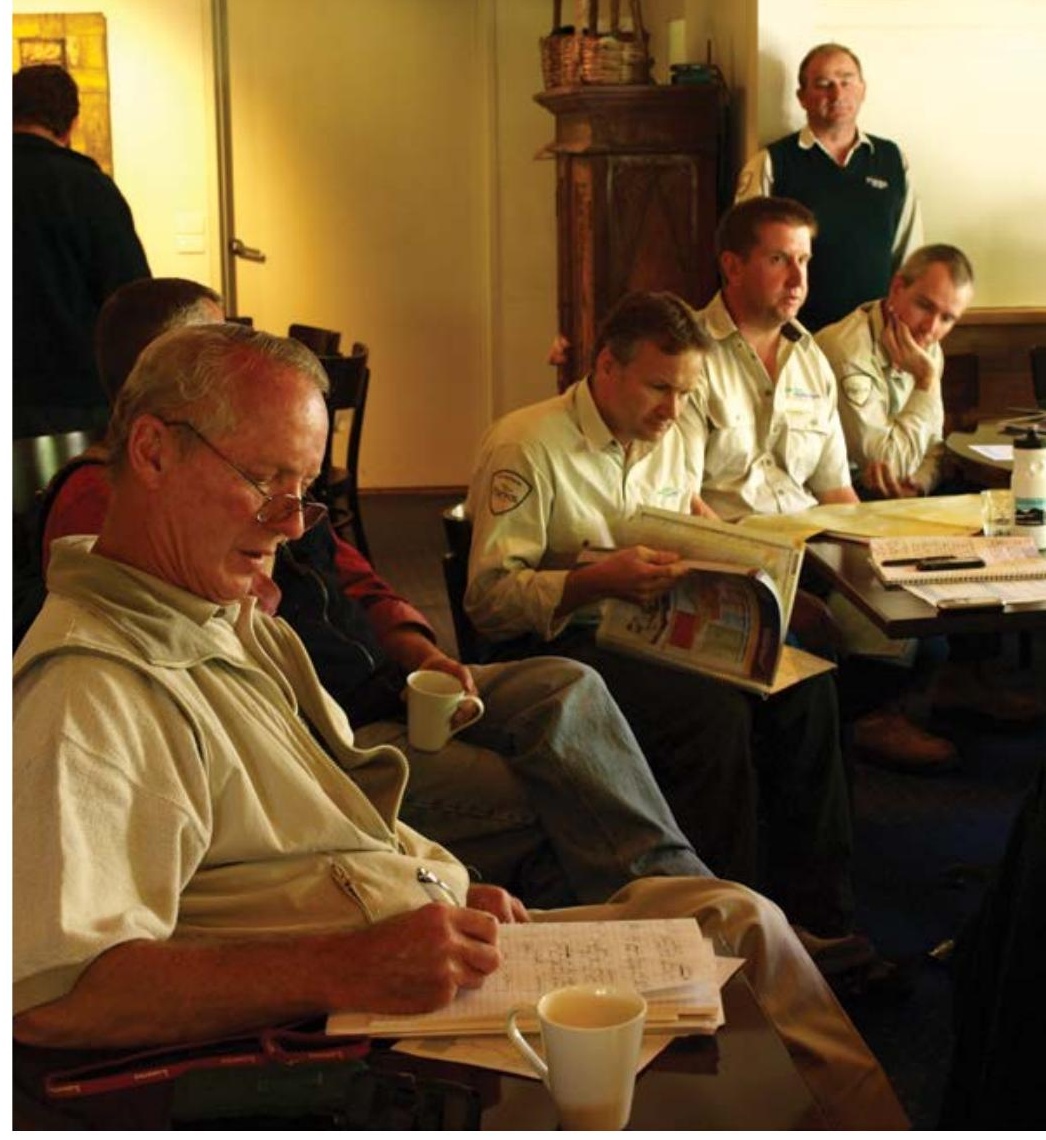

Researcher Roger Good recording condition and change in condition data provided by ranger staff for the Alpine National Park in Victoria, Australia Source: Graeme L. Worboys

conservation planning (Box 11.1). They rely on project cycles or adaptive management to achieve conservation goals.

In order to measure how well managed protected areas are and whether they are meeting their conservation objectives, a number of systems have been developed and are used around the world. In some cases these assessment mechanisms look at the management activities, and in others they look at monitoring trends in biodiversity responses. Protected area management effectiveness (PAME) assessments can use formats for data acquisition tailored towards the need of an organisation to be informed of the effective use of resources and to plan for further management. More than 40 PAME tools have been developed in recent years and the results of these assessments are summarised in Coad et al. (2013). A review of good evaluation methodologies for PAME can be found in Hockings et al. (2009) and Leverington et al. (2010) (see also Chapter 28).

Offences against wildlife, notably poaching, are some of the top threats to biodiversity requiring a particular approach to data gathering, monitoring and enforcement, and global initiatives such as the International Consortium on Combating Wildlife Crime (ICCWC) have come together to tackle this problem. The consortium has developed a wildlife and forest crime analysis toolkit, which provides guidance on data collection and analysis (ICCWC 2012). Data collection through dedicated 
tools such as the Spatial Monitoring and Reporting Tool (SMART) (Box 11.2) ensures that information collected through day-to-day enforcement activities in sites is standardised and fit for purpose.

\section{National reporting and tracking global change}

Countries have signed up to a range of regional and international agreements relevant to protected areassuch as the Convention on Biological Diversity (CBD) National Reports, Aichi Targets and National Biodiversity Strategies and Action Plans (NBSAP); the Convention on Wetlands of International Importance especially as Waterfowl Habitat (Ramsar Convention); the World Heritage Convention; and the Convention on International Trade in Endangered Species of Wild Fauna and Flora (CITES) National Reports and trade permit system. These agreements have varying levels of protected area reporting requirements for the countries (for an example of reporting to the European Nature Directives, see Box 11.3). In some cases, detailed site-level information is needed, while in others the information can be generalised at a national level. In all cases, they emphasise the need for reporting to be based on good-quality and relevant information. The reporting required of countries to multiple different agreements is complex and demanding. This has resulted in poor compliance among lower-capacity countries. As a result, efforts are now being made to streamline and harmonise the reporting requirements across all multilateral environmental agreements. The development of online reporting systems-still in its early stages for protected areas-is aimed at reducing the reporting and data access burden (for example, CITES; Box 11.4).

In 2010 the parties to the $\mathrm{CBD}$ agreed on a new strategic plan (CBD 2011) that includes a set of targets (the Aichi Targets). This plan provides an overarching framework for biodiversity, not only for the biodiversity-related conventions, but also for the entire UN system and all other partners engaged in biodiversity management and policy development. Protected areas underpin several of the targets, but are particularly relevant to Target 11 , which states:

By 2020, at least 17 per cent of terrestrial and inland water areas, and 10 per cent of coastal and marine areas, especially areas of particular importance for biodiversity and ecosystem services, are conserved through effectively and equitably managed, ecologically representative and well-connected systems of protected areas

\section{Box 11.3 National reporting obligations under the European Nature Directives}

Within the European Union, two directives are focused on nature conservation: the Birds Directive (79/409/ EEC; 2009/147/EEC) and the Habitats Directive (92/43/ EEC), collectively known as the Nature Directives. These directives cover many issues relating to biodiversity but two are particularly relevant in terms of data collection. First, the directives require countries to designate and collect information on a series of protected areas to protect a prescribed set of habitat types and species. As of February 2014, there were 27221 sites covering an area of more than 1 million square kilometres, which equates to approximately 18 per cent of the land area and 4 per cent of the marine area of the European Union. Second, the directives require countries to collect biodiversity datasets on prescribed habitats and species. Data are collected on the distribution, area, population, trend and overall conservation status of the species and habitat types listed under these directives. The data collected under this process form a central part of the overall biodiversity strategy for the European Union, and are publicly available through the European Environment Agency.

\section{Box 11.4 Species+}

Species+, developed by the CITES Secretariat and the UN Environment Programme World Conservation Monitoring Centre (UNEP-WCMC), is a website designed to assist parties with implementing CITES, the Convention on the Conservation of Migratory Species of Wild Animals (CMS) and other multilateral environmental agreements. Species+ provides a centralised portal for accessing key information on species of global concern. In particular, Species+ contains information on all species that are listed in the appendices of CITES and CMS, as well as other CMS family listings and species included in the annexes to the EU Wildlife Trade Regulations.

- Kelly Malsch and Alison Rosser (UNEP-WCMC 2014)

and other effective area-based conservation measures, and integrated into the wider landscape and seascape. (CBD 2011) 


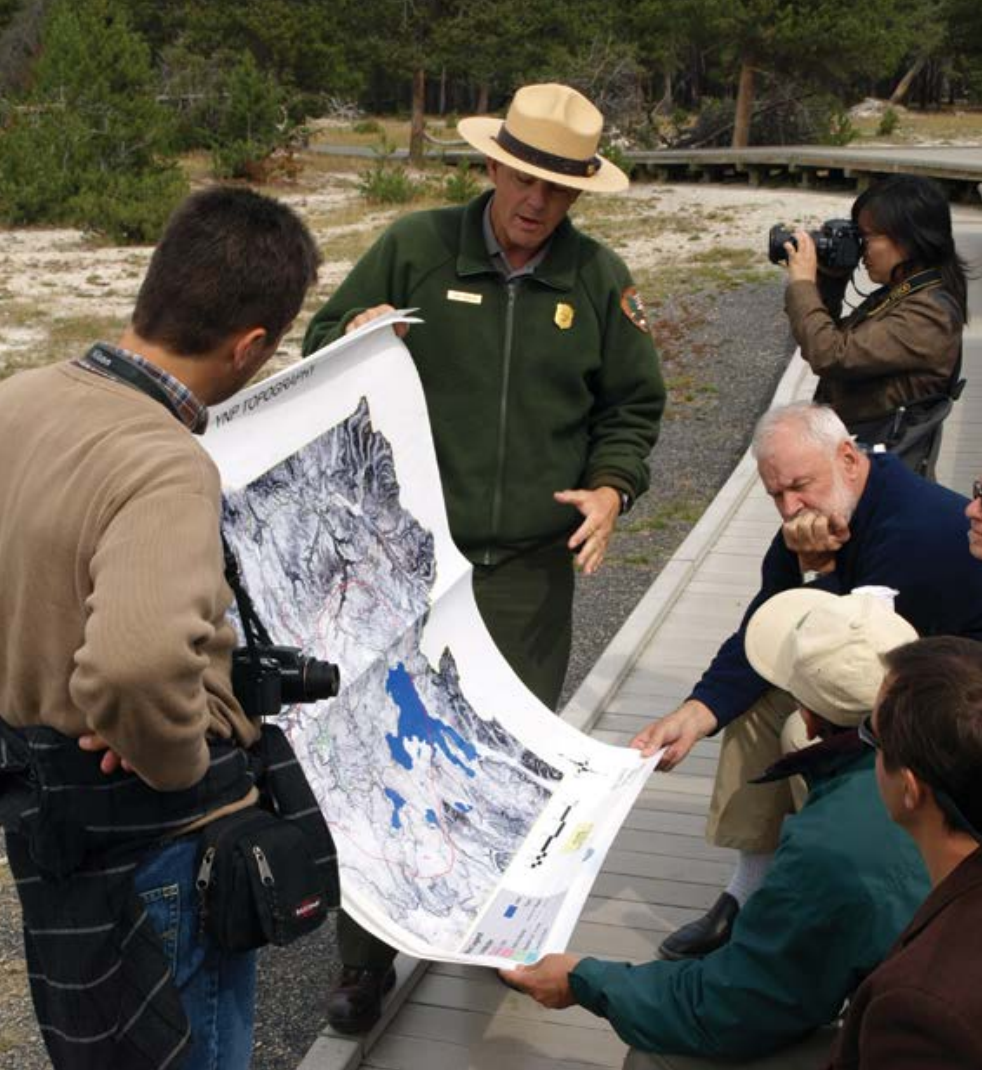

US National Park Service geologist briefing protected area experts on geothermal crustal expansion measurement, monitoring and mapping in the vicinity of Old Faithful Geyser, Yellowstone National Park, USA

Source: Graeme L. Worboys

In order to track progress on Target 11 , countries supported by global initiatives need to mobilise and interpret a huge volume of baseline and monitoring data, on all aspects of protected area location, coverage, designation, management and governance. Indicators are used to track progress (Box 11.5). A further global initiative was launched in 2012, the Intergovernmental Platform on Biodiversity and Ecosystem Services (IPBES), as an independent intergovernmental body focused on strengthening the science-policy interface, such that:

- scientific information is relevant to policy demands and is formulated in a way that is accessible to policy and decision-makers

- policy and decision-makers take into account available scientific information in their deliberations and they formulate their demands or questions in a way that is accessible for scientists to provide the relevant information.

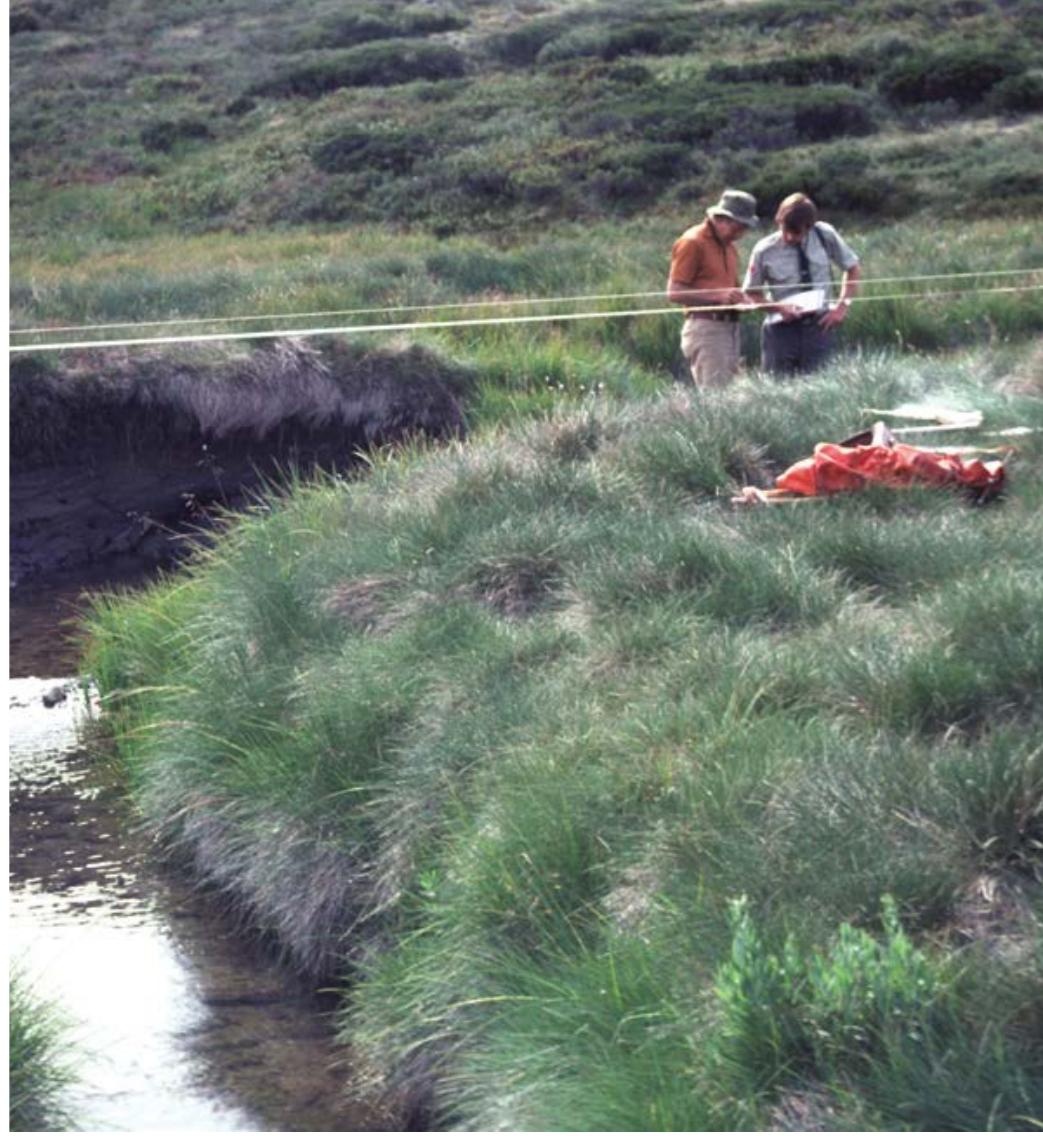

Long-term ecological research plot established in Kosciuszko National Park in the 1960 s post alpine stock grazing removal from the park, to track the recovery of the Australian alpine environments and to measure continued active stream erosion

Source: Dane Wimbush

\section{Inputs for knowledge generation}

In addition to there being a multitude of drivers and motivations for collecting data and information, there are also numerous tools and methods for collecting these data and information. These need to be considered and developed in the context of the project or purpose for which the data are collected. As such it is worth considering five main knowledge categories when discussing data types: 1) scientific knowledge collected as part of field-based surveys; 2) scientific knowledge gathered from remote sensing; 3) knowledge on 'values' such as economic values or human benefits; 4) knowledge gathered through citizen science; and 5) the huge body of traditional knowledge.

In all knowledge categories, given the significant resources required for data collection and analysis to generate information, it is important that the 'collect once, use often' principle is employed where possible. Responsible parties must consider the lifespan of the data they collect beyond the scope of the project they are undertaking at that time. The addition of one or two parameters can often increase the applicability of datasets and their value beyond a single project, and global datasharing mechanisms and standards can ensure the data can be integrated and reused by another party or project at a later time. 
'Collect once, use often' is a core principle of a number of online data-collection systems. In order to avoid duplication, the various national, regional and international collection systems need to be able to communicate with each other so countries can report once and the data can be used by other systems. Initiatives such as the Global Biodiversity Information Facility (GBIF) can accept data collected for multiple purposes and make it freely available to other researchers around the world (see Box 11.16). A key element in this 'collect once, use often' ideal is the need for data to come with associated metadata—often referred to as 'data about data'. Metadata allow future users of data and information to understand the background of how those data were collected, for what purpose, at what scale and level of accuracy, and any conditions on the use of the dataset. In addition, metadata can include information on sensible uses of a dataset or information product, and thus reduce inappropriate or misleading results being obtained for future analyses. Additional detail on some of the common data standards in use for both biodiversity and protected areas is presented later in this chapter.

\section{Scientific field knowledge}

Probably the largest body of information relevant to protected areas is collected as part of scientific surveys, surveillance and monitoring programs. These programs cover all facets of the biodiversity, environmental, management and socioeconomic processes. They rely on scientific methodology and experimental designs to make results more robust and comparable between sites and over time. Data collection can be done by field researchers or local people who are trained in sampling techniques and data management skills-for example, use of spreadsheets and simple analysis.

At the most basic level of data collection are surveys that generate lists or inventories, geological mapping and/or socioeconomic indicators that can serve as a baseline for further studies and monitoring. Often these data are used for proposals for new protected areas or management plans. Some scientific data, however, come from long-term projects like long-term ecological research sites and may not be readily available, although some long-term projects have policies that specifically promote sharing data from their sites and use a modified rapid assessment protocol to standardise methods to make them more comparable between the sites and also cheaper (for example, PPBio).

Monitoring is the term used to refer to this repeated observation or measurement to determine status and trend, assessed as change against a baseline

\section{Box 11.5 What is a successful indicator?}

According to the Biodiversity Indicator Partnership (2011), a successful indicator should be:

- scientifically valid: a) there is an accepted theory of the relationship between the indicator and its purpose, with agreement that change in the indicator indicates change in the issue of concern; and b) the data used are reliable and verifiable

- based on available data: so that the indicator can be produced over time

- responsive to change in the issue of interest

- easily understandable: a) conceptually, how the measure relates to the purpose; b) in its presentation; and c) in the interpretation of the data

- relevant to a user's needs

- used: for measuring progress, early warning of problems, understanding an issue, reporting, awareness raising, and other needs.

measurement—often referred to as an indicator. Surveys, in comparison, are where measures are generally made at a single point in time (for example, to determine the distribution of a species). Gardner (2010) classifies biodiversity monitoring in three broad types according to their purposes.

- Implementation monitoring: Checks if management processes and recommendations are being implemented.

- Effectiveness monitoring: Used to gather information on the condition (status and trend) of a measured outcome. In other words, if a conservation management target has been achieved or not. Does not ask why it succeeded or failed.

- Validation monitoring: Gathers information towards validation of management interventions, analysing whether they were successful and why. This is a central component of adaptive management (see Box 11.1).

Biodiversity monitoring is required in many international agreements - for example, in the strategic plan of the CBD (2011), which outlines the Aichi biodiversity targets; the convention also asks countries in Paragraph 25 on support mechanisms to 'monitor the status and trends of biodiversity, maintain and share data'.

In order to focus the information-gathering exercise and collect the relevant information in a sufficiently large sample size to produce robust analyses and reliable 


\section{Box 11.6 PROBUC: Program for monitoring biodiversity and natural resource use in the Amazon State- protected areas}

This program was set up by the Amazonas State Government in Brazil in 2006 to acquire information on the presence and use of biodiversity in State-level 'sustainable use' protected areas. These protected areas are defined in Brazil as natural areas that house traditional populations whose existence is dependent on systems based on the sustainable use of natural resources. These systems have been adapted throughout the ages to the local ecology, which has a strong role in the protection of nature and the maintenance of biodiversity, and the areas meet the criteria for IUCN protected area Category VI. The program aims at training and using local knowledge to acquire information on the subsistence use of fauna and flora (such as hunting and fishing, and brazil nut harvesting) and also of threats (such as illegal poaching, illegal deforestation and goldmining) to help monitor species trends and threats and plan the needed management actions.

Members of the local villages are trained to fill in questionnaires and to conduct fauna transect monitoring with emphasis on species hunted for food. They also acquire information on turtle populations (the annual release of baby turtles is promoted by local residents) and boat traffic inside the protected area. The acquired information is relayed to the State environmental agency to be analysed for relevant management information and stored in databases that can be accessed by researchers and other institutions. Feedback is given to the local communities, when results are presented and explained in a comprehensive manner during community meetings, including to the protected area community council meetings. Training has constant follow-ups to increase data accuracy and reliability.

Sources: Fonseca et al. (2011); de Lima et al. (2012)

results, indicators are often used in monitoring projects. Indicators are a useful way of reducing the number of complex parameters that need to be measured, which is particularly important when staff, time and financial resources are tight. Indicators are ideally quantitative (easily measureable, such as the population size of a species or nitrogen levels in soil), but can also be qualitative (such as the presence of an indicator species or the perceived condition of a habitat) and are often hierarchical, feeding up from site to national-level assessment (Box 11.5).

\section{Knowledge from citizens}

Traditionally, surveys and monitoring have been undertaken by qualified researchers, but increasingly 'citizen science' approaches are being used to engage and educate communities and the general public (Box 11.6). If done well, these projects have the added advantage of potentially speeding up the data-collection process, as well as increasing sample size and coverage. Recent research (Bird et al. 2014) highlights the value of citizen science data as long as constraints around data collection, management, analysis and bias are put in place. Similarly, research has shown the potential value and benefits of using local communities for natural resource monitoring of tropical forests (Danielsen et al. 2014a) and to monitor progress on biodiversity indicators (Danielsen et al. 2013). With careful protocol design, especially through data-entry templates, to minimise the amount of inaccurate data entering the system, citizen science projects can work to improve our knowledge and increase public engagement. Technologies such as smart phones and tablets with geolocation capabilities make citizen science an attractive approach; however, considerations such as data quality, quantity and complexity must be made at the project design stage, as well as whether citizen science is the most appropriate mechanism for engaging the community or collecting data on a particular problem. Projects such as Nature's Notebook (Rosemartin et al. 2014) and Instant Wild (Box 11.7) are excellent examples of citizen science in action.

\section{Remotely sensed knowledge}

In addition to field surveys, data also come from remotely sensed sources, ranging from those images acquired via satellite to images and laser scanning data derived from conventional airborne platforms and the emerging use of remotely operated unmanned aerial vehicles. Over the past decade there has been a rapid evolution of enhanced quality, reduced cost and simplified availability in remotely sensed data. These changes have greatly facilitated the use of remotely sensed data to analyse changes in habitat within protected areas over time, including sophisticated comparisons with comparable areas outside protected areas. As these datasets become increasingly detailed they also become much larger, which has increased the challenges of downloading, processing and analysing them.

The huge potential has been recently demonstrated by Hansen et al. (2013), who used 30-metre resolution satellite data from the freely available 'Landsat' archives to show the extent of global forest change. This example illustrates the potential value of remote sensing for 
protected area monitoring, at scales and levels of precision that could not possibly be measured by means of field-based survey or reviews of national indicators. As an example, deforestation in Virunga National Park in Central Africa is shown from 2000 to 2012 from data analysed by Hansen et al. (2013; Figure 11.3).

Change detection for other habitat types or ecosystems can be much more challenging as the variations of the pixel 'signature' can be harder to detect and it is therefore easy to confuse habitats-for example, a natural grassland would look similar to a cropped area (Mello et al. 2012).

\section{Knowledge on 'value"}

Increasingly, the scientific and economic cases for biodiversity conservation are being made through the promotion of the value of 'ecosystem services' and 'natural capital' to human wellbeing and the global economy. In order to develop scientifically rigorous approaches to this valuation and subsequent decisionmaking, data on ecosystem services are being gathered and incorporated into planning processes and used to develop new policy frameworks and finance mechanisms. Initiatives such as The Economics of Ecosystems and Biodiversity (Kumar 2010) have expanded, refined and improved the methodologies used in these assessments.

\section{Box 11.7 Instant Wild}

The Zoological Society of London's Instant Wild iPhone Application (app) is a unique citizen science tool that enables members of the public to identify and discuss images that have been instantly transmitted from motion-triggered camera traps set up across the globe. In the first 24 months after its launch, it had more than 100000 downloads and participants initiated more than one million image identifications, with an identification success rate of more than 90 per cent. The app empowers the general public to get involved in field conservation work and improves awareness and knowledge of the species in camera locations. It also means that the society has the ability to instantly know if a rare and threatened species has been spotted-for example, the critically endangered Javan leopard (Panthera pardus melas) was seen on the society's Indonesian camera in 2013 and the incredibly rare mountain mouse-deer (Moschiola meminna) was sighted on the society's Sri Lankan camera. There are cameras transmitting from Kenya, Namibia and the United States. As more cameras go online, the app has the potential to save conservationists thousands of hours of work, as members of the public help sort the images by species group, enabling faster data analysis.

- The Zoological Society of London, Conservation Technology Unit, London, 2014

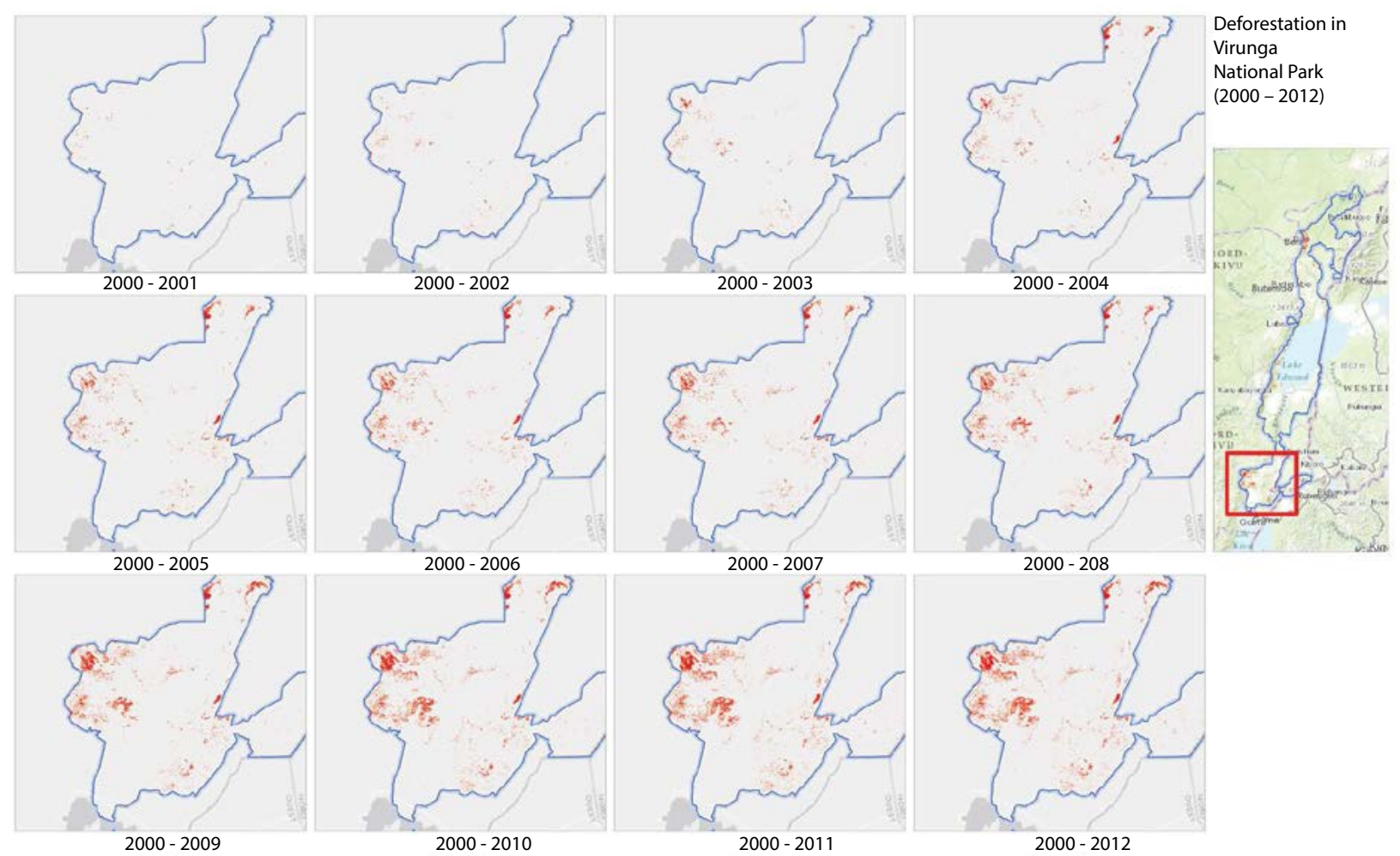

Figure 11.3 Deforestation (red areas) in Virunga National Park (outlined in blue), Democratic Republic of Congo, measured from 2000 to 2012

Source: Adapted from Hansen et al. (2013) 


\section{Box 11.8 Toolkit for Ecosystem Service Site-based Assessment}

The Toolkit for Ecosystem Service Site-based Assessment (TESSA) guides local non-specialists through a selection of relatively accessible methods for identifying which ecosystem services may be important at a site, and for evaluating the magnitude of benefits that people obtain from them currently, compared with those expected under alternative land uses. The toolkit recommends the use of existing data where appropriate and places emphasis on enabling users to collect new field data at relatively low cost and effort. By using TESSA, the users could also gain valuable information about alternative land uses, and data collected in the field could be incorporated into regular monitoring programs.

Source: Peh et al. (2013)
A detailed guide to the assessment, including information requirements, of the social and economic benefits of protected areas is available in Kettunen and ten Brink (2013). Several tools have also been developed to allow non-specialists to assess the ecosystem services important at a site, such as the Toolkit for Ecosystem Service Sitebased Assessment (TESSA) (Box 11.8).

\section{Traditional knowledge}

Information and knowledge, including techniques and best practices, accumulated over time by communities and passed from generation to generation - often referred to as traditional knowledge or indigenous knowledgecan be difficult to measure and understand, but are no less important aspects of the protected area knowledge base. This information is often ignored in protected area planning and management, which can have problematic consequences. Data on seasonality, resilience, medicinal properties, traditional management practices and their conservation or restorative values can all be collected from communities, as can information such as on land tenure, property rights and protected area impacts. Traditional knowledge can also help with monitoring the abundance of and changes in key species and habitats within the protected area, and the trends generated by these methods can be as reliable as ground-based surveys by scientists (Danielsen et al. 2014a). Another value of traditional knowledge comes in raising hypotheses for further scientific investigation.

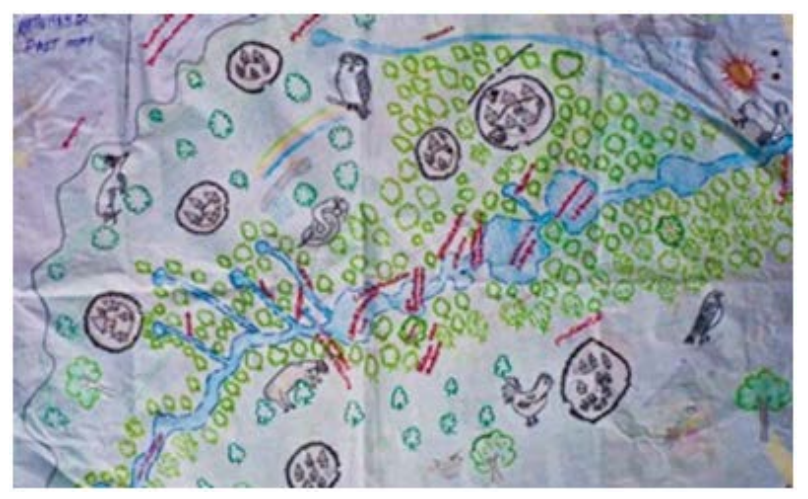

Ancestral map of the past, showing the ecological order of the territory in Venda, South Africa

Source: Dzomo la Mupo, Mupo Foundation, Gaia Foundation

As many ecological systems and landscapes have been modified over time by the human communities they support, an understanding of the traditional management practices and community-based resource management systems can be key to building a good understanding of the management of protected areas (Box 11.9). This is especially important for those protected areas that permit 


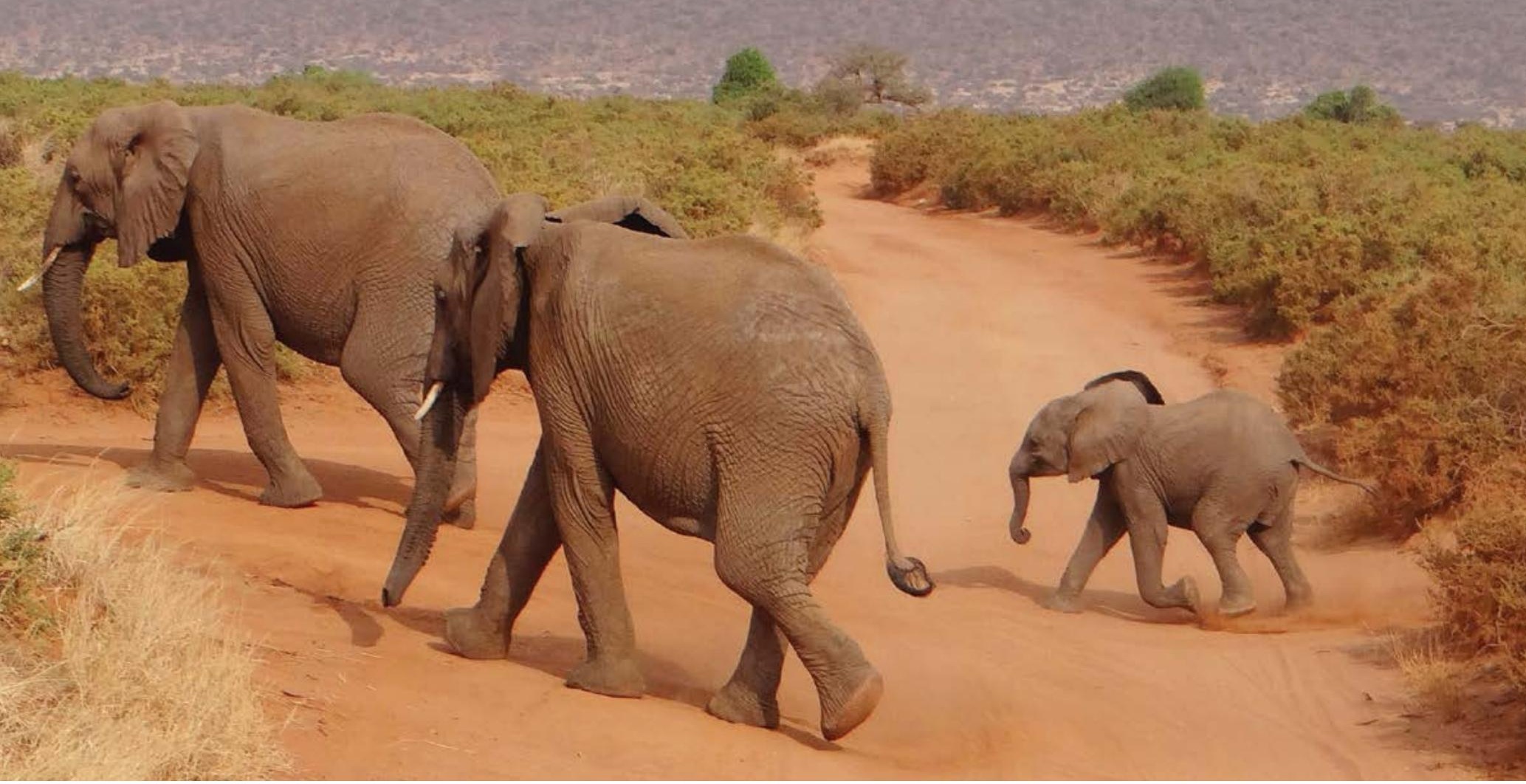

Elephants crossing, Samburu National Reserve, Kenya, an IUCN Category II protected area

Source: Geoffroy Mauvais

human populations to be residents or to explore for and exploit natural resources. One of the challenges here is to translate this traditional knowledge-often based on metaphors-into information that can be used for conservation planning and monitoring trends in key species or habitats. Oba et al. (2008), for example, describe how the traditional knowledge of herders in central Uganda can help identify best practices for the conservation of landscapes and associated fauna and flora. In another study, Constantino et al. (2008) show how the traditional hunting knowledge of the Kaxinawá ethnic group in Brazil can help biodiversity monitoring by enhancing fauna species lists. Danielsen et al. (2014b), working in Nicaragua, found that supplementing research findings with indigenous and local knowledge could increase the amount and geographical scope of information available for assessments. An example of a database that sets out to record information on traditional knowledge is the global Indigenous Peoples' and Community Conserved Territories and Areas (ICCA) Registry (Box 11.10), but several national-level databases are also maintained or in preparation (Kothari et al. 2012).

\section{Importance of standards}

A critical component of any data collection, management or analysis process, not just related to protected area information, is the need to have data standardsdocumented profiles for the uniform representation and formatting of data. At their most fundamental, data

\section{Box 11.10 Indigenous Peoples' and Community Conserved Territories and Areas Registry}

The ICCA Registry has been set up to build a knowledge base that increases information about these special areas, documents their values, enhances understanding and recognition of their purposes and impacts, and increases the engagement of local and traditional communities in biodiversity conservation and policy arenas. The two main types of information stored include: 1 ) descriptive information, such as the main habitats within the ICCA and the names of the community or communities living within or near the ICCA; and 2) spatial information, such as the size, location and boundaries of the area. Additional details are included where available, such as information about the history, governance, customary laws and management of an area, details on community decision-making processes and socioeconomic factors. Multimedia data, such as photos and videos, are incorporated within case studies to broaden the visual features of communities and the richness of their knowledge and conservation efforts. The ICCA Registry adheres to the principle of 'free prior informed consent' (FPIC), so any communities registering their permission for the information to be included in the ICCA database can additionally specify whether this information should be kept confidential and not released. The ICCA Registry is maintained by the ICCA Consortium and the UNEP-WCMC. 


\section{Box 11.11 The World Database on Protected Areas data standard for protected area information}

The World Database on Protected Areas (WDPA) is a joint project between the UN Environment Programme (UNEP) and the International Union for Conservation of Nature (IUCN) that is managed by the UNEP World Conservation Monitoring Centre (UNEP-WCMC), based in Cambridge, United Kingdom. The WDPA started as the UN List of Protected Areas, produced under mandate from the UN General Assembly since 1962, and has developed into a spatial geographical information systems (GIS) mapping database on protected areas throughout the world. It includes information on protected areas of all IUCN categories and governance types. In collaboration with governments, non-governmental organisations (NGOs), academia and industry, the WDPA is the most comprehensive global database of marine and terrestrial protected areas, comprising both spatial data (that is, boundaries) with associated attribute data (that is, tabular information). The WDPA is made available online through the Protected Planet website (<www. protectedplanet.net>), where the data are both viewable and downloadable.

The WDPA Data Standard was developed in 2009 as a mechanism to make the requirements for inclusion of data in the WDPA clear for all data providers, and to ensure interoperability of the dataset. This standard was expanded in 2014 in order to streamline the WDPA with the requirements of Aichi Target 11, which stresses the importance of 'other effective area-based conservation measures'.

Under the new data standard, the WDPA will continue to incorporate sites that fit the IUCN and CBD definitions of a protected area, alongside sites that do not fit these definitions but nevertheless have conservation value. This distinction will be clearly made within the attribute data, providing data users with the option to easily differentiate between those sites that fit the definition and those that do not.

Data submissions must meet the following five requirements to be included in the WDPA.

1. The site must either fit the IUCN/CBD definition of a protected area or have clear conservation value and a long-term commitment in place.

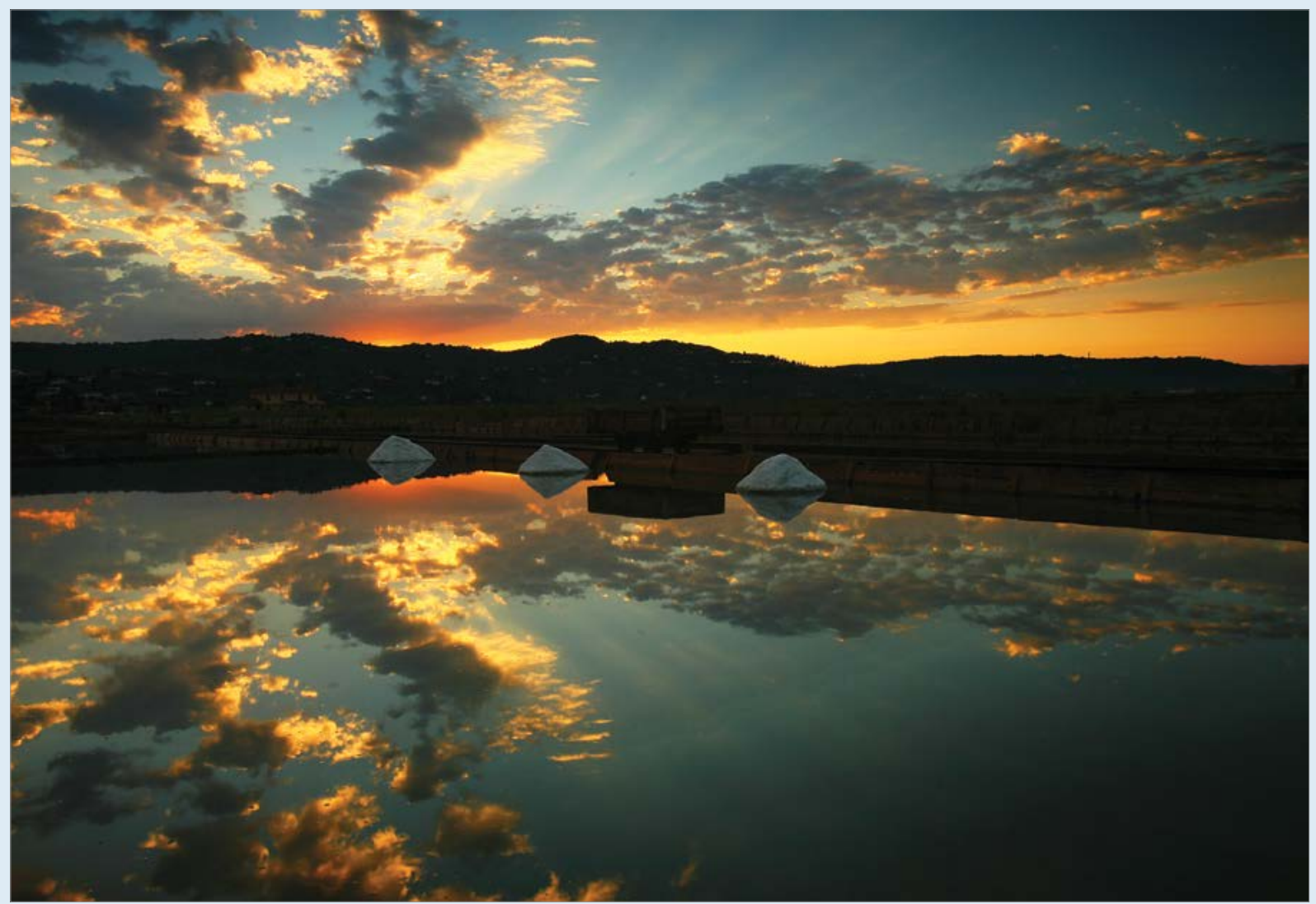

Sečovlje Salina Nature Park, Slovenia, a Category IV and Category V protected area that includes an important bird wetland area and an active and sustainable salt production industry based on methods used at the site for hundreds of years

Source: Andrej Sovinj 
2. The spatial boundaries of protected areas should be provided as shapefiles in multi-part polygon format, where possible. Where boundary data are unavailable, the central geographical point location (latitude and longitude) must be given as a reference point for the protected area instead. Therefore, each protected area in the WDPA is represented as either a polygon boundary or, if unavailable, a point location. Spatial data must be provided, preferably in shapefile format. A maximum of two shapefiles should be submitted-one containing all the polygon data and the other all the point data for any protected areas without boundary data. The WDPA is based on the geographic coordinate World Geodetic System (WGS), therefore all data should ideally be submitted in this reference system. It is preferred that GIS data are in shapefile format, but other formats such as .gdb and .kml files are also accepted.

3. Recording accurate source information in the WDPA is important to ensure that ownership of the data is maintained and traceable. The WDPA Source Table conforms to the minimum geographical information and service standards as outlined in the ISO guidance report on geographic information (SIO/TC 211). A data submission will only be accepted if the minimum source information is provided. Under the new WDPA Data Standard, data will be stored in both the data source and by the party responsible for verifying the data, where applicable.

4. Attributes represent essential pieces of information about the spatial data that aid in the analysis, reporting and tracking of trends in the growth and coverage of the world's protected areas. There are 25 attributes associated with every protected area in the WDPA, with these categorised as 'minimum', 'core' or 'enhanced' attributes. The minimum basic requirement for data to be accepted into the WDPA is that the minimum attribute information is provided.

5. The data must be either provided or verified by a national government or other authoritative source. Data contributors that provide data for inclusion in the WDPA are requested to sign the WDPA Data Contributor Agreement. This ensures that there is a written record of the data provider agreeing for their data to be in the WPDA. The agreement specifically states how the data provided will be used and that they will be subject to the WDPA Terms and Conditions. A data submission will only be accepted if the WDPA Data Contributor Agreement is signed.

Source: UNEP-WCMC (2014) standards allow for the collection of data in a qualitycontrolled manner, leading to improved quality and an associated confidence in the use of the data collected. The more datasets that exist within a system, the more important it is that there are clear data standards for each dataset. All of this highlights the importance of ensuring that at the onset of a data-collection process, there are clear data standards outlined that allow for the collection of the relevant scientific information as well as ensuring the data can be managed effectively.

As geographical information or geospatial data become more available and more web-based, the need for such standards is crucial. Both the International Organisation for Standardisation (ISO) and the Open Geospatial Consortium have developed a set of standards for geographical information. The ISO has created an entire series of standards covering geographical information (ISO 19100 series).

Biodiversity Information Standards, also known as the Taxonomic Databases Working Group, has developed a set of standards for the exchange of biodiversity data. These are exemplified by the 'Darwin Core', which includes a set of terms relating to taxa and their occurrence in nature, and a set of practices regarding the use of these terms in the publication of biodiversity data and information (GBIF 2010). The Darwin Core is used by the GBIF and many national biodiversity data nodes.
For protected areas, the WDPA acts as the global standard (Box 11.11), with a set of core attributes any site must have in order to be listed. Standards also ensure the mobilisation of biodiversity information. The Biodiversity Heritage Library is one such collaborative resource enabling open access to major natural history literature collections put together by a group of organisations from around the world.

A basic requirement for data systems is the need for each object or measurement (for example, protected areas) to have a unique identifier. Unique identifiers should as a minimum satisfy two basic criteria: they should be:

1. unique - that is, the identifier should be unique across the organisation

2. persistent - the identifier should remain unchanged for the life of that object.

With the advent of increasingly user-friendly global positioning system (GPS) surveying and the availability of digital datasets, there are increasing possibilities for the collection of highly accurate spatial biodiversity data. As an example, in the case of protected area boundary digitisation, the exact scale used is a function of the resources available. Detailed surveying of sites will produce highly accurate boundaries but at a high cost, while digitising the boundaries from digital cadastral maps at an appropriate scale can provide relatively accurate boundaries in a cost-effective manner. 


\section{Knowledge sharing}

Data sharing means the disclosure of data-in this case, biodiversity data - from one party to a third party either within an organisation or to external organisations. The sharing of data can be influenced by a number of factors, both positive and negative, including: the presence or lack of organisational best-practice documents relating to data sharing; ownership of the data; copyright of the data or indeed the base maps from which data are created; technical challenges; national laws relating to data use and downloading of data; and restrictions on disseminating data to third parties. The ownership of data can be tied up in institutional rules, copyright issues and commercial sensitivities, and the dissemination by digital means may not be covered by national laws or the laws may not cover the use of digital data in online systems and the subsequent downloading of data. There can be restrictions on allowing third parties to disseminate the data. On the positive side, there are a number of national and regional agreements on the use and dissemination of public data, such as the Conservation Commons (2006), which encourages the release of biodiversity data in order to facilitate biodiversity conservation.

The inability to share data is a critical problem in the assessment of global biodiversity: with incomplete data, an incomplete picture emerges. Where there are issues surrounding data sharing, solutions should be found, either in adopting best practice from other countries or organisations or in having clear data-sharing agreements. In the case of ICCAs and many other aspects of traditional and indigenous knowledge, data-sharing restrictions can relate to national laws, cultural sensitivities or ownership information. All sites submitted to the ICCA Registry (Box 11.10) undergo an agreed FPIC process. This allows the communities involved to choose whether or not their data are made publicly available.

\section{Knowledge management}

In recent years, and as the importance of knowledge management has been recognised, national governments and research organisations in many countries have been putting in place biodiversity information facilities or data centres. These facilities use a range of approaches and models very much dependent on the data and information being gathered, the user base of the system, how accessible the information needs to be and the resources available.

Community-level knowledge management can, however, take a very different approach. Corrigan and Hay-Edie (2013) provide insights into sharing knowledge in ICCAs and other community-led conservation areas, including documenting and mapping, local management planning, monitoring, adaptive learning, communication and sustainable financing. Regional structures also play a role here, particularly in developing regions, as they ensure best practices in information management and access for decision-making, often in some of the world's most biodiverse places, while reducing the management burden and resources required for a state-of-the-area data centre. Examples include the Association of SouthEast Asian Nations (ASEAN) Centre for Biodiversity (Box 11.12) and the Shared Environmental Information System (SEIS) (Box 11.13).

The CBD calls on parties to the convention to implement and expand national-level clearing-house mechanisms (Article 18.3). A clearing-house mechanism sets out to provide a web-based information portal and discovery services to facilitate the implementation of national biodiversity strategies and action plans. Such mechanisms have also been implemented at regional and global levels.

Global initiatives play an important role in data management and mobilisation. The IUCN knowledge products make conservation-related knowledge available (Box 11.14). In other cases, global information initiatives allow tracking of global biodiversity targets-such as the Biodiversity Indicators Partnership and the WDPA, both managed by the UNEP-WCMC (Box 11.15).

Thematic networks, such as BirdLife International, the Ocean Biogeographic Information System or the Global Invasive Species Database (GISD), play an important role in focusing on the information requirements of specific issues, biomes or taxonomic groups. The use of global data management standards, however, ensures that the thematic data can be interchanged seamlessly with regional systems or other networks. In some cases, they allow for the repatriation of data between regions-for example, from museums in the developed world to protected area managers in developing countries where the specimens were collected through the GBIF (Box 11.16).

\section{Knowledge use}

Access to the best available data on biodiversity is an essential requirement for successful conservation outcomes (Box 11.17). In making available the various biodiversity-related datasets that are held by different bodies, conservation practitioners from researchers to policymakers are able to make decisions based on the best data available. In addition, by making datasets available, new and novel analysis and products are created similar to the proliferation of 'mashups' available 


\section{Box 11.12 ASEAN Centre for Biodiversity}

TheASEAN Centre for Biodiversity is an intergovernmental regional centre that facilitates cooperation and coordination among the 10 ASEAN member states on the conservation and sustainable use of biological diversity, and the fair and equitable sharing of benefits arising from the use of such natural treasures. To assist the organisation of the biodiversity information that forms the basis of assessments, decisions and policies, the Centre for Biodiversity adopted the Darwin Core Archive and WDPA as a standard data structure for sharing and publishing data on biological diversity. With this standard, the centre hoped the member states would be equipped to populate their clearing-house mechanisms for biodiversity and therefore be able to provide and process the necessary information for biodiversity conservation.

Both online and offline encoding facilities were developed based on the standardised format to improve interoperability and aid the digitisation of species and protected area information in the ASEAN region. The primary purpose of the Darwin Core Archive and the WDPA was to create a common structure for sharing biological diversity data that are harmonised and reuse metadata standards from other dataset domains. All clearing-house mechanism focal points were informed of these developments and were encouraged to engage in a cost-sharing training arrangement to improve the capacity of their staff and partners in data management. The Biodiversity Information Management Unit developed a regional clearing-house mechanism to organise biodiversity information at the regional level and present interactive trends and maps where useful for analysis. Both online and offline encoding tools were made accessible on the regional clearing-house mechanism website to assist member states in digitising their biodiversity data.

- Christian Elloran, ASEAN Centre for Biodiversity

\section{Box 11.13 Shared Environmental Information System}

The Shared Environmental Information System (SEIS) aims to create an improved environmental information system for Europe. The goal is to base it on a network of public information providers that share their environmental data and information. Their existing systems and processes would be simplified, streamlined and modernised, including being web-enabled. The overall system would be decentralised but integrated. Quality, availability, accessibility and understanding will be improved as a result. The SEIS is also about a shift in approach, from individual countries or regions reporting data to specific international organisations, to their creating online systems with services that make information available for multiple users-people and machines.
The SEIS is based on seven 'principles'. Information should be:

- managed as close as possible to its source

- collected once, and shared with others for many purposes

- readily available to easily fulfil reporting obligations

- easily accessible to all users

- accessible to enable comparisons at the appropriate geographical scale, and to enable citizen participation

- fully available to the general public and at the national level in the relevant national language(s)

- supported through common, free open software standards.

Cutting across the principles above, a key goal of the SEIS is to maximise and expand use.

Source: European Commission (2008:111-12) on the Internet. These 'mashups' have at their heart the principle of using data from multiple sources to present the data in a new manner or to create new products (such as IBAT; Box 11.18). This also serves to highlight the key requirements, and the challenges, necessary to expand and enhance the use of the existing datasets. In addition, they remind us of the importance of sustained investment in data collection, collation, management and dissemination; without investment the quality and currency of the data cannot be maintained, and the relevance and accuracy of the 'mashup' decrease.
The key challenges faced have been discussed in previous sections, but it is worth reiterating them as it this issue which acts to link them together (Boxes 11.19 and 11.20). Biodiversity data are often very heterogeneous and not centralised, as they are often located in several organisations, both nationally and internationally. As highlighted in the section on the 'Importance of standards', there is a lack of global standards and procedures relating to quality control of the data, and even data collection can vary dramatically depending on the aims of a project and the organisation involved. It is 


\section{Box 11.14 Knowledge products delivered through the IUCN}

As a science-based organisation, the IUCN provides a wide range of knowledge to inform society's decisions on how to value and conserve nature equitably. It is through this union, under the mandate of the IUCN 201316 program, that knowledge products are developed, maintained, updated and disseminated.

The IUCN has six knowledge products in different phases of development (Figure 11.4). Knowledge products are combinations of standards, data, processes, tools and products developed and maintained by the IUCN as global public goods put towards the conservation and sustainable use of the world's biodiversity.

The following characteristics are common to all datasets.

- They are scientifically driven, transparent and repeatable. All engage scientists (from the IUCN's six commissions, membership, the Secretariat and beyond) in their development and maintenance.

- They are structured to ensure independent governance and avoid political manipulation. In particular, processes to maintain their standards and respond to petitions are accountable to the relevant chairs of the IUCN commissions.

- They are inclusive; their standards and data are developed through international, participatory processes (for example, 'framing workshops') with all relevant and interested stakeholders. Gaining consensus amongst such stakeholders is fundamental to success and makes the resulting product much more robust than it would otherwise be.

- They are supported through engagement with the IUCN Secretariat, often in collaboration with many other partner institutions.
- They require expert review prior to acceptance and publication.

- They are not targeted to specific, narrow applications, but rather are applicable, often in combination with other information, to increase awareness of biodiversity and to inform decision-making in policy and practice-not only in the conservation sector but also in society at large.

- They are (or will be) maintained over time, and through such time series inform indicators for monitoring.

- They are delivered by the IUCN (commissions, members and the Secretariat) and partners as freely available for non-commercial applications in scientific research, biodiversity conservation and sustainable use.

- Commercial applications may, through agreed policies and where appropriate, contribute resources towards maintaining the quality and currency of the underlying data.

The IUCN maintains many other databases and information systems, such as the Global Invasive Species Database (GISD) and four library catalogues, including ECOLEX, which serves the world's most comprehensive and authoritative catalogue of environmental law. Each of the knowledge products is fundamental in its own right. There is, however, potential for them to deliver even more than is possible through each of the parts individually.

- Jane Smart, Thomas Brooks and Diego Juffe-Bignoli*, IUCN (*now with UNEP-WCMC)

\section{NATURAL RESOURCE GOVERNANCE FRAMEWORK ${ }^{3}$ : effectiveness, rights, equity and benefits}

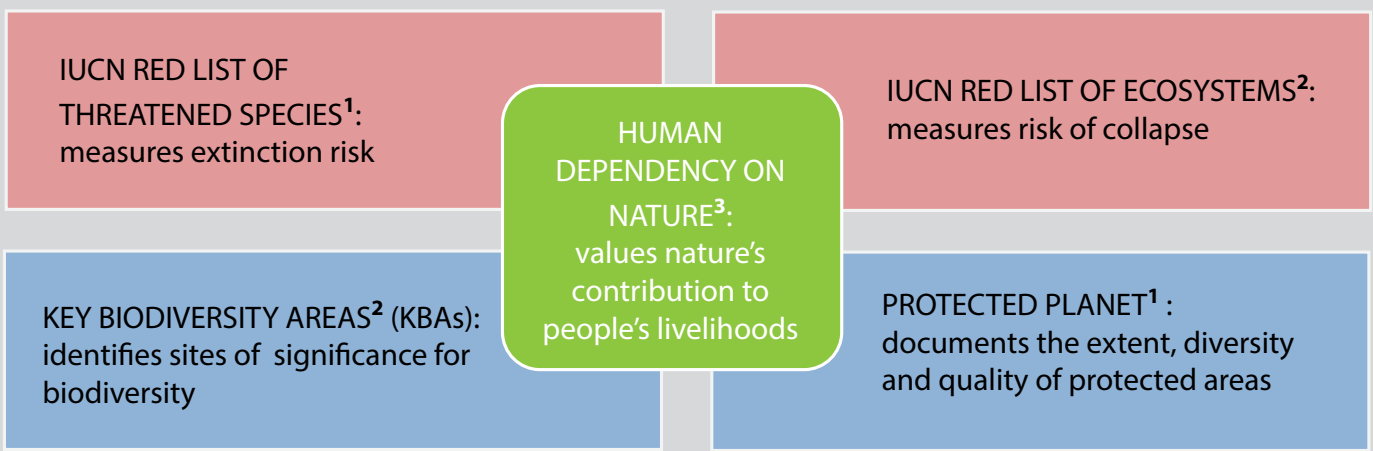

Figure 11.4 The six knowledge products delivered through the IUCN

1) Advanced, widely published and agreed and global datasets available

2) Undergoing active consolidation and revision. Global datasets for key biodiversity areas available

3) At inception phase or early stages of development 


\section{Box 11.15 UNEP World Conservation Monitoring Centre}

Working with partners worldwide, the UNEP-WCMC is the specialist biodiversity assessment arm of the UNEP, based in Cambridge, in the United Kingdom. The WCMC provides objective, scientifically rigorous products and services to help decision-makers learn about the value of biodiversity and apply this knowledge. The centre not only collates and verifies data on biodiversity and ecosystem services but also undertakes analysis and interpretation, making the results available in accessible forms.
The vision of the WCMC is a world in which decisionmakers in all sectors and at all levels recognise and take full account of the values of biodiversity as the bedrock of a global green economy and human wellbeing. The mission is to provide authoritative information about biodiversity and ecosystem services in a way that is useful to decision-makers who are driving change in environment and development policy. In partnership with the UNEP and IUCN, the UNEP-WCMC manages the World Database on Protected Areas (WDPA) (see Box 11.11).

\section{Box 11.16 Global Biodiversity Information Facility}

The GBIF is an international open data infrastructure, funded by governments, which ensures that anyone, anywhere can access data about all types of life on Earth, shared across national boundaries via the Internet. By encouraging and helping institutions to publish data according to common standards, the GBIF enables research not possible before, and informs better decisions to conserve and sustainably use the biological resources of the planet.

The GBIF operates through a network of nodes, coordinating the biodiversity information facilities of participant countries and organisations, collaborating with each other and the secretariat to share skills, experiences and technical capacity. It provides a single point of access (through this portal and its web services) to more than 400 million records, shared freely by hundreds of institutions worldwide, making it the biggest biodiversity database on the Internet.
The data accessible through the GBIF relate to evidence about more than one million species, collected during three centuries of natural history exploration and including current observations from citizen scientists, researchers and automated monitoring programs. More than 900 peer-reviewed research publications have cited the GBIF as a source of data, in studies spanning the impacts of climate change, the spread of pests and diseases, priority areas for conservation and food security. About 20 such papers are published each month. Many GBIF participant countries have set up national portals using tools, codes and data freely available through GBIF to better inform their citizens and policymakers about their own biodiversity.

Source: GBIF (2012) often not possible for the datasets to communicate with each other, therefore they are not interoperable. There is a need for the skills of information management, technology and biology to overlap to ensure the data that are collected are scientifically robust and stored, managed and disseminated in a manner that will allow them to be used by the wider community.

Using data to generate improved knowledge necessitates that the data are open to be shared and made accessible, are based upon international standards so that the different datasets can be understood, and the data need to be credible (quality checked, scientifically robust). If these conditions can be fulfilled, the potential for meaningful analysis and interpretation of biodiversity datasets will be greatly enhanced. There are, however, issues of sensitivity and risk to be considered, and users should always familiarise themselves with the terms and conditions for the use of data, and review metadata to ensure use cases are appropriate and not liable to misinterpretation. In addition, where there is a likelihood that communities or specific groups (such as women, landowners or pastoralists) may be impacted by the use of the data or the resulting decisions, consideration should be taken of the potential outcomes.

\section{Resourcing considerations}

The collection of data, information and knowledge is often seen as an end in itself, without consideration of the longer-term value of managing knowledge as a resource. Too often projects and their associated websites or data management processes end once the project ends and funding dries up. This means that a large amount of potentially valuable information is lost to local managers, communities, scientific and policy communities and on-ground decision-makers. From the outset, projects 


\section{Box 11.17 The use of comparative analyses for the assessment of World Heritage nominations under biodiversity criteria}

Under the UN Educational, Scientific and Cultural Organisation (UNESCO) World Heritage Convention, state parties submit nomination proposals to the World Heritage Committee, which determines, based on the recommendations of its advisory bodies, whether the nomination meets at least one of the necessary criteria to be inscribed on the World Heritage List. One of the IUCN's roles under the World Heritage Convention is to provide technical advice to the World Heritage Committee on the nominations of natural sites. For sites nominated under biodiversity criteria, Criteria (ix) and (x), the UNEP-WCMC provides comparative analyses to help inform the IUCN's recommendations to UNESCO.

The spatial analyses use global datasets in order to answer a number of questions to inform the assessment of the outstanding universal value of the site.

For Criterion (ix):

- Does the nominated property represent ecosystems/ communities that are currently underrepresented or not represented on the World Heritage List?

Spatial analyses are carried out to find the number of existing World Heritage sites and Tentative List sites found in the same biogeographical units as the nominated property: Udvardy province; terrestrial realm, biome or ecoregion; and marine province or ecoregion, if applicable.

- Are these ecosystems/communities globally significant, and is the nominated property the best example, or one of the best examples, of these ecosystems/communities?
Spatial analyses are completed to determine whether the nominated site belongs to one of the following broad-scale conservation priorities using the following global datasets: Terrestrial Biodiversity Hotspot, High Biodiversity Wilderness Area, Terrestrial/Freshwater/ Marine Global 200 Priority Ecoregion, Endemic Bird Area and Centre of Plant Diversity.

For Criterion (x):

- Is the nominated property the most diverse and/or representative, or one of the most diverse and/or representative, of its kind?

- Has the nominated property been identified as a global conservation priority-for example, for globally threatened or restricted-range species?

If the nomination file provides a list of threatened species, it is checked against global data on the IUCN Red List of Threatened Species. The IUCN also looks at the indicative number of threatened species that may be found on the property based on their geographic ranges using globally assessed species on the Red List. Spatial analyses are undertaken to assess whether the nominated site belongs to one of the following site-scale global conservation priorities: Alliance for Zero Extinction (AZE) sites and key biodiversity areas other than AZE sites (for example, important bird areas). The results of these global spatial analyses are used to inform the evaluations of the IUCN World Heritage Panel, which considers all nominations of natural and mixed properties to the World Heritage List. The meeting of the IUCN World Heritage Panel then leads to recommendations to UNESCO on the IUCN's position in relation to each new natural nomination.

\section{Box 11.18 Integrated Biodiversity Assessment Tool}

The Integrated Biodiversity Assessment Tool (IBAT) is an innovative online system designed to facilitate access to accurate and up-to-date biodiversity information to support critical decision-making. The tool is the result of a groundbreaking conservation partnership between BirdLife International, Conservation International, the IUCN and the UNEP-WCMC. Through a state-of-theart online mapping system, users can view, overlay and interrogate global biodiversity datasets including the WDPA, Key Biodiversity Areas, AZE sites, the IUCN Red List of Threatened Species, Biodiversity Hotspots, Endemic Bird Areas and High Biodiversity Wilderness Areas. and initiatives should plan for the full life cycle of the information collection and long-term management. This includes sufficient resource and funding allocation to the preparation of data for long-term maintenance, including submission to global repositories, scientific publications and proper organisation and filing.

Increasingly, national governments are taking note of the value of managing knowledge, and are building policy frameworks and technical infrastructure that mobilise knowledge for public use and ensure it is available for tracking trends in the longer term. Funding is necessary for all activities in the cycle and should be incorporated in the government's budget to guarantee its continuation through long-term financial sustainability alongside proper legislation on data collecting, sharing and storage-as this can be not only time-consuming but also expensive if not done properly. Costello et al. (2014) 


\section{Box 11.19 Knowledge use in Mexico}

The Mexican Commission for the Knowledge and Use of Biodiversity (CONABIO) is an inter-ministerial commission dedicated, among other activities, to the development, maintenance and updating of the National Biodiversity Information System; to the support of projects and studies focused on the knowledge and use of biodiversity; to advising governmental institutions and other sectors; to undertaking special projects and programs and sharing knowledge on biological diversity; to following up on international agreements on topics related to biological diversity; and providing services to the public. Its mission is to promote, coordinate, support and carry out activities aimed at improving our understanding of biological diversity, as well as its conservation and sustainable use for the benefit of Mexican society.

Chishui National Nature Reserve, Guizhou Province, China, a World Heritage property protecting outstanding Danxia landscapes Source: Graeme L. Worboys

recommend that for long-term sustainability databases should become integrated into larger collaborative projects and curated by an organisation or institution with a suitable mandate. In the case of protected area information, this would include organisations such as the IUCN, UNEP-WCMC and the GBIF.

For data acquisition, agencies should consider the costs of field expeditions, continuous training and capacity building of data collectors and analysts. At the field level, data can be collected by researchers or local communities. In both cases the most cost-effective method is to implement permanent plots and transects that can be surveyed by different thematic teams over several years. Such sampling areas need to be maintained as well and protocols should be standardised. To avoid bias and misinterpretation of data and to fine tune data entry (for example, species name, sighting positions along transects) teams need to have frequent training sessions and discussions-all of which have financial implications.

For data analysis and storage, ideally agencies should maintain a permanent team to work on the data as part of the general management of protected areas. If this is not possible, data analysis standards, protocols and metadata should be in place to allow new personnel to continue with work of the same quality. Important initiatives on protected area management have failed due to the higher turnover of trained staff because of variable funding sources and the lack of standard protocols for data collection, analysis and storage.

The CONABIO advises policy and decision-makers to conserve and use biodiversity in a sustainable way by providing data, information and knowledge. It is a leader and innovator in biodiversity informatics and efficient processes, and maintains high-quality products and services. Some activities and achievements of the CONABIO are:

- creation of the World Information Network on Biodiversity (REMIB) and of an automated system of early warning of wildfire detection for Mexico and Central America

- the Mexican priority regions program for biodiversity conservation

- development of BIOTICA curatorial information manager

- publication of more than 350 titles and research papers.

Furthermore, the CONABIO acts as the scientific authority of CITES and as the focal point of the clearinghouse mechanism, the Subsidiary Body on Scientific, Technical and Technological Advice (SBSTTA), The Global Taxonomy Initiative and the Global Strategy for Plant Conservation of the CBD. At the national level, the CONABIO also coordinates the implementation of the Mesoamerican Biological Corridor in Mexico, and the elaboration of the Second Biodiversity Country Study, the National Biodiversity Strategy and similar processes for every State/Province in Mexico, among others. CONABIO provides data, information and advice to various users and implements the national and global biodiversity information networks, complying with international commitments on biodiversity entered into by Mexico, and carries out actions directed towards the conservation and sustainable use of biodiversity in Mexico.

Source: CBD (2014) 


\section{Box 11.20 Protected Areas Resilient to Climate Change in West Africa}

The Protected Areas Resilient to Climate Change (PARCC) project, implemented by the UNEP-WCMC, aims to assess the vulnerability of protected area networks in West Africa to the impacts of climate change, enhance their resilience by improving the effectiveness of their management, and build capacity in the region to ensure that the new tools and strategies can be used effectively after the project's completion.

To achieve these aims, the project relies on effective data sharing between all the project partners, including the IUCN Central and West Africa Protected Areas Programme, the governments of the five project countries (Chad, Gambia, Mali, Sierra Leone and Togo), and several world-class scientific partner institutions involved in the development of new science-based methodologies (Figure 11.5). Effective production and sharing of global and regional data are in place.

- National liaison officers and consultants, and national governments are involved in data collection at the national level (for example, on climate, species distribution and policies).

- The Meteorological Office Hadley Centre provides high-resolution climate data and future regional climate change scenarios to feed into the vulnerability assessments.
- BirdLife International contributes data on the avifauna of West Africa, which are incorporated into species vulnerability assessments.

- Durham University develops species distribution models focused on West Africa and applies them to future climate scenarios over the protected area network.

- The IUCN Global Species Programme provides data on species extinction risk and vulnerability to climate change based on their specific biological characteristics.

- Durrell Institute of Conservation and Ecology, University of Kent, develops-based on all the data provided by other partners on climate change and species vulnerability-systematic conservation planning systems for the West African region.

These planning systems are then used to inform the development of climate change strategies and policy recommendations for West African countries. In order for the scientific information provided to be accurate and hence the methodology sound and the project successful, all the data exchanged between the various partners have to be interoperable, follow data standards and go through a rigorous quality check.

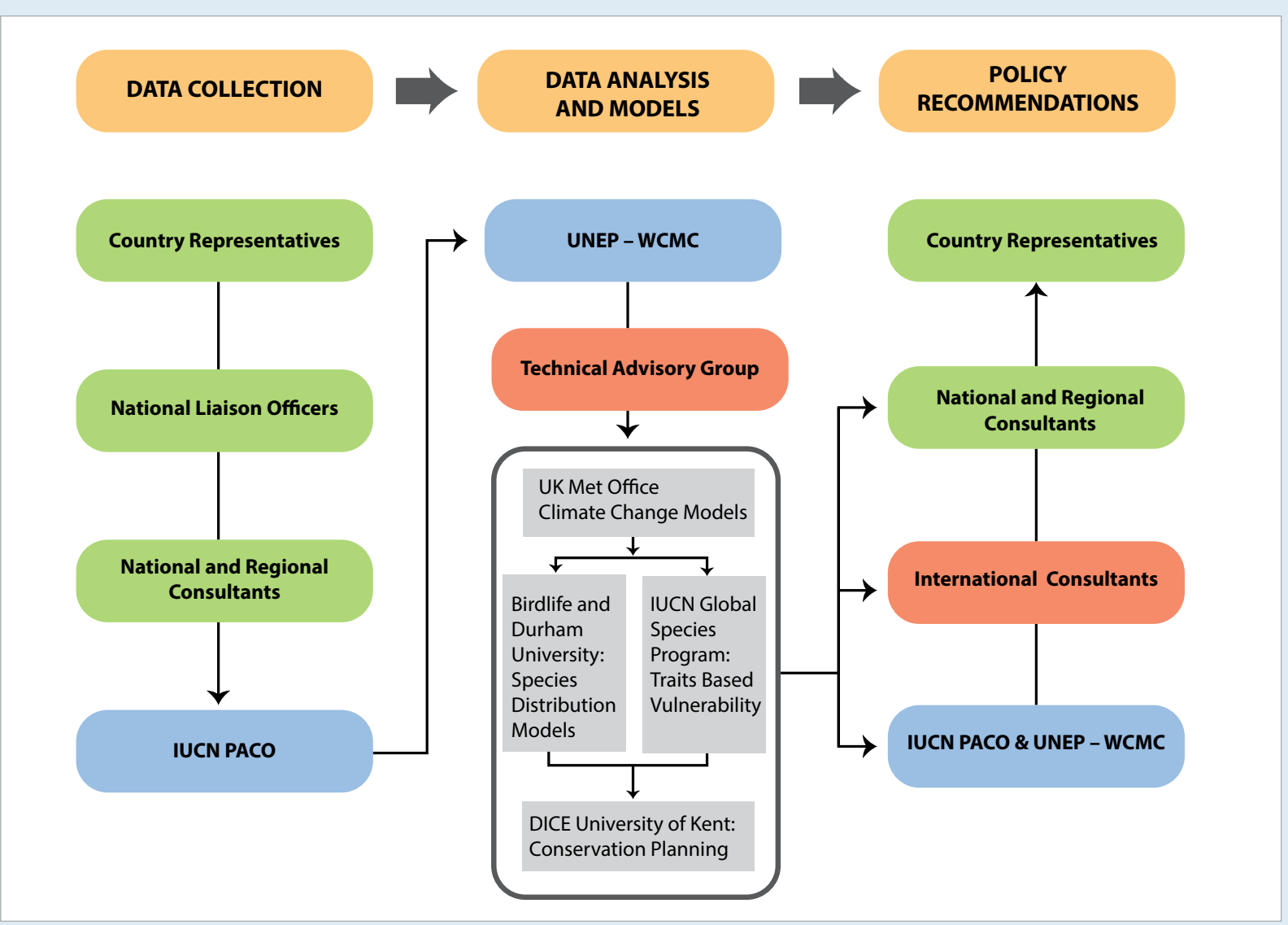

Figure 11.5 PARCC project process for production and sharing of global, regional and national data 


\section{Conclusion}

There are a number of basic principles for consideration when working at the various points in the cycle of the acquisition and generation of data, their analysis and interrogation to provide meaningful information, and the understanding and communication of the resulting knowledge.

- There are many reasons for collecting data, and the data required and the scale of collection will depend on the uses for that information, so those responsible for information gathering must consider whether the data they are collecting are appropriate for the question being asked at the project design stage.

- Consider the lifespan of the data being collected beyond the scope of the project, and potentially modify the data-collection protocol to increase the applicability of datasets and their value beyond a single project.

- The use of global data standards and sharing mechanisms will ensure that the data can be integrated and reused by another party or project at a later time, and will be interoperable with other similar datasets.

- Maintenance of metadata ensures that future users understand how and why the data were collected, and what an appropriate and sensible use or interpretation of the information would be.

- Organisations, individuals or projects generating data should endeavour to ensure that they are made available through one of the global facilities, but at the very least make it available through an online and open-access resource where possible.

- Publication of data through official channels should be encouraged to ensure the above.

- The terms of conditions and appropriate use of data and information must be respected, particularly where there might be an impact on sensitive species, habitats, community groups or sites.

- The long-term resourcing to ensure proper maintenance and accessibility of data needs to be built into project design and close-off.

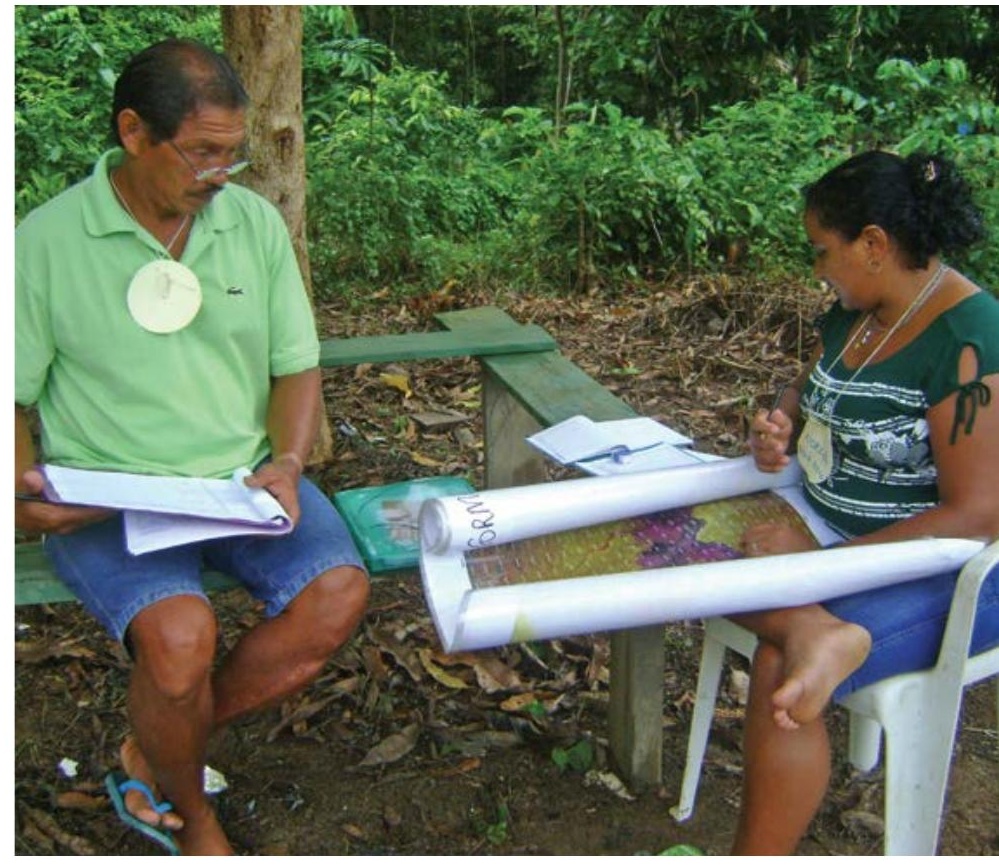

River dwellers receiving training towards satellite imagery interpretation for biodiversity resource monitoring in the Unini river, central Amazonia. Taken during a capacity building course for monitors of biodiversity resources of the River Unini, Central Amazonia run by the Fundação Vitória Amazônica, a Brazilian NGO.

Source: Fundação Vitória Amazônica 


\section{References}

Recommended reading

Bertzky, B., Shi, Y., Hughes, A., Engels, B., Ali, M. K. and Badman, T. (2013) Terrestrial Biodiversity and the World Heritage List: Identifying broad gaps and potential candidate sites for inclusion in the natural World Heritage network, IUCN, Gland, and UNEPWCMC, Cambridge.

Biodiversity Indicators Partnership (2011) Guidance for National Biodiversity Indicator Development and Use, UNEP-WCMC, Cambridge.

Bird, T. J., Bates, A. E., Lefcheck, J. S., Hill, N. A., Thomson, R. J., Edgar, G. J., Stuart-Smith, R. D., Wotherspoon, S., Krkosek, M., Stuart-Smith, J. F., Pecl, G. T., Barrett, N. and Frusher, S. (2014) 'Statistical solutions for error and bias in global citizen science datasets', Biological Conservation 173: 144-54.

Bowles-Newark, N. J., Arnell, A. P., Butchart, S., Chenery, A., Brown, C. and Burgess, N. D. (2014) Incorporating and Utilising Spatial Data and Mapping for NBSAPs: Guidance to support NBSAP practitioners, UNEP-WCMC, Cambridge.

Cleveland, H. (1982) 'Information as resource', The Futurist (December): 34-9.

Conservation Measures Partnership (CMP) (2013) Open Standards for the Practice of Conservation. Version 3.0. <www.conservationmeasures.org.

Coad, L., Leverington, F., Burgess, N. D., Cuadros, I. C., Geldmann, J., Marthews, T. R., Mee, J., Nolte, C., Stoll-Kleemann, S., Vansteelant, N., Zamora, C., Zimsky, M. and Hockings, M. (2013) 'Progress towards the CBD protected area management effectiveness targets', Parks 19(1): 13-24.

Conservation Commons (2006) Joint statement to the parties to the Convention on Biological Diversity on open access to biodiversity data and information. <conservationcommons.org/media/document/ docuwdsvdq.pdf>

Conservation Measures Partnership (CMP) (2013) Open Standards for the Practice of Conservation. Version 3.0. <www.conservationmeasures.org>
Constantino, P. A. L., Fortini, L. B., Kaxinawa, F. R. S., Kaxinawa, A. M., Kaxinawa, E. S., Kaxinawa, A. P., Kaxinawa, L. S., Kaxinawa, J. M. and Kaxinawa, J. P. (2008) 'Indigenous collaborative research for wildlife management in Amazonia: the case of the Kaxinawá, Acre, Brazil', Biological Conservation 141: 2718-29.

Convention on Biological Diversity (CBD) (2011) Strategic Plan for Biodiversity 2011-2020 and the Aichi Targets, Secretariat of the Convention on Biological Diversity, Montreal. <www.cbd.int/ decision/cop/?id=12268>

Convention on Biological Diversity (CBD) (2014) The Mexican Commission for the Knowledge and Use of Biodiversity. <www.cbd.int/cooperation/ conabio.shtml>

Dd Corrigan, C. and Hay-Edie, T. (2013) A Toolkit to Support Conservation by Indigenous Peoples and Local Communities: Building capacity and sharing knowledge for Indigenous Peoples' and Community Conserved Territories and Areas (ICCAs), UNEPWCMC, Cambridge.

Costello, M. J., Appeltans, W., Bailly, N., Berendsohn, W. G., de Jong, Y., Edwards, M., Froese, R., Huettmann, F., Los, W., Mees, J., Segers, H. and Bisby, F. (2014) 'Strategies for the sustainability of online open-access biodiversity databases', Biological Conservation 173: 155-65.

Dd Danielsen, F., Jensen, P. M., Burgess, N. D., Altamirano, R., Alviola, P. A., Andrianandrasana, H., Brashares, J. S., Burton, A. C., Coronado, I., Corpuz, N., Enghoff, M., Fjeldså, J., Funder, M., Holt, S., Hübertz, H., Jensen, A. E., Lewis, R., Massao, J., Mendoza, M. M., Ngaga, Y., Pipper, C. B., Poulsen, M. K., Rueda, R. M., Sam, M. K., Skielboe, T., Sørensen, M. and Young, R. (2014a) 'A multicountry assessment of tropical resource monitoring by local communities', BioScience 64: $236-51$.

Danielsen, F., Jensen, P. M., Burgess, N. D., Coronado, I., Holt, S., Poulsen, M. K., Rueda, R. M., Skielboe, T., Enghoff, M., Hemmingsen, L. H., Sørensen, M. and Pirhofer-Walzl, K. (2014b) 'Testing focus groups as a tool for connecting indigenous and local knowledge on abundance of natural resources with science-based land management systems', Conservation Letters 7: 12-24. 
Danielsen, F., Pirhofer-Walzl, K., Adrian, T. P., Kapijimpanga, D. P., Burgess, N. D., Jensen, P. M., Bonney, R., Funder, M., Landa, A., Levermann, N. and Madsen, J. (2013) 'Linking public participation in scientific research to the indicators and needs of international environmental agreements', Conservation Letters 7: 12-24.

de Lima, M. G., Cooper, A. H., Boubli, J. P. and Lemos, P. (2012) Wildlife Conservation Society Workshop on Participatory Biodiversity Monitoring in Amazonas State, WCS Brazil, Manaus.

Dudley, N. (ed.) (2008) Guidelines for Applying Protected Area Management Categories, IUCN, Gland.

European Commission (2008) Communication from the Commission to the Council, the European Parliament, the European Economic and Social Committee and the Committee of the Regions: Towards a Shared Environmental Information System (SEIS), European Commission, Brussels. <eur-lex.europa.eu/legalcontent/EN/TXT/PDF/?uri=CELEX:52008DC004 6\&from $=\mathrm{EN}>$

Fonseca, S. F. Jr, Marinelli, C. E., Carlos, H. H. S., Weigand, R. Jr, Fernandes, R. B., Campos e Silva, J. V., Lemos, P. F. and Calandino, D. (2011) Programa de monitoramento da biodiversidade e do uso de recursos naturais-ProBUC: a experiência das unidades de conservação estaduais do Amazonas [Biodiversity and Natural Resource Monitoring Program-ProBUC: The experience in state protected areas in Amazonas], State Centre for Protected Areas, Manaus.

Gardner, T. (2010) Monitoring Forest Biodiversity: Improving conservation through ecologically-responsible management, Earthscan, London.

Global Biodiversity Information Facility (GBIF) (2012) Darwin Core Quick Reference Guide. Version 1.3, contributed by J. Wieczorek, R. de Giovanni, D. Vieglais, D. P. Remsen, M. Döring and T. Robertson, Global Biodiversity Information Facility, Copenhagen.

Hansen, M. C., Potapov, P. V., Moore, R., Hancher, M., Turubanova, S. A., Tyukavina, A., Thau, D., Stehman, S. V., Goetz, S. J., Loveland, T. R., Kommareddy, A., Egorov, A., Chini, L., Justice, C. O. and Townshend, J. R. G. (2013) 'Highresolution global maps of 21 st-century forest cover change', Science 342(6160): 850-3.
Dockings, M., Stolton, S., Dudley, N. and James, R. (2009) 'Data credibility: what are the "right" data for evaluating management effectiveness of protected areas?', New Directions for Evaluation 122: 53-63.

International Consortium on Combating Wildlife Crime (ICCWC) (2012) Wildlife and Forest Crime Analytic Toolkit, United Nations, New York.

Kettunen, M. and ten Brink, P. (eds) (2013) Social and Economic Benefits of Protected Areas: An assessment guide, Earthscan, London.

Kothari, A., Corrigan, C., Jonas, H., Neumann, A. and Shrumm, H. (eds) (2012) Recognising and Supporting Territories and Areas Conserved by Indigenous Peoples and Local Communities: Global overview and national case studies, Secretariat of the Convention on Biological Diversity, ICCA Consortium, Kalpavriksh and Natural Justice, Montreal.

Kumar, P. (ed.) (2010) The Economics of Ecosystems and Biodiversity: Ecological and economic foundations, Earthscan, London.

Leverington, F., Lemos Costa, K., Courrau, J., Pavese, H., Nolte, C., Marr, M., Coad, L., Burgess, N., Bomhard, B. and Hockings, M. (2010) Management Effectiveness Evaluation in Protected Areas: A global study, 2nd edn, University of Queensland, Brisbane.

Margules, C. R. and Pressey, R. L. (2000) 'Systematic conservation planning', Nature 405: 243-53.

Mello, A. Y. I., Alves, D. S., Linhares, C. A. and de Lima, F. B. (2012) 'Classification techniques for Landsat TM imagery under different landscape patterns in Rondônia', Revista Árvore 36: 537-47.

Oba, G., Byakagaba, P. and Angassa, A. (2008) 'Participatory monitoring of biodiversity in East African grazing lands', Land Degradation \& Development 19: 636-48.

Dd Peh, K. S.-H., Balmford, A., Bradbury, R. B., Brown, C., Butchart, S. H. M., Hughes, F. M. R., Stattersfield, A., Thomas, D. H. L, Walpole, M., Bayliss, J., Gowing, D., Jones, J. P. G., Lewis, S. L., Mulligan, M., Pandeya, B., Stratford, C., Thompson, J. R., Turner, K., Vira, B., Willcock, S. and Birch, J. C. (2013) 'TESSA: a toolkit for rapid assessment of ecosystem services at sites of biodiversity conservation importance', Ecosystem Services 5: 51-7. 
Pino-Del-Carpio, A., Ariño, A. H., Villarroya, A., Puig, J. and Miranda, R. (2014) 'The biodiversity data knowledge gap: assessing information loss in the management of biosphere reserves', Biological Conservation 173: 74-9.

Rodriguez-Navarro, G. (forthcoming) 'Traditional knowledge: an innovative contribution to landscape management', in K. Taylor, A. St Clair Harvey and N. Mitchell (eds) Conserving Cultural Landscapes: Challenges and new directions, Routledge, Abingdon, UK.

Rosemartin, A. H., Crimmins, T. M., Enquist, C. A. F., Gerst, K. L., Kellerman, J. L., Posthumus, E. E., Denny, E. G., Cuertin, P., Marsh, L. and Weltzin, J. F. (2014) 'Organizing phenological data resources to inform natural resource conservation', Biological Conservation 173: 90-7.

UN Environment Programme World Conservation Monitoring Centre (UNEP-WCMC) (2014) Data Standards for the World Database on Protected Areas, UNEP-WCMC, Cambridge. 


\section{CHAPTER 12}

\section{LEADERSHIP AND EXECUTIVE MANAGEMENT}

\section{Principal authors:}

Julia Miranda Londoño, Jon Jarvis, Nik Lopoukhine and Moses Wafula Mapesa

\section{CONTENTS}

Introduction

- Leadership

- Executive management

- Executive management: Working with people

- Conclusion

- References

IUCN 5 WCPA 


\section{PRINCIPAL AUTHORS}

JULIA MIRANDA LONDOÑO is Director-General of the National Parks Service of Colombia and a Regional Vice-Chair for South America of the International Union for Conservation of Nature World Commission on Protected Areas (IUCN WCPA).

JONATHAN JARVIS is the Director of the US National Park Service.

NIKITA LOPOUKHINE is a former chair of the IUCN WCPA and was recently honoured with the J. B. Harkin Award for his lifelong commitment to Canadian conservation.

MOSES WAFULA MAPESA is a former chief executive officer of the Uganda Wildlife Authority, and is currently the Regional ViceChair for the IUCN WCPA for Eastern and Southern Africa and a board member of Leadership for Conservation Africa.

\section{ACKNOWLEDGMENT}

Appreciation is expressed to Andre Sovinj for his contribution to this chapter.

\section{CITATION}

Londoño, J. M., Jarvis, J., Lopoukhine, N. and Mapesa, M. W. (2015) 'Leadership and executive management', in G. L. Worboys, M. Lockwood, A. Kothari, S. Feary and I. Pulsford (eds) Protected Area Governance and Management, pp. 353-380, ANU Press, Canberra.

\section{TITLE PAGE PHOTO}

Mount Everest, 8848 metres, Sagarmatha National Park, Nepal: the highest point on the Earth's surface and a World Heritage property

Source: Ian Pulsford 


\section{Introduction}

\section{Julia Miranda Londoño}

This chapter addresses a subject that in principle might appear not to have a direct relation with protected areas because its scope normally refers to private business administration or public affairs. Nevertheless, it is absolutely clear that now, more than ever, strong and firm leadership is essential to achieve the effective conservation of protected areas around the world. Leadership is required in order to direct the course of the institution in charge of protected area management. It is also required for planning, for providing direction, for guiding and inspiring protected area staff and for defining and promoting conservation. It is also necessary in order for people to understand why protected areas are essential for the development of countries, the wellbeing of people and the health of the planet. Leadership is also required for working with other sectors of the economy, as well as with local and national governments and the media, so that they understand the role of conservation and thus support it within their own capacities and responsibilities.

Our planet is quickly changing. It is thus necessary for those responsible for exercising leadership in the conservation of the environment and biodiversity to abandon old criteria and to be more creative and willing to take risks in designing strategies that influence the public, thus bringing them closer to nature. This will allow us to achieve an efficient response for its protection and conservation. A world authority on leadership, Ronald Heifetz, who is Director of the Leadership Education Project at Harvard University's John F. Kennedy School of Government, says the new role of a leader is changing for the better. This new role is to help people face reality and to mobilize them to make change' (Taylor 1999). Taylor (1999) notes that in making change—and again quotes Heifetz-'[p]eople are afraid that they will lose something that's worthwhile. They're afraid that they're going to have to give up something that they're comfortable with.'

Heifetz recognises the challenges of leadership along with the pain of change, but he says this:

shouldn't diminish anyone's eagerness to reap the rewards of creating value and meaning in other people's lives. There's a thrill that comes with the creation of value - and of course there's money and status-and those rewards are surely worth the pain that comes with the territory. There are lots of things in life that are worth the pain. Leadership is one of them
... The real heroism of leadership involves having the courage to face reality-and helping the people around you to face reality. (Taylor 1999)

He develops many interesting ideas applicable to protected area management. Heifetz states:

[L]eadership means influencing the organization to face its problems and to live into opportunities ... mobilizing people to tackle tough challenges ... is what defines the new job of the leader ... At the highest level, the work of a leader is to lead conversations about what's essential and what's not. (Taylor 1999)

These leadership matters are discussed in this chapter. Three highly qualified chief executive officers (CEOs) of protected area agencies from different parts of the world have contributed their thoughts and lessons learned in very personal accounts. Each CEO has played a major role in the 21 st-century history of protected areas in their own country and the conservation of protected areas worldwide, so we are indeed privileged to receive the benefit of their insights here. This is a different approach to what you will find in more traditional textbooks about leadership. Here you will 'hear through words' the lived personal experience of each CEO as they present their section, for each has lived and worked in protected areas all of their careers and each has been happy to tell their story and pass on their lessons learned.

At the time of writing in 2014, Jon Jarvis is the Director of the US National Park Service (NPS); Nikita Lopoukhine is a former director-general of Parks Canada; and Moses Mapesa is a former CEO of the Uganda Wildlife Authority (UWA). We have presented their accounts of leadership and executive management for their organisations as three parts to this chapter that cover two functional areas. They reflect important lessons learned while they worked in their protected area organisations. Brief context-setting statements for the organisations for which they worked are also included in each section (Boxes 12.2, 12.3 and 12.4). Background on my own organisation is given in Box 12.1.

We have divided this chapter into three main parts that deal with two protected area themes: 'leadership' and 'executive management'. The reason for this division, in Jon Jarvis's words, is that ' $[\mathrm{f}]$ rom my experience, there is a distinction between leadership and management. Leadership is about inspiration, vision and strategic decision-making. Management is about working with budgets, staff, teams, and the day-to-day operations of a protected area.' To best serve our protected area community, this chapter will 


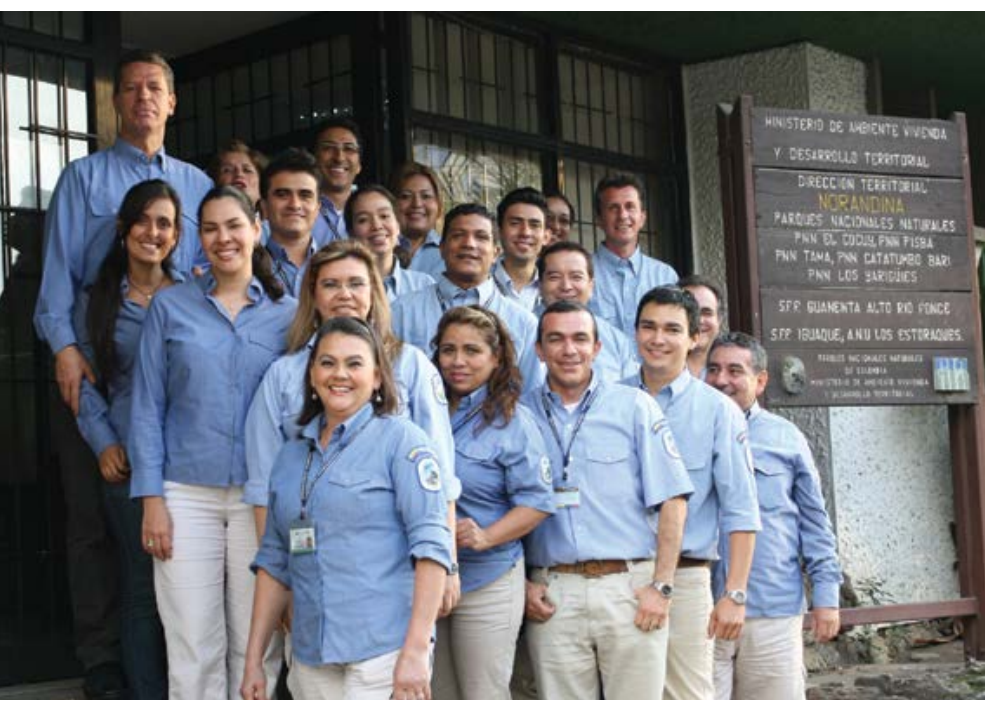

Some staff of the National Parks Service of Colombia Source: National Parks Service of Colombia

\section{Box 12.1 National Parks Service of Colombia}

The National Parks Service of Colombia is a government agency, administratively and financially autonomous under the political mandate of the Ministry of Environment and Sustainable Development. The agency as such was created by law in 1993 (the first Colombian national park was declared in 1960) as an administrative unit of the National Environmental System (Law 99 of 1993), aimed at managing the areas in the national parks system and coordinating the national system of protected areas, to conserve in situ the biological and ecosystem diversity of the country, provide and safeguard environmental goods and services, protect the cultural heritage and natural habitats of traditional cultures and contribute to sustainable human development. The National Parks Service is directly in charge of managing 59 protected areas, and articulates the basic management criteria for 440 protected areas at the regional and local levels, including private areas and forest reserves. With an overall budget of US\$33.3 million and 1250 full-time staff, the National Parks Service protects 14269644 hectares, which is 9.98 per cent of the terrestrial land area of Colombia and 1.48 per cent of the marine territory.

address both, but separately, so the reader can understand that it is possible for one to be an excellent manager, but not a great leader, or an excellent leader and not a good manager. A career progression in protected areas often begins with management and turns to leadership. In small protected areas, one person can do both, but in large areas or at the CEO level, these duties are often divided (as they should be). The CEO needs to either split their time appropriately between leadership and management or delegate the role of management to a deputy or team of assistants.

In the first part of the chapter, Jon Jarvis describes leadership of the NPS, one of the world's largest and oldest government protected area organisations. In the second part, under the theme of executive management, Nik Lopoukhine describes his thoughts and experiences about operating at the highest executive management levels in Parks Canada and elsewhere; and in the third part, Moses Mapesa presents his account of working with people based on his experiences as the CEO of the UWA. Moses's account is also under the theme of executive management. His account of his rewarding and turbulent experience as a CEO is compelling and it is an important lesson for all concerning personal integrity and courage that have succeeded over the corrupt behaviour of others.

Each of these three accounts is different-it is situational and personalised-but there are some very important CEO leadership messages for protected areas that are recurring, and we provide a concluding section in which we reflect a little on these matters by providing guidance for the future. What is particularly important in the rapidly evolving world of protected area management is that this chapter is about the executive leadership of protected areas, for protected areas and by experienced protected area chief executives.

\section{Leadership}

\section{Jon Jarvis, Director, US National Park Service}

\section{Concept}

We who serve as leaders of the world's protected areas are in the perpetuity business. There is much written about leadership in the private sector but far less about leadership in the public sector and even less about leadership of protected areas. Unlike private sector leaders who provide products and services to the public over a given time frame, our working assumption is that society will always need protected areas and our decisions must consider the long-term conservation and preservation of the resource and the benefits to the general public. Our stewardship is carried out on behalf of the trust placed in us by the public; therefore they deserve the very best leaders and managers. This chapter is specific to the qualities and attributes of great leaders of protected areas. 


\section{Attributes of a leader}

Leadership of protected areas, first and foremost, is based on core values of conservation and preservation. Without a deep and abiding belief by the leader that conservation and preservation are essential to our survival, all decisions will be seen as shallow and motivated by external factors. The leader must also have vision that things can and will get better through their work. Optimism is essential to effectiveness, especially since we know that protected areas will rarely have the level of funding and staffing that we believe they deserve. Perseverance is also essentialpursuing each threat or opportunity with patience and a dogged determination to succeed. Unfortunately, no leader of a protected area is armed with the complete science, past experience with the issues or a sage-like ability to see outcomes. Instead, the leader requires a certain comfort with ambiguity. A great leader is an excellent communicator of his or her ideas, vision, commitment and optimism. A great protected area leader inspires others both within and outside the organisation to take action. A great leader sees all the parts interacting and puts them into a strategic plan that results in marked improvement of the effective protection of these legacy lands. A great leader encourages innovation and creativity. He or she can navigate the treacherous waters of politics, knowing when to give in and when to push back. Lastly, protected area leadership is lonely, and while a peer network is important, one must develop the self-confidence to defend the protected areas when outnumbered and overwhelmed.

There is no greater calling than to be a great protected area leader, as they give a voice to those who cannot speak for themselves, a voice to those of the past who handed us this responsibility, a voice to the animal and plant kingdoms with whom we share the Earth and a voice to future generations, who are counting on us to leave them a world in which they will want to live.

\section{Leadership and ethical values}

Protected area conservation leadership is a public trust carried out for the benefit of all people, not just some of the people; therefore, ethical behaviour by the leader is essential to success. In addition, unlike many other jobs, the ethical value of conservation leaders continues 24 hours a day, seven days a week, and 365 days a year, on and off duty. Any leader who is working in conservation or preservation can fully expect that those who oppose his or her efforts will at some point attack the leader's personal integrity. If they cannot destroy your policy, they will try to destroy your reputation and, by doing so, undermine your initiative and effectiveness. If they find

\section{Box 12.2 US National Park Service}

The National Park Service (NPS) is a bureau of the US Government within the Department of the Interior. With a full-time staff of 25000 , approximately 10000 seasonal staff and hundreds of thousands of volunteers, the NPS is the steward of more than 32 million hectares in 401 national parks, monuments, historical sites and recreation areas in every State and Territory of the United States. The NPS hosts 280 million visitors to these parks annually, with an operating budget of US\$2.8 billion. The NPS has additional program and grant responsibilities for historic preservation and recreation in communities throughout the country. The NPS will be 100 years old in 2016 and is preparing for its second century of stewardship and public engagement.

any departure from the highest standards, even in an offduty status, it will be used against you. At the end of your term as a protected area leader, even if you lose some battles, you must never lose your integrity. The leader also sets the tone of ethical behaviour for all employees. If the leader displays unethical behaviour, it will be impossible to expect higher standards of subordinates.

\section{The ability to promote enthusiasm}

Author and famous US conservationist Aldo Leopold said that to have an ecological education is to walk in a 'world of wounds' (Leopold 1993:165). At a meeting of biologists and historians, discussing the impacts to natural and cultural resources from climate change, a biologist commented that at least the cultural professionals had a method to document a doomed resource and to say goodbye. There is, however, no equivalent process in the natural resource field. It is not uncommon to see depression and low morale in staff who work in the conservation field. Therefore it is essential that the leader conveys a sense of optimism and enthusiasm. This can be accomplished by the leader demonstrating honest interest in the detailed work of the employees and celebrating success, no matter how small. Spending time with each employee, regardless of their level within the organisation, can convey to them a sense of worth. It is also important for the leader to focus attention on the wins rather than the losses. One area of positive impact is in the restoration of habitat for a locally extirpated species. Such restoration of a natural resource can also restore enthusiasm and morale. There are no more enthusiastic users of the outdoors than children, whose sense of wonder is infectious and can be contagious. For the 373 383-hectare Olympic National 
Park in Washington State in the western United States, when staff were ready to release a population of 'fishers' to reintroduce them to this north-western forest, the NPS team allowed high school students to do the release and soaked up their excitement.

\section{Excellence in communications}

A great leader is also a great communicator. The leader does not have to know everything about an area, issue or topic, but they must be able to communicate key components to various audiences. The style, depth, delivery and tone of the leader's communication must be tailored to the different audiences. Speaking to an elected representative is very different to speaking with an indigenous leader. The key to becoming a great communicator is first to watch and emulate those who do it well and second to practise, practise and practise. Take a hint from the great comedians: they practise their routines over and over in front of live audiences until they get it right. As an NPS field manager, particularly in rural communities, I always made sure that I reached out to community leaders long before there was a crisis that required me to do so. Early establishment of open communications will lead to much better relationships when there are issues to resolve. Crises require more frequent communications than normal.

\section{Teamwork}

The days of command and control are long gone, as are the days of the heroic leader. The best accomplishments are the result of effective teamwork. There are many books on team development, function and effective management, and I would recommend any leader who works with a team researches the literature on team dynamics. Below are some of the guiding 'nuggets' or lessons I have gleaned and successfully applied.

- Assemble a team of people who want to work together and who have complementary skills.

- Aim for diversity and a diagonal cross-section of the structure of the protected area organisation.

- Give the team a meaningful task and clear goals, but be careful not to dictate the process by which they will work. Telling them not only what but also how will inhibit both creativity and team function.

- Keep it small. Teams which are expected to make decisions should have between six and 10 members. Larger teams have difficulty reaching consensus.

- Observe the team's interactions and prevent one voice from dominating. Create space for the minority voice on the team so that all voices are heard.
- Look for early wins by the team and reward success; then increase their challenges.

- Take their advice and use it. If you do not then you are wasting their time and talents.

- If the issue is field based, take the team to the site and have the discussion on the ground.

\section{Strategic decision-making}

The ultimate role of a leader is to make the final decision. The three most important components of good decisionmaking are as follows.

1. Use the best available sound science and other scholarly information. Note that this is the 'best available', which implies that the science may be incomplete but it is still informative and relevant. Also note 'sound science' implies peer-reviewed, published or well-documented information.

2. Maintain accurate fidelity to the law. We operate within a body of law and policy and a great leader must understand the legal foundation of those laws, as well as the letter of the law. Deviation from fidelity to the law puts the decision and the resource at risk.

3. Act in the long-term public interest. Given we are in the 'perpetuity business' with protected areas, decisions must be based on the long-term view of what is in the best public interest and must not be made for short-term political expediency.

These principles establish the foundation for making decisions. The leader must also have a strategy for making a decision stand the many tests it will be subjected to. Remember that 'sunlight is a great disinfectant' or, in other words, the decision must withstand the scrutiny of the public and therefore must be made in the open, not behind closed doors. It also must be consistent with policy, past practice and other decisions made in similar circumstances. If there is significant deviation from these principles, the leader must be able to clearly explain the reasoning behind the discrepancy.

\section{Dealing with change}

As they say, the only constant is change. Public opinion, demographics, economics, funding, politics and the climate are all changing. The leader must be able to monitor and keep abreast of these and communicate effectively to various constituencies, especially employees and partners. Great leaders can use change to their advantage to make strategic, positive corrections 
recreational parks and protected areas as components of their community protection. When these investments are geographically linked, ecosystem function can be restored and native species can thrive.

\section{Perseverance}

On the high, windblown ridges of the Great Basin National Park in Nevada, western USA, stand the gnarly trunks of bristlecone pines (Pinus spp.). Some individuals are 5000 years old and have been growing in that spot since before the first pharaoh ruled Egypt in 3000 BC. From such grand old trees, we can draw our inspiration for perseverance. Nature perseveres in spite of human efforts to subjugate it. In addition, the wonderful thing about nature is that, given a chance, it can recover as well. Great leaders have the ability to persevere in spite of significant setbacks, because they are in it for the long term.

\section{Restoration at Elwha River}

Choices of direction: protected area, Taiwan. Typically, strategic decision-making is not simple and requires the three components of good decision-making described above

Source: Graeme L. Worboys

to the organisation, its policies or even its structure. For instance, a shrinking economic environment presents an opportunity for more collaboration and innovation within the organisation. One major challenge for leadership in the world of conservation is that climate change is affecting our protected areas in ways we do not completely understand. It is therefore essential that we begin to plan for that change and allow for multiple futures, while building as much resilience into the system as possible.

\section{Creative solutions for change}

Since we know that change is inevitable, as leaders, we need to embrace it. Great leaders articulate a vision and use change as an opportunity to drive towards that vision. Let us take the example of sea-level rise affecting coastal protected areas. A simple question would be which area is going to be the next coastal wetland created by the new sea-level, and to ensure that area, if possible, is included within the protected area's boundaries via acquisition. This could ensure that the coastal environment will have the resiliency to withstand sea-level rise. Likewise, rising sea-levels and increased storm surges are beginning to show that 'green infrastructure' such as mangroves may be far more resilient and sustainable than traditional 'grey infrastructure' such as seawalls. This can then result in major investments by coastal communities in open space,

It is also useful to reflect on the need for perseverance as a leader. Some projects take decades of leadership to achieve success. One such project with which I have been involved for more than 20 years is the removal of two dams on the Elwha River. This river drains 181 square kilometres of pristine habitat within Olympic National Park and then hits two hydroelectric dams before flowing into the Pacific Ocean. More than 100 years ago, the river was the lifeline for hundreds of thousands of salmon and was the lifeblood for the Lower Elwha Klallam Native American tribe. Work by a team over 20 years means the dams are now in the process of being removed, completely reopening the park again—after 100 years - to the return of various species of salmon and steelhead (Oncorhynchus mykiss irideus), another species of fish. Persistence, patience, partnerships, consistency and continuity have achieved what many thought was impossible. My personal involvement has been on and off during the entire period, with a key leadership role for 10 years as regional director of the region that oversees Olympic National Park and director of the entire NPS. This has required me to secure nearly US $\$ 350$ million in funding for the project, overcome periodic opposition, shore up fragile partnerships, work with politicians, select contractors, celebrate successes and hire new people to lead the park-all the while doggedly keeping my eye on the ultimate goal of dam removal. This has been an extraordinary team effort. 


\section{Building supportive networks}

The management of protected areas through networks is an emerging field, and this concept can be applied to the land itself and to the organisation. At the landscape scale, networks of interconnected protected areas can create corridors for wildlife and build long-term resilience into the ecosystem. Like an organisational ecosystem, great leaders develop a network of support, advice and counsel over time, which they can rely on when faced with a daunting issue. They may not know the answer, but they know whom to call. They also reciprocate when given the chance. Protected area networks also include partners, other agencies, local communities, volunteers, advocates and visitors, all of whom contribute to the long-term vision. Great leaders build and nurture these networks.

\section{Managing organisational change}

Organisational change is difficult and the leader must devote enormous personal effort to accomplishing significant positive change. Before any major organisational change is attempted, a leader must selfassess their own commitment and capacity to see it through. First, the leader must communicate to the employees why change is happening, whom it will affect and when. The best leaders take on board feedback and accumulate input into alternatives to accomplish the objectives. Once the direction is decided, the leader must stay involved and abreast of the reactions. Frequent communication is essential. An assessment of the results and a commitment to review and correct mistakes must also be honestly made.

\section{Innovation}

Innovation is essential to any protected area organisation in that the challenges constantly require new ideas. Well-respected author and organisational consultant Margaret Wheatley (2006) concluded that innovation and creativity already exist in any organisation and it is the responsibility of leadership to find it, highlight it, nurture it and it will grow. Great leaders embrace this focus on innovation and create a space in which innovation and creativity can flourish. Leadership then selects which innovation should be nurtured and therefore the direction of the organisational change driven by this innovation.

\section{Investing in new ideas and new systems}

New ideas are a great way to adapt the organisation to change and new systems are important additions to accomplishing the work. That said, all new ideas need to be tested and new systems can be expensive, timeconsuming and a distraction from the core work. Great leaders encourage new ideas, but field test them before imposing them on the full organisation.

\section{Communication and advocacy}

Protected areas need advocates, and great leaders know how to nurture and communicate with key advocates and advocacy organisations. Great leaders are by their nature also advocates for the protected area, for the resources within and for their staff and partners. Advocacy is, however, a carefully honed skill. In some countries, 'advocacy' organisations have a special legal status and can be party to litigation. Great leaders learn to walk a fine line between their own advocacy and that of the outside advocate. When communicating with advocacy organisations, the leader must show both passion and restraint.

\section{Protected area messages for life's sake}

Issues as important as conservation and the management of protected areas should never be reduced to a soundbite. That said, the public loves a catchy phrase and can be motivated by them. Leaders of protected areas who use these types of messages must be able to go deeper into the meaning behind them or the phrase will soon lose all appeal.

\section{Dealing with community protests against key conservation decisions}

It is not uncommon for a decision regarding a protected area that is made for the good of all the public to also restrict an activity undertaken by the local community. This is particularly problematic when it restricts a traditional activity that may have been done for generations, but now has been recognised as having a significant impact on the purposes and values of the protected area. First and foremost, the great leader must do everything in his or her power to engage the community before they resort to public protests. At all costs, do not let the protest be about a lack of engagement with the community, but rather about the decision itself. One of my favourite quotes is from a mentor of mine, who used to say 'any idiot can say no; it is a lot harder to get to yes'. Any protected area leader can gauge when an 
issue will result in a negative response by the community, so with that knowledge, it is necessary to engage with the community to find where there is common ground. For example, a great leader must be able to explain the rationale of a decision that is going to restrict a community's activity but provide some other benefit such as an increase in the overall economic benefit to the community because more visitors will be attracted or because the environment or ecosystem services will be restored to provide a healthier environment.

\section{Defining an issue}

An old mentor of mine always said 'how you see things depends on where you stand'. It is one of the prime responsibilities of leadership to be able to define all the pertinent elements of an issue-the science, the politics, the practicality, the history, the public opinion, the risk and the legal ramifications - and put them into context. This process is done by bringing all the experts on this issue into the same conversation and giving each one the opportunity to speak openly and honestly. Issues that are unclear need to be assigned to someone to conduct further analysis and bring it back to the group. On any issue there are often strong opinions on all sides. It is the responsibility of the leader to ensure all opinions are heard. Spend time trying to discern what you know and what you do not know. Great leaders seek out those who have opposing opinions on an issue and listen to their views even when there is disagreement.

\section{Defining the consequences of no action}

No action or no decision 'is a decision' because the resources we manage are not static, they are not frozen in time and procrastination or delay only allows the present to continue, often with unintended consequences. In addition, the longer an activity that is incompatible with the purposes of a protected area is allowed to continue, the harder it will be to eliminate or restrict. 'No action' over a long period allows incompatible activities to become standard practice and acceptable — and almost impossible to alter. There are times when no action is appropriate but it always must be viewed in the same light as a decision rather than just procrastination or an inability to make up one's mind.

\section{Describing with clarity the response needed}

The role of the great leader is often to bring clarity to an issue so that the actions are obvious to all. The key is to listen intently and articulate the core or essence of what you have heard. The leader must then coalesce all of the input into a clear vision of the direction needed to resolve the issue. Very few leaders can do this without a great deal of practice and experience with complex issues. With practice, leaders can become very good at this essential task. If the decision or response is complex, the leader must be very specific as to what needs to be the next step, who is going to do it and when. Orchestration of the response can be as important as the decision itself.

\section{Securing support of politicians}

Politics is a reality that every protected area leader must learn to live with, embrace and use effectively. Some politicians operate under the principle that virtue and public service are their own reward' and these are the easiest to work with because of the intrinsic value found within protected areas. That said, all politicians are driven by several factors: the desire to be re-elected by their constituents, taking credit for accomplishments and positive media attention. Protected areas can effectively deliver all three. The first step is to build a working relationship with a politician so that you may contact them directly when there is an opportunity for them to be seen by their constituents doing something positive, when there is an announcement they can take credit for or when there is positive media attention from an event or action at the protected area in which they can participate. Offering this kind of opportunity will build the support needed when there are tough political issues and when you need them to stand up for protected areas. There is no room for corruption, back-room deals or special considerations for politicians, their friends or colleagues. Compromise of the integrity of the leader or the protected area for the benefit of a politician, no matter how powerful, should never be considered.

\section{Anticipating and planning media interest}

Like politics, the media is a part of our lives. Every protected area should have at least one person who is trained to work with the media, write press releases and be on the scene with reporters and their cameras. The media is interested in good and bad stories, interesting sidelines, scary stuff and human interest, especially interesting characters. Protected areas have all of these stories. The media will want to talk to the 'leader' of the protected area and great leaders are always willing to talk to the press. This is an area where practice makes perfect. Do not be afraid to go in front of the camera. Critique your performance brutally. Look at everything from the clothes you wear to the way you look at the reporter, to the confidence used in your answers. If the reporting area has traditional media, as 


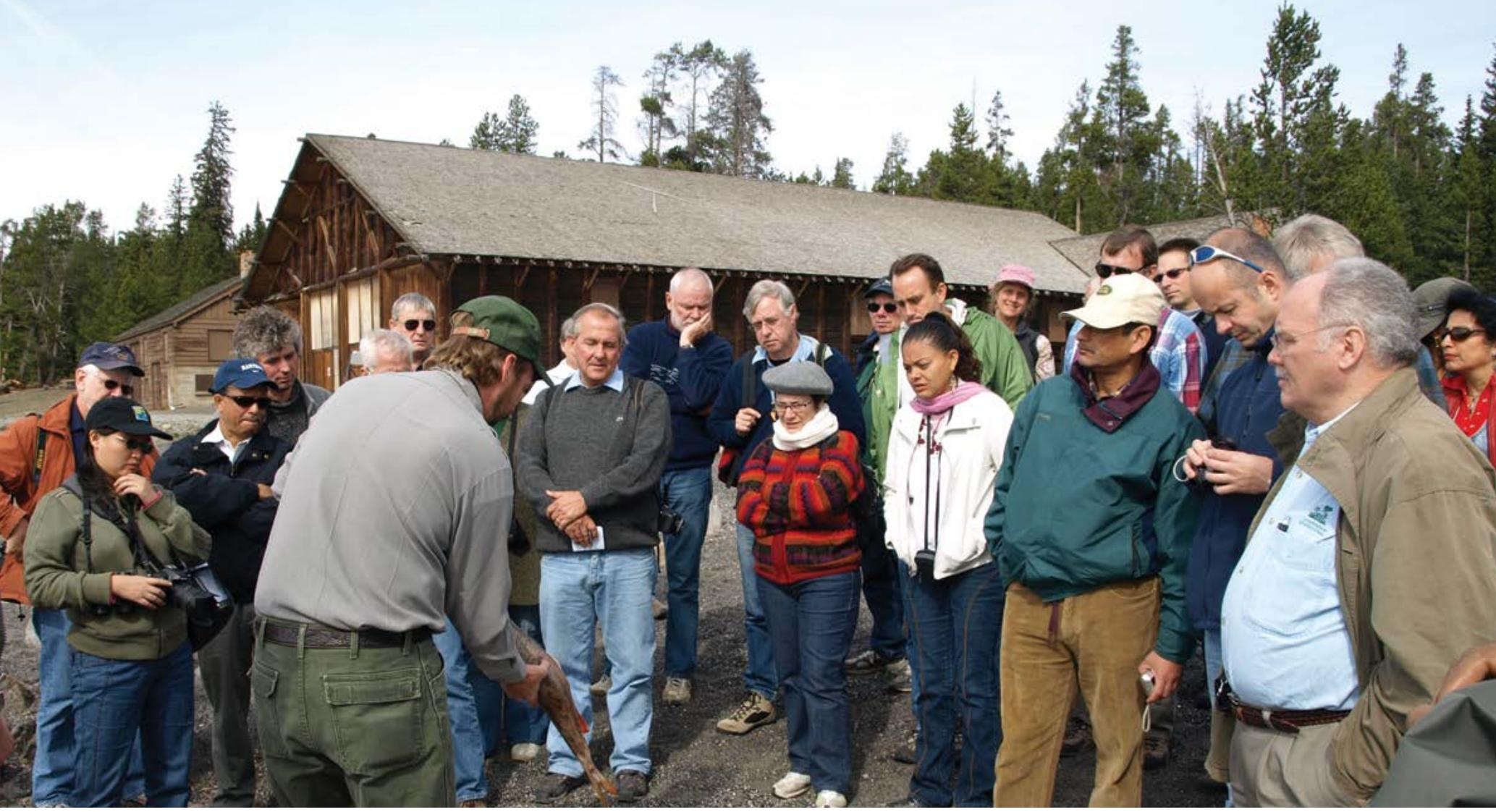

US NPS researchers briefing protected area management leaders from around the world about their research and advice for management in relation to introduced fish, Yellowstone Lake, Yellowstone National Park, USA

Source: Graeme L. Worboys

in newspapers, radio and television, a relationship can be built so that 'scoops' can be granted to specific media. Develop a relationship with the reporter who frequently covers activities in the protected area. Invite them out at slow times so they get a sense of the protected area's operation and its complexity. Push stories to them that you think they will like. Hold press conferences when issues are complex and controversial and take questions, answering them honestly. Never attack the media itself, as that is a losing proposition.

\section{Securing action to achieve conservation outcomes}

Essentially this is the crux of the matter. As leaders, we must have a strategy to accomplish our conservation goals. Nature needs us, as there are many forces, from climate change to extractive industries, which, without our active engagement, could have a negative impact on the protected areas within our stewardship. A great leader combines all the elements of science, media, politics, staff effort, community support and public engagement into a series of strategic actions that result in a positive outcome for protected areas and for the long-term view of the public interest. There can be few greater callings.

\section{Executive management}

\section{Nikita Lopoukhine}

\section{Concept}

Protected area agencies consist of a headquartersnormally near the seat of government - and a system of geographically dispersed protected areas. Communication can be instantaneous in the 21 st century, which permits issues to be dealt with collectively. Each component of the agency is faced with unique situations and different stakeholders. Executive managers must be equipped to deal with issues as they emerge locally while also being cognisant of global, national and regional-level interests. This is the common reality of each executive manager of a protected area agency, which includes the CEO through to the superintendent of a protected area. To be successful, protected area executive managers must have interpersonal and personal skills that include clear communication. Armed with such skills, a manager is well served in the planning and the realisation of both short-term and long-term strategies. 


\section{Attributes of an executive manager}

\section{Inspirational leadership}

Jon Jarvis has described CEO leadership earlier in this chapter. It is a quality that every successful executive manager has and, while easy to dissect, it is not so much taught as being an acquired skill. Demonstrated leadership is inspirational to staff. Characteristics of decisiveness, fairness and strategic leadership instil confidence in those who work with and report to executive managers. To be sure, a manager's responsibilities can be difficult, as they often face decisions that, in extreme circumstances, may affect the lives of people. Where possible, the manager must be open to the views of people and consider the concerns and interests of those affected; however, the final decision is his or hers.

\section{Communicating with people}

Protected areas, whether private or public, are run by people, depend on people and, as a societal construct, are for people. While a principal objective of a protected area is to conserve biodiversity, success is dependent on the ability to manage people. Management of people is undertaken through the communication of ideas, plans and the regulatory regime. Internal protected area agency communication is as critical as external communication. A successful executive manager devotes time and effort to communicating with employees. This is critical to ensure that agency employees are apprised of common objectives, purposes and intentions. In turn, frontline staff can instil an understanding among stakeholders of the values of and the plans for protected areas. Hence, it is paramount to invest in the development of communication skills for both the executive manager and the frontline staff.

\section{Listening}

Communication is a two-way skill. Using a variety of media to push one's views is not valid communication. If there is not an equivalent effort devoted to listening, communication will inevitably fail in delivering the results that are wanted. Listening encompasses opportunity for feedback and responding to the feedback. Indeed, responding signals that one has been heard.

\section{Negotiation skills}

Along the way to making decisions, executive managers negotiate through alternative and in some cases conflicting views. The decision needs to account for the source of the views while keeping track of the overall strategic direction and overall plans. Political

\section{Box 12.3 Parks Canada}

Parks Canada is an agency of the Government of Canada, under the responsibility of the Minister of the Environment, who mandates it to 'protect and present nationally significant examples of Canada's natural and cultural heritage, and foster public understanding, appreciation and enjoyment in ways that ensure the ecological and commemorative integrity of these places for present and future generations' (Parks Canada 2012:5). Parks Canada manages 44 national parks (including seven national park reserves), four national marine conservation areas, one national landmark and 167 national historic sites. The annual budget for Parks Canada is approximately US $\$ 450$ million and the agency has 4000 employees, a large number of whom are seasonal.

interests and the views of labour unions are perhaps the most difficult to negotiate. Political masters are at times indifferent to the reality of policy, legislation and approved long-term plans. Likewise, unions may have a greater agenda than the immediate benefits accruing to protected area employees. In addition, a business owner whose business may be compromised by a new protected area plan is equally difficult to convince of the benefit of such a plan. To get through such situations and arrive at a decision that is supportive of the overall strategic direction of the agency use communication skills, clarity of purpose and be open to solutions that can assuage the union, the politician or the business owner with whom one is negotiating.

\section{Conflict resolution}

Negotiations lead to solutions but along the way conflict can occur. This can happen when differences perceived by one or both parties are viewed as threatening to their interests. New ideas, different approaches and methods, and change in responsibilities can all lead to conflict. Much has been written on how to resolve conflict and there are two fundamental approaches identified: working on understanding the differing viewpoints of protagonists and developing trust. For an executive manager with responsibility for dealing with conflict, it is critical that he or she understands the basis for the differences and has the trust of both parties. Avoiding biases is a critical step to resolving a conflict. While being fair is important, it is also important that the conflict or a specific viewpoint does not lead to a diversion of organisational plans or directions that have been set by an executive manager. 


\section{Delegation}

Delegation involves empowering a subordinate to take decisions for which the executive manager remains accountable. Through delegation (which is the opposite of micro-management), the executive manager shares responsibilities, but more importantly, builds capacity, trust and efficiency in staff members of the organisation. Good delegation requires clear instructions that set out expectations as well as providing feedback on results. Delegation is recognised widely as a most important management practice. It also requires the executive manager to clearly know which decisions and tasks to delegate, when to delegate them and, most important of all, to whom to delegate.

\section{Strategic decision-making}

\section{Dealing with species conservation decisions}

The International Union for Conservation of Nature (IUCN) identifies the primary purpose of a protected area as the conservation of nature. In effect, nature trumps other values, of which there are many. As valuable as other values are, such as tourism or other socioeconomic benefits, they cannot compromise nature. Hence, when decisions may affect a native species or the function of an ecosystem, an executive manager must be cognisant of this fundamental purpose of a protected area. Governing legislation, in any case, provides an overall guideline to all decision-making.

\section{Beyond experience-based decision- making}

While the benefit of experience is invaluable, an executive manager cannot always delay a decision until information gained from operational experience is available. Indeed, executive managers are faced with myriad decisions that have human, fiscal and of course ecological implications. Management must decide. Not taking a decision has repercussions that are equal to taking action. There are outcomes in both instances. Decisions taken with inputs from colleagues, science and socioeconomic considerations overcome shortfalls in experience.

\section{Facilitating the optimum analysis of data}

Quality data are an executive manager's best friend. Good decisions are expedited based on information developed from good evidenced-based data. Quality data, however, require advanced planning as well as a commitment to long-term data gathering. Specific problems require specific data. One cannot solve a park's fiscal budgetary problem, for example, using data on the state of carnivores. Income and expenditure data are needed to address budgetary issues and the carnivore data are needed to manage wildlife species. An executive manager needs to invest in data gathering such as this for the immediate term and, more importantly, for the future.

The costs of data collection may seem exorbitant; however, if it is standardised (consistent data fields) and if it is oriented to address primary objectives, the benefits for protected area management are overwhelming. Without standardisation the risk is adopting methods and data sampling that are not compatible from one year to the next, data are quite useless for long-term monitoring purposes and in effect a waste of resources. It is imperative to invest in the up-front design of replicable data collection. Doing so will assure an optimum analysis of data and decisions made according to evidenced-based information and not perceptions. The prioritisation of data collection will always depend on the main objective of the analysis that has to be made and the main issues that affect the park.

\section{Assessing risk}

Risk assessment calls on an executive manager's judgment about a perceived hazard, its imminent threat status and the extent of the threat. Responses to the threat are based on an assessment of the risk and vulnerabilities. As an example, a forest fire's projected trajectory in relation to a national park facility guides the decision on how to minimise risks, which may consist of evacuating people or changing firefighting tactics. Once assessed, the risk factor is thereafter managed. While fire is used in this example, assessing risk is an element in all decisions affecting a protected area. A large infrastructure project has risks of cost overruns with implications for the park's budget. Furthermore, the implications for not proceeding with the project also require a risk assessment. Promoting one employee over another has human-resource risk implications. Negative implications are at the time inevitable and should not be cause for inaction. Good or bad decisions are evaluated as such only after they are made.

\section{Judgment in decision-making}

Judgment is perhaps the most difficult management attribute to quantify. Yet, judgment - the ability to discern and apply wisdom in decisions - often defines a good executive manager. Judgment is unavoidable whenever uncertainty is involved. Twenty-first-century technology provides access to information at unprecedented levels. 


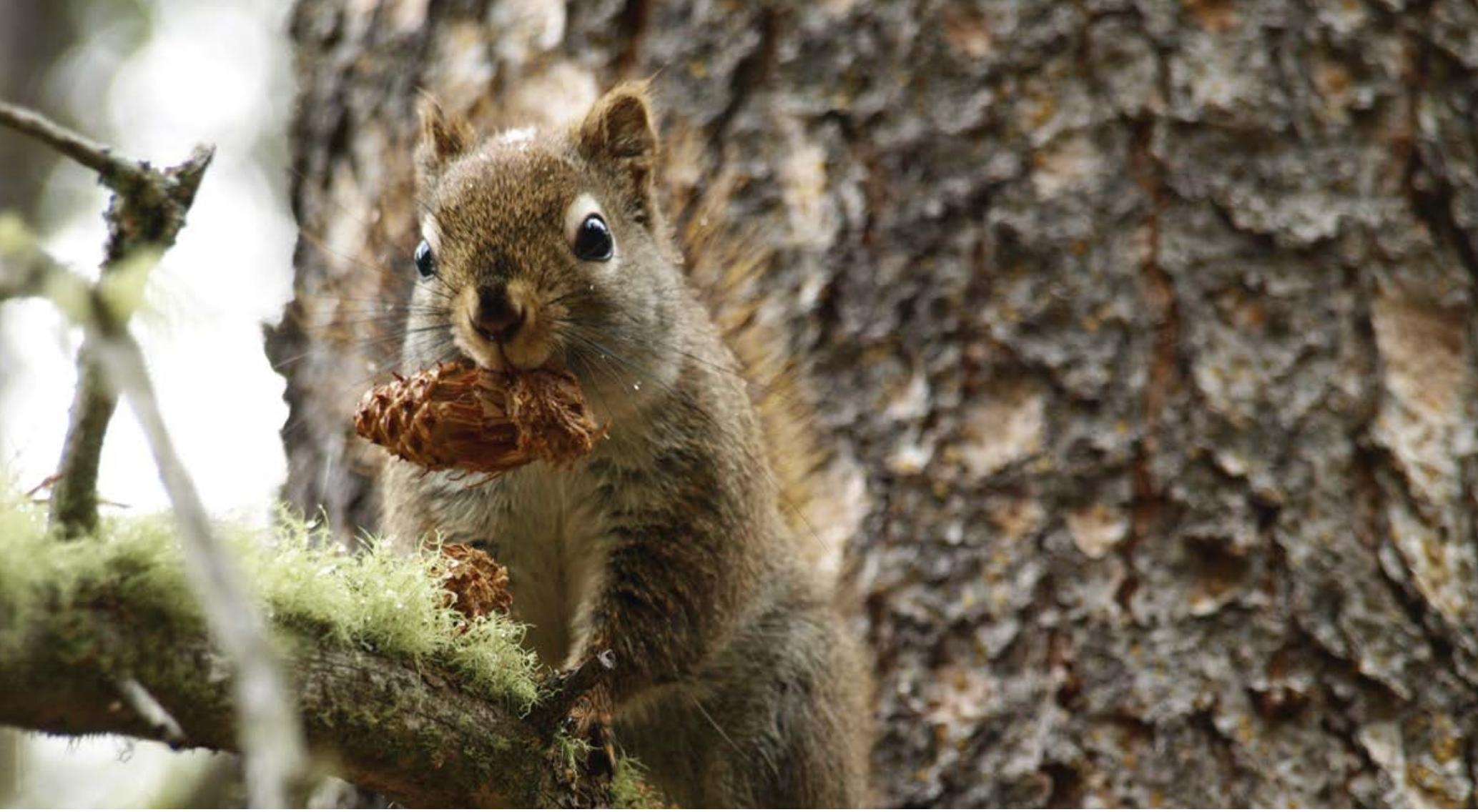

Red squirrel (Tamiasciurus hudsonicus), Banff National Park, Canada: a relatively common mammal found across boreal Canada and in areas up to 800 metres in altitude, and an important part of the biodiversity of this outstanding World Heritage property

Source: Graeme L. Worboys

Yet information, tools, processes or techniques will not yield an answer to management issues. Using these tools, however, helps to make an informed decision that is combined with sound judgment.

\section{Organisational structure, goals and objectives}

The world's many models of protected area organisations and other governance structures for managing protected areas preclude pointing to any one organisational approach as being better than others. There are a number of attributes among these different models that help to assure a successful governing body that meets its goals and objectives.

\section{Defining protected area management goals}

Goals are defined by people with an interest in protected areas. The people in such instances could be indigenous people interested in their traditional lands, politicians, citizens and even tourists from abroad. In all instances, the legislative framework that governs the allocation of land use, occupancy and authority provides the context for goal setting for a protected area agency, be it at a national, regional or community level. A legislative framework in the context of an indigenous or local community may draw on traditional practices or beliefs as a guide to where and what to protect. At the national and regional

levels, the goals might focus on ecological representation of the country, or capturing aesthetic or unique aspects of the country. In all cases, however, for protected areas, the primary purpose is the safeguarding of nature. Other goals - such as provision of visitor experiences, working with neighbouring communities and assuring aboriginal and local community involvement in management-are all important and can be written as additional goals.

The best process of defining organisational goals is through a consultative process that involves staff as well as stakeholders. With an open, consultative process, it is possible to achieve a set of goals that will stand up to scrutiny and time. To be clear, such a process does require effort, incurs expense and requires commitment from political interests and executive managers.

\section{Managing budgets}

The simplest and often the most common approach to budgeting is to follow the previous year's allocations. While simplistic, this is not progressive and absolutely ignores priority setting. Budgets should reflect strategic decisions for a protected area agency—not the other way around. To achieve an organisation's goals and objectives, an executive manager needs to have an adequate budget and human resource capacity. 
Circumstances are often such that budgets require revision. Delays brought on by myriad causes or at times even completion of a project in advance dictate the reallocation of funding. Depending on the governing structure for money management, some funds could be rolled over to the next year, lent to another project as an advance or simply returned to be used elsewhere by the agency. Allocations must be reviewed through the course of a year and increasingly as the year comes to a close. Variance reporting is a critical means of determining fiscal commitments. Audits and other mechanisms such as comptrollers are important as well to assure that funding is used in accordance with approvals. Where budgets are dependent on external sources or project funding, a particular effort needs to be devoted to focusing part of the project on the ways in which to finance the project beyond the allocation.

\section{Measuring accomplishments and success of plans}

Robert Burns, in his poem To a Mouse, wrote that ' $[\mathrm{t}]$ he best-laid plans of mice and men often go awry' (Burns 2004). Organisational plans set out ideas of what should happen for a protected area organisation and identify the goals and the means by which they are to be accomplished. Changes are to be expected as circumstances change for an organisation and unforeseen factors come into play. The reality of change should not deter one from putting considerable effort into consultation with the community and the review and updating of these plans. Also, avoiding input from stakeholders and the community can lead to confrontation.

Organisational strategic plans must be reviewed periodically with a commitment to report on these findings. This is particularly true where protected areas are public lands. Citizens require a periodic report on the intended achievement and whether this was accomplished. Many agencies are producing a 'state of the park report', which is an excellent form of communication with stakeholders. It equally provides for candid exposure to the challenges that a protected area manager faces. Ecological, fiscal and human challenges should equally be featured in any such report. The review of organisational plans is particularly beneficial for preparing subsequent plans where lessons learned can be reflected in the new plan and new directions can be formulated on the basis of past experience.

Canada, presenting the dramatic folded rock sequences of the Rocky Mountains: Parks Canada establishes the goals for managing this worldfamous protected area

Source: Graeme L. Worboys

\section{Efficiency and effectiveness}

Effectiveness is about usefulness, while efficiency is how well one does things. If both are reflected in the formulation of a protected area management plan and carried out accordingly, the protected area in question will be very well managed. To be effective, one needs to think through what needs to be done to achieve a goal. Using the right steps and avoiding trial and error assure efficiency. Training, for example, undertaken in an expeditious and optimal manner is efficient, but if desired change within the organisation is not (consequently) brought about by such training, it is not effective. Another way of stating the difference is that effectiveness is focused on the achievement of objectives while efficiency is the process of achieving the objectives with the least amount of resources.

Patrolling a protected area by one ranger may be as effective as a patrol with two rangers and leads to the conclusion that it is clearly more efficient, if measured by salary expended and time away from other duties. For safety purposes, however, a two-ranger patrol may be more effective should there be difficulty or risk to life encountered along the way. 


\section{Executive management: Working with people}

\section{Moses Wafula Mapesa}

This section emphasises the fact that protected area wildlife managers (executive managers) work with people. It has always been erroneously assumed that wildlife managers work with animals and therefore care about animals more than they care about people. Sometimes the actions and even behaviour of some wildlife managers have lent credence to this argument. Ideally, there should be a balance, and wildlife managers should strive to show they have the same care and concern for people as they have for animals and plants. This includes their own staff, the communities living within or neighbouring their protected areas, the people involved in the tourism industry, politicians, traditional leaders and other government functionaries. All of these categories of people play a role in the fulfilment of protected area management, so the interaction should elicit support and complementary effort as well as stem conflict. Although policies and laws exist regarding the management of protected areas, these should be understood as guiding principles that are subject to change with changing political and legal circumstances and input from all relevant stakeholders, thus reinforcing the need to work with all of these categories of people.

\section{Working with people within the protected area agency}

A protected area agency comprises protected areas and whatever infrastructure and equipment there may be in place as well as staff and their family and dependents. There may also be other people living legally within or regularly coming into protected areas to provide support services to staff and tourists.

Protected area executive managers must therefore, of necessity, establish a working relationship with these people supported by guidelines and guiding principles. Schemes for accessing transport, schooling, medical care, recreation, electricity, water and sewage, waste disposal and shopping must be put in place. A key issue is to control the numbers of people living within or coming into the protected areas, as this has a direct bearing on the management costs and the general protected area environment. Restrictions and policing alone may not be enough in the control of numbers and activities of these people since they are either family or friends of staff or they provide necessary services such as health, education, transport, food and other essentials. Executive managers should engage with these people, appreciate their

\section{Box 12.4 Uganda Wildlife Authority}

The Uganda Wildlife Authority (UWA) is a government parastatal agency. It is semi-autonomous with a board of directors and a CEO. The agency was established in 1996 as a merger between the then Uganda National Parks, established in 1952, and the Game Department, established in 1896. Prior to the 1960s, the key operations of the Game Department were wildlife control and hunting, while Uganda National Parks was responsible for preservation of wildlife and its habitats. Science, working with communities and human resource management became components of the management of protected areas only in the 1960s, 1990s and 2000s. Major policy reforms happened from 1994, leading to the creation of the UWA, which has to date implemented all the changes, making it one of the leading protected area agencies in Africa. The agency employs 1500 permanent staff and more than 500 temporary staff. It is responsible for the management of all wildlife resources in Uganda, including 10 national parks, 12 wildlife reserves and 14 wildlife sanctuaries. The annual budget is about US\$120 million. The board reports to the minister responsible for tourism and wildlife.

supportive role to protected area staff and plan with them how best they can provide services and interact with staff without an undue expansion of numbers in the protected area. Some of the guiding principles may include options for the establishment of staff infrastructure within the protected areas, on the periphery or right outside the protected area, and creatively initiating schemes that address social issues as they arise. All these options will have a cost, as well as ecological and social implications, which must be assessed in line with the IUCN category and management objectives (see Chapter 2) of the protected area. In many cases, it will be prudent to locate staff establishments either on the periphery or outside protected areas to allow for access to existing social amenities and service providers either already outside the protected areas or as they may be planned by local government. Where such options are not possible, however, well thought-out mechanisms for working with people within protected areas need to be developed at the agency level in the form of guiding policies and then implemented.

For harmonious living and to address social issues such as alcoholism, disease epidemics and personal development, protected area executive managers must implement programs that deal with these issues, especially where staff establishments are located inside protected areas. Such programs must be regular and effectively supervised and not left to occasional visits by social workers when 
problems are already well entrenched and are already taking a toll on staff performance (see also 'Staff relations and wellbeing' subsection below).

The people within the protected area agency are very important as their presence and social and infrastructure needs and services in the protected area result in direct management costs and all of this has long-term environmental implications.

To illustrate the point about working with people in a protected area, I would like to share an experience of some protected area colleagues in the Virunga National Park in the Democratic Republic of Congo. The park headquarters was established at Rumangabo on the periphery of the national park in the 1920s. This was to house the administrative infrastructure and accommodation for staff. Staff numbers have continued to grow and so have the numbers of other people living at the headquarters, and infrastructure has expanded. Park management has gone through many cycles of turmoil with the different political forces at play. This has resulted in rather difficult working conditions that have forced the executive management to think critically about the plight of people other than staff, especially their family members and dependants.

Between 2000 and 2012, the park had to house up to 200 widows and family members of former rangers killed in the line of duty. Many more rangers continue to die, leaving behind widows, orphans and dependants. After an incident in 2013, a fellow ranger had this to say about a fallen colleague: 'a Virunga ranger, Paluku Matembela, killed in today's attack, leaves behind a six-month-old son whose mother died in childbirth and their 14-yearold daughter' (Virunga National Park 2014). Chief Warden de Merode had this to say:

At times like this in the past, Virunga's global family has embraced those left behind and I sincerely hope we can all come together again to support those who have paid the ultimate price for defending Virunga National Park. Even in peacetime, life in eastern Congo is incredibly hard, so it is difficult to put into words what a ranger family goes through when they lose the head of their household, a husband, father, and usually a family's only income. (Virunga National Park 2014)

He added: 'We would like to raise enough money for the next five years as part of the Fallen Rangers' Fund commitment to support the families of our staff killed in the line of duty' (Virunga National Park 2014). Virunga National Park set up the Fallen Rangers' Fund to assist

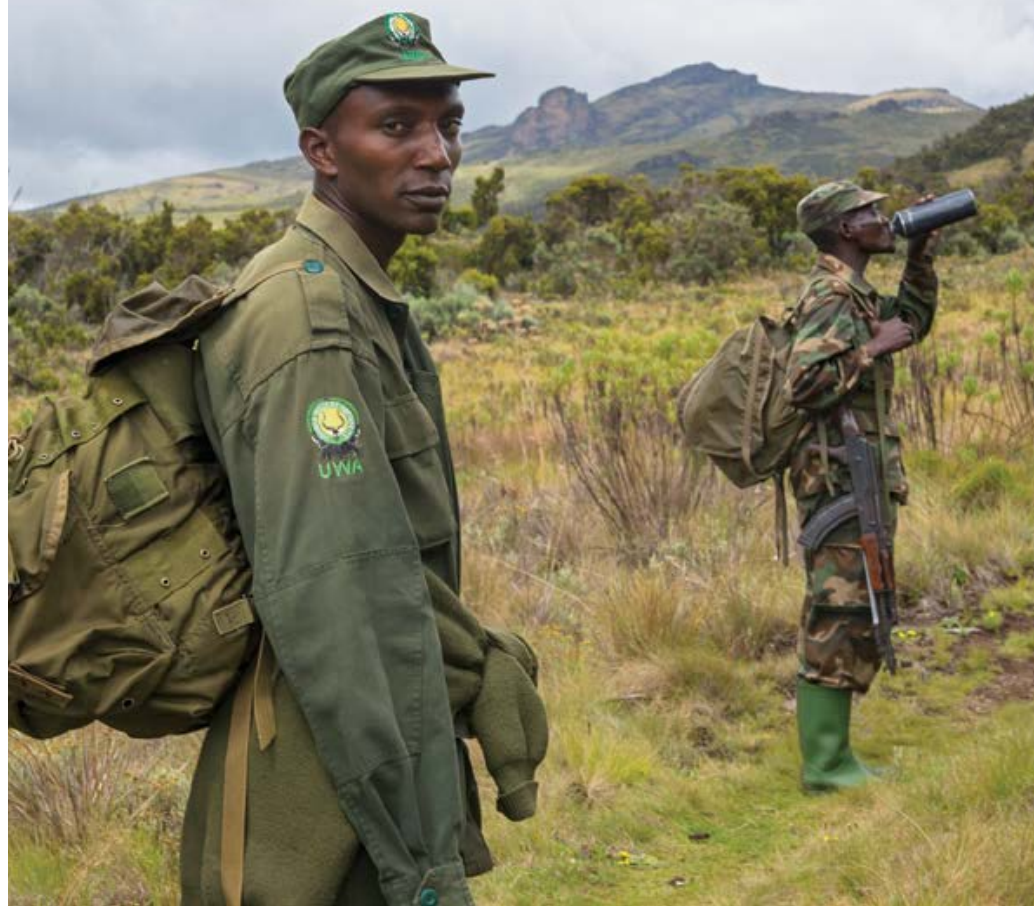

Uganda Wildlife Authority rangers in a highaltitude area of Mount Elgon National Park, Uganda: the park is a transboundary national park with Kenya and is located on an extinct shield volcano

Source: Stuart Cohen

the widows and orphans of rangers killed on duty with start-up funding from donors, private foundations and individuals.

The empathy shown by the chief warden towards the families of fallen rangers has had a powerful boost to morale in the rest of the staff in the park and endeared the community surrounding the park (from where these people hail) to the park management. Of course, the chief's decision is a huge administrative cost; the fallen rangers have to be replaced, and the families of the new rangers require similar support. It is a doubling of the cost; but by creatively coming up with the Fallen Rangers' Fund, the administrative and cost burden has been shifted from park management, and widows and families can be moved out of the Virunga National Park with some start-up capital. It is a win on three fronts.

\section{Working with people in the neighbouring community}

Neighbouring communities are an important category of people with whom to work and interact in managing protected areas. They are neighbours in the first place and in some cases they actually own the land where the protected area is located or they owned it in the past and still lay claim to it. They have a wealth of knowledge about ecology and social interactions over time. In many 
cases, they and their ancestors lived within the protected area ecosystems for hundreds of years before they were reserved. They coexisted with the ecological systems long before contemporary management systems were established. These time-tested management systems/ community norms and traditional knowledge are what the protected area executive manager needs to tap into. Often this is not documented and, even if it were, it would differ from place to place. The community has a wealth of information on errant persons in their midst who are wont to poach, encroach or engage in destructive activities, but they will often be indifferent towards or protective of these people if the working relationship with the protected area management is not mutually productive and respectful or if they feel dispossessed of the protected area's resources.

Recognition of the strong link between neighbouring communities and protected areas must therefore guide and inform the executive manager's working relationship with the community. Often the communities derive livelihoods from the protected areas including direct extraction of products such as food, medicines and construction materials, yet there are restrictions.

Interaction between protected area agencies and communities must not be left to staff in the community conservation departments alone. The protected area manager should regularly interact with communities on topical issues such as resource extraction and use, management zoning, infrastructure development, service provision, monitoring, law enforcement and tourism developments, through dialogue that feeds into planning. Whereas reports from staff and experts may be helpful, regular field interaction adds enormous value, and executive managers must find the time to engage with communities directly. Winning over community support and joint implementation and monitoring of conservation and development programs will be greatly boosted by the direct involvement of protected area managers at a senior level. Such regular interaction will avert conflict and allow for constructive dialogue and negotiation even in the most difficult of situations such as after the loss of property or human life to problem animals.

\section{Working with traditional leaders}

Many communities still have traditional leadership systems that are entrenched within their societies. In such societies traditional leaders wield strong authority and influence over the community. Even where traditional values have been greatly eroded by contemporary systems, there remains vestigial cultural authority held by traditional leaders that is beneficial to conservation and protected area management. This is in addition to the wealth of knowledge in terms of traditional norms that can be reignited such as societies or clans which identify with certain animals, plants or localities that they hold sacred and therefore protect.

Although in some cases traditional leaders can be very demanding, they should not be ignored but rather engaged by executive managers to harness their knowledge, win over their support and work with them to influence the wider community. This takes into account (especially) the cultural aspects that are compatible with contemporary conservation efforts. Traditional leaders and healers can also be powerful as change agents in respect to destructive societal norms such as initiation rituals requiring rare plant and animal parts, and can help in finding substitutes or abandoning or moderating such practices.

\section{Working with political leaders}

Political leaders today assume the role of champions of the people. In many cases, they present themselves not only as representatives of the people but also as the person with solutions to all people's problems. To win an election they will even promise to change laws governing protected areas or to degazette the whole or portions of protected areas to benefit the people. Indeed, many boundary changes have occurred to protected areas and in some cases a protected area's status has changed at the behest of politicians.

In many countries public officers are barred from 'active' participation in politics and therefore when politicians are campaigning for office protected area managers are hard pressed to provide truthful information to an anxious public. In some instances, the public is in conflict with executive managers over the existence of a protected area or use of its resources. Such situations call for strategic thinking and planning by protected area managers well ahead of time and at regular intervals, since the electoral cycle is usually predictable. These situations must be anticipated well in advance and there must be active and non-partisan engagement of key political players and leaders at various levels.

Effective information sharing on protected area objectives and management programs undertaken continuously at various political and leadership levels via documentation and reports, the media, formal meetings and one-to-one engagements have proved to be a useful tool in creating harmony and productive working relationships. Politicians have influence over 
populations, and even when they are unpopular they still influence or make decisions, so there is no room for indifference, failure to engage or for simply ignoring them on the part of protected area managers. Engaging political leaders can be time-consuming as they might simply be out to appease the electorate, and individual leaders change. This engagement is when negotiation skills, effective communication, knowledge of the subject and understanding of the social dynamics have to be put to use either directly by the executive manager or through teamwork and possibly external technical support. By working in this manner, the electoral cycle becomes less disruptive of protected area management while at the same time issues that arise repeatedly can be addressed in a systematic manner through dialogue.

\section{Working with the tourism industry}

When it comes to justifying the existence of protected areas in economic terms, protected area managers often resort to tourism. For many countries, protected areas possess many tourist attractions including unique and spectacular landforms, rare plants and plant communities and a diversity of wildlife. Most protected areas are promoted as tourist attractions. Inevitably, tourist infrastructure is developed in and around protected areas. A key aspect of this is striking the optimal balance between the level of tourism development and conservation objectives. Whereas foreign income is good for national economies and tourism spurs development, it does have an ugly side for both conservation and social norms, which protected area managers should take seriously.

In practice, tourism industry players strive to acquire the best sites within protected areas to gain maximum financial returns. Protected area managers must always remember that conservation is their core and primary responsibility and that tourism development is secondary. Site selection for tourist infrastructure development has to be weighed strongly against ecological as well as aesthetic considerations, not by simply bending to the desires or pressures of often powerful tourism industry players. Scenically attractive sites should not be exclusive but rather should be accessible to all. With protected areas increasingly under development pressure, it is best to locate as few tourism developments and facilities inside protected areas as possible. As with the example of management of staff infrastructure, peripheral tourism developments allow for fewer ecological impacts and social exclusion of workers while enabling staff and their families to access other social amenities. Protected area executive managers should have the capacity to articulate clear management objectives for a given ecosystem and bring out the optimal capacities for tourism developments to enhance both revenue generation and conservation goals. Options for low-impact tourism developments should be assessed, taking into account tourism carrying capacity and cumulative impacts over time. Only when armed with such information can protected area managers professionally negotiate for tourism concessions and monitor them. Tourism developments happen at site level, therefore the direct and firm engagement of tourism industry players by protected area executive managers is essential.

Owing to high economic returns and prospective investments, tourism industry players have access to high-level decision-makers who may be swayed by the economic arguments in total disregard of any environmental considerations. Given this, protected area executive managers should not rely only on ecological arguments in making decisions or recommendations about investments, but should take a holistic approach in assessing a variety of options, which they should share with prospective tourism industry players in a transparent manner, providing the necessary briefs to high-level decision-makers. The limits of acceptable use need to be negotiated based on a scientific approach with inherent monitoring measures. Business skills or sound business advice should inform interaction with the tourism industry in addition to social and ecological expertise.

\section{Working with other government agencies}

Protected areas are found in varied landscapes where other management activities are continuing, and in practice there are linkages with other departments and agencies at both local and national levels. Protected areas occupy land that can often be put to alternative use such as for agriculture, livestock grazing, forestry or for the extraction of resources such as minerals or water. In many instances, the protected area policy and legislative framework exclude any other activity or access to any resources. In other cases, they are inclusive but require collaboration. In reality, there is always debate and a desire to consider alternative land uses, or there are overlaps of mandates depending on the above and below-ground resources in a given area.

There is a tendency for protected area managers to be 'protective' of their areas of jurisdiction, citing policies and laws. Generally, the remote locations of protected areas also limit the regular interaction of managers with other agency colleagues, save for crisis situations. Experience has shown that the protective tendency only 
elicits resentment and conflict from other agencies. In addition, policies and laws are subject to change and indeed changes have occurred to allow for resource access and collaboration depending on the protected area category.

In extreme cases, conflicts have arisen over protected area resources with respective local governments and blame has been levelled against protected area agencies in situations of drought that have led to the deaths of humans and livestock due to shortages in food and pasture, or as a result of crop and livestock raiding by wildlife. Sometimes the issues are access to water or hydropower generation development opportunities or access to timber resources. In other scenarios, the problem is disease and pest control. In such situations, protected area agencies have been blamed for being too conservative, protective and insensitive to the needs of people and uncooperative with sister agencies. Such situations are avoidable by simply working proactively with the relevant agencies to find means of collaborating and creatively addressing the issues without compromising protected area conservation values. Protected area executive managers do not need permission or express instructions in order to engage with counterparts in other agencies, but they should obviously consult with and report to their superiors. If snubbed, they need not despair, but should be consistently resilient and persuasive. The types of collaboration may be broad, stretching to many agencies to include health (in the case of disease outbreaks or risk of outbreaks) and industrial developments (in respect of pollution). So, in practice, it may be tough to draw boundaries for collaborative involvement, however, this is where risk and threat assessment come into play as well as prioritisation based on comprehensive environmental impact assessments/studies at both strategic and site levels. Some of the issues are one-off or temporary, or cyclic such as disease outbreaks, flooding or drought, and may be predictable, thus allowing for reasonable time to consult, share and plan well in advance.

Protected area executive managers must live with the reality that with a scarcity of resources like water, pasture, energy, food and other basic necessities that may otherwise be readily obtainable from protected areas and the growing human population, there will always be a demand both from other government agencies and from people for access to these resources. Therefore collaboration, cooperation and a strong resolve for collective effort in the form of participatory landscape planning with other government agencies, especially at the local government level, are more critical than simply citing and enforcing the law. Again, scientific and cultural information about a given protected area become crucial for all involved to inform the decision-making process on land use or access to resources. Whereas trade-offs may be negotiated, this may only happen in as far as the protected area's purpose and objectives are not compromised.

\section{Leadership: One personal experience}

An experience I would like to share, which could be inspirational to executive managers, happened towards the end of my contract as CEO of the UWA. About one year before the end of my five-year contract as CEO at the UWA in 2009, the term of the Board of Trustees of the UWA was due to expire. I alerted the minister responsible (in writing) three months before the board's term of expiry, drawing attention to the legal provisions of the criteria for the appointment of new members. It was also about the time of the national general election. Despite several official reminders, the board's term expired and no new board was appointed. I worked without a board for nine months. Meanwhile, my contract term was also running out and I drew this to the attention of the minister as well. He responded immediately by offering me reappointment. I humbly protested, advising that he had to first appoint a board of trustees, which in turn would manage the process of hiring a new $\mathrm{CEO}$ or recommend me for reappointment after assessing my performance. The minister wrote to me, officially reappointing me for another five years. Next, he proposed names for board appointments and instructed me to secure their curriculum vitae for submission to cabinet. On scrutinising the $\mathrm{CVs}$, I found that seven of the nine nominees did not meet the prerequisite legal requirements to be appointed to the board. I again respectfully pointed this out to the minister. He ignored my advice and submitted the names to cabinet. At cabinet level, questions arose but the minister was powerful enough to prevail over his colleagues. When the board was announced, there was concern from stakeholders. Once the new board started business it was clear that their sole collective interest was to access funds earned from internal revenue. These funds has been saved and invested over seven years while we had World Bank funding support. The board members needed access to these funds as most were heavily involved in election campaigns at the time.

Now I had to make some hard choices. First, I had been reappointed without following legal process. Second, the board had been appointed without following the legal criteria as stipulated in the Wildlife Act. Third, the board and the minister were determined to fraudulently access millions of US dollars of UWA funds saved 
over seven years. It was clear to me that my fraudulent reappointment was meant to weaken my position. I could have resigned or I could have succumbed to pressure and done as instructed. I chose to stop the looting and re-create order. It was a tall order that nearly cost me my life or life imprisonment, as the minister accused me of treason, among other charges. After trying an internal solution by engaging the minister and the prime minister and failing, I went to the high court and won. The minister was ordered to disband the board and was then transferred. A new board was appointed as per the law and a new CEO hired following proper procedure. The funds were saved. Most importantly, the UWA's protected area programs were not significantly disrupted and, if anything, the UWA has continued to register growth. Although the first two layers of managers were removed (the CEO and directors) as part of the fallout, the third layer was strong enough to collectively 'hold the fort' for the UWA. This institutional strength was due to a deliberate capacity-building effort I had helped put in place during my term. As for me, my contract had expired anyway and I moved on. I look back with satisfaction despite the hard time I went through to uphold acceptable leadership principles.

\section{Staff management}

While I was attending a short course on governance and leadership in Montreal in 2007, the facilitator once said to our class: 'People do not want to be managed. They want to be led.' And he went on to ask, 'have you ever heard of a world manager?' He then answered his own question: 'A world leader, yes; educational leader, political leader, religious leader, Scout leader, community leader, labour leader, business leader-yes to all', and he went on to assert 'they lead; they don't manage'. One can manage a bank, a museum, a protected area and even a home, but when it comes to people, and for that matter staff, what they need is a leader-leadership_-because management is about resource allocation and control.

What, then, do we mean by 'staff management'? It is all about leading staff, providing effective leadership to staff so they can be productive in their respective jobs. There is of course some level of control in the form of guidelines, and resource allocation, to facilitate staff to do their work. So what is entailed in leading staff and what is leadership? Scanning through the literature, there are several definitions of leadership, including the following: 'The ability to achieve priority results through people; the ability to move yourself and others towards who you want to be; asking the right questions and inspiring others to work through individual and collective action as opposed to instructing them on what to do' (D’Souza 1994).

The heading for this section could have been 'leading staff', but for the sake of conventional wisdom, the terminology 'staff management' is used. Jon Jarvis has described leadership in some inspiring detail. Here I wish to focus on staff leadership. Staff leadership (or management) is about team building, staff welfare and relations, capacity building, professional development, mentoring, understanding different types of people and cultures and industrial relations.

\section{Teamwork}

Ordinarily, teamwork is about a group of people who agree on what they would like to achieve, they have or subscribe to a vision and a mission and they go ahead to set goals and define the desired results. They then decide how they want to attain the desired results. Every team must have a leader and every team must have guidelines. Resources must be available, roles clearly spelt out and accountability forthcoming. At the end of every effort, there will be consequences both positive and negative, depending on the level of attainment of the desired results. The leader must be quick to recognise weaknesses in the team and either help the weak members improve or replace them.

Teams are built, and it takes time and careful selection to build winning teams. Characteristics of teams include the following.

- An assemblage of top-class people. They must be qualified with skills in different but complementary fields, intelligent, trustworthy, with diverse perspectives and some of them with experience. In practice, there are always several teams that come together to form one great team. Protected area managers will, for instance, have teams in community conservation, finance, law enforcement, tourism, engineering, and so on-all coming together to form one great team for the protected area. Individual protected areas then come together to form an even greater team for the agency.

- Guidelines must be in place but must also allow for flexibility. It is pointless to hire intelligent people only to take away the opportunity for them to be creative and to take the initiative.

- Each team must have a leader who must have a vision or be committed to one, which is shared by the team members. The leader must allow for creativity but should also be a shield in the event that some of the novel ideas backfire. 
a protected area executive manager to experience and check out welfare needs such as medical provisions, food rations, camping gear, uniforms and transport. It is not enough to rely on written reports and policy guidelines, and it is useful to regularly check if practice is in line with policy and if management plans are being implemented. The interaction also allows for feedback that helps in management planning and policy reviews.

Obviously there will be cases of carelessness, omissions and mistakes among staff-some grave enough to be of a criminal nature-but the handling of these must be in conformity with policy guidelines, operating manuals, and labour and other relevant laws. Malice, backstabbing, favouritism, nepotism and other negative vices are bound to occur; an executive manager must always check the facts, hear out the victim and offer a chance for reform.

Social welfare arrangements/provisions/schemes are critical for staff loyalty and productivity. Such arrangements should, as much as possible, cover immediate family members, especially in countries where public social services are poor. Such schemes may include medical insurance, education, transport and housing. These schemes, in addition to competitive salaries, mitigate against corruption, embezzlement and fraud, and misuse of equipment. They also improve relations with the wider community neighbouring the protected area as some of them will access the services directly or indirectly and some of the staff will come from or retire into this community. This may reduce conflicts and the occurrence of illegal activities or enhance cooperation in addressing these issues.

Another aspect of staff welfare is motivation. Having a creative and free working environment is a motivational factor, as are attractive staff welfare schemes; however, the personal performance of individual staff needs to be recognised and there are many ways to do this. Recognition can also be given to teams, but even then each individual team member should receive a personal accolade. Recognition could include letters of commendation, certificates, awards, holiday offers, gifts, bonuses, further training opportunities, salary increments and promotions_consistent, of course, with organisational guidelines.

\section{Learning from failure: A protected area ranger's experience}

In 1993, as a new law enforcement warden in Kidepo National Park in Uganda, I was confronted with the challenge of large numbers of artisanal goldminers coming into the park with livestock. They also engaged in poaching. I planned and implemented three ranger patrols to address the problem, all of which failed. I led the third patrol myself, and one evening an elderly ranger asked me what I would do if the ongoing operation failed just like the previous two. I instinctively responded that we would 'celebrate' the failure and think again - in other words, try to learn from the three failures and plan again, as a way of keeping morale high. In fact, I was considering disciplinary action against the patrol leaders. True to the ranger's fears, we found lots of people, mainly women and children, involved in the artisanal goldmining, lots of livestock attended to by a few young men and the carcasses of freshly poached kudu and ostrich. We 'arrested' more than 150 people-threequarters were juveniles and women. As with the past two operations, we cautioned and released all of them since we had no capacity to move them even to the park headquarters (90 kilometres away) or the nearest police station (150 kilometres away). The backlash from these three failed operations included accusations by the police, local leaders and the community that park management was harassing 'innocent' locals mining gold for survival and that we had illegally confiscated large quantities of gold. I had almost believed the same allegations against the rangers and had considered disciplinary action before I chose to lead the third operation myself. Meanwhile, the communities mobilised in even larger numbers to go into the park, and armed themselves with automatic rifles since they had been emboldened by their leaders. This is when we chose to review our failures, decided against any disciplinary measure and, in a 'celebratory mode' (local brew and food were served with a local musical performance), invited all the rangers to contribute ideas on how to address the problem.

In summary, we agreed that the reasons the park was being invaded were a prolonged dry season, which meant there was no food, an externally driven incentive for goldmining by a licensed company operating outside the park, but most importantly, the operational mistakes of releasing those arrested without involving local leaders and the police while confiscating all their tools. So in the fourth operation, all the local police chiefs and local leaders were ferried to the site, and rather than confronting the communities with the law, we engaged in dialogue to find out why they had invaded in large numbers and worked out the solutions together. After four days of dialogue, it was agreed that the artisanal goldmining in the park must stop, and with it the poaching and livestock grazing, but park management would help access food from the World Food Program 
that was supplying food in the region anyway. Persistent offenders would be arrested and charged by the police with the full knowledge of the local leadership.

\section{Capacity building}

Capacity building is a continuous process through one's career because we live and work in a changing environment-ecologically, economically, socially and technologically. Staff must have equal opportunity for capacity-building programs, both in-house and external. Capacity-building programs must aim at enhancing competencies and skills for better performance as opposed to earning promotions. In many countries, after undergoing capacity-building programs, some staff erroneously demand promotions or bigger assignments, which they may not yet be ready for or which may not even be available in the agency. This often results in staff leaving the organisation at the expense of the capacity-building effort. Staff retention schemes must therefore be put in place and emphasis must be placed on performance enhancement in existing placements.

\section{Training programs and professional development}

Staff have an inherent desire for academic and professional growth at varying levels. This should be encouraged and supported. Staff who manifest this characteristic are relatively easier to handle because they presumably have an interest in improvement. They will, however, also need guidance so that the desire for improvement is not overridden by ambition to reach the top too quickly. Such staff may be good candidates for long-term research programs that create or add knowledge. Those who do not exhibit the desire for improvement may be encouraged to take on shorter competency or vocational skills-based training. For better results, staff undergoing training programs for professional development should be allowed reasonable time for training in their position in a protected area. Immediate personnel requirements sometimes disrupt such professional development programs. Agencies could hire short-term staff for temporary and urgent manpower requirements rather than disrupt ongoing professional development programs. Professional development programs should aim at filling critical gaps in the agency to address specific management requirements such as responding to climate change issues as they may impact on protected area management and for disaster risk reduction.

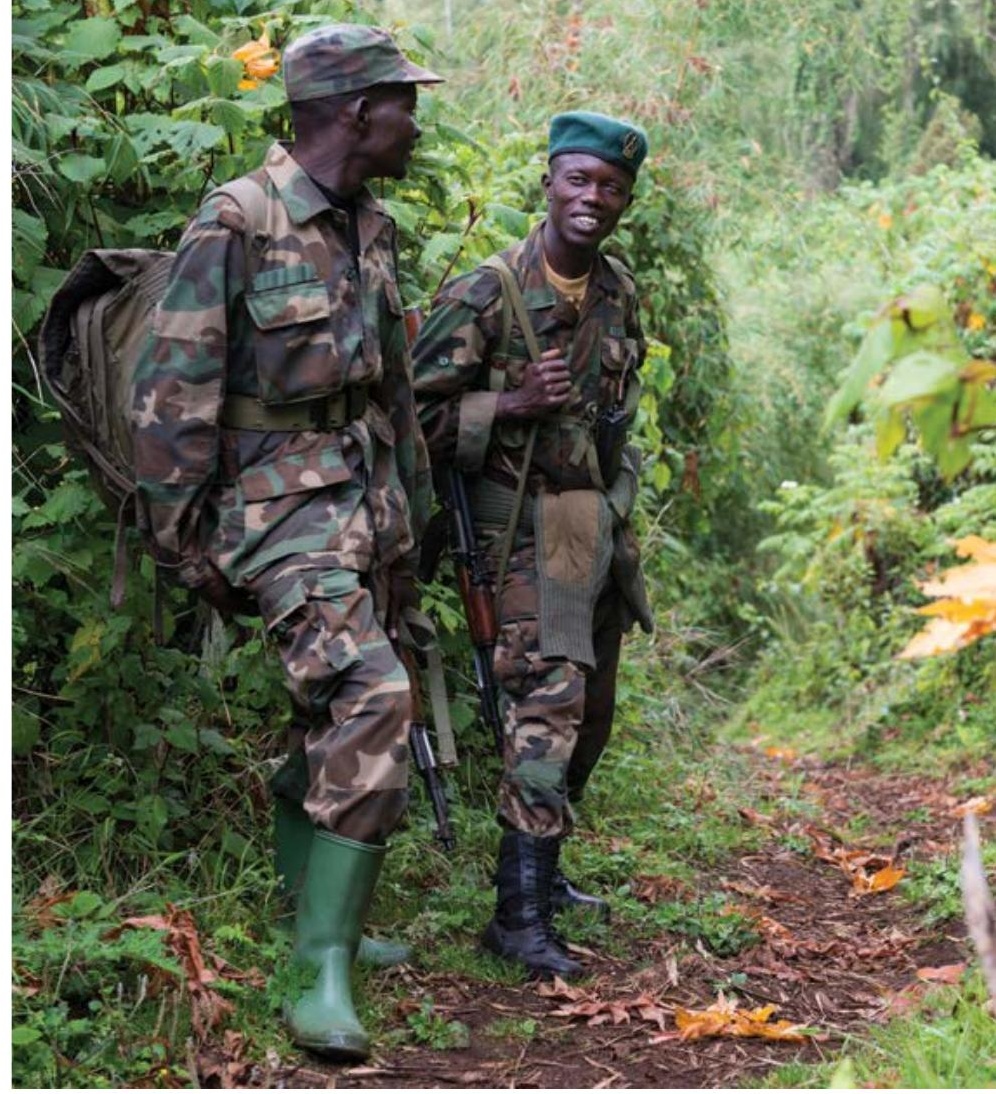

Uganda Wildlife Authority rangers on patrol in a forested area on the lower slopes of Mount Elgon National Park, Uganda

Source: Stuart Cohen

\section{Mentoring and acting opportunities}

In any given protected area management scenario, staff will time and time again be away from their positions for various reasons and key positions will fall vacant that may not immediately be filled. Prudent leadership requires that such scenarios be anticipated and mechanisms built to address them. Deliberate efforts have to be undertaken to nurture and mentor staff to act in the absence of executive managers for short periods or to ultimately fill such positions when the need arises within the agency or elsewhere.

Care must be taken to ensure that mentoring and acting assignments do not overburden the beneficiary. An effective mentoring approach is delegation. In such a relationship, everyone must be clear on the purpose and direction, and guidance must be forthcoming from the supervisor/mentor. Trust and commitment are essential and a sense of optimism-an 'I can do it attitude'-is important for the beneficiary. Mentoring, to a large extent, enhances the effectiveness of the supervisor, increases the productivity of the unit and develops the professional capacity of the staff. Mentoring is achieved through the assignment of tasks. When such tasks are assigned, the mentor transfers the task with very clear objectives and requirements; passes on the authority needed to perform the task; allows for flexibility; and when completed, provides acknowledgment and credit for success. This provides an opportunity for 
the development of staff; however, the mentor retains control, accountability and benefits from the support of the staff being mentored.

In protected area systems, the protected areas are spread out geographically and in some instances are very large, so in practice executive power has to be delegated to site or section-based managers. This means a mentoring process is always ongoing. The executive manager supervisors, however, have to be alert to this fact and rather than trying to keep the authority at the protected area head office they should devolve it to the sites and provide guidance. A successful mentoring process should ideally result in a three-layered executive leadership model and practice at all levels in the agency. The three-layered leadership model ensures a clear hierarchy in leadership roles with decision-making authority. The effect is that there will always be a stand-in officer (acting assignment) in the event that the top two layers are away for whatever reason.

\section{Understanding culture and different types of people}

Cultural practice forms an identity for different types of people. One can read about different cultures and different people and gain very useful insights. A key aspect of understanding different cultures and different people is to realise and accept that differences exist. A positive attitude and a desire to understand rather than influence, impose or abuse the different cultures and peoples are required. The simple rule is that 'no culture is superior and no culture is better-period'. Culture and people are in a continuum of change and it is best to appreciate the spontaneity of change even when influence has to be exerted.

A simple, practical and powerful way to understand different cultures and different people is to engage in conversation and interact with them informally. Attending informal (and formal) functions in a given locality and especially honouring personal invitations, even for lunch, tea or an evening drink, afford a very good opportunity to understand culture and people.

Elderly people I have engaged in conversation have argued that in this day and age, when problems are increasingly complex and there is no simple cause and effect, one cannot imagine how stressful it is to be a leader and to pretend to have all the answers. An affirming leader is one who knows how to rely on and use the art of conversation that exists everywhere in communities. These leaders act as hosts and stewards of other people's creativity and intelligence. This kind of leader does not give us the answers but gathers us together so that together we can discover the answers.

By respecting different cultures and peoples, one is able to defuse conflict, win over support and learn about many aspects of nature conservation in all parts of the world, for culture and conservation have always been intertwined and have continued to evolve amid new developments. All peoples have a rich culture, which when understood and respected (you do not have to believe in it), has inherent and effective conservation mechanisms. It is the reason there is so much talk early in the 21 st century about indigenous knowledge and working with communities; the reason also the UN Educational, Scientific and Cultural Organisation (UNESCO) recognises the link between culture and nature, and why increasingly, many World Heritage properties are referred to as mixed properties that embed both cultural and natural outstanding universal values.

\section{Industrial relations}

Industrial relations is the link between employers (owners of business or enterprises) and employees. In many cases, this results in a third-party arrangement to broker relations between employees and employers to benefit staff development and guarantee conducive working terms. In practice, sometimes employers resent the third-party arrangement in the form of trade unions, but in protected area governance arrangements, employees usually serve governments and there are designated boards, trusts or commissions that serve the role of employers. Private protected areas and community conserved areas, however, now exist and have the potential to grow. Accordingly, there are statutory arrangements in place that provide guidelines on employer-employee relationships.

What is important under industrial relations is recognition that third-party arrangements give a voice to employees and serve as a practical and useful tool for checks and balances that ensure statutory provisions are being followed. They also allow for creativity for enhancing productivity and staff wellbeing. Such staff support schemes may include access to personal loans for individual staff development, healthy living counselling (HIV, alcohol, drug abuse), career guidance, retirement and social responsibility clubs. Interestingly, there are many examples of senior officers in agencies who shun industrial relations arrangements or even stifle their existence or operations only to fall back on these staff support systems in times of personal trouble. 
inclusivity, guidance and coaching much more than directing, which is now often the norm. The leader must avoid solving problems with an 'I am the boss and I have the answers' approach, but rather on the basis of listening and deciding accordingly. To be sure, leaders in the future will still need to be decisive; however, a decision becomes easier to make when the leader instils a culture that empowers individuals and thus encourages creativity. The need is for a leadership style of openness with clear ethical values. Overarching bureaucracies and the paramilitary organisations of the past will not be nimble enough to survive the rapid changes that are expected to shape our future.

An overriding consideration in all of the above is that leading a protected area agency is one of the most noble and satisfying callings. Protecting nature for future generations and helping people to discover themselves through contact with nature are but two of myriad benefits that are derived from leading a protected area High-altitude flora, Mount Elgon National Park, Uganda

Source: Stuart Cohen

\section{Conclusion}

\section{Julia Miranda Londoño}

What is the future for leaders of protected areas? Most likely, it will be one of increased instability. Changes in the operating environments of protected area agencies can be expected to be rapid and abrupt. Climate is but one anticipated driver of such change. Biotechnological advances such as DNA manipulation are poised to challenge the definition and authenticity of natural environments that are the raison d'être of protected areas. The global reach of communications through the Internet can instantly build up or destroy the reputation of protected area agencies, which can carry significant repercussions for revenues and government decisions. Demographics are another driver of change, albeit at a somewhat slower rate; within some countries mean ages increase while in others they decrease. Unparalleled levels of urbanisation around the globe and with them an increasing segment of people without personal contact with nature present an increasing dilemma for future, if not present, managers to face. To survive in the future, organisations and their leaders must learn to adapt continuously to what will be an increasingly volatile environment.

Managing within the complexity of the future is a leader's challenge. The future will require, more than ever, a team approach that encourages bottom-up rather than hierarchical top-down approaches. To provide leadership in this milieu puts the onus on listening, agency. Protected area leaders must give voice to the voiceless: those who came before and charged the leaders of today with this responsibility by leaving a legacy of conservation; those of the future, who expect that we will give them a natural world within which they will want to live; and nature itself, which cannot speak when decisions are being made about its future. Drawing inspiration from these responsibilities can only help to provide responsible leadership that avoids corruption, abuse of rank, myopia and ignorance, which could undermine leaders and the very organisation they are asked to lead.

Before ending this chapter, I would like to present case studies of the work of two outstanding protected area leaders with whom I have had the pleasure of working. One describes the outstanding work of Fabio Villamizar Durán from my home country of Colombia (Case Study 12.1) and the second is about the excellent work of my IUCN World Commission on Protected Areas (WCPA) colleague Andrej Sovinc, in Slovenia. Andrej is the head of Sečovlje Salina Nature Park in Slovenia and Deputy Director of Soline Salt Making Limited. He is the protagonist of the story he tells (Case Study 12.2). These two case studies help to demonstrate the importance of leadership in managing protected areas and what may be achieved when there is great clarity of direction, purpose and initiative combined with perseverance, tact and a desire to protect Earth's nature and culture. 


\section{Case Study 12.1 Leadership in Colombia}

Fabio Villamizar Durán has headed the North-East Andean Regional Division of National Park Service of Colombia, where eight national parks are located, for nine years with exceptional leadership. In 2014, aged 53, Fabio is an economist specialised in finance and telecommunications management and regulation. He manages to undertake his functions both within and outside the organisation, with an innate exemplary leadership.

Within National Parks, he works directly with the park managers and their staff, knows their jobs closely and is in control of the on- ground reality of the protected areas. He provides confidence to his staff, shows interest in their personal situations and supports them, and at the same time he is rigorous and demanding. They undertake planning together, define the strategic lines and establish operational plans to address important issues such as land tenure and control by the state, restoration, environmental law enforcement, research, monitoring and control and surveillance, with an approach that promotes community participation, which he has developed through a close relationship with peasant families and indigenous communities. He arranges constant follow-up and evaluation meetings to measure progress. His priority 'is the protected areas that are the reason for the institution to exist; we are devoted to them, and they need all our support'. 'There is no room for doubt or apathy', he says. tenure and subsequent land restoration-one of the most demanding problems faced by the parks in Colombia. He has built projects with international cooperation, with local and regional governments, as well as with private companies for more than US\$50 million to accomplish this.

Fabio has gained respect and recognition in other public institutions both in his region and at the national level, because of his highly qualified, technical and serious work. He actively participates in regional land-use planning processes with other public agencies and private entities by providing a joint and articulated view and getting them involved and convinced about the importance of conservation.

He has participated in conservation strategies with páramo landscapes, fostering creation of regional protected areas, participating in climate change discussions, land-use planning and in promoting the recognition of indigenous communities' rights. His strategy has been one of generating trust based on an ample knowledge of his region, always making use of solid arguments, persuasion and negotiation skills to interact with potential donors. Fabio's first concern is to satisfy the needs of the protected areas rather than the donor's wishes. The results of his work are crucial and undeniable for the whole country.

Fabio has developed innovative and very successful initiatives to raise the money required to undertake studies, buy the properties within parks that are under private

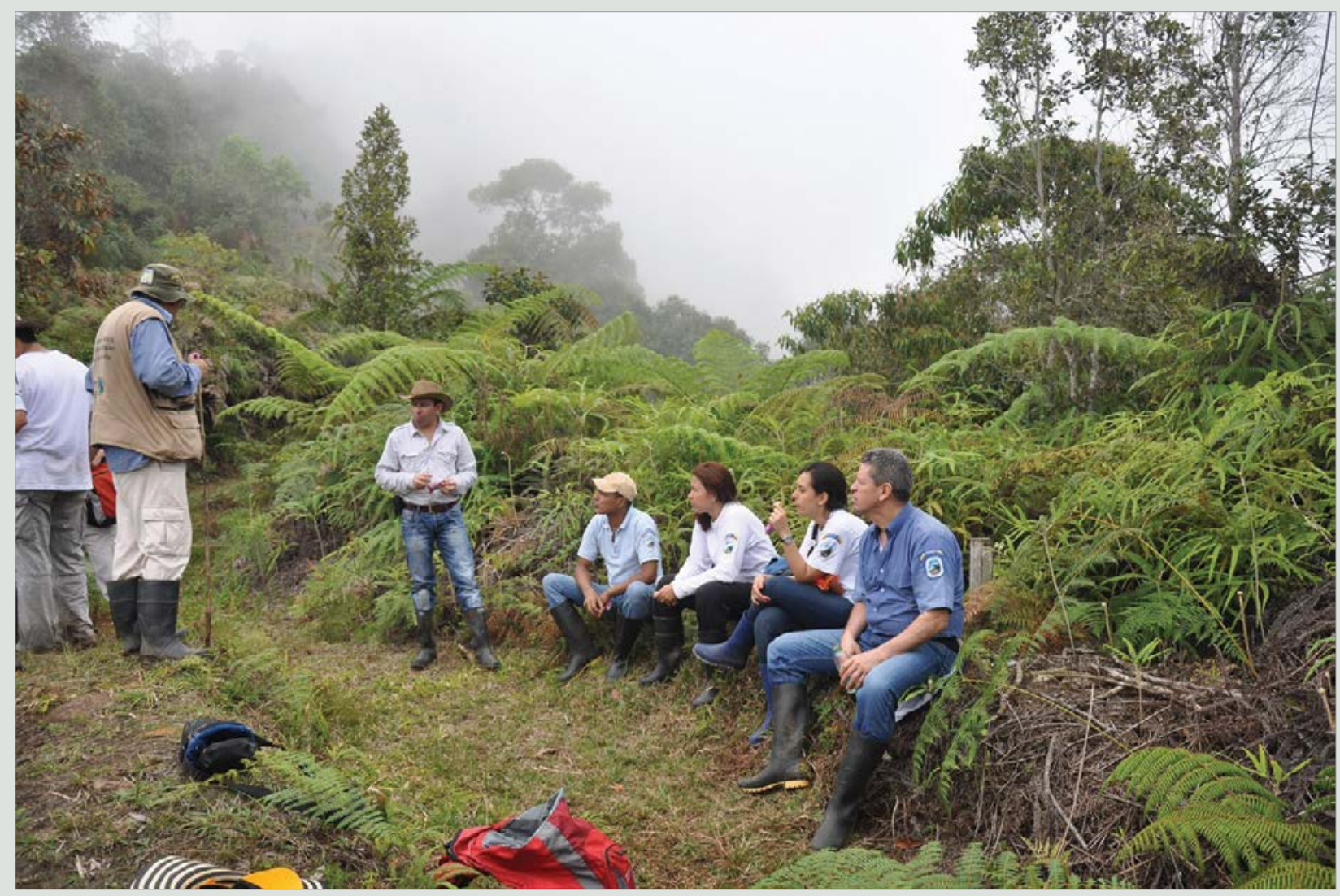

Fabio Villamizar Durán (far right), North-East Andean Regional Division, National Park Service of Colombia, and staff resting during a protected area field inspection

Source: National Parks Service of Colombia 


\section{Case Study 12.2 Leadership and executive management in Slovenia}

The Sečovlje Salina Nature Park is situated on the Adriatic coast in the northernmost part of the Mediterranean Sea. It covers more than 6.5 square kilometres and is considered one of the most important natural and cultural heritage sites in Slovenia. It is designated an IUCN Category V Nature Park, Ramsar site, Natura 2000 site and a cultural monument of national importance. The area is known as one of the key biodiversity hotspots in Slovenia. Sečovlje Salina Nature Park is home to some 300 bird species, several salt-loving plants and endangered habitat types, which are dependent on the highly saline environment.

Sečovlje Salina represents one of the last traditional saltpans in the Adriatic Sea. Due to difficulties in the European salt market following the arrival of salt produced mainly in North Africa, where the production costs were lower, the majority of traditional saltpans in the northern Mediterranean were abandoned after World War II, and transformed into mass-tourism destinations or urban areas, or used for aquaculture. This almost happened in Sečovlje-traditional salt-making processes were almost stopped by the end of the 20th century.

A major change happened in 2002, however, when the company Soline, with the licence for production of salt, was bought by a mobile phone company. Soline has a specific status in terms of management of the stateprotected Sečovlje Salina Nature Park. The company has been given a concession, issued by the Government of the Republic of Slovenia, by which the company is responsible for management of the nature park and the use of its natural resources. All the land and properties in the park remain state owned.

The new owner of the company divided its activities into commercial (traditional salt-making and tourism) and the implementation of the public service of nature conservation (management of the park, including visitor management). New products, based on purely artisanal salt, rich in minerals, were developed and new target groups of buyers were approached. More than 25 basins for traditional salt production were restored, together with basic infrastructure for visitation. Salt is again being produced using 700 -yearold methods and is now available in several countries, from Japan to the United States and across Europe. The marketing skills of the mobile phone company were used to develop, promote and sell the traditional salt product.

Active management of the park and its promotion increased the number of visitors by more than six times in the past 10 years. Sečovlje Salina is now considered to provide added value for ecotourism development for the community of Piran-the most developed tourism community in Slovenia. Parts of the saltpans are strictly protected areas, provided for the maintenance of favourable ecological status for several endangered habitats and species. No commercial activities are allowed in these areas and even visitation is limited and strictly controlled. Population trends in recent years for the key biodiversity indicator species are stable or even increasing. Key support for biodiversity conservation in the park is sought from EU funding programs, especially LIFE projects.
The number of employees of Soline has risen from 16 workers in 2002 to more than 90 in 2013. There are more than 30 additional seasonal jobs offered during the summer. There are direct and indirect benefits in this public-private partnership. The mobile phone company decided to invest in protection of nature and cultural heritage in Sečovlje to generate direct benefits by selling salt and collecting fees from park visitors and those attending specific programs for the visitors of the park (for example, the 'Become a Salter for a Day' program). The company also plans to invest in development of major tourism infrastructure outside the park area.

Even more important benefits for the company in this joint venture are indirect. The company's corporate reputation has improved: several customers expressed their appreciation of its environmental responsibility investing in the protection of natural and cultural heritage, and thus became the company's clients.

One should not forget that this model of state-delegated management would not be possible without the involvement of senior managers of Soline who have high personal regard for conservation and awareness of the importance of the preservation of cultural heritage and tradition.

Experience in the creation and management of the Sečovlje Salina Nature Park demonstrated that commercial activity (traditional salt-making and tourism) can coexist with the requirements of the protection of nature, cultural heritage and tradition in the nature park. Conservation efforts are also seen as an added value both for the development of sustainable land-use practices and for the provision of benefits for the local community.

- Andre Sovinj

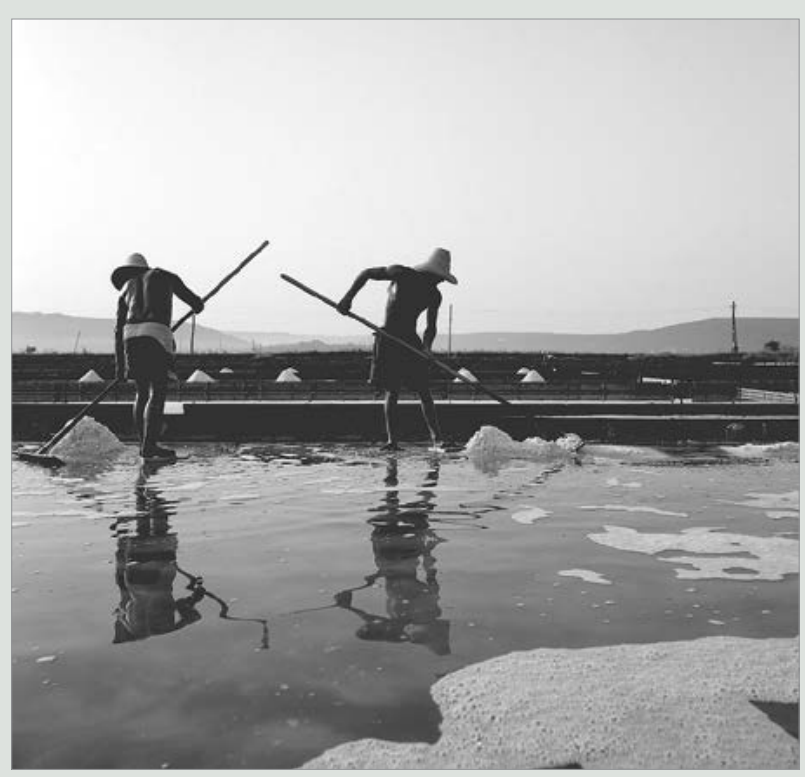

Traditional salt harvesting, Sečovlje Salina Nature Park, Slovenia

Source: Andre Sovinj 


\section{References}

Decommended reading

Dd Abrashoff, D. M. (2001) 'Retention through redemption', Harvard Business Review 79(2): $136-41$.

Dd Bartol, K., Martin, D., Tein, M. and Mathews, G. (1998) Management: A Pacific Rim focus, McGraw-Hill, Sydney.

Dd Bazerman, M. (1998) Judgement in Managerial Decision Making, 4th edn, John Wiley, New York.

Burns, R. (2014 [1786]) 'The best-laid plans of mice and men often go awry', The American Heritage New Dictionary of Cultural Literacy, 3rd edn, [Online]. <dictionary.reference.com/browse/thebestlaidplansofmiceandmenoftengoawry>

D’Souza, A. (1994) Leadership: Trilogy on leadership and effective management, Kolbe Press, Limuru, Kenya.

Heifetz, R. A. and Laurie, D. L. (2001)

'The work of leadership', Harvard Business Review 79(11): 131-41.

Dd Heifetz, R. A. and Linsky, M. (2002) 'A survival guide for leaders', Harvard Business Review 80(6): $65-74$.

Dd Heifetz, R. A., Grashow, A. and Linsky, M. (2009) 'Leadership in a (permanent) crisis', Harvard Business Review 87(7-8): 62-9.

Leopold, L. B. (ed.) (1993) Round River: From the journals of Aldo Leopold, Oxford University Press, New York.

Parks Canada (2012) Corporate Plan 2012-2013/20162017, Parks Canada, Gatineau, Quebec.

Dobbins, S. P. and Coulter, M. (2005) Management, 8th edn, Prentice Hall, Englewood Cliffs, NJ.

Dobbins, S. P., Bergman, R., Stagg, I. and Coulter, M. (2003) Foundations of Management, Prentice Hall, Sydney.

Dd Stayer, R. (1990) 'How I learned to let my workers lead', Harvard Business Review 68(6): 66-83.
Taylor, W. C. (1999) The Leader of the Future: Harvard's Ronald Heifetz offers a short course on the future of leadership, Fast Company \& Inc. $<w w w$. fastcompany.com/37229/leader-future>

Virunga National Park (2014) Rebels Attack Ranger Patrol, Killing Three, Virunga National Park Archives, Democratic Republic of the Congo. $<$ virunga.org/archives/rebels-attack-ranger-patrolkilling-three/>

Wheatley, M. J. (2006) Leadership and the New Science: Discovering order in a chaotic world, Berrett-Koehler Publishers, San Francisco. 


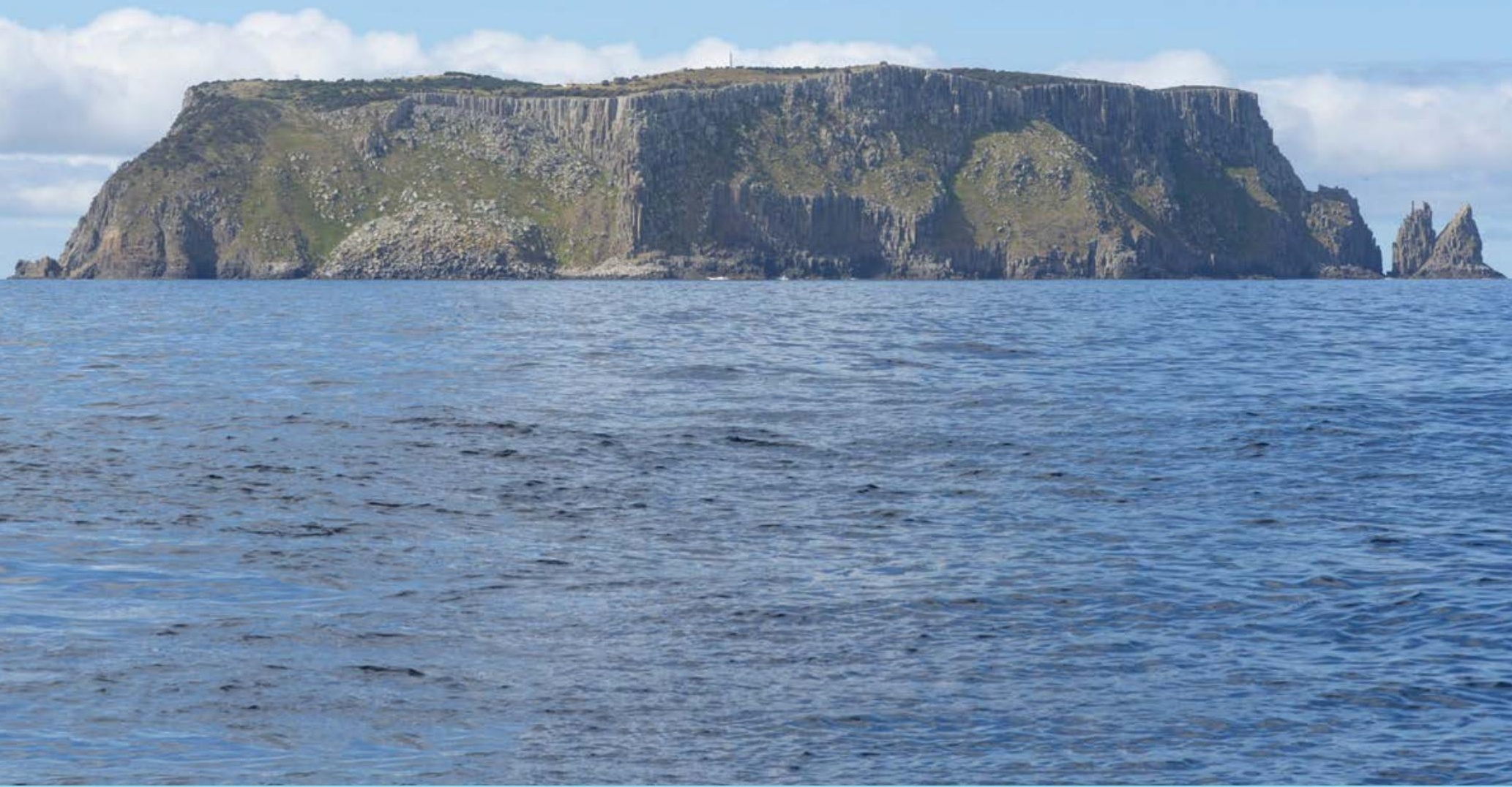

\section{CHAPTER 13}

PLANNING

\section{Principal author:}

Penny Spoelder

\section{Supporting authors:}

Michael Lockwood, Stuart Cowell, Patrick Gregerson and Alistair Henchman

\section{CONTENTS}

- Introduction

- Types of plans relevant to protected areas

- Approaches to planning

- Planning for protected area networks

- Protected area management planning

- Conclusion

- References 


\section{PRINCIPAL AUTHOR}

PENNY SPOELDER is a senior consultant with TRC Tourism.

\section{SUPPORTING AUTHORS}

MICHAEL LOCKWOOD is an Associate Professor, Geography and Spatial Science, School of Land and Food, University of Tasmania, Australia.

STUART COWELL is Director, Conservation Management, Hobart.

PATRICK GREGERSON is Chief, Park Planning \& Special Studies, US National Park Service.

ALISTAIR HENCHMAN is Director, SAJE Consulting, Australia.

\section{CITATION}

Spoelder, P., Lockwood, M., Cowell, S., Gregerson, P and Henchman, A. (2015) 'Planning', in G. L. Worboys, M. Lockwood, A. Kothari, S. Feary and I. Pulsford (eds) Protected Area Governance and Management, pp. 381-412, ANU Press, Canberra.

\section{TITLE PAGE PHOTO}

Tasman Island, part of Tasman National Park, Tasmania, Australia.

Source: Graeme L. Worboys

The Tasman National Park is administered by the Parks and Wildlife Service of Tasmania and is managed consistent with its 2011 plan of management. In the 2010's, Tasman Island was infested with a feral cat population that impacted nesting seabirds. The management plan advised eradication and a very carefully researched, planned and executed feral cat eradication plan was successfully implemented. On-ground implementation was made possible by philanthropic grants from the Pennicott Foundation and an estimated 50,000 sea birds per annum have been saved thanks to this work. 


\section{Introduction}

Planning involves deciding on a future desired state and the course of action to get there. In its simplest form, the purpose of planning is to establish how to get from where we are today (here) to where we want to be tomorrow (there). In order to do this we need to be clear about where we are, where we want to get to and our proposed path to get there. It is something that most of us do every day and it is a key function of management.

Concepts such as ecosystem services, resilience and connectivity conservation are bringing new and innovative approaches to planning. Once the domain of government-led processes, protected area planning is now more often than not a result of the collaborative efforts of scientists, practitioners, communities, indigenous peoples, non-governmental organisations (NGOs), individual landowners, large corporations and international bodies. Planning approaches are being reengineered to reflect the interests of these groups and new governance arrangements.

To be effective protected area practitioners, we need to understand what planning is, why it is essential and the important role it plays in protected area governance and management. We also need to understand the various approaches to planning, their limitations and practical application in order to build and strengthen protected area systems that can counter, mitigate and adapt to global socioeconomic and biophysical change.

Planning brings many benefits to protected areas and to the organisations and individuals responsible for their governance and management. In particular, effective planning can strengthen the capacity of protected area practitioners to:

- meet global responsibilities under agreements such as the Convention on Biological Diversity (CBD) to build a comprehensive network of protected areas

- meet the statutory obligations within which they operate

- increase effectiveness by directing management towards achieving goals

- forecast risks and take the necessary precautions to avoid these

- optimise utilisation of all available resources to achieve goals

- reduce wastage of important resources and increase overall efficiency

- coordinate short, medium and long-term plans across geographical and functional areas
- provide accountability and continuity in management

- control and monitor effectiveness and adapt to change

- collaborate with, involve and partner with stakeholders in the community in decision-making

- build capacity among practitioners and the community (Thomas and Middleton 2003; Lockwood 2006).

One of the problems with much of the writing about planning, and with many plans themselves, is a lack of clarity about key planning terms. In this chapter:

- goals are statements of desired outcomes that are not measurable, but which set a broad direction for protected area establishment or management

- objectives refer to measurable, challenging yet attainable outcomes that management is seeking to achieve

- policies specify the instruments and types of activities that constitute the means by which goals will be addressed

- actions are statements of specific activities that are intended as the means to achieve an objective

- strategies are a type of plan that feature a combination of goals and policies.

First, we describe the types of plans typically associated with protected areas, the evolution of protected area planning approaches and their practical application to the establishment and management of reserve networks. We also provide examples of how various planning approaches have been successfully applied to protected areas around the world.

\section{Types of plans relevant to protected areas}

Planning for protected areas involves many different types of planning at various geographic scales and organisational levels. A typical planning hierarchy associated with protected area management is presented in Figure 13.1.

\section{Corporate plans}

Corporate plans at the highest level will typically state the overall objectives of the organisation and usually include a statement about how the organisation would like things to be in the future (a vision statement). Typically, a corporate plan may have a life of five to 10 years with reviews scheduled annually or every few years. A robust 


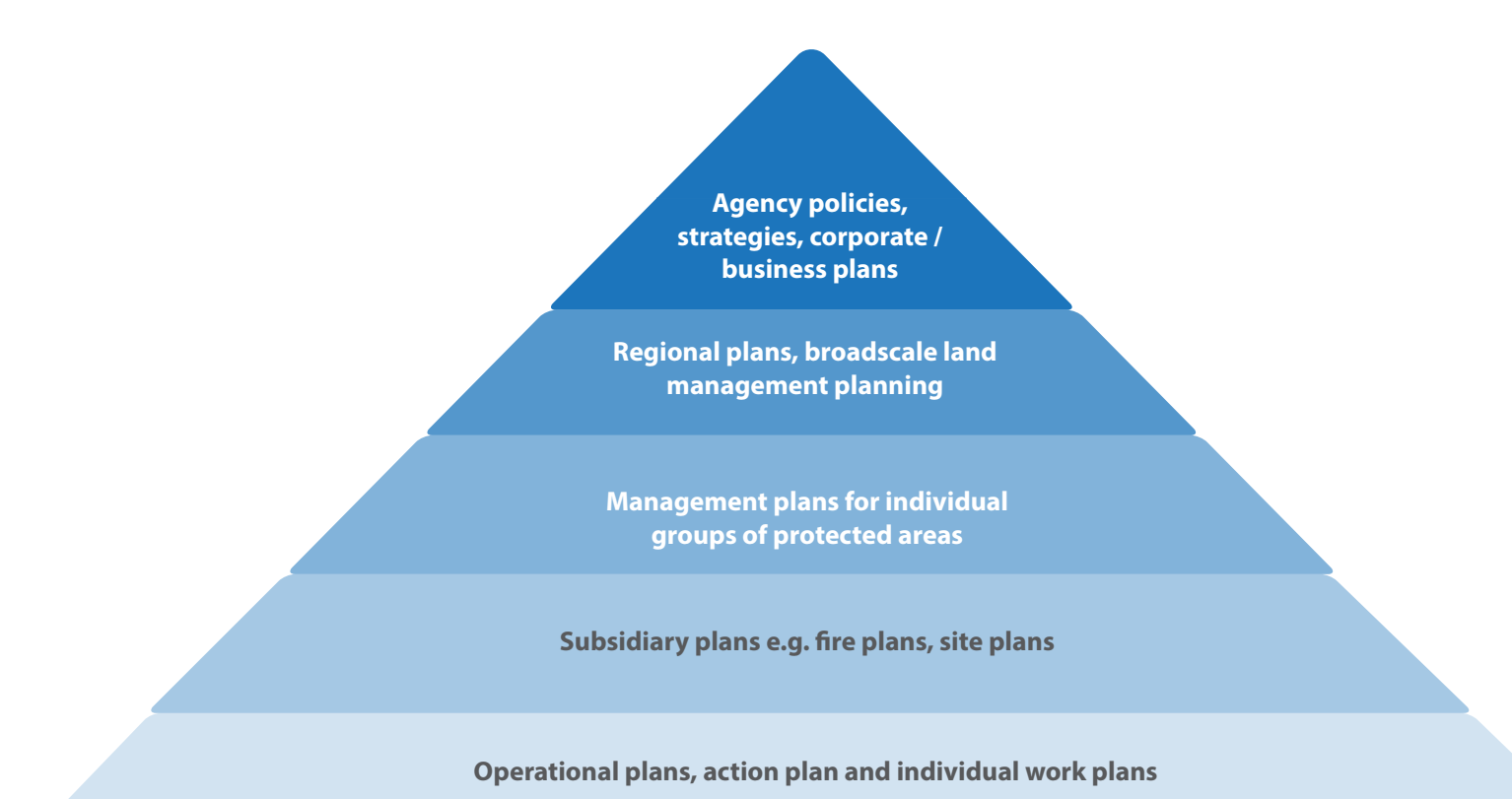

Figure 13.1 The planning hierarchy

Source: Adapted from Thomas and Middleton (2003:12)

corporate plan should be a powerful management tool that guides an organisation's activities. Typically, the recommendations of these plans are inputs to the operational planning process. Government agencies, NGOs and some privately protected authorities often have corporate plans to guide their activities. Such plans are less relevant for community-governed protected areas and those owned by individual landholders.

\section{Land and sea-use plans}

Land and sea-use planning is the process of determining what lands and marine environments will be used for what purposes. Many jurisdictions have legislated processes for settlement, and natural resource and conservation planning, which determine which areas will be used for residential, commercial and industrial development, forestry, fishing, conservation and other uses. In this chapter, the focus will be on processes for determining which areas should be, or will be, designed as a protected area and how they should be managed.

\section{Area or reserve management plans}

Area management planning is concerned with how to manage the area of land consistent with its reservation under the land-use planning scheme. Management plans are reserve or place-specific plans that look at the values of an area, the issues and threats that may affect that area, and actions required to best manage the place to maintain or improve its conservation and other values.

Area management plans for reserves are also closely linked to functional or subsidiary plans such as conservation management plans, precinct plans, fire management plans, visitor management plans and pest species plans, which contribute to or flow from the area management plan.

Specific actions in management plans are included in operational plans to ensure resources are made available for their implementation. Recommended policies and significant threats may also need to be considered in the strategic and corporate plans of the agency responsible for the area.

The importance of planning to the US National Park Service and how it uses planning to bring logic, analysis, public involvement and accountability into the decision-making process for particular areas are discussed in Case Study 13.1, which also illustrates the interrelationship between various levels and types of plans, the importance placed on the values of the park, and the responsive and flexible approach adopted to protect these values. It helps managers determine the best way to comply with law and policy, and the best way to deal with the many competing interests in parks that are not directly addressed by law or policy. Park planning and decision-making are conducted as a continuous, dynamic cycle. Each park is able to demonstrate to 


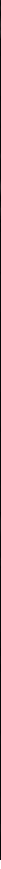

Wetlands of the Everglades National Park, Florida, USA, an intensively planned and managed protected area Source: Ashish Kothari

decision-makers, staff and the public how decisions relate to one another in terms of a comprehensive and logical approach.

Management planning for protected areas is considered in detail later in the chapter.

\section{Subsidiary plans}

Subsidiary plans focus on more specific policy information and operate on a shorter time frame than reserve management plans. Thomas and Middleton (2003) provide a list of potential subsidiary plans that are often linked to reserve management plans such as development plans, conservation plans and site management plans.

\section{Operational plans}

Lower-level operational plans are used to state how the high-level objectives in the corporate plan will be implemented. While corporate plans may set objectives to achieve things that cannot currently be resourced, operational plans should only include activities that are currently achievable with existing staffing and other resources. Typically, operational plans are developed for parts of the organisation responsible for functional areas (for example, wildlife conservation or asset management) and for geographic areas (regional and local area management). Operational plans are typically completed each year. Such plans are also relevant for community-governed protected areas as they can be used to guide resource allocation decisions that reflect the intent of the higher-level plans. These plans are less relevant for conservation reserves owned by individual landholders.

\section{Approaches to planning}

Before we examine the specifics of reserve selection and management planning, it is useful to consider how one might, in theory, approach a planning problem. According to Alexander (1992), theory is a way of understanding the world-a framework to organise facts and experience and interpret them in a systematic way. Planning theory informs planning practice, and is used to guide and establish various approaches to protected area planning. Practice needs theory not only to structure the world and the environment, which are the objects of actions, but also to explain the actions to the actors themselves (Alexander 1992). Theory also allows us to see the assumptions and value judgments that underpin planning practice and provides a way to understand planning processes that are external to our own experience, intuition or common sense (Lockwood 2006). 


\section{Case Study 13.1 US National Park Service planning framework}

The US National Park Service plans for one reason: to ensure that the decisions made for each park achieve the park's purpose as cost-effectively and consistently as possible. Each park's purpose is defined in part by the fundamental purpose of the National Park Service (NPS), which is to conserve park resources and values and to provide for their enjoyment in ways that leave them unimpaired, and in part by more specific direction included in each park's individual authorising legislation or presidential proclamation. Because each park has a particular purpose, the NPS management policies allow for considerable management discretion in determining the best course of management for each park, based on its purpose and significance, the interrelationships that exist among the park's resources and values, the range of stakeholder interests, knowledge of best practices, and other factors.

The NPS planning framework is based on the following principles.

- Enhance planning capacity service-wide through integration of other NPS program planning needs into regional and national planning programs.

- Confirm the park foundation document (described below) as a baseline for all future planning and decision-making at the park.

- Introduce the concept of the 'planning portfolio' to implement a responsive and flexible approach to meet park planning needs.

The principle of program integration is being implemented as opportunities arise. The idea is to enhance the broad potential for programs across a wide spectrum to contribute to park planning more effectively. The framework recognises the profile of planning within the NPS and builds on existing capacity to improve the effectiveness of park planning.

\section{The park 'foundation document'}

Each unit of the national park system is required to have a formal statement of its core mission that will provide basic guidance for all planning and management decisions-a foundation for planning and management. The park foundation document can be useful in all aspects of park management to ensure that primary management objectives are accomplished before addressing other factors that are also important, but not directly essential to achieving the park's purpose and maintaining its significance. It provides information necessary to effectively manage the park over the long term and to protect park resources and values that are integral to the purpose and identity of the park unit.

The primary advantage of developing and adopting a foundation document is the opportunity to integrate and coordinate all types and levels of planning and decisionmaking from a single, shared understanding of what is most important about the park. The park foundation document is developed as a collaborative effort among park staff and specialists in various program areas. The multidisciplinary approach provides the opportunity for a variety of sources and hierarchies of information about a park unit to be compiled and integrated. The information is then refined and focused to determine the most important attributes of the park.
The components of a park foundation document are as follows.

- The park's purpose statement identifies the specific reason(s) for establishment of a particular park and what is most important about the park. It is developed through an analysis of the enabling legislation that established the park and the legislative history that influenced its development.

- Significance statements express why a park's resources and values are important enough to merit designation as a unit of the national park system. They describe the distinctive nature of the park and why an area is important within global, national, regional and system-wide contexts.

- Fundamental resources and values are those that warrant primary consideration during planning and management processes because they are essential to achieving the purpose of the park and maintaining its significance.

- Other important resources or values are those that are determined to be integral to park planning and management, even if they are not related to the park's purpose. They warrant special consideration in planning processes. For example, interpretative themes are the key stories or concepts that visitors should understand after visiting a park-they define the most important ideas or concepts communicated to visitors about a park unit.

- Many management decisions for a park unit are directed or influenced by special mandates and administrative commitments with other federal agencies, State and local governments, utility companies, partnering organisations and other entities. Some park-specific legislative or judicial requirements, along with some administrative commitments, may be worthy of discussion and special consideration because: 1) they are unusual (such as a special provision in a park's establishing legislation to allow grazing); 2) they add another dimension to an area's purpose and significance (such as the designation of an area in the park as part of the national wilderness preservation system, the inclusion of a river in the national wild and scenic rivers system, a national historic landmark designation for part of a park, or the designation of a park as a World Heritage site or a biosphere reserve); or 3) they commit park managers to specific actions (such as an action required by a court order).

The assessment of planning and data needs presents planning issues, the planning projects that will address these issues and the associated information requirements for planning, such as resource inventories and data collection, including geographical information systems (GIS) data. The assessment includes: 1) an analysis of fundamental and other important resources and values; 2) the identification of key issues and associated planning and data needs; and 3) the identification of planning and data needs (including spatial mapping activities or GIS maps).

The park atlas is a component of the park foundation document. The atlas is a GIS-based planning support tool that presents geographic data elements important for park management, such as natural and cultural resources, 
visitor use patterns, facilities and the regional setting of the park unit. It serves as a reference for park projects and facilitates planning decisions.

The NPS Park Planning Program is spearheading the effort to complete foundation documents in all 401 park units by 2016. Park managers have responded enthusiastically to this initiative, and regional administrators - having seen the benefit of a shared understanding about a park-are advocating for foundation documents to be prepared for newly established parks.

\section{Park planning portfolio}

Foundation documents are at the core of each park's 'planning portfolio' - the assemblage of individual plans for a park unit. The concept is based on the assumption that a park's planning needs are met through the totality of planning documents currently in use at the park, updated as needed to provide timely guidance. This is a contrasting approach to the comprehensive plan template previously in place for park planning, in which a single plan document for each park set the stage for subsequent planning efforts. For some time, the agency had attempted to deal with the lengthy time lines and high costs associated with large-scale comprehensive plans and to support a more nimble and responsive way of delivering park planning products. The portfolio structure introduces greater flexibility for park managers, supporting formal planning efforts for some issues while acknowledging that existing plans and guidance are adequate for other issues.

The portfolio can be visualised as a loose-leaf binder, in which particular planning elements can be removed and updated, and new elements added, without revising the entire body of work. In some parks, the portfolio may take on the physical structure of a shelf or bookcase filled with plans; in others, it might exist electronically as a virtual compilation of crossreferenced documents. Whatever the format, the portfolio represents a series of building blocks to guide future actions for park management and resource staff, with individual items updated as needed.

- Patrick Gregerson, Chief, Park Planning and Special Studies, US National Park Service

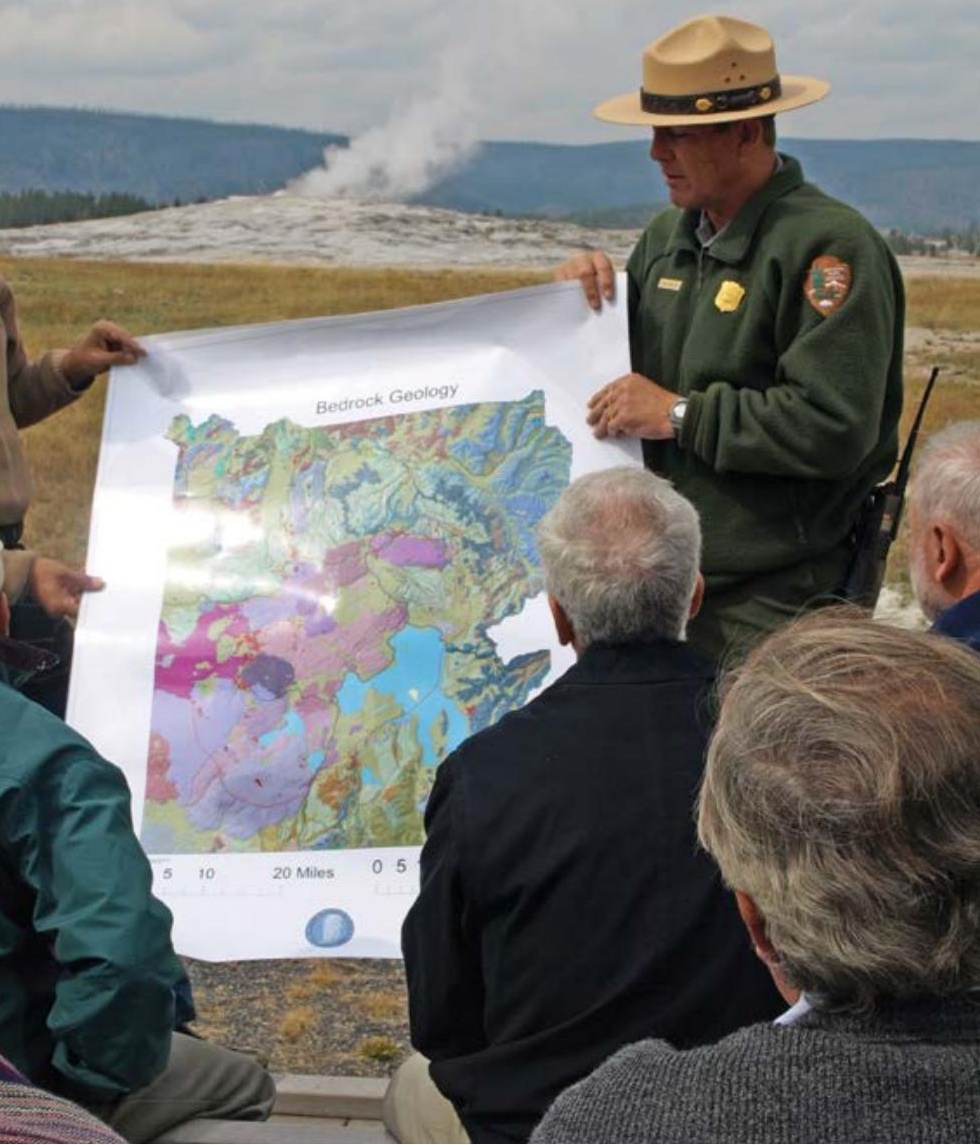

US National Park Service resource specialist, Old Faithful geothermal area, Yellowstone National Park Source: Graeme L. Worboys

Protected area planning is continually being redefined by new approaches. Over the years our scientific understanding of conservation biology has evolved, and so too has our understanding of the role and importance of planning and the benefits and pitfalls of various approaches. Over time, the ideas that were first generated from research in ecology and other disciplines such as social and economic science have been successfully integrated into what we know today as protected area planning. Over this same period planning has grown more, rather than less, complex (Alexander 1992) and the challenges for protected area planners have multiplied.

The complexity and uncertainty associated with the management of natural systems continually impact on how we plan for the future. Barber et al. (2004) suggest that complexity, uncertainty, change and conflict are the key forces that influence our approach to conservation planning. These forces are described as follows. 


\section{Complexity}

The interdependence of natural systems and the ramifications of interactions of human activity with the natural environment are complex. Our understanding of the different components, processes and their interactions has developed over time (Alexander 1992; Barber et al. 2004; Figgis et al. 2012). In response to this complexity, planning approaches have shifted in focus from biodiversity conservation centred on threatened species and habitat management to ecosystem functions across large-scale, 'permeable' landscapes and resiliencebased approaches to conservation planning (Pirot et al. 2000; Figgis et al. 2012; Wardrop and Zammit 2012).

\section{Uncertainty}

Due to the complexity of socioeconomic and ecological systems, it is unlikely we will ever have complete information about all the factors influencing our planning decisions (Alexander 1992). Nevertheless, decisions have to be made despite the lack of information about the area for which the decision is likely to have consequences. Planning approaches now recognise this uncertainty and allow us to adapt our actions based on learning.

\section{Change}

Environmental and socioeconomic systems are always changing. Many of these changes are triggered by human activities. Approaches to protected area planning have developed over time to consider possible changes and are now designed to be flexible enough to be able to respond (Wardrop and Zammit 2012).

\section{Conflict}

Different, and often conflicting, values and perspectives are usually involved in resource allocation and use decisions. As we look to broad-scale landscape approaches to achieve conservation objectives, the need to engage with, motivate and factor in the rights and perspectives of other landowners and managers has also become an important factor in protected area planning (Figgis et al. 2012). Over time, approaches to community engagement have recognised the needs and aspirations of local communities and have moved towards more shared decision-making models (Barber et al. 2004; Wardrop and Zammit 2012; Davies et al. 2013).

Observations of how complexity, uncertainty, change and conflict have influenced our approach to protected area planning over the past few decades have been described by Barber et al. (2004) and Wardrop and Zammit (2012) and others, as summarised in Table 13.1. Resilience thinking has become particularly influential. Building or maintaining resilience within the protected area network is increasingly cited as a means to achieve long-term conservation goals in the face of climate change and other human impacts (Figgis et al. 2012). Resilience planning is an application of adaptive planning and there is an emerging trend by protected area practitioners to use this type of planning to develop strategies for coping with uncertainty and change (see Chapter 10).

Resilience planning involves identifying a desired state and developing strategies to reduce vulnerabilities, increase adaptive capacity and monitor system feedbacks. The approach involves constructing a conceptual model of a system that includes resources, stakeholders and institutions, and identifies potential thresholds between alternative system states in order to provide insight into factors that build or erode a system's resilience. Resilience approaches to planning are increasingly being applied to marine protected area networks, catchment areas and the Arctic (Resilience Alliance 2014) as well as in local communities in Chile, Nepal, China and Thailand (IUCN 2014).

Whereas a traditional planning approach may focus on maintaining current conditions (for example, composition and abundance of native species) or promoting system efficiency (for example, maximum sustainable yield), a resilience-based approach focuses more on the desired system regime and maintaining functional and response diversity.

Planning theorists such as Friedmann (1987), Briassoulis (1989) and Allmendinger (2009) also offer various ways of classifying planning approaches. The four of most relevance for protected area planners are rationalcomprehensive, adaptive, participatory and advocacy approaches. As general types, these approaches are rarely used in their pure form and most planning projects can be described in terms of mixtures of these approaches (Lockwood 2006). 
Table 13.1. Shifts in approach to conservation planning

\begin{tabular}{|c|c|c|}
\hline Focus & $\begin{array}{l}\text { Previous approaches to } \\
\text { conservation planning }\end{array}$ & $\begin{array}{l}\text { Current and future approaches to } \\
\text { conservation planning }\end{array}$ \\
\hline Biodiversity conservation & $\begin{array}{l}\text { Threatened species and habitats } \\
\text { Protected areas considered the } \\
\text { highest priority } \\
\text { Terrestrial focus } \\
\text { Limited private land involvement } \\
\text { Government-led processes }\end{array}$ & $\begin{array}{l}\text { Systematic conservation planning reflecting } \\
\text { ecosystem functions } \\
\text { Multiple stakeholders involved in assessment } \\
\text { Various tenures } \\
\text { Landscape and resilience-based approaches to } \\
\text { conservation planning } \\
\text { Critical species identified } \\
\text { Species distribution and abundance management } \\
\text { across landscape (tenure blind) } \\
\text { Resilience framework for strategies and regional } \\
\text { planning } \\
\text { Marine and seascapes identified }\end{array}$ \\
\hline Science input & $\begin{array}{l}\text { Static ecosystem structures } \\
\text { Models of predictable change } \\
\text { Optimisation and economic tools } \\
\text { used to assist decision-making }\end{array}$ & $\begin{array}{l}\text { Nonlinear dynamics and complex systems } \\
\text { Shocks, feedbacks and thresholds } \\
\text { Cross-scale interactions } \\
\text { Complex social ecological interactions } \\
\text { Market-related concepts for valuation }\end{array}$ \\
\hline Objectives & $\begin{array}{l}\text { Mixed approaches } \\
\text { Short-term objectives } \\
\text { Fixed targets } \\
\text { Mixed methods to measure } \\
\text { effectiveness }\end{array}$ & $\begin{array}{l}\text { Changed mix of approaches } \\
\text { Longer-term objectives } \\
\text { Flexible/adaptable targets } \\
\text { Learning incorporated into planning and capacity- } \\
\text { building }\end{array}$ \\
\hline Management models & $\begin{array}{l}\text { Rigid institutional structures } \\
\text { Whole-of-government coordination } \\
\text { Linear management }\end{array}$ & $\begin{array}{l}\text { Integration across institutions and community } \\
\text { Integrated planning across multiple scales } \\
\text { Indigenous involvement and ownership } \\
\text { Adaptive governance and structures } \\
\text { Devolved sharing and decision-making drawing } \\
\text { on a range of knowledge including indigenous } \\
\text { communities } \\
\text { Ecosystem-based partnerships }\end{array}$ \\
\hline Community engagement & $\begin{array}{l}\text { Government-led consultation } \\
\text { Limited integration of science and } \\
\text { community } \\
\text { Dispersal of information to increase } \\
\text { understanding }\end{array}$ & $\begin{array}{l}\text { Engagement and decision sharing } \\
\text { Range of tools available (digital) } \\
\text { Community-led consultation } \\
\text { Recognition of indigenous knowledge, } \\
\text { participation and ownership } \\
\text { Learning and capacity-building part of } \\
\text { consultation process } \\
\text { Knowledge sharing }\end{array}$ \\
\hline
\end{tabular}

\section{Rational-comprehensive planning}

The rational-comprehensive approach (also known as synoptic planning) is the dominant tradition and the point of departure for most other planning approaches, which represent either modifications or reactions against it (Alexander 1992). The rational-comprehensive approach to planning involves achieving a desired future state by defining goals and objectives and articulating the specific actions required to achieve them. It involves a number of stages that link thoughts to action resulting in decisions that are based on reason/logic. Typically, the stages in a rational-comprehensive planning approach involve:
- comprehensive documentation of the system under examination

- articulating goals and objectives

- identifying relevant resources and constraints

- designing alternative solutions or courses of action

- projecting the likely outcome of these alternatives

- evaluating these in light of objective criteria

- selecting one or more actions that the analysis suggests will best meet the objectives (Alexander 1992; Worboys et al. 2005). 
Rational planning often produces decisions that can be clearly explained and justified. It typically looks at problems from a systems viewpoint, using conceptual or mathematical models relating ends (objectives) to means (actions). Debate about the issues tends to focus on technical issues such as the reliability of data. The central assumptions underpinning the rational-comprehensive approach to planning can be summarised as:

- it is possible to find the best solution to all planning issues

- the environment is controllable by using scientific knowledge and modern technologies

- solutions are found in the collection and examination of data

- there is a common public interest to solving the problem or finding a solution

- it requires the evaluation of alternative courses of action and the creation of systems for implementation

- change has to be engineered from the top (Alexander 1992; Allmendinger 2009).

The formality and rigour of the rational-comprehensive approach are both a strength and a weakness. On the strength side, rational-comprehensive planning should produce decisions that can be clearly explained and justified (Lockwood 2006). This is particularly evident when applied to large-scale, long-term, complex processes such as conservation planning when the connection between intention and outcome becomes more contingent (Madanipour 2010). Debate about the decisions tends to focus on technical issues such as the reliability of the data used or the validity of the models used to process the data.

It is unlikely, however, that a planner would have sufficient quality or quantity of information to adopt this approach for every aspect of a planning project. The rationalcomprehensive approach also tends to be inflexible and often ignores social and political factors. Uncertainty and risk are very difficult to accommodate. The outcomes from a rational-comprehensive process may therefore not reflect community values or aspirations, and ignore political and institutional limitations. As a result, plans developed using this approach may not provide realistic guidance to managers, and can rapidly become out of date. There is a real risk that such plans will 'sit on the shelf' and fail to act as a practical guide for ongoing management, and therefore will not be implemented (Lockwood 2006).

\section{Adaptive planning}

An approach that seeks to overcome the challenges of uncertainty and change is adaptive planning. This approach analyses problems systematically, integrates new information and learning insights continuously, and adjusts the management response accordingly (Braus 2011). Rather than attempting to be comprehensive, adaptive approaches use systems understandings to identify key aspects of the system as the focus of planning and management intervention.

Planning and implementation are treated as an iterative process of review and revision, not as a series of fixed prescriptions (as in the rational-comprehensive approach). Interventions are seen as a series of successive and continuous adaptations to variable conditions. The approach emphasises flexibility, requires willingness to learn through experience and may require sacrificing present or short-term gains for longer-term objectives (Briassoulis 1989). The emphasis is on learning how the system works through management interventions that are both issue-oriented and experimental. Three key elements of adaptive planning are:

- testing assumptions: systematically trying different interventions to achieve a desired outcome

- adaptation: systematically using the information obtained through monitoring to take action that improves the efficiency and effectiveness of management

- learning: systematically documenting actions, processes and results so that lessons can be integrated into decision-making and shared with practitioners and researchers.

In the context of protected areas, this means that planners can study the changing relationship between ecosystems, social systems and land and natural resource use, and apply this information to develop new strategies and actions to achieve objectives (Barber et al. 2004). Advocates of this approach (Madanipour 2010; Barber et al. 2004; Wardrop and Zammit 2012) suggest that adaptation is a key requirement of conservation projects because in many instances there is insufficient knowledge to identify the 'best' answer to a conservation problem, and therefore actions need to commence based on the best available information and then be adapted as the project evolves. They also suggest that the time required to achieve improvements in biodiversity can be many decades; therefore projects need to define activities and expected results, and then measure short-term outputs in a way that builds confidence in the delivery of long-term 
South African National Parks' (SANParks) network of 19 protected areas traverses extensive environmental gradients and biodiversity, and is exposed to ever-changing and intensifying global population pressure. In response, SANParks has adopted an adaptive management approach to biodiversity conservation. SANParks' thresholds of potential concern form an integral part of the strategic adaptive management framework. The system involves a streamlined system of data collection, analysis, presentation of results and knowledge feedback. Data are collected to monitor the state of the environment. To ensure the accuracy of the data is preserved and the collection process standardised, a hand-held computer application (CyberTracker) is customised for each monitoring program. This icon-based system allows field workers to record observations, with latitude and longitude coordinates, using a personal digital assistant device that features an integrated global positioning system. In this way, data collected in the field are simultaneously captured electronically using graphic checklists, which enhance data accuracy. The data collection process can enable field rangers to contribute directly to the management and research of each park by simply collecting basic environmental data during their regular daily patrols (for example, distribution of rare and endangered species, availability of surface water and disease outbreaks).

The information gathered during the ranger patrols is used by SANParks management to:

- plan section patrols for area integrity mapping

- provide an early warning system for disease outbreaks
- identify trends in illegal exit and entry points

- enable the detection and control of invasive alien species

- report fence breaks to the State Veterinary Department for animal health purposes.

Data stored in the SANParks database are used in standardised routine analyses to assess whether the thresholds of specific ecological variables have been exceeded. This approach allows for a certain amount of ecosystem change brought about by resource use, provided it remains within the natural limits of variation. Consequently, these thresholds create a feedback loop between monitoring and management, which serves as an early detection system for undesirable changes to ecosystems and prompts informed management interventions to promote cyclical learning. There is also a socioeconomic component to sustainable resource use, as the process of developing monitoring indicators and thresholds is resource-intensive and time-consuming. This process entails the active involvement and support of all stakeholders to ensure effective monitoring of sustainable resource use and adherence to the rules. Stakeholder participation in resource use management is encouraged, including the incorporation of local knowledge in monitoring and evaluation systems. The roles and responsibilities of stakeholders vary according to the local context and purpose of the resource use.

Source: Adapted from Kruger and MacFadyen (2011) outcomes. It is an iterative process that leads to stronger strategies and actions based on measured outcomes from prior iterations.

Adaptive planning also acknowledges the changes that occur in a team as they understand and develop responses to their planning context. Put simply, the things a planning team and their stakeholders and partners learn while making a plan change the way they understand the context and responses to that context; the plan a team first develops and implements is simply a 'stepping stone' to the next, and so on.

As noted above, systems understandings in adaptive planning are increasingly based on resilience thinking and associated analyses of social-ecological systems (see Chapter 10 for more detail on this thinking). In a protected area context, management planning for Kruger National Park in South Africa is a leading example (Case Study 13.2). The key lessons for protected area planners from the Kruger experience are:

- long-term monitoring data and appropriate ecological and socioeconomic indicators of change are needed for adaptive management to be effective
- an effective support structure for data collection, reflection and dissemination of knowledge to facilitate timely management decisions and associated actions is essential

- the participation of local resource users and other stakeholders can support data collection, incorporate local knowledge and give greater legitimacy to management decisions regarding sustainable resource use.

For adaptive planning to be effective, strong institutional capacity, governance and systems for capturing and drawing on corporate memory and learning are critical. This is more than simply a database, which is frequently a suggested solution in some agencies, but rather providing a supporting framework to apply key learning. Implementing the adaptive planning approach is, however, an ongoing challenge. In most cases, people are the primary driving forces behind change or the adoption of new technology within an organisation. If one or more of these drivers, or change agents, disappears from the system, the programs previously under their supervision may be at risk of collapse if the proper structures are not in place to 


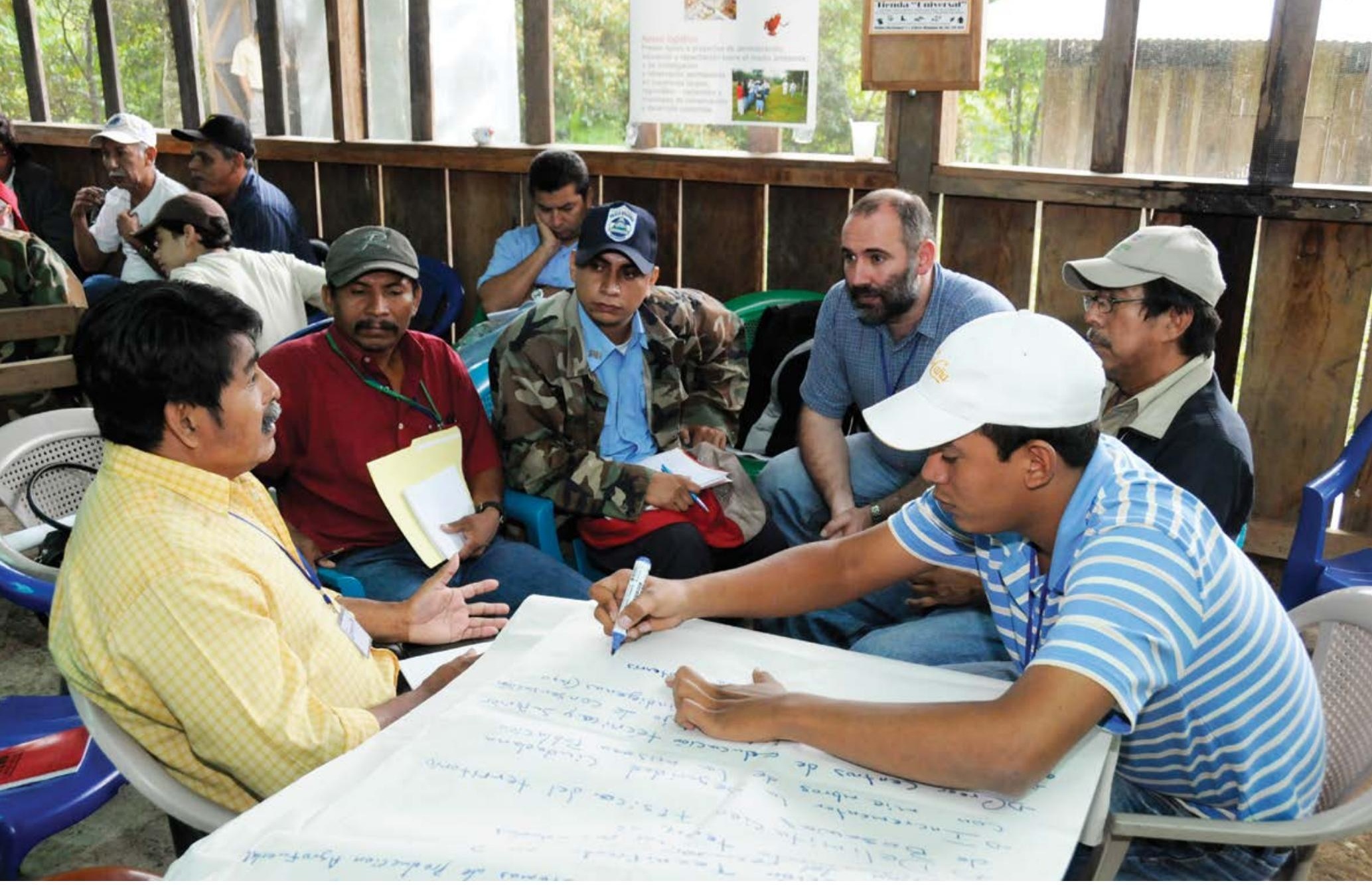

Bosawas Biosphere Reserve management planning, Nicaragua

Source: Eduard Müller

absorb the impact (Kruger and MacFadyen 2011). The time between assessment (an immediate evaluation of significance or performance) and reflection (a lengthy, deep consideration) is an important component of adaptive management leading to learning (Biggs et al. 2011). Managers are often faced with issues associated with: 1) maintaining ongoing stakeholder engagement and support over a long period; 2) securing political and financial support for the experimental approach; 3) testing innovations that will have some degree of risk associated with them; and 4) sustaining leadership effort and attention to both assessment and reflection to improve learning and management decisions. These difficulties are particularly acute for government protected area agencies. Community-based and private or NGO-governed areas may be better placed, as they often have more agility and flexibility to respond to new information, take advantage of emerging opportunities and be less constrained by political needs and agendas.

\section{Participatory planning}

Along with adaptive planning it is increasingly recognised that participative ways of planning are essential to protected area management. Participation has become a basic principle of protected area planning, since it has been recognised that without participation by the beneficiaries of the plan, implementation and outcomes will often fail. It assumes the importance of recognising the many voices, competing interests and goals, and shifts in interests and alliances in the planning process (Dawkins and Searle 2003).

The term 'community engagement' broadly captures public processes in which the general public and other interested parties such as interest groups, political decision-makers and local organisations are invited to participate in and contribute to plan-making or to comment on particular proposals or policy changes. The types of people who may be involved when preparing a plan include individuals and organisations likely to have a strong interest in or knowledge of the issue or geographical area, including indigenous people, government representatives, recreation user groups, researchers, conservation groups, tourism organisations and businesses.

Establishing and managing a protected area can result in costs and benefits for various stakeholders. Planning can involve competition and confrontation as it impacts on the value of land and quality of life, and is often the intersection between public and private-sector interests. In the face of diverse views and interests, it is 
difficult to achieve universal consensus; however, it is widely acknowledged that early engagement with the community in both plan-making and implementation offers considerable benefits for all parties involved. It can assist better planning outcomes as a result of taking account of a wide range of views, increasing the integrity and quality of decisions.

As our knowledge of what to conserve has developed over the decades, so too has our understanding of how protected areas should be planned and managed. For government protected area authorities, community engagement has shifted from merely making information available or gathering the opinions and attitudes of interested individuals and organisations to a more active exchange of information and viewpoints between the sponsoring organisation, stakeholders and the general community, which, in some cases, leads to shared decision-making. For community-governed protected areas, greater community awareness, sharing of knowledge, capacitybuilding and collaborative decision-making strengthen the 'ownership' of the protected area and management of the associated issues.

For NGO and privately owned protected areas, collaboration can facilitate projects that create physical linkages across the landscape and offer options that are often too difficult for governments to achieve.

As well as producing a more effective plan, the involvement of outside organisations and individuals in planning for protected areas has the following benefits:

- it promotes the role of various organisations and communities in conservation

- it provides a mechanism for organisations and the community to make positive and meaningful contributions to the decision-making process and building capacity

- it generates external ideas and thinking that can lead to innovation

- it fosters understanding of a park's values and issues, and development and acceptance of the management solutions set out in a plan

- it builds a stronger and improved relationship between the protected area and the community

- it fosters broad cross-sectoral partnerships and alliances that can increase access to financial and other resources (Lockwood 2006; Figgis et al. 2012).
The goals of any participatory planning need to be explicit from the outset and understood by both the person coordinating the participation process and those involved. For example, in addition to deciding the reason for involving other parties, it is important to determine

- how people should be organised to facilitate the planning process

- who are the interested parties and/or the people involved

- who should have the power to make decisions

- what is the best way to ensure effective participation for various groups

- what planning methods or procedures should be used

- who should decide what the planning objectives should be

- what criteria should be used to select the best courses of action and who decides (Lockwood 2006).

Based on the above questions, a decision can be made as to the most appropriate means of participation, which can take different forms and varying degrees. There are many excellent examples of participatory planning in protected areas around the world and some are presented in Case Studies 13.4 and 13.7. Key learning from these case studies includes:

- participation should be an open, collaborative, interactive process that is established to enable community values, aspirations and needs to be identified and brought into the plan-making process

- participation and engagement strategies should be designed to effectively involve individuals and groups with an interest in the plan and its outcomes

- participation should be seen as a continual process in protected area management and extend beyond planmaking to implementation, evaluation and continual improvement

- developing participation strategies with those who need to be involved in planning before it commences is more likely to be effective and relevant over the long term

- planners need to be clear about the purpose of the participation, the various strategies available, and the financial and human resources required to make participation effective and meaningful

- the purpose of participation and the constraints need to be explained in an honest and clear manner so the community understands the process and purpose of participation, while it may disagree with the content of the plan. 
The premise of participatory planning is that there is the possibility of achieving consensus among participants about objectives and required actions. Arriving at such consensus can be difficult because participants often have different and sometimes conflicting interests and objectives. In many respects, participatory processes are processes of negotiation that aim at resolving and managing existing and potential conflicts (between and among resource users, between resource uses, or between resource management objectives and strategies).

When dealt with in an appropriate manner, conflicts that arise in participatory planning present opportunities for assessment and evaluation and can act as a catalyst for change. In the context of participatory planning, conflict can help address issues that could hinder management at a later stage in the process. If not managed properly, however, conflict can be counterproductive and can undermine protected area management.

Conflict management is one of the unavoidable responsibilities of protected area managers, who are often required to play a range of different roles in the planning process, from facilitator to negotiator to decision-maker. In instances where the management agency is one of the parties in conflict, it is the responsibility of the manager to identify a method for dispute resolution and conflict management that will be appropriate and acceptable to all involved. Effective communication is the essential tool for conflict management, and techniques such as self-negotiation, facilitation, mediation and arbitration should be considered depending on the nature of the conflict.

\section{Advocacy planning}

The concept of advocacy planning arose in the 1960s partially as a reaction to the failure of rationalcomprehensive and incremental planning approaches to deal with poverty and exclusion. Public participation is a central tenet of this model, which seeks to ensure that all people are equally represented in the planning process by advocating for the interests of the underprivileged and seeking social change. A plurality of public interests is assumed, and the role of planner is essentially as a facilitator who advocates for either social reform or social transformation agendas (Friedmann 1987).

In a protected area context, planners can be advocates for nature and/or cultural heritage conservation, advocates for fair and inclusive planning decision-making, as well as advocates for particular forms of human-nature interactions. A well-known example of advocacy planning is the Yellowstone to Yukon Conservation Initiative
(Y2Y). Originating from an alliance between scientists and activists, $\mathrm{Y} 2 \mathrm{Y}$ is an advocacy-based environmental NGO focused on habitat connectivity from Yellowstone National Park to the Yukon for grizzly bears (Ursus arctos horribilis) that began in the early 1990s. Y2Y works with local communities, through education and stewardship programs, to encourage conservation of the area. Y2Y covers five US States, two Canadian Provinces, two Canadian Territories and the traditional territories of 31 First Nations groups (Y2Y 2014).

\section{Planning for protected area networks}

Historically, protected areas have been established for a variety of reasons, from conserving sites of particular beauty to protecting habitats of high-profile species. Establishment was mostly incremental or ad hoc and often based on factors such as opportunity (the site is not seen as having any commercial value such as for agriculture), scenery, recreation and tourism potential, or protection for activities associated with hunting or water supply (Langhammer et al. 2007). Over time, conservation planning goals and associated strategies have evolved, and notions of protected area planning have changed accordingly (Barber et al. 2004).

Planning for protected area networks - that is, deciding which lands and seas should be considered for protected area designation-is undertaken at global, national and subnational scales. This section will first address key planning frameworks at the first two scales, and then consider the associated method of 'systematic conservation planning'.

\section{Global-scale protected area network planning}

Over the past 25 years, planning for conservation at a global scale has been established primarily through international conventions. These conventions establish global priorities for biodiversity conservation and assist individual countries to plan for biodiversity conservation through reserve establishment and geographical and species protection and management. These conventions establish the primary goals and conservation targets to which nations should aspire. They are the bedrock of the conservation planning framework.

At the 1992 Earth Summit in Rio de Janeiro, world leaders agreed on a comprehensive strategy for sustainable development. One of the key agreements adopted was the Convention on Biological Diversity (CBD). This 
agreement among most of the world's governments sets out commitments for maintaining the world's ecological values as countries strive for economic development. The CBD establishes three main goals: 1 ) the conservation of biological diversity; 2) the sustainable use of its components; and 3) the fair and equitable sharing of the benefits from the use of genetic resources (CBD 2013). The CBD recognises that protected areas play a critical role in the achievement of these goals.

A central principle of the CBD is an 'ecosystem approach' to conservation planning (referred to later in this chapter), which expands the focus to broader landscapes and seascapes. This has involved the development of methodologies for dividing up the Earth into discrete spatial units possessing distinct biological and ecological characteristics and a strategic assessment of areas needing protection (CBD 2013).

In 2004, the CBD parties made a comprehensive and specific protected area commitment by adopting the Programme of Work on Protected Areas (PoWPA). The PoWPA enshrines development of participatory, ecologically representative and effectively managed national and regional systems of protected areas, where necessary stretching across national boundaries. The PoWPA is considered the defining framework for protected area planning for the coming decades (CBD 2013). It is a framework for cooperation between governments, donors, NGOs and local communities to plan for and establish a network of protected areas around the world (Barber et al. 2004).

In 2010, as considered in Chapter 2, the parties to the CBD adopted the Strategic Plan for Biodiversity 20112020 and the Aichi Targets (CBD 2011). This plan presents the overarching framework for biodiversity of the entire UN system and is used to inform the biodiversity strategies and action plans for each nation. Target 11 of the strategic plan recognises that the establishment of comprehensive, ecologically representative, effectively managed and financially secured protected area networks is a critical strategy not only for biodiversity conservation, but also for securing ecosystem goods and services and supporting climate change adaptation and mitigation.

This planning target seeks to ensure that ecosystems, species and genetic diversity are safeguarded in both the land and the seascape, that key habitats are protected and that species migration and movement can occur. The target recognises protected areas as the cornerstone of conservation actions and as such is one of the main tools at a country's disposal to reduce habitat loss.
Several methods are also being used by NGOs to help determine global conservation priorities that focus on irreplaceability, targeting areas with highly diverse and endemic plant, bird or terrestrial vertebrate taxa. Some of these priority-setting approaches are considered proactive, focusing on sites with low threat but high irreplaceability, and others are reactive, prioritising both threat and irreplaceability (Brooks et al. 2006).

Perhaps the most widely known method for setting geographic conservation priorities at the global level is the 'hotspot' approach, which has been widely adopted in recent years among the conservation community. Simply stated, these are areas that are locally, nationally and globally important for the manifestation of biodiversity (at genetic, species and ecosystem levels). These areas cover different taxa. For example, the key biodiversity area (KBA) approach uses four criteria for setting priorities that stress irreplaceability and vulnerability. Using consistent global criteria of vulnerability and irreplaceability, the KBAs are mapped by national conservation organisations. KBA identification is focused on land, freshwater and marine environments under national jurisdiction. This is an important approach for national gap analyses and prioritisation to increase the effectiveness and establishment of protected areas. The LifeWeb Zero Extinction Campaign represents another example of biodiversity priority setting at a global scale. The campaign advances Aichi Biodiversity Target 12 to prevent the extinction of known threatened species. The campaign advances two main approaches to address the threat of extinction: 1) protection of key unprotected sites; and 2) enhanced protection of currently protected sites. An example of a reactive approach to biodiversity conservation planning is the Last of the Wild initiative of the Wildlife Conservation Society (WCS) (Sanderson et al. 2002). Last of the Wild places are identified using biodiversity indices in combination with threat indicators, such as human population density, accessibility of the regions to human development and land transformation (Sanderson et al. 2002; Naro-Maciel and Sterling 2008).

\section{National-scale protected area network planning}

Globally, the integrity and effective management of protected areas at the national level remain the highest priorities. A system plan is the design of a total reserve system covering the full range of ecosystems and communities found in a particular country (Davey 2008). 
The plan should be a means to establish the priorities for a workable national system of protected areas and should address the following points:

- define the priority of protected areas as a worthwhile national concern and of strategic importance

- define the relationships between: a) different units and categories of protected areas; and b) protected areas and other relevant categories of land

- define the roles of key players in relation to protected areas and the relationships between these players, such as building support and a constituency

- identify gaps in protected area coverage (including opportunities and needs for connectivity) and deficiencies in management

- identify current and potential impacts, both those affecting protected areas from surrounding lands and those emanating from the protected areas that affect surrounding lands (Davey 2008).

A good example of a planning approach and conservation priority-setting at a national scale is in Australia (Case Study 13.3). A whole-of-government decision by the Council of Australian Governments in 1992 agreed to a strategic policy framework to establish a comprehensive, adequate and representative system of protected areas throughout Australia (Government of Australia 2010). Twenty years on, this remains one of Australia's key conservation policies, reflected most recently in Australia's Strategy for the National Reserve System 2009-2030. This commitment was followed some years later with a decision by the Australian and New Zealand Environment and Conservation Council to pursue a National Representative System of Marine Protected Areas (Government of Australia 2014).

The scientific foundation that underpinned and guided the strategy represented more than 25 years of significant collaboration between all governments and numerous scientific bodies to establish both the Interim Biogeographic Regionalisation for Australia (IBRA) and the Interim Marine and Coastal Biogeographic Regionalisation for Australia. Both have continued to be refined as new information and data become available.

This sound conservation planning approach has enabled governments and NGOs to develop strategies for new declarations and purchases of land. It has also been a major catalyst in building partnerships between government and NGOs and the community. For example, the private land trust sector has been able to leverage the Australian Government's two-for-one funding formula to attract major donors. New models for conservation management have developed and as a result four types of protected areas are now recognised in the National Reserve System (NRS):
- public (or government-owned) reserves

- Indigenous Protected Areas (IPAs)

- private protected areas

- shared management reserves.

Despite the strength of the planning approach and the steady growth of the protected area system in Australia, the challenges remain. Australia is not succeeding in stemming the loss of species and ecosystems, and it is becoming increasingly apparent that protected areas cannot be managed in isolation from other land management issues such as increased fragmentation, inappropriate fire management, resource use and uncontrolled invasive species, which weaken both species and ecosystems at a national scale. With government leadership and the resourcing capacity of the NRS diminishing in recent years, leadership from private donors, NGOs and community organisations will be vital for the ongoing implementation of the strategy.

Over the past decade there has been a shift in governance of land, water and natural resources and ownership and/or management to NGOs, communities, indigenous peoples and private parties - either alone or in partnership. This shift from the establishment of government-managed protected areas to new models of governance has also resulted in new approaches to planning. This is best illustrated by the model of the Indigenous Protected Area (IPA) - an entirely voluntary contract model between traditional owners and the Australian Government to manage land for agreed conservation priorities (Case Study 13.4). This concept has been successful with 55 IPAs declared as of 2014, covering 43 million hectares or 5.6 per cent of Australia, with many more communities expressing interest in developing an IPA (IUCN 2014). This is a significant contribution to the comprehensiveness, adequacy and representativeness of the protected area system in the 20 per cent of the continent under Indigenous ownership. It also provides important social benefits to Indigenous communities and helps maintain and strengthen attachment to the land.

While IPAs are inherently different from public protected areas in terms of formal security of conservation tenure and their governing institutions, management arrangements to secure biodiversity conservation are made through other effective means such as management plans that specifically take into account Indigenous cultural issues.

These approaches have broadened the types of partners contributing to the NRS and the planning, management and governance arrangements. These arrangements will inform and hopefully encourage other approaches to expanding Australia's NRS and perhaps areas further afield. 


\section{Case Study 13.3 Australia's National Reserve System}

Australia has an evolving National Reserve System (NRS) of terrestrial parks and reserves that conserves examples of its natural landscapes and ecosystems. It also has an extensive marine protected area network that includes the Great Barrier Reef Marine Park, as well as fish habitat reserves, fish sanctuaries, aquatic reserves, conservation areas, marine parks and marine and coastal parks.

\section{Land and inland freshwater protected areas}

Australia's NRS is a national network of public, Indigenous and private protected areas covering land and inland fresh water. The goal of the NRS is to develop and effectively manage a comprehensive, adequate and representative national system of protected areas, as the primary means for securing long-term protection for Australia's terrestrial biodiversity.

Comprehensiveness refers to the aim of including samples of the full range of regional ecosystems recognisable at an appropriate scale within and across each IBRA bioregion.

Adequacy refers to how much of each ecosystem should be sampled to provide ecological viability and integrity of populations, species and ecological communities at a bioregional scale. The concept of adequacy incorporates ecological viability and resiliency for ecosystems for individual protected areas and for the protected area system as a whole.

Representativeness is comprehensiveness considered at a finer scale and recognises that the regional variability within ecosystems is sampled within the reserve system.

The NRS complements other efforts (in particular, actions to improve vegetation, habitat and water quality) to conserve biodiversity across terrestrial, inland fresh water and marine ecosystems and to meet Australia's international obligations to protect native species and habitats.

The NRS strategy 2009-30 (Government of Australia 2010) provides guidance for improved coordination and supports collaborative action by protected area managers and key stakeholders. The strategy identifies priority actions to provide a nationally coordinated approach under each theme, including the following national targets for an NRS:

- examples of at least 80 per cent of all regional ecosystems in each bioregion by 2015

- examples of at least 80 per cent of all regional ecosystems in each subregion by 2025

- core areas for the long-term survival of threatened ecosystems and threatened species habitats in each of Australia's bioregions by 2030

- critical areas for climate change resilience, such as refuges, to act as core lands of broader wholeof-landscape scale approaches to biodiversity conservation by 2030 .

Actions to meet the national targets are supported by:

- clear identification and adequate protection of the biodiversity assets of each bioregion through collaborative and integrated management with other landowners and managers using a whole-of-landscape approach to address conservation priorities
- $\quad$ rigorous science and robust monitoring

- $\quad$ effective and adaptive management regimes

- consistent approaches informed by the development of national frameworks for management effectiveness and protected areas on private lands

- strong partnerships between governments, private landholders, Indigenous peoples, industry, local communities and NGOs

- routine reporting to a well-informed and supportive Australian community.

Each State and Territory in Australia is required to prepare a five-year plan to implement the strategy. These plans support the strategy and reflect the regional differences in conserving biodiversity across the landscape and the conservation challenges they pose.

The terrestrially based NRS has laid the cornerstone for biodiversity conservation in Australia and is recorded in a national database, the Collaborative Australian Protected Area Database (CAPAD), along with each reserve's classification in accordance with the IUCN protected area categories (Chapter 2). CAPAD is updated every two years and provides the official record of progress for reporting against numerous national and international obligations, making it quantifiable and open to public scrutiny and accountability (Government of Australia 2014).

\section{National Representative System of Marine Protected Areas}

The creation and management of marine reserves form an important strategy for the conservation and sustainable use of the marine environment. Marine reserves, when well designed and managed effectively, make an important contribution to maintaining the overall health and resilience of the world's oceans (Chapter 20).

This is recognised by the primary goal of Australia's National Representative System of Marine Protected Areas (NRSMPA), which is to establish and manage a comprehensive, adequate and representative system of marine protected areas to contribute to the long-term ecological viability of marine and estuarine systems, to maintain ecological processes and systems, and to protect Australia's biological diversity at all levels (Government of Australia 2014). The NRSMPA goals allow for a broad spectrum of activities, including recreation, tourism, shipping and the use or extraction of natural and living resources, where such activities are compatible with the primary goal (Government of Australia 2014).

The creation of the NRSMPA has been ongoing since 1998 following an agreement between the Australian Government, the States and the Northern Territory. The States and the Northern Territory are establishing marine protected areas in their coastal waters, while the Australian Government is establishing marine protected areas in Commonwealth waters around Australia. Once completed, the NRSMPA will meet Australia's international commitments as a signatory to the CBD to establish a representative system of marine protected areas within Australia's Exclusive Economic Zone (Government of Australia 2014). 
Principles used in selecting areas suitable for inclusion in the NRSMPA include:

- the capacity of a marine reserve to mitigate identified threats to conservation values

- the occurrence of spatially defined habitats for and/ or aggregations of threatened and/or migratory species

- the occurrence of ecologically important pelagic features that have a consistent and definable spatial distribution

- the occurrence of known small-scale ecosystems associated with the benthic/demersal environment

- relevant available information about small-scale distribution of sediment types and sizes and other geo-oceanographic variables

- occurrence of listed heritage sites (where inclusion in the marine reserve network would improve administration of protection regimes)

- socioeconomic costs.

The Goals and Principles for the Establishment of the NRSMPA in Commonwealth Waters (Government of Australia 2014) guide the identification of areas representative of the diverse ecosystems and habitats in Commonwealth waters. They provide guidance about how to design regional networks of marine reserves that meet the principles of 'comprehensiveness', 'adequacy' and 'representativeness'. Planning for the uses and management of marine reserves currently utilises the following inputs:

- scientific information for each bioregion

- data on the location and distribution of human activities in a marine region

- the views of ocean users and stakeholders in each marine region

- consideration of the contribution that existing spatial management measures can make to the NRMSPA

- consideration of potential management effectiveness-for example, the feasibility of compliance (Government of Australia 2014).

\section{Systematic conservation planning}

While we are developing a far better global sense of where the highest priorities for conservation lie, progress has also been made in developing tools for finer-scale systematic conservation planning of protected area systems based on explicit and quantifiable biodiversity conservation criteria at a regional scale. This encompasses size, shape, replication, complementarity and connectivity of protected areas. Conservation planning at regional and local levels addresses not only the content and location of individual protected areas and sets of protected areas, but also their design, which includes variables such as size, connectivity and alignment of boundaries for maximum effectiveness.

According to Margules and Pressey (2000), science is a fundamental component supporting systematic conservation planning and its effectiveness comes from its efficiency in using limited resources to achieve conservation goals, its defensibility and flexibility in the face of competing land uses, and its accountability in allowing decisions to be critically reviewed.

Margules and Pressey (2000) describe systematic conservation planning as a process in six stages, which has many feedback loops. The framework applies equally well to many problems in 'off-reserve' conservation, including habitat restoration. They suggest that systematic conservation planning at national and regional levels requires:

- decisions about the features to be used as conservation targets (species, communities or habitats, or environmental features related to vegetative cover and geographic features) for overall biodiversity in the planning process

- clear goals translated into quantitative operational targets

- recognition of the extent to which conservation goals have already been met in existing reserves

- simple methods for locating and designing new reserves to complement existing ones

- application of criteria for implementation, especially with respect to phasing actions when it is unlikely that all actions can be undertaken simultaneously

- objectives and mechanisms for maintaining conditions in reserves required to support key natural features, monitoring and adaptive management.

Margules and Pressey (2000) outline the stages in systematic conservation planning as follows. An example application of these stages is given in Case Study 13.5. 


\section{Case Study 13.4 Management planning for Indigenous Protected Areas}

Indigenous Protected Areas (IPAs) are areas of land and/ or sea over which the Indigenous traditional owners or custodians have entered into a voluntary agreement with the Australian Government for the purposes of promoting biodiversity and cultural resource conservation (Davies et al. 2013).

IPA management plans are based on making connections between Indigenous people, country, traditional law, custom and culture with the Australian and international systems for protected area management. IPA management plans are most effective if they make sure Indigenous peoples drive and determine how protected area management requirements will be met.

The IPA management plans provide a basis for formal government recognition of Indigenous lands as part of the Australian national system of protected areas and are also seen by the Australian Government as an important mechanism for supporting and invigorating the use of Indigenous ecological knowledge in biodiversity conservation. Development of a management plan has been integral to declarations made by 50 Indigenous groups in Australia of their intent to manage all, or part of, their customary estates for conservation outcomes in perpetuity as IPAs.

Most early IPA plans adopted a conventional distinction between natural and cultural values, reflecting a foundational principle of modernist Western thought that can make deep cross-cultural communication difficult (Davies et al. 2013). These concerns led IPA program managers to initiate the development of guidelines for use by traditional owners and IPA planners with the aim of ensuring that management plans reflected the distinctive characteristics of IPAs. Recent innovations in developing management plans appropriate to Indigenous and community conserved areas described by Davies et al. (2013) allow protected area managers to better understand and adjust to community settings when developing plans.

New approaches in some recent IPA management plans documented by Davies et al. (2013) include:

- overt recognition of the primacy of customary governance

- strategic planning formats that reflect interlinkages between people, place, plants and animals

- planning frameworks that encompass customary territories, identify cross-scale issues and challenge power relations embedded in colonial tenures

- a suite of planning documents for varied audiences and purposes, with an emphasis in the main plan on visual and spatial communication modes that facilitate accessibility to traditional owners.

These innovations are not widespread across existing IPA management plans, but their inclusion in management plan guidelines will encourage their wider adoption and ongoing innovation and will no doubt promote confidence among traditional owners about maintaining control of IPA governance, management and knowledge.

\section{Compile data on the biodiversity of the planning region}

- Review existing data and decide which data sets are sufficiently consistent to serve as surrogates for biodiversity across the planning region.

- If time allows, collect new data to augment or replace some existing data sets.

- Collect information on the localities of species considered rare and/or threatened in the region (these are likely to be missed or under-represented in conservation areas selected only on the basis of land classes such as vegetation types).

\section{Identify conservation goals for the planning region}

- Set quantitative conservation targets for species, vegetation types or other features (for example, at least three occurrences of each species, 1500 hectares of each vegetation type or specific targets tailored to the conservation needs of individual features). Despite inevitable subjectivity in their formulation, the value of such goals is their explicitness.
- Set quantitative targets for minimum size, connectivity or other design criteria.

- Identify qualitative targets or preferences (for example, as far as possible, new conservation areas should have minimal previous disturbance from grazing or logging).

\section{Review existing conservation areas}

- Measure the extent to which quantitative targets for representation and design have been achieved by existing conservation areas. A general 'gap analysis' (Case Study 13.6) can also be conducted.

- Identify the imminence of threat to under-represented features such as species or vegetation types, and the threats posed to areas that will be important in securing satisfactory design targets.

\section{Select additional conservation areas}

- Regard established conservation areas as 'constraints' or focal points for the design of an expanded system.

- Identify preliminary sets of new conservation areas for consideration as additions to established areas. Options for doing this include reserve selection 
algorithms or decision-support software to allow stakeholders to design expanded systems that achieve regional conservation goals subject to constraints such as existing reserves, acquisition budgets or limits on feasible opportunity costs for other land uses.

\section{Implement conservation actions}

- Decide on the most appropriate or feasible form of management to be applied to individual areas (some management approaches will be a fallback from the preferred option).

- If one or more selected areas prove to be unexpectedly degraded or difficult to protect, return to stage four and look for alternatives such as restoration.

- Decide on the relative timing of conservation management when resources are insufficient to implement the whole system in the short term (usually).

\section{Maintain the required values of conservation areas}

- Set conservation goals at the level of individual conservation areas (for example, maintain several habitats for one or more species for which the area is important). Ideally, these goals will acknowledge the particular values of the area in the context of the whole system.

- Implement management actions and where possible zonings in and around each area to achieve the goals.

- Monitor key indicators that will reflect the success of management actions or zonings in achieving goals.

- Modify management as required.

\section{Gap analysis}

Although the growth in number and area of global protected areas has been spectacular in recent decades, it does not yet come near to fulfilling the objectives of the PoWPA or the needs of species and ecosystems, given that a large number of species, ecosystems and ecological processes are not adequately covered in existing protected areas (CBD 2013). One important development in the past decade is the use of ecological gap analysis to assess how well protected areas conserve biodiversity, and where the highest priorities are for expanding and reinforcing protected areas (Langhammer et al. 2007; Dudley 2010; Figgis et al. 2012).

The two main criteria to determine conservation targets and priorities are irreplaceability and vulnerability (CBD 2013). These criteria can be applied across all biogeographic regions and taxonomic groups and are designed for application through a national or regional level, bottom-up iterative process involving stakeholders (Langhammer et al. 2007).

Ecological gap assessment analyses the extent to which key biodiversity features (species, natural communities, ecological systems and the ecological processes that sustain them) are sufficiently represented within a protected area network. The aim is to identify those key biodiversity features that are not well represented. Ecological representation provides a unifying methodology to address gaps in a protected area system at a national scale.

\section{Protected area management planning}

Management plans are reserve or place-specific plans that look at the values of an area, the issues and threats that may affect that area, and the strategies and actions required to best manage the place to maintain or improve its conservation and other values.

The purposes of management plans are generally to:

- ensure reserves are managed to achieve objectives of legislation, stakeholder expectations (including local indigenous communities), corporate goals and conservation management objectives: quality assurance, consistency and prevention of incremental degradation through ad hoc decision-making

- gain public involvement in reserve management: give the community a way to have their say about management

- develop a shared understanding of and a vision for a reserve: identify the significance of an area, consolidate legislative and policy issues, integrate various elements of management, and convey to the public and management staff how the reserve will be protected and visitors provided for

- provide public accountability: a 'statement of intent' for the community, what we want to achieve and how, and the criteria by which the performance of management under the plan will be assessed.

As indicated in Lockwood (2006), in the 1970s and 1980s, management plans tended to include a lot of resource information that was not directly relevant to management strategies. Also, the planning process was often drawn out and involved specialist planners or planning teams. More recently, the trend has been towards leaner, more strategic management plans. There is greater emphasis on setting and meeting targets for 
The Maputaland Centre of Endemism, which forms part of the Maputaland-Pondoland-Albany hotspot, is an area of approximately 17000 square kilometres that lies in Mozambique, South Africa and Swaziland (Steenkamp et al. 2004). A little more than half of the area is within South Africa, of which 28 per cent is located within reserves. This area is referred to as Maputaland. Maputaland is the focus of a number of conservation initiatives, which resulted in the need for a systematic conservation planning exercise to guide the land manager, Ezemvelo KwaZulu-Natal Wildlife (EKZNW), and other stakeholders when selecting preferable locations for new conservation-compatible projects outside the state-managed reserves.

From its inception, it was determined that the process would need to be supported by biodiversity data with a fine spatial scale, however, these data were limited. As a result, a preliminary planning analysis was undertaken of the distribution of the region's land-cover types, as these could be mapped at relatively low cost from satellite imagery.

\section{Producing the GIS data}

A land-cover map was produced from Landsat images. The land-cover classification was based on an existing system developed for northern Maputaland and modified to reflect more recent work on the region's vegetation communities. Five ecological zones were identified, which contained 29 natural habitat types and five types that had been transformed by agriculture or urbanisation. Its accuracy was measured by recording the actual and predicted land-cover types at 723 points throughout the study area.

\section{Setting the biodiversity targets}

The biodiversity targets were developed by EKZNW staff with experience in conservation planning and the ecology of Maputaland. Staff decided that targets should be based on original land-cover extent to avoid under-representing highly transformed habitats. Expert opinion and data on the current transformation levels of each of the ecological zones assisted the process. It was also decided that land-cover types endemic to the Maputaland Centre of Endemism, or that were perceived to be at greater risk of transformation, should have higher conservation targets. Targets were therefore set as being 20 per cent of original extent for most land-cover types and 40 per cent of original extent for endemic and threatened land-cover types.

\section{Identifying areas of high conservation value}

The data were analysed using MARXAN, a conservation planning program that uses simulated annealing techniques to identify a large number of near-optimal sets of planning units (where each set is called a portfolio) based on an iterative improvement method that incorporates occasional backward steps. MARXAN measures the effectiveness of a portfolio of planning units by calculating its portfolio cost, which in this case was based on three elements. The first element was the combined planning unit cost, which was set as being the combined area of the planning units, measured in hectares. The second element was the combined target penalty cost, which is the sum of the costs for not meeting individual representation targets. Ideally, these penalty values should have practical relevance, allowing MARXAN to make trade-offs between the costs of including more planning units in a portfolio and the cost of not meeting a target. The third element was the total perimeter length of the planning unit portfolio or 'boundary length', multiplied by a boundary length modifier. MARXAN minimises this boundary length cost by choosing patches of planning units, rather than a series of isolated units.

The simulated annealing process involved running the software a number of times, as it is based on an iterative selection process that generally identifies different portfolios at the end of each run. MARXAN then identifies the best of the portfolios it has produced-that is, the portfolios with the lowest total cost based on summing the planning unit, target penalty and boundary costs. In addition, it produces the summed solution output, which calculates the number of times each planning unit appeared in the different portfolios produced by the different runs. Increasing the number of iterations and the number of runs increases the likelihood of identifying low-cost portfolios but this also increases the amount of computer processing time.

The process used 37943 planning units in the analysis, with each unit having an area of 25 hectares. Planning units with more than 50 per cent of their area within existing reserves were set as being already conserved. In addition, planning units were excluded from any possible conservation portfolio if more than 25 per cent of their area consisted of commercial agriculture, or if more than 80 per cent of their area consisted of subsistence agriculture. These units were excluded because MARXAN can select areas based on their connectivity value alone and it was felt these highly transformed units would not be suitable for such a role, with highly transformed commercial agriculture being less suitable than subsistence agriculture.

\section{Results}

The current protection afforded to land-cover types by the existing set of reserves ranged from 8.8 per cent for Lebombo grassland to 100 per cent for dune thicket. The summed solution map produced by MARXAN identified 316 planning units ( 0.8 per cent of the planning region) that were part of every planning portfolio identified by the 200 runs. All of these irreplaceable units bordered existing reserves and contained 20 different natural land-cover types, with Terminalia woodland and floodplain grassland best represented. An additional 3244 units (8.6 per cent of the planning region) were identified as being part of half or more of the different conservation portfolios. Most of these high-scoring units were found in areas that were adjacent to existing reserves; however, important patches of coastal plain vegetation were also identified.

The analysis showed that most of the land-cover types are well represented, although many of these reserves are ecologically isolated. In addition, this exercise provided valuable data on the location of important conservation areas in the region and this information has already helped inform local land-use decisions. In particular, EKZNW used the summed solution map to identify where new eucalyptus plantations should not be located, illustrating the role of conservation assessments in reducing the risk of losing important biodiversity.

Source: Adapted from Smith et al. (2006) 


\section{Box 13.1 Examples of management planning for ICCAs}

Indigenous peoples and local communities that govern ICCAs (see Chapter 7) have planned the management of their territories and areas for centuries. However, planning is not a distinct activity, but an integral part of their lives and customs, as a response to external challenges, or as a means of securing the future. Most ICCAs continue to engage in such informal planning. Some, however, have begun to make planning a distinct and formal activity, especially as a means of seeking or responding to their recognition by government.

In Iran, norms and customs of indigenous peoples and local communities have sustained various ways of life and forms of natural resource management over thousands of years. In the case of mobile or nomadic peoples, this applies particularly to the planning of migration, the sharing of benefits from natural resource management, restoration (qoroqs) of degraded areas, customary management of rangelands and forests, collection and dispersal of seeds, sustainable use of plants and animals, and conflict resolution. The knowledge and practices embodied in these activities form the basis of recent initiatives at securing their territories for conservation, including sustainable use and livelihoods enhancement. This involves a set of planning and visioning exercises, facilitated by the civil society group Cenesta. A proposal for a territory-based Rangeland Management Programme aims at improving rangeland management and conservation, recognising the importance of traditional knowledge in the management of ecological complexity (including non-equilibrium ecosystems), and community-based mapping and monitoring.

In Kenya, beach management units (BMUs) are associations of fishers, traders, and other fishery users and stakeholders centered around coastal landing sites. These BMUs are able to develop and enforce rules governing their fishery, including demarcating its boundaries and excluding non-members from outside the area, with the support and sanction of the Department of Fisheries. They may create their own management plans for this. Examples of regulations developed under this framework includes the designation of certain areas as no-take zones or otherwise regulated for particular uses, levying fees or taxes on fish landings or other activities such as tourism, regulation of the types of fishing gear that may be used, and restriction of use of the fishery to registered fishermen and boats. The BMU thus provides a clear governance framework for local fishery users to circumscribe and regulate their fishery. This converts the fishery from a general open-access governance context to one based on establishment and enforcement of local territorial and access rights over marine resources. The Department of Fisheries plays a key role in registering BMUs and facilitating the development and eventual approval of local management plans, and provides general oversight of the BMUs as well to ensure local rules are being followed.

In the Philippines, indigenous peoples who obtain a title to their traditional territories under the Indigenous Peoples' Rights Act are enabled to prepare Ancestral Domain Sustainable Development and Protection Plans (ADSDPP). Groups such as KASAPI (the national association of indigenous peoples) and the NGO PAFID help in their preparation. Financial assistance is given for ADSDPPs by the National Commission on Indigenous Peoples. However, many indigenous peoples are critical of the prescribed uniform format for the formulation of ADSDPPs, arguing that it violates their right to selfdetermination and governance. This illustrates the pitfalls of top-down formalisation of ICCAs and their planning processes.

Sources: Naghizadeh (2012); Nelson (2012); Pedragosa (2012)
The content, support and effective implementation of management plans are influenced by stakeholders and communities involved in participatory planning approaches. Case Study 13.7 presents an example of a participatory planning approach for one of Australia's most complex protected areas. This case study illustrates that the long-term advantages of involving a wide variety of communities and groups in the development of the plan include ongoing support and advocacy for the plan's implementation.

The increased significance of community-based governance of protected areas is beginning to generate new approaches to management planning, as presented in Case Study 13.4. This case study illustrates some of the characteristics that management plans should have in order to be appropriate to Indigenous Peoples and
Community Conserved Territories and Areas (ICCAs) in which communities, rather than government, are the major decision-makers (Figgis et al. 2012). Box 13.1 provides examples of how the governors of ICCAs approach management planning for their territories.

\section{Processes for preparing management plans}

Whilst there are no prescribed formulas for preparing a management plan, there are some steps that are common to the development of most plans. The IUCN guideline on protected area management planning (Thomas and Middleton 2003) outlines the elements of good practice 


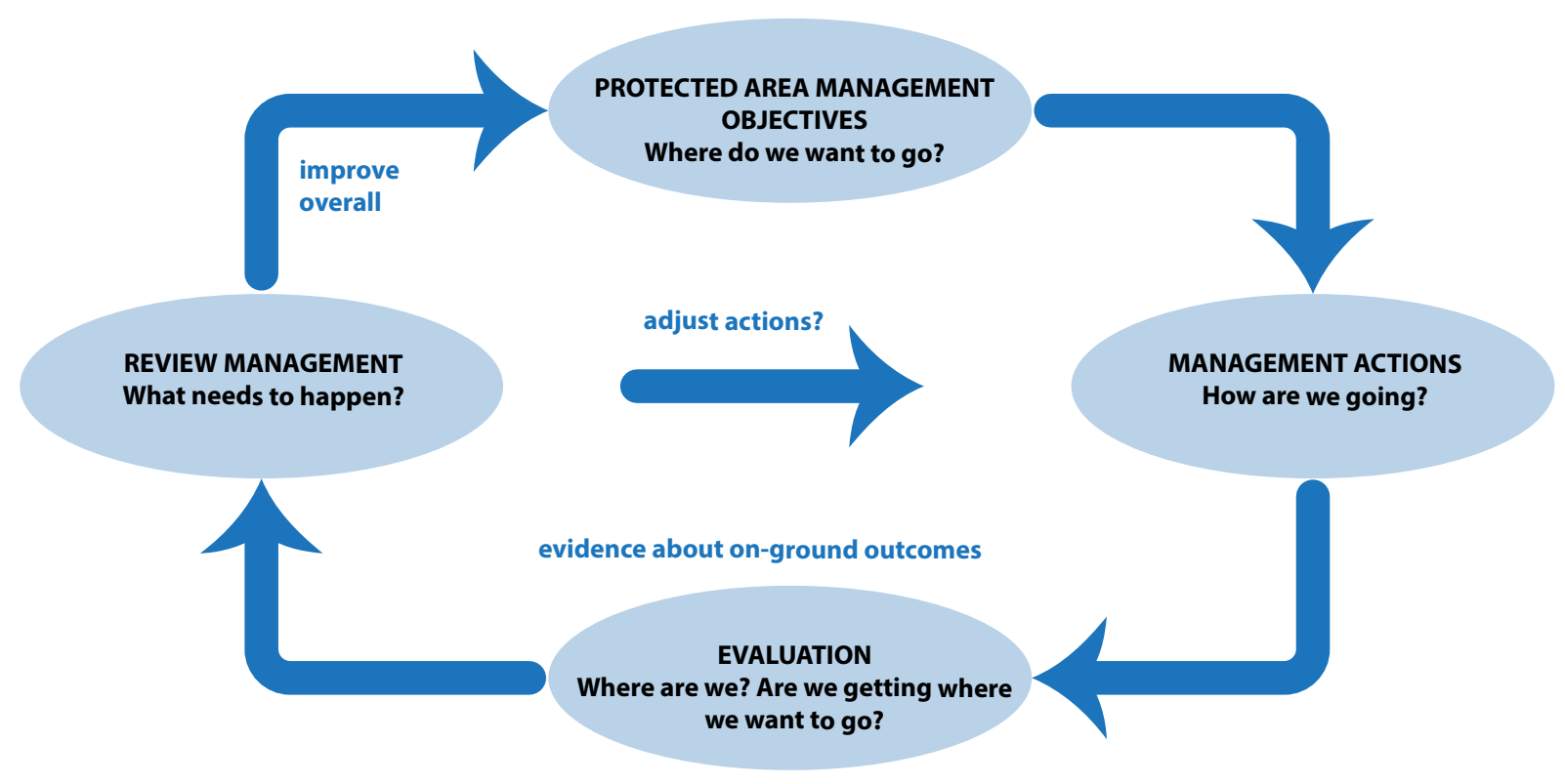

Figure 13.2 Rational, adaptive and participatory planning process

Source: Adapted from Lockwood (2006)

for management planning, recognising that it has drawn primarily on the experiences of government-managed terrestrial protected areas.

In summary, the most effective management plans are succinct documents that identify the key features or values of the protected area, clearly establish the management objectives to be met and indicate the actions to be implemented. They are flexible enough to cater for unforeseen events that might arise during the currency of the plan. The process of developing a management plan may be more or less complex depending upon the objectives of the protected area, the risks or threats to these objectives, the number of competing interests, the level of stakeholder involvement and the issues arising from outside the protected area.

Whether the plan is simple or complex, sound planning principles should be applied to guide the planning process and help ensure that the completed management plan can be implemented. The factors that determine whether this will be the case are outlined in Thomas and Middleton (2003) and can be summarised as:

- the process used during plan preparation

- the presentation, style and content of the resulting plan

- the context within which the plan must operate

- the resources, commitment and capacity to implement the plan.
In this section, two planning processes are summarised and their contributions to good practice considered: a mixed rational, adaptive and participatory process (Case Study 13.7); and an adaptive process called 'Open Standards' (Case Study 13.8). Case Study 13.7 demonstrates the value of participation in the design and execution of the planning process and the resources, commitment and capacity to implement the plan. Case Study 13.8 demonstrates the importance of designing a practical process for plan preparation that recognises the community's needs and values and recognises the context within which the plan must operate.

\section{A mixed rational, adaptive and participatory process}

This model demonstrates how a particular mix of approaches guiding the planning process will influence exactly how each step is carried out, their relative importance and their relationship to one another. An example of a management planning process that incorporates rational, adaptive and participatory elements is presented in Figure 13.2 and outlined in Case Study 13.7. 


\section{Case Study 13.7 A plan of management for Kosciuszko National Park}

Kosciuszko National Park is the largest national park in New South Wales and one of the largest and most important conservation reserves in Australia. The park contains glacial landforms and possesses a diversity of alpine plant communities and species that provide habitats for a number of rare and unusual animal species. Elsewhere, the park contains significant karst systems, deep river valleys and frost hollows, as well as vegetation communities ranging from snow gum woodlands and subalpine grasslands to extensive eucalypt forests, pockets of cool temperate rainforest and stands of native cypress pines. The snowfed rivers of the mountains provide some of Australia's most important water catchments. The park contains major commercial interests in the form of alpine resorts and the Snowy Mountains Hydro-Electric Scheme, which contribute significantly to State and regional economies. The park is also rich with evidence of, or associations with, Aboriginal culture and the phases of historical land uses, scientific endeavour and the recreation and conservation efforts of many generations.

The review of the Kosciuszko National Park Plan of Management commenced in January 2002, involving wide public consultation. Planning involved the general community, as well as park users, neighbours, scientists and interest groups. This approach was considered the cornerstone to help build public understanding, ensure sound decision-making and increase the probability that the plan would be supported by all groups. The final plan gave greater recognition to the social and cultural values of the park, the importance of community involvement in park management and environmental stewardship by all agencies and organisations operating in the park. Some community representatives who were involved in the planning process later became representatives on the park's Advisory Committee, suggesting that the planning process also resulted in capacity-building and ongoing stewardship. Details of the consultation process are found elsewhere (Worboys et al. 2005) and this case study will focus on the outcomes of the planning process and an overview of the plan's implementation.

The new plan acknowledges the importance of the park's cultural and social values, and the need to protect these values from key threats, such as inappropriate fire regimes, climate change, introduced plants and animals, inappropriate development and unmanaged increases in visitation. The condition of these values in the park is assessed each year, both as an important measure of management effectiveness and as a tool for informing adaptive management. To do this, the condition of each value and the trend in condition are tracked in an integrated monitoring and evaluation program, making use of the results of monitoring programs, independent scientific information and other data recorded by staff or corporate reporting.

The plan requires that a public annual report be prepared each year, which outlines the progress being made on the plan's implementation. Six annual reports have now been prepared and each one summarises the main management achievements, research and monitoring programs, the annual condition assessment of the park's values as well as a review of the plan itself (five years after its adoption). In the 2011-12 reporting period, of the 17 values assessed, nine were found to be in acceptable condition under the current management regime. The other eight values have a current condition of concern and adaptive management actions are required.

Since the plan's completion there has been an ongoing commitment by the land manager, the NSW National Parks and Wildlife Service, to allocate revenue from park entry fees to the adaptive actions required to maintain or improve the values of the park on an annual basis.

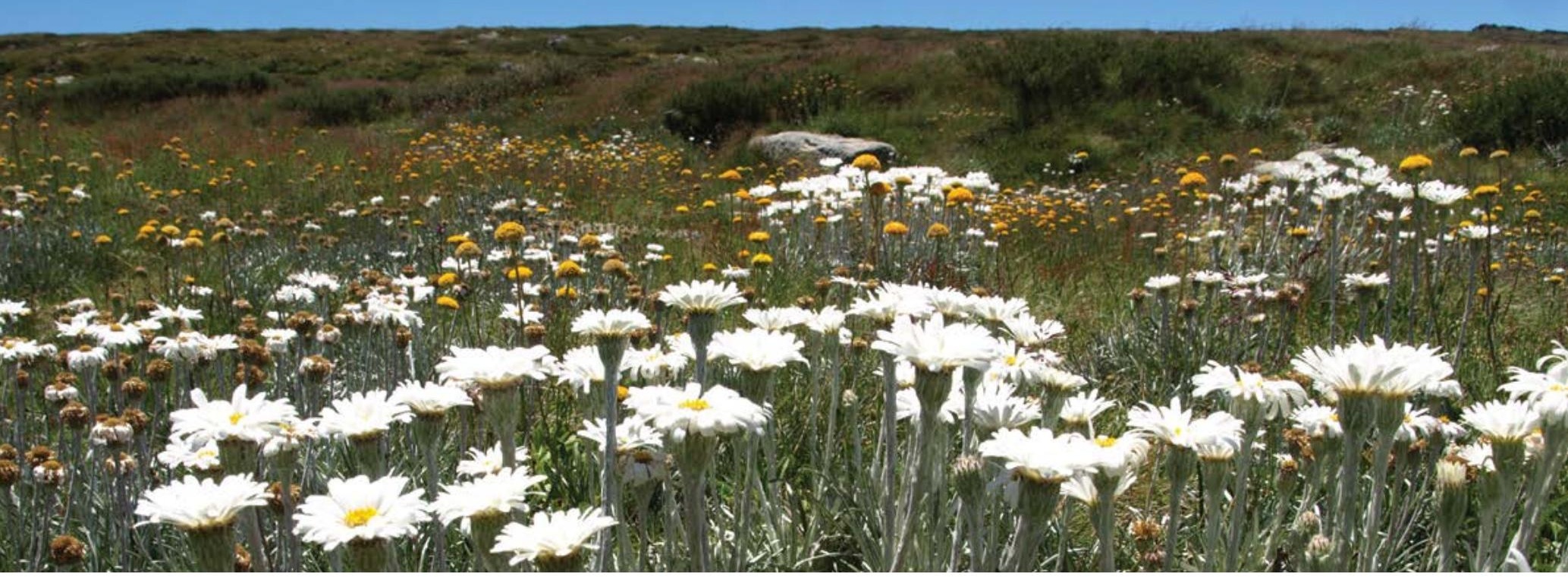

Summer wildflowers, alpine area, Kosciuszko National Park

Source: Graeme L. Worboys 


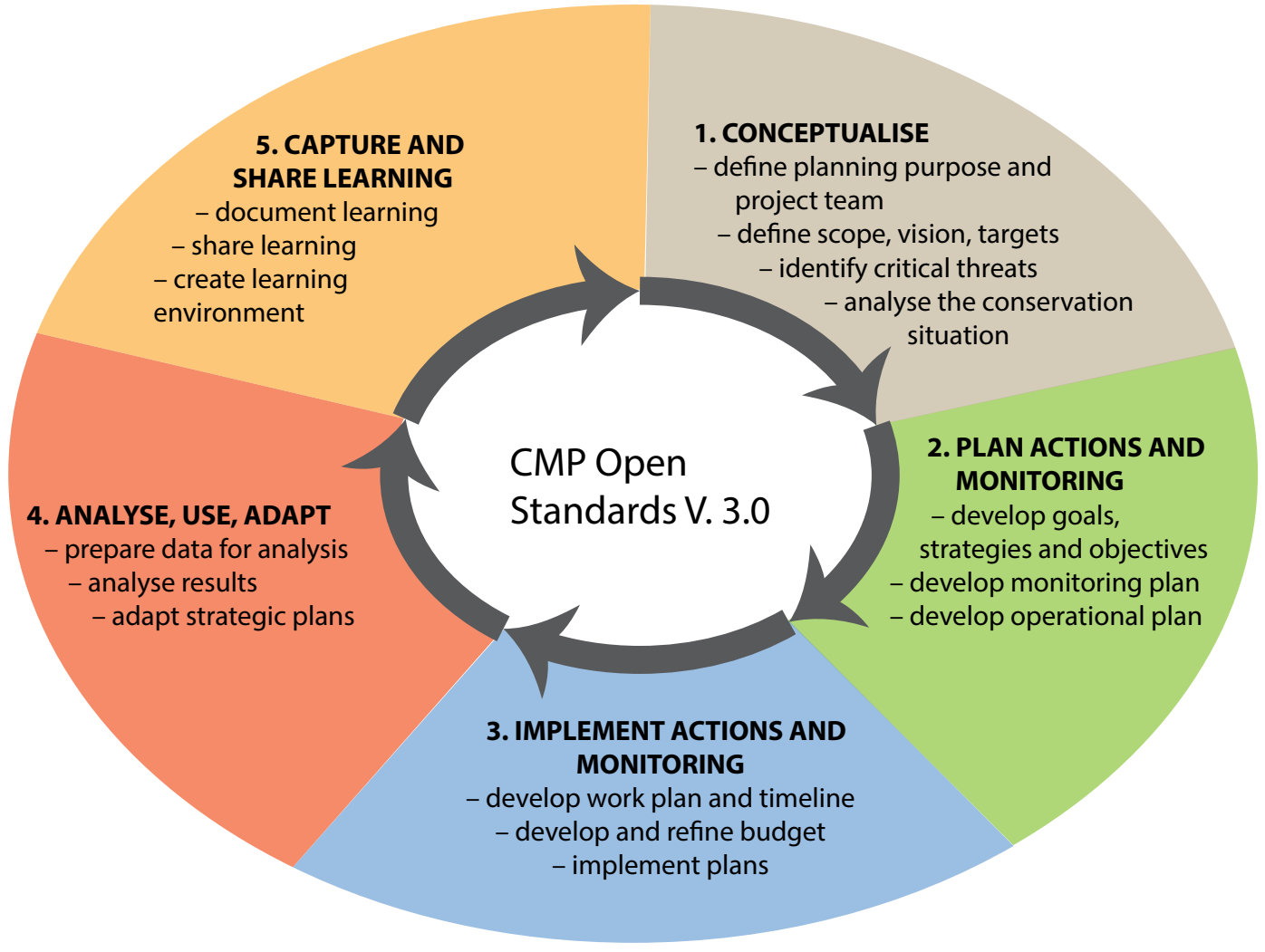

Figure 13.3 The Open Standards for the Practice of Conservation

Source: Adapted from CMP (2013)

\section{An adaptive planning process: Open Standards}

Some of the world's leading conservation organisations have collaborated to pool their experiences and develop a 'best-practice' process for developing, managing and improving conservation projects through adaptive planning. Developed out of a meeting of conservation practitioners in 2002 (Schwartz 2012), the Open Standards 'bring together common concepts, approaches, and terminology in conservation project design, management, and monitoring in order to help practitioners improve the practice of conservation' (CMP 2013:1). This process is called 'Open Standards for the Practice of Conservation' (Open Standards). Open Standards set out the step-by-step process for defining, planning, implementing and analysing conservation projects. In particular, Open Standards encompass:

- adaptive management: in which projects are adapted as they progress, based on the outcomes being achieved

- results-based management: an approach that integrates project design, management and monitoring to provide a framework for systematically testing assumptions, promoting learning and supplying timely information for management decisions; the focus is on performance and the achievement of outputs, outcomes and impacts on biodiversity.

The Open Standards draw on and combine a rich intellectual approach to planning with a pragmatic action-based approach to planning. Key forerunners are:

- the WCPA Evaluation Framework (for example, Hockings 2000)

- program logic (for example, Tucker 2005)

- evidence-based practice (for example, CEBC 2008)

- monitoring, evaluation, reporting and improvement (for example, ANAO 2004).

Open Standards aim to improve the quality of plans, guide their implementation and analyse the results being achieved so that plans can be adapted as implementation progresses. Open Standards establish a common language and standard set of steps (Figure 13.3). The use of consistent terms at some scale allows for improved aggregation to understand the cumulative impacts of action, but also to see how smaller-scale conservation can contribute to a larger scale. Open Standards use a 'common taxonomy' for threats and management actions. 
The above steps are combined in a process that identifies key targets (or 'objects', following Ungar and Strand 2012, or building blocks), identifies and ranks threats (issues), evaluates the factors that contribute to those threats, and identifies prioritised strategies and actions that will mitigate threats or restore targets. In setting out an approach, the Open Standards propose that teams record their assumptions about how their targets function, how they are being impacted and how they expect interventions will make an impact, which fosters transparency (Schwartz et al. 2012).

The Open Standards require that practitioners are as clear and specific as possible in stating goals and objectives that are, as much as possible, 'SMART': specific, measurable, actionable, realistic and time-bound. The Open Standards then focus on 'repeated evaluation and prioritisation based on measured results [that are] central to maintaining a coherent project plan' (Schwartz et al. 2012:171). The Open Standards are, therefore, by their nature an adaptive approach. While the Open Standards provide a basic adaptive management 'framework', their implementation requires the capacity and willingness to adapt the framework to and use it in a specific project context. An example application of Open Standards is given in Case Study 13.8.

In their review of the use of Open Standards, Schwartz et al. (2012) suggested five areas that need consideration in their use and applicability. These are consistent with a number of issues identified in the Wunambal Gaambera case study and the practitioners' own experience. They highlight the need for the consideration of Open Standards both in terms of the theory of adaptive management and in the practical application of the approach.

\section{Structure versus flexibility}

As mentioned previously, the structured guidelines of the Open Standards provide a framework within which to establish a reasonable approach to establishing conservation actions. They are not a prescriptive tool and require flexibility and adaptability in their application to real-world situations.

\section{Integrating multiple perspectives}

Supporting Ungar and Strand's (2012) assertions about the impact of different cultural perspectives on the definition of plan targets (assets/building blocks), these need to include cultural and livelihood elements, not simply biophysical ones. The use of an ecosystem services approach (as currently outlined in the Open Standards) is insufficient to incorporate significant cultural differences. Further, it can be the case that one person's threat is another person's livelihood, and these need to be carefully and sensitively managed and understood.

\section{Using many tools}

Open Standards do not prescribe specific tools to be used in each step, but rather propose inputs and outputs. There are many specific planning tools that can be applied at each step of the process according to the specific needs of the particular project and the capacity of the team, and particularly where a high level of technical competence might be required (see Chapter 8).

\section{Science and scientific method}

A related point is that the Open Standards are 'a set of tools to help practitioners plan and implement conservation management, nothing more' (Schwartz et al. 2012:175). That is, they are not in and of themselves the conducting of conservation science, particularly in relation to determining the contribution and attribution of measures implemented through a plan to changes seen in the targets or threats being addressed. This requires well-constructed research programs with their concomitant resource requirements (time, capacity, funds). Game et al. (2012) further emphasise this point.

\section{Cost/benefit}

The Open Standards can be applied at many scales spatially and in time and expectations, and the use of tools needs to be adjusted accordingly. A process such as the Wunambal Gaambera project, establishing a 10-year strategic plan for 2.5 million hectares involving a large community, will clearly require a greater investment than a small short-term project. It is important for practitioners to be clear about the scale of investment that is appropriate for the context, and to adjust the use of tools accordingly.

\section{Conclusion}

Protected area planning processes have evolved to include clear articulation of overarching conservation imperatives defined by global priorities and links to larger-scale strategies, providing a strategic focus at a landscape scale. Successful planning has involved integration across various disciplines and inclusive and accessible processes, sophisticated and accessible systems of research, monitoring and communication, and experienced people to guide processes and implement the plans. 


\section{Case Study 13.8 Wunambal Gaambera Healthy Country planning process}

The application of the Open Standards in a cross-cultural context was first contemplated in Australia as part of the Wunambal Gaambera Healthy Country planning process, and has subsequently given rise to a significant number of planning projects under the general Healthy Country planning approach. Wunambal Gaambera country (homeland) covers 2.5 million hectares of north-western Australia. The region is rich in both cultural and biophysical heritage, with a number of nationally important wetlands and rivers as well as a significant number of plants and animals of importance for conservation.

In 2007, the Wunambal Gaambera people sought the support and assistance of a number of organisations to develop a Healthy Country framework to guide their aspirations for looking after country and economic development. As the planning began, it quickly became apparent that it was not suitable to the context in terms of language and core concepts, and that targets needed to include wellbeing and cultural heritage (Figure 13.4). The process was adapted to allow local governance to better guide the process and content. Second, the core concepts were amended to better incorporate a Wunambal Gaambera world view. Both adaptations now form the core of regular training in northern Australia.

Wunambal Gaambera have now established a regular and permanent review committee, comprising both Indigenous and non-Indigenous members, to regularly review the plan. For a detailed discussion of the Wunambal Gaambera project, see Moorcroft et al. (2012).

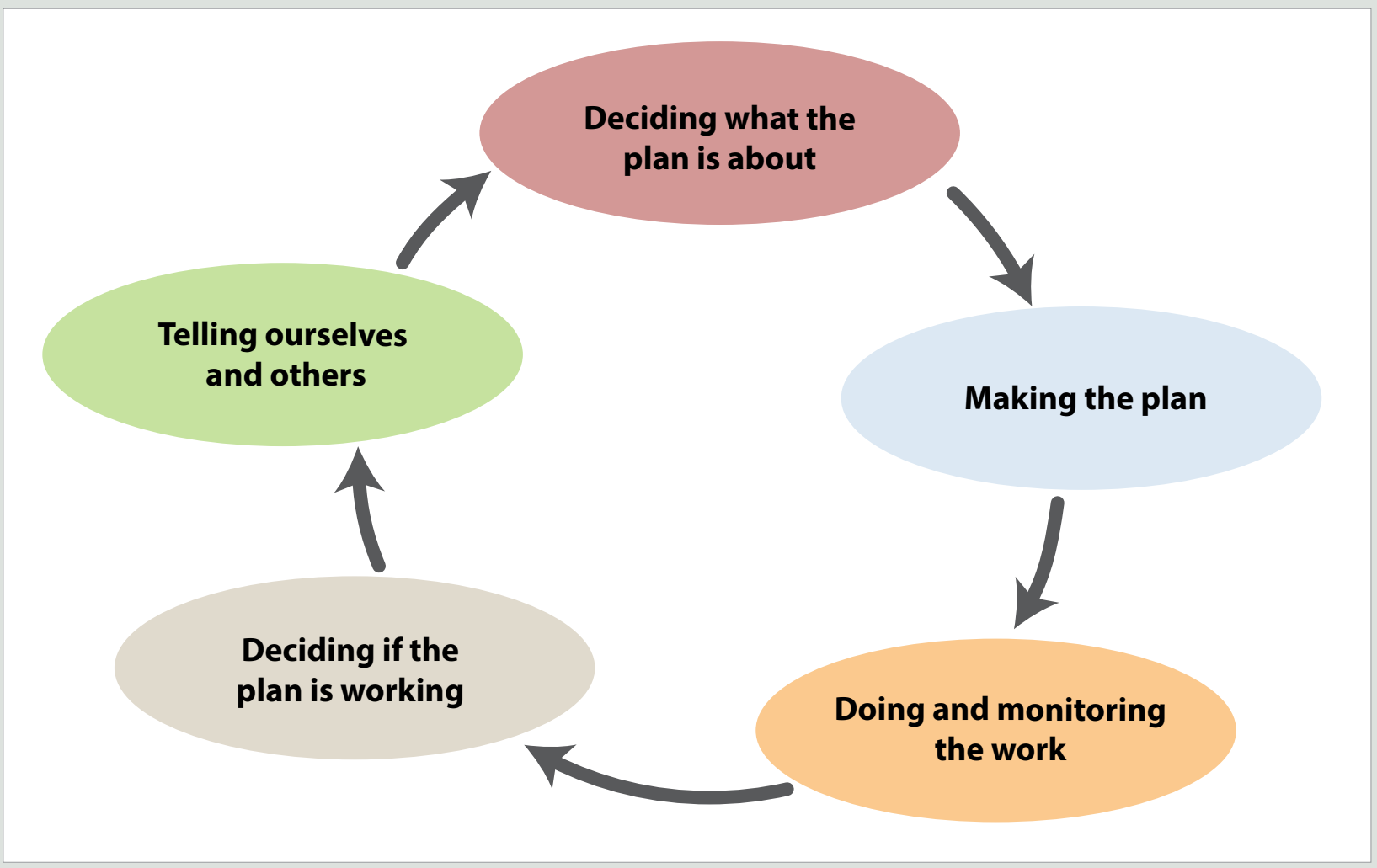

Figure 13.4 Revised Open Standards Approach as Healthy Country Planning using more appropriate language and simplified concepts

Source: Adapted from CMP (2013)

The importance and centrality of values (both agency and environmental values), a clear understanding of the issues affecting them (as illustrated by Case Study 13.1), linkages between objectives and actions that are clear and measurable, effective and adaptive management regimes, transparent decisions and routine reporting (illustrated by Case Study 13.7), and institutional frameworks that support the plan implementation and adaptation are all important elements of sound planning.
A key theme that emerges from this chapter is the centrality of participation and collaboration in planning processes and in improving the management of protected areas. The move towards adaptive and participatory planning is in part recognition that a community which appreciates the importance of biodiversity and healthy ecosystems is a critical ingredient to maintaining the momentum of inclusive, innovative conservation of these areas into the future. 


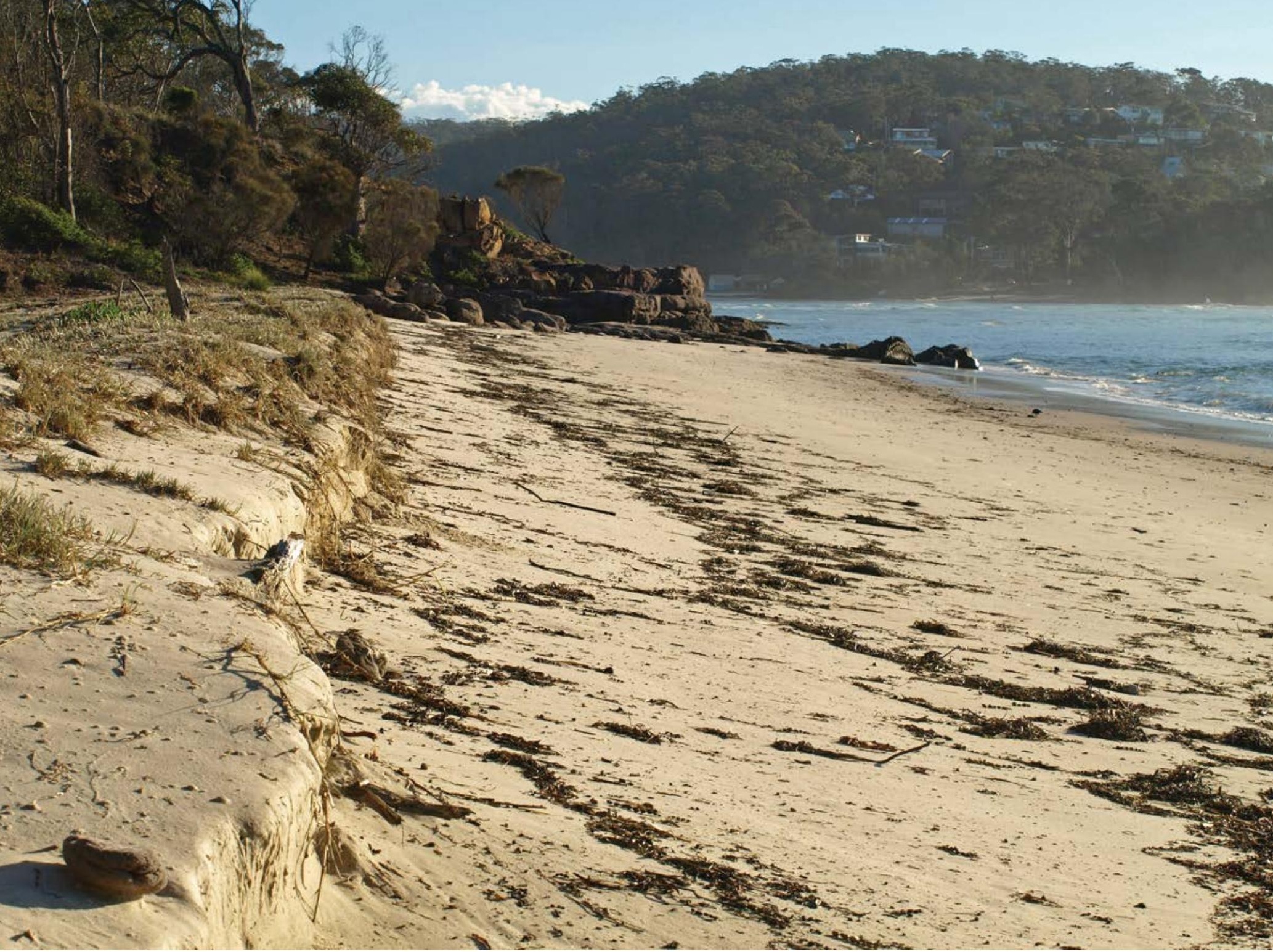

Storm surge erosion, at Bar-mouth Beach, Ben Boyd National Park, NSW south coast, Australia. As sea-levels rise under the influence of forecast climate change (see Chapter 17), planners will need to deal with the consequences of more aggressive sea erosion of coastal areas including considering the associated environmental, social and political consequences.

Source: Graeme L. Worboys

\section{References}

Decommended reading

DD Alexander, E. R. (1992) Approaches to Planning: Introducing current planning theories, concepts and issues, Gordon \& Breach Science Publishers, Luxembourg.

Dd Allmendinger, P. (2009) Planning Theory, 2nd edn, Palgrave, New York.

Australian National Audit Office (ANAO) (2004) Better Practice Guide: Better practice in annual performance reporting, Commonwealth of Australia, Canberra.
Barber, C. V., Miller, K. R. and Boness, M. (eds) (2004) Securing Protected Areas in the Face of Global Change: Issues and strategies, IUCN, Gland.

Biggs, H., Breen, C., Slotow, R., Freitag, S. and Hockings, M. (2011) 'How assessment and reflection relate to more effective learning in adaptive management', Koedoe 53(2): 1001. <doi:10.4102/koedoe.v53i2.1001>

Braus, J. (2011) Tools of Engagement: A toolkit for engaging people in conservation, National Audubon Society, New York.

Bridges, A. (2013) 'Territory eco-link: large framework, small budget', in P. Figgis, J. Fitzsimons and J. Irving (eds) Innovation for 21st Century Conservation, pp. 72-7, IUCN, Gland. 
Brooks, T. M., Mittermeier, R. A., da Fonseca, G. A. B., Gerlach, J., Hoffmann, M., Lamoreux, J. F., Mittermeier, C. G., Pilgrim, J. D. and Rodrigues, A. S. L. (2006) 'Global biodiversity conservation priorities', Science 313: 58-61.

Centre for Evidence Based Conservation (CEBC) (2008) Guidelines for Systematic Review in Conservation and Environmental Management. Version 3, School of The Environment and Natural Resources, University of Birmingham, Birmingham.

Dd Conservation Measures Partnership (CMP) (2013) Open Standards for the Practice of Conservation. Version 3.0. <www. conservationmeasures.org>

Convention on Biological Diversity (CBD) (2011) Strategic Plan for Biodiversity 2011-2020 and the Aichi Targets, Secretariat of the Convention on Biological Diversity, Montreal. <www.cbd.int/doc/ strategic-plan/2011-2020/Aichi-Targets-EN.pdf>

Convention on Biological Diversity (CBD) (2013) Convention on Biological Diversity. <www.cbd.int/ doc/strategic-plan/2011-2020/Aichi-Targets-EN.pdf>

Dd Davey, A. G. (1998) National System Planning for Protected Areas, IUCN, Gland.

Davies, J., Hill, R., Walsh, F. J., Sandford, M., Smyth, D. and Holmes M. C. (2013) 'Innovation in management plans for community conserved areas: experiences from Australian indigenous protected areas', Ecology and Society 18(2): 14. <dx.doi. org/10.5751/ES-05404-180214>

Dawkins, J. and Searle, G. (2003) Direct application of theory to practice: collaborative place management of Sydney Harbour 1998-2002, Paper presented at Australia and New Zealand Association of Planning Schools Conference, University of Auckland, Auckland.

Department of Water Affairs and Forestry (2005) Systematic Conservation Planning for the Forest Biome of South Africa, Department of Water Affairs and Forestry, Republic of South Africa, Pretoria.

Dudley, N. (2010) 'Nature conservation: leaving space for biodiversity', in N. Dudley and S. Stolton (eds) Arguments for Protected Areas: Multiple benefits for conservation and use, pp. 239-52, Earthscan, London.
Fazey, I., Salisbury, J. G., Lindenmayer, D. B., Maindonald, J. and Douglas, R. (2004) 'Can methods applied in medicine be used to summarize and disseminate conservation research?', Environmental Conservation 31(3): 190-8.

Figgis, P., Fitzsimons, J. and Irving, J. (eds) (2012) Innovation for 21st Century Conservation, Australian Committee for IUCN, Sydney.

Friedmann, J. (1987) Planning in the Public Domain: From knowledge to action, Princeton University Press, Princeton, NJ.

Game, E. T., Karieva, P. and Possingham, H. P. (2012) 'Six common mistakes in conservation priority setting', Conservation Biology 27(3): 480-5.

Government of Australia (2010) Australia's Strategy for the National Reserve System 2009-2030, Australian Government, Canberra.

Government of Australia (2013) Land. <www. environment.gov.au/topics/land>

Government of Australia (2014) Marine Reserves. $<w w w . e n v i r o n m e n t . g o v . a u / t o p i c s / m a r i n e / m a r i n e-$ reserves/marine-reserves-review>

Hockings, M. (2000) Evaluating Protected Area Management: A review of systems for assessing management effectiveness of protected areas, University of Queensland, Brisbane.

International Union for Conservation of Nature (IUCN) (2014) Key Biodiversity Areas, IUCN, Gland. <www.biodiversitya-z.org/areas/22>

International Union for Conservation of Nature, Parks Australia and NSW National Parks and Wildlife Service (2014) Australia's Indigenous Protected Areas. <worldparkscongress.org/drupal/node/34>

Kramar, R. M. S. R. (1997) Human Resource Management in Australia, Addison Wesley Longman, Melbourne.

Kruger, J. M. and MacFadyen, S. (2011) 'Science support within the South African National Parks adaptive management framework', Koedoe 53(2): 1010.

Langhammer, P., Sechrest, W. and Tordoff, A. W. (2007) Identification and Gap Analysis of Key Biodiversity Areas: Targets for comprehensive protected area systems, IUCN, Gland. 
Lockwood, M. (2006) 'Management planning', in M. Lockwood, G. Worboys and A. Kothari (eds) Managing Protected Areas: A global guide, pp. 292327, Earthscan, London.

Mackey, B., Sobey, E., Letcher, R. A. and Cuddy, S. M. (2007) InCReMent Phase 1: Design \& feasibility, The Australian National University, Canberra.

Madanipour, A. (2010) 'Connectivity and contingency', Planning Theory 9(4): 351-68.

Dd Margules, C. R. and Pressey, R. L. (2000) 'Systematic conservation planning', Nature 405: 243-53.

Melick, D. R., Kinch, J. P. and Gowan, H. (2012) 'How global biodiversity targets risk becoming counterproductive: the case of Papua New Guinea', Conservation and Society 10(4): 344-53.

Moorcroft, H., Ignjic, E., Cowell, S. Goonack, J., Mangolomara, S., Oobagooma, J., Karadada, R., Williams, D. and Waina, N. (2012) 'Conservation planning in a cross cultural context: the Wunambal Gaambera Healthy Country project in the Kimberley, Western Australia', Ecological Management \& Restoration 13(1): 16-25.

Naghizadeh, N., Abbas, D. and Farvar, T. (2012) 'Recognition and Support of ICCAs in Iran', in A. Kothari, C. Corrigan, H. Jonas, A. Neumann and H. Shrumm (eds) Recognising and Supporting Territories and Areas Conserved By Indigenous Peoples and Local Communities: Global overview and national case studies, Secretariat of the Convention on Biological Diversity, ICCA Consortium, Kalpavriksh, and Natural Justice, Montreal, Canada, p. 132.

Naro-Maciel, E. and Sterling, E. (2008) Protected Areas and Biodiversity Conservation I: Reserve planning and design synthesis, American Museum of Natural History, New York. <ncep.amnh.org/linc>

Nelson, F. (2012) 'Recognition and Support of ICCAs in Kenya', in A. Kothari, C. Corrigan, H. Jonas, A. Neumann and H. Shrumm (eds) Recognising and Supporting Territories and Areas Conserved by Indigenous Peoples and Local Communities: Global overview and national case studies, Secretariat of the Convention on Biological Diversity, ICCA Consortium, Kalpavriksh, and Natural Justice, Montreal, Canada, p. 119.
Pedragosa, S. (2012) 'Recognition and Support of ICCAs in the Philippines', in A. Kothari, C. Corrigan, H. Jonas, A. Neumann and H. Shrumm (eds) Recognising and Supporting Territories and Areas Conserved By Indigenous Peoples and Local Communities: Global overview and national case studies, Secretariat of the Convention on Biological Diversity, ICCA Consortium, Kalpavriksh, and Natural Justice, Montreal, Canada, p. 134.

Pirot, J. Y., Meynell, P. J. and Elder, D. (2000) Ecosystem Management: Lessons from around the world, IUCN, Gland.

Pullin, A. S. and Knight, T. M. (2001) 'Effectiveness in conservation practice: pointers from medicine and public health', Conservation Biology 15(1): 50-4.

Resilience Alliance (2014) Resilience Assessment. <www. resalliance.org/index.php/resilience_assessment>

Salafsky, N., Salzer, D., Stattersfield, A., Hilton-Taylor, C., Neugarten, R., Butchart, S., Collen, B., Cox, N., Master, L., O'Connor, S. and Wilkie, D. (2008) 'A standard lexicon for biodiversity conservation: unified classifications of threats and actions', Conservation Biology 22(4): 897-911.

Sanderson, E. W., Jaiteh, M., Levy, M. A., Redford, K. H., Wannebo, A. V. and Woolmer, G. (2002) 'The human footprint and the Last of the Wild', BioScience 52(10): 891-904.

Schwartz, M. W., Deiner, K., Forrester, T., GrofTisza, P., Muir, M. J., Santos, M. J., Souza, L. E., Wilkerson, M. L. and Zylberberg, M. (2012) 'Perspectives on the Open Standards for the practice of conservation', Biological Conservation 155: 16977.

Smith, R., Goodman, S. and Matthews, W. (2006) 'Systematic conservation planning: a review of perceived limitations and an illustration of the benefits, using a case study from Maputaland, South Africa', Oryx 40(4): 400-10.

Steenkamp, Y., van Wyk, B., Victor, J., Hoare, D., Smith, G., Dold, T. and Cowling, R. (2004) 'Maputaland-Pondoland-Albany', in R. A. Mittermeier, P. Robles Gil, M. Hoffmann, J. D. Pilgrim, T. M. Brooks, C. G. Mittermeier and G. A. B. da Fonseca (eds) Hotspots Revisited: Earth's biologically richest and most endangered ecoregions, pp. 219-28, CEMEX, Monterrey, Mexico. 
DD Thomas, L. and Middleton, J. (2003) Guidelines for Management Planning of Protected Areas, IUCN, Gland.

Tucker, G. (2005) A Review of Biodiversity Conservation Performance Measures, Earthwatch Institute, Oxford.

Ungar, P. and Strand, R. (2012) 'Inclusive protected area management in the Amazon: the importance of social networks over ecological knowledge', Sustainability 4(12): 3260-78.

Wardrop, M. and Zammit, C. (2012) 'Innovation in public policy for conservation of biodiversity', in $\mathrm{P}$. Figgis (ed.) Innovation for 21st Century Conservation, pp. 56-65, Australian Committee for IUCN, Sydney.

Worboys, G. L., Lockwood, M. and de Lacy, T. (2005) Protected Area Management, 2nd edn, Oxford University Press, Melbourne.

Yellowstone to Yukon Conservation Initiative (Y2Y) (2014) Yellowstone to Yukon Conservation Initiative. <www.y2y.net> 


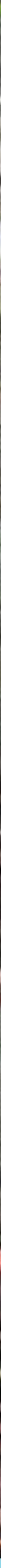

CHAPTER 14

ENGAGEMENT AND PARTICIPATION

IN PROTECTED AREA MANAGEMENT:

WHO, WHY, HOW AND WHEN?

\section{Principal authors:}

Stephen Dovers, Sue Feary, Amanda Martin,

Linda McMillan, Debra Morgan and Michael Tollefson

\section{CONTENTS}

\section{Introduction}

- The emergence of collaborative arrangements

- General principles of engagement

- Engage with whom?

- Why: The purposes of engagement

- How: Forms of engagement and participation

- When should engagement occur?

- Conclusion

- References

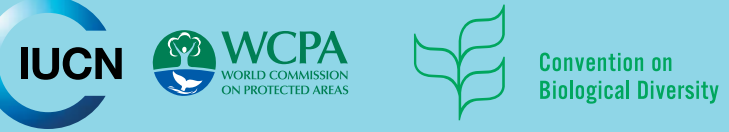




\section{PRINCIPAL AUTHORS}

STEPHEN DOVERS is a Professor and the Director of the Fenner School of Environment and Society, The Australian National University, Canberra.

SUE FEARY is an archaeologist and national park manager, with 25 years' experience in management of natural and cultural heritage and consulting with Aboriginal Australians.

AMANDA MARTIN is the Executive Officer of the Australian Environmental Grantmakers Network, Melbourne.

LINDA MCMILLAN is Deputy Vice-Chairman, Communications, of the International Mountaineering and Climbing Federation (UIAA); President of the Mountain Protection Commission; and a member of the International Union for Conservation of Nature World Commission on Protected Areas (IUCN WCPA) Connectivity Conservation and Mountains.

DEBRA MORGAN is Philanthropy Manager of the Australian Environmental Grantmakers Network, Melbourne.

MICHAEL TOLLEFSON is the President of the Yosemite Conservancy, USA.

\section{CITATION}

Dovers, S., Feary, S., Martin, A., McMillan, L., Morgan, D. and Tollefson, M. (2015) 'Engagement and participation in protected area management: who, why, how and when?', in G. L. Worboys, M. Lockwood, A. Kothari, S. Feary and I. Pulsford (eds) Protected Area Governance and Management, pp. 413-440, ANU Press, Canberra.

\section{TITLE PAGE PHOTO}

Manuel Castellanos, a Lacandon Indian, discussing ecosystem restoration with visitors in Montes Azules Biosphere Reserve, intheState of ChiapasinsoutheastMexico Source: Eduard Müller 


\section{Introduction}

This chapter explores the demands on, and opportunities provided to, protected area managers when engaging with individuals, communities and organisations whose interests intersect with protected area management. The first section notes the emergence of collaborative arrangements in resource and environmental management and how these apply to protected area management. Then general principles applying to engagement and public participation are introduced. The last four sections explore four questions: with whom protected area managers engage; why these individuals and groups engage with protected area management, and their values and motivations; how, or the forms of and strategies for engagement and participation; and when engagement should occur.

Engagement with other individuals, organisations and communities involves very different values and aspirations - they can be thought of as clients, customers and collaborators-and is complex, occurring across a diversity of geographical, social and political settings. The detail of how to engage successfully will be dependent on the specific context, so this chapter does not prescribe what to do in a specific situation, but rather presents concepts and principles to allow managers to recognise this diversity and to adopt approaches suited to their circumstances, selecting from an array of tools and strategies. To indicate this finer level of detail, the chapter ends with five case studies demonstrating how the themes of the chapter will play out in different contexts and the different stakeholders with whom protected area staff and managers work.

1. Case Studies 14.1 and 14.2 discuss engagement with indigenous peoples, emphasising how stakeholders will have a variety of interests and motivations, how different strategies will be required depending on the cultural context, and how care is needed in understanding who 'the community is' and who speaks for that community.

2. Case Studies 14.3 and 14.4 explore philanthropic engagement with protected area management, emphasising the need for clear understanding of managers' and stakeholders' expectations, and the importance of transparency and good process.

3. Case Study 14.5 explores engagement with recreational users, illustrating a core theme of the chapter: the variety of motivations of those who interact with protected areas. It also emphasises the importance of careful, respectful processes required to satisfy diverse needs in a mutually beneficial fashion.
Successful community engagement demands skill and application, executed in a manner sensitive to specific situations. Further detail is available in materials referenced below and in the literature dealing with participation in natural resource and environmental management (for example, Beierle and Cayford 2002; Creighton 2005; Evans-Cowley and Hollander 2010; O'Faircheallaigh 2010). This chapter intersects with issues of governance, management and leadership covered in Chapters 7, 8, 12, 16 and 27 of this book.

\section{The emergence of collaborative arrangements}

Protected areas are but one sector and profession where, in recent years, we have seen increasing requirements to collaborate with a diversity of stakeholders. Environmental and natural resource management has evolved away from a top-down, regulatory style, to one that features close and diverse partnerships and collaborations between management agencies and local communities, resource users, other management agencies, non-governmental organisations (NGOs) and the private sector. This is consistent with broader arguments regarding the role of citizens and the sharing of power and participation in political and policy decisions, and a move from direction by government to a more inclusive governance involving multiple parties (for example, Rhodes 1997; and see Chapter 7). This debate and trend have been particularly focused on environmental and natural resource management, with most literature coming from industrialised democracies (for example, Healey 1997; Dobson 2003; Paehklke 2003; Dryzek and Niemeyer 2010; Holley et al. 2012).

Community engagement and collaborative management are in some situations required to some degree in formal planning and policy processes; in other situations they have been pursued by communities and agencies not as a mandatory requirement but voluntarily to achieve management outcomes and community aspirations. In the protected area management sector, engagement with stakeholders may be a formal part of planning and management processes, such as in the creation of management plans, and in some cases is a formal part of international agreements such as with World Heritage properties.

Early work in public participation focused on arguing the need for greater engagement, and on the degree of participation. Arnstein (1969) presented an influential definition of the 'ladder' of citizen engagement, where 
higher up the ladder indicates a greater level of citizen or public power. The rungs on the ladder, from top to bottom, are:

- citizen control
- delegated power
- partnership
- placation
- consultation
- informing
- therapy
- manipulation.

These degrees of engagement all feature in protected area management. Towards the upper end of Arnstein's 'ladder' there are strongly collaborative management arrangements such as reserve co-management, where community representatives hold formal positions on a management board with shared or delegated decisionmaking power. Such participation may involve a substantial role in setting strategic directions-being part of the governance of one or more protected areas. In the middle might be a national park advisory committee with input but not formal power, and at the bottom end visitors are subject to regulatory controls over use and engaged by materials that make these regulations known. It is not the case that one level of engagement is betterit depends on the context. For example, strict controls on visitor behaviour and use- or even total exclusionare appropriate for highly sensitive areas, and most visitors accept, and indeed understand, that the special values they come to experience only exist because of such controls.

Arnstein's ladder shares similarities with other categorisations of the degree and purpose of engagement. In the context of community engagement in heritage management, Hall and McArthur (1998) categorise the objectives of engagement as information giving, information receiving, information sharing and participatory decision-making, and map techniques against these objectives (see the section 'How: Forms of engagement and participation' below).

The more recent work cited above focuses on multiple engagement and collaboration strategies, and on the quality and longevity of collaborative relationships. There are numerous terms and concepts used in the environmental and natural resource management literature and in practice to denote this evolving, more engaged style of governance: multi-centric or polycentric governance, adaptive management, adaptive governance, collaborative management, multi-stakeholder partnerships, and participatory resource governance.
These multiple terms and concepts can create confusion. Box 14.1 summarises relevant trends in contemporary natural resource management.

Collaborative governance arrangements, and adaptive management undertaken within those arrangements, expand the context of natural resource management in terms of the range of organisations and groups of people involved, demanding a good understanding of the policy and organisational contexts (Table 14.1). Any natural resource management operates within institutional and organisational settings with some basic elements, which are shown in Figure 14.1 (adapted from Dovers and Hussey 2013; see also Howlett et al. 2009). The details of arrangements will vary across jurisdictions and political contexts, but two general principles apply. First, the rates of change through the three levels vary significantly, between slow institutional change and more rapid change in management actions. Second, the opportunities for participation in changing arrangements are different across the three levels. Later sections of this chapter expand on these two points.

\section{Collaboration in protected area management}

Increasing moves towards cross-tenure or landscape-scale biodiversity and natural resource management, such as integrated catchment management and connectivity conservation (Fitzsimons et al. 2013; Worboys et al. 2013; Chapter 27), place protected areas as part of a wider system of resources, values, organisations and actors (Fitzsimons and Wescott 2008; Lockwood 2010a; Wyborn 2013). Even where protected areas are not part of a wider connectivity conservation initiative, managers will—and indeed must—establish relationships with neighbouring landholders, other government agencies, visitors and NGOs. This adds social considerations to the mix of natural, legal, financial and institutional considerations to be recognised and dealt with (Anderson and James 2001; Lockwood 2010b; McCool et al. 2013; McNeely 2006). Some community engagement is required in, for example, developing management plans. There is, however, typically a practical requirement for more and different forms than those stipulated in legislative or planning processes: protected area management occurs within a complex matrix of interests and groups. These social considerations include matters relating to different cultural groups who use protected areas or have an interest in their management, and therefore include issues of cross-cultural understanding and communication. 


\section{Box 14.1 Adaptive management and governance}

Contemporary natural resource management, including of protected areas, is increasingly influenced by ideas such as collaborative or adaptive governance, following theory and practice developed over recent decades. In the face of uncertainty about ecosystem function and optimal management strategies, and multiple stakeholders and diverse values, the concept of adaptive management encourages management interventions as intentional 'experiments' to inform ongoing improvement in understanding and management. The shift from 'management' by government to 'governance' by multiple stakeholders recognises the importance of social structures and relationships and of both formal and informal institutions (Chapter 7). Governance sets the policy and strategy and thus the directions for operational management (see further below; and Nkhata and McCool 2012; Plummer et al. 2013). Adaptive governance recognises participation among diverse stakeholders as an alternative to rigid bureaucratic management arrangements relying only on 'expert' inputs of knowledge. Four key concepts shape adaptive governance.

1. Collaboration involving the sharing of rights and responsibilities among stakeholders, and resolving diverse aspirations.

2. Social learning that involves partnerships to support collective activities and ongoing mutual production and ownership of knowledge.

3. Flexibility, in an institutional sense, providing the capacity to adapt policy and management over time as knowledge or circumstances change.
4. Polycentricism (or multi-centrism), where management is undertaken not through a single authority, but where multiple, semi-autonomous but interlinked nodes of authority and decision-making exist including multiple state and non-state actors (Holling 1978; Ostrom 1990; Lee 1993; Folke et al. 2005; Keen et al. 2005; Armitage et al. 2009; Bäckstrand et al. 2010; Lockwood 2010a; Cundill and Rodela 2012; McCool et al. 2013; Ojha et al. 2013).

Adaptive management may be fully controlled by a government agency or other singular organisation with little participation; however, recent literature and practice recommend that flexibility and learning are difficult without the broader engagement of stakeholders. Adaptive governance explicitly includes multiple stakeholders and admits their role in setting goals and strategic directions, not just in implementation of those goals.

The evolution of natural resource management towards adaptive governance-and of participatory protected area management-is an ongoing and difficult process of management, organisational and professional change. The aim is both to create inclusive processes that engage the necessary players and to achieve tangible outcomes. Traditional legislative and administrative arrangements within which government agencies operate do not always make long-term, shared, experimental and flexible management easy (Wyborn and Dovers 2014).
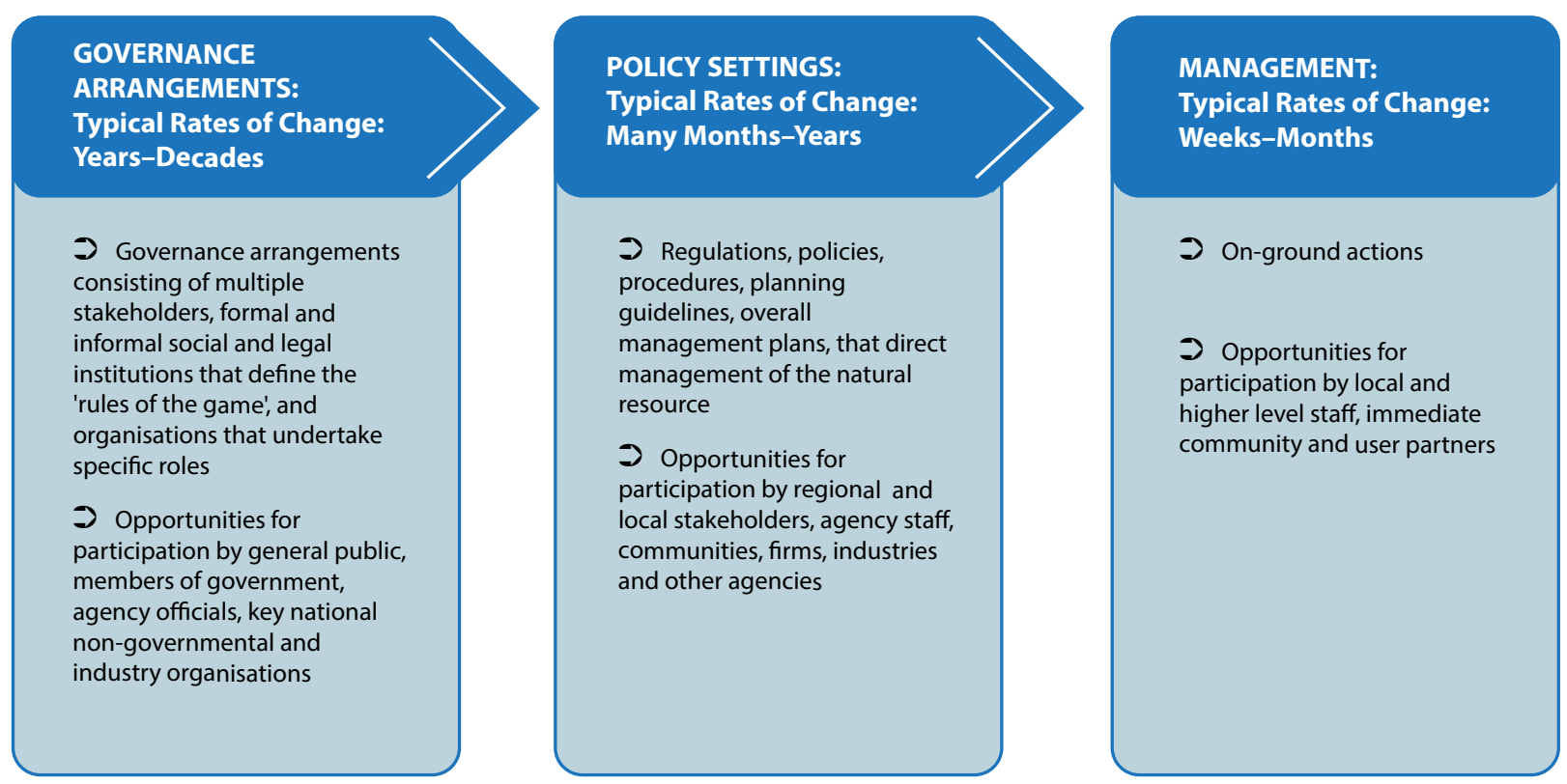

Figure 14.1 Hierarchy of governance and participation 
Protected area management exists within a political context, which will vary between countries and localities, where different values and expectations regarding natural areas and human use of them influence management. In some jurisdictions, park agencies and similar organisations have considerable status, authority and resources; in others they may not. Hence the relationships between these organisations and other agencies, NGOs and communities will vary, and styles of engagement will need to be fashioned according to the political context. A factor influencing the political context is the degree of freedom of the media, the interest of the media in conservation and the attitude of powerful media interests. What works in one place may not work in another, depending on political and legal rules and structures, the strength of different social values and the power of different groups.

Working with multiple stakeholders places different requirements on management and the agencies responsible (for example, a national park service), and different demands on the time and skills of management staff at all levels and in all roles. Community engagement, stakeholder liaison, management of public-private partnerships and inter-agency collaborations have become part of the role statement for protected area agencies and staff. Consider the range of individuals and organisations that have clear roles or interests in the management of protected areas:

- neighbours-private sector or community landholders and tenants, whether residential, agricultural or private conservation

- local communities in the surrounding area, including indigenous communities and nearby urban residents

- indigenous and local communities who reside in a protected area and/or are reliant on resources in them for their livelihoods (see Chapter 25)

- other public sector land or natural resource management agencies and their staff, at the same level of government-forest agencies, environmental protection authorities, catchment management authorities or water commissions, or maritime and fisheries agencies in the case of coastal and marine reserves

- other public agencies, at the same level of government, which may require access to or collaboration with protected areas-emergency management, military, police or infrastructure and transport suppliers

- agencies in levels of government other than those responsible for the protected area, across the spectrum of local, regional, provincial/state, national and international-for example, European Union or United Nations

- politicians and political parties or movements who influence (positively or negatively) protected area policy and management

- NGOs interested in nature conservation, including advocacy groups, those engaged in collaborative management and philanthropic organisations contributing to reserve acquisition or management

- tourists and recreational users, local or from a distance, regular or occasional, individuals or organised interest groups

- local or regional private sector (commercial) interests, such as tour guide firms and accommodation operators, generally of a small scale but who may be linked to larger firms or networks

- larger commercial interests (with or without a permanent local presence), up to the scale of powerful transnational corporations

- research organisations whose activities rely on access to protected areas or inform management.

This list indicates a huge array of interests, which is realistic anywhere there is a significant protected area estate. Across these groups there are partners and potential partners, those who are interested or disinterested, opponents, collaborators with a common interest, and those focused on commercial opportunities. Some individuals will play multiple roles_-for example, a member of the local community who visits the protected area for recreation and who is also involved in tourism promotion as an elected local government member and a local businessperson.

Within protected area management agencies, different staff will engage with different parties for different reasons. Senior executives will engage formally with senior officials from other agencies, with industry bodies or recreational user lobby groups and the media, whereas operations staff will interact on a day-to-day basis with locally based agency staff, local communities and businesses, local politicians, immediate neighbours and visitors. Similarly, engagement will vary according to the type and location of a protected area-that is, remote or near a city. The International Union for Conservation of Nature (IUCN) definition of a protected area is 'a clearly defined geographical space, recognised, dedicated and managed, through legal or other effective means, to achieve the long term conservation of nature with associated ecosystem services and cultural values' (Dudley 2008:8). 
There is clearly a great diversity of 'stakeholders': individuals and groups who have an interest in the management of protected areas, whether a single area or a system of protected areas. This is matched by the diversity of protected areas and the aims of these areas. The IUCN defines six categories of protected areas, being areas that are managed mainly for (see Chapter 8):

I. strict protection: Ia, strict nature reserve; Ib, wilderness area

II. ecosystem conservation and protection (national park)

III. conservation of natural features (natural monument)

IV. conservation through active management (habitat/ species management area)

V. landscape/seascape conservation and recreation (protected landscape/seascape)

VI. sustainable use of natural resources (managed resource protected area).

These categories define different primary purposes, and thus different relationships that groups in a society will have with protected area management and staff. They also indicate a greater or lesser degree of control over use of or visitation to a protected area, often defined in legislation and other formal policy. For example, a strict nature reserve (Category Ia) or a natural monument (Category III) may have tight regulatory controls over other uses, whereas Category V-VI areas may permit recreation, tourism operators, fishers, miners or subsistence food harvesting in a more or less managed fashion. Categories V-VI are managed as cultural landscapes where nature conservation exists alongside resident communities' livelihoods and social practice; engagement between communities and managers is not optional in these situations but is essential to the core purpose of land management.

These purposes are, however, what an area is mainly managed for, and most often there is a mix of uses and users, and thus of relationships with individuals, societal groups and organisations. This mix of users comprises the clients, customers and collaborators of protected area management-those whose services are sought and used by managers, those who use or purchase the services provided by protected areas, and those who work with protected area managers towards a common purpose. These are fundamentally different relationships, based variously on shared values and goals, commercial obligations, expectations of service provision, or regulatory or policy requirements to be met.
Simplistically, the relationships and interactions between protected area managers and 'others' are thought of as primarily involving recreational users and tourists who utilise the area so as to enjoy its natural amenity, possibly extending to illegal or unwelcome visitors, commercial operators within or adjacent to the national park and landholders abutting the park. Protected area managers themselves know there are many more: environmental NGOs, voluntary rangers, resource extraction firms, local communities dependent on the protected area in some way, a variety of other government agencies, and so on. The list of those with whom a protected area manager 'engages' can be very long, and as the move towards whole-of-landscape conservation and land management continues, the list and variety will inevitably grow.

Protected area management is not alone in moving towards partnerships and collaborative governance, as this has become more important in water and catchment management, forestry, fisheries, urban planning, climate adaptation policy and other areas, and valuable perspectives have emerged from the broader field (for example, Borrini-Feyerabend et al. 2007; Lockwood et al. 2010). Protected area managers can look to their peers in other agencies and sectors within their jurisdiction for insights from other participatory processes.

The remainder of this chapter places protected area management within a broader framework of public participation and community engagement, working through four questions: who might participate in protected area management, why they would wish to be invited to do so, how that engagement might be undertaken, and when and how often engagement should take place. In this way, the chapter encourages close attention to the nature of the subsets of what are too often loosely labelled 'the community', their imperatives and motivations, and the means through which engagement occurs. The nomenclature and general arguments are drawn from Dovers and Hussey (2013) and the wider body of participatory environmental management literature.

\section{General principles of engagement}

The following principles reflect generic issues in collaborative resource management and public participation more widely. These principles are general, they overlap to some extent (for example, recognising motivations, reciprocity and clarity) and may be in tension (for example, persistence and limits to volunteerism). 
1. Recognition of different motivations: Although protected area managers engage with other parties around the common concern of the management of a protected area or areas, or the implications of that management for other areas and interests, the motivations will rarely be the same. The manager will be concerned with the protected area above all else, whereas the other party may be concerned with biodiversity conservation more broadly, regional fire management, local livelihoods and economic development, maintenance of cultural sites, or tourism and recreational access. Even within one user group there will be different motivations, such as with recreational users of a protected area (see Case Study 14.5 for an example). At the extremes, there will be those who may oppose protected areas as a means to pursue nature conservation, or those who agitate strongly for stricter conservation measures than managers can countenance. Such varied motivations may coincide, or may be the possible basis for compromise, or create conflict. It may in fact be difficult to discern the primary motivation of a stakeholder, such as where private profit may be conflated with community economic development, or where deep cultural attachment may be conflated with nature conservation. Different motivations need to be clearly identified and openly discussed, to avoid 'hidden agendas' or tensions that remain unrecognised and therefore not properly dealt with.

2. Reciprocity: Consistent with different motivations, the purpose of engagement and participation is, for a protected area manager, the integrity and protection of the area in question, whereas for a client, customer or collaborator that may not be the main purpose. Bluntly, people will want something out of the relationship, whether that is the protection of a species, recreational opportunities, business prospects, protection of a culturally significant site, clean water downstream, access to food sources or information. Case Studies 14.3 and 14.4 emphasise this from the perspective of philanthropic partners. Engagement strategies, and the attitude and approach of protected area managers to engagement, must recognise these wants and view engagement as a reciprocal arrangement aimed at satisfyingif possible-these different wants. At the least, an understanding of why some needs and demands cannot be met can be reached in a transparent fashion.

3. Clarity and transparency: Openness and honesty are the basis of relationships and of collaboration, or at least of compromise and toleration, and even of unresolved conflict that nonetheless ends with mutual respect for each party. Engagement and participation in protected area management should be based on clarity over the purpose of engagement, what is on the agenda and who will make decisions. Communities or commercial interests accept limited engagement, but not false expectations of how much influence they have. For example, if ongoing community input into the management of a particular protected area is only advisory then that should be clear in the title and terms of reference, not implying otherwise or leaving the degree of possible influence unclear. Transparency in process is similarly important, from the duration of the process and the terms of reference and timing of meetings to information flows and feedback. Particular attention must be paid to individuals and groups for whom engagement in formal consultations is an unfamiliar experience.

4. Persistence: Engagement takes time and effort and there is an understandable tendency to cease a process of engagement or a partnership once an immediate need is met. Interest groups and local communities view 'on again, off again' consultation dimly, and become negative rather than positive partners if they feel they are used simply to serve the near-term purposes of managers and governments. Relationships are not quickly built but can be quickly destroyed, and persistence and long-term engagement are likely to be required in many situations.

5. Limits to volunteerism, and the capacity to engage: Engagement takes time and effort on the part of protected area staff, but it is part of their job (or should be). The skills of staff, however, will vary in their ability to engage and communicate with external parties, so training and capacity building may be needed. For many others, particularly local communities or NGOs, contributing to protected area management is voluntary, whether or not the relevant management agency has invited their input. This must be recognised and the limits to volunteerism respected, by not placing onerous expectations or demands on people and by respecting their capacity to engage (time, travel costs, technological support and so on). Some community members may require financial or technical assistance to allow participation. This principle is explored and emphasised in Case Study 14.1 in the case of indigenous people.

6. Exclusion and inclusion can interact: When a participatory process is established, some people and interests may be intentionally or unintentionally 


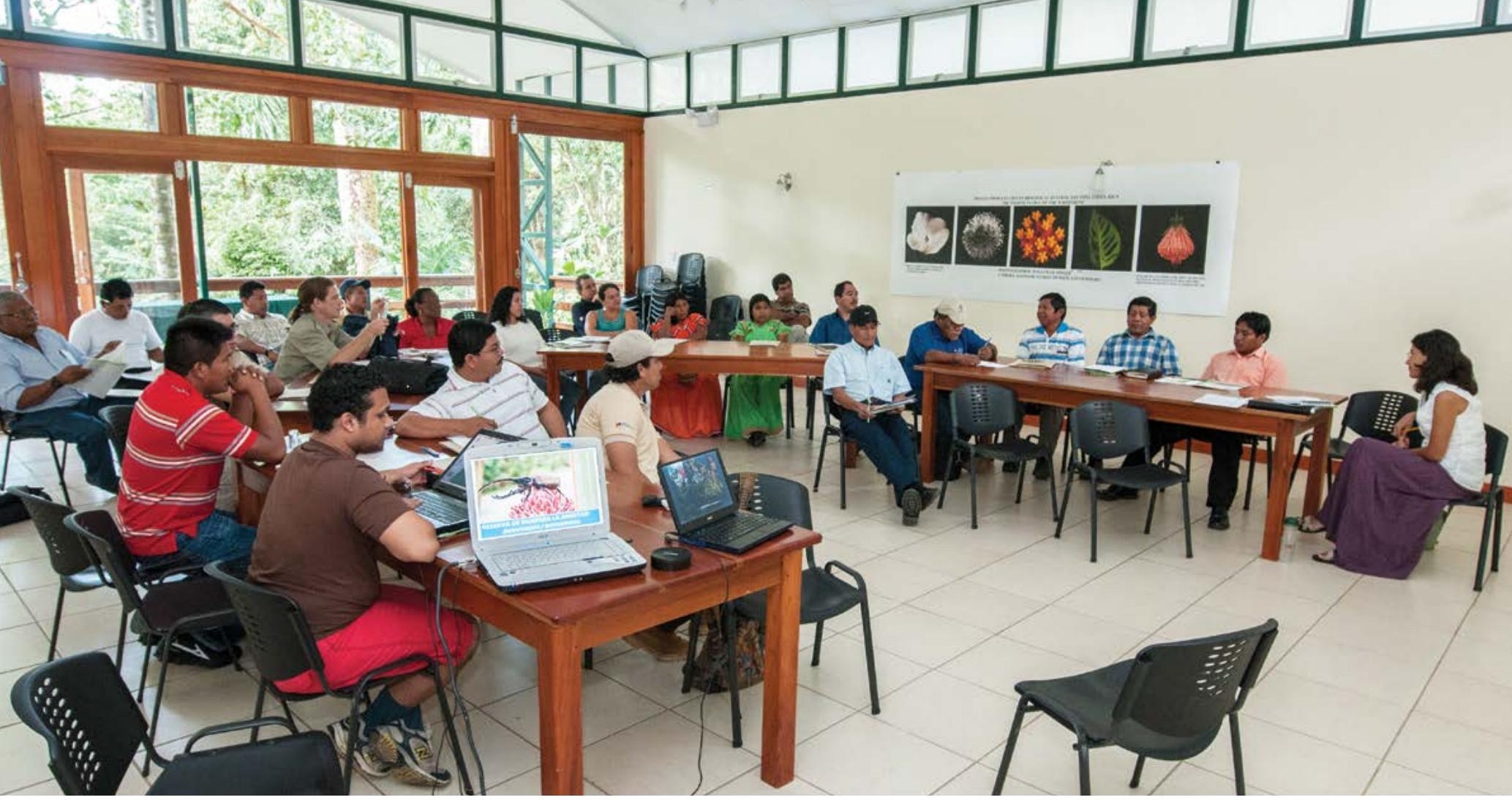

Engagement and capacity building with indigenous leaders from Central America, Costa Rica Source: Eduard Müller

excluded by the way in which the process is structured. As the political scientist Schattschneider (1983:102) put it, 'whoever decides what the game is about decides also who can get into the game'. Managers and governments make decisions about the geographical scale of a consultation (and thus who is included), the topics that are relevant (and thus who will be interested) and the timing and location of meetings or the accessibility of webbased or written materials (and thus who can access the process). Such decisions may make engagement easy and obvious for some groups and individuals, or difficult or impossible for others.

7. Representativeness: Engagement strategies involve deciding who will be involved (see the section 'Engage with whom?' below), and this often involves a decision regarding which particular individuals or organisations can best represent relevant interests. This requires protected area managers to be aware of the relevant interests and groups, and to ensure that the process is sufficiently representative to be fair and defensible and to produce outcomes that will be accepted or at least understood by interested parties. For example, a local chamber of commerce may or may not represent the specific businesses most concerned with the protected area, and a residents' or community group may or may not represent those people who live close to and are most affected by management plans. One individual may have difficulty representing a 'community' that is not homogenous in its views. Especially important is being aware of the difficulties of engagement for, and gaining representation of, marginalised groups in society, such as the poor, remotely located, young people and women. Representation may be a very different matter with many local, indigenous or tribal communities (Case Study 14.1) compared with organised business or conservation groups, and strategies such as a series of community meetings may be required to identify representatives. Asking a person to 'represent' a particular group may constrain their input and limit their role to defending or advancing only that set of interests. In some situations, involving people on the basis of their knowledge and expertise may be advisable, allowing them to have a wider scope of input. A mix of representative and expert-based membership of advisory or consultative groups can be effective.

8. Skills and resources for collaboration: Engagement takes time, requires resources and demands appropriate skills. Engagement processes that are rushed, poorly designed or inadequately implemented may create tensions and can damage valuable relationships. Engagement and participation require skills that should be engendered and valued, from survey design through written communication to the running of community meetings. Engagement also may take considerable time, and management processes (such as a management plan review) should recognise this and cater for it. Engagement also requires resources such as adequate funding, staff allocation and information. 


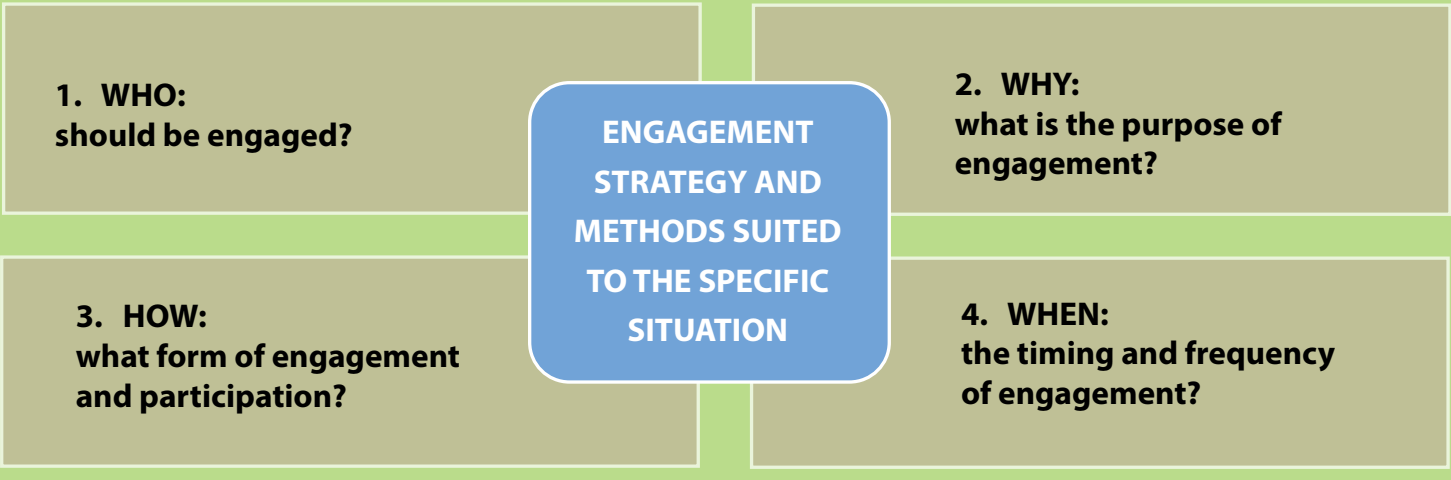

It is important to recognise that engagement strategies will typically involve compromises in terms of the time available, staff and other resources and the number of stakeholders who can be involved.

\section{Figure 14.2 General framework to inform design of an engagement strategy}

These are guiding principles not rules or the ingredients of a recipe, but they reflect the lessons accrued from participatory processes in natural resource and environmental management over many decades. If considered early and carefully, application of these principles will increase the likelihood of positive engagement.

The next four sections set out the four central variables of engagement and participation-who, why, how and when - as a basis for protected area managers in a specific situation to ask and answer four questions as part of designing and then implementing strategies for engagement and participation (Figure 14.2).

1. Who has an interest in protected area management in this particular situation, and thus which individuals and groups should be engaged with?

2. Why are these groups interested and what are their values? Or, what is the purpose of engaging these other parties in protected area management in this particular situation?

3. What is the appropriate form (or forms) of participation and engagement in protected area management for these groups and purposes, in this particular situation?

4. When is engagement required or best timed, and at what intervals?

Consideration of each of the principles above, and the frameworks and checklists presented in the following four sections, will increase the likelihood of selecting a suitable approach in a specific situation.

It is important to recognise that engagement strategies will typically involve compromises in terms of the time available, staff and other resources, the number of stakeholders who can be included in discussions and the degree to which all values and expectations can be dealt with. Trade-offs will be made by both protected area managers and other groups, and the principle of transparency instructs that at least these limitations be made apparent so that all involved have a shared understanding of the process in which they are engaged.

\section{Engage with whom?}

'Engagement' and 'participation' are bywords of modern politics, public policy and management, directing policymakers and agency staff to interact with the 'public', 'communities' and 'stakeholders'. The reasons for such engagement are often clear (see above, and 'Why: The purposes of engagement' section below), but who exactly is to be engaged-who constitutes the public or the community, and who has a stake or interestmay not be clear. As noted, different individuals and groups will have distinctly different reasons for being engaged with protected area management, whether invited to do so by park management or wishing or demanding to do so. There is no single or homogenous 'community', as people form communities around many, varied common interests. Table 14.1 defines the major different communities relevant to public participation and community engagement, and indicates the relevance of these to protected area management. Some of these are obviously relevant to protected area management, such as local (spatial) or recreational communities, and some less so, such as cultural or economic communities, but the latter structure social relationships and may be relevant or even crucial in some situations. 
Table 14.1 Communities and stakeholders in environmental and natural resource management, with examples relevant to protected area management

\begin{tabular}{|c|c|}
\hline Type of community & Basis of common interest \\
\hline Spatial (place-based) & $\begin{array}{l}\text { Determined by affinity with or stake in the condition of a spatially defined natural or } \\
\text { human system (locality, district, region, jurisdiction). Local communities will have } \\
\text { an interest in nearby protected areas, in terms of recreational opportunities, scenic } \\
\text { amenity, employment, commercial prospects such as tourism, fire management, water } \\
\text { catchment health, and so on }\end{array}$ \\
\hline $\begin{array}{l}\text { Placed-based communities } \\
\text { within protected areas }\end{array}$ & $\begin{array}{l}\text { A particular category of spatial or placed-based communities (above), who live within a } \\
\text { protected area or who live nearby and are directly dependent on resources within those } \\
\text { areas for cultural or livelihood reasons. Indigenous groups are especially important in } \\
\text { relation to some protected areas }\end{array}$ \\
\hline Political/electoral & $\begin{array}{l}\text { Also geographically defined, but as citizens of the jurisdiction in which a particular public } \\
\text { function is located and managed, and thereby can seek to influence management } \\
\text { through voting or through contact with elected representatives - for example, a state/ } \\
\text { province where the government of that jurisdiction is responsible for protected areas, or } \\
\text { a local government area where reserves are managed at the municipal level }\end{array}$ \\
\hline Familial & $\begin{array}{l}\text { Members of a located or extended family or kin network. A primary structuring variable } \\
\text { of all societies, and more likely to be a secondary but possibly relevant consideration for } \\
\text { protected area managers in engaging with communities }\end{array}$ \\
\hline Cultural & $\begin{array}{l}\text { Communities, possibly spatially defined but often not, linked by culture, ethnicity, } \\
\text { religious belief, social ideology, and so on. Similar to familial, likely a secondary but } \\
\text { influential variable for protected area management, defining opportunities for community } \\
\text { information strategies through social networks or, for example, varied community } \\
\text { attitudes to matters such as wildlife utilisation }\end{array}$ \\
\hline Professional/economic & $\begin{array}{l}\text { Recognisable groups of people, often spatially dispersed, linked by profession } \\
\text { or employment within a particular career or business type. Individual interests or } \\
\text { members of a broader grouping - for example, ecotourism operators, game guides, } \\
\text { accommodation chains, professional nature photographers and so on-with an interest } \\
\text { in the viability of or access to protected areas }\end{array}$ \\
\hline $\begin{array}{l}\text { Defined by incidents and } \\
\text { events }\end{array}$ & $\begin{array}{l}\text { Often organisational or professional, but the interest is defined by specific events } \\
\text { wherever they may occur, such as military in times of conflict that affect protected } \\
\text { areas, emergency and rescue services during disasters or accidents, and health } \\
\text { services during disease outbreaks }\end{array}$ \\
\hline Knowledge/epistemic & $\begin{array}{l}\text { Communities defined by a knowledge system-for example, an academic discipline } \\
\text { or special interest group, such as conservation biology, tourism studies or a geological } \\
\text { heritage society }\end{array}$ \\
\hline Issue-related & $\begin{array}{l}\text { Groups given identity and purpose by interest in or commitment to a substantive issue, } \\
\text { such as social services, disabled access to buildings, specific health issues and so } \\
\text { on-for example, wildlife conservation societies, environmental NGOs, international } \\
\text { conservation organisations, animal rights groups }\end{array}$ \\
\hline Organised recreation & $\begin{array}{l}\text { Groups linked through participation in or promotion of recreational activities (sporting } \\
\text { groups, service clubs, and so on); game and hunting groups, bushwalking clubs, } \\
\text { mountaineers, and so on }\end{array}$ \\
\hline Tourism industry and tourists & $\begin{array}{l}\text { Both providers and consumers of organised/promoted visitation and user services. } \\
\text { While a combination of the economic and recreational categories above, they are } \\
\text { significant enough to warrant separate recognition in the context of protected areas }\end{array}$ \\
\hline $\begin{array}{l}\text { Illegitimate or illegal } \\
\text { individuals or communities }\end{array}$ & $\begin{array}{l}\text { Individuals or networks of individuals engaged in illegal or unacceptable activities in } \\
\text { the relevant context-for example, wildlife poachers, illegal hunters, drug producers, } \\
\text { informal settlers (squatters), recreational users defying regulations }\end{array}$ \\
\hline
\end{tabular}

Source: Adapted and extended from Dovers and Hussey (2013) 
These are broad categories and contain much variation, such as within illegal, recreational or epistemic communities. As such, the specific people and organisations, issues and concerns will vary greatly across places and situations. Importantly, one person may belong or relate to more than one community, such as a local community member who is a recreational user of a national park and also a member of, say, a birdwatching association or an industry alliance. Protected areas have multiple values and affect even more values outside their borders, and these resonate with deep-seated beliefs held in society; values are fundamental to people and must be taken seriously. Communities or networks of people form around common values and concerns and operate to pursue or protect those values, whether the values are recreational, commercial, criminal, cultural or environmental. The categorisation above is a device to encourage consideration of multiple values and therefore multiple communities.

Dealing with very different segments of the 'community' or 'public' will require careful choice of the style and means of communication. Some stakeholders and partners will expect formal communication, whereas others may only be comfortable with informal contact and discussion. Communication, including the format of meetings, should always be fashioned to suit the expectations of others, including being sensitive to cultural norms and standards. For example, formal meeting procedures involving a chair, set agenda and procedures for speaking may be inappropriate in some social and cultural settings. Local representatives are very useful in advising on the appropriate styles of engagement and communication.

Different groups within a society or community have varying degrees of power and resources, and different levels of access to information and thus uneven access to opportunities to engage. Also, certain groups with particular interests may dominate public discussions or engagement processes at the expense of other groups. Knowledge of a local community and of the political context of protected area management can inform strategies to ensure that all relevant groups have the opportunity to be heard.

Often, a particular 'community' may not have obvious relevance to protected area management, but may be valuable as an avenue for communication with others. Informal institutions (as distinct from formal ones) are important in natural resource management, particularly in rural and regional areas, representing social bonds, norms of behaviour and local knowledge (for example, Connor and Dovers 2004). Informal institutions and networks offer means of communication and

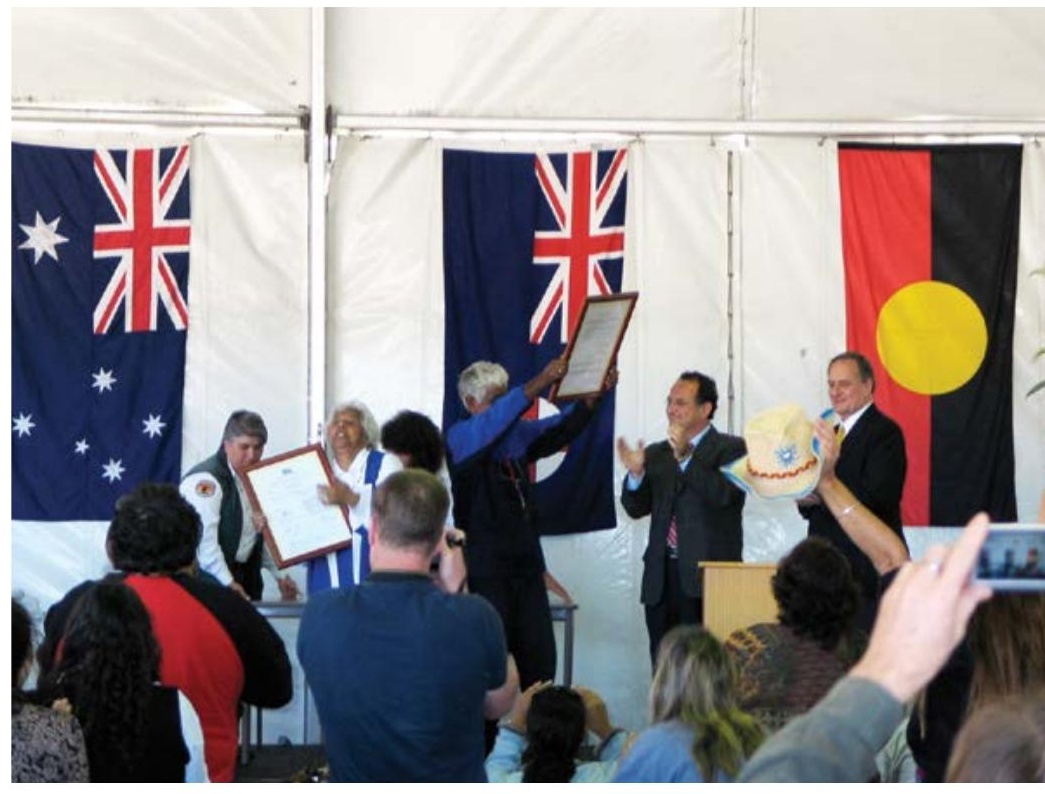

An example of successful engagement. Celebration near Bega in 2006 of the 'handback' of Biamanga National Park by the former New South Wales Government Minister for Aboriginal Affairs the Hon. Milton Orkopoulos and Minister for the Environment the Hon. Bob Debus AM (far right) to the Elders representing the Yuin Nation for future joint management with the NSW National Parks and Wildlife Service, Australia.

Source: lan Pulsford

engagement. The knowledge of a local community that is held by locally based reserve workers can inform managers about the informal institutions and social networks that may be difficult to identify from the 'outside'; however, while the local worker may have the greatest understanding of local conditions and people, they may or may not have latitude in dealing with people with whom they interact - they may be required to adhere to agency policies and practices set by their superiors.

Note that the general description of these 'communities' could apply to a great variety of sectors and issues, such as health, equity or employment, as well as to protected area management. That is worth emphasising, as it reminds us that engagement and participation are major concerns in many other areas. Two considerations arise: first, that ideas and methods of engagement can be found in other areas, and second, that there will always be other calls on the time and attention of citizens, community groups and private and public sector organisations. On the latter, and recalling the general principle of respecting the limits of volunteerism and community capacity, the issue of 'burnout' has arisen in natural resource management (Byron and Curtis 2001). 
Often the identification of 'communities' or stakeholders will be a matter of local or professional familiarity on the part of managers, and sometimes will be defined in a management plan, a regulatory process or by senior decision-makers. There are, however, more formal and detailed methods for identification of stakeholders, which may be used in cases where managers are unfamiliar with affected communities or where the import of the matter to be decided justifies greater effort. Stakeholder analysis and social network analysis are the principal methods employed and have been used in protected area contexts (for example, Eadens et al. 2009; Prell et al. 2009). Visitor and community surveys and public opinion polling may be used to identify those with an interest in protected area management or attitudes towards nature conservation and park management.

A final consideration relates to the membership of different communities by protected area managers and staff themselves, and to the local staff of other government agencies closely associated with protected area management. From Table 14.1, these individuals belong to the professional and knowledge communities as protected area employees, or employees of a forest agency or similar. Staff will also, however, be members of familial or local communities as residents of nearby settlements, and closely connected to family members, neighbours or members of social groups with quite different values. In many remote or regional areas, such staff may be among the small subset of the community with professional or tertiary qualifications, and often the only ones with formal qualifications in specific areas such as ecology or land management. Two important issues arise. First, identification of any conflict of interests should be part of designing an engagement exercise, where management staff may represent, or be expected to represent, interests that may conflict with management interests. Second, an engagement strategy may need to be designed in a sympathetic manner to prevent staff being placed in difficult or dangerous situations in their own communities by having to argue positions seen as counter to the interests of that community.

The core message of this section is that protected areas have many values, and thus are of interest to many individuals, communities and organisations who may be located nearby or at a distance. Protected area managers must recognise these multiple interests and be thorough in identifying and engaging all those who have a stake in the protected area/s in question, whatever their interest. This section has provided general guidance on answering the important question: who has an interest in protected area management in this particular situation?

\section{Why: The purposes of engagement}

In the section above, we see a wide range of individuals and groups with interests in protected areas. It follows that their interests and values - why they are interested-will vary also. Engagement strategies need to allow these different values to be identified and dealt with in a consultation or similar process. It may be that a government or protected area management body will decide that some interests (the who and the why) will not be attended to, and will decide the amount of power sharing or decision-making that others will enjoythat is, the point on Arnstein's ladder (see above). Such decisions may be rational and defensible, but should be based on transparent consideration of the many possible purposes, so that purposes not included are excluded for a reason and not simply overlooked or forgotten. Table 14.2 describes broad categories of purpose along with examples from protected areas.

Identification of the purpose/s along with identification of stakeholders will inform the design of an engagement exercise. It is important that all those involved have a similar understanding of what the purpose of an engagement exercise is, and, equally importantly, what is not the purpose. If a consultation around protected area management cannot consider changes to certain management rules, that should be made clear. Should a change to a broader policy on access be outside the scope of a management plan review, that should be clearly understood to avoid misunderstanding or unrealistic expectations.

The core message of this section is that engagement with communities and other organisations is not singular in its purpose, but is undertaken to allow the realisation of different goals held by different individuals and groups. Protected area managers need to be clear about the goals to be achieved through engagement- that is, their own motivations but also those of partners-so that these purposes are more likely to be achieved. This section has provided general guidance on answering the important question: what is the purpose of engaging other parties in protected area management in this particular situation? 
Table 14.2 The purposes of participation, with examples relevant to protected area management

\begin{tabular}{|c|c|c|}
\hline Purpose & Explanation & Examples from protected area management \\
\hline Social debate & $\begin{array}{l}\text { Allow debate about broader social } \\
\text { values and goals }\end{array}$ & $\begin{array}{l}\text { Public debates and political debates over nature } \\
\text { conservation, access, land-use conflicts, tourism } \\
\text { development, user group conflict, major developments }\end{array}$ \\
\hline Policy formulation & $\begin{array}{l}\text { Define policy problems, formulate } \\
\text { policy or develop policy principles }\end{array}$ & $\begin{array}{l}\text { Input into policy processes concerning protected } \\
\text { area declarations, management and use, via inquiries, } \\
\text { interdepartmental liaison or input, the media, public } \\
\text { opinion surveys, and so on }\end{array}$ \\
\hline $\begin{array}{l}\text { Statutory or } \\
\text { management } \\
\text { responsibility }\end{array}$ & $\begin{array}{l}\text { To acquit professional or regulatory } \\
\text { responsibilities, including law } \\
\text { enforcement }\end{array}$ & $\begin{array}{l}\text { Other land management agencies and so on who are } \\
\text { engaged in policy and management interactions with } \\
\text { protected area managers and agencies }\end{array}$ \\
\hline $\begin{array}{l}\text { Response to events } \\
\text { or threats }\end{array}$ & $\begin{array}{l}\text { To respond as a professional or } \\
\text { community member to a specific } \\
\text { event }\end{array}$ & $\begin{array}{l}\text { For various reasons including community safety (for } \\
\text { example, fire, flood, social conflict, war), ethical or } \\
\text { cultural reasons (for example, threats to cultural sites, } \\
\text { animal welfare) or economic or livelihood-related reasons } \\
\text { (for example, illegal harvesting of locally important food } \\
\text { resources) }\end{array}$ \\
\hline Information and skills & $\begin{array}{l}\text { Draw on particular expertise or } \\
\text { information }\end{array}$ & $\begin{array}{l}\text { Expert advisory boards or individual scientific advice, } \\
\text { community reference groups }\end{array}$ \\
\hline $\begin{array}{l}\text { Policy implementation } \\
\text { and program delivery }\end{array}$ & $\begin{array}{l}\text { Implement or aid implementation of } \\
\text { policy }\end{array}$ & $\begin{array}{l}\text { Distribution of information relating to protected areas, } \\
\text { assisting with regulatory monitoring or enforcement }\end{array}$ \\
\hline Management & $\begin{array}{l}\text { Engage in management or on- } \\
\text { ground works }\end{array}$ & $\begin{array}{l}\text { Protected area advisory boards or committees, park } \\
\text { care or friends' groups, voluntary rangers, weed-control } \\
\text { programs using volunteers }\end{array}$ \\
\hline Research & $\begin{array}{l}\text { To use protected areas as sites for } \\
\text { research }\end{array}$ & $\begin{array}{l}\text { Wildlife ecology, fire science, tourism research, and so } \\
\text { on, often linked to monitoring }\end{array}$ \\
\hline $\begin{array}{l}\text { Environmental } \\
\text { monitoring }\end{array}$ & Monitor environmental conditions & $\begin{array}{l}\text { Water-quality monitoring, bird counts, weed surveys, } \\
\text { and so on, undertaken by volunteers and community } \\
\text { groups }\end{array}$ \\
\hline $\begin{array}{l}\text { Livelihood } \\
\text { maintenance or } \\
\text { commercial gain }\end{array}$ & $\begin{array}{l}\text { Subsistence, income, maintenance } \\
\text { of cultural assets and values }\end{array}$ & $\begin{array}{l}\text { Commercial operators in or near protected areas, natural } \\
\text { resource users, local and indigenous communities }\end{array}$ \\
\hline
\end{tabular}

\section{How: Forms of engagement and participation}

There is a large array of engagement and participatory frameworks and methods available, forming the 'toolbox' from which strategies can be constructed (for example, Hall and McArthur 1998; Beierle and Cayford 2002; Creighton 2005; Evans-Cowley and Hollander 2010; O'Faircheallaigh 2010). The scoping of 'who and why' above can guide the choice of approach, rather than selecting the means before the ends - that is, choosing the method before sufficient consideration of the intent and context.
A categorisation of forms of participation relevant to protected area management is presented in Box 14.2 (for another version, see Hall and McArthur 1998:75). Within each of these, more specific methods and processes will be available to managers.

There are multiple forms of engagement and public participation. Within each of the above there are choices of precise tools and methods. For example, seeking public input into policy or management proposals may be undertaken through online publication and submissions, mail-out surveys to identified recipients, local community meetings, liaison with relevant agencies, or a combination of these. Similarly, there are degrees of formality of possible arrangements for voluntary rangers or the activities of 'care' or 'friends' groups. The capacities of the management organisation and its staff, available resources, communication technologies available to the 


\section{Box 14.2 Forms of participation in environmental and natural resource management, with comments on the relevance to protected areas}

Note: Any individual or group may be engaged in more than one form of participation, at the same time or over a period.

- As voters at different levels of government (national, state/provincial, local) in democratic systems, and as individuals via letters to political representatives or newspapers, submissions to government inquiries (now often online), giving opinions on talkback radio, and so on. Protected area managers will have little engagement with this form of public participation, although senior officials may be required to advise or respond publicly on behalf of their governments should reserves or conservation policy become politicised. As the visible face of protected areas, however, staff on the ground will be influential in how the public perceives protected areas and their worth.

- As members of interest and pressure groups, such as environmental NGOs, farmer groups, political parties or consumer associations. Protected area managers at both operational and senior levels will often have close and sustained relationships with such groups, at a single protected area scale or across an agency or jurisdiction. The interests and aims of such groups may be similar or in sharp opposition to those of protected area management.

- As holders of rights that are specified in law, management plans or contracts defining the use and allocation of resources. Local peoples residing within protected areas or dependent on and with rights to resources within them (in particular indigenous peoples), or commercial entities with access rights guaranteed by formal agreement.

- As consumers, through the fashioning of consumption and purchasing choices to support or avoid particular goods, services or issues. As some reserve systems adopt more full user costing (for example, entry fees) and/or incorporate commercial operations, visitors and users become as much consumers (paying for a desired experience) as citizens (enjoying a state-supplied recreational opportunity). This shift is likely to change the expectations of the visitor, and their relationship with protected area managers and workers. For example, user expectations of free facilities will likely be lower or more forgiving than the expectations of users who have paid for facility use.

- As employees and workers in many industries, trades and professions implementing new environmental practices and engaging with other firms or public agencies. Employees of firms or agencies supplying services to protected area or park agencies (fencing contractors, tour operators, cleaners at lodges, vehicle maintenance businesses, and so on) often have a close and sustained relationship with protected area agencies and their staff, will be required to comply with regulations and expectations and will convey to others perceptions regarding the worth of protected areas or the quality of management.

- As recipients of information, including scientific information about environmental change or messages about policy choices, changes or implementation. Visitors to reserves are often targeted with both specific and general messages regarding environmental protection, biodiversity conservation, heritage, and other matters.

- As passive providers of information, acting as targets of researchers, policy analysts or opinion polling firms who will inform policy choices and policy design, or as active participants in research and monitoring projects in resource and environmental management that will inform policy. Visitors and users of protected areas are often surveyed or otherwise monitored (passively), or more actively engaged in gathering and even analysing data. This covers monitoring environmental conditions (bird counts, weed surveys) and the success of management interventions. Users may also be utilised more intensively in research through participation in deliberative processes such as participatory 'charrettes' used in planning, citizens' juries or consensus conferences, the outcomes of which may influence management.

- Through general statutory rights in environmental and natural resource planning, including freedom-ofinformation laws, rights to object to or comment on development proposals, legal standing in courts or through environmental or social impact assessment processes. The declaration of reserves, proposals for management change or physical developments in or adjacent to protected areas may involve approvals and public comment processes under the regulatory regimes of the jurisdiction.

- Through mediation or conflict-resolution processes run to allow debate about and resolution of specific issues. Governments often utilise negotiation processes to resolve differences over specific matters and such processes may be used with regard to protected areas and their declaration or management, bringing managers into close engagement with an array of community and stakeholder groups.

- Through input to policy proposals or development approval processes such as government green or white papers, planning tribunals or panels, commissions of inquiry, parliamentary inquiries, policy discussion forums or task groups, and so on. Protected area matters may be the subject of such processes or part of the agenda of such (for example, around biodiversity or tourism generally), requiring managers to engage with the policy and political processes, supplying information or appearing before forums of this kind. 
- Through input into management plans, constructed within broader policy processes. In many jurisdictions, this is a major opportunity for stakeholder engagement in protected area management, when management plans are created or periodically reviewed.

- Through representation on advisory boards, committees, and so on, tasked with advising government on policy or management in a particular area (for example, biodiversity conservation, forest management) or in a broader sense (for example, a national council on sustainable development).

- Through inclusion on statutory management boards or committees with a legal and administrative mandate and actual management function (as distinct from purely advisory functions). Many protected areas and reserve systems within jurisdictions have advisory boards or community representative committees and similar bodies, providing input to, commentary on or collaboration in management. These vary considerably in the degree of engagement and actual influence over management.

- Through participation in community-based monitoring groups and programs, whether community-led or government-sponsored or a combination of the two, targeting a specific issue and locality such as weeds or water quality, and as members of community-based management groups engaged in resource and environmental management targeting a specific problem in a particular locality. There is a diverse array of volunteer and community-based groups which are active in protected area management, such as park care groups, ornithological clubs, game associations, and so on, who often work in close collaboration with agencies and managers and provide data, physical activities or other services that supplement agencies' work.

- In community-based or cooperative management arrangements (co-management), where actual management responsibilities are defined and devolved and a strong degree of local autonomy exists. These arrangements may be limited to management within a set management plan, or extend to broader goal-setting and governance of the protected area. Multi-use protected areas, both terrestrial and marine, fishery conservation management zones and buffer zones operate in some places in a collaborative governance model where local communities and/ or resource users are party to formal management arrangements. Many protected area systems engage local community members as voluntary rangers, with at least semi-formal status within the agency and the management regime.

Source: Adapted from Dovers and Hussey (2013) local community, and the regulatory and policy settings governing protected area management will influence which specific methods are most appropriate.

An important consideration in choosing a form of engagement is the suitability of different media for communication between protected area managers and others (Chapter 15). The capacity of communities and other organisations is one determinant of the best means of communication: whether internet/email is appropriate, the literacy levels in certain community groups, the use of visuals such as maps or interactive programs, and the availability of media. The rapid evolution of information and communications technology, including social media, along with more traditional forms of communication, has expanded the range of options available. It is unlikely, however, that all members of, for example, a local community will have the same access to different communication mechanisms, and care is required to ensure that some people are not inadvertently excluded from engagement opportunities.

The core message of this section is that there is a range of participatory strategies and methods available, and communications media, to suit different purposes and people. As with anyone reaching into a toolbox, protected area managers should consider the who and why, and then select the form of participation - the 'how' - suited to their situation. This section has provided general guidance on answering the important question: what is the appropriate form of participation and engagement in protected area management in this particular situation?

\section{When should engagement occur?}

The appropriate timing for an exercise in engagement will vary according to the context, influenced by the need for engagement and the groups engaged. Table 14.3 presents a simple three-way typology of how often engagement may be needed that can inform better organisation and planning of an overall engagement strategy. As a rule, one key principle applies, notwithstanding that urgent issues will occasionally arise: earlier is better than later. Too late or effective communication will alienate partners and insufficient warning will frustrate or appear tokenistic (see Chapter 15). 
Table 14.3 The timing of engagement, with generic examples from protected area management

\begin{tabular}{|l|l|l|}
\hline Timing and regularity & Rationale & Examples \\
\hline One-off or ad hoc & $\begin{array}{l}\text { For specific purposes that arise at irregular } \\
\text { or unpredictable intervals (note: the process } \\
\text { for handling these circumstances may be } \\
\text { guided by management plans or other } \\
\text { regulatory or policy documents) }\end{array}$ & $\begin{array}{l}\text { Consultation over tourism, and so on, } \\
\text { development proposals in or near the } \\
\text { protected area } \\
\text { Unexpected outbreak and control programs } \\
\text { for a pest species }\end{array}$ \\
\hline Regular but occasional & $\begin{array}{l}\text { An issue that is not constantly on the } \\
\text { agenda but arises with some predictable } \\
\text { regularity }\end{array}$ & $\begin{array}{l}\text { Seasonal fuel reduction for fire protection } \\
\text { Review of management plans at set intervals }\end{array}$ \\
\hline Ongoing & $\begin{array}{l}\text { Matters that are constantly on the agenda } \\
\text { and thus need to be catered for by ongoing } \\
\text { engagement provisions }\end{array}$ & $\begin{array}{l}\text { Visitor experience surveys or opportunities } \\
\text { to comment } \\
\text { Meetings of management or advisory } \\
\text { committees involving outside parties } \\
\text { Planning with or feedback to park care or } \\
\text { friends' groups or monitoring volunteers }\end{array}$ \\
\hline
\end{tabular}

The value of reviewing engagement against the appropriate timing and frequency is that maintenance and preparedness of such things as information and communication strategies, contact lists and staff resources will be regularised in work programs and thus not be forgotten or only attended to hastily. Not only can protected area managers be well prepared for effective engagement, but also due warning and preparation on the part of other individuals and groups will be possible.

The core message of this section is that engagement with communities and other organisations varies in the timing, requirements for preparation and regularity of contact and communication. Timing will vary across purposes and forms of engagement. This section has provided general guidance on answering the important question: when does an engagement strategy or process need to occur, at what intervals, and how can protected area management be prepared?

\section{Conclusion}

Protected area management involves negotiation, consultation, partnerships and sometimes conflict with neighbours, clients, customers and collaborators. These relationships embed protected areas within complex social, economic and institutional landscapesfar from the idea of reserves being managed in isolation as 'islands' in the landscape. This presents managers with both the challenge of how best to engage with diverse groups and individuals and the opportunities for better outcomes that these relationships offer. Engagement and collaboration have become-and will increasingly feature as - core competencies of protected area managers, requiring time, resources and skills. Also, adaptive management is most likely to succeed if the knowledge and skills of communities can be harnessed as well as communities being supportive of management initiatives. 
Indigenous people are the original stewards of the environment, and in the 21st century they remain custodians of some of the most biologically diverse areas of the world. Some of these areas are owned and managed by indigenous peoples; in others rights of use and engagement are recognised in management; and in others these rights and uses remain unrecognised. Formal recognition of the importance of protected areas to indigenous peoples is recent. Since 1945, the United Nations and other organisations such as the International Labour Organisation (ILO) have been redressing historical legacies of dispossession and injustice experienced by indigenous communities, including removal from land declared as protected areas. Consultation with contemporary indigenous communities will therefore never be about conservation alone, but will always include issues around rights, social justice and reconciliation.

\section{Who are indigenous people?}

The United Nations and other international agencies choose not to have a formal definition, relying instead on a process of self-identification, and a working definition:

Indigenous communities, peoples and nations are those which, having a historical continuity with preinvasion and pre-colonial societies that developed on their territories, consider themselves distinct from other sectors of the societies now prevailing on those territories, or parts of them. They form at present non-dominant sectors of society and are determined to preserve, develop and transmit to future generations their ancestral territories, and their ethnic identity, as the basis of their continued existence as peoples, in accordance with their own cultural patterns, social institutions and legal system. (United Nations 2004:2)

This definition does not include indigenous peoples who form a nation's majority population and/or hold government power-for example, in most Pacific Island countries.

Under this definition, indigenous people make up about 5 per cent of the Earth's human population across some 90 countries (United Nations 2009). Geopolitical variation is considerable, from the largely integrated New Zealand Maori, who make up 15 per cent of the national population, to the tiny marginalised populations of Ainu in Japan and the Dyak of Borneo, and the widely scattered forest-dwellers of Central African rainforests and Saami reindeer herders of north Asia and Scandinavian Europe. They represent 15 per cent of the world's poor and many eke a living from the land as subsistence agriculturalists, pastoralists or hunter-gatherers.

Because of their position as original stewards, their continuing spiritual connections with nature and their often marginalised position in society, indigenous peoples' relationship with protected areas (and their managers) is unique. Meaningful consultation with indigenous peoples demands special attention by protected area managers, not least because indigenous people do not see themselves as just another stakeholder to be consulted-as a quote from an Indigenous Australian demonstrates:

However it is not really an appropriate term to use when talking about Aboriginal communities. We have a very long association with the land, with deep spiritual connections. This means we view ourselves as owners of the land in a very real and unique way. These bonds we have with the land are only poorly captured by the term Stakeholder. (ANUTECH Development International 1998:8)
From the 1980s, a raft of national and international conventions, policies and legislation heralded a 'new paradigm' in nature conservation discourse that recognised the need for harmonising conservation goals with social and economic needs, with explicit statements around improving the way protected area agencies were engaging with indigenous people (Alcorn 2010). In 2008, the United Nations affirmed the rights of indigenous peoples, developed goals emphasising their participation and included some qualitative benchmarks (Larson 2006). The 2003 World Parks Congress (WPC) had a high level of representation from indigenous peoples who were very active throughout the congress in making their voices heard as 'rights-holders' (DeRose 2004). The WPC has been critical in progressing indigenous participation in protected area management.

\section{Indigenous engagement in protected area management}

All protected area categories invite some degree of participation from indigenous people within the broader milieu of engagement with civil society; however, the level of that participation varies greatly as does indigenous peoples' satisfaction with the outcomes. In protected areas where formal ownership by indigenous peoples exists, they are the managers, not simple participants. The 'rules of engagement' developed in the international arena encourage a process that goes beyond consultationintended to do more than inform indigenous people about proposed actions in the protected area or seek comment on a draft management plan. Protected area Categories $\mathrm{V}$ and $\mathrm{VI}$ offer the greatest opportunities for collaborative arrangements with indigenous and local communities, encouraging equal partnerships and finding common objectives.

Successful partnerships have been forged in the context of other categories, the best known being joint management of national parks, particularly in New Zealand, Australia and North America. In this model, the land is owned by an indigenous group/organisation and leased back to the government as a national park, managed by a board of management containing a majority of indigenous traditional owners (Smyth 2001). This model gives almost equal decision-making power to the indigenous group and the other partner-usually the government. Australia also has a system of Indigenous Protected Areas (IPAs), which are premised on collaborative planning with Aboriginal landowners (Hill et al. 2011).

An example comes from the remote Kimberley region of Western Australia where the Uunguu people have prepared a 'healthy country' plan for the Wunamabal Gaambera IPA in collaboration with an NGO, Bush Heritage Australia (WGAC 2010). While Western science-based conservation action planning (CAP) (Chapter 13) has provided the framework for participatory planning, it was recognised that the process needed major adaptations in order to respect and support local priorities, governance structures, knowledge, capabilities and objectives. First, to support meaningful contributions by planning participants, the process, instead of being driven by conservation planners and facilitators, incorporated Indigenous governance structures, local protocols and priorities, including having meetings on country and adopting flexible time frames. Second, core CAP concepts, based on ecological processes and systems, were modified to incorporate categories defined by Wunambal Gaambera traditional owners and Indigenous cultural knowledge (Moorcroft et al. 2012). 
The ensuing healthy country plan is a success in crosscultural conservation planning in that it has been informed by Western approaches to conservation planning, while respecting and complementing Indigenous knowledge and approaches to land and water management. This demonstrates that traditional owners' aspirations to drive the conservation planning agenda for their ancestral estates can be achieved (Moorcroft et al. 2012).

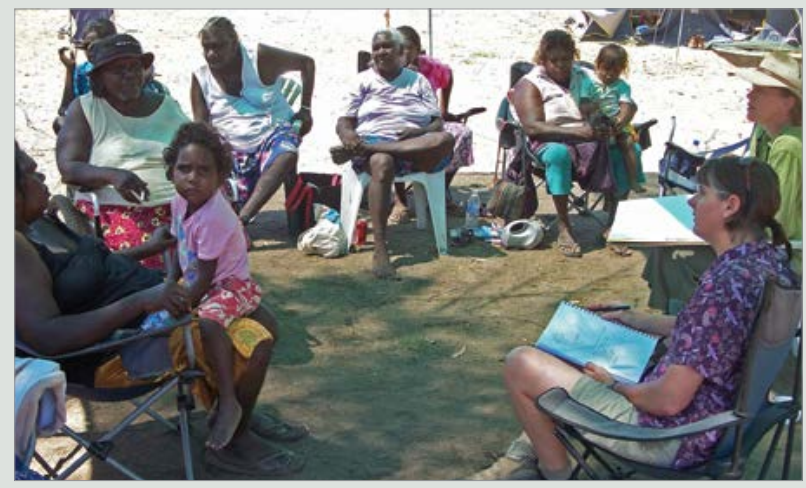

A Wunambal Gaambera women's group discussing targets for their healthy country plan with Heather Moorcroft from Bush Heritage Australia

Source: H. Moorcroft

Outside formal protected areas, the IUCN recognises Indigenous Peoples' and Community Conserved Territories and Areas (ICCAs) as areas of high conservation value where collaborative governance with local and indigenous people is the basis for management. There are strong advocates for greater indigenous participation in all forms of natural resource management, to enhance conservation outcomes and maintain sustainable livelihoods (Ross et al. 2011).

Two important points emerge. First, proper consultation is a fundamental element of effective protected area partnerships with indigenous people. Poor systems of communication will see partnerships fail. Second, as a general rule, indigenous people view consultation as a means to an end-an end that is not confined to greater involvement in protected area decision-making but includes achieving social justice, jobs, empowerment, equality and reconciliation, and most importantly the right to care for cultural landscapes.

A vast social science literature exists on how to consult with indigenous people. For decades, global NGOs such as the Forest Peoples Programme and the International Institute for Environment and Development have witnessed serious cases of the removal of opportunities and denial of rights by multinational companies wanting to exploit the resources of poor countries. Much of the inequity is due to inadequate consultation, leading to misunderstandings and consent-giving that was far from fully informed. In response, these agencies have developed processes and policies to ensure that consultation and dialogue lead to equitable partnerships (Mayers and Vermeulen 2002). This knowledge base, together with a strong international framework, is an enabling environment in which protected area staff can engage with indigenous communities.

While each specific place and group of people is different and protected area managers must understand and respect those differences, there is a set of fundamental considerations in terms of why one should consult with indigenous people, and factors to consider when doing so.

\section{Why consult with indigenous people?}

Consultation with indigenous people is critical for the following reasons.

1. They are the original owners, who may have been removed from their land or are still living within a protected area. They have basic rights as original owners to participate in decision-making regarding the protected area.

2. Indigenous people hold traditional ecological knowledge that is applicable in a contemporary management context.

3. Indigenous people have a major stake in protected areas because they are some of the few places left on Earth where their traditional cultural landscapes remain relatively intact, which is important for cultural identity and as a basis for power-sharing arrangements.

4. Protected areas have been known to fail if they do not have the support of local indigenous people.

\section{What are the important factors to consider?}

1. Indigenous engagement in protected area management is invariably rights-based. Thus, there are always multiple agendas. A subject may seem 'off topic' but could be central to the community's interests.

2. If you are representing a government agency, the community may not trust you due to historical legacies. Building trust at an individual level is central.

3. Indigenous people are often disadvantaged, resulting in serious inequalities of power, which makes it difficult to negotiate in an equitable manner. Feelings of powerlessness tend not to lead to equitable negotiation outcomes. Indigenous people may not have the required skills and capacity to negotiate effectively or, in some cases, to understand fully what is being negotiated or discussed. They may not have the governance systems in place to respond to requests for information or to organise attendance at meetings.

4. Representation in indigenous communities is different from most other societies. The scale of consensus in indigenous communities is normally a few elders in a clan group or other social group. A protected area may involve many such groups who have no traditional systems for consensus across them all. You may find yourself negotiating with the wrong person or group or you may be frustrated because no-one is prepared to speak on behalf of anyone else.

5. Although subtle, cultural differences in interpersonal communications can be the cause of failure in consultation. For example, it is inappropriate to send a junior member of staff to negotiate with a senior knowledge-holder in the community (there are other examples; see Annandale and Feary 2009).

6. Everyone comes to the negotiating table with different agendas and expectations. Those of indigenous people will differ from those of a protected area manager, so it is critical that there are sufficient meetings and discussions to make everything clear.

7. In conclusion, indigenous peoples are special 'stakeholders', requiring special attention and respect. It is through the mechanism of effective participation that indigenous people can maintain or renew their connection with land and water, bringing with it a raft of benefits including social justice and improved protection of nature through the use of traditional knowledge. 


\section{Case Study 14.2 Cullunghutti Aboriginal Area: A partnership for protecting a mountain}

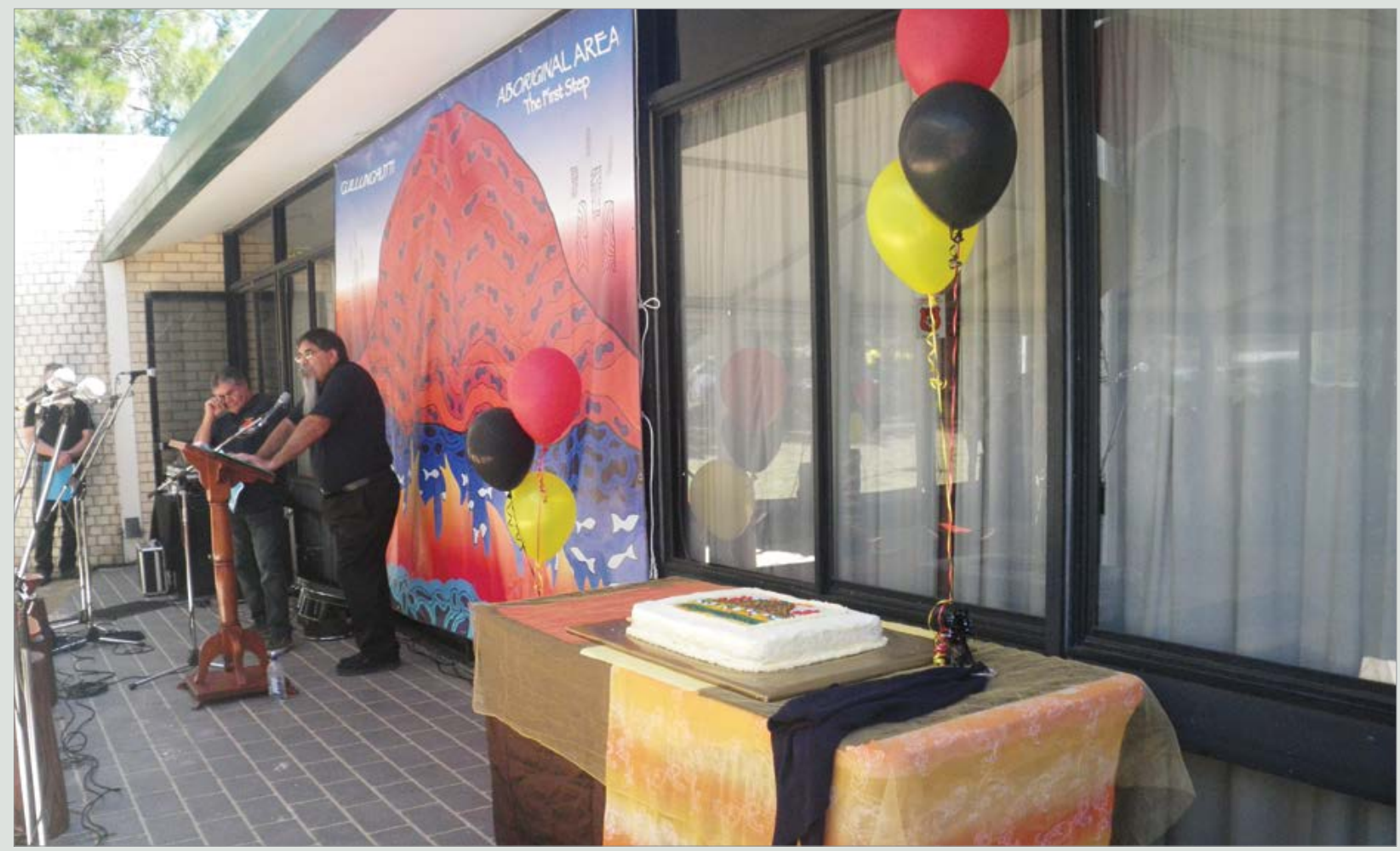

Celebrating Cullunghutti: Rod Wellington (Jerrinja elder and Office of Environment and Heritage cultural heritage officer) delivers a speech at a gathering to celebrate declaration of the Cullunghutti Aboriginal Area, New South Wales, Australia, October 2013

Source: S. Feary

Cultural heritage projects where Indigenous people share cultural knowledge with protected area staff can lead to longer-term partnerships for protection of culturally significant places. Such was the case in the formal recognition of a sacred mountain near Nowra in southeastern Australia. Although the cultural significance of Coolangatta Mountain (or Cullunghutti) to local Aboriginal communities had long been known to the NSW Office of Environment and Heritage $(\mathrm{OEH})$, there had never been adequate documentation to support its legal protection. In 2004 the NSW National Parks and Wildlife Service (NPWS, a division of $\mathrm{OEH}$ ) commenced an Aboriginal cultural heritage study aimed at informing management of several new nature reserves in the area. During this study, which involved extensive oral history research, the significance of the mountain became apparent (Waters and Moon 2005).

A few years later, a NPWS staff member noticed an advertisement for the sale of 67 hectares of private land on the slopes of Coolangatta Mountain and alerted the relevant section of OEH. Departmental staff met with local Aboriginal people to discuss the proposed purchase of the land, as their support was fundamental if the purchase was to proceed. There was majority support and the land was purchased in 2008. In 2011 it was declared as an Aboriginal Area under the NSW National Parks and Wildlife Act. This rarely used category protects places and features of outstanding cultural value to Aboriginal people.

From these early meetings, an informal committee of Aboriginal people representing organisations, community groups and families evolved, and meets regularly with protected area staff to discuss management of this small parcel of land. Creation of the Aboriginal Area has enabled discussion (and disagreement) about the issues of landownership, empowerment, the right to speak for 'country' and how best to protect land with cultural values. So, although the road has been and remains challenging, there are many very positive outcomes from the purchase and gazettal of the Cullunghutti Aboriginal Area.

Although the Cullunghutti Aboriginal Area is only small, its gazettal has meant the value of the whole mountain is appreciated and more widely understood by the nonAboriginal community. This understanding has been augmented through a detailed 'Cullunghutti Living History Study', which has documented the values, stories and contact history of people from the district (Waters Consultancy Pty Ltd 2013). In October 2013, a joyous and moving Celebration Day was held to mark the establishment of the Aboriginal Area. This was the first time local Aboriginal communities had publicly told the story of the mountain and its cultural meaning. 


\section{Case Study 14.3 Engaging with philanthropists: The Yosemite experience}

'Donors will solve all our fiscal problems.' While this might be true, to have a successful philanthropic program requires a major commitment of time and resources by the staff of the organisation, its board and the protected area agency. Protected areas are best served when both government and citizen stewards who are committed to the area work together for that common purpose. When citizens care enough, they also are committed enough to give of their personal time and financial resources. Philanthropy is the natural offspring of that caring.

Philanthropic groups, however, provide many important functions, not just fundraising, for protected areas. Many of these groups view protected areas as temples or their special place for spiritual restoration. Through their passionate communications, stewards are developed and nurtured. Through these groups, individuals with varying views and motives can share their love of place.

Private-public partnerships bring the best of both worlds together. These partnerships provide the margin of excellence for the protection of the resource and enhancement of the visitor experience well beyond what a government budget will ever accomplish. Private individuals and organisations can add extra value to the public resourcing of protected areas that forms the necessary foundation of conservation.

From the early history of the US National Park Service (NPS), personal philanthropy played a critical role in building the park system. In some areas, portions of land were privately purchased and donated to the NPS. Schoolchildren donated pennies during the 1920s and 1930s to help purchase the land that became Great Smoky Mountains National Park. In Yosemite National Park, the first museum on NPS land was built with a generous donation. As a result, the first NGO was established to manage the museum in 1923. Ninetyone years later, the Yosemite Conservancy carries on that tradition. These types of philanthropic partners were and are critical to the sustainability of our protected areas.

As this chapter makes clear, there are many different motivations for individuals and organisations to engage with protected areas; this is true of philanthropy as well. The focus here, however, will be on one primary aspect: stewardship. Besides raising funds to support a protected area's various needs, philanthropy can inspire individuals who are committed to the greater good of protecting the area. This connection to an area helps build the desire to protect and support a protected area. Stewardship is the commitment of both personal time and fiscal resources.

The Yosemite Conservancy donors make it possible to provide grants to Yosemite National Park to help preserve and protect Yosemite today and for future generations. The conservancy is dedicated to enhancing the visitor experience so that individuals are able to gain the most from their time in Yosemite; its supporters are the stewards of Yosemite. The conservancy provides more than 43000 individuals with the opportunity to express how much they value Yosemite through their commitment of support. Part of the conservancy's mission is to enrich the visitor experience, thereby helping to create potential new stewards for Yosemite. A key part of building new stewards is focusing a major grant area on youth. Yosemite Conservancy helps about 27000 young people to appreciate the park each year.

Wildlife and resource management projects are, of course, also an important aspect of Yosemite's grant program. Yosemite Conservancy has provided grants to reintroduce bighorn sheep (Ovis canadensis sierra), help protect peregrine falcons (Falco peregrinus) and study and reintroduce yellow-legged frogs (Rana sierra), to name a few. Habitat restoration is another important component of the conservancy's grant program. The restoration of the Mariposa Grove of giant sequoias (Sequoiadendron giganteum) is the next major grant effort of the conservancy, which will commemorate the 150th year of Yosemite as a protected area.

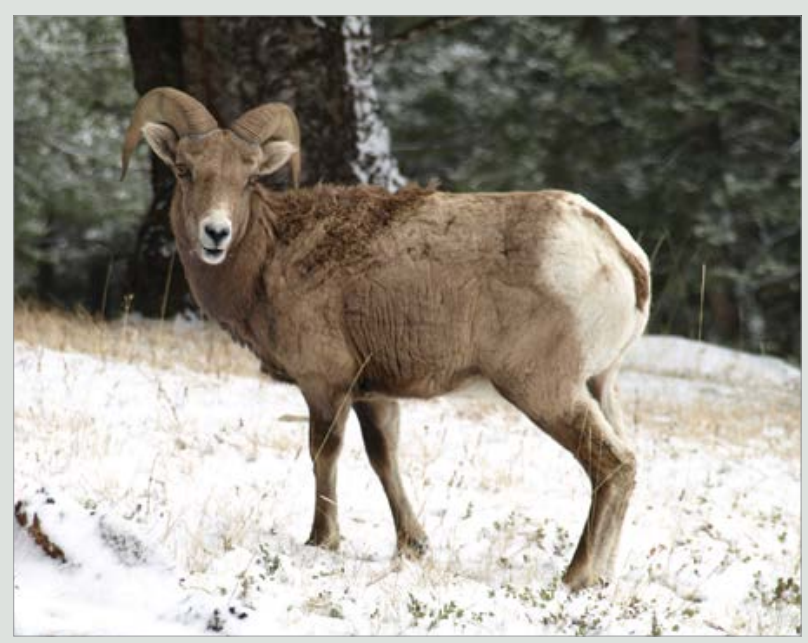

Bighorn sheep (Ovis canadensis), Banff National Park, Canada

Source: Graeme L. Worboys

\section{Important lessons}

Philanthropy is a partnership that needs to be nurtured. The agency's role is to manage the protected area; the philanthropic group's role is to provide support in the form of grants, projects and programs. Both entities need to respect each other's roles and responsibilities - a hard task that takes vigilance. One entity attempting to manage the other can only lead to the downfall of the partnership. The key to avoiding this downfall is a comprehensive signed agreement that sets the framework for the relationship between the two organisations.

A philanthropic group should not focus on advocacy. The primary purpose is to support the needs of the managing agency for the protected area with grants that are supported by its donors.

How do you keep donors engaged and excited? They need to be kept informed of the activities of both the non-profit organisation and the protected area. Donors want to see their resources being effectively used. They want to know that their donations will not offset the government agency's budget but rather will be in addition to government funds. Grants need to be expended on time and within budget while achieving the goals of the project. Transparency and reporting back to donors are essential. Yosemite Conservancy's success on more than 450 projects with more than US\$80 million over the past few years is based on a partnership with the NPS that delivers completed grants and projects that donors can see and be proud of.

Every year, the NPS provides Yosemite Conservancy with a list of grant requests. The board of the conservancy selects the projects that they feel will most excite donors and that will provide that margin of excellence above the government budget. This process works well for the conservancy. Hopefully, you too will find your perfect formula for your successful partnership. 
Philanthropic organisations and individuals have been significant catalysts in the growth and development of public and private protected areas in Australia and are likely to play an increasing role in environmental conservation. With overall giving levels as a percentage of gross domestic product (GDP) being slightly lower in Australia than in the United Kingdom and Canada, and much lower than in the United States, and the contributions of wealthy individuals being lower, philanthropy in Australia has strong potential for growth.

\section{The giving landscape}

Government initiatives are key to the strengthening of the sector. According to Philanthropy Australia (2014), the peak body for philanthropy in Australia, the implementation of tax incentives, the growth in workplace giving programs and an increased public awareness of the benefits of philanthropy are leading to increases in giving.

Philanthropy Australia (2014) estimates there are approximately 5000 foundations in Australia giving between A $\$ 500$ million (US\$466 million) and A $\$ 1$ billion (US\$932 million) annually. In addition, individual taxpayers claimed more than $\mathrm{A} \$ 2.2$ billion (US\$2.05 billion) in deductable donations in 2010-11, which represents a substantial investment in philanthropy. According to a Credit Suisse report (Sydney Morning Herald 2013), however, by some measures Australians are the richest in the world and the richest 10 per cent of Australians have seen the biggest income growth over the past three decades-a growth as yet unmatched in the level of giving.

Australians direct about 7 per cent of their total philanthropic giving to environmental issues. While this is not insignificant, and there are gains being made in the area of environmental conservation, the escalating threats are such that more people need to give more. The Australian Environmental Grantmakers Network, an organisation supporting environmental grant makers, has more than 80 members including individual philanthropists, trusts and foundations.

In 2011-12, the Australian Government reported public donations of about $\mathrm{A} \$ 130$ million (US\$121 million) 'to assist the protection and enhancement of the natural environment' (SEWPAC 2013:193). Research by the network suggests the majority of those donations go to biodiversity funding, with about 65 per cent of network members supporting biodiversity. Support for biodiversity protection includes grants to community groups for the acquisition and management of private protected areas and for advocacy towards more and better-managed public protected areas.

While the most noticeable tranches of funding go to land acquisition and large projects, smaller donations collectively also contribute substantially to biodiversity protection. There remain many funders who support smaller projects with tangible aims such as invasive species control, tree planting and species monitoring. Individual donors also support community groups advocating for the environment with smaller amounts of money. Indeed, a large number of small donations helped achieve the world's first comprehensive set of marine national parks along Victoria's coastline in 2002, and a collaboration of foundations and individuals funded advocacy for a new national network of marine parks in 2013-the world's largest.

\section{Catalysts and leaders}

In recent decades there have been a number of individuals and organisations who have played a catalytic role in the growth of Australia's protected areas.

In the early 1990s, an individual philanthropist, Martin Copley, funded the purchase of five properties in Western Australia covering 450000 hectares in the Kimberley, south-western Australia and the World Heritage-listed Shark Bay. His passion for the land and its native animals led him to establish the Australian Wildlife Conservancy, which, with the support of contributions from a diverse group of Australians, now owns and manages more than 3 million hectares across the country.

Another individual philanthropist, David Thomas of The Thomas Foundation, leveraged an additional A $\$ 12.6$ million (US\$11.7 million) of private money and A\$6.2 million (US\$5.8 million) of government funding, on top of his foundation's commitment of $A \$ 10$ million (US\$9.3 million), to contribute to a range of protected area projects. One of these was Gondwana Link in south-western Australia-a biodiversity hotspot. Operating at a large landscape scale, Gondwana Link represents a new way of integrating public, private and Indigenous land to ensure biodiversity protection. Philanthropic support such as Thomas' has ensured that this grand vision can be realised and is an inspiration for many similar projects. Organisations as well as individuals have pioneered private and philanthropic involvement in nature conservation and protected area initiatives; in Australia and other countries, two examples are the World Wide Fund for Nature (WWF) and Earthwatch.

\section{Engagement considerations}

In engaging with philanthropists to enlist support for future projects, a complex range of factors needs to be considered.

Private protected areas are largely supported by philanthropic funding and managed by organisations such as the Australian Wildlife Conservancy and Bush Heritage Australia. The philanthropic support is often made up of large, catalytic contributions (often for land acquisition or a key project) from an individual or foundation (often matched by government), which is then bolstered by many small donations by individuals. The support for protected areas and for biodiversity generally is an attractive proposition for those seeking to donate, because of people's personal connections to particular landscapes, the appeal of areas of great natural beauty and the long-term benefits of the investment in land acquisition and management. Such considerations of what motivates and inspires philanthropists need to be taken into account, and are also relevant given current opportunities for involvement in protected area projects.

The opportunity for philanthropic participation in protected area management has increased in response to an expansion of protected areas under Indigenous, not-forprofit or joint management. Currently, Indigenous people govern just more than 30 per cent of Australia's natural reserve system (SEWPAC 2012). With these opportunities come further challenges in engaging funders; increasingly, philanthropic funds are being applied to projects that are multidimensional in their approach and aim to address not just the environment, but also health, social justice and education. Indigenous Protected Areas (IPAs) and 


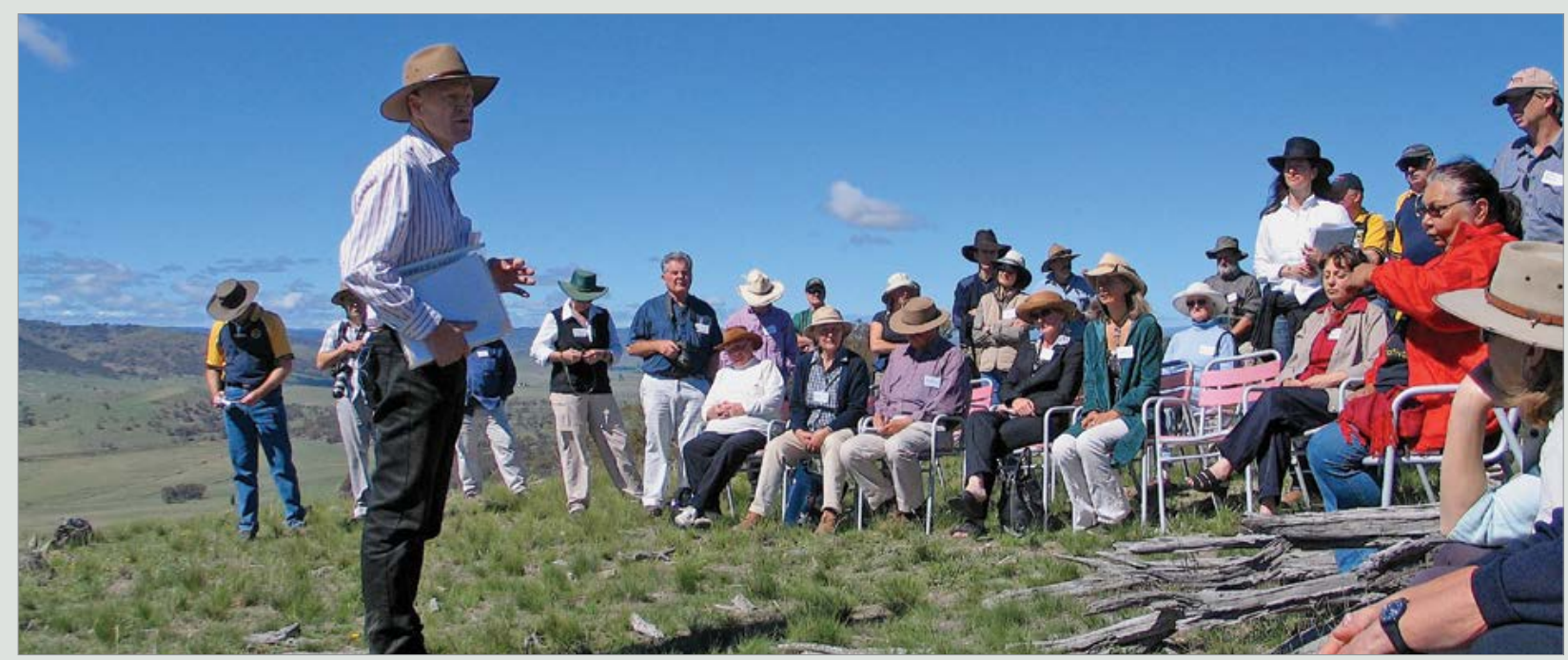

Doug Humann, former CEO of Bush Heritage Australia (a conservation NGO), speaking to community representatives including donors at the launch of Scottsdale Conservation Reserve in southern New South Wales. The land was purchased with funding from philanthropic donors and the Australian Government's National Reserve System program in March 2007, for protection of the Southern Tablelands endangered box gum grassy woodlands under an in-perpetuity conservation agreement. Source: Ian Pulsford

Indigenous land and sea management programs are projects of this nature.

In addition to these considerations, despite the popularity for environmental philanthropists of supporting protected areas, most environmental NGOs agree that accessing philanthropic funding is difficult. Outside regular fundraising campaigns (usually seeking small amounts of money from supporters and members), the vast majority of philanthropic funds, and particularly the large donations, come from unadvertised sources, and most commonly at the instigation of the philanthropist and not the organisation seeking funds.

For philanthropists and grant seekers, there are also legal and taxation issues to consider. Depending on the vehicle for funding, most philanthropists and philanthropic entities require their beneficiaries to have deductible gift recipient (DGR) status. Securing DGR status is often a complex and time-consuming process, and one that is prohibitively onerous for smaller, volunteer-run groups.

Furthermore, despite the large number of foundations in Australia, the vast majority have relatively small distributions, and few or no staff. Indeed, many trusts and foundations have limited capacity to accept applications and undertake research, do not have open granting processes and there is limited information on individual trusts available publicly. There are limited requirements for the philanthropic sector to report on its activities publicly.

In the context of securing funds, it is worth remembering that in most cases, philanthropists are not obliged to give. They do so because of their passion, their generosity and their desire to leave a positive legacy. Good communication, honesty and respect are key to fostering and maintaining strong philanthropic relationships.

\section{Project Janszoon: A New Zealand example}

Project Janszoon (2014) is a privately funded trust, working in partnership with the Abel Tasman Birdsong Trust, New
Zealand's Department of Conservation (DOC) and the community, to ensure biodiversity values are restored and enhanced in Abel Tasman National Park. This iconic national park is located at the top of the South Island and although it is New Zealand's smallest at 23500 hectares, it attracts 150000 visitors annually, who enjoy its great beauty and birdlife while tramping and kayaking. Like most national parks, however, Abel Tasman has its fair share of weeds and feral animals, and DOC recognises the critical role of philanthropy in addressing these problems.

Successful reintroduction of key bird, plant and animal species into Abel Tasman National Park is a high priority for Project Janszoon, which is currently targeting the removal of exotic weeds, rats and stoats. The latter were introduced in the late 1880s to control introduced rabbits and hares and are now a major threat to native birds and animals. Since 2012, Project Janszoon, together with the DOC and assistance from local high schools, has laid out more than 2000 stoat traps across the park. Stoat numbers are now sufficiently low to allow the first mainland reintroduction of a critically endangered species. Early in 2014, 12 specially bred kakariki or yellow-crowned parakeets (Cyanoramphus auriceps) were released to join the few remaining individuals still surviving in more remote corners of the park.

Janszoon is the middle name of Abel Tasman, a Dutch explorer who sighted New Zealand in 1642. Project Janszoon Trust was established by a philanthropic family from the North Island and has been operating since 2012. With strong community support and a very positive relationship with the DOC, Project Janszoon has been able to set itself the goal of transforming the ecology of the park over the next three decades, leading up to the December 2042 celebration of the 400th anniversary of Abel Janszoon Tasman's visit to this land, and the centenary of the formation of Abel Tasman National Park. 


\section{Case Study 14.5 Collaborating with recreation stakeholders: The International Mountaineering and Climbing Federation experience}

In the first decade of the 20th century, a collaborative and productive relationship between US President Theodore Roosevelt and a diverse group of recreational users such as fishers, horseriders, hunters, hikers and mountain climbers led to the creation of 17 million hectares (170 000 square kilometres) of national forests, 53 national wildlife refuges and 18 areas of 'special interest' such as the Grand Canyon National Park. Today, these protected areas continue to draw millions of recreationalists and other visitors from around the world each year to enjoy their spectacular natural, recreational and cultural resources.

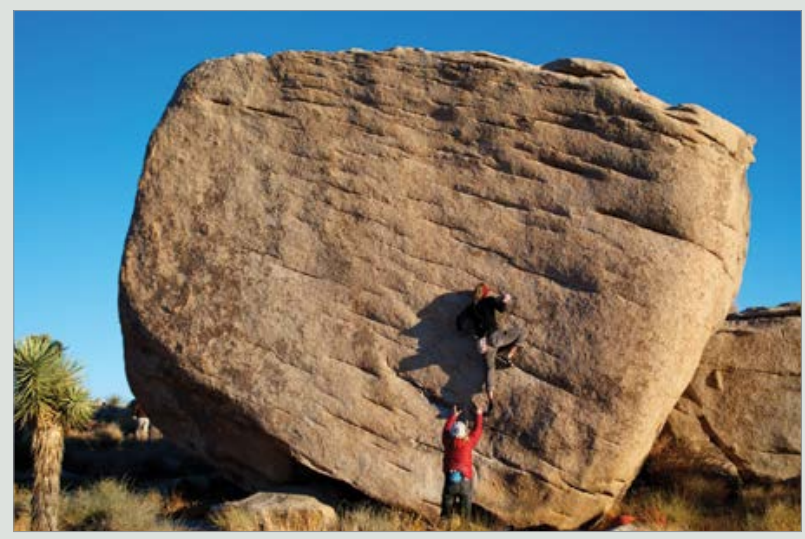

Recreational 'bouldering' is a popular activity for developing climbing skills in Joshua Tree National Park in California, USA

Source: Clancy Pamment

By forging a respectful, mutually beneficial and collaborative working style and a shared vision for the conservation of these special places they all cherished, Roosevelt and these diverse protected area stakeholders also created a radical shift in the concept and scale of land management in the world. The result was the creation of a continental network of national parks, national forests, national seashores, national wildlife refuges and preserves, open to all visitors at little or no cost. This system remains a global model for creating and sustaining parks and other types of protected areas.

From the beginning of his presidency in 1901, Roosevelt understood that he could not succeed in creating his large-scale conservation vision for America on his own, but needed the help of the powerful recreational stakeholders of that era, who all wanted continued access to protected areas to pursue their activities. He focused on creating a viable 'path to stewardship' by finding ways to bring the stakeholders together positively and constructively to discuss their competing and shared goals, special interests, ideas and concerns. He then pointed out the long-term benefits to all of them if they adopted and supported his grand conservation vision, which offered a prestigious shared sense of stewardship and pride.

Today, recreationalists are still highly concerned about issues of access to pursue their activities in protected areas. Their power and influence are formidable. In 2012 the US outdoor recreation industry estimated that it generated approximately US\$646 billion in economic activity and 6.1 million direct jobs, making it three times larger than the oil and gas industry (OIA 2012). These totals include the other sectors the outdoor recreation industry relies on, such as manufacturing, retail and sales, transportation and warehousing, and accommodation and services near outdoor recreation sites.

The collaborative 'path to stewardship' process used by Roosevelt is equally useful today to help recreational stakeholders support protected areas. It can also be an important tool for recreationists and other protected area stakeholders to find innovative ideas and effective ways to minimise their impacts on protected areas. Two examples follow.

\section{Promoting stewardship}

In 2012 the International Mountaineering and Climbing Federation (Union Internationale des Associations d'Alpinisme: UIAA) sought a way to promote mountain stewardship and minimise the impacts of mountain travel, mountaineering and rock climbing around the world. Their first impulse was to simply seek out and fund a number of worthy mountain protection projects. Although this sounded simple, it proved time-consuming, limited geographically and difficult to fairly compare the value of the projects.

The UIAA realised it would have greater success in finding valuable projects if it instead collaborated as a 'stakeholder bridge' between the much larger worlds of mountain tourism and mountain protection. So in 2013, the UIAA successfully launched its Mountain Protection Award for Stewardship (UIAA 2013a). This annual award offers a generous cash prize to a guide service, community, association or travel agency whose work in a mountain region of the world effectively addresses at least one of the following long-term stewardship issues:

- conservation of biodiversity

- sustainable energy and resource management

- waste management and disposal

- adaptation to, or mitigation of, the effects of climate change

- preservation of local and indigenous cultures and promotion of education for all.

With this system, the UIAA can showcase and promote a number of well-designed mountain stewardship projects or programs around the world on its website each year, and then reward one of them with focused global media attention and a significant cash prize to help them continue their programs and achievements. This approach, as opposed to investing in a small number of separate projects, serves to have a wider impact through recognition and communication of good practice, reaching the wider community of recreational stakeholders and others engaged in protected area management.

\section{From conflict to collaboration}

Since the mid-20th century, spontaneous access to outstanding and diverse recreational opportunities has greatly increased public interest in and support for protected areas around the world. As urbanisation continues to spread and societies adopt modern communication technologies, more people are choosing to move to regions in or near protected areas. Today, protected areas are not only perceived as natural places to enjoy as a contrast with 'civilisation'. Those with a variety of recreational opportunities are now also perceived as highvalue, low-cost, health-enhancing regional amenities. 
Although the increased popularity of protected areas can increase visitation pressures and impacts, it can also create stronger public engagement and political support for continued protection. Protected area managers who engage proactively, regularly and productively with recreational users often discover that they can be motivated and skilled stewardship partners.

When engaging with diverse recreational users, collaborative governance and adaptive management (explored in this chapter) offer protected area managers a framework to create a valuable role for each type of recreational user (hikers, mountaineers, horseriders, fishers, and so on). By actively engaging and meeting with recreational user groups periodically, managers can better understand their special values, interests, motivations and concerns, and how they connect-physically and mentally-to protected areas.

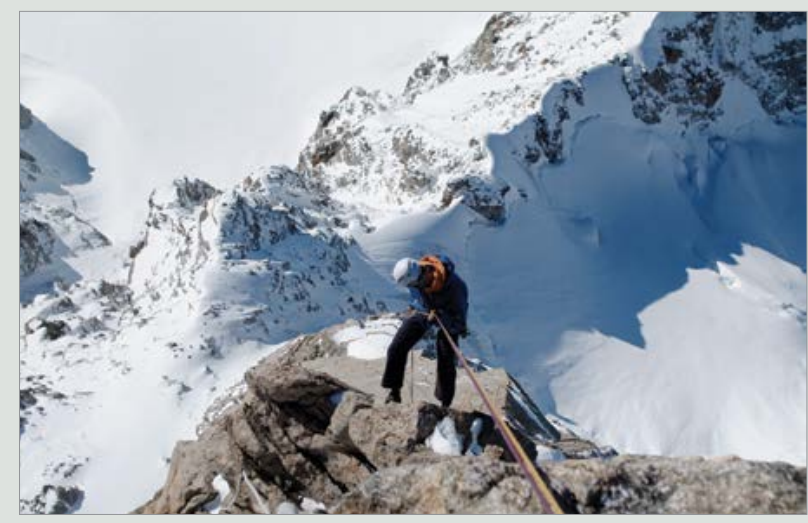

Mountaineering on the Dent du Géant, Mount Blanc Massif, France

Source: Clancy Pamment

Managers need to recognise that each type of recreation has its own, different set of shared values, history and style of communication. An effective way to engage with various recreational user segments is to pair them with staff members or local community members who are also enthusiasts of that recreation. These individuals then serve as key contacts for the protected area-a trusted link between the protected area managers and recreational users. This simple step can create a great leap forward in building a relationship with recreational users.

For example, mountaineers and rock climbers around the world have a long history of leadership in helping to create and promote protected areas, especially in mountain regions; however, their unconventional and individualistic sport cultures can sometimes lead to conflicts with management. In 1997 the UIAA, representing 4.5 million members of the global climbing community (UIAA 2013b) helped the American Alpine Club (AAC) to engage collaboratively with the US National Parks Service (NPS) to represent rock climbers from around the world, as historical and traditional stakeholders in Yosemite National Park, a UN Educational, Scientific and Cultural Organisation (UNESCO) World Heritage site.

After a cataclysmic flash flood on the Merced River raged through Yosemite Valley in 1997, part of the initial NPS recovery plans called for rebuilding hotel rooms away from the river, placing them instead adjacent to Camp 4, the rustic, traditional climbers' campground, which is on higher ground. Alerted by the AAC and the UIAA, climbers from around the world voiced their strong opposition to this plan, which they felt would degrade the natural camping experience at Camp 4. Initial discussions between the NPS and AAC failed to resolve the issue and a lawsuit was filed to stop the planning process.

The situation improved greatly, however, when the NPS sent one of their planning staff, a well-known and respected Yosemite climber, to meet with AAC and UIAA representatives and leaders from the local climbing community. He was very effective in communicating the huge challenges the NPS planners faced in crafting a realistic recovery plan that balanced the interests of all Yosemite stakeholders during the flood recovery effort. The climbers regarded him as a trusted messenger, able to effectively communicate their needs, concerns and ideas back to the NPS.

This colleague bridged the divide between stakeholders and enabled the first tentative interactions that eventually bloomed into a collaborative relationship between 'the climbers and the rangers'. A lasting tribute to this successful collaboration arrived in 2003, when Camp 4 was officially listed on the National Register of Historic Places by the US Department of the Interior. An official bronze plaque placed near a popular climbing boulder in Camp 4 now reminds campers and visitors of this special designation.

The more valuable outcome of this contention, however, has been the strong, respectful and collaborative stakeholder relationship that has expanded since that time. By using the 'spark' of this trusted emissary who shared the values of both groups, climbers and NPS officials ignited a warm and mutually beneficial dialogue that led to common ground on this issue in Yosemite National Park.

Impressive progress can be made in protected area management when recreational users are not seen as 'part of the problem' but rather are productively engaged as respected partners who can be 'part of the solution'. By developing a mutually beneficial and collaborative working style such as this, based on mutual respect and a shared vision for these places, protected area stakeholders can optimise the concept and scale of land management. 


\section{References}

Recommended reading

Alcorn, J. (2010) Indigenous Peoples and Conservation, Conservation White Paper Series, MacArthur Foundation, Chicago.

Anderson, T. L. and James, A. (eds) (2001) The Politics and Economics of Park Management, Rowman \& Littlefield, Lanham, MD.

Annandale, M. and Feary, S. (2009) Consulting with Aboriginal and Torres Strait Islander communities: agroforestry in north Queensland, RIRDC Report No. 08/168, Rural Industries Research and Development Corporation, Canberra.

ANUTECH Development International (1998) Ecological Sustainable Forest Management and Native Title, ANUTECH Proprietary Limited, Canberra.

Armitage, D. R., Plummer, R., Berkes, F., Arthur, R. I., Charles, A. T., Davidson-Hunt, I. J., Diduck, A. P., Doubleday, N. C., Johnson, D. S., Marschke, M., McConney P., Pinkerton, E. W. and Wollenberg, E. K. (2009) 'Adaptive co-management for socialecological complexity', Frontiers in Ecology and the Environment 7: 95-102.

Arnstein, S. (1969) 'A ladder of citizen participation', Journal of the American Institute of Planners 35: 216-24.

Bäckstrand, K., Khan, J., Kronsell, A. and Lövbrand, E. (eds) (2010) Environmental Politics and Deliberative Democracy: Examining the promise of new modes of governance, Edward Elgar, Cheltenham, UK.

Beierle, T. C. and Cayford, J. (2002) Democracy in Practice: Public participation in environmental decisions, RFF Press, Washington, DC.

Borrini-Feyerabend, G., Pimbert, M., Farver, M. T., Kothari, A. and Renard, Y. (2007) Sharing Power: A global guide to collaborative management of natural resources, Earthscan, Sterling, VA.

Byron, I. and Curtis, A. (2001) 'Landcare in Australia: burned out and browned off', Local Environment 6(3): 311-26.

Connor, R. and Dovers, S. (2004) Institutional Change for Sustainable Development, Edward Elgar, Cheltenham, UK.
Creighton, J. L. (2005) The Public Participation Handbook: Making better decisions through citizen involvement, Jossey-Bass, San Francisco.

Cundill, G. and Rodela, R. (2012) 'A review of assertions about the processes and outcomes of social learning in natural resource management', Journal of Environmental Management 113: 7-14.

DeRose, A. (2004) 'Overview of community participation at the Vth IUCN World Parks Congress', Parks 14(2): 18-29.

Dobson, A. (2003) Citizenship and the Environment, Oxford University Press, Oxford.

Dovers, S. and Hussey, K. (2013) Environment and Sustainability: A policy handbook, 2nd edn, The Federation Press, Sydney.

Dryzek, J. S. and Niemeyer, S. (2010) Foundations and Frontiers of Deliberative Governance, Oxford University Press, Oxford.

Dudley, N. (2008) Guidelines for Applying Protected Area Management Categories, IUCN, Gland.

Eadens, L. M., Jacobson, S. K., Stein, T. V., Confer, J. J., Gape, L. and Sweeting, M. (2009) 'Stakeholder mapping for recreational planning of a Bahamian National Park', Society and Natural Resources 22: 111-27.

Evans-Cowley, J. and Hollander, J. (2010) 'The new generation of public participation: internet-based participation tools', Planning, Practice and Research 25: 397-408.

Fitzsimons, J. A. and Wescott, G. (2008) 'Evolving governance arrangements in multi-tenure reserve networks', Environmental Conservation 35: 3-7.

Fitzsimons, J., Pulsford, I. and Wescott, G. (eds) (2013) Linking Australia's Landscapes: Lessons and opportunities from large-scale conservation networks, CSIRO Publishing, Melbourne.

Folke, C., Hahn, T., Olsson, P. and Norberg, J. (2005) 'Adaptive governance of social-ecological systems', Annual Review of Environment and Resources 30: 441-73.

Hall, M. C. and McArthur, S. (1998) Integrated Heritage Management: Principles and practice, Stationery Office, London. 
Healey, P. (1997) Collaborative Planning: Shaping places in fragmented societies, Macmillan, London.

Hill, R., Walsh, F., Davies, J. and Sandford, M. (2011) Our Country Our Way: Guidelines for Australian Indigenous protected area management plans, CSIRO and Australian Government, Cairns, Queensland.

Holley, C., Gunninham, N. and Shearing, C. (2012) The New Environmental Governance, Routledge/ Earthscan, New York.

Holling, C. S. (ed.) (1978) Adaptive Environmental Management and Assessment, Wiley, Chichester, UK.

Howlett, M., Ramesh, M. and Perl, A. (2009) Studying Public Policy: Policy cycles and policy subsystems, 3rd edn, Oxford University Press, Don Mills, Ontario.

International Union for Conservation of Nature (IUCN) (2014) Hope for a Protected Planet with Protected Areas, IUCN, Gland. <www.iucn.org/ about/work/programmes/gpap_home/pas_gpap/>

Keen, M., Brown, V. and Dyball, R. (eds) (2005) Social Learning in Environmental Management: Towards a sustainable future, Earthscan, London.

Larson, P. (2006) Reconciling indigenous peoples and protected areas: rights, governance and equitable cost and benefit sharing, Discussion Paper, IUCN, Gland.

Lee, K. N. (1993) Compass and Gyroscope: Integrating science and politics for the environment, Island Press, Washington, DC.

Lockwood, M. (2010a) 'Good governance for terrestrial protected areas: a framework, principles and performance outcomes', Journal of Environmental Management 91: 754-66.

Lockwood, M. (2010b) 'Scoping the territory: considerations for connectivity conservation managers', in G. L. Worboys, W. L. Francis and M. Lockwood (eds) Connectivity Conservation Management: A global guide, pp. 34-51, Earthscan, London.

Lockwood, M., Davidson, J., Curtis, A., Stratford, E. and Griffith, R. (2010) 'Governance principles for natural resource management', Society and Natural Resources 23: 986-1001.
DeCool, S., Nkhata, B., Breen, C. and Freimund, W. A. (2013) 'A heuristic framework for reflecting on protected areas and their stewardship in the 21st century', Journal of Outdoor Recreation and Tourism 1-2: 9-17.

McNeely, J. (ed) 2006. Friends for Life: New partners in support of protected areas, IUCN, Gland.

Mayers, J. and Vermeulen, S. (2002) CompanyCommunity Forestry Partnerships: From raw deals to mutual gains, IIED, London.

Moorcroft, H., Ignjic, E., Cowell, S., Goonack, J., Mangolomara, S., Oobagooma, J. and Waina, N. (2012) 'Conservation planning in a cross-cultural context: the Wunambal Gaambera Healthy Country Project in the Kimberley, Western Australia', Ecological Management and Restoration 13(1): 16-25.

Nkhata, B. A. and McCool, S. (2012) 'Coupling protected area governance and management through planning', Journal of Environmental Policy and Planning 14: 394-410.

O’Faircheallaigh, C. (2010) 'Public participation and environmental impact assessment: purposes, implications, and lessons for public policy making', Environmental Impact Assessment Review 30: 19-27.

Ojha, H., Hall, A. and Sulaiman, R. (eds) (2013) Adaptive Collaborative Approaches in Natural Resource Governance: Rethinking participation, learning and innovation, Routledge/Earthscan, New York.

Ostrom, E. (1990) Governing the Commons: The evolution of institutions for collective action Cambridge University Press, Cambridge.

Outdoor Industry Association (OIA) (2012) Ensuring the Growth and Success of the Industry, Annual Report, Outdoor Industry Association, Boulder, CO. <outdoorindustry.org/PDF/2012-OIAAnnual-Report-med-res.pdf>

Paehlke, R. C. (2003) Democracy's Dilemma: Environment, social equity and the global economy, MIT Press, Cambridge, MA.

Philanthropy Australia (2014) Frequently Asked Questions, <www.philanthropy.org.au/toolsresources/frequently-asked-questions-faq/> 
Plummer, R., Armitage, D. R. and de Loë, R. C. (2013) 'Adaptive co-management and its relationship to environmental governance', Ecology \& Society 18: 1-15.

Prell, C., Hubacek, K. and Reed, M. (2009) 'Stakeholder mapping and social network analysis in natural resource management', Society and Natural Resources 22: 501-18.

Project Janszoon (2014) Together Restoring the Abel Tasman, Project Janszoon, Nelson, New Zealand. $<$ www.janszoon.org/>

Rhodes, R. A. W. (1997) Understanding Governance, Open University Press, Maidenhead, UK.

DD Ross, A., Sherman, K., Snodgrass, J., Delcore, H. and Sherman, R. (2011) Indigenous Peoples and the Collaborative Stewardship of Nature, Left Coast Press, Walnut Creek, CA.

SEWPAC [Department of Sustainability, Environment, Water, Population and Communities] (2012) CAPAD National Summary. <www.environment. gov.au/noide/34737>

SEWPAC [Department of Sustainability, Environment, Water, Population and Communities] (2013) Annual Report 2012-13. Commonwealth of Australia, Canberra.

Schattschneider, E. E. (1983 [1975]) The Semisovereign People: A realist's view of democracy in America, Holt, Rinehart \& Winston, Fort Worth, TX.

Smyth, D. (2001) 'Joint management of national parks', in R. Baker, J. Davies and E. Young (eds) Working on Country, pp. 60-74, Oxford University Press, Melbourne.

Sydney Morning Herald (2013) Aussies the world's richest people: Credit Suisse. <www.smh.com.au/ business/the-economy/aussies-the-worlds-richestpeople-credit-suisse-20131009-2v7qy.html>

UIAA (International Climbing and Mountain Federation) (2013a) UIAA Mountain Protection Award, UIAA, Bern. <www.mountainprotection. theuiaa.org>

UIAA (International Climbing and Mountain Federation) (2013b) Website. <www.theuiaa.org>

United Nations (2004) The Concept of Indigenous Peoples, UN, New York.
United Nations (2009) State of the World's Indigenous Peoples, UN, New York.

Waters Consultancy Proprietary Limited (2013) Cullunghutti: The mountain and its people, Office of Environment and Heritage, Nowra, NSW.

Waters, K. and Moon, C. (2005) Lower Shoalhaven River Valley Aboriginal cultural mapping places project, Community report, NSW National Parks and Wildlife Service, Nowra, NSW.

Worboys, G. L., Francis, W. L. and Lockwood, M. (eds) (2013) Connectivity Conservation Management: A global guide, Earthscan, London.

Wunambal Gaambera Aboriginal Corporation (WGAC) (2010) Wunambal Gaambera Healthy Country Plan_Looking after Wunambal Gaambera country 2010-2020, WGAC, Garmbemirri, WA.

Wyborn, C. (2013) 'Collaboration across scales: the governance challenges of linking landscapes', in J. Fitzsimons, I. Pulsford and G. Wescott (eds) Linking Australia's Landscapes: Lessons and opportunities from large-scale conservation networks, pp. 267-76, CSIRO Publishing, Melbourne.

Wyborn, C. and Dovers, S. (2014) 'Prescribing adaptiveness in agencies of the state', Global Environmental Change 24: 5-7. 


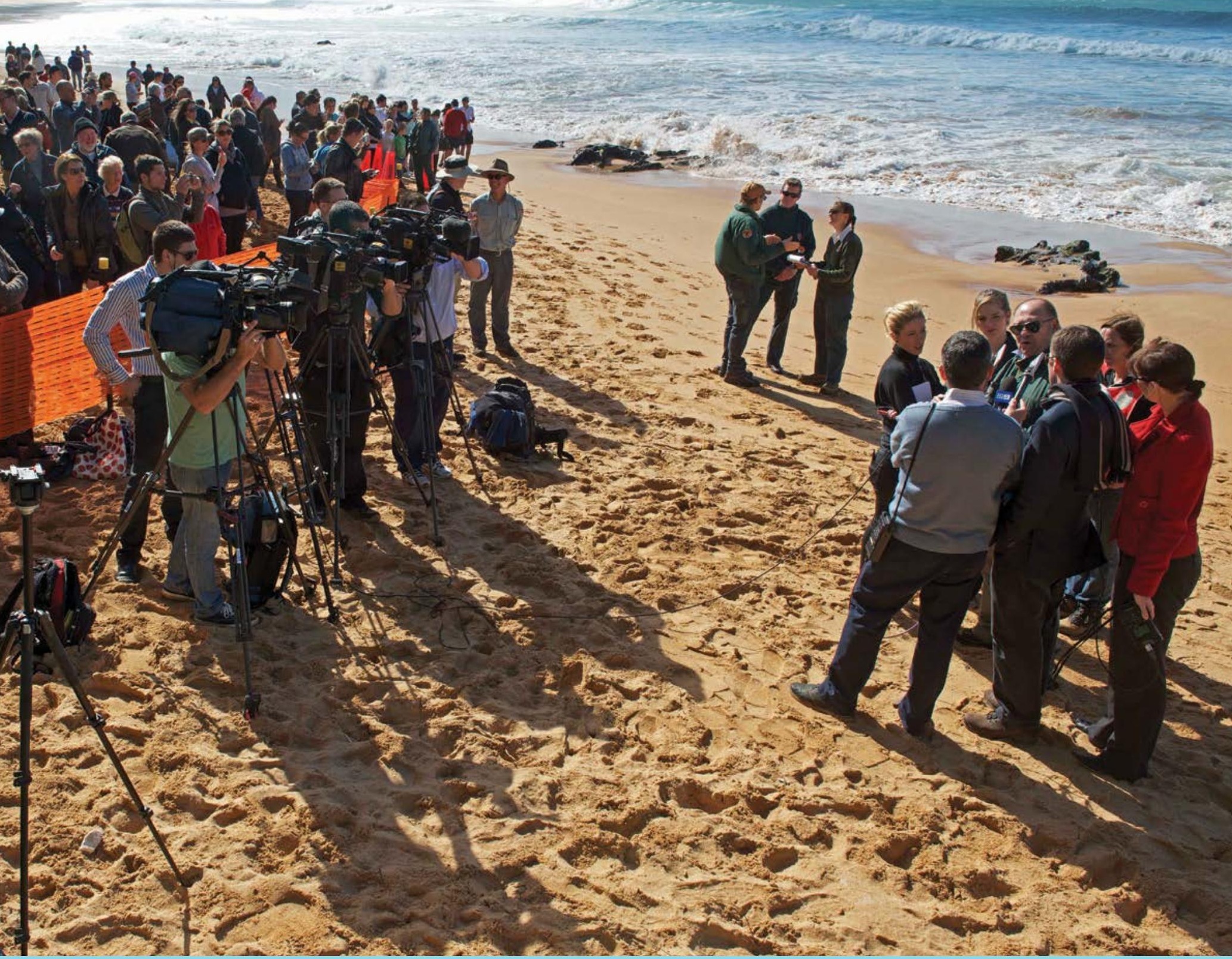

\section{CHAPTER 15}

THE MEDIA AND PROTECTED

$A R E A S$

Principal author:

Stuart Cohen

\section{Supporting authors:}

John Dengate, Lucy Morrell and Kimberley Lee

\section{CONTENTS}

Introduction

- Types of media

- Strategic use of the media

- Media planning

- News releases and media interviews

- Media management skills

- Communication planning

- Media management at major incidents

- Conclusion

- References
IUCN 


\section{PRINCIPAL AUTHOR}

STUART COHEN is Senior Public Affairs Officer for the NSW Office of Environment and Heritage, Australia.

\section{SUPPORTING AUTHORS}

JOHN DENGATE is a media naturalist and author, and previously public affairs manager for the NSW Environment Protection Authority and the National Parks and Wildlife Service, Australia.

LUCY MORRELL works in media and public relations for the NSW Government, Australia.

KIMBERLEY LEE is a freelance digital and social media consultant based in New South Wales, Australia.

\section{CITATION}

Cohen, S., Dengate, J., Morrell, L. and Lee, K. (2015) 'The media and protected areas', in G. L. Worboys, M. Lockwood, A. Kothari, S. Feary and I. Pulsford (eds) Protected Area Governance and Management, pp. 441-472, ANU Press, Canberra.

\section{TITLE PAGE PHOTO}

NSW National Parks and Wildlife marine specialist Geoff Ross briefing the media in relation to a marine mammal incident, Newport Beach, Sydney, Australia

Source: Stuart Cohen 
So you must be crafting your messages and approach in a far more complex manner that considers the different modes of delivery, from newspaper and television to email, from Facebook to Twitter and so on.

\section{Types of media}

\section{Traditional mainstream mass media}

Throughout the 20th century, the definition of the media covered the three primary mediums of radio, television and print, but digital and internet technologies of the past decade in particular have changed significantly the range and types of media that are now in use. The traditional mainstream media and the newer social media have merged to become multifaceted communication platforms. Few of the mainstream traditional media, for example, function today without a website offering the full range of media within. A traditional newspaper, while continuing to exist in hardcopy, also exists as a digital version that can be accessed on mobile devices. This system offers additional access to video and photography, infographics and podcasts plus the ability for the reader to interact and respond in a way that is instant and constant. There are also a growing number of newspapers that do not print hardcopy and exist solely online. Furthermore, the arrival of social media and the massively increased range of options for the audience to source daily news have resulted in a steady and marked decline in the audience of traditional mainstream media and a resultant drop in profits that has impacted significantly on the capacity of the media to report news as it has done in times past. This has had a big impact on how news is gathered and by whom, with the result that the media - previously quite particular about what it will report-is now more likely to run your story if it is well presented.

What all this means is that traditional media still exists, but now alongside the new digital media as independent and overlapping mediums for communication. This is because some people, particularly older generations, will continue to access their news and information in traditional ways while a younger cohort has clearly started moving away from this as they adopt faster, more instantaneous and interactive digital news formats accessible on a growing range of mobile devices such as the smart phone and tablet.

It is very important to realise that within the traditional media there are various shades, colours and attitudes highlighting differing sociopolitical agendas. Despite an underlying philosophy of maintaining objectivity within the news gathering and reporting process, commercial and public broadcasters and newspapers can approach the issues around protected area management with vastly different attitudes. Even the notions of objectivity and balance can no longer be taken for granted as the democratisation of information in the internet age has blurred the lines between traditional reporting and commentary. As a protected area manager, you need to be aware of these attitudes, as they will govern the direction a journalist will take on any particular story.

Bear in mind that, aside from publicly funded media, the media in general is there to make a profit primarily through advertising, and to do that newspapers must be sold and there must be an audience for radio and television. Therefore the content provided by the media must attract, engage and maintain a readership or audience and this drives the approach taken in the reporting of news. More commercial television stations may take a much harder or more emotive line in reporting conflict than might a publicly funded station. Some newspapers (and journalists) will be more sympathetic towards the environment than others. It will always pay to know just where they stand before you pitch or explain a potential story to a journalist.

\section{Social media}

The advent and rapid manifestation of social media and internet communications have revolutionised the dissemination of information and the ability of people to correspond and connect. Communication of one to one, one to many and many to many has never been easier on hyper-local and global scales. The public is no longer reliant on receiving news and information from traditional mass media sources.

The ability to instantly share events and news as it happens using mobile devices has given momentum to the phenomenon of 'citizen journalists' and 'online influencers' who can establish their own broadcast channels from the thousands of social media platforms available. Many of these have an integrated function, which enables publishing to one platform and pushing the content to many others at the same time.

What was once the exclusive domain of large media companies with the capital to afford expensive infrastructure is now within the reach of the general public. In 1990 the production of television news, for example, and the ability to broadcast were only possible with the backing of financial and technical resources well beyond the average individual. Today the same 


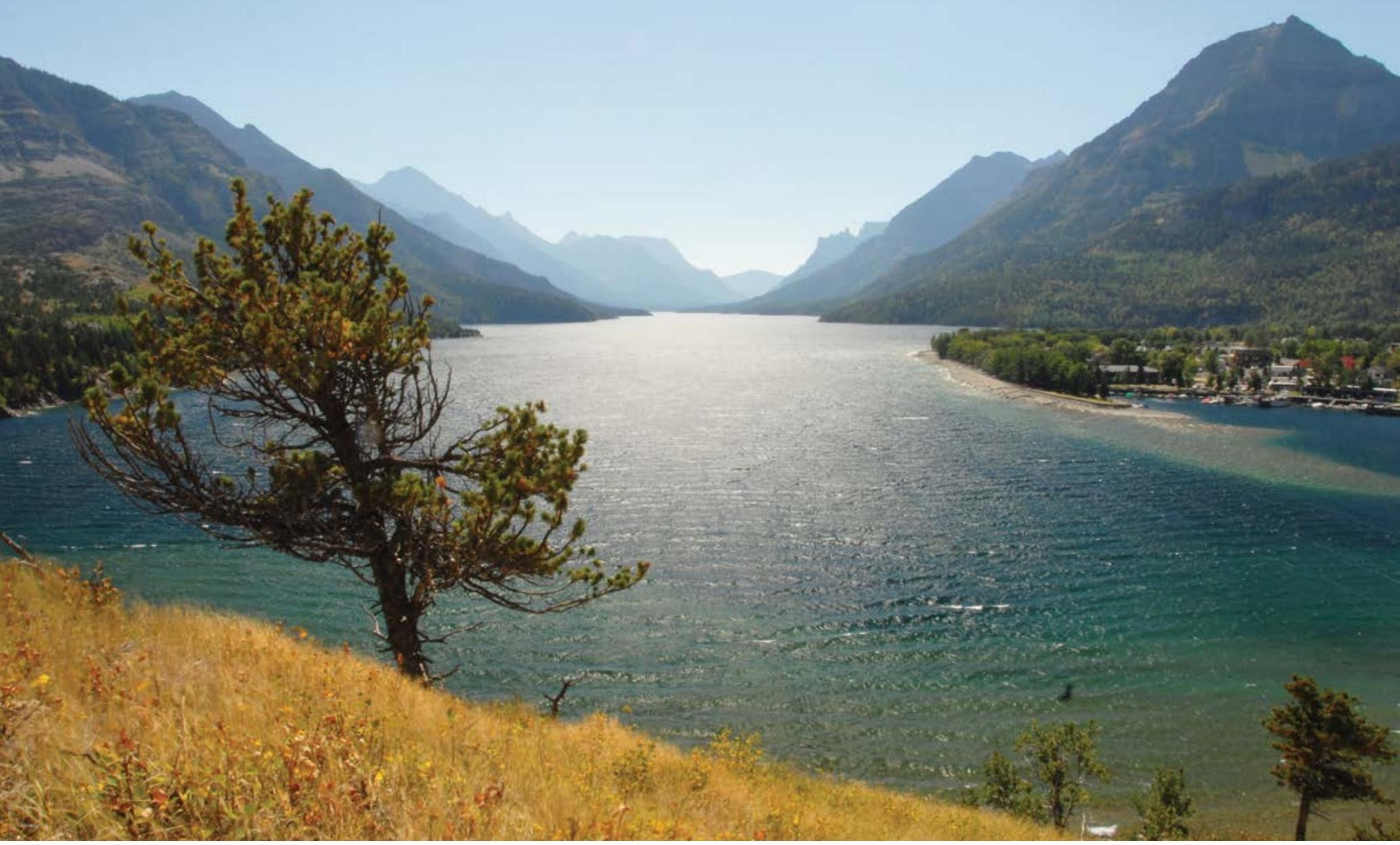

The spectacular landscape of Waterton National Park, an International Peace Park, Canada

Source: Charles Besançon

individual can shoot, edit and produce a high-quality multimedia news broadcast from their bedroom using a single smart phone or tablet.

The ease of content creation has, however, resulted in an overload of available information, and the ability to filter out accurate information is clouded by this massive volume of noise online. This means those with recognised governing roles and responsibilities, such as government agencies, need to strengthen their voice as the official source of information.

Social media allows you to share information directly with stakeholders and communities more easily and efficiently. You can now publish as much information as needed as often as needed without relying on traditional media for dissemination.

Social media has an unquenchable thirst for stunning imagery in the form of photos and video content, so for protected area managers the world over this is incredibly beneficial in promoting conservation values because the subject matter within protected areas is so photogenic, whether it is a panoramic landscape or a newly discovered species of insect.

\section{The social media broadcast channel}

A typical social media broadcast might look like this: a piece of news is published on the organisation's blog that may sit within their website or as a sub-brand. If the blog post contains images, video or audio, this content may be hosted on a specific platform such as Flickr, YouTube, Vimeo or SoundCloud that sits embedded in the blog post. Then a link to the news is shared with the headline or other appropriate descriptor via a number of social media platforms each with a specific purpose and audience such as Facebook, Twitter, Instagram and Vine.

Social media has enabled the development of a constantly evolving news service with information relevant and interesting to an audience which has opted in to receiving content. Offering 'push notifications' available on some social networks such as Twitter can alert people to news items in real time. This audience can grow to become a robust online community whose members share, comment and engage in conversation with one another and with the organisation or agency.

The fundamental difference between people's use of traditional news media compared with social media platforms is the facilitation of interaction with and 


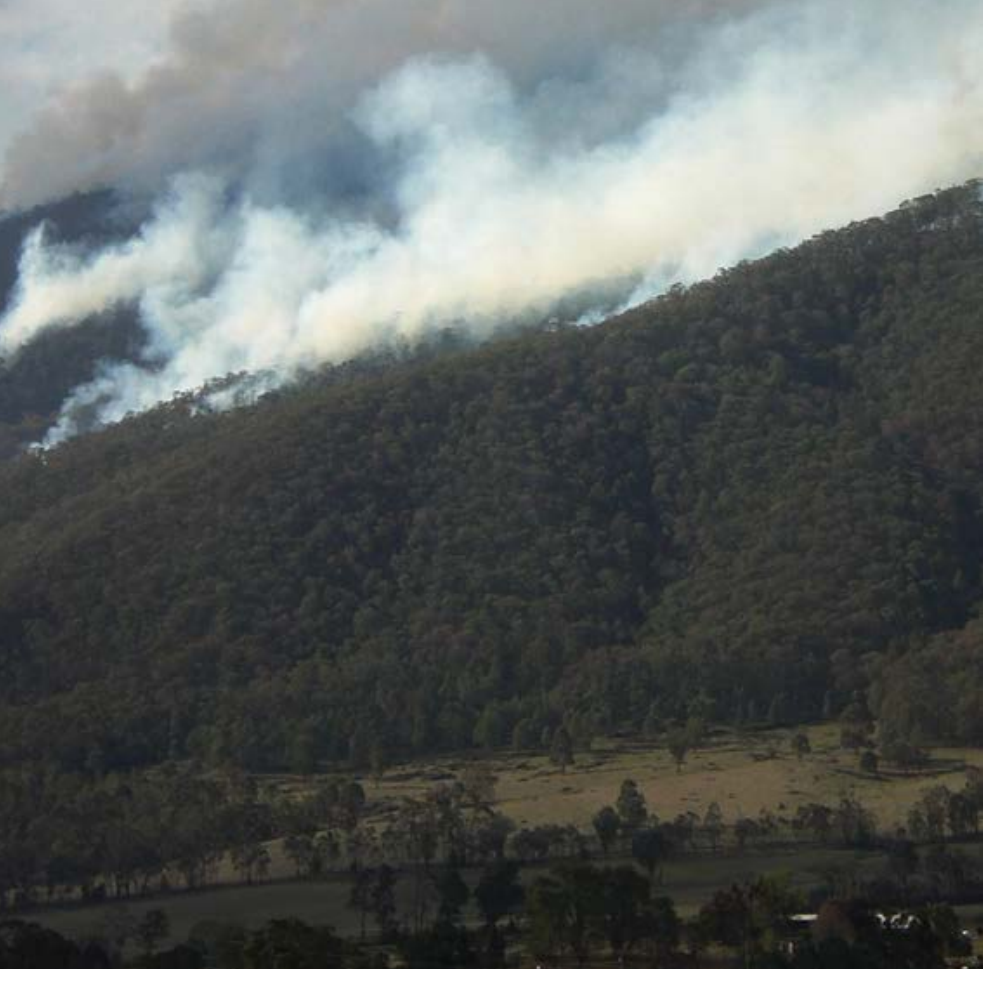

Prescribed burning to reduce fire fuels, Victorian Alpine National Park, Australia

Source: Graeme L. Worboys

between anyone also using that social network in a manner that traditional news media in the past did not offer. It is important, however, to note the integration of social media with traditional news and how the media uses social networks to stay relevant and connected with their audiences. The traditional media is also looking to social media for news items, sources and content. The relationship between traditional news media and social media is evolving at a rapid pace so it is important to stay up to date with how they are being used together.

While your audience will take time to build, it is possible to grow an online community with bigger reach than traditional media channels. While your audience may at times be small, one of its most valuable qualities is that it is one that has come to you willingly and with a direct interest in the news and information you have to share. In the management of protected areas around the world, the establishment of your social media broadcast channel is increasingly important in selling messages that help meet your management objectives.

Sharing news and content can help an organisation drive the discussion agenda. Conversely, listening to conversations online about your organisation and relevant themes and topics can help an organisation better understand sentiment, stakeholder needs and assist with issues and crisis management.

The opportunity truly exists and will at times surprise you, when content you post strikes a chord with an audience and suddenly goes viral and is viewed overnight by thousands, and if you have really hit the mark, millions.

\section{Strategic use of the media}

No matter how large or small, any conservation agency or non-governmental organisation (NGO) managing protected areas must consider media management strategically. Failure to do so is fraught. Careful consideration needs to be given to many aspects of media management. Your agency's media strategy must consider the following.

- Objectives: What exactly are you trying to achieve for protected area management in the process of engaging the media?

- Messaging: What are the key messages the agency wants to promote?

- Resources: What equipment will be necessary to implement effective media management such as office infrastructure, computers, sound recorders and cameras?

- Staffing: How many people will be required and what skill sets will they need?

- Spokespeople: Who will be chosen as the primary spokespeople for the agency and do they present well? Which people will be best able to represent the agency on specific subjects?

- Media policy and protocols: To whom will you delegate the responsibility to talk to the media? What steps should staff take when contacted by a journalist? When should a media issue be escalated to higher authorities?

\section{Using the media to build your case}

The media will play an important role in building your case or argument on a subject of importance to the management of protected areas. It might be about fire or pest management or issues related to visitor access, but a carefully considered media plan can be very helpful in swinging public opinion in the direction you need. The aim is to find situations and circumstances related directly to the issue and promote them in the media over an extended period in a way that continues to validate and strengthen your argument. 

a minor disaster on a localised level can be just as impactful and therefore relevant to a country-town newspaper.

- Conflict: Much of our daily news is about conflict, whether it is distant wars or arguments between political parties. Conflict is a primary ingredient of what constitutes news.

- Proximity: The location of a story and how close it might be to a given audience combined with other news values may make a news story. In other words, if the event, incident or conflict occurred within the broadcast area of a radio station, proximity will ensure it is a lead story in a bulletin.

- Magnitude: When something is big on a scale that is noteworthy to an audience, it has a magnitude that makes it a news story.

- Oddity: When something is odd or very much out of the ordinary it can be newsworthy-for example, the discovery of an unusual creature, odd events or behaviours. It was once said that 'dog bites man' is not newsworthy, but 'man bites dog' is.

- Negativity: Everyone knows bad news sells a newspaper better than good news. When something goes wrong or when someone does something wrong it is far more likely to be reported than when the opposite has happened.

- Celebrity: Someone who is famous, locally or internationally, is also assured of space in a news bulletin and often not for doing anything of particular note other than just being well known.

- The 'st' factor: If you are describing the magnitude or scale of something in words that end in 'st' then you more or less have a certain news story. In other words, if it is the biggest, widest, longest, fastest or worst, it is very likely to be covered by the media.

Ultimately, the single biggest factor is relevance to the audience. Editors ask themselves, 'How much does this event affect my audience?' If the answer is 'a lot' then the item has news value.

\section{The news gathering process}

The process of gathering news is endless and relentless. No sooner is one story used than another must replace it in a round-the-clock process. To gather news, journalists must seek information from a wide variety of sources, analyse it quickly and decide whether it carries enough 'news values' for it to warrant publication or broadcast. This information comes to the journalist from a variety of sources, both formal and informal. Perhaps the most common is in the form of the 'press release', also

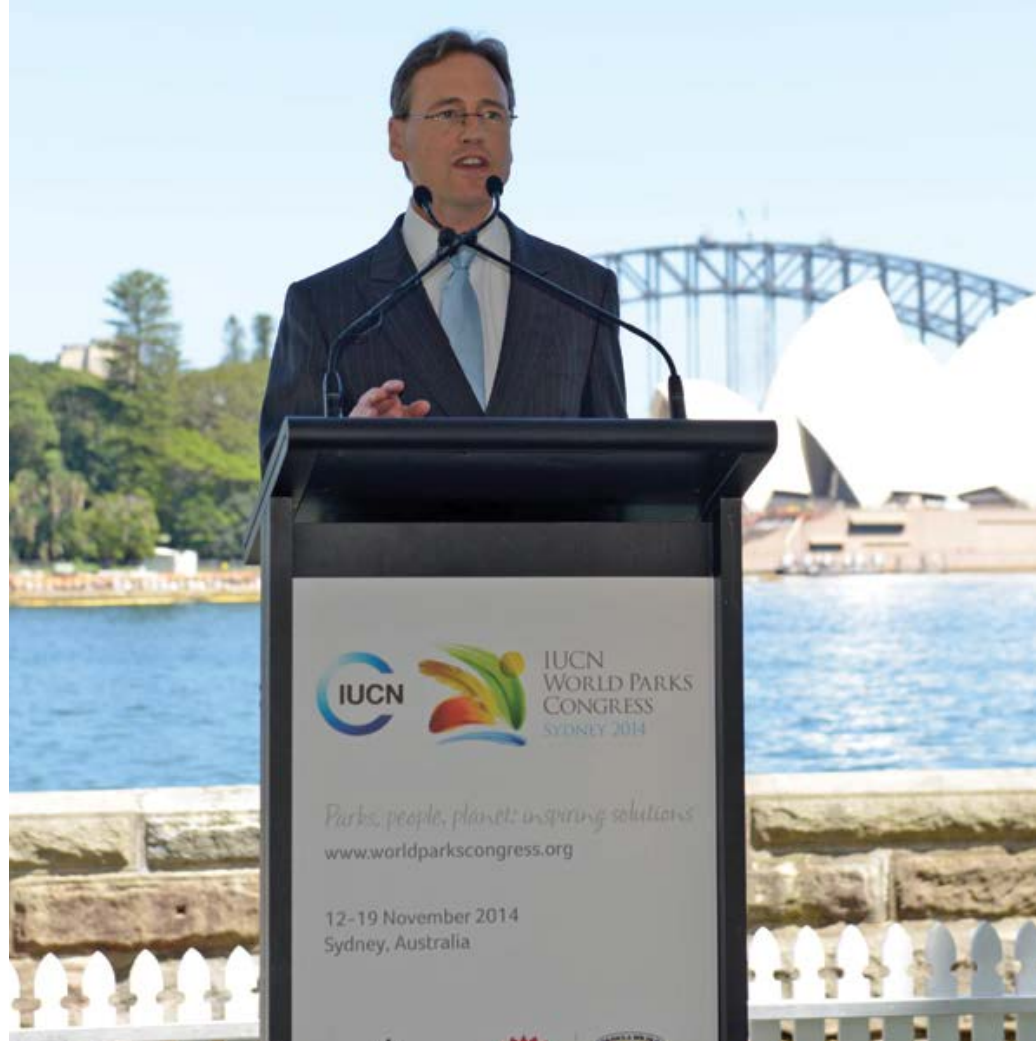

Australian Government Minister for the

Environment, The Honourable Mr Greg Hunt MP, launches the official commencement of the Sydney November 2014 IUCN World Parks Congress preparation, Sydney Harbour, Australia

Source: Graeme L. Worboys

called a 'news release' or, better still, 'media release'. These documents are generally sent to the journalist from individuals or organisations seeking to pitch story ideas to promote their particular agendas, messages or needs.

Journalists also receive information directly by phone, email or by monitoring other news organisations. Importantly, 'personal contacts' are a mainstay in the news gathering process. Journalists will maintain and nurture a good contact as a primary source of news. This relationship is usually one that is beneficial to both the journalist and the contact. Social media has become another important tool in the news gathering process. A recent survey of more than 400 Australian journalists found that 40 per cent sourced stories from social media on a daily basis, with two-thirds saying social media has made it easier for journalists to source content and 89 per cent saying social media spreads stories more quickly to increase readership (Newsmaker 2013).

There are also news organisations known as 'wire services', such as Reuters and Associated Press, which do not broadcast directly to the public but which produce news around the clock for other news organisations that pay for this service. 


\section{Media planning}

\section{Preparation of a media plan}

Inevitably, planning to engage media on a particular subject is usually part of a larger plan aimed at communicating targeted messages to a specific audience. Media plans are rarely complicated but need to consider some strategic objectives. Key considerations include:

- objective

- key messages

- audience

- targeted media

- spokesperson or spokespeople

- whether a media release is required

- whether other supporting materials are required

- supplying video and/or photos

- transport

- locations

- news conference

- monitoring.

\section{Types of media event}

\section{Openings and launches}

You will want good reason to undertake an opening or launch of any type, as they frequently require a lot of resources and staff. There are two reasons for staging an opening or launch. The first is good stakeholder management-that is, an opportunity to celebrate an achievement for which the community and stakeholders can be praised and where media coverage is of less importance. The second reason is if the potential media coverage is likely to be worth the trouble and definitely positive.

An event of this nature may involve:

- executive approval

- guests of honour and VIPs

- carefully considered invitation lists-do not invite people likely to be critics at an event if this can be helped

- invitation lists: you need to ensure you have invited the most appropriate people with due regard to those who might be offended if they have been left off this list

- information: reports, facts sheets and media kit containing additional information

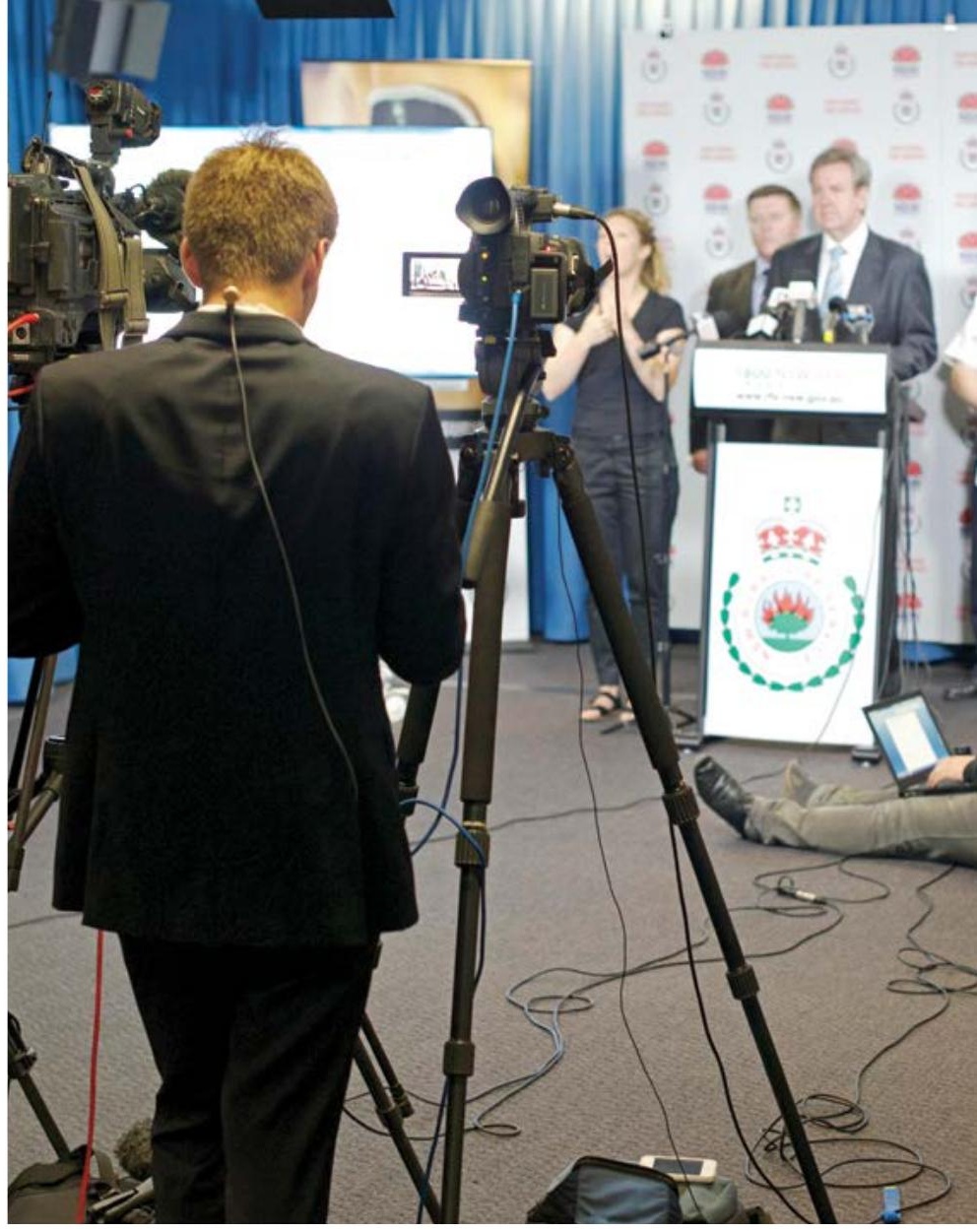

Media conference involving the Premier of New South Wales, State Operations Centre, Sydney Source: Stuart Cohen

- location and venue organisation: is the venue appropriate and easy to access for the media and invitees?

- consideration of timing so the event or launch does not conflict with other events, holidays or major sporting or cultural events

- transport, especially for groups or individuals who might be disadvantaged financially or socially

- speech notes and background briefing for key speakers and guests

- photographers-make sure you have a photographer or videographer on hand if possible and use the opportunity to tweet images and video or even post to Facebook or YouTube to promote the event.

\section{News conferences}

As with any major event, you will want to think carefully about why you would want to host a news conference. You will decide to stage a press conference for two reasons. The first is because the announcement you have to make is of such importance that you are likely to receive so many requests for media interviews so the easiest way to manage large numbers of media is to stage a single news conference where all media can be present at once. The other reason is that you want to give the announcement greater impact. Having a large group of journalists gather in one location to hear the details of 


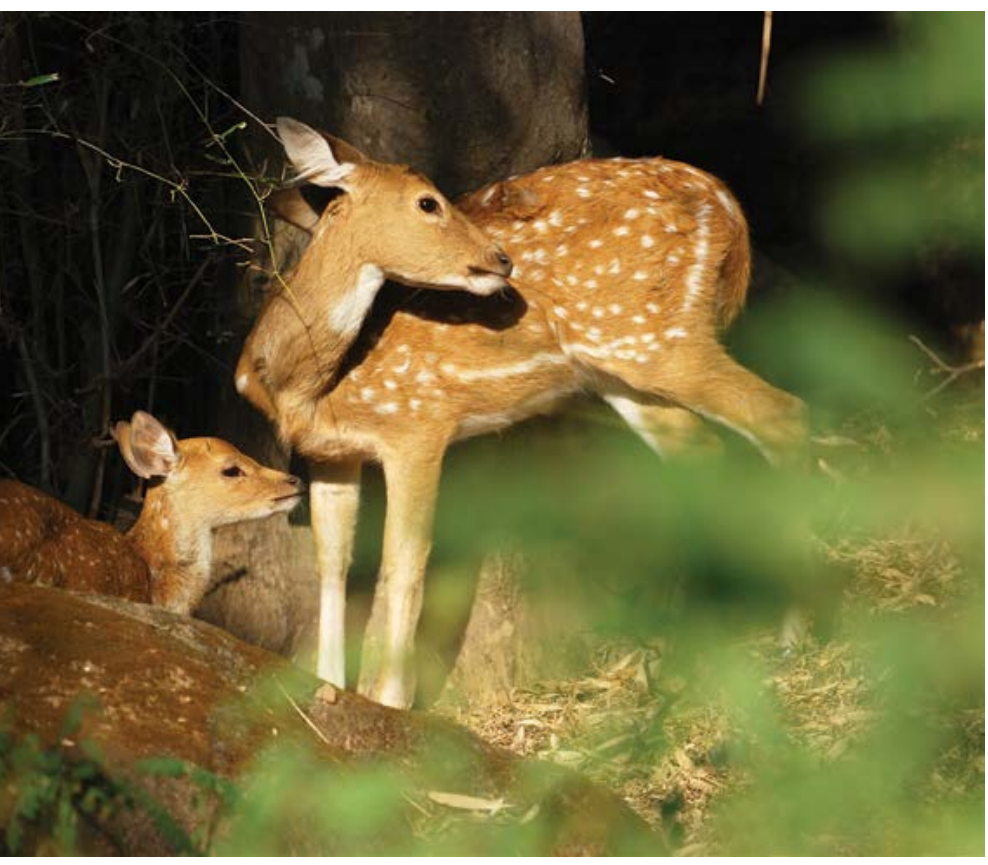

Indian spotted deer (Axis axis), Bandhavgarh National Park, India

Source: Ashish Kothari

your announcement provides additional impact, which gives your announcement a sense of gravitas that would not otherwise be achieved by one-on-one interviews.

It is good to remember that your announcement must be important in the truest sense of the word. It can be embarrassing to stage a news conference at which there is little or no media attendance. If you have bad news to convey, you need to think very carefully about whether a news conference is wise. Gatherings of large numbers of media to announce anything that may be greeted negatively or with suspicion can result in an atmosphere of real tension when the media starts an aggressive line of questioning of the key spokespeople presenting at the conference.

\section{Type of media targeted}

When deciding how best to present the issue or story you want to promote in the media, you will need to give thought to the type of media that best suits. Frequently, a story you want to push to the media will work on all mediums; however, not every story will work for all types of media. A radio story may not be suitable for television and a television story may not work for a newspaper.

\section{Television}

This is a highly visual medium. No pictures can often mean no story. 'Vision'-that is, video imageryis essential to illustrate the narrative in the story.
Fortunately, most stories regarding protected areas lend themselves well to television because of the very nature of the subject and the imagery that matches. Frequently, however, because protected areas can be remote from major television stations, it may pay for you to provide video you have organised separately in advance.

\section{Print}

Newspapers and magazines are not dissimilar to television in the desire for visual impact although photos are not essential. The promise of a great photo, however, frequently provides additional motivation for a journalist to chase a story without which he or she might not write. A good photo can and often will lift the prominence of your story from the back pages of a magazine or newspaper to the front news pages. A spectacular photo can result in a relatively average news story making it to page one. With smaller regional newspapers, which lack the resources of large metropolitan dailies, it is always a good idea to provide good-quality photos with your media release.

\section{Radio}

The primary attribute of radio from a news perspective is its immediacy. Radio has the capacity to broadcast things as they happen in real time. Stations that produce news and current affairs as part of their staple will generally produce news bulletins on a half-hourly or hourly basis and program talk and current affairs content in between, with the added capacity to break into regular programming to update the audience on important events that have just occurred. While on many occasions stories might not suit television or print because obtaining vision or photos might not be possible, radio can generally cover most issues.

\section{Social media}

There are hundreds of social media platforms available that are valuable tools for promoting protected areas and their management. An integrated approach to social media and traditional media management will provide more robust communication and engagement with your stakeholders. Social media tools are evolving rapidly. While many government agencies around the world appear slow to adopt the numerous social media channels as a means of communicating compared with the private sector, the pace of growth in this area is gaining momentum.

As a means of publishing, blogging is one of the oldest social media practices although not necessarily the most widely used. One of the advantages of developing a blog is the hub functionality it provides for housing all content 
moves towards a monetary spend requirement from brands, this impacts the reach and success of content on Facebook.

Listed here are some of the available social networks that are widely used, but you should research the gamut of social networks available and which best meet your objectives.

\section{Facebook}

It is important to consider that people use Facebook for social sharing and recording special moments in their lives. To date, this social network has given protected area agencies the opportunity to become broadcasters directly to stakeholders who opt in to receive messages, bypassing the need to go via traditional mainstream media. As a brand on Facebook, you need to research guidelines and best-practice case studies for managing your reputation and opening a direct line of communication with your audience in a very public domain. Define why you want to use Facebook, what you want to achieve, associated risks, required resourcing, expectations for success and how your audience wants your brand to behave on Facebook.

Media photographer, Langshan National Park, China

Source: Graeme L. Worboys

\section{YouTube}

Not long ago the only way to broadcast video news was through a television station. Today, posting to YouTube is instantaneous and possible with a smart phone and internet access. The cost of more sophisticated equipment and editing tools has also become affordable so anyone can shoot, edit and broadcast news and current affairs. Protected area agencies the world over are beginning to embrace YouTube with great results. YouTube can be embedded into your website and shared via other social networks, and the use of tags, titles and descriptions allows people to discover content more easily. It is also one of the most used search engines after Google.

Video-hosting social network YouTube has also had a significant impact on content creation that has positioned this social network as one of the most popular online search engines. Facebook has also captured mass attention and the investment of time and emotion in sharing updates, likes, pokes and photos by users, although as the business model of the platform changes, so do usage and sentiment about the social network.

More and more agencies are establishing Facebook pages, as this platform has been one of the most widely used social networks and one of the first to gain mass popularity. You should assess, however, whether this is really the most suitable platform to meet your objectives as users change the way they use Facebook and how they feel about brands on Facebook, and, as the global giant

\section{Vimeo}

This has similar functionality to YouTube but allows the broadcaster to maintain copyright ownership. Some agencies are now using Vimeo as a cloud storage facility to keep and share broadcast-quality video footage that can be easily sent with a link directly to television broadcasters. This is enormously beneficial when television stations can utilise the footage, as increasing financial pressures limit the ability to justify travelling to remote destinations to cover stories. A protected area agency with staff skilled in shooting reasonable-quality video can store and send the raw footage to a station that is then able to be 'recut' as a news or current affairs story, and because you have provided the vision you have more 
control over what exactly is broadcast. Quality vision can also generate media coverage you may not have otherwise garnered without it. You can even provide interviews that contain precisely the messaging you want.

\section{Twitter}

Twitter is an online social network and microblogging service that enables users to publicly send and receive 'tweets', which are text messages limited to 140 characters. Images can be added directly to tweets and links to sites like YouTube can also be uploaded to a tweet at the cost of a portion of the 140 characters. It is a fast and simple way of communicating with large audiences. Tweets can be shared by 're-tweeting', which can help gain wider exposure to other users' audiences, which can also help build a Twitter following. The more you engage in conversation with other Twitter users, the faster your Twitter community will grow, but remember to refer back to your social media strategy so that tweets and cross-promotion with other Twitter users stay relevant. Responding to tweets should also be timely as the expectation of immediacy is greater on Twitter than on many other social networks. Twitter is popular among influential people such as politicians and celebrities, with the average Twitter user over thirty years of age.

\section{Flickr}

Aside from being a cheap and reliable image library, this is perhaps the most useful site for sharing high-quality photos to a broad audience, especially the news media. Gone are the days of having to email small groups of images to the news media; now you can simply load a large quantity of photos to your Flickr account as a 'set' and then email or tweet a link directly to the media, which can then easily and quickly download the photos. Your agency maintains copyright control and it is a useful cloud storage facility.

\section{Instagram}

The visual nature of this photo and video-sharing social network has attracted a wide audience. Its popularity is growing among those with visually interesting content to share, and it is used by celebrities, influencers and brands to provide a different perspective of information or news being shared publicly. The use of hashtags and re-posting can assist with the discovery of content, which helps grow your following.

\section{Podcasts}

Telling stories is the crux of social media and podcasting provides an effective way to share interviews, discussions, readings, music and sounds best communicated as a direct recording. For example, night-time noises in a protected area can be overlaid with a voiceover that tells the story of nocturnal activity. You may also share recorded statements with traditional media when audio is required or where it adds media value to your pitch.

\section{News releases and media interviews}

\section{Writing a news release}

Journalists decide within seconds on the value of a media release. This may be just seeing your subject line in their email inbox. If you get past this first hurdle, they will open the email and invest a further 10-20 seconds scanning the first few paragraphs for newsworthiness. If a journalist invests time in your media release only to decide it is non-news, you then risk being ignored and they may not bother to open an email from you in future. If you get it right and they like the content then you are on your way to establishing a productive and fruitful relationship with that journalist.

The news release encapsulates the message or story you wish to present and it is issued explicitly to elicit a response from the media. In other words, when you issue a news release to the media you are inviting them to contact you for more information and probably an interview. Therefore you must make yourself available to the media agency to which you have sent the release. Frequently-and this is especially the case for smaller regional media outlets-the news release is reproduced as a news story without calling you for an interview.

The benefits of issuing a news release are many and varied. The news release should always be a well-crafted, considered document written for news, which saves time for any journalist in understanding the issue and it helps to ensure the journalist receiving it gets key facts and figures correct.

The news release, written properly, should get straight to the heart of the matter at hand. It will usually include direct quotes that cannot be used out of context and it is often used word for word. It enables you to clear information for approval with senior management and it sets out your argument in a logical, well-articulated and easily digestible fashion, containing key messages that you will repeat if an interview is required.

At present the media mostly wants to receive releases via email, with web links to images, video and audio where available. Direct email is best because the recipient can 
reply, however, paid distribution services are useful backups if you lack media contacts in a region or for a particular subject.

Be strategic developing and distributing media releases. No matter how valuable your story idea, you are basically requesting free advertising so the content needs to be instantly judged as high quality.

A well-written media release can be used exactly as you have sent it and this is particularly true for resource-poor regional and local newspapers. It will therefore pay to make sure that your media release is well crafted and written as news for news outlets. Traditionally, media releases are written in newspaper style rather than like radio or television news copy. When writing a media release, consider:

- ensuring the top of the page says in large font 'Media release'

- having the agency brand or logo alongside the agency name prominent next to the 'media release' title

- making sure it is clearly dated at the top of the page, and if sending out more than one release on the same subject during the course of a day, such as during incidents like a bushfire, make sure you show the time the release is being issued

- including a punchy headline that summarises the story in a few words

- the very first sentence should encapsulate just what the release or story is about; it contains your news 'hook' or 'angle' - this is the most critical part of the media release as it will tell a journalist whether it is newsworthy

- making sure your release contains the who, how, what, when, where and why but not necessarily in that order

- remembering the key points of newsworthiness

- telling a story

- including critical facts and figures

- using direct quotes

- avoiding the use of agency jargon, in-house terminology and acronyms

- always writing the agency's name in full when first used and then the acronym after that

- always making sure there is a contact name and other contact details such as telephone numbers and email addresses at the bottom so the media can contact you at all hours

- double-checking all facts and figures

- using simple, active, lively and engaging language
- fitting the media release onto one page in a readable font with normal margins

- including relevant links to useful internet sites such as Flickr or Vimeo where photos or broadcast video footage can be downloaded by the journalist.

\section{Where do you send your news release?}

It is fundamental to the management of media that you have a comprehensive media contact list. Building one is essential and it will constantly change as journalists come and go.

The way you decide to structure your list is also important. For most protected area managers, you will need to develop lists that contain the regional media outlets that have a direct interest in what you do as an organisation. For large areas, you might want to consider breaking this list into smaller regions. A newspaper in the far north of your region may have absolutely no interest in protected areas in the south, so you do not want to be sending all your releases to one large list for fear of wasting the time of journalists.

One region may have three or four newspapers, a radio station and television station as a media contact group. You might have half a dozen different groups like this and on occasion when you need to communicate a message that is relevant to all media within the area you manage you will simply send your release to all of the groups. You will also establish a metropolitan media contact group or groups when there is an issue that will be relevant to a much broader audience and this usually pertains to major incidents.

You should also consider establishing a contact list based around particular interests - possibly lifestyle and recreation groups that contain magazines and programs with recreational interests that relate to the protected areas you manage. They could be fishing and boating, camping and bushwalking media outlets. Another group to seriously consider is one based around major incidents and emergencies. Having an email list to which you send urgent information in an emergency will be very important to you and something you do not want to be developing when the incident occurs (see Chapter 26).

\section{Fact sheets}

Facts and figures fascinate the media. They are important additions to your package of information that best illustrate what you are trying to say. A media release, while carrying many facts, cannot always contain all of them, so a fact sheet can be a useful addition to send 


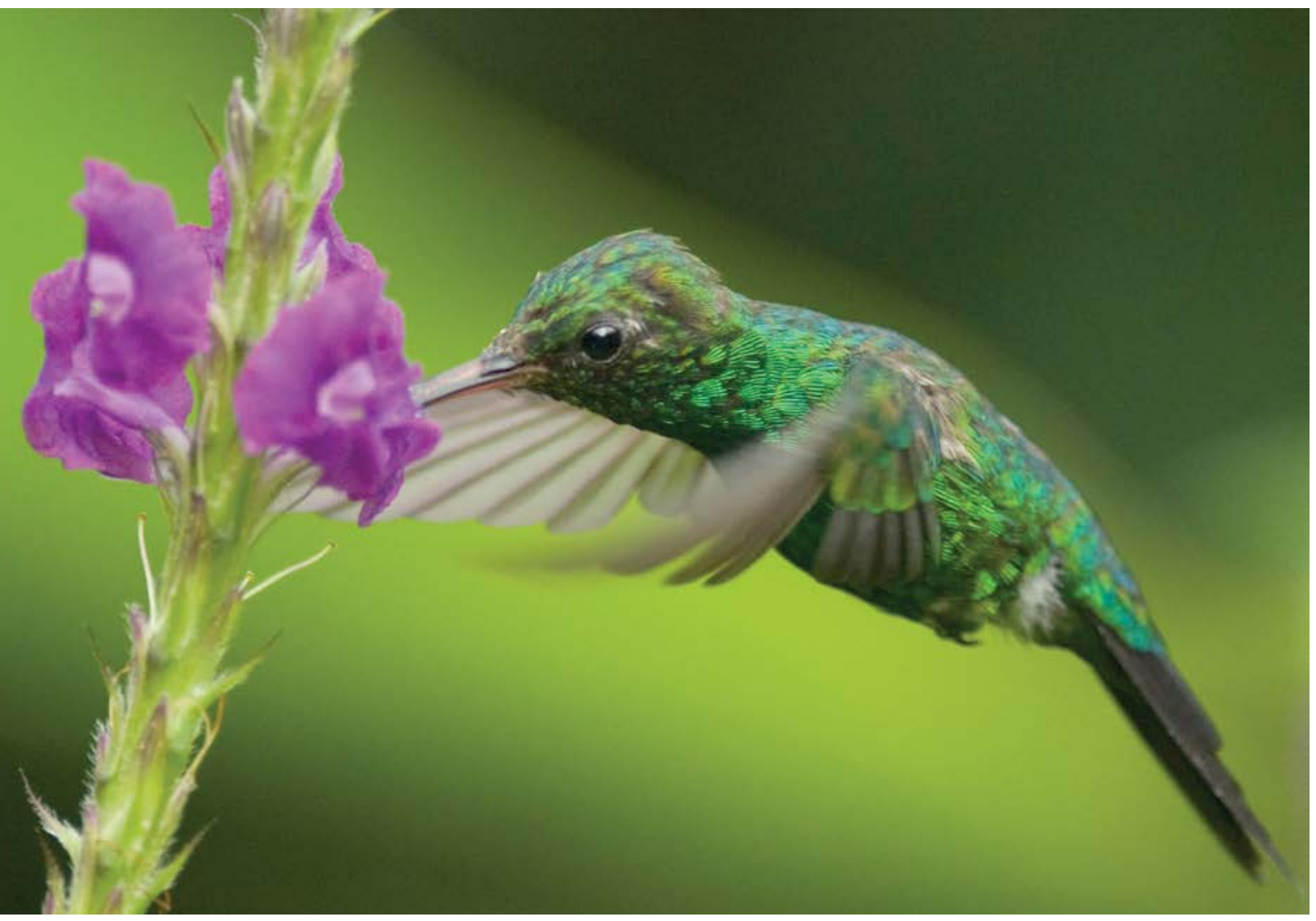

The magnificent garden emerald hummingbird (Chlorostilbon assimilis), an endemic species to Costa Rica and western Panama, protected area, Costa Rica

Source: Charles Besançon

along with a media release. It is always smart to build a series of fact sheets on a variety of issues, from pest management to fire management and tourism, and so on.

\section{Video, photos and other useful tools}

The ability and capacity to provide video and photography to the media that best illustrate your story have never been so important as they are today for achieving good coverage for protected areas. The media will generally appreciate access to good video footage and photography, especially of places too remote for their access. Sometimes the quality does not even have to be that good. Video footage is being seen on television and on the websites of newspapers and radio stations that has been shot on smart phones and tablets by journalists or by members of the public.

It is very easy using today's smart phones and tablets to shoot reasonable-quality vision and photos that can be instantly edited in camera, then 'shared' directly with news outlets, and this is especially true during incidents such as bushfires where firefighters themselves take images and video and upload from the fire line to a video or photo social media platform.

There is another real benefit of having a quality video and photo library and that is that these images of beautiful landscapes and amazing plants and animals offer a constant rationale for maintaining protected areas. It is a soft sell but it works. Infographics, maps and diagrams that can be reprinted and broadcast can also be very useful tools.

\section{Spokesperson}

When issuing a media release it is always essential to consider well beforehand just who will be representing the agency or issue once you receive a call from the media requesting an interview. Generally it will be the person quoted as the spokesperson in the media release, however, it does not have to be. Due to time constraints and availability, it is worth considering back-up options and selecting a second person to be interviewed in certain circumstances. 
think about the 'news cycle'- that is, when in the daily news cycle are journalists looking for information to fill newspapers, radio and television news bulletins?

Radio news in a metropolitan context is a 24-hour process as most metro stations will run at least hourly bulletins and many will run a half-hourly service from the early morning. Daily consumption of radio news is usually reaching a peak in the mornings, so it is obvious that issuing a media release around six in the morning is best. By nine in the morning, the peak is over.

Television news, however, is focused on a nightly bulletin and journalists in this field are beginning the news gathering process around 9 am when the chief of staff in any metro television newsroom will be talking to journalists about what stories to cover during the course of the day for the nightly bulletin. Daily newspapers follow a similar timetable to television. They have the capacity to include late stories but the daily newspaper is often 'put to bed' by around $8 \mathrm{pm}$. What all this means is that pitching a media release to metropolitan news media is best done in the morning unless of course it is related to an incident or emergency, in which case the release is issued as soon as it is appropriate. Daily newspapers lead the daily news cycle. Morning radio takes its content from the first few pages of the paper, and if you are featured in the paper, there will be high radio and television interest in the story.

Dealing with regional media can be quite different as they have a somewhat different news cycle. Many of the smaller town and regional newspapers, for example, may be weekly, biweekly or even triweekly, so deadlines will be different. You need to know the deadlines for each. There are circumstances when you will issue a media release to a region in which there are several small newspapers all with somewhat different deadlines. Think about which of them is the most important to you in terms of readership and impact and aim to meet that paper's deadline rather than trying to please all of them.

If you have developed a good working relationship with your media contacts, it is often quite alright to discuss the story in advance with a journalist with regard to the timing of the release and how it might fit with the journalist's other stories planned for the same paper. The journalist might even suggest you going earlier with the announcement or holding off to a later edition to get better coverage.

Just when you send your media release is an important question to consider in order to give yourself the best possible media exposure. You must first and foremost 


\section{The interview}

So now you have issued your media release at the right time and the journalist has responded by telephone requesting an interview. You know who will be the spokesperson and you are looking forward to ensuring you get the best possible result. Just how you handle an interview will depend very much on which medium you are dealing with, the nature of the inquiry - that is, negative or positive-and whether it will be a news interview, extended print feature or a program piece for television or radio.

Never go into an interview without a plan, whether it is a good-news story or a negative one. Critical to your interview will be the 'key message', and the best way to think about what this message should be is to ask yourself, 'what is the most important thing I want someone listening to my interview to remember and take away with them?' Consider it carefully, phrase it carefully and make sure it is the same message that appears in the media release, in social media posts, in your interview and any other form of communication you have with the outside world on the same issue. Always take time to predict what the likely questions will be and think through, if not actually write down, the answers.

If this is a 'news' interview where the journalist is seeking grabs, you will take every opportunity to repeat that grab, increasing the likelihood that this will be the one the journalist uses in the news bulletin or the newspaper as a quote. This we will call your 'A' points.

Your 'B' points are a series of secondary, but nevertheless important, facts or statements that you might also want to use to illustrate your point if the opportunity prevails.

It also pays to be aware of the nasty issues you may be questioned about and how you will answer them. And finally, the interview is not over until either you or the journalist has left the location. More than one person has been caught out continuing to talk after they thought the interview was over, only to find that the more relaxed and sometimes less constrained answer makes its way into print or broadcast.

Before going into a media interview, consider the following questions, where relevant.

- Have I notified my supervisor and the media professionals within the agency?

- What audience is the interview intended for?

- Do the time and arrangements for the interview suit me?
- Did I ask the interviewer what points might be raised and the general area the interview might cover?

- Have I avoided using industry acronyms and jargon?

- Have I made sure I make reference to my agency in full and not as an acronym?

- Have I considered what questions might be asked?

- What are the main points I will want to make in my interview (A points)?

- What other information might I want to impart (B points)?

- Is there anything negative that I might be asked on this subject?

- Is there any additional material that I can provide that might be useful for the journalist such as photos, video or maps?

- Did I do a 'dummy' run with someone to rehearse the interview?

\section{Radio}

There are generally two types of interviews on radio. The first is a 'news' interview, frequently done over the telephone. This will involve a series of fairly obvious questions usually around the matters of who, what, when, where, why and how. They will record the interview and then take one or two short sections (known as 'grabs' or 'sound bites'), generally no longer than 15 seconds, and insert these into a news bulletin with an introduction read by a newsreader.

Because the 'news' interview is being cut, it is usually quite acceptable to stop mid interview and ask to start that part of the interview again if you are unhappy about the way you have phrased your answer. Remember the journalist interviewing you wants to tell a clear and coherent story so it is within their interests to give you the chance to be clear and tell the story as best you can.

Given you have a fair idea of the likely questions, it pays to think in advance about what your 'grab' or 'grabs' might be: how you phrase it, what words you might use, what tone you might apply. You will have a key message that you want to get across and the important point is to stick to the message.

The extended interview for programs will generally run for approximately five minutes and not much longer unless it is a highly contentious topic. These interviews are generally run in their entirety so there is not the same flexibility to stop and start. They are preferably 'live' interviews - that is, broadcast in real time-although they can be prerecorded in order to deal with issues of availability. Such interviews are by nature wide ranging and exploratory. 


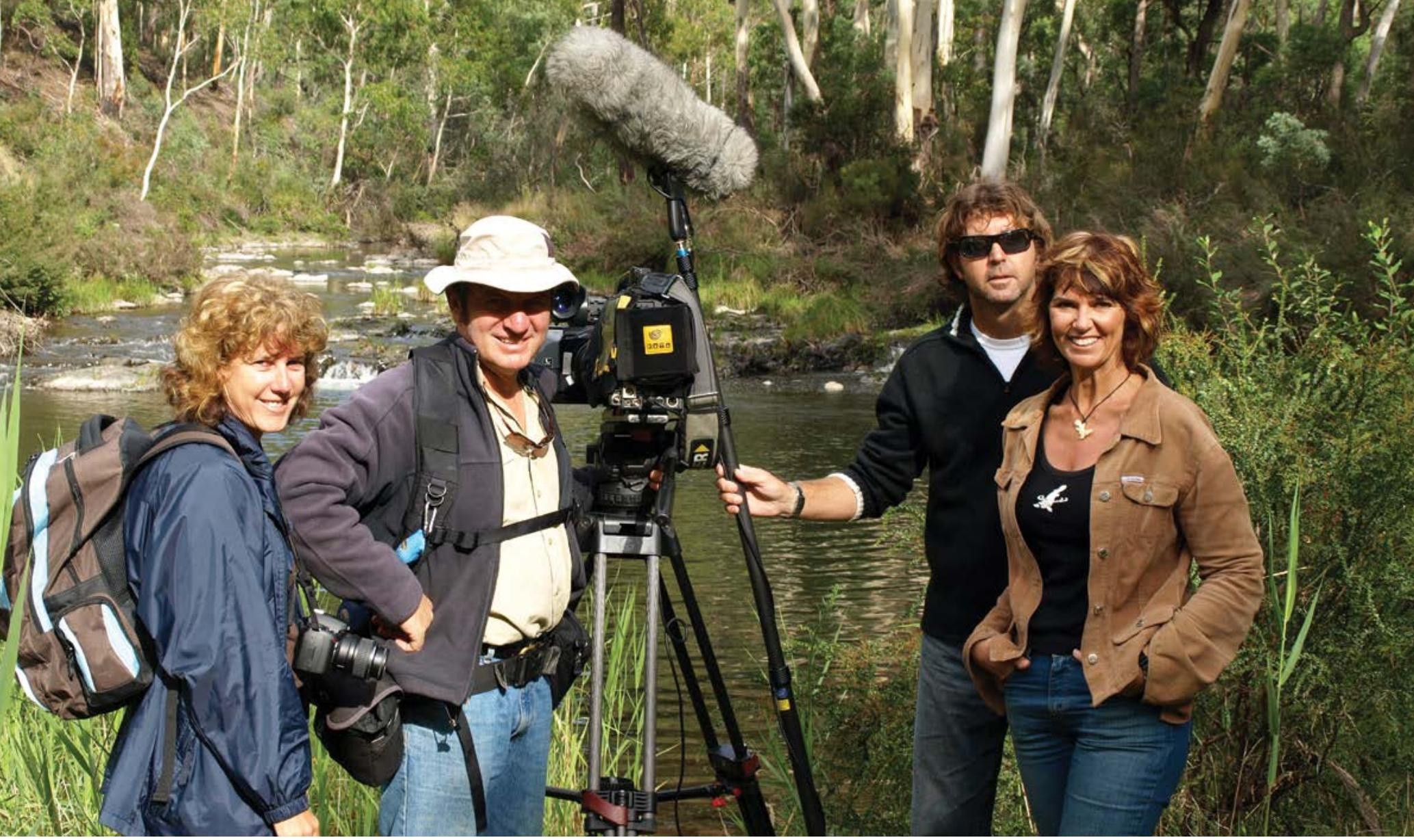

Documentary film crew, Kosciuszko National Park, New South Wales, Australia, including camera person, sound engineer, interviewer and still photographer

Source: Graeme L. Worboys

You are going to use this as an opportunity to tell an entire story that covers the basics of the issue. For protected area managers, these are gifts of an opportunity to really sell your key messages and promote the value of the protected areas you are managing to a wider audience. Make the most of this. Do not enter an interview like this without having first thought through at least a basic plan. If you are expecting hard questions then you must think and plan before you walk into such a situation.

\section{Television}

Television is a somewhat different creature to radio in that the logistics of the interview and setting them up are more involved, requiring the cooperation of more people, more distance to be travelled and more gear. In the majority of cases, the television interview is faceto-face either on location or in a studio and usually involves at least a journalist and camera operator and on occasion a sound engineer. More and more, however, you will be received and interviewed by a lone journalist operating a camera.

Television news interviews are similar to those on radio. A series of questions will be asked to be cut into a written script read by the journalist, but today's television news grabs are frequently much shorter than those on radio and can be as short as a few seconds. As with radio, it is often acceptable to ask to stop and rephrase your answers unless this is an adversarial situation in which case it is best to keep going.

There are occasions when your agency or organisation might be asked to provide a spokesperson for extended interviews for current affairs programs. You should always prepare for these properly and ensure that the spokesperson is well briefed and has a plan for tackling the interview.

\section{Newspaper}

There are obvious similarities with radio and television but because the interview is not being delivered to an audience as a recorded piece of information there is ample opportunity to 'discuss' issues with a journalist rather than approach it as if it were a recorded interview. You can stop and start your answer to rephrase it but remember that at all times you can still be quoted almost as if you were being recorded so if you do stumble in an answer it is entirely possible the very same words will appear in print. The better your relationship with the journalist, the less likely this is to happen. More often than not you have dealt with the journalist before and you will have the ability to ensure that your quotes are correctly phrased as you wish. In rare cases, a journalist may read the story back to you to ensure accuracy before going to print, but do not expect this. 


\section{Supportive media}

Protected areas are often well supported by communities which understand their importance to the general health and wellbeing of both people and the planet. This view is widely shared by many journalists and it is well worthwhile nurturing and fostering these relationships for the longer term, and there are many ways this can be achieved.

\section{'Hook' or 'angle'}

First and foremost is being able to identify stories and issues that possess real news values that make them worthwhile to report to the broader audience. This means finding the 'angle' or 'hook' to a story that will most appeal to a journalist. Once you have this in hand, you must consider the needs of the journalist reporting on the story. What photographic or video opportunities can be exploited to best illustrate your message? What facts, figures and anecdotes may make the story more interesting and set it apart from other stories of the day? Do you have a spokesperson who tells a story well, is engaging, entertaining, authoritative, credible? Can you provide transport and even accommodation? Can you offer exclusivity for a period?

\section{Exclusive stories}

'Exclusivity' can be an important way of achieving high-profile coverage through a relationship with a particular journalist on a story that might not ordinarily achieve coverage if you were to issue a media release to the broader media simultaneously. It means offering to give a story only to that journalist so that he or she has the lead on that story. To the editor, this is far more appealing than a story that might be given to all media. Frequently, an exclusive will get good coverage with the media or journalist you have worked with and they in turn will put in more effort and more often than not will send a photographer or television news crew to cover it. Exclusivity can also ensure greater prominence, pushing your story to the front pages of a newspaper, for example, whereas it might ordinarily have been buried in the back pages.

\section{Building relationships with the media}

For protected area managers it is very important to maintain good relations with local or regional media who generally cover the day-to-day stories you want covered that metropolitan media will not, because the smaller stories do not have the higher news values that the city media wants. It can be very disheartening for a regional newspaper editor, for example, to discover that you have given an exclusive to a metropolitan news outlet without first supporting the regional media who covers the less important stories for you on a regular basis. So it always pays to consider your local media in this equation by making sure they are informed of your higher-profile story in a way that allows them to cover this at around the same time as the story is covered in metropolitan media. While this can often be somewhat challenging to achieve, failure to do this can sour your relationship with local media and that is not good.

\section{Timing a story}

'Timing' the release of information or a media release on a high-profile story is critical. Always attempt to ensure that the release of information to the local media can coincide as closely as possible with the publishing of the same exclusive story by the metropolitan news journalist you have been working with.

\section{Off record versus on record}

What you say or write to a reporter is, in practical terms, always on the record and it may be quoted or paraphrased. They may attribute it to you by name, even if you request otherwise. Many professional communicators live by the adage 'there is no such thing as off the record', and this is certainly the safest stance, but there is a place for providing background or information that will help a journalist get a better understanding of an issue; however, there are caveats to this approach.

Speaking off the record gives the journalist (and usually their management) credit for adhering to their code of ethics. Sadly, this credit is not always due. As with all communications, your off-the-record divulgences must be honest and accurate.

Providing off-the-record comment can have powerful benefits. It can strengthen your relationship with a journalist, it can stave off negative media coverage or it can provide valuable context to guide a reporter towards a more balanced story.

Speaking off the record is generally not something you would do when dealing with a journalist for the first time. It is something you should only consider with someone with whom you already have a good understanding through previous regular contact. 
If a journalist asks for off-the-record comments the same rule should apply. Be strategic and only divulge off-therecord comment if you know the journalist and have dealt with them extensively beforehand. Off the record has a mutual benefit so many journalists will honour this, but remember there is always risk.

\section{Do not underestimate the cadets}

While an established aggressive reporter may make life challenging, some of the most dangerous reporters are actually new recruits or even students. They are unlikely to appreciate the value of having a relationship with you and are trying to impress their bosses or teachers. Where time and circumstances allow, assist these people, but warily. Treat them with great caution until you have established a relationship of mutual trust and respect.

Another side to this is recognising that journalism students, cadets and new recruits are forming their professional standards and work methods and you carry some responsibility. You have nothing to gain from making an enemy of a student who may go on to become an influential journalist. Your colleagues worldwide will not thank you for turning a reporter off conservation issues or, worse yet, making them interested but antagonistic.

\section{Managing social media}

A social media strategy developed to meet overall goals and communication objectives will keep content and activity focused and with purpose. This should sit across the organisation or agency, and social media plans developed specifically for all programs, campaigns or initiatives should be in line with the strategy.

\section{Social media team}

You may need a staff member or team dedicated to managing all social media activity to ensure your objectives are met and to keep the organisation updated and informed about relevant online activity.

\section{Plan thoroughly}

Have a plan. Alongside your strategy, develop a riskmanagement plan that has protocols and processes for dealing with conflict on your social media channels. Consider how you will respond to vocal critics who attack your brand on your social channels: how will you monitor your social networks, how long will it take for you to respond, what is the escalation process for questions or comments for which you need to consult with others?
Best practice for reputation management online means you need to monitor conversations about your agency happening on social channels. How will you find these mentions online? How will you respond in a manner appropriate to that social network and for that community?

A content management plan will help you organise the creation and dissemination of content to ensure social media activity is strategic and meets objectives. Below are suggestions for what to include in your plan.

- Idea: What is the overall concept or idea you want to bring to life via social media?

- Rationale: Why do it? What is it going to achieve? How does it meet business goals?

- Social platforms: What social media platforms will you use-for example, a video hosted on YouTube embedded into a blog post that is shared via Facebook and Twitter?

- Implementation: Operational logistics of what needs to be done, how it will be done, who will do it and when it will be done.

- Reporting: How will success be measured?

- Budget: What resources will you need and how much will it cost?

\section{Be transparent}

Be honest with your audience and provide helpful information that positions your organisation as accessible and open. Transparency is paramount and has a huge impact on the success of your social media activity. If your brand is seen to be secretive, reluctant to share information, is unavailable to answer questions or if you ignore conversations online, you will breed negative sentiment and distrust, which are damaging to your reputation.

\section{Be interesting}

Your presence on social media should be engaging, entertaining, useful and interesting, to generate conversation and be shared by others. Tell stories and share timely news, interesting facts and insights that help build a relationship with your audience so you have a loyal and engaged community who will support and amplify your agency. Take people behind the scenes and introduce them to the people behind your brand. Make it personal and build a human connection. 


\section{Be nimble}

Conversations that happen on social media happen in real time. You need to build a consistent and constant social media presence as part of your broader communications strategy in the management of protected areas. Engagement with your community should happen as quickly as is possible, but you can manage expectations of your availability online by including details about this in the profiles of your social networks and via messages to your community in real time.

Immediate response can be difficult for protected areas managed by bureaucracies, as responses may need to be escalated to others, so it is important to communicate the expectation and process for those involved prior to engaging online. A holding statement should be developed for immediate response online until further information is provided.

\section{Tone of voice}

Consider the style of content you will develop, the tone of voice and the language used in your posts and responses. Generally, communication should be conversational, colloquial, vernacular and engaging so the community feels compelled to ask questions and share their opinions and stories.

\section{Listen and respond}

Social media is a powerful tool for building your community and communicating with your audience, but it can equally be disruptive and damaging to your cause if not planned thoroughly from the beginning. Do your homework and listen to what is being said about your agency and any relevant person, organisation or topic before you engage online.

Understand the nuances of different social networks and who the dominant voices are in those communities. When you do interact online, be helpful, approachable, friendly and inclusive and know when to take conversations offline if they are inflammatory or irrelevant to the wider audience.

\section{Reach out to peers and influencers}

Identify complementary social media users and engage with them in conversation or to contribute to your content. These might be conservation volunteers, similar agencies, celebrities sympathetic to your work and journalists. Share their content and promote relevant posts via your social channels. Conversely, if you are approached to engage online in this way you should oblige unless there is good reason not to as this will also help build your network and strengthen your relationship with influencers.

\section{Resourcing}

Social media requires an investment of time and there are social media tools available at a cost for community management, marketing and analytics that enable more efficiency and quality data than free tools. You need to investigate the need for employing paid platforms or services and the associated costs of these, and human resourcing of those who will be managing social media. You may also need to seek consultation from specialists for social media training, strategy development and community management, so this should also be considered as a cost.

Another budgetary allowance to be considered is the cost of paid content. In recent years there has been an increase in online influencers and personalities charging a fee for working with brands to generate awareness among their fans via social media. Professional bloggers, YouTube users and Instagrammers, for example, may even be managed by a talent agent who will negotiate a fee for activity. Targeted advertising on blogs and social networks can also be an effective way to reach a large audience and should be considered when planning social media activity.

\section{Adversarial media}

The rules for dealing with adversarial approaches are very different from normal media relations. Protected areas around the world are frequently under pressure from certain quarters to relax their rules and regulations. Some sectors of the community want to exploit natural resources or obtain access for recreation in ways that might be damaging to the values for which the area has been reserved. When conservation agencies take responsibility for an area, they sometimes close off access to areas that are very important to community members-for recreation, gathering firewood, beekeeping or other activities.

As a result there is rarely a shortage of people ready to criticise management. Given the media's strong attraction to the news value of 'conflict', there are many media organisations and journalists keen to report on such conflict and in some cases provide a platform to attack the fundamental reasons for conserving protected areas. As a consequence, many protected area managers find themselves engaged in long-running public debates in the media arguing a case on behalf of their protected area. 
This is a very tricky place to be. You need to judge when engaging in a debate will be a smart move and when it will not. In many adversarial situations, arguing your case will be the right thing to do, but in other circumstances you might find you are providing oxygen to a debate that, without your involvement, will wither, whereas engagement may add further fuel. It is a judgment that is best made based on experience. More often than not, however, dealings with the media, negative or positive, are an opportunity to state your case.

When your management of or rationale for conserving protected areas comes under attack, this is an opportunity to restate your case. Failure to respond or failure to engage often means that criticisms will go unanswered, leaving the public hearing only one side of a debate. It is a common reaction of many to appease and to avoid conflict, and equally common is fear that a strong response to criticism will only exacerbate conflict, and certainly this can occur. In the majority of occasions, however, the debate is based on self-serving assumptions by critics that need to be addressed immediately.

It is often the case that your arguments in defence of the way you manage your protected area will be based more soundly on common sense and science than those of your critics. Conservation of our cultural, natural and historical heritage is often a selfless endeavour. It frequently involves restraint on the part of communities and on occasion individuals, so as a protected area manager you will hold the moral high ground. Use it and respond.

In the realm of social media, however, it is wise to exercise considerable caution since the ability of critics to wage campaigns anonymously can result in a considerable number of participants berating managers. Your response in traditional media can ultimately find itself the subject of viral condemnation in social media so when weighing up whether to engage and respond you will need to consider how the debate might transfer across to social media platforms.

It is generally fairly obvious from the first contact by email or phone that you are dealing with an adversarial journalist. You will generally hear it in the tone and type of questions being asked. As soon as you realise there is a likelihood that a journalist will take a position critical of your management, you need to start thinking about how to get the best outcome from a difficult situation.

Never provide an instant comment. Buy some time: 'I just need to check the latest information on that' or 'I'll need to talk to some of our field staff/scientists to get the details you need-I want to make sure I get back to you with accurate information'.
Be as methodical as the situation warrants, and consider the following general 'rules of thumb'.

1. Get a thorough list of the points the journalist wants to cover.

2. Contact your agency's media professionals. They will have been through this before and know best how to act. Work with them to craft the agency's response.

3. Think carefully about the line of questioning. What points will be the most difficult to answer? What is the slant the journalist might take and how might you best defend your position? Write down the likely questions and those you would least like to be asked and prepare answers or 'talking points' that best present your arguments.

4. The talking points will cover the content of the interview, but that is only half the issue. The other half concerns your image. A spokesperson can deliver the content perfectly and still have a disastrous result if the image was a negative one. For instance, a person strongly defending their agency's safety record might appear extremely uncaring in the wake of a tragic event.

5. Consider the visual imagery that might be captured by media intent on exposing you to criticism. Think about where you would prefer to be interviewed. If you are in an office wearing a suit, you risk looking out of touch with the real world. Think about what your critics will be wearing (you probably know them quite well). Make sure you match their image.

If, for instance, you are defending the agency's management of swimming water quality, consider doing it at the beach in a wetsuit. If the agency spokesperson is happy getting in the water, the visual image it sends to viewers is worth a thousand words. Will you wear a uniform? Will you appear in vehicles marked with the agency's brand or logo?

At the end of this process you will have worked out two things: the key message you want to present and the way you want to present it. How your spokesperson conducts the adversarial interview is absolutely critical. The journalist will be looking to present the organisation in a particular, negative way. To get the truth across to the audience, the spokesperson needs to stick to the key message.

The spokesperson must answer every question in a way that presents the agency's key message and the appropriate image. The message is the content of the answers, but just as important is the way the answers are presented. 
shortcomings. It will result in greater scrutiny of where the fault lies and the added embarrassment that you have attempted to avoid accepting blame for your mistake.

This ultimately damages your reputation, creates distrust with the community and erodes your credibility. When approached by the media in a circumstance where your agency or organisation has faltered, it is best to concede that mistakes were made, and as quickly as you can. It is then vital to provide a statement looking to the futurepointing out what the agency is doing to make sure the mistake is not repeated and, ideally, finishing with a call to action by the community. The damage to reputation can be limited and the debate closed although adversarial groups will frequently attempt to keep this debate alive after which it is often wise to avoid further provocation.

Where your agency or organisation is featured in a negative print story, there will be high radio interest the next day. You can use this to your advantage by having your spokesperson contact all the local radio newsrooms early the next morning to provide radio with the real facts.

NSW National Parks and Wildlife Service marine specialist Geoff Ross responding by phone in relation to a marine mammal incident

Source: Lucy Morrell

It is not easy giving much the same answer to a dozen or more questions, but it has to be done. If you do not want to see it on the news tonight, do not say it now. This is not a conversation; it is a business transaction.

A useful approach is to address the question and then bridge to your key message-for example:

- 'That is an important question, but my concern here today is ...'

- 'I can see why people would ask about that, but my message to them today is ...'

- 'Yes that is part of the picture, but I would suggest the key point is ...'

- 'Wouldn't it begreat if thingswere that straightforward, but it is actually much more complicated ...'.

While the approach outlined above can help the agency deal with adversarial media bent on mischief, it is very important to acknowledge when you or your agency has made a mistake. While it is often difficult to admit to mistakes, the temptation to deny or be evasive must be avoided. It will frequently make the situation with regard to media coverage much worse. More often than not it will prolong the public discourse on your agency's

Case studies 15.1 and 15.2 illustrate how you might respond to two other difficult media situations.

\section{Communication planning}

While the media plays a very important role in communicating key messages about protected areas, as has been said at the beginning of this chapter, it is really part of a bigger communication process that involves thoughtful planning. More often than not media engagement will be a final, albeit critical, step in a staged process of communicating with stakeholders. This is because there is always much to be done communicating the most important messages to the most influential people before the media informs the wider world. To do otherwise is disrespectful to your stakeholders and risks damaging your relationship with them.

The very best communication is credible and trusted. Direct communication methods such as a phone call, or even a personal letter or face-to-face meetings, help build trust and credibility in ways that media reportage cannot. But this process takes careful planning.

There are any number of ways you can communicate more directly with an audience and in ways that build trust and credibility, and you are only limited by your imagination in how you do this. It is certainly best to adopt the motto 'whatever works' to guide you. In other words, think of the message you want to convey and use 


\section{Case Study 15.1 A parent's worst nightmare}

A ten-year-old child tragically fell to his death from a lookout in a national park managed by an agency. Although the area was fenced, few of the agency's lookouts had childproof fencing. The child managed to get past the fencing and lost his footing.

That afternoon, with emotions running very high in the community and the agency, several television outlets requested interviews on the subject. The agency suspected they were aiming to show that the fencing was inadequate and to depict the agency as uncaring

The temptation for the agency spokesperson was to strenuously defend the adequacy of the fencing by pointing out how more than a million people visit the site each year and there had never been any incidents like this before.

The danger with this approach is that the agency could be so caught up in defending its safety record that it would look callous and disrespectful. It was agreed that the key message would be:

- the incident was a tragic freak accident

- our hearts go out to the parents

- there will be a full investigation.
Also vital was that the spokesperson was empathetic and respectful in this terrible situation.

The interviews turned out to be adversarial, with allegations that the fencing was inadequate and the site poorly managed. The spokesperson maintained an appropriate demeanour throughout, respectful of the parents' shocking loss.

Although the story received a mention in the news that night, none of the networks presented the agency in a bad light and none used footage of the agency spokesperson-a reasonable result from a situation that was harrowing for the parents, the agency staff and the spokesperson.

\section{Case Study 15.2 Some decisions are not worth the media damage}

Picture this situation. A conservation agency media officer takes a call from a ranger about a proposed feral deer cull: 'We're going to feed the deer a sedative mixed with food,' says the ranger. 'When they go to sleep we'll shoot them, then take the carcasses to the garbage tip.'

The media officer asks if the drive to the tip will be through any settlements. 'Ah, yes,' says the ranger, 'we have to go through Springfield' (a town of 5000 people).

'Look, I just need to check this with the regional manager,' says the media officer. 'We'll get back to you this morning and thanks very much for letting us know.'

The media officer runs to the regional manager's office, apologises for interrupting an important meeting and paints a picture of a truck full of dead feral deer rumbling down the main street of Springfield. The manager rings the area supervisor and nicely points out how the public outrage that will come from the culling program will likely outweigh the conservation benefits. He notes how much the media frenzy that might attend the operation will likely impact on their minister's popularity, and that both the agency's budget and their jobs might be impacted should field operations keep generating problems for the minister.

The cull was changed in a major way to ensure the local community was aware of it and that inappropriate images were not broadcast. The important point here is that media work in an agency is a two-way street. Media professionals have the role of helping to maximise public support for the agency's actions, but they also help agency managers realise when a proposed course of action constitutes corporate suicide, and when the community or political costs far outweigh the conservation gains.

Media professionals can exert significant influence over other organisations through their contact with their professional colleagues in other agencies. Another department may be taking decisions that are damaging to conservation and therefore unpopular with the general community. Simply alerting the media professionals in that department may be all it takes to have them use their influence to prevent the negative outcome.

At the end of the day, the political process in a democracy means that an agency or organisation only thrives when it has public support.

A significant risk to such support is taking decisions that run counter to community expectations. Conservation agencies will always need to take unpopular decisions, but they need to manage this. The last thing they need is poorly managed unpopular decisions that undermine conservation benefits. 


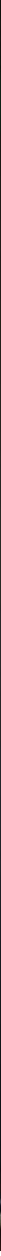

Street theatre with a protected area conservation message, in a community adjacent to the Great Himalayan National Park, India

Source: Graeme L. Worboys

whatever tool at your disposal, no matter how outlandish, which you think will achieve your ultimate goal-to push key messages and information that will help achieve conservation management objectives for your protected area. From staging of street theatre to video production, to guided walks and the more conventional face-to-face meeting, if you think it is the best way to communicate and build trust and credibility then it probably is and ought to be tried. Always remember 'whatever works'. Think outside the box.

\section{Writing a communication plan}

There is no standard template (nor should there be) for a communication plan better than common sense. We are by nature a highly sophisticated, communicative species. We are capable of the most extraordinary and complex forms of communication, social media being just the latest example of how exceptional we have become in communicating with each other.

'Communication' is what we are good at but when you are asked to write down and plan to communicate with a small or even a broad audience, there is an endless array of methods-but the plan is far less complicated than you might expect. In the world of public relations and mass media communications, the idea of developing a 'communication plan or strategy' might at first seem daunting for the inexperienced but it is something we achieve daily and learn to do at the earliest age and refine throughout our years. It involves the principles of common sense and 'whatever works'.

A communication strategy can be a 100-page document involving incredible detail or it can be one page long or it can be just in your head. A word on language: like everything else related to communicating messages, if you make things complicated, longwinded and full of jargon and bureaucratese then it is going to be hard for people to understand the message. Keep the language simple and engaging. A complicated plan is always a challenge so do not make things harder than they need to be.

The following simple template suggests the important elements to consider in preparing a communication plan for managing an issue or event. You could also call it an issues management plan. But the structure can just as easily be applied to most communications issues with a bit of tweaking. Do not treat this as a precise formula. Some bits might not be relevant to your issue. 


\section{Define the issue}

What exactly is the issue? Sometimes this can be more complex than you think, but it is worth pausing to consider this and starting with a question like 'what is the problem?' Define the issue in a single sentence. Be sure you are actually addressing the right issue.

\section{Issue owner}

Ultimately, who in your agency has final responsibility for this plan? Who is responsible for it being implemented properly? It might be a couple of names or just one. Whose professional reputation is on the line if it all goes wrong? This is necessary to define to ensure that those actually responsible for getting the job done have their name attached to the plan and the outcome.

\section{Context (background)}

So what is going on? What is the background to this issue or event? What is so important, and why, that you need a 'plan' to communicate? Within this you might like to talk about the 'nasties' that necessitated the plan being drafted as well as the benefits of what is being proposed.

\section{Organisational position (optional)}

Where does what is being proposed fit into the overall objectives of the organisation? This is usually captured in a single sentence or two. It is a statement from the organisation. It is a view on why this is important and why it should be done. There is no need to make it longwinded but it helps to make a clear statement about the organisation's position on the 'issue'.

\section{Action team}

You do not ever want to be implementing some of these big plans on your own so the plan needs broader ownership. You also need the imprimatur of management so it pays to get them all on board from the beginning in helping develop a plan. Sometimes there is a team involved and they need to be identified and the plan agreed to so they are locked in and cannot get out of their responsibility after the first meeting. It really helps to share the work and the responsibility. Putting their names in a list titled 'action team' right at the start means that eyes are upon them and expectations that they will 'deliver' have begun. You will not be alone.

\section{Stakeholders}

Who are you dealing with? List them and maybe group them.

\section{Stakeholder analysis}

Where are the stakeholders coming from? Who are the 'make its' and 'break its' and why? And by this we mean who are the people with the capacity to have the greatest positive or negative influence on the issue or event? What are they saying about your organisation? It will pay to look closely at the motivations of each of the stakeholders involved. This can be as detailed as you need it to be, but at times it helps to refine how you will communicate slightly different messages.

\section{Objectives}

This is arguably one of the most important elements of a communication plan. Your objectives need to be clearly considered and well thought through. What are you trying to achieve with this plan? In the more complex plans you will need to refer back to these time and again to ensure your actions are actually going to help deliver your objectives. It will be your objectives against which you will eventually measure the success of your plan after implementation. Often there will be about three objectives, maybe even four or five, but at times there might be only one.

\section{Key messages}

Given your objectives, what is the message? The key messages are the 'mantra' that appears basically the same in everything you do. It is the same well-crafted 'simple' message or statement that will be repeated in media releases, letters, social media posts and news grabs. For more detailed plans, you might even road test the key messages among a pilot group to see if they actually 'get' what you are trying to say. The key message is at the heart of what you are trying to convey so it needs to be very clear and easily understood.

\section{Actions}

Considering the objectives, what actions are you going to take to help you achieve those objectives? This is the real business part of the plan and provides the broad outline of how each action fits together. There may be many parts to this depending on how complex your plan is going to be.

\section{Timing}

Absolutely critical to the success of the plan is timing. Your actions will need to occur at quite specific moments and those moments need to be clearly identified at the very beginning. All the dominoes in the plan need to fall at precisely the right moment and in the right order and this can be the most important aspect of the plan. So it can pay to be explicit in the plan about timing and the 
need for everyone to synchronise their watches. Usually (but not always) you will have the timings explicitly stated in the task spreadsheet mentioned below, but you might like to make a special reference to 'timings' if it is necessary and helpful to the plan.

\section{Terminologies}

Make sure everyone is using the same terminologies and there are not two ways of saying the same thing, which can bring the best-laid plan completely undone. Agree on the description of names for things and places. Reduce jargon to something everyone is happy with. Too often people get stuck on this point when it should be simple. In some situations it might even pay to have a glossary as an appendix.

\section{Task list}

This is usually a spreadsheet that identifies who does what, when and how, and maybe includes estimates of costs.

\section{Support materials}

What things will you need: maps, brochures, Facebook page, scripts, photos, video, websites, social media tools and letters, PowerPoint presentation? What support materials will you employ to achieve your objectives?

\section{Monitoring}

This can be challenging but it is necessary to keep track of whether your key messages are resonating with people in a way that achieves your communication objectives. Have you, through your actions and key messages, managed to achieve the behaviour or attitudinal change your objectives identified? If not, what changes or modifications might you need to make to achieve your objectives? Monitoring is also something you do so you can tune in to whether the key messages need tweaking. There are a number of paid social media tools as well as Google Analytics and Facebook statistics that can help you measure success or otherwise.

\section{Evaluate}

This is underestimated but important, especially for large plans. It can be a get-together for a debriefing or a round of emails or even just time to stop to have a think about whether the plan worked. In other words, did the plan meet the objectives? Go back to objectives as the starting point for your evaluation. In staged communication plans this is a good opportunity to regroup and tweak for the next stage. This is the final step in what is called 'adaptive management': plan, implement, monitor, evaluate, adjust and then repeat the cycle (see Chapters 8 and 13).
An example of an effective communication plan is given in Case Study 15.3.

\section{Media management at major incidents}

Protected areas around the world encompass a vast array of landscapes and seascapes, often covering large expanses within which incidents, either natural or human-made, can and do occur, presenting protected area managers at all levels with major challenges managing impacts on people as well as the natural environment. Floods, storms, bushfires, earthquakes, tornadoes, cyclones and chemical spills are among the many catastrophes that can occur, leaving destruction and devastation that may destroy or significantly alter the natural environment and leave countless people in danger. In large events, the response, in all likelihood, will involve the cooperation of multiple agencies, while in smaller-scale incidents the protected area managers may be left alone to contend with the complex and difficult challenges that such events can cause (see Chapter 26).

In each case media management can play a critical role in alleviating and forecasting dangers to people and impacts on the environment. In the first instance, the protection of life and property is and should always be the numberone priority and to that end good media management will play a vital role as the media, both traditional and social, is key to providing information rapidly and in real time. Bushfires, for example, are always frightening events but under extreme conditions they can be utterly terrifying, even for veteran firefighters. Managing public information in this environment is about providing concise, honest, accurate and timely information that can help individuals and communities overcome their fears and allow them to make good decisions in the midst of chaos. Public information during an emergency should neither panic people nor make them complacent, but should seek to achieve a balance that creates vigilance and compels individuals to make preparations. Critical in an emergency is providing honest information, and if certain key details and facts are unknown it is important to say, 'here's what we know for sure at this time', rather than pretend or omit.

In the midst of chaos people need detailed information in real time, not summaries that vaguely describe what might be happening. Choosing the mode of delivering information will also prove critical, and while the media will play a major role, it is certainly not the only medium to use in a crisis. In today's digital world social media 


\section{Case Study 15.3 Wilderness assessment communication plan}

In 1999, the NSW National Parks and Wildlife Service (NPWS) was presented with a difficult and complex communications dilemma after a prominent conservation organisation used the State's wilderness legislation to nominate 17 large areas of private and public land for 'wilderness assessment' in the south-east of the State. The areas nominated were primarily national park but the nominations also included areas of private lands and State forests that were managed mainly for timber production. Once an area was assessed as having wilderness values as described in the Wilderness Act, these areas could be declared wilderness and managed accordingly.

Once the areas were declared wilderness, only self-reliant recreational activities were permitted. In other words, only bushwalking was legally permitted. All other forms of recreation were prohibited: vehicles, horseriding, even bicycle riding (at the time) were prohibited activities within declared wilderness. The primary difficulty presented to the NPWS by the nomination was that several hundred private landholders had parts of their lands 'nominated' for assessment to determine whether the areas qualified under the legislation as true wilderness. Importantly, while private land could be nominated, it could not eventually be declared wilderness without the written consent of the landholder. The primary concern was that the traditional critics of the NPWS would likely attempt to scare private landholders whose properties had been nominated for assessment, by claiming the assessment process was an attempt by the Government to confiscate their lands once they had been assessed as having wilderness values, even though this was impossible without landholder consent.

To limit the possibility of this occurring, the NPWS developed a detailed and comprehensive communication plan aimed primarily at allaying the concerns of private landholders before news of the wilderness assessment process was announced to the broader public. This meant communicating with those landholders with detailed information that explained the process clearly, emphasising that even if their lands were assessed as having wilderness values, they could not be declared wilderness without their consent and that they could in fact just ignore the process altogether if they wished. The first step in the process of developing a communication plan around the wilderness assessment was deciding to communicate first and foremost with those most affected by what had been proposed: the landholders themselves. A small 'action team' was formed to discuss and consider communication options and a detailed communication plan was developed in close consultation with the NPWS field managers who would largely be responsible for implementing the plan. Clear objectives were identified, key messages developed along with a media strategy, talking points for interviews, maps, fact sheets, letters to landholders, PowerPoint presentations and a detailed task list to identify who did what and when.

The cornerstone of the plan was a decision that NPWS field managers would contact each and every affected private landholder by telephone within a few days to explain just what was happening, that they had nothing to be concerned about, that their properties could not be declared wilderness without their consent and to offer further face-to-face briefings in the field if the landholder wanted. Critical to the plan's success was reaching all the landholders with a clear message before others, who might want to derail the wilderness assessment, had time to muster a media campaign that could seriously undermine the wilderness assessment and damage relations with NPWS neighbours whose properties were being assessed. There were approximately 350 landholders who needed to be contacted over a handful of days. A team of some 30 NPWS officers was fully briefed and given a script to follow when calling landholders to ensure the message was consistent. Once the landholders had been fully briefed, another list of important stakeholders with a keen interest in the wilderness assessment and who had the capacity and influence to have a major negative or positive impact on public debate was identified well beforehand and also briefed, but only after the landholder briefings were complete. When all briefings were complete, within a week, a media release was finally issued explaining the wilderness assessment process.

When finally news of the assessment reached the media, everyone who had an interest in the process or may be affected by it in some way was already well informed and, most importantly, landholders whose properties fell within the nomination understood clearly that their properties could not be declared wilderness without their consent. Throughout the assessment process, which lasted several months, not a single media story critical of the NPWS or the process was aired or published and this is because the key messages were delivered clearly to the people who mattered most: the landholders. The main reason this communication plan was so successful is that the people most affected by the wilderness assessment process, the landholders, had been told directly, before anyone else, what was happening and how it would and would not affect them. They did not wake up one morning and read a slightly skewed or potentially critical story in a newspaper.

A debriefing on the entire process was held, with all staff involved attending and it was universally accepted that the direct approach, while novel at the time, was critical to the success of the plan. Interestingly, all staff who were involved in the telephone briefing process noted that the response of landholders who had been contacted was at once surprised but also very appreciative of the attention and communication. 
is proving more important and more effective than ever in helping people to make lifesaving decisions in a fastmoving and fluid emergency situation.

Typically, an individual or small team of people will manage public information and media during a regional crisis, but under catastrophic conditions where there has been considerable devastation over a wide area team numbers can balloon, as more and more hands are needed to meet the increasing demand for information. The need to properly resource public information cannot be emphasised enough. Inadequate resourcing for public information can prove disastrous in a crisis.

The challenges facing a public information unit will be many and varied. Media coverage cannot be relied upon to deliver timely, accurate information all the time so contingencies must be planned for. Increasingly in the developed world, new social media platforms such as Facebook and Twitter are being relied upon to quickly deliver information directly from the emergency management agencies to the affected public.

It is important to emphasise that what the public wants is detailed and honest information related to their specific set of circumstances and they want it in real time. For example, the public in a bushfire situation will not be interested in knowing where the fire has been. They want to know where it is going, how fast and when it might arrive on their doorstep so that the lifesaving decision on whether to leave or stay with a home can be made well in advance. All channels of communication should be used simultaneously to ensure that every opportunity to communicate critical messages is realised. This means using traditional media and in this situation radio will be the most important medium because it can be broadcast instantly. Similarly, social media platforms Twitter and Facebook are very helpful, but increasingly emergency agencies are developing new smart phone and tablet applications that can be readily downloaded to provide the user with access to detailed, real-time information. The NSW Rural Fire Service (RFS) in Australia, for example, has deployed an app called 'Fires Near Me', which provides information people in fire-affected areas need to know.

When the dust has settled and the emergency has passed, it is critical to undertake a detailed evaluation of the public information effort to determine what worked and what did not, thereby allowing for improvements in delivery of information at the next emergency incident.

An example of effective communication and media management at a major incident is given in Case Study 15.4 .

\section{Conclusion}

For any manager of protected areas, engaging with the media should be part of a broader integrated management strategy. You want a community which understands why protected areas are important and that your management objectives are ultimately of benefit to the environment and in turn the broader community. Engagement with the media will not achieve all of this but it will play a critical role and cannot be ignored.

Engaging with the media cannot be done tentatively or half-heartedly. You must engage confidently, with clear objectives in mind. It is also strongly recommended that you always consider what alternative means of communication might achieve your management objectives before you engage the media because once you start talking to the media on a given subject, there is no going back.

Media engagement should be part of a broader communication strategy that looks at ways of getting information directly to the people and communities most affected by your agency. There is plenty of work to be done communicating with people before you start communicating with the media, which is often the last step in a communication plan.

Social media must be included in your communication strategy and considered separately from the traditional understanding of 'the media' before you can employ an integrated approach to media and social media as complementary capabilities. Social media is an information revolution that has just begun. It moves very quickly in all directions, so develop a strong social media strategy, systems and processes that underlie a nimble and responsive execution of tactics.

Social media is occupying the space and function of traditional media in many ways, consuming what we now describe as print, radio and television to become a single communication form known as 'content' that is print, audio and visuals. Take full advantage of the benefits of social media as an affordable way to communicate with the world, engage directly with stakeholders and build an audience in ways not possible when relying solely on traditional media.

For those who manage our protected areas, stepping into media relations and broader communication may seem a daunting task, and perhaps not one they anticipated when they dedicated themselves to their work. Where resources permit, it is best to hire a professional or invest in training a keen member of your team so that media and communication are a pleasure and a challenge, 


\section{Case Study 15.4 Public information and media management for a major fire event}

In January 2003, under appalling weather conditions, lightning ignited 45 separate bushfires across the 675 000-hectare Kosciuszko National Park in southern New South Wales, Australia, as well as hundreds of other fires across New South Wales and the State of Victoria to the south. Firefighting authorities were faced with an unprecedented demand for information from the multitude of small communities, townships and landholders surrounding the park.

A public information unit (PIU) was soon established as part of the main incident management team structure put in place to manage the fire. At its peak, 16 people were employed within the team. The primary objective of the PIU was to ensure that local communities took the appropriate preparations and considered all contingencies in the event they came under attack from wildfire.

The challenges facing the PIU were many and varied. National media attention did not focus on the fires in Kosciuszko National Park, but rather fires closer to major urban centres where much larger numbers of people and homes were under threat, so the communities adjacent to Kosciuszko National Park did not initially fully recognise the gravity of the situation and hence did not completely appreciate the need to prepare against the threat of fire.

While the media remains the traditional tool for getting critical information out quickly, it has obvious limitations. Stories are often rewritten, reinterpreted and homogenised in order to streamline the product. Control over broadcast times and frequency is also limited. In response, the PIU adopted additional means to ensure everyone in the community had access to detailed information.

The cornerstone of the PIU's information campaign was the Fire Facts Summary, a document that contained facts on the fires, their status, the firefighting strategies employed, weather forecasts, road closures, emergency service updates, information about livestock management, health warnings and any other details that would assist the local communities. A map, updated daily to provide a visual aid in understanding the progress of the fires, accompanied this. Importantly, these were delivered by both fax and email to a constantly evolving list of stakeholders. Today of course much of this would be delivered via a range of social media channels directly to smart phones and tablets, but the principle, with regard to the quality and nature of the information as well as the target audience, remains the same.

The summary and map, which were updated twice daily during the peak of the emergency, were posted on a number of websites. Emails allowed information to be directed specifically at a very large but targeted audience. They contained detail that the media could not convey with the same frequency or to such a specific audience and they were easily forwarded on to others. This allowed up-todate information to be distributed, virtually instantaneously, to a large number of people with specific interest in the emergency. Estimates put the number of people receiving the summary at somewhere between 10000 and 40000 people daily, and it could easily have been more.

Each day hardcopies of the Fire Facts Summary and map were enlarged and put on display in 75 prominent locations throughout the region, including post offices, general stores and pubs. The PIU also delivered a total of 21000 newsletters to outlying communities, held 18 public meetings for 3000 people, conducted regular briefings with key local stakeholders and kept up a constant flow of community service announcements on local radio. Interviews with the media were constant throughout the day and night.

Another effective means of providing the public with information was via a heavily advertised, 24-hour public information telephone service. The operators worked from the Fire Facts Summary and map and were updated as developments occurred. More than 20000 callers used this service during the peak of the crisis.

PIU field liaison officers were sent to outlying areas under threat, while other unit staff telephoned several hundred landholders on properties adjacent to the park to ascertain each property owner's vulnerability and ability to defend their property. In many instances, the PIU was able to allay immediate fears, offer advice and assess the relative risk to different people.

In the aftermath of the Kosciuszko bushfires, a detailed analysis of the PIU's performance and outputs found that the community was overwhelmingly satisfied with the way in which public information had been provided during the fires. The Fire Facts Summary proved to be the most popular information tool while email, websites and the 24-hour public information line and radio were popular means of accessing information.

The PIU ensured the community was well informed about how to be prepared for the threat of fire. This was achieved through a multifaceted approach to information management that was able to make the most of internet technology at the time.

This event took place in a period before apps and the highly advanced nature of the internet today. If it were to occur again tomorrow there would be a range of additional social media tools that would be deployed, but what this case illustrates is the need to find a broad range of communication channels to ensure as many people as possible can be reached with information quickly and to ensure that the team managing public information has all the resources possible to complete the task at their disposal.

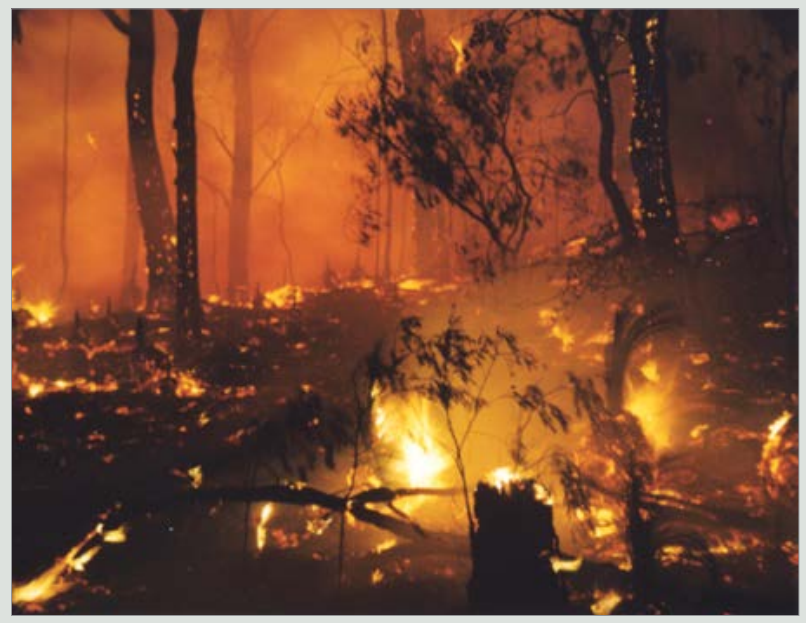

The 2003 Australian Alps fires burning in Kosciuszko National Park

Source: Michelle Watson 
not a cause for panic or a nuisance. Once you have one skilled person who can interact with a journalist or run a social media campaign, they will empower more and more in your ranks to feel comfortable and see the value of telling your stories.
As protected land managers, you speak for the flora, fauna and land features that have no voice. Tell their stories well and you will increase their value among your community and your leaders.

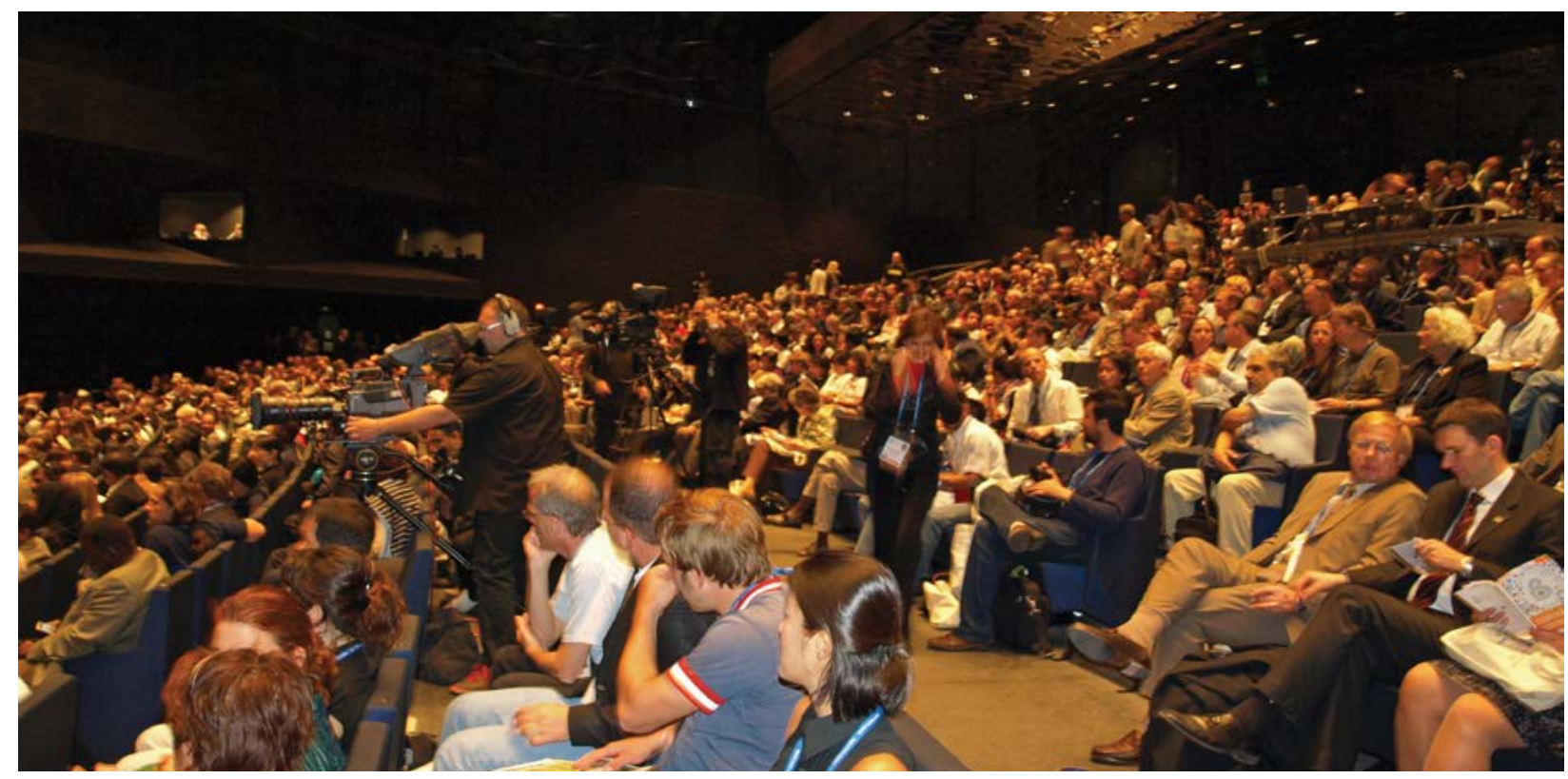

Media at the opening ceremony of the 2008 IUCN World Conservation Congress in Barcelona, Spain. Live broadcasts of such globally significant events ensure that messages of the IUCN Congress are transmitted instantly to audiences around the world, thus benefiting far more than just those with the opportunity to be present.

Source: Graeme L. Worboys

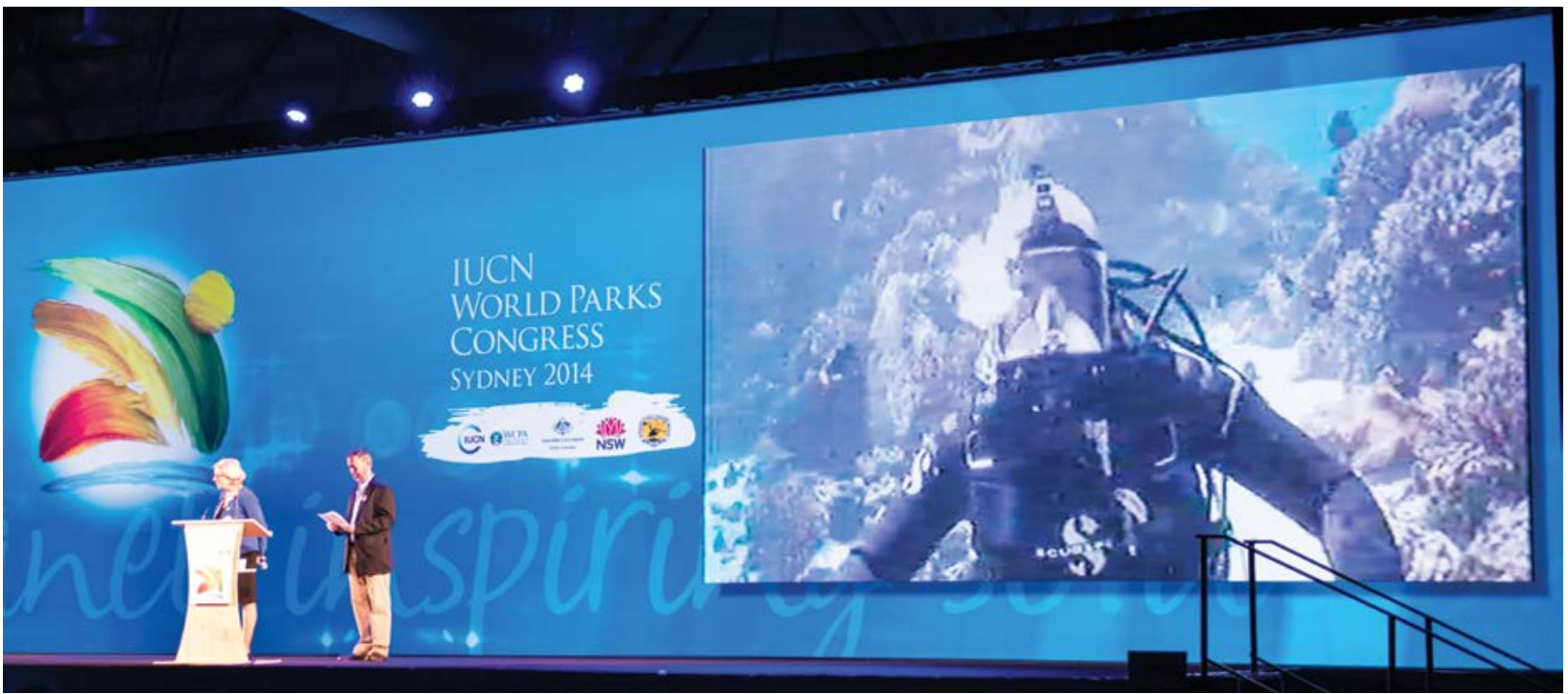

Using media to communicate a message in a spectacular way at the 2014 Sydney IUCN World Parks Congress, with IUCN Director General Julia Marton-Lefèvre and IUCN WCPA Chairperson Ernesto Enkerlin conversing live with a submerged diver at the live coral aquarium exhibit, Great Barrier Reef Marine Park Authority Headquarters, Townsville, Queensland. The conversation reinforced key messages about the importance of the World Heritage Great Barrier Reef Marine Park and the need to protect it from all threats.

Source: Graeme L. Worboys 


\section{References}

D Recommended reading

DD Farmery, A. (2014) The Engaging Brand Podcasts. <www.blubrry.com/engaging/>

Dd Jackobson, S. K. (2009) Communication Skills for Conservation Professionals, 2nd edn, Island Press, Washington, DC.

Newsmaker (2013) Newsmaker Australian Media Survey 2013. <www.newsmaker.com.au>

Dd Pearson, M. and Polden, M. (2011)

The Journalist's Guide to Media Law, 4th edn, Allen \& Unwin, Sydney.

Dd Scott, D. M. (2014) Web Ink Now Blog. $<$ www.webinknow.com/>

Dd Tymson, C., Lazar, P. and Lazar, R. (2006) The New Australian and New Zealand Public Relations Manual, Tymson Communications, Sydney. 


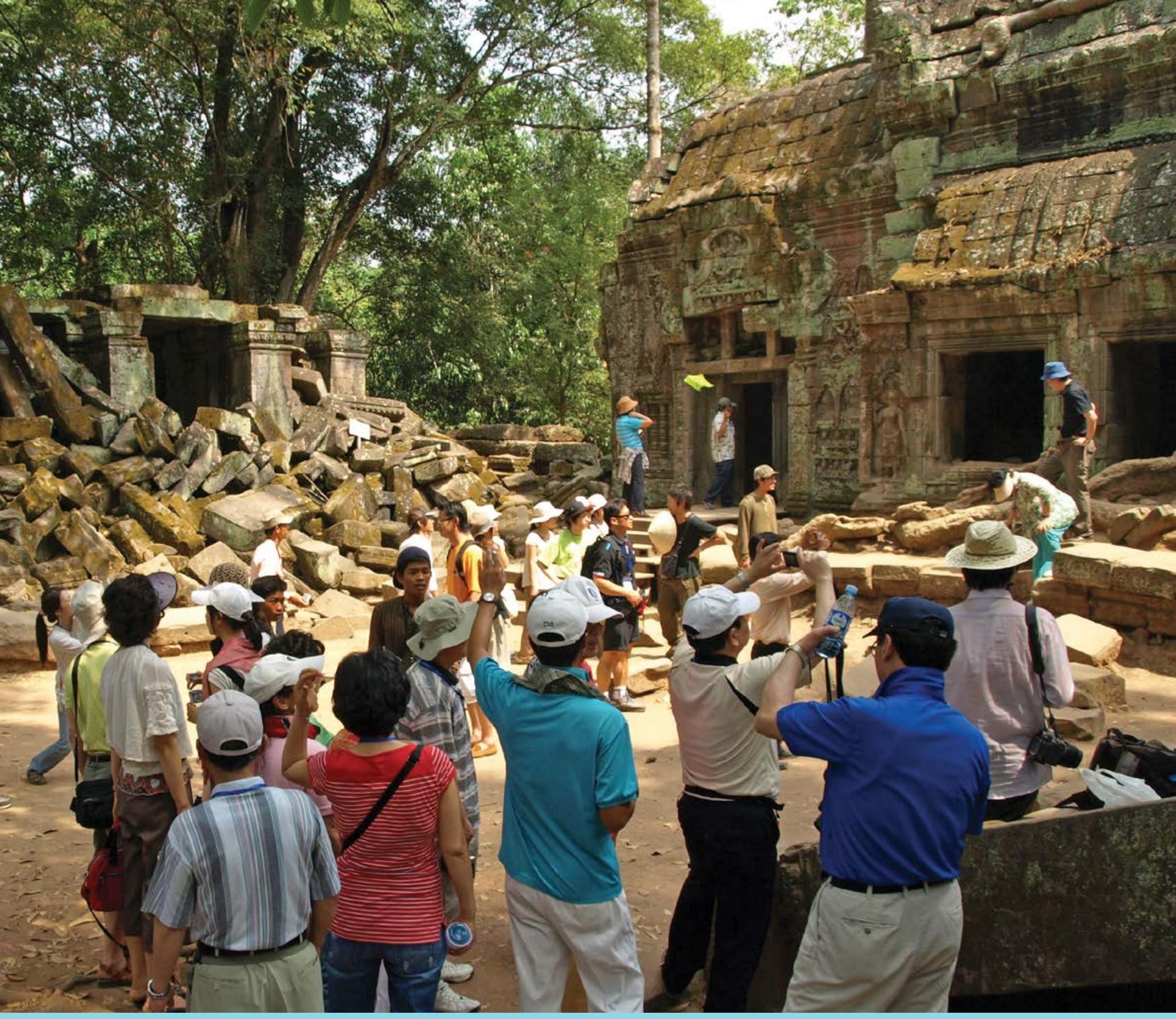

\section{CHAPTER 16}

\section{MANAGING THREATS}

Principal authors:

V. B. Mathur, Malvika Onial and Geoffroy Mauvais

\section{CONTENTS}

- Introduction

- Classification of threats

- Threat assessment and management

- Governance dimensions of addressing threats

- Conclusion

- References

IUCN 5 WCPA 


\section{PRINCIPAL AUTHORS}

VINOD MATHUR is the Director of the Wildlife Institute of India, Dehradun; Regional Vice-Chair of the International Union for Conservation of Nature World Commission on Protected Areas (IUCN WCPA); and a member of the UN Intergovernmental Panel on Biodiversity and Ecosystem Services Multidisciplinary Expert Panel.

MALVIKA ONIAL is a consultant at the Wildlife Institute of India, Dehradun, where she is reviewing and reporting on India's commitments to the Convention on Biological Diversity.

GEOFFROY MAUVAIS is a veterinarian based in Nairobi who joined the IUCN in 2006, and runs the Programme on African Protected Areas and Conservation.

\section{ACKNOWLEDGMENTS}

The authors would like to express their appreciation to the following individuals and organisations who have contributed to the development of this chapter and its case studies: Ashish Kothari, IUCN WCPA; Ninad Sastry Mungi, Qamar Qureshi and Asha Rajvanshi, Wildlife Institute of India; and Graeme Worboys, IUCN WCPA.

\section{CITATION}

Mathur, V. B., Onial, M. and Mauvais, G. (2015) 'Managing threats', in G. L. Worboys, M. Lockwood, A. Kothari, S. Feary and I. Pulsford (eds) Protected Area Governance and Management, pp. 473-494, ANU Press, Canberra.

\section{TITLE PAGE PHOTO}

Visitors viewing Ta Prohm near Angkor Wat, Cambodia, a World Heritage property: the sheer numbers of people and frequency of visits to cultural (and natural) destinations may be a threat to the values of such destinations and such visitor use needs active management Source: Graeme L. Worboys 


\section{Introduction}

Protected areas inter alia aim to support the persistence of biodiversity and the conservation of natural and cultural heritage. While the definition of protected areas (see Chapter 2) may be interpreted in more than one way, the concept of protected areas has been adopted by countries across the world and adapted according to their specific national or local contexts. Protected areas do perform important conservation functions and protect biodiversity, especially from indiscriminate destruction; however, even when protected areas appear to be maintaining their values, they may be undergoing imperceptible changes and declines, leading to halfempty forests' with loss of biodiversity (Peres and Palacios 2007). Protected areas all over the world are beset by a host of threats that undermine the aims of conservation. Protected area management needs to develop the capacity and apply innovative and adaptive approaches for handling a range of complex and often interrelated threats that not only stem from issues specific to an individual protected area but also are driven by factors well beyond protected area boundaries and control.

This chapter provides, first, a description of threats to protected areas and offers a classification of the nature and characteristics of threats based on the protected area threat classification given by Worboys et al. (2006). Next, the chapter discusses generic approaches to responding to threats like encroachments on protected areas, human consumption of ecological assets, poaching of wildlife, fertiliser use (nitrogen deposition), overharvesting of fish stocks and climate change. As a concrete example, it focuses on the process of managing invasive species threats, giving examples from Africa and Asia, as this threat to biodiversity has been identified as being among the major pressures globally (Butchart et al. 2010). Human-wildlife conflicts are also used as an example of how to address a threat. Finally, the chapter discusses the importance and the application of principles of good governance in managing for threats.

\section{Classification of threats}

The Convention on Biological Diversity (CBD) has defined a threat to a protected area as 'any human activity or related process that has a negative impact on key biodiversity features, ecological processes or cultural assets within a protected area' (CBD 2014a). Threats to protected areas may also arise from natural causes and events such as natural fires, earthquakes, floods, and so on. Threats jeopardise the protected area's values (see Chapter 6) and are closely linked to them. Thus, they are very diverse in nature and what may be a threat somewhere may not be seen as such in another protected area or may evolve through time and go on to become a threat. It is difficult to establish a comprehensive global list of threats to protected areas, although various threat assessment frameworks have classified and assessed threats to protected areas, biodiversity and ecosystems.

They have done this in different ways (Carey et al. 2000; MEA 2005; Salafsky et al. 2008; WWF 2012). The International Union for Conservation of Nature (IUCN) Conservation Measures Partnership (CMP), for example, developed a classification of threats to biodiversity in order to provide a unified scheme for classifying threats globally (Salafsky et al. 2008). This Unified Classification for Threats and Actions is constructed in a tiered manner, with direct threats classified at three levels (analogous to families, genera and species in the Linnaean system of biological classification). What this means is that a threat to biodiversity identified at the first level is subdivided into several second-level entries that in turn are subdivided at a third level (Figure 16.1).

With specific regard to protected areas, Worboys et al. (2006) developed a classification of threats and underlying causes that drive threats, both direct and indirect, to protected areas. This classification, while not organised in a hierarchical or tiered fashion as in the classification by Salafsky et al. (2008), shares a similar conceptual approach to analysing threats to protected areas as direct and indirect, identifying the underlying causes and managing protected areas for conservation actions that address such threats. Worboys et al. (2006), in particular, distinguished direct and indirect threats by their spatial characteristics, as explained in the next section.

Understanding threats through such a framework is intended to help protected areas managers and frontline staff to identify threats in their protected areas, learn about other protected areas and the kinds of threats faced, and how these can be tackled. Threats have also been classified into external and internal threats in the context of Indigenous Peoples' and Community Conserved Territories and Areas (ICCAs), which are often vulnerable to the negative impacts of threats in a way that is different from other types of protected areas (Box 16.1). 


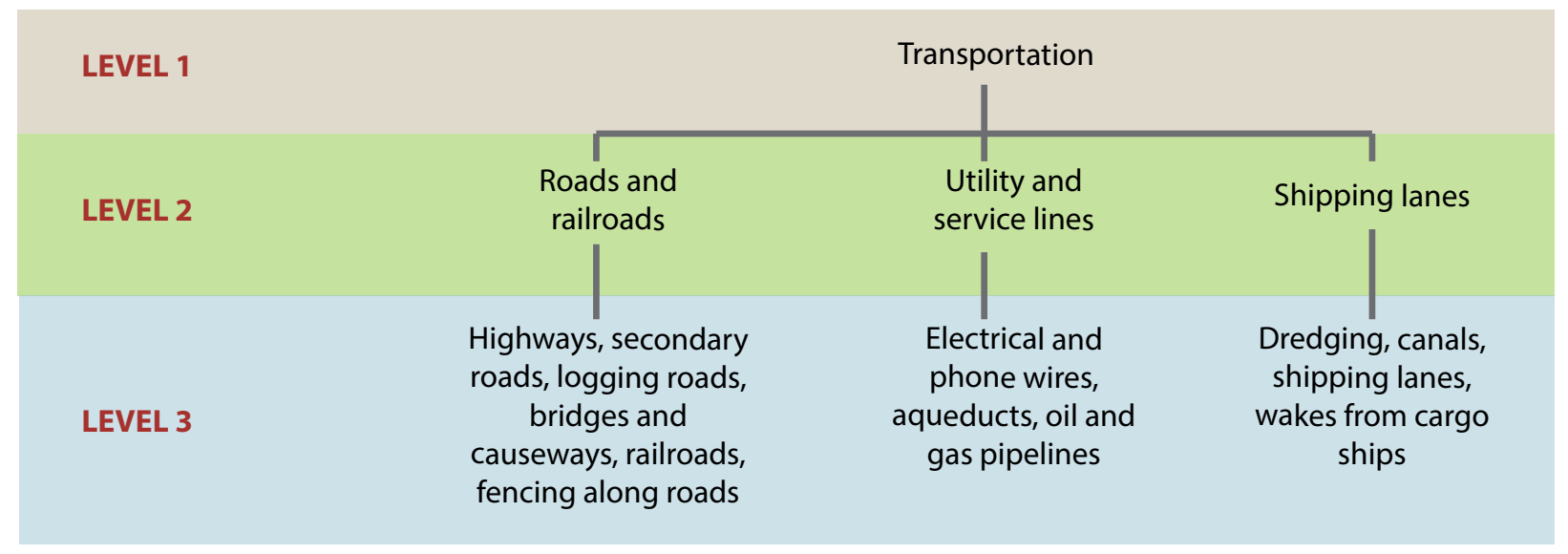

Figure 16.1 Example of a three-level threat classification Source: Adapted from Salafsky et al. (2008)

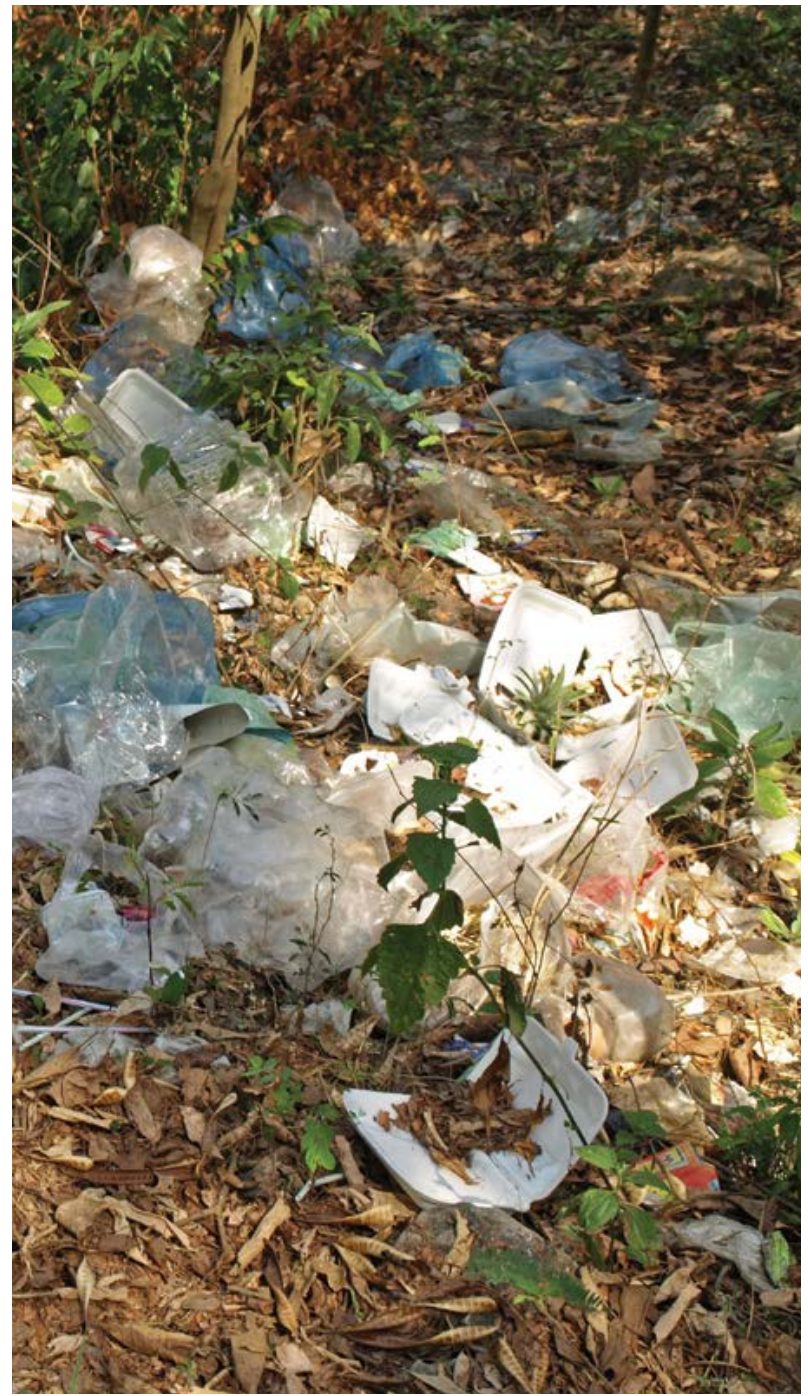

Despite the best efforts of protected area managers, dumped garbage (such as in this protected area in Asia) is a constant source of frustration and part of the real cost of actively managing protected areas

Source: Graeme L. Worboys

\section{Direct threats}

Direct threats result from proximate (in general, within the protected area) human activities or processes that cause the degradation of protected area values and hinder progress towards meeting its conservation goals. Direct threats can often be-but are not always-caused by human activities that may be tackled by appropriate management interventions. Direct threats also result from natural events such as fires and tsunamis, among other extreme natural events or cataclysms. Direct threats range from on-site pollution, water withdrawal and tourism infrastructure development within the protected areas to illegal activities, invasive species and war and civil conflict.

A description of direct threats and their consequences for protected areas is given in Table 16.1, and Case Study 16.1 provides an example of a direct threat (poaching) in Ghanass national system of protected areas. 
Table 16.1 Threats to protected areas: Examples of direct threats

\begin{tabular}{|c|c|c|}
\hline Direct threat & Potential consequences & $\begin{array}{l}\text { Related chapter(s) } \\
\text { in this book }\end{array}$ \\
\hline $\begin{array}{l}\text { On-site pollution, impacts of } \\
\text { chemicals }\end{array}$ & $\begin{array}{l}\text { Damage to natural ecosystems and species, tourism } \\
\text { and recreation values, human health }\end{array}$ & $19,20,23,24$ \\
\hline $\begin{array}{l}\text { On-site impoundment/ } \\
\text { diversion of streams and rivers, } \\
\text { groundwater withdrawal }\end{array}$ & $\begin{array}{l}\text { Damage to natural ecosystems and species, blocking } \\
\text { of migration passages }\end{array}$ & 19 \\
\hline Excessive livestock grazing & $\begin{array}{l}\text { Damage to natural ecosystems and species, tourism } \\
\text { and recreation values }\end{array}$ & 25 \\
\hline Mining & $\begin{array}{l}\text { Damage to natural ecosystems and species, tourism } \\
\text { and recreation values, cultural heritage }\end{array}$ & 25 \\
\hline $\begin{array}{l}\text { Infrastructure and industrial } \\
\text { development within the protected area }\end{array}$ & $\begin{array}{l}\text { Damage to natural ecosystems and species, cultural } \\
\text { heritage }\end{array}$ & 24 \\
\hline Unsustainable tourism & $\begin{array}{l}\text { Damage to natural ecosystems and species, social } \\
\text { and cultural heritage }\end{array}$ & 23 \\
\hline $\begin{array}{l}\text { Excessive resource extraction; } \\
\text { overharvesting including poaching, } \\
\text { hunting, fishing, fodder and fuel-wood } \\
\text { extraction, logging (legal and illegal) }\end{array}$ & $\begin{array}{l}\text { Damage to natural ecosystems and species, cultural } \\
\text { heritage, tourism and recreation values }\end{array}$ & 25 \\
\hline War and civil strife & $\begin{array}{l}\text { Damage to natural ecosystems and species, social } \\
\text { and cultural heritage, infrastructure, human life }\end{array}$ & 26 \\
\hline $\begin{array}{l}\text { Inadequate or incompetent technical } \\
\text { and protected area management } \\
\text { actions, processes and resources }\end{array}$ & $\begin{array}{l}\text { Damage to natural ecosystems and species, social } \\
\text { and cultural heritage, infrastructure, human life }\end{array}$ & $8,12,13,24$ \\
\hline Invasive species of plants and animals & Damage to natural ecosystems and species & 21 \\
\hline $\begin{array}{l}\text { On-site cataclysmic natural events } \\
\text { (such as fire, flood, earthquakes, } \\
\text { volcanic activity) }\end{array}$ & $\begin{array}{l}\text { Damage to natural ecosystems and species, } \\
\text { infrastructure, property, human life }\end{array}$ & 24,26 \\
\hline
\end{tabular}

Source: Adapted from Worboys et al. (2006)

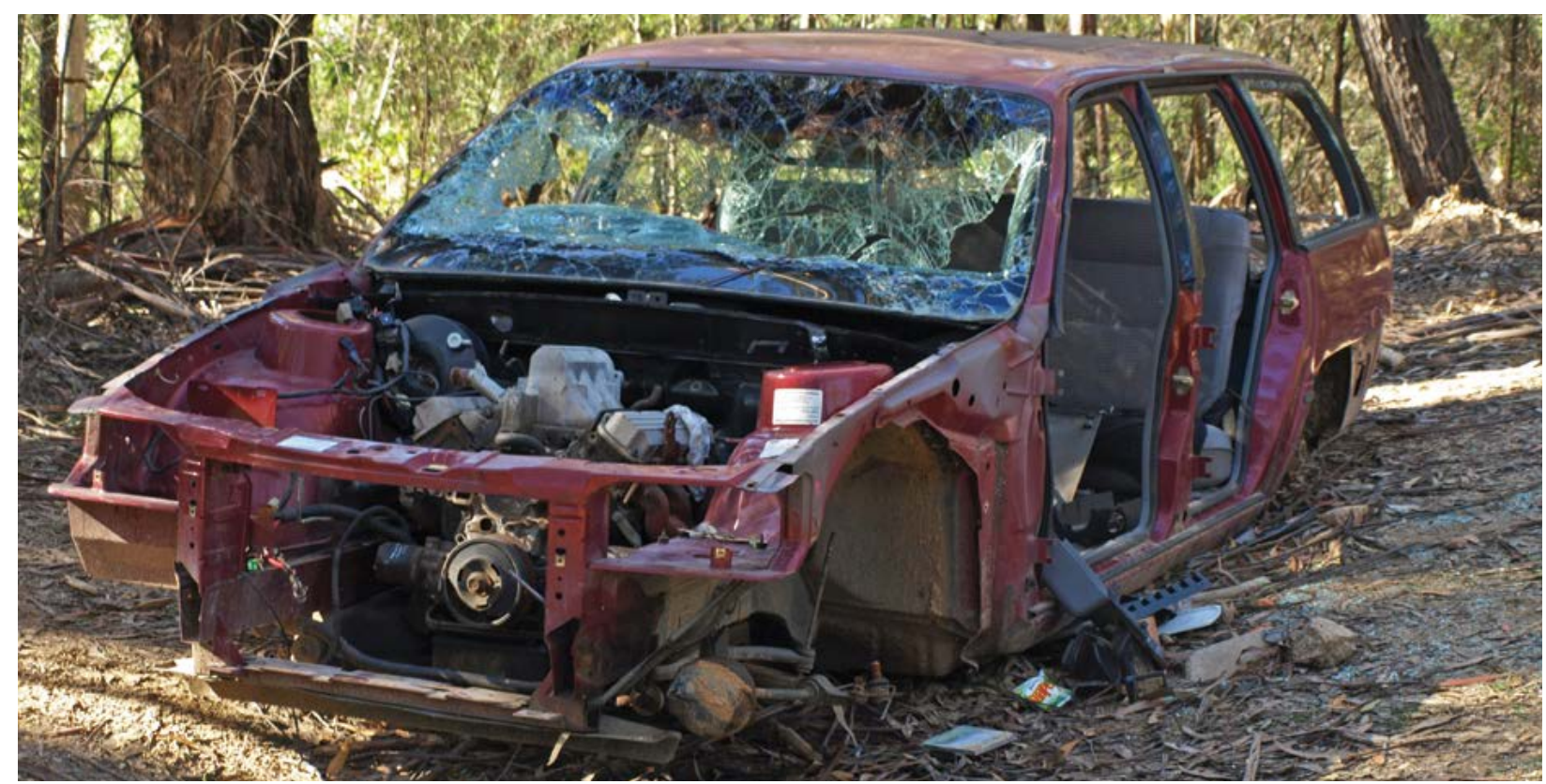

A wrecked and looted car dumped in protected area bushland in southern New South Wales, Australia: the urban-protected area interface in particular is affected by such illegal acts and rangers constantly need to clean up such garbage

Source: Graeme L. Worboys 


\section{Case Study 16.1 Assessing threats to protected areas in Ghana: The case of poaching}

The three main threats identified in the protected area system of Ghana through the Rapid Assessment and Prioritisation of Protected Area Management (RAPPAM) methodology, conducted in December 2009, are: poaching, bushfire and land conversion mainly due to agriculture around the protected areas (Figure 16.2). Other threats mentioned are illegal fishing, invasive species (plants) and pollution, but they affect the protected areas to a lesser extent. Poaching is the most widely distributed threat and its intensity varies from one park to another.

Indeed, poaching exists in all protected areas of Ghana at different degrees of severity (Figure 16.3). It is particularly high in Kakum National Park, despite the good law enforcement strategy in place, and also present in Ankasa, Shai Hills and Mole national parks. There is a high demand for bushmeat all over the country. Rattan is poached for craft, elephant is poached for tusks and leopard for skin. In Bia, the killing of animals is mostly as a result of human-wildlife conflict. In Kyabobo, this pressure is very low, despite the high demand for bushmeat. This is because of the enhanced law enforcement leading to highly reduced poaching activities. Furthermore, the park has encouraged the creation of community resource management committees that regulate the harvesting of non-timber forest products, which contributes to decreasing effects from poaching. Regarding Bia, there are small local markets near its international borders that are seriously involved in the bushmeat trade; the wildlife population outside the parks is limited, so protected areas are the major source of bushmeat-mainly to meet the protein requirements of the local population.

Source: IUCN PAPACO (2010)

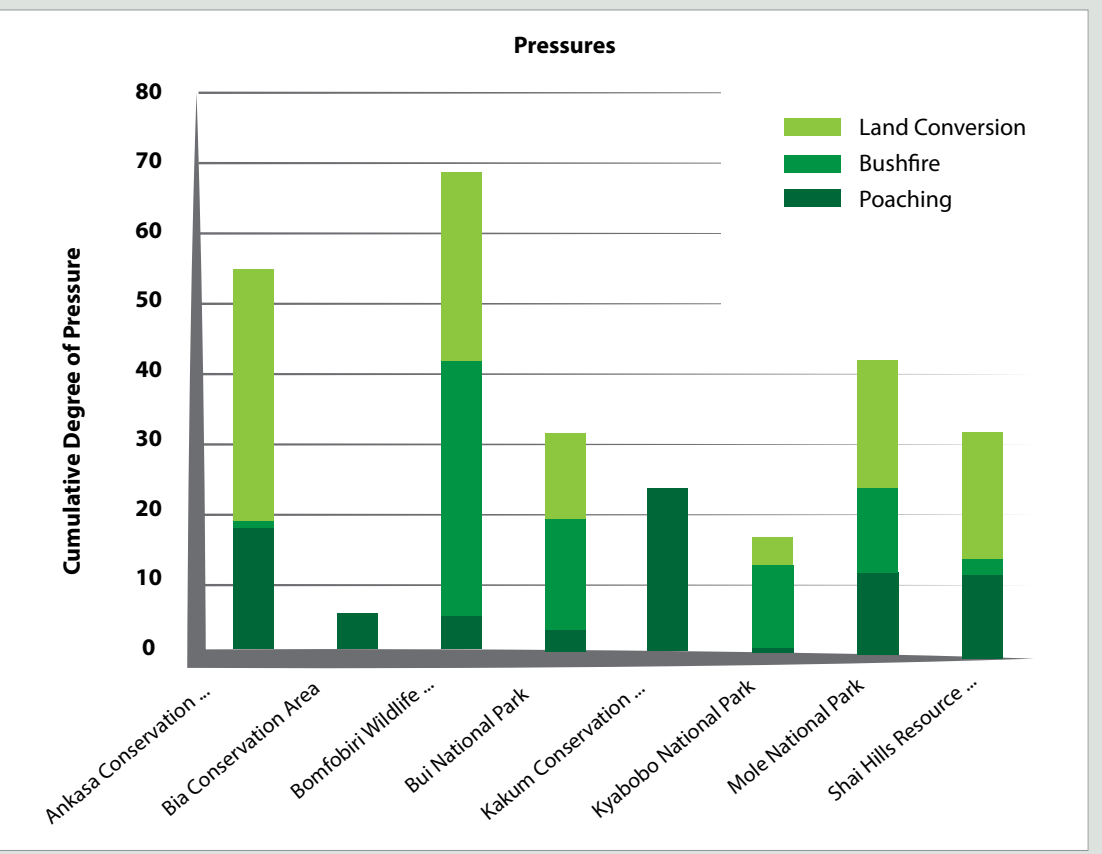

Figure 16.2 The main threats to the protected area system of Ghana

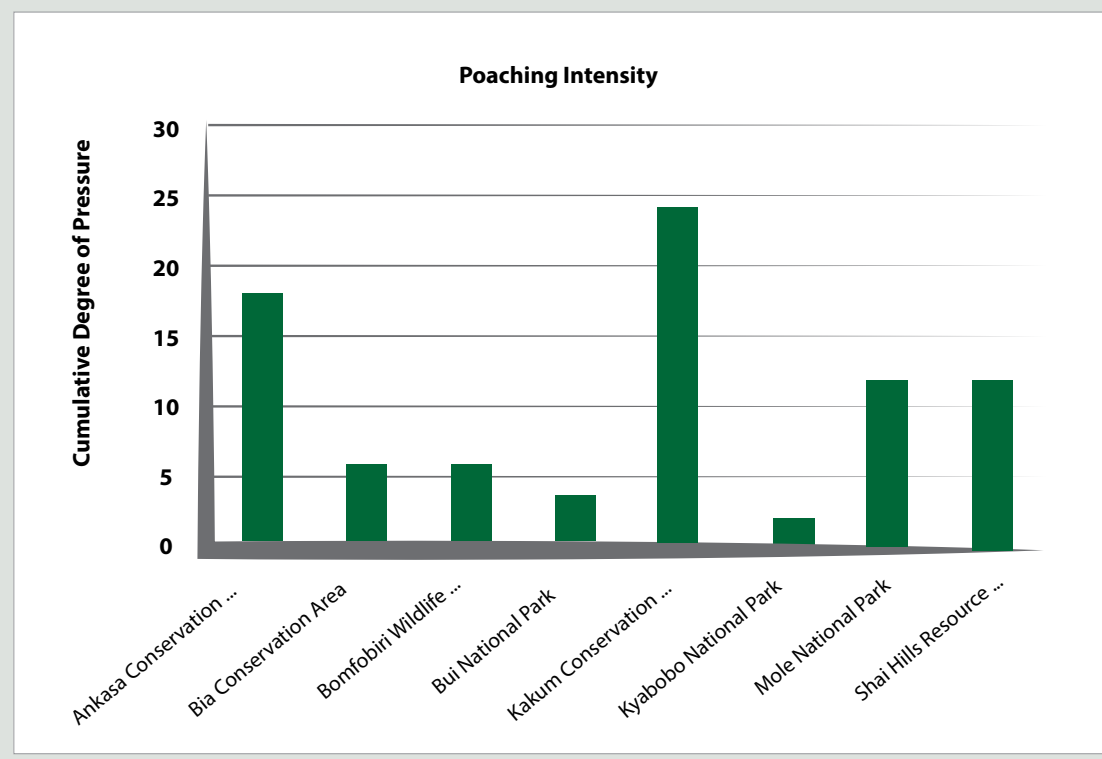

Figure 16.3 Poaching intensity in the protected areas of Ghana 


\section{Underlying causes}

Underlying causes are the factors that ultimately drive threats to protected areas. These are usually economic, social, political, institutional or cultural factors that contribute in an interrelated way to create one or several direct and indirect threats. Among the many underlying causes of threats are human population growth, growth in consumption, economic development aspirations and activities, weak or inadequate legal systems, powerful vested interests, imbalance of power, poor decisionmaking, lack of political will, absent or weak tenure and rights regimes, policy failures, and contradictory or opposing values. An example of opposition between conservation and extractive industries, in Guinea, is provided (Case Study 16.2). A lack of information, awareness and education, and inadequate funding for conservation are also issues (Table 16.3).

\section{Table 16.3 Threats to protected areas: Examples of underlying causes}

\begin{tabular}{|c|c|c|}
\hline Underlying causes & Potential consequences & $\begin{array}{l}\text { Related chapter(s) } \\
\text { in this book }\end{array}$ \\
\hline Human population growth & $\begin{array}{l}\text { Unsustainable consumption of natural resources, } \\
\text { waste generation }\end{array}$ & 5 \\
\hline $\begin{array}{l}\text { Higher consumption, material } \\
\text { aspirations }\end{array}$ & $\begin{array}{l}\text { Unsustainable consumption of natural resources, } \\
\text { waste generation }\end{array}$ & 5 \\
\hline $\begin{array}{l}\text { Inadequate economic systems, } \\
\text { inequitable economic growth, } \\
\text { inappropriate socioeconomic, political } \\
\text { and governance mechanisms }\end{array}$ & $\begin{array}{l}\text { Failure to account fully for environmental costs and } \\
\text { benefits } \\
\text { Poverty and lack of choices, lack of options to adopt } \\
\text { sustainable practices } \\
\text { Ability by rich to extract resources without feeling } \\
\text { negative feedback } \\
\text { Harmful subsidies, lack of incentives for } \\
\text { environmentally positive activities } \\
\text { Lack of resources for protected area management } \\
\text { and conservation } \\
\text { Inequitable management, ownership and costs and } \\
\text { benefit sharing } \\
\text { Profit motives prioritised above all else }\end{array}$ & 5 \\
\hline Inadequate legal and political systems & $\begin{array}{l}\text { Policies that fail to secure environmental protection } \\
\text { Lack of political will and commitment } \\
\text { Prevalence of corruption leading to enforcement, } \\
\text { management and governance failure } \\
\text { Weak, absent or inappropriate legal tenure and rights } \\
\text { over land and resources } \\
\text { Absent, weak or inappropriate recognition of } \\
\text { conservation practices of non-governmental actors, } \\
\text { including indigenous peoples and local communities } \\
\text { Excessively centralised control, lack of public } \\
\text { participation in governance }\end{array}$ & 5 \\
\hline $\begin{array}{l}\text { Breakdown or dysfunction of social, } \\
\text { cultural or political relations }\end{array}$ & $\begin{array}{l}\text { War, conflicts and civil strife that hinder protected } \\
\text { area management or destroy protected areas }\end{array}$ & 5 \\
\hline $\begin{array}{l}\text { Values and attitudes incompatible with } \\
\text { conservation goals }\end{array}$ & $\begin{array}{l}\text { Impairment of protected area management, } \\
\text { conservation failure }\end{array}$ & 5 \\
\hline $\begin{array}{l}\text { Inappropriate governance and } \\
\text { management }\end{array}$ & $\begin{array}{l}\text { Damaging management policies and actions, poor } \\
\text { planning, improper implementation, incompetent } \\
\text { execution, iniquitous or poor governance }\end{array}$ & $7,8,12,13$ \\
\hline $\begin{array}{l}\text { Lack of information, knowledge and } \\
\text { education, inadequate recognition of } \\
\text { relevant knowledge systems }\end{array}$ & $\begin{array}{l}\text { Lack of awareness of threats to protected area } \\
\text { values and benefits of protected areas }\end{array}$ & $5,6,11$ \\
\hline $\begin{array}{l}\text { Lack of technical and human capacity, } \\
\text { low levels of human resources for } \\
\text { protected area management }\end{array}$ & $\begin{array}{l}\text { Improper or inadequate identification of problems } \\
\text { and solutions to environmental problems, inadequate } \\
\text { management response, inability to implement }\end{array}$ & $8,9,10,12,13$ \\
\hline
\end{tabular}




\section{Case Study 16.2 Mount Nimba: A World Heritage site under great pressure}

The strict nature reserve of Mount Nimba has been classified as a biosphere reserve and UN Educational, Scientific and Cultural Organisation (UNESCO) World Heritage property since 1981. It is located between Ivory Coast, Guinea and Liberia. Mount Nimba is both a very rich and specific ecosystem and a very large iron ore reserve. In theory, Mount Nimba is totally protected, however, iron ore deposits are mined both in Liberia, with a railway linking Mount Nimba to the Buchanan mining port, and in Guinea, where an area with high mineralisation was declassified as World Heritage to enable prospecting to be carried out. Given Liberia's economic and political instability, Guinea plans to construct more than 1000 kilometres of railway line between Mount Nimba and Kamsar mining port. The planned line would pass along the boundary of the strict natural reserve of the Ziama mountain range.

For more than 20 years, the mining of Mount Nimba iron ore in Guinea has been an issue of contention between environmental activists and mining supporters. There is a unique mountainous ecosystem harbouring endemic species and in particular the western Nimba toad (Nimbaphrynoides occidentalis) and the Nimba otter shrew (Micropotamogale lamottei). The altitude of Mount Nimba influences the climate of the region. Then there is a project worth several billion dollars (the railway line and deep-water port of Conakry were estimated in 2008 to be worth US\$4 billion, to which can be added several hundred million dollars to develop the mine itself) with tens of thousands of jobs and royalties guaranteed for about 20 years.

To date, the project is restrained by the high investment cost. If, however, metals maintain their current prices, the project could soon begin. On the Ivorian side, preliminary prospecting has also been noted.

Source: IUCN PAPACO (2014)
Although threats identified in Tables 16.1, 16.2 and 16.3 have been presented as individual issues, for managers they are often interacting and interrelated. For example, threats to protected areas associated with recreation and tourism can include development of infrastructure, fragmentation through roads and powerlines, pollution, increased risk of wildfire, hunting and fishing, and increased human populations in adjacent areas.

Both evaluation and planning for improved management need to take into account the interrelationships between the threats and to identify their root causes, if effective and sustainable management solutions are to be devised and implemented. Moreover, many threats relate to the interface between conservation and human welfare and therefore are very challenging to resolve. This is even more so in regions with rapidly growing populations and developing economies. Many other threats relate to deeply set patterns of development and consumption that are hard to change, which is especially so in industrialised countries and among rich populations of all countries. Some of the threats facing ICCAs are described in Box 16.1.

\section{Threat assessment and management}

According to the CBD's Programme of Work on Protected Areas (PoWPA), a protected area threat assessment should include an analysis of the type, extent and impact of a range of threats on the health and integrity of biodiversity within a protected area (CBD 2014a). The typical steps involved in assessing threats to protected area biodiversity are described in Figure 16.4.
A number of management tools are available for assessing threats and some of these may be found on the CBD website (CBD 2014b), including an e-course on threat management. Other tools are included in protected area management effectiveness assessments (see Chapter 28) such as the Management Effectiveness Tracking Tool and the Rapid Assessment and Prioritisation of Protected Area Management (RAPPAM) methodology. With these tools, threats are usually linked to the values that the protected area is trying to conserve, as exemplified by Kakum National Park in Ghana (Case Study 16.3).

\section{Planning conservation actions to address threats}

General management actions include setting priorities, developing a situation analysis, designing and implementing a strategic plan, developing and implementing a monitoring plan, and analysing and communicating results (CMP 2013). They also include fundraising, reporting, administrative work, and developing and managing the institutions associated with a protected area. At times they may involve the creation or strengthening of institutional structures for the purpose. Specific conservation actions, in contrast, are specific interventions to counter specific threats to biodiversity or restore degraded biodiversity targets. Strategies and action plans for managing threats must be guided by desired conservation outcomes that should be identified as clearly as possible early in management planning. 


\section{Box 16.1 Threats to Indigenous Peoples' and Community Conserved Territories and Areas}

The IUCN defines ICCAs as 'natural and modified ecosystems with significant biodiversity, ecological and related cultural values, voluntarily conserved by indigenous peoples and local communities through customary laws or other effective means' (Kothari et al. 2012:16). They are increasingly recognised as areas of significant biodiversity and cultural diversity that need not only appropriate recognition but also support in order to combat threats to their continued existence. Key threats affecting ICCAs have been broadly classified into indirect (or external-that is, those threats originating from outside actors or phenomena) and direct (or internalthat is, arising from within the community or people).

\section{Direct threats}

- Inequalities between economic and social classes and gender groups within the community, leading to conflicts about the management of natural resources and benefits arising from their use.

- Changing values, integration into the dominant society and economy, loss of interest in traditional knowledge and practices, and loss of the group's original language, particularly among young people.

- Population growth or, conversely, depopulation leading to increased pressure on the natural resources of ICCAs or loss of traditional knowledge and institutional arrangements, respectively.

\section{Indirect threats}

- Lack of or inappropriate recognition of the ICCA by the state or civil society, which makes it vulnerable to other threats such as those from landuse change. For example, in Iran, there is mostly no official recognition of ICCAs and natural resource management controls remain with the state despite the nomadic peoples having conserved grazing lands for long periods.
- Weak or inadequate legal tenure or rights over ICCAs and their resources. For example, in subSaharan Africa, customary land rights and common property natural resource governance regimes are widely unrecognised, and communities are effectively tenants of the state.

- Development and resource exploitation processes, such as mining and fossil fuel extraction, logging, industrial fishing, dredging, conversion to monocultures (including agro-fuel crops), dams, urbanisation, roads, ports, airports and tourism). For example, in many countries dams have resulted in loss of biodiversity, displacement of local communities or indigenous peoples and loss of cultural heritage.

- Increasing pressure on resources from demands of the larger external market economy. For example, in Australia, employment and other benefits offered by mining companies often win over traditional landowners' resistance despite veto rights against mining on their lands.

- Encroachment on the ICCA by state-sponsored policies or by unauthorised but more powerful interests.

- Inappropriate forms of recognition that create a conflict between the traditional governance systems of the ICCAs and systems imposed by top-down arrangements or legislation. For example, in England, traditional governance systems of the commons can be in conflict with systems imposed under relevant legislation or in relation to protected areas.

- Inappropriate and active acculturation of communities-for example, through education programs that are disrespectful of local cultures, livelihoods and values, or evangelisation programs of different faiths.

Source: Adapted from Kothari et al. (2012)

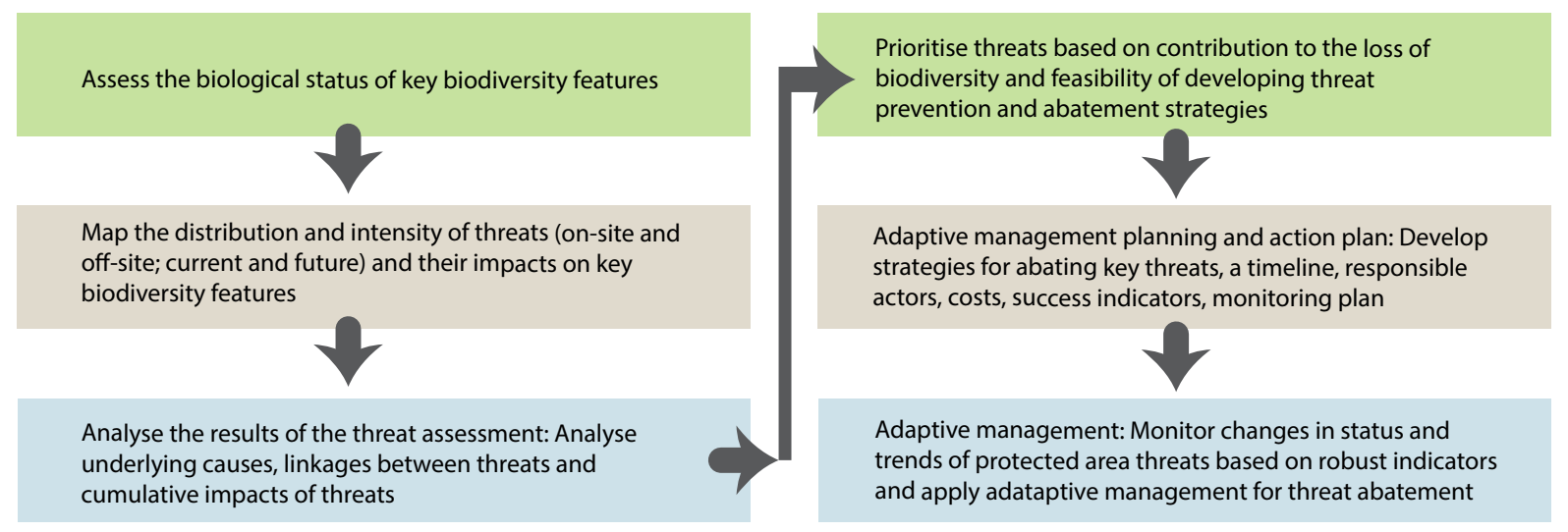

Figure 16.4 Key steps in assessing threats to biodiversity in protected areas

Source: Adapted from CBD (2014a) 


\section{Case Study 16.3 Kakum National Park, Ghana}

Threats can be quite easily identified through a rapid consultative assessment of management effectiveness. The 36 000-hectare Kakum National Park (IUCN Category II) in southern Ghana was assessed using the Management Effectiveness Tracking Tool in 2011, to help with the revision of its management plan and with developing an adaptive management response to help protect its main values.

The natural, cultural and social values identified for Kakum National Park were:

- a network of rivers

- highlands, swampy and muddy area landscapes

- a sample of a pristine rainforest ecosystem

- a typical reafforestation model of the upper Guinean rainforest

- endangered species such as the bongo (Tragelaphus euryceros), forest elephant (Loxodonta cyclotis), blackand-white colobus monkey (Colobus sp.), yellowbacked duiker (Cephalophus silviculter) and Diana monkey (Cercophithecus diana)

- charismatic species such as leopard (Panthera pardus), giant forest pangolin (Manis pangolin) and various birds and butterflies
- cultural values including sacred sites and traditional rites closely related to the rainforest such as the use of drums

- economic values including climate change mitigation and control at local, regional and global levels; the protection of the sources of the main rivers bringing water to surrounding populations; the conservation of plants of economic value; and tourism.

The main threats related to these values were identified as:

- poaching

- overuse by tourists in certain areas

- invasive species (plants)

- pollution of rivers with chemicals used for fishing purposes or coming from the surrounding croplands

- harvesting of vegetation products (such as raffia for roof making, medicinal plants and wood for fuel).

Source: IUCN-PAPACO (2011a)

Any entity (government, non-governmental, community or co-management) responsible for managing a protected area would ideally have a management plan (formal or informal) that is designed to take into account actual and potential threats to the protected area, the consequences of such threats and ways in which to avoid or mitigate them (see Chapter 13). Although managing threats to protected areas is based on the precautionary principle, particularly for threats with severe and potentially irreversible consequences, often management responses may be driven by situational factors specific to the local history and prevalent economic and political climates. The importance of applying adaptive management based on the evaluation of results and lessons learnt so that it can evolve according to the dynamic requirements of protected area conservation is also well recognised (CMP 2013). At the same time, a focus is needed on specific conservation activities that address threats and the management and monitoring of these actions are important (Box 16.2).

\section{Management zoning and sustainable-use limits}

Management planning for protected areas typically employs planning tools, zone management schemes, models and techniques that address threats and seek to minimise their negative effects. Some protected areas baits that target foxes

Source: Graeme L. Worboys 


\section{Box 16.2 Monitoring Information System Tool: Software for monitoring the application of law and addressing poaching in protected areas}

The fight against poaching-one of the main threats in African protected areas-is subject to the application of current legislation. This requires not only initial knowledge of the law but also the subsequent capacity to use limited human and material resources effectively and efficiently. To do so, access to pertinent, regular and timely spatial-temporal data regarding threats to the protected area is essential to enable protected area managers to take enlightened surveillance decisions (planning, patrols and activity assessment). These data can only be gathered by rangers. 'Ranger-based monitoring' is a system to organise data collection by rangers in such a way that they can be used for both managerial and strategic needs. The data provided by rangers are used to monitor conservation efforts, discourage illegal activities, identify the most endangered areas and assess future or potential threats.

The Monitoring Information System Tool (MIST) software has proved to be an effective application for ranger-based monitoring. It facilitates planning and monitoring while avoiding the problems encountered with geographical information systems (GIS) software, which require too much specialised assistance and equipment. MIST works on normal computers and, once set up, it can be managed by a non-specialist and the information can be easily and rapidly shared or backed up between sites by email. As well as its user-friendliness, MIST can be used to rapidly produce patrol maps and make a simple or sophisticated analysis of aggregated data.

Finally, MIST can store data on legal monitoring when infringements are registered. For example, the national parks network in Gabon has used MIST since 2011. The information gathered by rangers during their rounds is summarised in monthly, quarterly and annual reports. This information is used by park managers in their decisions regarding surveillance strategies and one can now see the efforts made to cover national parks and the results. The new version of MIST, baptised SMART, is in 2014 being tested in five African countries (including Gabon) and in five Asian countries.

Source: IUCN PAPACO (2011c) are spatially differentiated into zones with specific management objectives that will address the potential threats-for example:

- a core zone where human activities are disallowed other than for necessary management or occasional sociocultural uses

- a buffer zone, which is intended to act as a buffer for the protected area nested in the larger landscape; a buffer zone is often a multiple-use zone where management allows for different levels of resource use and extraction, which may be carried out based on rights-based approaches for local communities or for government revenue collection

- a recreation or tourism zone where visitor management is key.

Limits on resource use or visitor numbers are applied by protected area management to ensure sustainable use-for example, the amount of small timber that may be extracted by forest-dependent communities, the number of grazing permits for livestock or the number of tourists allowed to visit a protected area each day. Defining limits on resource use is increasingly sought through a consultative process by or with communities, researchers and protected area managers using a rightsbased approach that respects traditional and customary rights (Chapter 25).

Prescriptions for visitor-use limits need to be clearly worked out if threats to the natural and cultural heritage values of protected areas from excessive tourist numbers or inappropriate tourism are to be avoided. Recreational planning frameworks such as the recreation opportunity spectrum and other recreational opportunity management systems as well as visitor impact management frameworks can help identify threats and minimise social and environmental impacts (see Chapter 23). Moreover, community-based and community-run tourism offers opportunities for equitable management of protected areas and promotes sharing of tourism revenue and other benefits with local communities.

\section{Using environmental impact assessment to address threats}

Environmental impact assessment is a process that many countries around the world follow to help harmonise development proposals with conservation needs (Byron 2000; UNEP 2002). Sometimes, however, the nature of developmental activity is such that addressing threats effectively lies beyond the scope of a conventional environmental impact assessment process. 


\section{Case Study 16.4 Oil and gas environmental impact appraisals in West Africa}

For any protected area, oil and gas exploration and/ or extraction is a serious threat. It is the same for the development of a mine. Generally, however, oil laws differ significantly from mining laws. A survey conducted in West Africa showed that oil exploration blocks are delineated by the government and granted through a call-for-tender process or by direct negotiation with oil companies. Oil exploration and production licences are entirely covered by oil agreements or contracts that govern the holders' rights and obligations more specifically than do mining laws. While standard oil agreements are in the public domain, the agreements themselves are not, and it is impossible to know their specific content.

By way of example, the standard oil agreement in GuineaBissau contains the following clauses:

- The (oil) company recognises and accepts that oil operations can cause environmental damage. Therefore, during execution of this contract, it must ensure that the environment and natural resources are conserved. To this end, the company must: a. use techniques compliant with good oil industry practices to prevent damage

b. when environmental damage is inevitable, limit the effects on people and goods in compliance with legislation and good oil industry practices.

An environmental impact appraisal is compulsory, but the relationship between mining licences and protected areas is rarely specified and a good number of oil exploration blocks contain protected areas (for instance, in Mauritania, Senegal, Mali and Guinea-Bissau), including national parks and areas inscribed or proposed for inscription as World Heritage properties such as Banc d'Arguin (Mauritania), the Archipelago of Bijagos (Guinea-Bissau), Djoudj National Park (Senegal) and the Saloum Delta (Senegal).

Source: IUCN PAPACO (2011b)

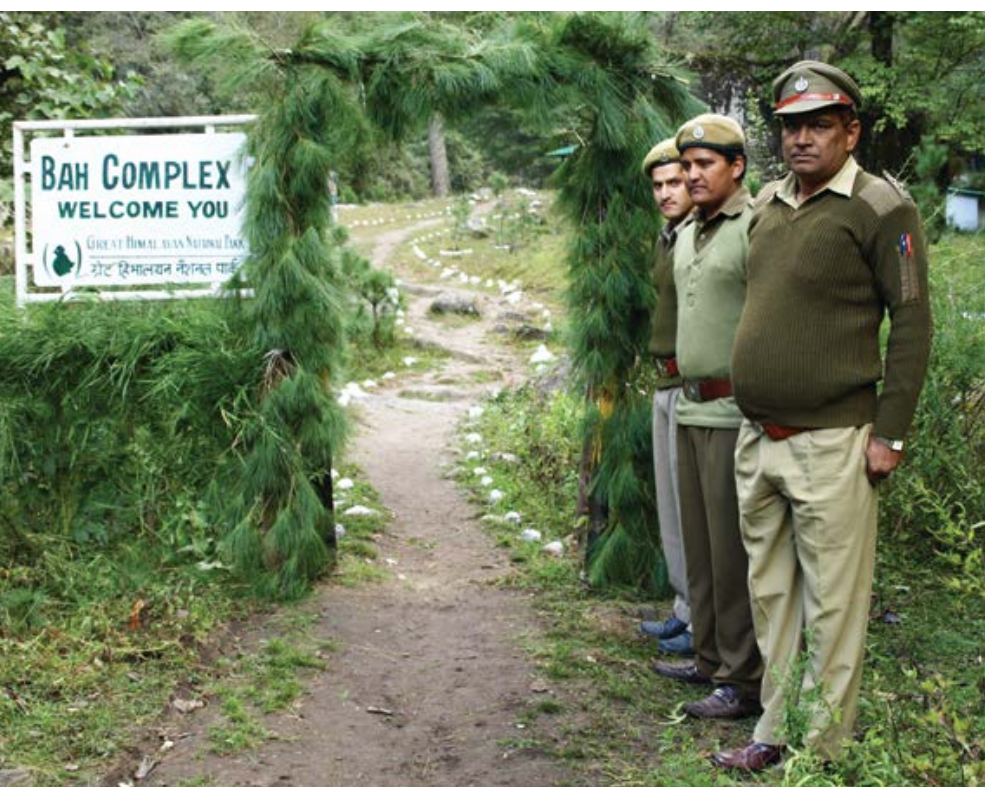

Forest guards and the entrance station to the Great Himalayan National Park, India: providing protection to the park from illegal use such as native herb extraction. The park staff have facilitated the cultivation of herbs in the adjacent buffer area as an alternative source.

Source: Graeme L. Worboys

illicit resource extraction, hunting and poaching, was the most common threat discussed. Wildlife crime also poses serious challenges to protected areas (Dudley et al. 2013). Other frequently mentioned threats included mining, quarrying and oil drilling, pollution of various kinds, fragmentation caused by roads and other utility lines, severe weather and climate change.

\section{Invasive alien species}

While invasive alien species are not the only threat to protected areas, they are a serious existing and emerging threat that is often not recognised due to gaps in information on these species. While the potential threat from invasive alien species is appreciated, 'the state of knowledge and level of management of invasive alien plants in protected areas differs considerably across the world' (Foxcroft et al. 2014:621). Moreover, 'many invasive plants have, or have the potential to, greatly lessen the potential of protected areas to achieve the things they were proclaimed to do-provide refugia for species, habitats and the ecosystem services that they sustain' (Foxcroft et al. 2014:621-2).

Invasive species constitute an increasingly serious threat to biodiversity in marine ecosystems also but remain inadequately understood (Molnar et al. 2008; IPBES 2013). Threats from these species need to be addressed to preserve the values and functions of protected areas and the support they provide to the livelihoods of millions of people. Economic losses from invasive species are very high and it has been estimated worldwide that the cost of damage from invasive alien species exceeds US $\$ 1.4$ trillion, amounting to 5 per cent of the global economy (IPBES 2013).

The CBD guidance on assessing and managing invasive species within protected areas ( $\mathrm{Tu} 2009$ ) provides a comprehensive overview of the strategies, methods, techniques and development of management plans for use by protected area practitioners. In addressing threats 


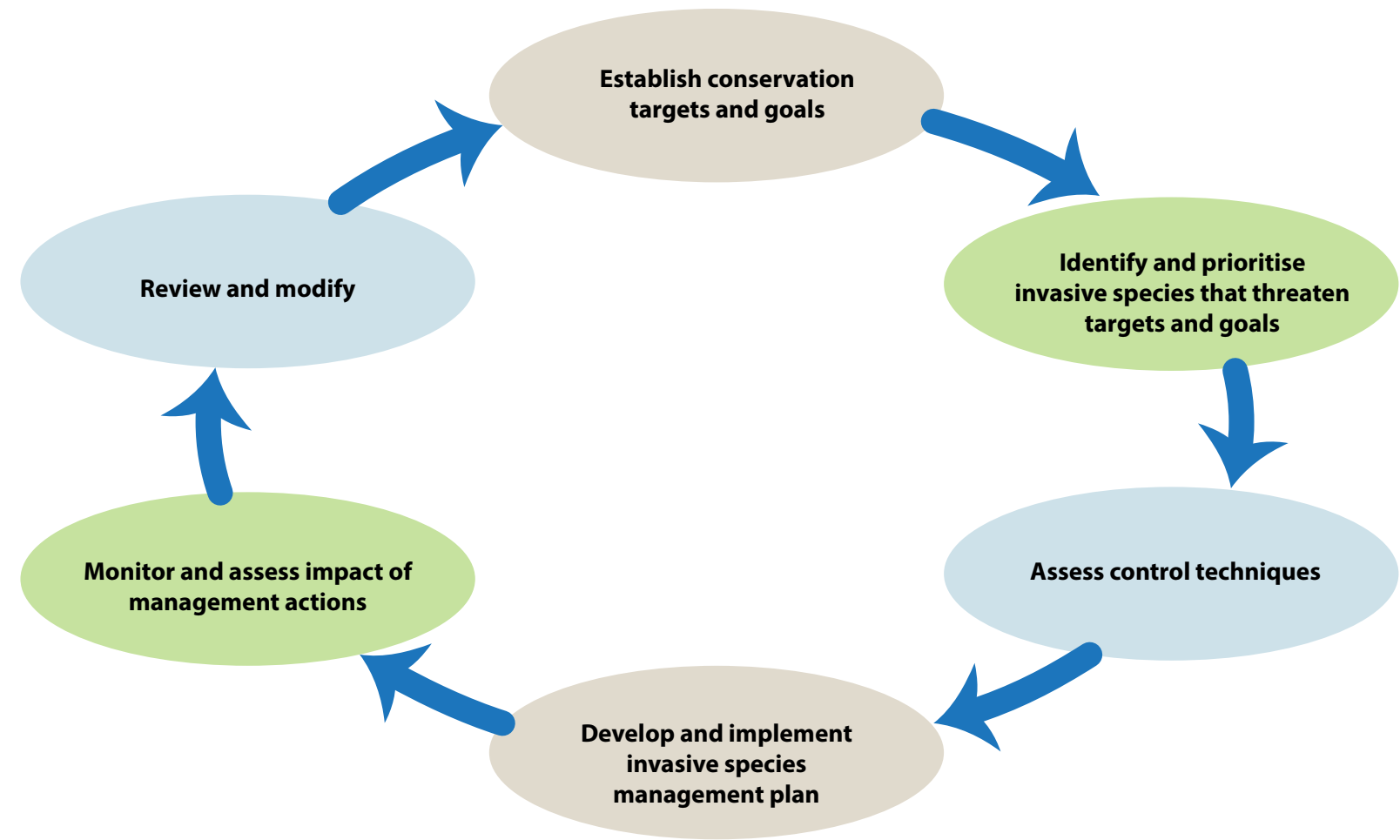

Figure 16.5 Adaptive management approach for invasive species

Source: Adapted from Tu (2009)

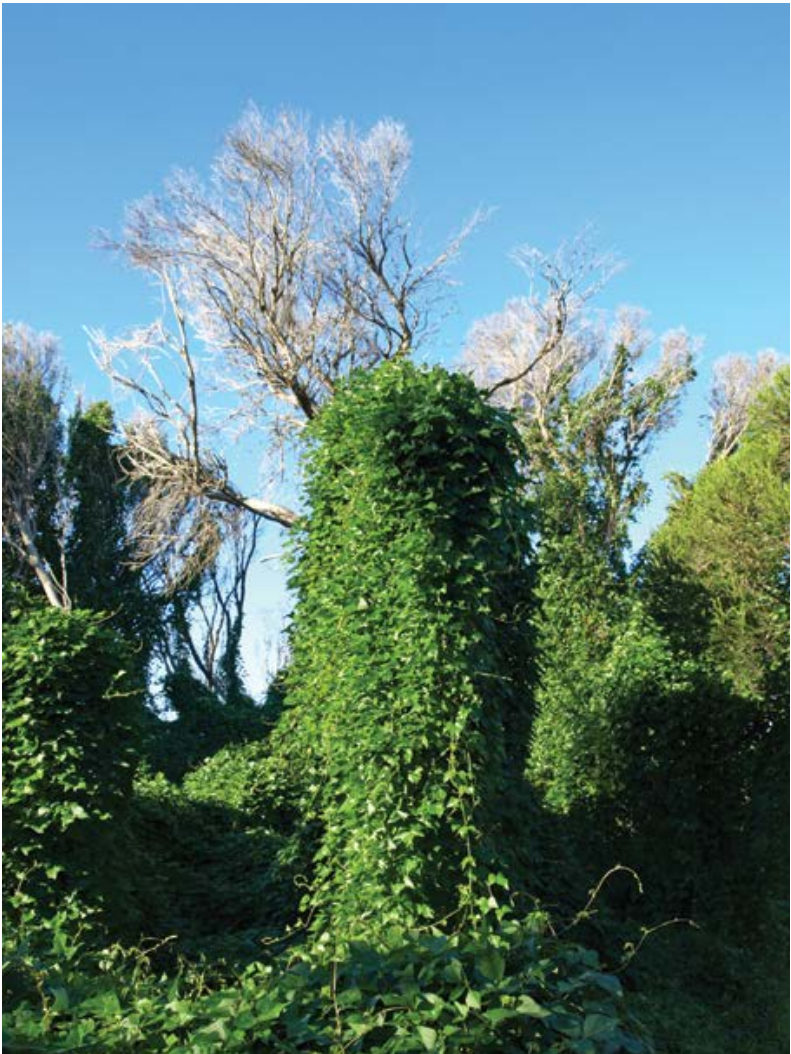

Invasive weed for Australia: Cape ivy (Delairea odorata) invading and overwhelming native flora, NSW South Coast coastal reserve area

Source: Graeme L. Worboys from invasive species, the guide describes prevention, early detection and rapid response, management, control and restoration as key steps. These steps could be adapted to deal with most threats that concern protected areas (Figure 16.5). Examples of assessing and managing invasive species threats in protected areas have been provided (Case Studies 16.5 and 16.6).

\section{Human-wildlife cohabitation}

Human-wildlife conflict is a major challenge in many protected areas. This is particularly true in humandominated landscapes. With a growing population in most countries and the loss of space and connectivity for wildlife, conflicts between humans or human activities and 'nature' are becoming more and more frequent and less and less acceptable to people. This represents an increasing problem for which new responses need to be identified (Case Study 16.7). While conflicts between humans and wildlife are often quite difficult to handle, they are sometimes the basis for developing a people (community) protected area collaboration that may not only solve the issue but also enhance conservation on the ground (Case Study 16.8). 


\section{Case Study 16.5 Assessing invasive plant species occurrence and distribution in India}

Identification, monitoring and management of invasive alien species are a major global challenge. India has made a start in identifying and assessing the extent of coverage of invasive plant species as part of a nationwide study of the 'Status of Tiger, Co-predators and Prey Species, 2010', carried out by the National Tiger Conservation Authority and the Wildlife Institute of India. A protocol was developed for habitat assessment that included gathering data on invasive plants from 17 tiger range States in India in 200910. While the assessment exercise focused on tiger, copredator and prey species and included an unprecedented effort of about 477000 person-days by forest staff and
37000 person-days by professional biologists, valuable datasets were created on various habitat parameters in a spatial domain. Data analysis revealed the presence of 15 invasive species in the States that were surveyed, of which maps for four representative species are shown in Figure 16.6. Work is in progress to plan and implement appropriate management interventions to deal with these four species to mitigate threats to protected areas in the 17 States and in a prioritised manner.

Source: Mungi et al. (2013)

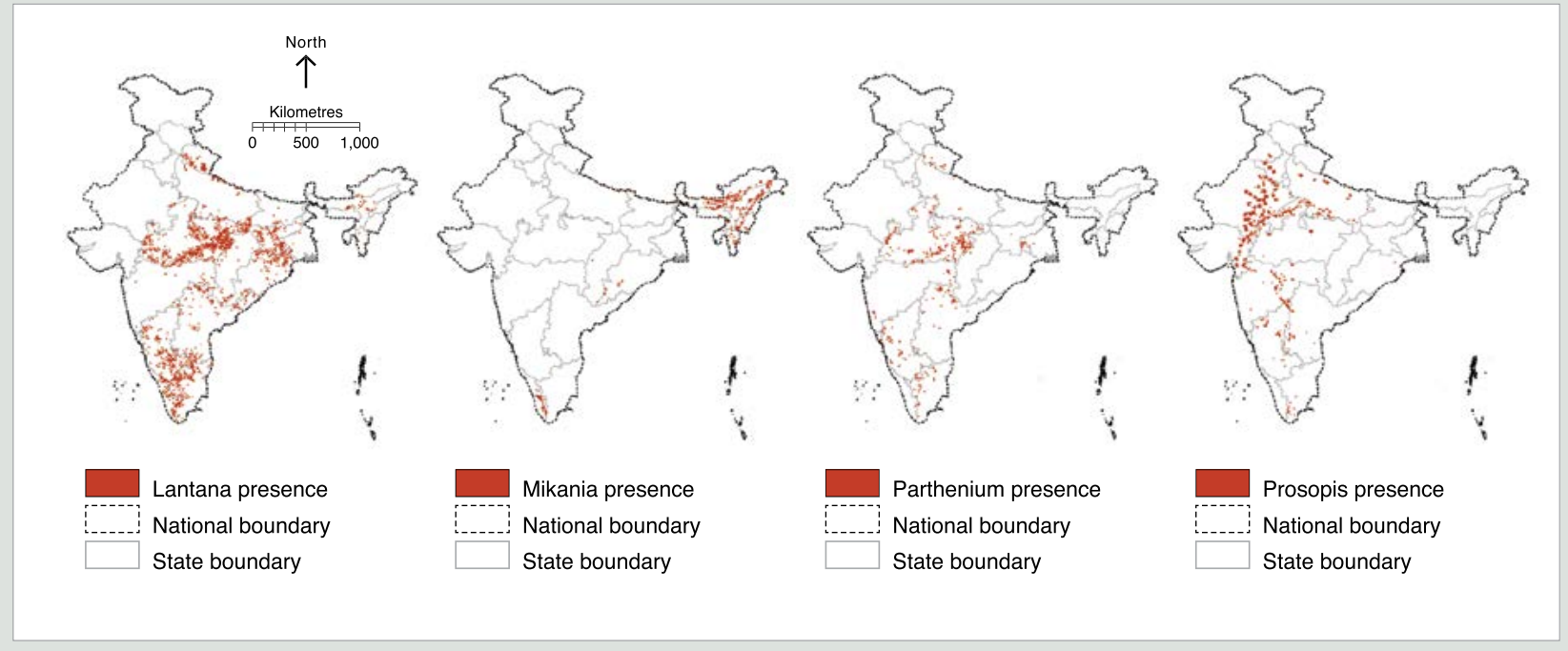

Figure 16.6 Distribution of four representative invasive species, India

\section{Case Study 16.6 Invasive plant species management in Zambia, Africa}

The Removing Barriers to Invasive Plant Management in Africa project was implemented in four African countries (Ethiopia, Ghana, Uganda and Zambia) between 2005 and 2010. Under this project in Zambia, 800 hectares of infested floodplain in the Lochinvar National Park were cleared of giant sensitive plant (Mimosa pigra). The clearing operation, carried out with assistance from the Government of Zambia, reduced the extent of mimosa infestation within the Chunga Lagoon sector of the park by roughly 30 per cent. After clearing under the project, increases were recorded in the numbers of individual birds and animals and species, as well as in the number of species. Species which returned to the area following clearing included the endangered wattled crane (Grus carunculatus) and several other bird species, mainly waders.

In the Mosi-oa-Tunya National Park, Zambia, the project was key in successfully clearing lantana (Lantana camara) from an area of about 30 hectares, which was more than 6 per cent of the total affected area of about 524 hectares.
Using a combination of uprooting, cutting back and applying systemic herbicides, entire thickets of lantana were removed from stretches of riverbank. In the cleared areas, seedlings of a variety of indigenous trees and shrubs, grown in nurseries set up in the compounds of local hotels and tourist establishments, were planted to supplement the natural regeneration of germinating seedlings within the soil's existing seed bank. All rehabilitated areas were closely monitored to gauge ecosystem recovery. Biocontrol agents, imported from South Africa under the terms of Zambia's Plant Quarantine and Phytosanitary Act, were also employed. The leaf-mining beetle (Uroplata girardi) was used as a biocontrol agent. It feeds on the leaves of Lantana camara and retards its growth, thus slowing its spread.

Source: Adapted from Roy and Witt (2013) 


\section{Case Study 16.7 Managing threats from human-wildlife conflict in human- dominated landscapes}

Protected areas in many regions of the world are now found in human-dominated landscapes. Threats from wild animals (such as tigers, leopards and elephants) to human life and property and threats to these animals in the form of retaliatory killings have become frequent (Lenin 2010). In both cases, the conservation cause suffers. The National Tiger Conservatory Authority (NTCA) in India in 2014 prepared a standard operating procedure to deal with emergencies arising due to tigers straying into human-dominated landscapes (NTCA 2014). The aim of the document is to ensure that straying tigers are handled in the most appropriate manner, to avoid death/injury to human beings, the tiger and cattle and loss of property.
The procedure also includes:

- a protocol on the immobilisation and restraint of tigers

- guidelines for the declaration of big cats as 'man-eaters'

- preventive/proactive measures to be followed in straying tiger incidents

- monitoring of tigers in the landscape.

There is a need to develop similar procedures for other wild animals in order to reduce or minimise such threats in and around protected areas.

Source: Mungi et al. (2013)

\section{Case Study 16.8 From poaching to protection in Periyar Tiger Reserve, Kerala, India}

\begin{abstract}
For years, the Periyar Tiger Reserve in India battled the problem of illicit collection of vayana bark (Cinnamomum sp.), but that is no longer the case. The turnaround came more than 15 years ago when the reserve's managers began working with men who were previously engaged in illegal harvesting of the vayana bark. Now, the poachers have turned protectors of the forest. This all started when a local non-governmental organisation (NGO) helped set up an ecodevelopment committee with former bark collectors through a participatory program that involved local NGOs, hoteliers, Periyar staff and tour operators (Alers et al. 2007). With their intimate and extensive knowledge of the forests, the ecodevelopment committee has put in place a model of ecotourism that encourages protection. Under the program, small groups of tourists are taken to camp in the tourist zones of the forests-areas where previously these bark collectors 'poached'. Their presence is a deterrent to poachers and smugglers, who stay away from the tourist camps.
\end{abstract}

More than two-thirds of the earnings go into the ecodevelopment committee's account to be distributed equally among the members, while the remaining money is disbursed equally for revenue to government and honoraria to forest field staff, on food expenses and to the community welfare fund. Though committee members may have earned more previously from the sale of the vayana bark than they do now, they have benefited in other ways. Before, they had to give away a large part of their earnings in fines, bribes and as cuts to middlemen. Now, they are free of these impositions. Also, their social status has improved and their relationship with the community has benefited considerably. The forest, too, has improved under this program. Ecological monitoring has shown a reduction in debarking damage and improvement in the regeneration of vayana. Patrolling has increased in these areas and ecodevelopment committee members have caught offenders and brought legal cases against them. All this has resulted in more animal sightings in the tourism zone. This initiative has provided livelihood support on the one hand and has enhanced the natural wilderness experience for tourists on the other.

Sources: Uniyal and Zacharias (2001); Alers et al. (2007); Gubbi et al. (2009)

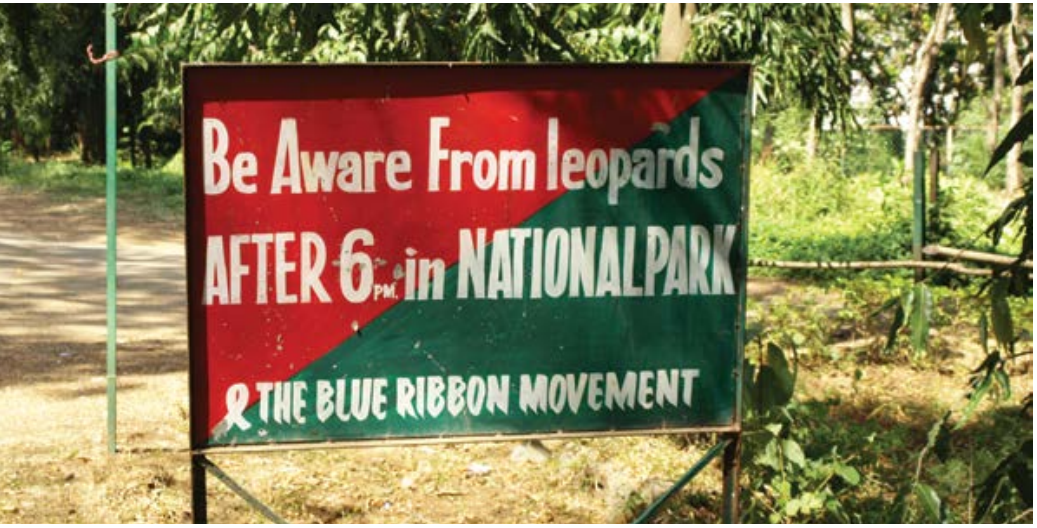

Advice sign for visitors about resident wild leopards (Panthera pardus), Sanjay Gandhi National Park, Mumbai, India

Source: Graeme L. Worboys

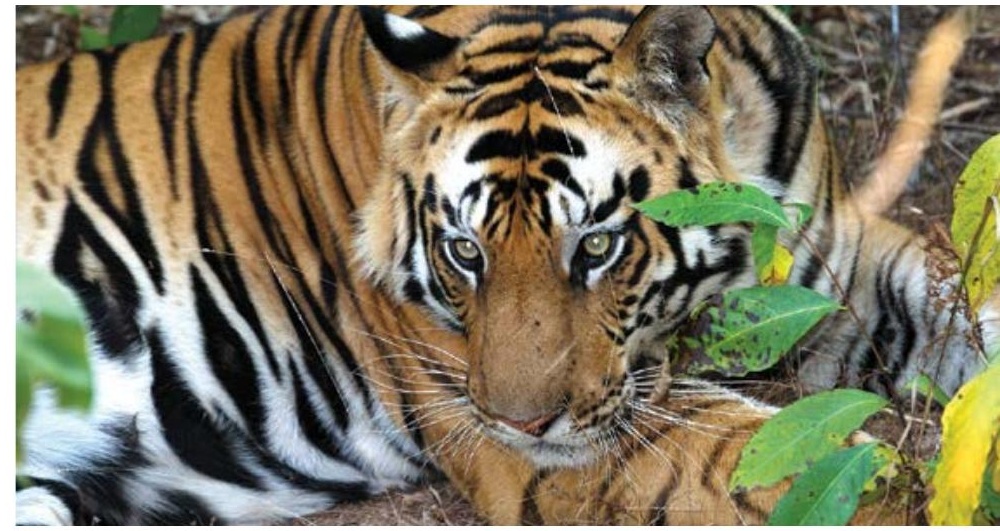

A tiger (Panthera tigris tigris) resting in

Bandhavagarh National Park, India

Source: Ashish Kothari 


\section{Case Study 16.9 Participatory planning within and beyond protected areas in Bhutan}

Bhutan has developed a well-organised system of local government. According to Alers et al. (2007), this system has contributed in large measure to the empowerment and development of local communities, and to solving locally the threats that were identified. In Bhutan, each district (dzongkhag) is divided into a number of subdistricts called geog. Each geog has its own development committee. Both the dzongkhag and the geog work towards the socioeconomic development of the local communities. Each geog prepares a five-year plan and an annual plan based on the needs and requirements of the community as identified by its members. Therefore, these plans reflect the concerns and priorities of the communities and generally cover subjects such as provision of health facilities, education as well as fodder supplementation and livestock improvement, and creating livelihood support and alternative income opportunities.
This is achieved through well-integrated conservation and development plans such that there is not much difference between the administration of local government inside and outside protected areas. Protected area staff are represented on geog and dzonkhag development committees and are directly involved in local planning processes so they can efficiently address any possible threats. Thus, management planning is not restricted solely to a protected area but entails interaction and participation in decisions that affect the protected area and its surrounding landscape. This allows for identification and management of existing as well as potential threats that arise from decisions and processes beyond protected area boundaries.

Source: Adapted from Alers et al. (2007)

\section{Governance dimensions of addressing threats}

Managing threats is not only about what to do to address threats but also about who takes the responsibility. It invariably involves taking decisions that have farreaching consequences for not only biophysical characteristics of the protected area but also the lives of people associated with the protected area-in particular, local communities and indigenous peoples. It is therefore crucial to analyse the governance issues of threat management. These issues may start very early, from recognising the establishment of a protected area (who plans for and recognises it - a national authority or local community authorities or any other body) to active management of a protected area (how and by whom are the management plan, resource use rules and other permits developed and approved? How and by whom are managers appointed? Who holds authority, responsibility, power and accountability in executing plans and enforcing rules?). In any case, when dealing with threats and threat management, one must determine who or what is impacted by these threats and who is in a position to manage them. The quality of governance of the protected area (or the system of protected areas) is therefore crucial to ensure that all stakeholders will be effectively involved and able to make their contribution (Case Study 16.9).

The importance of key concepts of protected area governance was emphasised by the parties to the CBD in their decision to establish the PoWPA. These concepts (Box 16.4) apply well to managing threats to protected areas (see also Chapter 8, and Chapters 20, 21, 25 and 27 in the context of marine protected areas, biodiversity management, resource use, and managing threats to connectivity conservation corridors, respectively).

\section{Box 16.4 Governance of protected areas: Key concepts for threat management}

Participation: Site-based management planning and decision-making must ensure the full and effective participation of relevant rights-holders and stakeholders, including local communities and indigenous peoples, and with due recognition of customary rights, gender considerations and social equity.

Innovation: Protected area and other area-based conservation measures should be effectively managed through new and innovative governance approaches. These may include protected areas managed and governed by government agencies, community conserved areas, indigenous peoples' conserved territories, private protected areas and areas under shared governance.

Respect: Livelihood needs, rights, contributions, local/ traditional knowledge, practices and institutions must be respected.

Benefit sharing: Benefits need to be shared equitably with local communities with recognition of the disproportionate burden of costs arising from establishing and managing protected areas that they may bear.

Free, prior and informed consent: Decisions regarding limits or changes in access to protected area resources or relocation and resettlement of local and indigenous communities require their free, prior and informed consent.

Good governance: Decision-making for management should follow general principles of good governance that include fair access to information and promotion of constructive dialogue; accountability in decisionmaking; respect for rights and the rule of law; and dispute resolution through fair and just institutional procedures.

Source: Adapted from Borrini-Feyerabend et al. (2013) 
Byron, H. (2000) Biodiversity and Environmental Impact Assessment: A good practice guide for road schemes, The RSPB, WWF-UK, English Nature and the Wildlife Trusts, Sandy, UK.

Carey, C., Dudley, N. and Stolton, S. (2000) Squandering Paradise? The importance and vulnerability of the world's protected areas, WWF, Gland.

Dd Conservation Measures Partnership (CMP) (2013) Open Standards for the Practice of Conservation. Version 3.0 April 2013, The Conservation Measures Partnership. <www.conservationmeasures.org/wp-content/ uploads/2013/05/CMP-OS-V3-0-Final.pdf>

DD Convention on Biological Diversity (CBD) (2014a) Programme of Work on Protected Areas, Secretariat of the Convention on Biological Diversity, Montreal. <www.cbd.int/protected/pow>

Convention on Biological Diversity (CBD) (2014b) Tools for Managing Threats, Secretariat of the Convention on Biological Diversity, Montreal. $<$ www.cbd.int/protected/tools/>

Dudley, N., Stolton, S. and Elliott, W. (2013) 'Wildlife crime poses unique challenges to protected areas', PARKS 19(1): 7-12.

Ervin, J., Mulongoy, K., Lawrence, K., Game, E., Sheppard, D., Bridgewater, P., Bennett, G., Gidda, S. and Bos, P. (2010) Making Protected Areas Relevant: A guide to integrating protected areas into wider landscapes, seascapes and sectoral plans and strategies, CBD Technical Series No. 44, Secretariat of the Convention on Biological Diversity, Montreal. <www.cbd.int/doc/publications/cbd-ts44-en.pdf>

Foxcroft, L. C., Richardson, D. M., Pyšek, P. and Genovesi, P. (2014) 'Invasive alien plants in protected areas: threats, opportunities, and the way forward', in L. C. Foxcroft, P. Pyšek, D. M. Richardson and P. Genovesi (eds) Plant Invasions in Protected Areas: Patterns, problems and challenges, pp. 621-39, Springer, Dordrecht.

Gubbi, S., Linkie, M. and Leader-Williams, N. (2009) 'Evaluating the legacy of an integrated conservation and development project around a tiger reserve in India', Environmental Conservation 35(4): 331-9.
Intergovernmental Science-Policy Platform on Biodiversity and Ecosystem Services (IPBES) (2013) Initial Scoping for the Thematic Assessment of Invasive Alien Species and their Control, IPBES/2/16/Add.3, Intergovernmental Science-Policy Platform on Biodiversity and Ecosystem Services, Panama City. <www.ipbes.net/images/K135340-en.docx>

International Union for Conservation of Nature Programme on African Protected Areas and Conservation (IUCN PAPACO) (2010) Assessment of Protected Area Management Effectiveness in Ghana, IUCN, Gland. <www.papaco.org>

International Union for Conservation of Nature Programme on African Protected Areas and Conservation (IUCN PAPACO) (2011a) Assessment of Five Protected Areas in Ghana, IUCN, Gland. $<$ www.papaco.org >

International Union for Conservation of Nature Programme on African Protected Areas and Conservation (IUCN PAPACO) (2011b) Mining Sector Development in West Africa and its Impact on Conservation, IUCN, Gland. <www.papaco.org>

International Union for Conservation of Nature Programme on African Protected Areas and Conservation (IUCN PAPACO) (2011c) Report of the Weotenga Meeting, 2011, IUCN, Gland [adapted from R. Starkey and R. Calaque, WCS Gabon]. <www.papaco.org>

International Union for Conservation of Nature Programme on African Protected Areas and Conservation (IUCN PAPACO) (2014) Evaluation of the Impact of World Heritage Classification on West African Protected Areas, IUCN, Gland. $<$ www.papaco.org $>$

International Union for Conservation of Nature and Conservation Measures Partnership (IUCNCMP) (2006) Unified Classification of Threats and Conservation Actions. Version 1: June 2006, IUCN and The Conservation Measures Partnership, Gland. $<$ www.iucn.org/themes/ssc/sis/classification.htm>

Kothari, A., Corrigan, C., Jonas, H., Neumann, A. and Shrumm, H. (eds) (2012) Recognising and Supporting Territories and Areas Conserved by Indigenous Peoples and Local Communities: Global overview and national case studies, CBD Technical Series No. 64, ICCA Consortium, Kalpavriksh and Natural Justice, Montreal. 
Lenin, J. (2010) 'Sugarcane leopards', Current Conservation 4(4): 22-7.

Leverington, F., Costa, K., Courrau, J., Pavese, H., Nolte, C., Marr, M., Coad, L., Burgess, N., Bomhard, B. and Hockings, M. (2010) Management Effectiveness Evaluation in Protected Areas: A global study, 2nd edn, University of Queensland, Brisbane.

Mercier, J. (2004) Strategic Environmental Assessment: The structured learning program at the World Bank, Environment Department, The World Bank, Washington, DC.

Millennium Ecosystem Assessment (MEA) (2005) Ecosystems and Human Well-Being: Synthesis, Island Press, Washington, DC.

Molnar, J. L., Gamboa, R. L., Revenga, C. and Spalding, M. D. (2008) 'Assessing the global threat of invasive species to marine biodiversity', Frontiers in Ecology and the Environment 6. <doi:10.1890/070064>

Mungi, N., Qureshi, Q. and Jhala, Y. V. (2013) Species Distribution Modelling of Select Invasive Plants in India, Wildlife Institute of India, Dehradun.

National Tiger Conservation Authority (NTCA) (2014) Standard Operating Procedures to Deal with Emergencies arising due to Straying of Tigers in Human Dominated Landscapes, NTCA, New Delhi. $<$ www.projecttiger.nic.in>

Partidário, M. R. (2012) Strategic Environmental Assessment Better Practice Guide: Methodological guidance for strategic thinking in SEA, Portuguese Environment Agency and Redes Energéticas Nacionais, Amadora, Portugal. <www.iaia.org/ publicdocuments/special-publications/SEA\%20 Guidance\%20Portugal.pdf>

Peres, C. and Palacios, E. (2007) 'Basin-wide effects of game harvest on vertebrate population densities in Amazonian forests: implications for animalmediated seed dispersal', Biotropica 39: 304-15.

Rajvanshi, A., Arora, R., Mathur, V. B., Sivakumar, K., Sathyakumar, S., Rawat, G. S., Johnson, J. A., Ramesh, K., Dimri, N. K. and Maletha, A. (2012) Assessment of cumulative impacts of hydroelectric projects on aquatic and terrestrial biodiversity in Alaknanda and Bhagirathi basins, Uttarakhand, Technical Report, Wildlife Institute of India, Dehradun.
Roy, G. and Witt, A. (2013) Invasive Alien Plants and their Management in Africa, UNEP/GEF Removing Barriers to Invasive Plant Management Project International Coordination Unit, UNEP, Nairobi.

Sadler, B. and Verheem, R. (1996) SEA: status, challenges and future directions, Report 53, Spatial Planning and the Environment, Netherlands Ministry of Housing, The Hague.

Dd Salafsky, N., Salzer, D., Stattersfield, A. J., Hilton-Taylor, C., Neugarten, R., Butchart, S., Collen, B., Cox, N., Master, L. L., O'Connor, S. and Wilkie, D. (2008) 'A standard lexicon for biodiversity conservation: unified classifications of threats and actions', Conservation Biology 22(4): 897-911.

Slootweg, R., Kolhoff, A., Verheem, R. and Höft, R. (eds) (2006) Biodiversity in EIA and SEA: voluntary guidelines on biodiversity —inclusive impact assessment, Background Document to CBD Decision VIII/28, Secretariat of the Convention on Biological Diversity, Montreal. <www.cbd.int/doc/ publications/imp-bio-eia-and-sea.pdf >

Tu, M. (2009) Assessing and Managing Invasive Species within Protected Areas, Protected Area Quick Guide Series, ed. J. Ervin, The Nature Conservancy, Arlington, VA.

United Nations Environment Programme (UNEP) (2002) Environmental Impact Assessment Training Resource Manual, 2nd edn, UNEP, Nairobi. <www. unep.ch/etu/publications/EIAman_2edition_toc. htm>

Uniyal, V. and Zacharias, J. (2001) 'Periyar Tiger Reserve: building bridges with local communities for biodiversity conservation', PARKS 11(2): 14-23.

Worboys, G. L., Winkler, C. and Lockwood, M. (2006) 'Threats to protected areas', in M. Lockwood, G. L. Worboys and A. Kothari (eds) Protected Area Management: A global guide, pp. 223-61, Earthscan, London.

World Wide Fund for Nature (WWF) (2012) Living Planet Report 2012, WWF International, Gland. 


\section{PRINCIPAL AUTHORS}

ANGAS HOPKINS is an environmental consultant working in Australia and South American countries.

RICHARD MCKELLAR is a Research Fellow at Curtin University Sustainability Policy Institute, Australia.

GRAEME L. WORBOYS is Co-Vice-Chair, Connectivity Conservation and Mountains, International Union for Conservation of Nature World Commission on Protected Areas and an Adjunct Fellow at the Fenner School, The Australian National University.

ROGER GOOD is a Visiting Fellow at the Fenner School of Environment and Society, The Australian National University, and Research Associate, Australian National Botanic Gardens, Canberra.

\section{ACKNOWLEDGMENTS}

Appreciation is expressed to Adrienne Nicotra for preparing specialist text dealing with prioritising management responses to species in a climate change environment. Our thanks are extended to Michael Dunlop for reviewing parts of the manuscript.

\section{CITATION}

Hopkins, A., McKellar, R., Worboys, G. L., and Good, R. (2015) 'Climate change and protected areas', in G. L. Worboys, M. Lockwood, A. Kothari, S. Feary and I. Pulsford (eds) Protected Area Governance and Management, pp. 495-530, ANU Press, Canberra.

\section{TITLE PAGE PHOTO}

The Athabasca Glacier with the Columbia Icefield behind, Banff National Park, Canada: the 1890 peg identifies a historical location of the snout of the glacier and the extent of the terrain across which it has receded over the past 120-plus years. In general, glaciers are retreating almost worldwide as average global temperatures rise. Source: Graeme L. Worboys 


\section{Introduction}

In the early part of the 21st century, evidence for the overall warming of the Earth's climate system due to human-generated greenhouse gas pollution of the atmosphere is unequivocal. The leading international body for the scientific assessment of climate change, the Intergovernmental Panel on Climate Change (IPCC), has reported that 'changes in climate have caused impacts on natural and human systems on all continents and across the oceans' (IPCC 2014a:6). The average of global surface temperatures for land and ocean increased by $0.85^{\circ} \mathrm{C}$ between 1880 and 2012 , and the global mean surface temperature increased by $0.12^{\circ} \mathrm{C}$ per decade between 1951 and 2012 (IPCC 2013a). Sea-levels are also rising. "The rate of sea rise since the mid-19th century has been larger than the mean rate during the previous two millennia' (IPCC 2013a:11).

The findings of the IPCC present a grim picture. Regrettably, greenhouse gas emissions continued to grow in 2014. After considering a broad range of future development and greenhouse gas emission scenarios, the IPCC has reported that global surface temperatures are likely to be more than $1.5^{\circ} \mathrm{C}$ higher in 2100 than the average surface temperatures in the period 1850-1900. Some development and emission scenarios are, however, worse. Global mean surface temperatures in 2100 are likely to increase by more than $2^{\circ} \mathrm{C}$ compared with $1850-1900$, and could exceed $4^{\circ} \mathrm{C}$ surface warming under the scenario described as 'business as usual with no mitigation action' (IPCC 2013a).

More frequent high temperature extremes are virtually certain over most land areas on both the daily and the seasonal scales. Ocean temperatures will increase at all depths and will affect ocean circulation. The volume of glaciers will continue to decrease; sea-levels will continue to rise. The IPCC forecasts that changes to precipitation will not be uniform. 'The contrast between wet and dry regions and between wet and dry seasons will increase, although there may be regional exceptions' (IPCC 2013a:20). Ecosystems are already being affected by climate change: 'Many terrestrial, freshwater, and marine species have shifted their geographic ranges, seasonal activities, migration patterns, abundances, and species interactions in response to ongoing climate change' (IPCC 2014a:4).

It is clear that these effects will be profound for protected areas. Climate change represents one of the greatest threats to species and ecosystems that people of Earth face, and this includes protected area organisations and communities responsible for protected areas. In this chapter, we focus on climate change in relation to the governance and management of protected areas. To set the scene, we introduce key climate change research findings for current trends and forecast changes and describe the implications. We introduce a 'nature-based solution' approach and present possible mitigation and adaptation responses for climate change, with a focus on climate-ready responses by protected area managers. The chapter then focuses on being 'climate-ready', and we provide explanatory information about this important concept as well as a range of governance and management considerations that consequently may be important for managers to assess.

\section{Climate change research findings}

In 2013, the Fifth Assessment Report of Working Group I of the IPCC synthesised recent research on the physical science basis for climate change (IPCC 2013a). This included both the situation in 2013 and the projections of possible future climate conditions. We summarise some of the key findings here.

\section{Climate change findings}

\section{The climate system}

'Warming of the climate system is unequivocal, and since the 1950s, many of the observed changes are unprecedented over decades to millennia. The atmosphere and ocean have warmed, the amounts of snow and ice have diminished, sea-level has risen, and the concentrations of greenhouse gases have increased' (IPCC 2013a:4).

\section{Human influence}

'Human influence on the climate system is clear. This is evident from the increasing greenhouse gas concentrations in the atmosphere, positive radiative forcing, observed warming, and understanding of the climate system' (IPCC 2013a:15).

\section{The atmosphere}

'Each of the last three decades has been successively warmer at the Earth's surface than any preceding decade since 1850 ... In the Northern Hemisphere, 1983-2012 was likely the warmest 30-year period of the last 1400 years (medium confidence)' (IPCC 2013a:5). 


\section{Box 17.1 Glossary of some acronyms used by the Intergovernmental Panel on Climate Change}

\section{AR5}

The IPCC Fifth Assessment Report.

\section{CMIP5}

Couple Model Inter-comparison Project Phase 5 of the World Climate Research Programme. This is a multimodel context for better assessing climate models, including poorly understood feedback between the carbon cycle and clouds, examining climate predictability and examining the different models.

\section{RCP}

Representative concentration pathways. These are four greenhouse gas concentration (not emissions) trajectories adopted by the IPCC for its fifth assessment report. They describe four possible climate futures and are described as RCP2.6, RCP4.6, RCP6 and RCP8.5.

\section{RCP2.6}

This RCP assumes small constant net negative emissions after 2100 and implies net negative carbon dioxide emissions after about 2070 and throughout the extension; carbon dioxide concentrations slowly reduce towards 360 parts per million volume (ppmv) by 2300.

\section{RCP8.5}

This RCP assumes stabilisation with high emissions between 2100 and 2150, then a linear decrease until 2250. RCP8.5 stabilises concentrations only by 2250 , with carbon dioxide concentrations of approximately 2000 ppmv -nearly seven times the pre-industrial level.

\section{SPM}

Summary for policymakers.

Sources: IPCC (2012, 2013a, 2013b)

\section{Box 17.2 Projections for climate change phenomena other than temperature \\ Some broad projected changes have been illustrated by \\ Sea-level} the two climate scenarios (Figure 17.1).

\section{The water cycle}

'Changes in the global water cycle in response to the warming over the 21st century will not be uniform. The contrast in precipitation between wet and dry regions and between wet and dry seasons will increase, although there may be regional exceptions' (IPCC 2013a:20).

\section{Oceans}

Reflecting an overall warming trend, the IPCC stated for oceans that '[t]he global ocean will continue to warm during the 21 st century. Heat will penetrate from the surface to the deep ocean and affect ocean circulation' (IPCC 2013a:24).

\section{Cryosphere (places where the Earth's water is in a solid form as snow or ice)}

'It is very likely that Arctic sea ice cover will continue to shrink and thin and that Northern Hemisphere spring snow cover will decrease during the 21st century as global mean surface temperature rises. Global glacier volume will further decrease' (IPCC 2013a:24).
'Global mean sea level will continue to rise during the 21 st century ... Under all RCP scenarios, the rate of sea level rise will very likely exceed that observed during 1971 to 2010 due to increased ocean warming and increased loss of mass from glaciers and ice sheets' (IPCC 2013a:25).

\section{Carbon and other biogeochemical processes}

'Climate change will affect carbon cycle processes in a way that will exacerbate the increase of $\mathrm{CO} 2$ in the atmosphere (high confidence). Further uptake of carbon by the ocean will increase ocean acidification' (IPCC 2013a:26).

\section{Climate stabilisation}

'Cumulative emissions of CO2 largely determine global mean surface warming by the late 21 st century and beyond ... Most aspects of climate change will persist for many centuries even if emissions of $\mathrm{CO} 2$ are stopped. This represents a substantial multi-century climate change commitment created by past, present and future emissions of CO2' (IPCC 2013a:27).
The language of the IPCC is acronym rich. To assist the reader, we have prepared a glossary of some of their abbreviations (Box 17.1), and this is especially relevant for interpreting the supporting information for two of the IPCC's figures presented in this chapter (Figures 17.1 and 17.2).

Two temperature projections prepared by the IPCC are illustrated in Figure 17.1. The RCP of 2.6 identifies reductions in carbon dioxide concentrations towards
2100 (Box 17.1). Both scenarios show gradual warming, with the greatest warming for the curve approximating a future scenario titled 'business as usual with no mitigation action' (RCP8.5) (Figure 17.1). Greater levels of warming are projected for the northern hemisphere than for the southern hemisphere, with landmasses warming more quickly than the oceans. 
RCP 2.6

RCP 8.5

(a) Change in average surface temperature (1986-2005 to 2081-2100)

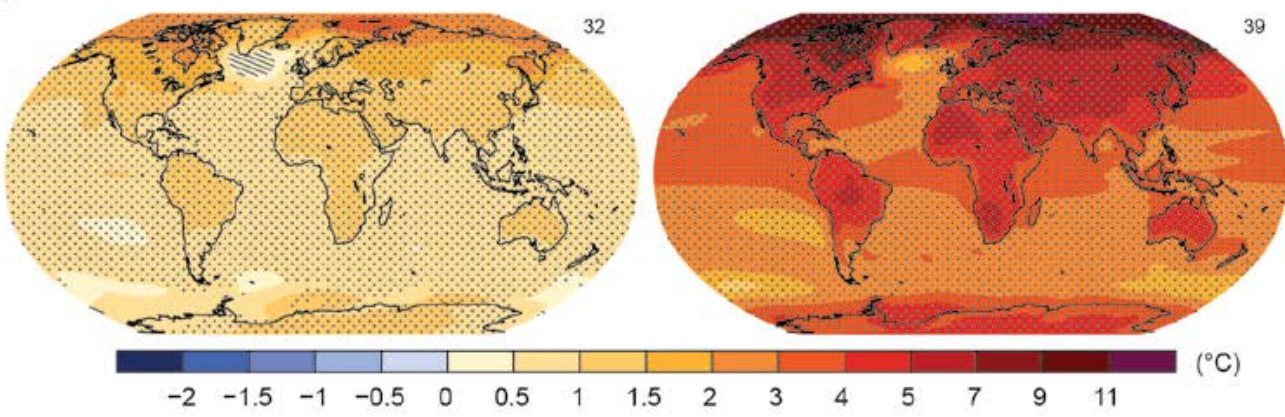

(b)

Change in average precipitation (1986-2005 to 2081-2100)

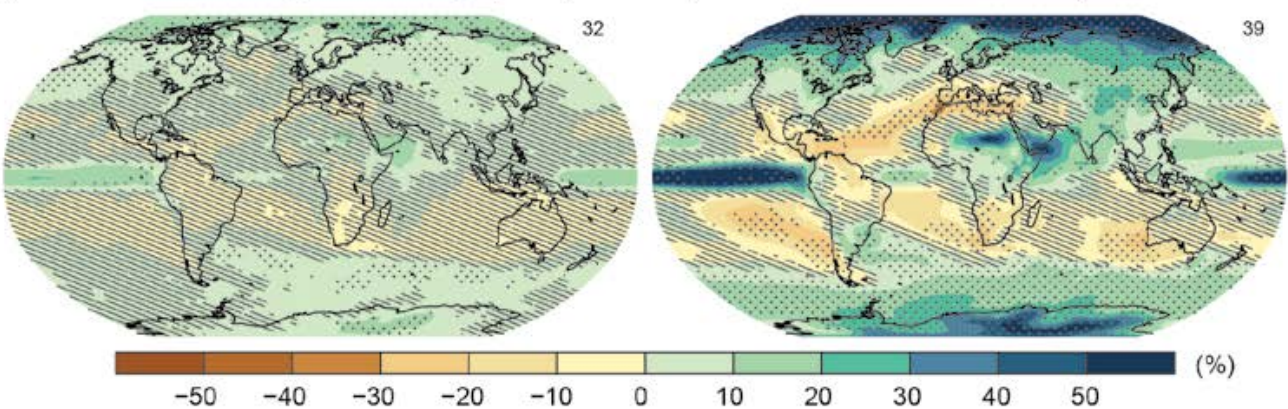

(c) Northern Hemisphere September sea ice extent (average 2081-2100)
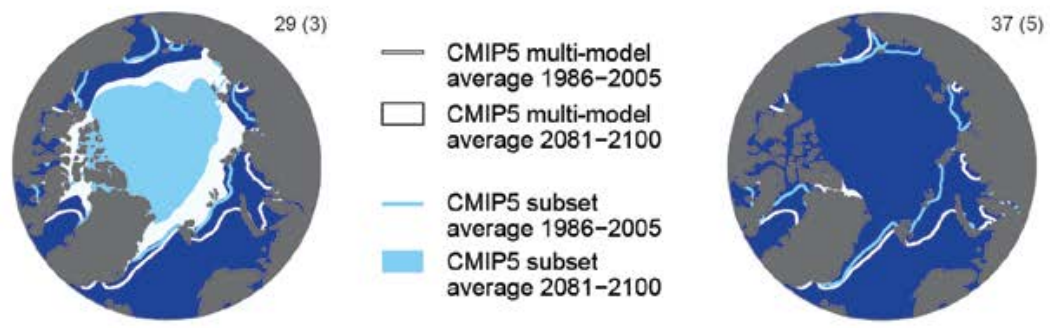

(d)

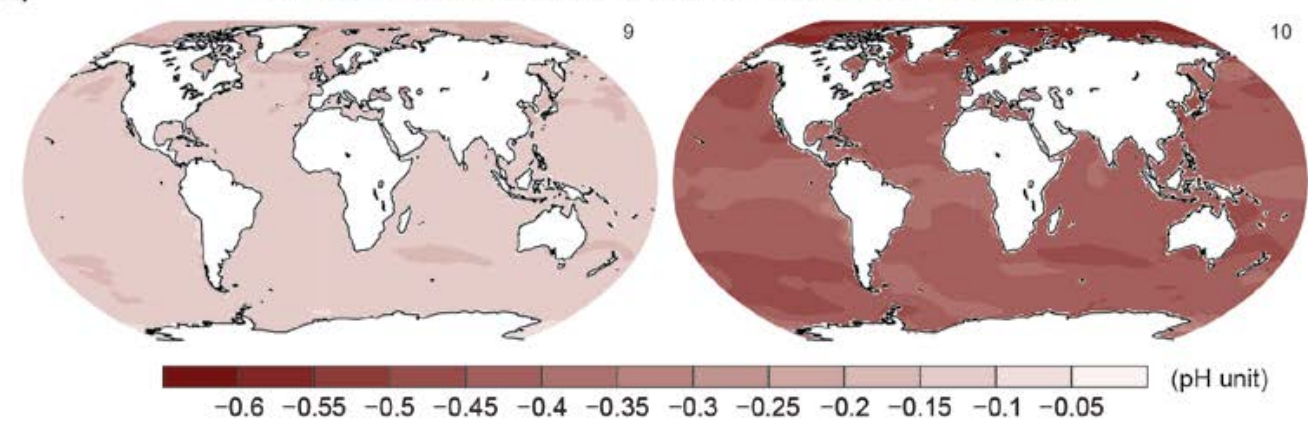

Figure 17.1 IPCC climate change projections for two carbon dioxide concentration levels for temperature, precipitation, sea-ice extent and ocean surface $\mathrm{pH}$

Notes: Maps of CMIP5 multi-model mean results for the scenarios RCP2.6 and RCP8.5 in 2081-2100 of: a) annual mean surface temperature change, b) average percentage change in annual mean precipitation, c) northern hemisphere September sea-ice extent, and d) change in ocean surface $\mathrm{pH}$. Changes in panels (a), (b) and (d) are shown relative to 1986-2005. The number of CMIP5 models used to calculate the multi-model mean is indicated in the upper right-hand corner of each panel. For panels (a) and (b), hatching indicates regions where the multi-model mean is small compared with natural internal variability - that is, less than one standard deviation of natural internal variability in 20-year means. Stippling indicates regions where the multi-model mean is large compared with natural internal variability (that is, greater than two standard deviations of natural internal variability in 20-year means) and where at least 90 per cent of models agree on the sign of change. In panel (c), the lines are the modelled means for 1986-2005; the filled areas are for the end of the century. The CMIP5 multi-model mean is given in white; the projected mean sea-ice extent of a subset of models (number of models given in brackets) that most closely reproduce the climatological mean state and 1979-2012 trend of the Arctic sea-ice extent is given in light blue.

Source: IPCC (2013a:10), reproduced with the permission of the IPCC; see IPCC (2013a:10) for the complete figure caption. 


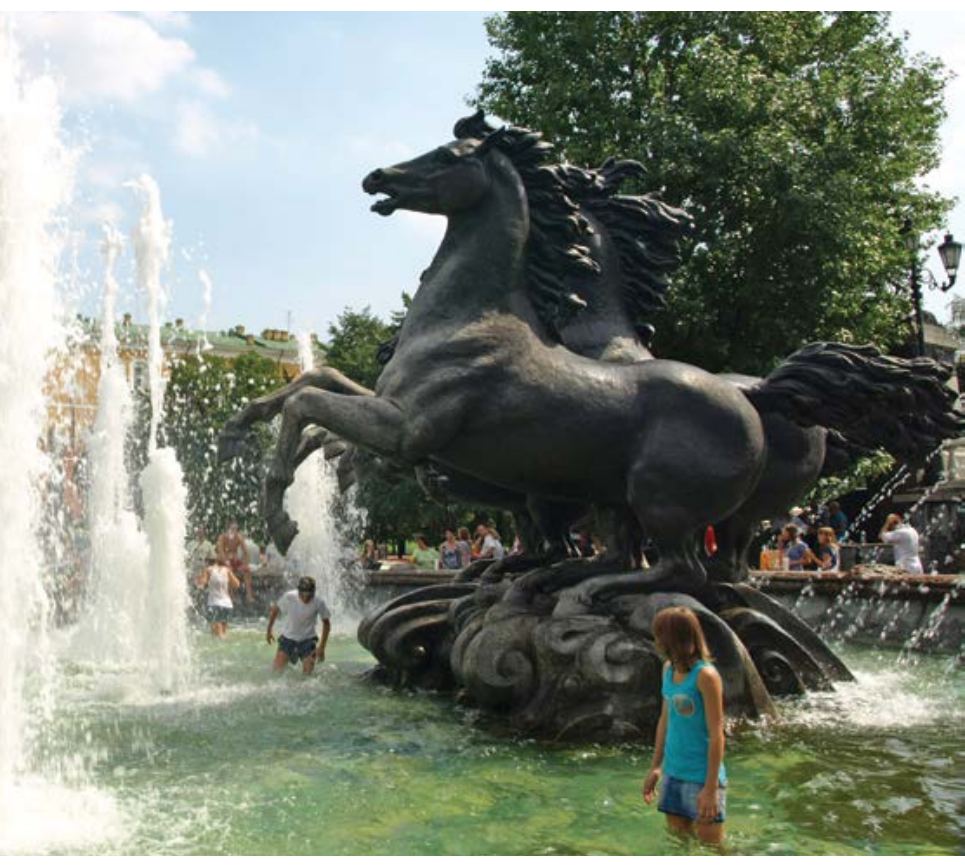

Cooling off in a central Moscow park, 21 July 2010, during the record-breaking great Russian heatwave of 2010 that included 28 consecutive days of temperatures above $35^{\circ} \mathrm{C}$ from 14 July. The extreme heat was unprecedented and led to forest and peat fires, heat-related deaths and drownings. Source: Graeme L. Worboys

\section{Other climate projections}

The IPCC Fifth Assessment Report also provided projections from 2081 to 2100 for phenomena other than temperature and these are summarised in Box 17.2.

\section{Extreme events}

The changing occurrence and nature of extreme events form the most challenging climate change trend. This is because the relationship between the climate mean and extreme events is not linear (IPCC 2013b), and these nonlinear relationships are shown schematically (Figure 17.2). As the mean surface temperature increases, the proportion of days over a defined temperature threshold will increase exponentially and there will be a marked increase in the number of extreme hot periods (days or several days). These extreme hot periods, for example, are what will drive some of the most important changes in biological systems and will impact on protected areas and their management. The occurrence of extreme climate events could change in frequency, intensity, spatial extent, duration and timing. Extended years of droughts, hotter or extended heatwaves, larger floods or more extreme storm events are some of the potential implications. The graphs in Figure 17.2 illustrate how small average changes in temperature between present and future climates could affect the potential for extreme events.
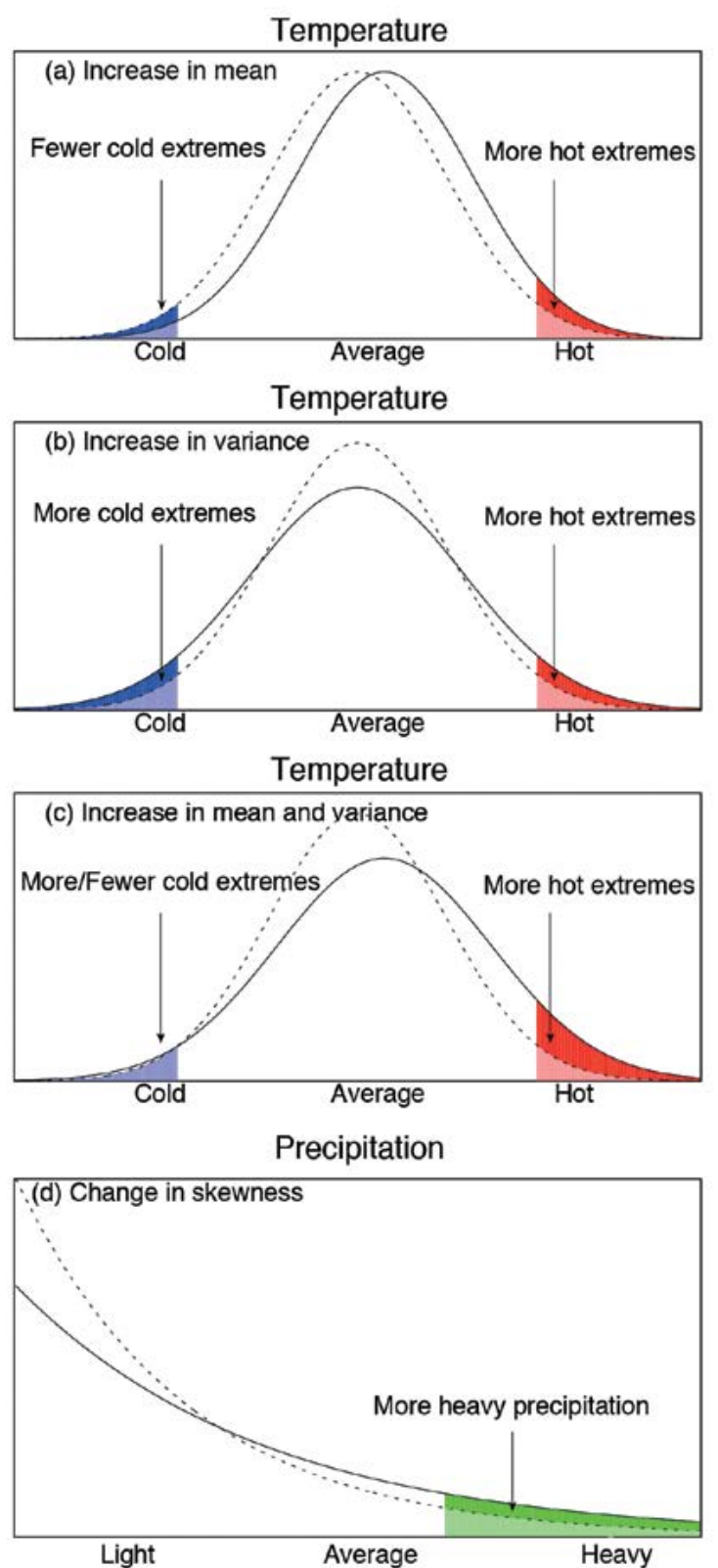

Figure 17.2 Climate extremes: probability schematics

Notes: Schematic representations of the probability density function of daily temperature, which tends to be approximately Gaussian, and daily precipitation, which has a skewed distribution. Dashed lines represent a previous distribution and solid lines a changed distribution. The probability of occurrence, or frequency, of extremes is denoted by the shaded areas. In the case of temperature, changes in the frequencies of extremes are affected by changes: a) in the mean, b) in the variance or shape, and c) in both the mean and the variance. d) In a skewed distribution such as that of precipitation, a change in the mean of the distribution generally affects its variability or spread, and thus an increase in mean precipitation would also imply an increase in heavy precipitation extremes, and vice versa. In addition, the shape of the right-hand tail could also change, affecting extremes. Furthermore, climate change may alter the frequency of precipitation and the duration of dry spells between precipitation events. (Parts a-c modified from Folland et al. 2001, and d modified from Peterson et al. 2008, as in Zhang and Zwiers 2012.)

Source: IPCC (2013b:134), reproduced with the permission of the IPCC; see IPCC (2013b:134) for the complete figure caption. 


\section{Box 17.3 Definitions: climate change mitigation and adaptation}

There are two broad responses to climate change. Mitigation is about avoiding or reducing greenhouse gas emissions as well as increasing the sequestration of greenhouse gases, and adaptation is about coping and responding to climate change. The IPCC has defined both of these terms.

\section{Mitigation definition}

'Mitigation is an anthropogenic intervention to reduce the anthropogenic forcing of the climate system: it includes strategies to reduce greenhouse gas sources and emissions and enhancing greenhouse gas sinks' (IPCC 2007:878). This can been defined more simply as a human intervention to reduce the sources or enhance the sinks of greenhouse gases (IPCC 2014b).

Protected areas can help mitigate climate change by storing carbon (preventing the loss of carbon that is already in vegetation and soils) and capturing carbon by sequestering carbon dioxide from the atmosphere in natural ecosystems.

\section{Adaptation definition}

Adaptation is:

[t]he process of adjustment to actual or expected climate and its effects. In human systems, adaptation seeks to moderate harm or exploit beneficial opportunities. In natural systems, human intervention may facilitate adjustment to expected climate and its effects. Adaptation may be incremental (where the central aim is to maintain the essence and integrity of a system or process as a given scale) or transformational (adaptation that changes the fundamental attributes of a system in response to climate and its effects. (IPCC 2014c:1)

Protected areas can adapt to climate change by protecting or maintaining ecosystem integrity, buffering local climate and reducing the risks of and impacts from extreme events. Protected areas can also provide essential ecosystem services that help people cope with change.

Sources: IPCC (2007); Dudley et al. (2010)

\section{Nature-based solutions}

All nations of Earth need to reduce anthropegenic greenhouse gas emissions and to employ every advantage possible to reduce atmospheric carbon dioxide and other greenhouse gas concentrations. The natural terrestrial and marine environments of Earth play a substantial role in mitigating the effects of climate change and in assisting adaptation responses (Box 17.3). Protected areas are a key part of this natural world and exist over a substantial part of the Earth's surface, with 15.4 per cent of the Earth's terrestrial surface area and 3.4 per cent of its oceans protected in 2014 (IUCN and UNEP-WCMC 2014). A protected area's vegetation can help to sequester carbon from the atmosphere through photosynthesis and the carbon is stored in the ecosystem as living and dead biomass and soil. These important roles have been recognised as a 'nature-based solution' to climate change.

The benefits of protected areas as a nature-based solution were highlighted in 2010 by the publication of Natural Solutions, prepared by a consortium of organisations including the International Union for Conservation of Nature (IUCN), The Nature Conservancy (TNC), the UN Development Programme (UNDP), the Wildlife Conservation Society, the World Bank and the World Wide Fund for Nature (WWF) (Dudley et al. 2010). The Natural Solutions text presented cost-effective response options that could contribute to the mitigation of and adaptation to climate change (Box 17.3).

\section{Mitigation}

Almost all natural and semi-natural ecosystems, including areas designated as protected areas, capture and store carbon by sequestering carbon dioxide from the atmosphere through photosynthesis (Dudley et al. 2010). The UN Environment Programme World Conservation Monitoring Centre (UNEP-WCMC) has estimated that 312 gigatonnes of carbon are stored in the world's protected area network and this is 15 per cent of the world's terrestrial carbon stock (Dudley et al. 2010). Such protected status reduces the likelihood of loss of carbon that is already present in vegetation and soils, and some protected areas may be actively managed to maintain or increase their sequestration potential. Actively managed protected areas promote mitigation by:

- avoiding conversion to other land uses and avoid habitat destruction and the loss of carbon

- providing opportunities for the ecological restoration and protection of degraded, carbon-rich sites such as disturbed peatlands and the regrowth of disturbed forests

- providing opportunities for helping to sequester carbon including for inland water areas, estuaries and peatlands (Dudley et al. 2010).

\section{Adaptation}

Protected areas reduce the impact of climate change on local communities and provide ecosystem support services. With protection, this ecosystem-based adaptation helps to maintain ecosystem integrity, buffer local climate, and reduce 
risks of and impacts from extreme events such as storms, floods, droughts and sea-level rise (after Dudley et al. 2010). Protected areas directly help to:

- deal with floodwaters by providing space for water dispersal and through natural absorbing impacts of vegetation

- minimise landslides with natural vegetation stabilising soil and snow to prevent slippage and to absorb impacts if a slip does occur

- minimise the impacts of coastal storm surges through the presence of mangroves, coral reefs, barrier islands, dunes and marshes

- reduce grazing pressure and consequently improve catchment protection, soil water retention and minimising the effects of drought and desertification

- actively manage for fire through fuel-reduction programs and initial response capability (Dudley et al. 2010).

Maintaining essential ecosystem services in protected areas helps people cope with changes caused by climate change to water supplies, fisheries, incidence of disease and agricultural productivity (Dudley et al. 2010). Active protected area management helps increase the resilience of essential natural resources and services and helps reduce the vulnerability of livelihoods including:

- for water, helping to retain water quality, flow regimes and yield through well-managed and noneroding catchments

- for marine and freshwater fish resources, helping to conserve and rebuild fish stocks

- for food resources, helping to conserve crop wild relatives to facilitate crop breeding and pollination services and helping to provide sustainable food for communities

- for health, helping to slow the expansion of vectorborne diseases that thrive in degraded ecosystems and for retaining access to traditional medicines (Dudley et al. 2010).

Protected areas also help to improve the resilience of ecosystems to climate change.

\section{Investments that respond to climate change}

When considered in their totality, protected areas have been established over a substantial area of Earth, and consequently, how they are managed for climate change is important. Nature-based solution approaches form an integral part of an international response to

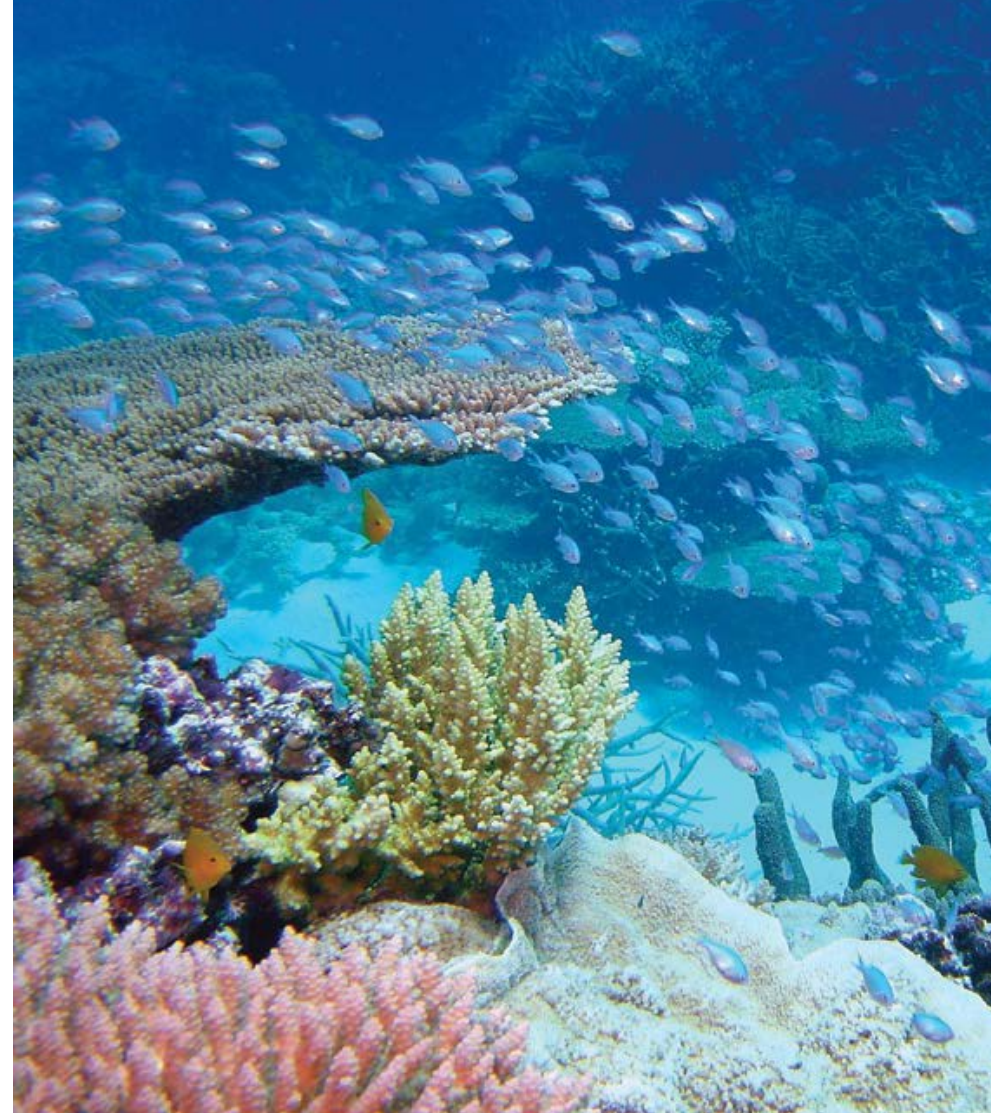

Healthy reef environment, Great Barrier Reef Marine Park, Queensland, Australia: coral reef systems around the world (including the Great Barrier Reef) are being impacted by coral bleaching through higher temperatures and rising acidity levels

Source: (C) Great Barrier Reef Marine Park Authority

dealing with climate change threats. With this larger context in mind, this chapter further develops what is possible for responding to (mitigation) and working with (adaptation) the effects of climate change and for achieving such actions. Scientists advise us that the world of the future will be different—very different-and protected areas will change. We assess the implications of climate change for protected area managers in the following sections.

\section{Implications for biodiversity}

Changes to ambient temperatures, concentrations of carbon dioxide, availability of water (for terrestrial organisms) and the nature of extreme events are serious impacts of climate change on natural systems. These changes will affect protected areas both directly and indirectly, and the responses to changes in climate parameters or events will vary between species and ecosystems. Some impacts on biodiversity are described in Table 17.1. 
Table 17.1 Examples of impacts on biodiversity from changes in climate and atmospheric parameters

\begin{tabular}{|c|c|}
\hline Parameter & Impacts and responses \\
\hline $\begin{array}{l}\text { Temperature and solar } \\
\text { radiation }\end{array}$ & $\begin{array}{l}\text { 'Increasing temperatures will interact with water stress for both plants and animals, and } \\
\text { will affect the timing of important life cycle events such as reproduction and diapause (a } \\
\text { quiescent period during a life cycle). Advances in spring events and delays in autumn events } \\
\text { are probable for many species' (Steffen et al. 2009:73) } \\
\text { Temperature during organism development affects the sex ratios for many reptile species, } \\
\text { while temperature extremes will influence fundamental geographic ranges of many plant } \\
\text { and animal species, with some species seeking higher and cooler elevation refugia and/or } \\
\text { sheltered and cooler aspects. Increasing ambient temperatures will contribute to increasing } \\
\text { risk of extreme weather events such as storms and lightning activity, leading to greater fire } \\
\text { and flood impacts on species and communities. In high mountain areas, reduced cloud cover } \\
\text { will contribute to extended exposure of the biota, particularly plants, to ultraviolet light, with } \\
\text { subsequent impacts on flowering, seed setting and germination percentage. This will be } \\
\text { particularly noticeable for species currently protected by semi-permanent snow cover }\end{array}$ \\
\hline $\begin{array}{l}\text { Carbon dioxide } \\
\text { concentrations }\end{array}$ & $\begin{array}{l}\text { Increased carbon dioxide levels in the atmosphere and/or water will result in higher } \\
\text { photosynthetic rates until the carbon dioxide concentrations or another factor (such as light } \\
\text { or nutrients) become limiting. Higher carbon dioxide levels also increase water-use efficiency } \\
\text { by reducing stomatal conductance. Carbon dioxide-driven changes in productivity are usually } \\
\text { accompanied by changes in plant chemical composition and plant structure. The increased } \\
\text { plant growth, for example, will contribute increased fire fuel accumulations in many grassland } \\
\text { and forest situations. Oceans and freshwater bodies will become more acidic as they absorb } \\
\text { more carbon dioxide. This will increase the solubility of calcium carbonate, which is a principa } \\
\text { component of skeletal material of aquatic organisms }\end{array}$ \\
\hline $\begin{array}{l}\text { Water yields and } \\
\text { supplies }\end{array}$ & $\begin{array}{l}\text { 'Water is critical for all terrestrial organisms, and water-together with ambient } \\
\text { temperatures - ultimately sets the fundamental distributional limit for all species' (Steffen et } \\
\text { al. 2009:73). Water stress from extended droughts and floods, as well as seasonal rainfall } \\
\text { regimes, may increase; however, increasing atmospheric carbon dioxide may also mitigate } \\
\text { water stress for some plants. Reduced snow occurrence and extent may have considerable } \\
\text { impact on water yields from catchments and runoff regimes into major river systems. } \\
\text { Reduced snow cover duration may impact on many plant and animal species that otherwise } \\
\text { survive extreme cold protected by an insulating layer of snow cover }\end{array}$ \\
\hline $\begin{array}{l}\text { Extreme events } \\
\text { (storms, floods, wildfire } \\
\text { and droughts) }\end{array}$ & $\begin{array}{l}\text { 'Extreme weather events such as floods, droughts, storms and fire can affect population } \\
\text { dynamics, species boundaries, morphology, reproduction, behaviour, community structure, } \\
\text { composition, and ecosystem processes. Changes in the frequency, intensity and seasonality } \\
\text { ["seasonal drift"] of extreme events are likely to have larger impacts on many species, } \\
\text { communities and ecosystems than individual, directional shifts in temperature and changes } \\
\text { in rainfall patterns' (Steffen et al. 2009:73). The extreme events may provide an ecological } \\
\text { advantage to many invasive species that (consequently) will threaten the survival of some } \\
\text { native species. In marine environments storm surges and sea-level rise will threaten the } \\
\text { continued existence of natural communities/ecosystems that currently are natural barriers to } \\
\text { coastal storm damage (coral reefs, mangroves and seagrass beds, fore-dune communities } \\
\text { and coastal wetlands). The loss of communities such as mangroves and wetlands will result } \\
\text { in carbon dioxide being released, further enhancing atmospheric greenhouse gas levels }\end{array}$ \\
\hline
\end{tabular}

Source: Modified from Steffen et al. (2009)

Some major taxonomic groups of plants and animals may be especially vulnerable or more adaptable than others to the impacts of climate change. Using the Australian situation as an example, some of these vulnerabilities are described in Table 17.2. The effects identified would be indicative of the effects to taxonomic groups elsewhere. 
Severe mainland-bound ocean storm, southern New South Wales, Australia

Source: Graeme L. Worboys

Table 17.2 Factors that will increase the vulnerability of Australian taxonomic groups to climate change

\begin{tabular}{|c|c|}
\hline Taxonomic group & Potential vulnerability \\
\hline Mammals & $\begin{array}{l}\text { Generally, mammals are mobile and able to disperse } \\
\text { Some 'narrow-ranged endemics particularly in montane or alpine regions that are susceptible } \\
\text { to rapid climate change in situ' will be vulnerable (Steffen et al. 2009:93) } \\
\text { There may be 'changes in competition between grazing macropods (plant eating Australian } \\
\text { marsupial mammals that include kangaroos and wallabies) in tropical savannahs mediated } \\
\text { by changes in fire regimes and water availability; herbivores affected by decreasing nutritional } \\
\text { quality of foliage as a result of CO2 fertilisation' (Steffen et al. 2009:93) }\end{array}$ \\
\hline Birds & $\begin{array}{l}\text { Generally, birds are highly mobile and able to disperse } \\
\text { There will be phenological changes including to migration and egg laying } \\
\text { Increased competition for breeding grounds } \\
\text { Breeding sites of waterbirds and coastal species will be susceptible to reduced freshwater } \\
\text { flows into wetlands, rising sea-levels and storm surges, and saltwater intrusion } \\
\text { Top predator species will be vulnerable to changes in food supply and earlier or later migrations } \\
\text { in response to seasonal shift movements }\end{array}$ \\
\hline Reptiles & $\begin{array}{l}\text { For reptiles, there is a range of mobility but generally there is poor dispersal } \\
\text { The warming temperatures may alter sex ratios; some species may be able to modify their use } \\
\text { of microhabitats } \\
\text { Shore-nesting species will be susceptible to rising sea-levels and storm surges }\end{array}$ \\
\hline Amphibians & $\begin{array}{l}\text { Amphibians have a high habitat specificity and a range of mobility and dispersal characteristics } \\
\text { Frogs may be the most at-risk terrestrial taxa. The effect of the pathogenic Chytrid fungus } \\
\text { (Batrachochytrium dendrobatidis) may change with changes in host susceptibility and } \\
\text { pathogen activity } \\
\text { Drying and burning of bogs and peaty soils will affect breeding sites for some species }\end{array}$ \\
\hline Fish & $\begin{array}{l}\text { There is limited capacity for freshwater fish species to migrate } \\
\text { Freshwater species will be vulnerable to reduced water flows and water quality (including acidity), } \\
\text { increased water temperatures and reduced shading from riparian vegetation; all species will be } \\
\text { susceptible to flow-on effects of warming on the phytoplankton base of food webs } \\
\text { Marine species will generally be mobile but species confined to rocky or coral reef habits may } \\
\text { be less mobile and so vulnerable to loss of habitat } \\
\text { Species are vulnerable to changes in ocean currents that otherwise provide nutrients and } \\
\text { disperse young } \\
\text { There are sea temperature thresholds for reproduction and most species are susceptible to the } \\
\text { effects of increasing acidity on the development of bony structures }\end{array}$ \\
\hline
\end{tabular}




\begin{tabular}{|c|c|}
\hline axonomic group & Potential vulnerability \\
\hline $\begin{array}{l}\text { Terrestrial } \\
\text { invertebrates }\end{array}$ & $\begin{array}{l}\text { Invertebrates are 'expected to be more responsive than vertebrates due to short generation } \\
\text { times, high reproduction rates and sensitivity to climatic variables ... Flying insects such } \\
\text { as butterflies may be able to adapt by shifting ranges if they are not limited by host plant } \\
\text { distributions; non-flying species with narrow ranges are susceptible to rapid change in situ' } \\
\text { (Steffen et al. 2009:93) } \\
\text { Invertebrates of restricted wet forests and montane environments may be threatened as these } \\
\text { habitats disappear } \\
\text { Genetic changes already observed in some widespread species such as Drosophila spp. and } \\
\text { invertebrate herbivores also affected by reduced foliar quality under elevated carbon dioxide } \\
\text { concentrations (Steffen et al. 2009:93) } \\
\text { Aquatic invertebrates will be affected by altered flows, water quality and temperatures. It is } \\
\text { likely that surface waters will become more acidic and this will erode exoskeletons } \\
\text { All marine species with calcium carbonate in shells, plates, spicules and tubes will be affected } \\
\text { by increased acidity of the ocean. The most notable group affected are the corals but the } \\
\text { impacts of increased acidity will be pervasive; corals will also bleach with rising temperatures }\end{array}$ \\
\hline Plants & $\begin{array}{l}\text { Longer-lived plants such as trees may be highly vulnerable if climate change affects recruitment } \\
\text { and establishment opportunities } \\
\text { Narrow-ranged endemic plants will be vulnerable if their required conditions are rare; elevated } \\
\text { carbon dioxide will increase photosynthetic rates where other factors, such as water and } \\
\text { nutrients, are not limiting } \\
\text { Productivity may be increased in some regions by a combination of increased carbon dioxide } \\
\text { and longer growing seasons; higher carbon dioxide levels will increase water-use efficiency but } \\
\text { total water use may not decrease due to decreased total leaf area and increased evaporation } \\
\text { from the soil } \\
\text { Competition between C3 and C4 plants (C3 and C4 refer to evolutionary traits for the way } \\
\text { plants capture carbon dioxide, with C3 plants being more primitive) may be affected by } \\
\text { elevated carbon dioxide, but soil moisture may be a stronger influence than photosynthetic } \\
\text { pathways } \\
\text { Changes to fire regimes will have significant impacts on vegetation } \\
\text { Changes in plant phenology and insect life cycles will affect pollination and some forms of } \\
\text { dispersal; hybridisation and speciation may increase as plants suffer increasing pressure and } \\
\text { stress } \\
\text { Aquatic and marine plants may be affected by increasing acidity; algae with calcium carbonate } \\
\text { crusts, rinds, blades and shells will be particularly vulnerable }\end{array}$ \\
\hline
\end{tabular}

\section{Shifts in plant and animal distributions}

The present distributions of most living organisms (with the notable exception of Homo sapiens) are defined by climate parameters-conditions that define their niche (along with other features). As these parameters change locally, species population dynamics play out, with the combination of dispersal and colonisation of new habitats and local extinctions giving the impression that the species and communities are moving across the landscape, although the apparent 'movement' of species is a result of complex dynamic processes. As a general rule, species will tend to move along the thermal gradients that run from the Equator towards the poles, and from low elevations towards higher elevations. For example, a meta-analysis of data for more than 1700 species (Parmesan and Yohe 2003) found an average shift of 6.1 kilometres per decade polewards but an increase of only metres per decade in elevation, with key spring events advancing by an average of 2.3 days per decade.

This general rule is, however, complicated by dispersal capacity (species and taxonomic groups differ in their capacity to disperse in response to stimuli), obligate requirements (some species have narrow requirements for soil type, pollinators, food sources or seasonal climate conditions) and habitat types (habitats may not be continuous and may not support dispersal even for the most mobile species- thus the requirement for greater connectivity; see Chapter 27). Protected area managers can use bioclimatic models to gain insights into how species and assemblages may be redistributed, but these analyses are limited by uncertainty about future climate conditions (Yates et al. 2010). In addition, species are often affected most significantly by combinations of climate factors, and information about critical climateinduced factors such as drought, heatwaves and fire is 
20th Century EVE Biomes

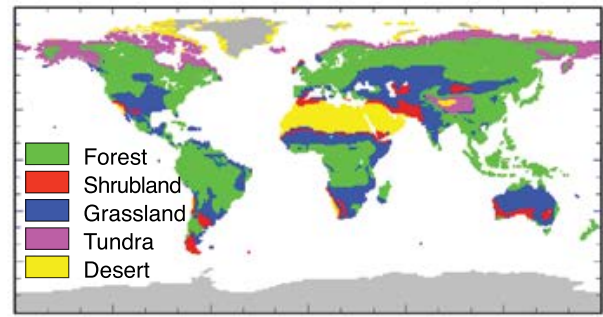

21st Century Shrubland Changes

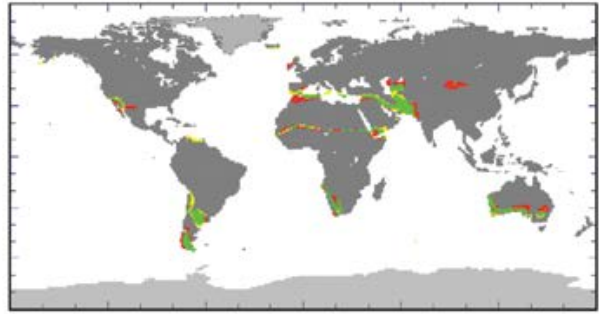

21st Century Tundra Changes

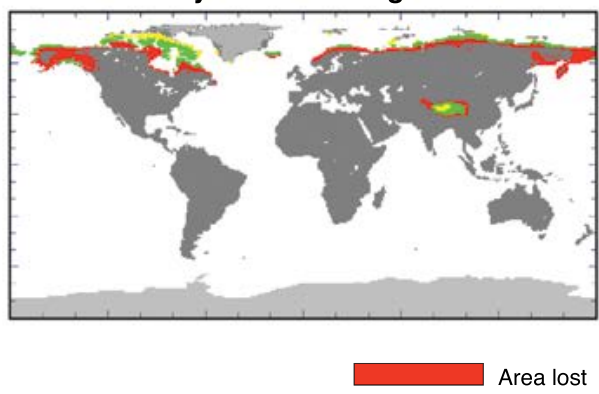

21st Century Forest Changes

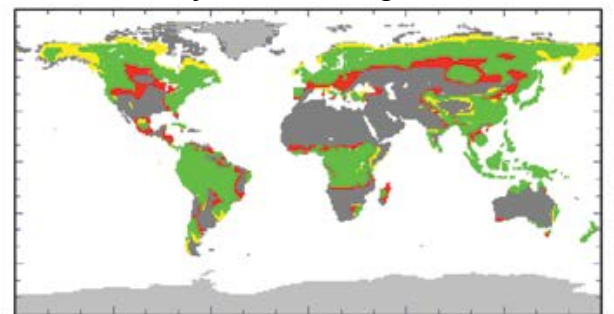

21st Century Grassland Changes

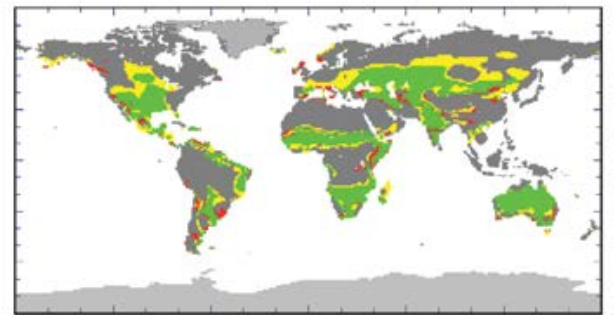

21st Century Desert Changes

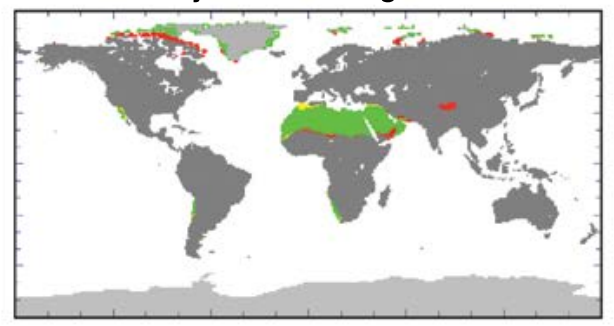

Unchanged

Area gained

Figure 17.4 Forecast changes in the distributions of five major biomes to the end of the 21st century Note: Derived from the Equilibrium Vegetation Ecology (EVE) model's 110 life-form fractional cover maps, as determined using EVE variables for the IPCC 'near-to business as usual' scenario, on a $1^{\circ} \times 1^{\circ}$ grid.

Source: Adapted from Bergengren et al. (2011)

and the associated lengthening of the growing season, for example, results in invasion by slower-growing boreal forest tree species. For this reason, identifying physiological thresholds through laboratory research or monitoring is very important. While research from other biomes may provide guidance, it is challenging to apply research findings from relatively less complex ecosystems to relatively more complex ecosystems (McKellar et al. 2010). Anticipated changes, for example, for five major biomes-forests, shrubland, grassland, tundra and desert-are illustrated in Figure 17.4.

\section{Implications for values people and communities obtain from protected areas}

Impacts from recent climate-related extremes, such as heat waves, droughts, floods, cyclones, and wildfires, reveal significant vulnerability and exposure of some ecosystems and many human systems to current climate variability
... Impacts of such climate-related extremes include alteration of ecosystems, disruption of food production and water supply, damage to infrastructure and settlements, morbidity and mortality, and consequences for mental health and human well-being. For countries at all levels of development, these impacts are consistent with a significant lack of preparedness for current climate variability in some sectors. (IPCC 2014a:6)

Climate change will affect the values people and communities obtain from protected areas. The overall value of the natural world to humans consists of economic values and broader cultural and other non-economic values and can be captured by a typology presented in Chapter 6, and a suite of cultural values that has been recognised in Chapter 4. Indicative impacts of climate change on these values are described in Table 17.3. 
Table 17.3 Examples of impacts from changes in climate on values held by humans for natural and cultural phenomena

\begin{tabular}{|c|c|c|}
\hline $\begin{array}{l}\text { Protected area natural } \\
\text { values (Chapter 6) }\end{array}$ & Description & Example climate change impacts \\
\hline Direct use values & $\begin{array}{l}\text { These values refer to the direct use we make } \\
\text { of natural values and ecosystem services, } \\
\text { which may include harvesting of some } \\
\text { resources and fishing }\end{array}$ & $\begin{array}{l}\text { Ecosystem function may remain } \\
\text { unchanged through active management, } \\
\text { but traditionally used species may no } \\
\text { longer be available in the wild with climate } \\
\text { change }\end{array}$ \\
\hline Indirect use values & $\begin{array}{l}\text { These values tend to be in a more diffuse } \\
\text { form such as clean water from catchments, } \\
\text { forests that help prevent avalanches and } \\
\text { vegetation that prevents soil erosion on } \\
\text { steep slopes }\end{array}$ & $\begin{array}{l}\text { Extreme weather events, droughts and } \\
\text { catastrophic fire events may impact } \\
\text { forests and catchments and affect the } \\
\text { indirect values; restoration management } \\
\text { may be implemented }\end{array}$ \\
\hline $\begin{array}{l}\text { Non-use values (future use } \\
\text { values) }\end{array}$ & $\begin{array}{l}\text { These values may be option values, which } \\
\text { relate to maintaining an area in case it is } \\
\text { needed for its natural resources in the future; } \\
\text { bequest values of leaving things in place for } \\
\text { future generations; and existence values that } \\
\text { we consider important even though we do } \\
\text { not benefit ourselves }\end{array}$ & $\begin{array}{l}\text { The specific values of an area may } \\
\text { change with time though the overall } \\
\text { natural value will be retained given there } \\
\text { is active management to minimise non- } \\
\text { natural threats }\end{array}$ \\
\hline \multicolumn{3}{|c|}{ Protected area cultural values (Chapter 4) } \\
\hline Aesthetic value & $\begin{array}{l}\text { These values include sensory perceptions } \\
\text { such as form, scale, colour, texture and } \\
\text { material of the fabric or the smells and } \\
\text { sounds associated with the place and its use }\end{array}$ & $\begin{array}{l}\text { The cultural landscape setting may } \\
\text { change and this may impact on the } \\
\text { aesthetics }\end{array}$ \\
\hline Historic value & $\begin{array}{l}\text { The place has influenced, or has been } \\
\text { influenced by, a historic figure, event, phase } \\
\text { or activity; site of an important event }\end{array}$ & $\begin{array}{l}\text { The context and setting of a historic event } \\
\text { or place may change }\end{array}$ \\
\hline Scientific/research value & $\begin{array}{l}\text { Importance of the data; rarity, } \\
\text { representativeness, degree to which the } \\
\text { place may contribute further substantial } \\
\text { information }\end{array}$ & $\begin{array}{l}\text { A scientific reference site may become } \\
\text { more important for its baseline role in } \\
\text { measuring change }\end{array}$ \\
\hline Social value & $\begin{array}{l}\text { Qualities for which a place has become a } \\
\text { focus of spiritual, political, national or other } \\
\text { cultural sentiment to a majority or minority } \\
\text { group }\end{array}$ & $\begin{array}{l}\text { Climate change may change the things } \\
\text { that you used to do such as a coastal } \\
\text { beach transformed to a wetland. The } \\
\text { social values of a site may change }\end{array}$ \\
\hline Spiritual value & $\begin{array}{l}\text { Used to capture the attachment between } \\
\text { humans and the natural environment/place, } \\
\text { being more specific than social or aesthetic } \\
\text { values }\end{array}$ & $\begin{array}{l}\text { The spiritual values of a place may be } \\
\text { diminished, such as the permanent drying } \\
\text { up of a waterhole }\end{array}$ \\
\hline
\end{tabular}

These changes to human natural and cultural values may mean that in the future, in some circumstances, there are tense environmental challenges accompanied by social and political pressures for responses. To illustrate this, we have described some climate change impacts that will affect people and communities in the future and the types of responses with which protected area managers could be associated (Table 17.4). There is a very clear underlying message here. Working with local people and as part of a local community will be needed more than ever before, for this will help communities fully value and support the special qualities and intergenerational benefits of protected areas.
Most protected area managers will be fully aware of the need to work with communities (Chapter 12). In addition, the natural resource management expertise of protected area managers may be especially valuable to local communities, particularly in rural and remote areas: 'protected area agencies have the potential to be major facilitators of natural resource management in the wider landscape, thereby contributing to sectoral and community-based adaptation' (Dudley et al. 2010:93). 
Table 17.4 Examples of climate change impacts and working with communities

\begin{tabular}{|c|c|c|}
\hline Climate impact & $\begin{array}{l}\text { Potential impact on region and } \\
\text { communities }\end{array}$ & $\begin{array}{l}\text { Working with communities in managing } \\
\text { protected areas }\end{array}$ \\
\hline Marine inundation & $\begin{array}{l}\text { Coastal communities, industries and } \\
\text { infrastructure are gradually displaced } \\
\text { as sea-levels rise and the effects of } \\
\text { storm surges impact further inland }\end{array}$ & $\begin{array}{l}\text { There is a need for ongoing cooperative work } \\
\text { with communities to retain support for the } \\
\text { conservation of local remnant (non-inundated) } \\
\text { protected areas. Protected area managers would } \\
\text { work with communities to help with the functional } \\
\text { re-establishment of settlements, industries and } \\
\text { infrastructure }\end{array}$ \\
\hline $\begin{array}{l}\text { Extreme and } \\
\text { prolonged drought }\end{array}$ & $\begin{array}{l}\text { Existing food and water supply sources } \\
\text { and systems are disrupted and short- } \\
\text { term alternative arrangements may be } \\
\text { needed }\end{array}$ & $\begin{array}{l}\text { Managers will need to work with local communities } \\
\text { to assist with support needs. Long-term effective } \\
\text { education and information programs will be needed to } \\
\text { help local communities understand and respect that } \\
\text { drought-stressed protected areas and their wildlife } \\
\text { also need special protection during times of drought }\end{array}$ \\
\hline $\begin{array}{l}\text { Migration from other } \\
\text { regions }\end{array}$ & $\begin{array}{l}\text { Displaced people will mean increased } \\
\text { local population numbers that could } \\
\text { result in increased illegal use of natural } \\
\text { resources from protected areas }\end{array}$ & $\begin{array}{l}\text { Managers will need to work closely with State, } \\
\text { national and aid organisations and local officials to } \\
\text { help with the welfare needs of displaced people as } \\
\text { well the special protection requirements of reserves. } \\
\text { Partnerships could be established with the military } \\
\text { to achieve short-term protection needs until order is } \\
\text { established }\end{array}$ \\
\hline $\begin{array}{l}\text { Perennial glacial } \\
\text { ice and snow cover } \\
\text { reduced or lost }\end{array}$ & $\begin{array}{l}\text { Perennial to ephemeral river water } \\
\text { supplies may be lost or reduced, } \\
\text { affecting security of regional water } \\
\text { supplies, including water needed for } \\
\text { irrigation }\end{array}$ & $\begin{array}{l}\text { Managers will need to work with local authorities to } \\
\text { assist with the management of the available water } \\
\text { from the protected area in a manner that assists local } \\
\text { communities and is consistent with the conservation } \\
\text { needs of the protected area }\end{array}$ \\
\hline $\begin{array}{l}\text { Extreme events: } \\
\text { storms, winds }\end{array}$ & $\begin{array}{l}\text { Lands and waters inside and outside } \\
\text { protected areas may be damaged } \\
\text { because of the extreme nature of } \\
\text { storms and weather events }\end{array}$ & $\begin{array}{l}\text { Managers need to be an integral part of the } \\
\text { community response to incidents and assist with the } \\
\text { recovery (Chapter 26) }\end{array}$ \\
\hline
\end{tabular}

\section{Mitigating climate change}

Given the implications of climate change are so farreaching, so insidious to life on Earth and so threatening to the prosperity and welfare of humans, there is an optimistic assumption by this book that the interests of the greater good for today's generation and future generations will prevail, and nations of Earth will reduce their greenhouse gas emissions to well below the current dangerous levels. Everyone will need to do their bit. Protected area managers are managers of the environment and they should indeed lead by example. This is especially important for climate change. As a first principle, they should, wherever and whenever possible, minimise the amount of greenhouse gases they generate.

\section{Minimising greenhouse gas emissions}

A leadership role in low-emission protected area management operations includes reducing both direct and indirect uses of energy derived from fossil fuels. This approach needs to develop an action plan that includes as many of the following points as possible:

- establishing and implementing organisation-wide emission reduction targets

- using official carbon offset mechanisms such as biodiverse restoration plantings within the protected area system to respond to unavoidable energy consumption such as the use of aircraft during incidents or for official travel

- implementing purchasing policies such as the purchase of green electricity; changing the vehicle fleet (where practical) to electric, hybrid or fuelefficient vehicles; and undertaking life-cycle (energy consumption) assessments of products prior to purchase 
Adaptation strategies need to be integrated into local, regional and national (and sometimes international) planning frameworks to ensure their sustainability and to help achieve ownership by local communities. For protected areas, adaptation practice would normally be an integrated part of protected area management-albeit with very clear and well-informed intent. It is important to be clear about what objectives are sought for climate change adaptation practices.

\section{Climate-ready objectives}

Dunlop et al. (2013) provide important guidance for establishing 'climate-ready' objectives for adaptation management. Their approach helps protected area practitioners to conceptualise the climate change issues at hand and to frame the types of governance and management adaptation responses needed. Preparing for climate change adaptation is a major task. Changing conditions will mean that the characteristics of a nation's protected areas and management needs will be very different in the future. Assessing strategic climateready objectives is critical and, in part, is a matter of identifying what is actually possible and practical in a rapidly changing world. The biodiversity outcomes that can be feasibly achieved - the ends of conservation management-are fundamentally constrained by climate change:

[A]daptation should include reassessment of the intended outcomes or objectives of biodiversity conservation that are articulated in strategic conservation documents. By objectives we mean statements of outcomes for biodiversity that are desired by society and that management should be focused on trying to achieve. These objectives are embodied in multiple stages of the conservation policy, planning and implementation process. Under a climate-ready approach, the critical question becomes: are the biodiversity objectives of a conservation strategy ecologically feasible given the potential impact of climate change? And, if not, how can climate-ready objectives be developed? (Dunlop et al. 2013:18-19)

Dunlop et al. (2013), in their work on climate-ready conservation objectives, have considered a landscape with a range of tenures. For protected areas, the focus would be more specifically on managing for natural ecological processes; however, importantly, what is being exemplified here is a process of rethinking and refining management objectives so that they are climate-ready. Such a process is most important for protected areas.
We have used this concept of setting climate-ready objectives in this book to help guide the specification of potential protected area climate-ready management actions. Consequently, we have provided more detail on this concept, including some of the terms used (Box 17.6) as well as the 'conservation policy cycle' (Figure 17.5).

\section{Three examples of climate-ready conservation objectives}

Dunlop et al. (2013) developed three prototype 'climateready' objectives for biodiversity conservation to help illustrate elements of the climate-ready approach for landscapes. Objectives were prepared for 'species' (Box 17.7), 'ecosystem' (Box 17.8) and 'landscape' (Box 17.9). The 'species', 'ecosystem' and 'landscape' examples for climate-ready conservation objectives are valuable for fine-tuning a climate-ready thinking approach to be taken by managers in selecting appropriate protected area adaptive management actions. Each objective for the three examples consists of three key elements):

1. an action (reduce or maintain a biodiversity outcome)

2. a biodiversity outcome that is the focus of the objective (what it is trying to conserve)

3. a biodiversity outcome that is seen as transientthat is, change in it is deemed acceptable, by virtue of the inevitability of that change under climate change (Dunlop et al. 2013).

A key feature of this approach is the consideration of community and social goals. The importance of retaining and managing for natural ecological processes in protected areas would be reinforced as a key social goal.

In managing for species in a climate-ready environment, some tough management decisions may be needed. In Box 17.10, Adrienne Nicotra and Roger Good present a conceptual approach that may assist such decisionmaking. Clear, climate-ready objectives of management are critical, for their establishment is the precursor to well-considered management actions. Operationalising these objectives as actions would include planning; there would be organisation to achieve implementation and there would be follow-up evaluation. We have used these four functions of management (Chapter 8) as a framework to present a range of climate-ready considerations for protected area practitioners. Ideally, any situational responses identified would be prepared as a climate-ready response plan for a protected area. 


\section{Box 17.6 Climate-ready conservation objectives for a landscape}

[Text provided to stimulate interest in and discussion of the concept of climate-ready objectives and their potential use for protected areas.]

In considering and interpreting climate-ready conservation objectives and the policy cycle (Figure 17.5) for landscapes of multiple tenures, the following abbreviated points from Dunlop et al. (2013) are important. They reinforce that establishing climate-ready objectives is about rethinking the future and adjusting management to deal with these new futures.

- Management actions are the means by which biodiversity outcome ends are met, and conservation objectives are statements of the desired ends.

- Objectives are tools to help diagnose the extent to which policy and planning are climate-ready and to help scope the nature of the task of accommodating the climate change propositions into various decision-making processes with their multiple inputs and constraints.

- The process of revising policy and planning will be far more complex than simply updating objectives: it is potentially a multi-decade process and will depend on the specific context of different institutions. Thinking about the need to recalibrate objectives and the factors that make objectives climate-ready will help develop the capacity of decision-makers, stakeholders and researchers to start addressing the issue.

- Climate-ready objectives might be substantially different from current objectives.

- Policy objectives should reflect social goals, community aspirations and preferences, especially when planning adaptation policy; this framing step in the policy cycle is called 'community biodiversity values' (Figure 17.5).

- Values' in this approach do not mean biodiversity assets (which might be valuable) or dollar values (market or non-market); they refer to preferences and aspirations that are products of the relationship between people and nature.

- Such values can be expected to change as a result of people's understanding of nature changing, including understanding the inevitability of various changes to species, ecosystems and landscapes.

- Community biodiversity values are critical motivators of conservation. Climate-ready conservation objectives are products of recalibrating the current conservation outcomes so they reflect biodiversity outcomes that are both technically feasible and socially desirable under future climate change. For protected areas, this would include society wishing to manage for the retention of natural ecosystem processes and the associated biodiversity.

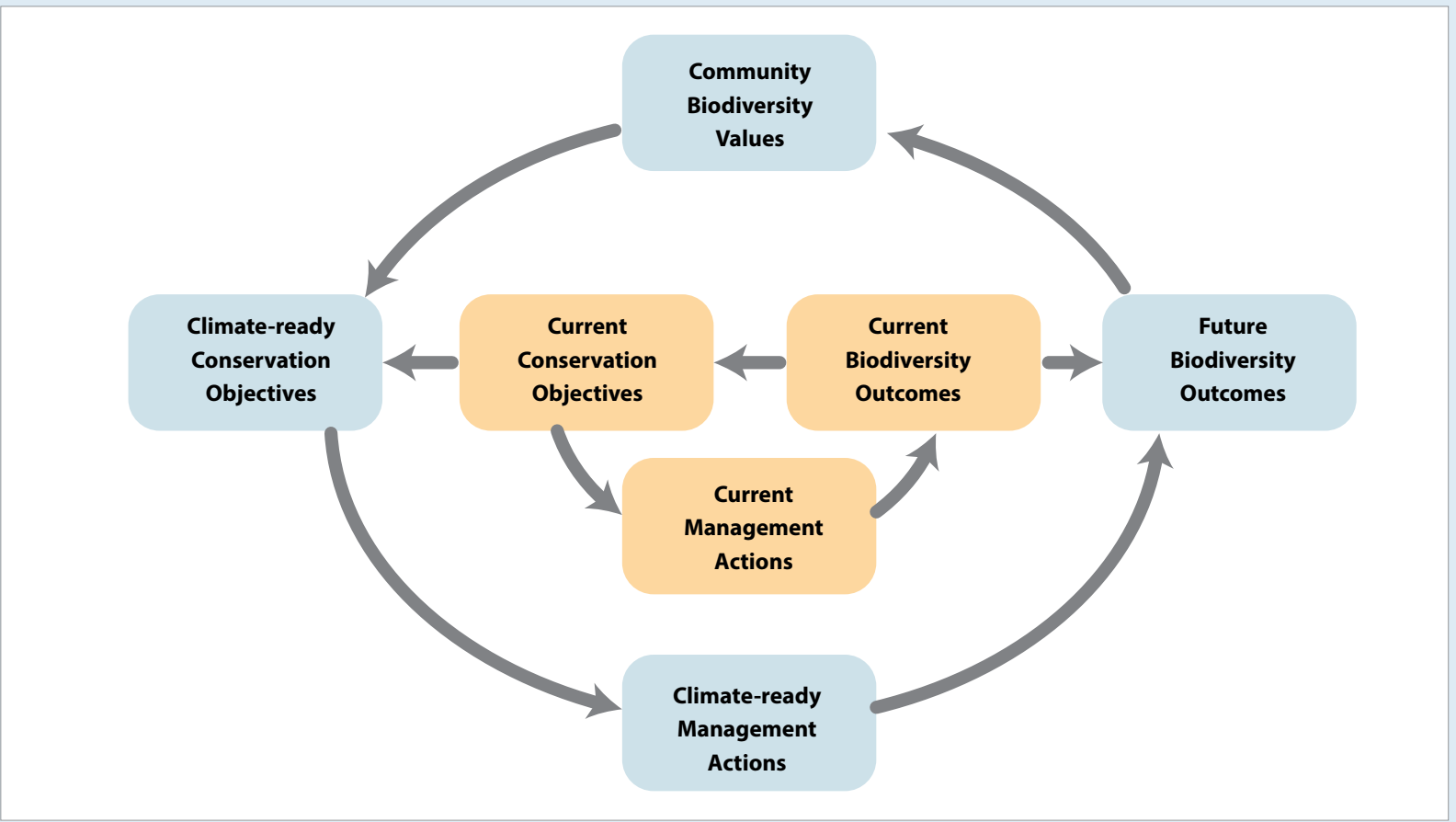

Figure 17.5 The conservation policy cycle

Note: The cycle incorporates recalibrated objectives that describe feasible desired biodiversity outcomes that lead to updated management and revised outcomes.

Source: Dunlop et al. (2013:20) 
- Climate-ready management actions are the set of activities needed to implement the new objectives; they are likely to be similar types of actions but possibly implemented in different ways and different places for different ends. Future biodiversity outcomes are the result of new management, evolving threats, climate change impacts and other drivers.

'Preliminary criteria for assessing the extent to which objectives for biodiversity conservation may be climate-ready have been developed that are applicable to all (forward-looking) objectives that seek to conserve biodiversity in the face of any threats, not just those specifically addressing climate change. In this way, addressing climate change becomes mainstreamed into conservation as a whole. These preliminary criteria for assessing the climate-ready status of conservation objectives are as follows.
- The objective accommodates large amounts of ecological change and the likelihood of significant climate change-induced loss in biodiversity.

- The objective remains relevant and feasible under the range of possible future trajectories of ecological change.

- The objectives (as a set) seek to conserve the multiple different dimensions of biodiversity that are experienced and valued by society.

- Objectives need to be detailed enough to explicitly meet the criteria, not merely being possibly consistent with them.

Source: Adapted from Dunlop et al. (2013:19-20)

\section{Box 17.7 'Species' climate-ready conservation objective for a landscape}

[Text provided to stimulate interest in and discussion of the concept of climate-ready objectives and their potential use for protected areas.]

\section{Objective}

Reduce species extinctions as abundance and distribution change.

\section{Explanation}

The objective explicitly recognises that populations of species may vary considerably over time, and that as these changes occur it may be feasible to reduce the chance of species going extinct, but that it is also infeasible to prevent all extinctions due to climate change (and other threats).

\section{Conceptual issues}

- How much reduction in extinction is sought?

- Hybridisation: potentially a mechanism for genes to survive, but it is currently recognised as a threat.

- Distribution shifts into different ecological communities: good for the moving species but potentially threatens the extant community.

- What levels of species richness and turnover between sites are desirable?

- How much does society value other types of diversity (higher taxonomic levels, functional, and so on)?

- Is the presence of any species acceptable in any location, at any abundance?

\section{Residual losses}

There will be losses due to the changes in species abundance and distributions and losses associated with those species that do go extinct, given an acceptance that some level of extinction is inevitable.

\section{Climate-ready management for species}

- Maintain habitat in a wide variety of environment types (so species can hopefully find suitable habitat somewhere across the landscape as they move in response to climate change).

- Minimise the impact of other threats (pests, weeds, habitat loss and degradation, water extraction) so that species have less competition to establish populations in new areas (as well as potentially persist in their current distributions).

- Maintain and enhance connectivity of vegetation and waterways to facilitate movement of species to areas where they may survive better.

- Protect refuges to help species survive increased climatic and environmental variability and extremes.

- Protect currently outlying populations as potential sources for populations in new areas.

\section{Social considerations}

Species and place are strongly linked, and this is potentially a barrier to adopting the climate-ready objective. If some level of extinction is inevitable, how are choices made about which species are preserved? How can the community gauge success if some (uncertain) amount of loss is inevitable?

\section{Institutional considerations}

There is a need to develop aspatial or more spatially dynamic ways of characterising species and their future conservation needs. There is extensive work on characterising diversity patterns, but translating this into forms that can be incorporated into objectives or priorities is more complex.

Source: Abbreviated from Dunlop et al. (2013) 


\section{Box 17.8 'Ecosystem’ climate-ready conservation objective for a landscape}

[Text provided to stimulate interest in and discussion of the concept of climate-ready objectives and their potential use for protected areas.]

\section{Objective}

Maintain ecosystem health as type, composition, structure and function change.

\section{Explanation}

The objective focuses on the quality or health of an ecosystem found at a particular location, with the specific type of ecosystem at that location seen as transient. It explicitly recognises that changes in species abundance and distributions and changes in disturbance regimes will affect the composition, structure and function of ecosystems -their defining features. There is, however, an intuitive concept that any type of ecosystem could be in a healthier or more degraded condition, and as type changes it would be desirable for a location to transition from having a healthy ecosystem of the current type to a healthy ecosystem of a new type rather than a degraded version of the original type (or the future type). Ecosystem health could be seen as the potential of an ecosystem to provide ecosystem services.

Ecosystem, in this objective, means the system of the interacting ecological processes and individual organisms. As such, an ecosystem could be small (a patch of vegetation) or very large. This objective focuses on the biodiversity of a location as it comes and goes and changes, not on the fate elsewhere of the individual species or ecosystem types currently occurring at the location.

\section{Conceptual issues}

- The objective is about the properties of ecosystems that people experience and value directly, not about managing ecosystems for the conservation of species per se.

- How should ecosystem health be defined? What parameters should be included?

- Some loss of health might be inevitable during (continual) transition, depending on the rate of change.

- If change in type is deemed acceptable, due to being inevitable under climate change, how much is change in type due to human activities also acceptable?

- How should health benchmarks for novel or transitioning ecosystems be determined?

- While ecosystem health applies to all ecosystems, which places might have higher priority? Should we aim for examples of very good ecosystem health or acceptable ecosystem health everywhere?

\section{Residual losses}

Residual losses in this objective arise from changes in types of ecosystems occurring at specific locations, and potentially the extent to which some ecosystem types reduce or disappear completely. There may also be some loss of value associated with some reductions in ecosystem health as they enter a phase of continual transition in response to continual climate change, so that they are essentially always out of equilibrium with the climate of the day.

\section{Climate-ready management for ecosystems}

- Manage disturbance to avoid any erosion of key parameters (such as soil, trophic structures, primary productivity).

- Limit 'over-dominance' of key species (monocultures, over-predation).

- Manage extractive pressures (such as grazing, harvests).

- Manage for diversity of functional types and manage for ecological redundancy.

- Manage for resilience of key processes.

\section{Ecological considerations}

- An agreed definition of ecosystem health; many aspects that might intuitively align with health are well defined ecologically (such as species richness, functional diversity, primary productivity, response to disturbance).

- A variety of measures related to ecosystem health (such as condition) that is decoupled from the type of ecosystem.

- Defining suitable benchmarks as the climate changes. Some changing benchmarks might be predictable from current theory, mechanistic models and statistical analysis of patterns, such as potential primary productivity or species richness. It is unclear, however, if these predictions or extrapolating from similar contemporary climates will be precise enough or actually suitable.

\section{Social considerations}

How much of the value held for the ecosystem at a place is associated with the type of ecosystem and with its health? How much does the rate of change in type matter socially? How much does familiarity with the current ecosystem affect perceptions of change in type and health?

\section{Institutional considerations}

There are many possible different measures relevant to ecosystem health, but few are well enough characterised to provide simple tools to be built effectively into institutions.

Source: Abbreviated from Dunlop et al. (2013) 


\section{Box 17.9 'Landscape' climate-ready conservation objective}

[Text provided to stimulate interest in and discussion of the concept of climate-ready objectives and their potential use for protected areas.]

\section{Objective}

Maintain a balance between human and natural domination of ecological processes, as ecosystems and land/water uses change.

\section{Explanation}

The intent of this objective is to focus on the amount of nature in a landscape, with the particular native ecosystems and human uses in the landscape seen as transient. It recognises landscapes as places with a mixture of natural and human influences, and it focuses on the balance between those influences. Like the ecosystem objective, this one is place-based, but here the place is recognised as having multiple ecosystem types (including natural and human) and the focus is on the 'quantity of nature' across those different ecosystems or the quantity of resources available for nature, not the quality. Whereas the ecosystem objective related to the ability of a place to provide ecosystem services, this objective relates more to the quantity of ecosystem services provided by the landscape. The objective can apply to any scale-for example, a continent or an urban backyard.

\section{Conceptual issues}

The objective is about the properties of landscapes that people experience and value directly, not about managing landscapes for the conservation of species perse.

- What 'balance' of human and natural domination is right? While this is clearly a significant question in society, this objective focuses on the impact of changes in the balance due to climate change. Where the balance (not just the types) affects how people experience and value a landscape, it may be desirable for any change in the balance to be managed (stopped, slowed, maybe encouraged) rather than just allowed to happen.

- Climate change could drive the balance towards more or less natural domination. Either could be desirable.

- Is the pattern of natural and human activities, and how they are spread across the landscape, important, as well as their relative amounts?

- What aspects of ecosystems, ecological processes and human impacts should be used to judge the extent to which they are naturally dominated? How should human impact on variation be considered (such as flow regimes)? How might impacts on viewscapes and sound-scapes be considered?

\section{Residual losses}

Residual losses in this objective arise from changes in the types of ecosystems and land and water uses occurring in the landscape. Clearly, specific ecosystem types and human uses are valued in many landscapes, and change in these will lead to some losses.

\section{Climate-ready management for landscapes}

- Understand the institutional and physical drivers of particular balances in landscapes, and their sensitivity to climate change, both directly and via changed land and water use.

- Set aside land and water resources for biodiversity.

- Include the naturalness of semi-natural ecosystems and rivers in quantification of landscape balance (as opposed to simply area of native habitat versus cleared area).

- Maintain natural influences over variability in hydrological systems and disturbance regimes.

- Adjust harvesting (of timber, fishing, grazing) in response to changing productivity.

\section{Social considerations}

Sense of place is a powerful concept in culture; how much of it is tied to familiar types of ecosystems, as opposed to a balance? If types change, how much connection might remain? Is the balance worth retaining if the types change?

\section{Institutional considerations}

There are few readily available tools for effectively characterising the degree of human and natural influence along the spectrum of balance in a landscape.

Source: Abbreviated from Dunlop et al. (2013) 


\section{Box 17.10 The assignment of priority species, assemblages and ecosystems for adaptation research and conservation management}

[A potential 'first stage' climate-ready framework for managing for species.]

Considerable protected area-specific ecological and restoration research will be required to successfully manage adaptation challenges. The research requirements for many protected areas will be difficult to determine and clearly articulate and, where identified, will be difficult to address in the short term. In terms of biodiversity, the assignment of priority species, assemblages and ecosystems for research and conservation can be assisted by using an expert systems approach, as described below. It should be noted that this 'first stage' in a thinking approach to dealing with species does not include social and political considerations and these would be a critical input to any final decision about management action.

\section{Assigning species to an adaptation management response space}

This conceptual framework (Figure 17.6) provides a useful starting point for prioritising actions, but it must be recognised that assignment of species to these categories is not simple. Resilience or adaptive capacity depends on three interacting factors: innate ecological characteristics (such as life-history traits); genetic variation, which confers the potential for an adaptive evolutionary response; and plasticity, which may buffer the impact of climate change, broaden environmental tolerance and/or provide time for adaptive evolution and range shifts to occur. Assignment of taxa on the framework should therefore be an iterative process, taking into consideration what expert opinion and historical data are available, and then cross-checking with research on the above areas for those species seen to be most important in the system.

\section{The framework}

Using a combination of expert opinion, historical data compared with contemporary data, and research on ecological characteristics and adaptive capacity, it is possible to assign species to an 'adaptation' space with axes representing functional importance and resilience (but see caveat below).

\section{$X$ axis}

The $x$ axis represents the functional contribution of the taxon to the ecosystem. Taxa would score as having high functional importance if they were keystone species or highly abundant and making large contributions to ecosystem function.

\section{Y axis}

The $y$ axis represents the resilience (or adaptive capacity) of a taxon. Taxa that are already showing signs of decline in abundance, slowed growth or reproduction, or increased sensitivity to pests and diseases would score low. In addition, taxa known to have narrow environmental limits or low genetic variation would be likely to fall on the low side of this axis. Taxa that either do not show current impacts of climate change or are increasing in the community would score as highly resilient. From a management perspective, identification of these categories provides a starting point for allocation of conservation and management actions.

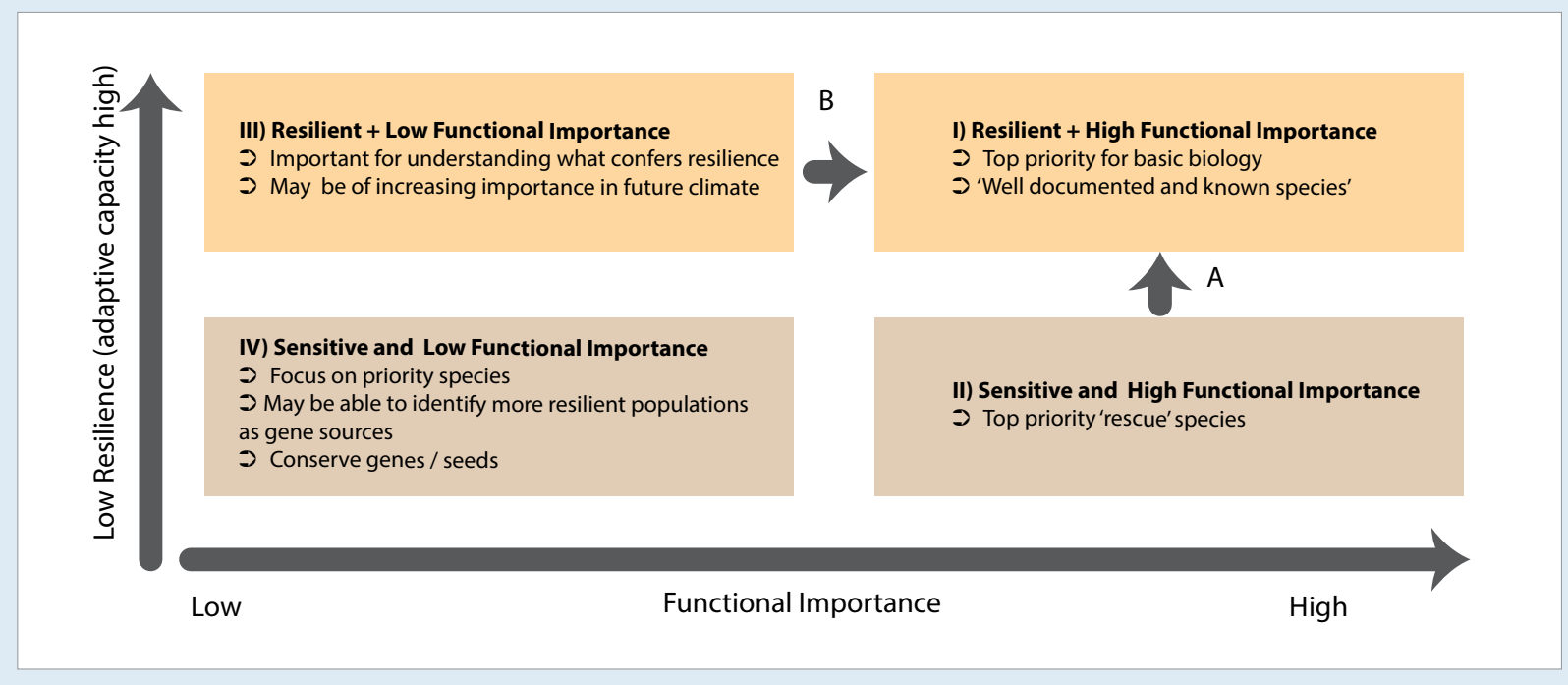

Figure 17.6 Assigning species to an 'adaptation management response space'

Note: This approach uses a combination of expert opinion; historical data compared with contemporary data; and research on ecological characteristics and adaptive capacity.

Source: Nicotra et al. (2014) 


\section{Quadrant I}

Taxa falling into Quadrant I are both functionally important and resilient. These should be the 'bread and butter' species for restoration efforts. Though conservation and protective actions often overlook the common taxa, they are important species to maintain in ex situ conservation and about which to obtain basic biological information as they may play a key role in responding to disturbance as a result of climate change. Basic biological information could include a better understanding of the environmental tolerances of the species and of patterns of genetic variation within the species.

\section{Quadrant II}

Taxa falling into Quadrant ॥ are currently of high functional importance but show signs of negative impacts from climate change. These should be considered as species for which 'genetic rescue' might be considered. Alternatively, these are species that are likely to be replaced in the community and preparation for that change should be considered. For some such species, genetic variation may exist within the species that will provide more resilience, and where possible, such variants should be favoured for conservation and restoration (Arrow A).

\section{Quadrant III}

Taxa falling into Quadrant III are apparently highly resilient, but currently play a small functional role in the system. Climate change indirectly, or directly through management, may serve to increase the role these taxa play in the community (Arrow B). Taxa in Quadrant III also may be of interest in that they can contribute to our understanding of what makes a resilient taxon.

\section{Quadrant IV}

Taxa falling into Quadrant IV both show signs of low resilience and currently play a low functional role in the community. These may include taxa that are rare or at the current edge of their distribution. Quadrant IV taxa should be conserved ex situ as potential gene resources and may be of interest from the perspective of future genetic contribution. These taxa are, however, likely to include those least likely to persist in future communities and therefore should be a lower priority for management efforts.

- Adrienne Nicotra and Roger Good

\section{Climate-ready planning}

Many protected planning area considerations are described hereunder that could help facilitate climateready objectives. For each of the climate-ready topics identified, the planning consideration has been presented as a question in preference to a specific management action. This approach focuses on the further conceptual development and definition of actual climate-ready response actions that will be needed rather than presenting actions as a checklist of tasks. How each adaptation planning action is actually developed will also vary depending on management policy needs (Box 17.11).

The 'planning' considerations that may form response actions to climate-ready objectives include: managing for risks, protected area system considerations, mitigation planning, planning process considerations, asset management and business planning. The considerations have been based on a number of guiding references including Welch (2005), Jarvis (2007), Mackey et al. (2008), Laffoley and Grimsditch (2009), OEH (2011) and IPCC (2014c).

\section{Risk management planning}

What are the key climate change impacts that may affect a protected area? Understanding the vulnerability and risks of a protected area or protected area system provides a planning context for management responses. The IPCC (2014d) identifies some criteria that may be used to identify key climate change vulnerabilities:

- magnitude of impacts

- timing of impacts

- persistence and reversibility of impacts

- likelihood (estimates of uncertainty) of impacts and vulnerabilities and confidence in those estimates

- potential for adaptation

- distributional aspects of impacts and vulnerabilities

- importance of the system(s) at risk.

What climate change-associated risks are there to local communities and neighbours and cultural heritage values? Undertaking climate-ready risk assessments allows protected area managers and local communities to assess what risks are likely and to prioritise any planning and preparation relative to the likelihood and consequence of an incident (Chapter 26). Climate change-enhanced risks could include flooding and inundation, more frequent extreme temperatures, droughts, bushfires, changing rainfall intensities, severe snowstorms, extreme weather, 


\section{Box 17.11 Approach to planned management actions}

Early adaptation response actions are considered a wise investment, and planning is the critical first step. In an environment of planning uncertainty, some of the clearly identified planning considerations may be the following.

- No-regrets actions: These are actions that yield benefits even in the absence of climate change and where the costs are low.

- Win-win actions: These are actions that have the desired result in terms of minimising climate risks or exploiting potential opportunities but also have other social, environmental or economic benefits.

- Reversible and flexible: Which are actions that allow amendments to be made.

- Expanded: These are actions for which safety margins have been provided to ensure reliance for a range of climate change effects.

- Delayed: Identified actions that provide no benefit when undertaken immediately.

Source: ECAP (2014)

coastal erosion, and many others (Chapter 16). Rising sea-levels and storm surges, for example, may inundate coastal heritage resources of cultural significance (such as an indigenous occupation site), and there may be the need for community consultation and potentially some recovery actions associated with these assets.

From a climate-ready perspective, what risks to natural values exist for individual protected areas and for protected area systems? Such a risk assessment will help to identify the types of changes that may be forecast for a nation's natural values as well as for individual protected areas. It establishes a context for responses such as reviewing the adequacy of the protected area system, anticipating areas that may be inundated and lost, identifying areas that will be different, and providing special management for areas that may be refugia or connectivity conservation areas.

What risks are there to staff, visitor and local community safety? Safety considerations for staff and visitors to protected areas from a climate-ready perspective may include aspects such as changed fire behaviour, dealing with severe heat, unstable slopes in mountains due to the melting of frozen soils, melting glaciers where waters are temporarily dammed and suddenly released, higher sealevels, wild seas along coastlines in severe weather, and other considerations. These staff safety risks will need to be assessed and managed.

\section{Protected area systems planning}

Is the protected area system adequate? Based on regional-level climate change modelling and biome shift forecasting, identify biomes that are at risk and undertake practical response planning. This includes assessing the boundaries of some protected areas and determining if they can be improved to assist biodiversity conservation (Chapter 13).

'Protected area systems will need to be adjusted and often expanded to fulfil their potential climate response roles of mitigation and adaptation, with implications for planning, assessment, policy and training. Individual protected areas will need adaptive management to meet changing conditions' (Dudley et al. 2010:93).

If possible, select and reserve new protected areas that may assist in maintaining a diversity of species and ecosystems based on forecast changes. Specific climate change-forced challenges may include:

- managing for the conservation of specific values, such as the establishment of 'mobile protected areas' in the marine environment to ensure that specific values are protected even though the location of those values changes

- managing for migration routes for terrestrial species, where those routes change with time, and the special protection this may require, irrespective of tenure.

Are protected areas adequately protected in a climate change world? Governance of protected areas will be placed under enormous pressure as the effects of climate change deepen. Special leadership, community support and political support efforts will be needed to keep protected areas 'protected' given 'backsliding' pressures caused by climate change issues are anticipated (Chapter 5). Pressures may, for example, come from:

- proposals for impoundments and the flooding of natural areas

- proposals for hydroelectric energy and the impounding of natural streams

- proposals for use of open space for electricity generation from solar, wind and tides

- drought-relief stock grazing into drought-impacted natural areas

- people seeking natural resources given they are no longer available anywhere else.

Does the protected area system adequately protect refugia sites? Species can persist by range reduction to microhabitats that retain the necessary niche and habitat requirements-the so-called refugia. Locations can 
function as refugia as a result of species responses to longterm or short-term environmental change. Remnant natural bushland patches in a fragmented landscape can also provide important refugia for species.

Are protected areas an integral part of larger connectivity conservation areas? Where possible and beneficial, protected areas should be embedded in large-scale networks of connectivity conservation areas. Action should be taken to minimise the barriers to the movement of wildlife through these areas (Chapter 27). Protected areas would form core areas for these connectivity conservation areas, which might also be very large and continental in scale. Habitat destruction and fragmentation should be minimised.

\section{Mitigation planning}

Have protected areas been adequately considered for the role of restoration in sequestering carbon and mitigating the effects of climate change? For example, restoration of tidal salt marshes and mangrove communities is an excellent way to increase natural carbon sinks. The management of seagrasses and kelp forests may also be considered. In terrestrial environments, the restoration of wetlands and forests, for example, can play an important role in sequestering carbon as well as improving habitat for species.

\section{Planning processes}

Have protected areas clearly defined and implemented their climate-ready objectives? Committing quality time and resources to prepare clear climate-ready objectives at strategic, tactical and operational levels of protected area management is a critical investment.

\section{Plans of management for individual reserves}

Have protected area plans of management included climate-ready objectives and actions? Climate-ready objectives for individual protected areas will be geographically more specific, but would generally still focus on maintaining ecosystem processes and biodiversity rather than specific species or biomes. The plans could feature enhanced information gathering through monitoring and provide additional support for research into condition and trend in condition. Climate forecasts could provide planned guidance for future restoration investments.

\section{Environmental impact planning}

Has an environmental impact assessment of a development proposal or a leasing and licensing proposal adequately included climate-ready considerations? These appraisals are very important and they need to consider the implications of climate change carefully. The commercial success of leasing or licensing proposals, for example, may require access to resources such as snow or to sites in bushfire-prone areas where access is guaranteed for the term of the lease. The decline or absence of snow within the term of a lease, or the closure of tourist destinations due to more frequent fires, could have legal implications for the lessor if this is not managed carefully.

\section{Condition and trend in condition of protected areas}

Have managers described the condition and trend in condition of their protected areas? Are they using such information as a basis for keeping track of long-term trends for their protected area? Climate change means that, more than ever before, there is a need to understand the condition of protected areas that are being managed and their trend in condition. This is a long-term program that would need to be institutionalised. It will be critical in helping to define management priorities. The information would be linked to information secured from modelling research that helps to forecast climateready futures. This may be a new capability for protected area organisations and it could include:

- legislated (mandated) ecological integrity assessments (Chapter 21)

- new partnerships with research organisations

- routine employment of on-ground and adequately qualified ecosystem management specialists such as postdoctoral qualified staff

- new and improved approaches to communicating effectively to the public about the condition and trend in condition of their local protected area or their protected area system.

Is there adequate investment in forecasting climate futures to assist with planning and management of protected areas? Managers will be faced with rapidly changing environments. The more information they have about potential futures, the better will be their response to these anticipated changes. Planning for and implementing research investments that include 
modelling and forecasting will provide improved information that can be used for managing individual protected areas and protected area systems.

\section{Asset planning}

Are climate-ready planning and forecasting being used in preparing long-term asset management operational plans? Piers, wharves, boat-launching ramps, bridges and other protected area coastal infrastructure will need to be revamped as sea-levels slowly rise. Historic buildings may need special attention as more intense rainstorm events occur, and walking tracks and roads in mountainous or high-latitude terrain may be impacted by melting permafrost. Asset management systems will need to recognise these changes as part of their planning (Chapter 24). The role of the asset management system in helping to minimise greenhouse gas generation is another important consideration.

\section{Business planning}

Are climate-ready planning forecasts being taken into account when entering into new legal (leasing or licensing) agreements? This is a basic question, for longterm leases and licences are legal documents and if the natural resource condition changes during the lease or licence period due to climate change influences (such as beaches becoming submerged, water aquifers drying up or an absence of snow), is the lessor liable in any way?

Are climate-ready planning forecasts guiding the management of existing long-term leasing and licensing agreements? Climate change will mean that the condition of protected area destinations may change. It could mean changes in how wild animals behave (such as the great African wildlife migrations), how safety arrangements for visitors differ (such as for more extreme bushfire conditions) and changes in the nature of attractions (such as snowfields and dwindling snow resources). Managers will need to assist lessees with managing for this dynamic. One potential threat, however, is lessees securing, through lobbying, the further adjustment of existing lease opportunities to establish commercial developments inconsistent with the objectives of the protected area (such as urban infrastructure developments). This potential scenario will have to be managed for (Chapter 23).

What climate-ready revenue management forecasts need to be made? Revenue planning for organisations will need to factor in changes in visitor use patterns resulting from climate change.

\section{Climate-ready organisation}

Organisational considerations, especially governance, will form a critical part of a climate-ready approach. Legislation and policy frameworks under which protected areas may be established and managed, for example, need to support effective climate-ready management. Three criteria could be used to evaluate existing or proposed biodiversity conservation legislation, policies and strategies for their suitability under a changing climate. They should:

- accommodate change

- be relevant and feasible under a range of possible climate change trajectories

- strengthen support from a broad cross-section of the community (Dunlop et al. 2013).

Most existing biodiversity conservation instruments seek to maintain the status quo of conserving species, communities, habitats, ecosystems and ecosystem processes as and where they have been for millennia. Climate change, however, will alter the distribution of species, the composition of species assemblages (communities) and the nature and functioning of ecosystems. The present focus of legislation and policy on the identification and management of threatened species, communities and ecosystems will need to be reconsidered.

Other 'organisational' considerations that may be implemented in response to climate-ready objectives have been described here and include those under the themes of governance and administration, policy and systems development, capacity development, and working with the community. These considerations have been guided by references prepared by Welch (2005) and Dunlop et al. (2013). For each of the climate-ready topics identified, the organisational consideration has been presented as a question in preference to a specific management action to focus on the further conceptual development and definition of the actual climate-ready response actions needed.

\section{Policy and systems development}

Are protected area organisational systems and policies climate-ready? This would include both the removal of maladaptive policies and practices by organisations and the establishment of climate-ready policies and governance arrangements. Increased delegations to onground managers may be an important improvement. 


\section{Capacity development}

Do protected area staff working at strategic, tactical and operational levels possess climate-ready management competencies? Organisations may need to implement a range of climate-ready awareness training programs, and specific competency development training for staff. This may include high-level training for dealing with catastrophic fire events in extreme conditions, specialised training for monitoring, and vocational-based training for restoration management. Special training and skills development in working with the local community will also be needed.

\section{Working with the community}

What special governance arrangements are needed to help establish the tough climate-ready policy decisions that will need to be made? Values of special importance to communities will be impacted by climate change. In Australia, for example, many Aboriginal coastal midden deposits made over thousands of years will be impacted by sea-level rise. It will be essential for Aboriginal communities to participate in decisions about how rising sea-level impacts on the middens will be dealt with, and the special governance arrangements established to help with this.

\section{Adaptive environmental governance}

What information is made available by protected area managers to facilitate the adaptive capacity of communities to respond to climate change? Local communities are increasingly implementing the sustainable use of ecosystems and landscapes and they need to reconcile a range of individual and collective values. Processes for collaboration, governance arrangements and implementation responses may benefit from information provided, such as condition and trend in condition information for adjacent protected areas. The ways in which institutional arrangements may evolve to satisfy the needs and desires of the community in a changing environment (adaptive governance) may be influenced by this information.

\section{Climate-ready implementation}

There is a range of climate-ready implementation considerations that may respond to climate-ready objectives, including: adaptive management, management information, ecosystem integrity, resilience management, preservation management, landscapescale management, transition management and working with the community. These considerations have been guided by references prepared by Welch (2005), Jarvis (2007), Taylor and Figgis (2007), Dunlop and Brown (2008), Dudley (2008), The Australian National University (2009) and Mantyka-Pringle et al. (2012). As for 'planning' and 'organising', the implementation considerations have been presented as questions.

\section{Adaptive management}

Are protected areas sufficiently ready to introduce adaptive management? Adaptive management is especially suited for ecosystem restoration and species management in a dynamic climate change environment. The system does, however, need adequate resourcing, top-level management support and support from the community and politicians for its full implementation (Chapter 8).

\section{Information use}

Is the information that is needed to manage for a climate-ready situation readily available for operational managers, and is the available information effectively utilised? Organisations need to carefully consider how the available information is provided for protected area managers. Wherever possible, the information should be pre-analysed and automated so that it forms part of a regular monthly or quarterly review of protected area condition, trend in condition and operational response processes. The information should be highly accessible.

\section{Managing for ecosystem integrity}

Have managers effectively communicated to the community the benefits of protected areas for reducing the risks of and impacts from extreme climatic events? Protected areas can help reduce the impacts of all but the worst natural disasters including floods, landslides, storm surges, droughts and desertification. These benefits should be communicated.

Are protected areas sufficiently climate-ready to respond to the very worst incidents that may impact protected areas? Such incidents could include catastrophic fire events, cyclones, tornadoes, severe snowstorms and other extreme phenomena driven by climate changeinfluenced atmospheric energy levels. Such events will need incident management responses (Chapter 26) and personnel training and competency levels that are 
at a very high level, including managing sophisticated incident modelling and planning computer software. The response would form part of a larger community response.

\section{Maintaining essential ecosystem services}

Have managers effectively communicated the vital role protected areas play in maintaining essential natural resources and services? Protected areas are critical for helping to provide water, fish resources and food, and for health. This important message needs to be constantly reinforced.

\section{Managing for resilience}

Is there a capacity to rapidly respond to disturbance events and to undertake restoration work? Climateready planning will anticipate the inevitability of severe incidents, and protected areas and their staff will need to be trained, equipped and organised to respond. Restoration implementation for severely burnt areas to minimise the effects of erosion following post-fire heavy rainfall events is one such example.

What threats to natural ecosystem processes exist and are management responses adequate? Minimising threats to natural processes could include controlling introduced (non-native) animals, removing introduced plants where practical, managing the frequency of fire and providing greater protection from threats such as hunting, fishing and poaching (Chapter 16). Weeds, for example, may have increased vigour in a climate change environment and may need enhanced responses.

Have climate change refugia been identified and have they been adequately protected? Refugia are places where favourable habitat persists or develops as the climate changes. Many protected areas will be climate refugia for some species and they may need active management to help retain such special qualities.

Have natural carbon stores been identified and have they been adequately protected? Some features in protected areas have high value for carbon storage, including oldgrowth forest and peat. These sites need to be protected so this additional carbon is not lost to the atmosphere.

Have climate-ready restoration policies been prepared to guide managers in restoration management? Such policies will need to guide managers on the nature of restoration work and whether the selection of species for use includes climate-ready species or species that are found at the site naturally. Whatever the treatment, protected area practitioners will have a special responsibility to document this work.

For some species, is it appropriate to engineer habitats such as latitudinally (further polewards) or altitudinally (up-mountain)? This question may need to be considered carefully for some species in some locations in the future as original habitats are lost. It is assumed that the community would participate in such decisions and they would be linked to the concept of translocation of species.

\section{Preservation management}

Are special interventions necessary to preserve genetic seed stocks for some flora species? As part of being climate-ready, it may be necessary to conserve seed stocks of wild flora (such as the wild varieties of staple foods) in dedicated ex situ seed banks. This would be an insurance policy to help protect future food supplies. Seed collection may be undertaken for other distinctive flora that is forecast to be lost in a future climate change world.

Does the community wish to retain captive populations of wild species that will otherwise become extinct due to climate change? Due to community demand, there may be many species that are retained as captive populations locally in zoos or in larger urban zoos long after the natural habitats and ecosystems that supported them have disappeared. Protected area managers may have a special role in looking after these species, or they may have a special partnership arrangement with zoos to help manage for these species.

Is it appropriate to translocate species as a climateready response? Translocating species from changed and climate-hostile habitats to climate-friendly habitats may be a management response where the species is otherwise unable to migrate naturally.

\section{Landscape-scale management}

What partnerships and collaborative arrangements are being implemented to respond to landscape-scale processes in order to be climate-ready? Contributing as a partner to multi-agency responses to wildfire in a local landscape (Chapter 26) is a good example of this type of work.

How can embedded protected areas within large connectivity conservation areas better facilitate the area being climate-ready? The effective management of protected areas will increasingly be linked to and 

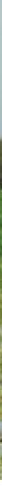

Spectacular monsoonal storm and freshwater wetlands, Kakadu National Park World Heritage Property, Northern Territory, Australia. Climate change forecasts advise that low-lying areas of the Kakadu Wetlands will be vulnerable to salinity as a result of sea-level rise and saline intrusion into ground water that will convert freshwater wetlands to saline mudflats Source: Graeme L. Worboys

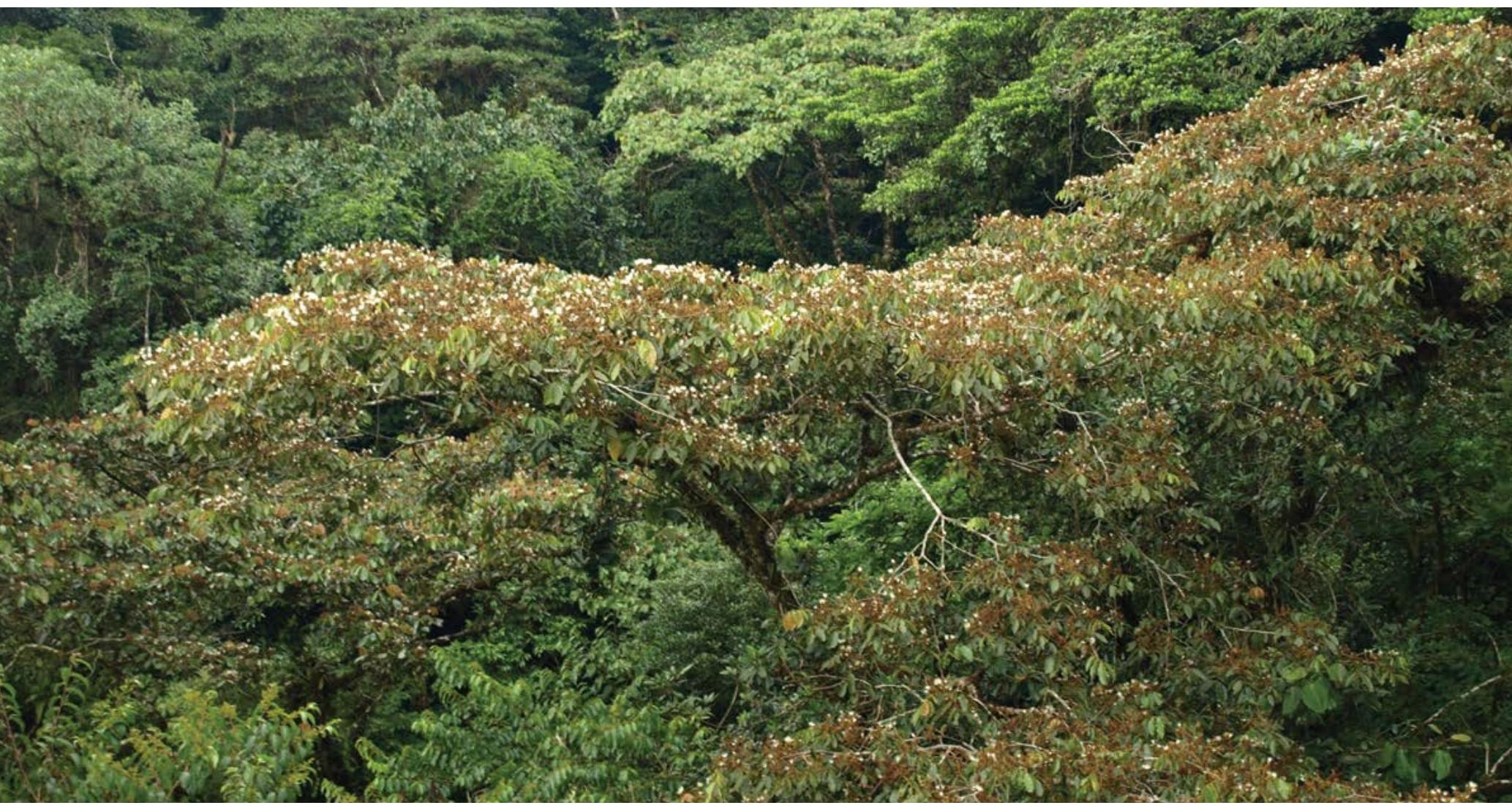

Dense rainforest canopy, Monteverde Cloud Forest Reserve, Costa Rica. Climate change forecasts suggest that the low-level cloud cover will be reduced, leading to warmer conditions and potentially a drying and changing of the forests and their ecosystems

Source: Graeme L. Worboys 


\section{References}

Recommended reading

Bergengren, J. C., Waliser, D. E. and Yung, Y. L. (2011) 'Ecological sensitivity: a biospheric view of climate change', Climatic Change 107: 433-57.

Colls, A., Ash, N. and Ikkala, N. (2009) EcosystemBased Adaptation: A natural response to climate change, IUCN, Gland.

Dudley, N. (ed.) (2008) Guidelines for Applying Protected Area Management Categories, IUCN, Gland.

DD Dudley, N., Stolton, S., Belokurov, A., Krueger, L., Lopoukhine, N., MacKinnon, K., Sandwith, T. and Sekhran, N. (eds) (2010) Natural Solutions: Protected areas helping people cope with climate change, IUCN WCPA, TNC, UNDP, WCS, The World Bank and WWF, Gland, Washington, DC, and New York.

Dunlop, M. and Brown, P. R. (2008) Implications of Climate Change for Australia's National Reserve System: A preliminary assessment, March, Report to the Department of Climate Change, Canberra.

DD Dunlop, M., Parris, H., Ryan, P. and Kroon, F. (2013) Climate-Ready Conservation Objectives: A scoping study, National Climate Change Adaptation Research Facility, Gold Coast, Queensland.

Enser, J. and Berger, R. (2009) 'Community-based adaptation and culture in theory and practice', in W. N. Adger, I. Lorenzoni and K. O'Brien (eds) Adapting to Climate Change: Thresholds, values, governance, Cambridge University Press, Cambridge.

European Climate Adaptation Platform (ECAP) (2014) How to Factor Uncertainty into Adaptation Decision Making, European Climate Adaptation Platform. $<$ climate-adapt.eea.europa.eu/>

Ferrier, S., Harwood, T. and Williams, K. (2010) Using generalised dissimilarity modelling to assess potential impacts of climate change on biodiversity composition in Australia, and on the representativeness of the national reserve system, Report to the Department of Sustainability, the Environment, Water, Population and Communities by CSIRO Ecosystem Sciences for the Impacts of Climate Change for the National Reserve System Project, Canberra.
Folland, C. K., Karl, T. R., Christy, J. R., Clarke, R. A., Gruza, G. V., Jouzel, J., Mann, M. E., Oerlemans, J., Salinger, M. J. and Wang, S.-W. (2001) 'Observed climate variability and change', in T. Houghton, Y. Ding, D. J. Griggs, M. Noquer, P. J. van der Linden, X. Dai, K. Maskell and C. A. Johnson (eds) Climate Change 2001: The scientific basis. Contribution of Working Group I to the Third Assessment Report of the Intergovernmental Panel on Climate Change, pp. 101-81, Cambridge University Press, Cambridge.

Holling, C. S. (1978) Adaptive Environmental Assessment and Management, John Wiley \& Sons, London.

Intergovernmental Panel on Climate Change (IPCC) (2007) Climate Change 2007: Working Group II. Impacts, adaptation and vulnerability: Glossary, Intergovernmental Panel on Climate Change. $<$ www.ipcc.ch/publications_and_data/ar4/wg2/en/ annexessglossary-a-d.html>

Intergovernmental Panel on Climate Change (IPCC) (2012) 'Glossary of terms', in C. B. Field, V. Barros, T. F. Stocker, D. Qin, D. J. Dokken, K. L. Ebi, M. D. Mastrandrea, K. J. Mach, G.-K. Plattner, S. K. Allen, M. Tignor and P. M. Midgley (eds) Managing the Risks of Extreme Events and Disasters to Advance Climate Change Adaptation. A special report of Working Groups I and II of the Intergovernmental Panel on Climate Change (IPCC), pp. 555-64, Cambridge University Press, Cambridge.

Dd Intergovernmental Panel on Climate Change (IPCC) (2013a) 'Summary for policymakers', in T. F. Stocker, D. Qin, G. K. Plattner, M. Tignor, S. K. Allen, J. Boschung, A. Nauels, Y. Xia, V. Bex and P. M. Midgley (eds) Climate Change 2013: The physical science basis. Contribution of Working Group I to the Fifth Assessment Report of the Intergovernmental Panel on Climate Change, pp. 3-29, Cambridge University Press, Cambridge.

Intergovernmental Panel on Climate Change (IPCC) (2013b) 'Introduction', in T. F. Stocker, D. Qin, G. K. Plattner, M. Tignor, S. K. Allen, J. Boschung, A. Nauels, Y. Xia, V. Bex and P. M. Midgley (eds) Climate Change 2013: The physical science basis. Contribution of Working Group I to the Fifth Assessment Report of the Intergovernmental Panel on Climate Change, pp. 111-58, Cambridge University Press, Cambridge. 
dd Intergovernmental Panel on Climate Change (IPCC) (2014a) 'Final draft: summary for policymakers', in Report of Working Group II to the Fifth Assessment Report of the Intergovernmental Panel on Climate Change, Cambridge University Press, Cambridge.

Intergovernmental Panel on Climate Change (IPCC) (2014b) Criteria for Assessing Key Vulnerabilities, Intergovernmental Panel on Climate Change. $<$ www.ipcc.ch/publications_and_data/ar4/wg2/en/ ch19s19-2.html>

Intergovernmental Panel on Climate Change (IPCC) (2014c) IPCC WGII AR5 Glossary, Report of the Intergovernmental Panel on Climate Change, pp. 1-30, Cambridge University Press, Cambridge. $<$ ipcc-wg2.gov/AR5/images/uploads/WGIIAR5Glossary_FGD.pdf>

Intergovernmental Panel on Climate Change (IPCC) (2014d) 'Final draft: Chapter 19 Emergent risks and key vulnerabilities', in Report of Working Group II to the Fifth Assessment Report of the Intergovernmental Panel on Climate Change, Cambridge University Press, Cambridge.

International Union for Conservation of Nature (IUCN) and United Nations Environment Programme World Conservation Monitoring Centre (UNEP-WCMC) (2014) World Database on Protected Areas Statistics, August 2014, World Conservation Monitoring Centre, Cambridge.

Jarvis, J. (2007) 'An inarticulate truth: communicating the science of global climate change', The George Wright Forum 24(1): 82-90.

Laffoley, D. and Grimsditch, G. (eds) (2009) The Management of Natural Coastal Carbon Sinks, IUCN, Gland.

Mackey, B., Watson, J., Hope, G. and Gilmour, S. (2008) 'Climate change, biodiversity conservation and the role of protected areas: an Australian perspective', Biodiversity 9(3-4). <www.uq.edu.au/ spatialecology/docs/Publications/2008_Mackey_ EtAl_ClimateChangeBiodiversity.pdf>

Mantyka-Pringle, C. S., Martin, T. G. and Rhodes, J. R. (2012) 'Interactions between climate and habitat loss effects on biodiversity: a systematic review and meta-analysis', Global Change Biology 18: 1239-52.
McKellar, R., Midgley, G. F., Yates, C. J., Abbott, I., Gioia, P. and Le Maitre, D. (2010) 'The need to develop a coherent research approach for climate change vulnerability impact assessment and adaptation in high biodiversity terrestrial ecosystems', Austral Ecology 35(4): 371-3.

Nicotra, A. B., Hoffmann, A. A., Morgan, J. W. and Millar, A. D. (2014) Adaptive restoration and management in the Australian Alps catchment, Presentation at Alpine Ecology Symposium, Australian National Botanic Gardens, Canberra.

Office of Environment and Heritage (OEH) (2011) Guide to Climate Change Risk Assessment for Local Government, NSW Office of Environment and Heritage, Sydney. <www.environment.nsw.gov.au/ resources/climatechange/20110593riskassesslg.pdf>

Parmesan, C. and Yohe, G. (2003) 'A globally coherent fingerprint of climate change impacts across natural systems', Nature 421: 37-42.

Peterson, T. C., Anderson, D. M., Cohen, S. J., Cortez-Vázquez, M., Murnane, R. J., Parmesan, C., Phillips, D., Pulwarty, R. S. and Stone, J. M. R. (2008) 'Why weather and climate extremes matter', in T. R. Karl, G. A. Meehl, C. D. Miller, S. J. Hassol, A. M. Waple and W. L. Murray (eds) Weather and Climate Extremes in a Changing Climate. Regions of Focus: North America, Hawaii, Caribbean, and U.S. Pacific Islands, pp. 11-33, A report by the US Climate Change Science Program and the Subcommittee on Global Change Research, Washington, DC.

Dd Steffen, W., Burbidge, A. A., Hughes, L., Kitching, R., Lindenmayer, D., Musgrave, W., Stafford Smith, M. and Werner, P. A. (2009) Australia's Biodiversity and Climate Change: $A$ strategic assessment of the vulnerability of Australia's biodiversity to climate change, CSIRO Publishing, Melbourne.

Taylor, M. and Figgis, P. (eds) (2007) Protected Areas: Buffering nature against climate change, Proceedings of a WWF and IUCN World Commission on Protected Areas Symposium, 18-19 June 2007, Canberra, WWF-Australia, Sydney. 
The Australian National University (2009) Implications of climate change for Australia's World Heritage properties: a preliminary assessment, A report to the Department of Climate Change and the Department of the Environment, Water, Heritage and the Arts by the Fenner School of Environment and Society, The Australian National University, Canberra.

Dd Welch, D. (2005) 'What should protected areas managers do in the face of climate change?', The George Wright Forum 22(1): 75-93.

Yates, C. J., Elith, J., Latimer, A. M., Le Maitre, D., Midgley, G. F., Schurr, F. M. and West, A. G. (2010) 'Projecting climate change impacts on species distributions in megadiverse South African cape and southwest Australian floristic regions: opportunities and challenges', Austral Ecology 35: 374-91.

Zhang, X. and Zwiers, F. (2012) 'Statistical indices for diagnosing and detecting changes in extremes', in A. Agha Kouchak, D. Easterling, K. Hsu, S. Schubert and S. Sorooshian (eds) Extremes in a Changing Climate: Detection, analysis and uncertainty, pp. 1-14, Springer Science+Business Media, Heidelberg and New York. 


\section{PRINCIPAL AUTHORS}

ROGER CROFTS is an International Union for Conservation of Nature (IUCN) World Commission on Protected Areas (WCPA) Emeritus, was Founding CEO of Scottish Natural Heritage (19922002), WCPA Regional Vice-chair for Europe (2000-08), and is Chair of the Royal Scottish Geographical Society.

JOHN E. GORDON is a Deputy Chair of the WCPA Geoheritage Specialist Group, and an honorary professor in the School of Geography \& Geosciences, University of St. Andrews, Scotland, United Kingdom.

\section{SUPPORTING AUTHOR}

VINCENT SANTUCCI is Senior Geologist and Palaeontologist with the US National Park Service, USA.

\section{ACKNOWLEDGMENTS}

We are grateful for helpful comments on the draft text from: Jay Anderson, Australia; Tim Badman, IUCN, Switzerland; José Brilha, University of Minho, Portugal; Margaret Brocx, Geological Society of Australia, Australia; Enrique Díaz-Martínez, Patrimonio Geológico y Minero (IGME), Spain; Neil Ellis, Joint Nature Conservation Committee (JNCC), United Kingdom; Lars Erikstad, Norwegian Institute for Nature Research (NINA), Norway; Murray Gray, Queen Mary University of London, United Kingdom; Bernie Joyce, University of Melbourne, Australia; Ashish Kothari, Kalpavriksh, India; Jonathan Larwood, Natural England, United Kingdom; Estelle Levin, Estelle Levin Limited, United Kingdom; Sven Lundqvist, Geological Survey of Sweden, Sweden; Colin MacFadyen, Scottish Natural Heritage, United Kingdom; Colin Prosser, Natural England, United Kingdom; Chris Sharples, University of Tasmania, Australia; Kyung Sik Woo, Kangwon National University, Korea and, Graeme Worboys, The Australian National University, Australia.

\section{CITATION}

Crofts, R. and Gordon, J. E. (2015) 'Geoconservation in protected areas', in G. L. Worboys, M. Lockwood, A. Kothari, S. Feary and I. Pulsford (eds) Protected Area Governance and Management, pp. 531-568, ANU Press, Canberra.

\section{TITLE PAGE PHOTO}

Old Faithful geyser and geothermal area, one of the outstanding geoheritage sites of the world, Yellowstone National Park and World Heritage property, USA

Source: Graeme L. Worboys 


\section{Introduction}

The Earth is a dynamic planet with a remarkable geodiversity. The continental masses and oceans on the surface of the Earth have changed continuously over much of geological time. Oceans have opened and closed, and continents have fragmented and collided, accompanied by plutonic igneous activity, volcanism and large-scale crustal deformation. Earth's abiotic processes have operated both continuously and episodically over vastly different time scales, from hundreds of millions of years to minutes, and over different spatial scales, from whole continental plates to the microscopic. Mountain ranges have formed and been eroded, and the rock debris deposited and recycled. As the continents have changed and migrated across the surface of the globe and through different climatic zones, rocks have formed in many different environments. The history of life on Earth is also archived in the fossil record contained in these rocks. Long-term global climate change has influenced surface processes, leading to periodic 'icehouse' and 'hothouse' conditions. All of these processes and events have left a legacy in the rock record and have created the diversity of landscapes and landforms evident across the globe. Our geoheritage is the story of the Earth; a narrative through time preserved in its rocks, landforms, fossils, minerals and soils that provides a strong case for geoconservation.

The Earth's geodiversity contributes fundamentally to most of the ecosystem services recognised in the Millennium Ecosystem Assessment (MEA 2005). It provides the foundation for plants, animals and humans, and is a vital link between people, nature, landscapes and cultural heritage. It contributes to sustainable development and benefits public health through providing assets for outdoor recreation and enjoyment of the natural world. Knowledge and understanding of how the Earth works are also essential to informing management of the land, rivers and the coast at a time of great uncertainty about the effects of climate change and sea-level rise. It is vital, therefore, that geodiversity and geoheritage are fully integrated into the management of protected areas and accorded a level of importance equivalent to biodiversity as part of an ecosystem approach that recognises the value and integrity of both abiotic and biotic processes in nature conservation.

This reasoning has been accepted by the International Union for Conservation of Nature (IUCN) with the passing of Resolutions 4.040 at Barcelona (IUCN 2008) and 5.048 at Jeju, Korea (IUCN 2012), which both clearly state that geodiversity is part of nature and geoheritage is part of natural heritage.

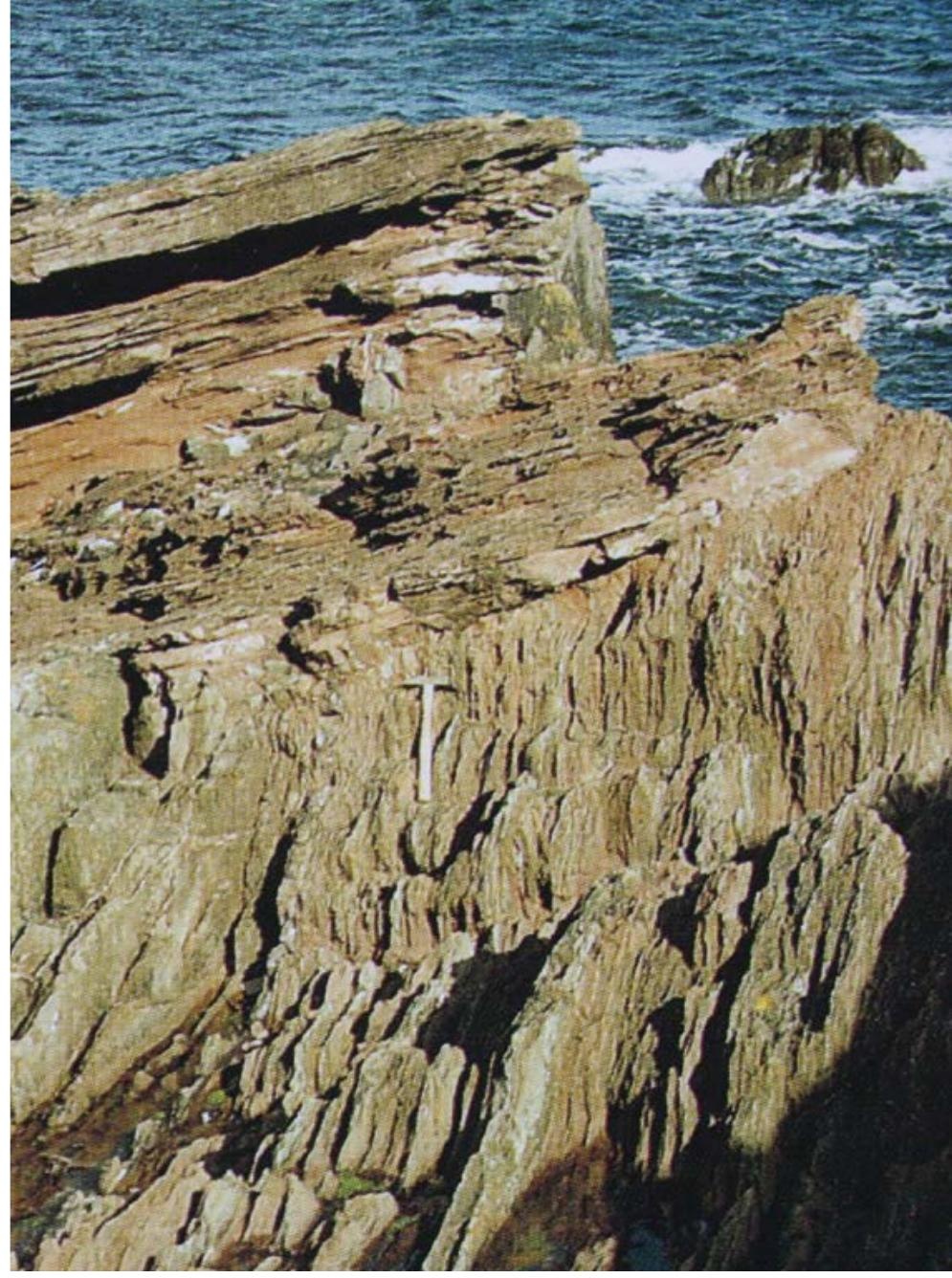

Siccar Point, a Site of Special Scientific Interest, Scotland, United Kingdom, which conserves the historical site where James Hutton, the founder of modern geology, observed a huge gap of time in the rocks (an unconformity)

Source: Lorne Gill/Scottish Natural Heritage

A number of important definitions have been developed in recent years as the practice of geoconservation has evolved. The following definitions capture the key elements. For definitions in Spanish of all the key terms, see Carcavilla et al. (2012).

\section{Geodiversity}

Geodiversity is 'the natural range (diversity) of geological (rocks, minerals, fossils), geomorphological (landforms, topography, physical processes) and soil and hydrological features. It includes their assemblages, structures, systems and contributions to landscapes' (Gray 2013:12).

'Geodiversity is the variety of rocks, minerals, fossils, landforms, sediments and soils, together with the natural processes which form and alter them' (Dudley 2008:66).

Geodiversity is a relatively recent term; its first use in English was in Tasmania, Australia (Sharples 1993; Gray 2008). Despite some initial resistance and concerns about the validity of implied parallels with biodiversity, the term is now widely accepted (Gray 2013). Geodiversity is the abiotic equivalent of biodiversity and therefore is a 
The Tay Estuary, Scotland, United Kingdom, a Site of Special Scientific Interest and a Ramsar site. The river supplies sediment that maintains reed beds that in turn support important biodiversity interest and illustrates the links between geodiversity and biodiversity.

Source: Roger Crofts

natural complement to biodiversity rather than a separate and unassociated subject. It covers past and present Earth processes, embraces static features that have a range of ages and reflect the variety of processes during the Earth's history, and includes modern processes that significantly influence biodiversity. The relationship between geodiversity and geoheritage is discussed by Durán et al. (1998), Nieto (2001) and Carcavilla et al. (2008).

\section{Geoheritage}

Geoheritage comprises those elements of the Earth's geodiversity that are considered to have significant scientific, educational, cultural or aesthetic value (DíazMartínez 2011; GSA 2012). They include special places and objects (specimens in situ and in museums) that have a key role in our understanding of the abiotic and biotic evolution of the Earth (ProGEO 2011). A site or area of high geoheritage significance can comprise a single feature of value, and does not need to have a diversity of features present.

\section{Geoconservation}

Geoconservation has been defined as 'the conservation of geodiversity for its intrinsic, ecological and (geo)heritage values' (Sharples 2002:6).

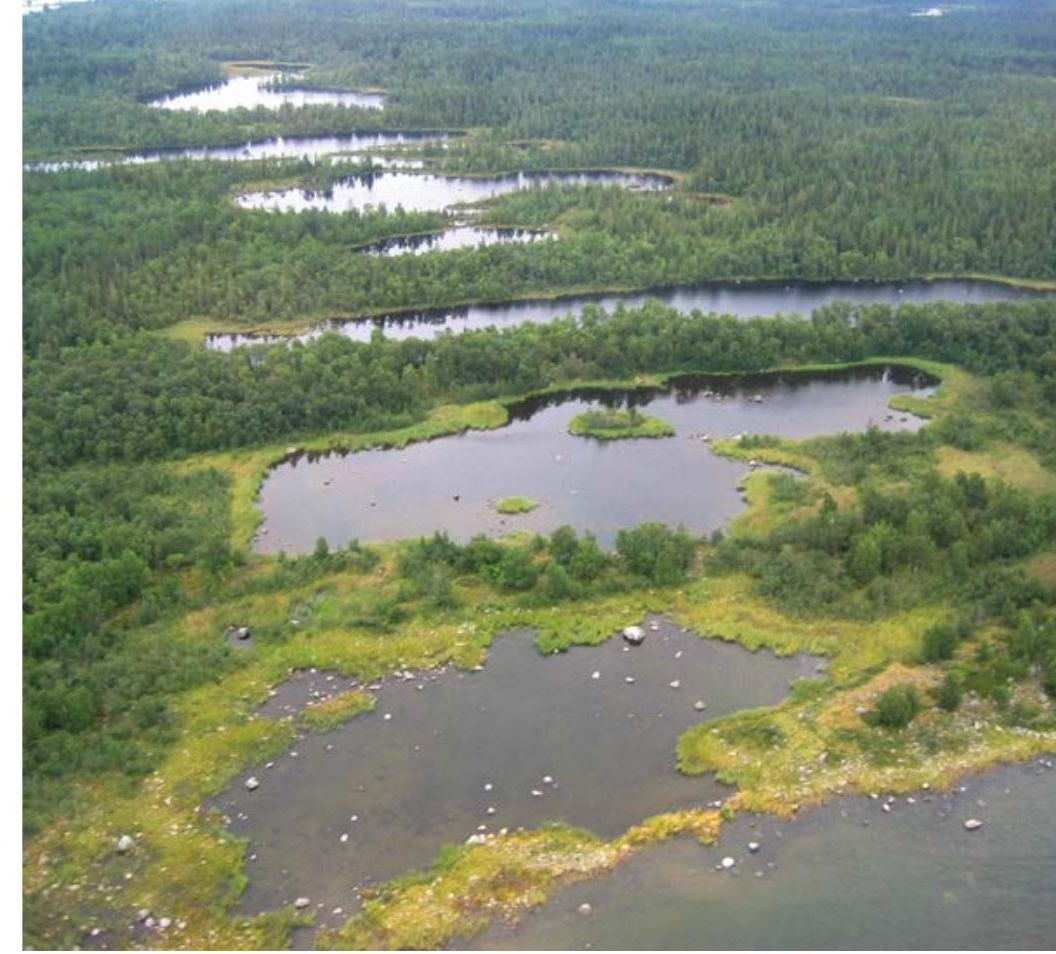

Kvarken World Heritage Site, west Finland, where new land is emerging from the sea as a result of rebound (glacio-isostatic uplift) following the melting of the Scandinavian ice sheet, the weight of which had depressed the land surface Source: UNESCO

A broader definition is 'action taken with the intent of conserving and enhancing geological, geomorphological and soil features and processes, sites and specimens, including associated promotional and awareness raising activities, and the recording and rescue of data or specimens from features and sites threatened with loss or damage' (Prosser 2013:568).

In some traditions, geology and geomorphology are considered to be separate but linked subjects; in others, geomorphology is part of geology. Regardless of which approach is followed, it is important to emphasise that both geology and geomorphology are explicitly included within geodiversity, geoheritage and geoconservation as defined above, and that the term 'geosites' can embrace both geological and geomorphological features. Sometimes 'geological diversity', 'geological heritage' and 'geological conservation' are used to include both geological and geomorphological interests. Thus, to avoid confusion, we strongly recommend use of geodiversity, geoheritage and geoconservation as defined above-that is, embracing both geological and geomorphological features.

This chapter provides protected area managers and staff with practical information and generic guidance on the role of geoconservation in protected areas. Emphasis is placed on both the importance of protecting geoheritage in its own right and the value of understanding the formative influence of geodiversity on flora and fauna at site, habitat, landscape, ecosystem and biome scales. 
The chapter is in two sections. The first sets out the case for geoconservation in protected areas; and the second provides advice on the guiding principles of site assessment and conservation. Detailed guidance will be prepared as an IUCN World Commission on Protected Areas (WCPA) 'Best Practice Guideline on Geoheritage Site Conservation and Management'.

\section{The need for geoconservation in protected areas}

\section{Geoheritage values}

Many protected area managers and staff, and their advisers, will be familiar with the fundamental importance of biodiversity conservation. As this subject is the basis of the Convention on Biological Diversity (CBD) 1992, and has an associated program of work on protected areas, biodiversity conservation is seen by many as the raison d'etre of protected areas and their management. The underlying rocks, sediments and soils, their evolution and the recent and current Earth processes to which they are subject are, however, also vital. Why?

Gray (2004) summarised the keyvalues of geoconservation as: intrinsic, cultural, aesthetic, economic, functional, and for research and education. Generally, the emphasis has been on the value of geoheritage for scientific research and education, but there is now much greater awareness of the wider significance of geoconservation, especially in an ecosystems context (Gray 2013).

Many protected areas are designated because of their geoheritage values, including one of the world's first national parks: Yellowstone, USA. Some are global or regional type sites for critical stages in the history of the Earth and the marker horizons in rocks representing the boundaries between different geological periods. Others are examples of past geological processes representing major events in the evolution of the continents and oceans, such as the collision between the Indian and Eurasian tectonic plates to create the Himalaya and the Tibetan Plateau. Yet others are designated for their research significance, such as the inverted rock sequences resulting from tectonic plate collisions and the thrusting of older strata above younger strata, displayed, for example, in the Moine Thrust Zone in Scotland. Many are significant because their fossils exhibit key stages in the evolution of life on Earth, such as the Burgess Shale in Yoho and Kootenay National Parks, British Columbia, Canada.
Others are significant for the type of minerals found there, reflecting complex geochemical evolution. And some are significant for their current geological processes such as tectonic plate separation in Iceland, or the development of glacial landforms on the Antarctic Peninsula.

Furthermore, many protected areas are designated because their geological and geomorphological features are visually and scenically dominant in the landscape, and quite often have an iconic significance in the cultural history of the area and the nation. The Golden Mountains of Altai in the Russian Federation, Bogd Khan Mountain in Mongolia and Triglav National Park in Slovenia are examples. Many components of geodiversity also have direct cultural significance, such as caves that preserve the paintings and inscriptions or other sacred values from earlier periods of human occupation.

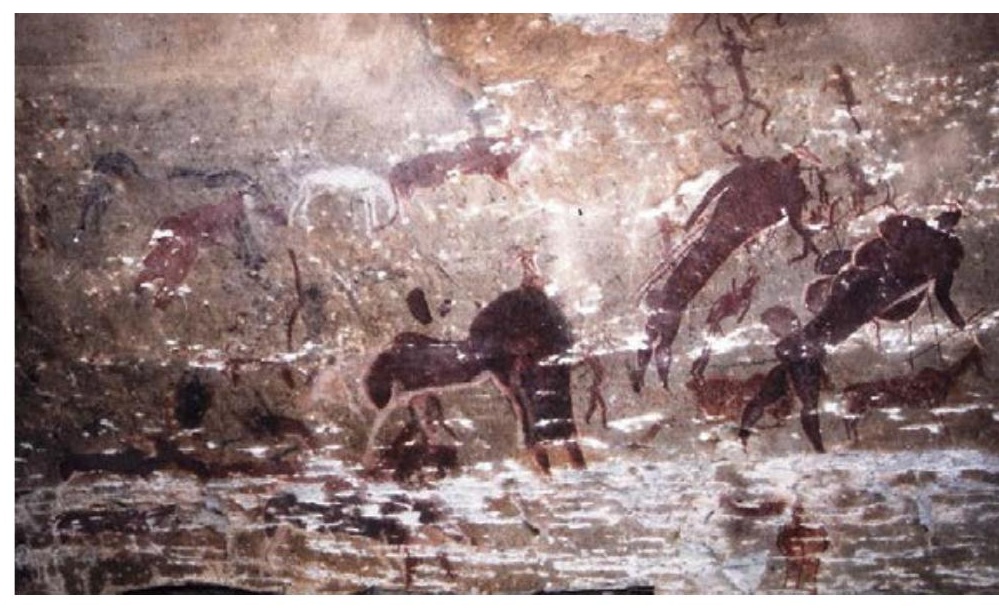

Rock art at Royal Natal National Park, KwaZuluNatal, South Africa, illustrating cultural associations with natural caves

Source: Roger Crofts

Geoheritage in protected areas can exist at a number of scales, from small individual features, such as windsculpted stones (ventifacts) in desert environments and rocks (erratics) transported long distances by glaciers, to whole mountain chains and large river basins. All scales are important, and geoconservation needs to take into account features and processes across the whole continuum, from site to landscape scale. But areas need not exhibit high geodiversity to qualify for protected area status. For example, a thick sequence of deep-water limestones may represent an important part of basin history and exhibit the evolution of life. The apparent low geodiversity in the rocks may hide a rich biodiversity that is not so evident to the naked eye, but is crucial as a type section or reference locality for a particular evolutionary phase or change. 
Table 18.1 Principal human-induced threats to geoheritage in protected areas

\begin{tabular}{|c|c|}
\hline Threats and pressures & Examples of impacts on geoheritage in protected areas \\
\hline $\begin{array}{l}\text { Urbanisation, construction (including } \\
\text { commercial and industrial developments } \\
\text { inland and on the coast), infrastructure, } \\
\text { onshore wind farms and related activities }\end{array}$ & $\begin{array}{l}\text { Destruction of landforms and exposures of sediments and rocks } \\
\text { Fragmentation of site integrity and loss of relationships between features } \\
\text { Disruption of geomorphological processes } \\
\text { Changes to soil and water regimes; destruction of soils and soil structure }\end{array}$ \\
\hline $\begin{array}{l}\text { Mining and mineral extraction (including } \\
\text { extraction from opencast mines, pits, } \\
\text { quarries, dunes and beaches, riverbeds, } \\
\text { marine aggregate extraction and deep- } \\
\text { sea mining) }\end{array}$ & $\begin{array}{l}\text { Destruction of landforms and exposures of sediments and rocks } \\
\text { Fragmentation of site integrity and loss of relationships between features } \\
\text { Disruption of geomorphological processes } \\
\text { Destruction of soils and soil structure } \\
\text { Changes to soil and water regimes }\end{array}$ \\
\hline $\begin{array}{l}\text { Changes in land use and management } \\
\text { (including agriculture, forestry) }\end{array}$ & $\begin{array}{l}\text { Landform damage through ploughing, ground levelling and drainage } \\
\text { Loss of landform and outcrop visibility and access to exposures } \\
\text { Stabilisation of dynamic landforms (for example, sand dunes) } \\
\text { Soil erosion } \\
\text { Changes to soil chemistry and soil water regimes } \\
\text { Soil compaction, loss of organic matter }\end{array}$ \\
\hline $\begin{array}{l}\text { Coastal protection and river management } \\
\text { and engineering (including dams and } \\
\text { water abstraction) }\end{array}$ & $\begin{array}{l}\text { Damage to landforms and exposures of sediments and rocks } \\
\text { Loss of access to exposures } \\
\text { Disruption of geomorphological processes } \\
\text { Inhibition of erosion allows exposures to become degraded }\end{array}$ \\
\hline $\begin{array}{l}\text { Offshore activities (including } \\
\text { dredging, trawling, renewable energy } \\
\text { developments, hydrocarbon exploitation } \\
\text { and waste disposal) }\end{array}$ & $\begin{array}{l}\text { Physical damage to landforms and sediments } \\
\text { Disruption of geomorphological processes } \\
\text { Seabed and sub-seabed surface scour/penetration }\end{array}$ \\
\hline Recreation and geotourism & $\begin{array}{l}\text { Physical damage to landforms, rock outcrops, processes and soils } \\
\text { (compaction) through visitor pressure } \\
\text { Fragmentation of site integrity } \\
\text { Footpath erosion and other localised soil erosion and loss of soil organic } \\
\text { matter }\end{array}$ \\
\hline Climate change & $\begin{array}{l}\text { Changes in active system processes } \\
\text { Changes in system state (reactivation or stabilisation) } \\
\text { Loss of key features, such as ice caps and glaciers, glacial lakes and } \\
\text { outflows }\end{array}$ \\
\hline Sea-level rise (anthropogenic causes) & $\begin{array}{l}\text { Loss of visibility and access to coastal exposures and outcrops through } \\
\text { submergence } \\
\text { Loss of exposures through enhanced erosion } \\
\text { Changes in coastal exposures and landforms } \\
\text { Loss of all or substantial parts of protected areas } \\
\text { New features developed from, for example, storm surges }\end{array}$ \\
\hline $\begin{array}{l}\text { Restoration of pits and quarries (including } \\
\text { landfill) }\end{array}$ & Loss of exposures and natural landforms \\
\hline $\begin{array}{l}\text { Stabilisation of rock faces (for example, } \\
\text { road cuttings) with netting and concrete }\end{array}$ & Loss of exposures \\
\hline $\begin{array}{l}\text { Irresponsible fossil and mineral collecting } \\
\text { and rock coring }\end{array}$ & Physical damage to rock exposures and loss of fossil record \\
\hline
\end{tabular}

Sources: Adapted from Gordon and Barron (2011); Brooks (2013); Gray (2013)

\section{Threats to geoheritage}

Often the argument is made that geoheritage does not need conservation in protected areas because it is unchanging and no evident threats from human activities can undermine the state or value of the features of interest. This is not correct. Many conservation disputes have centred on threats to geodiversity-for example, the dispute in Tasmania about hydro-electricity development at Lake Pedder (Houshold and Sharples 2008). In fact, the pressures and threats facing geoheritage are many and varied (Table 18.1), and may arise through economic drivers for development and changes in agriculture and forestry policy that affect land-use decisions. Those 


\section{Links to biodiversity, ecosystem functions and services}

Geoconservation in protected areas delivers many important contributions to biotic nature and to society. It supports landscape and biodiversity conservation, economic development, climate change adaptation, and sustainable management of land and water, historical and cultural heritage, and people's health and wellbeing (for example, Johansson 2000; Brilha 2002; Stace and Larwood 2006; Gordon et al. 2012; Gray et al. 2013). Perhaps most significantly, geodiversity underpins or delivers most of the ecosystem services identified in the Millennium Ecosystem Assessment (MEA 2005). It is a key component of supporting services, and contributes significantly to provisioning, regulating and cultural services (Figure 18.1). Without the contribution of geodiversity, many of the ecosystem services essential to supporting life on Earth would simply not exist or would require vastly more expensive technological alternatives-for example, provision of fresh water, regulation of water and air quality, and soil formation and nutrient cycling for food production. Geodiversity also provides additional, indispensable goods and services (for example, minerals, aggregates and fossil fuels) that are non-renewable capital assets, as well as substantial 'knowledge' benefits (for example, records of past climate changes, understanding of how Earth systems operate and ecosystem service trends).

At its simplest, geodiversity provides the foundation for life on Earth and for the diversity of species, habitats, ecosystems and landscapes. Most species depend on the abiotic 'stage' on which they exist (Anderson and Ferree 2010), not only rare or specialised ones (for example, those associated with limestone pavements or metallogenic soils), and there is a close connection between flora and fauna, the soil and the underlying rocks, and the topography and water and other nutrients on which they depend for growth and survival (for example, Semeniuk et al. 2011). Now that we concentrate much more on the continuing ecological health of ecosystems and their

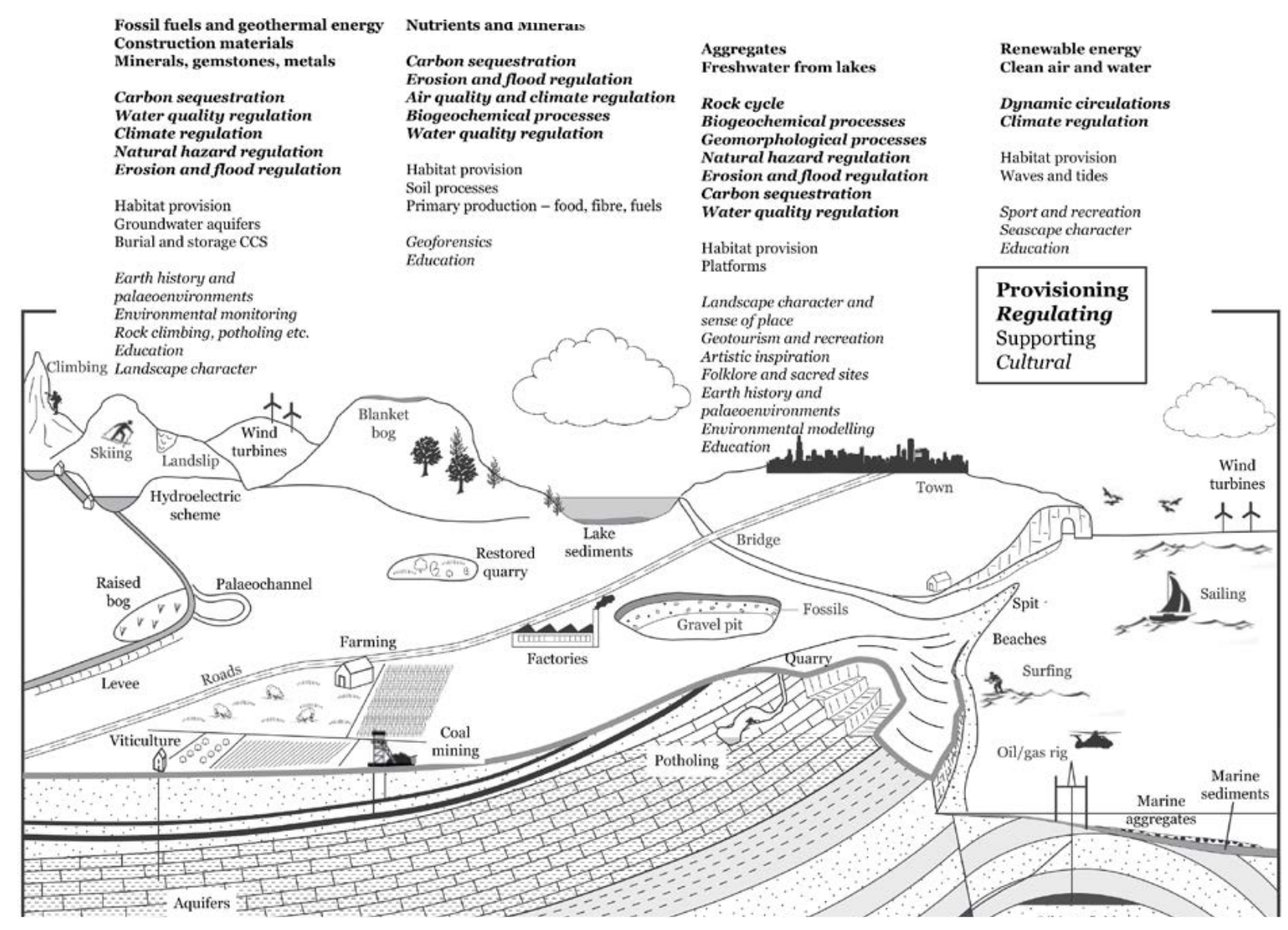

Figure 18.1 Schematic illustration of the goods and services derived from geodiversity: the grey layer above the bedrock represents soil

Source: Reprinted from Gray et al. (2013), reproduced with permission from Elsevier 
taken of the contribution of natural abiotic processes to ensure that restoration is likely to be successful and that geodiversity is not adversely affected.

Consequently, geoconservation is crucial for sustaining living species and habitats, to maintain both the abiotic setting or 'stage' and the natural processes (for example, floods, erosion and deposition) necessary for habitat diversity and ecological functions. There is a strong case for more integrated approaches to the management of protected areas that would benefit both biodiversity and geoconservation (Hopkins et al. 2007; IUCN 2012; Matthews 2014).

\section{Relevance of the IUCN definition for geoconservation in protected areas}

The revised IUCN definition of a protected area refers to abiotic nature for the first time by substituting the narrower term 'biodiversity' with the broader term 'nature': 'A clearly defined geographical space, recognised, dedicated and managed, through legal or other effective means, to achieve the long-term conservation of nature with associated ecosystem services and cultural values' (Dudley 2008:8).

The use of the word 'nature' is quite deliberate for a number of reasons. It allows specific recognition of the abiotic elements in protected areas that were excluded in the previous definition referring only to biodiversity. It recognises that many protected areas exist to conserve abiotic nature in some form or other. It also recognises that abiotic nature is important for its own sake, as it is an intrinsic element of any definition of nature.

In the elaboration of the guidelines, 'nature' is explained as always referring 'to biodiversity, at genetic, species and ecosystem level, and often also refers to geodiversity, landform and broader natural values' (Dudley 2008:Table 1, p. 9).

The use of the term 'nature' is further elaborated in IUCN Resolution 5.048 (IUCN 2012:66), 'to ensure that, when reference is made in the IUCN Programme 2013-2016 to nature in general, preference be given to inclusive terms such as "nature", "natural diversity" or "natural heritage", so that geodiversity and geoheritage are not excluded'.

The example given in the 2008 guidelines is the Rum National Nature Reserve in Scotland, established to protect unique geological features, specifically separation

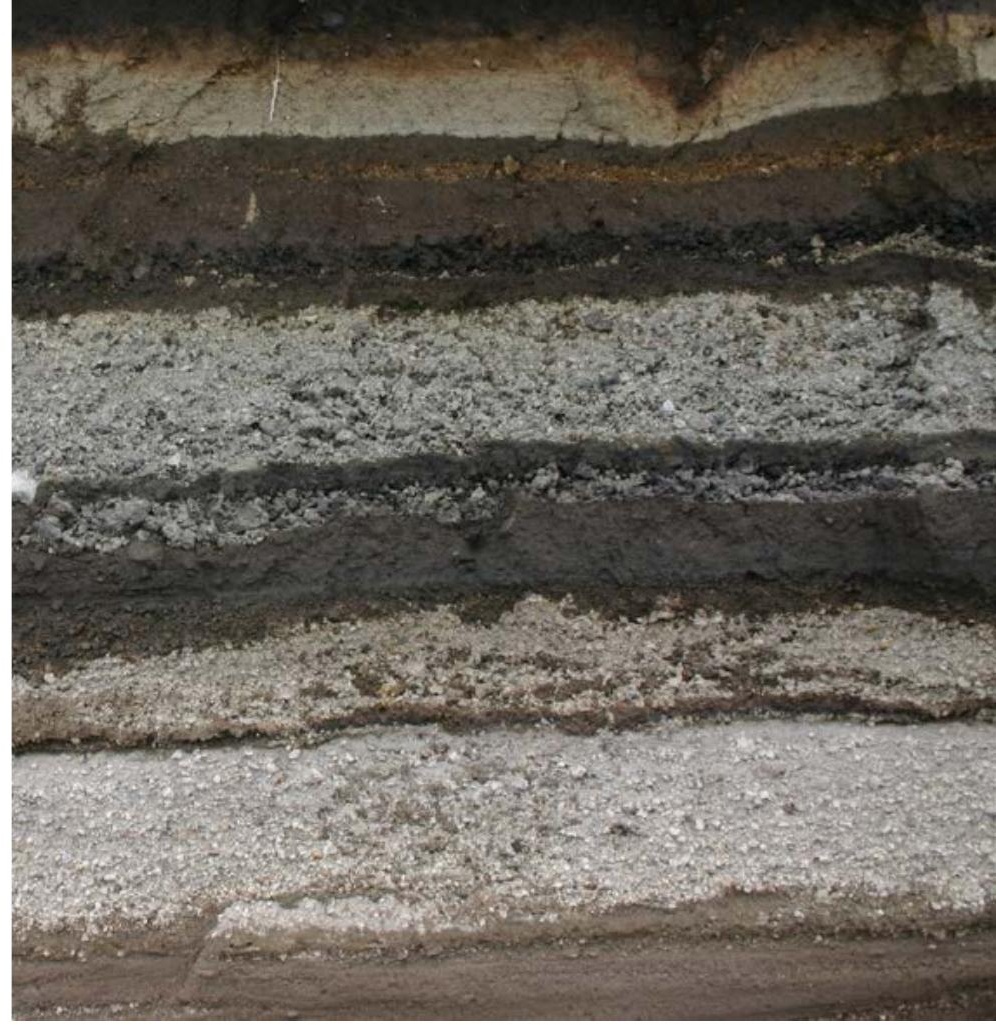

Cotopaxi National Park, Ecuador, where chronologies of volcanic activity have been constructed from successive volcanic ash (tephra) layers

Source: Roger Crofts

and layering of magma chamber rocks during Palaeogene igneous activity; it is also of European regional significance for its bird species.

\section{A systematic approach to identifying geoconservation interests}

A clear, logical and objectively based methodological framework is essential for the identification of features and sites of geoheritage interest (Sharples 2002; ProGEO 2011). This applies at all levels, from international assessments to local inventories. Without such an approach there will be no means of judging whether all aspects of geoheritage are included, the extent to which the areas selected are representative, rare or unique, and how the system can be extended as knowledge increases and new geoheritage interest is recognised.

In the following text, we provide examples of methodologies that may be applied at a range of scales, from international assessments to local inventories of geoheritage interests that could be developed and applied by individual protected area managers.

Nations and organisations embarking on the development of protected areas for geoheritage are advised to seriously consider using the systems and classifications already in existence as they represent careful attention to all of 


\section{Box 18.1 Site categories in the Geological Conservation Review in Great Britain}

1. Sites of international importance: interval or boundary stratotypes; type localities for biozones based on fossils and time zones based on particular rock strata; key localities for particular rock types, minerals or fossils, and landforms; historically important sites where significant discoveries were made or knowledge was significantly increased, or where features and phenomena were first discovered and described.

2. Sites that are scientifically important because they contain exceptional features that are exceedingly rare in their formation or their existence.

3. Sites that are nationally important because they are representative of a geoheritage feature, event or process that is fundamental to Britain's Earth history.

the issues. Clearly, modifications and additions to suit national circumstances should be made, but within a tried and tested international system.

One systematic approach that is relevant, in the generality, to other countries is the Geological Conservation Review (GCR) in Great Britain (England, Scotland and Wales), developed and applied over the past three decades (Ellis 2011). Three distinct, but complementary, categories of site are incorporated in this geoscience-based system (Box 18.1).

Sites were assessed under seven broad groupings: stratigraphy, palaeontology, Quaternary geology, geomorphology, igneous petrology, structural and metamorphic geology, and mineralogy. For practical purposes, these groupings were, in turn, subdivided into thematic subject 'blocks' according to stratigraphical age, type of formation, geographical area or different geological and geomorphological processes. Obviously, other countries and regions might choose different groupings according to their specific geology and geomorphology. Also, depending on the purpose of the inventory, the criteria may in addition to scientific value include aesthetic, cultural, educational, historical, economic and ecological values, as well as potential use and vulnerability (see below).

It is proposed that seven key elements provide the basis for a comprehensive geoheritage protected area system for any region or country (Table 18.2).
Table 18.2 Key elements of a geoheritage protected area system

\begin{tabular}{|c|c|}
\hline Key elements & Geosites demonstrating: \\
\hline $\begin{array}{l}\text { Key stages in } \\
\text { Earth history }\end{array}$ & $\begin{array}{l}\text { Interval or boundary stratotypes, } \\
\text { type localities for biozones based } \\
\text { on fossils and type localities for time } \\
\text { zones based on particular rock strata }\end{array}$ \\
\hline $\begin{array}{l}\text { Major structural } \\
\text { features }\end{array}$ & $\begin{array}{l}\text { Tectonic events/episodes associated } \\
\text { with plate movements. Examples } \\
\text { include features associated with } \\
\text { plate collisions resulting, for example, } \\
\text { in formation of mountain chains, } \\
\text { accompanied by thrusting, folding } \\
\text { and compression of strata. Other } \\
\text { examples associated with the } \\
\text { convergence of plates include the } \\
\text { formation of island arcs, central } \\
\text { volcanoes and extensive lava flows }\end{array}$ \\
\hline $\begin{array}{l}\text { Formation of } \\
\text { minerals }\end{array}$ & $\begin{array}{l}\text { Rare and representative mineral } \\
\text { deposits and types of mineral } \\
\text { locations }\end{array}$ \\
\hline Evolution of life & $\begin{array}{l}\text { Fossils and fossil assemblages } \\
\text { representing stages in the } \\
\text { evolution of life and gradations and } \\
\text { interruptions in life sequences in the } \\
\text { fossil record reflecting evolutionary } \\
\text { trends and catastrophic events, such } \\
\text { as meteorite strikes and eruptions of } \\
\text { supervolcanoes }\end{array}$ \\
\hline $\begin{array}{l}\text { Modern Earth } \\
\text { processes }\end{array}$ & $\begin{array}{l}\text { Features representative of active } \\
\text { processes particularly associated } \\
\text { with tectonic plates, such as different } \\
\text { types of volcanoes and other eruptive } \\
\text { forms, and those associated with } \\
\text { the interface between land and sea } \\
\text { around coasts and estuaries, river } \\
\text { systems, and glacial and periglacial } \\
\text { environments }\end{array}$ \\
\hline $\begin{array}{l}\text { Representative } \\
\text { surface and } \\
\text { subsurface } \\
\text { features }\end{array}$ & $\begin{array}{l}\text { Features representative of particular } \\
\text { periods of Earth's history, or particular } \\
\text { rock formations or Earth processes, } \\
\text { or that are unusual or distinctive-for } \\
\text { example, cave systems, earth pillars, } \\
\text { domed and other upstanding rock } \\
\text { formations }\end{array}$ \\
\hline $\begin{array}{l}\text { Records of past } \\
\text { environmental } \\
\text { conditions }\end{array}$ & $\begin{array}{l}\text { Past environmental conditions, such } \\
\text { as glacial, periglacial and interglacial } \\
\text { phases of the Quaternary period, and } \\
\text { including landforms, sediments and } \\
\text { rock sequences from all periods of } \\
\text { Earth's history }\end{array}$ \\
\hline
\end{tabular}

To ensure the protection of geoheritage, conservation management is required through dedicated networks of protected sites, as one of a number of possible strategies. As far as possible, geoconservation should be integrated into the conservation management of all categories of protected area. In doing so, there is a need to make the 


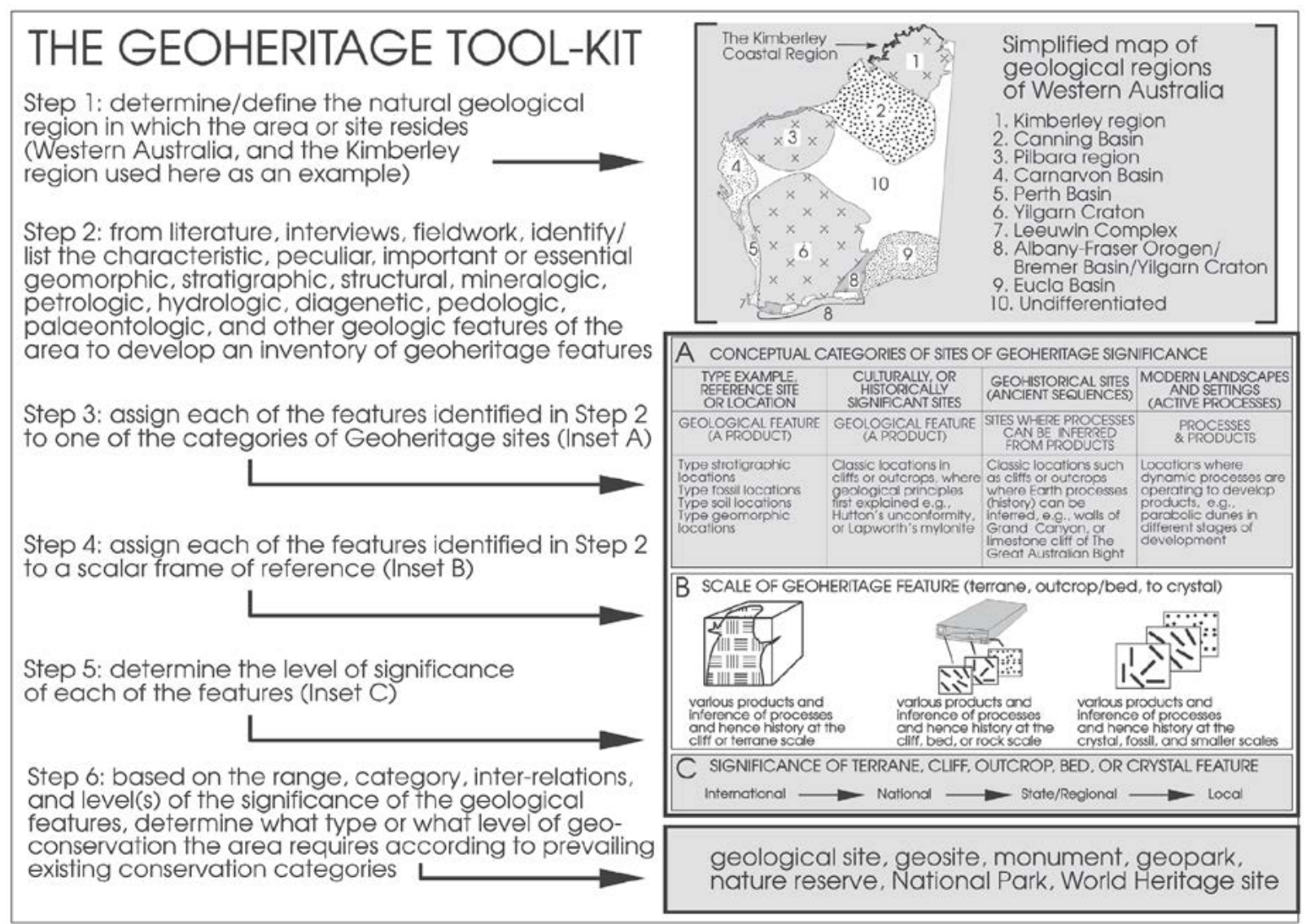

Figure 18.2 Steps in the use of the Geoheritage Toolkit to identify and assess sites of geoheritage significance

Source: Brocx and Semeniuk (2011). Illustration reproduced by permission of the authors and the Royal Society of Western Australia.

links between geodiversity and biodiversity much more explicit in conservation planning and the selection of protected areas and, as for biodiversity, to optimise the synergy with ecosystem services in conservation planning.

\section{Geoheritage protected area toolkit}

Many different protected area assessment systems are in operation at international, national and local levels. At all levels, a fundamental requirement is for a geoheritage inventory and a full understanding of key sites that need to be protected (Sharples 2002; ProGEO 2011). The Geoheritage Toolkit, developed in Western Australia to identify and assess protected areas of geoheritage significance for science and education, illustrates the main steps (Figure 18.2) (Brocx and Semeniuk 2011). The Geoheritage Toolkit is a category-based method in which distinct regions are first identified, then an inventory of key geological and geomorphological features is produced at all scales (from mountain-scale to micro-scale), the features are allocated to a category of geoheritage, and their significance is assessed using the semi-quantitative evaluation of Brocx and Semeniuk (2007).

\section{Geoconservation and protected area designations}

There are many types of geoheritage protected area systems-some international, some national and some local. The main types are described.

\section{International}

\section{World Heritage}

The World Heritage Convention recognises geoheritage values both directly, through inscription of properties on the UN Educational, Scientific and Cultural Organisation (UNESCO) World Heritage List under Criterion (viii) either on its own or in combination with other natural or cultural criteria, and indirectly, through recognising the supportive role of geoheritage values in underpinning biological, cultural and landscape diversity (Dingwall et al. 2005). To be included on the World 
Heritage List, sites must be of outstanding universal value and meet at least one of 10 selection criteria. Of the 981 sites inscribed by 2013 on the World Heritage List, 759 are cultural, 193 are natural and 29 are mixed sites. Around 80 sites are inscribed primarily because of their geoheritage interest under Criterion (viii) as 'outstanding examples representing major stages of Earth's history, including the record of life, significant on-going geological processes in the development of landforms, or significant geomorphic or physiographic features'. Some sites may also qualify under Criterion (vii): 'to contain superlative natural phenomena or areas of exceptional natural beauty and aesthetic importance.' Dingwall et al. (2005) proposed 13 geological and geomorphological themes as a basis for assessing properties for World Heritage potential.

\section{Geoparks}

Geoparks are areas with outstanding geoheritage established primarily to promote geotourism and to support local economic development. They are not protected areas per se, but they may wholly, or in part, be covered by protected areas. They are not systematically identified and classified as a comprehensive global network; many are based on community-led, voluntary initiatives and others on top-down designation. Nevertheless, the Global Network of National Geoparks or Global Geoparks Network (GGN), assisted by UNESCO (Figure 18.3), provides an international framework to conserve and enhance the value of the Earth's heritage, its landscapes and geological formations, and the creation of geoparks will probably de facto provide a level of landscape-scale coordination of conservation, sustainable use and complementary social and economic development, though not always in the strict definitions of IUCN categories. In 2014 the network comprised 111 national geoparks worldwide (UNESCO 2014a).

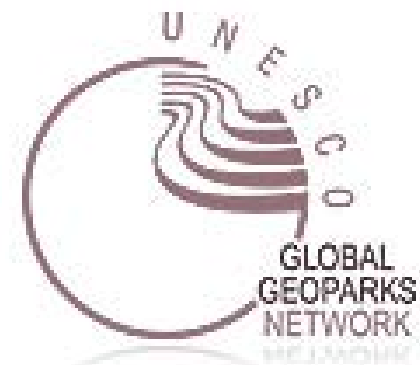

Figure 18.3 Logo of the UNESCO-assisted Global Geoparks Network

Source: UNESCO
Geoparks combine conservation of geoheritage with encouragement of its enjoyment, understanding and education and support for sustainable socioeconomic and cultural development through geotourism (McKeever et al. 2010). The GGN operates in close synergy with the World Heritage Convention, the Man and the Biosphere (MAB) World Network of Biosphere Reserves, and with national and international non-governmental organisations (NGOs) and geoheritage conservation programs. Sites within the GGN are required to meet criteria relating to size and setting; management and local involvement; economic development; education; and protection and conservation (UNESCO 2010). Geoparks are not necessarily specifically protected areas, and are subject to four-yearly reviews of their performance and management. Should a geopark fail to meet the criteria and the issues raised are not addressed within two further years, it is removed from the GGN list.

Dingwall et al. (2005) recommended that the GGN should be seen as a complementary approach to World Heritage listing; however, it should be recognised that the GGN is not primarily a listing of important sites; they are sites selected for tourism and promotion purposes. There remains a need for an international listing of important geosites alongside World Heritage sites and geoparks since each has a different role to play in international geoconservation.

\section{Internationally important geosites}

As a contribution to the global geosites inventory program (Wimbledon et al. 2000), some countries, such as Spain (García-Cortés et al. 2001, 2009) and Portugal (Brilha et al. 2005), completed inventories of internationally important sites. Geosites identified under this program are incorporated into national protected area systems to ensure their proper management. Originally adopted by the International Union of Geological Sciences, and later abandoned due to financial problems, the global geosites program is currently under development in many other European countries (Wimbledon and Smith-Meyer 2012) and its principles remain valid for the identification and global comparison of geological frameworks and geoheritage sites of international relevance.

A major gap in the international network of protected sites for geoheritage is the network of more than 100 Global Stratotype Sections and Points (GSSPs) established by the International Commission on Stratigraphy, a commission of the International Union of Geological Sciences (Gray 2011). This network comprises all the key sites for the stage, system and series boundaries of the geological column, which form the fundamental building blocks of stratigraphy. 

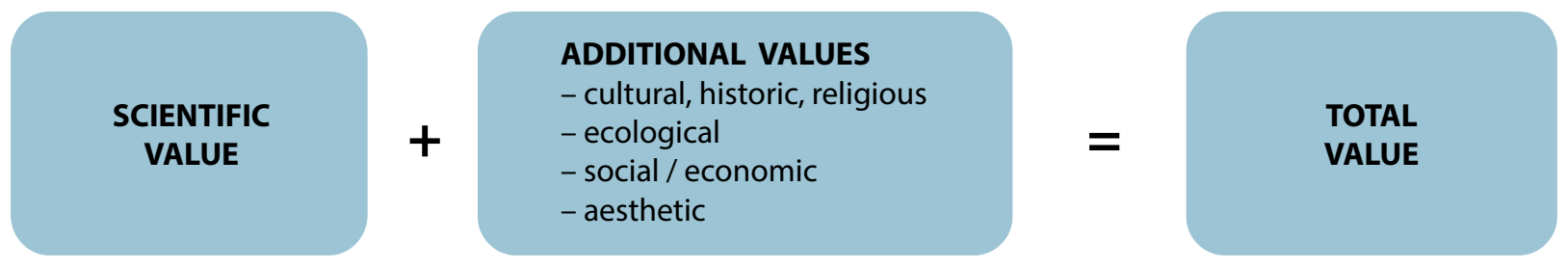

Figure 18.4 Core and additional values of geoheritage

Source: Adapted from Reynard (2009b)

\section{National}

Many countries have adopted site assessment systems for geological and geomorphological features using a range of criteria (Wimbledon and Smith-Meyer 2012). The majority are based on criteria that include scientific value, representativeness, rarity, diversity of features and integrity (Lima et al. 2010), and comparative assessment and published information provided by experts on the area, working to a defined geological framework (Erikstad et al. 2008; ProGEO 2011). Assessments are usually based on an expert judgment approach, but in some cases numerical parametric approaches have been adopted or proposed (for example, Lima et al. 2010; Bruschi et al. 2011). The latter are probably more useful where a wider range of criteria is being applied (for example, educational and tourism use, vulnerability) and different weightings can be allocated to different criteria. Where the focus is specifically on the scientific value, parametric scoring approaches risk losing sight of the fundamental scientific reasoning. Hence, it is vital that full scientific justification is provided, as in the case of the Geological Conservation Review (GCR) in Great Britain.

The GCR, and the analogous Earth Science Conservation Review in Northern Ireland (National Museums Northern Ireland 2003), are good examples of a systematic national assessment (see above). The underlying rationale is that sites are selected solely for their scientific interest through a process of expert review, and must make a special contribution to the understanding and appreciation of Britain's geoheritage. More than 3000 sites have been selected and most are designated as Sites of Special Scientific Interest (SSSIs) and have statutory protection. In Scotland, this type of approach has been extended to the marine environment to identify key areas for geodiversity on the seabed from the coast out to the edge of the continental shelf (Brooks et al. 2013). Given resource constraints and the difficulties in managing and monitoring submarine areas, a pragmatic approach may be to prioritise action on the basis of the sensitivity and vulnerability of the geoheritage interests and to align marine geoconservation with biodiversity conservation as far as possible through an integrated approach (Gordon et al. 2013). For example, in Norway, the application of 'nature areas' mapping in the marine environment is intended to provide a basis for integrated conservation, reflecting the close links between marine geodiversity and biodiversity (Dolan et al. 2009; Thorsnes et al. 2009).

Outside Europe, systematic national site assessments have generally not been completed and this is seen as a major gap. In Australia, however, a great deal of work has been undertaken throughout the continent, with the Geological Society of Australia playing a leading role alongside State bodies (Sharples 2002; Brocx 2008; Joyce 2010; Worboys 2013). The Tasmanian Geoconservation Database (TGD) (DPIPWE 2014) provides a good existing model. The TGD is an extensive inventory of sites of geoconservation significance and was initially compiled from a range of previously ad hoc inventories. Over the past 15 years it has been actively managed by a specialist reference group appointed by the relevant government agency (Department of Primary Industries, Parks, Water and Environment: DPIPWE) and, as a result, is gradually developing into a more systematically organised and comprehensive geoheritage inventory. Despite having no statutory power, it has become a key tool in land management in Tasmania (DPIPWE 2014).

In addition to scientific value, other approaches have recognised the aesthetic, cultural/historical, economic and ecological values of protected areas for geoconservation (Kiernan 1996; Panizza 2001; Coratza and Panizza 2009; Reynard 2009a). Reynard (2009b) proposed geological value as the core value and the others as additional values (Figure 18.4).

Some approaches have also applied quantitative methods to site assessment incorporating both scientific and wider values-for example, in Switzerland (Reynard et al. 2007), Spain (Bruschi et al. 2011; Pellitero et al. 2011), Portugal (Pereira et al. 2007) and Greece (Fassoulas et al. 2011). Rovere et al. (2011) extended this approach to assess geoheritage in two underwater areas off the coasts of Greece and Italy. Some approaches have focused on subsets of geosites. For example, the International Association of Geomorphologists has addressed the assessment and conservation of geomorphological sites (Reynard et al. 2009). 
The value of soil has tended to be overlooked in geoconservation assessments, although it is addressed in ecosystem service assessments (for example, Haygarth and Ritz 2009; Dobbie et al. 2011). For soils in Scotland, however, Towers et al. (2005) developed a methodology for a soil conservation index based on assessing soil rarity, representativeness and diversity using soil pedological characteristics.

\section{Local}

There are many different approaches to local geoconservation around the world. In Great Britain, for example, networks of sites of regional or local importance have been identified. These are variously known as Local SitesorLocal Geological Sites(England), Local Geodiversity Sites (Scotland) and Regionally Important Geodiversity Sites (Wales) (DEFRA 2006; Scottish Natural Heritage 2006). They have discretionary protection guidance on dealing with development applications and their value lies in the fact they can be designated for a much broader range of criteria than SSSIs, including educational, aesthetic and historical significance (Burek 2012). Other countries, too, have identified regional networks of geosites, such as Spain (see, for example, Fuertes-Gutiérrez and FernándezMartínez 2010). For local planning purposes, including management of large protected areas such as national parks, recognition of geoheritage values will be important even if they do not appear on national lists or meet normal criteria as stand-alone protected areas (Erikstad 2012).

\section{Principles of geoconservation}

This section sets out general principles for geoconservation in protected areas.

\section{The role of IUCN management categories and geoconservation}

Geoconservation in protected areas applies to all of the IUCN protected area management categories and it specifically applies to Category III. The 2008 guidelines (Dudley 2008) set out the situation in both cases and are quoted below.

\section{Relevance of all categories}

The IUCN protected area management categories (Chapter 2) have a wide application to the management of geoheritage. This reflects the linkage between abiotic and biotic conservation, as well as cultural values. As a result, geoconservation can apply to the management of protected areas assigned to any one of the six management categories as well as to those assigned to Category III.
Examples are given in Table 18.3. Geoheritage values can also apply to all of the other categories. The 2008 guidelines provide the examples given in Table 18.4.

\section{IUCN Category III protected areas}

Traditionally, Category III has been regarded as the only one for conservation of specific geoheritage features and processes. This is not entirely the case, as will be discussed below. The detailed definition of this category is:

Category III protected areas are set aside to protect a specific natural monument, which can be a landform, seamount, submarine cavern, geological feature such as a cave or even a living feature, such as an ancient grove. They are generally quite small protected areas and often have high visitor value. (Dudley 2008:17)

As defined in the guidelines, the primary objective of Category III is 'to protect specific outstanding natural features and their associated biodiversity and habitats' (Dudley 2008:17). Other objectives can also apply, such as:

- to provide biodiversity protection in landscapes or seascapes that have otherwise undergone major changes

- to protect specific natural sites with spiritual and/ or cultural values where these also have biodiversity values

- to conserve traditional spiritual and cultural values of the site (Dudley 2008:17).

A Category III protected area could include some of the following elements.

1. Natural geological and geomorphological features: such as waterfalls, cliffs, craters, caves, fossil beds, sand dunes, rock formations, stratotypes and stratigraphic sections; valleys and marine features such as seamounts or coral formations.

2. Culturally influenced natural features: such as cave dwellings and ancient human tracks.

3. Natural-cultural sites: such as the many forms of sacred natural sites (sacred groves, springs, waterfalls, mountains, sea coves, and so on) of importance to one or more faith groups.

4. Cultural sites with associated ecology: where protection of a cultural site also protects significant and important biodiversity, such as archaeological and historical sites that are inextricably linked to a natural area. 
Table 18.3 Examples of geoheritage protected areas in the IUCN management categories

\begin{tabular}{|c|c|c|}
\hline Category & National examples and reason & World Heritage property examples \\
\hline $\begin{array}{l}\text { la. Strict Nature } \\
\text { Reserve }\end{array}$ & $\begin{array}{l}\text { Greenland Ice Cap, Greenland: ice cap and } \\
\text { nunataks } \\
\text { Geysir Valley, Kronotsky Zapovednik, Russia: } \\
\text { volcanic features }\end{array}$ & $\begin{array}{l}\text { Macquarie Island Nature Reserve, } \\
\text { Australia: Earth mantle rocks } \\
\text { Surtsey, Iceland: biotic and abiotic } \\
\text { processes on new island formed in } \\
1963-67\end{array}$ \\
\hline Ib. Wilderness Area & $\begin{array}{l}\text { Maspalomas Dunes Special Nature Reserve, } \\
\text { Spain: saltmarshes within Pleistocene dunes } \\
\text { Noatak Wilderness, Alaska, USA: river basin }\end{array}$ & Putorana Plateau, Russia: basalt plateau \\
\hline II. National Park & $\begin{array}{l}\text { Grand Canyon National Park, USA: stratigraphic } \\
\text { record and arid land erosion }\end{array}$ & $\begin{array}{l}\text { Dolomit Bellunesi National Park, Italy: } \\
\text { karst, glaciokarst and reefs }\end{array}$ \\
\hline $\begin{array}{l}\text { III. Natural Monument } \\
\text { or Feature }\end{array}$ & $\begin{array}{l}\text { Jenolan Karst Conservation Reserve, Australia: } \\
\text { karst system } \\
\text { Bosques Petrificados, Argentina: petrified forest }\end{array}$ & $\begin{array}{l}\text { Boodjamulla (Lawn Hill) National Park, } \\
\text { Australia: terrestrial vertebrate fossils } \\
\text { Dinosaur National Park, Canada: dinosaur } \\
\text { fossils }\end{array}$ \\
\hline $\begin{array}{l}\text { IV. Habitat/ } \\
\text { Species Management } \\
\text { Area }\end{array}$ & $\begin{array}{l}\text { Montserrat Mountain Partial Natural Reserve, } \\
\text { Spain: sedimentary rocks, caves and mountain } \\
\text { erosion forms } \\
\text { Lord Howe Island Marine Park, Australia: } \\
\text { volcanic seamount }\end{array}$ & $\begin{array}{l}\text { Galápagos National Park, Ecuador: } \\
\text { modern geological processes }\end{array}$ \\
\hline $\begin{array}{l}\text { V. Protected } \\
\text { Landscape/ } \\
\text { Seascape }\end{array}$ & $\begin{array}{l}\text { Cairngorms National Park, UK: Earth history and } \\
\text { modern geomorphological processes } \\
\text { Cabo be Gata-Níar Natural Park, Spain: volcanic } \\
\text { and Quaternary history } \\
\text { Lyngsalpan landscape protected area, Norway: } \\
\text { alpine mountains with glaciers, moraines, } \\
\text { geodiversity protection }\end{array}$ & $\begin{array}{l}\text { Škocjan Caves Regional Reserve, } \\
\text { Slovenia: sinkholes, caves and } \\
\text { underground rivers }\end{array}$ \\
\hline $\begin{array}{l}\text { VI. Protected Area with } \\
\text { Sustainable Use of } \\
\text { Natural Resources }\end{array}$ & $\begin{array}{l}\text { Nublo Rural Park, Spain: volcanology, } \\
\text { geomorphology } \\
\text { Sečovlje Salina Nature Park, Slovenia: salt } \\
\text { extraction }\end{array}$ & $\begin{array}{l}\text { Great Barrier Reef Marine Park, Australia: } \\
\text { coral reef system evolution }\end{array}$ \\
\hline
\end{tabular}

Sources: Lockwood et al. (2006); Dudley (2008); UNESCO (2014b); for Spanish examples, E. Díaz-Martínez, Personal communication; for Norwegian examples, L. Erikstad, Personal communication

Table 18.4 Geoheritage and the appropriate IUCN management category

\begin{tabular}{|l|l|}
\hline Aspect of geoheritage & Suitable IUCN category \\
\hline $\begin{array}{l}\text { Protection is aimed primarily at an individual feature of interest (natural } \\
\text { monument such as a waterfall or cave) or a site of national or international } \\
\text { value for understanding the Earth's history (for example, a stratotype) }\end{array}$ & Primarily Category III \\
\hline $\begin{array}{l}\text { An assemblage of landforms (for example, glaciated valley system, } \\
\text { cordillera) and/or processes, or geological features }\end{array}$ & Primarily Categories la, Ib, II and V \\
\hline The features have potential for interpretation and stimulating geotourism & Primarily Categories II and III \\
\hline $\begin{array}{l}\text { The geoheritage interest is itself a foundation for habitats and species (for } \\
\text { example, calcium-loving plants or species adapted to dynamic sand dunes) }\end{array}$ & Primarily Categories la, Ib, II, IV, V and VI \\
\hline $\begin{array}{l}\text { Geoheritage has important links with cultural landscapes (for example, } \\
\text { caves used as dwellings or landforms adapted to terraced agriculture) }\end{array}$ & $\begin{array}{l}\text { Primarily Category V, and also Categories } \\
\text { II and III }\end{array}$ \\
\hline $\begin{array}{l}\text { Geoheritage is the basis for sustainable management (activities associated } \\
\text { with natural processes, such as volcano tourism, or use of floodplains as } \\
\text { traditional rice-growing areas) }\end{array}$ & $\begin{array}{l}\text { Primarily compatible with Categories V } \\
\text { and VI }\end{array}$ \\
\hline $\begin{array}{l}\text { Protection that includes geological features that have particular spiritual or } \\
\text { faith-based values for a proportion of stakeholders }\end{array}$ & Primarily Categories la and III \\
\hline
\end{tabular}


Table 18.5 Category III protected areas compared with other categories

\begin{tabular}{|l|l|}
\hline Categories la and Ib & $\begin{array}{l}\text { Category III is not confined to natural and pristine landscapes but could be established in } \\
\text { areas that are otherwise cultural or fragmented landscapes. Visitation and recreation are often } \\
\text { encouraged and research and monitoring limited to the understanding and maintenance of a } \\
\text { particular natural feature }\end{array}$ \\
\hline Category II & $\begin{array}{l}\text { The emphasis of Category III management is not on protection of the whole ecosystem, but } \\
\text { of particular natural features; otherwise Category III is similar to Category II and managed in } \\
\text { much the same way but at a rather smaller scale in both size and complexity of management }\end{array}$ \\
\hline Category IV & $\begin{array}{l}\text { The emphasis of Category III management is not on protection of the key species or habitats, } \\
\text { but on protection of particular natural features and processes }\end{array}$ \\
\hline Category V & $\begin{array}{l}\text { Category III is not confined to cultural landscapes, and management practices will probably } \\
\text { focus more on stricter protection of the particular feature and processes than in the case of } \\
\text { Category } \mathrm{V}\end{array}$ \\
\hline Category VI & Category III is not aimed at sustainable resource use \\
\hline
\end{tabular}

Biodiversity components of Category III protected areas are of two main types:

1. biodiversity that is dependent on the conditions of the natural feature-such as coastal wetlands dependent on tidal inundation, the spray zone of a waterfall, the ecological conditions in caves, plant species confined to cliffs, or the grasslands confined to low limestone plains or alvars

2. biodiversity that is surviving because the presence of cultural or spiritual values at the site has maintained a natural or semi-natural habitat in what is otherwise a modified ecosystem — such as some sacred natural sites or historical sites that have associated natural areas. In these cases, the key criteria for inclusion as a protected area will be: 1) the value of the site as a contribution to broad-scale conservation; and 2) prioritisation of biodiversity conservation within management plans.

Category III has been suggested as providing a natural management approach for many sacred natural sites, such as sacred groves. Although sacred natural sites are found in all categories and can benefit from a wide range of management approaches, they may be particularly suited to management as natural monuments.

Category III is really intended to protect the unusual rather than to provide logical components in a broadscale approach to conservation, so their role in landscape or ecoregional strategies may sometimes be opportunistic rather than planned. In other cases-for example, cave systems - such sites may play a key ecological role identified within wider conservation plans. Important natural monuments can sometimes provide an incentive for protection and an opportunity for environmental/ cultural education even in areas where other forms of protection are resisted due to population or development pressure, such as important sacred or cultural sites. In these cases, Category III can preserve samples of natural habitat in otherwise cultural or fragmented landscapes.

Category III is distinctive from the other categories as management is usually focused on protecting and maintaining particular natural features and the processes that ensure their continuation (Table 18.5).

The fact that an area contains an important natural monument does not mean it will inevitably be managed as a Category III area-for instance, the Grand Canyon in Arizona is managed as Category II, despite being one of the most famous natural monuments in the world, because it is also a large and diverse area with associated recreational activities, making it better suited to a Category II model. Category III is most suitable where the protection of the feature is the sole or dominant objective.

\section{Establishing new geoheritage protected areas}

Within the systematic frameworks for identifying protected areas for geoconservation (see above), opportunities will arise for new sites to be designated. These will result from a number of circumstances, such as new knowledge and understanding of features and processes, new exposures arising from natural erosion or from quarrying, new site surveys in areas previously overlooked, and the formation of new territory with associated mineral deposits on land and below sea-level as a result of tectonic and volcanic activity. In judging whether to add new protected areas, the fit within the existing systematic framework should be considered and any adjustments made to the site network to take into account the new knowledge or interpretations. 


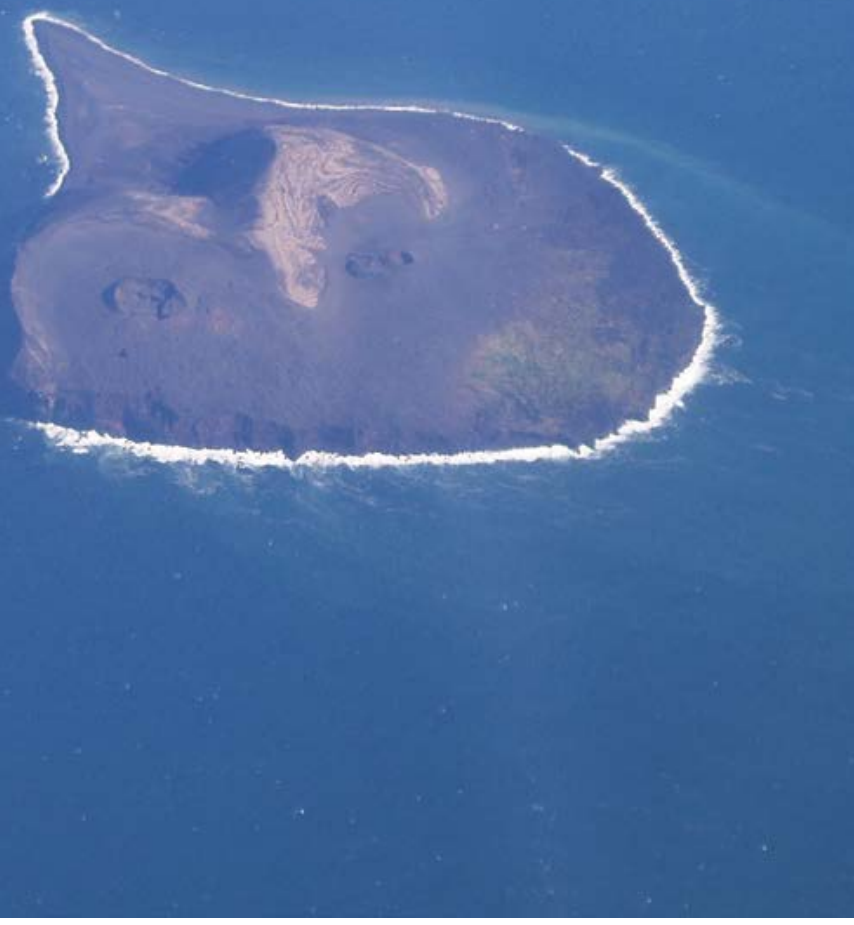

Surtsey World Heritage Property, Iceland: a new island formed between 1963 and 1967 at the geological plate separation zone along the Mid-Atlantic Ridge

Source: Roger Crofts

\section{Guidance from geoconservation strategic frameworks}

A hierarchy of guidance for geoconservation can be a valuable part of the toolkit for protected area management. The cascade from a national geodiversity framework, through regional and local geodiversity action plans to geoconservation protected area management plans, allows the management of the protected area to be placed in a wider context, and linkages to be established that will reinforce management and place responsibilities on other parties to act in supportive ways. Specific applications must match local conditions, legislation and management systems.

At a national level, a geodiversity framework can be particularly helpful in developing a strategic approach to geoconservation, setting out high-level objectives that can be used to measure and report on progress, help enlist partners and coordinate activities, and promote geoconservation (for example, Gordon and Barron 2011). Geoconservation strategies and action plans are currently being developed in many European countries (Wimbledon and Smith-Meyer 2012). Examples of national frameworks include the UK Geodiversity Action Plan (UKGAP) and Scotland's Geodiversity Charter (Box 18.2).
At a local or regional level, local geodiversity action plans (LGAPs) are needed to evaluate potential uses of protected areas, to target and prioritise resources, and to target appropriate management and interpretation of protected areas (English Nature 2004; Burek and Potter 2006). There are now many examples of LGAPs in the United Kingdom (for example, Lawrence et al. 2007). In some cases, they are integrated with local biodiversity action plans. In Italy, the proactive management of the geological heritage in the Piemonte (PROGEOPiemonte) program aims to develop action planning for geoheritage management with the participation of local partners and to meet the needs of local communities in respect of tourism, sustainable development and geohazard awareness (Ferrero et al. 2012). Such plans can also provide a model for developing the protection of geoheritage and its integration into the conservation management of different categories of protected area.

The fundamental building block for local action plans is an inventory or audit of geodiversity sites and resources within an area, as developed, for example, in the United Kingdom (for example, Lawrence et al. 2004) and Tasmania (for example, DPIPWE 2014).

\section{Guiding principles for geoconservation in protected areas}

Development of more integrated approaches to the management of natural systems depends, in part, on the effective application of geoconservation principles. These are of general application and also relevant specifically to protected area management (Box 18.3). These principles are easier to list than to implement in practice, as there will inevitably be resistance to accepting change and adapting to new approaches. It will take time and patience to bring all interests onside and think creatively. Key protected area personnel will need expertise in negotiation and resolving conflict.

Many of these principles are now being applied in protected area management. This is exemplified in shoreline management plans and integrated river catchment management. It is also recognised in comprehensive, ecosystem-based planning frameworks developed, for example, in the Oak Ridges Moraine Conservation Plan, Ontario (Ontario Ministry of Municipal Affairs and Housing 2012). The ecosystem approach, in particular, has been adopted as a primary framework for action under the $\mathrm{CBD}$ and provides a means for closer integration of geodiversity and biodiversity on a wider scale. 


\section{Box 18.2 Strategic frameworks for geoconservation: UK experience}

The UK Geodiversity Action Plan (UKGAP 2014) provides a strategic framework for geodiversity action across the United Kingdom, linking national, regional and local activities. Agreed by organisations, groups and individuals currently involved in geodiversity activities, it provides a mechanism for encouraging partnership, influencing decision-makers, policymakers and funding bodies, and promoting good practice. The UKGAP comprises six themes:

1. furthering the understanding of geodiversity

2. influencing policy, legislation and development design

3. information gathering and management

4. conserving and managing geodiversity

5. inspiring people to value and care for geodiversity

6. sustaining resources (people and financial) for geodiversity.

Each theme has a set of objectives and targets (areas of work that contribute to delivering the objectives).

The Scottish Geodiversity Forum promotes Scotland's geodiversity and seeks to widen the profile of geodiversity and to influence national and local policies in education, community involvement and health, the development of tourism and the wider economy. Members include local geoconservation groups, geoparks, industry, education and academic sectors, related government and NGOs and interested individuals. Scotland's Geodiversity Charter, produced by the forum, sets out a strategic approach to geoconservation focused on an ecosystem approach, including a vision that Scotland's geodiversity is recognised as an integral and vital part of the environment, economy, heritage and future sustainable development, to be safeguarded and managed appropriately for present and future generations (Scottish Geodiversity Forum 2013). The signatories (currently 51) commit to contributing to the activities of the forum and delivering the objectives of the charter through four main areas of activity:

1. raising awareness of the importance of geodiversity and its wider links with landscape, culture and sense of place, and encouraging a sense of pride through education (at all levels, including schools, universities and lifelong learning), promotion, outreach and public interpretation

2. integration of geodiversity in relevant policies to ensure sustainable management of the natural heritage, land and water at landscape and ecosystem scales

3. conservation and enhancement of geoheritage and its special character, within existing designated sites and areas, by further designation of nationally and locally important sites, and in the wider rural, urban and marine environments

4. research to improve understanding of the role of geodiversity in providing benefits to ecosystems and people, and to address key knowledge gaps such as the functional links between geodiversity and biodiversity in terrestrial, freshwater and marine environments.

\section{Site planning guidance}

Some sites will not be designated and managed purely for geoconservation. Geoconservation interests will be included in sites managed for various aspects of biodiversity conservation or for ecosystem services or for cultural reasons, in accordance with the IUCN definition. In all cases, whatever the balance of significance between the different reasons for designation of a protected area, a comprehensive approach to managing all of the valued interests will be required.

It is essential in all of these situations for the geoconservation component to be included in all of the site documentation and site management specification, as well as in the work plans and activities of all staff. This material should be an intrinsic part of the protected area management plan described in Chapter 13. The site documentation material for geoconservation, to form part of the protected area management plan, should include:

- the reasons for conserving the geoheritage interest (for example, scientific, educational), including the type of interest and the level or scale of relevance (local, regional, national and international)

- specification of the particular elements (for example, materials, structures, landforms), systems and processes to be conserved, including their classification (for example, stratigraphy, tectonics, geomorphology, palaeontology, mineralogy, hydrogeology, petrology) and precise locations within the site (established through mapping and photography)

- specification of the degree of fragility, risks of damage and potential threats and other causes of loss of interest to the features and processes

- links to other aspects of nature and culture being protected 


\section{Box 18.3 Guiding principles for geoconservation in protected areas}

1. The inevitability of natural change should be recognised: no system or element of a system is static forever, and change will occur particularly as a result of global climate change. The traditional approach of maintaining the current state to preserve features should be reconsidered in cases where preservation is not the management objective (see also Chapter 10 for more explanation).

2. Changes resulting from global climate change, irrespective of the extent attributed to natural or anthropogenic factors, will inevitably challenge management objectives. Careful consideration will be needed where, for example, the features are lost and/or processes are lessened or intensified, and so change the basis for protection. It may mean that the protection status can no longer be justified.

3. Natural systems and processes should be managed to maintain natural rates and magnitudes of change and to maintain their capacity to evolve through the action of natural processes.

4. Natural systems and processes should be managed in a spatially integrated manner-for example, to achieve complementary objectives, such as geodiversity, biodiversity and landscape diversity conservation.

5. Any management and intervention should work with, rather than against, natural processes: mimicking nature and natural processes is more effective than trying to impose human solutions that seek to control or halt natural processes.

6. Natural systems should be managed within the limits of their capacity to absorb change: some systems will be more able than others to absorb change and others will be very fragile with a low threshold for change.

7. The sensitivity of natural systems should be recognised, including the potential for irreversible changes if limiting thresholds are crossed. It is rarely the case that abiotic systems are robust and can absorb any change imposed upon them. If certain types or levels of change are made, the conservation effort will be negated as the original features and processes will have been irreversibly changed.

8. Conservation management of active systems should be based on a sound understanding of the underlying physical processes-for example, the implementation of coastal cells in the preparation of shoreline management plans; the integration of river, soil and slope processes in catchment management plans; monitoring active processes.

9. Engineering solutions that are based on 'hard' structures, such as concrete, should be avoided as they can wreck the features and processes of the protected area. Instead, 'soft' approaches to management should be adopted using natural materials that mimic nature as far as possible-for example, removal of mangroves that serve as a natural form of protection of the coastal edge and are protected for their biological interest and replacing them with solid structures such as concrete walls should be avoided.

Note: These principles have been further developed in Crofts and Gordon (2014).
- potential conflicts with the management of the non-abiotic interests, especially biotic and cultural interests, and how these can be resolved

- the management requirements to maintain or enhance the interests, depending on the reasons for the designation, and the need to minimise conflict with other reasons for designation

- management arrangements within the area, including boundary definition, core and buffer zones, and assignment to the appropriate IUCN management categories and governance types

- a protocol for monitoring and reviewing the state of conservation of the geoheritage interest.

Wimbledon et al. (2004) provide an exemplary case study of the application of such a methodology to geosite management in Wales.

\section{The use of core and buffer zones}

The identification of core and surrounding buffer zones should be an important element of the management arrangements for geoconservation. The two concepts are closely linked and the buffer is a necessary complement to the core zone, as without it, it will be much more difficult to protect the features in, and the integrity of, the core zone. The UNESCO Man and the Biosphere Reserve approach provides a practical basis for identifying the two zones. For biosphere reserves, they are defined as follows.

- Core area(s): Securely protected sites for conserving biological diversity, monitoring minimally disturbed ecosystems, and undertaking non-destructive research and other low-impact uses (such as education). In addition to its conservation function, the core area contributes to a range of ecosystem services, which, in terms of the development functions, can be 
calculated in economic terms (for example, carbon sequestration, soil stabilisation, supply of clean water and air, and so on). Employment opportunities can also complement conservation goals (for example, environmental education, research, environmental rehabilitation and conservation measures, recreation and ecotourism).

- Bufferzone: Usually surrounds or adjoins the core areas, and is used for cooperative activities compatible with sound ecological practices, including environmental education, recreation, ecotourism, and applied and basic research. In addition to the buffering function related to the core areas, buffer zones can have their own intrinsic, 'stand-alone' functions for maintaining anthropogenic, biological and cultural diversity. They can also have an important connectivity function in a larger spatial context as they connect biodiversity components within core areas with those in transition areas (UNESCO 2014c).

Although this is written from the standpoint of conserving biological diversity, for our purposes, the phrase 'abiotic or geoconservation' can be substituted or added.

A single core surrounded by a buffer zone will not always be the correct approach. There will be situations where there are a number of significant geoheritage elements requiring conservation within a protected area, and multiple core zones and surrounding buffer zones will be the most appropriate approach in those situations.

In practical terms, identification and management of core and buffer zones for geoconservation protected areas depend on the specific reason for designation and therefore the type of area being protected. There is likely to be a substantial difference between the definition of core and buffer zones for small discrete areas-for example, to protect a particular geoheritage feature, such as a national monument-and large geoheritage sites that combine many features and where maintaining the effective functioning of Earth processes is critical.

\section{Approach for Category III sites}

If the feature(s) being protected is relatively static, inactive or relict, the core area can usually be drawn quite tightly around its areal extent. The definition of the boundary will depend on the need to control external activities that will have a detrimental effect on the site, such as excessive visitor numbers, geological investigations for research or education requiring removal of large samples, or vegetative growth that would obscure the interest. In addition, activities that damage the key interests being protected should be prohibited in the core area and similarly restrictions imposed in the buffer area, with statements made in the management plan and at the site itself to indicate the restrictions and the reasons they are in place. A larger boundary may also be required where sites need to be excavated periodically to maintain clear exposures, or to allow space for exposures to retreat where they are eroding naturally (for example, at the coast).

\section{Approach for larger-scale geoheritage protected areas}

Many geoheritage protected areas will be substantial in area and a different approach will be needed to ensure protection of the key features and the processes operating there. A comparable way of looking at this aspect is to think of the requirements to protect a biodiversity site designated as a nesting and roosting area for birds. Without also protecting the areas of food supply through some suitable measures, such as through buffer zones or extending the core area, the nesting and roosting site will become redundant if the birds have no ready supply of food.

Similarly, for geoheritage protected areas the buffer should be defined as the area needing conservation management to protect the features and forms, and the systems and processes that are the reason for the protection. For example, a gravel-bed river system on a modern sandur or outwash plain will only retain its dynamic interest if the fluctuating water supply from the glacier or ice cap is maintained. Therefore the sandur should be designated as the core protected area and the water sources should be protected (for example, from dams and abstraction for hydro-electricity) through designation in the buffer zone. Similarly, cave systems are susceptible to land-use activities in their wider hydrogeological catchment areas that affect water and sediment discharge into the cave passages and so require appropriate buffer zones. Buffer zones may also be required for dynamic process features-for example, in river and coastal environments-to ensure the natural processes can continue to operate across their full range of natural variability (for example, the migration of a meander belt across a floodplain).

\section{Managing geoconservation in protected areas}

Conservation requires the development of clear management objectives and periodic monitoring. In the United Kingdom, generic conservation management 
Table 18.6 Classification of geosite types for conservation management in the United Kingdom

\begin{tabular}{|c|c|}
\hline Category & Type of site \\
\hline \multirow[t]{8}{*}{ Exposure or extensive } & Active quarries and pits \\
\hline & Disused quarries and pits \\
\hline & Coastal cliffs and foreshore \\
\hline & River and stream sections \\
\hline & Inland outcrops \\
\hline & Exposures in underground mines and tunnels \\
\hline & Extensive buried interest \\
\hline & Road, rail and canal cuttings \\
\hline \multirow[t]{4}{*}{ Integrity } & Active process geomorphological \\
\hline & Static geomorphological \\
\hline & Caves \\
\hline & Karst \\
\hline \multirow[t]{4}{*}{ Finite } & Finite mineral, fossil or other geological \\
\hline & Mine dumps \\
\hline & Finite underground mines and tunnels \\
\hline & Finite buried interest \\
\hline
\end{tabular}

Source: Prosser et al. (2006)

principles have been developed for different categories of geoconservation protected area, with an important distinction between 'exposure', 'integrity' and 'finite' sites (Table 18.6). These are explained below, as they may be equally applicable in other parts of the world. Examples of the application of this system in England can be found in Natural England (2014).

\section{Exposure sites}

Protected areas with exposures contain geological features (rock units or sediments) that are spatially extensive below ground level, so that if one site or exposure is lost, another could potentially be excavated nearby. They include exposures in active and disused quarries, coastal and river cliffs and foreshore exposures, road and rail cuttings, and natural rock outcrops inland. The basic conservation principle is that removal of material does not necessarily damage the resource as new exposures of the same type will be freshly exposed. The principal management objective for such sites is to achieve and maintain an acceptable level of exposure of the features of interest, but the precise location of the exposure may not be crucial. Exposure sites are not usually damaged by quarrying or erosion, but the exposures can be obscured by landfill and dumping of rubbish. Loss of exposures can, however, be offset by mechanical excavation of new conservation exposures at appropriate locations elsewhere.

\section{Integrity sites}

Integrity sites are geomorphological sites that include both static (inactive) features (for example, Pleistocene glacial landforms) and active features such as those formed by river, coastal, karst and contemporary glacial processes. Such sites may be large and include assemblages of both static and active features. Damage to one part of an integrity site is likely to impact on the value of the whole site. The prime management objective for static features is to protect the integrity of the resource: if damaged or destroyed, they cannot be reinstated or replaced since they are unique or the processes that created them are no longer active. They are also susceptible to partial damage and fragmentation of the interest, so that the integrity of important spatial relationships between individual landforms may be lost. There are usually few options for reconciling conservation and development through management or offsetting. Mitigation will depend on local circumstances and may include resiting of parts of the development to avoid key landforms. Occasionally, landform reconstruction or replication may be possible for aesthetic or educational purposes, although integrity will be lost.

The principal conservation management objective for active geomorphological sites is to maintain the capacity of the active processes to evolve naturally, allowing them to operate across most or all of their natural range of variability and hence to maintain natural rates and magnitudes of 
change and the connectivity between different features (for example, between rivers and their floodplains). A consequence is that the landforms produced by them may change over time and some may be transitory. For example, gravel bars in a riverbed may be destroyed in a large flood but may reform as the discharge and sediment transport readjust to 'normal' flow conditions. They may also reform in different locations. Active process sites are also susceptible to changes outside the conservation site boundary-for example, through upstream changes that affect river discharge and sediment inputs. This is more likely to occur on sites with river, coastal, cave or slope (mass movement) processes and their associated features. Some active geomorphological sites may also contain inactive landforms that form part of the total landform assemblage.

\section{Finite sites}

Finite sites comprise features of limited extent that will be depleted and damaged if any of the resource is removed or lost. Examples include geological type sites, occurrences of Quaternary interglacial deposits and fossilbearing horizons. They may occur in a range of locations, including active and disused quarries and coastal and river sections. In some cases, the interest may become buried because of practical difficulties in maintaining exposures in soft sediments or intentionally as a practical conservation measure to protect a particularly vulnerable interest (for example, Bridgland 2013). Finite sites require close control over the removal or loss of material and include many mineral and fossil deposits, mine dumps, underground mines and buried interests (where the interest is known to occur under the ground and can only be exposed by excavation). Generally, mitigation or offsetting measures will rarely be possible. Depending on the type and level of the main use of a site (for example, public interpretation or research), it may not be practical or necessary to maintain an exposure. In such cases, access should be maintained for excavation as and when required (for example, for scientific research).

In general, there must be a presumption against development in protected areas that would damage the area and undermine the reasons for its protection. Where a development would result in significant damage to a geoheritage protected area that cannot be prevented or adequately mitigated, suitable alternative sites should be sought for the development. In the absence of any such alternatives, development that would adversely affect the site should only be permitted where there are overriding reasons of sustainability or national importance supporting the need for the development. In this case, compensation measures should be sought, including exposure creation or site enhancement elsewhere if practical, to maintain, restore and wherever possible enhance the geoheritage value of the site or area.

\section{Risk management}

\section{Robustness and sensitivity}

As noted above, geosites and features show varying degrees of sensitivity to different types of human activity. Some features may be relatively robust (the degree to which they can withstand disturbance) and therefore require relatively little management intervention. Others, however, are highly sensitive (susceptible to damage or degradation from human activities). Most, however, with the exception of some small-scale active process features (for example, periglacial patterned ground or gravel bars in a river), have limited resilience (the ability to reform if damaged or destroyed). These are important considerations in prioritising the management of sites and features in protected areas. Building on earlier studies, Kirkbride and Gordon (2010) compiled a sensitivity assessment of relict landform and active geomorphological process sites to a range of human activities in the central part of the Cairngorms National Park in Scotland. The evaluation of relict landform sensitivity is relatively straightforward, based on a simple assessment of the likely scale of impact and loss of interest. For active geomorphological systems, however, additional factors to be considered are resilience of the system and its potential dynamic response including prolonged readjustment (that may or may not lead to recovery) or change in state (for example, from a braided to a meandering river).

\section{Risk assessments}

There will be a variety of natural processes operating beyond the protected area that affect it and the features, forms and processes that are the basis of its designation. Determining the likely impact and the options for responding is, therefore, an important component of management. Risk assessments and prioritisation of management action will need to be undertaken of the likelihood and potential effects, especially of:

- plate tectonic activity, such as earthquakes and other seismic activity, volcanic eruptions and lava flows, tsunamis, landslides and mudflows

- global climate change, including extreme events especially in mountain areas, along rivers and at the coast, changes in precipitation regimes, increases in unpredictability of the weather, sea-level rise, melting glaciers and glacial lake outbursts, and melting of permafrost. 
It is important to be realistic as in either set of circumstances some features will be more vulnerable and will be lost or damaged and others radically changed. Careful judgment will be required, however, to ensure the management response does not have a more damaging effect than the natural phenomenon. Systematic assessment of the impacts on geoheritage, as undertaken for the Tasmanian Wilderness World Heritage Area (Sharples 2011), would allow risk-based prioritisation for action. In the case of hard-rock features, it is questionable whether any effective management intervention would be beneficial or indeed practical. In line with the principle of making space for natural processes, the preferred response for geomorphological systems will be to allow natural processes to evolve undisturbed and to manage the consequences of change (for example, adapt site boundaries) rather than attempt to 'fix and control'. Where other interests are threatened, soft forms of intervention that have a minimal impact on the protected area features should be the preferred option (for examples of river and coastal management, respectively, see The RRC 2013; Scottish Natural Heritage 2000). Where this is not possible, the most realistic response will be to record or archive samples ex situ. In the case of dynamic geomorphological sites, where the interest is in active processes or where mitigation of hazards to visitors is impractical, an assessment of the enhanced risk will be essential, as will be the implementation of appropriate actions, including exclusion or rerouting of visitor access and management of visitor expectations.

\section{Managing specific threats to geoheritage in protected areas}

Inevitably, there will be interactions and potential conflicts between geoconservation in protected areas and biodiversity and cultural conservation, as well as conflicts with other activities, particularly those seeking to exploit natural resources for human use, legitimately or otherwise (see Table 18.1). Some of the main threats are dealt with in turn and build on the general guidance provided above.

\section{Mineral exploitation}

Interaction with mining and mineral extraction at the surface and below the surface has been a longstanding issue. Dialogues between the IUCN WCPA and industry, represented by the International Council on Mining and Minerals (ICMM), have resulted in a protocol by the industry (ICMM 2003) and the IUCN's position statement for World Heritage sites (IUCN 2013).
There is a still a view held particularly by some mining interests and shared by some members of the WCPA that mining is prohibited in IUCN Categories I-IV protected areas, but can be allowed in Categories $\mathrm{V}$ and VI protected areas. This position has created problems in many Category V landscape protected areas in Europe. For example, approval exists for goldmining in the Loch Lomond and The Trossachs National Park in Scotland and stone quarrying in the Peak District National Park in England. In contrast, a joint resolution by indigenous peoples and the IUCN Commission on Environmental, Economic and Social Policy states that mining should not be allowed in protected areas, World Heritage sites, indigenous territories and sacred natural sites (see Chapter 5). This is an unfortunate unresolved matter that requires urgent attention within the IUCN as a whole. In the meantime, a cautious approach is recommended to ensure that any ongoing mining activities do not result in loss of or damage to the geoheritage interest. For new mining proposals, it is essential that an appropriate risk assessment is undertaken before any decisions are made. In all cases, local communities, whose lives and livelihoods might be affected, should be fully consulted before any decisions are made.

It should be recognised that not all extractive activity has a negative impact on the geoheritage interest, as new exposures provide the opportunity for investigation and bring new understanding of Earth evolution both at the site and of more general application. Care must be taken, however, that new exposures or valuable specimens are not lost in the commercial imperative to remove as much material as possible as soon as possible. If extraction is consented for the site, therefore, legally binding agreements should be made between the managing authorities and the resource owners, including the placing of financial bonds for restoration of the site or for maintaining certain exposures for research and teaching as part of the restoration plan. Decisions will also need to be taken about how much of the resource it is permitted to extract. Often, it will be valuable from a geodiversity perspective to leave some of the resource in the ground to allow for future investigations and for teaching and demonstration.

When applications are made for mining beneath protected areas, such as for coalmining or oil and gas extraction, including fracking, detailed assessments need to be undertaken of the potential effects on the geoheritage interests - the features and forms at the site and most especially the processes operating there. 


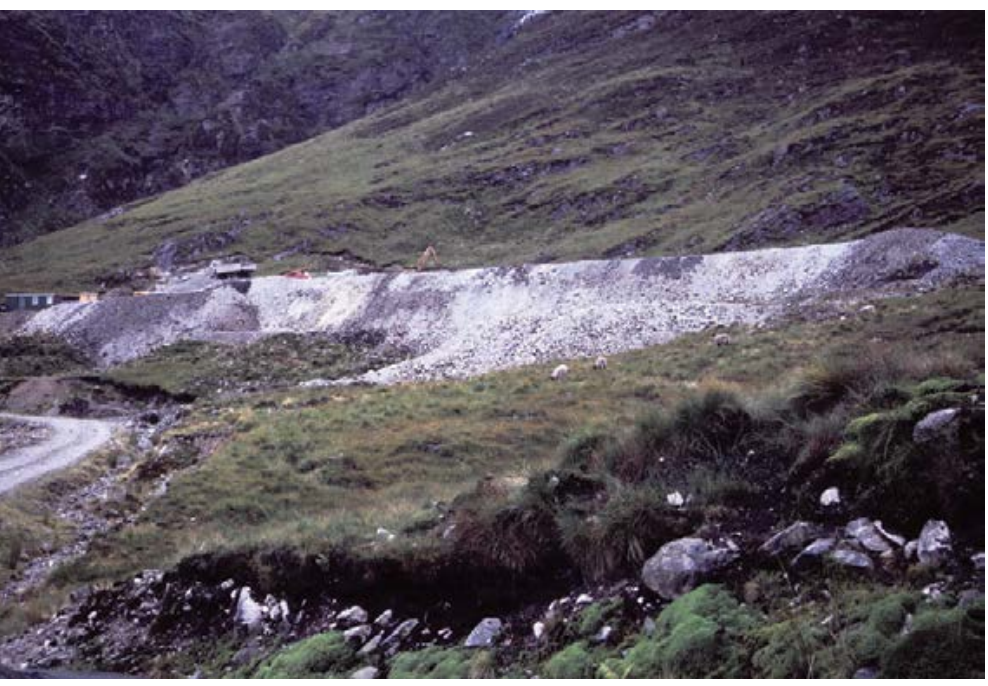

Loch Lomond and The Trossachs National Park, Scotland, United Kingdom (an IUCN Category V protected area), where spoil from the Cononish goldmine creates water and visual quality problems but provides specimens for examination Source: Roger Crofts

Legal mining under protected areas remains a vexed issue. The removal of a non-renewable resource is not sustainable, can cause the surface to collapse and can have wider impacts. If approval is given, it should be accompanied with regulations, including robust legal agreements with compliance monitoring and enforcement of the agreements.

Artisanal and small-scale mining can have profound effects on protected areas and care needs to be taken in assessing potential effects and defining solutions. A methodology has been devised and tested in Africa and provides a toolkit of six elements focusing on assessing the extent of the problem, and working with relevant stakeholders to identify solutions and alternative approaches (ASM-PACE 2013).

Once extraction is complete or in long-disused quarries, there is often a demand to use them as sites to deposit waste materials from industrial, residential or other sources. This will especially be the case where there are few other locations locally where waste material can be disposed. It is essential that the local, national and international importance of the exposures and their value for teaching and research purposes are assessed before decisions are reached.

\section{Development and development planning}

Development of infrastructure of all types - transport, commercial buildings, houses, and so on-will have an impact on geoheritage conservation in protected areas.
The most sensitive will be in existing protected areas or adjacent to them, where the effects will transfer across the protected area boundary. Key issues to be addressed before any decisions are made about actual development or before development proposals are written into plans are to consider the potential loss of features and the loss of natural processes that secure their conservation.

Large commercial, industrial and residential developments will affect the natural processes and could lead to permanent loss of protected areas. Attempts should be made to retain these areas within developments and ensure an adequate buffer zone is designated to safeguard their integrity.

Culverting and canalisation of water courses and flood prevention works along riverbanks are, for example, too damaging to be allowed where the natural processes of water flow and the features and forms created are the reason for protection. Similarly, these works will also hide key protected exposures in riversides, and should not be permitted unless there are exposures of equal value to be preserved nearby.

\section{Coastal protection}

Exposure of sections along the coast can reveal new sources of information about the evolution of life on Earth and about the processes that have operated in the past. Attempts to stop coastal erosion by construction of barriers will automatically conceal these interests and the rationale for the protected area status will be lost.

Many natural coastal systems are large in scale and highly dynamic and their perpetual protection is justified. Attempts to remove materials, especially sands, gravels and pebbles, for use in construction, and the placement of barriers made of wood or stone on the beach to halt the natural flow of sediments will inevitably undermine the rationale for protection and should be avoided.

Rising sea-levels and increased storminess in some parts of the world raise demand for greater protection of developed coastlines by the construction of hard engineering structures such as seawalls. These will irreplaceably damage adjacent protected area interest. Attempts should be made to use new solutions, such as allowing the coastline to retreat naturally inland and at the same time to relocate activities from the coastal edge to sites further inland so they are likely to be less affected. Where that is not an option, an alternative may be to utilise 'green infrastructure' (for example, through stabilisation of existing barrier islands by planting natural vegetation) or to develop artificial bars at or near the shoreline. These are challenging issues, as protection against potential loss of property is likely to be regarded 
Managed realignment of the coast between artificial rock headlands at Montrose has helped to maintain sediment supply to the adjacent St Cyrus and Kinnaber Links Site of Special Scientific Interest and St Cyrus National Nature Reserve, Scotland, United Kingdom

Source: Roger Crofts

as of greater importance than loss of protected sites. In a landmark legal case in England, however, on an eroding coast where property was threatened, the fundamental principles of site designation and geoconservation, including allowing natural processes to take their course, were upheld by the courts (Prosser 2011).

\section{Biodiversity conservation}

Interactions between geoheritage and biodiversity conservation can be both positive and negative. The positive elements have been described earlier in this chapter. The negative elements need to be recognised and solutions found by protected area managers. The essence of the resolution should be recognition of the interconnections between the biotic and abiotic features and the processes that brought them into existence and those processes that maintain them. Taking a onedimensional approach, favouring either geoheritage or biodiversity conservation is unlikely to result in a resolution benefiting conservation as a whole. Questions that will need to be addressed include the following.

- What is the basis of the conflict between the biotic and abiotic interests in and around the protected area?

- Is the conflict capable of resolution without undermining both interests or is it more fundamental?

- If the latter, is one of the interests more important than the other in the long term to national and international nature conservation and needs to be safeguarded and the other sacrificed?
There will also be practical questions to be addressed, such as the following.

- Is vegetation growth damaging or obscuring the geoheritage interest and would its removal or restraint damage the biodiversity interest? Alternatively, should the geoheritage interest be taken off-site or allowed to be obscured provided that if re-examination in the light of new knowledge is justified it can be periodically re-exposed?

- Are current Earth processes-for example, glacier melt or river erosion-which are important for maintaining the geoheritage interest, having a damaging effect on the biodiversity interest? If so, can manipulation of the processes to have minimal effect on their natural pattern be undertaken to achieve biodiversity conservation benefits?

Sometimes it will not be possible to achieve a solution at the protected area level, and the wider context of the habitat, ecosystem or biome will need to be taken into consideration in determining the relative merits of conserving one element in one place and the other in another place within the biogeographical unit.

Finally, it is important to discourage attempts to maximise habitat/species diversity by landscape modifications that result in the creation of incongruous landforms/landscapes-for example, through raising the land surface by infill in areas of flat topography or creation of ponds with shapes that are atypical of local natural features (Gray 2013). 


\section{Box 18.4 National Fossil Day, USA}

In 2010, National Fossil Day was established in the United States as an educational partnership to promote the scientific and educational values of fossils. Nearly 300 partners, including museums, professional science and teacher organisations, amateur palaeontology groups, fossil sites, universities, libraries and other categories, are distributed in all 50 States and provide fossil-related educational outreach and activities to children and families at the local level. National Fossil Day has become a nationwide celebration in the United States, which is hosted in the second week of October during Earth Science Week.

Source: National Park Service (2014a)

\section{Mt. Baker:}

A Furnace Encased in Ice

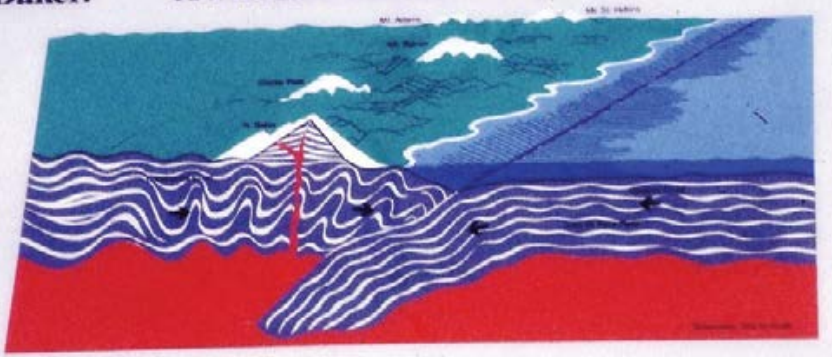

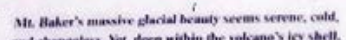

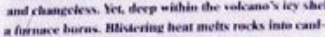

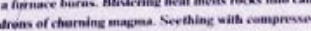

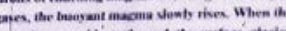

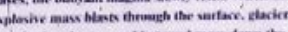

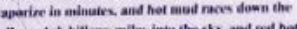

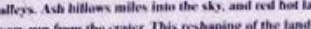

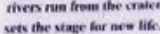

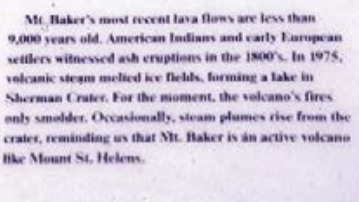

Mount Baker, North Cascades National Park, Washington State, USA: easily understandable sign interpreting the geological evolution of the landscape

Source: Roger Crofts

\section{Geoheritage education and interpretation}

Alongside site protection and management, raising wider awareness and involvement through education and interpretation is a key part of geoconservation. The purpose should be to inform and entertain as well as to educate, as recognised in the far-sighted aspiration of James Hutton (1785) that study of the Earth 'may afford the human mind both information and entertainment'. Education spans a broad spectrum, from learning through formal didactic education and informally by experience provided through interpretation. It also spans a broad spectrum of audiences from those simply wishing to 'be there' to those actively seeking education as a primary focus. Much of the conventional geoheritage interpretation is aimed at a broad sector in the middle. Effective geoconservation will ultimately depend on better public awareness, understanding and support.

Interpretation of geodiversity and geology-based tourism (geotourism) are not new, as demonstrated by the longstanding appeal of and cultural interest in show caves, glaciers, sacred mountains and other natural wonders. In the 18th and 19th centuries, people engaged with the physical landscape in an experiential way, and natural features, places and past events inspired a sense of wonder through connections with landscape, literature, poetry, art and tourism. Traditional geological interpretation, however, has been based on a didactic approach providing information rather than interpretation, with geologists using explanatory boards and leaflets. The problem has been that these are not aimed at the needs of the visitor as they are too detailed and use far too technical language, so the general user cannot understand them. Unfortunately, there are too many examples of this approach. Lessons could be learnt from the approaches taken by indigenous peoples and traditional local communities who have lived with and interpreted landscapes or landscape elements (or seascapes) in many different ways. They have integrated them into their daily lives, often according them spiritual, cultural and other significance, and often using them for crucial livelihood and ecological functions (for example, Cruikshank 2005).

Recent developments have been a more experiential approach in geo-interpretation, embracing the cultural dimension of geodiversity and resulting in more effective communication, through partnerships (Box 18.4) and the production of more appropriate materials, presented in stimulating ways using a range of media and based on the best interpretative practices and sound educational principles (for example, Tilden 1977; Ham 1992, 2007; Veverka 1994; Brown 2004; Scottish Natural Heritage 2011). Protected area managers can learn from these best-practice developments in interpreting and promoting geoheritage in a sustainable way. Innovative approaches include more integrated interpretation, linking, for example, geology, landscape, cultural heritage and industrial archaeology. The UNESCO-supported geoparks initiative has emerged as an important driver for innovation in geo-interpretation, with an agenda to engage with a wide and varied audience through promoting geotourism and related activities (Box 18.5). 


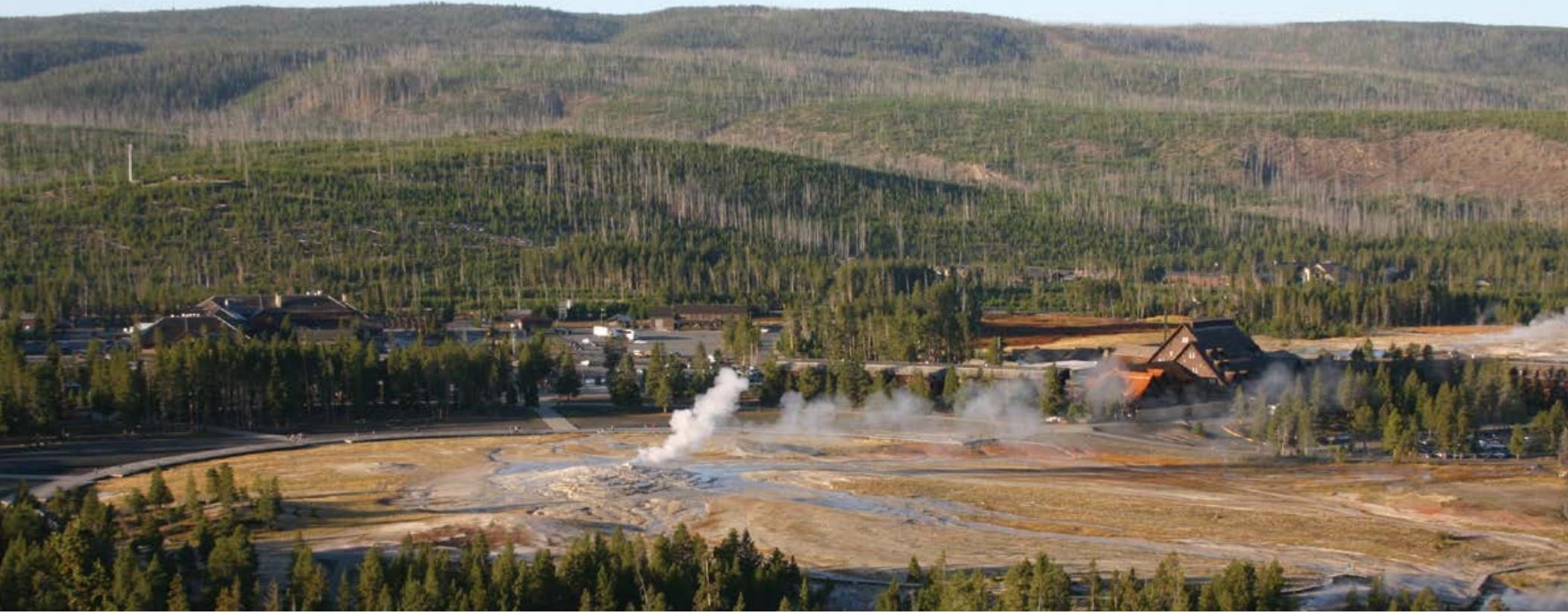

Old Faithful visitor precinct, Yellowstone National Park, USA: compatible visitor facilities alongside maintenance of geothermal hot springs

Source: Roger Crofts

\section{Box 18.5 Geoparks and geotourism}

The geoparks rationale is to promote the conservation of geoheritage, as well as sustainable economic and social development, through understanding and experience linking geology, natural heritage and cultural heritage. Most geoparks emphasise the links between geological evolution of the landscape, biodiversity and people's lifestyles and cultural traditions, protecting and utilising geological assets through sustainable tourism development and linked with education, lifelong learning, guiding and wider environmental protection initiativesfor example, Jeju in Korea, the Oki Islands and San'in Kaigan Geoparks in Japan, and Stone Forest (Shilin) and Sanqingshan Geoparks in China. Many have developed innovative interpretation linking these different themes through the common thread of geology. For example, Katla Geopark in southern Iceland has developed innovative interpretation integrating the area's geological and cultural histories based on trails and on-site panels, digital tools and novel exhibits and installations designed to stimulate people's interest rather than simply present information, along with creative engagement with local schools (Katla Geopark 2014), while North Cascades National Park in Washington State, USA, has informative interpretation plaques on trails on subduction zones and evocative signs including John Muir's poetic prose (National Park Service 2014b). Exploring geoheritage in this way can enable protected area managers to

1. help local people and visitors to (re)discover a sense of wonder about geoheritage and its links with cultural roots and sense of place

2. provide opportunities for creative ways for people to engage with, and appreciate, geoheritage through different cultural experiences

3. promote a more holistic understanding of the natural world.

For further information and case studies on geotourism, see Dowling and Newsome (2010) and Newsome and Dowling (2010).

\section{Monitoring and evaluation}

Measuring and monitoring the condition of geoheritage protected areas are essential to establish their condition and state, and how these are changing. The US National Park Service has established guidelines for monitoring geological and palaeontological resources (Santucci and Koch 2003; Santucci et al. 2009). Similarly, the Geological Survey of Spain is currently developing an indicator system to assess and follow-up on the state of conservation of geoheritage (García-Cortés et al. 2012).
In Great Britain, protocols for monitoring SSSIsthe basic domestic protected area system for abiotic and biotic interests-are in place (Ellis 2004). The geomorphological component is based in part on the work of Werritty et al. (1998), who provided a conceptual and methodological framework for monitoring geomorphological features and systems. The key attributes measured and the targets based on the classification in Table 18.6 are:

1. protected area attributes to be monitored

- 'visibility': factors to be monitored will be lack of concealment from vegetation/soil/talus buildups/engineering constructions 
- quality of appearance or lack of disturbance to the internal structure of features: the physical condition of rock, sediment, landform, spoil heap (for example, lack of disruption of sediments in a landform that are not yet visible); lack of fragmentation of exposure, no physical damage to important parts of rock faces, sediment stacks and landforms; quality and visibility are intimately linked attributes

- extent of features: for example, the quantity of geological material such as the volume of important spoil material in a mine dump, or area of rock face in an exposure site where it is advantageous to have a greater amount of rock exposure to study

- process dynamics: freedom of geomorphological processes to evolve naturally and unimpeded.

2. key indicators of favourable conservation condition

- landform elements remain unconcealed

- physical composition, morphology and internal structure of the key landforms and sediments remain intact and undisturbed by anthropogenic interventions

- extent of key geomorphological features is not diminished through physical damage or fragmentation

- natural geomorphological processes are unimpeded: the levels of activity of the geomorphological processes and their spatial domain retain the capacity to operate across their full range of natural variability

- geological exposure remains unconcealed, intact and unmodified by anthropogenic intervention

- extent of key geological features has not diminished: both vertical and lateral extent of features constant or increasing (Ellis 2004).

A broadly similar approach has been developed by the Tasmanian Government, which has identified three broad categories of geoconservation indicators

- data coverage indicators give the status of knowledge of geodiversity, which governs our ability to ensure the successful conservation of it

- site integrity indicators apply to sites of particular geoconservation significance, where the degree of physical integrity (or degradation) of the sites and features has been identified (for example, in the Tasmanian Geoconservation Database)

- process integrity indicators measure the degree of integrity or degradation of geomorphological and soil processes: these processes govern the longterm integrity of sites, features and systems of geoconservation significance, and the integrity of ecosystem processes generally. Process integrity indicators will provide a measure of the sustainability of natural landform and soil processes (RPDC 2013).

\section{Geoconservation expertise requirements and opportunities in protected area management}

The variety of geoheritage protected areas and the amount and variety of knowledge required to identify and manage them effectively mean there is a great need for specialist geoconservation expertise. Geological and geomorphological scientific knowledge is essential if the protected areas are to be robustly identified and placed within wider Earth heritage systems and if the networks of areas are to be kept up to date with new knowledge and new interpretations. The safety of workers and visitors is of paramount concern in geoconservation protected areas, so expertise in risk assessments and management prescriptions is essential. Predicting and coping with the effects of floods, tsunamis, earthquakes, volcanic eruptions and active geothermal sites, slope failures, cliff instability, and glacial and permafrost melt are all examples of the need for technical knowledge. There should be scope for employing local experts to undertake specialist jobs as well as ensuring that local and traditional knowledge is pursued to best effect.

Management of specific types of geoheritage protected areas, such as sites with moveable heritage (fossils, minerals) or with active processes (coastal areas, rivers, and so on), is needed to ensure the key values are maintained, and that external actions and changes do not deleteriously affect the key features and processes. The ability to communicate the importance of the features and processes of protected areas in a manner the public can understand and be inspired by is also an important requirement of specialist staff.

Protected area management teams should progressively incorporate Earth science expertise with the aim of achieving an integrated approach to nature conservation. Bringing together geological, biological and cultural heritage specialists in teams will help to ensure full comprehension and conservation of natural resources (Díaz-Martínez and Díez-Herrero 2011). 


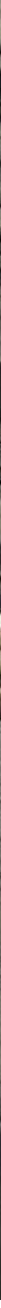

A spectacular massed Jurassic Ammonite fossil deposit (often referred to as an Ammonite graveyard) is exposed on an erosion-resistant shoreline pavement near Lyme Regis, Jurassic Coast, Dorset and East Devon World Heritage Property, England. This is a Site of Special Scientific Interest. The circular fossil Ammonites may be seen, as can their location across the platform as identified by multiple circular pools of water that pinpoint the selectively eroded fossils.

Source: Graeme L. Worboys

\section{Conclusion}

The Earth's geodiversity is an essential consideration in protected area management, particularly in the context of managing for nature, both abiotic and biotic. Geoheritage is constituted by those elements of geodiversity that have significant scientific, educational, cultural or aesthetic values. Such special geoheritage may be systematically categorised according to key stages in Earth's history; structural features; formation of minerals; evolution of life; Earth process; surface and subsurface features and records of past environmental condition (Table 18.2). Key examples of geoheritage phenomena need to be protected, such as in geoparks, as IUCN Category III protected areas, or within other IUCN protected area categories. Once established, active responses by protected area managers are needed to address threats such as mineral exploitation and infrastructure development. Responses incorporate planning and on-ground works, while guiding principles of management (Box 18.3) establish a framework for such action. As with other natural phenomena, monitoring condition, and trends in condition, form an integral part of active management.

\section{References}

Recommended reading

Anderson, M. G. and Ferree, C. E. (2010) 'Conserving the stage: climate change and the geophysical underpinnings of species diversity', PLoS ONE 5(7): e11554.

ASM-PACE (2013) Projects. <www.asm-pace.org/ projects.html>

DD Barettino, D., Wimbledon, W. A. P. and Gallego, E. (eds) (2000) Geological Heritage: Its conservation and management, Instituto Technológico Geominero de España, Madrid. <www.igme.es/patrimonio/ publicaciones/congresos/Barettino\%20et\%20al\%20 2000\%20-\%20ProGEO\%20Symposium $\% 20$ Madrid\%201999\%20EN.pdf> [English] and <www.igme.es/patrimonio/publicaciones/ congresos/Barettino\%20et $\% 20 \mathrm{al} \% 202000 \% 20$ -\%20ProGEO\%20Symposium \%20Madrid\%20 1999\%20ES.pdf> [Spanish]. 
Bridgland, D. R. (2013) 'Geoconservation of Quaternary sites and interests', Proceedings of the Geologists' Association 124: 612-24.

Brilha, J. (2002) 'Geoconservation and protected areas', Environmental Conservation 29(3): 273-6.

DD Brilha, J. (2005) Património Geológico e Geoconservação [Geoheritage and Geoconservation], [in Portuguese], Palimage, Braga. <geoduma.files. wordpress.com/2010/02/jb_livro.pdf>

Brilha, J., Andrade, C., Azerêdo, A., Barriga, F. J. A. S., Cachão, M., Couto, H., Cunha, P. P., Crispim, J.

A., Dantas, P., Duarte, L. V., Freitas, M. C., Granja, M. H., Henriques, M. H., Henriques, P., Lopes, L., Madeira, J., Matos, J. M. X., Noronha, F., Pais, J., Piçarra, J., Ramalho, M. M., Relvas, J. M. R. S., Ribeiro, A., Santos, A., Santos, V. and Terrinha, P. (2005) 'Definition of the Portuguese frameworks with international relevance as an input for the European geological heritage characterisation', Episodes 28: 177-86.

Dd Brocx, M. (2008) Geoheritage: From global perspectives to local principles for conservation and planning, Western Australian Museum, Perth.

Brocx, M. and Semeniuk, V. (2007) 'Geoheritage and geoconservation-history, definition, scope and scale', Journal of the Royal Society of Western Australia 90: 53-87.

Brocx, M. and Semeniuk, V. (2011) 'The global geoheritage significance of the Kimberley coast, Western Australia', Journal of the Royal Society of Western Australia 94: 57-88.

Brooks, A. J. (2013) Assessing the sensitivity of geodiversity features in Scotland's seas to pressures associated with human activities, Scottish Natural Heritage Commissioned Report No. 590, Inverness, Scotland. <www.snh.gov.uk/publications-dataand-research/publications/search-the-catalogue/ publication-detail/?id=2036>

Brooks, A. J., Kenyon, N. H., Leslie, A., Long, D. and Gordon, J. E. (2013) Characterising Scotland's marine environment to define search locations for new marine protected areas. Part 2: The identification of key geodiversity areas in Scottish waters, Scottish Natural Heritage Commissioned Report No. 432, Inverness, Scotland. <www.snh.gov.uk/publicationsdata-and-research/publications/search-thecatalogue/publication-detail/?id=2037>
Brown, E. J. (2004) Development of a framework for interpreting ice age landscapes in the Loch Lomond and The Trossachs National Park, Scottish Natural Heritage Commissioned Report No. 036, Inverness, Scotland. <www.snh.org.uk/pdfs/publications/ commissioned_reports/f98ac106a.pdf>

Bruschi, V. M., Cendrero, A. and Cuesta Albertos, J. A. (2011) 'A statistical approach to the validation and optimisation of geoheritage assessment procedures', Geoheritage 3: 131-49.

Burek, C. V. (2012) 'The role of LGAPs (Local Geodiversity Action Plans) and Welsh RIGS as local drivers for geoconservation within geotourism in Wales', Geoheritage 4: 45-63.

Burek, C. and Potter, J. (2006) Local Geodiversity Action Plans-setting the context for geological conservation, Natural England Report No. 560, Natural England, Sheffield. <publications.naturalengland.org.uk/publi cation $/ 137007$ ? category $=30050>$

Carcavilla, L., Delvene, G., Díaz-Martínez, E., GarcíaCortés, A., Lozano, G., Rábano, I., Sánchez, A. and Vegas, J. (2012) Geodiversidad y Patrimonio Geológico [Geodiversity and Geological Heritage], [in Spanish], 2nd edn, Instituto Geológico y Minero de España, Madrid. <www.igme.es/patrimonio/ novedades/Folleto_Patrimonio2edicion.pdf>

Carcavilla, L., Durán, J. J. and López-Martínez, J. (2008) 'Geodiversidad: concepto y relación con el patrimonio geológico [Geodiversity: concept and relationship with geological heritage]', [in Spanish], Geo-Temas 10: 1299-303. <www.igme.es/ patrimonio/descargas/concepto_Geodiversidad.pdf>

DDd Carcavilla, L., López-Martínez, J. and Durán, J. J. (2007) Patrimonio geológico y geodiversidad: investigación, conservación, gestión y relación con los espacios naturales protegidos [Geoheritage and Geodiversity: Assessment, conservation, management and relationship with protected areas], [in Spanish], Cuadernos del Museo Geominero Volume 7 , Instituto Geológico y Minero de España, Madrid.

Coratza, P. and Panizza, M. (eds) (2009)

'Geomorphology and cultural heritage', Memorie Descrittive della Carta Geologica d'Italia 87.

Crofts, R. and Gordon, J.E. (2014) 'Geoheritage conservation in protected areas', Parks 20(2): 61-76. 
Cruikshank, J. (2005) Do Glaciers Listen? Local knowledge, colonial encounters, and social imagination, University of British Columbia Press, Vancouver, and University of Washington Press, Seattle.

Department for Environment, Food and Rural Affairs (DEFRA) (2006) Local Sites: Guidance on their identification, selection and management, Department for Environment, Food and Rural Affairs, London. $<$ archive.defra.gov.uk/rural/documents/protected/ localsites.pdf>

Department for Environment, Food and Rural Affairs (DEFRA) (2010) Charting Progress 2. The state of UK seas, Department for Environment, Food and Rural Affairs, London. <chartingprogress.defra.gov.uk>

Department of Primary Industries, Parks, Water and Environment (DPIPWE) (2014) Tasmanian Geoconservation Database, Tasmanian Department of Primary Industries, Parks, Water and Environment, Hobart. <dpipwe.tas.gov. $\mathrm{au} /$ conservation/geoconservation/tasmaniangeoconservation-database $>$

Díaz-Martínez, E. (2011) Typology of heritage: where does geoheritage fit in?, Forum GeoReg, Villeneuve d'Ascq, France, 23-27 October 2011, 'Résumés/Abstracts': 102. <www. igme.es/patrimonio/publicaciones/congresos/ D\%C3\%ADaz-Mart\%C3\%ADnez\%202011\%20 -\%20Typology\%20of\%20geoheritage \%20-\%20 GeoReg\%20\&\%20SW-ProGEO\%20Meeting.pdf>

Díaz-Martínez, E. and Díez-Herrero, A. (2011) 'Los elementos biológicos y culturales de interés geológico: un patrimonio a conservar [Biological and cultural elements with geological interest: a heritage for conservation]', [in Spanish], in E. Fernández-Martínez and R. Castaño de Luis (eds) Avances y Retos en la Conservación del Patrimonio Geológico en España [Advances and Challenges in the Conservation of Geoheritage in Spain], pp. 85-90, University of León, León. <www. igme.es/patrimonio/publicaciones/congresos/ Díaz-Martínez\%20y\%20Díez-Herrero\%20 2011\%20-\%20Elementos\%20biológicos\%20y\%20 culturales $\% 20 \mathrm{de} \% 20$ interés $\% 20$ geológico.pdf>

Dingwall, P., Weighell, T. and Badman, T. (2005) Geological World Heritage: A global framework. A contribution to the Global Theme Study of World Heritage Natural Sites, IUCN, Gland.
Dobbie, K. E., Bruneau, P. M. C. and Towers, W. (eds) (2011) The State of Scotland's Soil, Natural Scotland, Edinburgh. <www.sepa.org.uk/land/ land_publications.aspx>

Dolan, M. F. J., Buhl-Mortensen, P., Thorsnes, T., Buhl-Mortensen, L., Bellec, V. and Bøe, R. (2009) 'Developing seabed nature-type maps offshore Norway: initial results from the MAREANO programme', Norwegian Journal of Geology 89: $17-28$.

Dowling, R. K. and Newsome, D. (eds) (2010) Global Geotourism Perspectives, Goodfellow Publishers, Oxford.

Dudley, N. (ed.) (2008) Guidelines for Applying Protected Area Management Categories, IUCN, Gland.

Durán, J. J., Brusi, D., Pallí, L., López-Martínez, J., Palacio, J. and Vallejo, E. (1998) 'Geología ecológica, geodiversidad, geoconservación y patrimonio geológico: la Declaración de Girona [Ecological geology, geodiversity, geoconservation and geological heritage: the Declaration of Girona]', [in Spanish], in J. J. Durán and M. Vallejo (eds) Comunicaciones de la IV Reunión Nacional de Patrimonio Geológico [Proceedings of the 4th National Meeting on Geoheritage], pp. 69-72, Geological Society of Spain, Miraflores de la Sierra.

Ellis, N. (2004) Common Standards Monitoring Guidance for Earth Science Sites. Joint Nature Conservation Committee, Peterborough, UK. <jncc.defra.gov.uk/pdf/CSM_earth_science.pdf>

Ellis, N. (2011) 'The Geological Conservation Review (GCR) in Great Britain: rationale and methods', Proceedings of the Geologists' Association 122: 353-62.

English Nature (2004) Local Geodiversity Action Plans. Sharing good practice, Natural England, Peterborough, UK. <publications.naturalengland. org.uk/publication/76016? category $=30050>$

Erikstad, L. (2012) 'Geoheritage and geodiversity management-the questions for tomorrow', Proceedings of the Geologists' Association 122: 713-19.

Erikstad, L., Lindblom, I., Jerpåsen, G., Hanssen, M. A., Bekkby, T., Stabbetorp, O. and Bakkestuen, V. (2008) 'Environmental value assessment in a multidisciplinary EIA setting', Environment Impact Assessment Review 28: 131-43. 
Fassoulas, C., Mouriki, D., Dimitriou-Nikolakis, P. and Iliopoulos, G. (2011) 'Quantitative assessment of geotopes as an effective tool for geoheritage management', Geoheritage 4: 177-93.

Ferrero, E., Giardino, M., Lozar, F., Giordano, E., Belluso, E. and Perotti, L. (2012) 'Geodiversity action plans for the enhancement of geoheritage in the Piemonte region (north-western Italy)', Annals of Geophysics 55: 487-95.

Fuertes-Gutiérrez, I. and Fernández-Martinez, E. (2010) 'Geosites inventory in the Leon Province (northwestern Spain): a tool to introduce geoheritage into regional environmental management', Geoheritage 2: 57-75.

García-Cortés, A., Águeda Villar, J., Palacio SuárezValgrande, J. and Salvador González, C. I. (eds) (2009) Spanish Geological Frameworks and Geosites. An approach to Spanish geological heritage of international relevance, Instituto Geológico y Minero de España, Madrid. <www.igme.es/ patrimonio/GEOSITES/publication.htm>

García-Cortés, A., Rábano, I., Locutura, J., Bellido, F., Fernández-Gianotti, J., Martín-Serrano, A., Quesada, C., Barnolas, A. and Durán, J. J. (2001) 'First Spanish contribution to the Geosites Project: list of the geological frameworks established by consensus', Episodes 24: 79-92.

García-Cortés, A., Vegas, J., Carcavilla, L. and DíazMartínez, E. (2012) 'Un sistema de indicadores para la evaluación y seguimiento del estado de conservación del patrimonio geológico [An indicator system to assess and follow up the state of conservation of geological heritage]', Geo-Temas 13: 1272-5. <www.igme.es/patrimonio/publicaciones/ congresos/García \%20Cortés\%20et\%20al\%20 2012\%20-\%20Sistema\%20de\%20indicadores\%20 para $\% 20$ estado\%20conservación\%20PG.pdf>

Geological Society of America (GSA) (2012) GSA Position Statement: Geoheritage, Boulder, CO.

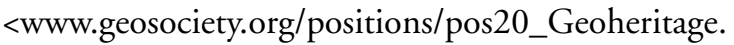
pdf>

Gillson, L. and Marchant, R. (2014) 'From myopia to clarity: sharpening the focus of ecosystem management through the lens of palaeoecology', Trends in Ecology and Evolution 29: 317-25.
Gordon, J. E. and Barron, H. F. (2011) Scotland's geodiversity: development of the basis for a national framework, Scottish Natural Heritage Commissioned Report No. 417, Inverness, Scotland. <www.snh.org.uk/pdfs/publications/ commissioned_reports/417.pdf>

Gordon, J. E., Barron, H. F., Hansom, J. D. and Thomas, M. F. (2012) 'Engaging with geodiversity-why it matters', Proceedings of the Geologists' Association 123: 1-6.

Gordon, J. E., Brooks, A. J., Rennie, A. G., James, B. D., Chaniotis, P. D., Kenyon, N. H., Leslie, A. B. and Long, D. (2013) The selection of Nature Conservation Marine Protected Areas (MPAs) _ assessment of geodiversity interests, Scottish Natural Heritage Commissioned Report No. 633, Inverness, Scotland. <www.snh.org.uk/pdfs/publications/ commissioned_reports/633.pdf>

Gray, M. (2004) Geodiversity: Valuing and conserving abiotic nature, Wiley, Chichester, UK. <geoduma. files.wordpress.com/2010/02/geodiversity.pdf>

Gray, M. (2008) 'Geodiversity: the origin and evolution of a paradigm', in C. V. Burek and C. D. Prosser (eds) The History of Geoconservation, Special Publications 300, pp. 31-6, The Geological Society, London.

Gray, M. (2011) 'GSSPs: the case for a third, internationally recognised, geoconservation network', Geoheritage 3: 83-8.

DD Gray, M. (2013) Geodiversity: Valuing and conserving abiotic nature, 2nd edn, Wiley-Blackwell, Chichester, UK.

Gray, M., Gordon, J. E. and Brown, E. J. (2013) 'Geodiversity and the ecosystem approach-the contribution of geoscience in delivering integrated environmental management', Proceedings of the Geologists' Association 124: 659-73.

Ham, S. (1992) Environmental Interpretation: A practical guide for people with big ideas and small budgets, North America Press, Golden, CO.

Ham, S. (2007) 'From interpretation to protection', Interpretation Journal 12(3): 20-3. <www.ahi.org. uk/include/pdf/TVSpapers/AHI_journal_The_ Vital_Spark.pdf> 
Haygarth, P. M. and Ritz, K. (2009) 'The future of soils and land use in the UK: soil systems for the provision of land-based ecosystem services', Land Use Policy 26S: S187-97.

Hopkins, J. J., Allison, H. M., Walmsley, C. A., Gaywood, M. and Thurgate, G. (2007) Conserving Biodiversity in a Changing Climate: Guidance on building capacity to adapt, Department for Environment, Food and Rural Affairs, London. <webarchive.nationalarchives.gov. uk/20110303145213/http:/ukbap.org.uk/Library/ BRIG/CBCCGuidance.pdf>

Houshold, I. and Sharples, C. (2008) 'Geodiversity in the wilderness: a brief history of geoconservation in Tasmania, in C. V. Burek and C. D. Prosser (eds) The History of Geoconservation, Special Publications 300, pp. 257-72, The Geological Society, London.

Hutton, J. (1785) Abstract of a Dissertation Read in the Royal Society of Edinburgh, upon the Seventh of March, and Fourth of April, MDCCLXXXV, Concerning the System of the Earth, its Duration, and Stability, Edinburgh. <facstaff.gpc.edu/ -janderso/ historic/hutton.htm>

International Council on Mining and Minerals (ICMM) (2003) Mining and Protected Areas: Position statement, London. <www.icmm.com/ document/43>

International Union for Conservation of Nature (IUCN) (2008) Resolutions and Recommendations adopted at the 4th IUCN World Conservation Congress. Resolution 4040: Conservation of geodiversity and geological heritage, IUCN, Gland. <https://portals.iucn.org/library/node/44190>

International Union for Conservation of Nature (IUCN) (2012) Resolutions and Recommendations, World Conservation Congress, Jeju, Republic of Korea, 6-15 September 2012, WCC-2012-Res-048-EN Valuing and conserving geoheritage within the IUCN Programme 2013-2016, IUCN, Gland, pp. 5-6. <https://portals.iucn.org/library/node/44015>

International Union for Conservation of Nature (IUCN) (2013) IUCN World Heritage Advice Note: Mining and oil/gas projects, IUCN, Gland. $<$ cmsdata.iucn.org/downloads/iucn_advice_note_ on_mining_in_wh_sites_final_060512_2_.pdf>
Johansson, C. E. (ed.) (2000) Geodiversitet i Nordisk Naturvard [Geodiversity in Nordic Nature Management; in Swedish], Nordic Council of Ministers, Copenhagen.

Joyce, E. B. (2010) 'Australia's geoheritage: history of study, a new inventory of geosites and applications to geotourism and geoparks', Geoheritage 2: 39-56.

Katla Geopark (2014) Katla Geopark. <www. katlageopark.is/>

Kiernan, K. (1996) Conserving Geodiversity and Geoheritage: The conservation of glacial landforms, Forest Practices Unit, Hobart.

Kirkbride, V. and Gordon, J. E. (2010) The geomorphological heritage of the Cairngorm Mountains, Scottish Natural Heritage Commissioned Report No. 348, Inverness, Scotland. <www.snh.org.uk/pdfs/publications/ commissioned_reports/348.pdf>

Lawrence, D. J. D., Arkley, S. L. B, Everest, J. D., Clarke, S. M., Millward, D., Hyslop, E. K., Thompson, G. L. and Young B. (2007) Northumberland National Park Geodiversity Audit and Action Plan, British Geological Survey Commissioned Report No. CR/07/037N, Hexham, UK. <www.northumberlandnationalpark.org.uk/ data/assets/pdf_file/0005/147524/geodiversity_ audit_hi.pdf>

Lawrence, D. J. D., Vye, C. L. and Young, B. (2004) Durham Geodiversity Audit, Durham County Council, Durham, UK. <content.durham.gov.uk/ PDFRepository/County_Durham_Geodiversity_ Audit.pdf>

Lima, F., Brilha, J. and Salamuni, E. (2010) 'Inventorying geological heritage in large territories: a methodological proposal applied to Brazil', Geoheritage 2: 91-9.

Lockwood, M., Worboys, G. L. and Kothari, A. (eds) (2006) Managing Protected Areas: A global guide, Earthscan, London.

McKeever, P. J., Zouros, N. and Patzak, M. (2010) 'The UNESCO Global Geoparks Network', European Geoparks Magazine 7: 10-13. <www. scribd.com/doc/80356479/EGN-Magazine-Issue-7> 
Matthews, T. J. (2014) 'Integrating geoconservation and biodiversity conservation: theoretical foundations and conservation recommendations in a European Union context', Geoheritage 6: 57-70.

Millennium Ecosystem Assessment (MEA) (2005) Ecosystems and Human Well-Being: Synthesis, Island Press, Washington, DC.

National Museums Northern Ireland (2003) Geological Sites in Northern Ireland: Earth science conservation review, Holywood. <www.habitas.org.uk/escr/index. html>

National Park Service (NPS) (2014a) National Fossil Day, National Park Service, Washington, DC. $<$ nature.nps.gov/geology/nationalfossilday/>

National Park Service (NPS) (2014b) North Cascades, National Park Service, Washington, DC. <www.nps. gov/noca/index.htm>

Natural England (2014) Geology and Geodiversity, Natural England, Peterborough, UK. $<$ http://publications.naturalengland.org.uk/ category/30050>

Newsome, D. and Dowling, R. K. (eds) (2010) Geotourism: The tourism of geology and landscape, Goodfellow Publishers, Oxford.

Nieto, L. M. (2001) 'Geodiversidad: propuesta de una definición integradora [Geodiversity: proposal of an integrative definition]', [in Spanish], Boletín Geológico y Minero 112(2): 3-12.

Ontario Ministry of Municipal Affairs and Housing (2012) Land Use Planning: The Oak Ridges Moraine. $<$ www.mah.gov.on.ca/Page322.aspx>

Panizza, M. (2001) 'Geomorphosites: concepts, methods and example of geomorphological survey', Chinese Science Bulletin 46: 4-6.

Pellitero, R., González-Amuchastegui, M. J., RuizFlaño, P. and Serrano, E. (2011) 'Geodiversity and geomorphosite assessment applied to a natural protected area: the Ebro and Rudron Gorges Natural Park (Spain)', Geoheritage 3: 163-74.

Pereira, P., Pereira, D. and Caetano Alves, M. I. (2007) 'Geomorphosite assessment in Montesinho Natural Park', Geographica Helvetica 62: 159-68. Supplement.
ProGEO (2011) Conserving Our Shared Geoheritage: A protocol on geoconservation principles, sustainable site use, management, fieldwork, fossil and mineral collecting, European Association for the Conservation of the Geological Heritage, Uppsala, Sweden. <www.progeo.se/progeo-protocoldefinitions-20110915.pdf $>$

Prosser, C. D. (2011) 'Principles and practice of geoconservation: lessons and case law arising from a legal challenge to site-based conservation on an eroding coast in eastern England, UK', Geoheritage 3: $277-87$.

Prosser, C. D. (2013) 'Our rich and varied geoconservation portfolio: The foundation for the future', Proceedings of the Geologists' Association 124: 568-80.

Prosser, C. D., Burek, C. V., Evans, D. H., Gordon, J. E., Kirkbride, V. B., Rennie, A. F. and Walmsley, C. A. (2010) 'Conserving geodiversity sites in a changing climate: management challenges and responses', Geoheritage 2: 123-36.

Dd Prosser, C., Murphy, M. and Larwood, J. (2006) Geological Conservation: A guide to good practice, Natural England, Peterborough, UK. <publications. naturalengland.org.uk/publication/83048>

Resource Planning and Development Commission (RPDC) (2013) 'Land, geodiversity and geoconservation', in State of the Environment Report: Tasmania, Hobart. <soer.justice.tas.gov.au/2003/ lan/2/issue/77/index.php\#zmanagement>

Reynard, E. (2009a) 'The assessment of geomorphosites', in E. Reynard, P. Coratza and G. Regolini-Bissig (eds) Geomorphosites, pp. 63-71, Verlag Dr. Friedrich Pfeil, Munich.

Reynard, E. (2009b) 'Geomorphosites: definitions and characteristics', in E. Reynard, P. Coratza and G. Regolini-Bissig (eds) Geomorphosites, pp. 9-20, Verlag Dr. Friedrich Pfeil, Munich.

Reynard, E., Coratza, P. and Regolini-Bissig, G. (eds) (2009) Geomorphosites, Verlag Dr. Friedrich Pfeil, Munich.

Reynard, E., Fontana, G., Kozlik, L. and Scapozza, C. (2007) 'A method for assessing "scientific" and "additional values" of geomorphosites', Geographica Helvetica 62: 148-58. 
Rovere, A., Vacchi, M., Parravicini, V., Bianchi, C. N., Zouros, N. and Firpo, M. (2011) 'Bringing geoheritage underwater: definitions, methods, and application in two Mediterranean marine areas', Environmental Earth Sciences 64: 133-42.

Santucci, V. L. (2005) 'Historical perspectives on biodiversity and geodiversity', George Wright Forum 22(3): 29-34.

Santucci, V. L. and Koch, A. L. (2003) 'Paleontological resource monitoring strategies for the National Park Service', Park Science 22(1): 22-5.

Santucci, V. L., Kenworthy, J. P. and Mims, A. L. (2009) 'Monitoring in situ paleontological resources', in R. Young and L. Norby (eds) Geological Monitoring, pp. 189-204, Geological Society of America, Boulder, CO.

Scottish Geodiversity Forum (2013) Scotland's Geodiversity Charter. <scottishgeodiversityforum. org/charter/>

Scottish Natural Heritage (2000) A Guide to Managing Coastal Erosion in Beach/Dune Systems, Scottish Natural Heritage, Battleby, Scotland. <www.snh. gov.uk/publications-data-and-research/publications/ search-the-catalogue/publication-detail/?id=112>

Scottish Natural Heritage (2006) Guidance on Establishing and Managing Local Nature Conservation Site Systems in Scotland, Scottish Natural Heritage, Battleby, Scotland. <www.snh. gov.uk/publications-data-and-research/publications/ search-the-catalogue/publication-detail/?id=562>

Scottish Natural Heritage (2011) Interpretive Planning, Scottish Natural Heritage, Battleby, Scotland. $<$ www.snh.gov.uk/policy-and-guidance/heritageinterpretation/interpretive-planning/>

Semeniuk, V., Semeniuk, C. A., Tauss, C., Unno, J. and Brocx, M. (2011) Walpole and Nornalup Inlets: Landforms, stratigraphy, evolution, hydrology, water quality, biota, and geoheritage, Wetlands Research Association, Western Australian Museum, Perth.

Sharples, C. (1993) A Methodology for the Identification of Significant Landforms and Geological Sites for Geoconservation Purposes, Technical Report, Forestry Commission Tasmania, Hobart.
Sharples, C. (2002) Concepts and Principles of Geoconservation, Tasmanian Parks and Wildlife Service, Hobart. <www.dpiw.tas.gov.au/inter. nsf/Attachments/SJON-57W3YM/\$FILE/ geoconservation.pdf>

Sharples, C. (2011) Potential Climate Change Impacts on Geodiversity in the Tasmanian Wilderness World Heritage Area: a management response position paper, Nature Conservation Report Series 11/04, Resource Management and Conservation Division, Department of Primary Industries, Parks, Water and Environment, Hobart. <www.dpiw.tas.gov.au/inter. nsf/Attachments/LJEM-8P983Y?open>

Stace, H. and Larwood, J. G. (2006) Natural Foundations: Geodiversity for people, places and nature, Natural England, Peterborough, UK. <publications.naturalengland.org.uk/ publication/60005>

The River Restoration Centre (RRC) (2013) Manual of River Restoration Techniques, The River Restoration Centre, Cranfield, UK. <www.therrc.co.uk/rrc_ manual.php>

Thorsnes, T., Erikstad, L., Dolan, M. F. J. and Bellec, V. (2009) 'Submarine landscapes along the LofotenVesterålen-Senja margin, northern Norway', Norwegian Journal of Geology 89: 5-16.

Tilden, F. (1977) Interpreting Our Heritage, 3rd edn, University of North Carolina Press, Chapel Hill.

Towers, W., Malcolm, A. and Bruneau, P. (2005) Assessing the nature conservation value of soil and its relation with designated features, Scottish Natural Heritage Commissioned Report No. 111, Inverness, Scotland. <www.snh.org.uk/pdfs/publications/ commissioned_reports/F03AC104.pdf>

UK Geodiversity Action Plan (UKGAP) (2014) UK Geodiversity Action Plan. <www.ukgap.org.uk/>

United Nations Educational, Scientific and Cultural Organisation (UNESCO) (2010) Guidelines and Criteria for National Geoparks Seeking UNESCO's Assistance to Join the Global Geoparks Network $(G G N)$, UNESCO, Paris. <www.globalgeopark.org/ UploadFiles/2012_9_6/GGN2010.pdf>

United Nations Educational, Scientific and Cultural Organisation (UNESCO) (2014a) Earth Sciences: Global Geoparks, UNESCO, Paris. <www.unesco. $\mathrm{org} /$ new/en/natural-sciences/environment/earthsciences/global-geoparks/> 
United Nations Educational, Scientific and Cultural Organisation (UNESCO) (2014b) World Heritage List, UNESCO, Paris. <whc.unesco.org/en/list>

United Nations Educational, Scientific and Cultural Organisation (UNESCO) (2014c) Main Characteristics of Biosphere Reserves, UNESCO, Paris. <www.unesco.org/new/en/natural-sciences/ environment/ecological-sciences/biosphere-reserves/ main-characteristics>

Veverka, J. A. (1994) Interpretive Master Planning, Falcon Press, Helena, MT.

Werritty, A., Duck, R. W. and Kirkbride, M. P. (1998) Development of a conceptual and methodological framework for monitoring site condition in geomorphological systems, Scottish Natural Heritage Research, Survey and Monitoring Report No. 105, Inverness, Scotland. <www.snh.org.uk/pdfs/ publications/research/105.pdf>

Wimbledon, W. A. P. and Smith-Meyer, S. (eds) (2012) Geoheritage in Europe and its Conservation, ProGEO, Oslo.

Dd Wimbledon, W. A. P., Barnard A. F. and Peterken A. G. (2004) 'Geosite management: a widely applicable, practical approach', in M. A. Parkes (ed.) Natural and Cultural Landscapes: The geological foundation, pp. 187-92, Royal Irish Academy, Dublin.

Wimbledon, W. A. P., Ishchenko, A. A., Gerasimenko, N. P., Karis, L. O., Suominen, V., Johansson, C. E. and Freden, C. (2000) 'Geosites: an IUGS initiative - science supported by conservation', in D. Barettino, W. A. P. Wimbledon and E. Gallego (eds) Geological Heritage: Its conservation and management, pp. 69-94, Instituto Technológico Geominero de España, Madrid. <www.igme.es/patrimonio/ publicaciones/Wimbledon_et_al_2000_english. PDF>

Worboys, G. L. (2013) Conserving Australia's Geoheritage, Department of the Environment, Canberra. <www.environment.gov.au/system/files/ pages/f4d5ba7d-e4eb-4ced-9c0e-104471634fbb/ files/essay-conserving-worboys.pdf> 


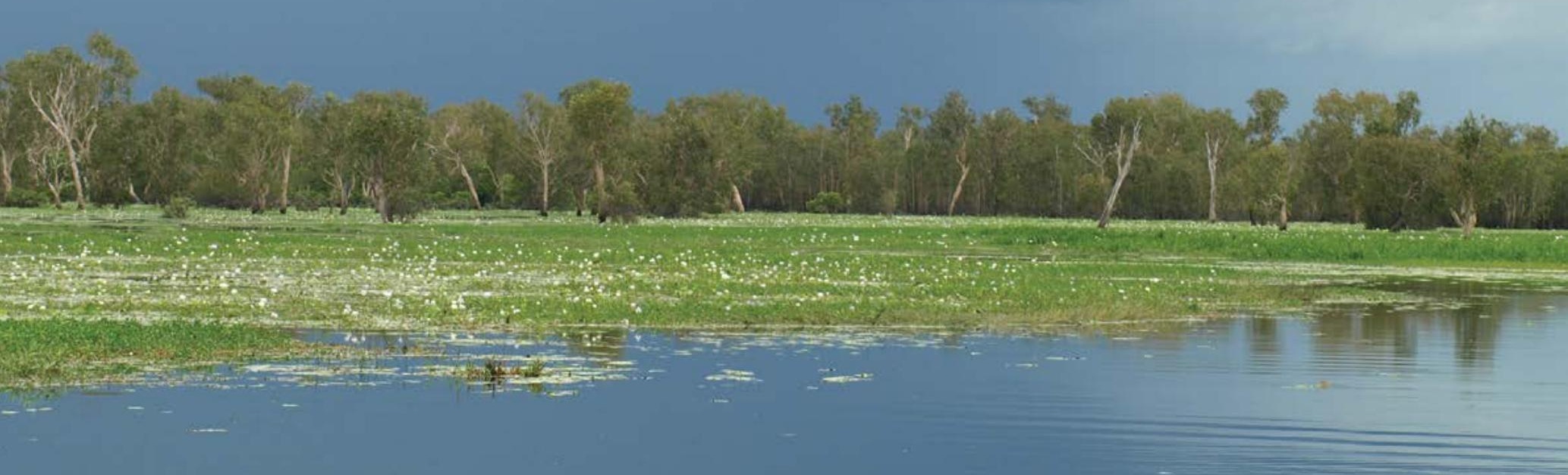

\section{CHAPTER 19}

\section{MANAGING FRESHWATER, RIVER, WETLAND AND ESTUARINE PROTIECTED AREAS}

\section{Principal author:}

Jamie Pittock

\section{Supporting authors:}

Max Finlayson, Angela H. Arthington, Dirk Roux, John H. Matthews, Harry Biggs, Esther Blom, Rebecca Flitcroft, Ray Froend, lan Harrison, Virgilio Hermoso, Wolfgang Junk, Ritesh Kumar, Simon Linke, Jeanne Nel, Catia Nunes da Cunha, Ajit Pattnaik, Sharon Pollard, Walter Rast, Michele Thieme, Eren Turak Jane Turpie, Lara van Niekerk, Daphne Willems and Joshua Viers

\section{CONTENTS}

- Introduction

- Freshwater ecosystems

- Managing specific freshwater ecosystems

- Managing freshwater protected areas in the landscape

- Conclusion

- References

\section{IUCN Biological Diversity}




\section{PRINCIPAL AUTHOR}

JAMIE PITTOCK is Associate Professor in the Fenner School of Environment and Society at The Australian National University, Canberra.

\section{SUPPORTING AUTHORS}

MAX FINLAYSON is Director of the Institute for Land, Water and Society and Professor for Ecology and Biodiversity at Charles Sturt University, Australia.

ANGELA H. ARTHINGTON is Emeritus Professor in the Faculty of Environmental Science at Griffith University, Brisbane, Australia.

JOHN H. MATTHEWS is Co-Chair of the Alliance for Global Water Adaptation (AGWA) and Director of Freshwater and Climate Change for Conservation International, USA.

DIRK ROUX is a freshwater conservation scientist at South African National Parks and at the Sustainability Research Unit, Nelson Mandela Metropolitan University, South Africa.

HARRY BIGGS is with South African National Parks.

ESTHER BLOM is Head of the Freshwater Programme for the World Wide Fund for Nature (WWF), the Netherlands.

REBECCA FLITCROFT is a Research Fish Biologist with the US Forest Service at the Pacific Northwest Research Station, Oregon, USA.

RAY FROEND is a Professor in Environmental Management and Director of the Centre for Ecosystem Management at Edith Cowan University, Australia.

IAN HARRISON is Senior Manager in the Center for Environment and Peace, Conservation International, USA.

VIRGILIO HERMOSO is a Research Fellow in the Australian Rivers Institute, Griffith University, Australia.

WOLFGANG JUNK is affiliated with the Working Group of Tropical Ecology at Max Planck-Institute for Limnology in Germany and the National Institute of Science and Technology in Wetlands (INCTINAU) at the Federal University of Mato Grosso, Brazil.

RITESH KUMAR is the Conservation Program Manager of Wetlands International South Asia, India.

SIMON LINKE is a Senior Research Fellow in the Australian Rivers Institute, Griffith University, Australia.

JEANNE NEL is a Principal Researcher at the Council for Scientific and Industrial Research in South Africa.

CATIA NUNES DA CUNHA is a Professor in the Instituto de Biociências at the Universidade Federal de Mato Grosso in Cuiabá, Brazil.

AJIT PATTNAIK is the Chief Executive of Chilika Development Authority, India.

SHARON POLLARD is Director of the Association for Water and Rural Development, South Africa.

WALTER RAST is Director of International Watershed Studies, Meadows Center for Water and the Environment, at Texas State University, USA.

MICHELE THIEME is a Senior Freshwater Conservation Scientist with WWF, USA

EREN TURAK is Senior Team Leader and Research Scientist at the NSW Office of Environment and Heritage, Australia.
JANE TURPIE is Director of Anchor Environmental Consultants and Deputy Director of the Environmental Economics Policy Research Unit at the University of Cape Town, South Africa.

LARA VAN NIEKERK is a Senior Scientist at the Council for Scientific and Industrial Research in South Africa.

DAPHNE WILLEMS is a senior river ecologist working in the field of integral nature development for Stroming BV/Daphnia-Vision on Rivers, the Netherlands.

JOSHUA VIERS is an Associate Professor in the School of Engineering, University of California Merced, USA.

\section{ACKNOWLEDGMENTS}

We thank Heidi Congdon for help in producing this chapter and the photographers who made their images available. Graeme Worboys and lan Pulsford were most patient managing editors. Lori Simmons (US NPS) and Clive Hilliker (ANU) did a wonderful job drafting and harmonising the figures. We also thank the anonymous reviewers and publishing staff who have enhanced this text, and our respective supporting agencies.

\section{CITATION}

Pittock, J., Finlayson, M., Arthington, A. H., Roux, D., Matthews, J. H., Biggs, H., Harrison, I., Blom, E., Flitcroft, R., Froend, R., Hermoso, V., Junk, W., Kumar, R., Linke, S., Nel, J., Nunes da Cunha, C., Pattnaik, A., Pollard, S., Rast, W., Thieme, M., Turak, E., Turpie, J., van Niekerk, L., Willems, D. and Viers, J. (2015) 'Managing freshwater, river, wetland and estuarine protected areas', in G. L. Worboys, M. Lockwood, A. Kothari, S. Feary and I. Pulsford (eds) Protected Area Governance and Management, pp. 569-608, ANU Press, Canberra.

\section{TITLE PAGE PHOTO}

Ramsar and World Heritage-inscribed wetlands, Kakadu National Park, Australia

Source: Graeme L. Worboys 


\section{Introduction}

Better practices for managing inland aquatic ecosystems in protected areas - including rivers, other brackish and freshwater ecosystems, and coastal estuaries - are the focus of this chapter. Most natural protected areas are designated as 'terrestrial' or 'marine', and the obvious question for most managers is 'why should I worry about the (usually) small portion of my protected area that involves freshwater habitat'.

On the contrary, in this chapter, we argue that freshwater and estuarine habitats are significant for conserving biodiversity in most land-based protected areas and that managers need to apply the freshwater-specific conservation tools outlined here to do a good job. Freshwater ecosystems have the greatest species diversity per unit area, a larger portion of freshwater and estuarine species are threatened, and the ecosystem services of these biomes are used unsustainably to a greater extent than any other biomes (MEA 2005; Dudgeon et al. 2006). Many terrestrial species depend on freshwater ecosystems. Rather than a marginal part of management, freshwater conservation is central to sustaining protected areas and their biodiversity.

We start by defining inland aquatic ecosystems. We then examine the principles and processes that are essential to conservation of freshwater ecosystems and aquatic species. Briefly, we introduce the threats to freshwater ecosystems and the flow-on implications for protected area design. A number of the counterintuitive implications for and conflicts between terrestrial versus freshwater protected area design and management are then detailed. Case studies are used to illustrate principles and practices applied around the world.

The next section of the chapter considers the specific management needs of rivers and swamps, lakes, peatlands, groundwater-dependent ecosystems and estuaries. Methods and options for providing environmental flows to conserve biodiversity and ecosystem services are summarised. We then turn to management of fresh waters in protected areas in the broader landscape, showing how natural resource governance processes can be harnessed to better manage freshwater biodiversity in protected areas. The final section is vital for all protected areas with freshwater components, addressing how we can adapt to climate change.

\section{Freshwater ecosystems}

\section{Defining freshwater ecosystems}

The terms (non-marine) wetlands and freshwater ecosystems are used interchangeably in this chapter. In the parlance of the Convention on Biological Diversity (CBD 2010), freshwater ecosystems are called 'inland waters'. Wetlands are places where water is the primary factor controlling plant and animal life and the wider environment, where the water table is at or near the land surface, or where water covers the land. The Ramsar Convention on Wetlands defines wetlands as 'areas of marsh, fen, peatland or water, whether natural or artificial, permanent or temporary, with water that is static or flowing, fresh, brackish or salt, including areas of marine water the depth of which at low tide does not exceed six metres' (Ramsar 2009a:Art. 1, Clause 1).

Consequently, saline wetlands are included in this chapter. Marine wetlands are considered in Chapter 20. Riverine and 'marshy' wetlands along rivers are the focus of the section on environmental flows and wetland water regimes. Peatlands, groundwater-dependent ecosystems, lakes and estuarine wetlands are discussed in separate sections. Next we describe the diversity and distribution of freshwater ecosystems in greater detail.

\section{Diversity and distribution of freshwater ecosystems}

There is a tremendous diversity of freshwater ecosystems and many approaches for classifying them at different scales (Finlayson and van der Valk 1995; Higgins et al. 2005). At the global scale, freshwater ecosystems have been grouped into 426 freshwater ecoregions that largely follow watershed divides and capture the distributions of freshwater fish and ecological and evolutionary patterns (Abell et al. 2008). Lehner and Döll (2004) used remote sensing to map wetland occurrence to present a global map of wetland distribution (Figure 19.1). At a more granular level, many governments have mapped wetland systems within their borders-for example, the State of Queensland in Australia (Government of Queensland 2014). Despite such efforts, data for wetland distribution and extent vary considerably (Table 19.1) due to differences in definitions and approaches used for mapping (Finlayson et al. 1999). 


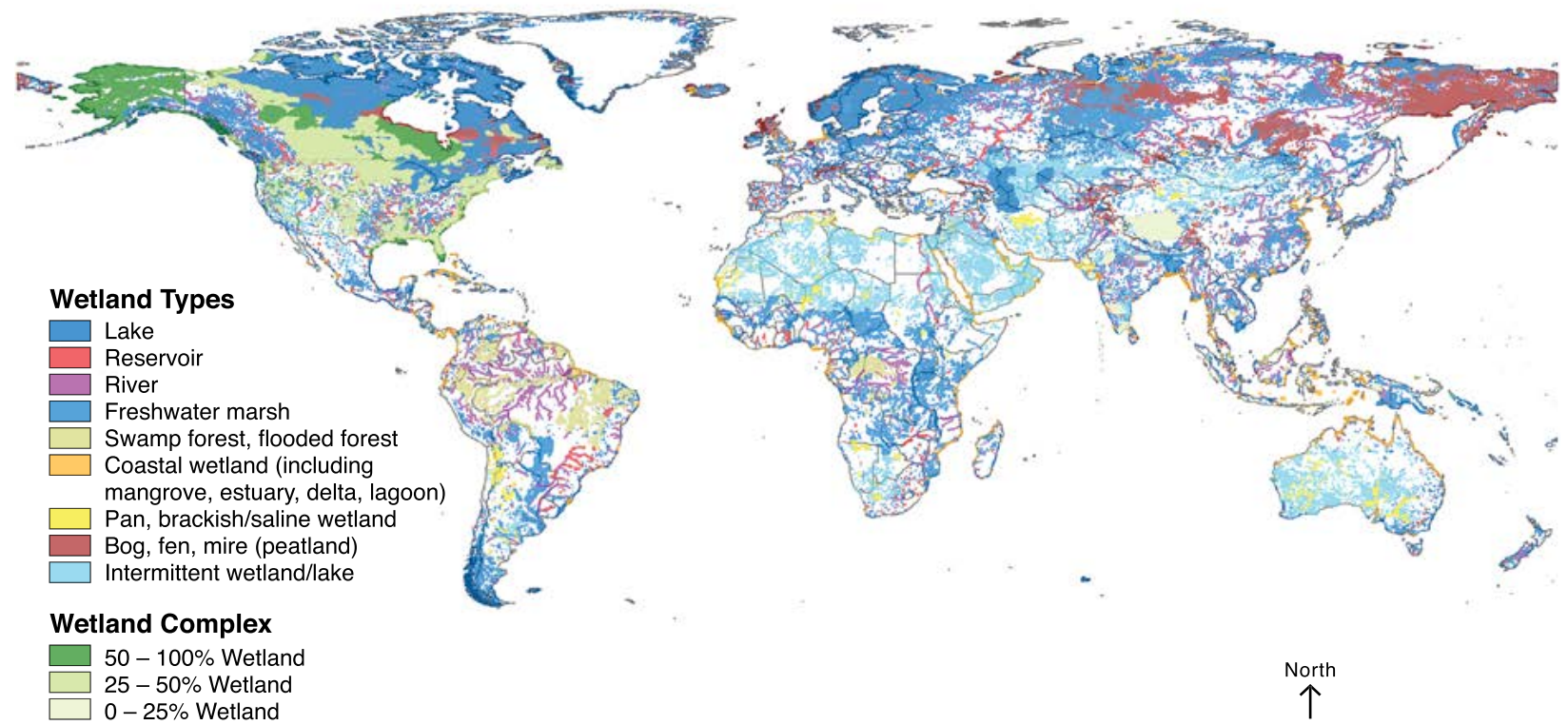

Figure 19.1 Global distribution of wetlands Source: Modified from Lehner and Döll (2004)

Table 19.1 Estimates of inland wetland area (million hectares)

\begin{tabular}{|l|c|c|}
\hline Region & Finlayson et al. (1999) & Lehner and Döll (2004) \\
\hline Africa & $121-4$ & 286 \\
\hline Asia & 204 & 26 \\
\hline Europe & 258 & 159 \\
\hline Neotropics & 415 & 287 \\
\hline North America & 242 & 28 \\
\hline Oceania & 36 & 917 \\
\hline Total & $12.76-21.29$ & 28 \\
\hline
\end{tabular}

Note: The large differences in the figures for wetland area in Europe and the Neotropics have not been analysed in the literature.

The estimated percentage of wetlands included in protected areas is relatively high compared with many terrestrial ecosystems - around 30 per cent in Europe and North and South America (Chape et al. 2008) _ but these areas have not been reserved systematically, and are rarely accorded priority in management.

\section{Freshwater ecological principles}

Freshwater ecosystems are expressions of the geophysical and ecological histories of the landscape through which water flows. The water present in any freshwater ecosystem forms part of the global water cycle-the movement of water throughout the Earth and its atmospheric system (Shiklomanov 1993). Freshwater and terrestrial ecosystems are intimately linked by the water flowing through them. Consequently, every land-use decision is effectively a water-use decision (Bossio et al. 2010).
The effect of reduced flows on terrestrial habitats and communities has been demonstrated very clearly in many parts of the world. For example, the excessive diversion of inflowing rivers for irrigated agriculture from the 1960s shrank the Aral Sea to 10 per cent of its former area by 2007, degrading the surrounding land with saline, polluted dust (Micklin and Aladin 2008). The importance of land cover, particularly forest cover, for hydrological flows is complex (Bruijnzeel 2004).

Effects from different upstream catchments are compounded as water moves downstream. This may be a challenge where multiple negative effects are compounded, or may provide solutions where the negative effects from one catchment are reduced by water flowing in from a non-impacted catchment (for example, the Olifants and Blyde rivers in South Africa; Kotze 2013). Freshwater flows carry carbon, nitrogen, oxygen and other substances that are essential for the 


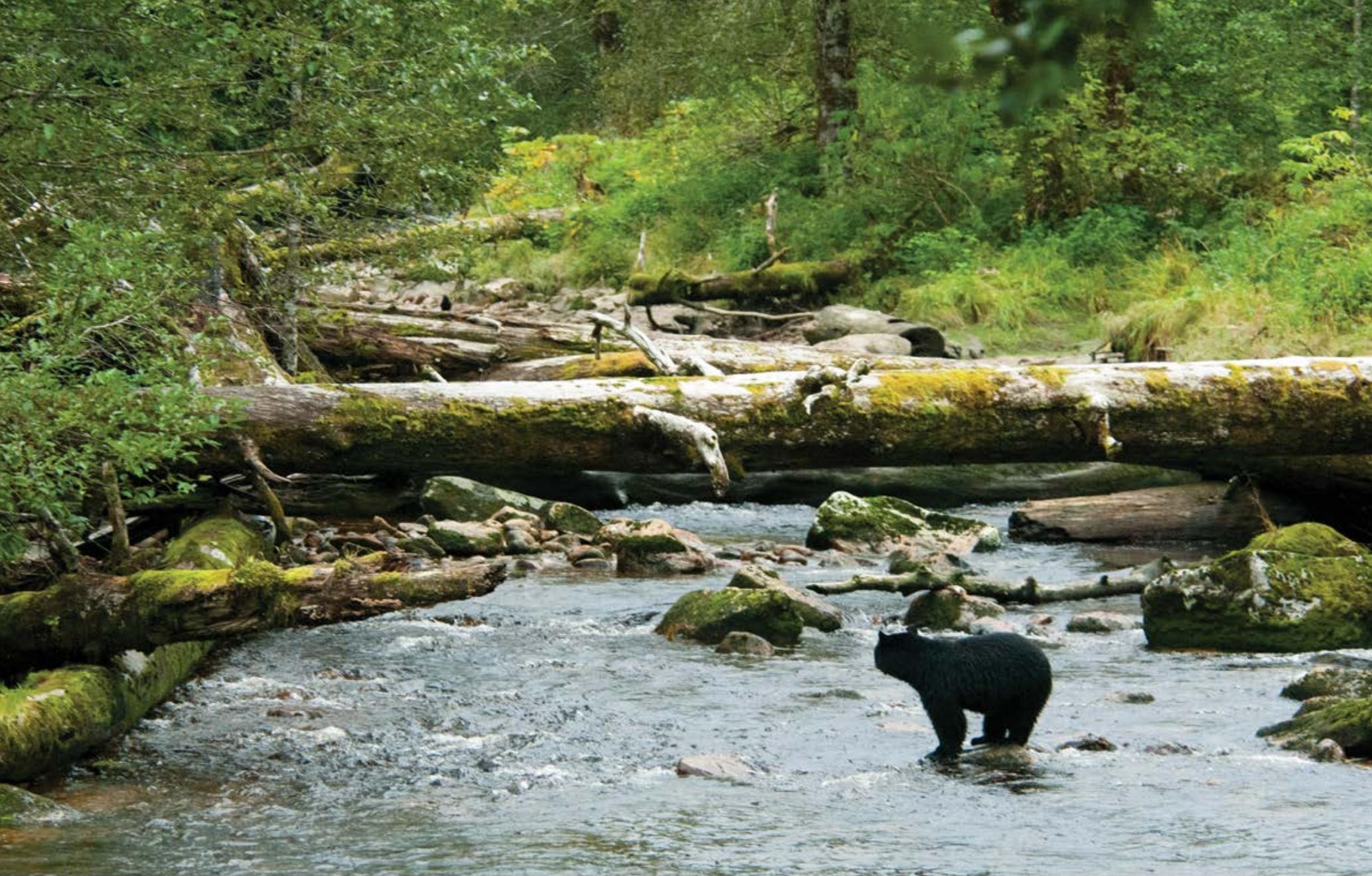

A black bear (Ursus americanus) in a river in Canada

Source: Rod Mast

functioning of downstream ecosystems, supporting a rich variety of life. These flows also carry sediments, washed in from upstream terrestrial habitats and eroding banks. The connectivity that exists across rivers, their tributaries and associated wetlands supports the diversity of species present, providing access to habitats for feeding and reproduction, and promoting population growth, community diversity and productivity (Bunn and Arthington 2002; Campbell-Grant et al. 2007).

In some cases, marine linkages are vital, such as when anadromous fish return to their natal river to spawn and, upon dying there, deposit many ocean-derived substances within freshwater systems. In the Pacific north-west of North America, for instance, there are some forests where much of the soil nitrogen is derived from marine sources via salmon migration (Helfield and Naiman 2006) (see photo above).

Freshwater ecosystems are dependent on the quantity, timing and quality of water flowing through them. Many changes in the natural flow regime can compromise the survival of species that are adapted to the historical regime (Laizé et al. 2014). Many wetland birds and terrestrial species undergo widespread migrations based on seasonal changes in the availability of water, habitat and food in rivers and wetlands. Disturbance of the flow regime in freshwater ecosystems can also promote the

invasion of introduced and alien species that can tolerate the modified flow conditions (Bunn and Arthington 2002). An important application of the concept of the natural flow regime is in the definition of 'environmental flows', which is detailed in a later section.

\section{Managing threats to freshwater systems}

Freshwater and estuarine ecosystems are among the most threatened in the world, with the Millennium Ecosystem Assessment (MEA 2005) describing freshwater ecosystems as being overused, under-represented in protected areas and having the highest portion of species threatened with extinction. People are inextricably linked to freshwater ecosystems, and both people and nature benefit by managing risks to the health of these habitats (Dudgeon et al. 2006; Vörösmarty et al. 2010). Primary direct drivers of degradation and loss of riverine and other wetlands include infrastructure development, land conversion, water withdrawal, pollution, overharvesting and overexploitation of freshwater species, the introduction of invasive alien species, and global climate change (MEA 2005; Dudgeon et al. 2006). The World Commission on Protected Areas (WCPA) outlines how freshwater biodiversity is particularly threatened because its conservation depends on maintaining ground and 
surface water flows, managing activities within the catchment and coordinating the activities of multiple management authorities (Dudley 2013).

Later sections provide advice on managing threats at the landscape scale, whereas management of threats to freshwater ecosystems within protected areas is briefly summarised here (see also Chapters 16 and 17).

\section{Water infrastructure and diversions}

Water diversions and infrastructure alter flows that are vital to maintaining freshwater biodiversity. Wherever possible, redundant water storages in protected areas should be decommissioned. There are a number of manuals available for removing dams (Bowman et al. 2002; Lindloff 2000). For example, in the United States, two large dams are being removed on the Elwha River to enable migratory salmon to recolonise habitat within Olympic National Park in Washington State (Howard 2012) (see Chapter 12).

Where infrastructure is retained, there are four key measures that will reduce but not fully compensate for the impact on freshwater ecosystems (Davies 2010; Pittock and Hartmann 2011): restoration of fish passage around dams; provision for release of environmental flows (see section below); building dam outlet structures that eliminate thermal pollution; and conservation of the river corridor below the dam-for example, by restoring riparian vegetation. Screening water diversion intakes to prevent loss of fish and other aquatic wildlife may also help (Baumgartner et al. 2009).

\section{Invasive species}

Alien animal and plant species, once introduced into water bodies, are particularly difficult to eliminate or control. To prevent introductions and control those that do occur:

- identify vectors for introduction of species (for example, aquaculture farms, ornamental gardens) and seek voluntary or regulatory measures to prevent pest releases

- monitor freshwater ecosystems to identify new problem species, drawing on information on pest species in your country or region

- eliminate newly observed populations of threat species (incursion management)

- prevent the spread of pest species (this may be a case where a barrier dam in a stream is used to protect upstream populations of indigenous species from exotic species spreading from downstream)

- institute control measures where this is feasible (Chatterjee et al. 2008).

\section{Recreational use of water bodies}

Freshwater ecosystems are a major focus of visitor activities in most protected areas, requiring tradeoffs between visitor use and biodiversity conservation (Hadwen et al. 2012) (see also Chapter 23). Riparian areas often provide a biodiverse corridor of moistureloving vegetation running through drier regions, creating moist microclimates and habitat for many species. Fragmentation and trampling of this vegetation can significantly impact on the freshwater ecosystem. Sediment-laden run-off from roads and tracks into water bodies can seriously harm aquatic biota, by reducing filter feeding and prey visibility and by smothering rocky substrates used for fish spawning and insect development. The smallest 'jump' up to or over a causeway or culvert across a water body may be a barrier to migration of aquatic species like fish and invertebrates.

Key management responses should include: zoning land access, siting visitor facilities away from water bodies, fencing visitors out of riparian areas, creating boardwalks and access points to water, and regulating use of motorised vehicles (Mosisch and Arthington 1998; Chatterjee et al. 2008). Roads and tracks should be located to drain run-off away from water bodies and onto land. Crossings should be built as bridges or broad culverts sunk into the stream bed so as to maintain passage for aquatic fauna. Regulating fishing activities is essential to conserve biodiversity (Ramsar 2005). Avoiding contaminated discharge and treating sewage are particularly important in preventing pollution of water bodies. Toilet facilities should be sited well away from water bodies.

\section{Pollution spills}

Protected area management requires use of chemicals such as fuels and herbicides that would have negative impacts if discharged into water bodies. Spills should be prevented wherever possible through good workplace health and safety practices, including siting chemicals away from water bodies, and securing and labelling stored chemicals. Potential pollutants should be stored and used on hard, internally draining surfaces that can contain accidental spills. Materials for soaking up any spills such as hay, sawdust or cat litter should be available on site, plus tools and bags for removing them for treatment. Spills into waterways require urgent advice to downstream authorities to close water diversions and prevent use of polluted water by people, wildlife and livestock wherever possible (see also Chapter 26). 


\section{Flood, drought and fire}

Floods, droughts and fire are natural processes in many ecosystems and plants and animals can normally tolerate or recover from them. In particular, many freshwater species and ecosystems are adapted to variability in water volumes and timing of flows and require variability to thrive, such that regulated water bodies should not be managed with unnatural, permanent or stable flows (Postel and Richter 2003). Some freshwater ecosystems are adapted to fire, such as floodplain forests in southern Australia, whereas others are destroyed by and should be protected from fire-for example, peat swamp forests in Borneo. Riparian forests are often naturally fire resistant even among other, flammable vegetation types. The traditional practices of local and indigenous peoples of cool patch burns around these ecosystems may conserve them from hot wildfires.

While this brief section on threats cannot detail all mitigation measures, a particularly concise source of information for managing wetlands in protected areas to avoid or mitigate these threats is Wetland Management Planning: A guide for site managers (Chatterjee et al. 2008). The resolutions and guidelines of the Ramsar Convention and the Ramsar Handbooks for the Wise Use of Wetlands (Ramsar 2011) provide excellent advice on good international practices for almost any wetland management challenge. An adaptive management approach is important to facilitate the engagement and empowerment of stakeholders and rights-holders, inclusive and iterative learning, and purposeful action amid inherent complexities (Kingsford et al. 2011). We now turn to the conservation of freshwater species and protected area design options that involve mitigating threats and maximising biodiversity protection.

\section{Conserving freshwater species}

Freshwater species include 'real aquatic species' which accomplish all or part of their life cycle in or on water and 'water-dependent' (paraquatic) species which show close and specific dependence on aquatic habitats (for example, for food or habitat). The first global freshwater animal diversity assessment (Balian et al. 2008) found that there were 126000 freshwater animal species, representing approximately 9.5 per cent of all recognised species.

Efficient investment of resources in protecting freshwater species within protected areas requires striking the right balance between actions targeted at the level of ecosystems and landscapes and those that target individual species. Actions at the landscape scale that address major threats to freshwater ecosystems can be effective in protecting a large proportion of freshwater species (for example, erosion control). Many significant threats to populations of freshwater species are not, however, reflected in the condition of surface water catchments-for example, downstream artificial barriers. Hence, there will often be a need for carefully planned actions to protect the populations of these species. This is particularly important where climate change is likely to lead to rapid expansion of invasive freshwater species, resulting in a decline in populations of native species (Rahel et al. 2008).

One of the first steps in developing action plans for managing freshwater species in protected areas is to access relevant data, which are often scattered among different custodians (for example, fisheries management agencies and university researchers). The Global Biodiversity Information Facility (GBIF 2014) and BioFresh data portal (BioFresh 2013) are two important sources of freshwater species data. Species observations made by volunteers (citizen scientists) and uploaded to databases using mobile phone apps, such as the Global Freshwater Fish BioBlitz (FFSG 2013), are increasingly important. Also there are a large number of national, regional and continental assessments-for example, for Africa (Darwall et al. 2011).

Prioritisation is then needed of species and interventions. Important factors to consider in this process include: International Union for Conservation of Nature (IUCN) Red List status (IUCN 2003); local threatened species legislation; community interest; species used in setting regional freshwater conservation targets (for example, Khoury et al. 2011); and species that are essential as sources of food or habitat for threatened species. Where occurrence data for a species of interest are limited, species distribution models can be used (Pearson 2007). These models can also assess the distribution of invasive species. These outputs can also be used in developing regional freshwater conservation plans (for example, Esselman and Allan 2011). Good protected area design is vital to conserving threatened species and biodiversity.

\section{Freshwater protected area design}

Freshwater conservation planning has traditionally lagged behind the systematic and quantitative planning for terrestrial and marine realms, mainly due to the spatial and temporal complexities characteristic of freshwater systems. Fortunately, conservation studies in recent years have provided the methods to plan better for freshwater systems (Collier 2011). 
To be effective, protected areas must consider some particularities of freshwater ecosystems. Spatialtemporal connectivity plays a key role in maintaining important ecological processes (Ward 1989), such as dispersal, gene flow or transport of energy and matter essential for the persistence of populations and species. There are examples of how to effectively incorporate connectivity in all its dimensions-longitudinal (Hermoso et al. 2011), lateral (Hermoso et al. 2012a), vertical (Nel et al. 2011) and temporal (Hermoso et al. 2012b)_into systematic conservation planning frameworks, which help design protected areas that are ecologically functional from a freshwater point of view. There also have been advances in integrating threats and degradation processes into conservation planning, to avoid the allocation of conservation efforts in areas where the existence of threats or their propagation could compromise the persistence of biodiversity (for example, Moilanen et al. 2011; Linke et al. 2012).

Planning for persistence of biodiversity through maintenance of ecological resilience requires consideration of the political and socioeconomic factors that influence aquatic systems. Social (Knight et al. 2011) and political (Faleiro and Loyola 2013) aspects of conservation play an important role in the success or failure of a plan. This phenomenon is widely documented and is addressed in cross-governmental initiatives at national (Pittock and Finlayson 2011) and international scales (Haefner 2013) in river science.

The final key to effective conservation for fresh waters is embedding protection schemes in a wider environmental context-ideally at the whole catchment scale. This issue was identified as a critical point for the success of freshwater conservation by Abell et al. (2007), who called for multiple tiers in freshwater protectionfrom strict protected areas to catchment management zones. The patchy reservation of the Pantanal wetlands in South America (Case Study 19.1) highlights these issues.

\section{Unique considerations}

\section{What is different from terrestrial systems?}

An obvious question for land-based protected area managers is 'why do I need to do anything different to conserve freshwater biodiversity'. The differences are well detailed in the Guidelines for Applying Protected Area Management Categories (Dudley 2013), and can be summarised as follows.
- Flow regimes: Water is critical for maintaining freshwater biodiversity, including the volume, timing and quality of surface water flows as well as surface water-groundwater dynamics.

- Longitudinal and lateral connectivity: Protecting water flows along rivers and from channels onto floodplains is essential. This involves preventing or removing artificial physical and chemical barriers, and providing bypass facilities for aquatic wildlife.

- Groundwater-surface water interactions: Protection of groundwater flows is needed since most surface waters depend to some extent or at some times on aquifers (the water table).

- Relationship to the broader landscape: Wetland systems in a protected area cannot usually be 'fenced off' from impacts arising in the wider terrestrial landscape, and will normally require integrated threat management at the catchment scale.

- Multiple management authorities: Different government agencies usually have overlapping and often conflicting responsibilities concerning freshwater management. Conservation is complicated by the need to coordinate management activities among government agencies with diverse mandates.

Upcoming sections suggest ways to manage these differences. Unique types of freshwater protected areas are now outlined as well as conflicts between terrestrial and freshwater conservation, before considering conservation of specific types of wetland ecosystem.

\section{Freshwater protected area types}

The unique characteristics of freshwater ecosystems mean that there is sometimes confusion as to what constitutes a freshwater protected area and insufficient recognition of some unique types of protected areas. The IUCN states that a 'protected area is a clearly defined geographical space, recognised, dedicated and managed, through legal or other effective means, to achieve the long term conservation of nature with associated ecosystem services and cultural values' (Dudley 2013:8).

Areas managed for conservation of freshwater biodiversity are protected areas even if they occur on a variety of land tenures or are managed without specific legislation or by non-governmental managers, as long as these are 'effective'. In this context, sites designated under the Ramsar Convention are protected areas even if they are not recognised in national law (see the section below on Ramsar). Similarly, the 'Heritage Rivers' of Canada are protected areas. Freshwater areas conserved by the traditional laws of indigenous peoples and the wetland portions of the non-legislated Indigenous 


\section{Case Study 19.1 Pantanal, South America}

The Pantanal is a large internal delta and, at 160000 square kilometres, is one of the largest wetlands in the world. It is divided between Brazil, Bolivia and Paraguay (Figure 19.2). An annual flood pulse has led to a dynamic mosaic of permanent terrestrial through to permanent aquatic habitats (Nunes da Cunha and Junk 2011). The Pantanal supports a traditional pastoral industry and can be considered a managed cultural landscape with high aesthetic value and large species and habitat diversity (Junk et al. 2006). Only 5 per cent of the Brazilian Pantanal is fully protected in Ramsar sites and other kinds of protected areas.

Hydro-electric power plants have begun to modify the flood pulses. Occupation of the catchment by large agroindustries has led to increased soil erosion and sediment loads. Agricultural developments are encroaching on the Pantanal and have led to renewed consideration of the 'hidrovia' canalisation of the Paraguay River. The Pantanal case study highlights the need to: better define the borders of the wetland and protect key habitats; collaborate with local communities for wetland-friendly livelihoods; and maintain near-natural flood pulses by controlling water releases from dams (Junk and Nunes da Cunha 2012).

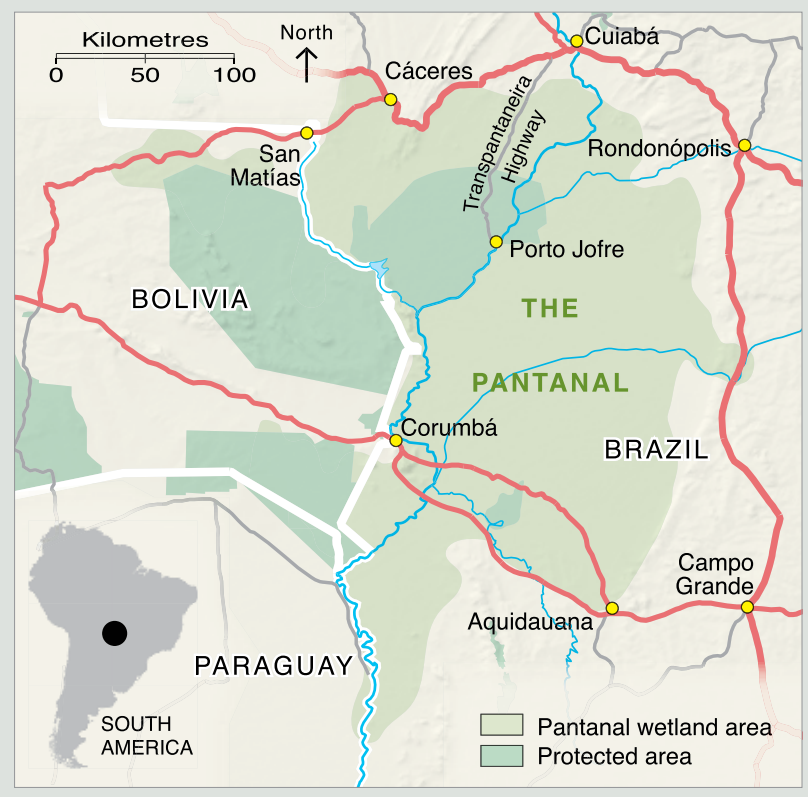

Figure 19.2 Pantanal wetlands, South America Source: US National Park Service
Protected Areas (IPAs) in Australia are protected areas. Reserves under fisheries legislation are another example. The Cosumnes River Preserve in the United States (Case Study 19.2) is an example of a freshwater protected area involving coordinated management by different organisations across tenures. The Guidelines for Applying Protected Area Management Categories should be consulted to assist managers assign freshwater areas to categories for protected area inventories (Dudley 2013).

\section{Conflicts between terrestrial and freshwater conservation}

Regrettably, many terrestrial protected areas are created as a trade-off for damaging freshwater ecosystems, and many erstwhile positive conservation measures have perverse impacts on aquatic biota and ecosystems. Protected area establishment is often linked to hydroelectric or water-supply dam development. For example, the establishment of the Kosciuszko National Park in Australia was intended to reduce erosion in the catchments of the Snowy Mountains Hydro-Electric Scheme constructed within the park from 1949 to 1974. It was only in 2002 that agreement was reached to restore minimal environmental flows to these degraded rivers (Miller 2005). More recently, protected areas have been established in mountain catchments in developing countries as a trade-off for the impacts of hydro-electric development. The Nam Theun II hydro-power project in Laos is an example of improved management of protected forest areas agreed to as an offset for degrading internationally significant river ecosystems (Porter and Shivakumar 2010).

In many places, hydro-electric power generators or water consumers are paying fees for the conservation of the watersheds of dams, including as protected areas (Postel and Thompson 2005). While payment for watershed services may benefit terrestrial conservation and the conservation of headwater streams, the significant environmental damage caused by the dams that are the source of the revenue is rarely recognised. Richness and abundance of aquatic species are often lower in upland protected areas (Chessman 2013). In freshwater ecosystems, the large mid-slope and lowland rivers are usually the ones that have the greatest aquatic species diversity and provide vital corridors for migratory animals. Usually these are the parts of rivers targeted for water infrastructure development (Sheldon 1988; Tockner et al. 2008).

Under these circumstances, managers have an obligation to ensure that any resources provided by water infrastructure developers contribute to conservation of freshwater biodiversity downstream, as well as upstream of dams. There are four key interventions-namely: restoration of fish passage around dams; provision for release of environmental flows; building dam outlet structures that can eliminate downstream thermal pollution; and the conservation of the river corridor below the dam, for example, by restoring riparian vegetation (Davies 2010; Pittock and Hartmann 2011). These measures will 


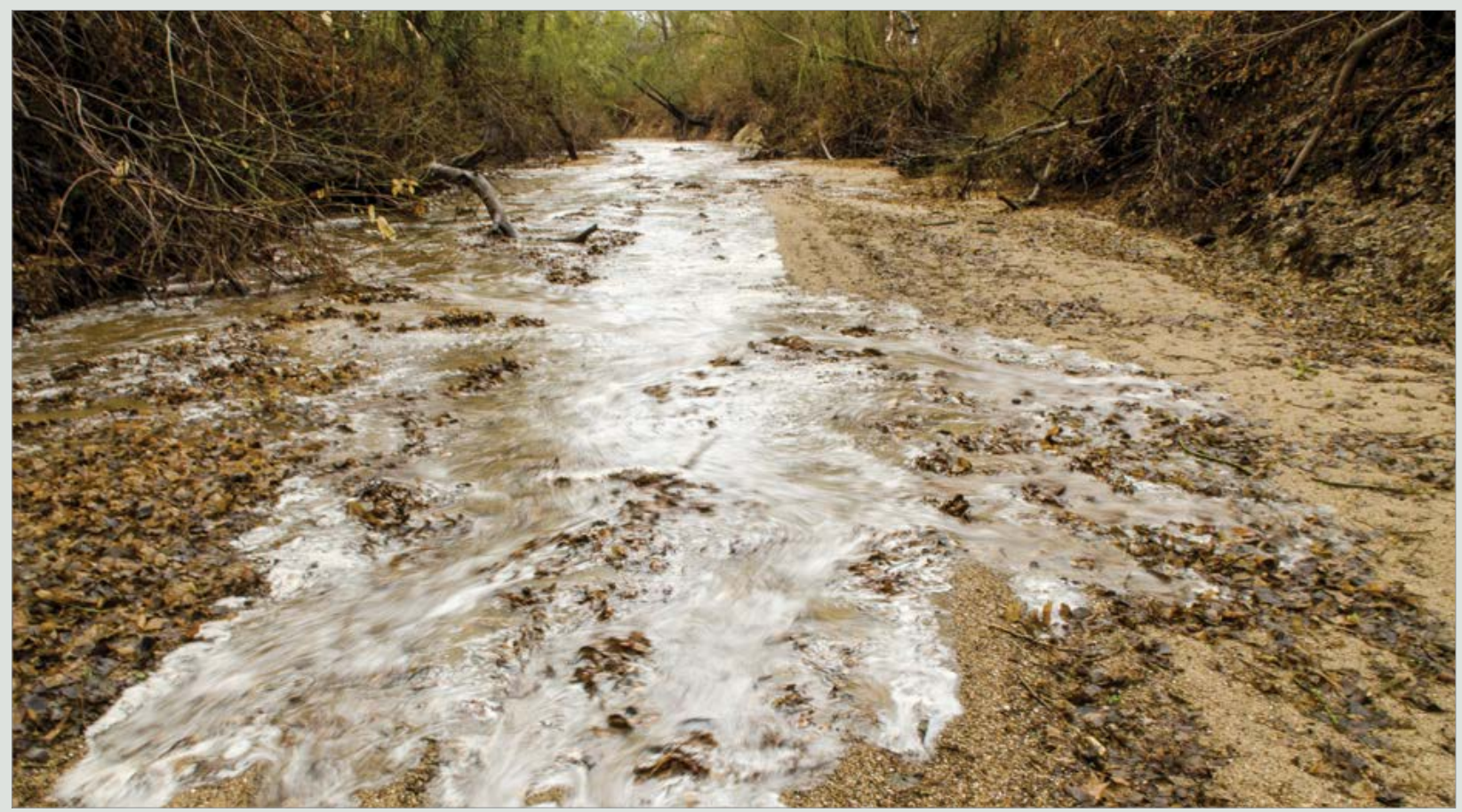

'Pre-wetting' the river bed aids conservation of fish in the Cosumnes River Preserve, USA

Source: Carson Jeffres

Water resources in California's Central Valley have been directed to drinking water and irrigated agriculture. Agricultural development has seen wetlands reduced to less than 6 per cent of the original 1.8 million hectares (Whipple 2012). The Cosumnes River Preserve conserves key remnants on 20000 hectares of managed floodplain and river ecosystems distributed over 150 square kilometres, and is managed via a formal partnership (Figure 19.3; Kleinschmidt Associates 2008). The Nature Conservancy and federal Bureau of Land Management are the primary landowners, with other contributions from six federal, State and local government agencies, a non-governmental organisation (NGO) and private lands in conservation easements. Memoranda between these entities encourage both nature protection and sustainable use of some lands, particularly because some practices, such as forage and rice production, create seasonal habitat for focal bird species (Kleinschmidt Associates 2008). This form of management is akin to IUCN Category VI. This example illustrates how a freshwater protected area can comprise many different land tenures, owners and legal agreements.

The primary management challenge is countering the abstraction of groundwater to meet municipal and agricultural demands, as the Cosumnes River and the adjacent mosaic of wetlands (Type II groundwater-dependent ecosystems; see sections below) are now disconnected from the water table and seasonally dry. 'Pre-wetting' the river channel with managed water prior to winter precipitation could maximise the biodiversity benefits from natural inflows (Fleckenstein et al. 2004). Other forms of adaptive management include the breaching of dykes and levees to reconnect former farmland to floodwaters and promote rearing of juvenile fishes like Chinook salmon (Oncorhynchus tshawytscha) (Jeffres et al. 2008).

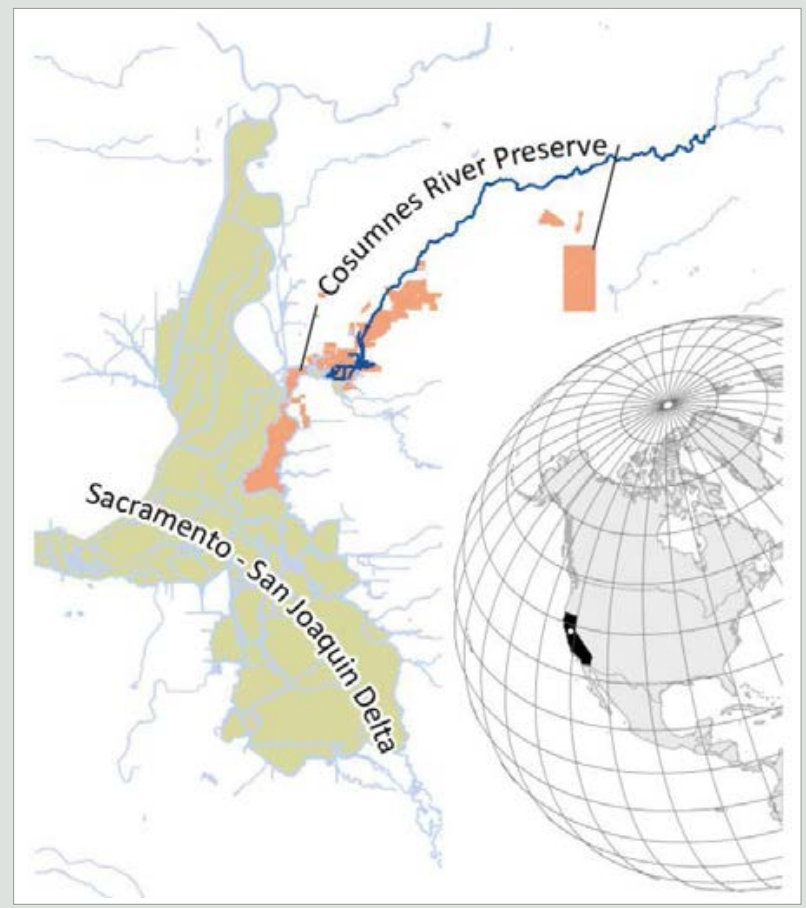

Figure 19.3 Cosumnes River Preserve, United States of America

Source: Modified from Josh Viers 
reduce but never fully compensate for the impact of water infrastructure on freshwater ecosystems. Hence, managers should resist the construction of water infrastructure impacting on protected areas. In an era of growing water scarcity, more proposals to exploit water resources within nature reserves are likely and should be resisted, but if imposed, the mitigation measures described above should be mandatory.

Many protected area managers have installed dams, either to supply staff and visitors or to enhance wildlife viewing. Establishing watering points for wildlife is a misguided notion that should only be considered in exceptional circumstances, such as part of a targeted threatened species recovery plan. Water should be accessed from groundwater, off-river storage tanks or small dams to reduce the ecological impacts of water supply infrastructure. Even small dams across streams can block the passage of aquatic wildlife. There are negative impacts on terrestrial and riparian ecosystems from concentrating grazing by herbivores. Generally, dams for wildlife and other redundant water storages in protected areas should be decommissioned, as is occurring in Kruger National Park (Brits et al. 2002).

New kinds of perverse impacts are emerging, often associated with climate change mitigation measures that consume a lot of water (Pittock et al. 2013). One example is planting trees to sequester carbon-an approach supported by many environmental managers as a way of funding biodiversity restoration. Planting forests, however, inevitably increases evapotranspiration and reduces inflows into freshwater ecosystems (Jackson et al. 2005; van Dijk and Keenan 2007). One projection for the overallocated Macquarie River in Australia suggested that reafforesting 10 per cent of the upper catchment would reduce river flows into the Macquarie Marshes Nature Reserve and Ramsar site by 17 per cent (Herron et al. 2002). There are ways of reconciling these conflicts-for example, by requiring acquisition of water entitlements for the environment to offset increased evapotranspiration by trees, or restoring vegetation in areas that contribute less water to rivers (Pittock et al. 2013). There may be acceptable trade-offs-for example, restoring riparian forests has many benefits for freshwater ecosystem conservation that may offset the consumption of water.

\section{Dodgy borders: Managing divided freshwater systems}

A great many of the world's land-based protected areas have boundaries defined in part by rivers. Obviously, the threats to freshwater biodiversity are greater where part of the water basin is outside the boundaries of a protected area. Among the likely threats are: diffuse pollutants and eroded sediments washing into water

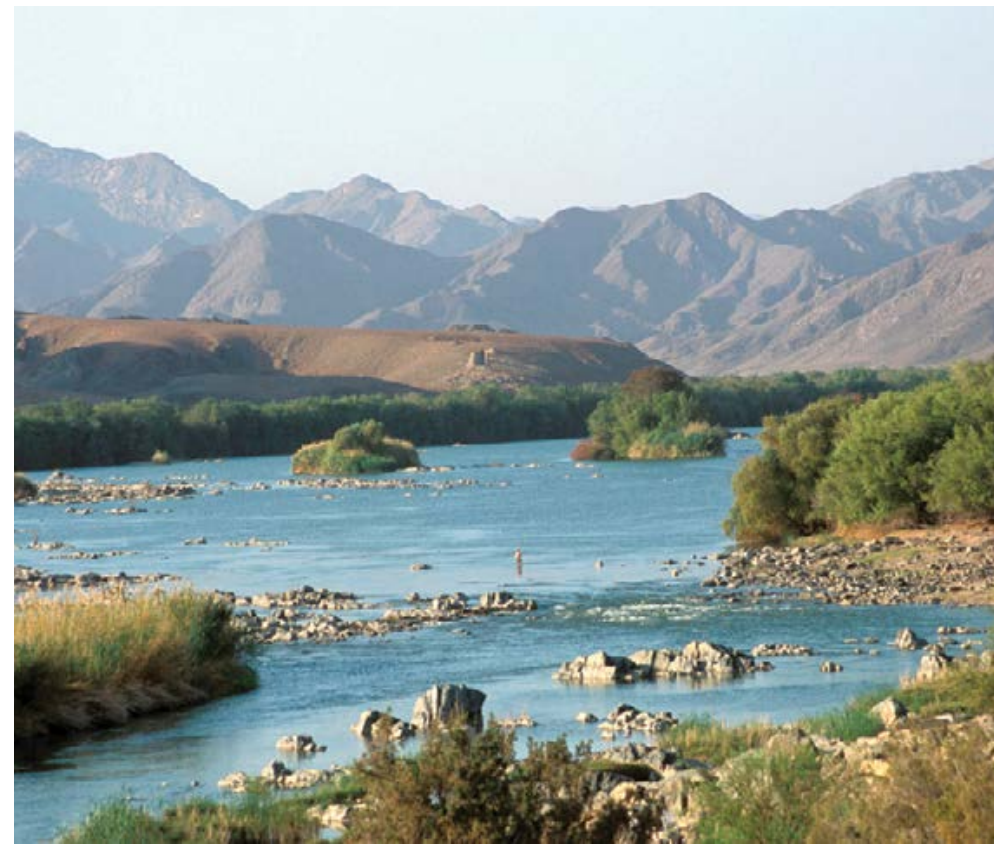

Conserve lowland rivers as well as headwaters: Richtersveld National Park, South Africa

Source: Conservation International/Haroldo Castro

bodies, point-source pollution discharges, water extraction, introduction of alien species, extraction of aquatic plants and animals, mining riverbanks and beds, and clearing of riparian forests. In one respect, having a river as a border is just one manifestation of not having an entire watershed inside a protected area; however, where a sinuous river forms the boundary, the border is usually longer, exposing freshwater ecosystems to dispersed conservation threats and making management responses more challenging.

How, then, should protected area managers enhance conservation in circumstances where the river is the boundary? Key among the approaches is engaging stakeholders and rights-holders outside the protected area in cooperative management arrangements. In the section below on landscape management, a number of these opportunities are outlined. Managers of Kruger National Park in South Africa have applied these approaches (Case Study 19.3).

\section{Managing specific freshwater ecosystems}

In this section, we consider the specific management requirements of particular freshwater ecosystems before reviewing landscape-scale management options. 


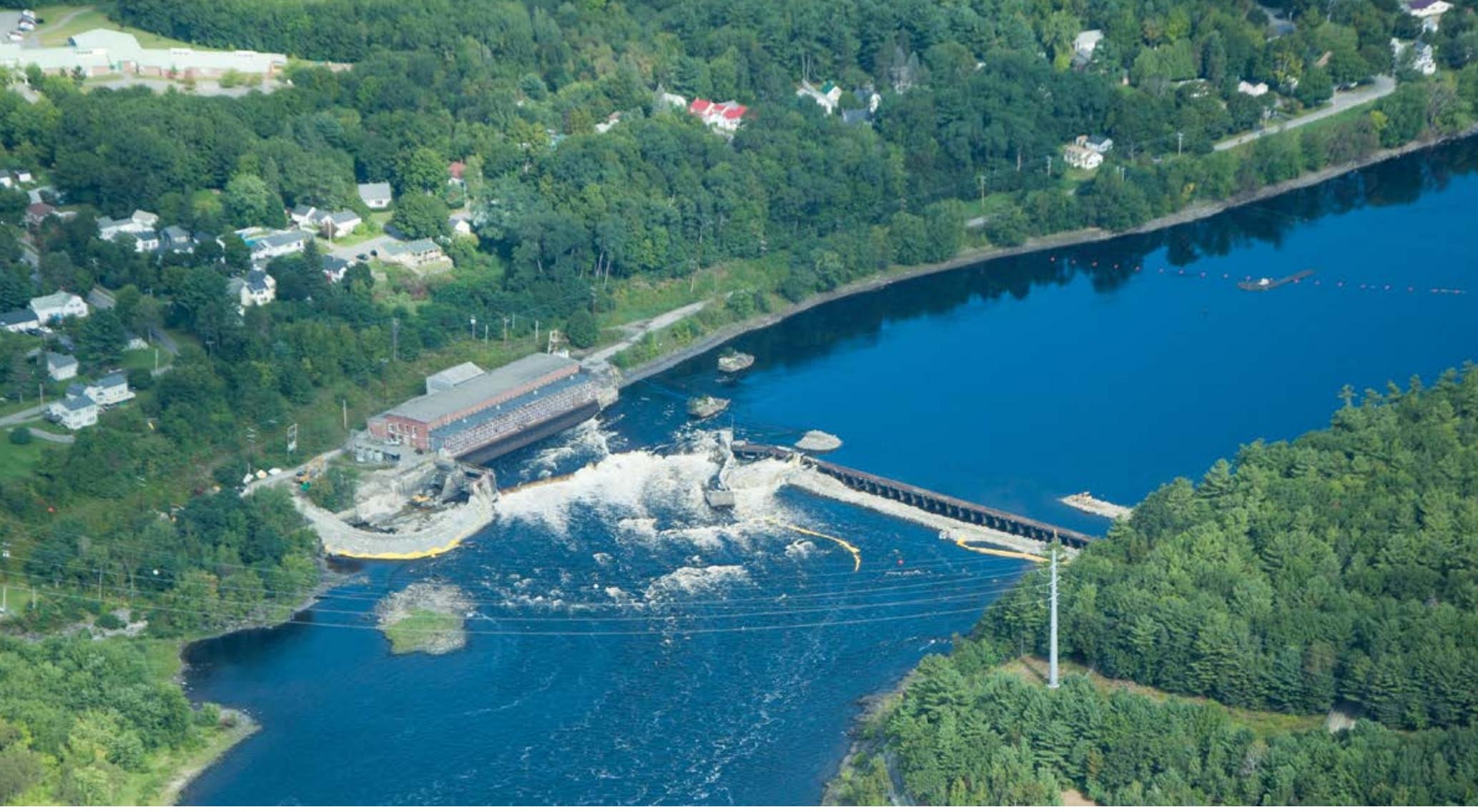

Dam removal restores river connectivity and fish passage, Veazie Dam, Penobscot River, USA

Source: Joshua Royte, The Nature Conservancy

\section{Environmental flows and wetland water regimes}

\section{Environmental flows}

To maintain freshwater biodiversity and ecological services inside protected areas, conservation reserve managers must try to ensure that the natural water regimes of lakes, wetlands and rivers are protected from overuse, diversion and impoundment. Freshwater management has been integrated into the broader scope of ecological sustainability through the provision of environmental flows, which are defined as 'the quantity, timing and quality of water flows required to sustain freshwater and estuarine ecosystems and the human livelihoods and wellbeing that depend upon these ecosystems' (Brisbane Declaration 2007).

There is now wide recognition that a dynamic, variable water regime is required to maintain species phenology (seasonal timing of events in the life cycle) and the native biodiversity and ecological processes characteristic of every river and wetland ecosystem. The natural flow regime and diverse ecohydrological principles (for example, Bunn and Arthington 2002) flesh out the influence of flow volume, seasonal timing and variability on aquatic biodiversity, population recruitment and ecosystem productivity. These ecohydrological principles inform assessment of the environmental flow requirements of aquatic plants and animals.
The key challenge for managers whose protected areas receive water from unreserved upstream catchments is to engage water managers and users to agree on a process for assessing and deciding on environmental flows. More than 250 practical methods, models and frameworks are available to link water volumes and patterns of flow to biodiversity and ecological processes (Dyson et al. 2003; Tharme 2003). While environmental flow assessment may seem complex, even daunting, a simple guide to the technical options available for protected area managers to assess what is required is given in Table 19.2. These methods focus largely on rivers; however, they are applicable in concept and practice to water bodies that rarely flow but nevertheless experience natural spatial and seasonal patterns of water-level fluctuation, wetting and drying, and links to groundwater. Estuaries also need to receive freshwater inflows (see section below). Methods and applications for all aquatic ecosystem types can be found in Arthington (2012).

\section{Setting limits to hydrologic alteration}

Despite tremendous advances in methods, setting a limit on hydrologic alteration remains the most challenging aspect of environmental flow science and sustainable water management. Simple methods set this limit as a percentage of the natural flow, or define the river discharge that maintains fish habitat and connectivity through the channel network. In the holistic 'downstream response to imposed flow transformations' (DRIFT) and 'ecological limits of hydrologic alteration' (ELOHA) frameworks (Table 19.2), and several 


\section{Case Study 19.3 Kruger National Park rivers, South Africa}

Five major rivers that traverse the breadth of Kruger National Park (KNP) (IUCN Category II) are crucial to conserving its biodiversity (Figure 19.4). Most of the rivers originate in or flow through highly developed, urbanised, industrialised, mining or agricultural areas, rendering the park particularly vulnerable to upstream impacts. South African National Parks (SANParks) initiated the multi-institutional KNP Rivers Research Programme (see Biggs and Rogers 2003) in response to the deteriorating quantity and quality of many of these rivers. SANParks sees the KNP as embedded in a wider socioecological system (the catchment) that needs to be managed adaptively and collaboratively with the surrounding communities. This approach has been strengthened through a number of initiatives, especially the work of the Association for Water and Rural Development, a research-based NGO, and the Inkomati Catchment Management Agency (Pollard and du Toit 2011).

Development pressure is resulting in a decline in the condition of all but one of the KNP rivers, including non-compliance with statutorily defined environmental flows for water quality and quantity. The advocacy by networks of competent actors, however, together with ongoing monitoring and adaptive responses, means the rivers are likely in a better shape than they would otherwise have been (Pollard and du Toit 2011). Moreover, the increasing mobilisation of opinion, effort and concerted action by catchment management agencies offers hope. SANParks' work highlights how park managers have an important watchdog role to play in the context of multi-scale catchment and water governance (Pollard and du Toit 2011).

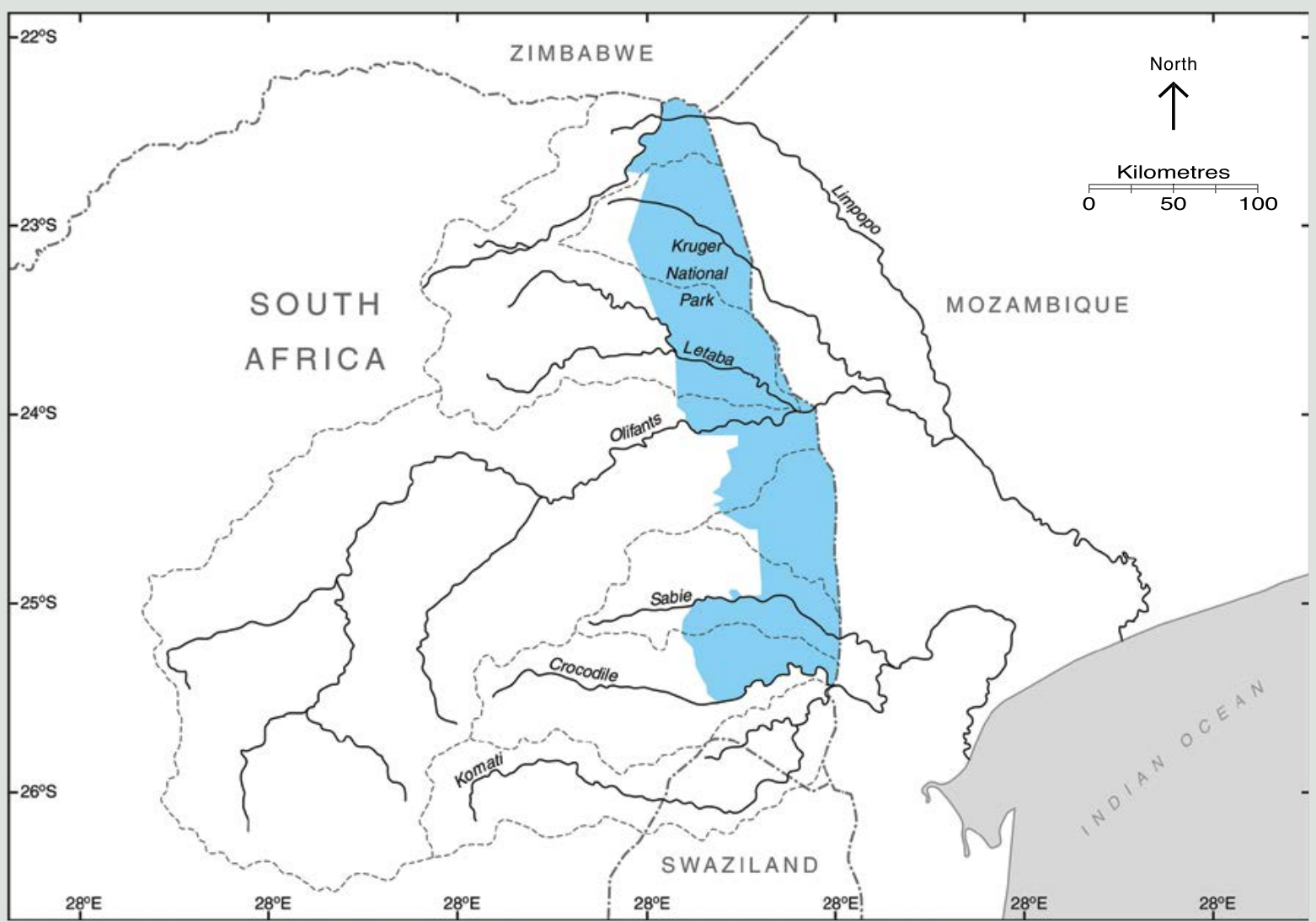

Figure 19.4 Kruger National Park, South Africa

Source: () Clive Hilliker, The Australian National University

restoration protocols (for example, Richter et al. 2006), scientists, stakeholders, rights-holders and managers give consideration to a suite of flow alteration-ecological response relationships for each system under study. An important concept is the idea of a threshold beyond which unacceptable ecological changes are likely to occur. Where there are clear threshold responses (for example, overbank flows needed to support riparian vegetation or provide fish access to backwater and floodplain habitats), a 'low-risk' environmental flow would be one that does not cross the threshold of hydrologic alteration for overbank flows. For a linear response where there is no clear threshold demarcating low from high risk, a consensus stakeholder process will be needed to determine 'acceptable risk' to a valued ecological asset, such as an estuarine fishery dependent on freshwater inflows (Loneragan and Bunn 1999). It is important to differentiate the scientific assessment of ecological limits to hydrologic alteration from the social process of finally deciding on the recommended flow (Arthington 2012). 
Table 19.2 Environmental flow methods: comparison of the four main types of methods used worldwide to estimate environmental flows = environmental water allocations (EWA)

\begin{tabular}{|c|c|c|c|c|}
\hline Туре & $\begin{array}{l}\text { River ecosystem } \\
\text { components }\end{array}$ & $\begin{array}{l}\text { Data } \\
\text { requirements } \\
\text { and resource } \\
\text { intensity } \\
\text { (time, cost } \\
\text { and technical } \\
\text { capacity) }\end{array}$ & $\begin{array}{l}\text { Resolution of output } \\
\text { (EWA) }\end{array}$ & $\begin{array}{l}\text { Appropriate levels } \\
\text { of application }\end{array}$ \\
\hline Hydrological & $\begin{array}{l}\text { Whole ecosystem, non- } \\
\text { specific, or ecosystem } \\
\text { components such as fish } \\
\text { (Tennant 1976) }\end{array}$ & $\begin{array}{l}\text { Low } \\
\text { Primarily desktop } \\
\text { Use virgin/naturalised } \\
\text { historical flow records } \\
\text { Some use historical } \\
\text { ecological data }\end{array}$ & $\begin{array}{l}\text { Low } \\
\text { Expressed as percentage } \\
\text { of monthly or annual flow } \\
\text { (median or mean), or as } \\
\text { limits to change in vital flow } \\
\text { parameters - for example, } \\
\text { range of variability approach } \\
\text { (Richter et al. 1996, 2006) }\end{array}$ & $\begin{array}{l}\text { Reconnaissance level } \\
\text { of water resource } \\
\text { developments, or } \\
\text { as a tool within } \\
\text { habitat simulation or } \\
\text { holistic (ecosystem) } \\
\text { methodologies } \\
\text { Used widely }\end{array}$ \\
\hline Hydraulic rating & $\begin{array}{l}\text { Instream habitat for target } \\
\text { biota }\end{array}$ & $\begin{array}{l}\text { Low-medium } \\
\text { Desktop, limited field } \\
\text { Historical flow records } \\
\text { Discharge linked to } \\
\text { hydraulic variables- } \\
\text { typically single river } \\
\text { cross-section }\end{array}$ & $\begin{array}{l}\text { Low-medium } \\
\text { Hydraulic variables (for } \\
\text { example, wetted perimeter) } \\
\text { used as surrogate for habitat } \\
\text { flow needs of target species } \\
\text { or assemblages }\end{array}$ & $\begin{array}{l}\text { Water resource } \\
\text { developments where little } \\
\text { negotiation is involved, } \\
\text { or as a tool within habitat } \\
\text { simulation or ecosystem } \\
\text { methodologies } \\
\text { Used widely }\end{array}$ \\
\hline Habitat simulation & $\begin{array}{l}\text { Primarily in-stream habitat } \\
\text { for target biota } \\
\text { Some consider } \\
\text { channel form, sediment } \\
\text { transport, water quality, } \\
\text { riparian vegetation, } \\
\text { wildlife, recreation and } \\
\text { aesthetics - for example, } \\
\text { the Physical Habitat } \\
\text { Simulation computer } \\
\text { modelling system } \\
\text { (PHABSIM) developed by } \\
\text { the US Fish and Wildlife } \\
\text { Service (Bovee 1982) }\end{array}$ & $\begin{array}{l}\text { Medium-high } \\
\text { Desktop and field } \\
\text { Historical flow records. } \\
\text { Many hydraulic } \\
\text { variables are modelled } \\
\text { at range of discharge at } \\
\text { multiple stream cross- } \\
\text { sections } \\
\text { Physical habitat } \\
\text { suitability or preference } \\
\text { data needed for target } \\
\text { species }\end{array}$ & $\begin{array}{l}\text { Medium-high } \\
\text { Output in form of weighted } \\
\text { usable area of habitat } \\
\text { for target species (fish, } \\
\text { invertebrates, plants). Can } \\
\text { involve time-series of habitat } \\
\text { availability }\end{array}$ & $\begin{array}{l}\text { Water resource } \\
\text { developments, often } \\
\text { large scale, involving } \\
\text { rivers of high strategic } \\
\text { importance, often with } \\
\text { complex, negotiated } \\
\text { trade-offs among users, } \\
\text { or as method within } \\
\text { holistic (ecosystem) } \\
\text { approaches } \\
\text { Primarily used in } \\
\text { developed countries }\end{array}$ \\
\hline $\begin{array}{l}\text { Holistic (ecosystem) } \\
\text { frameworks }\end{array}$ & $\begin{array}{l}\text { Whole ecosystem, all } \\
\text { or several ecological } \\
\text { components } \\
\text { Most consider in-stream } \\
\text { and riparian components, } \\
\text { some also consider: } \\
\text { groundwater, wetlands, } \\
\text { floodplains, estuary and } \\
\text { coastal waters } \\
\text { May assess social and } \\
\text { economic dependence } \\
\text { on species/ecosystem } \\
\text { (for example, downstream } \\
\text { response to imposed flow } \\
\text { transformations (DRIFT); } \\
\text { King et al. 2003) }\end{array}$ & $\begin{array}{l}\text { Medium-high } \\
\text { Desktop and field } \\
\text { Use virgin/naturalised } \\
\text { historical flow records } \\
\text { or rainfall records } \\
\text { compared with current } \\
\text { gauge records } \\
\text { Many hydraulic } \\
\text { variables - multiple } \\
\text { cross-sections } \\
\text { Biological data on flow } \\
\text { and habitat-related } \\
\text { requirements of biota } \\
\text { and some/all ecological } \\
\text { components }\end{array}$ & $\begin{array}{l}\text { Medium-high } \\
\text { Advanced fish methods } \\
\text { use data on movement } \\
\text { and migration, spawning, } \\
\text { larval/juvenile requirements, } \\
\text { water-quality tolerances; } \\
\text { exotic species included } \\
\text { (for example, downstream } \\
\text { response to imposed flow } \\
\text { transformations (DRIFT); } \\
\text { Arthington et al. 2003) } \\
\text { Ecological limits of hydrologic } \\
\text { alteration (ELOHA) quantifies } \\
\text { e-flow 'rules' for rivers of } \\
\text { contrasting hydrological type } \\
\text { at user-defined regional scale } \\
\text { (Poff et al. 2010) }\end{array}$ & $\begin{array}{l}\text { Water resource } \\
\text { developments, } \\
\text { typically large scale, } \\
\text { involving rivers of high } \\
\text { conservation and/or } \\
\text { strategic importance, } \\
\text { and/or with complex user } \\
\text { trade-offs } \\
\text { Simpler approaches (for } \\
\text { example, expert panels) } \\
\text { often used where flow } \\
\text { ecology knowledge } \\
\text { is limited, or there are } \\
\text { limited trade-offs among } \\
\text { users, and/or time } \\
\text { constraints } \\
\text { Used in developing and } \\
\text { developed countries }\end{array}$ \\
\hline
\end{tabular}

Source: Adapted from Tharme (2003); for examples, see Arthington (2012) 


\section{Adapting to climate change}

The natural environmental regimes that govern aquatic ecosystems, especially water regimes, have been replaced with altered regimes in many areas of the world under increasing human pressure for fresh water and in response to shifting climates. The combination of climate change and flow regulation is now driving structurally novel ecosystems that may require new concepts and a range of approaches to water management to cope with increasingly uncertain futures (Palmer et al. 2008). Research that identifies flow regime characteristics and associated ecological responses to variability is one of the best options for preparedness. The study of ecological responses along contemporary gradients of flow variability (wet to dry tropics, coastal to arid zone regions) may provide analogues for future climatic shifts (Arthington et al. 2006). Yet the surest way to advance understanding of the ecological roles of flow, and to improve water use for ecosystem and human benefit, is through well-designed monitoring of ecological outcomes over time (Arthington et al. 2010; Davies et al. 2014).

Conservation managers can take the lead in applying environmental flow concepts and methods to the diverse protected areas they manage. Common key steps in the different environmental flow methods outlined above include:

- consulting stakeholders and rights-holders to identify the different, flow-related elements of the environment that are valued, such as fish migrations

- identifying thresholds for the quality of water and volume and timing of flows needed to sustain those values-for example, the water required for waterbirds to successfully breed in a wetland

- considering the natural flow variability of their rivers and wetlands, and seeking to mimic important features as much as possible-for instance, with water releases from dams

- negotiating agreements with water agencies and other stakeholders and rights-holders, including water departments and utilities, to deliver the environmental flows

- monitoring the impact, and evaluating and adjusting the environmental flows to achieve the desired environmental and social objectives.

Environmental flows need to be applied to conserve lakes and estuaries, as described in the next subsections.

\section{Lakes}

Globally, there are an estimated 27 million natural lakes and half a million artificial lakes (reservoirs) greater than one hectare in area. The term 'lakes' is henceforth used to refer to both natural lakes and artificial reservoirs, noting that the biodiversity values of artificial lakes are generally much lower than those of natural ones. Lakes collectively contain more than 90 per cent of the liquid fresh water on the surface of our planet, and in addition to providing habitat for aquatic species, they provide extensive services to humanity. Lakes and reservoirs are easily polluted and degraded (Illueca and Rast 1996).

Managing these water bodies for their conservation is a complex undertaking involving a range of scientific, socioeconomic and governance elements. Lakes are hydrologically linked to upstream rivers or tributaries flowing into them, to downstream water systems into which they discharge, and sometimes also to subsurface groundwater aquifers (Figure 19.5). Downstream water needs can sometimes significantly dictate the management requirements of upstream lakes that supply water to them, an example being the Lake Biwa-Yodo River complex in Japan (Nakamura et al. 2012).

Lake conservation translates into managing lakes, their basins and their resources for sustainable ecosystem services (MEA 2005). The scientific considerations include the quantity and quality of surface and groundwater sources, drainage basin characteristics, flora and fauna, soils, topography, land use and climate-all of which collectively define the physical presence and condition of lake waters. Institutional aspects include the legal and institutional framework within a lake drainage basin, economic considerations, demography, cultural and social customs, stakeholder participation possibilities and political realities. The last arguably comprise the most important elements, in that they define the factors controlling how humans use their water resources (GWP 2000).

Effectively managing lakes for conservation and sustainability also requires recognition of three unique features: 1) an integrating nature; 2) long water retention time; and 3) complex response dynamics (ILEC 2005). Because of their location at the hub of a drainage basin, lakes are the flow regime integrators within the entire lake-river basin complex. The integrating nature of a lake refers to its function essentially as a 'mixing pot' for everything entering it from its surrounding drainage basin, and sometimes even from beyond its basin via the long-range transportation of airborne pollutants. The long water retention time refers to the average time water 
in the boreal zone, with 1375690 square kilometres in Russia and 1133926 square kilometres in Canada (Joosten 2009). Estimates of peatlands from pre-1990 sources in tropical regions range from 275424 to 570 609 square kilometres, although there has been extensive destruction in recent years (Hooijer et al. 2010).

Peatlands contain 10 per cent of the global freshwater volume and are significant for maintaining freshwater quality and the hydrological integrity of many rivers. They play an important role in maintaining permafrost and preventing desertification. In recent years, their importance as global carbon stores and sinks has come to the fore (Joosten 2009; Hooijer et al. 2010; Joosten et al. 2012). They support important biological diversity and are refugia for some of the rarest and most unusual species of wetland-dependent flora and fauna (Joosten and Clarke 2002). Under waterlogged conditions, they preserve a unique palaeoecological record, including valuable archaeological remains, and records of environmental contamination. They support human needs for food, fresh water, shelter, warmth and employment (Joosten and Clarke 2002).

Human pressures on peatlands are both direct-through drainage, land conversion (for example, for oil palms and oil sands), excavation and inundation-and indirect, as a result of air pollution, water contamination, water removal and infrastructure development. When they are destroyed, they release large amounts of carbon and are not easily restored. In response to the degradation of peatlands, the Ramsar Convention has adopted detailed Guidelines for Global Action on Peatlands (Ramsar 2002), including: establishing a global database of peatlands and detecting changes; developing and promoting awareness, education and training; reviewing national networks of peatland protected areas and implementing peatland management guidelines; and stimulating international cooperation on research and technology transfer.

More recently, guidance has been provided to limit the loss of carbon from peatlands and to encourage their retention and restoration as part of climate change mitigation measures (Joosten et al. 2012). This is particularly important given the past loss of peatlands globally and the more recent degradation of tropical peatlands (Joosten et al. 2012).

\section{Groundwater-dependent ecosystems}

Groundwater is often crucial to the maintenance of the hydrological regime supporting ecosystems: these are known as groundwater-dependent ecosystems (GDEs). The area of these ecosystems is often poorly defined.

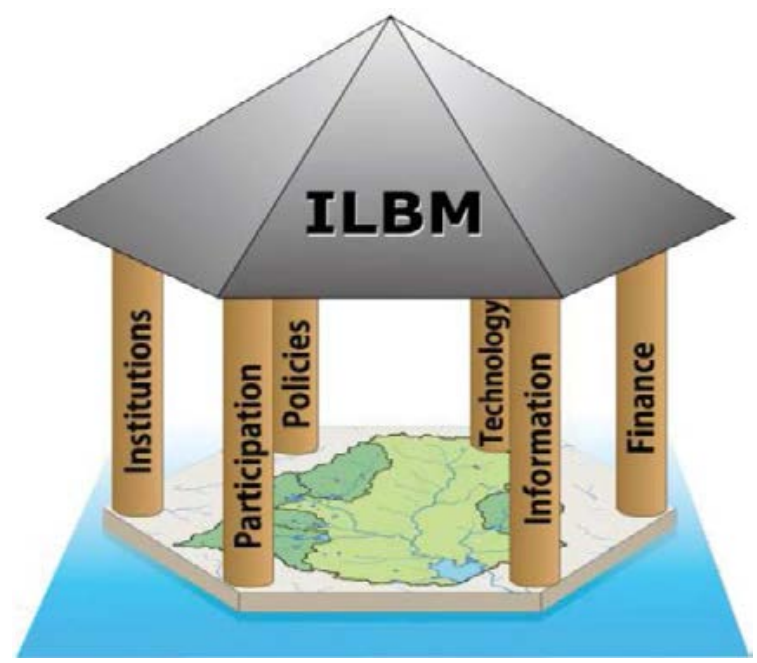

Figure 19.6 Integrated lake basin management

Source: Adapted from Nakamura and Rast (2012)

A change in the quantity or quality of groundwater, often associated with human activity, will impact on the state and condition of GDEs (Eamus and Froend 2006).

Richardson et al. (2011a) recognised three types of GDEs:

1. aquifer and cave ecosystems that provide unique habitats for organisms (for example, stygofauna and troglofauna-the animals which live underground), including karst aquifer systems, fractured rock and saturated sediments

2. ecosystems fully or partly dependent on the surface expression of groundwater, including wetlands, lakes, seeps, springs, river base flow, and some estuarine and marine ecosystems

3. ecosystems dependent on the subsurface presence of groundwater (via the capillary fringe), including terrestrial vegetation that depends on groundwater fully or on an irregular basis.

The degree of dependence on groundwater relative to other sources of water is important in differentiating these ecosystems and their response to changes in groundwater availability (Eamus et al. 2006). Of particular significance are the spatial and temporal variabilities in water tables and the nature of groundwater discharge into flowing or still surface water bodies. According to these interactions, different physico-chemical properties and species assemblages will develop (Horwitz et al. 2008).

Interest in GDEs has largely developed from a need to understand the consequences of direct use or pollution of aquifers. Both the quantity and the quality of groundwater are important as well as the spatial and temporary variability. These relationships can be disrupted by 


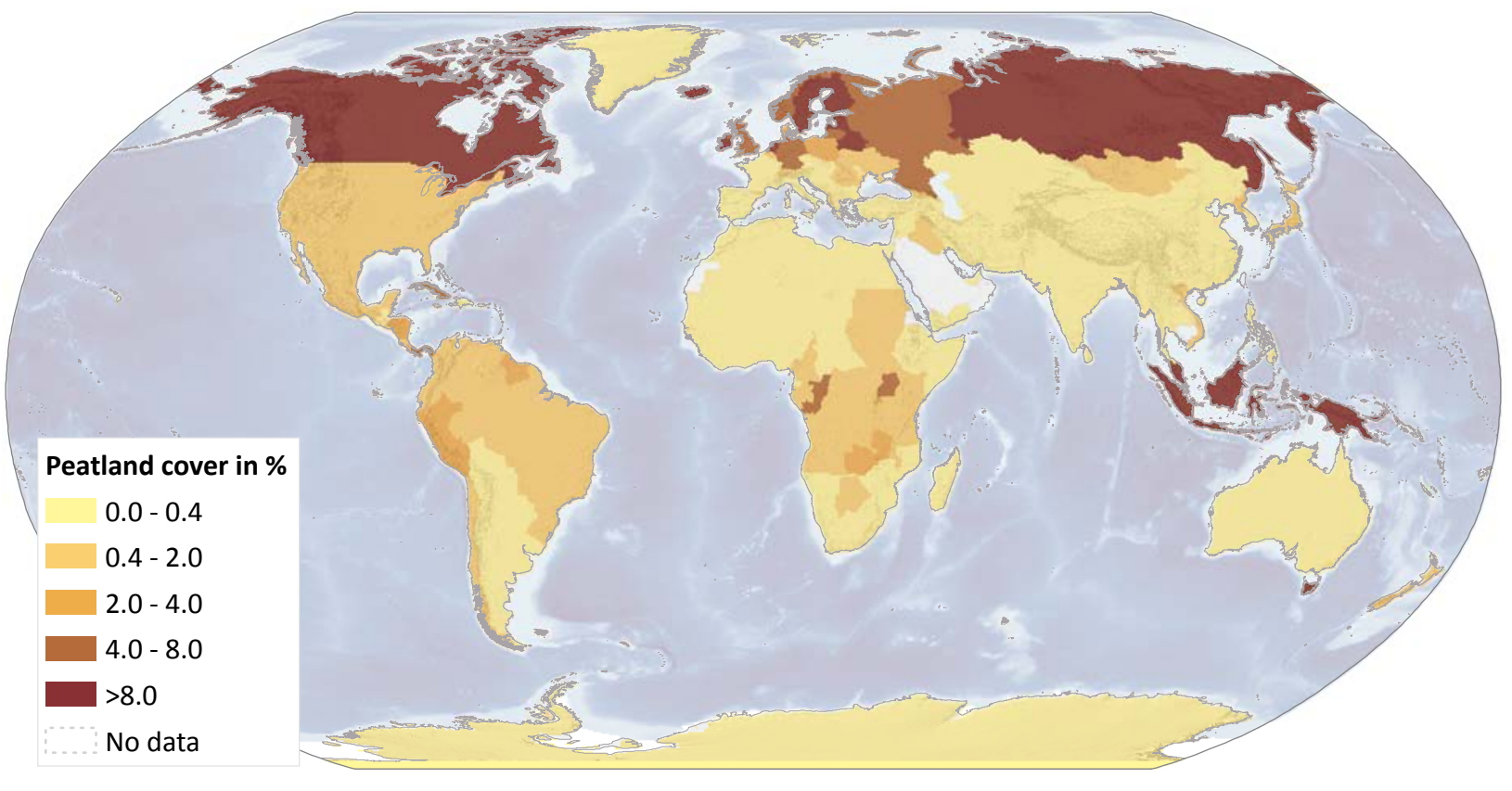

Figure 19.7 Global peatland distribution

Source: Adapted from IMCG Global Peatland Database 2014

changes to the groundwater through abstraction, pollution and reduction in rainfall recharge. Effective management of GDEs requires integration of associated surface and groundwater resources and necessitates an understanding of the origins, pathways and storages of water. For example, some GDEs are entirely maintained by continuous groundwater discharge while others are maintained by minor but critical groundwater inflows restricted to particular seasons or interannual episodes.

In general, processes that threaten GDEs are no different to those that threaten other ecosystems. Changes in groundwater can arise from reduced rainfall recharge, land clearing, forestry and agriculture, urbanisation and direct groundwater abstraction for water supply. The ecological changes brought about by these activities will vary between types of GDEs, depending on their hydrological requirements (Hatton and Evans 1998; Richardson et al. 2011a).

Identifying the importance of groundwater in ecosystems prior to development of groundwater resources (or other activities in a catchment) will inform resource planning and potential trade-offs. The array of current approaches to identifying groundwater requirements of GDEs is summarised by Richardson et al. (2011b), and ranges from measurement of groundwater transpiration by individual trees to hydrological water balances and remote sensing at the landscape scale. In most cases an integration of different approaches and associated disciplines and knowledge is required.
Management of GDEs can also be informed by understanding the potential for ecosystems to adapt to changes in groundwater availability. For example, some GDEs of the Swan Coastal Plain in Western Australia may have shifted to an alternative state (defined by biota and ecological processes) in accordance with changes in the groundwater regime (Froend and Sommer 2010; Sommer and Froend 2014). The potential of GDEs to adapt, however, can be limited under catastrophic (and largely irreversible) changes in the availability of groundwater, such as the widespread mortality of groundwater-dependent (phreatophytic) vegetation by groundwater abstraction in times of drought (Sommer and Froend 2011). In response, management agencies have assessed the threats to phreatophytic vegetation (Barron et al. 2013) and restricted groundwater pumping near vulnerable wetland ecosystems (McFarlane et al. 2012). In order to avoid such scenarios, integrating catchment management and balancing water demands with conservation are required.

\section{Estuaries}

The position of estuaries at the interface of the terrestrial and marine environment makes them vulnerable to the impacts of just about all human activities, whether land-based or marine, including the impacts of climate change. Estuaries are also a magnet for human activity. Thus, managing estuaries as protected areas can be particularly challenging, and its effectiveness often depends on managing external influences even more than on managing in situ activities. The successful 
management of estuarine protected areas hinges on cooperative governance between a number of community and government stakeholders.

Estuarine functioning is primarily driven by the quantity and quality of freshwater inputs and their temporal distribution, plus inputs from the marine environment (Borja et al. 2011; Whitfield et al. 2012). Mediated by freshwater inflows and tides, fresh and salt waters mix in a nutrient-rich environment that supports a diversity of aquatic species. Freshwater abstraction decreases the overall quantity of freshwater entering estuaries. On the other hand, interbasin transfer schemes, wastewater treatment works and increased run-off from 'hardened' catchments (for example, road networks) increase freshwater inflow (Nirupama and Simonovic 2007).

Ideally, the freshwater flow into an estuary should be maintained in all its variability to support its overall habitat structure and dynamics (van Niekerk and Turpie 2012). Base flows are generally responsible for maintaining the salinity regime, and in the case of temporarily open systems, their connectivity to the sea (mouth state). In contrast, floods shape the geomorphological aspects such as the size and shape of an estuary and its characteristic sediment structure. These processes help to maintain the linkages between estuaries and their surrounding terrestrial, freshwater and marine systems. There are many species whose life history strategies depend on movement between these systems, for which the maintenance of open mouth conditions at the right time of year is essential. This includes many marine species of conservation and commercial value. Thus, estuaries should not be managed as isolated systems (van Niekerk and Turpie 2012).

In addition to the quantity of water entering estuaries, catchment activities and infrastructure also affect the quality of this water, in terms of the loads of sediments, nutrients and other pollutants (Turner et al. 2004). This can result in smothering of habitats, increased turbidity and eutrophication - all of which can result in significant changes in biotic communities and local extinctions. While some of the pollution entering estuaries arises from estuary users and adjacent settlements, these are largely problems that arise from the entire catchment area and require protected area managers to collaborate with relevant stakeholders.

The protection of an estuary therefore entails ensuring that the quantity and quality of freshwater inflows are maintained as close to natural as possible, in order to maintain ecological functioning and biodiversity in a relatively natural state. In reality, estuary managers have to deal with many changes that are difficult to reverse to the

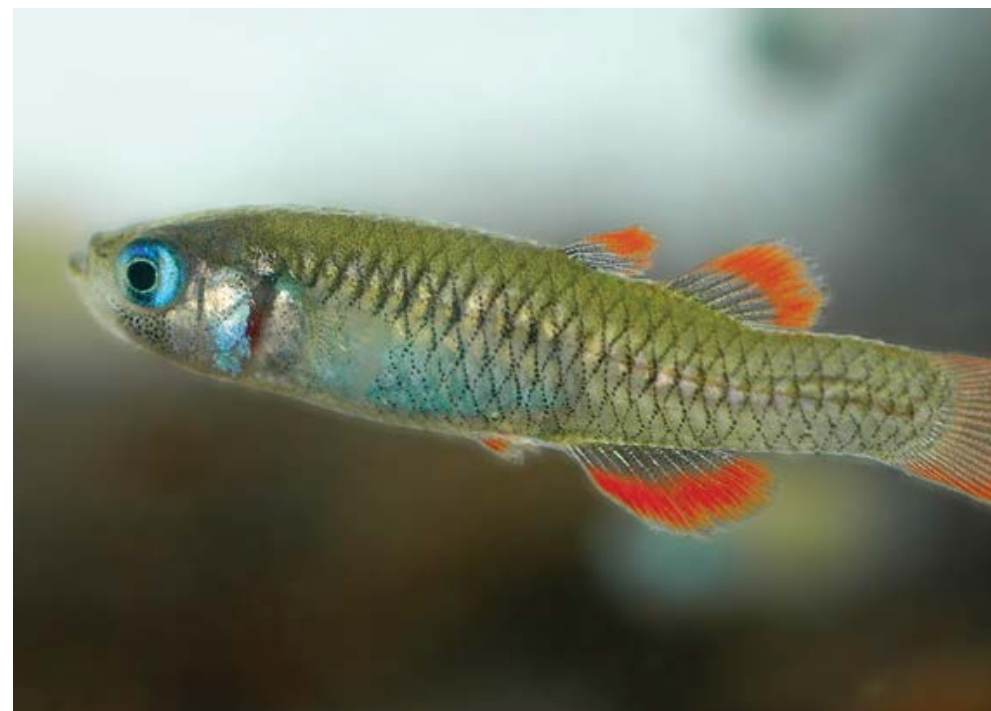

The endangered red-finned blue-eye (Scaturiginichthys vermeilipinnis) lives only in artesian springs, Edgbaston Reserve, Australia

Source: Adam Kerezsy

extent desired, if at all. Where this is the case, protection of estuaries can involve imposing artificial means such as flood-flow releases from dams and breaching the estuary artificially. These interventions are far more complex than trying to maintain natural processes, and require considerable investment in research and monitoring in order to devise strategies that achieve conservation goals. The Chilika Lagoon (Case Study 19.4) is such an example.

The main pressures that have to be managed within estuary systems are developments that encroach on estuary habitats, harvesting of resources such as fish and mangroves, aquaculture and the eradication or control of invasive alien species (Perissinotto et al. 2013). Managing the use of an estuary involves making trade-offs between the different types of values that it can generate (Turpie et al. 2007). For example, allowing subsistence fishing will impact on the provision of ecosystem services such as their functioning as nursery areas to support marine fisheries, and allowing excessive development and access will impact on the biodiversity of the system and its value as an ecotourism destination.

In order for the protection of estuaries to be successful, all of the following interventions at local to national scales are necessary:

- integrated conservation planning that takes landscape processes and socioeconomic trade-offs into account (Turpie and Clark 2007) 

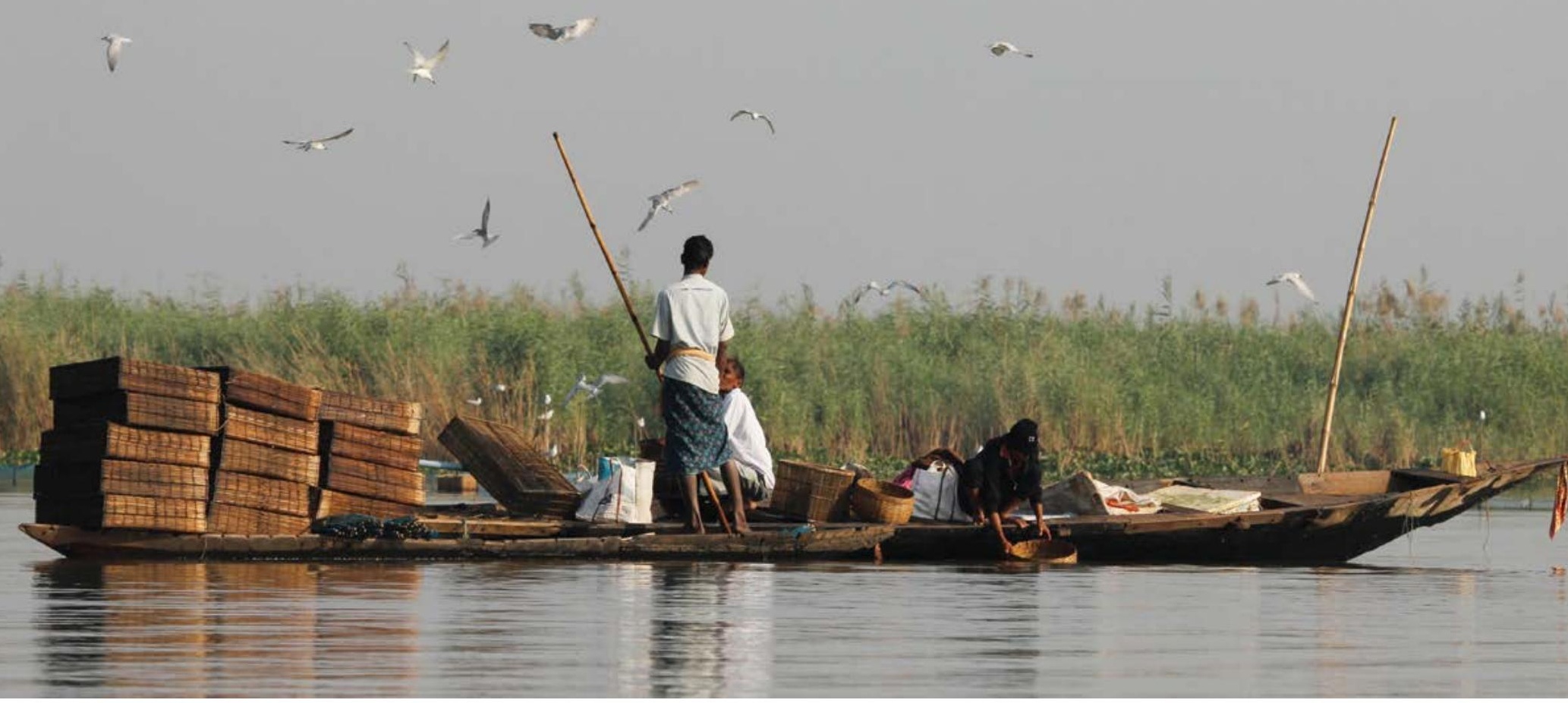

The restoration of Lake Chilika Ramsar site in India supports the livelihoods of fishers

Source: Ritesh Kumar

- catchment management and the setting of environmental flow requirements to assure provision of adequate quantity and quality of inflows to maintain the protected estuaries in a desired state of health (Adams 2013)

- management plans to control competing uses within estuaries

- restriction of consumptive use to prioritise conservation of biodiversity and the supply of regulating services such as nursery areas for crustaceans and fish, carbon sequestration and coastal protection

- delineation of development setback lines to protect landscape value as well as to accommodate estuary mouth migration, and water levels associated with changes in mouth state and sea-level rise.

EPA (2012) provides further information for good estuarine management.

\section{Managing freshwater protected areas in the landscape}

\section{Ramsar Convention on Wetlands}

The Convention on Wetlands of International Importance arose from concerns of governments and NGOs to conserve diminishing wetlands. It was the first modern environmental treaty and was agreed in the Iranian city of Ramsar in 1971. The Ramsar Convention also implements the inland waters program of work on behalf of the Convention on Biological Diversity (CBD) and complements the activities of the Convention on Migratory Species (and related treaties). While other treaties also cover specific sites or values, the Ramsar Convention is discussed in depth here due to its wetlands focus.

Contracting parties (countries) to Ramsar must designate at least one wetland for inclusion on the List of Wetlands of International Importance, known as the Ramsar List (Ramsar 2008). These sites are protected areas and are selected for designation using nine criteria (Table 19.3). 


\section{Case Study 19.4 Restoration of Lake Chilika, India}

Chilika is an estuarine lagoon in Odisha State that seasonally covers an area of 906 to 1165 square kilometres, and is flanked by an ephemeral floodplain of 400 square kilometres (Figure 19.8). Chilika comprises shallow to very shallow marine, brackish and freshwater ecosystems with estuarine characteristics and is a hotspot of biodiversity, with more than one million overwintering migratory birds (Kumar and Pattnaik 2012). Chilika was designated as a Ramsar site in 1981 (IUCN Category VI).

The livelihoods of some 200000 fishers and 400000 farmers depend on the lagoon but were threatened when increased sediment from a degrading catchment reduced the connectivity of the lagoon to the sea, causing a rapid decline in fisheries (Mohapatra et al. 2007). The introduction of shrimp culture as well as the decline in fisheries led to resentment between traditional fishers and immigrants (Dujovny 2009). To restore the lake, in 1991 the Government of Odisha created the Chilika Development Authority, chaired by the chief minister and comprising senior representatives of all concerned departments as well as representatives of the fishing communities. It has programs for catchment restoration, hydrobiological monitoring, sustainable development of fisheries, wildlife conservation, community participation and development and capacity-building.

In 2000 a channel was created to reconnect the lagoon to the sea, and restoration of the hydrological and salinity regimes (Ghosh et al. 2006) led to the recovery of the fisheries and biodiversity. An integrated management planning process involving key stakeholders and rights-holders was initiated in 2008 to guide ongoing conservation of Chilika. A management planning framework was developed (Kumar and Pattnaik 2012), with a plan released in 2012.

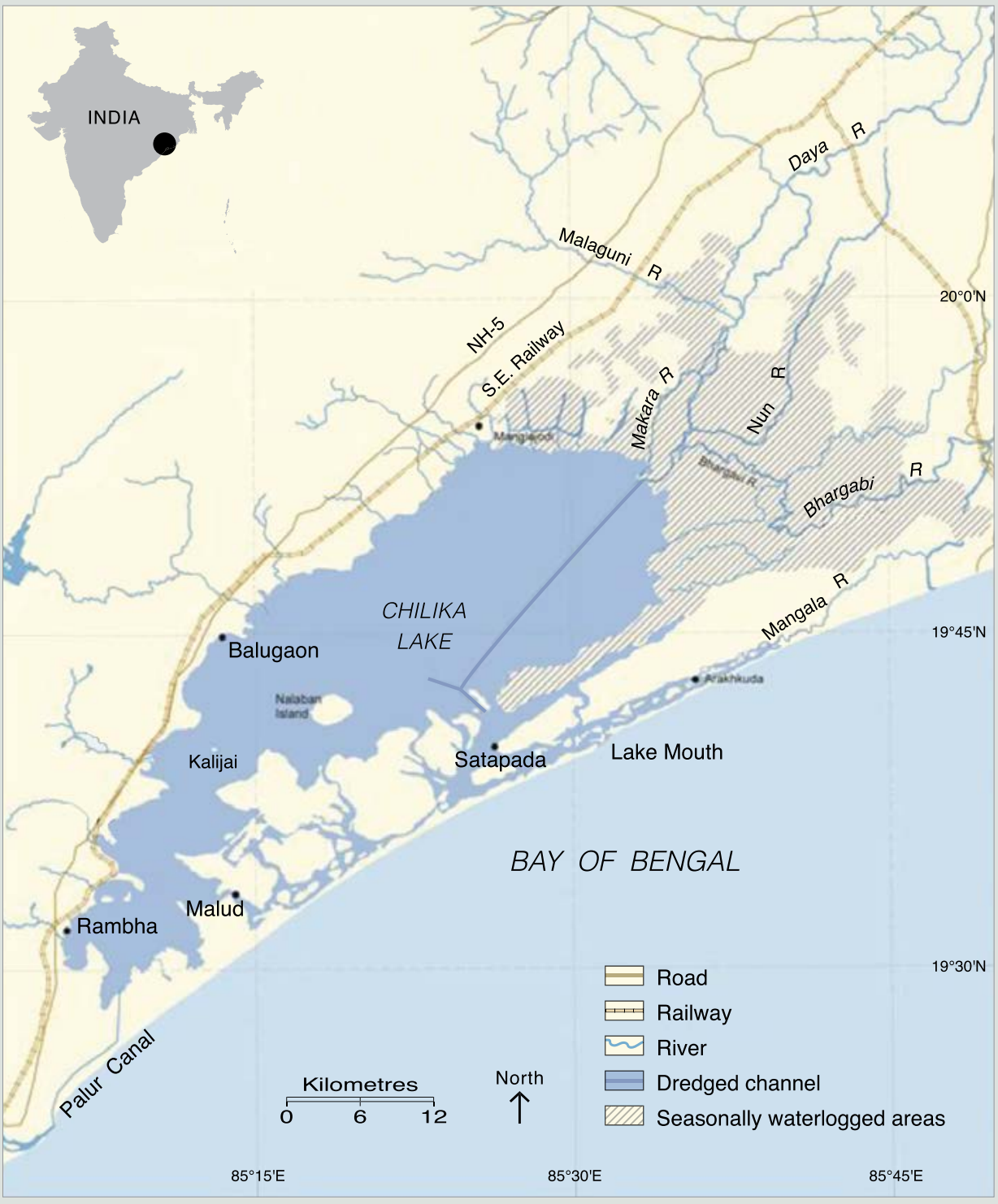

Figure 19.8 Chilika Lagoon, India

Source: Modified from Chilika Development Authority and Wetlands International 
Table 19.3 Criteria for listing Wetlands of International Importance and long-term targets for the Ramsar List

\begin{tabular}{|c|c|}
\hline Specific criterion & Long-term target \\
\hline $\begin{array}{l}\text { Contains a representative, rare or unique example of } \\
\text { a natural or near-natural wetland type found within } \\
\text { the appropriate biogeographical region }\end{array}$ & $\begin{array}{l}\text { Include at least one suitable representative of each wetland } \\
\text { type, according to the Ramsar classification system, which is } \\
\text { found within each biogeographical region }\end{array}$ \\
\hline $\begin{array}{l}\text { Supports vulnerable, endangered or critically } \\
\text { endangered species or threatened ecological } \\
\text { communities }\end{array}$ & $\begin{array}{l}\text { Include those wetlands that are believed to be important for } \\
\text { the survival of vulnerable, endangered or critically endangered } \\
\text { species or threatened ecological communities }\end{array}$ \\
\hline $\begin{array}{l}\text { Supports populations of plant and/or animal species } \\
\text { important for maintaining the biological diversity of a } \\
\text { particular biogeographical region }\end{array}$ & $\begin{array}{l}\text { Include those wetlands that are believed to be of importance for } \\
\text { maintaining the biological diversity within each biogeographical } \\
\text { region }\end{array}$ \\
\hline $\begin{array}{l}\text { Supports plant and/or animal species at a critical } \\
\text { stage in their life cycles, or provides refuge during } \\
\text { adverse conditions }\end{array}$ & $\begin{array}{l}\text { Include those wetlands that are the most important for } \\
\text { providing habitat for plant or animal species during critical } \\
\text { stages of their life cycle and/or when adverse conditions prevail }\end{array}$ \\
\hline Regularly supports 20000 or more waterbirds & $\begin{array}{l}\text { Include all wetlands that regularly support } 20000 \text { or more } \\
\text { waterbirds }\end{array}$ \\
\hline $\begin{array}{l}\text { Regularly supports } 1 \text { per cent of the individuals in a } \\
\text { population of one species or subspecies of waterbird }\end{array}$ & $\begin{array}{l}\text { Include all wetlands that regularly support } 1 \text { per cent or more } \\
\text { of a biogeographical population of a waterbird species or } \\
\text { subspecies }\end{array}$ \\
\hline $\begin{array}{l}\text { Supports a significant proportion of indigenous fish } \\
\text { subspecies, species or families, life history stages, } \\
\text { species interactions and/or populations that are } \\
\text { representative of wetland benefits and/or values and } \\
\text { thereby contributes to global biological diversity }\end{array}$ & $\begin{array}{l}\text { Include those wetlands that support a significant proportion of } \\
\text { indigenous fish subspecies, species or families and populations }\end{array}$ \\
\hline $\begin{array}{l}\text { Important source of food for fishes, spawning } \\
\text { ground, nursery and/or migration path on which } \\
\text { fish stocks, either within the wetland or elsewhere, } \\
\text { depend }\end{array}$ & $\begin{array}{l}\text { Include those wetlands that provide important food sources for } \\
\text { fishes, or are spawning grounds, nursery areas and/or on their } \\
\text { migration path }\end{array}$ \\
\hline $\begin{array}{l}\text { Regularly supports } 1 \text { per cent of the individuals in a } \\
\text { population of one species or subspecies of wetland- } \\
\text { dependent non-avian animal species }\end{array}$ & $\begin{array}{l}\text { Include all wetlands that regularly support } 1 \text { per cent or more of } \\
\text { a biogeographical population of one non-avian animal species } \\
\text { or subspecies }\end{array}$ \\
\hline
\end{tabular}

Source: Ramsar (2008)

The convention has a wide definition of wetlands that includes coastal, marine, artificial and inland ecosystems. A description of each designated wetland is provided by means of a Ramsar information sheet that includes data on scientific, conservation and management parameters and a map to delimit the boundaries of the site (Ramsar 2009b). Countries are encouraged to establish national wetland inventories as a basis for promoting the designation of the largest possible number of appropriate wetland sites. In 2012 only 43 per cent of countries had developed an inventory. A strategic framework provides a vision for the list to 'develop and maintain an international network of wetlands which are important for the conservation of global biological diversity and for sustaining human life through the maintenance of their ecosystem components, processes and benefits/services' (Ramsar 2008:Clause 6).

The strategic framework has objectives to:

- establish national networks of Ramsar sites that fully represent the diversity of wetlands and their key ecological and hydrological functions
- contribute to maintaining global biological diversity through the designation and management of appropriate wetland sites

- foster cooperation in the selection, designation and management of sites

- use the site network as a tool to promote national, supranational/regional and international cooperation over complementary environmental treaties (Ramsar 2008).

The list in 2014 contained 2177 sites covering 2.08 million square kilometres, which represents 16 per cent of the estimated 12.8 million square kilometres of global wetlands (Finlayson et al. 1999). There are 795 inland freshwater wetlands on the Ramsar List, covering a total area of 104.7 million square kilometres (Figure 19.9; Table 19.4).

A further requirement for countries under the Convention is to prepare and implement appropriate management plans for listed wetlands. Table 19.4 shows the regional extent of management planning instruments for inland 


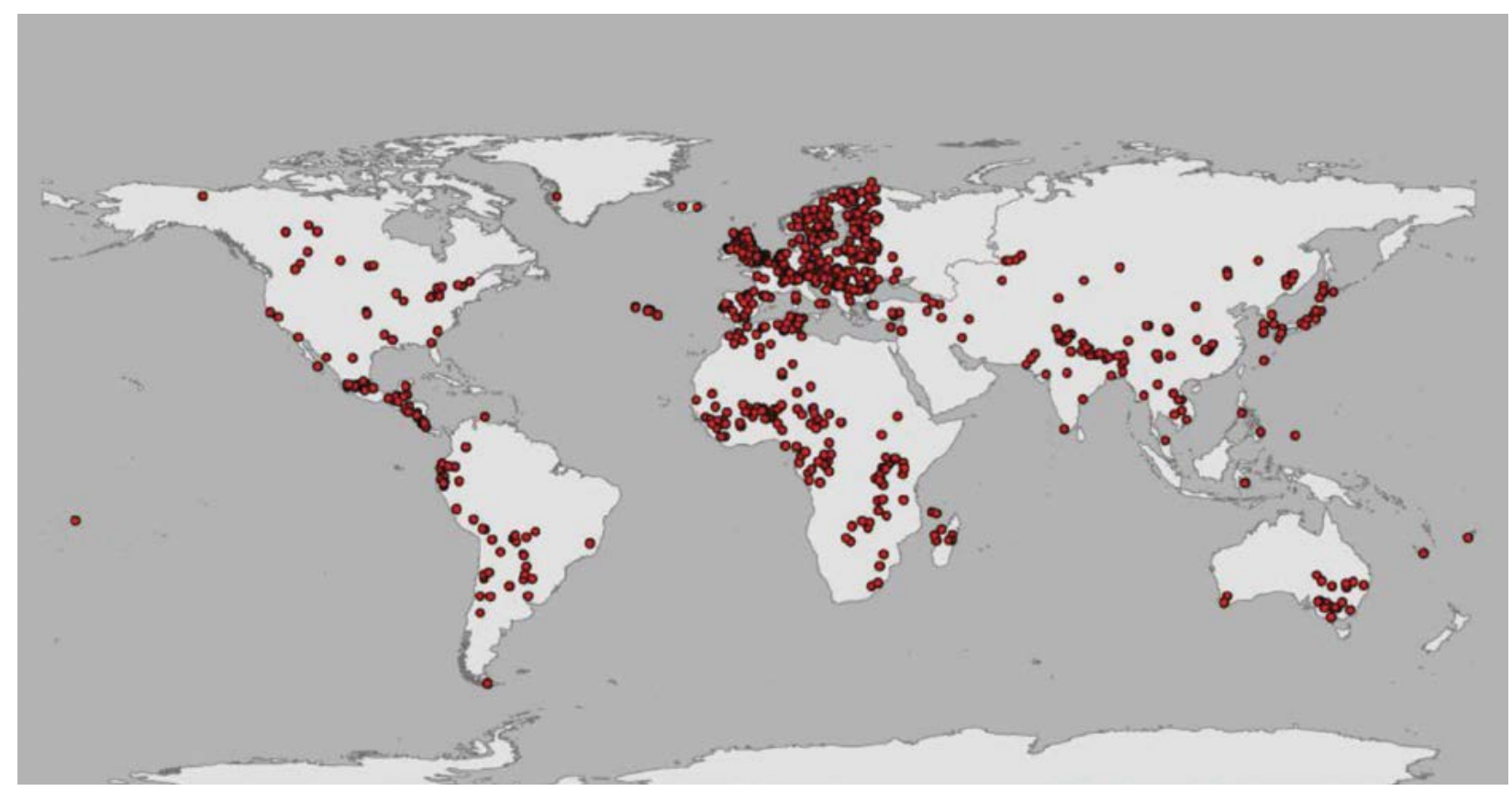

Figure 19.9 Distribution of inland freshwater Ramsar sites

Source: Adapted from Ramsar Sites Information Service

freshwater wetlands. The information provided does not indicate whether management plans are fully in place, regularly updated or effective in achieving the stated objective.

Countries undertake to make wise use of all wetlands and maintain their ecological character-the combination of the ecosystem components, processes and benefits/ services that characterise the wetland. The convention also records reports of adverse change in the ecological character of Ramsar sites (Finlayson et al. 2011). These commitments are supported by an extensive suite of guidance for managers (Ramsar 2011). Reviews of the convention's implementation suggest Ramsar sites have stronger legal status and are better conserved than non-Ramsar protected areas (Bowman 2002). Kakadu National Park in Australia is an example of a prominent Ramsar site (Case Study 19.5).

\section{Freshwater corridors}

Rivers are nature's natural corridors. The flow of water, nutrients and sediments and the movement of species along streams generate consistent habitat in riparian corridors across terrestrial landscapes. These riparian and floodplain corridors are particularly biodiverse and often form key habitat for animals in the terrestrial landscape (Naiman et al. 1993). Tockner et al. (2008:51) conclude that 'far more species of plants and animals occur on floodplains than in any other landscape unit in most regions of the world'.

Consequently, the maintenance and restoration of riparian corridors are conservation priorities for both freshwater and terrestrial ecosystems.

Table 19.4 Number of inland freshwater wetlands included in the Ramsar List as of February 2014

\begin{tabular}{|c|c|c|c|}
\hline Region & Number of wetlands & $\begin{array}{l}\text { Area of wetlands } \\
\text { (million sq km) }\end{array}$ & $\begin{array}{l}\text { Number of wetlands with } \\
\text { management plans }\end{array}$ \\
\hline Africa & 149 (19\%) & 71.2 (68\%) & 87 (58\%) \\
\hline Asia & 105 (13\%) & $4.9(5 \%)$ & 74 (70\%) \\
\hline Europe & 412 (52\%) & $5.5(5 \%)$ & 362 (85\%) \\
\hline Neotropics & 55 (7\%) & $16.8(16 \%)$ & 44 (80\%) \\
\hline North America & $51(6 \%)$ & $3.7(4 \%)$ & 47 (92\%) \\
\hline Oceania & $23(3 \%)$ & $2.6(2 \%)$ & 23 (100\%) \\
\hline Total & 795 & 104.7 & 637 (80\%) \\
\hline
\end{tabular}

Source: Ramsar Sites Information Service 


\section{Case Study 19.5 Wetlands of Kakadu National Park, Australia}

Kakadu National Park (IUCN Category II) is located to the east of Darwin in the north of Australia (Figure 19.10) and covers approximately 20000 square kilometres, including most of the catchment of the South Alligator River. Wetlands include mangroves, salt flats, freshwater floodplains, small lakes (billabongs) as well as springs and pools (Finlayson and Woodroffe 1996). The importance of the wetlands has been recognised by the Ramsar Convention and the World Heritage Convention.

The park is a living cultural landscape and is jointly managed by Indigenous traditional landowners and the Federal Government. The management plan supports joint management and aims to maintain 'a strong and successful partnership between traditional owners, governments, the tourism industry and Park user groups, providing world's best practice in caring for country and sustainable tourism' (Kakadu Board of Management 2007:8).

The management plan and Ramsar ecological character description outline the major management issues (BMT WBM 2010). The park has active teams of rangers who control incursions of key weeds and introduced animals. Climate change and sea-level rise pose an increasing threat, with increased saltwater intrusion into freshwater wetlands and inland movement of mangroves. The mining and processing of uranium ore in an enclave surrounded by the park pose an ongoing threat to the wetlands.

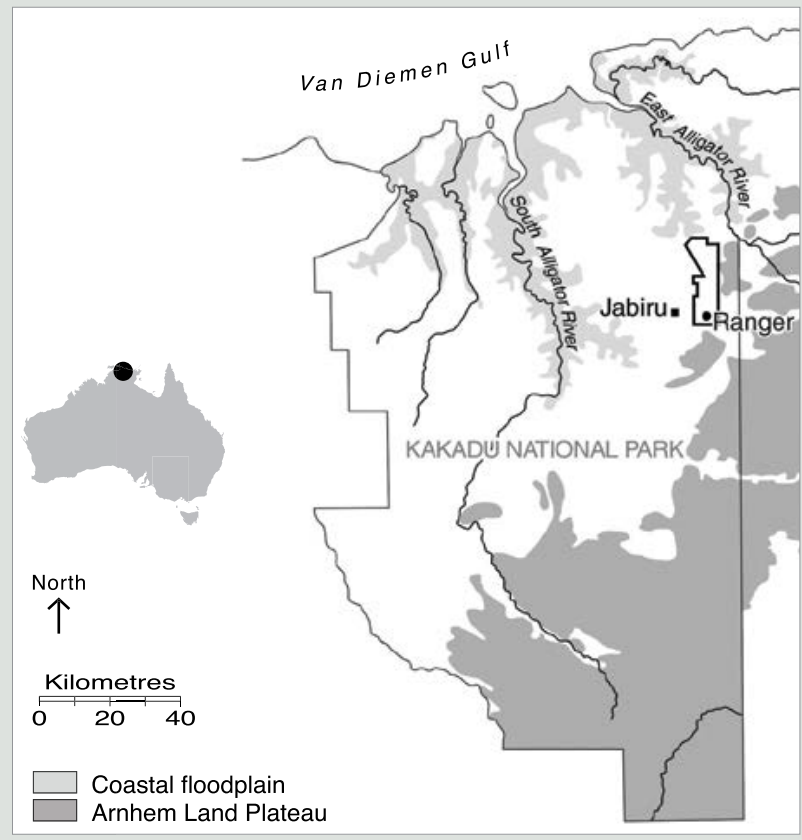

Figure 19.10 Kakadu National Park

Source: US NPS adapted from @ Clive Hilliker Australian National University
There are considerable benefits to be gained from restoring riparian forests (Lukasiewicz et al. 2013). Riparian forests play key roles in providing organic matter that drives the aquatic food chain, forming physical habitat, filtering out pollutants and maintaining appropriate water temperatures. As a result of their geomorphic evolution, rivers provide the most gentle elevation gradients in the landscape and thus the ideal corridors for changes in distribution of many species under climate change.

A key question for managers restoring riparian corridors in areas where land use is contested is 'how wide is wide enough'. The simple answer is as wide as possible but specific assessment is required in each case (Spackman and Hughes 1995). The minimal answer could be wide enough to enable full development of the vegetation canopy to maximise shade across the relevant water body and form an adequate mesic (moist, humid) microclimate. Riparian vegetation is often thick and forms extensive shade and reduces air movement, forming a mesic microclimate that supports particular species and resists fire. A more ideal answer is that the full width of the regularly inundated riparian land should be restored-that is, the floodplain as distinguished by wetland vegetation and soils (DWAF 2008; Kotze et al. 1996).

In recent years landscape-scale linkage projects (see Chapter 27) have commenced in many regions of the world, including Australia, the United States and Europe (Wyborn 2011; Fitzsimons et al. 2013). Surprisingly, very few of these initiatives are centred on river corridors, unlike many linkage projects that are replete with biophysical barriers. Exceptions are the 'room for rivers' floodplain restoration programs along major rivers, such as those along the Danube (Ebert et al. 2009) and Rhine (Case Study 19.6). These combine habitat restoration, corridor establishment and ecosystem-based adaptation to climate change and reducing flood risk.

\section{Catchment and water planning}

Anthropogenic land use is a critical driver of terrestrial conditions that directly affect the structure, function and resilience of aquatic ecosystems (Dudgeon et al. 2006), including within protected areas. Different places within a catchment will support varied movement pathways for biotic and abiotic elements, which, in turn, drive different aquatic processes (Figure 19.12). River catchments generally do not coincide with lines of human ownership, including protected area boundaries (Figure 19.13), requiring managers to engage in catchment-wide land and water-use planning outside protected areas. These processes may include catchment visioning, scenarios and trade-offs around water use and allocation, and granting of water licences for new developments outside the protected area. 
Unfortunately, conservation management has conventionally been separated from water resource management (Gilman et al. 2004). Protected area authorities, however, have a mandated responsibility to engage in planning for freshwater conservation. Where regional proactive development planning is absent, protected area authorities should catalyse these processes. Such proactive planning approaches will help to ensure that the water allocation and quality needed for freshwater conservation are met in downstream protected areas (Case Study 19.7). If the protected area is in a headwater catchment, protected area authorities may also wish to seek benefit-sharing opportunities for the water provided to downstream communities. Protected area authorities therefore act as powerful stakeholders and negotiators for freshwater conservation within integrated water resource management processes. Where water development (for example, the building of dams and other water schemes) upstream of a protected area is necessary, managers should insist on the establishment and enforcement of environmental flow requirements for sustaining ecosystems (Table 19.2; Hirji and Davis 2009).

Catchment management plans are a means of integrating the diverse land and water uses and owners, who, combined, may directly or indirectly influence the quality of a shared river system (Abell et al. 2007; Russi et al. 2013). They are opportunities for protected area managers to favourably influence stakeholders, rights-holders and neighbouring land users (Case Study 19.3). Successful examples of catchment management and planning usually involve collaboration between community, governmental and non-governmental stakeholders and rights-holders. Examples have been documented in the United States (Flitcroft et al. 2009), Australia (Curtis and Lockwood 2000), South Africa (King and Brown 2010) and Europe (Warner et al. 2013). More examples of what works and what does not are becoming available (Sadoff et al. 2008).

There are many names used globally for catchment management. The water sector often uses 'integrated water resources management' for management across water-using sectors and stakeholders/rights-holders (GWP 2000). To focus on ecological units, many organisations have focused on 'integrated river basin management' (WWF 2003) and 'integrated lake basin management' (as discussed above). In North America, the term 'watersheds' is often applied to catchments. The concept is also applied to groundwater basin management. Regardless of the jargon, good catchment management engages multiple stakeholders and rightsholders in applying a common vision for sustainably

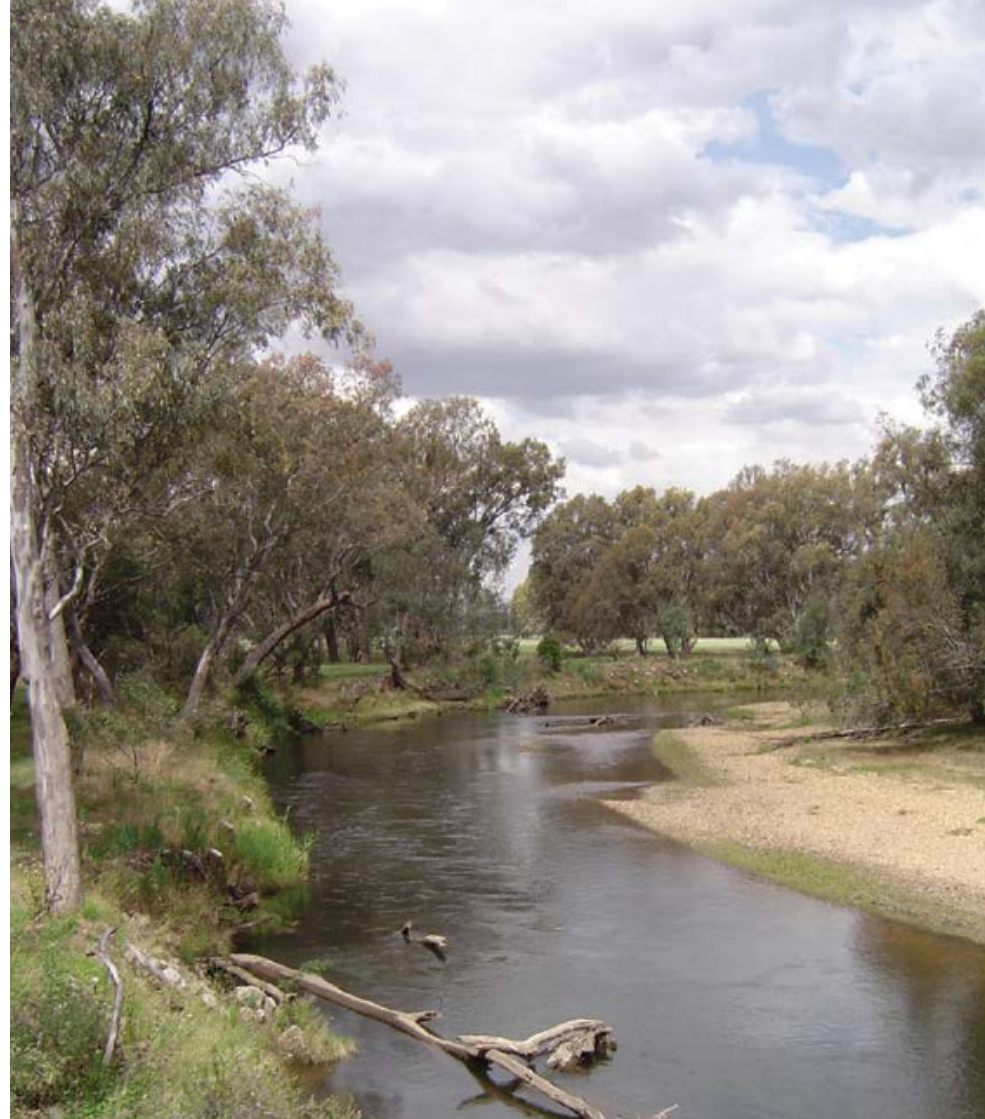

The Ovens River is protected as a free-flowing 'heritage river', Australia

Source: Jamie Pittock

managing a shared basin. Defining and managing for sustainable levels of water withdrawal and water quality are common elements and will reinforce conservation efforts within protected areas.

Learning forums help to build a common understanding, vision and policy around water use and protection, which are critical to stimulating the cooperation needed to support the sustainability of water resources (Ison and Watson 2007). To this end, protected area managers should convene or participate in cross-sectoral learning forums for effective integrated water resource management. At the grassroots level, protected area staff may focus mainly on building trusting relationships with other local stakeholders and rights-holders in the catchments, seeking a common agreement on how to collectively meet everyone's needs (Etienne et al. 2011). At the managerial level, engagement with water resource decision-makers is required to ensure their policy processes are aligned to the needs of the protected area (Collins et al. 2009). At the protected area systems level, these forums should seek a common vision and cross-sectoral cooperation between departments (Roux et al. 2008). 


\section{Case Study 19.6 Millingerwaard, the Netherlands}

The Millingerwaard is an area of former farmland on the floodplain along the Rhine River (Figure 19.11). Alluvial forests, marshlands, natural grasslands, surface waters and river dunes have been restored over two decades for nature conservation, recreation and flood management (Bekhuis et al. 2005). The 800 hectares are a Natura 2000 site and IUCN Category II area managed by the State Forestry Commission.

An agreement with commercial clay and sand extraction companies saw extraction of historical clay deposits following the underlying geographical relief to uncover the natural structure of the riverine landscape (Bekhuis et al. 2005). In this way river safety is improved by giving room for the river to manage flood peaks. Species like beaver (Castor fiber), badger (Meles meles), black stork (Ciconia nigra) and the white-tailed eagle (Haliaeetus albicilla) have returned to the floodplains. Old breeds of cattle and horses that mimic extinct herbivores roam the area and, together with beavers, deer and geese, control vegetation to improve spatial variety and create habitats for other species. Millingerwaard is a demonstration site for the 'Living Rivers' vision developed by the World Wide Fund for Nature (WWF) in the Netherlands in the 1990s (Helmer et al. 1992). The approach has been replicated along other parts of the Rhine River to contribute to reduced flood risk, recreation and biodiversity conservation.

The restored Millingerwaard has become a very popular recreational area, and it is estimated there has been an increase of $€ 6$ million a year in the regional economy (Bekhuis et al. 2005). Success factors include cooperation between businesses and nature and water management agencies, and the economic benefits from recreation. Challenges include maintaining high natural values and flood safety-for example, inundation-free refuges for the wild herbivores may obstruct river flow.

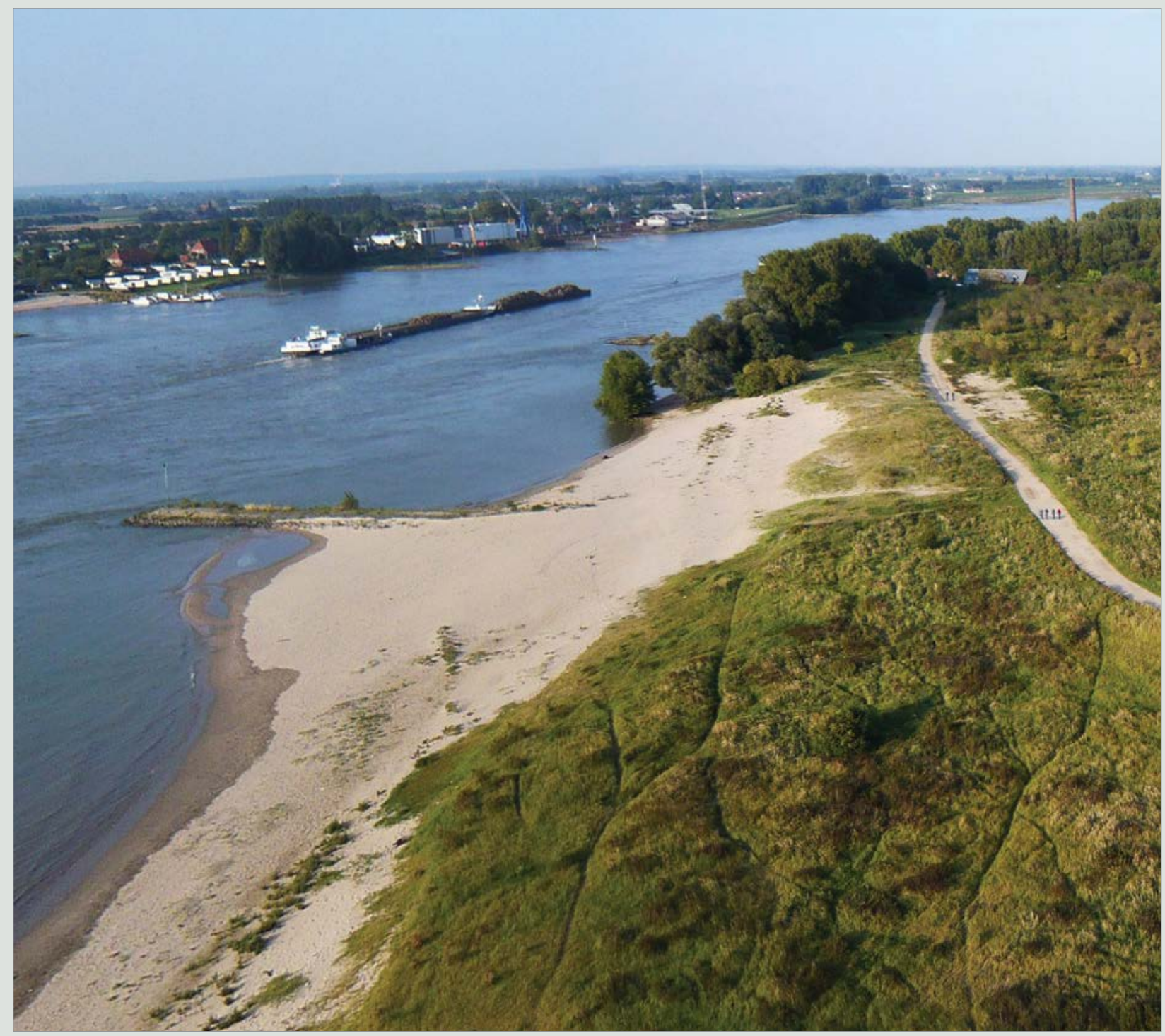

Floodplain restoration, Rhine River, at the Millingerwaard, the Netherlands

Source: Dirk Oomen, Stroming Ltd. 


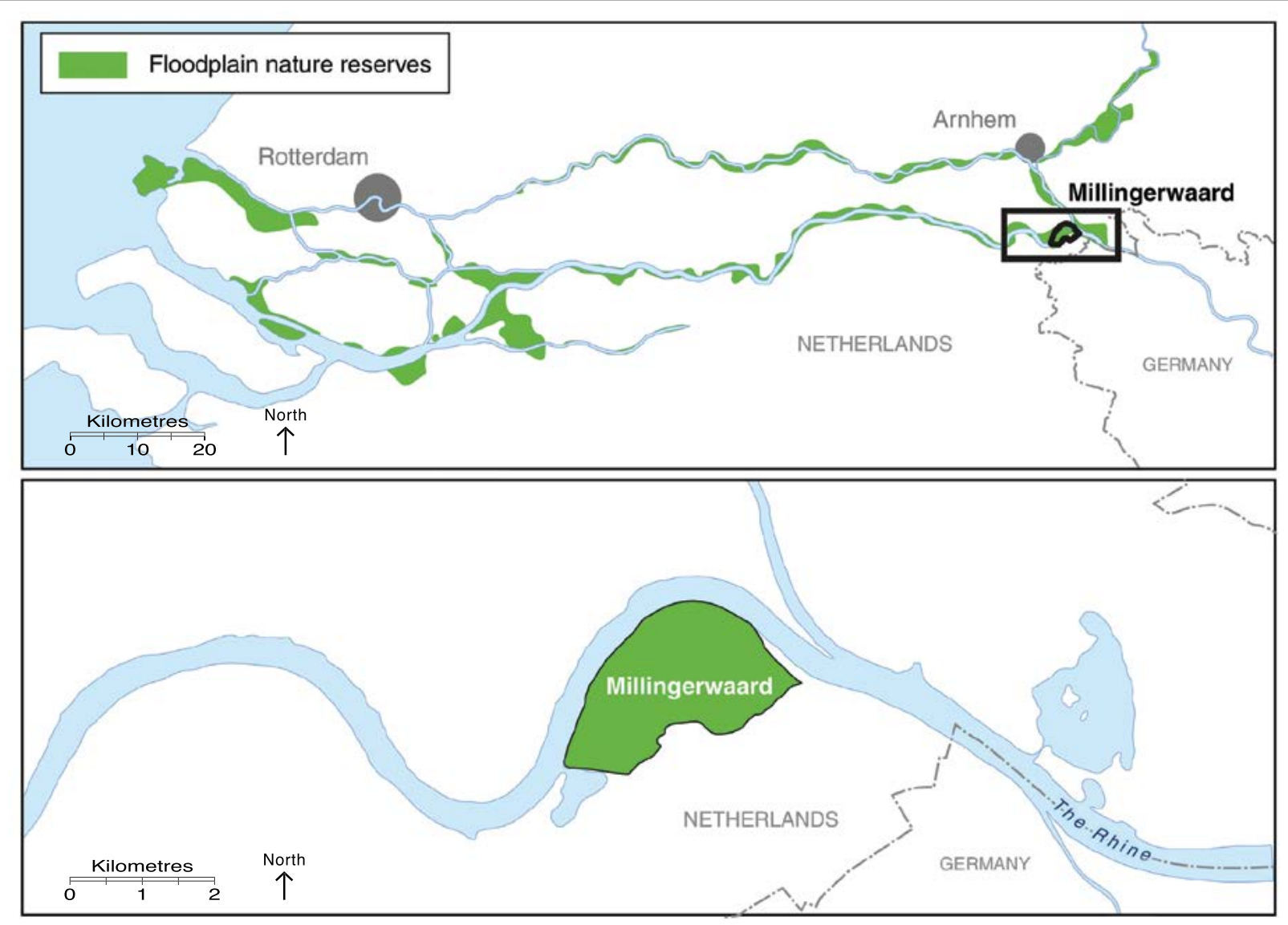

Figure 19.11 Millingerwaard, the Netherlands, showing nature reserves developed along the Rhine River Source: () Clive Hilliker, The Australian National University

\section{Climate change}

Climate has primary, direct and indirect sets of influences on the location, phenology and phenotypic expression of a water body, and the interactions within populations and between species (Parmesan 2006). Water flows and dependant biota are intimately linked to the climate (Poff and Matthews 2013). Climate change will see the extension of the range of 'new' native species into protected areas, and this may signal effective autonomous adaptation rather than a species invasion that should be resisted. Likewise, declines in abundance may be evidence of a range shift. Species will need to be monitored and managed at a regional scale (Poff et al. 2010). More sessile or isolated species may require assistance to disperse to and establish in new habitats (Hannah 2010). Further, managing for a fixed ecological community definition may be counterproductive to effective climate-adaptive management (Matthews et al. 2011; Catford et al. 2012).
A range of climate change adaptation interventions has been proposed to better conserve freshwater biodiversity in wetland protected areas and river systems, including a set of options detailed in Australia (Arthington 2012; Lukasiewicz et al. 2013). These involve identifying and prioritising conservation of parts of the freshwater landscape that may be more resilient to climate change and which can provide refugia, such as river reaches shaded by mountains or those that form corridors that may enable species to move to more favourable habitats. Another option is to manage environmental flows to counter climate change impacts (Olden and Naiman 2010; Poff and Matthews 2013). Generally these flow measures are only possible on rivers with operable dams (Pittock and Hartmann 2011). These approaches require management institutions to maintain infrastructure and make timely decisions_-for instance, to release water from dams. In contrast, free-flowing rivers do not require day-to-day management to provide the flows needed to conserve aquatic species, but they may be at risk from climate-induced changes that cannot be addressed without infrastructure (Pittock and Finlayson 2011). 


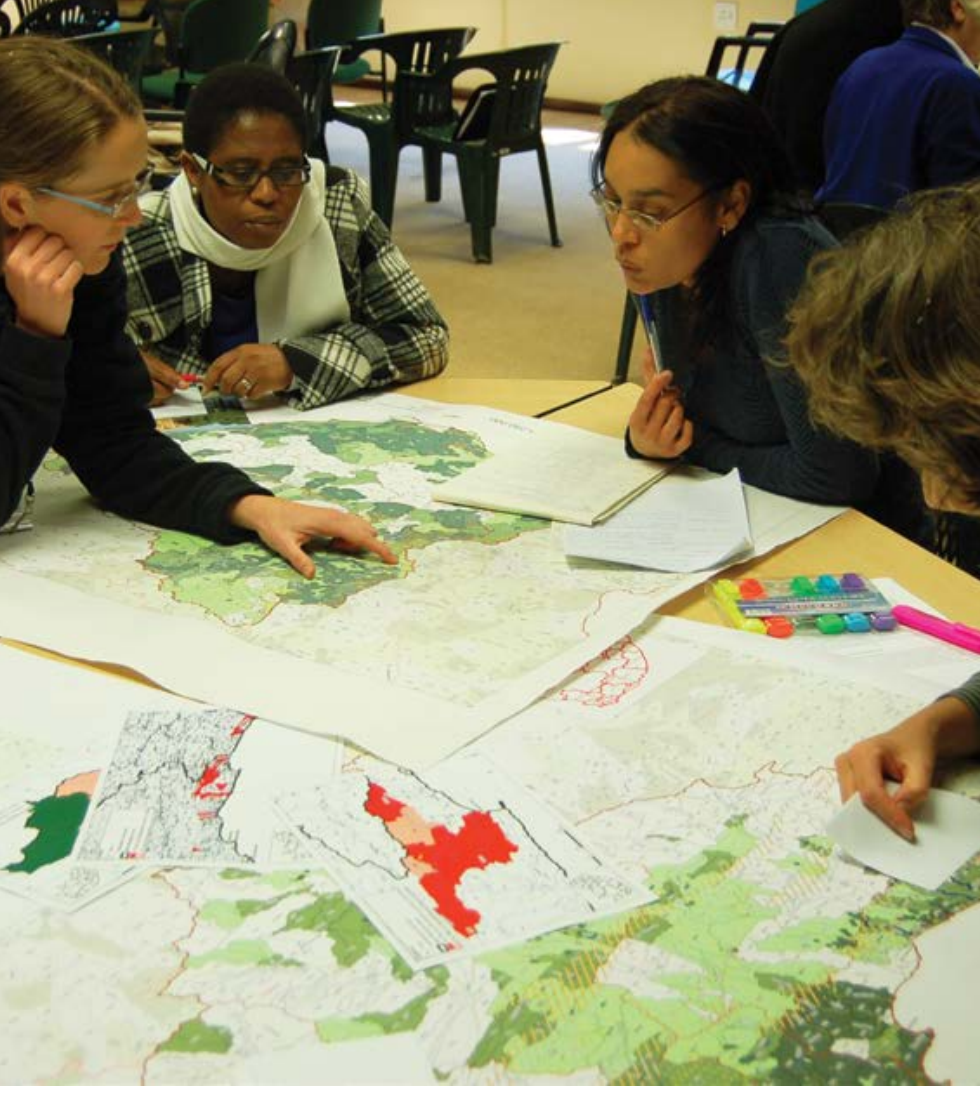

Planning for freshwater conservation by national and provincial agencies in South Africa

Source: Dirk Roux

Many adaptation measures are 'no regrets' measures that offer benefits for the environment and people regardless of climate change. The restoration of riparian forests to shade adjoining freshwater ecosystems and provide other conservation benefits is one example (Davies 2010). At Millingerwaard (Case Study 19.6), restoration of the Rhine River floodplain as a climate change adaptation measure reduces flood risk and conserves biodiversity. The co-benefits for different groups of people associated with these no-regrets adaptation measures provide opportunities to build greater support from stakeholders and rights-holders for conservation.

Upgrading the safety standards of existing water infrastructure for climate change provides opportunities for protected area managers to secure further changes to aid biodiversity adaptation, such as by installing fish passages on dams (Matthews et al. 2011; Pittock and Hartmann 2011). Proposed engineering interventions that use less water to conserve aquatic biodiversity, known as 'environmental water demand management' or 'environmental works and measures', are politically appealing but risk unforeseen environmental impacts and management failure, and should be considered with caution (Pittock et al. 2012; Case Study 19.7).

Infrastructure includes both built and 'natural' ecohydrological components of the landscape. Many institutions are promoting greater conservation of the environment to increase resilience to climate change impacts and aid adaptation. Jargon used to describe this approach includes 'green infrastructure', 'natural capital',

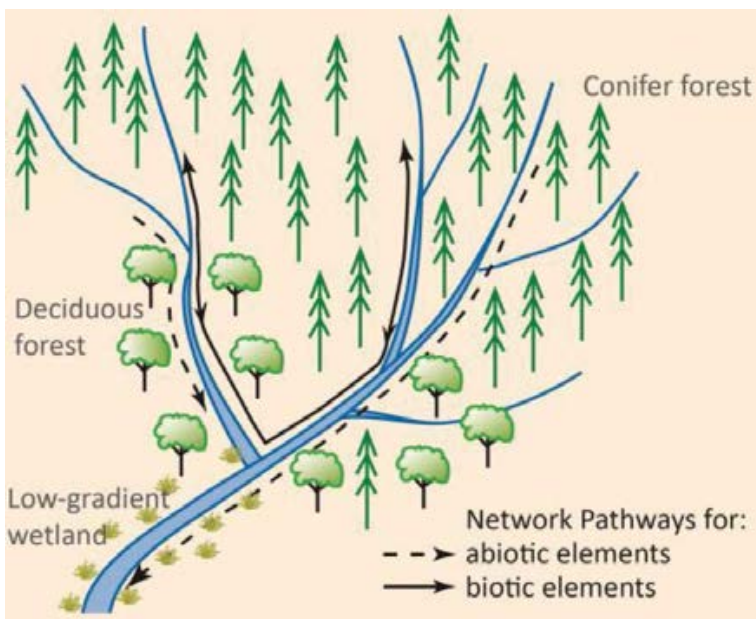

Figure 19.12 Ecological movement pathways: Movement pathways differ for biotic versus abiotic elements in a stream system; abiotic elements must move in the direction of water flow, compared with biotic elements that may also move against river flow

Source: US Department of Agriculture

'ecosystem management', 'ecosystem-based adaptation' and 'ecosystem services' (IEMP 2011). These approaches often favour conservation of freshwater ecosystems.

Too often, decision-makers fix their attention on one intervention when each adaptation option has risks and costs as well as benefits that should be identified. The adoption of a suite of different but complementary interventions may spread risk, maximise benefits and avoid perverse outcomes. The use of environmental flows on regulated rivers linked to protection of freeflowing rivers is an example. With this in mind, Lukasiewicz et al. (2013) developed a catchment-scale framework for working with stakeholders and rightsholders to assess the risks, costs and benefits of options for climate change adaptation. As climate change will impact most if not all protected areas, these measures can help managers to assess priorities and achieve the best possible outcomes (see Chapter 17).

\section{Conclusion}

Although Earth's area supporting freshwater and estuarine ecosystems is relatively small, the biodiversity these systems support is particularly threatened at a global scale. We have outlined the characteristics of diverse types of ecosystems and how their conservation is critical to a core mission of protected area managers in conserving biodiversity. 

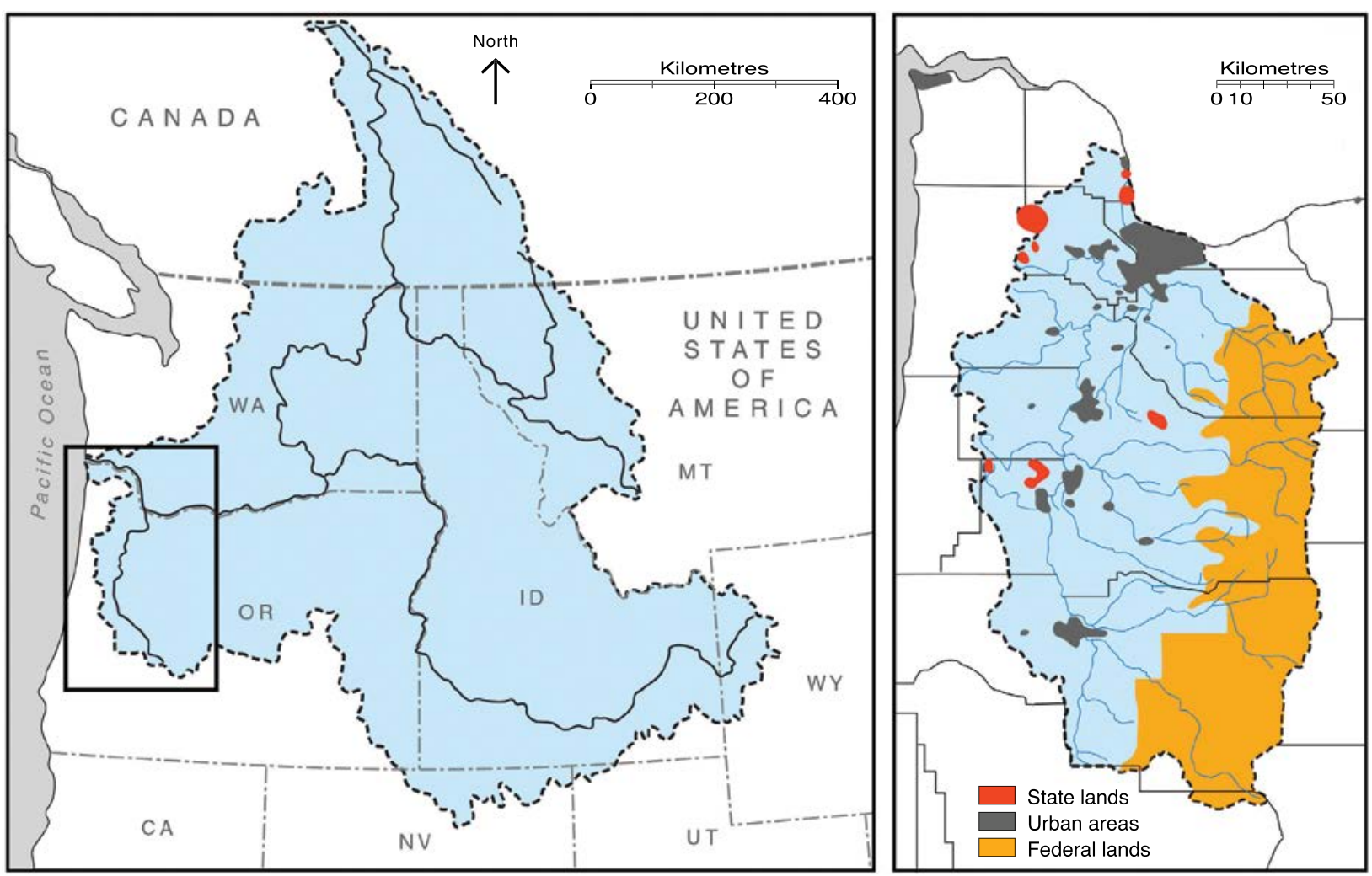

Figure 19.13 Catchments and jurisdictional boundaries: The Columbia River catchment crosses international and State/Provincial borders; the smaller Willamette River catchment crosses multiple local government borders and landownerships divided between the US Federal Government, the State of Oregon and private holdings

Source: (c) Clive Hilliker, The Australian National University

Freshwater ecosystems are challenging to conserve because the ecological processes that drive them, particularly water flows, are readily disrupted by people's demands for energy, food and water. People live by and irrevocably change freshwater systems, creating challenges but also opportunities for protected area managers to gain new audiences and supporters.

There are two golden rules for maintaining or restoring freshwater biodiversity. First, conserve the quality, timing and volume of water flows. Second, ensure connectivity is retained-along rivers, between water bodies and their floodplains, and vertically with natural variability in the depth of water bodies and connectivity with groundwater. This chapter has outlined why it is critical and how protected area managers can engage other stakeholders and rights-holders in landscape-scale water management. We urge managers to challenge development proponents and operators to ensure that existing and new water infrastructure are essential, and if so, that the structures and management regimes incorporate mitigation measures like environmental flows and fish passage facilities. Within protected areas, wildlife and visitor activities are usually focused on water bodies, making them a target and a challenge for managers.

Many terrestrially focused protected areas involve trade-offs and interventions that unwittingly degrade freshwater habitats. Hydropower and water-supply developments that establish or fund protected areas in catchments may do so at the expense of freshwater biodiversity. In these circumstances, managers have an obligation to ensure freshwater biodiversity is conserved as effectively as possible along the full length of rivers.

The reality of climate change will exacerbate competition between people and ecosystems for fresh water in many parts of the world. There are conflicts and positive synergies between different climate change mitigation and adaptation measures for water that protected area managers should engage. For example, planting trees to sequester carbon will normally diminish river flows, whereas strengthening dams to meet greater climatic extremes provides opportunities to mitigate ecological impacts, such as by adding fish passage facilities and providing environmental flows. Further, rivers are the 


\section{Case Study 19.7 Murray-Darling Basin Ramsar wetlands, Australia}

The Murray-Darling Basin covers about 1 million square kilometres (or one-seventh) of Australia (Figure 19.14). Large floodplain forests and other wetlands cover more than 5.7 million hectares (5.6 per cent of the basin), with 636300 hectares designated as 16 Ramsar sites (Pittock et al. 2010). The tenure of these site includes nature reserves (IUCN Category II) managed by state governments and NGOs, forestry and hunting reserves (IUCN Category VI) managed by state governments, and small areas of privately managed pastoral lands (IUCN Category VI). The waters of the basin are so exploited that median annual end-of-river flows have fallen to 29 per cent of pre-development levels. Vast areas of wetlands have suffered from changes in water flows, desiccation, salinity and acid sulphate generation (Pittock and Finlayson 2011).

In 2007-08 the national Water Act was adopted based on Australia's obligations to implement the Convention on Biological Diversity and the Ramsar Convention, and requires conservation of key environmental assets and ecosystem functions and services (Pittock et al. 2010).
In 2012 a basin plan was adopted that could see up to 3200 gigalitres per annum (29 per cent of the water diverted for consumption) returned to the environment by 2024 . The acquired water entitlements are owned and independently managed for conservation by the Federal Government's Commonwealth Environmental Water Holder (Connell 2011).

Engineering interventions known as 'environmental works and measures' are being deployed in an attempt to conserve wetland biodiversity with less water. They risk disrupting habitat connectivity and concentrating salt in wetlands, and rely on timely state government operations and maintenance (Pittock et al. 2012). While restoring adequate flows is important, other important actions have been overlooked, including restoring riparian forests, protecting remaining free-flowing rivers, re-engineering dams to eliminate cold-water pollution and restoring fish passage (Pittock and Finlayson 2011). As the basin plan is to be revised at least every 10 years, there is increased potential for further adaptive management of water allocations and other measures.

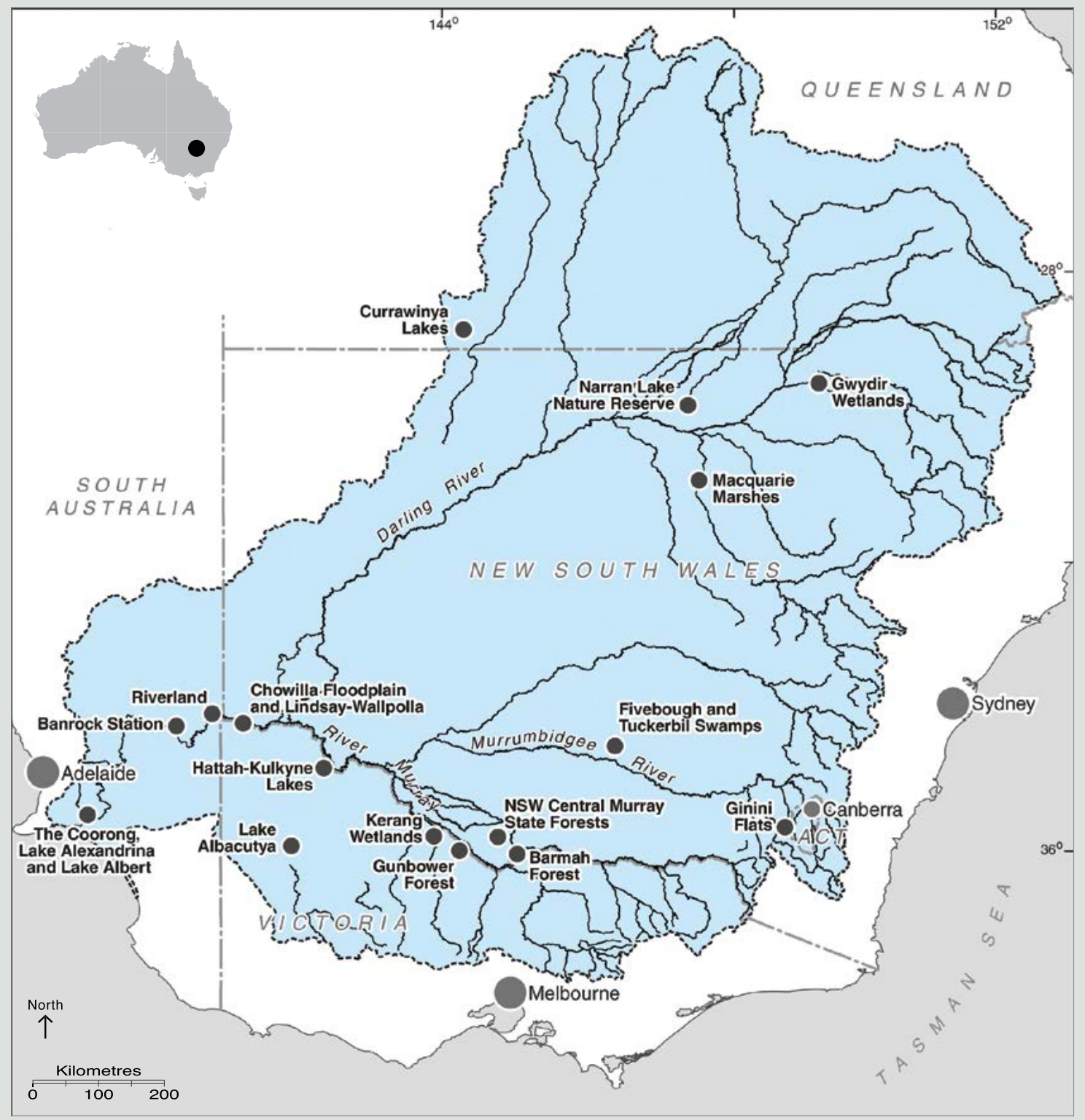

Figure 19.14 Murray-Darling Basin, showing the location of 16 designated Ramsar wetlands Source: @ Clive Hilliker, The Australian National University 


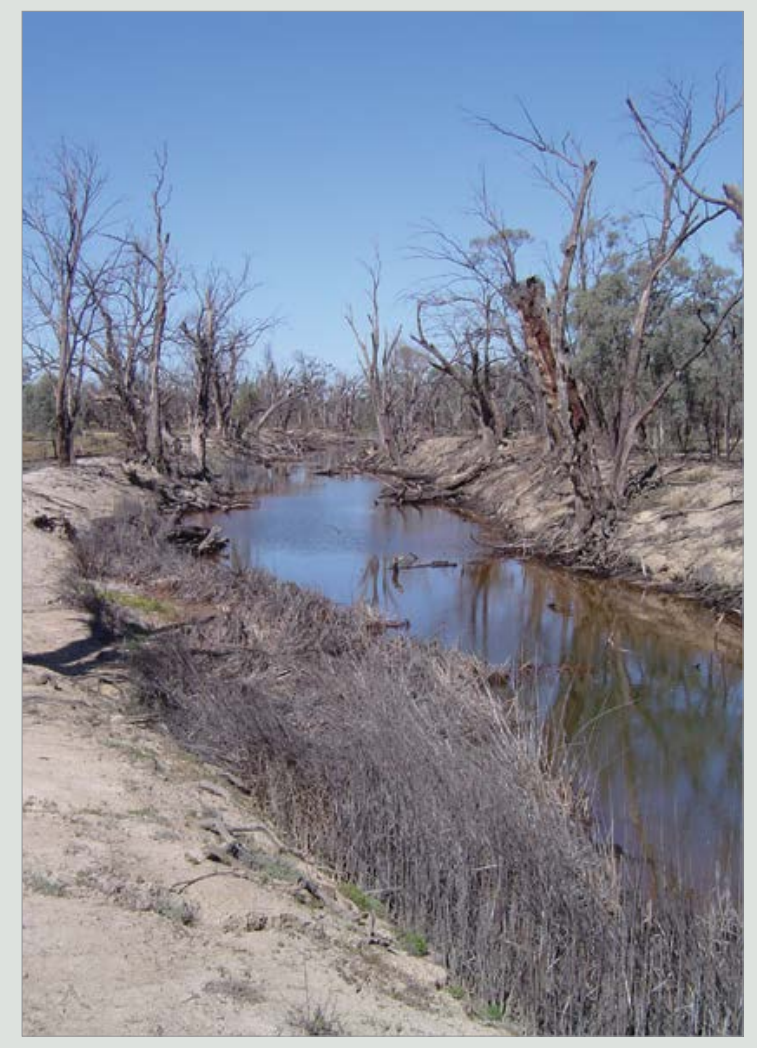

Needs water: the desiccated, acidified and salinised Bottle Bend floodplain, Murray River, Australia

Source: Jamie Pittock

natural landscape corridors with variable gradients, flows of water, nutrients and species for linking protected areas, including for climate change adaptation.

Conserving freshwater ecosystems also involves opportunities for securing the future of protected areas. People's interest in clean and secure water and in freshwater ecosystems is an opportunity to involve neighbours and the broader public in collaborative visioning and management activities.

Of course, conservation of each ecosystem is linked to outcomes for others, and none more so than in the case of freshwater and marine protected areas. Rivers and many aquifers discharge into the sea, bringing with them nutrients that stoke, or pollutants and silt that smother marine communities. Rivers and estuaries are critical breeding grounds for many largely marine species necessitating integrated management.

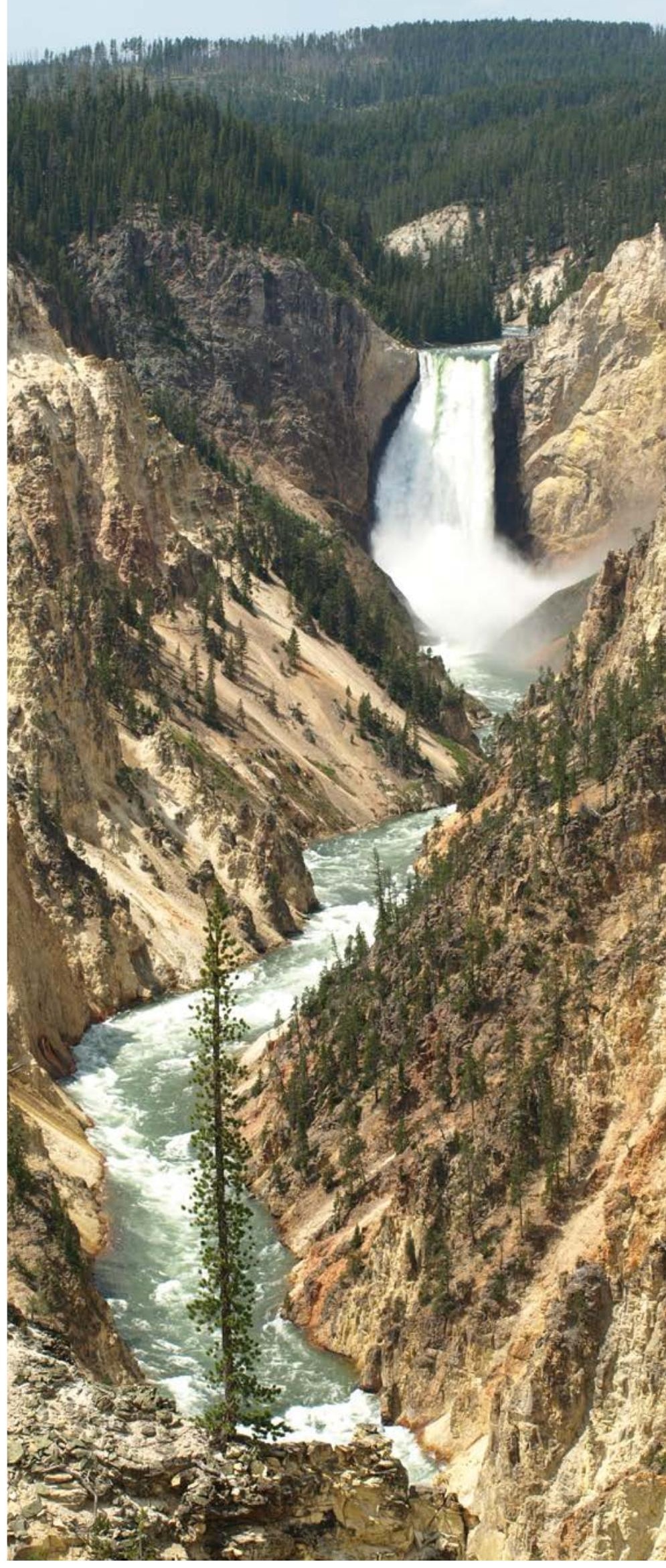

Yellowstone Falls and the Grand Canyon of the Yellowstone River, Yellowstone National Park, USA, a World Heritage property. This outstanding river is an undisturbed tributary of the Missouri River, which then flows to the Mississippi River before the waters reach the Gulf of Mexico.

Source: Graeme L. Worboys 


\section{References}

Recommended reading

Abell, R., Allan, J. D. and Lehner, B. (2007)

'Unlocking the potential of protected areas for freshwaters', Biological Conservation 134: 48-63.

Abell, R., Thieme, M., Revenga, C., Bryer, M., Kottelat, M., Bogutskaya, N., Coad, B., Mandrak, N., Contreras-Balderas, S., Bussing, W., Stiassny, M. L. J., Skelton, P., Allen, G. R., Unmack, P., Naseka, A., Ng, R., Sindorf, N., Robertson, J., Armijo, E., Higgins, J., Heibel, T. J., Wikramanayake, E., Olson, D., Lopez, H. L., Reis, R. E., Lundberg, J. G., Sabaj Perez, M. H. and Petry, P. (2008) 'Freshwater ecoregions of the world: a new map of biogeographic units for freshwater biodiversity conservation', Bioscience 58: 403-14.

Adams, J. B. (2013) 'A review of methods and frameworks used to determine the environmental water requirements of estuaries', Hydrological Sciences Journal 59: 451-65.

Arthington, A. H. (2012) Environmental Flows: Saving rivers in the third millennium, University of California Press, Berkeley.

Arthington, A. H., Bunn, S. E., Poff, N. L. and Naiman, R. J. (2006) 'The challenge of providing environmental flow rules to sustain river ecosystems', Ecological Applications 16: 1311-18.

Arthington, A. H., Naiman, R. J., McClain, M. E. and Nilsson, C. (2010) 'Preserving the biodiversity and ecological services of rivers: new challenges and research opportunities', Freshwater Biology 55: 1-16.

Arthington, A. H., Rall, J. L., Kennard, M. J. and Pusey, B. J. (2003) 'Environmental flow requirements of fish in Lesotho rivers using the DRIFT methodology', River Research and Applications 19: 641-66.

Balian, E. V., Segers, H., Martens, K. and Lévéque, C. (2008) 'The freshwater animal diversity assessment: an overview of the results', in E. V. Balian, C. Lévêque, H. Segers and K. Martens (eds) Freshwater Animal Diversity Assessment. Volume 198, Springer, Netherlands.
Barron, O., Froend, R. H., Hodgson, G., Ali, R., Dawes, W., Davies, P. and McFarlane, D. (2013) 'Projected risks to groundwater-dependent terrestrial vegetation caused by changing climate and groundwater abstraction in the Central Perth Basin, Western Australia', Hydrological Processes, [online]. <doi:10.1002/hyp.10014>

Baumgartner, L. J., Reynoldson, N. K., Cameron, L. and Stanger, J. G. (2009) 'Effects of irrigation pumps on riverine fish', Fisheries Management and Ecology 16: 429-37.

Bekhuis, J., Litjens, G. and Braakhekke, W. (2005) A Policy Field Guide to the Gelderse Poort: A new, sustainable economy under construction, WWFNetherlands, Zeist.

Biggs, H. and Rogers, K. H. (2003) 'An adaptive system to link science, monitoring and management in practice', in J. T. du Toit, K. H. Rogers and H. C. Biggs (eds) The Kruger Experience: Ecology and management of savanna heterogeneity, pp. 59-80, Island Press, Washington, DC.

BioFresh (2013) BioFresh data portal, BioFresh Project, Berlin. <data.freshwaterbiodiversity.eu/>

BMT WBM (2010) Ecological Character Description for Kakadu National Park Ramsar Site, Department of Sustainability, Environment, Water, Population and Communities, Canberra.

Borja, A., Basset, A., Bricker, S., Dauvin, J.-C., Elliott, M., Harrison, T. D., Marques, J.-C., Weisberg, S. B. and West, R. (2011) 'Classifying ecological quality and integrity of estuaries', in E. Wolanski and D. McLusky (eds) Treatise on Estuarine and Coastal Science, pp. 125-62, Academic Press, Waltham, MA.

Bossio, D., Geheb, K. and Critchley, W. (2010) 'Managing water by managing land: addressing land degradation to improve water productivity and rural livelihoods', Agricultural Water Management 97: 536-42.

Bovee, K. D. (1982) A guide to stream habitat analysis using the IFIM, US Fish and Wildlife Service Report FWS/OBS-82/26, Fort Collins, CO. 
Bowman, M. (2002) 'The Ramsar Convention on Wetlands: has it made a difference?', in O. S. Stokke and $\varnothing$. B. Thommessen (eds) Yearbook of International Co-Operation on Environment and Development 2002/2003, pp. 61-8, Earthscan, London.

Bowman, B., Higgs, S., Maclin, E., McClain, S., Sicchio, M., Amy Souers, A., Johnson, S. and Brian Graber, B. (2002) Exploring Dam Removal: A decision-making guide, American Rivers and Trout Unlimited, Washington, DC, and Madison, WI.

Brisbane Declaration (2007) The Brisbane Declaration. $<$ www.eflownet.org/>

Brits, J., van Rooyen, M. W. and van Rooyen, N. (2002) 'Ecological impact of large herbivores on the woody vegetation at selected watering points on the eastern basaltic soils in the Kruger National Park', African Journal of Ecology 40: 53-60.

Bruijnzeel, L. A. (2004) 'Hydrological functions of tropical forests: not seeing the soil for the trees?', Agriculture, Ecosystems \& Environment 104: 185228.

Bunn, S. E. and Arthington, A. H. (2002) 'Basic principles and ecological consequences of altered flow regimes for aquatic biodiversity', Environmental Management 30: 492-507.

Campbell-Grant, E. H., Lowe, W. H. and Fagan, W. F. (2007) 'Living in the branches: population dynamics and ecological processes in dendritic networks', Ecology Letters 10: 165-75.

Catford, J., Naiman, R., Chambers, L., Roberts, J., Douglas, M. and Davies, P. (2012) 'Predicting novel riparian ecosystems in a changing climate', Ecosystems 16: 382-400.

Chape, S., Spalding, M. and Jenkins, M. D. (2008) The World's Protected Areas, Prepared by the UNEPWCMC, University of California Press, Berkeley.

D. Chatterjee, A., Phillips, B. and Stroud, D. A. (2008) Wetland Management Planning: A guide for site managers, WWF, Wetlands International, IUCN and Ramsar Convention Secretariat, Gland.

Chessman, B. C. (2013) 'Do protected areas benefit freshwater species? A broad-scale assessment for fish in Australia's Murray-Darling Basin', Journal of Applied Ecology 50: 969-76.
Collier, K. J. (2011) 'The rapid rise of streams and rivers in conservation assessment', Aquatic Conservation-Marine and Freshwater Ecosystems 21: 397-400.

Collins, K., Colvin, J. and Ison, R. (2009) 'Building "learning catchments" for integrated catchment managing: designing learning systems based on experiences in the UK and South Africa', Water Science and Technology 59: 687-93.

Commonwealth of Australia (2012) Basin Plan, Commonwealth of Australia, Canberra.

Connell, D. (2011) 'The role of the Commonwealth Environmental Water Holder', in D. Connell and R. Q. Grafton (eds) Basin Futures: Water reform in the Murray-Darling Basin, pp. 327-38, ANU E Press, Canberra.

Convention on Biological Diversity (CBD) (2010) $X / 28$. Inland waters biodiversity, UNEP/CBD/ COP/DEC/X/28, Secretariat of the Convention on Biological Diversity, Montreal.

Curtis, A. and Lockwood, M. (2000) 'Landcare and catchment management in Australia: lessons for state-sponsored community participation', Society and Natural Resources: An International Journal 13: 61-73.

Darwall, W. R. T., Smith, K. G., Allen, D. J., Holland, R. A., Harrison, I. J. and Brooks, E. D. E. (2011) The Diversity of Life in African Freshwaters: Underwater, under threat. An analysis of the distribution of freshwater species throughout mainland Africa, Cambridge Publishers, Cambridge and Gland.

Davies, P. M. (2010) 'Climate change implications for river restoration in global biodiversity hotspots', Restoration Ecology 18: 261-8.

Davies, P. M., Naiman, R. J., Warfe, D. M., Pettit, N. E., Arthington, A. H. and Bunn, S. E. (2014) 'Flow-ecology relationships: closing the loop on effective environmental flows', Marine and Freshwater Research 65: 133-41.

Dudgeon, D., Arthington, A. H., Gessner, M. O., Kawabata, Z. I., Knowler, D. J., Lévêque, C., Naiman, R. J., Prieur-Richard, A. H., Soto, D. and Stiassny, M. L. (2006) 'Freshwater biodiversity: importance, threats, status and conservation challenges', Biological Reviews 81: 163-82. 
Dudley, N. (ed.) (2013) Guidelines for Applying Protected Area Management Categories, IUCN, Gland.

Dujovny, E. (2009) 'The deepest cut: political ecology in the dredging of a new sea mouth in Chilika Lake, Orissa, India', Conservation \& Society 7: 192-204.

Department of Water Affairs and Forestry (DWAF) (2008) Updated Manual for the Identification and Delineation of Wetlands and Riparian Areas, Department of Water Affairs and Forestry, Pretoria.

Dyson, M., Bergkamp, G. and Scanlon, J. (eds) (2003) Flow: The essentials of environmental flows, IUCN, Gland.

Eamus, D. and Froend, R. (2006) 'Groundwaterdependent ecosystems: the where, what and why of GDEs', Australian Journal of Botany 54: 91-6.

Eamus, D., Froend, R., Loomes, R., Hose, G. and Murray, B. (2006) 'A functional methodology for determining the groundwater regime needed to maintain the health of groundwater-dependent vegetation', Australian Journal of Botany 54: 97-114.

Ebert, S., Hulea, O. and Strobel, D. (2009) 'Floodplain restoration along the Lower Danube: a climate change adaptation case study', Climate and Development 1: 212-19.

Environmental Protection Agency (EPA) (2012) Estuaries and Coastal Watersheds, United States Environmental Protection Agency, Washington, DC. <water.epa.gov/type/oceb/nep/index.cfm>

Esselman, P. and Allan, J. D. (2011) 'Application of species distribution models and conservation planning software to the design of a reserve network for the riverine fishes of northeastern Mesoamerica', Freshwater Biology 56: 71-88.

Etienne, M., du Toit, D. R. and Pollard, S. (2011) 'ARDI: a co-construction method for participatory modeling in natural resources management', Ecology and Society 16: 44.

Faleiro, F. V. and Loyola, R. D. (2013) 'Socioeconomic and political trade-offs in biodiversity conservation: a case study of the Cerrado Biodiversity Hotspot, Brazil', Diversity and Distributions 19: 977-87.

Finlayson, C. M. and van der Valk, A. G. (1995)

'Wetland classification and inventory: a summary', Vegetation 118: 185-92.
Finlayson, C. M. and Woodroffe, C. D. (1996) 'Wetland vegetation', in C. M. Finlayson and I. von Oertzen (eds) Landscape and Vegetation Ecology of the Kakadu Region, Northern Australia, pp. 81-112, Kluwer Academic Publishers, Dordrecht.

Finlayson, C. M., Davidson, N., Pritchard, D., Milton, G. R. and MacKay, H. (2011) 'The Ramsar Convention and ecosystem-based approaches to the wise use and sustainable development of wetlands', Journal of International Wildlife Law \& Policy 14: 176-98.

Finlayson, C. M., Davidson, N. C., Spiers, A. G. and Stevenson, N. J. (1999) 'Global wetland inventory-current status and future priorities', Marine and Freshwater Research 50: 717-27.

Fitzsimons, J., Pulsford, I. and Wescott, G. (2013) 'Lessons from large-scale conservation networks in Australia', Parks 19: 115-25.

Fleckenstein, J., Anderson, M., Fogg, G. and Mount, J. (2004) 'Managing surface water-groundwater to restore fall flows in the Cosumnes River', Journal of Water Resources Planning and Management 130: 301-10.

Flitcroft, R. L., Dedrick, D. C., Smith, C. L., Thieman, C. A. and Bolte, J. P. (2009) 'Social infrastructure to integrate science and practice: the experience of the Long Tom Watershed Council', Ecology and Society 14(36). <www.ecologyandsociety.org/vol14/iss2/ $\operatorname{art} 36 />$

Freshwater Fish Specialist Group (FFSG) (2013) Global Freshwater Fish Bioblitz, IUCN Freshwater Fish Specialist Group, Chester, UK.

Froend, R. and Sommer, B. (2010) 'Phreatophytic vegetation response to climatic and abstractioninduced groundwater drawdown: examples of longterm spatial and temporal variability in community response', Ecological Engineering 36: 1191-200.

Ghosh, A. K., Pattnaik, A. K. and Ballatore, T. J. (2006) 'Chilika Lagoon: restoring ecological balance and livelihoods through re-salinization’, Lakes \& Reservoirs: Research \& Management 11: 239-55.

Gilman, R. T., Abell, R. A. and Williams, C. E. (2004) 'How can conservation biology inform the practice of integrated river basin management?', International Journal of River Basin Management 2: 135-48. 
Global Biodiversity Information Facility (GBIF) (2014) Global Biodiversity Information Facility, GBIF Secretariat, Copenhagen. <www.gbif.org/>

Global Water Partnership (GWP) (2000) Integrated Water Resources Management, Global Water Partnership, Stockholm.

Government of Queensland (2014) 'WetlandInfo', Queensland Wetlands Program, Government of Queensland, Brisbane. <wetlandinfo.ehp.qld.gov.au/ wetlands/>

Hadwen, W. L., Boon, P. J. and Arthington, A. H. (2012) 'Aquatic ecosystems in inland Australia: tourism and recreational significance, ecological impacts and imperatives for management', Marine and Freshwater Research 63: 325-40.

Haefner, A. (2013) 'Regional environmental security: cooperation and challenges in the Mekong subregion', Global Change, Peace and Security 25: 27-41.

Hannah, L. (2010) 'A global conservation system for climate-change adaptation', Conservation Biology 24(1): 70-7.

Hatton, T. and Evans, R. (1998) Dependence of Ecosystems on Groundwater and its Significance to Australia, Land and Water Research and Development Corporation, Canberra.

Helfield, J. M. and Naiman, R. J. (2006) 'Keystone interactions: salmon and bear in riparian forests of Alaska', Ecosystems 9: 167-80.

Helmer, W., Litjens, G., Overmars, W., Barneveld, H., Kink, A., Sterenburg, H. and Janssen, B. (1992) Living Rivers, WWF-Netherlands, Zeist.

Hermoso, V., Kennard, M. J. and Linke, S. (2012a) 'Integrating multidirectional connectivity requirements in systematic conservation planning for freshwater systems', Diversity and Distributions 18: 448-58.

Hermoso, V., Linke, S., Prenda, J. and Possingham, H. P. (2011) 'Addressing longitudinal connectivity in the systematic conservation planning of fresh waters', Freshwater Biology 56: 57-70.

Hermoso, V., Ward, D. P. and Kennard, M. J. (2012b) 'Using water residency time to enhance spatiotemporal connectivity for conservation planning in seasonally dynamic freshwater ecosystems', Journal of Applied Ecology 49: 1028-35.
Herron, N., Davis, R. and Jones, R. (2002) 'The effects of large-scale afforestation and climate change on water allocation in the Macquarie River catchment, NSW, Australia', Journal of Environmental Management 65: 369-81.

Higgins, J. V., Bryer, M. T., Khoury, M. L. and FitzHugh, T. W. (2005) 'A freshwater classification approach for biodiversity conservation planning', Conservation Biology 19: 432-45.

Hirji, R. and Davis, R. (2009) Environmental Flows in Water Resources Policies, Plans, and Projects. Findings and recommendations, The International Bank for Reconstruction and Development and The World Bank, Washington, DC.

Hooijer, A., Page, S., Canadell, J. G., Silvius, M., Kwadijk, J., Wösten, H. and Jauhiainen, J. (2010) 'Current and future $\mathrm{CO}_{2}$ emissions from drained peatlands in Southeast Asia', Biogeosciences 7(5): 1505-14.

Horwitz, P., Bradshaw, D., Hopper, S., Davies, P., Froend, R. and Bradshaw, F. (2008) 'Hydrological change escalates risk of ecosystem stress in Australia's threatened biodiversity hotspot', Journal of the Royal Society of Western Australia 91: 1-12.

Howard, B. C. (2012) 'Salmon re-enter Olympic National Park river thanks to Elwha Dam removal', National Geographic News Watch, 21 August 2012. <newswatch.nationalgeographic.com/2012/08/21/ salmon-enter-olympic-national-park-for-the-firsttime-thanks-to-elwha-dam-removal/>

Illueca, J. and Rast, W. (1996) 'Precious, finite and irreplaceable', Our Planet 8. <www.ourplanet.com/ imgversn/83/rast.html>

Intergovernmental Panel on Climate Change (IPCC) (2007) Impacts, Adaptation and Vulnerability. Intergovernmental Panel on Climate Change. Climate Change 2007: Working Group II. Contribution to the Intergovernmental Panel on Climate Change Fourth Assessment Report, Intergovernmental Panel on Climate Change, Geneva.

International Ecosystem Management Partnership (IEMP) (2011) Restoring the natural foundation to sustain a green economy, UNEP Policy Series on Ecosystem Management No. 6, International Ecosystem Management Partnership, United Nations Environment Programme, Nairobi. 
International Lake Environment Committee Foundation (ILEC) (2005) Managing Lakes and their Basins for Sustainable Use: A report for lake basin managers and stakeholders, International Lake Environment Committee Foundation, Kusatsu, Japan. <www.ilec.or.jp/en/pubs/p2/lbmi>

International Union for Conservation of Nature (IUCN) (2003) Guidelines for Application of IUCN Red List Criteria at Regional Levels: Version 3.0, IUCN Species Survival Commission, Gland and Cambridge.

Ison, R. and Watson, D. (2007) 'Illuminating the possibilities for social learning in the management of Scotland's water', Ecology and Society 12: 21. <www.ecologyandsociety.org/vol12/iss1/art21/>

Jackson, R. B., Jobbágy, E. G., Avissar, R., Roy, S. B., Barrett, D. J., Cook, C. W., Farley, K. A., le Maitre, D. C., McCarl, B. A. and Murray, B. C. (2005) 'Trading water for carbon with biological carbon sequestration', Science 310: 1944-7.

Jeffres, C. A., Opperman, J. J. and Moyle, P. B. (2008) 'Ephemeral floodplain habitats provide best growth conditions for juvenile Chinook salmon in a California river', Environmental Biology of Fishes 83: 449-58.

Joosten, H. (2009) The Global Peatland $\mathrm{CO}_{2}$ Picture: Peatland status and drainage related emissions in all countries of the world, Greifswald University and Wetlands International, Waganingen, Netherlands.

Joosten, H. and Clarke, D. (2002) Wise Use of Mires and Peatlands: Background and principles including a framework for decision-making, International Mire Conservation Group and International Peat Society, Saarijärvi, Finland.

Joosten, H., Tapio-Biström, M. L. and Tol, S. (eds) (2012) Peatlands: Guidance for climate change mitigation through conservation, rehabilitation and sustainable use, FAO and Wetlands International, Rome and Ede, Netherlands.

Junk, W. J. and Nunes da Cunha, C. (2012) 'Wetland management challenges in the South-American Pantanal and the international experience', in A. A. R. Loris (ed.) Tropical Wetland Management: The South-American Pantanal and the international experience, pp. 315-32, Ashgate, Farnham, UK.
Junk, W. J., Nunes da Cunha, C., Wantzen, K. M., Petermann, P., Strüssmann, C., Marques, M. I. and Adis, J. (2006) 'Biodiversity and its conservation in the Pantanal of Mato Grosso, Brazil', Aquatic Sciences 68: 278-309.

Kakadu Board of Management (2007) Kakadu National Park Management Plan 2007-2014, Government of Australia, Canberra.

Khoury, M., Higgins, J. and Weitzell, R. (2011) 'A freshwater conservation assessment of the Upper Mississippi River basin using a coarse- and fine-filter approach', Freshwater Biology 56: 162-79.

King, J. and Brown, C. (2010) 'Integrated basin flow assessments: concepts and method development in Africa and South-East Asia', Freshwater Biology 55: 127-46.

King, J., Brown, C. and Sabet, H. (2003) 'A scenariobased holistic approach to environmental flow assessments for rivers', River Research and Applications 19(5-6): 619-39.

Kingsford, R. T., Biggs, H. C. and Pollard, S. R. (2011) 'Strategic adaptive management in freshwater protected areas and their rivers', Biological Conservation 144: 1194-203.

Kleinschmidt Associates (2008) Cosumnes River Preserve Management Plan, Cosumnes River Preserve, Galt, CA.

Knight, A. T., Grantham, H. S., Smith, R. J., McGregor, G. K., Possingham, H. P. and Cowling, R. M. (2011) 'Land managers' willingness-to-sell defines conservation opportunity for protected area expansion', Biological Conservation 144: 2623-30.

Kotze, D. C., Klug, J. R., Hughes, J. C. and Breen, C. M. (1996) 'Improved criteria for classifying hydric soils in South Africa', South African Journal of Plant and Soil 13(3): 67-73.

Kumar, R. and Pattnaik, A. K. (2012) Chilika: An integrated management planning framework for conservation and wise use, Wetlands InternationalSouth Asia and Chilika Development Authority, New Delhi and Bhubaneswar, India.

Laizé, C. L. R., Acreman, M. C., Schneider, C., Dunbar, M. J., Houghton-Carr, H. A., Flörke, M. and Hannah, D. M. (2014) 'Projected flow alteration and ecological risk for pan-European rivers', River Research and Applications 30: 299-314. 
Lehner, B. and Döll, P. (2004) 'Development and validation of a global database of lakes, reservoirs and wetlands', Journal of Hydrology 296: 1-22.

Lindloff, S. (2000) Dam Removal: A citizen's guide to restoring rivers, River Alliance of Wisconsin and Trout Unlimited, Madison, WI, and Arlington, VA.

Linke, S., Kennard, M. J., Hermoso, V., Olden, J. D., Stein, J. and Pusey, B. J. (2012) 'Merging connectivity rules and large-scale condition assessment improves conservation adequacy in river systems', Journal of Applied Ecology 49: 1036-45.

Loneragan, N. R. and Bunn, S. E. (1999) 'River flows and estuarine ecosystems: implications for coastal fisheries from a review and a case study of the Logan River, southeast Queensland', Australian Journal of Ecology 24: 431-40.

Dd Lukasiewicz, A., Finlayson, C. M. and Pittock, J. (2013) Incorporating Climate Change Adaptation into Catchment Management: A user guide, Charles Sturt University, Albury, NSW.

McFarlane, D., Strawbridge, M., Stone, R. and Paton, A. (2012) 'Managing groundwater levels in the face of uncertainty and change: a case study from Gnangara', Water Science and Technology: Water Supply 12: 321-8.

Matthews, J. H., Wickel, B. A. and Freeman, S. (2011) 'Converging currents in climate-relevant conservation: water, infrastructure, and institutions', PLoS Biology 9: 1001159.

Micklin, P. and Aladin, N. V. (2008) 'Reclaiming the Aral Sea', Scientific American 298: 64-71.

Millennium Ecosystem Assessment (MEA) (2005) Ecosystems and Human Well-Being: Wetlands and water synthesis, World Resources Institute, Washington, DC.

Miller, C. (2005) The Snowy River Story: The grassroots campaign to save a national icon, $\mathrm{ABC}$ Books, Sydney.

Mohapatra, A., Mohanty, R. K., Mohanty, S. K., Bhatta, K. S. and Das, N. R. (2007) 'Fisheries enhancement and biodiversity assessment of fish, prawn and mud crab in Chilika lagoon through hydrological intervention', Wetlands Ecology and Management 15: 229-51.
19. Managing Freshwater, River, Wetland and Estuarine Protected Areas

Moilanen, A., Leathwick, J. R. and Quinn, J. M. (2011) 'Spatial prioritization of conservation management', Conservation Letters 4: 383-93.

Mosisch, T. D. and Arthington, A. H. (1998) 'A review of literature examining the effects of water-based, powered recreational activities on lakes and rivers', Lakes and Reservoirs: Research and Management 3: 1-17.

Naiman, R. J., Decamps, H. and Pollock, M. (1993) 'The role of riparian corridors in maintaining regional biodiversity', Ecological Applications 3: 209-12.

Nakamura, M. and Rast, W. (2011) Development of ILBM Platform Process: Evolving guidelines through participatory improvement, ILEC, Kusatsu, Japan.

Nakamura, M. and Rast, W. (2012) Primer: Development of ILBM Platform Process - Evolving guidelines through participatory improvement, International Lake Environment Committee, Kusatsu and Research Centre for Sustainability and Environment, Shiga University.

Nakamura, M., Yoshihiko, O., Michio, A. and Moriyasu, K. (2012) 'Evolving history of Lake Biwa and Yodo River basin management', in H. Kawanabi, M. Nishino and M. Maehata (eds) Lake Biwa: Interactions between Nature and People, pp. 371-417, Springer, Dordrecht.

Nel, J. L., Reyers, B., Roux, D. J., Impson, N. D. and Cowling, R. M. (2011) 'Designing a conservation area network that supports the representation and persistence of freshwater biodiversity', Freshwater Biology 56: 106-24.

Nirupama, N. and Simonovic, S. P. (2007) 'Increase of flood risk due to urbanisation: a Canadian example', Natural Hazards 40: 25-41.

Nunes da Cunha, C. and Junk, W. J. (2011) 'A preliminary classification of habitats of the Pantanal of Mato Grosso and Mato Grosso do Sul, and its relation to national and international classification systems', in W. J. Junk, C. J. da Silva, C. Nunes da Cunha and K. M. Wantzen (eds) The Pantanal: Ecology, biodiversity and sustainable management of a large neotropical seasonal wetland, pp. 127-41, Pensoft, Sofia.

Olden, J. D. and Naiman, R. J. (2009) 'Incorporating thermal regimes into environmental flows assessments: modifying dam operations to restore freshwater ecosystem integrity', Freshwater Biology 55: 86-107. 
Olden, J. D. and Naiman, R. J. (2010) 'Incorporating thermal regimes into environmental flows assessments: modifying dam operations to restore freshwater ecosystem integrity', Freshwater Biology 55(1): 86-107.

Palmer, M. A., Reidy Liermann, C. A., Nilsson, C., Flörke, M., Alcamo, J., Lake, P. S. and Bond, N. (2008) 'Climate change and the world's river basins: anticipating management options', Frontiers in Ecology and the Environment 6: 81-9.

Parmesan, C. (2006) 'Ecological and evolutionary responses to recent climate change', Annual Review of Ecology, Evolution, and Systematics: 637-69.

Parmesan, C., Duarte, C., Poloczanska, E., Richardson, A. J. and Singer, M. C. (2011) 'Overstretching attribution', Nature Climate Change 1: 2-4.

Pearson, R. G. (2007) Species Distribution Modelling for Conservation Educators and Practitioners: Synthesis, American Museum of Natural History, New York. <ncep.amnh.org>

Perissinotto, R., Stretch, D. D. and Taylor, R. H. (eds) (2013) Ecology and Conservation of Estuarine Ecosystems: Lake St Lucia as a global model, Cambridge University Press, New York.

Pittock, J. and Finlayson, C. M. (2011) 'Australia's Murray-Darling Basin: freshwater ecosystem conservation options in an era of climate change', Marine and Freshwater Research 62: 232-43.

Pittock, J., Finlayson, C. M. and Howitt, J. A. (2012) 'Beguiling and risky: "environmental works and measures" for wetlands conservation under a changing climate', Hydrobiologia 708: 111-31.

Pittock, J., Finlayson, C. M., Gardner, A. and McKay, C. (2010) 'Changing character: the Ramsar Convention on Wetlands and climate change in the Murray Basin', Environmental and Planning Law Journal 27: 401-25.

Pittock, J. and Hartmann, J. (2011) 'Taking a second look: climate change, periodic re-licensing and better management of old dams', Marine and Freshwater Research 62: 312-20.

Pittock, J., Hussey, K. and McGlennon, S. (2013) 'Australian climate, energy and water policies: conflicts and synergies', Australian Geographer 44: 3-22.
Poff, N. L. and Matthews, J. H. (2013) 'Environmental flows in the Anthropocence: past progress and future prospects', Current Opinion in Environmental Sustainability 5: 667-75.

Poff, N. L., Richter, B. D., Arthington, A. H., Bunn, S. E., Naiman, R. J., Kendy, E., Acreman, M., Apse, C., Bledsoe, B. P., Freeman, M. C., Henriksen, J., Jacobson, R. B., Kennen, J. G., Merritt, D. M., O’Keeffe, J. H., Olden, J. D., Rogers, K., Tharme, R. E. and Warner, A. (2010) 'The ecological limits of hydrologic alteration (ELOHA): a new framework for developing regional environmental flow standards', Freshwater Biology 55: 147-70.

Pollard, S. and du Toit, D. (2011) 'Towards adaptive integrated water resources management in southern Africa: the role of self-organisation and multi-scale feedbacks for learning and responsiveness in the Letaba and Crocodile catchments', Water Resources Management 25: 4019-35.

Porter, I. C. and Shivakumar, J. (2010) Doing a Dam Better: The Lao People's Democratic Republic and the story of Nam Theun 2 (NT2), The World Bank, Washington, DC.

Postel, S. and Richter, B. (2003) Rivers for Life: Managing water for people and nature, Island Press, Washington, DC.

Postel, S. L. and Thompson, B. H. (2005) 'Watershed protection: capturing the benefits of nature's water supply services', Natural Resources Forum 29: 98108.

Rahel, F. J., Bierwagen, B. and Taniguchi, Y. (2008) 'Managing aquatic species of conservation concern in the face of climate change and invasive species', Conservation Biology 22: 551-61.

Ramsar (2002) Guidelines for Global Action on Peatlands (GAP), Ramsar Convention Secretariat, Gland.

Ramsar (2005) Resolution IX.4: The Ramsar Convention and conservation, production and sustainable use of fisheries resources, Ramsar Convention Secretariat, Gland.

Ramsar (2008) Strategic Framework and Guidelines for the Future Development of the List of Wetlands of International Importance of the Convention on Wetlands, Ramsar Convention Secretariat, Gland. 
Ramsar (2009a) Convention on Wetlands of International Importance Especially as Waterfowl Habitat. Ramsar (Iran), 2 February 1971. UN Treaty Series No. 14583. As amended by the Paris Protocol, 3 December 1982, and Regina Amendments, 28 May 1987, Ramsar Convention Secretariat, Gland.

Ramsar (2009b) Information sheet on Ramsar wetlands (RIS), Ramsar Convention Secretariat, Gland.

Dd Ramsar (2011) The Ramsar Handbooks for the Wise Use of Wetlands, 4th edn, Ramsar Convention Secretariat, Gland.

Richardson, S., Irvine, E., Froend, R., Boon, P., Barber, S. and Bonneville, B. (2011a) Australian groundwater-dependent ecosystems toolbox part 1: assessment framework, Waterlines Report Series 69, National Water Commission, Canberra.

Richardson, S., Irvine, E., Froend, R., Boon, P., Barber, S. and Bonneville, B. (2011b) Australian groundwater-dependent ecosystems toolbox part 2: assessment tools, Waterlines Report Series 70, National Water Commission, Canberra.

Richter, B. D., Baumgartner, J. V., Powell, J. and Braun, D. P. (1996) 'A method for assessing hydrologic alteration within ecosystems', Conservation Biology 10: 1163-74.

Richter, B. D., Warner, A. T., Meyer, J. L. and Lutz, K. (2006) 'A collaborative and adaptive process for developing environmental flow recommendations', River Research and Applications 22: 297-318.

Roux, D. J., Ashton, P. J., Nel, J. L. and MacKay, H. M. (2008) 'Improving cross-sector policy integration and cooperation in support of freshwater conservation', Conservation Biology 22: 1382-7.

Russi, D., Ten Brink, P., Farmer, A., Badura, T., Coates, D., Förster, J., Kumar, R. and Davidson, N. (2013) The Economics of Ecosystems and Biodiversity for Water and Wetlands, IEEP, London and Brussels.

Sadoff, C., Greiber, T., Smith, M. and Bergkamp, G. (2008) Share: Managing water across boundaries, IUCN, Gland.

Sheldon, A. L. (1988) 'Conservation of stream fishes: patterns of diversity, rarity, and risk', Conservation Biology 2: 149-56.

Shiklomanov, I. A. (1993) 'World fresh water resources', in P. H. Gleick (ed.) Water in Crisis, pp. 13-24, Oxford University Press, Oxford.
Sommer, B. and Froend, R. (2011) 'Resilience of phreatophytic vegetation to groundwater drawdown: is recovery possible under a drying climate?', Ecohydrology 4: 67-82.

Sommer, B. and Froend R. H. (2014) 'Alternative states of phreatophytic vegetation in a drying Mediterranean-type landscape', Journal of Vegetation Science 25: 1045-55.

Spackman, S. C. and Hughes, J. W. (1995) 'Assessment of minimum stream corridor width for biological conservation: species richness and distribution along mid-order streams in Vermont, USA', Biological Conservation 71: 325-32.

Tennant, D. L. (1976) 'Instream flow regimens for fish, wildlife, recreation and related environmental resources', Fisheries 1: 6-10.

Tharme, R. E. (2003) 'A global perspective on environmental flow assessment: emerging trends in the development and application of environmental flow methodologies for rivers', River Research and Applications 19: 397-441.

Tockner, K., Bunn, S. E., Gordon, C., Naiman, R. J., Quinn, G. P., Standord, J. and Polunin, N. (2008) 'Flood plains: critically threatened ecosystems', in N. Polunin (ed.) Aquatic Ecosystems: Trends and global prospects, pp. 45-61, Cambridge University Press, Cambridge.

Turner, L., Tracey, D., Tilden, J. and Dennison, W. C. (2004) Where River Meets Sea: Exploring Australia's estuaries, Cooperative Research Centre for Coastal Zone, Estuary and Waterway Management, Brisbane.

Turpie, J. K. and Clark, B. M. (2007) The Health Status, Conservation Importance, and Economic Value of Temperate South African Estuaries and Development of a Regional Conservation Plan, AEC/07/01, Anchor Environmental Consultants, Cape Town.

Turpie, J. K., Sihlope, N., Carter, A., Maswime, T. and Hosking, S. (2007) 'Maximising the socioeconomic benefits of estuaries through integrated planning and management: a rationale and protocol for incorporating and enhancing estuary values in planning and management', in Profiling estuary management in integrated development planning in South Africa with particular reference to the Eastern Cape Province, Appendix 1, Water Research Commission Publication 1485/1/07, Water Research Commission, Pretoria. 
van Dijk, A. I. J. M. and Keenan, R. J. (2007) 'Planted forests and water in perspective', Forest Ecology and Management 251: 1-9.

van Niekerk, L. and Turpie, J. K. (eds) (2012) South African National Biodiversity Assessment 2011: Technical report. Volume 3: Estuary component, Council for Scientific and Industrial Research, Stellenbosch, South Africa.

Vörösmarty, C. J., McIntyre, P. B., Gessner, M. O., Dudgeon, D., Prusevich, A., Green, P., Glidden, S., Bunn, S. E., Sullivan, C. A., Liermann, C. R. and Davies, P. M. (2010) 'Global threats to human water security and river biodiversity', Nature 467: 555-61.

Ward, J. V. (1989) 'The four-dimensional nature of lotic ecosystems', Journal of the North American Benthological Society 8: 2-8.

Warner, J. F., van Buuren, A. and Edelenbos, J. (eds) (2013) Making Space for the River: Governance experiences with multifunctional river flood management in the US and Europe, IWA Publishing, London.

Whipple, A. (2012) Sacramento-San Joaquin Delta Historical Ecology Investigation: Exploring pattern and process, San Francisco Estuary Institute, Richmond, CA.

Whitfield, A. K., Bate, G. C., Adams, J. B., Cowley, P. D., Froneman, P. W., Gama, P. T., Strydom, N. A., Taljaard, S., Theron, A. K., Turpie, J. K., van Niekerk, L. and Wooldridge, T. H. (2012) 'A review of the ecology and management of temporarily open/closed estuaries in South Africa, with particular emphasis on river flow and mouth state as primary drivers of these systems', African Journal of Marine Science 34: 163-80.

World Wide Fund for Nature (WWF) (2003) Managing Rivers Wisely: Lessons from WWF's work for integrated river basin management, WWF, Gland.

Wyborn, C. (2011) 'Landscape scale ecological connectivity: Australian survey and rehearsals', Pacific Conservation Biology 17: 121-31. 


\section{CHAPTER 20 MARINE PROTECTED AREA MANAGEMENT}

\section{Principal authors:}

Jon C. Day, Dan Laffoley and Katherine Zischka

\section{Supporting authors:}

Paul Gilliland, Kristina Gjerde, Peter J. S. Jones, John Knott, Laurence McCook, Amy Milam, Peter J. Mumby and Aulani Wilhelm

\author{
CONTENTS \\ - Introduction \\ - Progress in establishing marine protected areas \\ - Types of marine protected areas \\ - Benefits of marine protected areas \\ - Governance of marine protected areas \\ - Management of marine protected areas \\ - Management effectiveness \\ - Conclusion \\ - References
}




\section{PRINCIPAL AUTHORS}

JON DAY was previously Director of Heritage Conservation at the Great Barrier Reef Marine Park Authority, and is now a PhD student at the Australian Research Council Centre of Excellence for Coral Reef Studies, James Cook University, Australia.

DAN LAFFOLEY is Senior Advisor, Marine Science and Conservation, International Union for Conservation of Nature (IUCN) Global Marine and Polar Program and Marine Vice-Chair of the IUCN World Commission on Protected Areas (WCPA), United Kingdom.

KATHERINE ZISCHKA is a marine research consultant, a member of the IUCN WCPA, and has worked in marine research, conservation, advocacy and management.

\section{SUPPORTING AUTHORS}

PAUL GILLILAND is Head of Marine Planning at the Marine Management Organisation, Cambridge, United Kingdom.

KRISTINA GJERDE is Senior High Seas Advisor to the IUCN Global Marine and Polar Program, USA.

PETER J. S. JONES is Senior Lecturer in the Department of Geography, University College London, United Kingdom.

JOHN KNOTT is Director of Knott and Associates, Hall, ACT, Australia.

LAURENCE McCOOK is Manager of Ecosystem Conservation and Resilience, Great Barrier Reef Marine Park Authority, Australia.

AMY MILAM is Protected Areas Program Officer with the UN Environment Programme World Conservation Monitoring Centre (UNEP-WCMC) in Cambridge, UK.

PETER J. MUMBY is Professor in the Marine Spatial Ecology Lab, University of Queensland, Australia.

AULANI WILHELM is Superintendent of the

Papahānaumokuākea Marine National Monument, National Oceans Atmospheric Administration, USA.

\section{ACKNOWLEDGMENTS}

Our thanks go to all the supporting authors listed above and the case study and box authors (Michael Coyle, Fanny Douvere, Charles Ehler, Erich Hoyt, Paul Marshall, Giuseppe Notarbartolo di Sciara, David Obura, John Roff and Rod Salm) for their assistance, and to John Baxter and Graeme Worboys for comments on earlier manuscript drafts.

\section{CITATION}

Day, J. C., Laffoley, D. and Zischka, K. (2015) 'Marine protected area management', in G. L. Worboys, M. Lockwood, A. Kothari, S. Feary and I. Pulsford (eds) Protected Area Governance and Management, pp. 609-650, ANU Press, Canberra.

\section{TITLE PAGE PHOTO}

Aerial view of the Great Barrier Reef Marine Park, Australia Source: (C) Great Barrier Reef Marine Park Authority 


\section{Introduction}

Globally, the protection of marine areas has been a comparatively recent initiative compared with the use of protected areas for terrestrial conservation and resource management. Oceans cover 70 per cent of the Earth's surface and contain 97 per cent of the Earth's water. They drive climate and weather, regulate temperature, generate much of the oxygen in the atmosphere, absorb much of the carbon dioxide, and replenish freshwater to both land and sea through the formation of clouds. Oceans make up more than 90 per cent of the planet's biologically useful habitat and contain most of the life on Earth, including nearly all of the major groups of animals, plants and microbes. This watery living system is critical to how our world works. Oceans supply food, provide leisure opportunities and generate billions of dollars for national economies.

In recent decades, considerable efforts have been directed worldwide to establishing marine protected areas (MPAs). There has been a growing understanding that far more needs to be done to adequately manage our use of coasts, seas and oceans in order to ensure environmental and economic sustainability. There is an emerging realisation that effective marine protection requires us to identify and protect representative examples of marine habitats, rather than trying to protect specific threatened species or special or scenic areas (Day and Roff 2000). To be effective in protecting marine biodiversity, this approach needs to be applied in offshore waters and the open sea, as well as in near-shore and coastal areas.

In this chapter, we outline the progress in establishing marine protected areas across the world's oceans, consider the various types of marine protected areas and their benefits, and describe key aspects of their governance and management.

\section{Progress in establishing marine protected areas}

For the oceans, little progress in protection was made until a little more than 100 years ago when the world's first MPAs were declared in Australia. The earliest of these-Royal National Park, part of which includes a large tidal inlet-is located on the southern outskirts of Sydney and was designated in 1879. Most of these early MPAs focused on the protection of iconic species or special habitats rather than taking an ecosystem-based approach. What some refer to as the world's first 'proper' MPA for ecosystems was the Fort Jefferson National Monument in Florida, USA, a coastal marine site designated in 1935 .

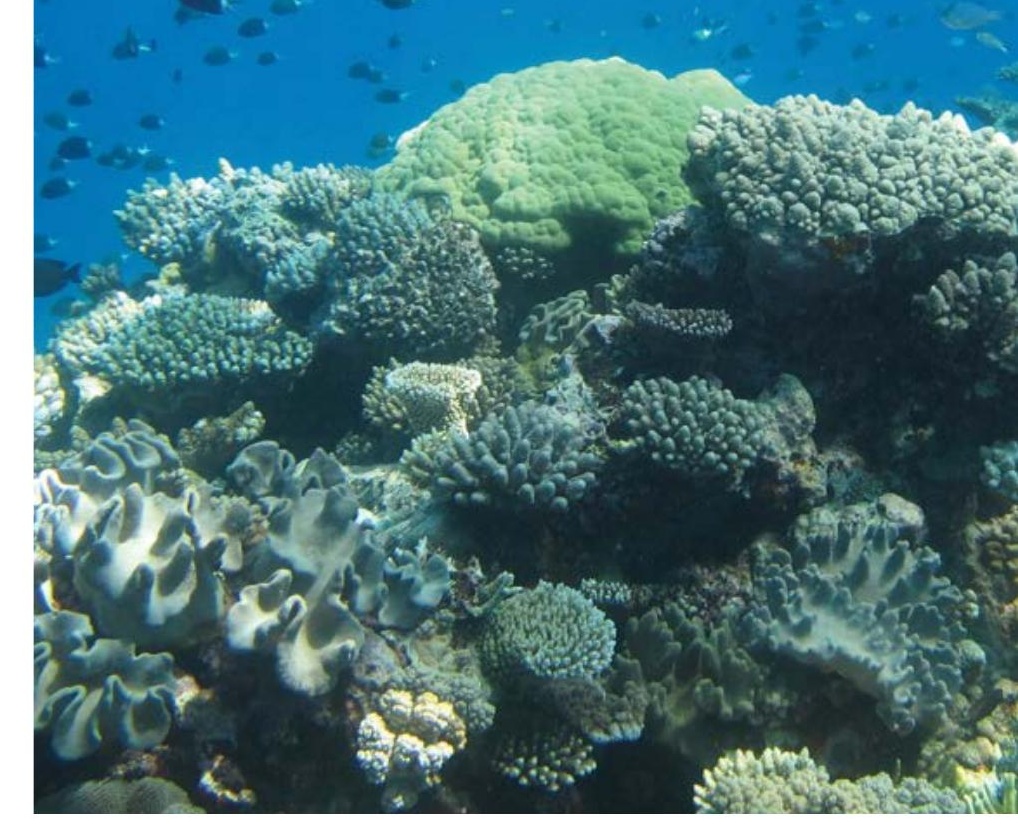

Coral Reef, Ha'apai Multi/Multiple Use Conservation Area, Kingdom of Tonga

Source: Katherine Zischka

The main impetus for MPAs, however, came much later with the World Parks Congress on National Parks in 1962, and a follow-up meeting in 1982 calling for the incorporation of marine, coastal and freshwater sites into the worldwide network of protected areas. The movement for MPAs grew in strength from that point, in the recognition that demand was outstripping supply of goods and services from the ocean to fuel an ever-increasing global population. The $1982 \mathrm{UN}$ Convention on the Law of the Sea (UNCLOS), the fundamental framework for marine governance globally, further obliged all states to protect and preserve the marine environment.

In 1995, a four-volume series recommended a globally representative network of MPAs (GBRMPA et al. 1995); this was the first real global focus on marine protection through MPAs, and was followed by a guide for MPA planners and managers in 2000 (Salm et al. 2000). The World Summit on Sustainable Development (WSSD) in 2002 called for the establishment of MPA networks by 2012 (UN 2002). Further supporting this goal, four years later, the UN Convention on Biological Diversity (CBD) reinforced the WSSD decision by setting a global target for at least 10 per cent of each of the world's marine ecological regions to be effectively conserved by 2012 (CBD 2004). In 2003, the recommendations of the fifth International Union for Conservation of Nature (IUCN) World Parks Congress broadened this- to 'establish by 2012 a global system of effectively managed, representative networks of marine 


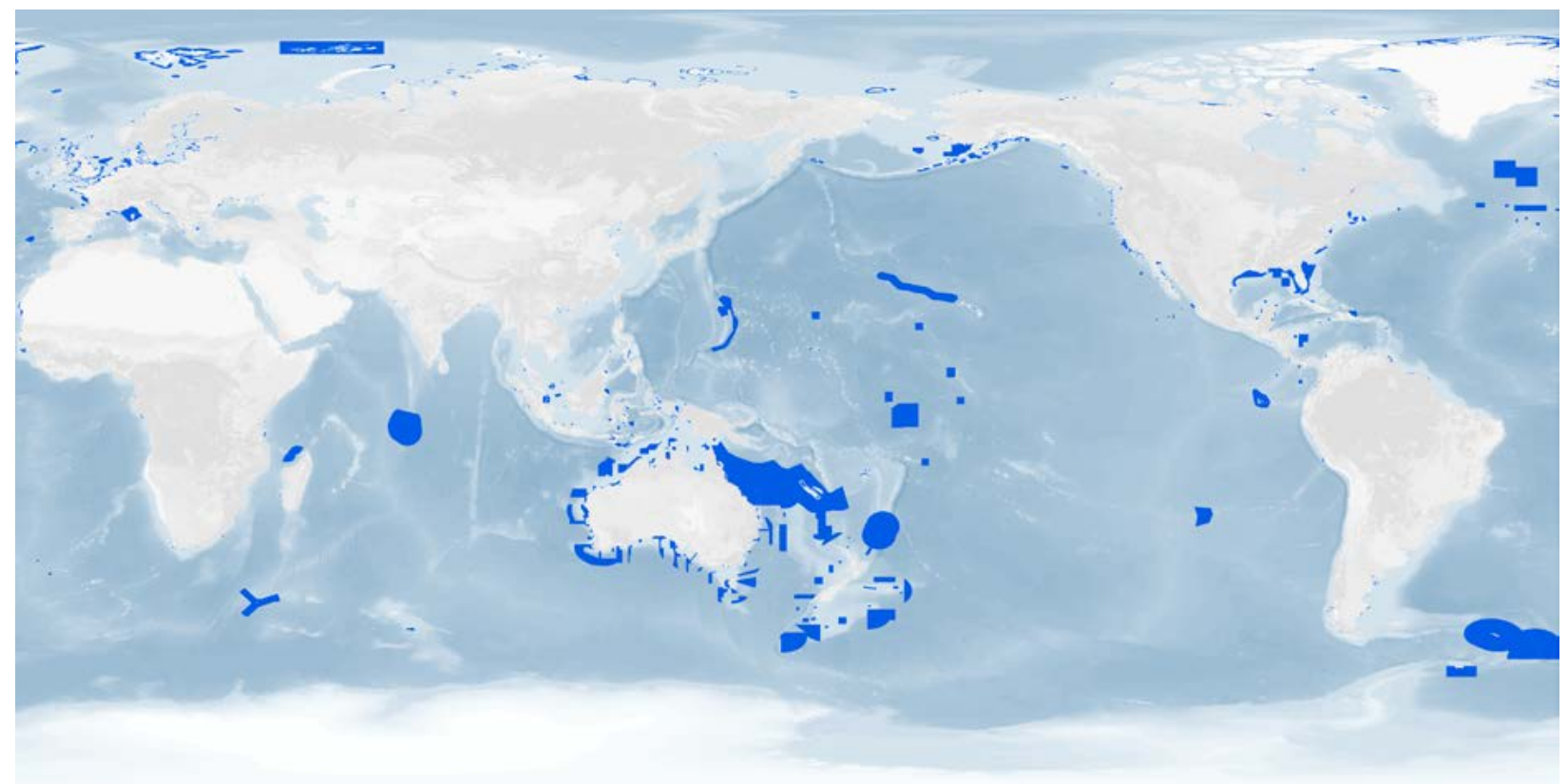

Figure 20.1 Global extent of Marine Protected Areas (MPAs). MPAs cover approximately $3.4 \%$ of Earth's oceans. For national jurisdiction (0-12 nautical miles), $8.4 \%$ is covered, for the Exclusive Economic Zone (12-200 nautical miles), 8.0\% is covered (UNEP-WCMC 2014).

and coastal protected areas' (IUCN WCPA 2003b:191), which was maintained in the CBD 2011-20 strategic plan (CBD 2011).

While the time scales may have changed more recently, these remain the principal global targets for MPAs. After setting the initial global target to effectively conserve at least 10 per cent of each of the world's marine ecological regions by 2012, the world acknowledged a decade later that the 10 per cent target was not going to be achieved and the deadline was extended to 2020, with a revised text:

By 2020, at least 17 per cent of terrestrial and inland water, and 10 per cent of coastal and marine areas, especially areas of particular importance for biodiversity and ecosystem services, are conserved through effectively and equitably managed, ecologically representative and well-connected systems of protected areas and other effective area-based conservation measures, and integrated into the wider landscapes and seascapes. (CBD 2011)

By including ecosystem services and stating that areabased protection must be effectively and equitably managed as well as ecologically representative, Aichi Target 11 has become a much more meaningful target for the world to achieve (Figure 20.1). The target is not only more meaningful for the ocean but also more attainable. It implies a scientifically driven, culturally inclusive and well-balanced effort by countries; however, there is still no guidance for countries to ensure their conservation efforts contribute to the newly revised targets that now include 10 per cent of marine areas. This lack of clarity effectively leaves each member country to decipher what it means within respective political contexts.

Despite evident growth in the MPA network, we are still far below the 10 per cent target for the global ocean. The reason is that growth in marine protection has occurred primarily in near-shore coastal zones (Spalding et al. 2014). Of the 3.4 per cent of the global ocean that is currently protected, the largest proportion is still concentrated in the territorial seas (within 12 nautical miles of shore). Beyond this point, protection drops sharply in exclusive economic zones (EEZs) (up to 200 nautical miles) and is further reduced in the high seas beyond national jurisdiction (Toropova et al. 2010). Based on these statistics, to meet the 10 per cent marine target in areas under national jurisdiction alone (0-200 nautical miles), it is estimated that an additional 6.5 million square kilometres of marine and coastal areas will need to be protected by 2020 .

Despite ongoing concerns about how and when the Aichi Target for MPAs will be met, the world continues to make significant progress in achieving increasingly higher levels of marine protection. Toropova et al. (2010) showed that the MPA network had grown by 150 per cent in seven years. In terms of ecological representativeness, recent estimates indicate that 59 per cent of the 232 marine ecoregions still have less than 1 per cent of their area protected (Bertzky et al. 2012). 
There are signs that the currently skewed level of marine protection could be starting to balance out as the number and extent of MPAs, including very large offshore MPAs and community-supported MPAs, have increased rapidly in recent years, and an additional 3.6 million square kilometres of marine reserves are planned for establishment over the next few years (Pala 2013).

\section{Types of marine protected areas}

\section{IUCN categories and marine protected areas}

So what counts as an MPA? As set out earlier in this book, a protected area as defined by the IUCN must have nature conservation as the primary objective. This definition forms the basis for defining MPAs, just as it does for terrestrial protected areas. Other existing values may be of similar importance, but in the event of a conflict between values, nature conservation must be considered the most important. Therefore, a site may be considered an MPA provided it: 1) has defined boundaries that can be mapped; 2) is recognised by legal or other effective means; and 3) has distinct and unambiguous management aims that can be assigned to a particular protected area category. The six management category types and four governance types are set out in Dudley (2008) (see Chapters 2 and 7).

In the sea, as on land, there are many managed areas that protect biodiversity indirectly, incidentally or fortuitously. It is indeed a principle of the CBD's ecosystem approach that all land and water management should contribute to conservation, and as a result the distinction between what is and what is not a protected area is sometimes unclear; however, such areas do not necessarily fulfil the IUCN definition of a protected area.

This is particularly the case in the marine environment, where spatial planning and management of activities often have no stated aim or interest in nature conservation; they are just an incidental link. While some areas may be relatively easy to classify, others may be harder to determine and the following types of area-based measures are not necessarily MPAs:

- fishery management areas (temporary or permanent) with no wider stated conservation aims

- community areas managed primarily for sustainable extraction of marine products (such as coral, fish and shells)
- marine and coastal management systems managed primarily for tourism, which also include areas of conservation interest

- wind farms and oil platforms that incidentally help to build up biodiversity around underwater structures and by excluding fishing and other vessels.

Given the challenges in interpreting Dudley (2008) for MPAs, supplementary guidelines were issued in 2012 to ensure the IUCN categories can be effectively applied to all types of MPAs, as well as to any marine components of adjoining terrestrial protected areas (Day et al. 2012). The guidelines are intended primarily for policymakers but are also useful to help MPA managers understand the management objectives for the category to which an MPA has been assigned and thus guide planning and implementation.

\section{Marine Indigenous Peoples' and Community Conserved Territories and Areas}

Indigenous Peoples' and Community Conserved Territories and Areas (ICCAs) are defined by the IUCN as 'natural and/or modified ecosystems containing significant biodiversity values, ecological functions and benefits, and cultural values voluntarily conserved by indigenous peoples and local communities both sedentary and mobile- through customary laws or other effective means' (Corrigan and Granziera 2010:1).

As with other governance types, community areas managed primarily for sustainable extraction of marine products would not be considered MPAs according to the IUCN definition unless nature conservation is the primary stated objective of the management regime.

Many ICCAs have been established by coastal communities in marine ecosystems (Box 20.1). The ICCA Registry is an online information portal and secure database developed by the UN Environment Programme's World Conservation Monitoring Centre (UNEP-WCMC) with support from the UN Development Programme's Global Environment Fund Small Grants Program, which documents indigenous and community conservation areas including in the marine environment (Day et al. 2012a). The ICCA Registry aims to increase awareness of the biodiversity values of areas managed by communities, and provides a wide range of information. It is hoped that further guidance on implementing the IUCN categories in marine ICCAs will be developed. Additional information is available through the ICCA Consortium and a primary reference is Dudley (2008) (see Chapter 8). 


\section{Box 20.1 Examples of community conserved marine areas}

In many parts of the world, indigenous peoples and local communities manage marine and coastal areas in ways that help ensure conservation. Such ICCAs include:

- in Fiji, 149 locally managed marine areas (LMMAs) governed by communities and recognised by law make up all of Fiji's MPAs, covering 1.77 million hectares (more than 50 per cent of the country's inshore marine area)

- in Madagascar, 16 LMMAs of varying size cover 394000 hectares

- in Kenya, several inshore reef areas are managed by fisher communities under the Fisheries Act, which allows for the creation of Beach Management Units to develop and enforce rules governing their fisheries, including demarcating boundaries and excluding non-members from outside the area

- in Japan, more than 1000 community protected or conserved marine areas have been documented, including 387 self-imposed no-catch community MPAs

- in Costa Rica, there are an increasing number of 'marine areas for responsible fishing' where fisher communities are authorised to make local rules and enforce them

- in Spain, marine ICCAs are governed by about 230 Cofradías, ancient local governance bodies that manage the common use of all coastal professional fisheries in the country

- in Australia, Canada, the Philippines and some other countries, several indigenous territories recognised or in the process of recognition cover marine areas crucial for biodiversity conservation

- communities protect marine turtle nesting sites in Chile, Costa Rica, Suriname and several countries of South Asia; in Suriname, several other marine species including the West Indian manatee (Trichechus manatus) also benefit from such protection.

Source: Kothari et al. (2012)

\section{Private marine protected areas}

Alongside traditional types of MPAs, there are a small but growing number of privately run MPAs, which like other protected areas must still meet the established IUCN criteria to count as an MPA. A good example is Chumbe Island Coral Park Limited (CHICOP). This is an awardwinning private nature reserve, first developed in 1991 for the conservation and sustainable management of uninhabited Chumbe Island off Zanzibar, one of the last pristine coral islands in the region. The company's

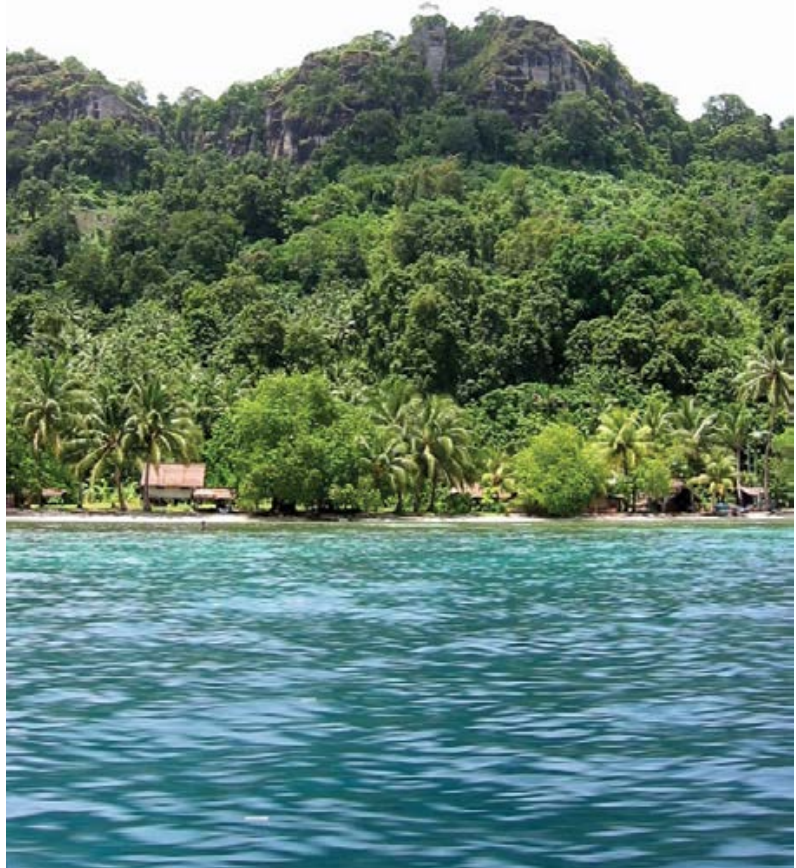

Locally managed marine area at Laitoko Village,

Solomon Islands

Source: Hugh Govan

objectives are non-commercial, while operations follow commercial principles. The overall aim of CHICOP is to create a model of financially and ecologically sustainable park management, where ecotourism supports conservation, research and comprehensive environmental education programs for local schools, as well as other benefits for local people (Kloiber 2013).

\section{High seas}

Until recently, most attention has focused on inshore areas within the national 200 nautical mile EEZ and the 12 nautical mile territorial sea, where countries have established policy and legal frameworks to provide for area-based measures such as MPAs. Significant attention, however, has been directed for some time towards Antarctic (Southern Ocean) waters and to other areas beyond EEZs, where relevant countries have agreed on cooperative actions (for example, the Mediterranean Sea and North-East Atlantic Ocean; see below).

\section{Ramsar sites}

Some coastal and estuarine MPAs have also been recognised as wetlands of international importance (that is, Ramsar sites; see Chapters 2, 19), including Shoalwater Bay and Moreton Bay (Australia), Delaware Bay Estuary and San Francisco Bay (USA) and Røstøyan Archipelago (Norway). 


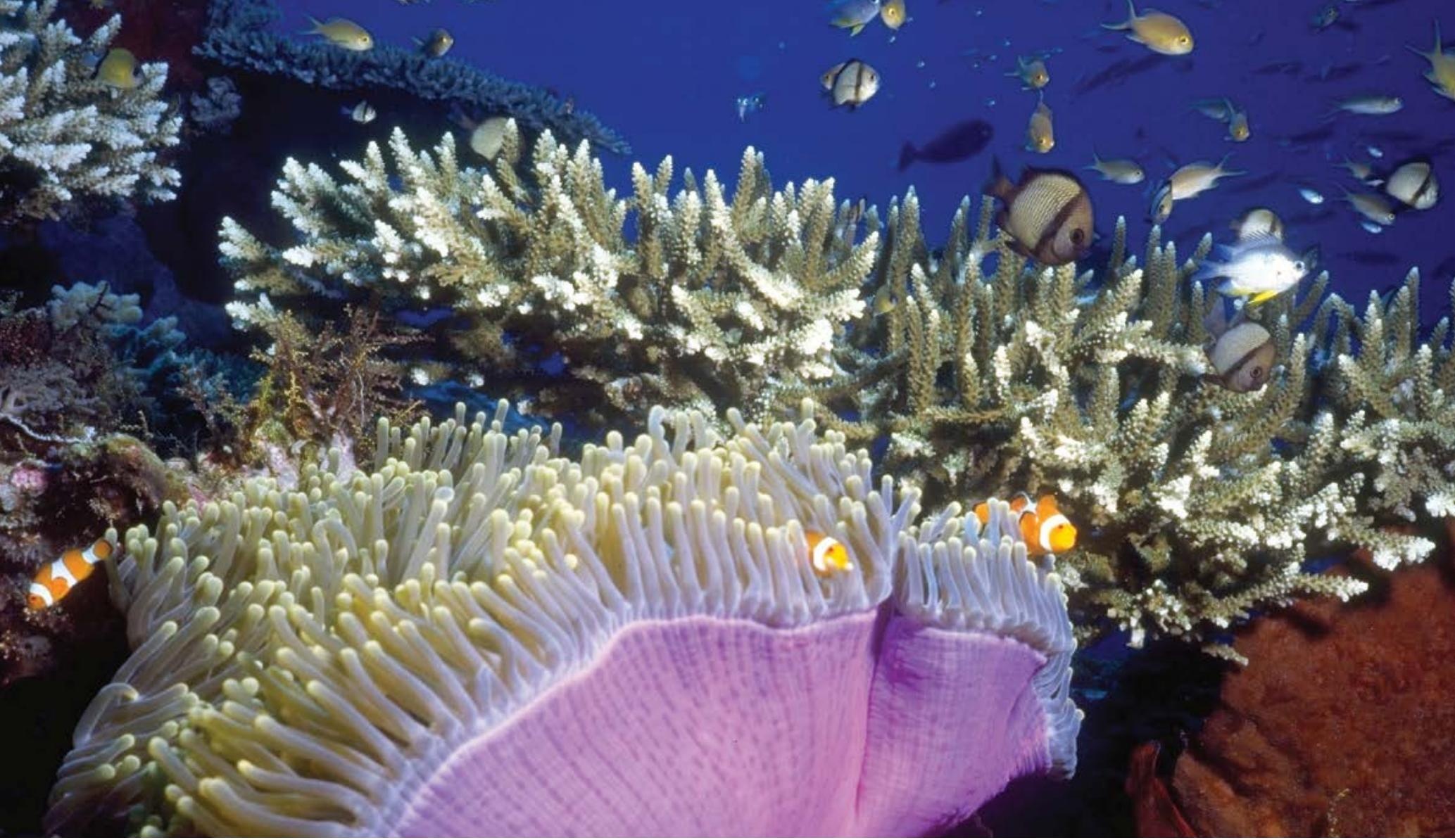

Corals and reef life, Great Barrier Reef Marine Park, Australia

Source: @ Great Barrier Reef Marine Park Authority

\section{World Heritage}

As of 2014, 46 MPAs have been inscribed on the World Heritage List. They include three of the world's 10 largest MPAs. One of the best-known is the Great Barrier Reef (Australia) and others include the Galápagos Islands (Ecuador), Tubbataha (Philippines) and the west Norwegian fjords.

\section{The recent move towards large- scale marine protected areas}

The past decade has seen a global trend towards the establishment of large-scale (very large) MPAs. The creation of the Northwestern Hawai ian Islands Coral Reef Ecosystem Reserve (now Papahānaumokuākea Marine National Monument) in 2000 has been followed by a number of other countries declaring large MPAs within their national jurisdictions. Between 2000 and 2012, five sites of similar size were established-all but one in the Pacific Ocean (Table 20.1). Several other sizeable ocean areas have been or are in the process of being established, with further areas proposed by both governments and non-governmental organisations (NGOs) (Wood et al. 2008; Leenhardt et al. 2013). These are largely located in remote areas with low or no human numbers, where anthropogenic impacts have been less severe. The areas contain some of the most intact and least impacted ecosystems left on the planet (Halpern et al. 2008).
The drivers towards protecting these recently designated ocean areas are varied. Some have been designated for their intrinsic natural or cultural value, others to advance global targets to increase the proportion of the ocean set aside for protection (Toonen et al. 2013), while others are to strike a balance between economic growth and biodiversity conservation. With the variation in goals follows a variation in management approaches. Some sites are complete no-take areas, while others allow for commercial fishing and other human use in defined areas, often by necessity. By a 2013 estimate, the pioneer large-scale sites (Table 20.1) accounted for 80 per cent of the area contained within all MPAs in the world (Toonen et al. 2013), thus evolving the definition and concept of MPA design and management.

Large-scale MPAs are not, however, a panacea. They are one of many tools to achieve ocean conservation. The most prevalent criticism of large-scale MPAs is that they are difficult to enforce. Given the high measures of biomass, these areas can be attractive to illegal, unreported and unregulated fishing, heightening the need for effective surveillance and enforcement. Enforcement is an obvious and costly challenge requiring remote surveillance and other technological capabilities to effectively monitor large areas. Fortunately, legal and technological advances may soon allow such monitoring and enforcement to become far more cost effective and feasible. 
Table 20.1 Pioneer large-scale marine protected areas

\begin{tabular}{|c|c|c|c|c|c|}
\hline Name & Country & Founded & $\begin{array}{l}\text { Size } \\
\text { (sq km) }\end{array}$ & $\begin{array}{l}\text { Proportion } \\
\text { of site that is } \\
\text { no-take }(\%)\end{array}$ & Comments \\
\hline $\begin{array}{l}\text { Great Barrier Reef } \\
\text { Marine Park }\end{array}$ & Australia & 1975 & 344000 & 33 & $\begin{array}{l}\text { UN World Heritage property } \\
\text { since } 1981\end{array}$ \\
\hline $\begin{array}{l}\text { Papahānaumokuākea } \\
\text { Marine National } \\
\text { Monument }\end{array}$ & $\begin{array}{l}\text { United States } \\
\text { of America }\end{array}$ & 2000 & 362074 & 100 & $\begin{array}{l}\text { Created as Northwestern } \\
\text { Hawai'ian Islands Ecosystem } \\
\text { Reserve in } 2000 \text { and became } \\
\text { a Marine National Monument } \\
\text { in 2006; UN World Heritage } \\
\text { property since } 2010\end{array}$ \\
\hline $\begin{array}{l}\text { Phoenix Islands } \\
\text { Protected Area }\end{array}$ & $\begin{array}{l}\text { Republic of } \\
\text { Kiribati }\end{array}$ & 2008 & 408250 & 4 & $\begin{array}{l}\text { Declared in } 2006 \text { and } \\
\text { established in 2008; } \\
\text { UN World Heritage property } \\
\text { since } 2010\end{array}$ \\
\hline $\begin{array}{l}\text { Mariana Trench Marine } \\
\text { National Monument }\end{array}$ & $\begin{array}{l}\text { Commonwealth } \\
\text { of Northern } \\
\text { Mariana Islands, } \\
\text { USA }\end{array}$ & 2009 & 246609 & $\sim 95$ & $\begin{array}{l}\text { Only protected deep-sea } \\
\text { trench in the world, but } \\
\text { surface waters remain open } \\
\text { to fishing }\end{array}$ \\
\hline $\begin{array}{l}\text { British Indian Ocean } \\
\text { Territory Marine } \\
\text { Protected Area }\end{array}$ & $\begin{array}{l}\text { UK Overseas } \\
\text { Territory }\end{array}$ & 2010 & 640000 & 100 & $\begin{array}{l}\text { British Indian Ocean Territory } \\
\text { consists entirely of the } \\
\text { Chagos Archipelago and } \\
\text { surrounding waters, with the } \\
\text { exception of Diego Garcia } \\
\text { Atoll out to } 3 \mathrm{~nm} \text {. }\end{array}$ \\
\hline $\begin{array}{l}\text { Motu Motiro Hiva } \\
\text { Marine Park }\end{array}$ & Chile & 2010 & $\begin{array}{r}150000 \\
\text { (with } \\
\text { planned } \\
\text { expansion } \\
\text { to } \\
411000)\end{array}$ & 100 & $\begin{array}{l}\text { Isolated reefs north-east of } \\
\text { Rapa Nui (Easter Island), } \\
\text { explicitly created to protect } \\
\text { one of the last pristine } \\
\text { ecosystems in the Pacific } \\
\text { Ocean and advance the } \\
10 \text { per cent goal of the Aichi } \\
\text { Biodiversity Targets }\end{array}$ \\
\hline $\begin{array}{l}\text { Cook Islands Marine } \\
\text { Park }\end{array}$ & Cook Islands & 2012 & 1065000 & TBD & $\begin{array}{l}\text { Remote atolls and high } \\
\text { volcanic islands surrounded } \\
\text { by fringing reefs and unsoiled } \\
\text { fauna associated with } \\
\text { underwater mountains- } \\
\text { management planning } \\
\text { process is still under way; } \\
\text { will likely contain a variety of } \\
\text { zones with different levels of } \\
\text { protection }\end{array}$ \\
\hline
\end{tabular}

\section{Benefits of marine protected areas}

MPAs provide a range of benefits to both natural ecosystems and human communities inhabiting marine and coastal areas. These include ecological benefits such as maintaining and increasing biological diversity and enhancing fish stocks; social benefits of nature appreciation and engagement; and economic benefits of facilitating sustainability in fisheries and tourism as well as recreational use of the marine environment. The importance of ocean health in relation to the world's climate is fundamental, since oceans absorb carbon dioxide and generate most of the world's oxygen. 
MPAs provide many benefits when implemented through a rigorous science-based approach, but they must not be considered as the sole management approach for conserving all marine biodiversity. Properly established MPAs are the best tool for protecting ocean biodiversity, but they in turn cannot protect themselves from external stressors such as pollution, land-based runoff and climate change. Consequently, MPAs should be considered in conjunction with other broad ecosystembased management approaches.

The biodiversity-related benefits of MPAs include:

- maintaining or restoring ecosystem structure, function and integrity by:

1. protecting habitats from physical damage of fishing and other human activities

2. avoiding biodiversity loss and productivity loss by maintaining genetic integrity, and restoring population size, age structure and community composition

3. protecting key ecological functions and processes that are driving forces of many marine systems - for example, maintaining food webs and trophic structure including avoiding trophic cascades and threshold effects, and maintaining the abundance of important keystone species

4. contributing to holistic ecosystem-based management and enhancing broad-scale ecosystem resilience to pressures.

- providing 'insurance' to mitigate any detrimental effects, especially in adjacent areas (for example, by overfishing)

- protecting areas that can provide reproductive 'seedbanks' from which eggs and larvae of marine species may be distributed to other areas (Day 2006).

\section{Ecosystem connectivity}

A 2014 study on global priorities for marine biodiversity conservation highlighted that 'protecting biodiversity and the essential ecosystem services it supports has become a priority for the scientific community, resource managers, and national and international policy agreements' (Selig et al. 2014).

Individual marine species exist as part of larger, connected and interdependent networks of ecosystems such as coral reefs, coastal mangrove habitats or deepsea hydrothermal vent communities. The connectivity of these ecosystems provides marine organisms with important ecological services such as the provision of

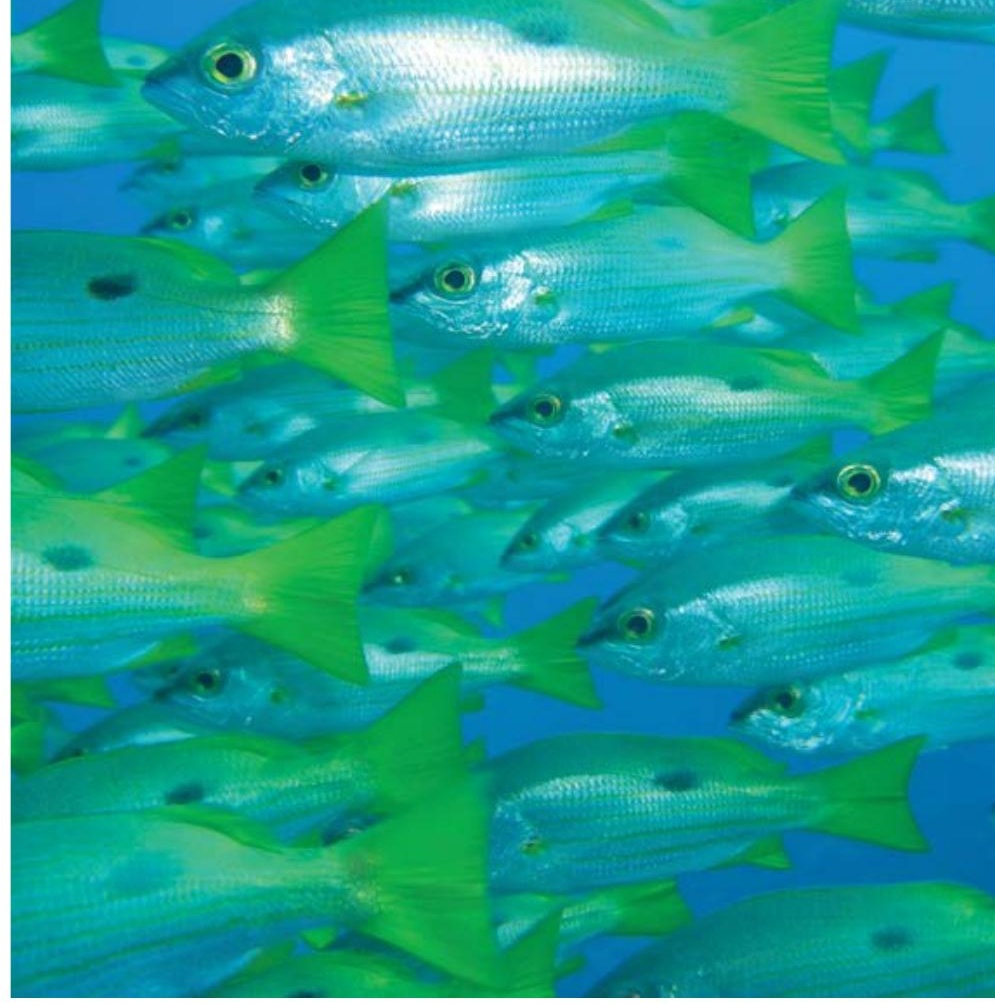

Anse Mais, Aldabra Atoll World Heritage Property, Seychelles

Source: Carl Gustaf Lundin, IUCN

food, breeding and nursery grounds, or shelter from predators during vulnerable planktonic development stages. The importance of marine connectivity can be seen in examples of cross-continental shelf connectivity (Box 20.2), where larval dispersal has the potential to occur over thousands of kilometres.

The interconnectivity of marine systems requires management that is broad and ecosystem based. MPA networks provide a key tool for protecting marine biodiversity on a broader, integrated and interconnected scale where the maintenance of holistic ecosystems results in greater overall ecological, economic and social benefits. The success of effective MPA zoning and how it contributes to protecting broader marine biodiversity are described further below.

\section{Ecosystem function}

Where MPAs have strong beneficial effects on ecosystem 'engineers', such as corals or kelps (Ling and Johnson 2012), the benefits may extend to important ecosystem functions and services. For example, services such as productive fisheries, tourism appeal and coastal protection from storms are all founded on the existence of a healthy reef with a complex structure (Done et al. 1996). Processes that kill corals and accelerate the erosion of reef structures could, however, shift the reef towards a negative carbonate budget, which means the reef will gradually erode over time. Reefs that experience 


\section{Box 20.2 Ecosystem connectivity: Habitats utilised during the life cycle of the red emperor}

Cross-shelf connectivity on a reef system is critical to maintaining habitats for recreationally and commercially important reef fish such as the red emperor (Lutjanus sebae) on Australia's Great Barrier Reef. The red emperor utilises a much wider range of interconnected habitats during various life-cycle stages than was initially believed, ranging from inshore estuaries to coral and deep-water seagrass communities (Figure 20.2).

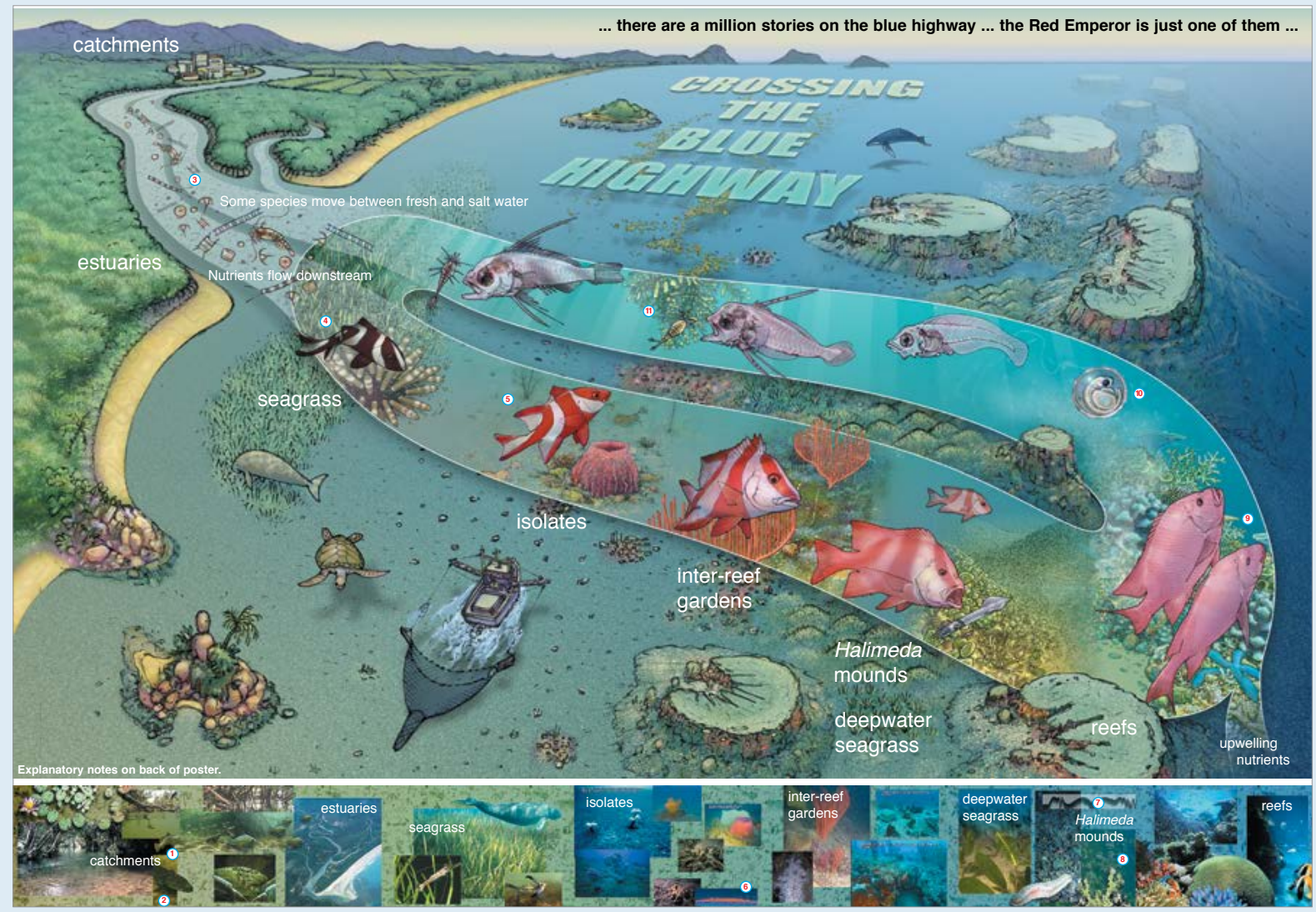

Figure 20.2 Ecosystem Connectivity

Source: Based on a concept developed by Russell Kelley and illustrated by Gavin Ryan; @ Cappo and Kelley (2001); reproduced with permission

net erosion will lose their complexity, biodiversity and function. In 2013, a model was developed that accounted for the impacts of global change on coral reefs including rising sea temperatures and ocean acidification (Kennedy et al. 2013). It found that positive carbonate budgets were still possible towards the end of the century but they required MPA-level local protection of the watershed and fishing, and aggressive action to reduce greenhouse gas emissions.

\section{Enhancing fish stocks inside and outside marine protected areas}

In addition to maintaining biodiversity, MPAs can play an important role in enhancing biological productivity, particularly of fish stocks-both inside and outside MPAs. The establishment of MPAs provides a protective refuge for fish during critical life-cycle stages such as spawning or juvenile growth. By protecting spawning and nursery ground habitats such as mangroves, seagrass meadows and reef systems, MPAs provide a safe refuge for juvenile fish as they develop and grow into adulthood, as well as protecting breeding fish such as in spawning aggregations. 


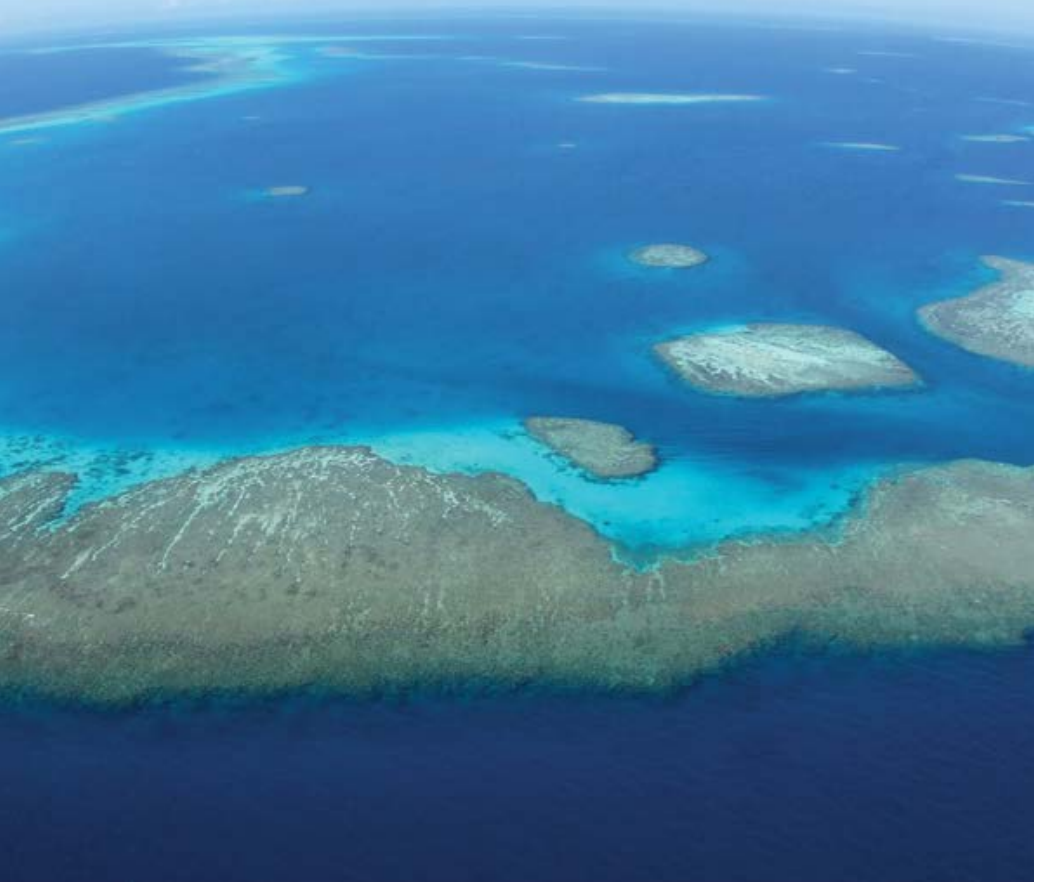

Coral reefs, Great Southern Lagoon, part of the marine World Heritage property, New Caledonia Source: Dan Laffoley

Safe havens are particularly important as recovery areas for species experiencing high-intensity fishing pressures. No-take MPAs or zones within large MPAs provide safe areas for fish stocks to increase, rebuild and expand in the absence of fishing pressure. As fish stocks increase within MPAs, a positive flow-on effect is created for adjacent areas when excess fish from healthy, flourishing stocks inside MPAs 'spillover' into adjacent non-protected areas. Termed the 'spillover effect', this leads to an overall increase in fish abundance in adjoining areas where fishing is allowed, ultimately facilitating broad-scale positive changes for various commercial, recreational or indigenous fishing.

The positive impact of MPAs on fish stocks has been widely documented (Box 20.3). Studies demonstrate that fish in no-take zones and other protected areas produce more offspring (that is, have higher fecundity) and are greater in size and abundance than fish outside such areas. Halpern (2003) reported that the average fish biomass across 89 marine reserves was nearly triple that of fish in unprotected areas, with a 20 to 30 per cent increase in average size. In 2009, a global analysis of almost 150 peer-reviewed studies of fully protected no-take marine reserves from 29 countries reported an overall increase in both fish size and biomass within the reserves (Lester et al. 2009).

\section{Box 20.3 The spillover effect: Examples from around the world}

One of the more well-studied benefits of reservesthe spillover of adults into neighbouring fished areas (Kellner et al. 2007)-has been revisited for fishing communities in the Philippines. Trap and gillnet catches near the Sumilon Island reserve increased 27 per cent within six years of the reserve being established, and catch increases of 41 per cent were found near Apo Island reserve after 20 years (Alcala et al. 2005).

The major outcomes of ceasing fishing are the increased size and abundance of fishes within a protected area (Halpern 2003). In a comparison of fish abundance among Kenyan marine parks of different age, McClanahan et al. (2007) found that some groups of reef fish, such as parrotfish, recovered within 10 years of protection whereas others, such as largebodied acanthurids (surgeonfish, tangs and unicorn fish), still showed no sign of reaching a plateau after 30 years. Data from the Philippines reveal that significant increases in fish biomass can be found within five years of reserve creation, but the biomass of large predators continued to increase after 19 years-the maximum duration of protection at the time of the census (Russ et al. 2005). Rapid increases of coral trout (Plectropomus spp.), however, entailing a rise in fish density of approximately 65 per cent, were observed within just two years of the formation of new no-take areas of the Great Barrier Reef Marine Park in 2004 (Russ et al. 2008). Reef shark abundance was also considerably higher in no-take zones of the Great Barrier Reef, but higher still in long-term 'no entry' zones (McCook et al. 2010).

Rapid recovery of fish populations is feasible, in part, because the dispersal of reef fish larvae appears to be fairly local. At one extreme, two-thirds of sea anemonedwelling clownfish (Amphiprion polymnus) were found to settle within 100 metres of their parents despite spending up to 12 days in the plankton (Jones et al. 2005). Dispersal is greater in larger reef fish, such as the squaretail coral grouper (Plectropomus areolatus), but even here evidence suggests that about 50 per cent of juveniles recruit within 14 kilometres of an adult spawning aggregation site and 95 per cent recruit within 33 kilometres of the spawning site (Almany et al. 2013). Indeed, new genetic studies have now confirmed that larval export of commercially important reef fish from reserves is significantly greater than that from fished areas, and can help replenish exploited fish stocks and form networks of larvae among reserves. In this case, reserves lay within 20 kilometres of one another (Harrison et al. 2012).

- Peter J. Mumby 
natural world, and as the place from which it is believed life originates and to which the spirits return after death. On two of the islands there are archaeological remains relating to pre-European settlement and use.

\section{Economic benefits of marine protected areas}

The ecological resources of the world's oceans provide humans with a variety of economic benefits. Since 2007, 'The Economics of Ecosystems and Biodiversity' (TEEB) initiative has drawn attention to the economic benefits of biodiversity and the growing cost of biodiversity loss and ecosystem degradation, and provides tools to support effective decision-making. While it is difficult to quantify the value of the many services, especially nonmonetary, that ecosystems provide, economic benefits resulting directly from a healthy marine environment are measurable in areas such as sustainable marine tourism and fisheries. In 2004, for example, the 166000 hectares of reef system off the main Hawai ian Islands were estimated at a value of US $\$ 360$ million per year (TEEB 2010). In Australia's Great Barrier Reef, the total combined economic contribution in 2012 to the Australian economy of tourism, recreation, commercial fishing and scientific research from the Great Barrier Reef catchment and World Heritage property was estimated at US\$5.7 billion (Deloitte Access Economics 2013) greatly exceeding the amount spent on protection (McCook et al. 2010).

\section{Sustainable tourism}

Globally, the appreciation of marine environments through commercial tourism activities such as scuba diving, snorkelling or whale watching is well established. In 2012, tourism in the Great Barrier Reef and adjoining catchment generated a profit of approximately US $\$ 4.9$ billion (or 90 per cent of the total economic contribution of the marine park to the national economy), and provided an equivalent of 64000 full-time jobs. Tourism also contributes US\$6.5 million annually to reef management (see 'Fees and charges' subsection below).

Species-specific ecotourism for marine megafauna protected by MPAs (for example, whales and sharks) is creating sustainable long-term economic benefits for local communities. A 2008 whale-watching study estimated the global industry generated more than US\$2.1 billion (O'Connor et al. 2009), and 2013 estimates for the global shark diving industry were US\$314 million annually (Cisneros-Montemayor et al. 2013). Whale-shark ecotourism is well established

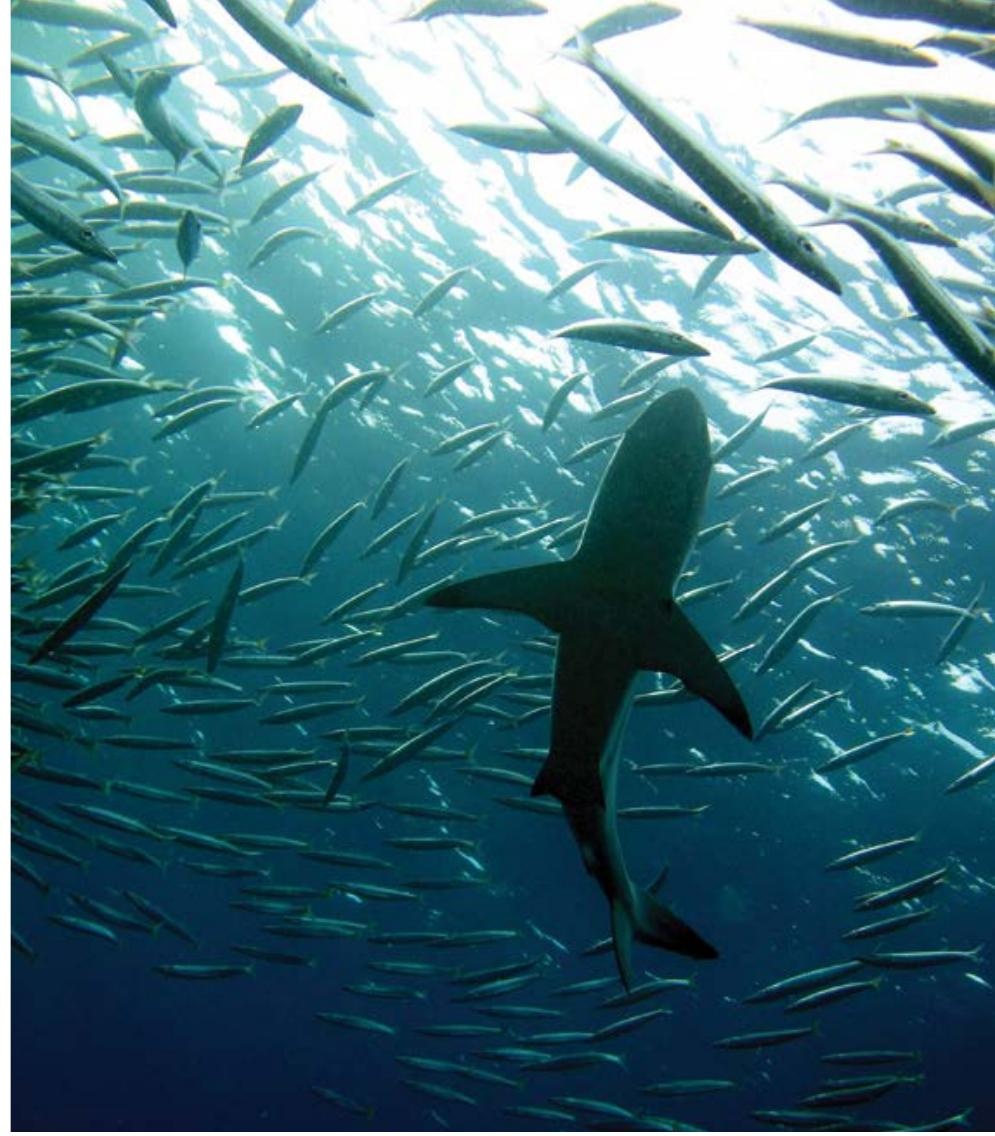

Shark and other fish, Great Barrier Reef Marine Park, Australia

Source: (c) Great Barrier Reef Marine Park Authority

in Western Australia (Ningaloo Reef), Mexico, the Seychelles and the Philippines—and is expanding around the world. The industry has been estimated to generate more than US\$47.5 million worldwide (Graham 2004). Shark-diving tourism in the recently established shark sanctuary of Palau was estimated to be worth US $\$ 200$ million over a shark's lifetime, based on the long-term value of 100 sharks (Vianna et al. 2012).

\section{Sustainable recreation}

The economic benefits of MPAs also include sustainable recreational (that is, non-commercial) use of protected areas such as surfing, snorkelling, fishing or boating. In 2008, more than 14 million recreational visitors were estimated to visit the Great Barrier Reef Marine Park from surrounding areas every year. Recreational activities ranked as the second-largest direct use of the Great Barrier Reef in 2012, generating US\$310 million and the equivalent of 2724 full-time jobs (GBRMPA 2013).

\section{Sustainable fisheries}

Fisheries provide significant economic support to coastal communities (particularly subsistence communities), with positive impacts from MPAs including increased fish abundance and size, protective habitats for fish growth and reproduction, and provision of sanctuaries for recovery from overexploitation. Many commercially valuable fish stocks are overexploited as a result of 


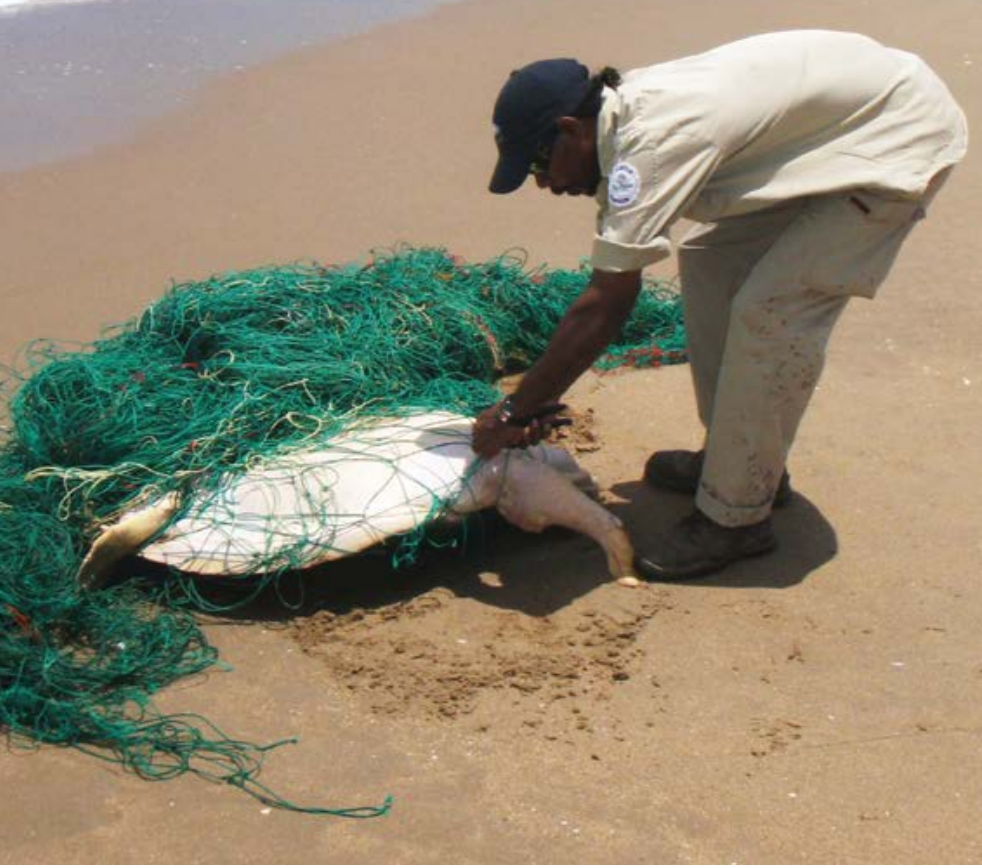

Indigenous Ranger at Mapoon, Queensland, Australia assisting a marine turtle

Source: Craig Wheeler

increased pressure from highly subsidised industrial fishing fleets, poor regulation and weak enforcement of rules (World Bank and FAO 2009). Across the 53 countries that contribute 95 per cent of global fisheries catch, MPAs have been estimated to provide US $\$ 870$ million worth of subsidies to fisheries (Cullis-Suzuki and Pauly 2008).

\section{Governance of marine protected areas}

The ecological, economic and social benefits of protected areas can only be enhanced and sustained when they are effectively managed through good governance. (Mulongoy and Gidda 2008:28)

Governance can be defined as the involvement of a wide range of institutions and actors in the production of policy outcomes ... involving coordination through networks and partnerships' (Johnston et al. 2000: 317). Historically, marine governance has been developed sporadically and in a fragmented way to suit individual management needs where they have arisen, and less in a holistic, long-term and ecosystem-based way.

The governance of protected area networks can be framed within various arrangements including international environmental conventions at the global level, coordination between neighbouring countries at the regional level, government legislation at the national level, and community and NGO-driven governance at the local level. The various types of governance and how these contribute to effective MPA management are covered in greater detail below (see also Chapter 7).

\section{International context}

The majority of coastal (and many non-coastal) countries around the world are signatories to international marine agreements or conventions. These provide legal frameworks to establish mechanisms for governing and managing marine areas under their national jurisdictions, or more simply, within their national waters. International environmental laws have been established to address a wide range of marine issues, from the basic designation of national maritime boundaries to navigation, fisheries management, international trade in endangered species, biodiversity conservation and the establishment of MPAs. Such international laws can include both hard (legally binding) and soft (non-binding) laws.

The UN Convention on the Law of the Sea (UNCLOS) is widely recognised as the overarching framework for marine governance. In force since 1994, it provides nations with the legal capacity to delineate national maritime boundaries (such as the EEZ), to regulate extractive activities such as fishing within those boundaries, and to establish protected areas within both the 200 nautical mile EEZ and the 12 nautical mile territorial sea of a national coastline consistent with the rights of international shipping. This convention is supported widely, with more than 160 signatory nations worldwide in 2014 (UN 2014).

Where UNCLOS provides an overarching legal framework for states to protect the marine environment, the CBD provides targets and action plans for implementation, particularly for the conservation of biological diversity, including providing the legally binding governance mechanism to frame the Aichi Targets discussed previously. Other conventions such as the International Whaling Convention, the Convention on International Trade in Endangered Species of Wild Fauna and Flora and the Convention on the Conservation of Migratory Species of Wild Animals also indirectly facilitate the establishment of MPAs - for example, by facilitating the establishment of whale sanctuaries as protection for individual endangered species (see Chapter 8). 


\section{Regional context}

Regional approaches, such as the UNEP's Regional Seas Program, have been established around the world to improve marine management, and information and benefit sharing, at the regional level. Established in 1974, it includes 18 regions around the world with separately established regional programs. Fourteen of these have now adopted legally binding conventions that provide a foundation for management programs further implemented through action.

\section{National context}

The majority of the world's MPAs are governed by laws and regulatory mechanisms established at a national or sub-national government level. In most coastal countries, the marine environment is not governed under a single law but is addressed through an often fragmented set of laws and mechanisms established to manage different aspects of the marine environment such as conservation, tourism, pollution or fisheries. Consequently, it is common for laws to be administered under separate jurisdictions and managed by a variety of stakeholders including national, regional Provincial/State/Territory or local government agencies, councils, NGOs or local communities. Jurisdictional overlap, gaps and lack of integration between multiple organisations can often lead to challenging MPA governance. Functional, holistic and cross-jurisdictional governance systems for MPAs are critical.

\section{Local context}

The local context is becoming increasingly important in MPA governance and management. Local governance, where coastal communities are responsible for governing and managing their own local marine resources, is often referred to as 'customary marine tenure'. This is common in regions such as the Pacific, where it has led to the establishment of LMMAs in several countries including Fiji, Papua New Guinea and the Solomon Islands. LMMAs are becoming increasingly important as a marine governance approach (Box 20.1).

In both Papua New Guinea and the Solomon Islands, inshore marine ecosystems are owned not by the national government, but by clans or tribes who claim customary ownership, and where ownership has varying degrees of recognition under national law. The Kimbe Bay region in Papua New Guinea contains an MPA network including nine LMMAs and represents an interesting case study of local governance by coastal communities (White et al. 2014; Case Study 20.1).
No matter whether MPAs are governed under national, regional or locally managed systems, for governance regimes to be most effective, clear international, regional, national and/or local regulatory obligations requiring effective management and law enforcement must be established (Jones 2014). A well-integrated and comprehensive management model that is widely regarded as effective by marine and coastal managers globally is the Great Barrier Reef Marine Park in Australia. This represents integrated and comprehensive collaboration between national and State management authorities, and these in turn with traditional owners, local councils and communities, industry and scientific research groups, in order to provide an effective ecosystem-based approach to marine management.

\section{Types of marine governance}

Governance systems can be broadly separated into three general approaches: top down, bottom up and governance based on market incentives. The top-down approach emphasises government-led governance from 'above', through the establishment of laws and other regulatory mechanisms that enforce biodiversity conservation. The bottom-up approach focuses on decentralising decision-making processes from national government to incorporate local community-based approaches, often with a focus on harnessing local or traditional knowledge bases. A system that integrates top-down and bottom-up governance has been shown to be the most effective. The market incentives approach focuses on the economic or monetary incentives that come from valuing nature and the services that ecosystems provide, such as supporting alternative livelihoods for communities through a shift from non-renewable extractive resource use to renewable ecotourism (Jones 2014).

The analysis of MPA governance by Jones (2014) using the 'MPA Governance Framework' has identified five broad governance approaches, each containing varying degrees of government, community and private sector involvement (Table 20.2). It is widely accepted that no one approach can provide a perfect governance system, and a collaborative co-management approach may maximise the effective governance of MPAs; this was highlighted in the Durban Accord from the fifth IUCN World Parks Congress in 2003. 
Kimbe Bay is in Papua New Guinea within the world's most biodiverse marine area: the Coral Triangle (Weeks et al. 2014; Figure 20.3). Approximately 100000 people live in coastal communities in the bay, relying on both land and marine resources for their livelihoods. The bay comprises a high diversity of both shallow and deep-water marine habitats of high conservation value, where land and sea ownership is clan-based and communities make decisions regarding local conservation and resource management (Green et al. 2009).

In 2006, The Nature Conservancy led the design of a resilient and science-based MPA network for Kimbe Baythe first of its kind in the Coral Triangle-by assessing biodiversity and socioeconomic values to identify 14 'areas of interest' (AOls) (Green et al. 2009). Since then, the Conservancy and partners have supported a community-based planning process, which has led to 14 communities establishing nine LMMAs within seven of the AOls, including co-management arrangements between some communities (Weeks et al. 2014). The LMMA design process involved: 1) community engagement; 2) community visioning; 3) participatory conservation planning; 4) community development of an LMMA plan; 5) preparation of a draft plan and agreement; and 6) stakeholder consultation and finalisation of the plan and agreement by the community (Green et al. 2009).
Substantial progress has also been made towards establishing a governance and management framework for Kimbe Bay, with marine management and protection laws (created for the three local governments with marine areas) providing a legal foundation for community-developed LMMA management plans. Further governance progress includes the establishment of the 'PNG Learning and Training Network', which aims to identify and share good practice tools and methods for community conservation and resource management; a memorandum of understanding between The Nature Conservancy and the Provincial government to develop a governance system for the Kimbe Bay Marine Management Area, which includes establishing a governing secretariat; and a steering committee comprising members from NGOs, government and private sectors, which has now taken ownership of the implementation process (Weeks et al. 2014).

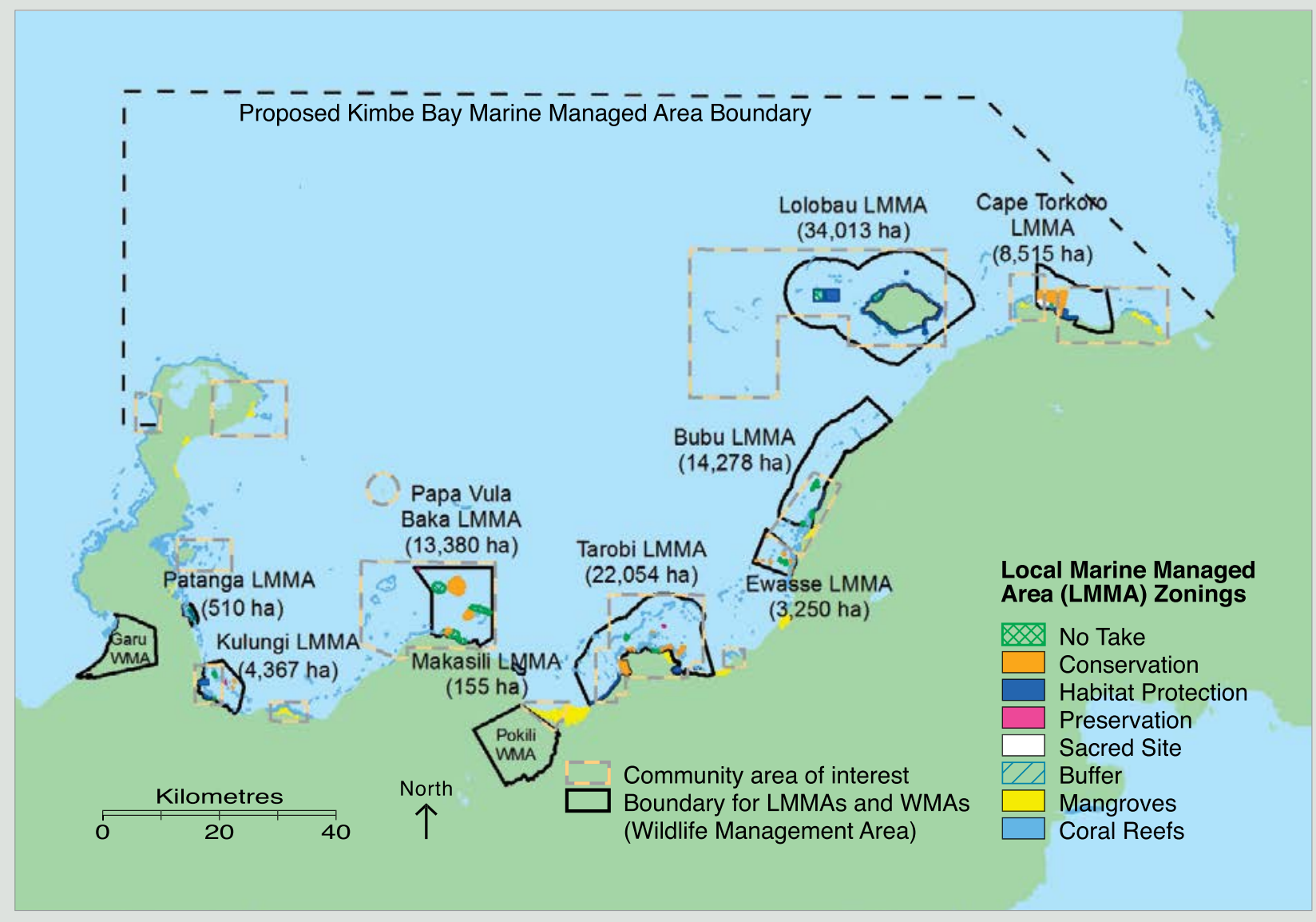

Figure 20.3 The Kimbe Bay Marine Management Area, including Locally Managed Marine Areas (LMMAs) established within areas of interest

Source: Modified from Weeks et al. (2014) 
Table 20.2 Five marine protected area governance approaches with examples

\begin{tabular}{|c|c|c|}
\hline $\begin{array}{l}\text { Governance } \\
\text { approach }\end{array}$ & Details of the approach & $\begin{array}{l}\text { Examples of MPAs in which the approach is } \\
\text { adopted }\end{array}$ \\
\hline Government-led & $\begin{array}{l}\text { Managed primarily by the government } \\
\text { under a clear legal framework }\end{array}$ & $\begin{array}{l}\text { Great Barrier Reef Marine Park (Australia) } \\
\text { Darwin Mounds candidate Special Area of Conservation } \\
\text { (United Kingdom) } \\
\text { North East Kent European Marine Site (United Kingdom) } \\
\text { Wash and North Norfolk Coast European Marine Site } \\
\text { (United Kingdom) } \\
\text { California Marine Life Protection Act (USA) } \\
\text { United States National Marine Sanctuary System (USA) }\end{array}$ \\
\hline Decentralised & $\begin{array}{l}\text { Managed in a shared approach } \\
\text { by the government with significant } \\
\text { decentralisation and/or influences } \\
\text { from the private sector }\end{array}$ & $\begin{array}{l}\text { Sanya Coral Reef National Marine Nature Reserve } \\
\text { (China) } \\
\text { Seaflower MPA (Colombia) } \\
\text { Galápagos Marine Reserve (Ecuador) } \\
\text { Karimunjawa Marine National Park (Indonesia) } \\
\text { Wakatobi National Park (Indonesia) } \\
\text { Tubbataha Reefs Natural Park (Philippines) } \\
\text { Ha Long Bay Natural World Heritage Property (Vietnam) }\end{array}$ \\
\hline Community-led & $\begin{array}{l}\text { Managed primarily by local } \\
\text { communities under collective } \\
\text { management arrangements }\end{array}$ & $\begin{array}{l}\text { Isla Natividad (Mexico) } \\
\text { Os Miñarzos Marine Reserve of Fishing Interest (Spain) }\end{array}$ \\
\hline Private-led & $\begin{array}{l}\text { Managed primarily by the private } \\
\text { sector and/or NGOs granted } \\
\text { property/management rights }\end{array}$ & $\begin{array}{l}\text { Chumbe Island Coral Park (Tanzania) } \\
\text { Great South Bay Marine Conservation Area (USA) }\end{array}$ \\
\hline $\begin{array}{l}\text { No clear governance } \\
\text { framework }\end{array}$ & $\begin{array}{l}\text { No clear effective governance } \\
\text { framework in place }\end{array}$ & $\begin{array}{l}\text { Baleia Franca Environmental Protected Area (Brazil) } \\
\text { Pirajubaé Marine Extractive Reserve (Brazil) } \\
\text { Cres-Lošinj Special Marine Reserve (Croatia) }\end{array}$ \\
\hline
\end{tabular}

\section{Marine protected area governance incentives}

Positive governance outcomes can be promoted through the use of incentives that 'provide for certain strategic policy outcomes, particularly biodiversity conservation objectives' (Jones et al. 2011:13). A global analysis of 20 MPA case studies by Jones (2014) identified five categories of incentives (Table 20.3).

Legal frameworks and incentives implemented through the top-down leadership of states play an important role in framing effective MPA governance. They provide the framework for enforcing compliance and can promote local community stewardship via legally enforced community property rights, which help to protect areas from external resource exploitation. It is important for states to enable and support local stewardship, or community ownership, if an MPA initiative is attempting to engage and gain the support of local communities as part of its governance approach.
In addition to state-driven legal incentives, economic incentives are identified as the most frequently used governance tool. The economic benefits of renewable long-term shark diving ecotourism in the recently established shark sanctuary of Palau, for example, were shown to greatly outweigh the income from nonrenewable shark-finning practices (Vianna et al. 2012).

Additionally, the bottom-up roles of traditional and local knowledge and participation, as well as the expert guidance of individuals or organisations such as environmental NGOs are important in driving and implementing MPA governance. Achieving an equitable balance between a healthy and thriving local community that has controlled access to local resources and ensuring appropriate protection to avoid resource over exploitation within MPAs is critical.

It is the combination of legal and economic incentives with other interpretative, knowledge and participatory incentives that are important for effective governance. Twenty global case studies identified that no single governance approach is likely to be most appropriate, and that a combined approach with a diversity of appropriate 
Table 20.3 Five categories of incentives

\begin{tabular}{|l|l|}
$\begin{array}{l}\text { Incentive } \\
\text { category }\end{array}$ & $\begin{array}{l}\text { Definition (number of incentives in this category employed in MPA Governance } \\
\text { Framework) }\end{array}$ \\
\hline Economic & Using economic and property rights approaches to promote the fulfilment of MPA objectives (10) \\
\hline Interpretative & $\begin{array}{l}\text { Promoting awareness of the conservation features of the MPA, the related objectives for conserving } \\
\text { them and the approaches for achieving these objectives, and promoting support for related } \\
\text { measures (3) }\end{array}$ \\
\hline Knowledge & $\begin{array}{l}\text { Respecting and promoting the use of different sources of knowledge (local-traditional and expert- } \\
\text { scientific) to better inform MPA decisions (3) }\end{array}$ \\
\hline Legal & $\begin{array}{l}\text { Establishment and enforcement of relevant laws, regulations, and so on, as a source of 'state } \\
\text { steering' to promote compliance with decisions and thereby the achievement of MPA obligations } \\
\text { (10) }\end{array}$ \\
\hline Participative & $\begin{array}{l}\text { Providing for users, communities and other interest groups to participate in and influence MPA } \\
\text { decision-making that could potentially affect them, in order to promote their 'ownership' of the MPA } \\
\text { and thereby their potential to cooperate in the implementation of decisions (10) }\end{array}$ \\
\hline
\end{tabular}

Source: Jones (2014)

incentives from different incentive categories increases the resilience of governance systems and maximises marine governance effectiveness. Just as diversity is the key to resilience for species and ecosystems, a diverse governance approach with multiple incentives combining the role of people, markets and the state is the key to best-practice governance.

\section{Governance challenges}

\section{Limits of marine governance: Maritime boundaries and high seas governance}

Among the main challenges to marine governance are the legal differences between terrestrial and marine ecosystems. Sixty-four per cent of the world's oceanand nearly half the surface of the Earth-is outside the legal powers of traditional national governance systems. Despite their vastness, marine ecosystems and species in the high seas and international seabed areas beyond national jurisdiction are threatened on multiple fronts, making efforts to address areas both within and beyond national jurisdiction vital to achieving international goals for marine conservation.

Establishing governance across the whole ocean is essential. Near-shore and offshore systems are linked in many ways: ocean currents move water masses, pollution and marine debris; marine animals such as cetaceans, sea turtles, sea birds and tuna undertake extensive migrations; many coastal marine species are found in the open ocean for large proportions of their life history (Ban et al. 2014). Fish stocks and seabed features such as seamounts, hydrothermal vents and cold-water coral reefs may straddle national and international boundaries. Spawning sites, breeding grounds and other habitats necessary for critical life-cycle stages of rare, threatened or endangered species as well as commercially important species may occur on either side of legal boundaries (Ban et al. 2014).

There is accordingly a critical governance gap for a large proportion of the global marine environment. A broad framework for cooperation to protect and preserve the marine environment, including in areas beyond national jurisdiction is set out under UNCLOS, under which all countries have a duty to protect and preserve the marine environment including rare and fragile ecosystems and the habitats of depleted, threatened or endangered species (Article 194.5), and to conserve high seas living resources (Article 117). There is, however, no specific legal framework for integrated and ecosystem-based management and no specific mandate for the establishment of MPAs for those bodies with the authority to regulate specific human activities. Progress in establishing representative networks of high seas MPAs to 2014 has thus been very slow (Gjerde and Rulska-Domino 2012).

Despite this, high seas MPAs have been established. The first high seas MPA was designated in the Mediterranean in 1999, partly on the high seas. The world's first MPA located entirely in high seas, the South Orkney Islands-Southern Shelf MPA, was established in the Southern Ocean in 2010. The same year, a network of high seas MPAs began to be established in the North-East Atlantic Ocean under the Convention for the Protection of the Marine Environment of the North-East Atlantic (OSPAR).

By December 2012, seven areas of the North-East Atlantic had been designated as MPAs in areas beyond national jurisdiction and in high seas. Approximately 


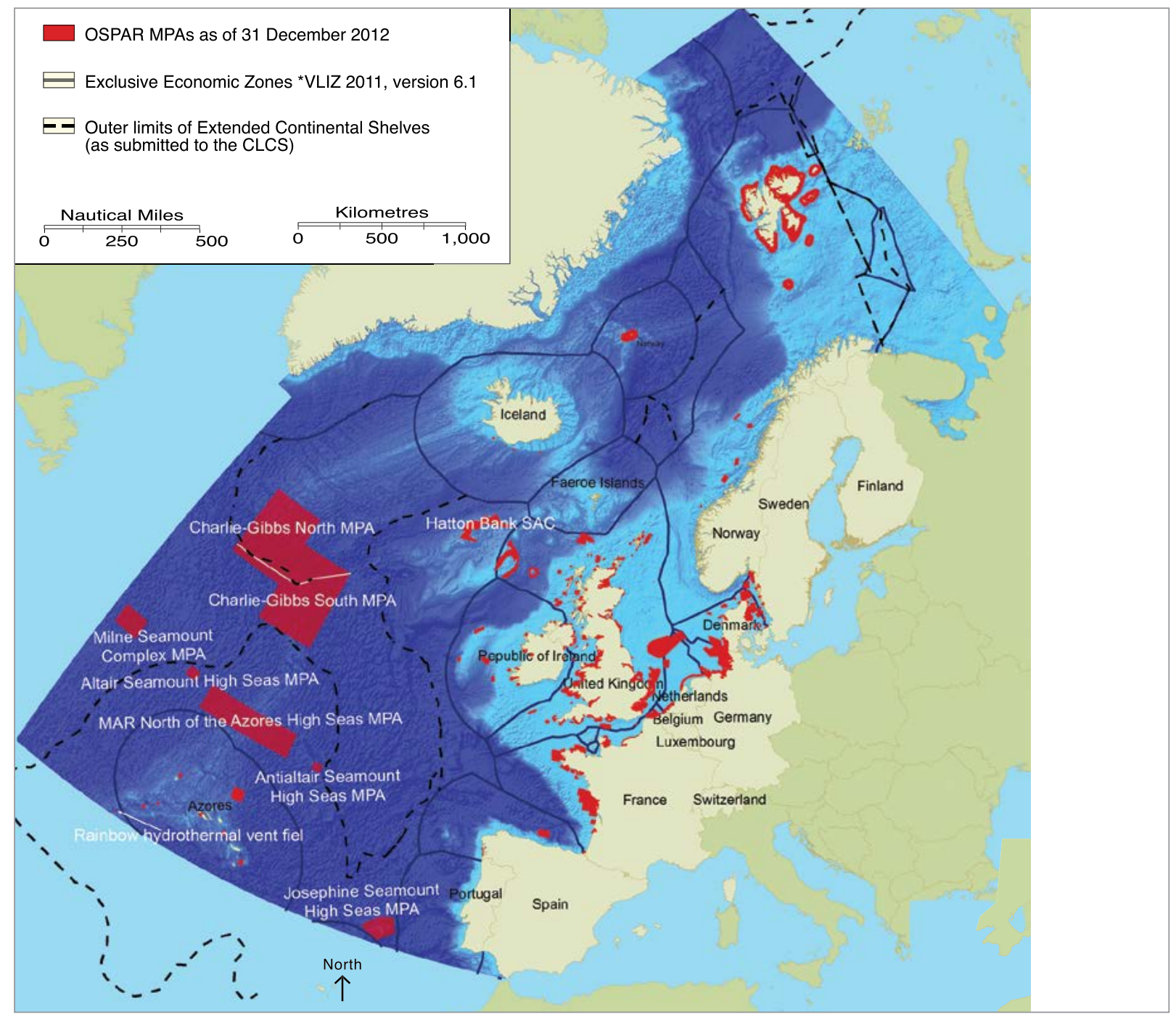

Figure 20.4 Convention for the Protection of the Marine Environment of the North-East Atlantic (OSPAR) network of MPAs, as of December 2012

Source: Modified from OSPAR Commission (2013), reproduced with permission from the OSPAR Commission, London

40 per cent of the OSPAR maritime area lies outside the national jurisdiction of coastal states (OSPAR Commission 2013; Figure 20.4). States in the Southern Ocean have committed to following this action by developing a full network of MPAs in this area (Gjerde and Rulska-Domino 2012). The establishment of high seas MPA networks represents early progress in high seas MPA governance, but highlights the fact that progress remains slow.

Alongside these specific actions, activity-based organisations can also apply area-based management tools that may have conservation benefits. Regional fisheries management organisations can adopt spatial or temporal closed areas or gear modifications. The International Maritime Organisation has criteria and guidelines for designating 'Particularly Sensitive Sea Areas', which provide an umbrella for the adoption of routeing, reporting, discharge or other protective measures within its competence. With respect to seabed mining, the International Seabed Authority has adopted a representative system of 'Areas of Particular Environmental Interest' in the Clarion-Clipperton Zone in the Pacific Ocean that could be replicated in other areas where seabed mining may occur. To date, however, these measures are not being applied as part of a systematic approach to develop a representative network of MPAs.

As noted above, some ocean regions benefit from preexisting regional seas conventions that provide a forum for cooperation to, among other things, identify and designate MPAs and manage specific activities. It is also possible to spur cooperation without a regional seas framework; the Sargasso Sea in the central Atlantic is a prime example (Freestone et al. 2014). To spur global cooperation and coordination, however, states at the United Nations have been discussing a possible new implementation agreement under UNCLOS for the 


\section{Case Study 20.2 Indigenous sea country governance in Australia: Traditional-use marine resource agreements}

In the Great Barrier Reef, local Aboriginal and Torres Strait Islander people have fostered connections to 'sea country' for tens of thousands of years. Today approximately 70 clan groups are recognised as having sea country ties to areas within the marine park. The Great Barrier Reef Marine Park Authority (GBRMPA) acknowledges the ongoing social, cultural, economic and spiritual connections of the Traditional Owners to the region and has established governance structures that aim to ensure effective partnerships including Indigenous land-use agreements and traditional-use marine resource agreements (Figure 20.5). These provide a collaborative working relationship between the Australian (Federal) and Queensland (State) governments and local traditional user groups.

In 2005, the Girringun Traditional Owners, comprising nine tribal sea country groups, were the first Traditional Owners in the Great Barrier Reef to establish a traditional use of marine resource agreement; this addressed the management of traditional take of turtle and dugong.

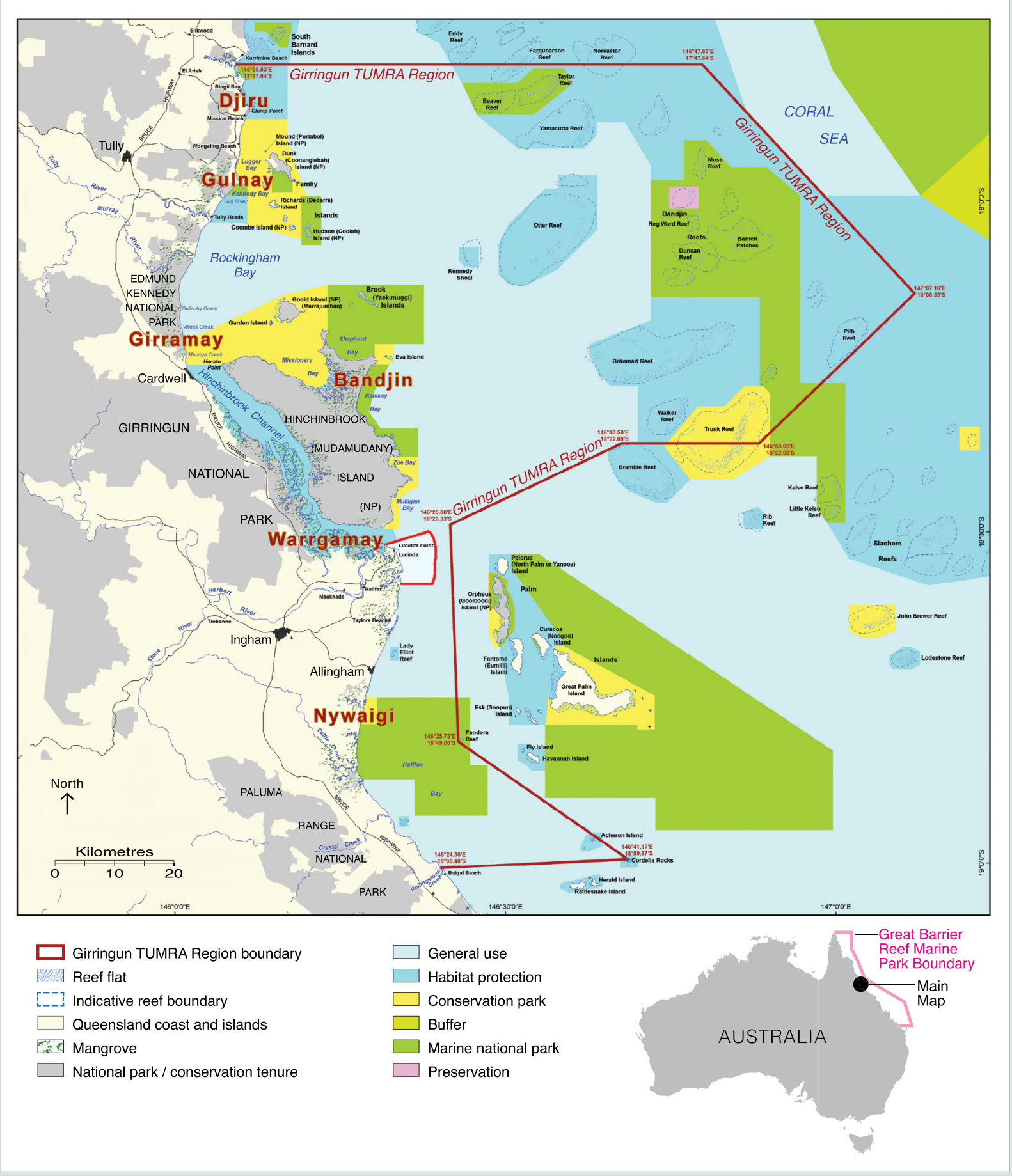

Figure 20.5 Traditional-use marine resource agreement area (TUMRA)

Source: Modified from Great Barrier Reef Marine Park Authority (2014) 
In the Nunavut Settlement Area of far north-eastern Canada, a collaborative government-traditional owner relationship has been established between the Canadian Government and Inuit of Nunavut, through the Inuit Impact and Benefit Agreement. Under this agreement, the three Ninginganiq, Akpait and Qaqulluit National Wildlife Areas, covering 4534 square kilometres of the north-eastern coast of Baffin Island, are co-managed by the local Inuit community and the Canadian Wildlife Service. This comanagement 'ensures that both the traditional knowledge and expertise of the Inuit and the best scientific data are combined effectively in all decision-making processes' (Department of Oceans and Fisheries Canada 2014). conservation and sustainable use of marine biodiversity beyond national jurisdiction. Such an agreement could provide a legal framework for the establishment of high seas MPAs, set standards for environmental impact assessment and accelerate progress towards integrated ecosystem-based management and governance (Gjerde and Rulska-Domino 2012). To build a scientific basis to assist nations and international organisations, in 2008 the CBD adopted the 'Ecologically and Biologically Significant Areas' criteria (CBD 2008) and in 2010 commenced a series of workshops to facilitate their description across all ocean basins (Dunn et al. 2014). Three-quarters of the total estimated ocean area-265.7 million square kilometres-has since been surveyed (CBD SBSTTA 2014).

\section{Traditional use of marine protected areas: Co-management in governance}

The importance of a diverse collaborative comanagement approach to governance was highlighted at the fifth IUCN World Parks Congress in 2003, where the Durban Accord urged 'commitment to innovation in protected area management, including adaptive, collaborative and co-management strategies' (IUCN WCPA 2003a:223).

Co-management has the potential to incorporate a diverse range of stakeholders and knowledge in decisionmaking processes to improve effective MPA governance:

The diversity of co-management approaches makes them capable of fitting different contexts. If properly understood and adopted, co-management can lead towards more effective and transparent sharing of decisionmaking powers, a more active, conservationfriendly and central role for indigenous, mobile and local communities in protected area management, and better synergy of the conservation capacities of different stakeholders. (IUCN WCPA 2003b:201)
Effective MPA governance requires a balanced approach that maintains and incorporates the cultural values, customs and knowledge of traditional communities living within and adjacent to marine areas. Around the world, governance arrangements have been established that integrate traditional communities with national governance through co-management arrangements. Traditional use and co-management arrangements from Australia and Canada are discussed in Case Studies 20.2 and 20.3 .

\section{Management of marine protected areas}

MPA managers rarely manage natural systems or specific marine species per se; what they generally do is manage the human impacts within or on their MPA (Day 2006). MPA management typically relies on using a combination of management tools (including spatial tools like zoning plans or plans of management; temporal tools like seasonal closures for nesting birds or key spawning periods; legislative tools like regulations; and/ or permits), along with various management approaches (such as education, impact assessment, monitoring, partnerships and enforcement). Such approaches are used to regulate access, and to control and/or mitigate impacts associated with activities (such as recreation, tourism, fisheries or shipping) or to address pressures (such as declining water quality or climate change). Many of these key management tools and approaches are discussed in more detail below.

Management is usually considered to be a continuous, interactive, adaptive and participatory process, comprising a set of related tasks that all need to be undertaken to achieve a desired set of goals and objectives. It is important that these goals and objectives are clearly established early in the life of an MPA, that they are widely known and are able to provide the benchmark against which the effectiveness of management is evaluated. 


\section{Box 20.4 Marine spatial planning and MPAs: From theory to implementation}

Marine spatial planning is:

[A] public process of analysing and allocating the spatial and temporal distribution of human activities in marine areas to achieve ecological, economic and social objectives that are usually specified through a political process. (Ehler and Douvere 2009:18)

Marine spatial planning provides a process for a strategic and integrated plan-based approach to marine management that makes it possible to look at the 'bigger picture' and to identify and manage current and potential conflicting uses, as well as the cumulative effects of human activities. It provides contextual information for the planning and management of MPAs. Processes become more transparent, and it provides greater certainty in the provision of permits, and for other planning and allocation processes for both developers and environmental managers. It is ideally conducted as a continuous, iterative and adaptive process and consists of at least three ongoing phases.

1. Planning and analysis: Generating and adopting one or more integrated, comprehensive spatial plans for the protection, enhancement and sustainable use and development of the sea and its resources. The planning and analysis phase will be based on a set of research initiatives (including mapping) that addresses both environmental and human processes.

2. Implementation: Implementing the plan through the execution of programs of work or investments, enabling change, encouraging improvement and through regulation and incentives, and enforcement of proposed changes and ongoing activities in, on, over and under the sea, in accordance with the plans.

3. Monitoring and evaluation: Assessing the effectiveness of the plans, their time scales and implementation mechanisms, considering ways in which they need to be improved and establishing review and adaptation procedures. Results of evaluation are fed back into the planning and analysis element of management, and the process begins again.

The ultimate decision on what space will be allocated for what use (or non-use) is a matter of societal and political choice. People are central to the decisionmaking process and relevant stakeholders, including the wider public, need to be effectively involved throughout the marine strategic planning process. All steps of this process need financing on a continuing basis to achieve management goals and objectives.

- Charles Ehler and Fanny Douvere
Patterns of use and technological approaches are constantly changing, so MPA management also needs to be flexible, adaptive and responsive. The marine environment itself is similarly dynamic and subject to both natural changes and differing patterns of use. Consequently, an adaptive management approach (Chapter 8) is essential for effective MPA management. Particularly in large MPAs, this is best achieved through regular interaction between agencies, across all levels of government and with local communities and interest groups.

\section{Marine spatial planning and management planning}

Planning an MPA frequently requires consideration of a range of national and/or State or Provincial legislation, especially to ensure that planning accords with the legal mandate(s) for the area. Planning may also be guided by specific obligations under relevant international conventions, and for ICCAs there may also be community requirements.

Planning in the marine environment includes numerous challenges, many of which are not faced when planning terrestrial protected areas—-for example:

- the interdependency on neighbouring ecological communities and the interconnectedness of the coastal and marine environments

- the impacts from adjacent land or sea areas that could threaten the integrity of even the best-managed MPA

- the three-dimensional (water column) aspects of an area requiring management (few MPAs are well known, easily viewed or easily 'delineated' for management purposes)

- the problem that most parts of the marine environment are not easily viewed or understood ('out of sight, out of mind')

- ownership issues_for most marine areas worldwide, open-access resources are poorly or insufficiently regulated (Day 2006) and jurisdiction at the coastal land-sea interface may be unclear.

Effective marine spatial planning should be both strategic and integrated (see Box 20.4). How a systematic planning process can be applied through the concept of 'ecoregions' is discussed in Case Study 20.4. Broadarea integrated management that has zoning within a large MPA is considered more effective than a series of small, isolated highly protected areas within a broader unmanaged area because: 


\section{Case Study 20.4 Systematic planning and management of MPAs: Applying the concept of ecoregions in practice}

The overall objectives of marine conservation should be to protect as many of the components of marine biodiversity as possible, while allowing for sustainable use such as fisheries. In order to accomplish this objective, the areas chosen for conservation-as MPAs-should include both 'representative' areas and 'distinctive' areas. Ecoregions provide a natural framework within which to deliver such an approach. For effective marine conservation, the designation of MPAs within an ecoregion should be based on the best available biogeographical and ecological information that has been assembled into a coherent framework.

An overall target for conserving at least 10 per cent of marine ecoregions (CBD 2011) is still rather arbitrarily defined. While this target is provisionally accepted in this example, some authors, such as Roff and Zacharias (2011), have suggested methods of defining a framework for regional MPAs that is non-arbitrary in total proportion of the area to be protected. The process of selecting MPAs based on a target of conserving all recognised components of biodiversity is a complex one, best accomplished by computer analysis of the array of options.
Using computer analysis, candidate sets of MPAs can be selected and presented to decision-makers, with additional political and socioeconomic factors then incorporated into decision-making processes. At the same stage of the planning process, an evaluation should be made to determine whether any chosen coherent set of MPAs could also form a true network of MPAs.

Planning a true MPA network involves knowledge of several additional factors including: local and regional oceanographic and atmospheric circulation patterns (tides, currents, wind stress, and so on), and development times of vertebrate and invertebrate larval forms (and/or other propagule types). With such information, the patterns of connectivity among the candidate MPAs of a region can be modelled or calculated, based on estimates of larval duration of important or representative species (usually fish larvae), and appropriate distances between MPAs can be decided.

- John Roff
- ecologically: it recognises temporal/spatial scales at which ecological systems operate and ensures the entire MPA remains viable as a functioning ecosystem

- practically: it is easier to manage; it buffers and dilutes the impacts of activities in areas adjacent to highly protected 'core' areas

- socially: it can help to resolve and separate conflicting uses and ensure all reasonable uses can occur with minimal conflict, as well as minimising confusion by a single management agency having responsibility rather than a multitude of differing agencies

- economically: integration within a larger area will generally have lower management costs per spatial area than a series of small MPAs managed separately (Day 2002).

A common misconception in MPA planning is the expectation that all activities and impacts can be effectively addressed in a single two-dimensional planning approach like zoning. In the Great Barrier Reef Marine Park, for example, zoning is only one of many management tools used, and many other spatial and temporal management tools or strategies are applied on top of the underlying zoning. These include:

- permits (often tied to specific zones or smaller areas within zones, and providing a detailed level of management arrangement not possible by zoning alone)
- plans of management for areas requiring more specific statutory management arrangements such as limiting numbers or applying approved policies

- site plans and special management areas for specific high-use areas or where special local arrangements might be applied

- other spatial restrictions (such as for defence training areas, shipping areas and agreements with traditional owners).

Zoning is not always the most effective way to manage all activities or impacts on the MPA and many management challenges, such as pollution from the land, increasing coastal development and even some impacts within an MPA, may be better managed using other spatial and temporal management tools.

A fully integrated approach to planning is the only way to achieve effective marine conservation, as well as longterm social and economic sustainability for communities and industries that are dependent on the marine environment. To be effective, integrated planning needs to consider and wherever possible involve:

- all relevant levels of government (national, provincial and/or local) that have a role within the MPA or any role with uses/activities that impact on the MPA

- all relevant sectoral/user/industry groups

- relevant social, economic and cultural aspects as well as the more obvious ecological aspects 
- the need to 'think outside the MPA square' (especially across the coastal-marine interface, as integration across this land-water boundary is essential for effective MPA management)

- taking into account 'shifting environmental baselines' (successive generations comparing changes against already altered baselines).

\section{Marine connectivity in conservation planning}

Given the high levels of connectivity both within and between marine ecosystems, MPA planning should aim to consider connectivity in the following ways:

- explicitly aim to protect representative examples of all habitat and community types (such as reefs, Halimeda macro-algae and seagrass meadows) and physical environment types (such as cays, channels, differing levels of exposure to environmental stressors such as ultraviolet radiation, wind, waves, and so on), utilising bioregionalisation planning and the application of the key biophysical planning principles (Fernandes et al. 2005)

- deliberately ensure cross-shelf, depth-range and latitudinal diversity are included in the MPA network to encompass potential connections within networks

- aim to ensure reserve networks incorporate a range of dispersal distances, but especially distances of less than 30 kilometres

- specifically design the MPA to maximise as many as possible of the known ecological processes and connectivity patterns (spatial and/or temporal), such as ocean upwelling, turtle and seabird nesting sites, fish spawning areas; and known 'sink' or 'source' reefs

- aim for replication of no-take areas by protecting multiple examples within each bioregion if possible in order to spread the risk of likely impacts (McCook et al. 2009).
A well-structured, systematic approach to the design and implementation of MPA networks can have broad, and sometimes unplanned, benefits. For example, McCook et al. (2010) discuss the expected and unexpected benefits of a systematic design approach for the Great Barrier Reef Marine Park.

\section{Site management arrangements}

Site management arrangements are localised plans for the use of a particular site. They identify significant values of the specific site and describe current management arrangements, concentrating on specific use issues and cumulative impacts at the site. For example, the Whitsundays Plan of Management in the Great Barrier Reef assigns most reefs, bays and coastal areas to a 'setting', ranging from intensively used (Setting 1) to protected (Setting 5), and prescribes the maximum limits for each setting (Table 20.4).

Recreational users are able to access all settings provided they adhere to the limits, whereas only a limited number of tourism operators who have relevant permit endorsements are able to access Setting 5 areas.

\section{Marine risk management and resilience}

A risk is the effect of uncertainty on the outcomes being sought, in terms of: a) the consequences of the risk, which can be either beneficial or detrimental; and b) the likelihood of the risk occurring (Standards Australia 2013). 'Effect' is a deviation from the expected (positive and/or negative), and 'uncertainty' is the level of certainty about information relating to an understanding or knowledge of an event, its consequences or its likelihood.

Risk management involves undertaking a risk assessment of the likelihood and consequences of impacts, such as human-caused pollution, on key species or habitats and/ or localities such as bays, islands or reefs. An effective risk assessment helps to make an informed management decision and should also consider the social, cultural, economic and reputational risks to the MPA.

Table 20.4 Limits for planning settings

\begin{tabular}{|l|l|l|} 
Setting & Vessel length & no limit \\
\hline 1. Developed & max. 70 metres & no limit \\
\hline 2. High use & max. 35 metres & max. 40 people \\
\hline 3. Moderate use & max. 35 metres & max. 15 people \\
\hline 4. Natural & max. 35 metres & max. 15 people \\
\hline 5. Protected & max. 20 metres & \\
\hline
\end{tabular}




\section{Box 20.5 Building resilience through effective management}

Operationalising resilience concepts in management has been the target of a number of key programs, requiring actions and policies from the level of grassroots/field agents, through protected area managers to agency decision-makers. Key aspects of resilience-based management include the following.

- Design and site selection issues, including decisions about the siting of MPA core zones, their size and number, and representation and replication of key habitats across the seascape (Grimsditch and Salm 2006; Salm et al. 2006; McLeod et al. 2009). An important question that is yet to be answered conclusively is whether it is more effective to establish fewer large no-take MPAs, multiple small no-take MPAs of equivalent area or larger still multiple-use MPAs with small no-take areas embedded in them. A desirable feature is the ability to adjust the zoning of MPAs in response to future threats and the condition of protected systems. Selecting critical areas in a seascape is an essential component of maintaining resilience, as some key sites (such as spawning aggregations or source areas for reseeding impacted areas) have unique importance in maintaining resilience over larger geographic areas.

- Reducing threats that undermine healthy ecosystems is the first line of defence against any disturbance, whether minor or catastrophic, temporary or longterm. Corals that are exposed to stressors such as pollution, siltation, damaging activities or overfishing, for example, are at greater risk of succumbing to further stress brought on by storms, elevated seawater temperatures and ocean acidification. Consequently, MPA managers need to prioritise the abatement of manageable stresses to the extent possible.

- Connectivity in marine ecosystems is a key determinant of larval replenishment and this is important for resilience after any major disturbance, as is retaining ecological processes such as productivity and the life cycles of many marine organisms. As outlined earlier, connectivity is now being considered more in MPA planning and management, with recent research demonstrating a greater degree of replenishment than previously thought (Harrison et al. 2012). Maintaining a connected network of healthy sites inside and outside MPAs will become an increasingly important management goal in coming decades, supported by improvements in connectivity science.

While the above factors focus on biological elements of resilience, the effectiveness of management (Salm et al. 2006; Chapter 28) remains a key determinant of success in using resilience concepts, applying to design aspects, threat abatement and managing people's behaviour. In many parts of the world, the effectiveness of management programs is dependent on the willingness of adjacent communities, especially resource harvesters, to abide by the regulations and support management efforts. To achieve such collaboration, managers need clear communication materials and measures, and to nurture community engagement in management planning and actions. Co-management of marine resources is increasingly being used at the grassroots level-for example, in fisheries management.

Management governance structures will need to make management practices and institutions more adaptive in the future, mirroring the concepts of ecological and social resilience (in promoting adaptive capacity). Currently, most management programs and governance structures for MPAs are too rigid to cope with change. Ideally, part and parcel of the process for review and revision of management plans and policies should include adjustment of MPA zones and boundaries to cope with emerging threats or opportunities. Ecosystem-based management, integrated coastal management, marine spatial planning and other area-based management approaches can be used to improve the application and adaptability of resilience-based approaches to management. One compelling example is the work by Harrison et al. (2012) demonstrating that well-planned and adequately protected marine reserve networks can make a significant contribution to the replenishment of fish populations in both no-take areas and fished areas within 30 kilometres of the protected area.

\section{- David Obura and Rod Salm}

Ecosystem resilience refers to the capacity of a marine ecosystem to withstand or recover from natural disturbances such as cyclones or disease, or from humanrelated impacts, and to maintain key functions without collapsing or changing to a different state. Resilient ecosystems are able to withstand or recover from impacts that would otherwise damage components of the system if they were to continue to occur over sufficient time.
In parallel with exponential growth in the study of ecological (and social) resilience in shallow marine ecosystems, the past decade has seen rapid expansion and innovation in the use of resilience concepts in managing MPAs (see Chapter 10). Effective management helps to build reef resilience (as outlined in Box 20.5), and has been facilitated in recent years through the development of a practical 'Reef Resilience Toolkit' for MPA practitioners (Box 20.6). An example of how marine mammal protected areas are providing connectivity and increasing resilience can be seen in Case Study 20.5. 


\section{Box 20.6 The Reef Resilience Toolkit}

The Reef Resilience Toolkit was developed as part of the Reef Resilience Program, a partnership led by The Nature Conservancy, which builds the capacity of reef managers and practitioners around the world to better address the local impacts on coral reefs from climate change and other stressors. Through resources such as networking, online training seminars and the dissemination of resilience science, the toolkit provides useful management actions to enhance survival prospects for coral reef communities. These include to:

- protect multiple samples of a full range of reef types, representing the likely complement of biodiversity, to spread among them the risk of any one being completely lost as a consequence of a stress event such as heat-related bleaching

- identify and fully protect coral communities that are at low risk of succumbing to events such as heat stress and coral bleaching, as these will survive to reproduce and seed susceptible areas, aiding in their recovery (West and Salm 2003)

- fully protect other critical habitats such as spawning aggregation and nursery sites and aim to include the full complement of critical life-stage habitats in notake areas

- restore functionality to degraded habitats, such as after bleaching events, managing and monitoring resilient areas to enable their recovery, as a basis for reproduction and effective reseeding of less-resilient sites

- manage susceptible sites to facilitate recoveryincluding, for example: removing coral predators, prohibiting or reducing fishing of herbivores, preventing destructive fishing practices, controlling tourism impacts and temporarily closing reef fisheries on and around bleached or otherwise damaged reefs

- nest MPAs into broader management frameworks such as large multiple-use reserves, integrated coastal management regimes or both, to enable effective control of threats originating upstream and in surrounding areas and to maintain high water quality (Salm et al. 2006)

- monitor MPAs against baseline data and compare with control reefs outside MPAs to determine the effectiveness of management strategies

- regulate developments upstream or in adjacent linked areas that could compromise the health of coral communities, such as beachfront developments that would cause run-off or discharge of sediments, fresh water or pollutants

- facilitate and foster scientific studies and research at the sites through partnerships with local universities and research scientists who can provide hard science data and third-party advice and generate agency credibility and political support for management actions to build resilience

- obtain and share information, through research, learning networks, education, interpretative programs and volunteer programs such as 'bleach watch'

- implement a management effectiveness evaluation system for the MPA, which allows for improvements in reef management, to maintain them as healthy as possible, and therefore better able to survive or recover rapidly from a stress event.

- Rod Salm, Paul Marshall and David Obura

\section{Cumulative effects}

A key aspect of resilience is the cumulative interaction between impacts: different impacts may combine or exacerbate each other so that the cumulative impacts may be far greater than any individual impact. They may interact simply (for example, additive, as in ' $1+1=2$ ') or in a more complex way (for example, synergistic, as in $' 1+1=3 \ldots$ or 4 ').

This has important consequences for MPA management including the need to manage as many impacts as possible so as to reduce cumulative effects, and the recognition that reductions in one impact may reduce the effects of other impacts, thus increasing the 'resilience' of the ecosystem to cope with other less manageable impacts such as those caused by climate change. While there is widespread recognition of the need to manage cumulative effects and there are a number of guidance documents on approaches and methodologies, it is proving difficult to make practical progress, even in well-established and well-researched MPAs.

It is important to consider the scale at which cumulative effects are occurring. Halpern et al. (2008) considered cumulative effects at the global scale, but, depending on the size of a site or the source of a pressure, the effects may be more readily addressed at the scale of an individual MPA. There appear to be few cases, however, where specific evidence has been shown of evaluating the effectiveness of managing cumulative effects. This is probably because it is too soon to draw conclusions from those examples where such intervention has occurred.

Cumulative effects may arise from multiple pressures, such as a bay receiving nutrient enrichment from both direct point-source discharges (for example, sewage) and diffuse agricultural run-off. Alternatively, it may be 
For marine mammals, resilience is partly created through replication of effectively managed MPAs. If animals in one area decline in number or disappear, other areas will be able to help protect that species. With marine mammals being long-lived, it may take many decades before the benefits of increased resilience result in improved conservation outcomes. While it is difficult to isolate the conditions responsible for success, there are many other benefits that accrue, such as greater public involvement and appreciation of these wide-ranging animals. The following are examples of success.

- Great Barrier Reef Marine Park in Australia: Has afforded improved protection for dugongs, reducing bycatch and other pressures as a result of rezoning and higher protection levels (Grech and Marsh 2008).

- Nine marine mammal sanctuaries in the Pacific Ocean: Covering the EEZs of Pacific Island countries, these have been able to afford greater protection and potential resilience for dugongs through the replication of good protected habitats. The connectivity at this scale is partly delivered by the shared approach to marine mammal conservation through the Secretariat of the Pacific Regional Environment Program.

- Critically endangered Mediterranean monk seals (Monachus monachus) in Madeira: Effectively protected on the Desertas Islands. These animals have flourished and have now begun to move to the main island of Madeira (Pires et al. 2008).

- Atlantic Ocean Sister Sanctuaries: The first sister sanctuary was established between the Stellwagen Bank National Marine Sanctuary in the Gulf of Maine,
USA, and the Marine Mammal Sanctuary in the Dominican Republic in recognition of the two key seasonal areas in the North Atlantic Ocean favoured by humpback whales (Megaptera novaeangliae)-the northern site for feeding and the Caribbean site for breeding. In 2009, the two sites joined with the newly created Agoa Sanctuary of Martinique, Guadeloupe, St-Martin and St-Barthélemy in the eastern Caribbean, to cooperate on humpback and other marine mammal conservation efforts (Hoyt 2012).

- Eastern North Pacific: The former intensive grey whaling grounds of Scammon's Lagoon (Laguna Ojo de Liebre) in Baja California became the first cetacean protected area in 1972. Later, Mexico protected a second lagoon, at San Ignacio, followed by Magdalena Bay and then an umbrella biosphere reserve called El Vizcaino. With these actions, the breeding grounds of this species were effectively protected with increased resilience offered through the replication of protection in the various lagoons and different management levels that could offer the chance to compare outcomes (Hoyt 2011). Grey whales (Eschrichtius robustus) are considered a conservation success story and have been the first (and so far only) whale to return to estimated pre-whaling levels.

- Erich Hoyt and Giuseppe Notarbartolo di Sciara the same pressure that is repeatedly affecting a feature over time, such as seabed features exposed to episodic fishing (such as trawling with bottom-towed gear), or different pressures arising from the same development acting cumulatively on the one feature-for example, development of infrastructure on intertidal mudflats leading to habitat loss (footprint) and disturbance (through increased use of vessels).

Ideally, when assessing cumulative effects there is an understanding of the degree of pressure or impact that is sustainable and will allow the achievement of conservation objectives for an MPA. While there are cases where quantitative thresholds are widely used (for example, water-quality standards), deriving ecological thresholds is difficult and assessment techniques will often involve either some form of predictive modelling or expert judgment. Practical tips on assessing and managing cumulative impacts on MPAs are provided in Box 20.7.

\section{Community engagement}

Rarely does a single MPA agency or community have jurisdictional control over all the activities occurring within an MPA, so there is usually a need to integrate effective MPA management across a range of agencies, industries and stakeholders. Since the early days of MPAs, there has been strong recognition of the importance of engaging local communities to help protect natural and cultural values. Early in the $21 \mathrm{st}$ century, this commitment to maintaining effective and meaningful partnerships with indigenous people, local communities and users is even stronger in order to conserve the values of an MPA as well as to enhance the resilience of the marine environment to cope with inevitable pressures. Community engagement is usually an ongoing requirement for effectively implementing an MPA and can occur in a number of ways:

- Establishing local marine advisory committees: These voluntary community-based committees can provide advice on management issues at a local level. Members may be independent or represent 


\section{Box 20.7 Practical tips on assessing and managing cumulative impacts on MPAs}

There are a number of practical issues to consider in using cumulative effects assessment as a systematic procedure for identifying and evaluating the significance of effects from multiple pressures and/or activities.

1. Be clear on what you are trying to achieve. Is the scope of assessment or decisions on cumulative effects work defined in legislation or specified in objectives, such as for management of an individual MPA? Whereas many assessments focus on activities or projects of the same type-like oil developmentsthose for MPAs will focus on the receptor(s) such as the habitat or species for which an MPA is designated and therefore could encompass the range of activities/ projects that interacts with those receptors.

2. Cumulative effects can occur over time, requiring caution in viewing a snapshot of ongoing activities. It is more than likely that cumulative effects had already occurred when a baseline was established-that is, when the MPA was designated. While it might be desirable to 'hindcast' to describe or quantify a prior un-impacted state, it may be better to focus resources, where limited, on avoiding further decline and promoting recovery of some kind.

3. Given the complexity of the subject, more will be achieved by narrowing the scope of cumulative effects work to as few receptors as possible. There is then a greater chance to gain a sufficiently deep enough understanding of the issues to justify management intervention. In MPAs this may be readily achieved where certain habitats or species are the main reason for designation.

4. Often a complex picture of multiple pressures can be made simpler by identifying the few 'dominant' pressures. For example, for the European Marine Strategy Framework Directive initial assessment, it was considered that for many characteristics of the ecosystem the cumulative effects of human pressures are dominated by one or a small number of pressures. Therefore, dominant pressures should be screened out to make assessments efficient and targeted.

5. To prioritise further it may be necessary to identify 'hotspots' with both a high diversity of conservation interest and high cumulative effects (see Halpern et al. 2008)

6. Management intervention to avoid or reduce identified cumulative effects will be more readily achieved if there is a clear mandate, such as provided by the legislation and objectives underpinning the MPA. Even where that is the case, action may require coordination amongst several agencies or bodies if more than one activity or more than one jurisdiction (such as national and State or local government) is involved. When in doubt, attempt to keep the approach as simple as possible. To simply map and then manage the impact of just three activities causing one pressure on one habitat or species are challenging enough.

- Paul Gilliland and Michael Coyle a community or industry group from which they coordinate feedback. The aim is to have a balanced representation of local people who are involved in the management or use of the MPA. Major benefits of committees include an opportunity for the two-way flow of information between the local community and managing agencies.

- Establishing expertise-based advisory committees: These may be established to provide advice to the managing agencies for specific issues-for example, a tourism or indigenous advisory committee. While they usually comprise nominated experts, such committees may include other community members to ensure any advice is balanced.

\section{- Undertaking regular communication:}

Communication with the community is conducted through a variety of means including email, Facebook posts or an electronic newsletter (see Chapter 15).

- Implementing 'Friends of XXX MPA' programs: These often incorporate volunteers as a key part of the program. The Reef Guardians Schools and Reef Guardian Councils programs as set up in the Great Barrier Reef are good examples of community engagement and partnerships, with 10 per cent of the entire population adjoining the reef now involved in these programs.

One example where additional resources were channelled into specific intense periods of community engagement in order to achieve important and specific outcomes is the participatory activities during the major rezoning of the Great Barrier Reef Marine Park in the late 1990s (Box 20.8) (see Day et al. 2012b).

Establishing effective and meaningful partnerships with indigenous peoples, local communities, the private sector and users is essential to protect cultural and heritage values and conserve biodiversity in an MPA. Partnerships are distinguished from other types of community involvement by the sharing of power and responsibility for its use among participants. Successful engagement is dependent on the willingness of the partners to engage in matters that are important to them, and on the level of commitment of managers to also get it right in how they engage. Informed and involved partners are essential if an MPA is to be used and managed in a way that recognises the close relationship between sustainable community livelihoods, recognition of community values and traditions, and the effective protection and management of the MPA. Some principles behind effective partnerships include: 
- shared power and responsibility among participants with no partner being made responsible for the decisions or actions of others

- realistic expectations, shared intent and relationship values

- partnership coordinators who have appropriate tenure to develop long-term personal relationships among, and between, participants (Oliver 2004).

\section{Compliance management}

Compliance management is a planned approach to ensuring that individuals and entities interacting with the MPA, for the purpose of deriving value from it, do so in accordance with legislation, regulations, permit conditions or lawful instructions. Compliance management involves a much wider consideration, however, than just enforcement. Human activity may include recreation, tourism, commercial fishing, extractive processes and/or shipping. Coastal MPAs may in addition be concerned about land-based activities that impact on water quality such as farming practices, community expansion and coastal development.

The effective management of compliance is therefore key to achieving the strategic goal of MPA management, balancing protection with sustainable use. Ideally, compliance is included as a key performance indicator and a key element of any external assessment of the MPA and its certification. When properly integrated into the MPA management cycle, compliance management supports the achievement of outcomes including conservation, use management, sustainability, industry, business and public involvement and indigenous engagement.

With a focus on monitoring, measurement and evaluation, an effective approach to compliance management will also indicate trends that may necessitate adjustments being made to the MPA management plan and permitted use.

The foundation of compliance management is grounded in a number of disciplines including law, law enforcement, human behaviour, risk management, data management, stakeholder management, measurement and evaluation, intelligence analysis and public relations. A structured approach begins with a detailed demographic analysis of the regulated community, analysing and categorising the behaviours, assessing the impacts of the behaviours, identifying and assessing threat and risk, and determining appropriate treatments to mitigate the risks. Enforcement and prosecution may be treatments of last resort, and other treatments may be more appropriate given the threat, human behaviour
Box 20.8 Lessons learned about effectively involving the public during a planning program for an MPA

- There is no simple way of creating a conflictfree consultative mechanism for many MPAs: While many decision-makers would like to have consensus-based decision-making, 'consensus is not an achievable goal for stakeholder processes dealing with issues of this magnitude' (Day et al. 2004:258 quoting Helms 2002).

- People need to understand there is a problem before accepting that a solution is required: It is usually necessary to inform stakeholders that an MPA is under pressure and that the level of protection of the biodiversity is insufficient before stakeholders are willing to accept that a new approach to management is part of the solution.

- Many stakeholders have little understanding of the key issues: Many people do not know what 'biodiversity' means, nor do they understand its importance for the future of marine waters, so there is a need to use simple language to communicate in laypersons' terms to the majority of stakeholders.

- Different messages for different target audiences: Different stakeholder groups have interests in different aspects of marine planning so communication needs to be appropriately tailored.

- Some elements of community engagement are more successful than others: Community information sessions in regional and local centres proved to be far more successful than public meetings for the Great Barrier Reef. While these sessions required considerable organisation and a large commitment in terms of resources and staff, the results were well worth the effort.

- There are those who support the proposed increase in the level of protection but who will not overtly state their views: The silent majority can often be 'drowned out' by the vocal minority who are highly motivated to voice their concerns. There is a need to encourage supporters to make the effort to voice their approval for increased protection.

Source: Adapted from Day et al. (2004)

and environmental impact. These include information, education, surveillance and monitoring, audit, caution, warning letters or infringement notices. The objective is to achieve informed self-regulation with the majority of users, focusing limited resources on high-impact noncompliant behaviours. 


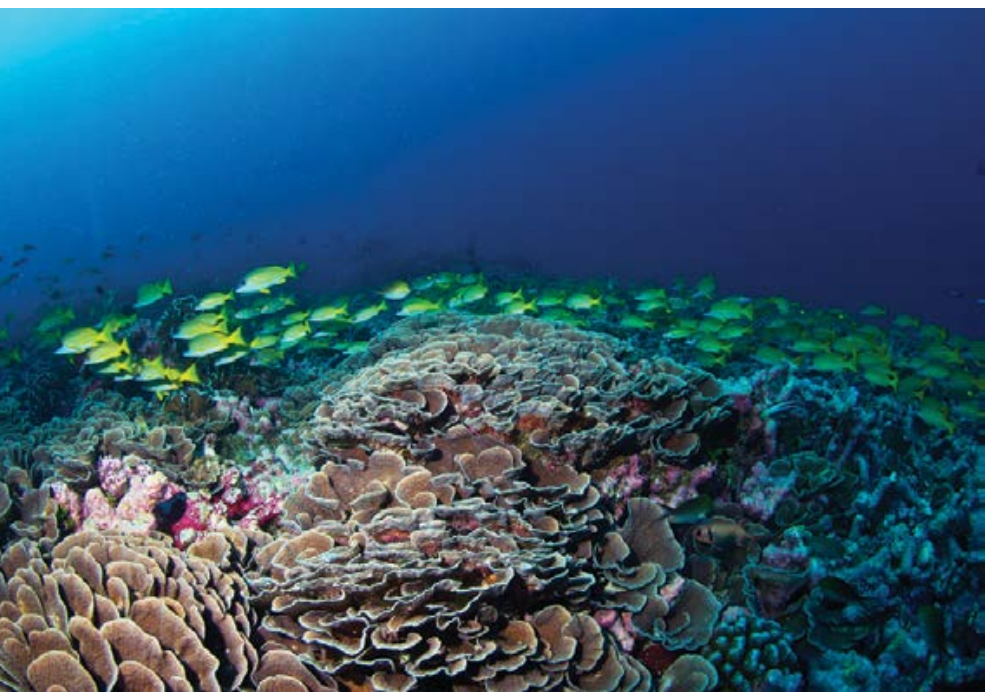

Coral (Echinopora lamellosa) with pink crustose coralline algae and fish (probably snapper, Lutjanus kasmira), Seychelles outer islands, Republic of Seychelles

Source: James Tamelander

Compliance management can involve a wide range of interests, and other regulatory and law enforcement agencies, whose primary responsibility may be shipping, fishing, tourism or communication, and who may be assisted by the MPA compliance team to deliver compliance outcomes relevant to their specialist areas.

This requires an effective approach to compliance management, beginning with a strategic plan with typically a three-year outlook. The first year of the rolling three-year plan, refined in more detail, identifies operations and resource requirements for the coming 12 months. This facilitates a thorough approach to targeting resources and the delivery and reporting of compliance outcomes. Failure to pay attention to a range of sensitivities around managing compliance could compromise the key objectives of the MPA.

In order to make decisions on threat, risk and the application of compliance management strategies, it is necessary to routinely gather, manage and analyse data. Apart from reporting the efficacy of the compliance management effort, data analysis indicates trends that enable better targeting of management effort. The requirement to justify resources by proving positive impact on both user behaviour and ecosystem outcomes requires input from marine specialists. Such collaboration helps focus on planning and implementing strategies that address protection and sustainable use. Reporting is regular and comprehensive in order to disseminate results throughout the organisation and to enhance accountability at all levels.
The development of a compliance management capability requires good planning, adequate resources and support from higher levels in the agency. Capability will mature over time as experience, lessons learned and staff competence grow and the value of captured data increases. The organisational structure of a compliance unit should aim to provide all of the key functions including intelligence, planning, operations, stakeholder management, measurement and evaluation, investigation and surveillance. Legal advice located within the unit is a distinct advantage. Audit expertise may be sourced externally. Given the diversity of functions, the range of stakeholders and the importance of compliance management to the delivery of strategic MPA objectives, strong leadership and a strategy for promoting its services and conveying them to others are important.

Systems are required to support surveillance, monitoring, data analysis and information management, ideally housed in a restricted-access room where data management and electronic monitoring equipment can be confidentially located.

Staff must be skilled to an appropriate level in compliance management against defined competency standards. There are enough range and diversity of activity in a compliance management unit to provide staff with a long-term career. Currently, there are few professional compliance managers so there is a requirement to support a comprehensive training program to provide specialist qualifications; the Great Barrier Reef Marine Park Authority has developed such a framework.

\section{Marine management issues}

\section{Climate change}

Of all the emerging issues facing MPAs and marine environments worldwide, climate change remains one of the most challenging. Increasing ocean acidity, warming sea temperatures, leading to shifts in circulation patterns and changed rainfall patterns, and increasing sea-levels are real, serious and long-term threats to marine ecosystems and the communities which live in the coastal zone.

The latest Intergovernmental Panel on Climate Change report (IPCC 2013) shows that a number of climate change variables are already changing, and based on a combination of global climate projections and regional observations and models, they are projected to change substantially more over the next 50 years (see Chapter 17). For example, coral reef scientists are concerned that coral bleaching is likely to become more frequent and more severe, even under optimistic climate scenarios produced by the IPCC. 


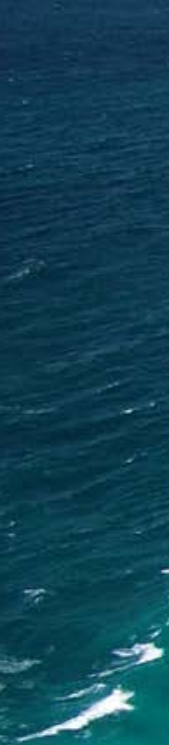

Coal loader aground on the Great Barrier Reef, Australia

Source: () Great Barrier Reef Marine Park Authority

Management activities in MPAs have a critical role to play in influencing how serious these consequences are, but ultimately, the rate and extent of changes to the global climate system will determine the long-term fate of susceptible marine ecosystems. MPAs can provide a buffer against the effects of climate change and an aid to the natural resilience of marine ecosystems.

\section{Pollution}

Marine pollution can occur when harmful, or potentially harmful, effects result from the entry into the ocean of chemicals, particles, industrial, agricultural and residential waste, noise or the spread of invasive organisms. Poor water quality and sediment quality are the most serious known pollution issues affecting many nations' coastal and marine environments. Pollution from land contributes up to 80 per cent of all marine pollution (NOAA National Ocean Service 2014) and is a major threat to the long-term health of near-shore marine systems, affecting ecological processes, public health and social and commercial uses of marine resources.

The pollution often comes from non-point sources such as agricultural run-off, windblown debris and dust. Excessive inputs of nutrients (usually nitrogen or phosphorus) are a primary cause of eutrophication of surface waters, which stimulates algal growth. When pesticides are incorporated into the marine ecosystem, they quickly become absorbed into marine food webs. Once in the food web, pesticides can cause mutations and diseases, which can be harmful to humans as well as to the entire food web.
Point sources for pollutants include urban run-off, sewage discharge, industrial pollution and unregulated coastal developments. Toxic metals can also be introduced into marine food webs. These can cause a change to tissue matter, biochemistry, behaviour and reproduction, and suppress growth in marine life. Marine toxins can be transferred to land animals via fishmeal in feed supplements, and may appear later in meat and dairy products.

\section{Dredging and port development}

Dredging and subsequent dumping at sea of dredge spoil can have major impacts, especially changing the hydrographical conditions within an MPA or in areas adjacent to an MPA. The extent of the effects depends on a wide range of factors, including the location of the dredged area and the disposal area, the method and rate of extraction, and the type of machinery, as well as the nature of the surface of the sea bottom, the sediments, the coastal processes and the sensitivity of habitats and species.

Unless appropriate controls are imposed, the impacts of dredging or the construction of port facilities can cause seabed disturbance, transport or re-suspension of contaminants, alteration of sediment movement and changes in coastal processes. These impacts can be significant, and unless precautionary and preventive actions are taken during the construction and operational phases, a port may cause significant short-term and long-term negative impacts on local communities (both ecological and social) in adjacent areas. 


\section{Mineral and sand extraction}

Marine sand and gravel, as well as minerals of interest found on or in the seabed, are non-renewable resources. The quantities of sand and gravel currently being exploited are very large. For example, in the North-East Atlantic Ocean alone, the extraction of sand and gravel was estimated to be an average of 40 million cubic metres per annum during the 1990s. Accordingly, pressure may come about to allow their extraction in MPAs, but the possible impacts are similar to those outlined for dredging (see above).

\section{Oil and gas}

Offshore oil and gas operations have increased dramatically and are expanding from shallow coastal waters to deeper offshore areas. Some activities associated with oil and gas operations, including surveys, drilling and production activities, may, if adjacent to MPAs, impact on the MPA in a variety of ways. The Deepwater Horizon oil spill in the Gulf of Mexico in 2010 was the largest accidental marine oil spill in the history of the petroleum industry and had a devastating effect on marine life in the gulf.

\section{Shipping impacts}

Shipping can potentially damage an MPA by collisions, groundings, the introduction of invasive marine pests, oil and chemical spills, the introduction of antifouling paints, waste disposal and anchor damage. Even a minor oil spill can cause local impacts to coastal species including mangroves, crabs and sediment-dwelling species. The potential for shipping activity to introduce non-native species into marine ecosystems is always present, and ballast water is a major source of introduced marine pests.

\section{Unsustainable fishing}

Fishing, whether commercial or recreational, can affect target species, non-target species and their habitats, and consequently has the potential to produce ecological effects in both fished areas and the marine environment as a whole. Ecosystem effects and the cumulative impacts of fishing are poorly understood. Scientific studies have shown that as well as affecting the abundance and characteristics of targeted species in fishing zones, fishing may also affect prey species and food webs more broadly. It is therefore important to develop a strategic approach to managing commercial, recreational and indigenous fishing in order to achieve ecological sustainability.
Many fishing techniques (for example, line, net and pot) may have little impact on habitats. Trawling, however, can cause habitat damage if not appropriately managed. Some fisheries management tools, such as bag and size limits, can help to protect the sustainability of a fishery, but do not fully address the impact of extractive activities on the ecosystem including on other non-target species. A good example of a comprehensive ecological risk assessment of a commercial fishery that looks at target species but also non-target species (bycatch), habitats and ecological processes is Pears et al. (2012).

\section{Unsustainable tourism}

If not regulated or limited, particularly in high-use areas, tourism can lead to impacts on both the marine environment and adjacent islands. For example, repeated anchoring of tourist vessels in the same locality has the potential to damage coral and seagrass habitats. A range of mandatory and voluntary arrangements can be used to minimise the impact of tourist operations.

Anchor damage can be reduced by the installation of public and private moorings in high-use areas, designated anchoring and no-anchoring areas, reef protection markers and by introducing best-practice guidelines. Sewage discharge by all users, including tourism operations, may be necessary if there are insufficient land-based facilities to service the pump-out requirements of the area. Planning for tourism should consider forecasts of the growth in tourism numbers as well as predictions of increasing impacts of use.

\section{Mariculture}

Unless appropriately managed, mariculture can modify, degrade or destroy marine habitat, disrupt trophic systems, deplete natural seed stock, transmit diseases and reduce genetic variability. The expansion of mariculture in coastal areas can not only lead to significant physical alteration of coastal environments, but can also reduce coastal protection and other functions of the ecosystem. Other impacts include pollution from nutrients, antibiotics and antifouling agents.

\section{Staff, assets, fees and licences}

The delivery of MPA management relies on the skills and commitment of staff (both field staff and office staff) and on the support they are given to perform their roles (see Chapter 8). Managers need to ensure access to:

- an appropriately sized and skilled workforce

- management infrastructure that is operational and appropriately located 
resource monitoring capabilities in an informed, contemporary and timely way at both remote and highrisk locations.

\section{Fees and charges}

While many protected areas, such as national parks and historic sites, have successfully implemented visitor entry fees (see Chapter 23), it is rarely so easy in an MPA, especially if there is a multitude of access points or no effective way to collect the fees. Where an MPA attracts a large number of tourists and a fee or charge can be effectively levied, significant income can be derived. There can, however, be drawbacks.

One major obstacle faced by government departments in implementing revenue-generating mechanisms like user fees, public donations or gift shop sales is that it is generally difficult to segregate such revenue for the MPA, where government income is expected to be paid into a consolidated fund and allocated according to national priorities (Geoghegan 1998). NGOs may not have adequate systems for financial accountability and their authority as revenue collectors may be questioned by users or management partners. In addition, the process for collecting fees may be so complex or unworkable that it may cost more to collect or enforce than the funds that are generated.

There are, however, some good examples around the world—such as the 'Environmental Management Charge' in the Great Barrier Reef, which generates more than US $\$ 6.5$ million annually (most of it from tourism). These funds are used for Great Barrier Reef management and research; however, other government funding appropriations for the Great Barrier Reef are influenced by the amount of Environmental Management Charge fees that are generated.

There are also good examples of successful fee processes in much smaller MPAs in the Caribbean: in Bonaire (Saba) and the British Virgin Islands, fees are levied on users of the marine resources, including scuba divers, and in the British Virgin Islands on yacht charterers as well. The userfee systems are implemented in close collaboration with the commercial dive and charter boat operators, who collect the fees from clients, keep records of use and perform basic interpretative information and surveillance functions on behalf of the protected areas (Geoghegan 1998). In some MPAs, visitor fees are supplemented with other funding sources such as souvenirs, gift shop sales or visitor donations (such as those generated by the "Friends of the Saba Marine Park').
When developing revenue generation strategies for an MPA, Geoghegan (1998) recommends starting by developing a desired budget for the MPA, creating a fundraising strategy through a consultative approach with all major stakeholders, ensuring that resilience is achieved through a diverse funding base with a year-on-year reduction of dependence on direct government support, and optimising partnerships and co-management agreements throughout to increase management efficiency and reduce costs.

\section{Licences and permits}

In some MPAs certain activities require a permit. For example, the following activities require a Marine Parks permit to operate in the Great Barrier Reef:

- conducting most commercial activities, including virtually all tourist operations

- installation and operation of structures such as jetties, marinas, pontoons and aquaculture facilities

- any works such as repairs to structures, dredging and dumping of spoil, and placement and operation of moorings

- anchoring or mooring for an extended period

- waste discharge from a fixed structure

- research (except for limited-impact research).

Complementary arrangements under both the national and the State MPA legislation mean only a single permit is required in the Great Barrier Reef and a permit is not required for any recreational activities. The information necessary to apply for a permit and the assessment process are both set out in the legislation; and experience over many decades has shown the need for a clear permit process, including unambiguous definitions, clear assessment criteria, and the benefits of an effectively implemented permit system. If a proposal might restrict reasonable use of part of the marine park by the public, one of the requirements before a permit is issued is public notification of the proposal, inviting comments.

\section{Management effectiveness}

Evaluating the effectiveness of managing an MPA is a challenge facing the managers of most MPAs worldwide. Increasingly, there are expectations that management should be able to demonstrate that it is achieving its goals and objectives, but also that management is cost-effective, efficient and proactive. Consequently, management effectiveness needs to be assessed and demonstrated in a systematic way that will allow useful comparisons over time (Day et al. 2002). The IUCN 
combination of monitoring methods may provide a more reliable assessment than just a single method, and exploring opportunities for encouraging stakeholder participation or local input in the overall monitoring process (Day et al. 2002). Do not wait for all the answers or perfect science before taking appropriate adaptive management action arising from monitoring information.

\section{Conclusion}

The ocean makes up 70 per cent of our planet's surface and nearly 98 per cent of its viable living space. While the ocean is the ecological engine that powers our survival, multiple pressures-including unsustainable fishing, global climate change, habitat destruction, invasive species and pollution-have led to a decline in ocean health.

With the growing number of MPAs, we are now more likely to reach 10 per cent protection by 2020 than we were just a few years ago. The question 'is 10 per cent enough?' continues to raise concern, however, with some estimates of adequate ocean protection in the range of 20-30 per cent (or even higher) to ensure sustained ocean health (IUCN 2003). Further debate looms among stakeholders in the marine conservation community over what type of conservation strategies should be counted towards Aichi Target 11 as well as how to measure the effectiveness of MPAs.

Rapid expansion of marine protection, especially the establishment of mega MPAs, also comes with the challenge of implementing effective management. Furthermore, to successfully achieve the target, the MPA network will need to be ecologically representative, equitably and effectively managed and of particular importance for ecosystem services, as alluded to in the text of Aichi Target 11; but without clear guidance it will remain a lofty goal and the world will struggle to maintain a globally consistent pace. In conclusion, achieving the 10 per cent quantitative target will be a significant first step, but only a first step.

If the very feat of MPA designation were not enough, two major issues continue to burden the system: one is a longstanding issue - the notion of 'paper parks'; the other is a more recent creation-the notion of 'regression' in progress. Paper parks are areas that are designated by name but not protected by management actions. A key step in moving the MPA agenda forwards involves addressing the widespread concern that many
MPAs around the world are mostly legislative exercises and do not provide the levels of protection needed (World Bank 2006).

Globally, few hard data exist to truly quantify and categorise the level of management effectiveness at local or larger scales. Most management effectiveness evaluations have taken place in terrestrial protected areas, but there is growing international recognition of the need to evaluate and understand the degree to which MPA management efforts are effective and meeting their objectives, and how best to improve their effectiveness (Hockings et al. 2000, 2006; Toropova et al. 2010).

Regression—or 'backsliding' - is the reversal of progress and actions by governments on MPA commitments. Often blamed on the global financial slowdown in 2008, this situation has now been used by governments as an opportunity to reduce their commitments to ocean protection, and in the worst cases, to unpick existing designations and conservation agreements. Many countries including the United Kingdom and Australia have been accused by some of dramatically scaling back plans for MPAs, alongside reducing or removing areas from network plans that contain high levels of protection for marine species and ecosystems. Such backsliding is highlighted by the World Wide Fund for Nature Protected Area Downgrading, Downsizing, and Degazettement (PADDD) program (WWF 2014).

Effective planning and management of MPAs will help address many of the challenges facing our oceans; but MPAs alone are not the sole answer to countering such complex challenges as climate change. More effective management of all our oceans and our catchments is also required. We cannot wait, however, until we have all the answers or even all the information; we must act now and be prepared to adaptively manage as we learn more. 


\section{References}

Recommended reading

Alcala, A. C., Russ, G. R., Maypa, A. P. and Calumpong, H. P. (2005) 'A long-term, spatially replicated experimental test of the effect of marine reserves on local fish yields', Canadian Journal of Fisheries and Aquatic Sciences 62: 98-108.

Almany, G. R., Hamilton, R. J., Bode, M., Matawai, M., Potuku, T., Saenz-Agudelo, P., Planes, S., Berumen, M. L., Rhodes, K. L., Thorrold, S. R., Russ, G. R. and Jones, G. P. (2013) 'Dispersal of grouper larvae drives local resource sharing in a coral reef fishery', Current Biology 23(7): 626-30.

Ban, N. C., Bax, N. J., Gjerde, K. M., Devillers, R., Dunn, D. C., Dunstan, P. K., Hobday, A. J., Maxwell, S. M., Kaplan, D. M., Pressey, R. L., Ardron, J. A., Game, E. T. and Halpin, P. N. (2014) 'Systematic conservation planning: a better recipe for managing the high seas for biodiversity conservation and sustainable use', Conservation Letters 7: 41-54. <doi:10.1111/conl.12010>

Bertzky, B., Corrigan, C., Kemsey, J., Kenney, S., Ravilious, C., Besançon, C. and Burgess, N. D. (2012) Protected Planet Report: Tracking progress towards global targets for protected areas, IUCN and UNEP-WCMC, Gland and Cambridge.

Cappo, M. and Kelley, R. A. (2001) 'Connectivity in the Great Barrier Reef World Heritage Area-an overview of pathways and processes', in E. Wolanski (ed.) Oceanographic Processes of Coral Reefs: Physical and biological links in the Great Barrier Reef, pp. 161-87, CRC Press, Boca Raton, FL.

Cisneros-Montemayor, A. M., Barnes, M., AlAbdulrazzak, D., Navarro-Holm, E. and Sumaila, U. R. (2013) 'Global economic value of shark ecotourism: implications for conservation', Oryx 47(3): 381-8.

Convention on Biological Diversity (CBD) (2004) COP 7 Decision VII/28, Seventh Meeting of the Conference of the Parties to the Convention on Biological Diversity, Kuala Lumpur, Malaysia, 9-20 February.

Convention on Biological Diversity (CBD) (2008) COP IX Decision VIII/20, Eighth Meeting of the Conference of the Parties to the Convention on Biological Diversity, Bonn, Germany, 19-30 May.
Convention on Biological Diversity (CBD) (2011) Strategic Plan for Biodiversity 2011-2020 and the Aichi Targets, Secretariat of the Convention on Biological Diversity, Montreal. <www.cbd.int/doc/ strategic-plan/2011-2020/Aichi-Targets-EN.pdf>

Convention on Biological Diversity Subsidiary Body on Scientific, Technical and Technological Advice (CBD SBSTTA) (2014) Progress report on describing areas meeting the criteria for ecologically and biologically significant marine areas, Submitted to the 18th meeting of the Subsidiary Body on Scientific, Technical and Technological Advice, Montreal, 23-28 June.

Corrigan, C. and Granziera, A. (2010) A Handbook for the Indigenous and Community Conserved Areas Registry, UNEP-WCMC, Cambridge.

Cullis-Suzuki, S. and Pauly, D. (2008) 'MPA costs as "beneficial" fisheries subsidies: a global evaluation', Coastal Management 38: 113-21.

D Day, J. C. (2002) 'Zoning-lessons from the Great Barrier Reef Marine Park', Ocean \& Coastal Management 45: 139-56.

Day, J. C. (2006) 'Marine protected areas', in M. Lockwood, G. L. Worboys and A. Kothari (eds) Managing Protected Areas: A global guide, pp. 497-527, Earthscan, London.

Day, J. C. and Roff, J. C. (2000) Planning for Representative Marine Protected Areas: A framework for Canada's oceans, WWF Canada, Toronto.

Dd Day, J. C., Dudley, N., Hockings, M., Holmes, G., Laffoley, D., Stolton, S. and Wells, S. (2012) Guidelines for Applying the IUCN Protected Area Management Categories to MPAs, IUCN, Gland.

Day, J. C., Fernandes, L., Lewis, A. and Innes, J. (2004) 'RAP — an ecosystem level approach to biodiversity protection planning', in Proceedings of the Second International Tropical Marine Ecosystems Management Symposium, pp. 251-65, ICRI, Manila.

Day, J. C., Hockings, M. and Jones, G. (2002) 'Measuring effectiveness in marine protected areas_-principles and practice', in Proceedings World Congress on Aquatic Protected Areas, Cairns, Queensland. <www.researchgate.net/ publication/43465429> 
Day, J. C., Wren, E. and Vohland, K. (2012b) 'Community engagement in safeguarding the world's largest reef: Great Barrier Reef, Australia', in A. Galla (ed.) World Heritage: Benefits beyond borders, pp. 18-29, UNESCO, Paris, and Cambridge University Press, Cambridge.

Deloitte Access Economics (2013) Economic Contribution of the Great Barrier Reef 2011-2012, Great Barrier Reef Marine Park Authority, Townsville, Queensland.

Department of Oceans and Fisheries Canada (2014) Spotlight on Marine Protected Areas in Canada, Department of Oceans and Fisheries Canada, Ottawa. <www.dfo-mpo.gc.ca/oceans/marineareaszonesmarines/mpa-zpm/spotlight-pleinsfeux/indexeng.htm>

Done, T. J., Ogden, J. C., Wiebe, W. J. and Rosen, B. R. (1996) 'Biodiversity and ecosystem function of coral reefs', in H. A. Mooney, J. H. Cushman, E. Medina, O. E. Sala and E. D. Schulze (eds) Functional Roles of Biodiversity: A global perspective, pp. 393-429, Wiley, Chichester, UK.

Dudley, N. (ed.) (2008) Guidelines for Applying Protected Area Management Categories, IUCN, Gland.

Dunn, D. C., Ardron, J., Bax, N., Bernal, P., Cleary, J., Cresswell, I., Donnelly, B., Dunstan, P., Gjerde, K., Johnson, D., Kaschner, K., Lascelles, B., Rice, J., von Nordheim, H., Wood, L. and Halpin, P. N. (2014) 'The Convention on Biological Diversity's ecologically or biologically significant areas: origins, development, and current status', Marine Policy 49: $137-45$.

Ehler, C. and Douvere, F. (2007) Visions for a sea change. Report of the First International Workshop on Marine Spatial Planning, IOC Manual and Guides No. 48, IOCAM Dossier No. 4, Intergovernmental Oceanographic Commission and Man and the Biosphere Programme, UNESCO, Paris.

Dd Ehler, C. and Douvere, F. (2009) Marine spatial planning: a step-by-step approach toward ecosystembased management, IOC Manual and Guides No. 53, ICAM Dossier No. 6, Intergovernmental Oceanographic Commission and Man and the Biosphere Programme, UNESCO, Paris.
Fernandes, L., Day, J. C., Lewis, A., Slegers, S., Kerrigan, B., Breen, D., Cameron, D., Jago, B., Hall, J., Lowe, D., Innes, J., Tanzer, J., Chadwick, V., Thompson, L., Gorman, K., Simmons, M., Barnett, B., Sampson, K., De'ath, G., Mapstone, B., Marsh, M., Possingham, H., Ball, I., Ward, T., Dobbs, K., Aumend, J., Slater, D. and Stapleton, K. (2005) 'Establishing representative no-take areas in the Great Barrier Reef: large-scale implementation of theory on marine protected areas', Conservation Biology 19(6): 1733-44.

Freestone, D., Johnson, D., Ardron, J., Killerlain Morrison, K. and Unger, S. (2014) 'Can existing institutions protect biodiversity in areas beyond national jurisdiction? Experiences from two ongoing processes', Marine Policy 49: 167-75.

Geoghegan, T. (1998) Financing Protected Area Management: Experiences from the Caribbean, Caribbean Natural Resources Institute, Port of Spain, Trinidad. <www.canari.org/finance.pdf>

Gjerde, K.M. and Rulska-Domino, A. (2012) 'MPAs beyond national jurisdiction: some practical perspectives for moving ahead', International Journal of Marine and Coastal Law 27: 351-73.

Graham, R. T. (2004) 'Global whale shark tourism: a "golden goose" of sustainable and lucrative income', Shark News 16: 8-9.

Great Barrier Reef Marine Park Authority (GBRMPA) (2013) Great Barrier Reef Region Strategic Assessment: Strategic assessment report-Draft for public comment, Great Barrier Reef Marine Park Authority, Commonwealth of Australia, Canberra.

Great Barrier Reef Marine Park Authority (GBRMPA) (2014) Traditional Use of Marine Resources Agreements, Great Barrier Reef Marine Park Authority, Townsville, Queensland. <www.gbrmpa. gov.au/our-partners/traditional-owners/traditionaluse-of-marine-resources-agreements>

Great Barrier Reef Marine Park Authority (GBRMPA), World Bank and International Union for Conservation of Nature (IUCN) (1995) A Global Representative System of Marine Protected Areas. Volumes I-IV, eds G. Kelleher, C. Bleakley and S. Wells, The World Bank, Washington, DC.

Grech, A. and Marsh, H. (2008) 'Rapid assessment of risks to a mobile marine mammal in an ecosystemscale marine protected area', Conservation Biology 22(3): 711-20. 
Green, A., Smith, S. E., Lipsett-Moore, G., Groves, C., Peterson, N., Sheppard, S., Lokani, P., Hamilton, R., Almany, J., Aitsi, J. and Bualia, L. (2009) 'Designing a resilient network of MPAs for Kimbe Bay, Papua New Guinea', Oryx 43(04): 488-98.

Grimsditch, G. D. and Salm, R. V. (2006) Coral Reef Resilience and Resistance to Bleaching, IUCN, Gland.

Halpern, B. S. (2003) 'The impact of marine reserves: do reserves work and does reserve size matter?', Ecological Applications 13: 117-37.

Dd Halpern, B. S., Walbridge, S., Selkoe, K. A., Kappel, C. V., Micheli, F., D’Agrosa, C., Bruno, J. F., Casey, K. S., Ebert, C., Fox, H. E., Fujita, R., Heinemann, D., Lenihan, H. S., Madin, E. M. P., Perry, M. T., Selig, E. R., Spalding, M., Steneck, R. and Watson, R. (2008) 'A global map of human impact on marine ecosystems', Science 319(5865): 948-52.

Harborne, A. R., Renaud, P. G., Tyler, E. H. M. and Mumby, P. J. (2009) 'Reduced density of the herbivorous urchin Diadema antillarum inside a Caribbean marine reserve linked to increased predation pressure by fishes', Coral Reefs 28(3): 783-91.

Harrison, H. B., Williamson, D. H., Evans, R. D., Almany, G. R., Thorrold, S. R., Russ, G. R., Feldheim, K. A., van Herwerden, L., Planes, S., Srinivasan, M., Berumen, M. L. and Jones, G. P. (2012) 'Larval export from marine reserves and the recruitment benefit for fish and fisheries', Current Biology 22(11): 1023-8.

Helms, G. (2002) Quoted in an article titled 'Balancing ecology and economics: lessons learned from the planning of a marine reserve network in the Channel Islands (US)', MPA News 4(6), December 2002. $<$ depts..washington.edu/mpanews/MPA37.htm>.

Hockings, M., Stolton, S. and Dudley, N. (2000) Evaluating Effectiveness: A framework for assessing the management of protected areas, IUCN WCPA, Gland.

Hockings, M., Stolton, S., Leverington, F., Dudley, N. and Courrau, J. (2006) Evaluating Effectiveness: A framework for assessing management effectiveness of protected areas, 2 nd edn, IUCN, Gland.
Hoyt, E. (2011) Marine Protected Areas for Whales, Dolphins and Porpoises. A world handbook for cetacean habitat conservation and planning, 2nd edn, Earthscan, London and New York.

Hoyt, E. (ed.) (2012) Proceedings of the Second International Conference on Marine Mammal Protected Areas (ICMMPA 2), Fort-de-France, Martinique, 7-11 November 2011.

Intergovernmental Panel on Climate Change (IPCC) (2013) 'Summary for policymakers', in T. F. Stocker, D. Qin, G.-K. Plattner, M. Tignor, S. K. Allen, J. Boschung, A. Nauels, Y. Xia, V. Bex and P. M. Midgley (eds) Climate Change 2013: The physical science basis. Contribution of Working Group I to the Fifth Assessment Report of the Intergovernmental Panel on Climate Change, pp. 1-35, Cambridge University Press, Cambridge.

International Union for Conservation of Nature World Commission on Protected Areas (IUCN WCPA) (2003) The Durban Accord, Fifth IUCN World Parks Congress, Durban.

International Union for Conservation of Nature World Commission on Protected Areas (IUCN WCPA) (2003b) Fifth IUCN World Parks Congress Recommendations, IUCN WCPA, Gland.

International Union for Conservation of Nature (IUCN) and United Nations Environment Programme World Conservation Monitoring Centre (UNEP-WCMC) (2014) Global Statistics from The World Database on Protected Areas: August 2014, UNEP-WCMC, Cambridge.

Johnston, R. J., Gregory, D., Pratt, G. and Watts, M. (2000) The Dictionary of Human Geography, 4th edn, Wiley-Blackwell, Oxford.

Jones, G. P., Planes, S. and Thorrold, S. R. (2005) 'Coral reef fish larvae settle close to home', Current Biology 15(14): 1314-18.

Dd Jones, P. J. S. (2014) Governing Marine Protected Areas: Resilience through diversity, Earthscan, London.

Jones, P. J. S., Qiu, W. and de Santo, E. M. (2011) Governing marine protected areas: getting the balance right, Technical Report, United Nations Environment Programme, Nairobi. 
Kellner, J. B., Tetreault, I., Gaines, S. D. and Nisbet, R. M. (2007) 'Fishing the line near marine reserves in single and multispecies fisheries', Ecological Applications 17(4): 1039-54.

Kennedy, E. V., Perry, C. T., Halloran, P. R., IglesiasPrieto, R., Schönberg, C. H. L., Wisshak, M., Form, A. U., Carricart-Ganivet, J. P., Fine, M., Eakin, C. M. and Mumby, P. J. (2013) 'Avoiding coral reef functional collapse requires local and global action', Current Biology 23(10): 912-18.

Kloiber, U. (2013) Chumbe Island Coral ParkConservation and education, status report 2013, Zanzibar, Tanzania.

Kothari, A., Corrigan, C., Jonas, H., Neumann, A. and Shrumm, H. (eds) (2012) Recognising and Supporting Territories and Areas Conserved by Indigenous Peoples and Local Communities: Global overview and national case studies, Technical Series No. 64, Secretariat of the Convention on Biological Diversity, ICCA Consortium, Kalpavriksh and Natural Justice, Montreal.

Leenhardt, P., Cazalet, B., Salvat, B., Claudet, J. and Feral, F. (2013) 'The rise of large-scale marine protected areas: conservation or geopolitics?', Ocean \& Coastal Management 85(Part A): 112-18.

Dd Lester, S. E., Halpern, B. S., Grorud-Colvert, K., Lubchenco, J., Ruttenberg, B. I., Gaines, S. D., Airamé, S. and Warner, R. R. (2009) 'Biological effects within no-take marine reserves: a global synthesis', Marine Ecology Progress Series 384: 33-46.

Ling, S. D. and Johnson, C. R. (2012) 'Marine reserves reduce risk of climate-driven phase shift by reinstating size- and habitat-specific trophic interactions', Ecological Applications 22(4): 1232-45.

McClanahan, T. R., Graham, N. A. J., Calnan, J. M. and MacNeil, M. A. (2007) 'Toward pristine biomass: reef fish recovery in coral reef marine protected areas in Kenya', Ecological Applications 17: 1055-67.

McCook, L. J., Almany, G. R., Berumen, M. L., Day, J. C., Green, A. L., Jones, G. P., Leis, J. M., Planes, P., Russ, G. R., Sale, P. F. and Thorrold, S. R. (2009) 'Management under uncertainty: guidelines for incorporating connectivity into the protection of coral reefs', Coral Reefs 28: 353-66.
McCook, L. J., Ayling, T., Cappo, M., Choat, J. H., Evans, R. D., de Freitas, D. M., Heupel, M., Hughes, T. P., Jones, G. P., Mapstone, B., Marsh, H., Mills, M., Molloy, F. J., Pitcher, C. R., Pressey, R. L., Russ, G. R., Sutton, S., Sweatman, H., Tobin, R., Wachenfeld, D. R. and Williamson, D. H. (2010) 'Adaptive management of the Great Barrier Reef: a globally significant demonstration of the benefits of networks of marine reserves', Proceedings of the National Academy of Sciences 107(43): 18 278-85.

McLeod, E., Salm, R., Green, A. and Almany, J. (2009) 'Designing marine protected area networks to address the impacts of climate change', Frontiers in Ecology and the Environment 7: 362-70.

Mulongoy, K. J. and Gidda, S. B. (2008) The Value of Nature: Ecological, economic, cultural and social benefits of protected areas, Secretariat of the Convention on Biological Diversity, Montreal.

Mumby, P. J., Dahlgren, C. P., Harborne, A. R., Kappel, C. V., Micheli, F., Brumbaugh, D. R., Holmes, K. E., Mendes, J. M., Broad, K., Sanchirico, J. N., Buch, K., Box, S., Stoffle, R. W. and Gill, A. B. (2006) 'Fishing, trophic cascades, and the process of grazing on coral reefs', Science 311: 98-101.

National Oceanic and Atmospheric Administration (NOAA) National Ocean Service (2014) What is the Biggest Source of Pollution in the Ocean?, National Oceanic and Atmospheric Administration National Ocean Service, Silver Spring, MD. <oceanservice. noaa.gov/facts/pollution.html>

O'Connor, S., Campbell, R., Cortez, H. and Knowles, T. (2009) Whale Watching Worldwide: Tourism numbers, expenditures and expanding economic benefits, a special report from the International Fund for Animal Welfare, International Fund for Animal Welfare, Yarmouth Port, MA.

Oliver, P. (2004) 'Developing effective partnerships in natural resource management', in C. Richards and L. Aitken (eds) Social Innovations in Natural Resource Management: A handbook of social research in natural resource management in Queensland, pp. 58-60, Department of Natural Resources and Mines, Brisbane.

OSPAR Commission (2013) 2012 Status Report on the OSPAR Network of MPAs, OSPAR Commission, London. 
Pala, C. (2013) 'Giant marine reserves pose vast challenges', Science 339: 640-1.

Pears, R. J., Morison, A. K., Jebreen, E. J., Dunning, M. C., Pitcher, C. R., Courtney, A. J., Houlden, B. and Jacobsen, I. P. (2012) Ecological Risk Assessment of the East Coast Otter Trawl Fishery in the Great Barrier Reef Marine Park: Summary report, Great Barrier Reef Marine Park Authority, Townsville, Queensland.

Pires, R., Costa Neves, H. and Karamanlidis, A. A. (2008) 'The critically endangered Mediterranean monk seal Monachus monachus in the archipelago of Madeira: priorities for conservation', Oryx 42(2): 278-85.

Dd Roff, G. and Mumby, P. J. (2012) 'Global disparity in the resilience of coral reefs', Trends in Ecology and Evolution 27(7): 404-13.

Roff, J. C. and Zacharias, M. A. (2011) Marine Conservation Ecology, Earthscan, London.

Russ, G. R., Cheal, A. J., Dolman, A. M., Emslie, M. J., Evans, R. D., Miller, I., Sweatman, H. and Williamson, D. H. (2008) 'Rapid increase in fish numbers follows creation of world's largest marine reserve network', Current Biology 18: 514-15.

Russ, G. R., Stockwell, B. and Alcala, A. C. (2005) 'Inferring versus measuring rates of recovery in notake marine reserves', Marine Ecology Progress Series 292: 1-12.

DD Salm, R. V., Clark, J. and Siirila, E. (2000) Marine and Coastal Protected Areas. A guide for planners and managers, 3rd edn, IUCN, Gland.

Salm, R. V., Done, T. and McLeod, E. (2006) 'Marine protected area planning in a changing climate', in Coral Reefs and Climate Change: Science and management, pp. 207-21, American Geophysical Union, Washington, DC.

Selig, E. R., Turner, W. R., Tröeng, S., Wallace, B. P., Halpern, B. S., Kaschner, K., Lascelles, B. G., Carpenter, K. E. and Mittermeier R. A. (2014) 'Global priorities for marine biodiversity conservation', PLoS ONE 9(1).
Spalding, M. D., McIvor, A. L., Beck, M. W., Koch, E. W., Möller, I., Reed, D. J., Rubinoff, P., Spencer, T., Tolhurst, T. J., Wamsley, T. V., van Wesenbeeck, B. K., Wolanski, E. and Woodroffe, C. D. (2014) 'Coastal ecosystems: a critical element of risk reduction', Conservation Letters 7(3): 293-301.

Standards Australia (2013) Risk Management Guidelines - Companion to AS/NZS ISO 31000:2009, Standards Australia, Sydney.

Steneck, R. S. and Dethier, M. N. (1994) 'A functional group approach to the structure of algal-dominated communities', Oikos 69: 476-98.

The Economics of Ecosystems and Biodiversity (TEEB) (2010) The Economics of Ecosystems and Biodiversity: Mainstreaming the economics of nature-A synthesis of the approach, conclusions and recommendations of TEEB, TEEB, Nairobi.

Toonen, R. J., Wilhelm, T. A., Maxwell, S. M., Wagner, D., Bowen, B. W., Sheppard, C. R., Taei, S. M., Teroroko, T., Moffitt, R., Gaymer, C. F., Morgan, L., Lewis, N., Sheppard, A. L. S., Parks, J. and Friedlander, A. M. (2013) 'One size does not fit all: the emerging frontier in large-scale marine conservation', Marine Pollution Bulletin 77(1): 7-10.

Toropova, C., Meliane, I., Laffoley, D., Matthews, E. and Spalding, M. (eds) (2010) Global Ocean Protection: Present status and future possibilities, Agence des aires marines protégées, Brest, France; IUCN WCPA, Gland; UNEP-WCMC, Cambridge; The Nature Conservancy, Arlington, VA; and UNU, Tokyo.

United Nations (UN) (2002) Plan of Implementation of the World Summit on Sustainable Development, A/CONF.199/20, Chapter 1, Resolution 2, September, Johannesburg.

United Nations (UN) (2014) Chronological Lists of Ratifications of, Accessions and Successions to the Convention and the Related Agreements as at 29 October 2013, Division for Ocean Affairs and the Law of the Sea, Office of Legal Affairs, United Nations, New York. <www.un.org/depts/los/ reference_files/chronological_lists_of_ratifications. htm> 
Vianna, G. M. S., Meekan, M. G., Pannell, D. J., Marsh, S. P. and Meeuwig, J. J. (2012) 'Socioeconomic value and community benefits from shark-diving tourism in Palau: a sustainable use of reef shark populations', Biological Conservation 145: 267-77.

Weeks, R., Aliño, P. M., Atkinson, S., Beldia, P., Binson, A., Campos, W. L., Djohani, R., Green, A. L., Hamilton, R., Horigue, V., Jumin, R., Kalim, K., Kasasiah, A., Kereseka, J., Klein, C., Laroya, L., Magupin, S., Masike, B., Mohan, C., da Silva Pinto, R. M., Vave-Karamui, A., Villanoy, C., Welly, M. and White, A. T. (2014) 'Developing marine protected area networks in the Coral Triangle: good practices for expanding the Coral Triangle Marine Protected Area System', Coastal Management 42(2): 183-205.

Weil, E. and Rogers, C. S. (2011) 'Coral reef diseases in the Atlantic-Caribbean', in Coral Reefs: An ecosystem in transition, pp. 465-91, Springer, Netherlands.

West, J. M. and Salm, R. V. (2003) 'Resistance and resilience to coral bleaching: implications for coral reef conservation and management', Conservation Biology 17(4): 956-67.

White, A. T., Aliño, P. M., Cros, A., Fatan, N. A., Green, A. L., Teoh, S. J., Laroya, L., Peterson, N., Tan, S., Tighe, S., Li, R. V., Walton, A. and Wen, W. (2014) 'MPAs in the Coral Triangle: progress, issues, and options', Coastal Management 42(2): $87-106$.

Williams, I. D. and Polunin, N. V. C. (2000) 'Differences between protected and unprotected reefs of the western Caribbean in attributes preferred by dive tourists', Environmental Conservation 4: 382-91.

Wood, L. J., Fish, L., Laughren, J. and Pauly, D. (2008) 'Assessing progress towards global marine protection targets: shortfalls in information and action', Oryx 42(3): 340-51.

World Bank (2006) Scaling up marine management: the role of marine protected areas, Report No. 36635, The World Bank, Washington, DC. <siteresources. worldbank.org/ENVIRONMENT/Resources/ Scaling_Up_MPA_ESW-May2011.pdf>
World Bank and Food and Agriculture Organisation (FAO) (2009) The Sunken Billions: The economic justification for fisheries reform, The International Bank for Reconstruction and Development and The World Bank, Washington, DC, and FAO, Rome.

World Wide Fund for Nature (WWF) (2014) PADDDtracker: Tracking protected area downgrading, downsizing, and degazettement, [Beta version]. $<$ www.PADDDtracker.org> 


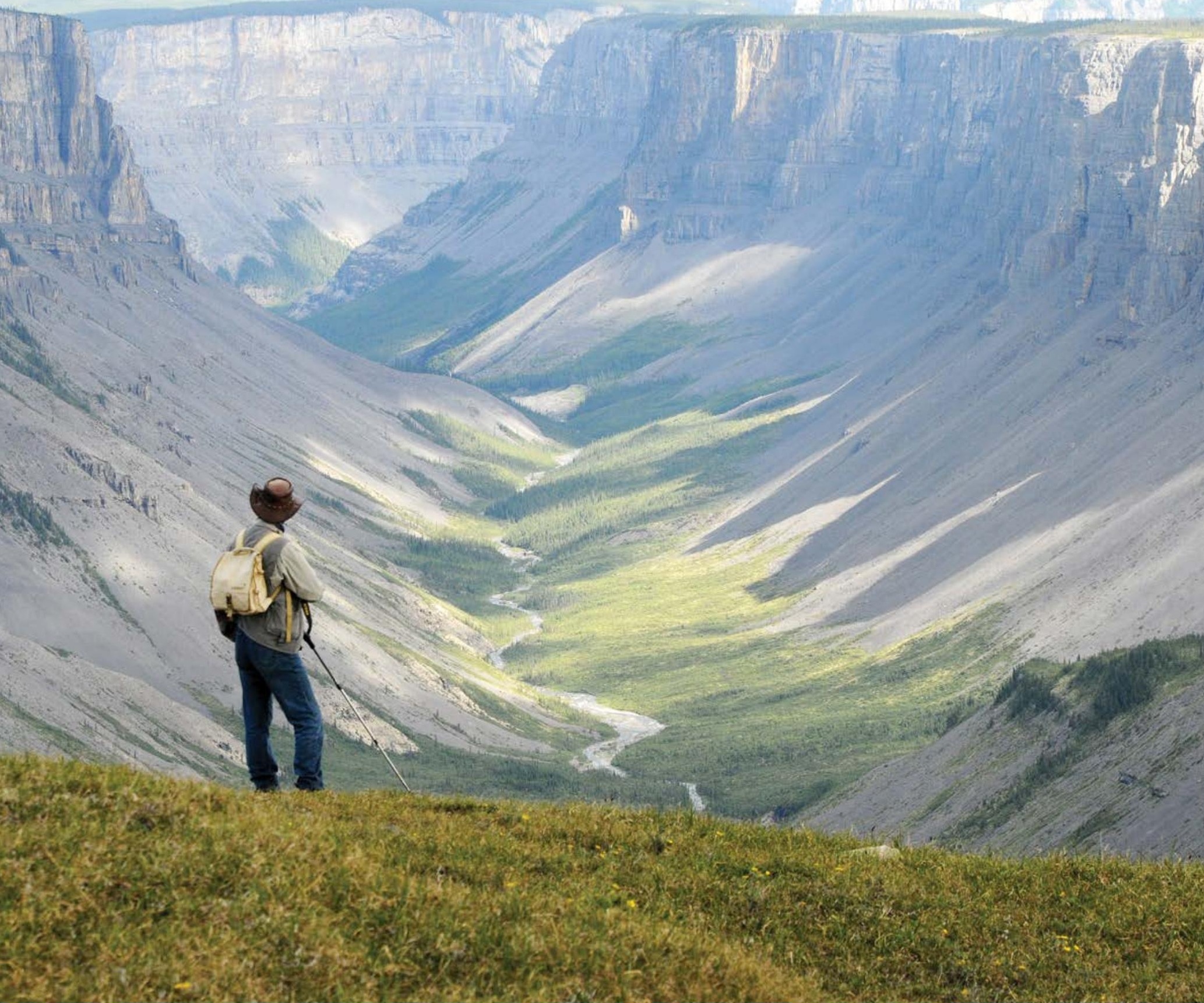

\section{CHAPTER 21}

\section{MANAGING PROTECTED AREAS FOR BIOLOGICAL DIVERSITY AND ECOSYSTIEM FUNCTIONS}

\section{Principal authors:}

Stephen Woodley, Kathy MacKinnon, Stephen McCanny, Richard Pither, Kent Prior, Nick Salafsky and David Lindenmayer

\section{CONTENTS}

Introduction

- The relationship between biodiversity and ecological function

- Assessing protected area condition: Ecological integrity

- Managing protected areas for biodiversity

- Managing threats to protected areas

- Monitoring and assessment of ecological condition in protected areas

- Conclusion

- References 


\section{PRINCIPAL AUTHORS}

STEPHEN WOODLEY is an ecologist who works with the International Union for Conservation of Nature (IUCN) World Commission on Protected Areas (WCPA), Canada.

KATHY MACKINNON is the Deputy Chair of the IUCN WCPA, United Kingdom.

STEPHEN MCCANNY leads the Monitoring and Ecological Information group for Parks Canada.

RICHARD PITHER is a Species Conservation Specialist with Parks Canada.

KENT PRIOR is the National Lead for Active Management and Ecological Restoration with Parks Canada.

NICK SALAFSKY is Co-Director of Foundations of Success, USA.

DAVID LINDENMAYER is Professor of Ecology and Australian Research Council Laureate Fellow at the Fenner School of Environment and Society at The Australian National University.

\section{ACKNOWLEDGMENTS}

We thank lan Pulsford and three anonymous reviewers for helpful comments on the manuscript. Appreciation is extended to James Mackinnon for his contribution.

\section{CITATION}

Woodley, S., MacKinnon, K., McCanny, S., Pither, R., Prior, K. Salafsky, N. and Lindenmayer, D. (2015) 'Managing protected areas for biological diversity and ecosystem functions', in G. L. Worboys, M. Lockwood, A. Kothari, S. Feary and I. Pulsford (eds) Protected Area Governance and Management, pp. 651-684, ANU Press, Canberra.

\section{TITLE PAGE PHOTO}

Nahanni Ram Plateau in Nahanni National Park, Northwest

Territories, Canada

Source: Alison Woodley 


\section{Introduction}

Protected areas are the cornerstones of global efforts to conserve biodiversity. Biological diversity (biodiversity) and ecosystem functions are the fundamental components of any ecosystem (Box 21.1) that protected area managers must consider to be successful. This chapter looks at the relationship between biological diversity and ecological function, the threats to each, and how to assess and monitor ecosystems.

Increasingly, protected areas are the last places left for much of the planet's biodiversity. The International Union for Conservation of Nature (IUCN) Red List of Threatened Species that have a high risk of global extinction reveals that many of these species are now found only in protected areas (Le Saout et al. 2013). For example, Javan rhinos (Rhinoceros sondaicus) are found only in Indonesia's Ujung Kulon National Park. Similarly Indian rhinos (Rhinoceros unicornis), once widespread throughout Asia, are now restricted to protected areas, including Kaziranga National Park in India and Royal Chitwan National Park in Nepal. Conserving biodiversity in protected areas means conserving both species and the ecological functions upon which those species depend.

\section{The relationship between biodiversity and ecological function}

The need to manage for biological diversity, including ecological function, is inherent in the IUCN definition of a protected area. A protected area is '[a] clearly defined geographical space, recognised, dedicated and managed, through legal or other effective means, to achieve the long-term conservation of nature with associated ecosystem services and cultural values' (Dudley 2008:8).

From a conservation perspective, a key role of protected areas is to maintain ecological structures (genes, species and ecosystems) and the ecological functions that support those structures. In addition to protecting biodiversity, protected areas also have a key role in protecting ecosystem services, which underpin human welfare (see Chapter 6). Protected areas also conserve the non-living or abiotic elements of ecosystems. For example, protected areas protect geological diversity as well as the biodiversity associated with certain geological features (Chapter 18).

\section{Box 21.1 Key definitions}

Biological diversity, or biodiversity for short, means the variability among living organisms from all sources including terrestrial, marine and other aquatic ecosystems and the ecological complexes of which they are part; this includes diversity within species, between species and of ecosystems. Biodiversity is measured at three main hierarchical levels.

- Genetic diversity includes the different genes contained in all individual plants, animals, fungi and microorganisms. Species diversity is a measure, within an ecological community, of both the number of species and the evenness of their distribution. Ecosystem diversity includes all the different habitats, biological communities and ecological processes, as well as variation within individual ecosystems.

- Ecosystem functions are the physical, chemical and biological processes that contribute to the functioning of an ecosystem. Some definitions of biodiversity include ecosystem functions. Examples of ecosystem functions are primary productivity (conversion of sunlight to energy), nutrient cycling and the water cycle.

- Ecosystem services are those benefits that ecosystems provide to humanity, including products like food and clean drinking water, and processes such as pollination, the decomposition of wastes or regulation of flooding. Ecosystem services are a subset of biological diversity and ecosystem function, seen from a human perspective (Daily 1997).

The interaction of ecological structure, mainly species, with function is complex and still poorly understood. Key questions remain, such as, are some species redundant? If species are extirpated from an ecosystem (or a protected area), will this affect the ecological functions at that location? Understanding this relationship becomes more critical with the increased rate at which species are being eliminated from ecosystems through local extirpations (species disappearance from a given area) or even extinctions (complete species loss) (see Butchart et al. 2010).

Concern over the relationship between ecological structure and function has led to a range of scientific research, such as the Millennium Ecosystem Assessment commissioned by international bodies (Schulze and Mooney 1993; Heywood 1995) and work by the World Resources Institute (2005). An important review paper published in Nature (Cardinale et al. 2012) summarised the global literature on the relationship between ecological structure and function with six consensus statements (Box 21.2). 


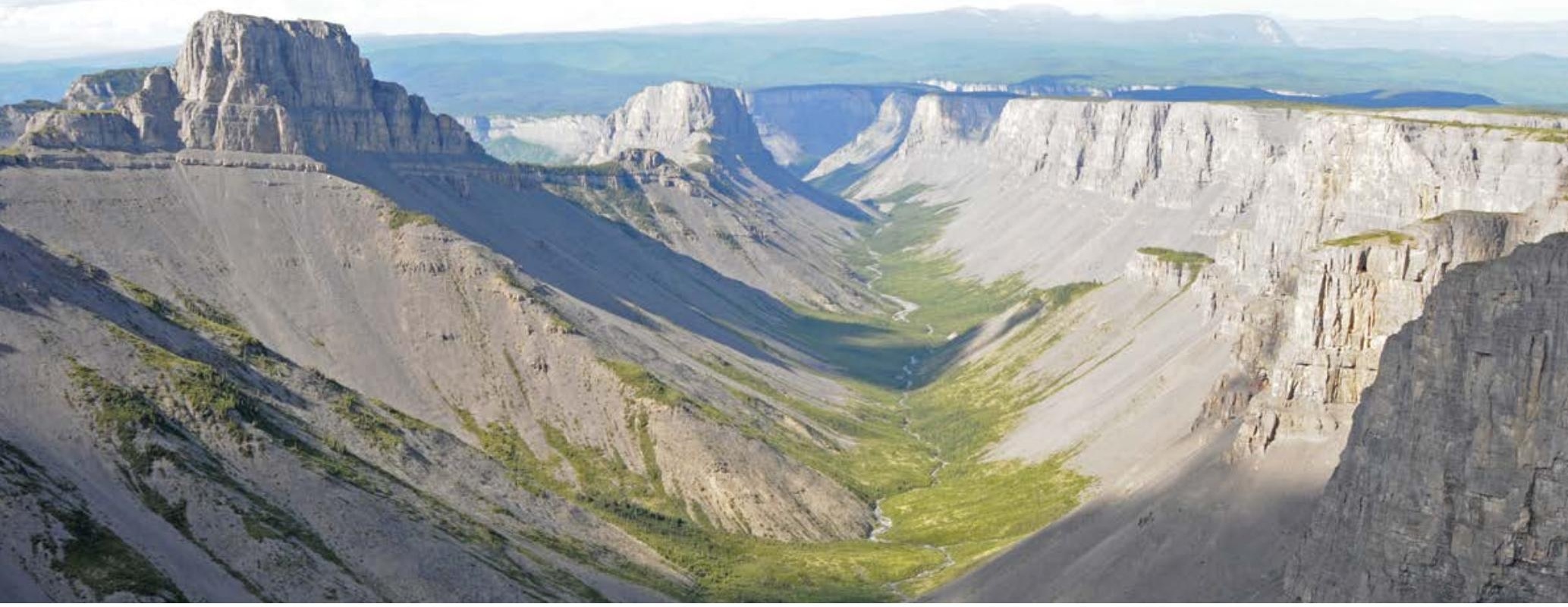

Nahanni National Park, Canada, contains some of the most spectacular wild rivers in North America, with deep canyons, huge waterfalls and spectacular karst terrain, cave systems and hot springs Source: Alison Woodley

\section{Patterns of global biodiversity}

The diversity of life in a protected area is determined by the same driving forces that determine patterns of life on Earth. In a general sense, these patterns are clear and easily described; however, when it comes to the biodiversity of an individual protected area, the large-scale global patterns are highly influenced by local factors. For a detailed review of the patterns of global diversity, readers are referred to Gaston (2000) (see also Chapter 3). Most analyses of spatial variation concern biodiversity as measured by the number of species observed or estimated to occur in an area (species richness). Most attention has been paid to latitudinal variation in species richness, and relatively little is known about variation in the diversity of genes, individuals or populations along latitudinal gradients.

The general patterns of biodiversity are as follows.

- In general, the majority of terrestrial and freshwater species occur in the tropics, with species richness declining from the tropics to the poles. This general pattern also holds for the oceans.

- In general, there are higher levels of biodiversity at lower elevations, in areas with higher levels of annual rainfall and in areas of warmer summer temperatures.

- In general, different taxa (categories of species, such as reptiles) show the same kind of variation regionally. For example, at a global scale, areas of high bird diversity will also have high diversity of plants or amphibians (see Figure 21.2). There is, however, enormous variation in this general pattern. At a regional level, it is not possible to reasonably predict the diversity of any taxon simply by knowing the diversity of another taxon.
- These general patterns are important at broad scales, but do not always well explain local conditions in protected areas. Biodiversity can be highly modified by terrain, slope, water, bedrock, soil type and development and the history of ecological colonisation and disturbances.

It is important to think about both the regional and the local biogeography in the management of a protected area (Box 21.3). There have been many efforts to systematically describe the global patterns of biological organisation (Klijn and de Haes 1994). Many different lists and ecological land classification schemes have been developed, based on the following examples.

- Biogeography: Ecological land classification is a set of approaches that organises global ecosystem types by patterns of climate, topography and vegetation. Some approaches, such as 'biogeographical provinces', take into account both flora and fauna.

- Botany: Botanists have identified 'floristic provinces' based on floral communities.

- Zoology: Zoologists have identified 'zoogeographic provinces' based on faunal communities, or even identified systems based on groups, such as 'mammal provinces'.

- Geology and pedology (soil study): The physical matter and energy that constitute the Earth.

Perhaps most useful for protected area management is the 'Ecological Land/Marine Classification System', which integrates a range of ecological factors, rather than focusing on only one element. Ecological units can be usefully described on the basis of bedrock, climate, physiography and corresponding vegetation, creating an ecological land classification system. 


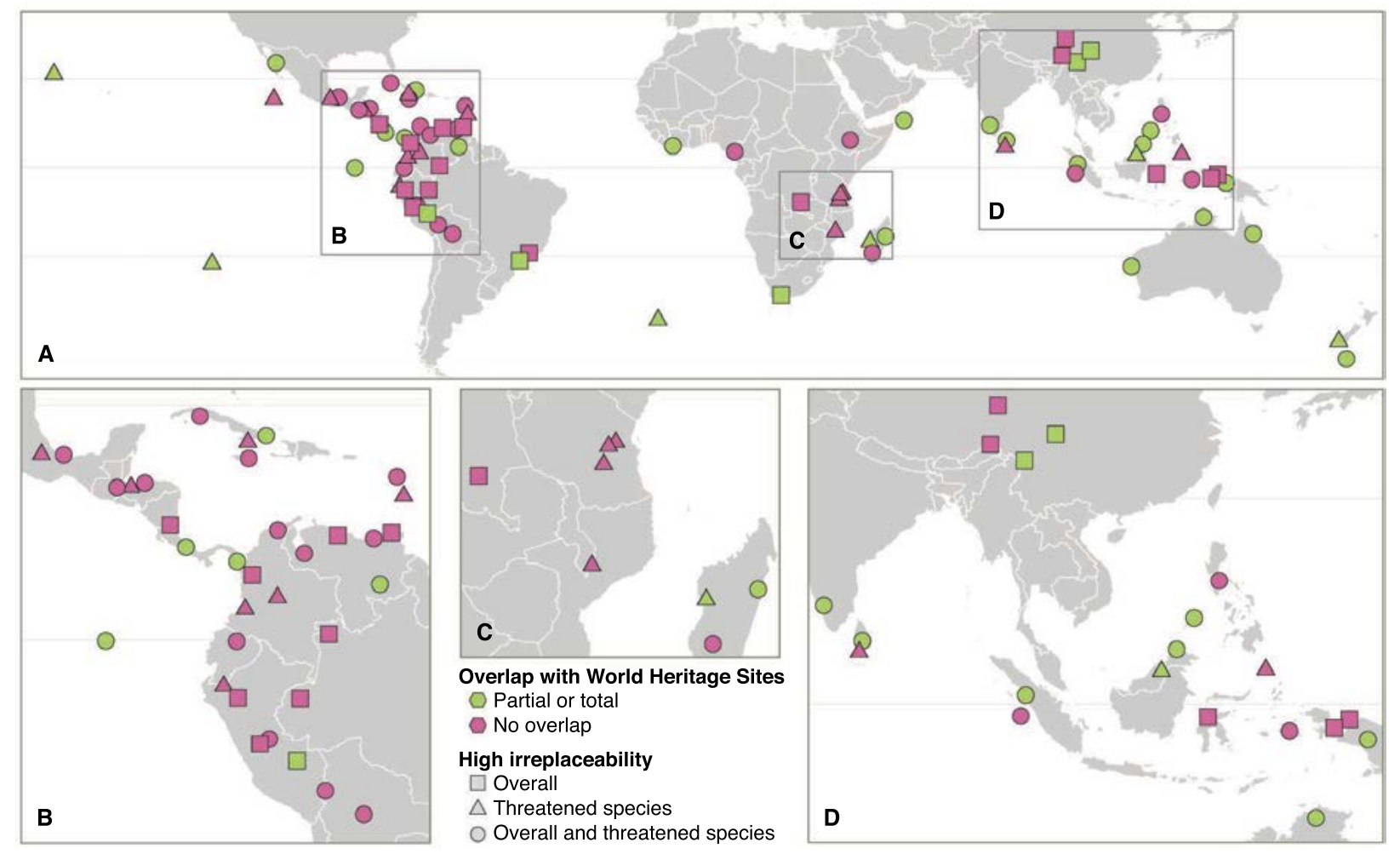

Figure 21.2 Some of the world's most important protected areas for conservation of amphibian, bird and mammal species: (A) Global distribution; (B) Central and South America; (C) East Africa; (D) South and South-East Asia

Source: Adapted from Le Saout et al. (2013)

\section{Box 21.3 A simple nested system of ecosystem classifications and their uses for protected area management}

Biome: A large naturally occurring community of flora and fauna occupying a major habitat-for example, forest or desert.

Ecoregion: A regional-scale pattern of ecosystems associated with characteristic combinations of soil, landforms and vegetation that characterise that region-for example, Acacia-Miombo woodlands.

Ecodistrict: A subdivision of an ecoregion with more uniform patterns of soil, topography and vegetationfor example, south-facing wooded acacia hills.

Source: Klijn (1994)

The classic references are the map and IUCN document prepared by Udvardy (1975) titled A classification of the biogeographical provinces of the world. From a protected area perspective, the World Wide Fund for Nature (WWF) has led the development of global systems of ecological classification, complete with online maps and descriptions. Readers are referred to the global descriptions of terrestrial ecoregions developed by Olson et al. (2001), as well as for the best available description of the terrestrial ecoregions. For coastal marine regions, readers should refer to Spalding et al. (2007).

These classification systems are essential for many aspects of protected area management such as:

- regional conservation planning to assess gaps in the protected area system

- setting targets for protected area representation and conservation planning

- determining the level of regional or global significance of a protected area

- assessing the status of ecological features (for example, mapping ecosystem types, intact watershed)

- state of the protected areas reporting

- studying natural disturbance regimes in a context larger than a protected area

- defining seed zones for restoration projects.

The spatial distribution of species at risk can be expressed by looking at where the existing protected area system contains species that are on the IUCN Red List (Figure 21.2). 


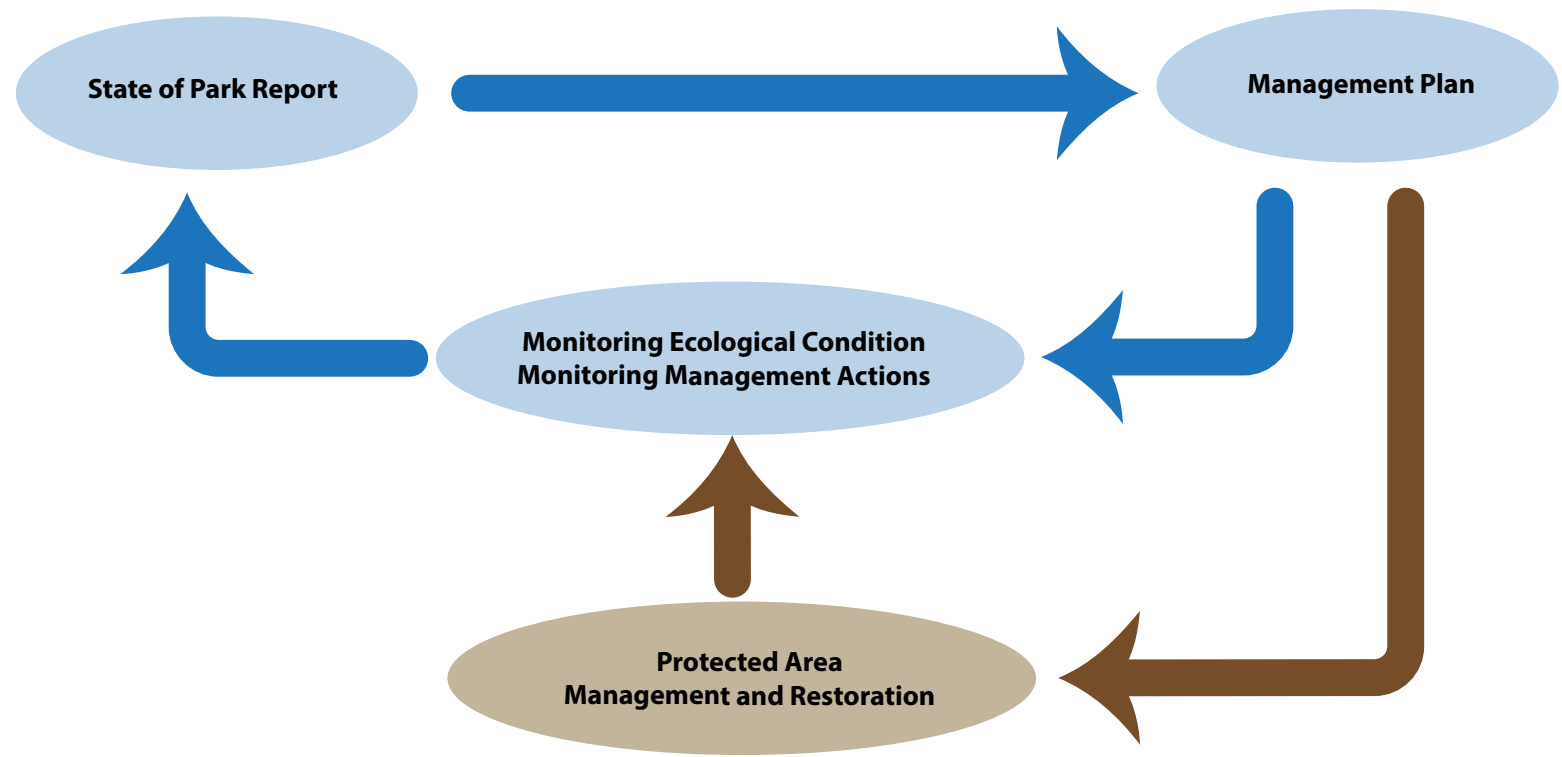

Figure 21.3 The protected area management loop

Source: Stephen Woodley

It is important to think about protected areas and protected area systems in the context of global patterns of biodiversity; however, just because a protected area is not located in a high biodiversity area, this does not diminish its value in conserving nature. Effective conservation requires adequate representation of all species and ecosystems within protected areas (Woodley et al. 2012). In addition, some key species of conservation concern occur in species-poor places, such as plants in highly mineral-rich environments.

\section{Assessing protected area condition: Ecological integrity}

By definition, protected areas are established to conserve nature, and the ecosystem must be in suitable condition so that it conserves its biodiversity in the long term. Protected area management depends on knowing the ecological condition of the protected area as a fundamental part of management. Based on this and other information, decisions can be made about management and restoration. The key tasks of protected area management are: 1) to understand how the ecosystem works; 2) to define suitable indicators to assess ecological condition; 3) to monitor those indicators and determine ecological condition; and 4) to take management action when those indicators are outside an acceptable range. Central to the management process is monitoring information on ecological condition and the results of management actions (Figure 21.3).

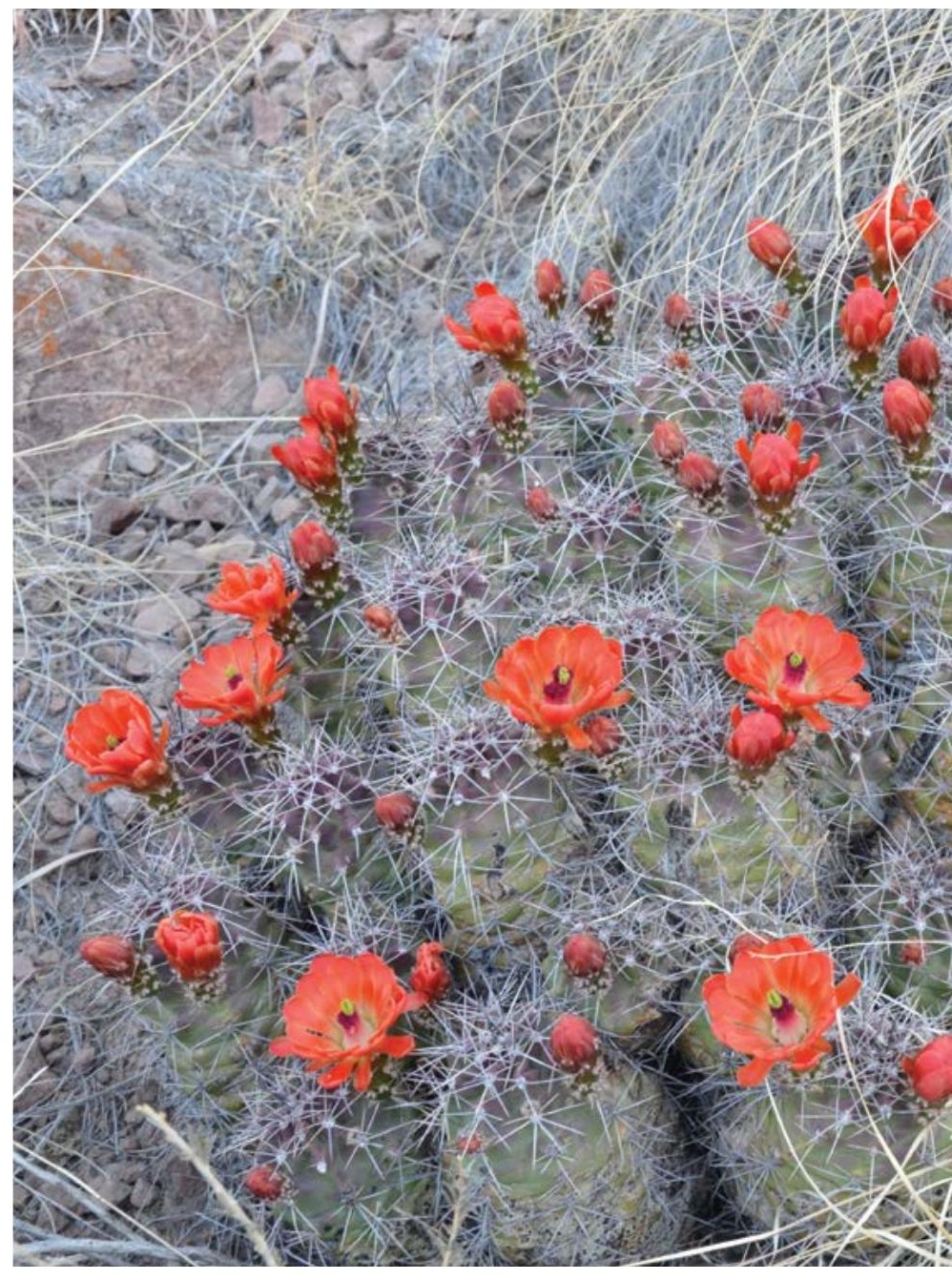

Opuntia cactus (Opuntia sp.), Big Bend National Park, Texas, USA

Source: Stephen Woodley 


\section{Managing for ecological integrity}

Historically, protected areas have been managed with goals that are imprecise, such as to conserve 'natural' or 'wilderness' areas. In reality, many protected areas have been managed with specific species conservation targets in mind, such as maintaining large game herds in African parks or flagship species such as tigers and elephants in major Indian parks (MacKinnon et al. 1986). The terms 'ecological integrity' and 'ecosystem health' are now increasingly being adopted by protected area managers to describe their goals for ecosystem management. Numerous statutes and official policy statements now articulate the concept of integrity as a goal including the Great Lakes Water Quality Agreement (International Joint Commission 1978) and the Convention on Biological Diversity (CBD 2004). The notion of ecological integrity has been discussed from many perspectives (Edwards and Regier 1990; Woodley et al. 1993; Pimentel et al. 2000). With respect to a protected area, ecological integrity means a condition characteristic of its natural region and likely to persist, including abiotic components and the composition and abundance of native species and biological communities, rates of change and supporting processes. Note that this definition is ecologically based and that it does not require the absence of people. In fact, ecological integrity is a concept that can apply to ecosystems with or without people present and playing a key ecological role.

The lessons for best practices in determining a protected area's ecological condition are as follows.

- All protected areas need to have clear management goals and objectives for biodiversity and ecosystem processes. Otherwise, the aim of management is unclear.

- Ecological goals should be included in the protected area's management plan.

- Consider using ecological integrity as a management end point. It has been adopted by many protected area agencies and there is considerable information available on how to measure it.

\section{Ecological integrity and protected areas}

Understanding ecological integrity in the context of protected areas requires careful thought about how an ecosystem is structured and how it is functioning. From the science of ecology, we understand that ecosystems exhibit a number of characteristics that are important to measure (Woodley 2010).

1. Protected areas should conserve all native species. Ecosystems lose integrity when they lose species.
Waterfowl rest at Padre Island National Seashore,

Texas, USA, during their annual migration

Source: Stephen Woodley

Some of the main causes of species loss are habitat loss and fragmentation; many protected areas lose species because they are too small. For example, western North American parks have experienced extinction rates that are inversely related to park size (Newmark 1995). Other examples of stressed ecosystems losing species include Canadian boreal forests subject to high sulphur dioxide emissions (Freedman and Hutchinson 1980); temperate deciduous forest subject to radiation exposure (Woodwell 1970); and estuarine diatom communities subject to heavy metal pollution (Patrick 1967).

2. The populations of species in protected areas should be viable. For practical reasons, it will only be possible for protected area managers to check the viability of a few species, called indicator species. There is a large literature on the selection of indicator species (see Simberloff 1998; Lindenmayer and Lichens 2010). The status of indicator species is usually determined by examining population vitality rates (for example birth, death, immigration and emigration) and using those metrics to determine the probability of survival (or conversely the probability of extinction), typically for 100 or 1000 years (Soulé and Simberloff 1986). 
3. Ecosystem trophic levels in protected areas should be intact. Ecosystems have characteristic levels and interactions of primary producers, herbivores and carnivores-often described as food webs. Highly impacted ecosystems tend to have food webs that are simple in comparison with unmodified ecosystems. For example, the loss of top carnivores can result in hyper-abundant ungulate populations, which have cascading adverse effects on plant communities (Estes et al. 2011; see also Case Studies 21.5 and 21.6).

4. Disturbance regimes in protected areas should operate to maintain biological communities with a mix of age classes. Ecosystems are inherently dynamic, driven by fire, climate, weather and herbivores. After disturbance, ecosystems pass through sometimes predictable successional stages. Repeated disturbance events create a mosaic of biological communities in both time and space. The resulting configuration of community types of different size and age determines the survival of individual species. Since some disturbances (for example, fire and herbivory) can be influenced by protected area managers, this aspect of ecological integrity is at least under partial management control (Case Study 21.1).

5. Productivity and decomposition in protected areas should operate within limits for system persistence. Most ecosystems are driven by primary productivity-the amount of organic matter produced by biological activity per unit area in a given period (Hooper et al. 2012). The onset of ecosystem problems occurs when subtle shifts in productivity occur, and major problems are indicated when energy is lost from the ecosystem in an uncontrolled manner. For example, in stressed systems, such as heavily logged forests, decomposition rates rise significantly. Productivity and decomposition operate within a range for specific ecosystems. When these vital processes move outside that band, the ecosystem is fundamentally impacted and loses its integrity. Changes in productivity can be measured using a readily available satellite-based index, called the 'normalised difference vegetation index' (NDVI) (Tucker et al. 2005).

6. Nutrient cycling in protected areas should be within limits for system persistence. In virtually all ecosystems, nutrient availability is a limiting factor and rates of nutrient cycling are critical to ecosystem function (Hooper et al. 2012). Ecosystems cycle and conserve nutrients at characteristic rates. As ecosystems become stressed and lose integrity, they lose their ability to retain nutrients, and exhibit changes in rates of nutrient cycling and in the relative abundance of nutrient pools (Likens et al. 1978). Ranges of nutrient cycling can be determined from values in the scientific literature and by comparison with healthy reference ecosystems.

Most critically, the concept of ecological integrity provides a measurable and clear foundation for protected area management. If protected area goals and objectives are not measurable, there is no way of knowing whether or not management is successful (Lindenmayer and Lichens 2010). This is particularly important where active management and intervention in ecosystem processes occur. Ecological integrity provides a framework that allows for the translation of broad, often vague natureprotection goals, into more specific and measurable end points, based on desirable ecological conditions that can be monitored.

\section{Managing protected areas for biodiversity}

Successful management of protected areas requires thinking of them as an integrated system that has a systemlevel goal, such as ecological integrity. The practical management of ecological integrity often means managing biological diversity (most generally, species) and ecological functions. Globally, protected areas form a primary tool for maintaining biodiversity. This section covers the principles of managing for the conservation of biodiversity in protected areas at all three levels: genetic, species and ecosystem. Example case studies are given for each level of biodiversity. Many more case studies are available online or by contacting protected area specialists in your region.

\section{Managing protected areas for genetic diversity}

Protected areas are often established to conserve unique features or to conserve representative ecosystems and species. Rarely are they established or designed with genetics explicitly in mind, even though genetic diversity represents the building blocks for evolution and adaptation (Hughes et al. 2008). A reduction in genetic diversity limits the potential for a population to adapt and is often linked to a reduction in fitness (Frankham 2005; Mattila and Seeley 2007). A reduction in ecological fitness at the individual level adds to the challenges already faced by small and isolated populations, contributing to what is called the 'extinction vortex' (Gilpin and Soulé 1986; Caughley 1994; Fagan and Holmes 2006). Genetic diversity has even been shown to have important effects on ecological processes, such as primary productivity (Hughes et al. 2008). 
Many factors underpin the design of protected areas including the species, communities, ecosystems or ecological processes targeted for conservation. Consideration of the impacts of major natural disturbances on biodiversity and key ecological processes is an important issue in the design of protected areas or systems. In ecosystems with recurrent, high-severity disturbances, these processes are essential for important ecological values as well as populations of species of conservation concern (Lindenmayer and Franklin 2002).

The mountain ash (Eucalyptus regnans) forests of the Central Highlands of Victoria, south-eastern Australia, provide a valuable illustration of the interrelationships between the design of protected areas and natural disturbance. These forests support some of the tallest flowering plants in the world, with old-growth trees reaching heights of 100 metres. Mountain ash forests provide habitat for many species, including the globally endangered Leadbeater's possum (Gymnobelideus leadbeateri) - a focal species in this ecosystem (Lindenmayer 2009).

Fire is the primary form of natural disturbance in mountain ash forests. Prior to European colonisation, the fire regime was infrequent, with wildfire that occurred in late summer (Ashton 1981) and at an intensity that allowed some tree survival. Mountain ash forests have been altered by more than a century of high-intensity logging, increases in wildfires and the combination of both fire and logging (Lindenmayer et al. 2011). About 20 per cent of mountain ash forest in the Central Highlands of Victoria is currently protected; however, the overall size of the protected area system is too small to maintain the forests and viable populations of species such as Leadbeater's possum. A more extensive area of protected forest is needed, particularly if additional fires occur in the next 50-100 years. Any expanded reserve system must be large enough to ensure that even in the event of a wildfire, there is sufficient forest habitat remaining to support viable populations of rare marsupial species (Baker 1995).
Several factors can be used to guide where an expanded area of reserved forest might be best located. Expansion should include places that both connect key areas of habitat for focal species such as Leadbeater's possum and connect existing reserves. Enhanced ecological connectivity enables the dispersal of species throughout forest landscapes, including those regenerating after wildfire. Second, an expanded area of reserved forest should encompass areas of old-growth forest as well as areas likely to be suitable habitat for focal species, such as Leadbeater's possum (Lindenmayer et al. 1999).

This case study highlights the importance of incorporating the effects of disturbances in the design and establishment of effective protected areas.

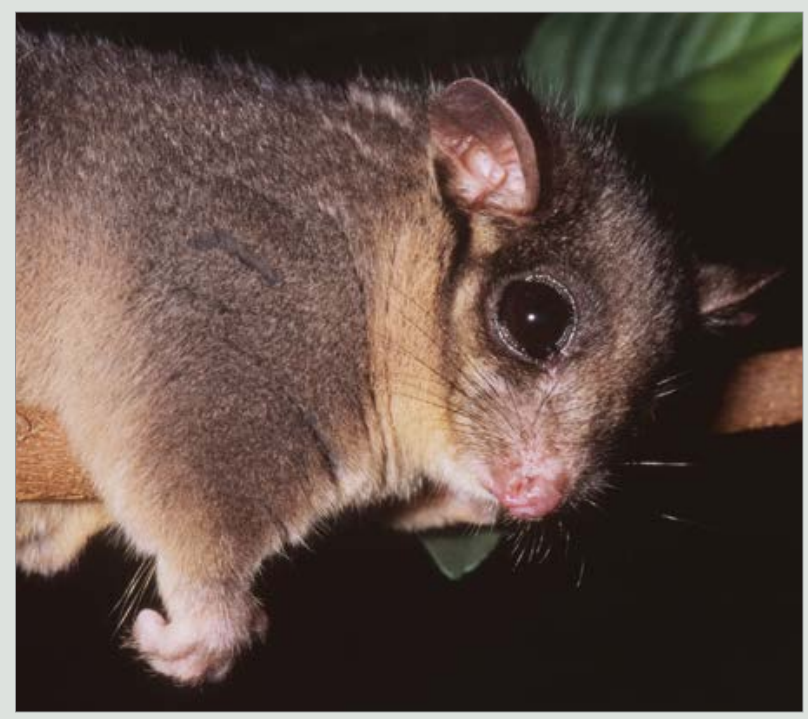

Endangered Leadbeater's possum

(Gymnobelideus leadbeateri), Victoria, Australia

Source: David Lindenmayer

\section{Best practices for managing genetic diversity}

Maintaining genetic diversity and avoiding the extinction vortex are major challenges for many small and isolated protected areas. Potential solutions include the following.

- Increasing the effective habitat size of the protected area so that it can contain more individuals of a given species. This can be done through land acquisition or ecological restoration (Case Study 21.2).

- Small populations can be augmented with the translocation of individuals from larger and healthier populations in order to increase local population size and genetic diversity (Bouzat et al. 2009). This is a well-established principle with many examples around the world, such as the reintroduction of tigers
(Panthera tigris tigris) to Sariska National Park in India, of golden lion tamarins (Leontopithecus rosalia) in the Atlantic forests of Brazil and of the greater prairie chicken (Tympanuchus cupido pinnatus) in the United States (Case Study 21.3).

- Working at landscape and regional levels to ensure ecological connectivity between separate protected areas and ensuring integration with populations using the working landscape around protected areas. Connectivity increases the effective population size and allows gene flow among protected and natural areas (di Minin et al. 2013; Sawaya et al. 2013; Case Study 21.4). 


\section{Case Study $\mathbf{2 1 . 2}$ Increasing the size of protected areas for genetic diversity}

In general, the smaller a protected area is, the more active management it will require to maintain important components of biodiversity. Whiteman Park, in the suburbs of Perth, Australia, includes the 50-hectare Woodland Reserve, an electrified predator-proof facility, designed for breeding and providing habitat for rare and endangered species, including the critically endangered woylie (Bettongia pencillata) (Pacioni et al. 2011). Managers were concerned about the long-term viability of the small and isolated populations of rare species within the reserve and asked a geneticist to help develop a management plan for the woylie. The plan called for an increase in the size of the reserve from 50 to 200 hectares, which analysis suggested would double the length of time that the colony would maintain an acceptable level of heterozygosity (a measure of genetic diversity), which is a key measure of genetic health (Rafferty and Pacioni 2012). The plan also recommended a regular program of supplementation with the introduction of woylie from elsewhere in order to maintain genetic diversity within the colony.

\section{Case Study 21.3 Translocations to maintain genetic diversity}

In south-eastern Illinois, USA, where almost all native prairie grasslands have been lost, managers have been trying to maintain the greater prairie chicken (Tympanuchus cupido pinnatus), an iconic species of the grasslands, including in two small protected areas (Westemeier et al. 1998). Past efforts included restoring the grasslands and increasing habitat for the species but proved to be insufficient to recover the population (Figure 21.4). Monitoring over 35 years indicated that as the population size continued to decline, so did fertility, nest success and genetic diversity (Bouzat et al. 1998). Concerned that the lower genetic diversity was contributing to the reduction in fitness and hence exacerbating the negative effects of small population size, managers enacted a translocation program, bringing in birds from larger, healthier populations further west (Westemeier et al. 1998). The translocations proved successful in that they restored genetic diversity, countered the effects of inbreeding depression and led to an increase in fitness (egg viability and nest success) and ultimately an increase in the long-term viability of the population (Bouzat et al. 2009). This illustrates the importance of managing specifically for genetic diversity in order to maintain biodiversity in protected areas.

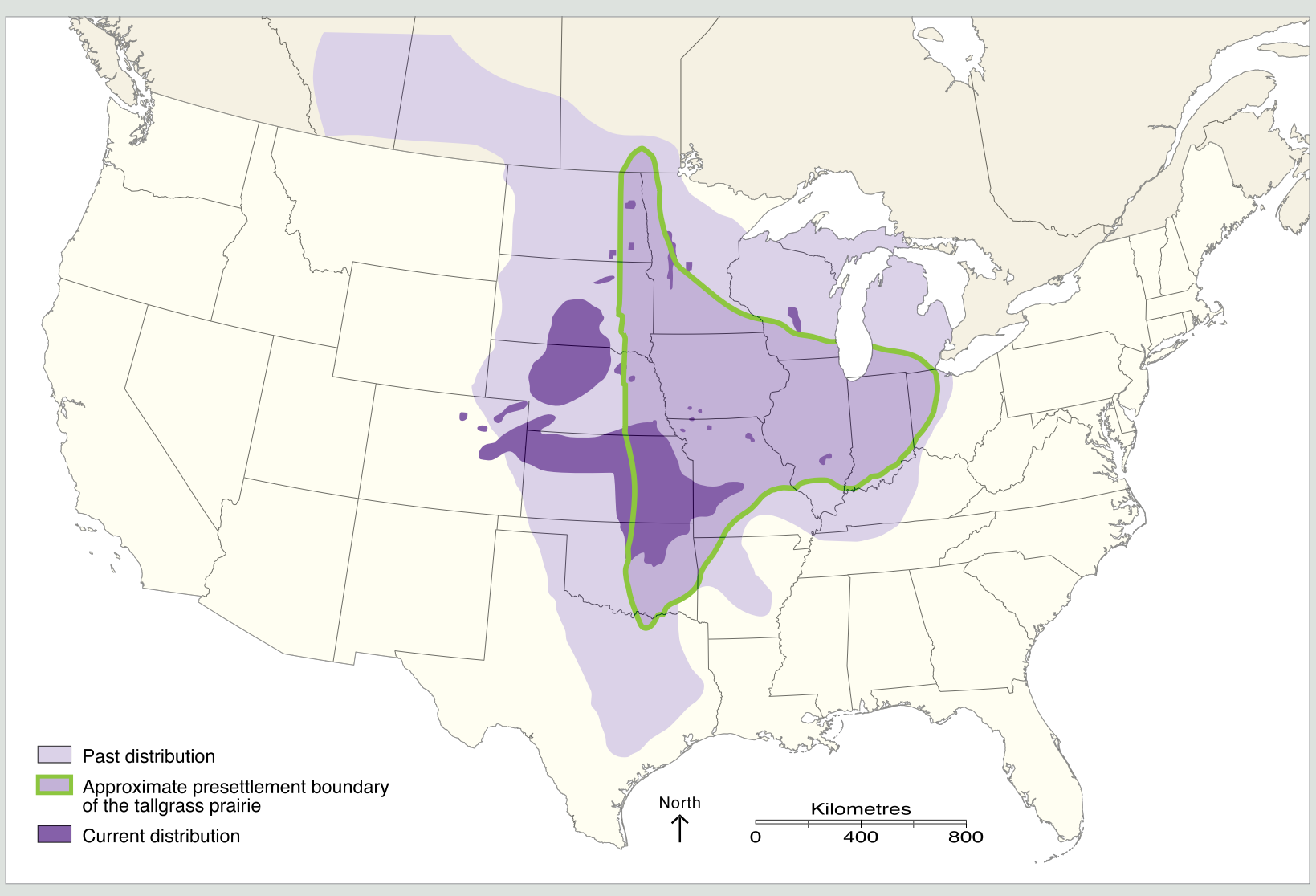

Figure 21.4 Current and historical distribution of the greater prairie chicken (Tympanuchus cupido pinnatus), USA

Source: Modified from W. Daniel Svedarsky, Northern Prarie Wildlife Research Centre, Jamestown, ND, USA 


\section{Case Study 21.4 Restoring connectivity in Banff National Park to maintain genetic diversity}

Banff National Park is home to the spectacular scenery of the Rocky Mountains and megafauna, attracting the most visitors of any national park in Canada. It is bisected by the Trans-Canada Highway and the main line of the Canadian Pacific Railway-both extremely busy transportation routes that fragment the natural habitats in the park and result in significant numbers of wildlife mortalities (Clevenger and Sawaya 2010). In an effort to restore connectivity and gene flow across the transportation corridors, Parks Canada constructed 38 wildlife underpasses and six overpasses, and installed fencing along stretches of the highway (Clevenger et al. 2009). About 30 years of monitoring has recorded more than 120000 crossings, including by most of the large mammal species: grey wolves (Canis lupus), coyotes (Canis latrans), cougars (Puma concolor), deer (Odocoileus virginianus), elk (Cervus canadensis), moose (Alces alces), grizzly (Ursus arctos horribilis) and black bears (Ursus americanus). In recent years, researchers have been testing non-invasive hair-snag techniques to collect DNA to assess the genetic and populationlevel effects of the wildlife crossings in Banff National Park (Sawaya et al. 2013). Although there is currently no empirical evidence indicating significant gene flow across overpasses, underpasses or along corridors (Corlatti et al. 2009), it seems likely that countering the effects of fragmentation would help improve genetic diversity, population viability and ultimately biodiversity in protected areas (van der Ree et al. 2009).

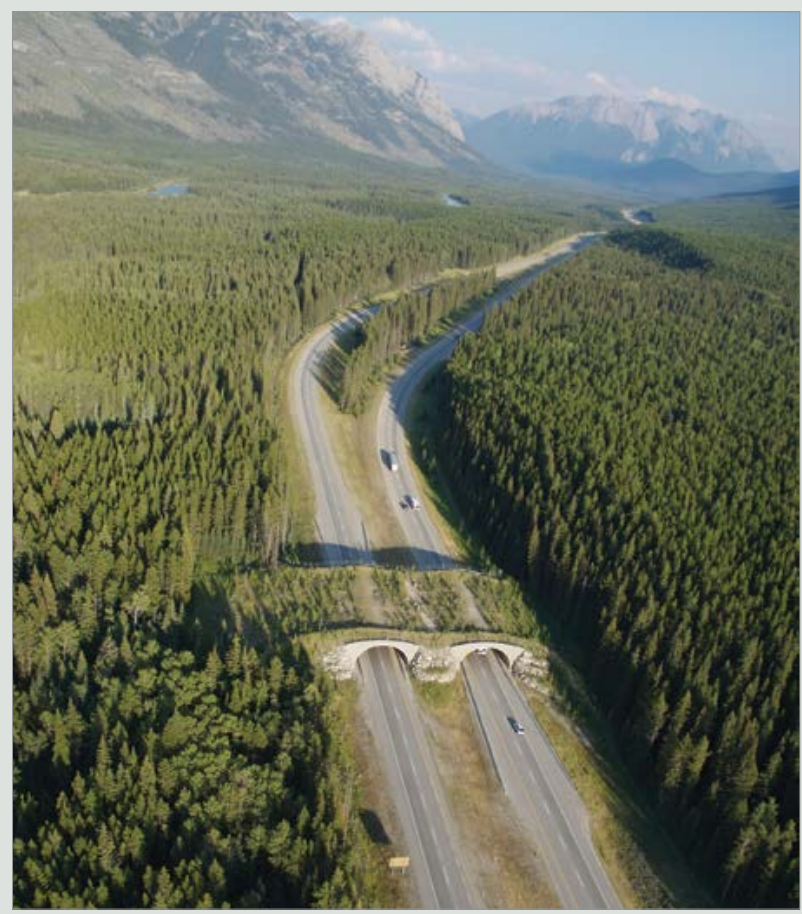

Wildlife crossing on the Trans-Canada Highway in Banff National Park, Canada

Source: Parks Canada

\section{Managing protected areas for native species diversity}

Many protected areas are currently managed to conserve rare and endemic species or species groupings. Managing protected areas for native species diversity can be very challenging because different species often require very different management actions. The challenge when financial and human resources are limited is deciding on which actions to focus. Below is a brief overview of several options, such as focusing on keystone species, trophic levels, pollinators, rare species and populationlevel management.

\section{Keystone species}

Species vary in their influences on ecosystems (Simberloff 1998). A few species exhibit effects disproportionate to their size and abundance on ecosystem structure and processes, and consequently on species composition (Mills et al. 1993). These are described as keystone species'. That term was first coined in 1969 by Robert T. Paine, whose research showed that removing a single species of starfish had a significant effect on a tidal plain ecosystem in Washington State, USA. Once the starfish was removed, the tidal zone became dominated by mussels - the starfish's prey-which in turn displaced other species and lowered the species diversity of the ecosystem (Paine 1969).

Similarly, the Magellanic woodpecker (Campephilus magellanicus) is considered a keystone species because it helps to create habitat structures that are used by eight other bird species and one mammal in Nahuel Huapi National Park, Argentina (Ojeda 2007). Exploitation of southern beech forests for logging in Argentina and Chile has led to a decline in the abundance of the woodpecker, with adverse impacts for the associated species. A key lesson from these studies is that managers need to understand the roles of individual species in order to manage, understand and restore ecological assemblages.

\section{Trophic levels and trophic cascades}

A trophic level refers to the position a species occupies in the food chain. In its simplest form, the food chain includes producers (for example, plants or algae), consumers (for example, herbivores and carnivores) and decomposers (for example, bacteria and fungi), with energy being transferred up the chain (Pimm 1982). Real ecosystems, of course, are far more complex, often with several trophic levels across multiple food webs (Estes et al. 2011). The management of protected areas requires an understanding of inherent trophic levels 


\section{Case Study 21.5 Sea otters and their impact on coastal ecosystems}

One of the best-known keystone species is the sea otter (Enhydra lutris), which eats a wide variety of prey. Most importantly, it consumes sea urchins, which feed on kelp. Left unchecked, sea urchins can denude seascapes of kelp, leading to trophic cascades. By helping to control the abundance of sea urchins, sea otters indirectly help to maintain the kelp forest ecosystems, which provide food and shelter for many other species (Duggins 1980). Unfortunately, harvesting of sea otters for their prized fur has resulted in the species' extirpation from many parts of its range and its listing as an endangered species in the United States (Benz 1996). In order to restore this important keystone species, there have been many attempted reintroductions (Raesly 2001). Several decades after a reintroduction effort in Checleset Bay, British Columbia, sea otters are once again abundant and the bay is home to a healthy kelp forest ecosystem. An ecological reserve was established specifically to protect sea otters and thereby the native kelp ecosystem.

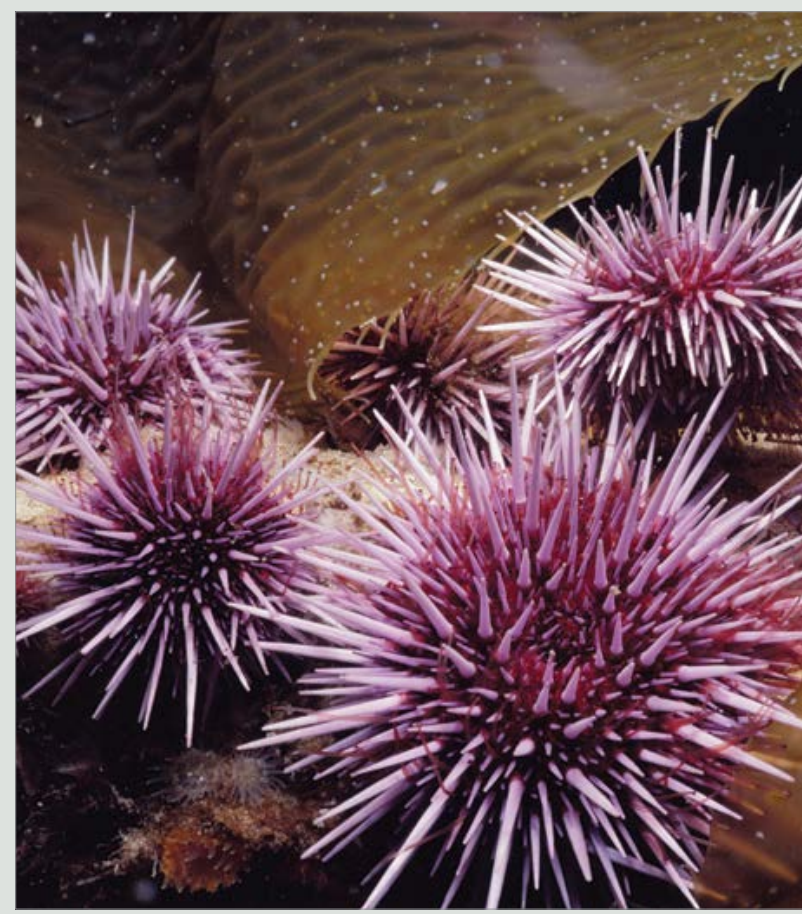

Purple sea urchin (Strongylocentrotus purpuratus) Source: @ Jeff Rotman because energy flows primarily between, not within, levels, and disruption of that flow could lead to major changes to ecosystems. Typically, such changes result from the removal or (re)introduction of predators, either releasing or controlling (respectively) herbivores, often resulting in dramatic changes to the ecosystem structure and nutrient cycling (Case Studies 21.5 and 21.6).

\section{Pollinators}

Large carnivores are not the only taxa affecting ecosystems; pollinators also play a key role. There are about 350000 species of flowering plants (WCSP 2008), and while some rely on wind for pollination, the vast majority (more than 85 per cent) depends on pollination by animals, highlighting the importance of pollinators in maintaining biodiversity (Ollerton et al. 2011). Pollinators include about 20000 species of bees, along with moths, butterflies, wasps, beetles, flies, bats, squirrels, monkeys and birds, among others.

Protected areas that have limited natural processes and/or are isolated from other natural areas often have to develop hands-on management techniques in order to maintain native biodiversity. For example, Fish Point Provincial Nature Reserve, which is located on a highly developed island in Lake Ontario, is one of the most southerly points in Canada and is home to several rare plants.
Recognising the reality of reduced regional pollinator diversity and abundance, the 2005 park management plan called for hand pollination, seed collection and assisted propagation as tools necessary to help maintain the park's plant diversity. A study in South Africa found that even in places rich in protected areas and biodiversity, pollination services declined with distance from natural areas. Thus, not only will a protected area's biodiversity benefit from the management of pollinators, neighbouring farms will also benefit (Janzen 1999; Carvalheiro et al. 2010; Chan et al. 2006).

The maintenance of pollinators within protected areas can benefit biodiversity over considerable distances. For example, Indooroopilly Island Conservation Park in Australia is an important roosting area for three flying fox bat species. The bats can fly as far as 100 kilometres each night to forage, potentially serving as important long-distance vectors for pollen. Therefore, the park's management efforts to conserve habitat for the flying foxes will also help to maintain genetic and biological diversity in the greater ecosystem (Martin 1990).

\section{Rare species}

Management of protected areas often gives priority to actions that maintain ecological integrity and that benefit common species but not necessarily rare species 


\section{Case Study 21.6 Trophic cascade from a top predator}

A well-known example of a trophic cascade resulted from the reintroduction of the grey wolf into Yellowstone National Park, USA (Fortin et al. 2005). Grey wolves (46 individuals) were reintroduced to Yellowstone National Park starting in 1995, after having being extirpated in 1926. The ecological cascade that resulted from the re-establishment of a top predator is well documented and illustrates the critical ecological role played by top predators (Ripple et al. 2001). In the absence of wolves and aboriginal hunting, the population of the herbivorous (Cervus elaphus) elk had risen to extreme levels, eliminating stands of quaking aspen tree and reducing the stream-side cover of willow shrubs. The dramatic reduction of aspen and willow had led to elimination of the dam-building beaver (Castor canadensis) from much of the park, which affected stream flow and caused stream erosion. The reintroduction of wolves has significantly reduced elk numbers, aspen and willow are recovering and beaver are returning to areas of the park. The entire process will take decades to unfold. This example illustrates not only the role of large predators in the top-down regulation of ecosystems, but also the role of protected areas as long-term research sites for ecological understanding. Protected area strategies that focus on the key role that indigenous carnivores play will greatly assist the maintenance of ecosystem integrity and biodiversity.

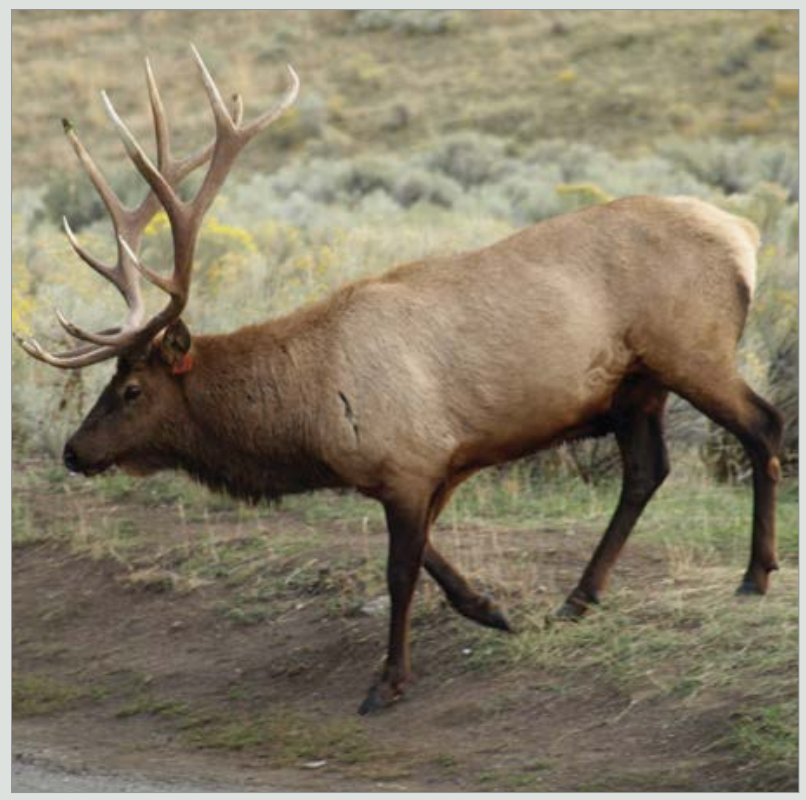

Bull elk (Cervus elaphus) at Mammoth in Yellowstone National Park, United States of America

Source: Graeme L. Worboys
(Simberloff 1998; Niemi and McDonald 2004) even though many species are rare and rare species contribute the most to a region's biodiversity - a pattern noted by Charles Darwin. For example, an analysis of tree species in the Amazonian lowlands found that half of all the trees belonged to 227 'hyper-dominant' species, while the rest were represented by 11000 species (Steege et al. 2013). In other words, the vast majority of species (more than 98 per cent) were rare, at least in terms of abundance; however, many of the species with few trees proportionally were widespread throughout the lowlands and had high total numbers of stems.

This raises the question: what does rare mean and how does one measure it? A species which might seem rare in one country may be abundant in another. Rabinowitz (1981) suggested that species could be considered rare if they had a small regional population size, a restricted geographic distribution or a restricted habitat distribution (high habitat specificity).

Managers also need to consider how threatened a species is-that is, its conservation status. The IUCN's Red List of Threatened Species is based on a series of criteria with precise thresholds including population size and trend, geographic range (as measured by the extent of occurrence and area of occupancy) or probability of extinction, if there are sufficient data to conduct an analysis (IUCN 2001). Based on a combination of the criteria, species are categorised as:

1. critically endangered (CR): extremely high risk of extinction in the wild

2. endangered (EN): high risk of extinction in the wild

3. vulnerable (VU): high risk of endangerment in the wild

4. near threatened (NT): likely to become endangered in the near future

5. least concern (LC): lowest risk; does not qualify for a more at-risk category.

As of 2012, the IUCN Red List included almost 4000 species listed as critically endangered, 5766 as endangered and more than 10000 as vulnerable, although most non-vertebrate groups have not been assessed. Given that many species are rare locally but still widespread, managers must sometimes use protected area networks to maintain populations. Often protected areas are too small to conserve a viable number of species and a network of protected areas is required. Managers of individual protected areas should be aware of what their peers are doing in other protected areas within the same ecoregion (Noss 1983). This was recognised in South Africa, for example, where the objective of 


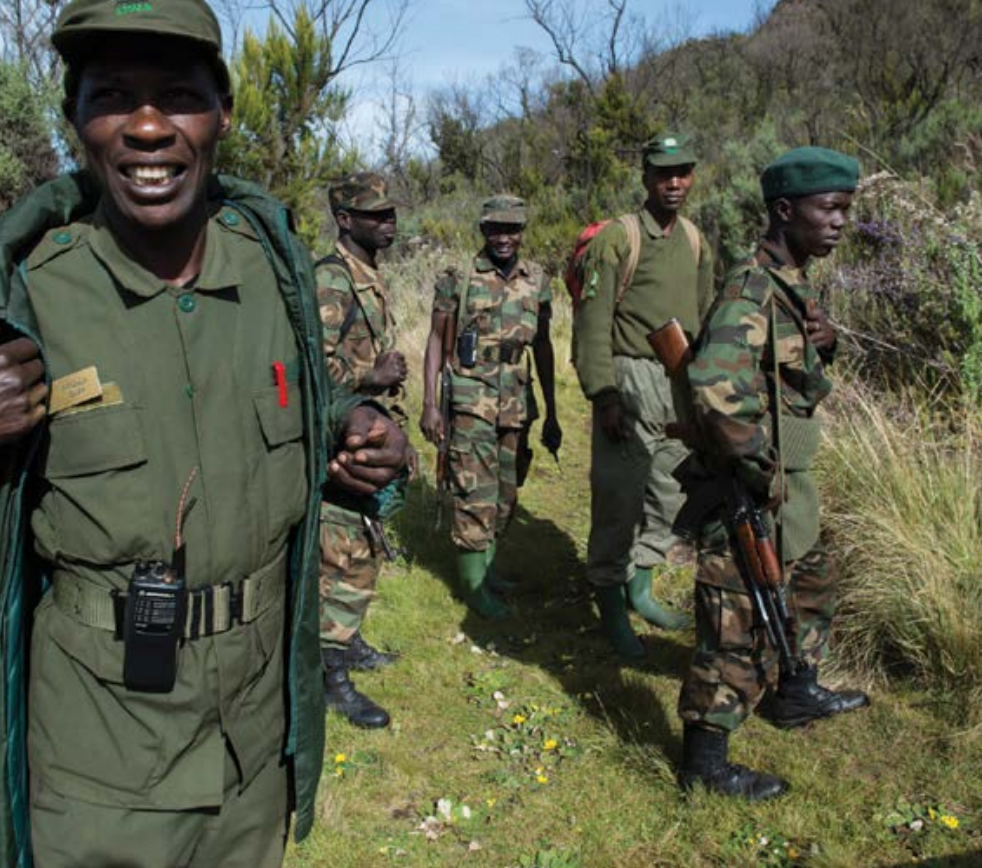

Armed Uganda Wildlife Authority rangers on patrol in Mt Elgon National Park to protect the park against poaching of rare and endangered wildlife and encroachment by neighbouring communities Source: Stuart Cohen

1. the intervention will not cause unacceptable impacts to the populations of the species or to other components and processes of the ecosystems that support them

2. the management of the population is necessary

- because the fluctuation is the result of human influences

- to protect rare species

- to protect humans and property.

\section{Meta-populations}

When managing protected areas for biodiversity, it is important to recognise that some species may exist as meta-populations. A meta-population generally comprises discrete sub-populations. Each subpopulation will have its own dynamics (rates of birth, death, immigration and emigration) (Hanski and Simberloff 1997). Meta-populations should not be confused with a single population that is simply patchy in distribution, but has the same dynamics. It is important that managers understand if they are managing a single population or a meta-population of a given species (Chapman et al. 2003). The implication for protected area management is that it is necessary to allow for connectivity among sub-populations or specific management actions for a sub-population.

\section{Population viability}

Perhaps the most common target cited when managing for populations in protected areas is that of a 'viable' population. Viability is best understood as the probability of a given species persisting over a defined period. The first population viability analysis (PVA) is credited to Mark Shaffer's 1978 calculation of extinction probability for grizzly bears (Ursus arctos horribilis) in Yellowstone National Park (Shaffer 1978). Since then, PVAs have become more sophisticated and complex, incorporating numerous variables that could potentially affect a species' viability (Gilpin and Soulé 1986; Traill et al. 2010), culminating in software that brought PVA to the computers of many park biologists (for example, RAMAS, VORTEX). The use of PVAs for protected area management decisions is, however, not without its controversies (Flather et al. 2011). Large amounts of data are required to perform robust PVAs, especially fieldwork-intensive and species-specific data (Beissinger and McCullough 2002). Furthermore, the results of PVAs typically have wide confidence intervals and are therefore prone to large errors (Flather et al. 2011). Nevertheless, PVAs can provide some insight into management decisions, as long as they are used cautiously, and are useful for determining which variables have the greatest influence on species viability (Akçakaya and SjögrenGulve 2000). For example, a study of a mountain zebra in the Gamka Mountain Nature Reserve in South Africa determined that frequent prescribed burning of preferred habitat was one of the most important management actions that could improve the viability of that endangered species (Watson et al. 2005).

\section{Managing threats to protected areas}

At a global scale the principal causes of biodiversity loss and species extinction are habitat loss and fragmentation, with other major threats including habitat degradation and pollution, overexploitation, the impact of alien invasive species and, increasingly, climate change. Although there is some evidence that protected area status may give additional protection to natural habitats (Geldmann et al. 2013), many protected areas are still threatened by habitat loss and degradation (Case Study 21.7).

Over the past two decades, the Conservation Measures Partnership has developed a common framework for identifying threats to biological diversity and ecosystem processes (Margoluis and Salafsky 1998; TNC 2000, 2007; Salafsky et al. 2003, 2008; CMP 2013). This framework can be applied to protected area management (Box 21.4 and Table 21.1). When dealing with protected areas, it is important to distinguish stresses (which are often internal to the protected area and may require restoration work) from direct threats (which generally come from outside the protected area). Often at an individual site, or even a system level, protected area 


\section{Case Study 21.7 Protected areas and forest loss}

Despite the legal status of protected areas, their designation does not in itself guarantee protection of ecosystems. Although protected areas generally reduce deforestation relative to unprotected areas, there may still be land-use change within them (Clark et al. 2008).

An analysis of deforestation in the humid tropics (Hansen et al. 2008) showed that between 2000 and 2005 an estimated 21 million hectares of humid tropical forest were lost globally-a 2 per cent reduction in forest cover. During this period, more than 1.7 million hectares were cleared within protected areas in the humid tropics $(0.81$ per cent of the forest they contained). Globally, more strictly protected areas (IUCN Categories I-II) had lower rates of humid tropical forest loss (0.53 per cent) than the protected area network as a whole. This has implications for both biodiversity and climate change. Based on the deforestation estimates, the UN Environment Programme World Conservation Monitoring Centre (UNEP-WCMC) calculated that forest loss in protected areas contributed as much as 990 megatons of carbon dioxide equivalent to global carbon dioxide emissions between 2000 and 2005 , or about 3 per cent of total emissions from tropical deforestation (Campbell et al. 2008).
In a systematic review of the effectiveness of protected areas in reducing forest loss and species population declines, Geldmann et al. (2013) concluded that there is good evidence that protected areas have conserved forest habitat. Nevertheless, evidence remains inconclusive about whether protected areas have been effective at maintaining species populations, although more positive than negative results are reported in the literature. Causal connections between management inputs and conservation outcomes in protected areas are rarely evaluated in the literature. Overall, the available evidence suggests that protected areas do deliver positive outcomes for biodiversity, but there remains limited empirical evidence of the conditions under which protected areas succeed or fail to deliver conservation outcomes.

Protected areas are ultimately about managing key features (species, ecosystems, recreational opportunities and heritage values) and safeguarding them from threats. In a world of limited staff and financial resources, protected area managers cannot necessarily take on all of the issues and problems facing these features. Instead, they need to be able to focus their actions and their monitoring efforts on the most important challenges. To this end, it is vital to be able to identify and design realistic strategies to counter threats to specific features in individual protected areas. managers can only deal with direct threats rather than the underlying root causes. This is especially true when threats to protected areas are driven by national or local policy and social and economic factors over which an individual protected area manager may have little or no influence-for example, government policies on agriculture and transport networks (MacKinnon 2005). On the other hand, direct threats within and immediately adjacent to protected areas can be addressed through management actions-for example, invasive species control, human-wildlife conflict and visitor management.

Conservation ultimately takes place through conservation 'projects' (Salafsky et al. 2008), which range in scale from efforts by a small community to manage their traditional fishing grounds to a global funding program to protect the world's oceans. Building on a review of terms used by different conservation practitioners, Salafsky et al. (2008) and the Conservation Measures Partnership (CMP 2013) have proposed definitions to describe the general components of any given conservation project (Box $21.4)$. For protected area managers, the project scope is usually defined by the boundaries of the protected area and any surrounding buffer zones (see Chapter 13).

\section{Classification of threats}

Table 21.1 illustrates the classification of threats according to the IUCN-Conservation Measures Partnership. The classification is constructed in a hierarchical fashion with three different levels, analogous to families, genera and species in the Linnaean system. The first level is denoted by whole numbers and bold text-for example, '1. Residential and commercial development'. The second level is denoted by decimal numbers and roman text-for example, '1.2. Commercial and industrial areas'. The third level is denoted by italic textfor example, 'Manufacturing plants'. The classification is designed to be comprehensive, consistent and exclusive for the first and second levels, meaning that all possible threats to biodiversity should be able to fit into the system, with each threat assigned to only one category.

\section{Assessment of threat magnitude for protected area management}

The final step in developing a systematic approach to threats involves developing a standard way of measuring and comparing threat magnitude. If one is interested in merely assessing a specific threat to a specific conservation target/feature or protected area over time, the obvious measurement is to directly assess and track the size of the threat using the best available quantitative indicatorfor example, the number of elephant poaching incidents 


\section{Box 21.4 Key definitions for understanding ecosystem threats}

- Biodiversity targets: The biological entities (species, communities or ecosystems) that a project is trying to conserve (for example, a population of a specific species of fish or a forest ecosystem). Some practitioners also include ecological and evolutionary phenomena and processes as targets (for example, fire regime, seasonal migration, gene flow)

- Human wellbeing targets: The components of human welfare affected by the status of biodiversity conservation targets. Examples might include human livelihoods from use of biological resources or spiritual values derived from natural systems.

- Stresses: Attributes of a conservation target's ecology that are impaired directly or indirectly by human activities (for example, reduced population size or fragmentation of forest habitat). A stress is not a threat in and of itself, but rather a degraded condition or 'symptom' of the target that results from a direct threat.

- Direct threats: The proximate human activities or processes that have caused, are causing or may cause the destruction, degradation and/or impairment of biodiversity targets (for example, unsustainable fishing or logging). Threats can be past (historical), ongoing and/or likely to occur in the future. Natural phenomena may also be regarded as direct threats in some situations.

- Contributing factors: The ultimate factors-usually socioeconomic, political, institutional or culturalthat enable or otherwise add to the occurrence or persistence of proximate direct threats (for example, government agricultural policies or market forces that increase the expansion of agricultural land or the overexploitation of resources such as fisheries).

- Conservation actions: Interventions undertaken by project staff or partners designed to reach the project's objectives and ultimate conservation goals (for example, reintroducing an endangered species or setting up a protected area). Actions can be applied to contributing factors, direct threats or directly to the targets themselves.

- Project teams: The groups of people involved in designing, implementing, managing and monitoring projects (for example, a partnership between a local non-governmental organisation or a community and the staff of a national park). or the percentage of buffer zone forest that is lost to an encroaching agricultural frontier. If, however, one is interested in comparing combined threat levels with different targets/features or with different protected areas across time and space, a more complex methodology is required.

Assessments of threat magnitude are important for a number of key tasks undertaken by protected area managers. In particular, without common measurements of threats, it is difficult for protected area managers to:

- set priorities: to compare protected areas within an overall system and set priorities for resource investment and to plan which of these prioritised places should be tackled immediately and which can be deferred until later

- develop effective strategies: to select which threats to address within a given protected area and to compare the potential leverage obtained by using different strategies and decide which to use

- measure conservation status and effectiveness: to determine and compare changes in the status of threats at one location over time and to determine the relative effectiveness of different conservation actions in relation to threat-based objectives

- learn from experience: to compare one manager's experiences with those of others, which is the foundation of any kind of systematic learning about how to effectively and cost-effectively counter each type of threat.

In the late 1990s and early 2000s, a number of conservation organisations began to develop systematic methods for assessing threat magnitude in a more standardised fashion (for example, Salafsky and Margoluis 1999; TNC 2000; Ervin 2002; WCS 2002). In the mid 2000s, a CMP Working Group reviewed these different systems and used them to create a standard methodology for rating threats that became the basis for the 'simple threat rating' methodology in Miradi software (Miradi 2007). 
Table 21.1 Threat categories and some examples of the current unified IUCN-Conservation Measures Partnership classification of conservation threats

Threats by level of classification

\section{Residential and commercial development}

1.1. Housing and urban areas

Urban areas, suburbs, villages, vacation homes, shopping

areas, offices, schools, and so on

\section{Agriculture and aquaculture}

\subsection{Marine and freshwater aquaculture}

Shrimp or fin-fish aquaculture, fish ponds on farms, hatchery salmon, seeded shellfish beds, artificial algal beds

\section{Energy production and mining}

3.1. Oil and gas drilling

Oil wells, deep sea natural gas drilling

\section{Transportation and service corridors}

4.1. Roads and railroads

Highways, secondary roads, logging roads, bridges and causeways, roadkill, fencing associated with roads, railroads

\section{Biological resource use}

\subsection{Hunting and collecting terrestrial animals}

Bushmeat hunting, trophy hunting, fur trapping, insect collecting, honey or bird-nest hunting, predator control, pest control, persecution

\section{Human intrusions and disturbance}

\subsection{Recreational activities}

Off-road vehicles, motorboats, jet skis, snowmobiles, ultralight aircraft, dive boats, whale watching, mountain bikes, hikers, birdwatchers, skiers, and so on

\section{Natural system modifications}

\subsection{Fire and fire suppression}

Fire suppression to protect homes, inappropriate fire management, escaped agricultural fires, arson, campfires, fires for hunting

\section{Invasive and other problematic species and genes}

\subsection{Invasive non-native/alien species}

Feral cattle, household pets, zebra mussels, Dutch elm disease or chestnut blight, Miconia tree, introduction of species for biocontrol, Chytrid fungus affecting amphibians outside Africa

\section{Definition}

Human settlements or other non-agricultural land uses with a substantial footprint

Human cities, towns and settlements including non-housing development typically integrated with housing

Threats from farming and ranching as a result of agricultural expansion and intensification, including silviculture, mariculture and aquaculture

Aquatic animals raised in one location on farmed or non-local resources; also hatchery fish allowed to roam in the wild

Threats from production of non-biological resources

Exploring for, developing and producing petroleum and other liquid hydrocarbons

Threats from long, narrow transport corridors and the vehicles that use them including associated wildlife mortality

Surface transport on roadways and dedicated tracks

Threats from consumptive use of 'wild' biological resources including deliberate and unintentional harvesting effects; also persecution or control of specific species

Killing or trapping terrestrial wild animals or animal products for commercial, recreational, subsistence, research or cultural purposes, or for control/ persecution reasons; includes accidental mortality/ bycatch

Threats from human activities that alter, destroy or disturb habitats and species associated with nonconsumptive uses of biological resources

People spending time in nature or travelling in vehicles outside established transport corridors, usually for recreational reasons

Threats from actions that convert or degrade habitat in the service of 'managing' natural or semi-natural systems, often to improve human welfare

Suppression or increase in fire frequency and/or intensity beyond its natural range of variation

Threats from non-native and native plants, animals, pathogens/microbes or genetic materials that have or are predicted to have harmful effects on biodiversity following their introduction, spread and/or increase in abundance

Harmful plants, animals, pathogens and other microbes not originally found within the ecosystem(s) in question and directly or indirectly introduced and spread into it by human activities 
Threats by level of classification

8.2. Problematic native species

Overabundant native deer, overabundant algae due to loss of native grazing fish, native plants that hybridise with other plants, plague affecting rodents

\section{Pollution}

9.2. Industrial and military effluent

Toxic chemicals from factories, illegal dumping of chemicals, mine tailings, arsenic from goldmining, leakage from fuel tanks, PCBs in river sediments

10. Geological events

10.2. Earthquakes/tsunamis

11. Climate change and severe weather

11.1. Habitat shifting and alteration Sea-level rise, desertification, tundra thawing, coral bleaching

11.2. Droughts

Severe lack of rain, loss of surface water sources

\section{Deffinition}

Harmful plants, animals or pathogens and other microbes that are originally found within the ecosystem(s) in question, but have become 'out of balance' or 'released' directly or indirectly due to human activities

Threats from introduction of exotic and/or excess materials or energy from point and non-point sources

Waterborne pollutants from industrial and military sources including mining, energy production and other resource extraction industries, including nutrients, toxic chemicals and/or sediments

Threats from catastrophic geological events

Earthquakes and associated events

Long-term climatic changes that may be linked to global warming and other severe climatic or weather events outside the natural range of variation that could wipe out a vulnerable species or habitat

Major changes in habitat composition and location

Periods in which rainfall falls below the normal range of variation

Source: IUCN-CMP classification of direct threats to biodiversity (Version 1.1) (CMP 2013)

\section{The Miradi simple threat rating method}

The Miradi Adaptive Management Software (Miradi 2007) is designed to be applied to assess the impact of a specific threat on a given conservation target, using a combination of scope (area) and severity (intensity) that, when combined, provides an indication of the magnitude of the threat. Miradi uses specific four-point rating scales for each criterion (very high, high, medium and low) that, where possible, are linked to specific percentages. The thresholds between criteria are designed to represent both ecologically and practically meaningful breakpoints between the categories. The Miradi threat assessment system should generally apply to protected areas of all types and sizes; however, the system may need to be adapted to handle assessments of non-conservation features as well as the stresses posed by threats such as climate change. Combining the scope and severity ratings gives an overall threat magnitude rating (Figure 21.5). It is also helpful to consider irreversibility (the degree to which the effects of a threat can be reversed) in combination with magnitude in order to compare or prioritise threats for management action (Figure 21.6). The effects of one threat on multiple targets or multiple threats on one target can be combined or rolled up using various rule-based systems (for more details, see Miradi 2007). This produces a final threat summary table (Figure 21.7).
The biodiversity conservation community has made great progress in the past few years in developing standardised methods for defining and measuring threats to species and ecosystems. There is great potential for using these tools in protected area management, but modifications will be necessary to optimise these methods to the specific needs faced by protected area managers.

\section{Monitoring and assessment of ecological condition in protected areas}

In this section, we refer to monitoring as both inventory and monitoring. Inventory is the essential first step and monitoring is generally repeated measures of the first inventory or parts of it. Very few protected areas are doing a good job of ecological monitoring even though it is essential to understand if the protected area is being successful in conserving nature and meeting its stated conservation objectives. Moreover, an investment in monitoring avoids surprises and irresolvable problems in the future. Building monitoring into park management should be considered a fundamental part of park management. In the long term, it can save money by preventing costly restoration projects (also see Chapter 28). 


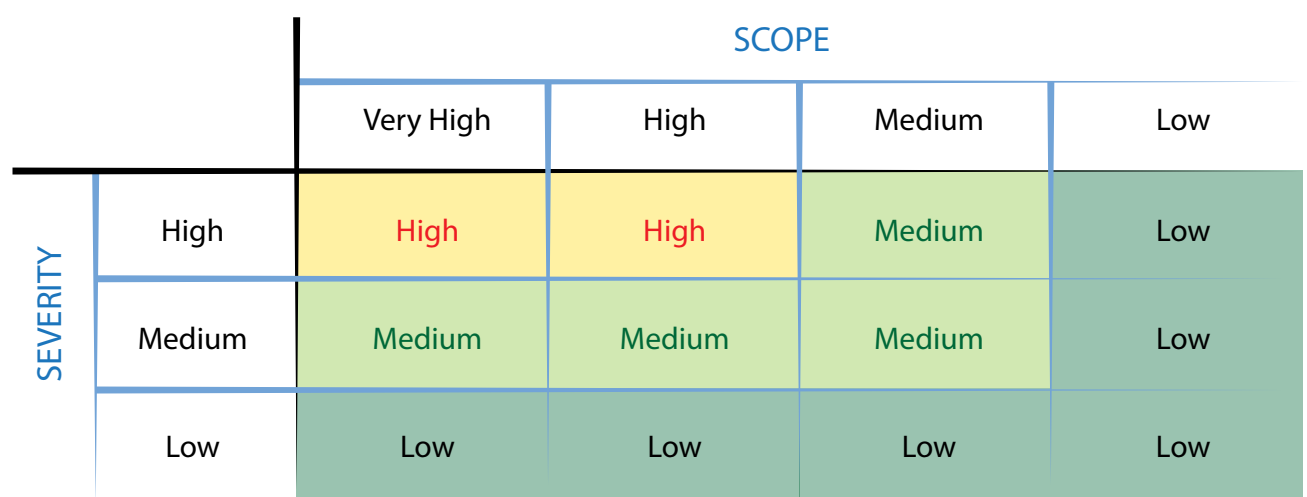

Figure 21.5 Combined threat and severity ratings to determine threat magnitude Source: Miradi (2007)

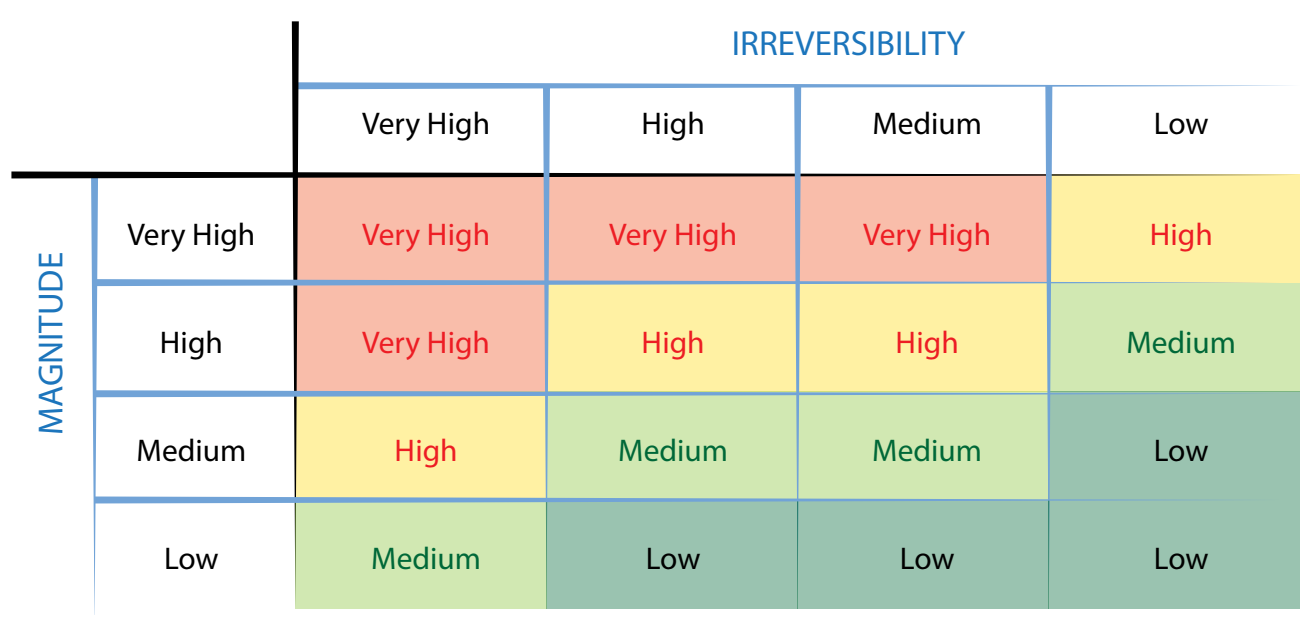

Figure 21.6 Combined assessments of threat irreversibility and magnitude to prioritise management actions

Source: Miradi (2007)

\begin{tabular}{|c|c|c|c|c|c|c|c|}
\hline $\begin{array}{l}\text { Threats vs } \\
\text { Values }\end{array}$ & $\begin{array}{c}\text { Asian } \\
\text { Elephant }\end{array}$ & $\begin{array}{c}\text { Forest } \\
\text { Ecosystem }\end{array}$ & $\begin{array}{l}\text { Functional } \\
\text { Corridor }\end{array}$ & $\begin{array}{c}\text { Grasslands } \\
\text { of Terai }\end{array}$ & $\begin{array}{l}\text { One-horned } \\
\text { Rhino }\end{array}$ & Tiger & $\begin{array}{l}\text { Summary } \\
\text { Threat Rating }\end{array}$ \\
\hline Cattle Grazing & & High & Low & High & & & High \\
\hline Encroachment & & Very High & Very High & High & & & Very High \\
\hline $\begin{array}{l}\text { Fuelwood } \\
\text { Collection }\end{array}$ & & High & Medium & & & & Medium \\
\hline $\begin{array}{l}\text { Illegal Wildlife } \\
\text { Killing }\end{array}$ & & & & & Very High & Very High & Very High \\
\hline Logging & & Low & Low & & & & Low \\
\hline $\begin{array}{l}\text { Overexploitation } \\
\text { of Non-timber } \\
\text { Products }\end{array}$ & & Low & Low & Low & & & Low \\
\hline $\begin{array}{l}\text { Summary Target } \\
\text { Rating }\end{array}$ & None & High & High & High & High & High & Very High \\
\hline
\end{tabular}

Figure 21.7 Threat summary rating for an example ecosystem

Source: Miradi (2007) 


\section{Case Study 21.8 Globally available wildfire monitoring}

Wildfires and fires for slash-and-burn agriculture are two of the most important causes of deforestation in Madagascar. The use of satellite remote sensing to detect fires can enable managers of protected areas and other forests to respond quickly to illegal fires. NASA's Moderate-Resolution Imaging Spectroradiometer (MODIS) instrument on board the Aqua and Terra satellites provides thermal and mid-infrared data four times daily, allowing the detection of fires. The data, however, require interpretation and analysis, which makes their use by field-based land managers difficult. To develop a user-friendly product, Conservation International, the University of Maryland and the Madagascar Forestry Department developed a fire alert system that provides daily email alerts to users based on their geographical area of interest.

In Madagascar, the fire alerts provide protected area and forestry staff with timely and accurate information of illegal fires and encroachment activity. This allows field managers to react rapidly to encroachment but it also provides valuable monitoring statistics for tracking the fire threat at different sites. The fire data can also be used to improve understanding of patterns of threats to forests at the national scale, and have been used to inform the development of the national strategy for mitigating climate change through the Reducing Emissions from Deforestation and Forest Degradation (REDD).

Initially, in 2002, the fire alert system sent registered users a simple list of detected fires with their exact position. A more advanced system developed in 2007 allows users to define the frequency of alerts and receive maps tailored to their specific areas of interest-for example, administrative regions, individual national parks and fires within natural forests. The system, known as Firecast, has since been expanded to include Bolivia, Peru and Indonesia, and now also includes fire-risk prediction alerts. Firecast is free and accessible (Firecast 2014).

- James Mackinnon

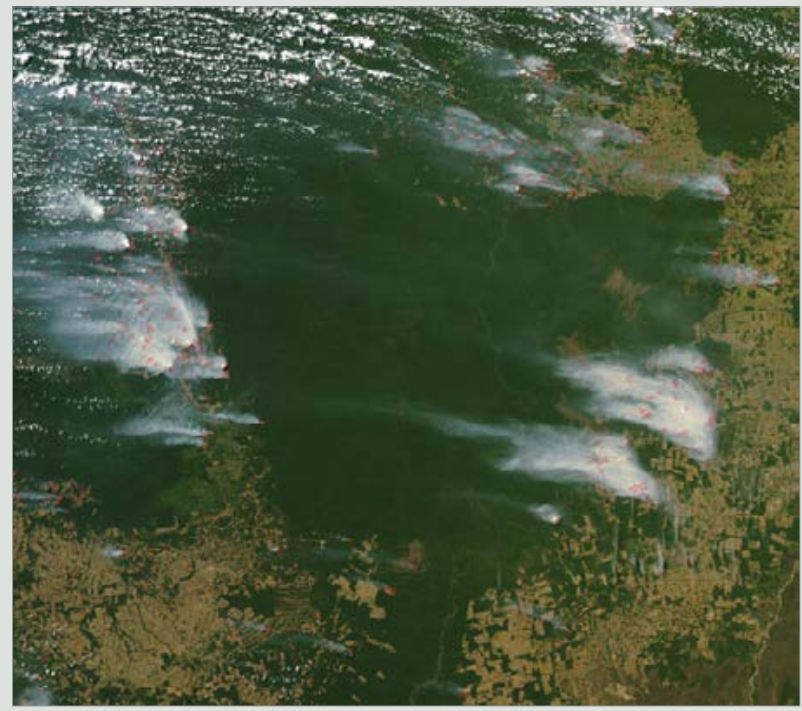

Fires near Xingu Indigenous Park, Brazil

Source: Jacques Descloitres, MODIS Rapid Response Team, NASA-Goddard Space Flight Center, <rapidfire.sci.gsfc.nasa.gov>
Even if there are no monitoring systems currently in place, most protected areas can find some useful data to assess ecological condition. Visitors, staff, scientists and indigenous and local peoples all make observations about the land and waters of protected areas on a regular basis. Global sensor systems, including satellites and weather stations, continually make observations and, increasingly, there is free satellite information available (Case Study 21.8). The initial step in developing a monitoring system for biological diversity and ecosystem processes is to catalogue and organise these existing data in order to provide the best available evidence for making management decisions.

There are two key monitoring questions for protected areas. This section will help with understanding and developing answers to these questions.

1. What is the ecological condition: do we need to take management action?

2. Have management actions been effective?

Managers will want to have the best possible information for answering these questions. This is indeed a challenge, as both these questions are complex. As a starting point, do not be overly concerned about the amount of money and expertise available for observing the protected area. Some information is better than none, although management decisions must be based on what is known and unknown. Even simple, well-organised information is more persuasive than the disconnected and poorly documented kind. The best practice is to work with what is available and build partnerships for long-term monitoring to supplement monitoring done by protected area staff.

This chapter will not provide a full guide for all the elements of designing a monitoring program, and collecting and analysing the data. Readers are referred to guidebooks on the subject, such as Lindenmeyer and Likens (2010) and Gitzen (2013). In addition, there are agency websites that contain details on monitoring and monitoring protocols, such as the US National Park Service Inventory and Monitoring Program (NPS 2014). Finally, there are a large number of taxa-specific and ecosystem-specific guides available online. This section covers basic considerations in thinking about the design and implementation of a biodiversity and ecosystem function monitoring program for protected areas. 


\section{What to observe?}

\section{Condition monitoring}

To answer the question 'what is the ecological condition: do we need to take management action', the first requirement is to know what should be measured to assess ecological condition. It makes sense to begin by assessing the species and processes referred to in the protected area's establishment document or management plans. Species that are immediately identified with the site and the ecological processes that maintain its characteristic look (for example, fire on savannah) are likely to be the most important place to start (see the 'Assessing protected area condition: Ecological integrity' section above). The protected area agency's policy and legislation may also provide guidance on selecting specific species and processes to monitor-for example, rare species and key conservation targets. It is important to maintain a systematic and unbiased approach to monitoring to avoid researcher bias. Protected area managers should use a structured framework to select indicators. In most cases, a set of indicators should be selected for each of the major ecosystems in a protected area-that is, forests, wetlands, grasslands, and so on. An example of a template for ecological monitoring used by Parks Canada, which includes biodiversity, ecosystem function and known stressors as components of a monitoring framework, is illustrated (Table 21.2).

After a candidate list of species, functions and threats has been selected, managers should give some consideration to the cost in time and money to measure these different aspects. There are often ways to do things more cheaply to achieve some useful results. For example, precise population counts might be replaced with a simpler index of abundance from dung counts. Ground-stationed wildlife cameras can produce useful information on species presence and distribution (O'Brien 2014). There is an online Handbook for Wildlife Monitoring Using Camera Traps (Ancrenaz et al. 2012). The spatial extent of a disturbance can be estimated using a global positioning system (GPS) on the ground rather than from an airplane.

\section{Effectiveness monitoring}

For protected areas that have active management and restoration programs, it is important to monitor whether or not the ecological goals of management actions have been achieved. Choosing what to measure is generally straightforward since efforts are usually targeted to certain species or habitat types and desired trends-for example, more abundant native species, less abundant invasive species or disturbances similar to those under low-density human habitation.

\section{Who can observe?}

Who can actually do ecological monitoring is not clearcut. Fundamentally, ecological monitoring is a sciencebased activity. Monitoring programs are ideally designed by people with a scientific background, properly field tested and peer reviewed. Once a clear method or monitoring protocol is designed, however, many people can be trained to collect monitoring information. For example, rangers and wardens are ideal candidates because they regularly patrol and observe large parts of protected areas. Increasingly, citizen scientists are being trained to provide monitoring data, even using devices such as smart phones.

The opportunity to include visitors and indigenous and local people in monitoring protected areas should be given some serious consideration. Engaging these people

Table 21.2 Example of a selection template for ecological integrity monitoring measures

\begin{tabular}{|c|c|c|}
\hline Biodiversity & Ecosystem functions & Stressors \\
\hline $\begin{array}{l}\text { Species lists } \\
\text { - } \quad \text { change in species richness } \\
\text { - numbers and extent of exotics } \\
\text { Population dynamics } \\
\text { - } \text { mortality/natality rates of indicator } \\
\text { species } \\
\text { - immigration/emigration of indicator } \\
\text { - species } \\
\text { - population viability of indicator } \\
\text { Trophic structure } \\
\text { - } \text { faunal size class distribution } \\
\text { - } \text { predation levels }\end{array}$ & $\begin{array}{l}\text { Succession/retrogression } \\
\text { - } \quad \text { disturbance frequencies and size } \\
\text { (fire, insects, flooding) } \\
\text { - vegetation age class distributions } \\
\text { Productivity } \\
\text { - remote or by site } \\
\text { Decomposition } \\
\text { - by site } \\
\text { Nutrient retention } \\
\text { - Calcium and nitrogen by site or } \\
\quad \text { watershed }\end{array}$ & $\begin{array}{l}\text { Land-use patterns } \\
\text { - land-use maps, road densities, } \\
\text { population densities } \\
\text { Habitat fragmentation } \\
\text { - } \quad \text { patch size, inter-patch distance, } \\
\text { forest interior } \\
\text { Pollutants } \\
\text { - } \quad \text { sewage, petrochemicals, and so on } \\
\text { - long-range transport of toxins } \\
\text { Climate } \\
\text { - weather data } \\
\text { - frequency of extreme events } \\
\text { Other } \\
\text { - park-specific issues }\end{array}$ \\
\hline
\end{tabular}

Source: Woodley (1993) 


\section{Case Study 21.9 Monitoring using citizens and traditional knowledge}

Project Noah (2014) is an innovative website that records the location and date of wildlife photographs taken by citizen scientists. The photographs are taken by interested people and there is a set of instructions to upload images of a certain kind. For example, The Birds of Sub-Saharan Africa has 101 participants and more than 1500 sightings of birds. It is easy to become a member and upload images from a smart phone. Photos can be constrained to a weekend bioblitz in a protected area or focused on topics such as pollination, phenology or invasive species.

\section{Inuit Qaujimajatuqangit, Canada}

Inuit Qaujimajatuqangit or $I Q$ is the hard-won wisdom of the indigenous people of the Nunavut Territory of
Canada-survivors in a harsh northern landscape. This local ecological knowledge is a key component of local governance, especially in the management of natural resources. Gilchrist et al. (2005) examined the effectiveness of $I Q$, especially with regards to recent population and distribution trends for four species of migratory birds. For two of the species examined, local knowledge identified population shifts that were previously unknown to Western science. In general, the degree of contact with the species was an important factor in determining the quality of observations. In one case, the species' distribution was poorly understood by local hunters despite seasonal harvests. Thus, like any source of information, there must be scrutiny of reliability. and respecting their insights will benefit a protected area in ways that go beyond the preparation of standard visitor information. Often these are the same people who will need to be convinced of the need for action in the protected area. Including people early in the process builds trust and understanding. The feelings and spiritual significance attached to observations by visitors and indigenous and local people are critical, although it may be difficult to include these observations in a common framework with those of staff and visiting scientists (Case Study 21.9).

A monitoring program has to be designed around the needs and unique situation of the individual protected area. In many cases, scientists will be situated nearby in universities, government agencies or non-governmental organisations (NGOs) and may be interested in conducting long-term monitoring studies. In other cases, a protected area will have trained staff. In many situations, however, and especially where protected areas lack their own research staff, local citizens and traditional land managers can provide useful additional understanding of their ecosystems. Perhaps the best way to think about who should be involved in monitoring is to see the program as a partnership, which can evolve over time. The challenge for a protected area manager is to ensure there are enough people, with enough training, to be able to report on the ecological conditions.

\section{Monitoring protocols}

Monitoring of any ecological entity will require the development of a monitoring protocol-that is, a set of written conditions that specifies the how, what, when, where and why of monitoring. It includes the following.

1. What is the monitoring question being asked? For example, what is the population of cranes in the protected area and is that population changing?
2. What is the ecological variable to be measured and how does it relate to the monitoring question? For example, a useful way to count cranes might be to conduct spring crane counts when the birds arrive for breeding, as they are very easy to see and count then.

3. What certainty is needed to detect change? This is both a management question and a statistical question. For example, if cranes are counted for two days each spring, it may only be possible to know the population with a variation of plus or minus 20 per cent. Therefore, depending on sampling frequency, the manager would not be able to detect year-to-year changes unless they were greater than 20 per cent. If the crane is a threatened species, however, the manager may wish to know if the population is changing with a certainty greater than 20 per cent. This analysis of the ability to detect change is called a 'power analysis'. There are guides to this in most statistical texts (for example, Ellis 2010), online or from a statistician. There is almost always a trade-off between the level of certainty to detect change and the cost of a monitoring program.

\section{Field methods}

A clear set of methods should be written to detect change. Following the crane example, the methods should specify all the details required for a spring count, including where to go, when to count, whether to count juveniles separately from adults, and so on. This methods section should be very specific so that methods can be easily repeated by different observers.

\section{Data collection and storage}

This part of a protocol includes how the data will be collected, how data will be stored and what quality controls are necessary. For example, there may be a field datasheet for crane counts with all the metadata 
(observer name, date, location, and so on) as well as the actual count data. The datasheet will then go into a file storage (perhaps copied for backup) and may be entered into a computer spreadsheet or database. A good protocol would include quality-control rules for ensuring that observations are transferred correctly from the field worksheet to the computer. Quality control might also include an independent person checking the numbers.

\section{Data analysis}

A protocol should specify how a set of measures will be analysed, including the statistical methods, and ways to determine the significance of the finding. For the crane example, if 10 years of data showed there was 95 per cent confidence that the cranes were declining at a rate of 2 per cent per year, would that result in a management action?

\section{Other requirements}

The final elements of a protocol should ensure that all other factors for success are considered. This includes training, specialised equipment, research permits and communications. Thus, all field staff engaged in a crane count might need training to successfully identify males from females or juveniles from adults.

\section{Interpreting monitoring results: Some general considerations}

Analysing and interpreting data collected from a monitoring program are perhaps the most difficult parts of monitoring biodiversity and ecosystem processes. It has become even more difficult in the current context of climate change and widespread exposure to invasive species.

There is rarely perfect clarity for the level of a chosen measure in a healthy ecosystem. Nonetheless, the following steps will help in making sense of observations:

- ask clear monitoring questions

- make sure that monitoring design can answer these questions

- choose indicators that are simple, repeatable and that will be interpreted in the same way by different observers

- summarise the answers to these monitoring questions and recommend whether action should be taken.

There are some basic questions that can be asked about the results from monitoring a species characteristic or ecological process.

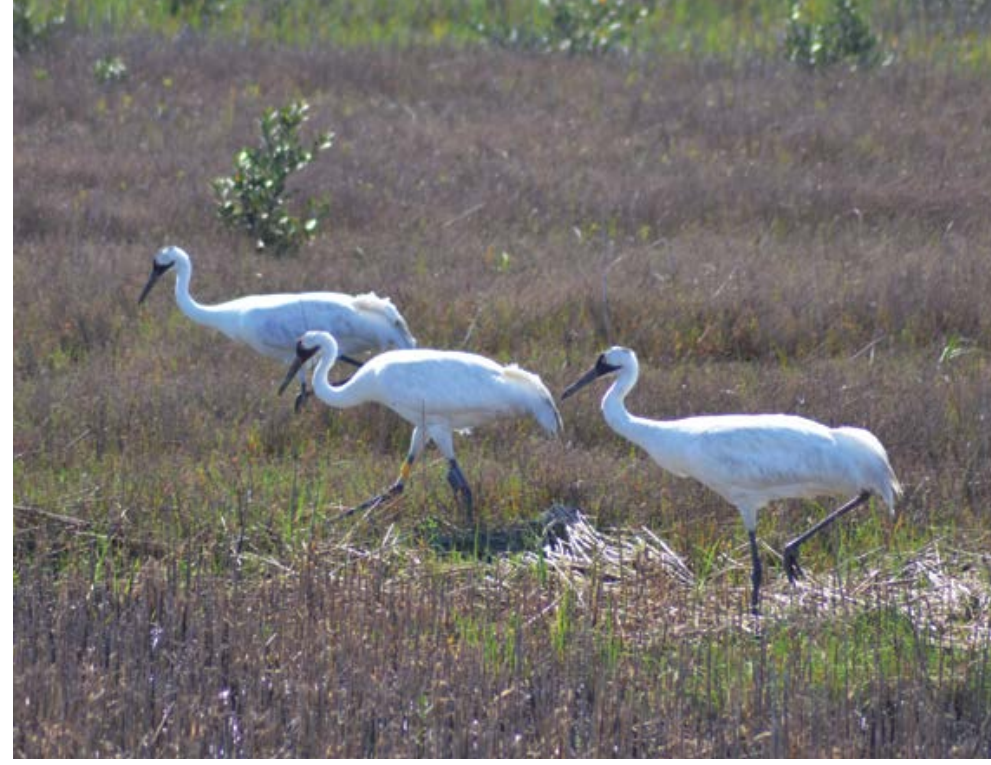

Whooping cranes (Grus americana) are an endangered species with only a small population remaining in the wild, USA

Source: Alison Woodley

1. Is it high or low within the range of possible values?

2. Is it changing? If it is changing, is that change in the desired direction (for example, an increase in the abundance of target species or a reduction in invasive species)? Often monitoring will focus on trends, rather than on absolute numbers.

3. Are the results affected by known conservation threats (Table 21.1)?

4. Is the result affected by interactions with other species or processes?

To answer these questions managers need a monitoring design. Any monitoring program makes a number of assumptions about the area of the reserve that will be affected, the changes that can be detected and levels of certainty. A statistician or scientist can help to name these assumptions and strengthen the design. Some guidance is provided on the minimum number of observations needed to answer certain questions (Table 21.3).

Monitoring is only useful if results are analysed and evaluated and built into follow-up management action. Table 21.3 recommends minimum sample sizes for detecting fairly obvious differences in an ecosystem. Each design in the table assumes a 20 per cent chance of a false-positive result and a 20 per cent chance of a false-negative result.

Analysing data to answer the question 'have management actions been effective' is generally easier to approach than condition monitoring. Instead of wondering what an ecosystem 'should' do, the manager is asking whether it did what was expected after a specific management treatment. It is often important to frame the effectiveness question in the time frame of practical management, regardless of the lifespan of the species involved or the speed of the processes, because project 


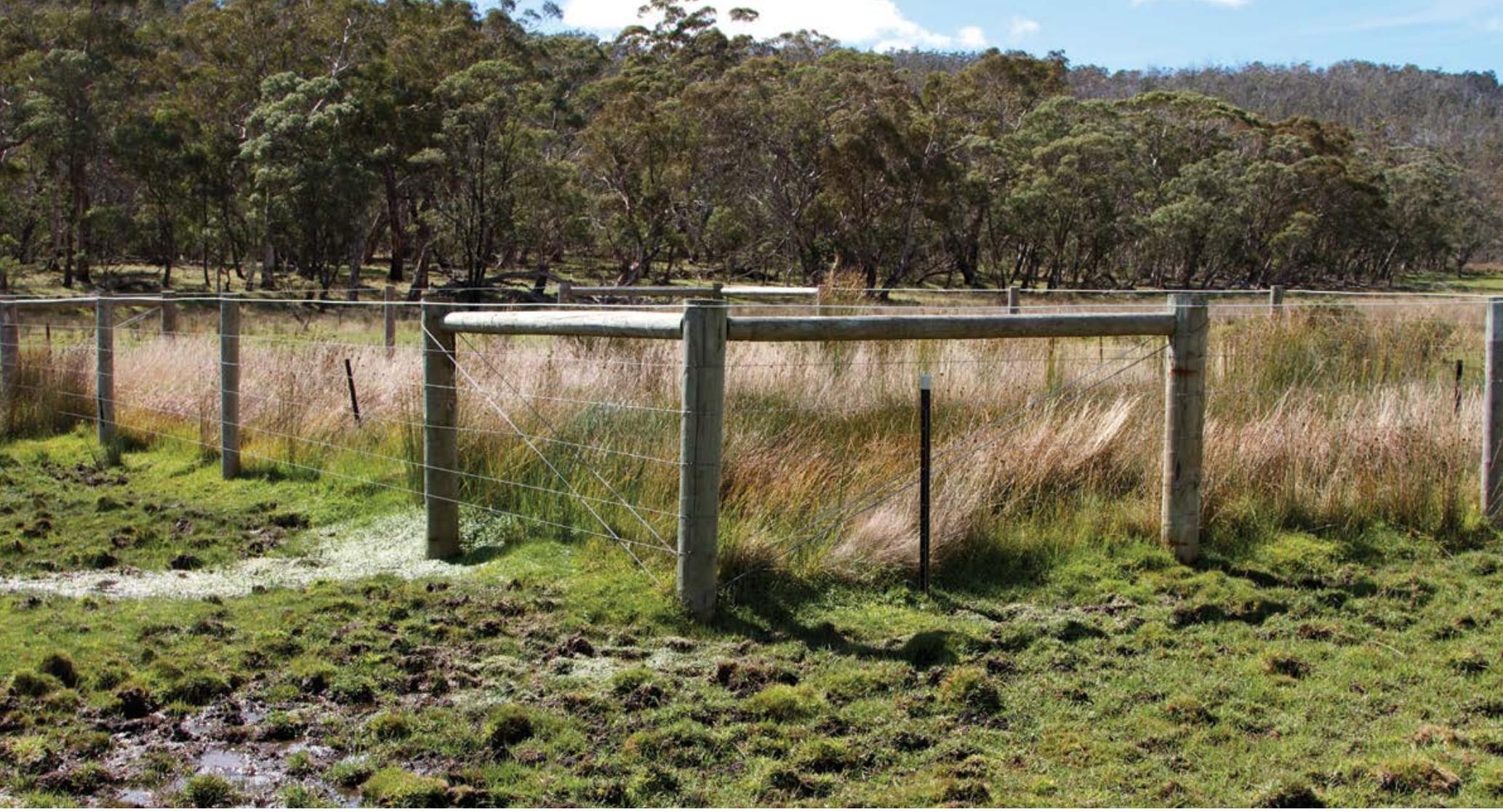

Long-term monitoring exclosures are used by park managers to determine the impacts of introduced species such as wild horses in the Victorian Alpine National Park, Australian Alps

Source: lan Pulsford

funding for protected area management is usually short term and thus requires short-term measures of success. Because ecosystems have response time lags, effectiveness monitoring should, however, also have longer-term measures linked to the condition-monitoring program for the protected area.

The targets for effectiveness monitoring can be clear expectations of impacts, such as the percentage of area successfully treated or species population size attained. These expected targets should represent a response by the ecosystem rather than a measure of the effort applied. Meeting these targets generally requires less attention to the statistical assumptions that are so important in condition monitoring.

\section{Long-term recording of monitoring observations}

Monitoring information should be stored in a location where it can be easily accessed, is safe in the long term and is properly documented. Most protected area organisations would benefit from improved data management. Many observations are lost in the long term or do not have adequate metadata. There are formal metadata standards that describe what needs to go along with the data collected, including how it was collected, who collected it, exact methods used, locations, and so on. Metadata are as important as the datum itself. For biodiversity data, a common metadata standard is the 'Darwin Core' and this is available online (Wieczorek et al. 2012). The Darwin Core is simply a checklist of things that should be in metadata such as date, species name and geographic coordinates. There is far too much data that is not useful simply because it is missing metadata.

Repeated observations by protected area managers and indigenous people can be translated into data management standards that strengthen understanding of the protected area over time. The keys to monitoring include: 1) clear monitoring protocols that maintain a consistent measurement technique across time, locations and observers; and 2) accessible data storage that moves the observations into the public realm. Finding a suitable repository is important (Box 21.5). 
Table 21.3 General guideline on the number of observations required to detect trends

\begin{tabular}{|c|c|c|}
\hline What do you want to detect? & Analysis and effect size & Number of samples \\
\hline An unusual year & $\begin{array}{l}\text { One sample t-test; } 1 \text { standard deviation difference } \\
\text { between unusual year and previous average }\end{array}$ & 7 annual observations \\
\hline A trend over time & $\begin{array}{l}\text { One-sample z-test; a strong correlation coefficient } \\
>0.7\end{array}$ & $\begin{array}{l}9 \text { independent observations } \\
\text { over a period }\end{array}$ \\
\hline A change in the average value & $\begin{array}{l}\text { Paired t-test; an average difference between } \\
\text { repeated measures on the same sites or individuals } \\
\text { that amount to half the standard deviation in the } \\
\text { data }\end{array}$ & $\begin{array}{l}19 \text { observations repeated in } \\
\text { each of two years }\end{array}$ \\
\hline $\begin{array}{l}\text { A difference between two } \\
\text { treatments }\end{array}$ & $\begin{array}{l}\text { Two sample t-tests; a difference of half the } \\
\text { standard deviation in the data between the average } \\
\text { values of two treatments }\end{array}$ & $\begin{array}{l}37 \text { observations in each } \\
\text { treatment }\end{array}$ \\
\hline
\end{tabular}

Source: Stephen McCanny

Posting monitoring data along with its protocol is not the end of conserving long-term data. Assuring the long-term (50-100 years) accessibility of monitoring data will require awareness of changes in electronic media. Electronic information, like paper files, must be curated. It faces the additional risk of being eliminated through faulty backup procedures. The best guarantee that monitoring data will survive is to ensure they receive regular use and updates by conservation organisations.

\section{Conclusion}

Managing protected areas is an increasingly complex job that requires a good understanding of the ecology of the place, as well as some fundamentals about how ecosystems work. Below is a summary of the key messages from this chapter for protected area managers.

1. Protected areas, as ecosystems, have both biodiversity and supporting ecosystem functions. The two are connected and affect each other. It is not possible to manage just for a species or an ecosystem type, without also considering the ecological processes that support them.

2. Monitoring ecosystem condition and management actions is a fundamental part of protected area management. Monitoring systems should be part of the overall management framework of a protected area. A monitoring system needs to be based on a fundamental understanding of ecosystem structure and function.

3. The applied science of conservation biology provides a range of well-developed tools and approaches for the management of biodiversity at all scales,

\section{Box 21.5 Finding a repository for storing monitoring information}

Many governments or NGOs may already have an open data catalogue where data can be posted (for example, <datacatalogs.org >). There may also be an internal website for posting information for staff access.

There are also a number of repositories specifically for protected areas and conservation. The Global Biodiversity Information Facility (GBIF) is an international open data infrastructure for biodiversity information. It allows anyone, anywhere, to access data about all types of life on Earth, shared across national boundaries via the Internet.

Protected Planet is a dynamic website (<www. protectedplanet.net>) hosted by the UNEP-WCMC, which seeks to describe the world's protected areas. The Open Parks Network is a knowledge pipeline for park professionals, which hosts digitised archives and hard-to-find information (OPM 2014).

from genetic to ecological community. Population management approaches are the best developed and include detailed considerations for managing genetic diversity, meta-populations and viability.

4. Management of ecological functions is possible and necessary in many protected areas. A good example is the use of fire in fire-adapted ecosystems.

5. Much protected area management is focused on the management of ecological threats. This chapter presents a formal, structured approach to defining, assessing and rating ecological threats in protected areas. 
The science behind applying management to biodiversity and ecosystem function is large and growing. This chapter aims to provide an overview of the key principles and understandings but cannot cover all areas. Protected area managers should take advantage of the volunteer expertise within the IUCN commissions, including the World Commission on Protected Areas, to help solve protected area management challenges.

\section{References}

Recommended reading

Akçakaya, H. R. and Sjögren-Gulve, P. (2000)

'Population viability analyses in conservation planning: an overview', Ecological Bulletins 9: 9-21.

Ancrenaz, M., Hearn, A. J., Ross, J., Sollmann, R. and Wilting, A. (2012) Handbook for Wildlife Monitoring Using Camera Traps, BBEC II Secretariat, Natural Resources Office, Chief Minister's Department, Sabah, Malaysia.

Ashton, D. H. (1981) 'Fire in tall open forests (wet sclerophyll forests)', in A. M. Gill, R. H. Groves and I. R. Noble (eds) Fire and the Australian Biota, pp. 339-66, Australian Academy of Science, Canberra.

Baker, W. 1. (1995) 'Long-term response of disturbance landscapes to human intervention and global change', Landscape Ecology 10: 143-59.

Balmford, A., Carey, P., Kapos, V., Manica, A., Rodrigues, A. S. L., Scharlemann, J. P. W. and Green, R. E. (2009) 'Capturing the many dimensions of threat', Conservation Biology 23: 482-7.

Beissinger, S. R. (2002) 'Population viability analysis: past, present, future', in S. R. Beissinger and D. R. McCullough (eds) Population Viability Analysis, pp. 5-17, University of Chicago Press, Chicago.

Beissinger, S. R. and McCullough, D. R. (eds) (2002) Population Viability Analysis, University of Chicago Press, Chicago.

Benz, C. (1996) 'Evaluating attempts to reintroduce sea otters along the California coastline', Endangered Species Update 13: 31-5.
Bouzat, J. L., Cheng, H. H., Lewin, H. A., Westemeier, R. L., Brawn, J. D. and Paige, K. N. (1998) 'Genetic evaluation of a demographic bottleneck in the greater prairie chicken', Conservation Biology 12: 836-43.

Bouzat, J. L., Johnson, J. A., Toepfer, J. E., Simpson, S. A., Esker, T. L. and Westemeier, R. L. (2009) 'Beyond the beneficial effects of translocations as an effective tool for the genetic restoration of isolated populations', Conservation Genetics 10: 191-201.

Boyce, M. S. and Daley, D. J. (1980) 'Population tracking of fluctuating environments and natural selection for tracking ability', American Naturalist 115(4): 480-91.

Bruner, A. G., Gullison, R. E., Rice, R. E. and Fonseca, G. A. B. (2001) 'Effectiveness of parks in protecting tropical biodiversity', Science 291: 25-128.

Burns, C. E., Johnston, K. M. and Schmitz, O. J. (2003) 'Global climate change and mammalian species diversity in US national parks', Proceedings of the National Academy of Sciences 100: 11474-7.

Butchart, S. H. M. and 44 others (2010) 'Global biodiversity: indicators of recent declines', Science 328: 1164-8.

Cairns, J. (1977) 'Quantification of biological integrity', in R. K. Ballentine and L. J. Guarraia (eds) The Integrity of Water, US EPA Office of Water and Hazardous Materials, US Government Printing Office, Washington, DC.

Campbell, A., Kapos, V., Lysenko, I., Scharlemann, J. P. W., Dickson, B., Gibbs, H. K., Hansen, M. and Miles, L. (2008) Carbon Emissions from Forest Loss in Protected Areas, UNEP-WCMC, Cambridge.

Cardinale, B. J., Duffy, J. E., Gonzalez, A., Hooper, D. U., Perrings, C., Venail, P., Narwani, A., Mace, G. M., Tilman, D., Wardle, D. A., Kinzig, A. P., Daily, G. C., Loreau, M., Grace, J. B., Larigauderie, A., Srivastava, D. S. and Naeem, S. (2012) 'Biodiversity loss and its impact on humanity', Nature 486: 59-67.

Carvalheiro, L. G., Seymour, C. L., Veldtman, R. and Nicolson, S. W. (2010) 'Pollination services decline with distance from natural habitat even in biodiversity-rich areas', Journal of Applied Ecology 47: 810-20.

Caughley, G. (1994) 'Directions in conservation biology', Journal of Animal Ecology 63: 215-44. 
Chan, K. M., Shaw, M. R., Cameron, D. R., Underwood, E. C. and Daily, G. C. (2006) 'Conservation planning for ecosystem services', PLoS Biology 4(11): e379.

Chapman, C. A., Lawes, M. J., Naughton-Treves, L. and Gillespie, T. (2003) 'Primate survival in community-owned forest fragments: are metapopulation models useful amidst intensive use?', in L. K. Marsh (ed.) Primates in Fragments: Ecology and conservation, pp. 63-78, Kluwer Academic/Plenum Publishers, New York.

Clark, S., Bolt, K. and Campbell, A. (2008) Protected areas: an effective tool to reduce emissions from deforestation and forest degradation in developing countries, Working Paper, UNEP-WCMC, Cambridge.

Clevenger, A. P. and Sawaya, M. A. (2010) 'Piloting a non-invasive genetic sampling method for evaluating population-level benefits of wildlife crossing structures', Ecology and Society 15: 7.

Clevenger, A. P., Ford, A. T. and Sawaya, M. A. (2009) Banff wildlife crossings project: integrating science and education in restoring population connectivity across transportation corridors, Final report to Parks Canada Agency, Radium Hot Springs, British Columbia.

Conservation Measures Partnership (CMP) (2005) Taxonomies of Direct Threats and Conservation Actions, Conservation Measures Partnership, Washington, DC.

D. Conservation Measures Partnership (CMP) (2013) The Open Standards for the Practice of Conservation, Conservation Measures Partnership, Washington, DC. <www.conservationmeasures.org>

Convention on Biological Diversity (CBD) (2004) Programme of Work on Protected Areas, Secretariat of the Convention on Biological Diversity, Montreal. $<$ www.cbd.int/programmes/pa/pow-goals-alone. pdf>

Corlatti, L., Hacklaender, K. and Frey-Roos, F. (2009) 'Ability of wildlife overpasses to provide connectivity and prevent genetic isolation', Conservation Biology 23: $548-56$.

Daily, C. (ed.) (1997) Nature's Services: Societal dependence on natural ecosystems, Island Press, Washington, DC.
Deguise, I. E. and Kerr, J. (2006) 'Protected areas and prospects for endangered species conservation in Canada', Conservation Biology 20(1): 48-55.

di Minin, E., Hunter, L. T., Balme, G. A., Smith, R. J., Goodman, P. S. and Slotow, R. (2013) 'Creating larger and better connected protected areas enhances the persistence of big game species in the Maputaland-Pondoland-Albany biodiversity hotspot', PloS ONE 8: e71788.

Dd Dudley, N. (ed.) (2008) Guidelines for Applying Protected Area Management Categories, IUCN WCPA, Gland.

Dufrene, M. and Legendre, P. (1977) 'Species assemblages and indicator species: the need for a flexible asymmetrical approach', Ecological Monographs 67: 345-66.

Duggins, D. O. (1980) 'Kelp beds and sea otters: an experimental approach', Ecology 61: 447-53.

Edwards, C. J. and Regier, H. A. (eds) (1990) An Ecosystem Approach to the Integrity of the Great Lakes in Turbulent Times, Special Publication 90-4, Great Lakes Fishery Commission, Ann Arbor, MI.

Ellis, P. D. (2010) The Essential Guide to Effect Sizes: An introduction to statistical power, meta-analysis and the interpretation of research results, Cambridge University Press, Cambridge.

Ervin, J. (2002) WWF Rapid Assessment and Prioritization of Protected Area Management (RAPPAM) Methodology, WWF, Gland.

Estes, J. A., Terborgh, J., Brashares, J. S., Power, M. E., Berger, J., Bond, W. J. and Wardle, D. A. (2011) 'Trophic downgrading of planet Earth', Science 333(6040): 301-6.

Fagan, W. F. and Holmes, E. E. (2006) 'Quantifying the extinction vortex', Ecology Letters 9(1): 51-60.

Ferraro, K. P. J., Pfaff, A., Sanchez-Azofeifa, A. and Robalino, J. (2008) 'Measuring the effectiveness of protected area networks in reducing deforestation', Proceedings of the National Academy of Science 105(41).

Firecast (2014) Firecast Forest and Fire Monitoring and Alert System for the Tropics. <firealerts.conservation. org> 
Flather, C. H., Hayward, G. D., Beissinger, S. R. and Stephens, P. A. (2011) 'Minimum viable populations: is there a "magic number" for conservation practitioners?', Trends in Ecology and Evolution 26(6): 307-16.

Fortin, D., Beyer, H. L., Boyce, M. S., Smith, D. W., Duchesne, T. and Mao, J. S. (2005) 'Wolves influence elk movements: behavior shapes a trophic cascade in Yellowstone National Park', Ecology 86: 1320-30.

Foundations of Success (FOS) (2014) Foundations of Success. <www.fosonline.org/>

Frankham, R. (2005) 'Genetics and extinction', Biological Conservation 126: 131-40.

Freedman, B. and Hutchinson, T. C. (1980) 'Long term effects of smelter pollution at Sudbury, Ontario, on surrounding forest communities', Canadian Journal of Botany 58: 2123-40.

Gaston, K. J. (2000) 'Global patterns in biodiversity', Nature 405: 220-7.

Deldmann, J., Barnes, M., Coad, L., Craigie, I. D., Hockings, M. and Burgess, N. D. (2013) 'Effectiveness of terrestrial protected areas in reducing habitat loss and population declines', Biological Conservation 161: 230-8.

Gilchrist, G., Mallory, M. and Merkel, F. (2005) 'Can local ecological knowledge contribute to wildlife management? Case studies of migratory birds', Ecology and Society 10: 20.

Gilpin, M. E. and Soulé, M. E. (1986) Conservation Biology: The science of scarcity and diversity, Sinauer Associates, Sunderland, MA.

Gitzen, R. A., Millspaugh, J. J., Cooper, A. B. and Licht, D. S. (eds) (2012) Design and Analysis of Long-Term Ecological Monitoring Studies, Cambridge University Press, New York.

Gurd, D. B., Nudds, T. D. and Rivard, D. H. (2001) 'Conservation of mammals in eastern North American wildlife reserves: how small is too small?', Conservation Biology 15: 1355-63.

Hall, J. A. and Fleischman, E. (2010) 'Demonstration as a means to translate conservation science into practice', Conservation Biology 24: 120-7.
Hansen, M. C., Stehman, S. V., Potapov, P. V., Loveland, T. R., Townshend, J. R. G., de Fries, R. S., Pittman, K. W., Arunarwati, B., Stolle, F., Steininger, M. K., Carroll, M. and di Miceli, C. (2008) 'Humid tropical forest clearing from 2000 to 2005 quantified by using multitemporal and multiresolution remotely sensed data', Proceedings of the National Academy of Sciences. <doi:10.1073/ pnas.0804042105>

Hanski, I. and Simberloff, D. (1997) 'The metapopulation approach, its history, conceptual domain, and application to conservation', in I. Hanski and M. E. Gilpin (eds) Metapopulation Biology: Ecology, genetics, and evolution, pp. 5-26, Academic Press, San Diego.

Hebblewhite, M., White, C. A., Nietvelt, C. G., McKenzie, J., Hurd, T. E., Fryxell, J. M., Bayley, S. E. and Paquet, P. (2005) 'Human activity mediates a trophic cascade caused by wolves', Ecology 86 : 2135-44.

Heywood, V. H. (ed.) (1995) Global Biodiversity Assessment, Cambridge University Press, Cambridge.

Hooper, D. U., Adair, E. C., Cardinale, B. J., Byrnes, J. E. K., Hungate, B. A., Matulich, K. L., Gonzalez, A., Duffy, J. E., Gamfeldt, L. and O'Connor, M. I. (2012) 'A global synthesis reveals biodiversity loss as a major driver of ecosystem change', Nature 486: 105-8.

Hughes, A. R., Inouye, B. D., Johnson, M. T., Underwood, N. and Vellend, M. (2008) 'Ecological consequences of genetic diversity', Ecology Letters 11: 609-23.

International Joint Commission (1978) Revised Great Lakes Water Quality Agreement of 1978, International Joint Commission, United States of America and Canada.

International Union for Conservation of Nature (IUCN) (2001) IUCN Red List Categories and Criteria. Version 3.1, Species Survival Commission, IUCN, Gland.

International Union for Conservation of Nature (IUCN) (2005a) Conservation Actions Authority File. Version 1.0, IUCN Species Survival Commission, Cambridge. <iucn.org/webfiles/doc/SSC/RedList/ AuthorityF/consactions.rtf> 
International Union for Conservation of Nature (IUCN) (2005b) Threats Authority File. Version 2.1, IUCN Species Survival Commission, Cambridge. $<$ iucn.org/webfiles/doc/SSC/RedList/AuthorityF/ threats.rtf $>$

International Union for Conservation of Nature (IUCN) (2006) Habitats Authority File. Version 1.0, IUCN Species Survival Commission, Cambridge. <iucn.org/webfiles/doc/SSC/RedList/AuthorityF/ habitats.rtf>

Janzen, D. (1999) 'Gardenification of tropical conserved wildlands: multitasking, multicropping and multiusers', Proceedings of the National Academy of Sciences 96: 5987-94.

Klijn, F. (1994) 'Ecosystem classification for environmental management', Ecology and Environment 2: 85-116.

Klijn, F. and de Haes, H. A. U. (1994) A Hierarchical Approach to Ecosystems and its Implications for Ecological Land Classification, Springer, Berlin.

Landres, P. B., Verner, J. and Thomas, J. W. (1988) 'Ecological uses of vertebrate indicator species', Conservation Biology 2: 316-28.

Landry, M., Thomas, V. G. and Nudds, T. D. (2001) 'Sizes of Canadian national parks and the viability of large mammal populations: policy implications', George Wright Forum 18(1): 13-23.

Le Saout, S., Hoffmann, M., Shi, Y., Hughes, A., Bernard, C., Brooks, T. M., Bertzky, B., Butchart, S. H. M., Stuart, S. N., Badman, T. and Rodrigues, A. S. L. (2013) 'Protected areas and effective biodiversity conservation', Science 15: 803-5.

Levins, R. (1970) 'Extinction', Lectures on Mathematics in the Life Sciences 2: 75-107.

Likens, G. E., Bormann, F. H., Pierce, R. S. and Reiners, W. A. (1978) 'Recovery of a deforested ecosystem', Science 199: 492-6.

Lindenmayer, D. B. (2009) Forest Pattern and Ecological Process: A synthesis of 25 years of research, CSIRO Publishing, Melbourne.

Lindenmayer, D. B. and Franklin, J. F. (2002) Conserving Forest Biodiversity: A comprehensive multiscaled approach, Island Press, Washington, DC.
Lindenmayer, D. B. and Lichens, G. F. (2010) Effective Ecological Monitoring, CSIRO Publishing, Melbourne.

Lindenmayer, D. B., Hobbs, R. J., Likens, G. E., Krebs, C. and Banks, S. C. (2011) 'Newly discovered landscape traps produce regime shifts in wet forests', Proceedings of the National Academy of Sciences 108: 15 887-91.

Lindenmayer, D. B., Mackey, B. G., Mullen, I. C., McCarthy, M. A., Gill, A. M., Cunningham, R. B. and Donnelly, C. F. (1999) 'Factors affecting stand structure in forests-are there climatic and topographic determinants?', Forest Ecology and Management 123: 55-63.

McCullough, D. R. (ed.) (1996) Metapopulations and Wildlife Conservation, Island Press, Washington, DC. MacKinnon, J., MacKinnon, K., Child, G. and Thorsell, J. (1986) Managing Protected Areas in the Tropics, IUCN and UNEP, Cambridge.

MacKinnon, K. (2005) 'Parks, peoples and policies: conflicting agendas for forests in Southeast Asia', in E. Bermingham, C. W. Dick and C. Moritz (eds) Tropical Rainforests: Past, present and future, pp. 558-82, University of Chicago Press, Chicago.

MacKinnon, K., Hatta, G., Halim, H. and Mangalik, A. (1996) The Ecology of Kalimantan: Indonesian Borneo, Periplus, Singapore.

MacKinnon, J., MacKinnon, K., Child, G. and Thorsell, J. (1986) Managing Protected Areas in the Tropics, IUCN, Gland.

Margoluis, R. and Salafsky, N. (1998) Measures of Success: Designing, managing, and monitoring conservation and development projects, Island Press, Washington, DC.

Margules, C. R. and Pressey, R. L. (2000) 'Systematic conservation planning', Nature 405: 243-53.

Martin, L. (1990) 'Flying foxes of the Brisbane River', in P. Davie, E. Stock and D. Low Choy (eds) The Brisbane River: A source-book for the future, Australian Littoral Society in association with the Queensland Museum, Brisbane. 
Mattila, H. R. and Seeley, T. D. (2007) 'Genetic diversity in honey bee colonies enhances productivity and fitness', Science 317(5836): 362-4. Mills, L. S., Soulé, M. E. and Doak, D. F. (1993) 'The keystone-species concept in ecology and conservation', BioScience 43(4): 219-24.

DD Miradi (2007) Miradi Adaptive Management Software for Conservation Projects. <www.miradi.org>

Murphy, C. and Robertson, A. W. (2000) Preliminary Study of the Effects of Honey Bees (Apis mellifera) in Tongariro National Park, New Zealand Department of Conservation, Wellington.

National Parks Service (NPS) (2006) US National Parks Service Management Policies: The guide to managing the national park system, US National Parks Service, Washington, DC. <www.nps.gov/policy/mp/ chapter4.htm>

National Parks Service (NPS) (2014) US National Parks Service Inventory and Monitoring Program, US National Parks Service, Washington, DC. <science. nature.nps.gov/im/>

Nel, P. (1997) Conservation and Management of Biodiversity in Protected Areas in the North West Province, Conservation Management Division, North West Parks and Tourism Board, Mafikeng, South Africa. <www.cbd.int/doc/meetings/nbsap/ nbsapcbw-seafr-01/other/nbsapcbw-seafr-01-nwptbpa-en.pdf>

Newmark, W. D. (1995) 'Extinction of mammal populations in western North American national parks', Conservation Biology 9: 512-26.

Niemi, G. J. and McDonald, M. E. (2004) 'Application of ecological indicators', Annual Review of Ecology, Evolution and Systematics 35: 89-111.

Noss, R. F. (1983) 'A regional landscape approach to maintain diversity', BioScience 33(11): 700-6.

Noss, R. F. (1990) 'Indicators for monitoring biodiversity: a hierarchical approach', Conservation Biology 4: 355-64.

Oakley, K. L., Thomas, L. P. and Fancy, S. G. (2003) 'Guidelines for long-term monitoring protocols', Wildlife Society Bulletin 31: 1000-3.

O’Brien, T. (2014) Camera Traps for Conservation: Monitoring protected area investment, Zoological Society of London, London.
Ojeda, V. S., Suarez, M. L. and Kitzberger, T. (2007) 'Crown dieback events as key processes creating cavity habitat for magellanic woodpeckers', Austral Ecology 32(4): 436-45.

Ollerton, J., Winfree, R. and Tarrant, S. (2011) 'How many flowering plants are pollinated by animals?', Oikos 120: 321-6.

Olson, D., Dinerstein, E., Wikramanayake, E. D., Burgess, N. D., Powell, G. V. N., Underwood, E. C., d'Amico, J. A., Itoua, I., Strand, H. E., Morrison, J. C., Loucks, C. J., Allnutt, T. F., Ricketts, T. H., Kura, Y., Lamoreux, J. F., Wettengel, W. W., Hedao, P. and Kassem, K. R. (2001) 'Terrestrial ecoregions of the world: a new map of life on earth', BioScience 51: 933-8.

Open Parks Network (OPM) (2014) Open Parks Network. <openparksnetwork.org/>

Pacioni, C., Wayne, A. D. and Spencer, P. B. S. (2011) 'Effects of habitat fragmentation on population structure and long-distance gene flow in an endangered marsupial: the woylie', Journal of Zoology 283: 98-107.

Paine, R. T. (1969) 'A note on trophic complexity and community stability', American Naturalist 103: 91-3.

Patrick, R. (1967) 'Diatom communities in estuaries', American Association for the Advancement of Science (83): 311-15.

Pechmann, H. K., Scott, D. E., Semlitsch, R. D., Caldwell, I. P., Vitt, L. and Gibbons, J. W. (1991) 'Declining amphibian populations: the problem of separating human impacts from natural fluctuations', Science 253: 892-5.

Pimentel, D., Westra, L. and Noss, R. (eds) (2000) Ecological Integrity: Integrating environment, conservation, and health, Island Press, Washington, DC.

Pimm, S. L. (1982) Food Webs, Chapman \& Hall, London.

Project Noah (2014) A Tool to Explore and Document Wildlife and a Platform to Harness the Power of Citizen Scientists Everywhere, Project Noah. $<$ www.projectnoah.org > 
Rabinowitz, D. (1981) 'Seven forms of rarity', in H. Synge (ed.) The Biological Aspects of Rare Plant Conservation, pp. 205-17, John Wiley \& Sons, Hoboken, NJ.

Raesly, E. J. (2001) 'Progress and status of river otter reintroduction projects in the United States', Wildlife Society Bulletin 29: 856-62.

Rafferty, C. and Pacioni, C. (2012) Woodland reserve, Whiteman Park: a case study in the conservation value of post-care animals, Australian Wildlife Rehabilitation Conference, Townsville, Queensland. $<$ www.awrc.org.au/uploads/5/8/6/6/5866843/ rafferty_pacioni_value_post_care_2012.pdf>

Ripple, W. J., Larsen, E. J., Renkin, R. A. and Smith, D. W. (2001) 'Trophic cascades among wolves, elk, and aspen on Yellowstone National Park's northern range', Biological Conservation 102: 227-34.

Rivard, D. H., Poitevin, J., Plasse, D., Carleton, M. and Currie, D. J. (2000) 'Changing species richness and composition in Canadian national parks', Conservation Biology 14: 1099-109.

Salafsky, N. and Margoluis, R. (1999) 'Threat reduction assessment: a practical and costeffective approach to evaluating conservation and development projects', Conservation Biology 13: 830-41.

Salafsky, N., Butchart, S. H. M., Salzer, D., Stattersfield, A. J., Neugarten, J., Hilton-Taylor, C., Collen, B., Master, L., O'Connor, S. and Wilkie, D. (2009) 'Pragmatism and practice in classifying threats: reply to Balmford et al.', Conservation Biology 23: 488-93.

Salafsky, N., Salzer, D., Ervin, J., Boucher, T. and Ostlie, W. (2003) Conventions for Defining, Naming, Measuring, Combining, and Mapping Threats in Conservation: An initial proposal for a standard system, Conservation Measures Partnership. <www.conservationmeasures.org>

Salafsky, N., Salzer, D., Stattersfield, A. J., Hilton-Taylor, C., Neugarten, R., Butchart, S. H. M., Collen, B., Cox, N., Master, L. L., O'Connor, S. and Wilkie, D. (2008) 'A standard lexicon for biodiversity conservation: unified classifications of threats and actions', Conservation Biology 22: 897-911.

Sawaya, M. A., Clevenger, A. P. and Kalinowski, S. T. (2013) 'Demographic connectivity for ursid populations at wildlife crossing structures in Banff National Park', Conservation Biology 27: 721-30.
Schulze, E. D. and Mooney, H. A. (1993) Biodiversity and Ecosystem Function, Springer Verlag, New York.

Shaffer, M. (1978) Determining minimum viable population sizes: a case study of the grizzly bear (Ursus arctos L.), $\mathrm{PhD}$ dissertation, Duke University, Durham, NC.

Simberloff, D. (1998) 'Flagships, umbrellas, and keystones: is single-species management passé in the landscape era?', Biological Conservation 83: 247-57.

Soulé, M. E. and Simberloff, D. (1986) 'What do genetics and ecology tell us about the design of nature reserves', Biological Conservation 35: 19-40.

Dd Spalding, M. D., Fox, H. E., Allen, G. R., Davidson, N., Ferdaña, Z. A., Finlayson, M., Halpern, B. S., Jorge, M. A., Lombana, A., Lourie, S. A., Martin, K. D., McManus, E., Molnar, J., Recchia, C. A. and Robertson, J. (2007) 'Marine ecoregions of the world: a bioregionalization of coastal and shelf areas', Bioscience 57: 573-83.

Steege, H. and 119 others (2013) 'Hyperdominance in the Amazonian tree flora', Science 342: 1243092.

Stokes, M. (2012) 'Population ecology at work: managing game populations', Nature Education Knowledge 3(10): 5.

d] The Nature Conservancy (TNC) (2000) The Five-S Framework for Site Conservation: A practitioner's handbook for site conservation planning and measuring conservation success. Volume I, 2nd edn, The Nature Conservancy, Arlington, VA.

Dd The Nature Conservancy (TNC) (2007) Conservation Action Planning: Developing strategies, taking action and measuring success at any scale, The Nature Conservancy, Arlington, VA.

Tilman, D. and Kareiva, P. M. (eds) (1997) Spatial Ecology: The role of space in population dynamics and interspecific interactions. Volume 30, Princeton University Press, Princeton, NJ.

Tingley, M. W., Estes, L. D. and Wilcove, D. S. (2013) 'Climate change must not blow conservation off course', Nature 500: 271-2.

Traill, L. W., Brook, B. W., Frankham, R. R. and Bradshaw, C. J. (2010) 'Pragmatic population viability targets in a rapidly changing world', Biological Conservation 143: 28-34. 
Tucker, C. J., Pinzon, J. E., Brown, M. E., Slayback, D. A., Pak, E. W., Mahoney, R., Vermote, E. F. and El Saleous, N. (2005) 'An extended AVHRR 8-km NDVI dataset compatible with MODIS and SPOT vegetation NDVI data', International Journal of Remote Sensing 26: 4485-98.

Udvardy, M. D. F. (1975) A classification of the biogeographical provinces of the world, IUCN Occasional Paper No. 18, IUCN, Gland.

Underwood, A. J. (1994) 'On beyond BACI: sampling designs that might reliably detect environmental disturbances', Ecological Applications 4: 3-15.

van der Ree, R., Heinze, D., McCarthy, M. and Mansergh, I. (2009) 'Wildlife tunnel enhances population viability', Ecology and Society 14(2). <www.ecologyandsociety.org/vol14/iss2/art7/>

Watson, L. H., Odendaal, H. E., Barry, T. J. and Pietersen, J. (2005) 'Population viability of Cape mountain zebra in Gamka Mountain Nature Reserve, South Africa: the influence of habitat and fire', Biological Conservation 122: 173-80.

Westemeier, R. L., Brawn, J. D., Simpson, S. A., Esker, T. L., Jansen, R. W., Walk, J. W., Kershner, E. L., Bouzat, J. L. and Paige, K. N. (1998) 'Tracking the long-term decline and recovery of an isolated population', Science 282: 1695-8.

Westman, W. E. (1990) 'Managing for biodiversity', Bioscience 40: 26-33.

White, C. A. and Fisher, W. (2007) 'Ecological restoration in the Canadian Rocky Mountains: developing and implementing the 1997 Banff National Park Management Plan', in M. Price (ed.) Mountain Area Research and Management, pp. 21742, Earthscan, London.

White, C. A., Hurd, T. E., Hebblewhite, M. and Pengelly, I. R. (2007) Mitigating fire suppression, highway and habitat fragmentation effects in the Bow Valley ecosystem, Banff National Park: preliminary evaluation with a before-after-controlimpact (BACI) design with path analysis, Paper presented at Monitoring the Effectiveness of Biological Conservation Conference, Richmond, British Columbia, 2-4 November 2004. <www.forrex.org/events/mebc/papers.html>

White, C. A., Olmsted, C. E. and Kay, C. E. (1998) 'Aspen, elk, and fire in the Rocky Mountain national parks of North America', Wildlife Society Bulletin 26: 449-62.
Whyte, I. J. (2001) 'Headaches and heartaches — the elephant management dilemma', in D. Schmidtz and E. Willot (eds) Environmental Ethics: Introductory readings, pp. 293-305, Oxford University Press, New York.

Wieczorek, J., Bloom, D., Guralnick, R., Blum, S., Döring, M., de Giovanni, R., Robertson, T. and Vieglais, D. (2012) 'Darwin Core: an evolving community-developed biodiversity data standard', PLoS ONE 7(1): e29715. <doi:10.1371/journal. pone.0029715>

Wildlife Conservation Society (WCS) (2002) 'Using conceptual models to set conservation priorities', Living Landscapes Bulletin 5: 1-4.

Williams, W. T. (1980) 'Air pollution disease in the Californian forests: a base line for smog disease on ponderosa and Jeffery pines in the Sequoia and Los Padres National Forests, California', Environmental Science \& Technology 14: 179-82.

Woodley, S. (1993) 'Monitoring and measuring ecosystem integrity in Canadian national parks', in S. J. Woodley, G. Francis and J. Kay (eds) Ecosystem Integrity and the Management of Ecosystems, pp. 155-76, St Lucie Press, Delray Beach, FL.

DD Woodley, S. (2010) 'Ecological integrity: a framework for ecosystem-based management', in D. N. Cole and L. Yung (eds) Beyond Naturalness: Rethinking park and wilderness stewardship in an era of rapid change, pp. 106-25, Island Press, Washington, DC.

Woodley, S., Bertzky, B., Crawhall, N., Dudley, N., Londoño, J. M., MacKinnon, K., Redford, K. and Sandwith, T. (2012) 'Meeting Aichi Target 11: what does success look like for protected area systems?', PARKS 18(1): 23-36.

Woodley, S., Francis, G. and Kay, J. (eds) (1993) Ecosystem Integrity and the Management of Ecosystems, St Lucie Press, Boca Raton, FL.

Woodwell, G. E. (1970) 'Effects of pollution on the structure and physiology of ecosystems', Ambio 11: $143-8$.

World Checklist of Selected Plant Families (WCSP) (2008) World Checklist of Selected Plant Families, The Board of Trustees of the Royal Botanic Gardens, Kew, UK. <www.kew.org/wcsp>

World Resources Institute (2005) Ecosystems and Human Well-Being: Biodiversity synthesis, World Resources Institute, Washington, DC. 


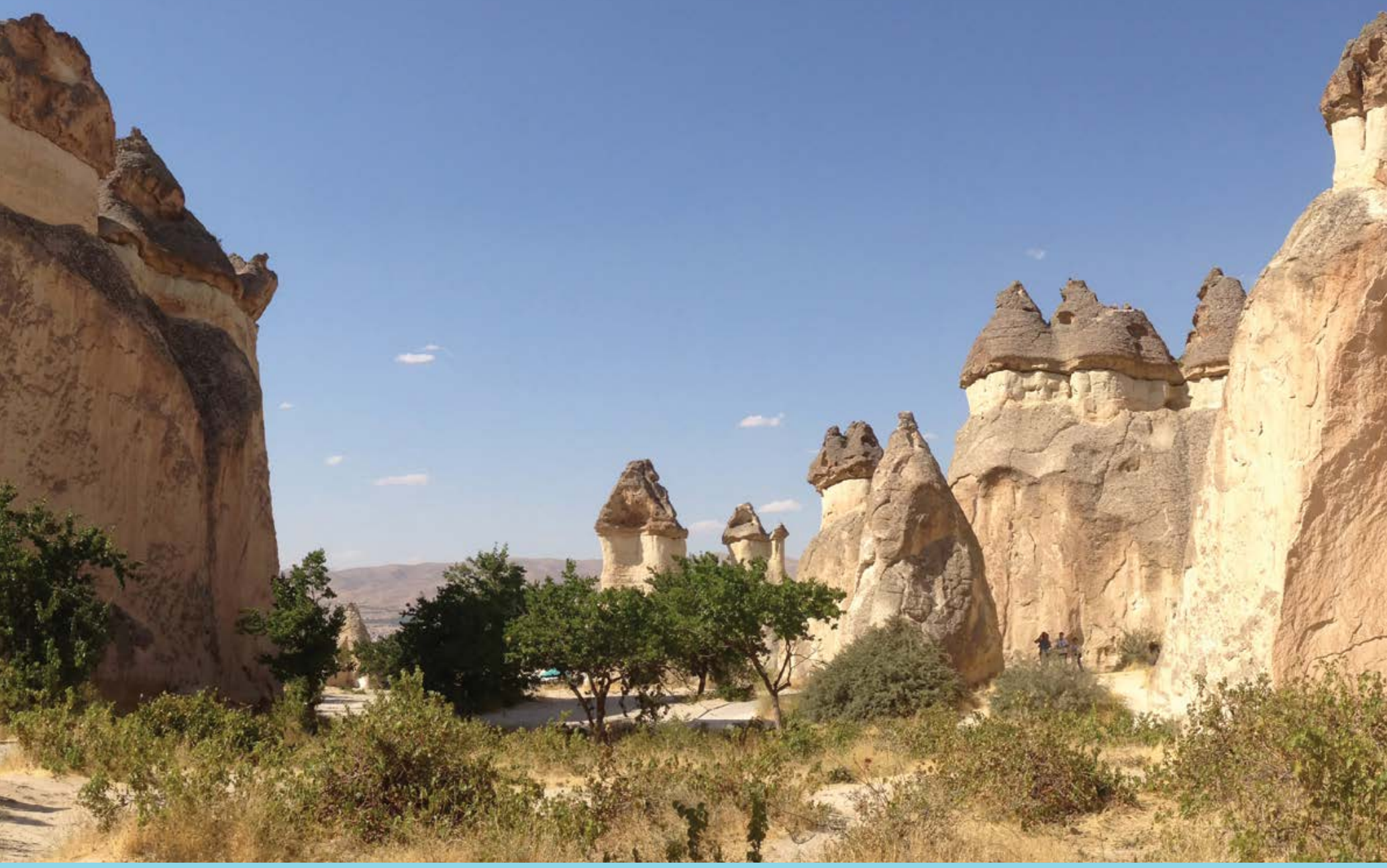

CHAPTER 22

MANAGING CULTURAL USES AND FEATURES

Principal authors:

Fausto Sarmiento and Edwin Bernbaum

\section{Supporting authors:}

Jessica Brown, Jane Lennon and Sue Feary

\section{CONTENTS}

- Introduction

- Managing for contemporary cultural practices

- Managing cultural use with integrative approaches

- Managing for cultural spiritual values

- Managing cultural use of sacred sites

- Managing cultural features (tangible cultural heritage)

- Conclusion

- References

IUCN 3 WCPA 


\section{PRINCIPAL AUTHORS}

FAUSTO SARMIENTO is the Professor of Geography and Director of the Neotropical Montology Collaboratory at the University of Georgia, Athens, USA.

EDWIN BERNBAUM is Co-Chair of the International Union for Conservation of Nature (IUCN) Specialist Group on Cultural and Spiritual Values of Protected Areas and Senior Fellow at The Mountain Institute, Berkeley, California.

\section{SUPPORTING AUTHORS}

JESSICA BROWN is Executive Director of the New England Biolabs Foundation, and chairs the IUCN World Commission on Protected Areas (WCPA) Specialist Group on Protected Landscapes/Seascapes.

JANE LENNON is a historical geographer with more than 30 years' experience in natural and cultural heritage management, and is Honorary Professor in Landscape Heritage at the University of Melbourne, Australia.

SUE FEARY is an archaeologist and national park manager, with 25 years' experience in management of natural and cultural heritage and consulting with Aboriginal Australians.

\section{ACKNOWLEDGMENTS}

The authors would like to thank Josep-María Mallarach, Thymio Papayannis, Mark Infield, Arthur Mugisha, Shalini Dhyani and Deepak Dhyani for their case study contributions. Also, thanks to Alejandro Argumedo for the example of the Potato Park and to Randall Borman for the example of the Cofán Bermejo Ecological Reserve. Thanks go to Sharon Sullivan for a critical and very useful review of an early draft of the chapter.

\section{CITATION}

Sarmiento, F., Bernbaum, E., Brown, J., Lennon, J. and Feary, S. (2015) 'Managing cultural features and uses', in G. L. Worboys, M. Lockwood, A. Kothari, S. Feary and I. Pulsford (eds) Protected Area Governance and Management, pp. 685-714, ANU Press, Canberra.

\section{TITLE PAGE PHOTO}

Göreme National Park and the Rock Sites of Cappadocia, World Heritage Property, Turkey: the soft volcanic rocks have been eroded into spectacular pillars and minaret-like forms. It has been settled since Roman times and includes many rock-hewn sanctuaries Source: Ingrid Iversen 


\section{Introduction}

In this chapter, we explore the administration of cultural uses and the management of cultural features within protected areas. Our review emphasises some of the emerging shifts in thinking about cultural heritage, such as the integration of the protection of natural and cultural objectives, emerging conservation paradigms of cultural landscapes and biocultural diversity, and the growing attention being paid to the role of indigenous peoples and local communities in stewardship of protected areas. We also discuss principles and practices applicable to management of cultural features, including built heritage and places of religious significance.

Humans use the modern protected area system in many different ways, and in one sense, all human use is cultural. Uses can be prompted by the protected area status itself, which may offer, for example, unique recreation, educational or commercial tourism opportunities. Uses can also include religious practices or activities that shaped the environment long before the protected area came into being.

Recognising that biological and cultural diversity have coevolved and that conservation of biological diversity is often linked to the traditional lifestyles of indigenous and local communities brought about important changes in protected area thinking. Use of terms such as 'biocultural diversity' and 'biocultural heritage' reflect a changing paradigm that envisages human activity as part of the ecosystem process. Cultural use encompasses all human activity within a protected area, and managing that use has many different dimensions. It can include law enforcement against illegal activities, through to devolution of power to local communities to manage their resource use within a protected area. In this chapter, we focus on integrated approaches for managing contemporary use of protected areas by indigenous and local communities. We also present information on the complexities of managing the use of sacred sites by different religious groups and the public.

As well as intangible heritage, most protected areas contain tangible evidence of past human use that can span many thousands of years. It may be valuable, rare or irreplaceable. These cultural features can include ancient archaeological sites, cultural landscapes, buildings, monuments or pathways, or complexes of features. Many continue to have great meaning to the people with whom they are associated. Managing these cultural features is therefore not only about managing or preserving historic evidence (sometimes termed 'fabric'); equally it can be about engaging with a local community, family

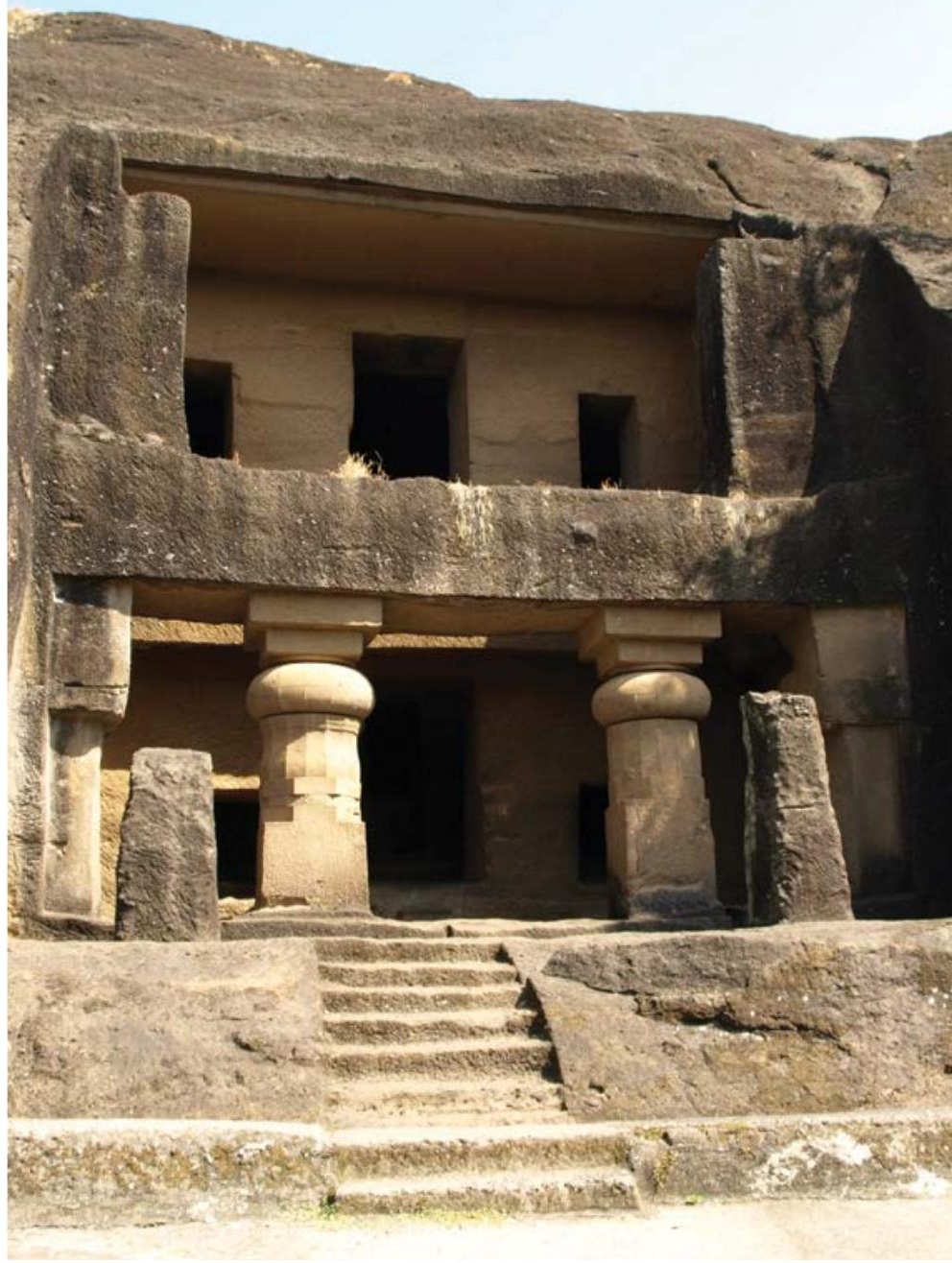

Buddhist caves, Kanheri, Sanjay Gandhi National Park, India: the carved caves in volcanic breccia illustrate Buddhist influence on the art and culture of India

Source: Graeme L. Worboys

or indigenous group whose ancestors constructed the building or created the cultural landscape. We apply the principles and practices of cultural heritage management to the conservation of cultural features.

\section{Managing for contemporary cultural practices}

The International Union for Conservation of Nature (IUCN) classification system-from Category I to Category VI-represents a decreasing degree of naturalness and an increasing degree of 'culturalness' (Dudley 2008; see Chapter 2, Figure 2.1). It offers guidance to those designating or managing protected areas at the site or system level. In the 21 st century, the majority of protected areas across the world experience some level of human use, which can vary from 'leave only footprints' to subsistence resource use by indigenous peoples and communities living in or close to protected areas. 
The objectives for different IUCN categories help prescribe the type and extent of cultural use. Hence Category I (nature reserve and wilderness) protected areas encourage low-impact bushwalking and passive enjoyment. Category II (national park) protected areas are often promoted for their recreational and tourism values and some receive very high levels of visitor use in pursuit of these values (see Chapter 23). Research and education, especially at primary and secondary school levels, are also the hallmarks of a national park. Category III (natural monument or feature) relates to natural features, but they may be highly significant as sacred sites and thus receive high levels of visitation from pilgrims as well as from the general public. Category IV (habitat/species management area) may have low levels of cultural use, unless the species habitat is a culturally determined one-for example, the Chimborazo Fauna Reserve in Ecuador. This reserve was created in the late 1970s to provide for the reintroduction of Andean camelids whose populations had almost disappeared in the region. The Ecuadorian Government reintroduced vicuña (Vicugna vicugna) to the area surrounding the Chimborazo volcano and also introduced llamas (Lama glama) for local indigenous communities to raise and manage.

Category $\mathrm{V}$ areas (protected landscape/seascape) are places visibly shaped by the interactions of humans with the natural environment-these are biocultural or cultural landscapes. Their existence relies on processes that sustain this relationship, achieved through the role local and indigenous communities have as stewards (Brown et al. 2005). Ongoing cultural use of protected landscapes is critical to their existence. Category VI areas combine ecosystem conservation with traditional natural resourceuse management systems. Most of the area remains in a natural condition with a proportion subject to low-level non-industrial use of natural resources. While traditional ecological knowledge is applicable and combined with Western science in all categories, it generally has its highest level of expression in Categories V and VI.

A useful tool for protected area managers and conservation practitioners is the matrix created by combining the vertical management categories with the horizontal governance styles (see Chapters 7 and 8). This matrix framework recognises that protected areas are created and cared for by a diverse array of stewards. This tool and other events have reinforced an important shift in thinkingfrom the conventional view that protected areas are created and managed only by governments, to one that recognises that they are also places created and managed by communities, private organisations or individuals in diverse arrangements. All protected areas-from a strict nature reserve to an extractive reserve-are capable of being managed by any of the governance regimes. Countries are now encouraged by the IUCN to expand their national protected area systems by incorporating the full range of governance types (Kothari et al. 2013). The protected area matrix can potentially facilitate inclusion of the biocultural heritage paradigm - appreciation of the coevolution of nature and culture-in all management categories and governance options (Dudley 2008; Borrini-Feyerabend et al. 2013).

The Fifth World Parks Congress in 2003 produced the Durban Accord, which enshrined the rights and responsibilities of indigenous and local communities, and raised the profile of diverse governance regimes, in particular those involving collaborative and community governance (Brown and Kothari 2011). At the congress, the role of communities in creating and managing protected areas was, for the first time, a central part of the debate, launching significant work on the theme of governance. The topic of protecting biocultural/cultural landscapes and seascapes also featured prominently, explored in a workshop bringing out case study experience from diverse regions, and resulting in a book on a new approach to working with local communities in meeting conservation objectives that integrate nature and culture (Brown et al. 2005).

Alongside the Durban Accord, the congress produced a 'Message to the Convention on Biological Diversity', with specific recommendations related to the involvement of indigenous and local communities and rights-based approaches to conservation. Importantly, these points were subsequently taken up in the Convention on Biological Diversity (CBD) Programme of Work on Protected Areas (PoWPA), thus helping to shape policy in the countries which are signatories to the convention (Kothari et al. 2013).

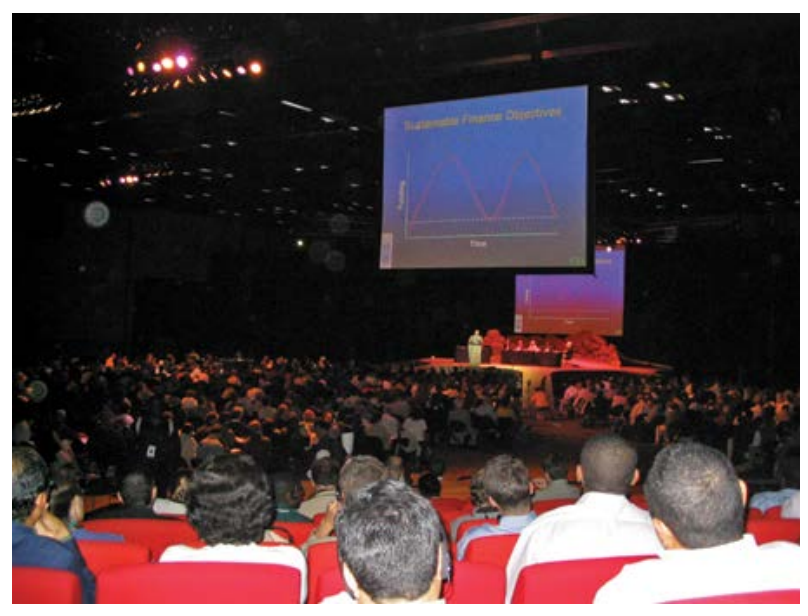

Plenary session of the 2003 Durban World Parks Congress, South Africa

Source: Graeme L. Worboys 


\section{Case Study 22.1 Ranger training by the Cofán people}

The Cofán people (or A'l) have been able to achieve stronger protection for their territory within the extensive Cofán-Bermejo Ecological Reserve in Ecuador, South America. They have trained a select group of indigenous rangers and tourist guides who are charged with patrolling the boundaries of the reserve and informing visitors about the key biodiversity protection mechanisms in place.
Under the leadership of Randall Borman, a multilingual shaman of the Cofán nation, they have been able to negotiate for environmental remediation of the oil-polluted riverine ecosystems of the headwaters of the Napo River watershed, including the Coca Falls (formerly San Rafael), one of the most photographed waterfalls in one of the most biodiverse ecoregions on Earth (Cepek 2012).
Appreciating and working with a diversity of cultures are now among the guiding principles in the administration and management of protected areas, with the realisation that protection of the natural and cultural world can be dependent on the support and knowledge of people living in or near protected areas. Local and indigenous communities once excluded now have a pivotal role to play as custodians of the landscape (Brown and Hay-Edie 2013). This reflects recognition that the stewardship practised by local and indigenous communities from antiquity has been important in retaining the very values that give the area its protected status (Rössler 2003). This trend of indigenous stewardship is illustrated with an example from Latin America (Case Study 22.1). This example highlights the increasing influence of community-driven initiatives for conservation 'from the ground up'. They contrast with the topdown approaches that characterised the declaration of protected areas in previous decades. The example also demonstrates indigenous cultural revival (Sarmiento and Hitchner in press) along with a more assertive participation by local cultural groups, mainly indigenous nations, at both the national political governance and the international intellectual leadership levels, and especially in the World Heritage program (Te Heuheu et al. 2012). Consideration of cultural uses and values is now a required step in conservation planning, and its importance is reflected in training and two-way learning programs (Case Study 22.2).

\section{Managing cultural use with integrative approaches}

Historically, conservation of nature through the formal designation of protected areas was driven, guided and sometimes controlled by ideals of the Western world (see Chapters 4, 5 and 7). It is now recognised that accommodating livelihood needs and recognising local and traditional ecological knowledge built over centuries to manage culturally modified landscapes are potentially ways to enhance conservation practices in protected areas of every designation. Protected areas are key elements in any strategy to conserve and sustain biodiversity in the landscape and seascape, and bridging the nature/ culture divide may be important for making protected areas meet human needs and future nature conservation challenges. We risk ignoring the full value of protected areas (Harmon and Putney 2003) unless we embrace a diverse array of values-natural and the tangible and intangible components of culture-in protected area planning, designation and management (Phillips 2003).

Three important trends in this direction are: creation of protected areas based on Category V; continuing progress in designation of World Heritage cultural landscapes in diverse geographical regions, particularly in nominations led by indigenous and local communities; and emergence of the concept of biocultural heritage.

\section{IUCN Category V protected areas}

IUCN Category V protected areas, long associated with the protected areas of Europe, have increasingly been taken up and applied in diverse regions of the world, in places like Andean South America, East Africa and Oceania (Brown et al. 2005; Dudley and Stolton 2012), including those associated with the protection of agrobiodiversity and food security (Amend et al. 2008). These relatively recent protected landscape/seascape designations typically draw on the Category $\mathrm{V}$ definition as presented in the IUCN guidelines and adapted to a specific national or provincial context. Following the 2008 review of IUCN protected area management categories, the following updated definition of Category $\mathrm{V}$ protected areas is included in the current version of the IUCN guidance:

A protected area where the interaction of people and nature over time has produced an area of distinct character with significant ecological, biological, cultural and scenic value; and where safeguarding the integrity of this interaction is vital to protecting and sustaining the area and its associated nature conservation and other values. (Dudley 2008:20) 


\section{Case Study 22.2 The integration of local cultural values into the management of Rwenzori Mountains National Park, Uganda}

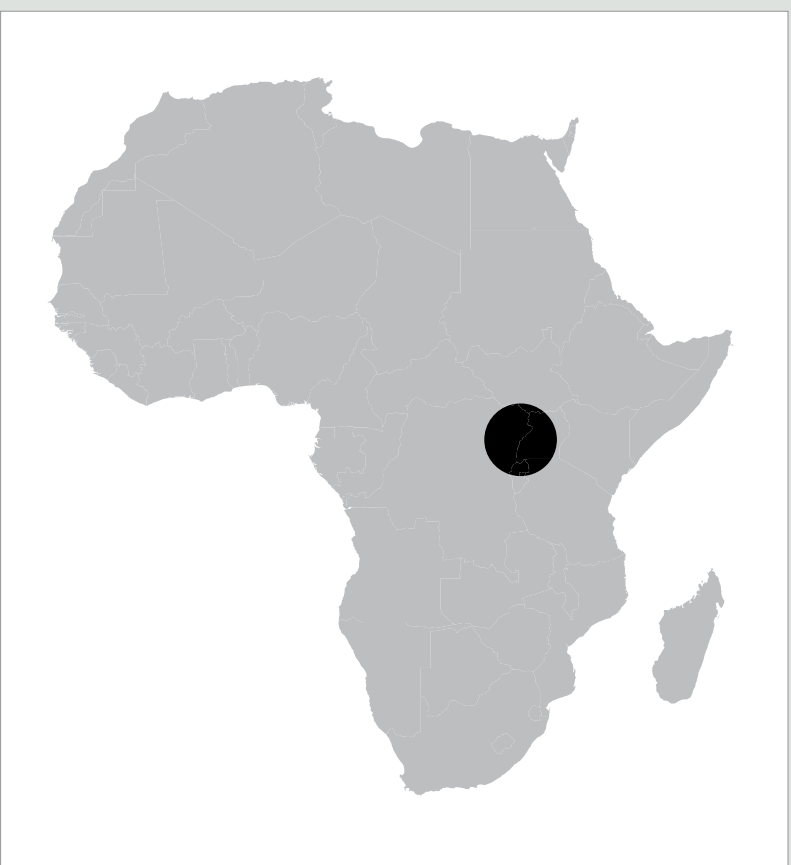

Figure 22.1 Indicative location on the African continent, Rwenzori Mountains National Park, Uganda

Source: US NPS

In 2006, Fauna and Flora International and the Uganda Wildlife Authority (UWA) began a partnership to integrate local cultural values into the conservation and management of the Rwenzori Mountains National Park. Conservation goals were not being met, however, due to lack of local and political support, and relations between the people and park managers remained difficult and distant. The Culture, Values and Conservation Project sought to improve this situation by recognising the importance of local values and interests for achieving conservation outcomes.

The principle underlying the project was that engaging communities by investigating their cultural values and working to integrate them into the management of the park would be more effective at creating local support and active engagement than describing the park's importance in terms of science and economics and explaining the need to protect it using Western values.

The Banyarwenzururu or mountain people have lived for centuries in the mountains, farming the foothills, harvesting resources in the forests and hunting in the highland moors and lowland plains. Social and political organisation is based on the mountain ridges that descend from the peaks to the plains. Each ridge is 'served' by a sacred site. Spiritual power originates with Kithasamba-who inhabits the snowcaps of the mountains-and protected areas pass to the King (Omusinga). From the King, power flows to clan chiefs (Ise' malhambo) and then to ridge leaders (Bakulu B'bulhambo) responsible for ceremonies to purify the ridges, protecting and bringing good fortune to the community. Ridge leaders also ensured appropriate and respectful behaviour of people harvesting or hunting in the mountains and hence sharing space with the gods.
Although not understood as conservation in the modern Western sense, these institutions and cultural norms helped sustain natural and social order. Ridge leaders effectively managed resource use by the ridge community in the forests above their ridge. Park management did not comprehend the effectiveness of this traditional governance working across ridges and they prevented access to the sacred sites, weakening the cultural connection between the people and the mountain.

To integrate Banyarwenzururu culture into the park, the project:

- introduced the wardens and rangers to the basic ideas of the approach and helped build capacity and interest in a cultural values approach

- engaged UWA's protected area planning team to integrate assessment of cultural values into formal park planning processes

- approached community groups and institutions to encourage them to work with the park and helped them assess the values of the Rwenzori Mountains that were important to them

- facilitated negotiations to help communities and park managers agree on key values for the park that could support both community and park interests and objectives

- supported local champions of the values and practices linking local people to the park and helped them engage with park staff to integrate local values into day-to-day park management

- helped UWA review their policies, practices and programs from a cultural values perspective using achievements, problems encountered and lessons learned

- encouraged cultural institutions and park authorities to negotiate mechanisms for collaboration that harmonised traditional and official interests

- helped draft memoranda of understanding and revise park management plans, explicitly reflecting agreements on cultural values.

Adopting a cultural values approach will not address all the challenges faced by conservation, but it offers promise for demonstrating mutually beneficial incentives for managing protected areas, surrounding landscapes and natural resources, and for creating a broader constituency for conservation that will protect biodiversity sustainably, more effectively and more equitably (Infield and Mugisha 2013).

- Mark Infield and Arthur Mughisa, Fauna and Flora International 
Recent examples from diverse regions are illustrative. Canada's Province of Quebec has created a designation called paysage humanisé (or 'living landscape') in keeping with Category $\mathrm{V}$ and modelled after the regional nature parks of France and Belgium. The Province introduced the designation as a means of increasing biodiversity conservation, particularly on private lands, while encouraging sustainable rural development (Blattel et al. 2008). Brazil's system of protected areas includes the Area de Proteçao Ambiental (or 'environmental protection area'), a designation similar to Category $\mathrm{V}$ (Lino and Britto de Moraes 2005). In Ecuador, with the introduction of a new Law of Cultures in 2014, the potential creation of an Ecuadorian Heritage Cultural Landscape designation is being explored. Such a designation would be based on values of Ecuadorian identity, sustaining biological as well as cultural diversity, and declaring heritage in the Andean sense of 'patrimony' worth protecting (Sarmiento and Viteri in press).

Recently, the expanded Dhimurru Indigenous Protected Area in Australia was formally recognised by the Australian and Northern Territory governments as a Category $\mathrm{V}$ protected area. The Indigenous Protected Area (IPA) now comprises some 550000 hectares, incorporating extensive areas of land and sea, consistent with coastal Aboriginal people's holistic view of land and sea as indivisible components of their traditional country (Gilligan 2006). The Dhimurru IPA management plan specifically spells out its match with the Category $\mathrm{V}$ definition and guidelines.

Establishment of the Resguardo Indigena (or Indian reservations) occurred during the Spanish colonisation of Colombia. Today 15 reservations are the communal property of local ethnic groups of the highlands in the Colombian Massif. They cover 27 per cent of the country, and include 43 per cent of its natural forest areas (SIAC 2014). In recognition of their biodiversity values, some of the reservations are classified as Reservas Naturales de la Sociedad Civil (or Nature Reserves of Civil Society). The nature reserves are recognised as part of the National System of Protected Areas (SINAPS) once they have been legally registered (SINAPS 2014).

Objectives for managing these culturally defined ecosystems include maintaining cultural management systems where these have a unique associated biodiversity. Continual intervention is needed because the ecosystem has been created or at least substantially modified by management.

\section{Cultural landscapes}

A major shift to facilitate the incorporation of cultural themes in nature conservation occurred in the USA in 1981, when the US National Park Service (NPS) recognised cultural landscapes as a specific type of cultural heritage, together with publication of Cultural Landscapes: Rural historic districts in the national parks system (Melnick 1984), which set out criteria for identifying and defining cultural landscapes. Since then, the NPS has provided intellectual and on-ground leadership through its register bulletins, publications, its own research, interpretation, treatment and management of cultural landscapes within the protected area system (Conservation Studies Institute 2005). The NPS (2014) defines a cultural landscape as 'a geographic area (including both cultural and natural resources and the wildlife or domestic animals therein), associated with a historic event, activity, or person or exhibiting other cultural or aesthetic values'.

When the category of 'Cultural Landscapes' was included within the framework of the World Heritage Convention in 1992, a new opportunity was created to inscribe sites that embody outstanding examples of the interactions between humans and nature and contain diverse tangible and intangible values (Rössler 2005; Finke 2013). Recent studies have documented the considerable overlap between Category V protected areas and World Heritage Cultural Landscapes (Phillips 2003; Rössler 2005; Finke 2012). The three categories that the UN Educational, Scientific and Cultural Organisation (UNESCO) has adopted — that is, clearly defined landscape, organically evolved landscape and associative landscape (see Chapter 4) - have developed principles that protected area managers can adapt and use (UNESCO 2009).

The associative cultural landscape category highlights the cultural, spiritual and aesthetic values of natural sites and landscapes in protected areas. The first two World Heritage sites to receive designation as associative cultural landscapes were Tongariro National Park in New Zealand and UluruKata Tjuta National Park in Australia_-both major sacred natural sites for indigenous peoples. The concept applies equally well to protected areas valued by the public for other than sacred reasons_ such as for their value as places of spiritual renewal and artistic inspiration and as icons of national and local identity. The Lake District National Park in the United Kingdom, for example, enshrines for the British people the poetry and art of the English Romantic Movement with its celebration of nature and the human spirit, as exemplified in the works of poets and artists such as William Wordsworth and John Constable 


\section{Box 22.1 Recommendations for fostering community stewardship of cultural landscapes}

Cultural landscapes-the result of a long and complex relationship between people and natureare with us today because of the past and presentday stewardship of those communities living in and near them. Sustaining this relationship into the 21st century will require approaches to conservation that embrace a wide range of governance and management options, and build on the human impulse for stewardship. A session on community stewardship at a 2012 conference at Rutgers University on 'Cultural Landscapes: Preservation challenges in the 21st century' explored these issues through case studies from diverse regions. Through presentations and discussion, a number of recommendations emerged. Supporting indigenous and local communities in stewardship of cultural landscapes will require new partnerships that take into account the need to:

- sustain the core values underlying stewardshipsuch as tradition, language, respect and loveensuring that these are reflected in education of the next generation and translated into the policies affecting communities

- reinforce the central role of communities not only in management but also in governance, whether as governance by communities or in collaborative relationships, and manage adaptively

- honour the importance of distinctive spiritual relationships with the land (enshrined as a human right by the United Nations) and the associated traditional practices and sacred places that are held in trust for the living, the dead and the unborn

- recognise traditional knowledge alongside Western systems of science, ensure that it informs management policies, and support communities in transmitting this knowledge and associated practices (such as indigenous languages, food ways, water management systems and handicrafts) across generations in ways that foster identity and pride

- support and develop livelihood opportunities, recognising the dynamic nature of this challenge in the context of globalisation, so that young people have the option of living in the communities from which they come (Brown in press [a]).

(Mallarach 2008). The Chinese treasure the spectacular peaks and twisted pines of Huangshan National Park as sublime subjects of poetry, art and photography (there is even an important school of landscape painting named for Huangshan) (Pungetti et al. 2012), and the Japanese regard Mount Fuji as a symbol of Japan (Bernbaum 2006).

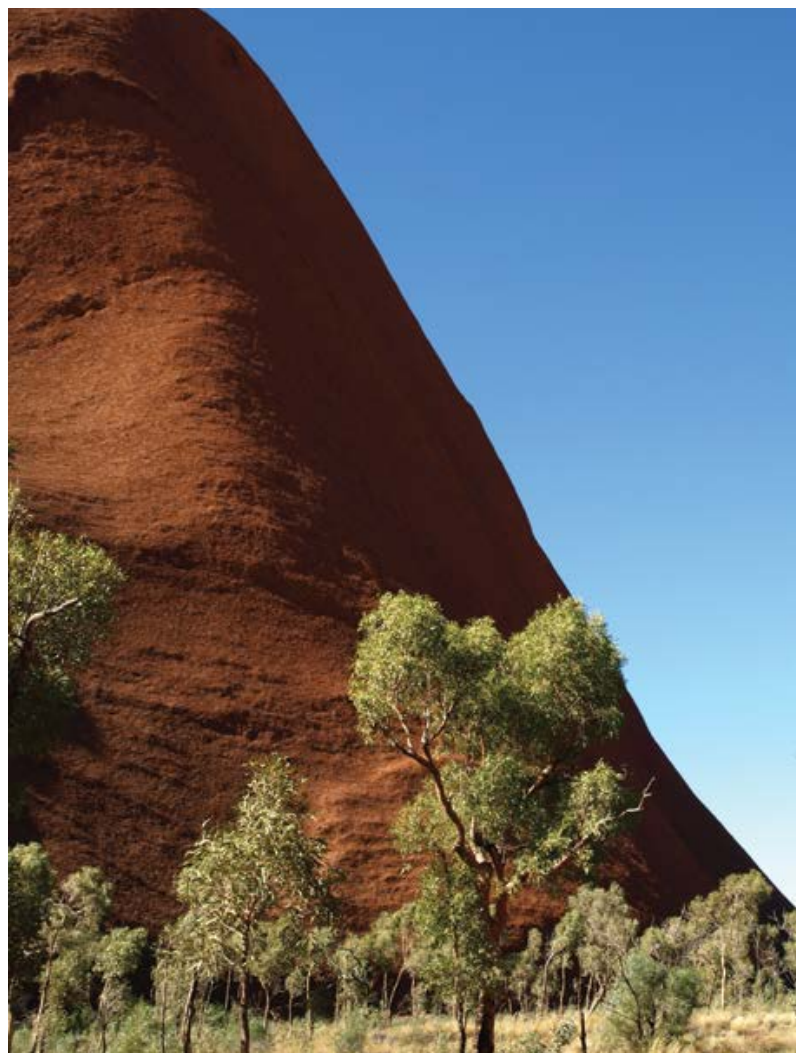

Uluru-Kata Tjuta National Park, Northern Territory, Australia

Source: Graeme L. Worboys

UNESCO has published a handbook for the conservation and management of World Heritage cultural landscapes organised around six guiding principles that can be adapted for application to the wider task of managing cultural uses in protected areas (Mitchell et al. 2009).

1. People who value the cultural landscape, no matter how distant from it, are important stakeholders.

2. Successful management is inclusive and transparent, and governance is shaped through dialogue and agreement among key stakeholders.

3. The values of the cultural landscape are based on the relationship between people and the environment.

4. The focus of management is on retaining the values of the cultural landscape, both natural and cultural.

5. Management of cultural landscapes is integrated into a wider context of larger ecosystems and cultural linkages.

6. Successful management contributes to sustainable means of support for local communities who protect the landscape and its values.

Recommendations for fostering stewardship are presented in Box 22.1. 


\section{Case Study 22.3 Russia's journey towards recognising biocultural heritage}

The history of nature conservation in Russia is closely aligned with dramatic changes in the political climate. The modern system of protected areas-Zapovedniks (meaning forbidden or protected) - began in 1916 under Tsarist rule and aimed to preserve models of intact nature (mostly by excluding people) and to encourage research into nature. The Bolsheviks assumed power after the Russian revolution and in 1922 the Union of Soviet Socialist Republics (USSR) was formed. Under Lenin, Zapovedniks received support from the government and local communities. Although the general population did not see protected areas as part of their everyday lives, scientists often worked with local communities who appreciated their efforts.

This changed dramatically when Stalin came to power. He saw Zapovedniks as enemies of socialism and opened them up for large-scale resource exploitation. During the 1970s and 1980s, the protected area system expanded but community support waned. After the USSR was dismantled, funding for nature conservation virtually disappeared and protected areas turned to local communities and regional governments for financial support. Getting that support meant a change in approach.

The historical exclusion of people caused conflict with local communities-angry they could no longer enter the park and use its resources. While this was partly overcome through effective environmental education programs with schoolchildren, developing collaborative partnerships with local communities has proved to be more fruitful.

The past decades have seen greater integration of Zapovedniks into the local socioeconomic structure by supporting rural agriculture and recognising the value of traditional knowledge in managing nature.

An example of the latter is employment of 'ranger beekeepers', who have the task of managing populations of wild bees in the Shulgan Task Zapovednik in the Ural Mountains. Knowledge about wild bee keeping goes back about 1000 years and is passed down through men in the family. Their knowledge is being used to maintain wild populations in artificial hives and is valuable for maintaining the wild bee population as well as the associated traditional knowledge.

Source: Williams (2003)

\section{Biocultural diversity}

Biocultural diversity is an inclusive term meaning the diversity of life in all its manifestations-biological, cultural and linguistic_-interrelated within a complex socio-ecological adaptive system (Apgar et al. 2011). This more people-centred paradigm is becoming increasingly accepted across the conservation spectrum, but is most prevalent in situations where cultural use is a defining feature of the protected area, such as Indigenous Peoples' and Community Conserved Territories and Areas (ICCAs), Category V and VI protected areas, and where there is collaborative management involving a local ethnic group—-for example, IPAs in Australia.

There are strong synergies between cultural landscapes and biocultural landscapes (also biocultural diversity or biocultural heritage), and distinguishing between them may not be that helpful from a management perspective. The former term, however, is seen by many as privileging Western protected area thinking and does not adequately reflect the interaction of nature and culture. The alternative term, biocultural heritage, explicitly recognises the social and cultural context in which ethnic societies across the world have transformed the nature/culture boundary through their long-term management. In paradigms of integrating nature and culture, biocultural heritage is synonymous with cultural heritage.

The concept of biocultural heritage seeks to integrate the collectively gained knowledge of indigenous and local communities with scientific approaches to nature

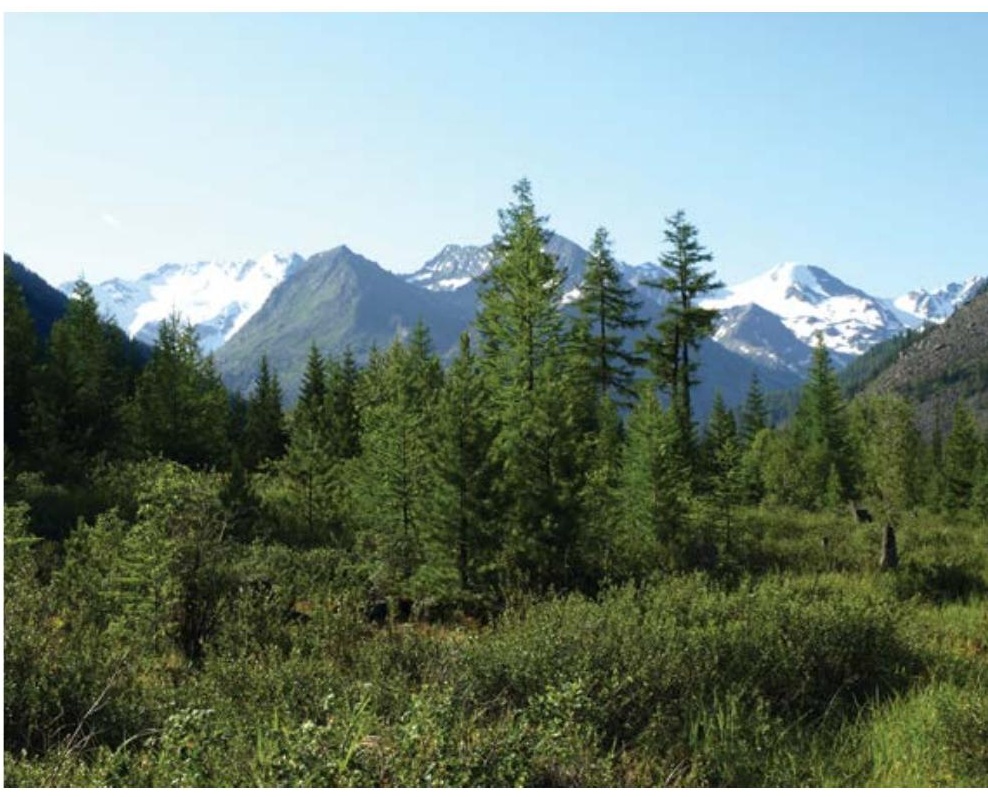

Katunsky Zapovednik, Altai Republic, southern Siberia, Russia

Source: Graeme L. Worboys

conservation management. This traditional knowledge encompasses a diverse field of information about, for example, crop and livestock varieties, medicinal plants, wild foods and wild crop relatives. Application of traditional knowledge in the use and management of natural resources has created a complex symbiotic system that has lasted centuries, even millennia (Berkes and Folke 1998). The development of biocultural heritage approaches in Russia, for example, is described in Case Study 22.3. 


\section{Case Study 22.4 Potato Park (Parque de la Papa)}

An example of an indigenous biocultural heritage area is the Potato Park (Parque de la Papa) in highland Peru, where local empowerment of some 6000 people of five Qeshwa communities around the town of Pisac, in the sacred Valley of the Inka, has transformed the area of the Sacaca, Chawaytire, Pampallaqta, Paru Paru and Amaru into one cohesive community-based enterprise. Before the Parque de la Papa, they were five groups, but now with the parque, they are one group. All projects are managed collectively by the communities to ensure effective participation and sharing of benefits.

Legally, the communities form part of the Association of Communities of Potato Park, which is the communal administrative body of the park. This ANDES Association, administering the rules and regulations regarding exploitation of natural resources within the biocultural heritage area, becomes de facto planner, manager and ranger of the reserve-thus, it is a true steward. Its members apply Andean principles of duality, reciprocity and balance. To protect their rights and their role as a centre of potato origin and diversity, the park's communities promote environmentally focused nature conservation.

Within Andean communities, customary laws have always placed an important role on the administration of biodiversity (including genetic resources, species and ecosystems), and above all, in creating equity, balancing power and maintaining free access to the resources of Pacha Mama (Mother Earth), and in the resolution of conflicts. The fundamental principles that make up the Andean cosmological vision are the foundation of patterns of behaviour and customary laws. In the case of the Potato Park, the epistemological bridges prescribed by the biocultural heritage area approach link traditional and science-based understandings of the multiple functions of agricultural biodiversity-including the close interaction between wild and domestic plant and animal diversityand how they sustain local livelihoods (Argumedo 2008).

A considerable portion of biocultural diversity today is found where indigenous peoples continue to live in ancestral territories (Loh and Harmon 2005). Therefore it is important to understand the underlying community processes that nurture biocultural diversity, which are rooted in historical interactions of people and nature, and the goals of which are the self-determination and wellbeing of communities within the environment in which they live. Understanding and supporting the self-determination of indigenous peoples are therefore important strategies for ensuring that biocultural diversity continues to be nurtured (Apgar et al. 2011). An example of a designated area aimed at conserving biocultural diversity by nurturing both the environment and the people is given in Case Study 22.4.

These developments and others during the past decade demonstrate the value of the landscape approach in conservation policy and practice, reaching beyond the existing boundaries of protected areas in ways that encompass diverse governance regimes and engage communities in nature stewardship (Brown in press [b]). They lay the groundwork for strategies that bring more closely together 'nature conservation policies' and those of 'territorial planning policies', affecting not only the broader landscape but also the national identity affirmation affecting local indigenous people. A key challenge remains in understanding the complex array of linkages between the two and, as per the IUCN Category $\mathrm{V}$ definition, safeguarding the integrity of this interaction, recognising that protected landscapes involve process, as well as place, and that sustaining a relationship between people and the land is basic to

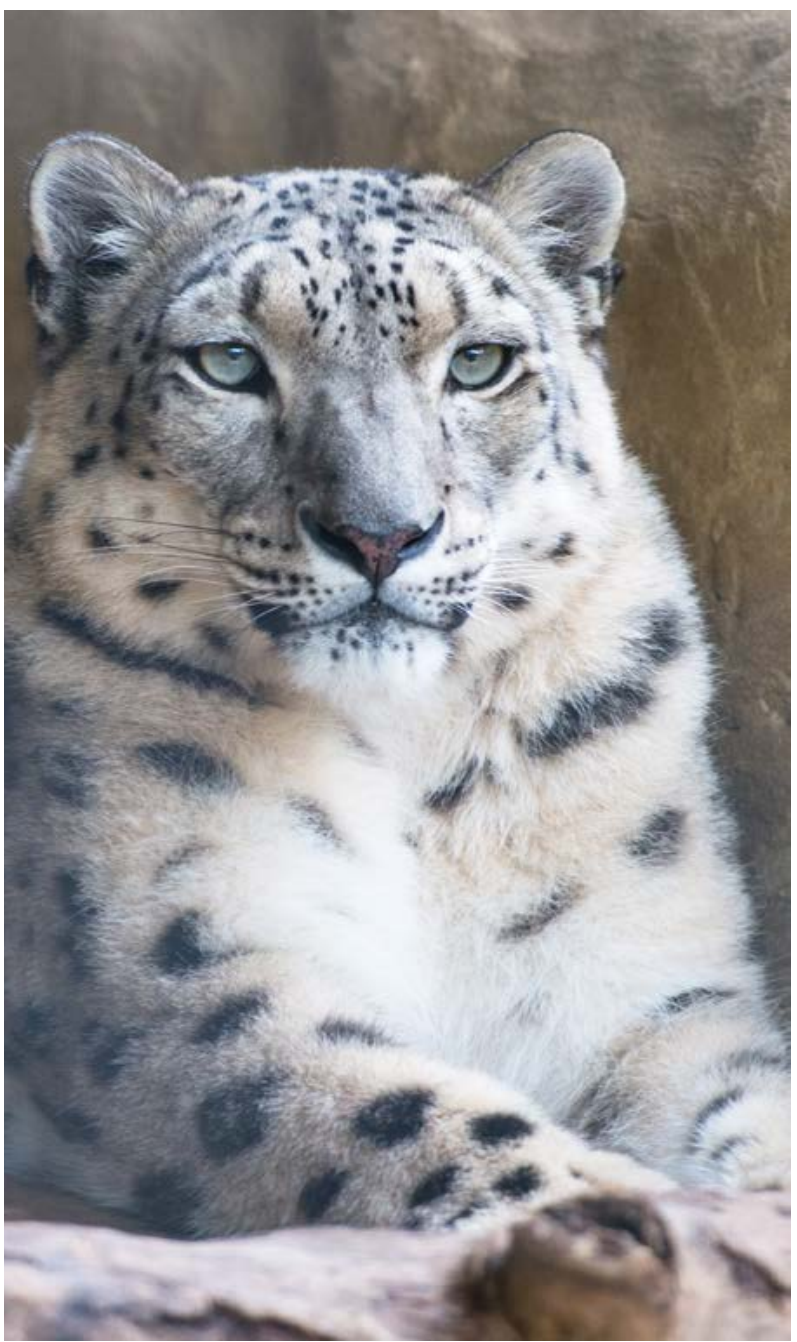

Snow leopard (Panthera unicia)

Source: Graeme L. Worboys their future. An example of this important integration is presented in Case Study 22.5. 


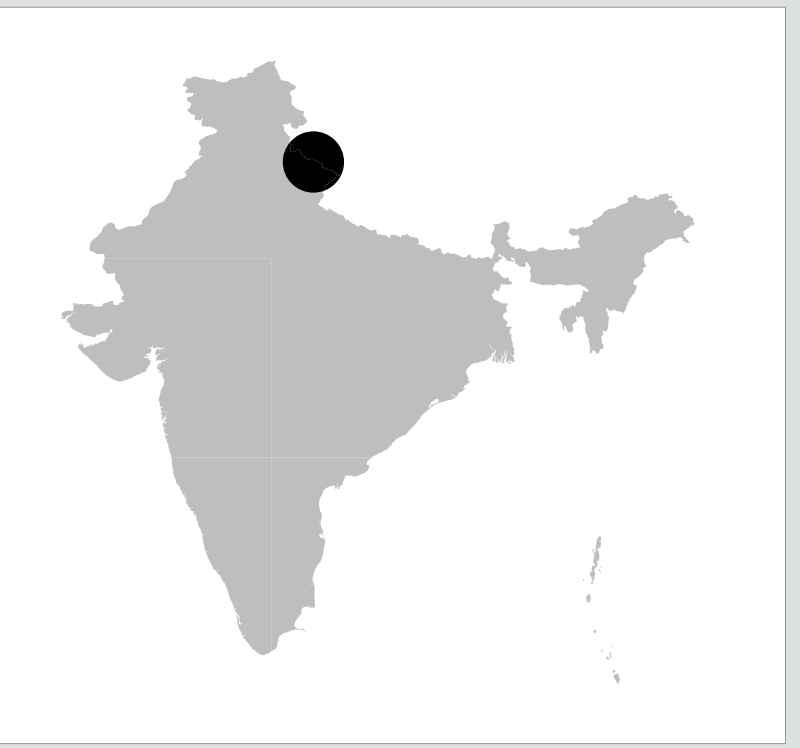

Figure 22.2 Indicative location on the Indian subcontinent, Nanda Devi Biosphere Reserve, India Source: US NPS

The Nanda Devi Biosphere Reserve, a World Heritage site and the second declared biosphere reserve in India, occupies a special place in the higher Himalayan region of the country. Tolchha and Marchha communities of the Bhotiya ethnic group are the main inhabitants of the Niti and Mana valleys in the Chamoli region of Garhwal that form the buffer zone of the reserve. These two communities practice transhumance and have two settlements, one at a higher and the other at a lower altitude. The Tolcha and
Marchha communities have been the main custodians of this cultural and spiritual landscape since before the area was declared a biosphere reserve. The entire reserve is treated as a cultural landscape. The highest peak in the area is Nanda Devi, which is recognised as a prominent Hindu goddess. Small temples of Nanda Devi are present in all villages in the reserve. Local people worship the mountain goddess and protect the forests of the area. Livestock rearing used to be their main livelihood option, but in the past few years, locals have shifted to medicinal and aromatic plant cultivation and ecotourism and home-stay alternatives to ensure minimal damage to their fragile environment. Only sustainable utilisation of forest resources-be it of fuel wood, fodder or medicinal and aromatic plants-is permitted by the locals. Village women practice rotational harvesting of resources from different forests to ensure proper regeneration of species and conservation of habitat for many unique wild flora and fauna, including the snow leopard (Panthera unicia), monal pheasant (Lophophorus impejanus) and musk deer (Mochus chyrsogaster). Urbanisation has still not affected the life of people dwelling in these villages, and they still follow a subsistence lifestyle.

The Kedarnath Wildlife Sanctuary is located in the Rudraprayag district of Uttarakhand State, and is bounded to the north by a series of ancient Hindu shrines. It is a managed nature reserve with five popular Shiva shrines, locally called the Panch Kedars: Kedarnath, Rudranath, Tungnath, Gopinath and Madhamaheshwar. These shrines are visited every year by a large number of pilgrims from India and abroad.

- Shalini Dhyani and Deepak Dhyani, Project Scientists, Uttarakhand, India

\section{A manager's road map for integrating culture and nature}

The effectiveness of a conservation program that emphasises the integration of nature and culture depends on a clear communication strategy. It should address the changing paradigm of cultural landscapes and biocultural heritage and invigorate the emergence of new paradigms of an increasingly urban world. For many conservation managers, culture and nature are no longer parts of a dichotomy in the decision-making process to administer an area. The following tenets of site management practice are recommended to ensure an integrated approach (Taylor and Lennon 2012).

- Acknowledgment of the interface between culture and nature: There is a new understanding of the link between nature and culture, where healthy landscapes have been shaped by human interaction and biological diversity often coincides with cultural diversity.
- Expressions of cultural diversity and people's identity as a response to the landscape: There is a new consideration of intangible values, social inclusion, community consultation and heritage as major anchors for cultural identity positioned at the heart of community development.

- Involvement of biodiversity through traditional practices in the landscape: The communities in which the integrity and diversity of language, social institutions, cultural traditions and land-use practices are maintained also contribute to the diversity and resilience of their surrounding ecosystems.

- Sustainability goals for land use, climate amelioration and livelihood protection: These living landscapes play a vital role in sustaining agrobiodiversity as well as inherent wild biodiversity values, ensuring ecosystem function, and supporting livelihoods and food security with a much reduced carbon footprint. 


\section{- Traditional ecological knowledge systems:} Retention of indigenous knowledge is dependent on its use; it is not solely embedded in people's minds, but also in the environment with which they engage.

- Intangible heritage expressed through rituals and lifestyles: Most ecosystems and landscapes must be seen as coupled social-ecological systems whose resilience depends also on these practices.

- Clear distribution of tasks and observance of the conservation matrix of sites with differential governance regimes: The repositioning of heritage as part of community development has brought changes, even in the Western world; the values of heritage no longer reside exclusively in its physical fabric and form, but in intangible concepts that by their very nature are in constant flux, and should be part of every conservation category with each governance type.

\section{Managing for cultural spiritual values}

The cultural and spiritual values people hold lead to strong feelings that can be harnessed to generate support for protected areas through community engagement and participatory processes that give greater emphasis to these values. One important issue that frequently comes up is management of wilderness areas. In addition to its scientific value for the preservation and study of ecosystems and biodiversity, wilderness in many societies today has great cultural and spiritual value. For many people, wilderness areas represent places of spiritual renewal, where they can return to the source of their being and recover the freshness of a new beginning (see Chapter 4). In Western societies the idea of wilderness as an example of unspoiled nature calls forth visions of the Garden of Eden and symbolises for many humanity's natural state of freedom. In East Asian cultures such as the Chinese, Japanese and Korean, landscape paintings of mountains and rivers evoke the Dao-the spiritual essence of reality that flows through nature (Bernbaum 1997). Appeals to these kinds of cultural and spiritual values are among the strongest sources of support that managers can draw on to engage and involve the general public in developing and implementing measures to establish and preserve wilderness areas.

Conversely, indigenous peoples regard wilderness areas not as pristine untouched spaces, but as places they have lived in and used for centuries or thousands of years, subtly or otherwise altering the appearance of the natural environment. They value these places for reasons that need to be identified and integrated into protected area management to address their concerns and aspirations.

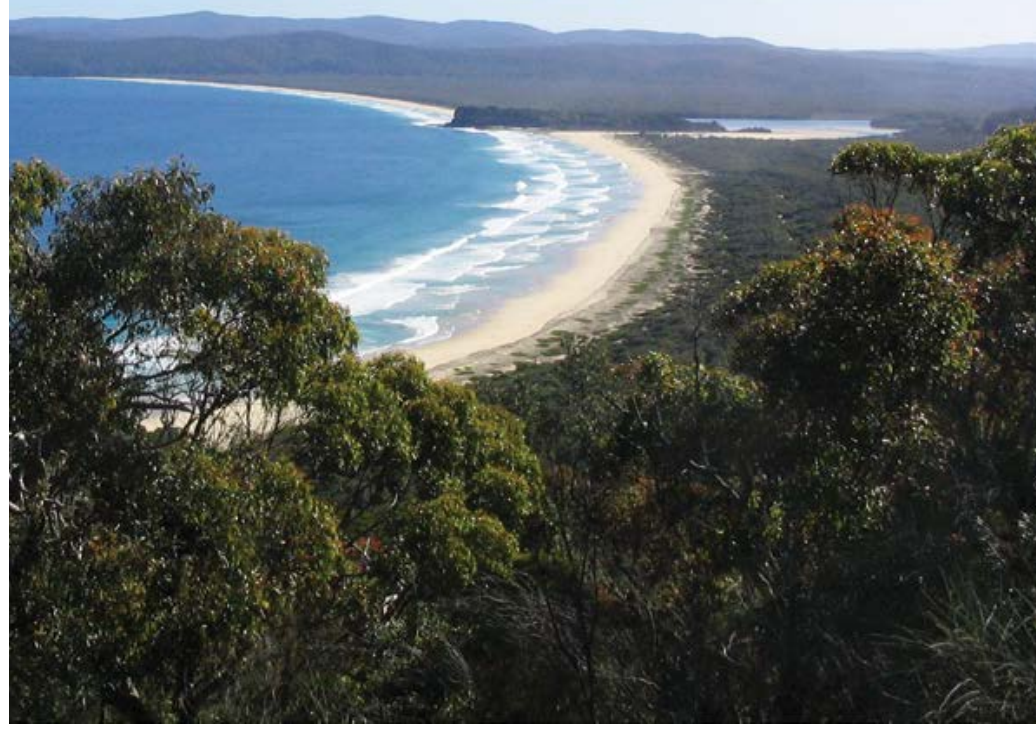

Disaster Bay and the proclaimed Nadgee

Wilderness Area in the centre-left distance (part of the Nadgee Nature Reserve). The image was taken from Ben Boyd National Park, southern New South Wales, Australia. The area is very important to local Aboriginal communities and has been frequented by Aborigines for thousands of years.

Source: Graeme L. Worboys

Another, related way of engaging the public is to work with non-governmental organisations (NGOs) that have an interest in a particular protected area or protected area management in general. Appeals to cultural and spiritual values can be particularly effective in galvanising public action and support for major needs and concerns. A striking example of this occurred in the 1960s when the US Congress was prepared to grant permission to dam the Colorado River in Grand Canyon National Park. The deal was all but done when the Sierra Club, an important environmental organisation in the United States, ran advertisements in newspapers around the country asking, 'Should we also flood the Sistine Chapel so tourists can get nearer the ceiling?' The implicit comparison with desecration of a famous sacred site of great aesthetic and religious value sparked widespread outrage. Congressmen were inundated with letters of protest from the public that forced them to reverse their decision and cancel construction of the dam (Nash 2001).

Cultural and spiritual values can also make it difficult to get things done. Managers need to deal with conflicts between the interests of their protected areas and those of various sectors of the general public, as well as conflicts among different groups which value protected areas 
for different reasons. For example, Rocky Mountain National Park in the United States wanted to set up a series of wayside signs highlighting the cultural and spiritual significance of mountains around the world. A small sector of the public vociferously objected, demanding an exclusive focus on the mountains in the park that they valued above all others as their mountains, and succeeded in killing the project. A major role of protected area managers is to maintain the support and interest of the public even when decisions go against the interests of some stakeholders.

Cultural associations must be maintained to keep the associative values alive. This requires cooperation and collaboration between community group leaders, knowledge-holders and protected area managers. It may include education programs, seasonal activities, intergenerational meetings or cultural camps where knowledge is passed on to younger generations, and festivals to transmit rituals and crafts, including teaching and using local language/dialects. These give a sense of pride in local costume and cuisine and help maintain ritual and religious behaviour.

In managing cultural heritage in protected areas, managers must know what cultural values occur in their landscapes and ensure that management regimes protect and enhance both the intangible expression of these values and their physical evidence. But like culture, values are dynamic: they evolve and change over time due to external influences. Management strategies must be cognisant of changing values in local communities. For example, until the 1970s in Australia, Aboriginal people were so disempowered they rarely spoke out about the impacts of developments on their sacred sites. Today, young Aboriginal people are much more vocal and influential about what happens within the nation's protected areas.

Training of staff in managing conflict around cultural and spiritual values is essential. As with any conflict resolution, this requires respect, a capacity to listen and an ability to create a situation in which different parties can find a solution themselves (see Chapter 14). The following groups can provide useful resources and assistance for training programs and other matters involving the cultural and spiritual values of sacred natural sites and cultural landscapes:

- IUCN World Commission on Protected Areas (WCPA) Specialist Group on Cultural and Spiritual Values of Protected Areas

- Sacred Natural Sites Initiative

- Delos Initiative on sacred natural sites and cultural landscapes in technologically developed societies
- Ramsar Culture Network

- World Heritage Centre

- Alliance for Religions and Conservation

- Forum on Religion and Ecology

- Cambridge Centre for Landscape and People, a focal point for research on the cultural and spiritual values of landscape and nature

- Sacred Land Film Project

- The WILD Foundation

- Community Management of Protected Areas Conservation Programme (COMPACT).

\section{Managing cultural use of sacred sites}

Sacred sites are viewed and revered in a multiplicity of ways-for example, as centres of the cosmos; places of power; abodes of deities, ancestors and spirits; sources of water, life and other blessings; symbols of identity; or places of revelation, contemplation and inspiration. Through the views they have of sacred sites and the beliefs and practices associated with them, people of different cultures and traditions, both modern and traditional, believe they experience a deeper reality that gives meaning and vitality to their lives, linking them to something greater than their individual selves (Verschuuren et al. 2010).

Sacred sites can be places created by humans, such as Macchu Pichu, the statues of Rapa Nui (Easter Island) or churches and monasteries belonging to different religions. Such places are often situated in dramatic natural settings and sacred sites frequently combine both natural and cultural elements.

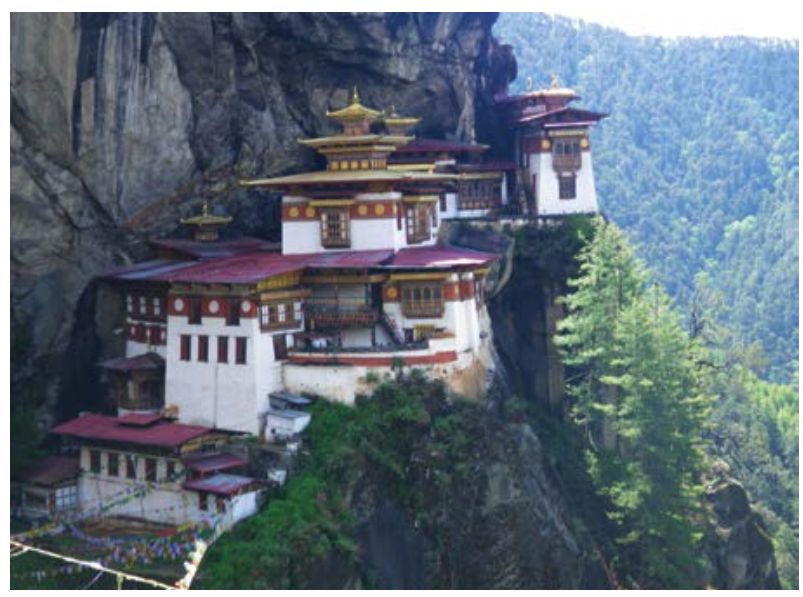

Taktsang Monastery (Tiger's Nest), one of Bhutan's most sacred and well-known Buddhist sites Source: Sue Feary 
Features of the natural environment such as mountains, waterholes or groves of trees can be sacred to indigenous and tribal cultures whose connection with the natural environment is fundamental to their cultural identity. The sacredness of a place in some cases resulted in protection of its biodiversity, and the links between indigenous/tribal cultural practices and conservation of biodiversity are being increasingly recognised. Natural sacred sites are, however, vulnerable to desecration through ignorance, inadequate legislation and injustice. Not surprisingly, recognition and protection of natural sacred sites have been a strong focus of international agencies such as the IUCN and UNESCO, leading to expansion of cultural heritage definitions to include intangible heritage (see Chapter 4).

Many protected areas set aside for biological and scientific reasons include natural features that have special cultural and spiritual importance for local communities and indigenous traditions, as well as for followers of mainstream religions who revere them as places of pilgrimage and contemplation. In some cases, the entire protected area is a sacred natural site-for example, Tongariro National Park in New Zealand and Mount Taishan in China. In addition, some protected areas are included within larger sacred natural sitesfor example, parks and biosphere reserves in the Indian Himalaya, where the entire mountain range is regarded as sacred in Hindu tradition.

Sacred natural sites are distinguished from other features of the environment by virtue of their association with intangible values: ancient webs of myths, beliefs and practices that envelop them and link local communities, indigenous traditions or mainstream religions to them. The Hopi, for example, regard the San Francisco Peaks of the American south-west as the abode of the katsinas (or kachina) - ancestral spirits whom they invoke and invite to bring life-giving rain through ceremonial dances they perform at their villages on mesas within sight of the sacred site. Hindus from throughout India believe that Shiva, one of the three forms of the supreme deity, dwells on the unclimbed summit of Mount Kailas in Tibet and many of them aspire to go on pilgrimage to make a ritual circumambulation of the sacred mountain.

The IUCN has published guidelines for protecting sacred natural sites in protected areas. The guidelines identify six general principles:

- recognise sacred natural sites located in protected areas

- integrate sacred natural sites into planning processes and management programs
- promote stakeholder consent, participation, inclusion and collaboration

- encourage improved knowledge and understanding of sacred natural sites

- protect sacred natural sites while providing appropriate management access and use

- respect the rights of sacred natural site custodians within an appropriate framework of national policy (Wild and McLeod 2008:21).

Another set of guidelines appears in the report of a 2006 UNESCO conference held in Tokyo, which highlights some additional principles for protected area managers to consider when managing natural sacred sites:

- the need for voluntary participation of local people in conserving sacred natural sites

- the importance of not putting pressure on local communities to compromise the secrecy of their natural sites

- allowing the harvesting of plant and animal species for ritual purposes

- utilising both modern science and traditional knowledge in the conservation and management of sacred natural sites

- establishing buffer zones around sacred natural sites and monuments to help protect them and allow for traditional activities

- the need for training and capacity-building programs in managing sacred natural sites and developing cultural sensitivity and social skills in interacting with local communities (Schaaf and Lee 2006).

These principles focus on sacred natural sites that have particular importance for local communities and indigenous traditions. Most natural sites sacred to indigenous and local communities have local significance and have meaning to fewer people when compared with mainstream religions. Furthermore, the location of such sacred places and the knowledge associated with them are often kept secret and may be known to only one person, such as in Australian Aboriginal society.

Custodians in indigenous traditions and local communities generally come from the immediate vicinity of a particular site. The position is often handed down through a family, which may well have economic as well as spiritual and cultural interests in the site, considering it their personal possession and valuing it as their source of livelihood. 


\section{Case Study 22.6 An integrated approach to the management of Mount Athos}

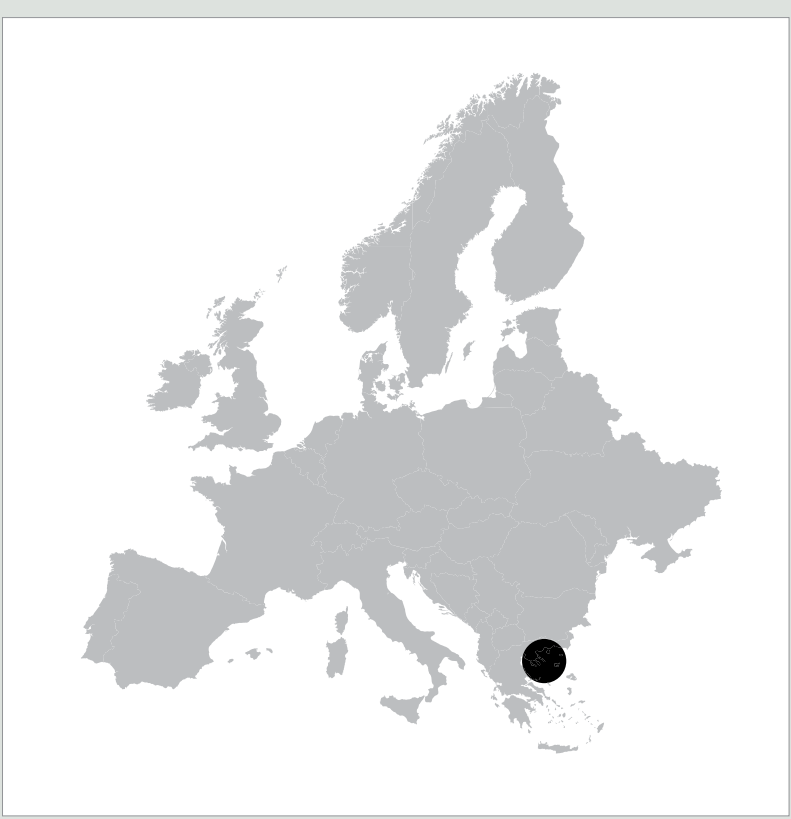

Figure 22.3 Indicative location in Europe, Mount Athos, Greece

Source: US NPS

In the north of Greece, the third peninsula of Halkidiki is dominated by the cone of Mount Athos, rising steeply to 2033 metres. The Athonite Peninsula, heavily wooded with Mediterranean forests and with high biodiversity, hosts 20 historic Eastern Orthodox monasteries and their dependencies with a millennial living tradition-cultural and spiritual. That is why the area was designated in 1988 as a World Heritage site for both nature and culture, and recently as a Natura 2000 protected area in its entirety. Until now, Mount Athos has been managed by its monasteries and their vibrant monastic brotherhoods in an essentially autonomous manner, with limited interventions by the Greek state through public services.
In 1994, when Prince Philip, president at that time of the World Wide Fund for Nature (WWF) International, visited Mount Athos, he tried to convince the holy community of the need for an integrated approach to the management of the peninsula in order to safeguard its rich natural and cultural heritage. Much later, a UNESCO mission to Mount Athos in 2006 identified the same need and the World Heritage Committee intervened strongly to promote the concept. In 2010, the integrated approach was accepted by the holy community, which represents the 20 sovereign monasteries, and in December 2012 it approved a preliminary study on the 'strategic framework for the conservation and management of the cultural and natural heritage of Mount Athos', prepared by a group of scientists and monks, coordinated by Thymio Papayannis. This preliminary document reviews the situation in Mount Athos and the challenges and threats it presents. It formulates a set of principles on which the entire management initiative should be based. And it indicates the priority areas to be addressed by the main study.

During 2013, the preparation of the final management study was launched in a positive climate of cooperation. Although the holy community maintains the initiative for the integrated approach to the management of the Athonite Peninsula, the Greek Ministry for Culture and the Ministry of Environment, as well as the World Heritage Centre, work closely with the monastic authorities to ensure wise management and effective conservation of this unique site, based on sound science and respect for the spiritual traditions of Mount Athos. An essential part of the exercise will be the development of an action plan that will ensure the effective implementation of the management study's recommendations and proposals. In this spirit, at the end of August 2013, an international and multidisciplinary workshop was held in Thessaloniki with the participation of the three sides (UNESCO, Greek ministries and the holy community), who debated the basic principles and contents of the integrated management study and reviewed its specifications.

- Thymio Papayannis
Numerous major natural features and protected areas also have great cultural and spiritual importance for mainstream religions and the general public-for example, Mount Fuji for Buddhism and Shintoism, as well as the Japanese people; and the peninsula of Mount Athos for Eastern Orthodox Christianity and much of the Greek public. These sites have important characteristics and requirements that differ from sacred natural sites associated with indigenous and tribal religions (Case Study 22.6). In the following sections, we examine ways in which protected area managers can work with mainstream religions to manage sacred sites, whether they are natural or built sites.

\section{Managing sacred sites by involving mainstream religions and the general public}

As discussed above, practices and beliefs (intangible heritage) associated with sacred sites of mainstream religions can differ from those associated with sites sacred to indigenous and local communities, with major implications for protected area management. The most obvious difference is the number of people for whom a site is sacred. Natural sites sacred to mainstream religions, such as Mount Sinai in the Saint Katherine Protectorate (an Egyptian national park) or Jebel Musa in the Saint Catherine's Area World Heritage site, Morocco, can have importance for millions of religious adherents and attract visitors from around the world in huge numbers, posing both challenges for protected area management 
and opportunities for disseminating messages of environmental conservation based on religious ideas. Many natural sacred sites of mainstream religions are revered places of pilgrimage, drawing large numbers of pilgrims from far away with little connection to or knowledge of local communities and environmental issues. Millions of Christians, for example, come to obtain blessings from an image of the Black Madonna hidden among the rock spires of Montserrat, within Montserrat Natural Park in Catalonia, Spain (Mallarach and Papayannis 2007). Buddhist and Daoist pilgrims climb Taishan, the most important sacred mountain in China, to worship at various shrines and, in the case of elderly women, to pray for grandchildren (Bernbaum 1997). Not all of these pilgrims will have concerns about their potential impacts on local cultures and the environment.

Monasticism is another distinguishing feature of mainstream religions. Religious traditions, from Christianity to Buddhism, have chosen places with sacred significance in remote natural settings such as forests, deserts and mountains in which to establish monasteries where monks and nuns can practise contemplation in solitude far away from the distractions of civilisation. In Japan, for example, most Zen monasteries are named 'mountains' in recognition of the fact that East Asian cultures have long regarded mountains as ideal places in which to meditate and attain enlightenment (Bernbaum 2007). Recognising the importance of protecting natural settings conducive to spiritual development, monasteries in places such as the peninsula of Mount Athos in Greece have traditionally managed the lands around them in ways that have preserved biodiversity otherwise lost in surrounding areas.

Many natural sites are revered because a well-known hermit, such as the Biblical prophet Elijah in Judaism and Christianity or the yogi Milarepa in Tibetan Buddhism, has lived and practised there, imbuing the site with an aura of sanctity. Followers of mainstream religions come to these sites to receive the blessings they believe were left behind by the spiritual power of such hermits. Monasteries of mainstream religions often have close connections to places of hermitage, having grown up around a place where a hermit enshrined in their tradition lived and meditated, attracting followers who eventually developed a monastic community. Since natural settings have often played important roles in the lives and practices of hermits-witness, for example, the importance of animals, plants, and other features of nature for Saint Francis of Assisi-there is a natural inclination to protect the environment associated with these places. Managers can draw on these natural inclinations to strengthen the measures they implement in conjunction with interested parties from mainstream religions (Papayannis and Mallarach 2009).

Sacred natural sites in mainstream religions have associated with them myths and beliefs shared by large numbers of people. Hundreds of millions of Hindus, Buddhists and Jains revere Mount Kailas in Tibet as the centre of the universe and the abode of major deities and enlightened beings in their respective traditions. The biblical story of Moses's encounter with God on Mount Sinai and the revelation and covenant believed to have taken place there have had a profound influence not only on Judaism, Christianity and Islam, but also on the course of Western civilisation.

According to myth, the Korean people as a wholeboth North and South-are descended from Paekdu or Changbai Shan, a volcano on the North Korean border with Manchuria (Price et al. 2013). Monotheistic religions of Judaism, Christianity and Islam revere sacred natural sites not as deities but rather as places of worship, like churches and synagogues, or as places of God's divine creation worthy of love and respect. Such beliefs, both monotheistic and non-monotheistic, have a powerful influence that can be enlisted in motivating millions of people to support protected areas in particular and environmental conservation in general.

The following points are offered as guidance for protected area managers working with mainstream religions.

1. Managers of protected areas need to work with religious authorities and pilgrimage associations to manage the flow of pilgrims, provide facilities and services for them, and educate them about the need to protect the natural environment and respect the local culture. The situation is generally quite complex, potentially involving many parties.

2. Managers of protected areas that include monasteries can work with the leaders of monastic communities to include them in their management plans and integrate their practices into their management systems (Papayannis and Mallarach 2009). Abbots of Tibetan Buddhist monasteries in Sagarmatha National Park in Nepal, for example, control sacred groves around their monasteries and have the power to designate 'lama forests' as places that local Sherpa communities have powerful motivations to respect, even more than areas officially protected by the park itself (Mallarach 2008).

3. Because they draw large numbers of pilgrims and are places of monastic communities, many sacred natural sites in mainstream religion have extensive 
human-made structures associated with them. A major pilgrimage shrine such as Badrinath in the Indian Himalaya needs to provide facilities and temples for housing and serving the religious needs of the 400000 pilgrims who visit the site each summer. Large monasteries with churches and living quarters for monks are perched on crags and hidden in forests in protected areas in various parts of Europe-in particular, the Balkans, as well as in the Cedars of Lebanon in the Middle East.

4. Managers need to pay particular attention to the challenges associated with maintaining humanmade structures and the traditions connected with them while at the same time preserving the natural environment that surrounds and gives them their special significance. This requires working closely with religious leaders and monastic authorities, in addition to local communities. An additional point to consider is that many monasteries in Europe and Asia have extensive landholdings that include large tracts of relatively unspoiled nature that may already be associated with existing protected areas or be candidates to become new areas of protection (Papayannis and Mallarach 2009).

5. Sacred natural sites for mainstream religions may be much larger than sites for indigenous traditions and local communities, although the ancestral 'Dreaming' tracks of the creation beings can link natural features across vast distances in the cosmology of Aboriginal Australians. Hindus in India, for example, regard the length of the Ganges River and the entire Himalayan mountain range as sacred. Such large natural features and landscapes may cross multiple protected areas, the management plans and systems of which could be strengthened by integrating the cultural and spiritual values that link them together, not only for the people who live near them, but also for the more distant followers of the religions that revere them. In a sense, they form cultural corridors similar in certain respects to wildlife corridors.

6. Some natural sites are sacred to more than one mainstream religion or may also be sacred to indigenous traditions. Lake Manasarovar, a Ramsar site in Tibet, is regarded as the most sacred lake in the world for Hindus and also for many Tibetan Buddhists - and it has special significance for the indigenous Bon tradition of Tibet. Adam's Peak in the Peak Wilderness Area of Sri Lanka is a major place of pilgrimage for Hindus, Buddhists, Christians and Muslims - all of whom need to be taken into account in managing the area (Bernbaum
1997). Natural sites that are sacred to more than one religious or indigenous tradition pose the challenge of addressing conflicts that can arise among these traditions. Managers may have to deal with the question of which tradition, if any, has primacy over a particular site, although that is best left to the parties themselves to work out (see discussion earlier in this chapter).

7. Many indigenous traditions today fear the encroachment of mainstream religions on their sacred sites - a fear that managers need to deal with in making sure that all stakeholders' views and interests are represented in management plans and systems. In addition, there are also conflicts among different indigenous traditions and local communities laying claim to the same site-for example, disputes among the Hopi and Navajo over sacred places in the American south-west, many of them in protected areas.

8. Custodians of sites in mainstream religions usually come from distant places and are assigned by leaders of religious institutions headquartered elsewhere. The head of Saint Catherine's Monastery in charge of Mount Sinai or Jebel Musa, for example, comes from Greece and receives his appointment from the hierarchy of the Eastern Orthodox Church (Mallarach 2008). An illustration of the monastic influence in the effectiveness of conservation is presented in Case Study 22.7.

9. Sites sacred to multiple religious and indigenous traditions can have a number of custodians who may be at cross-purposes, and managers need to recognise the diverse nature and interests of custodians. In Christianity the notion of stewardship is emphasised, rather than custodianship per se, shifting the focus away from ownership and control to obligation and responsibility. Hindus may consider the real custodian of a sacred site to be the deity who dwells there and has power over the place, such as the goddess Nanda Devi in the Nanda Devi Biosphere Reserve. For some sacred sites, there may be no person or persons singled out as custodians (or knowledge may have been fragmented or lost due to colonisation). Instead various stakeholders and religious and pilgrimage organisations may be responsible for taking care of the site-and in some cases there may be no-one charged with protecting the place.

10. Sacred sites that draw many pilgrims and other visitors offer the opportunity to disseminate religiously based ideas of conservation for a particular site, and the environment. Sacred natural 


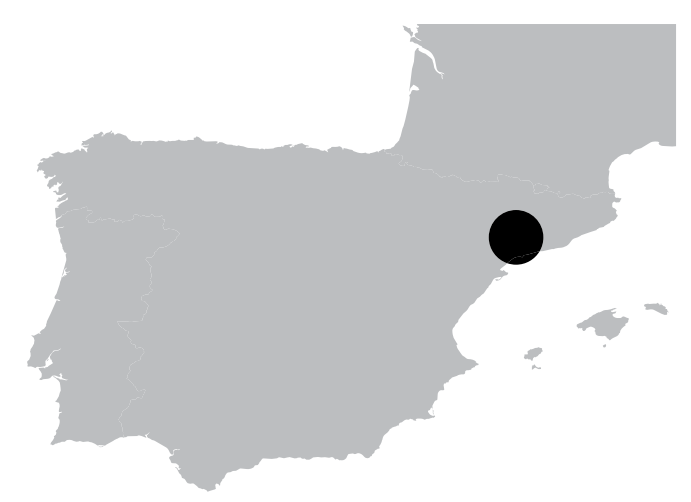

Figure 22.4 Indicative location on the Iberian Peninsula, Montserrat, Catalonia, Spain

Source: US NPS

Montserrat is located about 50 kilometres north of Barcelona. Despite its modest altitude (1120 metres) and relatively small size, the singular landform characterised by thousands of astonishing stony pinnacles makes it a unique, magical and majestic mountain. Montserrat includes outstanding geological heritage sites of national importance, more than 1200 Mediterranean vascular plant species, of which 40 are considered rare or endangered, and 29 animal species considered rare, endangered or vulnerable.

Nested into the mountain, over the cliffs, is the famous Benedictine monastery of Santa Maria, where the black image of the Holy Virgin is venerated. For many centuries, the shrine of the patroness of Catalonia-a masterpiece of sacred art from the 12th century-has been one of the most significant shrines of the Virgin in the Catholic world. In addition, the upper part of Montserrat has 12 hermitages, most of them clinging to rocky pinnacles, where hermits have been living for most of the past millennia. Two hermitages are still used by the monastic community for retreats, while two more are used as shelters for climbers. In 1954, on a ridge at a lower elevation, the monastery for nuns of Sant Benet was built. The tradition of pilgrimage by foot to venerate the holy image of the Virgin dates from medieval times. Today, although the majority of people use mechanical means, groups of pilgrims still climb by foot, following historical pilgrimage trails.

For all these and many other historical, political and sociological reasons, Montserrat is widely considered the identity and spiritual heart of Catalonia. In 1989 Montserrat was declared a Natural Park (IUCN Category V) with a Nature Reserve (IUCN Category III) by a decree of the Government of Catalonia. The protected area is about 9400 hectares, of which almost 2000 hectares is nature reserve. The entire massif has been included in the European Natura 2000 network. The Board of Montserrat is led by the President of Catalonia and the abbot of the monastery of Santa Maria.

The Benedictine community has been the main custodian of Montserrat for almost 10 centuries. The cultural influence and importance of the monastic community can be gauged from the following facts.

1. During the past four centuries it has had a significant school of liturgical music.

2. It has one of the oldest publishing houses in Europe.

3. Its library has more than 300000 volumes, including unique manuscripts.

4. The museum holds one of the best collections of landscape paintings of Catalonia.

5. The cultural work of the monks includes biblical studies, liturgy, theology, monastic history, musicology, as well as spiritual and pastoral themes, authoring or translating numerous works annually.

6. The monks organise numerous cultural activities.

In addition, the areas surrounding the Monastery of Santa Maria are an open air museum, including a number of sculptural groups of the 19th century that blend with the rocky walls along the trails.

- Josep-Maria Mallarach, Silene Association sites in protected areas can focus attention on and highlight in concrete ways such messages from major figures of mainstream religions on the pressing need to respect and care for nature. For instance, a project that had religious leaders and scientists working together to re-establish a sacred forest at Badrinath, a holy town in India, instituted treeplanting ceremonies that attracted a lot of attention and spread the idea of planting and taking care of trees elsewhere in India for reasons coming out of traditional Hindu beliefs and practices (Pungetti et al. 2012). The late Pope John Paul II and Patriarch Bartholomew I of Constantinople have used their religious authority to encourage the followers of their traditions to respect and care for the natural environment (Dudley et al. 2005).

\section{Managing tourists at sacred sites}

Many known sacred sites are major tourist attractions for the secular public, both national and international, because of their natural beauty and cultural interest. Large numbers of tourists come to see them, with potentially adverse impacts on the natural and cultural values of these sites. At the same time, these visitors bring revenue that can help support protected areas and local communities. In addition, major sacred natural sites, such as Mount Sinai and Mount Fuji, are well known to the majority of the public who do not have the opportunity to visit them but would like to know that they are being preserved for posterity. 


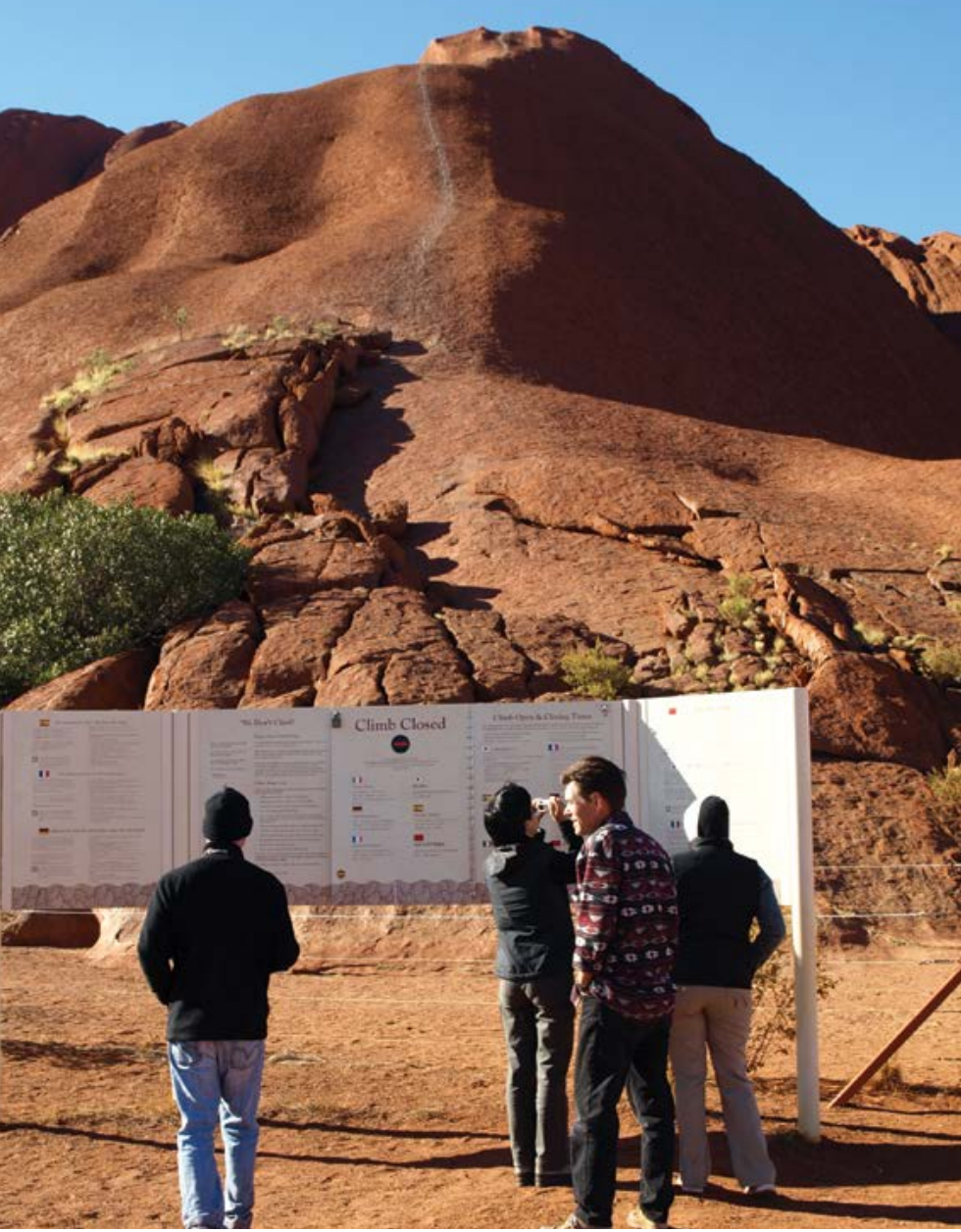

Sign provided at the base of the climb up Uluru, Uluru-Kata Tjuta National Park, Northern Territory, Australia

Source: Graeme L. Worboys

\section{Managing recreational use}

Recreational uses, in particular, such as rock climbing and skiing, can threaten the sanctity of sacred sites in the eyes of those who revere them. The Lakota and other tribes in Wyoming, for example, regard the ascent of Devil's Tower (or Mato Tipila) in Devil's Tower National Monument as an act of desecration, especially during their ceremonial season in June. The park managers tried to ban climbing during this period, but a small group of climbers contested this in court and won, saying it violated their rights. The management now asks people to voluntarily refrain from climbing the volcanic tower in June out of respect for Native American traditions, and the overwhelming majority of climbers have agreed to do so (Wild and McLeod 2008).

Expansion of the Arizona Ski Bowl and the use of waste water to create artificial snow on the sacred San Francisco Peaks have pitted tribes such as the Hopi and Navajo against the ski area and members of the skiing public. The Native Americans have gained the support of environmental organisations such as the Sierra Club, but up to this point, have not succeeded in court in stopping the use of waste water and other aspects of recreational skiing they regard as desecrations of the sacred mountain (Papayannis and Mallarach 2009).

\section{'We Don't Climb'}

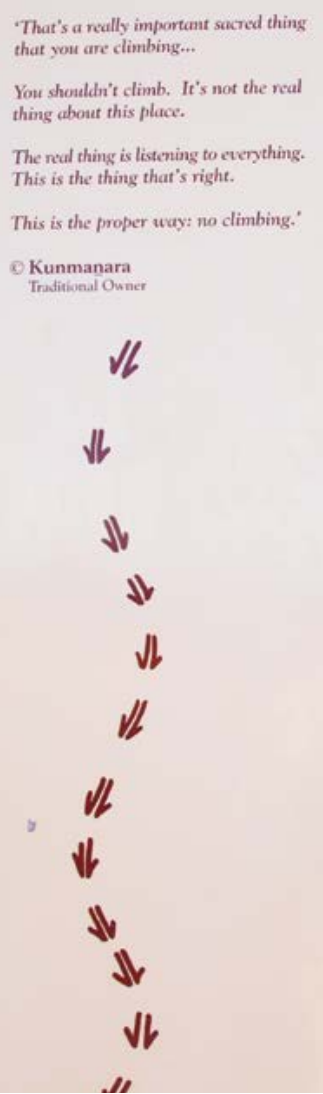

\section{Please Don't Climb Uluru}

Our traditional Law teaches us the proper way to behave. We ask you to respect our Law by not climbing Uluru.

What visitors call 'the climb' is the traditional route taken by ancestra Mala men upon their arrival at Uluru in the creation time. It has great spiritual significance.

We have a responsibility to teach and safeguard visitors to our land. 'The climb' is dangerous and too many people have died while attempting to climb Uluru. Many others have been injured while climbing. We feel great sadness when a person dies or is hurt on our land. We worry about you and we worry about your family.

Other things to do

$$
\begin{aligned}
& \text { There are other challenging and interesting things to do at the Uluru } \\
& \text {-Kata Tjuta National Park. } \\
& \text { - Walk around the base of Uluru (9.4 kilometres) } \\
& \text { - Challenge yourself to the Valley of the Winds Walk } \\
& \text { - Appreciate our culture while visiting the Cultural Centre } \\
& \text { - Join a free Ranger-guided Mala Walk } \\
& \text { - Go on a self guided Mala Walk ( } 2 \text { kilometres) and Mutitjulu } \\
& \text { walk (1 kilometre). Purchase the Insight Into Ulunu brochure to } \\
& \text { - Telp guide you } \\
& \text { - Visit Kata Tjuta for sunrise, sunset, day walks or a picnic } \\
& \text { - Look for animal tracks on a dune walk at the bus sunset area } \\
& \text { - Sit and listen to the wind, the trees, the birds and animals } \\
& \text { - Watch sunrise and sunset at Uluru } \\
& \text { - Picnic at the grounds near the Cultural Centre. } \\
& \text { When you visit the Cultural Centre you will learn more about the } \\
& \text { significance of Uluru in our Law and culture. Please do this before } \\
& \text { you decide whether to climb. } \\
& \text { If you look to your left you will see the start of the Mala Walk. } \\
& \text { Mala Trucks Artuonk Jemnifer Taylor }
\end{aligned}
$$

Detail of the sign provided at the base of the climb up Uluru, Uluru-Kata Tjuta National Park, Northern Territory, Australia

Source: Graeme L. Worboys

Another important example of the management of sacred natural sites comes from the Dai people living in the convergence of north-west Vietnam, eastern Myanmar, upper Laos, northern Thailand and the Yunnan region of south-west China. Before the introduction of Hinayana Buddhism with the Tang Dynasty, the Dai were animistic, linking the forces of nature with the spiritual realm through the idea of $S h u$, the mountain spirit. The Dai have maintained and increased the biodiversity potential and abundance of native flora and fauna on the sacred hills (or Nongs) by maintaining rituals to control the evil spirit of Shu, associated with the use of timber and other resources, such as medicine or food, only by community and religious consent. Harvesting timber from species such as Paramichelia baillonii, Cinnamomum comphora, C. glanduliferum and Gmelina arborea requires the consent of a village committee, which has retained forested hills in the otherwise transformed farmscape of rice paddies, home gardens and cultivated fields, thus satisfying the benevolent spirit of Shu. The Dai's respected souls of their chieftains reside in the forested hills of the local Nong Man or the larger Nong Meng, and reportedly help contribute to the preservation of local and regional landscapes (Xu et al. 2006). 


\section{Managing cultural features (tangible cultural heritage)}

Most protected areas have considerable tangible cultural heritage, but it is often of a fragmentary and subtle nature-archaeological rather than monumental. They do not typically consist of prominent buildings or wellknown rock art sites. The management of these more subtle and often more fragile heritage sites requires a range of sophisticated techniques, often in an environment of few resources. The protected area manager, as has been mentioned before in this chapter and in Chapter 4, is often someone without a background in cultural heritage management and may not recognise many of the cultural heritage values of a protected area without the aid of cultural heritage specialists and/or the local community. Locating, identifying, inventorying and assessing these sites and landscapes are prerequisites to formulating management strategies. Methodologies for management need to begin with a discussion of these issues and suggested strategies for their achievement. After this, often the best strategy is to write a management plan for the conservation of the cultural heritage generally rather than initially focusing on specific sites.

It is important to note here that we are not suggesting that tangible evidence, such as the built environment, is separate from the surrounding landscape; they are all part of an integrated holistic system involving nature and culture evolving together (biocultural diversity). Managing and protecting tangible evidence, however, commonly require specific technical expertise and management practices, and our discussion is focused on these special requirements.

The most important international policy document for conserving tangible cultural heritage-specifically built heritage-is the International Charter for the Conservation and Restoration of Monuments and Sites, known as the Charter of Venice, which resulted from the deliberations of practitioners about restoration of flooddamaged buildings in Venice in 1964 and which gave rise to the International Council on Monuments and Sites (ICOMOS) (Lennon 2006). Other global agencies connected with ICOMOS in the management and protection of cultural heritage include UNESCO, the International Centre for the Study of the Preservation and Restoration of Cultural Property, the International Council of Museums (ICOM), the World Heritage Convention and the IUCN. Various nations have adapted the guiding principles of ICOMOS to suit their particular circumstances, such as Australia's Burra Charter, established in 1979, the China Principles (2004), A Preservation Charter for the Historic Towns and areas of the United States of America (US/ ICOMOS 1992), and the Charter for the Preservation of Quebec's Heritage (ICOMOS Canada) (Lennon 2006). UNESCO's Hoi An Protocols (UNESCO 2009) provide professional guidelines for preserving the authenticity of heritage sites in the context of the diverse and enduring cultural identities of Asia. Despite these universal guidelines, best management practice varies from continent to continent, even from country to country, for a range of reasons, including the funds available to manage historic buildings and landscapes and the levels of visitation.

Historic buildings occur in protected areas across the world; sometimes they can even be the reason for the protected area, or they can be incidental to the main reason-for example, graziers' and miners' huts in Kosciuszko National Park, Australia (see Chapter 4). The significance of a built feature is often not immediately apparent to anyone, let alone a protected area manager. For example, it may not be the fabric or physical evidence that is significant, but the historical events associated with the place. Generally, the way a built feature is managed depends on its values and the level of significance of the values. The process of assigning values then assessing significance marks the onset of the conservation planning process, which is discussed further below.

\section{The conservation planning process}

As discussed in Chapter 4, managing and conserving cultural features, including cultural landscapes and biocultural diversity, should ideally be guided by careful and rigorous conservation planning-often by heritage experts. This involves a values-based assessment process followed by a series of well-defined steps, right through to reporting and monitoring on the status of the identified values (Figure 22.5). These steps are often articulated through a conservation management plan, particularly where the feature is substantial or of great significance. Any such plan would need to be consistent with any other plans relevant to the protected area.

Thorough research using all available sources leads to an understanding of the place and enables an assessment of its values. Heritage values can reside in the form, materials, craftsmanship and setting of the place and also in the associations and memories that people have with a place. Heritage values differ from culture to culture and for different periods of social history. They are closely tied to authenticity in both the fabric and the associated documentary evidence. Lennon (2006) contains useful information regarding values, authenticity and significance. ICOMOS Australia identifies five values, shown in Table 22.1 (see also Chapter 4). 
Table 22.1 Cultural heritage values

\begin{tabular}{|l|l|}
\hline Cultural value type & Description \\
\hline Aesthetic value & $\begin{array}{l}\text { Sensory perception such as form, scale, colour, texture and material of the fabric or the } \\
\text { smells and sounds associated with the place and its use }\end{array}$ \\
\hline Historic value & $\begin{array}{l}\text { A place has influenced, or has been influenced by, a historic figure, event, phase or } \\
\text { activity; site of an important event }\end{array}$ \\
\hline Scientific/research value & $\begin{array}{l}\text { Importance of the data; rarity, representativeness, degree to which the place may } \\
\text { contribute further substantial information }\end{array}$ \\
\hline Social value & $\begin{array}{l}\text { Qualities for which a place has become a focus of spiritual, political, national or other } \\
\text { cultural sentiment to a majority or minority group }\end{array}$ \\
\hline Spiritual value & $\begin{array}{l}\text { Used to capture the attachment between humans and the natural environment/place, } \\
\text { being more specific than social or aesthetic }\end{array}$ \\
\hline
\end{tabular}

Source: Australia ICOMOS (2013)

Once the values have been identified and there is a consensus among stakeholders (not always easy to achieve), an assessment of cultural significance demonstrates the degree to which the heritage features possess the defined values. A clear and concise statement of cultural significance is prepared, which can be for an entire feature or there can be separate statements for separate elements making up a large and complex feature.

While stage one focuses on the place itself, stage two is concerned with policy development, weighing the obligations arising from the significance assessment with external factors that may influence future management of the place. For example, it would not be useful to have a policy of total restoration of a building if there is no available funding.

Stage two is likely to involve lengthy discussions between the heritage practitioner, park managers and stakeholders. Once policies have been developed, a management plan can be prepared that operationalises the policies into objectives and actions that are prioritised and funded. An effective monitoring and review process should be included in the management plan. A conservation management plan should be clear on what is and what is not acceptable for the heritage feature, such as whether a building can be moved; whether movable heritage can be removed to a museum; the amount of new fabric that can be introduced; the appropriate type of furniture to use; and the amount of funding to be allocated to maintaining an old or derelict building. The following factors may be important to consider when developing a conservation management plan.

- Visitor use: The sustainability of visitor levels needs to be assessed to determine whether they are compatible with the retention of the cultural significance of the protected area.
- Interpretation: Methods for revealing the significant values of the place to the public should be outlined, if there is to be public use. This may involve treatment of the fabric to show historic meanings, the use of the place in a way consistent with its original use, the use of introduced interpretative material or use of local people as guides.

- Constraints on investigation: There may be cultural, social, ethical or religious reasons that prevent or limit investigation of the cultural landscape or access to historic sites by researchers, workers or the public.

- Future developments likely to occur: The conservation plan must examine possible future developments and their impact on the heritage values. Developments of any scale should also be assessed through environmental impact assessment procedures and appropriate mitigation strategies.

The aim is for a workable conservation plan that can be adapted to changing conditions while retaining the significance of the heritage values expressed in the place.

The management plan may incorporate conditions for alternative scenarios, allowing the manager to respond to changes in use or physical condition of the place. The treatment actions can range from cyclical maintenance and restoration to continuing traditional ways of living or adaptive reuse. The appropriateness of particular treatments should be carefully evaluated before any works commence. The appropriateness of treatments will also vary depending on the type of protected area and scale of impact. For example, in designed landscapes there may be reconstruction of missing elements, as at the World Heritage-listed Lednice-Valtice Cultural Landscape in the Czech Republic, one of the largest artificial landscapes in Europe; rehabilitation and restoration following damage at Hampton Court Palace gardens in the United Kingdom; and reconstruction 
via the replanting of 50000 trees at Versailles following severe storms in 1999, which devastated the formal French gardens dating back to Louis XIV.

The management principles for places listed on Australia's National Heritage register are also useful.

- The objectives in managing heritage landscapes are to identify, protect, conserve, present and transmit, to all generations, their heritage values.

- Management of heritage places should use the best available knowledge, skills and standards for those places, and include ongoing technical and community input to decisions and actions that may have a significant impact on their heritage values.

- Management of heritage landscapes should respect all values of the place.

- Management of heritage places should ensure that their use, presentation and interpretation to visitors are consistent with the conservation of their heritage values.

- Management of heritage sites should make timely and appropriate provision for community involvement, especially by people who have a particular interest in, or association with, the place, and may be affected by the management of the place.

- Indigenous people are the primary source of information on the value of their heritage and their active participation in identification, assessment and management is integral to the effective protection of indigenous heritage values.

- Management of heritage landscapes should provide for regular monitoring, review and reporting on the conservation of heritage values of the sites (Department of the Environment 2014).

Cultural associations must be maintained to keep the associative values alive as detailed in the significance assessment conducted as part of the conservation planning process. This requires cooperation and collaboration between community group leaders and knowledge-holders and protected areas managers. It may include education programs, seasonal activities, intergenerational meetings and festivals to transmit rituals and crafts, language and pride in local costume. Values can be dynamic, however: they evolve and change. Evaluation of condition and knowledge about these values must be updated, and therefore management strategies must be able to change to protect the protected areas' expressed values.

The popular ranger-guided Mala Walk at the base of Uluru and towards Kantju Gorge, Uluru-Kata Tjuta National Park, Northern Territory, Australia. This walk features spectacular overhangs and caves, Aboriginal paintings and sites of special significance to the Aboriginal community.

Protection of these features is provided by the design of elevated viewing platforms and the route of the track.

Source: Graeme L. Worboys

\section{Managing visitors at historic sites}

Many historic buildings are opened to the public, sometimes to raise funds to assist in their upkeep. The conservation plan for historic buildings should identify the type of circulation of visitors and their frequency along specific hallways, corridors or staircases. For instance, when visiting the Royal Palace in London, visitors can direct their attention to landmark statues or prime murals as indicators of the type of collections that will be on display. When visiting sensitive historic buildings, observance of silent reading or the use of audiovisual self-guided tours may be requested, with restricted visiting hours. When visiting historic temples in Kyoto, Japan, visitors may access certain rooms of the main floor only if they have removed their shoes or have the disposable shoe-covers provided by management. Historic buildings that display bibliographic collections provide authorised visitors with nose and mouth filters and cotton gloves. 
Other impacts on historic buildings and monuments can include soot and dust accumulation on exposed surfaces, and visual and sound contamination in urban areas. Heritage sites should have a buffer space-for example, a garden. That buffer could ameliorate these problems and provide a curtilage to the site.

High numbers of visitors can impact on built heritage, which can be ameliorated in several ways. Numbers can be limited to a maximum at any one time, or the building areas open to the public could be restricted, or the site could be closed at certain times of the year. Public support may diminish, however, unless there are good educational programs to explain why such measures are necessary. Revenue may also decline, which could have negative consequences for the management authority and local communities.

Alternatively, sites can be 'hardened'. At Throsby Park Historic Site, a grand Georgian sandstone homestead in New South Wales, Australia, fragile carpets were covered with thick plastic to enable visitors to walk through the building without causing damage. Elevated walkways can be built around archaeological sites such as at the World Heritage-listed 8000-year-old Çatal Hüyük in Turkey (see Chapter 4), or in rock shelters containing galleries of ancient paintings. Monitoring the impacts of visitors is crucial for ensuring that services are not overloaded and significant fabric is not damaged, and to identify when works are needed to retain the significance of the place.

Where appropriate, multilingual signage should be displayed. Brochures should be made available for site visitors, providing they will not cause a litter problem. A resource centre could also be developed at the site, where visitors could have access to relevant information about the site's history and cultural significance. Links to social media sites should be clearly exhibited for those who want to link with other people and blog about their experiences.

Most importantly, architects, archaeologists, rangers, communicators, ecologists, sociologists and other professionals involved in heritage sites should be given site instruction and training that introduces them to the philosophy and techniques of conservation, restoration and site operation as they apply to the specific location.

In some instances, tourists can experience cultural heritage without directly seeing it. For example, artwork on cave walls may be too fragile to be subjected to tourists and their carbon dioxide-rich breath. Visitors cannot enter such caves; instead, they receive their visual instruction at interpretation centres designed to

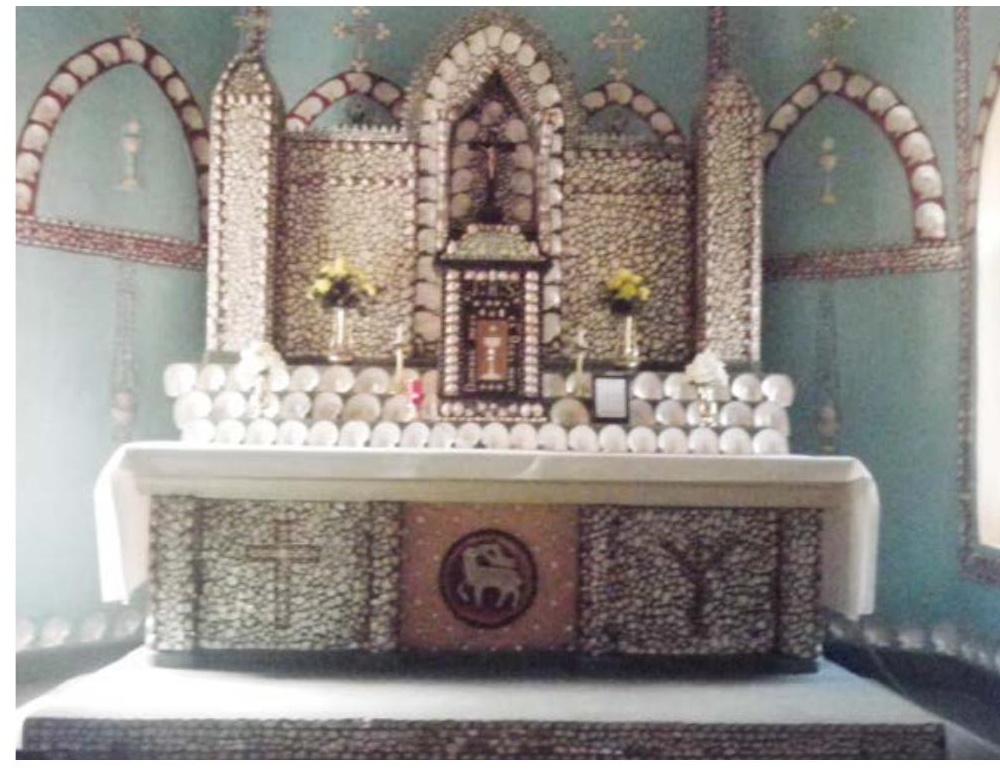

Mother-of-pearl inlaid alter, Sacred Heart Church, old Beagle Bay Aboriginal Mission, Dampier Peninsula, Northern Territory, Australia. The church was built in 1890 by French Trappist monks and attracts revenue for the local Aboriginal community from donations.

Source: Sue Feary

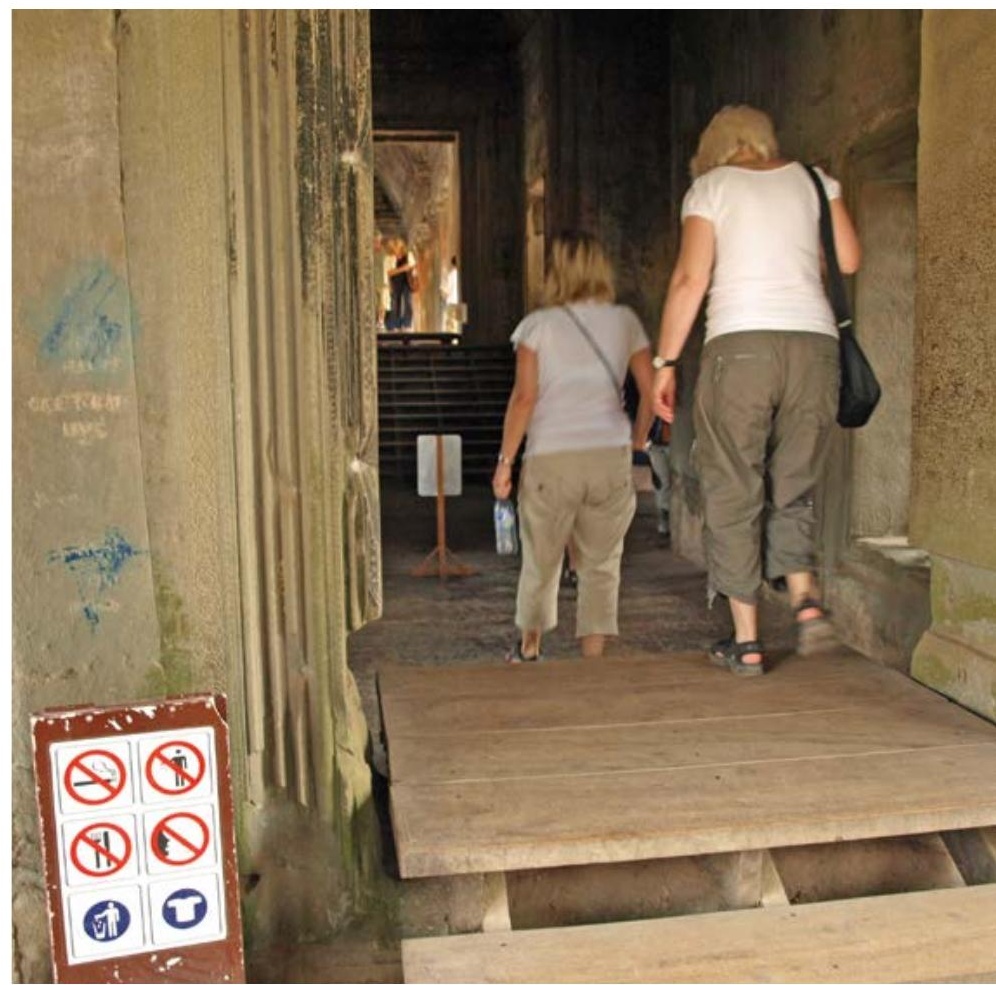

International regulatory signs at Angkor Wat, Cambodia, used to help protect the site from pollution (food scraps, cigarette butts and garbage), noise pollution and to achieve culturally acceptable dress. The wooden steps help to protect the stone doorway from heavy foot traffic. Source: Graeme L. Worboys 
accommodate a great number of people arriving at the premises, such as in the Altamira Caves near Antillana del Mar, Cantabria, in northern Spain.

If access to the site is needed, special paths can be marked with strict direction of circulation and clear signs that make the experience self-explanatory. Where possible, interpretation pathways with illustrative signage allowing disabled access are desirable. Notices about not using flash photography or other invasive observation practices may also be appropriate.

\section{Managing heritage features in a changing world}

Important heritage sites can be affected by many events, both natural and humanly determined. For example, climate change processes such as the melting of glaciers may threaten shrines in mountainous areas. An example of an extreme case of human intervention is removal of the Great Temple complex of Abu Simbel to allow construction of the Aswan Dam in Egypt. The structure was completely rebuilt at another location using the same materials and design of the original structure. The original feature was cut into blocks and the pieces reassembled in their new location (Fitzgerald 2008).

On the positive side, ancient structures that have been flooded due to natural or socio-political reasons can serve as in situ subaquatic displays that tourists can dive to see (see Chapter 4 on underwater heritage). Diving around submerged structures is a relatively new form of tourism becoming popular in the sunken villages of Ngibtal and Babeldaob in Palau, Micronesia, the Yucatán Peninsula in the Caribbean and in some shipwrecks of the Mediterranean Roman trade route. The sustainability of this activity has yet to be determined, as looting is an ever-present danger (Guérin et al. 2010).

\section{Managing research at archaeological sites}

While most nations and their teaching institutions have well-established principles and policies to guide research at heritage sites, each site has its own unique circumstances with which practitioners must become familiar. For example, when an archaeological dig in a protected area is needed to obtain data relevant to understanding or managing the site, best archaeological practice must prevail, not only in relation to excavation methodologies, but also to ensure safe removal and deposition of excavated sediment, maintaining the landscape integrity of the protected area or cultural goods and, where relevant, the tranquillity and soft pace of the lifestyle of the communities in the region.

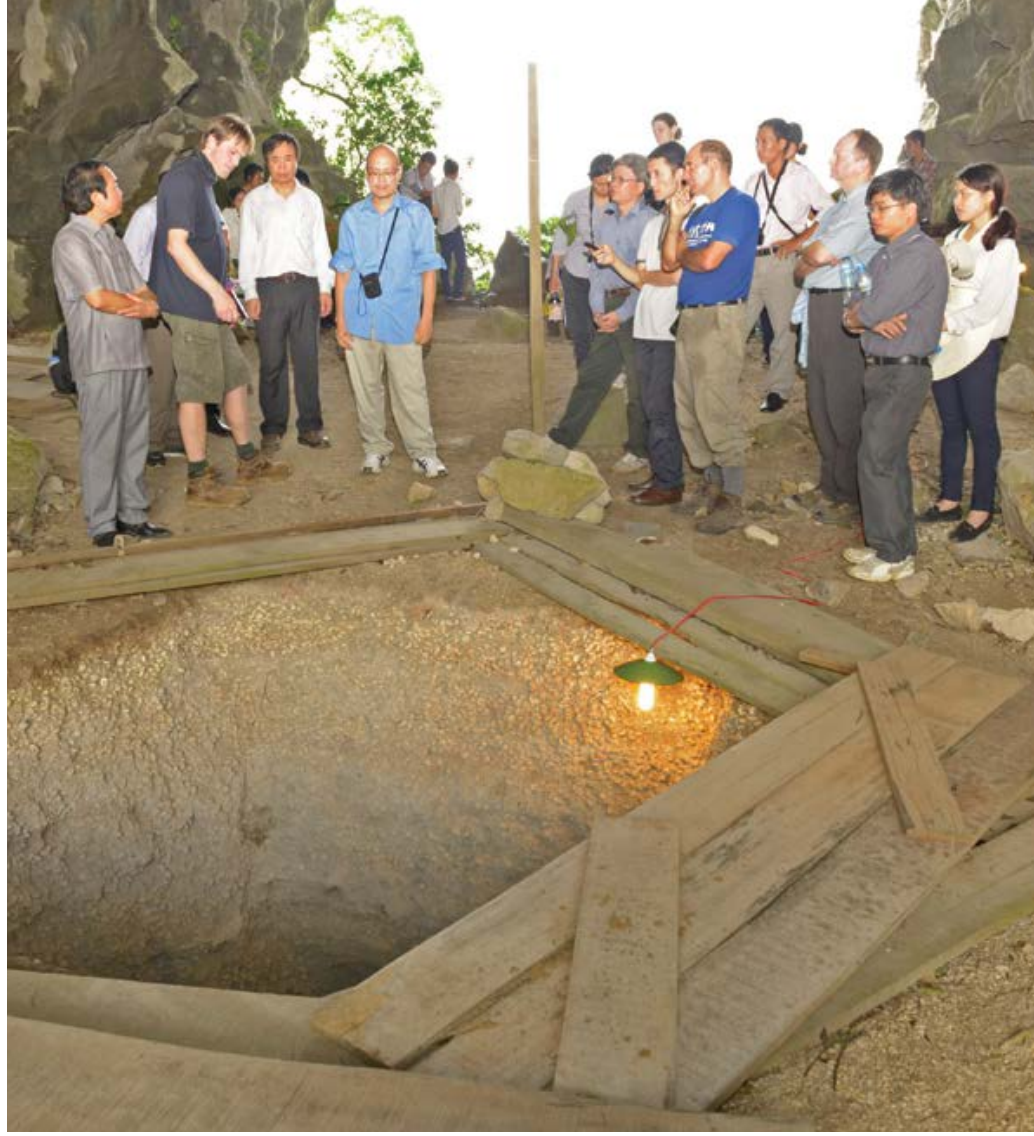

Archaeologists briefing visiting experts to Hang Trong Cave, Trang An Landscape Complex World Heritage Property, Vietnam, about the excavation of a human occupation deposit that dates back 24438 years. Visitor use restrictions to this area help protect the excavation site.

Source: Graeme L. Worboys

Generally, heavy excavation machinery is not permitted in archaeological excavations within a protected area, although this will be guided by relevant management plans and conservation strategies. Where possible, local community members should be employed to assist with archaeological research. This not only provides local employment; it also enables people to connect with their heritage through direct participation in research and management, such as with the Eastern Band of the Cherokee in the operation of the museum and community centre in North Carolina. Involvement of Aboriginal Australians in archaeological research is a requirement of State and national regulatory authorities and of ethics committees of most universities in Australia.

\section{Managing and conserving records}

While protected area managers in the Western world have been working with computer technology for many decades, there are countries where computer hardware and software are not readily available. Ideally, files, records, archival materials including maps, designs and photographs should be digitised and safeguarded within the electronic system, including at least three backups kept at different locations. The International Committee for Documentation of Cultural Heritage (CIPA), one of the technical branches of ICOMOS, advises on the 
acquisition of data and information for the purpose of documenting cultural heritage, and manages the information, and provides education and training at different levels. Good record-keeping of historical records, which are heritage in themselves, is a critical element of cultural heritage management. UNESCO has established guidelines to handle historically relevant records (CIPA 2007).

There are many countries where computing, archival and cataloguing facilities and services are limited, nonexistent or in their infancy. An example is the Solomon Islands, whose archives, located in the nation's capital, Honiara, hold many written records including those of British colonial settlement, and the history of activities of churches and missionaries over many decades. An unreliable electricity supply, natural disasters, lack of equipment and lack of training of local people put these valuable records at great risk. The Solomon Islands Government solved the problem by using Australian foreign aid and a partnership with The Australian National University to digitise many of its records. It also called for volunteers under the Australian Volunteers Abroad scheme, to write manuals and train staff in the management of records. Funds were also found to buy a generator to combat the inevitable daily electricity outages.

\section{Conclusion}

In this chapter, we have seen how protected area philosophies have responded and changed to accommodate new concepts such as cultural landscapes and biocultural heritage. These concepts recognise past and ongoing human use of protected area environments as well as showing us a way forward in managing protected areas and their precious natural and cultural values. In many parts of the world, an effective way for maintaining the cultural heritage values of protected areas is through their continued use by people for spiritual and cultural practices or for livelihood reasons. This continual use keeps the heritage value highlighted and in some instances could mean the best protection for both cultural and natural values.

This chapter has championed the importance of taking an integrated approach to managing culture and nature and has provided guidance on how to achieve this by way of case studies and examples. We have considered the importance of the conservation planning process in managing cultural heritage, and how values underpin assessment of cultural significance, which then forms a basis for policies and objectives in a rational and transparent way.

Management of some aspects of tangible cultural heritage has been explored, particularly the opening up of heritage buildings and religious sacred sites for mass tourism. A large proportion of the chapter has been devoted to discussion of managing sacred sites, both natural and built, of mainstream religions. Many such sites have recognised universal value and are well known and receive very high levels of visitation by pilgrims and tourists, requiring active management as a result.

\section{References}

\section{Recommended reading}

Amend, T., Brown, J., Kothari, A., Phillips, A. and Stolton, S. (eds) (2008) Protected Landscapes and Agro-Biodiversity Values, Values of Protected Landscapes and Seascapes Series Vol. 1, IUCN and GTZ, Kasparek-Verlag, Heidelberg.

Apgar, J., Ataria, J. and Allen, W. (2011) 'Managing beyond designations: supporting endogenous processes for nurturing biocultural development', International Journal of Heritage Studies 17(6): 555-70.

Argumedo, A. (2008) 'The Potato Park, Peru: conserving agrobiodiversity in an Andean indigenous biocultural heritage area', in T. Amend, J. Brown, A. Kothari, A. Phillips and S. Stolton (eds) Protected Landscapes and Agrobiodiversity Values, pp. 45-58, Protected Landscapes and Seascapes Series Vol. 1, IUCN and GTZ, KasparekVerlag, Heidelberg.

Australia International Council on Monuments and Sites (Australia ICOMOS) (2013) The Burra Charter: The Australia ICOMOS charter for places of cultural significance, Australia ICOMOS Secretariat, Melbourne.

Berkes, F. and Folke, C. (1998) Linking Social and Ecological Systems: Management practices and social mechanisms for building resistance, Cambridge University Press, Cambridge.

Bernbaum, E. (1997) Sacred Mountains of the World, University of California Press, Berkeley. 
Bernbaum, E. (2006) 'Sacred mountains: themes and teachings', Mountain Research and Development 26: 304-9.

Bernbaum, E. (2007) 'Great Smoky Mountains (shagonage) and Qualla boundary: Tennessee and North Carolina, southern Appalachian Mountains, United States of America', in J.-M. Mallarach and T. Papayannis (eds) Nature and Spirituality in Protected Areas: Proceedings of the first workshop of the Delos Initiative, pp. 201-18, IUCN and Publicacions de l'Abadia de Montserrat, Gland and Barcelona.

Blattel, A., Gagnon, G., Côté, J. and Brown, J. (2008) 'Conserving agro-biodiversity on the Gaspé Peninsula of Québec, Canada. A potential role for paysage humanisé designation', in T. Amend, J. Brown, A. Kothari, A. Phillips and S. Stolton (eds) Protected Landscapes and Agrobiodiversity Values, pp. 96-104, Protected Landscapes and Seascapes Series Vol. 1, IUCN and GTZ, Kasparek-Verlag, Heidelberg.

Borrini-Feyerabend, G. (2002) 'Interview on local communities and protected areas', Parks 12(2): 2-5.

1 Borrini-Feyerabend, G., Dudley, N., Jaeger, T., Lassen, B., Pathak, N., Phillips, A. and Sandwith, T. (2013) Governance of Protected Areas: From understanding to action, Best Practice Protected Area Guidelines Series No. 20, IUCN, Gland.

Brown, J. (in press [a]) 'Stewardship of protected landscapes by communities: diverse landscapes, diverse governance models', in K. Taylor, A. St Clair and N. Mitchell (eds) Cultural Landscapes: Preservation challenges in the 21st century, Routledge, New York.

Brown, J. (in press [b]) 'Bringing together nature and culture: integrating a landscape approach in protected areas policy and practice', in R. Gambino and A. Peano (eds) Nature Policies and Landscape Policies: Towards an alliance, European Documentation Centre on Nature Park Planning and Springer Verlag, Torino.

Brown, J. and Hay-Edie, T. (2013) COMPACT: Engaging communities in the stewardship of world heritage, UNDP, New York.

Brown, J. and Kothari, A. (2011) 'Traditional agricultural landscapes and community conserved areas: an overview', Management of Environmental Quality 22(2): 139-53.
Brown, J., Mitchell, B. and Beresford, M. (eds) (2005) The Protected Landscape Approach: Linking nature, culture and community, IUCN, Gland.

Cepek, M. (2012) A Future for Amazonia: Randall Borman and Cofán environmental politics, University of Texas Press, Austin.

Conservation Studies Institute (2005) A Handbook for Managers of Cultural Landscapes with Natural Resource Values, US National Park Service, Woodstock, VT. <www.nps.gov/csi>

Department of the Environment (2014) Managing National Heritage Places, Government of Australia, Canberra. <www.environment.gov.au/topics/ heritage/about-australias-heritage/national-heritage>

Dudley, N. (ed.) (2008) Guidelines for Applying Protected Area Management Categories, IUCN, Gland.

Dudley, N. and Stolton, S. (eds) (2012) Protected Landscapes and Wild Biodiversity, Values of Protected Landscapes and Seascapes Series Vol. 3, IUCN, Gland.

Dudley, N., Higgins-Zogib, L. and Mansourian, S. (2005) Beyond Belief: Linking faiths and protected areas to support biodiversity conservation, WWF, Equilibrium and the Alliance of Religions and Conservation (ARC), Manchester and Gland.

Environmental Information System of Colombia (SIAC) (2014) Indian Reservation. <www.siac. gov.co/Estado_Ecosistemas_Bosque/Resguardos_ indigenas 1. aspx>

Finke, G. (2012) Landscape Interfaces: World heritage cultural landscapes and IUCN protected areas, Thematic study published by the IUCN World Heritage Programme, IUCN, Gland.

Finke, G. (2013) Linking Landscapes: Exploring the relationships between World Heritage cultural landscapes and IUCN protected areas, IUCN, Gland.

Fitzgerald, S. (2008) Ramses II: Egyptian pharaoh, warrior and builder, Compass Point Books, New York.

Gilligan, B. (2006) The National Reserve System Programme Evaluation: Indigenous Protected Area programme, Australian Department of Environment and Heritage, Canberra. 
Guérin, U., Egger, B. and Penalva, V. (eds) (2010) Underwater Cultural Heritage in Oceania, The Society for International Cultural Exchange, UNESCO, Paris.

Dd Harmon, D. and Putney, A. D. (2003) Full Value of Parks: From the economics to the intangible, Rowman \& Littlefield, Lanham, MD.

Hay-Edie, T., Howard, P., Martin, G. and McCandless, S. (2011) 'The roles of local, national and international designations in conserving biocultural diversity on a landscape scale', International Journal of Heritage Studies 17(6): 527-36.

Infield, M. and Mugisha, M. (2013) Culture, Values and Conservation: A review of perspectives, policies and practices, Fauna and Flora International, Cambridge.

International Committee for Documentation of Cultural Heritage (CIPA) (2007) Recording, Documentation and Information Management for the Conservation of Heritage Places: Guiding principles, CIPA, ICOMOS and UNESCO, The Getty Conservation Institute, Los Angeles.

International Council on Monuments and Sites (ICOMOS) (1987) The Dresden Declaration on Colonial Buildings, UNESCO-ICOMOS, Paris.

Kothari, A., Camill, P. and Brown, J. (2013) 'Conservation as if people also mattered: policy and practice of community-based conservation', Conservation and Society 11(1): 1-15.

Lennon, J. (2006) 'Cultural heritage management', in M. Lockwood, G. L. Worboys and A. Kothari (eds) Managing Protected Areas: A global guide, pp. 448-73, Earthscan, London.

Lino, C. F. and Britto de Moraes, M. (2005) 'Protecting landscapes and seascapes: experience from coastal regions of Brazil', in N. Mitchell and M. Beresford (eds) The Protected Landscape Approach: Linking nature, culture and community, pp. 163-78, IUCN, Gland.

Loh, J. and Harmon, D. (2005) 'A global index of biocultural diversity', Ecological Indicators 5: 231-41.

Mallarach, J.-M. (ed.) (2008) Protected Landscapes and Cultural and Spiritual Values, IUCN, GTZ and Obra Social de Caixa Catalunya, Heidelberg.
Mallarach, J.-M. (ed.) (2012) Spiritual Values of Protected Areas of Europe: Workshop proceedings, BfN Bundesamt für Naturschutz, Bonn.

Mallarach, J.-M. and Papayannis, T. (eds) (2007) Protected Areas and Spirituality: The proceedings of the first workshop of the Delos Initiative, IUCN and Publicacions de l'Abadia de Montserrat, Gland and Barcelona.

Mallarach, J.-M., Comas, E. and de Armas, A. (2012) El patrimonio inmaterial: valores culturales y espirituales - manual para su incorporación en las áreas protegidas [Intangible Heritage: Cultural and spiritual values- $A$ handbook for inclusion in protected areas], Ed. Fundación Fernando González Bernáldez, Madrid.

Melnick, R. (1984) Cultural Landscapes: Rural historic districts in the national parks system, US National Park Service, Washington, DC.

Mitchell, N., Rössler, M. and Tricaud, P.M. (2009) World Heritage Cultural Landscapes: $A$ handbook for conservation and management, UNESCO World Heritage Centre, Paris.

Nash, R. (2001) Wilderness and the American mind, 4th edn, Yale University Press, New Haven, Conn.

National System of Protected Areas (SINAP) (2014) National System of Protected Areas (Sistema Nacional de Áreas Protegidas), Colombia. < runap. parquesnacionales.gov.co/index/contenido/seccion/ acercaderunap>

Papayannis, T. and Mallarach, J.-M. (eds) (2009) The Sacred Dimension of Protected Areas: Proceedings of the second workshop of the Delos Initiative, IUCN and Med-INA, Gland and Athens.

Parque de la Papa (2013) The Potato Park as an Indigenous Biocultural Heritage Area (IBCHA), Parque de la Papa, Peru. <www.parquedelapapa.org/ eng/03parke_01.html>

Phillips, A. (2003) 'Cultural landscapes: IUCN's changing vision of protected areas', in M. Rössler (ed.) Cultural Landscapes: The challenges of conservation, World Heritage Papers No. 7, UNESCO World Heritage Centre, Paris.

Posey, D. (ed.) (1999) Cultural and Spiritual Values of Biodiversity, UNEP, Nairobi. 
Price, M., Byers A., Friend, D., Kohler, T. and Price, L. (eds) (2013) Mountain Geography: Physical and human dimensions, University of California Press, Berkeley.

Pungettti, G., Oviedo, G. and Hooke, D. (eds) (2012) Sacred Species and Sites: Advances in biocultural conservation, Cambridge University Press, New York.

Rodwell, D. (2007) Conservation and Sustainability in Historic Cities, Blackwell, Oxford.

Rössler, M. (2003) 'Linking nature and culture: world heritage cultural landscapes', in M. Rössler (ed.) Cultural Landscapes: The challenges of conservation, World Heritage Papers No. 7, UNESCO World Heritage Centre, Paris.

Rössler, M. (2005) 'World heritage cultural landscapes: a global perspective', in J. Brown, N. Mitchell and M. Beresford (eds) The Protected Landscape Approach: Linking nature, culture and community, pp. 37-46, IUCN, Gland.

Russiaenhoven, F. J. W., Mijatovic, D. and Eyzaguirre, P. B. (2011) 'Social-ecological indicators of resilience in agrarian and natural landscapes', Management of Environmental Quality 22(2): 154-73.

Sarmiento, F. O. and Hitchner, S. (eds) (in press) Indigenous Revival and Sacred Sites Conservation in the Americas, Environmental Anthropology and Ethnobiology Series, Berghahn Books, New York.

Sarmiento, F. O. and X. Viteri O. (in press) 'Discursive heritage: sustaining Andean cultural landscapes amidst environmental change', in A. St Clair, K. Taylor and N. Mitchell (eds) Cultural Landscapes: Preservation challenges in the 21st century, Routledge, New York.

DD Schaaf, T. and Lee, C. (eds) (2006) Conserving Cultural and Biological Diversity: The role of sacred natural sites and cultural landscapes. International Symposium, Tokyo, UNESCO, Paris.

Sierra Nevada de Santa Marta (2014) Website. <www. sacredland.org/sierra-nevada-de-santa-marta/>

Taylor, K. and Lennon, J. (2011) 'Cultural landscapes: a bridge between culture and nature', International Journal of Heritage Studies 17: 6.

Dd Taylor, K. and Lennon, J. (eds) (2012) Managing Cultural Landscapes, Routledge, New York.
Te Heuheu, T., Kawharu, M. and Tuheiva, R. (2012) 'World heritage and indigeneity', World Heritage 62(1): 8-17.

United Nations Educational, Scientific and Cultural Organisation (UNESCO) (2001) Thematic Experts Meeting on Asia-Pacific Sacred Mountains, Final Report, UNESCO, Agency for Cultural Affairs of Japan and Wakayama Prefectural Government, Paris and Tokyo.

United Nations Educational, Scientific and Cultural Organisation (UNESCO) (2009) Hoi An Protocols for Best Conservation Practice in Asia, UNESCO, Bangkok.

United States National Park Service (NPS) (2014) Guidelines for the Treatment of Cultural Landscapes: Defining landscape terminology, US National Park Service, Washington, DC. <www.nps.gov/tps/ standards/four-treatments/landscape-guidelines/ terminology.htm>

DDd Verschuuren, B., Wild, R., McNeely, A. and Oviedo, G. (eds) (2010) Sacred Natural Sites: Conserving nature and culture, Earthscan, London.

DD Wild, R. and McLeod, C. (eds) (2008) Sacred Natural Sites: Guidelines for protected area managers, IUCN, Gland.

Williams, L. (2003) 'Keeping a sweet tradition alive', Russian Conservation News 32: 2-4. <www.wildrussia.org>

Xu, J., Ma, E. T., Tashi, D., Fu, Y., Lu, Z. and Melick, D. (2006) 'Integrating sacred knowledge for conservation: cultures and landscapes in southeast China', Ecology and Society 10(2): 7. <www. ecologyandsociety.org/vol10/iss2/art7/> 


\section{PRINCIPAL AUTHORS}

ANNA SPENCELEY is a consultant based in South Africa, Chair of the International Union for Conservation of Nature (IUCN) World Commission on Protected Areas (WCPA) Tourism and Protected Areas Specialist Group and member of the Global Partnership on Sustainable Tourism's Group of Experts.

JON KOHL, based in Costa Rica, is Coordinating Facilitator of the Public Use Planning Global Heritage Consortium as well as a specialist in heritage interpretation and visitor experience design.

SIMON McARTHUR is a consultant based in Australia working on special-interest tourism planning, feasibility and development. He has developed sustainable tourism models in China, the Bahamas, Australia and Canada.

PETER MYLES is based in South Africa, is registered with the UN World Tourism Organisation (UNWTO) as a tourism collaborator and is a member of the steering committee that founded the International Coastal and Marine Tourism Society.

MARCELLO NOTARIANNI is a consultant based in Italy, with more than 16 years' experience in sustainable development of tourism. He is panel expert for the UNWTO, IUCN WCPA and the International Labour Organisation (ILO).

DAN PALECZNY is Director of Policy, Planning and Aboriginal Relations with the Department of Environment in Yukon, Canada, and a member of the WCPA Tourism and Protected Areas Specialist Group.

CATHERINE PICKERING is a Professor in the Environmental Futures Research Institute, Griffith University, Australia.

GRAEME L. WORBOYS is Co-Vice-Chair of IUCN WCPA Connectivity Conservation and Mountains, and an Adjunct Fellow in the Fenner School, The Australian National University.

\section{ACKNOWLEDGMENTS}

Pema Bhutia and Katherine Turner prepared case studies for this chapter. The use of extracts from research studies on wildlife and protected areas published by the Sustainable Tourism Cooperative Research Centre, Australia, is recognised here.

\section{CITATION}

Spenceley, A., Kohl, J., McArthur, S., Myles, P., Notarianni, M., Paleczny, D., Pickering, C. and Worboys, G. L. (2015) 'Visitor management', in G. L. Worboys, M. Lockwood, A. Kothari, S. Feary and I. Pulsford (eds) Protected Area Governance and Management, pp. 715-750, ANU Press, Canberra.

\section{TITLE PAGE PHOTO}

Visitors, Yosemite Falls, Yosemite National Park, USA

Source: Graeme L. Worboys 


\section{Introduction}

There are many different types of visitors to protected areas. They may be official guests to a national park; researchers working in a strict nature reserve; volunteers assisting with a national park work program; educational groups learning about special natural or cultural heritage; or people who conduct their business within a protected area including contractors and shop owners. Importantly, visitors also include tourists and recreationists. In this chapter, we briefly examine the types of visitors protected area managers may need to deal with and management considerations associated with such visitor use. We, however, provide a focus on tourism and its management in this chapter. Depending on the International Union for Conservation of Nature (IUCN) protected area category, tourism and recreation are common visitor uses of most protected areas and important contributors to local and national economies. As part of managing protected areas for tourists, we describe a management framework for providing a range of recreation opportunities within reserves, the provision of visitor services and facilities and management responses to visitor impacts.

\section{The conservation imperative}

The International Union for Conservation of Nature (IUCN) facilitated the development of an internationally accepted definition of protected areas. This definition states that a protected area is '[a] clearly defined geographical space, recognised, dedicated and managed, through legal or other effective means, to achieve the long-term conservation of nature with associated ecosystem services and cultural values' (Dudley 2008:8).

Every word of the definition is important (see Chapter 2) and provides strong guidance for the management of tourism within protected areas. Specifically, 'dedicated' means a binding commitment to the conservation of nature for the long term for the protected area and 'managed' means active steps are being taken to conserve the natural (and possibly other) values for which the protected area was established. In addition, 'long term' recognises protected areas should be managed in perpetuity and not as a short-term or temporary management strategy, and 'nature' always refers to biodiversity, at genetic, species and ecosystem levels, and often also refers to geodiversity, landform and broader natural values (Dudley 2008). 'Cultural values' include those that do not interfere with the principal biodiversity conservation outcome (Dudley 2008).
This definition guides visitor and tourism management in protected areas, and, drawing on Dudley (2008), the following principles apply:

- conservation of biodiversity and other nature has primacy in decisions

- any exploitation or management practice that will be harmful to the objectives of designation must be prevented or eliminated where necessary

- visitor and tourism management must operate under the guidance of a management plan and a monitoring and evaluation program that supports adaptive management.

Visitor use of protected areas is an integral part of the day-to-day operation of protected areas (Tables 23.1 and 23.2). Visitor use provides educational opportunities, delivers recreational benefits, develops public support for protection and may deliver benefits to resident and local communities consistent with the other objectives of management (Dudley 2008). Such use may be in the form of low-impact scientific research activities and ecological monitoring related to and consistent with the values of the protected area for all IUCN protected area categories (Dudley 2008). For some protected area categories, tourism provides critical economic benefits. IUCN Category II protected areas in particular provide opportunities for visitor and tourism uses. The IUCN provides strong guidance for visitor use of Category II protected areas, and the supplementary objectives of management for this category are " $[t]$ o manage visitor use for inspirational, educational, cultural and recreational purposes at a level which will not cause significant biological or ecological degradation to the natural resources', and ' $[t] o$ contribute to local economies through tourism' (Dudley 2008:16).

There is regularly a tension for protected area managers and protected area agencies in managing these two objectives for Category II areas and some other protected area categories. Getting the balance right can be very difficult, especially in the context of an often demanding, pro-development and well-connected tourism industry. The tension can include two world views. One is to retain the natural condition of a destination for future generations (supported by the purpose for establishing the protected area) and the other is a tourism industry perspective that believes it is 'obvious' for such a prime, spectacular location to be developed for tourism. Often, there can be no compromise if the intergenerational natural condition of a destination is to be retained.

Pro-development lobbyists seeking access to prime locations sometimes have described protected areas as being 'locked up'. Opposing an aspect of this claim of 
Table 23.1 Types of official visitors to protected areas (including Indigenous Peoples' and Community Conserved Territories and Areas, and Private Protected Areas)

\begin{tabular}{|c|c|c|c|c|c|c|c|}
\hline \multirow[t]{2}{*}{ Visitors } & \multirow[t]{2}{*}{ Purpose of visit } & \multicolumn{6}{|c|}{ IUCN Protected Area Categories } \\
\hline & & $\mathbf{I}$ & II & III & IV & $\mathbf{V}$ & VI \\
\hline $\begin{array}{l}\text { Community members } \\
\text { responsible for a } \\
\text { protected area }\end{array}$ & $\begin{array}{l}\text { All aspects of conservation management of a } \\
\text { community conserved area and indigenous lands }\end{array}$ & $\checkmark$ & $\checkmark$ & $\checkmark$ & $\checkmark$ & $\checkmark$ & $\checkmark$ \\
\hline $\begin{array}{l}\text { Local community } \\
\text { members, indigenous } \\
\text { peoples or private } \\
\text { operators involved in } \\
\text { a protected area }\end{array}$ & $\begin{array}{l}\text { Potential ancestral or traditional community or a } \\
\text { private tourism venture with official and approved } \\
\text { sustainable use of natural resources from } \\
\text { (respectively) an indigenous area or a community } \\
\text { conserved area or a private protected area. This may } \\
\text { include reindeer herding, fishing and hunting (with } \\
\text { agreed levels of fish catch) or private hunting quotas }\end{array}$ & $\checkmark$ & $\checkmark$ & $\checkmark$ & $\checkmark$ & $\checkmark$ & $\checkmark$ \\
\hline $\begin{array}{l}\text { Protected area } \\
\text { manager }\end{array}$ & $\begin{array}{l}\text { Planning, monitoring, research, response to threats, } \\
\text { response to incidents, law enforcement, visitor } \\
\text { management }\end{array}$ & $\checkmark$ & $\checkmark$ & $\checkmark$ & $\checkmark$ & $\checkmark$ & $\checkmark$ \\
\hline $\begin{array}{l}\text { Protected area } \\
\text { worker }\end{array}$ & $\begin{array}{l}\text { Work program implementation such as pest animal } \\
\text { control including hunting, weed control, fire control } \\
\text { and soil erosion restoration }\end{array}$ & $\checkmark$ & $\checkmark$ & $\checkmark$ & $\checkmark$ & $\checkmark$ & $\checkmark$ \\
\hline $\begin{array}{l}\text { Protected area } \\
\text { contractor }\end{array}$ & $\begin{array}{l}\text { Delegated work program implemented on behalf of a } \\
\text { protected area organisation }\end{array}$ & $\checkmark$ & $\checkmark$ & $\checkmark$ & $\checkmark$ & $\checkmark$ & $\checkmark$ \\
\hline Military personnel & $\begin{array}{l}\text { Delegated program to protect heritage conservation } \\
\text { resources }\end{array}$ & $\checkmark$ & $\checkmark$ & $\checkmark$ & $\checkmark$ & $\checkmark$ & $\checkmark$ \\
\hline $\begin{array}{l}\text { Community service } \\
\text { personnel }\end{array}$ & $\begin{array}{l}\text { Officials from organisations such as police, fire } \\
\text { brigade or ambulance who have an official role within } \\
\text { the protected area }\end{array}$ & & $\checkmark$ & $\checkmark$ & & $\checkmark$ & $\checkmark$ \\
\hline Lessee & $\begin{array}{l}\text { Person or company with the legal right to } \\
\text { undertake certain use of a protected area such as } \\
\text { accommodation or guiding }\end{array}$ & & $\checkmark$ & $\checkmark$ & & & \\
\hline Licensee & $\begin{array}{l}\text { Person or company with the legal right to provide } \\
\text { services within a protected area such as visitor } \\
\text { transport or waste disposal }\end{array}$ & & $\checkmark$ & $\checkmark$ & & & \\
\hline $\begin{array}{l}\text { Very important } \\
\text { persons }\end{array}$ & $\begin{array}{l}\text { Official guest(s) of a government, of the protected } \\
\text { area organisation or of the protected area } \\
\text { administration }\end{array}$ & $\checkmark$ & $\checkmark$ & $\checkmark$ & $\checkmark$ & $\checkmark$ & $\checkmark$ \\
\hline
\end{tabular}

Source: Adapted from Dudley (2008)

Table 23.2 Indicative visitor use of protected areas

\begin{tabular}{|c|c|c|c|c|c|c|c|}
\hline \multirow[t]{2}{*}{ Type of visitor } & \multirow[t]{2}{*}{ Type of visitor use } & \multicolumn{6}{|c|}{ IUCN Protected Area Categories } \\
\hline & & $\mathbf{I}$ & II & III & IV & $\mathbf{v}$ & $\mathbf{V} \mathbf{I}$ \\
\hline \multirow{7}{*}{$\begin{array}{l}\text { Volunteers (officially } \\
\text { recognised and } \\
\text { supported) }\end{array}$} & Firefighters and search and rescue personnel & $\checkmark$ & $\checkmark$ & $\checkmark$ & $\checkmark$ & $\checkmark$ & $\checkmark$ \\
\hline & Historic site maintenance and restoration & & $\checkmark$ & $\checkmark$ & $\checkmark$ & $\checkmark$ & $\checkmark$ \\
\hline & Walking track maintenance & & $\checkmark$ & $\checkmark$ & $\checkmark$ & $\checkmark$ & $\checkmark$ \\
\hline & Introduced plant removal & $\checkmark$ & $\checkmark$ & $\checkmark$ & $\checkmark$ & $\checkmark$ & $\checkmark$ \\
\hline & $\begin{array}{l}\text { Fauna protection such as seasonal bird nesting site } \\
\text { protection surveillance }\end{array}$ & $\checkmark$ & $\checkmark$ & $\checkmark$ & $\checkmark$ & & \\
\hline & $\begin{array}{l}\text { Visitor service support such as volunteer campground } \\
\text { wardens or guides }\end{array}$ & & $\checkmark$ & $\checkmark$ & & $\checkmark$ & $\checkmark$ \\
\hline & $\begin{array}{l}\text { Researchers-such as those conducting a } \\
\text { biodiversity assessment }\end{array}$ & $\checkmark$ & $\checkmark$ & $\checkmark$ & $\checkmark$ & $\checkmark$ & $\checkmark$ \\
\hline $\begin{array}{l}\text { Researchers } \\
\text { (officially permitted) }\end{array}$ & $\begin{array}{l}\text { All aspects of natural heritage research including } \\
\text { baseline condition measurement, trends in condition } \\
\text { and ecosystem processes and social and cultural } \\
\text { heritage research }\end{array}$ & $\checkmark$ & $\checkmark$ & $\checkmark$ & $\checkmark$ & $\checkmark$ & $\checkmark$ \\
\hline
\end{tabular}




\begin{tabular}{|c|c|c|c|c|c|c|c|}
\hline \multirow[t]{2}{*}{ Type of visitor } & \multirow[t]{2}{*}{ Type of visitor use } & \multicolumn{6}{|c|}{ IUCN Protected Area Categories } \\
\hline & & $\mathbf{I}$ & II & III & IV & $\mathbf{V}$ & VI \\
\hline \multirow{2}{*}{$\begin{array}{l}\text { Commercial users } \\
\text { (officially permitted) }\end{array}$} & Nature-based filmmakers & & $\checkmark$ & & & $\checkmark$ & $\checkmark$ \\
\hline & $\begin{array}{l}\text { Visitor access services including pack animals, } \\
\text { bicycle, taxi, bus, aircraft, motor launch, snowmobile } \\
\text { and others }\end{array}$ & & $\checkmark$ & & & $\checkmark$ & $\checkmark$ \\
\hline \multirow{11}{*}{$\begin{array}{l}\text { Tourists and } \\
\text { recreationists } \\
\text { (sustainable use) }\end{array}$} & Education-focused visitors & & $\checkmark$ & $\checkmark$ & $\checkmark$ & $\checkmark$ & $\checkmark$ \\
\hline & Car-based sightseers, cycling, photography, painting & & $\checkmark$ & $\checkmark$ & & $\checkmark$ & $\checkmark$ \\
\hline & Picnicking, walking, bushwalking, camping & & $\checkmark$ & $\checkmark$ & & $\checkmark$ & $\checkmark$ \\
\hline & Nature study and cultural awareness & & $\checkmark$ & & & $\checkmark$ & $\checkmark$ \\
\hline & Orienteering, cross-country running & & $\checkmark$ & & & $\checkmark$ & $\checkmark$ \\
\hline & $\begin{array}{l}\text { Use of official horseriding, mountain biking, } 4 \mathrm{WD} \text { and } \\
\text { motorcycle routes }\end{array}$ & & $\checkmark$ & & & $\checkmark$ & $\checkmark$ \\
\hline & $\begin{array}{l}\text { Sustainable use (such as management-approved } \\
\text { hunting in private protected areas and fishing) }\end{array}$ & & & & & & $\checkmark$ \\
\hline & $\begin{array}{l}\text { Approved non-powered flight, hang-gliding, } \\
\text { paragliding, hot-air ballooning }\end{array}$ & & $\checkmark$ & & & $\checkmark$ & $\checkmark$ \\
\hline & $\begin{array}{l}\text { Water-based activities, fishing, swimming, sunbaking, } \\
\text { canoeing, boating, sailing, white-water rafting }\end{array}$ & & $\checkmark$ & & & $\checkmark$ & $\checkmark$ \\
\hline & Snow and ice-based skiers, snowboarders, ice climbers & & $\checkmark$ & & & $\checkmark$ & $\checkmark$ \\
\hline & Mountaineering and caving & & $\checkmark$ & $\checkmark$ & & $\checkmark$ & $\checkmark$ \\
\hline $\begin{array}{l}\text { Spiritual and cultural } \\
\text { users (officially } \\
\text { endorsed and } \\
\text { supported) }\end{array}$ & $\begin{array}{l}\text { Formal access to protected areas for spiritual, } \\
\text { ceremonial and cultural reasons such as traditional } \\
\text { access routes }\end{array}$ & $\checkmark$ & $\checkmark$ & $\checkmark$ & $\checkmark$ & $\checkmark$ & $\checkmark$ \\
\hline $\begin{array}{l}\text { Commemorative } \\
\text { users (officially } \\
\text { endorsed and } \\
\text { supported) }\end{array}$ & $\begin{array}{l}\text { Access to protected areas for commemorative } \\
\text { purposes such as visitors returning to sites of cultural } \\
\text { significance within a protected area }\end{array}$ & & $\checkmark$ & $\checkmark$ & & $\checkmark$ & $\checkmark$ \\
\hline
\end{tabular}

Source: Adapted from Dudley (2008)

\section{'Under the radar' people}

Some people visiting protected areas are not authorised and do not want to be detected while present, including those engaged in illegal and criminal activities. Such activities include the unauthorised harvesting of natural resources from protected areas (poaching, timber harvesting, farming), the cultivation of drug crops such as marijuana, and unauthorised people using the area as somewhere to live.

\section{Management considerations}

There is wide variation in the official and visitor use of protected areas. This immediately introduces a range of management considerations (Table 23.3). Identifying such visitor use management needs also exposes a key principle: protected areas should always be the protected natural destination where possible, with limited and lowkey infrastructure for visitors or other uses. Category V protected areas of course are managed differently (see Chapter 8). Exceptions may also occur for Category IIV protected areas for safety or logistical reasons such as accommodation within some of the very large African wildlife protected areas.

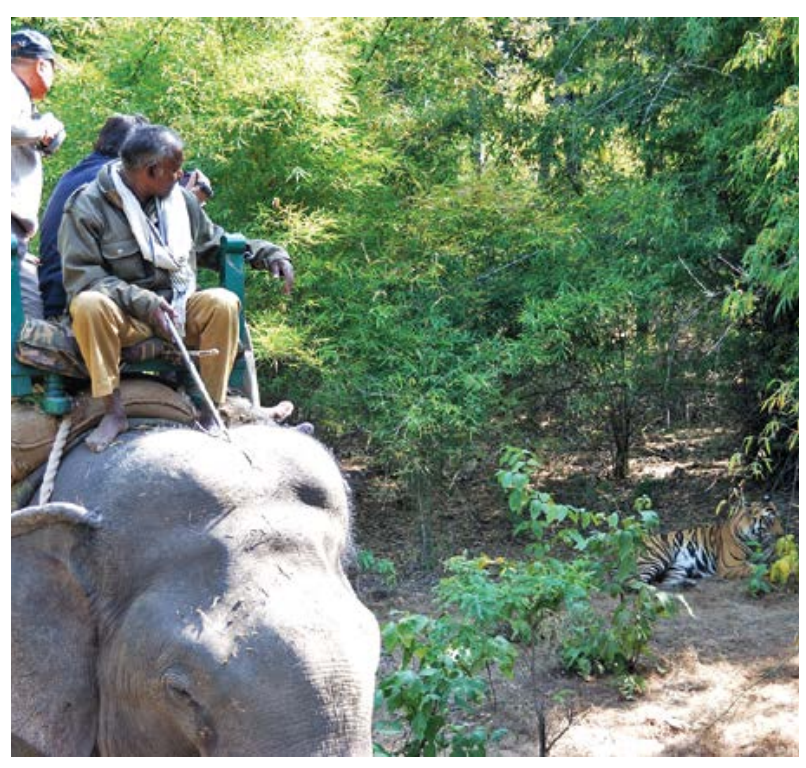

Safety considerations for visitors are critical. Wild Bengal tiger (Panthera tigris) observation from elephants (Elephas maximus), Bandhavgarh National Park, India

Source: Ashish Kothari 
Table 23.3 Visitor management considerations for protected areas

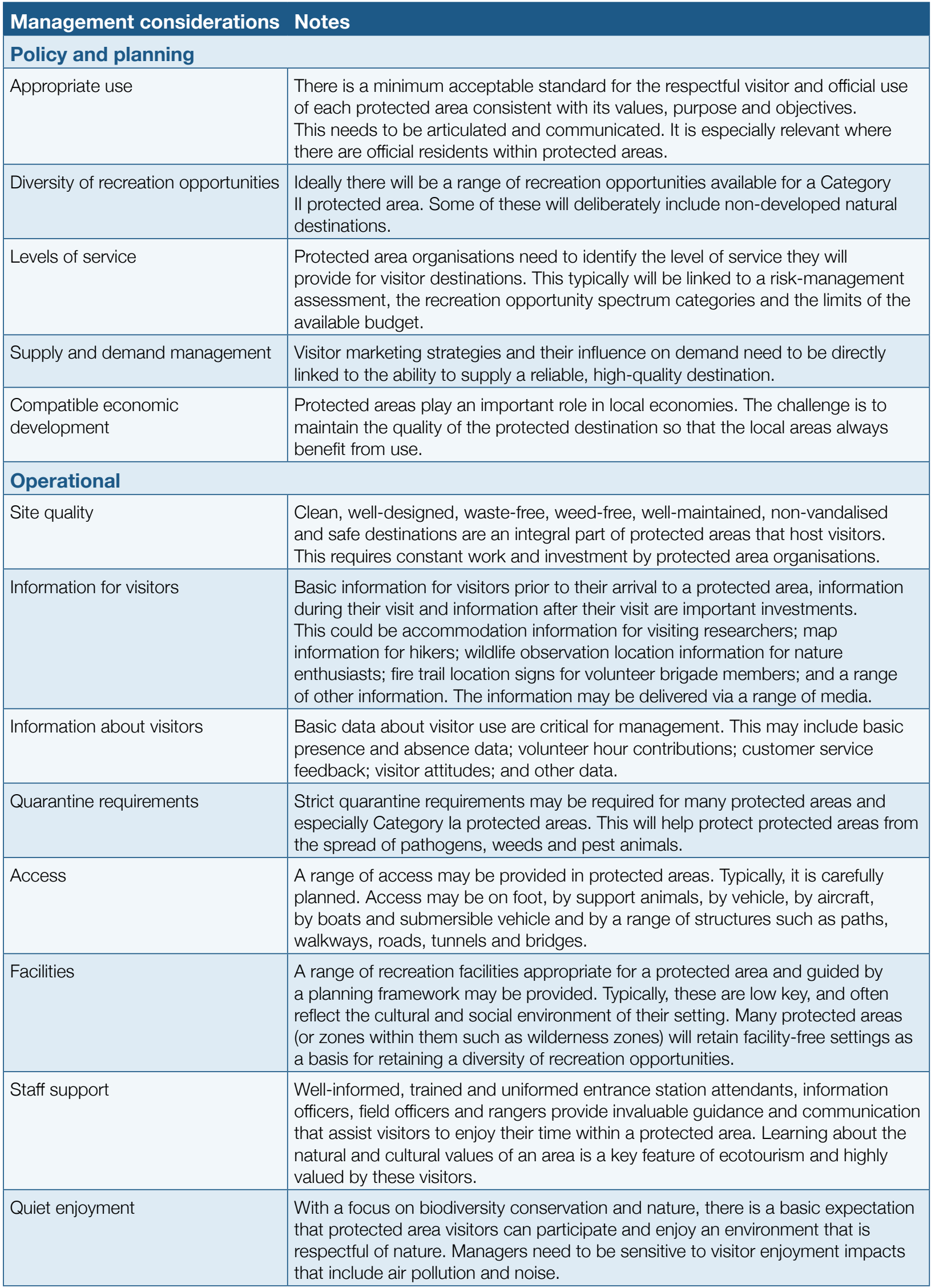




\begin{tabular}{|c|c|}
\hline Management considerations & Notes \\
\hline Crowd management & $\begin{array}{l}\text { Crowding may occur at popular destinations during peak times. Planned and } \\
\text { enforced visitor use limits for protected areas support ecologically sustainable } \\
\text { levels of use, and help to provide safe conditions by enabling access by } \\
\text { emergency responders. For those who prefer uncrowded areas, it offers a degree } \\
\text { of social comfort. }\end{array}$ \\
\hline Tensions between groups & $\begin{array}{l}\text { On some occasions tensions may arise between two or more people or between } \\
\text { groups of people. Recreational opportunity planning and zoning can help to } \\
\text { minimise these situations. Booking systems for site use can help minimise tension } \\
\text { between groups. }\end{array}$ \\
\hline Safety & $\begin{array}{l}\text { Visitor safety is paramount and vigilance is mandatory. Protected areas would } \\
\text { be expected to complete risk-management assessments, to ensure their staff } \\
\text { are adequately trained to deal with safety incidents and to ensure necessary } \\
\text { equipment or support is available, serviced and on standby. }\end{array}$ \\
\hline Toilet facilities & $\begin{array}{l}\text { Toilet facilities are typically necessary within protected areas. They may range in their } \\
\text { sophistication; however, they always need to be clean and adequately maintained. }\end{array}$ \\
\hline \multicolumn{2}{|l|}{ Administration } \\
\hline Revenue management & $\begin{array}{l}\text { Revenue management such as the collection of entrance or camping fees will } \\
\text { necessitate the handling of cash and other revenue and will bring with it security } \\
\text { and audit requirements. }\end{array}$ \\
\hline Accommodation management & $\begin{array}{l}\text { Accommodation may be provided for tourists, visiting researchers and } \\
\text { for protected area workers. Accommodation management brings with it } \\
\text { responsibilities for booking, revenue management, cleaning, servicing, } \\
\text { maintenance and safety considerations. }\end{array}$ \\
\hline Food and beverage & $\begin{array}{l}\text { Restaurant and self-catering facilities may be provided, either by the } \\
\text { administration or by a concessionaire or lessor. These can provide a rental to } \\
\text { protected area administrators, and provide a route for local employment and } \\
\text { procurement. }\end{array}$ \\
\hline Retail facilities & $\begin{array}{l}\text { Shops selling craft, gifts, maps, guidebooks, wildlife viewing equipment and food } \\
\text { items can be operated within protected areas. Such facilities will require support } \\
\text { services including utilities, security and health inspections. }\end{array}$ \\
\hline
\end{tabular}

\section{Tourism management}

Active tourism management in protected areas is crucial to ensure that the natural and cultural resources they protect can be enjoyed by future generations. It is important to learn about the tourism industry and the interests and behaviour of visitors to better plan facilities and activities in protected areas and define the right management strategies. Similarly, it is critical to understand the range, types and intensities of impacts from tourism and ways to prevent, minimise and ameliorate them.

Tourism management in protected areas is crucial because nature tourism can only be sustainable if the natural and cultural assets are conserved. There are many examples throughout the world of how tourism can be beneficial by providing motivation and support for environmental conservation. Indeed, without the financial incentive for conservation derived from tourism, many public sector bodies would probably pay less attention to the protection of the natural environment (Swarbroke 1988).
The major risk of nature tourism is that it also threatens to destroy the resources on which it depends. Therefore, the impacts of visitation on these resources must be carefully managed, directed and mitigated, and the key issue is to determine what impacts are acceptable (Eagles et al. 2002; Newsome et al. 2002). Learning more about the tourism industry and the interests and behaviours of these and other visitors is important for planning tourism in protected areas and identifying the right management strategies.

\section{Definition of tourism}

The United Nations World Tourism Organisation (UNWTO 2014a) provides the following definitions.

- Travel/tourism: Travel refers to the activity of travellers. A traveller is someone who moves between different geographic locations, for any purpose and any duration. The visitor is a particular type of traveller and consequently tourism is a subset of travel. 
- Tourist: A visitor (domestic, inbound or outbound) is classified as a tourist (or overnight visitor) if his/her trip includes an overnight stay.

- Visitor: A visitor is a traveller taking a trip to a main destination outside his/her usual environment, for less than a year, for any main purpose (business, leisure or other personal purpose) other than to be employed by a resident entity in the country or place visited. A visitor (domestic, inbound or outbound) is classified as a tourist (or overnight visitor) if his/ her trip includes an overnight stay, or as a same-day visitor (or excursionist) otherwise.

In relation to protected areas, in this chapter, we use a more specific definition wherein a tourist refers to someone who travels overnight from home for recreation or pleasure and the activities that go with this, and includes industries and services that aim to satisfy the needs of tourists (Worboys et al. 2005).

\section{Sustainable tourism}

One of the outcomes of the Rio Earth Summit in 1992 was a global action plan called Agenda 21. In relation to tourism, Agenda 21 promoted the formulation of environmentally sound and culturally sensitive tourism programs as a strategy for sustainable development (UN 1992). The United Nations stressed the need for a balanced approach to sustainable development, and suggests that economic development, social development and environmental protection are three interdependent and mutually reinforcing components of sustainable development (UN 1997). Elkington (1997) referred to this simultaneous pursuit of economic prosperity, environmental quality and social equity as the 'triple bottom line' of sustainable development. As such, sustainable tourism is defined as ' $[t]$ ourism that takes full account of its current and future economic, social and environmental impacts, addressing the needs of visitors, the industry, the environment and host communities' (UNEP and UNWTO 2005:11-12).

\section{Socially sustainable tourism in protected areas}

Socially sustainable use may also have a heightened sensitivity in protected areas, especially where there is the potential for impacts to communities within protected areas or where crowding may result in a less satisfying visitor experience. Special attention needs to be given to host communities such as in World Heritage sites with a desire to retain the cultural integrity of these communities.

\section{Financially sustainable tourism in protected areas}

The importance of sustaining tourism revenue for an individual protected area and to a protected area organisation ideally will be to help underpin quality customer service, and safe and clean destinations. Protected area managers need to be sensitive to business needs-for example, the timing of management operations such as burning off, pest animal control, weed control and maintenance tasks can be scheduled to avoid negative experiences for visitors.

\section{Ecologically sustainable tourism in protected areas}

Some interpretations of 'environmentally sustainable use' focus on considerations such as air quality, water quality, waste disposal and energy consumption. 'Ecologically sustainable use' focuses attention on ecosystems and biodiversity (CoA 1991). Tourism in protected areas needs to be managed for environmentally and ecologically sustainable outcomes. The World Heritage Convention and associated Operational Guidelines (UNESCO 2011) prescribe ecologically sustainable use for its natural World Heritage properties in order to protect the inscribed outstanding universal values. Operational Guideline 119 advises that the World Heritage properties may support ecologically sustainable use provided that such use does not impact adversely on the Outstanding Universal Values (UNESCO 2011). Many such World Heritage properties are protected areas.

The contribution of protected area management to ecologically sustainable tourism (hereinafter described as sustainable tourism) potentially includes:

- advising visitors of the special sustainable care being implemented in the protected area and how they are assisting with sustainable management

- providing special low-impact visitor use opportunities such as assisting researchers with their data collection in protected areas

- minimising impacts to natural destinations through planning for recreation opportunities, determining the nature of facilities to be provided (such as no facilities in some locations) and establishing visitor use planning limits for sites

- through good design and effective planning, harmonising any facilities to the environmental and social contexts of the protected area setting, and if appropriate, maximising energy efficiency and the use of renewable energy sources

- minimising impacts to native flora and fauna through research, monitoring and adaptive visitor use management and limits of use 


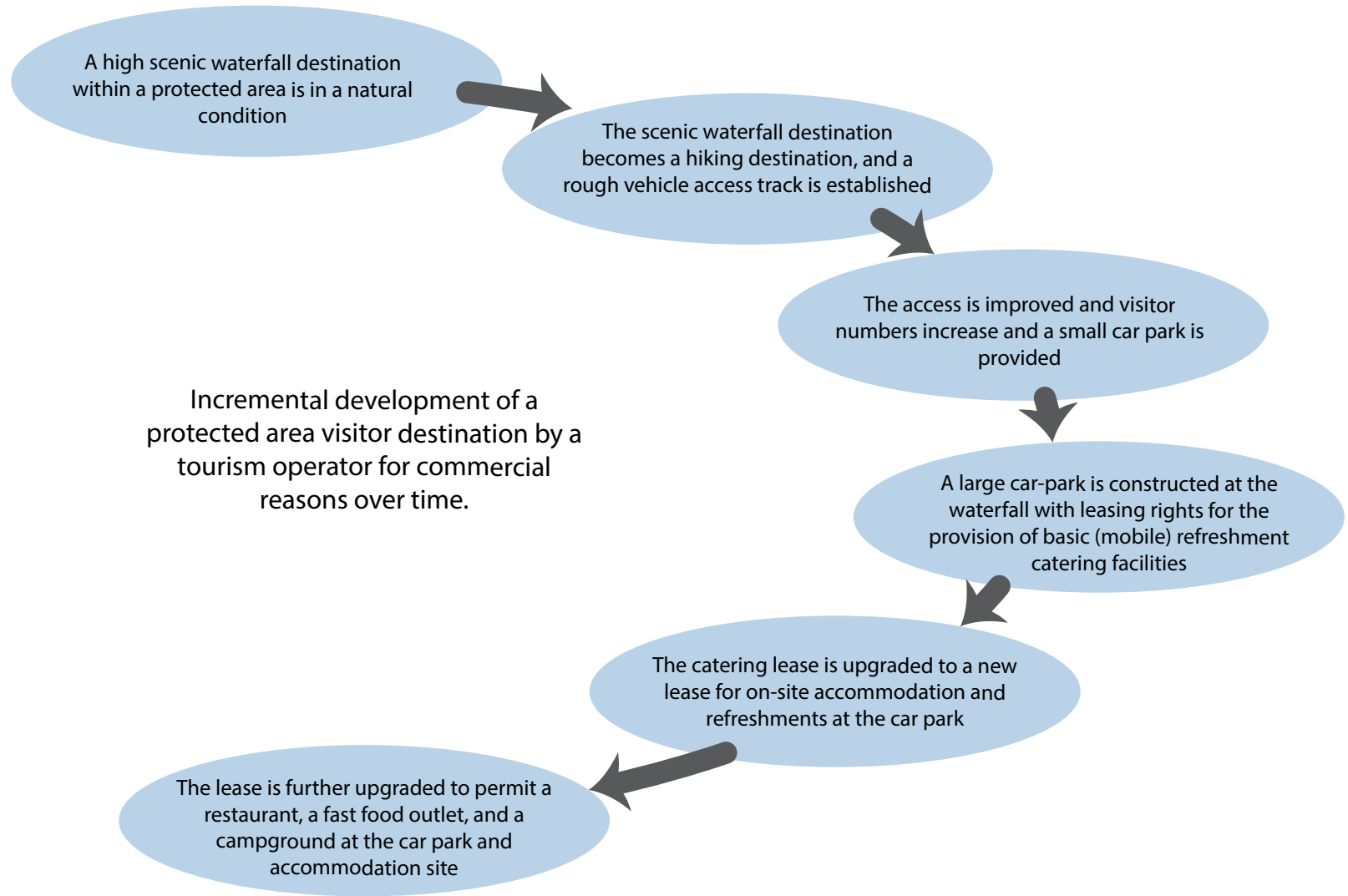

Figure 23.1 Illustration of incremental, tourism operator-driven developments within protected areas, for a hypothetical waterfall attraction

- minimising energy consumption that contributes to greenhouse gas emissions

- minimising, reusing and recycling solid and liquid waste

- minimising the consumption of freshwater resources

- with the tendering of licensed tourism opportunities, providing preference to tourism operators who have appropriate, recognised sustainable tourism industry credentials (such as industry eco-certification or awards for environmental management excellence)

- consistent with the protected area plan of management, providing economic opportunities for local communities and enterprises, including in the ownership of tourism businesses, the provision of products and services to the protected area and its visitors, and employment within the protected area

- sensitive commercialisation of cultural attractions, particularly those that are of interest to both tourists and residents.

Protected areas are preferred destinations for millions of people worldwide and of great interest to the tourism industry. For many tourism operators, they are a prime destination in which to secure revenue and achieve profits for shareholders. Profits are the focus, with the destination normally being a revenue resource. In the absence of clear management guidelines, gaining legal access to a protected area through a tourism lease or licence can, over time, lead to incremental commercial developments. Conscious, strategic and incremental commercial decisions can transform a former natural protected site to an urbanised site (Figure 23.1). Such overcommercialisation of land and water in Category II protected areas, for example, is creating challenges in many parts of the world (Dudley 2008). The management response is to ensure that the initial leases or licences are rigorous and help to protect the natural destination for the long term.

A way of considering protected area destinations over time is Butler's model of a tourist product life cycle (Butler 1980). Butler conceptualised a tourism product life cycle in which products go through various stages during their evolution including development, consolidation, stagnation and potentially ending in decline (Figure 23.2). The relevance of the destination life cycle to protected areas is in developing sustainable destinations and tourism products. This aim incorporates an objective of avoiding the potential stagnation and decline phases of the life cycle by emphasising stable tourism use from economic, environmental, social and cultural perspectives. 


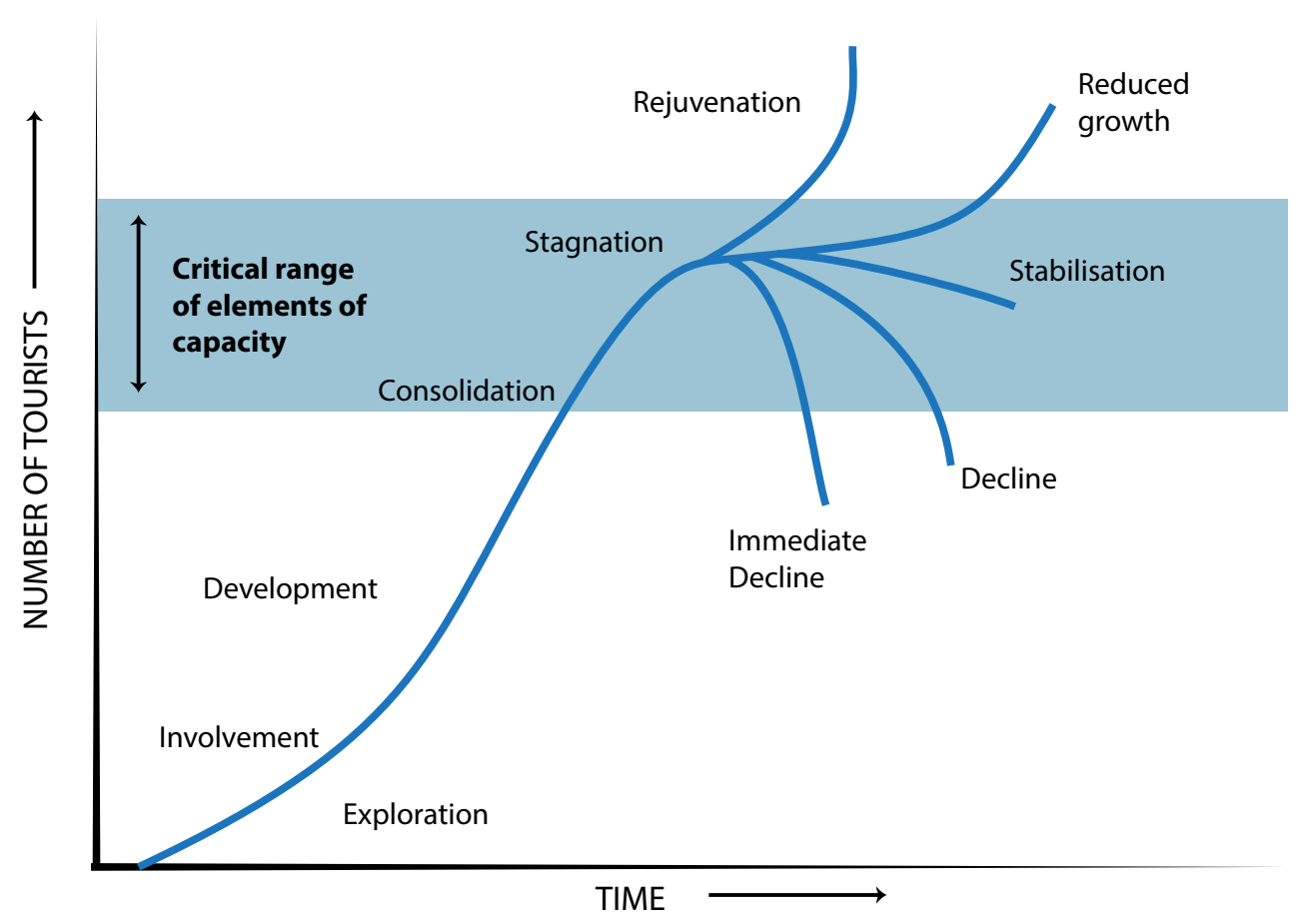

Figure 23.2 Butler's tourism destination lifecycle

Source: Adapted from Butler (1980)

\section{Types of tourism operators}

Working with tourism operators within protected areas is a critical part of achieving sustainable tourism outcomes. Every protected area tourism operation is different, and while all operations are typically respectful of their lease or licence requirements, protected area management experience has shown that operators deal with the protected status of the tourism destination in different ways. Three paradigms of tourism operator approaches to protected areas have been recognised and are described here (adapted from Worboys et al. 2005). Understanding these differences is especially important for protected area managers who may be negotiating legal agreements with tourism operators.

\section{Ecotourism operation}

An ecotourism operation within a protected area:

- is licensed to operate

- provides basic services such as accommodation, access, transport and food

- runs on a commercial basis; some profits may be returned to the protected area and to local communities

- has a corporate policy that affirms a commitment to the environment, society, culture and the local economy

- has appropriate industry (or other) sustainable tourism credentials
- has a pro-environment focus

- provides high-quality environmental education to visitors, and also to local residents

- employs local people and purchases local products and services to support the local economy

- invests in environmental management improvements

- works closely with managers to help protect the protected area.

\section{Routine tourism operation}

A routine tourism operation within a protected area typically:

- is licensed to operate

- provides basic services such as accommodation, access, transport and food

- is professional in working with the protected area organisation

- runs a 'for profit' operation

- provides some basic support information for visitors

- is not necessarily pro-protected area or proenvironment

- may make some occasional positive contribution to the protected area

- has no permanent staff with environmental qualifications. 
with high conservation significance and a historical use for grazing or agriculture is purchased, rehabilitated and managed for protected area conservation such as game reserves in Africa and Australian Wildlife Conservancy properties in Australia.

Cultural tourism is a tourism segment that focuses on the culture of a country including history, art, architecture and religion. It had its origins as part of the 'grand tour' of the European continent by the aristocracy in the 17th, 18th and 19th centuries (Chee et al. 1997). It can also include tourism in rural areas and protected areas that showcase cultural heritage such as ancient art sites, historic buildings and intangible heritage. Intangible cultural heritage comprises 'those practices, expressions, knowledge and skills as well as associated objects and cultural spaces that communities and individuals recognise as part of their cultural heritage' (UNWTO 2012:2).

Any type of holiday that includes voluntary service in the destination is considered volunteer tourism. The tourist does not receive any type of financial compensation while undertaking various types of work, and in many cases, must provide financial contributions. Volunteers at Montague Island Nature Reserve in New South Wales, for example, pay a fee to assist with volunteer work on the island (Pacey 2013).

Educational tourism involves travel to participate in educational experiences locally and overseas, but not enrolment in a study program abroad for credit. Many volunteer organisations that are mission driven offer learning trips for school groups (at all educational levels, and in some cases for adults) in which they gain practical experience in some cultural, scientific or community development fields including protected areas. The private Monteverde Cloud Forest Reserve in Costa Rica, for example, has a major educational focus (TSC 2014), as do most Category II protected areas.

Religious tourism, or faith tourism, is where people travel for pilgrimage, missionary or leisure purposes, such as access to important sites within the Great Himalayan National Park of India in respect of important religious ceremonies (Weaver and Lawton 2002).

Other types of tourism that may involve private protected areas and Category V and VI protected areas in particular include rural tourism, agrotourism and consumptive tourism (where wildlife or plants are collected, hunted or fished on a managed and sustainable use basis).

Recreation is activity voluntarily undertaken primarily for pleasure and satisfaction, during leisure time, and is a regular feature of protected areas (Worboys et al. 2005). For the purposes of this chapter, the term tourism is taken to also refer to recreation.

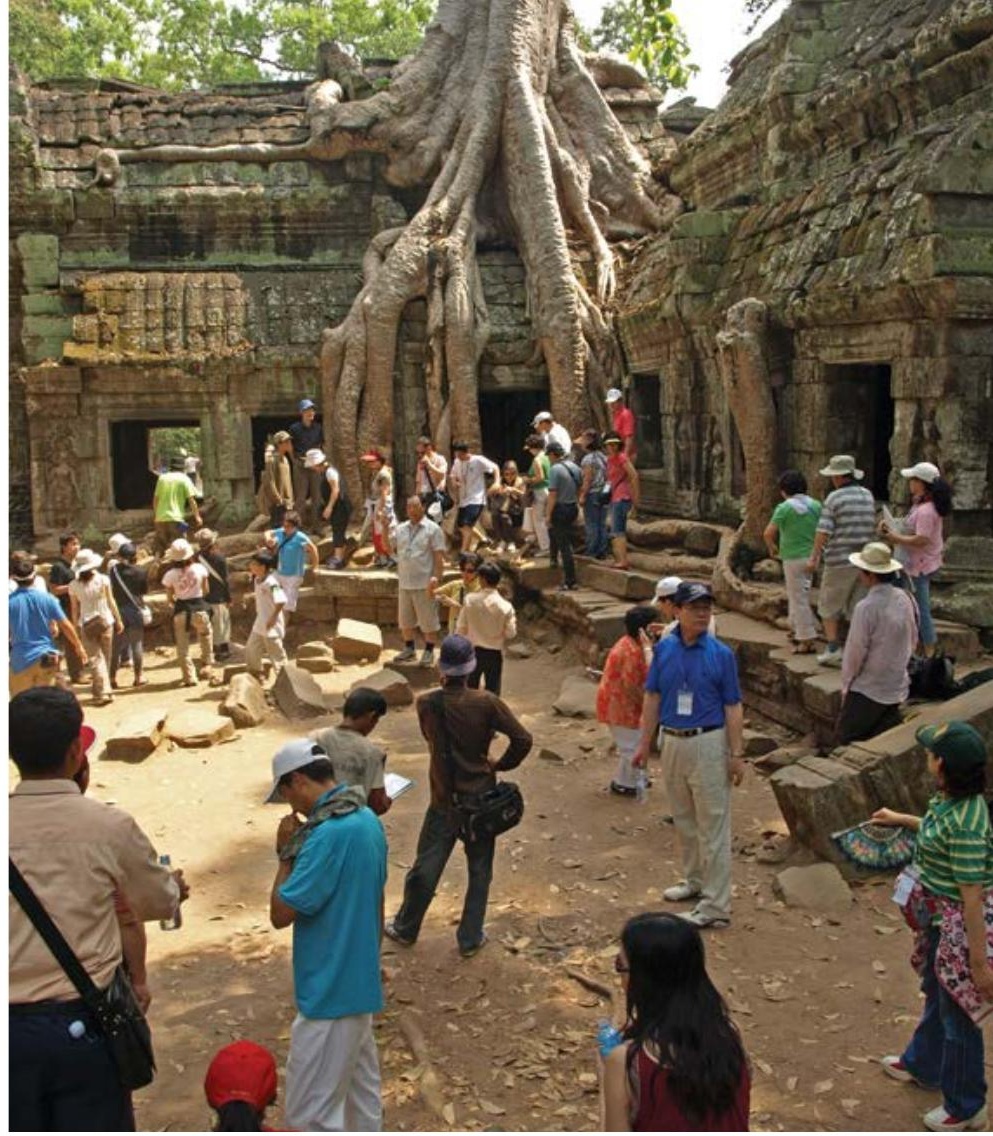

Visitors, Ta Prohm Temple, Angkor, Cambodia

Source: Graeme L. Worboys

\section{Domestic versus foreign tourists}

According to the UNWTO (2014a), inbound tourism comprises the activities of a non-resident visitor within the country of reference on an inbound tourism trip. Internal tourism comprises domestic tourism plus inbound tourism, encompassing the activities of resident and non-resident visitors within the country of reference as part of domestic or international tourism trips. Outbound tourism includes the activities of a resident visitor outside the country of reference, either as part of an outbound tourism trip or as part of a domestic tourism trip. Finally, international tourism comprises inbound tourism plus outbound tourism, including the activities of resident visitors outside the country of reference, as part of either domestic or outbound tourism trips and the activities of non-resident visitors within the country of reference on inbound tourism trips.

\section{Same-day versus overnight tourists}

Overnight tourists and day visitors will engage in different types of activities in protected areas, depending on their time availability and the facilities or products offered by the destination. Knowing how many visitors are same-day or overnight is important to help assess the types of accommodation, infrastructure and services that should be provided outside protected areas and for day destinations within parks. 


\section{Organised tours versus independent travellers}

Tourists can be part of organised tours or independent travellers. Potential protected area visitors could purchase a tour package from a local tour operator or travel agent, or through their hotel or all-inclusive resort or increasingly via the internet. Protected areas offer tourism companies the opportunity of adding value to the excursions they offer, and for many specialist tour operators, visits to high-quality sites with global recognition can be important for sales. Organised group tours will usually be led by licensed tour operators who are often responsible for clearly conveying to travellers information about their rights and obligations when visiting a protected area.

Some visitors may be free independent travellers who have made arrangements based on word-of-mouth, online social network recommendations or suggestions from a local hotel, guidebook, tourist information office and/or official websites. In some cases, it can be harder to manage the actions of individual tourists than those on organised tours in protected areas.

\section{Working with the tourism industry}

\section{Setting the context}

Protected area managers' work with the tourism industry typically starts with understanding needs, expectations and opportunities. Working together requires clear recognition that tourism in protected areas must be consistent with the goals of the protected areas, including the primacy of conservation objectives and recognition of the costs and benefits associated with tourism in protected areas. Costs include providing and maintaining tourism infrastructure and the environmental impacts of tourism (including the costs of minimising impacts and restoring damage once it occurs). Benefits include social and economic outcomes-for example, local employment and procurement, and local social service benefits.

\section{What tourism operators need from protected area managers}

The tourism industry needs safe, reliable, clean, accessible, well-managed and customer-friendly tourism destinations for their customers. They need the administration of their leases and licences to be orderly with long lead times for any changes (for example, to fees) to be respected. Protected area operations that could impact on tourism, such as roadworks, fire fuel reduction programs and pest animal and weed control programs, could be undertaken during times of low visitor use if possible. Such courtesies would form part of a healthy and positive partnership with tourism operators. Beyond these key needs are many more related and supporting requirements, such as to provide and maintain accessbased infrastructure; basic visitor facilities to enjoy the protected area, such as shelter and amenities; and relevant and interesting information and interpretation about the protected area for visitors.

\section{What protected area managers need from tourism operators}

Protected area managers have multiple responsibilities and are focused on a range of issues. They are assisted if tourism operators within the park can help with management by:

- communicating to their guests a message of the importance of the protected area and the work done behind the scenes by the managers that keeps the area special

- identifying any special help from guests that could protect the area-for example, not touching cave paintings

- identifying how their business is positively contributing to the improved management of the protected area

- respecting requests for protection of the reserve.

\section{Benefits of well-managed tourism to protected areas}

Well-managed tourism can contribute to protected area management by:

- raising the profile of the protected area at local, national and international levels

- bringing visitors to the protected area, particularly people needing services and facilities to make the journey

- interpreting the values, conservation issues and management issues for visitors

- providing economic justification for declaring and managing the protected area (generating visitor spending, employment and investment in the protected area or surrounding community)

- providing financial support to protected areas through payment of charges and fees

- providing human resource support through conservation tourism activity

- providing political support for the conservation of the protected area, and the resourcing needed to do this effectively. 


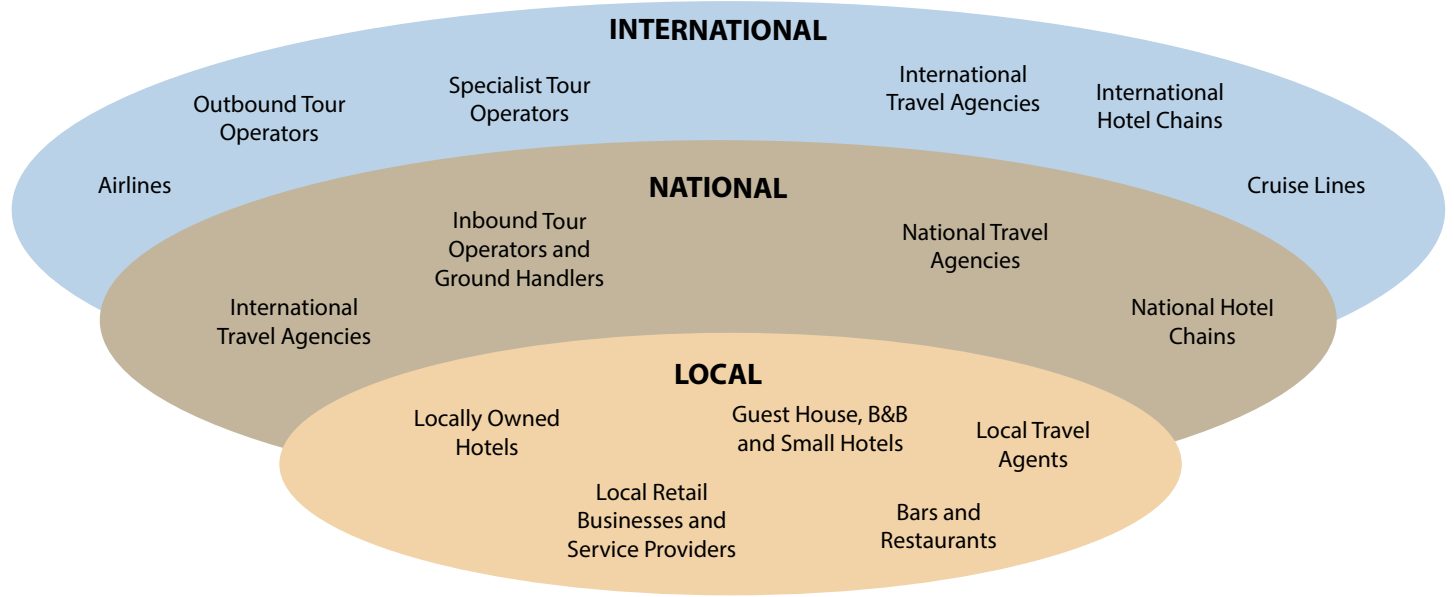

Figure 23.3 Scales of tourism businesses

Source: Adapted from UNEP (2005)

\section{Planning collaboration with the tourism industry}

The broad range of travel and tourism enterprises and tourists means that protected area managers will need to consider an array of strategies for collaborating with the tourism industry-there is not one standard model for developing such relationships, and each case needs to be considered in context (UNEP 2005). Because of the way the tourism industry is organised, outbound tour operators (or international tourism companies such as cruise lines) do not often have direct links with protected areas. While inbound tour operators generally have some links, locally based companies are likely to have the closest links with any nearby protected areas (Figure 23.3).

Strategies and activities for connecting protected area managers with the tourism industry will also be determined by how visits to a specific protected area are organised and how tourists learn about the area. The following three scenarios are a starting point for considering which strategies may be most suitable for working with the tourism industry (UNEP 2005).

1. If tourists come as part of a package bought abroad then connections with international tour operators-initially by making links with the local inbound operators that international companies use-are likely to be important.

2. If travellers purchase their trip or tours locally, links with local tour operators and travel agents will be more suitable.

3. If tourists are organising their own trip, links with local hotels, tourism information offices, visitors' centres, websites, social media and traveller web forums will be most important.
It is also relevant for managers to take into account whether they want to be 'actively' engaged in tourism by creating and managing tourism products and services themselves, or more 'passively' involved by hosting activities that are operated by others (for example, using concessions and managing contracts in outsourcing).

\section{Leases and licences}

A structured and clear framework for tourism within a protected area helps set expectations and creates space for opportunities. At the most basic level are legal contractual tools that a manager uses to approve a tourism operator accessing the protected area. Examples of these include concessions, permits, licences and leases. These contracts set the expectations for operation and any fees required. They have fixed time frames and may be extended with a simple payment or may require regular reviews and updates.

\section{Tourism policy and plans}

At a more advanced level are tourism policies and plans for protected areas. These shift management from reactive to proactive management by introducing strategic approaches to making tourism more sustainable. These can be integrated within management plans for a protected area or may be stand-alone documents.

Tourism policies can address:

- the rationale for permitting tourism in protected areas

- the types of tourism and activities permitted

- sustainable tourism elements, including conservation and local economic impact

- preferred types of tourism and activities

- contractual requirements

- fee collection. 
Tourism plans can address:

- current and forecast visitation

- current visitor profiles and desired target markets

- current tourism impacts and ways to minimise them

- improvements to tourism infrastructure and services

- improvements to interpretation

- zoning for different forms and levels of tourism development

- locations for new tourism investment, facilities or activities

- ideas for new tourism experiences.

\section{Tourism revenue}

Many protected area management agencies lack the funds to properly respond to tourism needs and management (Emerton et al. 2006a). Funds are typically larger in developed than developing countries, and often funds are greater where tourism activity and development are concentrated. The cost to manage these areas is, however, higher-typically cancelling out the gain. Under the principle of user pays, funds to manage tourism can be raised from direct and indirect sources.

\section{Entry fees}

The most common revenue from tourism is a direct entry fee to enter the protected area (Font et al. 2004), though revenue is also raised from activity fees. Protected areas with significant tourism concentration areas can attract 40-60 per cent of their funds from user fees (UNWTO 1995; Emerton et al. 2006b).

A major challenge is ensuring that the funds are reinvested into protected area management. Many governments transfer the collected funds into their centralised revenue management and do not equate redistributions to original income, so at best, one protected area pays for another, and at the greater extreme, protected area revenue may contribute to unrelated whole-of-government services, such as defence. Other governments use the fees to reduce their traditional allocation to the protected area, so if visitor fees decrease, management is left significantly underfunded. Park agencies permitted to manage their own funds are typically more autonomous, entrepreneurial and efficient (Phillips 2000; Lockwood et al. 2006). One protected area organisation, the NSW National Parks and Wildlife Service of Australia, for example, negotiated a formula with the NSW Government by which they retained revenue raised and were not overtly penalised for new revenue collection.

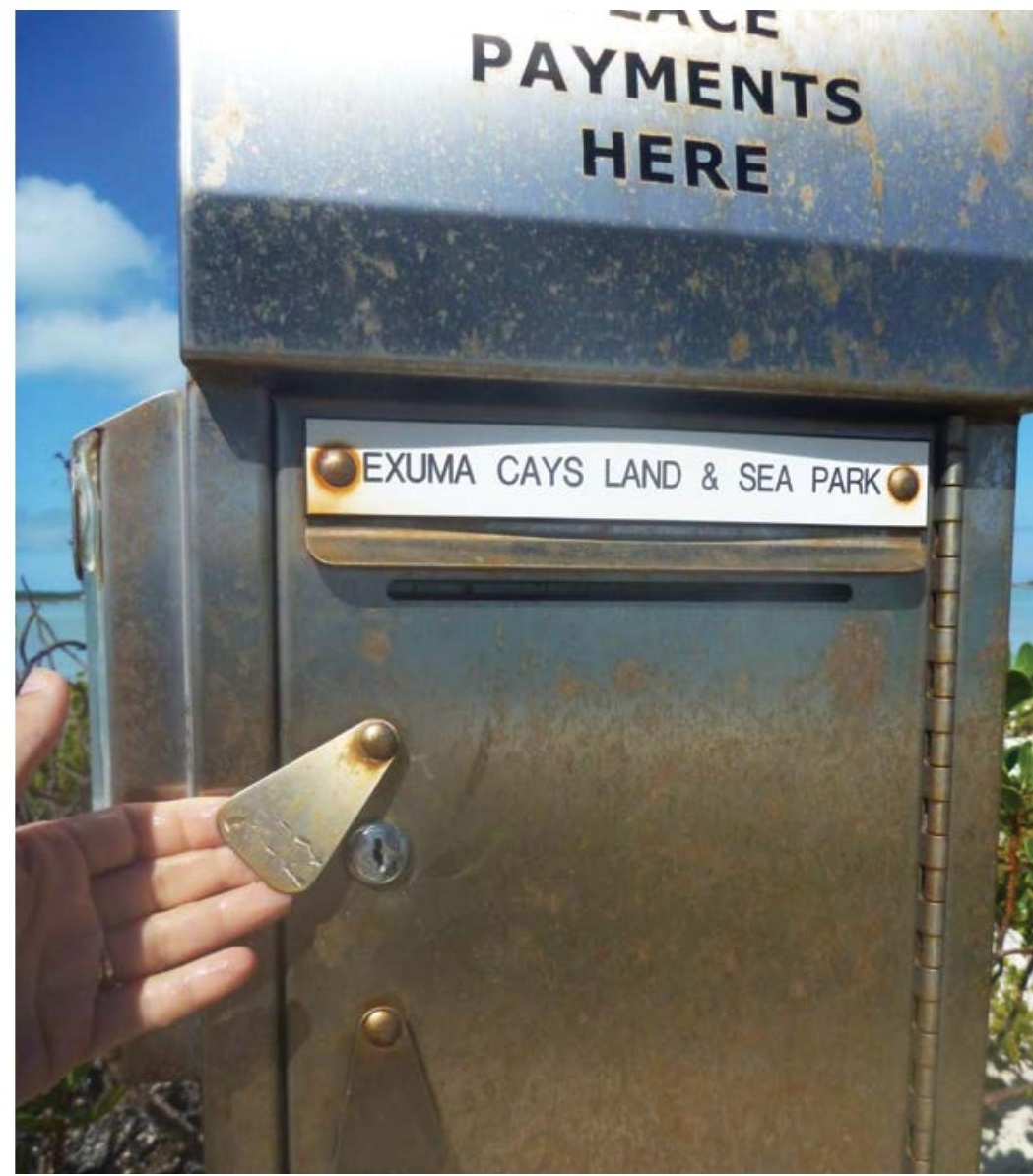

Exuma Cays, Bahamas, marine protected replenishment area: visitor fees collection box

Source: Simon McArthur

The second major challenge with collecting entry fees is to ensure the cost of collection is significantly lower than the revenue generated. It is often uneconomical to collect fees in remote areas, while in seasonal areas, it is often economical to charge in the peak period and not in the low season. If the profit margin is small, it is difficult to show where the revenue has been invested, reducing stakeholder support for the charge.

The third challenge is to set fees that reflect levels of use and subsequent management costs. A flat entry fee is often not seen as fair, because some visitors use the area more than others, create greater negative impacts than others or create more demand on management than others. Some alternatives to a standard entry fee are provided (Table 23.4).

Though more complex to manage, a user fee is more effective than an entrance fee because the price is better matched to use and subsequent management. 
Table 23.4 Alternative methods for entry charges

\begin{tabular}{|l|l|l|}
\hline Alternative & Explanation & $\begin{array}{l}\text { A car park with time-based parking } \\
\text { charges }\end{array}$ \\
\hline $\begin{array}{l}\text { Charging different } \\
\text { amounts to use } \\
\text { different areas }\end{array}$ & $\begin{array}{l}\text { Charging more for costly management areas and } \\
\text { less for low-cost areas, or more for visiting or using } \\
\text { highly desirable areas }\end{array}$ & $\begin{array}{l}\text { Higher pricing for beachfront camping } \\
\text { than inland camping }\end{array}$ \\
\hline User fee & $\begin{array}{l}\text { Charging more for activities requiring more } \\
\text { infrastructure and management }\end{array}$ & $\begin{array}{l}\text { Higher pricing for snow skiing entry } \\
\text { compared with summer visitors }\end{array}$ \\
\hline $\begin{array}{l}\text { Higher price for those } \\
\text { who can afford more }\end{array}$ & $\begin{array}{l}\text { Higher price for international visitors, discounted fee } \\
\text { for nationals, free entry for locals }\end{array}$ & $\begin{array}{l}\text { Charging more for international visitors } \\
\text { than for national or local visitors }\end{array}$ \\
\hline $\begin{array}{l}\text { Charging for peak and } \\
\text { off-peak use }\end{array}$ & $\begin{array}{l}\text { Charging higher rates for entry during the most } \\
\text { popular time of the year }\end{array}$ & $\begin{array}{l}\text { Higher fees during holiday periods, } \\
\text { or for skiers, during winter months }\end{array}$ \\
\hline
\end{tabular}

Table 23.5 Methods for collecting revenue from the tourism industry

\begin{tabular}{|c|c|c|}
\hline Operator charge & Explanation & Ideal tourism sector \\
\hline Permit fees & A small charge is levied annually or as needed & $\begin{array}{l}\text { For irregular operations, such as events } \\
\text { and functions, and very small seasonal } \\
\text { businesses and activities }\end{array}$ \\
\hline $\begin{array}{l}\text { Concessions and } \\
\text { licence fees }\end{array}$ & $\begin{array}{l}\text { A modest charge is levied on an annual basis } \\
\text { as part of a licence that documents how the } \\
\text { operation can occur within the protected area. } \\
\text { Often this can be provided with exclusivity } \\
\text { provisions, thus providing opportunities for } \\
\text { higher returns }\end{array}$ & $\begin{array}{l}\text { For regular small to medium-sized } \\
\text { operations, such as transport and tour } \\
\text { operators }\end{array}$ \\
\hline Lease-based rental & $\begin{array}{l}\text { A fixed amount of rent is charged on a } \\
\text { monthly or quarterly basis, usually increased } \\
\text { with inflation. Often this can be provided } \\
\text { with exclusivity provisions, thus providing } \\
\text { opportunities for higher rentals }\end{array}$ & $\begin{array}{l}\text { For businesses with fixed operations } \\
\text { drawing significant revenue and requiring } \\
\text { significant management support, such } \\
\text { as accommodation (resort, lodge, tented } \\
\text { camp), food and beverage (restaurant, } \\
\text { function centre, cafe), attraction (adventure } \\
\text { park, cable car) and major fixed transport } \\
\text { (airport, port, marina and trains) }\end{array}$ \\
\hline $\begin{array}{l}\text { Turnover charge/ } \\
\text { overage }\end{array}$ & $\begin{array}{l}\text { Once turnover is higher than an agreed } \\
\text { amount, the operator pays a proportion of } \\
\text { the additional turnover to the protected area } \\
\text { manager }\end{array}$ & $\begin{array}{l}\text { For businesses with potential to grow- } \\
\text { particularly through cooperative ventures } \\
\text { with protected area management }\end{array}$ \\
\hline $\begin{array}{l}\text { Shared service } \\
\text { agreements }\end{array}$ & $\begin{array}{l}\text { The operator agrees to undertake roles that } \\
\text { would otherwise be done by the protected } \\
\text { area manager, in exchange for lower financial } \\
\text { charges }\end{array}$ & $\begin{array}{l}\text { For businesses that can provide services } \\
\text { more cost-effectively through multi-tasking } \\
\text { employee roles, sharing infrastructure } \\
\text { and equipment-for example, road and } \\
\text { trail maintenance, amenity cleaning and } \\
\text { maintenance, interpretation provision and } \\
\text { basic conservation activities }\end{array}$ \\
\hline
\end{tabular}

\section{Operator charges}

Tourism businesses operate within and make money from using protected areas. Protected area managers, therefore, have a legitimate right to charge the operator for their use of the area. Some of the ways that revenue can be drawn from operator charges are described (Table 23.5).
Many operators will gladly consider shared agreements to reduce costs they would otherwise pay to the protected area manager. Greater use of this approach would jointly benefit tourism and protected area management. Most tourism businesses accept being charged, but like visitors, they expect to see the funds reinvested in protected area management and services where the revenue is raised. When the protected area organisation increases operator fees with less than a year's notice, there 
are significant impacts on business. Operators have long lead times for third-party bookings, so they have already set pricing and received payment for products sold and any increase in charges cannot be recouped.

\section{Protected area agency commercial businesses}

Some protected area management agencies choose to run their own commercial tourism business and collect revenue through business profit such as SANParks in South Africa (SANParks 2011). Protected area agencies can operate anything that the tourism industry does, including equipment hire, sale of food and beverages and merchandise, and guiding. Agencies usually choose to operate the business because:

- they believe they can make more revenue than the operator (due to them having a competitive advantage)

- there is little interest or capacity from the industry

- the agency wants to maximise control over the product or service.

Clear policy and procedures and strong management are needed to ensure a transparent, fair and non-corrupt operating environment (Font et al. 2004).

\section{Marketing}

Marketing of protected areas needs to be actively managed by a protected area organisation. Through such management, the important relationship between the supply of destinations within a protected area system and the demand for their use can be professionally managed. It is one important way in which protected area organisations ensure that destinations are not overrun by too many tourists with consequent impacts on biodiversity values and site degradation. It can also assist the long-term social and financial aspects of a sustainable tourism industry by guaranteeing the supply of high-quality visitor experiences. How, when and where protected area destinations are marketed should not be just delegated to the tourism industry; there needs to be a positive and active working partnership between tourism organisations and protected area organisations.

Marketing is one of the most powerful tools for effective visitor and tourism management. Marketing is much more than promotion and sales; it is the task of creating, promoting and delivering goods and services to consumers and businesses (Kotler 2003). Conventional marketing is based on the five 'Ps' (Aaker 1995).
1. What services and experiences to offer to whom (product).

2. How much to charge, to whom and under what terms and conditions (price).

3. Where to offer the product (place).

4. Who will deliver the product and how will they treat the customer (people).

5. How to raise awareness and interest in the product (promotion).

We focus here on the following strategic elements to effective marketing:

- visitor and market research

- market segments

- destination branding and positioning

- effective promotion.

\section{Visitor and market research}

No two visitors are the same in respect of who they are, what they want, what they did, what they thought of the protected area and whom they told about it. Visitor research is designed to answer these questions and subsequently empower managers with the knowledge of what to offer to whom and why. Without this knowledge, protected area managers end up trying to be 'all things to all people', impressing few people and becoming totally frustrated themselves. Some of the visitor research tools available to protected area managers are presented (Table 23.6). Visitation counting and straightforward questionnaires are typically completed by the protected area manager, while the other more sophisticated tools are typically completed by tourism and market research consultants. In choosing a tool, managers need to weigh up the typical trade-off between cost-effectiveness and the degree of insight and revelation that can be reliably generated. Getting expertise to help determine this is a small but often worthwhile investment. 
Table 23.6 Visitor research tools

\begin{tabular}{|c|c|c|}
\hline Visitor research tool & Strengths & Limitations \\
\hline Visitation counting & $\begin{array}{l}\text { Counting visitor numbers provides } \\
\text { indications of the level of use, and to } \\
\text { some extent the nature of use (timing, } \\
\text { length of stay, group size) } \\
\text { Visitation counting provides baseline } \\
\text { data to identify historical trends, } \\
\text { forecasts and for economic and } \\
\text { financial modelling }\end{array}$ & $\begin{array}{l}\text { If used on its own, a reliance on visitor numbers } \\
\text { can be dangerous, because it encourages thinking } \\
\text { that all visitors are the same } \\
\text { Counting is rarely accurate and has generated } \\
\text { some huge misperceptions (for example, visitation } \\
\text { can seem to increase when in fact the increase is } \\
\text { due to the introduction of more counters) }\end{array}$ \\
\hline Behavioural observations & $\begin{array}{l}\text { Very useful at exploring what is } \\
\text { unknown, for another research tool } \\
\text { to use as a frame of reference to } \\
\text { formulate its structure. Generally used } \\
\text { to map where a person goes, what } \\
\text { they do and for how long they do it. } \\
\text { Structured observations anticipate } \\
\text { behaviour and log data into tables that } \\
\text { can be further quantitatively analysed. } \\
\text { Unstructured observations regard } \\
\text { whatever happens and may use } \\
\text { qualitative analysis }\end{array}$ & $\begin{array}{l}\text { Generally human resource dependent, which } \\
\text { makes it expensive, particularly when there are } \\
\text { few visitors about and the observer still needs } \\
\text { to be paid. Requires careful analysis afterwards } \\
\text { and qualitative analysis skills are more difficult to } \\
\text { access }\end{array}$ \\
\hline Questionnaires & $\begin{array}{l}\text { Preset questions are typically } \\
\text { administered on paper, online or face- } \\
\text { to-face, providing a high degree of } \\
\text { control over the data and the ability to } \\
\text { easily analyse and compare results, } \\
\text { including statistical testing }\end{array}$ & $\begin{array}{l}\text { Poorly written questionnaires generate poor and } \\
\text { unreliable results. Results can be affected by } \\
\text { incorrect question order, irrelevant optional choice } \\
\text { answers and poorly phrased questions. Results } \\
\text { can be manipulated or misinterpreted to suit the } \\
\text { researcher's objectives }\end{array}$ \\
\hline Face-to-face interviews & $\begin{array}{l}\text { Similar to a face-to-face questionnaire, } \\
\text { but generally uses fewer questions. } \\
\text { The objective is to get the respondent } \\
\text { talking more freely and therefore } \\
\text { discover more in-depth information, } \\
\text { such as the underlying cause of issues } \\
\text { or how a solution could be developed } \\
\text { and implemented }\end{array}$ & $\begin{array}{l}\text { Generally human resource dependent, which } \\
\text { makes it expensive, particularly for time spent } \\
\text { travelling to each respondent for an interview. } \\
\text { Dependent on selection process choosing the } \\
\text { most appropriate interviewees, which are not } \\
\text { always those in power or with a high profile }\end{array}$ \\
\hline Focus groups & $\begin{array}{l}\text { Building on the face-to-face interview, } \\
\text { having a group of people can generate } \\
\text { greater discussion and revelation, } \\
\text { as people add value to each others' } \\
\text { contributions }\end{array}$ & $\begin{array}{l}\text { Much more expensive than questionnaires, and } \\
\text { requires considerable preparation to structure the } \\
\text { discussion, considerable facilitation expertise and } \\
\text { considerable time afterwards to analyse the results }\end{array}$ \\
\hline Social media & $\begin{array}{l}\text { Analysis of social media data about } \\
\text { protected area destinations is an } \\
\text { important information source }\end{array}$ & $\begin{array}{l}\text { User and recommendation data are available, for } \\
\text { example, from software applications such as Yelp }\end{array}$ \\
\hline
\end{tabular}

Sources: Adapted from Hall and McArthur (1998); Yeo (2005)

Market research samples non-visitors or past visitors to a protected area. Some of these people could be persuaded to become visitors, and some may even be a better match to the protected area than some of the existing visitors. Protected area managers use market research to identify profiles for these non-visitors (particularly their needs and wants) and then determine which profiles could be considered potential visitors for whom to design experiences and attract to the protected area. Since non-visitors are more difficult to find and interact with, market research typically uses online questionnaires to identify potential markets and then focus groups to further research needs and test new ideas. This work is sometimes done by tourism and market research consultants contracted by the protected area manager.

\section{Market segments and target markets}

Mass marketing is where there is mass production, mass distribution and mass promotion of one product to everyone (Tynan and Drayton 1987). Mass marketing creates the largest potential market, which leads to the lowest potential costs, which in turn can lead to lower prices or higher margins (Aaker 1995; Dibb and Simkin 2009). Mass marketing does not work for protected areas because their legislation prevents them 
from being 'all things to all people'. Mass marketing can result in some people coming to a protected area wanting to undertake activities that can compromise the place and other visitors.

The alternative is to break the mass market down into market segments, and choose the segments whose needs best match the product-the target markets (Hunt and Arnett 2004; Yeo 2005). Beyond this, the manager can focus experiential development, promotion and pricing on the needs of the target market. Visitor monitoring can then include questions to identify respondents, reflecting the characteristics of the target markets, and then treat their responses to other questions with greater importance (such as satisfaction and likelihood to return or refer a visit).

A market segment is a group of people with similar characteristics-especially a similar set of needs (Yankelovich and Meer 2006). Market segments are typically broken into:

- geographic (residence and workplace by local area, region, State, country or continent)

- demographic (age, gender, family size, life cycle, income, occupation, education, and so on)

- psychological (attitudes, risk, motivation, and so on)

- psychographic characteristics (lifestyle, activities, interests, opinions, needs and values)

- behavioural (brand loyalty, usage rate, benefits sought and used).

The tourism industry typically uses segmentation based on geographic and demographic characteristics, because they are simple and cheap to use. These characteristics, however, have limited value when developing a protected area's brand, positioning, product or experience, because they are too generic. Market segmentation offers a number of practical uses for the protected area manager, including being able to:

- define the market from a consumer's point of view

- rationalise policies for existing brands and products (to improve competitiveness and market share)

- position a range of brands and products

- identify gaps in the market that offer new opportunities (Lunn 1978, cited in Tynan and Drayton 1987).

It is possible to develop a questionnaire to determine which market segments visitors to a protected area come from. Another practical way to use market segments is to monitor the representation of target markets versus other markets within the visitors to a protected area.

\section{Destination branding and positioning}

A brand is the source of a distinctive promise for customers from a product, service or place (Baker 2012). Determining a brand for a protected area is more complex than most managers anticipate and it is also an initiative whose appropriateness needs to be carefully considered. Fundamentally, any brand developed for a protected area needs to be consistent with its protected area status. For a specific destination within a protected area, the brand also includes how people interpret the destination for themselves (Aaker 1997), so considerable consultation and market research are needed to understand how people perceive an area and the brand.

From consultation and research, a brand pyramid is created (Figure 23.4). The bottom two levels of the pyramid are the obvious attributes of the destination and the visitor benefits. Then the distillation starts and a brand personality is created. From this brand personality come brand value and subsequently the brand essence. The brand essence is the heart and soul of the brand, and is often reflected by a concise phrase or tagline. For example, the brand essence for Parks Victoria (Australia) is 'Healthy Parks, Healthy People'. Other elements include a logo, photographic image, writing style, fonts and colours.

Helping to communicate the brand is a unique set of visual, auditory and other stimuli that shape market perceptions. Two of the most useful communication elements for a protected area are the tagline and a single photograph, both of which need to be used relentlessly and consistently. A logo is not critical to marketing a protected area (but it is important for branding the agency). Everything a protected area manager does in collaboration with their partners and stakeholders should be designed to constantly deliver this marketing perception. The more people are aware of a brand, the more value or equity it has, and therefore the more an agency can use it to drive their own objectives. The brand can also be very useful as a frame of reference for considering the development of new visitor experiences by asking: does it reflect or dilute our brand?

Once the manager has developed the brand, they need to position it. For the protected area manager, positioning is the art of developing and communicating meaningful differences between the offerings of their area and those of their competitors serving similar markets (Baker 2012). Alternative ways to position a protected area are described (Table 23.7). The key to deciding on position is the alignment between sustainable protected area tourism opportunities and the needs of the market. 

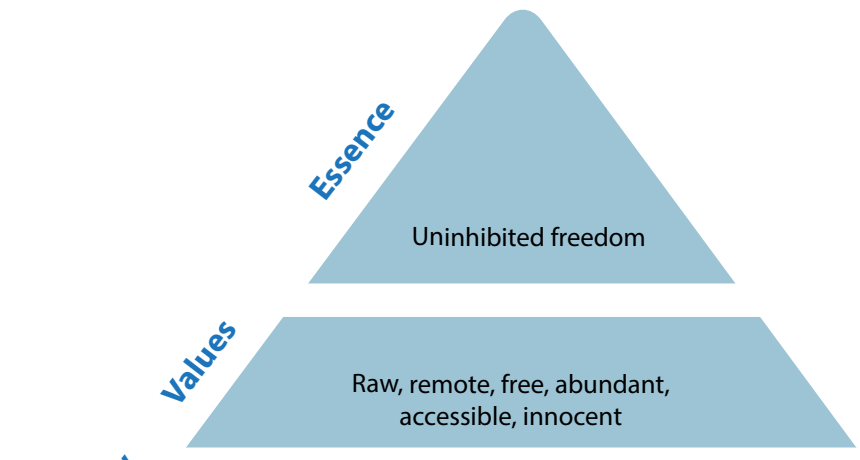

Wild, contrasting, innocent, raw, passionate and caring, down-to-earth and friendly. Very engaging and earthed. No pretences.

Climatic conditions evolved over thousands of years have created a visual splendour of extraordinary contrasts between ocean and land, earth and sky. The remoteness has protected the landscape now offering a spectacular array of marine life and other landbased national parks that cannot be viewed in the same way anywhere else in the world.

$1,500 \mathrm{~km}$ of coastline along the most westerly point of Australia offering extraordinary migratory seasonality linked with climatic change unique to the area. Some of the clearest skies in the world to view Stromatolites, Mt Augustus, national parks offering biodiversity in megafauna, species and phenomenal marine life. Whale Sharks, Manta Rays and Turtles nest along Ningaloo Coast. There are sea grass beds within a coral fringing reef, home to Dugongs. The contrasts, isolation and interaction make this landscape a truly unique World Heritage Area.

Figure 23.4 Brand positioning pyramid, Ningaloo-Shark Bay, Australia

Source: Adapted from Tourism Australia (2010)

Table 23.7 Positioning a protected area

\begin{tabular}{|l|l|}
\hline Positioning alternative & \multicolumn{1}{|l|}{ Example for a protected area } \\
\hline Sniqueness attribute & $\begin{array}{l}\text { A feature that is the biggest, smallest, highest, shortest, oldest, fastest, most prolific, } \\
\text { most dangerous, most venomous or an excellent representative of its class, and so on }\end{array}$ \\
\hline Product class & $\begin{array}{l}\text { Rare, vulnerable, endangered } \\
\text { Under attack, disappearing }\end{array}$ \\
\hline User need or benefit & Use World Heritage inscription
\end{tabular}

Source: Hall and McArthur (1998)

\section{Promoting a visitor experience}

The tourism industry has traditionally seen its role as the provider of saleable tourism products, such as tours, attractions, accommodation or restaurants. Most protected area managers have traditionally seen their role as the acceptance of certain activities and the provision of visitor infrastructure and facilities supporting them. Over the past decade there has been a move for both sectors to put more effort into the creation, marketing and occasional reinvigoration of tourism experiences (Wearing et al. 2007). 
A tourism experience is much more than an activity or product; it is the combination of activity, setting, social interaction and the personal connection that arises (Tourism Australia 2012). An experience engages the senses; it is physical, emotional or spiritual (or all three). An experience offers discovery and learning, and creates strong memories. Experiences go beyond nice places and good views; instead they connect visitors to the placethe environment and the culture (Tourism Australia 2012). A way to enhance these experiences is by creating a sense of place based on 'genius loci'. Tourists and visitors will learn and appreciate a protected area more when they can connect to the place they are visiting. This is called 'creating a sense of place' and is based on the natural and cultural resources and the 'spirit' of the area. It is based on the people, local communities living in the area, their 'knowhow' and their traditions.

To make a protected area an effective tourism destination, it should have:

- signature experience(s), often referred to in the tourism sector as a heroic or iconic experience because it stands out as totally reflecting the brand and leading the way in attracting visitor interest and satisfying visitors

- supporting visitor experiences, ideally reflecting parts or all of the brand, and offering opportunities complementary to the signature experience

- ancillary goods, services, products and infrastructure accessible to a protected area such as airports and access roads, service stations, car parks and visitor information.

If marketing of a protected area is done effectively, it can predominantly attract target markets rather than mass markets, and it can set the expectations of these people prior to their arrival (Hall and McArthur 1998; Reid et al. 2008). It is much easier and more proactive to set realistic expectations within marketing than it is to unnecessarily regulate, harden a site or try to change visitor behaviour on site.

The marketing of a protected area for tourism purposes should lead with the target market doing the signature experience, competitively positioned and reflecting the tagline and personality of the brand. Photographs need to be powerful in demonstrating these elements. They need to reflect the essence of the experience and the emotional impact it has on the target market. Unfortunately, most imagery used lacks power, so the promotional collateral is lost among other competitors or even other promotion. Figures $23.5 \mathrm{a}$ and $23.5 \mathrm{~b}$ compare the traditional landscape-driven approach to marketing a protected area with a contemporary experience-based marketing image. Ideally, protected area managers should engage a tourism marketing consultant to scope a photo shoot that captures all the elements. After this, the leading image of the signature experience needs to be slavishly featured and used in as much promotion as possible.

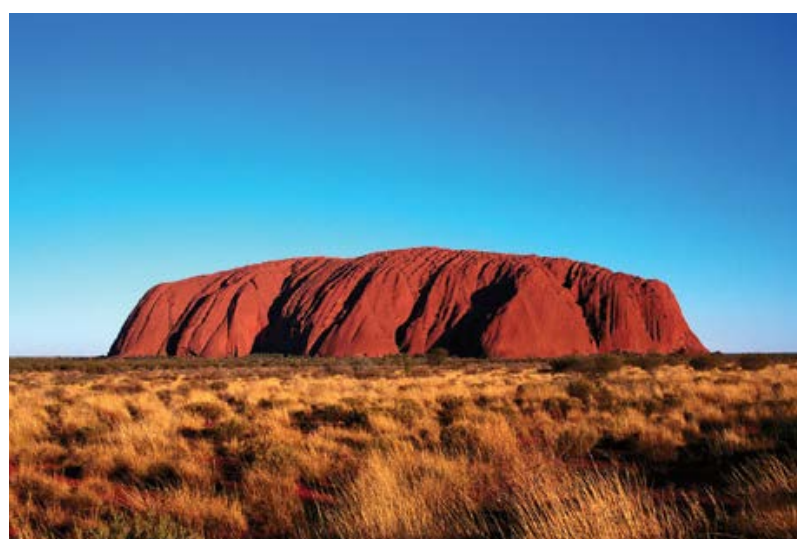

Figure 23.5a Uluru-Kata Tjuta National Park and World Heritage Property Australia: standard image Source: Simon McArthur (1999)

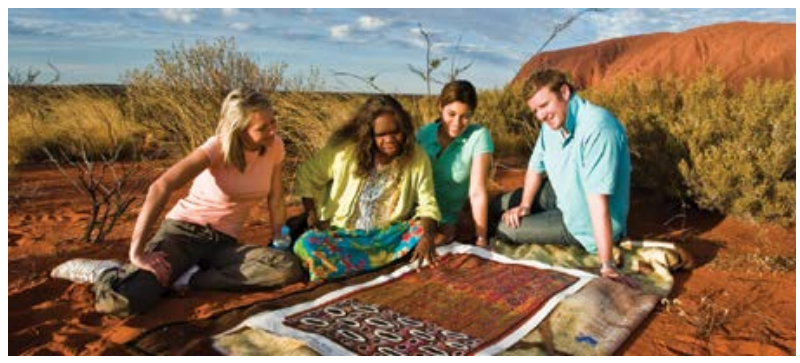

Figure 23.5b Uluru-Kata Tjuta National Park and World Heritage Property Australia: 'Uluru experience' Source: Melbourne Business Community (2013)

\section{Recreation opportunities management}

A key tool for planning and managing recreation opportunities is the 'recreation opportunity spectrum' (ROS). The ROS focuses on the protected area setting in which recreation occurs (Clark and Stankey 1979). A setting is the combination of physical, biological, social and managerial conditions that give value to a place. Thus, an opportunity includes qualities provided by nature (vegetation, landscape, topography, scenery), qualities provided by the sociocultural setting, qualities associated with recreational use (levels and types of use) and conditions provided by management (developments, roads, regulations). Multiple opportunities imply a choice for recreationists; people must be aware of the 
opportunities, and the opportunities must comprise conditions desired by recreationists. Thus, opportunities are a function of user preference and a product of management actions designed to provide desired settings and make people aware of their existence.

The basic assumption underlying the ROS is that quality in outdoor recreation is best assured through provision of a diverse set of opportunities (Clark and Stankey 1979). A wide range of tastes and preferences for recreational opportunities exists among potential visitors. Providing diverse settings varying in level of development, access and so forth insures that the broadest segment of potential visitors will find quality recreational/tourism experiences. People vary enormously in what they desire from their recreational pursuits, even for specific categories of recreationists; not all campers, hikers or wilderness users are alike. Building management programs around average tastes can miss the mark as they may not adequately account for variation in tastes (Shafer 1969).

Diversity ensures the flexibility necessary to mitigate changes or disturbances in the recreation system stemming from such factors as social change (such as changing age structure of a population) or technological change (such as increased availability of outdoor recreation vehicles). But diversity is only a means to an end. Quality recreation, producing desired satisfaction and benefits for participants, is the objective and concern of both managers and recreationists.

In managing for a diversity of recreation opportunities within a protected area, often the hardest long-term management task for protected area managers is to keep natural settings natural. Site hardening is often an intuitive managerial response to damage at a visitor destination but often it is exactly the wrong response. The more natural settings that are hardened, the fewer natural settings remain and the greater is the diminishment in a diversity of recreation settings in a protected area. As we move further into the 21 st century, the untouched recreation settings will be the ones that become the rarest and most valuable. There are other ways to manage impacts that retain the untouched values-this includes professionally rejecting constant calls for development. Actions could include establishing limits to visitor numbers and frequency of use for a site, precluding access on wet days, rotating the use of sites and other actions (Box 23.1). A danger is a shift in focus when the tour of duty of one protected area manager ends and a new manager starts. This danger can be minimised by clear and precise ROS planning for all tourist destinations within a protected area system and thorough induction and briefing for new staff members.

\section{Box 23.1 Reducing impacts at visitor destinations}

In general, there are four strategic approaches that can be used to reduce the negative impacts of visitors on protected areas.

1. Managing the supply of tourism or visitor opportunities-for example, establishing quotas, by efficiently using the space or the time available to accommodate more use.

2. Managing the demand for visitation-for example, through restrictions on length of stay, the total numbers or type of use.

3. Managing the resource capabilities to handle usefor example, through hardening the site or specific locations, or developing facilities.

4. Managing the impact of use-for example, reducing the negative impact of use by modifying the type of use, or dispersing or concentrating use.

The principal question is to determine what degree of impact is acceptable.

\section{Visitor services and facilities}

Before providing visitor services and facilities for a protected area, managers must be sure why they are doing so. Service and facility provision should depend in large measure on desired visitor experience opportunities, which in turn emerge from underlying management objectives. Such objectives include protection, conservation, education, public relations, research, fundraising and recreation, among others.

While most managers recognise that tourists require a range of services and facilities to experience a site, other kinds of visitors also must partake of visitor services and facilities to experience the same site. School children need food, bathrooms and a place to eat; scientists need guides, laboratory facilities, food, trails, library resources and internet connections; reporters need to be attended by knowledgeable park staff; politicians obtain VIP attention and highly skilled information managers.

Frequently, the contributions visitors deliver in support of park objectives depend on whether they have enjoyed their stay. If they have a positive experience, their disposition to participate soars (Ham 2013). If they have a negative experience, not only would any sense of cooperation potentially plummet, but also their provoked inclination to spread negative recommendations could damage park public relations (Priskin and McCool 2006; Cole and Williams 2012). 
Recreation managers have been calling for greater diversity of recreational opportunities since the mid 20th century (Driver et al. 1987) to increase quality, meet the demands of a greater variety of visitors, leave them more satisfied and induce greater visitor support for management objectives (Manning 1985; Kohl 2007). Managers, however, cannot guarantee personal experiences, only opportunities for visitors to have experiences. An experience is highly personal, created in the mind of the visitor but dependent on numerous factors. Pine and Gilmore (1999) define an experience as follows: (EVENT [situation + activity + resources] $\rightarrow$ REACTION $\rightarrow$ MEMORY) $=$ EXPERIENCE.

Not only do visitors increasingly seek authenticity in the marketplace (for example, an experience that is more primitive than or different to their lifestyles), but also the degree of authenticity varies significantly, affecting the quality of their experience. For this reason, managers must understand both how authenticity influences visitor experiences and how to manage for it to improve those opportunities.

The experience, and hence services provided (or planned lack of services provided), is initiated long before the visitor arrives on site. The visitor fashions expectations based on information from websites, social media, promotional materials and word-of-mouth. The experience continues after the visitor returns home as they reflect on what happened to them as well as on any follow-up materials or communications received from service providers or people they met along the way. Once again, protected area managers can offer pre and post-trip information to round out the visitor experience. Other service providers also court travellers by offering information, transportation, accommodation and other services that can also influence the quality of the experience.

Though all visitors generate an experience, they do not all specifically seek them. Different visitors can be thought of as demanding opportunities at different levels. The lower the level on a 'hierarchy of visitor demands', the greater is the visitor's self-awareness (Driver and Brown 1978). This model posits that visitors demand activities (hiking, canoeing, birding) in certain settings (unmodified natural areas, places with some or total modification) to achieve certain experiences (solitude, insights), ultimately to benefit from specific socialpsychological outcomes (improve family relationships, fitness, nature appreciation, self-confidence). In light of such diversity, we can identify no such person as the 'average visitor'. Rather, each visitor pursues differing configurations of demand (Cole and Williams 2012).
Whether one categorises visitor experience opportunities using the ROS, market segmentation or some other classification, different visitors require different kinds of experiences and hence different combinations of services to meet their needs for quality, comfort, security, environmental settings and levels of authenticity.

\section{Types of services and facilities}

\section{Support services and facilities}

These are the types of services and facilities provided to help support, maintain and restore the 'basic' needs of visitors. What constitutes a 'basic' need is obviously context-dependent, with the 'basic' needs of some seen as 'luxuries' by others, or in other contexts. Therefore, basic support services and facilities could be a pit toilet and 'luxury' could be access to water that is safe to drink. Support services and appropriate facilities can be complex and encompass a diversity of services and facilities, as seen in some visitor centres. It is important for managers to know what types of needs, desires and expectations visitors might arrive with and how to match them to the reality of what appropriate facilities can be provided. This is why Recreational Opportunity Spectrum-based planning and zoning are so important in protected areas.

\section{Orientation services and facilities}

It is essential for managers to know what types of orientation services and facilities tourists may require. These types of services and facilities could include directional signage, informational brochures (prices, operating hours, procedures, ticketing, contact information, and so on), rangers and guides, designated meeting points, websites, maps, information hotlines, apps and other techniques that can help keep visitors oriented in time and space.

\section{Security services and safety facilities}

This category of services and facilities allows people to access places they would otherwise avoid due to danger and physical or social impediments. Often they go unseen and undervalued by visitors — such as the provision of park guards and perimeter controls - yet they must be calculated into overall costs. Examples include electronic security systems such as surveillance cameras, signage that explains rules and safety recommendations and visitor educational materials.

\section{Interpretation services and facilities}

Interpretation is a communication approach that connects people intellectually and emotionally with interpreted objects to deepen their appreciation of that object. In the 
The types and degree of impacts vary with the nature of activities, seasonal use, intensity of use, behaviour of users and resilience of ecosystems. For example, some types of activities such as horseriding have been demonstrated to have a greater range and intensity of impacts than others such as hiking. Visitor activities at some times of the year have more impact than at others. For example, noise and light pollution can have a greater impact on animal behaviour during the breeding season than at other times. Similarly, trampling damage to vegetation can be greater during the flowering season than when plants are dormant.

Greater use tends to cause more damage, but the form of this relationship can vary (Monz et al. 2013). For example, the relationship can be curvilinear, where most damage occurs with first use, and after a certain amount of use there is limited additional damage. It can be linear, where damage is consistently related to the amount of use. It can be sigmoidal, with limited damage at low levels of use, then rapidly increasing, and then flattening out again. Which form this relationship takes is very important for managers, as it affects which management options will be most effective, such as choosing between dispersed and concentrated use (Monz et al. 2013). Due to differences in behaviour, some visitors can cause more damage than others. Visitors can vary in their knowledge of and capacity and willingness to comply with minimum impact practices.

Infrastructure provided for visitors also has a wide range of impacts including during construction, maintenance and use. These impacts can be short-term and localised, but can also be severe, long-term and widespread. Careful selection, design and maintenance of infrastructure can dramatically reduce its environmental impact. A key issue for protected area managers is how to minimise and ameliorate these visitor environmental impacts (see, for example, Case Study 23.1).

\section{Social and cultural impacts of visitors}

Local communities are often seen as the intended beneficiaries of tourism, especially in terms of economic benefits derived from employment and the provision of services and products to protected area visitors. Tourism to protected areas, however, often presents negative social impacts, such as changes in economic and social status, daily routines, the quality of life, traffic, noise, safety and access to traditional areas. Working with or through local communities to identify and address the nature of the impacts of tourism on the protected area can be a complex undertaking (see Case Study 23.2). Social and environmental impact assessments are useful tools for helping to understand, predict and address potential impacts of tourism on protected areas and related developments. Social impact assessment focuses on the potential impacts of different scenarios on individuals and communities (Brown et al. 2006). Environmental impact assessment is often carried out with a wider focus to include the potential negative and positive effects of developments in protected areas on natural, cultural, social and economic components (Ontario Parks 2005). This more holistic approach recognises that all of these components are interrelated and should therefore be considered simultaneously.

Social impacts are not limited to local communities but also occur among visitors. The activities, behaviour and infrastructure provided for some visitors can affect the experience of other visitors-both positively and negatively. A major challenge for managers is dealing with potential conflict among different types of visitors. Conflict among visitors often revolves around issues such as the appropriateness of an activity, its environmental impacts, its social impacts and the danger it may pose for other users. In some cases, allowing one type of activity results in some visitors avoiding the protected area. Bird watching and hunting in a private protected area, for example, are not highly compatible activities, and permitting hunting may result in the displacement of other visitors.

\section{Responding to visitor impacts}

The array of possible environmental and social impacts arising from visitor use presents challenges that require management attention. These impacts may (Farrell and Marion 2002):

- compromise the realisation of the protected area's mandate and goals

- negatively affect natural and cultural values, and several impacts may be additive in their effect and cumulative over time

- lead to unintended consequences such as diminished visitation and economic benefits; this in turn may affect the welfare of local communities.

A number of proactive measures may be taken to avoid unintended impacts. These revolve around elements of the adaptive management approach — that is: undertake good planning at the outset, implement the prescribed actions, monitor the values for positive and negative effects, evaluate and learn from the results, and adjust management actions to further improve and fine tune the necessary interventions (see Chapters 8 and 13). 


\section{Case Study 23.1 Zero-waste initiative on the trekking trail of Sikkim Himalaya, India}

The Government of Sikkim created Khangchendzonga National Park in 1977. With an area of 1784 square kilometres, bordering Nepal and Tibet, the park has an elevation range of 1829 to 8586 metres above sea-level and includes Mt Khangchendzonga, the third-highest mountain in the world. It is a biodiversity hotspot and conserves endangered species including snow leopards (Uncia uncia). It is also a sacred landscape, with local communities considering it a protector deity. All the rivers, lakes, hills and caves are considered sacred and it is believed they were blessed by the Buddhist guru Padma Sambhava. It is for this reason that local communities have consistently opposed proposals to construct hydroelectricity projects in the region.

The park was opened to tourists in 1982 to promote adventure tourism and generate local employment. Initially, there were few organised groups visiting the park, as it was very difficult to obtain permits. In 1992, the permit system was relaxed, resulting in increased visitation. During this period, however, there was less concern for conservation among some tourists and operators. This resulted in a range of impacts, including the accumulation of garbage; deforestation for firewood for cooking, heating and campfires; overgrazing by pack animals; biopiracy by visitors collecting medicinal plants, alpine flowers, seeds and insects; haphazard camping in high-altitude meadows; poaching and hunting of wild animals by trekking staff; and pollution of high-altitude wetlands. Local people resented the consequent desecration of the sacred landscape.

To tackle these problems, a community-based nongovernmental organisation (NGO), the Khangchendzonga Conservation Committee, was formed in 1996 at Yuksam, the base for trekking in the park. This committee mobilised the local community and tourism stakeholders to undertakea range of conservation activities. This included the promotion of community-based ecotourism activities such as trekking trail clean-up campaigns, conservation education, training of tourism stakeholders, garbage management, monitoring of biopiracy and a ban on use of fuel wood inside the park. A code of conduct for conservation was developed, and strategies to minimise grazing impacts by pack animals and proper camping sites introduced. Homestays (amongst India's first) were also developed as a way for local families to earn more revenue.

To address the problem of garbage in the park in 2007 a clean-up campaign was organised along the popular trekking trail and campsites. Tourism staff, including porters, pack-animal operators, guides and cooks, along with community members and schoolteachers and students, were involved. Thereafter, several trail clean-up campaigns were organised by the Tourism Department, travel agents and some individuals.

Realising, however, that this alone was not a long-term solution, the committee conceptualised a new system called 'Zero Waste Trekking Trail'. Under this initiative, all the visitors to the park have to bring back all the nonbiodegradable waste declared on their entry form. At Yuksam, where they exit the trekking trail, officials, after satisfying that indeed all such waste has been brought out of the park, separate the garbage into tins, batteries and medicinal waste, cloth, silver foils and noodle packets, plastics, and paper and cartons.

This garbage is then taken to a nearby 'resource recovery centre' where it is cleaned and further segregated. All the recyclable items are sold, while items such as biscuit and chips packets, which are not recyclable, are shredded and used for making cushions or other products. Some recycled paper is made from the waste paper and cartons. The centre has itself become a popular visitor destination, providing a strong message that trekking must not be at the cost of the environment and local communities. Due to these efforts, the park's trails, which are used by about 6500 visitors annually, are virtually garbage free.

- Pema Gyaltshan Bhutia, Khangchendzonga

Conservation Committee
Actively managing visitor impacts can help minimise their effect (Farrell and Marion 2002). There have been a number of management frameworks introduced to help support protected area managers with minimising visitor impacts. An effective management framework is a step-wise process that enables protected area managers and planners to interpret and explain the issues at hand (McCool et al. 2007). A framework helps managers:

- identify trade-offs between the provision of recreation opportunities with the resulting local economic impacts and the protection of biodiversity values

- appreciate and address complexity

- accommodate the array of stakeholders with interests in the area or issue.
Decision-makers must evaluate the suitability of the frameworks for the specific use. Researchers have provided five criteria to assess the suitability of a framework for resolving issues of visitor management, and describe the enabling conditions for their successful application (McCool et al. 2007).

1. Salient: Not all frameworks were designed to address all issues. They should provide a process for working through the specific issues at hand.

2. Conceptually sound: Based on current science and theory.

3. Practical: In the context of the organisation's capacity, staff require the right set of technical skills and knowledge to use and apply the framework. Staff need to think at the systems level to consider the regional consequences or effects at different time scales. 
The Gitga'at First Nation Community of Hartley Bay on the north coast of British Columbia, Canada, and the Natural Resources Institute, University of Manitoba, collaborated on research examining community views on tourism development. A community-led proposal to move forward with tourism development provided a platform for community members to reflect upon their experiences with existing tourism developments, and discuss and identify a set of principles to guide future developments. We found that community members consider tourism developments appropriate and desirable, but only where they sustain and enhance the health of their lands, people and way of life.

Gitga'at see that their wellbeing depends on the ecological health of their land and water, sustained through their stewardship of land and sea. For those relationships to be strong, opportunities must be created to allow working people and their families to remain in the territory, rather than move to off-reserve urban centres. As one community member expressed, 'there are a number of things that are Gitga'at-that are precious to the Gitga'atand none of them can be compromised'. As a result, a fine balance must be sought between cultural, community and ecological integrity when considering the types of local economic development activities that are desirable. From this, principles for tourism development were distilled-all gravitating around a simple, powerful theme: 'we want to live here.'

- Cultural integrity: Traditional leadership and clans must be involved in decision-making, and commercial use of resources is best when linked with traditional practices and ways of life.

- Community integrity: Low-impact economic opportunities should be pursued, but the maximum benefits from development should be for Gitga'at and should be distributed equitably within the community.

- Ecological integrity: Other species should be respected and the ecological impacts of development must be minimised.

A number of mechanisms to support these principles were also identified:

- ensuring local control and management of any venture

- organising benefit sharing in a fair, reasonable and transparent manner
- establishing protocols and other agreements, particularly with visiting researchers, to protect Gitga'at resources and knowledge

- undertaking careful, regular monitoring and evaluation of the social and ecological impacts of any tourism activities alongside a meaningful, ongoing process of local consultation

- facilitating respectful cross-cultural relationships between visitors and community members through interpretation and visitor support from Gitga'at guides

- establishing 'off-limits' areas for visitors to protect community privacy and better ensure the safety of local resources, including knowledge (for example, information concerning medicinal plants) and physical spaces (for example, harvesting locations and special places, such as gravesites).

Researchers identified these mechanisms as important ways to safeguard the wellbeing of Gitga'at people and territory, which includes maintaining the flow of information and dialogue necessary to adapt tourism services to better reflect community needs and interests. When considering these principles, many people in the community drew on their experience with past or existing tourism ventures in the area, including wildlife viewing, cultural tours of the Hartley Bay Village, sportfishing and eco-lodges. Low ecological impact, community member involvement and employment, and businesses operating in accordance with Gitga'at cultural protocols, including respect for the decision-making authority of traditional and local leadership, were considered desirable features of some of these examples. The ability to generate more cultural, economic and ecological benefits for the Gitga'at through local controls, however, emerged as a priority for future tourism.

The project found that many Gitga'at see such principlebased tourism as a forum, coupled with a new type of motivation, in which young people and other community members learn about the Gitga'at culture and ways of life, including the Sm'algyax language, food harvesting and processing skills, traditional ecological knowledge, and other culturally important skills. As one community member explained: 'You need somebody to be able to tell the story about our people... And that is the same thingthat expertise that could be developed-could be used here when we have tourists come.'

- Katherine L. Turner
4. Ethical: Discussions should enable an understanding of who benefits from decisions and who may be paying the cost. The process must be open and deliberative to enable participants to engage in the discussions, in a safe environment.

5. Pragmatic: To enable efficient and effective results so that human and financial resources can be allocated to address the priority issues, and importantly, so that impacts can actually be addressed.
While the focus is on these formal frameworks, it is recognised that ground staff and local communities often apply informal frameworks and practices that allow them to understand the dynamic relationships at play. These include making daily observations that are recorded or reported back informally, occasional feedback to and from local communities and staff, thinking about and discussing alternative approaches to carrying out projects with consideration of the pros and cons, and other practices. In this chapter, we consider seven visitor management frameworks: 
Table 23.8 Carrying capacity definitions

\begin{tabular}{|l|l|}
\hline Focus & Definition \\
\hline Recreation & The level of use beyond which the recreation resource or recreation experience deteriorates \\
\hline Biophysical & $\begin{array}{l}\text { The maximum number of people who can use a given area for a specified period without reducing } \\
\text { that area's ability to sustain use }\end{array}$ \\
\hline Managerial & $\begin{array}{l}\text { The maximum number of people who can use a given area for a specified period without reducing } \\
\text { the level of satisfaction received by any of those persons in the area }\end{array}$ \\
\hline $\begin{array}{l}\text { The maximum number of people who can be accommodated on a given area for a specified } \\
\text { period and: a) not degrade the environment beyond a given level of acceptability; b) not cause } \\
\text { unacceptable sociocultural and economic impacts on local people; c) provide a given level of } \\
\text { satisfaction for a given percentage of the users, as set by the recreation manager's objectives for } \\
\text { the area }\end{array}$ \\
\hline
\end{tabular}

Source: British Columbia Ministry of Forests (1991)

- carrying capacity

- limits of acceptable change

- visitor activity management process and appropriate activity assessment

- visitor impact model

- visitor experience and resource protection

- tourism optimisation management model

- values-threats framework.

\section{Carrying capacity}

The concept of carrying capacity dates to the 1950s and 1960s when American wilderness areas were experiencing large increases in outdoor recreation and concern was growing about crowding and the appropriate levels of use. Carrying capacity has been defined in many different ways (Table 23.8).

Carrying capacity is a central concept that underlies many visitor impact frameworks. It is an easy concept to understand, and can be simpler, less expensive and more feasible to implement than other frameworks (Farrell and Marion 2002). It continues to receive the attention of academic researchers and public land management agencies today. This approach, however, has serious limitations. It is basically a restrictive concept, founded on limits and constraints. Though this may be suitable for very specific matters such as managing wildlife breeding areas, caves and other sensitive areas, it can also be seen as working against protected area objectives designed to encourage appropriate visitor enjoyment and valuation of protected areas. Researchers have identified significant issues in its formulation, conceptual validity and managerial utility:

- carrying capacity requires specific objectives, but agencies are often reluctant to develop those objectives
- because carrying capacity is a function of objectives, there are many carrying capacities for a site; if there are many, the concept loses its utility

- for most recreation management situations, impact issues are more a function of visitor behaviour or development actions than numbers

- there is often confusion in the literature about the nomenclature: carrying capacity, use-limit policies and processes such as limits of acceptable change

- the conditions needed to establish a carrying capacity are often not present on a recreation site

- because carrying capacity is a technical approach to fundamentally value-laden problems, there is little room for public engagement ( $\mathrm{McCool}$ et al. 2007:40-3).

In addition, a major premise underlying the notion of carrying capacity is that the natural area of concern is stable and unchanging ( $\mathrm{McCool}$ et al. 2007). It is recognised, however, that biological and social systems are dynamic, complex and filled with uncertainty. The human-induced changes that are the focus of carrying capacity can be hidden by natural variations such as those caused by climate, fire and floods. Therefore, when fixed carrying capacities are established in a state of flux, their validity is called into question.

Other researchers conclude that carrying capacity has been oversimplified in practice, places too much emphasis on limiting visitor use when other parameters could be adjusted, has failed to minimise visitor impacts in some cases and has not incorporated public involvement or local resource needs (Farrell and Marion 2002).

\section{Limits of acceptable change}

The 'limits of acceptable change' (LAC) framework (Stankey et al. 1984) builds upon the ROS concept. Similar to ROS, it identifies a variety of recreation experiences in different settings, but unlike ROS, it is 
problem-oriented (Haider and Payne 2009). It features the involvement of stakeholders who participate in the whole process, including setting the standards for the amount and extent of human-induced change that are believed to be acceptable for an area. The process also identifies the remedies that managers should provide. The selection of indicators and measurable standardsand the follow-up monitoring-is a key step as it provides the basis for judging whether a condition is acceptable or not. These are, however, challenging tasks that require technical capacity and time, and as a result can be costly to implement (Brown et al. 2006; de Lacy and Whitmore 2006). Depending upon the management objectives, physical, biological and social indicators may be selected.

LAC has been applied worldwide; it is more appropriately used at a landscape scale, and has been integrated into the 'visitor experience and resource protection' (VERP) framework (Haider and Payne 2009). LAC comprises nine steps towards deciding the most important and acceptable resource and social conditions.

1. Identify area concerns and issues.

2. Define and describe opportunity classes (based on the concept of ROS).

3. Select indicators of resource and social conditions.

4. Inventory existing resource and social conditions.

5. Specify standards for resource and social indicators for each opportunity class.

6. Identify alternative opportunity class allocations.

7. Identify management actions for each alternative.

8. Evaluate and select preferred alternatives.

9. Implement actions and monitor conditions (Stankey et al. 1984).

\section{Visitor activity management process and appropriate activity assessment}

The 'visitor activity management process' (VAMP) was developed by Parks Canada in the late 1980s. It combines social science principles with those of marketing to focus on the analysis of opportunity, rather than visitor impact. It is particularly useful for making strategic and operational decisions about target markets and market position, and for identifying appropriate interpretative and recreational activities, and service facilities (Brown et al. 2006). The steps in the VAMP process are as follows.

1. Produce project terms of reference.

2. Confirm existing park purpose and objectives statements.
3. Organise a database describing park ecosystems and settings, potential visitor educational and recreational opportunities, existing visitor activities and services, and the regional context.

4. Analyse the existing situation to identify heritage themes, resource capability and suitability, appropriate visitor activities, the park's role in the region and the role of the private sector.

5. Produce alternative visitor activity concepts for these settings, experiences to be supported, visitor market segments, levels of service guidelines, and roles of the region and the private sector.

6. Create a park management plan, including the park's purpose and role, management objectives and guidelines, regional relationships, and the role of the private sector.

7. Establish priorities for park conservation and park service planning and then implement the plan (Brown et al. 2006).

VAMP has exceptional capability and has been used to understand and manage human use, assess and manage risks, and identify appropriate activities in Canada's national parks (Haider and Payne 2009). VAMP has transitioned into 'appropriate activity assessment' (AAA), which recognises that not all types of activities are appropriate in protected areas. Through the following principles of AAA, recreational activities in Canada's national parks, national historic sites and national marine conservation areas will:

- sustain or enhance the character of place

- respect natural and cultural resources

- facilitate opportunities for outstanding visitor experiences

- promote public understanding and appreciation

- value and involve local communities (Haider and Payne 2009).

VAMP is based on ROS and is designed for regional planning. It can readily incorporate the principles of LAC, VIM and VERP.

\section{Visitor impact management}

'Visitor impact management' (VIM) was developed by researchers with the American-based National Parks and Conservation Association. It addresses three issues related to visitor impact-namely: 1) problem conditions; 2) potential causal factors; and 3) potential management strategies (Nilsen and Tayler 1998). The process employs both science and, importantly, professional judgment, and emphasises the need to understand the causal factors 
when identifying management strategies. In addressing visitor impacts, VIM is linked to ecological and social carrying capacity. As shown in the steps, managers must specify ecological standards and monitoring for protected areas (Haider and Payne 2009). There are eight key steps associated with the VIM process.

1. Conduct pre-assessment database review.

2. Review management objectives.

3. Select key impact indicators.

4. Select standards for key impact indicators.

5. Compare standards and existing conditions.

6. Identify probable causes of impacts.

7. Identify management strategies.

8. Implement the strategy (Nilsen and Tayler 1998).

VIM is a variant of LAC and has been incorporated into the VERP process (Brown et al. 2006). It is more suitable for use when there are fewer resources available for monitoring research.

\section{Visitor experience and resource protection}

Developed by the US National Park Service, the 'visitor experience and resource protection' (VERP) method integrates social and ecological carrying capacity issues with indicators and standards of quality (Haider and Payne 2009). The process includes a focus on spatial zoning to integrate resource and social conditions, which can be a challenging undertaking. VERP builds on LAC and VAMP frameworks and comprises nine steps.

1. Assemble an interdisciplinary project team.

2. Develop a public involvement strategy.

3. Develop statements of park purpose, significance and primary interpretative themes; identify planning mandates and constraints.

4. Analyse park resources and existing visitor use.

5. Describe a potential range of visitor experiences and resource conditions (potential prescriptive zones).

6. Allocate the potential zones to specific locations within the park (prescriptive management zoning).

7. Select indicators and specify standards for each zone; develop a monitoring plan.

8. Monitor resource and social indicators.

9. Take management actions (Haider and Payne 2009).

\section{Tourism optimisation management model}

The 'tourism optimisation management model' (TOMM) was developed in Australia in the 1990s for regional tourism planning that included protected areas (McArthur 1999). It aims to monitor and quantify the benefits and impacts of tourism activities and to assess emerging issues and alternatives for future sustainable tourism (Brown et al. 2006). While the model is based on the LAC process, the name de-emphasises the perceived negative connotation of 'limits'. TOMM extends the concept of LAC to parks and gateway communities by considering the commercial and community interests in all stages of implementation and monitoring (Haider and Payne 2009). Key strengths of this model include its application in the context of the economic, political and social environments in which tourism operates, as well as the involvement of stakeholders throughout the process. Given the wider coverage, it is information intensive, and therefore requires significant resourcing for data management and long-term commitment from a wide range of stakeholders. The TOMM framework comprises five dimensions:

- economic (financial contributions of tourism activity)

- market opportunities (key market profile characteristics and marketing activity)

- experiential (the nature of the core visitor experience provided)

- community (the quality-of-life of local residents and indigenous people with a connection to the area)

- environmental (the biophysical environment, ranging from biodiversity and wildlife status to energy consumption patterns) (McArthur 1999).

TOMM comprises six steps.

1. Plan the process and commence stakeholder involvement by identifying stakeholders and generating tourism scenarios.

2. Compile and write a context description to define the current situation. Review planning and policy documents for the region. Continue stakeholder involvement, and begin engagement by conducting a briefing with stakeholders.

3. Develop the monitoring program that identifies what and how to measure, and defines reporting standards. Draft a set of optimal conditions and investigate associated indicators. 
4. Refine the context description and monitoring program through a workshop process with stakeholders. Narrow the number of indicators, determining the acceptable range and benchmark for each indicator.

5. Prepare draft and final versions of a TOMM plan, and brief stakeholders.

6. Implement and refine the model. Commence monitoring. After the first cycle, identify indicators outside the acceptable range; identify potential cause and effect relationships to develop management responses. The iterative process continues with ongoing refinement of indicators, optimal conditions and ranges (McArthur 1999).

\section{Values-threats framework}

An alternative approach to addressing visitor impacts is through the application of values-threats approaches, where the protected area's natural values are the basis for examining threats against their viability. The Open Standards for the Practice of Conservation (CMP 2013) provide a robust, broad-based framework for resultsbased planning, management and monitoring. They are rooted in the concepts of adaptive planning and management (see Chapter 13). Paleczny (2010) adapted and applied this framework in a wider context in Egypt to explicitly address non-biodiversity values - that is, cultural, recreational, tourism and local community wellbeing values. The 'protected areas visitor impact management framework' (Farrell and Marion 2002) employed elements of the open standards framework in Central and South America.

\section{Conclusion}

Visitor use and official use of protected areas are integral parts of protected area management. Common types of visitor use of the six different IUCN protected area categories have been identified along with implications for the management of such use. Tourism is perhaps the single greatest use of protected areas, and the many aspects of the management of tourism in these special areas have been described. Working in partnership with the tourism industry is very important, and a basis for protected area managers working with the tourism industry and the potential benefits have been described. The key focus of this chapter has been to provide a range of tools and guidance for protected area managers to help look after the long-term natural condition of protected area visitor destinations as a basis for biodiversity and heritage conservation, and consequently, for truly sustainable visitor use.

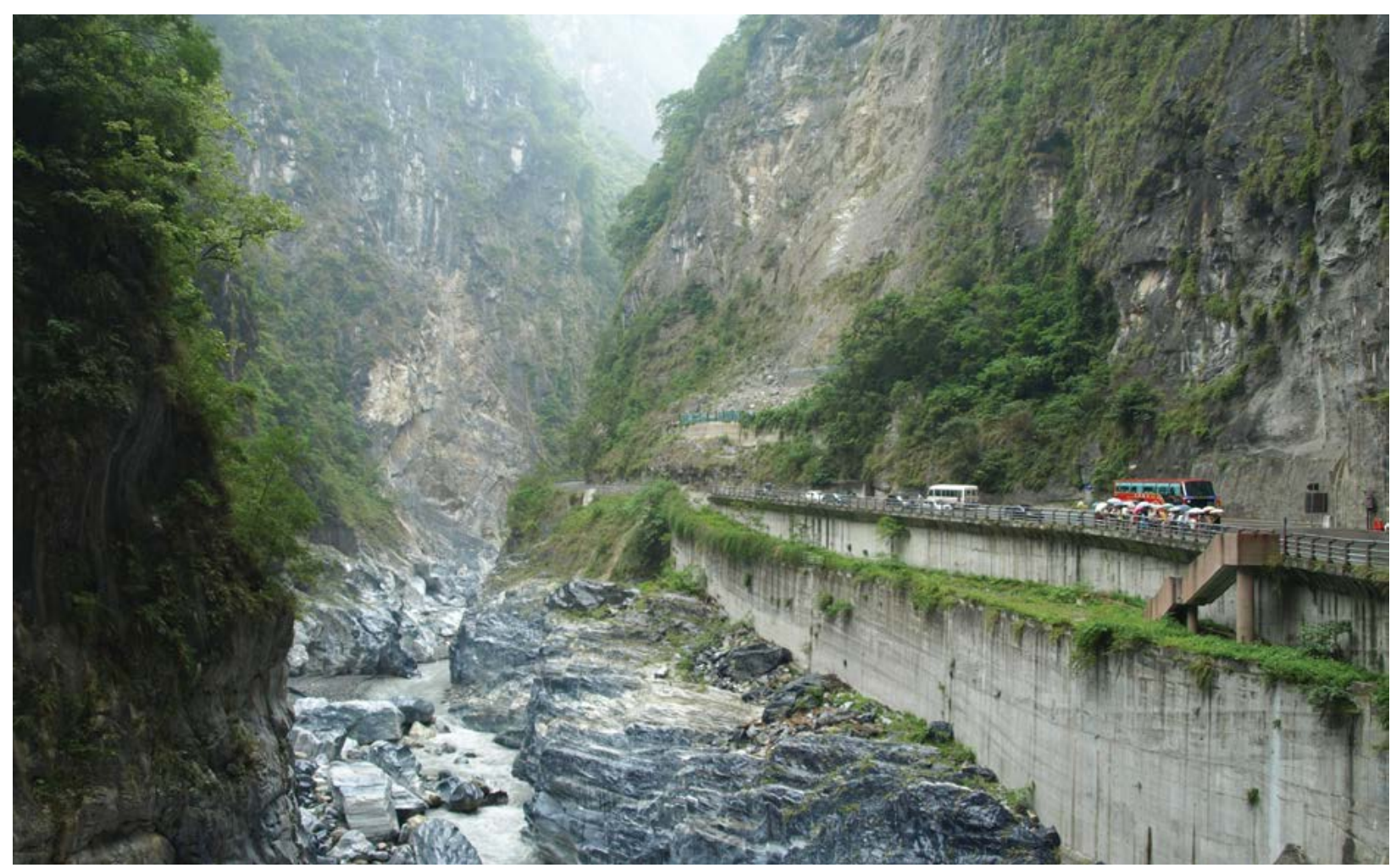

Visitors viewing the spectacular Liwu River gorge Taroko National Park, Taiwan. This is also known as 'The Marble Gorge' because of the river's incision into metamorphosed limestone rock.

Source: Graeme L. Worboys 


\section{References}

Recommended reading

Aaker, D. A. (1995) Strategic Market Management, Wiley, New York.

Aaker, J. L. (1997) 'Dimension of brand personality', Journal of Marketing Research 34(1): 347-56.

Baker, B. (2012) Destination Branding for Small Cities: The essentials for successful place branding, 2nd edn, Creative Leap Books, Portland, OR.

British Columbia Ministry of Forests (1991) Recreation Manual, Ministry of Forests, British Columbia, Canada. <www.for.gov.bc.ca/hfp/ publications/00201/>

Brown, G., Koth, B., Kreag, G. and Weber, D. (2006) Managing Australia's Protected Areas: A review of visitor management models, frameworks and processes, Sustainable Tourism Cooperative Research Centre, Griffith University, Gold Coast, Queensland.

Buckley, R. (2006) Adventure Tourism, CAB International, Wallingford, UK.

Buckley, R. (2010) Conservation Tourism, CAB International, Wallingford, UK.

D. Buckley, R., Pickering, C. M. and Weaver, D. (eds) (2003) Nature-Based Tourism, Environment and Land Management, CAB International, Cambridge.

Butler, R. W. (1980) 'The concept of a tourism area life cycle of evolution: implications for management of resources', The Canadian Geographer 24(1): 5-12.

Chee, C. G., Makens, J. C. and Choy, D. J. L. (1997) The Travel Industry, 3rd edn, van Nostrand Reinhold, New York.

Clark, R. N. and Stankey, G. H. (1979) The Recreation Opportunity Spectrum: A framework for planning, management, and research, General Technical Report PNW-98, US Department of Agriculture Forest Service, Washington, DC.

Cole, D. N. and Williams, D. R. (2012) 'Wilderness visitor experiences: a review of 50 years of research', in D. N. Cole (ed.) Wilderness Visitor Experiences: Progress in research and management, 2011 April 4-7; Missoula, Montana, Proceedings, RMRS-P-66, pp. 3-20, US Department of Agriculture Forest Service, Rocky Mountain Research Station, Fort Collins, CO.
Commonwealth of Australia (CoA) (1991) Ecologically Sustainable Working Groups: Final report, Commonwealth of Australia, Canberra.

Conservation Measures Partnership (CMP) (2013) The Open Standards for the Practice of Conservation. $<$ www.conservationmeasures.org/>

de Lacy, T. and Whitmore, M. (2006) 'Tourism and recreation', in M. Lockwood, G. L. Worboys and A. Kothari (eds) Managing Protected Areas: A global guide, pp. 497-527, Earthscan, London.

Dibb, S. and Simkin, L. (2009) 'Implementation rules to bridge the theory/practice divide in market segmentation', Journal of Marketing Management 25(3-4): 375-96.

Driver, B. L. and Brown, P. J. (1978) 'The opportunity spectrum concept and behaviour information in outdoor recreation resource supply inventories: a rationale', in H. G. Lund, V. J. LaBau, P. F. Folliott and D. W. Robinson (eds) Integrated Inventories of Renewable Natural Resources: Proceedings of the workshop, General Technical Report RM55, pp. 24-31, US Department of Agriculture Forest Service, Rocky Mountain Forest and Range Experimental Station, Fort Collins, CO.

Driver, B., Nash, R. and Haas, G. (1987) 'Wilderness benefits: a state-of-knowledge review', in R. C. Lucas (ed.) Proceedings: National Wilderness Research Conference issues, state-of-knowledge, future directions, General Technical Report INT-220, pp. 294-319, US Department of Agriculture Forest Service Intermountain Research Station, Ogden, UT.

Dudley, N. (2008) Guidelines for Applying Protected Area Categories, IUCN, Gland. <www.iucn.org/ pa_categories>

Eagles, P. F. J., McCool, S. F. and Haynes, C. D. A. (2002) Sustainable Tourism in Protected Areas: Guidelines for planning and management, IUCN, Gland.

Dd Eagles, P. and Legault, K. M. (2013) Guidelines for the Planning and Management of Concessions, Leases, Licenses, and Permits in Parks and Protected Areas, University of Waterloo, Ontario.

Elkington, J. (1997) Cannibals with Forks: The triple bottom line of 21st century business, Capstone, Oxford. 
Emerton, L., Bishop, J. and Thomas, L. (2006a) Best Practice Protected Area Guidelines Series, No. 013, IUCN World Commission on Protected Areas, James Cook University, Queensland.

Emerton, L., Bishop, J. and Thomas, L. (2006b) Sustainable Financing of Protected Areas: A global review of challenges and options, IUCN, Cambridge.

Farrell, M. and Marion, J. L. (2002) 'The protected area visitor impact management (PAVIM) framework: a simplified process for making management decisions', Journal of Sustainable Tourism 10: 31-51.

Font, X., Cochrane, J. and Tapper, R. (2004) Tourism for Protected Area Financing: Understanding tourism revenues for effective management plans, Leeds Metropolitan University, Leeds.

Frangialli, F. (2001) 'World Tourism organization perspectives on the International Year of Ecotourism', Industry and Environment 24(3-4) (July-December): 4. <www.uneptie.org/media/ review/vol24no3-4/UNEP_p1_49.pdf>

Goodwin, H. (1996) 'In pursuit of ecotourism', Biodiversity and Conservation 5: 277-92.

Haider, W. and Payne, R. J. (2009) 'Visitor planning and management', in P. Dearden and R. Rollins (eds) Parks and Protected Areas in Canada, 3rd edn, Oxford University Press Canada, Don Mills, Ontario.

Hall, C. M. and McArthur, S. (1998) Integrated Heritage Management: Principles and practice, The Stationery Office, London.

Ham, S. (2013) Interpretation: Making a difference on purpose, Fulcrum Publishing, Golden, CO.

Dd Higginbottom, K., Carter, R. W., Moore, S., Rodger, K. and Narayanan, Y. (2010) Current Practices in Monitoring and Reporting on Sustainability of Visitor Use of Protected Areas, Sustainable Tourism Cooperative Research Centre, Griffith University, Gold Coast, Queensland.

Hunt, S. D. and Arnett, D. B. (2004) 'Market segmentation strategy, competitive advantage, and public policy: grounding segmentation strategy in resource-advantage theory', Australian Marketing Journal 12(1): 7-25.
Kohl, J. (2007) 'Dodging cuts: surviving budget cuts for heritage interpretation means becoming relevant', Parks and Recreation Magazine, March. <www.jonkohl.com/publications/a-m/avoid-cuts. htm>

Kotler, P. (2003) Marketing Management, 11th edn, Prentice Hall, Upper Saddle River, NJ.

Liddle, M. (1997) Recreation Ecology, Chapman \& Hall, London.

Lockwood, M., Worboys, G. L. and Kothari, A. (2006) Managing Protected Areas: A global guide, 2nd edn, Earthscan, London.

McArthur, S. (1999) Visitor management in action: an analysis of the development and implementation of visitor management models at Jenolan Caves and Kangaroo Island, $\mathrm{PhD}$ thesis, University of Canberra, Canberra.

McCool, S. F., Clark, R. N. and Stankey, G. H. (2007) An assessment of frameworks useful for public land recreation planning, General Technical Report PNW-GTR-705, US Department of Agriculture Forest Service, Pacific Northwest Research Station, Portland, OR.

Manning, R. E. (1985) 'Diversity in a democracy: expanding the recreation opportunity spectrum', Leisure Sciences 7(4): 377-99.

Melbourne Business Community (2013) News: Business events in Northern Territory. <www. melbournebusinesscommunity.com.au/2013/07/ business-events-in-the-northern-territory>

Monz, C. A., Pickering, C. M. and Hadwen, W. L. (2013) 'Recent advances in recreation ecology and implications of different relationships between recreation use and ecological impacts', Frontiers in Ecology and Environment 11(8): 441-6.

Dewsome, D., Moore, S. A. and Dowling, R. K. (2002) Natural Area Tourism: Ecology, impacts and management, Channel View, Clevedon, UK.

Nilsen, P. and Taylor, G. (1997) 'A comparative analysis of protected area planning and management frameworks', Proceedings-Limits of Acceptable Change and Related Planning Processes: Progress and Future Directions, pp. 49-57, General Technical Report INT-GTR-371, United States Department of Agriculture, Forest Service, Intermountain Research Station, Ogden, UT. 
Ontario Parks (2005) A Class Environmental Assessment for Provincial Parks and Conservation Reserves, Ontario Ministry of Natural Resources, Peterborough.

Pacey, L. (2013) The Lure of Montague, 3rd edn, Laurelle Pacey, Narooma, NSW.

Paleczny, D. R. (2010) Protected area assessment and reporting: an examination of current approaches and evolving needs with application of an integrated model in Egypt, PhD dissertation, University of Greenwich and International Centre for Protected Landscapes, UK.

Phillips, A. (2000) Financing Protected Areas: Guidelines for protected area managers, IUCN, Cambridge.

Pine, B. J. II and Gilmore, J. H. (1999) The Experience Economy: Goods and services are no longer enough: Work is theatre and every business is a stage, Harvard Business School Press, Cambridge, MA.

Priskin, J. and McCool, S. F. (2006) 'The visitor experience challenge', [Editorial], Parks: The International Journal for Protected Areas Managers 16(2): 65 .

Reid, M., Wearing, S. and Croy, G. (2008) Marketing of Protected Areas as a Tool to Influence Visitors' PreVisit Decisions, Sustainable Tourism Cooperative Research Centre, Griffith University, Gold Coast, Queensland.

Shafer, E. L. (1969) The average camper who doesn't exist, US Department of Agriculture Forest Service Research Paper NE-142, Northeastern Forest Experiment Station, Upper Darby, PA.

South African National Parks (SANParks) (2011) 'Tourism sales and marketing report', in 2010-2011 Annual Report, pp. 18-27, SANParks, Pretoria.

Stankey, G. H., McCool, S. F. and Stokes, G. L. (1984) 'Limits of acceptable change: a new framework for managing the Bob Marshall Wilderness complex', Western Wildlands 103(3): 33-7.

Swarbroke, J. (1988) Sustainable Tourism Management, CAB International, New York.

The International Ecotourism Society (TIES) (2014) What is Ecotourism? The International Ecotourism Website. <www.ecotourism.org/what-is-ecotourism>
Tourism Australia (2010) Ningaloo-Shark Bay: A guide to making the most of your landscape positioning, Australia's National Landscapes Program, Canberra.

Tourism Australia (2012) Experience Development Strategies: Guidelines for Australia's National Landscape Steering Committee, 2nd edn, Australian Government Director of National Parks, Canberra.

Tropical Science Centre (TSC) (2014) Monteverde Cloud Forest Reserve Educational Programmes, Tropical Science Centre, San José, Costa Rica. <www.reservamonteverde.com/programs.html\#2>

Turner, K. L., Berkes, F. and Turner, N. J. (2012) 'Indigenous perspectives on ecotourism development: a British Columbia case study', Journal of Enterprising Communities, Special Issue: Indigenous communities, the bioeconomy and natural resource development 6(3): 213-29.

Tynan, C. and Drayton, J. (1987) 'Market segmentation', Journal of Marketing Management 2(3): 301-35.

United Nations (UN) (1992) Agenda 21, Earth Summit, United Nations, New York. <www. un.org/esa/sustdev/documents/agenda21/english/ agenda21 chapter $1 . h t m 12>$

United Nations (UN) (1997) Agenda for Development, United Nations, New York.

United Nations Educational, Scientific and Cultural Organisation (UNESCO) (2011) Operational Guidelines for the Implementation of the World Heritage Convention, UNESCO, Paris.

United Nations Environment Programme (UNEP) (2005) Forging Links between Protected Areas and Tourism Sector: How tourism can benefit conservation, UNEP, Paris.

United Nations Environment Programme (UNEP) and United Nations World Tourism Organisation (UNWTO) (2005) Making Tourism More Sustainable: A guide for policy makers, UNWTO, Madrid.

United Nations World Tourism Organisation (UNWTO) (1995) Technical Manual. Number 2: Collection of tourism expenditure statistics, UNWTO, Madrid. 
United Nations World Tourism Organisation (UNWTO) (2012) Summary: Study on tourism and intangible cultural heritage, UNWTO, Madrid. $<\mathrm{dtxtq} 4$ w60xqpw.cloudfront.net/sites/all/files/ docpdf/summaryview.pdf>

United Nations World Tourism Organisation (UNWTO) (2014a) Understanding Tourism: Basic glossary, UNWTO, Madrid. <media.unwto.org/en/ content/understanding-tourism-basic-glossary>

United Nations World Tourism Organisation (UNWTO) (2014b) World Tourism Barometer, UNWTO, Madrid. < dtxtq4w60xqpw.cloudfront. net/sites/all/files/pdf/unwto_barom14_02_apr_ excerpt.pdf>

Wearing, S., Archer, D. and Beeton, S. (2007) The Sustainable Marketing of Tourism in Protected Areas: Moving forward, Sustainable Tourism Cooperative Research Centre, Griffith University, Gold Coast, Queensland.

Weaver, D. and Lawton, L. (2002) Tourism Management, 2nd edn, John Wiley \& Sons, Brisbane.

Worboys, G. L. (2007) Evaluation subjects and methods required for managing protected areas, $\mathrm{PhD}$ thesis, Griffith University, Gold Coast Campus, Queensland.

Worboys, G. L., Lockwood, M. and de Lacy, T. (2005) Protected Area Management: Principles and practice, Oxford University Press, Melbourne.

Yankelovich, D. and Meer, D. (2006) 'Rediscovering market segmentation', Harvard Business Review 84(2): 112-31.

Yeo, G. (2005) 'Understanding users and use: a market segmentation approach', Journal of the Society of Archivists 26(1): 25-53. 


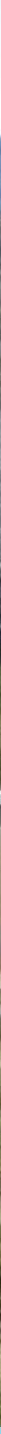

\section{CHAPTER 24}

\section{MANAGING OPERATIONS AND ASSETS}

Principal author:

Peter Jacobs

\section{Supporting authors:}

Graeme L. Worboys, Steve Mossfield and Tony Varcoe

\section{CONTENTS}

- Introduction

- Operations in protected areas

- Programming operations

- Planning operations

- Delivering operations

- Asset management and operations

- Reviewing the effectiveness of operations

- Conclusion

- References

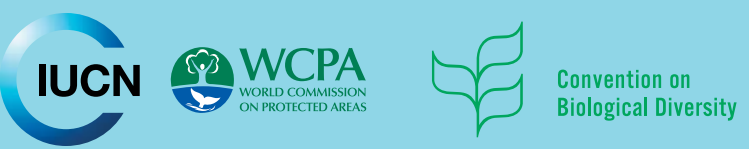




\section{PRINCIPAL AUTHOR}

PETER JACOBS is a retired Chief Ranger of the Victorian Alpine National Park with Parks Victoria, Australia, and is now a consultant to 'People in Nature'.

\section{SUPPORTING AUTHORS}

GRAEME L. WORBOYS is Co-Vice-Chair, Connectivity Conservation and Mountains, International Union for Conservation of Nature (IUCN) World Commission on Protected Areas (WCPA), and an Adjunct Fellow at the Fenner School, The Australian National University.

STEVE MOSSFIELD works for the NSW National Parks and Wildlife Service, Australia, and has contributed significantly to asset management and operations.

TONY VARCOE is the Manager of Science and Management Effectiveness for Parks Victoria, Australia, and has contributed significantly to decision-support tools.

\section{ACKNOWLEDGMENTS}

Appreciation is expressed to Patrizia Rossi, past director of Alpi Marittime Nature Park, Italy, and Peter Jenkins, the Sustainable Practices Coordinator with Parks Victoria, Australia, both of whom contributed to this chapter.

\section{CITATION}

Jacobs, P. J., Worboys, G. L., Mossfield, S. and Varcoe, T. (2015) 'Managing operations and assets', in G. L. Worboys, M. Lockwood, A. Kothari, S. Feary and I. Pulsford (eds) Protected Area Governance and Management, pp. 751-788, ANU Press, Canberra.

\section{TITLE PAGE PHOTO}

Trailhead, Wallace Hut Heritage Trail, Alpine National Park, Victoria, Australia

Source: Anthony Thomas 


\section{Introduction}

Setting aside areas for conservation is a great start for the protection of nature and culture and visitor enjoyment, but the land does not manage itself. Most protected areas require active management as they will most likely have experienced some human activity that impacts on natural processes; they will have an aim for visitors to experience and learn about the environment and will involve communities living in or around the area. Proactive and effective protected area management involves being responsive through carrying out a range of operational activities as appropriate to meet the objectives established for the area. Good stewardship of protected areas is achieved through the identification, planning and delivery of defined programs and projects. The effective implementation of an operational project involves converting management inputs and resources into positive protected area outputs and outcomes on the ground. This is the operations function of protected area management.

Importantly, on-ground operations in protected areas should only be carried out after a thorough and logical planning process, to ensure the works are the right response to an issue, impacts are considered and resources are used wisely.

This chapter presents the range of likely operations in protected areas and the four key steps in the pathway of operations for protected areas: programming operations, project planning, project delivery and review of effectiveness (Figure 24.1). It outlines the process of priority setting, detailed project planning steps to prepare for delivery and considerations for operational implementation and review. The chapter also considers the importance of built-asset management systems for protected areas. The management strategies outlined in this chapter have been developed over many years in Western economies and cultures such as Australia, New Zealand, North America and Europe; however, these approaches are likely to provide valuable guidance to managers everywhere.

\section{Operations in protected areas}

Operations in protected areas are the tactical implementation of projects associated with strategically focused programs (see Chapter 8). Projects can be expected to be principally associated with programs designed to meet the requirements of national and State legislation and the requirements of protected area management plans (see Chapter 13). Broadly, programs may include:

- managing threats to species, habitats and other environmental and cultural values

- presenting values and attributes of the protected area to visitors

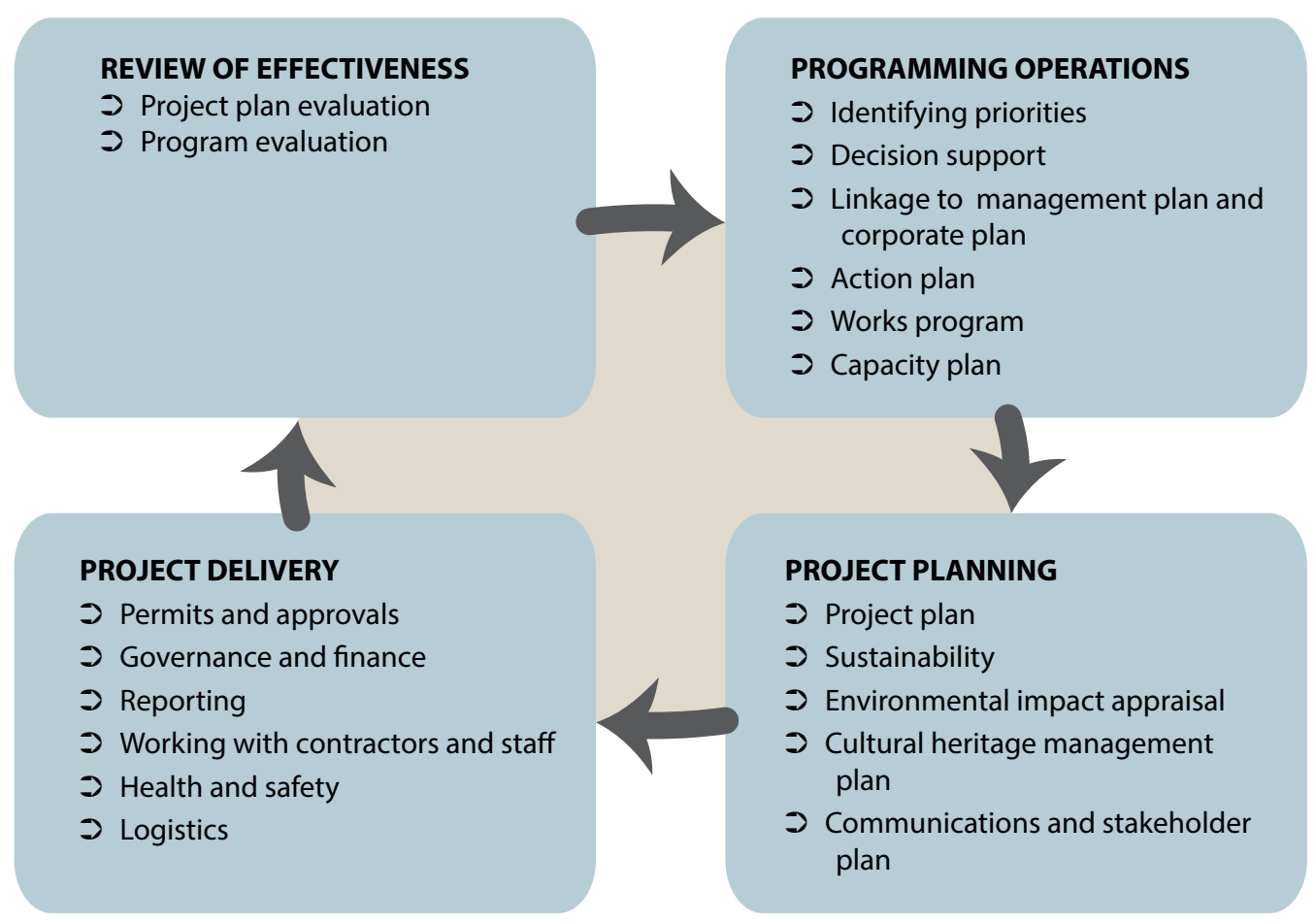

Figure 24.1 The operations cycle 
- providing recreation and tourism visitor experiences

- engaging and working with the community, including traditional owners

- supporting sustainable livelihoods that lawfully depend on protected areas

- implementing economic partnerships

- working with neighbours.

Ideally, projects are identified through a logical process of considered thinking and planning and must have a clear line of sight to organisational and protected area strategic priorities (Figure 24.2). They must be operationally well planned for effective delivery and include a review of effectiveness. There are, however, sometimes outside influences that alter the priorities.

\section{Types of operations}

Operations in protected areas are many and varied and field operational staff are confronted with a huge range of projects to implement. They may be carried out in terrestrial areas, marine environments, on the tops of mountains, in deserts or in urban settings. Fundamentally, when well planned and executed, they will contribute to the environmental health of the protected area and the community. There are many examples of operational activities and projects that fall within broad program areas in protected areas and some of these are introduced here.

\section{Environment, land and water programs}

\section{Introduced plant threats}

Projects are undertaken to contain or reduce the impact of introduced plants on biodiversity values, prevent the introduction of new plants and, if possible, eradicate new and emerging introduced plants where they are threatening conservation outcomes. Introduced plants are often very common and widespread, with control or eradication not feasible, therefore resources are targeted to those of highest risk to the highest values (see Chapter 16).

\section{Introduced animal threats}

Projects are undertaken to control the impact of introduced animals where they are threatening conservation outcomes. This includes introduced predators threatening native wildlife and large hardhoofed non-native animals impacting on sensitive environments.

\section{Threatened species and communities}

Projects to protect rare and/or endangered flora and fauna are implemented. This often targets the removal of threats such as visitor impacts, grazing, predators or introduced plants and may also include the reintroduction of species once found in the area or work that facilitates breeding programs.

\section{Habitat restoration}

Restoration works are completed for fragmented, damaged or altered environments. This work may include assisting nature with post-wildfire recovery through soil conservation works and reseeding; the protection of visitor-damaged coastal sand dunes; the rehabilitation of wetlands damaged by stock grazing; and the restoration of remnant biodiversity (see Chapter 21).

\section{Native animal management}

Overabundant native animal species may need to be controlled by actions such as translocation, fertility control and culling. Overpopulation of native species can occur due to the fenced isolation of a protected area, habitat fragmentation and reduction and/or loss of natural predators, which can lead to high impacts on plants and soils and population crashes.

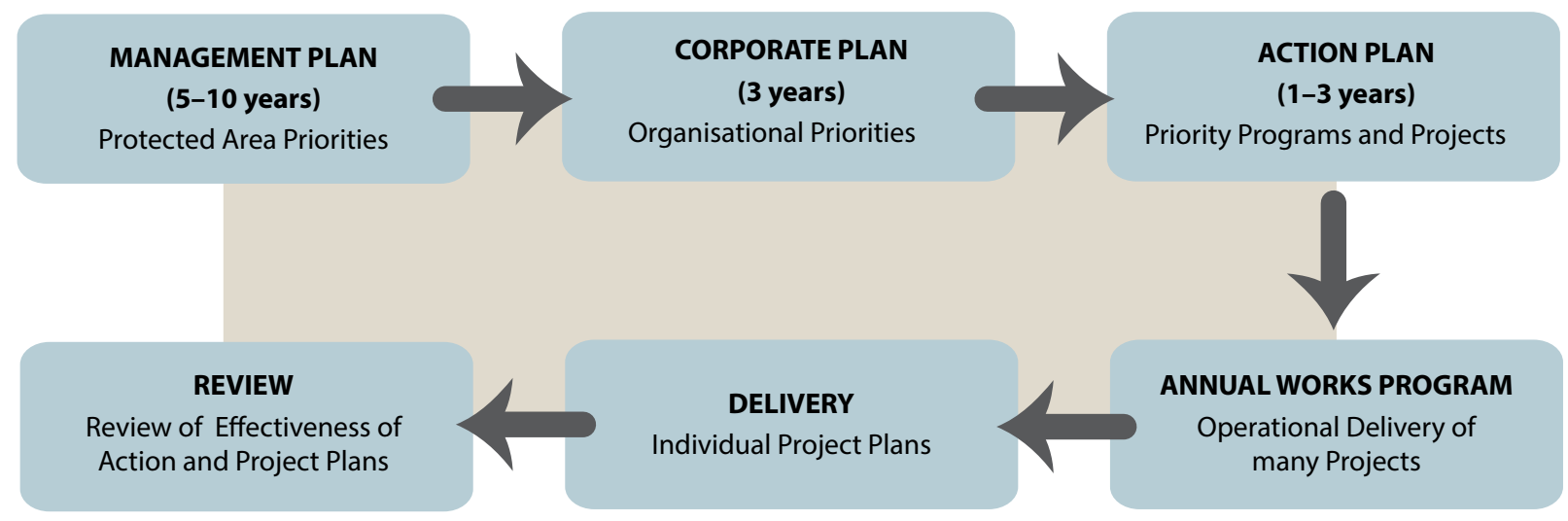

Figure 24.2 Corporate 'line of sight' to operations 


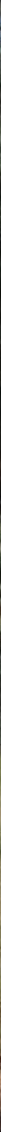

This predator-proof fenced enclosure at Mulligans Flat Woodland Sanctuary in the Australian Capital Territory, Australia, is enabling managers to reintroduce endangered and lost species such as the eastern bettong (Bettongia gaimardi)

Source: lan Pulsford

\section{Catchment and water}

Works are undertaken to restore altered hydrology and manage catchment soil and biodiversity conditions to help provide quality catchment health and water supplies. This may include peatland and wetland restoration and post-fire restoration of mechanical suppression disturbances. Healthy protected area catchments support many hydro-electricity, water supply and irrigation water storages around the world.

\section{Ecological fire}

Prescribed burning is undertaken in areas that require fire to sustain natural ecological processes, regeneration and health and that have artificially low fire frequency due to suppression of natural fire by fire authorities. This includes post-fire monitoring of flora and fauna conditions. The science-based reintroduction of managed fire into protected areas is becoming increasingly common in protected areas that have traditionally suppressed all fire, such as in Australia and North America.

\section{Visitor experience programs}

\section{Asset creation, renewal and replacement}

Capital improvement projects build and renew major assets associated with visitor facility structures, new roads and walking tracks and staff accommodation, offices and depots. They may include preservation or adaptive reuse of historic buildings. These projects often require specialist building and construction skills and are delivered as part of major works programs.

\section{Asset maintenance}

These projects involve the maintenance and repair of existing assets to meet design standards and serviceability condition requirements. They may include maintaining roads, walking tracks, bicycle trails, picnic areas, campsites, information signs, piers, jetties, staff offices and depots.

\section{Asset servicing}

Regular park cleaning and maintenance tasks, hygiene management and equipment servicing are key tasks. This is often carried out by contractors, and may include facility cleaning, grass cutting, gardening, general park presentation and amenity, and waste removal. For protected area administration, this includes office and depot cleaning, security and servicing of operational equipment such as vehicles, boats, chainsaws and tools of the trade.

\section{Asset condition assessment}

Administering an asset management system to monitor risk and compliance with regulatory standards and with regular asset inspections is a major on-ground and routine project. 


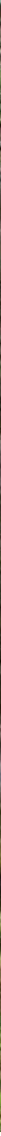

Maintaining historic sites such as Cascades Hut, Kosciuszko National Park, New South Wales, Australia, requires ongoing investment and community involvement

Source: lan Pulsford

\section{Visitor safety}

Projects are undertaken to ensure, as much as practical, that there is a low-risk environment for visitors within a protected area. Activities include ensuring facilities are in safe condition (relative to design standards), such as managing tree-limb fall risk around visitor sites, water safety and risks around cliff edges and snow avalanche areas.

\section{Commercial operations}

There are multiple projects that provide commercial services in protected areas to help achieve protected area organisation revenue targets in accordance with business plans for commercial sites (see 'Delivering operations' subsection below).

\section{Tourism and visitor engagement and management}

There are projects that provide support to visitors throughout their entire trip cycle and that aim to achieve high levels of visitor satisfaction. These include motivational marketing, provision of website content, supply of pre-visit and in-park information, organisation of information centre staffing and 'ranger' interpretation and education programs. This may also include the direct management of visitors for specific intense or higher-risk activities such as skiing, mountain biking, snow play, boating, climbing and abseiling and special event management. Successful delivery of these programs typically involves close collaboration with the tourism industry and tourism operators.

\section{Cultural heritage programs}

\section{Indigenous and local community place management}

This includes projects associated with the values and ongoing cultural connections to country of indigenous peoples with prior or current occupation of a protected area. This may include cultural conservation works to mitigate threats to indigenous cultural heritage sites and landscapes and intangible cultural heritage such as documenting and applying traditional knowledge.

\section{Historic place management}

Projects and programs are undertaken for heritage conservation that manages and mitigates threats to high-priority historic sites, collections, buildings and landscapes.

\section{Fire and other incident management programs}

\section{Readiness}

There are many projects associated with ensuring protected area staff are trained and prepared for fire and other incidents. This includes having a range of incident management plans in place and regularly tested such 


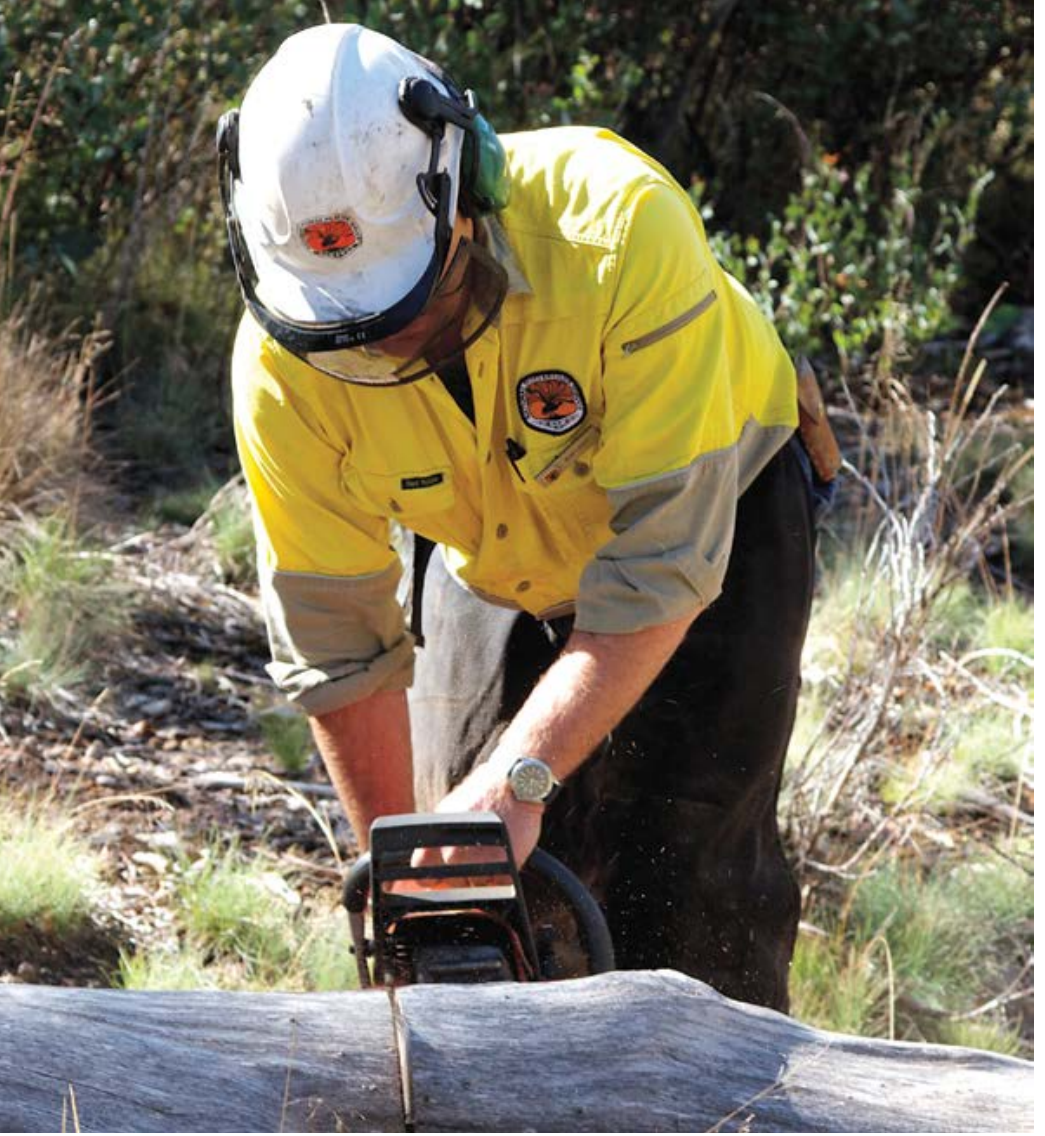

Clearing fire trails of fallen timber-an essential management operation for maintaining visitor access, enabling fire management operations and other essential management activities, Kosciuszko National Park, New South Wales, Australia

Source: lan Pulsford

as for fire, severe storm events, earthquakes, tsunamis, avalanches, search and rescue, pollution events, cetacean stranding and other wildlife incidents (see Chapter 26).

\section{Fire fuel reduction and community education}

The implementation of risk-based fire fuel reduction programs in and near protected areas and the running of community education programs about the danger of fire ignition in severe fire weather are major projects.

\section{Incident responses}

The facilitation of effective responses to incidents is a major project. This can include evacuation of injured visitors, search and rescue, vehicle and aircraft accidents, fire, flood or avalanches, cetacean stranding responses and clean-up of oil spills (see Chapter 26).

\section{Sustainable livelihoods}

Many protected areas such as Category V and VI protected areas support the sustainable livelihoods of people living in and around the area by providing for ongoing traditional community use of resources. This may include ecologically sustainable use like stock grazing, cropping, sourcing materials for building and community-based ecotourism. Operational programs regulate and support these activities.

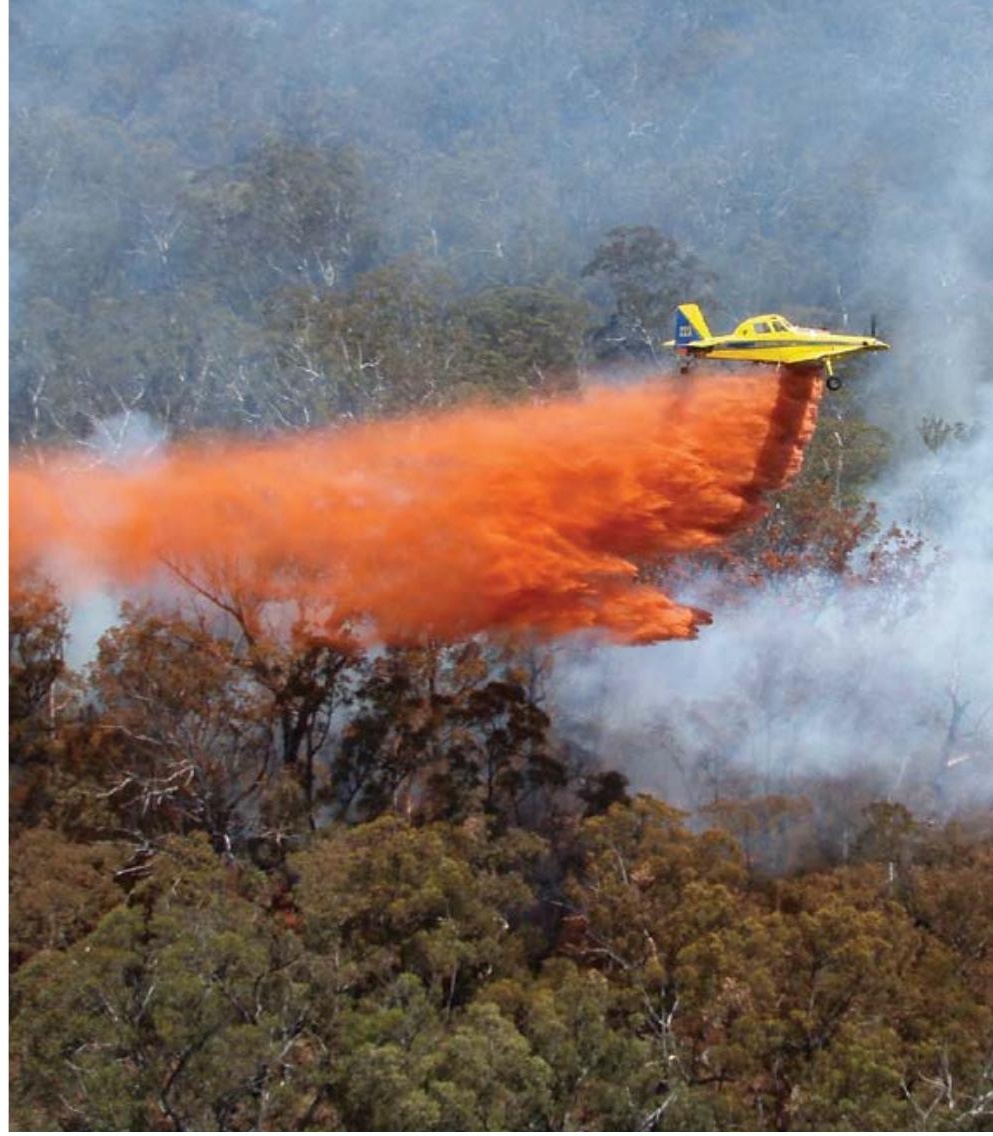

Aerial water bomber spreading fire-retardant chemical (Phos-Chek) to control wildfire, Morton National Park, New South Wales, Australia Source: Ross Constable

\section{Organisational effectiveness}

\section{Knowledge and management effectiveness}

This is the translation of research knowledge into information for use by protected area managers including the determination of the condition and health of protected areas and the measurement of the effectiveness of programs.

\section{Community programs}

These are projects that promote, enhance and manage community volunteer and partnership programs including the administration of grants for projects (see Chapter 14).

\section{Compliance}

Compliance projects ensure that regulations established for the safeguarding of protected areas are respected and are assisted by patrol and enforcement activities, the use of surveillance technology and education programs. These can vary from minor regulation infringements to major and dangerous enforcement operations such as against the poaching of ivory in Africa and illegal commercial-scale fishing on the high seas. 


\section{Box 24.1 Examples of decision-support and multi-criteria decision-analysis tools}

\section{Program logic}

Program logic is a planning, communication and evaluation tool that seeks to articulate what the program is, what it expects to do and how success will be measured. Program logic models provide a framework built around a series of structured steps that link program outcomes (short, medium and long term) with program outputs and inputs. Program logic models are particularly useful for clarifying assumptions and developing links between desired outcomes, actions and measures of success.

\section{Conceptual models}

Ecological or socioecological conceptual models are used to examine, compare and contrast hypotheses that can explain observed patterns of human and nonhuman influences in natural systems (White 2012b). Conceptual models seek to bring together the best available knowledge of how a complex system operates with alternative management options. For protected area management, conceptual models can identify and integrate the significant environmental and/or social drivers, attributes, management objectives, threatening processes and indicators for management effectiveness and enable the testing of assumptions about alternative management interventions. A range of conceptual model types has been developed and applied to park and conservation management. These include causal maps, fuzzy cognitive maps, state-transition models and Bayesian networks (White 2012a).

\section{Open Standards for the Practice of Conservation}

Open Standards for the Practice of Conservation are a set of guidelines for adaptive management, developed through the international Conservation Measures Partnership. The goal of this partnership is to create a common 'language' and structured process to improve the standards of conservation planning, delivery and reporting, and share this knowledge broadly. The open standards (which in some organisations are referred to as conservation action planning or CAP) are organised into a five-step project management cycle:

- conceptualise the project's vision and context

- plan actions and monitoring

- implement actions and monitoring

- analyse data, use the results and adapt

- capture and share learning.

The CAP process is being widely implemented across landscapes around the world at various scales, from national and bioregional to catchments and individual reserves (see Chapter 13).

The Open Standards for Conservation Practice have also served as the framework for the development of Miradi adaptive-management software. The software guides practitioners through a 'wizard', working through each step of the CAP process. Users build up visual models and text boxes that demonstrate interactions between

focal assets, threats, viability assessment, objectives, contributing factors and management strategies. Priority monitoring, work plans, result chains and dashboard reporting functions are also built into the software.

\section{Structured decision-making}

Structured decision-making (SDM) is an established framework for thinking critically about decisions, providing an organised and evidence-based approach to identifying and evaluating creative alternatives and making defensible choices in difficult decision situations (Gregory et al. 2012). There are six steps in SDM:

1. define the decision frame

2. define objectives

3. develop alternatives

4. estimate expected consequences

5. evaluate trade-offs and select an alternative

6. implement and monitor.

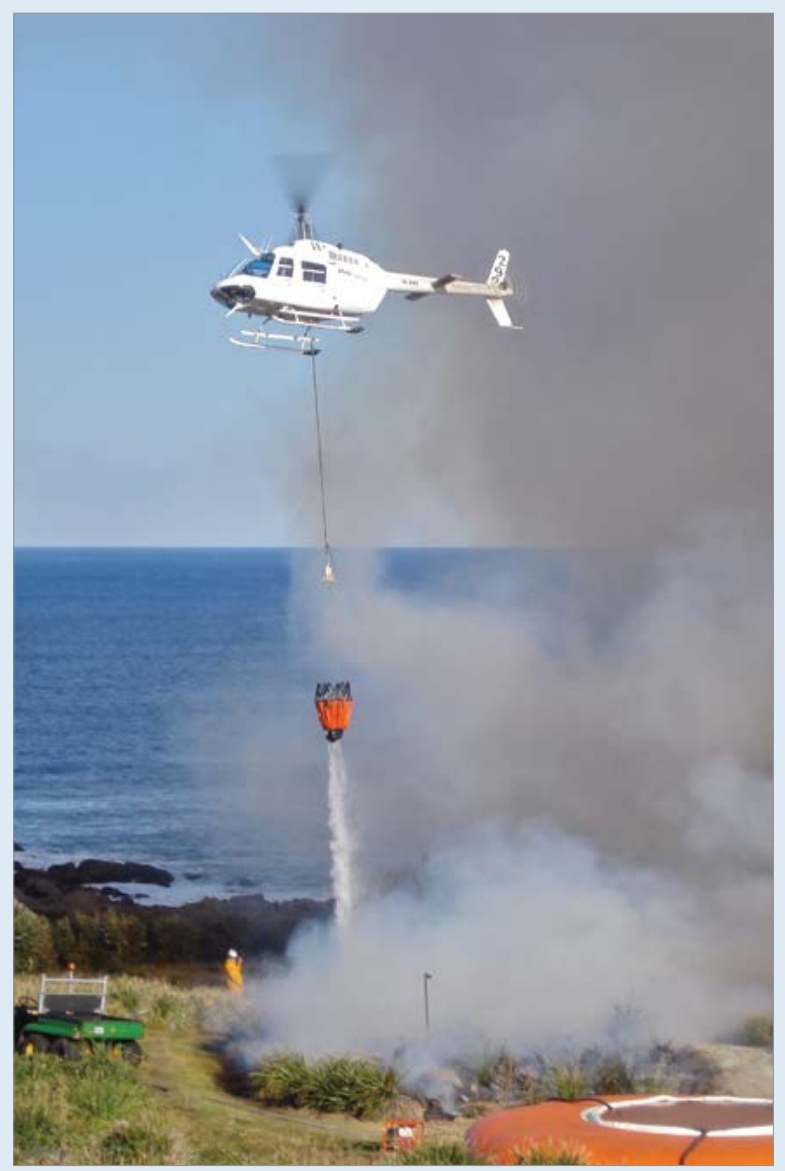

Helicopter water bombing a controlled burn as part of a program to restore the breeding habitat of the threatened little penguin (Eudyptula minor) on Montague Island Nature Reserve,

New South Wales, Australia

Source: Ross Constable 
An emphasis on the development of possible alternatives is a key component that sets SDM apart from other decision-assessment methods. SDM can be used to integrate cause-and-effect judgments concerning the effectiveness of management alternatives in conserving identified park values, and value judgments concerning trade-offs between the conservation of identified park values, costs and other relevant considerations. SDM can quantify trade-offs, calculate overall decision scores for each alternative and build in levels of uncertainty. It generally uses expert elicitation (experts, staff) to go through these tasks.

\section{Benefit-cost analysis}

Benefit-cost analysis involves comparing options based on their financial performance and selects the best option based on financial outcomes, and is often used for built-asset management.

\section{Multi-criteria decision-analysis tools}

Multi-criteria decision analysis considers a number of characteristics that competing options have and makes a decision based on an accumulative total of individual characteristic comparisons. There are many decision-support and multi-criteria decision-analysis tools available, both open source and proprietary products. Many of these tools include a spatial analysis function. A number of spatially based multi-criteria analysis tools are available. These include the MultiCriteria Analysis Shell for Spatial Decision Support (MCAS-S) tool (Lesslie et al. 2008), developed by the Australian Bureau of Rural Sciences.

\section{Risk based}

A risk-based framework looks at asset management decisions through a risk-elimination or a risk-reduction prism.

\section{Applications}

Decision frameworks have recently been applied to better inform management priorities and decisions for protected areas in Victoria, Australia. Structured decision-making and Bayesian models were used to rank a series of potential alternative management strategies to address specific conservation objectives within protected areas in south-western Victoria. Structured decision-making and modelling were applied to inform spatial priorities for the control of invasive willows within the Alpine National Park.

\section{Standards for public and employee wellbeing}

Protected area organisations are responsible for the safety and wellbeing of employees, contractors and the public in protected areas, and there are major projects that are associated with compliance with regulations and statutes. Non-compliance could expose the land manager to litigation. This may include regulations associated with accommodation standards, fire detection and fire warning requirements, the provision of risk and road safety signage, the provision of safe drinking water, structures built to design standards, and the provision of a safe workplace based on occupational health and safety standards. Employee assistance programs provide advice and counselling services to support staff health and wellbeing.

\section{Programming operations}

The effective programming of operations is critical to achieving good on-ground outcomes, efficient use of resources, value for money and a committed and supportive protected area team. The operations cycle (Figure 24.1) outlines the components of the operations programming phase. The programming process involves:

- identification of tasks and actions needed to meet protected area management objectives

- prioritising actions for funding bids

- building approved actions into a ratified action plan

- preparing a work program for timely delivery of the action plan

- developing a capacity plan to identify resources and skills needed

- after delivery, reviewing project and program effectiveness.

Operation activities need to be determined and programmed through a planning framework and a thorough and defendable decision-support process that, if done effectively, leads to a project being supported.

\section{Decision-support tools to inform operational planning and resource allocation}

Most natural systems are complex, with many interacting components and many potential outcomes from management actions (White 2012a). These interact with equally complex social systems, with many public demands and expectations on protected areas. Park managers are faced with the challenge of meeting many competing environmental and social obligations 


\section{Environmental and cultural heritage programs}

Determining and assigning 'levels of protection' are step processes that can be used for developing and programming operational priorities for environmental, land and water and cultural heritage programs and can incorporate elements of the decision tools described in Box 24.1. This aims to identify key environmental and cultural values of the protected area and to prioritise threats relative to those values, to determine the most appropriate response and to make best use of the response resources available.

The process does rely somewhat on the available information on values and threats, and decisions may need to be made based on limited information. In the case of inadequate information, a judgment needs to be made and the principle of precaution should be used while sufficient data are gathered. The process of applying the levels of protection step process to determine operational priorities for environmental and cultural programs is illustrated in Figure 24.3.

\section{Visitor experience programs}

Determining and assigning 'levels of service' are step processes that can be used for developing and programming operational priorities for visitor experience programs and can incorporate elements of the decision tools described in Box 24.1. This aims to provide the most appropriate visitor experiences in the right place at the right time and makes best use of the resources

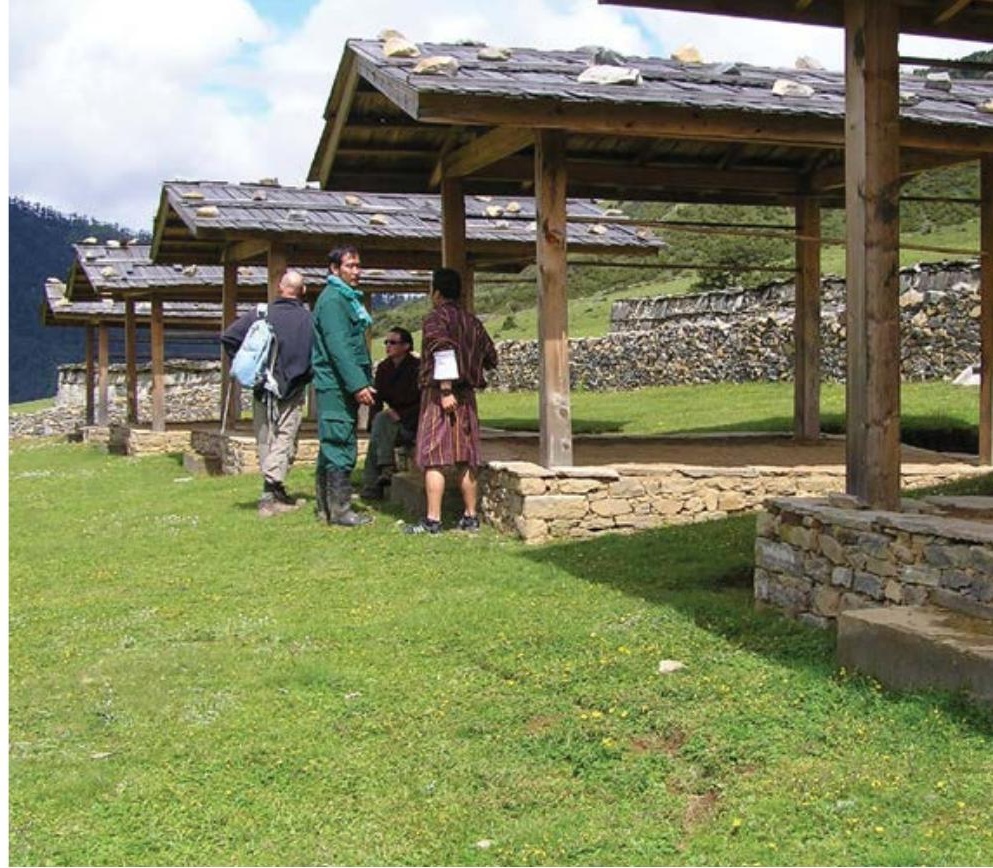

Camping areas established to support a community-based ecotourism program, Sakteng Wildlife Sanctuary, Bhutan

Source: Gillian Anderson

available to the protected area. It also guides planning for rationalising and meeting savings constraints if needed and runs parallel with 'levels of protection' to ensure the right match between visitor experience and environmental protection.

Service levels are considered across a landscape, taking into account key visitor experiences, journeys and destinations. Visitor sites or precincts in the protected area are then assessed as to their importance and value in contributing to the visitor experience and what level of service is required to maintain that value. The assigned service level will vary across a spectrum, from very highly maintained sites to sites with only a basic level of service.

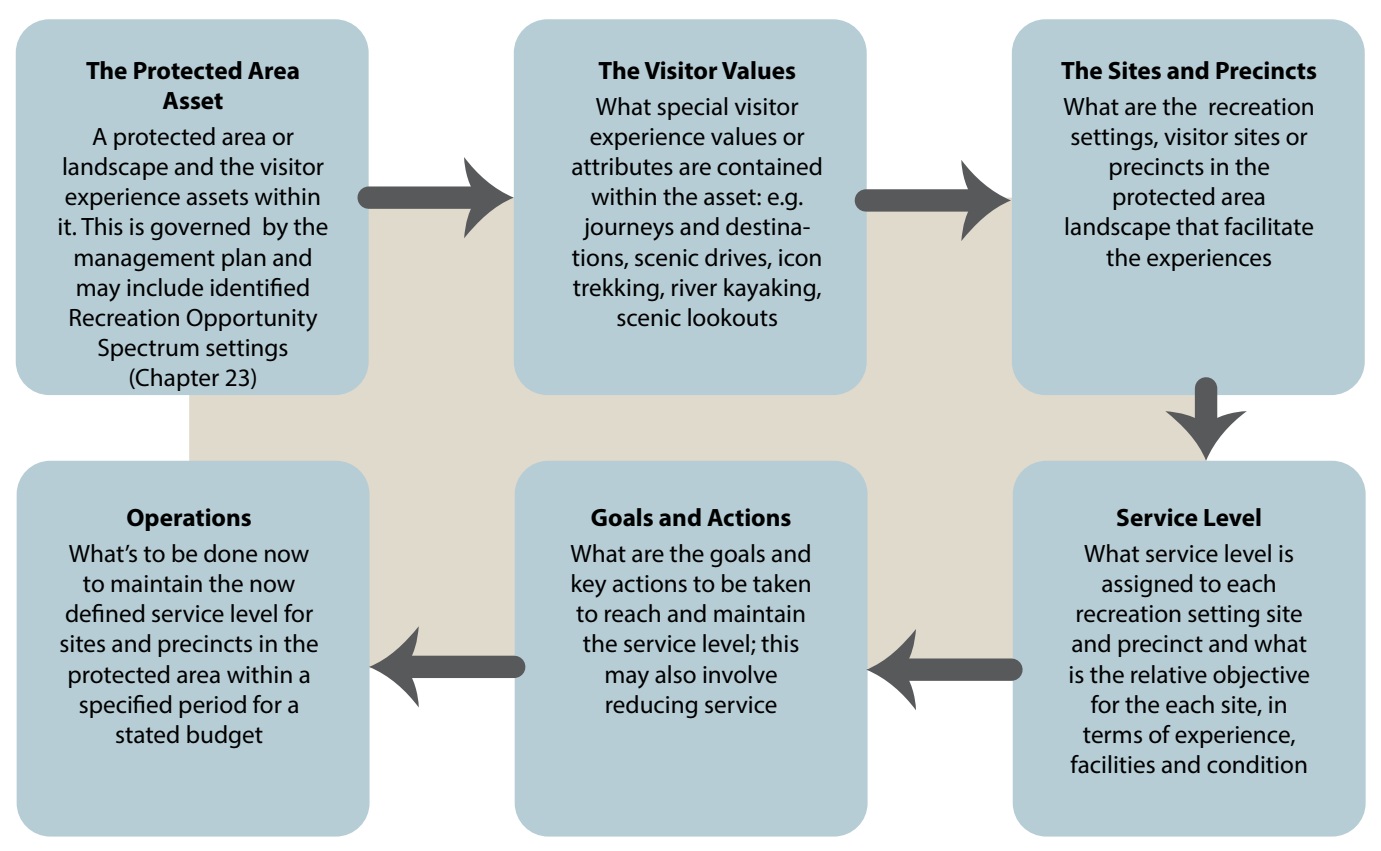

Figure 24.4 'Levels of Service' step process for determining visitor experience program operational priorities 
This, then, guides programming investment and operational resource allocation for:

- access

- amenities

- information, interpretation and education

- recreational facilities

- management services.

The visitor service can be provided under a lease or licence to a private operator (see 'Delivering operations' section and 'Lessees, licensees and concessionaires' subsection below). The process of applying the 'levels of service' step process to determine operational priorities for visitor experience programs is illustrated in Figure 24.4.

Reducing visitor services to align priorities with available funding can result in a very negative community reaction, which may have other consequences for protected area agencies. A communication strategy is a necessary component of such action (see subsection on 'Stakeholder and communication plan' below).

\section{Funding projects}

All projects will need to secure funding to proceed. This funding may be one of the following:

- Tied funding: This is grant funding that is provided by governments, non-governmental organisations (NGOs), communities, sponsors or donors for a particular initiative or outcome, and will have specific reporting requirements.

- Recurrent funding: This is base funding usually available within organisations for recurring services and is allocated on an annual basis. This is often the funding source for asset servicing and maintenance and protected area administration and business operations.

\section{Action plan}

A number of priority projects may be planned for a protected area, and these may be organised further. Some organisations use the concept of a protected area 'action plan'. The action plan process evaluates proposed actions against available fund sources (which may be scarce) and the corporate priority criteria used for approval. An action plan lists all the programs of approved works that will be carried out for a specified period in the protected area and directs the operational business of the work group. The period is typically a one-year budget cycle but may include an outlook over a period of three or more years. The action plan identifies the 'line of sight' from a protected area organisation's corporate programs area to actions on the ground. An action plan would, at a minimum, have the components indicated in Figure 24.5. On-ground operations should only proceed once this planning and programming process has been considered and approved.

\section{Works programming}

A work centre or group in a protected area responsible for works will face myriad operational, planning and administrative tasks during the implementation year, with critical 'time and event' elements for delivery. The orderly arrangement throughout the year of the delivery of operational tasks identified in an action plan is typically done through a 'works program'. When the action plan is approved, a works program is prepared for delivery. This includes effective resource planning so delivery is timely, well organised and meets objectives. The works program also informs the development of individual staff 'work plans' so they understand their responsibilities and expectations in contributing to the delivery of the action plan. The works program needs to consider the whole cycle of project delivery including adequate provision of project

PROTECTED AREA ACTION PLAN

\begin{tabular}{|c|c|c|c|c|c|c|}
\hline $\begin{array}{c}\text { Corporate } \\
\text { Program } \\
\text { Description }\end{array}$ & $\begin{array}{c}\text { Program } \\
\text { Objectives }\end{array}$ & $\begin{array}{c}\text { List of } \\
\text { Projects/ } \\
\text { Actions }\end{array}$ & $\begin{array}{l}\text { Priority } \\
\text { D High } \\
\text { Dedium } \\
\text { D Low }\end{array}$ & $\begin{array}{c}\text { Risk } \\
\text { Assessment } \\
\text { O Potential losses } \\
\partial \text { Reputation } \\
\partial \text { Financial } \\
\partial \text { Legal } \\
\partial \text { Injury } \\
\partial \text { Business } \\
\text { interruption } \\
\partial \text { Environmental } \\
\partial \text { Cultural }\end{array}$ & $\begin{array}{c}\text { Budget and } \\
\text { Fund } \\
\text { Source }\end{array}$ & $\begin{array}{c}\text { Accountable } \\
\text { Person and } \\
\text { Support }\end{array}$ \\
\hline
\end{tabular}


Table 24.1 Indicative operations business milestone checklist

\begin{tabular}{|l|l|}
\hline Operations business milestone & \multicolumn{1}{l|}{ Checklist task } \\
\hline Planning & Complete planning and programming of operational activity \\
\hline Action plan & Preparation and approval of the action plan \\
\hline \multirow{2}{*}{ Staff } & Budget loading \\
\hline \multirow{2}{*}{ Project plan } & Preparation and approval of staff work plans \\
\cline { 2 - 2 } Staff rosters & Preparation of capacity plans \\
\hline \multirow{2}{*}{ Project evaluation } & Preparation and approval of the project plan \\
\hline Operational preparedness & Monthly rosters submitted for approval \\
\hline Review of assets & Monthly reporting on delivery \\
\cline { 2 - 2 } & Review and refinement of the project plan \\
\hline Occupational health and safety review & Annual review of emergency management plans \\
\hline Staff review & Asset condition validation and reporting \\
\hline
\end{tabular}

planning (including design aspects). Not allowing enough time for operational project planning and preparation is a common cause of delivery failure.

\section{Capacity planning}

Capacity planning is when resource and skill availability is considered in the works program to determine if any resource or skills gaps appear. The 'capacity plan' is most effective when applied by matching the works programs with the whole work group to share skills and availability across the team. Where resourcing requirements exceed availability, other options need to be considered rather than trying to make them fit. These include looking to other parts of the organisation, buying in the labour and skills through contractors, seeking volunteer support or, if necessary, reviewing the work programs and removing lower-priority tasks.

\section{Annual business diary}

The annual operational business cycle of protected area organisations will typically have a number of key reporting and corporate milestones that will need to be met throughout the year. These are essential to a wellfunctioning operations environment. The operations manager will have corporate milestone tasks programmed into the work unit's capacity, to ensure they are dealt with smoothly and efficiently. A useful approach is to develop an annual operations calendar that designates the known business milestones throughout the year to assist staff (Table 24.1).

\section{Major works and specialists}

Operational tasks fall into two broad categories: major and minor. Major works are projects with large budgets and highly technical design and standards, and are typically complex. These projects are often associated with buildings and structures, roads and bridges, and service infrastructure such as water, sewerage and power. These operations require technical specialists and are most effectively managed through major works divisions of organisations or contracted out to project managers. Minor works are the more regular operations that protected area staff are skilled and resourced to undertake. These include most environmental projects, fire and emergencies, visitor facility maintenance and servicing, and less-complex facility development such as minor walking tracks. It is important that the level of technical skill required is understood and resourced correctly before embarking on more complex operations.

\section{Planning operations}

Once an action plan is approved and works programs and capacity plans are in place, it is time to start project planning and organisation. The operations cycle (Figure 24.1) outlines the components of the operations planning phase. This includes project governance, design aspects, environmental impact assessments, research needs, contractor tendering, stakeholder consultation where appropriate, partner agreements, liaison with neighbours, occupational health and safety requirements, meeting project objectives, securing permits and approvals, evaluating success and many others. Without good management of a project, a lot can go wrong. 
This is where on-ground operational project management starts, and with that, the importance of a clear and approved project plan is crucial to successful delivery. Allowing sufficient time for the preparation and approval of a project plan is a key part of works programming. The nature and complexity of the project should reflect the complexity of the plan.

\section{The project plan}

Protected area organisations have developed guidelines for managing projects, and a distillation of these is presented in Table 24.2. Project planning frameworks such as the Conservation Measures Partnership framework and its supporting Miradi software or the CAP framework (Box 24.1 and Chapter 13) also support project planning.

This project planning outline has been presented in its most comprehensive form and represents best-practice guidance for large projects being managed through wellresourced programs as well as by established protected area agencies. Some projects may be smaller and less complex and aspects of these guidelines will not be relevant, so the table should be adapted to suit local circumstances. Specialist advice, guidelines and manuals (Case Study 24.1) are critical resources when planning operations.

Table 24.2 Components of a project plan for operations

\begin{tabular}{|c|c|}
\hline Component & Description \\
\hline Project name & A name that briefly and clearly identifies the title and nature of the project \\
\hline $\begin{array}{l}\text { Corporate and administrative } \\
\text { details }\end{array}$ & $\begin{array}{l}\text { Identify connection to organisational business priority actions, file numbers, project } \\
\text { codes, budgets, funding source, project manager, workforce allocation and expected } \\
\text { budget outlook for the next three years. Time lines for commencement of planning, } \\
\text { implementation period and expected completion date }\end{array}$ \\
\hline Business risk assessment & $\begin{array}{l}\text { An assessment of the project's negative risk to the business by considering the } \\
\text { likelihood and consequence of the project failing to deliver. The assessment may find } \\
\text { - the risk to business of delivery failure is below an established corporate threshold } \\
\text { (or low) and a brief project plan only is needed } \\
\text { - the risk to business of delivery failure is above an established threshold (or high) and } \\
\text { the project plan process would be more inclusive including a full risk assessment, } \\
\text { an environmental impact assessment and a communications management plan }\end{array}$ \\
\hline Project description & $\begin{array}{l}\text { This is where the project detail is described in readiness for approval. The project } \\
\text { description will outline the vision, describe why it is being done, what it involves, } \\
\text { how it will be delivered, when it will be completed and who will undertake the work. } \\
\text { The description will include consideration of skills, the resources and competencies } \\
\text { needed, the design or industry standards that may apply and the project logistics. } \\
\text { The description will also provide a geographical context statement for the project } \\
\text { including a very brief description of the protected area, its significance and its special } \\
\text { values }\end{array}$ \\
\hline Objectives & $\begin{array}{l}\text { List the key objectives the project is aiming to achieve in its vision. Ensure the written } \\
\text { objectives are clear and presented as 'succinct, measurable, achievable, resourced } \\
\text { and timely' (SMART) statements }\end{array}$ \\
\hline Performance measures & $\begin{array}{l}\text { Each objective must have a related performance measure to ascertain how success in } \\
\text { meeting the objectives is to be measured and reported }\end{array}$ \\
\hline Project evaluation plan & $\begin{array}{l}\text { Prepare a project evaluation plan for the entire project that includes performance } \\
\text { evaluation measures for each key milestone }\end{array}$ \\
\hline $\begin{array}{l}\text { Operational, environmental } \\
\text { and cultural risk assessment }\end{array}$ & $\begin{array}{l}\text { The likely operational risks associated with carrying out a project are identified, } \\
\text { assessed and rated and their treatment described. A risk rating is the consideration of } \\
\text { likelihood (the probability or frequency of occurrence) and consequence (the degree } \\
\text { of outcome or impact of the occurrence) that are presented in a matrix. Operational } \\
\text { delivery risks where treatment may be required could include: } \\
\text { - the timely availability of resources, services and skills } \\
\text { - favourable weather } \\
\text { - } \quad \text { effective communications } \\
\text { - minimising disruption to the community and visitors } \\
\text { - } \quad \text { political sensitivities } \\
\text { - the health and safety of staff, contractors and the public. } \\
\text { 'Environmental and cultural risks are considered. Procedures to guide this are in the }\end{array}$ \\
\hline
\end{tabular}




\begin{tabular}{|l|l|}
\hline \multicolumn{1}{|l|}{ Component } & $\begin{array}{l}\text { Description } \\
\text { Defining the project scope describes when each task is to be completed, and what } \\
\text { support and resources are needed. Tasks and milestones are best presented in a Gantt } \\
\text { chart for complex projects }\end{array}$ \\
\hline $\begin{array}{l}\text { Review of sustainability } \\
\text { considerations }\end{array}$ & $\begin{array}{l}\text { The project scope includes the selection of materials and the method of } \\
\text { implementation (see 'Sustainability in operations and asset management' subsection } \\
\text { below) }\end{array}$ \\
\hline Budget phasing & $\begin{array}{l}\text { The breakdown of the total budget into expected monthly expenditure of budget and } \\
\text { resources provides a 'monthly phasing' that may be used for budget-control reviews }\end{array}$ \\
\hline $\begin{array}{l}\text { Approvals, permits and } \\
\text { notifications }\end{array}$ & $\begin{array}{l}\text { Projects will need to meet internal and external planning approvals and there is a need } \\
\text { to consider all possible planning permits, and legislative and other legal requirements. } \\
\text { These may include government planning schemes, environmental regulations, } \\
\text { biodiversity conservation requirements, discharge licences, pesticide regulations, } \\
\text { cultural heritage approvals and occupational health and safety regulations. Permits or } \\
\text { advice from authorities responsible for essential services may also be relevant }\end{array}$ \\
\hline $\begin{array}{l}\text { Stakeholder communication; } \\
\text { communications planning }\end{array}$ & $\begin{array}{l}\text { For large and complex projects, it is common to prepare a comprehensive stakeholder } \\
\text { and media communications plan (see 'Stakeholder and communication plan and media } \\
\text { management' subsection below) }\end{array}$ \\
\hline Project plan sign-off & $\begin{array}{l}\text { A project plan is typically prepared by the project manager (and key staff) and approved } \\
\text { by a senior officer with the appropriate delegations }\end{array}$ \\
\hline Project evaluation & $\begin{array}{l}\text { Performance evaluation of the project is undertaken (based on the evaluation plan) } \\
\text { during the project and at its completion (see 'Reviewing the effectiveness of operations' } \\
\text { subsection below). }\end{array}$ \\
\hline
\end{tabular}

\section{Environmental impact assessment}

It is a fundamental responsibility of protected area managers to ensure that a full assessment is made of any potential impact of operations on the natural and cultural heritage values of a protected area (Chapters 3 and 4). The level of impact assessment will depend on the complexity, scope and nature of the operations works. The approach to environmental impact assessment (EIA) will vary internationally depending on legislation and policy, and terms used may have different meanings; however, the general principles are shared.

An initial risk-assessment step in project planning (Table 24.2) will help determine the level of impact assessment required. The outcome of that initial assessment may be:

- simply a list of identified risk-management measures in the approved project plan

- an environmental management plan (EMP) to support an approved operation that further identifies impacts and prescribes mitigating actions that need to be built into project delivery to avoid or minimise effects

- an internal 'review of environmental factors' or equivalent document that carefully follows a protected area organisation's thorough environmental impact appraisal procedures involving many specialists, for assessing and approving a proposed operation

- a full environmental impact statement (EIS), which is only employed in the case of potentially high-impact and high-consequence projects where legislation may direct the need for a full EIS to be prepared for approval by the executive level of government.

Such documents reflect a protected area organisation acting responsibly (and consistently) and can also provide an internal peer-reviewed checking mechanism to ensure that an operation has little or no impact. They can be time-consuming and expensive to prepare, review and approve, so sufficient consideration of lead time for their development to meet operations delivery schedules is vital.

\section{Environmental management plan}

The purpose of an EMP is to support a more complex project, as prescribed in the approved project plan. The EMP will identify in more detail than in the project plan the potential impacts and prescribe mitigating actions that need to be built into the project delivery to avoid or minimise those impacts and, where necessary, direct ongoing management: The EMP should:

- describe the project scope

- identify in detail environmental, water and catchment values and attributes including biodiversity and soils

- identify legal constraints, requirements and approvals

- outline an overall environmental management strategy with objectives and performance measures

- identify risks and control measures 


\section{Case Study 24.1 A manual for management of walking tracks in Alpi Marittime- Mercantour trans-frontier protected area}

Alpi Marittime and Mercantour are two adjoining mountain protected areas in the south-western Alps, in Italy and France. Because of the geographic situation and the history of the area, they are connected by a dense network of mountain mule tracks and footpaths, leading from one country to the other and often crossing the national borders at very high altitude (2800-3000 metres). From the beginning it was clear to the managers that it was necessary for the two countries to cooperate not only in the field of wildlife management but also for footpath maintenance and restoration.

First, there was an agreement regarding the common signposting to be placed on the mountain passes on the border, and then it was decided to extend this cooperation to entire footpaths on both sides. Thanks to grant funds from the European Union for trans-frontier cooperation, the two parks produced a manual, in French and Italian, aimed not only at the operational staff of both parks but also at the technical services of local French and Italian administrations.

The text is complemented with several pictures of path work, and in particular with practical technical drawings. The information that was put together is in part local traditional knowledge of path-building from both sides of the mountains, but also some innovative technical solutions and new materials tested by the field staff of both parks. The manual provides information for the operations staff and communities with a connection to the area on the following topics.

- History of the footpaths: The area has origins from time immemorial-from the Neolithic to the Roman Empire, from the Middle Ages to the Industrial Revolution; the salt routes in the Alps, the big changes in the 19th and 20th centuries; the religious connections, the hunting tracks for the king, the military roads and, after World War II, the first tourists.

- Path assessment and problem analysis: Guidance on how to segment and assess a footpath, analyse and observe its degradation, compile a grid/checklist for the analysis of the problems, plan the works, and provide common questions and answers.

- Footpath restoration and maintenance: Technical information on path surfacing, drainage, paving, managing gradients, dry-stone walls, bank and slope stabilisation and path definition.

- Some practical examples from the field.

- Footpaths in the wider French/Italian national/regional context.

The manual promotes the values of footpaths.

- Footpaths have multiple functions: They had important commercial, agricultural and pastoral (transhumance) uses in the past, and a religious function for pilgrimages. In the 21 st century, their purpose is mainly recreational and for visitors. For this reason they are an important economic resource. In Europe, some 10 million people use pathways.

- They are a physical cultural heritage: They are an important component for understanding and discovering the social, economic and cultural history of a whole territory. Paths are, however, also a place for the spirit and self-regeneration, because they put us in contact with the beauty of nature and its relaxing landscapes.

- They are a tool for discovery and communication in the context of protected areas. A well-managed footpath gives a positive impression of the general management of the whole protected area. They are also an important management tool to steer or redirect visitor flows and to monitor use through eco-counters. This provides important information on visitor patterns and needs.

Footpaths are increasingly a tool for sustainable development. When planning path works, the following principles should be considered:

- the project should have the support of local stakeholders; they should be consulted and their suggestions taken into account

- the project should generate benefits to the local population, including sustainable economic returns

- the technical solutions chosen should fit with the environment, respect the territory and its history, and interpret the 'spirit of the place'; the material used should reflect this and where appropriate should be locally sourced, according to local tradition

- any negative impact, direct or indirect, should be avoided

- any decision should consider the long-term outlook, including funds being available for ongoing path maintenance.

Under our feet, footpaths tell us unique stories about times gone by. They are a collective memory, and the means through which we can approach nature. Our footpaths are precious; let us do our best for their conservation.

\section{- Patrizia Rossi}

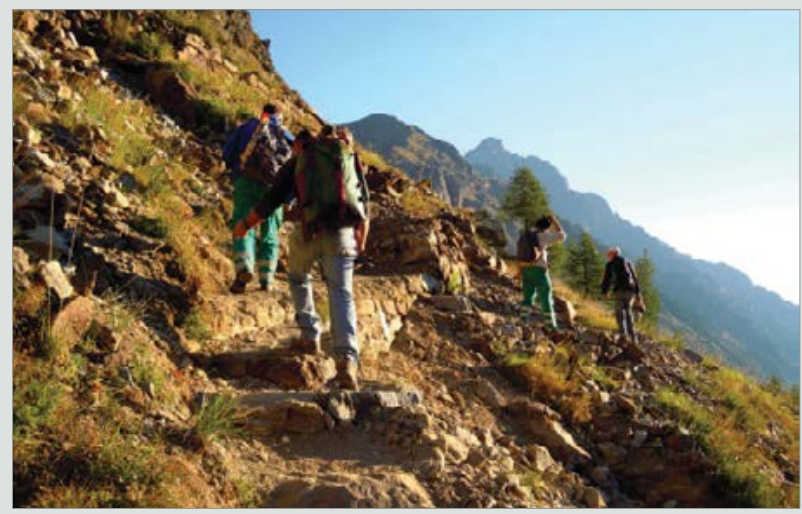

Reconstruction of an ancient walking path in Alpi Marittime-Mercantour trans-frontier protected area, Italy

Source: PNAM 
be given and may prescribe the need for an EMP to be prepared to direct the activity. The review also assists the determination of whether the activity is likely to have a significant effect on the environment, in which case an EIS will need to be prepared and considered before approval may be granted. A REF can include many items and often they are in the form of a checklist, as follows:

- climate

- geology and geomorphology

- soils

- plants (species and communities)

- animals (species and habitats)

- water catchment and water quality

- significance for indigenous and local communities

- historic sites

- recreation and visitor settings

- landscape values

- traditional and existing uses

- air quality (Worboys et al. 2006:233).

The environmental impacts that may be of concern could include:

- air pollution

- noise pollution

- vehicle traffic

- aircraft movements

- disturbance to geoheritage sites including karst sites

- disturbance and erosion of soils

- disturbance to streams and the pollution of water

- impacts to native animal species and habitats

- impacts to native plant species and communities

- introduced plant species impacts

- introduced animal species impacts

- introduction of unscheduled fire(s)

- disturbance to cultural heritage and sacred sites

- disturbance impacts (poaching, theft, vandalism, wildlife disturbance) to protected area values

- project disturbance to neighbours, local communities and the tourism industry (Worboys et al. 2006:233).

There are operational matters that should be, as a matter of course, considered as part of minimising the impact of a project at any level. These include:

- the layout of a temporary worksite and its containment

- the safe storage of chemicals and fuels
- the planned movement and parking/location of plant and vehicles

- hygiene regimes for vehicles and machinery to prevent introduced plants and pathogens

- avoiding and minimising disturbance to biodiversity and, if necessary, offsetting impacts

- avoiding and minimising disturbance to soil, sediment and water movement

- taking care in the use of chemicals given their potential to impact on non-target values

- introducing measures for dust and noise control

- organising for the removal of project waste off-site and preferably off-protected area

- implementing fire-prevention measures

- being prepared for project incidents such as the management of spills and emergencies

- retaining 'guarantee funds' for project site restoration and any follow-up works

- implementing biodiversity recovery monitoring as part of the extended 'project'.

\section{Cultural heritage}

A project plan should identify the need for permits and/or more specific plans to be prepared for managing environmental heritage, cultural heritage and historic values. This need, underpinned by either legislation or judiciousness, provides the basis for cultural heritage management plans to be prepared prior to project approval. If the operations are expected to disturb sensitive cultural landscapes or registered sites, permits and/or an approved cultural heritage management plan will be required. Their preparation generally requires detailed knowledge and skills and usually involves many different specialists including traditional owners.

The requirement for a cultural heritage management plan may be associated with legislation related to indigenous traditional ownership or association with the land or with registered historic sites and landscapes (Case Study 24.2). The cultural heritage values may be associated with indigenous peoples and traditional ownership, historic associations of indigenous and nonindigenous people, or both. If the nature of the project is such that a cultural heritage management plan is not required by law, the project manager may nevertheless choose to include cultural heritage assessment as part of the environmental impact appraisal process. The purpose of a cultural heritage management plan is to:

- assess and document the presence of cultural heritage and its associated values 
- investigate the extent and nature of the values and legal status

- identify cultural heritage values at risk

- identify and work with indigenous traditional owners as appropriate

- identify and work with communities and people with historic connections where relevant

- consider if harm to values can be avoided, or, if harm cannot be avoided, to prescribe strategies to minimise harm

- obtain approval to proceed based on the plan.

In many countries, this will require communication with the government body responsible for implementing indigenous and historic cultural heritage legislation. The International Council on Monuments and Sites (ICOMOS) principles and guidelines underpin historic cultural heritage planning across the world (Chapters 4 and 22).

\section{Sustainability in operations and asset management}

While protected areas play a vital role in preserving our planet's natural and cultural heritage assets, it is hard to see how these areas will not come under growing pressure in the future without a widespread commitment to environmental sustainability principles and practices. It could be said that the manner in which humans behave outside the boundaries of protected areas could prove the key determinant in the destiny of protected areas. It is for this reason that protected area managers must seize the opportunity to demonstrate leadership in the area of environmental sustainability.

\section{Sustainability policy}

Protected area organisations can demonstrate leadership in sustainability through the development of a strong sustainability policy. The organisation's position is then delivered typically through an environmental management system or protocol (EMS) that contains environmental objectives and targets, and identifies review mechanisms and roles and responsibilities. This will build sustainability thinking into organisations by supporting environmental impact assessment and guiding operations.

\section{The business case for environmental sustainability}

Sustainability policies and procedures should reflect a triple bottom line (TBL) approach (DEH 2003), meaning that environmental, social and economic benefits are all considered. The TBL framework best supports the business case needed to justify environmental sustainability improvements as it helps quantify the return on investment (ROI) using a more holistic understanding of benefits. ROI is a common business term that can support the communication of outcomes sought to a conventional business-minded audience.

Energy efficiency projects can in some cases have a relatively attractive ROI as the energy cost savings that come with energy efficiency improvements can enable the investment to be repaid quickly. Once the cost of the works has been recovered, the ongoing savings can be used to implement more energy efficiency works or can be redirected to other operational priorities. Reduced fossil fuel energy consumption contributes to a reduction in greenhouse gas emissions and other atmospheric and land-based impacts. This in turn may provide broad environmental, social and economic dividends for the general community.

\section{Key sustainability principles for operations in protected areas}

There are four key sustainability principles that should be considered by project managers for operations in protected areas.

Leadership: Exercise leadership to achieve sustainability principles and practice when carrying out operations and making asset design and material decisions.

Triple bottom line: Environmental, social (including cultural) and economic sustainability objectives guide built-asset design, construction, maintenance and endof-life disposal. Design decisions that aid environmental sustainability are an investment, not simply a financial cost. Some examples of practical triple bottom line leadership considerations for operations in protected areas include:

- undertaking appropriate environmental, social and cultural impact assessments (see 'Planning for operations' above) and implementing required actions to avoid or minimise impacts

- collaborating with local communities and traditional owners to be sensitive to needs, encouraging participation and ownership and minimising or avoiding impact on social and cultural values

- developing a TBL-based business case that gives the most appropriate return on investment and influences investment in good design

- ensuring work is carried out in a manner that is safe for workers and the community

- giving preference to using non-toxic materials or materials of low toxicity 


\section{Case Study 24.2 Planning for Indigenous cultural heritage: Hotham-Dinner Plain trail in the Alpine National Park, Victoria, Australia}

The Aboriginal landscape of the Australian Alps is interconnected and interwoven with significant and sacred places linked by travel routes and pathways, frequented by a rich array of language groups and Aboriginal clans. Occupation has been recorded over 20000 years (Flood 1996), with a rich history in inter-clan gatherings and ceremony. The advent of European settlement from the 1830s decimated the Aboriginal population through disease, massacres and displacement, causing severe social disruption.

Today, the Australian Alps are a popular year-round visitor destination serviced by alpine resorts and villages. A new 13-kilometre multipurpose trail linking the alpine villages of Dinner Plain and Mount Hotham has been established, in Victoria's Alpine National Park and the adjoining Mount Hotham Alpine Resort. The theme for interpretation along the trail is 'travel with traditional owners along an ancient mountain pathway to learn of the past, understand the present and discover the future aspirations of the Aboriginal peoples of the alps'. The trail may be walked, run, skied or ridden on bicycle. The construction method proposed involved removing sod and soil along the 2 metre-wide trail, 200 millimetres deep, for inlaying with gravel.

The entire route of the trail follows an ancient pathway for Aboriginal people seeking a safe and secure route from lowlands to the high country for gatherings and moth feasting or across the alps (Muhlen-Schulte 2010). For the traditional owners-the Gunaikurnai, Dhudhurhoa and Yaithmathang-this route represents an important attachment to place, kinship and country, and its richness and diversity complement other parts of their traditional country. The Victorian Aboriginal Heritage Regulations 2007 required the preparation and approval of a cultural heritage management plan (CHMP) as the work constituted a highimpact activity. This is defined in this case by disturbance using machinery in a sensitive area (a national park). The CHMP assesses and documents the presence, nature and extent of Aboriginal cultural heritage and determines if harm can be avoided and, if not, minimised. The plan must then be approved by the registered Aboriginal party or, in the case of no registered Aboriginal party, by Heritage Victoria, the statutory authority for Aboriginal heritage in the State of Victoria.

The CHMP for the Hotham-Dinner Plain multipurpose trail (Muhlen-Schulte 2010) was prepared in collaboration with representatives of the three traditional owner groups who participated in site surveys. They identified and described 19 'Aboriginal places'. These are places of cultural significance to Aboriginal people of Victoria and are registered under the Aboriginal Heritage Act 2006. The plan concluded that the proposed activity may proceed under the following conditions (in summary):

- a supervisor will direct works and remain on site to ensure ground disturbance is minimised

- all contractors and workers are to have a site induction with the traditional owners and the CHMP author prior to work commencing, for cultural heritage awareness and to ensure legal responsibilities are clear

- the entire activity area is to be marked with flagging tape to ensure no disturbance occurs outside it

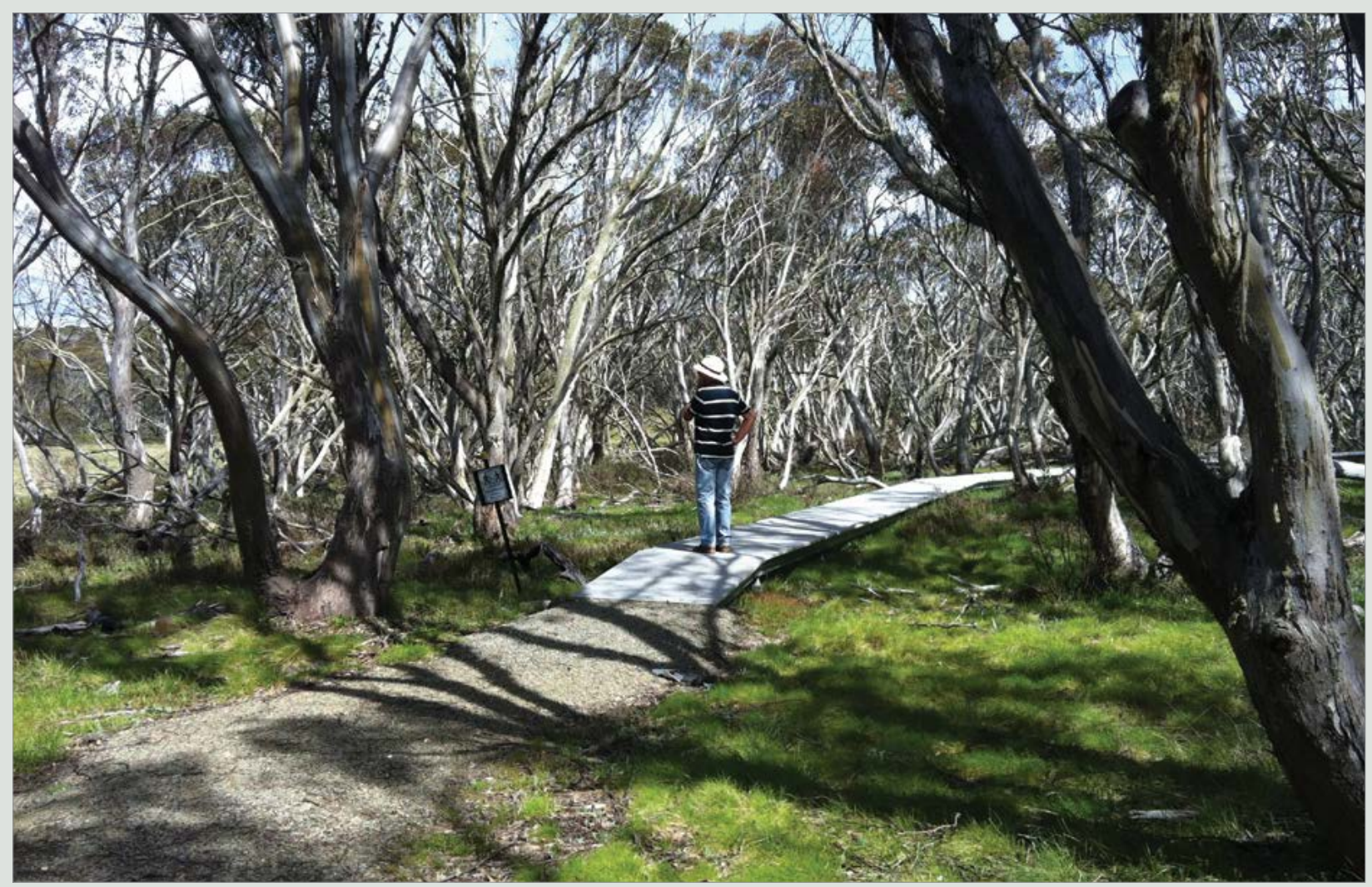

Elevated walkway built to protect a high-value Aboriginal place in the Alpine National Park, Victoria, Australia

Source: Gillian Anderson 
- the extents of the 19 Aboriginal places are to be clearly marked to minimise harm

- two Aboriginal places identified as the most significant are not to be disturbed-for one, an elevated walkway is to be installed with no machinery allowed and an archaeologist is to be on site during construction to record and restitute artefacts; and for another, gravel is to be laid over geofabric

- no trail markers are to be used in Aboriginal places, and installation of interpretative signs in Aboriginal places must involve an archaeologist to record and restitute any artefacts disturbed

- the trail is to be renamed with an appropriate Aboriginal name by traditional owners

- all artefacts collected are to be restituted in collaboration with the traditional owners.

The key values and outcomes the CHMP brought to this project are:

- greater understanding of the Aboriginal cultural and scientific significance of the area

- opportunities for land managers to work with traditional owners through their reconnection with country

- the opportunity for visitors to safely and comfortably enjoy the nature and culture of the Australian Alps while learning about Aboriginal history, traditional owner connection to country and their future aspirations
- avoiding or minimising impact on Aboriginal heritage.

The key learnings for the protected area operational manager were as follows.

- Research early (through the project plan) the potential impact of the activity and determine if a CHMP (or similar) is needed. It may be possible to avoid a CHMP by reviewing the project scope and/or methodology. This is entirely legitimate as it encourages impact avoidance.

- Budget for significant costs and time associated with the CHMP preparation. This will involve consultant fees and survey work and analysis with the traditional owners, who, as consultants and knowledge-holders, require payment for their services.

- There may be disputed traditional owner interests; this may take time to resolve.

- Allow for the cost of implementing conditions that may arise from the CHMP.

- Appreciate the valuable information and relationships that a CHMP will reveal for the area and the professional development that will come with the experience.
- maximising economic value to local communities and utilising local materials and services where possible

- using sustainable building materials that meet contemporary and internationally accepted accreditation standards (such as certified sustainable timbers)

- considering the carbon footprint of works and minimising or offsetting this pollution.

Whole-of-life asset thinking: The evaluation of environmental and material costs and benefits of a built asset is undertaken in a holistic fashion by looking at all stages in an asset's life including design, fabrication, construction, maintenance and end-of-life disposal. Considerations for whole-of-life thinking for operations include:

- designs that seek to optimise scope for environmentally sensitive fabrication, construction and maintenance techniques

- life-cycle costs minimised by using low-maintenance materials and equipment, with maximum expected useful life.
Resource efficiency: Considering the modest and diminishing budgets available for many protected areas, resource efficiency in operations is critical as well as globally responsible. Costs can be minimised by good design, type of materials and maintenance requirements. Examples of where resource efficiency may be achieved in operations include:

- designing built assets that are proportional to needs and adaptively reusing existing facilities where feasible

- designing built assets to minimise resource consumption, energy, water and waste

- meeting predetermined quantity and quality standards for energy consumption and waste generation and disposal

- using recovered or recycled content materials where practical and safe to do so

- maximising the recovery of materials at the end of the asset's life

- incorporating renewable energy systems where practical, feasible and cost-effective

- minimising the use of building materials with high embodied energy 


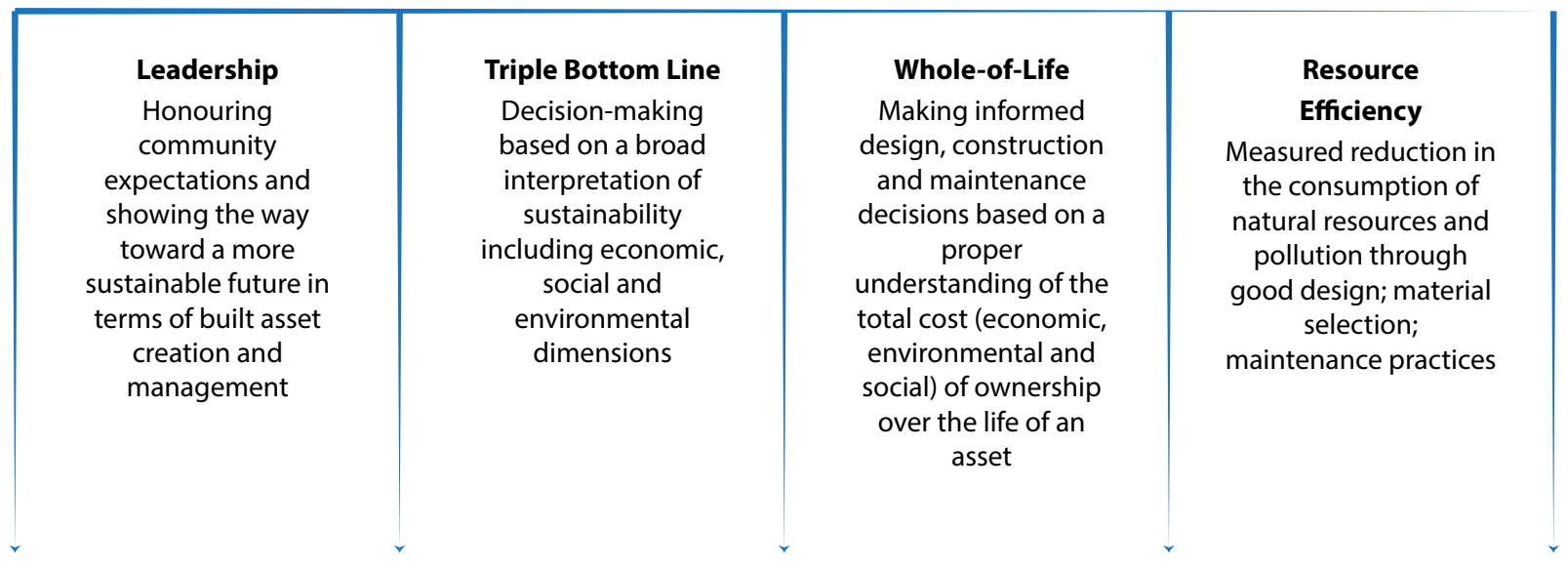

SUSTAINABILITY BENEFITS

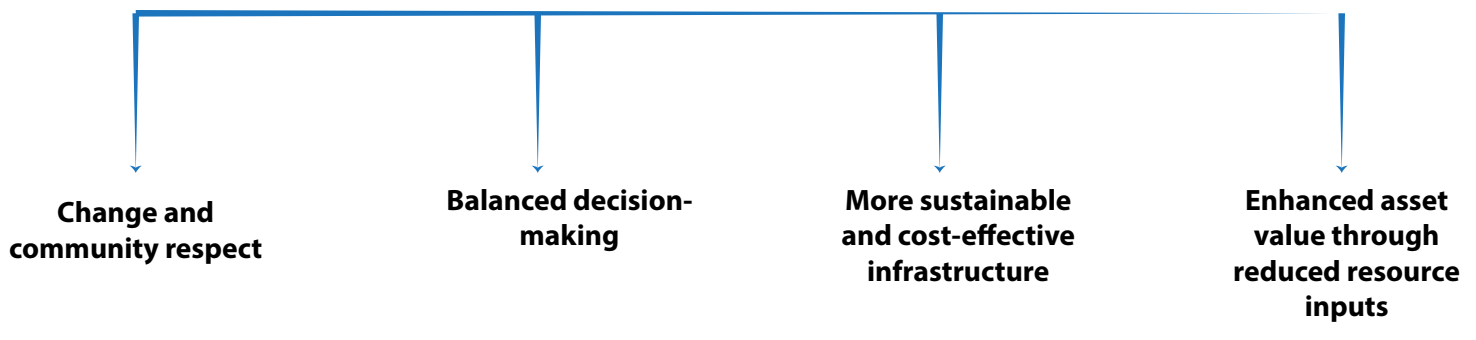

Figure 24.6 Sustainability principles and benefits

- designing landscaping using local protected area species to facilitate year-round, safe moderation of the internal climate of buildings

- targeting a low carbon future for the completed project that may include greenhouse gas offsets.

The relationships between these principles and sustainability benefits are summarised in Figure 24.6.

\section{Stakeholder and communication plan and media management}

During the delivery of a project, positive and negative issues involving the community and other stakeholders may arise. They can range from minor queries from individuals to community outrage. The most effective way to manage this is through pre-planning and being proactive with communications. During the preparation of the project plan, an assessment of the complexity and risk of the project will direct whether the communications and media issues are low risk and can simply be addressed in the project plan, or if a more comprehensive stakeholder and communication plan is required (Chapter 15). A comprehensive plan could save valuable time later by avoiding issues that have arisen from poor communication. Some potentially controversial issues that would benefit from being addressed in a stakeholder and communications plan include:
- smoke impacts from planned fuel reduction burning

- closure of roads, walking tracks and facilities for safety or maintenance

- removal or control of introduced plants or animals and culling of native animals

- removal of structures, especially in regard to historic structures

- development of facilities

- reduction of visitor services due to budget pressures

- delivery of a service or facility that is not proceeding at the planned pace.

The aim of a stakeholder and communications plan is to inform and engage with the community and stakeholders, so they do not feel excluded from decision-making, and to explain why operational actions are being taken and the benefits arising. The executive level of government may be a key stakeholder identified by the plan. The plan should be developed with the project delivery team and includes nine key sections (Figure 24.7).

\section{Delivering operations}

The process of identifying operational priorities, securing funding, programming the work, identifying capacity, preparing a project plan and seeking approvals 


\begin{tabular}{|c|c|}
\hline Scope of the Project & $\begin{array}{l}\text { Describe the project and what is potentially controversial, likely to impact } \\
\text { on stakeholders and any opportunities for positive messaging. }\end{array}$ \\
\hline Communication Goal & $\begin{array}{l}\text { Describe what is to be achieved through communication and what the key } \\
\text { messages to deliver are. }\end{array}$ \\
\hline Key Audience and Stakeholders & $\begin{array}{l}\text { Identify who the communication messages are aimed at. List the stakehold- } \\
\text { ers both within and external to the organisation and government, their } \\
\text { interests, expected attitude to the project and relevant message. }\end{array}$ \\
\hline $\begin{array}{l}\text { Identify Opportunities for Public } \\
\text { Participation }\end{array}$ & $\begin{array}{l}\text { Identify aspects of the project where the public can engage in decision-making } \\
\text { and provide feedback, and how that will be communicated and managed. }\end{array}$ \\
\hline Tools & $\begin{array}{l}\text { Identify the most effective tools for each audience and stakeholder. These } \\
\text { may include web site information, media stories, newsletters, targeted } \\
\text { meetings, personal briefings and communications, signage, education and } \\
\text { intepretation programs or establishing a specific stakeholder group. }\end{array}$ \\
\hline Accountability and Timing & $\begin{array}{l}\text { Identify when during the delivery phase each tool will be used and who } \\
\text { is accountable. }\end{array}$ \\
\hline Frequently Asked Questions & $\begin{array}{l}\text { Prepare a list of likely questions that may be asked about the project and } \\
\text { prepare answers. These may be released publically at the start of the } \\
\text { project or used as an internal tool if issues arise. }\end{array}$ \\
\hline Spokesperson & $\begin{array}{l}\text { Identify the spokesperson for this project. This must be strictly adhered } \\
\text { to so the messaging is consistent and accurate. The person must be } \\
\text { media savvy and confident in public speaking. The media, community } \\
\text { and stakeholders prefer to have a regular contact. (See Chapter 15). }\end{array}$ \\
\hline Budget & $\begin{array}{l}\text { Budget and allocate adequate project funding for communication and } \\
\text { stakeholder management. }\end{array}$ \\
\hline Performance Measures & Identify key performance measures to assess the success of implementing the Plan. \\
\hline
\end{tabular}

Figure 24.7 Key sections in a stakeholder and communications plan

is now complete and signed off. It is time finally to start the work and deliver the project. Presented here are some key considerations that are important for successfully delivering operations.

\section{Leadership}

Implementation of operations requires effective leadership, showing confidence and focus on efficient organisation and processes and quality and timely outputs and outcomes. Challenges arise constantly that need timely action and effective decisions to keep the project on track. A good operations leader manages and delegates effectively, provides consistent and positive direction to staff and contractors, keeps stakeholders well informed, insists on high standards of behaviour, work practices, quality and governance, keeps focus, has attention to detail and manages the unit's workload effectively to reduce stress. Such leadership also means maintaining effective communication and informing progress up and down the management chain and not hesitating to seek specialist advice should problems arise (see Chapter 12). Above all, a leader ensures the work is carried out in a safe workplace, compliant with occupational health and safety regulations.

\section{Working with staff}

The delivery of projects relies heavily on protected area staff either through direct actions or through their management of contractors. Staff involvement in project delivery is typically identified in their annual work and capacity plan so that their annual priorities and the relationship between projects are clear. This 
- closing areas recovering from landscape-scale events such as fire and flood

- providing suitable and appropriate warning signs at worksites.

Closures of protected areas for safety reasons may require high-level approval. This needs to be planned and achieved well ahead of project operations.

\section{Implementation: The project plan}

The project plan and associated documents such as environmental, cultural heritage, risk and communication management plans must firmly direct the implementation of the project, with careful attention to the time frames and critical path (see Planning Operations, above). Situations might arise where the original project plan needs review; indeed, flexibility and adapting to changing circumstances or new information are normal for projects. Any changes, however, must be formally amended on the project plan and reapproved.

\section{Approvals, permits and notifications}

The project plan has identified all approvals, permits and notifications needed to implement the work. Some approvals may require follow-up reporting and monitoring. Project implementation would not proceed until all approved documents are received and any conditions required are carefully built into the project plan.

\section{Project management support}

To keep more complex projects on track, communication and decision-making may need to involve a wider group of stakeholders and staff. Depending on the nature of the project, project governance, steering, consultation and technical reference groups may be formed. These may require administrative support. For complex projects, it is often prudent to establish a small project control group to govern the project. This is normally led by either the project sponsor or a senior manager and involves other key decision-makers. The project manager reports to the project control group but is not part of it, to ensure its independence in governance. The small project control group is not a technical or consultative group, rather, its key role is to direct project procedure and governance.

A project steering committee may be established for large projects. This brings together a range of internal staff with various skills and functions related to the project, to guide it to a successful outcome. For projects that involve many stakeholders or projects of community interest, it is wise to establish a stakeholder reference group to ensure key stakeholders are kept informed throughout the project. The stakeholder reference group can be a larger group and operate like a round table to collaborate and provide advice, but is not a decision-making group. Projects of a highly technical nature will benefit from establishing an expert group to advise on technical issues as they arise and advise on relevant research.

\section{Reporting}

A project manager will provide regular reports to the organisation and stakeholders on project delivery progress. Commonly, reports are completed monthly and report on progress of the four key stages of a project: planning, procurement, delivery and review. The use of corporate 'traffic-light reporting' each month is a simple reporting system. Green indicates the project is on track to be delivered on time and budget; yellow indicates there is a risk to delivering the project on time; red indicates likely failure. Yellow and red indictors require proposed actions as part of the report. If the stakeholder reference group is formed, qualitative project progress reporting is typically provided.

\section{Contingencies}

Planning for the unexpected may be a contradiction in terms; nevertheless it is critical. Project planning involves considering contingencies to deal with the unexpected and how they might be managed. Some examples include:

- material and/or contractor costs being higher than expected

- fires and other incidents that impact on staff availability and the availability of contractors

- unseasonal weather that affects delivery schedules

- key staff becoming unavailable

- contractors failing to meet contract conditions

- machinery and equipment unavailable when scheduled.

Some of these contingencies can be managed by allowing a proportion of the budget (often about 10 per cent) to deal with financial issues. Having business continuity arrangements in place for high-risk periods such as fire or flood seasons is also prudent. This may include having contractors positioned to operate independently or other supervisors and specialists brought in should key staff become unavailable. A good project manager is thinking ahead all the time and predicting potential project interruptions. 


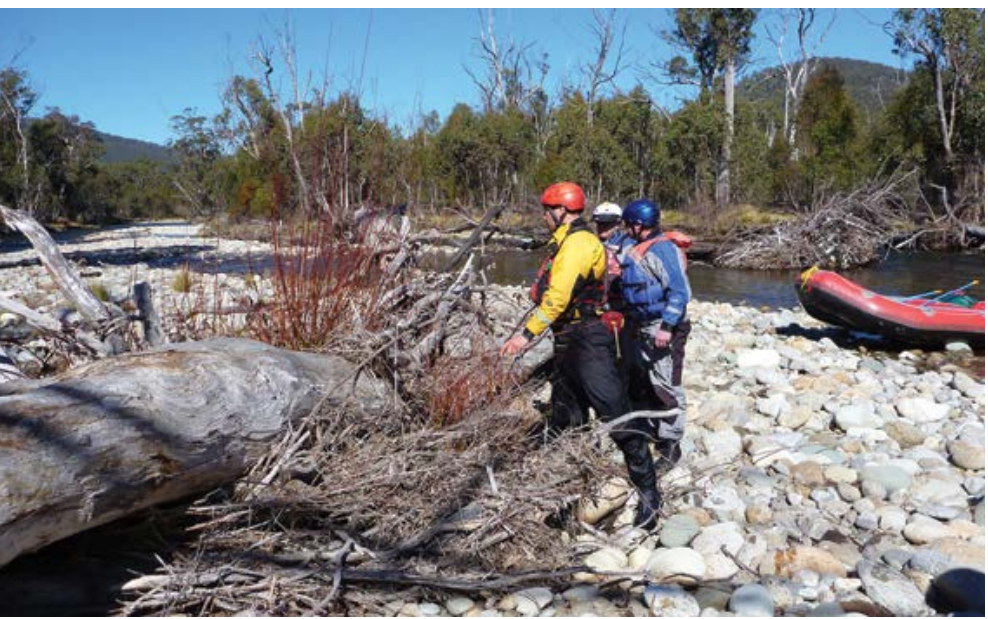

Contractors delivering specialist weed-control services, Alpine National Park, Victoria, Australia Source: Rick Box

\section{Lessees, licensees and concessionaires}

Protected area services may be provided by partnerships with external businesses through formal licence or lease arrangements. These may be associated with services across a large area such as a park or a group of parks, a particular site or a service that is mobile. These may include:

- cafes and restaurants

- visitor centres

- revenue collection

- campgrounds

- roofed accommodation in safari-style tents, huts or hotels

- visitor education and interpretation

- porter and guiding services.

The operations manager must establish a strong relationship and partnership with the business to ensure there is a mutual understanding of the balance between the values and objectives of the protected area and the commercial business environment. The more successful a business is in a protected area, the more likely it is that the values of the area are well understood and managed by the business and the relationship with the protected area manager is healthy.

\section{Working with contractors}

Contractors can be a critical resource for delivering operations in protected areas. They provide specialist skills and labour that can be regularly drawn on. Staff working with contractors should have appropriate training in contract management and relevant organisational procedures. Some common uses of contractors for protected area operations include:
- road and walking track construction and maintenance

- building and facility construction, maintenance and servicing

- introduced plant and animal control works

- restoration work for disturbed sites

- project management services

- environmental and cultural heritage impact assessment for proposed works

- fire protection and suppression works involving machinery

- nursery supplies for restoration work

- security services

- transportation services including helicopter services

- conducting research and monitoring

- preparing management plans and strategies

- visitor services.

Maintaining a good relationship with specialist contractors and building a thorough understanding of competencies and standards expected provide an efficient and effective resource base and capacity for protected area managers. This can be more efficient than building those skills, machinery and resources internally into the capacity of the organisation. Having external resources available for operational delivery also reduces the likelihood of failure to deliver when organisational resources are redirected to other demands such as fire and emergencies. It is important, however, to align with the intent of relevant industrial relations agreements in regard to the appropriate use of staff and contractors and be clear on the role of contractors in representing the public face of the organisation.

The importance of having a well thought through 'offer of services' or 'brief' for a contractor cannot be overstated. Many protected area organisations have standard legal documents for offers of services, tenders and contracts. Time and effort put into the brief save problems later with ill-defined contracts. Based on the project plan, the tender brief should provide a clear indication to the contract tenderer of:

- the setting where the works are required and any environmental, cultural or community constraints or specialised climate conditions

- the business arrangements of the protected area organisation seeking a contractor

- the task and exactly what outputs and outcomes are sought, where, when and why

- key milestones to be met 
- accreditations, insurance, occupational health and safety policies and procedures and other business requirements of the contractor

- payment method, payment milestones and budget.

Contracts for products and services are commonly awarded using one of two main payment methods: 'lump-sum payment' or 'schedule of rates' payment.

Lump-sum contracts require a single final quote for the total cost of delivery. Two approaches may be used. First, the budget available for the project may be disclosed to guide the contractor on scope, in which case the successful contractor is selected for best likelihood of quality delivery. Second, an undisclosed budget seeking a lump-sum quote is used when price is the key differential. Lump-sum contracts are best suited to works that can be clearly specified and articulated. The positive value of lump-sum quotes is knowing the project delivery cost prior to starting. The negative value is contractors will build significant risk into their quotes, particularly if the specifications are imprecise, and the project may not get the best value for money.

Schedule of rates contracts are where quotes are sought based on an hourly or daily rate for services and are best suited to works that are less able to be fully specified or articulated and where some flexibility is needed by the project manager to adapt to changing circumstances. The positive value is flexibility and contractors are more competitive given they do not need to build in risk as they are simply paid for the time they work. The negative value is the project manager must manage budgets more closely to ensure the project stays within budget and there is no guarantee that all project outcomes will be met within the budget.

The brief or offer of services must include a clear indication to a project tenderer of the selection criteria used to select the successful contractor. Some common selection criteria include:

- appropriate qualifications or accreditation required for the task

- demonstrated experience in the field of work

- quality of personnel and equipment

- value for money

- availability at critical times

- good safety record and company occupational health and safety policy

- demonstrated ability to complete the task.
A tender committee is usually put together to assess the tenders and make a recommendation to the operations manager. To avoid any potential for corruption, members of the tender committee will need to have declared any links with any of the tenderers and the nature of those links. In some circumstances, they will not be able to remain on the tender committee. A background check and referees substantiate the character and quality of work of the contractor. Finally, it is wise to verify who will actually be on site and carrying out the work. You may think you have engaged a quality operator and find that the work is actually carried out by other employees or subcontracted out.

The use of 'preferred supplier panels' of contractors is an efficient way of engaging contractors. This reduces the need to call for quotes or tenders for each project to meet governance requirements. Panels are established to preapprove contractors for different groups of operational functions, such as an introduced plant and animal control' panel. The preferred-supplier panel of contractors is set up by inviting potential contractors to submit their particulars on relevant business details such as insurance and occupational health and safety plans, skills and competencies, personnel employed, equipment and schedules of rates. Suppliers who are considered to meet appropriate standards are then approved to be a member of the panel. The project manager can then go directly to the panel to invite and select the most appropriate contractor based on the best match of competencies, resources and rates for the work.

\section{Contractor management}

Contractors should be managed following the principles of fairness, respect, trust and mutual benefit. Managers must also understand and respect the business needs of contractors including their need to be profitable. Building a fair and healthy relationship with quality contractors is an important achievement for the protected area manager.

Contractors must be managed as one would an employee and ensure the contractor meets all organisational and community standards expected. Some of the key factors to consider when managing contractors are the following.

\section{Contractor briefing and induction}

The principal contractor must have a clear understanding, prior to work starting, of the contract agreement, the use of subcontractors, the scope of works and performance measures, and the requirements of all relevant plans. A full induction to the protected area workplace would 
then be carried out with contractors, their employees and subcontractors prior to commencing work. The induction typically includes:

- geographic context information about the protected area project site

- a code of ethics and appropriate behaviour

- workplace safety, public safety, risk identification and job safety analysis

- emergency response and evacuation procedures

- environmental and cultural issues

- key personnel and their roles

- key stakeholders

- communication tools and channels.

It is prudent to provide induction notes and to have all those who attend the induction sign a statement that they have attended the induction and understand all topics raised. Should new subcontractors or employees be engaged on the job, the contractor must ensure they are also inducted.

\section{Contractor supervision}

The key to effective contract supervision is clear and decisive communication, ensuring two-way communication channels exist between the project supervisor and contractor. The contract needs to be clear on authority so contractors are not receiving instructions and comments from a range of staff. This can lead to the contractor being confused about directions, leading to poor outcomes and claims by contractors for variations due to wasted time.

The project supervisor must develop a good professional and trusting working relationship with the contractor. This is best achieved by means of regular scheduled contractor meetings rather than constant surveillance and interference by the project supervisor, and the supervisor must be responsive to the contractor when requested.

\section{Reporting, compliance and renewable bonds}

Regular contractor/supervisor meetings will provide progress reports and link with critical milestones so progress payments can be authorised. For on-ground works, this involves reporting on the progress of delivery of outputs and outcomes. For licensees or concessionaires, this is a scheduled meeting with a standard agenda of items related to the protected area/licence area relationship and licence conditions. This is the time to discuss compliance with contract or licence conditions and raise any issues that need addressing. Should serious compliance issues be identified, these should be put in writing to the contractor or licensee, seeking a formal response for rectification. In the case of compliance with conditions not being adequately addressed, following allowance for a fair and reasonable time to do so, this can show cause for withdrawing the contract or licence and potentially for seeking compensation to rectify a situation. Contracts should include a clause for settling disputes, nominating an independent arbitrator.

In some instances, contracts are prepared that include a 'renewable' bond fee. The contract manager can use this bond fee to restore any unauthorised disturbance to the protected area. Under the contract, the amount set aside is automatically replenished immediately it has been used, and can be used again if there is another infringement.

Contractors may also be required to record and report the locations of their activity. This is common, for example, with weed-control work where the contractor is required not just to treat the weed species, but also to record using GPS the location, date, herbicide used and other information required by the manager. This is invaluable when the protected area manager is preparing data for weed mapping and control activity to help determine overall performance of the programs and future needs. In this case, the skill of the contractor to provide this information correctly is as important as applying the herbicide appropriately.

\section{Performance and payment considerations}

Contract payments will be subject to meeting defined performance outcomes identified in the contract. The clearer the definition of the expected output in the contract, the clearer it is to authorise payment or defend non-payment. Larger contracts will involve part payments on reaching defined milestones. The contractor would provide a written report on reaching those milestones to claim the payment due. The contract manager would assess the report, observe results on the ground and determine if the milestone has been adequately met to the standard required to authorise payments. Contractors may seek early payment for cashflow purposes. While this may be tempting in order to maintain working relationships, this must be avoided to prevent any professionally embarrassing experiences where a contractor abandons a project having received payment for work not completed.

Contractors will from time to time underperform in their agreed obligations. It is important for the contract supervisor to look for the signs of potential underperformance early in the project and deal with them decisively. Early signs may include slippage in 
delivery times, cutting corners, unreliable attendance at a worksite, evasive communications or poor reporting. Poor performance is identified and discussed at contractor meetings, either regular meetings or a special meeting. The project supervisor must formally present underperformance issues, seeking redress, noting them in the meeting minutes and following up in writing with the contractor for evaluation at the next meeting. Should poor performance continue, a letter would be sent to warn the contractor that failure to improve performance could result in contract termination. The first step in managing performance is to be clear on performance expectations in the contract. It is neither acceptable nor defendable to hold a contractor to account for unstated performance measures.

The project supervisor may also not perform to an expected standard-for example, non-supply of important maps or briefings in a timely manner. The contractor should have an avenue for complaint if it becomes necessary.

\section{Logistics}

Planning logistics is a fundamental task for efficient project delivery. The skill and time invested in lining up the right tools, vehicles, machinery and equipment, materials, human resources and support services at the right time cannot be underestimated. If the project is being delivered by a contractor, it is wise to build the logistics role as much as possible into the contractor's responsibilities so that any costs with delays must be met by the contractor. Typical logistical considerations for projects are as follows.

\section{Transport}

Transport is needed to get personnel, machinery, equipment, materials and waste materials on and off the project site efficiently. Transport may include bicycles, motorcycles, four-wheel drives, trucks, buses, boats, hovercraft, fixed-wing aircraft, rotary-wing aircraft and other transport support. In remote mountain areas, this may include use of animals such as yaks, llamas, horses, donkeys and mules. Project managers need to carefully balance the impacts, logistics and efficiency associated with transport options to select the most appropriate means.

\section{Quarantine considerations}

Restricting the spread of particular pathogens or invasive species is an aim of many protected areas. Some have stations where humans must clean their boots and equipment before entering or require watercraft

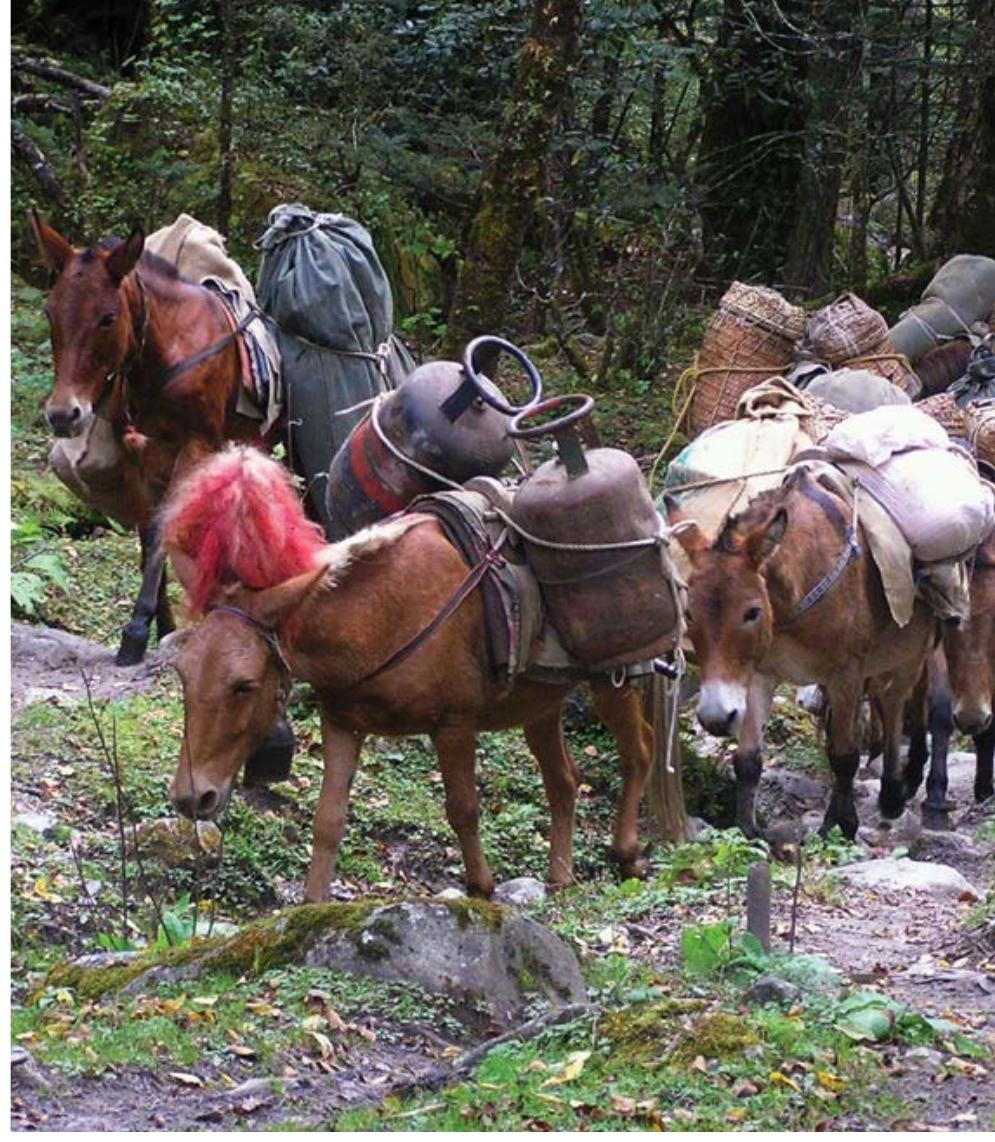

Mules transporting goods in Sakteng Wildlife

Sanctuary, Bhutan

Source: Peter Jacobs

to be washed before launch. Many protected areas are important wildlife sanctuaries with quarantine provisions in force. Wash stations for heavy machinery being moved during wildfire operations are becoming normal practice. The thorough cleaning and disinfecting of all equipment entering a protected area is considered to be a desirable basic practice for all protected areas, particularly in areas known for weeds and/or pathogens.

\section{Accommodation and food}

Some project sites may have accommodation nearby with food, shelter and toilet facilities, while others are isolated, meaning long travel times to remote base camps. Whatever the case, the provision of healthy food and water, first-aid facilities, clean accommodation and toilet facilities, and allowing for good sleep patterns and after-hours leisure activity are vital. For work in remote areas, workplace agreements may allow for longer onsite day shifts to be introduced in exchange for a shorter working week and/or special salary loadings.

\section{Project sites}

Project sites need to be carefully designed, located and constrained, with segregation of areas for animals, vehicles, aircraft landing, equipment, materials and waste from areas for shelter, sleeping, kitchens and toilet facilities. 


\section{Machinery and equipment}

The project manager needs to ensure that project machinery is appropriate, accredited, operational and available by checking that spare parts, maintenance tools, fuels and oils are available and routine servicing is carried out during the project. Securing access to aircraft can be challenging. Acquiring the right aircraft, securing specialist equipment and personnel to undertake flight operations, preparing operations plans and approvals and securing authorised landing areas are complex.

\section{Materials}

The project manager needs to ensure that materials required for the job are procured and securely stored on site well before they are required. Considerations include:

- is the material the best fit for purpose

- is the material compatible with the project site

- is the material from a local, sustainable and accredited source

- are there manufactured sustainable alternatives available in steel and artificial materials

- is the material free of potentially harmful chemicals

- is the material free of introduced plant species and pathogens?

\section{Personal protective equipment}

Project managers should ensure that site personnel are supplied with appropriate personal protective equipment for the job, such as hard hats, overalls, boots, ear protection, face masks and, where chemicals are being used, overalls, specialised gloves, face masks as well as post-work washing facilities.

\section{Security}

Project sites in protected areas are vulnerable to nonauthorised access, vandalism, theft and, in some cases, terrorism. Project managers will need to consider providing a secure worksite proportionate to the threat. This may include security fencing and security service attendance.

\section{Governance of operations}

Governance refers to processes by which organisations are directed, controlled and held to account (Chapter 7). Governance is a fundamental operating function for protected area organisations and some 'good governance' principles for operations are described here. Operations managers must ensure they are well informed of governance requirements for projects they manage. Matters to consider include:

- project approval authority

- financial approval authority

- organisation-approved business plans, action plans and project plans

- organisational policies and procedures, particularly regarding procurement of goods and services

- relevant legislation

- organisation-approved contracts, consents and documents.

Good governance requires that:

- procurement of goods and services is undertaken in an open, fair and transparent manner free from discrimination or unfair advantage

- all projects and contracts are managed to achieve the best possible results for the money available

- all projects and contracts are managed in accordance with approved legal obligations, action plans, project plans and contracts and any variations are approved and recorded

- all purchasing, procurement and other transactions including contracts and key decisions are recorded and filed in the organisation's official filing system and are available for audit at any time

- official standard documents are used for all agreements and contractual arrangements (unless otherwise approved by legal advice)

- personnel declare any conflict of interest and remove themselves from decision-making if deemed necessary

- personnel ensure that all decisions and actions they take are within their authority and are implemented in a way that is consistent with the law and their organisation's policies and procedures

- any recommendations must be made following a full consideration of risks relative to the expected results

- for complex projects, provision of legal advice in the planning phase is most prudent.

\section{Asset management and operations}

Protected area operations rely on a range of built assets for their effective implementation. Assets may be portable or capital in nature, owned or leased. Portable assets are typically plant and equipment and range from hand 
tools, chainsaws, all-terrain vehicles, guns, animal cages, boats, lawnmowers and brush-cutters to spray units, trucks and tractors. Capital assets commonly include workshops, offices, visitor centres, storage sheds, visitor facilities and infrastructure such as roads, walking tracks and bridges. The range and nature of built assets will be influenced by the type of protected area (Chapter 2) and the resources of the protected area organisation. This section describes how protected area organisations manage their built assets.

The definition of an asset can be broad across industries (IPWEA 2011; IASB 1998). For the purposes of protected areas, however, they are defined here as 'physical objects that are built by people to provide services for the enjoyment or management of a protected area'. Under this definition, assets are real objects and are not intangible ideas such as intellectual property or goodwill. They are not wildlife or landscapes or people. Being built, they inevitably fail to function effectively at some stage. Assets:

- exist to provide services, which may include inherent value such as community or heritage significance

- have a financial value that changes over the life of an asset

- have fiscal value and this means they are accounted for, and are formally tracked and managed within larger organisations using asset-tracking tools.

Many categories and varieties of built assets are commonly used or are in place to support management of protected areas. These may be owned, leased or contracted by the protected area organisation. Examples include:

- fences, barriers and gates

- walking tracks, roads, car parks, bridges and signs

- visitor facilities

- offices and depots

- firebreaks, helipads and aircraft landing strips

- utilities, power, water and sewerage systems

- communication towers, phones and radios

- vehicles and heavy plant

- minor plant, equipment and hand tools

- computers and associated software

- technical tools such as meteorological devices, global positioning systems and others.

The number, value and purpose of built assets in a protected area vary in accordance with management objectives. Iconic protected areas such as Yosemite National Park in the USA have a high number of assets of large financial value. Conversely, IUCN Category I protected areas typically have a limited number of assets, which are provided for management purposes only. Assets are important for:

- natural and cultural heritage protection-through minimising visitor impacts by provision of sustainable access and information and access for management activity

- visitor experiences-by supporting a range of safe visitor experiences through provision of infrastructure and facilities

- operations-through provision of offices, accommodation, workshops and plant and equipment

- local economies-through available, high-quality visitor destinations that provide economic returns

- local communities-through protected area organisations being a good neighbour and their capability to assist with plant and equipment during joint operations and incidents.

Management of built assets is a fast-developing field of protected area management, and asset management systems are integral to a professional and systematic approach to how assets are organised and maintained. Most protected areas require specialist officers responsible for ensuring that built assets are suitably maintained, have support systems to manage them and standards that ensure they are safe and appropriately designed.

The International Infrastructure Management Manual defines (built) asset management as the 'systematic and coordinated activities and practices of an organization to optimally and sustainably deliver on its objectives through the cost-effective lifecycle management of assets (i.e. from manufacture or construction to effective retirement)' (IPWEA 2011:xii).

Asset management is most effective when it is undertaken in a strategic and inclusive manner. Three important questions need to be addressed by a protected area organisation.

1. What service is to be delivered by the assets?

2. What asset life-cycle strategies enable the assets to deliver the services?

3. What is needed to support asset management planning and decision processes? 


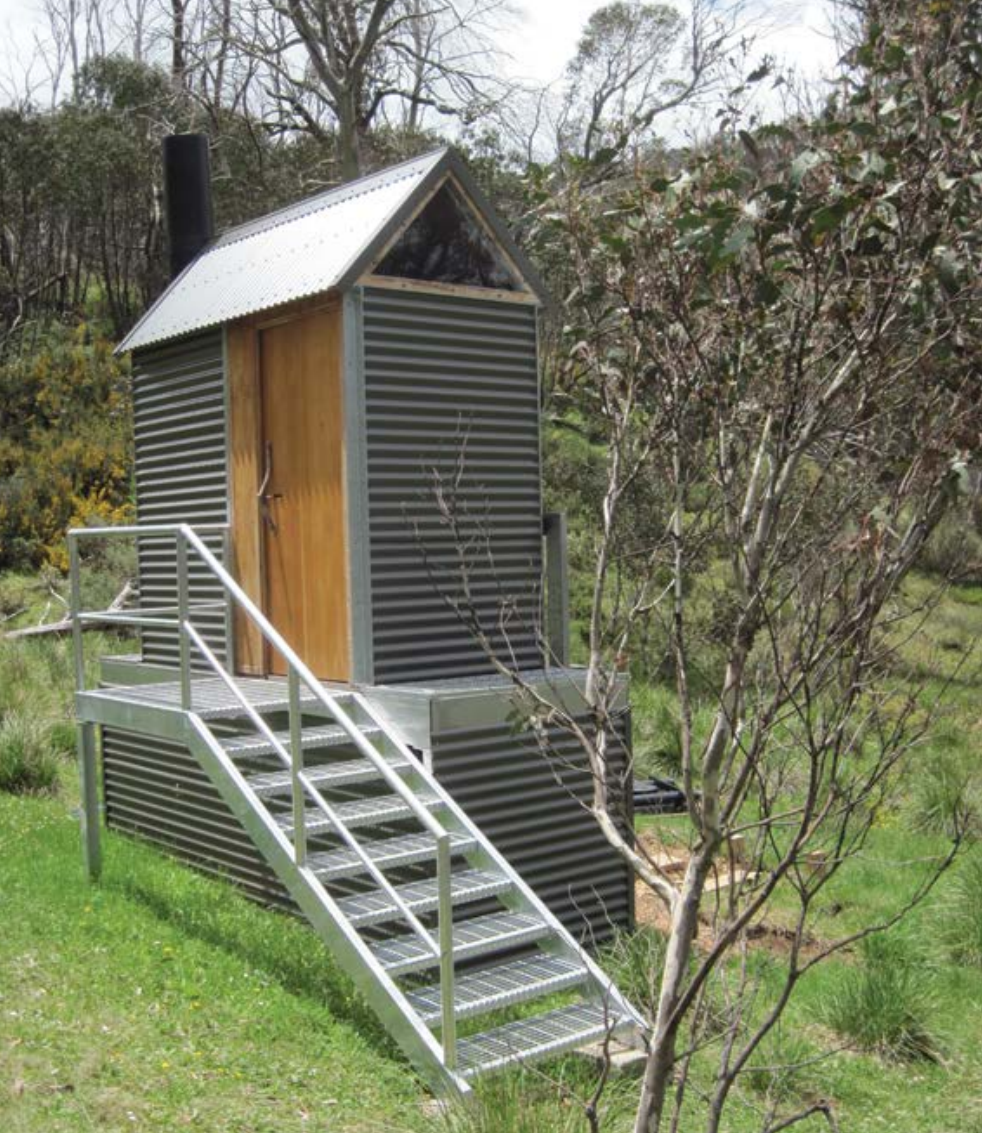

Contemporary-design 'fly-out waste' toilet at Dibbin Hut Camping Area to replace the old earth pit, Alpine National Park, Victoria, Australia Source: Kevin Cosgriff

\section{Asset management systems}

Asset management systems (AMSs) (IPWEA 2011) encompass all aspects of managing assets and comprise the inputs, processes and outputs that deliver asset management services pertaining to a group of assets. These systems can be simple or sophisticated. The type of AMS used should be guided by a protected area organisation's size, risk exposure, asset portfolio and budget. Components of an AMS are as follows.

\section{Policy and planning}

Establishing an asset management policy is the first step in designing an AMS. A policy such as 'asset management will help protect the values for which this protected area system has been established' quickly captures the essence of asset management across the organisation. An asset management plan for a protected area, region or organisation reflects the policy and provides direction to ensure that the required services are being delivered and align with other corporate planning priorities. The plan will highlight life-cycle strategies and gaps and indicate planning needs for future asset-related decisions.

\section{Roles and responsibilities}

The roles and responsibilities for asset management need to be carefully defined and allocated to suitably qualified staff. An organisation's asset management team may be structured in many ways including separating the asset owner, asset manager and service delivery provider roles.

\section{Asset information system}

Protected area organisations need to know what they own and in what condition these assets are in. They need to establish, as a minimum, an asset register or, in a more sophisticated form, an asset information system (AIS). Such a register enables the storage of a range of asset data. Asset information would typically include the asset identification and type, its location, its value and replacement costs, condition, maintenance requirements and remaining life.

The AIS enables the analysis of these data to assist strategic asset management decisions. The AIS provides the ability to forecast future capital replacement costs to estimate rates and charges for asset use, to predict the decline in asset condition (and the consequent maintenance programs) and to model 'what if' scenarios for asset management. Establishing an AIS is resource intensive and needs organisational support for regular updating. Not all data are always necessary so care needs to be taken to start with critical assets and critical data. The AIS should be integrated with other protected area management business systems if possible and this can range from simple spreadsheets and supporting processes to whole-of-enterprise software.

\section{Asset condition}

The asset condition will be recorded in the AIS and may range from very good to unserviceable. Assessing the condition of an asset involves examining its physical condition and focuses on whether the asset is capable of delivering the service it was designed for, and for what period. Asset condition assessment critically evaluates risk to users and the organisation and underpins the asset maintenance and replacement programs. It should include information such as the likelihood of asset failure, the appropriate maintenance treatment needed, age and remaining life. The effort put into condition assessment should be determined by the type, size and functional importance of the asset or group of assets. The assessment of asset condition needs an appropriate level of staff skill and expertise and must be validated on a regular basis (Case Study 24.3). Historic building condition assessment is a particular specialist skill where inherent asset values are not expressed simply as condition. 


\section{Case Study 24.3 Cave Creek: A tragic case of asset management failure}

Cave Creek is in Paparoa National Park on the South Island of New Zealand. The park is known for its limestone karst system, and Cave Creek weaves its way around, under and through this landscape. Activities are diverse and many assets have been built to cater for such activities. In 1994, the New Zealand Department of Conservation (DOC) erected a viewing platform above a 30-metre deep chasm at Cave Creek. At this time, the general procedures and framework for erecting such a structure were not guided by appropriate design or construction standards or by resourcing and staffing protocols.

On 28 April 1995, the viewing platform collapsed, resulting in the deaths of 14 people. On the day of the tragedy, a group of students was visiting the park with two officers from the DOC. The group split in two, with most of the students and one of the DOC officers reaching the platform first. As they reached the front of the platform, it toppled forward into the chasm. Carolyn Smith, a survivor, described the scene: 'Suddenly and with no warning, except for yells of surprise, the platform was falling under our feet. It began sliding down at approximately 30 degrees and then tripped and fell vertically with everyone falling in front of it' (New Zealand Department of Internal Affairs 1995:13). Of the 17 students who fell with the platform, 13 were killed and four survived with serious injuries. The DOC officer with them was also killed.

A commission of inquiry was held to determine the cause of the collapse. In summary, the inquiry found that:

- the platform was not designed and approved by a suitably qualified engineer

- the construction of the platform was not managed appropriately

- statutory requirements for buildings and health and safety were not followed

- there was a lack of inspections and an inspection regime

- there was a lack of warning signs regarding load limits

- there was a failure of corporate systems, particularly a lack of project management systems.

The commission also found that the DOC operated in a tight resourcing environment and was frequently forced to accept poor-quality standards. It recognised that DOC quickly and appropriately acknowledged its failures and undertook remedial action.

After the collapse, DOC put in a number of measures to improve its operations. More than 520 structures were inspected in protected areas around New Zealand and 65 were closed for repairs. The review also led to the removal of a large number of structures on public land, and many safety notices appeared on the remainder relating to load limits. Eighty engineers were hired to write safety standards, and design new and modified structures. Extra funding was allocated to continue the upgrade of visitor infrastructure. The 13 000-kilometre network of tracks throughout New Zealand was walked and every building and structure, including signs, was documented, photographed, assigned a number and assessed for required maintenance. All of this information was recorded in a new and central visitor asset management system. The use of a visitor asset management system brought to attention some high-risk structures that had previously been overlooked. Ongoing resourcing limitations often meant that if DOC was unable to maintain a hut, bridge or other structure to a standard judged as 'safe', it might instead be removed. In some cases, removal was contentious and community organisations agreed to voluntarily keep them maintained to an agreed standard. The Government also commissioned a full review of DOC, which led to changes in reporting and accountability processes. Importantly, DOC examined numerous corporate systems including project management and risk-management systems and now operates an asset management-conscious environment.

The tragedy of Cave Creek is a stark reminder to protected area managers of the importance of asset management. The key lessons are as follows.

- Asset failure can lead to deaths. An asset management system that addresses the following questions is critical.

a. Planning. Does the asset meet the desired needs and the planning framework of the relevant legislation? Have all the approvals been obtained? Is the planning undertaken by appropriately qualified people?

b. Standards. Are standards in place, understood, accessible and used? Does the design comply with appropriate standards?

c. Construction. Is construction consistent with the plan and is it undertaken by qualified people?

d. Use. Does the asset have appropriate information about its use and is this information available to staff and users?

e. Inspection. Does the asset have an adequate inspection regime during and after construction and is it undertaken?

f. Maintenance. Has a systematic maintenance regime been established and is it undertaken?

g. Renewal. Does the asset undergo timely and appropriate renewal based on current and future needs?

h. Decommissioning. Does the asset undergo decommissioning in a timely and appropriate manner?

- Ongoing risk assessment is an important part of asset management.

- Asset management decisions must be made in the full knowledge of funding and resource constraints.

- Systems are needed to record, maintain, update and communicate information and designated responsibilities for asset management decisions. This needs to be done across the whole organisation and be consistent with organisational policy.

- Steve Mossfield 


\section{Critical assets}

Critical assets are identified as a priority in the AIS. They are those assets of high importance that have a higher risk of failure and that can have a great impact on an organisation achieving its objectives. These critical assets need to be identified and the business risks assessed. Risk assessments help to identify these critical assets. A risk-management assessment process involves establishing the risk-management context, identifying and evaluating treatment options, implementing treatment and monitoring and review. The critical assets with a high chance of failure and consequence would therefore receive priority maintenance or replacement ahead of other assets.

\section{Levels of service}

Levels of service are outputs a customer receives from an organisation and are determined by the visitor experience or other management service provided (IPWEA 2011). The notion that an asset is in place to supply a defined level of service, rather than for its own sake, is fundamental for operations and asset management.

\section{Forecasting future demand}

An ability to forecast the demand for services allows a protected area manager to better plan for the expansion, contraction, adaptation or change of individual assets or a collection of assets and informs the asset management plan. This can be a difficult task, however, and reducing service can result in a hostile response from stakeholders. Managers should first monitor the current demand for a service and look at the issues that are leading to that demand. For visitor use, this monitoring and analysis could include assessing changes to a nation's population size and composition, economic growth, leisure trends or even climate change influences. There are wellestablished social science mechanisms for monitoring these trends. Demand forecasts can be developed and scenario modelling undertaken. It is also advantageous to look at these scenarios over different time frames and with new information.

\section{Asset management life-cycle strategies}

Consideration needs to be given to asset life-cycle use and costs. This includes defining the purpose and use, funding, creation, operations, maintenance, rehabilitation, upgrading, renewal, revaluation, depreciation and disposal. This enables long-term financial forecasts to be undertaken, which ensure future service needs are matched by funding. This information is compiled for the AIS and asset management plan.

\section{Operational asset plans}

Operational strategies and plans help determine how an asset will be used efficiently and effectively. This will help to achieve the optimum use of expensive equipment such as earthmoving equipment. Important planning considerations include:

- the nature and pattern of use

- the amount of programmed use available versus demand

- the probability of non-forecast incidents impacting on programmed use

- planned maintenance programs.

Successful implementation of these plans can result in reduced risk of asset failure, can defer asset replacements or upgrades and provide better service delivery from the assets. It also provides the basis for the day-to-day activities of protected area staff or contractors and thereby has a strong link with works programs. Ideally, organisations should strive to keep all maintenance as a planned activity.

\section{Capital investment procedures}

Capital asset investments are usually significant longterm financial decisions and need to be carefully planned (see 'Programming operations' section above). The AMS will include a structured procedure for capital investment decisions. Those decisions compare the need for a new asset with replacement or renewal of existing assets or rethinking the level of service and need for the asset. When capital investments are being considered, thought should also be given to sharing the ownership with other organisations with similar needs to share costs.

\section{Decision-support tools}

Decision-support tools are described in the 'Programming operations' section above. Asset decisionmaking methods and frameworks allow a manager to assess various asset management options. Outcomes will be improved where there are quality data, underlying assumptions and objectives are tested, sensitivities are identified and options and estimates presented. An AMS should incorporate an appropriate decision-support tool.

\section{Service delivery and quality}

Quality management, high levels of customer service and continuous improvement are outcomes that a good asset management system can contribute towards meeting the objectives of the protected area. Historically, service delivery models have meant that protected area managers and staff have done all the work themselves. 
Increasingly, however, this is no longer the case and other delivery models need to be considered. Partnering with a stakeholder is one method of delivering the services. Other methods include public-private partnerships or contracting and leasing.

\section{Reviewing the effectiveness of operations}

Management effectiveness evaluation across a protected area involves a wide range of considerations and processes (Chapter 28). The evaluation of the management effectiveness of an operation makes an important contribution to the strategic evaluation of whole programs, a protected area or system of protected areas. The evaluation of an operation may be guided by the IUCN management effectiveness framework (Hockings et al. 2006) and would typically use an evaluation plan developed specifically for the project and early in the planning stage of the project. The task of reviewing operational effectiveness is not left to the end of the project; rather it starts in the project planning phase and is built into the scope and tasks throughout the project plan. The IUCN framework provides guidance to what may be included in the project evaluation plan:

- planning: the constant need to refine and fine tune the project plan during the project

- input: how well and how timely financial resources, human resources, materials and plant are being secured

- process: checks on whether procedures and standards of implementation and environmental protection are being correctly undertaken

- output: may be linked to major milestones within the project, with each output potentially being measured for its contribution to the overall project objective

- outcome: identifies how well the objectives of the project have been achieved.

The project plan identifies the objectives for the project and then, importantly, defines quantitative and/or qualitative performance measures for each objective. Well-considered and planned performance measures at the start of the project make the continuous project review process more meaningful and efficient.

The process of review of performance measures, to determine if the project objectives were achieved, should be carried out by the project manager and involve the whole project team, specialists and contractors and, in some cases, external stakeholders. If they were not met, the question 'why not?' could be asked, along with 'what can be learnt and adapted'. This process may also reveal that the performance measures were not well aligned to the objective. The project effectiveness review forms part of the planning process and is submitted to the project approver for sign-off. The outcome of the review will then influence:

- planning and programming: inform the next business planning and programming round, which will consider continuing the project in future action plans, adapting to address underperformance, increasing or decreasing budgets, or ceasing

- operational delivery: identify effectiveness of operational delivery and any lessons learned, with operational staff considering adapting project management techniques to meet any underperformance in the delivery phase

- a revised project plan: should the operational project be approved again in the next action plan, the revised project plan will adapt to address underperformance issues raised in the review.

\section{Conclusion}

Key principles for managing operations and assets are as follows.

1. Protected areas require active management. Proactive and effective protected area management involves carrying out a range of operational activities as appropriate to meet the objectives established for the area. Good stewardship of protected areas is achieved through the identification, planning and delivery of defined programs and projects.

2. The effective programming of operations is critical to achieving good on-ground outcomes, efficient use of resources, value for money and a committed and supportive protected area team and stakeholders. Operational activities need to be determined and programmed through a planning framework and a thorough and defendable decision-support process. This ensures the project is the right response to an issue, threat or initiative and has the organisational support, adequate funding and capacity to deliver.

3. A clear and comprehensive project plan is crucial to successful operational delivery and no project in a protected area should proceed without one. Allowing sufficient time for the preparation and approval of a project plan is a key part of works programming. The nature and complexity of the project will reflect 
the complexity of the project plan and the level of environmental impact appraisal required.

4. Sustainability in operations means that built assets should embody sustainable materials and sustainable design considerations; they should maintain resource efficiency throughout their life and their sustainable use functions should help educate the community. The four key sustainability principles of leadership, triple bottom line, wholeof-life asset thinking and resource efficiency should be exercised by operations and project managers.

5. Implementation of operations requires effective leadership, showing confidence and focus on efficient organisation and processes and quality and timely outputs and outcomes. Such leadership also means excellence in staff and contractor management, maintaining effective communication, informing progress up and down the management chain and not hesitating to seek specialist advice. Above all, a leader ensures the work is carried out in a safe occupational health and safety-compliant workplace.

6. Governance is a fundamental operating function for protected area organisations, and operations managers must ensure they are well informed of the governance requirements, procedures and tools available for projects they manage.

7. Management and engagement of stakeholders and effective communication with the community, media, key stakeholders and within organisations are vital to achieve efficient operational delivery and stakeholder support. A stakeholder and communication plan will save valuable time later by avoiding issues that may have arisen from poor communication.

8. Built assets are a fundamental component of protected areas. Management of built assets is most effective when it is undertaken in a strategic manner, in collaboration with the community, when it has support systems to manage them and standards that ensure they are safe and appropriately designed. An AMS is an effective framework to achieve this.

9. The evaluation of the management effectiveness of an operation is vital for learning and adapting and contributes to the strategic evaluation of whole programs, a protected area or a system of protected areas. The task of reviewing operational effectiveness is not left to the end of the project; rather it starts in the project planning phase and is built into the scope and tasks throughout the project plan. Wellconsidered and planned performance measures at the start of the project make the continuous project review process more meaningful and efficient.

Operational activities in protected areas can be complex and varied in nature, both technically and politically. The framework and procedures outlined in this chapter will assist managers to technically program, plan and carry out operations in an efficient and effective manner to achieve great outcomes for protected areas. Influences from outside the operational manager's capacity and extent of control are inevitable, however, due to the high degree of political sensitivity and wide range of community attitudes to protected areas and opinions on how they should be managed. This is intrinsic to a community engagement approach to managing protected areas, but can be challenging for managers trying to implement important programs and projects.

In the face of political and stakeholder challenges, protected area managers should continue to work from sound principles and put forward thorough evidencebased decision-making founded on good science. If, however, political influences distract operations, it is not a reflection of the abilities of the operational manager if sound process is followed. 
Muhlen-Schulte, R. (2010) Hotham-Dinner Plain Multi-Purpose Trail, Alpine National Park, NE Victoria, Aboriginal Cultural Heritage Management Plan, Aboriginal Affairs Victoria Management Plan Project No. 10320, Aboriginal Affairs Victoria, Melbourne.

National Parks Service (NPS) (2013) National Parks Service Director's Order 12: Conservation planning, environmental impact analysis and decision making, US National Parks Service, Washington, DC.

New Zealand Department of Internal Affairs (1995) Commission of Inquiry into the Collapse of a Viewing Platform at Cave Creek near Punakaiki on the West Coast. Part 1, Department of Internal Affairs, Wellington.

$1 d$ Stasinopoulos, P., Smith, M. H., Hargroves, K. and Desha, C. (2009) Whole System Design: An integrated approach to sustainable engineering, Earthscan, London.

Thomas, I. (2001) Environmental Impact Assessment in Australia: Theory and practice, 3rd edn, Federation Press, Sydney.

White, A. L. (2012a) Conceptual models for Victorian ecosystems. Pilot programs: grasslands, Parks Victoria Technical Series No. 64, Parks Victoria, Melbourne.

White, A. L. (2012b) Ecosystem conceptual models for Victorian ecosystems, Parks Victoria Technical Series No. 65, Parks Victoria, Melbourne.

Worboys, G. L., Winkler, C. and Lockwood, M. (2006) 'Threats to protected areas', in M. Lockwood, G. L. Worboys and A. Kothari (eds) Managing Protected Areas: A global guide, pp. 223-61, Earthscan, London. 
W. (3)

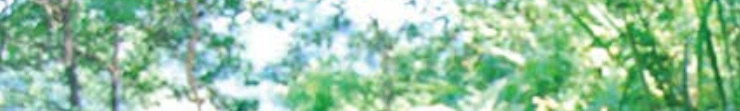

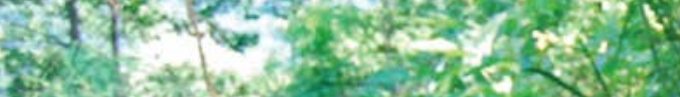

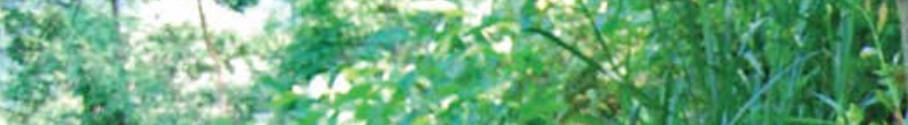

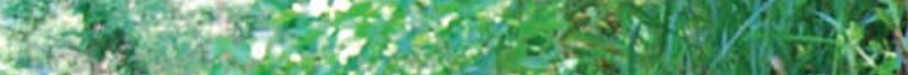

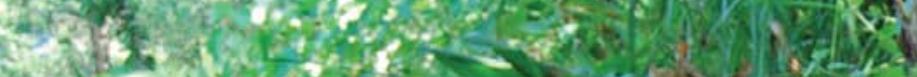
(5)

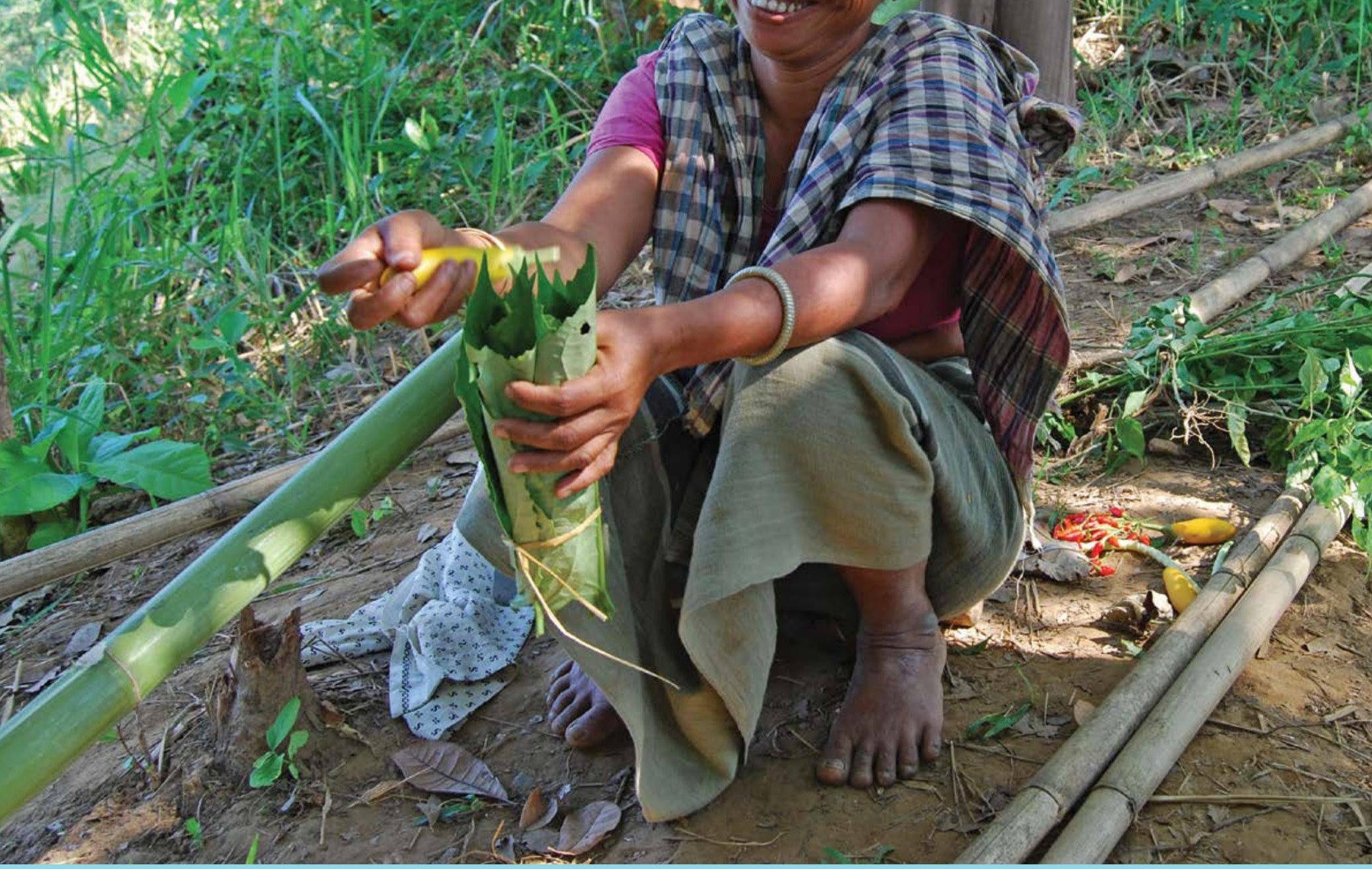

\section{CHAPTER 25}

\section{MANAGING RESOURCE USE}

AND DEVELOPMENT

\section{Principal authors:}

Ashish Kothari and Rosie Cooney

\section{Supporting authors:}

Danny Hunter, Kathy MacKinnon, Eduard Müller, Fred Nelson, Krishna Oli, Sanjeeva Pandey,

Tahir Rasheed and Lubomira Vavrova

\section{CONTENTS}

\section{Introduction}

- Resource use in and around protected areas

- Development and protected areas

- Conclusion

- References

IUCN 5 WCPA 


\section{PRINCIPAL AUTHORS}

ASHISH KOTHARI is a founding member of Indian environmental group Kalpavriksh, has taught at the Indian Institute of Public Administration, co-chaired the International Union for Conservation of Nature (IUCN) Theme Group and Strategic Direction on Governance, Livelihoods, Equity in Relation to Protected Areas (TILCEPA), and helped found the global ICCA Consortium.

ROSIE COONEY is Chair of the IUCN'S Commission on Environmental, Economic and Social Policy (CEESP)/Species Survival Commission (SSC) Sustainable Use and Livelihoods Specialist Group (SULi), and a member of the UN Scientific Advisory Board. She is a consultant in biodiversity policy to governments, non-governmental organisations and the private sector and lectures at the Institute of Environmental Studies, University of New South Wales.

\section{SUPPORTING AUTHORS}

DANNY HUNTER is a Senior Scientist at Bioversity International and member of the IUCN WCPA.

KATHY MACKINNON is Deputy Chair of the IUCN WCPA, and was lead biodiversity specialist at the World Bank, working on projects in Africa, Central and South America, South Asia, East Asia, Central Asia and Eastern Europe.

EDUARD MÜLLER is Vice Chair, Education and Learning, International Union for Conservation of Nature World Commission on Protected Areas, President, Universidad para la Cooperación Internacional, Costa Rica, UNESCO Chair for Biosphere Reserves and Natural and Mixed World Heritage Properties, and Coordinator of the WCPA Global Partnership for Professionalising Protected Area Management.

FRED NELSON is the Executive Director of Maliasili Initiatives, an organisation that promotes sustainable natural resource management and conservation in Africa. He helped establish the Tanzania Natural Resource Forum.

KRISHNA PRASAD OLI worked with the International Centre for Integrated Mountain Development (ICIMOD) until his retirement, and before that with several other agencies including the IUCN in Nepal.

SANJEEVA PANDEY, as an officer of the Indian Forest Service, is working as Additional Principal Chief Conservator of Forests in the Himachal Pradesh Forest Department of India, and has been director of the Great Himalayan National Park (GHNP).

TAHIR RASHEED is currently affiliated with LEAD Pakistan as General Manager, and has focused his work on sustainable use, climate change adaptation and policy research, and implementing integrated conservation and developmental projects.

LUBOMIRA VAVROVA is a freelance consultant who has worked at the State Nature Conservancy of the Slovak Republic in Banská Bystrica (2002-06), and with the IUCN Program Office for SouthEastern Europe in Belgrade (Serbia) as Biodiversity Project Officer.

\section{ACKNOWLEDGMENTS}

Appreciation is expressed to Thora Amend, Richard B. Harris, Ernesto Noriega, Tatjana Puschkarsky, Mikko Rautiainen, Vivienne Solis for their inputs to this chapter.

\section{CITATION}

Kothari, A., Cooney, R., Hunter, D., MacKinnon, K., Muller, E., Nelson, F., Oli, K. P., Pandey, S., Rasheed, T. and Vavrova, L. (2015) 'Managing resource use and development', in G. L. Worboys, M. Lockwood, A. Kothari, S. Feary and I. Pulsford (eds) Protected Area Governance and Management, pp. 789-822, ANU Press, Canberra.

\section{TITLE PAGE PHOTO}

Forest produce from community conserved forest, Chittagong Hill Tracts, Bangladesh

Source: Ashish Kothari 


\section{Introduction}

Resource use and development activities of various kinds are commonplace in and around protected areas. These have various impacts on conservation values, are related in diverse ways to the lives and livelihoods of local peoples and other sections of society, and are being dealt with in varying ways in protected area governance and management. This chapter provides a broad sweep of the experience with resource use and development within and adjacent to protected areas.

The first major section of the chapter deals with resource use. It is generally recognised that sustainable use of ecosystems and biological resources can play an important role in the management and conservation of protected areas. There are, however, complex issues of the scale and kind of use, and the kinds and fragility of ecosystems and wildlife populations where such use is taking place. Conventional approaches of separating people and protected areas, or in other ways restricting resource use, have begun to give way to more inclusive approaches. This chapter contributes to an understanding of how sustainable use models contain ingredients such as common values, defined roles, rights and responsibilities, conflict-resolution mechanisms, and other measures that are essential for equitable governance and effective management of protected areas. The general approach is that protected area management is as much a matter of managing human use and recognising people's links with the rest of nature as it is a matter of the intrinsic features of natural systems. A set of processes that connects resource use and development, integrated conservation and development projects (ICDPs), is also addressed.

The second major section deals with development and infrastructure projects and processes in and around protected areas. One aspect of this is projects that are carried out for the protected area itself; this is dealt with in Chapter 24. The second aspect is those carried out for other purposes, such as meeting the needs and aspirations of populations within or outside the protected area, or of people further away, including extractive and other industries, infrastructure, power generation, and so on. These can often have negative impacts on the conservation values of protected areas, and therefore need to be dealt with through appropriate legal, social and managerial responses.

\section{Resource use in and around protected areas}

Across the world, protected areas have, for the most part, been traditionally inhabited or used by humans. Resident, mobile or seasonal uses of lands, waters and wild species within such areas are both age-old and widespread. Comprehensive assessments at a global level are not available, but extrapolations based on indicative studies from various regions and countries cited below suggest that a very large proportion, if not a majority, of protected areas are likely to be inhabited and/or under resource use by people.

Available figures from a few regions or countries suggest that the number of people who currently use resources within protected areas is at least several tens of millions. A global analysis of the situation at the end of the 1990s found that around 70 per cent of the more than 30000 (then) sites on the United Nations' list of protected areas permitted some local use of natural resources (Pretty 2002). In India, 69 per cent of about 250 protected areas surveyed in the late 1980s were inhabited, and 64 per cent had community rights, leases or concessions inside them; there are between three and four million people living within protected areas, and several million more in adjacent areas who use the resources within them (Kothari et al. 1989). The situation is unlikely to have changed significantly since then. At least five protected areas reported a population of more than 100000 people living within them. Almost 90 per cent of the 1984 national parks declared until 1991 in South America were found to be inhabited or under resource use (Amend and Amend 1995). A substantial number of protected areas in Europe also contain human populations.

If one includes the 'new' governance types of protected areas (see Chapter 7) that are not necessarily part of the formal system, such as Indigenous Peoples' and Community Conserved Territories and Areas (ICCAs) and Private Protected Areas (PPAs), there is an even greater share of areas that are inhabited or used, and the number of people involved increases several-fold. No comprehensive figures exist, however, for these types of protected areas.

\section{Types of resource use and their importance for local populations}

Human occupation of protected areas and use of the resources in them range from permanent to seasonal settlements, from sedentary agriculture to shifting cultivation, and from resident to seasonal and nomadic 


\section{Case Study 25.1 Example of resource use within protected areas in Pakistan}

In Pakistan, protected areas provide goods and services to a large number of people (Pakistan Forest Act 1927; Pakistan Wildlife Act 1974; Jan 1992). Forest protected areas (initially declared for sustaining forest resources, but more recently also oriented towards wildlife conservation) are divided into state-owned and private/communityowned categories: according to Jan (1992), 66 per cent are state forest while 34 per cent are owned by the local communities or privately. Certain use rights and privileges are included in both categories. Designated protected forests (state-owned) allow some rights and concessions including grazing, grass cutting and collection of dry wood, unless these are prohibited by the Government.
Guzara (subsistence) forests (privately/communally owned) were set aside to meet the bona fide needs of local communities, especially in Malakand and Hazara areas of Pakistan. In these forests, customary rightsholders are entitled to 60-80 per cent of proceeds from timber harvesting (carried out by the Forest Department), to cut green trees (through permits) and gather NTFPs. Both customary rights-holders and other residents within an 8-kilometre radius are allowed to collect dry wood and graze animals. For most of the protected areas, buffer zones are created primarily for providing products of use or value (cash crops) to local people.

\section{Attitudes towards resource use in protected areas}

\section{A history of exclusion: The Yellowstone model}

In many parts of the world, the establishment of formal protected areas has followed the 'Yellowstone model', established in 1872 with the declaration of the Yellowstone National Park in the United States. This paradigm was generally protectionist and exclusionary, with the central underlying beliefs that human use is necessarily or inherently detrimental to conservation objectives, and that the state apparatus is the most effective governance approach to achieve conservation objectives (Neumann 1988; Kothari et al. 1995; Adams 2004). The approach in Yellowstone itself and many other protected areas has since evolved. Yet the exclusionary approach remains prevalent in many parts of the world, and moves to restitute customary rights where they were previously taken away are rare.

Government-managed protected areas have often been established without consultation with the communities living or using the resources within them. Wildlife and resource tenure are typically legally vested in the state, resulting in the deterioration of customary tenure systems and even expulsion of local residents or user communities from their ancestral areas-Native Americans from Yosemite and other national parks, the Maasai from the now-iconic reserves like Serengeti in Tanzania, the Batwa ('Pygmies') from Bwindi in Uganda, the Karen from reserves in Thailand, several forest-dwelling communities from tiger reserves in India, the Basarwa ('Bushmen') of Botswana from Central Kalahari Game Reserve (from areas they had occupied for 30000 years), and others (Spence 1999; West et al. 2006; Dowie 2009; Lasgorceix and Kothari 2009). This only added to the dispossession and disempowerment of communities for the purposes of colonisation and industrialisation.
In some regions, however, such as Europe and parts of the Amazon Basin, existing resource use and local populations were integrated from the beginning into the vision and management of protected areas, examples of which appear later in this chapter.

Early game laws in South Africa and East Africa were largely aimed at colonial settlers whose actions were leading to the depletion of large mammals (for example, by ivory traders, trophy and sport hunters), or to clearing areas of wildlife for agricultural settlements (Anderson and Grove 1987). Initial protected areas in East Africa maintained local communities' customary land rights and resource use (Nelson et al. 2007). During the first half of the 20th century, protected area policies shifted towards a more exclusionary stance, discouraging local communities' residence and resource uses. Major debates took place in the period before and after independence in East Africa, for example, around the residency of pastoralists in key wildlife reserves such as Amboseli National Park in Kenya and Serengeti National Park in Tanzania (Neumann 1998). This shift towards exclusion was often driven more by externally introduced notions of the need for 'pristine and inviolate wilderness' rather than any empirical analysis of local communities' positive or negative impacts on conservation (Homewood and Rodgers 1991; Neumann 1998), though, as acknowledged below, this does not mean that communities have always been in harmony with their natural surrounds.

In several countries, where local resource use privileges have been maintained within state-protected areas, it is typically more as exceptions to the general rule, in particular with reference to areas broadly under IUCN Categories I, II and IV. Again, the history of the Serengeti in Tanzania is instructive. When the Maasai communities were evicted and Serengeti National Park gazetted as an exclusionary protected area in 1959, it was based on a compromise with those 
communities, excluding the Ngorongoro highlands and adjacent portion of the Serengeti Plains from the park and including them in the new multi-use Ngorongoro Conservation Area (NCA) (Homewood and Rodgers 1991). The NCA was explicitly - and, in East Africa, quite uniquely-established as a state-run conservation area with the mandate to balance wildlife conservation and local economic development. Maasai customary rights to residence and resource uses, mainly through traditional pastoralist livestock grazing, are explicitly built into the NCA charter and management system.

In South Africa, the Makuleke community was awarded approximately 20000 hectares of land within Kruger National Park in 1998, through the post-Apartheid land-claims process and related negotiations with the national park authority (Reid 2001). This claim was, however, only recognised on the basis that conservation land use would not be permitted to change, and that the Makuleke would lease their land back as a contractual national park to South Africa National Parks. Protected area managers in many parts of Africa remain generally resistant to incorporating local use or co-management into major protected areas, particularly national parks (Steenkamp and Uhr 2000).

In the Indian subcontinent, there is a long history of conservation and protection in a wide diversity of ways, both by communities and by rulers. In more modern times, however, it is the Yellowstone model that has been uniformly adopted for the declaration of formal protected areas (Saberwal et al. 2001). Biodiversity is often concentrated in areas where poverty (in the conventional sense of the word) tends to be pervasive and where the reach of government development programs is often limited (Pandey and Wells 1997). The setting up of a protected area in such situations often results in disruption of resource use by the community. Anywhere between 100000 and 600000 people have been physically evicted in India, and many hundreds of thousands more have been deprived of their livelihood resources (Wani and Kothari 2007; Lasgorceix and Kothari 2009).

Latin America has a more mixed history. In Costa Rica, Chile and Argentina, protected areas were established relatively early in their history, mostly under the concept of 'national parks', where land is mostly owned by the state (though in cases like Costa Rica, the Government still owes the original landowners the payment for expropriation of a little less than half the land now included in protected areas) (Programa Estado de la Nación 2006). In Mexico, only a small percentage of land in protected areas is owned by the Federal Government, with a high percentage under community or private property regimes, meaning the protected area system has to permanently negotiate with the landowners for their protection (Bezaury-Creel and Carbonell 2009).

\section{Moving from an exclusionary approach}

The latter part of the 20th century witnessed a reexamination of some of these approaches to biodiversity conservation. Conservation planning has often employed 'top-down' and centrally planned approaches that pay little attention to the needs or aspirations of local communities (Hunter and Heywood 2011). These 'command-and-control' strategies often perpetuated the poverty, inequality and power structures that hindered the realisation of biodiversity conservation and sustainable wellbeing goals in the first place. Local and indigenous communities in biodiversity-rich countries have been closely linked to their natural environments for millennia and have intimate knowledge of habitats and their wild plant and animal species - a relationship that has often been disrupted by conventional conservation approaches (UN 2009). For example, the territorial maritime zone in Costa Rica has excluded small-scale fishers and coastal communities from access to land and resources on which they depend (Fonseca 2009). Increasingly, it is recognised as neither politically feasible nor ethically justifiable to deny local communities the use of natural resources without providing them with alternative means of livelihood, or to manage protected areas without their empowerment and support (McNeely et al. 1990; Wells et al. 1992; WRI et al. 1992). Regulated resource use can also provide revenue flows for protected area management in some instances.

The growth of common property scholarship since the late 1980s, and recent studies, have highlighted the ability of local people to sustainably and effectively manage natural resources and ecosystems (Berkes 1989; Ostrom 1990; Hayes 2006; Porter-Bolland et al. 2011; Nelson and Chomitz 2011). By no means is this universal, and there is also evidence of unsustainability in several situations (Terborgh 2004), including extinctions caused by ancient peoples, but it is a widespread enough phenomenon to require greater attention than that paid by conventional conservation policies. A particularly important factor is the ability of communities to make and enforce the rules that govern resource use, which highlights the need to devolve clear rights to local resource users in and around protected areas (Chhatre and Agrawal 2009). These scientific findings have increasingly built legitimacy for more community-based forms of protected area governance and management, and highlighted that in many situations multiple-use protected areas or indigenous lands may actually be as or more effective as conservation instruments as strict 
Category I or II protected areas, especially when there are comparable pressures (Nelson and Chomitz 2011). This is not to say that indigenous peoples and local communities are in all situations and cases conservation oriented; many are subject to external and internal influences that affect their traditional or customary ways, and there are also multiple pulls and pressures for younger generations to adopt unsustainable lifestyles. All other factors remaining equal, though, it appears that participatory, rights-based approaches need to be increasingly adapted for effective conservation.

Due to these multifaceted dynamics, strict exclusion of resource use, where necessary and beneficial in situations of such use being inherently detrimental to local species or ecosystems (such situations are dealt with later in this chapter), can also at times have perverse and detrimental impacts. These include: alienating local communities from conservation efforts, removing any incentive to cooperate with protected area managers and regulation; losing the conservation and management benefits of traditional knowledge and resource management practices; worsening illegal use; shifting resource use to other areas, with intensified impacts; increasing illegal use by 'outsiders' through removing the rights and presence of traditional custodians; upsetting complex food webs with unintended consequences on target conservation species; and removing options for much-needed sustainable financing of protected areas. Removal of domestic sheep from the proposed Patagonia National Park is one factor that inadvertently could lead to a decline of the species this move is meant to protect, the Huemul deer (Hippocamelus bisulcus) (Wittmer et al. 2013); a ban on buffalo grazing in India's iconic Keolodeo (Bharatpur) National Park is believed to have led to habitat changes detrimental to the conservation of the endangered Siberian crane (Vijayan 1991); and the ban on forest fires in a tiger reserve in southern India is documented to have led to negative ecological impacts that indigenous people could have foreseen (see Case Study 8.1 on fire and the Soliga tribe).

\section{Changing paradigms: Greater inclusion and new models for protected area management}

Increasingly, the mission of government-protected areas has expanded from biodiversity conservation to incorporating considerations of improving human welfare. The result is a shift in favour of protected areas allowing local sustainable resource use (NaughtonTreves et al. 2005), or recreational, research, education or commercial forms of resource use that benefit local people and communities. Although protected areas are designated or meant primarily for biodiversity conservation, increasingly, they are also seen as drivers and providers of social and economic benefits (Brandon et al. 1998).

Community participation is now typically regarded as fundamental to the attainment of the economic, political, social and environmental objectives that underpin conservation, while exclusionary conservation is questioned on social, institutional and sustainability grounds (Saberwal et al. 2001). There is increasing recognition of the rights and claims of indigenous peoples and local communities to their traditionally held lands and resources, and recognition of the negative impacts the establishment of protected areas has often had on these (West et al. 2006). Global surveys and comparative case study analyses have highlighted that conservation professionals and managers now regard participation as one of the most important success factors for management (Stoll-Kleemann and Welp 2008), although participation does not necessarily always translate into economic benefits for local people (Galvin and Haller 2008).

Others refer to this shift as the move away from the 'preservation approach'-trying to isolate and maintain biodiversity in protected areas by excluding indigenous and local communities-towards a more biocultural (the inextricable links between nature and culture) approach, allowing human activity as part of the process and thereby rendering a much more successful conservation strategy (Hunter and Heywood 2011) (see also Chapters 4 and 23). Maintaining or enabling various forms of resource use in protected areas will often form part of these approaches. For example, the Niassa National Reserve in northern Mozambique is the largest (42000 square kilometres) in the country's wildlife protected area system, with about 80 per cent of the elephants in Mozambique, and it incorporates customary local use, residence and coexistence, having a resident population of around 35000 people (Wikipedia 2014; Niassa Carnivore Project 2013).

Community-based natural resource management (CBNRM), one of the more common inclusive models to emerge, represents a shift from a centralised to more devolved approaches. CBNRM is basically a catch-all term denoting a wide range of practices whereby local collective institutions or groups of people, organised formally or informally, manage and utilise their lands, resources and common property. This may or may not involve a protected area. A recent review of the impact of CBNRM approaches in Africa has highlighted some notable ecological, economic and institutional achievements (Roe et al. 2009). As many reviews during the past two decades have noted, however, CBNRM is ultimately contingent on the devolution of authority 
and tenure over land and resources to the local level, often hindered by political-economic barriers (Gibson 1999; Nelson 2010; de Beer 2013).

Integrated conservation and development project (ICDP) is a subset of these more inclusive approaches, linking biodiversity conservation, often in or around protected areas, with local social and economic development (Wells et al. 1999). ICDPs usually target both the protected area (by strengthening management) and local communities (by providing incentives, such as rural development opportunities, to reduce the pressure of activities damaging to natural habitats and resources). ICDPs often started as small NGO-led initiatives but really took off when international donors embraced the concept of linking conservation to poverty alleviation. Today many protected areas are engaged in ICDP models that range in size and scope from site-based efforts to major programs that attempt to integrate conservation with regional development (for example, see Cadman et al. 2010). They offer an almost irresistible cocktail of perceived benefits-biodiversity conservation, increased local community participation, more equitable sharing of benefits and economic development for the rural poor. Some have achieved remarkable and inspiring successes, but many ICDPs have failed to meet either their conservation or their development objectives (Brandon et al. 1998; Hackel 1999; Oates 1999; Wells et al. 1999; McShane and Wells 2004; Alers et al. 2007).

This mixed experience with ICDPs is illustrated in the case of India. At some sites, ecodevelopment committees have empowered villagers with information and avenues of participation, created youth and women's groups, enabled villagers to access additional livelihood opportunities and development resources through local government (panchayat) schemes, freed tribal communities and other poor villagers from moneylenders, and greatly increased cooperation between communities and forestry officers. At Periyar Tiger Reserve, cinnamon bark collectors were encouraged to abandon their poaching activities and instead use their forest knowledge to guide tourists. Although their income from tourism was less than from illicit activity, they were no longer in conflict with the Forest Department or in debt to moneylenders to cover fines, and their social standing within the community was enhanced (Periyar Tiger Reserve 2012). At many other sites, however, these gains have not materialised; nationally, the ongoing ecodevelopment scheme has been characterised by serious conceptual weaknesses, inadequate or no monitoring of impacts, no independent assessments, and no sharing of decision-making power with local communities (Das 2007; Shahabuddin 2010; see also Case Study 25.2). At Periyar itself, an independent study suggests that benefits to local communities may be less than officially claimed (Gubbi et al. 2008).
Major weaknesses common to many ICDP interventions are unrealistic and often conflicting objectives, failure to correctly identify the source of threats and target interventions accordingly, poor monitoring so that it is difficult to effectively link improved conservation to project activities, and lack of long-term support to continue to build capacity and sustain gains beyond the project's lifetime (Alers et al. 2007). Others include failure to identify and promote indigenous/local traditions, knowledge, practices and world views that aid conservation, since much of the time local people are seen as 'pressures' on the ecosystem and wildlife, and failure to meaningfully share decision-making power.

Promoting new livelihood opportunities is just one way to benefit local communities; other strategies may be more effective in encouraging long-term support for changing behaviours, including employment opportunities through tourism ventures (see Chapter 23) or in the protected area itself providing labour or clearance of invasive alien species. Elsewhere protected areas have attempted to address the issues of equity and sustainability through microfinance or longterm financing mechanisms to provide resources for development activities-for example, in a number of protected areas in Peru (PROFONANPE 2012).

It is critical to monitor all ICDP activities against the objectives of reducing threats and conserving biodiversity. In some places there will be a clear link between improved protection and conservation-for example, increasing fish stocks in marine protected areas or development activities and habitat protection. Elsewhere the linkages may be less clear. When monitoring focuses more on numbers of beneficiaries than on biodiversity outcomes and reduction of threats, it is increasingly difficult to understand when, and where, interventions are effective for conservation. Unless the linkages between project activities and conservation goals are clear to, and endorsed by, local stakeholders, offering new livelihood opportunities is unlikely to lead to conservation benefits. Participatory monitoring by community members can be a useful supplement to monitoring by government protected area staff and research institutes (Margoulis and Salafsky 2001; Danielsen et al. 2005).

Sustainable resource use is often a key objective and pillar of protected areas and other conservation sites governed by non-governmental actors, including ICCAs and PPAs (see Chapter 7). It is the basis, for instance, of thousands of community forests in South Asia, hundreds of locally managed marine areas in the South Pacific, South-East Asia and some African countries, vast territories of mobile peoples in Central Asia and the Horn of Africa, and many other ICCAs (Borrini-Feyerabend et al. 2010; Bassi and Tache 2011; Kothari et al. 2012; Naqizadeh 


\section{Case Study 25.2 Ecodevelopment in Great Himalayan National Park, India}

In the 1990s, ICDP approaches were introduced at various locations in India, including the Great Himalayan National Park (GHNP). The program here started with a World Bankaided Forestry Research Education and Extension Project (FREEP) in 1994, which had an additional sub-project, Conservation of Biodiversity (CoB) (Pandey and Wells 1997). On project completion, the park managers initiated livelihood-based programs in the buffer area aimed at setting up alternative community-based systems of natural resource management and resolving human-animal conflicts through a participatory mode of management (Tandon 2002; Pandey 2008).

Women belonging to the poorest households, most dependent on the park's resources, have been organised through capacity-building programs into Women's Savings and Credit Groups (WSCGs) in the buffer zone. Nearly 1000 women in 95 WSCGs have been provided with alternative income-generating activities: vermicomposting, apricotoil production, hemp products, ecotourism, street theatre and wage labour. Mechanisms are being developed so that the WSCGs strengthen the village council (panchayat) and become sustainable.

The ecodevelopment approach in the GHNP has also received criticism from researchers and activists. There was no democratic process to determine whether a national park, which by law requires removal of all human uses, was the appropriate conservation category to apply here; no consideration of an integrated conservation and livelihoods approach; and inadequacy of compensation compared with the loss of livelihoods from stoppage of activities like herb collection (Baviskar 2003; Chhatre and Saberwal 2006). Also, while people's traditional uses have been stopped, the park has been subjected to highly damaging hydro-electricity development. The process at GHNP thus mirrors the contradictions of the conventional protected area approach prevalent in India (Saberwal et al. 2001).

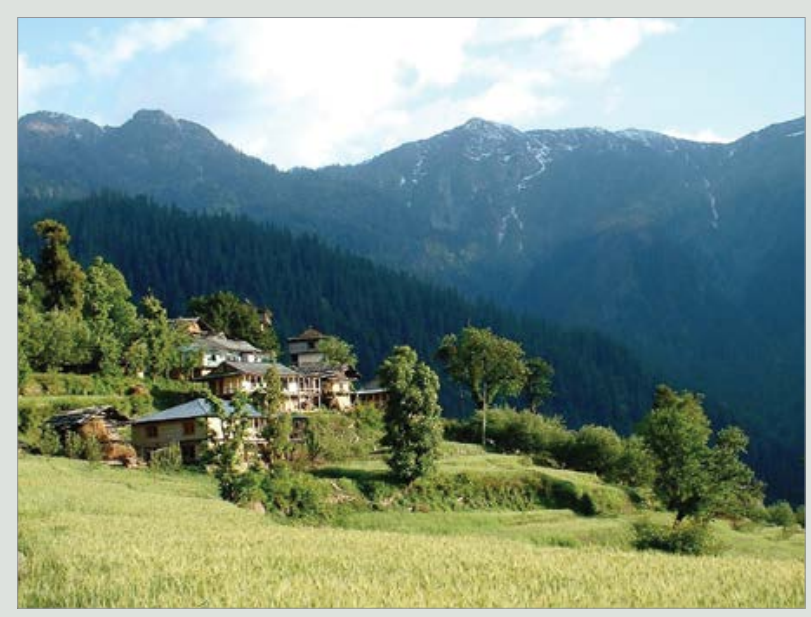

Village in the buffer zone of Great Himalayan National Park, India

Source: Sanjeeva Pandey et al. 2012; see also Chapters 7, 20 and 21). It is also a key motivation for PPAs such as those conserving large mammals (and associated wildlife) in several African countries (see elsewhere in this chapter).

\section{Recognising the role of sustainable use in conservation}

There is increasing recognition that sustainable resource use may often be quite compatible with and contribute to conservation objectives. Traditional human uses have been in some cases part of shaping the landscape or seascape in ways that conservationists consider important, or they may provide incentives for protection and conservation efforts, or generate much-needed revenue to finance protected areas. In some cases, harvesting can actually increase density of the resource-for example, in the Western Australian desert, sand monitor lizards are most abundant where hunting is most intense due to the patch-burning techniques used by Aboriginal hunters (Bird et al. 2013), though it is not clear what the overall biodiversity impacts are.

In Guatemala, the sustainable harvest and trade of small palms (for floristic use in developed countries) have allowed local communities to generate important income while providing incentives for them to maintain the resource, thus conserving the forest. In the Maya Biosphere Reserve, Guatemala's most important protected landscape, sustainable use concessions underpin an array of private and community-based management practices, leading to more effective conservation (Radachowsky et al. 2012). At Ostional National Wildlife Reserve, Costa Rica, tens of thousands of leatherback turtles arrive almost simultaneously to nest each year. Local communities are allowed to harvest a percentage of the 'early' laid eggs, many of which would have been destroyed by later arrivals. This approach has built enormous local community support for conservation and virtually eliminated the illegal poaching of eggs locally, while the turtle population continues to rise (Campbell et al. 2007). In Brazil, the traditional harvesting of brazil nuts from the Amazon forests for economic returns has resulted in strong protection of these forests by the harvesters against loggers and ranchers (Amazon Conservation Association 2013).

In Central Europe, the Morava River floodplains are semi-natural ecosystems that are now fully dependent on human management. A large area of the floodplains (almost 5000 hectares) in Slovakia has been included 
in the Landscape Protected Area of Záhorie. The most suitable form of management to maintain biodiversity values is hay production. This prevents meadows being overgrown by vegetation and spreading invasive species, and keeps suitable biotopes for endangered flora (for example, orchids) and fauna (for example, butterflies). Monitoring has confirmed that biodiversity is significantly higher on meadows regularly managed than on those that are not (Rybanič et al. 1999). Maintaining this use therefore benefits both biodiversity conservation and local socioeconomic development. Another example highlighting the compatibility of conservation and resource use is Lonjsko Polje Nature Park, located on the Sava River floodplains in Croatia. This park is a unique example of an organically evolved landscape maintaining traditional land uses, with a preserved medieval system of pasturing on commons land that was typical for the whole of Central Europe until the second half of the 19th century (Gugić 2009). This traditional animal husbandry system is run with indigenous breeds of horse, pig, cattle and goose.

In Ireland, the unique local geology and climate of the Burren (a karst landscape in north-west County Clare, much of which is designated as a special area for conservation) has not only given rise to unique landscapes, but also contributed to the development of a distinct form of transhumance referred to as 'winterage'-a traditional grazing practice that has moulded its cultural and natural heritage (Parr et al. 2010). Over the past 40 years, socioeconomic factors have contributed to significant changes in agriculture with detrimental impacts on biodiversity. This trend has recently been reversed through the concept of 'farming for conservation', which has revitalised interest in farming on winterages, playing a pivotal role in restoring the landscape and its biodiversity. BurrenLIFE is the first major 'farming for conservation' project in Ireland as well as marking the first working partnership between the National Parks and Wildlife Service, the Agriculture and Food Development Authority and the Burren branch of the Irish Farmers' Association (BurrenLIFE 2014).

In eastern and southern Africa, protected areas (with their globally exceptional wildlife populations and viewing conditions) not only serve conservation purposes, but also generate revenues and jobs through tourism. These revenues in turn fund conservation efforts and create incentives locally and nationally for investments in wildlife management (Spenceley 2008; Child 2004).

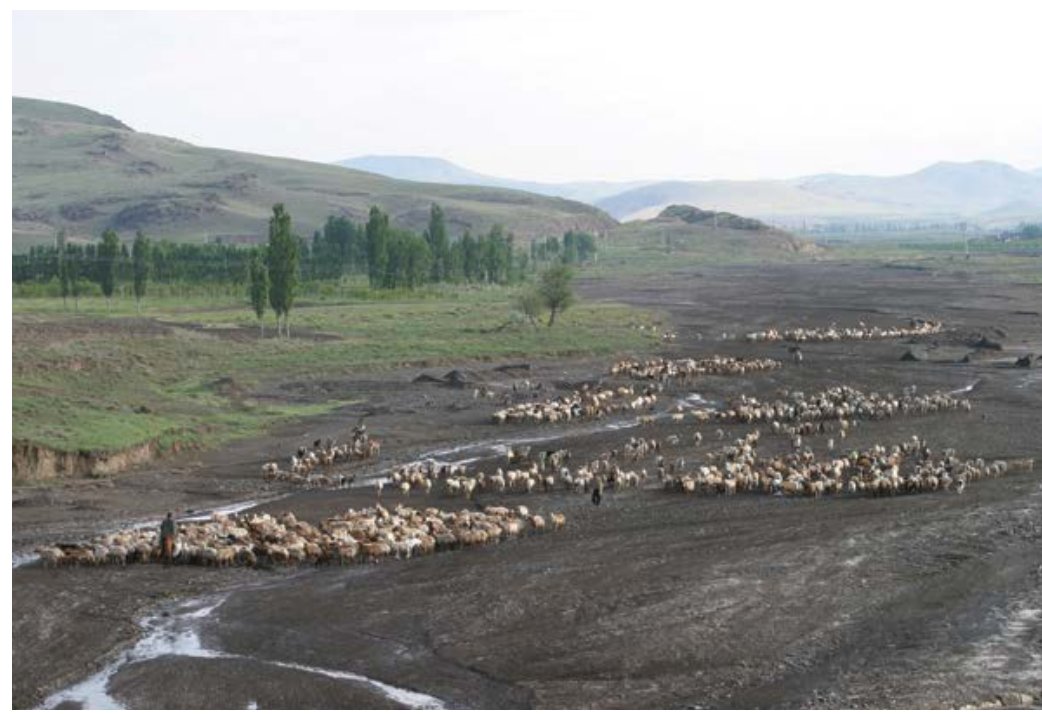

Mobile peoples on migration through their ICCA, Iran

Source: CENESTA

The satoyama and satoumi landscapes and seascapes of Japan, known for highly productive resource use, are increasingly being recognised as examples of sustainable use contributing to conservation (Bélair et al. 2010; UNU-IAS OUIK 2011).

\section{General principles and approaches for resource use in protected areas}

\section{Rights to use and governance}

Who holds rights to access and extract resources from a protected area (terrestrial or marine) and who has the right to be involved in management are important and sometimes controversial issues (see Chapter 7). Rights may arise out of indigenous, customary or traditional tenure and practices, or may be developed through policy and legislation. They may be communally or individually held, and may be permanently assigned or transferable by purchase. Management rights specify who is to be involved in protected area management decision-making: they may be held by governments, by indigenous peoples and local communities, or by some combination of the two (comanagement). Use rights specify who may have access to a protected area or a resource (access rights) and how much activity (for example, the number of harvesters or fishing days) or extraction (for example, the volume of fuel wood or tonnes of catch) is allowed (withdrawal rights) (Charles and Wilson 2009). Appropriate and equitable recognition of these resource use rights are increasingly viewed as critical in achieving effective sustainable resource use management (Charles and Wilson 2009; Charles 2011). 
An ongoing process of restitution or recognition of rights is that of India's Scheduled Tribes and Other Traditional Forest Dwellers' (Recognition of Forest Rights) Act 2006. Under this law, individual and community rights to forest lands and resources that have traditionally existed but have not been recognised since colonial times can be recognised and recorded. Included in this are the right and powers to govern forests. Since 2008 when the law came into force, these have been recognised over more than 6000 square kilometres of forest land (including a couple of government protected areas), and in several instances communities are making plans for how best to conserve and sustainably use them, as well as exclude what they consider to be destructive 'developmental' and logging activities (Vasundhara and Kalpavriksh 2012; Desor 2013).

\section{Traditional and indigenous knowledge}

Effective resource management needs to be based on good information, which may be either embedded in indigenous and traditional science or knowledge systems and cultural practices where they are still prevalent or derived by Western scientific methods, and ideally a combination of these (Posey 1999; Failing et al. 2007; Tebtebba Foundation 2008; Parrotta and Trosper 2012). Indigenous/traditional and local knowledge can be of central importance in, for example, mapping habitat and resource use areas, establishing workable and socially acceptable resource use zones, strategies focused on landscape restoration, increasing resilience of ecosystems and better adapting to climate change (see Case Study 25.3). This is particularly important in marine protected areas, for example, where local resource users tend to have deep knowledge of resource distribution, abundance and environmental conditions, in a context where resources are mobile and monitoring is difficult (Drew 2005). In Eastport, on Newfoundland island in Canada, the knowledge of local community fishers of potential juvenile lobster-rearing habitat formed the basis of decision-making about where to close areas to lobster fishing, to enhance egg production and increase recruitment (Charles and Wilson 2009). Such an approach is typical of many ICCAs, and provides lessons for government-managed and private or formal protected areas (see Chapter 7).

\section{Sustainable and equitable use}

Managing use to achieve sustainability and equity is a critical priority for maintaining biodiversity values. The IUCN Policy Statement on Sustainable Use of Wild Living
Resources (IUCN 2000) recognises that sustainable use is an important conservation tool because it provides people with incentives for conservation in the form of social, cultural and economic benefits. This is most relevant to protected areas. It also highlights the importance of adaptive management, the biological limitations of species and ecosystems, governance structures, whether users have a formal or informal stake in the resources they are using and the removal of perverse incentives. The importance of clear and secure tenure over land and resources as a basis for motivating local users to achieve sustainable use has also been clearly demonstrated through an IUCN-led process of regional analyses and global case studies (Oglethorpe 1999).

Under the Convention on Biological Diversity (CBD), principles for achieving sustainable use (one of the convention's three main objectives) have been elaborated in the Addis Ababa Principles and Guidelines (CBD 2004). These principles and associated documents provide an important framework for managing the use of resources in protected areas.

As with sustainability, socioeconomic equity is a crucial component of resource use. For instance, incorporating gender aspects into thinking, strategy and management of all forms of protected areas is critical, else women's access to and use of resources risks marginalisation (FAO 2012; Harper et al. 2013). Within fisheries, the importance of women in particular in the pre and postharvest sectors should be recognised. Women in fishing communities often lack access to fish, and may be denied a role in decision-making due to existing cultural norms, as well as facing broader problems of lack of credit and transport services and undervaluation of their work. Similarly, inequities in access to resources, such as those between different ethnic groups, classes, castes and other social divisions, could seriously hamper the sustainable use of resources, and need to be dealt with sensitively.

\section{Management of resource use in protected areas: Approaches and examples}

Management of resource use in protected areas needs to be highly context-sensitive and responsive to the form of use involved, the characteristics of the resource and the socioeconomic context. In this section, some of the main types of use are discussed, drawing on examples from a wide variety of regions. 


\section{Case Study 25.3 Protecting the Sangha-Sangha ancestral fishing grounds, Central African Republic}

The Sangha-Sangha is a fishing community in the buffer zone of the Dzanga-Ndoki National Park, Central African Republic. Due to its outstanding biodiversity values, the area was inscribed as the Trinational de la Sangha World Heritage site jointly with bordering parks in Cameroon and Congo in 2012. Together with the Baka hunter-gatherers, the Sangha-Sangha are the first inhabitants of this region. Over time, they have developed an intimate, synergistic relationship with their territory, which has defined their values, shaped their social organisation, and generated sophisticated environmental knowledge and management systems. An example of this is an interconnected system of channels and flood zones the Sangha-Sangha ancestors created along the River Sangha, which allows fish to retreat and breed.

Since the incursion of logging companies in the 1980s and 1990s, new settlers have practised unsustainable fishing techniques including poison. In response, in 2008 the Sangha-Sangha created the Association pour le Développement Sangha-Sangha (ADSS), with the aim of reinstalling local governance and customary practices. In 2012, ADSS initiated a dialogue with the national park management and other local authorities, and received a municipal decree that prohibited the use of toxic substances of industrial origin and non-conventional equipment for fishing, assigned exclusive fishing rights to specific families or clans recognised by the traditional authorities and declared that non-compliance with these provisions could result in criminal proceedings. Trespassing into the ancestral Sangha-Sangha territories and unsustainable fishing methods have been rendered criminal offences. ADSS has since undertaken activities to promote sustainable resource use, and encourage the transmission of ecological knowledge and cultural techniques, especially among youth.

- Ernesto Noriega and Tatjana Puschkarsky

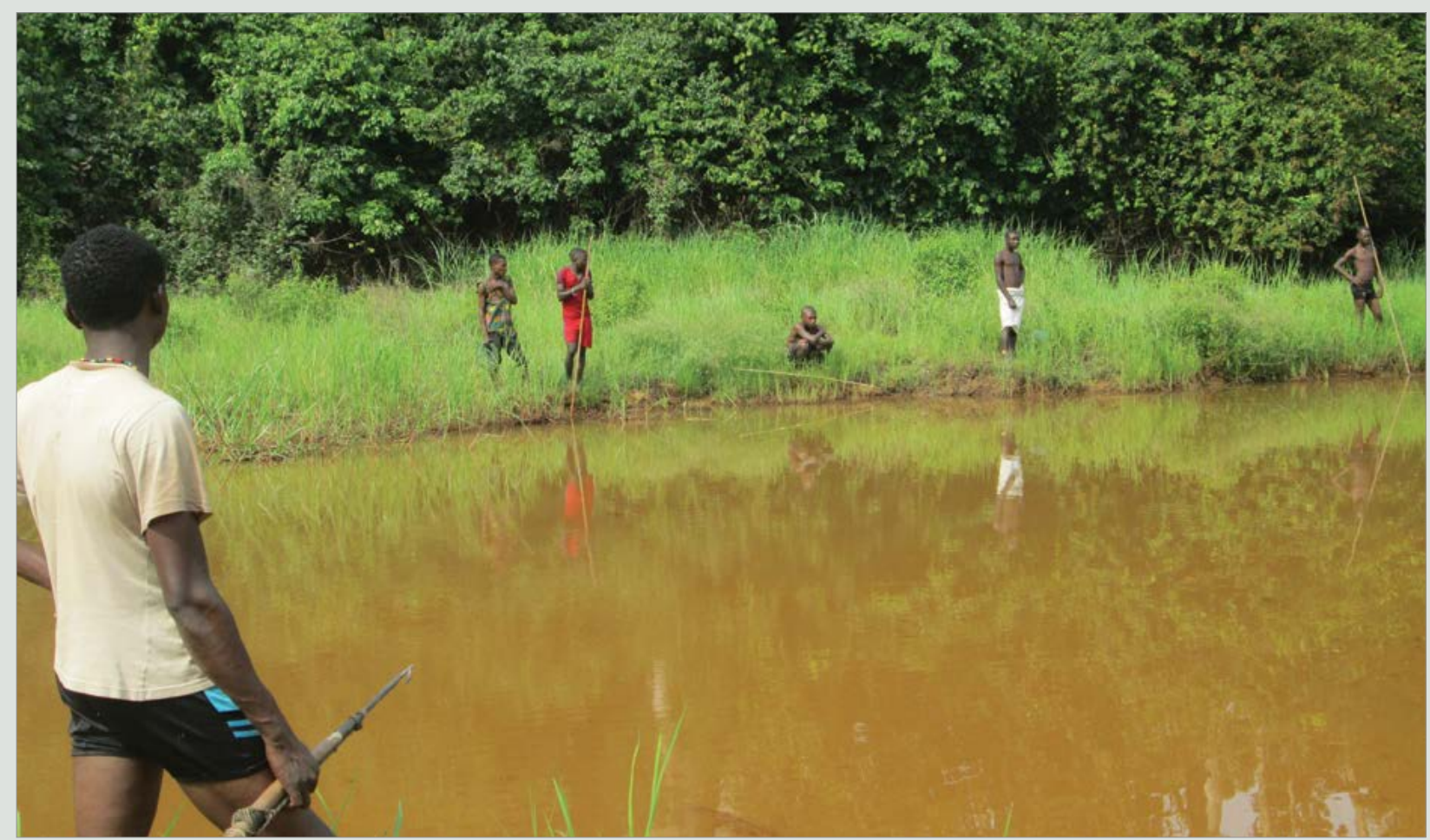

Sangha-Sangha community members at a wetland

Source: José Martial Betoulet

\section{Harvesting wild plant products (local use and trade)}

Protected forests, wetlands, grasslands and marine environments are the source of a wide range of non-timber forest products (NTFPs), defined as all biological material other than industrial round wood and resulting products that are harvested from within and on the edges of natural, manipulated or disturbed forests (Chamberlain et al. 2004). While the term can include both plant and animal products, this section focuses primarily on plant products, with animal products discussed in the following section. NTFPs are of major economic and livelihood value. For example, Schippmann et al. (2006) estimate that up to 70000 species of higher plants (about 20 per cent of the estimated global flora) are used as medicine worldwide, of which around 3000 are traded internationally. Further, it has been estimated that for 80 per cent of the world's population, plants are the major available form of medicine (Kamboj 2000; Parrotta and Trosper 2012). In India alone, about 275 million people depend on NTFPs, 
using more than 10000 species of plants and animals for food, fuel, fodder, medicine, housing, implements, and cultural uses (TPCG and Kalpavriksh 2005). The global value of NTFPs in 2005 totalled US $\$ 16.839$ billion (FAO 2010). This includes extensive and widespread use in and around protected areas.

NTFP harvesters are increasingly becoming involved in commercial ventures driven by national and global market demand, with traditional management structures breaking down, threatening the sustainability of the resource base. For example, the alternative health industry in Europe, North America, Australia and New Zealand uses a wide variety of herbal medicines, and has adopted many of the practices of Ayurvedic, Buddhist and Chinese traditional medicines so that the industry has become a fast-growing multibillion-dollar industry. Harvesting wild medicinal plants has thus become an organised commercial venture in many places, where agents employ local people to do the harvesting (Battharai et al. 2003). This is also a concern with other wildlife products, such as ivory, with a significant recent rise in poaching to meet the demand from newly enriched consumers in Asia (CITES 2013).

Plant biodiversity hotspots typically occur in low Human Development Index (HDI) countries, in the tropics, where the pressure to increase economic and human development can be high. In many protected areas, managers are given the responsibility to determine if long-term plant harvesting, grazing or other such uses have beneficial, detrimental or neutral implications for achieving management objectives; in others, it is a responsibility taken by the user communities or civil society organisations. In some, there are well-established and scientifically rigorous systems for measuring, monitoring, evaluation and reporting on activities (see Chapter 28). It is also necessary to determine at what level the activity is sustainable and to establish limits, which is best done by or with the participation of local user communities. For example, harvesting grass from a wetland area may be beneficial to bird habitat, but increasing or decreasing the harvest or changing the way in which it is carried out may make the activity detrimental. Where possible, ongoing monitoring of environmental and social conditions to assess the impact of such activities is desirable. A number of co-managed protected areas and ICCAs across the world are employing monitoring methods, ranging from traditional indicators and baselines often based on centuries of observation, to modern, often more quantified ones (Case Study 25.4).

Measures to avoid overharvesting are being incorporated into new tools for evaluating the sustainability of the collection of medicinal and other wild-harvested plants, such as the FairWild Standard, and others to assess both the ecological and the social aspects (FairWild 2009; Kathe et al. 2010; Kathe 2011; Unnikrishnan and Suneetha 2012). Species management plans are also a mechanism to monitor and prevent overharvesting (Case Studies 25.4 and 25.5). International policy efforts around the sustainable use of plant resources include the Guidelines on the Conservation of Medicinal Plants (currently under revision) of the World Health Organisation (WHO) and others, and the Global Strategy for Plant Conservation under the CBD (Unnikrishnan and Suneetha 2012). Negotiating with communities to stop practices that are damaging the protected area may be needed in the case of government-managed protected areas. In the case of ICCAs, such negotiations are usually carried out internally by community members and could involve dealing with both internal and external pressures (Case Study 25.3). Novel approaches to safeguarding and conserving medicinal plants include the establishment of medicinal plant conservation areas (MPCAs) and medicinal plant conservation parks (MPCPs) in India (Unnikrishnan and Suneetha 2012). Until 2012, 112 MPCAs had been established across 13 Indian States. Other strategies include limiting resource extraction to certain areas, allowing only specific people to collect the resource, establishing quotas based on a sustainable yield and doing plantations of coveted species outside the protected area.

\section{Hunting and fishing}

A number of forms of hunting and fishing take place in some protected areas, legally and illegally, both for subsistence and for commercial purposes. Wild game has long been important for rural communities, and many protected areas permit limited subsistence hunting and fishing. Bushmeat is a term commonly used to describe meat gained from hunting wild animals, mostly in forest environments in countries where domestic livestock is not common. It is now an important subsistence and commercial activity in Africa and to a lesser extent in South America and Asia. It meets the majority of human needs for protein and fat in some areas, such as the Congo Basin. With little requirement for a capital outlay to engage in it, young men in poor communities can participate easily, and decentralised trade means a large proportion of the value of the goods goes to the primary producer (the hunter) (Nasi et al. 2008, 2011; van Vliet et al. 2012; Schulte-Herbrüggen et al. 2013).

In Africa, 42 mammalian species of global conservation concern are involved in the bushmeat trade, including chimpanzees, elephants and gorillas (CITES 2000; 


\section{Case Study 25.4 Dealing with overharvesting through negotiation and community action in Uganda and India}

Kibale National Park in Uganda (IUCN category not set) illustrates the success of a negotiation approach. The park is surrounded by 27 parishes in which approximately 120000 people live. The boundary communities extract more than 20 products from the park to meet some of their subsistence, commercial, cultural and medicinal needs. While prohibition was the first management strategy attempted, it was found that law enforcement was becoming very time-consuming and expensive for park managers. It was found that most illegal activity was coming from the boundary communities. With the aid of the Kibale Semuliki Conservation and Development Project, collaborative resource management agreements were negotiated with local boundary communities, setting agreed limits on who could harvest in the park and what products could be taken. It took two years to identify, negotiate and sign the first agreements, then six months on average for the following agreements. The success of the collaborative agreements was greater where assistance was given to develop alternatives to harvesting park resources. Community/park relations improved, a significant drop in illegal activity was noted and community members became involved in reporting illegal activity (Chhetri et al. 2003).

Mendha-Lekha village in India, with a communityconserved forest of nearly 2000 hectares, has led a number of assertive movements to regain community forest rights and stop a paper mill from depleting the local bamboo habitat. After obtaining legal title under the Forest Rights Act 2006, it has reinforced its customary rules and regulations, and updated them to include sustainable harvesting of bamboo (which previously the state Forest Department had control over). Now the village is earning substantial revenue from this and the money is deposited in the account of the village, and is being used to generate livelihoods for the village through activities related to forest development, designating wildlife habitats and other activities. The village is now able to provide fair wages and timely loans not only to the residents but also to other villagers who would like to work in the village (as long as they follow local rules) (Pathak Broome and Dash 2012).

\section{Case Study 25.5 Species management plan for Cinnamomum capparu-coronde}

Cinnamomum capparu-coronde is a highly threatened endemic medicinal species in Sri Lanka. The KanneliyaDediyagala-Nakiyadeniya (KDN) Biosphere Reserve in southern Sri Lanka hosts substantial populations, known locally as 'Kapuru Kurundu'. There are 78 villages surrounding the reserve; 50 per cent of the households live below the poverty line and depend on the forest for timber and NTFPs. Cinnamomum capparu-coronde is locally used to cure bronchitis, rheumatism, snakebites, fractures and tooth ache, among many other ailments. Eugenol is an important chemical ingredient extracted from the plant.

In an attempt to prevent overharvesting of this important endemic species, the KDN forest reserve was selected to develop and implement a species management plan. The objective is to maintain the population of Kapuru Kurundu through monitoring the density changes from 2009 to
2019 in two macro-plots within KDN reserve. The plan is implemented by the Forest Department with the assistance of local communities and researchers from the University of Ruhuna and other agencies. The broader economic and cultural needs of communities living on the periphery of the reserve have also been taken into account by the Forest Department in the Reserve Management Plan, to which the species management plan is linked.

Sources: Sathurusinghe et al. (2010); Hunter and Heywood (2011)
Redmond et al. 2006). Weak governance structures at the local level and poor industrial practices make regulation and management of the trade difficult.

Market forces can create value for wildlife and provide incentives for private or community conservation, and also drive overexploitation of populations. In Cuc Phuong National Park, Vietnam, illegal hunting has reduced populations of large mammals and conflicts with local human populations hamper effective management (Compton and Le 1998; McNeely
1998). Many aquatic protected areas face problems of overfishing caused by incursion from neighbouring communities or by the illegal presence of larger-scale operations. On the Great Barrier Reef in Australia, large-scale prawn trawling, both licensed and illegal, has halved populations of some species; for every tonne of prawns caught, 6-10 tonnes of other marine life was killed. The Australian Government's research body, the Commonwealth Scientific and Industrial Research 
Organisation (CSIRO), identified 50 illegal operators in the 362400 square kilometre area (Australian Committee for IUCN 1999; Zinn and Vidal 1999).

Where such activities have been prohibited or curtailed, sometimes compensation has been offered for the loss of revenue (particularly if the use was legal). This is the case with medicinal plant harvesting in the Indian Himalaya (see Case Study 25.2). This is also often done in the case of ICCAs, where a collective decision to stop some resource-use activity, or change land use, is compensated through new livelihood opportunities like communitybased tourism or provision of land elsewhere. In the community-protected wetland of Mangalajodi, in India, a community decision inspired by a civil society organisation to stop hunting of waterfowl was followed up by an ecotourism venture that has employed some of the erstwhile hunters (Kothari 2010). In such instances, however, the compensatory measures may not match the scale of the loss.

Where well managed, hunting can be sustainable and contribute to protected area management and conservation (Case Study 25.6), and it is increasingly recognised that confronting the bushmeat problem, as in Africa, requires establishing legally regulated sustainable use of wild meat resources (Nasi et al. 2008). In some cases, this has been achieved through agreements with local communities and/or by making wildlife management the responsibility of the local communities. In many of the relatively new ICCAs, a mix of traditional and new restrictions may be adopted (see Chapter 7). In the State of Nagaland in India, for instance, several dozen villages have declared seasonal prohibitions on hunting, and/or designated forest areas where hunting is totally prohibited (Kothari and Pathak 2005). Private protected areas may involve sustainable hunting to raise revenue-for example, the commercially operated Campbell Private Game Reserve in South Africa provides hunting experiences resembling those of the Bushmen of the Kalahari, within sustainable limits (Campbell Private Game Reserve 2004, cited in Lockwood et al. 2006).

Tourist or 'trophy' hunting with substantial fees occurs in many forms of protected area across sub-Saharan Africa, southern Africa and Tanzania in particular. The bulk of these trophy-hunting activities take place on private lands and some communal lands, with some carried out in state-managed protected areas. In Tanzania, about half of all hunting concessions are located in state protected areas called game reserves, where no people reside, as well as game controlled areas (GCAs), where human residence and use have recently been prohibited under the Wildlife Conservation Act 2009. This provision of the 2009 Act is extremely problematic, as GCAs were, prior to 2009 , not exclusive protected areas, and nationwide are home to between 500000 and one million people. In 2013 there was a major conflict over the Loliondo GCA, following a government proposal that 1500 square kilometres of former community lands would become an exclusive GCA or 'wildlife corridor' (Ngoitiko and Nelson 2013). Such struggles over wildlife conservation, commercial uses such as hunting, and local land and resource rights have been debated in Tanzania for 50 years. Hunting in game reserves is based on division of these protected areas into 'blocks' or concession areas, and an annual quota for each block is granted by the Ministry of Natural Resources and Tourism. Hunting provides an important economic justification for retaining this land as wildlife habitat, although considerable weaknesses with respect to hunting governance and regulation, including corruption, are evident (Leader-Williams et al. 2009; Nelson et al. 2013).

In Namibia, under the communal conservancy model, communities generate revenue through photographic and hunting tourism, sales of live game and 'game cropping' for meat and skins. This approach has dramatically increased the social and economic value of wildlife for people, changing attitudes and leading to large-scale changes in land use from degraded pastoral land to wildlife conservation, with rebounding populations of species such as elephant and black and white rhino (Naidoo et al. 2011; Nelson et al. 2013).

Trophy hunting of big game in Pakistan has emerged as a conservation approach that helps enhance local livelihoods (Frisina 2000; Frisina and Tareen 2009). Markhor, urial and ibex are a few major wildlife species found in different parts of Pakistan that have an international market for trophy hunting. Populations of these and other species have, however, been on the decline since colonial times, due to large-scale hunting and habitat loss. The idea of organised, legal trophy hunting as a means of reversing this decline was first developed by the Agha Khan Rural Support Programme, WWF-Pakistan and the Society for Torghar Conservation Protection. Markhor hunting started in 1997 when the Convention on International Trade in Endangered Species of Wild Fauna and Flora (CITES) approved a quota. Regulated by national and provincial wildlife departments under law, 80 per cent of the proceeds from trophy hunting are returned to the local communities. Community elders through a traditional jirga (meeting of elders) impose a ban on any commercial activity or illegal hunting in their areas, and set rules for equitable distribution of the proceeds. With substantial income for collective benefits, local attitudes have become increasingly positive about conservation. There were 


\section{Case Study 25.6 Management of hunting in state-owned protected areas, northern Finland}

In northern Finland, including regions of Lapland, Kainuu and parts of Northern Ostrobothnia, hunting is allowed for local residents in most national parks and other protected nature reserves if it does not threaten conservation or recreational objectives. In northern Finland, there are about 50000 people with such rights. Hunting is also allowed for non-residents, with a licence, in most of the other protected nature reserves. Hunting is banned in strict nature reserves.

The regulations for hunting are described in the decree or law of each nature reserve. Restrictions can be temporal or territorial, and species-specific. Management plans are prepared with the participation of local stakeholders. All game species have national or regional hunting seasons outside the breeding or vulnerable periods. If a population becomes threatened, the hunting season is restricted through a decree by the Ministry of Agriculture and Forestry.

The main stakeholders with traditional use rights include reindeer herders represented by herding associations and their national federation (their area in northernmost Finland covers one-third of the country), and Sámi people who have their traditional homeland areas here. More than 90 per cent of this area is state owned and administered by Metsähallitus, the Finnish national protected area agency. The Sámi people have long traditions in reindeer herding and trapping of willow grouse (Lagopos lagopus). Game management associations represent the interests of resident hunters.

The results of wildlife censuses demonstrate natural fluctuations and long-term stability in the game populations in northern Finland. Based on this, the game management system can be considered ecologically sustainable. The bigger challenges relate to social sustainability, affecting the volunteer work on which depend the wildlife triangle censuses and control measures of invasive predators, the raccoon dog (Nyctereutes procyonoides) and American mink (Neovison vison).

- Mikko Rautiainen an estimated 200 urials (Ovis arientalis) and less than 100 markhors (Capra falconeri) in the Torghar area of Balochistan when the jirga resolved to try this approach; by 2005 , the markhor population increased to 2540 and that of the urial to 3145 (Arshad and Khalid 2008).

In the United States, management of huntingregardless of categorisation as sport, recreational, trophy or subsistence-is generally the domain of the individual States, all of which have publicly funded agencies tasked with this responsibility (Bolen and Robinson 2003; United States Fish \& Wildlife Service 2014). Federally recognised Native American tribes manage hunting separately from the State governments, and most have their own management agencies.

\section{Agriculture}

Both subsistence and market-oriented agriculture are widely practised in certain types of protected areas, especially (but not only) IUCN Category V (Amend et al. 2008). Crop-livestock systems are frequently supplemented by resources from natural ecosystems. Nearby forests and wetlands are used for a number of purposes including collection of leaf litter, pest control products, medicines, food, fodder and fuel.

Shifting cultivation, or swidden, is widely practised as a form of subsistence farming across the world, particularly in parts of Asia, Africa, the Pacific Islands and Central and South America (Heywood 1999; Cairns 2014). Typically under low population densities, and when practised by traditional swiddeners, shifting cultivation has minimal long-term impact on a tropical forest. Such a system is generally viewed as sustainable where the period the land lies fallow is between seven and 20 years (Shriar 1999). Several factors, including entry of market forces and increase in local populations, have in many places reduced the sustainability of swidden.

In some government protected areas, zoning defines areas where agriculture is permitted. In the National Park of American Samoa, the US National Park Service (NPS) has leased the land and marine environment in the park for 50 years from several villages, who wanted to protect the forest. The NPS manages the land and reefs within the park but the villagers reserve the right to traditional use, including subsistence agriculture, while clearing and cultivation are prohibited in primary and mature secondary forest (Graves 2004; NPS 2014). In Spain, at the La Garrotxa Volcanic Zone Natural Park in Catalonia, the park authorities actually encourage the revival of traditional horticultural practices as these are linked to the conservation of many elements of nature (Bassols Isamat et al. 2011).

Several ICCAs provide exemplary instances of such interactions-shaped as they are by the dynamic interaction of people and nature over time, and rich in agricultural biodiversity as well as wildlife and cultural and spiritual values. They can be seen as biocultural systems whose resilience is dependent on community practices. Many also contain important genetic reservoirs of the wild relatives of domesticated crops and livestock (Brown and Kothari 2011; van Oudenhoven et 
al. 2011). In Oaxaca, Mexico, 126 sites of community conservation spread over 375500 hectares incorporate agroforestry and agroecology systems, such as milpas and shade coffee plantations, making these areas important reservoirs of wildlife and agro-biodiversity. In the el Parque de la Papa (Potato Park) near Pisac, Peru, six indigenous Quechua communities are conserving their landscape for optimising ecologically sustainable, biologically diverse farming and pastoralism (Argumedo 2008).

\section{Livestock grazing and pastoralism}

Studies have found that certain levels of grazing are sustainable, but also they can be essential to maintain certain highly diverse grasslands, with the removal of people and livestock leading to decreases in biodiversity in the protected area (Infield 2003; Parr et al. 2010; Nelson 2012). In Africa and western Asia, nomadic pastoralists grazed cattle in some areas on a sustainable basis for centuries. Where traditional cultures were based on herding livestock, the systems they established over long periods have often shaped the landscape, with their use of it becoming integral to maintaining ecological processes and biodiversity (Farvar 2003; Borrini Feyerabend et al. 2004; see also references under the 'Agriculture' section above). In Europe, much of the biodiversity in protected areas has co-developed with traditional pastoral practices (Case Study 25.7).

Even where livestock grazing is not part of a longestablished biocultural landscape, it can sometimes be useful in meeting protected area management objectives. For instance, in Costa Rica, grazing has been used in the restoration of the dry tropical forest ecosystem of the Guanacaste National Park for seed dispersal, exotic grass control and generating local support (Evans 1999). In the Palo Verde Refuge, also in Costa Rica, livestock grazing has supported the conservation of a particular wetland (Vaughan et al. 1996).

Decisions on grazing livestock in protected areas, however, must be made very much on a case-by-case basis. In Australia, extensive research has shown that livestock grazing causes significant damage to alpine and subalpine native vegetation, soils and waterways in Kosciuszko National Park and the Alpine National Park (Williams 1990; Wahren et al. 1994). In some protected areas, pressures to increase agricultural production have led to overgrazing, but rather than prohibition, participatory measures have been developed to minimise the damage (Case Study 25.7). In many ICCAs (see Chapter 7)-for instance, community forests in

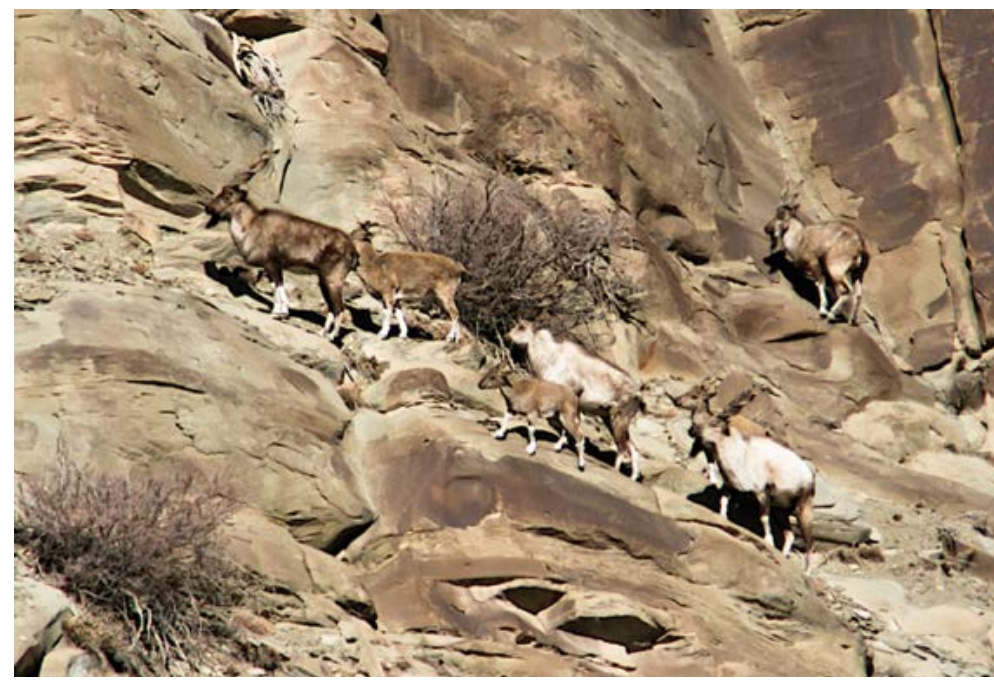

Markhor (Capra falconeri) at Torgarh Community Conserved Area, Balochistan, Pakistan

Source: Tahir Rasheed

South Asia-communities voluntarily regulate grazing through a temporary or seasonal stoppage of all grazing activity, allowing degraded landscapes to regenerate.

\section{Coastal and marine resource use}

Coastal ecosystems in marine protected areas (MPAs) often have significant resource use, for both subsistence and commercial purposes (Spalding et al. 2013). Harvests include edible resources such as finfish, shellfish, marine mammals and seaweeds; resources for construction such as mangrove poles, coral blocks, sand and lime; resources for ornamental use such as shells, pearls and coral; for scientific use, which includes a wide array of species; for industrial use, such as giant clams and species yielding pharmaceuticals; and for mariculture such as mussels and oysters. Increasingly, ecotourism and education are important components of the use of the marine environment.

The safeguarding of sustainable fisheries is in many cases a primary objective of the designation of the MPA. The community-based Eastport MPA on the island of Newfoundland in Canada was motivated by the local community's long historical reliance on fisheries, after the collapse of groundfish stocks and catch declines in lobster fisheries, as a means to safeguard lobster stocks (Charles and Wilson 2009). Likewise, part of the motivation for communities in establishing and managing the now extensive locally managed marine areas (LMMAs) network in the South Pacific is to ensure the sustainable flow of fisheries benefits from these areas (Govan 2009). 


\section{Case Study 25.8 Soufriere Marine Management Area, St Lucia}

The Soufriere Marine Management Area in St Lucia is a multiple-use area including no-take marine reserves, fishing priority zones and other use zones. Prior to its establishment in 1994, there were numerous ongoing conflicts between the local traditional fishers, tourists, day visitors and yachters cruising the West Indies. Visiting divers cut holes in fish traps to release reef fish; yachtsmen anchored in sandy bays, interfering with local fishing for coastal pelagic fish; and access to the beach and sea had been restricted by tourist facilities. The reef fish populations were under threat from illegal spearfishing and pot fishing, and anchors were damaging the reef (Salm et al. 2000).

In 1992 the Department of Fisheries and the Caribbean Natural Resources Institute initiated negotiation, conflict resolution and participatory planning. Mapping of all uses was undertaken, and a preliminary agreement was arrived at for zoning 11 kilometres of coastline. Implementation of this was successful, however, only for two to three years, after which it broke down due to violations by some parties, the agreement not having any legal backing. After a full institutional review, a new management regime was developed based on a clear agreed mission, transparent management structure and strong legal basis (Salm et al. 2000; Geoghegan and Renard 2002).

In 2005, the Soufriere Marine Management Area celebrated its tenth anniversary. A study prior to that showed that commercial fish biomass in the marine reserve had a fourfold increase and there was a threefold increase in the fishing zone. The area had become financially selfsufficient, thanks to diving and yacht mooring fees. Institutional capacity increased in all stakeholder groups and tourism was bringing benefits to the local community (Gell and Roberts 2002). Challenges continue to arise, but there is a commitment from all the stakeholders to deal with them.

\section{Global changes and resource use}

Projected climate change impacts on protected areas in many parts of the world will force a rethink of their role in biodiversity conservation and sustainable use (Hunter and Heywood 2011; see also Chapter 17). The political boundaries of protected areas are fixed but the biological landscape is not. Significant rethinking in the design of such areas will be necessary, which has major implications for protected area management (Schliep et al. 2008).

Global change is expected to drive the number of environmental refugees to increase by around 200 million by the middle of this century (Myers 1997). The impacts of this on the conservation and use of biodiversity could be significant in that these people will migrate into territories not able to support or feed them without large-scale disruption. It will also lead to increased incidents of conflict between resource users. By their very nature, displaced people rely heavily on their surrounding environment for food, fuel wood and other subsistence needs, often leading to forest and other resource degradation or loss (Hunter and Heywood 2011).

Achieving conservation and sustainable use of resources in these contexts will require a paradigm shift in how we approach protected area management, design and connectivity, and will necessitate more effective partnerships between protected area administrations, forestry and agricultural departments working through traditional agro-ecosystems and indigenous and social movements (Perfecto et al. 2009; Padulosi et al. 2011).

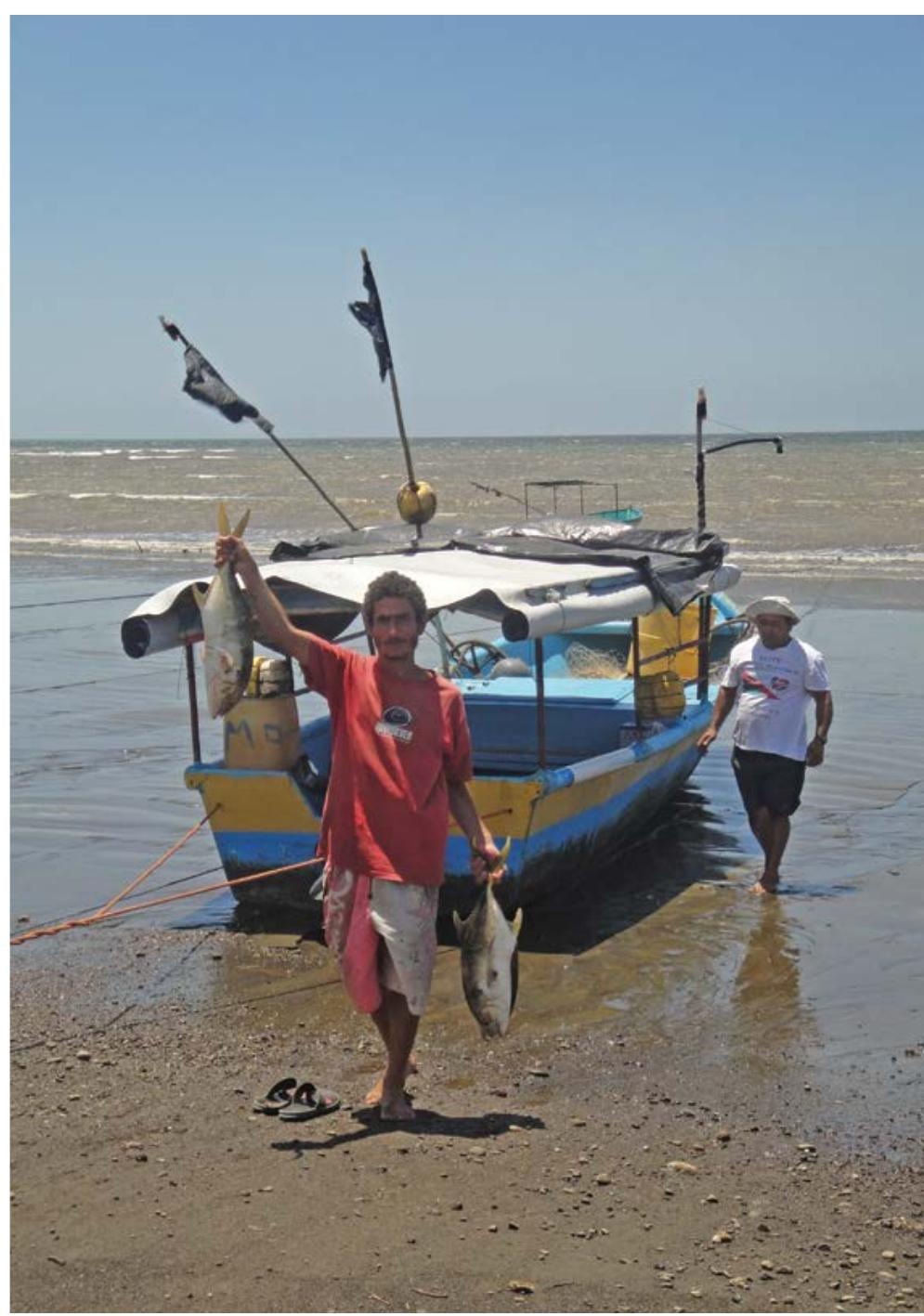

Tárcoles Marine Responsible Fishing Area, Costa Rica

Source: CoopeSolidar RL 


\section{Case Study 25.9 Countering external threats at Coron Island, the Philippines}

Often community struggles to maintain or revive sustainable use have been embedded in or led to wider political struggles for rights and control; this is especially the case of many ICCAs. The Tagbanwa people of the Philippines inhabit the stunningly beautiful limestone island of Coron for which they have established stringent use regulations (Ferrari and de Vera 2003) (see title page photo, Chapter 8). The forest resources are to be used for domestic purposes only. All the freshwater lakes but one are sacred. Entry to those lakes is strictly forbidden for all except religious and cultural purposes. The only lake accessible for highly regulated tourism is Lake Kayangan.

Until recently, the Tagbanwas' territorial rights were not legally recognised, leading to encroachment by migrant fishers, tourism operators, politicians seeking land deals and government agencies. This led to impoverishment of marine ecosystems and resources. In the mid 1980s, the islanders organised themselves into the Tagbanwas Foundation of Coron Island (TFCI), lobbying to regain management control over their natural resources. They first applied for a Community Forest Stewardship Agreement (CFSA), which was granted in 1990 over the 7748 hectares of Coron Island and a neighbouring island, Delian, but not over the marine areas. The Tagbanwa continued their struggle and, in 1998, were granted a Certificate of Ancestral Domain Claim for 22284 hectares of land and marine waters. Finally, in 2001, after having produced a high-quality map and an Ancestral Land Management Plan, they managed to obtain a Certificate of Ancestral Domain Title (CADT), which grants collective rights to land.

\section{Development and protected areas}

Large-scale projects that are part of national or subnational economic growth and development strategies can often be within or adjacent to a protected area. They include mining and other forms of extraction, hydro-electricity and irrigation projects, roads and highways, ports, sports and tourism facilities, communication and power transmission lines, urban expansion, and others. Many of these present serious threats to ecosystems and species, and to human populations, within protected areas.

There are few national or regional assessments of the level and kinds of threats that development poses to protected areas. The national survey of protected areas in India (Kothari et al. 1989) found that 62 per cent of the 293 protected areas surveyed had one or more of the following within them: roads, railway tracks, mining, dams, canals, industry or transmission lines. A recent study by the Indian NGO Kalpavriksh found that between 1998 and 2009, nearly 300 projects that required diversion of lands within protected areas came to the Central Government's National Board for Wildlife for approval; while many remained pending a decision, of those disposed of, most were cleared and few rejected (Menon et al. 2010). Interestingly, almost all mining proposals were approved, which is hard to understand given that mining is extremely damaging.

One of the most discussed issues in regard to the infrastructure development affecting protected areas in Central Europe is the building of motorways and highways. Motorways and highways very often cross habitats or important migration corridors of protected species such as brown bears (Ursus arctos), Eurasian lynx (Lynx $\operatorname{lyn} x$ ), wild cats and wolves (Canis lupus). Find'o et al. (2007) found the majority of bear-vehicle collisions happened during the period when bears require high levels of nutritious food, from mid July until hibernation in November-December, when they cover big areas crisscrossed by roads. The result is that many bear-vehicle collisions are happening within and outside protected areas. This is a serious problem globally, though there have been recent advances in the design of overpasses and underpasses that enable freer movement of wildlife from one side to the other (see, for example, Locke 2010).

In Latin America, during most of the past century, deforestation was due to expansion in farming. In recent years, however, greater deforestation has taken place mainly due to corporate agencies and their activities. With the rise in intensity of consumption patterns due to globalisation, there has been increased pressure on protected areas for biofuel and soybean production, energy (geothermal and hydro-electricity), mining and oil. Many countries are currently facing enormous threats from governments trying to degazette, downsize or downgrade areas (WWF 2014). For example, soybean production in Argentina, Paraguay and Brazil, and more recently in Bolivia, has encroached on many hundreds of thousands of hectares of protected areas. Palm-oil plantations for biofuel production are likely to be the biggest cause of land-use changes in tropical Asia, including within government protected areas and on many indigenous and community lands that could constitute ICCAs (Campbell et al. 2008). 


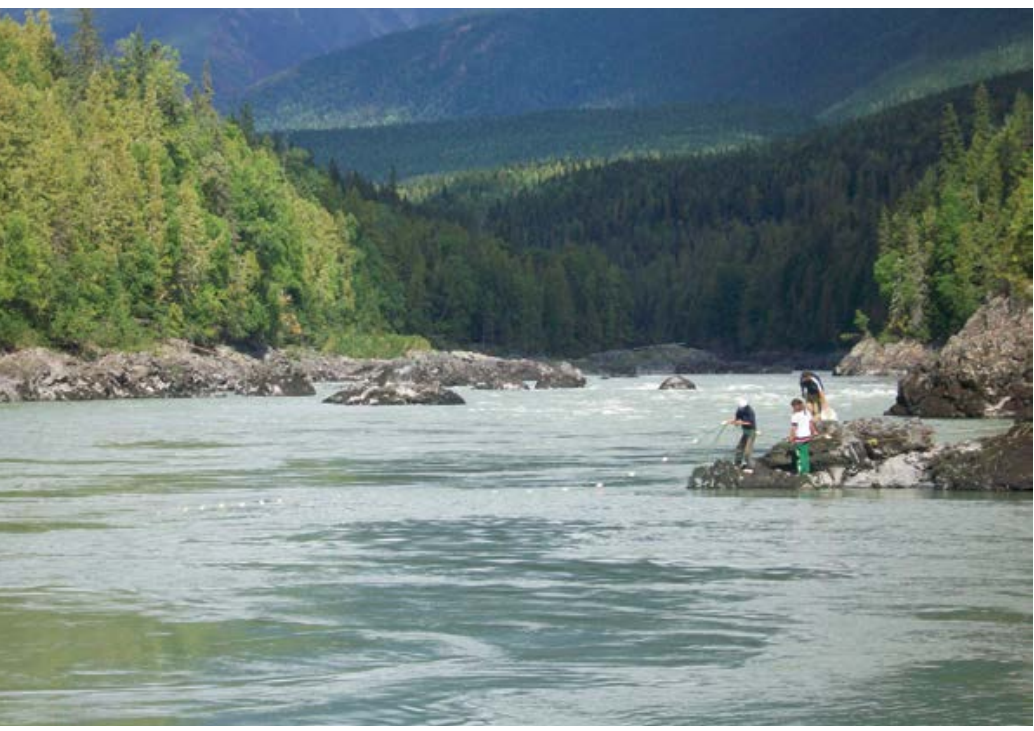

Skeena River, Gixtsan Indigenous Territory, Canada

Source: Francois Depey

ICCAs and other areas crucial for conservation are threatened elsewhere too. In Chile, a legal battle including at the Inter American Court for Human Rights has been going on between the Government and the MapuchePehuenche indigenous groups due to the construction of several hydro-electricity dams in the BioBio River (OLCA 2014). In Brazil, the construction of the Belo Monte Dam will have devastating consequences in an area of more than 1500 square kilometres of rainforest and will result in the forced displacement of between 20000 and 40000 people (Washington Post 2013). The need for 'clean energy' (itself a misnomer, given that large reservoirs have serious ecological and climate change impacts) has been placed well above the need for conservation and the rights of communities. The Skeena watershed in British Columbia, Canada, which is home to several indigenous groups and contains significant wildlife, is under threat from proposed oil and gas pipelines, mines, commercial fisheries, forestry and powerlines (Skeena Watershed Conservation Coalition 2014; SkeenaWild Conservation Trust 2014).

In the ecozone of India's Great Himalayan National Park (see Case Study 25.2), there are substantial ecological changes caused or threatened by mega-hydro-electricity projects such as the Parvati Hydel Project (Chhatre and Saberwal 2006). More than 1000 hectares of prime forest land within the protected area was diverted for hydroelectricity development, and several more big and small such projects on various streams adjacent to the park are further restricting the home ranges of different species. This is ironic considering the less-intrusive activities of villagers within the adjacent GHNP were stopped in the name of conservation (see Case Study 25.2).

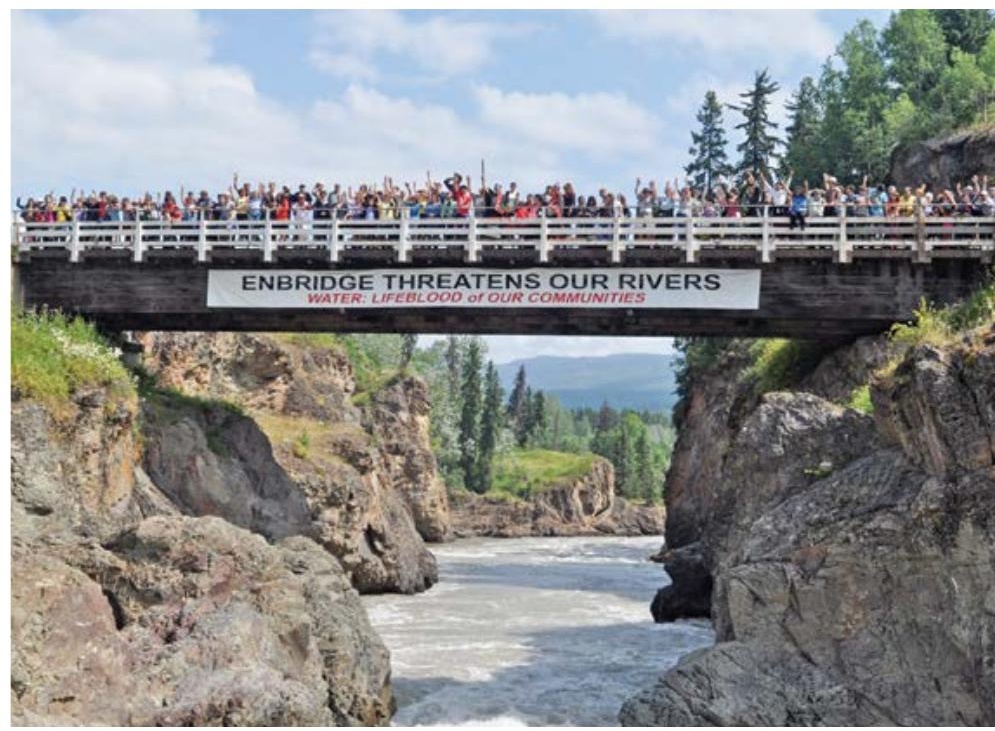

Resistance against proposed pipeline through Skeena indigenous territories

Source: Leah Macknak

ICCAs, PPAs and other conservation initiatives that do not have formal protected area status, or official recognition, face even greater threats from development and infrastructure projects (Borrini-Feyerabend et al. 2010; Kothari et al. 2012). At least in the case of formal protected areas, most countries have some legal or policy mechanisms that can be used to regulate such developments, but this is not the case for unrecognised conservation sites and initiatives.

Due to the large size of eastern and southern Africa's protected area network, and the scale of the region's economic development needs and aspirations, most protected area management agencies have frameworks for carrying out general management plans that rationalise the development of infrastructure such as roads, water, staff facilities, tourism facilities and services, as well as planning for conservation and landscape management. These frameworks, often described in national wildlife or protected area legislation, also tend to define requirements for environmental and social impact assessments (ESIAs) to be carried out when planning infrastructure developments in protected areas. ESIA requirements and procedures are in turn a central feature of environmental management acts, which, for example, were adopted in Kenya, Uganda and Tanzania during the 1990s and have gradually been implemented, to varying degrees, across the region (see Chapter 24).

The nature of ESIA processes and findings, and the legally actionable nature of environmental legislation in terms of holding state decision-makers accountable for environmental regulatory decisions and impacts, plays a major role in debates around infrastructure development 
in major regional protected areas. The most notable among these in recent years has been the proposal by the Tanzanian Government to build a highway across the northern part of Serengeti National Park in order to link different urban areas in that part of the country. Biologists have raised concerns that such a highway could lead to substantial increases in mortality in the annual north-south wildebeest migration between the Serengeti Plains and the Maasai Mara National Reserve to the north in Kenya (Dobson et al. 2010; Norwegian University of Science and Technology 2013). A number of compromise designs for a road to link Lake Victoria's large human populations to urban centres to the east have been proposed, and additional ESIA studies commissioned, and the ultimate design of this road remained unclear in 2014. A similar though more spatially limited debate took place in Kenya 2010s around a new Nairobi ring-road that would have encroached on the boundaries of Nairobi National Park, which lies adjacent to the nation's capital city. This road was recently successfully challenged in court and its ultimate design and construction are now uncertain (Koross 2013).

In southern Tanzania, a major new uranium mine has been developed on land that was recently excised from the Selous Game Reserve (Tairo 2014). The Selous reserve is a World Heritage property, where mining is not permitted, so the excision first had to be approved by the UNESCO World Heritage Committee. Such processes, however, raise the spectre of degazettement of other protected areas, even those with such a high level of international recognition, when there are competing commercial or infrastructure interests that come into play (see Case Study 25.2).

In a global context, there is little balance between development and conservation. More generally, the global context of economic growth, the rise in consumption levels, economic and financial globalisation, climate change and other such factors is having a serious impact on various ecosystems. The Millennium Ecosystem Assessment, focusing on the ecosystem changes that have taken place on a global scale in the past 50 years, predicts that the harmful consequences of the degradation that has set in on Earth may become worse in the next 50 years (MEA 2005). Numerous editions of the Global Biodiversity Outlook (CBD 2010) have given similar warnings.

The long-term sustainability of protected areas and conservation efforts will depend on the establishment of effective institutional mechanisms and interventions to better address the real causes of biodiversity loss. Protected area authorities usually have responsibility only for management within the reserves, yet most threats emanate from outside the protected area boundaries. This requires protected area managers to work with other agencies and the private sector to ensure that considerations of park integrity and conservation are integrated with local and regional planning. In some cases, a single agency may have responsibility for both protected area management and sectoral development planning-for example, in Madagascar, the National Association of Management of Protected Areas (Association National de Gestion des Aires Protégées: ANGAP) has responsibility for both tourism and protected areas but this is the exception, rather than the rule. Local governments can be valuable partners to ensure that development planning complements protected area goals. Ensuring such cooperation requires not only good personal relationships, but also strong support and coordination at the state/provincial level and between ministries at the national level. Local governments are more likely to support conservation where they recognise the benefits that protected areas provide either in fuelling local economic growth (for example, tourism in many countries) or in maintaining crucial ecosystem functions like water supplies (for example, Chingaza National Park in Colombia, the water source for the capital, Bogota; see Natural National Parks of Colombia 2008).

One of the few attempts at dealing with this systematically and at a global level is the IUCN's advocacy to safeguard certain categories of protected areas. For instance, at the second IUCN World Conservation Congress (in Amman, Jordan, in 2000), members adopted Recommendation 2.82 (protection and conservation of biological diversity of protected areas from the negative impacts of mining and exploration), which: 1) calls on state members of the IUCN to prohibit mining exploration and extraction in Category I-IV protected areas; 2) recommends strict controls over such activities in Category $\mathrm{V}$ and VI protected areas; 3) urges strict standards governing changes to protected area boundaries to accommodate mining activities; and 4) recommends environmental impact assessments to ensure that mining activities outside protected areas do not negatively impact on them.

While this has not been widely accepted, the IUCN and UNESCO did manage to persuade the International Council of Mining and Metals (ICMM) to a voluntary moratorium on mining in World Heritage sites in 2003 (ICMM 2003). But this leaves out many protected areas that are just as important for conservation; the moratorium is only voluntary and liable to violation in several countries where environmental governance is weak; the ICMM 
does not include many mining companies; and, possibly most importantly, protected areas that are not formally recognised (like most ICCAs and PPAs, as pointed out above and in Chapter 7) receive no protection from it. Mining critics allege that the agreement is mere 'greenwashing', with the industry paying little or no cost but gaining credibility. In addition, some governments are often willing to excise land from protected area boundaries to enable such activities (such as the example of Selous given above). New developments in oil exploration, including fracking, threaten to further damage natural ecosystems in many parts of the world.

\section{Conclusion}

A few concluding remarks are in order for both the aspects dealt with in this chapter: resource uses, and development projects.

Resource use can contribute in a number of ways to achieving conservation objectives, in ecological terms (for example, where biodiversity values are maintained by use), economic terms (for example, where allowing sustainable use generates revenue for park management) and in social terms (for example, where allowing local sustainable use builds or maintains local support and 'buy-in' for conservation). Conservation policy and practice need to be flexible to accommodate existing resource use by local communities, especially those crucial for survival and livelihoods, where they are or can be made compatible with conservation objectives (assuming these objectives have been set in democratic ways, using the best available knowledge and the 'good governance' principles and practices outlined in Chapter 7). This tends to often happen in the natural course of events in the case of ICCAs, and to some extent in comanaged protected areas, but may need special attention in many government-managed protected areas.

Where such resource use can in no situation be compatible with conservation objectives, action has been taken in many instances to place restrictions, and simultaneous provision or facilitation of alternatives (for example, in Kibale National Park; see Case Study 25.4). However, these alternatives may not always adequately compensate the losses (as in the case of the Great Himalayan National Park; Case Study 25.2), or may not be culturally appropriate and economically feasible. Such shortcomings are a key lesson from the ICDP initiatives in various parts of the world (as discussed above), and need to be specially considered in protected area management planning.

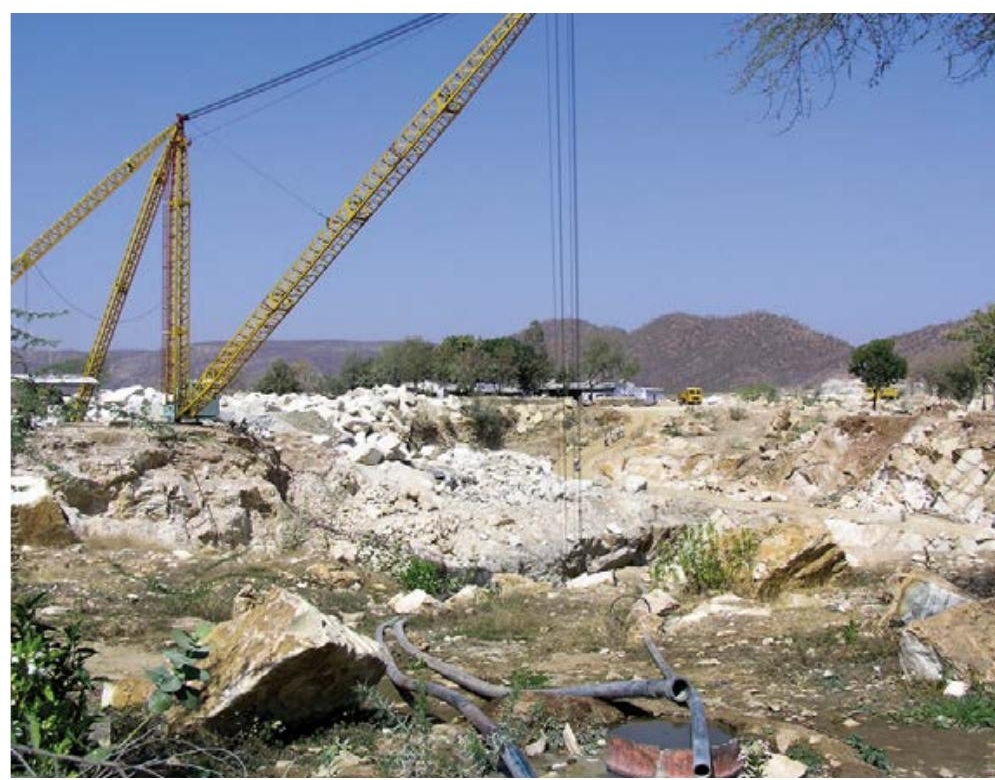

Mining inside Sariska Tiger Reserve, India

Source: Ashish Kothari

It is important to realise that every situation is unique; exactly what works to make resource use sustainable at one site may not work at another. Some commonalities between sites and situations can be drawn out, and lessons learnt that can be taken across sites, but for every site and situation, fresh assessment, study and monitoring based on local and external knowledge are necessary. Inter and intra-community conflicts, especially related to land tenure and holding, access to resources and distribution of the benefits of such uses, need to be resolved for the effective participation of the whole community in conservation.

Security of tenure, territorial rights, resource rights, the right to participate in decision-making and concomitant responsibilities towards conservation and fellow people are increasingly considered crucial for the involvement of local populations in all kinds of protected area governance types, as well as for the sake of clarity of roles and responsibilities of government agencies in the case of government-managed protected areas (see Chapter 7).

Effective resource management needs to be based on good information, which may be either embedded in indigenous and traditional science, knowledge and cultural practices or derived by modern scientific methods. Indigenous/traditional and local knowledge can be of central importance in mapping habitat and resource use areas and establishing workable and socially acceptable resource use zones.

It is important to incorporate strategies to deal with various kinds of social and economic lack of privilege, including gender inequities, ethnic biases and 
inequalities, elite capture of benefits, and other factors that could distort the equitable distribution of decisionmaking powers and capacities, and of conservation benefits.

Lessons can be learnt across various governance typesfor example, many ICCAs have worked out adaptive modes and institutional processes of figuring out levels and kinds of resource use that do not endanger the relevant ecosystems and species, from which government and others can learn. Many governmentmanaged protected areas have evolved robust systems of management planning, from which ICCAs could learn. At national and subnational levels, platforms for such sharing and learning need to be created.

Ongoing and potential global factors, such as climate change, are likely to alter the situation of resource use within and around protected areas. Considerable resilience and flexibility, connectivity across large landscapes and seascapes, and collaboration amongst various rights-holders and stakeholders will be needed to adapt to such changes.

Development and infrastructure projects and processes that have an impact on protected areas and other conservation sites need to go through knowledge-based and democratic processes of screening and decision-making, in which the protected area authorities and local populations should have a central voice. Ideally, national policies should designate sites that are crucial for ecological and biodiversity conservation purposes as no go areas to large-scale activities that will have detrimental impacts; this should apply also to the 'catchment' or 'impact area' outside the protected area where such activities could have an impact on the protected area.

While such measures, or more global efforts such as the IUCN's advocacy for certain categories of protected areas to be off-limits for mining, are steps towards limiting the adverse impacts of development on protected areas, there is also increasing focus on the need to reorient the framework of development itself. Without this, widespread ecological damage by extractive industry, infrastructure and other such 'development' processes that are inherent to a model that places economic growth above all else will continue to undermine both biodiversity and communities, especially those most dependent on the natural environment. One strand of such reorientation is taking the pathway of 'sustainable development', in which environmental impacts are integrated more centrally into development planning, and the economy moves towards greener processes, technologies, accounting and other such measures. This is the thrust of the outcome declaration from the Rio +20
Conference on Sustainable Development (UNCSD 2012), and of the ongoing negotiations for a post2015 agenda to replace the Millennium Development Goals (Sustainable Development Knowledge Platform 2014). Another strand holds that this will be inadequate since development remains dependent on economic growth, which is impossible to sustain in a world with ecological limits. It therefore calls for a fundamental shift in direction towards non-growth-based strategies and indicators of human wellbeing that are in sync with nature's limits, and more attuned to directly achieving security of basic needs (water, food, shelter, sanitation, clothing, learning, health, social relations, and so on) for all (Rijnhout et al. 2014). This volume is not the place to go into these issues in detail, but protected area managers, rights-holders, stakeholders and all those interested in conservation will need to engage themselves in one way or another with this larger context of developmental and wellbeing pathways.

\section{References}

Recommended reading

\section{Adams, W. M. (2004) Against Extinction: The story of conservation, Earthscan, London.}

Alers, M., Bovarnick, A., Boyle, T., Mackinnon, K. and Sobrevila, C. (2007) Reducing Threats to Protected Areas: Lessons from the field, The World Bank and United Nations Development Programme, New York.

Amazon Conservation Association (2013) Amazon Conservation Association. <www. amazonconservation.org/ourwork/livelihoods.html>

Amend, S. and Amend, T. (1995) National Parks without People? The South American experience, IUCN and Parques Nacionales y Conservacion Ambiental, Quito.

Dd Amend, T., Brown, J., Kothari, A., Phillips, A. and Stolton, S. (eds) (2008) Protected Landscapes and Agrobiodiversity Values, Values of Protected Landscapes and Seascape Volume 1, IUCN and GTZ, Kasparek Verlag, Heidelberg.

Anderson, D. and Grove, R. H. (eds) (1987) Conservation in Africa: Peoples, policies and practice, Cambridge University Press, Cambridge. 
Argumedo, A. (2008) 'The Potato Park, Peru: conserving agrobiodiversity in an indigenous biocultural heritage area', in T. Amend, J. Brown, A. Kothari, A. Phillips and S. Stolton (eds) Protected Landscapes and Agrobiodiversity Values, Values of Protected Landscapes and Seascape Volume 1, pp. 45-58, IUCN and GTZ, Kasparek Verlag, Heidelberg.

Arshad, M. and Khalid, U. (2008) Ungulate population estimate of Torghar, Pakistan, Unpublished manuscript.

Australian Committee for IUCN (1999) Great Barrier Reef World Heritage Area: Condition, management and threats, Australian Committee for IUCN, Sydney.

Bassi, M. and Tache, B. (2011) 'The community conserved landscape of the Borana Oromo, Ethiopia: opportunities and problems', Management of Environmental Quality: An International Journal 22(2): 174-86.

Bassols Isamat, E., Perramon Ramos, B., Mallarach Carrera, J. M. and Falgarona Bosch, J. (2011) 'The conservation of the agrobiodiversity of La Garrotxa Volcanic Zone Natural Park', Management of Environmental Quality: An International Journal 22(2): 233-49. <www.emeraldinsight.com/journals. htm? issn $=1477-7835 \&$ volume $=22 \&$ issue $=2 \&$ PHPS $\mathrm{ESSID}=$ gnubmq2ks8b72aepclqldtg7v2>

Battharai, B., Ojha, H., Ram Banjade, M. and Luintel, H. (2003) Effect of NTFP Market Expansion on Sustainable Local Livelihoods, Forest Resource Action Team, Nepal.

Baviskar, A. (2003) 'States, communities and conservation: the practice of ecodevelopment in the Great Himalayan National Park', in V. Saberwal and M. Rangarajan (eds) Battles over Nature: Science and the politics of conservation, Permanent Black, New Delhi.

Dd Bélair, C., Ichikawa, K., Wong, B. Y. L. and Mulongoy, K. J. (eds) (2010) Sustainable use of biological diversity in socio-ecological production landscapes. Background to the 'Satoyama Initiative for the benefit of biodiversity and human wellbeing', Technical Series No. 52, Secretariat of the Convention on Biological Diversity, Montreal.

Berkes, F. (1989) Common Property Resources: Ecology and community-based sustainable development, Belhaven Press, London.
Bertzky, B., Corrigan, C., Kemsey, J., Kenney, S., Ravilious, C., Besançon, C. and Burgess, N. (2012) Protected Planet Report 2012: Tracking progress towards global targets for protected areas, IUCN, Gland, and UNEP-WCMC, Cambridge.

Bezaury-Creel, J. and Gutiérrez Carbonell, D. (2009) Areas naturales protegidas y desarrollo social en México, en Capital natural de México. Volume II: Estado de conservación y tendencias de cambio [Protected Areas and Social Development in Mexico: Natural capital of Mexico. Volume II: State of conservation and changing trends], Conabio, México.

Bird, R. B., Tayor, N., Codding, B. F. and Bird, D. W. (2013) 'Niche construction and Dreaming logic: Aboriginal patch mosaic burning and varanid lizards (Varanus gouldii) in Australia', Proceedings of the Royal Society B: Biological Sciences 280(1772): 20132297.

Bolen, E. G. and Robinson, W. L. (2003) Wildlife Ecology and Management, 5th edn, Pearson Benjamin Cummings, San Francisco.

Borrini-Feyerabend, G., Kothari, A. and Oviedo, G. (2004) Indigenous and Local Communities and Protected Areas: Towards equity and enhanced conservation, IUCN WCPA Best Practice Series No. 11, IUCN, Cambridge.

Borrini-Feyerabend, G. (2010) Strengthening what works: recognising and supporting the conservation achievements of indigenous peoples and local communities, Briefing Note No. 10, IUCN WCPACEESP TILCEPA, ICCA Consortium, CEESP TGER, GEF SGP, WAMIP, Cenesta, and GTZ, Gland.

Brandon, K., Redford, K. H. and Sanderson, S. E. (eds) (1998) Parks in Peril: People, politics and protected areas, The Nature Conservancy and Island Press, Washington, DC.

Brown, J. and Kothari, A. (2011) 'Traditional and agricultural landscapes and community conserved areas: an overview', Management of Environmental Quality: An International Journal 22(2): 139-53.

BurrenLIFE (2014) The BurrenLIFE Project, Carron, Ireland. <www.burrenlife.com/> 
Cadman, M., Petersen, C., Driver, A., Sekhran, N., Maze, K. and Munzhedzi, S. (2010) Biodiversity for Development: South Africa's landscape approach to conserving biodiversity and promoting ecosystem resilience, South African National Biodiversity Institute, Pretoria. <www.undp.org/content/ undp/en/home/librarypage/environment-energy/ ecosystems_and_biodiversity/biodiversity_ fordevelopment/>

Cairns, M. F. (2014) Shifting Cultivation and Environmental Change: Indigenous people, agriculture and forest conservation, Routledge, Oxford.

Campbell, A., Kapos, V., Lysenko, I., Scharlemann, J. P. W., Dickson B., Gibbs H. K., Hansen, M. and Miles, L. (2008) Carbon Emissions from Forest Loss in Protected Areas, UNEP World Conservation Monitoring Centre, Cambridge.

Campbell, L., Haalboom, B. and Trow, J. (2007) 'Sustainability of community-based conservation: sea turtle egg harvesting in Ostional (Costa Rica) ten years later', Environmental Conservation 34(2): $122-31$.

Chamberlain, J. L., Cunningham, A. B. and Nasi, R. (2004) 'Diversity in forest management: non-timber forest products and bush meat', Renewable Resources Journal (Summer): 11-19.

Charles, A. (2011) 'Human rights and fishery rights in small-scale fisheries management', in R. S. Pomeroy and N. L. Andrew (eds) Small-Scale Fisheries Management: Frameworks and approaches for the developing world, pp. 59-74, CAB International, Wallingford, UK.

Charles, A. and Wilson, L. (2009) 'Human dimensions of marine protected areas', ICES Journal of Marine Science 66: 6-15.

Chhatre, A. and Agrawal, A. (2009) 'Trade-offs and synergies between carbon storage and livelihood benefits from forest commons', Proceedings of the National Academy of Sciences 106(42): 17 667-70. <doi:10.1073/pnas.0905308106>

Chhatre, A. and Saberwal, V. K. (2006) Democratizing Nature: Politics, conservation and development in India, Oxford University Press, New Delhi.

Chhetri, P., Mugisha, A. and White, S. (2003)

'Community resources use in Kibale and Mt Elgon National Parks, Uganda', Parks 13: 28-49.
DDild, B. (ed.) (2004) Parks in Transition: Biodiversity, rural development, and the bottom line, Earthscan, London.

Compton, J. and Le, Q. H. (1998) Borderline: An assessment of wildlife trade in Vietnam, WWF Indochina Programme, Hanoi.

Convention on Biological Diversity (CBD) (2004) Addis Ababa Principles and Guidelines, Convention on Global Biodiversity Secretariat, Montreal. $<$ www.cbd.int/sustainable/addis.shtml>

Convention on Global Biodiversity (CBD) (2010) Global Biodiversity Outlook, Convention on Global Biodiversity Secretariat, Montreal. <www.cbd.int/ $\mathrm{gbo} />$

Convention on International Trade in Endangered Species of Wild Fauna and Flora (CITES) (2000) Bushmeat as a trade and wildlife management issue, CoP11 Doc. 11.44, Eleventh Meeting of the Conference of the Parties, 10-20 April, Gigiri Kenya. <www.cites.org/eng/cop/11/doc/44.pdf>

Convention on International Trade in Endangered Species of Wild Fauna and Flora (CITES) (2013) Status of African elephant populations and levels of illegal killing and the illegal trade in ivory: a report to the African Elephant Summit, December 2013, CITES Secretariat, IUCN/SSC African Elephant Specialist Group and TRAFFIC International, Geneva.

Danielsen, F., Jensen, A. E., Alviola, P. A., Balete, D. S., Mendoza, M., Tagtag, A., Cistodio, C. and Enghoff, M. (2005) 'Does monitoring matter? A quantitative assessment of management decisions from locallybased monitoring of protected areas', Biodiversity and Conservation 14: 2633-52.

Das, P. (2007) 'The politics of participatory conservation - the case of Kailadevi Wildlife Sanctuary, Rajasthan', in G. Shahabuddin and M. Rangarajan (eds) Making Conservation Work, pp. 113-46, Permanent Black, New Delhi.

de Beer, F. (2013) 'Community-based natural resource management: living with Alice in Wonderland?', Community Development Journal 48(4 October): 555-70. <journals.ohiolink.edu/ejc/article.cgi?i $s s n=00103802 \&$ issue $=v 48 i 0004 \&$ article $=555$ cnrmlwaiw> 
Desor, S. (2013) Citizens' report 2013 on community forest rights under Forest Rights Act, Kalpavriksh, Pune, and Vasundhara, Bhubaneshwar, with Oxfam India, Delhi, on behalf of Community Forest Rights Learning and Advocacy Process.

Dobson, A. P., Borner, M., Sinclair, A. R. E., Hudson, P. J., Anderson, T. M., Bigurube, G. and Davenport, T. B. B. (2010) 'Road will ruin Serengeti', Nature 467(7313): 272-3.

Dowie, M. (2009) Conservation Refugees: The hundredyear conflict between global conservation and native peoples, MIT Press, Cambridge, MA.

Drew, J. A. (2005) 'Use of traditional ecological knowledge in marine conservation', Conservation Biology 19(4): 1286-93.

Dudley, N. (ed.) (2008) Guidelines for Applying Protected Area Management Categories, IUCN, Gland.

Evans, S. (1999) The Green Republic: A conservation history of Costa Rica, University of Texas Press, Austin.

Failing, L., Gregory, R. and Harstone, M. (2007) 'Integrating science and local knowledge in environmental risk management: a decision-focused approach', Ecological Economics 64: 47-60.

FairWild (2009) FairWild Foundation, Cambridge and Zurich. <www.fairwild.org/>

Farvar, M. T. (2003) 'Myths, challenges and questions on mobile pastoralism in West Asia', Policy Matters 12: 31-41.

Ferrari, M. F. and de Vera, D. (2003) 'A "participatory" or a "rights-based" approach? Which is best for protected areas and indigenous peoples in the Philippines?', Policy Matters 12: 166-70.

Find'o, S., Skuban, M. and Koreň, M. (2007) Brown Bear Corridors in Slovakia, Carpathian Wildlife Society, Slovakia.

Food and Agriculture Organisation (FAO) (2010) Second Report on the State of the World's Plant Genetic Resources for Food and Agriculture, Food and Agriculture Organisation, Rome.

Food and Agriculture Organisation (FAO) (2012) The State of World Fisheries and Aquaculture, Food and Agriculture Organisation, Rome.
Fonseca, A. (2009) Decimosexto Informe Estado de la Nación en Desarrollo Sostenible. Informe Final. Estado de la Nación en la zona marino costera [Sixteenth State of the Nation in Sustainable Development. Final Report: State of the nation in coastal and marine areas], Proyecto Estado de La Nación Costa Rica, San José.

Friedlander, A., Sladek Nowlis, J., Sanchez, J. A., Appeldoorn, R., Usseglio, P., McCormick, C., Bejarano, S. and Mitchell-Chui, A. (2003) 'Designing effective marine protected areas in Seaflower Biosphere Reserve, Colombia, based on biological and sociological information', Conservation Biology 17(6): 1769-84.

Frisina, M. R. (2000) Suleiman markhor (Capra falconeri jerdoni) and Afghan urial (Ovis orientalis cycloceros) population status in the Torghar Hills, Balochistan Province, Pakistan, Unpublished report to the Society for Torghar Environmental Protection and the United States Fish and Wildlife Service.

Frisina, M. R. and Tareen, S. N. A. (2009)

'Exploitation prevents extinction: case study of endangered Himalayan sheep and goats', in B. Dickson, J. Hutton and B. Adams (eds) Recreational Hunting, Conservation and Rural Livelihoods: Science and practice, pp. 141-56, Wiley-Blackwell, Oxford.

Galland, P. (2013) Appraisal Report: Retezat National Park with extension to Piatra Craiului (Romania), Convention on the Conservation of European Wildlife and Natural Habitats, T-PVS/DE(2013)3, Council of Europe. <wcd.coe.int/ViewDoc. jsp?id $=2042185 \&$ Site $=>$

Galvin, M. and Haller, T. (2008) People, Protected Areas and Global Change: Participatory conservation in Latin America, Africa, Asia and Europe, NCCR North-South, University of Bern, Bern.

Gell, F. R. and Roberts, C. M. (2002) The Fishery Effects of Marine Reserves and Fishery Closures, WWF, Washington, DC.

Geoghegan, T. and Renard, Y. (2002) 'Beyond community involvement: lessons from the insular Caribbean', Parks (Special Issue on Local Communities and Protected Areas) 12(2): 16-26.

Gibson, C. C. (1999) Politicians and Poachers: The political economy of wildlife policy in Africa, Cambridge University Press, Cambridge. 
Govan, H. (ed.) (2009) Status and Potential of Locally Managed Marine Areas in the South Pacific: Meeting nature conservation and sustainable livelihood targets through widespread implementation of LMMAs, Initiative for the Protection and Management of Coral Reefs in the Pacific, SPREP/WWF/ WorldFish-Reefbase/CRISP, Nouméa.

Govan, H., Jupiter, S. and Comley, J. (2012) 'Recognition and support of ICCAs in Fiji', in A. Kothari, with C. Corrigan, H. Jonas, A. Neumann and H. Shrumm (eds) Recognising and Supporting Territories and Areas Conserved by Indigenous Peoples and Local Communities: Global overview and national case studies, $\mathrm{pp}$. 138-9, CBD Technical Series No. 64, Secretariat of the Convention on Biological Diversity, ICCA Consortium, Kalpavriksh and Natural Justice, Montreal.

Graves, A. (2004) Mapping Subsistence Agriculture in the National Park of American Samoa, National Park Service, US Department of the Interior, Washington, DC. <www.nps.gov/gis/mapbook/ tech/30.html>

Gubbi, S., Linkie, M. and Leader-Williams, N. (2008) 'Evaluating the legacy of an integrated conservation and development project around a tiger reserve in India', Environmental Conservation 35: 331-9. <doi:10.1017/S0376892908005225>

Gugić, G. (2009) Managing Sustainability in Conditions of Change and Unpredictability: The living landscape and floodplain ecosystem of the Central Sava River Basin, Lonjsko Polje Nature Park Public Service, Krapje, Croatia.

Hackel, J. D. (1999) 'Community conservation and the future of Africa's wildlife', Conservation Biology 13: 726-34.

Harper, S., Zeller, D., Hauzer, M., Pauly, D. and Sumaila, R. U. (2013) 'Women and fisheries: contribution to food security and local economies', Marine Policy 39: 56-63. <doi:10.1016/j. marpol.2012.10.018>

Hayes, T. M. (2006) 'Parks, people, and forest protection: an institutional assessment of the effectiveness of protected areas', World Development 34(12): 2064-75.
Heywood, V. H. (1999) 'Trends in agricultural biodiversity', in J. Janick (ed.) Perspectives on New Crops and New Uses, pp. 2-14, ASHS Press, Alexandria, VA.

Homewood, K. M. and Rodgers, W. L. (1991) Maasailand Ecology: Pastoralist development and wildlife conservation in Ngorongoro, Tanzania, Cambridge University Press, Cambridge.

Hunter, D. and Heywood, V. H. (2011) Crop Wild Relatives: A manual of in situ conservation, Earthscan, London.

Infield, M. (2003) 'National parks as cultural entities', Policy Matters 13: 64-70.

International Council on Mining and Metals (ICMM) (2003) ICMM Position Statement on Mining and Protected Areas, International Council on Mining and Metals, London. <www.icmm.com/publication s/497ICMMPositionStatementonMiningandProtec tedAreas.pdf>

International Union for Conservation of Nature (IUCN) (2000) IUCN Policy Statement on Sustainable Use of Wild Living Resources, Resolution 2.29 of the first World Conservation Congress, IUCN, Gland.

International Union for Conservation of Nature (IUCN) (2004) 'Themesheet I6: Octopus and sea cucumber fisheries', in Managing Marine Protected Areas: A toolkit for the Western Indian Ocean, IUCN Eastern African Regional Programme, Nairobi. <wiomsa.org/mpatoolkit/Themesheets/ I6_Octupus_and_sea_cucumber_fisheries.pdf>

International Union for Conservation of Nature (IUCN), United Nations Environment Programme (UNEP) and World Wildlife Fund (WWF) (1980) World Conservation Strategy: Living resource conservation for sustainable development, IUCN and WWF, Gland, and UNEP, Nairobi.

Jan, A. (1992) Review and Analysis of Forest Polices of Pakistan, Government of Pakistan, Islamabad.

Kamboj, V. P. (2000) 'Herbal medicine', Current Science 78(1): 35-9.

Kathe, W. (2011) 'The new FairWild standard—a tool to ensure sustainable wild-collection of plants', Medicinal Plant Conservation 14: 14-17. 
Kathe, W., Pätzold, B., Leaman, D., Timoshyna, A., Newton, D., Khou, E., Kinhal, G., Sapkota, I. B., Pasha, M. K. S., Ndam, N., Melisch, R., Bundalo, S., Honnef, S., Osborn, T., Buitrón, X. and Liu, X. (2010) Wild for a Cure: Ground-truthing a standard for sustainable management of wild plants in the field, TRAFFIC International, Cambridge.

Koross, K. (2013) 'Bypass stopped from encroaching on Nairobi National Park', The Star [Nairobi], 31 May. <www.the-star.co.ke/news/article-122527/bypassstopped-encroaching-nairobi-national-park>

Kothari, A. (2010) 'The birds are back', The Hindu Sunday Magazine, 7 March. <hindu.com/thehindu/ mag/2010/03/07/stories/2010030750400700.htm>

Kothari, A. and Pathak, N. (2005) 'Tragopans and tribals: a Naga transformation', Sanctuary Asia 25(5): 60-3.

Kothari, A., Corrigan, C., Jonas, H., Neumann, A. and Shrumm, H. (eds) (2012) Recognising and Supporting Territories and Areas Conserved by Indigenous Peoples and Local Communities: Global overview and national case studies, CBD Technical Series No. 64, Secretariat of the Convention on Biological Diversity, ICCA Consortium, Kalpavriksh and Natural Justice, Montreal.

Kothari, A., Pande, P., Singh, S. and Variava, D. (1989) Management of National Parks and Sanctuaries in India: A status report, Indian Institute of Public Administration, New Delhi.

Kothari, A., Singh, N. and Suri, S. (1995) 'Conservation in India: a new direction', Economic and Political Weekly 30(43) (28 October): 2755-66.

Lasgorceix, A. and Kothari, A. (2009) 'Displacement and relocation of local communities from protected areas in India: a synthesis and analysis of case studies', Economic and Political Weekly XLIV(49) (5 December): 37-47.

Leader-Williams, N., Baldus, R. D. and Smith, R. J. (2009) 'The influence of corruption on the conduct of recreational hunting', in B. Dickson, J. Hutton and B. Adams (eds) Recreational Hunting, Conservation and Rural Livelihoods, pp. 296-316, Wiley-Blackwell, Oxford.
Leida, R., de Zoysa, U., Kothari, A. and Healy, H. (2014) 'Towards a global agenda of sustainability and equity: civil society engagement for the future we want', UNEP Perspectives 12. <www. unep.org/civil-society/Portals/24105/documents/ perspectives/ENVIRONMENT_PAPERS_ DISCUSSION_12.pdf>

Locke, H. (2010) 'Yellowstone to Yukon Connectivity Conservation Initiative', in G. L. Worboys, W. Francis and M. Lockwood (eds) Connectivity Conservation Management: A global guide, Earthscan, London.

Lockwood, M., Worboys G. L. and Kothari, A. (2006) Managing Protected Areas: A global guide, Earthscan, London.

McNeely, J. A. (1998) Mobilising Broader Support for Asia's Biodiversity: How civil society can contribute to protected area management, Asian Development Bank, Manila.

McNeely, J. A., Miller, K. R., Reid, W. V., Mittermeier, R. A. and Werner, T. B. (1990) Conserving the World's Biodiversity, The World Bank, Washington, DC, and IUCN, Gland.

McShane, T. O. and Wells, M. P. (2004) Getting Biodiversity Projects to Work. Towards more effective conservation and development, Columbia University Press, New York.

Madrigal Cordero, P. and Solís Rivera, V. (2012) 'Recognition and support of ICCAs in Costa Rica', in A. Kothari, with C. Corrigan, H. Jonas, A. Neumann and H. Shrumm (eds) Recognising and Supporting Territories and Areas Conserved by Indigenous Peoples and Local Communities: Global overview and national case studies, pp. 127-9, CBD Technical Series No. 64, Secretariat of the Convention on Biological Diversity, ICCA Consortium, Kalpavriksh and Natural Justice, Montreal.

Margolius, R. and Salafsky, N. (2001) Is Our Project Succeeding? A guide to threat reduction assessment for conservation, Biodiversity Support Programme, Washington, DC.

Martin, G., Camacho Benavides, C., del Campo Garcia, C., Fonseca, S. A., Chapela Mendoza, F. and Gonzalez Ortiz, M. A. (2011) 'Indigenous and community-conserved areas in Oaxaca, Mexico', Management of Environmental Quality: An International Journal 22(2): 250-66. 
Menon, M., Kohli, K. and Samdariya, V. (2010) 'Diversion of protected areas: role of the Wildlife Board', Economic and Political Weekly XLV(26-27): 18-21.

Millennium Ecosystem Assessment (MEA) (2005) Millennium Ecosystem Assessment, Island Press, Washington, DC. <www.maweb.org>

Myers, N. (1997) 'Environmental refugees', Population and Environment 19(2): 167-82.

Naqizadeh, N., Abbas, D. and Farvar, T. (2012) 'Recognition and support of ICCAs in Iran', in A. Kothari, with C. Corrigan, H. Jonas, A. Neumann and H. Shrumm (eds) Recognising and Supporting Territories and Areas Conserved by Indigenous Peoples and Local Communities: Global overview and national case studies, pp. 132-4, CBD Technical Series No. 64, Secretariat of the Convention on Biological Diversity, ICCA Consortium, Kalpavriksh and Natural Justice, Montreal.

Naidoo, R., Weaver, L. C., Stuart-Hill, G. and Tagg, J. (2011) 'Effect of biodiversity on economic benefits from communal lands in Namibia', Journal of Applied Ecology 48(2): 310-16. <doi:10.1111 /j.1365-2664.2010.01955.x>

Nasi, R., Brown, D., Wilkie, D., Bennett, E., Tutin, C., van Tol, G. and Christophersen, T. (2008) Conservation and Use of Wildlife-Based Resources: The bushmeat crisis, CBD Technical Series 33, Secretariat of the Convention on Biological Diversity, Montreal, and Center for International Forestry Research, Bogor.

Nasi, R., Taber, A. and van Vliet, N. (2011) 'Empty forests, empty stomachs? Bushmeat and livelihoods in the Congo and Amazon Basins', International Forestry Review 13(3): 355-68.

National Park Service (NPS) (2014) National Park of American Samoa: Laws and Policies. <www.nps.gov/ npsa/parkmgmt/lawsandpolicies.htm>

Natural National Parks of Colombia (2008) Parque Nacional Natural: Chingaza. <www. parquesnacionales.gov.co/PNN/portel/libreria/ php/decide.php?patron $=02.02021202 \& f_{-}$ patron $=02.020212>$
DDd Naughton-Treves, L., Holland, M. B. and Brandon, K. (2005) 'The role of protected areas in conserving biodiversity and sustaining local livelihoods', Annual Review of Environment and Resources 30: 219-52. <doi:10.1146/annurev. energy.30.050504.164507>

Nelson, A. and Chomitz, K. M. (2011) 'Effectiveness of strict vs. multiple use protected areas in reducing tropical forest fires: a global analysis using matching methods', PLoS One 6(8): e22722. <doi:10.1371/ journal.pone.0022722>

Nelson, F. (ed.) (2010) Community Rights, Conservation and Contested Land: The politics of natural resource governance in Africa, Earthscan, London.

Nelson, F. (2012) 'Natural conservationists? Evaluating the impact of pastoralist land use practices on Tanzania's wildlife economy', Pastoralism 2(1): 1-19.

Nelson, F., Lindsey, P. and Balme, G. (2013) 'Trophy hunting and lion conservation: a question of governance?', Oryx 47(4): 501-9.

Nelson, F., Nshala, R. and Rodgers, W. A. (2007) 'The evolution and reform of Tanzanian wildlife management', Conservation and Society 5(2): 232.

Neumann, R. P. (1998) Imposing Wilderness: Struggles over livelihood and nature preservation in Africa. Volume 4, University of California Press, Berkeley.

Ngoitiko, M. and Nelson, F. (2013) 'What Africa can learn from Tanzania's remarkable Masai lands rights victory', The Guardian, 8 October. <www. theguardian.com/global-development/povertymatters/2013/oct/08/africa-tanzania-masai-landrights-victory>

Niassa Carnivore Project (2013) Niassa Carnivore Project. <niassalion.org/index.php>

Norwegian University of Science and Technology (2013) 'Serengeti road divides biologists: will a road across the northern tier of Serengeti National Park ruin it?', ScienceDaily, 23 May. <www.sciencedaily. com/releases/2013/05/130523082921.htm>

Oates, J. (1999) Myth and Reality in the Rain Forest: How conservation strategies are failing in West Africa, University of California Press, Berkeley. 
Observatorio Latinoamericano de Conflictos Ambientales (OLCA) (2014) Center for Latin American Environmental Conflicts, Santiago. <olca.cl/oca/chile/region11/represas56.htm>

DD Oglethorpe, J. A. E. (ed.) (1999) Tenure and Sustainable Use, IUCN, Gland.

Onishi, N. (2005) 'South Korea’s "sea women” trap prey and turn tables', The New York Times, 15 February. <www.nytimes.com/2005/02/15/ international/asia/15udo.html?_r=0>

Ostrom, E. (1990) Governing the Commons: The evolution of institutions for collective action, Cambridge University Press, Cambridge.

Padulosi, S., Hunter, D., Jarvis, A. and Heywood, V. (2011) 'Underutilized crops and climate changecurrent status and outlook', in S. Yadav, B. Redden, J. L. Hatfield and H. Lotze-Campen (eds) Crop Adaptation to Climate Change, pp. 507-21, WileyBlackwell, Ames, IA.

Pandey, S. (2008) 'Linking ecodevelopment and biodiversity conservation at the Great Himalayan National Park, India: lessons learnt', Biodiversity and Conservation 17: 1543-71.

Pandey, S. and Wells, M. (1997) 'Ecodevelopment planning at India's Great Himalayan National Park for biodiversity conservation and participatory rural development', Biodiversity and Conservation 6(9): 1277-92.

Parr, S., Dunford, B., Moran, J., Williams, B. and Conchuir, R. (2010) 'BurrenLIFE_farming for conservation in the Burren', in C. Belair, $\mathrm{K}$. Ichikawa, B. Y. L. Wong and K. J. Mulongoy (eds) Sustainable Use of Biological Diversity in SocioEcological Production Landscapes: Background to the Satoyama Initiative for the Benefit of Biodiversity and Human Well-Being, pp. 142-8, CBD Technical Series No. 52, Secretariat of the Convention on Biological Diversity, Montreal.

Parrotta, J. A. and Trosper, R. L. (eds) (2012) Traditional Forest-Related Knowledge, Springer, New York.
Pathak Broome, N. and Dash, T. (2012) 'Recognition and support of ICCAs in India', in A. Kothari, with C. Corrigan, H. Jonas, A. Neumann and H. Shrumm (eds) Recognising and Supporting Territories and Areas Conserved by Indigenous Peoples and Local Communities: Global overview and national case studies, pp. 130-2, CBD Technical Series No. 64, Secretariat of the Convention on Biological Diversity, ICCA Consortium, Kalpavriksh and Natural Justice, Montreal.

Perfecto, I., Vandermeer, J. and Wright, A. (2009) Nature's Matrix: Linking agriculture, conservation and food sovereignty, Earthscan, London.

Periyar Tiger Reserve (2012) India Eco Development Project, Periyar Tiger Reserve, Thekkadi, Kerala, India. <www.periyartigerreserve.org/indian.php>

Peruvian Trust Fund for National Parks and Protected Areas (PROFONANPE) (2012) Peruvian Trust Fund for National Parks and Protected Areas, Lima. <www.profonanpe.org.pe/index.php/en/projects>

Pfeiffer, C. (2009) 'Mermaids of the deep', Sydney Morning Herald Traveller, 7 February. <www. smh.com.au/travel/activity/surfing-and-diving/ mermaids-of-the-deep-20090204-7xbg.html>

Porter-Bolland, L., Ellis, E. A., Guariguata, M. R., Ruiz-Mallen, I., Negrete-Yankelevich, S. and Reyes-Garcia, V. (2012) 'Community managed forests and forest protected areas: an assessment of their conservation effectiveness across the tropics', Forest Ecology and Management 268 (March): 6-17. <doi:10.1016/j.foreco.2011.05.034>

Posey, D. (ed.) (1999) Cultural and Spiritual Values of Biodiversity, United Nations Environment Programme, Nairobi, and Intermediate Technology Publications, London.

Pretty, J. (2002). 'People, livelihoods and collective action in biodiversity management', in $\mathrm{T}$.

O'Riordan and S. Stoll-Kleemann (eds) Biodiversity, Sustainability, and Human Communities: Protecting beyond the protected, pp. 61-86, Cambridge University Press, Cambridge.

Programa Estado de la Nación (2006) Duodécimo informe Estado de la Nación en Desarrollo Humano Sostenible/Programa Estado de la Nación [Twelfth State of the Nation in Sustainable Developmentl Human Development Program State of the Nation], San José, Costa Rica. <www.estadonacion.or.cr/files/ biblioteca_virtual/006/info6cap4.pdf > 
Radachowsky, J., Ramos, V. H., McNab, R., Baur, E. H. and Kazakov, N. (2012) 'Forest concessions in the Maya Biosphere Reserve, Guatemala: a decade later', Forest Ecology and Management 268: 18-28. <doi:10.1016/j.foreco.2011.08.043>

Redmond, I., Aldred, T., Jedamzik, K. and Westwood, M. (2006) Recipes for Survival: Controlling the bushmeat trade, World Society for the Protection of Animals, London.

Reid, H. (2001) 'Contractual national parks and the Makuleke community', Human Ecology 29(2): $135-55$.

Rijnhout, L., de Zoysa, U., Kothari, A. and Healy, H. (2014) 'Towards a global agenda of sustainability and equity: civil society engagement for the future we want', UNEP Perspectives 12 (March): 1-12. <www.unep.org/post2015/Publications/ TowardsAGlobalAgendaOfSustainabilityAndEqui/ tabid/133352/Default.aspx>

Roe, D., Nelson, F. and Sandbrook, C. (eds) (2009) Community Management of Natural Resources in Africa: Impacts, experiences and future directions, Natural Resource Issues No. 18, International Institute for Environment and Development, London.

Rybanič, R., Šeffer, J. and Čierna, M. (1999) 'Economic valuation of benefits from conservation and restoration of floodplain meadows', in J. Šeffer and V. Stanová (eds) Morava River Floodplain Meadows-Importance, restoration and management, pp. 147-60, DAPHNE-Institute of Applied Ecology, Bratislava.

Saberwal, V., Rangarajan, M. and Kothari, A. (2001) People, Parks and Wildlife: Tracts for the times 14, Orient Longman, New Delhi.

Salm, R. V., Clark, J. R. and Siirila, E. (2000) Marine and Coastal Protected Areas: A guide for planners and managers, IUCN, Gland.

Sathurusinghe, A., Seneneyake, S. J. G. N., Wijesundara, D. S. A. and Wijesekara, G. A. W. (2010) 'Species management plan for Cinnamomum capparu-coronde Blume', in B. Marambe and A. Wijesekara (eds) Conservation and Utilization of Crop Wild Relatives of Sri Lanka, pp. 35-6, Department of Agriculture and Ministry of Environment and Natural Resources, Sri Lanka.
Schippmann, U., Leaman, D. and Cunningham, A. B. (2006) 'Cultivation and wild collection of medicinal and aromatic plants under sustainability aspects', in R. J. Bogers, L. E. Craker and D. Lange (eds) Medicinal and Aromatic Plants: Agricultural, commercial, ecological, legal, pharmacological and social aspects, Springer, Dordrecht.

Schliep, R., Bertzky, M., Hirschnitz, M. and StollKleemann, S. (2008) 'Changing climate in protected areas? Risk perception of climate change by biosphere reserve managers', GAIA 17(1): 116-24.

Schulte-Herbrüggen, B., Cowlishaw, G., Homewood, K. and Rowcliffe, J. M. (2013) 'The importance of bushmeat in the livelihoods of West African cashcrop farmers living in a faunally-depleted landscape', PloS One 8(8): e72807.

Shahabuddin, G. (2010) 'India ecodevelopment project: a fragmented legacy', in G. Shahabuddin Conservation Crossroads: Science, society and the future of India's wildlife, pp. 166-86, Permanent Black, Delhi.

Shriar, A. (1999) 'Resource conservation and rural neglect: an example from Petén, Guatemala', Delaware Review of Latin American Studies 1(1). <www.udel.edu/LASP/vol1Avrum.html>

Skeena Watershed Conservation Coalition (2014) Skeena Watershed Conservation Coalition, Old Hazelton, British Columbia. <skeenawatershed. com>

SkeenaWild Conservation Trust (2014) SkeenaWild Conservation Trust, Terrace, British Columbia. $<$ skeenawild.org $>$

Spalding, M. D., Meliane, I., Milam, A., Fitzgerald, C. and Hale, L. Z. (2013) 'Protecting marine spaces: global targets and changing approaches', Ocean Yearbook 27: 213-48.

Spence, M. (1999) Dispossessing the Wilderness: Indian removal and the making of the national parks, Oxford University Press, New York.

Spenceley, A. (ed.) (2008) Responsible Tourism: Critical issues for conservation and development, Routledge, New York.

Steenkamp, C. and Uhr, J. (2000) The Makuleke Land Claim: Power relations and community-based natural resource management, International Institute for Environment and Development, London. 
Stoll-Kleemann, S. and Welp, M. (2008) 'Participatory and integrated management of biosphere reserves', GAIA 17: 161-68.

Sustainable Development Knowledge Platform (2014) Sustainable Development Knowledge Platform. <sustainabledevelopment.un.org>

Tairo, A. (2014) 'Tanzania gives go ahead to uranium mining in Selous Game Reserve', eTurboNews, 13 May. <www.eturbonews.com/45745/tanzaniagives-go-ahead-uranium-mining-selous-gamereserve>

Tandon, V. (2002) Getting women to choose: case study on sustainable livelihoods and poverty alleviation, Mountain Forum E-Consultation for the UNEP/Bishkek Global Mountain Summit, Bishkek, Kyrgyzstan, 29 October - 1 November.

Tebtebba Foundation (2008) Indicators Relevant for Indigenous Peoples: A resource book, Tebtebba Foundation, Baguio City, Philippines. <www. tebtebba.org/index.php/content/123-indicatorsrelevant-for-indigenous-peoples-a-resourcebook $\% 20 \% 20>$

Technical and Policy Core Group (TPCG) and Kalpavriksh (2005) Securing India's future: final technical report of the National Biodiversity Strategy and Action Plan, Technical and Policy Core Group and Kalpavriksh, Pune. <www.kalpavriksh. org/index.php/conservation-livelihoods1/72biodiversity-and-wildlife/national-biodiversitystrategy-action-plan/224-nbsap-final-technicalreport.html>

Terborgh, J. (2004) Requiem for Nature, Island Press, Washington, DC.

United Nations (UN) (2009) State of the World's Indigenous Peoples, United Nations, New York.

United Nations Conference on Sustainable Development (UNCSD) (2012) The Future We Want, A/Conf.216/L.1, United Nations, New York. <www.uncsd2012.org/content/ documents/774futurewewant_english.pdf>
United Nations University Institute of Advanced Studies Operating Unit Ishikawa/Kanazawa (UNUIAS OUIK) (2011) Biological and Cultural Diversity in Coastal Communities: Exploring the potential of satoumi for implementing the ecosystem approach in the Japanese Archipelago, Technical Series No. 61, Secretariat of the Convention on Biological Diversity, Montreal.

United States Fish \& Wildlife Service (2014) RefugeSpecific Hunting and Sport Fishing Regulations, National Wildlife Refuge System. <www.fws.gov/ refuges/hunting/huntfishregs.html>

Unnikrishnan, P. M. and Suneetha, M. S. (2012) Biodiversity, traditional knowledge and community health: strengthening linkages, UNU-IAS Policy Report, United Nations University Institute of Advanced Studies, Yokohama, Japan. <www. ias.unu.edu/resource_centre/Biodiversity $\% 20$ Traditional $\% 20$ Knowledge $\% 20$ and $\% 20$ Community\%20Health_final.pdf>

van Oudenhoven, F., Mijatovic, D. and Eyzaguirre, P. (2011) 'Social-ecological indicators of resilience in agrarian and natural landscapes', Management of Environmental Quality: An International Journal 22(2): 154-73.

van Vliet, N., Nasi, R., Abernethy, K., Fargeot, C., Kumpel, N. F., Obiang, A. N. and Ringuet, S. (2012) 'The role of wildlife for food security in Central Africa: a threat to biodiversity?', in C. de Wasseige, P. de Marcken, N. Bayol, F. Hiol-Hiol, P. Mayaux, B. Desclee, R. Nasi, A. Billand, P. Defourny and R. Eba'a Atyi (2012) The Forest of the Congo Basin: State of the forest 2010, pp. 12335, Publications Office of the European Union, Luxembourg. <doi:10.2788/47210>

Vasundhara and Kalpavriksh (2012) A National Report on Community Forest Rights under Forest Rights Act: Status and issues. An output of the Community Forest Rights Learning and Advocacy Process, Vasundhara, Bhubaneshwar and Kalpavriksh, Delhi and Pune.

Vaughan, C., McCoy, M., Fallas, J., Cháves, H., Barboza, G., Wong, G., Rau, J., Carranza, M. and Carbonell, M. (1996) Management and Development for Palo Verde National Park and Lomas Barbudal Biological Reserve, National University of Costa Rica, Heredia. 
Vijayan, V. S. (1991) Keoladeo National Park Ecology Study: 1980-90. Final report, Bombay Natural History Society, Bombay.

Wahren, C.-H., Papst, W. A. and Williams, R. J. (1994) 'Long-term vegetation change in relation to cattle grazing in subalpine grassland and heathland on the Bogong High Plains: an analysis of vegetation records from 1945 to 1994', Australian Journal of Botany 42: 607-39.

Wani, M. and Kothari, A. (2007) 'Protected areas and human rights in India-the impact of the official conservation model on local communities', Policy Matters 15: 100-14.

Washington Post (2013) 'In Brazil, Amazonian Indians protest hydroelectric dam', Washington Post, 27 May. <www.washingtonpost.com/world/ in-brazil-amazonian-indians-protest-hydroelectricdam/2013/06/10/f90539b6-cee5-11e2-8845d970ccb04497_gallery.html\#photo=1>

Wells, M., Brandon, K. and Hannah, L. (1992) People and Parks: Linking protected area management with local communities, The World Bank, WWF and US Agency for International Development, Washington, DC.

Wells, M., Guggenheim, S., Khan, A., Wardojo, W. and Jepson, P. (1999) Investing in Biodiversity: A review of Indonesia's integrated conservation and development projects, The World Bank, Washington, DC.

Dd West, P., Igoe, J. and Brockington, D. (2006) 'Parks and peoples: the social impact of protected areas', Annual Review of Anthropology 35: 251-77.

Western, D. and Gichohi, H. (1993) 'Segregation effects and the impoverishment of savanna parks: the case for ecosystem viability analysis', African Journal of Ecology 31(4): 269-81.

Wieting, R. (2004) Sustainable Land Use in European Protected Areas, IUCN Regional Office for Europe, Brussels.

Wikipedia (2014) Niassa Reserve. <en.wikipedia.org/ wiki/Niassa_Reserve>
Wildlife Institute of India (WII) (1999) An Ecological Study of the Conservation of Biodiversity and Biotic Pressures in the Great Himalayan National Park Conservation Area: An ecodevelopment approach. Volumes 1-6, Final Report, Forestry Research Education and Extension Project-Great Himalayan National Park, Wildlife Institute of India, Dehradun.

Williams, R. J. (1990) 'Cattle grazing within subalpine heathland and grassland communities on the Bogong High Plains: disturbance, regeneration and the shrub-grass balance', Proceedings of the Ecological Society of Australia 16: 255-65.

Wittmer, H. U., Mark Elbroch, L. and Marshall, A. J. (2013) 'Good intentions gone wrong: did conservation management threaten endangered huemul deer Hippocamelus bisulcus in the future Patagonia National Park?', Oryx 47(3): 393-402. $<$ doi:10.1017/S0030605312000531>

World Resources Institute (WRI), International Union for Conservation of Nature (IUCN) and United Nations Environment Programme (UNEP) (1992) Global Biodiversity Strategy: Guidelines for action to save, study, and use Earth's biotic wealth sustainably and equitably, WRI, IUCN and UNEP, Gland.

World Wildlife Fund (WWF) (2014) PADDDtracker: Tracking protected area downgrading, downsizing, and degazettement. <www.PADDDtracker.org>

Zinn, C. and Vidal, J. (1999) 'How prawn cocktails and tourists are taking the life out of the Great Barrier Reef', The Guardian, 14 January. <www. theguardian.com/world/1999/jan/14/johnvidal> 


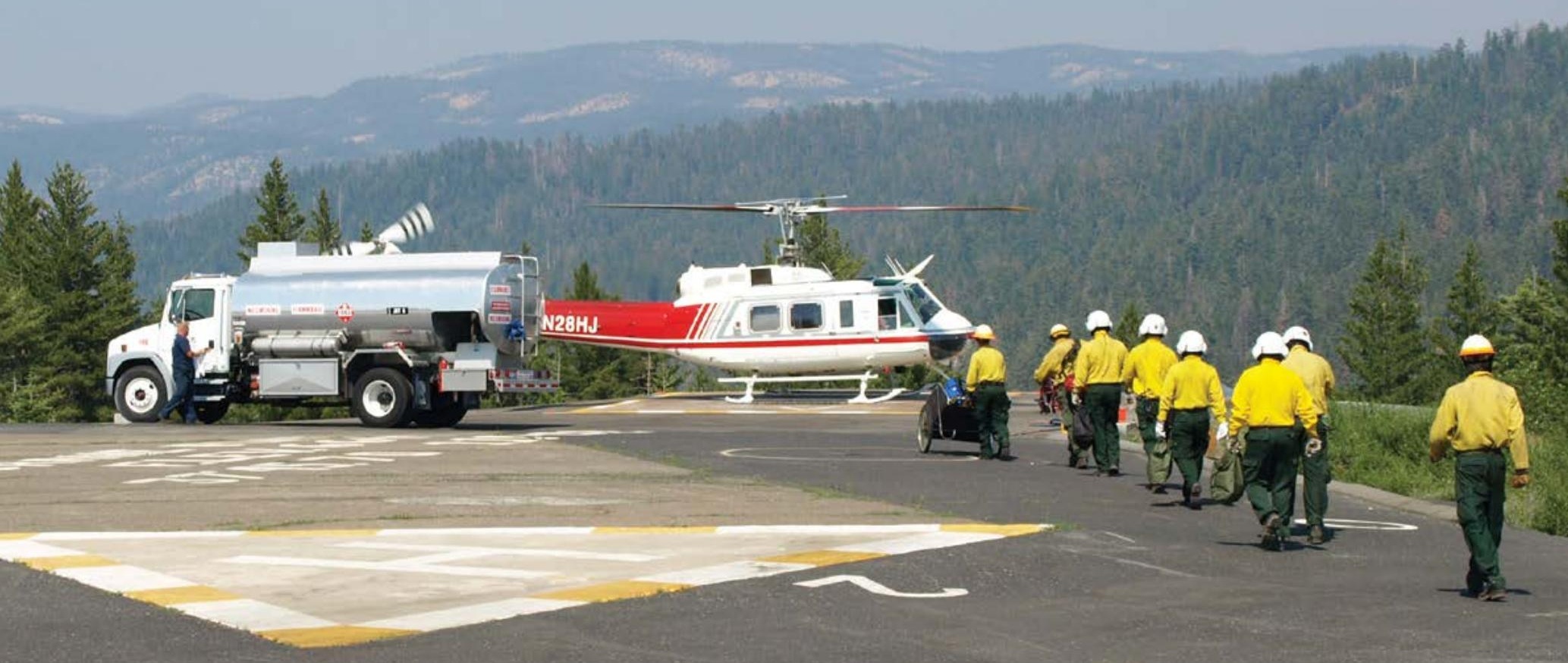

CHAPTER 26

MANAGING INCIDENTS

Principal author:

Graeme L. Worboys

\author{
CONTENTS \\ - Introduction \\ - Types of incidents \\ - Pre-incident planning and preparation \\ - Responding to incidents \\ - Managing incidents \\ - Recovery \\ - Conclusion \\ - References
}




\section{PRINCIPAL AUTHOR}

GRAEME L. WORBOYS is Co-Vice-Chair, Connectivity Conservation and Mountains, International Union for Conservation of Nature World Commission on Protected Areas, and an Adjunct Fellow in the Fenner School, The Australian National University.

\section{ACKNOWLEDGMENTS}

Appreciation is expressed to Dr Malcolm Gill of The Australian National University, Stuart Ellis of the Australasian Fire and Emergency Services Authority Council and Gregor Manson of the Australian Government for their reviews of the chapter manuscript. My thanks are extended to Dr Malcolm Gill for his preparation of Boxes 26.5 and 26.6.

\section{CITATION}

Worboys, G. L. (2015) 'Managing incidents', in G. L. Worboys, M. Lockwood, A. Kothari, S. Feary and I. Pulsford (eds) Protected Area Governance and Management, pp. 823-850, ANU Press, Canberra.

\section{TITLE PAGE PHOTO}

Helicopter based remote area fire initial attack crew departing on a mission, Yosemite National Park, California, USA

Source: Graeme L. Worboys 


\section{Introduction}

Natural or human-caused incidents regrettably are common events in protected areas. Our aim in this chapter is to help prepare protected area practitioners to deal with such incidents. We do this by describing common incident types, how climate change is influencing the nature of incidents, pre-incident planning and preparation that may be undertaken, the actual management of incidents (using globally accepted systems for multi-organisation responses) and a description of post-incident follow-up requirements.

Our approach in this chapter has been to describe incident management in the context of moderate to high Human Development Index (HDI) country responses to protected area incidents. These countries often have the opportunity to have a depth of supporting logistical resources such as in the case of wildfire (also referred to as bushfire or unplanned fire) with fire tankers, bulldozers and water-bombing aircraft and can also access a range of incident management response information supplied from sources such as remote-sensing satellites, aircraft observers and incident computer-based modelling and forecasting capabilities. It is understood that many low HDI countries will not always have access to such resources and that incident responses may need to rely more on less machine-focused responses. Nevertheless, the principles of incident management still apply. They also apply across all protected area governance environments especially given that most large-scale incidents will involve many organisations and communities and the incident management system provides a very suitable framework for doing this. It would, for example, be a very suitable governance system for a protected area incident that includes multiple international relief agency support.

So, exactly what is an incident? We introduce two definitions here, with the first more general (less technical): 'as an event or cluster of events which may be accidental, intentional or natural in origin and which requires an emergency or law enforcement response' (Worboys and Winkler 2006:474). A more technical definition from an incident-control perspective is:

[A]n event, occurrence or set of circumstances that has a definite spatial extent; has a definite duration; calls for human intervention; has a set of concluding conditions that can be defined; and is or will be under the control of an individual who has the authority to make decisions about the means by which it will be brought to a resolution. (AFAC 2013:1)

Whilst this chapter focuses on operational considerations, we are mindful that dealing with emergency management and incidents requires dealing with strategic policy development and procedural matters at the highest levels of organisations and government (Handmer and Dovers 2013). Such high-level considerations are the subject of Chapter 12.

\section{Types of incidents}

There are many different types of natural incidents that occur in or affect protected areas and people and many other human-caused incidents that involve or impact humans and these areas (Table 26.1). Protected areas are usually large and mostly natural land and sea areas that exist in a dynamic world. They face, in a 24-hour-aday, seven-days-a-week management operation, a reality that incidents will happen, sooner or later. Anticipating this inevitability and managing for it are an integral part of day-to-day management. Understanding what types of incidents may occur and when and how they may happen is important, and this approach is typically linked to risk-management assessments by protected area organisations (see Chapter 8).

The types of natural and human-caused incidents identified may affect part or all of a protected area, they may be confined to a single site, they may have a local influence and, in the most severe events, they may be regional in scale. This means that managers of protected areas will typically be part of an incident response and part of a cooperative multi-organisation team dealing with an incident. Dealing with incidents in isolation is a thing of the past. It is rare indeed that a single emergency service can manage an emergency without some form of cooperation or assistance from other emergency services or supporting agencies (Yates 1999). This also means that the process of identifying the risk of particular incidents is quite critical since this underpins the development of organisational capacity (see Chapter 9), preparedness and preparation for working with other organisations. 
Table 26.1 Incidents relevant to protected areas

\begin{tabular}{l} 
Natural incidents that may affect \\
protected areas \\
\hline Cyclones, hurricanes, typhoons \\
\hline Tornadoes \\
\hline $\begin{array}{l}\text { Storms that could include strong wind, dust, dry } \\
\text { lightning, hail, intense cold or intense heat }\end{array}$ \\
\hline Storm surges \\
\hline Floods \\
\hline Mudslides and landslides \\
\hline Glacial lake bursts \\
\hline Blizzards and snow avalanches \\
\hline Droughts \\
\hline Wildfires \\
\hline Earthquakes \\
\hline Tsunamis \\
\hline Volcanic eruptions and associated events such as ash- \\
cloud fallout, nuée ardente and lahars \\
\hline Geological structure collapses \\
\hline Meteorite impacts (a rare but historical event) \\
\hline Pest plagues \\
\hline Diseases including human and wildlife disease outbreaks \\
\hline Wildlife trauma/mass die-offs \\
\hline Cetacean strandings \\
\hline
\end{tabular}

\section{A changing world}

Historical events can provide a broad guide to what incident risks a particular protected area may face, as can predicted conditions. The reality of climate change and the tracking of global carbon dioxide pollution at the highest forecast levels (see Chapter 17) in the early part of the 21 st century bring with them a suite of atmospheric energy-enhanced and changed weather phenomena that protected area managers need to anticipate and prepare for. This is different from issues faced by previous generations of protected area managers. Despite extreme events such as droughts, major bushfires, cyclones, tornadoes and other weather incidents, past managers did not have to deal as much with the dynamic of rapid changes and greater extremes in weather. Such variation has been directly linked to carbon dioxide pollution of the atmosphere by humans and consequent climate change. Incident managers in protected areas (and elsewhere) are dealing with a changing world, and it is wise to examine some of the implications of climate change. Researchers, with their sophisticated climate models, are able to

\begin{tabular}{l} 
Incidents in protected areas caused by \\
or involving people \\
\hline $\begin{array}{l}\text { People lost in terrestrial and marine environments } \\
\text { and underground }\end{array}$ \\
\hline Injured or sick people or people requiring rescue \\
\hline Infrastructure collapse \\
\hline $\begin{array}{l}\text { Vehicle accidents including trucks carrying toxic } \\
\text { chemicals, pollutants or other injurious materials }\end{array}$ \\
\hline Aircraft accidents \\
\hline Marine vessel accidents \\
\hline Pollution events \\
\hline Radioactive fallout \\
\hline Wildlife-human incidents \\
\hline Wildlife poaching \\
\hline Wildlife trafficking \\
\hline Accidental fires \\
\hline $\begin{array}{l}\text { Arson and other felonies, murders, assaults, sexual } \\
\text { assaults and acts of terrorism }\end{array}$ \\
\hline Resource theft \\
\hline Social unrest and protests \\
\hline War and conflict \\
\hline Refugees and displaced people \\
\hline Drugs \\
\hline
\end{tabular}

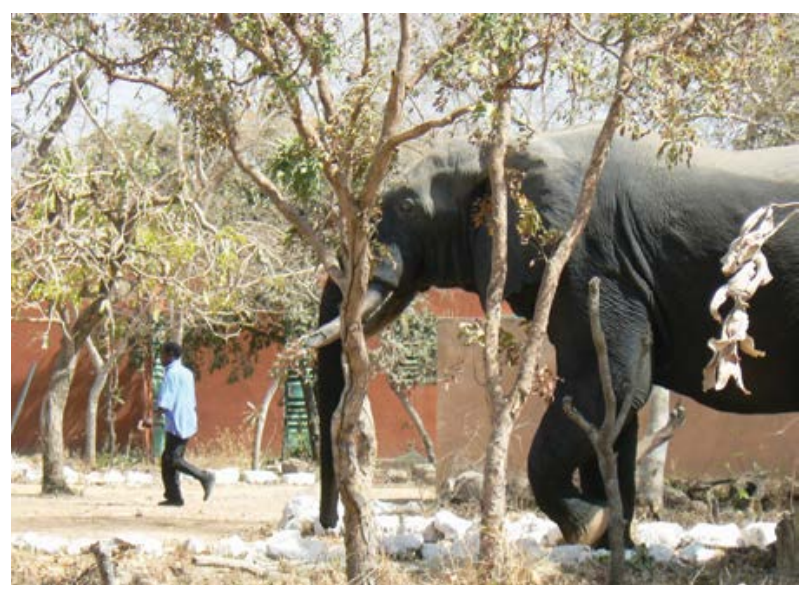

Humans and wildlife sharing space, Nazinga,

Burkina Faso, West Africa

Source: Geoffroy Mauvais

provide some insights for the future, and some of their climate change predictions and implications for incident management have been identified here (Table 26.2). 
Table 26.2 Climate change predictions and implications for incident management

\begin{tabular}{|c|c|c|}
\hline Phenomenon & Prediction & $\begin{array}{l}\text { Risk implications for protected area } \\
\text { incident management }\end{array}$ \\
\hline Carbon dioxide & $\begin{array}{l}\text { Higher carbon dioxide levels provide a fertiliser } \\
\text { effect on vegetation in some areas (the atmospheric } \\
\text { concentrations of carbon dioxide, methane } \\
\text { and nitrous oxide in } 2013 \text { had risen to levels } \\
\text { unprecedented in at least the past } 800000 \text { years) }\end{array}$ & $\begin{array}{l}\text { Potentially more severe fire events through } \\
\text { enhanced woody vegetation growth and } \\
\text { higher levels of fire fuel }\end{array}$ \\
\hline Temperature & $\begin{array}{l}\text { Higher average temperatures, greater than } 1.5^{\circ} \mathrm{C} \\
\text { by } 2100 \text { (each of the past three decades to } 2013 \\
\text { was successively warmer than any previous } \\
\text { decade to 1850) } \\
\text { (In } 2013 \text {, Australia experienced its hottest year } \\
\text { on record) }\end{array}$ & $\begin{array}{l}\text { More fire incidents due to longer periods of } \\
\text { hotter conditions } \\
\text { Higher average daytime temperatures } \\
\text { affecting fire behaviour } \\
\text { Higher average night-time temperatures } \\
\text { during wildfires affecting incident control } \\
\text { and safety } \\
\text { New native fauna incidents through the } \\
\text { movement of wildlife towards the poles } \\
\text { New disease incidents through expanded } \\
\text { home ranges of disease vectors such as } \\
\text { mosquitoes } \\
\text { More water-based incidents through greater } \\
\text { visitor use of beaches and water bodies }\end{array}$ \\
\hline Drought & $\begin{array}{l}\text { An increase in drying in many parts of the world } \\
\text { including an increase in the number of droughts }\end{array}$ & $\begin{array}{l}\text { Human-wildlife incidents arising from drought } \\
\text { conditions } \\
\text { Drought-influenced social unrest and human } \\
\text { drought refugee incidents }\end{array}$ \\
\hline Extreme heat & $\begin{array}{l}\text { An increase in frequency of extreme heat } \\
\text { conditions (in Australia in January 2014, a 'dome' } \\
\text { of hot air formed in Western Australia and moved } \\
\text { anticlockwise around Australia causing extreme } \\
\text { and prolonged } 40^{\circ} \mathrm{C} \text { plus temperatures across } \\
\text { multiple States and Territories) }\end{array}$ & $\begin{array}{l}\text { Extreme heat creates extreme fire behaviour } \\
\text { conditions and very dangerous fire behaviour } \\
\text { control conditions for any fire incident } \\
\text { Heatwaves, their impact on protected area } \\
\text { visitors and the potential for emergency first- } \\
\text { aid incidents are increased }\end{array}$ \\
\hline Wildfires & $\begin{array}{l}\text { An increase in the number of extreme fires } \\
\text { because of higher temperatures, reduced rainfall, } \\
\text { the increased availability of fire fuel and changes } \\
\text { in wind conditions (the average Forest Fire Danger } \\
\text { Index [Box 26.1] in Australia increased in many } \\
\text { locations from } 10 \text { to } 40 \% \text { during the period } \\
2001-07 \text { compared with the period 1980-2000) }\end{array}$ & $\begin{array}{l}\text { The implementation of upgraded fire response } \\
\text { safety procedures for incidents } \\
\text { The potential for fire-generated meteorological } \\
\text { phenomena such as fire tornadoes } \\
\text { Enhanced training for incident controllers and } \\
\text { planners }\end{array}$ \\
\hline Extreme weather & $\begin{array}{l}\text { Warmer conditions and higher energy in the } \\
\text { atmosphere that lead to more severe storms }\end{array}$ & $\begin{array}{l}\text { Severe storm incidents include the effects of } \\
\text { thunderstorms, mini-tornadoes, tornadoes, } \\
\text { lightning, strong winds and hail } \\
\text { Dry lightning storms can cause multiple fire } \\
\text { ignitions across a landscape } \\
\text { Cyclone (hurricanes, typhoons) incidents are } \\
\text { more powerful, with extreme wind, storm } \\
\text { surges and heavy rain and flooding }\end{array}$ \\
\hline Extreme cold & $\begin{array}{l}\text { Extreme cold weather events will still occur within } \\
\text { a context of overall climate change warming }\end{array}$ & $\begin{array}{l}\text { Snowstorm and blizzard incidents such } \\
\text { as search and rescue for lost personnel in } \\
\text { remote protected areas }\end{array}$ \\
\hline Snow & $\begin{array}{l}\text { Reduced or enhanced winter snow deposition in } \\
\text { higher latitude and mountain environments and } \\
\text { greater variation in winter temperatures }\end{array}$ & $\begin{array}{l}\text { Incidents involving avalanches may be } \\
\text { triggered due to wetter snow layers during } \\
\text { warmer conditions that lead to more unstable } \\
\text { snow accumulation }\end{array}$ \\
\hline Ice & $\begin{array}{l}\text { The continued worldwide melting of permafrost, } \\
\text { glaciers and ice sheets }\end{array}$ & $\begin{array}{l}\text { Incidents associated with the collapse of } \\
\text { unstable geological rock faces in steep } \\
\text { mountain environments following the melting } \\
\text { of permafrost } \\
\text { Flood incidents down-valley caused by } \\
\text { collapsed glacial melt lakes }\end{array}$ \\
\hline
\end{tabular}




\begin{tabular}{|c|c|c|}
\hline Phenomenon & Prediction & $\begin{array}{l}\text { Risk implications for protected area } \\
\text { incident management }\end{array}$ \\
\hline $\begin{array}{l}\text { Precipitation: } \\
\text { amount and pattern }\end{array}$ & $\begin{array}{l}\text { Warmer temperatures may mean increased } \\
\text { evaporation and enhanced rainfall events }\end{array}$ & $\begin{array}{l}\text { Incidents caused by flooding of protected } \\
\text { areas, which may involve stranded wildlife }\end{array}$ \\
\hline Rapid run-off & $\begin{array}{l}\text { More frequent extreme storms and torrential } \\
\text { rainfall that cause rapid run-off and flooding }\end{array}$ & $\begin{array}{l}\text { Incidents in protected areas where } \\
\text { infrastructure is impacted and people are } \\
\text { trapped by floodwaters }\end{array}$ \\
\hline Floods & $\begin{array}{l}\text { More frequent flooding due to greater atmospheric } \\
\text { moisture }\end{array}$ & $\begin{array}{l}\text { Incidents where protected areas are flooded, } \\
\text { and people, infrastructure and wildlife are } \\
\text { potentially affected }\end{array}$ \\
\hline $\begin{array}{l}\text { Sea-levels and storm } \\
\text { surges }\end{array}$ & $\begin{array}{l}\text { Global sea-levels are rising with the melting } \\
\text { of the ice caps and glaciers (global sea-levels } \\
\text { have risen an average } 0.19 \text { metres from } 1901 \text { to } \\
\text { 2010). Higher sea-levels and more intense storms } \\
\text { increase coastal impacts through storm surges }\end{array}$ & $\begin{array}{l}\text { Incidents affecting coastal protected areas, } \\
\text { especially during storms when the coastline } \\
\text { is battered by higher water levels and large } \\
\text { waves }\end{array}$ \\
\hline
\end{tabular}

Sources: ANU (2009); Williams et al. (2009); Climate Council (2013); Hannam (2013, 2014); IPCC (2013)

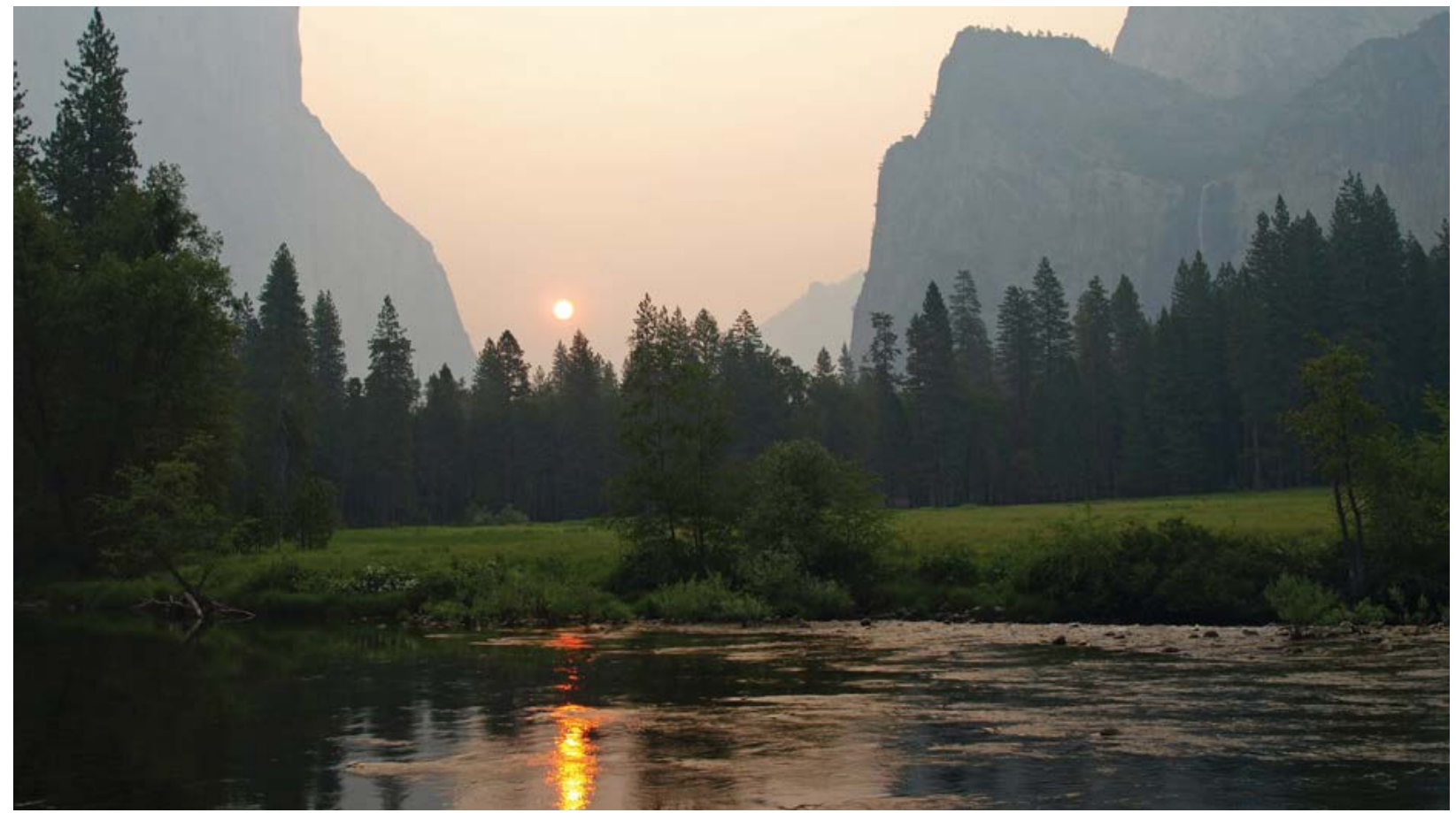

Smoke-filled Yosemite Valley, Yosemite National Park, USA, from wildfires burning in July 2008 Source: Graeme L. Worboys

One example of an incident influenced by the effects of enhanced climate change temperatures is the 2009 catastrophic bushfire episodes in Victoria, Australia, which burnt through a range of different land-use types including protected areas (Case Study 26.1).

\section{Pre-incident planning and preparation}

Anticipating incidents is a critical part of pre-incident planning and preparation. Once the potential has been identified, a risk-management assessment provides an important planning tool for protected area organisations to respond to such potential. Risk-management frameworks such as the standard AS/NZ ISO 31000 may be used to guide this process. The NSW National Parks and Wildlife Service (NPWS) in Australia, for example, with its system of 867 protected areas covering more than 7 million hectares (8.8 per cent of the State) (CAPAD 2010), operates within a very fire-prone part of eastern Australia. In undertaking its risk assessment for fire incidents, the NPWS has identified major areas of responsibility for its risk-based management approach (NPWS 2012) (Table 26.3). 


\section{Case Study 26.1 Victoria's 2009 catastrophic fire events}

On 7 February 2009 in Victoria, Australia, the capital city, Melbourne, experienced a record-breaking temperature of $46.4^{\circ} \mathrm{C}$; and in the worst of bushfire danger days, storm-force wind speeds were recorded generally at 90 kilometres per hour with gusts to 115 kilometres per hour; the humidity was 6 per cent and the Forest Fire Danger Index (FFDI) (Box 26.1) exceeded its highest 100 'Extreme' calibration measure to read more than 150. In 2009, Victorian fire authorities had to deal with 316 fire events during these conditions (PoV 2010). Looming above the worst of these fires were rapidly upwelling and powerful convective columns that developed pyrocumulus clouds to 8500 metres. These phenomena and an unstable atmosphere complicated the unfolding fire events with their own strong winds and lightning (Tolhurst 2009). Record-breaking firebrand spotting distances to 35 kilometres were recorded, as were mass short-distance spotting phenomena (PoV 2010). Regrettably, these multiple severe fire events caused the death of 173 people, and consequently 15 of these severe fires were the subject of a Royal Commission (PoV 2010). In post-fire media interviews, very experienced volunteers and professional firefighters advised, one after another, that they 'had never seen anything like this before' (ABC 2010). History shows that the 2009 Victorian fires were one of Australia's worst natural disasters, and it has led to the creation of a new FFDI category that is beyond 'Extreme'-called 'Catastrophic' or 'Code Red'. The extreme fire behaviour witnessed has been a potent warning for the future, since scientists are predicting that catastrophic fire events such as this will be more frequent, especially given higher temperatures and drier conditions. For the 2009 Victorian fires, Australia's research organisation, the Commonwealth Scientific and Industrial Research Organisation (CSIRO), advised that the extremely high temperatures of the fire event were part of a human-influenced global warming trend (CSIRO 2009).

\section{Box 26.1 The Forest Fire Danger Index}

The McArthur Forest Fire Danger Index (FFDI) incorporates temperature, wind speed, humidity and a measure of fuel dryness. It was developed in Australia in the 1960s and calibrated on a scale from zero (no fire danger) to 100 for both forests and grasslands based on Australia's worst fire event in recorded history at that time, the 'Black Friday' fire event of 1939. An FFDI above 50 indicates that, due to fire crowning and spotting behaviour in Australia's eucalypt-dominated forests, weather becomes the dominant indicator of fire behaviour, the fire becomes very intense and it is difficult to fight a running forest fire front (Campbell 2009).

Table 26.3 NSW National Parks and Wildlife Service risk management for fire management

\begin{tabular}{|l|l|l|}
\hline Risk & $\begin{array}{l}\text { Control mechanism to } \\
\text { reduce risk }\end{array}$ & \multicolumn{1}{l|}{ Risk-reduction actions } \\
\hline $\begin{array}{l}\text { Risks to the health and safety of staff } \\
\text { and visitors including injury and death }\end{array}$ & $\begin{array}{l}\text { Planning and procedural } \\
\text { documents for: } \\
\text { prevention } \\
\text { preparedness } \\
\text { response } \\
\text { recovery }\end{array}$ & $\begin{array}{l}\text { Use of approved and assessed equipment } \\
\text { Use of the incident management system } \\
\text { Individual burn plans for prescribed burning } \\
\text { Incident action plans for bushfire } \\
\text { suppression } \\
\text { Appropriate training and competencies for } \\
\text { all personnel } \\
\text { Incident debriefing } \\
\text { Counselling } \\
\text { Actions to ensure the safety of visitors and } \\
\text { neighbours }\end{array}$ \\
\hline $\begin{array}{l}\text { Risks to natural and cultural heritage } \\
\text { values }\end{array}$ & $\begin{array}{l}\text { Priority areas for specific fire } \\
\text { management action specified }\end{array}$ & $\begin{array}{l}\text { Natural and cultural values are recognised in } \\
\text { protected area fire management strategies } \\
\text { Fire management minimises pollution events }\end{array}$ \\
\hline $\begin{array}{l}\text { Risks to the community including } \\
\text { disruption of economic activity and } \\
\text { social structure and fabric and loss of } \\
\text { confidence in the NPWS }\end{array}$ & $\begin{array}{l}\text { Public and stakeholder input } \\
\text { into fire management } \\
\text { Meeting regulations and } \\
\text { statutory requirements }\end{array}$ & $\begin{array}{l}\text { NPWS fire management involves } \\
\text { cooperation with neighbours and minimising } \\
\text { impacts of bushfires on public and private } \\
\text { assets including business }\end{array}$ \\
\hline $\begin{array}{l}\text { Risks to administration and finance } \\
\text { and especially the excessive level of } \\
\text { expenditure in suppression operations }\end{array}$ & $\begin{array}{l}\text { Fire operations follow } \\
\text { procedures established by the } \\
\text { financial manual }\end{array}$ & $\begin{array}{l}\text { The incident controller has financial } \\
\text { accountability for expenditure during the fire } \\
\text { event }\end{array}$ \\
\hline
\end{tabular}

Source: NPWS (2012) 
Table 26.4 Potential protected area incident management plans

\begin{tabular}{|c|c|c|}
\hline $\begin{array}{l}\text { Potential incident } \\
\text { management plan }\end{array}$ & Type of incident event & Some specific planning considerations \\
\hline \multicolumn{3}{|l|}{ Wildlife } \\
\hline Cetacean stranding plan & $\begin{array}{l}\text { The plan deals with stranding on } \\
\text { coastlines of marine mammals } \\
\text { which may include whales and } \\
\text { dolphins }\end{array}$ & $\begin{array}{l}\text { The plan could include: } \\
\text { Species identification guide } \\
\text { Rescue response needs for individual species } \\
\text { Safety considerations for rescuers, especially for } \\
\text { cold water } \\
\text { Management requirements for onlookers } \\
\text { Specialist rescue support equipment } \\
\text { The participation of marine mammal experts } \\
\text { Incident governance protocols and stakeholder } \\
\text { liaison checklists }\end{array}$ \\
\hline Rogue animal incident plan & $\begin{array}{l}\text { The plan provides guidance for } \\
\text { responding to rogue animals } \\
\text { such as crocodiles, elephants } \\
\text { and tigers impacting humans } \\
\text { and their livelihoods }\end{array}$ & $\begin{array}{l}\text { The plan could consider: } \\
\text { Policy and safety considerations for people } \\
\text { Safety considerations for wildlife managers } \\
\text { Specialist capture and transport equipment } \\
\text { Veterinarian support } \\
\text { Euthanising approval procedures } \\
\text { Incident governance protocols }\end{array}$ \\
\hline $\begin{array}{l}\text { Marine oil pollution incident } \\
\text { plan }\end{array}$ & $\begin{array}{l}\text { The plan deals with oil spills in } \\
\text { a marine setting that impacts } \\
\text { protected area shorelines and } \\
\text { native wildlife species }\end{array}$ & $\begin{array}{l}\text { This document would typically form part of a larger } \\
\text { incident response plan involving many organisations } \\
\text { and could include: } \\
\text { Procedures for de-oiling impacted wildlife } \\
\text { Procedures for de-oiling coastline environments } \\
\text { Incident governance protocols and stakeholder } \\
\text { liaison checklists }\end{array}$ \\
\hline \multicolumn{3}{|l|}{ Visitors } \\
\hline Search and rescue plan & $\begin{array}{l}\text { The plan deals with visitors to } \\
\text { protected areas who become } \\
\text { lost or require assistance in } \\
\text { extreme events }\end{array}$ & $\begin{array}{l}\text { The plan could include: } \\
\text { Vocational capacity development guidance such as } \\
\text { skill development for: remote area first aid, navigation, } \\
\text { aerial observation, vehicle use, water-based access, } \\
\text { snow-based access, caving and mountaineering } \\
\text { Governance guidance, the identification of } \\
\text { partnerships and liaison checklists with other } \\
\text { organisations and especially the police, who may } \\
\text { have overall responsibility for the incident }\end{array}$ \\
\hline $\begin{array}{l}\text { Visitor emergency } \\
\text { evacuation plan }\end{array}$ & $\begin{array}{l}\text { This plan will be most commonly } \\
\text { used for medical evacuation } \\
\text { emergencies, but it assists in } \\
\text { dealing with safety evacuations } \\
\text { caused by wildfires or severe } \\
\text { storms that impact protected } \\
\text { areas }\end{array}$ & $\begin{array}{l}\text { The plan would provide guidance for: } \\
\text { The competency levels for first-aid training required } \\
\text { by protected area staff } \\
\text { Logistical aspects such as methods to be used for } \\
\text { medical evacuations, radio communication systems, } \\
\text { helicopter operations and safety considerations } \\
\text { Incident governance protocols }\end{array}$ \\
\hline \multicolumn{3}{|l|}{ Wildfires } \\
\hline $\begin{array}{l}\text { Wildfire incident } \\
\text { management plan }\end{array}$ & $\begin{array}{l}\text { This plan would deal with } \\
\text { all aspects of responding to } \\
\text { unplanned fire events in a } \\
\text { protected area }\end{array}$ & $\begin{array}{l}\text { The plan would detail aspects such as: } \\
\text { Detection, initial attack, mapping, forecasting fire } \\
\text { behaviour and the triggering of incident control } \\
\text { system procedures } \\
\text { Staff competencies required, training needs, } \\
\text { equipment preparation, staff roster and standby } \\
\text { arrangements, and detection responsibilities } \\
\text { The pre-assessment of fire fuels, terrain fire risk and } \\
\text { fire potential } \\
\text { Fire incident governance arrangements, reporting } \\
\text { arrangements and key organisations with whom } \\
\text { collaborative partnerships need to be established }\end{array}$ \\
\hline
\end{tabular}




\begin{tabular}{|c|c|c|}
\hline $\begin{array}{l}\text { Potential incident } \\
\text { management plan }\end{array}$ & Type of incident event & Some specific planning considerations \\
\hline \multicolumn{3}{|c|}{ Terrestrial pollution events } \\
\hline $\begin{array}{l}\text { Pollution incident response } \\
\text { plan }\end{array}$ & $\begin{array}{l}\text { The plan would provide } \\
\text { guidance for responding to a } \\
\text { range of pollution events such } \\
\text { as air pollution (fires); stream or } \\
\text { river pollution (such as petroleum } \\
\text { product discharge); and vehicle } \\
\text { accident pollution (such as toxic } \\
\text { chemicals) }\end{array}$ & $\begin{array}{l}\text { The plan could include: } \\
\text { Staff competencies needed for awareness of and } \\
\text { responses to toxic pollutant incidents } \\
\text { Pre-planned responses for each different pollution } \\
\text { event type } \\
\text { Pollution event governance arrangements and } \\
\text { incident response protocols } \\
\text { Advisory contact lists for pollution incidents }\end{array}$ \\
\hline \multicolumn{3}{|c|}{ Natural disaster incidents } \\
\hline $\begin{array}{l}\text { Natural disaster incident } \\
\text { management plan }\end{array}$ & $\begin{array}{l}\text { The plan would provide } \\
\text { guidance for protected areas } \\
\text { for reserves with a high } \\
\text { probability of being affected } \\
\text { by natural disasters such as } \\
\text { floods, cyclones, earthquakes, } \\
\text { tsunamis, volcanic eruptions and } \\
\text { lahars }\end{array}$ & $\begin{array}{l}\text { The plan could include: } \\
\text { Natural incident governance arrangements } \\
\text { The role of the protected area organisation as part } \\
\text { of a larger incident response } \\
\text { The deployment of equipment and personnel to } \\
\text { assist with disaster responses } \\
\text { The identification of vocational training required for } \\
\text { dealing with such incidents }\end{array}$ \\
\hline
\end{tabular}

\section{Preparedness}

The planning and preparedness for incidents are undertaken at strategic, tactical and operational levels within protected area organisations.

\section{Strategic preparedness}

Organisational policies and procedures for dealing with each individual incident type will have been established and will be very clear. For staff, these could include matters such as occupational health and safety requirements, uniforms and protective clothing, minimum training standards, competency requirements, insurance and remuneration, and rostering arrangements. For plant and equipment, asset management systems would ensure the replacement of old equipment with new on a systematic basis (see Chapter 24), and minimum competency standards would be identified for personnel to operate such equipment. For organisational budgeting, there would be allocations provided for vocational training that ensured sufficient staff with the right skills and competencies were available for incident operations. For protected area organisations dealing with other organisations at a whole-of-government level, the message about the status, function and special conservation role of protected areas needs to be embedded within the psyche and incident modus operandi of organisations such as defence, forestry, emergency services, bushfire services, fire brigades, the police and departments of agriculture.

\section{Tactical preparedness}

Frontline staff of agencies and their national or subnational protected area systems are typically located in or near individual protected areas and consequently they are dispersed across a national or sub-national area. When an incident impacts on an individual protected area, local cooperative incident response efforts are usually made by many organisations. For protected area managers, the numbers of their incident response staff may be bolstered by staff from other areas of the larger (perhaps national) protected area system. This is particularly important where an incident is large and needs multiple staff resources and support equipment, or is long in duration and needs relief incident crews to rest operational crews, or both. Tactical preparedness would ensure plans and procedures for mobilising and supporting the transfer of protected area staff during incidents are available. Tactical preparedness would ensure that cooperative incident management arrangements are in place across a larger region that may include multiple protected areas and that there are good working relationships between agencies and volunteer groups. Many incidents are much larger than individual protected areas, and may need preincident planning and preparation at a much larger scale. The impacts of a tropical cyclone (hurricane or typhoon) are one example of a larger-scale event.

\section{Operational preparedness}

For individual protected areas and their staff, a range of preparedness measures is typically implemented. Depending on the nature of the potential incident, staff rosters that anticipate incidents could be implemented and staff with the appropriate training could be placed on standby. Plant and equipment would be serviced and functional, and some may be held in readiness in certain weather (such as a fire unit in extreme fire conditions). Some special ranger patrol operations may be implemented when the probability of incidents is high and precautionary actions may be implemented 
such as protected area fire bans, weather alerts, wildlife alerts or even temporary protected area closures. For fire operations, fire observation towers would be operational, fire-spotting fixed-wing aircraft flights after thunderstorms would be completed and water-bombing aircraft would be organised and on standby. All incident management plans would be up to date and a document that identifies all contact and other logistical information needed during an incident (the incident action plan) is current.

\section{Prevention}

Nature will guarantee that incidents will always occur. There are some incidents, however, for which a risk assessment identifies that either they can be prevented or the frequency of their occurrence can be lowered. Some of these prevention actions have been described (Table 26.5).

\section{Surf lifesavers and swimmer safety (swim between the flags) at Wilson's Promontory National Park, a popular camping and beach destination in Victoria, Australia \\ Source: Graeme L. Worboys}

Table 26.5 Prevention actions to minimise incidents

\begin{tabular}{|c|c|c|c|}
\hline $\begin{array}{l}\text { Potential } \\
\text { incident }\end{array}$ & $\begin{array}{l}\text { Protected area } \\
\text { prevention action }\end{array}$ & Notes & Implications of the action \\
\hline Avalanche & Reafforestation & $\begin{array}{l}\text { Restoration of disturbed forests } \\
\text { helps to stabilise snow layers } \\
\text { and prevent avalanches }\end{array}$ & $\begin{array}{l}\text { The number of avalanches is } \\
\text { reduced }\end{array}$ \\
\hline $\begin{array}{l}\text { Extreme stormwater } \\
\text { run-off }\end{array}$ & $\begin{array}{l}\text { Catchment vegetation } \\
\text { cover restoration }\end{array}$ & $\begin{array}{l}\text { Restoration includes soil } \\
\text { erosion control and vegetation } \\
\text { replanting }\end{array}$ & $\begin{array}{l}\text { Vegetation slows water run-off and } \\
\text { lowers downstream impacts }\end{array}$ \\
\hline Landslides & $\begin{array}{l}\text { Catchment vegetation } \\
\text { cover restoration }\end{array}$ & $\begin{array}{l}\text { Vegetation restoration binds } \\
\text { steep mountain slopes }\end{array}$ & $\begin{array}{l}\text { The risk of slope instability and } \\
\text { landslides is lessoned }\end{array}$ \\
\hline Wildfire & Fuel reduction burning & $\begin{array}{l}\text { Strategic fuel reduction such as } \\
\text { near an urban-protected area } \\
\text { interface }\end{array}$ & $\begin{array}{l}\text { Reduced fuel increases the potential } \\
\text { for successful fire suppression and } \\
\text { control of any local ignition }\end{array}$ \\
\hline Wildfire & $\begin{array}{l}\text { Grass cutting and } \\
\text { vegetation slashing }\end{array}$ & $\begin{array}{l}\text { Mowing of grassland and } \\
\text { slashing of vegetation at the } \\
\text { protected area-urban interface }\end{array}$ & $\begin{array}{l}\text { Reduced fuel increases the potential } \\
\text { for successful fire suppression and } \\
\text { control of any local ignition }\end{array}$ \\
\hline Wildfire & Fire trail maintenance & $\begin{array}{l}\text { Constant maintenance of fire } \\
\text { trails provides rapid official } \\
\text { access for fire suppression } \\
\text { purposes }\end{array}$ & $\begin{array}{l}\text { Rapid initial attack of fires helps to } \\
\text { suppress wildfires }\end{array}$ \\
\hline Wildfire & Protected area fire ban & $\begin{array}{l}\text { The banning of all fires in the } \\
\text { open }\end{array}$ & $\begin{array}{l}\text { Fire bans reduce the chance of } \\
\text { accidental fires }\end{array}$ \\
\hline Wildlife & $\begin{array}{l}\text { Wildlife barrier } \\
\text { construction }\end{array}$ & $\begin{array}{l}\text { Electric fences and other } \\
\text { practical wildlife barriers }\end{array}$ & $\begin{array}{l}\text { Barriers help to minimise human- } \\
\text { wildlife incidents including crop } \\
\text { destruction by large animals such } \\
\text { as elephants }\end{array}$ \\
\hline Floods & $\begin{array}{l}\text { Protected area } \\
\text { swimming ban }\end{array}$ & $\begin{array}{l}\text { The closure of a popular } \\
\text { protected area river swimming } \\
\text { location }\end{array}$ & $\begin{array}{l}\text { Swimming bans officially prevent } \\
\text { swimming in dangerous flooded } \\
\text { river conditions }\end{array}$ \\
\hline $\begin{array}{l}\text { Beaches: strong surf } \\
\text { or strong currents }\end{array}$ & $\begin{array}{l}\text { Swim between the flags } \\
\text { or beach closure }\end{array}$ & $\begin{array}{l}\text { Surf lifesavers may need to be } \\
\text { contracted by the protected } \\
\text { area organisation }\end{array}$ & $\begin{array}{l}\text { Safety of visitors to the protected } \\
\text { area is increased }\end{array}$ \\
\hline Extreme weather & Protected area closure & $\begin{array}{l}\text { The closure of a protected area } \\
\text { due to extreme weather such } \\
\text { as cyclonic winds, extreme } \\
\text { heat or extreme cold }\end{array}$ & $\begin{array}{l}\text { Protected area closures minimise } \\
\text { or prevent search and rescues, the } \\
\text { threat of tree fall and the threat of } \\
\text { heat or cold exposure }\end{array}$ \\
\hline
\end{tabular}





\section{AlIMS principles}

The Australasian incident management system is based on five underpinning principles that help to make the system easily understood and workable. AIIMS is adaptive, situational, relies on clarity of purpose, is designed to not be too unwieldy and is very clear about who is in charge and what the principal tasks are. It is a key reason the system is essentially successful at (potentially) the most chaotic of times. The five principles are as follows (AFAC 2013:11-20).

1. Flexibility: A flexible approach is taken with the implementation of AIIMS given it is employed across many different types of incidents.

2. Management by objectives: Management by objectives is a process of management (see Chapter 8) where the desired outcomes for the incident are established, and these incident objectives are communicated to everyone involved. The objectives are reviewed regularly against progress in resolving the incident.

3. Functional management: Functional management is about structuring an incident response organisation into sections and units based on the work to be performed. Eight functions are commonly recognised and may be delegated by an incident controller as a managerial responsibility as part of an incident response. These functions are described in this section.

4. Span of control: Span of control relates to the number of groups or individuals who can be successfully supervised by one person. The ideal ratio is $1: 5$, but this may vary.

5. Unity of command: Unity of command reinforces that there is one set of objectives for an incident that generates one plan for all incident responders.

\section{Levels of incidents}

Communicating the nature of incidents is routine and important, and a common language has been developed to describe how large and complex an incident is. Identifying the 'levels' of an incident immediately helps potential participants to identify the degree of response that may be required and who might be involved. For this reason, the AIIMS recognises three classes of incidents.

Level one incidents are generally local and typically can be dealt with by an initial response team. Level two incidents are more complex and are characterised by the deployment of resources beyond the initial response or an incident that has been broken up into response

\section{Box 26.2 Definitions of key terms}

AlIMS uses the following definitions in managing multiagency incidents that may involve interstate and even international personnel.

\section{Command}

Command is the internal direction of the members and resources of an agency in the performance of the organisation's roles and tasks, by agreement, and in accordance with relevant legislation.

\section{Control}

Control refers to the overall direction of emergency management activities in an emergency situation. Authority for control is established in legislation or in an emergency plan. Control carries with it the responsibility for tasking other organisations in accordance with the needs of the situation. Control relates to situations and operates horizontally across organisations.

\section{Coordination}

Coordination is the bringing together of organisations and other resources to support an emergency management response. It involves the systematic acquisition and application of resources (organisational, human and equipment) in an emergency.

Source: AFAC (2013:18)

sectors or has witnessed the establishment of functional sections, or a combination of these responses. Level three incidents are complex and may require the establishment of divisions for effective management and the delegation of all functions to a larger incident management team (AFAC 2013:22). Some incidents that are very large, complex and protracted may be split (geographically or functionally) into two or more incident teams for more effective management (AFAC 2013:25).

\section{Managing an incident}

\section{Pre-incident}

The AIIMS is applied in the Australian context of legislative responsibilities and arrangements in place with State and Territory organisations (AFAC 2013:28). For protected area organisations, there is an imperative for top-level and middle-level managers to ensure that incident management organisations, their senior staff and potential incident controllers are well briefed and aware of the special needs of protected areas. Anticipating incident events, pre-planning responses and thoroughly briefing key stakeholders on the protection of special sites such as karst areas would be part of this work. 


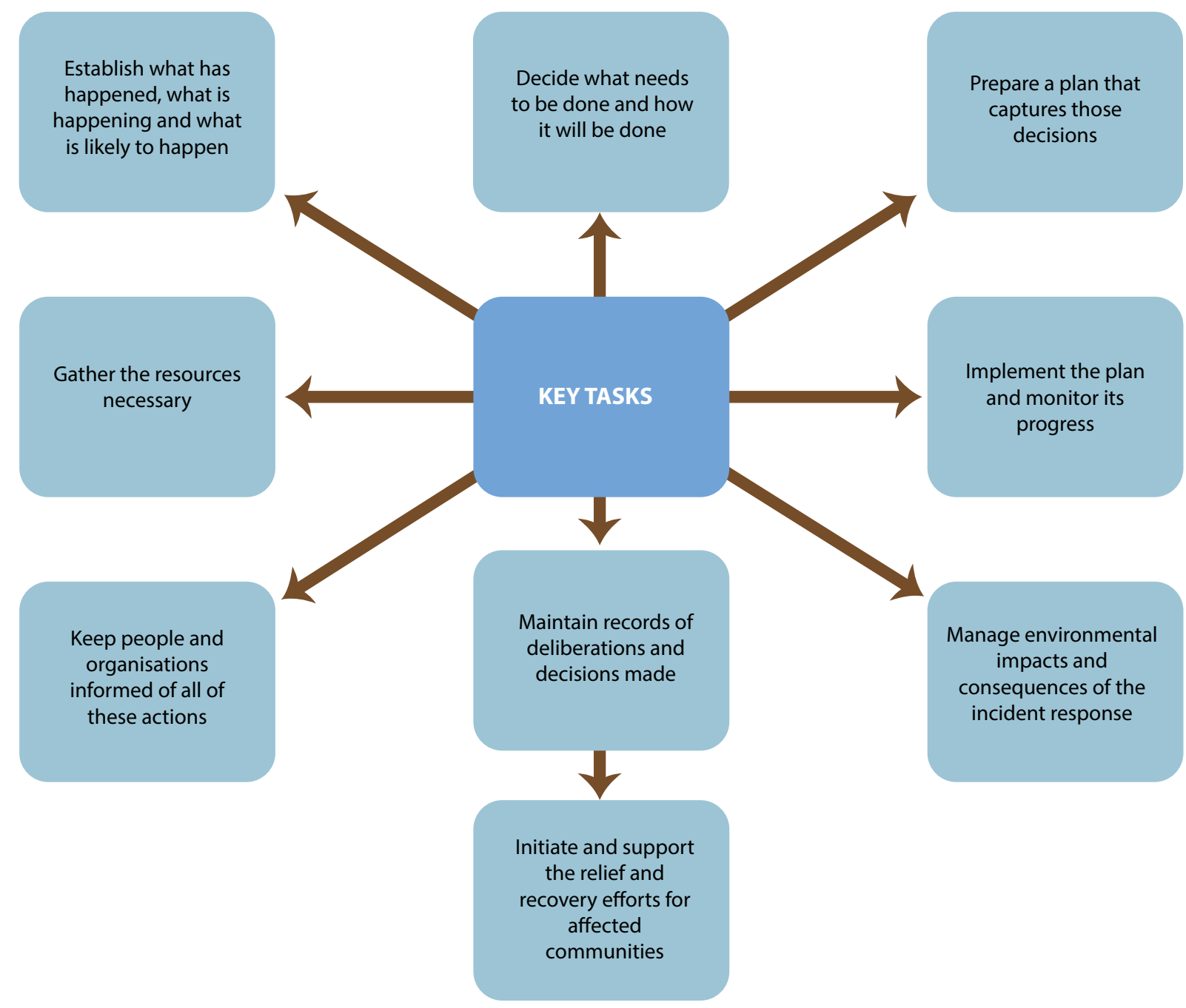

Figure 26.1 Key tasks for the incident controller

Source: AFAC (2013:32)

\section{Responding to an incident}

For level two and level three incidents, the incident controller typically establishes an incident management team, and for larger and more complex incidents, delegates most of the key managerial functions. This incident management team works within a network of supporting agencies, with each organisation's chain of command operating beyond the team's structure (AFAC 2013:31). The key tasks of the incident controller and the incident management team are reasonably common sense, but they are not necessarily sequential and may evolve in a somewhat 'disorganised but becoming organised' environment of the initial response (Figure 26.1).

The incident controller and the incident management team will meet regularly and will assess the status of the incident including the planning, resourcing, implementation, safety and welfare of people controlling the incident, impacts to infrastructure and the environment, and the effectiveness (and efficiency) of the incident operation.

\section{Shift change (changeover)}

The changeover from one shift to the next is a critical stage of an incident operation. Shift changes will be frequent during a 24-hour period, the actual frequency depending on the nature of the incident. For wildfires in protected areas, the changeover is commonly every 12 hours. For marine incidents such as whale strandings, where respondents are often immersed in water for periods, the changeover frequency will be much greater.

The changeover includes the transfer of information from the operational incident team to the new team. For a fire incident, for example, the system benefits by each new incident team possessing very similar skills and competencies to the incident team which preceded them. This is of course part of the responsibilities of the 


\section{Case Study 26.2 Incident controller changeover briefing}

\section{The incident}

The AlIMS incident control system has been operational in Australia since the 1980s and lessons learned and experiences gained over many years have contributed to improved practice. One such lesson about efficient changeovers was learned during the summer of 1994. A prolonged drought had affected many parts of eastern Australia at this time; it was hot and tinder dry and lightning storms had set alight large tracts of bushland in national parks to the west of Sydney. These included the Blue Mountains and Wollemi national parks. The fires were large, they had been fought for many weeks and it was time for the scheduled relief of one incident controller to provide for some much needed rest. It was clear that, without rain, the fires were highly likely to continue for many more weeks and this brief rest period was needed. The relief controller was flown northwards from the Blue Mountains to the Hunter Valley, and towards a seemingly continuous north-south line of fire and extensively billowing smoke more than 30 kilometres in length. On approach, it was clear that this large fire front was actually a series of fire fronts vigorously moving eastwards under strong winds.

\section{The context}

The Hunter Valley of New South Wales lies to the north of Sydney and immediately east of the Wollemi National Park, with the park's grand cliffs and escarpments providing a majestic setting for the valley. This valley is well known in Australia for its fine horse studs, its picturesque vineyards and fine wines, and is perhaps infamous for its expansive open-cut coalmines that produce high-quality black coal for industry and export. The 1994 Bulga fire was a large fire burning on the eastern escarpment of the park and it was the destination of the relief incident controller. Immediately east of the Bulga fire was one of the Hunter Valley's great coalmines and a north-south mined (ready for transport) inverted-v wedge-shaped stockpile of black coal many kilometres long. The coal stockpile was at right angles to the fire front, it was downwind and just a few kilometres from the fire, with a severe weather change forecast.

\section{The changeover}

The pre-twilight changeover briefing was memorable. It was to the point. Severe wind strengths capable of extending the fire to the stockpiled coal and even beyond were forecast. There was more. Between the coal dump and the fire, there were storage sheds for explosives used in the mines, and to the south, there was a bushland military training area with unexploded ordnance-a nogo area for any firefighting personnel or equipment. The briefings included details of the weather front, the 24hour weather forecast, the safety of personnel and an offer of major plant (bulldozers) by the coalmining companies. The incident control plan provided to the new incident team was clear. A massive fuel break control line was to be bulldozed north-south along the Hunter Valley floor to help cut off the rapidly easterly moving fire. Massed fire tankers from New South Wales and interstate were on site to help stop the fire on this all-important fuel break.

Given the circumstances, the actual changeover had to happen quickly and the incident action plan also had to be put into operation straight away. During the night, with the assistance of some of the world's largest bulldozers sourced from the deepest parts of the nearby Hunter Valley coalmine, a control line many kilometres long and at least 50 metres wide was constructed and then patrolled by multiple tankers. The fire was stopped on its eastern flank and suppressed and the coal stockpiles did not catch fire. The changeover briefing had been clear, to the point and successful, and the fire plan objectives were successfully implemented for that 12-hour shift.

\section{Preparing for the next changeover}

Following the drama and volatility of the night's events, the next edition of the incident action plan still had to be developed and the briefing for the new incident control team's shift prepared, for the fire had been controlled on just one flank, and was still burning. two incident controllers who manage their combined 24-hour operation to ensure there is a harmonisation of individual personnel competencies across both 12-hour shifts. If such a fire incident extends for many weeks, incident controllers would also need to consider an effective replacement/resting strategy for their highly skilled teams as key individuals take some well-earned rest days. At a changeover, a typical incident controller briefing session could include the following key details:

- current situation

- incident objectives and strategies for the incident

- special hazards

- key risk exposures (political, economic, social, public health and environmental)

- current incident action plan
- incident action plan to be inherited by the new shift

- key contacts (such as inter-organisational and community contacts) (AFAC 2013:33).

Case Study 26.2 illustrates a changeover briefing: the circumstances and interaction between two incident controllers at a major wildfire event in the Hunter Valley, Australia. Changeovers at a large incident can be logistically complex and difficult to implement. Typically, they take far longer than planned for, and an aim of incident controllers is always to refine changeovers so they are efficient. Changeovers can also be dangerousfor example, if there are delays in replacing crews at key fire-control sites. Given this complexity, some changeover management tips are provided by the AIIMS (Box 26.3). 


\section{Box 26.3 Changeover tips}

Lessons learned to improve the efficiency of changeovers include:

- changeover is best done during daylight hours

- they need to be planned and prepared for

- planning needs to be at all operational levels

- changeover briefings specific to each operational level should be developed

- crews should changeover at a suitably safe area close to their operational area

- personnel should be transported in groups relative to their destination
- the incoming shift should be fed before the changeover and the outgoing shift fed after the changeover

- avoid changeover times that are critical to the incident management operation (AFAC 2013:34).

For fire incidents, changeover times are usually in the cool of the evening and early morning to avoid the dangerous fire behaviour that occurs during the heat of the day. Major weather changes of course will influence such timing.

\section{Box 26.4 Incident action plan contents checklist}

Incident action plans are constantly developed and refined and underpin an incident controller's actions. For fire operations, with their 12-hour shifts, two plans are developed every 24 hours. Some organisations have pro-forma plans to be filled out for efficiency, given there is very little time to get this work completed. The contents of an incident action plan may include:

- the current situation

- predictions of the likely development of the incident and risk

- incident response objectives

- contingency plans and alternative strategies

- risks and mitigating actions

- incident management structure and personnel

- management arrangements (such as the establishment of sectors and divisions and their roles)
- resources to be allocated

- maps of the incident and the governance geography of the response (divisions, sectors)

- medical plan and occupational health and safety issues such as dealing with dangerous chemicals, hostile animals or response equipment that may be dangerous

- communications plan including information on all agencies

- timings of meetings and changeovers

- accommodation and welfare arrangements

- logistical arrangements

- traffic management plan for the incident

- an information plan for managing inquiries (AFAC 2013:49).

\section{Incident action plans}

These plans are developed and continually refined in a dynamic environment. They may be informal or, as the scale and complexity of an incident increase, they may be formal documents. The planning includes the gathering and analysis of information, a risk assessment for incident responders and, to those directly affected by the incident, the setting of incident objectives and strategies and the implementation of the plan. The plan is developed with input from the entire incident management team's functional leaders and others. Generally, a plan does not detail the tactics as to how a strategy will be achieved; rather this level of detail is prescribed by the operations team (Figure 26.2). The possible content of an incident action plan has been described by AIIMS (Box 26.4).

\section{The common operating picture}

The common operating picture is important AIIMS language for the agreed and shared description of an incident (AFAC 2013:65). It describes what has happened, what is happening now and what is forecast to happen, and provides a common situational awareness of the incident. It is part of the language of an incident that helps make incident management work. Given the incident controller is responsible for all aspects of an incident, he or she is also responsible for ensuring clarity with the common operating picture if this is needed. 


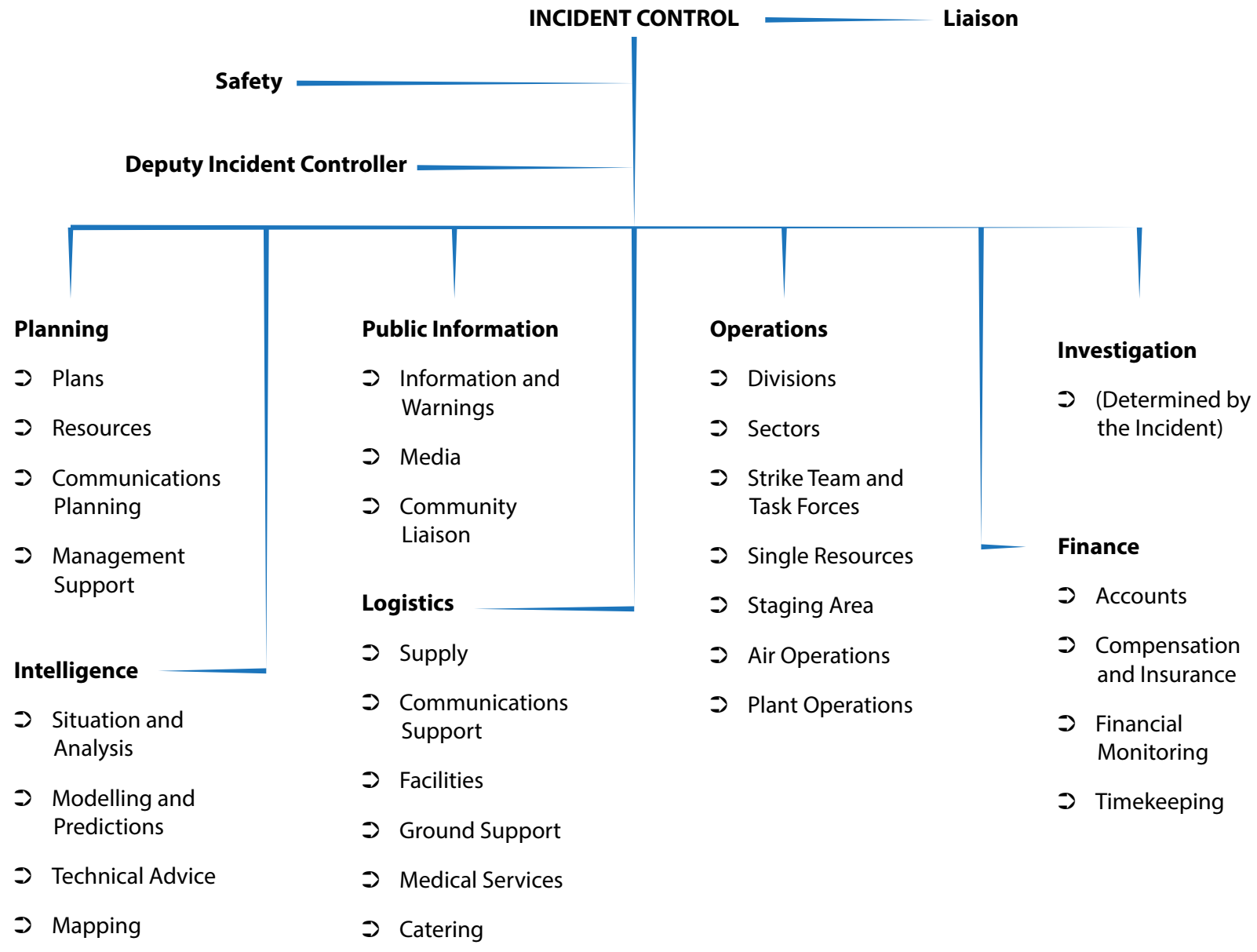

Figure 26.2 Incident management team structure

Source: AFAC (2013:40)

\section{Briefings}

It is critical for any incident that people are thoroughly briefed about all aspects of the incident prior to dispatch, before being deployed, at regular intervals during the incident and especially during changeovers. Debriefing after each shift and prior to dispatch from the incident is critical (AFAC 2013:68).

\section{The incident management team}

An incident management team structure may include incident control and seven key supporting functions as well as liaison, safety and a deputy incident controller position (Figure 26.2).

\section{Incident controller}

The incident controller takes responsibility for managing all activities related to an incident. This is potentially an enormous task and the appointed office will typically have had extensive experience and advanced training. Experienced protected area managers may be appointed

as incident controllers, particularly where an incident is confined to a protected area. The incident controller's responsibilities may include the need to:

- take charge and exercise leadership of the response and the response team

- establish a management structure

- set response objectives (including the safety of affected communities)

- develop and approve the incident action plan

- implement the incident action plan

- provide information and warnings to others

- establish effective liaison and cooperation with all relevant stakeholders

- obtain and maintain the necessary human support and other resources and services

- apply a risk-management, safety-focused approach

- ensure relief and recovery considerations are addressed and services provided to those impacted

- ensure collaboration between response and recovery agencies (AFAC 2013:80). 


\section{Planning}

Planning is a role protected area management staff commonly find themselves having to undertake within a multi-agency incident response. This often reflects their knowledge of the local incident area and their extensive training in natural resource management. The planning officer's responsibilities may include:

- analysing information on the current and projected incident situation

- identifying new and emerging risks (political, economic, social, public safety or environmental risks)

- developing alternative incident objectives and strategies for decision makers

- disseminating information relevant to controlling the incident and potential safety issues (Figure 26.2)

- documenting the incident action plan for the subsequent operations period

- developing a communications plan for the incident (based on the latest incident action plan), including guidance for the incident controller and the public information team

- planning for any contingency in the implementation of the incident action plan

- maintaining an effective register of all resources requested, en route, allocated to and released from the incident

- considering recovery and rehabilitation in the incident action plan

- developing changeover and demobilisation plans

- collecting, collating and storing incident records (AFAC 2013:92).

\section{Intelligence}

Responsibility for this commonly lies with the planning team, though for large, complex incidents it may be established as a section in its own right. It may be assisted by a situation and analysis unit, a modelling and predictions unit, a technical advice unit and a mapping unit. It would normally be supported by incoming information from a range of sources including ground and air observers, local knowledge, weather forecasts and other sources. Intelligence analysis will include addressing a number of key questions in relation to the incident (AFAC 2013:103).

- What is happening?

- Why is it happening?

- How can different accounts of what is happening be reconciled?
- What is likely to happen next?

- What are the emerging risks/opportunities at the incident?

- What is the worst-case scenario?

\section{Public information}

This critical function ensures that accurate and timely information is made available to incident stakeholders and the greater community outside the incident management team. This work includes the provision of warnings and information, dealing with the media and managing any media issues, and consultation and liaison with affected communities (AFAC 2013:111). This media work may involve briefings, press conferences, media releases, media inquiries and media inspections of the incident area. Working with local communities may mean arranging community meetings and preparing community information updates. There is also a role in collecting information such as from social media from the general public and news media for feedback to the intelligence unit.

\section{Operations}

The operations officer has the responsibility of implementing actions to help resolve the incident and for looking after all of the people and equipment assigned to the operations section. The operations officer typically has a constantly changing situation and needs to be adept at dealing with such change. Rapidly changing fire conditions with weather changes is an example of such a dynamic environment. For a large incident, operations may have division commanders, sector commanders, staging area managers, air operations managers and plant operations managers reporting to them (AFAC 2013:123). The responsibilities may include

- ensuring the safety and welfare of operations personnel

- helping to develop the incident action plan

- establishing processes for adequately briefing personnel prior to deployment

- ensuring personnel are properly equipped

- keeping personnel informed of the situation at the incident (especially safety matters)

- establishing processes for debriefing personnel post shift or post stint

- providing regular progress reports to the incident controller

- identifying new and emerging risks at the incident and ensuring they are managed effectively (AFAC 2013:121). 


\section{Investigations}

Complex incidents may require an investigations unit to be established. Investigations may be required, for example, to establish the point of origin of a fire incident; for floods, the evaluation of flood levee bank performance or breaches; for a biosecurity matter, to determine how a disease entered a region or how it spread (AFAC 2013:133). The responsibilities of an investigations officer may include:

- documentation in the incident action plan of the purpose and expected outcome of the investigation

- development of an investigation plan

- communicating with other functional areas of the incident management team

- keeping the incident controller informed of the need for liaison with external bodies such as the police (AFAC 2013:134).

\section{Logistics}

The logistics officer provides support for the control of an incident that includes human resources, facilities, services and materials (AFAC 2013:139). This can be a very difficult role, particularly when logistical support may be required over a very large area such as a fire front. Just think of ensuring, for a rough, rugged and remote fire perimeter, how firefighters are to be fed, how their vehicles are to be fuelled and their equipment serviced, and how their safety and health considerations are looked after. Then double this challenge because you are dealing with two shifts a day as well as adding the complexity of the fact that one of the shifts is at night.

To undertake such tasks, logistics may be supported by a supply unit that acquires and distributes equipment and materials, a communications support unit (radio, communications and information technology), a facilities unit (feeding, sanitation, accommodation), a ground support unit (transport for personnel, food and resources), a finance unit, a medical services unit and a catering unit. The responsibilities of a logistics officer may include:

- providing a safe working environment for logistics personnel

- developing the logistics section of the incident action plan

- planning how the logistics section will work

- procuring human resources as required

- procuring other physical resources, facilities, services and materials

- establishing effective liaison

- providing progress reports on logistical support
- estimating future service and support requirements

- facilitating the establishment of staging areas in support of the operations section (AFAC 2013:139).

\section{Finance}

Unless an incident is very large and prolonged, logistics will typically look after the finances for an incident. The finance officer may be supported by an accounts unit, a compensation and insurance unit, a financial monitoring unit and a timekeeping unit. Complexity comes into this work, for example, where industrial awards for workers of organisations are linked to the number of hours worked and where additional penalty payments may need to be made if they exceed certain hours worked. Where a finance section is established, the responsibilities of a finance officer may include overseeing all financial management and financial recordkeeping, and overseeing the management of insurance and compensation claims arising from the incident (AFAC 2013:148).

\section{Managing incidents}

This chapter has described natural and human-caused incidents that may affect protected areas. Pre-planning in anticipation of such incidents has been discussed and the AIIMS approach for coordinating multi-agency incidents, particularly as they relate to protected areas, has been introduced. In this section, we will describe how protected area organisations may deal with some more common incidents that occur in or affect protected areas.

\section{Wildfire incidents}

Wildfire events may be anticipated for many protected areas of the world and there are many pre-season and fire-season actions that can be undertaken. Many of these actions have been described in Worboys and Winkler (2006). Here we focus more on the climate change world of the early 21 st century in discussing additional protected area fire incident response considerations.

\section{Information needs}

It is anticipated that enhanced data and access to timely analysed information will need to be secured to service the increasingly sophisticated modelling used for planning and forecasting fire behaviour. This could include:

- increasing sophistication in the collection and use of real-time ambient protected area condition data such as for site-based temperatures, humidity, soil dryness, fuel loads and fuel availability 


\section{Box 26.5 A grand array of fire phenomena}

'Fire phenomena' may be seen as the spectacular, such as fire tornadoes (McRae et al. 2013), pseudo-flame fronts (Byram 1959) and pyro-cumulonimbus clouds (Fromm et al. 2010), but some phenomena can appear to be mundane-ignition, spread and fire shape-yet important to gaining an understanding of fires, being safe during fires and predicting fire behaviour. The 'mundane' can become more interesting as inquiry becomes deeper: thus, 'ignition' becomes more interesting when spontaneous combustion (Armstrong 1973), arson (Willis 2004) and the various forms of lightning (Fuquay et al. 1979) are considered. Below, only a few phenomenasome spectacular, some mundane-are considered.

The usual sequence for a fire event is: ignition when fuel dryness allows it; fire spread when the fuel is continuous-or when discontinuities can be overcome because of spread uphill or in winds that cause flames to lean over and connect patches; acceleration until a quasi-equilibrium rate of spread is reached (Cheney and Sullivan 2008:32); a period of quasi-equilibrium rate of spread, which varies according to weather, fuels and topography; a cessation of spread; and a time when all flames and smouldering have ended. The maximum quasi-equilibrium rate of spread in Australian grasslands is about 6 metres per second (Noble 1991), while that in forests is about half of this (Gould et al. 2007:100).

If flames are tall enough, fire may reach into the canopies of shrubs and trees ('torching') or even spread there ('crown fires') (van Wagner 1977). If there is a peaty substrate beneath the soil surface, fire may spread into it by smouldering, but at a very slow rate of 3-12 centimetres per hour (Wein 1983). If a fire above the organic soil surface sets multiple fires in the peaty surface, the area covered in any given period will increase. Peat fires can be a major cause of smoke pollution, causing health problems and great expense over a number of months, as in Indonesia and a number of neighbouring countries in 1997-98 (Cochrane 2009a).

Fire heats the air around it, causing the heated air and smoke to expand and rise. With rising heat and smoke, air is drawn into the base of the fire and at higher levels in the convection column. Flames will be drawn away from the unburnt fuel unless the ambient wind or slope can overcome the effect. In large and extremely intense fires, the ambient wind can be captured by the convection column and effectively act as a windbreak (Raupach 1990). Fire whirlwinds (vortices) can develop at the perimeter of fires and these can be great or small, horizontal or vertical (Forthofer and Goodrick 2011). The most extreme vortex is the fire tornado (McRae et al. 2013).

In light winds, the smoke rises vertically or at a high angle and may develop a pyro-cumulus cloud at its peak due to condensation of moisture in the convection column. In a large, intense fire, the billowing clouds of smoke may be topped by a pyro-cumulonimbus cloud reaching up to 15 kilometres or so above the ground and from which black hail may emerge and tornadoes may be spawned (Fromm et al. 2006); smoke may be transported internationally via the stratosphere (Fromm et al. 2010).

The classical elliptical shape of the wind-blown fire (burning with, at right angles to and against the wind) narrows as wind speed increases (Alexander 1985). South-eastern Australia's tragic 2009 bushfires showed an almost rectangular shape just before a strong wind change led to fingering of the fire from one flank (Cruz et al. 2012:Figure 7). The fire's perimeter is not always smooth (see, for example, Coen 2011).

Sharples et al. (2012) detected ribbons of fire spreading rapidly, perpendicular to the wind direction, along a ridge in rugged terrain ('channelling'). Albini (1993) observed a ribbon of fire emerging from the fire's flank and spreading parallel to, and faster than, the main front, while Radke et al. (2000) observed 'fingers of death' and Coen et al. (2004) saw 'flaming fingers' emerging from fire perimeters. A fingering pattern can develop downwind after a sharp wind change, with the overall shape of the perimeter changing dramatically as the fire dies (see, for example, Cruz et al. 2012:Figure 7).

According to the patterns of ambient wind and convection throughout the profile of the fire, pieces of burning material-firebrands-may be lofted and dropped at various places ahead of the main fire front, setting 'spot fires' up to 33 kilometres ahead of the fire (Cruz et al. 2012). Near the front itself, firebrands may be common and cause spot fires; in extreme cases, these may be so numerous that the front of the fire consists of burning spots rather than an identifiable line-the pseudo-flame fronts of Byram (1959).

Fires burn a vast array of fuels in a wide range of topographic situations with great fluctuations of weather. They may cause darkness to descend prematurely on the ground or light up a night sky; they may trickle along or race up steep slopes; they may crackle and pop or create a roar so loud that shouting to someone nearby cannot be heard. Landscape fires exhibit a complex and intriguing spectrum of phenomena that challenge our understanding yet are important to public safety and the prediction of damage and recovery of our social, economic and environmental assets (Gill et al. 2013).

- A. Malcolm Gill 


\section{Box 26.6 Fire regimes and biodiversity}

Extreme fires make headlines. As such, a particular fire, or episode of fires, demands attention mostly because of its dire consequences for human life and property. When flora and fauna are of concern, however, consideration of more than one fire occurrence at any one place may be necessary if the effects of fires are to be understood (see, for example, Bradstock et al. 2002, 2012). This has special significance to the conservation of biodiversitythe range of indigenous ('native') plants, animals and other organisms.

In a large fire-a fire event-the fire burns through a range of vegetation types in fuels of varying composition and quantities arrayed in various ways, and with various moisture contents; the fire may cross hills and dales throughout the day and night and burn under various changing weather. Along the way it may affect various environmental, economic and social assets.

As it progresses, the fire affects populations of animals and plants to various degrees, according to the variations in its properties as it spreads. Some plants are readily killed when all their leaves and buds are killed, but this does not necessarily occur everywhere within the fire for all populations of the same species because of the variation in local fire intensity-the rate of heat release per metre of fire perimeter (Byram 1959). Populations of a different plant species might be fully defoliated by fire but readily re-sprout. Some animals might die but many survive. Dead birds and large animals may be obvious after a large, intense fire but they may constitute only a fraction of the population; the extent of population survival for different species needs to be determined before judgment is made about the effects of the fire event.

The immediate effects of fires constitute their 'severity' (see, for example, Keeley 2009; Medler 2010). The 'severity' of the fire, in its simplest terms, is whether individual plants or vegetation in general have tops that are green, brown (scorched) or black (charred) (Gill 2009). Whether the fire burns and removes a deep organic substrate or only burns above ground-'fire type' (Gill 1975, 1981) - can be significant to plant survival. Thus, removal of the substrate can lead to the death of even tall trees as many of the roots are destroyed and they topple over into what may be still-burning substrate. 'Severity' may then be measured as the extent of root damage.

Recovery from the severity of the fire may depend on such things as: seed supplies; local breeding populations; the amounts and types of precipitation at various times after the fire; food-shelter mixes for grazers; distance to nearest reproducing source; time to flower and fruit or breed; and the level of predation (for animals) or grazing (for plants). Left too long, some plants may reach old age and die without replacement; other plants may spread during the inter-fire period. Some animals may proliferate as their habitats improve, then decline as another habitat develops in the same place just as populations of other animal species increase.
Factors associated with fire occurrence (intensity, season, type and interval) and factors associated with the local environment (heights of trees, distances to reproductive sources, species present, and so on) can be important for the persistence of a species locally. The factors of fire occurrence together constitute the variables of the fire regime-'a key concept in many scientific domains' (Krebs et al. 2010:53) - while the factors relating to the environment provide the context within which species operate and which help determine their success or otherwise. 'Fire regimes' represent the relevant history of fires and their properties at a point in the landscape as far as the fire-effects application is concerned.

With each fire event centred in a different place, and in time, a pattern of ages of fuels develops. The footprint of the original fire event being considered is gradually covered by the footprints of other fires. The extent of overlay varies widely not just because of the position of each fire but also because of the large variation in areas of fires (Williams and Bradstock 2008). At any one point through time a series of varying intervals, intensities and types of fires may occur in a fire-prone landscape. In short, the variables of the fire regime vary temporally, about an average, as well as spatially.

In trying to understand and predict the effects of fire regimes on plant and animal species, most attention has been paid to fire interval, as in the classic paper of Noble and Slatyer (1980) in which fire responses of plants, timing of seedling regeneration and life history markers were used. Increasingly, intensity and season are coming into consideration. 'Type of fire' is rarely considered so far perhaps because peat fires may not occur in the area of concern or are only small.

The many millions of species of organisms that fires encounter around the world-whether in rainforests (Cochrane 2009b) or deserts (Brooks and Minnich 2006) or the many environments and ecosystems in betweenbehave in many different ways as a response to present and past fire regimes. Attention to the nature of future fire regimes and environments is now essential. Fire regimes are changing as a direct consequence of rising human populations and their impacts (such as fire suppression, prescribed burning, unwanted ignitions, changing fuels) or indirectly (such as through changing atmosphere and climate, more intensive management, more land being cropped).

Changing atmospheric composition changes the rates at which plants grow and fuels accumulate; changing climates are likely to involve more extremes in temperatures (warmer), precipitation (up or down), relative humidity, wind speed and possibly lightning ignitions-all affecting the nature of fire regimes (Cary et al. 2012). The challenge is to consider the effects of all fire regime components on all fire-prone organisms (Gill and Stephens 2009) in a changing environment as a guide to predicting the success or otherwise of our efforts to conserve biodiversity.

- A. Malcolm Gill 


\section{Humanitarian disasters}

Natural and human-caused humanitarian disasters regrettably will continue to happen during the 21 st century. Protected areas may be directly affected by these events, including the translocation of people from their homes to temporary emergency accommodation centres. Protected area managers will need to be sympathetic and helpful, but also vigilant. If possible and appropriate, they may need to assist with the emergency management of people in need, as the potential for a protected area to be immediately and severely impacted to supply basic needs such as fuel wood, materials for constructing shelter and food and water will be high. These needs will have to be met and the challenge will be to achieve this without the destruction of the protected area. Protected area managers, if possible, should help to provide solutions and some considerations may include:

- participating with the organisation responsible for managing an evacuation centre (the equivalent of an incident management team) and for dealing with humanitarian needs

- working with leaders of evacuees at the evacuation centre as a basis for responding to basic needs that may otherwise have been sourced from the protected area and securing assistance to help conserve the protected area

- establishing security arrangements that help protect the protected area.

At times of human conflict in or near protected areas, the first priority is to save lives and staff may be withdrawn from impacted protected areas. For any protected area managers who decide to stay, the advice is to maintain neutrality and impartiality and to build trust (Worboys and Winkler 2006), though clearly the situation could be difficult and dangerous. The safety of protected area staff is always the first priority in such situations.

\section{Recovery}

In the immediate aftermath of an incident, protected area managers would be expected to participate in or organise:

- confidential counselling services for any staff who may need such a service through an employee assistance program

- an internal protected area organisation debriefing

- a multi-organisation debriefing

- meetings with community organisations concerning the incident
- restoration of any cultural heritage sites that have been disturbed

- restoration of any disturbance to the protected area

- responses to any native fauna which may be impacted.

The aim is simply to ensure that any incident management improvements necessary can be made, that the community has had an opportunity to contribute to those improvements and that any interagency improvements needed have been identified. For larger, more complex incidents, or where there has been a loss of property or life, protected area managers would be expected to contribute to more formal inquiries established to review the incident.

Incidents (regrettably) will always be a routine part of protected area management. Anticipating these inevitable events includes identifying potential incidents (based on history and experience), pre-incident planning and preparedness that includes staff training, standby arrangements and prevention works. Being trained in incident management systems such as the AIIMS system is also critical, for it places protected area managers in the position of being a valued member of a typically larger, multi-organisation incident management team during incidents.

\section{Conclusion}

Incidents (regrettably) will always be a routine part of protected area management. Anticipating these inevitable events includes pre-incident planning, preparedness that includes staff training and prevention works. Being conversant with incident management systems such as the AIIMS system is also critical, for it places protected area managers in the position of actively contributing as part of a larger incident team during incidents. 


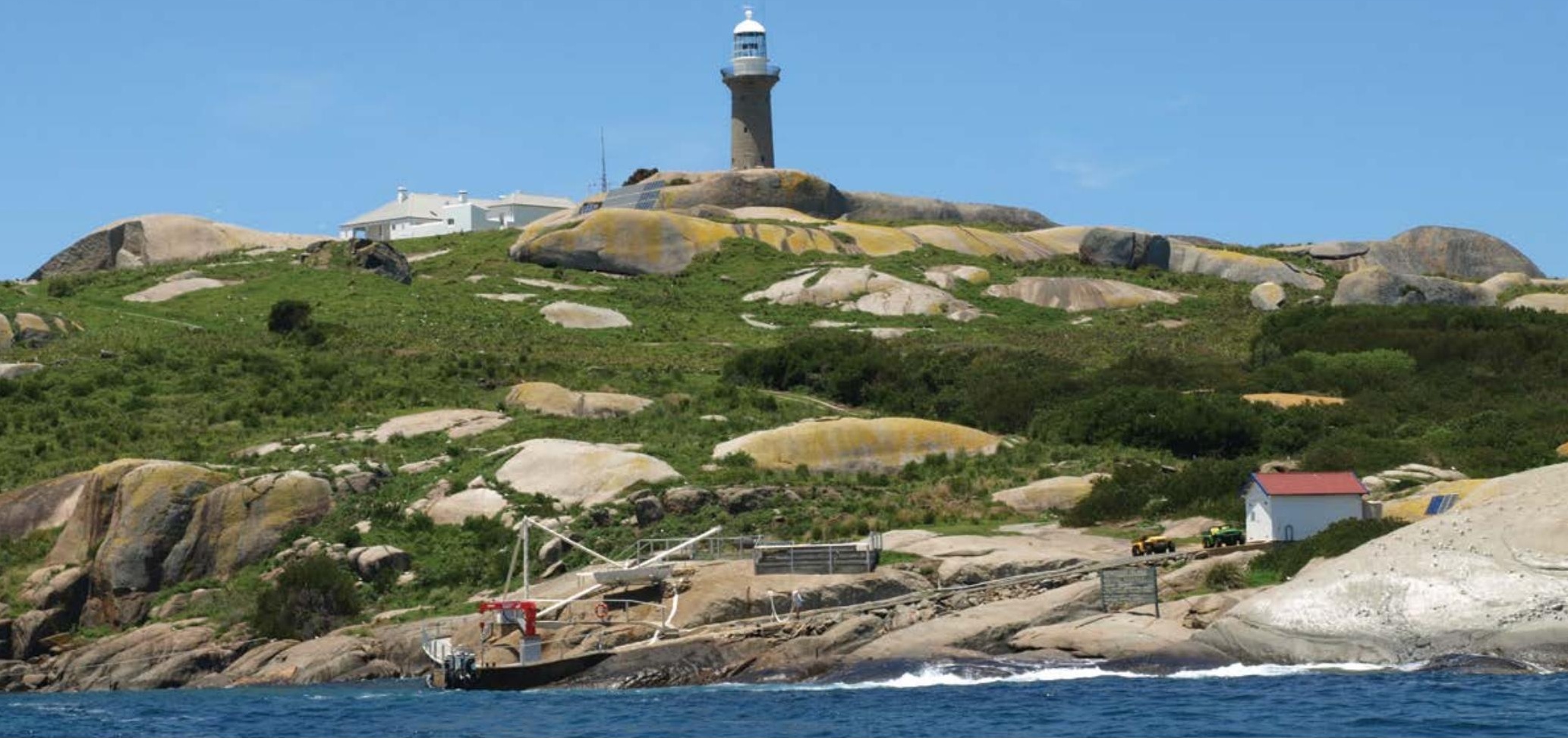

Montague Island Nature Reserve is an important bird breeding and seal haulage site located several kilometres offshore from Narooma on the south coast of NSW, Australia. Service boat access to the island is from Narooma and via an infamously dangerous narrow 'Narooma Bar' entrance where fast- flowing estuarine waters meet open ocean swells in an often chaotic sea. The NSW National Parks and Wildlife Service maintains a permanent staff presence on the island, and incident planning has recognised the potential for medical emergencies (including an inability to evacuate personnel in rough seas), lightning strike fires, structure fires, pollution events and maritime incidents such as boating accidents.

Source: Graeme L. Worboys

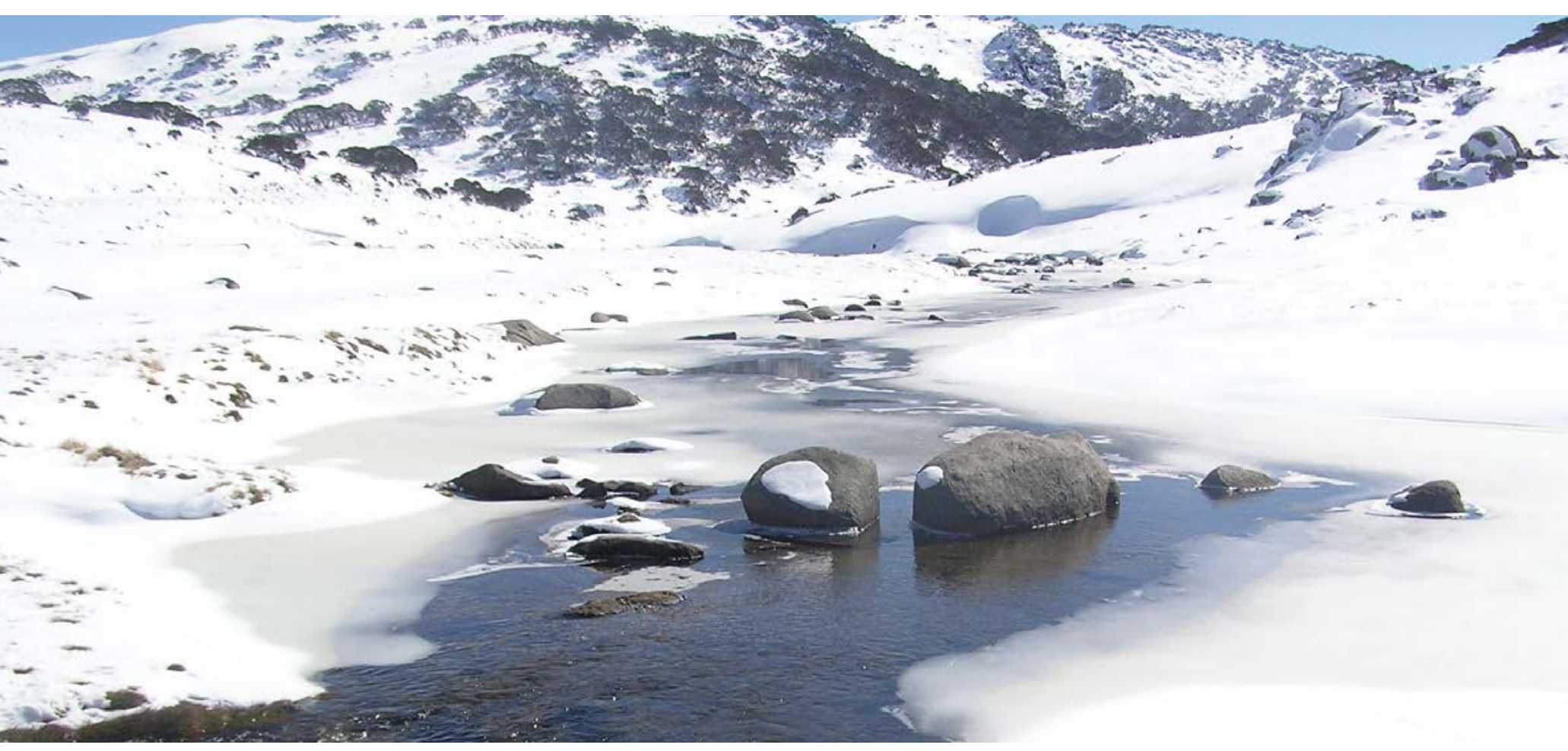

Spencers Creek, Kosciuszko National Park, is an alpine headwater stream of the Snowy River, one of Australia's iconic rivers. Charlotte Pass Village and its snowbound winter skiing facilities are found at the very headwaters of Spencers Creek. Based on historical precedents of accidental fuel oil pollution of Spencers Creek, fires and lost people, incident planning by the park managers has been critical to minimise potential impacts.

Source: Roger B. Good 


\section{References}

Recommended reading

Albini, F. A. (1993) 'Dynamics and modelling of vegetation fires: observations', in P. J. Crutzen and J. G. Goldammer (eds) Fire in the Environment: The ecological, atmospheric, and climatic importance of vegetation fires. Proceedings of the Dablem Conference 1992, pp. 39-52, Wiley \& Sons, New York.

Alexander, M. E. (1985) 'Estimating the length-tobreadth ratio of elliptical forest fire patterns', in L. R. Donoghue and R. E. Martin (eds) Proceedings of the Eighth Conference on Fire and Forest Meteorology, Detroit, Michigan, pp. 287-304, Society of American Foresters, Bethesda, MD.

Annelli, J. F. (2006) 'The National Incident Management System: a multi-agency approach to emergency response in the United States of America', Revue scientifique et technique (International Office of Epizootics) 25(1): 223-31.

Armstrong, J. (1973) Spontaneous combustion of forest fuels: a review, Information Report FF-X-42, Canadian Forestry Service, Forest Fire Research Institute, Ottawa.

Australian Broadcasting Corporation (ABC) (2010) Inside the Firestorm: The story of Australia's worst peacetime disaster, ABC DVD, Sydney.

Australian Fire and Emergency Service Authorities Council (AFAC) (2013) The Australasian Inter-service Incident Management System: A management system for any emergency, 4th edn, Australian Fire and Emergency Service Authorities Council Limited, Melbourne.

Australian National University (ANU) (2009) Implications of Climate Change for Australia's World Heritage Properties: A preliminary assessment, Report to the Department of Environment, Water, Heritage and the Arts by the Fenner School of Environment and Society, The Australian National University, Canberra.

Bradstock, R. A., Gill, A. M. and Williams, R. J. (eds) (2012) Flammable Australia: Fire regimes, biodiversity and ecosystems in a changing world, CSIRO Publishing, Melbourne.
Bradstock, R. A., Williams, J. E. and Gill, A. M. (eds) (2002) Flammable Australia: The fire regimes and biodiversity of a continent, Cambridge University Press, Cambridge.

Brooks, M. L. and Minnich, R. A. (2006) 'Southeastern deserts bioregion', in N. G. Sugihara, J. W. van Wagtendonk, K. E. Shaffer, J. Fites-Kaufman and A. E. Thode (eds) Fire in California's Ecosystems, pp. 391-414, University of California Press, Berkeley.

Bushfire Cooperative Research Centre (Bushfire CRC) (2009) 2009 Victoria Bushfire: Research response. Interim report, 2009 Victorian Bushfires Royal Commission, State Government of Victoria, Melbourne. <www.royalcommission.vic.gov.au/ getdoc/237e7653-8d96-437f-8252-45c3a1170470/ CRC.300.001.0001_R.pdf>

Byram, G. M. (1959) 'Forest fire behaviour', in K. P. Davis (ed.) Forest Fire Control and Use, pp. 90-123, McGraw-Hill, New York.

Campbell, A. (2009) Thoughts on the Victorian bushfires, 10 February. <www.myenvironment. net.au/index.php/me/Work/Fire/Fire-Resources/ Thoughts-on-the-Victorian-Bushfires $>$

Cary, G. J., Bradstock, R. A., Gill, A. M. and Williams, R. J. (2012) 'Global change and fire regimes in Australia', in R. A. Bradstock, A. M. Gill and R. J. Williams (eds) (2012) Flammable Australia: Fire regimes, biodiversity and ecosystems in a changing world, CSIRO Publishing, Melbourne.

Cheney, P. and Sullivan, A. (2008) Grassfires: Fuel, weather and fire behaviour, 2nd edn, CSIRO Publishing, Melbourne.

Climate Council (2013) Off the Charts: 2013 was Australia's hottest year, Climate Council, Sydney. $<$ www.climatecouncil.org.au>

Cochrane, M. A. (2009a) 'Fire in the tropics', in M. A. Cochrane (ed.) Tropical Fire Ecology: Climate change, land use and ecosystem dynamics, pp. 1-23, Springer, Berlin.

Cochrane, M. A. (ed.) (2009b) Tropical Fire Ecology: Climate change, land use and ecosystem dynamics, Springer, Berlin.

Coen, J. L. (2011) 'Some new basics of fire behaviour', Fire Management Today 71: 37-42. 
Coen, J., Mahalingam, S. and Daily, J. (2004) 'Infrared imagery of crown-fire dynamics during FROSTFIRE', Journal of Applied Meteorology 43: 1241-59.

Collaborative Australian Protected Area Database (CAPAD) (2010) Collaborative Australian Protected Area Database, Department of Environment, Government of Australia, Canberra. <www. environment.gov.au/topics/land/nrs/science/ capad/2010>

Commonwealth Scientific and Industrial Research Organisation (CSIRO) (2009) Climate Change and the 2009 Bushfires, Report prepared for the 2009 Victorian Bushfires Royal Commission, CSIRO, Canberra.

Cruz, M. G., Sullivan, A. L., Gould, J. S., Sims, N. C., Bannister, A. J., Hollis, J. J. and Hurley, R. J. (2012) 'Anatomy of a catastrophic wildfire: the Black Saturday Kilmore East fire in Victoria, Australia', Forest Ecology and Management 284: 269-85.

Forthofer, J. A. and Goodrick, S. L. (2011) 'Vortices and wildland fire', in P. A. Werth, B. E. Potter, C. B. Clements, M. A. Finney, S. L. Goodrick, M. E. Alexander, M. G. Cruz, J. A. Forthofer and S. S. McAllister (eds) Synthesis of Knowledge of Extreme Fire Behavior. Volume 1 for Fire Managers, pp. 89-105, PNW-GTR-854, US Department of Agriculture Forest Service, Portland, Ore.

Fromm, M., Lindsey, D. T., Servranckx, R., Yue, G., Trickl, T., Sica, R., Doucet, P. and Godin-Beekman, S. (2010) 'The untold story of pyrocumulonimbus', American Meteorological Society 91: 1193-209.

Fromm, M., Tupper, A., Rosenfeld, D., Servranckx, R. and McRae, R. (2006) 'Violent pyro-convective storm devastates Australia's capital and pollutes the stratosphere', Geophysical Research Letters 33(L05815). <doi:10.1029/2005GL025161>

Fuquay, D. M., Baugham, R. G. and Latham, D. J. (1979) A model for predicting lightning ignition in wildland fuels, Research Paper INT-217, US Department of Agriculture Forest Service, Ogden, UT.

Gill, A. M. (1975) 'Fire and the Australian flora: a review', Australian Forestry 38: 4-25.
Gill, A. M. (1981) 'Adaptive responses of Australian vascular plant species to fires', in A. M. Gill, R. H. Groves and I. R. Noble (eds) Fire and the Australian Biota, pp. 243-72, Australian Academy of Science, Canberra.

Gill, A. M. (2009) Underpinnings of Fire Management for the Conservation of Biodiversity in Reserves, rev. edn [online], Victorian Department of Sustainability and Environment, Melbourne. <www.dse.vic.gov.au/fire-and-other-emergencies/ publications-and-research/fire-research-reports/ research-report-73>

Gill, A. M. and Stephens, S. L. (2009) 'Scientific and social challenges for the management of fire-prone wildland-urban interfaces', Environmental Research Letters 4: 1-10.

Gill, A. M., Stephens, S. L. and Cary, G. J. (2013) 'The worldwide "wildfire" problem', Ecological Applications 23(2): 438-54.

Gould, J. S., McCaw, W. L., Cheney, N. P., Ellis, P. F., Knight, I. K. and Sullivan, A. L. (2007) Project Vesta, Fire in Dry Eucalypt Forest: Fuel structure, fuel dynamics and fire behaviour, Ensis-CSIRO Canberra and Department of Environment and Conservation, Perth.

Dd Handmer, J. and Dovers, S. (2013) Handbook of Disaster Policies and Institutions, Routledge, London.

Hannam, P. (2013) 'Typhoon Haiyan influenced by climate change scientists say', Sydney Morning Herald, 11 November. <www.smh.com.au/ environment/climate-change/typhoon-haiyaninfluenced-by-climate-change-scientists-say20131111-2xb35.html>

Hannam, P. (2014) 'Heatwave one of the most significant on record says Bureau of Meteorology', Sydney Morning Herald, 20 January. <www.smh. com.au/environment/weather/heatwave-one-ofthe-most-significant-on-record-says-bureau-ofmeteorology-20140120-314od.html>

Intergovernmental Panel on Climate Change (IPCC) (2013) 'Summary for policymakers', in Climate Change 2013: The physical science basis, pp. 1-35, IPCC, Geneva. <www.climatechange2013.org/ images/uploads/WGI_AR5_SPM_brochure.pdf>

Keeley, J. E. (2009) 'Fire intensity, fire severity and burn severity: a brief review and suggested usage', International Journal of Wildland Fire 18: 116-26. 
Krebs, P., Pezzati, G. B., Mazzoleni, S., Talbot, L. M. and Conedera, M. (2010) 'Fire regime: history and definition of a key concept in disturbance ecology', Theory in Biosciences 129: 53-69.

Lauder, S. (2013) 'Climate Council links NSW bushfires to climate change', The World Today, 25 October. <www.abc.net.au/news/2013-1025/climate-council-links-bushfires-to-climatechange/5046164>

McRae, R. H. D., Sharples, J. J., Wilkes, S. R. and Walker, A. (2013) 'An Australian pyro-tornado genesis event', Natural Hazards 65: 1801-11.

Medler, M. J. (2010) 'Pyrogeography: mapping and understanding the spatial patterns of wildfire', in N. Hoalst-Pullen and M. W. Patterson (eds) Geospatial Technologies in Environmental Management. Geotechnologies and the Environment. Volume 3, pp. 29-47, Springer, New York. <doi:10.1007/97890-481-9525-1_3>

New South Wales National Parks and Wildlife Service (NPWS) (2012) Fire Management Manual, 20122013, Office of Environment and Heritage, Sydney.

Noble, I. R. and Slatyer, R. O. (1980) 'The use of vital attributes to predict successional changes in plant communities subject to recurrent disturbances', Vegetatio 43: 5-21.

Noble, J. C. (1991) 'Behaviour of a very fast grassland wildfire on the Riverine Plain of southeastern Australia', International Journal of Wildland Fire 1(3): 189-96.

Parliament of Victoria (PoV) (2010) Final Report. Volume 1: 2009 Victorian Bushfires Royal Commission, Government Printer, Melbourne.

Radke, L. F., Clark, T. L., Coen, J. L., Walther, C. A., Lockwood, R. N., Riggan, P. J., Brass, J. A. and Higgins, R. G. (2000) 'The Wildfire Experiment (WiFE): observations with airborne remote sensors', Canadian Journal of Remote Sensing 26(5): 406-17.

Raupach, M. R. (1990) 'Similarity analysis of the interaction of bushfire plumes with ambient winds', Mathematical and Computer Modelling 13(12): 113-21.

Sharples, J. J., McRae, R. H. D. and Wilkes, S. R. (2012) 'Wind-terrain effects on the propagation of wildfires in rugged terrain: fire channelling', International Journal of Wildland Fire 21: 282-96.
Tolhurst, K. (2009) Report on the Physical Nature of the Victorian Fires occurring 7th February 2009, 2009 Victorian Bushfires Royal Commission, State Government of Victoria, Melbourne.

van Wagner, C. E. (1977) 'Conditions for the start and spread of crown fire', Canadian Journal of Forestry Research 7: 23-4.

Wein, R. W. (1983) 'Fire behaviour and ecological effects in organic terrain', in R. W. Wein and D. A. MacLean (eds) The Role of Fire in Northern Circumpolar Ecosystems, pp. 81-95, John Wiley \& Sons, Toronto.

Williams, R. J. and Bradstock, R. A. (eds) (2008) 'Large fires and their ecological consequences', International Journal of Wildland Fire Special Issue 16(6).

Williams, R. J., Bradstock, R. A., Gary, G. J., Enright, N. J., Gill, A. M., Liedloff, A. C., Lucas, C., Whelan, R. J., Anderson, A. N., Bowman, D. J. M. S., Clarke, P. J., Cook, G. D., Hennessy, K. J. and York, A. (2009) Interactions between Climate Change, Fire Regimes and Biodiversity in Australia: A preliminary assessment, Department of Climate Change, Department of the Environment, Water, Heritage and the Arts, Canberra.

Willis, M. (2004) Bushfire Arson: A review of the literature, Australian Institute of Criminology, Canberra.

DD Worboys, G. L. and Winkler, C. (2006) 'Incident management', in M. Lockwood, G. L. Worboys and A. Kothari (eds) Managing Protected Areas: A global guide, pp. 474-96, Earthscan, London.

Yates, J. (1999) 'Improving the management of emergencies: enhancing the ICS', Australian Journal of Emergency Management 14(2) (Winter): 22-8. 


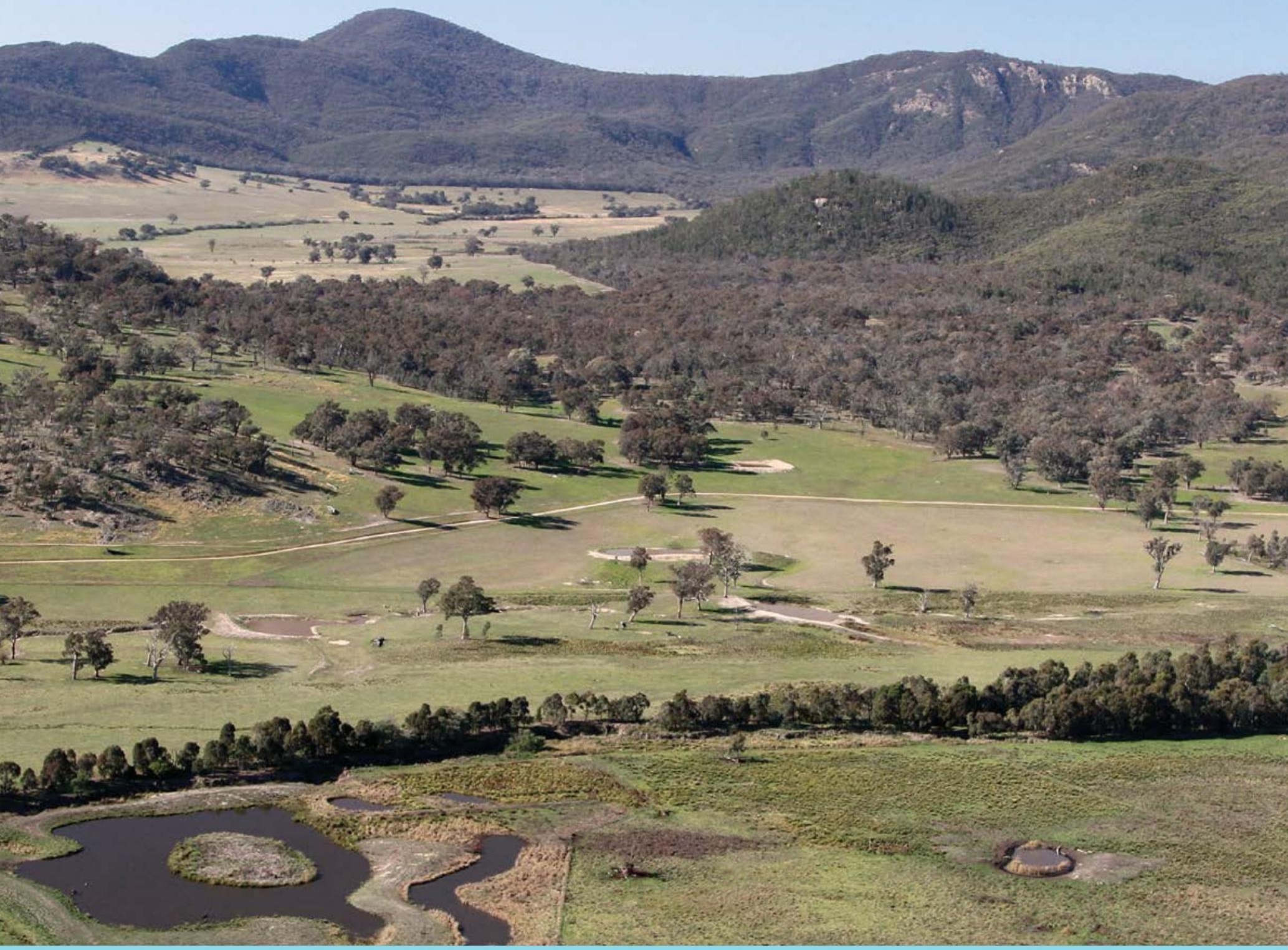

\section{CHAPTER 27}

\section{CONNECTIVITY CONSERVATION MANAGEMENT}

\section{Principal authors:}

lan Pulsford, David Lindenmayer,

Carina Wyborn, Barbara Lausche,

Maja Vasilijević and Graeme L. Worboys

\section{Supporting author:}

Ted Lefroy

\section{CONTENTS}

- Introduction

- The science of connectivity conservation management

- The global network of connectivity corridors

- Managing connectivity conservation corridors

- Monitoring and evaluating corridor performance

- Connectivity conservation governance

- Transboundary corridor governance

- Legal considerations

- Conclusion

- References

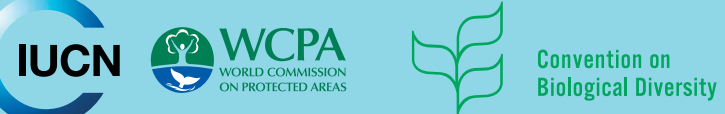




\section{PRINCIPAL AUTHORS}

IAN PULSFORD is an independent consultant and is a member of the International Union for Conservation of Nature (IUCN) World Commission on Protected Areas (WCPA) Connectivity, Conservation and Mountains theme, Australia.

DAVID LINDENMAYER is a Professor of Ecology and Australian Research Council Laureate Fellow at the Fenner School of Environment and Society at The Australian National University, a member of the Australian Academy of Science and of the New York Academy of Science, Australia.

CARINA WYBORN is a social scientist at the University of Montana, USA, and a member of the IUCN WCPA Oceania section, Young Professionals Network and Mountains and Connectivity theme.

BARBARA LAUSCHE is the Director of the Marine Policy Institute, Mote Marine Laboratory, and is a member of the IUCN World Commission on Environmental Law (WCEL) and WCPA, Florida, USA.

MAJA VASILIJEVIĆ is the Director of Eco Horizon, and is Chair of the WCPA Transboundary Conservation Specialist Group, Croatia.

GRAEME L. WORBOYS is Co-Vice-Chair, Connectivity Conservation and Mountains, IUCN WCPA and an Adjunct Fellow at the Fenner School, The Australian National University.

\section{SUPPORTING AUTHOR}

TED LEFROY is Professor of Environment and Director of the Centre for Environment at the University of Tasmania, Australia.

\section{ACKNOWLEDGMENTS}

We wish to acknowledge the enormous contributions over recent decades by large numbers of landholders, community groups (including indigenous groups), government agencies, local government, businesses and researchers in restoring landscape linkages and working towards improved conservation of biodiversity and more sustainable management of the land. We also gratefully acknowledge the advice of the editors and independent peer reviewers.

\section{CITATION}

Pulsford, I., Lindenmayer, D., Wyborn, C., Lausche, B., Worboys, G. L., Vasilijević, M. and Lefroy, T. (2015) 'Connectivity conservation management', in G. L. Worboys, M. Lockwood, A. Kothari, S. Feary and I. Pulsford (eds) Protected Area Governance and Management, pp. 851-888, ANU Press, Canberra.

\section{TITLE PAGE PHOTO}

Holbrook Landcare: landholders (including protected area practitioners) work together to restore linkages between forests, woodlands, riparian and wetland areas on private land and Woomargama National Park in the Slopes to Summit section of the Great Eastern Ranges corridor, New South Wales, Australia Source: Ian Pulsford 


\section{Introduction}

As the global human population grows rapidly past the seven billion mark, the overexploitation of our planet goes on unabated to such an extent that there is now unequivocal evidence that Earth is experiencing the sixth major mass extinction of species in its evolutionary history (Wilson 1992, 2002), that warming of the global climate system is occurring and that this is almost certainly attributable to human activities (IPCC 2013). The global destruction and fragmentation of habitats resulting in the parcelling up of landscapes have been caused by human population growth and development activities. This has resulted in the sixth mass extinction of biodiversity in the Earth's evolutionary history and the first for 65 million years (Wilson 2002). Problems of this scale require big solutions.

In response, we are witnessing a social and political revolution in the care and management of global biodiversity (Worboys and Mackey 2013). In recent decades landholders, grassroots organisations and governments have been undertaking action to address the massive destruction of habitat. One critical response of this global movement has been the establishment of systems of protected areas on every continent to conserve the most significant remaining strongholds of biodiversity and heritage, although certainly for the past decade, more strategic concepts such as comprehensiveness, adequacy and representativeness have driven this establishment. Unfortunately, this action is widely recognised as being insufficient on its own to prevent the ongoing loss of species (CBD 2011). This is partly because the reserve system will never be big enough to retain all species and ecosystems. Protected areas often remain 'islands' in the midst of unsustainable land and water uses. Many species need to move between protected areas and the surrounding landscape either seasonally or as ecosystems change.

Connectivity conservation has emerged as a big-thinking response to a range of threats to biodiversity that include habitat degradation and destruction, fragmentation, changed fire regimes, the spread of introduced species and a changing climate. Connectivity conservation management is a strategic approach that helps to link habitats across whole landscapes, which can enable species and their ecosystems to move or adapt as conditions change. Connectivity conservation is a way of maintaining connections for nature by involving people. So, what is the scientific basis for connectivity conservation, how is this being put into practice and what are the benefits? In this chapter, we aim to address these questions by bringing

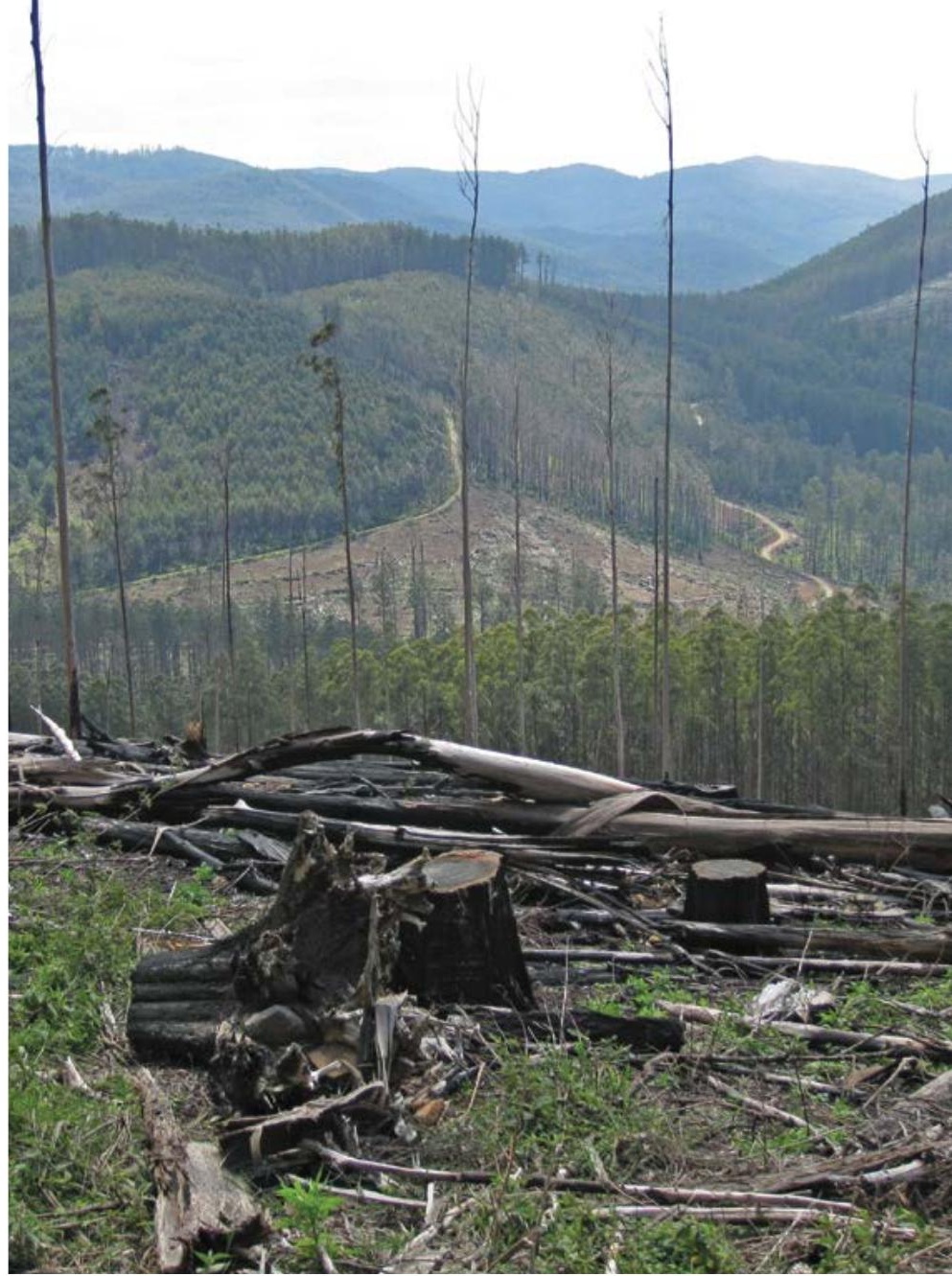

Industrial logging of mountain ash (Eucalyptus regnans), the world's tallest flowering plant, is a significant threat to the endangered arboreal Leadbeater's possum (Gymnobelideus leadbeateri) in the upper Yarra Valley, Victoria, Australia

Source: lan Pulsford

together a range of experts who have worked extensively in the field of connectivity conservation science, other knowledge, governance and management. The focus of this chapter is on the management of connectivity conservation corridors or areas.

\section{The science of connectivity conservation management}

The term 'connectivity' is widely used in the literature on landscape change and conservation practice and generally refers to the ease with which organisms move between particular landscape elements, the number of connections between patches of habitat relative to the maximum number of potential connections or the interlinkages of key processes within and between ecosystems (Lindenmayer and Fischer 2007). There are other forms of knowledge that are also important and can be included, such as the knowledge systems of indigenous peoples and other local communities, but these are not the focus of this section. The scientific concept of 
connectivity incorporates relationships between key ecological processes and the spatial pattern and scale of vegetation cover, not only in natural landscapes, but also in semi-natural and even highly modified landscapes (Forman 1995). The concept of connectivity has become increasingly important in the past three decades as a result of modification of ecosystems and subsequent declines in biodiversity resulting from a range of direct and/or indirect human influences including vegetation clearing (and resulting habitat loss), altered fire regimes, invasion by exotic species and climate change (Crooks and Sanjayan 2006; Fitzsimons et al. 2013a).

Given the multiple and multifaceted meanings of connectivity, it is not surprising that while the concept is universally agreed to be important, it is often conceived very broadly, thereby rendering it difficult to use in practice and sparking much academic debate (for example, on the ecological value of wildlife corridors; see Simberloff et al. 1992; Beier and Noss 1998; Lindenmayer and Fischer 2007).

\section{Landscape connectivity and other connectivity concepts}

To best clarify various themes associated with connectivity, it is useful to make an explicit distinction between four types of connectivity (Lindenmayer and Fischer 2007). First, habitat connectivity can be defined as the connectedness between patches of suitable habitat for an individual species; it is the opposite of habitat isolation (in which areas of habitat suitable for a given species are subdivided and made smaller). Second, landscape connectivity can be defined from a human perspective of the connectedness of patterns of vegetation cover in a given landscape. This typically entails physical connection of natural vegetation between two otherwise physically isolated patches of natural vegetation. Third, ecological process connectivity can be defined as the connectedness of ecological processes across multiple scales including processes related to highly dispersive species, highly interactive species, disturbance regimes and hydro-ecological flows (Lindenmayer and Fischer 2006; Soulé et al. 2006; Mackey 2007; Mackey et al. 2013). Fourth, evolutionary process connectivity refers to spatially based natural processes that pertain to both macro-evolution (leading to speciation) and microevolution including coevolutionary interactions and local adaptions by a population to environmental conditions. The spatial dimension of evolutionary processes relates to the exchange of genetic material between populations, the extent to which populations are open or closed to inflows and outflows, the degree to which climate change will result in forced movements and the impacts of other threatening processes. For many large animals and dispersive species, evolutionary processes involve the movement of these species over long distances (Soulé et al. 2006; Worboys and Mackey 2013).

Although these connectivity concepts are interrelated, they are not synonymous with one another. Landscape connectivity may increase habitat connectivity for some species but not for others (Driscoll et al. 2014). Similarly, low habitat connectivity for functionally redundant species (sensu Walker 1992) may have relatively little impact on the overall connectedness of ecological processes. For other species that fulfil irreplaceable ecological functions, however, the loss of habitat connectivity can have major impacts on ecological connectivity. For example, some bat and bird species in Central America are instrumental in dispersing the seeds of rainforest plants across agricultural areas (Galindo-González et al. 2000), thereby contributing to the genetic viability of plant populations (Cascante et al. 2002). The loss of habitat connectivity for these vertebrate species would have severe implications for ecological connectivity because the key ecological process of seed dispersal would be lost with likely negative consequences for numerous plant species and the animals that depend on them.

The following section of this chapter focuses primarily on a human perspective of ecosystems, and therefore its primary focus is on landscape (Box 27.1). Other forms of connectivity are discussed later in the chapter. Where appropriate, links between habitat connectivity, landscape connectivity, ecological process connectivity and evolutionary process connectivity are identified.

\section{Negative effects of reduced landscape connectivity}

Landscapes that retain more connections between patches of otherwise isolated areas of vegetation and therefore have higher levels of landscape connectivity are assumed to be more likely to maintain populations of various species that inhabited the original landscape (Brown and Kodric-Brown 1977; Haddad and Baum 1999). Conversely, a lack of landscape connectivity can have a range of negative impacts on assemblages. It may result in vegetation patches remaining unoccupied for suites of species (Robinson 1999; Driscoll et al. 2014), meaning that the spatial distribution of these taxa may not directly correspond with the spatial distribution of available habitat for them (Stenseth and Lidicker 1992; Wiens et al. 1997; Driscoll et al. 2014). This is illustrated by some forest bird taxa that are unable to cross gaps and avoid open areas (Desrochers and Hannon 1997). 
Similarly, sets of species in patches of remnant vegetation where the surrounding matrix is unsuitable for foraging are more likely to suffer extinction than those assemblages where the matrix provides landscape connectivity (Laurance 1991; Driscoll et al. 2013).

A particular case of reduced landscape connectivity is the dissection (sensu Forman 1995) of formerly continuous vegetation by roads. Roads can negatively influence a wide range of species, thus not only fundamentally altering landscape pattern, but also reducing habitat connectivity for many individual species and changing ecological processes (that is, impairing ecological connectivity). As an example, roads have major negative impacts on the migration of populations of elk (Cervus canadensis) as well as the movement of predators like wolves (Canis lupus) and grizzly bears (Ursus arctos horribilis) in North America (Foreman 2004; Canadian Parks and Wilderness Society 2013).

Species whose primary habitat does not correspond with human-defined patches of vegetation also can be negatively affected by reduced landscape connectivity because of altered ecological processes. For example, Gray et al. (2004) examined the effect of landscape structure on two species of frogs in wetland playas of the Southern High Plains in the central United States: the New Mexico spadefoot (Spea multiplicata) and the plains spadefoot ( $S$. bombifrons). They found that increased agricultural development increased levels of sedimentation and decreased the length of time areas supported water. This in turn reduced landscape connectivity for both amphibian species.

Finally, reduced landscape connectivity can alter ecological connectivity, thus leading to a range of cascading effects. For example, the loss of landscape connectivity may alter the structure of food webs (Holyoak 2000; Galetti et al. 2013) and disrupt ecological processes such as the decomposition of wastes (Klein 1989), seed dispersal (Cordeiro and Howe 2003) or pollination (Paton 2000; Tscharntke et al. 2012).

\section{Features contributing to landscape connectivity and wildlife corridors}

One of the key aims of landscape management is to increase landscape connectivity. Three broad types of features can contribute to landscape connectivity: 1) wildlife corridors, 2) stepping stones, and 3) a 'soft' matrix. Different features will result in increased habitat

\section{Box 27.1 Landscape connectivity versus habitat connectivity}

Landscape connectivity reflects human perceptions of landscape connectivity of the vegetation patterns of a landscape. A given landscape pattern can correspond with low habitat connectivity for some species, but high habitat connectivity for other species, even within the same assemblage.

In the Tumut Fragmentation Experiment in southeastern New South Wales, Australia (reviewed in Lindenmayer 2009), species such as the red wattlebird (Anthochaera carunculata) and golden whistler (Pachycephala pectoralis) were among a suite of taxa significantly less abundant in areas with low levels of landscape connectivity and many spatially disconnected patches of remnant vegetation than in areas where remaining areas of native eucalypt forest were consolidated as a small number of contiguous stands (Lindenmayer et al. 2002).

In contrast, the common ringtail possum (Pseudocheirus peregrinus) and the crimson rosella (Platycercus elegans) showed the reverse response, possibly because they are edge-attracted species (Youngentob et al. 2013) and the longer boundaries created in landscapes characterised by many spatially separated patches made these areas more suitable for them (Lindenmayer 2009). This emphasises the fact that higher levels of landscape connectivity as perceived by humans will not always directly correspond with higher levels of habitat connectivity for a given individual species, or vice versa. It also reinforces the rationale for the key distinction between habitat connectivity for individual species and landscape connectivity as the human-defined connectedness of vegetation cover within a landscape.

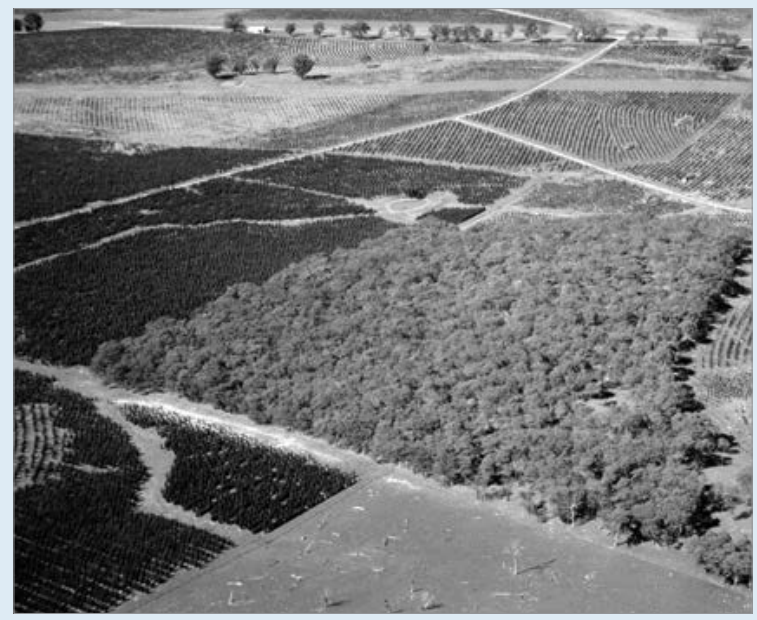

Remnant island of eucalypt forest retained in recently planted pine forests near Tumut, New South Wales, Australia

Source: David Lindenmayer 


\section{Box 27.2 Wildlife corridors: Landscape connectivity, habitat connectivity and ecological connectivity}

Levey et al. (2005) studied seed dispersal by birds in relation to wildlife corridors in a forest ecosystem in South Carolina, USA. They set up eight experimental landscapes, each of which contained a mix of forest patches connected by wildlife corridors and unconnected patches. The study focused on the wax myrtle (Myrica cerifera) and one of its major seed dispersers, the eastern bluebird (Sialia sialis). Observations of the behaviour of the eastern bluebird suggested the species was more likely to travel along the edge of wildlife corridors than cross the nonforested matrix. This mode of corridor use inspired the 'drift-fence hypothesis', which states that vegetation corridors intercept and direct the movement of species that may otherwise move through the matrix (Levey et al. 2005). In addition, Levey et al. (2005) were interested in where in the landscape seeds of the wax myrtle were dispersed. A particular question was whether seeds were more likely to be dispersed between patches that were connected by wildlife corridors than between unconnected patches. To answer this question, Levey et al. (2005) sprayed the fruits of the wax myrtle in some patches with a dilute solution of fluorescent powder. Using this method enabled defecated seeds of the wax myrtle to be identified in forest patches elsewhere in the landscape. The results demonstrated that, on average, seeds were 37 per cent more likely to be dispersed to connected patches than to unconnected patches. This study demonstrated that wildlife corridors can sometimes provide habitat connectivity-for the eastern bluebird and the wax myrtle. Finally, by maintaining an important ecological process-that is, seed dispersal-throughout the landscape, the study also demonstrated that wildlife corridors have the potential to enhance ecological connectivity.

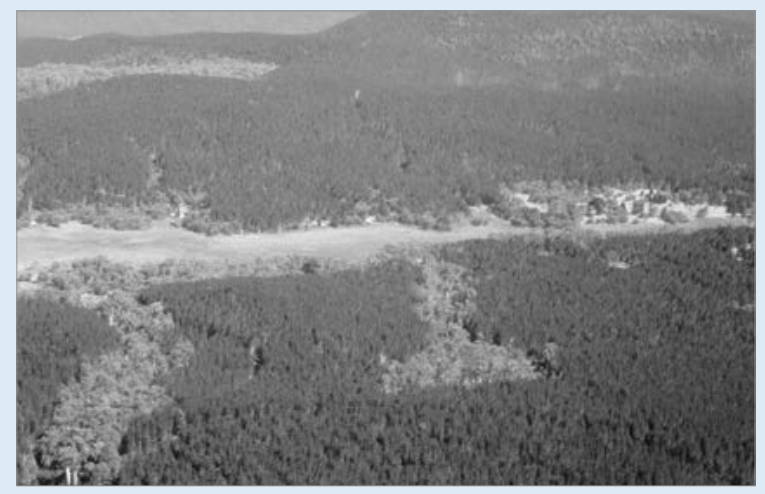

Remnant eucalypt forest corridor within the fragmented Tumut pine plantation landscape matrix, New South Wales, Australia

Source: David Lindenmayer connectivity for different species, and will maintain different aspects of ecological connectivity. The focus of the remainder of this section is on wildlife corridors.

Wildlife corridors are physical linkages between patches of native vegetation (for example, Bennett 1998) including within and between core protected areas. Wildlife corridors contribute to landscape connectivity and can facilitate increased habitat connectivity for some species (for example, Bennett 1990; Beier and Noss 1998). Many studies have attempted to examine the contribution that wildlife corridors can make to landscape connectivity. A detailed set of studies by Haddad (1999a, 1999b) and colleagues (for example, Tewksbury et al. 2002; Haddad and Tewksbury 2005; Levey et al. 2005) explored the responses of a range of biota to the establishment of wildlife corridors in a plantation forest ecosystem in South Carolina, USA. Many interesting results have been generated from this pioneering work. For example, wildlife corridors directed the movement of various animal species, although some taxa also moved through the matrix (Haddad et al. 2003). Population densities of several groups of species were significantly higher in connected patches than in isolated ones (Haddad and Baum 1999). Perhaps most significantly, the work has demonstrated that the landscape connectivity provided by corridors has the potential to enhance both the habitat connectivity of some species and the ecological connectivity of some key ecosystem processes (Box 27.2).

Some species may benefit from wildlife corridors that link suitable habitat (Gilbert et al. 1998; Haddad et al. 2003), including species that do not use areas outside corridors such as open areas (Berggren et al. 2002) as well as those that disperse only through suitable habitat (for example, Nelson 1993; Driscoll et al. 2014).

Not all species use corridors (Lindenmayer et al. 1993), and their use may depend on the ecology of the species in question-for example, their scale of movement (Amarasekare 1994), patterns of behaviour (Lidicker 1999) or social structure (Horskins 2004). Similarly, attributes of corridors such as their width and length, habitat suitability for a particular species, location in the landscape, and a range of other factors can affect corridor use by wildlife.

\section{Protected areas and connectivity}

Large ecological reserves and protected area networks provide important connectivity over extensive areas and through time (Soulé et al. 2004; Worboys et al. 2010). For example, recent work in southern Africa has shown that networks of protected areas have been instrumental in assisting the distributional movements of an array 


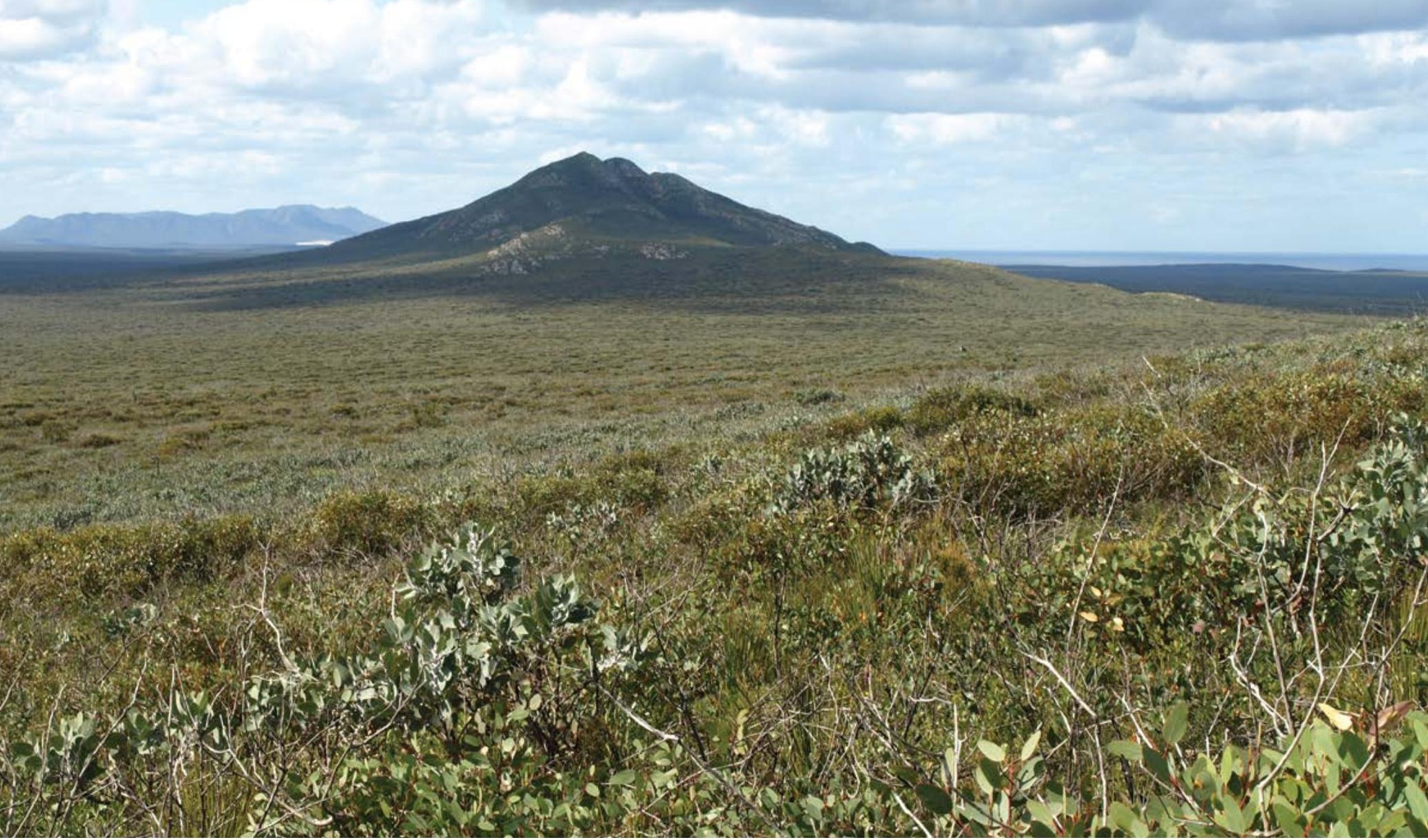

Fitzgerald River National Park is part of an internationally recognised biodiversity hotspot in Western Australia's Gondwana Link corridor

Source: Graeme L. Worboys

of bird species in response to changes in climate (Beale et al. 2013). Networks of connected areas have formed the basis for establishing very large corridors that extend across regional to even continental scales-for example, Yellowstone to Yukon, Great Eastern Ranges, Terai Arc and the Mesoamerican Biological Corridor (Bennett 1998; Foreman 2004; Fitzsimons et al. 2013a).

\section{Maintenance of connectivity as a key principle for conserving biodiversity}

In summary, the ecological importance of the four broad forms of connectivity outlined above means that the maintenance of connectivity is one of the key principles for conserving biodiversity and ecosystem function and therefore a key principle in informed landscape management (Lindenmayer et al. 2008; Worboys et al. 2010). The best way to maintain connectivity will vary according to the ecosystem in question, patterns of landscape heterogeneity, the species and processes targeted for conservation, and the processes threatening a given area. The approaches to maintain and/or enhance connectivity may vary, from setting aside large ecological reserves (Beale et al. 2013), protecting smaller (meso- scale) reserves such as riparian or streamside buffers, and planning roads and other human infrastructure to avoid subdividing areas (Foreman 2004) to 'softening' the matrix by retaining or replanting trees and other vegetation in areas outside reserves (Franklin 1993; Gustafsson et al. 2012). In many cases, a combination of these approaches at different scales will better meet the requirements of a diverse set of species and key ecosystem processes and hence deliver positive outcomes for the maintenance of habitat connectivity, landscape connectivity, ecological connectivity and evolutionary process connectivity.

\section{The global network of connectivity corridors}

Historically, wildlife corridors are a relatively recent concept, implemented initially at small scales, usually to fulfil notions of landscape amenity and for the retention and movement of wildlife and for recreation including hunting (Crooks and Sanjayan 2006). During the last phases of the 20th century, industrial-scale land clearing accelerated globally, removing or fragmenting in many places nearlyall the native vegetation. This mostlyoccurred in the most arable and productive lowlands in many 
countries, dramatically disrupting ecosystem function and diminishing the space available for wild species. As the global population increased, mass extinction of wild species accelerated rapidly (Crooks and Sanjayan 2006; Hilty et al. 2006). Until the 1990s, most conservation efforts focused on establishing networks of protected areas as a response to the onslaught of land clearing. Protected areas were established to conserve parts of natural landscapes, though many remained as 'islands' in a sea of cleared agricultural land. Corridors of native vegetation were often accidental, being made up of what was left over after the most valuable land had been cleared. Retained vegetation was often restricted to roadside strips, areas that were too steep or arid, or along the banks of creeks and rivers. Local communities and enlightened landowners often retained other forest patches for various purposes. In recent decades, programs involving farmers and other landholders in many countries have established small linear corridors as windbreaks and clumps of trees to conserve wildlife or to improve productivity and redress land degradation.

From the 1990s onwards, grassroots action informed by the emerging science of conservation biology also helped to drive the conservation agenda to conceive a new, much larger and more inclusive landscape conservation approach. A bold new approach to conservation thinking was required. This new approach went way beyond the bounds of linking the habitats or landscapes of a single bioregion or biosphere reserve. The first of the many really large continental-scale conservation corridor networks was the 'Yellowstone to Yukon' or 'Y2Y Conservation Initiative'. Y2Y was conceived in 1993 (Chester 2006). Y2Y extends along more than 5150 kilometres of the Rocky Mountains from Yellowstone National Park in the United States to the Yukon region in north-western Canada, and was eventually to encompass 1.2 million square kilometres and involved more than 300 conservation organisations (Chester 2006). Since then many large and continentalscale corridors, including transboundary corridors, have been established on every continent except Antarctica and across all the world's terrestrial biogeographic realms (Worboys et al. 2010) (Figure 27.1).

\section{Managing connectivity conservation corridors}

This section outlines the principles of connectivity corridor establishment and management, provides a summary of the International Union for Conservation of

\section{Establishing corridor management}

Experience gained by many connectivity initiatives has shown that establishing a large conservation corridor is a major undertaking fraught with many challenges, including securing funding and other demands (Fitzsimons et al. 2013b; Pulsford et al. 2013). To be successful, a mutually agreed vision has been found to be very important. There must also be inspirational and skilled leadership; a careful assessment of biodiversity values; a clear understanding of social and political contexts; strategic whole-of-corridor planning and prioritisation of investment; and skilful implementation (see 'Governance principles and requirements' subsection below). Success requires a long-term commitment by many organisations to implement adaptive management to ensure that ecological processes and functions are 


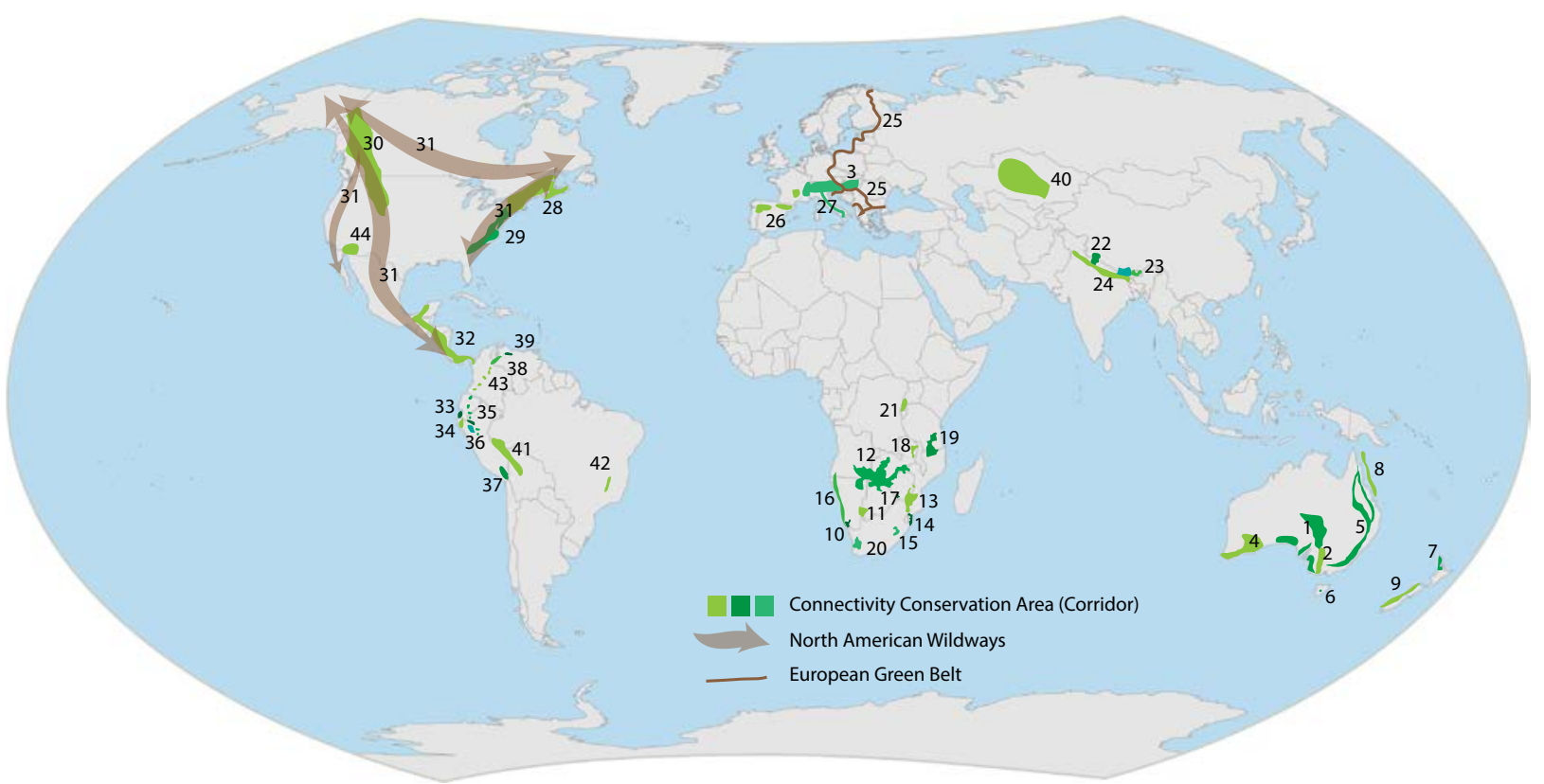

\begin{tabular}{|c|c|c|}
\hline & $\begin{array}{l}\text { CONNECTIVITY CONSERVATION } \\
\text { AREA (CORRIDOR) }\end{array}$ & COUNTRY/IES \\
\hline 1 & South Australian Nature Links & Australia \\
\hline 2 & Habitat 141 & Australia \\
\hline 3 & $\begin{array}{l}\text { ALPARC Alpine Ecological Network and } \\
\text { Protected Areas }\end{array}$ & $\begin{array}{l}\text { France, Italy, Switzerland, } \\
\text { Germany, Austria, Slovenia, } \\
\text { Principalities of Liechsten- } \\
\text { stein and Monaco }\end{array}$ \\
\hline 4 & Gondwana Link & Australia \\
\hline 5 & Great Eastern Ranges & Australia \\
\hline 6 & Midlandscapes & Australia \\
\hline 7 & Reconnecting Natural Northland & New Zealand \\
\hline 8 & Great Barrier Reef Marine Park WHA & Australia \\
\hline 9 & $\begin{array}{l}\text { Te Wāhipounamu South West New Zealand } \\
\text { World Heritage Area }\end{array}$ & New Zealand \\
\hline 10 & Ai /Ais - Richtersveld Transfrontier Park & South Africa and Namibia \\
\hline 11 & Kgalagadi Transfrontier Park & Botswana and South Africa \\
\hline 12 & $\begin{array}{l}\text { Kavango Zambezi (KAZA) Transfrontier } \\
\text { Conservation Area }\end{array}$ & $\begin{array}{l}\text { Angola, Botswana, Namibia, } \\
\text { Zambia and Zimbabwe }\end{array}$ \\
\hline 13 & Great Limpopo Transfrontier Park & $\begin{array}{l}\text { Mozambique, South Africa } \\
\text { and Zimbabwe }\end{array}$ \\
\hline 14 & $\begin{array}{l}\text { Lubombo Transfrontier Conservation and } \\
\text { Resource Area }\end{array}$ & $\begin{array}{l}\text { Mozambique, Swaziland } \\
\text { and South Africa }\end{array}$ \\
\hline 15 & $\begin{array}{l}\text { Maloti-Drakensberg Transfrontier } \\
\text { Conservation and Development Area }\end{array}$ & Lesotho and South Africa \\
\hline 16 & $\begin{array}{l}\text { lona - Skeleton Coast Trans Frontier Con- } \\
\text { servation Area }\end{array}$ & Angola and Namibia \\
\hline 17 & $\begin{array}{l}\text { Greater Mapungubwe Transfrontier Conser- } \\
\text { vation Area }\end{array}$ & $\begin{array}{l}\text { Botswana, South Africa and } \\
\text { Zimbabwe }\end{array}$ \\
\hline 18 & $\begin{array}{l}\text { Malawi-Zambia Transfrontier Conservation } \\
\text { Area }\end{array}$ & Malawi and Zambia \\
\hline 19 & $\begin{array}{l}\text { Selous and Niassa Wildlife Protection } \\
\text { Corridor }\end{array}$ & Mozambique and Tanzania \\
\hline 20 & Greater Cederberg Biodivesity Corridor & South Africa \\
\hline 21 & Greater Virunga Biodiversity Corridor & Uganda, Rwanda \\
\hline 22 & Kailash Sacred Landscape & China, India and Nepal \\
\hline
\end{tabular}

\begin{tabular}{|l|l|l|}
\hline & $\begin{array}{l}\text { CONNECTIVITY CONSERVATION } \\
\text { AREA (CORRIDOR) }\end{array}$ & COUNTRY/IES \\
\hline 23 & Bhutan Biological Conservation Complex & Bhutan \\
\hline 24 & Terai Arc & India and Nepal \\
\hline 25 & European Green Belt & *see list below \\
\hline 26 & $\begin{array}{l}\text { Cantabrian Mountains Pyrenees-Massif } \\
\text { Central -Western Alps Great Mountain } \\
\text { Corridor }\end{array}$ & Spain, France, Italy \\
\hline 27 & Espace Mont Blanc & France, Italy, Switzerland \\
\hline 28 & $\begin{array}{l}\text { Northern Appalachian/ Acadian Region } \\
\text { Connectivity Initiative }\end{array}$ & USA/Canada \\
\hline 29 & Southern Appalachian Ecoregion & USA \\
\hline 30 & $\begin{array}{l}\text { Yellowstone to Yukon Conservation } \\
\text { Initiative }\end{array}$ & USA/Canada \\
\hline 31 & North American Wildways Network & Mexico/ USA/ Canada \\
\hline 32 & Mesoamerican Biological Corridor & $\begin{array}{l}\text { Mexico, Guatemala, Belize, } \\
\text { Honduras, El Salvador, Nica- } \\
\text { ragua, Costa Rica, Panama }\end{array}$ \\
\hline 33 & Amotape & Peru \\
\hline 34 & Bosque seco & Peru \\
\hline 35 & Amazonas & Peru \\
\hline 36 & San Martin & Peru \\
\hline 37 & Sur & Peru \\
\hline 38 & $\begin{array}{l}\text { Corredor Sierra Nevada - Sierra de La Culata } \\
- \text { Tapo Caparo }\end{array}$ & Venezuela \\
\hline 39 & $\begin{array}{l}\text { Corredor San Esteban - Henri Pittier - } \\
\text { Codazzi - Macarao }\end{array}$ & Venezuela \\
\hline 40 & Altyn Dala Conservation Initiative & Kazakhstan \\
\hline 41 & Vilicambia - Amboro Conservation Corridor & Bolivia, Peru \\
\hline 42 & Serra do Espinhaço Biosphere Reserve & Brazil \\
\hline 43 & Llanganates - Sangay Ecological Corridor & Ecuador \\
\hline 44 & International Sonoran Desert Alliance & USA/Mexico \\
\hline
\end{tabular}

* EUROPEAN GREEN belt COUNTRIES: Finland, Russia, Norway, Estonia, Latvia, Lithuania, Poland, Germany, Czech Republic, Austria, Slovakia, Hungary, Croatia, Slovenia, Italy, Serbia, Romania, Bulgaria, Macedonia, Kosovo (in accordance with UNSCR 1244 and opinion of ICJ), Montenegro, Albania, Greece, Turkey

Figure 27.1 Indicative map of actively managed large-scale connectivity conservation areas (corridors) on Earth

Source: lan Pulsford (2014). Compiled from data aggregated by Rod Atkins and lan Pulsford, WCPA International Connectivity Conservation Network, Canberra, Australia. 


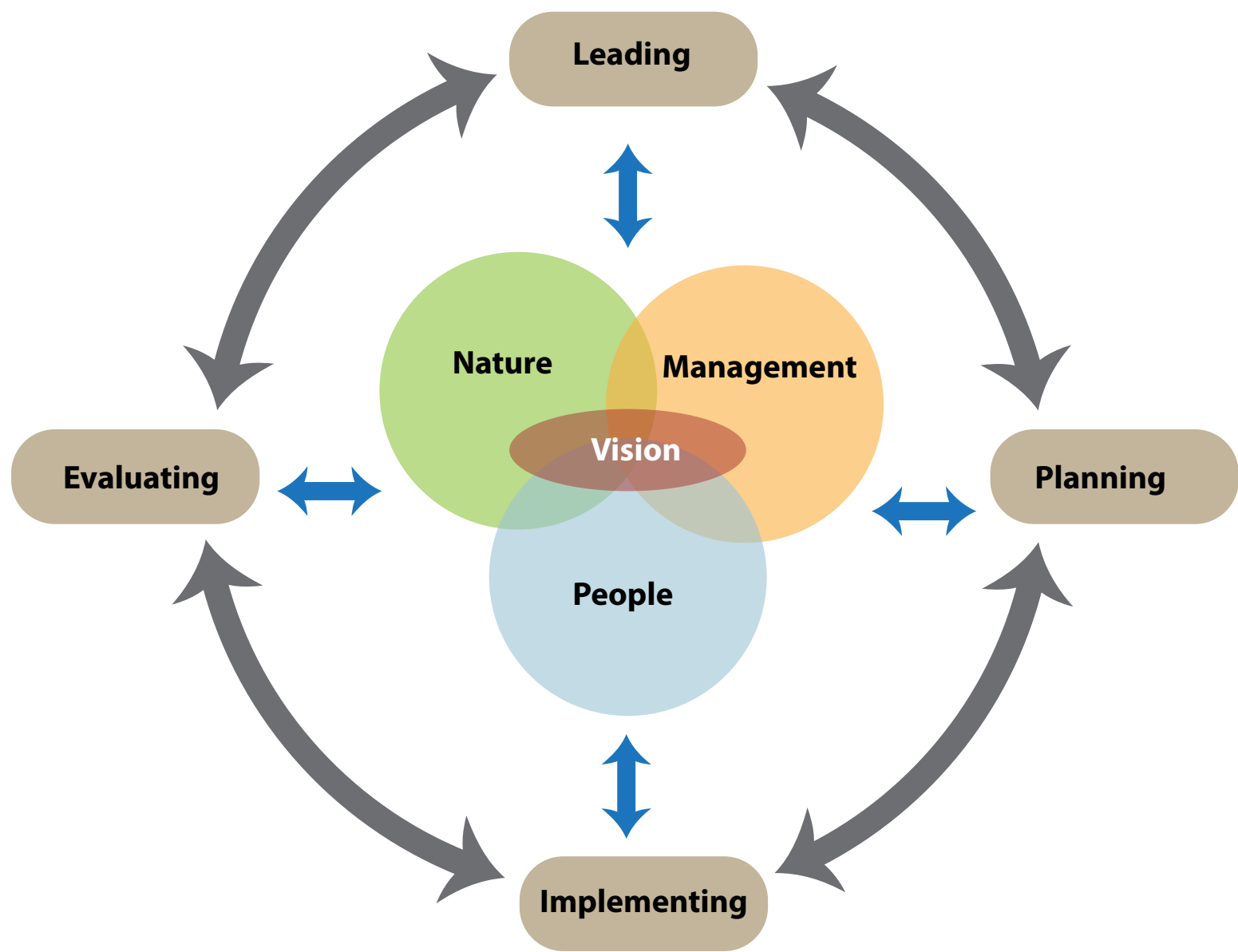

Figure 27.2 IUCN WCPA Connectivity Conservation Management Framework

Source: Worboys et al. (2010)

that people and communities are appropriately informed and engaged. Without people's engagement and support, it is unlikely that the vision and goals will be achieved.

\section{Governance and management context}

Assessing the governance and management context involves:

- identification of how land is legally and institutionally organised, planned and managed, including community requirements and laws and policies of governments, the tenure of the land and how it is managed, and the planning status of lands

- legislation or other governing instruments that may facilitate or encourage landholder involvement

- identification of programs and incentives for achieving conservation actions on the ground that need to be tailored to the individual needs of communities.

Corridor management must take into account a long history of prior government and community decisions. It is also important to understand the capacity and skills of land managers and local communities.

\section{Management functions}

Active management of a corridor area will have regard to the ever-changing context and will have prioritised management and effort based, in part, on those inputs. Implementing management within a corridor will have regard to four important management functions that may occur at three levels: whole of landscape, regional landscape, and site or project.

\section{Leadership}

Leadership of any initiative is the most crucial function of all. Charismatic and skilled leaders can inspire and motivate participation. For leadership to be successful, a truly collaborative approach will be required that inspires ownership of the initiative by many people and organisations. Leadership is best if it ensures that one individual or organisation does not dominate the organisation. In general, leaders are people who are visionary, consistent, have a deep understanding of connectivity conservation, are courageous, determined, flexible and have the ability to take action that changes the status quo (IUCN WCPA 2006). 


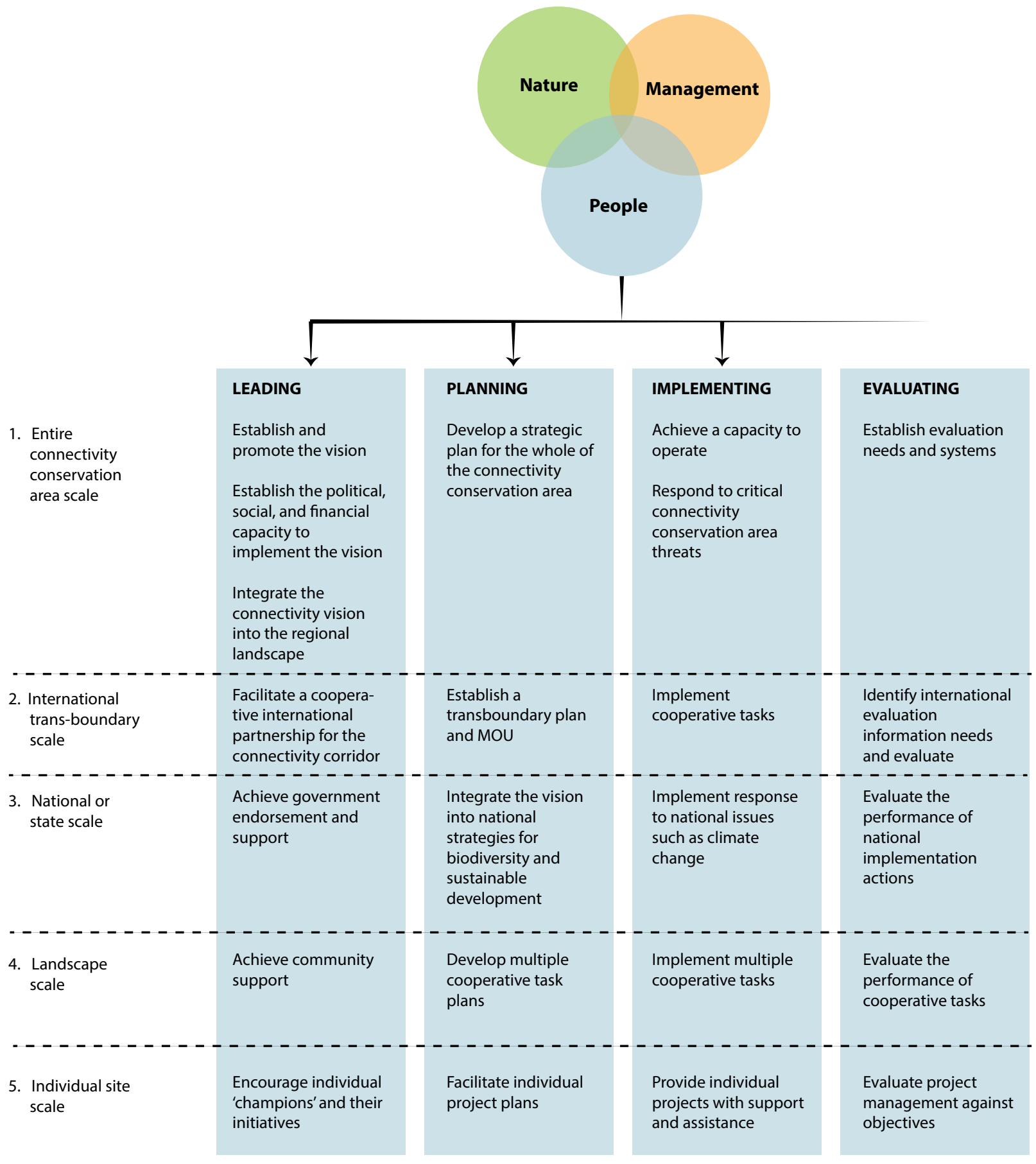

Figure 27.3 Application of the IUCN WCPA Connectivity Conservation Management Framework at various spatial scales

Source: Worboys et al. (2010)

\section{Planning}

Planning is a process to determine goals for a future course of action required to achieve a desired outcome. Landuse (corridor) planning can occur at various geographic and organisational scales. Planning can be completed for the whole corridor and there can be separate plans that detail the actions that will need to be undertaken in core conservation areas, buffer zones and connectivity gaps. Planning can identify areas where critical action should be undertaken and identify the timetable for achieving this, including how the community can be involved. Commonly, plans are undertaken at three levels of detail. The overall purpose of the corridor, organisational goals and direction, and the ways to achieve those goals are outlined in a strategic plan that passes down the hierarchy into a series of regional or tactical and operational plans. 'Bottom-up' planning is also undertaken, and influences these three types of planning. 


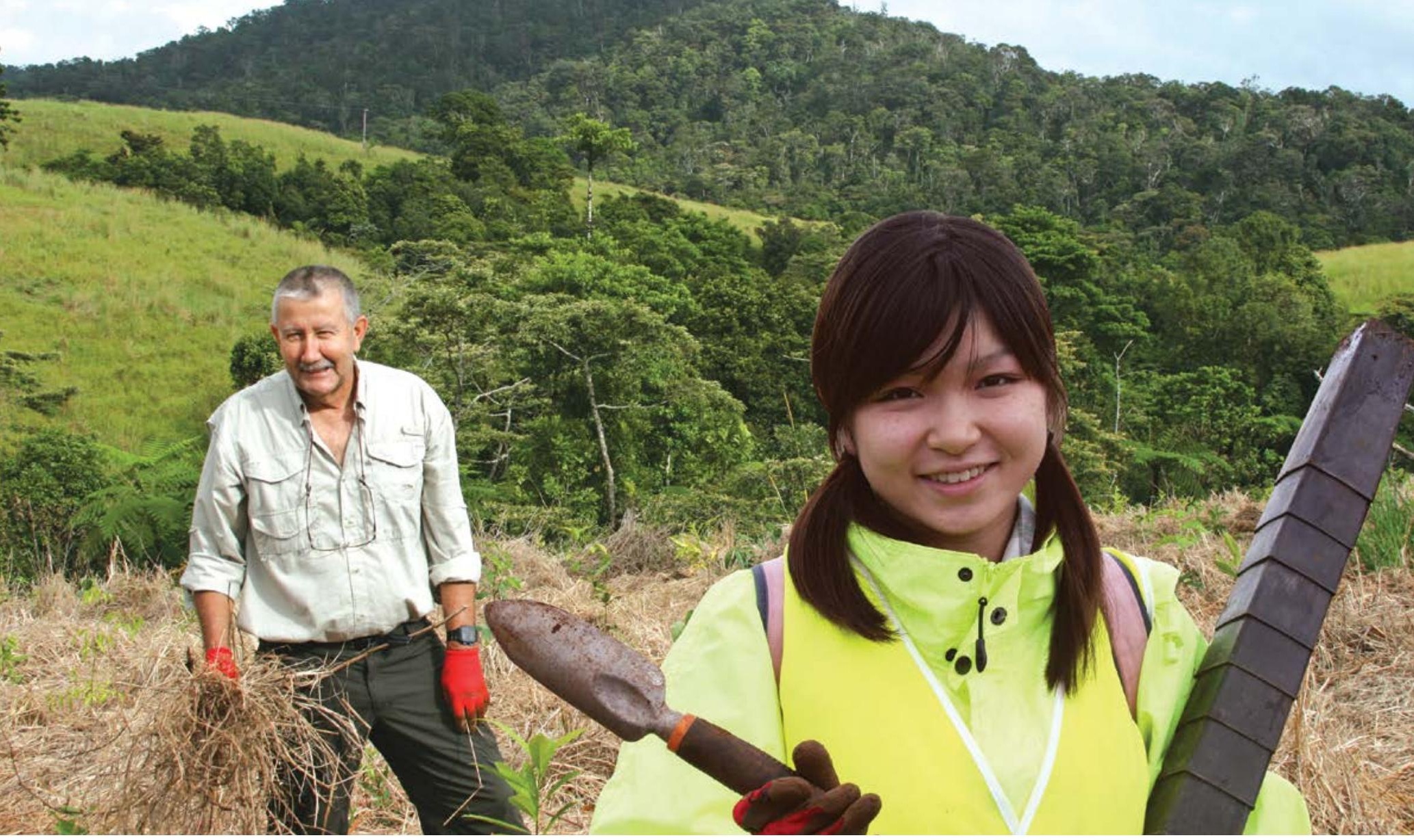

Private landholders on the Atherton Tableland, Queensland, Australia, work together to replant and reconnect remnant rainforest habitat of several climate-sensitive endangered arboreal marsupial possum and tree kangaroo species

Source: Campbell Clarke

delivery of conservation programs. A wide range of instruments may be used (see section on 'Legal considerations' below and Case Study 27.4). The instruments can be used most effectively if targeted at landholders whose properties are located in areas identified as connectivity conservation priority areas.

3. Actively manage for threats (stressors) (such as responding to introduced species): A major threat to connectivity conservation and land management is the threat to ecosystem integrity from the impacts of introduced species, changed fire regimes, pollution and other disturbance. A strategic and timely management investment by all public and private land managers in a corridor is required. Corridor strategic plans can identify areas that require priority investment to control weeds and pest animals such as in connectivity gap areas, in buffer areas around protected areas and throughout the corridor matrix including both public and private lands. If implemented effectively, a key benefit will be the likely improvement of the sustainability and productivity of farms, particularly for those landholders who rely on their land for their livelihoods.

4. Assist with the management of incidents: Management of incidents by key agency or land-use authorities in the corridor includes management of wildfire, storm impacts such as flooding, pollution events and other environmentally damaging or illegal activities such as poaching of wildlife or unauthorised logging. Effective management of incidents requires a significant and usually government agency-coordinated response. The corridor partner and land management organisations and community volunteers would typically contribute to the response.

5. Strive for sustainable resource use: An important component of corridor management is the sustainable and productive use of natural resources. Sustainable use helps to ensure that all parts of the corridor matrix help sustain wildlife and people in the long term. Sustainable resource use may include using protected areas for recreation and tourism; using government, community or private forest timber, seed supplies or grazing; and ensures that water supplies including groundwater are used in a way that maintains biodiversity, agriculture, towns and industry in the long term.

6. Rehabilitate degraded areas (using methods such as large-scale ecological restoration): Rehabilitation of degraded areas and gaps in connectivity corridors requires long-term and well-planned investments informed by the best available science and techniques. The field of 
restoration ecology is underpinned by a large and growing body of scientific and practical knowledge such as the restoration guidelines prepared by the IUCN (Keenleyside et al. 2012). Carefully selecting priority focal areas to target restoration activities can provide the most cost-efficient and biologically beneficial outcomes.

7. Provide and manage research opportunities: An understanding of conservation biology provides an important contribution to connectivity conservation management principles and actions. Spatial analysis of biological values provides the ability to prioritise investment for on-ground conservation activities that need to be delivered in the right places in the most cost-effective way. Connectivity conservation research provides a basis for understanding the changes taking place in corridor landscapes, for evaluating threats and for measuring the corridor condition and the effectiveness of conservation actions, which often need to be assessed at multiple scales.

\section{Crosscutting tasks}

1. Working with partners: Connectivity conservation promotes innovative models of collaborative governance to connect landscapescale science with local-scale action. It is founded on the premise that the collaborative whole will have a greater conservation impact than the sum of the parts. Establishing effective long-term relationships with a wide range of partners is a complex, crucial and challenging task. To be successful there need to be good formal and informal institutional linkages between these governance levels.

2. Working with stakeholders, communities and rights-holders: Connectivity conservation involves working with many hundreds if not thousands of stakeholders located in cities, towns, villages and farms throughout the corridor landscape. It is by working and communicating with, motivating and involving large numbers of stakeholders that landscape-scale conservation can be achieved. Landholders are key stakeholders who must be supportive to take action to help restore and manage landscapes. Without their support and cooperation little can be achieved. Key delivery partner organisations can offer on-ground conservation programs using a range of voluntary conservation instruments that can include incentive payments. Different partners may participate at different levels. At the whole-of-corridor scale, corridor initiatives may establish partners that could include national governmental organisations to assist with tasks such as management of large-scale wildlife migrations, trans-boundary management and environmental data management.

3. Undertaking communications (such as constantly marketing an inspiring vision): Connectivity conservation requires frequent effective communication and marketing of an inspiring vision as well as feedback about the programs, projects and individual contributions that have been implemented to help achieve this vision. A strategic communication plan for the whole corridor is important and in some cases a communication plan in parts of a corridor or for specific projects. Products include corridor information brochures, corridor science books, videos and a website that is actively managed and from which press releases, audio/radio technologies, progress reports, scientific and technical reports and other downloadable material can be made available to the widest possible audience (Pulsford et al. 2013). As far as possible, this should happen in locally used languages. Communication tools that use social media may be employed including technology such as smart-phone and specialist applications for citizen science data recording (such as wildlife observations) and reporting threats to and impacts on corridors (see Chapter 15).

\section{Monitoring and evaluating corridor performance}

Monitoring is the process of recording the condition of a feature to determine the extent to which it matches some predetermined standard or objective. Monitoring provides a systematic framework for answering questions such as 'connectivity for what, where, when, by whom and how'. There are three main types of monitoring that can be used to help answer these questions (Table 27.1).

1. Compliance monitoring involves determining if actions have been carried out in accordance with an agreed plan. While connectivity conservation is a means of achieving ecological outcomes, it is a complex activity carried out by a mixture of diverse groups and individuals over large spatial scales and long periods and so relies on a sound monitoring process.

2. Response monitoring involves testing hypotheses. This means testing using robust statistically valid designs to measure the extent to which management actions are achieving their intermediate outcome of 
Table 27.1 Types of monitoring indicating their purpose, targets and associated risks

\begin{tabular}{|l|l|l|l|}
\hline Monitoring type & \multicolumn{2}{l}{ Compliance } & Response \\
\hline Target & $\begin{array}{l}\text { Management actions } \\
\text { Action 1 } \\
\text { Action 2 } \\
\text { Action 3, and so on }\end{array}$ & $\begin{array}{l}\text { Response to management actions } \\
\text { Output 1 } \\
\text { Output 2 } \\
\text { Output 3, and so on }\end{array}$ & $\begin{array}{l}\text { Outcomes } \\
\text { Viability of species, } \\
\text { communities and ecosystem } \\
\text { processes }\end{array}$ \\
\hline Risks & $\begin{array}{l}\text { Procedural } \\
\text { Internal: failure to carry } \\
\text { out agreed actions due } \\
\text { to lack of resources, lack } \\
\text { of commitment or lack of } \\
\text { clarity of responsibility } \\
\text { External: changes in } \\
\text { tenure, zoning or planning } \\
\text { that render actions } \\
\text { impossible or irrelevant }\end{array}$ & $\begin{array}{l}\text { Scientific } \\
\text { The relationship between action and } \\
\text { output relies on an understanding of } \\
\text { the links between interventions and } \\
\text { improved functional connectivity; the } \\
\text { major risk is inadequate understanding } \\
\text { of these links, which is very common } \\
\text { as available data are frequently at } \\
\text { inappropriate or insufficient temporal } \\
\text { or spatial scales to detect change }\end{array}$ & $\begin{array}{l}\text { Deliberative } \\
\text { Lack of clarity of outcomes, } \\
\text { unachievable outcomes, } \\
\text { inadequate scale of } \\
\text { intervention, insufficient } \\
\text { time elapsed between } \\
\text { interventions and the } \\
\text { anticipated responses, } \\
\text { new threats such as invasive } \\
\text { species and diseases }\end{array}$ \\
\hline
\end{tabular}

maintaining or improving functional connectivity in a landscape, region or whole corridor, and the extent to which they are achieving their ultimate outcome of maintaining or improving the viability of populations, communities and ecosystem processes.

3. Effectiveness monitoring is tailored specifically to evaluate and report the high-level outcomes of management programs or interventions. While the task is more complex when monitoring the effectiveness of connectivity conservation in landscapes with mixed tenures, management effectiveness approaches used in protected area management offer useful precedents (see Chapter 28).

Monitoring requires the selection of a range of suitable indicators, metrics and spatial analysis to measure whether established clear goals are being achieved and so that timely changes in priorities for the most appropriate action can be determined. The ability to measure change in a connectivity conservation project will always be challenging as management actions usually take decades to have a measurable impact given that interventions need to occur over large areas before any change is detectable, and outcomes can be influenced by many natural and human factors other than the planned interventions.

\section{Connectivity conservation governance}

Governance refers to the structures and processes used to negotiate and reach collective goals (Lemos and Agrawal 2006). Governance applies to the internal mechanisms of a single entity, public or private, but can also relate to interactions, partnerships, collaborations or networks among actors. Governance includes both formal rules-laws, regulations, negotiation, mediation, conflict resolution, elections, public consultations and informal interactions - and norms and principles shaping decision-making. Beyond power-sharing and the equitable distribution of resources, governance should engender shared purpose, trust and mutual understanding (IUCN 2007).

Connectivity conservation includes and promotes the recognition and support of diverse governance types across a landscape (see Chapter 7). These require a governance mosaic approach that respects the mandates and legal requirements of different governance types of protected areas as 'other effective area-based conservation measures' in order to spread and strengthen connectivity conservation management across the landscape. These measures include Indigenous Peoples' and Community Conserved Territories and Areas (ICCAs), a generic term that includes specific names used in different countries, such as community conserved areas (CCAs), indigenous protected areas (IPAs), biocultural heritage sites, community reserves, locally managed marine areas, and so on. ICCAs are potentially as widespread and cover as much area as government protected areas (if not more), and have significant conservation, cultural, livelihood and other values (Couto and Gutiérrez 2012; Kothari et al. 2012; see also Case Study 27.1 and Chapter 7).

\section{Land tenure, land use and property rights}

Lands beyond protected area boundaries are managed for diverse uses: conservation, agriculture, forestry, recreation, tourism and mining. These land uses often correlate with different tenure and regulatory requirements, which challenge coordinated landscapescale conservation (Binning and Fieldman 2000). 
Land tenure embodies the legal property rights, implied or prescribed land use and rules of access, yet property rights are also cultural, reflecting deep-seated values of ownership, motivations and expectations of the rights of an individual to manage their land.

Connectivity conservation provides a framework for integrating a whole-of-landscape strategic approach to fostering conservation on lands with diverse land uses, tenure and ownership. Consequently, connectivity conservation cannot be adequately implemented without a collaborative, multi-person and multi-agency approach. Effective conservation planning requires that land managers be included in decision-making, with planning embedded within institutions responsible for program delivery (Knight et al. 2006).

\section{Social and cultural considerations}

Connectivity conservation is actively framed as a people-centred approach to biodiversity conservation. Without social and institutional connectivity, the ecological goals of connectivity conservation are unlikely to be met. Much like the need to work within the existing legal requirements of land tenure, connectivity governance requires sensitivity to the local social and cultural dynamics. Engaging in on-ground connectivity conservation partnership activities is usually voluntary, creating a need for these initiatives to inspire rather than enforce participation. The support of local communities is more likely to be established when an initiative respects the values and relationships the community has with the landscape. Where a connectivity initiative traverses large regions and crosses international or national political boundaries, it is important to recognise the diverse aspirations of communities living in a connectivity area.

\section{Connectivity and development}

Areas of lower socioeconomic development, particularly in lower Human Development Index (HDI) countries, present different conditions for connectivity governance compared with more developed nations. In these cases, the progress of conservation can create real or perceived threats to economic development (see Chapter 25). Through decentralised decision-making, connectivity governance has the potential to provide a necessary voice for local actors in conservation. Decentralisation can, however, also reinforce local power structures, undermining democratic aspirations to give voice to marginalised communities (Ribot 2008). These issues are acute in areas where local communities do not have the social, financial and human capital to effectively participate in decision-making.

\section{Cross-scale considerations}

Worboys and Lockwood (2010) identify five scales of operation relevant to connectivity conservation: individual site; landscape; entire connectivity area; nation or state; and (where relevant) international trans-boundary scale (Figure 27.3). Decisions made at one scale will influence outcomes at another, and focusing activities at one of these scales is insufficient to achieve the desired landscapescale conservation outcomes. Effectively operating across and between multiple scales requires coherent governance where the rules operating at one scale do not undermine the capacity of participants at other scales to meet their goals. As these actors are often distributed across vast distances, however, operating in different social, ecological and institutional contexts, connectivity governance requires mechanisms to support cross-scale coordination and communication.

\section{Governance principles and requirements}

The principles of good environmental governance (see Chapter 7) readily apply to connectivity governance. In brief, this involves developing processes to build trust, integrity, inclusivity, transparency, accountability, flexibility, reciprocity and communication as foundations of good governance and collaboration (Lockwood et al. 2010). Governance should facilitate work towards shared values and goals while creating mechanisms to deal with diversity and conflict (Schliep and Stoll-Kleemann 2010). Collaboration requires strong leadership, particularly in dispersed networks challenged by spatial scales that separate actors across a landscape (Folke et al. 2005). Collaboration, however, must not rely solely on the strength of one or two key individuals. Institutionalising collaborative management will enable ongoing momentum after key individuals move on, while building individual and institutional capacity (Carr 2002). Given that many of the partners involved with connectivity conservation are likely to be distributed across large landscapes, the importance of communication mechanisms-websites, emails, print newsletters, human messengers, phones, radio, TV/cable and face-to-face meetings-cannot be overstated (see Chapter 15).

\section{Governance across scales}

Successful connectivity governance requires attention to how an initiative functions at multiple scales. Governance of larger-scale collaboration often involves nesting smaller decision-making units within a larger framework (Ostrom 2005). In Australia, many leading connectivity conservation initiatives operate on three scales: site-scale implementation, regional-scale planning and governance 
across the whole connectivity area. Not all partners work across the entire region so smaller planning units operate at a scale that enables planning to be tailored to, and negotiated within, the specific context. This requires an initiative to consider which tasks are best performed at local, regional or whole-of-initiative scales (Wyborn and Bixler 2013).

\section{Collaboration}

Collaboration commonly entails: involvement of diverse stakeholders; equal opportunity to participate in decisionmaking; decision-making processes building towards consensus; and a sustained commitment to collective problem solving (Margerum 2008). In practice, the term is applied broadly, referring to sharing information, coordinating actions or integrated decision-making. Any of these approaches are appropriate for connectivity governance; however, partners should have shared expectations of the collaborative processes and outcomes. Collaboration with equitable distribution of power and consensus decision-making are time and resource intensive. If such collaboration is the goal, necessary resources must be found to enable it. If, however, the goal is to ensure that regional conservation actions meet a particular outcome, a more modest interpretation of collaboration, or a different approach to governance (regulatory or market-based), may be more efficient or effective (Case Study 27.1).

\section{Public engagement}

Connectivity governance includes broader community engagement. Connectivity conservation areas cover public and private land tenures; this creates an ethical and practical imperative for an initiative to consider the perspectives of local and regional communities. Effective participation can improve the quality, legitimacy and capacity of environmental decision-making while building community trust (Dietz and Stern 2008). Community input can be gained through various formal and informal mechanisms. The International Association for Public Participation lists a 'toolbox' of approaches that can provide further guidance (IAP2 2006).

\section{Flexible and adaptive governance}

Effective governance is not static; rather effective institutions evolve in response to changed circumstances. Social, political and ecological systems are constantly changing at different rates in response to internal or external stressors: actors and policies change with fluctuations in government; and knowledge of a system and its stressors changes in response to broader social, political or ecological dynamics. Governance itself is an evolving process: a workable arrangement for the startup phase of an initiative is unlikely to remain viable as collaborations solidify and start to attract large sums of money. Connectivity initiatives are guided by long-term (50 to 100-year) visions for landscape change. Operating across these time frames requires flexible and adaptive governance and strong leadership in order to remain relevant in the face of change.

\section{Tasks of governance}

While specifics should be negotiated in context, governance tasks can be broadly grouped into four areas: 1) maintaining internal and external communication; 2) strategic planning; 3) obtaining financial resources; and 4) ensuring accountability (Mitchell and Shortell 2000). In addition to these generic tasks, connectivity governance requires coordination and supporting collaboration among diverse actors, and mechanisms of dialogue and dispute resolution. The mechanisms of connectivity governance should support internal alignment with the characteristics of the partners and external alignment with the context and needs of specific landscapes and communities.

\section{A framework for connectivity governance}

Connectivity governance can be thought of as operating at the intersection of four domains: context, knowledge, vision and collective action (Wyborn 2013). Connectivity governance will be most effective when the arrangements have been tailored to suit a particular landscape; draw on the best available local, scientific and sociological knowledge; have a clearly articulated vision; and provide a coherent framework to support actors to work towards the vision. Articulating and negotiating the elements covered by these four domains provide a framework for connectivity practitioners to tailor governance arrangements to their context.

\section{Context}

Context considers the social, ecological and institutional dimensions of an initiative. This involves identifying the key actors in the process, the landscape context (major land use, threats, conservation assets and targets), the economy of the region, major market drivers, the organisations involved or affected, and the overall institutional and regulatory context that constrains or enables collective action. A thorough understanding of contextual factors is desirable in order to most effectively tailor governance to the specifics of a particular place. Identifying financial resources is critical, as the availability of resources shapes the nature of governance and implementation. 
The mountain landscape stretching from the Nandadevi Range to the Askot Valley in the State of Uttarakhand in India's Western Himalaya is home to several globally important plant and animal species, unique human cultures and critical ecosystem functions that provide benefits to millions of people. Currently this landscape is governed and managed in a variety of ways, including under governmentdesignated protected areas like Nanda Devi National Park and Askot Sanctuary, ICCAs like van panchayats (forests under formal management of village committees), sacred natural sites, reserves and protected forests under government management, and other governmental, community and private lands. A substantial part of the west of this region is under the Nanda Devi Biosphere Reservealso designated as a World Heritage site. Several of these designations or land uses overlap-for instance, one-third of the Askot Sanctuary is under van panchayats or other village commons. Moreover, when seen on the same map, the various governance types together form much larger areas of contiguity and connectivity than if only the formally designated protected areas were considered (see Figure 27.4). One of India's biggest conservation landscapes, spread over more than 2500 square kilometres, can be envisaged through such an approach.

There have, however, been few attempts in the past to see this landscape in terms of connectivity. Second, lack of consultation and participation in the designation and management of the government protected areas has in the past caused hostility, alienation and loss of livelihoods among local communities. Finally, lack of interdepartmental coordination in the State Government has allowed the establishment of a number of hydro-electricity and other projects that have threatened both biodiversity and local communities.

In 2010, the Wildlife Institute of India and the NGO Kalpavriksh initiated a dialogue process among government officials, local community members, civil society organisations and wildlife researchers. The aims were to discuss and resolve the above issues of contention, and collectively envision the landscape as one in which conservation and livelihoods can be integrated through a mosaic approach. There are a number of ongoing processes that could be opportunities for such an approach: the presence of the biosphere reserve where such an integrated view is already intended (and includes some ecodevelopment inputs to villages); the Government of India's Biodiversity Conservation and Rural Livelihoods Improvement Project (funded by the World Bank, with Askot as one of the main sites); the possibility of recognising rights-based community conservation under the Forest Rights Act 2006; and mobilisation among communities for securing livelihoods including through new approaches like community-led ecotourism.

Four dialogues have been held, including two for the participation of a range of rights-holders and stakeholders in the Nanda Devi and Askot areas, and one in the State capital to bring on board senior officials of the forest bureaucracy and wildlife scientists who have been working in these areas. These were co-organised with the Uttarakhand State Forest Department, and NGOs like Alliance for Development and Himal Prakriti. These have come up with a number of recommendations on how the various governance types and management categories can be brought together, what kinds of livelihoods can be encouraged and enhanced, and how principles of good governance such as participation (see Chapter 7) can be incorporated. A discussion paper on a possible institutional arrangement for integrated governance, planning and management of the region was circulated. All these have also been sent to the State Government for consideration. The going has been slow, as the approach suggested is fairly new to India, and has to overcome institutional, informational and attitudinal challenges including the creation of trust among the various parties concerned and creating greater transparency in governmental functioning. Continued top-down planning of hydro-electricity projects is also a constraining factor. In 2014, the initiating organisations were planning the next set of consultations and actions.

- Ashish Kothari, Kalpavriksh, Pune, India

\section{Knowledge}

The knowledge required to support connectivity conservation and connectivity governance is diverse. The knowledge context of an initiative will shape how conservation, management and governance challenges are understood; how governance, planning and intervention are monitored and evaluated; how learning is shared and accumulated over time; and what counts as credible and relevant knowledge in the context of a particular problem.

\section{Vision}

An initiative's vision requires practitioners to imagine a desired future. A bold connectivity conservation vision is a critical element that provides the context for local individual actions. The vision is a key component of the management framework (Figures 27.3 and 27.4) and provides the 'glue' that provides guidance to multiple stakeholders implementing actions across the landscape at multiple scales. A vision should be compelling and motivating. Stakeholders need to believe that the vision is achievable and that their own individual actions can make a difference. Vision statements that work best utilise powerful imagery and are easily grasped and accepted (Robinns et al. 2003). An example is the vision statement of the Great Eastern Ranges Initiative:

To conserve and manage a $3,600 \mathrm{~km}$ 'continental lifeline' of habitats, landscapes and people, that will support the continued survival of native plants and animals along the Great Eastern Ranges from the Grampians in Victoria to far north Queensland and maintain the natural processes on which they depend. (OEH 2012:2) 


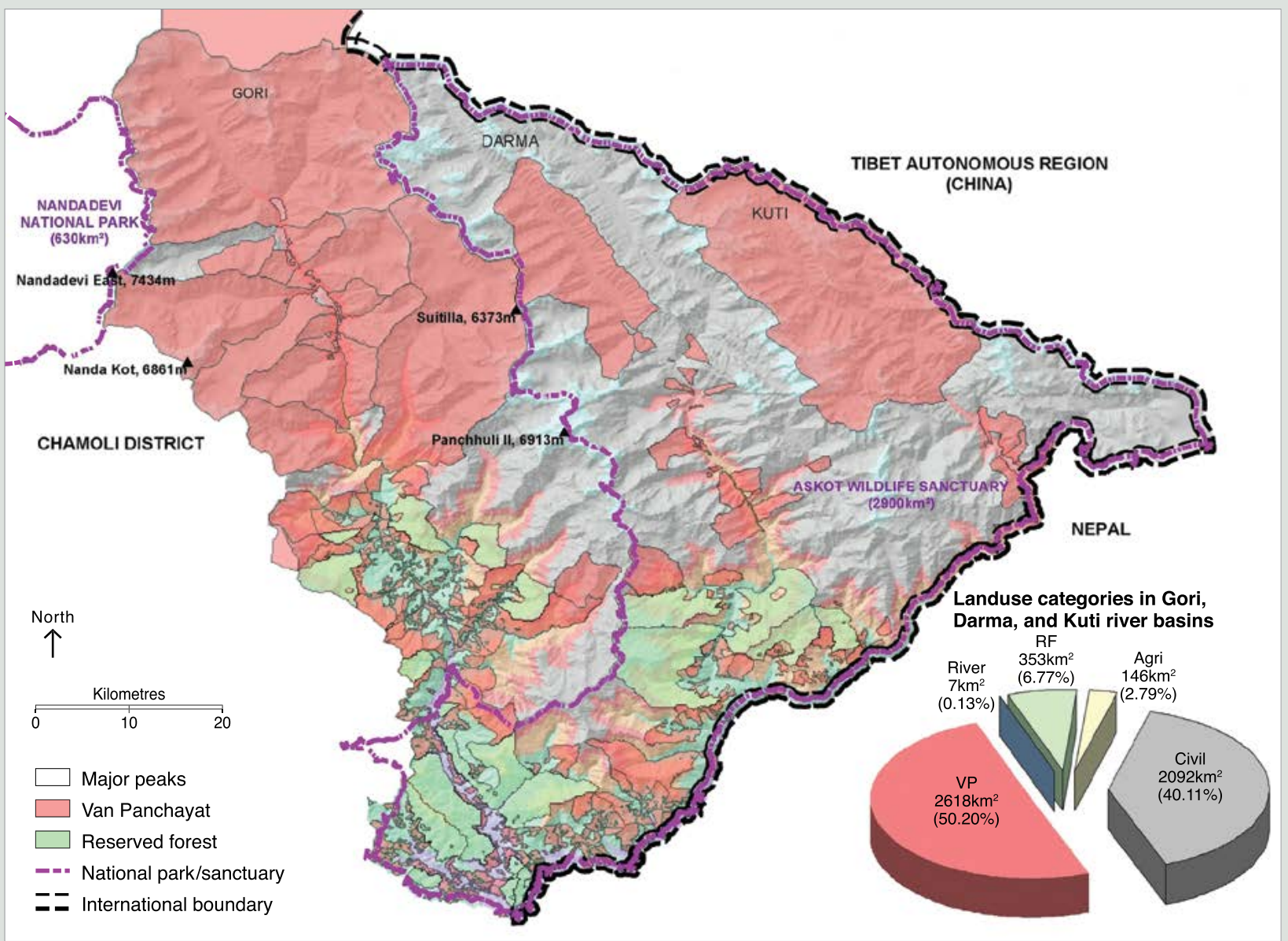

Figure 27.4 Community and State Protected Areas of the Gori, Darma and Kuti River Basins in the Western Himalaya

Source: Modified from Foundation for Ecological Security

\section{Collective action}

The collective action dimensions of connectivity governance concern the social and institutional dimensions of moving from vision to action. These dimensions of governance revolve around processes of leadership, building trust among participants, and creating an environment where the group can learn from each other and learn together (social learning) and build the necessary social capital to create viable working relationships. The culture and relationships that emerge from these interactions form the informal, often unwritten, rules and norms of governance. Beyond informal rules come more formal processes and the structural dimensions of governance. This involves having clear lines of accountability, transparent decision- making processes, clarity around the respective roles and responsibilities of actors and inclusive decision-making processes.

\section{Corridor benefits to the community}

Effective corridors and their governance provide many benefits for biodiversity, people and communities. For example, maintaining connected landscapes increases landscape amenity for recreation and enjoyment, may help to increase farm productivity and sustainability, can maintain or increase connectedness with nature and other land managers and provides for human physical, spiritual and economic wellbeing. This is because corridors extend across multiple tenures that may be used for many purposes and may include protected areas and areas used for settlements, forestry, agriculture, pastoralism, fishing and even mining. 


\section{Box 27.3 Six potential governance models for connectivity conservation}

1. Single, 'top-down' organisation: Authority is vested in a single organisation with wideranging powers and/or resources with sole responsibility for an initiative. This model is likely to be adopted by a governmental agency or a large NGO with the capacity to undertake the tasks of governance and coordinate with local actors.

2. Single, 'bottom-up' organisation: Another singleorganisation approach, however, a community organisation or local indigenous group assumes the primary governance role. As many localscale initiatives have limited reach across a large landscape, this approach often revolves around connecting a number of local initiatives across the landscape.

3. Decentralised authority: Decentralisation is a process whereby a centralised authority (usually a government) devolves responsibility for decisionmaking to regional or local authorities. This could involve devolving certain aspects of decisionmaking to different organisations, or a governmental agency relegating authority to a local organisation. Problems can arise when responsibility for decision-making is devolved without the necessary power or resources to act.

4. Representative authority: Representative governance involves an electoral process whereby the governing body is legitimised through formal voting. Given the diversity of interests in a connectivity area, the question of who gets to vote can be difficult: is voting restricted to residents in the landscape, to organisations in a collaboration, to anybody who is interested in the region?

5. Representative federation: Governance through a federation emerges when a group of organisations formalises their collaboration or partnership. While the rules and structures of governance will vary depending on the context, federations tend to involve partners collectively shaping an initiative's strategic direction. In this approach, the federation is often considered a separate entity comprising more than the collective sum of the partners.

6. Loose confederation: Under a loose confederation, partners focus on a common vision; however, under this model the individual partners operate somewhat independently of each other. Each partner is free to implement activities under the vision without having to consult with other partners. The collective effort is the sum of the partners' efforts.

Source: Adapted from Worboys and Lockwood (2010)

\section{Types of governance arrangements}

Connectivity conservation strives to provide flexible governance that is responsive to the local context while maintaining coherence and alignment across vertical (jurisdictions) and horizontal (land tenure) scales. This can be achieved through a variety of different means: multi-level partnerships that link local organisations and national governments; multi-sectoral collaborations involving public, private and civil society actors; or multi-organisational partnerships with groups from the same background or sector working together (Box 27.3).

\section{Partnerships}

Regardless of the governance model developed, partnerships are central to connectivity conservation. The nature of the partnerships will depend greatly on the organisations present and the level of diversity represented in the partners. Partnership complexity increases in more heterogeneous collaborations and these partnerships may take longer to reach agreement or consensus (Huxam 2003). Partnership composition as well as the expectations of collaboration will influence the nature and formality of governance arrangements. Partnerships based on information sharing between organisations of similar size and backgrounds are unlikely to need complex governance structures. In contrast, multi-party partnerships between public, private and civil society organisations seeking to collectively raise and distribute funding are more likely to require formalised governance outlining the roles and responsibilities of the different partners.

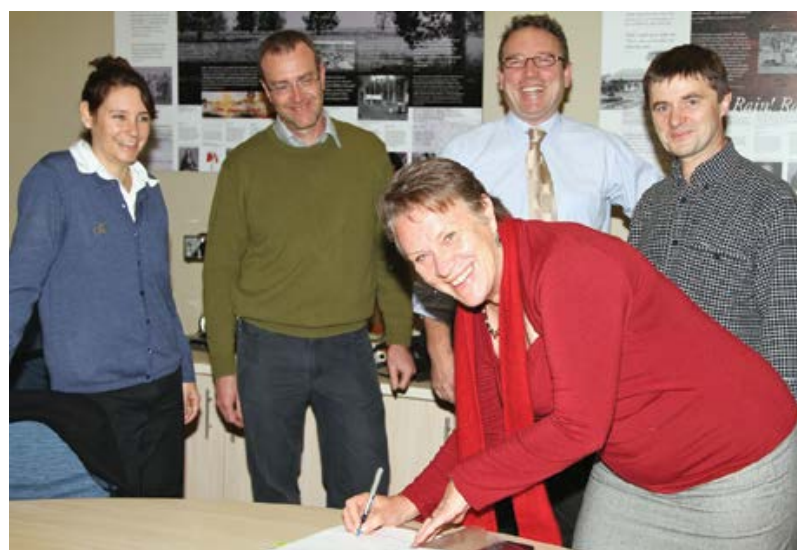

Representatives of four non-governmental organisation (NGO) lead partners (OzGreen, National Parks Association, Greening Australia and Nature Conservation Trust) and the NSW Department of Environment, Climate Change and Water witnessing the signing of a memorandum of understanding in May 2010 to provide leadership for the Great Eastern Ranges Initiative

Source: lan Pulsford 


\section{Case Study 27.2 European Green Belt: A continent-wide wildlife migratory corridor}

Transboundary migratory corridors can range from very local to continental scales (Vasilijević and Pezold 2011). A prominent example of a continental-scale trans-boundary migratory corridor is the European Green Belt. In addition to having biodiversity conservation benefits, the European Green Belt addresses specific symbolism of reconciliation and renewed cooperation after the long period of the 'Iron Curtain'. This initiative aims to consolidate a network of protected areas located at border areas of sovereign countries spanning from a Fennoscandian part of northern Europe to the Adriatic and Black seas in the south. While this example is relevant to the issue of scale, it is also an example of the significant challenges protagonists face in the development of transboundary initiatives where there are vastly different socioeconomic and sociopolitical dynamics and circumstances.

- Maja Vasilijević, Director of Eco Horizon, Croatia

\section{Secretariat}

A number of tasks need to be considered to support a connectivity initiative extending beyond the remit of partnerships focused on implementation on the ground. These include: leadership to promote the vision; developing strategic planning for the whole initiative; supporting administrative and operational capacity to communicate and coordinate across partners; working to integrate the vision into land-use planning; establishing, supporting and collating ongoing evaluation across scales (Worboys and Lockwood 2010). In more formalised initiatives, this work often falls to a 'secretariat' that acts as the public face of an initiative and performs many of these tasks in collaboration with partners. For example, in 2014 the secretariat in the Great Eastern Ranges Initiative in Australia consisted of a director, conservation manager, communications expert and a web designer.

\section{Top down or bottom up?}

The question of whether governance is more effective when directed through a top-down hierarchy or decentralised grassroots initiatives is largely a philosophical one. For those in favour of a hierarchy, this brings clear lines of accountability and efficient decision-making as the directives flow from an executive director or a board. Top-down governance can, however, lack the local connections necessary to truly connect a connectivity initiative to a place.

In contrast, grassroots governance is seen to provide better connections to a place, local knowledge, communities and the 'boots on the ground' undertaking the conservation work. Without coordination between disparate efforts, however, the cumulative landscape-scale impact may be lost. A centralised 'face' or coordinator can collate and promote what would otherwise be disparate local efforts. Their cumulative impact can provide a greater voice for a region in policy or land-use planning debates that drive landscape change; however, passion and connection to place provide the vision and motivation for connectivity conservation.

\section{Role of protected area managers in corridors}

Protected area managers of community, private and public protected areas can provide a critical role in the leadership and governance of connectivity conservation partnerships (Worboys et al. 2010). This is because they manage permanently protected lands, and these areas are often the most intact and important core habitats remaining within a corridor. Protected areas are an essential foundation stone of connectivity conservation. In addition, protected area managers bring specialist conservation management skills that are valuable for the larger corridor area and its management. If the purposes for the establishment of the protected area are to be fulfilled, managers must manage the ecosystems within the reserve. Often, this can only be achieved if managers work beyond protected area boundaries to

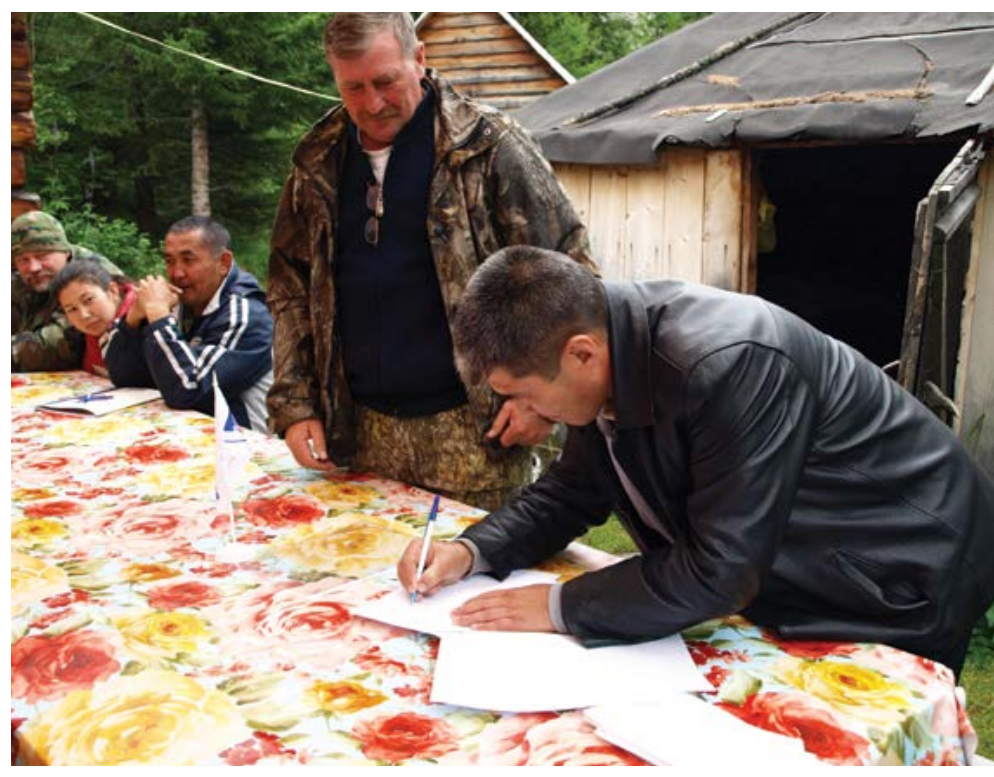

Protected area managers re-signing a fiveyear transboundary agreement of cooperative management, Katunsky Zapovednik (Russia) and Katon-Karagay State National Nature Park (Kazakhstan), part of the proposed Altai-Sayan mega-connectivity conservation corridor

Source: Graeme L. Worboys 
ensure that protected areas are interconnected into larger landscapes. They achieve this by working in partnerships with landowners and many governmental and non-governmental organisations that operate at various scales. The creation of new protected areas can play an important role in catalysing the connectivity conservation initiatives. For example, in Australia the purchase of significant private land by NGOs to establish protected areas often resulted in the formation of connectivity initiatives extending beyond their boundaries (Fitzsimons and Wescott 2005).

\section{Transboundary corridor governance}

Many biodiversity conservation corridors that form part of connectivity conservation areas span international borders. They are important for conserving habitats that enable movement and maintenance of viable species populations, while conserving ecosystem services that enhance the welfare of local communities and socioeconomic systems further afield. Trans-boundary conservation can enable the free movement of wildlife and the migration of species, especially of those animals requiring large areas (it also enables ecological connectivity-for example, the free flow of waterways). Such undisturbed migration of species leads to easier genetic exchange and less isolation, resulting in the reduction of the risk of biodiversity loss. Trans-boundary conservation enables maintenance of healthy and viable populations of species through coordinated management measures across borders. It can be an effective approach for the conservation of biodiversity in that crossborder threats can be dealt with through coordinated action; however, establishing shared governance and cooperative management-a necessity in transboundary conservation approaches-is usually a long-term dynamic and complex process (Case Study 27.2).

\section{Assessing the need for transboundary conservation}

Transboundary approaches in conservation provide new opportunities through opening new channels of cooperation and can result in multiple benefits if planned and managed well. They are probably one of the most complex 'types' of conservation due to a variety of elements that need to be negotiated between two or more countries. This is why careful assessment of needs and potential opportunities and benefits must be performed prior to engaging in a transboundary initiative. Vasilijević (2012) presents a practical diagnostic tool for trans-boundary conservation planners that enables self-assessment through a questionnaire, completion of which helps in deciding whether or not to engage in a transboundary initiative. The tool is designed in such a way as to assist protected area authorities and other governmental agencies, NGOs, local communities and all interested parties in examining their readiness to initiate a transboundary conservation process, while not neglecting the ecological or biodiversity reasons for transboundary conservation, and the accompanying opportunities and potential risks. The diagnostic tool enabling automated report generation is available from the IUCN (Vasilijević 2012).

\section{Benefits of transboundary approaches}

While biodiversity conservation is the core objective of transboundary migratory corridors, transboundary conservation may have many other potential benefits and can provide important opportunities that may not have existed prior to establishing a transboundary initiative (Case Studies 27.2 and 27.3). It enables regular interaction between protected area authorities and continuous sharing of information; it supports a learning process; it establishes connections between cultures, enabling the development of trust and friendships between local communities; it provides for economic development of the given area; and it enables the establishment or strengthening of bilateral and multilateral diplomatic relations. This list is not all inclusive and the potential benefits and positive implications of trans-boundary conservation potentially go way beyond those suggested here. What is important though is the development of trust between key stakeholders. Without mutual trust and understanding, the chances of achieving good cooperation will be limited.

\section{Legal considerations}

This section provides an overview of key international and national legal instruments supportive of corridor management and connectivity conservation, along with their governance considerations. It draws from The Legal Aspects of Connectivity Conservation: A concept paper (Lausche 2013) and the parent document, Guidelines for Protected Areas Legislation (Lausche 2011). 


\section{Case Study 27.3 Kgalagadi Transfrontier Park}

In the far north-western corner of South Africa there is a small portion of land that is squeezed in between Botswana to the east and Namibia to the west, for approximately 235 kilometres. Here, the boundary between South Africa and Botswana is the Nosob River, while that between South Africa and Namibia is a straight line running north to south. While both of these boundaries have been derived through various political processes, the former is a clear illustration of the need for trans-boundary cooperation to achieve conservation objectives. This is particularly true considering this area is in the southern Kalahari Desert, where the scarcity of water is a key driver of ecosystem functionality, and therefore where it would make sense for Botswana and South Africa to see their international boundary as one that needs to be cooperatively managed.

South Africa proclaimed the Kalahari Gemsbok National Park in 1931 and Botswana proclaimed the Gemsbok National Park in 1971. Cooperative management of these adjacent areas has, however, been in de facto existence since 1948 through a verbal agreement between the two countries. Since 1964, the warden of the Kalahari Gemsbok National Park and some of the rangers have been recognised as ex-officio honorary game wardens in Botswana. On 7 April 1999, the Kgalagadi Transfrontier Park was formally recognised through the signing of a bilateral agreement between Botswana's Department of Wildlife and National Parks and South African National Parks (SANParks), thus bringing into being the first formal trans-frontier park in Africa. On 12 May 2000, Botswanan President, Festus Mogae, and South African President, Thabo Mbeki, officially opened the Kgalagadi Transfrontier Park. This was preceded by the establishment of a joint management committee between the respective conservation agencies in June 1992 and the approval of the reviewed management plan in 1997.

Not only has the establishment of this 35551 square kilometre trans-frontier park (Figure 27.5) allowed for the maintenance of ecosystem processes and the uninterrupted movement of large mammals, it also has ensured that important cultural linkages and features have been reinstated. Although Namibia does not contribute to the trans-frontier park in terms of landmass, the opening of the Mata-Mata tourist access facility on 12 October 2007 reunited local communities, as it is a historical access point between Namibia and South Africa. In addition, a successful land settlement agreement between the $¥$ Khomani San and Mier communities, and the South African Government and SANParks, has seen a 500 square kilometre portion of land within the Kalahari Gemsbok National Park transferred to the communities.

- Kevan Zunckel, ZUNCKEL Ecological and Environmental Services, South Africa

The information presented in this case study has largely been obtained and abridged from the Peace Parks Foundation (2014), unless otherwise indicated.

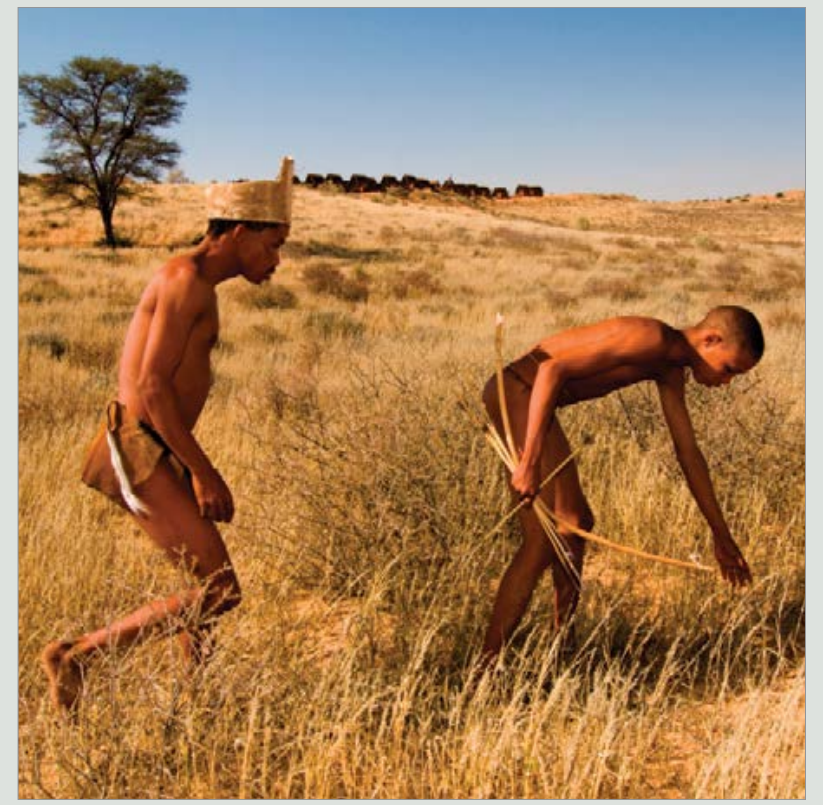

Representatives of the $¥$ Khomani San and Mier communities tracking within the !Ae!Hai Kalahari Heritage Park, with the !Xaus Lodge on the skyline in the background, South Africa

Source: !Xaus Lodge

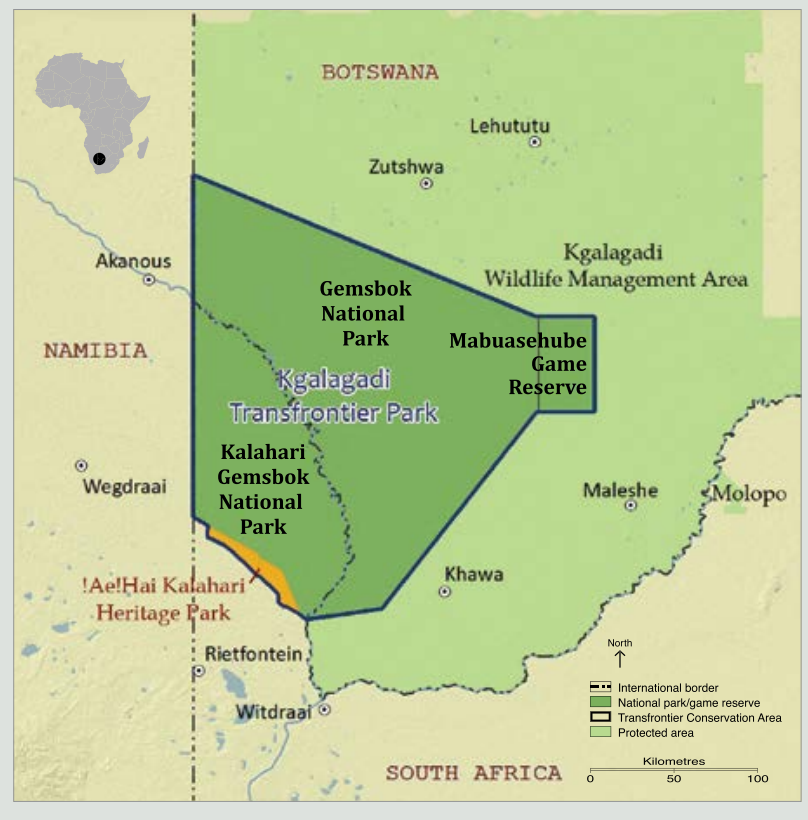

Figure 27.5 The location of the Kgalagadi Transfrontier Park and its constituent national parks in Botswana and South Africa

Source: Modified from Peace Parks Foundation 


\section{International legal frameworks}

Key international legal instruments with global or regional scope for their role in promoting connectivity conservation directly or indirectly include the following.

\section{Global instruments}

- Convention on Biological Diversity (CBD). While not addressed in so many words, several convention provisions are directly relevant, particularly Article 8 on in situ conservation. That article calls for establishing systems of protected areas and other areas where special measures need to be taken to conserve biodiversity - such measures necessarily including connectivity. The CBD Programme of Work on Protected Areas is clear about the need for ecological networks, ecological corridors and buffer zones as part of protected area frameworks. Several Aichi Biodiversity Targets (5,11 and 14) also directly reinforce the need for connectivity, as do subsequent decisions of the parties. For example, Target 11 calls for 'well connected systems of protected areas and other effective area-based measures, and integrated into the wider landscape and seascapes' (CBD 2011:2). For further examples and discussion, see Lausche et al. (2013).

- UN Framework Convention on Climate Change. Mechanisms created to further implement this convention-in particular, Reducing Emissions from Deforestation and Forest Degradation (REDD) and REDD+_-may generate 'co-benefits' for connectivity conservation by providing incentives for conservation of natural forests and their ecosystem services. This is because the movement from REDD to REDD+ in 2010 reflected a changing perspective and more conservation-oriented purpose for the mechanism itself. REDD + does not view natural forests just as carbon stock, but far more importantly, it views natural forests also as part of natural systems that support biodiversity and provide ecosystem services that in turn help to keep landscapes and seascapes stable in retaining and enhancing their carbon storage. REDD+ provides incentives to take action, including connectivity conservation action, which aids climate change mitigation while also playing a significant role in conserving biodiversity and ecosystems.

- Convention on the Conservation of Migratory Species of Wild Animals (CMS). The parties to the CMS have acknowledged that the objectives of the convention cannot be achieved without ensuring adequate connectivity conservation and protecting ecological networks (see, for example, Resolution 10.3, 2011). For endangered species in Appendix
1, Article III(4) calls upon the parties to prevent, remove, compensate for or minimise adverse effects of activities or obstacles that seriously impede or prevent migration of the species, and agreements made under the convention are to conserve and where required and feasible restore habitats of importance in maintaining a favourable conservation status (Article IV[1][4]). CMS ancillary instruments (agreements and memoranda of understanding) are important for promoting connectivity conservation for specific groups of species.

- Convention on Wetlands of International Importance especially as Waterfowl Habitat ('Ramsar Convention'). Parties to Ramsar are obliged to formulate and implement plans for conservation of listed wetlands and wise use of all wetlands as far as possible. Because wetlands, such as rivers, provide essential connectivity functions, and 'wise use' (interpreted as 'sustainable use') also should provide for sufficient degrees of connectivity, obligations under the convention contribute to connectivity conservation.

- World Heritage Convention (WHC). Each party to the WHC is to integrate the protection of their natural heritage into comprehensive planning programs as much as possible and to take appropriate measures (including legal measures) to protect, conserve and rehabilitate this heritage (Article 5). Operational guidelines instruct parties to provide for specific connectivity measures, such as buffer zones, to such heritage sites. In that context, WHC obligations may extend to connectivity conservation.

- UNESCO Man and the Biosphere Programme (MAB). Supplementing legally binding instruments such as those noted above, there are other relevant global arrangements that are not legally binding. A notable arrangement is the UN Educational, Scientific and Cultural Organisation (UNESCO) Man and the Biosphere Programme, with its biosphere reserve concept applicable to terrestrial, coastal, marine and island areas. Important connectivity functions are served by biosphere reserves beyond their core areas (normally a formal protected area) as they require extensions to buffer zones and transition zones (which may not be formal protected areas) (UNESCO 2013).

\section{Regional and supranational instruments}

- Regional treaties. Many regional legal instruments have relevance to connectivity conservation. Examples include: African Convention on the Conservation of Nature and Natural Resources (1968, revised in 2003, not yet in force); Convention 
on the Conservation of European Wildlife and Natural Habitats (Bern Convention, 1979); Convention on Nature Protection and Wild Life Preservation in the Western Hemisphere (Western Hemisphere Convention, 1940); Convention for the Conservation of the Biodiversity and the Protection of Wilderness Areas in Central America (1992); European Landscape Convention (2000); the Alpine Convention (1991) and in particular its Protocol on the Conservation of Nature and the Countryside (1994); Carpathian Convention and its Protocol on Conservation and Sustainable Use of Biological and Landscape Diversity (2003); Protocol on Environmental Protection to the Antarctic Treaty (1991); and a range of CMS ancillary instruments.

- European Union (EU) Natura 2000. As a supranational body, the EU legislature has enacted two principal legal instruments that support biodiversity and connectivity. These are the Birds Directive (Directive 2009/147/EC) and the Habitats Directive (Directive 92/43/EEC). Among other things, the directives call for the establishment of an ecological network ensuring the favourable conservation status of target species and natural habitats. Taken together, these directives have facilitated the creation of a coherent, continent-wide European ecological network, called Natura 2000. The legal framework for this network includes a legally binding set of rules for all $27 \mathrm{EU}$ member states (Article 3, Habitats Directive).

\section{National legal tools for connectivity conservation}

Most national legal systems already contain an array of legal tools that can be used for promoting and managing corridors and other area-based connectivity conservation measures. Following a short note on governance considerations, the remainder of this section reviews key instruments in national law that can be used to support corridors and connectivity.

\section{Legal governance approaches}

Governance approaches for connectivity conservation are still in the early stages of development in most legal systems. Early lessons from case studies and research suggest that the conventional approach to protected area governance-state-owned or state-controlled areasis not significant in the connectivity conservation context. This is because most areas outside a protected area system important for connectivity are owned or controlled by other entities—namely, private individuals, local communities or indigenous peoples, NGOs, or corporations.

Just as no single model of governance will work for protected area systems, no single approach works for connectivity conservation areas. Diverse governance approaches need to be possible-from those appropriate for small-scale connectivity sites (for example, hedgerows, patches of plants, small woods, urban parks) to those appropriate for large-scale sites (major river systems, chains of islands, coastal zones, seas and oceans). This means that responsive laws and policies need to provide authority, rules and incentives to support such diversity, and need to provide flexibility for changing partnerships, biophysical conditions (including climate change) and management needs (Worboys and Pulsford 2011).

\section{Conservation and sustainable use laws to support corridors and connectivity}

In order to achieve their goals, most conservation and sustainable use laws require or are linked to natural connectivity in some manner.

- Stand-alone connectivity legislation: While research found no enacted legislation of a generic nature, some site-specific legislation exists-for example, the South Korea Act on the Protection of the Baekdu Daegan Mountain System (BDMS) 2003 (Act No. 7038, as amended in 2009).

- Protected area legislation: Protected area legal frameworks are a foundation tool for biodiversity conservation. As such, connectivity conservation should be a consideration throughout the legislation, from system design to selection of sites, management planning, coordination, governance and monitoring.

- Biodiversity/nature conservation laws: Some countries have enacted national biodiversity or nature conservation laws as framework laws-for example, Australia's Environment Protection and Biodiversity Conservation Act 1999. These require consideration of connectivity conservation to achieve their biodiversity goals.

- Wildlife conservation laws: Most countries have legislation on wildlife conservation, generally in one or more instruments, and typically covering endangered or threatened species, general wildlife conservation and hunting. These laws generally assume or require certain standards for species management and protection that make connectivity conservation an essential consideration. 
- Sustainable use laws for resources or ecosystems: Laws to secure sustainable use of natural resources (forests, soils, peatlands, prairies, fisheries, agricultural lands) and specific ecosystem types (watersheds, wetlands, coastal zones, hydrologic flows) are becoming increasingly common around the world. The goal is to maintain the connectivity of biological systems that support resource production and healthy ecosystem functioning with time, including in the face of ongoing threats and global change such as climate change.

\section{Land and development control instruments}

Land-use planning law (also sometimes referred to as 'spatial planning' law) has an important role to play in setting regulatory ground rules to support connectivity conservation. The focus is on future development and the use of such regulatory tools as zoning to control, develop and protect significant conservation areas, including for connectivity, from incompatible future development. Several points are relevant here.

- Land-use planning relies on direct regulation to control proposed future development. It does not rely on the voluntary cooperation of landowners or rights-holders, although it sets the framework within which voluntary initiatives can advance specific conservation objectives in the land.

- Modern land-use plans should incorporate conservation plans and be consistent with the provisions of such plans by identifying areas that are ecologically significant, along with the specific conservation values needing protection in those areas, including connectivity conservation.

- Environmental impact assessment legislation plays a crucial role in the implementation of land-use plans and supportive development controls consistent with the conservation needs and values of a landscape or site as well as ensuring compliance with other environmental laws (for example, on pollution control).

- Regulation of development is essential not only in maintaining connectivity but also in ensuring that fragmented landscapes being restored continue to be protected from inconsistent development.

- Jurisdictions with fully developed urban and rural land-use plans have the greatest potential for delivering comprehensive controls over development and maintaining or restoring important connectivity values across a landscape. Particularly in Europe and Australia, legally binding land-use planning is a wellestablished tradition for both urban and rural areas.

\section{Economic and market-based tools}

In contrast with land-use planning (which focuses on regulation of future uses, not existing uses), economic instruments provide an additional tool with respect to existing uses. Economic instruments can be used to encourage and direct active management of existing uses, including to better support voluntary connectivity conservation. Economic instruments introduce the element of choice. They use negative incentives (for example, taxes and charges) and positive incentives (for example, management payments and tax credits) to influence people to change their behaviour.

In practice, economic and market-based tools are frequently used in combination. Direct regulation can be used to protect existing areas from proposed development where it is incompatible with connectivity conservation; economic incentives can be used to encourage landowners and rights-holders to voluntarily change existing practices in support of connectivity conservation (for example, to implement traditional agricultural or forestry practices and restoration projects).

The economic tool called 'payment for ecosystem services' (PES) is an example of a specific economic incentive. PES is a contractual arrangement whereby a landholder agrees to provide and sustain certain ecosystem services through land uses that are compatible with the production of those services (for example, protecting a watershed for its water resources) and in return the beneficiary (for example, a public or private utility) promises to pay an agreed amount for that service for an extended duration.

As another example, an emerging market-oriented tool being recognised in some legal systems, and now being tested mainly in Western countries, is 'conservation banking'. This is a mechanism that allows private landholders to create conservation credits through active conservation management actions on their land to enhance its biodiversity values, and sets out arrangements for guaranteeing the long-term security of those credits.

\section{Special legal instruments for voluntary conservation}

Voluntary conservation arrangements need some legal recognition to be secure for all parties over the long term. The most common tools to provide a legal basis for voluntary conservation, including for connectivity conservation, are conservation agreements, easements and covenants. 


\section{Voluntary conservation agreements}

Many countries (for example, Australia, the United Kingdom, the United States and several countries in Latin America) provide for the use of conservation agreements to set forth commitments and other elements for voluntarily conserved areas. Such commitments may be for areas important for connectivity conservation that qualify to be part of the formal protected area system or they may be outside the formal system but important for supporting the connectivity needs of the system. The extension of this tool to areas important for connectivity conservation is particularly important in light of the diversity of governance situations, mainly dominated by private or community lands, likely to exist on lands or resources within or outside the formal protected area system but important for its sustainability. A conservation agreement-in some jurisdictions called a 'voluntary conservation agreement' or simply an agreement - is a legally binding contract between parties recording mutually agreed long-term conservation and other voluntary arrangements and associated conditions. Ideally these agreements should apply in perpetuity; however, even a fixed-term agreement can form a building block for gaining permanent commitment.

In formal systems, long-term voluntary conservation agreements attached to land are normally registered at the land office so that the public and future owners or rights-holders are informed that the conservation measures 'run with the land' whoever the owner is. Any incentives that may be conditional on the permanent arrangement (for example, reduced taxes, revenue benefits, security of tenure) should be clearly identified in the agreement and also should remain in place even if owners change. In order to give it full legal force and effect, the agreement normally is approved or endorsed by a high-level government body responsible for overseeing implementation.

One of the important elements to cover in a voluntary conservation agreement is the governance arrangement that will apply to the site. This includes the specific institutions taking the lead in governance and in management, whether these functions are joined, separate or combined in one institution or entity. Where it is anticipated that governance arrangements may change with time, it is advisable for the legislation to allow separating documents into a framework document and a management plan so that management changes can be made without amending the framework agreement.

\section{Easements and covenants}

Easements and covenants are used in some legal systems for conservation purposes and are sometimes called 'conservation easements'. There are important legal distinctions on how different jurisdictions may apply, use or recognise the terms 'conservation agreement' and 'conservation covenant' (or easement). This is because they have evolved with differing legal frameworks. A conservation easement is a particular form of formal legal agreement that commits the landowner or rightsholder to certain obligations with respect to the land or resource. It may limit the type or amount of development on the property (normally protecting the land from unwanted development) - legally understood as a negative easement. Or it may oblige the party to carry out specific actions on the land or to use the land in a certain way related to active management and conservation-legally understood as an affirmative easement. After the easement is signed, it is recorded with the appropriate official land registry responsible for land deeds, and all future owners are bound by the easement. As such, it works essentially as 'a covenant running with the land'.

A conservation easement or covenant running with the land may be attractive for a government (or a conservation organisation that may purchase the easement) because it secures a partial legal interest in the land for conservation without requiring that the government or conservation organisation purchase the land. It is of interest to private landowners because they retain title and ownership, allowing continued use in perpetuity as long as it is consistent with the terms of the covenant or easement, with successors being equally bound.

In the United States, the United Kingdom, Australia and some countries in Latin America, tax incentives are provided for concluding such easements as long as the easement is perpetual and meets certain conditions. To receive these tax incentives, typically in the form of tax deductions, the property must normally be determined to have significant conservation value (Case Study 27.4).

\section{Legal tools for strategic planning}

In some countries, a legal tool for broader strategic planning for connectivity conservation is the strategic environmental assessment (SEA). This tool represents a way of integrating conservation considerations into national strategic and land-use planning processes. In an SEA, the impact on the environment of a draft land use or development plan has to be assessed. Major infrastructure projects and large spatial developments, such as new residential areas, can obviously have a major impact on connectivity as they may form massive barriers for wildlife. It is important that connectivity requirements, using the best scientific information available, are well presented and assessed in SEAs, so that they are taken into account at this level. This instrument is a new and emerging tool and has had limited experience with application to date. 


\section{Case Study 27.4 Legal instruments: Great Eastern Ranges Initiative}

The Great Eastern Ranges (GER) Initiative aims to establish a conservation corridor inland of the east coast of Australia, stretching 3600 kilometres from north to south. The corridor is primarily defined by the Great Dividing Range and the Great Escarpment of eastern Australia (Mackey et al. 2010).

There is no legislation in Australia that specifically recognises connectivity conservation, although biosphere reserves that inherently incorporate connectivity conservation are recognised under the federal Environment Protection and Biodiversity Conservation Act 1999 (EPBC Act). A recent Draft National Wildlife Corridors Plan (National Wildlife Corridors Advisory Group 2012) recommended a National Wildlife Corridors Act, but this would only have provided a legal process for community nomination and government declaration of national wildlife corridors, not the tools for achieving this. The proposed legislation was subsequently abandoned in favour of a non-legislative process (Government of Australia 2012).

In practice, the Australian States and Territories have traditionally undertaken responsibility for environmental management, and one of the legal challenges is that the corridor runs through four jurisdictions - the States of Victoria, New South Wales and Queensland, and the Australian Capital Territory-each with its own environmental legislation. The Federal Government may, however, make legislation relating to 'external affairs' (Australian Constitution, s. 51[xxix]). This allows it to implement Australia's obligations under international nature conservation conventions (Commonwealth v Tasmania [1983] 158 CLR 1), including the CBD. The EPBC Act identifies a number of 'matters of national environmental significance', including species and ecological communities listed as threatened at a national level. Any activity likely to have a significant impact on these matters must be assessed and approved by the Federal Government, in addition to obtaining approvals required under State law (EPBC Act, Part 3, Division 1). What this means is that the Federal Government may impose stringent conditions on development approved at the State level, and even veto it completely.

Another legal challenge is posed by the variety of land tenures. In New South Wales, while 59 per cent of the corridor is public land, including 39 per cent in protected areas, 41 per cent is privately owned. In Queensland the corridor incorporates significant areas of privately leased public land and private land (Pulsford et al. 2012). Privately controlled gaps between protected areas provide a challenge to the development of the corridor. These areas are the ones that have been the primary interest of the initiative so far.

Activity is focused on the State of New South Wales, although new GER alliances have formed recently in the other jurisdictions. The initiative in New South Wales is led by a lead partners' group (three conservation NGOs, a semiindependent statutory body and the NSW Government environmental agency). Eight GER regional partnerships have been set up, covering different sections of the corridor. These involve from 10 to 35 organisations, including NGOs, industry groups, governmental agencies, local government, Indigenous groups and academic institutions. Each regional partnership has its own approach to planning and implementation. Various strategic planning processes are being utilised even though they have not been specifically designed for connectivity conservation. For example, the priorities for on-ground conservation investment in one area are being informed by two regional multi-species/ecological community recovery plans that set out the actions necessary for maximising longterm survival in the wild. Recovery plans can be harnessed to achieve connectivity objectives because enhancing habitat connectivity is a key strategy for maintaining species' dispersal capacity and viability in the context of climate change (DECCW 2010:42). In another section of the corridor, strategic biodiversity conservation planning is coalescing around strategic assessment, under the EPBC Act, of proposed coalmines that are likely to have a significant impact on matters of national environmental significance.

When it comes to implementation of on-ground conservation actions on private land, NGOs must necessarily rely on voluntarism. Even where government plays a role, it emphasises voluntary instruments rather than regulatory ones (OEH 2013).

The voluntary instruments used include outright purchase of land by conservation NGOs and management agreements with landholders. Agreements that bind both the existing and the future owners of the land in perpetuity remain the holy grail of private land conservation. In Australia, however, unlike the United States, NGOs cannot usually enter into such arrangements. They are only available to statutory bodies, under legislation, although NGOs may enter into cooperative arrangements. These statutory bodies may also employ 'revolving funds', allowing them to purchase land and then sell it subject to the attachment of a covenant upon sale, investing the proceeds in further purchases.

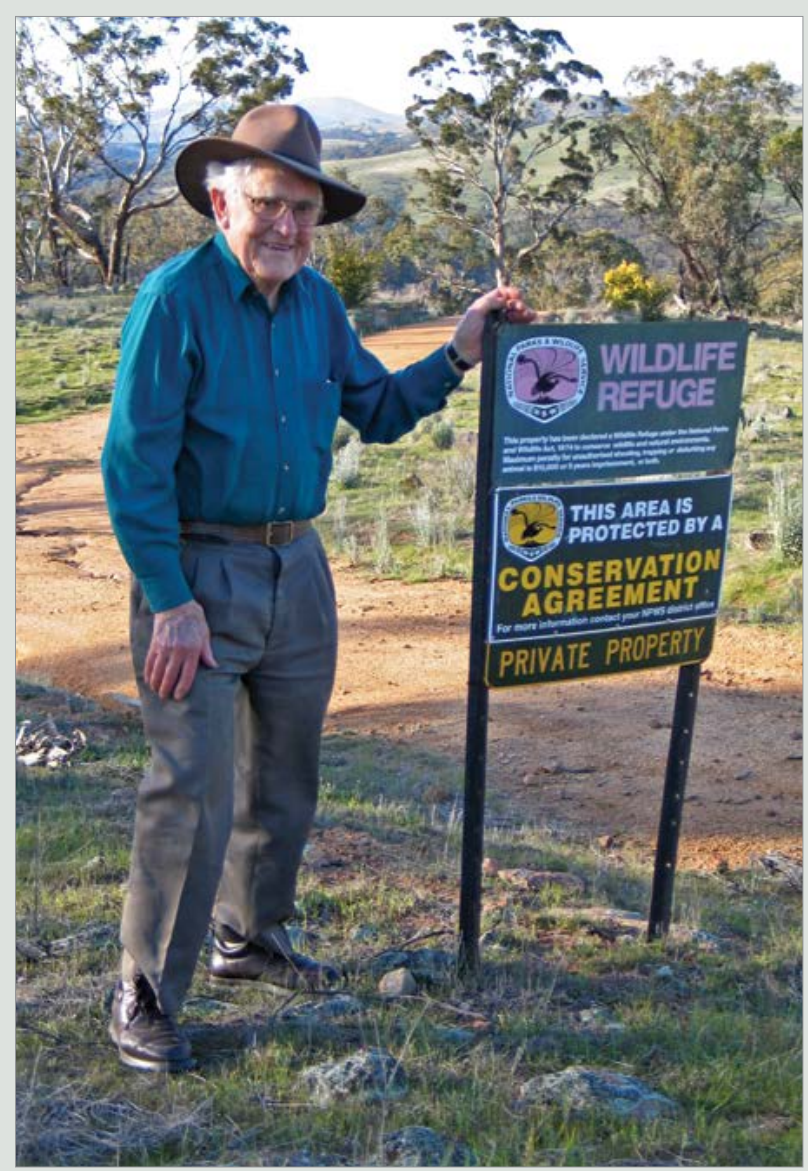

Garth Dixon OAM, at his 'Warriwillah' property near Canberra, who signed in perpetuity conservation agreement with the NSW National Parks and Wildlife Service in the Kosciuszko to Coast section of the Great Eastern Ranges Initiative

Source: lan Pulsford 
Landholders who enter into perpetual covenants, or purchase land already subject to them, are usually motivated by an environmental ethic rather than specific incentives, although they are rewarded with tax benefits and, in New South Wales, relief from local government rates. At the other extreme, there are agreements and registration schemes that are primarily symbolic, lasting only as long as the landholder chooses. The aim is to secure an initial commitment in the hope of extending the length and depth of this over time.

In between these extremes, practice varies. The aim of obtaining an enforceable commitment providing longterm security must be balanced against landholder reluctance if incentives are insubstantial, even in a context where enforcement action is unlikely. One approach requires agreements for at least five years where required management interventions are modest (for example, grazing management) but a minimum of 15 years where restoration (revegetation, fencing for stock exclusion and weed management) is involved. If the only objective is feral animal control, or weed suppression by a landholder after weed removal by the other party to the agreement, there may be few formalities and no legally binding commitments.

A voluntary rather than regulatory approach is essential to securing the cooperation of private landholders in ongoing active management. A regulatory backdrop, however, controlling proposed development that threatens existing connectivity is an essential precursor. In the GER, this is provided by State controls over development and clearance of native vegetation and Commonwealth regulation of proposals that have a significant impact on matters of national environmental significance. In addition, local government planning schemes may seek to protect corridors through zoning or through environmental overlays that have to be considered in determining development applications. The existence of direct regulation fundamentally improves the bargaining position of those seeking to negotiate management agreements with landholders. These regulatory processes were established long before the emergence of connectivity conservation, with its emphasis on voluntarism. Connectivity conservation is not their objective, but they are important building blocks in achieving it.

- David Farrier, Faculty of Law, University of Wollongong, Australia

\section{Conclusion}

Connectivity conservation is a 21 st-century approach to managing landscapes and ecosystems. In today's rapidly changing world and in the future, it is not possible for protected areas on their own to adequately conserve biodiversity. It is only by working to understand and effectively manage protected areas as part of the surrounding and interconnecting landscapes that we will ensure that the greatest possible number of species and ecosystems can move and adapt as climate and other conditions change. Connectivity conservation has many benefits for people and nature, and provides a natural solution for helping to mitigate the effects of climate change. Connectivity conservation is underpinned by a sound scientific basis. The concept is now sufficiently mature that a global management and governance framework has been developed by the IUCN for people to work together over large regions. These approaches are being implemented all over the world including many initiatives that reach across jurisdictional borders. This framework begins to address the need for connectivity conservation to be supported by many legal instruments and tools that already exist in most national legal systems. A two-pronged approach is needed: making better use of existing instruments and strengthening existing frameworks with new and innovative tools and processes as feasible. Readers may refer to two principal source documents (Lausche 2011, Lausche 2013) and their extensive reference lists of articles, reports and websites for more detailed analyses of these topics and additional reading on law and connectivity conservation. 


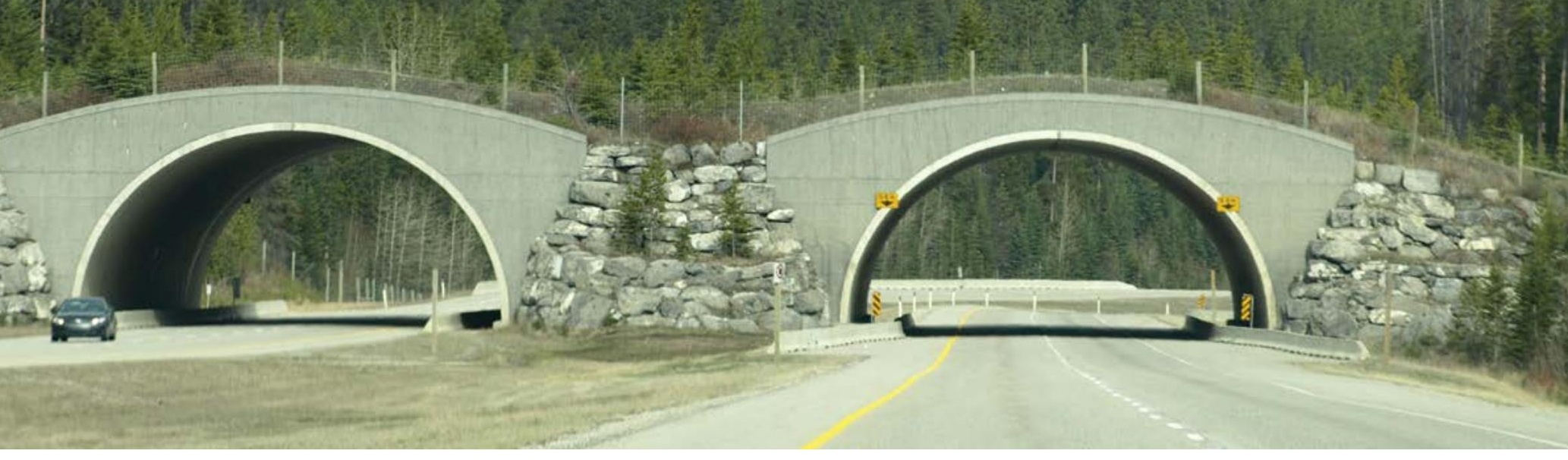

Wildlife crossing, Banff National Park: the Trans-Canada Highway and other roads cut across a major north-south migratory corridor for wildlife, part of the Yellowstone to Yukon (Y2Y) corridor. In response to this situation, forty-four overpasses and underpasses have been constructed in the park and many animals including black bear (Ursus americanus), grizzly bear (Ursus arctos), gray wolves (Canis lupus), cougar (Felis concolor) and wapiti (Cervus elaphus) are using them. The structures help to maintain the connectivity for wildlife, they maintain the effectiveness of the Y2Y corridor and have lowered the number of vehicle-wildlife incidents on park roads.

Source: Graeme L. Worboys

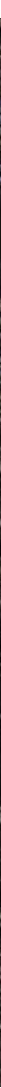

The Australian snowgum (Eucalyptus pauciflora) at its altitudinal limit, Charlotte Pass, Kosciuszko National Park, New South Wales. The park is part of the Great Eastern Ranges Initiative, and this connectivity conservation area extends over 3000 kilometres northwards from Victoria, through Australia's alpine national parks all the way through New South Wales to the Wet Tropics of Queensland World Heritage area and beyond Source: Graeme L. Worboys 


\section{References}

Recommended reading

Amarasekare, P. (1994) 'Spatial population structure in the banner-tailed kangaroo rat, Dipodomys spectabilis', Oecologia 100: 166-76.

Beale, C. M. Baker, N. E., Brewer, M. J. and Lennon, J. J. (2013) 'Protected area networks and savannah bird biodiversity in the face of climate change and land degradation', Ecology Letters 16: 1061-8.

Beier, P. and Noss, R. (1998) 'Do habitat corridors provide connectivity', Conservation Biology 12: 1241-52.

Bennett, A. F. (1990) Habitat Corridors: Their role in wildlife management and conservation, Department of Conservation and Environment, Melbourne.

Bennett, A. F. (1998) Linkages in the Landscape: The role of corridors and connectivity in wildlife conservation, IUCN, Gland.

Berggren, A., Birath, B. and Kindvall, O. (2002) 'Effects of corridors and habitat edges on dispersal behaviour, movement rates and movement angles in Roesel's bush-cricket (Metriopetra roeseli)', Conservation Biology 16: 1562-9.

Binning, C. and Fieldman, P. (2000) Landscape conservation and the non-government sector, Research Report 3, National Research and Development Program on Rehabilitation, Management and Conservation of Remnant Vegetation, Environment Australia, Canberra.

Bottrill, M. and Pressey, R. L. (2009) Designs for Nature: Regional conservation planning, implementation and management, Best Practice Protected Areas Guidelines Series, IUCN, Gland.

Brown, J. H. and Kodric-Brown, A. (1977) 'Turnover rates in insular biogeography: effect of immigration on extinction', Ecology 58: 445-9.

Canadian Parks and Wilderness Society (2013) Yellowstone to Yukon. <cpaws-southernalberta.org/ campaigns/yellowstone-to-yukon>

Carr, A. (2002) Grass Roots and Green Tape: Principles and practices of environmental stewardship, Federation Press, Sydney.
Cascante, A., Quesada, M., Lobo, J. J. and Fuchs, E. A. (2002) 'Effects of dry tropical forest fragmentation on the reproductive success and genetic structure of the tree Samanea saman', Conservation Biology 16: 137-47.

Chester, C. (2006) Conservation Across Borders, Island Press, Washington, DC.

Convention on Biological Diversity (CBD) (2011) Strategic Plan for Biodiversity 2011-2020 and the Aichi Targets, Secretariat of the Convention on Biological Diversity, Montreal. <www.cbd.int/sp/ targets/default.shtml>

Cordeiro, N. J. and Howe, H. F. (2003) 'Forest fragmentation severs mutualism between seed dispersers and an endemic African tree', Proceedings of the National Academy of Sciences of the United States of America 100: 14 052-6.

Couto, S. and Eugenio Gutiérrez, J. (2012) 'Recognition and support of ICCAs in Spain', in A. Kothari, with C. Corrigan, H. Jonas, A. Neumann and H. Shrumm (eds) Recognising and Supporting Territories and Areas Conserved by Indigenous Peoples and Local Communities: Global overview and national case studies, pp. 143-5, Technical Series No. 64, Secretariat of the Convention on Biological Diversity, ICCA Consortium, Kalpavriksh and Natural Justice, Montreal.

Dd Crooks, K. R. and Sanjayan, M. A. (eds) (2006) Connectivity Conservation, Conservation Biology 14, Cambridge University Press, Cambridge.

Department of Environment, Climate Change and Water (DECCW) (2010) Border Ranges Rainforest Biodiversity Management Plan: NSW \& Queensland, NSW Department of Environment, Climate Change and Water, Sydney. <www.environment.gov. au/biodiversity/threatened/publications/recovery/ border-ranges/>

Descheemaeker, J. (2013) Auñamendi Encyclopedia 2013, [in Spanish], Eusko Media Foundation, Facería, Spain. <www.euskomedia.org/ aunamendi/53956>

Desrochers, A. and Hannon, S. J. (1997) 'Gap crossing decisions by forest songbirds during the postfledging period', Conservation Biology 11: 1204-10. 
Dietz, T. and Stern, P. C. (eds) (2008) Public Participation in Environmental Decision Making, National Academies Press, Washington, DC. <www. nap.edu/catalog.php?record_id=12434>

Driscoll, D., Banks, S., Barton, P., Ikin, K., Lentini, P., Lindenmayer, D. B., Smith, A., Berry, L., Burns, E., Edworthy, A., Evans, M., Gibson, R., Howland, B., Kay, G., Munro, N., Scheele, B., Stirnemann, I., Stojanovic, D., Sweaney, N., Villaseñor, N. and Westgate, M. (2014) 'The trajectory of dispersal research in conservation biology', PLoS ONE 9(4): e95053. <doi:10.1371/journal.pone.0095053>

Driscoll, D. A. and Lindenmayer, D. B. (2009) 'Empirical test of metacommunity theory using an isolation gradient', Ecological Monographs 79: 485-501.

Driscoll, D. A., Banks, S. C., Barton, P. S., Lindenmayer, D. B. and Smith, A. L. (2013) 'Conceptual domain of the matrix in fragmented landscapes', Trends in Ecology and Evolution 28(10): 605-13.

Fitzsimons, J., Pulsford, I. and Wescott, G. (eds) (2013a) Linking Australia's Landscapes: Lessons and opportunities from large-scale conservation networks, CSIRO Publishing, Melbourne.

Fitzsimons, J., Pulsford, I. and Wescott, G. (2013b) 'Challenges and opportunities for linking Australia's landscapes: a synthesis', in J. Fitzsimons, I. Pulsford and G. Wescott (eds) Linking Australia's Landscapes: Lessons and opportunities from largescale conservation networks, pp. 287-96, CSIRO Publishing, Melbourne.

Fitzsimons, J. A. and Wescott, G. (2005) 'History and attributes of selected Australian multi-tenure reserve networks', Australian Geographer 36: 75-93.

Folke, C., Hahn, T., Olsson, P. and Norberg, J. (2005) 'Adaptive governance of social-ecological systems', Annual Review of Environment and Resources 30: 441-73.

Foreman, D. (2004) Rewilding North America: A vision for conservation in the 21st century, Earthscan, London.

Forman, R. T. (1995) Land Mosaics: The ecology of landscapes and regions, Cambridge University Press, New York.
Franklin, J. F. (1993) 'Preserving biodiversity: species, ecosystems, or landscapes?', Ecological Applications 3: 202-5.

Galetti, M., Guevara, R., Cortes, M. C., Fadini, R., von Matter, S., Leite, A. B., Labecca, F., Ribeiro, T., Carvalho, C. S., Collevatti, R. G., Pires, M. M., Guimaraes, P. R., Brancalion, P. H., Ribeiro, M. and Jordano, P. (2013) 'Functional extinction of birds drives rapid evolutionary changes in seed size', Science 340: 1086-90.

Galindo-González, J., Guevara, S. and Sosa, V. J. (2000) 'Bat- and bird-generated seed rains at isolated trees in pastures in a tropical rainforest', Conservation Biology 14: 1693-703.

Gilbert, F., Gonzalex, A. and Evens-Freke, I. (1998) 'Corridors maintain species richness in the fragmented landscapes of a microsystem', Proceedings of the Royal Society of London Series $B$ 265: 577-82.

Government of Australia (2012) National Wildlife Corridors Plan: A framework for landscape scale conservation, Department of Sustainability, Environment, Water, Population and Communities, Canberra. <www.environment.gov.au/biodiversity/ wildlife-corridors/index.html>

Gray, M. J., Smith, L. M. and Leyva, R. I. (2004) 'Influence of agricultural landscape structure on a Southern High Plains, USA, amphibian assemblage', Landscape Ecology 19: 719-29.

Gustafsson, L., Baker, S. C., Bauhus, J., Beese, W. J., Brodie, A., Kouki, J., Lindenmayer, D. B., Lõhmus, A., Martínez Pastur, G., Messier, C., Neyland, M., Palik, B., Sverdrup-Thygeson, A., Volney, J. A., Wayne, J. and Franklin, J. F. (2012) 'Retention forestry to maintain multifunctional forests: a world perspective', BioScience 62: 633-45.

Haddad, N. M. (1999a) 'Corridor and distance effects on interpatch movements: a landscape experiment with butterflies', Ecological Applications 9: 612-22.

Haddad, N. M. (1999b) 'Corridor use predicted from behaviours at habitat boundaries', The American Naturalist 153: 215-27.

Haddad, N. M. and Baum, K. A. (1999) 'An experimental test of corridor effects on butterfly densities', Ecological Applications 9: 623-33. 
Haddad, N. M. and Tewksbury, J. J. (2005) 'Lowquality habitat corridors as movement conduits for two butterfly species', Ecological Applications 15: 250-7.

Haddad, N. M., Bowne, D. R., Cunningham, A., Danielson, B. J., Levey, D. J., Sargent, S. and Spira, T. (2003) 'Corridor use by diverse taxa', Ecology 84: $609-15$.

Dd Hilty, J. A., Chester, C. C. and Cross, M. S. (eds) (2012) Climate and Conservation: Landscape and seascape science, planning, and action, Island Press, Washington, DC.

Dd Hilty, J. A., Lidicker, W. Z. and Merenlender, M. A. (2006) Corridor Ecology: The science and practice of linking landscapes for biodiversity conservation, Island Press, Washington, DC.

Holyoak, M. (2000) 'Habitat subdivision causes changes in food web structure', Ecology Letters 3: 509-15.

Horskins, K. (2004) The effectiveness of wildlife corridors in facilitating connectivity: assessment of a model system from the Australian wet tropics, $\mathrm{PhD}$ thesis, Queensland University of Technology, Brisbane.

Huxham, C. (2003) 'Theorizing collaboration practice', Public Management Review 5(3): 401-23.

Intergovernmental Panel on Climate Change (IPCC) (2013) 'Summary for policymakers', in T. F. Stocker, D. Qin, G.-K. Plattner, M. Tignor, S. K. Allen, J. Boschung, A. Nauels, Y. Xia, V. Bex and P. M. Midgley (eds) Climate Change 2013: The physical science basis. Contribution of Working Group I to the Fifth Assessment Report of the Intergovernmental Panel on Climate Change, Cambridge University Press, Cambridge.

International Association for Public Participation (IAP2) (2006) The IAP2's Public Participation Toolbox, International Association for Public Participation. <c.ymcdn.com/sites/www.iap2.org/ resource/resmgr/imported/06Dec_Toolbox.pdf>

International Union for Conservation of Nature (IUCN) (2007) Connectivity Conservation: International experience in planning, establishment and management of biodiversity corridors, IUCN, Gland.
International Union for Conservation of Nature World Commission on Protected Areas (IUCN WCPA) (2006) 'Attributes of a connectivity conservation leader', Minutes of the IUCN WCPA Papallacta meeting, Ecuador, November 2006. <www. mountains-wcpa.org>

Keenleyside, K. A., Dudley, N., Cairns, S., Hall, C. M. and Stolton, S. (2012) Ecological Restoration for Protected Areas: Principles, guidelines and best practices, IUCN, Gland.

Klein, B. C. (1989) 'Effects of forest fragmentation on dung and carrion beetle communities in central Amazonia', Ecology 70: 1715-25.

Knight, A. T., Cowling, R. M. and Campbell, B. M. (2006) 'An operational model for implementing conservation action', Conservation Biology 20: 408-19.

Kothari, A., with Corrigan, C., Jonas, H., Neumann, A. and Shrumm, H. (eds) (2012) Recognising and Supporting Territories and Areas Conserved by Indigenous Peoples and Local Communities: Global overview and national case studies, Technical Series No. 64, Secretariat of the Convention on Biological Diversity, ICCA Consortium, Kalpavriksh and Natural Justice, Montreal.

Lambert, J. (2013) 'Social aspects of linking the people and their landscapes', in J. Fitzsimons, I. Pulsford and G. Wescott (eds) Linking Australia's Landscapes: Lessons and opportunities from large-scale conservation networks, pp. 245-54, CSIRO Publishing, Melbourne.

Laurance, W. F. (1991) 'Ecological correlates of extinction proneness in Australian tropical rainforest mammals', Conservation Biology 5: 79-89.

Lausche, B. (2011) Guidelines for Protected Areas Legislation, IUCN, Gland. < portals.iucn.org/library/ efiles/documents/eplp-081.pdf>

Lausche, B., Farrier, D., Verschuuren, J., La Viña, A. G. M., Trouwborst, A., Born, C.-H. and Aug, L. (2013) The Legal Aspects of Connectivity Conservation: A concept paper, IUCN, Gland. <data. iucn.org/dbtw-wpd/edocs/EPLP-085-001.pdf>

Lechner, A. and Lefroy, E. C. (2014) GAP-CLoSR: A general approach to planning connectivity from local scales to regions, Landscapes and Policy Hub, University of Tasmania, Hobart. 
Lemos, M. C. and Agrawal, A. (2006) 'Environmental governance', Annual Review of Environment and Resources 31(1): 297-325.

Levey, D. J., Bolker, B. M., Tewksbury, J. J., Sargent, S. and Haddad, N. M. (2005) 'Effects of landscape corridors on seed dispersal by birds', Science 309: $146-8$.

Lidicker, W. Z. (1999) 'Responses of mammals to habitat edges: an overview', Landscape Ecology 14: $333-43$.

Lindenmayer, D. B. (2009) Large-Scale Landscape Experiments: Lessons from Tumut, Cambridge University Press, Cambridge.

Lindenmayer, D. B. and Fischer, J. (2006) Habitat Fragmentation and Landscape Change: An ecological and conservation synthesis, CSIRO Publishing, Melbourne.

Lindenmayer, D. B. and Fischer, J. (2007) 'Tackling the habitat fragmentation panchreston', Trends in Ecology and Evolution 22: 127-32.

Lindenmayer, D. B., Cunningham, R. B. and Donnelly, C. F. (1993) 'The conservation of arboreal marsupials in the montane ash forests of the Central Highlands of Victoria, south-east Australia. IV. The distribution and abundance of arboreal marsupials in retained linear strips (wildlife corridors) in timber production forests', Biological Conservation 66: $207-21$.

Lindenmayer, D. B., Cunningham, R. B., Donnelly, C. F., Nix, H. A. and Lindenmayer, B. D. (2002) 'The distribution of birds in a novel landscape context', Ecological Monographs 72: 1-18.

Lindenmayer, D. B., Hobbs, R. J., Montague-Drake, R., Alexandra, J., Bennett, A., Burgman, M., Cale, P., Calhoun, A., Cramer, V., Cullen, P., Driscoll, D., Fahrig, L., Fischer, J., Franklin, J., Haila, Y., Hunter, M., Gibbons, P., Lake, S., Luck, G., MacGregor, C., McIntyre, S., MacNally, R., Manning, A., Miller, J., Mooney, H., Noss, R., Possingham, H., Saunders, D., Schmiegelow, F., Scott, M., Simberloff, D., Sisk, T., Tabor, G., Walker, B., Wiens, J., Woinarski, J. and Zavaleta, E. (2008) 'A checklist for ecological management of landscapes for conservation', Ecology Letters 11: 78-91.
Lockwood, M., Davidson, J., Curtis, A., Stradford, E. and Griffith, R. (2010) 'Governance principles for natural resource management', Society \& Natural Resources 23(10): 986-1001.

Mackey, B. (2007) 'Climate change, connectivity and biodiversity conservation', in M. Taylor and P. Figgis (eds) Protected Areas: Buffering nature against climate change, pp. 90-6, Proceedings of a WWF and IUCN WCPA Symposium, Canberra, 18-19 June 2007, WWF-Australia, Sydney.

Mackey, B., Watson, J. and Worboys, G. L. (2010) Connectivity conservation and the Great Eastern Ranges corridor, Independent report to the Interstate Agency Working Group (Alps to Atherton Connectivity Conservation Working Group) convened under the Environment Heritage and Protection Council/Natural Resource Management Ministerial Council. <www.environment.nsw.gov. $\mathrm{au} /$ resources/nature/ccandger.pdf $>$

Mackey, B. G., Possingham, H. P. and Ferrier, S. (2013) 'Connectivity conservation principles for Australia's national wildlife corridors', in J. Fitzsimons, I. Pulsford and G. Wescott (eds) Linking Australia's Landscapes: Lessons and opportunities from largescale conservation networks, pp. 233-44, CSIRO Publishing, Melbourne.

Margerum, R. (2008) 'A typology of collaboration efforts in environmental management', Environmental Management 41: 487-500.

Margoluis, R. and Salafsky, N. (1998) Measures of Success: Designing, managing and monitoring conservation and development projects, Island Press, Washington, DC.

Margules, C. R. and Pressey, R. L. (2000) 'Systematic conservation planning', Nature 45: 243-53.

Mitchell, S. M. and Shortell, S. M. (2000) 'The governance and management of effective community health partnerships: a typology for research, policy, and practice', Milbank Quarterly 78(2): 241-89.

National Wildlife Corridors Advisory Group (2012) Draft National Wildlife Corridors Plan, National Wildlife Corridors Advisory Group, Canberra. $<$ www.environment.gov.au/biodiversity/wildlifecorridors/publications/pubs/draft-wildlife-corridorsplan.pdf> 
Nelson, M. E. (1993) 'Natal dispersal and gene flow in white-tailed deer in northeastern Minnesota', Journal of Mammalogy 74: 316-22.

Office of Environment and Heritage (OEH) (2012) The Great Eastern Ranges Business Plan 2012-15, NSW Office of Environment and Heritage, Sydney.

Office of Environment and Heritage (OEH) (2013) Great Eastern Ranges, NSW Office of Environment and Heritage, Sydney. <www.greateasternranges.org. $\mathrm{au} /$ office-of-environment-and-heritage-nsw>

Ostrom, E. (2005) Understanding Institutional Diversity, Princeton University Press, Princeton, NJ.

Paton, D. C. (2000) 'Disruption of bird-plant pollination systems in southern Australia', Conservation Biology 14: 1232-4.

Peace Parks Foundation (2014) !Ae!Hai Kalahari Heritage Park in the Kgalagadi Transfrontier Park, Peace Parks Foundation, Stellenbosch, South Africa. <www.peaceparks.org/programme. php?pid=25\&mid=1112>

Pressey, R. L., Watts, M. E., Barrett, T. W. and Ridges, M. J. (2009) 'The C-plan conservation planning system: origins, applications and possible futures', in A. Moilanen, K. A. Wilson and H. Possingham (eds) Spatial Conservation Prioritisation: Quantitative methods and computational tools, pp. 211-34, Oxford University Press, London.

Pulsford, I. (2014) Indicative map of actively managed large scale connectivity conservation corridors on Earth, Compiled from data aggregated by Rod Atkins, WCPA International Connectivity Conservation Network, Canberra, Australia.

Pulsford, I., Howling, G., Dunn, R. and Crane, R. (2013) 'Great Eastern Ranges Initiative: a continental-scale lifeline connecting people and nature', in J. Fitzsimons, I. Pulsford and G. Wescott (eds) Linking Australia's Landscapes: Lessons and opportunities from large-scale conservation networks, pp. 123-34, CSIRO Publishing, Melbourne.

Pulsford, I., Worboys, G. L., Howling, G. and Barrett, T. (2012) 'Australia’s Great Eastern Ranges corridor', in J. A. Hilty, C. C. Chester and M. S. Cross (eds) Climate and Conservation: Landscape and seascape science, planning, and action, pp. 202-16, Island Press, Washington, DC.
Ribot, J. (2008) Building Local Democracy through Natural Resource Interventions: An environmentalist's responsibility, World Resources Institute, Washington, DC.

Robbins, S. P., Bergman, R., Stagg, I. and Coulter, M. (2003) Foundations of Management, Pearson Education Australia, Sydney.

Robinson, W. D. (1999) 'Long-term changes in the avifauna of Barro Colorado Island, Panama, a tropical forest isolate', Conservation Biology 13: 85-97.

Rudnick, D. A., Ryan, S. J., Beier, P., Cushman, S. A., Dieffenbach, F., Epps, C. W., Sandwith, T., Shine, C., Hamilton, L. and Sheppard, D. (2001) Transboundary Protected Areas for Peace and CoOperation, IUCN, Gland.

Schliep, R. and Stoll-Kleemann, S. (2010) 'Assessing governance of biosphere reserves in Central Europe', Land Use Policy 27(3): 917-27.

Simberloff, D., Farr, J. A., Cox, J. and Mehlman, D. W. (1992) 'Movement corridors: conservation bargains or poor investments?', Conservation Biology 6: 493-504.

Soulé, M. E., Mackey, B. G., Recher, H. F., Williams, J. and Woinarski, J. C. (2006) 'The role of connectivity conservation in Australian conservation', in K. R. Crooks and M. A. Sanjayan (eds) Connectivity Conservation, pp. 649-75, Cambridge University Press, Cambridge.

Soulé, M. E., Mackey, B. G., Recher, H. F., Williams, J. E., Woinarski, J. C. Z., Driscoll, D., Dennison, W. C. and Jones, M. E. (2004) 'The role of connectivity in Australian conservation', Pacific Conservation Biology 10: 266-79.

Stenseth, N. and Lidicker, W. (eds) (1992) Animal Dispersal, Chapman \& Hall, London.

Tewksbury, J. J., Levey, D. J., Haddad, N. M., Sargent, S., Orrock, J. L., Weldon, A., Danielson, B. J., Brinkerhoff, J., Damschen, E. I. and Townsend, P. (2002) 'Corridors affect plants, animals and their interaction in fragmented landscapes', Proceedings of the National Academy of Science 99: 12 923-6. 
Tscharntke, T., Tylianakis, J. M., Rand, T. A., Didham, R. K., Fahrig, L., Batary, P., Bengtsson, J., Clough, Y., Crist, T. O., Dormann, C. F., Ewers, R. M., Frund, J., Holt R. D., Holzschuh, A., Klein, A. M., Kleijn, D., Kremen, C., Landis, D. A., Laurance, W., Lindenmayer, D. B., Scherber, C., Sodhi, N., Steffan-Dewenter, I., Thies, C., van der Putten, W. H. and Westphal, C. (2012) 'Landscape moderation of biodiversity patterns and processes-eight hypotheses', Biological Reviews 87: 661-85.

United Nations Educational, Scientific and Cultural Organisation (UNESCO) (2013) The Man and Biosphere Programme: Ecological sciences for sustainable development, UNESCO, Paris. <www. unesco.org/new/en/natural-sciences/environment/ ecological-sciences/man-and-biosphereprogramme/>

van der Linde, H., Oglethorpe, J., Sandwith, T., Snelson, D. and Tessema, Y., with Tiéga, A. and Price, T. (2001) Beyond Boundaries: Transboundary natural resource management in sub-Saharan Africa, Biodiversity Support Program, Washington, DC.

Vasilijević, M. (2012) 'Diagnostic tool for transboundary conservation planners: suggested questions to determine feasibility for transboundary conservation', in B. Erg, M. Vasilijević and M. McKinney (eds) Initiating Effective Transboundary Conservation: A practitioner's guideline based on the experience from the Dinaric Arc, pp. 42-58, IUCN Programme Office for South-Eastern Europe, Gland and Belgrade. <www.tbpa.net/page.php?ndx=22>

Vasilijević, M. and Pezold, T. (eds) (2011), Crossing Borders for Nature: European examples of transboundary conservation, IUCN Programme Office for South-Eastern Europe, Gland and Belgrade.

Walker, B. H. (1992) 'Biodiversity and ecological redundancy', Conservation Biology 6: 18-23.

Wiens, J. A., Schooley, R. L. and Weekes, R. D. (1997) 'Patchy landscapes and animal movements: do beetles percolate?', Oikos 78: 257-64.

Wilson, E. O. (1992) The Diversity of Life, Belknap Press, Cambridge, Mass.

Wilson, E. O. (2002) The Future of Life, Alfred E. Knopf, New York.
DDd Worboys, G. L., Francis, W. L and Lockwood, M. (eds) (2010) Connectivity Conservation Management: A global guide, Earthscan, London.

Worboys, G. L. and Lockwood, M. (2010) 'Connectivity conservation management framework and tasks', in G. L. Worboys, W. L. Francis and M. Lockwood (eds) Connectivity Conservation Management: A global guide, pp. 301-41, Earthscan, London.

Worboys, G. L. and Mackey, B. (2013) 'Connectivity conservation initiatives: a national and international perspective', in J. Fitzsimons, I. Pulsford and G. Wescott (eds) Linking Australia's Landscapes: Lessons and opportunities from large-scale conservation networks, pp. 7-22, CSIRO Publishing, Melbourne.

Worboys, G. L. and Pulsford, I. (2011) Connectivity conservation in Australian landscapes, Report prepared for the Australian Department of Sustainability, Environment, Water, Population and Communities on behalf of the State of the Environment 2011 Committee, DSEWPaC, Canberra.

Wyborn, C. (2013) Adaptive governance and connectivity conservation: examining the interplay between science, governance and scale, PhD thesis, The Australian National University, Canberra.

Wyborn, C. and Bixler, P. R. (2013) 'Collaboration and nested environmental governance: scale dependency, scale framing and cross-scale interactions in collaborative conservation', Journal of Environmental Management 123: 58-67.

Youngentob, K. N., Wood, J. T. and Lindenmayer, D. B. (2013) 'The response of arboreal marsupials to landscape context over time: a large-scale fragmentation study revisited', Journal of Biogeography 40(11): 2082-93. 


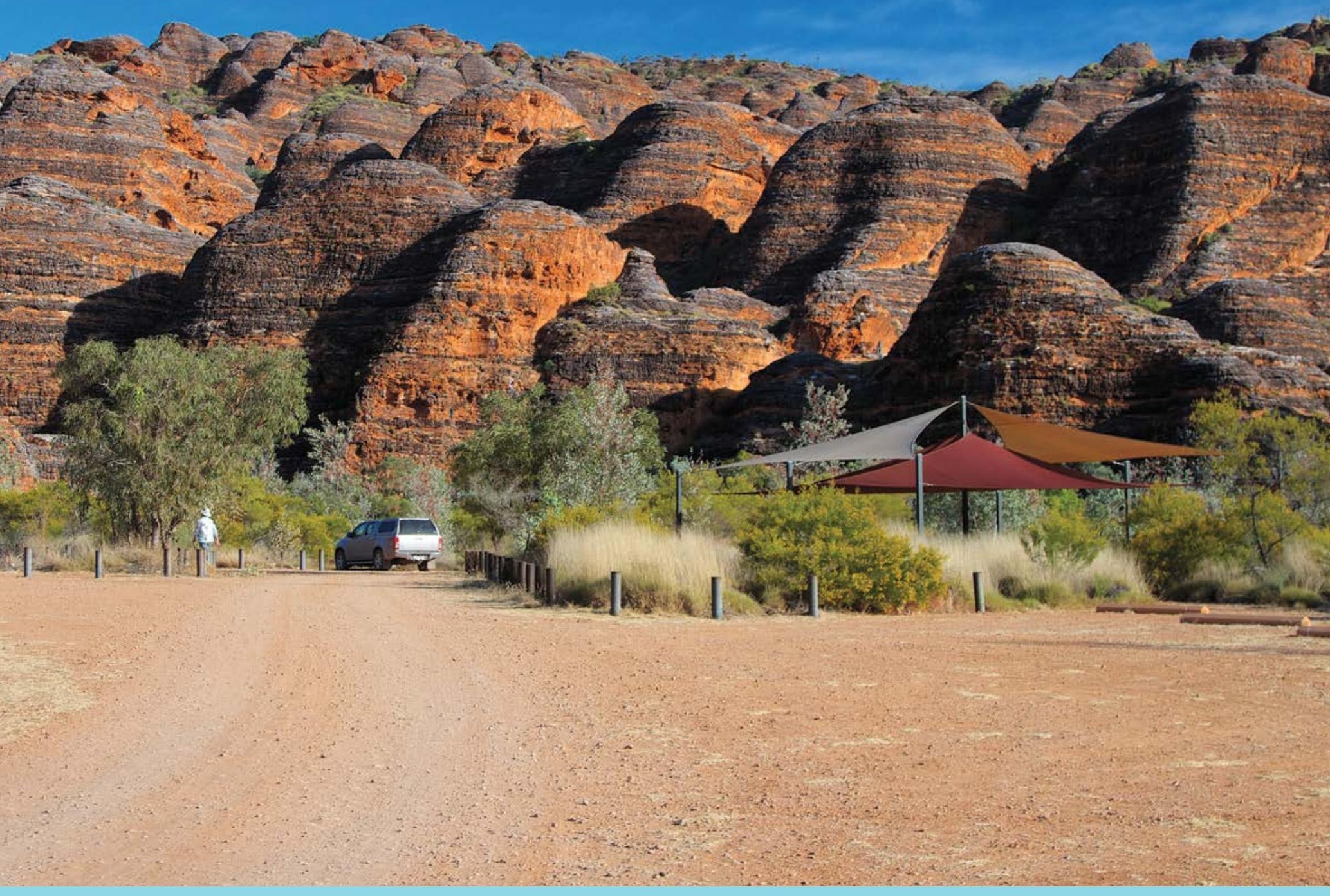

\section{CHAPTER 28}

\section{PROTECTED AREA MANAGEMENT EFFECTIVENESS}

\section{Principal authors:}

Marc Hockings,

Fiona Leverington

and Carly Cook

\section{CONTENTS}

- Introduction

- What is protected area management effectiveness evaluation?

- Purposes of protected area management effectiveness evaluation

- Protected area management effectiveness evaluation globally
- The IUCN protected area management effectiveness framework

- Designing and implementing assessments

- Making a difference: Towards more effective management

- Conclusion

- References

\section{IUCN 5 WCPA}




\section{PRINCIPAL AUTHORS}

MARC HOCKINGS is a Professor and Program Manager for Environmental Management in the School of Geography, Planning and Environmental Management at the University of Queensland, Brisbane and Senior Fellow, UNEP World Conservation Monitoring Centre.

FIONA LEVERINGTON is a Director of the consultancy Protected Area Solutions and an Adjunct Research Fellow at the School of Geography, Planning and Environmental Management at the University of Queensland, Brisbane.

CARLY COOK is Lecturer in Ecology in the School of Biological Sciences at Monash University, Melbourne.

\section{ACKNOWLEDGMENTS}

Recognition is extended to Diane Matar, Geoffroy Mauvais, Andrew Growcock, Tony Varcoe and Gail Cleaver-Christie for their Case Study contributions.

\section{CITATION}

Hockings, M., Leverington, F. and Cook, C. (2015) 'Protected area management effectiveness', in G. L. Worboys, M. Lockwood, A. Kothari, S. Feary and I. Pulsford (eds) Protected Area Governance and Management, pp. 889-928, ANU Press, Canberra.

\section{TITLE PAGE PHOTO}

Carefully located track head, parking and visitor information facilities developed in consultation with the traditional indigenous owners provide access to the spectacular Bungle Bungle Range in the World Heritage property, Purnululu National Park, in the Kimberley region, Western Australia Source: lan Pulsford 


\section{Introduction}

As far back as 1746, the British statesman Philip Stanhope gave his son the advice that 'whatever is worth doing at all, is worth doing well' (Widger 2012). It is advice we could well follow today in managing the growing network of protected areas around the world. Earlier in this book, the changing paradigm of protected areas and the spectacular growth in the number and coverage of protected areas have been documented. We have clearly decided that protected areas are 'worth doing' and we have abundant advice on how to manage them well, as is evident in the preceding chapters of this book. We have, however, limited knowledge of whether we are following this advice and keeping true to Stanhope's counsel to manage them well.

The growing interest in the effectiveness of management of protected areas can be traced through the emergence of the topic at the decadal World Parks congresses (Hockings et al. 2004) - first emerging in papers at the third congress (in Bali) in 1982, gaining momentum at the fourth congress (in Caracas) 10 years later and then being one of the priority topics discussed at the fifth congress in Durban in 2003 after a significant effort by the International Union for Conservation of Nature (IUCN) and others to advance work on this issue in the intervening period. Protected area management effectiveness is now a key element of a broader examination of progress towards the Convention on Biological Diversity (CBD) strategic plan and its constituent Aichi Targets-especially Target 11, which addresses the contribution that an effectively and equitably managed protected area system can make to the overall goals of the convention:

By 2020, at least 17 per cent of terrestrial and inland water, and 10 per cent of coastal and marine areas, especially areas of particular importance for biodiversity and ecosystem services, are conserved through effectively and equitably managed, ecologically representative and well-connected systems of protected areas and other effective area-based conservation measures, and integrated into the wider landscapes and seascapes.

(CBD 2011; emphasis added)

Woodley et al. (2012) have analysed this target in detail, drawing the linkages between management effectiveness and other key issues for protected area success. They argue for a 'holistic interpretation of Target 11 as a way for the global community to use protected areas to change the current unacceptable trends in global biodiversity loss' (Woodley et al. 2012:23).

After the fourth world parks congress in Caracas in 1992, a number of methodologies for assessing the management effectiveness of protected areas were developed, primarily in Central and South America (Courrau 1997; de Faria 1993; Izurieta 1997) and Australia (Hockings 1998). In 1996, the IUCN World Commission on Protected Areas (WCPA) commenced work on a framework and guidelines for assessing the management effectiveness of protected areas, which led to the first edition of the IUCN guidelines for Evaluating Effectiveness: A framework for assessing the management of protected areas (Hockings et al. 2000). This framework, revised in 2006 (Hockings et al. 2006), has formed the foundation for most of the protected area evaluation systems developed and applied around the world since that time. It is extensively referred to in this chapter as the IUCN WCPA framework.

The expansion of protected area management effectiveness evaluations is in keeping with the general rise in evaluation and performance assessments within governments and other public bodies across the world. In the environmental sector, donors, governments and other bodies are increasingly requiring management bodies to show evidence that their money is well spent (Saterson et al. 2004; Keene and Pullin 2011). The importance of evaluation in effective management and project cycles has been progressively recognised in many fields of endeavour, including health and international development as well as conservation, during the past 15 to 20 years. New methodologies and approaches have developed in a number of fields, with many common issues and some productive exchanges of ideas across the sectors (Foundations of Success et al. 2003). Protected area management involves biophysical, cultural, socioeconomic and managerial factors as well as numerous stakeholders, so monitoring and evaluation must draw on tools from a wide range of disciplines. Approaches such as participatory rural appraisal and project-cycle management have offered many useful ideas.

In this chapter, we will outline the main approaches to assessing the effectiveness of the management of protected areas, the purpose and process of evaluation and how the assessment methods and processes can be designed to produce relevant and reliable results. This guidance is aimed at practitioners who might be responsible for designing and implementing evaluation systems as well as senior managers who are responsible for policies and programs and who will be among the significant 
Table 28.1 Approaches to assessing the effectiveness of protected areas

\begin{tabular}{|c|c|c|}
\hline \multicolumn{2}{|c|}{ Approach } & Key questions that underpin the approach \\
\hline 1 & $\begin{array}{l}\text { Assessment of extent and location of protected } \\
\text { areas, including their coverage of biological and } \\
\text { landscape diversity }\end{array}$ & $\begin{array}{l}\text { How many protected areas are there in a country or region, } \\
\text { and what is their total area? } \\
\text { How effectively do the protected areas cover key ecoregions } \\
\text { or habitats? } \\
\text { How well do protected areas represent the diversity of } \\
\text { ecoregions and habitats? } \\
\text { How effectively do the protected areas represent other } \\
\text { features such as landscape elements, wetland types and } \\
\text { species? }\end{array}$ \\
\hline 2 & $\begin{array}{l}\text { Assessment of the effectiveness of protected areas } \\
\text { as a conservation mechanism at larger scales, and } \\
\text { the impact of protected areas on people }\end{array}$ & $\begin{array}{l}\text { Have protected areas reduced deforestation and other } \\
\text { habitat loss? } \\
\text { How have protected areas affected local communities- } \\
\text { have they increased or alleviated poverty? }\end{array}$ \\
\hline 3 & $\begin{array}{l}\text { Assessment of overall protected area management } \\
\text { effectiveness (PAME) }\end{array}$ & $\begin{array}{l}\text { How well designed is the protected area and the protected } \\
\text { area system? } \\
\text { Are adequate and appropriate planning, resources and } \\
\text { processes in place to enable management? } \\
\text { Are protected areas achieving their objectives and } \\
\text { conserving their values? }\end{array}$ \\
\hline $3 \mathrm{~A}$ & $\begin{array}{l}\text { Outcomes of protected areas in conserving their } \\
\text { biodiversity values (a subset of approach } 3 \text { but } \\
\text { focused just on outcomes) }\end{array}$ & $\begin{array}{l}\text { Are protected areas protecting species and habitats? } \\
\text { Are values such as endangered species being conserved } \\
\text { or restored? } \\
\text { What is the impact of protected areas on communities? }\end{array}$ \\
\hline
\end{tabular}

users of evaluation results. The chapter concludes with advice and examples of how management effectiveness assessments can be used to adapt and improve management. While many of the examples used in the chapter relate to management effectiveness evaluations undertaken by protected area management agencies or non-governmental organisations (NGOs) across a large number of sites, the principles and approaches are applicable to all protected areas and systems regardless of their size and governance type.

\section{What is protected area management effectiveness evaluation?}

Four complementary management effectiveness evaluation approaches can be taken when considering the impact of protected areas and protected area systems (Leverington et al. 2010a), as shown in Table 28.1.

\section{Approach one: Protected area extent and location}

The first approach assesses the extent and location of protected areas, especially in relation to the range of biodiversity values that protected areas aim to conserve. The well-known graph showing the steeply rising number and global extent of protected areas (Chapter 2, Figure 2.2) is the simplest measure of this aspect, but increasingly attention is turning to the location of protected areas in relation to the distribution of species and habitats. Approaches to identifying such sites include Important Bird Areas (IBAs) and the Alliance for Zero Extinction (AZE) sites (Butchart et al. 2012), and are more generally covered under current efforts to identify key biodiversity areas and use these as an important guide for the establishment of new protected areas (Eken et al. 2004; see also Chapter 3). Systematic conservation planning studies (Margules and Pressey 2000) also fall within this approach but focus on representation of ecoregions and habitats rather than species or species collections (see Chapter 13). 


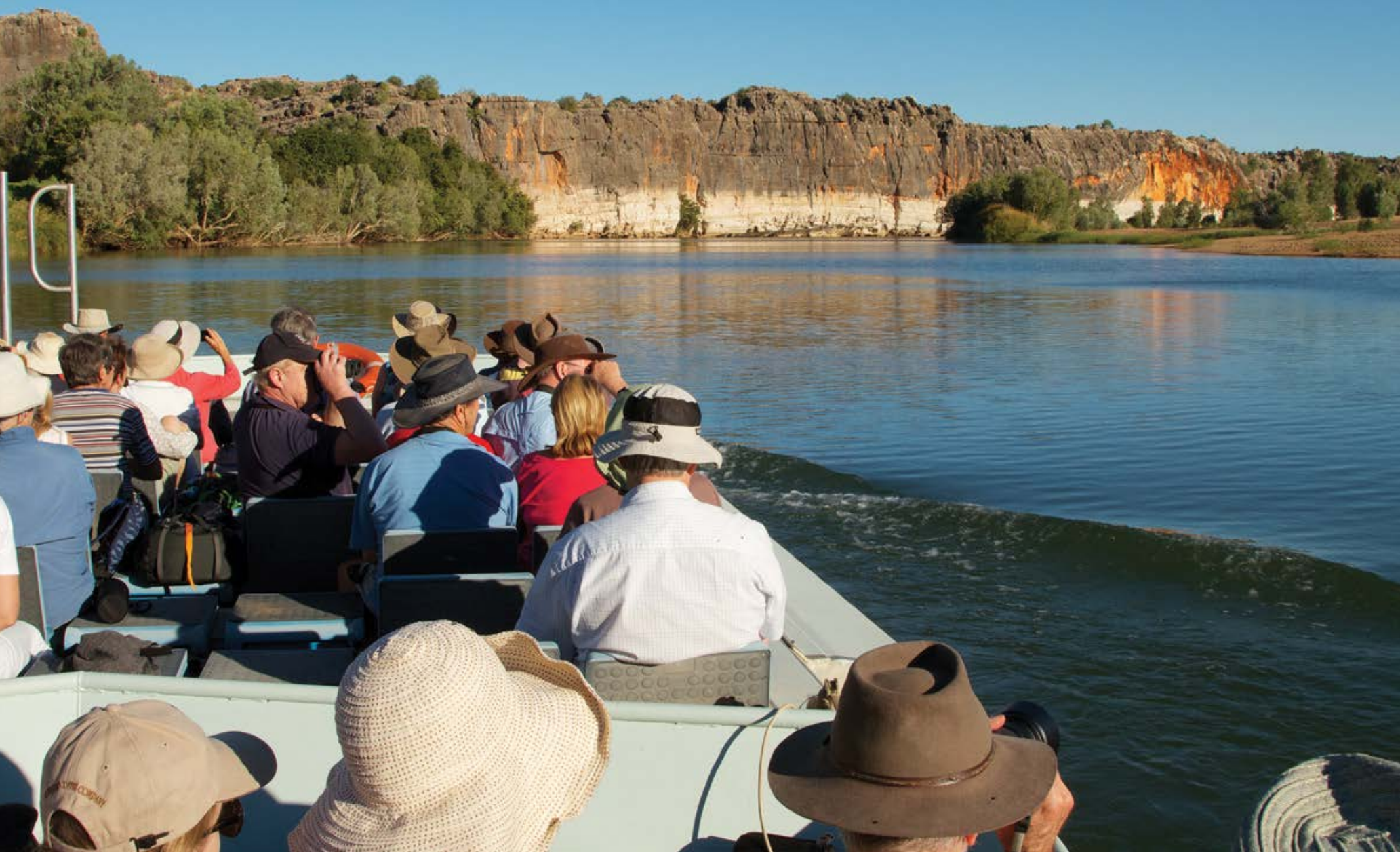

Visitors viewing the limestone cliffs in Geikie Gorge National Park, which are remnants of an ancient uplifted Devonian reef that straddles the remote Kimberley region, Western Australia

Source: lan Pulsford

\section{Approach two: Large-scale assessments}

A second approach assesses the extent to which protected areas can be shown to reduce large-scale impacts such as forest clearing or habitat degradation, or at least the extent to which the location of protected areas can be correlated with lower levels of impact. Most studies have been in tropical forest environments (Bruner et al. 2001; Scharlemann et al. 2010; Barber et al. 2012; Green et al. 2013), but studies have also examined marine systems (Selig and Bruno 2010). While results from these studies are mixed, most have demonstrated the effectiveness of protected areas in reducing rates of habitat change (Geldmann et al. 2013). The economic as well as environmental impacts of protected areas at a national scale can be assessed using economic and spatial tools (Sims 2010, 2014).

\section{Approach three: Protected area management effectiveness}

Assessments using the third approach are generally referred to as 'protected area management effectiveness' (PAME) evaluations. This approach forms the main focus of this chapter. Since the late 1990s, significant efforts have been made to develop and apply PAME evaluations of individual protected areas, groups of sites and whole systems of protected areas (Leverington et al. 2010a). Management effectiveness evaluation is defined by the IUCN as 'the assessment of how well the protected area is being managed' (Hockings et al. 2006:1).

\section{Approach three (A): Protected area outcomes}

A developing approach to management effectiveness evaluation that constitutes a subset of PAME examines the outcomes of protected area management based on detailed monitoring and reporting on the condition and trend of protected area values, especially biodiversity values (Geldmann et al. 2013). Methodologies for directing, undertaking and reporting on such detailed studies in a systematic way that aids adaptive management have been developed by groups such as The Nature Conservancy (Parrish et al. 2003) and park management agencies in South Africa, Australia and Canada (Growcock et al. 2009; Timko and Innes 2009). Ideally, such detailed information should underlie judgments about outcomes that may be made in broader PAME assessments and linked to other elements of the evaluation cycle (Box 28.1). 


\section{Box 28.1 Management effectiveness definitions}

The evaluation of management effectiveness is generally achieved by the assessment of a series of criteria (represented by carefully selected indicators) against agreed objectives or standards. The following definitions refer specifically to the context of protected area management effectiveness.

- Management effectiveness evaluation: This is defined as the assessment of how well the protected area is being managed-primarily the extent to which it is protecting values and achieving goals and objectives. The term management effectiveness reflects three main themes:

1. design issues relating to both individual sites and protected area systems

2. adequacy and appropriateness of management systems and processes

3. delivery of protected area objectives including conservation of values.

- Assessment: The measurement or estimation of an aspect of management.

- Evaluation: The judgment of the status/condition or performance of some aspect of management against predetermined criteria (usually a set of standards or objectives) -in this case, including the objectives for which the protected areas were established.

- IUCN WCPA Management Effectiveness Evaluation Framework: A system for designing protected area management effectiveness evaluations based on six elements-context, planning, inputs, processes, outputs and outcomes. It is not a methodology in itself, but is a guide to developing comprehensive assessment systems.

- Element: A major component of the evaluation framework defined by the aspect of management that is being assessed. The elements relate to the steps in a strategic planning and management cycle. Performance within each element is assessed by reference to a number of defined criteria.

- System: A specific process for undertaking monitoring and evaluation, generally accompanied by steps or guidance (equivalent to an evaluation approach as defined by Stem et al. 2005).

- Criterion: A major category of conditions or processes-quantitative or qualitative-which helps define the thing being measured. A criterion is characterised by a set of related indicators.

- Indicators: Quantitative or qualitative variables that provide useful information about a criterion and can be used to help compile a picture of the status and trends in protected area effectiveness.

- Tool: An instrument that aids in the actual undertaking of evaluation-for example, a questionnaire or scorecard (Stem et al. 2005).

- Monitoring: Collecting information on indicators repeatedly over time to discover trends in the status of the protected area and the activities and processes of management.

Source: Hockings et al. (2006:xiii)
The limited monitoring of species populations in protected areas, however, means that the availability of such detailed data from protected areas tends to be the exception rather than the rule. Where detailed monitoring information is available, PAME studies (approach three) can play a critical role in interpreting the information and making it relevant to managers so it is actually used in decision-making. For example, Growcock et al. (2009) indicate that the state of the parks assessment system in New South Wales (Australia) is not a substitute for species, site or issue-specific monitoring and research but that it has made the results of such studies more available for decision-making by considering the results within a management effectiveness evaluation framework.

\section{Purposes of protected area management effectiveness evaluation}

Increasingly, management effectiveness studies are an accepted part of the management cycle in large organisations, but what is their purpose? There are a number of reasons people and organisations wish to assess management effectiveness. Broadly speaking, such evaluations can:

- enable and support an adaptive approach to management by providing essential information to managers at all levels about the extent to which management interventions are being implemented and are being successful

- assist in effective resource allocation by indicating gaps and areas of highest need and likelihood of success-in some cases, facilitating 'triage' where resources are scarce 
- promote accountability and transparency through providing senior management, funding bodies, stakeholder groups and the public with information about how resources are being used and decisions made

- involve the community, build a constituency to support protected areas and promote protected area values at a particular site or more generally across a system of protected areas.

As well as these substantive benefits, the process of assessing management effectiveness can itself provide a number of procedural benefits such as improved communication and cooperation between managers and other stakeholders. Managers have an opportunity to reflect on the challenges they face in managing their sites and systems from a different perspective, away from the day-to-day concerns of management. Many managers have commented that the major benefits to them have come during the assessment process rather than from any formal report produced from the PAME process. Growcock et al. (2009) indicate that the management effectiveness evaluation process in New South Wales, Australia, seeks to achieve all four purposes and has facilitated adaptive management, supported planning and decision-making and provided clarity to managers in determining priorities. In a survey of 62 management effectiveness studies in 19 countries, 97 per cent of respondents said the process had been useful to staff (Paleczny 2010).

In addition, evaluation has benefits in exposing protected area managers and other stakeholders to 'evaluation culture' - a way of thinking that may otherwise be quite foreign and new to many practitioners, but which helps them to better interact with funding bodies and toplevel management. The benefits of this 'learning how to learn' process may last much longer than the findings of the initial evaluation (Patton 1998). Birnbaum and Mickwitz (2009) point out that evaluation has been slow to develop in the environmental arena, in part due to the complexity of environmental problems and the difficulties this entails for evaluation.

Examples of the values of evaluation include: clarity, specificity and focusing; being systematic and making assumptions explicit; operationalising program concepts, ideas and goals; distinguishing inputs and processes from outcomes; valuing empirical evidence; and separating statements of fact from interpretations and judgments. These values constitute ways of thinking that are not natural to people and that are quite alien to many. When we take people through a process of evaluation - at least in any kind of stakeholder involvement or participatory process - they are in fact learning things about evaluation culture and often learning how to think in these ways (Patton 1998:226).

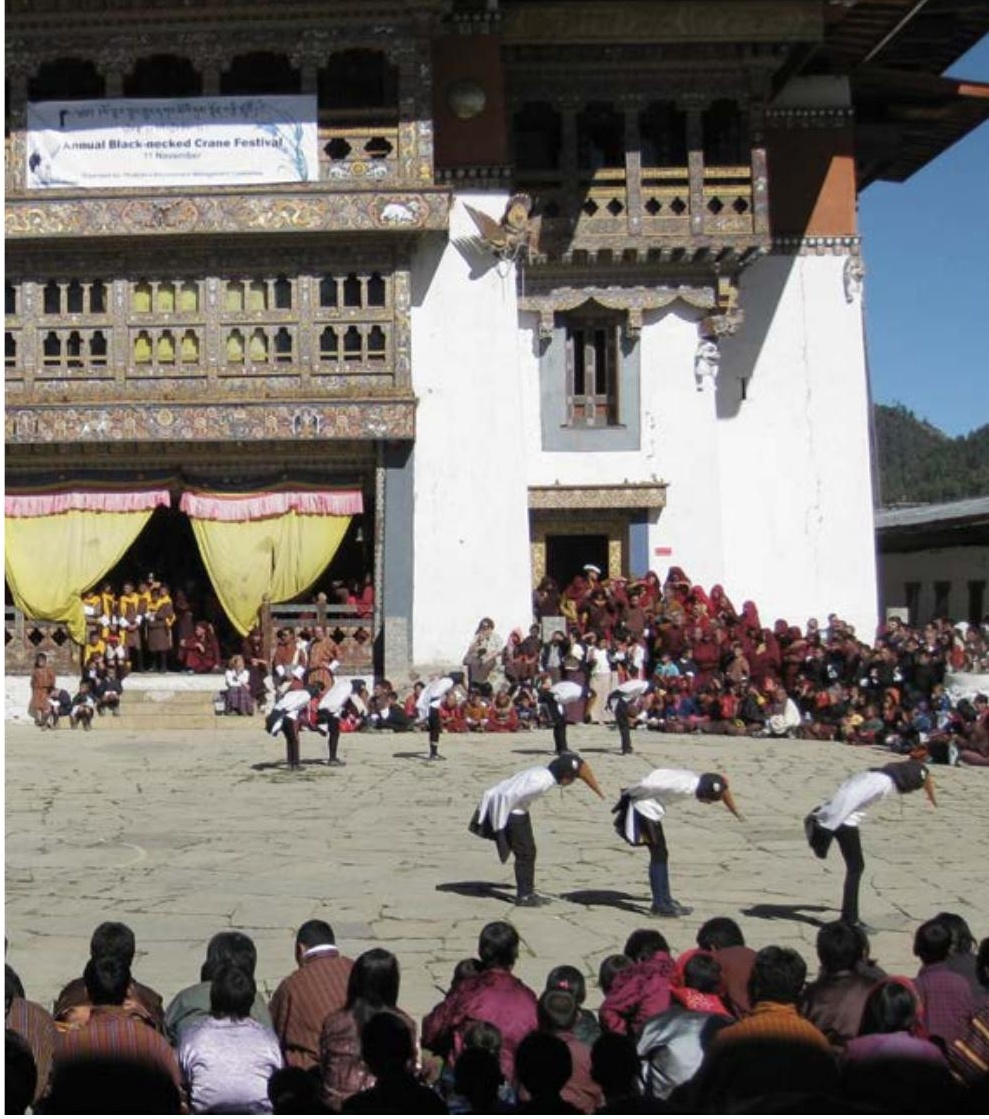

Community involvement: schoolchildren performing the black-necked crane (Grus nigricollis) dance for the community at the fifteenth annual black-necked crane festival in the Phobjikha Valley adjacent to Black Mountain National Park, Bhutan, to raise community awareness of and support for the conservation of this highly endangered migratory species Source: lan Pulsford

\section{Protected area management effectiveness evaluation globally}

PAME has grown rapidly from a new and untried concept in the 1990s to become an integral part of global and national conservation agendas. The Global Environment Facility (GEF) has adopted, as a standard requirement, the use of the Management Effectiveness Tracking Tool (METT), which had been developed by the World Bank and the World Wide Fund for Nature (WWF) as a means to track progress against their joint forest initiative target of improving the management of 70 million hectares of forest protected areas. The GEF has required the use of the METT to assess management effectiveness at the initial, mid-term and final evaluation of all funded projects in protected areas.

Following on from the recommendations of the Fifth IUCN World Parks Congress, the CBD developed its Programme of Work on Protected Areas (PoWPA) in 2004 (CBD 2004) with a goal and associated targets to promote the development and adoption of PAME systems (Box 28.2). This has been perhaps the most significant development at an international policy 


\section{Box 28.2 CBD Programme of Work on Protected Areas}

The PoWPA explicitly addressed management effectiveness as part of Goal 4 dealing with standards, assessment and monitoring. Although the 2010 target date for the PoWPA has passed, the targets remain relevant to countries in the current period of the $\mathrm{CBD}$ Aichi Targets leading up to 2020. The PoWPA Target 4.2.2 was updated at the meeting of the CBD Conference of the Parties in 2010 as follows.

\section{Goal 4.2 To evaluate and improve the effectiveness} of protected areas management

Target: By 2010, frameworks for monitoring, evaluating and reporting protected areas management effectiveness at sites, national and regional systems, and transboundary protected area levels adopted and implemented by Parties.

\section{Suggested activities of the Parties}

4.2.1 Develop and adopt, by 2006, appropriate methods, standards, criteria and indicators for evaluating the effectiveness of protected area management and governance, and set up a related database, taking into account the IUCN WCPA framework for evaluating management effectiveness, and other relevant methodologies, which should be adapted to local conditions.

4.2.2 Implement management effectiveness evaluations of at least 30 percent of each Party's protected areas by 2010 and of national protected area systems and, as appropriate, ecological networks (updated to $60 \%$ of the total area of protected areas by 2015).

4.2.3 Include information resulting from evaluation of protected areas management effectiveness in national reports under the Convention on Biological Diversity.

4.2.4 Implement key recommendations arising from site- and system-level management effectiveness evaluations, as an integral part of adaptive management strategies.

Suggested supporting activities of the Executive Secretary

4.2.5 Compile and disseminate information on management effectiveness through the clearinghouse mechanism and develop a database of experts in evaluation of protected area management effectiveness and consider the possibility of organizing an international workshop on appropriate methods, criteria and indicators for evaluating the effectiveness of protected area management.

4.2.6 In cooperation with IUCN WCPA and other relevant organizations, compile and disseminate information on best practices in protected area design, establishment and management. (CBD 2010b)

Source: CBD (2004)

level promoting the need for effective management of protected areas and the monitoring and reporting systems needed to drive this improvement. While the target of assessing management effectiveness of 30 per cent of protected areas had not been reached by 2010, progress had been so encouraging that the Conference of Parties to the CBD decided to call on parties to 'expand and institutionalize management effectiveness assessments to work towards assessing 60 per cent of the total area of protected areas by 2015 using various national and regional tools and report the results into the global database on management effectiveness' (CBD 2010a; emphasis added).

Information about management effectiveness assessments across the world has been compiled in a global database linked to the UN Environment Programme World Conservation Monitoring Centre (UNEP-WCMC) World Database on Protected Areas (WDPA). The management effectiveness database records the date, location and methodology used, and where possible the results of each assessment, and includes written reports where available (Leverington et al. 2010a, 2010b;

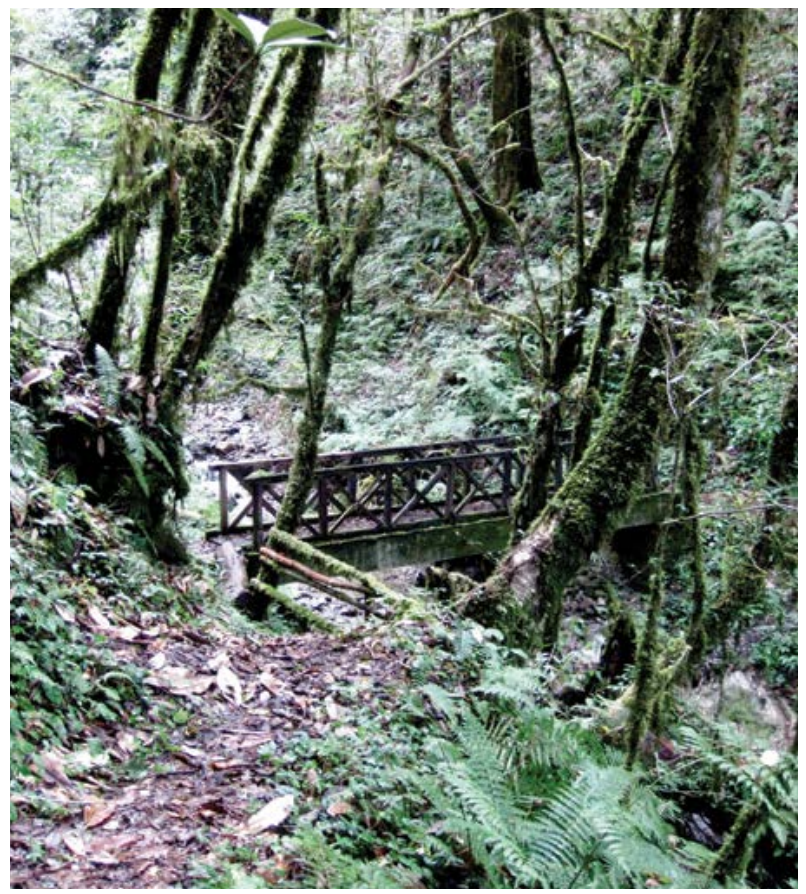

Serchu Nature Trail in the Royal Botanic Park, Nepal

Source: Ian Pulsford 


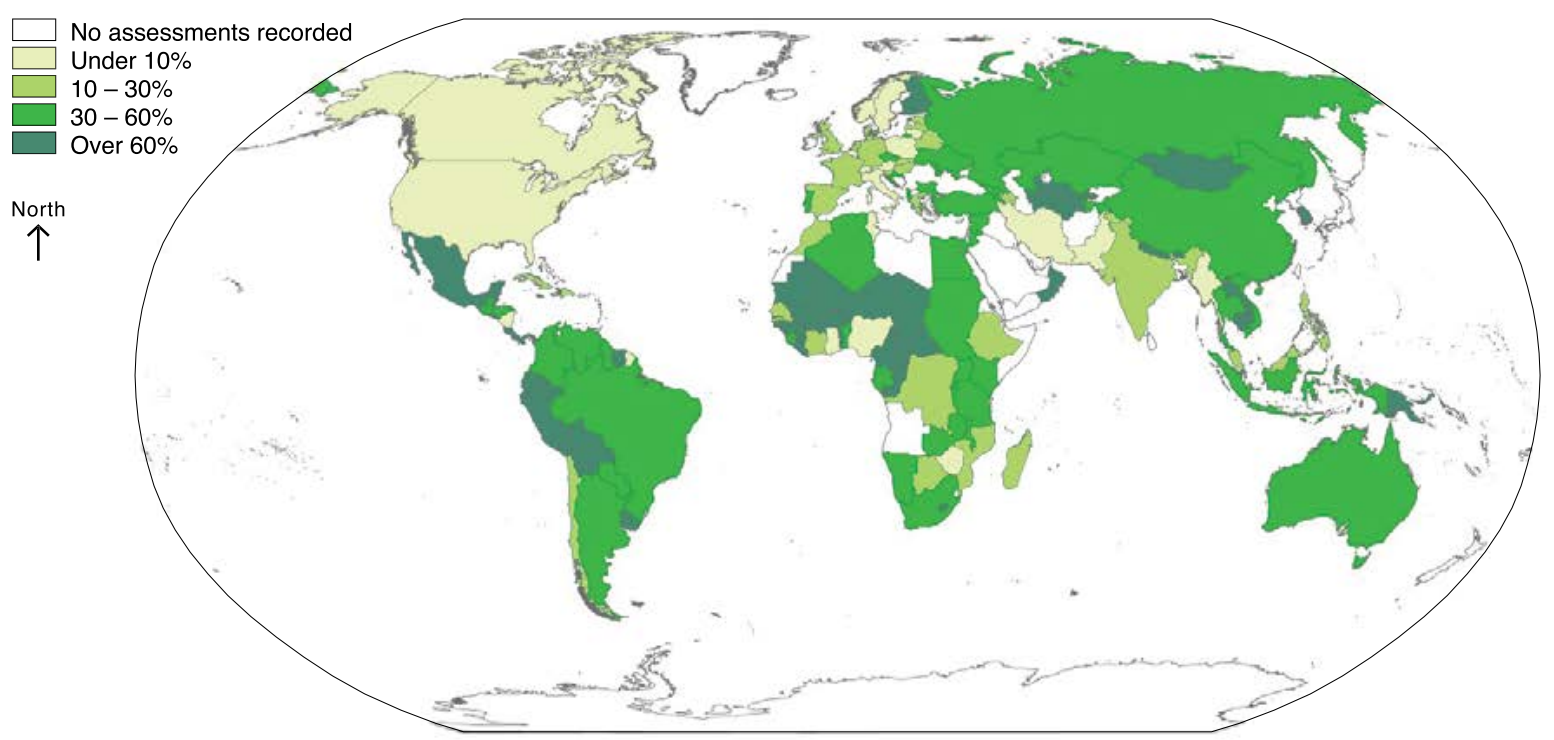

Figure 28.1 National progress towards the CBD 30 per cent and 60 per cent targets for PAME assessments

Note: Progress is measured by the percentage of the total area of the nationally designated protected area network that has been assessed.

Source: Coad et al. (2013)

Nolte et al. 2010). This compilation has been made possible through a collaborative study by the University of Queensland, the IUCN, Oxford University, the UNEP-WCMC, the Biodiversity Indicator Partnership and major NGOs such as WWF and The Nature Conservancy, and has been supported by many partners in the desire to compile global information on the effectiveness of management of protected areas.

Coad et al. (2013) used this information to assess progress towards the PoWPA PAME target (Figure 28.1). By the end of 2012, at least one PAME assessment had been recorded for 29 per cent of the area of nationally designated protected areas, with greatest progress in Africa and Latin America (Coad et al. 2013). Of the 194 parties to the convention, 90 countries had met the 2010 target of 30 per cent of protected areas assessed, with 45 countries already having achieved the 60 per cent target set for 2015 (Coad et al. 2013).

There was a bias in where assessments had been conducted, with larger protected areas and IUCN Category II sites more likely to have been assessed. More assessments had been recorded in countries with low Human Development Index (HDI) scores (Coad et al. 2013), although these countries also had lower overall scores (Leverington et al. 2010c). This association between the extent of PAME and HDI is likely to be a result of both the focus of GEF projects in low HDI countries (and consequent METT assessments; see
Box 28.3) and the concentration of NGO-sponsored assessments in these countries using a variety of PAME assessment methods.

Management effectiveness of protected areas has also been adopted by the CBD as one of the protected area indicators used to assess progress towards meeting biodiversity conservation targets, and information on both coverage and results of assessments is being collected to track this indicator (Leverington et al. 2010a; Coad et al. 2013). At a national level, many countries have adopted PAME as part of their national policy for protected areas - such as in Australia, where the Natural Resource Management Ministerial Council included PAME in the policy for the national protected area system (NRMMC 2009)—or have implemented comprehensive evaluation systems across their protected area networks (for example, Colombia, Republic of Korea, South Africa). Most of these assessments have been undertaken using evaluation methodologies developed from the evaluation framework developed by the IUCN WCPA.

The needs, aims and circumstances of protected area evaluations are diverse. As discussed above, management effectiveness studies can serve a number of purposes, and the demand for information comes from a range of sources. Managers, local communities and others directly involved in management of a protected area site or system will be most interested in information that can be used to support planning and adaptive management (Case Study 28.1). Senior administrators, donors and 


\section{Box 28.3 Two widely used management effectiveness evaluation methodologies: RAPPAM and METT}

The Rapid Assessment and Prioritisation of Protected Area Management (RAPPAM) methodology (Ervin 2003) has been implemented in more than 50 countries and more than 1800 protected areas in Europe, Asia, Africa, Latin America and the Caribbean. The methodology is questionnaire-based and is implemented through one or more workshops bringing together protected area managers with other stakeholders and experts to compile and share knowledge. It is designed for broadlevel comparisons among many protected areas, which together make a protected area network or system. It can:

- identify management strengths, constraints and weaknesses

- analyse the scope, severity, prevalence and distribution of a variety of threats and pressures

- identify areas of high ecological and social importance and vulnerability

- indicate the urgency and conservation priority for individual protected areas

- help to develop and prioritise appropriate policy interventions and follow-up steps to improve protected area management effectiveness.

It can also answer a number of important questions.

- What are the main threats affecting the protected area system, and how serious are they?

- How do protected areas compare with one another in terms of infrastructure and management capacity? And how do they compare in effectively producing outputs and conservation outcomes as a result of their management?

- What is the urgency for taking actions in each protected area?
- What are the important management gaps in the protected area system?

- How well do national and local policies support the effective management of protected areas? Are there gaps in legislation and what are the governance improvements that are needed?

- What are the most strategic interventions to improve the entire system?

The Management Effectiveness Tracking Tool (METT) (Stolton et al. 2007) has been implemented in more than 100 countries and more than 2000 protected areas, and is required at the beginning, midpoint and end of all protected area projects resourced through the World Bank and the Global Environment Fund.

The methodology is a rapid assessment based on a scorecard questionnaire. The scorecard includes all six elements of management identified in the IUCN WCPA framework (context, planning, inputs, process, outputs and outcomes), but has an emphasis on context, planning, inputs and processes. It is basic and simple to use, and provides a mechanism for monitoring progress towards more effective management over time. It is used to enable park managers and donors to identify needs, constraints and priority actions to improve the effectiveness of protected area management.

It is designed primarily to track progress over time (rather than to compare sites) and can reveal trends, strengths and weaknesses in individual protected areas or in groups. It is rapid to complete, with only 30 questions; however, if it is applied in a workshop situation, it leads to a good deal of discussion and reflection. If it is fully completed, with comments and 'next steps', it can be valuable in setting directions and in evaluating progress towards improving protected area management. policymakers are likely to be seeking information that can be used to improve resource allocation as well as being interested in accountability and efficiency. While the information relating to accountability is primarily to inform external audiences, managers will also be interested in this aspect of evaluation. Some stakeholders may hope for assessments to reveal shortcomings in funding or policy, while scientists are interested in whether protected areas can be shown to effectively protect particular values.

This diversity means that a single system for evaluating management effectiveness will not be able to address all needs and circumstances. For this reason, the IUCN WCPA proposed a framework for assessing management effectiveness. The framework has been used to develop specific methodologies for assessment to match particular purposes, capacities and other needs while still retaining a common underlying logic and approach to evaluation, similar criteria and, in some cases, common assessment methods and tools (Case Study 28.2). Use of a common framework can also lend credibility to and promote greater acceptance of the assessment system because people can see that the evaluation approach and assessment criteria accord with an international standard. 
Amid a frantic political and socioeconomic context, determined groups of people are resilient in their efforts to conserve the natural and cultural heritage of the mountains of Lebanon. This small eastern Mediterranean country (10 452 square kilometres) is known for its iconic cedar tree (Cedrus libani)-featured on the national flag-as well as for its rich ecosystem and biodiversity values. Lebanon is also a preferred resting spot on an avian seasonal flyway. Internationally designated sites include the UN Educational, Scientific and Cultural Organisation (UNESCO) Biosphere Reserves of Shouf and Jabal Moussa. These sites, cogoverned by national authorities and NGOs, demonstrate interesting cases of PAME initiatives at different stages of planning and implementation (Abu-Izzedin 2013).

\section{Management effectiveness evaluation: Integral to management planning-Jabal Moussa Biosphere Reserve (JMBR)}

Jabal Moussa (meaning 'Mountain of Moses' in Arabic) is a mountainous biosphere reserve situated 40 kilometres from the capital, Beirut. The reserve extends over 65 square kilometres, and its core area constitutes a nationally protected forest and natural site. Jabal Moussa's conservation value is of national and international importance, as it hosts more than 720 plant species, of which 26 are nationally endemic, and more than 19 mammals including the grey wolf (Canis lupus), striped hyena (Hyaena hyaena) and rock hyrax (Procavia capensis). More than 137 bird species have been observed in the reserve, of which some are globally threatened-hence its designation as an Important Bird Area.

Although relatively new in the region, JMBR was able to accomplish many of its objectives in a short period. These include: setting up a qualified team, mostly recruited from the local community; defining its vision and long-term goals; and building good relationships with national and international partners. This could partially be attributed to proactively tapping knowledge from different international and local sources, and learning from more established biosphere reserves.

One essential project responding to the requirements of UNESCO's Man and the Biosphere (MAB) program is the 10-year management plan. The plan was developed using an innovative approach that blends recognised planning guidelines and concepts from both protected areas and biosphere reserve systems (Jaradi and Matar 2012).
Its integrated strategies build on a comprehensive inventory of biodiversity and cultural values, and are centred on the functional zonation scheme of biosphere reserves, while emphasising the importance of establishing strong partnerships with rural communities.

On the basis of the systematic conservation planning guidelines and the CBD requirements, the management plan included monitoring and evaluation as essential parts of its detailed action plan. For more concrete implementation, this objective was further detailed into actions with corresponding indicators (biological and management) that allow for follow-up. For this and other objectives, resources and priorities were allocated. In this perspective, the case of JMBR demonstrates that effective PAME starts at the planning stage, though success ultimately lies in implementation and follow-up. Recent field observations by local scientists, staff and visitors have shown that flowering plant populations such as the Lebanon cyclamen (Cyclamen libanoticum; endemic to JMBR) and the peony Paeonia kesrouanensis (endemic to the region) are increasing in number. Moreover, encounters with mammals such as the rock hyrax have become more frequent, indicating improvements in habitat condition.

\section{Management effectiveness evaluation for adaptive management: Shouf Biosphere Reserve}

The Shouf Biosphere Reserve (SBR) consists of a core zone (161 square kilometres), a buffer zone (54 square kilometres) and a development zone (233 square kilometres). The core area was declared a nature reserve in 1996. The reserve hosts three magnificent cedar forests with the largest stands of Lebanese cedars (Cedrus libani), representing 25 per cent of the remaining cedars in the country. The biosphere reserve is home to 32 species of wild mammals, of which nine are of international significance, in addition to 270 bird species and 27 species of reptiles and amphibians.

The SBR is among the best-managed biosphere reserves in the region. It is particularly renowned for its strong partnerships with local communities in ecotourism and sustainable production of rural produce that focuses on the empowerment of women. In 2011, the reserve was selected, from 106 applicants, by the UNESCO MAB International Advisory Committee as one of the few winners of the 'Michel Batisse Award', which recognises management efforts that meet international standards.

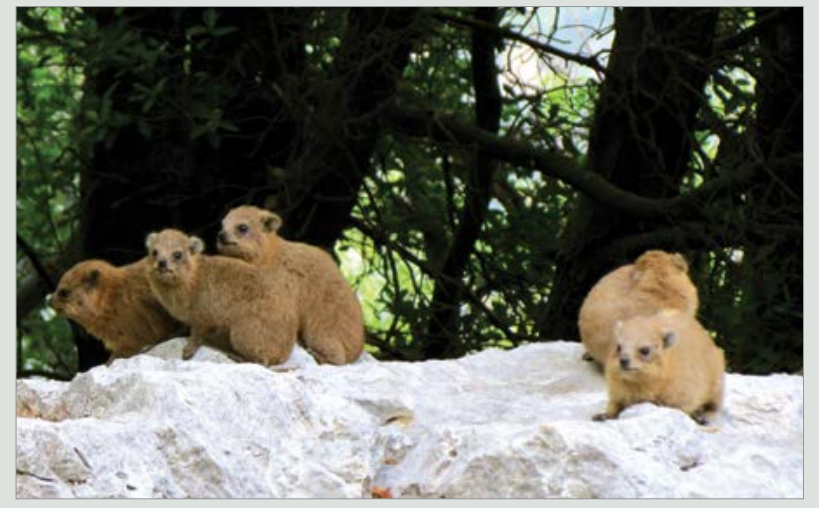

Family of rock hyraxes (Procavia capensis) in Jabal Moussa Biosphere Reserve, Lebanon

Source: Association for the Protection of Jabal Moussa

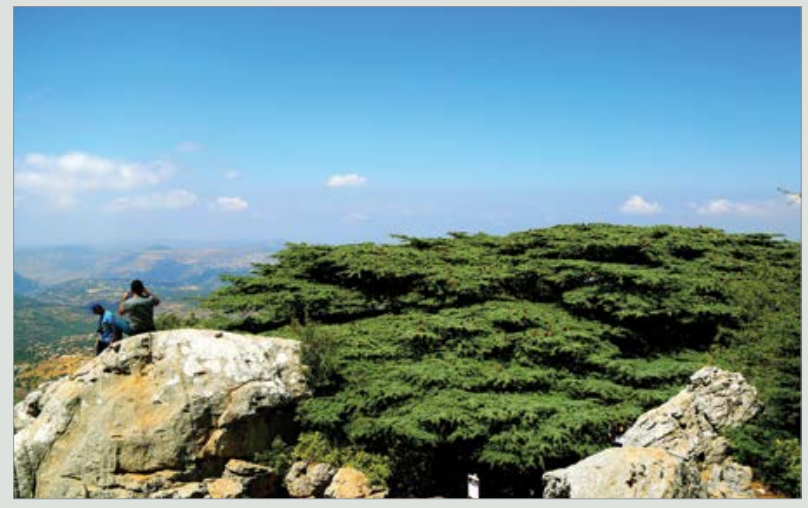

Lebanese cedar (Cedrus libani) in Shouf Biosphere Reserve, Lebanon

Source: Nizar Hani 
In 2009, an evaluation of threats to conservation values was conducted for the first time in SBR using the modified version of the Threat Reduction Assessment (mTRA) tool in a participatory workshop with staff (Matar and Anthony 2010). The TRA is a method created by Salafsky and Margoluis (1999) and modified by Anthony (2008) to account for negative trends in threats. It is used to quantitatively assess the trends in threats to biodiversity and protected areas over a defined period, as an indirect measure of reaching conservation targets.

The MTRA tool was rated as very useful by the team for examining trends in local threats such as overgrazing by goats, human-induced fire and recreational hunting. The mTRA index showed that the management team was able to successfully decrease the overall threats by 51 per cent over a three-year period to 2009. The assessment results were integrated into the latest SBR management plan, which was updated to include appropriate threat-abatement actions (AbuIzzedin 2013). The case demonstrates a good use of PAME tools such as the MTRA, as part of an adaptive management approach.

Other PAME initiatives have taken place in Lebanonmost notably, the successful evaluation of two marine protected areas using the METT as part of a joint IUCN-Ministry of Environment project that aims at developing and strengthening the national marine protected area network. Evaluation results led to useful recommendations for improving marine protected area management in the country (Allam Harash and El Shaer 2011).

The PAME initiatives in Lebanon reflect a recently increased awareness of its international importance; however, they are so far done as 'one-off' evaluations within specific projects and lack follow-up on the implementation of resulting recommendations. The key factors that will determine future success are: 1) building internal capacity for staff to run systematic evaluations rather than relying on external resources; 2) finding reliable financing mechanisms to take adaptive action; 3) mainstreaming PAME into national protected area strategies and follow-up on implementation. If these challenges are overcome, compliance with the $\mathrm{CBD}$ requirement to implement and report on PAME results will also be improved.

In the framework of conflict, economic difficulties and limited resources, management accomplishments recorded to date demonstrate a great level of perseverance and passion for nature. Protected areas in Lebanon, as in many other countries experiencing conflict, hold a message of hope for reconciliation and peace.

- Diane Matar, Environmental Sciences and Policy, Central European University, Budapest

\section{The IUCN protected area management effectiveness framework}

The IUCN Management Effectiveness Evaluation Framework is based on a simple management cycle (Figure 28.2) that:

- begins with understanding the context of the protected area, including its values, the threats it faces and opportunities available, its stakeholders, and the management and political environment

- progresses through planning: establishing vision, goals, objectives and strategies to conserve values and reduce threats

- allocates inputs (resources) of staff, money and equipment to work towards the objectives

- implements management actions according to accepted processes

- eventually produces outputs (goods and services, which should usually be outlined in management plans and work plans)

- results in impacts or outcomes, hopefully achieving defined goals and objectives.

The assessment of outcomes-including biodiversity, social, cultural and economic outcomes of protected area management-is a critical component of PAME. Understanding outcomes alone, however, is not sufficient. If PAME is to achieve any of the four purposes of evaluation outlined above, we need to also understand the other five elements in the evaluation cycle and the relationships between them. This is especially critical for using evaluation results to support adaptive management where an understanding of the factors leading to or limiting success is important.

More detail about elements of the cycle and how it can be applied can be found in the IUCN WCPA guidelines for management effectiveness evaluation (Hockings et al. 2006). According to evaluation terminology, PAME might be regarded as an evaluation system, as it has all four of the criteria required, as outlined by Leeuw and Furubo (2008):

1. a distinctive perspective and discipline

2. evaluation activities carried out by evaluators within organisational structures and institutions and not only (or largely) by individual evaluators without connection to management agencies

3. permanence or longer-term use

4. a focus on the intended use of results of evaluations. 


\section{Case Study 28.2 Management effectiveness assessment in West and Central Africa, 2008-2011}

Management effectiveness of protected areas is becoming an increasing concern to the world of conservation. The IUCN Program on African Protected Areas and Conservation (IUCN PAPACO) undertook a major project with the support of the French Global Environment Facility and the French Development Agency. This project aimed at improving management of protected areas in West and Central Africa and their capacity to fulfil their missions and, consequently, their results. It covered sub-Saharan Africa, from Mauritania (in the west) to Burundi (in the east), a region where most protected areas do not yet achieve their goals of conservation and/or development.

System or site-level assessments were based on the global methodology developed by the IUCN WCPA. The project adapted this framework to the regional context, then trained a team of African evaluators and carried out multiple pilot evaluations. Fourteen country systems have been evaluated, as well as four networks of sites (marine protected areas, Ramsar sites, forest protected areas of Central Africa and World Heritage properties) and individual sites, finally including about 170 sites using methodologies such as RAPPAM, METT or Enhancing our
Heritage (EoH). These evaluations have allowed the IUCN PAPACO to develop a brief synthesis of all assessments and bring technical support to selected sites with targeted training courses to respond to the main issues identified (with the support of the Senghor University of Alexandria, Egypt). The project gave particular attention to the use of assessment results in developing new projects, capacity building and related initiatives to improve site management and conservation.

A scientific and technical committee, comprising IUCN WCPA members and other relevant experts, was created at the beginning of the project to ensure coordination of the assessments. The project helped to identify management strengths and weaknesses and examples of best-practice management on the ground. The results were used to conduct studies of aspects of protected area management and to start work on more formal recognition of good management practices as a way of improving management.

- Geoffroy Mauvais, IUCN PAPACO, Nairobi

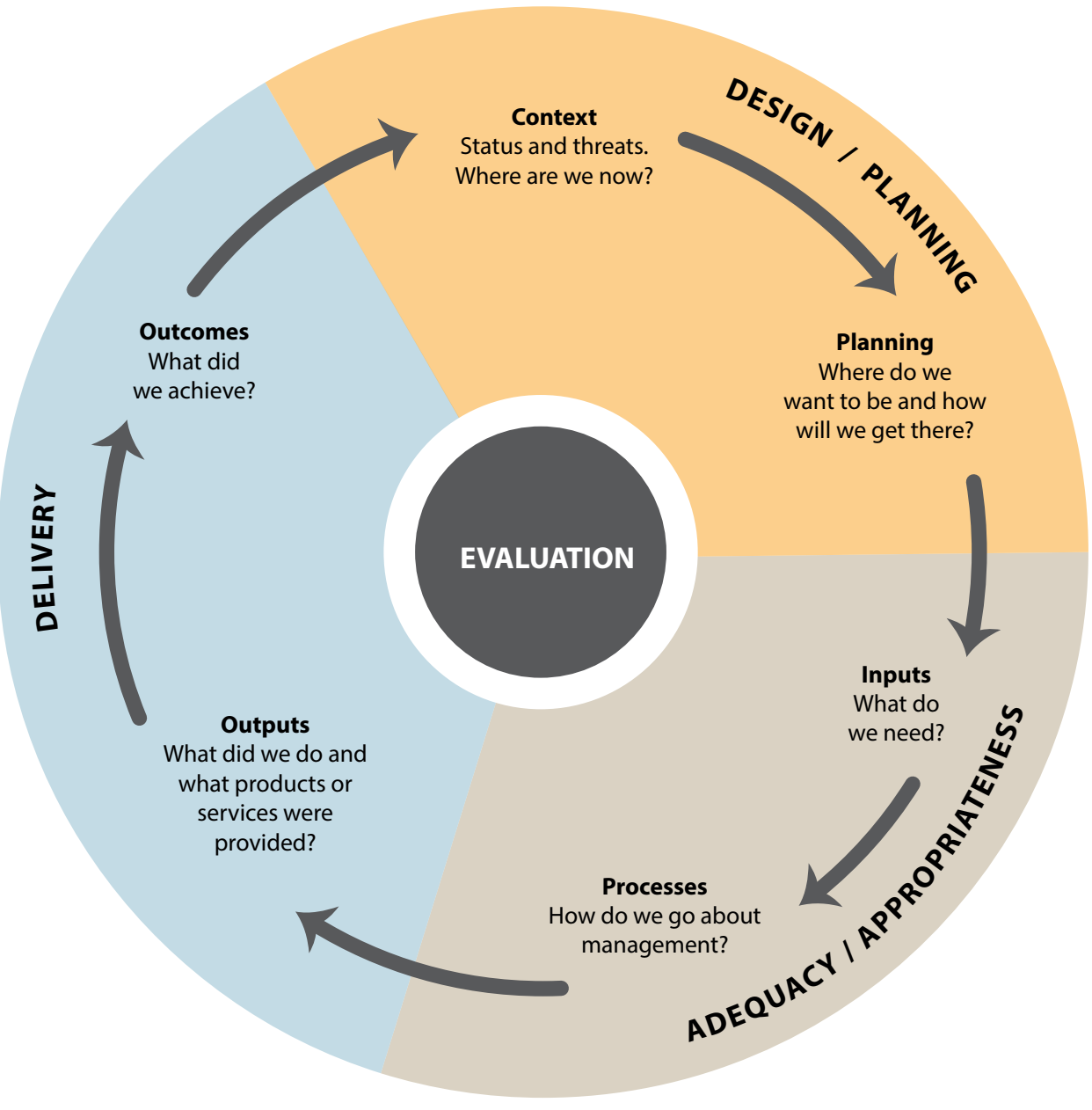

Figure 28.2 IUCN Framework for evaluating Protected Area Management Effectiveness (PAME)

Source: Hockings et al. (2006) 
The IUCN PAME framework has been used to design a number of assessment methodologies, which vary in scope and scale (Hockings 2003; Leverington et al. 2008), from relatively rapid, questionnaire-based assessments that are conducted by a few protected area staff and through workshops with stakeholders to more extensive assessments based on field monitoring as well as workshops and stakeholder consultation (Hockings et al. 2009a; Carbutt and Goodman 2013).

In addition to assessments undertaken in response to the GEF and other donor requirements, PAME assessments have been widely applied by NGOs such as WWF and The Nature Conservancy (Ervin 2002, 2003) and by international organisations such as the IUCN and UNESCO (Hockings et al. 2008). Increasingly, PAME systems have been integrated into the operations of management agencies with prominent examples from Colombia (Mayorquin et al. 2010), South Africa (Cowan et al. 2010; Carbutt and Goodman 2013), South Korea (Korean National Parks Service 2009; Heo et al. 2010), and the States of New South Wales (DEC 2005; Hockings et al. 2009a) and Victoria (Parks Victoria 2007) in Australia.

\section{Designing and implementing assessments}

In this section, we outline eight key principles and four phases for designing and implementing a management effectiveness evaluation program. We then describe each of these steps in more detail and provide some of the underpinning theoretical concepts. This section compiles some of the findings from the past two decades of protected area management effectiveness evaluations, as documented in workshops, the IUCN WCPA guidelines, journal papers and other experience. The extensive literature on evaluation from other fields, including health, international development, forestry and agriculture, has contributed much to the development of PAME. There are some excellent associations, publications and websites to assist and encourage evaluations, which are both effective and ethical (CMP 2004; Kusek and Rist 2004; DAC 2006; UNDP 2009). Practitioners who are particularly interested in this field are encouraged to explore these resources. The concept and practices of 'utilisation-focused evaluation' (Patton 1997) are particularly appropriate, as they concentrate on improving management and the achievement of outcomes, rather than being academic assessments.
In the protected area context, a number of writers have listed characteristics of 'good' management effectiveness evaluations. Basic principles were defined by Courrau (1999) and recommended in the Regional Environmental Program for Central America (Programa Ambiental Regional para Centroamérica: PROARCA) manual (Corrales 2004a). An excellent synthesis of guidelines was also presented in the report on strengthening PAME in the Andes region (Cracco et al. 2006). The IUCN WCPA guidelines on management effectiveness (Hockings et al. 2006) are highly recommended reading and provide detailed guidance on how evaluations can be planned and implemented, and some of the material in this chapter is drawn from these guidelines, while recommendations and summaries relating to methodologies can be found in documents produced by the global study (Leverington et al. 2010b, 2008) and a study of PAME in Europe (Leverington et al. 2010c; Nolte et al. 2010).

Drawing from all the sources, eight principles for PAME are included in this section. In summary, these principles state that evaluations of management effectiveness of protected areas should be:

- part of an effective management cycle, linked to defined values, objectives and policies and part of strategic planning, park planning and business and financial cycles

- practical to implement with available resources, giving a good balance between measuring, reporting and managing

- useful and relevant for improving protected area management; for yielding explanations and showing patterns; and for improving communication, relationships and awareness

- logical and systematic: working in a logical and accepted framework with a balanced approach

- based on good indicators, which are holistic, balanced and useful

- accurate: providing true, objective, consistent and up-to-date information

- cooperative and participatory: with good communication, teamwork and participation of protected area managers and stakeholders throughout all stages of the project wherever possible

- focused on positive and timely communication and application of results. 


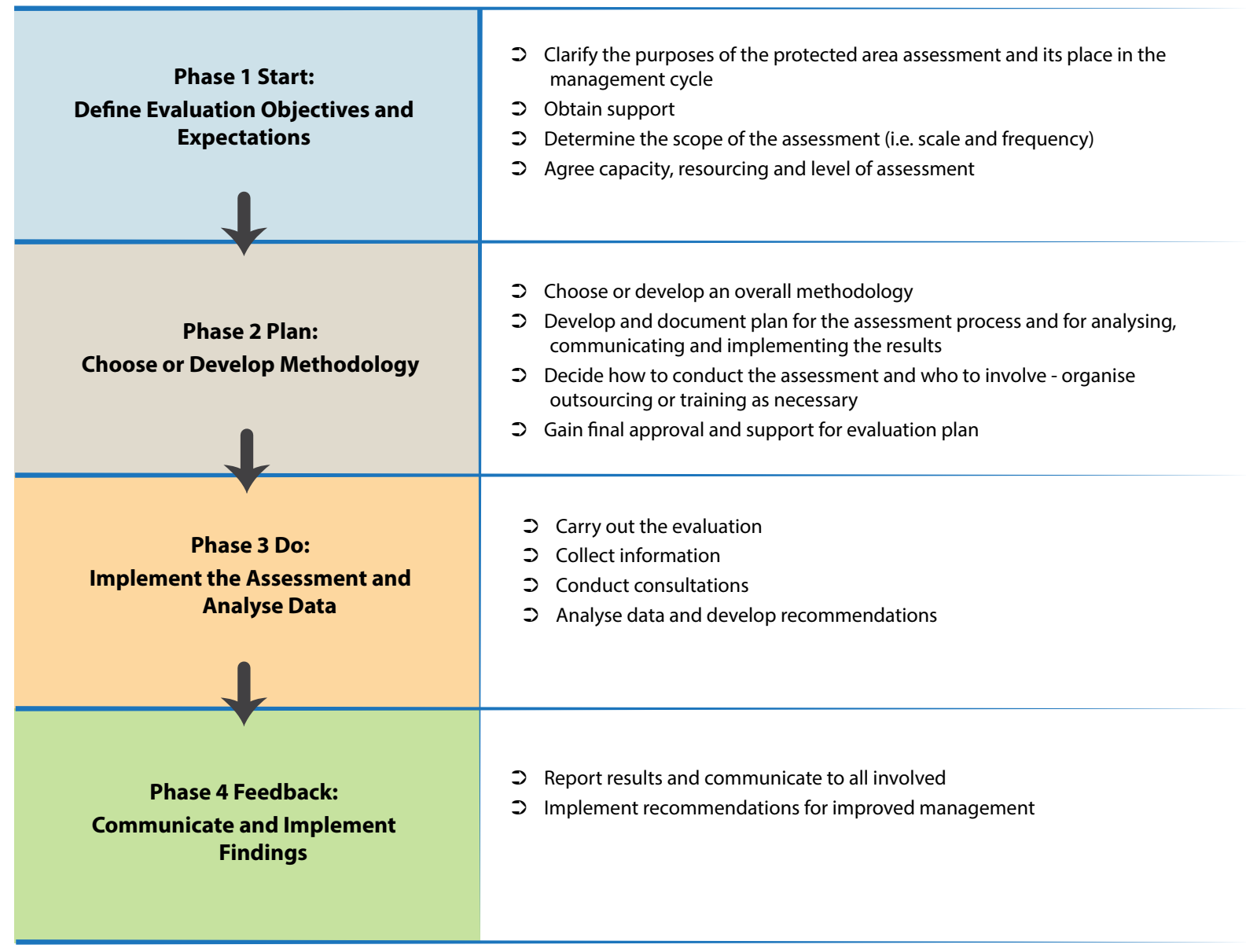

Figure 28.3 Process of designing and implementing PAME

The process of a PAME assessment, as shown in Figure 28.3, can be divided into four major phases.

1. Defining exactly why an assessment is being undertaken and ensuring it fits into a management learning cycle.

2. Planning the assessment and choosing or developing a good methodology.

3. Implementing the study-collecting and analysing the data.

4. Reporting, communicating and implementing the findings.

\section{Phase one: Objectives and expectations}

Management effectiveness evaluation is undertaken for a range of reasons, and this greatly influences how it will be planned and implemented. Clear purpose, scope and objectives for the assessment are essential to avoid later confusion and disputes - that is, it is important at the beginning of an evaluation project to know what it is expected to achieve, and to understand the levels of resourcing and support that can be expected. Agreement among all partners on assessment objectives and scope should be secured before a more detailed methodology is selected or developed. In all likelihood, however, there will be some changes during the process, and expectations should not be too rigid. In most cases, a PAME study should be an integral part of the management cycle of the management agency or another organisation involved with the protected area. This is the first principle of management effectiveness.

- Principle 1: The evaluation should be part of an effective management cycle-linked to defined values, objectives and policies.

Evaluations that are integrated into management culture and processes are more successful and effective in improving management performance in the long term. PAME should be part of the core business cycle and reporting requirements of the agency, closely linked with protected area planning, monitoring, research and annual work programs. 


\section{Box 28.4 System-wide evaluations}

As well as compiling information about site-level assessments, there is a need to evaluate how well entire systems of protected areas are being managed. Under the CBD requirements, countries have committed themselves to develop frameworks for reporting on management effectiveness at national and sub-national levels as well as at site level.

Robust and effective management is needed at the system level, where critical financial disbursement and management, protected area acquisition, widescale community engagement, and overall planning and policy initiatives usually occur. For national or regional agencies, these important activities are often concentrated at central office or district headquarters level. Support for site-level management from these centres is also vital. PAME systems that consider these indicators as well as those concerned with individual protected area management will gain a better measure of progress in protected area management on country and system-wide scales.

Some methodologies, notably RAPPAM (Ervin 2003), are intended to assess protected areas over an entire protected area system, and include a number of questions that relate to the design and management of the system as a whole. Such studies have been undertaken in many countries including Brazil, Russia, Papua New Guinea, and in countries across Eastern Europe and West Africa. A valuable study conducted in Finland (Gilligan et al. 2005; Heinonen 2006) was aimed at the system level, and while the assessors visited a number of parks and considered information relating to individual protected areas, all the indicators were at the system level. Other assessments of protected area systems include a similar study in Lithuania (Ahokumpu et al. 2006) and an extensive, ongoing assessment in India (Vinod Mathur, pers. comm.). System-level assessments have also been conducted in Korea, Colombia and Thailand (marine parks) (Heo et al. 2010; Hockings et al. 2012).

In other studies, data are gathered at the protected area level, but reports available to the public 'roll up' the data and present results at the system or group of protected areas level. These studies are often conducted as the core element of a 'state of the parks' assessment system that is repeated on a regular cycle, usually every three years. Examples include Colombia, South Korea, South Africa and the States of New South Wales and Victoria in Australia. In this way, the evaluation is presented as an evaluation of the system as a whole rather than of individual areas. Sometimes agencies are reluctant to publicly discuss evaluation results at the protected area site level and are more likely to share and transparently report on results at the system level.

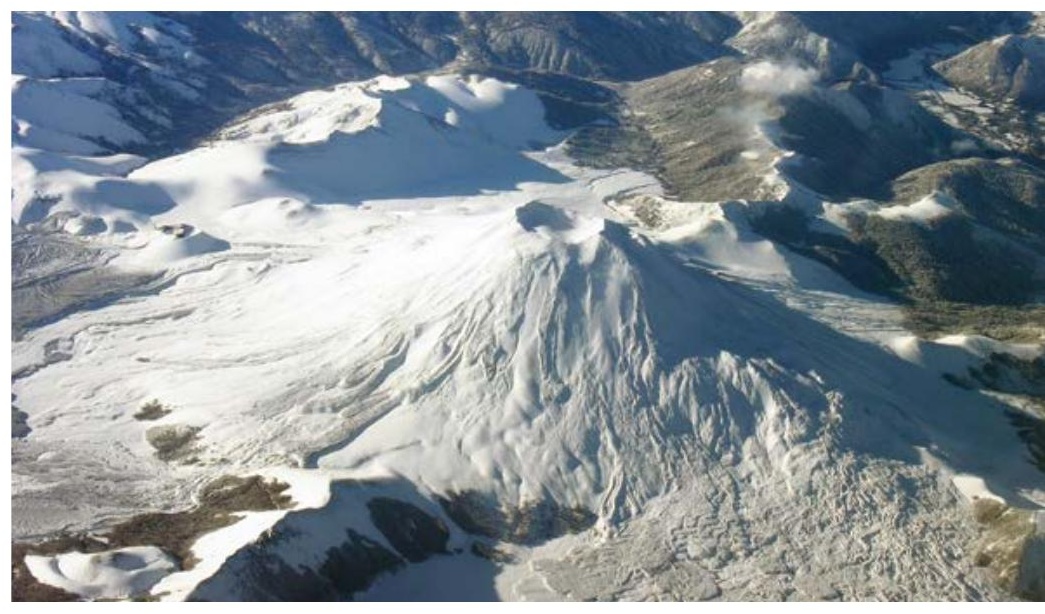

Puyehue Volcano in Puyehue National Park, Patagonia, Chile-before serious eruptions began in 2011

Source: Eduard Müller

\section{The initial step}

The first step in conducting a management effectiveness evaluation therefore is to define the overall objectives for the exercise, by considering its purpose and scope (including scale and frequency) in light of the resources available for assessment and the subsequent level of the assessment to be attempted. Evaluation can be undertaken at the scale of:

- an individual protected area (or sometimes part of a large protected area)

- a group of protected areas (grouped geographically, by category, by biome or linked to specific projects)

- all protected areas managed by a single agency (including communities or organisations)

- all protected areas within a country (Box 28.4).

\section{Frequency}

In some cases, a one-off assessment might be conducted for a particular purpose, but in general, evaluation is most useful as a tool for improving management effectiveness if it is repeated at regular intervals, because this gives better information on trends and also shows if management changes are improving site condition. When protected areas are in an establishment or strengthening phase or under particular threat, yearly assessments may be necessary, but usually two to fiveyear intervals are adequate to reveal changes and guide management. 


\section{Level of assessment}

The level of the evaluation-that is, whether it is a relatively quick assessment based on available data or a more in-depth assessment-will be determined by the purpose, the resources available and the organisational capacity and willingness to undertake an assessment.

The quickest and cheapest assessments need little or no additional field research and use established assessment methodologies. This type of evaluation will rely largely on literature research and the informed opinions of site or system managers and/or independent assessors, assessing the context of the protected area network or individual site along with the appropriateness of planning, inputs and processes of management and limited assessment of outputs and outcomes. A more detailed assessment is likely to include some additional monitoring, particularly of outputs and outcomes of management and the methodologies. The most detailed and thorough assessments will place the greatest emphasis on monitoring the extent of achievement of management objectives through focusing on outputs and outcomes as well as context, planning, inputs and processes. This leads us to the question of resourcing. The second principle relates to the balance of resourcing given to PAME compared with other aspects of management.

- Principle 2: The assessment should be practical and not too expensive to implement, giving a good balance between measuring, reporting and managing. Evaluation is important but should not absorb too much of the resources needed for management. Methodologies that are too expensive and timeconsuming will not be repeated, and are less acceptable to staff and stakeholders. An ability to make the most of existing information (from preexisting monitoring and research) is important. It is critical that all monitoring and evaluation processes within a particular area are aligned and information is shared as much as possible, and that repetition by different organisations and methods is avoided.

\section{Phase two: Planning the assessment}

\section{Finding a methodology}

Once executives and practitioners are clear about what they wish to achieve, the next step in planning an evaluation will be to select, adapt or develop a methodology. There are advantages in adopting or adapting a PAME methodology that has already been widely used and tested: apart from savings in time and money, the prior experience of other people can be used, and evaluators will be able to share data and

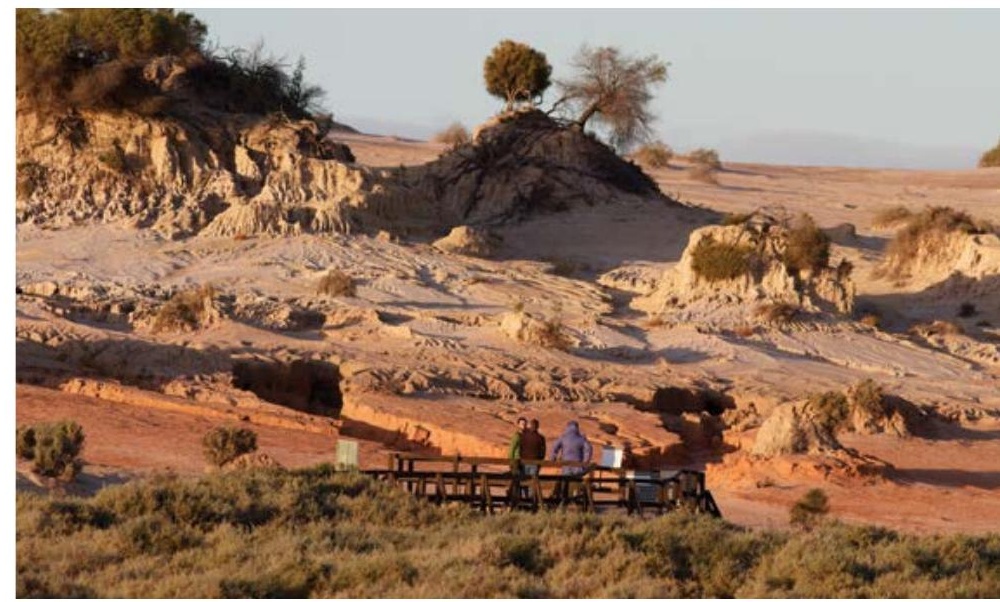

Elevated walkways and viewing areas provide restricted visitor access to the eroding, highly culturally significant and sensitive 'Walls of China' dune in Mungo National Park World Heritage Property, New South Wales, Australia. Mungo is one of the most important places in Australia for studying the environment of the past and the people who lived there.

Source: Ian Pulsford

findings across protected areas and boundaries. Using a 'module' approach, all or parts of the more common methodologies can be taken and combined to develop a methodology that will suit the circumstance.

The most commonly applied PAME methodologies are as follows.

- RAPPAM (Ervin 2003), which measures effectiveness across a group of protected areas in a region or country, has been used in more than 57 countries across the world.

- METT (Stolton et al. 2007) is a requirement for all GEF projects on protected areas and has been applied in at least 110 countries.

- PROARCA/CAPAS scorecard evaluation (Corrales 2004b), which has been applied across six Central American countries on a number of occasions.

- Parks in Peril Site Consolidated Scorecard (The Nature Conservancy Parks in Peril Program 2004), which was applied in 15 Latin American countries as part of the Parks in Peril aid program.

- State of parks assessments in the Australian States of New South Wales and Victoria (for example, Growcock et al. 2009; and Case Study 28.3), which have assessed more than 1200 protected areas at least three times in the past decade. The assessment system, based on a common approach, has been adapted to suit individual management systems in each of the States and has also been used as a model for the development of assessment systems in South Korea and Thailand. 
- Enhancing our Heritage methodology (Hockings et al. 2008), developed by the IUCN and UNESCO for application in natural World Heritage sites but which has subsequently been adapted and applied in other protected areas. It represents one of the most detailed site-level evaluation systems.

Principles three, four and five relate to the design of methodologies and might be considered by practitioners when choosing what is most appropriate for their needs.

- Principle 3: The methodology is useful and relevant in improving protected area management, yielding explanations and showing patterns and improving communication, relationships and awareness.

All protected area management assessments should in some way improve protected area management, either directly through on-the-ground adaptive management or less directly through improvement of national or international conservation approaches and funding. The process benefits should also be clear and lasting. The indicators used need to be clearly relevant to the protected area and management needs and should help in understanding whether protected area management is achieving its goals or making progress. The initial context step in the IUCN WCPA framework specifies the definition or clarification of protected area values as the basis for the assessment process. This can be useful in itself because many protected areas lack an explicit definition of values. The methodology will allow useful comparisons across time to show progress and, if desired, will also allow comparison or priority setting across protected areas. Even simple analyses will show patterns and trends and allow for explanations and conclusions about protected area management and how it might be improved.

\section{Scaling of indicators}

Many methodologies use a hierarchical structure that contains different layers of indicators or questions assessing any particular element or dimension. Layers of questions should proceed logically and link from the very general level (for example, biodiversity or community relations) to a more specific and measurable level (for example, the population of one animal species recorded at one time in one place; or the opinions of stakeholders about a particular issue). This hierarchical, nested structure means that information can be 'rolled up' or desegregated easily to answer different needs and reporting requirements.
- Principle 4: The methodology is logical and systematic, working in a logical and accepted framework with a balanced approach.

A consistent and accepted evaluation system such as the IUCN WCPA framework provides a solid theoretical and practical basis for assessment and enhances the capacity to harmonise information across different assessments. It is preferable for a methodology to be published, or at least clearly documented and available, so the results are defendable and clearly related to a sound approach.

While some methodologies might focus on particular aspects of management, it is desirable to measure all six elements of the IUCN PAME framework, balancing the need to assess the context, inputs, planning, process, outputs and outcomes of management. There should also be a balance between the different themes or dimensions of management-for example, governance and administration, natural/ecological integrity, cultural integrity, and social, political and economic aspects.

Where assessments are closely tied to management planning or project planning, the systematic methodology may also draw on ideas such as program logic, where the causal chains and assumptions between strategies and desired outcomes are clearly identified.

\section{Topics and indicators: What do we assess?}

Topics and indicators in PAME represent the aspects of management that are considered essential if a protected area is to be considered 'effective'. Development or adoption of sound indicators is a key step in management effectiveness evaluation. The fifth principle for PAME emphasises the need for balance as well as usefulness in informing management.

- Principle 5: The methodology is based on good indicators, which are holistic, balanced and useful. The indicators and the scoring systems are designed to enable robust analysis.

The indicators chosen have some explanatory power, or are able to link with other indicators to explain causes and effects.

The selection of evaluation topics and indicators tends to reflect the interests and viewpoints of people designing or conducting the evaluation; so, for balanced assessments, care needs to be taken to avoid bias. For example, academics and scientists may consider that only outcomes of management are important, while senior management tends to be interested in efficiency and value for money. Indicators chosen by Aboriginal 
Table 28.2 Criteria for each element in the IUCN WCPA Framework

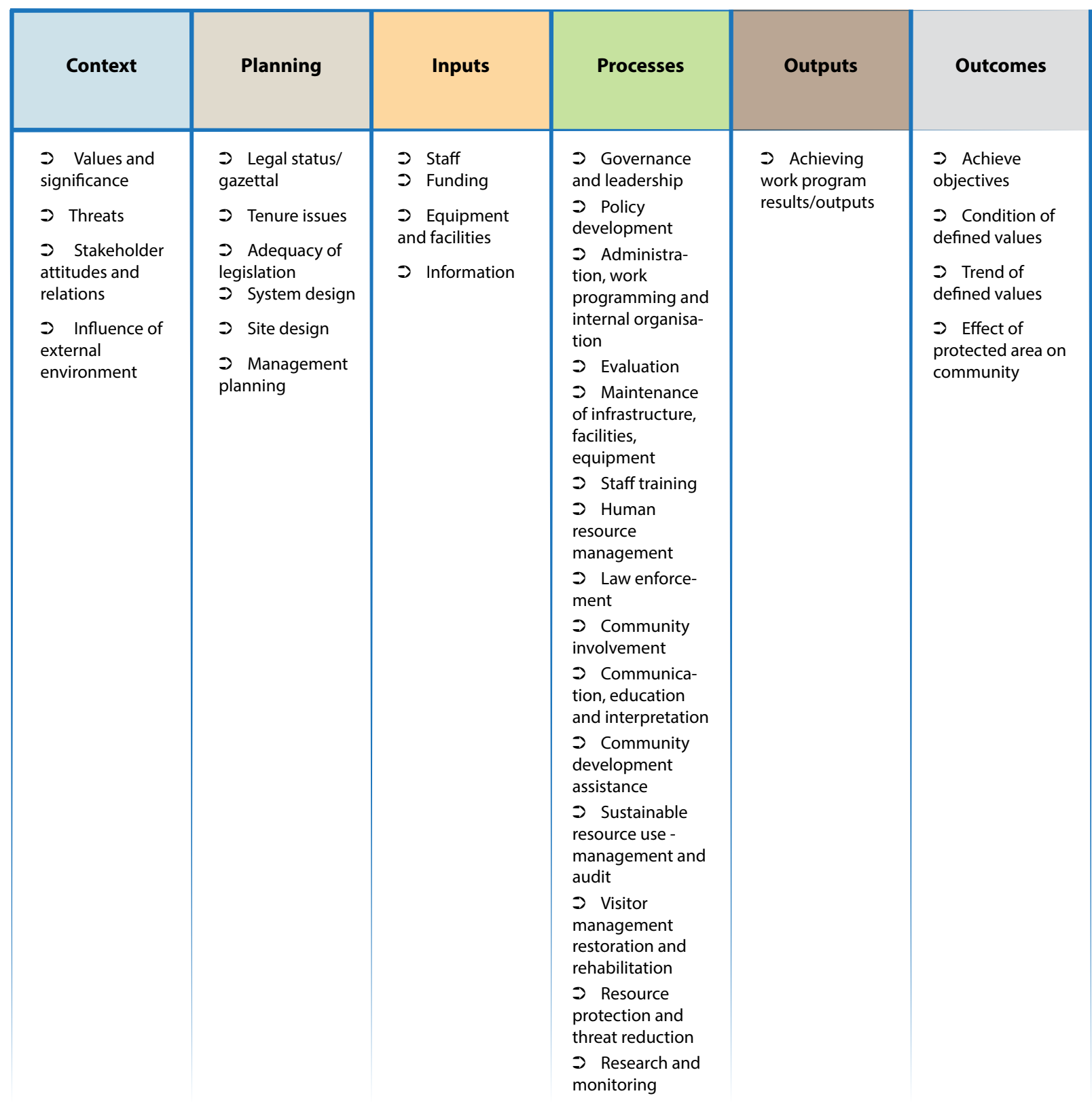

traditional owners to evaluate protected areas in Australia mostly focused on processes, particularly related to governance and social relationships (Stacey et al. 2013). In the global study review (Leverington et al. 2010a), the lack of indicators relating to cultural and social aspects of management was notable.

Most PAME methodologies use a hierarchical approach with between two and five levels of organisation. Names for these levels vary, so we shall refer to them here as topics and indicators. At the first level are a small number of broad topics - often some combination of the following: administration, social and political issues, management of natural and cultural resources, community participation and legal aspects. Other methodologies specifically use the elements of the IUCN WCPA framework as the first level of organisation.

Features that are important to good management at the next, more specific level are then listed, and standards and expectations set. Common factors identified at this level include: good systems of financial administration, adequate staffing and funding, communication with stakeholders, environmental education programs, management planning, law enforcement and boundary marking. At the last level of organisation, specific indicators for each of these aspects are chosen and described. 
Table 28.3 Headings for the indicator matrix

\begin{tabular}{|c|c|c|c|c|c|c|c|c|c|c|c|c|c|c|}
\hline $\begin{array}{l}\text { Dimensions of } \\
\text { Management }\end{array}$ & \multicolumn{4}{|c|}{$\begin{array}{l}\text { Natural } \\
\text { Integrity }\end{array}$} & \multicolumn{4}{|c|}{$\begin{array}{l}\text { Cultural and } \\
\text { Spiritual }\end{array}$} & \multicolumn{6}{|c|}{$\begin{array}{l}\text { Socio-economic, Community } \\
\text { Engagement and Recreation }\end{array}$} \\
\hline Elements & $\begin{array}{l}\frac{\lambda}{n} \\
\frac{\bar{n}}{2} \\
\frac{2}{0} \\
\frac{0}{\infty}\end{array}$ & 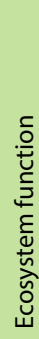 & 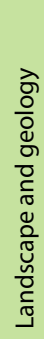 & 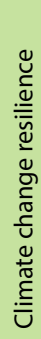 & 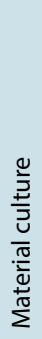 & 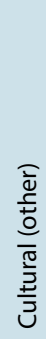 & 晃 & 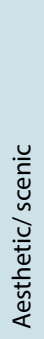 & 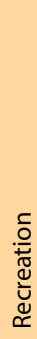 & 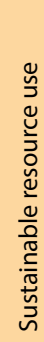 & 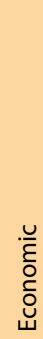 & 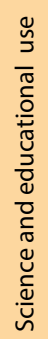 & 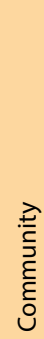 & 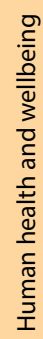 \\
\hline \multicolumn{15}{|l|}{ Context } \\
\hline \multicolumn{15}{|l|}{ Planning } \\
\hline \multicolumn{15}{|l|}{ Inputs } \\
\hline \multicolumn{15}{|l|}{ Process } \\
\hline \multicolumn{15}{|l|}{ Outputs } \\
\hline Outcomes & & & & & & & & & & & & & & \\
\hline
\end{tabular}

Note: Only the elements of management are shown in the row headings, but a full matrix would also include the more detailed criteria shown in Table 28.2.

Where methodologies specifically use the IUCN WCPA framework, the primary basis for organising indicators may be the cycle of management. By working with the framework's elements, methods pay systematic attention to all parts of the management cycle, including context issues (values, threats and external influences on management), outputs (achievement of work programs, products and services) and outcomes (achievement of objectives, changes in values and effects on the community). Some of these elements can be underrepresented in rapid-assessment methodologies that focus on 'input' and 'process' indicators. Where methodologies have been designed using different ways of organising indicators, the IUCN WCPA framework can still be applied, by coding or tagging the questions or indicators appropriately. Perhaps the most useful approach organises or analyses indicators according to both the framework's elements and the more commonly nominated fields of management.

A grid matrix represents a convenient way to view the complex array of potential and existing indicators. As we have seen above, the elements of the management cycle are the basis for the IUCN WCPA framework, and provide evaluations with powerful tools for understanding and improving management. Under each element are a number of criteria (Table 28.2).

Methodologies often organise indicators according to what protected areas manage, reflecting management agency organisation and reporting needs. For example, headings relate to biodiversity conservation, weed management or recreation management, or to a capacity issue like staffing, context and planning. We refer to these as the dimensions (and below them, fields) of management.

A matrix provides a way of understanding the diversity and similarities of indicators more easily, by ranging the elements and criteria of the IUCN WCPA framework against dimensions of park management. Most management issues, questions and indicators can be fairly easily mapped into a cell on the grid, though sometimes a question covers two or more cells. In many cases, multiple questions will be asked about one cellfor example, the 'biodiversity value' cell.

This matrix can be used to map or to generate indicators for studies at any level, from very general to very detailed. During the process of the global study, more than 2000 indicators were mapped on a matrix based on that shown in Table 28.3, to understand the most common questions asked in evaluations. This analysis was then used to help generate a 'common reporting format', which allowed analysis of PAME studies using a wide range of methodologies.

While there is a huge array of potential indicators and questions of interest, it is important to keep the number of indicators to a reasonable level. One way to do this is to focus on the most important aspects of management affecting protected areas. While this will vary from region to region or be affected by other circumstances surrounding a protected area system, some subjects are likely to be generally regarded as important in many parts of the world. 
Table 28.4 Example of a four-point scale measuring aspects of ecological integrity

OVERALL VIABILITY SUMMARY - EAST MOLOKAI - HAWAII

\begin{tabular}{|c|c|c|c|c|c|}
\hline \multicolumn{2}{|c|}{ CONSERVATION TARGETS } & Landscape & Condition & Size & Viability \\
\hline 1 & North Shore Forests and Cliffs & Fair & Good & Fair & Fair \\
\hline 2 & Montane Wet Forest & Fair & Very Good & Fair & Good \\
\hline 3 & $\begin{array}{l}\text { South Slope Mesic Forest and } \\
\text { Shrubland }\end{array}$ & Poor & Good & Poor & Fair \\
\hline \multicolumn{5}{|c|}{ OVERALL BIODIVERSITY HEALTH RANK } & Fair \\
\hline
\end{tabular}

Source: TNC (2000)

\section{Scales and scoring}

A range of different rating and scoring systems is used in PAME methodologies. Once topics and indicators of evaluation have been defined, most methods follow a four-step process.

1. Defining the ideal situation for each indicatoror in some methodologies, the target is set as an achievable level over a chosen time frame.

2. Defining a scoring and rating system. Usually the lowest score represents no progress, negligible progress or a very poor situation, and the highest represents the current situation. Some methodologies, including most of those adopted in Latin American countries, use a five-point scale, as proposed by Cifuentes et al. (2000). Most of these then measure or estimate the current state as a percentage of a defined optimum or achievable state. Other methodologies including METT and RAPPAM follow a four-point scale, to avoid the tendency of responses to cluster at a midpoint. The four-point scale also corresponds well with the ecological evaluation work being undertaken by The Nature Conservancy (TNC), which proposes that a scale of 'poor', 'fair', 'good' and 'very good' has scientific merit (Parrish et al. 2003), as shown in Table 28.4. The meaning of these four categories has been clearly defined, and in our experience the scheme is well accepted by protected area managers. This four-point scale using red to green colours has also been well accepted by traditional owners in Australia, with the visual presentation of information considered very effective (Stacey et al. 2013).
3. Defining the meaning of grades or scores, which represent levels of progress towards achieving the optimum state. Most methodologies either carefully define what each of these levels represent (that is, define precise criteria for each score level) or set guidelines for the individual park or system to define these standards. In some cases, quite detailed instructions or sub-indicators are included to ensure that an objective and quantitative method is used to calculate scores for staff, finances or equipment. The more clearly the categories are defined for local circumstances, the more accurate and consistent will be the responses. Sometimes subjective termssuch as 'adequate', 'sufficient' and 'appropriate'are deliberately used to ensure that assessment categories can be applied to protected areas with a range of different contexts. For example, the level of visitation appropriate to a nature reserve that is protected specifically for important biological features will be very different to that for reserves protected as spaces for recreation. In these cases, it is important to ensure that definitions of what is appropriate are clear to all assessors, to avoid errors derived from using poorly defined language (Regan et al. 2002).

4. Considering weightings for indicators, so that scores for individual indicators can be combined or 'rolled up' into the level or levels above. The indicators at each level may be weighted to reflect the relative importance and contribution to the field. Any weighting should be carefully developed and explained, with assumptions outlined, or the validity of the evaluation can be reduced. 


\section{Ensuring accuracy in assessments}

There is an increasing level of scrutiny of PAME assessments, and issues of credibility and accuracy are being raised in the literature (for example, Carbutt and Goodman 2013). A current focus for practitioners is on finding ways to increase and clearly demonstrate the reliability of results, as discussed in the sixth principle.

- Principle 6: The methodology is accurate, providing true, objective, consistent and up-to-date information.

Results of evaluations can have far-reaching implications and must be genuine and able to withstand careful examination. Data gathered need to be as accurate and objective as possible to ensure credibility. In most protected areas there are significant constraints on the quality of certain kinds of information, particularly those that are useful for the measurement of outcomes and the status of park values. Often, evaluation must make the most of what information is available; however, evaluation of management effectiveness is enhanced if it is backed up by information obtained from robust, long-term monitoring of the status of key values and of trends in such indicators as natural resource use and visitor patterns. Links to clear planning, and clarification of assumptions, are important so that any inferences derived from the assessments can be substantiated.

\section{Careful wording}

Most management effectiveness evaluations are based on 'expert elicitation' using workshops, interviews or questionnaires, which capture the knowledge of assessors. As such, they are prone to errors and cognitive biases (Burgman 2001; Martin et al. 2010; Speirs-Bridge et al. 2010). In particular, qualitative assessment tools can be prone to what are known as framing effects, whereby people have variable interpretations of what they are being asked to assess (Fischhoff 1995). Loosely defined assessment questions can lead to several aspects of the way a question is framed (the assessment frame) being misinterpreted, particularly the scope (which aspects of management are being considered), the scale (which parts of the protected area are being considered) or the time frame (the period over which outcomes are being considered) (Cook et al. 2014a). These types of error are called framing effects and mean that assessors consider different things when making their judgments, such that evaluations cannot be confidently compared between different protected areas. For example, one assessor may evaluate outcomes across the whole protected area, while another only evaluates the area of the reserve under active management. To minimise framing effects, it is important to make sure that these aspects

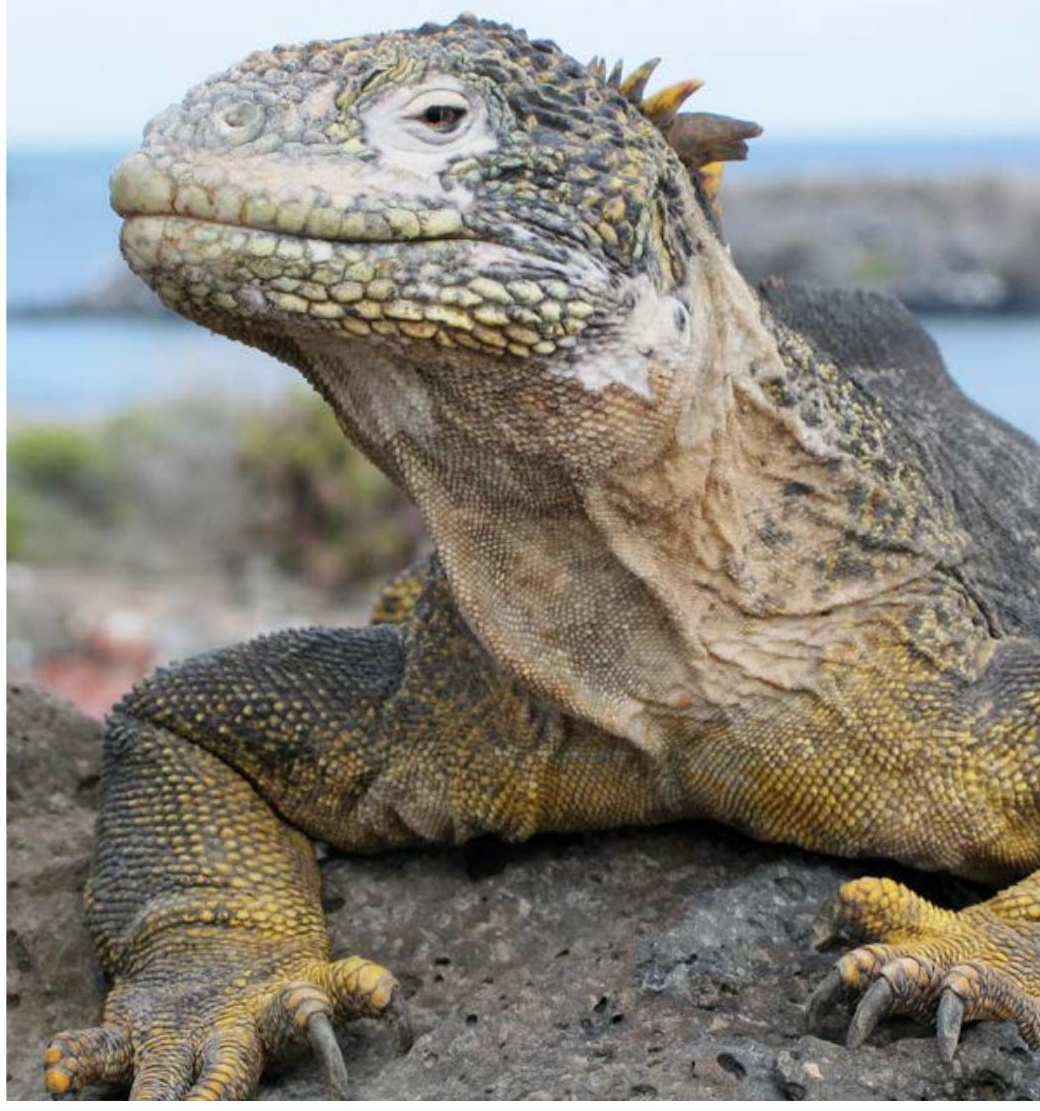

The unique wildlife such as the Galápagos land iguana (Conolophus subcristatus) in the Galápagos National Park, Ecuador, are conserved because visitor impacts are lowered by strict enforcement of limitations to visitor numbers and activities Source: lan Pulsford

of the evaluation are made clear in the wording of the assessment questions (Cook et al. 2014a). It cannot be assumed that assessors will understand what is expected of them without explicit directions.

It can be particularly difficult to gain consistent responses to questions that assess several different things simultaneously and offer response choices that are quite complicated-for example, questions that measure both the numbers and the capacity of staff, or those that assess the availability and implementation status of management plans. These should be avoided. To enable greater consistency across different methodologies and studies, some aspects of management effectiveness can draw on standard classifications and lexicons (CMP 2013), such as the standard threat classification (Salafsky et al. 2008).

\section{Measuring trends}

Another aspect of evaluations that needs to be made explicit is how evaluations monitor trends in the effectiveness of management over time. Trends can be captured in one of two ways:

1. Using assessment categories that capture the current trend in a management issue-for example, the impacts of invasive plants is increasing, stable or decreasing. 
2. Using assessment categories that capture the current status of a management issue (such as the impacts of invasive species are minor, moderate or major) and then using consecutive assessments to build a picture of change over time.

The advantage of evaluations that assess current trends is that multiple years of assessments are not required to determine whether the trajectory for a management issue is positive or negative. This can be particularly important if evaluations are unlikely to be conducted on a regular basis for a prolonged period. The disadvantage of capturing trends within the assessment categories, however, is that subsequent evaluations can be difficult to interpret. For example, if the current impacts of invasive species are assessed as increasing, the impacts may have increased from 5 to 10 per cent or from 90 to 95 per centtwo very different situations. Likewise, an assessment that impacts are increasing in one evaluation period followed by an assessment that impacts are decreasing in a subsequent assessment period may indicate a very large or a very small change in impacts. In these cases, it is more meaningful to record the current status and then provide an indication of the trend in impacts from the previous assessment period (for example, increase, stable, decrease) alongside the current status. In these cases, it would be helpful to encourage assessors to provide more detail about trends in an explanatory field.

\section{Descriptive versus quantitative scores}

Assessment scores can be defined using qualitative statements that provide general descriptions of the status of management, such as descriptive categories of the extent to which the natural values of the protected area are intact or degraded (Hockings et al. 2009a). Alternatively, assessment categories can be defined as quantitative thresholds (Timko and Innes 2009), such as the proportion of native vegetation communities within the acceptable fire frequency threshold, or the proportion of the protected boundary adequately demarcated (Corrales 2004a).

The choice of whether to use qualitative or quantitative assessment categories can depend on the management issue being assessed. Quantitative assessment categories tend to be best suited to aspects of management that can be measured numerically, such as the status of biological attributes (for example, population status or vegetation condition) and the number of visitors to a protected area. Some aspects of management, however, are less suited to quantitative metrics, such as whether protected area managers have sufficient information about protected area values to make informed management decisions. In these cases, qualitative descriptions are required to capture the relevant information.

Management effectiveness evaluations are commonly based on a set of four or five assessment categories. Ideally, these categories reflect an even rating scale of management standards, such that the interval between the poor and moderate management standards is equal to the interval between good and very good management standards. The advantage of using quantitative assessment categories is that it limits subjectivity in the assessment process, so there is no ambiguity about which assessment category should be selected for any particular value. When 50 per cent of vegetation communities are within fire frequency thresholds, the assessment will always be 'moderate' and when 60 per cent are within the threshold, the assessment will always be 'good'regardless of who is conducting the evaluation. Another advantage of a quantitative assessment scale is that the reason for a particular assessment in any given year is also transparent and can be verified by consulting the available data.

Conversely, using qualitative statements for assessment categories introduces additional subjectivity to the assessment process, so assessments may vary between assessors and between different assessment periods due to differences in how categories are interpreted and applied (Cook et al. 2014a). Several methodological approaches can be employed, however, to limit the influence of subjectivity in assessments, such as providing assessors with face-to-face training and written guidelines that describe how qualitative assessment categories should be interpreted (Cook and Hockings 2011). Some methodologies also bring on-ground protected area managers and stakeholders together to complete assessments in a workshop setting. These workshops facilitate discussion and can standardise how assessment categories are applied to different protected areas and help to minimise the influence of any particular point of view (Cook and Hockings 2011).

\section{Qualitative versus quantitative assessment process}

Whether the assessment categories are defined using qualitative statements or quantitative values, selecting the appropriate grade or score for the protected area being assessed should be based on the best available evidence. The type of evidence best suited to support an assessment is influenced by the type of management issue being evaluated (Hockings et al. 2009b). Evaluating the outcomes of management, such as ecological condition assessments, is best suited to empirical data 
(for example, research and monitoring data), while management process measures, such as the adequacy of management directions, are better suited to qualitative evidence (for example, expert opinion or experience). While empirical data may be the most appropriate data in some circumstances, often these data are not available to inform assessments, so assessors must rely on other sources of evidence, such as qualitative survey data (for example, visitor satisfaction surveys), expert opinion (for example, scientists or other experts with detailed knowledge of the protected area) or local knowledge (for example, traditional owners and protected area managers) (Cook et al. 2010).

The advantage of using empirical data is that they can be objective sources of evidence, which reduces subjectivity and provides an independent reference point for those wishing to understand why a particular assessment was given. Conversely, qualitative information can be more subjective, meaning that the reason for a particular assessment is less transparent and therefore may be less repeatable in subsequent years. This type of subjectivity may also mean similar information is interpreted differently by different individuals, leading to variation in how assessments are made between different protected areas. The distinction between the reliability of quantitative and qualitative evidence can be a false dichotomy, with the quality of the evidence available being the most important factor in which type of evidence is the most robust (Sechrest and Sidani 1995). Expert elicitation processes can be designed, tested and calibrated to provide a high degree of rigour, and this is important where decisions will be made based on the results of the evaluation (Martin et al. 2012).

It is valuable for assessors to record the evidence used to inform the assessment and the rationale for their judgment. The sources of evidence used to inform the assessment can be recorded through the use of generic categories, such as 'monitoring data', 'management plan' and 'local knowledge' (Hockings et al. 2009a). Evidence sources can also be documented in detail. The rationale for an assessment can be captured in a free text field, placing the assessment in context (for example, a recent fire in the protected area destroyed all infrastructure) and ensuring that the reasoning is transparent. Capturing this additional information can provide a valuable source of information for those conducting future assessments.

\section{Reviewing assessments}

It can be important to include review processes within management effectiveness evaluations, whereby assessments are checked by line managers, peer reviewers or a steering committee to ensure consistency between protected areas. It is important, however, to ensure that this process is constructive. When the original assessment for a protected area is changed due to a review process highlighting an inconsistency, a manager's assessment should not simply be overruled. A non-consultative review process can make assessors feel that their perspective is not valued. One option to avoid a review process being a negative experience is to ensure that it is collaborative, where reviewers discuss any concerns they have about assessments with the assessor in a constructive way and all parties agree on the need for a change.

\section{Triangulation}

Triangulation is a process in which several different pieces of evidence are sought to verify or refute a particular conclusion, and it has long been recommended to increase the validity of qualitative data (Patton 1997). There is uncertainty associated with any piece of evidence, through measurement error or other forms of bias (Regan et al. 2002), but when multiple different sources of evidence support a particular view they provide greater confidence that a conclusion is correct (Sechrest and Sidani 1995). Triangulation can be incorporated into an evaluation process by encouraging assessors to consult a range of different types of evidence, leading to more confident assessments. Given that protected area managers do seek multiple lines of evidence to support their management decisions (Cook et al. 2012), a triangulation process can also lead to more complete assessments, which capture the relevant ecological, social, political and economic perspectives. For example, a ranger's response to a questionnaire asking for the level of threat from invasive species could be backed up by spatial mapping and by an external expert.

\section{Pilots}

It is unlikely that the initial design phase will lead to a perfect management effectiveness evaluation tool. There can be great benefits to designing a preliminary assessment tool that is piloted with a cross-section of assessors to ensure the questions are clear and that evaluations will represent the full range of management contexts being considered. This pilot stage is likely to provide valuable feedback that can be used to achieve a more effective and representative evaluation tool. It can also be a cheaper alternative to conducting a full survey to find that the evaluation tool needs to be modified.

Any changes made to an assessment tool will mean that at least some of the data collected cannot be compared between subsequent evaluations periods. The trade-off between ensuring the best evaluation tool is developed and achieving continuity between evaluation datasets 
means it is best to invest in the redevelopment of the tool as early as possible. This can be achieved by conducting one or more rounds of piloting the tool with a broad cross-section of protected areas before conducting the initial survey across the network. Another advantage of testing the tool in this way is that it can ensure assessors become familiar with the assessment questions.

\section{Phase three: Implementing the assessment and analysing information}

\section{Communities, partners and stakeholders}

Protected area management practice has increasingly moved towards the recognition of the rights of local communities, neighbours and other stakeholders in planning and decision-making. This participatory approach should wherever possible also apply to the assessment of management effectiveness. As recognised in the seventh principle, a cooperative approach should be adopted from the beginning of the assessment process, including the planning phase.

- Principle 7: The evaluation process is cooperative, with good communication, teamwork and participation of protected area managers and stakeholders throughout all stages of the project wherever possible.

Gaining the approval, trust and cooperation of stakeholders, especially the managers of the protected areas to be evaluated, is critical and must be ensured throughout the assessment. Assessment systems should be established with a non-threatening stance to overcome mutual suspicion. Evaluation findings, wherever possible, should be positive, identifying challenges rather than apportioning blame. If the evaluation is perceived to be likely to 'punish' participants or to reduce their resources, they are unlikely to be helpful to the process.

Ideally the assessment should involve a partnership between many players, sharing the power, information and benefits that derive from such a process. Community members have different perspectives and often have longer history and more in-depth knowledge of some aspects of management than protected area staff. Their participation in the evaluation process is important both because they may have information and insights not shared by managers and because their views on the site are closely bound up with overall management success. Involving partners and local people in the assessment can also help all parties understand other viewpoints. In indigenous and community-managed protected areas, it is essential that collaborative evaluation is a measure of joint management as well as protected area performance, and is a process of negotiation and trust-building (Stacey et al. 2013). The participatory approach improves accuracy, completeness, acceptance, use of information, transparency and cooperation; although it is more expensive and timeconsuming to implement, it achieves more credible and sustainable results than processes that are purely internal (Paleczny and Russell 2005; Paleczny 2010).

To help ensure effective stakeholder involvement in evaluation, stakeholders and partners should be regularly informed about:

- the planning process for monitoring and evaluation and their own role in the process - including in some cases decisions about indicators and methodologies

- opportunities to participate in the evaluation exercise

- issues on which they will be asked for their opinion

- how their opinions will be used

- how they will be informed of the progress of the evaluation and the final outcomes

- how the results will be used.

Once all the partners have been identified, it will be necessary to clarify expectations and roles, and in particular to avoid giving participants a false impression of what the assessment offers. For the evaluation process to be rigorous, particularly if it is based on the selfassessment approach, it is advisable to build a team of stakeholder representatives to work with managers to develop and agree on the monitoring and assessment process. This team should include both key protected area personnel (for example, the site manager) and a number of other individuals involved in management issues. The process of conducting meetings and interviews needs to be carefully managed, and it is important to consider how to manage any conflicts that may arise from discussion of management performance.

\section{Internal or external assessors?}

An important consideration in planning a management effectiveness evaluation is who will lead or conduct the assessment. In many cases, assessments are conducted by the on-ground protected area managers (selfassessment). This has the advantage of accessing their in-depth knowledge of the management processes and conditions within the protected area. It can also be a valuable time for managers to come together and reflect on management outcomes, share information and facilitate strategic planning activities. Self-assessments may, however, be inaccurate if managers are concerned that negative assessments will reflect badly on their job 
performance, particularly in cultures where self-criticism and 'losing face' are avoided. Conversely, a desire to attract additional funding for on-ground management actions may give managers an incentive to provide overly pessimistic assessments (Cook et al. 2010). In addition, new staff members may not have the understanding needed for the evaluation. These issues can be resolved if line managers review assessments to check for accuracy and consistency, though this process could also be open to misrepresentation.

The few studies that have investigated the accuracy of self-assessments of management effectiveness have found no evidence to suggest managers conducting self-assessments misrepresent the management of their protected area (Cook et al. 2014b). Preliminary attempts to validate self-assessments for one protected area network in Australia suggest that 75 per cent of protected area managers provide assessments of protected area conditions that match quantitative data. When managers made assessments that did not match measured assessments they tended to be conservative in their judgments of condition, underestimating the outcomes of management relative to measured assessments (Cook et al. 2014b).

External assessors also conduct evaluations, either independently or on behalf of the management agency. External assessors may be consultants, scientists or members of civil organisations. One advantage of external assessors is that they are independent of the management process and, depending on their origins, may be more impartial than managers and stakeholders. They can bring a freshness of vision and have greater expertise in facilitation and assessment procedures; they are also likely to raise issues that have been missed. The disadvantage of external assessors is that detailed knowledge of current and historical conditions and the protected area's management history may not be captured. In addition, managers may be wary of admitting failures and issues in front of external assessors. When outsiders complete the evaluation, they also often take with them much of the information and perspectives gained, which are then no longer available to management. Unfortunately, local managers and local communities have sometimes been marginalised in the evaluation of international conservation projects carried out by teams of visiting experts who may only visit the area for a brief period. A code of ethics similar to that used by UNDP evaluators (UNDP 2009) may be desirable.
To achieve the best of both approaches, external assessors can work cooperatively with protected area managers and other partners and stakeholders to capture the local on-ground knowledge and the other sources of evidence available to make an objective assessment.

\section{How should information be collected?}

As discussed above, some of the information used in PAME assessments is derived from pre-existing data including monitoring data, which can be compiled and interpreted at any stage of the assessment. It is often useful for assessors to have this information, including up-to-date maps or spatial data, before workshops or questionnaires are applied.

Depending on the circumstances, expert elicitation processes can be conducted through online or written surveys, individual interviews, focus groups or workshops with protected area staff, managers, partners and other stakeholders. Guidelines for conducting such processes ethically and to maximum effect are contained in some of the management effectiveness methodologies, and also in other manuals on extension and fieldwork generally. Well-planned and organised workshops with good facilitation and record-keeping are essential; if workshops are chaotic or boring, people will not want to participate the next time. A wide range of techniques is available to engage all participants in the process. For example, more detailed protected area evaluation exercises with communities can make use of tools such as visual aids, oral histories and storylines, which were developed for participatory rural appraisal, adaptive management and allied methods (Chambers 1997; Salafsky et al. 2001; UNDP 2009; Petheram et al. 2012).

'Conceptual models' that visually represent values, threats and chains of cause and effect in conservation (Margoluis et al. 2009) are particularly useful for workshops where outcomes as well as processes are being discussed, and can work well with indigenous communities as well as protected area staff and experts (C. Mitchell, pers. comm.). These can be incorporated into computer-based planning and evaluation programs such as Miradi, which is used as an evaluation tool as part of an integrated process by a number of NGOs and protected area managers (CMP 2013; see Chapter 13). Where resources allow, the use of projected spatial images can also be a powerful tool, so threats, values and other elements of protected area management can be mapped and recorded with participants in workshop situations. These maps are then included in assessment reports and presentations and the spatial data stored with other information. 


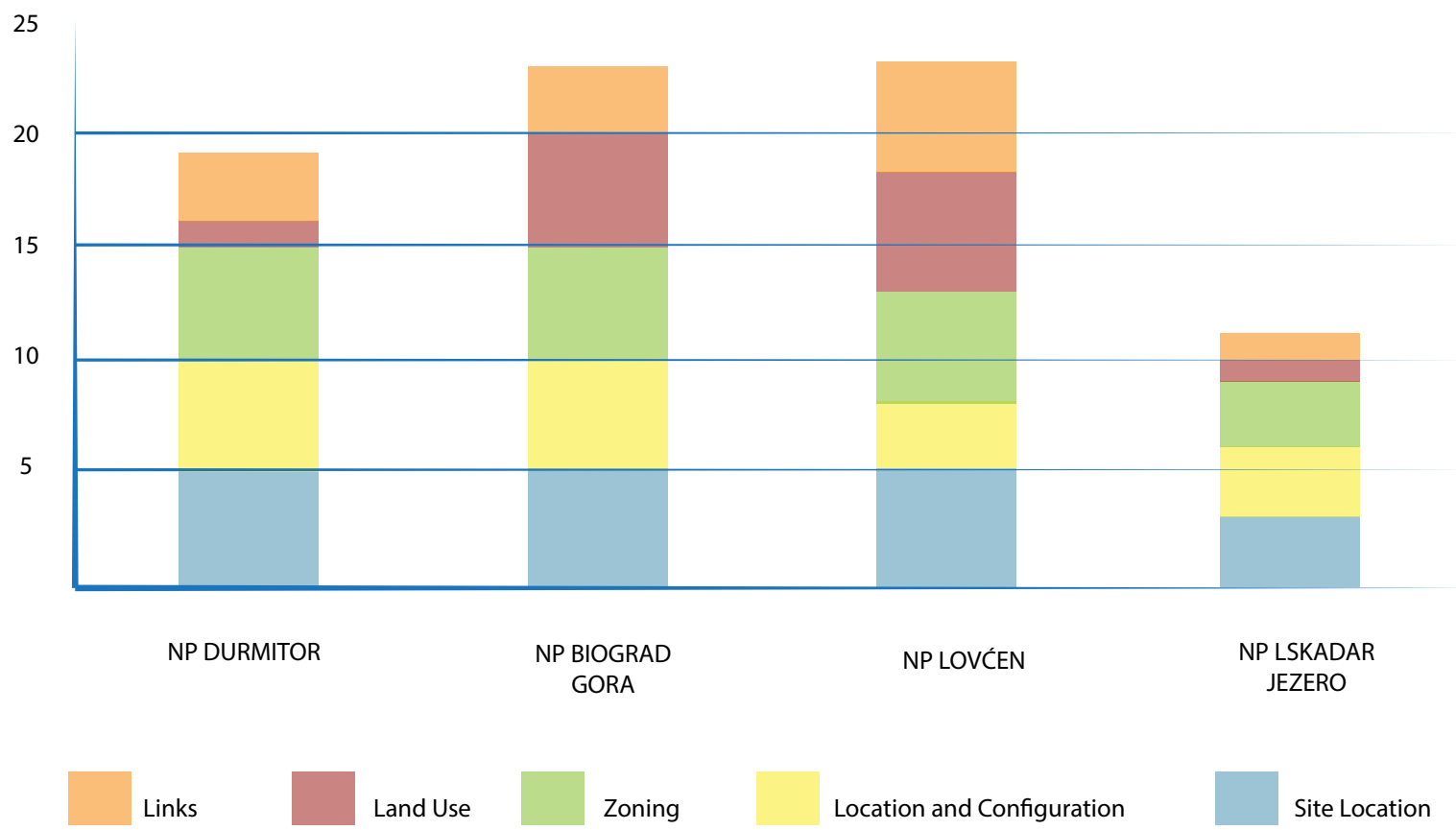

Figure 28.4 Example of simple graphical reporting, from a RAPPAM report

Note: The scale on the y axis represents cumulative scores of the five indicators on a one-to-five scale.

Source: Stanišić (2009)

Online computer-based tools to facilitate streamlined data collection, storage, analysis and reporting have been used very successfully for some management effectiveness methodologies. Online tools can now be used through smartphones, tablets or other portable devices in the field and in workshops, as well as through computers. The advantage of these tools is that the data input into the online interface are transferred automatically into a database. These systems can also enable the dataset to be queried for different purposes and can enable assessors to see and display relevant information, including details from past assessments, while conducting the current assessment. These systems are possible, however, only where there is access to the necessary computer skills, equipment and infrastructure.

Studies evaluating existing management effectiveness evaluation tools provide the following recommendations for how to streamline evaluations and make them easier for assessors to complete (Hockings et al. 2009a; Cook et al. 2014a).

- Ensure the assessment frame is clear and front of mind for assessors when making their assessment. This can be achieved by making explicit in the wording of the questions the important aspects of how assessors should frame their assessments.

- Provide mechanisms to enable assessors to resolve concerns about how to interpret assessment questions.
There are many different options to minimise the bias associated with aspects of the evaluations that may be open to interpretation. These include providing training sessions, facilitated workshops, written guidelines and a hotline that assessors can call to seek advice during the assessment period. Any or all of these approaches can help assessors seek clarification about what they are being asked to evaluate (Cook and Hockings 2011).

- Allow assessors to indicate when they feel there is insufficient information to be confident about making a judgment for a particular management issue. Allowing assessors to opt out of answering questions will prevent assessors feeling they must guess, introducing higher levels of uncertainty into some assessments and potentially leading to inaccurate assessments. Having a record of issues and protected areas that lack adequate information can allow management agencies to identify knowledge gaps. Best practice in eliciting expert opinion includes asking experts to indicate their confidence in the judgment they have provided (Speirs-Bridge et al. 2010).

- Encourage assessors to record as much information as possible during the assessment. Completing comprehensive management effectiveness assessments can be time-consuming, and protected area managers may be reluctant to spend time providing 
detailed assessments. Yet there are many benefits to encouraging assessors to document the considerations they make, the rationale for their judgment, the evidence they used and any difficulties they had in completing the assessment. These additional details provide valuable context for consistency checking, assist assessors making evaluations in the future and provide important information to interpret the results of current evaluations. This information can be an invaluable resource for new protected area managers and can form the basis of an induction to the protected area.

\section{Storage and analysis of data}

Though data storage and analysis are listed as part of this third phase of evaluation, it is vital that these are thoroughly considered at the outset of the evaluation process, to save wasting time and resources. Data systems that can collect and collate information and allow for different analyses and reporting without re-entering data will obviously save time and minimise the chances of errors. In addition, thinking about future analyses from the outset will influence what data (including metadata) are collected and how they are organised. This can benefit both local analysis and the compilation of national and international data. For example, recording consistent information about the protected area such as the WDPA code, current reserved area, budget, visitor numbers and number of staff will enable patterns of management success to be analysed in relation to many other protected areas. As management effectiveness evaluation datasets can be very large, it is important to have good systems to store and manage data.

Analysis of data can be undertaken at a number of levels. The first level of analysis is a simple compilation of collected data, either for one site or across sites, usually in the form of tables and graphs (Figure 28.4).

\section{Summary results}

Many evaluation methodologies can derive summary results, which summarise many data for each protected area into one score or a small number of headline indicators. Such summary scores provide a quick and easy way for an audience to determine comparative conditions. While protected area managers generally want more detailed reporting, quantitative data and analysis, scores are attractive to policymakers and NGOs as they give an instant overview of relative success and a way of comparing protected areas. Visual reporting with colours representing progress is particularly effective for communicating with a range of audiences including senior decision-makers.
Total or average scores, however, risk oversimplifying complex issues, distorting results and being misinterpreted. When people summarise or average scores to produce one overall result, two assumptions are made.

1. They assume that the assessment categories provide a linear scale, whereby the difference between good and very good performance is equal to that between good and moderate performance. This can be difficult to achieve when defining assessment categories using qualitative statements.

2. They assume that all the indicators and subindicators are of equal importance. This is rarely true, and a lot of thought should be put into how the scores are 'rolled up' or combined. Methods such as the 'analytical hierarchy process' (Saaty 1995) can be used in a participatory process to ensure that weighting reflects perceptions about the relative importance of indicators.

\section{Statistical analysis}

It may be possible for more advanced statistical analyses to be conducted, looking at trends in data and attempting to draw out broader patterns (Kelman 2010). Manipulating results through summing and averaging, however, or assigning weights to different indicators, and through the use of scales and indexes, can give misleading results, particularly if the data are limited in either quantity or quality. In particular, any qualitative data that are converted into quantitative data should be treated with care and their limitations fully recognised.

Multivariate analyses can provide important insights into whether greater financial investment in management will lead to better management outcomes, and where there may be factors, such as proximity to densely populated areas, that may provide intractable challenges for the management of protected areas. The potential use of evaluation data for any or all of these purposes should guide how the evaluation tool is designed.

Statistical advice might be necessary if advanced analyses are considered. Most management effectiveness data can be regarded as 'ordinal', where ratings are in order from lowest to highest. The gaps between the different scores are not entirely even and consistent, and are sometimes difficult to quantify. A purely ordinal dataset, however, would just order responses from the best to the worst, while all PAME methodologies have attempted to develop ratings that reflect steps towards ideal management that are as even as possible. So although we cannot definitively say that a score of four is twice as good as a score of two, this is as close to the truth as possible (Leverington et al. 2010a). These scores are 
in many ways analogous to the Likert scales commonly used in much sociological research (Likert 1932), and there is much debate in the literature about the nature of data derived from such questionnaires.

\section{SWOT analysis}

A 'strengths, weaknesses, opportunities and threats' (SWOT) analysis can be a useful tool for analysing information further-usually carried out in a workshop with agency staff and/or other stakeholders. SWOT involves categorising data and initial assessments under one or another of these headings. This method can provide a quick summary of management effectiveness in a format that is appropriate for communication with busy top-level managers and politicians and is also a valuable way of identifying the next steps for management (see Chapter 8).

\section{Conceptual models}

Management of protected areas is a complex process and it can be very difficult to attribute results and outcomes to any single cause. Generally, it is important to understand as fully as possible the reasons for outcomes. If we cannot understand the reasons for management success or failure, attempts to improve performance or to emulate successful programs may be ineffective. Evaluation that assesses all the elements discussed above with clearly framed questions, carefully chosen indicators, good monitoring and sound methodology is most likely to reveal some useful links and explanations. Conceptual models to understand the dynamics of the protected area and its management can greatly aid in the interpretation of results (Margoluis et al. 2009).

\section{Comparative analysis}

Analysis is often strengthened by looking at changes over time or space, such as by comparing several protected areas within a system or measuring how the effectiveness of a single protected area changes over time. Comparison between protected areas can be valuable but needs to be treated with caution, particularly if different assessors have been involved (or even different assessment systems). The WWF RAPPAM methodology (see above) is designed to assess all the protected areas within a country or district, in a workshop situation, where managers provide a certain amount of peer review for each area. Comparisons are useful for identifying trends (including, for instance, common threats or weaknesses) that may need to be addressed at a systems level and also for identifying protected areas that are particularly stronger or weaker than average. Comparison between countries also provides interesting data, but here the risks of distortion are comparatively greater and results should always be treated with caution.
Comparing individual protected areas over time is probably more valuable. It is usually worth repeating assessments at intervals to check on progress and to identify trends. Except in the case of special-purpose single-event evaluations, repeat evaluations are almost always desirable and it is important to adopt an assessment system with low enough costs to allow this. Very simple assessments could be applied annually, while more expensive, timeconsuming exercises will probably only be worth undertaking every few years. This approach is applied in Colombia with annual, mid-term and long-term elements to their evaluation system. Assessment does not need to cover all aspects every time. For example, most protected area managers will wish to track implementation of management plans and work plans quite regularly, and evaluations are often required on a regular basis for specific projects within protected areas.

The desire to compare between evaluations over time is sometimes in conflict with the opportunity to improve the assessment system. Evaluation is itself a learning experience, and better indicators, changed circumstances and access to improved technology will all tend to shape evaluation projects over time. Participatory evaluations, by their nature, need to be flexible and respond to people's needs and perceptions. Changing methodology or indicators will, however, obviously make it much more difficult to compare results over time. In general, changes in survey instruments should be minimised to those that are really important and statistical and other possible adjustments made to help keep results comparable.

\section{Phase four: Communicating results and implementing findings}

The best PAME study will be ineffective or have negative impacts if there is no follow-through to result in improved management, or if the process of evaluation causes serious friction and loss of trust between the parties. Where evaluations show negative trends, sensitive handling of the situation is essential so that improvements are encouraged. Evaluation teams should discuss in advance how to deal with cases where assessments uncover real incompetence or, in the worst scenario, deliberate misuse of power or resources.

- Principle 8: Communication of results is positive and timely and undertaken in a way that is useful to the participants. Short-term benefits of evaluation should be demonstrated clearly wherever possible.

Findings and recommendations of evaluation need to feed back into management systems to influence future plans, resource allocations and management actions. 


\section{Case Study 28.3 'State of the parks' management effectiveness evaluation tools}

The 'state of the parks' (SoP) is a system-wide approach to evaluating the effectiveness of protected area management focused on assessing all or most of the protected areas in a network (Hockings et al. 2009). The approach uses consistent indicators across all sites, although the specific indicators used are tailored to the jurisdiction, rather than employing a one-size-fits-all approach. The goal of SoP evaluations is to improve management by using the best available knowledge about the status of park values and their key threats, achievements, gaps and emerging issues to inform future priorities; however, there are often multiple purposes, such as informing strategic planning decisions and increasing accountability through public reporting of the condition of and pressures on protected areas (Leverington et al. 2008). The SoP approach has been used in many different countries, including Canada, the United States, Brazil, Finland and Australia (Hockings et al. 2009).

In Australia, the SoP approach has been widely adopted, and this case study focuses on the approach developed by two management agencies in particular: the NSW Office of Environment and Heritage (NSW OEH) and Parks Victoria (PV). In the NSW OEH, SoP evaluations are used to assess all of the protected areas managed by the agencies, while the SoP tool developed by PV is used to assess the 300 most significant protected areas and other parks within their jurisdiction (10 per cent of the number of parks but approximately 90 per cent of the area managed). In both cases, the evaluation tools have the main purpose of informing and improving management decision-making. While these two SoP evaluation systems were ordained for the same purpose and share many features in common, they are two distinct evaluation tools designed for the specific context and needs of each agency.
Australian protected area management systems are charged with protecting the natural and cultural assets within reserves, along with facilitating the public enjoyment of these publicly owned spaces. The SoP evaluation tools provide a comprehensive view of the effectiveness of management across these different aspects of management. Both the NSW OEH and the PV SoP tools have been developed around the different aspects of the IUCN framework (Figure 28.2), with all these aspects being evaluated within the tool. The context for each protected area is captured by recording the most significant values, threats and stakeholders relevant to the reserve. The important plans relevant to the reserve are recorded. Management inputs, processes, outputs and outcomes are evaluated through a series of targeted assessment questions addressing a wide range of different aspects of management, such as adequacy of information, planning and direction setting, law enforcement, asset management, along with visitors, indigenous heritage and biodiversity management. The emphasis on management outputs and outcomes is rare within management effectiveness assessment tools (Cook and Hockings 2011), but provides a much clearer understanding of the condition of and pressures on individual reserves, as well as across the protected area system.

The assessment questions within the SoP tools are built around four qualitative assessment criteria (see Hockings et al. 2009), which reflect management standards-for example, considering the condition of a value from poor, to moderate, good and very good-and are evaluated by the primary reserve manager or management group. To ensure that the qualitative statements that form the assessment criteria are applicable to protected areas within a wide range of contexts, they are built around subjective terms,

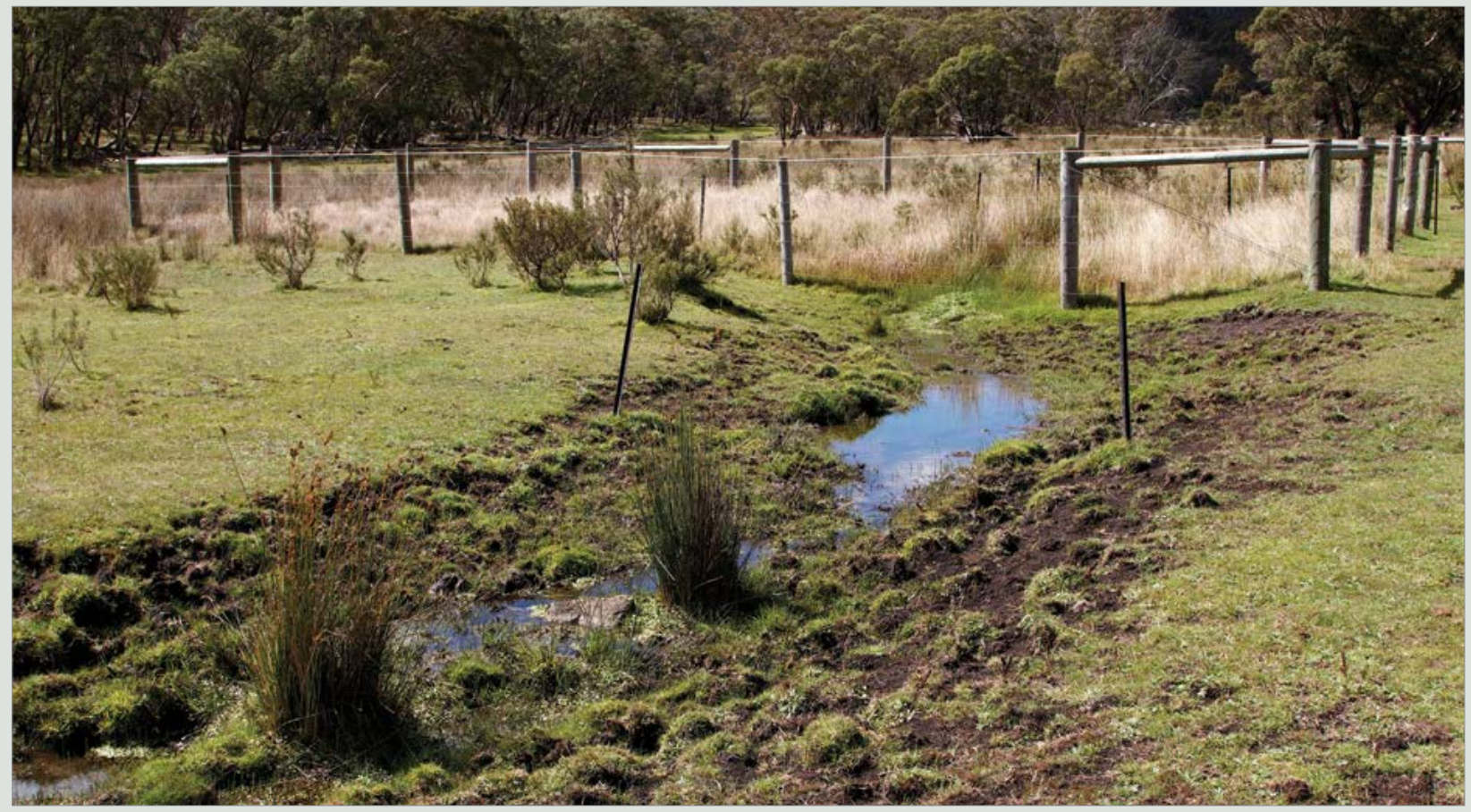

A herbivore-proof exclosure located in montane forests at the headwaters of the Murray River in the Alpine National Park, Victoria, Australia, provides scientific proof of the impact of grazing and tramping by a large population of wild horses (brumbies) for State of Parks reporting.

Source: Ian Pulsford 
such as 'adequate', 'sufficient' and 'appropriate', which are interpreted according to the circumstances for the reserve and defined in guidelines. For example, in both jurisdictions, nature reserves are set aside primarily for the protection of biodiversity and visitation is discouraged. Therefore, the appropriate visitor facilities in nature reserves are significantly different to those in multipurpose reserves such as national parks.

Wherever possible, the qualitative categorised assessments are based on measured information (for example, biodiversity monitoring results), but where this is not possible assessments are based on specialist opinion and other knowledge. In other cases (for example, the extent of community involvement in decision-making), qualitative assessments are the most appropriate method.

These qualitative assessments are accompanied by a justification where the rationale for the assessment is given, providing vital context for interpreting evaluations. The justification also allows managers to record important events, such as wildfires, that may have significantly altered the condition of the reserve from one assessment period to the next. Managers are also asked to record the evidence available to support their assessments. In Victoria, this is done through generic categories, such as systematic monitoring or anecdotal evidence. In New South Wales, the generic categories are accompanied by the capacity to provide specific details, such as the name of management plans, research papers or underlying monitoring data.

While qualitative assessments can introduce bias into assessments, there are several features of the SoP tools that attempt to minimise this. Each assessment question enables managers to opt not to assess when they are unsure because insufficient information is available. To maximise consistency and minimise bias, both agencies have established comprehensive quality-assurance processes. While public reporting of SoP results has been undertaken, both agencies have focused heavily on application of the SoP tool for knowledge and adaptive management through an extensive program of 'closing the loop' workshops with park staff. In both agencies, this includes the development of web-based user-focused reporting tools to enable all agency staff to access and share results.

One of the most important features of the SoP program from both agencies is the active follow-up of results through 'closing the loop' workshops with parks staff. These workshops feed results back to managers, ask 'why' a particular evaluation result was achieved and seek to inform management responses for the next planning period.

- Carly Cook, Monash University; Andrew Growcock, NSW Office of Environment and Heritage; Tony Varcoe, Parks Victoria
While there is a focus on data from management effectiveness studies, reports that provide context, explanation and recommendations for improvement may be more useful in leading to improved management. Evaluation reports should be clear and specific enough to improve conservation practices-and realistic, addressing priority topics and feasible solutions.

All participants and stakeholders should be provided with some form of feedback as soon as possible, in a format that suits the intended audience. Methods of presentation, language and terminology should be commonly understandable, though more technical language will be appropriate for some audiences. Very brief and pointed reports with attractive visual elements are often needed for senior executives and politicians.

Possible methods of communication include interactive internet sites; reports in hardcopy and available on the Internet; attractive publications and brochures to increase public interest; presentations to managers, decision-makers, interest groups and other stakeholders; field days and special events; media coverage and displays.

Limitations and flaws in the process and potential improvements should be identified in the assessment report. Strengths and weaknesses of management should be identified and clear recommendations made for improving management. Evaluations should spell out the need for planned change or should encourage reinforcement of what is going well at the site or organisational level.

\section{Making a difference: Towards more effective management}

Management effectiveness evaluations are worthwhile where they lead to improved management and better outcomes, both ecological and social (Case Study 28.4). This can result quickly and directly from the evaluation process, leading to better cooperation, to clearer understandings and to learning among all partners. Protected area managers can be exposed to new sources of information and new viewpoints, while other stakeholders gain a greater understanding of the challenges facing managers and communities. In some cases, an evaluation workshop also inspires or reminds managers to take immediate action to remedy a situation or begin a new initiative.

The more formal process of 'substantive' improvement occurs where results are analysed so that shortcomings can be addressed. Cases where targeted actions are taken to raise management effectiveness scores appear to be 
In 2008 the national government body responsible for conservation in South Africa, the Department of Environmental Affairs (DEA), developed the South African Management Effectiveness Tracking Tool (METT-SA) in order to provide a uniform performance evaluation tool assessing the management effectiveness of protected areas in the country. The METT-SA was conducted in all protected areas in South Africa and the results were published in the DEA report Management Effectiveness of South Africa's Protected Areas (Cowan et al. 2010).
The DEA, in agreement with the CEO forum on protected areas, set the national norm for management effectiveness for protected areas in South Africa at a minimum of 68 per cent.

After the report by Cowan et al. (2010), actions were identified at protected area (site) level, organisational (Provincial) level and national level (Table 28.5). CapeNature developed action plans for each reserve in order to address at least five issues per annum pertaining to the METT-SA.

Table 28.5 A summary of actions taken to improve management effectiveness in South Africa, 2010-14

\begin{tabular}{|c|c|c|c|}
\hline $\begin{array}{l}\text { Management } \\
\text { effectiveness }\end{array}$ & $\begin{array}{l}\text { Protected area } \\
\text { (site) level }\end{array}$ & Organisational (Provincial) level & National level \\
\hline $\begin{array}{l}\text { Legal status } \\
\text { and boundary } \\
\text { demarcation }\end{array}$ & $\begin{array}{l}\text { Title deeds and surveyor- } \\
\text { general diagrams } \\
\text { obtained for land verified }\end{array}$ & $\begin{array}{l}\text { Verification of declarations and boundary } \\
\text { descriptions of protected areas } \\
\text { Secondment of staff member to assess } \\
\text { state land transfer required from national } \\
\text { to Provincial government in order } \\
\text { to secure land in terms of National } \\
\text { Environmental Management: Protected } \\
\text { Areas Act (NEMPAA) }\end{array}$ & $\begin{array}{l}\text { Guidelines for the declaration of } \\
\text { protected areas } \\
\text { Development of geo-database } \\
\text { of South African protected and } \\
\text { conservation areas (2013) }\end{array}$ \\
\hline $\begin{array}{l}\text { Protected area } \\
\text { expansion }\end{array}$ & $\begin{array}{l}\text { Management of } \\
\text { additional land as part of } \\
\text { the protected area }\end{array}$ & $\begin{array}{l}\text { CapeNature (Provincial) Protected Area } \\
\text { Expansion Plan (Purnell et al. 2010) } \\
\text { Protected area expansion in partnership } \\
\text { with WWF-SA and Leslie Hill Succulent } \\
\text { Karoo Trust with the purchase of more } \\
\text { than } 100000 \text { ha }\end{array}$ & $\begin{array}{l}\text { Outcome } 10-\text { national } \\
\text { protected area expansion } \\
\text { targets } \\
\text { National Protected Area } \\
\text { Expansion Strategy (2008) } \\
\text { Intervention with the Department } \\
\text { of Minerals and Energy } \\
\text { regarding their objection to the } \\
\text { proclamation of the Knersvlakte } \\
\text { Nature Reserve }\end{array}$ \\
\hline $\begin{array}{l}\text { Protected area } \\
\text { regulations }\end{array}$ & & $\begin{array}{l}\text { Legal review to align Provincial ordinance } \\
\text { with new legislation, including NEMPAA } \\
\text { (Biodiversity Bill in draft) }\end{array}$ & $\begin{array}{l}\text { Brenton Blue Special Nature } \\
\text { Reserve Cape Floral Kingdom } \\
\text { World Heritage site application } \\
\text { NEMPAA } 2003 \text { regulations for } \\
\text { the proper administration of } \\
\text { nature reserves (2012) } \\
\text { Draft norms and standards for } \\
\text { the management of protected } \\
\text { areas (2013) }\end{array}$ \\
\hline $\begin{array}{l}\text { Strategic plans } \\
\text { and conservation } \\
\text { development } \\
\text { frameworks }\end{array}$ & $\begin{array}{l}\text { Management plans } \\
\text { completed for } 21 \\
\text { protected areas }\end{array}$ & $\begin{array}{l}\text { The establishment of multidisciplinary } \\
\text { management planning teams to guide } \\
\text { the development of action plans and } \\
\text { processes to ensure that the results } \\
\text { from monitoring and research inform } \\
\text { management decisions as part of the } \\
\text { management planning process } \\
\text { Implementation of strategic management } \\
\text { planning through the development and } \\
\text { implementation of the so-called } 71 \text {-Step } \\
\text { Plan } \\
\text { The prioritisation of conservation } \\
\text { development frameworks for protected } \\
\text { areas with high tourism potential and a } \\
\text { process to develop sensitivity zonation of } \\
\text { protected areas }\end{array}$ & $\begin{array}{l}\text { Guidelines for the development } \\
\text { of a management plan for a } \\
\text { protected area in terms of } \\
\text { the NEMPAA (Cowan and } \\
\text { Mpongoma 2010) }\end{array}$ \\
\hline $\begin{array}{l}\text { Advisory } \\
\text { committee/ } \\
\text { neighbours/ } \\
\text { community }\end{array}$ & $\begin{array}{l}\text { The establishment } \\
\text { of protected area } \\
\text { advisory committees } \\
\text { to ensure community } \\
\text { input into protected } \\
\text { area management } \\
\text { planning processes and } \\
\text { implementation }\end{array}$ & $\begin{array}{l}\text { Guidelines for the establishment of } \\
\text { protected area advisory committees } \\
\text { developed }\end{array}$ & \\
\hline
\end{tabular}


CapeNature conducted METT-SA assessments in 2008, 2011, 2012 and 2013 for protected areas, including marine protected areas, and the results are summarised in Table 28.6. METT scores increased from only five protected areas meeting the national norm (5 per cent) in 2008 to 92 protected areas (84 per cent) in 2013.

Initially the METT-SA assessments were met with some resistance by staff, but as CapeNature has evolved and lent support to protected area managers to address the higher-level challenges, their buy-in to this process has been overwhelming. A very valuable lesson learnt has been the role the four regional ecologists have played to ensure consistency in the interpretation of questions and the resulting scoring. This has ensured consistency across the Province. The increase in scores from 2008 to 2011 could largely be attributed to the effort made in ensuring the regional ecologists agreed on the interpretation of the questions. The improvement of METT scores has been linked to individual performance management in CapeNature, which has ensured staff is rewarded for good work.

Table 28.6 CapeNature METT-SA Results
The highest improvement in management effectiveness can be seen where the entire protected area management team, including all support services, works together efficiently. The lowest METT scores have been linked to a lack of teamwork and resources.

The partnership and commitment by all levels of government to address shortcomings have significantly improved management effectiveness in South Africa and Western Cape Province. Continued efforts to improve management effectiveness are bringing good results.

- Gail Cleaver-Christie, CapeNature, Directorate: Conservation Management, Stellenbosch, Republic of South Africa

\begin{tabular}{|c|c|c|c|c|c|c|}
\hline Year & $\begin{array}{l}\text { No. of } \\
\text { protected } \\
\text { areas } \\
\text { assessed }\end{array}$ & $\begin{array}{c}\text { Area } \\
\text { assessed } \\
\text { (ha) }\end{array}$ & $\begin{array}{l}\text { No. of protected } \\
\text { areas with METT- } \\
\text { SA score } \\
>67 \%\end{array}$ & $\begin{array}{c}\text { Percentage } \\
\text { with METT-SA } \\
\text { score } \\
>67 \%\end{array}$ & $\begin{array}{c}\text { Area (ha) } \\
\text { with METT- } \\
\text { SA score } \\
>67 \%\end{array}$ & $\begin{array}{l}\text { Percentage } \\
\text { area (ha) with } \\
\text { a score } \\
>67 \%\end{array}$ \\
\hline 2008 & 93 & 789923 & 5 & 5 & 32192 & 4 \\
\hline 2011 & 97 & 817907 & 36 & 37 & 347936 & 43 \\
\hline 2012 & 100 & 822535 & 54 & 54 & 538020 & 84 \\
\hline 2013 & 111 & 839120 & 92 & 84 & 753818 & 90 \\
\hline
\end{tabular}

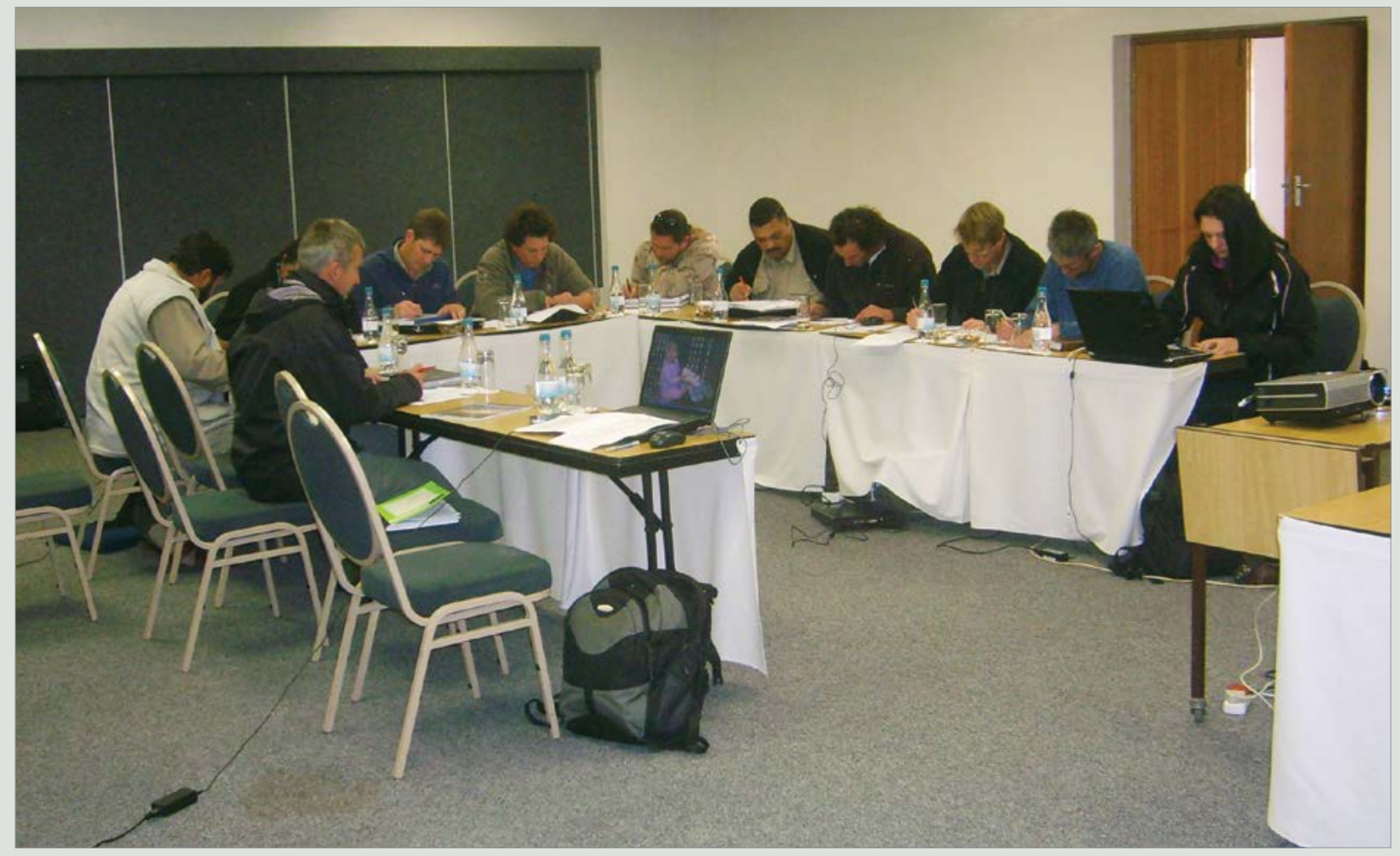

Marine management workshop, Lamberts Bay, South Africa, September 2010

Source: Gail Cleaver-Christie, CapeNature 


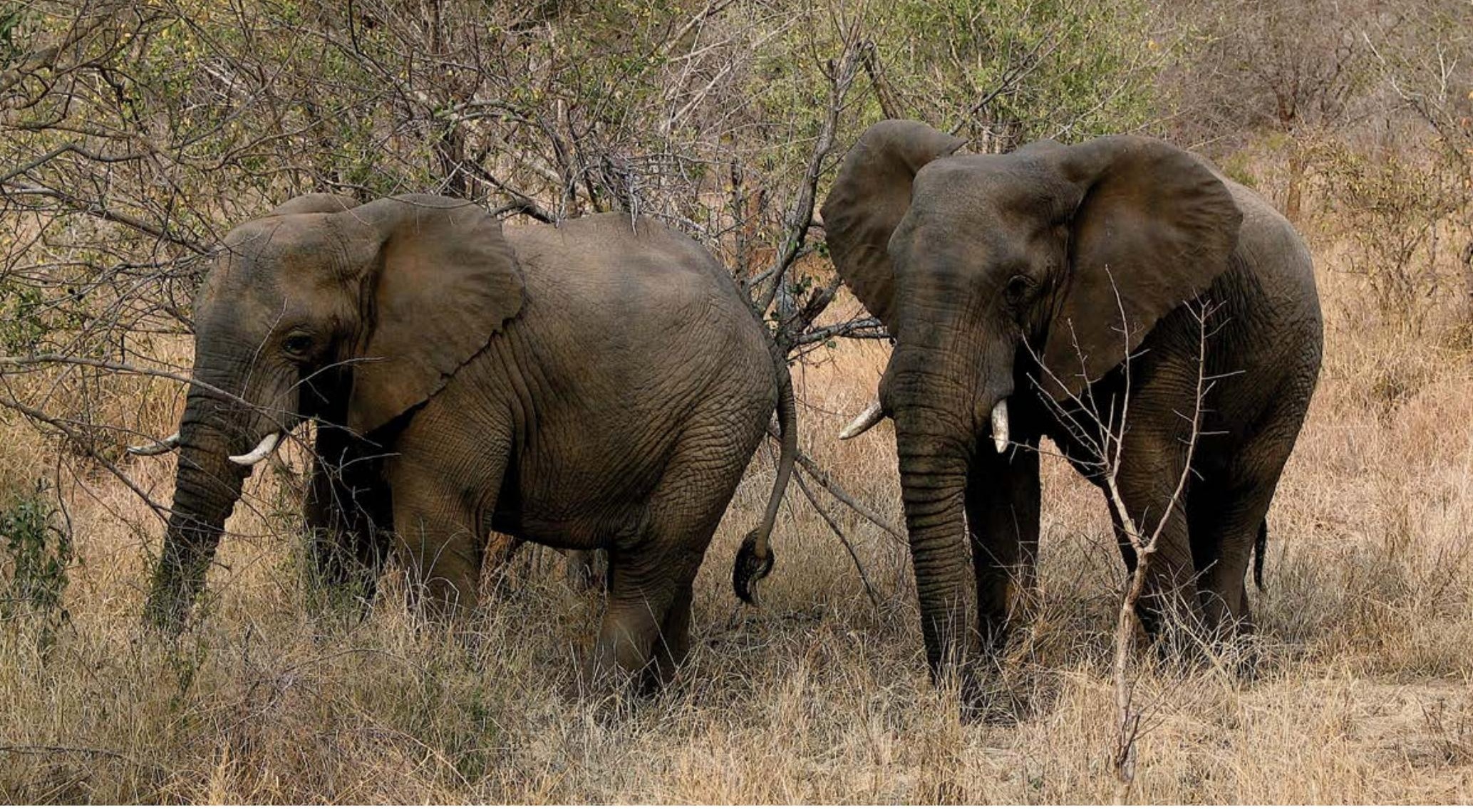

African bush elephants (Loxodonta africana) in Kruger National Park, South Africa. Maintenance of healthy populations of iconic species such as elephants provides powerful evidence of management effectiveness

Source: Ian Pulsford

very successful provided sufficient resources are available. For example, protected areas in South Africa's Eastern Cape Province improved management effectiveness scores by 33 per cent over a three-year period, due to a concerted effort to address management gaps and raise all the reserves to be considered as 'soundly managed' (Jeckelman et al. 2012). Two key factors determine whether evaluation findings will make a practical difference to management:

- a high level of commitment to the evaluation by managers and owners of the protected areas

- adequate mechanisms, capacity and resources to address the findings and recommendations (Hockings et al. 2006).

\section{Conclusion}

Over the past two decades, management effectiveness evaluation has become an integral part of good protected area management. Increasingly, policymakers, senior managers, donors, stakeholders and protected area managers on the ground are looking to this information as a key part of their planning and decision-making armoury. Most importantly, the process of management effectiveness evaluation is becoming institutionalised within management systems. This gives confidence that management effectiveness evaluation will not be a 'passing fad' but part of a contemporary approach to best-practice management. The adaptive approach to planning and management that good PAME can support will certainly be needed if protected areas are to fulfil their role as the key element of global nature conservation efforts. Many challenges remain. Improving the evaluation of social, economic, community and governance aspects of protected area management is one of these. Establishing more explicit standards to guide protected area managers and making the case for more extensive monitoring of key protected area values are others that the IUCN and its WCPA will continue to work on over coming years. 


\section{References}

Recommended reading

Abu-Izzedin, F. (2013) Shouf Biosphere Reserve Management Plan, [Internal document], Shouf Biosphere Reserve, Lebanon.

Ahokumpu, A., Brueggemann, J., Gullbiinas, Z. and Kotiimäkii, T. (2006) 'Management effectiveness of Lithuanian protected areas', in Institutional strengthening and modernization of state protected areas service administrations, Report of Phare Project EuropeAid/114746/D/SV/LT, Savcor Indufor, Metsahallitus, COWI SA, Lithuanian University of Agriculture Consortium, Lithuania.

Allam Harash, K. and El Shaer, H. (2011) Management effectiveness evaluation of two nature reserves in Lebanon (Tyre Coast Nature Reserve-Palm Islands Nature Reserve), Report prepared under IUCN project from the Lebanese Ministry of Environment, Beirut.

Anthony, B. (2008) 'Use of modified threat reduction assessments to estimate success of conservation measures within and adjacent to Kruger National Park, South Africa', Conservation Biology 22: 1497-505.

Barber, C. P., Cochrane, M. A., Souza, C. and Veríssimo, A. (2012) 'Dynamic performance assessment of protected areas', Biological Conservation 149: 6-14.

Birnbaum, M. and Mickwitz, P. (2009) 'Environmental program and policy evaluation: addressing mythological challenges', [Editor's notes], New Directions for Evaluation 122: 1-7.

Bruner, A. G., Gullison, R. E., Rice, R. E. and da Fonesca, G. A. B. (2001) 'Effectiveness of parks in protecting tropical biodiversity', Science 291: 125-8.

Burgman, M. A. (2001) 'Flaws in subjective assessments of ecological risks and means for correcting them', Australian Journal of Environmental Management 8: 219-26.

Butchart, S. H. M. and 42 others (2012) 'Protecting important sites for biodiversity contributes to meeting global conservation targets', PLOS ONE 7: e32529.
Carbutt, C. and Goodman, P. S. (2013) 'How objective are protected area management effectiveness assessments? A case study from the iSimangaliso Wetland Park', Koedoe 55(1): 1-8.

Chambers, R. (1997) Whose Reality Counts? Putting the first last, Intermediate Technology Publications, London.

Cifuentes, M., Izurieta, A. and de Faria, H. (2000) Measuring Protected Area Management Effectiveness, WWF, GTZ and IUCN, Gland.

Coad, L., Leverington, F., Burgess, N. D., Cuadros, I. C., Geldmann, J., Marthews, T. R., Mee, J., Nolte, C., Stoll-Kleemann, S., Vansteelant, N., Zamora, C., Zimsky, M. and Hockings, M. (2013) 'Progress towards the CBD protected area management effectiveness targets', Parks 19: 13-24.

Conservation Measures Partnership (CMP) (2004) Open Standards for the Practice of Conservation, Conservation Measures Partnership. <www. conservationmeasures.org/CMP/Library/CMP Open_Standards_v1.0.pdf>

Conservation Measures Partnership (CMP) (2013) Open Standards for the Practice of Conservation. Version 3.0, Conservation Measures Partnership. <www.conservationmeasures.org>

Convention on Biological Diversity (CBD) (2004) Programme of Work on Protected Areas, Secretariat of the Convention on Biological Diversity, Montreal.

Convention on Biological Diversity (CBD) (2010a) COP 10 Decision X/31, 19a, Secretariat of the Convention on Biological Diversity, Montreal. $<$ www.cbd.int/decision/cop/?id=12297>

Convention on Biological Diversity (CBD) (2010b) COP 10 Decision VII/28, Secretariat of the Convention on Biological Diversity, Montreal. <www.cbd.int/decision/cop/?id=7765>

Convention on Biological Diversity (CBD) (2011) Strategic Plan for Biodiversity and the Aichi Targets, Secretariat of the Convention on Biological Diversity, Montreal. <www.cbd.int/doc/strategicplan/2011-2020/Aichi-Targets-EN.pdf>

Cook, C. N. and Hockings, M. (2011) 'Opportunities for improving the rigor of management effectiveness evaluations in protected areas', Conservation Letters 4: 372-82. 
Cook, C. N., Carter, R. W. and Hockings, M. (2014a) 'Measuring the accuracy of management effectiveness evaluations of protected areas', Journal of Environmental Management 139: 164-71.

Cook, C. N., Carter, R. W., Fuller, R. A. and Hockings, M. (2012) 'Managers consider multiple lines of evidence important for biodiversity management decisions', Journal of Environmental Management 113: 341-6.

Cook, C. N., Hockings, M. and Carter, R. W. (2010) 'Conservation in the dark? The information used to support management decisions', Frontiers in Ecology and the Environment 8: 181-6.

Cook, C. N., Wardell-Johnson, G., Carter, R. W. and Hockings, M. (2014b) 'How accurate is the local ecological knowledge of protected area practitioners?', Ecology and Society 19(2): 32.

Corrales, L. (2004a) Midiendo el éxito de las acciones en las áreas protegidas de Centroamérica: Medición de la Efectividad de Manejo [Measuring the Success of Actions in the Protected Areas of Central America: Measurement of management effectiveness], Tegucigalpa, PROARCA/APM, Guatemala de la Asunción, Guatemala.

Corrales, L. (2004b) Manual for the Rapid Evaluation of Management Effectiveness in Marine Protected Areas of Mesoamerica, PROARCA/APM, USAID and TNC, Guatemala City.

Courrau, J. (1997) Estrategia de monitoreo de áreas protegidas de Centro América, PROARCA/CAPAS, Resultados del Primer Taller de Monitoreo de Areas Protegidas de Centroamérica [Monitoring Strategy for Protected Areas in Central America, PROARCA/ LAYERS: Results of the first workshop on monitoring of protected areas of Central America], Tegucigalpa, Honduras.

Courrau, J. (1999) Strategy for Monitoring the Management of Protected Areas in Central America, PROARCA, CAPAS, CCAD and USAID.

Cowan, G. I. and Mpongoma, N. (2010) Guidelines for the Development of a Management Plan for a Protected Area in terms of the National Environmental Management: Protected Areas Act, 2003. Department of Environmental Affairs, Pretoria.
Cowan, G. I., Mpongoma, N. and Britton, P. (2010) Management Effectiveness of South Africa's Protected Areas, Department of Environmental Affairs, Pretoria.

Dd Cracco, M., Calvopiña, J., Courrau, J., Medina, M. M., Novo, I., Oetting, I., Surkin, J., Ulloa, R. and Vásquez, P. (2006) Fortalecimiento de la Efectividad de Manejo en los Ande, Análisis comparativo de herramientas existentes, UICN, Quito, Ecuador.

de Faria, H. H. (1993) A procedure to measure the effectiveness of protected wildlands management and its application in two protected areas of Costa Rica, MSc thesis, Tropical Agricultural Research and Higher Education Center, Costa Rica.

Department of Environment and Conservation (DEC) (2005) State of the Parks 2004, NSW Department of Environment and Conservation, Sydney.

Development Assistance Committee (DAC) (2006) DAC Evaluation Quality Standards (for Test Phase Application), DAC Evaluation Network, OECD, Paris.

Eken, G., Bennun, L., Brooks, T. M., Darwall, W., Fishpool, L. D. C., Foster, M., Knox, D., Langhammer, P., Matiku, P., Radford, E., Salaman, P., Sechrest, W., Smith, M. L., Spector, S. and Tordoff, A. (2004) 'Key biodiversity areas as site conservation targets', BioScience 54: 1110-18.

Ervin, J. (2002) WWF Rapid Assessment and Prioritization of Protected Area Management (RAPPAM) Methodology, WWF, Gland.

Ervin, J. (2003) 'Rapid Assessment of Protected Area Management Effectiveness in four countries', Bioscience 53(9): 833-42.

Fischhoff, B. (1995) 'Risk perception and communication unplugged-20 years of process', Risk Analysis 15: 137-45.

Foundations of Success, Wildlife Conservation Society and Conservation International (2003) Conservation synthesis for the measuring conservation impact study, Draft.

Geldmann, J., Barnes, M., Coad, L., Craigie, I. D., Hockings, M. and Burgess, N. D. (2013) 'Effectiveness of terrestrial protected areas in reducing habitat loss and population declines', Biological Conservation 161: 230-8. 
Gilligan, B., Dudley, N., Fernandez de Tejada, A. and Toivonen, H. (2005) Management Effectiveness Evaluation of Finland's Protected Areas, Nature Protection Publications of Metsähallitus, Series A 147, Finland.

Green, J. M., Larrosa, C., Burgess, N. D., Balmford, A. Johnston, A., Mbilinyi, B. P., Platts, P. J. and Coad, L. (2013) 'Deforestation in an African biodiversity hotspot: extent, variation and the effectiveness of protected areas', Biological Conservation 164: 62-72.

Growcock, A., Sutherland, E. and Stathis, P. (2009) 'Challenges and experiences in implementing a management effectiveness evaluation program in a protected area system', Australasian Journal of Environmental Management 16(4): 218-26.

Heinonen, M. (2006) 'Case study V: "Management effectiveness evaluation of Finland's protected areas"', in M. Hockings, S. Stolton, N. Dudley, F. Leverington and J. Courrau (eds) Evaluating Effectiveness: A framework for assessing the management of protected areas, pp. 73-8, 2nd edn, IUCN Best Practice Protected Area Guidelines Series, IUCN, Gland.

Heo, H. Y., Hockings, M., Shin, W. W., Chung, H. J., Dudley, N., Shadie, P., Vaisanen, R., Vincent, G., Kim, H., Park, S. Y. and Yang, S. W. (2010) 'Management effectiveness evaluation of Korea's protected area system', Journal of National Park Research 1: 169-79.

Hockings, M. (1998) 'Evaluating management of protected areas: integrating planning and evaluation', Environmental Management 22: 337-45.

Hockings, M. (2003) 'Systems for assessing the effectiveness of management in protected areas', BioScience 53: 810-23.

Hockings, M., Cook, C. N., Carter, R. W. and James, R. (2009a) 'Accountability, reporting, or management improvement? Development of a state of the parks assessment system in New South Wales, Australia', Environmental Management 43: 1013-25.

Hockings, M., Ervin, J. and Vincent, G. (2004) 'Assessing the management of protected areas: the work of the World Parks Congress before and after Durban', Journal of International Wildlife Law and Policy 7: 1-12.
Hockings, M., James, R., Stolton, S., Dudley, N., Mathur, V., Makombo, J., Courrau, J. and Parrish, J. (2008) Enhancing our Heritage Toolkit: Assessing management effectiveness of natural World Heritage sites, UNESCO, Paris.

Hockings, M., Shadie, P., Vincent, G. and Suksawang, S. (2012) Evaluating the management effectiveness of Thailand's marine and coastal protected areas. Report for the Mangroves for the Future project, IUCN Asia Office, Bangkok.

Hockings, M., Stolton, S. and Dudley, N. (2000) Evaluating Effectiveness: A framework for assessing the management of protected areas, IUCN, Gland.

Hockings, M., Stolton, S., Dudley, N. and James, R. (2009b) 'Data credibility: what are the "right" data for evaluating management effectiveness of protected areas?', New Directions for Evaluation 122: 53-63.

Hockings, M., Stolton, S., Leverington, F., Dudley, N. and Courrau, J. (2006) Evaluating Effectiveness: A framework for assessing management effectiveness of protected areas, 2nd edn, IUCN Best Practice Protected Area Guidelines Series, IUCN, Gland.

Izurieta, A. (1997) Evaluación de la eficiencia del manejo de áreas protegidas: validación de una metodología aplicada a un subsistema de áreas protegidas y sus zonas de influencia, en el Área de Conservación Osa, Costa Rica [Evaluation of the effectiveness of the management of protected areas: validation of a methodology applied to a subsystem of protected areas and their zones of influence in the Osa Conservation Area, Costa Rica], MSc thesis, Turrialba, CATIE, Costa Rica.

Jaradi, G. R. and Matar, D. (2012) Jabal Moussa Biosphere Reserve Management Plan 2013-2023, [Internal document], Association for the Protection of Jabal Moussa, Lebanon.

Jeckelman, J., Fielding, P. and Norval, M. (2012) ECPTA Provincial Nature Reserves METT Assessment Report 2012, Eastern Cape Parks and Tourism Agency, East London, South Africa.

Keene, M. and Pullin, A. S. (2011) 'Realizing an effectiveness revolution in environmental management', Journal of Environmental Management 92: $2130-5$. 
Kelman, J. (2010) Analysis of Protected Area Management Effectiveness Evaluation Data and its Application for Increasing Understanding of Management, University of Queensland, Brisbane.

Korean National Parks Service (2009) Korea's Protected Areas: Evaluating the effectiveness of South Korea's protected areas system, Korean National Parks Service, Seoul.

Kusek, J. Z. and Rist, R. C. (2004) Ten Steps to a Results-Based Monitoring and Evaluation System: A handbook for development practitioners, The World Bank, Washington, DC.

Leeuw, F. L. and Furubo, J. E. (2008) 'Evaluation systems: what are they and why study them?', Evaluation 14: 157-69.

Leverington, F., Costa, K., Pavese, H., Lisle, A. and Hockings, M. (2010a) 'A global analysis of protected area management effectiveness', Environmental Management 46: 685-98.

Leverington, F., Costa, K. L., Courrau, J., Pavese, H., Nolte, C., Marr, M., Coad, L., Burgess, N., Bomhard, B. and Hockings, M. (2010b) Management Effectiveness Evaluation in Protected Areas: A global study, 2nd edn, University of Queensland, IUCN WCPA, TNC and WWF, Brisbane.

Dd Leverington, F., Hockings, M., Pavese, H., Costa, K. T. and Courrau, J. (2008) Management effectiveness evaluation in protected areas - a global study. Supplementary report No. 1: Overview of approaches and methodologies, University of Queensland, TNC, WWF and IUCN WCPA, Brisbane.

Dd Leverington, F., Kettner, A., Nolte, C., Marr, M., Stolton, S., Pavese, H., Stoll-Kleeman, S. and Hockings, M. (2010c) 'Protected area management effectiveness assessments in Europe: overview of European methodologies', BfN-Skripten 271b, German Federal Agency for Nature Conservation, Vilm, Germany.

Likert, R. (1932) 'A technique for the measurement of attitudes', Journal of Social Psychology 5: 228-38.

Margoluis, R., Stem, C., Salafsky, N. and Brown, M. (2009) 'Using conceptual models as a planning and evaluation tool in conservation', Evaluation and Program Planning 32: 138-47.
Margules, C. R. and Pressey, R. L. (2000) 'Systematic conservation planning', Nature 405: 243-53.

Martin, T. G., Burgman, M. A., Fidler, F., Kuhnert, P. M., Low-Choy, S., McBride, M. and Mengersen, K. (2010) 'Eliciting expert knowledge in conservation biology', Conservation Biology 26: 29-38.

Matar, D. A. and Anthony, B. P. (2010) 'Application of modified threat reduction assessments in Lebanon', Conservation Biology 24: 1174-81.

Mayorquin, A., Valenzuela, S. and Rangel Ch, J. (2010) 'Evaluación de la efectividad de manejo en reservas naturales de la sociedad civil: una propuesta metodológica [Evaluation of the effectiveness of management in natural reserves of civil society: a methodological proposal]', Caldasia 32: 381-97.

National Reserve System Task Group, Natural Resource Management Ministerial Council (NRMMC) (2009) Australia's Strategy for the National Reserve System 2009-2030, National Reserve System Task Group, Natural Resource Management Ministerial Council, Canberra.

Dd Nolte, C., Leverington, F., Kettner, A., Marr, M., Nielsen, G., Bomhard, B., Stolton, S., StollKleeman, S. and Hockings, M. (2010) 'Protected area management effectiveness assessments in Europe: a review of applications, methods and results', BfN-Skripten 271a, German Federal Agency for Nature Conservation, Vilm, Germany.

Paleczny, D. (2010) Protected Area Assessment and Reporting: An examination of current approaches and evolving needs with application of an integrated model in Egypt, University of Greenwich, UK.

Paleczny, D. R. and Russell, S. (2005) 'Participatory approaches in protected area assessment and reporting', in Proceedings of the Parks Research Forum of Ontario, pp. 87-95, University of Guelph, Ontario.

Parks Victoria (2007) Victoria's State of the Parks Report, Parks Victoria, Melbourne.

Parrish, J., Braun, D. P. and Unnasch, R. S. (2003) 'Are we conserving what we say we are: measuring ecological integrity within protected areas', BioScience 53: 851-60.

Patton, M. Q. (1997) Utilization-Focused Evaluation: The new century text, 3rd edn, Sage, Thousand Oaks, CA. 
Patton, M. Q. (1998) 'Discovering process use', Evaluation 4: 225.

Petheram, L., Stacey, N., Campbell, B. M. and High, C. (2012) 'Using visual products derived from community research to inform natural resource management policy', Land Use Policy 29: 1-10.

Purnell, K. Kirkwood, D. and Maree, K. (2010) CapeNature Protected Area Expansion Strategy and Implementation Plan 2010-2015. CapeNature, Bridgetown, South Africa.

Regan, H. M., Colyvan, M. and Burgman, M. A. (2002) 'A taxonomy and treatment of uncertainty for ecology and conservation biology', Ecological Applications 12: 618-28.

Saaty, T. (1995) Decision Making for Leaders: The analytical hierarchy process for decisions in a complex world, RWS Publications, Pittsburgh.

Salafsky, N. and Margoluis, R. (1999) 'The threat reduction assessment (TRA) approach to measuring conservation success: a practical and cost-effective framework for evaluating project impact', Conservation Biology 13: 830-41.

Salafsky, N., Margoluis, R. and Redford, K. (2001) Adaptive Management: A tool for conservation practitioners, Biodiversity Support Program, Washington, DC.

Salafsky, N., Salzer, D., Stattersfield, A. J., HiltonTaylor, C., Neugarten, R., Butchart, S. H. M., Collen, B., Cox, N., Master, L. L., O’Connor, S. and Wilkie, D. (2008) 'A standard lexicon for biodiversity conservation: unified classifications of threats and actions', Conservation Biology 22: 897-911.

Saterson, K. A., Christensen, N. L., Jackson, R. B., Kramer, R. A., Pimm, S. L., Smith, M. D. and Wiener, J. B. (2004) 'Disconnects in evaluating the relative effectiveness of conservation strategies', Conservation Biology 18: 597-9.

Scharlemann, J. P., Kapos, V., Campbell, A., Lysenko, I., Burgess, N. D., Hansen, M. C., Gibbs, H. K., Dickson, B. and Miles, L. (2010) 'Securing tropical forest carbon: the contribution of protected areas to REDD', Oryx 44: 352-7.

Sechrest, L. and Sidani, S. (1995) 'Quantitative and qualitative methods: is there an alternative', Evaluation and Program Planning 18: 77-87.
Selig, E. R. and Bruno, J. F. (2010) 'A global analysis of the effectiveness of marine protected areas in preventing coral loss', PLoS One: 5(2). <doi:10.1371/journal.pone.0009278>

Sims, K. R. E. (2010) 'Conservation and development: evidence from Thai protected areas', Journal of Environmental Economics and Management 60: 94-114.

Sims, K. R. E. (2014) 'Do protected areas reduce forest fragmentation? A microlandscapes approach', Environmental and Resource Economics 58: 303-33.

Speirs-Bridge, A., Fidler, F., McBride, M., Flander, L., Cumming, G. and Burgman, M. (2010) 'Reducing overconfidence in the interval judgments of experts', Risk Analysis 30: 512-23.

Stacey, N., Izurieta, A. and Garnett, S. T. (2013) 'Collaborative measurement of performance of jointly managed protected areas in northern Australia', Ecology and Society 18(1): 19.

Stanišić, N. (2009) Results of the Initial Evaluation of Protected Area Management in Montenegro using RAPPAM Methodology, Ministry of Tourism and Environment of Montenegro and WWF Mediterranean Program, Podgorica.

Stem, C., Margoluis, R., Salafsky, N. and Brown, M. (2005) 'Monitoring and evaluation in conservation: a review of trends and approaches', Conservation Biology 19(2): 295-309.

Stolton, S., Hockings, M., Dudley, N., MacKinnon, K., Whitten, T. and Leverington, F. (2007) Reporting Progress in Protected Areas: A sitelevel management effectiveness tracking tool, 2nd edn, World Bank/WWF Forest Alliance, Gland.

The Nature Conservancy (TNC) (2000) The Five-S Framework for Site Conservation: A practitioner's handbook for site conservation planning and measuring conservation success, The Nature Conservancy, Arlington, VA.

The Nature Conservancy Parks in Peril Program (2004) Measuring Success: The Parks in Peril site consolidation scorecard manual, [Updated 10 May], The Nature Conservancy, Arlington, VA.

Timko, J. and Innes, J. (2009) 'Evaluating ecological integrity in national parks: case studies from Canada and South Africa', Biological Conservation 142: 676-88. 
Protected Area Governance and Management

United Nations Development Programme (UNDP) (2009) Handbook on Planning, Monitoring and Evaluating for Development Results, UNDP, New York.

Widger D. (ed.) (2012) 'Letter 1 Bath, October 9, 1746', in The Project Gutenberg Edition of Chesterfield's Letters to His Son, by the Earl of Chesterfield, Project Gutenberg. <snowy.arsc.alaska. edu/gutenberg/3/3/6/3361/3361-h/3361-h.htm>

Woodley, S., Bertzky, B., Crawhall, N., Dudley, N., Londoño, J. M., MacKinnon, K., Redford, K. and Sandwith, T. (2012) 'Meeting Aichi Target 11: what does success look like for protected area systems', Parks 18: 23-36. 


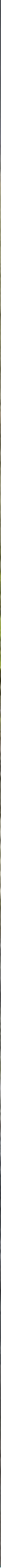

\section{CHAPTER 29}

CONCLUSION

Principal authors:

Sue Feary, Ashish Kothari, Michael Lockwood, lan Pulsford and Graeme L. Worboys

IUCN 


\section{PRINCIPAL AUTHORS}

SUE FEARY is an archaeologist and national park manager, with 25 years' experience in management of natural and cultural heritage and consulting with Aboriginal Australians.

ASHISH KOTHARI is a founding member of Indian environmental group Kalpavriksh, has taught at the Indian Institute of Public Administration, co-chaired the International Union for Conservation of Nature (IUCN), Theme Group and Strategic Direction on Governance, Livelihoods, Equity in Relation to Protected Areas, and helped found the global ICCA Consortium.

MICHAEL LOCKWOOD is an Associate Professor, Geography and Spatial Science, School of Land and Food, University of Tasmania, Australia.

IAN PULSFORD is an independent consultant and is a member of the International Union for Conservation of Nature, World Commission on Protected Areas (IUCN WCPA), Connectivity Conservation and Mountains theme, Australia.

GRAEME L. WORBOYS is Co-Vice-Chair, Connectivity Conservation and Mountains theme, IUCN WCPA and an Adjunct Fellow at the Fenner School, The Australian National University.

\section{CITATION}

Feary, S., Kothari, A., Lockwood, M., Pulsford, I. and Worboys, G.L. (2015) 'Conclusion' in G. L. Worboys, M. Lockwood, A. Kothari, S. Feary and I. Pulsford (eds) Protected Area Governance and Management, pp. 929-932, ANU Press, Canberra.

\section{TITLE PAGE PHOTO}

Cascading waterfalls over natural travertine ramparts and associated boardwalks and visitors, Plitvice Lakes National Park World Heritage Property, Croatia. The park is famous for its superlative limestone karst scenery, its 20 lakes; cliff-lined valley scenery, travertine waterfalls, and its associated natural fauna and flora. It is a well-managed and popular tourist destination, and receives about 1.2 million visitors per annum.

Source: Graeme L. Worboys 
This book has demonstrated that protected areas make a significant contribution to the conservation of the Earth's biodiversity, geodiversity and cultural heritage. They help to maintain ecological processes and functions that are essential for the health and wellbeing of ecosystems and people, and they mitigate the impacts of climate change. They are an intergenerational investment. At a time when human impacts on Earth are rapidly increasing and as pressures on the world's species and ecosystems intensify, protected areas are subject to ever more threats and demands for unsustainable use-and they are becoming increasingly important.

Although protected areas are now a significant presence in almost all parts of the globe, more reservations are needed, particularly in marine environments, if the Earth's natural and cultural heritage is to be conserved. In addition to their extent, the effectiveness of protected areas in achieving their objectives is a key consideration. It is clear that designation is not sufficient on its own to guarantee that they are effective in conserving natural and cultural heritage values. Even as protected area coverage has increased, biodiversity loss has been steadily rising, despite the fact that wildlife populations in protected areas are doing better than the global average. This is a sobering reminder that much needs to be done to: (a) make protected areas more effective; and (b) spread conservation practices across various other kinds of land and water uses including recognising other effective areabased conservation measures.

The diverse social, cultural, economic, political and environmental contexts in which protected areas are embedded demand complex choices about appropriate forms of governance and suitable management approaches. Ethical integrity and effectiveness in achieving outcomes are two essential guides for such choices. As laid out in a number of chapters in this book, diversifying the system of protected areas in each country to include government-managed, indigenous people's and local community conserved, privately protected, and co-governed areas has great potential to increase and make more effective conservation coverage. There is a need to ensure that protected areas are governed according to principles of legitimacy, equity, participation, transparency and respect for local rights. Each protected area also needs mechanisms for monitoring and evaluation that test whether outcomes are in accordance with management objectives, and provide a foundation for learning and improvement.

There is much to be done on diversification of governance types, and on good governance principles; on synergistic use of various forms of knowledge including local/ traditional and scientific; on recognising various world views and modes by which conservation is achieved; and on expanding these beyond protected areas into the landscape and seascape in general such that conservation is not restricted to islands while the rest of the Earth is heading towards ecological decline.

Protected areas are highly dynamic, requiring sevendays-a-week, 24-hours-a-day operations that address a wide range of historical, contemporary and emergent threats. At a global level, the most pressing and pervasive of these is climate change and there is a need for governance and management to respond by either supporting social-ecological resilience or negotiating system transformation with minimum loss of value. Constant change and complexity are the norm. There is no panacea; no one size fits all. Again, diverse governance forms and management approaches, supported by diverse forms of knowledge, need to be deployed, tested and refined, or discarded, through ongoing learning and adaptation or transformation.

This book and its predecessors highlight increasing global recognition of the need for professionalism in protected area governance and management and the fostering of skilled community conservation practitioners, the latter commonly building on holistic ways of life in which conservation is an inherent characteristic. The International Union for Conservation of Nature World Commission on Protected Areas has been acutely aware of the need to invest in this and subsequent generations of protected area governors and managers - the book is a response to this need. Book chapters have provided information that will assist capacity development of people in field and operational management as well as those in senior and executive positions across all categories of protected areas. This information is part of a long-term investment by the International Union for Conservation of Nature in the ethical and effective governance and management of protected areas around the world.

As with any text, this book captures moments in the continuing evolution of protected area management and governance and its guiding philosophies. It is about a 21 st-century approach, but has shown how this approach is framed and informed by temporal change on two fronts. On the one hand are the biocultural traditions, knowledge, practices and world views of indigenous peoples and local communities who are driving social change. Key themes in this change are adoption of ecologically sustainable development principles, respect for social justice and rights, recognition of biocultural knowledge and traditions, and alleviation of poverty. These themes were eloquently articulated at the 2003 World Parks Congress in Durban and included in the 


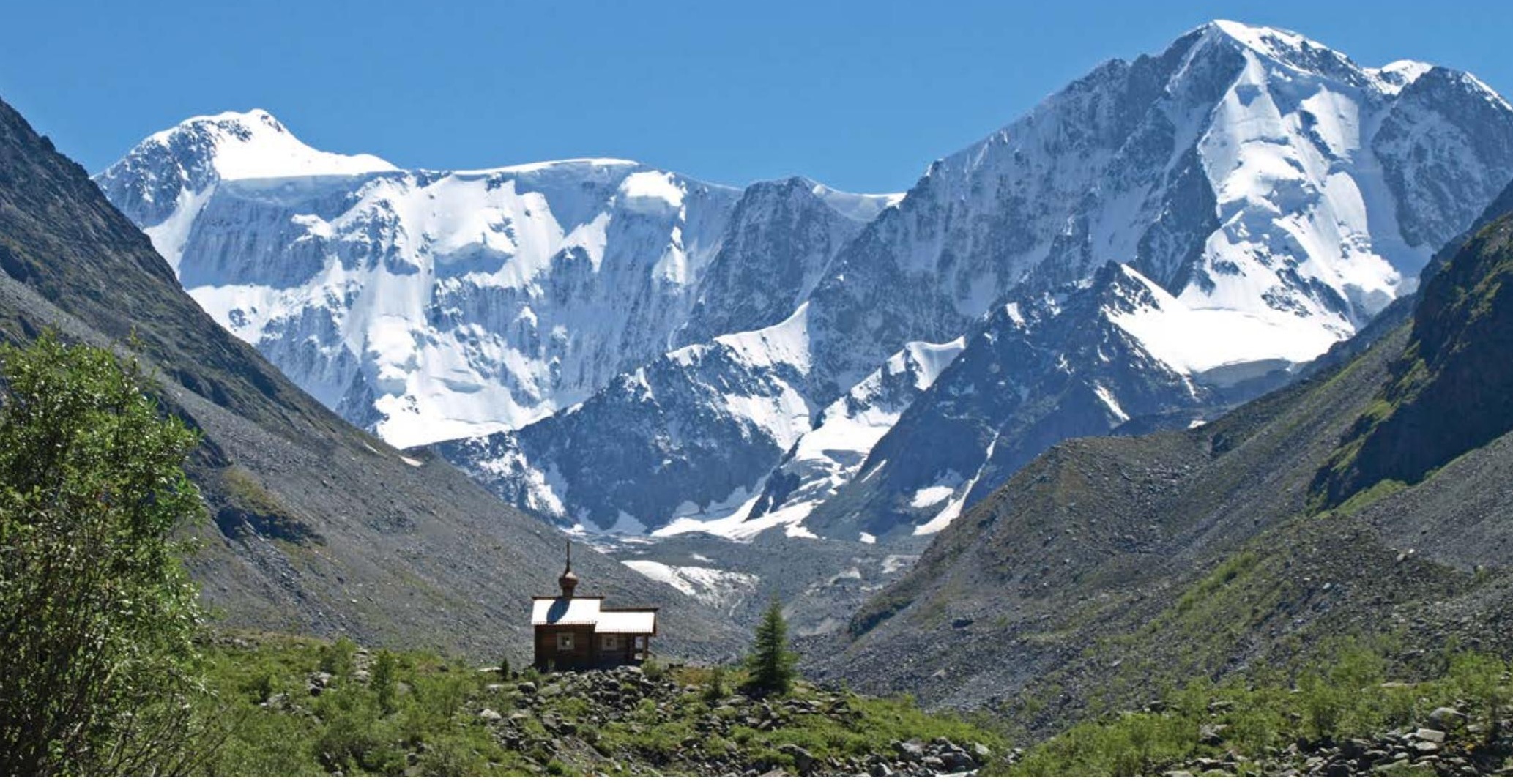

Mount Belukha (4,506 metres) and the Brothers of Tronov Glacier, Golden Mountains of Altai World Heritage Property, Altai Republic, Russia. The mountain and its glacier are the headwaters of the Katun River, a tributary to the mighty Ob River that flows all the way to the Arctic Ocean. Mount Beluka is a protected area, it is of special spiritual and cultural importance to many peoples and it is an important destination for visitors.

Source: Graeme L. Worboys

Convention on Biological Diversity's Programme of Work on Protected Areas. On the other hand are the great advances in science and technology that are enabling sophisticated systems for capturing data on the biophysical environment and monitoring environmental and behavioural change, which in turn inform effective management responses.

Compared with a similar book written, say 25 years ago, now, protected areas have become more numerous, exist in more diverse forms and have become more multi-functional. They have also become increasingly important for protecting natural and cultural systems in the face of cumulative development and industrial-scale resource extraction. Increasingly they are seen as critical for equitable human wellbeing. They exist at a time of geopolitical and climatic uncertainties and unpredictable waxing and waning in citizen support. This book has teased out these challenges and shown ways of dealing with them.

Finally, this book is not only about how to manage and govern protected areas through human capacity building; it also has persuasive arguments as to why protected areas are critical. Inevitably the how will change over time but we are optimistic that investments in the why will be enduring commitments by peoples, communities and nations of Earth. 


\section{Index}

Abel Tasman Birdsong Trust 435

Abel Tasman National Park 435

Aberdare National Park 164

abiotic 73, 534

characteristics 54,557

conservation 546,552

dynamics 162

elements 541, 592, 596, 653, 658

environment 53, 739

interests 557,559

nature 50,541

processes 533, 538, 540-1, 551, 547

stage of existence 539,541

Aboriginal (Australian) 13, 85, 86, 94, 103, 430, 697, 770

archaeological sites 90, 246, 710

'caring for country' $86,103,408,592$

connections to sea $620,628,691$

cultural heritage 90, 246, 405, 432, 523, 770

Dreaming 701

fire management 85, 199, 797

knowledge 399, 431, 432, 698, 708

land management 94, 138, 434-5, 592, 880, 909

rainforest peoples 197

rock art 88, 100, 708

sacred species 13,86

significant sites 432, 708, 696, 770-1

see also Indigenous Protected Areas

aboriginal 188, 199, 227, 365, 664

Aboriginal and Torres Strait Islander 628

Access and Benefit Sharing of Genetic Resources

(ABS Protocol) 137

'access and benefit sharing' (ABS) 160, 229

accidents 239, 423, 464, 757, 825, 826, 832

acidification 50, 120, 152, 498, 499, 599, 618, 633

action plans 384, 395, 780, 785, 899, 920

approval of 763

capacity 268

capacity development 267, 277

'Durban Action Plan' 226

for emissions reduction 510-11

for marine areas 622

for operations 759, 762

for species 261, 575

for threat management 481, 482

global 723

implementation 342, 699

incident 829, 833, 837, 838, 839, 840, 841

local biodiversity 549

local geodiversity action plans (LGAPs) 549

'Madrid Action Plan' 24 working with xxiv

see also conservation action planning, UK Geodiversity Action Plan

adaptability 182, 407, 633

adaptation 45,46

assets 784

and capacity development 269

of ecosystems 289, 300, 659

of flora 62, 152

of humans $84,96,171,200$

management 322, 860, 931

monitoring and evaluation 630

planning 390, 408

of systems 303

strategies 538

adaptation to climate change $130,152,272,436$,

501-2, 571

autonomous 595

benefits of 164,596

challenges 270,518

definitions 269, 502

ecosystem-based responses 512, 592, 596

of ecosystems $583,586,881$

education 289

of fauna $164,504,506,881$

of flora 504, 881

of habitat 152

of humans $164,512-13$

management 512, 518, 519, 595

natural solutions 526, 538, 539, 599

'no regrets' measures 596, 597

policy 419, 514

potential for 519

preparation 513

responses $497,502,503,520$

solutions 270

strategies 272, 538, 595, 799

supporting 395, 502, 596

adaptive 31

capacity 212, 262, 264-5, 388, 518, 523, 633

cycle 312

processes 199, 318

radiation 47

responses 50, 475, 526, 581

reuse $707,755,771$

adaptive governance 194, 195, 198, 299, 321, 523, 869

absence of 303

approach 295, 389

challenges of 196

ideas 416,417 
need for 201

requirements for 300

learning 342, 388

adaptive management 182, 227, 253, 302, 321, 482

accomplishing 271, 483, 429

actions 513, 644

approach 190, 246, 265, 391, 487, 575, 630, 740, 894, 900, 922

components of $315,335,392$

concept 195, 222, 298, 302, 416, 417

definitions 222, 416, 467

evaluation 899, 906

forms of 578

framework 407, 437

guiding principles 692,758

implementation 246, 319, 523, 858

need for 295, 520, 581

potential for 598,723

practices 239, 331, 633

regime 397,408

response 483, 492

strategies 220, 398, 523, 896, 629

support for $17,717,893-5,897,900$

tools 331, 332, 405, 406, 914, 919

adaptive planning $302,388,390-1,392,404,406-8$, 430, 746, 922

Addis Ababa Principles and Guidelines for the Sustainable Use of Biodiversity (AAPG) (2004) 122, 123, 130

Adriatic Sea 379, 873

advocacy 263, 360, 403, 433, 434

approaches 388

by IUCN 810,812

engaging in 190

organisations 360, 394, 418, 581

planning 394

pressures 30

Africa 12, 62, 85, 804, 805

archaeological heritage 88-9

biodiversity 15,575

biomes 56, 60

colonisation 12

customary rights 129,193

environmental issues 137, 148

extractive industry 133,556

human origins in 49,83

invasive species 475, 488, 669

land privatisation 136

marine protected areas 257,796

poaching 757

protected area history 123,875

protected area management 658, 665, 720, 727, 794

protected area monitoring 484,898

protected areas $126,367,484,797,897$

ranger deaths 239 resource management 795, 801, 803

sacred sites 97, 123

species conservation $45,186,797,801,803$

species migration $60,65,522$

threat management 492

wetlands 572, 591

see also Central Africa, East Africa, eastern Africa,

Horn of Africa, North Africa, northern Africa, southern Africa, sub-Saharan Africa, West Africa

African Biodiversity Network 138

African Charter of Human and Peoples' Rights 129

African Convention on the Conservation of Nature and Natural Resources 876

African Field Ranger Training Services 288

Agave Landscape and Ancient Industrial Facilities of Tequila 104

agricultural

areas $15,26,581,854$

biodiversity $28,694,804$

conservation 418

conversion of land 148, 478, 479, 536

cycles 99

demands 30, 578

development 28, 85, 293, 577, 578, 669, 793, 855

ecosystems 28,152

encroachment 373, 668

land 294, 858, 878

landscapes 104

policy $135,667,668,807$

practices 239,878

productivity 503,805

run-off 634,639

systems 84, 149, 511

transformation 147,401

use $137,537,766$

waste 639

agriculture 791, 867, 871, 902

agencies xxiv, 308, 318, 798, 804, 832

changes in 536,798

commercial 401, 804-5

decision-making 135, 268

early $84,88,92,101,547$

employment in 164

expansion of 293, 537

and genetic modification 119

land transformation 65, 123, 147, 148, 401, 536

and pollination 153

pressure on 151

pressures of $30,172,402$

and protected areas 370, 394, 727

protection of 107

and quarantine 236, 237

slash-and-burn 85, 672

small-scale 135 
subsistence $164,430,401,804$

threats from 669

traditional 102, 159

water for $48,244,572,578,586,865$

agro-biodiversity 28, 101, 689, 694, 695, 804, 805

agro-ecosystems 807

agro-environmental 162

agro-fuel 482

agro-industry 577

agroforestry 805

agronomy 270

agrotourism 727

Aichi Biodiversity Target 11 121, 132, 178, 198

achieving xxi, 612, 891

contents 28, 66, 254, 33, 394, 644, 876, 891

goals of 30,223

progress 179, 223, 224, 334, 644

requirements xxi, 67,340 ,

Aichi Biodiversity Target 5876

Aichi Biodiversity Target 12395

Aichi Biodiversity Target 14876

Aichi Biodiversity Targets xxi, 66, 261, 333, 335, 395, 622

goals of 223, 254, 616, 896

progress $72,121,616,891,896$

Alaska 61, 547

alien invasive species, see invasive species

Alliance for Religions and Conservation 697

Alliance for Zero Extinction (AZE) 6, 53, 63, 70-2, 346, 892

Alpi Marittime-Mercantour trans-frontier protected area 766

alpine 58, 62, 505, 760

flora 405, 492, 540, 741

landscapes 492, 547, 805

resorts 405,770

stock grazing $171,334,806$

see also subalpine

Alpine Convention (1991) 877

Alpine National Park 332, 770, 805

fire management 446, 760, 767

pest species $676,759,776,918$

visitor facilities 752,782

Altai 498, 535, 932

Altai Mountains 3, 60

Altai Republic 17, 373, 498, 693, 932

see also Golden Mountains of the Altai

Altai-Sayan Mountains 160, 240, 873

altruism 121, 123, 127, 241

Amazon Basin 55, 104, 265, 308, 793

Amazon region 308, 309, 336, 797

Amazon River 59, 726

Amazonia 150, 349, 664

Amber Mountain National Park 155

Amboseli National Park 164, 793
American Alpine Club (AAC) 437

'analytical hierarchy process' 916

Ancestral Domain Sustainable Development and Protection Plans (ADSDPP) 403

'ancillary conservation' 177, 178, 181, 200

Andes Mountains 56, 60, 102, 308, 378, 688, 689, 691, 694, 902

Angkor 12, 90, 490, 709, 727

Animal Health for the Environment and Development (AHEAD) initiative 302

animals 11, 58, 454, 585, 702, 741, 870

and adaptation 60, 61, 575

aquatic $575,580,669$

attitudes to $307,310,338$

conflict with humans 239, 245, 485, 489, 797, 833

culturally significant 93, 94, 99, 101, 369, 700

density 127, 488, 489, 906

description 53,319

disease 245, 293, 669, 670

distribution 51, 299, 504, 506, 635, 844

diversity $61,575,653,694$

domestic 94, 691, 739, 806

exploitation of $6,369,579$

functions of $48,52,663$

habitat 27, 161, 213, 216, 405, 408, 540, 590, 591

health 391, 639

husbandry 798

impacts on 490, 739, 740, 768

introduction of 301

killing of $110,478,485,489,669,739$

management 367,399

marine $62,65,611,626$

migration $200,216,577,854,856,874$

native $246,434,435,754,768,772,844,870$

in nature $52,533,571$

pack 288, 720, 721, 741, 779

protection of 12,189

research 229

as resource $84,107,225,293,403,669,698,800,801$

rights $294,305,309,314,357,423,426$

terrestrial 47, 669

tourism 165

see also bushmeat, culling, dangerous animals, hunting, pest animals, poaching

Antarctic

biomes 56, 61

ice cap 49, 498

Peninsula 535

Treaty 877

waters 614

Antarctica 3, 30, 63, 66, 67, 68, 216, 858

human impact on $28,85,104$

Anthropocene 119, 120, 139, 171

anthropocentrism 124 
anthropogenic 157, 552, 592

climate change, see climate change-anthropogenic

ecosystems 246

emissions 498

impacts 615, 643

interventions 502, 560

sea-level rise 536

anthropology 88, 93, 94, 196, 270, 298

Appalachian 161, 859

'appropriate activity assessment' (AAA) 743, 744

aquifers 150, 172, 174, 194, 200, 522, 576, 583, 585, 599

Arabian Peninsula 149

Aral Sea 572

archaeological

heritage 88-90, 93, 94, 585, 621, 705, 767

record $83,84,85,88,89,90,101$

sites $88,89,90,108-10,546,687,709,710$

archaeology 88-90, 92, 93, 95, 96, 108, 558, 709, 710, 771

Arctic 61, 85, 94, 388, 498, 499, 500, 540, 932

Arctic Laponian Area 94

Area de Proteçao Ambiental (environmental protection area) 691

area-based conservation $26,53,120,136,140,171,173-9$, 189, 193, 198, 199, 491, 613, 614, 627, 633, 877

see also other effective area-based conservation measures

'areas of interest' (AOIs) 624

Argentina 547, 662, 794, 808

Arkhangelsk 165

Armenia 151

Asia 89, 430, 475, 492

animals 58, 61, 653

biomes 51, 57, 58, 60

capacity building 288, 289

colonisation 12

cultural heritage 705, 801

customary recognition 193

economic engagement 133

land use 701, 804, 805, 808

medicine market 32

protected area management 476, 484, 898

value of nature $97,98,126$

wetlands 572, 591

see also Central Asia, East Asia, South Asia,

South-East Asia

Asia Parks Congress (APC) 126

Asia-Pacific 290

asset information system (AIS) 782, 784

asset management 385, 519, 522, 641, 753, 759, 765,

769, 780, 781-4, 918

asset management systems (AMSs) 219, 522, 525, 755,

781, 782-3, 784, 786, 832
Association of South-East Asian Nations (ASEAN) 275, 343

Regional Centre for Biodiversity Conservation 275,

342,343

'associative landscapes' 104, 691

Atherton Tableland 865

Athonite Peninsula 699

Atlantic Ocean 186, 244, 549, 614, 626, 627, 635, 640

atmosphere 47-9, 54, 73, 120, 140, 151, 152, 157, 194, $497,499,502,504,524,525,827,829$

atmospheric

change 50,120, 844

circulation 48, 631

composition 47, 828, 844

conditions $73,769,826,842$

oxygen $47,48,611$

pollution $30,226,497,826$

pressure 48

system 572

turbulence 45

Augrabies Falls National Park 89

Australasia 56, 67, 83, 289

Australasian Fire and Emergency Service Authorities Council 834

Australasian Inter-service Incident Management System (AIIMS) 834, 835, 837, 838, 841

Australia 94, 99, 105, 139, 801, 878

biodiversity 397,595

biomes $57,58,61,106,397,575$

climate change $504,523,827$

colonisation $12,85,94,133,770$

cultural heritage 95, 246

customary recognition 193, 432, 697

economy 621

ecosystems 85, 99

education 270,710

fauna 99, 226, 505

fire $85,485,511,755,828,829,837,843$

flora 507

foreign aid 711

geoheritage 545,547

Government 26, 139, 199, 227, 396, 399, 435, 628,

691, 703, 802

incident management 834-7

invasive species 485

land clearing 100

media 448

mining 482

National Heritage register 708

National Reserve System (NRS) 26, 396, 397, 434

Open Standards application 408

refugees 98-9

States and Territories 103, 397, 880, 905

tourism 735, 745

water resources 405, 579, 598 
see also Aboriginal (Australian), Indigenous Protected Areas (Australian), individual States and Territories

Australian conservation 877, 879

attitudes to 13,397

connectivity projects $592,859,868,873,880$

frameworks 218, 227

management 753

planning 396, 593

policy 396,397

Australian protected areas 90, 154, 198, 396, 718, 897

collaboration 288-9

management 45, 94, 399, 430, 629

management assessment 891, 893, 907, 914, 918

marine protected areas (MPAs) 611, 614, 644

planning 403, 660

private protected areas 21, 26, 192, 434-5, 727, 874

Australian Aboriginal, see Aboriginal (Australian)

Australian Alps xxii, 151, 334, 447, 492, 507, 676, $770-1,805$

Australian and New Zealand Environment and

Conservation Council 396

Australian Bureau of Rural Sciences 759

Australian Capital Territory (ACT) xxii, 753, 880

Australian Centre for International Agricultural Research (ACIAR) 270

Australian Environmental Grantmakers Network 434

Australian Wildlife Conservancy 26, 434, 727

Badrinath 701, 702

Baffin Island 629

Bahamas 620, 730

Baja California 127, 635

Balkans 159, 701

Banc d'Arguin 486

Banff 665

Banff National Park 23, 82, 366, 496, 511, 526

visitors 210,718

wildlife 365, 433, 662

Bangladesh 62, 789-90

Basarwa ('Bushmen') 793

Batwa ('Pygmies') 793

Bayesian 758, 759

beauty $11,12,15,30,51,64,101,102,104,154,181$, $183,210,394,434,435,544,702,766$

bees 30, 153, 160, 461, 663, 693. See also insects

Belarus 289

Belgium 691

Belize 150, 153, 191, 859

Ben Boyd National Park 216, 696

bequest values 107, 156, 157, 161, 509

Bering Strait 83

Bern Convention, see Convention on the Conservation of European Wildlife and Natural Habitats best practice $176,228,238,253,272,276,338,339$, $342,386,592,658,672,915$

approach 24, 406

case studies 330, 451

developments 282, 558

governance 626

guidelines xxiii, 183, 276, 280, 289, 535, 640, 764

ideas 24,288

learning from 162

management 222, 460, 660, 901, 922

materials xxiii, 342, 896

standards 180

transfer 273, 338

Bhutan 137, 491, 697, 761, 779, 859, 895

Bijagos Archipelago 186, 486

Biligiri Rangaswamy Temple Tiger Reserve 239

biocultural 795, 931

diversity 183, 196, 687, 693-4, 705

heritage 137, 242, 687, 688, 689, 693, 694, 695,

711,867

landscapes 103, 188, 232, 688, 693, 805

systems 125,804

biodiversity

agricultural 28, 694, 804, 805

aquatic 50, 64, 66, 571, 573-89, 594-9, 611-15,

$618,622,629,631,634,891$

areas for $6,21,31,73$

assessment 346, 719

Australian 397

awareness 344

balance of 150,160

benefits of $621,654,721,796,873$

changes in $85,120,221,503-4,512,540,797$

condition 221

criteria 346,522

data on $72,329,333,335,341-3,345,346,347$, 399, 401, 676, 677

definition 45, 52, 83, 149, 270, 541, 637, 653, 717

determinants 50

distribution of 54,65

and ecosystem services 7

and fire 842,844

in forests 402

framework 333, 395, 862, 877

function of $653,654,677,695$

funding 434

global 24, 72, 342, 590, 653, 655, 853, 931

high 239, 657, 699, 794, 899

hotspots 70, 71, 346, 379, 395, 401, 402, 434, 589,

636, 741, 801, 857

importance of 30, 223, 408

increasing 616, 662

indicators 336, 906, 908, 909

indices 395 
indigenous 665

international agreements 347

issues 333

key features 400, 475, 482, 735

key species 379

landscape scale 397, 416

levels of 56, 58, 61, 70, 71, 106, 127, 178, 637, 659, $664,745,794,798$

loss 32, 53, 119, 120, 123, 125, 126-7, 132, 140, $147,195,197,223,282,475,482,621,654,666$, $805,810,853,854,891,931$

maintaining $147,521,590,616,659,661,663,689$, 768, 795, 798, 799, 865

management 33, 308, 491, 541, 653, 659, 677, 678, 918

managing for 5, 6, 659, 661, 666

of mangroves 62

marine 50, 64, 66, 611

measuring 52, 345, 653

monitoring 335, 336, 339, 349, 672, 673, 675,

768, 919

need to conserve 14

objectives 110

offset initiatives 181

patterns $72,655,657$

plant 136

potential of 17

protection of $15,18,19,30,123,134,174,230,434$, $552,690,810,919$

resources 158,164

responses 332

restoration $175,199,390,481,754,755,798$

role of 223

role of forests 57

role of mountains 63,436

strategies 245, 333, 342, 395

study of 347,696

supporting 434, 585, 876, 877

sustainable levels 127

targets 342, 401, 668

terrestrial 64, 397

threats to $69,73,119,120,135,137,214,241,301$, 329, 331, 332, 475-6, 481-2, 486, 666, 660, 667-70, $853,870,900$

trends $120,335,891$

use of $343,344,723,807$

values $15,24,27,109,132,159,233,271,282,345$, $435,514,613,624,691,695,732,741,746,754$,

$765,800,811,842,858,878,892,893,899$

see also agro-biodiversity, key biodiversity areas

Biodiversity and Protected Area Management

(BIOPAMA) 15

biodiversity conservation

achieving 29, 794 agencies 309

approaches $391,397,518,540,545,794,863$,

868,874

capacity 275

cost of 28

criteria 398

enforcement 623

facilitating 224, 239, 342, 520

gaps 31

and ICCAs 24, 26, 185, 242, 482

issues 237

and IUCN management categories 22, 227, 230, 232, 546, 548

management 26, 29, 49, 209, 216, 237, 331, 526, 550

mechanisms 15, 26, 73, 689

need for $119,337,535$

needs 31

objectives $363,388,513,625,658,874$

outcomes 15, 26, 213, 216, 238, 513-16, 717,

796, 900

planning $395,549,880$

priorities 69-70, 216-18, 394, 864

and private protected areas 240, 241, 636

and protected areas 3, 11, 21, 32, 109, 210, 222,

224-7, 237, 246, 254, 319, 330, 400, 475, 533, 535,

$653,795,807,881$

role of culture 97, 110, 698

promotion of $26,399,427,691$

requirements for 185,765

responsibility for 254

science 54,337

support for 379

targets 223, 876, 897

tools $21,156,280,877$

traditional systems 123, 183, 339, 399, 694, 695, 700, 704, 806

Biodiversity Heritage Library 341

Biodiversity Indicators Partnership 342

Biodiversity Information Standards (also known as the

Taxonomic Databases Working Group) 341

biogeochemistry 85, 498, 499

biohistory 86

biological diversity, see biodiversity

biology 267, 270, 345, 387, 423, 518, 540, 677, 858, 866

biosphere $54,65,73$

reserves $23,24,25,27,66,103,225,301,302,386$,

481, 551, 635, 695, 698, 701, 797, 802, 806, 858,

$870,876,880,899$

terrestrial 85

biotic 73, 539

characteristics 54

communities 53, 84, 231, 232, 587

conservation 546

dependency 538 
diversity 122

dynamics 162

evolution 534

features $557,592,596$

interests 551, 557, 559

processes 533,547

BirdLife International 342, 346, 348

Black Sea 873

Blackstone River Valley National Heritage Corridor and Augusta Canal 104

blended learning 260, 266, 267, 282, 290

Blue and John Crow Mountains National Park 244

Blue Mountains 13, 154, 837

Blue Mountains National Park 154, 837

Blue Mountains World Heritage Property 13

Bogd Khan 123, 535

Bolivia 56, 136, 193, 276, 282, 577, 672, 808, 859

Bonaire (Saba) 642

Borneo 51, 60, 430, 575

Botswana 88, 793, 859, 875

Brahmaputra River 98

Brazil 129, 300, 660, 904, 918

biomes 56, 58, 577

customary rights 193, 309

dam-building 577, 809

economy 133

private protected areas 21,192

protected areas $11,59,244,625,672,691,859$

resource use 307,808

sustainable use 150, 336, 797

traditional knowledge 339, 349

Britain 12, 13, 84, 85, 95, 545, 691, 711. See also United Kingdom

British Columbia 175, 535, 663, 742, 809

British Empire 109

British Indian Ocean Territory 616

British Virgin Islands 642

buffer zone 23, 25, 57, 152, 159, 233, 244, 245, 255, $267,268,402,428,484,486,551-2,556,667$, $668,695,698,709,793,797,800,857,862,865$, 876,899

buildings 22, 86-95, 106, 155, 165, 246, 522, 687, 705, 708-9, 711, 727, 755, 756

Bukhansan National Park 244

Bulgaria 155, 859

Burkina Faso 490, 826

Burra Charter, Australian 106, 218, 705, 706

Burundi 901

Bush Heritage Australia 26, 430, 431, 434, 435

bushfire, see fire

bushmeat 478, 490, 669, 801, 803

Bushmen, see San, Basarwa
Caesarea National Park 95

Cairngorms National Park 163, 547, 554

Cairngorms Outdoor Access Trust (COAT) 163

Calanques National Park 244

California 13, 61, 101, 244, 436, 578, 625, 834

Cambodia 12, 90, 268, 490, 709, 727

Cambridge Centre for Landscape and People 697

Cameroon 56, 57, 800

Canada 59, 61, 63, 151, 275, 434, 573, 663, 665, 799, 805, 809

border with United States 155, 157, 161

boreal forests 58, 104, 365, 585, 658

Government 161, 363, 629

indigenous areas 175, 193, 614, 629, 674

management of protected areas 179, 199, 744,

893, 918

protected areas $210,221,254,363,394,535,547$,

576, 655, 662, 691, 858, 859

see also British Columbia, North America, Parks

Canada, Quebec

Canadian Shield 161

capacity development 5, 212, 238, 253, 523, 931

approaches 261, 263, 272

communities and 525

concepts 253, 256, 262

context 262

impact of activities 269

information 11

initiatives 262

in protected area systems 254

institutional 259, 264, 269, 288, 522

management 277

needs assessment 269, 274

planning 267, 277

processes 255, 269

programs 266, 276, 280

scale 261

skills development 831, 834

strategies 255

CapeNature 920, 921

carbon dioxide 52, 499, 512, 709

atmospheric levels 47, 48, 49, 152, 498, 499, 503, 504, 506, 827

farming 199

financing 152

footprint 695,771

loss 151, 502, 511

and oceans 49, 499, 504, 611, 616

offsetting 510, 772

pollution 48, 499, 500, 826

protected areas as stores of 48, 151-2, 157-8, 502,

$511,524,525$

reduction 502

release $157,504,585,667$ 
sequestration $48,151-2,157,158,308,502,511$, $521,552,579,588,597$

sinks 48, 511, 521, 585, 876

see also climate change, greenhouse gases, pollution

Caribbean 15, 56, 275, 289, 620, 635, 642, 710, 807,898

'caring for country' 86, 103, 592

Carpathian Convention and its Protocol on Conservation and Sustainable Use of Biological and Landscape

Diversity (2003) 877

Carpathian Mountains 155, 806

carrying capacity 298, 370, 665, 743, 745

Carthage 95

Çatal Hüyük 88, 89, 709

catchment, see water catchment

categories, see IUCN category

Catlin, George 12

Caucasus 57

CBD see Convention on Biological Diversity

Central Africa 337, 430, 901

Central African Republic 56, 57, 800

Central America 57, 92, 347, 854, 864, 877, 902, 905

Central and West Africa Protected Areas Programme 348

Central Asia 60, 88, 796

Central Europe 797, 798, 808, 859

Central Kalahari Game Reserve 793

Centre for People and Forests (RECOFTC) 268

Cerrado Protected Areas 59

Certificate of Ancestral Domain Title (CADT) 808

certification 16, 253, 257, 261, 273, 275-82, 314, 637, 724

cetaceans 99, 626, 635, 757, 826, 831, 845

Chad 348

Charles Darwin University 289

chemical processes 48, 50, 52, 147, 498, 499, 504, 535, $538,585,653,802$

chemicals 576

pollution $477,483,639,670,673$

safety $574,768,774,780,838$

spills 467, 640, 826, 832

use of 172, 239, 574, 757, 768, 774

see also herbicides, pesticides

Chief Roi Mata's Domain 104

Chihuahuan Desert 61

Chile 27, 61, 88, 388, 809,

flora 102, 177, 271, 662

marine protected areas 614,616

private protected areas 26,192

protected areas 10, 121, 276, 794, 904

Chimborazo Fauna Reserve 688

China 84, 88, 99, 103, 801

agriculture 85,148

biomes 52

cultural heritage 91, 96, 109 economy 133, 134

geoheritage 559

protected area governance 458, 625

protected area system 109, 388

protected areas 101, 102, 347, 451, 692

sacred places 98, 692, 696, 698, 700, 704, 859

Yangtze River 58, 84, 85

Yunnan 58, 97, 704

'China principles' 705

Chumbe Island Coral Park Limited (CHICOP) 614, 625

'citizen journalist' 443, 444

Cliff of Bandiagara 91, 92

climate $47-9,50,52,53,54,57,58,60,63,139,172$, $377,481,526,583,595,611,616,655,659,695$,

$743,768,798$

contemporary 24,501

data 348,673

instability $119,120,125,136,140$

models 499, 826

parameters $506-7$

projections 498, 501, 507, 521, 638

readiness $497,513-17,519,520,521,522-6$

regulation 147,151

seasonal 506

shifting 29, 583

stability 120, 202, 298

system $497,498,502,639,853$

variability 508,512

climate change 48-50,121, 151, 197, 222, 263, 266, $298,358,498,521,538,551,554,595-7,617,629$, 638, 644, 784, 810, 812, 841, 853

anthropogenic 49, 73, 85, 120, 140, 195, 497, 502, $526,826,854$

awareness-raising 242, 243, 265, 512, 523, 525, 526

benefits 73,517

capacity development 269, 523

challenges of $48,73,270,271,520,644$

context 3, 164, 675, 880

drivers of $140,377,809$

effects of $28,49,50,73,151,164,497,498,507-8$,

$522,526,639,710$

effects on protected areas 359, 362, 490

and extreme events 152, 259, 499, 501, 508, 519,

$523,526,554,670,825,826,827-8,844,845$

impact on biodiversity 504, 515, 540, 666, 667

impacts xxiii, 32, 345, 348, 357, 498, 509-10, 519,

586, 596, 634, 807

managing protected areas for $73,267,271,497,503$,

$511,512,513,515-17,520,522,526,595$

mitigation 130, 269, 395, 436, 483, 497, 498, 502-3, $510-11,518,520,521,526,579,585,595,597,672$, 876, 881, 931

modelling impacts $507,512,520$

natural solutions $3,11,270,282,502,881$ 
past $24,84,533,539$

and pests and diseases $153,164,524,575$

planning $242,519,521,522,524-5$

refugia 524,540

research 230, 497, 525, 526

resilience 73, 164, 271, 348, 388, 397, 402, 512, 518, 520, 595, 596, 634, 908

responses to $31,63,151,200,266,348,375,502$,

$519,526,862,877$

restoration $524,585,860$

scenarios 348, 497, 498, 499-500, 507, 522, 638,

$827-8$

and species distribution 63, 301, 497, 522, 592, 854, 857,881

threat $7,24,32,209,214,282,405,475,479,486$, $497,503,536,538,592,670,878$

trends 29, 501, 526

uncertainty about impacts 506, 533

vulnerable species 348, 447, 505-6, 515, 519,

524, 865

see also adaptation to climate change, global warming

CITES, see Convention on International Trade in

Endangered Species of Wild Fauna and Flora

Coastal Resources Center at the University of Rhode Island 278

Cochabamba Declaration 136

code of practice

research 229

coevolution 103, 104, 687, 688, 854. See also evolution

Cofán-Bermejo Ecological Reserve 689

collaboration 194, 201, 262, 311, 312, 370, 371, 393,

420-1, 429, 434, 487, 525, 638, 690, 868-9, 872-3

community 93, 189, 428, 577, 581, 599, 633, 697,

708, 769, 786

cross-border 45

cross-sectoral xxiii, 255, 302, 340, 344, 345, 383, 418,

$528,623,872$

inter-agency $188,418,839$

with the media 458

organisational 194, 196, 238, 359

scientific 302, 396

stakeholder 26, 181, 278, 383, 415, 419, 420, 587,

593, 642, 698, 775, 812

with tourism $642,729,756$

with traditional owners 240, 430-1, 629, 690, 693,

769, 770-1

collaborative

action 397

agreements 802

approaches 861,868

arrangements 415-16, 430, 524

co-management 623, 629

conservancies 183

decision-making 189, 393 efforts 276, 383, 386

governance 181, 182, 187-9, 194-5, 243, 311, 416, $417,419,428,431,437,523,688,866,867$

learning 190

management 197, 236, 240, 397, 415, 416, 418, 428, 599, 620, 633, 693, 868, 913

planning 406, 408, 430, 729

processes 869

projects 347

relationships 229, 416, 436-7, 628, 692, 831

research 221, 229, 288-90, 742, 897

resource management 419,802

resources 341, 419

technologies 273

Collaborative Australian Protected Area Database (CAPAD) 397

'collect once, use often' 334, 335

Colombia 308, 356, 377, 691

biomes 58

indigenous conservation 193, 199, 338

protected area management 308, 378, 897, 902,

904, 917

protected areas $307,308,625,806,810,859$

colonisation 12, 123, 126, 129, 131, 133, 184, 308, 691, 701,793

ecological 153, 506, 574, 655

European 90, 109, 124, 125, 126, 133, 660

human 49,83

Commission on Environmental, Economic and Social Policy (CEESP) 131, 135, 138, 555

Commission on National Parks and Protected Areas (CNPPA) 14

commodification of nature 108, 119, 122, 133, 136

commons 127, 137, 183, 184, 200, 482, 798, 870

Commonwealth Environmental Water Holder 598

Commonwealth Scientific and Industrial Research Organisation (CSIRO) 802-3, 829

communication $6,119,132,171-2,189,191,198,200$, $246,313,342,363,373,377,636,637,721,738$,

779, 868-9, 902

and advocacy 360,435

benefits of protection 160, 523, 524, 560, 728

cross-cultural 399, 416, 431, 620

of data 329, 332, 335, 345, 521, 903, 906, 917, 919

effective 265, 269, 358, 370, 394, 437, 463, 525, 558,

$764,786,866$

institutional 265, 769, 916, 917

of knowledge 196, 228, 349, 783

and leadership 212, 357, 358, 360, 773

organisational 213, 373, 406

planning 407, 443, 463-8, 753, 758, 764, 765,

$772-3,775,786,838-40,866$

professionals 458, 459, 525, 709, 873

sector 7, 200, 243, 428, 447, 450, 458 
skills $256,266,271,303,304,362,363,420-4$

speed of $29,119,362$

with stakeholders 366, 450, 463, 765, 767, 772, 775,

866, 895, 907, 913

strategies 246, 253, 264, 429, 458, 461, 465, 469,

$470,695,762,863$

systems $259,267,431$

targeted messages 30, 162, 443, 449, 453, 456, 463,

469,525

technology 265, 282, 314, 426, 428, 436

tools 218, 221, 234, 443-4, 465, 633, 675, 734, 766,

$778,831,841,866$

see also social media

community-based natural resource management

(CBNRM) 795

community conserved areas (CCAs) 16, 27, 132, 236, 242, 376, 399, 491, 719, 867

Community Forest Stewardship Agreement (CFSA) 808

Community Management of Protected Areas

Conservation Programme (COMPACT) 697

competence standard 211, 257, 273-5, 276, 289

competence-based learning 253

complexity thinking 5, 7, 296, 302, 304, 307

Conference of Parties, see Convention on Biological

Diversity-Conference of Parties

conflict with animals, see animals_conflict with humans, dangerous animals

Congo Basin 55, 57, 801

connectivity $14,119,140,175,266,280,396,398,399$,

$401,576,620,662,807,853-81$

ecological 617, 660, 854-7, 860, 874

evolutionary 854,860

function 552,876

habitat 394, 479, 506, 515, 573, 598, 618, 854-7, 860,880

landscapes 131, 132, 140, 553-4, 854-7, 860

marine $617,618,620,631-3,635$

of rivers $554,573,576,580,587,589,597$

seascapes $131,132,140$

social 99

social-ecological 104, 139, 200

spatial-temporal 576

of species $73,487,666,856$

terrestrial-marine $119,139,812$

zones 267,552

connectivity conservation $18,132,282,289,383,416$,

$853,861,863-70,872-4,876,877-81$

areas $7,19,31,218,224,232-3,242,255,485$,

$520-1,524,853,856,860,862,863,868-9$,

872,877

corridors 28, 63, 218, 224, 225, 230, 232-3, 491,

$525,853,856-60,862,865,873,880$

global network 857,859

governance $200,853,861,864,867,868$ governance models 866

landscape 73,131

legal frameworks 14, 869, 874, 876

legal instruments $877-9$

management 5, 218, 853, 858, 860-2, 863, 866

monitoring and evaluation $858,863,866$

science 853

transboundary 874

conservation action planning (CAP) 218, 220, 430, 758, 764

Conservation International 14, 346, 402, 672

Conservation Measures Partnership (CMP) 222, 331, 475, 485, 492, 666, 667, 668, 669, 758, 764

Convention against Torture and Other Cruel, Inhuman or Degrading Treatment or Punishment 129

Convention Concerning the Protection of the World Cultural and Natural Heritage, see World Heritage Convention

Convention for the Conservation of the Biodiversity and the Protection of Wilderness Areas in Central America (1992) 877

Convention for the Protection of the Marine Environment of the North-East Atlantic (OSPAR) 626, 627

Convention for the Safeguarding of the Intangible Cultural Heritage 96

Convention on Biological Diversity (CBD) 66, 130, 160, $171,191,225,229,333,896$

adoption of 129,394

agreement to 14

Article 2 52, 177

Article 8 15, 130, 876

Article 10130

basis of 535

commitment to 24

concepts in 72,132

Conference of Parties (COP) 121, 122, 130, 132, 137, 160,896

decisions of $\mathrm{xxi}, 199$

definitions in 54, 177, 340, 475, 571, 629

design of 128

Fifteenth Subsidiary Body on Scientific, Technical and Technological Advice 120

Global Strategy for Plant Conservation 801

guidance 267, 486

meeting aims of 383

'message to' 688

methodology 199

objectives 276, 395, 549, 611, 613, 658, 799, 897

obligations under 179, 342, 383, 395, 397, 598, 880, 899, 900, 904

parties to xxiii, 3, 178, 198, 201, 223, 333, 395, 491

PoWPA, see Programme of Work on Protected Areas progress towards 891,897

recommendations 209 
reporting to 179

resources 280, 481

Secretariat 276, 289

signatories 120, 147, 223, 397

sponsorship 199

Strategic Plan 2011-2020 xxi, 14, 21, 24, 30, 32,

$66,121,152,178,198,223,224,333,335,395$,

612,891

subsidiary bodies 347

targets 55, 622

thematic programs 54

see also Addis Ababa Principles and Guidelines for

the Sustainable Use of Biodiversity, Aichi Targets,

Programme of Work on Protected Areas (PoWPA)

Convention on International Trade in Endangered Species of Wild Fauna and Flora (CITES) 14, 225, 332, 333, $347,622,803$

Convention on International Trade in Endangered Species of Wild Fauna and Flora Monitoring the Illegal Killing of Elephants (CITES-MIKE) 332

Convention on Nature Protection and Wild Life Preservation in the Western Hemisphere (Western Hemisphere Convention) (1940) 877

Convention on the Conservation of European Wildlife and Natural Habitats (Bern Convention) (1979) $876-7$

Convention on the Conservation of Migratory Species of Wild Animals (CMS) 225, 333, 588, 622, 876, 877

Convention on the Elimination of All Forms of Discrimination against Women 129

Convention on the Law of the Sea, see United NationsConvention on the Law of the Sea

Convention on the Means of Prohibiting and Preventing the Illicit Import, Export and Transfer of Ownership of Cultural Property 93

Convention on the Rights of Persons with Disabilities 129

Convention on the Rights of the Child 129

Convention on Wetlands of International Importance, especially as Waterfowl Habitat, see Ramsar Convention

Cook Islands 616

cooperative management $127,428,579,873,874,875$

Coral Triangle 624

Cordillera del Cóndor Transboundary Protected Area 155

corridors 152, 671, 857, 858, 860-7, 871, 873-4, 876,877

cultural 701

riparian 402, 574, 577, 591, 592, 595, 599

transportation 244, 662, 669

vegetation $245,574,856,857$

wildlife $360,577,662,665,701,803,808,854$,

855-6, 857, 873, 874, 880

see also connectivity conservation-corridors

corruption 127, 238, 361, 374, 377, 480, 777, 803
Costa Rica 27, 805

marine protected areas $614,807,859$

private protected areas $8,148,192,727,864$

protected area training 267, 276, 289

protected areas 454, 794, 797, 806, 859

Cosumnes River Preserve 577, 578

Couple Model Inter-comparison Project Phase 5 of the World Climate Research Programme (CMIP5) 499,500

Croatia 18, 154, 625, 798, 859

crop wild relatives (CWR) 151, 152, 162, 503

cross-cultural 132, 399, 408, 416, 431, 742

Cuc Phuong National Park 802

culling 294, 296, 299, 307, 309, 464, 754, 772, 774

Cullunghutti Aboriginal Area 432

cultural heritage 22, 83, 91, 105, 110, 693, 765, 769, 798

appreciation of 109,245

approach to 90,687

assessment 107, 108, 768

awareness 770

benefits of 147

categorisation 88, 93, 109

consideration of 31

contemporary 98

creation of 85

definitions 86-8, 106, 109, 110, 698

degradation 227

discourse 87

disturbance to 768

diversity of 88,91

documentation of 711

Earth's 5, 6, 7, 88, 931

education 717

emphasis on 87

experiencing 709

expressions of 87

focus on 89

forms of 92

and geoconservation 539

and geodiversity 533

history of ideas 83,86

identifying 92, 213

impacts on 477, 519, 726, 768, 776

importance of 110

intangible 87, 96, 105, 107, 109, 110, 727, 756

legislation 769

linkages 558, 559

loss of 482

maintenance 227, 231

meaning of $83,86,87,105$

movable 93

national 85

nature as $83,97-8$

of genocide 86 
physical 766

practices 87,110

priorities 92,109

programs 432, 756, 761

recognising $22,83,85,92,96,110,727$

relationships with 83

representations of 22,88

research 719

resources 213

restoration 846

showcasing 727

significance 107, 108

specialists 560,705

tangible 96, 105, 107, 109, 110, 165, 705, 711

tools for 32

traditions 110

types $88,90,691$

understanding 83, 86

underwater 94, 95, 96

viability of 96

cultural heritage conservation xxi, 3, 4, 15, 18, 29, 30, 32,

$45,92,227,356,462$

advocates for 394

agencies 105,705

assessment 216

assets 781

basis for 246

benefits of 110

capacity for 109

conservation outcomes 216

encapsulating 83

focus on 227

importance of 31,379

integration 105

investment in 379

management 209, 213, 697, 705, 711

motivation for 106

protected areas for $110,475,931$

and rangers 290

recognition of 227

sites 225,899

and traditional owners 231

cultural heritage management $7,31,83,105-6,108$,

320, 705

effective 110, 458

goals of 109

perceptions of 110

planning 753, 768, 769, 770, 775

practices 110

skills 109

cultural heritage management plan (CHMP) 753, 768, 770-1 cultural heritage sites 22, 105, 244, 379, 760

in Australia 91, 408, 432, 770

in Cambodia 490

in Canada 363

in Greece 699

indigenous 756, 770

in Russia 165

in Slovenia 379

cultural heritage values $87,91,106,108,705,707,765$,

767, 768, 931

identifying 213

maintaining 711

threats to $484,769,829$

cultural landscapes 200, 509, 547, 693, 695

approach 105, 106

categorisation $88,548,691$

concept of 103-4, 109, 711

conservation of $11,110,687,688,692,705,768$

creation of 687,688

definition 87, 88, 103-5, 691

designation 689, 691

diversity of 234

documentation of 110,707

examples of 89, 91, 104, 106, 577, 592, 695, 707

features of $91,104,105,687$

maintenance of 101,431

management of 232, 419, 691, 692, 705

recognition of $22,105,110,691$

types $88,101,104,431$

values of 692,697

cultural significance 92, 199, 720, 771

access to information about 709

assessing 107, 108, 707, 711

indigenous 771

maintaining 707

management approach to 107,558

of mountains 63, 432, 697, 932

of protected areas 3, 230

cultural values xxi, 4, 19, 51, 83, 85, 99, 103, 432, 509, 534,548

assessment of $159,863,899$

conservation of $4,17,172,182,546$

construction of 106

definitions 16, 106, 107, 108, 176, 541, 542, 691, 717

of ICCAs 24, 26, 27, 185, 482, 613, 804, 867

identifying 761

integration of 690,701

of IPAs 26, 399, 405

and knowledge 319, 721

links with other values 546

maintenance of 172,426

managing for 696-7, 711

of marine areas 615, 629, 635, 636

of mountains 63, 155 
of nature $229,508,696$

of protected areas 11, 110, 147, 155, 483, 509,

689, 691

protected areas for conservation of xxi, 15, 176, 178,

$418,576,653,717,718$

recognition of $15,105,689,829$

threats to $702,740,746,753,769$

understanding role of 127

culturally significant

animals 93, 94, 99, 101, 229

places $84,93,228,229,420,432,520,535,770,905$

significant plants 94, 99, 101, 104, 229

culture $83,92,105,201,697,705,727,736,792$,

799, 914

alignment with nature 130, 550, 620

Australian 771

Chinese 109

and colonisation 129

commitment to 725

conservation of $11,122,123,128,176,376$

definitions of $86,103,338$

different 83, 94, 99, 195, 372, 376

East Asian 696, 700

evaluation of 895

evolution of 198,705

and governance 189, 311, 871

human $86,119,120,183$

incorporation of $198,620,695$

Indian 687, 870

indigenous 92, 99, 104, 185, 399, 405, 436, 620, 690,

698, 703, 742

and learning 190, 201

material 89, 908

modern 86, 697

nature dichotomy 100, 103, 104, 105, 232, 233, 244,

$376,688,689,693,695,795$

negating 100

organisational 195, 196, 245, 261, 272, 302, 321,

373, 377, 903

place of nature in $139,140,171$

pride in 28

priorities of 119

production of 184

protecting $159,377,550,753$

respect for 202, 376, 482, 700

responding to 269

role of 702

and sense of place 517

support for 158

territory 175

traditional 101, 194, 356, 697, 805

tribal 698

understanding 372,376

value of $107,176,689,690$
Western 12, 753

wilderness 228

Curramore State Forest 106

custodianship 120,124, 130,135, 137, 138, 139, 140, 575

changes in $119,120,125,139$

community $123,127,135$

discussion of 120,127

duties $119,120,125,137$

human 119, 140

local 119, 120, 123, 125-6, 127, 128, 130, 131-2,

134, 139, 689, 698

religious $124,125,701$

rights 130, 131, 138, 698

systems 123, 125, 128

traditional 125, 129, 130, 139, 399, 430, 689, 695, $698,701,702,795$

customary

authorities 124, 176, 198

governance 179,399

institutions $124,176,181,193$

law 16, 24, 27, 28, 175, 176, 178, 180, 193, 339,

$482,613,694,806$

management 127, 239, 339, 403

organisations 185,192

ownership 623

practices $27,132,176,235,239,795,798,800$

rights $127,130,179-80,181,185,191,482,484$, 491, 793, 794

rules $15,127,176,185,802$

tenure $125,181,623,793,798$

territories 27, 399

use $126,130,793,795$

dam building 124, 593, 809

dams 28, 30, 90, 552, 597

Alamo Dam 584

artificial lakes 583

Aswan Dam 710

Belo Monte Dam 809

Colorado River 696

controlled water releases 577, 583, 587, 595

downstream conservation 574, 577

Elwha River 574

environmental damage 482, 577, 809

fish passage around 574, 577, 580, 596, 598

Hetch Hetchy Valley 13

hydroelectricity 359, 485, 577, 809

impacts of 85, 479, 482, 536, 809

in protected areas 579,808

removal 295, 359, 574, 580

as species barrier 574,579

and tectonic activity 50

and thermal pollution $574,577,598$ 
Three Gorges Dam 85

upstream conservation 577

Veazie Dam 580

as water supply 577

as wetlands 23

and wildlife 293, 294, 295, 299, 579

dangerous animals 228, 489, 665, 831

death of humans 369

incident management 838, 842, 845

see also animals — conflict with humans

Danube River 592

'Darwin Core' 341, 343, 676

Darwin, Charles 12, 46, 47, 664

Darwinism 94

decision-support

process 759,785

tools $220,400,758,759,760,784$

Declaration on the Rights of Indigenous Peoples, see

United Nations-Declaration on the Rights of

Indigenous Peoples

deductible gift recipient (DGR) 435

deforestation 85, 152, 336, 337, 667, 672, 741, 808, 892

degazettement 810 . See also protected area downgrading, downsizing and degazettement

Delos Initiative 697

Democratic Republic of Congo 337, 368

desert 797, 844

biome $47,55,56,58,61-2,68,508$

climate 49

communities 138

geoheritage 535

protected areas 11, 754

desert and xeric shrublands 47, 55, 58, 61, 62, 508, 656

geoheritage 535

plant species 64,844

protected area coverage $11,68,754$

resource use 138,797

sacred areas 700

types 62

desertification 129, 148, 149-50, 152, 503, 508, 585, 670

'designed landscapes' 104, 707

Devil's Tower National Monument 704

DICE world 298, 304, 348

Dinaric Arc 159

Djoudj National Park 486

Dominican Republic 635

Donaña National Park 155

downstream response to imposed flow transformations (DRIFT) 580, 582

Drakensberg Park 89, 859

'drift-fence hypothesis' 856

drought 16, 371, 504, 506, 526, 575, 826, 837

animal mortality 294, 299, 371

benefits of protected areas 150, 523 conditions 58, 59

effects on wildlife 293, 510

enhanced 29, 48, 49, 164, 501, 827

and grazing 294, 520

human displacement 198, 827

human mortality 371

impacts of 503, 508, 509-10, 519, 670, 826-7

risk 519

tolerant plants 58, 151

and water stress 504, 586

drylands 54, 148, 149, 150, 152, 171, 174, 200

Durban Accord 130, 623, 629, 688

Dzanga-Sangha 800

Earth Charter (2000) 122

Earth Science Conservation Review in Northern Ireland 545

Earth Summit 129, 189, 394, 723

Earthwatch 434

East Africa 58, 793

customary rights $792,793,794$

protected areas 656, 689, 793

resource use 792, 793

East Asia 57, 58, 257, 696, 700

East Atlantic Flyway 65

Easter Island, see Rapa Nui

eastern Africa 60, 83, 150

protected areas 26, 798, 809

Eastern Europe 136, 155, 904

eco-development 489, 796, 797, 870

ecological integrity 135, 363, 523, 657-9, 742, 906

breakdown of 120,140, 658, 659

impacts on xxiii, $199,584,865$

maintaining 173, 502, 617, 654, 663, 664

measuring 221, 521, 673, 909

programs 217,533

of protected areas 20, 481, 658

protecting $18,19,140,228,502$

ecological limits of hydrologic alteration (ELOHA) 580, 581,582

ecological process connectivity, see connectivity —ecological

ecologically or biologically significant marine areas

(EBSAs) 72

ecoregions 6, 54, 548, 689

Antarctic 68

classification 14, 656

concept of 45, 630, 631

for conservation $69,664,892$

freshwater 55, 62, 571

marine 55, 62, 67, 69, 346, 612, 631

priority 70,346

terrestrial 55, 62, 67, 68, 346, 656

tropical 56 
ecosystem

in Aichi Biodiversity Target 11 30, 66, 176, 223, 333,

612,891

approach 407, 596

assessment 159, 546

competencies 253, 271, 338

concept 159, 270, 383

conservation in protected areas $3,17,18,30,161$, $502,551,653,717,718$

conservation of 123, 136, 182, 243, 265, 271

conservation through geodiversity 533, 538, 539, 550

data 337,345

of freshwater ecosystems 571, 576, 583

maintenance of $149,223,361,503,517,524$

of marine systems 587, 617, 644

of mountains 63

provision of $148,223,516,517$

recognition of $15,147,149$

role of connectivity $860,874,876$

services $15,16,66,156,176,178,418,541,543,717$

threats to $148,160,282,329,486$

trends 539,540

types $147,149,653$

use of $156,265,512$

value of 108, 133, 147, 148, 160, 254, 271, 337, 509

see also Intergovernmental Platform on Biodiversity

and Ecosystem Services, payment for ecosystem

services, Toolkit for Ecosystem Service Site-based

Assessment

ecotourism 27, 192, 379, 423, 587, 623, 797, 803, 805

and conservation 26, 489, 552, 614

community based $695,741,757,761$

in protected areas 154, 721, 725-6, 792

profits from 157, 181, 241

species-specific 621,625

Ecuador 56, 155, 189, 198, 691, 726

Government 183, 688

protected areas 46, 47, 149, 183, 540, 541, 547, 615, $625,688,689,859,910$

Egypt 88, 95, 104, 359, 699, 710, 746, 901

el Parque de la Papa (Potato Park) 102, 694, 805

Elwha River 359, 574

Emerson, Ralph Waldo 12

engagement 103, 105, 132, 138, 140, 163, 189, 193, 196, $197,201,240,259,262,301,304,336,357,369$, $393,415,450,461,559,575,593,690,743,745$, 756, 774, 786, 869, 904, 908

community $315,339,360,388,389,392,416,418$, 624, 633, 635, 696, 860, 904, 908

forms of 426

indigenous peoples 415, 430, 432, 637

media 463, 469

philanthropists 433, 434

principles 419 purposes 425

timing 429

England 12, 95, 482, 542, 546, 553, 555, 557. See also

Britain, United Kingdom

Enhancing our Heritage (EoH) 221, 901, 906

'entangled landscapes' 83, 103

environmental

management plan (EMP) 765, 767

management system (EMS) 218, 769

monitoring

refugees 510, 807, 827

water allocations (EWA) 582

'water demand management' or 'works and measures' 596, 598

environmental and social impact assessments (ESIAs) 809,810

Environmental Education Centre for Zapovedniks 289 environmental impact assessment (EIA) 371, 484, 486, $521,768,769,810,878$

approach 485,765

level of 767,786

for planning $753,763,764$

processes 484-5, 740, 765, 767, 768

standards for 629

as a tool 218,740

environmental impact statement (EIS) 765, 767, 768

erosion $50,133,160,506,536$

coastal 50, 520, 538, 556, 557

control 575, 833

of coral reefs $617-18$

costs of 157

of dunes 62, 90, 905

factors of 540

and geoconservation 541

and geoheritage 538, 547, 548, 553

as geological process $45,46,48,50,533,536,552$

and glacial melt 557

industry 577

mitigation 147,152

in Pacific Islands 85

post-fire 524

prevention 509, 516

reducing 164, 577

restoration 719

riparian 263, 334, 538, 557, 573, 579, 664

soil 220, 509, 536, 719, 739, 768

estuaries 65, 244, 534, 586, 599, 614

freshwater inflows 580, 587

inshore 618

managing 586-8, 599

managing use of 587,588

to sequester carbon 502

tropical 171

as wetlands 23 
estuarine

conservation $580,583,587-8$

ecosystems $31,573,585,596$

fishery 581

function 587

habitats 571,587

inundation 29

management $571,586-8$

pollution $30,587,658$

protected areas 5, 6, 571, 589, 614

species 571,658

systems 397, 542, 582, 587

Ethiopia 27, 488

Euphrates River 84

Eurasia 65, 83, 535

Europe 101, 126, 155, 159, 193, 702, 707, 766, 902

19 th-century 12,87

attitude to conservation 12,307

biodiversity 805

countries of 544,549

environmental projects 592, 593

forests in 57

hunting reserves 26,240

industry in 801

land use 878

northern 873

protected areas in $154,555,689,701,707,791$,

793, 898

spread of technology in 85

wetlands in 572, 591

see also Central Europe, colonisation-European,

Conservation of European Wildlife and Natural

Habitats, Eastern Europe

European

birds 60, 541

continent 727

continental shelf 96

economic system 124,753

heritage 246

industrialisation 124

salt market 379

species 152

European Centre for Development Policy Management 263

European Commission 96

European Diploma of Protected Areas 806

European Environment Agency 333

European Green Belt 859, 873

European Landscape Convention (2000) 877

European Marine Strategy Framework Directive 636

European Nature Directives 333

European Russia 165

European Union (EU) 333, 379, 418, 766, 877

Wildlife Trade Regulations 333 evolution

abiotic 534

adaptive 518

argument for 46

building blocks for 659

climatic 51,735

of coral reefs 547

dynamics of 45

Earth 54, 83, 555

of ecosystems 60

geochemical 535

geological 535, 535, 540, 558, 559

geomorphic 553, 560, 592

human 83,95

of life 55, 534, 535, 542, 556

macro 854

micro 854

natural 93, 551

opportunities for 18

of plants $48,85,150$

response to 12

showcase of 47

of societies 92, 198

of species 233

supporting 47

see also coevolution, culture-evolution of, 'organically evolved landscapes'

evolutionary

change 45, 535

development 51,52

enlightenment 298

heritage 11

history 55,853

patterns 55, 542, 571

phenomena 668

potential 17

process connectivity 854,860

processes 3, 18, 47, 57, 156, 540, 555, 854, 551

responses 73,518

significance 310

specialisation 47

state 228

traits 506

exclusionary conservation 128, 139, 316, 793, 794-5, 806

exclusive economic zone (EEZ) 21, 67, 225, 397, 612,

$614,622,635$

executive management 355

capacity building 375

communication 358,363

conflict resolution 360,363

ethical values 357

concept 362

leadership 357, 363, 378, 379

staff management 372

working with people 367-71, 376 
existence values $12,156,157,161,509$

extinction $237,573,794,855$

causes of 666

of domestic species 101

effects on ecosystem 654

global 653

hotspots 63

imminent 71

increased risk of $53,71,479$

inevitability of 515

local 506, 587, 653

mass event 47,51

measuring risk of 344,348

preventing $395,515,524$

probability of $658,664,666$

rates $53,147,653,658,858$

reducing 515

risk of 664

sixth major $21,51,53,853$

species mimics 594

'vortex' 659, 660

see also Alliance for Zero Extinction, extirpation of

species, LifeWeb Zero Extinction Campaign

extirpation of species 357, 653, 654, 663, 664

Ezemvelo KwaZulu-Natal Wildlife (EKZNW) 401

Fallen Rangers' Fund 368

Fauna and Flora International 690

feedback loops 277, 280, 282, 305, 307, 316, 317, 319, 391,398

'fences and fines' approach, see exclusionary conservation

Fiji 221, 614, 620, 623

Finland 859

protected area governance 123, 124, 165, 199

protected areas $124,186,534$

resource use 804,806

state of parks reporting 221, 904, 918

fire 501, 743, 767, 779, 826, 912

adapted species $58,61,575,654,677$

in Australia 828, 829, 837, 842, 843

Australian management 485, 511, 660, 829, 830, 834

bans 833

behaviour $842,843,829$

cessation of 239, 795

changed behaviour 214, 520, 827, 829

conditions $498,511,522,840$

control 270, 719, 757

danger to staff $219,239,842$

detection 347,759

ecosystem disturbance 659, 660, 673

firebreaks 152, 781

forecasting 364, 831, 841

Forest Fire Danger Index 827, 829 frequency threshold 911

fuel accumulation 504, 827

fuel assessment 831

fuel reduction 299, 330, 429, 446, 447, 503, 511,

$728,757,833$

history 61,844

impacts of 479, 508, 509, 739, 768, 844, 865

inappropriate management 396, 405, 669

incident management 756-7, 830, 831, 832, 834,

$836-8,841$

increased incidence of xxiii, 479, 481, 519, 521, 526,

$654,669,827$

increased severity of xxiii, 296, 479, 504, 827

indigenous management of $85,239,575,792,795$

information 506, 721, 757, 919

investigations 841

management 236, 299, 307, 420, 423, 511, 524, 757

management plans $384,775,776$

media management 467, 469, 470

media planning $446,453,454$

modelling 842,843

monitoring 672,673

natural mitigation 152,592

natural regimes $58,59,61,475$

North Kimberley Fire Abatement project 199

operations $234,364,719,775,824,832,833$,

$836-8,841$

phenomena 827,843

in pre-European Australia 85, 660

prescribed 755,844

prevention $172,768,776$

prohibitions 173

prone areas $521,828,844$

recovery $754,755,760,775,844$

regime 668,844

regime changes $505,506,853,854,865$

research 106, 426

responding to $237,426,523,524,825,827,833$

role of 239

suppression 239, 295, 296, 299, 307, 321, 669, 755,

833,844

susceptibility 830

threat from 24, 29, 209, 299, 402, 476, 477, 478,

$826,864,900$

trails $721,757,833$

training 523,763

in United States 307, 828, 834

in urban protected areas 243,245

and US Forest Service 295, 296, 318, 321

use of $85,172,307$

warnings 759

see also Australasian Fire and Emergency Service

Authorities Council, Forest Fire Danger Index

firewood collection 99, 150, 461, 741 
First Nations 161, 175, 394, 742. See also Native American

Florida 152, 385, 611

Forest Fire Danger Index (FFDI) 827, 829

Forest Peoples Programme 431

Forestry Research Education and Extension Project (FREEP) 797

'fortress conservation', see exclusionary conservation

Forum on Religion and Ecology 697

France 65, 95, 193, 198, 244, 437, 691, 708, 709, 766,859

Fraser Island 90

'free prior informed consent' (FPIC) 339, 342

French Development Agency 901

French Global Environment Facility 901

freshwater 197, 309, 346, 611

climate change 595

conservation 575

corridors 591

ecological principles 572

ecosystems 571

environments $31,45,53,62,64,70,72,150,236$,

$395,397,550,724,808$

management $571,579,588$

planning 592

plants 152

rights 123

species 497, 503, 505, 655, 669

threats 573

types 576

freshwater ecoregions of the world (FEOW) 55

\section{Gabon 484}

Gaia Foundation 137, 138

Galápagos Islands 46, 47, 615, 718

Galápagos Marine Reserve 47, 183, 625

Galápagos National Park xxi, 540, 547, 910

Gambia 27, 348

game controlled areas (GCAs) 803

Ganges River 701

geoconservation 50,531

biodiversity 539

climate change 538

definition 534, 541

education 558

frameworks 549

identifying interests 541

management 542,552

marine 545,550

monitoring and evaluation 559

need for 535

principles 546, 549

protected area designations 543 risk management 554

threats 555

Geoheritage Toolkit 543

Geological Conservation Review (GCR) 542, 545

Geological Society of Australia 545

Geological Society of London 120

Geological Survey of Spain 559

Georges River National Park 99

Georgia 155

Germany 64, 65, 859

Ghana 476, 478, 481, 483, 488

Global 200 70, 346

Global Biodiversity Information Facility (GBIF) 330, 335, 341, 342, 345, 347, 575, 677

Global Biodiversity Outlook 810

Global Biodiversity Outlook 3 (GBO-3) 120, 133

Global Environment Facility (GEF) 289, 895, 897, 901, 902, 905

Global Environment Fund 613, 898

Global Geoparks Network (GGN) 24, 544

Global Invasive Species Database (GISD) 342, 344

Global Network of National Geoparks, see Global Geoparks Network

global positioning system (GPS) 258, 341, 391, 673, 778,781

Global Protected Areas Program (GPAP) 276

Global Strategy for Plant Conservation 347, 801

Global Stratotype Sections and Points (GSSPs) 544

Global Taxonomy Initiative 347

global warming 48, 120, 670, 829. See also climate change

Golden Mountains of Altai 373, 498, 535, 932

Gondwana Link 434, 857, 859

governance $11,24,26,29,31,69,119,123,125,139$, $171,211,216,226,232,254,261,270,296,303$, $316,332,339,376,383,396,408,415,428,522$, $611,763,775,803,830$

adaptive management $195,417,437,523$

coastal 278

connectivity conservation 861,867

diversity 180

of fire incidents 842

framework 344, 365, 403, 430

frontiers 198

improving 199, 898

institutions 149

legal 877

local $674,692,800$

marine protected areas 622-9

of operations 780

protected areas 179, 240, 253, 293, 311, 896

quality $188-93$

systems $124,127,136,301,313,482$

threat management 491

transboundary corridor 864,874 
types $16,20,24,45,66,131,209,218,234,235$, $242,246,255,340,513,551,613,688,696,791$, $811,892,931$

units 172

vitality 193

water 581,582

Grand Canyon National Park 436, 547, 548, 696, 726

Great Barrier Reef 65, 618, 619, 621, 643

community engagement 636, 637

economic contribution of 621,642

Indigenous use 90, 628

research in 642, 643

threats to $118,139,503,639,802$

visitors 643, 718

Great Barrier Reef Marine Park 397, 503, 609, 615, 616,859

management of $623,625,631,632,641$

no-take areas 619

operating in 642

success of 635

visitors to 621

zoning 631, 636

Great Barrier Reef Marine Park Authority (GBRMPA) 139, 628, 638

Great Barrier Reef World Heritage Area 305

Great Basin National Park 359

Great Dividing Range 106, 880

Great Eastern Ranges 291, 852, 857, 859

Great Eastern Ranges (GER) Initiative 807, 872, 873, 880,881

Great Himalayan National Park (GHNP) xxiv, 31, 465, 486, 727, 797, 809, 811

Great Smoky Mountains National Park 433

Greece 91, 545, 699, 700, 701, 859

Green Economy Initiative (GEI) 133

greenhouse gases 48

concentrations $497,499,502$

emissions 120, 133, 298, 497, 498

emissions reduction 199, 498, 502, 510, 526, 618, 769

levels 504

limits on 226

minimising emissions $510,522,724$

mitigation 511

offsets 772

pollution 226, 497

sequestration 502

see also carbon dioxide, pollution

Greenland 49, 61, 498, 547

Green List of Well Managed Protected Areas 221, 237, 261, 901

groundwater-dependent ecosystems (GDEs) 571, 578, 585-6

Guadeloupe 635

Guatemala 91, 92, 797, 859
Guinea 480, 481, 483, 490

Guinea-Bissau 186, 486

Gulf of California 64

Gulf of Mexico 640

Gunung Mulu National Park 51

Ha Long Bay World Heritage Site 231, 625

Hawai'i 123, 615, 616, 620-1

'Healthy Parks Healthy People' 103, 154, 163, 243, 734

herbicides 239, 488, 574, 778

Hetch Hetchy Valley 13, 30

Himalaya 57, 98, 535, 695, 698, 701, 741, 803. See also Great Himalayan National Park, Sacred Himalaya Landscape, Western Himalaya

Himalayas 535

Hiroshima 11

Honduras 25, 150, 158, 859

Hong Kong Country Parks 244

Horn of Africa 796

Hortobágy National Park-the Puszta 91, 101

Huangshan National Park 692

human-animal conflict, see animals_-conflict with humans, dangerous animals

Human Development Index (HDI) 261, 801, 825, 897

human evolution, see evolution-human

human footprint index 65

human impact, see anthropogenic

human-induced climate change, see climate changeanthropogenic

Hungary $88,91,101,859$

hunting 394, 664, 792

as cultural heritage $88,110,239,766$

commercial 178, 792, 801, 803

elite privilege 181,240

and gathering 83-4, 92, 125, 171, 172, 430, 690, 792, 800

illegal 150, 423, 802, 803

impacts of $123,739,741$

indigenous 797,804

overhunting 150, 477

private reserves 26,192

prohibitions 524, 803

recreational 423, 436, 719, 792, 793, 857, 900

regulation of $308,367,720,740,804,877$

reserves 598, 803

for subsistence 336, 801

sustainable $27,336,727,803$

threat from 477, 481, 485, 486, 669, 900

traditional knowledge 339, 674

trophy $669,719,793,803,804$

Iceland 61, 535, 547, 549, 559

Idaho 295

important bird areas (IBAs) 70, 72, 346, 892, 899 
important plant areas (IPAs) 72

incident command system (ICS) 834

incident management 470, 756, 825, 835, 841

plans $828,830-2,838$

responding to 834

systems $220,490,834$

India xxiv 98, 122, 125, 137, 173, 535, 800, 801

biomes 56, 62

CCAs in 27

community conservation 29, 192, 242, 741, 802, 803

conservation 290, 486, 702, 794, 795, 859

economy 133

ICCAs in 26, 27, 263

and ICDPs 796, 797

indigenous rights 193, 799

invasive species 488

protected areas 92, 450, 588, 589, 653, 658, 687, 695,

791, 808, 870, 904

sacred places 123, 695, 698, 701, 702, 859

tiger conservation 45, 239, 488, 489, 658, 660, 720,

793, 795, 811

see also Himalaya, Wildlife Institute of India

Indigenous and Community Conserved Areas (ICCAs), see Indigenous Peoples' and Community Conserved

Territories and Areas

Indigenous Australian, see Aboriginal (Australian)

Indigenous Peoples' and Community Conserved

Territories and Areas (ICCAs) 132, 185, 188, 242, 808

benefits of 28

characteristics of 185,186

conservation value of $24,28,242,431$

decision-making in 196, 799

definition 186, 482, 613

extent of 21,867

governance 235

as governance type 3, 20, 791, 867

guidance for 218

knowledge sharing 342

management of 109, 209, 210, 212-13, 235, 242

management planning 403, 630, 812

management plans 399, 403

marine $185,613,614$

members of 234

monitoring 801

need for 45

overlap with protected areas 186,188

protecting 242, 806

recognition of $24,132,224,233,242,482,811$

rights over 482, 808

role of 242

status of 209, 224, 242, 809

threats to $475,481,482,809$

types $26,27,870$ use of $693,796,801,803,804,805,806,808$,

811,812

visitors to 719

see also community conserved areas, Indigenous

Protected Areas

Indigenous Peoples' and Community Conserved Territories and Areas (ICCA) Consortium 242, 339, 613

Indigenous Peoples' and Community Conserved Territories and Areas (ICCA) Registry 339, 342, 613

Indigenous Protected Areas (IPAs) 193, 242, 867

Indigenous Protected Areas (IPAs) (Australian) 109, 396, 430, 577

benefits of 26, 197

definitions 26, 399

development of 26, 396

Dhimurru IPA 691

extent of 26, 396

governance of 27, 199, 628

governance under 198, 399

management of 27, 240, 396, 399, 614

in National Reserve System 26, 396, 397

and philanthropy 434-5

as type of ICCA 27, 693

use of fire in 199

Wunamabal Gaambera IPA 430

Indo-Malayan

archipelagos 55

biome 51, 56, 67

Indochina 56

Indonesia 14, 193, 268, 337, 620, 625, 653, 672, 843

Indus River 84, 98

Industrial Revolution 12, 85, 124, 766

information management 342, 345, 470, 638

insects

adaptation 506

collecting 669, 741

development 574

impacts on $153,574,673$

migration 103

new species 445

pests 153

pollinating 148, 153, 506

presence of 59, 62

taxonomy 47, 52

see also bees

Integrated Biodiversity Assessment Tool (IBAT) 343, 346

integrated conservation and development project (ICDP) 791, 796, 797, 811

integrated lake basin management (ILBM) 584, 585, 593

integrated river basin management 593

integrated water resources management 593

Intergovernmental Panel on Climate Change (IPCC) 14, 497, 498, 499, 500, 501-2, 507, 508, 512, 519, 638 
Intergovernmental Platform on Biodiversity and

Ecosystem Services (IPBES) 132, 334

Interim Biogeographic Regionalisation for Australia (IBRA) 396, 397

Interim Marine and Coastal Biogeographic Regionalisation for Australia 396

International Association for the Study of the Commons 137

International Association of Geomorphologists 545

International Centre for the Study of the Preservation and Restoration of Cultural Property (ICCROM) 105, 705

International Charter for the Conservation and Restoration of Monuments and Sites, see Venice Charter

International Commission on Stratigraphy 544

International Committee for Documentation of Cultural Heritage (CIPA) 710

International Consortium on Combating Wildlife Crime (ICCWC) 332

International Convention for the Protection of All Persons from Enforced Disappearance 129

International Convention for the Regulation of Whaling 225

International Convention on the Protection of the Rights of All Migrant Workers and Members of their Families 129

International Council of Museums (ICOM) 93, 105, 705

International Council on Monuments and Sites (ICOMOS) 87, 89, 93, 102, 105, 106, 218, 705, 706, 710, 769

International Covenant on Civil and Political Rights 128,129

International Covenant on Economic, Social and Cultural Rights 128, 129

International Geosphere-Biosphere Programme 120

International Institute for Environment and

Development 431

International Labour Organisation (ILO) 184, 274, 430

International Lake Environment Committee (ILEC) 584

International Maritime Organisation 627

International Mountaineering and Climbing Federation

(Union Internationale des Associations d'Alpinisme: UIAA) 436, 437

International Organisation for Standardisation (ISO) 218, 341,828

International Ranger Federation 275, 281, 290

International Scientific Committee for Archaeological Heritage Management (ICAHM) 89

International Seabed Authority 627

International Seminar on Protected Area Management 315,316

International Union for Conservation of Nature (IUCN) xxi, xxiii, 4, 14, 15, 90, 137, 678, 705

advocacy 810,812

biogeographic classification 55, 656 capacity development work 11, 261

Central and West Africa Protected Areas

Programme 348

classification system 687,717

data sharing 224, 330, 347

draft Code of Practice for Research 228, 229

evaluations 102, 103

Global Partnership for Professionalising Protected Area

Management Development 211

Global Species Programme 348

governance types 21, 66, 188, 189, 198, 209, 874

guidance xxi, 15, 32, 189, 689, 698, 717, 866

Guidelines for Protected Area Legislation 181

ICCA recognition 186, 431, 482, 613

indigenous recognition 130, 131

Integrated Biodiversity Assessment Tool 346

knowledge products 282, 342, 344

management guidance 209, 211, 227-8, 230-4,

403, 891

marine protected area definition 14, 613, 614

methodology 199, 906

Policy Statement on Sustainable Use of Wild Living

Resources 792, 799

position on mining 138, 139, 555, 810

private protected area recognition 24, 183, 240

Programme on African Protected Areas and

Conservation (IUCN PAPACO) 901

protected area definition xxi, 14, 15, 17, 26, 175, 176-

80, 182, 340, 364, 418, 541, 550, 576, 613, 653, 717

Protected Area Matrix 181, 187, 236, 688

Protected Planet portal 280

publications 14, 15, 39-41, 280, 502, 897

resolutions $199,533,541$

Secretariat 276, 344

system/process $131,138,799$

threat classification 485, 669

World Conservation Congress 14, 130, 138, 276, 810

World Heritage advice 346, 555

World Heritage Panel 346

World Heritage review 102

see also Conservation Measures Partnership, Red List of Threatened Species, World Commission on Protected Areas, World Database on Protected Areas, World Parks Congress

International Union for Conservation of Nature (IUCN) categories 21, 100, 181, 689

data on $22,66,340,397$

description of 5, 16-20, 419, 544

in determining visitor use $688,717,718,719-20$,

746, 792

role of 109,187

role in geoconservation 546, 547-8, 549, 551

role in marine protected areas 613

use of $30,31,177,367$ 
IUCN Category Ia: Strict Nature Reserves 17, 721, 792 description 17, 18, 20, 419

geoconservation $547-8$

management 228, 236, 243

IUCN Category Ib: Wilderness Areas 547-8

description 18, 20, 100, 419, 792

management 187, 228, 230, 236

IUCN Category II: National Parks 548, 667, 724, 792, 795,897

African examples 244, 339, 483, 581

Asian example 577

Australian examples 244, 592, 598

Caribbean example 244

description 18, 19, 20, 209, 419

European examples 244, 594

and geoconservation 547,548

management of 187, 230, 231, 236, 243

North American example 548

South American examples 244, 727

visitor use $688,717,718,721,793$

IUCN Category III: Natural Monument or Feature 548, 552,702

description 19, 20, 419, 688

and geoconservation $546-8$

management 187, 230, 231, 236

visitor use 719-20

IUCN Category IV: Habitat/Species Management Area 229, 548

description 19, 20, 419, 688

examples 244,340

and geoconservation $547-8$

management 22, 187, 227, 232, 236

resource use $555,688,792,793$

visitor use 719-20

IUCN Category V: Protected Landscape/Seascape 430, 689, 693

Asian examples 244

Australian example 691

description 19, 20, 109, 419, 688, 694

European examples 340, 379, 555, 556, 702

and geoconservation 547,548

management 22, 187, 232, 233, 236, 243, 720

North American examples 244, 691

resource use 30, 555, 792, 804, 810

South American example 691

visitor use 419, 719-20, 727

IUCN Category VI: Protected Area with Sustainable Use of Natural Resources 227, 430, 687

description 19, 20, 22, 109, 243, 336, 688, 693

examples 589, 598

and geoconservation $547-8$

management 187, 232, 233, 235, 236, 578

resource use 109, 150, 232, 233, 419, 555, 792, 810

visitor use 419, 719-20, 727
International Union of Geological Sciences 544

International Whaling Commission 225

International Whaling Convention, see International Convention for the Regulation of Whaling

Inuit 629, 674

invasive species xxiii, 120, 239, 504

control 153, 173, 245, 391, 434, 587, 667, 759,

796, 804

costs of 486

detection 164, 391, 674, 675, 867

distribution 575, 673, 675

eradication 131, 164, 174, 587, 796

impact of 644, 666, 910,911

introduction of 29, 229, 243, 245, 573, 574, 579, 640

management 73, 164, 396, 486, 488

prevention 228,798

responding to threat of 73

spread of $164,575,639,779$

threat from 476, 477, 478, 483, 486, 669

threat level 153, 485, 912

threat management 475, 490

vulnerability to 402

see also Global Invasive Species Database

Investment Framework for Environmental Resources

(INFFER) 220

Iran 27, 184, 188, 193, 403, 482, 798

Ramsar 14, 23, 225, 588

Iraq 85

Ireland 798

Israel 95

Italy 193, 545, 547, 549, 739, 766, 859

Ivory Coast 481

Jabal Moussa Biosphere Reserve (JMBR) 899

Jamaica 95, 244

Japan 121, 137, 160, 223

cultural heritage 88, 96

importance of mountains 63, 98, 154, 692, 696,

699, 700

indigenous population 430

productive ecosystems $27,126,185,379,798$

protected areas 559, 614

sacred places 11,708

water resources 583

Jasper National Park 103

Jenolan Caves Reserve 13

João Vieira-Poilão National Park 186 
Kakadu National Park 88, 90, 91, 569, 591, 592, 845

Kakum National Park 478, 481, 483

Kalahari Desert 88, 875

Kalahari Gemsbok National Park 875

Kalahari Heritage Park 875

Kalahari peoples 97, 803, 875

Kalpavriksh 808, 870

Kamchatka Peninsula 46, 63

Kanneliya-Dediyagala-Nakiyadeniya (KDN) Biosphere Reserve 802

Karen 793

Karnali River 98

Katla Geopark 559

Kazakhstan 60, 240, 289, 873

Kedarnath Wildlife Sanctuary 695

Kenozersky National Park 165

Kenya 337, 402, 403

cultural species 94, 99

ICCAs 27

protected areas 164, 199, 244, 339, 368, 619, 793, 810

resource management 109, 614, 809

Kenya Wildlife Service 164, 244, 277

Keolodeo (Bharatpur) National Park 795

key biodiversity area (KBA) 70, 72, 344, 346, 395, 892

keystone species 518, 617, 662, 663

Kgalagadi Transfrontier Park 859, 875

Khangchendzonga National Park 741

Kibale National Park 802, 811

Kidepo National Park 374

Kimbe Bay 623, 624

Kiribati 616

Klaserie Private Nature Reserve 294

Kosciuszko National Park 151, 443, 447, 512, 577

bushfires 470, 757, 830

damage 512, 805

huts $93,705,706,756$

management plan 405

research 334

stock grazing 334, 805

visitors 457, 492

Kosciuszko to Coast corridor 880

Kruger National Park 26, 294, 581

animal management 305, 309, 922

animals in 44, 295

establishment 123, 293

land claims 794

management 302, 391, 579

poaching 32

research 301, 302

'thresholds of potential concern' 217

visitors 718

water for wildlife 295, 579

Kruger to Canyons Biosphere 302

Kublai Khan 95
Kuk Early Agricultural Landscape 88

Küre Mountains National Park (Küre Dağları Milli Parkı, KDMP) 159

Kuwait 148

KwaZulu-Natal Province 184, 535

La Garrotxa Volcanic Zone Natural Park 804

Lagoons of New Caledonia 65

Lake Chilika 588, 589

Lake District 12, 154

Lake District National Park 691

Lake Manasarovar 98, 701

Lake Mungo 90

Lake Nakuru National Park 164

Lake Ontario 663

Lake Pedder 536

landscape connectivity, see connectivity-landscapes

Laos 577, 704

Lapp, see Saami

Las Médulas 88

Latin America 197, 485

deforestation 808

indigenous stewardship 689

political economy 133, 289

protected area management 289, 898, 905, 909

protected areas 794, 879, 897

water resources 150, 152

Latin American School for Protected Areas (ELAP) 260 , 267, 289

leadership 210, 212, 223, 238, 253, 257, 262, 275, 278, 298, 303, 309, 355-79, 392, 437, 510, 520, 625, 641, 689, 769, 773, 786, 861, 869, 871, 873

attributes 357

concept 356

local 742

political 269

program 290

League of Nations 128

learning by doing, see adaptive management

Lebanon 99, 701, 899, 900

Leopold, Aldo 357

Lesser Sundas 56

Liberia 481

LifeWeb Zero Extinction Campaign 395

limits of acceptable change (LAC) 221, 298, 743-4, 745

Linnansaari National Park 124, 806

List of Wetlands of International Importance, see Ramsar Convention-list

lithosphere 46, 54, 73

Lithuania 859, 904

locally managed marine areas (LMMAs) 27, 233, 614, 623, 624, 796, 805, 867

Locally Managed Marine Areas Network 221 
Lochinvar National Park 488

London 88, 156, 708

London Wetland Centre 244

Lonjsko Polje Nature Park 798

Lushan National Park 91

Ma'dan Marsh Arabs 85

Maasai 94, 99, 793, 794

Maasai Mara National Reserve 810

Machu Picchu 88

Macquarie Island 228, 547

Macquarie Marshes Nature Reserve 579

Macquarie River 579

Madagascar 56, 155, 174, 275

deforestation 672

indigenous tenure 193, 806

marine areas 27,614

protected areas $198,806,810$

Madeira 635

Mali 27, 91, 348, 486, 490

Man and the Biosphere (MAB) Programme 14, 23, 544, 876,899

World Network of Biosphere Reserves 544

Management Effectiveness Evaluation see Protected area management effectiveness (PAME)

Management Effectiveness Tracking Tool (METT) 481, 483, 895, 897, 898, 900, 901, 905, 909

Mandela, Nelson 104, 130, 131

Manú National Park 88

Mapuche-Pehuenche 177, 809

Mapungubwe Cultural Landscape 89

Mapungubwe National Park 89, 859

Maputaland 401

Maputaland Centre of Endemism 401

marine ecoregions of the world (MEOW) 55

marine protected areas (MPAs) 27, 96, 257, 613, 15, 629,631

benefits of $156,616-18,620-2$

biodiversity conservation 491, 599, 617, 618, 622, 636

climate change impacts 50, 638-9, 644

community involvement 636, 637, 806

community-supported 613, 614, 805

compliance management 637,638

defining 14, 613, 615, 627, 631

diversity within 632

establishment 226, 611, 618, 622, 626, 644

evaluation 625, 634, 636, 637, 642-3, 644, 900, 921

extent of $45,67,612,613,614,644$

frameworks 631, 634

governance 622, 623, 625, 629, 633

'Governance Framework' 623, 626

governance incentives 625,626

high seas 626, 627, 629 impacts on 629, 631, 634, 635, 636, 637, 639, 640

increasing fish stocks $618,619,621,796,805$

large-scale 615, 616, 619, 630, 644

no-take 619, 633

objectives 635,638

planning 630, 631-2, 633, 637, 644

practitioners $278,633,641$

resource use $150,625,640,792,799,805$

tourism in 621, 642

traditional use 629, 792

types $611,613,614$

zoning 617, 619, 630, 631, 633

see also National Representative System of Marine

Protected Areas, Western Indian Ocean Certification

of Marine Protected Area Professionals program

marine protected areas (MPAs) management 623, 630-4,

635, 636, 639, 642-3, 644, 806

agencies 278, 635, 641

delivery 620, 640, 641

effectiveness 630, 635, 900

objectives $613,629,637$

standards 275, 278

tools 629

see also locally managed marine areas

marine protected areas (MPAs) networks 397, 612, 623,

$627,631,632,900,901$

benefits 617,620

representative $611,612,626,627,644$

resilience 388, 624

Martinique 635

massive open online courses (MOOCs) 267, 290

Mauritania 486, 901

Maya 91, 92

Maya Biosphere Reserve 797

M'bororo 123

media $125,191,196,200,243,246,272,355,361,363$, 369, 418, 428, 558, 677, 721, 786, 919

communication planning 463

management 221, 458, 467, 772, 840

news gathering 448,829

news releases 452

planning 449, 765

social media 314, 444, 709, 729, 733, 738, 840, 866

strategic use of 446

types 444,450

medicinal plant conservation areas (MPCAs) 801

medicinal plant conservation parks (MPCPs) 801

Mediterranean

biome 56, 61, 68, 699

climate 61

region 61,899

species 635,702

Mediterranean Sea 244, 379, 614, 626, 710

Mekong River 58 
Melanesia 99

Melbourne 154, 829

Mesoamerican Biological Corridor 347, 857, 859, 864

Mesopotamia 84, 85

Meteora 91

Mexican Commission for the Knowledge and Use of Biodiversity (CONABIO) 347

Mexico 265, 280, 347, 421, 621, 805

biomes 56, 57, 61

protected areas 13, 64, 103, 104, 301, 625, 635, 794, 859

Middle East 84, 98, 99, 701

Migratory Species Convention, see Convention on the Conservation of Migratory Species of Wild Animals

Millennium Development Goals, see United NationsMillennium Development Goals

Millennium Ecosystem Assessment (MEA) 147, 533, 539, $573,653,810$

Millingerwaard 594-5, 596

Miradi 220, 331, 668, 670, 758, 764, 914

Moderate-Resolution Imaging Spectroradiometer (MODIS) 672

Mombasa 164

Monarch Butterfly Biosphere Reserve 103, 301

Mongolia 26, 98, 123, 535

Monitoring Information System Tool (MIST) 484

Montague Island Nature Reserve 727, 758

Montana 295

Monterey Bay 101

Monteverde Cloud Forest Reserve 8, 148, 727, 864

Montserrat 547, 700, 702

Morocco 699

Moscow 165, 289, 501

Mosi-oa-Tunya National Park 488

mountains 46, 48, 51, 54, 84, 88, 156, 164, 447, 546, $547,690,754$

biome 55,62

sacred 558

special values 63, 97, 123, 696, 697, 899

Mount Athos 699, 700

Mount Elgon National Park 368, 375, 377, 666

Mount Everest 46, 63, 186, 353. See also Sagarmatha National Park

Mount Fuji 63, 692, 699, 702

Mount Kailas 11, 98, 698, 700, 859

Mount Kazbegi 155

Mount Kenya National Park 164

Mount Nimba 481

Mount Sanqingshan National Park 102, 559

Mount Sinai 699, 700, 701, 702

Mount Triglav 155, 535

Mozambique 401, 795, 859

Muir, John 12, 13, 30, 559
Multi-Criteria Analysis Shell for Spatial Decision Support (MCAS-S) 759

Murray River 599, 918

Murray-Darling Basin 598-9

Myanmar 704

Nagoya Protocol on the Access and Benefit Sharing of Genetic Resources (ABS Protocol) 137, 160

Nairobi 244, 810

Nairobi National Park 244, 810

Nama 89

Namib Rand Nature Reserve 26

Namib Sand Sea 62

Namib-Karoo biome 61

Namib-Naukluft Park 62

Namibia 26, 62, 199, 337, 859, 875 community conservancies 27, 127, 192, 198, 330, 803 human-wildlife conflict 303, 318

Nanda Devi Biosphere Reserve 695, 701, 870

National Aeronautics and Space Administration (NASA) 281,672

national biodiversity strategies and action plans (NBSAP) xxiv, 333, 342

National Incident Management System (NIMS) 834

National Interagency Incident Management System (NIIMS) 220, 834

National Park of American Samoa 804

National Park Service of Colombia 308, 356, 378

National Representative System of Marine Protected Areas (NRSMPA) 396, 397-8

National Reserve System, see Australia-National Reserve System

National Tiger Conservation Authority (NTCA) 488

national vocational qualifications (NVQs) 275

Native American 12, 86, 359, 704, 793, 804. See also First Nations

Natura 2000 379, 699, 702, 877

natural evolution, see evolution

Natural Resource Management Ministerial Council (NRMMC) 897

NatureServe 330

Near East 84

Nearctic 56, 58, 59, 67

Neotropic 47, 56, 59, 61, 67, 572, 591

Nepal 98, 151, 388, 741, 863 animals 45, 653 protected areas 186, 700, 859, 896

Netherlands, the 64, 65, 95, 435, 594, 595

Nevada 359

New Caledonia 56, 65, 88, 619

New South Wales 13, 435, 505, 837

Aboriginal engagement 424, 432

Aboriginal heritage 93, 94, 432, 696 
community engagement 424

cultural heritage 709

environmental management 246, 487, 855-6, 880-1

fauna $216,226,855$

fire $470,757,758,830,837$

flora 246

Government 94, 246, 449, 730, 872, 880

private reserves 435

protected area management 105, 641

protected areas $246,470,477,512,525$

state of parks reporting 221, 894, 895, 902, 904, 905 , 918-19

New South Wales National Parks and Wildlife Service (NPWS) 216, 405, 424, 468, 880

areas managed 244, 246

cultural heritage management 93, 110, 432, 706

fire management 828,829

management framework 217

marine management 455, 463, 641

revenue 405,730

New South Wales Office of Environment and Heritage (OEH) 432, 918

New South Wales Rural Fire Service (RFS) 469

New Zealand 83, 127, 131, 435, 538, 801

biomes 57

conservation initiatives 435,859

Department of Conservation (DOC) 213-14, 435, 783

indigenous management 430

protected area management 275,753

protected areas 213, 783

Newfoundland 799, 805

Newton, Isaac 298

Ngorongoro 794

Niassa National Reserve 795, 859

Nicaragua 339, 392, 859

Niger 138

Nile River 84

Ningaloo, see Shark Bay

Nobel Prize 120, 123

non-timber forest products (NTFPs) 239, 478, 485, 792, 793, 800-1, 802

non-use values $156,157,509$

'normalised difference vegetation index' (NDVI) 659

North Africa 379

North America 12, 85, 307, 801, 859

biomes 57, 59, 60, 572

extinctions 658

fauna $12,45,59,86,855$

fire 307,755

freshwater systems 591, 593, 655

indigenous people 86,620

marine systems 573

protected area management 430, 753

settlement 100, 133 see also Canada, Mexico, United States

North Cascades National Park 558, 559

North Korea 700

northern Africa 150

Northern Ireland 545

Northwestern Hawai ian Islands Coral Reef Ecosystem

Reserve 615, 616. See also Papahānaumokuākea

Marine National Monument

Nunavut 629, 674

Ocean Biogeographic Information System 342

Oceania 56, 67, 288, 572, 591, 689

Okavango Delta 60

Olifants River 302, 572

Olympic National Park 357-8, 359, 574

Ontario 161, 549

Open Geospatial Consortium 341

Open Standards for the Practice of Conservation 220, 222, 331, 404, 406-7, 408, 746, 758

operations 180, 210, 215, 219, 234, 278, 304, 332, 427, 598, 638, 802, 831, 838

asset management and 780

commercial 756

delivery of 772

effectiveness 785

forestry 106

logistics 779

management 4, 237, 510, 723, 902

officer 840

planning 763

programming 759

staff 418

tourism 640,726

types 754

'organically evolved landscapes' 691, 798

Organisation for Economic Cooperation and

Development (OECD) 260, 262

Orinoco River 308

Ostional National Wildlife Reserve 797

Ostrom, Elinor 123, 127, 135, 136

'other effective area-based conservation measures' (OECM) xxi, 28, 30, 32, 66, 132, 178, 223, 333, 340, $612,867,876,891$. See also area-based conservation 'outstanding universal value' (OUV) 22, 45, 94, 102, 225, $346,376,544,723$

Pacific Islands 85, 430, 620, 635, 804

Pacific Ocean 47, 65, 244, 359, 615, 616, 627, 635

Pacific Rim National Park Reserve 175

Pakistan 793, 803, 805

Palaearctic 57, 58, 60, 61, 66

palaeoanthropology 83 
palaeoclimatic 96

palaeoecology 85, 585

Palaeolithic 84

palaeontology 88, 542, 550, 558, 559

Palau 621, 625, 710

Panama 27, 454, 859

Pantanal 60, 576, 577

Papahānaumokuākea Marine National Monument 615, 616, 620

Paparoa National Park 783

'paper park' 6, 29, 178, 210, 644

Papua New Guinea 58, 60, 88, 623, 624, 904

Paraguay 277, 577, 808

Parc National de Dzanga-Ndoki 57

Parc National de Lobeké 57

Parc National de Nouabalé-Ndoki 57

Parks Australia 289

Parks Canada 161, 363, 366, 511, 662, 665

ecological monitoring 217, 221, 673

management 355, 356, 744

Parks in Peril Site Consolidated Scorecard 221, 905

Parks Victoria (PV) 289, 734, 760, 918

Patagonia 904

Patagonia National Park 795

payment for ecosystem services (PES) 158, 159, 162, 878

paysage humanisé (or 'living landscape') 691

pelagic 55, 62, 398, 807

Pelican Caye World Heritage Site 150, 153

Periyar Tiger Reserve 489, 796

permafrost 58, 60, 498, 522, 554, 560, 585, 827

Peru 56, 88, 672, 859

protected areas 102, 155, 694, 796, 805

pest animals 229, 435, 739

control 236, 524, 525, 592, 719, 723, 728, 776, 777 , 865,881

preventive measures 574,721

removal 772

threat from 405, 477, 754, 768

pests, see invasive species

pesticides $149,153,239,479,639,765$

pharmaceutical $147,151,805$

philanthropy $136,181,415,418,420,433,434-5$

Philippines 27, 88, 199, 208, 621

ICCAs 27, 170, 193, 403, 614

marine protected areas 615, 619, 620, 625, 808

Phong Nha-Ke Bang National Park 46, 212

planning 6, 29, 30, 50, 54, 69, 131, 133, 181, 196, 211, $230,236,255,310,319,331,348,378,415,483$,

511, 514, 809, 862, 899, 905, 913

adaptive $390-1,406$

approaches 383, 385, 388, 389

bioregional 23

business 215

capacity development 267 catchment 592

climate-ready 519

conservation $72,153,339,398,430,543,575,587$,

596, 705

development 556

economic 132, 137

framework 218

marine spatial 630-3

media 449

operations 763

participatory $159,392,491,624$

pre-incident 828,830

protected area 394, 400, 660

site 550

strategic 214

threat management 481

tourism 729

types 383

Plitvice Lakes National Park 18, 154, 930

poaching $120,133,373,720,826$

anti-poaching measures 209, 288, 298, 332

death of rangers 239

defending against 198, 239, 757

impacts of 741, 768

increase in 109, 288, 490, 801

increased threat of 24,30

information on 336, 369, 667

patrolling 209, 228, 666

prevention 524,797

redirection of poachers $374,489,796$

response to $228,234,475,484,845$

threat management 229, 423, 865

threat of 209, 332, 476, 477, 478, 483, 486

poaching, see also animals_killing of

Polynesian 83, 123

Pomor 165

Port Royal 95

Portugal 92, 544, 545

Potato Park, see el Parque de la Papa

pre-European 85, 90, 621

pre-industrial 86, 498, 499

'predictability, linearity, understandability and stability' (PLUS) 298, 318

PROARCA/CAPAS scorecard evaluation 902, 905

Programme of Work on Protected Areas (PoWPA) 24, 128, 189, 226, 261, 588, 932

adoption of xxi, 14, 132, 395, 491

Goal 3.2 254, 255,

Goal 4896

implementation 289, 130

objectives 400, 895

obligations under 190, 267, 395

progress of 120,897

recommendations 188, 481, 688, 876, 896 
Project Janszoon 435

Protected Area Benefit Assessment Tool (PA-BAT) 159

protected area downgrading, downsizing and degazettement (PADDD) 136, 644

protected area management effectiveness (PAME) 7, 69, 193, 198, 269, 405, 633, 760, 891-922

achieving 253, 277, 900

adoption of $895,897,905$

approaches 131,867

components of 900,902, 906

development of 895, 902

potential 398

processes $212,397,895$

protected area management effectiveness (PAME)

evaluation 29, 190, 221, 254, 261, 485, 634, 642-4,

673, 892-922

advancement of 268

application of 893,902

benchmarks 629

consultative 483

format of 332

framework 221, 332, 643, 785, 894, 896-8, 900-2,

906-8, 918

improving 198, 201, 209, 278, 331, 348, 390, 644, 902

indicators 758, 906

initiatives 899, 900

levels of 16, 276, 620, 644, 897, 922

methodologies 896, 905, 907, 909, 914, 915, 916

need for 786

process $217,785,903$

responding to 213

reporting 221, 485

responsibility for 189

results 268,900

studies 125, 268, 894, 902, 903, 908, 917

systems 221, 634, 892, 902, 904

tools 332, 481, 900, 905

see also Management Effectiveness Tracking Tool,

Rapid Assessment and Prioritisation of Protected Area

Management

Protected Area Matrix, see International Union for

Conservation of Nature-Protected Area Matrix

Protected Areas Resilient to Climate Change (PARCC) 348

Protocol on Environmental Protection to the Antarctic Treaty (1991) 877

Protocol on the Conservation of Nature and the

Countryside (1994) 877

purpose 11,15

Quaternary 61, 542, 547, 554

Quebec 139, 691, 705

Quechua 102, 805

Queensland 197, 571, 622, 663, 865, 870, 880

Government 628
Ramsar Convention 14, 23, 54, 66, 191, 225, 333, 571, $575,576,585,588,598,876$

Culture Network 697

list 23, 588, 590, 591

sites $23,188,379,534,570,577,579,588,589$,

590-1, 598, 614, 701, 901

Rapa Nui (Easter Island) 83, 616, 697

Rapid Assessment and Prioritisation of Protected Area Management (RAPPAM) 478, 481, 492, 898, 901, 904, 905, 909, 915, 917

'recreation opportunity spectrum' (ROS) 218, 220, 221, 484, 721, 736-7, 738, 743-4, 761

Red List of Threatened Ecosystems 53, 344

Red List of Threatened Species 53, 244, 344, 346, 575 categories 229

criteria 664

species on list 152, 346, 653, 656, 664

Reducing Emissions from Deforestation and Forest Degradation (REDD and REDD+) 152, 672, 876

Reef Resilience Program 634

Reef Resilience Toolkit 633, 634

refugia 486, 504, 520-1, 524, 585, 595

Removing Barriers to Invasive Plant Management in Africa project 488

representative concentration pathways (RCPs) 498, 499, 500

Republic of the Congo 56, 57, 800

research 155, 335, 426, 497, 518, 707, 719, 866

archaeological sites 710

code of practice 229

visitor research tools 733

Reservas Naturales de la Sociedad Civil (or Nature Reserves of Civil Society) 691

reservoirs, see dams

Resguardo Indigena (Indian reservations) 691

Retezat National Park 182, 806

Rhine River 592, 594, 595, 596

Rift Valley 164

Rila National Park 155

Robben Island 104

Rocky Mountain National Park 697

Rocky Mountains 63, 103, 366, 662, 858

Romania 182, 806, 859

Roosevelt, Theodore 436

Rousseau, Jean-Jacques 12

Royal National Park 210, 244, 611

Royal Society for the Protection of Birds 26

Russia 124, 240, 289, 501, 693, 859

biomes $57,58,61,585$

protected area management 3, 276, 904

protected areas 17, 46, 61, 160, 165, 289, 547, 693

see also Soviet Union

Ruta Sagrada del Condor-Wiracocha 102

Rwenzori Mountains National Park 690 
Saami (Lapp) 94, 430

Sacred Himalaya Landscape 860

Sagarmatha National Park 46, 63, 186, 188, 353, 700, 860. See also Mount Everest

Saloum Delta 486

Salween River 58

San (Bushmen) 89, 97, 803, 875

Sangha Trinational 56, 57, 800

Santa Monica Mountains National Recreation Area 244

Sargasso Sea 627

Saryarka-Steppe and Lakes of Northern Kazakhstan 60

Sayan 160, 240, 873

Scandinavia 61, 94, 430, 534

Scotland 163, 538

geoconservation 541, 542, 545, 546

Geodiversity Charter 549, 550

national parks 554, 555, 556, 557

Sites of Special Scientific Interest 533, 534, 535, 537,557

Scottish Geodiversity Forum 550

Sea of Cortez 64

Sečovlje Salina Nature Park 340, 377, 379, 547

Secretariat of the Pacific Region Environment Program 289, 635

Selous Game Reserve 139, 810, 811, 859

Selway-Bitterroot Wilderness 295

Senegal 199, 201, 486, 490

sequestration, see carbon dioxide-sequestration

Serengeti National Park 793-4, 810

Serengeti Plains 794, 810

Seychelles 617, 621, 638

Shared Environmental Information System (SEIS) 342, 343

Shared Governance or Collaboratively Managed Protected Areas 24

Shark Bay Marine Park Area 101, 434, 735

Shouf Biosphere Reserve (SBR) 899-900

Shulgan Task Zapovednik 693

Sierra Club 696, 704

Sierra de la Macarena National Park 308, 859

Sierra Leone 348

Sites of Special Scientific Interest (SSSIs) 533, 534, 537, $545,546,557,559$

sixth major mass extinction, see extinction — sixth major

Slovakia 797, 859

Slovenia 155, 340, 377, 379, 535, 547, 859

Snowdonia National Park 156

Snowy Mountains Hydro-Electric Scheme 405, 577

sociocultural $86,289,484$

context 213, 736, 290

wellbeing 28, 743

soil erosion, see erosion-soil

Solomon Islands 97, 614, 620, 623, 711

Sonoran Desert 64, 859

Soufriere Marine Management Area 807
South Africa 14, 89, 130, 338, 488, 663, 875

biomes 61, 293, 402

customary recognition 193,794

Department of Environmental Affairs (DEA) 920

economy 130, 133

game laws 793

game reserves 184, 654, 774, 803

Government 296, 309, 875

PAME assessment 897, 902, 904, 920-1

private protected areas 192, 803

protected area management 302, 402, 664-5, 893, 920

protected area training 276, 288

protected areas 89, 244, 401-2, 859, 875, 922

resource management 302

water resources 572, 579, 593, 596

wildlife management 296, 299, 666, 688, 732

South African Management Effectiveness Tracking Tool (METT-SA) 920, 921

South African National Parks (SANParks) 130, 217, 244, 309, 391, 581, 732, 794, 875

South African Qualifications Authority 288

South America 46, 689, 746, 791, 801, 804, 891

biomes 57, 58, 60

wetlands 572, 576, 577, 656

South Asia 27, 62, 290, 614, 796, 805

South Carolina 856

South Korea 276, 533, 559, 877

cultural heritage 96, 696, 700, 806

protected areas 221, 224, 897, 902, 904, 905

South-East Asia 58, 85, 98, 148, 275, 290, 656, 796

southern Africa

biomes 60,61

cultural heritage 89

elephant management 307, 309

private protected areas 26,803

protected areas 798, 803, 809, 856

Southern Africa Development Community 288

Southern African Wildlife College 288

Southern Ocean 614, 626, 627

Soviet Union 133, 134, 136, 693

Spain 138, 691, 859

cultural heritage 88,95

geoheritage 533, 544, 545, 546, 547, 710, 804

marine protected areas 614,625

sacred places $155,700,702-3$

Spatial Monitoring and Reporting Tool (SMART) 332, 333

species disappearance, see extinction, extirpation of species

Species Survival Commission (SSC) 261

Species+ 333

Sri Lanka 337, 701, 802

St Lucia 806, 807

St-Barthélemy 635

St-Martin 635

Stankey, George 221, 222 
'state of the parks' (SoP) reporting 213, 221, 237, 366, 656 system 894, 904

tools 221, 918-19

Stockholm Declaration (1972) 128-9

Stone Age, see Palaeolithic

strategic adaptive management (SAM) 302, 391

strategic environmental assessment (SEA) 485, 879

strategic plan, see Convention on Biological Diversity

(CBD)—Strategic Plan 2011-2020

structured decision-making (SDM) 758, 759

sub-Saharan Africa 674

customary rights 482

protected areas 803,901

subalpine 405, 512, 805

Submerged Prehistoric Archaeology and Landscapes of the Continental Shelf (Splashcos) Project 96

Subsidiary Body on Scientific, Technical and

Technological Advice (SBSTTA) 120, 347

subsistence agriculture, see agriculture-subsistence

Sumeria 85

Summit for Sustainability in Africa 122

Sundarbans National Park 62, 92

Suriname 27, 614

Sutlej River 98

Swaziland 401, 859

Sweden 94, 124, 540

Switzerland 63, 545, 859

SWOT (strengths, weaknesses, opportunities and threats) analysis 214,917

Sydney xxiv, 99, 154, 442, 448, 449, 455, 837

Sydney Harbour National Park 246, 247

System of Environmental-Economic Accounts 133

Table Mountain National Park 244

Tagbanwas Foundation of Coron Island (TFCI) 808

taiga $56,58,59,60,68$

Taiwan 359

Tanzania 134, 199, 809, 810

ICCAs 27, 193

protected areas $139,625,793,810,859$

tourism 154,803

Tasman, Abel 435

Tasmania 90, 228, 545, 549, 560, 880

geodiversity 533,536

protected area management xxiii, 258, 260

protected areas 382, 555

Tasmanian Geoconservation Database (TGD) 545, 560

Tasmanian Land Conservancy 26, 289

Tasmanian Parks and Wildlife Service 220, 289, 330, 382

Taxonomic Databases Working Group, see Biodiversity Information Standards

Tegucigalpa 150

terrestrial ecoregions of the world (TEOW) 55, 62
Teuchitlan 104

Thailand 388, 704, 793, 904, 905

The Economics of Ecosystems and Biodiversity (TEEB) $122,133,157,337,621$

The Nature Conservancy (TNC) 897, 902, 909

management tools 218, 221, 281, 502, 893

programs 634, 905

reserves $26,578,584,624$

thermal pollution, see dams-and thermal pollution

The Thomas Foundation 434

The WILD Foundation 697

Theme on Indigenous and Local Communities, Equity, and Protected Areas (TILCEPA) 122, 131, 242

Thousand Islands National Park (TINP) 161

Threat Reduction Assessment (TRA) 900 modified Threat Reduction Assessment (mTRA) 900

threats $7,12,24,28,48,63,69,73,134,136-7,139$, $152,193,199,214,402,918$

addressing 481, 484, 491

biodiversity 15, 120, 303, 332, 590, 864

causes 480

climate change 503,515

direct 476

fire 470

freshwater systems 573

geoheritage 536, 555

human-induced 536

ICCA 482

indirect 479, 490

invasive alien species 73, 153, 243, 391, 402, 485,

486, 488

magnitude 667

management 230, 232, 268, 298, 329, 400, 406, 426, 481, 485, 633, 643, 666, 760, 796, 808, 900

movable heritage 93

operations $754,767,853$

sacred sites 704,710

species $45,53,59,60,65,101,346,388,389,399$, $447,522,626,653,664,758,802,877,912$

types 24, 29-32, 336, 395, 397, 475, 667

values-threats framework 746

Three Gorges Dam 85

Three Parallel Rivers of Yunnan Protected Areas 57, 58

Tibet 11, 98, 698, 700, 701, 741

Tibetan Plateau 58, 60, 535

Tigris River 84

Tijuca National Park 244

Tikal National Park 91, 92

Tikopia 97

TILCEPA 122, 125, 131, 242

Tla-o-qui-aht Tribal Parks of British Columbia 175

Togo 348

Tongariro National Park 63, 104, 691, 698, 703 
Toolkit for Ecosystem Service Site-based Assessment (TESSA) 338

tourism 91, 107, 126, 136, 164, 230, 271, 303, 367, 454, $710,808,899$

definition 722

ecotourism 26, 27, 157, 181, 192, 241, 423, 489,

$761,803,870$

geotourism $544,547,558,559$

management 379, 402, 484, 722, 756

operators 725

recreation and 153

revenue 730

sustainable 621,723

threats 477

unsustainable 640

working with 370,728

'tourism optimisation management model' (TOMM) 743, 745,746

Triglav National Park in Slovenia 535

Tsavo East National Park 164

Tsavo West National Park 164

Tsodilo Hills 88

tundra 49

biome 56, 60-1, 62, 66, 68

loss of $507,508,670$

Tunisia 95

Turkey 88, 89, 159, 686, 709, 859

Uganda 488, 665, 793, 802, 809

cultural knowledge 339, 690

protected areas $374,665,859$

Uganda Wildlife Authority (UWA) 355, 367, 690 rangers 368, 375, 666

uKhahlamba-Drakensberg World Heritage Site 89

Ukraine 289

Uluru-Kata Tjuta National Park 15, 692, 703, 704, 708,736 cultural heritage 88,691

Unified Classification for Threats and Actions 475

Union Internationale des Associations d'Alpinisme, see International Mountaineering and Climbing Federation

Union of Soviet Socialist Republics (USSR), see Soviet Union

United Kingdom (UK) 156, 340, 345, 348, 434

cultural landscapes 691, 707-8

geoconservation $542,545,546$

geoheritage $545,547,549,550,559,718$

marine protected areas $616,625,644,879$

nature for health 154, 163

private protected areas 26,192

protected area management $275,552-3$

protected areas 2, 156, 244
Geodiversity Action Plan (UKGAP) 549, 550

see also Britain, England, Northern Ireland,

Scotland, Wales

United Nations (UN) 120, 128, 130, 723

Conference on Sustainable Development (UNCSD)

812

Conference on the Environment and Development

(UNCED). See Earth Summit

Convention on the Law of the Sea (UNCLOS) 225,

226, 611, 622, 626, 627

Convention to Combat Desertification 129

Declaration on the Rights of Indigenous Peoples

(UNDRIP) 128, 129, 130, 184, 191, 225

General Assembly 340

and indigenous rights 129-30, 430, 692

instruments 122, 129, 189

Millennium Development Goals 14, 137

protected area list 14, 340, 791

protected area management 418

system 128, 129, 131, 138, 333, 395

see also Global Environment Facility, World Heritage

United Nations Development Programme (UNDP) 502, 613, 914

United Nations Educational, Scientific and Cultural

Organisation (UNESCO) 346, 376, 705, 810

assessment tools 221, 902, 906

biosphere reserves 23, 25, 66, 551, 806, 899

Centre on World Natural Heritage Training and

Management 290

Chair for Biosphere Reserves and Natural and Mixed

World Heritage Sites 289

conventions 105

Convention on the Protection of the Underwater

Cultural Heritage 94

culture-nature linkage 376

cultural heritage protection 93, 96, 105, 130, 692, 711

General Conference 24

geoparks 24, 544, 558

heritage definitions 87, 93, 104, 691, 698

Hoi An Protocols 705

see also Man and the Biosphere Programme

United Nations Environment Programme (UNEP) 14, 225, 340, 345

Green Economy Initiative (GEI) 133

Regional Seas Program 623

World Conservation Strategy 14

United Nations Environment Programme World

Conservation Monitoring Centre (UNEP-WCMC) 62

calculations 151, 502, 667

projects $342,348,667,897$

Protected Planet portal 280, 677

tools 333, 345, 346

see also ICCA Registry, World Database on Protected

Areas 
United Nations Framework Convention on Climate Change (UNFCCC) 14, 129, 171, 226, 876

United Nations World Tourism Organisation (UNWTO) $722,726,727$

United States (US) 14, 161, 290, 337, 379, 447, 918

border with Canada 155, 157, 161

Congress 696

connectivity 592, 856, 859

conservation movement $12,86,357,696$

cultural heritage 705

Department of the Interior 437

fauna $658,660,662,663,664,675,855$

fire management 295, 296, 299

Fish and Wildlife Service 582

flora 359, 657

Forest Service 218, 221, 222

Forest Service fire management 295, 296, 307, 318, 321

geoheritage $547,558,559$

Government 301, 357, 597, 768, 834

incident management 220, 239, 834

indigenous recognition 24,193

marine protected areas $611,614,616,625,635$

National Heritage Areas 104

philanthropy 434

political ideology 134, 135

private protected areas 26,192

protected areas $244,357,858$

recreation industry $436,726,804$

resource management 123,307

voluntary conservation agreements 879,880

water resources $574,577-8,580,584,593$

wetlands 385

wilderness designation 100

see also individual States, North America

United States National Park Service (NPS) 355, 356, 357, 359,433

monitoring 559, 672

park management $234,275,691,767-8,804$

planning 384, 386-7, 437

recreation management 244,437

research 362, 691

training 290, 334

visitor management 357,745

wildlife management 358, 665

Universal Declaration on Human Rights 128, 129

University for International Cooperation (UCI) 260, 289

Ural Mountains 693

Uttarakhand 695, 870 values, see bequest values, biodiversity—values, cultural heritage values, cultural values, existence values, nonuse values, World Heritage_-values

Vanuatu 104

Venezuela 14, 58, 102, 859

Venice Charter 87, 105, 705

Victoria 511, 660, 770, 853, 902

connectivity 870,880

fire $446,470,828,829$

protected areas $434,759,833,834$

state of parks reporting 221, 904, 905, 919

see also Parks Victoria

Victoria Falls World Heritage Site 315, 718

Vietnam 46, 99, 212, 231, 625, 704, 710, 802

Virunga National Park 337, 368, 859

'visitor activity management process' (VAMP) 743, 744

'visitor experience and resource protection' (VERP) 743, 744,745

'visitor impact management' (VIM) 484, 739-46

visitors

impacts 739, 754, 781, 910, 209, 484

management 220, 255, 267, 379, 384, 484, 667,

720,722

services and facilities 737

types 718,726

Wadden Sea 64, 65

Wales 156, 542, 546, 551

Washington State 21, 358, 558, 559, 574, 662

Washpool National Park 106

water catchment 27, 122, 149, 479, 509, 572, 575, 577, $586,587,592,593,596,597,621,765$

and caves 552

and erosion 577,589

and forests 150,579

health $423,592,768$

management 302, 416, 418, 419, 549, 551, 574, 576,

580, 581, 586, 588, 593, 644

and mountains 151, 405, 577

planning 388, 592, 812

pollution of 479,587

protection of $173,503,512,576$

restoration 589, 755, 833

yields 504

watersheds 123, 175, 571, 579, 593, 673, 809

logging in 148

management of $178,656,878$

protection of $172,577,618$

remediation 164,689

value of $148,150,156$

Waterton-Glacier International Peace Park 155, 157, 445

West Africa 123, 348, 826

extractive industry 486,490

protected areas 348, 901, 904

West Indies 807 
Western Australia 61, 543, 586, 827

Indigenous initiatives 408, 430

private protected areas 434, 586, 661

protected areas $797,857,890,893$

wildlife tourism 101, 621

Western Cape 921

Western Cape Nature Conservation Board 920

Western Ghats 173

Western Hemisphere Convention, see Convention on Nature Protection and Wild Life Preservation in the Western Hemisphere

Western Himalaya 242, 870, 871, see also Himalaya

Western Indian Ocean (WIO) 278

Western Indian Ocean Certification of Marine Protected Area Professionals (WIO-COMPAS) program 275, 278

Western Indian Ocean Marine Science Association 278

Wetlands of International Importance, see Ramsar Convention

whales, see cetaceans

Whaling Convention, see International Convention for the Regulation of Whaling

wildfire, see fire

wildlife corridors, see corridors-wildlife

Wildlife Institute of India 218, 289, 290, 488, 870

Willandra Lakes National Park 90

Wilson's Promontory National Park 833, 834

Wollemi National Park 837

Wood Buffalo National Park 58, 59

Wordsworth, William 12, 156, 691

World Bank 221, 371, 502, 797, 870, 895, 898

World Charter for Nature (1982) 122

World Commission on Protected Areas (WCPA) xxi, xxiii, $14,377,678,931$

attitude to mining 138,555

Best Practice Guideline on Geoheritage Site

Conservation and Management 535

best-practice guidelines xxi, 5, 276, 280

capacity building 288-9

Education and Learning Task Force 257

framework for connectivity conservation management $218,858,860,861,862,863,881$

freshwater management 573-4

Global Partnership for Professionalising Protected Area

Management (GPPPAM) 275, 276, 282, 289

Global Partnership for Professionalising Protected Area

Management Development 211

guidance 5, 15, 232, 261

initiatives 131, 273, 931

management effectiveness evaluation framework 217 , $221,406,785,891,893,894,896-8,900-2,906$, 907-8

natural solutions 15

private protected areas $240-1$

public use measurement and reporting system 219 publications 39, 131

Specialist Group on Cultural and Spiritual Values of

Protected Areas 697

standards 275, 922

World Conservation Congress, see International Union for Conservation of Nature-World Conservation Congress

World Conservation Strategy 14, 39, 177

World Database on Protected Areas (WDPA) 329, 340, 342, 345, 346, 896, 916

Data Standard 340-1, 343

establishment 14, 340

reporting to 21,225

statistics from 21, 66

World Geodetic System (WGS) 341

World Health Organisation (WHO) 801

World Heritage

achieving status 22

assessment of nominations 346, 544

case studies 55

listings 22, 84, 544, 735

program 689

values 91

see also 'outstanding universal value'

World Heritage Centre 697, 699

World Heritage Committee 139, 346, 699, 703, 810

World Heritage Convention (WHC) 66, 225, 346, 544 , 592, 691, 705

adoption $14,22,45$

criteria 22, 102, 346, 543

definitions 102

Operational Guidelines for the Implementation of the World Heritage Convention 103, 723

parties to 876

recognised areas 22

reporting requirements 333

use of 54,191

World Heritage List 22, 225, 85, 102

inclusions 45, 63, 103, 104

inscriptions 346, 544

World Heritage sites 31, 45, 138, 920 archaeological 88, 89, 709, 710, 905

assessment 221, 901

boundary violations 137

community engagement 415

connectivity areas 859

cultural 91, 244, 544, 695, 699

cultural landscapes 88, 101, 104, 689, 691, 692

declassification 481

designation 22, 386, 870

designed landscapes 707

distribution 46

extractive industry in $133,138-9,481,486,555,810$

geoheritage $543,547,549,555,686,718,739$ 
indigenous heritage 90

industrial 88

marine areas $615,616,617,619,621,625,735$

mixed 90, 376, 544

mountains 63, 244

natural 91, 347, 534, 540, 544, 699, 723, 906

resource use in 723

threats to $32,139,481$

World Information Network on Biodiversity (REMIB) 347

World Parks Congress (WPC) 302, 430, 611, 891

1982 (WPC 3) 14, 891

1992 (WPC 4) 14, 891

2003 (WPC 5) 14, 128, 130, 131

definitions from 26, 241

Durban Accord 623, 688

Durban Action Plan 226

goals 255

governance issues 201, 629

recommendations $\mathrm{xxi}, 275,611,895$

topics 891,931

2014 (WPC 6) xxiv, 72, 139, 140, 448

World People's Conference on Climate Change and the Rights of Mother Earth 136

World Summit on Sustainable Development (WSSD) 611

World War II 13, 87, 128, 379, 766

World Wide Fund for Nature (WWF) 14, 656, 699,

803, 897

'Living Rivers' 594

Black Rhino Range Expansion Project 184

conservation initiatives 434, 902, 920

Natural Solutions 502

PADDD program 644

SMART Partnership 332

World Bank Tracking Tool 221, 895

see also Rapid Assessment and Prioritisation of

Protected Area Management

Wrangel Island Reserve 61

Yangtze River 58, 84, 85

Yellowstone National Park 14

aesthetic values 154,155

animal management 362, 664, 666

cultural heritage 91, 235

gazettal $83,123,793$

geoheritage 334, 387, 532, 535

human-wildlife interactions 313, 485, 845

visitors 314, 318, 559, 718

'Yellowstone model' 793-5

Yellowstone to Yukon Conservation Initiative (Y2Y) 394 , $857,858,859$

Yosemite Conservancy 433

Yosemite Falls 46

Yosemite National Park 30, 433, 781, 793 fire 824,828

visitors $210,437,716$

Yosemite Valley 101, 437, 828

Yucatan Peninsula 265, 710

Yukon, see Yellowstone to Yukon Conservation Initiative

Yunnan 57, 58, 97, 704

Zambezi River 315

Zambezi savannah 58, 60

Zambia 315, 488, 859

Zanzibar 614

Zapovedniks 17, 547, 693, 873. See also Environmental Education Centre for Zapovedniks

Zimbabwe 127, 315, 859

Zoological Society of London 332, 337

Zululand Rhino Reserve 184 